$f:-x+2 x$

2

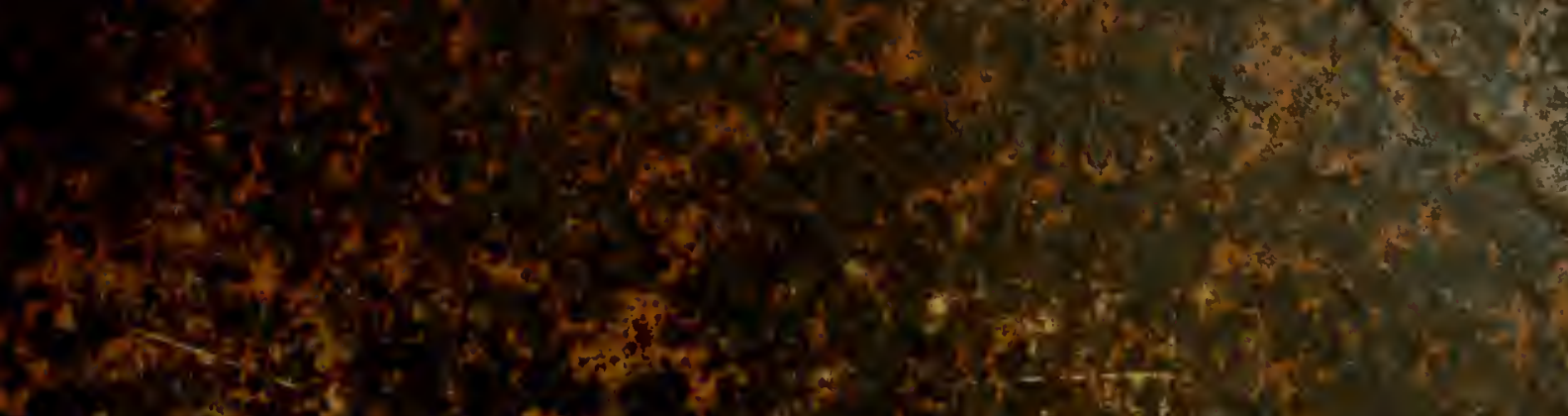

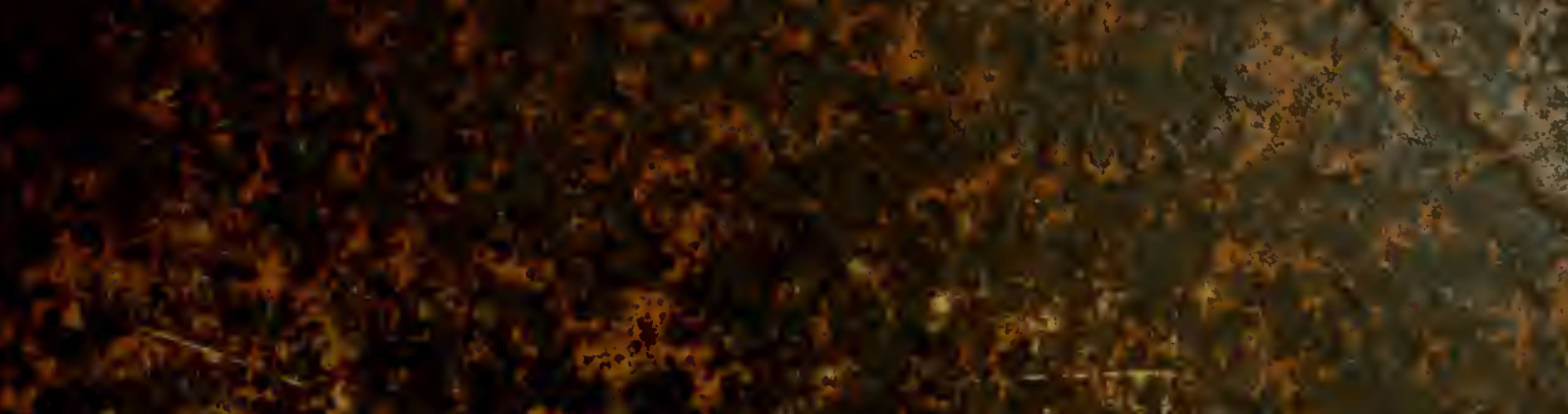

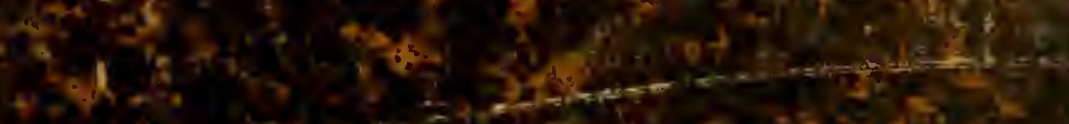

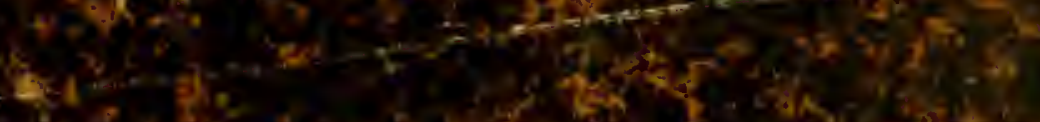

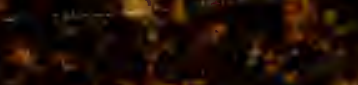

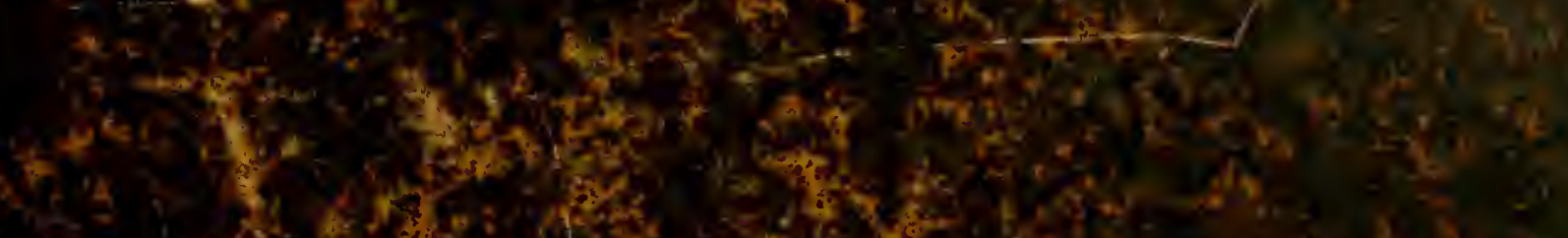

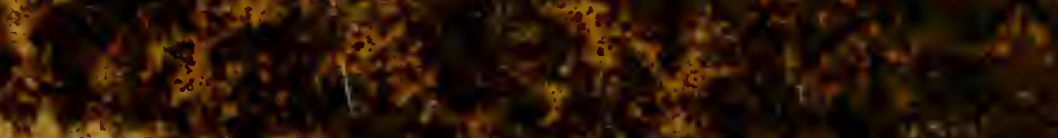

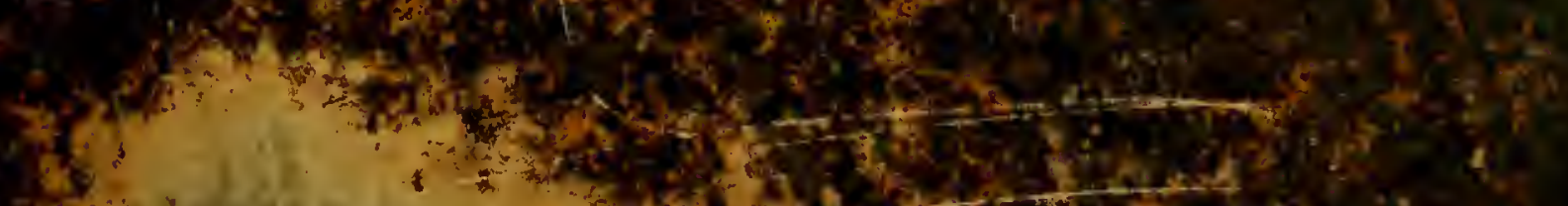

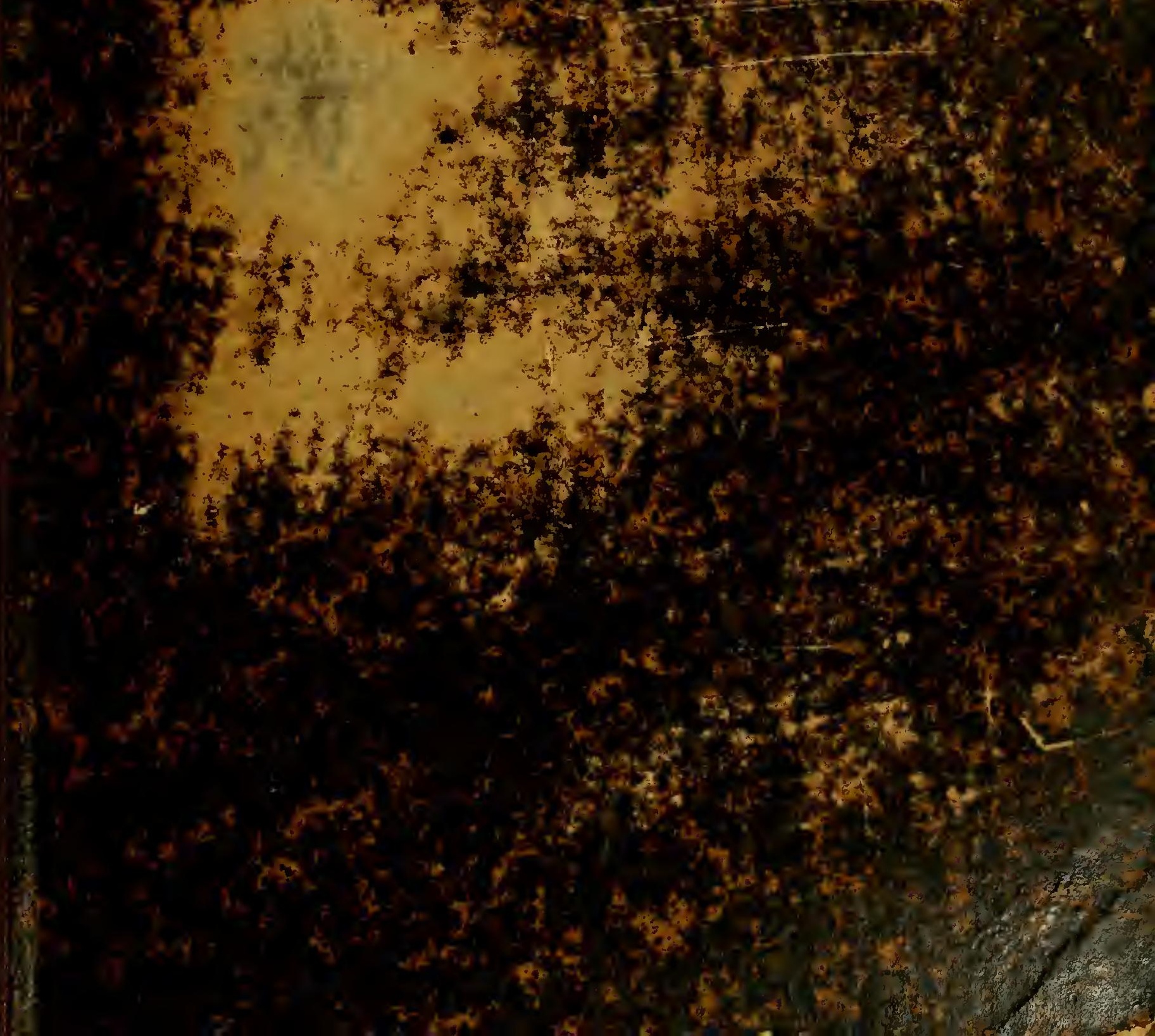




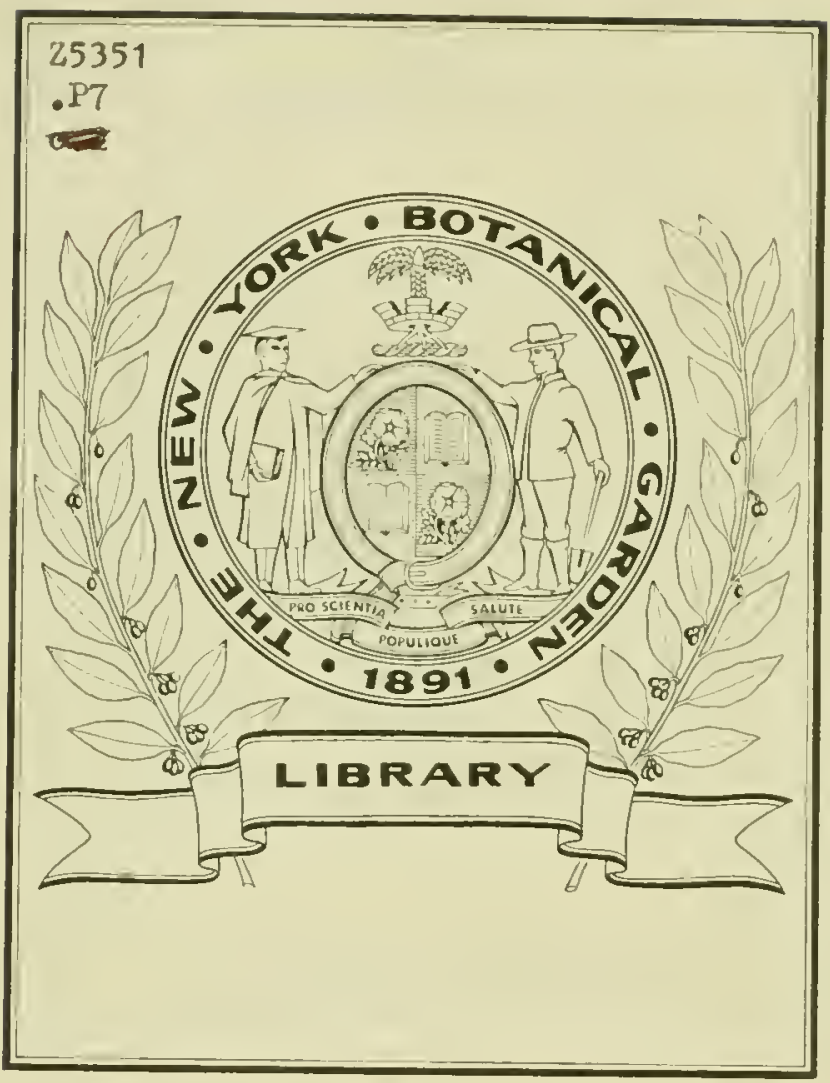







\title{
THESAURUS
}

\section{LITERA'TURAE BO'TANICAE}

\author{
OMNIUM GENTIUM
}

INDE A RERUM BOTANICARUM INITIS AD NOSTRA USQUE TEMPORA, QUINDECIM MILLIA OPERUM RECENSENS.

\section{G. A. P R I 'T Z E L.}

$$
\begin{aligned}
& \text { L I P S I A E: } \\
& \text { F. A. B R O C K H A U S. } \\
& 18851
\end{aligned}
$$




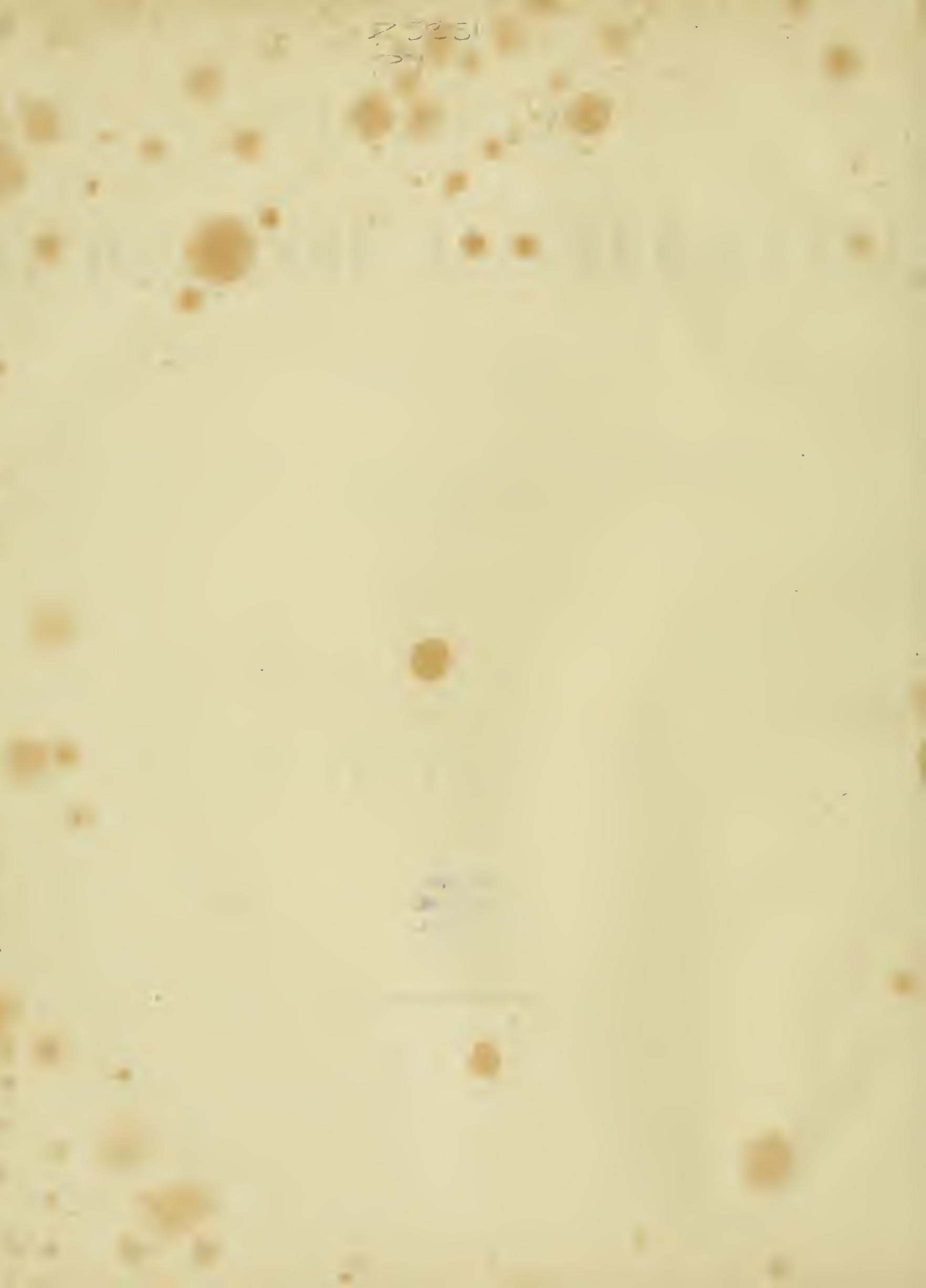




\section{VIRIS OPTIMIS}

\section{ALPHONSO DE CANDOLLE}

\section{EDUARDO FENZL пкововов:s!}

\section{LEONI HENCKEL vox DONNERSMARCK мerseruncessa}

HADRIANO DE JUSSIEU paralirsas

FRIDERICO KLOTZSCH венопе:s!

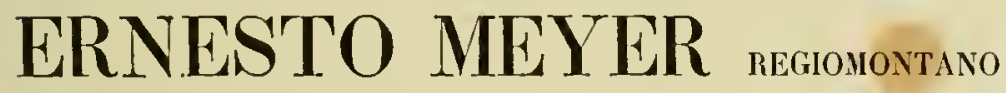

\section{PHILIPPO BARKER WEBB P.MIIIx:se}

QUI LIBERALISSIME ME EXCEPERUNT EXCEPTUM CONSILIIS ET AUXILIO ADIUVERUNT

HOC OPUS

PII GRATIQUE ANIMI DOCUMENTUM ESSE VOLUIT

AUCTOR. 


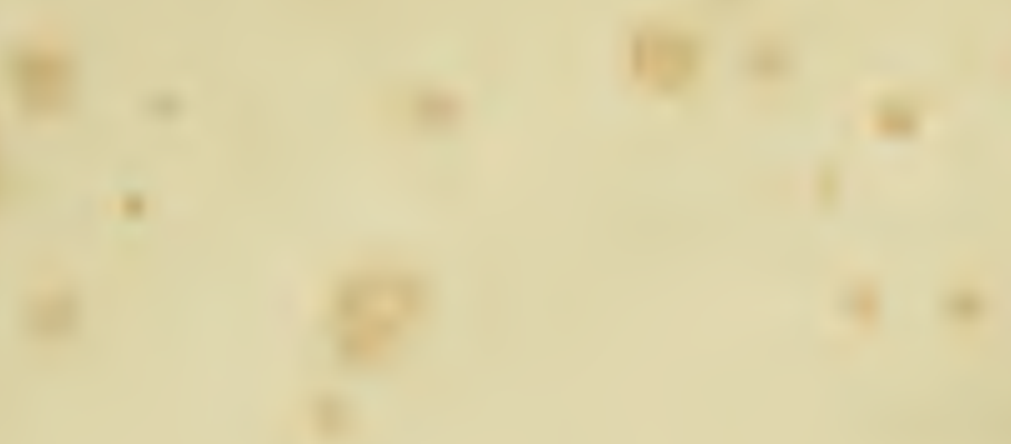
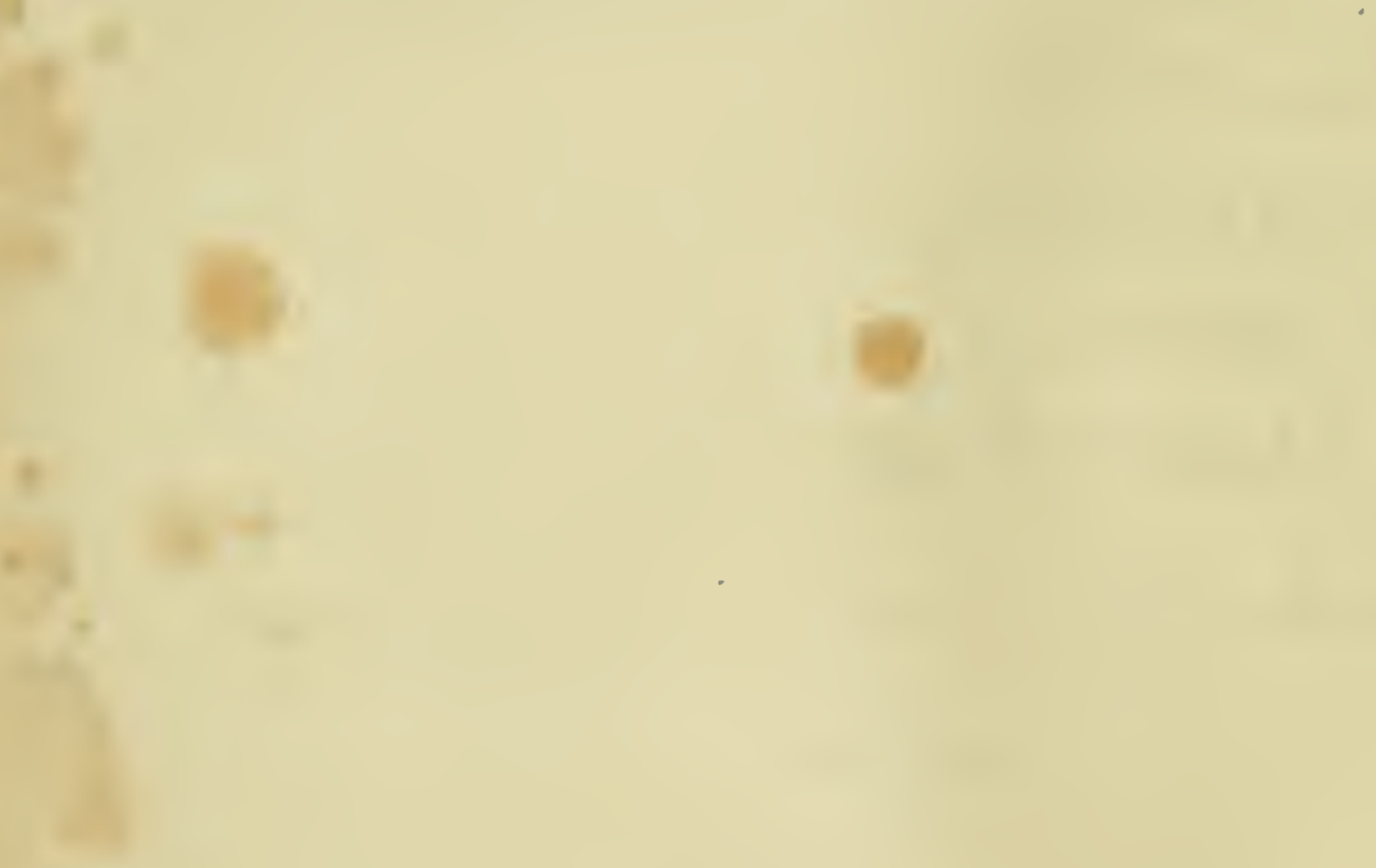


\section{$\operatorname{LiRMATR}$ \\ and \\ $=$ \\ PRAEFAT I 0.}

Post Seguierum, Limmaeum, Hallerum, viros pracstantissimos, qui sacculo practerito libros de literatura botanica gravissimos ediderunt, unus, qui postremus in bac re opcram posuit, nominandns est Bibliothecac Banksianae antor aeterna memoria dignus Jonas Dryander. Cujus viri opus quamvis inter reliquos de literatura botanica libros omnibus rebus quam maxime excellat, tamen tam raro invenitur, ut vel publicarum billiothecar'um subsidiis vix acquiratur.

Neque qui componendorum tam late patentium librorum diffenltates reputaverit, edita Bibliotheca Banksiana intra quinquaginta annos nullum (monographiis quibusdam, ut Wikstroemii de Succiae, Adamsliii de Poloniae, Haberlii de Hungariae, Sternbergii de Bohemiae, Trautvetteri de Russiae literatura botanica disserentium exceptis) librum editum esse mirabitur, in quo literaturae botanicae ingentes copiac collatae legantur atque dispositae.

At quum hujus literaturac in dics crescentis accuratam cognitionem omnibus qui studium et operam in herbis cognoscendis collocarent, esse difficillimam intelligerem, ncque equidem nescirem quantum literis detrimento esset, si plurimi de aliis, qui antea de iisdem rebus quaesiverunt, scriptoribus securi rem it intactam vel inviti gcrerent, jam antc hos decem annos Dierbachii beati colloquiis incitatus hujus libri scribendi cepi consilinm. Quo in opere id maxime mihi agcndum esse credidi, ut omnes literaturae botanicae fontes non solum tam accurate recenserem, ut cos posthac inspicere jam nulli necesse esset, sed etiam ut omnia, quae in Thesauro meo traderentur, libris ipsis evolutis ipse cognovissem. Quod moum consilimm reliquorum periculis et majus et accuratius undique quam maxime comprobatum atque adjutum est.

Perlustravi igitur accuratissime bibliothccas libris botanicis pracclaras Germaniac atgue Galliac, Regias publicas Bcrolinensem, Dresdensem, Parisiensem, Bruxcllensem; rccensui collectiones egregias virorun clarissimorum Linkii, Schlechtendalii, Kunzii, Candollei, Jussieui, Delessertii, Webbü, Gayi, Leveillei, Montagnei, Grisebachii, aliormm; splendidam privatam Imperatorum Francisci et Ferdinandi bibliothecam; Palätinam Vindobonensem et insignem illam, quae in Horto Endlicheri et Fenzelii auspiciis orta nunc fere omnium ditissima facta est; bibliothecam Horti regii Parisiensis (Jardin des plantes) admodum pauperem; denique illas universitatum Lipsiae, Gottingae, Leodii et quae sunt aliae clarissimae. Quibus in bibliothecis fere semper uniuscujusque libri titulum cum rebus collectis comparanti paullatim quadraginta milia librorum evolvisse et inspexisse contigit. Atque ut qui opere meo utuntur viri docti, ubi inveniantur ipsi libri, facilius cognoscant, libris a me in Germania inspectis asteriscum * in Gallia aut Gencvae evolutis crucem + adscripsi, libris denique rarioribus nomen bibliothecac in qua asservantur, distincte addidi. Quibus libris nullum adjectum est signum (sunt antem perpauci) illos ipse inspicere non potui, atque his quidem post libri titulum plerumque addidi literam, qua patefiat, unde libri notitiam consecutns sim. 
Ac quamquam multi nonnullas libri mei rationes praecipue rerum allatarun ordinem vituperabunt, quamquam de libris ex vicinis botanicae finilous aut receptis aut omissis (qua in re plerumque Dryandri viri clarissimi judicium atque exemplun secutum me esse fateor) mecum dissentient, tamen plura in libro meo inesse scio quac viri harum rerum peritissimi existimaverunt laude dignissima. At jui libro meo ad sublevanda studia evoluto aliqua diligentiae vestigia deprehendant, cos ue obliviscantur rogo, quanta sit opera, innumeraliles priorum errores longinquis sacpe atque molestissimis quaestionibus detectos climinare omnes atque effugere.

Neque facere uon possum, quin hac data publica potestate amicis meis omnibus et propinquis et remotis gratias agam pro liberalitate atque studiis, quil)us me in hoc octo annorum labore diligenter adjuverint, quin gratias agam et multis literarum nostrarum amicis pro liumanitate, qua librum meum exceperint et viro honestissimo de me optime merito qui libri mei ornate edendi sumtus integre fecerit.

Denique vel postea et hujus operis complendi curam subibo addito buic operi supplemento, in quo, et quae nunc casu quodam omissa sunt et quae abline novissima scripta crunt, accurate recensebo. Deinde in animo est, nisi temporun angustiis premar, peculiari libro recensere dissertationes botanicas, quae aut in actis academiarum socictatumque literariarum, aut in diariis commentarissue literariis ab bujus sacculi initio dispersac leguntur *). Atque illud quidem opus, quamvis jam dudum pracparatum sit, tamen et propter rerum multitudinem et propter exiguum temporis spatium una perfici non potuit. Allatas vero esse in hoc meo libro nonnunquam diariorum dissertationes attulerim, quac a re proposita omnino abhorreant, jam me poenitere libere fateor.

Scriluebam Berolini 15. Nov. 1831.

PRITZEL. 


\section{INDEX CONTENTORUM PARTIS SYYSTEMATICAE.}

Historia boitances p. 355 .

Vilae botanicorum p. $356-360$.

Effigies botanicorum p. $360-361$.

Epistolarum cellectiones p. $361-362$

Plantae sacrorum Biblierum p. $362-363$.

Phytotheologi p. 363 .

Symbola e plantis desumta p. $363-364$.

Poemata de plantis p. $364-365$.

De plantis Veterum Critici p. $365-366$.

Plantarum mythicarum et magjearum historia p. $366-367$.

Collectanea. Miscellanea. Diaria p. $367-368$.

Lexica varia botanica p. $368-369$.

Encomia botanices p. $369-370$.

Nomina plantarum p. $370-371$.

Methodus studii betanici p. 371 .

Termini botanici p. $371-372$.

Artes botanicae p. 372-378.

a. germanicàe p. $372-376$.

b. gallicae ]). $375-376$.

c. anglicae p. $376-377$.

d. succicae et danicae p. 377 .

e. helgicae p. 377 .

f. hispanicae et lusitanieae p. 377.

g. italicae p. 378

h. aniericanae p. $37 x$.

i. polonicae et rossicae p. 378 .

k. variae p. 378.

Collectio herbarioruu p. $378-379$.

Ectypa plantarum p. 379.

Herti butanici p. 379 .

publici ltaliae p. $379-381$.

privati Italiae p. $381-382$.

publici Britanniae p. 382 .

privati Britanniae p. $382-383$.

publici Germanjae p. $383-\mathbf{3 8 5}$.

privati Germaniae p. $385-386$.

publici Galliae p. $386-357$.

privati Galliae p. 388 .

publici Belgii p. $388-389$.

privati Belgii p. 389 .

Ilelveliae p. 389 .

Hispaniae p. 389 .

Hungariae p. 389 .

Poloniae p. 390.

Rossiae p. 390 .

Daniae p. 390 .

Sueciae P. $390-391$.

extra Eurepam p. 391.

Catalegi hertulanorum p. 391.

Musea varia p. 392 .

linera p. $392-397$.
Geographia plantarum p. $398-\$ 00$.

Florae p. 400.

—_ Britamniae p. 401-402.

Belgii foederati p. 402 .

Galliae p. $402-405$.

llispaniae p. 405 .

- Insitanae p. 405 .

- Ilelveliae p. 405-406.

Italiae p. $406-407$.

- Germariae p. $407-412$.

- Galiciae p. 412 .

- llungariae p. 412.

- Dalmatiae p. 412-413.

- Seandinaviae p. 413 .

- Daniae p. 413-414

- Rossiae p. 414.

- Graeciae p. 414-415.

- Turciac p. 414-415

- Asiae p. $415-416$.

- Americae p. 416-418.

- Africae p. $418-419$.

—_ Oceaniae p. $419-420$.

Calendaria Florae p. 420.

Plantae fossiles p. $420-422$.

Monegraphiae p. $422-447$.

Plantae eryptegamde p. $\{2,-\{2\}$.

Fungi p. $423-426$.

Algae p. 426-427.

Lichenes p. $127-428$

Hepaticae p. $428-129$.

Musci frondosi p. 429

Equiseta p. 429.

Fulices p. 430.

llydropterides p. 430.

Selagines p. 430.

Plantae phanerogamae p :30-ih.

Acanthaceae p. 4 .

Acerineae p. 't'k.

Alisinaceae p. 432

Amarantaccae p. 436.

Amaryllideae p. 433 .

Ampelideae p. 463

Amygdaleae p. 4 íf.

Anacardiaceae p. 4is.

Anoriaceae p. 4 l.

Apocyneae p. $\$ 38$.

Araliaceae p. 4 tl.

Aroideae p. 43 .

Artncarpeae p. 436.

Asclepiadeae p. $\$ 35$.

Asperifoliae p. 439.

Aurantiaceae p. 4 ht.

Balanophoreae p. 431.

Balsamilluae p. 456.

Balsamineae p. 45 .

Betulaceae p. 435.

Bignoniaceae p. 440 .
Bisaceae p. H't.

Bromplaceae [1. 43$\}$.

Brumiaceae j. 4 H.

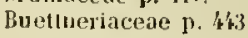

Cacteae p. 'tr3.

Calyeantheae p. $\$ 46$.

Campanulaceae p. 38 .

Caryophylleae $\{, 4\}$

Cedrelaceae p. t'r.

Celastrineae p. 4h.

Ceratophylleae p. Aiti.

Chailletiaceae p. Ho.

Characeae $\boldsymbol{\mu}$. $\$ 30$.

Chenopedieae p. R36.

Chleranthaceae $\mathrm{p}$. his:

Chrysobalaneae p. 46

Cislineae p. Lit.

Combretaceae p. 16.

Compesitae p. 437.

Comferae p. 435.

Connaraceae 1). htio

Contertae p. 438.

Convolvulacear [1, \$39.

Corneae p. 4t.

Crassulaceae p. $\$ 1$.

Cruciferae p. 4t2.

Cucurbitaceae p. 4h.

Cupuliferae p. \{3̈.

Cuscuteae p. 4\%9.

Cycadeae p. 430.

Cyperaceae p. 132.

Cytineae p. $\mathbf{k} 3 \mathbf{3}$.

Daphnoudeae p. 436

Datisceae p. \$t2.

Dioscoreae p. $43 \mathrm{k}$

Diosmeae p. 4 is.

Dipsaceae p. 437.

Dipterocarpeae $\mathrm{p}$. i $\}$.

Droseraceae p. H't.

Eberaceae p. $\$ 40$.

Eleagneae p. 437.

Ensatae p. 433

Ericaceae 40

Eriocauloneae p. 432.

Erythroxyleae p. 4h.

Euphorbaceae p. this

Gentianeae p. 438.

Geraniaceae p. $4 \%$.

liesucriaceae p. 4 ho

Gramineae p. 431.

llaemodoraceac p. 133

Jalorageae p. 4.55 .

Ilydrocharideae [0. 1.3.3

llydroleaceae p. $\$ 39$.

Hypericineao p. 4't

Hyposideae p. 433.

lrideae $p$. 43.1.

Juglandeae p. 4t5.

Juneaceae p. 432

Kingiaceae p. 43:.

Labiatae p. 438.

Laurineae p. 439

Leguminosae p. 4 ' 6.

Lemnaceae p. 43'. 
Liliaceac p. 432.

Lincae p. 4 tis.

Loascae p. 42

Lobroliacoa p. 438.

Loganiaceae [. 438 .

Lonicereac p. 138.

Loranthaceac $\$$ l.

Lyturaricac $4 \mathbf{t}$.

Magnoliaceae [3. 'th].

Maluighiaceac p. kt

Malvaceae 0. 43

Maregravipac p. pti

Melanthaceae p. 432

Melastomaceae 4 h.

Veliaerae p. 4 t.

Mesembrianthemeac p. $4 \mathbf{4} 3$.

Himoseas 14 i.

Nonimiacear $\$ 36$.

Moreae p. $\$ 36$.

Myriceae p. 433 .

Mfrsincae p. 't 10 .

Myrtaceac p. 466 .

Najadeae p. 43 '

Napoleoneae p. 40.

Nepentheae p. 437.

Nyctagineae p. 436

Nymphacacede $p .42$

Ochnaceac 0.45.

Oenothereat p. 4 iै.

Olacincae p. 5 t'

Oleaceae p. 4.38.

Orchidene p. 43 ;

Orobancheac p. 4to.

Oxalicleae p. 4 hi

Palmae p. $43 \%$.

Pandaneae 1. 43t.

Papaveraceae p. 112

Papilionaccac p. 446.

Passiflereae p. '4t2.

Pelalineas p. $\$ \mathbf{k}$.

Pliytolacceae p. $4 \mathbf{4 3}$.

piperaceae p. 433.

Pittosporeae p. 4 't.

Plantagineae p. 437.

plumbagineae p. 437.

Polemoniaceac 0.439

polygaleae p. 4t's.

Polygoneac p. 436.

Pomaceae p. 166

Pontederaccas p. 432

Portulaceav p. $4 \$ 3$

Promulaceae 1). $4 \$ 0$.

Proteaceac p. 437.

Rafllesiaceae p. 431.

Rauuneulaceae p. ptl.

Ritpateae pi 432 .

Resedaceae p. 142

Restiaceac p. 132 .
Rhamneae 1. His.

Rhizantheae p. 4:31.

lihizoholeae p. hk k

Ribesiacrac 1. 4 1.

Rosaccae p. 4 if.

Rosiflorae 1). 4 \$6.

Rubiaceae 1. 438

liutaceae p. 4 th.

Salicineae p. 436

Santalaceae p. 436 .

Sapindaceae p. Yk

Sarracencae p. 4 2

Saurureae p. 433 .

Saxifragaceac p. kh.

Schizandraceac p. 4 t.

Seitaminear p. 43'

Serophularineae p. 439.

Sclagineac p. 439 .

Simarnbeac p. 4t5.

Smilaceac p. 433.

Solanaceae p. 439

Sterculiaceae p. 4 . 3 .

Stilhincae p. 439.

Swartzieae p. 446 .

Synanthereae p. $\mathbf{4 3 7}$.

Terebinthineae p. $4 \%$.

Ternstroemiaceae p. 4 k.

Theaceae p. 4 t

Tiliaceac p. 4 í.

Trapeae p. 155

Tropaeoleac p. 4 to.

Typhaceac p. 43 t.

IImactac p. $\$ 36$,

Umbelliferae p. 4 to.

Urticaceae p. 436.

Utricularieac p. tho.

Valerianeae p. 437.

Vellozicae p. $\$ 33$.

Verbenaceac p. 439.

Violaricae p. 4 ?

Zamiae p. 430.

Monogyaphiae plantarnm officinalium p. 447 464.

Cultura arborum pomiferarnm P. $464-466$

Betanica hortensis p. $466-470$

Cultura florum hortensium p. $470-471$.

Botanica oeconomica p. $471-474$.

Cultura et usus plantarum singolarum p. 474477.

Plantae tinctoriae p. $477-478$.

Plautae utiles p. $478-479$.

Materia alimentaria p. $479-480$.

Viria potus genera p. 480.

Botanica saltuaria p. $480-484$.
Materia medica regetabilis p. 484- 190 .

Medicamenta varia p. $490-491$.

Classes medicamentorum 1.491.

Virium investigatio p. 492.

Signatura plantarum ก. 492.

Plantae renenatae p. $492-493$.

Microscopium p. $493-494$.

Comparatio plantarum et animalium p. 494.

Actiones vitales [0. 494-495.

Calor et electricitas plantarum p. 495.

Efroctus externi in plantas p. $495-496$.

Chemia generalis. Nutritio J. 496-497.

Motus fluidorum p. 497.

Chemia specialis p. $497-498$.

Resurrectio plantarum p. 498 .

Coler plantarum p. 498 .

Odor plantarum p. 498 .

Respiratio plantarum p. 499.

Arbores velustae p. 499.

Morbi plantarum p. $499-500$.

Anatomia. Organographia. Plyysiologia p. $500-$ 503.

Radix p. 503.

Truncus p. $503-504$.

Plantarnm superficies et epidernis p. 504 .

Folia p. 504.

Defoliatio p. 504.

Foliorum ramarumque situs p. 504 .

Mletamerphosis plantarum p. $504-505$

Monstra. Plantac hybridae p. 505.

Perigonium P. 505.

Nectarium p. 505-506.

Anthera p. 506 .

Sexus plantarum. Generatio p. $506-507$.

Fructus p. 507.

Germinatio p. 507.

Trausmutatio specierum p. 507.

Opera varia ante Linnacnm $0.50 \mathrm{~S}-510$

lcones florum et plantarum p. 510-5 11 .

Nethodus plantarun p. 511-513.

Genera plantarum p. 513 .

Pinaces. Systemata p. $513-514$.

Nomenclatores p. 514 .

Observationes botauicac p. $514-516$. 
1\% (Aa, Petrus van der.) Icones arborum, fruticum et herbarum exoticarum quarundam a Rojo. Mentzelio, aliisque botanophilis quiden descriptarum, ast non delineatarum. Ut el animalium peregrinorum rarissimorum, tam volatilium quam quadrupedum ac aquatilium in extremis oris ac desertis Ineliarum et aliis locis repertorum. Lugduni Batavorum apud Petrum van der Aa. s. a. in forma olslonga. 2 foll., 80 tab. aen.

2 Abacher, N.J. Dervollkommene Blumengărtner. Regensburg 1819. 8. $(7 / 12(h)$.

$3+$ Abbene, Angelo. Saggie fisiologico-chimico sulla influenza della Mlagnesia nativa (giobertite) nella germinazione, regetazione e fruttificazione delle piante. Torino $1838,8.15 \mathrm{p}$.

$4 \div$ Abbot, Charles. Flora Bedfordiensis, comprehending such plants as grow wild in the county of Bedford, arranged according to the system of Linnaeus, with occasional remarks. Bedford 1798. 8. xil, 351 p., ind. el 6 tal). col. $(6 s, 6 d$.

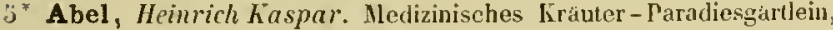
in welchem die bewahrtesten Krăuterarzneimittel zu finten, nebst Erörterung einiger botanischer Fragen. Frankfurt 1740.12.

$6^{*}$ Abendroth, Jilhelm Friedrich. De Coffea. D. Lipsiae 1825. 4. $72 \mathrm{p}$.

7 Abercrombje, David. Nova medicinac clavis sive ars explorandi medicas plantarum facultates ex solo sapore. Londini $1685.8 .36 \mathrm{p}$. (Redit in Huseo di piante rare di Boccone, 1. $930-105$ et p. 13.j-136.)

\& Abercrombie, John. The complete forcing gardener. London 1781. 12

germanice: Der Treibhausgartner. Wien 1792. 4. $\left(1 \frac{1}{6}\right.$ th. - col. 2 th. $)$

(2s. 6u.)

$10 t$ The propagation and Lotanical arrangements of plants and trees, usefull and ornamental, proper for culivation in every department of gardening, nurseries, plantations anel agriculture ctc. London 1784 . If voll. 8. v111, 843 p. et effigies Joannus Abercrombie. The hot-honse gardener. London 4789. 8. ( 6.8 .) 496 p. B.

$13 \div$ The garden Vademecum, or compendiun of generat gardening; aul descriptive display of the plants, flowers, shrubs, trees and fruits and general culture. etc. London 1789. 12. $\mathrm{xt}_{\text {, }}$ 585 p. (4s.)

$1: \div-$ The complete kitclen gardener and hot - bed forceretc. London 4789.12 .509 p., ind. (5s.)

15) The gardeners pocket journal and daily assistant in the modern practice of english gardening. London $4786.12 .-$ Ed. XXV: London 1842.12.

16 The gartener's companion or horticultural ealendar divisted of technical directions, being a monthly index or remembrancer. Edited from an original manuseript of J. A., by J. Mean. London 1818. 12. - Eel. VIII : Londen 1838. 12

$17 t-1$ general system of trees and shrubs, for all useful and ornamental plantations etc. London s. a. $4.224 \mathrm{p}$.

18 Abildgaard, Sören. De caespite bituminoso. Haviae 4761. danice. $\mathrm{H}$.

germanice: Abhandlung voun Terf. Kopenhagen 176i. 8. 9' p. (1/8th.

19. Acerbi, Giuseppe. Delle viti italiane ossia materiali per servire a lla classificazione, monografia et sinonimia, preceututi dal tentativo $\mathrm{dli}$ una classificazione geopenica delle viti. Milano $1825.8 . x v, 33 s$ p.

pritzeL, Thes. lit. bat.
20* Acerbi, Giuscppe. Travels through Sweden, Finland and Lapland to the Forth cape in the vears 1798 and 1799. In two volumes illustrated with 17 elegant engravings. London 1802. 4. - 1: xx14 396 p. - Il: v1II, 380 p., 17 tab. col. et nigr. (p. 257-263: of Laplant Botany.) (3l. $3 s$.)

germanice: ubersetzt von lleiland. Beslin 1503. S. (2//2/h.) gallice: traduit jas Petil-Radel et Lavallee. Paris 180 '. III voll. 8. et Atlas. ( $27 \mathrm{fr}$.)

21 - Briefe uber Scluweden, veranlassl durch Acerbi's Reisen aus der schwedischen llandschrift (von C. G. Leopold) herausgegeben von $F$. Ruhs. Halle 1804.8 . 1v, $242 \mathrm{p}$. w. (1 th.)

22. Achard, Franz Karl. Verzeichniss einer Sammlung Troib-, Gewhichs - 12. Oraugerichauspllanzen, wie auch im lreien ausdauernder Báume, Stráucher ouler Gewächse, welche in meinem Garten cultivirt elc. werden. Berlin 4796. 8.64 p. B.

23 Ausfubrliche Beschreibung der Methode, nach welcher bei der Cultur der Runhelube verfahren werden muss. etc. Berlin 1799.8. 63 p. B.

gallice: + traduit par Copin: Instruction sur la culuure et la récolte des hetleraves. etc. Paris, Tastu. 1811. 8. xxul, $8 \%$ p., 5 tal, (3 ir.) - traduit jar Angar, avee des notes el olsservations par $L$. Devosne. Paris, Colas. PSiz. 8. (6 fr.) Q. traduit par un anonyme. Paris, lluzard. 1812. 8 . (2 fr. 30 c.) $Q$.

2.* Acharius, Erili. Lichenographiae Suecicae Prodromus. Lincopiac 1798. 8. xxiv, 264 p., 2 tab. (col. $2 \frac{1}{2}$ th. - nigr. 2 (h.)

$25^{*}$ — Methodus, qua omnes detertos Lichenes secundum orsana carpomorpla at genera, species et varietates redigere atque observationihus illustrare tentavit. Stockholmiae 1803. Il sectiones et suppl. \&. Ly, 393,52 p., 8 tab. (col. 6 th. - nigr. 4 th. - absque tab. $1 \frac{1}{2}(h$.

$26^{*}$ Lichenographia universalis, in qua Lichenes omnes detectos, adjectis olsservationilus et figuris horum vegetabilium naturam ef organosum carpomorphorum structuram illustrantibus, at genera, species, varietates differentiis et observationibus sollicite definitas redegit. Goettingae 1810, 4. viI, 696 p., 14 tab. (col. $11^{3} / 8$ th. - nigr. 8 th.

$27^{*}$ Synopsis methodica Lichenum, sistens omnes hujus ordinis naturalis detectas plantas, quas, secundum genera, specics et varietates disposuit, characteribus et differentiis emendatis definivi, nec non synonymis et ohserrationibus selectis illustravit. Lundae 1814: 8 . XII, $392 \mathrm{p}$, et effigies Acharii. (2 th.)

IS Ackermann. Nachricht u. Beschreibung einer vollständigen Sammlung von Obstsorten. 1. Theil. Birnen. Sorau 1804.8.

29* Ackermann, Jakob Fidelis. Ueber die Natur des Gewachses. Eine philosophische Einlesitung in seine botanischen Vorlesungen. Maunheim 1812. 4.54 p. $(3 / 4$ th. $)$

30 Ackern, Johann Karl von. De Valeriana, ejusque characteribus, viribus atque ellectibus. D. Lalae 1789.8 .

31* Acosta, Christoval. Tractado de las drogas y medicinas de las Indias orientales con sus plantas debuxadas al vivo, que las vio ocularnente. Burges, por Mlartin de Victoria. 1578.4 .448 , 38 p. praef, et ic. $x y \log r$. i. t.

latine: Aromatum et medicamentorum in orientali lndia nascentiun liber: plurimun lucis adferens iis, quae a 1 . Garcia de Orto in hoc genere seripta sunt; Caroli Clusii opera ex lispanico sermome latinus factus, in epitomen contractus el quibusdam notis illustratus. Autwerpiae 458. 8. $88 \mathrm{p}$ - + Ed. II. impr. cum Garciae ab Horto Aromatum historia. ib. 1593 . p. $2200-312 .-{ }^{*}$ Ed. 1Il. in Clusii Exot:cis p. $2333-20)^{\prime}$.

* ilfalice: Trattato della historia natura et virtu delle droghe medicinali et altri semplici carissimi, che vengono portati dille Indic orientali in Europa. Con le tigure delle piante ritratte e disegnate dal vivo 
boste a fuoghi proprif. Nuovamente rreato dafla spaguuola. Venetia,

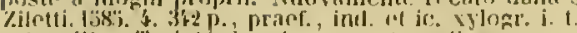

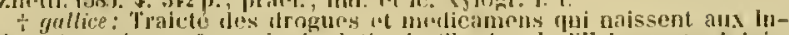

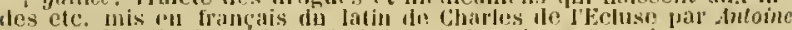

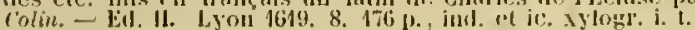

32 Acosta, Josc. Historia natural y uoral do las Indias, Sevilla 1590.

4. - Barcelona 1591.8. 345 foll. - Madrill 1608.4 .535 foll.

- latine: lirilleofulti 1602. for. 362 p.

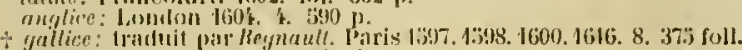

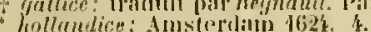

ilalice: Vindijs liso. 4 .

$33^{*}$ Actuarius (al.Johannes), domeilicamentorum composilione, Rurtlio interprete. Parisiis, per Conradun Neobarium. 1539. 8. 196 foll. et prinef.

(Folia ullima recnsentur 192. 176. 182. 17k. Elitio elegantissima

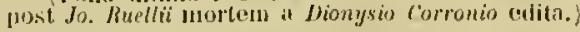

$34^{*}$ - - cum succelateorum nelicaminum tabula per Conradum Gesnerum. il. 15 10. 8.240 p., ind. et 89 p., ind.

3ij" Acxtelmeier, Stanistaus Reinharl. Ebenhilut der Natur in dem Eutwurt" dem Gewälısen, Ungeziellern und einigen Thieren von vermischter Art ete. Ed. H. Augspury 1715. 8. 524 p., praef., ind. ct tal).

36 Adam, Georg. Teher die Verellung des Obstes und die Veranderung der Ohstkernstamme. Erfurt 1800. 8. 126 p.

$37^{*}$ Adami, Ernst laniel. Freye Gedanken wher das Selne und Betrachtenswurdige an einem zu landeslut 1755 gefalltem Buchenbaum. Uresianu 1756.8 .77 p., 1 tab.

(Tractat de characteribus ligoo vivo incisis et cum eo connatis.)

$38^{*}$ Adami, Johann Anton. De oleo Cajeput. D. Goettingae 1783, 4. $32 \mathrm{p}$.

39) Adams, George, pater. Micrographia illustrata or the knowledge of the microscope explain'd. etc. London 1746. 4. xvi, 263 p., 65 (al). (p. $165-235$ ad anatomen plantarmm acleunt.) - El. Il: ib. 1747. 4. - E!. 1V: ib. 1771.8 .

$40^{\circ}$ Adams, George, filius. Essays on the microscope; containing a mractical alescription of the most improved microscopes ete. will a view of the organization of timber. etc. Lomdon 1787.4 . xxuI, 724 p., 31 เab.

1) Adams, John. A sliort account of the growth and flowering of a variegated Imeriean Noe, from the first appearance of the spire or steni. s. i. fol. 1 p. B.

12* Adamski, Max Joseph Adalbert Andreas Anton. Dissertatio sistens Prodromm historiae rei herbariae in Polonia a suis initiis usque arl nostra tempora. Tratislaviac $1 \$ 25.8,56$ [).

'3 Adanson, Aglae. Calalogue des arlires, arbrisseaux, arbustes et plantes vivaces cultivées en jleine terre a Baleiue près Moulin, Depart. de l'Nllier. Paris 1825,12 . a.

1.: Adanson, Hichel. Ilistoire naturelle du Sénigal, avec la relalion abrigév d'un voyage fait en ee pays, en 1749-1753. Paris 1757. 4 (Vojage: 190 p. Coipuillages: xcvi, 275 1., 20 tab.)

* anglice: London I739. 4. burg 1773.8 .

von Schreber. Leipzig 1773. 8 .

$1 j^{*}$ Familles des plantes. Paris, Vincent. 1763. 1] voll. 8. I: Contenam une préface historigue sur l'état ancien et actuel de la botanique et une Théorie de ectte science. cccxxy, 189 p., 1 tab. - II: (24) $640 \mathrm{p}$. (15 fr.)

( hlansonium, Michatelis ex fratre filiun, unvam palrui operum editioncol pararo, legs. Impressa sunt alictuli; equiden vero nihil vidi.)

i.6 *Adelburg, Eduard von. Entwichlung einer analytisch-loxikalischen Methote als leichtestum und sichersten Mitels zur Erkennung der Gewächse. Angewandt auf dic in Europa naturliclı wachsenden Pflanzengattungen, mit Darstellung einer ueuen analytischen Beschreibungs-

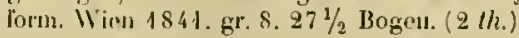

f.7 Adelkofer, Marquart. Grundliche Gartenschule. Augsburg 1792. S. $(1 / 2, h$.

$48^{*}$ Adler, 11 ilhe/m. Flora des Ziegenrucher Kreises und der umliegenten Gegenden, etc. Neustadt u. Ziegenruck IS19. 8. xvit, 334 p $\left(1 \frac{1}{2}\right.$ (h.)
$49^{*}$ (Aehrenthal, Johann Lexa, Freiherr von.) Deutschlands Kernobstsortun, dargestellt in Alshlolusgen uach der Natur mit erlautermilon Auszugrn aus Viel's Versucli einer systenatischen Beschreibung rer in 1)eutschland vorlanulewen Kernobstsorten. Leimeritz 1833-1842. 4.- 1: 1833.227 \%., iud., 40 tal, col. - Il: 1837. vi, 224 p., (ab. col. 41-76. - III: 1842. 96 p., tab. col. $77-9$. (con(iutuatur.) Bibl. Imp.

$80^{*}$ (—_ Systenatische Cobersicht aller in Deutsehland vorhandenen firmobstsorten. Leitmeritz 1833. 4. vol, $96 \mathrm{p}$.

3j) (—) Verzeichniss derjenigen Olsstsorten, welehe in den lireilierrl. v. Aelırentlal'selıen Gärtu, Auligen u. Baumschulen etc. vorbanden sind. I,eitmeritz 1840.8. $\$ 8 \mathrm{p}$.

32* Mnleitung unter den in Deutschland behantesten Kernobstsortun olne Beilitfe wisienschafticher Systcme eine den verscluiedencu Zweeken entsjurechunde $\mid V a h l$ sellost trellien zu konnea. etc. Prag 1845.8. 190 p., 3 tals.

33* Aengelen, Petrus van. Ilerbarius of de natucrlijke secrelen van kruyden, boomen, bloenen, .... ende mineralien der aerden. etc. Amsterdam 1663. III voll. 8. - 1:368 p. - II:95 p. - III: 164 p., ind $3 \mathbf{p}^{*}$ Versiandige gardenier. Amsterdan 1663.4. H - germanice: ller verstiudice Gátner ute. Nun zum fuaftorn ma vernebrt und teutsch ausigefertigt von Georg Graflinger. 1667. 12. 231 [1. pricof.

53. Affaitat, Casimiv. Il semplice ortolano in villa e l'accurato niardiniere in citta', ete. Accresciuta in questa ultima impressione di vari bellissimi segreti. Milano 1845. 8. 192 J.- Mediolani 1734. 12. s

$366^{*}$ Afzelius, Adam. De vegetabilibus suecanis observationes et experinenta. D. Upsaliac $1785.4,36 \mathrm{p}$. (non continuata.)

$37^{*}$ _._. De Rosis suecanis. D. (Tentamen I-XI.) Upsaliae 18041813. 4. 74 p. (Opus haud continuatum.)

$38^{*}$ - Genera plantarum Guineensium revisa et aucta. D. Upsalite 1804.4.26 p. et tab. in tit. cmm explicatione.

$39^{*}$ _ Remenlia Guimeensia. D. Lpsaliae $1813-17.4 .78 \mathrm{p}$.

$60^{*}$ Stimpiun in Guinen medicinalium species novac. D. Upsaliae 1818 .4. 8 p. - Fase. 11: il. 1829. 4. p. 9-16.

61 Stirpium in Guinea medicinalium species connitae. 1). et II. Unsaliae ! $\$ 25.4$. w.

62 De origine Myrrbae comtroversa. D. I-V. Upsaliae 1825 $-29.40 \mathrm{p}$. W.

63* Afzelius, Pehr, pr. De virilus atque usu Digitalis purpurnac. D) Upsaliae $1806.4 .18 \mathrm{p}$.

64t Agardh, Carl Adolph. Caricographia scanensis. D. Lundae 1806 4. $22 \mathrm{p}$.

(Dissertatio demum quarto die Martii 1807 pullice proposita est.)

$63^{*} \longrightarrow$ Dispositio Algarum Succiae. D. 1-11. Lundae $1810-12$. 4. $45 \mathrm{p}$.

$66^{*}-1$ Mgrum Decales I-IV. Lundac 1812-1815.4. 56 [. 3 tab.

$67^{*}$ Synopsis Algarum Scaulinaviac, adjecta dispositione universali Algarum. Lundae 1817. 8. xL, $135 \mathrm{p} .(1 \mathrm{t} / 3$ th.)

$68^{*} \longrightarrow$ Aphorismi hotanici. D. I-XVI. Lundao 1817-1825 8. $246 \mathrm{p}$.

69 Couspectus specierum Nicotianae. Några ord om Tobaksod-lingens forblattring. Lund 1819.12.

germanice: Conspectus specierum Nicotianae. Finige Worte uber die Ferbesserung des Tabachbiuses. Kopenhagen $1520.8 .23 \mathrm{p}$. (1/2 th.

$70^{*} \longrightarrow$ Dissertatio de metanorphosi Algarum. Lund 1820.8. 18 p.

If $^{*}$ Icones Algarum inelitae. Lumlae $1820-1892$. 4. Fase. 1: 1820. X tab. - Fasc. II: 1822. X tab. (4 th.)

$72^{*}$ — Species Algarum rite cognitae cum symonis, differentiis specificis et descriptionibus succinctis. Grypliac. 8. - Vol. 1: $1823.531 \mathrm{p}$. Val. II, sectio prior. 1828 . Lxxv, $189 \mathrm{p} .\left(4 \frac{1}{2} \mathrm{th}\right.$.)

$73^{*}$ Systema Algarum. Lialdae 1824. 8. xxxvil, 312 p. (2 (h.)

74. - Classes plantarum. D. I et II. Lumbe 1825. 8. $2 \geq 1$ 1 (a), conspectum familin rum sistens.

75 - Stirpes agri Rotnoviensis. D. L. Lumblac 1826.8

76 Flora parochiae Brankyrka. D. 1-lll. Upsaliae 1827.8.

$77^{\circ}$ - Antiquitates Limacanae. Programma acadenicum. 1,undae 1\$26. folio. (1\& p.) (vigl. Wikstrum. Jahresberichte 1826/27. p. $214-216$. 
78t Agardh, CarlAdolph. Berdttelse on en botanisk Resa till Oesterrike och Nordöstra ltalien, år 1827. Stockholm 4828. 8. 15 p. germanice: von Creplin in Flora 1831.

Pauca lanlum exemplaria separata Iojus dissertationis impressa sunt, Imuquam in bibliopolis yenalia.

$79^{*}$ Essai de réduire la pbýsiologie végétale à des principes fondamentaux. Lund 1828.8 .56 p. $(5 / 12$ th. $)$

$80^{*}$ — Ieones Algarum europaearum. Représentation d'algues européennes suivie de celle d'espèces exotiques les plus remarıuables recemment découvertes. Leipzic $1828-35$. 8. 40 foll., 40 tab. col. $\left(6^{2} / 3\right.$ th. $)$

$81+\longrightarrow$ Om Inskrifter i lefvande träd. D. Lund $1829.8 .18 \mathrm{p}$ Bibl, horti Paris.

82* - Essai sur le développement intérieur des plantes. Lunt (1829).8.90 p., praef.

83* Lurobok i Bolanik. Forsta Afdeluingen: Organografi. Malmo 1829-30.8.416 p., praef., 4 tab. - "Andra Afdeluingen: Váxt-Biologie. Nalmö $1830-32.8$. v111, 460 p. (Quaeque sectio proprio titulo instructa est.)

"germanice: Lelirsuch der Botanik. Erste Antheilung: Organographis. A. d. sehwedischen voll $L$. Mleyer. Mit Vorrede von $J$. H. Hornemann. Kopenhagen 1831 . 8. x11, $36 \mathrm{p}$., 4 ab. - Zweite Ablheilung

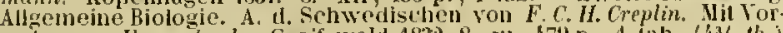
rede von Hornschuch. Greifswald 1832.8 . vi, $479 \mathrm{p} ., 1$ (ah. $\left(\mathrm{s}^{3} / \mathrm{t}\right.$ th. danice: hiobula vn 1831. 8.

8: * Conspectus criticus Diatomacearum. D. I-IV. Lundae $1830-3$ Q. 8.66 p. $(2 / 3(h)$.

$83^{*}$ __ Enumeratio plantarum in regione Landseronensi creseenlium. D. I. Lund $1835.8 .16 \mathrm{p}$.

$36^{*}$ Agardh, Jakob Georg. Do Pilularia. D. Lundae 1833.8 .29 p., 1 tab.

$\mathrm{Sit}^{-}$Om hafs-algers germination. Stockliohn $1834.8 .10 \mathrm{p} ., 2$ tab. * germanice: Linnaea 1830. p. 44 .

$88^{*}$ Synopsis generis Lupini. Lundae 1835 . 8. xiv, 43 p., 2 tab.

$89^{*}$ Novitiae Florae Sueciae ex Algarum familia. D. Lundae 1836. $5.16 \mathrm{p}$

$90^{*}$ Recensio specicrum generis Pleridis. Lundae 1839. 8. vi, $86 \mathrm{p} \cdot(2 / 3$ th. $)$

$91^{*}$ Algae maris mediterranei el adriatici, observationes in diagnosin specierum et dispositionem generum. Paris $4842.8 . x, 164 \mathrm{p}$. $\left(1 \frac{1}{3} t h.\right)$

$92^{*}$ In systemata Algarum horlierna Adversaria. Lundae 1844. S. $56 \mathrm{p}$.

13* Agnethler, Michael Golllieb. De Lauro. D. IIalae 1751. 4.60 p.

94* Agosti, Joseph. De re botanica tractatus in quo praeter generalem methodum et historiam plantarum eae stirpes peculiariter recensentur, quae in agro Bellunensi et Fidentino vel sponte crescunt vel arte excoluntur. Additis adnotationibus quibus plurimarum plantarum vires iudicantur. Belluni, typ. Tissi. 1770. 8 max. (Cust. A-Ab.) 400 p. (In Bibl. B. forma folio nuncupatur.)

95* Agricola. Miscellaneous observations on planting and training timber-trees; particularly calculated for the clinate of Scotland. In a series of letters. Edinburgh 1777. 8. $230 \mathrm{p}$.

$96^{*}$ Agricola, Georg Andreas. Neu- und nieerhörter, doch in der Natur und Vernunft wohthegründeter Versuch der Universalvermelırung aller Bäume, Stauden und Blumengewäclıse, das erstemal theoretice als praetice experimentiret, auch mit unterschiednen raren Kupfern ausgezieret. Regensburg 1714, folio. (50) 184 p. et efligies Agricolae et ic. i. 1. - Andrer Theil. ib. 1717. folio. (34) 82 p., ind. et ic. i.t. - ${ }^{*}$ Frankfurt und Leipzig 1752. folio. (non differt.) - * Versueh einer allgemeinen Vermehrung aller Báme, Stauden u. Blumengewabhse. 2 Theile mit vielen Kupfern erláutert, anitzo auls neue ubersehn durch C. G. Brauser. Regenslurg 1772. folio. 164,80 p., ic. i. . et ind. ( 3 th.)

" gallice: L'agriculture parfaite nu nouvelle déeouverte tonchant la culture el lid noltiplication des arbres, des arbustes, el des theurs. Amsterdam $1720-1732$. Il voll. 8. 3 lab $^{2}$

+ hollandice: Nienwe en ongehnorde dog in de natumr welgegronde Queekionst van hoomen, heesters en blomgewassen etc uyt't

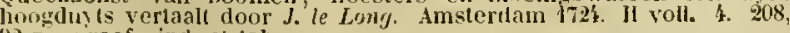
$92 \mathrm{p}$. , praef, ind. el tab.

97* Agricola (Paürle), Johann. Nedicinae herbariac libri duo. etc. Basileae 4539. 8. 336 p., ind.

Joannes Agricola, cosnomine Ammonius, Germanus, in Nicoliti AleAandrini mediei graeci librum de compositione medic, secundum loca insudavit, uhi difficiliora el obscuriora cuuaeque enodando et apericndo, herbarum quoque materiem non perfunctorie tetigit, Liber Ingolstadii prodiit apud Alexandrum Weissenhoru, anno D. 13 t. 4 .

98t Aguillon, Camille. Calendrier horticultural Toulonnais, ou description de toutes les operations d'agriculture, floriculture et d'arboriculture à exécuter durant le cours de l'année. Tuulon 1832 . \& VIII, $94 \mathrm{p}$.

99 Ahlich, J. Den Srenshe Lust-Örte och Trä-Gärden eller Hortus suecicus bulborum, florum, olerum arborumque frugiferorum generibus instructus. Stockliolm 1722. 8. H.

$100^{*}$ Ahlquist, Abraham. Anmärhningar om Ölands physiska Beshaffenhet oeh Vegetation. Stockholm 182.8. $39 \mathrm{p}$.

$101-$ Flora Runsteniensis. D. I-Y. Upsaliae 1\$15-17.4.32p (Dissertationem sub umbone Thunbergit inehoatam Ahlquistio autori tribuit liikstrom.

102 Ahlward, Peter. Betrachtung uber die Endtc. Stralsund 1747. \&, H.

$103^{*}$ Ahnfelt, Nicolaus Olof. Dispositio muscorum Scaniae hypnoideorum, adjectis locis ubi singulos lectos habet, notisque quibus a deseriptionibus convenientissimis recedere visi sunt. D. Lundae $1835^{\circ}$. 8. 24 p.

(Cf. Fries Novit. Florae suce. Ed. H. p. 290-302.)

104 Aignan, Le prôtre médecin, avee un traité du calé et du thé de France. l'aris 1696. 12. H.

105 Aiguehelle, Charles $d$. Ilomographie, ou choix ale 20 plantes indigènes et coloniales, jar brevet diwention, de perfectionnement et l'importation. Paris i 828 . gr. folio. ( $10 \mathrm{fr}$; $15 \mathrm{fr}$. sur papier de Chine.) (v. Bulletin des sc. wat, Avril 1829. ]. 103.)

106 Ajkin, J. The Woolland companion or a deseription of british trees. London 1802.8 . DC.

107 Aikin, William $E$. A. Catalogue of phaenogamous plants and ferunative or naturalized near Ballimore. 1836 or 1837 . w.

108+ Ainslie, Whitelaw. Materia indica; or, some account of those articles which are empleyed by the Hindoos, and other Eastern nations, in their medicine, arts, anl agriculture; comprising also formulae, witl practical observations, names of diseases in various Eastern languages, and a copious list of oriental books immediately connected with general seience ete. Lomion 1826. II voll. 8. - I: xxir, 654 l. - II : $\operatorname{xxxIx,604~p.(2l.)}$

(Materia medicia of flindostaan. Naelras 1813. 4. ast editio prior ejusdem operis, hatu vilis montenti atl illustrandam historian phantarum sicuti literaturam orientalem botanices.

$109^{*}$ Aiton, William. Hortus liewensis, or, a Catalogue of the plants cultivated in the royal botanic Garden at kew. London 1789 . Ill voll. 8

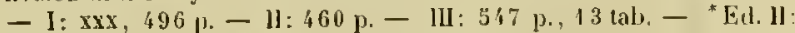
enlarged ly William Townsend Aiton. $1810-13$. T' roll. 8. - I 1810. XL, 407 p. $-11: 1811.432$ p. - 111: 1811.432 p. $-1 \mathrm{~V}: 1812$. $522 \mathrm{p}-\mathrm{V}: 1813.568 \mathrm{p}$.

(Altera biec editio usque al Dodecandriae fuem curis Jonat Dryandri, a classe vero Xill usque ad Cryptogamiam a hoberto brown redacta est.)

$110^{*}$ Aiton, 11 illiam Townsend. An epitome of the second edit ofl of Hortus kewensis for the use of practical gardeners; to which is adted a selection af esculent regetables and fruits cultivated in the royal gardens at kew. With references to figures of the plants. London 1814. 8. $\mathrm{xv}, 376 \mathrm{p}$

111 Aken, Franz Joachim von. Sveuska Medicinal och $\Lambda$ pothehar Vasterna efter Gepera och Species uppstallue. Örebro 1764. $8.40 \mathrm{p}$. w.

112* Alamanni, Luigi. La coltivatione, al christianissimo re framescu primo. Parigi, typ. Roberti Steplani. $1546.4 .154 \mathrm{p}$.

(IIaec cot Hallero editio urinceps; apud Wurr Aduot, ad Bibl. Hallerianam superiorem Venet, 1339 offendi. dis dit pluries: Firenze 1566. 1?.Firenze 45t9 8 - Firronze 1590. 8. - "Padova 1716 (et fraude bislio-

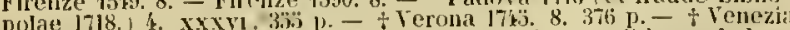

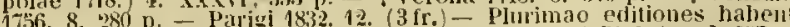
vitam et effienen intoris; de ipso crimine ef. Hall. Bibl. bot. J. 2y7.)

113 Alaymus, Marcus Antonius. De succedaneis medicamentis opusculom. Panormi 1637. 4. H.

114* Alberti, Antonio. Flora medica ossta catalogo alfabetico ragionatu delle piante medicinalitlescritto in lingua italiana. Milano 1817.17 voll. 8. $244,239,244,245,239,240$ p., 360 tab. col. - Ed. Il: Milano 1836.8 .

$115^{*}$ - Del molo di conoscere i fungi mangereeci e distinguerli dai sospetti o velenosi. Milano 1829.4 .94 p., ind., 34 lab. col 
$116^{*}$ Alberti, Friedrich non. Die Gelsirge des Köniwreiclıs Würtemberg in besouderer Bezieluny aul llalurgie. Nit Ammerkungen und Beilagen (Ilohemunssungen) von Prof. Sckebler. Stutteart u. Tubingen 1826 . 8. $x x, 326$ p. 3 colorirte geognostisehe Karten. ( 3 th.)

$117+$ Alberti, Jacopo. Jell' epidemica mortalita 'lo' gelsi e della cura e coltivarione loro Tratlato. Salo $1773.4 . x+x, 191 \mathrm{p}$.

118+ Alberti, Mirhuel, pr. De Roremarino. 1). Halac 4718. 4. 32 1.

$119 t$ 1) Aruicae verae us11. 1). Jalae 1719.4.24 p.

120 1) campliorae usu medico. D. Ilalae 1722.4.31 p. B.

$121^{*}$ De sifuilla. D. Halae 1722.4. $37 \mathrm{p}$.

$122-$ De Valerianis officinalibus. 1). Ilalae 1732.4 .20 p. B.

$123+$ De erroribus in pharmacopoliis ex neglecto studio botanieo obviis. D. Ilalae $1733.4 .24 \mathrm{p}$.

124. De Bellalonna. S. Jalae 1739.4. $35 \mathrm{p}$. B

125* Alberti, Salomon. Tres orationes. Norimbergae 1585. S. sigu. $\mathrm{A}^{4}$ $-C^{2}$.

Prima oratio quindecim foliorum inseripta est: De cogatione herbarun, tirsui medicinae apprime necessilfii.)

126 Antidotarium medicamentorun simpliciun. folio

127 * Albertini, Johamn Baptista de, et Levis Davin de Schweinitz. Conspectus fungorum in Lusatiae superioris agro Niskiensi crescenlium; e methodo Persooniana. Cum tabulis Xll aeneis pietis, species novas 93 sistentibus. Lipsiac 1805.8 mij. xxtv, $376 \mathrm{p}, 12$ tab. col. ( $7 / h$. - charta alb. $8(h)$.

128* Albertinus, Legidius. Der Welt Tummel- und Schauplatz, sammt der bittersussen Wahrheit. etc. etc. Munchen 1612.4. $104 \mathrm{~S}$ 1., praef. ind. (Pars VI. p. 666-808 agit de plantis.)

129* Albertus Magnus, Comes in Bolstatten. De vegetabilibus et plantis libri septem.

(1)pas genuinum botanicum summi viri, meritis Ernesti Jleyer Regiomontani ex obliyinne erutum, nun!tum seorsim impressum fuit; exstat in Oporum a Marco Antomio Zimarn editorum Volumine primo, Veue-

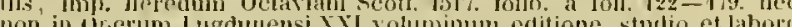

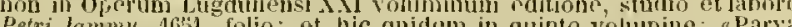
Petri tammy. J63l. folio; et hic quidem in quinto volunine: a Parva naturalia" inseripte, a p. 3\%2-507. - Qui suh ejus nomine ferebatur myarum mysticarum miserrimus anonymi "liber agoregationis s, seeretorum de viltutibus herharum a sexernties inpressus el translatus in Anomymis quacerendits est. - Cf. "Albertus Mugnus, ein Beitrag zur Gesihicht" der Botanik im 13. Jahrluutert ", voll Ernst Meyer in non Schlechtendnl's Linnacil, Band X. p. 6h.1 - 7hl und dessen zweiter

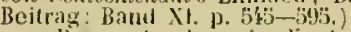

"ber ersten Ausgabe licut eine Handschrift der Bibliothek zu Padua zum Grunde, die chiveder sehr feliferhaft sciu oder selur lluchtig abgedruckt srin muss. Die Vergleichung mit bessern llandachriften hat

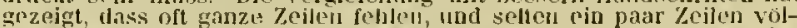
lizy correct sind. Ob Zimara dje sclauld tragt, ist ungewiss. In der bedication des Bandes, der das butanische Werk enthalt (worin er Cimara genant wird), spricht er unr von seiten Bemubungen um dias Werk te causis ef proprietalibus rementorum. Es seheint dahe as Werk de vegrt. et plant. dem Drurhere ganz alleio therlassen zu sein. Jammy hat wenigstens fur das Werk de veget. et plant. nichts gethan, als die Orthographie modernisirt, mud unerstandliche ode nur von ilm aus thangel an Sachemntniss unyerstandeoo stellen

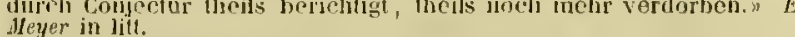

130 Albinus, Bemhard. De Thee. D. Francofurti 1684, 4. 31 p. B.

131 De Tabaco. D. il). 1695. 4. 32 p. B.

132* Albinus, Bernhard Siegfried. Acallemicarum annotationm liber J-VIII. Leidae 1734-1768.4. el tab. (Pauca iusunt phytographica.)

133 Albonico, Johan Ileimrich. Nützliche Bemerkungen für Gartenund Blumenfreunde. Leipzig 1795-1800.9 1lefte. 8. $\left(2 \frac{1 / t}{t}\right.$. $)$ (incompl.)

13i Allgemeines deutsches Gartenmagazin. Weimar 1804

133 Albrecht, Benjamin fottlieb. Do aromatum exoticorum noxa et nostratium praestantia. Erfordian 1740.4. H.

136 Albrecht, Johann Peter. Klar entdechte Unschuld der Thee-und Kafleegetränke. Bremen 1696. 8. н.

137* (Albrecht, Johann Sebastian.) De salicum rosis fictis neque bonorum neque malorum nunciis. (1'rogramma.) Coburgi 1748.4. (8 p.)

$138^{*}$ Albret, $d$ '. Cours theorique et pratique de ta taille des arbres fruitier's. Eul. lil. revue et considérablement augmenté. Paris 48 io. 8. iv, $272 \mathrm{p}, 7 \mathrm{tab}$.

139 Alcinet, José. Nuevas utilidades de la China. Madrid 1763. 4. H

$140^{*}$ Alderson, John. Versuch über das Rlus Toxicodendron. Aus dem Englischen von Dr. Froriep. Jena 1799. 8. 71 ). $(1 / t$ th. $)$
141" Aldrovandus, Clysses. Dendrologiae naturalis seilicet arborum historiae libri duo. Sylva glandaria, acinosumpue pomarium. Clbi eruclitiones omnum generum una cum lotanicis soctrinis ingenia cquacmunue non jarum juvant ot oblectant. Oridius Montalbanus opus sumno lalıore: collegrit, dligesnit, coneinnavit. Bononiae, typ. Ferroni. 1668. (in tergo: 1667.) folio. 660 \%, ind. et ic. $\lambda$ logr. i. t. - 'Francofuti, typ. Ilsuer. 1671 . folio. 480 p., frotof, ind. et ir. xyglogr. i. I - El. III. Montalbani nomine inserijta, cum pracfatione Geargn Franci. Francofurti at .11. 1690. folio.

$1 / 2$ Jomarium curiosum ex millo ancentis autoribus collectum, coutinens deseriptionem singularem arborum; earundern loca natalia; foecunditaten ef proliticationem; sympatham et antipathinm: culuram, usum oecononicun etc. Bononiat 1692 . folio. 480 p., ic. sylogre. i. t.

1.3* Aleksandrowitsch, $G$. о Ссиянствт, виресковыхт растеній

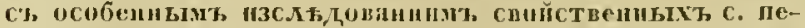
телоургской флорћ. De familia plantarum ericacearum praecipua ratione flabita earuol, quae lilorae Petropolitanao sunt propriae. Petropoli 1844. 8.11, 112 p., 5 tab.

15.t (Alezandre, Nicolas.) Dictionuaire hotanique et pharmaceutique. Par une socicté des médecins, de pharmaciens et dles naturaliste-. P'alris 1802 . I] roll. 8. Lvi, 757 p., 17 tab. - * Eul. 11: Paris 1817. 11 voll. 8. xLvin, 874 p., 17 tals. ( $18 \mathrm{fr}$.)

Sunt editiones lexici primum a Nicolno Alexandre Benedictinn $(t \mathrm{~Pa}-$ risiis 1728) annu 1716 ennseripti ex annis 1731. 1768. 1791, quas omnes vinti.

$11: 3$ "Alexandrinus, Julius. Ad Remberlum Dodonaeun epistola apologertica. Francofurti $4584,8,23 \mathrm{p}$.

(De fabis veterum agitur.)

1 1.6 Salubrium s. de sanitate tuenda libri XXXII. Coloniae 1573. folio. H.

(Ejus apologia pro Galeno in Matthioli operibus exstat.)

14. Alfroy. Catalogue des arbres fruitiers, arbores d'alignement et forestiors, arbustes et plantes etc., gui se trouvent dans la pepinière de Lienrsaint. Paris 1821. (60 c.) D.

11.8* Alibert, J. L. Nauveaux élémens de therapeutipue et de matière médicale. etc. Eul. V. revue, eorrigée et augmentée. Paris $1 \$ 26$. IJ] roll. 8. - I: XLvil, 729 p. - II : vir, 395 p. - III : vir, 824 p. (25 fr.) †Edit. J. il. 4804.8 .

149 Alix. Calalogue des arbres, arbustes et autres plautes eultivées dans ses jardins et pépinières. Lyou 1819.8.46 p.

150 Allemandi-Ehinger. Die Mlaubeerbáume und Seidenwurmer in der Schweiz. Eine Jahuresschrifi. Basel 1837. 8. (2 th.)

151 Allent, $B$. Les végétaux curieux on recueil des particularités Jes jus remarquables, qu'ofrent les plantes considérées sous leurs rapports naturels. etc. Paris 1824 . 12. avec figures. ( 2 fr. 50 c.) Ed. Il. ib. 1835.12.

(Autor pseudonymus est hibliopola Parisiensis Eugène Balland.)

152* Alleon du Lac, J. L. Hélanges d'histoire naturelle. Lyon $1763-$ 1765. Vl voll. S. avec figures.

$153^{*}$ Mémoires pour servir a l'histoire naturelle des provilues de Lyomois, Forez et Beaujolois. Lyon 1765 . 11 voll. 8. 1: 334 p., 2 tab. - $11: 319$ p., 4 tab.

15.** (Allcts, des.) Lagronome. Dictionnaire portatif des cultivateurs Paris 1760 . II voll. 8. xIx, 666,664 p. - ils. 4763 . Il voll. 8 . H.

15. Alleyne, James. New english dispensatory, London 1733. 8. н.

156 * Allione, Carlo. Rariorum Pedemontii stirpium specimen J. Augustae Taurinomum 1755.4. 55 p., 12 tab.

$157^{*} \longrightarrow$ Stirpium praceipuasum litoris et agri Nicaeensis enumeratio methodica, cum elencho alifuot animalium ejusdem maris. Parisiis 1757. 8. xx11, $255 \mathrm{p}$.

$158^{*} \longrightarrow$ Synopsis methudica stirpium horti Taurinensis. $(1760$. 4. $76 \mathrm{p}$.

$159^{*}$ Flora Pedemontana sive Enumeratio methodica stirpiun indigenarum Pedemontii. Augustac Taurinorum 1785 . IJJ vell. folio. 1: xix 344 p. - 31: 366 , xxiv p. - IIJ: Xw p., LXXXXu tab.

$160^{*}$ Auctuarium ad Floram Pedementanam eum nolis et emendationilus. Augustae Taurinorum 1789. 4. 53 p., 2 1ah.

$161+$ Allman, llilliam. A syllabus of botanical lectures and demonstrations, to be given before the university of Dublin. Dublin 1817. S. $10 \mathrm{p}$. 
$162+$ Allman, William. Analysis, per differenlias constantes viginti, inchoata, generum plantarum phinerostemonum quae in Britanuis, Gallia et Helvetia, ultraquo hos fines sponte sua crescunt. (Commencement of analysis etc.) London 1828. 4. x, 44 ].

$163^{*}$ Alpinus, Prosper. De plantis Aegypti liber. etc. Accessit etian liber de Balsamo alias editus. Venetiis, ap. Franciscum de Fr. Seneosem. 1592. 4. 80 foll., ind. et ic. i. t. - ${ }^{*}$ Ed. Il. emendatior cum observationibus et notis Joannis Veslingui et Alpini libro de Balsamo. Patarii, typ. Frambotti. 1640.4. 144 f., ind., ic. i. t. practer Dialogum de Balsamo: 54 p. et leslingii ohservationes: 80 p. $-{ }^{*}$ Ed.JII. exstat in ejus Historiac naturalis Aegypti parte 11. p. $1-70$.

$16 k^{*}$ De plantis exoticis libri luo. Opus completum editum studio ac opera Alpini Alpini auctoris filii. Venetiis, apud Jo. Gucrilium. 1629 . 4. 344 p., ic. aen. i. t.

(Sunt exentplaria anni 1627. in Ribl. Schlechtendaliana; et anni 16 ï6 in Bibl. V'indobonernsi.)

165* - Opera posthuma. Lugduni Batavorum 1735. II voll. 4. Pars 1: Rerum Aegyptiacarum libri IV: 248 j., praef., ind., 25 tab. - Pars II: De plantis Aegypti liber auclus et emendatus; etc. de Laserpitio et Loto Aegyptia; accedunt V'eslingii Opobalsami veteribus cogniti vindiciae: $306 \mathrm{p}$., ind, 72 tab.

$166^{*}$ De Balsamo Dialogus. In quo verissima balsami plantae, opobalsani, carpobalsami ef xilolsalsami cognitio plerisque antiquorum et juniorum medicorum occulta nune elucescit. Venetiis 1591.4. (6) 27 foll.

- rallice: Ilistoire du haulme, ou il est prouvé que nous avons vraie connaissance de la plante tin produict lo baulne, et par consequent de son fruict et de son hois. Cuntri" lopmion commune de plusieurs medecins et apolicaires anciens et modernes. Version trancoise firée de Prosper Alpin. par Antoine Colin. Livrc quatriesme. Lyon 1619. 8. $102 \mathrm{p}$., ind. et ic. $\mathrm{x}$. $\log r$. $i$. t.

$167^{*} \longrightarrow$ De Rhapontico disputatio, in qua Rhapontici planta, quam hactenus nulli viderunt, medicinae stullosis nunc ob oculos ponitur. ipsiusque cognitio accuratius expenditur atque proponitur. Patavii 1612. 4. 30 p. - †Lugluni Bativorum 1718. 4. 23 p., 1 tal.

$168^{*}$ Alschinger, Andreas. Flora Jadrensis complectens plantas phaenogamas hucusque in agra Jadertino detectas et secundum systema Linneano-Sprengelianum redactas. Jaderac $1832.8 .24 \mathrm{~s} \mathrm{p}$. $(11 / 12 \mathrm{th}$.)

169 Alston, Charles. Inles plantarum praecipue officinalium, quae in horto medico Edinburgensi demonstrantur. Edinlurg 1740. 8. xxv, el 66 p. praeter Linnaei Fundamenta. B. - ${ }^{*}$ Redit in cjus Tirocinio botanico. il). $1753.8 .120 \mathrm{p}$.

$170 \div-$ Tirocinium botanicum Edinburgense. Edinburgi 1753. 12. $116,120 \mathrm{p}$.

$171^{*}-$ A dissertation on botany. Translated from the latin (ex tirocinio) by a plysician. London 1754.8. $x, 136 \mathrm{p}$

172 Alströmer, Clas de. Finylliga fär afweln. 1770.8. н.

1 ว3 - Beskrifning på Svenska Slok Granen (Pinus viminalis.) w.

17\%. Alströmer, Johann de. De cultu pattatas. Stockliolm 1777. 12. B.

$173 \div$ Alten, Joham Wilheln von. Atugshurgische Blumenlese, oder systematisches Verzeichniss der in der Gegend un Augsburg wild wachsenten Pflanzen, als Einleitung zu ciner Flora von Augsburg. Augsburg 1822.8. xil, $215 \mathrm{pl}$. (2/3 th.)

$176 \div$ Althen. Mémoire sur la culture de la garance. Paris 1772.4.18 p. I lab. - ib. 1779, 4. o.

(Tire du Journal de physique, tom. 1l. p. 132-162.)

$177^{*}$ Altmann, Karl Neponulk. Analysis plantarum antiscorhuticarum, et tentamen, num in iis sal volatilis alcalinus pracexistat? D. Viennac $1766.8 .40 \mathrm{p}$

17xt Alyon, Pierre Philippe. Cours de botanique pour servir à l'eriucation des enfans de S. A. le Duc d'Oṛleans, ou l'on a rassemble les flantes indigènes et exotiques employées dans les arts et dans la médecine. Paris (1787-1788.) folio. 36 p., 101 tab. col.

(1)pus pulchris, quas Jean Aubry sculpsit, tabulis splendidum, pluribus prodiit fasciculis, et fere semper incompletum oflenditur.)

179 Amati, Michael. De Opobalsami specie ad sacrum charisma conficiendum requisita. Neapoli 1722. 8. H.

190 * Ambodik, Nestor Maximowitsch. IIс $\rho$ пона'јахьныя основа-

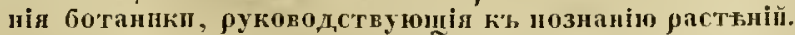
C. Петср6. 1796. 2 ขаст. (Botanicae elementaris fundanenta.) Petropoli 4796. 11 voll. 8. - I: xv, 218 p. - Il: xxix, 270 p.: 21 tab. col. (rossice.)
181 Ambodik, Nestor Maximowitsch. Новый 60танщескій с.10-

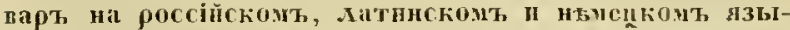
kaxт. C. IIcrep6. Novun Dictinnarium botanichun rosso-latinogermanicum, conscriptun jussu socictatis occonomicate. Detropoli 1808.4. $\mathrm{r}$.

(Est amplificatio tlictionarii botanici, quod societas oeconomic: jan anno 1759. 4. edi curaverat.

182 Ambrosinus, Bartholomaeus. De capsicorum varietate cum sui. iconilus lırevis histeria : cui accessit Panacea ex herbis, guac a Sanctis denominantur, Bononiae, ap. heredes Victorii Benacii. 1630 . 12 . s

183† Ambrosinus, lyyacinthus. Hortus studiosorum (Bononiae comsitus, s. catalogus arbosum, fruticum, suffruticum, stirpium et plantarmu omnium, quae hac anno 1657 in studiosorum horto publico liononiensi coluntur. (Bononiae) 1657.4,67 p. (Affixa: Novarum plantarum hactenus non scuptarum historia, eodem autore. p. 69-103.) et ic. xylogr. i. t.

184. - Phytologiae h.e. de plantis partis primae tomus primus, in quo herbarum nostro saeculo descriptarum nomina, aequiveca, synonyma ac etymologiae investigantur. Additis aliquot plantarum vivis iconibus. Bonnuide 1666 . folio. 576 p. ( 34 foll.), praef., ind.

(Sunt exemplatiat anni 1664. E. M. - Opus imperfectum remansis, auctore anno 1671 morte sublato; nt altera pars numpuan protliit. Ci. Fentucci, Scritt. Bolngth. 1. 1. 219.

$183^{*}$ Amici, Ciovanni Ballista. Osservazioni sulla circolazione de] sul'chio nella Chara. Modena 1818 . 4. 22 p., 1 tab. (Atti d. soc. ital. in Modena t. Xilll.)

$186^{*}$ Osservazioni microscopiche sopra varie piante. Medena 1823. 4. 55 p., 6 tah. (Atti d. sne. ital. in Hodena t. XIX.)

$187^{\circ}$ Descrizione di un' Oscillaria vivente nelle acque terminali di Chianciano. Firenze 1833.8.14 p., 1 tal.

$188^{*}$ Ammann, Johann. Stirpium rariorum in imperio rutheno simnte provenientium icones et descriptiones. Instar supplementi ad Comment. Ac. sc. imper. Petropoli 1739.4 .210 p., praef, ind., 35 tab. $(17 / 8$ th.

189 Ammann, Paul, pr. Antiquartii Peruviani historia. D. Lipsiae 1663. 4. $\mathbf{s}$.

$190^{*}$ Ad demonstrationes herbarum programmata (duo) invitatoria. Lipsiae 1664-1668.4.(16 p.)

Est calalogus aeminum ef commentatio: Plantil est homn inversus.)

$191^{*}$ - Suppellex botanica, h. ๔. Enumeratio plantarum, quar non solum in hortn medico Academiae Lipsicnsis sed etiam in aliis circa $u r b e m$ viridariis, pratis ac silvis progerminare solent: cui brevis accessit ad Naterian medican manuductio. Liosiae 1675. 8. 138. 195 p., prace, ind.

$192^{*}$ ㄴaacter plantarum naturalis a fine ultimo videlicet fructificatione desumtus, ac proemisso fundamento methodi genuinae cognoscendi plantas jer canones et exempla digestus. Lipsiae 1676 12. - Francofurti et Lipsiae 1683.12 .438 p., praef. - "Auctior et correctior reddlitus notisque illustratus a Dan. Yébelio. Francofurti a. NJ. $1700.12 .636 \mathrm{p}$, praef.

(† Sunt exemplaria mulato titulo anni 4701.$)$

$193^{*}+$ Curae secundae, quibus cliaracter plantarum naturalis anno praeterito $1685 \mathrm{vel}$ auctior vel correctior redditus fuit. Lipsiae $1686.12 .95 \mathrm{p}$

19 Hortus Bosianus, quoad exotica solum descriptus. Lipsiae Krüger. $1686,4.38 \mathrm{p}$. B.

(Editio anni 1687. 4. Cat. Brit. Afus.)

$195 t$ Ammersin, Wendelinus. Brevis relatio de electricitate propria liqnorum. Lucernae 1754. 12. 27 p. Bibl. Turic.

196 Amoretti, Carlo. Della coltivazione delle Patate. Jilano 4804. 8. DC. $197{ }^{\circ} \longrightarrow$ Degli efletti de' turbini sulle piante Iettera. Pavia 1813. 4. $9 \mathrm{p}$.

(Inserita nell' ottavo tomo del Giorn. di fisica, chimica etc. del Sign. Brugnatelli.)

195 Elettrometria de' vegetali (in Elementi di Elettrometria animale.) Miiano 1846.8 .60 p., tal. H. v. D.

199- (Amoreux, Pierre Joseph.) Traité de l'olivier, contenant l'hisıoire et la culture de cet arbre, etc. Ed. 11. augmentee et corrigce. Nontpellier 1784. 8. xil, $356 \mathrm{p}$.

$200 \div(\longrightarrow$ Recherches sur la vie et les ouvrages de Pierre Ricker de Belteval. fondateur du jardin botanique donné pas lleuri IV. it la faculté de médecine de Montpellier en 1593 ; pour servir at l'histoire de cette faculte et à celle de la botanique. Avignen $1786 \%$ VIII, $78 \mathrm{p}$. 
201 Amoreux, linre Joseph. Recherches el expreriences sur les disers lichens d'usage en medecine et dius les ints. Lyou 1787.8.

$202+$ Traito des haies vives atc. El. Il. revuc, corrigee et consislerablement augmentie. Montpellier 1809. S. si, 464 [., 1 tals. - E.l. 1: Paris 1787.8. (2 fr. $50 \mathrm{c}$.)

2013 ( Dissertation sur les poumes d'or des Ilespérides. s.1. 1809.8

30 it - Btat de la vemetation sous lo climat do Montpellier ou 1.poupues dies neuraisons of des jroductions végétales. Hontpellier $1809.8 .254 \mathrm{l}$.

$203 \div$ ( Disscrtation historique el critique sur l'origine du Cachou. Montpellier 1849.8.56 p

- Dissertation philologịue sur les plantes religieuses. ac. Nontpellier 1817.8. a.

- Notice historique sur Antoine Gouan. Paris 1822. 8. (Eir. d. Men. de la Soe. Limn. de l'aris.)

208 Ampsing, Johann Assueris. We Theriaca senioris Andromachi oritio. Rostockii 1611.4.- 1623.8. H.

20 Ancher, Peter. De succino. D. (danice.) Ilavniao 1737. 4. B.

210 Andalorius, Anereas. Il cafféc descritto ed esaminato. Messaniae 1703.12. s.

$14^{\circ}$ Andersen, Jirgen unl Folynarl Iversen. Orientalische Reisebeschreibung, herausgegeben durch Adam Otearius. Schleswig 1669. folio. $223 \mathrm{p}$., praef, ind.

$212 *$ Anderson, Andreac. An Inaugural Dissertation on the Eupatorium perfoliatun of Linnaeus. New York $1813.8 .75 \mathrm{P}$.

213* Anderson, Gerory and Piter. Guide to the Highlands and Islands of Scotland, including the Orkney and Shetlani, descriptive of their scenery; statistics, antiquities and natural history; with numerous historical notices. Lonclon $1834.8 .750 \mathrm{p}$.

2l Anderson, James. Correspondence for the introduction of cochineal insects from . Inerica; the varnish and tallow trees from China; the discosery and culture of white lac; the culture of red lac; and also for the introduction of mulberry trees and silk worms. Madras 1791. S. Cat. Brit. Mus.

213 Letters for the culture of bastard cedlar trees on the coast of Coromandel. Mladras 1794.4. Cat. Brit. Mus.

$216^{*}$ Anderson, Johamm. Nachrichten von Island, Grönland und der Strasse Davils. Hamburg 1746.8 - Inllandice: Reschrvviug van Isliusd, Groenland en de Strat Davis ot mil der wivenschappen en den koophandel. Amsterdam 17ä0. 4.

256 p.ipraef. int. maturelle de lislande. Paris 1730. 11 roll. 8 .

217 Anderson, Nicolaus Johames. Plantae vasculares circa Quickjoch Lapponiae Lulensis, quarum entmerationem propunit. D. Upsaliac 1844-1843. $8.36 \mathrm{p}$.

218 Salices Lapponiae; cum figuris XXYII sjecierum. D. Lpsoliae 1845. 8. 90 p., 2 tab.

219) Andreae, Jakob Ueinrich. Charahteristitin indedischer Forstbüume. Franhfurt $1790 .(2 / 3(h)$.

$220^{\circ}$ Andrews, $H e^{\prime} n r y C$. Bolanists Repository, comprising colour'd engravings of new and rare plants only with botanical descriptions in Intin and english after the Linnean system. London, s. a. 1797-1804. (ex Catal. Brit. Mus. - 1811.) gr. 4. X voll. 664 1al), col. totidemque foll.text. - + Recensio plantarum lueusque in Repositorio botanicorum depictarum. A review of the plants hitherto ligured in the Botanists Repository. With a translation of the essential and specifie characters Index duplex. Lonton 1801. 4. 74 p., iud. (26l. - 13l. A. Lon(lon 1842.)

221" - Coloured engravings of Healhs. The trawings taken from living plants only; with the ajpropiate specific charaeter, full cleseription, native place of wrowlls and lime of flowering of each; in latin and english etc. London $1802-4809$. W voll. (a 72 tab.) fulio. 288 tal col totidy. foll. text.

(lix Cat. Brit. Mus. faseiculi usque ad annum 1830 cditi sunt.)

2.2. 2 The Heathery; or a monograph of the genus Erica, containing coloured engravings with latin and englıs/, descriptions, dissections etc. of all the hnown species of that extensive and distinguishet tribe of plants. London 1804 . II voll. grt. 8.300 tab. col. totidenuque foll. tex.
223" Andrews, /lemmy C. Geraniuns: or a monograph of the genus Geranium, containing colourind figures of all the hnown species and numcrous beautiful varieties, drawn, engraved, described and coloured from the living plants. londen 1805 . It voll. 4. - I24 lath. col. totilemijue foll Imt., int. Bibt. Imp. Ferdinandi.

221 - Roses; or a muthograph of the genus Rosa, containing coloured figures of all the hnown species and beautiful varieties, Iran'n, engraved, described and coloured from the living plants. L.rmulon is $05-1828$. Il voll. 4. (129) tab. col. tatidemque foll. te.t. Bibl. Imp. Ferdinandi.

220 Andrieux. Catalogue raisonné des plantes, arbres et arbusles, dont on trouve des graines, dies bulbes of du plant chez le Sr. Andrieux. Paris $1771.8 .64,64$ p. B.

226 Andricux, Frangois Guillame Jean Stanislas. Lolivier, Io figuier, la vigne of le lusisson: fable de Joathan, tirce de la bible. Juges e. IX. v. 8. (Paris 1793.) 8

227* Andromachus. Autiquissimum de theriaca carmen ad imperatorem Neronem, recusum occasione theriacae recens paratae in officina Leintieriana. Norimberac 1754.4 .24 p. graece et latine.

228* Andrzeiowski, Anton. Czachia, genre detemine et decrit. Krzcmieniec $1818.4 .7 \mathrm{p}$.

229 Ane.Jli. Cenui medici sulla Salvia ghtinosa, sul Lamazio acuto e modo di prevenire gli avrelenamenti dei funghi. Milano 1808 . 4 H. v. D.

230* Angelstein, Karl. De Senegae radice, remedio opluthalmiatrico pricstantissimo. D. Berolini 1831.4 .24 p.

231 * Angran de Rueneuve. Obscrvations sur l'agriculture et le jardinage. Paris 1712 . II voll. $8.384,406$ p., praef., ind. - ib. 1740. Ill voll. 12.

232* Ángström, Johann. Dispositio museorum in Scandinavia hucusque cognitorum. Lpsaliac 1842.12.33 p

233* Anguillara, Luigi. Semplici, lituali in piu Pareri a diversi nobili buomini scritti apaiono. Nuovamente da .1. Giovanni IIarinello mandati in luce. Vinegia, Ivp. Valgrisi. 1561. 8. 304 p., ind. (Ilall. 1 . 329. - Spreng. Ilist. 1. 333. - Spreng. Gesch, der Bot. I. 289-293.)

latine: cun notis Casparis Bauhini. Basileae, ap. Henric. Petrun. 1393. 8. (Liber perrarus.

(Sequierus ithan protitionem laudat eodem anno in eadem officina Valurisiana jupressan, sed yuarta forma el duabus figuris, Chamaeleoiltis scilicet et sedi arborescentis, ditiorem.

234. Anguisola, Antonizs. Compendium simpliciun et conpositorum merlicaneutorum, etc. Placentiae, Bazachius. 1587. 1z. s.

$233^{*}$ Anjou, Friedrich. De radice Caryophy llatae rulgaris offic. sive Geo urbano Linn. D. Goettingae $1783.4,15,36 \mathrm{p}$.

236 Anomoeus, Clemens. Sacrarun arborum, fruticum et herbarum Decas 1 et II. Ḱreuzgarten der Heiligen Schrift. Nurnberg 1609. 8. 2 Thieile. - I: 79 foli. $-11: 144$ foll. et ic. sylogr. i. t. B.

237 Anquetin, $N$. $P$. Sanuel de physique, de elimie ef de botaniugue: linsige iles aspirans au grade des lacheliers des sciences. Paris 18.6. 18. (3 fr.) a.

238 Ansclmo, Gabriele. Discorsi fisiologici. Torino $\{\$ 15.8$. H. v. D.

239 Anslijn, $\boldsymbol{N}$., $\left(\boldsymbol{N}^{*}\right.$.) Jandleiding in de leer der Botanie, of Kruidhundig leerboch, inzondorhejd voor hen, die tot de Artzenijmengkunde worden opseleid; berattende na cene inleiling in de Kruidkunde. rene Sijstematische beschrijving dier gewassen, welke in de Nederlamlsche Apotheeh vermeld zijn. Amsterdam 1831. S, wet platen. (2 fr. $60 \mathrm{co})$

240 Jlandleiding tot te Kennis der artzenij-gewassen, welh in to nederlaudsche apotheek zijn opgenomen, voornamelijh ingerigt ten behoeve van hen, die zich der geneesheel-en artzenijunenghuude wijllencle ctc. Leijel $1 \$ 35-3 \$ .8 .6$ tab. ( 5 fr. 70 c.)

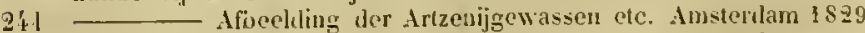
-39. folio. Allevering 1 - 53. a $1^{\sharp / 5} \mathrm{fl}=95 \mathrm{fr}$. $40 \mathrm{c}$. (cf. Oskamp.

21.2* Anthon, Ernst Friedrich. Handworterbuel der chenisch-pharmareutischen und pharnacognostischen Nomeshlaturen, orler [̈ebersicht aller lateinischen. dleutschen und franzissischen Benemungen der chemisch-pharmaceutischen Prtiparate, so wie der im Handel vorkommenden rohen .trzneistutte. Nurnherg $\$ 833.8$. vin, $794 \mathrm{p} .(3 / \mathrm{h}$ )

$213^{*}$ — Tabelle uber die in Deutschland vorkommenden naturliclien Pllanzenfamilien. Nürnberg 1 \$33. gr. folio. ( $1 / 2 / h$. 
24. Antoine, $A$. Les beautés de la nature, ou description des arbres, plantes ctc. Paris 1814.12 avec 6 figures. $(2 \mathrm{fr} .50 \mathrm{c.}$ ) a.

$293^{*}$ Antoine, Frans. Die Coniferen nach Lambert, Loudon und Anderen; frei bearbeitet. Wien $1840-1846$. folio. 10 Hefte: 108 p., 48 tab. $\left(13 \frac{1}{3}\right.$ th. - col. $20 t h$.) (Continuatur.)

$21.6 *$ Antommarchi, $F$. Derniers momens de Napoléon. Paris 1825. II voll. 8 . ( $14 \mathrm{fr}$.), Atlas in folio de $4 \mathrm{pl}$. et 1 frontispice. (26 fr.) II voll. 12. $(7 \mathrm{fr}$.)

(Sunt reimpressiones fraudosae Rruxellenses. In volumine secundo inest: Lsquisse de la Flore de st. Hélene.

$27^{*}$ Antz, harl Caesar. Tabaci bistoria. D. Berolini $1836.8 .58 \mathrm{p}$.

248 und $R$. E. Clemen. Flora von Düsseldorf. Dusseldorf 1846. 8. $(2 / 3$ th. $)$

$2 \$ 9^{*}$ Apicius, Caelius. De opsoniis et conlimentis s. arte coquinaria libri X. Venetiis, per Bernard. Venetum. [1500.] 4. - " ${ }^{*}$ b. per Job. de Cerclo. 1503. 4. (Cust. a-h.) - "Tiguri 1542. 4. - "Basileae 1541.4.- "Lugduni 1541. 8. - "Anstelortami 1709. 8 (lmpressiones antiquissimas, Venctam s. a. et Mediolanensem anni 1498 ef. in Hain liepert. Nir. 1282 et 1283 .)

$250 \div$ Apollinaris, Quintus. Kurzes Handbuchlein und Experiment vieler Arzneien ete. sammt lebendiger Abkontrafactur etlicher der fürnehunsten Kráuter etc. Strasburg 1633. 8.212 foll., ind., ic. i. t. et pluries.

latine: operd Rudolphi Goclenii, cum 12't plantarum iconibus. Francofurti 1610 . 8. S.

201 Appel, Johann Justus. Tabaci hibulus. Colon. Brandenl. 1703. 8. H.

252 Curieuse Untersuchung einiger Nineralien, Thicre und Kráuter. 1703. 8. H.

203 Apulejus. Incipit Ilerbarium Apuleji Platonici ad Mlarcum Agrippam. (Romae) Jo. Pl. de Limamine. 4. 101 foll., ic xylogr. i.t.

(Epistola muneupatoria ad Julianum de liuvere Cardinalem differt ab evemplo Bibliothecae Casanatensis descriptio als Andiffredo in Catalogo Romanarum editionum saeculi XY. p.33l. Editio mon est posterior anto 1'71, quo Cardinalis de Ruvere Pontifex electus fuit Maximus. B. - Cf. Hain Repert. Nir. 1322.)

234 De Herbarum virtutibus. Impr. c. Galeno de plenitudine. Paris 1528. folie. foll. 15-34. B. - * Basileae 1528. folio. - ${ }^{*}$ ib. 1532. folio. - ib. 1549. folio. H. - Argentorati 1533 . folio.

$233^{*} \longrightarrow$ De medicaminibus herbarum liber I. per Gabr. Humelbergium Isinae (Tiguri) 1537.4.303 p., praef., ind.

$256 \div-$ De viribus berbarum, ad veterum exemplarium fidem magna diligentia excusus: cui adscripta est nomenclatura, qua officinae, herbarii et vulgus gallicum efterre solent. Parisiis, apud Petrum Drouart. 1543 . 8. 32 foll.

Q̈77 De medicaminibus berbarum. Impr. cum Sexto Placilo de medieamentis ex animalibus ex recensinne et cum notis $J$. Chr. G. Ackermann. p. 125-350. Norimbergae et Altdorfii 1788. 8. B. (Antonio Musae falso adseriptus liber de herla I'toniea sistit caput primum hujus operis de medieaminibus herbarum, ef fere 11 onmibus ejus erlitimnibus exstat. - Quis vero autor fuerit, ambigitur. Lucius Apulnjus at Apulcjus Celsus e erte non sunt. Sprengel Gesch. der Bol. 1. 18't. 199. credit, inscii seculi $\mathrm{Xl}$ aut Xll menachi esse, qui pro temporis more clarum antiquitatis nomen itlfectayit.)

938 * Aquaeus, Stephanus (Etienne de l'Aigue). In ommes Plinii Seeundi naturalis historiae libros Commentaria. Parisiis 1530. folin. CCCLIX foll., praef., ind.

$2.89+$ Encomium brassicarum sive caulium. Parisiis 1531. 8. $70 \mathrm{p}$.

260 Aqueta y Vigil, Antomio de. Cartilla de la agricultura de Morenas y arte de criar la seda. Nadrid 1761. 4. н.

261 Aquilanus, Maximus. Origine, qualita e spezie de' peponi, e altro. Firenze 1602. 4. S.

262 Archer, John. A compendious herbal. Printed with: Every man his own Doetor, Jy the same author. London 1673.8. 143 p. B.

$263^{\circ}$ Ardene, Jean Paul Pome $d$. Traile des Renoncules, avec des observations physiques el des ronarques pour l'agriculture et le jardinage. Paris 1746.8 .279 p., 6 tal,

tyermanice: Tractat ron dell Ranunkeln, worinnen nebst andern physisehon Wahrnehmungen auch zum Feldhau tund zur Gúrtuerei gehoriges mutzliche Anmerhungen vorkonnen. Nurnberg 17ïk. 8. (31 t60 p., 6 tab. col. $\left(1 / 2 t_{.}-\right.$eol. $2 / 3$ th.

$26 \xi^{\circ}-$ Trailé sur la connaissance et la culture des Jacintes Avignon 1759. 12. 156 p., 2 tab.

- ilalice: Viterbe 1763. 8. 112 p., 2 tab. $265^{\circ}$ Ardene, Jean Paul Rome d'. Traté des oeillets. Avignon 1762. 12 403 p., 3 lab.

$266 \div-$ Traite des Tulipes etc. Avignon 1765.12 .252 j.. 2 tab.

267* Ardoynis, Santes de. Incipt liber de venenis quem magister santes de artoynis de pēsauro ctlere cepil venctiis die octavo novembris 1424 et ipsun ibidè dinino metiante fauore finivit die 14 Madii 1426. Explicit: Impressum Venetiis opera Bernardini riçij de nouaria: enenelatūque per ... Dñicum de Canali feltrēsez ete. 1492. die IIX mensis Julii, regnante Augustino Barbadico, inclvfo Venetorum principe. folio. (3) 101 (et I) foll. Bibl. Goett. - (Hain Rep. Nr. 1554.)

268 Opus te venenis, in qun naturalis primum historia venenatorum omnitum, sive naturi, sive arte constent, fidelissime expom nitur. etc. Deintle ratio praccavendi venena, tum curatio. Additus est commentarius Ferdinandi Ponzetti, Carclinalis tituli S. Paucratii. Venetiis, apud Oetavianum Scotum. 1492. folio. s.

$269^{*}$ Opus de venenis, a multis lıactenus clesileratum et nume tandem castigatissime ellitum. Basileae (per Henricum Petri et Petrunı Pernam. 4562 ). folin. 514 p. et praef. Theodori Zwinger.

(Adbacrent Ferdinandi l'onzetli de venenis libri tres: p. 510-573.)

270* Arduino, Luigi. Della coltura del Solano di Guinea, pianta utilissima per l'arte tintoria lstruzione ete. Padova 1793. 8. 15 p. (Opuse. scelti XVII.)

27 Disscrtazione concernente la proprieta e gli usi del SoIanum guinense. (Opuse. sceli IV.) B.

272 - Nemoria botanico-georgica sopra la coltura e gli usi ceonomici dell' Arena altissima. 1792. S. DC.

$273^{*}$ - Istruzione sull' olco di Cafreria. Ed. Il. riformata ed accresciuta. Padova 1811.8 .47 p., $f$ tab.

$274 t$ Nuovo metodn per estrarre lo zucchero dalle canne dell olco di Cafreria. Pikdova ISI3. S. 19 p.

275* Arduino, Pietro. Aninuallersionum Lotanicarum specimen. Patavii 1759. 4. 27 p. 12 tab. - * Specimen alterum. Venetiis 1764. 4. 42 p., 20 tals.

Sunt exemplaria speciminis alterius anı 1763.

$276^{*}$ _ Memnrie di osservazioni e di sperienze sopra la coltura e gli usi di varie piante, che servono o che servir possono utilmente alla tintura, all' economia, all' agricoltura ctc. Tomo I. Padova 1766. 4. xuiv, 105 p., 19 tab.

277 Modi di preparare la semenza, per preservare il frument del carbone. Venezia 1770. 8. Dc.

278 Memoria sopra la coltura desl herba Pimpinclla. Venezia 1773. 8. DC.

$279-$ Istruzione per coltivare il Kali. Venezia 1780 . DC.

280 Wel genere degli Olclii o Sorghi. Pailova 1786.8 . DC.

281 Del genero delle avene. delle sue specie e varieta della cultura ed usi economici. Padova 1789.4 .27 p., 6 tab.

282 Catalogo prino delle piante che si coltivano nel real orto di agricoltura di Padova, non meno else di quelle elie vi crescono spontance; a cui si aggiumge l'elenco (lelle opere si stampate che inedite di Pietro Arduino, e di Luigi di lui figlio. Patova 1807. 8. Sch.

$283^{\circ}$ Arena, Filippo. La natura e cultura de' fiori fisicamente exposta in clue trattati con muove ragioni, osservazioni e spericnze. Palermo Ill voll. 4. - I: 1767 . vir, 440 l. - II: 4768 . vm, 446, 167 p., ind. - Ill: (Tavole) 1767.65 tal), folin oblit).

(De. meminit edit. Cosmopoli, 177.8 .

28:* Arendt, J.J.F. Tabellarisehe Velersicht ter Flora ties mittleren und nórdlichen Deutseblands nach dem Liunè'schen Sexualsystem. verbunden mit der Nethoule der natürlichies Pllanzen-Fanilien, aufgestellt nach P. F. Curie's Anlcitung. 2. Aufl. 1828 . Osnabrück 1831. i Bogen folio. $(1 / \hbar(h$.)

$285^{*} \longrightarrow$ Scholia Osnalorugensia in Chloridem Hannoseranam d. Is. Zusâtze und Beriehtigungen, unsre vaterlantische Flora betreffent. mit Berucksichnigung der Osnahruchschen Speeialflora; eine huchst nothwendige und wichtige Zugabe zu der Chloris Hannoverana. Osnaloruck 4837. $8.35 \mathrm{p} .(1 / 6 t h$.

$286^{*}$ (Arenstorff, $C . F$ ) Comparatin nominum plantarum officinalium cum nominibus lontanicis Linnaei et Tournefortii. Oder kurze Bcschreibung von melir als 300 in denen tpotheken gebrabulichen Pflanzen. Stauden u. Baumen, etc. Berlin 1762.8. 10 i p., ind. 
287. Areschoug, John Erhart. Stirpes in regione Cimbritshamnensi

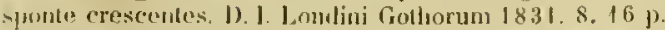

J) Mscritatio hated suld praesidiu Elice Ilugni Fries defensa. quantun

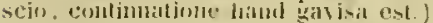

$288^{\circ}$ - Hantae cotyledoneae Florar Kothoburgensis quas secumlum faniliarum maturalium ordinem priesianum disposuit et descripssit. Londini Gothorum 1836. 8. xiv, 150 et val p. (2/3 (h.)

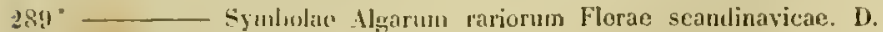
I.molae 1838. \&. $14 \mathrm{fl}^{\mathrm{k}}$

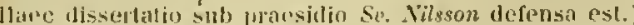

2906 De lỵdrodictyo utrieulato. D. Lundae 1839.8 .23 p., 1 tab.

29) Aretius, Beneticlus. Stochhomii ef Nessi Ilelvetiae montium et nascentium in ris stipium descriptio. Impr. c. operibus faterii Cordi. Argentorati 1361 . folio. foll. $432-\underline{2} 33$.

299. $2^{\circ}$ Arici, C'esare. La coltivazione degli ulivi. (Brescia 1818. 8. Dc.) extat in Raccolta di I'oemetti didascalici originali o tradotti, vol. $\mathbf{L}$. p. 217-302. Nilano 1829. 8.

$293^{\circ}$ Aristate. Instruetion pour le jarlin potager. etc. Paris 1678. 8. $89,56 \mathrm{p}$.

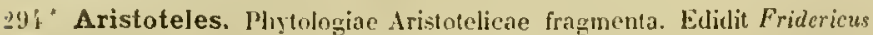

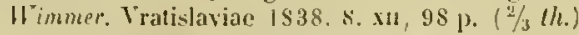

Illustrantia Aristotelem seripta:

Gretscher, Jahob. De plantis ex Iristolele polissimum colleeta. 1). Ingolstalii 1591.4

Gallisch, Friedrich Andreas. De Aristotele rei naturalis seriptore. Epistola @ratulatoria. Lipsiae 1776.4 . $16 \mathrm{p}$.

Eenschel, Augutst II ilhelm Eluurd Theodor. Commentatio de Aristotele botanico philosupho. Vratislaviae $1894.4 .58 \mathrm{p}$. ( $1 / 2$ th. $)$

Fries, Elias Magmus. Gruntelragen af Aristotelis Vaxt-Lura. D. I-111. Lipsala 1849. $8.48 \mathrm{p}$.

(liedit in ejusdem anturis o Bot. Clutygter, p. 43-82.)

germanice: von Creplin in Hornschuch's Arehiv shind. Reitrage 1. p. 6-40. Ind in Auszuge ron Beilschmied in Jahresber. 1839-1842. p. $3919-397$.

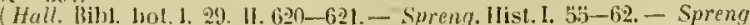

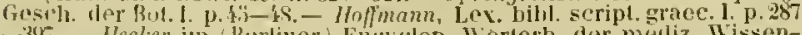

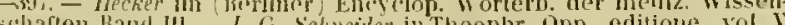
schaften Band III. - J. Gr. Schreider in Theophr. Opp. editione, vol.

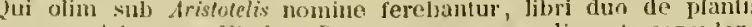

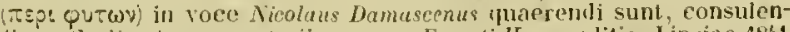

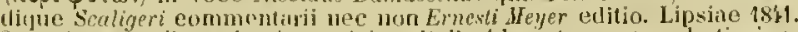
8.; cui vero tribuendia sint: "Aristotelis l'roblennata, "quae id stirpium gemus et olerneea pertuent," ommino me fugit; impressa subt cum Eubani Ulessi Buna valefmlinis conservandae praeceptis. Argentorati,

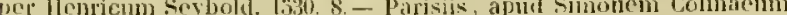
1533. 8 - porro iu Jutoni Jlusae lirasavoli Examine onutum simpli-

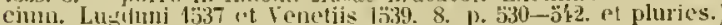

29:3* Arma, Joamnes Fremiseus. Opus de venenis in dialogos, ab opere Petri de Abbuno extractum. Taurini 1557. $8.95 \mathrm{p}$.

296 Armano, Filippo. Catalogus plantarum horti r. botanici Braydensis (Brera zu Mailand) arl annum 1812. Milano 4\$12. S. H. v. D.

$2 ! 97^{\circ}$ Arnaldus a Villanova. Consilium al regen Arogonem de salubri hortenxium usu. Impr. c. Diocdis ab Hippocrate epistoda. Parisiis 1607. s. p. $y-25$

$298^{*}$ Armaud, J. A. MI. Flore du Département de la Haute-Loire, ou Taljlean des plantess yui y ernissent, disjosées snivant la méthode waturelle. Puy 1823 . S. xx, 108 p. (I fr. 73 c.

$299 \div$ - Suppliment it la Flore du be partement de la Ilaute-Loire ou indieation des plantes il y ajouler arec guelgues torrections et observations. Puy $1830,8.39 \mathrm{f}$.

300 Arnaud, J. B. Calentrier répullicain botanique et historique. etc. Arignon 1799. 12. $296 \mathrm{p} . \quad 0$.

301 Arnauld de la Nobleville, Inuis Danicl a et Salerne, Description abrégée des plantes usuelles employces dans le Manuel des Dames de Charilé Paris el Orleans 1767. 12. н.

302" Arnemann, Jtstus. Commentatio de oleis unguinosis. Goettingae 1785. 亿. $83 \mathrm{p}$.

$303^{\circ}$ Arnold. Reise narh Mariazell in Steyermark. Wien 1785. 4. $94 \mathrm{p}$ 1 tab. col. (Pinus nigra.) ( $1 / t / h$.

301. * Armold, Georg Christian. De monumentis historiae naturalis Poloniae literariis usque ad linem saeculi decini sexti editis D. Varsaviac $1818,8.15,88 \mathrm{p}$ $303^{\circ}$ Aromatariis, Joseph de. Epistola de generatione plantarum ex seminibus. Venctiis 1625 . 4. \& p.

("Redit in Diseursu de rubie conlagiosa. Franeofurti 1626. D.7

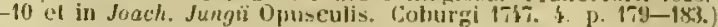

306 " Arrhenius, Johann I'cler. Nonographia Ruborum Sueciac. Ljsaliae $1840,8.64 \mathrm{j}$.

307 Uthast till Vaxtrikets Terminologie. Lpsala 1842.8.

308 Elementar-Kurs i Botaniken. Lipsala 1845. 8. vu, $295 \mathrm{p}$. et lab.

309 Arrieta, Juan de Baruerde. De la fertilidad y abundancia de Espanna, y la razon porque se dido antarciendo, con el remedio. Madrial 1578. 8, H.

310 Arrosto, Fr. Honografia degli agrumi traltati relativamente alla botaniea; all' agricoltura e all" economia rurale. Messina 1835.8. W.

311 . Arruda da Camara, Manoel. Dissertaçao sobre as plantas do Brazil, que podem dar lindıs proprios para muitos usos da sociedade, e suprir a falta do Canhamo. Kio de Janeiro, lla impr. regial. $1810.8 .49 \mathrm{p}$

$312^{*}$ Artis, Edmund Tyrell. Antediluvian Phytodogy, illustrated by a collection of the fossil remains of plants, peeuliar to the coal formations of Great Britain. London, Cumberlankl ete. 1825. 4. xIII, 24 p., 24 tab. - $\div$ London, typ. Nichuls and son. 1838. 4. (non differt.) (2l. 10s.)

$313^{\circ}$ Arvers, Louis Alexandre. Essai sur le tabae. Thèse. Paris 1815. 4. $32 \mathrm{p}$.

314" Ascherson, F. M. De fungis renenatis. Commentatio a facultate mediea univ. Berol. praenio aureo ornata. Berolini 1828. 8, vus, $52 \mathrm{p} .(3 / \mathrm{s}$ (h.)

$313^{*}$ - Pharmaceutische Botanih in Tabellenform. Eine hurzefasste Andeitung zur hemntniss sammtlicher, in der 5. Ausgabe der preussischen Pharmakopoe aufgefuhrten, und vicler andern mit ihuen rerwandten Pflanzen. Nebst einer fasslichen Darstellung der uflizinellen Pllanzentamilien naelı Jussieu's naturlichen Systeme. Berlin \{\$31. 4. Iv, 82 \}), 2 tab. ( 1 th.)

316 Asham, Anton. A littel herbal of the properties of herbes newly amended, - deelaring what herbs has dependences upon eertain constellations etc. London $4550.12 .-1559.8$. H.

317 * Aspegren, Gustaf Carsten. Forrsok till en Blekingsk Flora. Carlscrona $1823,8 . x v i, 106 \mathrm{p}$.

$318^{*}$ _... Vàt-Rikets Fanilje - Trad. Carlserona 1828. 1 tab. folio. max. (Systemdarstellung durch eineu Baum.)

319 Asseler, Thomas. Viridarium adriaticum. Augsburg 16S6. 8. H.

320 - Roma regina mundi, oder die hoclıberulımte Stadt Rom Augsburg 1688 . H.

$321^{*}$ (Asso y del Rio, Iynacio Jordande.) Synopsis stirpium indigenarum Aragnniae. Auctore C. A. R Caesaraugustano. Massiliae 1779. 4. xxiv ; $160 \mathrm{j}$., ind. et 9 tab. - Mantissa stirpium indigenarum Aragoniae, 1781. p. $159-184$, praef. et lab. $10-11$.

$322^{*}$ - Enumeratio stirpium in Aragonia noviter deteetarum. impr. eum ejus Oryctographin Aragoniae. 1784. 8. p. 157-183.

$323+$ Astheimer, lomanus. Plyytologia generalis. D. Neoburgi 1773. 4 1,0 p., adn. Bibl. s. Gallensis.

32 ' Asti, Felice. Lettera intorno alla nuova China-ehina del reano di Sinta Fé. (Opuseoli seelti t. VIII. p. 276-980.) B. - Ed. II : Venezia 1791.4.

$320 \%$ Astolfi, Guiseppe. Breve istruzione intorno alla colturn del rise cliamato seeco o chinese e risultamenti di un terzo esperimento reJativo alla medesima. Bologina 1827.8.27 p.

$326^{\circ}$ (Astruc, Jean.) Mémoires jour l'luistoire naturelle de la provinee de Langurdoc, divisés en trois parties. Ornés de figures et de eartes. Paris 1737. 4. xxit, $630 \mathrm{p}$.

327"Aubert du Petjt-Thouars, Aubert C. M. Ilistoire des veigetau recueillis sur les isles de France, La Réunion (Bourbon) et Madagasear. Premiere partie. Contenant les deseriptions et figures des plantes qui forment des genres nouveaux, ou qui perfectionnent les anciens; accompagnees de dissertations sur diffèrens points de botanique. Paris (1804.) 4. 14 , 10 p. 10 tab 
328" Aubert du Petit-Thouars, Aubert C. Il. Ilistoire des vegeitaux recupillies dans les isles fustrales d'Afriçue. l'renière partic, contenant les descriptions ef figures des plantes qui forment des genres nouveaus on qui perfectionnent les anciens. Paris 1806. 4. 31 , $72 \mathrm{p}$., 24 till, col.

- Notice historique sur je genre Canirum ou Stryehnos de Linnaeus Strasburg 4806 . \&. 14 p.

Evtr. du Dietionnaire des se. nat.

130" Essais sur l'organisation des plantes, consudérée eomme resultat du cours annuel de la vegetation. Paris 1806 . o $r, 26 \mathrm{p}$

$331^{*}$ Genera nova Madagascariensia sceundum methodun Jussicuanam disposita. (Paris 1806.) 8. 29 I.

$332^{*}$ - Eutrait d'une mémoire sur les espèces de Pandanus observées aux iles de France, de Bourhon et do Madagasear. 4. 7 p. (Bull. des se. par lit soc, philomatiyue, Aout 1808.)

$333^{*}$ Essais sur la végètation considérée dans le développement des bourgeons. Paris 1809.8 . x, 304 p., 2 tab. (6 fr.)

$334^{*}$ Mélanges de botaniquo el des voygages. Premier recucil. Paris 1811 . 8. 32, 48, 29, 80, $46 ; 48$ p., A carte, 18 tab. (6 fr.

$33 \%{ }^{*}$ - Histoire d'un morceal cle bois, précédée d'un essai sur la sève considéée conme résultat de la végétation; et de plusieurs autres morceaux tendant à confirmer la théorie de physiologic regetale. Paris $1815 . x \times x v, 192 \mathrm{p}, 1$ lab. $(2 \mathrm{fr} .50 \mathrm{c}$ )

$330^{5}$ - Recueil des rapports et des memoires sur la eulture des arbres fruitiers, lus dans les séanees particuliòres de la sociéti d'agrieulture de Paris. Paris 1815 . 8, xil, 256 p., 8 tab. - Ribliotheque chronologique: VII p. ( $6 \mathrm{fr}$.)

$3.37 \div-$ Le verger français ou traité general de la culture des arbres fruitiers qui eroissent en pleine terre dans les environs de Paris. Divisé en cinq volumes in 8 , contenant chaeun une partie distincte mais dépendante d'un plan général; second recueil de moreeaux detachés, contcnant un mémoire sur les effets de la gelée dans les plantes. Paris 1817 . 8. Observations préliminaires et introduetion: XLvin p. Némoire sur les effets de la geleie tlans les plantes: 84 p. (3 fr.)

$338 \div-\ldots$ Revue générale des matériaux de botanique et autres fruit de 35 années d'observations, dont dix passées sous les tropi(pues; servant de prospectus pour les uuvrages qu'il est prêt a publier et qu'il propose par souseription et d'annonce pour ceux qu'il a publiés devant seize ans qu'il est de retour en Europe. Paris 1819 8. $10 \mathrm{p}$.

$339 \div$ Cours de phytologie on de botanique gimérale. Premiere séance. Introduction. Paris 1819.8. 8, 16 p. cum effigie Joachimi Jungii. - Seconde séance: Phytognomie. Paris 1820. 8. 32 p. ( 2 fr.)

$3: 0 \div$ La physiologie végétale devoit-elle être exelue du coneours pour le prix fondé par M. de Mlonthion? Paris (1822. 8. $21 \mathrm{p}$.

$341^{*}$ - Histoire particulièro des plantes Orchidées recueillies sur les trois iles australes d'Afrigue, de France, de Bourbon et de Madagastar. Paris 1822.8 . vm, 32 p., 2 tableaux, 108 tab. (36 fr.

(Tab. 72 bis. post tab. 97 sequmitur signaturae: 99. 99. 100. 102 107. 107. 106. 109. 108. 108.)

$3: 2^{*}-$ Sur la formation des arlsres, naturelle ou artificielle Paris 1823. 8. $16 \mathrm{p}$.

$34.3 \div$ Notice historique sur la pépiniere du roi au Roule faisant suite à uj discours sur l'enseignement de la botanique, prononeé dans cet etablissement le 24 mai 1824. Paris 1825. 8.64 p.

34 t (Aubin, L. G. P.) Élemens suceincts de la langue et des prineipes de botanifue a l'usage des Dames. Ouvrage orne de seize planches en taille-douce, avec leur explication. Paris 1803,8, 77 p., 16 tab (3 fr. $50 \mathrm{c}$ ) - Ed. nova: ib. 1807. 8. 76 p., 16 tah.

3 3:5* Aublet, Fusée. Histoire des plantes de la Guiane française, rangèes suivant la méthode sexuelle avec plusieurs memoires sur différens objets intéressants, relatifs a la culture et au commerce de la Guiane francaise et une notice des plantes de l'isle de France. Ouvrage nrné de près de quatre cents planches en taille-douce, oú sont représentees des plantes qui n'ont point encore décrites ni gravées ou qui ue l'ont été qu'imparfaitement. Londres et Paris 1775. N voll. 4. xxxı, $976,52,160$ p., 392 tab. (30 fr., gr. pap. 45 fr.)

(Icones operis praecenentis originariae in Bibl. Banksiana exstant, exceptis nomullis ap. B. 11.189. recensitis; praeterea in B.B. servabant-

Pritzel, Thes. lit. bot. tur: Desseins des plantes non publies, foll. 60. in 4. et loseriptione variarum plantarun (buintensium, alise impressac in historia ejus, aliae ineditae, 132 foll. Mannstr. autoris in foliu.

$366+$ (Aubry de la Mottraie.) Exereices d'histoire naturelle a l'ecolw centrale du Dép. du Morbuan. Vannes. IIl calniers pour les annees $0-11$ de la liberti. $4.75,31,26 \mathrm{p}$

(Plantes indigenes de Morbihan.)

$37^{*}$ Aubuisson de Voisins, $J . F . d$. Traité de géognosic, wu evpose des connaissances actuelles sur la constitution physique et mintrale du glohe terestre. Ed. nova emendata: Paris $1898-34$. 11 voll. 8. 1: is28. xLvil, 524 p., I tab. cul. - Il: (par Burat.) 1834. vit, 650 p. 8 tal. $(23 \mathrm{fr}$ )

$318^{*}$ Aucher-Éloy. Relations de voyages en Orient de 1830 a 1838 , revies et annotées par Mr. le Conte Jaubert, acconıaguées diuc earte grograplique oú sunt tracés tous les itineraires suivis par Aucherliloy. Puris 1843. 8. Partic l et 11 : xxı, 775 p., 1 carte.

$35.9 \div$ Audibert. Catalogue(s) des principaux arbres, arbustes et autres plantes, tant indigenes qu'exotiques, eultive's dans les jardins et fepinies'es du Sieur Audibert, ainé, à Tonnclle près Tarascon, Jhip. des Bouches-du-Rhone. Arignon et Taraseon $1810-1838$. s

$330 \div$ Audouin, Victor. Recherehes anatomiques et plysiologiqu's sur lit maladie contagieuse qui attaque les rers a soie, et qu'on dísigue seus le nom de Muscardine. Paris 1838 , 8. 19 p., 2 tab. col.

$3 \mathrm{3} 1 \div$ Nouvelles experiences sur la nature de la maladie contagieuse qui attaque les vers a soie. Paris $1838.8 .18 \mathrm{p}$

35.2* Aufmkolk, Friedrich Wilhelm. De cortice caribaco cortici peruviano substituende. D. Goettingae 1793.8. 39 p.

33̈3† Augier, Auguslin. Essai d'une nouvelle elassifieation des régètaux. conforme a l'ortre que la nature parait avoir suivi dans le riogne végétal; d'où résulte une méthode qui conduite a la connaissance des plantes et de leurs rapports naturels. Lyon 1801 . \&. vili, 240 p. 1 talleau (arbre botanique). ( 3 fr. $50 \mathrm{c.}$ )

30 f $^{*}$ Augustin, Samuel. Prolegomena in systema sexuale botanicomu. D. Viennae 1777.8 .84 p., 6 tab.

$355^{*}$ Aurifaber, Andreas. Succini historia, ein kurzer, grundliclier Bericht, woher der Agt-oder Bornstein ursprunglich homme, dass er hein Baumhartz sei, sonderu ein Gesclileelıt des Bergwachs, und wie nan ilnen mannigfaltiglich in artzneien möge gebrauchen. Konigsbera in Preussen, gedruckt durch Hans Lufit. 25. Martii 1551. 4. (A-L.) - 1552. S. -1579.8 . Bibl. Reg. Dresd.

$336^{*}$ Ausius, Henrili, jr. De plantis in genere. D. Ipsaliae 1644. ' ( 16 j.)

$357 \div$ Austen, Ralph. A treatise of fruit-trees cte. Oxford 1653. 4. (24), $97 \mathrm{p}$. Aceedit: The spiritual use of an orchard $\mathrm{m}^{\circ}$ garden of fruitrees: 41 p. - Ëd. Il: Oxford 1657. 4. 140, 208 p. B. - ${ }^{*}$ Ed. III: Oxforel $1665.8 .(44), 260$ p.

$358^{*}$ Observations upon some part of Sir Francis Bacon's natural listory, as it concerns fruit-trees, fruits and flowers. Oxford 1658.4.- "Oxford 1665.8. (7) $82 \mathrm{p}$.

359 Dialogue or a fumiliar discourse and conference between husband and fruit-trees. London 1670.4.

$360^{*}$ Autenrieth, Hermann Friedrich. Disquisitio quaestionis acad. de discrimine sexuali jam in seminibus plantarum dioicarum apparente praemio regio ornata. Additis quibusdam de sexu plantarum argumentis generalibus. Tuebingae $1821.4 .61 \mathrm{p}, 2$ tab. $(2 / 3$ th.

$361^{*}$ Ueber die ticlite Angustura-Rinde. D. Stuttgart 18 i 8. $16 \mathrm{p}$.

362* Avé-Lallemant, Julius Leopold Eluard. De plantis quibuselanı Italiae berealis et Germaniae australis rarioribus. Berolini $1829 \quad 4$. 19 p., 1 tab. ( $1 / 3$ (h.)

$363^{*}$ Avellino, liulio. Sulla necessita di creare nelle provincie all di quá del faro nuove industrie agrarie, ed a preferenza della coltivazion del Rhus Coriaria detto altrimenti Sommacco discolso. Napoli 1842. 8. $13 \mathrm{p}$.

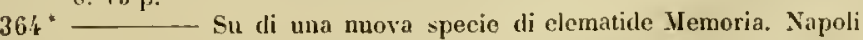
1842.8. $8 \mathrm{p}$

$365^{*}$ - Nota sulla Pastinaca latifolia. Napoli 1843 . 8. 8 p.

$366^{*}$ Axtius, Johann Konrad. Tractatus de arboribus coniferis et pice confieienda, aliisque ex illis arboribus provenientibus. Jenae 1679. 12. $118 \mathrm{p.}, 5$ tab. 
"W7" Aycke, Johann Christian. Jiagmente zur Naturgeschichte des Berusteins, Dinzig 1835. 8. vil, 107 p. $(3 / 4(h)$.

$368^{*}$ Azalus, Pompilius P/acentimus, Do omilus relus natumlibus quae continentur in mudo videliet coelestibus at terrestrilus nec non mathematiris, et de angelis nutoribus, yuae coelorum. Venetiis, ap. Octavianum scotum, 1544, fulio, 142 foll.

(Libri quinti contulum XX: de arboribus at plintis, foll. 122-12\%.

$369^{*}$ Azara, Frlix de. Voyages dans l'Amérifue méridionalo dejuis $1781-1801$, publices par C. A. IIalckenaer. Mc. Paris 1809. IV voll. s. arec un atlas de 25 planches, $-1: 389$ p. $-11: 562$ p. -111 : 479 \%. IV: 380 p. (42 fr,; sur pap. vélin av. pl. col. $130 \mathrm{fr}$.

(Vol. II. p. 482-3it inl botaniém spectant.)

370" Azuni, Domenico Alberto. Histoire gréographique, politique et naturelle dr: Ia Sardaigne. Jid. Ul: Paris isog. Il voll. 8. - I: xix, 369 p. - II: 404 p., L eliarte. Tabulac ad zoologiam sjectant. (Régno vegital: Jl. p. 367-398.) (12 fr.) - Edi. I: 1798.

\section{B.}

371* Baalen, Prtrus ran. De cortice Penviano cjusque in Sed)ribus internittentibus usu. Lugduni Batavorun 1735. 4. $38 \mathrm{p}$.

$372^{*}$ Babel, August. De graminum fabrica el occonomia. I). Jalae 1804 4. 31 p., I tab. col.

$373+$ Babey, C. IT. Philibert. Flore Jurassienne on description des plantes vasculaires croissant naturellement daus Jes montagnes du Jura at les plaines, qui sont au pied, reunies par familles naturelles ef disposies suivant la methode de DeCandulle, avec lindication des propriétés et des usages des espèces le plus généralement ronployées on médecine et dans les arts. suivic d'un tableau tes genres d'ajres le systime sexuel de Linné. Paris 1843 . IV voll. 8. - I: XLı, 456 11. - 11: 523 p. - 111: 501 p. - IV: 332 p.

$37\} \div$ Babington, Charles C. Flora Bathoniensis: or a catalogue of the plants indigenous to the vicinity of Bath. London and Bath 1834, 12 VI, 62 p., ind. - Supplement: ils. 1\$39. 12. p. 63-105, ind.

$373^{*} \longrightarrow$ Primitiae Florac Sarnicae, or an Outline of the Flota of the Channel lstands of Jersey, Guernsey, Alulerney and Sork. Containing a Catalogue of the plants indigenous to the Islands: with occasional observations upon their distinetive characters, affuities and nomenclature. London 1839.8 . xvı, 132 p. (4s.)

$376^{*}$ - Manual of british lotany, containing the flowering plants and ferms arranged according to tho natural orders. London 1843 , 8. $\mathrm{x} \times 1 \%, 400 \mathrm{p}$.

3 it - Monograph of the british Aripliceae. (From the Transact. Bot.Soc. Edinb. vol. I. 1840.8.)

378 - synopsis of the builish Ruli. (ibid. $34 \mathrm{pr}\{2 s$.

37! " Babo, L. Freiher ron, und J. Metzger, die Wein - und Tafoltrauben der Jentschen Weinlserge und Gärten. Nannhein 1836 8. xvi, 254 p. $\left(1 \frac{1}{2}\right.$ th. $)$ Nit cillem Adas von 5 tab. in 9 Liefermyen. $(9$ th. $)$

$380^{*}$ Der Weinstoch und seine Varictaten. Resclureibung und Synonymik der vorzuglichsten in Deutschland cultivirten Wein - und Tafeltrauben mit Hinweisung auf die bekannteren Rebsorten andrer europaischer Weinlánder. Frankfurt a/M. 1844.8 .784 p. $\left(3 \frac{1}{6}\right.$ th. $)$

381 * Baboo Radhakant Deb. Translation of an extract from a horticultural work, in Persian, by Bahoo Radhakant Del, of Calcutra. (In Miscellaneous translations from oricntal languiges. vol. II: London 1834.) 8. 32 p. Bibl. Caesar. Vindob.

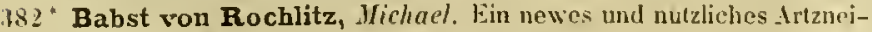
Kunst und Wumlerbuch etc. Nühausen 1590.4.

383 * Gifljagendes Kunst - u. Jlausluch. etc. Leipzig 1591. 4. $375 \mathrm{p}$.

$38 i^{*}$ Juniperetum oder Wachlıoldergarten. Eislehen 1605.4

38;i Baccanellus, Johannes. Liber de consensu medicorum in cognosecndis simplicibus. Lutetiac, apud Carolum Stephanum. 1554. 12 $140 \mathrm{p}$. (impr. cum ejus: de concensu medicorum in curandis morlis.) $B$.
386 * Baccanellus, Johannes. De ratione instituendi medicamina. Innsteledtami 1680.8 .

38 i Bacci, Andrea. Taluula simplicium medicamentorum. Romac. apud Josephum de Angelis. 157i. 4. s.

$388^{*}$ De venenis et antidolis firolezomena. Romac 1586. 4. 83 3. - ib. 1588 . 4. - Vemetis 1596. folio. \&.

$389^{*}$ —— De naturali vinurum historia, de vinis haliae et te conviviis antipuorum libri VII; accedit do factitiis rinis et de cererisia.

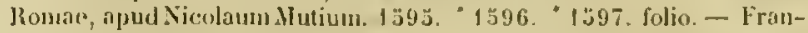
colurti 1607. folio, s.

390 Bache, $\boldsymbol{N}$. Lit par ord til pullicum i anledhing af ten usanulfarrdige beretuing om den Kongelige botanishe haugen of lins farturer, som IIr. Ricgels i sil shrift de fatis chirurgiat lar indfort. Hafniac 1787. 4. 7 p. B.

391 - Kanmerrand Lunds angreb jaa den botanishe haves forfatning besvaret. ib. $1788.4 .52 \mathrm{p}$. B.

392 Bachman, $J$. Catalogue of yhaenogamous plants and ferus. native or naturalized, found in the vicinity of Charleston, s. C. 1834. 8.

$393^{*}$ Backer, Gerarl. De radicum plantarus plyýsiologria, earumque virtutibus medicis plantarum phỵsiologia illust'andis. D. Inıstelodani 18ะ9.8. $\mathrm{xw}, 108 \mathrm{p}$.

391. Bacon, Lord I'erulam, Viscount St. Alban, Francis. Sylva sylyamum or a naturall historie, publiwhed after tho authors deatl $\div 1626$ ly 11 illium Rauley. London 1627. Solio. 266 p. - Ld. II. Lonton 1670. folio. 245 p. praeter History of life and death ete. B.

Editionem fortasse principen laulitt sisssmilch. London 1621. \&.

gullice: Histoire naturelle, traduit du latih par l'ierre Amboise Sr. de la Magdelaine. Paris 1631. 8. s.

† Intine: por Jacobum Gruterum. Lugduni Batavorum. 16its. 12. 612 p. perarf ind. - Amstclodami 1661. 12. - inl Operum collectione, Francofurti al Moenum $166 \%$. folio.

De libro ipso ef. Hall. Bily. hot. 1. p. 127. $-R$. Austenius ofservationes in Baconis Centurias edidit anglice. Oxonii ja:js. 4 .

39̈̈ Badanus, Georg. Alnotationes 100 in simplicia Mesuac. Papiae $156 \mathrm{~S}, 8$. H.

$396^{*}$ Baer, Johann Ernst. Experimenta chemica de Gummi-resinis nonmullis instituta. D. Erlangae 1788. 4. 26 p.

$397 \div$ Baeumlein, Ernst Christian Friedrich. De Scutellaria galericulata s. tertianaria. D. Erlangae 1789. 4. 22 j.

$398^{*}$ Baeumler, . $. J / h$. A. Quaedam animadversiones de l'iperis Cubebae efficacitate. D. Cassellis I $\$ 26.8$. s 1 p.

$399^{*}$ Baier, Johann Jakob, pr. De Tisco. D. Altdorfi 1706. 4. 36 p.

(Baier, qui catalogum omnium operum suorum fecil, dissertatonem hance non dgnoscit; Respondens fuit Leonhart lriedrich Ilornung.

$400^{*} \longrightarrow$ De Tride. D. Altdorfi 1710.4.20 p. (Respondens: Albert Heering. )

$101^{*}$ Dr sanguine J)raconis. D. Althorf I712. 4. 24 p. (Respon(dens: Johann Friedruch Ochs.)

$1.02 \div-$ De malo Punica. D. Altdorfi 1712. 4. $28 \mathrm{p}$. (Respondens: Johann Christoph Weiss.)

4036 Millefolium. D. Altdorfi 1714. 4. 22 p. (Respondens: Georg Jakob Lang.)

401* —— De Scilla. D. Altiorf 1713.4 . Ii p. Respondens: Georg Ludvig Corvinus.)

$403^{*}-$ De Asparago. D. Altdorfi 1715. 4. $24 \mathrm{H}$. (Respondens Anton a Clericis.)

$406^{*}$ De Lilio convallium. D. Attlorf 1718.4. 18 p. (Respondens: Johumn Georg Zucharias Doederlin.]

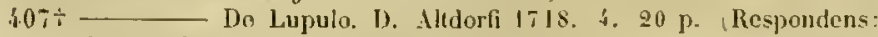
Juhann Ehinger.)

$408 \div-$ De Aristolochia. D. Altdorfi 1719. 4. 20 p. (Respondens: Hithelm Emmanuel Forster.)

409" Johunn Kourad Klein.)

$410 \div-$ De Artenisia. D. Altdorfi 1720. 4. 94 p. (Respondeus. Gottlob Ephraim Hermann.)

$411 \div-$ De Asaro. D. Altdorli 1721.4.20 p. (Respondens: Jakiob Christoph Schefler.

$4.12^{*} \longrightarrow$ De Fuligine. D. Nttorfi 1792. \&. H. (Respontmas: Leut- 
1.13* Baier, Johamn Jakob. Ilorti medici Aendemiae Altdorfiensis Historia curiose conquisita. Accedit ejus Commenoratio celebriorum Germaniae hortorum botanico-medicorum. Attorfi 1727. 4. 56 (non 65) p., praef., 1 tab.

(In hoc libro cintinentur:

I. De hortis Germaniae butanico-medicis colebrioribus prolusio. ii. Oratio de origine progressu el fatis horti medici Academicac Altdortiensis.

III. Carmen seculare, quod ad primun cjusdem horti festum celebraluni est.

15. Ludorici Jungermami invitatio ad fautores Florar Aldorfinae.

1. Lnseripliones in horlo medien Attorliensi passin Jegrendae.

17. Teslimonia quaedam clar. virorum de eroflem horto.

III. Carmen quo societas philiatrorum congratulata est seculari memoriae II. M. A celebratae.

vill. Poema vernaculum, quo eadem societas horlulani benemeriti jubilaeo, in anno 1723 incidenti, applaudere voluit.

1.1. ․ De Helleboro nigro. D. Altiorfi 1733.4 .16 p. (Respondens: Goltlob Karl Bachovius.)

4. $13^{*}-$ De Semna, D. Altdorfi 1733.4.24 p. (Respondens: Johann Konrad Senner.)

(Disserlationes Joannis Jacabi Baieri maxima ex parte non uisi Respondentis nomine iustructae sunt.)

116* Bailey, J. II. American Bacillaria, Part I \& II: Desmidiaceac et Naviculacea. \&. 24,20 p., 4 tab.

Ameriean Jourual of Sc. and Arts rol. 41 et 42 .

$\$ 17 \div$ Baillard, Elme. Discours du tabac, ou il est traité particulièrement du tabac en poudre. Paris 1668 . 8. 125 p., praef., ind. - ib. 1693. B. praeter titulum vix differt.

$418+(\longrightarrow)$ Le bon usage du tabac en poudre. Paris 1700.12 $68 \mathrm{p}$

$\$ 19 \div$ Bailly, Charles François. De l'incision annulaire, de ses causes de ses effets et particulierement de son emploi dans la culture de la vigne. Paris 1825.8 .340

420 Hanuel complet théorique et pratique du jardinier, ou l'arl de culliver et de composer toules les jardins. Paris 1824 . Il voll. 18. ( 5 fr.)

421 Baines, Henry. The Flora of Yorkshire. London $4840.8 .(7 \mathrm{~J} / 2 \mathrm{~s}) \mathrm{w}$

422 Bakie. Observations on the Nei]gherries. Calcutta 1838. 8. (London, Allen et Co. 15s.) w.

123† Balan. Nouveau traité sur l'arbre nommé Acacia. Ed. II. Bordeaux 1766. 8. 92 p.

q2': Balbis, Giovanni Battista. Elenco delle piante crescenti ue' contorni di Torino. Turino 180 1. 8. $102 \mathrm{p}$.

$4: 5^{*}$ Miscellanea botanica, ubi et rariorum horti botanici stirpium minusque cognitarum descriptiones, ac additamentum alterum ad Floram Pedemontanam et ad elenchum plantarum circa Taurinensem urbem nascentium; I vationes botanicae continentur. $(1804-1806$.) 4. - I: $68 \mathrm{p}$. 11 tab. - II: 43 p., 2 tah. - (Mlem. de l'Acad. de Turin, vol. VTl.)

i. $26+$ Enumeratio plantarum officinalium horti botanici Taurinensis Augustae Gallorum lmperatricis Josephinae. Taurini anuo Xlll. 1805. 4 min., $62 \mathrm{p}$.

$4 Z 7+$ - Flora Taurinensis sive Euumeratio plantarun circa Tanrineusem urben nascentium. Taurini 1806. 8. xvi, $224 \mathrm{p}$

$428^{*}$ Catalogus stirpium horli bol. Taurinensis. Taurini 1807. $8.63 \mathrm{p} .-$ tad annum 1810 . ib. $67 \mathrm{p}$., Appendix: 8 p. - "ad annun 1812. ib. 80 p. — " ad anuum 1813 ib. 83 p., Appendix: $1814.18 \mathrm{p}$. (Indicantur praeterea catalogi annorum 1804. 1805. 1811.)

$429^{*}$ Ilorti Academiae Taurinensis stirpium minus cosnilarum aut forte novarum icones el descriptiones. Fasc. l. Taurini 1810.4. 28 p., $7 \mathrm{tab}$.

430 Materies medica praelectionibus academicis accommodata. Taurini 1811.11 voll. 8.

$431^{*}$ - Flore Lyonnaise ou description des plantes qui crnissen dans les environs de Jyon et sur le Mont-Pilat. Lyon. ll voll. 8.l. 1 et $2: 1827$. xvt 890,30 p. - II: 1828. (Cryptogames) vilI, $371 \mathrm{p}$. - tSupplément. Lyon 1835. 8. 91 p., 1 tab.

432 Baldinger, Ernst Gollfried. Calalogus dissertationum, quae medicamentorum historiam, fata et vires exponunt. Altenburgi 1768. 4. 128 p. B.

$433^{\circ}$ Ueber das Studium der Botanik und die Erlernung derselben. Jenta 1770.4. $18 \mathrm{p}$.

434. — pr., De filicum seminibus, D. Jenae 1770. 4. 28 p. (Respondens: J. Ph. Wolff.)
433 Baldinger, Ernst Gollfricel. Praefatio programmatis acadenici, do'ens, Secale cornutum perperan a nunnullis ab infamia liberari. Jenae $1771.4 .8 \mathrm{p}$.

$436^{*} \longrightarrow$ Index plantarum horti et agri Jenensis. Goettingae $177:$ 8.75 p., praef.

$437^{*}-$ pr.. Vires Chamonillae. D. Gocttingae 1775.4.42 p. (Respondens: J. D. Carl.)

$43 \mathrm{~S}^{*}$ - Alexiteria et aleviplarmaca contra diabolun. Programma. Goettingae $1778.4 .15 \mathrm{p}$.

439* - Oratio in laudes neritorum Alberti de IInller. Goettingate 1778. 4. 29 p

$4.05-$ Litteralura universa materiac medicac alimentariae, to:40cologiae, pharmaciae, et therapiae generalis medicte atque chirurgicas potissinum academica. Mlarburgi $1793.8 . x x, 359$ p. et effigies Baldingeri.

$41^{*}$ - Ceher Literargeschichte der theoretischen und practischen botanik. Marburg 1794. 8. $117 \mathrm{p}$

$4.22^{*}$ Baldini, Baccius. Tractatus de cucumeribus. Florentiae, ap. Barth. Sermatellium. 1586. 4. 16 p. (Sunt antiquitates cucumerum.)

$4.3 *$ Baldini, Filippo. De' pomi di tersa ragionameuto. Napoli 178: 8. $35 \mathrm{p}$.

4t: Baldus, Baldus. Opobalsami orientalis it conficienda theriaca Roinae adhibiti medicae propugnationes. Romae 1640. 4. 69 p. - " redit Norimbergae cum libo lolcameri de Opulalsami orientalis examine et sinceritale. 1644,12

italice: Due letiere sopra il balsamo, Romae 160,4 . $\mathrm{H}$. - Del vero Opobalsamo orientale discorso apologetico, dato

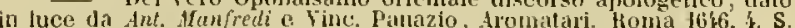
Hall. Bibl. I. 460.)

445 Baldus, Jakob. Satyra contra abusum tabaci. Monachii 1657! 19. H.

$\$ 46$ Badus (i. e. Baldus), Sebastian. Cortex Peruvianus redivivus, profligator febrium, assertus ab impugnationibus Melippi Protimi. medici Belgae. (i.e. Topiscus Fortunulus Plempius.) Genuae 1656. 12. s. ("llic aliquando Buldi in Badi cognomen mutavit. Non mirum, inquit ille in pracf. Anastasis, si mutato Baldi agnomine, Badus in posterum dicor:" $\mathrm{S}$.

$4: 47^{*}$ Anastasis corticis Peruviae s. Chinae chinae defensio contra ventilationes Joh. Jac. Chifletii gemitusque I"opisci Fortunati Plempii. (ienuae 1663.4.278 p., pracf., int.

it8+ Baldwin, Ililliem. Reliquiae Baldwinianae: selections from the correspondence of the late Willirm Baldwin, M. D. Surgeon in the U. S. navy. With occasional notes and a short biographical menoir. Compiled by William Darlington. Philaclclphia, Kimber \& Sharples:. 1843. 8. 346 p. et effigies Raldwini.

4.9 $9^{*}$ Balfour, J. II., Charles C. Babington and IV. II. Campbell. A catalogue of british plants. Part first, containing the llowerimg plants and ferus. Ed. II. Edinburgh 1841, 8. 16 p. ( 3 (l.)

450 - — and Charles $C$. Babington. $\mathrm{Au}$ account of the vegetation of the outer hebrides. (Edinburgh 1841.) \&. 24 p.

451 t Balmis, Francisco . Favier. Demonstracion de las edicaces virtudes nuevamente descubiertas en las raices de los plantas de Nueva España, especies de Agave y de Begonia, para la curacion del vicio venéreo y escrofuloso y de olras graves enfermedades que resisten a] uso del Mercurio y demas remedios conocidos. Madrid 1794 8.347 p., praef, ind. ef \& tab. col.

* germanice: Ueber die amerik. Pllanzen Azave us. Begonia, deutsch von kreyssig. Leipzig 1797. 8. vin, 156 p., 2 tah. $(2 / 3, h$. $)$

\{52 * Balog, Joseph. D. sistens praccipuas plantas in Transsylyatil sponte provenientes. Lugduni Batavorum 1779. 4. $37 \mathrm{p}$ (Usteri, Delectus vol. i.)

$\{53 \div$ Balsamo, cognomine Crivelli, Guiseppe Cabriel. De Solanacearum familia in genere addita Verbascorum ftaliae indigenorum monograpluia. J). (auspice Dom. Nocea.) Ticini regii 1894. 8.47 p.

454* * - et Jos. de Notaris, Synopsis muscorum in agro MledioJanensi hucusque lectorum. Mediolani 1833. 8. $27 \mathrm{p}$.

$455^{*}$ —_ Prodromus Bryologiae Mediolanensis. Mlediolani $1834.8 .194 \mathrm{p} .(5 \%$ lire.)

456 Banal. Catalogue dles plantes usuelles suivant Vordre de leurs vertus (Montpellier 1755.) 8.56 p. B.

$457 \div$ - fils ainé. Catalogue des plantes usuelles, rangées suivant la méthode de Mr. Linneus. Montpellier 1780, 8, 96 p. - ib. 1786. 8. 110 p. B. 
4.̈8t Banal, Antoinr. Calalngue des plantes méelicinales et écomoniques, suivant leu:s caracteres géneriques ot speciliques, conformement at la metlode sexuelde du Chev. Linms. Hontpeltior 1784. 8. vit, $99 \mathrm{p}$.

fön Bancroft, Elloard. An essay on the natural history of Guiana. Lontlon $1769.8,402 \mathrm{~J}$., I tals. germanice: tripkig 1769.8.

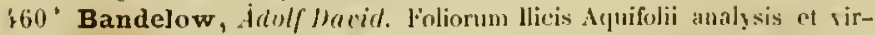
tutcs mediean. 1). Ilalae 1789. 8. 24 p.

$461^{*}$ Banesius, Faustus Nairon. De saluberrima potione Cahve sen Cafo nuncupata discursus. Romae 1671. 12. 37 p.

4.12 Bang, Axel Olof. De Jumipern. 1). Hafuiae 1708, 4. н.

in63 Bang, Christian firiedrich. De plantis quilusdan sacrae botanicae. D. 1. Havniace 1767. S. 26 p. B.

66:" Banister, John. Catitogus plantarum in lirunia olkervatarum. (Eustat in Raje Itistoria plant. 11. 11. 1926.)

$463 \div$ Banks, Ceorge. An introduction th the study of english botany; with a glossary of terms. Lil. 11 : Lonclon 4832 . 8. 80 P., glossary, 37 tab. el effigies Limnnei. (9s.)

$366 \div$ Banks, Joseph. $A$ short accumt of the cause of the disease in corm, called by farmers the blight, the mildew and the rust. London 1805 . s. 15 p., I tals. (1.s. 6 d. - or with the plate accurately coloured Qs. 6 d.) - impr. cun quarta editione Curtis l'ractical observatious of the british grasses.

$4.67^{*}$ Banning, Florentius. De herba Nicotianae. D. Berolini 1824.8 .30 p.

\$.68* Barbeu-Dubourg, Jacques. Le botaniste français, conjrenant toutes les plantes communes et usuelles disposees suivant une nuuvelle méthode el tlécrites en langue vulgaire. Paris 1767 . II voll. 8.1: $\mathrm{xr}, 244,182 \mathrm{p},-1 \mathrm{I}: 508 \mathrm{p}$.

$469-$ Usage des plantes. Paris 1767.11 roll. 12.

Est continuatio libri pracecentis.)

70 Manuel de botanique. Paris 1768 . 12.

$471^{*}$ Barbier, Jean Baptisle Gregoire. Traité élémentaire de matirre médicale. Paris. IIl roll. 8. - 1: 1819. xi, $636 \mathrm{p} .-11: 1819.650 \mathrm{p}$ III : $1820.555 \mathrm{p} .-\div$ lid. Ill. Paris 1830 . III voll. $8 .-\mathrm{J}$ : xxill, vill, 659 p. $-11: 694$ p. $-111: 722$ p.

$4: 7+$ Principes généraux de pharmacologie ou de matière midicale. Paris $1806.8, x, 556 \mathrm{p}$.

1.73* Barbieri, Paolo. Osservazioni micruscopiclue. Mentoria physiologico-botanica. Mantova 1828.8. 24 1), 1 tab.

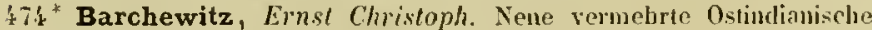
Reiselueschreibung clc. Eurfurt 1752.8.687 p., intl. - Ell.1: Chemnilz 1730.8.

17:; Barckhausen, Golllieb. Specimen bolanicum sistens fasciculum plantarum ex Flora comitatus Lip]piaci. D. Goettingae 1775. 4. 28 p.

1.76* Barentin. Die Vegetation in der Mark Brandenlurg. Programm Berlin 1840. 4. $22 p$.

477 Barham, Henry. Hortus americamus: cuntaining an account of the trees, shrulss and other regetalle productions of South-America and the West-India Islands, and particularly of the island of Jamaica; interspersed with many curiuus aum useful observations, respecting their uses in nedicine, diet ond mechanics. To which are added a Linnean Index. Kingston, Jammica, typ. Aikman. 1794. 8, 7, 212 p., ind.

178 t Barjolle, Jean Baptiste. Antabacum lentum sit hemini vinenum? D. Paris 1731.4 .4 p.

4.79* Barisch, Bernhard Joham. Observatienes playtotomicae. D. IIalae (s. a. 18..) 8. 31 n.

$480 \div$ Barnades, Miguel. Priucipios de bolanica, sacades de los mejores escritores, y puestos en lengua castellana, Parte prinera. Madrid 1767. 4. 220 p., praef., incl. et 13 tab. Bibl. Juss.

¿\&1" Barnéoud, F. Marius. Jecherches sur le développement, la struchure générale et la classification des Plantaginées et des Plumbaginées. (Accedit: De l'origne des lacs.) Theses pour les Doctorat. Paris 1844. 4. 44 p. 1 tab.

482* - Nonographio générale de la famille cles Plantaginées. Paris $1845.4,52$ p.

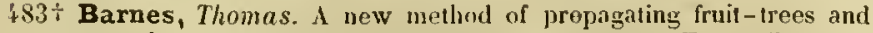
flowering shrubs. Londen 1759.8. 42 p., 2 tab. - Ed. III ib. 1762. 8. 40 p., 2 tab. B.

(Excerpta germanica in Berlin. Nagazin 1. 199-208.)
48:- Barnet, James. An accunt and deseription of the different varielies of strawberries. which have been coultivated and examiued in the garlon of the Horticultural society of London. London $18 \geq 5$ 4. 50 r.

Frim the Iforticulturil Transactions.)

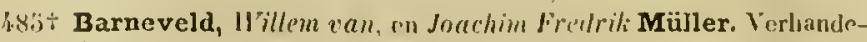
ling over het planten van lwumen biunen en rumbun de steilon litrecht 1793. 8. 189 p. (I fr. $25 \mathrm{c}$.)

486 Earnstein, (/lenricus?), Miraculum tabacei. lirancofurli 1673. Linn.

4.87 Barnstorff, Bernhard. P'regramma de resuscitatione plantarum. Rostorhii 1703. 1. 1 plag. B.

488 t Baron, $\boldsymbol{N}$. Flore de.s Dejuartemens merilionaus de la France et principalement de celui de Tam of (iaronne ou Description des plantes qui eroissent uatureflement dans cess eleipartamens ete. Montauban 1823. 8. xxxv1, $468 \mathrm{p}$

(Guerarto autlit P. Alexis Buron.)

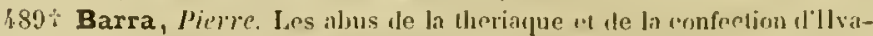
cinthe. Lyou 1667. 12. (') 75 \%.

4.90 Barratt, J. Saliess americande. Aliddletown. Connecticut, 1840, \%.

491 _ Eupatoria verticillata. 4.

$492-$ North American Carices. Midelletown 18:0. 4. Cat. B. L.s.

4937 Barraud, jure ot fils. Catalngne des rosiers, geraniuns et dlintliemis a grandes fleurs. Lansanne $1 \$ 22.8 .11 \mathrm{p}$.

49:" Barreira, Frey Isidoro de. Tractato das signilicacoens das plantas, flores e fructos que le referem ua sagrada escriptura. Tiradas ilr divinas ot humanas letras con smas breves consideracōes. Em Linlon, pur Pedro Craesbeeck. 1629. 4. 582 p., pracf, inl. (a p. 37T. incipjit parte II.) Bibl. Cáes. Vindab.

\$ $93^{*}$ Barrelier, Jacques. Plantie per Galliam, Hispaniam et ltaliam observatac iconibus aeupis exhilitae. Opus posthumum, cura et sludio Antonio de Jussien, medici. Parisiis 1714. folio. 8, 140 p., xxvı p. ind. cum 1324 ironibus in $33 \mathrm{~h}$ tabulis. (1.6/\%. Berlin. $-13-20$ -38 [r. Brunet.)

(Jacobi Barrelieri [n. Parisiis $1606 \div$ Parisiis 17. Sepl. 1673] codices mannseripti, quotquot e llammise erepti sunt, "xastant in Bibliotheed IJadriani de Jussieu: annus botanicum sive rariorum plantarum schedia n. - "Plantae gemanicae, ex itincre recugnitae et descriptae." "Fungorum historia, Irecentas continens species." - ablservationes. motare of intices in Patris Matthari a. $\$$. Josepho Viridarium orientale. 11all. Bint. 1. 3071. - Spreng. Ilist. 11. 173-176.-Querard, France lit. I. 192.

$496 \div$ Barrère, Pierre. Question de médecine, dans laquelle on examine, si la theorie de la botanirpe ou la connaissance des plautes est nécessaire à un méelecin? Narbonne 1740.4.16 p.

$49 \div \div$ Essai sur l'histoire naturelle de la France équinoxial ou denombrement des plantes, des animaux et des minéraux, qui se trouvent dans l'ile de Cayenne, les iles de Remire, sur les cótes do la mer, et dans lo Continent de la Guyane, etc. Paris 1741. 8. xxiv. 215 1. (Première partie: Plantes p. 1-119.) - ib. 1749.8. a

$498^{*}$ Nouvelle relation de la France équinoxiale, contenant la description des cotes te la Guiane et de l'ile do Cayenne. ete. Paris 1743. 8. IV, $250 \mathrm{p}$. et planches.

$499^{*}$ Barrow, John. An account of travels into the interior of southern Ifrica in the years 1797 and 1798: including cursory nbsersations on the geology and geography of the southern part of that contiuent: the natural history of such objects as occurrel in the animal, regetable and nineral lingdoms, etc. J.outon 1801-1804. 11 voll. 4. I: 1501. vu, 419 p., 1 mappa geogr. - 11: 1804. xi, 452 p., 7 tah. * gallice: par L. Degrondpré. Paris 1801. 11 voll. 8. yermanice: vous Sprenyel. Neimar $1801-150 \%$. \&. (33/, th.

$300^{*}+A$ royage to Cochinchina in the years 1792 and 1793. etc. London 1806. 4. xvitI, 447 p., 21 tab. col. (Iss. A. London.) gallie: pall Nolle Brum. Paris 1807. 8.

301 Travels in China. Lnrodon 1804.4. gallice: par rastera. Paris 180\%. 8.

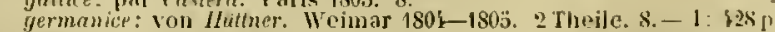
$-11: 317 \mathrm{p}$. 7 tah. (3 $\mathrm{th}$.)

$502 *$ A clironological history of royages into the arelic regions ete. Landon $1818,8,379,48$ p. et map of the arclic regions. (Botanica vix insunt.)

503* Barruel, Jean Pierre, ot Maximin Isnard, Mémoire sur J'extractien en grand du sucre des betteraves et quejques considerations sur leur culture. Paris 1811 . 8. 31 p. 
วั0 " Barry, Edward. Observations historical, critical and medical on the wines of the ancients and the analogy between them and motern wines. London 1775. 4. $479 \mathrm{~F}$. (A. 14s. Londan.)

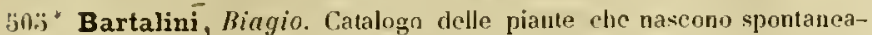
mente intorno alla citta di Siena, coll' argiunta d'altro catalogo dei corpi marini fossili che si trovano in deto luogro. Siena 1776. 4. W, 144 p. (a pag. 125 incipit catalogus fossilium.)

: $066^{\circ}$ Raguaglio di alcune produzioni naturali dell' agro Senese. Siena. 4. Dc.

„07" Bartels, E. D. A. Ceber innere und aussere lBewegung im Pflanzenund Tbierreiche; und insbesondere ulber lirsatz der ausseren durch innere oder chemische; mit Ruchsicht auf Gestaltungsverschiedenheit. Narburg 1898. 8.26 p. $(1 / 8, h$.

(Evtraabdruch aus Marburger Schriften, Bamul II, lleft ?.)

¿08 $\div$ Bartholinus, Thomas. Disseriatio prima (et seeunda) de Theriaca in officina Christophori Heerford 1. Febr. 1671. dispensata. Ilafniae 4. $40,40 \mathrm{p}$.

$: 309-$ Cista medica Hafniensis. Hafniae 1662. 8. s.

;10 Evistola de simplicibus merlicamentis inquilinis coguoscendis, praefixa Ilermunni Grube Commentario de modo simpliciun medicamenturum facultates cognoscendi. Ilafnice et Francofurti 1669. 8. s

¿11" Bartholomaeus Anglicus (Bartholomaers de Glanvilla, ordinis Minorum). Liber de proprictatibus rerum. inpr. per Jo. Koelhotf. 1481.4. - "Norimbergae per Antonium Koburger. 1483. Folio. *Coloniac 1483. - *Argentinae 1485. folio. - " s. 1. 1488. folio."Argentinae 1491. Solio min. (323 foll.) "Norimbergae, per A. Koburger. 1492 . folio min. (360 foll.) - ${ }^{*}$ Ar.tentinae 1505 . folio. Bibl.Goett. (In libro XVIl bujus encyclopediar agitur de plantis.)

$\div$ gallice: Le proprielaire des choses tres intile of protitable anx corps numains ete. (traduit de latin de Bortholamapus Anglicus par le frere Jehan Corbichan, maistre en theologie. Nourellenient imprime a Paris 152:3 le 20 jour te may par Phelippe lo noir. folio. Bibl. Juss.

* hollandice: Harlem thsö. folio.

* anglice: translated at Berkeley. 1397. Londun 13̈33. folio. Bibl. Goett.

a12* Bartling, Friedrich Gottlieb. De littoribus ac insulis maris liburnici. D. geographicu-lotanica. Hannoverae 1820. $8.48 \mathrm{j}$. $(1 / \mathrm{t}$ th.

$\$ 13^{*}$ und Heinrich Ludwig Wendland. Beitráge zur Botanik. Gocttingen 1824-1825. 2 llefte. 8. - 1: Diosmeae descriptac et illustratac. 1824 . x, 214 p., 2 tab. - 11: 1825.210 p. (11/2 th.)

$51\}^{*}$ - Ordines naturales plantarum eorumque characteres et affimtates adjecto generum enumeratione. Goettingae 1830.8 . $498 \mathrm{p} .\left(2 \frac{1}{3} \mathrm{th}\right.$. $)$

31:̈* Der botanische Garten zu Goltingen i. J. 1837. Eine Skizze. Gouttingen $1837.4 .8 \mathrm{j}$., 1 tab. $(1 / 2$ th.)

$316 \div$ Barton, Benjamin Smith. Collections for an essay towards a Materia medica of the L'nited Slates. Two parts. Philadelphia, typ. Carr

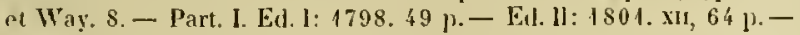
Part. 11: $1804.53 \mathrm{p}$.

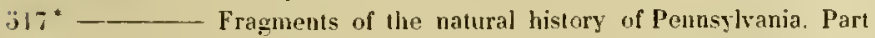
first. Philadelphia, typ. Way \& Groff. 1799. folio. xvm, 24 p. Progress of vegetation in the year 1791.)

$318^{*}$ _ Elements of botany: or outlines of the natural history of vegetables. Illustrated by forty plates. Ed. II. aucta: Philadefphia. x. 1: 1812. xvur, 324 p., ind. - II: 1814. Iv, 180, 44 p., 40 tab. - Pil.1: Philadelphia 1803. 8. - $\div$ Revised and corrected with the adulition of hritish exemples and occasional notes, by the english editor. London, typ. Gold. 1804. 8. xi1, 344 j., 35 p., 30 tab.

319 - Flora virginica, sive plantarum praecipue indigenarum Virguinize historia inchoata, iconibus illustrata. Pars 1. (Pliladelphia.) 1812. 8. 74 p. absque tabulis; desinit in Tetrandria.

("This work has never yet been pullished; though I have some mascm for believing Dr. Barton tonk it will him in his last royage rdition of the Flora virginica of Clayton and Granovius., ) William Bartor.

$320 \div-$ Specimen of a geographical view of the trees and sbrubs, and many of the herbaceous plants of Nortl-America, between the latitudes of seventy-one and twenty-five. Illustrated by plates. (Philadelphia) 1809. 4. 10, $26 \mathrm{p}$. Bibl. Juss. (incompl.)

321 Barton, John. A lecture on the geography of plauts. Lonilon 1827. $12.95 \mathrm{p}$. with 4 maps in folio. w.

+ gallice: Lecture sur la gèographie des plantos; augmentee de notes par J. Marchal. Bruselles is29. 8. $81 \mathrm{p}$., i tab. geogr.
5222 Barton, J. II. and J. Castle. The British Flora medica. Londen 1837-38. II voll. 8. with plates. (2l. 6s.) w.

5923* Barton, II illiam P. C. Hlorae Philadelphicae Prodromus; plantarum quae hactenus exploratae fuere, quaeque in ipso opere ulterius describentur, exhibens enumerationem, or Prodromus of the Flora Philadelphica, exhibiting a list of all the plants to be deseribed in that work, which have as yet been collected. Philadelpbia, typ. Maxwell. 1815. 4. $100 \mathrm{p}$.

32:'* _ _ A bingraplical shetch read pursuant to appointment before the Philadelphia medical society of their late President, Prof. (BenjaminSmith) Burton. Philadelphia, typ. Maxwell. 1846. 8. 34 p. effigies Benj. Smith Rurtar. Bibt. Goett.

$323^{*}$ _ Some account of a plant used in Lancaster County, Pennsylvania, as a substitute for Chocolate, Holcus bicolor Willel. PhilaIlelpbia, ty. Palmer. $1816.8 .8 \mathrm{p}$.

$526^{*}$ Cegetab]e materia medica of the United states; ur Medical botany: containing a botanical, general and medical history of medicinal plants indigenous to the Inited states. Philadelphia. Carey. $4817-18$. Il voll. 4. - 1: $x v, 273$ p. - II: xvi, 243 p., 50 tal). (2l. $8 s$.

327* - Compendium Florae Philadelphicar, containing a doseription of the indigenums and naturalized plants foumd within is circuit of ten miles aronurt Philarlelphia. Philadelphia, Carey. 18 18. II voll. 8. - I: 251 p. 11: 234 p. - ib. 1824

$528^{*}$ — A Flora of North America. Illustrated by original coloured figures drawn from nature. Philadelphia, Carey aul son. Ill voll. 4. - 1: 1820. xIx, 138 p., tab. cal. 1-36- 11: 1822. x, 107 p., tah col. $37-70 .-$ Ill: 1823. vil, 100 \%., tah. col. $71-106$.

Ed. 11: 1823. \%. Ill voll. verosimiliter eadem impressio.

$529^{*}$ Bartram, John. Observations etc. in his travels from Pensilvania In Onundago, Oswego and the Lohe Ontarin in Canada; with an accoult of the eataracts of Niagara, by Peter Katm. London 1751. 8. 94 1. ( $s .6 d$.)

$530 *$ Bartram, William. Travels trough North and South Carolinct. Georgia, East and West Floricla etc. containing an aceount of the soil and natural productions of those regions. Plsiladelpbia 1791 . \&. - London, reprinted for J. Johnson, 1794. \&. xxIv, 520 p., int. S tab.

* germanice: Reisen durch Yord- und Sudharolina. Ost- nnd West-

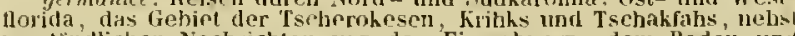
umstandtichen vachrichten von dest Eimwohnern, dem Boden unc den Naturyroduhten dieser wenig lokkannten grossen Lander. Aus dens Englischen mit erlauternden Anmerhumgen ion Zinmermam. Bertil 1743. 8. $\times x \times 1,469$ p. 8 tab.

* gallice: Vovage dans les parties du sud de rimériyue septentrinnale, traduit par Benoint. Paris, an IIt. (1799.) II voll. 8. avec gravires et une carte. (10 fr.)

$\dddot{3} 1^{*}$ Baruffaldi, Girolamo. La tabaccheide. Ditirambo con le annotazinni. Ferrara 1714. 4. $240 \mathrm{p}$.

¿32 — $2^{*}$ Il canapajo libri Vil. con le annotazioni. Bologna 1741. 4. $227 \mathrm{p}$.

Adligata: C. Ant. Berti, Coltivazione dolla Canape, 3.k p., 2 tah.

$533^{*}$ Basiner, Theodar Friedrich Julius. Enumeratio monographica specierum generis Hedysari. Petropoli 1846. gr. 4.53 p., 2 tab. $(1 / 2 / h$. (E) scriptis Aead. sc. Pollopolitanae.)

$53 \% \div$ Baskerville, Thomas. Affinities of plants: with srome olsservations upon progressive development. London 1839. 8. $x, 1 / 4$ ) 1 tal. col.

¿33̈* Bassi, Agostino. Dell utilita ed uso del pomo di terra e del metodo migliore di coltivarlo. Lodi $1817.8 .47 \mathrm{p}$.

$336^{*}$ Nuova maniera di fabricare il vino a tino coperto senzil l'uso di alcuna macehina. Fd. Il. aucta. Lodi 1825.8 .48 p. ( $11 / 2$ lire.

$537 *$ Del mal del segno, calcinaceio o moseartino. (malattia che afflige i bachi da seta.) Lodi $1835-36$. 8. $\mathbf{~} 1,67$, xIv, $60 \mathrm{p}$.

338* Bassi, Ferdinando. Ambrosina, novum plantae genus. Bononiar 1763. 4. vil p., 1 tab.

(Est seorsim impressa e comment. Bonon val V. - lijusdem autoris Novae plantarum species, ih. vol. 13. p. 13-20.)

539+ Bastard, T. (al. Batard). Essai sur la Flore du Departement de Maine et Loire. Angers 1809. 8. xxri $443 \mathrm{p}$.

$540 \div$ Supplément a l'essai sur la Flore du Département do Maine et Loire. Angers 1812. 8. xII, 58 p.

$5 \$ 1 \div-$ Notice sur les végétaux les plus intéressans du jardin des plantes d'Ingers. Angers 1810. 12. xxIY, $272 \mathrm{p}$. 
"3.2" Baster, Job. Opuscula subseciva, olservationes miseellaneas de animalculis et plantis quibusdam unarinis rormmge aviaris el seIninibus continentia. Harlemi 1762. II voll. 4. - 1: libris III: 1762. 1763.1761 .148 [3., inl., 16 tab. col. - II: libris III. 1762. 1763. 1765.150 p., ind., 13 tals.

$313^{\circ}-$ Verbandeling aver de vondtelling der dieren en planten,

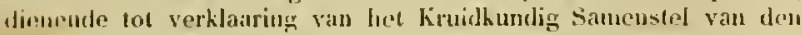
Ridkder Linnacus; en uthreiding der korte inleiding lot de kiruidhunde, van Philiph ihllir; greplaatst vour deszolfs maandelykse tuinaclieningen. Brichiswze opgestedd. Haarlem $1768.8 .120 \mathrm{p}$.

$$
\text { Hali. hibl. II. hlis. - Spreng. Ilist. II. 33s., }
$$

Sir Bastien, Jean Frencois. Inner du jarliuage; otrvage extrait de tous les moilleurs auteurs, tant ancions que inodernes. Paris 1799. II inll. \$. 9 [r.) 0.

ij ïj Cileudrier du jardinier ou Journal de son travail. El. III. J'aris $1812.12 .(6 \mathrm{fr}$.) $a$.

iifi Dictomane botanique et pharmaceutigue. Paris 1809. II volt. \$. a.

íit - La Furo jardinierre, contentint la description de toutes les plantes tout indigènes qu'esutiques, cultives on France dans le's jardins potagers, fruitiers, de botanigae ete. Paris 1809. 8. 11, iso p., 9 tab.

its - Noweau manuel du jartinier. Paris 1807. Il voll. 12. 0.

3i.?" Bateman, Jemes, Est]. The Orchillaceae of Nexico and Guatemala. London, lyp. Ridgway and sons, for the author. (1837-43.) folio eleph. 16 p., (10 foll.), 40 ab. color. (20 Guin.) Bibl. caes. Viobob, et Bibl. Reg. Dresd.

\#.50 Batsch, August Johann Georg Karl. Elenchus Fungorum. (Gattongen und Arten der Scliwammo.) Accedunt jeones 57 fungorum nonnullorum agri Jenensis secundun naturan ab auctore depictac, aeri incisae of vivis coloribus fucatae a. J. S. Capieux. Ilalae 1783 4. $183 \mathrm{~J}, 12 \mathrm{tab}$ - Continuatio I el II: $1786,1789.279, \mathrm{xL}, 163 \mathrm{P}$. tab. col. $13-42 .(13 \mathrm{th}$.

:55 $1^{*}$ - Dispositio generum plantaruın Jenensium secundum Linnaeum et familias naturales. 1). Jenae $1786.4 .65 \mathrm{p}$., ind. $(1 / 3$ th.

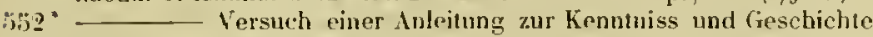
der Pllanzen, fir ak. Forl. entworfen, und mil den nöthigsten Abbildungen versehen. Halle. II voll. 8. - I: $1787, \mathrm{~W}, 38 \uparrow \mathrm{J}, 6$ tab.II: 1788.676 P., tab. $7-11$.

3i3:" - Analyses florun e diversis plantarum generibus omnes rtian minutissimas eorum externas partes demonstrantes, et earun$\mathrm{dem}$ harum partium eharacterem gencricum, philosophiam botanicam, el generum intiminres affinitates a natura statutas. (Blumenzeroliederungen etc.) Halae 1790. 4. Vol. I. fasc. 1 et $11.9 \$ ; 120$ p., g(l tal. col. [atine el germanice). $\left(9 \frac{2 / 3}{3}\right.$..$)$

$5011^{*}$ - Botanische Bemerhungen. Erstes (und pinziges) Stuck. Halle 1791. 8. xis, 104 J.. 6 tab. cum 140 ic. $(5 / 6$ /h.)

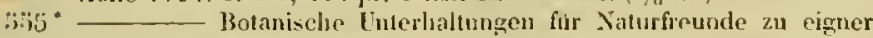
Belehrung uher die Verhältnisse der Plianzenbildung entworfeu. Jena 1793. 2 Theile. $8 . x \times 11,621$ p. $\left(1 \frac{1}{2}\right.$ th.

iij $\mathrm{f}^{*}$ — Synopsis universalis analytica generum plantarum fere omnium hucusque cognitorum quam secuntum methodum sexualem, corollinam el carpologican adjunctis ordinibus naturalilus exaravit. (1). I et 11.) Jenae 4794. 4. $126 \mathrm{p}$.

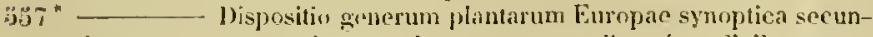
dum systema scxuale emendatom exarata adjunetis ordinibus naturalibus. Jenae $1794.4,136 \mathrm{p}$. , maef. $(1 / 3, \mathrm{~h}$.

fiast (— Cronspectus liorti botanici duralis Jenensis secundun areolas systematice dispositas in usum botanicorum Jenensium. Jenae 1795. 4. $17 \mathrm{p}$. , ind.

33̆9: (-) Catalogrus plantarum lonti botanici ducalis, Jenae Thuringurum vere anni 1794 fundati, fiur ami 1797 couscripus. Jenae 1797. folin. 6 p. (absigue annotillionibus.)

$: 360^{*}$ Butanik fur Frauenzimmer und Pllanzenlichlaber, welche keine Gelehrten sintl. Weimar 1793.8 . v111, 184 p., 4 tab. col. grllice: Butalique pour les femmes of les anteurs des plantes Arec 101 tighrs colotices. Oarrage illemand mis en francais " augmente de notes ot d'autres additions, l'ar J. Fr. B(ourgoing), membre assiocie do l'inslitut national de lirance. Weimar, Paris ti strasbur: 1794. 8. xve $198 \mathrm{pe}, 4$ lab. col

danice: Botanik for Fruentimmer og Planteyndere, som ilike ere haerde overs. if $F$. C. Kielsen. Kiobnhavi 1801. 8. viti, $152 \mathrm{p}$, \& lail, col. $(80$ schill.)

stretice: Órehro 1810. 8. 139 (6) p. \& tab. col. W.
¿61 t Batsch, August Johann Geor! Karl. Der zeolfnete Blumengarte॥ (Le jardin ouvert). theils nach dem linglischen ven Curlis Bolanical Magazinc neu hearbeitet: theils nit newen Originalien loreichert, und zur Exlanterung ther lianenzimms - Botinik fur I'llanzenlieblaber. welche keine felelurtun sind. Lid. II: Weinar 1802. 8. 100 tab. col, 100 foll. trat. gallice "t germanice, cum prace. et ind. $\left(6 \frac{1}{3}\right.$ th. $)$

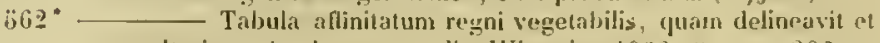

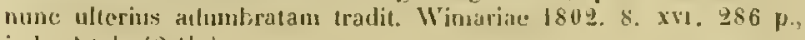
inel., I tal. ( $2(h$.)

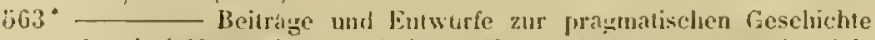
der drei Naturreiche nach ihren Perwandsehaften. fiewachseich.

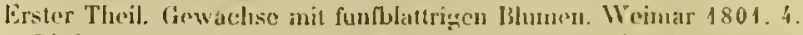
1. Lieferung. 96 p. (Opos morte autoris interruphum.)

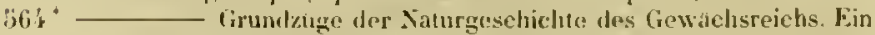
Handinch fur Lolsrer auf Gymasien und fur Naturfounde zum rignen Unterricht. Eirster Theil, 1. u. 2. Abtheidung. Weimar 1801. $8.96,96 \mathrm{p})(3 / 2, h$.

(Morte pramatura autoris $\because \div 29$. Sept. 1802.] Btraque seetio in(ompleta.)

36:" Batso, Valentin. De Aspidio filice mare. (Ifistorisch-chenisehe Betrachlung tidser die Wurzel des manulichen farmbrates.) [. chemica. Vindobuna $1826.8 .37 \mathrm{f}$

$\$ 66^{*}$ Battarra, Antonio. Fungorum agri Ariminensis historia. Faventiae. typ. Ballanti. 1755 . 4. vil, 80 p., $40 \mathrm{lab}$ - - Edit. II. Hec aucla nec diminuta. ib. typ. Martini. 1759.4.

$567^{t}$ Epistola selectas de re naturali ubservationes complectens. Iceessere ex historia naturali curiosa nonulla et tabulac elegantes. Arimini 1774, 4. $25 \mathrm{p}$.

¿68 Battus, Carolus. Het secret boek - van hoomen, planteu, blomen. hruydeu en Zaaden etc. Leeuwarden 1694. 12. H.

$\$ 69$ Battus, Konrad. Oratio prima botanologica. Hegiomonte 1601. 4. H.

\$70* Bauer, Ferdinand. Ilustrationes Florae Novae Hollandiae. sive lcones generum quae in Prodromo Florae Novae Ilollandiae el insulae van Diemen descripsit Robertus Brozn. Londini is 13 . fol. max. vil p., 15 tab. col.

(Prodiit 3 faseicalis, quisque pretio 5s. tab. nigris; tab. col. 11. 11s. $6 d$.

571* Bauer, Frañ. Delineations of exotick plants cullivated in the royal garden at liew. Irawn and coloured, and the botanical characters displayed accorting to the Limnean Systmon. Published by W.T. Aiton. London 1796. folio. (Nr. I et 2.) 20 tal. coll. (Erieae) cum praefatione of derlicatione.

In Catal. Lambertiano Nor. 162 . recensentur: "Thirty plates of Ericas, somer proofs before the letlers o anmis $1791-1800$ editae.,

$572^{*}$ Sitrelitziu deficta or croloured ligures of the hnown species of the genus Strelitzia from the drawings in the Banhsian library.

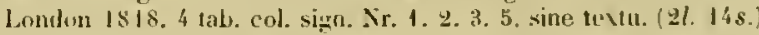

$373^{*}$ Some "xperiments on the fungi which constitute the colmuring matter of the red snow discovered in Baflin's Bay. London 1820.4 . $9 \mathrm{l}$. (From the Philos. Transactions.)

574* _ Microscopical observations on the suspension of the muscular inotions of the Vibrio Tritici. London 1823, 4, 16 p., 2 tab. (From the Philos. Transactions.)

$576^{\circ}-$ Illustrations of Orchidaceous plants. With notes and prefitory remarks by John Lindley. London $1830-38$. folio. 14, 20 foll., xiv l. pratef., 14, 20 tab. eol.

5:6* Bauernschmitt, Joseph Erhardt Franz Lothar. Die Phanzenwelt, cin Spiegellild des Gottlichen und Heiligen. Poetische Versache. Sulabach 1846.8 . vil, $208 \mathrm{p} .(1 / 2$ th. $)$

67: Bauhardt, L. Grundliche Anleitung zum Einlegen tler Pfanzin, und wie man sclione und daterlsafte Herbarien anlegt. Ein Handbuch fur Apothekerlehrlinge, angebende Botanitier und Dilettanten. Weimar 1823.8 . xis, $356 \mathrm{p}$. (1 $1 / 3$ th.

$578^{*}$ Bauhin, Gaspard. Pliytopinax seu Enumeratio plantarum ab HerLariis nostro saeculo descriptarum, cum earun differentiis: cui plurimarum hactenus ab iisdem nou descriptarun suesinctae descriptiones et denominationes accessere: additis aliquot hactenus non sculplarum plantarum vivis iconibus. Basileae, per Sebastianum Henricpetri. 4. (1596.) 669 p., praef, ind. et app. cum \& ic.

(Editio, a Willdenowio el Linkio laudata : Basileae 4698. 4. fietilia est.) 
5i9* Bauhin, Gaspard. Animadversiones in historiam generalem planlarum Lugduni editam. Item calalogus plantarum circiler quadringentarum eo in opere bis terve positarum. Francufurti a/M., 1yp. Hartmaun. $4604.4 .95 \mathrm{p}$.

$380 \div-$ De reuediorum formulis graecis, arabiluus of latinis usitatis .... libri duo. Francofurtia/M., Treudel. 1619.8 .370 p., praef. et ind.

381 " Mpoôpopos Theatri hotanici in ruo plantae supra sexcentae ah ipso primum descriplae cum plurimis figurjs proponuntur. Francol. a. M., typ. Treudelii. 1620.4 .160 p., pracf., ind. et 138 ic. vylogr. j. t. - ${ }^{*}$ Ed 11. emendatior. Basileae, impensis Joanns Regis. 167 I. 4. 160 p., ind. et ic. xylogr. iisdem.

$682^{*}$ - Catalogus plantarum circa Basileam spme nascentium cum earundem syonymis of locis in quihus reperjuntur, in usum scholac medicae, quae Basileae est. Basileae, typ. Genathï. 162. 8. $143 \mathrm{p} \%$, ind.

(Duo arlsint exempla, quae in indion differunl; horum altrum indicem platuarum praemittit catalowo duetornm, allerum vice versa hujusque index tot nomina plantarum nou continet quot illius. B. - Ed. III. auclior. Basileac, typ. Jol. Rod. Genathil. 1671.8 . 113 p. ("ö p. ind.)

i83 * Pinax theatri butanici, sive Index it Theophrasti, Dioscoridis, Plinii cl Bolanicormm qui a saeculo scripserunt, opera: plantarum eirciter sex millium ab ijssis exhibitarum nomina cum earundem stnonymis et differentiis methodice secundum earum et genera et sprecies proponens. Opus XI, annorum hactenus non editum smmmopere expetitum et ad auctores intelligendos plurimum faciens. Basiliae llelvet., sumtibus et typis Ludovici Regis. 1623 . 4. 522 p., ind. - Basiliae, inpensis Joannis Regis. 1671. 4. 518 p., ind.

Cf. Roberti Jorison, Hollucinationes Caspari Bauhinj in Pinace a invidiosum opus " Hail.) in ejus Pracludiis, Londini 16li9. 12

In Ribliotheca Candolleana exstat exemplar adjectis a Candolli patris manu recentiorum syonymis; examintavit enim vir egregins, systenti? regni regetabilis editurus, olim herbalium Banlyinianum, quod es pacto una cum herbario Hemeri de la chenal $[\div 4802\}$ in posscissionem universitatis Basiliensis transierat.

58.: * - Theatri botanici sive Ifistoriae plantarum ex veterum et recentiorum placitis propriague ubservalione concintatae liber primus (unicus) editus opera el cura Jo. Casp. Buthini. Basiliae, apull Joamem König. 1658. folio. $683 \mathrm{p}$., ind. et 254 ic. (ad Gramina ef Liliaceas pertinentes). - Basileac 1663 . fol. L. (milji non visa.) (IIall. I. 384-386. - Spreng. Hist. 1. 445-462.)

$383^{*}$ Bauhin, Jean. De plantis a divis sanetisve nomen haljentibus. Caput ex magno volumine de consensu el dissensu autorum cire: stirpes desumtum. Additae sunt Conradi Gesneri epistolae hactenus non editae a Cusp. Buzhino. Basileae, ap. Conrad Waldkircl. 1591. S. 89 p. praeter Gesneri epistulas, quae sunt a p. 91-163.

"386" - De plantis Absynthii nommen habentilus, eaput desumtum ex... Bauhini laboriosissimo plantarum lihro, cui conseosus ot dissensus circa stiryes titulus est. Tractatus item de absynthiis Cloudii Rocurdi. Alontisbeligarli $4593.8 .170 \mathrm{p}$, praef., ind.

ij8 - Historia novi el admirabilis fontis balneiquo Bolleusis in Ducatu Wirtembergico ad acjulas Goepingenses. Montislueligardi 1598.4. s.

gerneanice: a Duxid Forster. Stultgarl 1:39s. to. S.

(Mutato titulo "De aquis inedientis novi nelhodus s jterum pro(ijit dullis 1603.1607 el 1512 . Oua frade multi deerpti duos libros cx uno fecerunt, etsi nihil atiud mutam sit quam editionis anus of titulus. Liber quartus. quem Sprengeluts falso seorsim editum in-

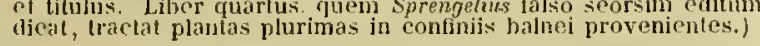

- Johann Heindich Cherler. Historiae plautarum generalis movae et absolutissimae quinquaginta anmis elaboratae jam prelo commissac Prodromus: quo velut in sciagraphia quadam $\%$.

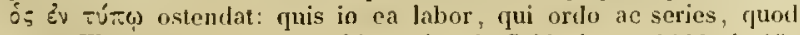
opus. Ebroduni, ex typographia societatis Caldorianae. 1619.4. (5) 12 ' 1 l.

$3899^{*}$ Historia plautarum universalis. Quam recensuit et auxit Dominicus Chabraeus. D. Gener. Juris vero publici fecil Fr. Lud. a Graffenried, Dominus in Gertzensee. elc. Ebroduni (Yverdun) III voll. folio. et (3600) ic. xylogr. i. 1. - I: 1650.601 , 440 p. cl 9 p.iul. - II: 4651.4074 p., ind - III: $4651.212,882 \mathrm{p}$. el 12 p. ind.

¿90 Baumann, Aegidins. Kurzer Lnterrich in der Obstbaumzucht. Ed. III. Bamberg is 13.8. ( $1 / 6$ th.)

591- Baumann, Charles A. et Napoleon. Les Camellia de Bollwiller. (Bollweilerer Camelliensammlung.) IIonographie dédiée à Mr. Ie
Prof. A. P. de Candolle. Bollweiler 4829-1831. II Liyraisons. Lulio (17) p., 25 tab) cal. ( 13 fr.)

Fasciculus lertius operis, quantum scio, nunq̨uam prodiit.

ä92* Baumann, D. Mémoire sur l'utilité de la culture et do la fabrication de la clacorée ent liance. Paris 1818. $8.16 \mathrm{p}$. 0.

$393^{*}$ Baumann, Jakob. Ueber die Cultur der spanischen PfolTerpllanz' und die Anwendung ihrer Fruclite als Pfeffer-Surrogat. Wien ot Triest 1812.8.32 p.

5̈9'. Baumann, Johan Nicoletus. De tabaci virlutibus, usu ot abusu. Basileae 1629. 亿. S.

ə̈9b Baumann, Josua. Miscellanea medico-batanjea. D. Marpurgi 1791. 8. 58 1. B.

$596 \div$ Baumé, Antoine. Mémoire sur les marrons d'lnde. etc. Paris 1797. 8. 1,92 p.

397* Baumgaertner, Florian. Garten-Memorial. Nurnherg 1662. \&.

598 Baumgaertner, Johann Christian. Vollstandige, liebliche und annebmliche Gartenlıst. Nüruberg 1730.8. H.

599 Gartenlust in Gehcinnissen rarer zur Gartnerci gehörigen Kunste. Nurnberg 1732. 8. H.

$600^{*}$ Baumgarten (Pomarius), Johannes. Der hostliche Agtslein inder Burnstein, mit seinem Ursprung, Xatur, Farben, Art, Eigenschaft. liraft und Wirkung, auch seiner geistlichen, allegorischen und geleimen Bedeutung. Hagdelurg typ. Kirehner. 458 7. 12. sign. $\mathrm{A}-\mathrm{O}^{\mathrm{i}}$ et tab. Bibl. Reg. Dresa.

601* Baumgarten, Johann Christian Golllob. Sertun Lipsicum seu stirpes omnes, praeprimis exoticas circa urbem olim maximequr uuperrime plantatas digessil et descripsit secundum mellodum Linneanam. Lipsiac $1790.8 .4 \mathrm{~S}$.

$602^{*}$ _ Flora Lipsiensis sistens plantas in agris circuli Lipsici tam sponte nascentes quam frequentius cultas secundum systrma sexualere visum atque emendatum. Lipsiae 1790.8 .741 p., 4 tab.

$603^{*}$ le corlieis Ulmi eampestris natura, viribus, usulyus medico. D. Lipsiae 1791. 4. 36 p.

$604^{*}$ _. Enumeratio stirpium Magno Transsilvaniae princinatui praeprimis indigenarum, in usum nostratum botanophilorum conscripti in que ardinem sexuali-naturalem concinnata. Vinclobonae 18 16. 111 voll. 8. - 1: xxvn, \{27 p. - II: 392 p. - III: xu, $340 \mathrm{p} .\left(8 \frac{2}{3} \mathrm{th}\right.$.

(Florae Transsilvaniae pars guarla, curante Michaele Fuss. Professore llermannstadtiensi. mos is prelo prodiluit, tribus, uti decreImm est, faseiculis, yuorum primus vegetahilia eryprogama i" si'hedis brati Baumgarten, alter supplenenta priorum volumisum, tertiss indicen totius operis continebit.)

$603^{*}$ Baumgarten in Braitenbach, Martinus a. Peregrinalio in Aeg!jutm, Aralian, Palaestinam et Syriam. Noribergae, typ. Gerlach 1394 . 4. 173 P.

anglice: in Churehills collection of voyages, vol. 1. p. 313-384.

(1100 iter anmo 1507 insitutum interdum cum co bernardi de Breydenbach confinditur.)

606 Bauthor. Manière et façon d'enter; semer et faire pépinieres de meuriers blancs, arec l'utilité et profil d'iceux. Paris 1604. 14. S.

$607+$ Bautier, Alcxandre. Tableau analytique de la Flore Parisienne d'après la méthode adoptée dans la Flore française de La March el DeCandolle, contenant toutes les espices phanérogames de nos entvirons et la description des familles naturelles. ele. Paris 1827.

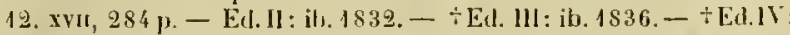
ib. 1839.12 .383 p. $-\div$ Ed. V.revue et augmentée. Paris 1843.12 396 p. $(3$ fr. 50 c.)

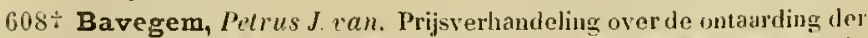
aardappelen; op Kosle der Kasselrije van Audenaerde. Dordrecht 1782. 8. 92 p. (16 stuivers.)

$609 \div-$ Jort Joch noodzahelijh hericht tot het lantvolk, om dw. aerlappels (pataters) in hun waare dengd, geanalheit en vorr 'i Krollen te bevaaren. Dordreclat 17S3. 8.27 1.

Commenlationes harece satis memorahiles antiquissimos testes di Solani tuberosi peruiciosa calanitate, annis $1778-1779$ in helyio observata afferunl. ef Anciennes Ménoir'es de rAcademie de Bruxelles. 1. Ir. p. XXiv. - Dummtier, Notice sur la cloque de la pornme de terre. Bruxelles 184.i. 8. p. 12.)

$610^{*}$ Baxter, William. British phaenogamous Botany; or figures and descriptions of the genera of british flowering plants. Ed. 11. Oxford 1834-43. VI roll. 8.510 foll., ind., 509 tab. col. (5l. $15 s .-$ col. $9 \%$ 
(i) " Bayje, Frangois. Dissertationm physicae ete. Ilagae Comitis 1678. 12. $\$ 08$ P... praef.

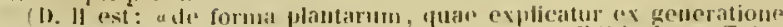

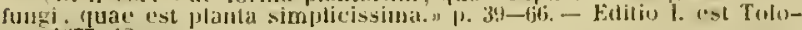
sile lin7. 12

$612 \div$ Bayle-Barelle, finseppe. Tarole analitien-elementari di botanica

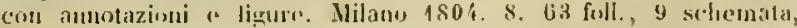
1 lats. folin.

$613^{\circ}$ Descrizjone esatta dei fungli nocisi o sospetti con finure colorate. Milenes 1808. 4. 58 p., 2 tab. eol. Iu textu viginti recensentur labulie. ?

61\%" Monogratia agronomica dei Cereali. Del formento iratt:th diviso in tre parti con sei tavole. Mlilano 1809. s. 209 p., 6 lah

ijli _... Triticorum definitiones atque synonyma. Itini 1812.

(i) li Della malattia della golpe del gran tureo usservazioni rel experinuze. Milaso s. a. 8.21 p., I tab.

617" Bazin, Gilles Augustin. Observations sur les plantes et leur anaJogie avee les insectes, précédées de deux discours, l'un sur l'accroissenant du eorjos humain, l'autre sur la eause pour lapuelle las Lestes nâgent naturellement et aur l'homme est obligé d'en étudier Jes muyeus. Strasluturg $1741.8 .8 \mathrm{vi}, 134 \mathrm{p}$.

germanice: in llimburger Magazin, Bind is und ?

(ilst Beatson, Aleramore. Tracts relative w the islind of St. Helena. written during a resilenec of five sears. Illustrated witl views ("ngraved by Mr. IIm. Duniell, from the drawings of Sumuel Darcis Fisif London 1816. \&. xIx, Lxxxvil, 330 p. et tah (a p. 2913-3:26. Apprendix: An atphahetical list of plants seen by Dr. Roxburgh growing on the Island of St. llelena in 1813-14.

$619 \div$ Beaunier, Stanislas. Precis sur les gretfes, faisant suite au guide des proprietaires et des jardinicrs. Paris 1821. 8. 47 p., 5 tab (1 fr. 75 c.)

620 - Le guile des proprictaires et des jardinier's pour le choix, la plantation el la eulture des arbres. Paris $182 \mathrm{I}$. 8. (3 $\mathrm{fr}$. soc.) a.

621 Beccadill, tiuscppe. Istruzioni sulla nuova manufactura dell olio di Napoli. Napoli 1776. 8. DC.

622* Becher, Johann Joachim. Parnassus medicinalis illustratus, oder ein neves und dergestalt vormalen noch nie gesehenes Thierlirauter-und Berghuch, sampt der Salernischen Scluul. Ulin 1663. folio.

Sumt quatuor parles, quarun allera: Pbytologia, d. i. das hríuterbuch. ib. 1662. fol t32 p. et ie. sylogr. Matitholi et Cancrarii.)

623 Bechstedt, Johann Kaspar. Vollstandiges niedersaclssisches Laudund Gartenbuch. Flensburg $1772-73.3$ Theile. 8. $(21 / 2 / \%$.)

62 - Der Küchengartenbau. Sehleswig 1795. 8. $332 \mathrm{p}$. ( $1 / \mathrm{h}$.)

6ə2: Bechstein, Johan Mathaeus. Kurzgefasste gemeinnützige Naturgeschichte der Gewaelıse des In-und Auslandes. Leipzig 1796. 2 Bande. 8. x, 1316 p., 2 tal.

$6: 6^{*}$ — Taschenblatter der Forstbotaoik. Die in Deutschland einJeimisclien und athlimatisehen Báme, Sträuche und Stauden entlialtend. Zweite selur vermehrte Aullage, bearbeitet von Stephan Behten. Weiouar 1828. 8. v, 32g p. $(1 \%$ th. $)$ - Ed. 1. ib. 1798. 8 .

$627^{*}$ - Forsthotanik oder Naturgesclichte der deutschen Holzgewachse. Erfurt 18 10, 8. - Ed. IV. Gotha 1821. 8. xxrili, $948 \mathrm{p}$. 9 tab. pro parte col. $\left(5 \frac{1}{2} / h\right.$.) - t Fünfte von Furstmeister Prof. St Behlen durchgesehene und vermelurte Ausgabe. Erfurt 18 4 3. 8. xxvit, $88 \&$ p., 11 tab. nigr. el col. $\left(4 \frac{1}{6}\right.$ h. $)$

6.8* Beck, Lewis C. Botany of the northern and milland states, or a description of the plants found in the Lnited-States, north of Virginia, arranget according to the natural system; with a synopsis of the genera acenrling to the linuean sistom, a sheteh of the rudiments of bolany and a glossary of terms. Albany 1833. 8. LV, 471 p.

6\$9 Beck, Michat. Iva magna Canana*'d. D. Jenae 1679.4.26 p. B.

630 Becker, Daniel. De pipere et opio. Regiomonti 1642. 4. Н.

631

Kleine Hausapothek oder Beschreibung von Hollunder uud Wathholder. Konigsberg 1650. 8. - Ed.IV: Leipzig 1685. 8. s.

632. Becker, Hermann Frichich. Ueber hultur, künstliche Bildung und Failung des schiffsbauholzes. Preisschrift. Leipzig 1804. S. xIy 184 p., 1 tab. ( $2 / 10$ th.

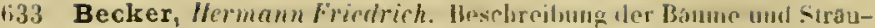
cher, welche in Mechleuburg wild wachsen. Rustuck 1791. s. 87 p. B. - F.d. Il : Leipzig 1805. \$. (T/1) $(\mathrm{h}$.

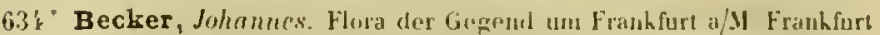
1\$28. S. 2. Ablheilungen. I: Planeroganio. 557 p. - Jl: Kryphegatuic. $813 \mathrm{l}$. - Zweite Ilalfe. Keruschwanume. $111 \mathrm{p} .\left(7^{2 / 3}\right.$ (h.)

633. Becker, Johunn Frieflrich .ldolph. liperimenta cired Imutatiuue.m colorum ynorundan vegetabiliun al corporibus salinis, cum colcollariis. D). Goettingae $1779.4,58 \mathrm{p}$.

631" Becker, Johann Konrat. Lupatorium fraecorum seu Igrimoniar. vires. D). litfordicle 1783. 4. $28 \mathrm{p}$.

637" Becker, Johann Philipp. Chemisthe I'utersuchung ter Pflanzen und deren Salze nebst auderu dahin gehorigen Matorien. I.cipzis 1786. 8. хххи, 286 p.

$638^{*}$ Becker, ITilhelm Gotllieb. Taschenbuch fur Gartronfreunde. 5 Jahrgánge. Lejpziy 1795-1799. S. $\left(6^{2} / 3 \mathrm{l} / \mathrm{r}\right.$.

639 Beckerstedt, Carl Jacob. En Öntrooh, trycht med sine rosor och

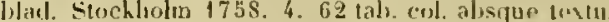

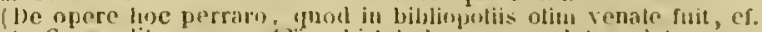
Hikstr. Consp. lit. suec. p. 12,2, ubi tabularun completan dat recensionem.

610* Beckmann, Johann. I, exienn botanicum, exhibens etynolugiam. urthographiam et prosodian nominum botanicorum. Goellingar 1501 . s. v111. 230 p. $(\% / /$..$)$

$6 \%$ " Plysikaliseh-shonmuiselne Bibliothek. Goettingeu 1770 - 1805.23 Bande. $8 .(19 \%(h)$.

$612^{*}$ B___ Beilrage zur Geschichte der Erfindungen. Leipzig 1780 -1786.5 Bánde. $8 .\left(6^{2} / 3 / h\right.$. $)$

$613^{*}$ Literatur der altern Reiselseschreibungen. Gottingen 1808. 2 Biinde. 8. ( $42 / 3$ th.

64." Beckmann, Johamn Christoph. Jlemoranda Francofurtana. Francofurti an Oderam 1676. 4 .

Inest: Culalogus plantarum in tractu Franenfurtano sponte nascentium p. 72 - 80 . - germatice inuction recunus in IIolfgang Jobst, Besehreibung der Stadi Frashfurt. its. 1706. folio.)

$6 \mathrm{HS}^{*}$ - und Bernhard Ludwig Beckmann. Historische Beselıreibung der hur u. Narh Brandenburg. Berlin 1751. Il volJ. folio. (luest Catalogus plantarum Narchiae Bratidenburgieae, a Gleditschu auctus et emendatus.)

646 Beckmann, J. II'. Minnen af lediga stunder. Stuckholm 1824. 8. w. (Spectat ad vitam Linuaci.)

$67^{*}$ Beek, A.van, et Cornelis Adrian Bergsma. Observations thermoidectriques sur l'élevation de temperature des fleurs de Culocasia mora. Cirecht is38. 4. 14 p., 7 tableaus et I tab.

$618+$ Beeldsnijder. Catalogue des plantes, yui se trouvent a Rupelmonde, province d Utrecht (1823.) S. 1 , 29 p. - Continuation: 14 p., 1 tab. Zania Beeldsnijderiana.) - Ed. Il : Iv, 36 p.

649 Been, Joharres Nicolai. Dissertatio evineere contendens, quod spinae et tribuli ante lapsum producti exstiterint. Havniae 1702.4. (s p.) B.

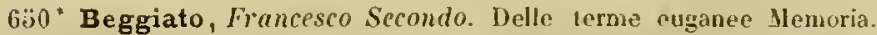
Padova 1533. 8. 72 p. 4 lal). (Ad Algologiam spectat.)

6iif " Per le fuustissime nozze Mainardi-Valvasori: Cenni sopra la nuova specie di gelso delle Filippine. Padova $1836,8,32$ f.

$632 \div$ BeguiJJet, Edme $B$. De principiis regetationis et agriculturac et de eansistriplieis culturae in Burgundia disquisitio physica. Divione et Parisiis 1769. S. a

gallice: per fratrem autoris in fine voluminis ll. libri inseripti: Variétés littéraires de d'Orbessall. Barb.

633 (-) Oenologie ou discours sur la meilleure mithode de faire les vins et de cultiver la vigne. Dijon 1770. 12. a.

634 Dissertation sur l'ergot ou bled cornu. Dijon 17i1. 4 . 31 1).

6ö3 Béheré, Jean Bapliste Josıph. Tableau mélhodique du systime corolliste ne Tournefort. pour servir d'introduction a la botanique. Paris 1802. ur. folin coloumb. 4 foll. ( 3 fr.) a.

(Ejustlem autoris Muscologia Rothonagensis, ou Tableau aualytigue de toutes les mousses deconvertes jusqu id ce jour aux environs de fouen. s. a. 8. 1\% 77-120. nescio c quil collectionc depromta haud raro in bibliothecis botanicis mithi obvia fuit.

$656 \div$ Behlen, Stephan. Klima, Lage und Boden in ihrer Wechselwirkung auf die Waldvegetation. Bamberg $1 \$ 23.8 .66 \mathrm{p} .(1 / 4$ th.) 


\section{BEHLEN}

$657^{*}$ Behlen, Stephan. Der Spessart. Versuch einer Topographie dieser Waldgegend, mit besonderer Rueksieht aul Gebirgs-Forst-Erdund Volkskunde. Leipzig 1823-27. Ill voll. 8. - I: 1823. x, $274 \mathrm{p}$ 1 Karte - II: 1823. vi, 192 p. - III: 1827. vitl, 220 p. (41/2 th. (Die Flora des Spessart im I. Bande n. 78-138.

638

\section{a/M. 1824,8 . (2 th.}

$659^{*}$ - Botanisehes Haudbueh oder Diagnostik der einheimischen und der rorzuglichsten in Deutschland im Freien forthommenden Forstgewachse, mit besondrer Hinweisung aul den Schönbusch bei Aschaffenburg. Bamberg 1824. 8. xvı, 349 p. ( 3 th.)

$660^{*}$ — und F. A. Desberger. Naturgesclichte und Beschrejbung der deutsehen Forstkryptogamen. Erfurt und Gotha 1835 . 8 794 p. $\left(2 \frac{1}{2}\right.$ th. $)$

661 Behr, C. A. L. von und F. Münzel. Das Ganze der Nelkenzuch oder System der Nelke nach der Natur au[gestellt. Leipzig 1810. 2 Theile, 8. 218 p., 24 tab. col., 3 tab. nigr. $\left(3 \frac{1}{2}\right.$ th. $)$

662 Behr, Geory Heinrich. De Carduo benedieto. D. Argentorati 1 738.4.H.

663 Behrens, Georg Henning. Hercynia curiosa, Hartzwald, das ist, sonderbare Beschreibung und Bezeichnung derer euriosen Holenseen, Brunnen, Bergen etc. Nordhausen 1703.4. s.

664" Behrens, Karl Friedrich. Reise durch die Sudlander und um die Welt (1721-1723). Frank furt und Leipzig. 1737. 8. 331 p.,2 tab. B.

$663^{*}$ Beilschmied, Karl Theodor. Pflanzengeographie nach A.v. Humboldis Werke uber die geographisehe Vertheilung der Gewáchse mit Anmerkungen, grösseren Beilagen und andern pflanzengeograploischen Sehriften und einem Exeurse uber die bei pilanzengeographisehen Floren-Vergleichungen nöthigen Rücksichten. Breslau 1831. 8. xul, 201 p., 1 mapp. isogeotherm. $\left(1 \frac{1}{2} t h\right.$.

$666^{*}$ Jahresberichte der Königl. Schwedischen Akademie der Wissenschaften uber die Fortschritte der Botanik in den letzten Jahren vor $1820-1842$ von $J_{o h} . E m$. Wikstrom. Uebersetzt und mit llinweisungen au neuere Arbeiten und mit Registern versehen, von Dr. Karl Theodur Beilschmied. Breslau 1834-1846. 15 Bánde. 8. (I, III-XIV: $14 \frac{2}{3}$ th. $)$

I: (über die letzten Jahre von und bis $1820,1821,1822,1824$. 1838. 239 p. (1 th. $)$

11: (über 1823 u. 1825 ron Joh. Muller.) 1839. Iv, p. $101-$ 228 u. $131-216$.

IH: (uber 1826-1827.) 1839. x, 283 p. (1 $1 / 6$ th.)

IV: (uber 1828) $1 \$ 35$. vil, 128 p. $(7 / 12$ th.)

V: (über 1829) 1834. vil, 102 p. $(5 / 12$ th.)

VI: (uber 1830) 1834. vIII, $166 \mathrm{p} .(2 / 3$ th.)

VIl: (über 1831) 1834. xvi, 200 p. ( $11 / 12 \mathrm{th}$.)

VIII: (uber 1832) 1835. viI, 185 p. $(3 / 4$ th.)

IX: (uber 1833) 1835. x, 223 p. (1 th.)

$X$ : (uber 1834) 1836. xII, 232 p. (1 th.)

$\mathrm{XI}$ : (uber 1835) 1838. xiv, $422 \mathrm{p} .(15 / 12$ th.

XIl: (uber 1836) 1840. vil, $362 \mathrm{p} .\left(1^{3 / 4}\right.$ th. $)$

XIII: (uber 1837) 1841. vul, 435 p. ( 2 th.)

XIV: (uber 1838) 1843.531 p. (2) (h.)

XV: (uber 1839-42) 1845 - $1846.442 \mathrm{p}$., ind.

(Haee ad duetum Annatium botanieorum Aeadentiae scientiarum Holmiensis a llikstromio editorum germanitati donata collectio minime translationem solummodo, immo proprium opus meritissimi Beilschmied sistit. Summa nobis persererantia Repertorium literaturae Reilschmied sistit. Stmma nobis persererantia Repertorinter fontes mei
recentioris paravit, aeque copia sua ac fide insigne, inter for operis haud intimum. Proprio hand exiguo sumtu imprimi omnia voluit vir ingenuus. Recentiores quaedam series (1837 el 1838) editae sunt in Berghaus Annalen der Erdhunde: nuperrima eontinuatio (1839 -1812) cum Flora Ratisbonensi ; omnes seorsim prostant Vratislaviae apud Max et sneios.)

667 Beintema, Johann Ignaz Worp et J. L. W. de Peima. Tabacolugia of verhandeling over le tabak. Ilagae 1690. S. H. germanire: Panacea oder das allgemeine Hulfsmittel des Tabacks. geipzig 1691.12 .

Leipzig 1691 . 12 .

erlaubt. Mit Vurredeng ob dem Frauenzimmer Taback zul rauchen 1713. 8. $\mathrm{\text {H. }}$

668 Bejtbe, Stephan. Füves konyv linveknek, és fáknak nevekröl, természetekröl, és hasznokról, irattatot es szereztetett magyar nyelven à fó Doctorok, és természet tudó Orvosoknak, Dioscoridesnek, és Mathiolusnak bölts lrảsokhỏl. Németh-Ujvàrot 1595. 4.

(Ilujus rarissimi herbarii pannonici autor, theologus helvetieae confessionis, concomitatatus est Clusium per potiores llungariae pro-

Pritzel, Thes. lit. bot vincias et ab eo collaudatur tanquam regetabilimm valde gnarus. Ejus «Stirpium nonenclator pannonieus" in quo eireiter 330 plantarum nomina latino ac humgarico idiomate reeensentur, exstat cun Clusio Antwerpiae 1584. 8 . ( 8 foll.)

669\% Bélanger, Charles. Notice nécrologique sur M. Auguste Dumu. Paris 1832. 8.8 p.

$670^{\circ} \longrightarrow$ et Jean Baptiste M. A. G. Bory de Saint-Vincent. Voyage aux Indes orientales pendant les années 1825-1829. Paris, Arthus Bertrand. s. a. (Botanique. Phanérogamie. 15 tab. in 4. - Vix continuabitur.

671" Belcher, Capt. Sir Edward. Narrative of a voyage round the world, performed in luer Majesty's Slip Sulphur, during the years $1836-1842$, including details of the naval operations in Clina from Dec. 1840 to Nov. 1841. London 1843. Il vall. 8. - 1: xu 387 p., 3 tab. geogr. el 8 tab. - Il: v1, 474 p., 11 tab.

Inest: Kichard Brinsley llinds, The regions of vegetation; teins an analysis of the distribution of veyetable forms over the surface of the tobe in connevion with climate and physical agents. vol. II. p. $320-60$.

Plantae in hoc itinere colleetae a Georgio Rentham describebautur.

672 Belgrove, IVilliam. A treatise upon lusbandry and planting Boston, New England. 1755.4.86 p. B

673 Belidas, Johannes. Tabula simplicium medicamentorum septem linguarum nomenclaturam et facultates continens. Embdae, apud Nic. Biestcauum. 1576.8. Bumald.

674 Bell, George. De physiologia plantarum. "D. Edinburgi 1777. \&. anglice: in Men. of the society of Manchester, vol. II. p. 394-\$19.

$675^{*}$ Bella, Luigi dalla. La coltivazione gli usi ed i vantaggi delle $\mathbf{P a -}$ tate. Verona $1816.8 .32 \mathrm{p}$.

676 Bellamy, IV. Natural history of South Devon. With engravings. London 1840. crown 8. (12s.) w.

$677^{*}$ Bellani, Angelo. Sulle funzioni delle radiei nei vegetabili. Milano 1843. 8. $108 \mathrm{p}$.

$678 \div-$ Delle rotazioni agrarie riflessioni. Pesaro $1843.8 .9 \mathrm{p}$

679 Bellardi, Carlo Antonio Lodovico. (De Mimosa sentiente.) D. Torino 1764.8. H.

$680^{*}$ Osservazione botaniche con un saggio d'appendice alla Flora Pedemontana del medieo Lodovico Bellardi indirizzate al Signor Conte Felice S. Martino sopra aleune piante nominate mella topografia medica di Ciamberi e sua difesa. Torino 1788.8.63 p.

$681^{*}$ Appendix ad Floram Pedemontanam. Angustae Taurinorum 1792. 4. 80 p., 7 tab. col

Ev aetis Taur vol $v$ p. 004 -286. - Omissis tahulis aeneis in Usteri's Annalen. Stuck 13. .)

682 Saggio botanico georgico intorno l'ibridismo delle piante. e tre nuove razze di fromento ottemute mediante arteficiale spuria fecondazione. Milano 1809.8. et tab. H. v. D.

$683+$ Bellenghi, Filippo. Processo sulle tinte che si estragono dai legni ed altre piante indigene. Ancona 1811 . 4. (28) $80 \mathrm{p}$.

684* Bellermann, Johann Barlhotomaeus. Abbildungen zum Kabinet der vorzuglichsten in-und auslandischen Holzarten nebst deren Besehreibung. Erfurt 1788. folio. 60 Blătter Text und 60 ill. Taf. (Dazu gehoren ' 2 Kástehen mit 60 Stuck Holzarten.)

685 Bellery. Dissertation sur la tourbe de Picardie. Paris et Amiens 1754. 12. a.

686 Mémeire sur la tourbe de Pieardie. Paris 1795. 8. a. (Exirait du tome I1. du Journal des Mnes.)

687t Belleval, Chevalier de.) Beautés méridionales de la Flore de Montpellier, par un ancien herboriste de cette ville. Nontpellier 1826.8. $194 \mathrm{p}$

(Autoris nomen, quod liber tacel, indicat Querard, Frauce lit. I. 263. et nota manuscripta Delitii in Bibl. Delessert. - Richerium Bellevil atavum gloriatur autor.

688+ Belleval, Pierre Richer de. Onomatologia seu nomenclatura stirpium, quae in horte regio Nonspeliersi recens consiructo coluntur, Richerio de Belleval, medico regio, anatomicu et botanico Professore imperante. Nonspelii, apud Joannem Giletum. 1598. 12. (39 foll.) Bibt. Juss.

$689^{*}$ Dessein touchant la recerche des plantes du pays de Langueduc, desdié à Messieurs les gens des treis estatz dudit pay's. Montpellier, par fillet. 1605.8 . 8 p., 5 tab. Bibl. Reg. Berol.

690 - Remontrance et supplieation au Roy Henry IV touchant la continuation de la recherche des plantes de Languedoc et peuplement de son jardin de Montpellier. 4. cum 3 fig. plant. s. 
691. Belleval, Pierre licher de. Opuscules, auxquels un a joint un traite d'Olivier de Serres. Nouvelle édition d'après les exemplaires de Ja billiothèque du roi par $P$. M. A. Broussonet. Paris 1785. 8. 8, $38,4,8$ p., 5 [al).

(Sunl libelli tres supra recensiti reinpressi. - Ejusden tabulae posthumae 260, jaut Tournefortio dietac (Voyage II. 297.) partim a (rilibert edit: sunt; ineditas vero yij vidi in Bibliotheca Hadriani de Jussieu.)

692 - Bellucci, Toma. Plantarum index lorti Pisani. Flurentide 1662. 12. $64 \mathrm{p}$.

$693^{*}$ Bellus, Honorius. Epistolac ejus de rarioribus quibusdam plantis creticis, Aegyjtiis novis, ab anno $1594-1598$ datae exstant in Clusii historia plantarum p. 297-314. - Nonnullae ejusdem stirpes insignes in Creta observatae, additae sunt secundae editioni Joannis Ponae Plant. montis Baldi, Basileae 1608. 4, nec non in Raji Stirpium europaearum Sylloge. (Spreng. Hlist. I. 386.)

69:" Belon, Piorre (latine Belonius v. Bellonius Cenomanus). De arboribus coniferis, resiniferis, aliis quoque nonullis sempiterna fronde virentibus, cum earundem iconibus ad vivum expressis. etc. Parisiis 1553. 4. (8) 32 foll., ic. xylogr. i. t.

$695^{*}$ __ Les observations de plusieurs singularités trouvées en Grèce, Asie, Judée, Egypte, Arabie. Pdris, Cavellat. 1554.3 voll. 4. - * Ed. II: Anvers 1555. 8. - tParis 1588.4. (24) 468 p.

latine: per Clusium: Plurinarum singularium et menorabiljum rerum in Giraceia etc. Antwerpiae 1589. 8." 495 p. - "Lugd. 1609, folio. - et in Exolicis Clusit.

$696^{*}$ Les remonstrances sur le default du labour et culture des plantes et de la cognoissance d'icelles contenant la manière d'affranchir et apprivoisir les arbres sauvages. Paris 1558. 8. 80 foll * latine: De neglecta stirpium cultura atque earum cognitione libellus, edocens qua ratione silvestres arbores cicurari et mitescere queunt; latine per $c_{i .}$ Clusium inpr. c. ejus versione latina observationum Rellonii. Antwerpiao 1589. 8. 87 p. et in Exoticis Clusii l]. p. $209-2 \div 2$.

697* Portraits d'oyseaux, animaux, serpens, herbes, arbres, lommes et femmes d'Arabie el d'Egyple. Paris 1557. 4. - Paris 1618.4.

698 Below, Jakol Fredrik. De vegetabilibus in genere. D. Londini Gotherum 1700.4.25 p. B.

699 Belus, Lucianus. Quaestio de Ruabarbaro. Bononiae 1533. 4. s. (Exstat ctiam cum commentario A. M. Belli in Avicennam. Bonnniae 1560 . folio.)

$700^{*}$ Bemich, Friedrich Euslach. Geschichte der Anwendung der Belladonna in der Medizin. D. Würzburg 1831. 8. $75 \mathrm{p}$.

$701+$ Bender, Christoph Bernhard. Gleeoma hederacea L. egregium in atrophia medicamentum. D. Erlangae 1787. 4. $32 \mathrm{p}$. et epimetrum.

702 Benekendorff, Karl Friedrich. Abhandlung von Baumschulen, deren Anlegung und Wartung. Berlin 1776. 8. 132 p. - ib. 1792. 8. $(1 / 6, h$. $)$ $703 \frac{1}{1792.8 .(1 / 6 / h .)}$ Abhandlung von Anlegung eines Obstgartens. Berlin

70: * Benedetti, Alexander (Iatine Benedictus). De re medica opus insigne. Basileae 15/9. Folio, 623 p., praef, ind

(Pauca intermivta sunt de simplicibus remediis.)

T05 (Benemann, Johann Christian.) Gedanken uber das Reich derer Blumen. Dresden und Leipzig. 1740.8.480 p. B.

$706^{\circ} \longrightarrow$ Die Tulpe zum Ruhm ihres Schopfers und Vergnïgung edler Gemüther beschriehen. Dresdell und Leipzig 1741. 8. $\geq 76$ p., praef.

707 (-) Die Rose, zum Ruhm ihres Schopfers und Vergnügung edler Gemuther beschrieben. Leipzig 1742. 8. 223 p. B.

$708^{*}$ Benkö, Joseph. Transsylvania. etc. Vindobonae 1778. Il voll. 8. (In tom. I. p. $102-126$ de regno vegetahili disseritur, et Florae suae Transsilvauo-Siculae mox edendae memisit autor.)

709* Bennet, John J. Plantae javanicae rariores descriptae iconibusque illustratae, quas in insula Java annis 1802-1818 legit et investigavit Thomas Horsfield. E) siccis descriptiones et characteres plurimarum elaboravit John J. Bennè ; observationes structuran et affuitates praescrtin respicientes passim adjecit Robertus Brown. Londini 1838-1844. Colio. - Part 1: 1838, vui, 104 p., tub. col. 125. (3l. 10.s.) - Part Il: 1840. p. $105-196$, tab. col. $26-$ 40. (2). 10s.) - Part III: 1844. p. 197-238., tab. col. $41-45$. (1l. I.s.)
710 Bennet, Stephan. Berattelse om Lins planterande och tilberedning. Stockholn 1738.4, 40 Joll. B.

711" Bennett, Frederich Debell. Narrative of a whaling voyage round the globe from the year 1833-1836. etc. Lorrdon 1840.8. - I: xv, 402 p., 2 tab, - II: vII, 395 p., 1 tal,

a pag. $327-395$ : Botany, a descriptive catalogue of the plants collected during the Tuscan's voyace.

7.12* Bennett, Georye. Wanderings in New South Wales, Batavia, Pedirconst, Singapore and China; being the Journal of a naturalist in those countries, during 1832, 1833 and 1834. London 1844. Il voll. 8. - I: xv, 440 p., I tab. - II: vII, 428 I., I tab. (1l. $8 \mathrm{~s}$.)

713 Benoit. Botanist's Companion. 1838. 32. (1 $1 / 2 s$.) w.

ilik (Benoit, Madame.) Herbier élémentaire ou recueil des gravures au trait onbré, contenant la collection complete des plantes utiles, agréables et nsuclles, „jui croissent sans nueune culture aux environs de Paris. etc. Paris $181 \mathrm{I}$. folio. $1^{\text {re }}$ livraison. Sch.

715* Bentham, George. Catalugue des plantes indigènes des Pỵrenes et du bas-Languedoc avec des notes et ulsscrvations sur les espèces nouvelles on peu connues; précélé d'une notice snr un vuyage botánique fait dans les Pyrénées pendant l'été de 1825 . Paris 1826. 8. $128 \mathrm{p} .(3 \mathrm{fr}$.)

$716^{*}$ Report (I \& II) on some of the more remarkable hardy ornamental plauts raised in the Horticultural Society's Garden from seeds reecived from Mr. David Douglas in the years 1831, 1832, 1833. London 1834, 4, 13,8 p., 3 tab. col

(From the Horticultural Transactions.)

$117^{*}$ __ Scrophularineae indicae. A synopsis of the East Indian Scrophularineae contained in the collectiuns presented by the East India Company to the Linnean Society of London, and in those of Mr. Royle and others; with some general observations on the alfinities and subdivions of the order. London $1835.8 .57 \mathrm{p}$.

$718^{*}-$ Scrophularinearum revisio. $8.6 \mathrm{p}$

(From the Botanical Register, June 183\%.)

$719^{*}$ Labiatarum genera et species: or, a descriplion of the genera and species of plants of the order Labiatae; with their general history, characters, affinities and geographical distribution Loudon $1832-1836$. 8. Lxvili, 783 p., et charta.

$720^{*}$ - Commentationes de Leguminosarum generibus. Vindobonae 1837.4 max. $78 \mathrm{p}$, prael., ind.

(Annaler des Wiener Museums, 2. Theil.)

$721^{*}$ Plantas Hartwegianas imprimis mexicanas adjectis nonnullis Grahamianis enumerat novasque describil. Londini 1839 1846.8.283 p. (continuantur.)

$722 \div$ - The Butany of the Voyage of H. M. S. Sulphur, under the command of Captain Sir Edward Belcher, during the years 1836 -1842. Published under the authority of the Lords Commissioners of the Ardmirality. Edited and superintended by Richard Brinsley Hinds, attached to the expedition. The botanical descriptions by George Bentham. London 18 4. 4. VI fasc. 195 p., 60 tab. (3l. 3s.)

$723+$ Bérard. Mémoire sur la maturation des Iruits, couronné par l'Académie des sciences. Paris. $8.58 \mathrm{p}$.

(Extrait des Anmales de chimic et de physique.)

724 Berch, Anders. Nätra sokns Lin-säde i Augermanland. D. Upsala 1753. 8. 33 p., I tab. B.

720̈ Berchoire, Pierre (v. Berchore, Bercheur, Bercheure). Reductorii moralis libri IIV perfectam officiorum atque morum ralionem ac pene totan naturae complectentes historiam; usiquan hactenus excusi gentium. Daventriae 1477. fulio, et postea pluries. s

(De plantis agit in libris Xll el .ilv.)

726 " Berchtold, Friedrich Graf von, und J. Swalopluk Presl. o Prirozenosti Rostlin, aneb) Rostlinár. etc. IV Praze 1820, 4. 322 p.

$797^{*}$ __ Die Kartoffeln (Solanum tuberosum Casp. Bauh.), deren Geschichte, Charahteristik, Nützlichkeit, Schädlichkeit, Kultur, Kranklieiten etc. Nit ausfuhrlichen Angaben ihrer industriellen Verwendung. Monographisch bearbeitet nach Jassnüger, Plaff, Viborg, Putsche, Bertuch etc. und eignen Ansichten. Prag 1819. 8. xi!, 573 p., 2 tab. $(1 \% / 12$ th. $)$

$728^{*}$ — Oekonomisch-teclinische Flora Bohmens nach einem ausgedehnteren Plane bearbeitet, oder systematische Besclureibung der in Bölmen wildwachsenden und kultixirten Gewachse mit genauer Angabe jlırer Nützlichkeit und Schâdlichkeit, ilırer. Inwendıng und Belıandlung in Künsten, Gewerben, Land-Forst-und Ilaus- 
wirtlschaft. In okonomisch-technischer Hinsicht von F. Grafen von Berchtold, in hotanischer von $11^{\circ}$. B. Seidl, P. M. Opiz, Franz Yaver Fieber. Prag 1836-1841. III voll. 8, - I: 1836. xv, 508 p. - II: 1838-39.297, 275 p, - 111: 1841. p. 279-542. (continuatur.)

$729^{*}$ Berens, Reinhold. De Dracone arbore Clusii. 1). Goetlingae 1770. 4. 52 p., 1 tab.

Hic noster, quum postea in Rossia commoraretur, Reinhold von Belirens audiebat; cf. Trautvetter Grundriss p. 16 et 112.

$730^{*}$ Berg, Alexander. Anleitung zur Erkennung der in der Arzneikunde gebrauchlichen phanerogamen Gewachse ete. Berlin 1832 8. vi, $169 \mathrm{p} .(1 \mathrm{th}$.)

$731^{*}$ Berg, Ernstvon. Die Biologie der Zwiebelgewáchse oder Versuch, die merhwürdigsten Erscheinungen in dem Leben der Zwiebelpllanzen zu erkliren. Neustrelitz u. Neulrandenburg 1837.8.117 p. $(7 / 12$ th.

732* — Vollständiger Bericht uber einige bei verschiednen Pflanzeo beobachtete Ausartungen mit Erklärungsversuchen. Neubrandenhurg 1843.4 .24 p., t tab. (1/t th.)

$733^{*}$ Berg, Julius. De Angusturae cortice spurio. D. Vratislaviae 1844. 8. $29 \mathrm{p}$.

$734^{*}$ Berg, Otlo. Handbuch der pharmaceutischen Betanik fur Pharmaceuten uml Mediziner. Berlin 1845. 8. YIII, $437 \mathrm{p}$.

$735^{*}$ Charakteristik der fur die Arzueikunde und Technik wichtigsten Pflanzengenera in llustrationen nebst erláuterndem Texte nach seinem Handbuche der pharmaceutischen Botanik geordnet. Mit einem Vorworte von Dr. II. F. Link. Berlin 1845. 4. 4 Lieferungen: vil, 40 p., 32 tab. ( 2 th.) (continuatur.)

$736^{*}$ Bergamaschi, Giuseppe. Gita botanica agli Appennini boglelio e lesime. Pavia 1823. 4. $14 \mathrm{p}$.

$737^{\circ}$ Lettera seconda sopre varie piante degli Apennini etc. Pavin $1823.4 .29 \mathrm{p}$.

738 † $^{\circ}$ Berge, Fr. und Dr. V. A. Riecke. Giftpflanzenbuch oder allgemeine und besondre Naturgeschichte sammtlicher inlandischen so wie der wichtigsten ausländischen phanerogamischen Gewáchse, mit treuen Abbildungen sämmtlicher iulandisclıen und vieler auslandischen Gattungen. Stuttgart 1845, 4. xı, 329 p., 72 tab. col. $(6$ th. $)$

$739^{*}$ Bergen, Heinrich von. Versuch einer Monographie der China. (Hit 8 Kupfern in folio, 10 Tabellen.) Hamburg 1826. 4. x1, 348 p., $8 \mathrm{tab} . \mathrm{col}$. in folio. $(18 \mathrm{th}$.)

$7 \% 0^{*}$ Bergen, Karl August von. Propempticon inaugurale, quo breviter disquirit, utri systematum an Tournefortiano an Linneano potiores partes deferendae sint? (Francofurti a/V. 1749.) 4. 16 p. - Ed. Il: Lipsiae 1742. 4.

$741^{*}$ Catalogus stirpium indigenarum aeque ac exterarum quas hortus medicus Academiae Viadrinae complectitur. etc. Francofurti a/V. 1744. 8. 120 p., praef.

$742^{*}$ Epistola de Alchimilla supina ejusque coccis. Francofurti a/V. 1748.4. 16 p.

(Jam antea in Comm. lit. Nor. 1739 hunc scopum tetigit.)

$743^{*}$ - Flora Francofurtana mothodo facili elaborata; accedunt cogitata de studio botanices methodice et quidem proprio Marte addiscendae, terminorum teclnicorum nomenclator et necessarii indices. Francofurti a/V. 1750, 8. 375 p., praef., ind.

$744^{*}$ De Aleide. D. Francofurti a/V. 1753.4. 22 p., 1 tab.

$745^{*}-$ De Petasitide. D. Francofurti a/V. 1759. 4. 34 p.

$746+$ Berger, Claudius. An ex tabaci usu frequenti vitae summa brevior? D. Paris 1699.4. 8 p.

747 Berger, Christian Gotllieb. Taschenbuch für Blumenfreunde. Leipzig 1802. 2 Bande. 8. - Ed. Il. ancta: Leipzig 1805. 8. 400 p. ( 2 th.)

748t - Ideal eines Prachtgartens im Kleinen. Ein Beitrag zur ásthetischen Pflanzkunst. Posen und Leipzig 4803. 8. xvı, 272 p. Ed. Il. ib. 1810.8 . (1 th.)

749 Ausfulurliche Anweisung zur richtigen Aussprache der lateinischen Pflanzennamen. Leipzig 1804. 8. $(7 / 2, t h$.) (Extraabdruch aus dem Taschenbuch, Theil 2.)

750* Berger, Ernsı. Catalogus IIerbarii, oder vollstándige Aufzăhlung der phanerogamischen und kryptogamischen Gewachse Deutsch- lands. Nach Koch's Synopsis und Wallroth's Compendiun Fl. germ. crypt., Bruch und Schimper, Nees v. Esenbeck, link und Fries nebst Aufzálılung der bis jetzt bekannten ausländischen Pflanzen. Den Besitzern deutscher Herbarien zur Bequemlichkeit dargeboten Wurzhurg 1841-1846. 4 Theile. 12. - I: die dentschen Phanerogrmen enthaltend. 1841. vIII, 123 p. - 11 : Synonymik und Synonymenregister zum 1. Theile. 1843. vin, 238 p. - III: Die deutselıen Kryptogamen. 1846. 192 p. - 1Y: Synonymik und Synonymenregister zum 3. Theile (Kiryptogamen.) 1843. 194 p. (22/30 th.

$751+$ Berger, Friedrich Christian. Ilandbuch der Pflanzenkenntnis. fur Oekonomen, Gartenliebhaber, Forstleute etc. Leipzig 1801. 8 446 ]. $(12 / 3$ th. $)$

752 Berger, II. A. C. Versteinerungen der Pllanzen und Fische im Coburger Sandstein. Coburg 1832. 4. 29 p.. 4 tab.

$753^{*}$ Berger, Johann Ciottried, pr. De Chinchina ab) iniquis judiciis vindicata. D. Wittenbergae 1711.4.44 p.

754" — pr. De vi opii calefacienti. D. Wittenlsergae 1703.4

7ตร * Berger, J. G. Immortellen - oder Immerschönen-Taschenbuch fur die Entdeckungsjahre 1805-1816. Leipzig 18 17. 12. 174 p., (tal). col. $(1 t h$.

756 Berger, Samuel. Von der Páonienwurzel. Frankfurt 1599. н. (Seguiero Simon Berger audit.)

$757+$ Bergeret, $J$. Flore des Basses-Pyrénées ou description de toutes les plantes qui croissent naturellement qui sont ou qui pourraient ctre cultivées avantageusement dans le département des BassesPyrénées. Pau an XI. (1803.) 11 voll. 8. - I: CLxxy, 195 p. - I1: $416 \mathrm{p}$. (Desinit in fine Polyandriac.)

(Autor, teste Querard, a sequenti diversus.)

$75 S^{*}$ Bergeret (J.P.). Phytonomatotechnie universelle, c'est à dire, l'art de donner aux plantes des noms tirés de leurs charactères; nouveau systeme au moyen duquel on peut de soi-meme, sans le secours d'aucun live, nommer toutes les plantes qui croissent sur la surface de notre globe. Paris 1783 - 1784. Ill voll. folio. 240 , 252,176 p., 328 tab. col.

(in Vol. 111: Cruciferes francaises.

Opus incompletum; prodili 27 fasciculis, teste Candollio jam annis $1773-1775$ editis; fasciculi inscripti sunt 1-28; vigesimus primus semper deest. Pretium fisciculi tahulis nigris \& fr. 50 c. - tab. col. $9 \mathrm{fr}$; t tab. col in eharta holl. $18 \mathrm{fr}$. Ilujus editionis completa cellectio 80 'fi. L'hérilier.)

759 Berggren, J. Resor uti Europa och Österländerne. Stockholm 1826 -1828 . 11 voll. 8 .

(Bihang I. voluminis secundi : Vảst-forteckning. Vaxter i Österländerne amlade uf J. Berggren; och nogare bestanidit af $G$. Wahlenbera. $70 \mathrm{p}$. De hac appendice Wahlbergii fusius agit Wikström Jahresber. v. Beilschmied. 1827. D. 200-207. - 1828. p. 105-107.)

* germanice: Reisen in Enropa und im Morgenlande. A. d. Schwe dischanice: Reisen in Emropa und im Morgenlante. A. d. Schwedischen von Ungewitter. Leipzig und Darmstadt 1833 . 3 Theile. 8.- I $396 \mathrm{p} ., 1$ Karte - II : $410 \mathrm{p}$., 2 Karten. - II : $2 \mathrm{k}$. p. (Appendix botanica
Wahlenhergii in hac traductione desideratur.) (herahgesetzt auf $3 t$.)

760 Berghes, C. de. Albbildung súmmtlicher Holzpflanzen, welche in den Forstel des mittleren Europa vorkommen. Herausgegeben als Anhang zu Hartig's Forst-Lehrbuch. Erstes Ileft. Köln 1825. 8, 12 tab. col. (Continuatio haud prodiit.)

761 Bergius, Bengl. Tal om svenska angskötseln och dess frămjande genom lónande grásélag. Stockholın 1769.8. 94 p. - Ed. nova: Stockholm 1827.8. W.

$762^{*}$ — Tal am Làckerheter, báde i sig sjelfva sådana, och for sådana ansedda genom Folkslags bruk oclı iubildning. Förra Delen. Stockholm 1785, 8. 272 p.

(Pars prior hujus libri : cujus indicem edidit Blom, est de vegetabilibus; pars posterior, ib. 1788. 8.328 p. ab Odnanno edita, prae-

cipue do animalibus.) Forster und Kurl Sprengel. Halle 1792. 2 Theile. 8.

763 Bergius, Peter Jonas. Rón om spannemåls-bristens ársăttjande medelst Quickrot. Stockholm 1757. 4. 11 p. B.

764* Descriptienes plantarum ex capite bonae spei cum differentiis specificis, nominibus trivialibus et synonymis auctorum justis. Secundum systema sexuale ex autopsia concinnavit atque sollicite digessit. Stockholmiae 1767. 8, 360 p., praef, ind. et 5 tab.

$765+$ Nateria medica e regno vegetabili, sistens simplicia officinalia pariter atque culinaria. Stockholmiae 1778. Il voll. 8. 908 p. B. - +Ed. II. correctior. Stockholmide 1782. II voll. 8. xIv, $972 \mathrm{p}$. 
$766^{*}$ Bergius, leter Jonas. Tal on frukt trảgảnlor. Stockholm 1780. 8. $1.18 \mathrm{p}$. germanice: 1.ejpzing $179 \% .8$.

i6it Bergsma, Cornelis Adrian. De Thea. D. Trajecti ad lkhenum 18.5. 8. 52 13. (Sequitur Catalogus chronologicns autorum, qui de llera seripserunt: $50 \mathrm{p}$.)

$768^{*} \longrightarrow$ De andappel epidemio in Nederland in den jare 1845 Utrecht 1845.8 .39 1).

769: Beringer, Johann Bartholomaeus Adam, et Lorenz Anton Dercum. I'lantarum quarundam exoticarmm pereunimm in horto medico Herlsipolensi anto 1721 noviter erecto reperiunlarum Catalogus pro anno 1722. folio. $12 \mathrm{p}$.

$770^{*}$ Berkeley, M. J. Gleanings of British Algac; being an appendix to the supplement to English Botany. London 1833. 8. 50 p. with notice, inl., 20 tab. col. 7i) * $\frac{}{\text { (1s. })}$ British Flora. Fungi. Lonlon 1836. 8. 32, 386, xv p.

(Ilon mornii mycolagi opus scortim non proulit; sistit enim partem afterum voluminis sicundi libri inseripti: "Ilooker, Brifish Fora

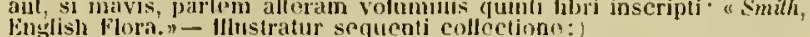

$772 \div-$ British Fungi: consisling of dried specimens of the species describer in vol. V. part Il. of the English Flora; together with such as may hereafter be discovered indigenons to Britain. London 1836-1843.4. - Fasc. 1: 1836. specics 1-60. - Fasc. II: 1836. species $61-120$. - Fasc. III : 1837. specics 121-240. - Fasc. IV 1843. species 241-350. (In herlbario Hontagne.)

773 - Observations botanieal and physiological on the Potato Murrain. (King's Clifle, Nov. 22. 1845.) 8. 28 p., 4 tab.

(From the Journal of the Horticultural Society, vol. 1. part. 1.)

7it Berkenhout, John. Clavis anglica linguae botanicae or a botanical Lexicon, in which the terms of botany are applied, derived, explained, constructed and exemplified. London 1761. 8. 28 plagg. dimicl. $B$.

$773^{*}-$ Outlines of the natural history of Great Britain and Ireland. London 1770. 8. - Ed. 11: London 1789. 8

vol. 11. 380 p. continet: The vegetabte kingdom.)

$776^{*}$ (Berkenkamp, W. A.). Catalogus plantarum herti botanici Coloniensis. Coloniac Agrijpinac, typ. Thiriart. 1816. 8. 130 p., ind (lompressor Thiriarl jam anno 1806 catalogun) horti Coloniensis ipse curaverat.)

777 " Berkhey, Johann le Franeq van. Expositio cliaracteristica structurae llorum qui dicumtur Compositi cum figuris al naturam expressis. Lugd. Batavorum 1761. 4. 15.1 p., pracf., 9 tab. (sign. 1-8.) (Exempia anni 1760 practer titulum haud differunt.)

7 78 $\div$ Berlandier, Jean Louis. Mémoire sur la famille des Grossulariées. Geuève 1828, 4. p. 43-60, 3 tab.

(Mem. He la societé de physique et d'histoire naturelle de Geneve, vol. III. 1836.

IIdem autor elaboravil Grossularieas in DC. Prodr. 1II. p. 477-483.

$779 \div$ Berlèse, Laurent. Iconngraphie du genre Canellia ou Collection des Camellia les plus beaux et les plus rares peints d'après nature dans les serres te Nr. l'tblue Berlése par $J$. J. Jung, avec la description exacte do chaque fleur, accompaynée d'obscrvations pratiques sur la culture de cetle plante et des soins, qu'elle exige pour lleurir aboudamment. Paris 1839 . suiv. folio.

780 - Mlonoguliphie du geure Camellia et traite conplet de sa culture, sa deseription et sa classification. Ed. II: Paris 1840.8. avec planches. ( $5 \mathrm{fr}$.)

germanice: Ueber Camellien oder Versuch uber die Cultur und fratungen terselben. Mit tumerhungen. Berlin 1838. 8. vi1, 210 p. $(1 \mathrm{~h}$.

Cultur und Beschreibung der schensten his jetzt hehannten Camelien ete. feutsch von G. P. v. Geminden. Weissenseo 1838 . 8 . VI11, 128 p., 3 lab. ( $\left.t / h_{0}\right)$ - Nachtrag ib. $18 \% 1.8 .\left(3 / 4 h_{0}\right)$

1838. 8. vi1, $107 \mathrm{p})(3 / \mathrm{s}$, $)$ W. Cultur der Camellia elc. Quedlinburg

* Berlu, John Jacob. The treasury of drugs unlockd. London 1693 12. - Ed. Il: London 1724, 12. 166 p. - Ed. III : London 1733. 12. Bibl. Goett.

$782 \div$ Bernard. Promier mémoire sur l'Amandier, qui a romporté le prix au jugement de l'Académie en $1777.4 \mathrm{~min}$. $115 \mathrm{p}$.

783 - Némoires pour servir à l'histoire naturelle de la Provence. Paris 1787-1788. Il voll. gr. 12. - 1: 1787. (Mémoire sur le figuier, sur la folle aroine et le caprier.) 362 p., ind., 2 tab. - II : 1788. (Nèmoire sur l'Olivier.) 559,7 p., 3 tab. istt Bernard, Pierre Fredirie B., de Moutbeliard.) Tableau de la l'Iore lu Jura et de l'ancienne Franche-Comté, des Vosges et de l'ancieune Alsace. Strisslurg (1823), 8, $10 \mathrm{p}$.

78:3" Bernard, P., L. Couailhac, Gervais et Emmanuel Lemaout. le jartin des plantes, description complete, historigne ot pittoresijue du Museum d'histoire naturelle, de la nemagerie, des serres, des galeries de mintralogie at d'andtonie ot do la vallée suisse. Paris 1842. gr. 8. xx/v, 416 p., 133 tals. (Botanique: p. $159-286$. par Emm. Lemaout.) - Deniène partic. ib. 1843. 8. 664 p. et planches.

$786 \div$ Bernhard, Martin. Catalegus plantarun tum exoticarum quam indigenarum, quae annu 1651 in hortis regiis Varsaviae, el circa eandem in locis sylvaticis, pratensiluns, arrnosis et paludosis ndscuntur, collectarum. Dautisci 1652. 12.80 p., praef. - " Ilufniac 1653 cum viridariis S. Pauli

$787+$ Bernhardi, Johann Jakob. Catalogus plantarun horti Erfurtensis. 1799. 8. 16 p. - Supplementum l-YI. $1801-1808.14$ p.

$788^{*}$ __ Systematisches Verzeichusss der Pflanzen, welche in der Gegend um Erfurt gefunden werden. Eister Theil. Eirfurt 1800. 8. xxvis, 346 p. $(1 / h$. $)$

$789^{*} \longrightarrow$ Lichenum gelatinosorum illustratio. (Schrader's Journ. 1. Stuck. p. $1-17$.

$790^{*}$ Ueber Asplenium und einige ihm rerwandte Gattungen der Farrenkianter. Erfurt 1802.8. 18 1), 1 tab.

$791^{*}$ Auleitung zur Kenntniss der Pllanzen, zum frebrauch bei Vorlesungen. (Ilandluch der Botanik.) Erster Band. Erfurt 1804. 8 VIII, 410,40 p., 5 tab. $(12 / 3$ th. $)$

$792^{*}$ —_ Beobachtungen uher Pflanzengelasse und cine nove Art derselhen. Erfurt $1805.8 .11,82$ p., 2 tab. $(7 / 12$ h. $)$

$793^{*}$ _- Ueber cinige minder bekannte Ehreupreisarten des sudliclien Deutsclılands. Erfurt 1806. 8. 43 P., 1 tal).

$79 \xi^{*}$ Ueber den Begriff der Planzenart und seine Anwendung. Firlurt 1834. 4. vill, $68 \mathrm{p} .(2 / 3, \mathrm{~h}$. $)$

(Bernhardi est editor Ephemeridum, quibus titulus: aThuringischo Gartenzeiturg" et "Allemeines deutsches Gartenmagazin ", cujus VIII voll. ab auno 1815-182k curavit.)

795 Bernouilli, Daniel. Positiones anatomico-botanicac. Basileae 1721. 4. H.

796 Berreau, Pierre, et J. Ben. Winslow. Cerealia et olera agri Parisiensis salulıria. Paris 1703. 4. н.

797* Berryat, Jean. Recueil de Némoires ou Collection de pieces acadèmiques. Dijon 1754-1779. XVII voll. 4.

$98^{*}$ Berta, Tommaso Luigi. leonografia di scheletri di diverse foglic indigene ed esotiche preparati ed impressi. Parma 1828, 4. i, 4 p., 50 tal.

$799^{*}$ Nemoria sull' anatomia delle foglie delle piante. Parma 1829.4. $15 \mathrm{p}$

$800^{*}$ Iconografia del sistema vascolare delle foglie messo a nudo ed impresso. Parma 1830.4 . 15, $117 \mathrm{p} ., 60$ tab.

In initio hujus operis redit: "Memoria sull anatonia delle foglie," anno praecedenti pubici juris facta.)

801 Bertani, Pellegrino. Osservazioni intorno al Dizinnario dell Tinelli, coll' agiunta in fine di quattro tavole. Mantova 1809.8. H. v. D.

$802^{*}-$ Nuovo Dizionario di Rotanica. Nantova Ill roll. $s,-$ I: 1817. A-E. VII, 3 14 p. - II: 1817. F- N. 451 p. - III: 1818 $\mathrm{N}-\mathrm{Z} .336 \mathrm{p}$.

$803+$ Bertero, Carlo Giuseppe. Specimen medicum nonmullas indigenas stirpes continens exoticis succedaneas. D. Taurini $1811.4 .36 \mathrm{p}$.

80 t Berthelot, Sabin. Coup d'ocil sur les forets canaricnnes, sur leurs changements et leurs alternances. Paris 1836. folio. 75 p., 7 tah.

(Eaisant partie de l'uistoire naturelle des lles Canaries par liebs et Berthelot.)

$805+-$ Observations sur l'accroissement et la longévité de plusieurs espèces d'arbres des envirens de Nice. Genève 1832. 8 . $38 \mathrm{p}$.

806* Berthold, Adolph Ileinrich. De seminis Phellandrii aquatici virtutibus medicis eum ejus annalysi chemica. D. Halae 1818.8. 44 p.

$807^{*}$ Bertholdi, Ifermann. Der Pflanzensammler oder vollstăndige Anweisung, ein Herbarium anzulegen, nebst einer spezielleren Vebersicht von den vorzijglichst anerkannten Pflanzensystemen. Berliu 1840. 12. v, 433 p., 4 Tabellen. $(2 / 3$ th. $)$ 
\$08* Bertholon. De l'électricité des végétaux, omrage dans lequel on traite de l'électricité de l'atmosphere sur les plantes, de ses effets sur l'économie des végétaux, de leurs vertus medico et nutritivo électriques, et principalement des moyens de pralique de l'appliquer utilement à l'agriculturc, avec l'invention d'un électro-végétometre. Paris et Ixon 1783. 8 . xvi, 468 p., 3 tab.

germanice: Leipzig 1783. 8

809t Bertin, Exuperius Joseph. An potus ex foliis The ad sannrem didetam apud nos pertineat? D. Paris 1739.4. 4 p.

810 Bertolini. IRapporlu sullo stato dell' orto agrario della R. Universita di Bologna. Milano 1812. 8. H. v. D.

(Nomen fortasse, ut imsumera, lapsu calami oltum.)

$811^{*}$ Bertoloni, Antonio. Rariorum Liguriae plantarum Decas I. Genuae 1803. 8. 29 p. - " Decas II. Pusis 1806 8. $47 \mathrm{p}$. - " Decas III. Accedit specimen zowphytorum Portus Lunae. Pisis $1810.8 .125 \mathrm{p}$. (III titulis Jecadum if et III loco Liguriao legitur: Italiae.)

S12* Plantac genuenses, quas annis $1802-3$ observavit et recensuit. Genuae 1804. 8 . $145,11 \mathrm{p}$.

$813^{*}$ ___ Amoenitates itilicae sistentes opuscula al rem herbarian et zoologiam Italiae spectantia. Bononiae 1849 . 4. $472 \mathrm{p}$. 6 tab. ( 18 lire.)

81'* —— Excerpta de re herbaria. Bononiac 1820. 4. 16 p., 1 tab.

$8.13 \div$ - Dlenchus plantarmm vivarum quas cum aliis vivis plantis conmutandas exhibet hortus botanicus Archigymnasii Bononiensis anno 1820. Bononiac 1820.4.8 p.

$816^{*}$ - Lucubrationes do re herbaria. Bononite $1822.4 .40 \mathrm{p}$. 1 lab.

$817 t$ - Viridarii Bononiensis vegetalulia cum aliis vegetabilibus commutanda ad anmum 1824 . Bononiae $1824.4 .8 \mathrm{p}$.

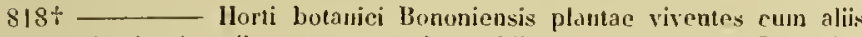
plantis viventibus conmutandae exhibentur anno 1826. Bononiae 4. $7 \mathrm{p}$.

$819+$ Sylloge plantarum horti botanici Bononiensis quae viventes cum aliis plantis viventibus commutandae exhibentur anno 1827. Bononiae 1827.4.7 p. (Omnes cum diagnosibus.)

$820+$ Descrizione de' Zafferani italiani. lBologna 4826. 4. 5 foll.

$821 \div$ Conlinuatio historiae horti botanici ot scholae botanicac Archigynmasii Bononiensis adjectis descriptionibus trium novarum plantarum. Bonomiae 1827, 4. Is p., 2 tab, col.

$822^{\circ}$ — Praelectiones rei, herdariae et prolegomena ad Floram italicam. Bononiac 1827. 8. vu, 334 p. (6 lire.)

$823^{t}$ - Nemoria sopra alcuse produzioni naturali nel golfo della Spezia. Modena 1832. 4. 15 p., I tab. col.

$826^{*}$ — Nantissa plantaruu Florae Apium Apuauarum. Bononiae 1832. 4.74 p., ind.

$823^{*}$ _ Disquisitio de quibusdam plantis novis aliisque minus cognitis. Bononiae 1832.4. 12 p., 1 tab. col.

$826^{*}-$ Dissertatio re quibusdam novis plantarun specicbus et de Bysso antiquorum. Bononiae 1835. 4. 18 p., 2 tab. col.

$827^{*}$ C Commentarius de Nandragoris. Bononiac $1835.4 .13 \mathrm{p}$. 3 taly. col.

$828^{*} \longrightarrow$ Deserizione di un nuovo genere $e$ di una nunva specie di pianta gigliacea. Modena 1835.4 . 6 p., 1 tab. col. (Strangwoja hyacinthoides Bert.).

$829^{*}$ - Elogio \&lel professore Ottaviano Targioni-Tozzetti. ( $1 \mathrm{l} \mathrm{cm}$. della Soc. it. delle scienze in Modena tom. XXI.) Modena 1837. 4. 8 p. et effigies Targionii-Tozzelli

$830 \div-$ Commentarius de itinere neapolitano aestato anni 183 h suscepto. Borsoniae 1837.4. 23 p., 3 tab. col.

$831+$ Lettere inedite di Carlo Limeo. Bologna 1838. 8. 8 p. (Nuovi anuali delle scienze naturali, fasc. HI.)

832 * - Ilorti botanici Bononiensis plantac novac vel minus cogıitae. Bononiae. Il fasc. 4. - I: 1838. 10 p., b tab. col. - Il: 1839. 14 p. 4 tah. col.

$833^{*}$ Florula Guatimalensis sistens plantas nonnullas in Guatimala sponte nascentes. Bononiac 1840.4.43 p., ind., 12 tab. col.

$8.34^{*}$ Iter in Apenninum Bononiensem. Bononiac 1841. 4. 25 p., 2 tab. col.

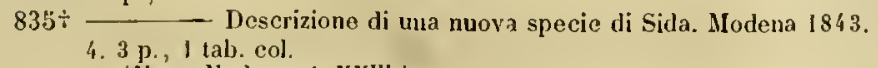

(Mem. Mlodena, t. xxIll.)
836* Bertoloni, Antonio. Miscellanea hotanica. Bumoniae 1842-1840. V fasc. 4. - I: 1842.22 p., 3 tab. col. - Il: 1843.24 p., 3 tab.col. III: 1844.21 p., 6 tab.col. - IV: $\quad-\mathrm{V}: 18461810.6 \mathrm{tab} . \mathrm{col}$

$837^{\circ}$ Flara italica, sistens plantas in Italia et in insulis cilrumstantibus sponte nascentes. Bononiae $1833-1846$. VI voll. \&. - Vol.I: 1833.882 p. Mouamdria-Triandria. - Vol. II: $1833.800 \mathrm{p}$ Tetrandria-Pentandria-Monouguia. - Vol. III : 1837.637 p. PentanIria - Vol.IV: 1839.800 p. llexandria-I)ecandria.- Vol. V: 1842. 654 p. Dolecandria-Polyandria, - Vol. VI: 1844 . fasc. 1-4:512 p. Dislynamia-Tedradynamia, $(28 \mathrm{2} / 12$ h. $)$ (continusulur.)

838* BerwaId, Joharn Gollfried. AJhandinng vam Geschlecht des l'flanzen und der Befruchtung. Zuin Nutzen der Blumenliebhaber zusanmengetragen. IJamburg 4778, 8. is $\mathrm{j}$.

$839^{*}$ Berzelius, Jens Jacob. Iärbok i Kemien. Stockholm 1826-1828. 8. (Vol. IV et V: 1300 p. contirsent ehemiam botanicam.)

germanice: Lehrbuch der Clyemie. Aus der schwedischen llandschrift des lerf ubersetzl von $F$. Wohler. Viente verh. Uriginalahllage. Leipzig u. Oresden 1838-1842. 8. (vol. Vil: 1838. xi11, 630 13. continet prae ceteris chemiam regni vegetabilis. Ed. nova, quinta, sub prelo est.

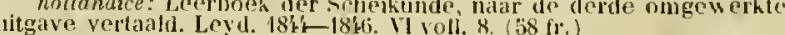

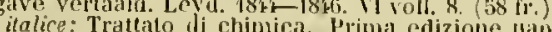

italice: Trattato di chimica. Prima edizione mapolitana, conformo

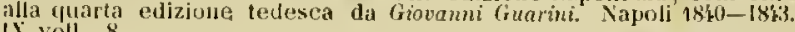

gallice: Traité de chimin traduit par A. J. L. Jourdan et Esslinger sur les manuserits incidlits de l'alutem. lairis 1820-33. Vill voll. 8 . ( $35 \mathrm{fr}$.)

$8 \% 0^{*}$ Besler, Basilius. Ilortus Eystettensis sive diligens of acrumati omnium plantarum, florum, stirpium ex variis orbis terrae partibus singulari studio collectarum, quae in celeherrinis viridariis, al'cem episcopalem ibiden cingentibus hoc tempore conspiciuntur, delineatio et ad vivum repraesentatin; in quatuor partes divisus. s. I. 1613. folio max. 366 foll, et tabulac aeuea totidem aversa pagina textus impressae, numeris nou inscriptae.

Classis verna: foll. $14,18,17,17,13,14,15,8,9,9=134$

Classis autumnalis: foll. $13,13,9,7=\{2$.

Classis aestiva: fol. $14,16,16,10,12,12,10,12,12,12,12,10$ $10,11,14=183$

Classis hyberua: foll. 7. - (llane editionem virli in IJibl. Reg. Berolinensi tabulis coloratis; ibiflenı servatur exemplar manuscriptum, de quo ef. Jfoehsen, de manuscr. med. Bill, Berolin. p. 64.)

"Ed. II : auspiciis Morquardi II. Episeopi Eistetensis. 1610. Solio 361 tab. numeris inscriptis. (quac editio figuris rutiorilus primae inferior est.)

*Ed. Ill : 1743. folio. 367 tab. alısıue rexiu latino. (Elitio valde rara; duae aliae reimpressiones laudautur, quas non vidi: anni 1727 teste Hoehsen, Epist. p. 75. et anni 1750 , teste Falkenstein, Bibliothek zu Dresden, p. 198.)

(Autor omnino dubius est; Rasilius Besler, pharmacopola Norimbergensis [n. $1561, \div 1629]$, semel ipsun esve fatitur; sed quum illiteratus tatinique sermonis minime gnarus fuerit, llieronymum fratrem Tui praefatinnem scripsit, jpsius aperis etiam autorem ferhibent Baier Biogr. Prof. Altdorfens. P. 82-83. Ludocico Jungermam tribuit Nec aliter de horto ipso, qui ut Germaniae antiquissimus ilis sul acvi celeberrinus a Joanne Conradn a Gemmingen, episcupo Eichstaedinsin in monte Seti Witihaldi condilus fuit guo tempore ac nodo interiprit, nuntii omnimo desiderantur; of. Hall. Bibl. 1. 413.3 - Spreng Ilist. 11. 125-127. - Ut Limeanis nominilus nomenclatural splendidi operis illustraretur, Dr. $F r$. llidumann Norimbergae, e typogriphia Felssecheriana anmo 180 s edidit Catalogun srstemnticum onmum arborum fruticum el plantarum celeberrimi horti Erstettensis, in quarla forma 79 paginarum. Est alia editio fiallorum liugua seripia et Josephinae Imperatrici dicata. Eystett 1806 . 4.80 p.

$8.1+\longrightarrow$ Fasciculus rariorum el asjectu dignorum varii generis, quae collegit et suis impensis acri al virum incicli curavit atcpue evulgavit. Anno ChrIsII DoMInI SerVatorIs VerI (= 1616.) 4 ob]. 24 tab. aen., quarum sex posteriores fruges plantarum illustrant. † Continuatio anno ....... se VerI. $=1623$, 4,32 tals. Bibl. Cand.

842* Besler, Nichael liuperl. Gazophylaciun rerum naturalium e regno vegetabili, animali et minerali depromptarum, numruam hactenus in Jucem editarum, fidelis cum figuris apneis ad vivum incisis repraesentatio. (Lipsiac, typ. Wittigau.) 1642. Solio. 24 tab., 1 p. - Lipsiae et Francofurti, apud Klosium. 1716. folio. et ib. 1733. folio. 35 tab. 4 foll.

843 Rariora musei Besleriani, quae olim Basilius el Michael Rupertus Beslerz collegerunt, aeneisque tabulis ad vivum incisa evulgarunt, nunc commentariolo illustrata a Johunne Henrico Lochner. denuo luci publicae commisit Michael Fridericus Lochner. s. I. 1716 folio. 112 p., 40 tal., quarum 24 eaedem ac in cditione anni 1642. modo dicla. B. 
81't Besnier, IIenri. Le jardinier botanist", Paris 1705. 12. a. - ib. 1712. 12. s.

840 - Abrégé curieux touchant les jardinages. Paris 1706. 12. a.

8:6* Bessa, $P$. Fleurs el fruils gravés el coloriés sur les peintures aquarelles faites d'aures nature. Paris 1808 . folio max. Bibl. Imp. Ferdin. (Sex fasciculi cun 2 '́ tah). indicabantur; cquidem vidi 8 tab. col.)

S1.7 Besser, Otto Ludwiy von. De Salicinio. U. Berolini 1831. 8. 32 p.

84.8* Besser, Wilhetm S. J. L. Primitiae Florae Galiciae Austriacae utriuspue. Encliciridion ad excursiones botanicas concinnatun. Viemae 1809 . II voll. 12. - I: 399 p. - II: 423 p. $(22 / 3 / h$.)

$819^{*}$ Catalogue des plantes du jurdin butanique du gymnase de Volliynie á Krzenieniec. 1810. 8. 88 p. - " Krzemieniee 4811.

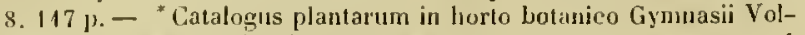
Uynicusis Gremeneci cultarum. Gremeneci 1816. 8. 161 p., praef. Est editio nova, cum tribus supplementis annorum 1812-14. Joeupletati.)

$850^{*}$ Enumeratio plantarom hucusque in Volhynia, Podolia, gub. Kïioviensi, Bessarabia Cis-tyraica et circa Odessam collectarum, sinul cum olsservationibus in Primitias Florae Galiciae austriacae. Vilnae 1822.8. vur, 111 p. $(1 / h)-$. tEtl. I. ib. 1821.8. $79 \mathrm{p}$.

$8 \mathrm{I}^{*}$ _ _ _ Tentamen de Abrotanis seu de sectione secunda Artemisiarum Linnaei. $1832.4 .92 \mathrm{p}$, 5 tab.

(Extrait des Nouv. Mém. de Moscou t. III.)

\$52.* - De Seriphidiis seu de sectione tertia Artemisiarum Linnaei Dissertatio botanica. (Cremeneei 1833.) 8. 46 p.

853* Betcke, Ernst Friedrich. Animadversiones botanicae in Valerınellas. D. Rostuekii 1826.4 .28 p.: 1 tab.

$854+$ (Bettinelli.) I misteri di Flora. s. I. 1806. 12. 15, xv, 102 p., 2 tab. (Poema.)

85:5 Beunie, Johann Eaptista de. Antwood op de vraege, welk zyn de profytelykste planten van dit land, ende welk is hun gebruyk zoo in de Hedicyuen als in andre Konster. Brussel 1772.4.70 p. B.

856 Bexell, Johann Jacob. Hallands Historia och Beskrifning. Delen I. Il et III. Götheborg 1817-1819. 8. W.

(Vol. i. p. 386-40k: Hallands Flora secundum Osbeckij et Montinii adnotaliones.)

857 Beyer, J. Quaestiones de plantis. Basileae 1623. 4. н.

858 Beyer, J. $M$. Tabellarische Uebersicht der Kuchengewachso. etc. Halle 1815. 4. ( $1 / 6$ th.)

S59t Beze, Claude de. Deseription de quelques arbres et de quelques plantes de Malacque. Exstat in Mémoires pour servir à l'histoire naturelle des plantes dressés par $\boldsymbol{M}$. Dodart. Amsterdam et Leipzig, Merkus. 1758. 4. p. 637-644.

860 Bianchi, Casimir. Vademecum botanico continente li caratteri secondo la 40. edizione del Linnaeo elc. Firenze 4763. 8. н.

$861^{*}$ Bianconi, C. Giuseppe. Di alcuni movimenti che si osservano nelle piante per la diffusione de' semi. Bologna 1841.8.26 p. 9 tab.

862* Biasoletto, Bartolommeo. Di alcune alghe microscopiche Saggio. Trieste 1832.8.69 p., 99 lab. col

$863^{*}$ Yiaggio di S. H. Federico Augusto re di Sassonia per I'Istria, Dalmacia e Montenegro. Trieste 4\$41. 8. 264 p., 3 tab. col. $\left(2 \frac{2}{3}\right.$ th. - nigr. 2 th. $)$ germanice: in Auszug ubersetzt mit Anmerkungen von Gutschnid. Dresden 1812. 8. $(2 / 3$ th.

(Conspcetus plantarum oeconomicarum Istriae antore Biasoletto est in libjo: "Pittoreshes Oestreich, Nr. 13. Istrien. Wien 1840. 4.")

864 Biber, Joachim Andreas. Btatterskelete. Gotha, s. a. 1. Zehend. (1/2 Louisd'or.) (Vgl. Göttinger Gel. Anz. 1774. I. 481.)

865 Bicheno, J. E. On systems and methods in natural history. Lendon 1827. 4. 20 \%. (Frum the Transactions of the Linnean Society.)

866 Bidault de Villiers, $F$. F . Essai sur les propriétés médicales de la digitale pourprée. Ed. III. Paris 1812.8. (2 fr. 75 c.) a.

$867+$ Bidet. Traité sur la nature el sur la culture de la vigne. Paris 1752. 12. - Ed. augmentée. Paris 1759. II voll. 12. germanice : Leipzig $173 \%$. 8 italice: Yevezia 1757,8
868" Bidloo, Collfried. Oratio in funere Puuli llermanni dicta. Lugduni Batavorum 1695.4.32 p.

869* Bidloo, Lambert. Dissertatio de re herbaria, praemissa Joannus Commelini Catalıgo plantarum Hollandiae. Ansterdam 1683.8.82 P - Lugdoni Bat. 1709.8.80 p.

$870^{\circ}$ Biedenfeld, Ferdinand Freiherr von. Das Bach der Rosen. Eine populare Monograplie fur Dichter, Botaniker, Gartner und Blunenfreunde. Weimar 1840.12 . vit, 521 p. (2 th.)

87. Biehler, Johan Friedrich Theodor. Plantarum novarum ex herbario Sprengelii Centuria. D. Halae 1807. $8.46 \mathrm{p}$.

872 * Biel, Johann Christian. Lixercitatio de lignis ex Libano ad templum Ilierosolymitanum aedilicandom petitis, qua per ligna illa Il. Paral. 11. 8. cedrina, cupressina et pinea intelligenda esse, ostenditur. ete. Brunsvigae 1740.4. (6) 61 p. - Ed. II. Brunsvigae 1749.4.

873 * Bigelow, Jacob. American Medical Botany, being a collection of the native medical plants of the United States. etc. Boston $1817-$ 1821. III voll. 4 min. - I: 1817.198 p. - II: 1819.200 p. - III : 1820-1821. 198 p., 60 tab. col. (24 Doll.)

874 - Facts serving to shew the comparative forwardness of the spring in different parts of the United States. Cambridge, University press. $181 \mathrm{~S} .4 .11 \mathrm{p}$.

$875^{\circ} \longrightarrow$ Hlorula Bostoniensis. A collection of plants of Boston and its vicinity, with their generic and specific characters, pritcipal synonyms, descriptions, places of growth and time of flowering and occasional remarks. Third edition enlarged, and containing a glossary of botanical terms. Boston, Little and Brown. 1840. 8. v1, $468 \mathrm{p}$. - ${ }^{*}$ Ed. J. jb. 1814. 8. vilt, 268 p. - ${ }^{*}$ Ed. II : ib. 1824. 8. 5, 422 p.

876 Bigoutier, Claude (latine Bigotherius). Rapina seu Raporum encomiun. (Poema?) Lugduni, Paganus. 1541. 8. - ic. 1548.8 . H.

877 Billberg, Gustav Johannes. Botanicon Seandinaviae s. plantarum in Suecia et Norvegia sponte erescentium icones; plerumque ad vivum coloratae cum descriptionibus succinctis, synonymis selectis et differentiis specificis. Ilolmiae 1822.8 .

(Opus hocce easdem continet tabulas ac Srensk Botanik, Forsta Bandet. tab. 1-36; sed textus a Billbergio conscriptus; haud continnatum est; ef. W. Consp. lit. suec. p. 32.

878 Äminnelse-Tal öfver etc. C. F. Thunberg, hållet infor K. Vet. Acad. den 21 Mars 1829. Stackholm 1832. 8.48 p. w. Billberqus operis Svensk Botanik post obitum Suarlaii a numero $91-99$ et tab. $54-591$ textum composuit, et ligararum sculpturam inspexit; ef. Palmstruch.)

879* Billerbeck, Julius Heinrich Ludwig. Flora classica. Leipzig 1824. 8. vili, 285 p. $\left(1 \frac{1}{3}\right.$ th. $)$

880 Bingley, William. Useful knowledge; or a familiar and explanatory account of the various productions of nature. Vol. II: Vegetables. Philadelphia 1808. 8

881 Biörlingsson, Carl Julius. De elementis physiologiae planlarum in usum practicum spectantibus. D. I. Upsaliae 1828.4 .10 p. w.

882 Biörn, S. Ueber die Érlen und deren Belıandlung. Danzig 1819 8. $(1 / \mathrm{g}$ th. $)$

$883^{*}$ Biörnlund, Benedict. Fundamentum differentiae specificae plantarum verum et falsum. D. Gryphiswaldiae $1761.4 .18 \mathrm{p}$.

88'* Birch, Johannes. De Opio. D. Lugduni Balavorum 1716.4. 17 p.

$885^{*}$ Biria, J. A. J. Histoire naturelle et médicale des Renoncules, précédée de quelques obscrvations sur la famille des Renonculacées. D. Montpellier 1814.4.53 p., 2 Lab.

886* Birkbolz, Adam Michael, pr. De Arnicae virtute propria atque specifica. D. Lipsiae 1785. 4. 24 p.

$887^{*}$ De corticis Peruviani virtute propria atque specifica. D Lipsiae 1785. 4. 32 p.

$888+$ Biroli, Giovanni. Flera economica del Dipartimento dell' Agogna. Vercelli $1805.8 .114 \mathrm{p}$.

$889^{*}$ - Flora Aconiensis seu plantarmm in Novariensi provincia sponte nascentium descriptio. Ex typographia Viglevanensi 4 S0s. Il voll. 8. - I: xxiv, 218 p. - II: 260 p.

$890+$ Georgica del Dipartimento dell Agogna. Novara 1809. 8. $70 \mathrm{p}$.

$891+$ Memaria sulla coltivazione del nocciuola da lerra (Arachis hypogaea) e del Cypero esculento. Novara 1809. 8. 24 p. 
$892+$ Biroli, Giovanni. Catalogus plantarum horti botanici Novariensis, ad annum 4810. Novariae 4810.8.35 p.

$893^{*} \longrightarrow$ Catalogus plantarum regii horti botanici Taurinensis. Augustae Taurinorum 18.5. 8.86 p., praef.

$89 \mathrm{k}+$ Del riso trattato economicn rustico. Milano 1807. 8. 154 p. $-{ }^{*}$ Ed. Il: ib. 4825.8 .125 p. ( 1 lire 50 c.)

$895 \div$ (Biron, Claude.) Curiositez de la naturo et de l'art, apportées dans deux voyages, l'un aux Indes d'occident en 1698 et 1699 et l'autre aux Indes d'orient en 1701 et 1702 . Paris 1703 . 12. xxxul, $2 \$ 2 \mathrm{p.}$, ind., tab.

896 Biruega, Francisco. Examen pharmaceutico-galenico-historico. Madril 1761.8. H.

897* Bisceglie, Vilo. Flora della provincia di Bari. Napoli 1809. S. $59 \mathrm{p}$.

(Iisserito nel tomo Xvill della biblioteca di Campagna.)

898* Bischof, Gustav. Die Wärmelehre ries Innern unsres Erdkörpers, ein Inbegriff aller mit der Warme in Beziehung stelsender Erscheinungen in und auf der Erde. Nach physikalischen, chemischen and geologischen Untersuchungen. Umgearbeitete Ausgabe einer gekrönten Preisschrift. Mit eingedruckten Holzschnitten. Leipzig 1837. 8. xxiv, 312 p. $\left(2 \frac{1}{2} t h.\right)$

$899^{*}$ Bischoff, Gotllieb IVilhelm. Die botanische liunstsprache in Umrissen nebst erlautemden Texte. Zum Gebrauch bei Vorlesungen und zum Selbstunterricht. Nürnberg 1822. folio. Iv, 114 p., 21 tab. $\left(2 \frac{1}{2}(h)\right.$.

$900^{*} \longrightarrow$ De plantarum praescrtim cryptagamicarum transitu et analogia Commentatio. Heidelbergae 1825.8 .59 p. $(1 / 3$ th. $)$

901 —_ Die kryptogamischen Gewächse mit hesondrer Berücksichtigung der Flora Deutschlands und der Schweiz organographisch, auatomisch, physiologisch und systematisch bearbeitet. Nurnberg 1828. 4. 2 Lieferungen: Chareen, Equiseteen, Rhizocarpen und Lycopedeen. $x, 131$ p., 13 tab. $\left(4^{3} / 4, h\right.$. $)$

$902^{*} \longrightarrow$ Plantac medicinales, secundum methodum Candollii naturalem in conspectum relatie, adjectis medicamentis, quae praebent, simplicibus. Heidelbergae $1829.4 .24 \mathrm{p} .(3 / \mathrm{s} t \mathrm{~h}$.

$903^{*}$ Uebersicht des Linnéschen Sexualsystems. Heidelberg 4829. folio. ( $1 / 6$ th.

$904^{*}$ _. Grundriss der melicinisehen Botanik als Leitfaden bei Vorlesungen, so wie zum Selbststudiun, und besonders zum repctitorischen Studium fur Studirende. Nach den naturlichen Familien des Gewächsreichs bearbeitet. Heilelberg 1831. 8. xxiv, 584 p. $(31 / 4, h$.

$903^{*}$ Lehrbuch der allgemeinen Botanik. (Naturgesclichte der drei Reiche, Band 4 und 5.) 3 Abtheilungen. Stutgart 18341839. 8. - I: 1834. LXx, 479 p. - II: 1836.548 p. - III: 1839. 839 p., 16 tab. (13 l/h.)

$906^{*}$ De Hepaticis inprimis tribum Marchanticarnm et iicciearum commentatio. Heidelbergae $4835.4 .40 \mathrm{p}, 1_{\text {tal. }}$

$907^{*}$ —__ Wörterbuch der beschreibenden Botanik oder die Kunstausdrucke, welche zum Verstehen der plyytographischen Scluriften nothwendig sind. Lateinisch-deutsch und deutsch-lateinisch bearbeitet, alphabetisch geordnet und crklärt. Stutgart 4839. $8.283 \mathrm{p} .(1 \mathrm{~h} / \mathrm{.})$

$908^{*}$ _ Handbuch der botanischen Terminologic und Systemkunde. Nürnberg 1833-1844. III Bánde. 4. - I : 1833. xvi, 581, 44 p., 47 tab. - 11: 1842. x, p. 583-4047, 30 tab. sign. 48-77. et y0 p. Erklarung. - III: 4844 . v1, p. $1031-1609$. (16 $1 / 3$ th.; gegen ba ar ein Naclilass.

(Volumen primum sistit terminos plantarum phanerogamarum: 6 Thlr. - volunen alterum terminologiam cryptogamarum: $5^{1 / 2}$ Thir. - volumen tertium cognitionem systematum et indices: ${ }^{2} \mathrm{k} / 2 \mathrm{Thl}$.

$909^{*}$ Medizinisch-pharmaceutische Botanik. Ein Handbuch fur Deutschlands Aerzte und Pharmaceuten. lirlangen 1843, 8. xiI, 875 p. $(41 / 2$ th. $)$

$910^{*}$ Bischoff, Ludwig Wilhelm Theodor. De vera vasorum plantarum spiralium structura et functione Commentatio. Bonnae 1829.8.93 p., I tah. $(7 / 12$ th. $)$

$911^{*}$ Bishop, David. Cansal botany; on a treatise on the causes and character of changes in plants, especially of changes which are productive of subspecies or varieties. London 1829. 8. w.
912 + Bissari, Pietro. Metorlo sicuro e facile di liberare dal grongo o lovero (Cuscuta europaea L.) i trifogli e le erbe spagne, praticato. Milano 1809. $8.14 \mathrm{p}$, I tab.

$913^{*}$ Bivona-Bernardi, Anlonio Barone. Sicularum plantarum Centuria 1 (et lI.) Pancrni 1806.4 min. 84,73 p. 13 tab.

914* 는 Mongrafia delle Tolpidi. Palermo 1809. is p., s tab

$915^{*}$ Stirpium rariorum minusque cognitarum in Sicilia sponte provenientium descriptiones nornullis iconibus auctac. Manipulus I-IV. Panormi $1813-$ I6. 4. (32) 30,39 p. et 44 tab.

$916 \div$ Scinaia, Alyarum marinarum novum genus. (Palermo 1822.) 8. 3 J., I tab. Bibl. Cand.

1 Biographian scripsit Filippo Parlatore: $\div$ Brevo cermo sulla vita e sullo opere del Barono Antonio Bivona-Jiernardi. Palerno 1837. 8. $19 \mathrm{p.j}$

$917^{*}$ (Blackstone, John.) Fasciculus plantarum circa llarefield (Middlesex) sponte nascentium cum appendice ad loci historiam spectante. London 1737. 12. vi11, $118 \mathrm{p}$.

$918+$ Specimen botanicum, quo plantarum plurium rarisrum Angliae indigenarum loci natales illustrantur. Londini 1746.8. $106 \mathrm{p}$., pracl., 1 tab.

$919^{*}$ Blackwell, Flizabeth. A curious herbal, containing 500 ents of the most useful plants, which are now used in the practice of plyysick: to which is added a short description of the plants and their conmon uses in physick. London 4737. Il voll. folio. - I : Descriptio 1-63., tab. col. 1-252.- II : Descriptio 64-125., tab. col $253-500$

$920^{*}$ L Lerbarium Blackwellianum emendatum et auctum. i. e. Elizabethae Blackwell Collectio stirpium, quae in pbarmacopoliis ad medicum usum asservantur. Eulidit et pracfatus est Christoph Jakob Trew; figuras excudit Nicolaus Friedrich Eisenberger. (Vermehrtes und verbessertes Blackwell'sches lirauterbuch. 38. (sic) Auflage.) Nuruberg 1750-1773. Centuria I-VI. folio. 600 tab. col. 1exi. (12 th. A.)

(Quas uxor infelicis medici Alexandri Blackwell, qui funesta in Suecia morte periit, ex anicormn consilio ad vitan sustentandan artificiosa delineaverat manu plantas medicatas aericue inscripserat. has hac ornatiori auctioripue edilione publici juris anglicn germaniJas hac ornatiori anctioripue edilione publici juris anglico germani-
coque sermone fecit Trewius. Histurian operum botanicorum ox coque sermone fecit Trewius. Histurian operum botanicorum ox
plenissima sua billiotheca addidit, nec non centum tabularum a plenissima sua bibliotheca addidit, nec non centum tabularum a
Blactivellia omissarum, appendicem. Posterioribus voluminibus priBlackwellia omissarun, appendicem. Posterioribus voluminibus primam C. G. Ludwiy, inde L. G. Bose et polissimum Georgius Rudolphus
Boehmer adhibuerunt manum. Pretium operis pro chartac differentia fuit 40,50 et $66^{2} / 3, h$.

921 Fungus pulverulentus turriculam fornicatam referens ab Elizabeth Blackwell delineata et sculpta. B.

922 Blagrave, Joseph. Supplement or enlargement to Nich. Culpepper's English Physician; containing a description of the form, names. place, time, caelestial governement of all such nedicinal plants as grow in England, and are omitted in his book called "The English Plyysician, and supplying the additional virtues of such plants wherein he is defective. London 1666 . 8. - Ed. II. cui aceessit: The description, kinds, names, place, time, nature, planetary regiment, temperature and pliysical vertues of all such trees, herhs. roots, flowers, fruits, excrescencies of plants, gums, ceres and condensate juices as are found in any part of the world. London Obadialı Blagrave. 1674. 8. s.

923* Blair, Patrick. Miscellaneous observations in the practise of plysic, anatomy and surgery, with remarks in botany. London 4718.8. 149 p., 2 tah. Bibl. Goett.

924* Botanih essays. In two parts. The first containing the structure of the flowers and the fructification of plants. with their various distributions into method: and the second, the gencration of plants, with their sexes and manuer of impregnating the seed: also concerning the animalcula in semine masculino. etc. London 1720. 8.414 p., pracf., 4 tah.

$925^{*}$ Pharmaco-hotanologia, or an alphabctical and classical dissertation on all the british indigenous and garden plants of the new London Dispensatory. ete. London 1723-1728. VIl Decades 4. 343 p., 4 tab. (Desinit in Hedera.) Bibl. Goeth

926 Blake, Stephen. The compleat gardiners practice. London 1664. 4. s.

927t Blanc, Abbe. Essai de botauique pratique. etc. Embrun, Moyse. 1784. 12. viIt, $291 \mathrm{p}$. 


\section{BLANCHET}

928: Blanchet, Kodolphe.) Catalogue des plantes vasculaires qui croissmut naturellement dans le canton de Yaud, mulié far la socicte des sciences naturelles de ce canton. Vevey 1836. 8. xxiv, 128 ].

429:- lulluence de l'Ammoniaque ot des sels amroniacaux sur la végétation. lausioue 1843.8 .36 b. (5 Batzen.)

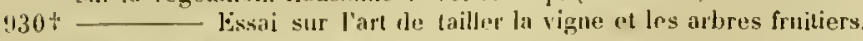
I.ausanne 1844.8.38 \%.

$931+$ De léplicténic des pommes de terte. (Lausanne 1845.) 8. $16 \mathrm{p}$.

4.32 - Blanco y Feruandez, Antonio. Tratado elmental de hotanion wórico-practice. Valencia, intprenta de Jaine Martinez. Jf voll. 1834 -1835. 4 min. - 1: P'arte teórica. 1834. 184 1. pracf., ind. - II: Parte practica. $1835.328 \mathrm{p}$. Bibl. Cand.

9:13* Blanco, Manoel. Flora de Filipinas. Segun el sistema sesual de Liuneo. Manila, en la imprenta de Sto Thouas por D. Candido 1.opez. 1837. 8. Lxxvi1, 887 p.

(Excrpta hujus operis cura ill. Walpers exstant in Linnaea 1812 1.iteraturbericht j. 1-68. et in (iabriel Lafond. Quinze ans de voyages autour du inonde. Paris 1840.8 . 380 l. - Autoren uliisse, editionenque alteran libri prodisso per ill. Kilotischium numtimu aecepi.)

1.3\% Blandow, O. C. Uebersicht der Nehlenburgsehen Monse uach alphabetischer Orduung. (Neustrelitz) 1809.8.16 p.

93̈ Blankaart, Stephen. Gebruik en nisbruek vill de Thee. ele. 's Gravenhage 1686.8 . s. germanice: llamburs $170 \%, 8$

136t — D De nederlandschen Ilerbarius, or Kruikbeck der vaornaamste hruiden. tot de medicyne, spyshereidingen en hunstwerken dienstig, handelende van zommige hier te lande wassende boomen, hruiden, hecsters, mossen, enz. Tweedell druk. Amsterlam, by Nic. tor Hoorn. 1714. 8. 614 p., praef, ind., tab. - Ed. J. ib. 1698. 8. $621 \mathrm{p}$. , tals. B.

937* Blegny, Nicolaus di. Zodiacus medico-gallieus s. miscollaneorum medico-pliysicorum. ete. V voll. Genevae 1680-1686.

938t - Le bou usage du thé, du calfé et du chocolat pour la preservatiun el pour la guerison des maladies. Paris et Lyon 1687. 12. $358 \mathrm{p}$., praef., ind, , lab.

939* Bleisch, Eduard. De Anygdalinio. D. V'ratislaviae 1838.8. 28 p.

940 Bloch, Georg Castaneus. Tentamen phoinicologiae sacrac s. Dissertatio emblematico-theologica de Palma. Havoiae 1767. 8.178 p. B.

4 il. Bloch, Johannes Erasmus. Horticultura danica, com descriptione vireti ad arcem Cronenburg prope llelsingoram. Havinae 1647. 4. tab. Br.

942 Blochwitz, Marlin. Anatomia sambuci, quae non solum sambucum et lujusdem medicamenta singulatim delineat etc. Lipsiae 1631. 12. 298 p., praef., ind.

anglice Anitonia siminci or the anatomie of the elder. London 16.0. 12. 281 p. - il). 163\%.12.230 p. B

- germance: Beschreibun des Hollunders in Daniel Beckers kleiner Ilausapothehe. Konigsherg 1650. 8. - Leipzig 1685. 8.

943 Blom, Carl Magmus. lieginter ofver Bengl Bergii Tal om láckerheter. Stochlolm 1785. 8.20 p. w.

914: Blondus, Michnel Angelus. De ancipiti ligni indici proprictate adversus pluriun opinionens. Venetiis, Nicolinus de Sabio. 1542. 12. (Exstat in ejustem autoris libro de origine norbi gallici, nec non in Uffenbachii Thes. chirurg. )

9 '13+ Blot, Natalis Sebastian. Quaestio botanico-medica (ao, ut naturali cuique plantarum classi jdem regetativus character, sic earlent medica facultas?) D. (Cadomi 1747.) 4.6 p. praeter dedicationem ad Bernardum de Jussieu.

946* Blottner, harl Ludwiy. De fungorum originc. D. Ilalae 1797. $8.46 \mathrm{p}$.

9:7* Blount, Thomas Pope. A natural history, containing many not comnon observations. London 4693. s. (16) $469 \mathrm{p}$.

44: Bluff, Mathias Joseph, et Karl Anton Fingerhuth. Compendium Florae germanicae. Norimbergae 1821-1833. IV toni. 12. - Sectio 1: Plantac phanerogamicae seu vasculosae. 11 tomi. 1825. - 1: xxIV 755 p. - H: xvit, 785 p., 2 tab. - Sectio Jl: Plantae cryplogamicae seu cellulosac. seu Flora cryptogamica Germaniae, autore Friedrich II ithelm II allruth. 1831-1833. II tomi. - I: xxvi, $654 \mathrm{p}$. - II: LV, 923 p. (10 th.) - Ed. Il. avcla et anılificata, curantibus

\section{BOCCONE}

I. J. BlufJ, C. C. Viees ron lisenbeck et J. C. Schuuer ib. 1836-1838. Il voll. 12. - I: 1.2. xvill, 648, 448 p. - II: 764, 159 p., ind. (s th. - is th. ill charta mel.)

919 Bluff, Mathias Joseph. Eintwicklunisscombinationen organischer Wesen. Kolı 1827. 8. ( $1 / 3$ th.

40̈0* - Ueber dic lleilkrafte der Kucliengewáchse. Numberg 1828. 8. vill, 96 p. (1/2th.)

yij) Blume, Karl ludwig. Catalogus van eenige der merhwaardigsto zoo in-als uilleemsche gewassen. to viuden in's lands plantentuir te Buitenzorg. Batavia, gedrukt ler Lands-1)ruhkerij (1\$23). 8. 112 p. lal. (Flora 1825, p. 97-160.)

932 Korte Heschrijving van de Patma der Javanen. Batavia 1825. 8

$933^{*}$ - Tabellen en I'laten voor de Jasaansche Orchideen. IaIavii, ter Lands 1)ruhikerij. 1825. folio. 5 Talsellen, 15 tab.

93." - Bijdragen tol de Flora van Kederlandsch Indie. Batavia ter Jands Druhkerij. 17 Stuk. 1825-1826. 8. 1169 p. (compleu.)

$950^{*}$ Enumeratio plantarum Javae el insularum adjacentium minus cognitarum vel novarum ex herbariis Reinwardtii, Kohtii IIasseltii el Blumii. Hagae 1830. 8. Fasc. I et II ceditionis novae. vi $x, 274$ f. (2 th.) - "Ed. I: Lugduni Balavorum 1827-1828. Il fasc 8. vi, $\mathrm{x}, 274 \mathrm{p}$, et $4 \mathrm{p}$. Addenda. ( $3 \mathrm{fr}$.)

$9: 36^{*}$ adjutore Johanne Baptista Fischer. Flora Javae nec non insularum adjacentium, cum tabulis lapidi aerique incisis fruxellis, Frank. 1828-29. fulio. x, 448 p., 197 tab., quarum 18 : coloribus sunt pictae.

Opus prodit, th e hibliopolarum liquet catalogis. 35 fasciculis, ţuae nitrrite $96 \% \mathrm{th}$, coloratac $117 \mathrm{th}$. Lipslae veludurtur. Nullus indicatu urdo, secundum quem singulae monographiae disponendac sum? quas in Linkiana ef vindoboneusi bibliothecil accurate comparavi, hic ego recenscho:

Rhizautheap: ...26 p., 6 tah. Lorautheae:.....24 p., 16 tah

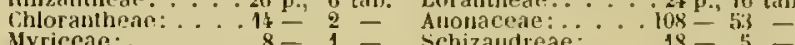
Myriccae:...8 8 - 1 - Achizandreae: .. $18-5=$ Balsamitluae:...12- 2 - Magnoliacede: . $40-12-$ Cupuliferae: : : $46-24-$ Filices:.... $152-65=$ sunt 458 p., $197 \mathrm{tab}$

$957^{*}$ De novis quibusdan plantarum familis expositio et olim jam expositarum enumeratio. (Lugduni Batavorum 1833.) 8 $32 \mathrm{p}$.

935t - comomine Rumphius. Rumphia, sive Commentationes botanicae imprimis de plantis lndiae orientalis tum penitus incognitis Ium quae in libris Rheedii, Rumphii, Roxburghii, Wallichii, aliorum, recensentur. Lugduni Batavorum. (Amsterdam, J. G. Sulpkc.) $1835-1846$. folio.

Tom. I. 1835.204 p., tab. col. 1-70. praeter tabulam in fronte artifice $H$. Vanderhaert.

Tom. 11. 1836. 176 p., tab. col. $71-137$. praeter tabulam, sepulcrum Rumphii gerens.

Tom. IlI. et ultimus certe prodiit, sed mili nondun obvius fuit integrum opus 36 fasciculis edere in consilio fuit Blumii. Bibl. Link. Vind. Cand. Deless. Lips. Goett.

989* Blumenhain, Eugen Ileinrich. Dic hrautartige Baunwollenpflanze (Gossypium lierbaceum) nit Beweisen der Möglichkeit und der Anleitung, diese Pflanze in den Slanten der ustreichschen Monarchie fruclubringend $7 u$ kultiviren und einheimisch zu machen. Bruut 1826. 8.43 p., 2 tab. col.

$960^{*}$ - Dic Pflatzenuhr im Garten und Zimmer. cte. Brunı 1826. 8. 32 n. - Ed. Jl: Jeipzig 1838. 8. (1/8 th.)

$961 \div$ Blytt, M. $N$. Enumeratio plantarum vascularium, quae circa Christianiam sponte nascuntur. Clristianiae $1844.4 .76 \mathrm{p}$

(In Programmate collegii academici ad celcbranda Oscari prini regis natalitia edito.)

962* (Bobart, Robert.) Gatalogus plantarum horli medici Oxoniensi latino-anglicus. Oxonii 1648. $8.54 \mathrm{j}$

Redit idem calilogus omissis syonmmis anglicis in Simon.

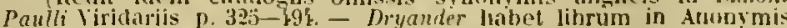
Spreng. llist. II. 16i. Jacobo Robmrio tribuil; sed exemplari Halleriano nilseripserat Dillenius, pro auctore haberi Robertum Bobartium seniorem, hortulanuso oxonieusem. In eanden senlentiam cointrat Rivinus.

963 Boccone, Paolo. Nonitum de Abrotano marino. Catancae 1668. fulio. 1 plag. $\mathbf{s}$ 
964 Boccone, Paolo. Manifestum botanicum de plantis siculis aut tantum tescriptis aut penitus novis in illo regno olsservatis. Cataneje, apud B. Rocean. 1668. folio. s.

965 - Elegantissimarum plantarum semina hotanicis honesto pretio ablata. Cataneae 16 fis. folio. S.

$966^{*}$ Recherelies et observations naturelles. Paris 1671. 12. 112 p. (Priores 82 payinac redeunt in ed. Amstelud. p. 118-124., 296-328, 44-52.) - Amsterdam 1674. 8. 328 p., (a).

967 Recherehes et olservations curjeuses. Paris 1671. 12. 69 p. (In ed. Amstelul. p. 1-23 et $284-295$.) в.

968 Epistola botanica. (Exstat in Gervasii libro: Bizarrie hotauiche. Napoli 1673. 4.) s.

$969^{*}$ _ Icones et descrijtioncs rariorum plantarum Siciliae. Melitae, Galliae et Italiae. Quarum unaquacque proprio charactere signata, ab aliis ejustem classis facile ulistinquitur. Oxonii, e theatro Scheldoniano. 1694.4.96 p., ind., (52) tah.

(Editor hujus aperis est Robertus Horison, qui manuscripla et icones a Carolu lluthonio Parisiensi acceperat.)

$970^{*}$ - Osservazioni naturali ore si contengono materie medieofisiche e di botanica, produzioni naturali, fosfori diversi, fuochi sotteranei d'talia ed altre curiosita. Disposte in trattati famigliari. Bologna 1684. 19. 400 p., 1 tal.

$971^{*}$ Museo di Física e di Esperienzo variato, e decorato di Osscrvazioni naturali, notize medicinali e ragionamenti segundo i principii de moderni, di $D_{0}$ Paolo Boccone, etc. ed al presente $D_{0}$ Silv io Boccone. Venetia, Zuccato. 1697. 4. 319 p.

$972^{*}$ Curiöse Ammerkungen aus seinem noch nie im Druck gewesenen Museo experimentali-physico zusammengezogen, und im Durchreisen dureh Deutschland zum Andenken seiner in teutscher Sprach zum Druck hinterlassen. Frankfurt und Leipzig 1697. 12. $301 \mathrm{p} ., 1 \mathrm{tab}$.

$973^{*}$ Museo di piante rare della Sicilia, Malta, Corsica, Italia, Piemonte e Germania. Venezia 1697.4.196 p., 131 tab.

(Inest: Appendix ad Andreae Caesalpini libros de plantis: p. 12:-132. In omnibus exemplaribus, quae vidi, paginae $129-138$ dupliees adsunt, diversae licet materiae. ?

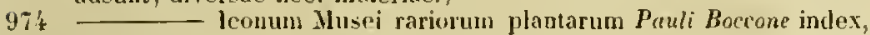
ab Arcadio Capello, medico Venero, edius, cum additamentis ex decadibus excerplis ad majorem stirjium notitiom. Venetiis s. a. 4. s.

975 - Appendix ad Museum de plantis sieulis. Venetis, apud Andream Poleti. 1702. 8. Rivin.

(Exstat in Biblitheca Iladrimi de Jussieu, matu Bernardi de Jussieu scriptunı.)

4:6* Bock, Friedrich Samuel. Versucl ciner kurzen Naturgeschichte des Preussisehen Bernsteins und einer neuen wahrscheiolichen Erhlärung seines Ursprungs. Konigsberg 1767. 8. 146 p. (cf. Naturforscher, 16. Stuck, p. 57-70.)

$977^{*}$ Bock, Mieronymus (latine Tragus). Ilerbarum aliquot dissertationes et cin]surac.

I Exstant cunt Brmfelsii llerbarii tomo secundo, edil. 1631. app. p. $136-163 .-$ edit. 1\%36. p. $272-281$.

$978^{*}$ New hreuterhuch rom Lnterscheide. Wurkung und Namen der Kreuter so in deutsehen Landen watisen. Strassburg 1539. folio absfue iconibus; in duan partes divisa.

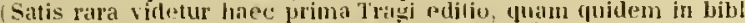
Goettingessi vidi, sed accuritius immpicere newlexi. Niamen der Kreuter, su in Deutschen Landen waclisen, auch derselligen eigenticher und wohlgegrundeter Gebrauch in der Artznei lleissig dargeben. Leibs fiesundheit zu behaiten und zu fürderu sehr nuzlieh und trostlich, Vorat tem gemeinen einfiltigen Man. Durch f. Ilierommum Bock aus limwiriger und gewisser erfarung beschriben und jetzund yon newen fleissig uhersehen, gelsessert und genehret, dazu mit lupschen artigen Figuren alkenthallseo sezieret. Darulver lindest du drei vollkonene nutzliche Register under welchen das erst die gemeine litteinische und griechischo Namen ter Kienter hat, das andre die Jentsehe, dis dritt die Anzeiz der Artznei und rhat fur allerlei hraltheiten und Leibsgepresten. (Straslury, sedrucht von Wendel Rihel.) 1546. foliu. (3 Theile.) $354,72 \mathrm{p}$. indices et ( 567$)$ ic sylogr. i.t.

(Omues insequentes editiones Argentorati jer Josiam lihelium impressae sumt, omaes surrmanicat lin:tun, iconibus instructi ommes

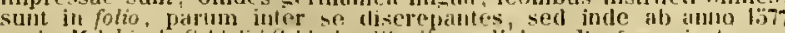
curis Jelchiorix Setizii Sebisch) silesin. medicinae Professoris Argen-

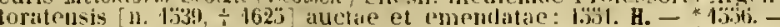

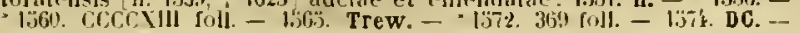
Prttzel, Thes. lit. loot.
- 157. 396 foll. praeter partron quartam modican: Vin vier Elemen-

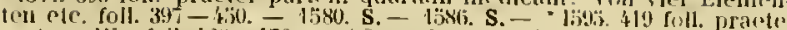

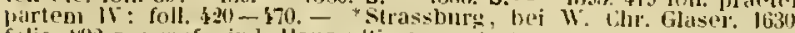
folio. \$92 p.,prace., ind. Ilaur ultimam puto.

* lutine: lie stirpium nasime samm quae in Grananit nostra nascuntur, usitatis nomenclaturis, propristye dillorentis, nepue nen I'mperaturis ae facullatibus, Commentarorum dibri tres, serumaie prinum lingua conseripti. nune in Intman conversi. interipete buvid hiybero Arentimensi. lis accesscrum contis

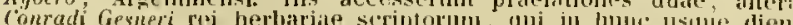

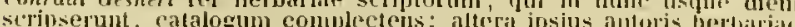

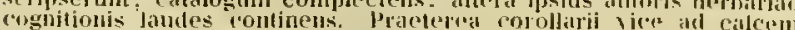

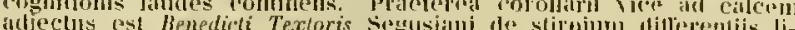
bellus. Argentinde, excudebal ventelimus Rilielius. praef. ind. et ic, sylowr. i. 1.

$980^{\circ}$ - Verao atque ad vivum expressae imagines omnium herbarum, fruticum et arborum, quarum nomenclaturaos $\mathrm{et}$ descriptiones vir lite in re citra contruversian doctissimus Hieronymus bock in suo tum germanico, tum latintati donato herbario com1) elsendif; nunc prinum lace minori forma in gratiam et utilitateo umnium herbariac rei studiosorum excusae. Eigentliche und wahrliaftige Albiltung mol Contrafactur etc. Strasburg bei Wendel Riliel. 1553. 4. 333 p., 6 jr. ind. et $(567)$ ie. $\lambda y \log r$ i. t.

(Sunt icours Fuchsii et propriae a Davide Kandel pulchre delinratae seorsim erlitae. Editio 1 . est anni 1530 . \&.

$981^{*}$ Teutsclie Speisthammer, in welcher du findest, was gesunden und hranken Menschen zur Leibesnarung und desselben wepresten von noten etc. Strassburg, bei Wendel Rihel. 1550.4 CXIX foll., praef., ind.

(Hall. Bibl. Jot. I. p. 267-268. - Spreng. Ilist. 1. 1). 315-321. Gescl. d. Bot. 1. p. 269-272.)

982* Bock, Johann Gotllob. De radice Ipecacuanluac. I). Jenae 1830 4. 23 p.

983* Back, Joseph. Pantarum secundum Pluarmacopoeam austriacam and 1820 officiualium quotguot in Magno Transsilvaniae Prineipatu slonte proveniunt, descriptio, Limaeo et praesertim Tlunbergio duce in systema sexuali-arteficiosum concinnatd. 1). Cibinii 1332 , \& $\mathrm{vi}, 58 \mathrm{p}$.

954 (Bocris, G. C.) Beschreibung aller in Handel vorkammeorlen Tabacksgattungen, ihrer Productionslioder etc. Bremen 4833. \$. 36j. $(1 / 2(h)$.

985* Bodard, Pierre Henri Hippolyle. Mémoire sur la Véronique cymbulaire. Pisa 1798, 8. 16 p.

$986^{*}$ Dissertation sur les plantes liypocarpozies, e'est á dire, qui ont la proprielé dintroduire leurs fruits en lerre. Pisa 1798. $8.74 \mathrm{p}$.

$987^{*}$ Analỵse du cours de botanifue médieale-comparée, ou l'on indique les plantes indigines qui peuvent etre substituécs aux plantes exotiques. Paris 1809.4 .49 p. $(90$ c.)

988 t — Cours de botanique médicale comparée ou exposé der substanees végétales exutiques cumparies aux plantes indigenes. etc. Paris 1810. Il voll. 8. - 1: cxil, 328 p. $-11: 445 \mathrm{p} .(15 \mathrm{fr}$.)

980 Essai sur les proprictés du Tussilago Petasites. Pari. 1809. 8.

990 Proprietes medicales de la chamomille nolle, employec comme febrifuge. Paris $1810.8 .(60 \mathrm{c})$ a.

$99.1 \div$ Tableau des plantes médicinales cxotiquos, et de leurs suceédanées indigrenes, extrait du cours de botaniıue médicale comparée. Paris 1815.4 .17 p. $(75 \mathrm{c.})$

$992{ }^{*}$ Bodenstein. Adam ron. Kurtze Besclıreibung und Nutz ler Kranler, so den zwolf himmlischen Zeichen in ilurer eygensehaft unt wurchung sich reres]cichell. Amberg 1611.8. (32 p.) folio.

$993^{*}$ Böck, $J . B$. Natırgetreue Abbildungsen der in Deutschland einheimischen wilden llobarten nebst erkaterudem Texte hierzi. Augsiburg $1844-1846.4$. Lieferung $1-9$ 28 j., 36 tals. col.

Continuatur. Visguti quinque fasciculos anmuntiarit bilsliopola quisque continebit tabulas coloratas, pretio $\% / \mathrm{s} t$

894* Boecler, Johamues. De Foeviculo. 1). Argentorati 1732.4 .40 p.

$993^{*}$ I) : negrlectn regetabilium circa Argentinam nascentium usu. Siecimen I et ll. Argentorati 1732 et 1733.4 .

$996^{*}$ __..._ De Coriandro, 1). Nromitorati 1739.4.

$997 "$ Boehler, Jaliob Julius. He Chininio suphurico. D. Lipsiac 1828. 4. 38 p. 
$999^{\circ}$ Boehn, Ernst Julius. De Conin maculato ejusque praeparatis inprimis de Coniino. 1). Vratislaviao 1844.8.28 p.

999 (Boehm, Johannes.) Catalogus ruriorum plantarum hortuli Johannis Boehm. Venetiis 1689.8. S.

$1000^{*}$ Bochmer, Georg Kudolph. Florae Lij)siao indigena. Lipsiae 1750. $8.340 \mathrm{p}$., praef., ind. $(3 / 4$ th. $)$

1001 " Billiotheca seriptorum historiae naturalis, oeconomiac aliarumyue artium ac scientiarum ad illam pertinentium realis systematica. (Systematisch-literarisches llandbuch der Naturgeschichte ric.) Lipsiae 1783-1789. V partes. 8. - Pars I. Scriptores generales. vol. 1: 1785 . xvut, 778 p. - vol. 2: 1786.772 p. - Parslli. Ploytologi. 1787. vol. 1: 808 p., vol. 2:642 p. - Pars V. llydrologi. Accedit index universalis. $1789 . x, 740 \mathrm{p} .\left(13 \frac{\mathrm{H}}{\mathrm{s}} \mathrm{th}\right.$.)

(Pars II. continet zoologos, pars W. minepalogos. - Liber satis diligenter chabratus est, sed autoris saepo libras absquo autopsia recensentis tides mimine intacta.)

$1002^{*}$ - Technische Geschichte der Pflanzen, welche bei IJandwerken, Künsten und Manufacturen bereits in Gebrauche sind, oder noch gebraucht werden können. Leipzig 1794. 2 Theile. 8. - I: $780 \mathrm{p} .-\mathrm{Il}: 670 \mathrm{p} .\left(3^{3} / \mathrm{t}\right.$ th. $)$

$1003^{*} \longrightarrow$ Lexicon rei horbariae triparlitum, continens etymologiam nominum et terninologiam parlim in descriptione partim in cultura plantarum assumptan. Lipsiae 1802. 8. xu, $392 \mathrm{p}$. et corrigenda. $\left(1 \frac{1}{2} t h.\right)$

\section{Programmata academica:}

$100 \mathrm{f}^{*}$ De plantis fasciatis. Wittenbergae 1752.4.16 p.

$1003^{*}$ _... De Melocacto ejusque in Cereum iransformatione. ib. 1757.4. 14 p.

$1006^{*}$ De ornamentis, quae praeter nectaria in floribus reperiuntur ib. 4758.4 .46 ).

1007 * De serendis vegetabilium seminibus monita. Pars I et II. ib. $1761,4,8,8 \mathrm{p}$.

$1008^{*}$ Dissertationis de nectariis florum additamenta. il). 1762. 4. 8 p.

$1009^{*} \longrightarrow$ Do plantarum superficie exercitatio J-IV. ib. 1770.4. $8,8,8$ et $8 \mathrm{p}$.

$1010^{*}$ Commoda, quae arborcs a cortice accipiuut. ib. 1773. 4. $8,8 \mathrm{p}$.

$1011^{*}-$ De dubia fungorum collectione. ib. $1776.4 .8 \mathrm{p}$.

$1012^{*}$ - De satione mixta. ib. $1784.4 .8,8 \mathrm{p}$.

$1013^{*}$ De cocruleo colore in frequenti florum corollariorum lusu valde raro. ib. $1786.4 .12 \mathrm{p}$.

1014* Cyano segretum nuper imputatum virus limitatur. ib. 1787.4.12 j.

$1013^{*}$ Dispositionem plantarum in tabulis synopticis nujer commendatam uunc exenplo Mesembryantheni illustrat. ib. 1789. 4. $12 \mathrm{p}$.

$1016^{*}$ Tabularum syuopticarum, quibus genera plantarum disponnntur, exempla proponit. Pars l et ll. ib. 1790. 4. 11, $16 \mathrm{p}$.

$1017^{*}-$ De veretationo plantarum inversa. ib. $1794.4 .10 \mathrm{~J}$.

$1018^{*}$ De foliis arborum deciduis. Specinen l et Il. ib. 1797. 4. $8,8 \mathrm{p}$.

$1019^{*}$ Plantas fabulosas inprimis mythologicas recenset. Specimina I-XV. jb. $1800-1803$. 4. $11,14,10,8,8,8,8,8,8,8,8$, $8,8,8,8 \mathrm{p}$.

(Prolusionum Boehmerianarum specimina VHl- $\mathrm{XV}$, autore $d . \mathrm{IV}$ Apr. 1803. Ingulsi morte erepto, paulo mutato titulo edidit Traugoth Carolus Lugustus Yoge.)

Praeside Boehmero dissertationes academicae:

$1020^{*}$ Plantao caule bulbifero. D. Lipsiac 1749. 4. 30 p.

$1021^{k}$ De vegetabilium celluloso contextu. D. Wittenbergae 1753. 4. $34 \mathrm{p}-{ }^{*}$ Editio altera cum commentalione de plantarum semine. Wittenbergae 1785.8 .

1022* - De nectariis florum. D. ib. $1758.4 .47 \mathrm{p}$.

$1023^{*}$ Do virtuto loci natalis in vegetabilia. D. ib. 1761. 4. 29 ]).

$1021^{*}$ - Planta res varia. D. ib. $1765.4 .30 \mathrm{p}$.

$1023^{*}$ Do justa plantarum indigenarum in pharmacopolis reformandis aestimatione. D. Wittenlergae 1770 . 4. $32 \mathrm{p}$.

$1026^{\circ} \longrightarrow$ De plantis in Cultorum memoriam nominatis. D. ib. 1770. 4. 60 p. - " Ed. nova continuata: Lijesiae $1799.8 .233 \mathrm{p}$ $(5 / 6, h$.
1027* Boehmer, Georg Rudolph. De sambuco in totum medicinali. D. Wittenbergae $1771.4 .36 \mathrm{p}$.

1028* _- Spermatologiac vergetabilis Pars 1-Vil. D. ib. 17771784. 4. 36, 34, 27, 47, 34, 26,22 1. - " Commentatio physicobotanica de plantarum semine, anteliac Spermatologiae titulo pes partes, nunc conjunctin edita et aucta. Accedit dissertatio do contextu celluloso vegetabilium. Wittenbergae $1785.8 .458 \mathrm{p} .(\mathrm{b} / \mathrm{th}$.)

$1029^{*}$ Commentatio de plantis segeti infestis; accedit conmentatio de plantis ancturitate publica exstirpandis, custodiendis, et e foro proscribendis. Wittenbergae et Servestae 179z. $4.128 \mathrm{p} .(3 / 12$ th.

$1030^{*}$ - De oleis expressis. I). Wiltenbergae 179z. 4. $38 \%$.

$1031^{*}$ De salibus a plantis paratis. I) ib. 179z.4.32 p.

1032* De Taxo biccato. D. il). 1796.4.32 p.

1033* - De plantis monadelphis praesertim a Cavanilles dispositis. ib. $1797.4 .18 \mathrm{p}$.

103:" — De Toxicodendra. D. it. 1800.4.20 p.

$1035^{*}$ De viribus Sassaparillae antisyphiliticis. D. Wittenbergae 1803.4.34 p. (Accedunt: Quaedam de Sassaparilla et Carico praemissa: 12 p.)

1036* Boehmer, Johann Benjamin. Radicis Rubiae tinctorum effectus in corpore animali. D. Jipsiae 1751. $4.42 \mathrm{p}$.

1037* Boehmer, Philipp Adolph, pr. De Hellebori nigri atque praesertim viridis usu medico. D. Halae 1774. 4. (4), 23 p.

1038* Boenninghausen, C. M. F. von. Nomenclator botanicus sistens plantas phanerogamas in circulo Coesfeldiae Westphalorum inquilinas, secundum normam Linneanam dispositus. Coesfeldiac (1821). 8. $20 \mathrm{p}$.

$1039^{*}$ Prodromus Florae Monasteriensis Westphalorum Phanerogamia. Monasterii 1824. 8. xiv, $332 \mathrm{p} .\left(1 \frac{\mathrm{l}}{3}(\mathrm{~h})\right.$.

$1040^{*}$ Boerhaave, Hermann. Index plantarum, quac in horto academico Lugduno-Batavo reperiuntur. Lugduni Batavorum 1710, 8. $278 \mathrm{p.}$ praef., ind.

$1041^{*}$ ___ Index alter plantarum; quae in borto academico Lugduno Batava aluntur. Lugduni Batavorum, sumtibus autoris apud Pelrum van der Aa. 1720.4.- I: 34,320 p. - IJ: 270 p., ind. et 40 tab. - * $\mathrm{ib}$. apud J. van der Aa. 1727. 4. (praeter titulun non differt.)

(In bibliotheca Nusei botanici Vindohonensis vidi aliam hanc impressionem anonymam, Hottonii laudibus in praefatione menorabilem. quam lherhavius in catalogo operum suorum non agnoseit: "Index flimtarum. quae in horto icallenico Lugduno Batavo aluntur, ut et plurimarum in eoden cultarun descriptiones et jcones. Lugduni, apud Janssonios. 1720 . S. Xv, $699 \mathrm{p.}$ tab.)

$1012 *$ Historia plantarum, quae in horto academico Lugduni Batavorum crescunt cum earum characteribus et medicinalibus virtutibus. Romae, apud $\mathrm{F}$, Gonzagam (revera Lugd. Bat.) 1727. 11 partes. $8.698 \mathrm{p}$., ind. - ${ }^{*}$ Ed. IJ. ancta et ab intinitis mendis purgata. Londini 1731 . 11 partes. 8.698 p., ind. - † Ed. III : Londini 1738. 8. $696 \mathrm{p}$.

(Maculosissimum el confusissimum opus ab Anonymo quodam conseriptum.)

$10.33^{*} \longrightarrow$ Sermo academicus, quem habuit quum bonesta missiono impetrata botanican et clienicam professionem publice poneret. IXVIll Ap. 1729. lugduni Batavorum 1729.4.38 p.

(Hall. Bibl. bol. I1. 17. 96-97. - Spreng. Ilist. 11. 199-200. - Spreng. Gesch. d. Bot. 11. $139-160$.

104* Boerner, Friedrich. De Aemilio Ifacro, ejusque rarioro hodie opusculo de virtutibus herbarum Diatribe. Lipsiae (1754). 4. 20 p.

$1045^{*}$ Boerner, Gottlob. Alphabetisches Verzeichniss grösstentheils nordamerikanischer und audrer auslandischer theils einheimischer Baume, Stráucher und Pflanzen etc. Dresden 1786. 8. 74 p. - Zweites Verzeichniss etc. ib. 1787.8 . $133 \mathrm{p}$.

101.6t Boëtius de Boot, Ansclmus. Flonm, herbarum ac fructtum selectiorum icones, et vires pleraeque hactenus ignotac; e bibliotheca Olivarii Vredii J. C. Brugensis. Accessit Lamberli Vossii Rosellani Jexicon novum herbarum tripartitum: latino-flandrobelgico-tgallicum, flandrolselgico-latinum et gallico-latinum. Brugis Flandrorum, apud J. B. et I.Kerchovios. 1610.4 obl. (8), 119 p., 30 tab. cum 60 figuris; praeter 27 et 28 omnino e Passaet IJorti floridi parte altera. mutato orline.

(E)titio prior a Seguiero citatur: Francofurti, apud .lamium. 1609.

$10177^{*}$ Boettger, Christoph Ucinrich. Beschreibung des botanischen Gartens zu Cassel. Prugramm. Cassel 1777. 4. 30 p. I tab. $(1 / 6 t /$. $)$ 
$104 \mathrm{~S}^{*}$ Boettger, Christoph Ileinrich. Verzeichniss der Baume und Siauden im Park zu Weissenstein. Zwei Programme. Cassel 1777. 4. 44, $76 \mathrm{p} .(1 / \mathrm{t}$ th. $)$

$10 \$ 9$ Bogsch, Johann. Anleitung nutzliehe Obstloüume und küchengewatichse zu zichen. Ed. Ill. Wien 1803. $8 .(1 / 3 / h$.)

$1050+$ Bohadsch, Johann Taufer. Abhandlung vom Gebrauch des Waidtes in der llaushaltung. Prag s. a. 4. 34 p.

$1051 \%$ Beschreibung einiger in der llausiraltung und Farbekunst nutzbaren Kratuter im Konimreich Bohmen. Prag 1755. S. 138 p., 3 tab.

$1032 \div-$ - Dienst und nutzharer patriotischer Vorschlag, wienach dem Königreieh Bohein ein ungemeiner Vartheil von sonderbarer Beträchtlichkeit jahrlich zuwachsen kinnte. Prag 1758. 8. $35 \mathrm{p}$. (Kultur der Rohinie.)

$1053+$ Bohler, $J$. Lichenes britannici or Specimens of the Lichens of Britain. In montlly fasciculi with descriptions and occasional remarks. Sheffield $1835-1837$. fasc. I-XVI. 8. 16 tab. col. (a) $S$ species desiceatae totidemque foll. explic. $=\mathrm{Nr}$. 1-128. à $3 s .6 d$.)

105." Bohman, John. Omberg (in Ostrogothia) och dess omgivuingar. Linkoping 1829. 8. 125, 3 p.

(lnest: Omberss Waxthistoria p. $33-48$.

$1035^{*}$ Wettern ach dess Küster. Andra Resan. Ett helt for sig, innefattande do Wetterns Special-Bestrifning, jemte hithörande aldre märkvärdigheter. Orebro 1940.8 , vil, $312,4 \mathrm{p}$.

(Plantac in monte Omberg erescentes recenscutur p. 152-168.

1056 Boiceau, Jacques. Traité du jardinage. Paris 1638. folio. - Paris 1707. 12. S.

1087* Bojer, W. Hortus Mauritianus ou ćnumération des plantes exotiques et indigènes qui croissent à l'ile Maurice, disposées d'après la méthode naturelle. Naurice, typ. Namarot et Co. 1837. 8 max. vil, 456 p. Bibl. Imp. Ferdin. et Cand.

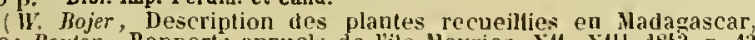
vide: Bouton, Rapports annuels de l'ile Haurice. dil-XIll. 1843. p. 13 -21. , p. $43-5$.

1058 ' Boisduval, Jean Alphonse. Flore française ou deseription synoptique de toutes les plantes phanérogames et eryptogames, qui croissent naturellement sur le sol français, avec les caractères des genres des agames el l'indication des principales especes. Paris 1898. III voll. 18. - 1: xx11i, 347 p. - II: 370 p. - II : 396 p. (10 fr.) (Sistit partem alteram libri inscripti: Manuel complet de botanique, chez Roret; accedit nappa: 120 tab. 18 fr. - tab. col. 36 fr.)

$10: 39^{*}$ Boissier, Edmond. Elencluus plantarum novarum minusque cognitarum, quas in itinere lispanico legit. Genevae, typ). Lador et Ramboz. 1838 . 8. 94 p. $(1$ th. $)-{ }^{*}$ Ed. (illegitima?): Erfordiae, Otto. 1840. 8. 66 p. $(1 / 3$ th. $)$

$1060^{*} \longrightarrow$ et George François Reuter. Diagnoses plantarum novarum hispanicarum, praesertim iu Castella nova lectarum. Martio 1842. Genevae 1842. 8. 28 p.

$1061^{*}$ Yoyage hotanique dans le midi de l'Espagne pendant l'anne 1837. Paris, Gide. $1839-1845$. Il voll. 4. - Tome I: Narration et géographie botanique. Planclues. $x, 248 \mathrm{p}$, 208 tab. col. sign. 1-181. $\left(1^{\mathrm{a}}, 4^{\mathrm{a}}, 6^{\mathrm{a}}, 9^{\mathrm{a}}, 14^{\mathrm{a}}, 14^{\mathrm{l}}, 26^{\mathrm{a}}, 40^{\mathrm{a}}, 64^{\mathrm{a}}, 80^{\mathrm{a}}, 84^{\mathrm{a}}, 85^{\mathrm{a}}\right.$, $92^{a}, 94^{a}, 98^{a}, 102^{a}, 108^{a}, 113^{i}, 118^{a}, 122^{a}, 123^{a}, 125^{a}, 126^{a}, 132^{a}$ duplices tab. 92.98. 115.) et un tablean synoptipue des hauteurs et limites des végétaux. - Tome 11: Enumération des plantes du royaume de Grenade. Additions ef corrections: $757 \mathrm{p}$

(Prodit elegantissimum optus fasciculis 22 , quisque pretio $18 \mathrm{fr}$ $=396 \mathrm{fr}$.)

$1062^{*}$ Diagnoses plantarum orientalium novarum. Lipsiae 1842 -1846. Yo. I-V11. \&. - 1: 1842.76 p. - I1: 1843.115 p. $-11 \mathrm{I}:$ 1843. 60 p. - IV: 1844. 86 p. $-\mathrm{V}:$ 1844. 91 p. $-\mathrm{Vl}: 1845$ $136 \mathrm{p} .-$ VIl: $1846.130 \mathrm{p} .(65 \%$ th.) (Continuantur.)

$1063+$ Boissieu, C. V. de. Flore d'Europe, contenant les détails de la floraison et de la fructification des genres eurupéens, et une ou plusieurs espèces de clıacun de cos genres dessinés et gravés d'après nature. etc. Lyon $1805-1807$. 8. Hil voll. ou 12 Livraisons à 20 planches $=240$ tah. totidemque foll. text. ( $60 \mathrm{fr}$. $-90 \mathrm{fr}$. $-144 \mathrm{fr}$.)

(In Bibliotheca Delessertiana 660 tah. duobus voluminibus comproliensa adsunt.

1064 t Boitard, Pierre. La botanique des Dames. Paris 1821. 111 voll. 12. - I: 203 p. $-11: 222$ p. $-111: 236$ p. (9 fr.)

$1060 \mathrm{t}+$ Flore de la botanique des Dames. Paris 1821. 12. $104 \mathrm{tab}$. col., explication et 8 p. ind.
1066 Boitard, Pierre. Manucl du naturaliste fréparateur ou l'art d'empailler les animaux et de conserver les végctaus et les minéraux. Paris 1825. 18. $244 \mathrm{p}$.

germanice: Hindbuch fur Naturaliensammler, oder grundliche Anweisung, dio Naturkirper aller drei Reiche zu saumeln, im Naturalienkabinet aufzustellen und aufzubewaluren ete, Frei nach d. Fran-

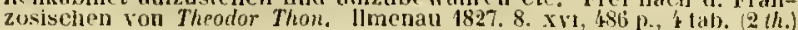

$1067+$ Nanuel complet de botanique ou Principes de hotanique élémentaire. etc. Paris 1826. 12. vi, 448 \%., 6 tab. (3 fr. 50 c) - Ed. Ill. corrigée el augmentée. Paris 1835. 12. 460 p. tal. ( 3 fr. 50 c.)

germonire: Dic Botanik in ihrer Anwendung, von Theador Thon. IImenau 1828. 8. $\left(1^{2} / 3\right.$ th. $)$

1068

1069 356 p., 2 tab. ( 3 fr.) a.

Traité de la culture du murier. Paris 1828. 8 . (7 fr.) a Manuel de physiologie végétale. etc. Paris 1829.12 (8 fr.) $a$.

$1071+$ L'art de composer et decorer les jardins. Ouvrage accompagné d'un grand nombre de planches. Ed. III: Paris (1834). 4 ohl. xiv, 172 p. et Atlas : 120 tab. (15 fr.)

1072 Botanique des demoiselles. Paris 1835. 8. Iv, $156 \mathrm{p}$. 64 tab. $(13 \mathrm{fr},-$ col. 26 fr.) a.

1073 - Slanuel complet de l'amateur de roses, leur monographie, leur histoire et leur culture. Paris 1836 . 12. 367 p., 15 tab. ( 3 fr. 50 c. - col. 7 fr.) a.

$1074+$ Le Jardin des plantes, description et moeurs des mammifères de la menagerie el du Mluséum d'histoire naturelle. Précédé d'une introduction historique, descriptive el pittoresque par Jules Janin. Paris 1842. 8. Lxxvi, 472 p. avee planehes et vignettes.

1075* Bokelmann, Johannes Friedrich. De Trifolio paludoso seu fibrino. Lugduni Betavorum 1718.4.13 p.

1076 Bolet, Louis Madelaine. Essai sur la culture du meurier blane of du peuplier d'Italie. Dijon 1766. 8 . a.

1077 Bolnest, Edward. A rational way of preparing animals, vegetables and mincrals for a pliysical use. London 1672. 12. s.

$1078^{*}$ Bolton, James. Filices britannicae; an history of the british proper ferns; with plain and accurate deseriptions and new figures of all the species and varieties etc. Part I: Leeds $(1785)$. 4. xvi, p. 1-59, ind, tah. col. 1-31. (1l. 7s.) - Part II: Huddersfield 4790.4. p. 60 $-84 .$, tals. col. $32-46$.

$1079^{*}$ - Au history of fungusses, growing about llalifax. In threc volumes (and Appendix or Supplement). Huddersfield 1788-1791. IIl voll. 4. xxxII, 182 p. 182 tab. col. (3/. $3 s$. A. London 1842.)

germanice: Geschichte der nrerkwurdigsten Pilze. A. d. Englisclien mit Aumerkungen von $K$. $L$. If illdenow. Berlin $1795-1820$. IV voll. 8. - I

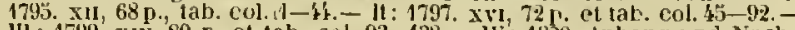
III : 1799. XIV, 80 p. et tab. col. 93-138. - IV: 1820. Anhang und Nachträge von Christian Gottfried und Friedrich Ludwig Nees von Esenbeck. cLxxx, 80 p., ind. et tab. col. 139-182. (221/2 th. -8 th. A. $)$

1080 Bolzano, Bermhard. Dr. J'incenz Julius von Krombholz, nach seinem Leben und Wirken geschildert. Nit dem Bildnisse Krombhols's. Prag 1845. gr. 4. 7 Bogen, 1 lab. (1/2 th.)

1081* Bonafous, Matthicu. De la culture des muriers. Lyon 1822.8 56 p. - +Ed. 11: ib. 1824.8 .53 p., 1 tab. - ${ }^{*}$ Ed. 111 : Paris 1827 8. xII, $62 \mathrm{p.}, 1$ tab.

$1082+$ Sul gelso delle Filippine (Morus cucullata). Torino s. a. $8.42 \mathrm{p}$.

$1083^{*}$ Des feuilles de Maelura aurantiaca, comme succédanćes de celles du murier. Paris $1835.8 .9 \mathrm{p}$.

(Exir. des Mém. de la société royale et centrale d'agriculture, annee 183.̈.

108:* Histoire naturelle, agricole et économique du Mais Paris 1836. folio. 181 p., 19 tab. col. (tab. 13-17 nigrae.) (100 f:.) $1085 \mathrm{t} \longrightarrow$ Della colivazione della barbabietola istruzione. Torino 1836, 8. 19 p., 1 tah).

$1086^{t}$ - Sull' introduzione di una nuova pianta indigofera (Polygonum tinctorium). Torino $1839.8 .10 \mathrm{p}$.

$1087^{\circ}+$ Traité de l'éducation des vers à soie et de la culture du murier, suivi de divers mémoires sur l'art séricicole. Quatrième édition revue et augmentéc. Paris 1840.8 . vil, 547 p., 5 tah. (quarum 1 col.) $(7 \mathrm{fr}$.)

1088* Bonamicus, Franciscus. De alimento libri V. Florentiae, Sermartellus. 1602, i. 
$10897^{\circ}$ Bonamy, Wrancois. I'lorae Nannetensis Prolromus. etc. Nannetis 1782. 12. XYr, $126 \mathrm{p}$. - Aldenda: ib. 1785. 12. 14 p.

1090* Bonato, Guiseppe Antonio. Pisaura automorpha o Coreopsis formosid, piante nuove. Pindova 1793.4. 27 p., 2 tal.

$1091^{\circ}$ - Catalngus plantarum lorti Paturini. P'adova 1811, 8. DC. - Padoya 1813.8. H. v. D.

$1092^{*}$ — Ossenvazioni sopra i fungli mangereccj. Padova 1815. $8.33 \mathrm{p}$.

$1093^{*}$ - Avertimenti al pop̧olo suli" uso de funghi. s. I. et a. 4. Ifi j.

(1)ubus pusteriorihus commentariolls una manum andbuerunt Augelo Jullic Hecrma et Valerin Luigi Brera.)

109 : Bonde, Gustaf, Grefce. Tal om Aske-tradets (Fraxinus excelsior) uytti. Stockbolm 1756.8.20 p.

(1)e ejusd'm intoris dissertintione: "Guds Linderverk uti naturen" viule W. Consy. lit. suce. ]3. 38-39.)

$1093^{*}$ Bondt, Nicolaus. De cortice Geoffreae suriumensis. D. Lugtuni l3atavorum 1788. 8. 106 p., praef. 1 lal.

* hollendice: door II. A. Balie. Lejal 1790. 8. (10 c.)

1096 Verhandeling over de overeentomst weschen dieren en planten. Amsterdam 1792.8. DC.

1097 De uilitate illorum laborum, quos recentiores in re botanica exercenda posuerunt, rite aestinanda. Amsterdam 1794. 4.

1098* Bonelli, Giorgio. Ilortus Romanus juxta systema Tournefortianum paulo strictius alistributus a Georgio Bonelli, specierum nomina suppeditante, priestantiorum, quas ipse selegit, adumbrationem dirigente Liberato Sabbati. Romac, sumtilus Boucliard et Gravier. VII voll. folin. - I: 1772. vul, 30 p., 100 tab. col. - II: 1774 . vi, $22 \mathrm{p}$. 100 al., col. -111 : 1775. iv, 18 p., 100 tab. col. - IV : 1776. 22 p.

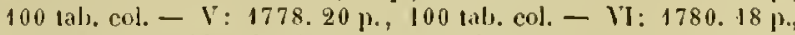
100 tah. col. - VIl: 1784.18 \%., 100 tab. col.

(Voll. II-Y. incerij)ti sunt: Iortus liomanus secundum systema Tournefurtii a Nicolao Hortellio Linneanis characteribus expositus, atjectis sincularun plantarum analysi ae viribus; species suppeditabat ac dencribubat Liberatus sabbati. - Voll. II et Vil inscripta sunt: liortus lomames a Nicolan Martellio, speeies suppeditatiat ac descri-

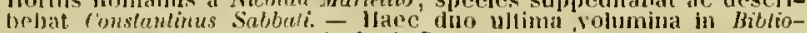
bribat ronstentimus Sabbati. - Hace duo ulima volumina in Biblothece Folessertima aculue ac in Regia Rerotinensi desitlerantur. - Icones
admotum malite smit.)

$1099 \div \div$ Memoria intorno al olio di Ricinn volgare. Roma 1782. 8. xxIII, $279 \mathrm{p} ., 1$ tab.

1100 Bonfiglioli, Giuseppe. Index plantarum Actuae; exstat in Petri Carrera "Il Mongibelio descritto." Catanea 1636. 4. - recusa in Graev. et Burmann Thes. sicil. 1om. X.

(Spreng. Nist. II. 181.)

1101 t Bongard, II. Gustat. Esquisse historique des Iraxaux sur la bolanique emtrepris en Russie, depuis l'ierre In Grand jusqu’à nos jours et de la part ique l'Aeadénic a tue aux progries lo cette science. 4. $26 \mathrm{p}$.

(Extr. du Reeucil des Actes te 183k.)

$1102^{*}$ Deseriptiones plantarum novarum. Petropoli (et Lipsiae) 1839. 4. $45 \mathrm{p}$., 22 talo. (1 $1 / \%$, th.)

(E) Acad. caes. sc. Comment. sor. VI. tom. i.)

$1103^{*}-$ und Karl Inton Meyer. Verzeichniss der im Jahre 1835 am Silisang-Nor und am lityseh gesammelten Pflanzen. Ein zweites Suplement zur Flora Nltaica. St. Petersburg 1841. 4.90 p., $16 \mathrm{tal}, \mathrm{s},(1 \mathrm{~s}, \mathrm{~h}$.)

(E) «Min, de l'Acid, des se. nat. tome 11 n seorsim impressa.)

110\%* Bonjean, Joseph. Ilistoire physiologique, chimigue, toxicologique el médicale alu seigle ergolé. Conromsé par la société royale do pharmacie de Paris. Paris et Lyon 1842. 8, 36 p.

$1103^{*}$ Bonnet, Charles. Recherehes sur l'usage des feuilles dans les plantes et sur quelques autres sujets relatifs a l'histoire de la vénétation. Gocllinguo et Lcide 1754.4. vil, 343 p., 31 tab. - * redil: Ocurres, tom. II. p. 179-459.

uplementum primm operis inest in Mém. étrangers de l'Aca-

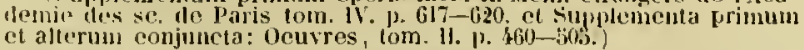

hollandice: Underznek van het gebruik der hladen in de plant-

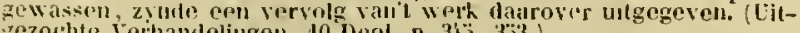
gezochte Ferhandelingen, $10 \mathrm{pect}$, p. $36.5-3 \mathrm{~m} 3$ )

* germanice: Untersuchungen uber den Ninzen der Blatter in den

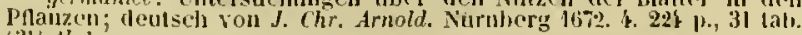
$\left(3^{\prime} t_{3} h_{h}\right)$

germanice: dassclbe, yermehrt von Bockh; herausgegensen von Gatterer. Lin 1803. k. tab. $(3 \% 3$ th.)
$1106^{*}$ Bonnet, Charles. Considerntions sur les cosps organiscis. Amsterdam 1762. II voll. 8. - 1: xul, 274 p. - 11: xx, 328 p.

germanice: Betrarbung vitur die or:anisirten horjer, uberselzt

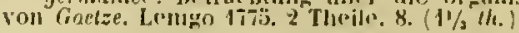

1107 " Contemplation de la nature. Amsterdam 4764. II voll. 8. - I: Ixxxiv, 298 j. - II: v1, 260 p. - Hamburg 1782. III voll. 8. germanire: Betrachtung uber die Vatur, von J. D. Titius. Leipzig 1803. 2 istint $1.8 .(2 \% / \mathrm{th}$.

(De antore cjusque ininoribus commentationibus vide llall. libil.

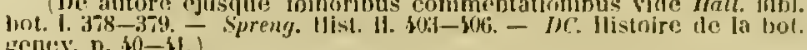
Hener. p. $30-41$.

$1108 \div$ Bonnet, Mareellin. Facies plinntarum. Carcassonne (1810?\%.3 fasc. folio. 4 plag. 45 tab, col.

1109* Bonpland, Jime. Description des plimes rares cultives à Malmaison el a Navarre. Paris 1813 . folio. 157 p., ind, et $64 \mathrm{tab}$. col. a Redouté delineatace. (L'entier est publie en 1 / livraisons. - Prix de pablication: Paplier firand-Jesus vedin 528 fr. et grand colombier vélin 1056 fr. a.)

$1110 \div$ Bontekoe, Cornelis. Tractat wan het excellendste Kruyd Thes. atc. Coffi, Chocolate. Ed. II. Gravenlage 1679. 367 p., praef. - Ed. JII. ib. 1685.8 , s.

$1111^{*}$ Bontius, Jacob. De medicina Indorum libri $\mathbb{~}$ I. Nutac in Garcian ah Ilorto. 2. De diaeta sanorum. 3. Meduodus medendi indica. 4. Olsservationes e cadaverilus. Lugrluni Batavorum 1642. 12. 212 p., ind. - "impr. cum Pinonis de Inliae utriusque re naturali et mediea. Amstelnd. 1658. folin. "impr. cum Prosperi slpini medicina Aegyptiorum. Lugd. Batav. 1718. 4. 109 p., ind.

1112 Bonvinius, Elias. De lheriaca. Breslau 1610.8. H.

1113 Boogh, J. Nederduitscls woorlenbock, of alphalseth van alle kruiden, wortels, zaaden, gommen etc. met een daar agter gevoegde: Catalogus generalis omnium fere simpliciun in thesauro sanitatis pracstantium secundum numerum et alphabetum eorum in ordinern redactus. Anisterdam 1794. gr. 8. (55 c.)

1114* Boon Mesch, Heinrich Karl ran der. Commentatio le vi lueis ad creanela principia regetalilium proxima, praemio ornata. Lugduni Batavorum 1819.4 .50 ). $(5 / 6$ (h.)

$1115^{*}$ De ratione, quae est inter structuram et forman externam plantarum. Commentatio praemio ornata. Lugduni Batavorunı 1819. 4.48 p. $(5 \%$, th. $)$

$1116^{*}$ Boos, Joseph. Schonbrunus Flora, orler systematisch georinetes Verzeichniss der in $k . k$. hollandiseh-botanischen Infgarten zu Schönlsrumn cultivirten Gewtichse. Wien und Triest 1816. 8. x. 393 p., app. $(12 / 3$ lh. $)$

1117* Booth, John. James Booth und Solme gegen I'rof. Lehmann in Betrelf der l'raclıtrose: "Konigin yon Dánemark." (Zum Besten der Armen.) Allona 1833.8.24 p. $(1 / 6$ (h.)

1118 Booth, J. G. Ueber die Aulegung und Erhaltung eines englischen Rasens, oder warum sind unsre Rasen nicht so schön, als man sic fast uherall in England antriln? Ilamburg (1838?). 4. w.

$1119^{*}$ Borch, Michel Jean, Comle de. Letres sur les truftes do Piimont. Nilan 1780. 8. vis, 51 p., 3 tab. col.

1120 Borchmeyer, Wilhelm Anton. Teutsclılands Baumzucht. Münster 1823. 8. 575 p. und G Bogen Talsellen. $(21 / 2 t h$.)

$1121^{*}$ Bordiga, Benedelto. Storia delle piante forastiere lo più importanti nell' uso medico el reonomico colle loro figure in rame. Milano 1791-1794.1Vvoll.4.-I: 1794. 204 p., tab.col.1-24.- I1: 1792. 204 p., tals. col. $25-48 .-$ III: 1793.196 p., tab. col. 49-72. IV: 1794. 205 p., 1al, col. $73-96$.

1122 Boreau, 4. Observations sur les enveloppes florales des vérgétaux monncotýlétons. Paris 1827.8.36 p. a.

$1123 \div$ - Voyage aux monlagnes du Norvan, suivi d'observations sur les végétaux de eette contrée. Nevers 1832. 12. 140 p.

$1124+\ldots$ Programme de la Flore du centre de la France suivi du catalogue des plantes olsservies daus le rayon de ectle Fluro et d'olservations relatives a quelques plantes eritiques. Nevers 1835. 8. $12 \mathrm{p}$.

1123 " — Flore du eentre de la France, ou deseription des plantes qui croissent spontancment dans la région centrale de la france el 
de celles, qui y sont eultivées en grand, avec l'analyse des genres et des especes. Paris 1840. If roll. 8. - I: IX, 330 |. - II: 589 I.

(Lettre a Saul et Repouse a Jferal, vide Cosson et Germain, Supplement etc. 1813. p. 19-39.)

$1126 \div$ Boreau, A. Catalogue des graines rẻcolties au jardin botanique de la ville d'Angers. 4. $1842.12 \mathrm{p} .-1843.4 \mathrm{p} .-1844.8 \mathrm{p}$.

$1127+$ Notes sur quelques expèces de plantes françaises. Angers $1844.8 .94 \mathrm{p}$.

$1128 \div-$ Comple-reodu des travaux de la section de botanique de la sixième réunion des savans italiens tenue a Mllan en 1844 extrait et tratuit par A. Boreau. Alljers 1846.8.16 j)

$1129 \div$ Borel, Picre (latine Borellus). Hortus seu armamentarium simplicium mioeralium, plantarum et aninalium ad arten medieam utilium. Cum lrevi el accurata juxta releberrimus autores eorum etymologia, descriptione, loco, temperie et viribus. Parisiis, apud Olivarium de Varenues. 1069.8 . (8) 384 (et 4 ) p.

(Editio in Bibl. Banksiana laudata: Cakstris 1666. \$. non Uiffert.)

$1130^{4}$ Boretius, Jfallhias Ernst. De Mieraciis prussicis. 1). Lugdun Bataverum 1720.4.21 p.

$131^{*}$ - De antome plautarum el animalium analoga. D. Regiomonti 1727. 4. $16 \mathrm{p}$.

$1132^{*}$ Borkert, Withelm. De radieis Ipecacuanhae effeclu. D. Vratislaviio $1841.8 .30 \mathrm{l}$.

113.3* Borkhausen, Moritz Balthrsar. Versueh einer forsthotanisehen Besclıreibung der in den Hessen-Darmstadtschen Landen, besonders in der Otergrafsehaft Catzenellenbogen im Freien wachseoden Holzarten. Frankfurt a/MI. $4790.8 . \mathrm{xL}, 397 \mathrm{p})(1 \mathrm{1} / \mathrm{th}$.)

113." —.._ Rheinisehes Magazin zur Erweiterung der Nalurkunde. Erster (und einziger) Band. Giessen 1793. 8. 724 ). (2 th.)

$1135^{*}$ _ Botanisches Wörterbuch oder Versueh einer Erhlarung der vornelmsten Begrille und Kunstworter in der Botanik.

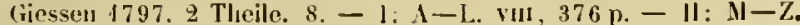
Nebst einer kurzen Geschichte der Botanik: 504 p. $\left(3 \frac{1}{3}\right.$ th. - herabgeselzt: $1 \frac{1}{3}$ th

(Liber anno 1816 noto tilub instructus est. - Nachtrige, vide Dietrich.

1136* Theoretisches prahlisches Ilandluch der Forstbotanit und Forstteclmologic. Fiessen 1800 . 2 Theile. 8. xVIII, $866 \mathrm{p}$. 6 th. - heralogesetzt $1 \frac{1}{3}$ th.

$1137^{*}-$ Tentamen dispositionis plantarum Germaniae seminiferarum secundum novam melhodum a staminum silu et proportione, eum characteribus generum essentialibus. Opus posthumum. Darmstatt 1809. $8.158 \mathrm{p}$, int., sehema. $(1 / 2 \mathrm{th}$.

(Eulitio prior laudatur amui 17.2.

1138* Born, Ignaz Edler von. Plyysihalische Arbeiten der eintrachtigen Freunde in Wien. Wien 1783-1788. 2 Jalırgange. 4. cum tab. (Perpauca hotanieam tangunt.)

1139 Bornholz, Alexander von. Der Truffelbau, oder Anweisung, die sehwarzen und weissen Trulfeln durch Kunst zu ziehen, und grosse Anlagen dazu zu machen. Quedlinburg 4825.8. $(1 / 3 \mathrm{th}$.)

$\div$ gallire: Do la culture des truffes, ou maniere dobthenir, frar des

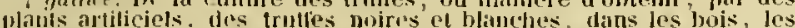
fossquets of les jarrlins. Trabluil de l'allemand par Jfichel Oegger. Piris 1826.8 . W 86 i p.

italice: Della coltivazione de' tartufi. etc. Versione tal tedesco. Milan! 1527. 12. $72 \mathrm{p}$.

$1140^{\circ}$ Bornitz, F. A. 1) eorticis Angusturae patria principiis usucpue medico. D. Trajecti a $/ \mathrm{V} .1804 .8 .25 \mathrm{p}$.

$11+1 \div$ (Borrer, IVilliam, iml Dauson Turner.) Specimen of a Lichenograpllia britanuica; or attempt at a listory of the British Lieliens. Imperfect, for private eirculation only. Sarmouth, printed by C. SloInant. 1839.8 . II, 240 p., $(8$ p.) ind.

(Vidi Parisiis in bibliothea Camilli Montagne. impressio libelli rarissinui for viginti sex anums distrahebatur; jousnuius Turner aululidit iulicem et filuluen nee tou a is. muntuin de Gyrophora.)

1112 "Borrich, Olof. De somno et somniferis maxime papavereis. D. Hafniac $1683.4 .40 \mathrm{p}$

$1143^{\circ}$ He usu plantarum indigenarum in medicina; de clysso flantarum, ete. Hafniae $1690.4 .101 \mathrm{p}$. * germanice: kurzor Begrilf von frehranch der cinliadiseben krauter in der Arizuey. llanhury $16 \% 6$. 8. 2ij p.

11 14" Bory de Saint-Vincent, Jean Baptiste M. A. G. Mémoire sur les genres Conferra et Byssus de Chevalier C. Limne. Bordeaux, 15p. Cavazza. an V. (1797.) 8. 58 p., 3 tab. col. dessineses it la main. Bibl. Camilli Montagne.

Scriptiuncula traces rarissima eacterum inumeris fy potuetare menrlis squalento, primus sedecim annos natus optimus liony botanircorum ingressus est castra.)

$1113^{*}$ Bory de Saint-Vincent, Jean Baptiste H. A. G. Voyage dans les quatre principales iles des mers d'Afrique, fait par urdre du zouvernement pendant les années $\mathrm{L}$ et $\mathbf{X}$ de la république ( 180 ) et $(802)$, avec: Ihistoire de la traversée lu Capt. Baadin justu'au Port Louis tle lisle Maurice. Paris 1804. Ill voll. 8. - I: xv, $408 \mathrm{p}$. - II: 431 p. - III : 473 p. - Mlas in 4: 58 tah. sign. $1-56$; (parum sedecin plantas tahibent. ( $48 \mathrm{fr}$.)

germanice: Reise narch deon vier vornohmsien Inseln der afrikanisehen Neere. I. 'Theil. Leipzig $1 \times 03.3 .8$. (1\%/3 th.

$1146^{*}$ Essais sur les isles fortunes et l'antique Allantide ou préeis de lhistoire génerale de l'Arehipel des Canaries. Paris an $\mathrm{Xl}(1803)$.4.522 p., 3 cartes, 7 tals. $(15 \mathrm{fr} .-18 \mathrm{fr} .-30 \mathrm{fr}$. Je la matière. Paris $1826.8,34 \mathrm{p}$

(Extrait du Dictionuaire classique d'hustoire naturelle, tome $x$.)

$1148^{*}$ Lissai monographinue sur les Oscillajes. Paris is 27

8. $31 \mathrm{p}$

(Exirait lu bietionnaire rassique d'bistoire naturelle, tome Xit.) $1149^{*}$ (E) Crymogamic. (Faisant partie du voyage autour th monde par L.J. Duperrey. l'aris 1828. 4.301 p. Atlas in folio: 39 lalı.)

(Tabulae signalie I-38; tab). 13 bis. - Tabular 1-2's sumt roloratare el sistunt Algas, Juace in sequenti opere seorsim redeunt; tahulac 2 -39 sunt ingrie, Ly eopodiaceas el Filices sistentes.)

$1180^{*}$ - Histoire des Ilydrophytes, on plantes agames "des

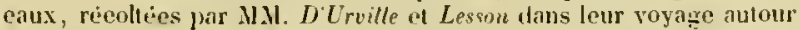
du monde sur la Coquille pendant les andes $1822-1825$. sous le commandenent du Capilaine Duperrey. Paris 1829. folio. 240 p. 24 tab. col.

(Sunt Algae ex collectione eryptogamantun itinteris modo dieta seorsinn editie.

$1.51^{*}$ _ Expédition seientificue de Moréc. Tone III, 2. partie Motaniuge. Paris 1832. 4. 367 p. et Allas in folio: 38 tab. quasum duae pictac. (103 fr.) Adohum elaborindo npere illustrissimus bory adjutores sibi assoeiarit

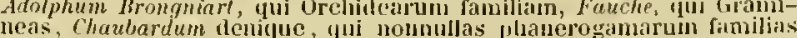
neas, (haubardu
adumbrivil.)

$1152^{*}$ - Nouvelle Flore du Péloponmese et des Cyelades, entièrement revue, eorrigée et augmentéc par H. Chaubard pour les phanérogames et M. Bory de Saint-l'ineent pour les cryplogames. les agames, les comsiderations geinerales, la distrilution des especes par familles naturelles et ee qui a rapport aux habitat. Paris et Straslinurg 4838.4 livraisons. folio. 87 p., praef., ind., 42 tab. ( 75 fr.)

$1133+$ Bosc, Joseph. Traité elementaire de physique vigctale appliquér a l'agrieulture. Paris (1824).8.116 p. (1 fr.) rossice: Moshovíae 1830.8 . $\mathrm{T}$.

113it Bosc, Louis Augustin Guillaume. Exposition du plan te travail adopté pour étudier et classer les diverses variétés de vignes cultivèes dans les pépinières du Luxeubourg. Paris s. a. 8.27 p.

Eutrait des don. de l'Agrieulturn francaise, toma vivil.

$1158 \div \div$ Hémoire sur les difrirentes espèces de chenes yui eroissent en Franee, et sur ceux ètrangers a l'empire qui se eultivent dans les jardins et pépinières des environs de Paris, ainsi que sur la culture génemale ef particuliere des uns et des autres. Paris 1808. 4. $69 \mathrm{p}$.

$1136 t-$ Collection de Memoires on de lettres relatives aux ellets sur les oliviers de la gelée du 11 au 12 Janvier 1820 . Paris 1822.8 . viII, $232 \mathrm{p}$.

1157 De la culture des arhres et de la menasoment iles forets. Paris 4821.8.

(Eltrait de IEneyclopédie méthodique.)

$1438+$ Bosch, R. B. van der. Enumeratio plantarum Zeelandiae Lelgicae indigenarum tertia. s. I. et a 8.22 p.

$11: 9^{*}$ Bose, Alolph Julian. De disquirendo charactere plantarum essenttiali simgulari. D. I Lipsiae $1765.4 .40 \mathrm{p}$.

$1160^{*}$ De motu humorum in plantis vernali tempore vividiore. D. Lipsiae 1764. 4. 8 p.

$1161^{*}$ Bose, Erust Goltlob. De nodis plantarum. I. Lipsiae 1747. 4. 24 p. $1162 *$ De radieum in plantis ortu et directione. 1). Lipsiae 1754. $4.35 \mathrm{p}$.

$1163^{*}$ Progranma de secretione humorum in plantis. Lipsiae 1755.4. 20 p. 
116." Bose, Ernst Golllob. Motum humorum in plantis cum motu liumorum in animalibus comparat. 1). Lipsiae 1763.4 .24 p.

$1163^{*} \longrightarrow$ Deolerum vernalium pracstantia. D. Lipsiae $1763.4 .16 \mathrm{j}$.

1166 Bose, Georg Matthias. Otia Wittebergensia. (Antiguitates sacchari.) Wittenbergae 1739.4. H.

11167 Tentamina electrica. Wittenbergae 1747.4. н.

(lusunt experimenta de vegetatione chectricitatis vi accelerata.)

11 (is * Bose, Johann Jakob, pr. We potimilus mortiferis ad illustrandos varios s. scripturae locos, iuprinis Marc. X11. 18. D. I. Lipsiae 1736. 4. 14 1. - I. I1: il. 1737. 4. 27 p.

$1169^{*}$ Bose, Laspar. Calyeen Touruefortii explicat. D. Lipsiae 1733.

$1170^{*} \frac{4.32 \mathrm{p} .}{4.56 \mathrm{p} .}$ De motu plantarum sensus acmulo. D. Lipsiae 1728.

$1171^{*}$ Bosse, J. F. WV Vollständiges l landbuch der Blumengarinerei oder genaue Beschreibung fast aller in Deutschland bekaun gewordenen Zierpflanzen uni Einschluss der Strúucher und vorzüglicheren Zierbaume etc. Zweite verbesserte Autlage. Ilannover 1840-1842. 3 Theile. 8. - 1: Abies-Dychia. xvi, 731 p. - II : Ebalium-Oxyura. 705 p. - III: Pachypodium-Zygophyllun. 678 p. $(72 / 3$ th. $)$

$1172^{*}$ Bosseck, Heinrich Otto. De autheris flerum. D. Lipsiae 1750. 4. $48 \mathrm{p}$.

1173 Bosson, A. .Mémoire sur l'influence du déboisement des forêts. Paris 1825.8. (75 c.) a.

1174 Bossu. Nouveaux vayages dans l'Amérique septentrionale. Amsterdam et Paris 1777. 8. Dc.

t anglice: Travels throusli that part of North-Ameriea formerly cailed Louistaua. Translated from lise french by John Reinhold Forster, illustrated with noles relative chicely to Haturat history. To which is added hy the Iranslator a systematic catalogie of all the known phants of Enstish vorth-America on a litorit tmericae Septentrionalis. London 1771. 11 rols. \&. - 1: v111, 607 1). - 11- 432 p. (Calalogus plantarum inericae septemtrionalis: vol. 11. p. 17-67. - Excerpta itineris Loe/lingii: vol. 11. p. 69-1;32.

$1175 \div$ Bostichi, Bernardo Davanzati. Toscana coltivazione delle viti e delli arbori. Firenze 1621, 4, 36 p.

1176* Botta, Carlo. Storia naturale e medica dell' isola di Corfu. Ed. II: Nilano 1823. S. xvi, 300 p., effigies autoris. - Ed. 1: ib. 1797. 8.

$1177^{*}$ Botta, Paul Emile. Relation d'un vayage dans l'Yémen, entrepris en 1837 pour le Huséun d'histoire naturelle de Paris. Paris 1841. 8. $148 \mathrm{p}$.

$1178 \div$ Bottione, Angela Maria. Stirpes, quas vivas pinxil in aemulatione naturae annis $1806-1812$. Augustac Taurinerum 1813.8. 15 foll (Catialogus.)

1179 Botton. Fsame critico e ragionato quanto alla parte betanica degli elementi di storia naturale del cittadino Miltin; sopra la versione reneta e la ristampa torinese. Torine 1799. 8 . Dc.

1180 Boubée, Nérée. Bulletin de nouveaux gisemens en France de botanique, jour servir de complément périodique à la Flore française. Paris et Strasbourg 1833. S. 24 p.

$1181^{*}$ Bouchardat. Recherches sur la végetation appliquées à l'agriculIure. ete. Paris 1846.12.197 p.

1182 Bouché, Karl David. Dio Blumentreiberei. ete. Berlin 1842. 8. 16 Bogen, 4 tab. $\left(1 \frac{2}{3}\right.$ th.

$1183^{*}$ Bouché, Farl Paul. Der Zimmer- und Fenstergarten. Reullingen 1812. 8.204 p., ind. - Ed. V'I: $1833.8 .(1 \%$ th.

1184 - Der Zimmergarten im Grassen. Berlin $1825.8 .5 \frac{3}{4}$ Bagen, 3 tal. $(1 / 2$ th. $)$

$1180^{\circ}$ Bouché, Peter Friedrich. Die Beliandlung der Pflanzen im Zimmer und in keinen Gärten. Berlin 1840. 8. 32 Bogen. (2 th.)

$1186 \div$ Boucher (de Crececoeur), Jules Armand Guillaume. Exirait de la Flore d'Abbeville et du Département do la Somme. Paris 1803. 8. XIr, $108 \mathrm{p}$

(Editio, quam autor curaterat, nova muquam prodiit.)

1187 Boucher, Pierre. Ilistoire veritable et naturelle des moeurs et productions du pays de la nouvelle france, vulgairement dite le Canada. Paris 1664 . 12. S

$1188^{\circ}$ Boucherie, A. Mẻmoire sur la conservation des bois. Paris 4840. 8. $45 \mathrm{p}$.

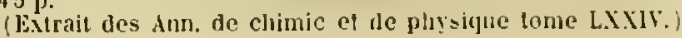

$1189 \div$ Bouchor, Adolphe. Du mode d'action et des effets therapeutiques clu seingle ergote. These. J'aris 1830.4. $20 \mathrm{p}$

$1190 \div$ Boué, Ami. Do methodo lionam resionis cnjusdam conducendi. exemplis e Flora seotica etc. ductis jllustrata. D. Ldiuburgi 1817 $8.63 \mathrm{p}$.

$1191^{*}$ Mémoires géologiques et palcontologiques. Tome I. Paris 1832. 8. $x \mathrm{W1}, 362$ [1. 4 tal.

$1192+$ Ja Turquie d'Europie ou olsservations sur la géographie. la géalogie, I'listoire naturelle - tle eet empire. Arec une earte nouvelle de la Turquic d' lurope. Paris 1830 . IV voll. $8 .(3 \geq \mathrm{fr}-1$

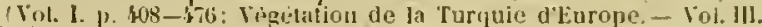
p. 1-39: Africulture, horliculture.

1993\% Bouillet, Jean. Lettre an sujet de la rlieubarbe. Beziers 172\%. 4. 8 p.

119. Boulay, Jacques. Naniere de bien cultiver la viqne dans l'Orléanais. Ed. Jl. Orleans 1712. 12. - Ed. Ill : il. 1723. 1 s. s.

$1198+$ Boullay, P.F. G. Disserlation sur l'histoire naturelle et chiroique de la coque du Jevant (Menispermum Cocculus). Examel sur son principe vénéneux considéré comme Alcali végétal et d'un nouvel acide partieulier à cette semence. Paris 1818. 8. 32 1. - - Deuxiome thèse. il. 1818.4. $21 \mathrm{p}$.

1196 Bourdon, J. B. Isidore. Principes de plyssiologie comparéc, on histoire des phénomenes de la vie dans tous les ctres qui en sont doucis, depuis les plantes jusqu'aux animaux les plus conplexes. Paris $1830.8 .616 \mathrm{p}$. a.

1197 Bourguet, Lonis. Leltres philosephirques sur la formation des sels et des cristaux el sur la generation el le mechanisme des plantes. Ansterdan 1729. 12. s.

1198+ Bourne, Edward. De planlarum irritabilitate. D. Edinburgi, 1794. 8. $66 \mathrm{p}$.

1199+ Bourru, Edmond Claude. Num Pili, plantae? D. Paris 1764. 4. $12 \mathrm{p}$.

1200 Bourwieg, E. W. Ahandlung uber den Hausschwamm, nebst Beschreilung eines von dem Herru Olyeramtmann Kastner zu Stcpenitz erfundenen zuverlissigen Yittels gegen densclben. Eo. Il. Stetiu 1827. 8. 4 Bogen, 2 tab. $(5 / 12$ th. $)$

$1201+$ Boutcher, Ililliam. A treatise on forest-trees, containing not only the best methods of their culture etc. Edinluurgh 1775. 4. XLvin, 259 p. - Ed. 11 : ib. 177 S. 4.259 p. B. (vix differt.)

$1202^{*}$ Boutelou, Claudio. Tratado de la luerta, ó métedo de cultivar torla clase de lortalizas. Nadrid 1801.4 min. 400 13. - Ed.II: Madrid ISI3. 4.

$1203^{*}$ Tratado de lis flores. Madrid 1804.4.- Ed. II: Madrid 1537.4.

$120: 5+$ Discurso acerca del origen y progresos de la agricultura, de sus ventajas y de la necessidad de su enseñanza. Alicante $1816.4 .41 \mathrm{p}$.

12030 Tratado del ingerto. Madrid 1817.4 .

$1206-$ Instruccion sobre cl cultivo del arroz de secano. Madrid $18 . .4$.

1207 Boutelou, Estcban. Memoria solore el cultiro de la vid en Jerez de la Frontera y Sanlicar de Barrameda. Madrid $18 . .4$.

1208* Boutelou, Pablo. Memoria acerca de la aclimatisacion de plantas ecsólicas. Sevilla $1 \$ 42.4 \mathrm{~min} .53 \mathrm{p}$.

$1209^{*}$ Bouton, Louis. Rapnorts annuels ( $\mathrm{X}$-XiIl) sur les travaux de la société d'histoire naturelle de likle Maurice. Maurice, typ. Gernéen 1839-1843.4.-X: 1839.88 p. - I]: 1841.77 p. - Xll-XllI $1843.111 \mathrm{p}$, , 1 tals.

( Nuperiores editas esse credo, ueque tamen vidi; "V1-1K. anni183:- I8t) inlidit Julien Desjurdin.

$1210 \div$ Bové, Nicolas. Observations sur les cultures de l'Éggpte. Paris $1835.8 .92 \mathrm{p}$.

(Extrail des Aunales de l"Institut horticole de Fromont, tome Vi.

121.1* Bowdich, T. Eduard. Excursions in Madeira and J'orto Saute during the autumn of 1823 , white on his third voyage to Africa etc. Londoin IS25. 4. XII, 278 1\%, tab. Botany: p. $244-267$.

* gullire: accompagne de notes de Mr. le Baron Cuvier et Mr. If

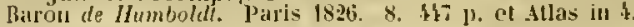

$1212^{*}$ Bowerbank, James Scott. I history of the fossil fruits and seeds of the London Clay. Part 1. Londen 1840.8. 144 p., 17 tab. (16s.) 
1213† Bowles, William. Introduccion a la historia natural $\mathrm{y}$ a la geografia fisica de España. Ed. 111 : Manlrid, en la imprenta real. 1789. 4. (26) 46.554 p. - Ed.l: ib. 1775.4 .529 p. B. gallice: Paris 176. 8.

2I!* Boym, Michael. Flora Sinensis, fruclus floresque lumillime porrigens etc. Viennae 1656 . folio. ( 36 foll.) 23 tab. col. gallice: Flora Sinensis, ou traite des fleurs, des fruits, des plantes, particuliers a la Chine. Impr. avec sa relatiou de la Chine; p. $13-30$ dans la seconde partie de la Relation de divers royiges par Thevenot Paris 1696 . Iolio. B.

$1213 \div$ Braconnot, Menri. De l'influenco du sel sur la vógétation; avec des observations sur ce mémoire par Soyer-Wittemet. Nancy 1845. S. $16 \mathrm{p}$.

Commentatinnes celeberrimi chemici satis diligenter recensentur in libro inscripto: Biographie des hommes du jour, t. V. partic preniere, p. 232. .

1216* Bradley, Richard. The history of succulent plants; containing tho Aloes, Ficoids, Torch-thistles, Melon-thistles, etc. envraved from the originals. (Historia plantarum succulentarum etc.) London 1716 -1727.4 . V Decarles. $(70$ p.) 50 tab. latine et anglice. (Conjunctim prodierunt novo titulo 173k.)

$1217^{*}$ (Cow Tew improvements of planting and gardening, looth philosophical and practical. London 1717.8. - Ed. V1: in three parts. London 1731.8 .608 p., praef., ind., taly.

$\div$ gallice: Nouvelles observations physiques et pratiques sur le jardinage. Paris 170̈6. 111 voll. 8.

$1218^{*}$ The gentleman and gardeners Kalendar etc. London 1718 S. xII, 116 p., 4 tab. - Ed. III: London 1720. 8. 111 p. B. gallice: Le Calendrier des jardiniers. Paris 17.3. 1730. 8. Q.

$1219^{*}$ The virtue and use of Coffee, with regard to the plague and other infections distempers; coutaining the most remarkable observations, etc. London 1721.8. 34 p., 1 tab.

$1220^{*}$ New experiments and observations, selating to the generation of plants, occasion'd hy a letter published in the Philosophical Transactions by Patrick Blair, M. D. Together with an account of the extraordinary vegetation of peaches, abricols, nectarines, plums, cherries, figs, wines, grossherries, currans etc. as they were arteficially cultivated this spring 1724 . London 1724.8 . Sloane.

$1221^{*}$ Dictionarium lotanicum, or a botanical dictionary for the use of the curious in husbandry and gardening. London 1728 . 11 voll. 8. - I: 30 plagg. - II: 30 plagg.

$1222^{*}$ The riches of a Hopgarden explain'd from the several improvement arising by that beneticial plant etc. London 1729. 8 . $104 \mathrm{p}$.

Ten practical discourses concerning the four elements as they relate of the growth of plants. Ed. Il: London $1733.8 .195 \mathrm{p}$

(. Multa alia ad agriculturam spectantia cedidit Polygraphus noster quae pro parte recenset Seguierus p. 313-3'st. - Spreng. Gesch. d. Bot. 11. p. $16.00-166$.

22.4 Braeuner, Johann Jaliob. Thesaurus sanitatis oder menschlicher Gesundheit. Dritter Theil oder Kräuterbuch. Frankfurt 1713. 8.ib. 1728.8 . s.

1223 Braeunicke, F. W. Neues allgemeines practisches Lehrbuch des Blumenbaues fur angehende Blumengärtner. Wien 1809. $8 .(5 / 6 \mathrm{~h}$.)

1226 Braguier, $B$., et Maurette. Tableau synoptique des végétaux du département des Deux-Sèves. Saint-גlaixent 18 42. 18.120 p. a.

1227 Brancaccio, Francesco Maria De usu et potu Chocolatae diatribe. An Chocolates aqua dilutus prout hodierno usu sorbetur ecclesiasticum frangit jejunium? Cum methodo ad concinnandi chocolatis potionem, ejusque physicae qualitatis. Romae, per Zachariam Ascamitek. 1664. 4. et pluries. s.

1228 Branche, Pierre. Jardinier de grande experience, c'est à diro uno manière très-utile pour traiter toutes sortes d'arbres fruitiers. Cologne 1692. 8. s.

$1229^{*}$ Brande, August Everard. Experiments and observations on the Angustura bark. London 1794. 8. 86 p. - Ed. ll: London 1793. 8. $133 \mathrm{p}$

1230 Brander, Fredrik Reinhold. Kort Begrepp af Natural-Historien. Westerås 1785 . 8. xvi, 189 p. w.

Terminologia plantarum p. Wositio systematis Linneani, cbaracteres generum plantarum suecicarum. p. k2-113.)

$1231^{*}$ Brandes, E. Die Flora Deutschlands unt der angranzenden Lïnder. Nach einem neuen Srsteme. durch wclches auch dem Anfänger in der Botanik das schnelle und richtige Bestimmen aller aulgefundenen Pflanzen moglich wird. Stollerg an Harz 1846. 12. Lxxv, 418, $40 \mathrm{p}$ $\left(1 \frac{1}{2}\right.$ th.

1232* Brandis, Joachim Dieterich. Commentatio de oleorum unguinosorum natura (praensio ornata). Goettingae 1785. 4.50 p.

1233 Brandon. Hortus regius Honselaerdicensis ou collection d'un frontispice et 97 planches de plantes et de fleurs lant indigènes qu'exotiques dessinees en couleurs. 1 vol. folio.

(Opus splendicium (manuscriptum?) fuit inter libros Meermannianos; vide: (at. Bibl. Neermanniante, t. 1. Hagae 48\%'. 8. p. 266. Xir.639.)

123:* Brandt, Joharn Friedrich. Flora Berolinensis seu descriptio plantarum phanerogamarum circa Berolinum sponte crescentium vel in agris cultarum, additis Filicilus et Charis. Berolini 1824. 12. LIV, 373 p. (I th.

(Exemplaria anni 4823. haud differunt.)

$1235^{*}$ Tabellarische Ueluersicht der officinellen Gewachse. Berlin 1829-4830. 3 Tafeln in folio. ( $1 / 2$ th. $)$

1236* — Philipp Phoebus unt J. T. C. Ratzeburg. Abbildung und Beschreibung der in Deutschland wild wachsenden und in Gärten im Freien ausdaueruden Giftgewächse. Nach naturlichen $\mathrm{Fa-}$ milien erlautert. Zwei Abtheilungen. Berlin $1838.4 .\left(8 \frac{2}{3}\right.$ th.)

Erste Abtheilung: Denlschlands phaneroganische Gewachse, von Brandt u. Ralzeburg. Zw eite verbesserte und vermehrte Ausyabe. v, $200 \mathrm{P}$. el is tab. col. pro parte. $\left(5^{2} / 3\right.$ th.) (Erste Ausgabe in $1011 \mathrm{le}-$ teil mit is Tafeln. ib. $1828-183$ t. 4 . $(91 / 2$ th.

$\mathrm{Zweite} A \mathrm{~b}$ theilung: Deutschlinds kryptogamische Giftgewichse, von Philipp Phoebur. XII, 11 i p., 9 tab. col. ( 3 th.)

1237* Nachträge zur ersten Abtheilung Berlin 1838.4.34 p., 1 tab. col. $(2 / 3 t h$.

1238 Brasavola, Antonius Musa. Examen omnium simplicium medicamentorum, quorum usus est in publicis disciplinis et officinis. Romae, apud Antonium Bladum de Asula. 1536. folio. s. (videtur editio princeps.) - t Lugduni, apud Vincentium. 1536. 8. - " Addlita sunt insuper Aristotelis Problemata, quae ad stirpium genus et oleracea pertinent. Lugduni, sub scuto Coloniensi apud Frellonios; excudebat Joh. Barbous. 1537. 8. 542 p. et Epistola nuncupatoria cum inclice. - ${ }^{*}$ Venetiis sub signo Putei. 1539. 8. (non dilfert.) *Lugduni, apud Pullonium de Tridino. 1544. 8. - ${ }^{*}$ Venetiis, apul Valgrisium. 1545.8. -28s.)

Hall. Bibl. bot. I. p. $277-278 .-$ Spreng. Gesch. d. Bot. 1. p. 287

Braune, Franz Anton ron. Salzburgische Flora oder Beschreibung der in dem Ėrzstifte Salzburg wildwachsenden Pflanzen. Salzburg 1797. HI voll. 8. - I: LXXY', 426 p., 3 tab. - II: XL, 836 p., 3 tal. - III : $x L, 380$ p., ind. $\left(3 \frac{1 / 3}{3}\right.$ h. $)$

$120^{*}$ - Salzburg und Berchtesgaden. Ein Taschenbuch fur Reisende und Naturfreunde. Wien 1821. 8. 503 p., 2 (pflanzengeographische) Tabellen. $\left(2 \frac{1}{3}\right.$ th. $\left.-2 \frac{2}{3} t h .-3 t h.\right)$

12 1 $\div$ Bravais, Louis F., el Auguste Bravais. Mémoires sur la disposition géométrique des feuilles el des inflorescences, précédés d'un Résumé des travaux des MII. Schimper et Braun sur le méme sujet, par Charles. Nartins et Auguste Bravais. Paris 1838. gr. 8. xxvi, 190 p. et 7 tab.

Essai sur la disposition générale des feuilles rectisériées. (Clermont-Ferrand 1839.) S. 53 p., 2 tab.

Extrait du sixieme volume ile la cotlection du Congrès scien-

tifique de France.)
* gernanice: Ueber die geometrische Anordnung der Blatter und * germanice: Ucher die geometrische Anordnung der Blatter und
der Blutenstande. Hit einem zweifachen Anhange: bericht uher die der Blutenstande. Hit einem zweifachen Anhange : Bericht uher die Arbeiten der Ilerren Schimper und Brath uber den nambichen Gegenstand, Von Charles Martins und A. Bravais, nud Beobachtungen uber die Auflosung der paarizen Blattstellung in die spiralige von Dutrochet. Ans item rratuz. ubersetzt bon llithelm Gerhard Walpers. Mit
einer Vorerinnerung von Dr. Christian Golfried Nees von Esenbeck. einer Vorerimnerung von Dr. Christian
Breslau 1839 . 8. xII, 258 p., 9 iab. $\left(2 \frac{1}{6} t h\right)$

$1243 \div$ - Analyse d'un brin d'herbe ou examen de l'inflorescence des Gramiuées. Mémoire présenté au congrès scientifiq̨ue du Mans (12 Sept. 1839). Mans 1840, s. 32 p., I tab.

124k* Bray, Francois Gabriel, Comle de. Voyage pittoresque dans lo Tyrol; aux salines de Salzbourg et de Reichenhall et dans une partie de la Baviere. Ed. III. revue et augmentée. Paris 1825. folio. 82 p., 24 tab. (Vix botanicam tangit.)

1245* —— Wissensehaftliches Vermächtniss an die Königl. botanische Gesellschaft zu Regenshurg. Regensburg 1833 . 4. $55 \mathrm{p}$. et effigies Comitis de Bray. 
12 ift Brayer, A. Notice sur une nouvelle plante de la fanille des Rosa-

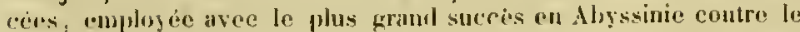
Taronia of apportéc de Constantinople. (Paris 1822.) 8. 8 p., 1 lab. (Israyma antheluintica kill.)

4247 Breda, J. G. S. van. Oratio de educatione vere liberali et listoriac? naturalis studio, inprinis ad illam conducente. Leovardiac 1818 4. ( $1 \mathrm{fr}$.

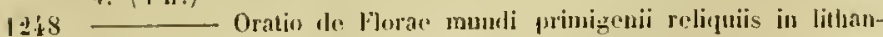
thracum fortuis prasertim conservatis. Gandavi 1823. 4.

$1299^{*}$ Genem ol species Orchidearum ot Asclepiadearum quas in itinere per insulam Java jussis el auspiciis Guilielui I coll. gertunt Ir. II. Kuht at I)r. J. C. van Ihasselt. Edlitionem at descriptisues curavit J. G. S. van Breda. Yol. I. fasc, 1-3. Gaudavi 1827 filio. 13 foll., 15 tab. col. $(14 \mathrm{th}$.)

$1240+$ Bredsdorf, Jacob I/ornemann. De regulis in classificatione rerum uaturalium ohservandis Conuocuatio. 1). Havonia 1817, 8, 69 p.

12011 Haandhog voll hotaniske excursioner i Ëgnen on Sorue. Kiobnhayn 1834-1835. Ilafte 1-2: 182 I. (Fasciculus tertius finem plantarum phaneroganarum commeralionis contincbit.) $w$.

1262 Breiter, Christian August. Horıus Breiterianus oder Verzeicluniss aller derjenigen Gewichse, welehe in Breiter'schen holanischen Garten zu Leipzig gezogen unl unterlalien wroten, nelst einem Theil der in Deutschiand einheimischen Pflanzon. Leiprig 1817. 8. L..., 558 [., A tah. (3 th.)

(Mens? Feluario cjusdem anu jam prodit particula hujus tibri. inscripta: "Verzerchuiss u. S. w, $32 \mathrm{p}$. $x$. $(1 / \mathrm{s}, \mathrm{h}$.

1253* Bremer, 11. 1. E. Brmelkungen und Erfahrungen wher die Wirksambeit der Rindo des Traubrukirschbaums (Cortex Pruni Padi). Berlin 1842. 8. 54 p., I als. col. ( $1 / 3$ th. ) (Aus llom's Arehir.)

12:4* Brendel, Alam, jr. De Rorella. D. Wittenbergae 1716. 4. 40 p.

1253 De plantis flore perfecto simplici regulari tetrapetalo. Wittenlergae 1718.4 . н.

1256 Brenner, Sophia Elizabeth. Ninne ofver dell Americansta Aloen, lıuilken uppà Noor longynte blumstras i Septembri 1708. Stochboln 1708. folio. 3 plagg. B.

$1237+$ Breon, $N$. Catalogue des plantes cultivées aux jarelins botanique ot de naturalisation de lile Bourbon. A Saint-Denis, jle Bourloon, le limprimerie du gouvernement. 1820.4. 58 p. - † Supplément. ih. $1822.4 .19 \mathrm{p} .-\div$ ib. $1895.4 .93 \mathrm{p}$. Bibl. Webb.

1238* Brera, Valerio Luigi. Programma de vitac vegrelabilis ac animalis analogia. Ticini 1796. 8. 44 [3.

$1259^{*}$ Del valore della Ballota lanata $L$. per la cura clelle affezione reumaticlse, artriticlie e gottose. Modena 1832. 4. 21 p. et 1 lałs.

$1260^{*}-1$ - Delle piante chinifere saggio. Modena $1832.4 .15 \mathrm{p}$

1261* Bresler, Morilz. Generis As]raragi listoria naturalis atque medica. D. Berolini $1826.8 . \mathrm{x}, 4 \mathrm{G}$.

1262* Breyn, Jakob. Exoticarum aliarumpue minus cognilarum plantarum Centuria jurina, cum fyguris arloeis sunmo stulio elahoratis. Gechani, typis, sumtibus ot in aedibus autoris evcudebat Rloctius 1678. folio. 195 1., prarf, ind., 10 tab. Acecelit: Appendis: VI p. et Withelm ten Rhyne, Ine frutice Thee et fasciculus rariorum plantarum: p. VIl-XXY.

$1263^{*} \longrightarrow$ Prodromus fasciculi rariorum plantarum anno 1679 in hortis celeberrimis Hollandiac etc. observatarum. Cui accedunt interrogationes de nonutlis plantarum ab auctore in Cont. I. descriptarum partibus etc. Golani, 19p. Bhetius. 1680. 4, 52, $7 \mathrm{p}$. et 3 tab.

1264* - l'rodromus fasciculi rariorum flantarum secundus, exhilıeus calalogum plantarum rariorum anno 1688 in liortis celeberrimis Hollandiae observatarum ete. Gedani, typ. Klactius. 1689. 4 . 108 P., 1 lab.

$1263^{*}$ Prodromi fasciculi rarionm plantarum primus et secundus, fuondam separatim nune nova hac editione multum chesiderata conjunctim editi, notulisque illustrati. Aecedunt icones rariorum it esoticarum planarum aeri ineisae, fascinulo olim promisso destinatıe: adjectis nominibus et succinctis descriptionibus. Quilus praenittuntur vita et effigies autoris, cura et studio Johannes PhiLppi Breynii, filii. Ilujus ad calcem amectitur Inssertatio hotanico- medica de radice Gin-sen seu Cini et herba Acmella curn additamentis. Liedani, typ. Seloreiber. 1739. 4. 108,54 p., 32 till.

$1266^{*}$ Breyn, Johumu Mhilipp. De radice Gin-Sem sou Nisi at Clirysantheno hidente zos lanico, Acmolla dicto. 1). (praeside Fr. Dekikers.) Lugduni Batavormin 1700, 4. 20 p., 1 tab. col.

$1267^{*}$ Te fungis oflicinalilus et eorum usu in unedicina. 1). Lugduni Batavorum 1702.4.41 p.

$1268^{*}$ Brez, Jaques. Ia Flore des insectopliles, precerlece al un discours

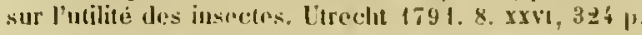

1269" BrickeII, John. The natural history of North-Carolina. cete. Inblin 1737. 8. xy, 408 13., 3 tab. (Vegetahles: p. 57-106.)

$1270^{*}$ Bridel-Brideri, Samuel Elisce. Muscologia recentiorum seu AuaIysis, historia el descriptio methorlica omnium muscorum frondosorum hucusque cognitorum ad norman II 4. - Tom. I: 1797. גม1v, 179 p. - Tom. Il. jars I: 1798. x, z22z p., 6 tal. - Tom. II. pars II: 1801. xII, 192 p., G tal., - Ton. II. pars III: 1803. 178 p., z tab. - Supplementa: Pars I: 1807. VII, 271 p. - l'ars II: $1812.257 \mathrm{p}$ - - Pars III: 1817. .xxu, $115 \mathrm{p}$. - Pars IV: 1822. (revria 1819.) vide: "Mlellodus nova." $\left(12 \frac{1}{2} / \mathrm{h}\right.$.)

127 I $^{*}$ - Nethulus nova nusscorum ad naturae normam melus instituta et Muscolugiac recentiorum accommodala. (Iuscologiale recentionm supplementum p. IV.) Gotha 1819. 4. Yvil, $2201 \%$ 2 tals. $(2 / h$.

$1272^{*}$ Bryologia unversa seu systematica ad Hovam methodum dispositio, listoria at descriptio omnium muscorum frondosorun hncuscue cognitorun cum symonyma ax anctoritus probaLissinis. Lipsiae. Il voll. $8 .-1: 1826$. xLv, 856 [?, 13 tal, -11 : 1827.848 ). $(10 \mathrm{th} .-11 \mathrm{th} .-12 \mathrm{th} .14 \mathrm{th}$.

1273* Brierre (de Boismont), A., et Pottier (de Bouen.) Elemens do Jotanique ou histuiro des plantes considicees sous le rapport de leurs proprictés nédicales et de lours usages dans l'ecouomic domostique et les arts industricls. Paris, Rinmund. 1825. gr. 12. su, $367 \mathrm{l}$. - Paris, Inelaforest. 1826. gr. 12. (non differt.) a.

1274* Briganti, Tincenzo. Clavis systematis sexualis Linnaci sistem plantarum classes, ordines corumque anomalias, in tres tahulas synopticas distributa atcue iconibus aeri incisis illustrata. Neapoli 1804. folio, $21 \mathrm{p}, 1 \mathrm{tab}$.

$1273^{*}$ - We nova Pimpinellae speece cui nomen Anisoides dissertatio. Nicapoli 1805 . folin. 19 p., 1 tab.

1276 Stirpes rariores, quae in regno Neapolitano aut spontc veniunt aut hospitantur. Penptas prima. Neapoli 1816. folio. 5 tab. Bibt. Radcliffe.

1277 De fumgis rariorihus rogni Neapolitani historia picturis ad naturam ductis illustrata. Teapoli $1 \$ 24$.

$1278-$ Sulla preparazione della pania dalle lacche del Loranto curopen. Sirapuli 1827. 4. 2 tal.

1279* Brignoli a Brunnhoff, Giocanni. Fasciculus rariorum plantarum Forojuliensium. Urluini $1810,4.320$

$1280 \div-$ Catalogur plantarum iu horto hotanico Archiggmasii Hutinensis cultarum. Alutinae 1\$17. \&. - ib. 1\$36. \$. 40 p,

1281 Acuni cenni sulle produzioni naturali del Dipart. del Metauro. Lrbiun 1813. 8. H. v. D.

1282* __ Horti hotanici R. Archigrmoasii Mutinensis Jistoria. Adjecta horti ejusidem iclonographia ef hy pocaustorum orthographia. Nutina 1842. 4.52 p., 2 tab.

$1283^{*}$ Brincken, J. von den. Mćmoire descriptif sur la forèt impériale de Bialowicza en Lithunie, rédigé par le Barou de Brincken. Orué de quatre gravures ct d'une carte. Varsurie 1828. 4. 127 p., praef., 5 tab.

128 : $^{*}$ - Ansichten ulher die Rewaldung der Steppent des curajuitishen Russlands, mit aligemejore Bezichung auf eine rationale Broprindung des Stiatswallwesens. Braunschweig 1833.4 . v, $230 \mathrm{p}$. 5 tal. $\left(3 \frac{1}{3}\right.$ th. $)$

12835 Bring, Ebbe. De morhis plintarum. W. I. Londini Gethorum 1758. 4. $29 \mathrm{p}$.

1286 Brisman, Sucno. Viun hunshaper un fiorin-grasel (Agrostis alla L.) med afseende pra dess Odling. lierguings-sitt, Xaringshraft och economisha warcle. Stochlolu Is 18 \&. 61 l . I tilb. W.

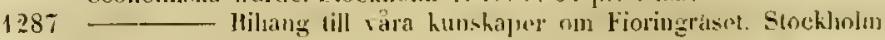
$1818.8,20$ p. w 
128st Brisseau-Mirbel, $C . F$. De l'influence do l'histsire naturel]s sur la civilisation. Discours prononed au Lyece Répulblicain a louserture do cours de hotanique le 9 Nivose an IX. Paris an IX. (1801.) 8. $32 \mathrm{p} \cdot(75 \mathrm{c}$.

$1289^{*}$ Traité d'anatomie of tw phrsiologie vegétales, suiv de la nonenclature méthodique ou raisonnér dis parties exterieures des plantes, et un expose sulecinct des systemess de botaniqne fess plus generalement adoptés. Ouvrage sorvant d'introduction a l'étude de li botanipues. Paris an X. 2 voll. $8 .-$ J: 378 p. et un tableau. II: $351 \mathrm{~J}$. $(9$ th. $)$

$1290^{*}-$ Ilistoire nalurelle générale et particulière des plantes; ouvrage faisant suite anx oeuvres de Lecterc de Buffon, et partio du cours complet d'histoire naturelle rédigé par C. S. Sonnini; comtinué par N. Jolyclerc. Paris $1800-1806$. XVIII roll. 8. 142 tab.

(. Hirbel non nisi volumina I. II. IV. V. et VI. scripsit.)

$1391^{*} \longrightarrow$ Exposition et défense de ma theorie de l'organisation végétale. (Filatuterung und Ferthcidigung meiner Theoric des Gewáchisbaus.) Publiée par le Dr. Bilderdyli. A la llaye 1808 . 8. xxxvit, $295,72 \mathrm{p}$. et 3 tal. (gallice et germanice.)

1292* - Exposition de lat theorie de l'organisation végutide, servant de réponse aur questions proposées en 1804 par la suciété royale de Göttingue. Paris 1809.8 . vir, 320 p., 9 tab.

(Est editio nova amplificata prancedentis operis.)

$1293^{*}$ - Elémens te plysiologie régètale et de botanique Paris 1815. III voll. 8. vill, LII, 921 (101) p., 72 1ab. (25 fr.) anglice: Genmal wservations on vegetation, tramslated from the french of $C . s$. Brisseau- Hirbel; to which are idded numerous and crensive notes, interuded to inspire young persons wilin a laste for botany, by presenting to them a birt's-eye view of the whole vegetable Kingdom. By' a Lady'. Lonicion $1838.8 .10 \mathrm{k}$. $(3 \mathrm{3} / 2 \mathrm{~s}$. $)$ W.

(llaud duhie framentum operis praecedentis.)

$1294+$ Recherches sur la distribution géographique des végćtaux phancrogames de l'ancien monde, depuis l'équateur jusiju'au póle arelique; suivic de la description de neuf espèces de la famille des Ameulacées. Paris 1827, 4. 132 p., 9 tab. (sign, 20 -28$.

(Exirait des Veimoires du Musénm dhistoire naturelle.)

$1293^{*}$ L Nouvelles notes sur le cambium extraites d'un travail sur l'anatomic de la rocine du datticr. Paris $1842.4 .79 \mathrm{p}, 12$ tah. (Extrait du tome XVHi des.lén. de TAc. des sciences. - Archives du Museum, Tom. I. p. 303-335.)

$1296+$ Analyses de plantes de diverses familles. folio. 12 lal, Bibl. Juss.

(Ouae tubulac nunquam editac autori ad scholas suas publicas ilustrantlis inservinnt.

1297 Britannus, Robert. Agriculturac cncomium. Parisis, apud Clıristianam Wechelium. 1539. 4. Bibl. Maz.

1298* Brocchi, Giamballista. Hemoria mincrologica sulla valle di Fassi in Tirolo. Milano $1811.8 . \mathrm{xxr}, 233 \mathrm{p}$

(Jnest botanica vallis geograpliti.

1249* Brocke, Heinrich Chistian won. Wahre Grunde der physikilischen und Experimental - allgemeinen Forstwissenschaft. Leipzig 1768-1775. 4 Thrile. 8 .

1300 - Beoharhtungen von cinigen Blumen, deren Bau und Zubereilung der Lirde. Leipzig 1771. 8. 264 [3. B.

$1301^{*}$ Brodin de la Jutais, fierre. L'abondance ou veritable pierre philosophale, qui consiste seolement a la multiplication tle toutes sortes de grains, do fruits, de fleurs et géneralement de tous les régctatiss. Paris $1752.12 .67 \%$

$1302^{*}$ Broecke, Jacob Cornelius van den. De usu radicis Colunalso. D. Lugduni Batavorum 1822 . 8. $11,40 \mathrm{p}$.

1303* Brögelmann, II: Beschreibung der vorzuglichsion nouen Pflanzen, welche in letztverflossenen Jithrzeheml zuctst sind entdeckt und hekaunt geworden. Frankfurt a/M. 1812.8 .232 p. ( 1 th. $)$

130 it Brohon, Jean. Je stirpibus vel plintis ordine alplabetico digestis epitome, longe quam antelac per Johannem Brohon Constaulinatem Jocupletior ementaliorque editi. Cui accesserunt volatilium, gressilium, piscium placentarumque magis frequentium apud Gallias nova per Leodegarium a Quereu. Caclomi 1511. 8. (32 foll.)

1303 Brokes, Barthold Heinrich. Irdisches Vergnigen in Gott. Ilanburg 1721. 8. - ib. 1737-1748. IA voll. 8 .

("Bartholdi Henrici Brokes poemata hue pertinent, guibus hene multas plantas concelebravit it descripsit, potissimum ejus virj: Irdisches largnugen in Gott." (Hall. Bibl. bol. li. 176.)

Pritzel, Thes. lit. bot.
$1306^{*}$ Bromelius, Olof. Lupologia eller en liten tractat om Jumle-gårdar. Sinchholm 1687. 12.92 (24 p.) - E.l. II: Stuchholm 1740.8.78 p. B. $1307 \div$ Chloris gothica S. Catalogus stirpium circal folloburgun nasceutinm, in equo edhibentor quolfunt hacteuss inventac sunt fuat sel sponte proveuiunt, vel in agris seruntor una cum synouymis selectioribus.tam latino quam stecico idioniate, holanieorumejue praecipuorum noninibus et observationibus quibustam non inutiliLus. Cinthohurgi 1694. 8. (4) 124 p. praeter Catalogrum librorum. Bibl. Juss.

$1308+$ Cillalogus librerum botinicorum ete. ex bibliotheca Bromelima, impr, ad calcem Chloridis gothicie ejusdem autoris, Gothoburgi 1694. 8. 10 fell. Bibl. Juss.

1309 BromeII, Maynus von. Lithogra|jhac suecanac specimen secundum, telluris suecande petrificata lapielesque figuratos varios exhibens. s. I. of a. 8 [3. Bibl. Bergiana Holmiensis.

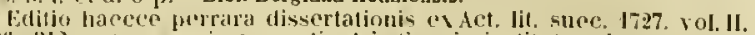
p. 306-312. recusate primas continet in suecial institulas ouservalione

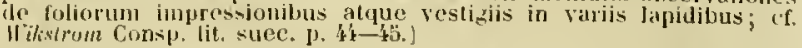

1310 Bromfeild, llilliam. An account of the english nimlushades and their ellects. Lourlon 1757.12 .94 p., 1 tab. col. B.

- gullice: Obserrations sur les vertus des dilférentes especes der Solanun gui croissent en Angleterre, Iraduits par M. Bromerilt le fils Paris 1761. 12. $12 \times 1$ in, 127 p.

1311t Brongniart, Alexandre. Nolice sur des vegetaux fossiles traversant les couches du terrain houiller. Paris $1821,4,15 \mathrm{p}, 1 \mathrm{tab}$.

$1312+-$ Des lignites. Paris $1823.8 .63 \mathrm{P}$

(E.1r. du 26. vol. du Diet. (les sc, nat.)

1313t Brongniart, Adolphe Théodor. Sur la classification et la distribution des végélaun fossiles. Paris 1822.4 .91 p., 6 tab.

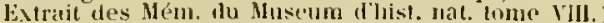

$1314 \div$ - Observations sur les végetux fossiles renfermés dans les gres de brer en Scanic. Paris 1825. 8.24 p., 2 tab.

(Extrait des Amuales des sc. Hat.)

$1313^{*}$ - Essai d'une classification naturelle des champiguons, ou tableau méthodípe des genres rapportés jusqu'a présent à celte famille. Paris 1825.99 p. \& 8 tals.

$1316^{*}$ Mémoire sur la famille des Rhamnées, ou histoire baturelle et médicale des genres, yui composent ce groupo des plantes. Paris $1826,4.78 \mathrm{p} ., 6 \mathrm{tab}$.

$1317 *$ Mcmoire sur la genération et lo dévéloppencut de l'emlryon dans les végétaux phanérogames. Paris 1827.8. $143 \mathrm{p}$. 11 tab.

(Livrait des Amales des sciences naturelles, tome XII.)

1318 - Nulice sur les plantes (fossiles) I'Armissan près Narbonne. Paris 1828. 8. 10 p., 1 tah.

(Extrail des Aun, des sc. nat.)

$1319^{*}$ Considerations générales sur la nature de la végétation yui couvrait la surface de la terre aux diverses périodes le la formation de son écoree. Paris $1828.8 .34 \mathrm{p}$.

Extrait des Antules des se. nat. tome XV.)

$1320^{*}$ Prodrome d'une histoire des végètaux fossiles. Paris 1828.8. vill, $223 \mathrm{p}$.

$1321^{*}$ Histoire des végétaux fossiles on rechrehes botaniques et géologiqu's sur les régétaux renfermés daus les diverses conclses du grohe. Paris 1898-1837. Il voll. 4. - 1. (fasc. 1-12. $1828 \times 11,488$ p., 166 tab. - II: (fasc. $13-15$.) 1837.72 p., 28 tab.

(Opus, quod post decimum quintum fasciculum editum in pubsicun non anptius prodieral, nuperrime ctarissimus autor denique continuaturum aggresisus est.')

4322* Considerations sur la mare des veigetaux, qui ont couvert la surface do la terre aux diverses éporques de sit fornation. Paris $\$ 838.4 .28$ l.

$1323^{*}$ - Notice historirge sur Antoine Laturent de Jussien. Paris 1837.8 . 20 \%. avec le portrait et Je Facsimile de A. L. de Jussieu. (Exirait des Allnales des sciences natureltes tum. III.)

132k * Botanique (Phanérogamie) du: "Voyage autour du monde exécute par ordre du roi sur la Corvette La Coquille pendant les années 1822-1825, publié par L.J. Duperrey.n Paris 1829.4. 232 p., 78 tals, in folio.

(Opus uescio qua negligentia a(luuc incompletum desinit in ver-

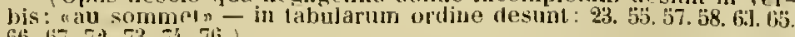
66. 67.79 .73 .7 . 7 . 76.$)$

$1325^{*}$ - Enumération des genres de plantes cultivès an Muséum d'histoire naturelle de Paris suivant l'ordre établi dans l'école de hotanique en 1843 . Paris 1843. 8. xxxII, $136 \mathrm{p}$. 
1326* Bronn, Heinrich Georg. De Inrmis plantarum leguminosarum primitivis el derivatis. Heidellergae 1822.8. 140 p., 1 tab. $(2 / 3 / h$.)

1327* Ergebnisse meiner naturhistorisul-okonomischen Reisen. Heidelberg 1826-1831. 2 Theile. 8. - 1: 1826. Xx, $652 \mathrm{p}$.

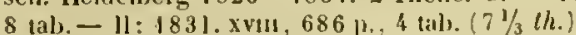

(Sunt itinera per liuropan merillonalem; paucissimis botanici argumenti adıotationibus.)

$1328^{*}$ - Letluaca geognostica oder Ablildungen und Beschreibungen der fur die Gelirgsformationen bezcichnendsten Versteinerungon. Stuttgart 4835-1838. 8. 2 Bánde. -1 : 1835-37. 1. 1 $-768 .-$ II : 1838. p. $769-1346 ., 48$ tab. 4. $(14 \%$ th.

$1329^{*}-$ Gedrangte Anleitung zum Sammelı, Zubereiten und Verpacken von Thieren, Pflanzen und Mlineralien fur naturhistorischo Iuscen, bearbeitet fur reisende und fernlandische Sammler. lleidelberg 1838. 12. 96 p. (1/3 th.) (Die Pllanzen p. 77-93.)

$1330^{*}$ Brookes, Gilberl. The complete british gardener. etc. London 1779. 12. xı, 204 p., 1 tab. (2s.)

1331 Brookes, $R$. Natural history of Chocolate. London 1730.8. н.

1332 Natural history of vegetables as wel foreign as indigenous. Lomlon 1763.12. H.

1333* Brookshaw, Gearge. Pomona britannica, or a collection of the most esteemed fruits at present cultivated in this country; together with the blossoms and leaves of such as are necessary to distinguish the various sorts from each other. Accurately drawn and coloured from nature with full descriptions of their various qualities, seasons etc. London, typ. Bensley. 1812. Foljo. v, 60 p., ind., 93 tab. col. (10 Guin. A. London 1842.) Bibl. Imp. Ferd. et Deless.

(In opere splendido eujusvis generis fructus exculenti in charla nigra vivis coloribus sunt pieti.)

133 ; The horticultural repository containing delineations of the best raricties of the different species of english fruits. London 1825. Il voll. 8 .

Brossard, J. Phytonynie générale ou Dictionnaire étymologique de tous les noms génériques des plantes connues, admis ou non dans la nomenclature botanique, présentant 1. leur étymologie greeque, latine, française etc.; 2. le nom du fondateur; 3. l'époque de la fondation ou l'ouvrage de l'auteur; 4. la fanille à laquelle chaque genre appartient. Ouvrage indispensable aux botanistes, médecins, pharmaciens, agronomes, horticulteurs titc. rédigé sous la direction du célèbre $D_{e}$ Candolle de Geneve, suivi d'une table de tous les noms vulgaires des plantes en France, avec renvoi au nom seientificue Lyon, chez Ch. Savy jeune, et Paris, chez Victor Masson. II soll. 8 (18 fr.)

("Prospectus operis nondum impressi, quod ultra $1 \mathfrak{k}, 000$ nominum numerum eoutinehit, divulgatus est die 2 t. Sept. 18\%3.)

1335 Brosterhusius, Johannes. Catalogus plantarum horti medici scholae Auriacae, quae est Bredae, quilus in ipsa origine instructus est. Bredac 1647.12.58 \%. B.

1336 Brotbeck, Johann Konrad (latine Brotbequius), De plantis. D. Tuebingac 1656.4. (24 p.) (Respondens: Elias Rudolf Camerarius.) B.

$1337^{*}$ Brotero, Felix (de) Avellar. Compendio de Bnanica. Paris et Lisboa, P. Mlartin. 1788. J voll. 8. $-1: 471 \mathrm{p} .-11: 411 \mathrm{p} ., 31$ tab. - Eul. 1l: Compendio de botanica do Doutor Felix de Avellar Brotero, addicionado e posto em harmonia com os conhecinentos actuaes desta sciencia, segundo os botanicos mais (celebres, como Nirbel DeCandolle, Richard, Lecocd e outros. Por Antonio Albino da Fonseca Benevides. Lisboa, typ. da Academia. 1837-1839. II voll. 8. I: 1837. XI, xxII, 401 p., 12 tab. - II: 1839. vII, vII, 668 p., 25 tab.

1338* Principios de agricultura philosophica. (Livro I: Anatomia e physiologia dos vegetaes.) Coimbra, na real imprensa da universidade. $1793.4 .115 \mathrm{p}$. Bibl. Goett.

$1339^{*} \longrightarrow$ Flora lusitanica, seu plantarum quae in Lusitania vel sponte crescunt, vel frequentins coluntur, ex florum praesertim sexubus systematice distributarum, Synopsis. Olissipone ex typographia regia. 1804 . II voll. 8 . - I: xvin, 607 p. - II: 557 p.

("Liher manuscriptus autoris exstat Berolini in Bibl. Linkiana.)

131.0 Historia natural dos Pinheiros e Abetos. s. I. 1817. I vol. 8

(Teste Gusmao in Revista literarea. Oporto 1833. Nr. 83.)

$13 \mathrm{k} 1$ - Phytographia Lusitaniae selectior seu novarum, rariorum et aliarum minus cognitarum stirpium, quae in Lusitania sponte veniunt, ejusdemque Floram spectant, descriptiones iconibus illustratae. Olisipone, ex typographia rewia. $1816-1827$. Il voll. fulio min. - I: 1\$16. 235 p. (3 foll.) tab. 1-82. - 11: 1827. 263 p. lab. $83-181$.

Vidi librum integrum, cujus pars prima eliam Rerolini est. in bildotheca Candnlleana. = Hlujus nperis fasciculus primus, plurimss laborans meudis typographicis, jau anno 1801. Ulisiponae e typngraphia ad arcen Caeci prodierat: in folio minori: $8 \mathrm{p}$ p et 8 tats. (Xistice of thi" Lifo and "rilings of br. Felix Arellar Brotero (n. Lisboae 1753, $\div$ Ajudise 3 . Aug. 1828. Professol of hotany in llie university of Coimbra and atulior of the "Flora lusitanica; by Dan (iusmao. Conmmnnicated by br. Scouler, Professor of natural bistory in the royal Dublin histitution, in: "Curlis latutincal Magazine, sept. and Oct. 1865. p. 37-12. - Extracta est ex: Hevista literarea of Uporto, 18 ' is. Nir. 83 .

13 t2 + Brouard. Calalogue des plantes du Departement de l'Eure. Éreux 1820. 12. xiv, 124 p.

$1313+$ Broughton, Arlhur. Eneluiridion botanicum, complectens characteres gencricos et specificos plantarum per insulas britannicas sponte nascentium ex Linuaeo aliisque desumtos. Londini 1782.8. II, $226 \mathrm{p}$, ind.

131. II Eastensis, or a catalogue of exntic plants in the garden of Hinton East Lisq. in the mountaius of Liguanta, at the lime of his decease. Kingston $1792,4,32$ p. B.

"Redit in Bryan Edwards Jistory of the british colonies, ed. IS vol. III. 1. $367-40 \%$.

1346 Hortus Eastensis, or a catalngue of exotic plant. cultivated in the botanic garden in the mountains of Liguanea; published by order of the Hon. Ilouse of Assembly. St. Jago de la lega $1794.4 .35 \mathrm{~F}$. B.

1346 A catalogue of the more valuable and rare plants growing in the public botanic garden in the mountains of Liguanca, in the Island of Jamaica: also of medieinal and other plants, growing in South and North America, the East ludies etc. the introduction of which would be a great acpuisition to the botanic gardens here. (St. Jago de la Vega) 1794, 4.6 p. B.

$1347 \div$ Broussonet, Jean Louis Victor. Corona Florae Monspeliensis. D. Monspelii I 790. 8. xrI, 48 H.

$1348+$ - Notice historique sur Pierre Richer de Belleval, Professeur d'anatomie et de botanique dans l'université de Montpellier. Montpellier 1838. 8. xut p. et le portrait de Belleval.

(Evtrait du Journal des sciences medicales de Jontpellier.)

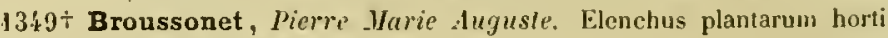
botanici Monspeliensis anno 1804. Monspelii 1805. 8. v111, 63 p. Appendix: 1806.18 p.

$4300 \div$ (Browallius, Jolannes.) Exanen epjeriseos in systema plantarum sexuale cl. Linnaei a. 1737 Petropoli evulgatae, auctore Joanne Georgio Siegesbeck. Jussu anicorum institutum a $J$. B. Aboae (1739). 4. (4) $52 \mathrm{p}$.

("Reimpressum ext cum Limnaei Oratione de necessitate peregrinationum iutra patriam. App. p. 1-ä3. Lugduni Batavorum 173. 8.

1351 De Comvallariae specie, vulgo lilium couvalliun dicta. D. I et II. Aboae 1741 et 1744.4 .38 p. B.

$1332^{*}$ De harmonia fructificationis plantarum cum genteratione animalium. D. Aboae 1744. 4. $25 \mathrm{p}$.

$1333^{*}$ Specimen de transmutatione specierum in regno vegetabili. D. I et 11. Abuac 1745. 4. 58 p.

135' Brown, Georg. De usu corticis Peruviani in febribus intermittentibus. D. Edinburgi 1779. 8. 45 p. B.

$1353^{*}$ Brown, J. P. Catalogue des plantes, qui croissent naturellement dans les emvirons de Thoune et dans la partie de l'Oberland Bernois, qui est le plus souvent visitée par les voyageurs. Thoune et darau 1843. 8. 150 p.

1356 Brown, Philipp. A catalogue of very curious plants, collected by the late Philipp Brown M. D. lately deceased, to be sold at his garden near Manchester. Nanchester 1779.8.30 p. B.

1357* Brown, Robert. Prodromus Flerae Norae Hollandiae et insulae Van-Diemen. Vol. I. Londini, Johnson. 1810.8 . vit, 592 p. (Liber rarissimus! In exemplari, quoul vidi, desiderantur paginae 1-144.) - ${ }^{*}$ Ed. nova (male impressa) curis redactionis Isidis. (1821.) 4. 184 p. $\left(2\right.$ th. $-{ }^{*}$ Ed. IIl : curis Chr. Godofredi Nees ab Esenbeck. Norimbergae 1827.8 , xiv 460 p. $(21 / 2$ th. $)$

( «L'auteur a snspendu la publication de la Flore de la Nouvelle Jollande, parcequon a eritique quelques fautes de latin." $A$. $P$. DeCandolle in litt.) 
1358 $\div$ Brown, Robert. On the natural order of phants called Proteaceae London 1810.4 .

(From the Trinsactions of the Limean Society, rol. $\mathbf{X}$, p. lä226. 9 ram

$1359^{*}-$ On the Asclepiarleae. (Edinhurgh 1810.$) 8.67 \mathrm{p}$.

- Hemoirs of the Wernerian Sociely, rol. I: 1808 - 1810. p. 12-78. transtulit Asclepiateas, recensitae a knd, bran'n. W idiomate anglico $(1 / 2$ th. $)$

$1360 \div \frac{12}{\text { (Fro }}$ On Wondsia, a new genus of frins. I.ondon 1812.4 174. From the Transactions of the Linnean sociel!, 1812. 1. 169Botauy of Terra Australis. London 1814.4.81 p., 10 tals.
General remarks geographical and systematic

$1362 \div-$ On some renarkable deviations from the usual structure of secils and fruits. London 1816.4 .

(From the Trunsactions of the Linnean Society, wol. Xll, p. 143 $1363 \div$ positae. Lonton 1817 . $136 \%+\frac{-1\} 2 .)}{2}$ belongs; and some rensarks on Leptostomum and Buxbaunia.

(From the Transactions of the Limean Society rol. Xill, p. 560
$1365 \div-\frac{-583 .)}{1817}$ Of three species of the natural order Orchideae. London 1817.4. 8 p., 2 lab. col

From the Journal of scieuce and the arts.

$1366 \div(-)$ Select Orchideae. ib. $4.2 \mathrm{p}$.

(From the Journal of science and the arts.)

$1367 \%$ Characters and descriptions of three new species of plants found in China by Clarke Abel Esq.; selected from a small collection of specimens, the only part of his Jerbarium that escaped the wreck of the Alceste. London 1818.4. 8 p., 2 tah.

$1368+$ Observations systenatical and geographical on the Herbarium colleeted by Professor Christian Smith in the vicinity of the Congo, during the expedition to explore that river under the command of Capt. Tuckey in the year 1816. London is18.4.66 p. gallice: Observations systematiques et géographiques de Rober Brown sur la colfection de plantes recueillies sur les bords du deuve Congo par te Professeur christian Smith. Dans la "Relation d'une expedition entreprise on 1816 sous les ordres du Capt. J. K. Tuckey

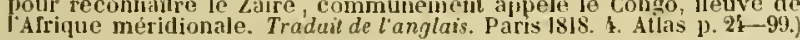

$1369 \div-$ List of plants collected on the coasts of Baffins Bay and at Possession Bay. S. I. et a. 4 . 4 p. (From: A voyage of discovery in 11. MI. ships Lsubella and Atexander, by John Ross. London 1819.) $\div$ London, typ. Straltam and Spottisvoode. s. l. et a. 8.7 p.

$1370^{*} \longrightarrow$ An account of a new genus of plants, named Raflesia. London 1821.4 .34 p., 1 tab. col., 7 tab. nigr.

(From the Transictious of Linneall Sociely vol. Xlli.)

$1377^{*}$ On the female flower and fruit of Rafflesia with ohservations on its affinities and on the structure of llydnora. $8.1 \mathrm{p}$. (Lintraean Sociely, June 17.)

$1372 \div-$ Clı loris Melvilliana. A List of plants collected in Melville Island, (latitude $74^{\circ}-75^{\circ} \mathrm{N}$., longilude $110^{\circ}-112^{\circ} \mathrm{W}$.) in the year 1820 ; by the officers of the voyage of Discovery under the orders of Captain Parry. With characters and descriptions of the new genera and species. London, pritted by W. Clowes. 1823,4. 52 p., 4 tab. - (Seorsim impressa ex: "A supplement to the Appendix of Capt. Parry's Voyage for the Discovery of a north-west passage in the years $1819-1820$, containing an account of the subjects of natural history. London, Murray. 1824. 4. Nr. Xl. p. CCLIX - CCCX. et Lab. $3-6$.)

"germanice: voll Gustav Kunze in Flora 182k. Beilage p. 65-115.

1373* Character and description of Kingia, a new genus of plants found on the south-west coast of New IJolland: with observations on the structure of its unimpregnated ovulum; and on the female flower of Cycadeae and Coniferae. (Read hefore tho Limnean Society of London, Nor. 1 et 15.1825 .) s. I. 8.38 p., 1 tab. - (In: King, Narrative of ..... Australia, vol. 11. p. 534-563. with I table.)

$1374 \div-$ Observations on the struclure and affinities of the more remarkable plants collected by the late Walter Oudney, M. D. and Major Denham and Captain Clapperton in the years 1822,1823 and 1824, during their expedition to explore Central Africa. London 1826. $4.41 \mathrm{p}$.
1373 * Brown, kobert. A brief account of nicroscopical observations nate in the moutlss of June, July and August 1827 , on the particles contained in the pollen of plasts; and on the general existence of active nolecules in organic and inorganic bodies. (London, printed by Richard Taylor. $1828.8 .16 \mathrm{p} .-$ "Additional remarhs on active molecules. 1829.8 .7 p. (Not published.)

* germanice: Mikroscopische Beobachtungen, welche in don Monaten Juni, Juli und August 1827 gemacht wurdien uber die Tlueilehen, welche im Pollen der Pflanzen enthalten sind, lud die itlgemeine Existenz selpststandig beweglicher Molehüle in organisehen und uIIorganisefun korperu. Aus dor englischen nicht in den Buchlatudel gehommenen Urschrift datirt yom 30. Juli 1828 ins Deutsche uhes-

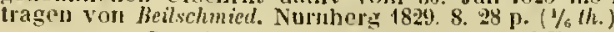

$1376^{*}$ _ Supplementum primum Prodromi Florae Navae Hollandiae, exhibens Proteaceas wovas guas in Australia legerunt DD. Baxter, Caley, Cunningham, Fraser et Sieber, et quarum e siccis exemplaribus characteres elaboravit. Londini 1830 . 8.40 p.

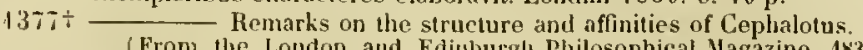

(From the London and Edisburglı Philosophical Magazine. 1832. Sepiember. p. $315-318$.

$1378^{*}$ Observations on the organs and mode of fecundation in Orchideae and Asclepiadeae. London, Octoher 1831, 8. 36, 2, 4 p.

(Transact of Limnean Society 1833, \&. p. $683-7 k 5,3$ tab. col. )

$1379^{*}$ Observations on the organs and mode of fecundation in Orchideae and Asclepiadeae. London 1833.4.

$1380+\frac{\text { col. }}{1}$ On Cyrtandreae. London, March 1838 - December 1839. folio. 3 p. et p. $105-122$.

(From Dr. Horsfield's Plantae javanicae rariores.

$1381^{*}+$ On the female flower and fruit of Rafflesia Arnoldi and on Jydnora afrieana. London 1844.4.27 p., 9 tab.

(From the Transactions of Limean Society vol. Xix. Pant III.)

$1382^{*}$ Pterocynbium, with observations on Sterculieae, the tribe to which it belongs.

(From Dr. Horsfield's "Plantare javanicae rariores." London, June \&. 48.'t folio. p. $219-238$, 1 tab.)

$1383 \div$ On the plurality and development of the embryos in the seeds of Coniferae. London 1844.8 .7 p., 4 tab.

(From the Arusals and Nagazine of natural Jistory for May $18 \mathrm{~h}$. (Robertus Brown dedit praeterea descriptiones ultini (an etian tertii ? fasciculi plantarum cry plogamicarum Dicksoniarum, nec non eas tertii voluminis plant. Coromand. Roxbur?hii,
alteram Horti hewensis a classe Xli ad XXYl?.)

1385* - Vermischte botanische Schriften. In Verbindung mit einigen Freunden ins Deutsche ubersetzt und mit Anmerkungen versehen von Christian Gallfried Nees von Esenbeck. Nürnberg $1825-$ 1 344.5 Bande. 8. - 1: 1 S25. xvir, 704 p., I tab. - Ji: 1826 . vir. 791 p. - III: 1827, xiv, 460 p. - IV: 1830 . vill, 548 p., 5 tab. V: $1834, x, 477$ p. 4 tab. (Band I u. $2: 3 \frac{1}{2}$ th. - Band $3: 2 \frac{1}{2}$ th. - Band 4: $3 \frac{1}{3} \mathrm{th}$. - Band 5: $3 \mathrm{th}$. - Alle 5 Bănde zusammen $8(h$.)

Erster Band: Yorrede von Nees von Esenbeck: p. 1-xw. - Allgemeine geographische und syslematische Bemerhungen uber die Flora Australiens; uhersetzl von Dr. Pauls. p. 1-166. - Systematische und geographische Benjerkungen uhet die von llerrn Prof. Christian Smith in der Naclubarschaft des CongosI roms gesammelten Pflanzen iibersetzt von Nees vion Esenbect. P. $167-333$. - Perzeichniss von Ptjanzen, welche an den Kisten der Baftin's-Bay zwischen $70^{\circ} 30^{\circ}$ und $76^{\circ}$ nordlicher Breite an der Ostseite, und der Possessionls-Bay bei $73^{3}$ nordlicher Breite an der Westscite gesanmelt worden sind; whersetzt von Ernst Jeyer. p. 337-33it. - Perzeichniss der Pllanzen, welche ron den offizieren der Eughisetien Eupedition zur Entdechuu einer nordwestlichen Durchrahrt auf der Melville's Jusel gesammeit wurden, nebst deu Charakteren und Beser ubersetzi ron Ernot Seyter Franklin's Bericht theyer. p. 33-46r. - Bolanischer Anhang zu capt Fanklin s Bericht hon einer keiso mach den kusten des ithtischen Meeres, von Dr. John Richardson, Chirurgen der Expedition. Mit Nuchträgen von R. Brown: uherselzt vont Nees van Esenbeck. - Verzejchniss von Pfianzen Yon dor ostlichen kuste Groulands. Mit einigen Benerkungen von Dr. Hooker. AIs Nachtrag zu der vorhergehende Ahliandlung und nit Einschaltung Labrador'scher Pllanzen nach Frany voln Paula Schrauk's "Aufzíthlung einjger Pllanzen aus Labrador" im

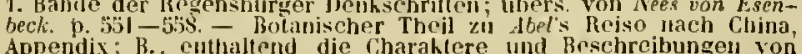
Appendix: B. enthaltend die Charahtere und Beschreibungen yon
drei nenen Pthanzenarten; uhers. von Nees van Bsenbech. p. 559-570. drei nenen Ptlanzenarten; ubers. vor Nees van Fisenbeck. P. 559-570. - Nachtrag zil der Anmerking, den rothen Schnne
Nees ron Esenbeck. p. 571-672. - Register: p. 673-70\%.

ZW eiter Ban if Yorrede von Nees von Esenbeck. - Genera et specins plantarum Orchidearum, quae in llorto kewensi coluntur p. 1-32. Uetore Jussiev's Proteaceen; ubersetzt von $C$. G. Ehrenberg. D. 53 3. 3. - Urber die Asklepiadeen, eine naturliclıe Ptjanzentamilie. welche von Jusvieu's Apocvneen abgesondert werden muss; uhers. von Nees van Esenbeck. p. 3k7-11'k. -- Gallungen und Arten aus den Familien der Orchidern der Synanthreen, der Leguminosen. Aus flen Botanical Register und den Jfortus Kewensis zusammengetra-

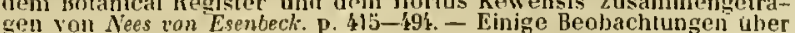
$5^{*}$ 


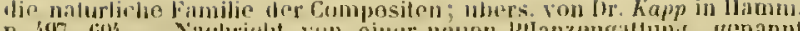

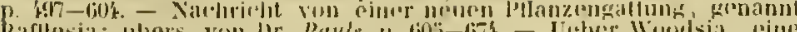

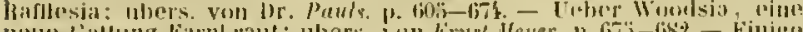

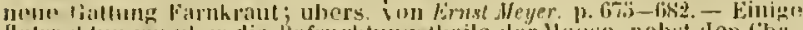

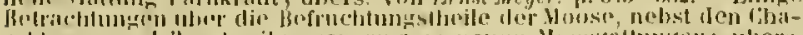

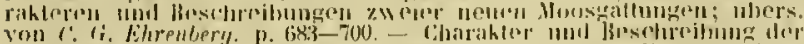

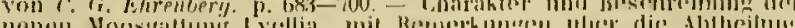

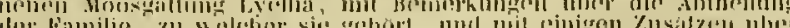

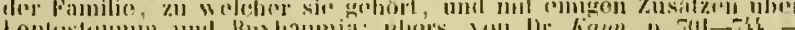

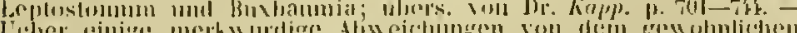

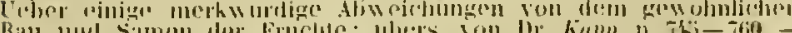

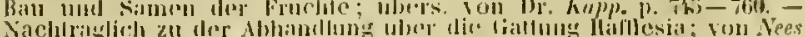

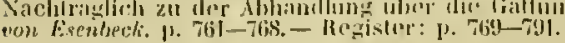

Dritire Band: Pracfatio Neesii, p. 1-xir. Prodromus Forae Novae Hollambliac: p. $1-460$.

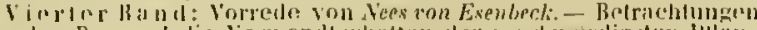

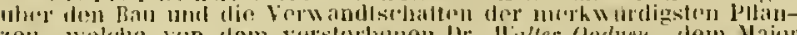

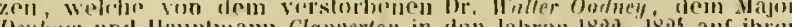

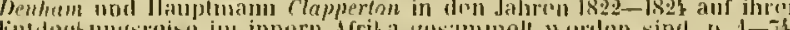

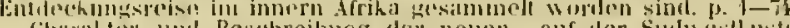

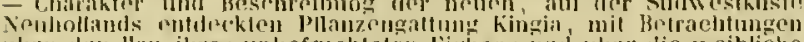

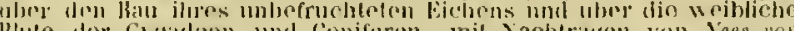

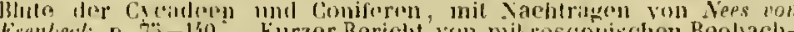

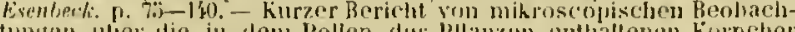

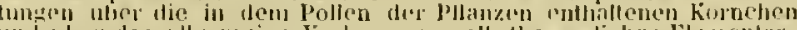

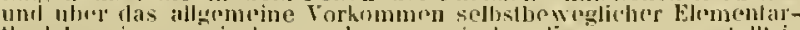
thellonen in organisehen und unorganischen linppern, angestellt in d'll .lom:aten Jinl, Juli und August 1827 ; Ibers. Vul Nees ron Esen-

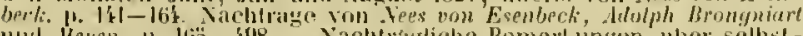

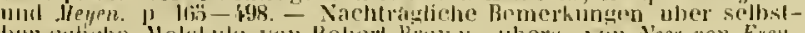

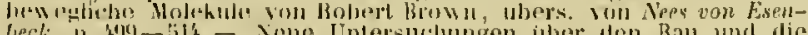
linture

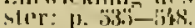

Funftri Band: Vorrede von Neps non Esemberk: p. I-vul. -

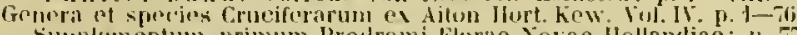

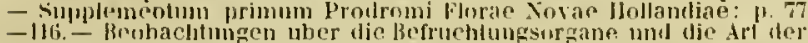

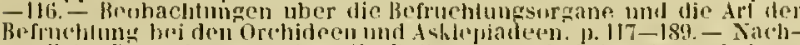

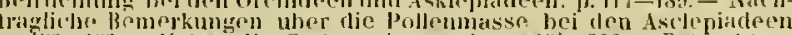
p. $190-193 .-$ Ueber die Gattung Apostasia. p. 19\%-206. - Belyachtur-

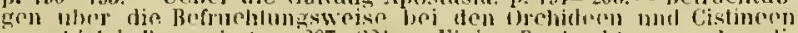

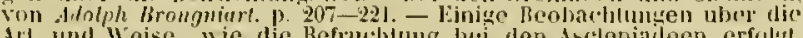

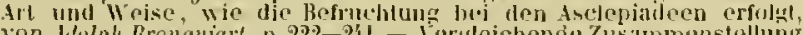
von . Whlph Bronguiar. p. 222-2k1. - Vergleichende Zusimmenstellung aller iher die Befruchmoswiong deg Asklepiadeen bisher anfueslablen Theorieen und rowiesenen Thatsachen. Wit besonderer Rurk-

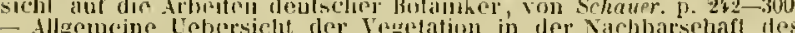

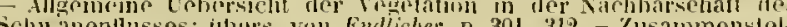
Sclum anenllusses; iburs. vou Endlicher. P. 301-312. Zusammenstel

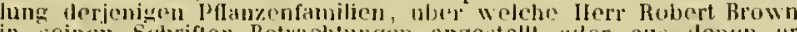

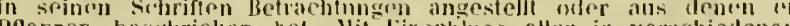

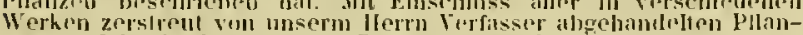

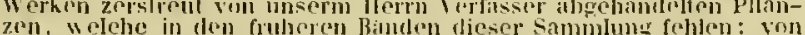

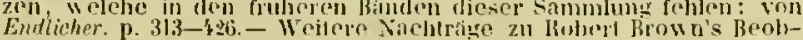

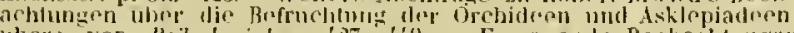

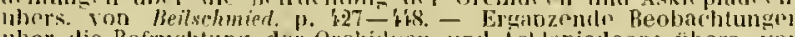

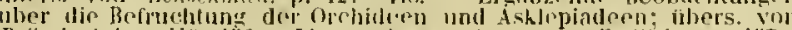

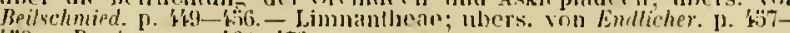
ha. - Regisier: 1). Lo-173.

1385: Brown, Samuel. East India plants will their names, vertues, deseription, and soms additional renaths Jy James Petieer. (Philosoph. Transaclions vol. XXII. p. 579-594.699-721.843-858.933$946.1007-1022$. vol. XXIll. p. $1055-1065.1251-1265.1450$ -1460$.

(Subt plantas as Samuele Brocerio, medice in ares $S$. Georgit Indias

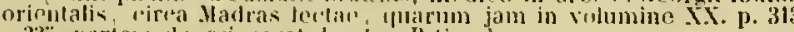
-33i. parten discripserat Jacobus Potiver.)

1386 Brown, Thomas. Enrpuiries in the vulyar errors. London 164 f folio. H - ib. I 650 . folio. (Spreng. Ilist. Il. p. 8.)

hollambire: Imstordam lotis. 8 .

gemanice: Frankfurt unt Lenipzig 1680 . \&

gallice: Paris 1733, 12.

1387 Browne, J. Sylva anericana, ur american forest trees. Bosion 1832. 8. W.

$1388^{*}$ Browne, Palrik. The civil and notural history of Jamaica in three parts. Lomblon, Oshorne. 1756. folio. 503 p., 50 tah. - - El. II. with four adclitional indexes. Lombun, White and son. 1789 . folio. vin $503,(23)$ p., 50 lab.

(Plantar recensentur p. 71-3\%k. et lab. 1-38. ef. Hall. Bibl. hot. Il 4.i.j. - Spreng. Hisi. II. $46-68$.

1389\% Browne, Peter A. An essay on Indian coru. Philadelphia, Iyp. Thompson. $1837,8,32$ [., | |al).

$1390 t$ (Browne, Jilliam.) Catalogus horti lotanicı Oxoniensis, cura Mhilıpi Stephani et Guilielmi Bronnci. Oxonii, Willimm Hall. 1658. 8. (9) 214 p. Bibl. Juss. - Editio prima multo inferior prodiit Oxonii afurl Henricuin Hall. 1648. 12. $\mathrm{s}$
1391* Bruce, James. Trivels. vol. I: Select speciments of natural history

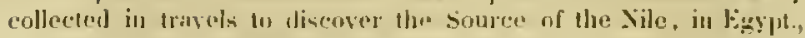
Arabia, Alyssinia and Subia. Edinhurah 1790. zr. 4. xiv, 230 j\% int. . 24 tal. plant., 19 tal. anim., 3 mapp. gengr.

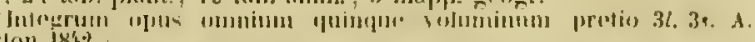
Lonilon ix'?

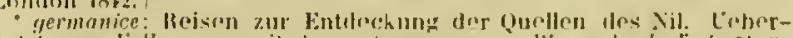

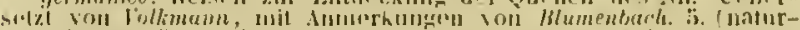

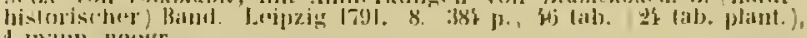

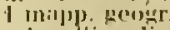

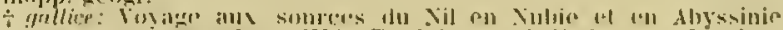

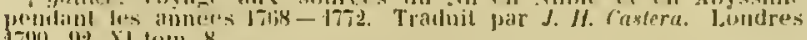
$790-12.81$ tom. 8.

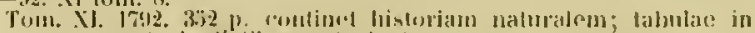
formil qualua : lab. 1-2't illuslrant plantas.]

$1392 \div$ Bruch, Friedrich llaniel. Observationes ipuedan practican de raelicis frutieis Juniperi decocto. 1). Argenteratli 1736. 4. 20 p).

1393 * Bruch, Karl Ludecig. The Inagallide. J). Argentorali 1758. 1. 49 p.

1395. Bruch, el II ilhelm /hilipp Schimper. Irygrolugia "urupara mat

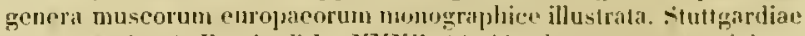
1837-1846. 4. Fasciviti 1-XXXll. (33i) lab. et lext. (so th.

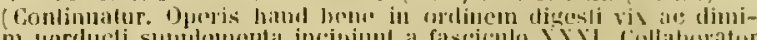

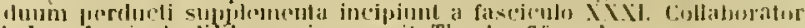
inde a fasciculo. X.fi. uperi necessil Theoulsor Gümpel.

$1393^{*}$ Brücknann, Franz E*nst. Specinen botanicum evhibens fungus subterianeos, whyo lubera lerac tictos. Jelmstacliac 1720. 4. 25 (3) p., I tab.

$1396^{*}$ Catalogus cxhibens appellationis el dennunationos ommium potus generum, quae olim in usu fucrun, et adlut sunt per totum terarum orbem. Ilelmstadiae 1722. 4. (10) $112 \mathrm{p}$.

$1397^{*}$ Relatio Irevis historien-physico-melicn de Cerevisia

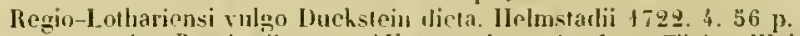

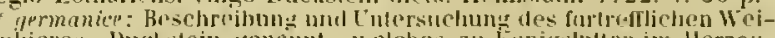
zenbieres, Duchstejn genaunt, welehres zu Kuniossuller im Herzo:-

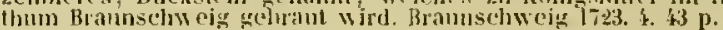

$1398^{*}$ Epistola de fungo hypoxylo tigitato. Helmstadii 1725. 4. 12 1)., 2 (al).

1399 De lapide violacen sylsae Hereynine. Guelpherbyti 1725. 4. 15 p. B.

$1400^{*}$ Specinen prius botanico-medicum exhibens fruticem lioszodrewina ejuntue balsanum lioszodrewinowy oley dictum. Brunsvigae $1827.4 .28 \mathrm{p}$.

$1801^{*}$ Sprcimen posterius unclico-botanieum exhibens arborem Linbow edrewo ejusque oleum Limbovi oley dictum. Brunsvigae 1727 . 4. 20 J., J tah.

$1402^{*}$ - Relatio Jrevis historico-botanico-merlica de Irellana mexicana vulgo Cacan ticta. Editio secunda priori auctior. Brunsvigac $1728.4 .29(3)$ p. ct 2 tab.

(Ellitio prior sul, pracsidio J. C. Spies llelmstadii 1721 prodijt.)

$1403^{*} \longrightarrow$ De Oeymastro flore viridi pleno oljservatio Lotanica. Wolfeuluticliae 1732. folio, cum tabula. s.

$1404^{*} \longrightarrow$ Epistola itineraria $\mathrm{XX}$ de Tuberibus terrae. Wolfenbutteliae 1730.4 .8 p.

$1: 03^{*}$ Epistola ilinejaria XXXYII de cerevisia Goslariensi. Wolfenlyülleliae 1735 .4. (16 p.)

$1406^{*} \longrightarrow$ Epistola ilineravia LIl de Humia Brunsvicensium. Wolferbulteliae 1736.4 .32 p., 1 tals.

Moliquae enistolir jtinerariae botatic argumenti in parte systematica operis indicantur.

1407 Sondselyeiben an J. H. Kuiphof, die Art, die Krauter nach iem Leben abzudrucken und also selur compendiose Jlerbaria pieta zu machen, vorstcollenul. Wolfenbultel 1733. 4. I playg. B.

1:08* Brückmann, Urban Frielrich Benedict. De nuce Been. D. Helmstadiae $1750.4 .28 \mathrm{j}$.

$14.09^{*} \longrightarrow$ Kurze Ablandlung vom Sego. Bramnschweig 1751. 4. $16 \mathrm{p}$.

$1+10^{*}$ Brückner, Adolph Friedrich. Florao Neohrandenburgensis Prodromus. D. Jenae iso3. \&. $88 \mathrm{p}$.

1 if Brüllow, Friedrich. Systemalische Fintheilung tles ['flanzenreichs nach naturlichen Familien für Schulen. Pusen is 45. 8. 11 \% Bogen, 3 lab. $(1 / 2(h)$.

1 1.12t Brugmans, Sebaldus Juslinus. Dissertatio praemio condecorata al quaestionem ab Academia Jivionensi propositam: Quaenam sunt plantae inutiles el venenalae, guae prata inficiunt, horumquo 
diminuunt fertilitatem; quaenam porro sunt media aptissima illis substifuenti plantas salubres ac utiles, mutrinentum sanum ac abundans pecori praebituras? Groningace 1783.8 . $90 \mathrm{p}$.

1413 Brugmans, Sebaldus Juslinus. Natumbuntige Verbandeling over een zwavelagtigen nevel don 24 Juni 1783 in ile provintis van stad en lande en nalunige lamelen waargenomen. Groningen (1783). \&. 58 p. B.

$11^{*} i^{*}$ Orationes duae, prima aditialis: de aceuratiori plantarum indigenarum nolitia maxime commendanda; altera valedictoria: do natura soli Frisici explorandi. lugluni Batavorum $1787.4 .84 \mathrm{p}$.

$1 \mathrm{H} \mathrm{B}^{*}$ _... De mutata humorum in regno organico indole a vi vitali vasorum derivanda. D. Lugeluni Batavorum $1789.8 .97 \mathrm{p}$.

$1.16^{*}$ (—) Elenolus plantarum, yuae in lorto Lugduno-Batavo coluntur. s. 1. $1818,8.39$ p.

1 \&17 Bruinsma, A. $F$. A. We Diosma erenata. D. Lugduni Batavorum 1835.4 .

If $18 \div$ Bruinsma, $J, J$. Flora Fvisiea, of natmlijst en henmarhen der zigtbaar-J)loejesnde planten van de provincie Friesland; benevens eene schets van derzelver verspreiding, en anwijzing van de grenceshrachligo, oxconomische en technische gewassen; vourafgegaan door eene korte beselsrijving van de naturlijke gesleldleid des Frieschen bodeus. Lecuwaten, W. Echholt. I840. 8. vil, 187 p. (2 Gulden.

I't9 Brulles. The mole of cultivating anl dressing hemp. (London) 1.790. 4. I5 p. B.

14.20 Brumann, Menricus. Index plantarum circa Zuollam in Transsilvania erescentium. 1662. \&. Desid. B.

$1421 \div$ Brun des Beaumes, de. Compte de quelques essais de culture faits en 1821 sur alix plantes Cerciales. Paris 1822.8. 27 p.

1422* Bruuacci, Gandenzo, Je cina-cina seu pulvere ad febres. Venetiis $1661.8 .150 \mathrm{p}$.

1423*' Brunfels, Otlo. Herbarum vivac eicones ad Jaturac imitationen summa cum diligentia et anteficio efligiatac, una cum ellectibus earundem in sratiam veteris illius et janjan renasceutis herbariae medicinac, per Oh. Brunf. reeens editae 1530 . Quibus adjecta at calcem Appentix isagogica le usu el administratione simplicium Item Index contentorum singulorun. Argentorati, apul Joamen Schottum. ( 1530 .) folio. $266(72)$ p., (86) ic. sylogr. i. t. - "Nuv Herbarii tomus ]l. prer Oth. Brumf. rouens edilus 1531. (in calee 1532.) Contiuens, quae versa pagina subuotatur: I: Appendix de vera herharm cognitione. - Il: Exegesis omnium simpliciumi Dioscoridis, et efuomodo iis, quae in officinis servantur, respondent - 111: Suribonii Largi de simplicibus fragmentun. - IV: Demonstrationes aliquo lierbarum ex corollariis llermolai Barbari, de quibus dulyum guibustam est, qualibus nominibus designentur apud auctores. - V: Joonnis Wuinardi l'errariensis medici annulationes aliquot simplicium ex scriptis ejus extractze. $\rightarrow$ I: Pandulphi Collinutii de interpretatione simplicium, (puae sunt apud Jlinium, calumniis Leoniceni responsio. - V1I: Leonarli Fuchsii imnotationos de simplicibus a medicis hactenus perperam intellectis et aestimatis. - VIIl : Comitis Ilernomni a Neünur censurac aliae lierbarum super eadem re. - IX: Joachimi Schylleri medici judlicium de caryoplyylis. - I: Hieronymi Tragi dissertationes fere 50 de herbarum quarundam nomenelaturis, - X]: Murri Gatharae medici Ticinensis aunotatio una el altera de Taraxaco, Cichorea, lva, Esula el Solela-

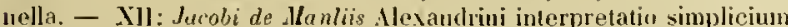
secundum ritum officinarum. - Xlll: Kieromymi Trugi Herbarii apudixis germanica, ex qua facile vulgares herbas omnes licebit jerdiscere: germanice. ib. (1531.) folio. 90,199 (5) p., ind., (49) jc. nylogr. i. t. - * Tomus luerbarii Othonis Brunfelviill (posthumus, cum salutatione Jocunis Scholli ad lectorem), corollariis operi praefisis, quibus respundet calumniatoribus suis, passim errata quaedam priorum tomorum diluens. it. 1536 . folio. 240 (2) p., ind., (103) ic. iylugr. i. $t$.

Sunt reinpressiones aliquac ex radem officina: Tomus I codem tirulo el ahsque mutatione anno * $155 \%$. una cum tomo II et III ann 13360 militi, anno * 1357 , boe titulo generali practixo: "Othonis bicutfelsii llerlarium tomis tribus exacto tambem studio opera of ingenio, candidatis medicinae simplicis ahsolutums qua iu, opera er menon

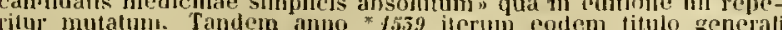
rifur mutaturl. Tandem anno * 1559 ifcrum codem titulo greneran cedentibus editionibus, sed non contentis, quibus dento accesserunt sox icones Plantaginis aquaticar. Dracontii majoris. Partelarine, Ari-

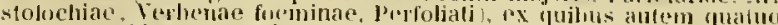

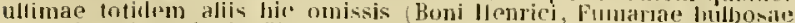
secundae. Sinecionis, Bifolij sine thore sell allendatale substituuntur.

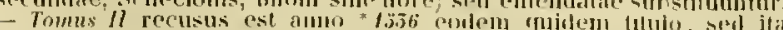

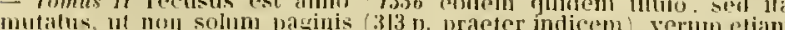

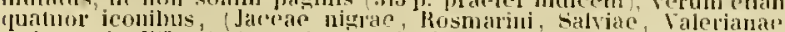
sid parvis dillorat; hace impressio juntilu, salvac, alelianas

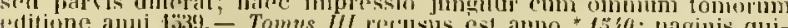

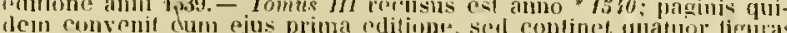

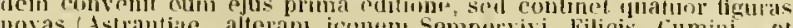

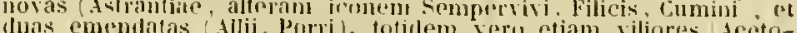
duas ementatas (Allii, porri), fotilem veru ctiam viliores froto-

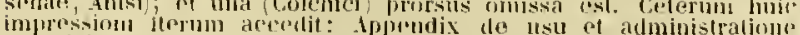

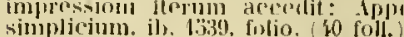

upera completil Brumfelsu, yui primus frermajorum jeones $\mathrm{x}$

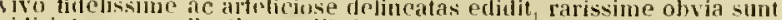

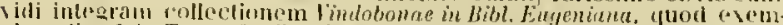
flar olim fuit Tourneforti: alias in Bibl. Fandolleana et Delessertiona.

germanice: Contrafayt hreutrolush nach rechtre vollhommusur

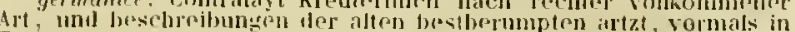

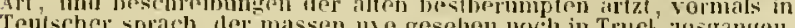

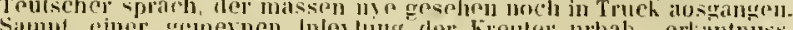

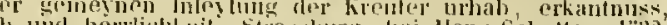

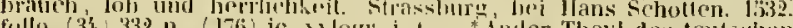
folto. (3k) 332 J., (176) ic. Byogr. i. t. - * Ander Theyl des teutschets

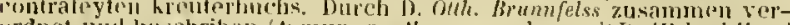
ordnet und lweshriben (tomum pushmmun adornavit D. Michael /lerr.i

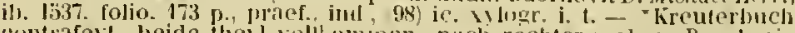
contrafest, beide theyl voljhommen, nacli rechter wahres Beselurei-

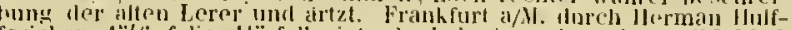

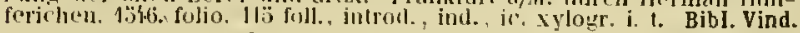

142 kt Brunfels, Otlo. Insignium medieorum Jonn. Serupions Arabis ale simplicibus medicinis opus pracedarum et ingens. Averois Arahis te cistum liber eximius. Rrsis filii Zachariae de eisden opuseulum perutile. Incruti item autoris de Centanio libellus baclenus faleno inscrijtus. Dictionum arabicarum justu atejue latinarun index valde necessarius. In quorum emenlata excusione ne juil omnino desylevetur Othonis Brunfelsii singulari fide rl diligentia cautum $\mathrm{s}$.

(Argentorati exeude) Gat Georgius l'Iricher Andlanus 1531.) 4.397 \%. Pracecdunt: praef., ind., 10 foll.

$1425^{*} \longrightarrow$ Theses s. communes loci totius rei medicae; itrm de usu pharmacorum, derjue artificio suppressam alvum cionli liber. Argentorati, excud. Genrogius Ulrieher Anullanus. 1332.8. 232 foll., jraef., iubl.

$1426^{*} \longrightarrow$ Onomastihon medicinac, continens omnia nomiua herJarum, fruticum, sulfuticum, arjorum, sentium, seminum, tlorum, radicum etc. etc. Argentorati, apud Juannem Schuttum, 1534. folio. (terniones $30: A \rightarrow G$. B B Bl. Goett.

(Lexicon, monenie dudun Gesnero, inmaturum et festine rongestum.)

$1127 t+\ldots$. Epilome ex gravissimis anthoribus, lotius rej melicae summan complectuns per Othonem Brunfelsium congesta: Imper vero emendata el locupletata. Parisiis, in officina Gulielmi Juliani. $1552.12 .104 \mathrm{foll}$. Bibl. Juss.

1428 In Dioscoridis historiam plantarum cortissima adaptatin, cum earundem icomum nomenclaturis sraceis, latinis el germanicis Ver kreuter rechte walılialfige contrafactur, erkanntuuss und uamen, hryechisch, lateinisch und deutsch, nach der Beschreilmug Diuscoridis. Argentorati, Jo. Schottus aero perennius dedit. 1543. folio. 372 p. (p. $108-111$. et $244-292$ semper omissae), I 1 index, ic. xylogr. i. $t$

("Continut hic liber 31t icones, cy quibus 271 earlem sunt. «ual"

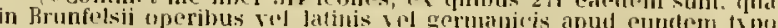

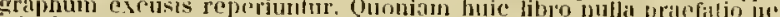
alia information praetica est incertum manel cuis

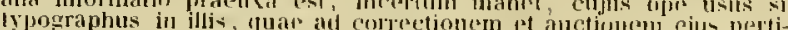

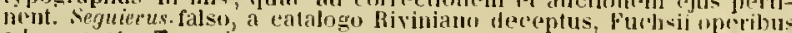
alnumerial, Trew.

1429 Bruni, Gerolamo. J)issertazione sulla potatura de' gelsi. Milani) 1784.4 .31 p. B.

$1430^{*}$ Brunn, Johann IJihelm. De vasis plantarum. D. llalas 1800. 8. $34 \mathrm{p}$.

1431+ Brunner, Charles. Observations sur liuflorescence du tilleul. Genève 1846.8 .7 [\%, 1 tab.

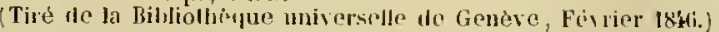

1432t (Brunner, Samuel.) Bericht uber die in der Engepromenate be Bern befindliche Sammlung von Bäomen und Sträuchern, welche bei uns in Freien ausrlanern, nebst cinem lithographirten Grundrisse Bern 1828.8 .32 p., 1 taL. (4 Batzen.)

$1433^{*} \longrightarrow$ Streifzug dureh tas ostliche Ligurien, EHba, die Osthıste Siciliens und klalta, zunachst in Bezug auf pllanzenkunde im Sommer

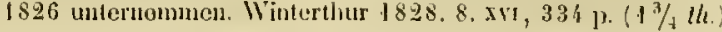


1434" Brunner, Samuel.) Ausflug uber Constaulinopel nach Taurien in Sommer 1831 . St. Gallen u. Bern. 4833.8 . xtI, 353 p. $\left(2 \frac{2 / 3}{3}\right.$ th.

$1 \mathrm{H}^{\circ}$ - Reise nach Senegambien und den Inseln des grunen Vurgelsirges im JaItro 1838. Bern 1840.8. xt 390 p., 1 tab. $(12 / 3$ th.)

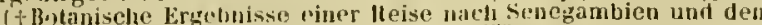
Inschli des grimen Frorglirges. s. I. et a. 8. 153 p.)

$1936^{*}$ - Einiges uber Ien Stevinlocherpilz (Polyporus Tuberaster Jacq. e( Fries) und die Pietra fungaja der Inaliener. Nenenburg 1842. 4. 19 j., 2 tab. col.

(vene Jentschr. Jel allg. schweizerischen (iesellsch. Band 7.)

1137 Bruntou, Johu. A catalogne of plants botanically arranged accorrinis to the syatem of Limnaens, most af which are cultivaterl and solld ly John Brunton and $C_{0}$. at their nursery, Perryhill. Birninghan 1777. 8.85 p. 8.

1:38t (Brunyer, Abel.) Hortus regius Blesensis. Parisiis, lyp. Antonii Vitré. 1653. 4. 67 p. - * Ed. altera, cui accessil 500 plantarum nomenclatura. Parisiis, typ. Antonii Vitró. 1655. folio min. 106 p.

(Spreng. Ilist. 11. 11!-115.)

I:39 Brusati. Catalugus plantarum horti regii botanici Ticinensis. Papiae 1793. 8. DC.

1t:0 Bruxius, Adam. Balsambuchslein oder Bericht von sieben und zwanzig Balsamen. Halle 1616. 12. H.

141 Bruyerinus, Johannes. De re cibaria libri XXII, omnium cihorum genera, omnium gentium moribus usu comprobata, complectentes. Lugduni, Sebastian Hunoratus. 1560. 8. s. - ${ }^{*}$ ab Othone Casnanno revisi. Francofurti, apud Palthenium. 1600. S. 863 p. - Norimbergae 1659.8 . s.

I'1-2* Bruz, Ludwig. De gramine Hannae sive Festuca fluitante. D. Viennae 4775. 8.48 p., 4 tab.

$1443+$ Bruzelius, Arvil, pr. Observationes in genus Charae. D. Londiui Gothorum 1824, 8. 24 p.

* yermanice: frei bearbeitet von Furnrohr in Flora 1826. p. 481- 49 \%.

14ht* Bry, Johaun Dieterich (Theodorus) de. Florilegium novum, boe est variorum masimeque rariurum florum ac plantarum singularium una cum suis radicibus el cepis eicones diligenter aere sculptae et ad vivun ut plurimum expressae. New Blumenbuch etc. Exhibitum nuperque auctum. (Oppenbeim) 1619. folio. (6 p.), 1ab. 1-78. et 9 tal, non siguatae.

Ilujus editionis partem II. 1Gl't. ot III. 1618. non vidli. Figurae plantarum hortensium nasima pro pirte es Passaeo el Petri Vallet horto regis ffenrici IV. petitae.

$145^{*}$ - Anthologia magna s. Florilegium novum et absalutum variorum maximeque rariorum germinum, florum ae plantarum, quas pulchritudu, fragrantia, etc. eicones elegantissimae etc. Francofurti in officina Bryana. 1626. folio. ( 6 foll.) 142 tah. aen.

Tal. 1 et 2. non simatae; in priori logitur: Folgende Gewichs haben theils in dirsem 1618. theils im neust vorgehenden Jahre samme anderen vielen deren Abriss in diesem Buch zu hinden, gesammt act in Acad. zu bluket in . Laurents

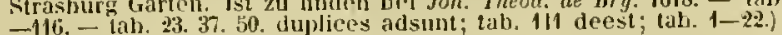

14.6* —_ Florilegium renuvatum et auctum. Francofurti, apud Matthaeum Merian. 1641. 4. 14 p., 32, 141 tab.

Post dedicationem et praefationrm pag. 14. sequilur icnographia horti Joh. Swindii e! tabulae aeneate 32 ex Ferrario de llorum eultura; dein tab. 80 prioris editionis. Tab. 81 inserihitur: Augmentatio wherior Florilegii antelhac coepti, jam iterum tocupletati, floribus nonnullis evoticis, visu jucundis per lohannem Theodor. de Bry anno 161\%. - Tab.115' inscribitur: sequentes plintae pirtim hoc 1618. partim superiorihus annis floruerunt, una cum flurimis aliis, quarum icones hoc in libro sunt expressae, in horto $\mathrm{N}$. Laurentii Thomae Halliseri, Prufessoris phil. pract. in Arcrontoratensi Academia. Sequuntur tabuprufessoris phsue, quae Yuccam gloriosan repraesentat, florentem lae ad 10. usclue, inlo Remigii Feschii J. C. - Ad calcem adjecta est tabula, exhibens ramum Rosae, annum hahens 167.)

$14,7^{*}$ Anthologia Neriana, 115 continens plantarum, florum maxime, egregie sculptas tabulas, addito indice, in quo tum antiquiora illarum, tum etiam Linneasa necurrunt nomina. Editio nova. Francofurti el Lipsiae 1776, folio. 6 p., 115 tal.

$1,48^{*}$ Bryant, Charles. An historical account of two species of Lycoperdon, in which the plants are accurately described. etc. London (1782). 8.52 p., 1 tab. (2s.)

$1449^{*}$ _- - Flora diaetetica, or history of esculent plants both domestic and foreign etc. London 1783. 8. xvı, 379 p., ind.

* germanice: Verzeichniss jer zur Nahrung dlegenden sowohl ein-

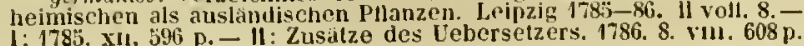

1.300 Bryant, Charles. A dietinnary of the arnamental trees, shruls and plants, nost comuonly culivated in Great-Iiritain. Norwich ( $1790 \%$ ) 8.73 plagg. dimid. B.

14:j Bryant, Jenry. A particular encuiry into the causes of that disease in wheat, commonly ealled Brand. Norwich (1784). $8.58 \mathrm{p}$. B.

14032 Bucci, Cabriel. Jiscorso della generazione delle piante, in quella manieru alcume nel corso dell' anno si spogliano delle foglie o perche altre conservino la perpetua lor verdura. Venczia $169 \%$. folio. $s$.

(Gilleria di Minerva, tom. II. p. 39\%.)

1':33* Buch, Leopold von. Reise durelı Norwegen und I.appland. IJerlin 1810. 2 Thuile. 8. - I: $x, 486$ 1., 2 Karten. - II: vi, 406 p., 1 karte. ( 4 th.) 113 suecire: liesa genom Lappmarhen och Sverige. Stochholm 1816. S.
\%.

gallice: Voyage en Norvege et en Laponie. Paris 1816. II voll. 8. 12 ir.) $Q$.

145\%" Allgemeine Uebersicht der Flora au wou Canarischen Inseln. Eine Abhandlung, vargelesen in der $k$. Pr. Akademie der Wiss. zu Berlin im Jahre 1\$17. Berlin 1819. 4. 48 p.

$1153^{*}$ _... Plnysikalische Beschreibung der Canarisehen Inselı. Berlin 1825. 4. 407 p., I tab., Atlas in folio: 9 tah. (Von p. $105-$ 199: Uebersielit der Flora der Canarischen Inseln.)

"gallice: Iraduit par (C. Boulanger: édition revue el augmention par l'anteur. Paris 183t.8. 1 tab.: Laurus foetens. Atlas: 12 tah. (2ï fr.)

$1456 *$ Bucher, Christian Traugott. Florae Dresdensis nomenclator, orter systematisebes Verzeichniss der in der Gegend von bresden wildwachsenden Sexualpflanzen. Dresden 1806.8 x. $236 \mathrm{p}$., inl. (i/sth.)

1457 Buchhave, Rudo/ph. Grunden til Plantelaeren. Saroo 1768. \&. 64 p. B.

$1458+\longrightarrow$ Observationes circa radicis Gei urbani sive Carroplyyllatae vires in praecipuis corporis humani affectionibus institutae. Ed. II. correcta el novis tentaminibus aucta. Hafniae el Lipsiae 1784 8. 262 1., 1 lab. - "Ed. 1: ib. 1781. 8. 14 1 p., 1 tab.

1459 t Buchner, Johann Andreas. Toxicologie. Zweite vermelrte und verl. Aullage. Nurnberg 1827. 8. xxxIv, 615 j. $(23 / 4$ th.) (1'flanzengifte: p. $169-366$.

suecice: Toxicologi eller Läran om Gifterna. Fahlun, typ. Arborelius. 1828 . 8. vil, 510 p. (Váxlgifter p. 1 个6-308.)

$1460^{*}$ Buchner, Ladwiy Andreas. Neue chemische Untersuchung der Angelica-Wurzel. Eine Jnaugural-Abbandlung. Nurnberg 1842.4 $16 \mathrm{p}$.

$1461^{*}$ Bucholz, Wilhelm Heinrich Sebastian. Versuche uber die antiseptischen Krafte des Walverlei (Arnica) mil Aubang. Erfurt 1 iS5 4. $31 \mathrm{p}$.

1462 - Buchoz, Pierre Joseph. Lettres périodiques sur la méthode de s'enricher promptement et de conserver sa santé par la culture des vegeitaux. Eel. Il: Paris 1759-1770. Y voll. $S$.

* germanict: Sammlung auserlesner Briefe zur Erhaltung der fresundheit, und dureh den Bau und die Erziehung der Gen ächse sich in hurzer \%eit zu bereichern. Nurnberg $1772-17 i\} .3$ Theile. 8.

$1463+$ Quatrième discours sur la botanique, de la génération des plantes. Pont-a-Nlousson 1760. 4. 13 p.

$1464^{t}$ Tournefortius Lotbaringiae ou calalogue des plames qui croissent dans la Lorraine et les trois Evechés. (Nancy 1764.) $\mathrm{S}$. vili, $288 \mathrm{p}$

$1460^{*}$ — Traité listorique des plantes, qui croissent dans la Lorraine et les trois Evẻchés. Paris, Fetil. 4770. X voll. 12. - I. 324 p. - II: 359 p., 34 tab. - Ill: 403 p., 18 tab. - IV: 161 p. 14 tab. - V: 243 p., 24 tab. - Vl: 426 p., 18 tab. - VIl: 249 p., 16 tab. - VIIl: 165 p., 18 tab. - LX: 304 p., tab. - X: 511 p. lab., ind.

(Editio : Nancy, Messin. 1762-1769. IX voll. 8. maxima ex parte eadem est injpressio. )

1466* - Manuel médical of usuel des plantes tant exotiques qu'indigènes. Paris 1770. II voll. 8. - I: vIu, 470 p. - II : xLvH, $400 \mathrm{p}$.

$1467^{*}$ Dictionnaire raisonné unirersel des plantes, arbres et arbustes de la France. Paris $1770-1771$. N voll. S. - I: $\$ 11,650$ p. - II: $651 \mathrm{p} .-\mathrm{III}: 643 \mathrm{p} .-\mathrm{IV}: 352$, ccxuv p.

$1468^{\star}$ __ Nanuel alimentaire des plantes tant indigènes qu'exotiques qui peuvent servir de nourriture et de boisson aux differens peuples de la terre. Paris 1771. 8.663 p. 
1469 (Buchoz, Pierre Joseph.) Toilette de Flore, ou essais sur les plantes, qui peuvent servir d'ormement aux dames, Paris 1771.12. Autor agnoscit opus anonymum in Dict. univ. des plantes II. p. 369.)

$1570^{*}$ Histoire universelle du regne veggetale ou nouveau dietionnaire physique et économique de toutes les plantes qui croissent sur la surface du globe. ete. Ourrage orné de 1200 planches gravées en taille donce par les meilleurs maitres et dessinees d'après nature. Paris $1775-1778$. Xll voll. folio. 180, 195, $209,213,199,217,198,213,210,247,227,203$ p. 1200 tab. Opus rlesinit it voce: Penn.

$1 \mathrm{il} \longrightarrow$ Première (et seconde) centurie des planches enluminces répresentaut au uaturel ce qui se trouve de plus intéressant et de plus curieux parmi les aninaux, les végétaux et les minèraux. Paris $1775-1778$ ). folio. 200 tab. col. cim explicatione.

Interdum eaetem tabnlae diuplices adsunt, nigrae aliae, aliae coloratae; additae inveniuntur trincinde triginta tabulae voluminis lertii. Reviennt ceterum umnes hae tabulae in aliis fraudosi autoris operibus.)

$1122^{*}$ Collection précieuse et enluminée des fleurs les plus belles et les plus curieuses, qui se cultivent tant dans les jardins de la Chine que dans ceux rle l'Europe. Paris $(1776)$. Il voll. folio. 200 tab. col., ind. - 1: Plantes de la Chine peintes dans le pays: 100 tal. col. - 11: Plantes les plus belles qui se cultivent daus les jardins de l'Eurupe: 100 tab. col.

$1473^{*}$ Les duns merveilleux et diversement coloriés de la nature dans le regne végétal. Paris $1779-1783$. Il voll. foliu. 200 tab. col.

1474 - Traités très-rares concernant l'histoire naturelle. Paris 1780. 12. DC.

I $77^{*}$ - Herbier ou collection des plantes médicinales de la Chine, d'après un manuserit peint, rui se trouve dans la hibliothéque de l'emperenr de la Chine. Paris 1781, foliu, 100 tab. col.

1776 Collection de Jacinthes. Paris 4781 . folio. 40 tab. cal. a.

1477 Collection des plus belles variétés de Tulipes. Paris $1781-1797$. folio. $60 \mathrm{tab}$. col. a.

$1478^{*} \longrightarrow$ Le jardin l'Eden, le paradis terrestre renouvele dans le jarlin de la réine à Trianon. Paris 1783. II voll. folio. 200 tab, col (Interdum non nisi 140 tabulae adsunt, adjectis septem aliis mutto majoribus.)

$1479^{*}$ Le grand jardin de l'univers. Paris 1785 . II voll. folio. 200 tab. col.

$1480 \div-$ Catalogue latin et français des plantes vivaces qu'on peut cultiver en pleine terre pour la décoration des jardins à l'anglaise et des parterres. Londres 1786 . 12. vur, 111 p. - Ed. nova: Paris 1801 . 12. (1 fr. 80 c.) Q.

$1481 \div-$ Dissertation sur le thé, sur sa récolte et sur les bons et mauvais elfets de son infusion. Paris et Liege. $1787.8 .65 \mathrm{p}$.

$1.482+\longrightarrow$ Dissertation sur le eafé, sa culture, ses differentes préparations ete. Paris et Liège $1787,8.94 \mathrm{p}$.

1' $83 \div-$ Dissertation sur le cacao et sur sa culture. Paris et Liège 1787.8.60 p.

$1484 \div-$ Dissertation sur le tabac el sur ses bons et manvai elfets. Paris et Liège 1787.8 .47 p.

1 1 $80^{*}$ - Nouveau traité plyysique et écunoniijue par forme de dissertations de toutes les plantes qui croissent sur la surfaco du globe. Eu. II. Paris 1787-1788. II voll. folio.

(liaec est collectio dissertationum monographicarum de plautis, iisten annis seorsin impressarum et editarum; insunt inter alia Ahricotier, Anis etoile, Arbre au pain, Attrape-mouche, Bandure, Barringtonia, Betterave, Blé de Turquie, Brucee, Cacao, Cachon, Café Caoutschouc, Citlre du Liban, Chausse-trappe, Dillenia, Durion, Fraisier, Gustavia. Illecebrum, lpo, Lagerstroenia, Mangostan, Niata, Noisetlier, Ortie grieche, Pain des Jtottentots pecher et Amandier Putiet, Ouassi, Ouinquina, Rocoulier, Rose, Salnfoin, Sophora, Sparmannia, Tabac, Thé, nouveau genre a' Trianon, Vigne, Violette etc.)

$1486^{*} \longrightarrow$ Le jardin du roi. Paris 1792 , folio. 30 tab. cul.

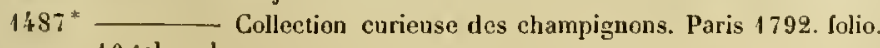
10 tab. col

1:48* (- Flore économique des plantes qui crossent aux environs de Paris etc. Par une société de naturalistes. Paris an VII. (1797.) 8. vill, $659 \mathrm{p}$.

$1489+$ Manuel tinctorial des plantes ou Iraité de toutes les plantes qui peuvent servir à la teinture et a la peinture. Ed. Y. Paris 1800.8. Xvi, $287 \mathrm{p}$.

1490 Le Lanrier et l'Olivier reunis. Paris 1802.8. a.

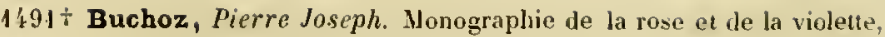
considérées sous leurs aspects d'utilité et d'agrément ete. Cette monographio est terminée par un mimoire sur l'Hortensia. Paris $1804.8 .272 \mathrm{p}$.

1492 Dissertations sur les Sorbiers et les Viornes. Paris 1804. 8. 0

$1493 \div$ Mémoires sur la Mélaleuque. Paris 1805 . 8 . IV, $29 \mathrm{p}$ $1494 \div$ - Mémoires sur l'llortensid. Ed. JV: Paris 1805.8.61 p.

$1495 \div$ Ilistoire naturelle du Thé de la Chine. etc. Paris 1806 8.92 p. $(2$ fr. $25 \mathrm{c}$.)

1496 - Dissertations sur le Cedre de Liban, de Platan et le Cytise. ele. Paris $1806.8 .96 \mathrm{p}$.

4.97 Avantage, fuon peut tirer des plantes meme les plus suspectes. ete. Paris 1806. 8. ( $1 \mathrm{fr}$.) $a$.

(Catalogus noster partem solummodo parram innumerabilium operum miserrini compitatoris [n. 27 Jan. $1731, \div 30$ Jan. 1807.] continet; recensui quae in bibliothecis holanicorum oftendi et alia quaedam Querardi. Fiaude ac ignorantia aeque eminens scriptor, 11 cujus ignominiam Llleritier Buchozian foetidam condidit, per semiseculum (7758-1807) ultra 500 volumina consareinavit.)

1498 Buchwald, Balthasar Johannes de. De diabetis curatione pracprimis per Rhabarbarun. Jlavniae 1737,4, .

1499 - Analy'sis risci, ejusque usus in diversis morbis. Ilavniae 1753, 4. $22 \%$ B.

1300 t Buchwald, Johanne's de. Specimen medico-practico-botanicum, scu brevis et dilucida explicatio virtutum plantarum et stirpiun indigenarum in officinis pharnaceuticis quam plurimum usitatarum. etc. Ilafuiae, $1 \mathrm{gp}$. Wieland. 1720.4 .320 p., praef., cum speciminibus siccis plantarum adglutinatis.

* germanice: Specinnen medico-practico-botanicnm, oder kurze und deutliche Erklarung derer in der Medicin gebräuchlichstell und iu Dennemark wildwachsenden ErdGowatuse plauzen und k'tuter. ete. Ins Deutsehe nibersetzt von Balth. Joh de Buchuald. Kopenhagen. typ. Ilopfner, 1721.8. 3 't p., praef. (Nit eingeleimten Medicinalkrautern : 2 Rdr. 3 Hark.)

1301* Buckland, William. Reliquiae Diluvianae: or observations on the organic remains contained in caves, fissures and diluvial gravel: and on other geological phenomena attesting the action of an universal deluge. - Ed. 1l: London 1824. 4. vil, 303 p., 25 tab. (2l. 2.s. A. Londun.)

$1502^{*}$ Geology and Mineralogy considered with reference to natural Theology. London $\$ 836$. Il voll. $8 .-$ I: xw, 599 p. - II : vil, $128 \mathrm{p} ., 69$ tab.

" germanice: voll Agassiz. Nenchatel 1838. If voll. 8. 603/s Bogen. 69 lab. (10 th.)

$1503+$ Bucquet, Jean Baptiste. Introduction a l'étude des corps naturels tirés du règne végétal. Paris 1773 . II voll. 8. - I: xvı, 455 p., 3 tab. - II: viII, $396 \mathrm{p}$.

1504* Büchner, Andreas Elias, pr. De genuinis principiis et effectibu. Arnicac. D. Erfordiae 1741. 4. - recusa: Ilalae 1749. 4. $36 \mathrm{p}$

1503 De Fraxinella. D. Erfordiae 1742. 4. H.

1506 _ De nuce Juglande ejusque usu medico. D. Erfordiae 1743.4. 38 p. B.

$1507^{*} \longrightarrow$ De Pareira brava ejusque virtutibus medicis. D. Erfordiae 1744. 4.

$1508^{*}$ De radice Ipecacuanha. D. Erfordiae $1745.4 .43 \mathrm{D}$

1509 De venenis et eorum agendi morlo. D. IJalae 1746. 4. H.

1310 _ D De genuinis viribus tabaci ex cjus principiis constitutivis demonstratis. D. Halae 1746.4 . H.

$1311-$ De oleis expressis eorumque modo agendi. D. Halae 1747. 4. H

1312 De Curcuma officinarum ejusque genuinis virtutibus. D. IIalae 1748 . 4. H.

1513 - De geuninis Opii effectilus in corpore lummano. D. Halae 1748. 4. H.

1514 Do damnis ex abusu resinae Jalappae. D. Ilalae 4750. 4. H.

De salutari et noxio Ellebori nigri ejusque praeparatorun usu. D. Halae 1751.4. H.

$1516 \longrightarrow$ De oleis essentialibus. D. Halae 1752.4. D.

1517 Observationes de quibusdam remediis frequentiori usui restitmendis. D. Halae 1752.4 . H.

$1518 \longrightarrow$ De Pinastro seu Pino silvestri. D. Ilalae 1754. 4. 29 p. B 
1ij19 Büchner, Audreas Elins, M. Do Iudo germanicn sise colore corviteo solido an glasto. 1). Ilalar 1756.4. $46 \mathrm{p}$. B.

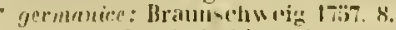

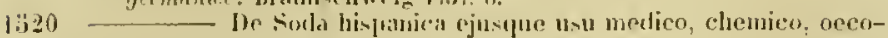
nomico. D. Halan 1758. 4. H

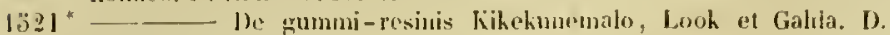
Ilalas $1764,4,20 \mathrm{l}$.

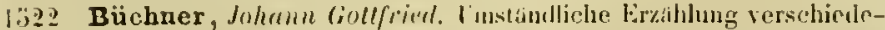

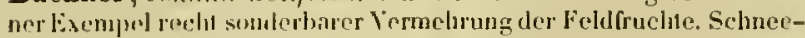
Lxorer $1798.4 . \quad$ H.

$13233^{\circ}$ - Jissentatiums epistolicae de memorabilibus Voigtlandiae

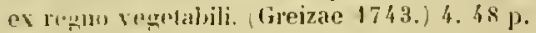

1:iz' Buée, Ilillimm Crban. A narrative of the suecessfinl manner of cultivating the clove tree in the islaul of Dominica, one of the wint-

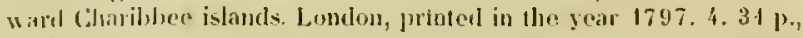
I tal). Bibl. Goett.

libnoltus rarikimus jubente britannioum rege in comnodum Indlar cecidentalis colonorum impre'ssus c'st. )

$1320 ̈$ Bühler, (; C. H. von. Der laufende schwamm in den Gebauden, scime lintstehung, Vertilgung etc. Stutgart 1845. 8. (1 1//8 th.)

$1396^{+}$Buek, $I$. II. Genera, speries et synonyma Candolleana alphabutieo urdine disposita seu Index generalis el specialis ad A. P. Decondolle P'rotromum systematis uaturalis regni vegetabilis. Berolioi 1840-1842. 8. - Jars I: continens thmos ojperis Caudolleani ujua[uor priures. 1842. $\mathrm{x1}, 423 \mathrm{j}$. (3/h.) - Pars Jl: continens tomos "peris Candulleani quintum, sextum et sectionem priorem septimi. $1840.11 .2231 \%(1 \% / 3$ th.

comtimationem libri acpue utilis ac diligenter elaborati petimus al) autere.

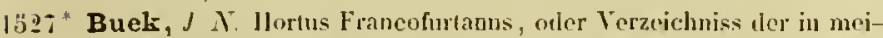
nem Garten culfivirten Gew achse, nut Jinzufugung der in ter Nathe Franklurts wildwaclssenden Pllanzen. Frankfurt a/0. 1824. 8. x $121_{1}$

1328 Buek, Johann Nicolans. Verzeichniss yon in-und auslandischen Batumen. Struchern, Pllanzon unl sanen, so zu behommen bei Johann Nicoluns Buet, Kauf- und Handelsgartner in Hamburg; nelss Ammerhumgen uber Wachsthum, Wartung und Warme nach ilsem Vaterlaude und unserm Hinmelsstrich. Bremen 1779. 8.200 p. B. $(5 / 12$ th. $)$

$1529-$ und J. P. Peters. Ankimdigung einer nenen und achten Pomologic. Hamburg 1787. 8. 3 tab. col. $(1 / 2 / h$.)

1830 Buek, Joham Peler. Catalogus von Bäumen und Stráuchern, welwhe um billige Prejse zu haben sind lyci lem Blumen-, Samen- und liaunhalmelled Johnm Peter Buek in Hamburg. Iliddesheim 1790. S. $152 \mathrm{p} . \mathrm{B}$.

1531* Buek, $l^{\prime}$. Nomina plantarm per annum 1811 in horto ill. Comitis G. II:. Orbrii cultarum. S. I. (1811.) 4.44 p).

133?* Bülow, C. II. von. Dentschlands Waither. Beiträge zur Forsigeographie. Berlin $1834.8 .11,336 \mathrm{p} .(12 / 3 / h$.

$1333^{*}$ Bünting, Johann Philipp. Sylva subterranea oder vortrefflicho Nutzbarkeit des unterirdischen Waldes der steinkohlen. IIalle 1693 19. $166 \mathrm{\mu}$.

1534* Bürckel, Johann Jaliob. De Gratinla. D. Argentorati 1738. 4. $26 \mathrm{p}$

1533* Bütner, I). S. Rudera dihvii testes i. '. Zeugen und Zeichen der Sumdlutlu. Leipzig 1710.4. (6) 314 p., ind., 30 tals.

(Intercurum verelabilia periticala (Mnerfurlensia.

1:336* Büttner, Dacid Sieymund August. Enmmeratio methodica plantarum carmine elarissmi Jounnis Christiuni Cuno recensitarum. Inpr. cum Curonis carmine: Amstelodani 1750. 8, J. $209-230 ., 1$ tal,. (Iloll. Bibl. bot. II. p. silt.

$1337^{*}$ Bugge, Frielrich Wilhelm. De Norphio. D. Berolini 1840.8. $29 \mathrm{p}$.

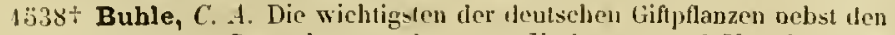
nothigsteu Bemerkungen tlazu zur Verhutung und Verminderung traturiger Vorfalle tabellarisch hearbeitet. Cothen 1804. folio, 4 p. 16 tab. col. (pessimis) in $S .(1 / h$.

$1339^{*}$ Buhle, Johann Golllicb. Calendarium Palaestinae oeconomicum. Commentatio praemio ornata. Goettingae 1785.4 . vแr. $56 \mathrm{p} .(1 / \mathrm{t}$.

$15 \% 0^{*}$ Bujack, J. G. Bolanisch-kritische Bemerhungen uber die Graser, besonders tiber tlie Getraidearten. Gỵmıasial-Programm. Königslerg $1830.4 .12 \mathrm{p}$.
15 blt Buisson, (J. I'.). Claswes el noms des flantes pour supplerer aux miguetes pendant le cours de lutanipue, yutil frera au colloge de phirmacie. Avec une introduction evtraite de ses leçons prélimi-

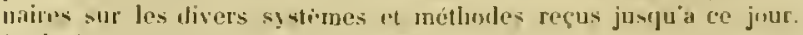
Paris 1779. 12. XLits, 115 j. (36 sols.) Bibl. Juss.

1ij? Buldaeus, Milippus. Beschreing der cost-indisebe kublen Malabar, Coromandel, Cieylon etc. Amserdan 16 it. fulio. S.

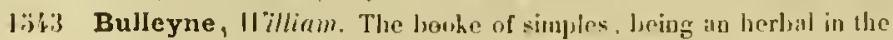
form of a dialogne. London 1362 . fulio. XC foll. pramer 3 p. fiecurarum lignu incisarum. в.

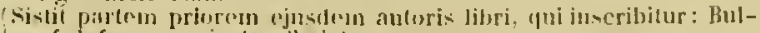
warhe of ellefence agajuste ill sithues.

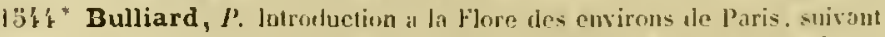

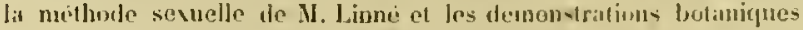
qui se font au jardin du roi. l'aris 1776. 8, 32 1).. 2 tab. cool Sistit partem voluminis primi operis semmontis.

$1093^{*}$ D"lora Parisiensis an olescriptions of firures des plantes, sui eroisonent aus environs de Paris avee les differens noms, elanses, orites et senres, qui leur convienment, raneres suivant la methode sevuelle de Mr. Lime ete. Paris 1776-1780. V woll. 8. 690 tab. col. cun tetiden foliis textus, altera tantum pagina inupressis. Judices: 52 et $10 \mathrm{p}$. (100 fr. - Paucil exemplaria in forma (juarta: $150 \mathrm{fr}$ )

$1316^{*}$ Ilixtuire des plantes venculuses el suspectes de la France. Paris 1784. Tolio, $x, 177$ \%. - "E.t. 11: Paris 1798. S. xru, 39 s 1. (4 fr. 50 c.)

$13\left\{7^{*}\right.$-... Ilisloire des champignons de la France ou Iraile dementaire, renferntant dims un ordse mithodipue les descriptions ot les lieures des champignons yui cruissent naturellement en France. Paris an V"1. ( 1791-17y8). folio. xir, $3 \$ 6,1 \times$ p. 4 tab.

$1338^{*}$ Dictionaire démentaire de hotanicue ou exposition alphabetigue des preceptes de la bolanicjue. Jaris 1783 . folio. Mu,

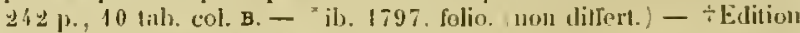
revine el presifue entierement refonlue jar Lous Claude Rirkard. Paris an VII! S. Lu, 228 p. 19 tah. - "Wel. Il: Paris 1802. 8. Lxiv. 228 p., 19 tals. - Ell. 111: Paris 1819. Folie. ( $50 \mathrm{fr}$.)

1549 Herbier de la France, ou collection complette des plantes indigenes de ce royaume. arec feurs dictails anatomicjues. leurs propriélés et leurs usages en mélecine. Paris 1780-1795. xill voll. folio. 600 tab. col. $(200-250$ [r. A.)

13306 Rejroduction des 601 et 602 . planches qui manqueut halituellement aux clampignons de Bulluurd, suivies de la table de la 13. annce de I'Allas, qui n'arait jamais ete publier avant ce jur: et precedée l'uoe notice jeonugraphique et bibliographique sur les oeurres de Bulliard, par F. I. Raspuil. Paris 1840. petit in folio. ( 5 p.), 2 tab. col. (sign. 601 et 602 .) (10 fr.)

$150 ̈ 1 \div$ Bunge, Altrander ron. Conspectus generis Gentianae, imprimis specjerum rossicarum. 1824.4.60 p.. 4 tah). (sign. 8-11.)

(Impressio searsim factil es Actis drosquensibus tom. VII.)

1302 De relatione methodi plantarmm naturalis in vires regetabilium medicinales. Dorpati 1825. 8 . $\quad$ r.

$13: 33^{*}$ Eoumeratio plantarum, quas in Chioa boreali collegit. (''etropoli 1831.) $4.73 \mathrm{p}$.

1835* S. $29 \mathrm{p}, 3$ tals.

$10303^{*}$ Verzeichniss der im Jahre $1832 \mathrm{im}$ ostlichen Theile des Altaigelirges gesammelten Pllanzen. Liin Supplement zur Flora Nitaica. St. Petersburg | 836. gr. \$. $114 \mathrm{p}$. ( $1 / 8 \mathrm{th}$.)

(Possessoribus Florae Altajeac en Mlem. de liacall. de St. Potersh. scorsim impresia.)

$13306 \div$ Delectus seninum quae in herio botanico universilatis caesareae Dorpatensis collecta, pro mutua communicatione offerunIur. Dorpati. 8. - 1836.8 p. - 1837.8 p. -1838.8 p. -1839. 8 p. -1840.8 p. -1841.8 p. -1842.8 p. -1843.8 p. $-184 \%$ 4. 8 p. cum adn. -1845.

$1307 t$ Buniva, Michele Froncesco. Reflexions sur tous les ourrages publies et indits du Doctenr Charles dltioni arec notices historiques concernant sa vie et plusicurs élahlissemens litteraires en Piemont. Turio s. a. 8. $150(8) \mathrm{p}$.

1568 De generatione plantarum. D. Augustae Taurinorum 1785. 8.54 P. B.

$130 ̈ 9^{*}$ - Nomenchator Liunaeanus Florae Pedemontanae. Augustac Taurinorum 1790. 12. sxsv, $189 \mathrm{p}$. 


\section{BUNSEN}

1:660" Bunsen, Pobert. De Ratanhiac radice ejusque usu medico. D. Cioctlingae 1828.8.30 p.

1561 Buonanni, Filippo. Mierographia curiosa. Imps. cum ejus Observalionilsus circa viventia. Romae 1691.4, $106 \mathrm{l}$., 40 lab. B.

1562 Burchard, Emst Friedrich. Epistola te calyce el calycistis. Roslock 1743. 4. H

1563 Epistola de naturali et optima florum anatome. Rostock 1743.4. H.

13iti. Burchardt, Th. II. O. Pomologische Billiotlech oder alphabelisches Verzeichniss der pomologischen Schriften; herausgegeben von Joham Butner. Coburg 1806. 8. $(5 / 12$ th. $)$

$1563^{*}$ Burchell, Ifilliam $J$. Travels in the interior of southern Africa. London 1822-1\$24. Il voll. 4. - 1: 1822. xII, 582 p., 10 tal. col. witl an entirely new map and numerous (50) engravings. - II: 1894. VI, 648 p., 10 tab. Wilh murerous (46) engravings.

(Omnes plantace in itinere lectao in adnotaliunibus operis recensitae sunt; hine inde aliquae descriptite of iconibus ejegantissimis ligno incisis beue illustralae.)

$1666^{*}$ The zoologieal and botanical imlex to Travels in the interior of southern Afriea. London 1824. 4. 8 p.

(In DC. Prodr. 1. p. 2öb. citalur ad Flacourtiam rhamnoidem: Cat. Afric, austr. Nr. 10 t2.

$1: 567^{*}$ Burckhard, Johann Heinrich. Epistola ad illustrem et excellentissimun virum Dominum Godofredum Guilelmum Leibnitzium polyhistoren consummatissimum qua characterem plantarum naturalem nec a radicibus nec ab aliis plantarum partilus minus essentialil,us peli posse ostendit, simulque in comparationom plantarum guam partes earum genitales suppeditant, paucis inruirit. Cum Laurentii Heisteri pracfatione, qua ete. Helmstadii, เyp. Drimborn. 1750. 4. 159 3., ind, 2 tab. col. - t!lelnstadii, ex officina Weygandiana. 1750. 8. 159 p., ind., z tab. col. (non tiffert.) (1'raefatio Heisteri p. I -98; epistola Burckhardi p. 99-159.)

(Eutitionem primam: Wolfenbuttel i702. f. non novi; the libro ef. Hall. Ribl. Hot. I1. 66. - Spreng. Jlist. rei harb. 11. 19:3-197.)

$1368^{*}$ Burckhard, Joham Jakol. De radice Senecha. D. Argentorati $1730.4 .20 \mathrm{p}$.

$1660^{*}$ Burger, Johaun. Follstandige Abhandlung uber die Naturgeschichte, Cultur und Benulzumg des Mais oder turkischen Weizens. Wien 1809. 8. xII, 438 p., 4 tab. (2 th.)

$1: 370$ Burggrave, Johann Philipp. Lexicon medicum universale. Francofurti 1733. folio

(1) s.sinil in litera B.- (llall, Bibl, bot, II. 26:5.)

$10 i 71$ Bedenken von dem Werhe der Erzeugung. Frankfurt 1737. 4. H.

$1572-$ De malo sinensi aureo, D. (exslat in Falentini Hist. simpl. p. $647-652$.) B.

$1373^{*}$ Burghart, (iollfied Heinrich. Iter sabothicum d. i. ausfulirliche Beschreitung einiger a. 1733 und die folgenten Jahre auf den Zothenberg gethanen Reisen. Breslau und Leipzig 1736. 8. (18) 176 p., 5 tab.

(Pilanzen des Zoblembergs p. 121-137.

1374" Burgsdorf, Friedrich August Ludwig con. Tersuch einer vollslimdigen Geschichte vorzüglicher Holzarien in systemalischen Abhaullungen zur Eiweiterunz der Naturkunde und Forshlhaushaltungswissenschaft. Berlin $4783-4787$. II voll. 4. $-1: 1783$. xvir, 234 p., 24 tab. pro parte col. - II: $1787 . x \times n, 492$ p., 9 lab. $(1)^{11 / 12}$ th. col. $16 \% \frac{12}{\text { th }}$. herabgesetzt auf 6 th. - col. 9 /h.)

(Continuatio voluminis If, it labulas continens, prodiit fortasse anuo 1800.$)$

1376 Aufmunterung zu sorgfaltiger Niterforschung der Verhallnisse, welche die Gewachsarten hei ihrer Veqetation gegen einander beolvachien. s. I. 1785.1 Bogen 4. und 1 Tabelle, gr. folio.

$1876^{*}$ - Anleitung zur sichern Erzichung und zweckmássigen Anjulanzung der einheinischen und frenden llolzarten, wolche in Deutschland und unter ähnlichem Klima im Freicn forthommen. Jis. II: Berlin 1790-1791. 2 Theile. 8. - J: 234 p., 3 lab. - H: $2 S 0$ p. - El. III : Marhurg 1S06.2 Theile. $8 .\left(1 \frac{1 / 3}{h}\right.$. $)$

$1: 577^{*}$ _ Einleilung in die I)endrologie oder systemaliseher Grumdriss der Forstnalurhunde und Naturgeschichte. Ed. IV : Berlin 1812. folio obl. 14 foll. - Ed. I: Berlin 4800 . folio. $(2 / 3 / \mathrm{h}$.

$1578^{*}$ Burmann, Joleames. Thesaurus zeylanicus, exhibens plantas in insula Zeylana nascentes; inter quas plurimae novae species ol ge-

Pritzel; Thes. lit. hot. nera inveniuntur. Omnia iconibus illustrata ac descripla. Amstelaedam 1737. 4. 235 p., ind., 110 Lab.

1579 * Burmann, Johames. Catalogi duo plantarum afrieanasum, quorum prior conplectitur flantas ah llermanno olservatas, posterior veru ruas Oldenlundus et Ilartogius indagarunt. Impr. cun Burmanni Thesauro zeylanico. Amstelacdarni 1737.4.33 p.

(Cataluns pusterior mixinam parten desumbus est e $\%$. Kolbe Beschryving van de hat de goxte lloop, I Deel p. $285-30$ '.

$1380^{*}$ Rariorum africanarum plantarum ad vivum delineatarum iconibus el descriptionibus illustratarum Deeas prina (- decinas) Anstelaedami 1738-1739. 4. vilr, 268 p., 100 tab.

$1381 *$ Wachendortia. Amstelacdani 1757. follo. 4 p., 4 tals.

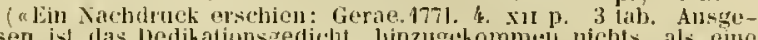

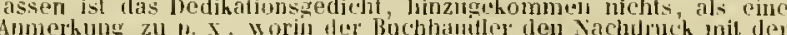
seltenheit des otiginals entschuldigt, ” E. M.

$1582^{*}$ - Flora Malabariea, sive index in omnes tomos borti malabarici, yuem juxta normam a botanicis liujus aevi recejtam conscripsit, et ordino alpluabelico digessit. Amstelaedami 1769. folio. $10 \mathrm{p}$.

$1583^{*} \longrightarrow$ Lndex alter in ommes tomos llerlarii Ambinensis at. (i. Everhurdi liumphii, ijuem de novo recensuit, auxit el emendavil. Lugduni Batavorum 1769. folio. (10, 20 p.)

1581" Burmann, Nicolaus Lorens. Specimen botanicum de Geraniis. Lugduni Batavolum 1759.4.52 p., 2 tab.

Arecolit: Casimin Christoph. Schmidel, De medulla radicis ad nurem pertingente. (1.2 ) $)^{2}, 1$ tab.

$1683^{*}$ Flora indica: eui accedil series zoophylorum imlicorum, nec non Prodronus Florae Capensis. Lugduni Batavorun 1769. 4. 241 p., iud., 67 tah. preter Prorlromum Florae Capensis: 28 p. (Hall. Bitl. bol. 11. 489. - Spreng. Ilist. 11. 430-132.)

1586 Burmeister, I/ermamn. Grundriss der Nalurgesehichte. Fur Gymnasien und holıcre Burgerschulen. Fünfte Auflage. Berlin 1845. 8. vin, $190 \mathrm{p} \cdot(1 / 2, h$.

4587* ___ Gescluichte der Schopfung. Eine Darslellung des Entwicklungsganges der Erde und ihrer Bewohner. Zweite vermehrte Auflage. Leipzig $1845.8, x, 574$ p. $(25 / 6$ th.

(Unterschinde des Thitr- und pilanzenreichs; System der Gewachse: $\mathrm{p}, 331 ;-37 \mathrm{k}$.

1588* (- Botanische Abjildungen zur Erláuterung des naturtichen Systens der Gewichse, sowie der Charactere fast aller einheimischen Pllanzengattungen. Berlin 1845 . 4. 8 p., 44 tab. $(31 / 3 / h$. Librum a. 1833 iuchnatun a. 18 '5 absolvit E. L. Taschenberg.

$1389^{*}$ Burnett, Gilbert T. Inaugural adtlress, delivered at a meeling of the medico-lotanical society of London. London 4833. 8. $24 \mathrm{p}$.

$4590 \div$ - Outlines of botany, inclueling a general bistory of the vegetable Kingrlom, in which plants are arranged aceording to the system of natural aflinities. London 4835 . 11 voll. 8 . vin, vir, $4190 \mathrm{p}$. ic. xylogr. i. t. (11. $14 \mathrm{~s}$.)

1391 Burtin, François Marier. Les bois fossiles découverts dası les dillérentes parties les Pays-Bas. llaarlem 1781.8. a.

1392* _ - Némoire sur la question: Quels sont Jes vigetanx indigènes que l'on pourrail substituer dans les Pays-Bas aux végétaux. exotipues relativement aux différens usağes de la vie? Bruxelles 1784. 4. Ix, $187 \mathrm{p}$.

tlatine: in epitomen coneimata a P. E. Wauters. Gandasi 17\%.̈. 8. $31 \mathrm{p}$.

$1393^{*}$ Bury, Edward. A selection of Hexandrian plants belonging to the natural orders Aneryllidae and Liliacae, from dIrawings by Mls. Edward Bury; engraved Jy R. Iavelt. London, published hy R. ITavell. s. a. folio max. 5 I tal. col. 56 foll. text. Bibl. Imp. Ferd.

Opus splendidissimmm, paucis impressum excmplarihus prodit annis |831-183't tecem lascicnlis pretio $10 \mathrm{Guin}$. Descriptionun autor anonymus est; talnlate secundmm plantas vivas horti Edinburgensis, eximia, glram Alquatinta vocall, irt* pielac. lit botanicortm Germa-

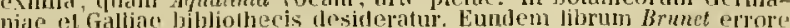
"Alexandrian plants" appr.llavit.)

159. Bussato, Marco. Giarlino di agrieultura, nol quale si tratta di tulto quello che appartiene á sapere a un giardiniero. Venezia, ty]\}. Fiorina. 1592. 4. Trew. - Venezia, Selyastian Combi. \{599. 4. S. ib. 1612.4 . S. - * Eul. V: Venezia 1781. 8.

1593* Busse, Ch. Fr. II. De Rhoo Toxicodentro et radicante. D. Berolini 1811.8 .48 p. 
$1596+$ Bussy, Alexandre, ot A. F. Boutron-Charland. Traité des unyens de reconuaitre les falsifications des drogues simples et composécs et d'on constater lo degré de pureté. Paris 1829. 8. XII, 507 p., 1 lals.

$1: 397$ Bute, John, Earl of. Botanical tables, containing the different familys al British plants, distinguislied by a few obvious parts of fructilication rang'd in a synoptical methol. s. a. et $]$. IX voll. 4.

Vol. 1: l'ost titulum et dedicationem aeri incisas sequitur: General plan of the tables, (seu conspectus classium et generum britannicorum suly singulis classibus militantiun, paginis 27 aeri incisis; unicuipue classi opponitur tabula aenca colorata, exhibeus plantam unam alteramve ox hac classe.) llas excipit: Introduction p. 1-39. - Observations on the generical claracters of British plants, and an account of the parts on which they are composed, p. $4-51$. Ciliaracters of the (British) zenera, p. 53-929. Appendix, tyronem docens quomodo plantam sibj obviam, in hac methodo inveniat, p. 3 et xxvu cum 26 talb, acn. col. Inclex: 1). $231-253$. Introduction to the general tables of plants, with a further cxplanation of the tabular arrangement: $51 \mathrm{p}$.

Vol. ll: Figures of the Genera. table 1-VII. p. 1-98. tabulae aen. col. totidem.

Vol. III: lïgures of the Genera, talile IX-XIV. p. 99-192. tah. totidem; practer tabulas duas, nescio cur, repetitas e priori volumine, p. 49 el 50.

Vol. IV: Figures of the Gencra. table XV-XVIll. p. 193-290. tab. tolidem.

Vol. V: Figures of the Genera. table XLX-XXIl. p. 291-387. lab. totidens.

Vol. Vi: Figures of the Genera. table XXIll-XXVll. p. 388-510. tah. tolidem.

In tabulis his a Johanne Miller delineatis et sculptis, exhibentur partes fructificationis unius speciei ex quoque genere plantarum Irriannicarum absque descriptionibus; textus enim solam explicationem ligurarum, ('amque sat inopem continet.

Vol. VII: The characters of the species of British plants, vol. I: p. $1-294$

Vol. Vill: The characters of the species of British plants, vol. II: p. $295-569$ el 28 p. index.

Vol. IX: Some observations on the terms emplayed in Botany, and particularly on thoso borrowed from the anatomical descriptions of animals: II p. Kigures of the different parts of plants: 90 tal,. aen. col. cum paginis totidem impressis, ubi definitiones terminorum frustra quaeras, serl qualescunque invenias in seruenti: 1 glossary containing an explanation of botanical terms, with latin translations and references $t 0$ the figures: $28 \mathrm{p}$.

(Operis hujus, splendidi magis quam utilis, duovecim tantum exemplaria impressil sunt. Tabulae, trminus bolanicos explicantes ompes redent ill Juanus Willeri lllustration of the termini botanic of Limzacus. Equidem librum non vidi; apposui Jryandri descriptionem ad verbun e Bibl. Bianks. sumlan.

$1698^{*}$ Butler, Charles. The feminine monarclio or the historie of bees London, typ. Ilavilland. 1623.4.- ib. 1634. 8. - "ib. 1673. 8.

(Plantar apibus gratice recensentur.

1599t Butret, Charles Baron de. Taille raisonnéc des arbres [ruitiers Treizieme édition depuis 1793. Paris 1809. 8. 72 p., 1 tab. El. XVl: Paris 1892. S. (2 fr. 25 c.) 0. germanice: von sickler. Weimar 1797. 8

1600 Butt, J. H. The botanical priner, heing an introduction to english hotany, adapted to the Linnean system and language. Landon 1827. 12. (6s.)

$1601^{*}$ Buxbaum, Johann Christian. Enumeratio plantarum accuratior in agro llallensi locisque vicinis crescentium una cum carum characteribus et viribus, qua variae nunquam antea descriptac exhihentur cum pracfatione Friderici Haffmami de methodo compencliosa plantarum vires et virtutes in medendo indagandi. Halae, in officina Rengeriana. 1721. 8.342 1., praef, ind., $2 \mathrm{tab}$.

(Seguierus aliam priorem editionem landat, Halae 1721. 8. "Praperato, inquit Hallerus, libum edjclit, quem metuebat a Coschucizia sibi surreptum iri.,")

$1602^{*}$ - Plantarum minns cognitarum centuriae, complectens plantas circa Byzantium et in Oriente observatas. Petropoli 17281740.4. - Centuria I: 1728. 48 p., 65 tab. - Centuria Il: 1728. 46 p., 50 talı. - Centuria III : 1729,42 p., 74 tab, - Cenluria IV:
1733. 40 p., 66 tals, - Centuria Y: 1740. 48 p., 7 i tab. et aupendicis figurae 44 . (22 $\frac{1}{2}$ th.

1603* Byczkowski, Meinrirh. Jas Vurhálıiss der Pflanzen zur Itmospluare. D. Dorpat $1846.8,77 \mathrm{p}$.

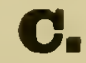

$1604+$ Cadet-de-Vaux, Antoine Alexandre. Instruction sur l'art de faire le vin. Paris, an Vlli. (1800).8.68 p.

$160 \ddot{0}$ Dissertation sur le eafi, son historique, ses proprictés et le procede pour en obtenir la lseisison la plus agreable, la plus salutaire et la plus éconamique; suivie de son analyse. P'aris. $1806.8 .118 \mathrm{p}$. ( 1 fr. $30 \mathrm{ce}$ )

$1606+$ Trate de la culturo du tabac et de la preparation de sa feuille, réduites a leurs vrais principes. Paris 1810 . \$. xxir, 78 p. ( 1 fr. 50 e.)

1607 Instruction sur la préparation des tiges et racines de (abac. Paris $1812.12 .(50 \mathrm{c}$ ) a.

1608t Cadet (de Gassicourt), Charles Louis. Ilimoire sur l'arbre eirier de la Louisiane et de la Pensylvanie. Paris s. a. 8.19 p.

$1609+$ Dissertation sur le Jalap. These. Paris 1817. 4. $84 \mathrm{p}$.

1610 Cadet (de Gassicourt), Félix. Notice sur le Diosma crenata. Paris $1827.8 .8 \mathrm{p}$. a.

1614 Caels, Theodor Peter. De Belgii plantis qualitate quadam lıominibus caeterisve animalibus nocira seu venenata praeditis, symptumatibus ab earum usu productis nee non antidotis adlibendis D. Bruxellis 1774. 4.66 p., ind.

1612* Caesalpino, Andrea. De plantis libri ẌV̈l. Ad serenissinum Franciscum Aledicem, Magnun Aetruriao Ducem. Florentiae, apud Georgium Narescottam. 1583. 4. 621, (50) ]\%.

1613 Appendix ad libros de plantis. Ramac, apud Jloysium Zanettum. 1603.4 . $19 \mathrm{p}$. praeter appendicem ad peripateticas yuacstiones. - * redit in Museo di piante rare di Roccone, p. 125-132.

(Hace appendix ubique a me frustral quacsita. nitiolissimo mamseripto exstat ad calcen exemplaris librortm irl de plantis in Mibl. Eugeniana lindob. Ill. Nr. 4.j. Sunt 13 p. Desinit in verbis: "nam in genere piperis non meminit abis. Jedicatio Caesalpini ad Baccium ingenere piperis non meminit albi.n lodicatio

161:* Caesius, Federicus, Princeps S. Angeli, et S. Poli. Pliytosophicarum tabularum pars I. impr. cum Ilernandez Ilistoria plantarum mexicanarum, p. $901-950$. Romae 1651. folio.

$1613 ̈+$ Caffin, Jacques Fr. Exposition inélıodique du rène vézétal, dans laquelle les plantes sont classces d'après les differences qu'elles présentent dans leur organisation et leurs fonctions. ctc. Paris 1822. 8. vi, 84 p. (2 fr.)

$1616^{*}$ Cagnatus, Marsilius. Variarum observationum libri IV, quorum duo posteriores nunc primum accessere. Romae, apud B. Donangelun, $1587.8,328$ p., prac fo, jnd.

$1617-$ De liguo sancto disputationes binac.

(Exstant cum variis opusculis hujus auctoris. Romae, Aloysius Zannettus. 1603. 4. S.)

1618* Cailliaud, Frédéric. Foyage à Méroé, au fleure blanc, au-dela de Fâzoql, dans le midi du royaume de Sennar a Syouah el dans cing autres onsis, fait tans les années 1819-1822; accompagné des eartes géographiques, de planches représentant les monumens de ces cuntrées avec des détails relatifs à l’ẻlat moderne $\mathrm{ct}$ à l'histoire naturelle. Paris 1826. Wvall. $8 .-1: 1826 . \mathrm{xr}, 429 \mathrm{p.}-\mathrm{II}$ : 1826. 442 p. - III: 1826.431 p. - IV: 1827. 416 p., 1 tab. (35 fr.) - Atlas: Paris 1823. folio; en deux parties a 75 planches el texte. (Vol. IV. 1. 293-402: Cenlurie de plantes d"Afrique du voyages at Méroé recueillies par M. Cailliaud et décrites par Ml. Raffeneau-Delille; arec trois planches botani(jues dans l'dtlas.)

$1619+$ Cailliot, Amédée. Essai chimique sur la Térébinthine des sapius a cône redressé. D. Strashourğ 1830.4 .86 p., incl.

1620 Cajus, Johammes. De rariorum animalium et stirpium listoria liber I. impr. cum ejus “De canibus Britannicis " libro. Londini 1570. 8. 30 foll. - cum eadem Jibro: Londini 1729. 8. 1) 37-122. B. 
1621 Calandrini, Jean Louis, jг. Theses plis sieao de regetatione et generatione plantarum. D. (autor Jacques Andre Trembley.) Genevae 1734. 4. 10 p. Bibl. publ. Genev.

1622 Caldarone, Giacomo. Epistola Jotanica. Exstat in libro Gervasii: Bizzarrie botaniche di alcuni semplicisti di Sicilia. Neapoli, Novellus de Bonis. 1674. 4. s.

1623* Caldenbach, Christoph, pr. De Lauro. 1). Tuebingae 1670. 4. $15 \mathrm{l}$.

$1624^{*}$ De Olea. D. Tuebingae 1679.4.16 p

$162 ;$ De Palma. D. Tuelingae 1679.4. H.

$1626^{*}-$ De Vite. D. Tuebingae $1683.4 .20 \mathrm{p}$.

1627 Callard de la Ducquerie, Jean Baptiste. Ager medicus Cadomensis sive hortus (catalogus Q.) plantarun, quae in locis paludosis, pratensilous, maritimis, arenosis et silvestribus prope Cadomum in Normannia sponte nascuntur. Parisiis 1714. folio. Dc. (Ouvrage très-rare! a.)

("Ce manuscril était entre les mains de l'autemr et lo titre de cet ourrage est rapporte dars le Journal litteraire de la llaye, Janvier 1715.9 .263 . M. Callord de la Dacquerie "st mort ters 17.66 . Parmi los mantscrits, quil a lasses, on a trouve une copic informe et tronquen du trate dont il sagit ici Cet exmptaire est entre le mains te.$M$. Desmoneus, Prof en merlecine of botanique a Caen, sique de la Frunce, p. 27t-273.)

1628- Calvel, Étienne. Traité complet sur les pépinières tant pour les arbres fruitiers et forestiers, que pour les adjrisseaux et les arbustes d'orrement. Paris 1803 . 12. 374 j., 2 tab. (3 fr.) - Ed. 111 . augmen1ée. Paris 183\%. 111 roll. 12. avec un portrait, un lableau el des planches. 0.

$1629 \div-$ Nanuel praticue des plantations. etc. Paris 1804. 12. x, 108 p., 1 tab. (1 fr. $80 \mathrm{c}$.)

$1630 \div-\ldots$ Du Melon et de sa culture dans les serres, sous chassis, sur différentes couches et en pleine terre. Nouvelle edition. Paris 1810.8.71 p., I tab.

$1631 \div-$ De la hetterave el de sa culture, considérée sous le rapport du sucre, (qu'elle renferme. Paris 1811 . \$. 67 p., I tab. Supplément: $8 \mathrm{p}$.

Ahbas Etieme ralvel alia multa scripta de horticultura edidit; $c f$. Q. France literaire II. 1. 26.)

1632 Calvius, Johannes. Commentarium inserviturum historiae Pisani vireti botanici academici. Pisis 1777. 4. 193 p. cum ichnographia horti eadem, quae est in Tilli Catalogo. B.

1633 Calzolaris, Francesco (latine Calceolarius). Il viaggio di Monte Baldo dalla magnifica eitta di Verona, nel quale si descrive con marariglioso orline il sito di detto monte e d'alcune alire parti ad esso contigue, et etiandio si narra d'alcune segualate piante e herbe clıe ivi nascono e clse all uso della medicina jiù cli tutte l'altre cunferiscono. Venezia, Vincenzo Valgrisi. 1566. 4. Bibl. Maz. ex $\mathbf{S}$. * latine: Iter Baldi ciritatis Verouar montis, in quo nnirahili ordine describitur montis ipsius alque aliarum reuarundam ipsum contingentimm partium sitns. Recensentur praeterea quaedan insinnes plantae ac herdace ibi hascentes, quac usui medico plus caeteris confermut. Impr. cum Epitome utilissima Malthioli de plantis. Vene-

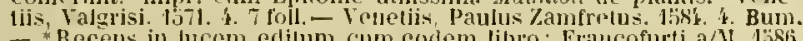
- Recens in lucens editum cum eorom libio: Frencofurti a/A1. 1586

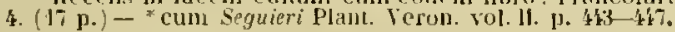

163\%+ Cambessedes, Jacques. Monographie du genre Spiraea, précédée de (quelques considúrations générales sur la famille des Rosacées. Paris 1824.8 .58 p., T 1ab.

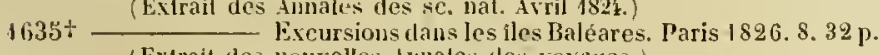
(Extrait des nouvelles Amales des voyages.)

$1636 \div-$ Enumeratio plantarum, yuạs in insulis Balearibus collegit, earumque cirea mare mediterranenm distributio geographica. Parisiis 1827.4 .168 p., 9 tal, sign. 10-18.

(Extrait des Mèm, du Musium.

$1637 \div$ Nemoire sur les familles des Ternstroemiacćes et des gultiferes. Paris 1828.4 .61 1., 4 1ab

(Exirait des Memoires du Musceum.)

$1638^{*}$ Cruciferarum, Elatinearum, Caryophillacearum, Paronychiarum Brasiliae meridionalis Synopsis. (Paris 1829.) 8. 8 p.

$1639^{*}$ - Portulacearum, Crassulacearum, Ficoidearum, Cunoniacearum Brasiliae meridionalis Synopsis. (Paris 1829.) 8. $4 \mathrm{p}$.

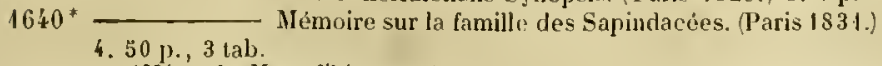

(Mèm. du Mus, dhist. nat.)
1651 (Cambry, Jacques.) Voyage daus le Finistère ou Fiat de ce dẻpartement en 1794 et 1795 . Paris an Vll. (1799.) 1ll voll. 8. 284, $314,282 \mathrm{p}$, tab. - Nouvelle édition, accompaynèc.... de la Flore du département par M. le chevalier de Freminville. Brest 1836. 8. ( 6 fr. 50 c.)

("C'est le premier ourrage de statistique, (nui a paru en France.n Q. - Vol. III. p. 2ł3-252: Platites du Finistire,

1642 Description du departement de l'Oise. Paris IX. (1803.) 11 voli. 8 . a.

("On trouve dans le deusieme volume une liste des plantes observies autour de onze villes of bourgs du departement et une note sur le Cares arenaria de Ia foret de Compiesue," Baron de la Fon in litt.)

1613 Notice sur l'agriculture des Celtes et des Germain: Paris 1806. 8. a.

164:* Camerarius, Alexander, pr. De botanica. D. Tuebingae 1717. 4 $28 \mathrm{p}$.

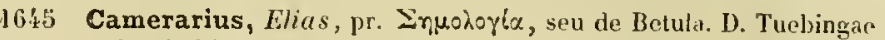
1727. 4.26 p. B.

1646 Camerarius, Elics Rudolf, pr. De Cichorio. D. prior. Tueliıgae 1690. 14 1). 4. B.

(Dissertatio posterior: ih. 1691. 4. apud Banksium desideratur.)

161.7* Camerarius, Joachim. Opuscula quaedam de re rustica, partinı collecta, partim composita, quorum Catalogus post praefalionem liabetur. Norilhergae 1577.4. 53 foll. - "Ed. iterata auctior. Nonmlergae, excudebat Paulus Kaufmanu. $1596.8 .239 \mathrm{p}$.

$1648^{*}$ - Hortus medicus et plilosophicus: in quo plurimarum stirpium breves descriptiones, hovae icones non paucae, indicationes lncorum natalium, olservationes de cultura earum peculiares atque insuper nonulla remedia euporista, nec non plitologica quaedam continentur. Cum Thulii Sylva Ilorcynia nunc primum editum. Francofurti a/MI., Jolı. Feyeraljend. 1588. 4. 184 p., praef.

$1649^{*} \longrightarrow$ Icones aceurate nunc primum delineatae praecipunrum stirpium, quarum descriptiones tan in Ilorto quam in Sylva Ilercynia suis locis habentur. Francofurti a/Ar., Joh. Feyerabend. 1588. 4. 47 et 9 icones xylogr. in totidem paginis.

(Adhacet fere semper Horto medico.)

$1650^{*}$ Symholorum et emblematum ex re herbaria desumtorum Centuria. Norilsergao 1590.4. 110 foll. cum 100 ic. elegantissine ligno incisis. - ${ }^{*}$ Norimbergae, typ. Voegeli. 1605.4 102 foll. cum praef., ic. - Moguntiae 1697.8. 201 p., ic. B.

$1651+$ Camerarius, Rudolph Jacob, pr. De plantis vernis. D. Tuebingae $1688,4.22 \mathrm{p}$.

1652* ${ }^{*}$ De llerba Nimosa seu sentiente. D. Tuebingae 1688 4. $20 \mathrm{p}$.

$1653^{*}-$ Epistola ad D. Mich. Bern. I'alentini de sexu plantarum. Tuebingae 1694.8. $110 \mathrm{p}$.

(Spreng. Gesclı. der Bot. II. $200-26$.)

$1654^{*}-$ De convenientia plantarum in fructificatione el viribus. D. Tuebingae $1699.4 .16 \mathrm{j}$.

$1655 \div-$ De Scordio. D. Tuebingae 1706.4.24 p.

$1656^{*}$ De ustilagine frumenti. D. Tuebingae 1709. 4. 16 p.

$1657^{*}$ De Lolio temulento. D. Tuebingae 1710.4. 24 p.

$1658^{*}$ Biga botanica sc. Cervaria nigra et Pini coni. (Linum etian catharticum.) D. Tuebingae 1712.4. $16 \mathrm{p}$.

1659 De Ulmaria. D. Tuebingae 1717.4. H

$1660^{*} \longrightarrow$ De Fumaria. D. Tuebingae $1718.4 .14 \mathrm{p}$.

$1661^{*}$ De Rubo idaeo. U. Tuebingae 1721.4.20 p

$1662^{*}$ Opuscula botanici argumenti collegit et edidit Johum Christiun Mikan. Pragae 1797. 8. vi, 224 p., effigies Cumerarii.

$1663 \div$ Campana, Antonio. Catalogus plantarum horti botanici regii Lycei Ferrariensis. Ferrariae $1812.8 .31 \mathrm{p}$

$1664^{*}$ - Farmacopea Ferrarese. Ed. V1. Firenze 18 18.8. $x 1,351$ 1.

1665* Campdera, F. Mlowographic des Rumex, précédée de juelques vues genérales sur la famille des Polygonées. Paris 1819.4.169p., 3 tab.

1666 Campi, Baldasar, e Michaele Campi. Al Signor A. Nanfredi in risposta adl alcune objettioni fatte nel lib. nostro del Balsamo Sig. Stef. de' Gaspuri. Lucca 1640.4.18 p. B.

- Inlucidazione di alcune cose state da noi dette nella risposta al Sig. Guspari. Pisa 1641.4 .12 p. B. 
$1608+$ Campi, Baldasar, e Michele Campi. Spicilegin Hotanico, Dialoggo, nel yjualo si manifesta lo sconosciuto cinnamomo delli anticlui. etc. Lueca, t5]. Marescandoli. 1634. 4. 123 p., pracf., ind., tab. ib. 1669.4 . S.

lifi! Canevarius, Demetrius. De ligno sancto commentarius, in juo priecipue ufualitates cjus et facultatos oumes exacta diligentia exprimuntur, ex illisque lignum cprodslam quonl nuper in Italia delatum et psendolignum sanctum et mullomorlo verum cjus fautorilsus accurato examine Jemonstratur. Romae, Guilelmus l'acciottus. 1602.8. 141 f. B.

$1670+$ Cannegieter, Kenricus. Wissertatio de Brittenburgo, matrilus lrittis, Isritamica herla, lorittia l'rocopio menorato, britaunorumgue antiguissimis per Gallian: et Germanian sedilous. Iujc accedunt ejustem Notae atgue olservationes ad Abrohami Huittingii dissertationem historico-medicam de vera intiquorum herba britamica. Hagae Cemilum 1734. 4, 179 p., prief, iuel, I tab.

1671 Canonhierius, Petrus Antreas. Je locli e i hiasimi del vino. Viterbo, Girolamo Discepolo. 1608. 12. Bibl. Maz. ex s.

1672 De admirandis viui qualitatibus libri tres, in quilrus multa ad vinum pertinentia tractantur. Antwerpiae, Hieronymus Verdussius. 1627. 12. Bibl. Maz. ex S.

$1673^{*}$ Caustein, Philipp Baron con. Einigo Begleitworte zur Karte von der Verbreituog der nutzbarsten P'flanzen uber den Erdkörjer. (Berlin 1834.) 8.16 p. - (Mit Karte $2 \% / 3$.)

1671. "Canvane, Peter. A dissertation on thu: Oleum Palmae Cluristi s. Oleum Ricini. or (as it is commonly called) Castor Oil. Bath ( 1766 ) 8. $88 \mathrm{p} ., 1$ lab.

gallice: Paris 1777. 8. DC.

$1673^{\circ}+$ (Canzoneri, Francesco.) Saggio sul castagno d'India, con l'aggiumta della scoverta di una nuova sostanza trovata nel frutto. Palermo 1823. 5. 57 p., 2 tab.

$1676+$ Cap, Paul Anloime. Princjpes dementaires de pharmaceutique ou exposition du systome des connaissances relatives à l'art du pharmacien. Paris 1837. S. xı, 431 p. (6 fr. 50 c.)

1677 Nicolas Lemery, chimiste. Eloge, qui a remporté le prix propose par l'académie de Rouen. Rouen, Périaux. 1838. $8.46 \mathrm{p} .-$ Paris, tyj]. Fain. 4839. 8.52 p. a.

1678 Moyse Charas. Eloge. Paris, l'ain. 1840.8. 19 p. a.

$1679^{*}$ Capece-Iatro, Giuseppe. Memoria su l'Apocino. (Asclepias syriaca.) E(l. III. Roma $1804,4,12$ J., 1 tal.

t qullice: Paris 180:3. $\$$. 8 .

$1680+$ (Capelli, Carlo.) Calalogus stirpium, yuae aluntur in regio borto botanico Taurinensi. Augustae Taurinorum 1821.8.67 p.

1681* Cappel, Johann Friedrich Ludwig. Verzeichniss iler um Helmstault wildwachsenden Pflanzen. Dessan 1784. 8. $x, 196 \mathrm{p}$.

$1682^{*}$ Cappeller, Morilz Anton. Pilati montis historia in pago Lucernensi Helvetiae siti; figuris aeneis illustrata. Basileae $1767.4 .188 \mathrm{p}$, 7 tab.

(Vegetabilia Pilati p. 73-107 et 187-185.)

1683 Cappellinus, Severinus Johamnis. Dissertationum physicarum de flantis prima. Ilarniae 1684 . 4. (6 foll.) B.

168\%. Cardanus, Ilieronymus. De sultilitate libri XXI. Basileae 4560. folio. 603 p. B. - $\div$ Lugduni, apud Steph. Nichaclem. 1580.8. 718 p., ind.

(Lib. Vilt. p. $290-350$ est de plantis.)

$1683+$ Carena, Ilyacinthus. De animalium el plantarum analogia. D. Taurini $1805.8 .130 \mathrm{p}$.

$1686^{*}$ Carl, Joseph Anton. Botanisch-medizinischer Garten, worinnen die hráuter in nalurhafte, heilsame und giftige eingetheilt sind. Ingolstadt $1770.8 .469 \mathrm{~J}$., pracf., ind.

$3687^{*}$ Carlowitz, Ilans Karl ron. Sylvicultura oeconomica oder llausswirthliche Nachricht und naturmássigo Anweisung zur wilden Baumzucht. etc. Leipzig 1713, folio. 414 j., praef., incl.

1688* Carmignani, Fincenzo. Mlemoria sulle mediche Tornata et Turbinata di Linneo e sulla Tulerculata e Aculeata di Willdenow. s. I. $18108.15 \mathrm{p}$.

(Estratto dal Giornale Pisano tom. Xil.)

16.9 *arminati, Bassano. IIygiene, terapeutice et materia medica. Papiae 1791-1795. N voll. 8. 404, 552, 422, 509 P.
1690 Caroleau. Oenologie françajse. Paris 1828 . \& 436 p., 6 tah. (6 $6 \mathrm{fr} .50 \mathrm{c.}$ )

169J Carpenter, II. Scripture natural listory. London 1828. 8. 608 11.

169 t Carradori, Ciocacchino. Della trasformazione del Nostoc in Tremellis verrucosa, in Lichen fascicularis ed in Lichen rupestris. In Prato jer Vestri o Guasti. 1797. 19.39 J.

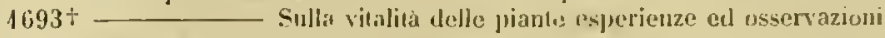
Milano 1807.8. 27 p.

169.t - D Degli organi assorbenti telle radici dolle piante. (Firenze s. a.) $\mathrm{S} .16 \mathrm{p}$.

16937 Sperienze el nscervazieni sopra l'irritalsilita della latuga con alcune rillessioni gronerali sull' irritabilita dri vegetabili. $1808.8,19 \%$.

(Estratu) dial tomo Xll. d. soc. ital. dellir scicuze.)

1696 t Carrère, Joseph Barlhelemi Francois. Traite Ies proprieles In

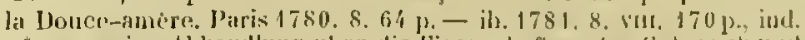
germunice: Abhandlung uber die Eigenschaften, deu Gebratuch numbt

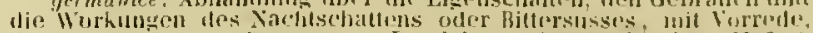

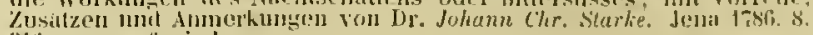
316 p., pretrit., int?.

1697* Carrichter, Barlholomaeus. Liruterlucl, darinnen lsegrillen, unter welehem Zeichen Zodiaci, auch in welchem Groulu ein jedes hraut stehe, wie sie in Leih und zu allen schaden zuzubrroiten, unt zu welcher Zejt sic zu colligieren seien. Vormals nie in truch aussgangen. Strasshurg, 1yp. Christian Muller. 13075. 8. 2223 p., prarf., int. - F.d. II : Strassburg, typ. Cliristian Mullor. 1577. 8. 2293 p. praef., ind. (nova sed immutata impressio!) - Strassburg 1597. \&. 223 p. practer partem practicam. B. - * Strassburg, Bertram. 1615 8. 224,80 p. - Strasshurg, Bertrani. 16 19. 8. - Nurnherg, Junmler. 1621. 8. - * Numberg, Dummler. 1652. 8. - Ximberg, Cardluccius. 1656. 8. - Tubingen 1739. S. B.

$1698^{\circ}$ - Des hochbegabten Herrn Curricher's uberaus furtreflicher und viel verlangter Tractat von ilm tituliret: das Buch von der Harmonie, Sympatbie und Intipathie der lirauter unt ihren vier ersten Haterien. Nuruberg, Endter. 1686. 8. 224 1).

(Fortasse itlem liber ac praecedens.)

$1699^{*}$ Ilon des Ileyls menschlicher Illudigkeit, ouler (irosKráuterbuch, darinn die hrater les Teutschenlauds auss dem Lieclı der Natur nach rechter Art der himmelisclien Ëinflessungen bescliriehen. llier ist zu End beigefugt das menschliche hrauterbild, nach denen zwolf himmolisclien Zeichen und vier elementarischen Complexionen aulf die innerliche und ausserliche Glieder de: mensehlichen Leibes gerichtet: zusammengetragen auss whyedachten Auctoris Schrimen von Theophilo Kraffen ron Gladenthach aus Ilessen. Franhfurt a/N., Götzens Erben. 1673. 4. $374 \mathrm{~J}$. cum ic. xylogr. i. t., praef., ind. - Ed.1: Strassburg, typ. Cluristian Huller. 1576. folio. - Strassburg, Bertram. 1595. folio. - "Strassburg, Bertram. 1606. folio. 181 p., praef, ind. et ic. xylogr. i. t. - "Strassburg, Bertram. 1619. folio. (9) iso foll., ind., ic. sylogr. i.t.

Ellitiones priores sunt sub pseudonymo Philomonsi Anonymi editae; ommes post mortem auctoris per $D$. Toxiten, (qui, ni fallor, dudit 1)r. Melchior sichinnfelde.)

$1700^{*}$ Carro, John de. Essay on the mineral waters of Carlsl)ad for physicians and patients. With observations on the microscopic animalcules about the lot springs of Carlsbad loy A. J. C. Corda, and a Flora of Carlsbat by C. B. Prest. Progue 1835. 12. 135 p., 6 tab.

1704 * Cartheuser, Johamn Friedrich, pr. De Cassia aromatica cjusdemijue differentia, principiis et viribus. D. Francofurtia/V. 1745.4. 32p.

1702 De ligno ueplaritico, colubriıo et semine santonico. D. Francofurti a/V. 1749.4 .24 p. B.

$1703^{*} \longrightarrow$ De Marrubio albo ot Alchimilla. D). Francofurti a/ $\mathbb{S}$. 1753. $4.24 \mathrm{p}$.

4704* lawan diclo. D. Francofurti a/V. 1753. 4. $34 \mathrm{p}$.

$1705^{*} \longrightarrow$ De praecipuis balsamis nativis. D. Francofurti a/ $\mathrm{V}^{*}$ 1753. $4.40 \mathrm{p}$.

$1706 *$ De Cardaminlo. D. Francofurti a/T. 4755.4 .24 j.

1707 De Chenoporlio ambrosiode. D. Francofurti $a / 1+157$. 4. 42 ]. B.

$1708 \longrightarrow$ De ratlice Sapronariae. D. Francofurti a/ V. 1760. 4. 94 J. B.

1709 1761. 4. 20 ]. B. 
1710 Cartheuser, Joham Friedrich, pr. De Saccharo. D. Francofurti a/ Y. $1761.4 .24 \mathrm{p}$, B.

1711 - De Lichene cincreo terrestri. D. Francofurti a/V. 1762. 4. $16 \mathrm{P} . \mathrm{B}$.

$1712-$ De radıcilus esculentis in genere. 1). Francofurti a/V. 4765.4. $26 \mathrm{~J}$. B.

1713 De ralice Mungo. D. Francofurti a/V. 1769.4

17. $1^{*}$ De genericis quibuslam plantarum principiis hactenus plerumque neglectis. l'rancofurti a/V. 1754. 8 , $78 \mathrm{f}$. † Ed. Ill. prioribus auctior. ib. 1764. $8.83 \mathrm{H}$.

$1718 \div \div$ Fundamenta materiae melicas. Lis. nova auctior. Parisiis 1769. N voll. 12. - El. I: ib. 1749-1752. II voll. 12.

$1716^{*}$ - Pharmacologia theoretico-practica praclectionilus academicis acconmudata. El. 11. emendatior. IBerolini 4770.8 .7481 r: praef, ind.

$1717^{*}$ Enumeratio systematica stirpium per Ducatum Negapolitanum Strelizense observatarum. Dissertationis appentix. Trajecti ad Viadrum $977 \pi$. 4. p. $33-40$.

171S Carver, Jonathan. A treatise on the culture of the Tobacco plant. Lonton 1779. S. 54 p., 2 tah. col. B.

1719 Casagrande, Giuseppe. Della pianta del sanguigno, dell' olio delle sanguinelle. Roma 4787. 8, Dc.

$1720+$ Casanova, J. N. Essai sur le Mladar (Calotropis Madarii indicoorientalis) contenä.t l'histoire naturelle de cette plante, ses proprietés physiques, chimiques et médicinales. Traduit de l'anglais par $L$. 4. Richy. Calcutta, imprimerie de la mission Baptiste. 1833. 8. V, 69 p., 1 tab.

$1721^{*}$ Casaretto, Giotami. Novarum stirpium Brasiliensium Decades. $(1-\mathrm{X}$.) Geluae $1842-4845.8 .96 \mathrm{p}$

(IIj deeem decadihus volunen jrimum absolutum est. Fortasse continuabitur opus.)

1722 Casaux, Charles, Marquis de. Systime de la petite culture des cannes à sucre. London 1779. 4. 7 / P., 1 tal). - redit dans le Traité du sucre de II. Lebreton. Paris 1789. 12. p. 25-82. B.

Essai sur l'art cle cultiver la came et d'en extraire le sucre. Paris $1781.8 .519 \mathrm{p}, 1$ tal. B.

172'. Caspari, Ihilipp Heinrich. De Scilla, D. Goettingae 1785. 4. 40 p.

$1790^{*}$ Cassebeer, Johann Heinrich. Veber alie Entwickelung der Laubmoose. Franhfurt a/Ml. 1823. 8, vin, 77 p. ( $1 / 4$ th. $)$

$1726^{*}$ Cassel, Franz Peter. Versuch uber die naturlichen Familien der Pllanzen mit Rucksicht auf ihre lleilkraft. Koln 1810.8 .174 p. $(2 / 3 t h$.

$1727^{*}-$ Lehrbuch der naturlichen Pflanzenordnung. Frankfurt a/Al. 1817.8 . vil, $403 \mathrm{p} .\left(1 \frac{1}{2}(h)\right.$.

$1728^{*}$ - Jorphonomia botanica sive observationes circa proportionem et evolutionem partium plantarum. Coloniae $\Lambda$ grippinae 1820. 8. $x, 172$ p., 8 tal..$(1$ th. $)$

$1729^{*}$ Cassini, Alexandie Henri Gabriel, Comte de. Opuscules plytnlogiques. Premier recueil, contenant 1. une ibauche de la synantherologie; 2. des mémoires ou articles de hotanique sur différens sujets étrangers a la synanthérologie; précédó d"un table indicative do tous les memeires et articles concernant la botanique, publies jusqu'à ce jour par l'auteur dans quelques journaux scientifiques et dans le Dictionnaire des se. natur. Paris 1826-1834. Ill voll. 8. I: 1826. Lxvi, 426 p., 8 tab. - II : 1826. 552 p. - III: (supplementaire) contenam 1. un rósumé de la synanthérologie; 2. quatre kittres elementaires sur la botanipue. 1834 . xxx, $221 \mathrm{p}$. (20 fr.)

$1730 \div$ Castagne, Louis. Observations sur quelques plantes acotylédonées de la famille des Urédinées et dans les sous-tribus des Nemasporées et des Aecidinèes, recueillies dans le Dép. đles Bouches-lu-khòne. Nr.J. Narseille 1842.8. 35 p., t tab. - Nr. Il. Aix 1843. 8. 24 p., 2 tah.

$1731+\longrightarrow$ Catalogue des plantes qui croissent naturellement aux environs de Marseille. Aix 1845.8. 263 p., 7 tab.

$1732+$ Castel, Renc Richard. Les plantes. Peime. Paris (1797). 12. vin, 150 f. - tEd. Il. revue corrigée et augmentée. Paris an VIl. (1799.) 12. xIII, 251 p., 5 tab. - Ed. III: Paris 1802. 12. - +Ed. I : Paris 1811. 12. xur, 319 p., 5 tab. - Ed. V: Paris 1832.12 . a. + latine: Botanicon libros quatuor c carmine gatlico viri clarissimi Rennti Richardi Castel in lathos rersus transtulit Clarus Ludovicus liokard. Anger's et Paris 1818 . 8. 100 p., praef. (2 fr. 50 c.)
1733 Castelli, Pietro, fielu nomine Tobias Aldinus, Casenas: ex sententia Leonis .1llatii. Ip. ('rb. j). 218.) Vera e natural c.figie delle fiauta indiana eliantata Maraen, Granatlilla e fior della passione D. X. S. Tenetia udi 28 Giuglio 1620. Tabula aenea long, 15 unc. lat. 17 une. $B$.

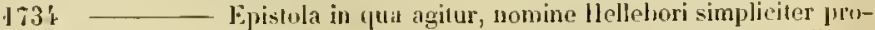
lato, tum aptul lippocratım, tum alios auctores, intelligentum alloum. Romae 16ㄹ․ 4. 28 \%, B.

1733 _- Epistola secumda de Hellehoro. Romac 1622. 4. 48 1. B. $1736^{*}$ (— Eiclissima descriptio rariorum quarund.m plantarum yuae continentur kumae in horto Farnesiano. Romae, typ. Mlescarili. 1625. folio, 101 l\%, prace, ind. (28) lab, aeri incis.

1737 Lelatio de qualitatibus frunenti cujusdam Messanan (lelati amo 1637. Neapoli 1637.4 . 16 1). B.

$1738+-$ Ilortus Messinensis. Messanae, typ. viduae Bianeo. 1640. 4. (16) 51 p. cum horti iconographia: 14 tab Bibl. Juss.

1739 Opobalsamum. Venetiis $1640.4 .163 \mathrm{p}$. B.

1740 Opolalsamum trumphats. (Venetiis, apud Petrum T()masinum. 1640.$) 4.51$ p. B.

175 - 1) Smilace aspera sententia botano-physica. An Smilax aspera europaca sit eadem ac Salsaparilla americana, et an altera alterius vice in lue venerea curanda usurpari possit? Mlessanae, apul hereles Petri Breae. 1632. 4. Sloane.

17 '2 Castellus, Edmundus. Oratio in scholis theoloricis halbita cum in Academia Cantahrigiensi praelectiones suas in secumbum Cannis. Aricennae librum auspicaretur, quilus via pracstruitur ex scriptoribus orientalibus at clarius enarrandam botanologicam S. Scripturae partem. Loudini, Thomas Roycroft. 1667. 4. Slnane.

1713 * Castiglioni, .ljcardo. Honografia dellor zatterano. Milanu 1829 $8.40 \mathrm{p}$.

$1744 \div$ Castiglioni, Luigi. Viaggio negli stati uniti dell Aucrica settentrionale, fatto negli anni 1785-1787; con alcune osservazioni sui regetabili più utili di quel praese. Milano 1790. IJ voll. 8. - I: MIr, 403 p., tab. 1-S. - II: vi, 402 1., tab. $9-14$. el 3 schemata.

(Vol.11. 1. 169-402: 0.servazioni sui vegetabili piu utili degli stati uniti.)

1740 - Sterid delle piante forestiere. Milano 1794. DC.

1746 - Castle, Thomas. An introtuction to systematical and plysiological botany. filtustrated with explanator'y engravings. London 1829.12 xvir, 285 p., intl., 8 tal, tool. (12s. 6rl. - plain 10s.)

1747 A synopsis of systematic botany. Lonton 1833.8

1718 _. A introduction to the neclical botany, illustrated will coloured figures. Third editim. London $1837.8 .(6.5$.

1749 The Limnean artificial system of botany. Lonton 1837 4. (5s.)

1730 Catelan, Leurent. Discours sur la Mandragore. Paris 1639. 12.

$1731^{*}$ Catesby, Hark. The natural history of Carolina, Florida and $11 \mathrm{~m}$. Bahama Islauds: containing the figures of birds, bedsts, fishes, serpents, insects and plants; particularly the forest-trees, shrubs and uther plants, not hitherto described, or very incerrectly figured by authors. Together with their descriptions in english and frencls. London $173 \mathrm{i}-1743$. If voll. folio, $-\mathrm{J}: 173 \mathrm{1}$. xLIV, xis, $100 \mathrm{p}, 100$ lab. col. - Il: 1743. 9, 100 p., 100 tab. col. (Accedil: An Licount of Carolina and the Bahma-lslands: 20 p., 20 tab. col. - tresis d by Edwards. London 1754. Jl voll. Lolio. - Ed. Jll. London 177ł. I] vell. folio.

(spreng. Gesch. der Bot. II. 203-20k)

germanice: von $G, C$, Ihuh. Nurnberg i7a., folio.

$1752^{*}$ llortus britanne-americamus, or a curious collection of Irees and shrubs, the produce of the british colonies in Forth America; adapted to the soil and climate of Englaid, with olscrvations on their constitution, growh and cultuse. ste. London, printed by WT. Richartson and S. Clarh for John Ryall. 1763, loblio. vi, 41 p. 17 tal), col.

$1733^{*}$ - Jorlus Europae americaus: or a collection of 85 curious trees and shruls, the probluce of North-dmerica; alapted to the climales aud soils of Greit-Britain, Ireland ant most parts of Europe ele, together with their blossoms, fruits and seeds; observations on their culture, growth, constitution and virtues; with directions liow to collect, pack up, and secure them in their passage. Adorn'il with 63 figures on 17 copper-plates, large imperial guato. 
Louden, printed for J. Nillan. 1767. folio. v, 41p., 17 ab. col. (1l. 11 s. $6 \mathrm{~d} l$.)

(lien liber ac pracedens; praeter titulum minime differt.)

170 '. Catinelli, harl. Kritische Bemerkumgan üler Dr. F. X. Hlubehs Beleuchtung der organisclien Chemie des Dr. Juslus Liebig. Wien is $43.8 . \mathrm{W}, 42 \mathrm{H} .(1 / 3, \mathrm{~h}$.

170̈3* Cato, Marcus I'orcius. De re rustica. (Cum scriptoribus rei rusticac, Eil. princeps. Venctiis, Vicol Jenson. 1472. folio. a foll. $21^{i}-42^{i}$ - Venetiis, Ndus. 1514. 8. - TVenetiis, Aldus. 1523.

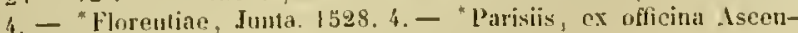
siana. 1529. folio. - Parisiis, apud Joh. Parvum. 1533. folio. "Hasileae, Herwag. 1535. 4. - "lugluni, apud fryphium. 1541.8. - "Parisiis, Rob. Stephanus. 1543. 8. - "Lugduni, apud Gryphium. 1549. \& - "Lugduni, Jlantinus. 1598. 8. - curavit J. H. Gesner. lipsias 1733. 4. - "Biponti 1787. 8. - Ex optimorum seripterum at!u" editorum fide of virorum doetorum eorjecturis correxit atupe interpretum omniun collectis el excerpitis commentaris sujs(que illustravit Johann Gottlob Schneider. Lipsine 1794. 8.

$1756 \div$ (Cattaneo, Antonio.) Catalogo delle piante piu interessanti del giardino Catsaneo, per l'anno is 12 . Noyara 1812.8 . 29 p.

$1757-$ Hortus Cattancus. Nusara 1807

$1738 \div$ (Cattaneo, Giacomo.) Della idropisia de' gelsi. (Nilano 1767.) 8. 145 p.

$1739 *$ Caus, Salomon de. Hortus palatinus a liriderico rege Bocmian electore Palatino, Heidelberyae exstructus. Francofurti, apud Joh Theod. de Bry. 1620. folio. 28 (30?) tab. aen. el 6 p. Préface au roi tet aus lecteurs. Bibl. Caes. Vindob.

Testum splendidi atque rarissimi operis, quod decora archicetonico hurti prilatisi lleidelbergenas post proelium ad monten

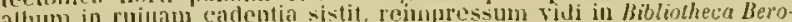
linensi:" Minulheim 179\%. $8.16 \mathrm{p}$.

$1760 \div$ Cause, II. II. De koninglyehe llovenim anwyende de middelen om bonmen, bloemen en hruyden, te zaayen, planten, aen queeken en voort teeten, met honstige hoperen platen verciert. Amsterdam ly Harcus Donmich. $(1676)$. folio. 224 )., ind., (al).

$1761^{*}$ Cavallini, Filippo. Brevis enumeratio plantarum praesenti anno á publico sapientiae romanae medicinaliun simpliciom Professore ostensarum et quae in hortum lyedualen redilactae asservantur. of Ronac, Wp. Nolo. \{689. 12. 144 \}. Bibl. Goett.

(1 11. ilis-129 incipit: Pugillus meliteus seu omnium herbarum in

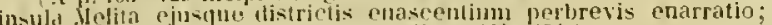
cf. Briclimum, lepist. itin. 62. Cent. II. p. 6it-691.)

$1762^{*}$ Cavanilles, Antonio Jose. Alonadelphiae classis Dissertationes decem. Mlatriti, ex typographia regia. 1790.4 . x, 463 p., 296 tal). In tituli-siltgularmm leguntur amui 178;-1790; Parisis, quantum seio typis J)idotii impressite sunt.

$1763^{*}$ Observationes in quintum fasciculum de LMeritier s. 1. et a. 4. 18 p.

gallice evtrait du Joumal de physiyue du mois de Jars 1789. 4. $10 \mathrm{p}$.

- Carla de D. Antonia Carmilles en respuesta a lia que se insprto ell la segunda parte del memorial literario del mes dr Septimbre de 1788, donte se hace critica de sus disertaciones hotinicas por uno que se titula recino de Lima. (Madrid 1789.) 12. $15 \mathrm{p}$. Bibl. Juss.

$1760^{*}$ - lcones et descriptiones plantarum, quae aut sponte in Lispania eresennt, aut in hortis hospitantur. Matriti 1791-1801. VJ roll. folio. - 1: 1791.67 j., tab. 1-100.- $11: 1793.79$ p., tals. $101-200 .-111: 1794, x, 52$ 1., tab. $201-300 .-11: 1797.8211$ tab. $301-400 .-V: 4799.11,74$ p. tab. $401-500 .-11: 1801$ 97 l. tab. $501-600$. (720 fr. A. Barcelona.)

$1766^{*}$ Observaciones sobre la historia natural, geografia agrieultura, poblacion y frutos del reyno de Valencia.'Madrid 1795 -1797 . Il voll. folio, $-1: 1795 . x 4, \geq 36$ 1), 29 tab. $-11: 1797$ 338 p., 25 tab. (so fr. A. Barcelona.)

$1767^{*}$ Coleceion de papeles solbre controversias botanicas. Con algunas notas del mismo a los escritos de sus antagonistis. Marlsid $1796.8 .274 \mathrm{p}$

In omnibu exemplaribus, quac comparavi, numerus paginarum (In ommibus edes.
ultra 274 non excedit.)

$1768^{*}$ - Suplemento a las observaciones sobre el eultivo del assoz en el reyno de Valencia, $y$ su infuericia en la salud publica en respuesta a la contestacion de $D$. Vicente Ignacio Franco. Modrid 1798. S, 38 \}. Bibl. Goett. $1769^{\circ}$ Cavanilles, Antonin José. Deseripcion de las plantas. que demostro en las lecciones publicas del año 1801 (y is0z precedlidá de los uriuripios rementales de la botanica. Madrid 1802. 8. cxrrvi. $625 \mathrm{p}$.

Stunt esemplarial. guie anmum 1827 in titulo gerunt: "Iatud dille-

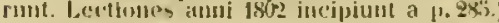

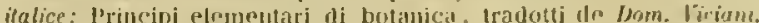
Genova iso3. \%. - Ed. 11: it). 1sus. 8

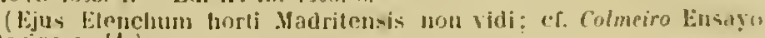
historico [3. \$1.

1770" Cavolini, Filippo (latime Caulinus). Znsterae oceanicae Linnei anthesis. Seapuli 1792, 4. 20 1)., ( tal).

$1771^{*}$ Pluneogrostidun Theophrasti anthesis. Xeapoli 1792. 4. 35 p., 2 tab.

$1772 \div$ Caylus, de. Ilistoire du rapprochement des vigélaux. l'aris 1806. 8.128 p., ind. Autor a sequenti disersis.

1773t Caylus, Anue Clande Philippe de Thubieres de Grimoard de lestels de Levy, Comte de. Dissertation sur le Papyros. Paris I 175 s. 4. 56 p., 4 tab

Lincubratiunculi (uh) aumpictis Berrardi de Jussien scripta r.u

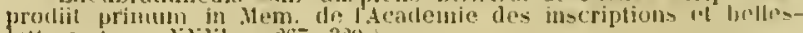
lettres, tome X.Xil. p $26-320$.

17\%. Cederhjelm, Baron Carl ll ihelm. Tal ou wilda trins planteriug i sverige. Lipsala 1740.8. (19 foll.) B.

$177^{*}$ Cels, Francois. Catalugue des arbres, arbustes et autres plautes de serre chaude, l'orangerie et de pleine terre, cultivcis dans l'ctablissement te F. Cels. Paris 1817.8.38, 4 p. - - Paris 1832 . 8. 11.

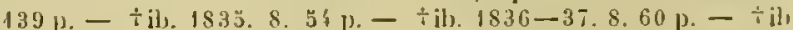
1839. 8. 50 p. - tils. $1840-41.8 .42 \mathrm{p} .-\div$ Paris $1842.8 .30 \mathrm{p}$.

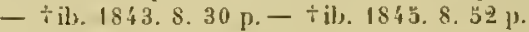

1776 Celsius, Hagnus Vicolaus. De plantis. Ljealiae 1647.4. s.

17 - Celsius, Olof. Botanici sacri exercitutio prima, qua p-- ex trabum seriptis illustratur. D. Lpsaliac 1702 . \&. 22y \}r. cum figura ligno incisa. B.

1778 Excreitationis de Palma caput primum. D. Linsaliae 1711. 8. 30 \%. B.

$1779-$ De arbore scientide honi et mali. D. Lipsaliae 1715. \&. 22 1). B

1 780 Nun.XI. 5. quinam et quales fuerint? D. Lugduni Batavorm $17 \geq 6.8$ 28 p. B.

(Redcunt omnes cum alijs ejusmodi argumenti ex tctis lit. Suec. in opere serpuenti.

$1781^{*}$ Hierobotanieon sive de jlantis sacrae scripturne Dissertationes loreves. Upsaliac, sumtu auctoris. $1745-1747$. Il roll. 8. 1: 1745.572 p. praef. $-11.1747 .600 \mathrm{p}$

llujus lilni inon nisi 200 expmplaria impressa sunt. quorum nonmulla novis titulis, additis rerhis: "Amstelodami, almd J. Wrotslen. 178." instructa sunt. - "Quoniom ill hoe opus contulerat antor sul per vilam omnem studia, crat conseryuens, ut immensac jule lectiobis veroeque laus pulyhistoriats orimtur. Pluseula corum. quae utrique ilsunt volumisi, partin forma disputationum aeadrmirarum, partim in Actis soc. L" psal. jam ante edjderat, quac denique conjuncta ceteris supplevit of expoliti. Quandoifuidom suo sumtu edere concus fuit autor, haud ateo multo "enmplaria prodiere ac rarescere

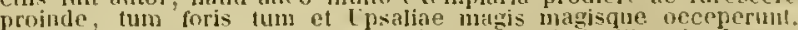
prove, the juotcirea Grettimgac in

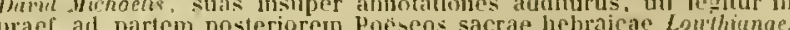
pract ad partem posteriorem poesesos sacras hehracae Lomphunae.

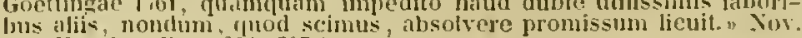

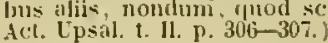

1782 Celsus, Aurelius Cornelius. De re medica libri 1711. Editio princeps. Florentiae a Nicalao impressus. 1478. foliv. Hain Nir. 4833 -4838 .

Vuperiores recensentur editiones a Seguiero p. 236-235. I

1783 Cervantes, licente de. l)iseurso pronunciado en el real jardin botanico (do Mexico. De resina dastica generatim, et de arbore Novae Ilispaniae resinam loujusmodi producente, speciatim.) Suplemento a la Gazeto de literatura. Hexico 2 de Julio 1794. 4. 35 p. 1 tab.

178:* Cesati, Tincenzo, Barone. Sugli sudii fito-fisiologici degli ltaliani e piu particorlamente sulla suida allo studio della fisiologia vegetabile o della botanica del Prof. Guiseppe IIorelti, Cenni critici. Jilano 1836. S. $42 \mathrm{p}$. 
$1780^{*}$ Cesati, Tincenzo, Barone. Saggie su la geografia botanica e su la flora della Lombardia. Milano 1844. 8. 74 p., 1 tab. botanico-geograplica.

$1786^{\circ}$ - Stirpes italiacae rariores vel novae, descriptionilus iconibusque illustratae. Accedunt animadversinnes in characteres plantarum pariter talulis adumbratae. (lconographia stirpium italicarum universa.। Mediolani, typ. Pirola, sumtibus autoris. fasc. 1-III. 1840. folio elephant. 24 tab. et text. ( 30 th. $)$

(De hoc opere disseruit de Schlechtendal in Bot. Zeit. 1846. p. 872 -87i.)

$1787^{*}$ Chabrey, Dominique (latine Chabraeus). Stirpium icones et sciagraplia: eum seriptorun circa eas consensu et dissensu ac caeteris plerisque mnibus, quae de plantarum natura, natalibus, sy̆onymis, usu et virtutibus scitu necessaria sunt. Genevae, typ. G. et J. de la Pierre 1666 . folio. 661 p., ind., ic. i. t.

(In exemplari Canlolleano legitur titulus : Stirpium sciagraphia et icones ex Musateo Dominici Chabraei, meticinale Doctoris. Coloniac Allohrogum 1666. - Redit paulo mutato titulo sequenti anno et 1677.)

$1788 \div$ - Omnium stirpium sciagraphia et icones, quibus plantarum et radicum tum in hortis cultarum, tum in urbium fossis et muris, pratis, arvis, montilsus, collibus, nemoralibus, fluviis, riguis et littoralibus, villis et pagis sponte provenientium, nomina, figura, uatura, natales, synonyma, usus et virtutes docentur. Cum doctissinorum scriplerum circa eas eonsensu et dissensu cum quadruplici indice nominum. Coloniae Allebrogum, sumtibus Samuelis de Tonrnes. 1677 . folio. 661 p., ind., ic. i. t.

(Idem opus ac praecedens; vis differt praeter titulum ab edilione anui 1606 .

1789 Chamberlaine, llilliam. A practical treatise on the efficacy of Stizolnbium or Cowhage, internally administered, in discases occasioned by worms. Fil. Y : London 1792. 8. 76 p. B.

1790* Chambers, William. De Rilses Arabum et ligno Rhedio. D. Lugduni Batavorum 1724.4.41 p.

1791 Ueber die orientalische Gartenkunst. Aus dem Englisclien. Gotha 1775.8

(Liber anglicus nihi nondum intotuit.)

- gallice: Disserlation sur te jartinage de I'Orient par (Guillaume) de Chambers. Ouvrage traduit re langlais. Londres 17.2 . k. 830 p.

$1792 \div-$ Discours servant d'explication par Tan Chet-Qua de Quung-Cheou-Fou, gentillımne; comme aussi Minuf, Tra, Cghmw et Attq; cidevant Athrhtpow; dans lequel les príncipes établis daus la dissertation précédente se trouvent éclaircis et appliqqués à la pratique. Londres 1773. 4. 51 p.

1793\% Chambray, Marquis de. L'art de cultiver les pommiers, les poiriers, et de faire des cidres selon l'nsage de la Normandie. Paris 1765. 8. 66 p., praef.

$1794 \div-$ Traité de la culture du melon sur couche-seurde et en pleine terre. Paris 1835.8 .87 p., 5 tab.

$1595 \%$ Traité pratique des arbres rísineux conifères à grandes dimensions, que l'on peut cultiver en futaie dans les climats temperés. Paris 1845.8 max. xitr, 429 p. et Atlas in folio obliquo: 7 tab. col.

1796* Chamisso, Adelbert von. Reise un die Welt mit der Remanzoffschen Entdeckungsexpedition in den Jahren 4815-1818 auf der Brigg Rurik, Cpt. Otto von lotzelıe. (Tagelonch, Bemerkungen und Ansichten.) Leipzig 1\$36. 2 Bunde. \$. - 1:436 p., effigies Chamissonis. - II : $396 \mathrm{p}$. (2 th.)

$1797^{*}$ Uebersicht der nutzbarsten und schádlichsten Gewichse, welche wild oder angebaut in Norddeutschland vorkommen. Nelsst Ansichten von der Pflanzenkunde und dem Pflanzenreiche. Berlin 1827. 8. viII, 326 p. (2 th.)

$1798+$ Champier, Simphorien (latine Campegius). llortus Gallicus pro Gallis in Gallia scriptus verumtamen non minus Italis, Germanis et llispanis quam Gallis necessarius, in quo Gallos in Gallia omnium aegritudinum remedia reperire docet, nec medieaninibus egere peregrinis, quum deus et natura de necessariis unicuique regioni provident. Lugduni, in aedibus Mlelchioris et Gasparis Trechsel. 1533. 8.83 p. ( 8 foll.)

$1799+\ldots$ Canpus Elysius Galliac amoenitate refertus: in quo sunt medicinae compositae, herbac et plantae virentes: in quo quicquid apud Indes, Arabes et Poenos reperitur apud Gallos reperiri posse demenstratur. Lugduni ib. eut. anne. 8.435 p. (4 foll.)

(Ejusdem autoris "Periarchon" qui ad calcem additus est, rem nostram minime tangit of in philosophicis versatur.)
$1800^{*}$ Champy. Flore Aigerienue, avec texte descriptif des plautes, arbustes et arbres indigenes, dont un grand nombre est cultivé au jardin des plantes a Paris, ornée de 40 planches dessineses et lithegraphices par Th. Toulet de Paris. Paris 1844. gr. 8 . vil, 53 p., 40 tab. pess. col. (9 fr.)

Liber miserrimus! - "L'ouvrage que nous publions, liest pas un traité de hotanique." Verba editoris.)

1801* Chandler, Alfred, and Hilliam Beattie Booth. Jllustrations and descriptions of the plants, rilich compose the natural order $\mathrm{Ca}$ melliae, anel of the varieties of Camellia japonica, cultivated in the gardens of Great Britain. The drawings by Alfred Chandler; the descriptions by Ifilliam Beattie Booth. London 1831 . folio. xII, 48 p., 40 tab. col. (pulcherrimae!)

(Prodiit decem fascieulis; quisque pretio 7s. tals. nigr.- 10s. tab. col. - Iss, in chart. mel. - In ultimo Ingitur: End of vol. i.)

$1802^{*}$ Camellia britanuica introduced by Chandler and Backinghum of Vauxhall. London 1825. 4. 22 p., \& tab. col. Bibl. Imp. Ferd.

1803* Chaptal, Jean Antoine Claude, Comte de, et Rozier, Parmentier et Dussieux. Traité théoriqque et pratique sur la culture de la vigne avec l'art de faire le vin, vinaigres simples et conposés. Ed. Il: Paris 1804 . Il voll. 8. - 1: xvi, 408 P., 12 tab. - II : x, 584 p., 9 tab. - L'art de faire le vin. Ed. lll. augmentée. Paris 1839. 8. 2 tab. ( 6 fr.) a.

* ilatice: Yenezia 1801.8.

germanice: Wien 180\%. 8

latine: De vitis cultura. Viennae 1808. 8

* hangarice: 1813.8.

anglice: A treatise on the culture of the wino, and the art of making wine; compiled from the works of Chaptal and other french writers and from the notes of the compiters dhring a residence in some of the wine provinces of France. Australia 1S25. 8. W. falso.)

$1804+$ Chimie appliquéc à l'agriculture. Paris 1823 . 11 volli. 8. - I: VI, LVI, 298 p. - 1]: 484 p. - El. II, augmentée: Paris 1829. ll voll. 8 . (1 $15 \mathrm{fr}$.)

1805* Charas, Moyse. Pluarmacopoea regia galenica et chymica, gallice ab autore couscripta, jam vero latinitati donata. Genevae 1683.4. Il voll. 496,404 p., praef., ind.

$1806^{*} \longrightarrow$ Operum tonus tertius, continens listoriam naturalem animalium, plantarum et mineralium, Theriacae Andromachi compositionem ingredientium ete. Genevae 1684. 4. $275 \mathrm{p}$, 5 tab.

+ gallice: Theriaque d'Andromacus avec une description particulière des plantes, des animaux et des minéraus, employez a celte grande composition. Nouvelle édition revue et augmentee. Paris 1691.8 . $303^{\circ}$ 12 p., praef, iml.

$1807^{*}$ (Chastenet, Victorine de.) Calendrier de Flore ou Etudes de

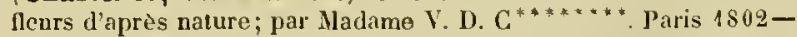
1803. III voll. 8. - I: xxxII, 397 p. - II: 535 p. - IlI: xv1, 522 p.

1808 Chatelain, Jean Jacques. Specimen inaugurale de Corallorhiza. Basileae 1760.4.15 p. B.

1809 t Chatin, Adolphe. Quelques considérations sur les théories de l'accroissement par conches concentriques, des arbres munis d'unc véritable écorce (arbres dicotylés). Thèsc. Paris 1\$40. 8. $32 \mathrm{p}$

$1810^{+}$Anatomie comparéc végétale appliquée à la classification. Traduction de l'nrganisation intérieure ou des parties cachées des végétaux, par celles placées à leur surface. Thúse. Paris 1840. 4. $35 \mathrm{p}$.

$1811^{*}$ Chaumeton, François $P$., Chamberet el Poiret. Flor'e médicale, peinte par Madame E. Panckoucke et par P. J. T. Turpin. Paris 1514-1820. VIII voll. 8. - I: 1S14. xvI, 209 p., tab. col. 1-58. - II: 1815. 236 p., tab. col. $59-116 .-$ III: 1816. 263 p., tab. col. $117-172,-$ IV : 1817.266 p., tab. col. 173-231 bis. $-\mathrm{V}$ : 1818. 280 p., tab. col. $233-291 .-\mathrm{VI}: 1818.271$ p., tab. col. 292 -349. - VII: 1819-20.: Partie élémentaire par Poiret, iconographie par Turpin. vil, 278,174 p., 56 tals. col. - VIll: 1820. Essai d'une iconographio élémentaire et philosuphiqque des végétaux par Turpin. 199, 32 j. et planches.

("Cot ouvrage assez mauvais s'est publié en 107 livraisens, de 4 planches chacune; pris de chaque livraison in 4.3 ir., papier vélit 12 fr. L'ouvrage conplet, edilion in $4 .: 21$ fr., edition sur papier vélin: $1284 \mathrm{fr}_{\text {. L }}$ Lition in folio et in $k$. conviennent dass la pagination; mais l'édition in 8. est difterente.., - Duo in membranla suit impressa exemplaria, quorum alterum vidi in Bibl.Imper. Francisci.Austriae, cui, dum anno is $\mathrm{f}$ Parisis commoraretur, jiretio $12,000 \mathrm{fr}$. ublatum est.)

$1812 \div$ Chauvin, J.F. Recherches sur l'organisation, la fructification et la classification de plusieurs genres d'algues, avec la description de 
yuelyues espeess inedites on pen conmurs. Essai diune répartition dew pulypicts ealeifires do Lamoumu dans la classe des algues. (Gilli 1812. 4. 132 p.

18136 (Chavannes, Edonard.) Introduction a la lore helvétipuo de Mr. Guturliu. Lansane 1\$30.8. 29 p.

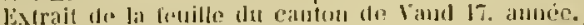

181\%" - Mrnographie des Antirrhineses. Paris 1833. \%. $x$

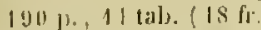

$1815^{*}$ Chemnitz, Johannes (latiun Chemnitius). Index plantarum circa Brunsvigan trun fere millinrum eirenitu nascantiun cun appendie' iconum. Brunsvigate. Zilliger. 1652.4. 35 p., 7 tals.

1816 Chesnecophorus, Johannes, pr. Disputatio plysica de plantis. 1). Upsaliae, typ. Matthiae. $1621.4 .(4,16$ 1).

Dinsertatio hatece primum ast opusculnu botanieum in Suecia milituin. W.

- Inisputatio physica decima nona de plantis. D. Upsaliac, t1 J. Natthiac. $1626,4 .(24 \%$ \%) w.

(llarum dissertationum, quac in Suecia perrarae sun, possidebal Itrllerte 19, Lpaliate 1620 -1626 editas.)

$1818+$ Chevalier, Charles Lomis. Nolos luetifieatives pout servir a Thistoiro des microscopes, adressées a Mss. Ins membres de l'Acadénio rosale des sciences en France. I'aris 1835.4 .281 ,

I\$19 Des microseojes el de lenr usage. Paris 1839. 8 . 5 tab. (9 fi.)

$18200^{\circ}$ Chevalier, J. Damien. Lettres a $H$. de Jan sur les maladies et sur les plantis de Si. Domingue. Paris 1752. 12. $224 \mathrm{p}$

1821* Chevallier, A., et Ichille Richard. Dictionnaire des drogues simplos et composées, uu Dictionnaire d histoire naturelle medicale, de pharmacologie et de chimie pharmaceutique. Paris 1827-1829. v voll. 8. - l: 1827. x11, $622 \mathrm{p}-11$ : $1827.650 \mathrm{p}-111: 1828 . \mathrm{v}$, 642 p. - W: 1829.598 p. $-V: 1899.378$ p., 16 เal. (Locos butanicm, elalmarunt Achille Richarl et Guillemin.)

$1822 \div$ Chevallier, Fancois-Fulyis. Dissertation sur les cignës indirenes, considerers comme poisons at comme mudicamens. These. Paris 1821.4 .36 ]

1823* - Ilistoire des Graphidées, accompagoé d'un tableau analytique des genres. Ourrage renfermant des observations anatomitues et physiologiques stur ces végcilaux. Paris 1824. 4. Xv, S6.p., 21 tah. col. $(36 \mathrm{fr} .-102 / 3 \mathrm{th}$.

(Fertur etiam titulo: Ilistoise générale des Hypoxylons. - aGraphitearum tlistorian Paris 1837. est nova inscriptio ejusdem operis.)

$1831 \%$ - Flore génerale des environs de Paris, selon la méllocte naturelle, description de toutes les plantes agames, cryptuuames et phanérogames qui y croissent spontanément, leurs pruprictés leur usage daus la médecine, les arts et l'économie domestirue: arec une classification naturelle drs agames et des eryploganes, basé sur l'organisation de ces régétaux. Paris 18261827. II voll. S. - I: 1\$26. xxuv, 676 p., tal, 1-14. - II: 1827. $9 \$ 3$ p. tal, $15-18$. ( $24 \mathrm{fr}$. - col, $32 \mathrm{fr}$.)

til ll. colrigée et augenentée: Paris, Ferra. 1836. III voll. 8. (18 fi.) Parisis nullibi milit olvia fuit.)

$189: 3^{*}$ _- Fungorum et Byssorum illustrationes, (quos ut pluri mum novos frecentos et ultra cum caeteris minus bene cognitis in diversis Europae regionilus collegit, al vivum delineavit, sculpsit et colorihus uaturalilous decoravit. Parisiis 18.37. fulio min. - Fasc. 1 (1837.) 52 tal. col. practer iconem Epigogii Gmelini in frontc operis et toticlem foll. text. $\left(30 \mathrm{fr} .-9 \frac{2}{3} t h\right.$. $)$ - Fasc. Il: 31 tab. col. Bibl. Musei Paris et Vindob.

(Opus morte autoris $[\div 2$ bec. $18 \%]$ interruptum.)

$1826 \div$ Chevandier, Engene. Recherches sur l'influence de l'eau sur la vegétation des forets. St. Germain 1844 . 8.32 p.

$1827 \div$ Recherches sur la composition clementaire des différents bois et sur le rendement aunuel d'un hectare de foréts. Paris $1846.8 .34 \mathrm{p}$.

1828 * Chiarelli, Francesco Paolo. Diseorso (dle' vantaggi dello studio della storia naturale di Sicilia). Palcrmo $1789.4 .10 \$ \mathrm{p}$.

1829 Chicoyneau, Franģois. Discours sur les plantes sensitives. Montpellier 1732.4. $\mathrm{s}$

$1830+$ Chiflet, Jean Jacques. Pulvis folsrihgus or\}is americani. s. I. 1633. 8. $45 \mathrm{p}$
1831 racolta di ujuscoli retat, alla storia naturale del riso. Ilantovia 1782 s. DC.

1832 Chiocchius, Indreas. I), l,alsani natura et viribus jusa Dioscuridis placita carmen. Veronac, Hieronymus Discipulus. 1396.4. Bibł. Maz.

$18333^{\circ}$ Chirat, Lulocic. Etude des fleurs, botanigue dementaire deacriptive el usuelle simplifice pour la jeunesse el les fandlas. I.yon 18 :1. II voll. 12. - 1: $740,11 \mathrm{p.}, 10$ (4h). $-11: 800 \mathrm{p.}(15 \mathrm{fl}$.

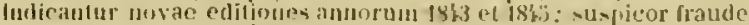
Jibliojolarum rrouvatos litulos.

183\%" Choisy, Jacques Denys. Protronus al une moncographic le da fa-

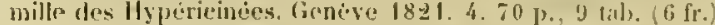

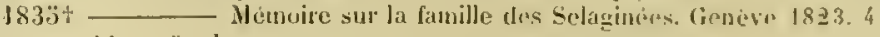
44 ]., 5 tals.

$4836^{*}$ Deseription des Hydroleacies. (Geneve 1833.) 4. 28 p. 3 tal.

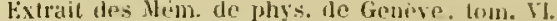

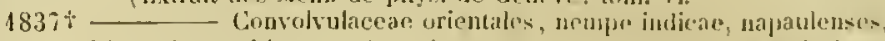
birmanicae, chinenses, japonicae nec non it fuarlam australasicac. ete. (Genevae 1834.) 4. 120,7 1, 6 talb. - t]) Conrolvulaceis 1)issertatio secunda. (Convolvulacrae rariores.) (Genevae 1838.) 4.

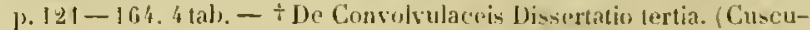
larum enuneratio.) (Genevar 1841.) 4. p. 163-192. 5 tals.

$1838 \div-$ Nute sur les Convoliulacess du brisil et sur le Marcollia, geure moureau de cette famille, Geneve 1844.4.8 p., I tab. (Narcellia villowa Choiky.)

183:) $\div$ Chomel, Pierre Jean Baptiste. Reponse à deux letres ecrites par Mr. P. C(ollel) sur la botanique. (Paris 1697.) gr. 8.48 p.

$1810^{*} \longrightarrow$ Catahgus plantarum ofliciualium sccundum earun faculıates disjusitus. Parisiis 1730.8. 116 \%.

$18: 1^{+}$- Alrégé de lhistoire des plantes usulles. ete. Paris 1712. S. 640 p. - "Nuurelle édilim augmente. Paris 1715 . Il voll. 8. xLvut, 830 p., ind. - Ed. IS. il. 1730.111 voll. 8.830 , 214 p. 'Ed. V. jh. 1738 . IIl woll. 8. xLrur, 830.214 .116 p. - "Edl. VI. ib. 1761. Ill voll. 8. - $\div$ Nouvelle édition. Paris 1782. 8. - $\div \mathrm{Ed}$. Vll alugnentce par J. B. N. Maillard. Beauvais et laris 1803 . Il woll. \&. - I: 504 p. - II: 518 p. (12 [r.) - Ecl. VIll. 1. Dubusson.)

18.2* Choulant, Ludweig. Ilandbuch der Bucherhunde fur die altere

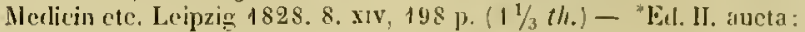
ib. $1841,8, x \times 1,434$ p. $\left(2 \frac{2}{3}\right.$ th. $)$

$1813 *$ Uie Vorwelt der organischen Wesen auf der Erde. Dresclen $1830.8 .90 \mathrm{p} .(3 / \mathrm{s} / \mathrm{h}$.

184. ${ }^{*}$ - Bibliotheca medicu-historica sive Catalogus librorum listoricontum de re medica et scientia naturali systenaticus. Lipsian $1842.8, x, 269 \mathrm{p}) \cdot\left(1 \frac{1 / 2}{\mathrm{th}}.\right)$

$181: 6 \div$ Choulette, $S$. Symopsis de la Flore de Lormaine el didsace ou description succincte et tableau anolytiejue des plantes phanerogames qui eroissent sponlaniment ou qui sont le pius geineralement cultives dans l'est de la France. Preniere partie: Tableau analyticue des grenres et des especes. Strasbuurg et Paris 1845. 12 284 p. $(2$ fr. 50 c. $)$

184.6 Christ, Joham Luthriy. Pomolugisch-lheoretisches practische-

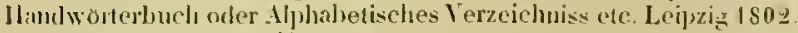
4. 1 , 431 D., 5 Lab. $\left(2 \frac{1}{2}\right.$ th. $)$

$1847^{*}$ Die lirankheiten, L'ebel und lieinto ter obstbanme und ihre Abhulfe. Nebst Vorschlagen, die Obsthultur zu befordern. Frankfurt a/ $/ \mathrm{II}$. Is08. S. vili, 310 p. (1 th. )

182.8 - Yollstandige Pomologie, oxler systematisches Verzeichniss aller kembaren Obstaorten. Franhfurt a/M. 1809-1813. 2 Bande. 8. $(7 / \mathrm{h} / \mathrm{h}$ ) (Die zu beiden Banden gehorigen 51 tab. 3 th. $-\mathrm{cos}$. $15 \frac{1}{3}$ th.

$18: 9$ — Handlsuch der Obstbaumzuch und Obslehre. Vierte nach de's Verf. Totle herausgegebene selar vermeinte Autlage. Fraukfurt a/ 11.1817 . S. $\left(2 \frac{2}{3}\right.$ th. $)$

1850 - Allgemeines praktisches Gartenbuch. Dritle vermelirte Aullage von Edurd Schmidlin. Ileilbronn 1842.3 Theile. 8. (1 $1 / 2$ th.)

1851t Christisou, liobert. On the poisonous properties of hemloch. (Coniun maculatum), and its alcaloved conia. Eilinburgh 1836 . 4 $35 \mathrm{p}$

From llue Transactions of the royal society of lidinburgh, vol. Xill.; 
1832 Ciancio, Antonio Pis. de. Catalogo delle piante del giardino suo a Cattanea. 1816. 8. DC.

1853t Ciassus, Johannes Maria. Meditationes de natura plantinun et tractatus physicomathenuticus de aequilibrio praesertim fiuidorum ac de levitate ignis. Venctiis, apurl Benedictum Milachum. 1677. 12. 108 p., praef. (Meditationes de natura plantarum p. 1-43.) Bibl. Reg. Par.

183\% Ciccarellus, Alphonsus. Opusculum de Tuheribus, cum opusculo de Clitumno flumine, Patavii, Lud. Bosettus. 1564. 12. Bibl. Maz. f gallice: Opuscule sur les trittes, traduction libre dul littin d'Atphonse Ciccarellus, auteur du Xrie siecle; avec des annolations sur fo texte et un préambule historiquo par $P$. $l$. Amoreux. Montpeltier le toxte et
1813. $\mathrm{s} .180 \mathrm{p}$

183: Cirillo, Domenico (latine Cyrillus). Ad botanicas instituliones intraductio. Neapoli 1766.4 . 28 p., 2 tals. - Edl. J1: Neapoli 1771. 4. $32 \mathrm{p}, 2 \mathrm{tab}$.

$18366^{*}$ De essentialibus nonnullarum plantarum characteribus commentarius. Neapoli 1784.8 .75 p., 4 tab.

$1857^{*}$ Fundamenta botanica sive philosophiac botanicae cxplicatio. Ed. III. auctior. Neapoli 4785-1787. Il voll. 8. - 1: 1785. 516 p. $-11: 1787.506$ p., ind., 2 tab.

$1858^{*}$ Plantarum rariorum regni Neaprolitani fasc. I ot ll. Neapoli $1788-1792$. folio. $-1: 1788.39$ p., 12 tals. col. $-11: 1792$. 35 1., 12 tal. col

Multae insunt plantao hortenses. Textus fasciculi ll. redit: Usteri, Annalen, 13. stuck, p. 4 - -63 .

$1839^{*}$ - Discorsi accademici. s. I. $1789.8 .335 \mathrm{p}$.

(Practer commentationem: "Del moto e della irritabilita de' segetabili " nihit rem nostram tangit.

$1860^{*}$ Tabulac botanicae elementares quatuor priores sive Icones partium guac in fundamentis botanicis describuntur. Neapoli 1790. folio min. 18 p., 4 tab.

$1861^{*}$ Cyperus Papyrus. Parma, in aedibus Palatinis typ. Rodonianis. 1796 . Colio max. 20 p., 2 tab. col. Bibl. Imp. Ferd. et Deless.

1862* Civinini, Giovanni Domenico. Della storia e natura del caffe discorso accalemica. Firenze 1731, 4. 46 p., 1 tal.

1863 Della storia degli agrumi lezione accadenica. Firenze 1734. $4.30 \mathrm{p}$. B.

186'. Claf, Cyriacus Lucas de. De ligni Cotonei natura, viribus et facultatibus libellus. Ingolstadii, apud Sartorium. 1550, 4. s.

$13635+$ Clarici, Paolo Bariolomeo. Istoria e coltura delle piante che sono pe'l fiore piu ragguardevoli e piu distinte per nrnare un giardino in tutto il tempo dell' anno; con un trattatu dechli agrumi. Yenezia 1726. 4. 761 p., praef., 2 tab. (icnographia horti Gerardi Sagredo.)

I sibit Clarion, J. Observations sur l'analyse des végétaux, suivies d'un travail chinique sur les rhubarbes exotique et indigeme. D. Paris 1808.8. 48 [3.

$1867^{*}$ Clarke, Elward Daniel. Travels in various comtries of Europe Asia and Africa. Lomlon 1813-1823. V'] voll. 4.- Part 1: Russia Tartary ant Turkey. Ell. III: $1813 . x \mathrm{xu}, 800$ p., 48 tab. - Part II, sect. 1-3: (Appendix V': Plants in the Crimen, p. 729-736.) Greece Egypt and the Holy Land. $4813-1816.720,822,735$ p., 39 tah. (Appendix 11: List of all the plants collected during these travels in Greece, Egypt, and the Iloly Land, alphabeticaliy arranged ]. 716724.) - l'art 111, sect. 1-2: Scamlinavia, 1819-1823,763,555 p., 46 tab. (S1. 8s. A. Londons.)

$1868^{*}-$ The Life and remains of the late Sir Edward Daniel Clarke. London 1824. 4. x, 670 p., effigies Clarkii.

1869 Claus, Karl. Grundzuge der analytischen Phytochemie. Erster Theil. Dorpat i837. 8. vi, 186 p.

1870 Clavena, Nicolaus. Historia Absynthii umbelliferi. Venetiis $\mathbf{1 6 1 0 .}$ 4. (8 foll.) I tab. в.

1871 Historia Scorzonerac italicae. Impr. cum ejus Ilistoria Absynthii umbelliferi. Venetiis 1610.4 . ( 8 foll.) B.

(Alias editiones budat Sequierus: Cenatao, apud Marcum Glaserium. 1609. 4. et lenotis, apud Antonium Turinum. 1611. 4.

$1872 \div$ Clavenna, Jacob Antonius. Clavis Clavennac apericus naturae thesaurum, ejuseque gemmas depromens, vires seilicet plantarum in generali earundem historin ex Dalechampio potissimum sumta, a Gulielmo Rovillio Lugrluni semel edita, sparsin descriptas, nunc collectas et omnibus ac singulis morhis ordine alphabetico altributas. Tarvisii, typ. Righettini. 1648 . folio. 1062 p., praef., ind., effigies autoris. Bibl. Juss.

Pratzel, Thes lit. Jot
1873 Clemens, Cynthius. Disputationes medica de natura et facultatibus Ligni sancti. Romae, Dominicus Liliottus. 1601. 4. s.

$187 \%$ Clerc, Louis. Manuel classique el élémentaire de botanique, d'anatomie et de plyysiologio végétale, contenant l'Jistaire naturelle de toutes les parties les plantes, leur fonction, l'exposition des diverses móthodes emplayées pour l'etude; enfin un article biographique des lotanistes francais et étrangers, avec l'indication des ouriages, qu'ils ont composés. Ouvrage orné le 8 jolies lithographlies rejrésentant 160 figures ot précédé d'une petite Flore lrançaise. Paris 1855. 4. 131 P., 8 tab. col.

1870 Clewberg, Chrislophorus, pr. Do רתמ arbore sub qua Elias prolugus recubuisse legitur 1 Reg. XIX. 4. 5. D. Lpsaliac 1758.4 19 p. B.

1876 De variis frumentorum et leguminum speciehus in Sac. Cod. Vet. Test. memoratis. D. Upsaliae 1760. 4. 42 p., 1 tab. B.

1877 Cleyer, Andreas. Herbarium parvum sinicis vocabulis indicis insertis constans. Francofurti 1680.4 . S.

$1878+$ Cloquet, J. Hippolyte. Dissortation sur les adeurs, sur lo sens et les organes de l'olfaction. Paris $1815.4 .175 \mathrm{p}$

1879 Cluyt, Outger (latine Augerius Clutius). Memorie der rreemder blom-bollen, wortelen, kruyden, planten, struycken, zaden ende vruchten, hoe men die sal wel gheconditioncent hewaren ende over seynden. Ansterlam 1631. 8. ( 4 foll.) B.

$1880^{*}$ __ Historia cocci do Maldiva Lusitanis, seu nucis medicae Maldivensium. Amsterodami 1634. 4. 60 p., 1 tab. praeter opusenlum de Ilemerobio.

188. * Coakley-Lettsom, Jolin. The natural history of the Tea-Tree, with observations on the mealical qualities of Tea and effects of Tea-drinking. London 1772. 4. vin, 64 p., 1 tab. - tEal. nova: it. 1799. 4. Ix, 102 p., 1 tab. nigr., 4 tah. col.

t gallice: Histoire naturelle du the arec des observations sur les qualites médicales et les effels, qui resultent do son usuge. Paris 1773. 12. 170 P., I tab.

1882 - Lo voyagcur maturaliste an instructions sur les moyens de ramasser les objets d'histoire naturelle et de les bien conserver. Amsterdaun et Paris 1775. 8. xxı, $210 \mathrm{p}$.

$1883+$ ( - ) Jortus Uptonensis or a catalogue of stove and greonhouse plants in Dr. Fothergill's garden at Upton at the time of his decease. (1781.) 8. 44 p., 1 tab), and calalogue of auction: $50 \mathrm{p}$.

188: Cobbett, Ililliam. A treatiso on Cobbett's corn (Zea Mays), containing instructions for the propagating and cultivating the plant rte. London 4898 . 8. (208 p.) 2 tab. (5s. $6 d$.)

1883* Cobres, Joseph Paul (von). Deliciac Cobresianac. Büchersammlung zur Naturgeschichte. (Augsburg 1782.) 2 Theile. 8. xxvit, 95611.

"Piblingraphisch guverlassig: dic wissenschaftlichen trtheile oft werthlos. Dic Bibliotlueh ward 1827 durch den Augsburger Antirquar W. Birclt vereinzelt." E. M.

1886 Cocchi, Antonio Coelestino. Oratio in aperitione horti Jotanici supra Janiculum. Romae 1726. 4.

$1887+$ Dissertatio continens vindicias corticis Peruviani. lugduni Batavorum $1750,8,63 \mathrm{p}$

1885* Coclenius, Rudolf. Mlirabilium naturac Jiber, concordias ol repugnantias rerum in plantis et animalibus manifestans, nugc jurims in lucem datus, Francofurti $1625.8 .303 \mathrm{p}$., praef.

1889* Cocquius, Adrianus. Observationes et exercitationes philologicophysiologicate ad velus testamentum, in quilsus contextus sacer illustratur, iuprimis ubi agitur de rebus naturalibus etc. Tlissingac, 1yj). Laren. 1671. 4. 263 p., praef.

(Liher in jisu textu inserihitur: Phytologia sacra sen plantarum sacrae scripturar enodatio libri I et ll. - Editio Banhsiana: Wlissingat 166i. 4. practer titulum non differt.)

1890" Coeler, August Friedrich. De Usnea scu museo cranii lumani. D. Lugduni Batarorum 1732.4.31 p.

1891 Cogrossus, Carolus Franciscus. Della natura, effetti cd uso della corteccia del Peri ossia Chinachina cousiderazioni fisico-mccanichu e mediche. Crema 1711. 4. - il). 1718.4. s.

$1892^{\circ}$ Cointrel, Pierre. Oratio in laulem botanices, habita in magnit conceutus anla coram amplissimo senatu hujus urbis, lnsulis hac rigesima prina Januarii 1749 . (Lille) 1749.4.7 p. 
1893 Cointrel, Pierre. Discours sur la botanique, prononcé en public le 29 mai 1750 . Lille $(1750) .12 .24 \mathrm{p}$.

$189 \% \div$ Catalogue des plantes du jardin botanique de Lille. Lille $1751.8 .118 \mathrm{p}$.

$1895^{\circ}$ Colbatch, J. Dissertation sur le ruy, rnnede specifique pour la eure des maladies convulsives; traduit de l'anglais par (Freman). Paris 1729. 12. $72 \mathrm{p}$.

1896 Colbiörnsen, Christian. Programna de sexu plantarum. Ilavnia 1782. folio. DC.

1897 t Colden, Cadwallader. Selections from the seientific correspondence of Cadwallader Colden with Gronovits, Limnaeus, Collinson and other naturalists; arranged by Asa Gray. New llaven, typ. Ilamlers. $1843.8 .51 \mathrm{p}$

(From thr American Journal of science amul art:.)

(Ilujus lilia Jenny Colden, uxor medici seotici Farquhar, deseripserat IIypericun virginieum in Essays by a soc. in Edinb. vol. II

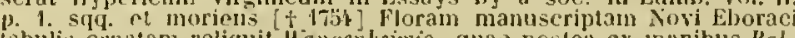
labulis ornatan reliquit liangenleimio. quae postea ex manibus Baldingeri in bibliorhecam Banksianam migravit. Schrad. Journ, 1800 . II 1). 46 .

1898 Coles, William. The art of simpling, an introduction to the knowledge and gathering of plants. London 1656.12 .123 p. praeter Discovery of the lesser world. $B$.

1899 Adam in Eden. or natures paradise; the history of plants, fruits, herhs and flowers. London 1657, folio. $629 \mathrm{p}$. B.

$1900 \div$ (Colius, Jacob.) Syntagma herbārum encomiasticum, carum utilitatem et dignitatem declarans; Abrahamo Ortelio quondam inseriptum. Lugduni Batavorum, apud Henricum de Haestens. 1606. 4. (26 foll.) - [.d. Il: (Antwerpiae) ex officina Plantiniana Raphelengii. 161\%. 4. 6 1 p. - Ed. 111: Lugduni Batayorum 1628.8.82 p. B.

1901 * Colla, Luigi. L'antologista botanico. Torino 1813-1814. VI voll. 8. - I: xxxu, 368 p., tab. 1-8. - II: vir, 411 p., tab. 9-13. III-V: 1267 p. - V1: III, 423 p., tab. $14-17$.

1902* 2 Observations sur le Limolornm purpureum de Mr. De Lomarck, et eréation d'un nouveau genre dans la famille des Orchidées. Paris 1824.8.14 p.

$1903^{*}$ Hortus Ripulensis seu enumeratio plantarum quac Ripulis coluntur. Augustae Taurinorum 1824 . 4. xu, 163 p., 40 tab. *Appendices inscripti: Illustrationes et icones rariorum stirpium, quae in ejus horto Ripulis florebant. - I : p. $111-138 ., 7$ tab. - II : (1825.) 4. p. $319-358 ., 9$ tab. - IHI : 54 p., 12 tab. - IV: (18271828.) 4. 60 p., 12 tab. nigr. et col.

190\%* Ménoire sur le Melanopsidium nigrum des jardiniers et formation d'un genre nouveau dans la famille des Rubiacées. Paris 1825. 8. 16 p., I tab.

$1903^{*}$ - Freyliniac genus addita jeone. (Taurini, s. a.) 4. 7 p., 1 tab. $1906+\frac{\text { Memoria sul genere Musa e monografia del medesimo. }}{4.74 \mathrm{p.}, 3 \text { tab. }}$

(Mem. di Torino t. X.IV.)

1907 - Storia e descrizione del Cactus senilis. Torino 1838. 4. $10 \mathrm{p}$.

1908 $\div$ Storia e descrizione del Cactus (Mammillaria) spiraeformis. Torino $1840,4,14 \mathrm{p}$.

$1909+$ - Memoria circa una nuova specie di Calonyetion ed osservazioni sul genere. Torino (1840.) 4. 13 p., 1 tal). (Calonyction maerantholeucum.)

$1910^{*}$ - Novi Scitaminearum generis de stirpe jam cugnita conmentatio. Taurini 1830 . 4. 12 p., 1 tab.

$1911^{*}$ E. Elogio storico dell' aceadenico Professore Giovanni Battista Balbis. (Torino 1832 .) 4. 30 p.

$1912^{*}$ Plantae rariores in regionibus Chilensibus a elarissimo Bertero nuper detcetae. Augustae Taurinorum 1832-1833. IV fase. $4,47,42,97,55$ p. 75 tab.

$1913^{*}$ - Herbarium Pedemontanum juxla mothodum naturalem dispositum additis nonnullis stirpibus exolicis ad universos ejusdem methodi ordines exhibendos. Augustae Taurinorum 1833-1837. IIIl voll. 8. - 1: Thalaniflorae. 1S33. Ix, 566 p. - II : Calyciflorae ad Uimbelliferas. 1834. 557 p. - III: Unbelliferae ad Campanulaceas. 1334. 587 p. - IV: Campranulacoae ad Clienopodeas. 1835.592 p. - V: Chenopodeae ad Gramineas. 1836. 571 p. - V'I: Granineac ad Fungos. 1836. 606 p. - VIl: Fungi et indices. 1837.672 נ). -
VIII : (in 4.) sistens indicen nominum vernaculorum, indicem iconum earumque explieationem, tum icoues. 1837.102 p., 97 tab. (modies? malae!) ( 85 lire $80 \mathrm{c.}$ )

1914 t Colla, Luigi. Olsservalions sur la familte rles Rutacées, sur le grenre Correa et formation du nourean genre Antommarchia. Turin 1843. 4. 31 p., 2 tab.

(Extrait des Mém. de l'Acal des seicnees tome v.)

$1915 \div-$ Camelliografia ossia tentatiyo di una nuova disposizione. naturale delle varieta della Camellia del Giappone e loro descrizione. Torino 1843. 8. Ix, 150 p., 2 tab. col. (4 lire.)

$1916^{*}$ Colladon, Louis Theodore Fréderic. Ilistoire naturelle et medicale des Casses et partieulierement de la Casse et de Sénés cmployés en médecine. Montpellier 1816.4.140 p., 20 tab.

1917 Colladon, Theodor. Adversaria seu Conmentarii medicinales critici, epanorthotiei, dialytiei, exegenatici ac didactiei. etc. Coloniac Illobrogum, typ. Jacobi Stocr. 1615. Il voll. 8. - 1:431 p., praef. - II: 414 p., ind. Bibl. publica Genev.

(Nostran reu fere unico tanguut tomi 11. p. $339-\$ 12$, contin errorum variorum de plantis medicis miscellanea.)

1918* Collaert, Adrian. Florilegium ab Hadriuno Collaert caelatum et a Philippo Galleo éditum. s. 1. et a, 4. 24 tah. acn. Bibı. Reg. Bruxell.

$1919 \div$ Collegno, $/$. de. Quelle est la distribution des rébris régétau dans les déprots, qui se forment de nos jours? D. Paris 1838. 4. 1 z p.

$1920 \div$ (Collet, Philibert.) Lettres sur la botanique (Paris 1697.) 12. 4i p. Bibl. Juss.

llarum epistolarunı editio originaria rarissima est; and Binnet Bourdelol missae sunt et reimpressae in 8 . majori : 27 p. cum responsione Chomelie.

$1921 \div$ Catalogue des plantes les plus considerables qu'on trouve autour de la ville de Dijon. Dijon, ehez Claude Micbard. (1702. 12. $116 \mathrm{p}$. Bibl. Juss.

192 2+ Collin, Nils. Förslag af några Nord-Americas Trad, som äro sảrdeles várde att i Srerige odlas. Stockbolm 1823.8. 32 p. (Ur Kongl. Vet. Ac. llaodi. fór âr 4822.)

1923* Collins. An account of the english colony in New South Walcs. etr. Londou 1801. 4. - Ed. 11: London 1804. 4. xvm, 562 p., 34 tab. pro parte eol.

(Res bolaniei argumenti fere plane desiderantur.)

192 ' Collins, Samuel. Paradise retrieved, demonstrating the most beneficial method of managing fruit-trees, with a treatise on mellons and cucumbers. London $1717.8,106$ p., 2 tab. B.

1925* Colmeiro, Miguel. Ensayo histórico sobre los progresos de la botánica desde su origen liasta el dia, considerados mas especialunente con relacion a España. Bareelona, typ. Brusi. 181z. 8. 71 p.

$1926 \div$ - Prineipj che devono regolare una Flora applieati particolarmente alla formazione della Spagnuola. Seconda parte delli Mlemoria sulla possibilita attuale di fare una Flora spagnuola, letta alla sezione di botanica del quinto congresso degli scienziati italiani. Lucca 1843. 8. $14 \mathrm{p}$.

Lat prima parte di questa Memoria e una introduzione storico estratta del: "Ensayo historico.")

$1927 \div-$ Catalogus plantarum in horto botavico Barcinunensi annis 1843 et 1544 cultarun seminumque nuper collectorum quac pro communicatione olferuntur. Bareinone, typ. Monfort. 1844.8. \pm 3 p.

1228 Colmenero de Ledesma, Anlonio. Curioso trallado de la naturaleza y calidad del Cliocolate, dividido in quatro puntos. Madrid, por Pranciseo Jartinez. 1631. 4. Bibl. Reg. Paris.

$\div$ Latine: curante Jarco Aurelio Severino. Norimbergae, 164. 12. $73 \mathrm{p}$. praef. ind

$\div$ gallice: Du ehocolate discours eurieux divise en quatre parties: traduit d'espagnol en francais sur l'impression faile al Madrid l'an losi. par Hene Moreau. Paris 1643. 4. 59 p., praef. - Lyon 16i71. 12. B. onglice: A treatise of the nature and quality of chocolate. London 168;. $12 . \mathrm{B}$

itolice: Della eioccolata. Bologna 169\%. 12 . iz p. B.

1929* Colombano. Collezione ragionata e fedele delle coutraddizioni degli errori di massima botanica, delle ealonuic ete. che si trovano nel libro che ha per titula: "Saggio su la maniera d'impedire la confusione. che tien dietro alla innovazione de' nomi, e alle inesattn descrizioni delle piante iu botanica.n s. I. 1800.8 .90 p.

1930 Colombina, Gasparo. Il bomprovifaceia, per sani el smalati. Padova, Tozzi. 1621. 8. 335 p. cum ic. ligno incisis, maxime rudibus. $\mathbf{B}$. 
193! Colonna, Fabio (latine Columna). (Duro,3xosvos sive plantarum aliquot historia. Neapoli, apud J. J. Carlinum. 1592. 4. 120,32 p. praef., ind., (36) ic. neri inc.- ${ }^{*}$ Editio altera, eui accessit Vita $F a b i i$ et Lynceorum notitia adnotationesque in Plyytobasanon, Jano Planco Ariminensi auctore. Florentiae, Viviani (in aliis exemplaribus: Mediolani) 1744. 4. LII, 134 \%., 38 tab.

1932. - Mimus cognitarum rariorumque nostro coelo orientium stirpinm Exppxes:, in qua non paucae ab antiquioribus Theophrasin. Dioscoride, Plinio, Galeno aliisque descriptae, praeter illas etiam in Puгe $3 x\ulcorner\alpha v \omega$ editas disquiruntur et declarantur. Iten de aquatilibus aliisque nonnullis aninalibus libellus. Omnia fideliter ad vivum delineata atque aeneis t!pis expressa, cum indice in calce voluninis locupletissimo. Romae, apud Jacobum Mascardum. 1616. 4. 340 , 99 p. praeter animalium observationes et libellum de purpura; cum 131 tabulis aeneis, in quibus 847 plantae repraesentantur; et effigies Columnae, aet. XXTTill. (20 ih. A. ex Willdenow!)

$1933^{*}$ Columella, Lucius Junius Moderatus. Do re rustica libri XII. et liber de arboribus. Venetiis, Aldus. 1523. 4. - Parisiis 1533. folio. - Basilene 1535. 4. - Parisiis 1543.8. - Mannhemii 1781. 8. Biponti 1787. 8. - Ex optimorum scriptorum atque editorum fide et virorum doctorum conjecturis correxil, atque interpretum omnium collectis ef excerptis commentariis suisque illustravit Johann Goltlob Schneider. Lipsiae 179/. 8 .

(Columellae antiquissimae recensentur editiones apud Hain, Repert. N. $549 k-5500$.

* germanice: Das Acherwerk Lucii Coluneelle el Paladii ete. verteutschet durch ifichael Herr. Strassburg, typ. Wendel lihel. 153s. folio 216 foll., praef. Bibl. Francof. Senckenb.

t gallice: Les douze livtes de Lucius Junius Moderatus Columella des choses ruetiques. Traduicts de Jatin en francois par feu maistre Claude Cotereau, chanoine de Paris. Paris, chez Jacques herver. $15 \%$ 4. (31) $573 \mathrm{p}$.

1934 Colsmann, Johannes. Prodromus descriptionis Gratiolae, sistens species a $D$. Köng cietectas. Hafniae 1793.8. 16 p. B.

$1935^{*}$ Comelli, Francesco. Intoruo alle alghe microscopiche del $\mathrm{Dr} . \mathrm{B}$. Biasolello relazione. Ldine $1833.8 .29 \mathrm{p}$.

$1936 \div$ - Intomo alle alghe di acqua dolce ed alle produzioni animali che si crederano alghe studio. Saggio primo. Udine 1835.8. 32 p. et 3 spec. siceae.

1937* Commelyn, Caspar (latine Commelinus). Flora Mlalaharica sive horti Mlalabarici catalogus exhibens omnium ejusdem plantarum nomina, quae e variis tum veteribus tum recentioribus botanicis collegit, et in ordinem alphabeticum digessit. Jugduni Batavorum, apud Ilaaring]ı. $1696.8 .284 \mathrm{p}$.

1938* (— - Botanographia, a nominum larbarismis xai aútapx six; obtentu restituta, quam Florae Nalabaricae nomine celebrem, recentior virorum illustrium industria successive illustrando ad publicun usum adornavit etc. Lugduni Batavorum, Langerak. 1718. folio. $71 \mathrm{p}$

Est idem liber ac praecedens. Banksius laudat impressionem ami 1696 . folio. 71 p., absque duhio traee nostra, quae sub praefaami 1696. Tolio. il [3., alssque

$1939^{*} \longrightarrow$ Plantarum usualium horti melici Amstelodanensis catalogus. Amstelodami (1698). 8.83 p. - ${ }^{*}$ Ed. Ill. auctior. ils. (1724.) 8. $107 \mathrm{p}$.

$1940^{*}$ Praeludia botanica ad publicas plantarum exoticarum demonstrationes; his accedunt plantarum rariorum, in Praeludiis botanicis recensitarum, icones el descriptiones. Lugduni Batavorum, apud Haringh. 1703.4.85 p., 33 tab. - *Lugduni Batavorum, apud J. du Vivie. 1715.4 .85 p., 33 tab. (non differt.)

$19: 1^{*}$ llorti medici Amstelaedamensis plantae rariores el exoticae ad vivum aeri incisae. Lugduni Batavorum, apud Haringh. 1706. 4.48 p., praef. 48 tab. - *ib. apud J. du Vivie. 1715. 4. (non dillert.)

1912 Oratio metrica in laudem rei herbariae. Amstelacdami 1715.4. 12 p. B.

$1913 \div$ Commelyn, Johan. Yederlantze Hesperides; dat is, Oeffening en gebruik ran de Limoen-en Oranje-boomen; gestelt ua den aardt en climaat der Nederlanden. Amsterdam, by Harcus Doornik. 1676. folio. $47 \mathrm{p}$., praef, ind., $27 \mathrm{tab}$. anglice: London 1683 . S. 19 p. B.

$1944^{*}$ - Catalogus plantarum indigenarum Hollandiae, eui praemissa Lamberti Bidloo Dissertatio de re herbaria. Amstelodani, Boom. 1683. 12. 82, 115 p. - ${ }^{*}$ Ed. II. Lugduni Bat, apud Langerack. 1709. 12. $117,80 \mathrm{p}$
19:50 Commelyn, Johan. Catalogus plautarum liorti medici Amstelaedamensis. Pars prior. Amstelodami, ex officina Commeliniana 1689. 8. 371 p., pracf. - "Eadem impressio novo titulo: Anstelodami, apud Wetstenios. 1702. 8 .

$19: 66^{*}$ - Horti medici Amstelodamensis rariorum tam orientalis, quam occidentalis Indiae, aliarumquo peregrinarum plantarum magno studio ac labore, sumtibus civitatis Amstelodamensis longa annorun serie collocatarum descriptio et icones ad vivum aeri incisae. Auctore Johonne Conmelino, urbis Amstelodamensis (dum viveret) Senatore. Opus posthumum. Latinitati donatum, notisque et olsservationilus: illustratum a Frederico Puyschio et Francisco Kiggelario. Amstelodami apud P. et J. Blaen. 1697-1701. Il voll folin. - Pars prima: 1697 220 p., 112 tab. - Pars altera, auctore Caspare Commelino: 1701. 224 p., ind., 112 p. (latine et belgiee.)

$19 i^{*}$ Comolli, Giuseppe. Plantarum in Lariensi provineia lectarum enumeratio, quam ipse in botanophilorum usu atque eommodo exhihet uti prodromum Florae Comensis. Novo-Comi 1824. 8. $\mathbf{x} x, 208$ p.

$1948^{*}$ Flora Comensis, plantas spoute in provincia crescentes atque illas, quae indigenatum nactae coluntur, exlibens, earumque proprietates et usus enumerans. Novo-Comi 1826. 8. 10 p. (Prospectus.)

$1949^{*}$ Flora Comense disposta seeondo il sistema di Linueo. Como 1S34-1836. Ill voll. 12. - 1: 1834. xxxvi, 368 p. -11 1835. $323 \mathrm{p} .-111: 1836.267 \mathrm{p}$.

(Opus, quantum seio, haud eontinuatum desinit in Dadecandria.

$1939^{*}$ Comparetti, Andrea. Prodromo di fisica vegetabile. Padova 1791 -1799 . Il voll. 8. - 1: 1794. 72 ]. $-11: 1799.80 \mathrm{l}$

Spreng. Gescli. der Bol. il. p. 308 - Pars illera plerumque desideratur.

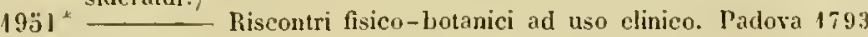
8. 128 p.

$1932+$ Comte, J. Achille. Cahier (second) d'hustoire naturelle à l'usag" des colleges. Nouvelle édition entièrement refaite: Botanique. Paris 1845. 8. 219 p., 9 tab. $(2 \mathrm{fr}$.

- germanice: Das Pilanzenreiels nach $A$. $L$. de Jussieu in methodisclier Uebersicht geordnet. Ein voul $T h$. Schmidt lithographirtes Blatt sclier Uebersicht geordnet. Ein vont Th. Schmidt lithographirtes Blatt mit vielen aus Mirbel's Elemens de physiologie ré
bilclungen. Weimar 1834.1 Btatt. imp. folio. $1 / 2 t h$.)

(Liber gallieus nihi non innotuit.)
(Liben

1933 Concius, Andreas. De succino. D. Regiononti 1660. 4. Desid. B.

1954 Confalonerius, Johannes Baplisla. De vini natura ejusque alendi ac medendi facultate disquisitio. Basileae 1535. 8.59 foll. B.

$1933^{*}$ Configliachi, Luigi. Discorso inaugurale intorno agli scritti del Cav. Antonio Iallisneri. Padova 1836 . folio min. 35 p.

$1956^{*}$ Conradi, Heinrich. De Nicotiana Tabaco. D. Goettingae 1838. 8. $53 \mathrm{p}$.

1957 Conradinus, Ballhasar. Spicilegium botanicum. Lucae, apud Franciscum Narescandolum. 1654.4. S

(Suspicor thune a Seguiero negligentia bis recensitum, eundem esse lihrum, quem supra in No. 1668. indicavi.)

1908 - Contant, Jacques et Paul. Les oeuvres divisées en cinc traictez. 1. Les commentaires sur Dioscoride. 2. Le second Eden. 3. Exagoge mirabilium naturae e gazoplyylacio. 4. Synopsis plantarum $\mathrm{cun}$ etymologiis. 5. Le jardin el cabinet poetique. Poictiers, par Julian Tboreau. 1628. folio. $250,79,90,59$ p., tab. Bibt. Juss.

$19597^{\circ}-$ Les divers exercices de Jaeques et Paul Contant. pere et fils, maistres apoticaires de la ville de Poictiers, ou sont esclaircis et resouldz plusieurs doultes qui se rencontrent en quelque's cliapitres de Dioscoride et qui ont travaillé plusieurs interpretes composez par le dit Jucques ef recueillies, reveus, augmentez et mis en bon ordre par le dit Paul, pour servir de commentaire aus simples. eseriptz dans son poesme intitule: le second Eden. Poictiers, par Julian Thoreau. 1628 . folio. 250 p., praef. Bibl. Juss.

1960 Conti, Livio Ignazio. Il vero silfio overo Laserpitio degli antichi. dopo lo spazio di piu di 1200 anni ch'e stato perso o incognito. muovamente discoperto e manifestato. (Giornale de' letterati. Venezia, Dec. 1673 . Giornale XV'l. ed aggiunta sopra l'istessa scoperta.) s.
1961 1962 1963 Iettera sopra la detta scoperta. Venezia, Vitali.1674.4. s. Risposta a questa lettera. Venezia, Dom. Miloceo.1674.4.s.

Conwell, W.E. E. Recherches sur les propriètés médicinales et l'emploi en medecine dé l'huile de Croton Tiglium et quelques propositions sur los maladies de l'Inde. Paris $1824.4 .24 \mathrm{p}$. 
196i Cook, . Moses. The manner of raising, ordering and improving forest trees. Eil. Jll. Londont 1724. 8. 273 p., 4 lab. B.

$1965^{+}$Cook, S. E. Sketches in Spain, during the zears 1829-1832; containing notices of some clistricts very Jittle known, of the manners of the people, gorernment, recent changes, commerce, fine arts and natural history. Loudon 1834 . II voll. S. $-1: x i x, 344$ p. 11: $336 \mathrm{p}$.

Autor noster non S. S. Cook, ut in titulo jihri legitur, sed S. E. Cooli aulit; jostea nonien suum in $S$. $E$. Widdringtun inutivit.)

$1966+$ Cooper, Daniel. Flora metropolitana; or botanical rambles within thirty miles of London: being the results of excursions in 18331835. etc. London 1837. 12. Xvi, 139 p. - Supplement: 36 p. (6s.)

1967 (Coppens, Bejward). Terminologic botanique, Gand 1797. \&. c. van Hultbetn.

1968* Corda, .Jugust Joseph C. Monographia Rhizospermarum et Hepaticorum. (Die Wurzelfarren und Lebermoose.) Erstes Ileft. Prag 1829.4. 16 p., 6 tab. ( $1 / 2$ lh.

$1969^{*}$ — Genera Ilepaticarum. Die Galtungen der Jebermoose. s. a. 8 .

(Brsondrer Aldruck aus Ph. Max. Opiz, Beitrage zur Naturgeschichte, P. 6r3-6ï̈.

$1970^{*} \longrightarrow$ Ueber den Bau des Pflanzenstammes. Prag 1836. 8. 35 p.

l.Ans Weitenwebers Beitrigen I, 2.

$1971^{*}$ Leber Spiralfaserzellen in dem Haargeflecbte der Trichien. Ein Schreibeu an $A, v$. Hunboldt. Prag 1837, 4, 8 p., 1 tab. $(i / 2+t h$.

$1972^{*}$ lcones fungorum hucusque cognitorum. (Abbildungen der Pilze und Schwámme.) Pragae 1837-1842. V voll. folio. - I: 1837. 32 p., 7 tab. - II: 1838.43 p., 8 tab. - HI: 1839.55 p., 9 taL, - IV: 1840.53 p., 10 Lab. - V: 1842.92 p., 10 tab. $(321 / 4$ th.

$1973^{*}$ Prachtflora europäischer Schimmelbildungen. Leipzig und Dresden 1839. folio. vil, 55 p., 25 tab. col. ( $15 / /$.)

* gallice: Flore illustrée de Mucctinées d'Europe. Leipzig 1840. folio.

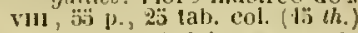

1974: ㄴ. Anleitung zum Studium der Mykologic, nebst kritischer Beschreibung aller bekannten Gattungen, und einer kurzen Geschiehte der Systematik. Prag 1842. 8. Cxxur, $2 \geq 3$ p., 8 tab. $\left(2^{2} / 3\right.$ th. $)$

$1973^{*}$ - Beiträge zur Flora der Yorwelı. Prag 1845.4 max. vill, 128 p., 60 tab. $(16$ th. $)$

$1976+$ (Cordienne, Alexandre Joseph.) Notice topo-phytographique abrégée de quelques lieux du Jura, de l'llelvétie et de la Savoie. Par un uvocal de Dole. Dole 1822. 8. 39 p.

$1977^{*}$ Cordier, F.S. Histoire et deseription des champignons alimentaires et vénéneux qui croissent sur le sol de la lirance. etc. Nouvelle édition. Paris, Rouvier. $1836.12, x, 247$ p., 11 tab. col. (4 fr. 50 c.) germanice: Quedlinhurg 1838. 8. $(2 / 3 \mathrm{~h}$.

$197 \mathrm{~S}^{*}$ _ Guide de l'amateur de champignons, ou précis de l'histoire des clampignons alinentaires, vénćneux et employés dans les arts, qui croissent sur le sol de Ja France Paris, Bossange. 1826. 12. 247 p., If tab. col.

(Suspicor eundem esse librum mutalo titulo.

$1979^{*}$ Cordus, Eurich. Botanologicon. Coloniane, apud J.Gymnicum. 1534 12. $183 \mathrm{p}$., ind.

Indes lujus libri impressus est cum Dinscoride per Rivium

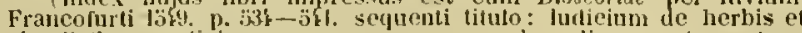
simplicibus medicinae ae eorum, quae apud medicos controvertuntur, decisio et exjuticalio.

$1980 \div-$ Bolanologicon. Elenchus meliorum rerum quac in eo eontinentur. I'alerii Cordi Adnotationes in Dioscoridis de medica materia Jibrns. Index loeupletissinus. Parisiis, apud Guilelmum HoreJium. 1551 . 12. 193 p., praef., ind., practer lalerii Cordi Adnotaliones : $395 \mathrm{p}$., ind. Bibl. Juss.

$1981 \div$ Cordus, Valerius. Dispensatorium h. e. pharmacorum conficiendorum ratio; cui accessit $D$. Jacoli Silvii appendix pro instructione jharmacopolarum utilissina. Lugduni, apud T/. Paganum. 1552. 12. (32) 445 p. - †ils, apurl Naire. 1618. 12. 547 p., praef., ind. Bibl. Juss.

$1982^{*}$ — Annotationes in Pedacii Dioscoridis Anazarbei de medica materia libros V. Cum ejusdem Historia stirpium et Sylva etc. - His accedunt Stochornii et Nessi stirpium ilescriptio Benedicti Aretii, et Conradi Gesneri de hortis Germaniae liber recens una cum descriplione Tulipae Turcarum ete. Omnia summo studio atque industria Conradi Gesneri collecta. Argentorati, excudebat Josias Rihelius.
1561. folio. 301 foll. cum pracfatione el literis Gesneri, ind., ic xylogr. i. t.

(uQnae asteriseo notantur annotationes Aemilii Stolbergi sunt, qu ut monet Thalius sylv. hercyn. p. 112, tuon Cordi nomen scriberet

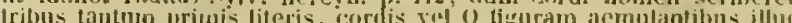
drisignabat. lloc signo deceptus, editor passim Odum pro Cordo edi(it." S.)

1983 t Cordus, Valerius. Stirpium deseriptionis liber quintus, qqua in Italia siloi visas describit in praecedentilus vel omnino intactas vel parcius descriptas lune autem morte pracventus perficere non potuit. Da morbo et ohitu Ialerii Cordi epistnla ITieronymi Schreiberi Norimbergensis. In ejusdem obitum Casparis Crucigeri elegia, encudationes quaedan et additiones in opera Vulerii Cordi Argentinae excusa apul Rilıelium 4560. Argentorati, excudelsat Rilıelius. 1563. $\div$ Editio mosa plurimis emendationilus el adnotationibus ex Gesneri codice desumtis aucta et recusa. Norinbergae 1751. folio. 130 p.

198:" Corinaldi, Ciacomo. Notizie storiche della Accademia Valdarnes: del Poggio elc. Pisa 1839.8 max. 72 p., 3 tab.

(Spectat ad botanican systematicam.)

1983: Cornarius, Jamus (nomine vernaculo: II anbul, Jaynbut, IIagenbut). Vulpecula excoriata. Francofurti, apud Christianun Egenolplum IJadamarium. 1545. mense Martio. 4. (19 foll.) sign. a $-\mathrm{e}^{3}$. Bibl. Reg. Paris.

1986:- - Nitra ac Brabyla, pro Vulpecula excoriata asservanda. Per Janum Cornarium medicnm physicum, Jlippocraticun in schola Narpurgensi Professorem. Ad Leonhartun Fuchsium. scholac medica" apud Tubingam Professorem. Franeofurti, typ. Egenolf. mense Augusto 4545.4 . (20 foll.) sim. $A-E^{3}$. Bibl. Reg. Paris.

$1987^{*}$ Orationes in Lennhartum Fuclsium medicum, sive Fucliseicles III. Quarum inscriptiones sunt: 1. Vulpecula exeoriata II. Vulpecula excoriata asservata, sive nitra ac brabyla pro Vulpecula excoriata asservanda. III. Vulpeculae catastrophe, scu qui debeat esse scopus, modus ac fructus contentionum. (Francofurti, apud Egenolphum.) 1546. 8. sign. A-L ${ }^{4}$. Bibl. Reg. Dresd.

$1988^{*}$ Cornarius, Janus. Theologiae vitis viniferae libri tres, lectu theologis aeque utiles ac philologis jucundi : editi studio 1 . Atruhami Scuttet, Grübergensis Silesii. Heidelbergae 1614.8.398 p., praef, ind.

(Autor non est Jamus Cornarius Zuiccariensis medicus, sed theologus Franeiae orientalis tlamelburgicus.)

$1989^{\circ}$ Cornelissen, $N$. Sur les tubera des ancieıs, considérés comnir étant les truffes de nos jours (Lycoperdon Tuber L.) et à celte oceasion sur deux passages de la traduction te Suétone par LaHarpe. s. I. el a. 8.12 p. Bibl. Juss.

(Exirait du Ilessager des sciences el des arts.)

$1990^{*}$ (Cornelius, Hermann.) Catalogus plantarum horti publici Amstelodamensis. Amstelodami 1661.8.53 p.

$1991^{*}$ Cornelius zon Ansterdam, Leonhart. Cibi, potus et condimentorum plurimorum consideratio medica. D. Lugduni Batavorum 1736. 4. $62 \mathrm{p}$.

1992* Cornuti, Jacques. Canadensium plantarum aliarumque nondum editarum historia. Cui adjectum est ad calcem Enehiridion botanicum Parisiense, continens indicem plantarum, quac in pagis, sylvis. pralis et montosis juxta Parisios Jocis nascuntur. Parisiis, S. le Noyne. 1635. 4. 238 p., praef, ind., tab. - tParisiis, venundantur apud Joannem d'Horry. 1662. 4. est eaden impressio novo titulo.

1993 Correa de Serra, Joseph. On the fructification on the submersed Algae. (1796.) 12 \}. B.

(From the Phitosoph. Transact. 1796. p. 49-303.)

199.4 Cortavilla y Sanabria, Diego de. Informacion y pareçer de l, que son Cubebas y quien las empeço a usar, y como non son el Carpasio de Galeno, y que las rue agora tenemos son las misinas que conocieron los primeros Arabes. s. I. et a. 4. s.

1998" Corthum, Elisabeth Louise. Verzeiclmiss und kurze Besclireibun der im Freien ausdauernden Stauden-, Zwiebel- und KnolJgewächse. etc. Zerbst 180 . $8.75 \mathrm{p} .(1 / \mathrm{t}$ th. $)$

1996 Corthum, Johenn Karl. Catalogus von Băumen und SIräucjıen, weJche im freien Lante fortkonmen. Zerbst $1803.8 .(1 / 3 \mathrm{th}$.)

1997 Handbueh fur Gartenliehhaber und Blumenfreunde. Leipzig $1814-1816.5$ Bande. $8 .(21 / 3$ th.)

$1998^{*}$ Corti, Bonatentura. Osservazione microscopiclie sulla Tremella e sulla circolazione del fluido in una pianta acrjuajuola. (Chara.) Lueca 1774. 8. 207 p., 3 tab. 
1999\% (Cortusi, Giacomo Antonio.) L'horto dei simplici di Padova, que si vede primieramente la forma di tutta la pianta con le sue misure: ed indi $\mathrm{i}$ suoi partimenti distinti per numeri in ciascuna arella, intagliato in rame. In Venetia, appresso Girolamo Porro. 1591 . 8. ( 72 foll.), efficies Cortusii et $\overrightarrow{3}$ tab. horti situm illustrantes, Bibl. Reg. Paris.

Edlitionen novam. texte Seguiern, euravit Joh. Geory Schenck, Francofarti 1608. 8. cui accessit Melchioris Guilandini Conjectanea synonymica plantarum.)

2000 Cosentino, Ferdinando. Saggio di botanica. Catanea 1805. DC. $2001^{*}$ Nuove osservazioni e ricerche sulla Zostera ozeanica. s. 1. (1828.) 4. 20 p.

2002\% (Cossigny, fils.) Lettre sur les arbres á épiceries avec une instruction sur leur culture et leur préparation: ct letIre sur le café. (Paris 1775.) 12.71 p.

2003 Cossigny de Palma. Ylemoir, containing an abridged treatise on the cultivation and manufacture of Indigo (with several Mlemoirs on the process observed in different parts of Inclia.) Calcutta 1789.4. $172 \mathrm{p}$.

(In exemplari Ranksiano additae erant icones pictae diversarum varietatum lndigoferae, nee gon delineationes instrumentorum in faecularum exlractione usitatorum.

2004: Cosson, Ernest, et Ernest Germain. Observations sur quelques plantes eritiques des environs de Paris. Paris 1840. 8. vilI, 68 p., 2 tab. ( 2 fr.)

$2003^{*}-$ et $A$. Weddell. Intraduction a une Flore analytique et descriptive des environs de Paris, suivie d'un catalogne raisonné des plantes vasculaires de cette region. Paris 1842.8. $163 \mathrm{p}$. (2 fr.)

$2006^{*}$ Supplément all catalogue raisonné des plantes vasculaires des environs de Paris, précedé d'une réponse an livre de 11. Merat, intitulé: Revue de la Flore Parisienne. etc. Paris 1843.8 .94 p. $(75$ c.)

$2007 \div$ Flore descriptive et analytique des environs de Paris ou description des plantes, qui eroissent spontanément dans cette région, et de celles qui y sont gènéralenıent cultivées, accompagnée de tableaux analytiques des familles, des genres et des espeeces et d'une carte des environs de Paris. Ouvrage faisant suite a la partic botanique du cours d'histoire naturelle par Jussien, MilneEdwards et Beudant. Paris 1845. 8. Il parties. LII, $731 \mathrm{p}$. ef 1 carte. (13 fr.)

$2008^{\circ} \longrightarrow$ Synopsis analytique de la Flore des environs de Paris oú description abreggée des familles et des genres, accompagnée de tableaux dichotoniques destines à faire parvenir aisément au nom des espèces. Paris 1845 . 8. xxxı 275 p. (3 fr. 50 c.)

$2009 \div$ Atlas de la Flore des environs de Paris ou Illustrations de toutes les espèces des genres difficiles et de la plupart des plautes litigieuses de cette région, avec des notes descriptives et un texte explicatif en regard. Paris 1845 . 8. 42 tab. a $D r$. Germain delincatde, totidemque foll. text. (9 fr.)

(Collectio hacce egregia, ni fallor, nondum absoluta est. 1llustrissimi autores, "1ui operibus suis satis ingeniose Floram Parisiensem illustraverunt, acstate praeterita, dun Paristis versabar, "Vademecum botanicum " prelo tradiderant, quod nondum, quantum scio, iul lucem editum est.

$2040 \div$ Costaeus, Johannes. De universali stirpium natura libri duo. Augustae Taurinorum 1578.4.496 p. cum dedicatione et ind. Bibl. Cand. (In Bumaldi Ribl. bot. laudatur editio: Augustae Taurinorum 40̈80. k.)

$2011 \div$ Coste et Willemet. Essais botaniques', chimiques et pharmaceutiques sur quelques plantes indigenes substituces avec succès à des végétaux exotiques. Nancy 1778. 8. $x, 120$ p.

$2012^{*}$ _ _._. Matière mélicale indigène, on Traité des plantes nationales substituées avec succès à des végétaux exotiques. etc. Nouvelle édition, considèrablement augmentée. Nancy 1793.8 . $x, 152$ p.. ind., 1 tableau.

$2013+(\longrightarrow)$ Prècis bistorique de l'importation et de la naturalisation en France du Rheum palmatum L. de la Tartarie chinoise, c'est a dire de la Rhubarbe de première qualité. Paris 1805 . 8. 90 p.

2014" Cothenius, Chrislian Andreas. Dispositio vegetabilium methodica a staminum numero desumta. Berolini 1790. 8. xIv, 34 p.

$2015^{*}$ Cotta, Heinrich. Naturbeobachtungen ther die Bewegung und Function des Saftes in den Gewdichsen, mit vorzugglicher llinsicht auf Holzpflanzen. Weimar 1806. 4. xiv, 96 p., 7 tab. col. (4 th. col. 5 (h.)
2016* Cotta, Karl Bernhard. Die Dendrolithen in Beziehung auf iliren innern Bau. Dresden v. Leipzig 1832. 4. 1x, 89 p., 20 tab. ( 5 th.)

$2017^{*}$ Cotte. Manuel d'histoire naturelle on tals]eaux systematiques des trois regnes. Paris $1787,8,180 \mathrm{p}$.

2018 Leçons élémentaices d'histoire naturelle. Paris 1787. 19 471 p. B.

2019 Coulon, Julius Vitr. De mutata humorum in regno organico indole. D. Lugduni Batavorum 1789. 8 .

(Spreng. Gesch. der Bot. ll. p. 317.)

2020* Coulter, Thomas. Mémoire sur les Dispacées. Genève 1823. 4 $49 \mathrm{p}, 2$ tab.

$2021 \div$ Couret-Villeneuve, Louis Pierre. Hortus Gandavensis centrali academiae annexus, juxta Linnaei methodum dispositus. (Description de toutes les plantes etc.) Gandavii an X. 12. 380 p., praef. ( 3 fr. 75 c.) Ejusdem antoris: "Prodromus Florae Aurelianensis, Orleans 178. 8. a Schullesio et Querardo lauddus, mihi non innotuit.)

$2022+$ Courrant, Louis. Essai sur les propriétés déléteres du camplre et de la coque du Levant. Thèse. Paris $1815.4 .22 \mathrm{p}$.

$2023 \div$ Courtois, Richard. Magazin d'horticulture, contenant la description, la synonymic et la culture des plantes les plus remarquables etc. Supplément aux ouvrages de Dumont-Courset, Noiselte, Vilmorı et Poituu. Tome premier. Liège 1833. 8. Lvin, 350, 159 et $45 \mathrm{p}$.

$2024 \div$ Couture. Traite de l'olivier. Aix 1786. II voll. 8. - Livre I: 344 p. 5 tab. - Livre ll: 436 p., 2 tab.

Accedit: Reponse aux olsservations sur le traite de lolivier, publices par M. Bernard dans le Jonrual de Provence: 20 p.l

$2025+$ Couverchel. Lettre à NII. les mombres de l'Académie des sciences. Paris 4833. 8. 28 p., 1 tableau.

$2026 \div \longrightarrow$ Traité des fruits; tamt indigenes qu'exotiques ou Dictionnaire carpologique, comprenant l'bistoire botanique, chimique, médicale, économique et industrielle des fruits. etc. etc. Paris 1839.8. svi, 747 p. ( 10 fi. $)$

(Vidi prospeetum libri ejusdem antoris: Botanjque du cultivateur, cun 600 tab. in folio, qui anno 4839 sub prelo fujt.

2027* (Covolo, Giovambatista, Conte dal.) Discorso della irritabilita d'alcuni fiori nuovamente scoperta. Firenze 1764.8. 25 p., 4 tab. anglice: A discourse concerning the irritability of some flowers. London $(1767)$. 8. $43 \mathrm{p} ., 1 \mathrm{tab}$ germanice: Hode uber dic Reizbarkeit einiger Blumen. (Naturforscher, b. Stick, p. 216-237.

2028 Cowell, Jolm. The courious and profitable gardener. etc. London $1730.8 .126,67$ p., I tal).

The curious fluit and flower gardener. Esl. ll. London 1732. 8. est eadem implessio ac praecedens, novo titulo et reimpresso ultimi folio. B.

$2029 \div$ Cowell, M. H. A Floral guide for East lient, etc. being a record of the habitats of indigenous plants fouml in the eastern division of the county of kent, with those of Faversham, particularly detailed and definitely exhibited. In two divisions illustrated by two maps. Favershan 1 \$39. 8 . xill, $98 \mathrm{p} .(5 s$.

$2030 \div$ Cowley, Abraham (latine Couleius). Poemata latina, in quibus continentur sex libri plantarun, duo herbarum, florum, sylvarum et unus miscellaneorum. Hluic editioni secundae accessit index rerum antehac desideratus. Londini 1668.12 .343 p., praef., ind.

(Pracedit: T. Sprat, De vita el seriptis A. Couleii. it p.)

$2031^{*}$ Plantarum libri sex ob raritatem et pracstantiam denuo editi. Basileac 1793. 8 . xxx, $384 \mathrm{p}$.

2032 Coxe, John $R$. View of the cultivation of fruittrees. Philadelphit 1817. 8 .

2033 A brief descriplion of the Agaricus atramentarius. Philadelphia $1842.8 .12 \mathrm{p}$. w.

$2034 \div$ (Coxhead, Henry.) Catalogue of the vasculares or phaenogamous plants of Great Britain arranged according to the natural system; with the synonyms of DeCandolle, Simith. Hooker, Reirhenbach and Lindley. With an index for the arrangement of specinens, etc. Lon(lon, Henry Coxhead. (1842.) imp. 8. 15 p. (6d.)

3033 Coyte, lYilliam Beeston. Hortus botanicus Gippovicensis, or a systematical enumeration of the plants cultivated in Dr. Coyte"s botanic garden at lpswich, in the county of Sulfolk. Ipswich 1796 . i $\$ 58$ p. B.

2036 Cramer, Johann Andreas. Anleitung zum Forstwesen. Braunscliweig 1766. folio. 200 p., 60 tab. B. 
$2037^{\circ}$ Cramer, Johann Christ. Enumeratio plantarum, quae in systemate sexuali Linnenno eas classes et orlines non obtiment, in quilsus secuntum numerum et strueturam genitalium reperiri debent. Marjurgi Cattorum 1803. 8. xxxir, $2 / 5 \mathrm{p}$. ( 1 th. $)$

$2038^{*}$ Cramer, Joham Rudolph, pr. We Myrto. D. plitologico-theolugiea. Tiguri 1731.4. 32 1.

2039 t Cramer, Wilhelm Christian Philipp. We Lichene islandico. D. Erlaıgao 1780.4.64 p.

2010 " Crantz, Heimrich Johann Nepomuk (von). Quaestio academica es materia melica et botanica: An plantarum oflicinalium etiam iliarum recepua nomina recte mutentur? D. Vienuae 1760.4 . (10 1$)$

$2011^{*}-$ Materia medica et chirurgica juxta systema naturae diresta. Viennae 4762 . Ill voll. $8,158,156$ et 162 p., praef., ind. "Ed. Il. correcta et aucta: Viennae 1765. 11] vull. 8. 208, 236 et $196 \mathrm{p} .$, praef., ind.

2012" - Stirjes austriacae. Vienuae et Lipsiae 1762-1767. III fasciculi. 8. - I: 1762. xx, 55 p., 3 tab. - Il : $1763 . x \mathrm{x}, 138 \mathrm{p}$. 6 tab. -111 : 1767.427 1., 6 tab. $-{ }^{*}$ Ed. Jl. aucta: Vienuac 1769. II prates. 4. - 1: xı, 229 p., 15 tals. -11 : (quae in editione priori desideratur) p. $230-508$, ind., 3 tab.

$2043^{*}$ - Institutiones rei herbariae juxta nutum naturae digestao ex haljitu. Viennac 1766. Il voll. 8. - I: LV1, 592 p. - II: 550 p., ind.

(Additameutum generum novorum, (rum eorundem speciehus cognitis, et specieruin novarum. lupp. cum Fr. Xizv. Hartmann: Primae lincar iristitutionum butanicarum Cranzii, Ed. 11. 1767. p. 75-9k.

20 k: * Classis Umbelliferarum emendata cum grenerali seminum tabula et figuris aeneis in necessarium Institutionum rei herbariae supplementum. Lipsiac 1767, 8, 125 p., 6 tab.

$204{ }^{*}$ * De dualsus Draconis arboribus lotanicorum. etc. Viennae 1768. 4. 31 \%., 1 tab.

$2046^{*}$ — Classis Cruciformiun ronendata eum figuris aeneis in necessarium institutionum rei lierbarjae supplenentum. Lipsiae 1769 8. 139 p., ind., 3 tab.

20.7 Crassus, Paulus. De Lolio tractatus, in summa annonae caritate anno 1591 , in tredecim capita redictus, cun epistola Utyssis Aldrovandi. Bononiae, apud J. B. Bellagamban. 1600 . 4. 64 p. B. et Bibl. Maz.

2048* Crell, D. L. Uelser das Vermögen der Pflanzen unul Thiere, Wárme zı erzeugen und zu vernicliten. Aus dem Englischen ubersetzt und mit einer eignen Abhandlung ublser deuselben Gegenstand vermelurt. Ilelmstedt 1778. 8, 94 I., praef.

(Sunt experimenta a Blagden, IIunter et Dobson instituta.)

$2049^{+}$Crell, Johann Frietirich, pr. De cortice Simaruba. D. Helmstadii 1746. 4. $36 \mathrm{p}$.

(“Johannis Friederici Crellii Oratimcuta de stutii botanici et cumprimis svstematis hiviniani praestantia, dicta Lipsiae d. 5. April. 172:3 [in Desid. B. reeensita] typis noudum excusa est." Honumentorun Crellii sylloze, llelnst. 177. folio. p. 21.)

$2050^{*}$ Crész, Johann. De Potentillis Hungariae, Croatiac, Transsylvaniae, Dalmatiae et litoralis Ilungarici. D. Pestind 1837.8 .30 p.

2051 * Creutz, Ludwig Albert Christian. De Colchico autumnali. D. Berolini 1826.8.40 p.

2052 Croft, John. A treatise on the wines of Portugal, also a dissertation on the nature and use of wines in general, imported into Great Britain. York 4787.8.27 p). B.

2053 Crolachius, Meinrich. Isatis herba, sive de cultura lsatidis quam Gualdum vulgo vocant, quamque Thuringia producit, ejusque praeparatione ad tingendas lanos narratio. Tiguri, apud Jacobum Gesnerum. 1575.42. Bibl. Reg. Paris.

2051: Crome, Georg Ernst Wilhelm. Sanumlung dentsclıer Laubmoose. Schwerin 1803. 4. 90 p. und 60 Arten aufgehlebter Laubinoose. Erste Nachlieferung: Scbwerin 1805.48 p. u. 30 Arten aufgeklehter Laubmoose, sign. 61-90. - Zweito Nachlieferung: Schwerin 1806. $48 \mathrm{p}$. und 30 Arten aufgeklebter Laubmoose. $\left(5 \frac{2}{3}(\mathrm{~h}\right.$. $)$

$2055^{*}$ - Botanischer Kinderfreund. Götringen 1807-1808. 6Hefte. 12. 24 tab. col. ( $31 / 2 t h$.)

Der Boden und sein Verbálniss zu den Gewächsen Hannover 1812. 8. vIII, $216 \mathrm{p}$. (11/12 th.)

2067 Handluch der Naturgeschichte fur Landwirthe. Erster und zweiter Theil : Pflanzenkumle. IIannover $1810-1811.8 .(6 \mathrm{l} / \mathrm{s}$ th.
2038 Cronberg, Friedrich. De Caplura. 1). Marpurai 1607. 4. s. (Caplura est uonion vetusiun pro camphora.)

2089 Croom, H. B., and II. Loomis. Catalogue of plants observed in the ueighbourhood of Newbern, Nuth Carolina. Newbern 1833. 8. Bibs. Acad. Phllad.

$2060 t-$ Olsservations on the genus Sarracenia; with inl accoun of a new species. Niw York 1837.8 .

(From the annals of the Lveeum of Nat. bistory, vol. IV, p. alj10\%, 1 tab. col.)

2061 t - A eatalogue of plants native or naturalized, in the ricinity of New-Bern, Nortl-Carolina; with remarks and synonyms. New-York, typ. G. C. Scott. 1837, 8, x, 521 .

(Opus posthumum a John Torrey edituru. Biograndian autoris infelicis adjecit Dr. Francis L. Hawks.

2062 Crosfield's Calendar of Floral with notes by James hendrick. Warrington 1810. 8. 34 p., int. Cat.

2063 Crüger, Johannes Bartholomacus. De succino. D. Regiomonti 1636.4.

2064* Crump, Geory. De arundine sacelarifera ejusque usu. D. Luggiuni Batavorum 1720.4.15 p.

$2065^{*}$ Cruse, Gustav Leopold. De Crotonis Tiglii oleo. J). Berolini 1824. 8. 51 1.

2066* Cruse, Wilhelm. De Rubiaceis capensibus, praecipue de genere Anthospermo. D. Berolini 1825.4.22 p., 2 lials. ( $1 / 2$ lh.)

$2067^{*}$ De Asparagi officinalis L. germinatione. D. Regiunouti 1828. 8. VIII, 34 p.

2068* Csiky de H. Oklánd, S. De Spilanthe oleracea. D. Pesthini 1836. 8.44 j., 1 tab.

2069 Cubières, Simon Louis Pierre, Marquis de. Mémoire sur le Cèdre ronge de Virginie. Paris s. a. 8 . DC.

2070 - Mimoire sur le Tulipier. Versailles 1803.8. a

$2071 \div$ - Mémoire sur l'Erable a feuilles de frene, ou Acer Negundo. Versailles $1804.8 .45 \mathrm{p}$

2072 Notice sur F. André Michaux, s. 1. 1807. S. a

$2073 \div$ - Némoire sur les micucuuliers uu Celtis de Linné. (Paris) 1808.8. $24 \mathrm{p}$.

$2074 \div-$ Mèmoire sur les cyprès de la Lonisiane. (Paris) 1809. 8. 30 p., 2 tab.

$2075 t$ - Mémoire sur le Nagnolier auricule (Magnolia auriculata). (Paris) $1810.8,18 \mathrm{p}, 4 \mathrm{tab}$

$2076^{*}$ Cürie, P. F. Anleitung die im mittleren und nördlichen Deutsclıland wachsenden Pfanzen auf eine leichte und sichere Weise durel eigne Untersuchung zu bestimmen. Zweite sehr vermehrte Aulhage. Görliz 1828. 8. xxxvı, 323 j. $(1 \%$ th. $)-$ Ed. V : Kittlitz 1843.8 xxxvi, $415 \mathrm{p} .\left(1 \frac{1 / 6}{6} \mathrm{~h}.\right)$

2077 Cullen. Traite de matiese medicale. Traduit de l'anglais sur la seule élition donne par l'auteur a Edinburgh en 1789 par Bosquilton Paris $1789-1790$. Il voll. 8. - I: $1789:$ vII , 437 p. - II: 1790. viIt, $637 \mathrm{p}$

2078 Cullum, Thomas Gery. Florae anglicae specimen, imperfectum ef ineditum anno 1774 inchoatun. S. 104 p. (Desinit in Dauco.) B.

2079 Culpeper, Nicholas. The english physitian enlarged. London 1653. 8. 398 p. B. - EdI. 1l. enlarged by IIumillon. London 479 g. Ill voll. 8. DC.

2080* Cunningham, A/lan. A specimen of the indigenous botany" of the mountain country between the colony round Port Jackson and the setilement of Bathurst.

(Fields, Geographical Memoirs on New Sud Wales. London 182*3 p. 323 squ.

* germanice: Lisnaca 1827. p. 120-11k.

$2081^{*}$ A few general remarks on the vegetation of certain coasts of Terra australis aud more cspecially of its north-westeru sliores.

(King, Narrative of a survey of the coasts of Australia. London 1S27. vol. 11. p. 497-633.)

germanice: voln Beilschmied in Flora Literalurbericht, 15:29. 11. p. $-37$.

2082* Cuno, Joham Christian. Ode uber seinen Garten. Nachmals besser. Zweite Auflage. Amsterdam, Cappelle. 1750. 8. 134 p. I tab (Accedunt: Liheltus Bielkii non Lujus loci: Joham Daniel Denso. Beweis der Gottheit aus dem Grase. p. 173-208. et Davil Siegmund August Buttner, Eunmeratio methorlica plantarum in carmine recensitarum, D. 209-230.) 
2083 Cupani, Francesco. Catalogus plantarum sicularum noviter adinventarum. Panormi, apud Petrum Coppolam et Carolum Adamum. 1692. folio. 4 p. s.

208: - Syllabus plantarum Siciliae nuper detectarum. Panormi apud Joannem Adamum. 1694. 16. s.

Syllabus est editio aucta et emendata Catalogi supra laudati. IJarum ptantarum icones promiserat cupani, quae nuiquan prodierunt.)

$2083^{*}$ _ Ilortus Catholicus s. ill. et exc. Principis Catholicae, Ducis Misilmeris etc. Neapoli, apud Fr. Benzi. 1696. 4. 237 p., praef. Supplementun: p. 238-262.- "Supplementum alterun. Panormi, [y]). Gramignani. 1697. 4.95, (3) p. Bibl. Berol., Goett. et Deless.

$2086^{*} \longrightarrow$ Panphyton siculum sive historia naturalis do animalibus, stirpibus et fossilibus, quae in Sicilia vel in circuitu ejus inveniuntur. Opus postlumum ad modum Rev. Patris Francisci Cupani imaginibus actiejs circiter septingentis e vero tractis. Panormi, ty]. Ant. Fipo. 1713. 4 max. 84 foll. utraque pagina signata $(1-168$.$) et$ iconibus aeneis plantarum impressa.

(liber ineditus rarissimus absque textu et tituln typis expresso exstat in Ribl. Mhus, bot. lindab. C'and. Dele's. Barlss. Roemer. - In Bibliotheca Mlusei botanici Vindabonensis pritetereil circiter to tabulae nol ligatae servantur, " juas beatus Jacquinius e sicilia ipse reportavit. Cf. Sureng. Gescli. der Bot. II. 133.)

$2087 t^{\circ}$ Pamphysis sicula sixe Historia naturalis animalium vegetabilium et mineralium tpuae in Sicilia vel in circuitu ejus inveniuntur. Opus incoeptum a R. P'. Francisco Cupani, tertii ord. S. Francisci, in Panpligto siculo, continuatum suppletumque ab Antonino Bonanno Gervasi Panormitano, et tandem absolutum a Jasepho, Stephano el Francisco Paulo Chiarelliis, Paoormitanis variarum academiarum sociis et in regia Panormi studiorum universitate chemicac et bistoriae naturalis demonstratoribus, et al hoc superstite typis mandatum. Sub auspiciis C.S. Rafinesque Schmaltz, ejusque observationibus annotationilusque locupletatum imaginilus aereis circiler 700 , ab ipsis Cupuni schematibus exscriptis et exacte denuo incisis per Salvalorem de Ippolito. Panormi, typ. (iiordano. 1807. 4. (Manifesto e Prospetto.) \& p., I tab. Bibl. Cand.

(Opus, quantum scio, iunquam prodiit.)

2088* Curtis, William. A catalogue of the plants growing wild in the environs of Lonclon. Londun 1774. 8. 401 .

$2089^{*}$ - Flora Londinensis, or plates and descriptions of sucl plants as grow wild in the environs of Loudon. Loudon 1777-1787. folio. 70 fasciculi; singulus tabularuo col. 6. , totidemque foliorum textus. (17/. 10s.)

$2090^{*}$ - Flora Londinensis : containing a history of the plants indigenous to Great Britain, illustrated lyy figures of the natural size. A new edition, enlarged by George Graves and Willian Jackson Hooker. Lomdon, minted for George Graves by Riclaard and Arthur

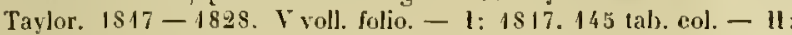
1821. 143 tal. col. - I11: 1826. 202 tab. col. - IV: 1821. 140 tab. col. - V: 1828. 72 tah. col. $=702$ tab. col. totidemque [oll. text et quatripliees indiees. (Wurde im Jahr 1839 von Weigel in Leipzig vol $680 \%$ / $/$. aul $220 \mathrm{lh}$. herabgesetzt.)

(Vol. If et V nonnisi Hookeri nomen in fronte gerunt.)

$2091 *$ The Botanical Magazine, or flower-garden displayed: in which tho most ornamental foreign plants, cultivated in the open sround, the green-liouse and the stove, will he accuratcly represented in their natural colours. To which will he added their names, chass, order, generic and specific characters, according to the celelorated Linnaeus; their places of growth and times of flowering: together with the most approved methorls of eulture. A work in tented for the nse of such Ladies, gentlemen and gardeners, as wish to become scientifically acquainted with the platts they cultivate. London 1787 - 1846. LXXIl voll. gr. 8.4274 tab. col. totidemque foll. text. et appendices. (Pretium voluminis : 42s.)

(A vol. XLIII : 1816 vol. LIV: 1827, vol. LXX1: 4865. incipiunt novar series. - A vol. XXXil : 1811. continuod by John Sims: a vol. LIY . 1827. conducted by samuel Curtis, the descriptions by ll illiam Jaclison Hooker:)

$2092^{*}$ - General indexes to the plants contained in the first fiflythrce volumes (or old serics complete) of the Botanical Magazine: to which are added, a few interesting memoirs of the author, Mr. William Curtis. Containing an alphabetical english and an alphabetical latin index, and a systenatical index; by Samuel Curtis. London 1828. 8. xxxu, 214 p., effigies Curtisii. (5s.)

$2093^{*}$ A companion to the botanical magazine, or a familiar introduction to the study of botany, being the substance of a cotrse of lectures, ehiefly explanatory of the Limnean System. London 1788. 8.33 p., 8 tab. with explication.

2094 Curtis, William. An enumeration of the britisl arisses. London 1787. folio. $4 \mathrm{p} .-{ }^{*}$ redit in ejus Practical observations on luritish grasses, p. 42-52.- Ed. 111. p. 46-57.

2093 - Explanation of the plate containing the fructification ete. of the mosses. $2 \mathrm{p}$. et I tub. aen. Jong. 8 unc. lat. 5 unc. inscripta Engraved for 11. Curtis botanic lectures 1776. B.

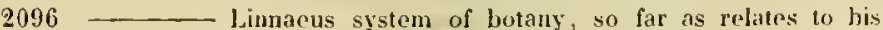
classes and orders of plants, illustrated by figures entirely new, with explanatory descriptions. London 1777,4 . $15 \mathrm{p}, 2$ tab, col. B. - London 1803.4. DC.

2097 A catalogue of certain plants, growing wild, chielly in the environs of Settle in Yorkshire, observed in a six weeks botacal excursion in 1782 . foliu. $11 \frac{1}{2}$ plag. B.

$2098^{*}$ A catalogue of the british medicinal, culinary and agricultural plants, cultivated in the London botanical garden. London 1783. $8.149 \mathrm{p}$.

(1.. $75-15.1$ : Cataloguce of british plants, arranged according to their periods of tlowernis.)

2099 The subscription catalogue of the Brompton lotanic garden for the years 1790. 1791. 1792. 1793. 1795. 1796. 1799. \&. $38,43,46,34,36,35$ et 36 p. B.

$2100^{*}$ Directions for cultivatiug the Cranbe maritima or Sea Kale for the use of the table. London 1799. 8,18 p., 1 tab. eol.

$2101+$ Practiral olservations on the British grasses, especially such as are best adapted to the laying down or improving of meddows and pastures: Jikewise an enumeration of the british grasses. The fourth edition with additions. To which is now added a short accomt of the discases in con, called by farmers the blight, the mildew an the rust, by Sir Jaseph Banks. London 1805. 8. 58 p., ô tab. et Opus Banksii. de qua alio Joco. (J̈s. - col. $7 s .6 d$.) "Ed. II : London 4790.8. 67 p., 6 tab, - " Ed. III: London 1798. \&. 73 p., 6 taly, col.

$2102^{*}$ Lectures on Botany, as delivered in the hotanic garden at Lambeth. Arranged from the manuscripts in the possession of his son-in-law, Samuel Curtis, Florist, Walworth. London 1805. 111 voll. 8 max. - 1: 131 p., tals. col. 1-48. - H: 108 p., tal). col. 49-95. - III : C 3 p., 24 tal,. col. (pro parte insecta illustrantes.) Ed. II. il, 1807. III voll. 8

Accedit: Shetch of the life and writings of the tate Mr. Nilliam Curtis, by Ir. Tharnton. 33 p.)

$2103+$ Cushing, $J$. The exotic garlener; in which the management of the lot-house, green-lıouse and conservatory etc. London 1812. 5. tEd. I1. much improved. London 1814. 8. x11, $236 \mathrm{p}$.

2104t Cuvier, George. Rapport historique sur les progres des sciences naturelles depuis 1789 et sur leur état actuel, pressentè a Sa Mlajesté l'Empereur etc. rédigé par Cuvier. Paris 1810. 4. xvı, 995 p.

(Botanique: p. 20\%-21k.)

2105* Recueil des doges historiques lus dans les séances jubliques de l'institut royal de France. Paris 1819-\$827. 111 voll. 8. - 1: 1819. v11, 430 p. (Daubenton, Lemonnier, l'Heritier, Gilbert. Darcet, Prieslley, Cels, Adanson, Broussonet, Lassus, I'entenut, Saussure.) - 11: 1819. 484 p. (Fourcroy. Desessarts, Carendish, Palles. Parmentier, Rumford, Olivier, Tenon, Therner, Desmarats, Riche, Brugiires.) - III: 1827.506 p. (Beawvois, Banks, Duhamel, Llavy, Berthollet, Richard, Thouin, Lacépide, Halle, Corvisart, Pinel, Fabbroni.)

$2.106^{*}$ Histoire des seiences naturelles depuis leur origine jusqu'à nos jours chez tous les peuples connus, professcie au college de France; completée, rédigée, annotée ef publiée par H. Magdeleine de Saint-Agy. Paris 1841-1843. IV voll. 8. - 1: 1841. 441 p. II : 1841.558 p. - III: 1841. 342 p. - 11: 1843.351 p.

$2107^{*}$ Cyrilli Alexandrini de plantarum et animalium proprietate liber nune primum in lucen editus. Cum S. Gregorii Nazianzeni carminibus selectis. Romae, apud Franc. Zannetum. 1590. 8. (8) 197 p. Bibl. Goett.

(Editor Hieronymus Brunellus soc. Jes. in pracfatione: "llis atjecimus, incuit, poema jumbicun de plantarum et antimalium projecimus, inchit, poema jambicum de plantasum et animalium proprietatibus , yuod a D. Consalso ponce de Leon munus acceperam,
inso vero olint ex Guliemi sirleti Cardinalis exemplo describendum curaverat. Adscribitur quidem, ut videtis, Cyrille Alesandrino, qui fuit olin et adhuc est non modo Graeciae totius, verun etiam ecelesiae universalo orthodoxite lumen. o) 
¿108 Czenpinski, Paul. Botanica dlá szkól Naradowyclı. Warszawie 1785. 8.238 p., 6 lab. B.

$2109^{\circ}$ Czompo, Joham. De Euphorbiaceis Hungariac, Croatiae, Transsylvaniae, Dalmatiae ot litoralis Hungarici. D. Pestini 1837. 8. $44 \mathrm{p}$.

\section{D.}

$2110^{\circ}$ Dachröden, Fricklich von. Beschreibung von 400 Arten Topfpflanzen melist Angabe ilwer Cultur. Nach eigner Erfahrung entworfen. Eisleben unl Leipzig $1831.8 .122 \mathrm{p}$. ("1//2, th.)

$2111+$ Daenzer, $F, G$. Des Euphorbiacées ol en particulier de celles uxitées en médecine, dans l'économic domestique et dans les arts. D. Straslourg $1834.4 .82 \mathrm{p}$.

$2112^{*}$ Dagoty, Gautier. Collection des plantes usuelles, curieuses et rtrangères, selon les systemes de Mr. Tournefort et Linnaeus etc. Paris 1767. folio. $40 \mathrm{tab}$. col. totilemque foll. text.

21136 Plantes purgatives dusage, tirées du jardin du roi et de celui de MIMI. les apoticaires de Paris, représentées avec leur couleur naturelle et imprimées selon le nouvel urt; avec leurs vertus et leurs qualités. Prenier cahier. Paris 1776.4 . xxiv, 24 p., 8 tab. col.

211'" Dahl, Andreas. Observationes hotunicac circa systema vegetabilium divi a Lime Goettingae 1784 . editum, quilus acedit justae in manes Limeanos pietatis specimen. Havniac 1787. 8.44 p.

(Est refutatio recensionis supplementi plantarum in Cotnmentaris Lipsiensibus; rellit in: Hagazin fur die Botanik, 4. Stuck, p. 20-46.)

2113 Dahlborn, Esaias. Vita, studia et gloria Paulliniana fide crena descripta. Lipsiae 1703. S. (47 p.)

2116 Dahlman, C. T. Den fárdige trädgårdmästaren. Stockholm 1728. 8. 230 p. B.

2117* Dahuron, Re'ne. Traité de la taille des arbres et de la maniere de les bien rlever. etc. Cell et Liege 1692. 12. 142 p. - † Nouvelle edition. Paris $1740.19 .286 \mathrm{p}$., praef. italice: Yenezia $170 \mathrm{k}$. folio. $\mathrm{s}$ germanice: Celle 1723. 8 . s.

2118* Dailledouze, J. P. et Jacques, Irires. Catalogue des arbres, arbrisseaux, arlustes et plantes de pleine terre cultivées dans les pépinières au Petit Sacconex près Genève. Genève 1S2S. \$. 40 p. - TGenère 1831.8 .5211 .

2119 Dale, Samuel. Pharmacologia seu manuductio ad materiam medicam. Londini 1693. 12. 389 p. - Supplementum: Londini 1705.12. - El. III : Londini 1737.4.460 p. B.

2120 " Dale, Thomas. De Pareira brava et Serapia officinarum. D. Lugduni Batavorum $1723.4 .19 \mathrm{p}$

2121* (Dalechamps, Jacques.) Historia generalis plantarum in libros XVIII per certas classes arteficiose digesta, haec, plusquam mille imaginibus plantarum locupletior supcriorilus, omnes propenorlum Inue aly antiquis scriptoribus graecis, latinis, arabibus, nominantur; nec non eas quac in Orientis atque Occidentis partibus ante seculum nostrum incognitis, repertae fuerunt, tibi exhiloct. llabes etiam earunlem plantarum peculiaria diversis nationibus nomina: habes amplas descriptiones, e quibus singularum genus, formam, uli crescant, et quo tempore vigeant, nativum temperamentum, vires denitue in medicina proprias cognosces. Aljecti sunt indices, non solum graeci et latin. sell aliarum quoque linguarum locupletissimi. Lugduni, apud Guliehum Rovillimn. 1587. (in aliis exemplarilus 1586.) Il roll. folio. cum ic. xylogr. i. t, - I: p. 1-1095. et (6 foll.) - 11: p. 1097-1922. Appendix: 36 p. et (3S foll.) indices.

(Johames Holinaeus (J)es Moulirs), medicus Lugramensis hame bistoriam ad umbilicum perduxit, ctuan halechumpius superventente

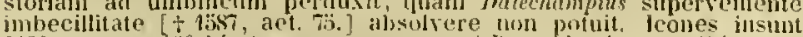

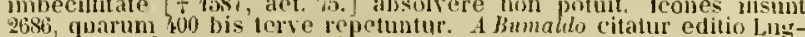
dunensis 1535.8 , quam inspicere non contigit; nemo alius eam vidit post Bumaldum.

* gallice: Ilistoire générale des plantes, contenant XVII livres exafrment departis en deux lomes sortie latino de la bibliotheque de Mr. Jacques Datechamp.s, puis faite francaise par Jean des Moulins. "te. Lyon, chez les léritiers de" Roville. 1613 . Il voll. folio. $-1: 960 \mathrm{p}$, ind.

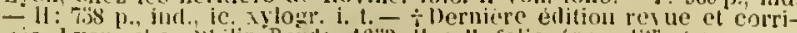
gie. I.yon, chez iphilip Rorde. 16.33. II voll fnlio. (non dittert.
2122* Dalibard, Thomas Francois. Florae l'arisiensis Prodromus, ou catalogue eles plantes qui naissent dans les environs de Paris. ropportées sous les dénominations moternes et ancienues, et arrangers suivant la méthode sexuclle de Linneus. Arec l'explication en français de tous les termes de la nouvelle nomenclature. Paris 1749. 8. LIV, 403 p., praef, iut., 4 tal.

2123 Dalla-Bella, Joaú Antonio. Mcmorias e olscriaçōes sobre () modo de aperleiçoar a manufactura do tzeile de Oliveira em Portugall. Lisbua 1784. 4. 137 p., 1 tab. B.

$2124 \div-$ Memoria sobre a cultura das oliveiras em Portugal. Coimbra 1786. 4. xix, $190 \mathrm{p}$.

2125 Dalla Bona, Giovami. Liuso e l'aluuso del Cafte. Verona 1751. 8. 70 p. - Verona 1760.4.99 p. B.

$2126+$ Dallaporta, Niccolo. Prospetto delle piante che si trovano nell' isola di Cefalonia, e che si jossono adoperare a titulo di alimento o di rimedio. Corfu, nella stamperia del governo. $1821.4, x 111,148 \mathrm{p}$.

$2127 \div$ Dambourney, $L$. A. Recucil de procédes et experiences sur Ips teintures solides que nos régétaux indigenes comnuniquent aux laines et aux lainages. Paris 1786.8.407 p. - Nouvelle (troisieme) éditiou augmentée. Paris 1793.8. a.

2128 Instruction sur la culture de la garance ent la manicre d'en préparer les racines pour la teinture. Paris 1788. 4. Q.

2129 Histoire des plantes. qui servent is la teinture. Paris 1792.8. a.

2130 Dammers, Ferdinand Ludwig. De Datiscae cannabinae in febribus intermittentibus sanandis usu. D. Goettingae 1799.4.19 p. B.

2131 Dampier, William. A new royage round the world. London 1697. 8. $550 \mathrm{p}$. cum tibulis. - ib. 1729.8 . (the first volume of a collection of voyages in 4 voll. non diffort.) - A supplement to the vayage round the world, in the 2 il volume of the same collection. 184 p. B. gallice: Amsterlim 1720. I' voll. 8. DC.

(1)e pluribus Americae mericlionalis plantis tractat in hoe itinere. quas lajus in llist. plant. 111. p. 22:'; retulit et descripsit.)

2132 Dancer, Thomas. Catalogue of plants, exotic and indigenous, in the botanical gardeu. Jamaica 1792. St. Jago de la Vega (1792). 4. $16 \mathrm{p} . \mathrm{B}$.

Decem paginae priores, de plantis exolicis. redeunt in Bryan Edward's thistory of the british colonies in the West Indies, Vol. 1. 1. 198 -211.)

2133\% Dandolo, Vincenso. Nuovi cenni sulla coltivazione de' pomi di terra e vantaggi della medesima , rapporto al ben essere dell nono e dello stato. Como (1510). $8.45 \mathrm{p}$.

2131* Danielli, Stefano. Raccolta di quistioni intorno a cose lli botanica notomia, filosofia e medicina, agitate gia tra qli colebratissimi pul,blici professori nella universita di Bologna, Marcello Malpighe e Giangirolamo Sbaragli, fatta per now degli stueliosi. Bologna 1723. \& 79 p. Bibl. Reg. Dresd.

2135 Dantz, Johamn. Talulae simplicium medicamentorum, quae alpurl Dioscoridem, Galenum et Plinium sunt omnium, exceptis is quae ab animalibus sumuntur, ficultates tam generales quam particulares continentes. Item de simplicium meticamentorum facultatibus. Dialogi quatuor. Basileae, apud Henricun Petrum. 1543. folio. Bibl. Maz.

2136 Dany. La manière de semer et faire pépinicres de sauvageanx. enter toutes sortes d'arbres etc. Paris, Giles Corroset. 1360 . 8. Nouvelle údition augmentéc. Orleans, Eloy Gibier, 1572. 12. s.

2137* Danzel, Johann Fr. Nicolaus. De Lycopodii herba et semine, D. Goettingae 1814. S. 7 .1 p.

2133 Darby, John. A manual of botany, adapted to the productions of the southern state: in two parts, arranged on the natural system. New York, Wiley and Putnam. 1841. 12. ( 1 Dollar $50 \mathrm{cts}$ )

2139* Dardana, Giuseppe Antonio. In Agaricum campestrem veneno et patlia infamen acta nd Vicloriam Picum. Augustae Taurinorum 1788. 8. $32 \mathrm{p}$.

2140* Dargassies. Lettres a Nanine sur b hotanique. Toulouse 1898 Il voll. 12. D.

2141* Darlington, llilliam. FIoruli Cestrica; an essiy towards a catalogue of the phaenogamous plants, mative and naturalized, groving in the vicinity of the borough of West-Chester, in Chester Comuly. Pennsylwania: with brief notices of their properties and uses in 
medicine, rural econony and the arts. To which is subjoined an appendix of the usefull eultivated plants of the same district. West Chester, Peunsylwania, typ. Siegfried. 1826.4 min. $x v, 152$ p., 3 tab. col. (1l. $4 \mathrm{~s}$.)

211.2* Darlington, William. Flora cestrica an attempt to enumerate and deseribe the flowering and filicoid plants of Chester-county in the state of Pennsylvania. With brief notices of their properties and uses in medicine, domestic and rural economy and the arts. WestChester, typ. Siegfried. 1837. 8. xxm, 640 p. et 1 mappa geogr. eol.

$9143+\ldots$ An essay on the development and modifieations of the external organs of plants. Compiled chiefly from the writings of $J$. Wolfgang von Goethe, for a public lecture to the class of the Chester county cabinet of natural science. West-Chester, Pennsylvania. $4839,8.38 \mathrm{p}$.

214 - $\div$ A discourse on the character, properties and importanee to man of the natural family of plants called Granineae, or true grasses. West Chester, Pennsylvania 1841. 8. 22 p.

2143\% Darluc, Michel. Histoire naturelle de la Provence, contenant ce qu'il $y$ a de plus remarquable dans les regnes régétal, minéral, animal et la partie géoponique. Avignon 1782-1786. lll voll. 8. 1: 1782. xv, $523 \mathrm{p} .-11: 1784, \mathrm{xx}, 315 \mathrm{p} .-111: 1786 . \mathrm{I1}, 373 \mathrm{p}$.

$2146 \div$ D'Artigues. Némoire sur la conservation des blés. Paris 1820. 8. 14 p., i tab.

2147t (Darwin, Erasmus.) The botanic garden, a poem in two parts. Part I: containing the economy of vegetation. Part II: the loves of the plants. Witl philosophical notes. London 1791. (Lielsfield 1789.) 4. - I: 214 , 126 p., 9 tals. - 11: 184 p., 8 tab. - †Ed. W : London 1799. 8. - I: xx, 492 p., tab. - Il : xri, 282 p., tab.

$\div$ gallice: Les amours des plantes, poème en qnatre chants suivi de notes et des dialogues sur la poesie. Onvrage traduit de langlais de Darwin par J. P. F. Deleuze. Paris an VIIt. (1800.) 12 . 412 g. (3 fr.) * ilalice: Amori delle piante poema con note lilosofiche di Erasmo Darein. Traduzione dall originale inglese con note di Giavanni Gherardini. Terza edizione Milanese riveduta dal traduttore. Milano 184k.
$4.191 \mathrm{p}$.

2148* Zoonomia or the laws of organic life. Ed. II. corrected with plates. London 1796. 11 voll. 4.

gallice: Gand 1810, 8. DC.

- italice: Milano 1834-1836. If voll. 8

* germanice: llannower $1790-1799.3$ Búnde. $8 .\left(6 \frac{1}{2}(h)\right.$.

$2149^{*}$ - Plyytologia or the philosophy of agriculture and gardening etc. London 1800.4 . vir, 612 p., ind., 12 tab. (10 s. A.) * germanice: Phy tonomie oder philosophisehe und physische Grundsatze des Acher- und Gartenbaus. Aus d. Englisehen von Dr. Hebenstreit. Leipzig 1801. 2 Bände. 8. vil, 399, 202 p., 6 lab. (3 th.)

21:50* Dassen, Michael. De Scillitino additis experimentis de venenorum vi in plantas. D. Groningae 1834.8 .42 p. cun 4 tabula venenorum a plantis alssurptorum.

$21: 1 \div$ Daubeny, Charles. An inaugural lecture on the study of botany, read in the library of the botanic garden, Oxford. Oxfurd 1834. S. 39 p., Appendix: 7 p., 2 tab. (Plans of the botanic garden.)

$2132 \div \div$ On the action of light upon plants and of plants upon the atmosphere. Lomlon 1836.4

From the Philosopinical Transactions, 1836. p. 149-173.)

$2133+$ Daudirac, Frangois. Dissertation sur l'utilité de la botanique en medecine. These. Paris 1828, 4. 22 ].

IIfbł: Daum, Franz von. Bemerkungen uber die Landwirthschaft, das Klima und die Vegetation in Sudfrankreich, Walschland und Malta wahrend einer Reise in Jahre 1842, und Versuch einer náberen Darstellung des landwirthschaftlichen Betriel;es in dicsen Ländern. Charlottenburg 1844. 8. xis, 364 p. (2 /h.)

$21333 \%$ David, (f. Némoire sur le Madia, suivi du Rapport. Caen 1842. 8. $44 \mathrm{p}$. Soc. royale de l'agr. el de comm. de Caen.

$215 \% 6$ Davids, Eugen. Commentatio de fontibus vergetationis plantarum. Lugduni Batavorum 1822. 4.

$2137 t$ Davies, IIugh. Welsh botanology; part the first (and second). A systematic catalogue of the native plants of the isle of Anglesey, in latin, enylish and welsh; with the habitats of the rarer species and il [ew observations. To which is added an Appendix, consisting of those genera, in the three first volumes of Flora britanuica, which are not of spontanrous growtly in Anglesey, rendered likewise into welsh. London 1 \& 13.8 . XIv. $8 v, 255$ p., 1 tah. (4s. 6d.)

Pritzel, Thes lit. bot.
$2138+$ Davy, Humphry. Elements of agricultural chemistry, in a course of leetures for the board of agriculture. London 1813. 4. vir, $323 \mathrm{p}$., 10 tab. with an Appendix: Account of the results of experiments on the produce and nutritive qualities of different grasses and other rlants, used as the food of animals, instituted by John Duke of Bedford. xLII P., ind.- New edition, with notes by Dr. John Dary. London 1839. 8. (15s.)

$\div$ gallice: Elemens de chimie agrieole en un cours de lecons yrur Is eonité dagrieulture. Traduit de langlais par bulos. Paris 1819. 11 voll. $8 .-1: 7,3$ k 2., 6 tab. - 11: 431 p., 2 tab.

2139 Deacon, Joln. Tobaceo lortured, or the fithic fume of tobaeco refined. Lonton, Richard Field. 1616. 4. Bibl. Reg. Paris.

$2160^{*}$ Deakin, lichard. Florigraphia britannica, or engravings and deseriptions of the flowering plants and ferns of Britain. London 1841-1845. Il voll. 8. - 1: 1841. Classes I-Y: 1. 1-460. Synojusis of the genera, ind., $88 \mathrm{tab}$. col. enm 524 figuris $(2 \mathrm{l} .17 \mathrm{~s}, 6 \mathrm{~d}$. - plain II. 10s.) - II: 1845. Classes V1-XV: p. 461-930, praef., ind., 92 tab. col. cum figuris 525-1076. Bibl. Caes. Vind. et Regıs Sax. (Continuatur. Opus miserrimum, biguris minutis pessimis e English botuny mulla magnitudinis partium ratione habita desumlis.

2161 t DeBrébisson, $L$. Alphonse. Coup d'oeil sur la végétation de la Basse-Normandic, considérées dans ses rapperts avee le sol et les terrains. Caen 1829. 8. 25 p.

$2162+\div$ el Godey. Algues des environs de Falaise, doerites et dessinces. Falaise 1\$35. 8. 66 p., 8 tab. col. ( 5 fr.)

$2163 \div$ Flore de la Normandie. Première partie. Plannérogamie. Caen et Paris 1836 . 12. xvi, 430 p. ( $5 \mathrm{fr}$ )

2164: $\mathbf{i}^{\circ}$ Considérations sur les Diatomées et essai diune classification des genres et des espèces apparlenant a cette famille. Falaise et Paris 1838. 8. 22 p.

$2165 t$ DeBrondeau, Louis. Description de deux champignons nouveau. découverts et dessinés. Suivie d'obscrvations el de la creation du neuveau genre Gyrocephalus, par C. H. Persoon. Paris 1824. \&. 7 p., 1 tab.

(Extrait des Ammales de la soe. Linn. de Paiss. 182t.)

$2166 \div-$ Observations sur l'Agaricus pilosus de lludson. Paris 1827.8. 7 p., 1 tal.

(Extrait des Amuales de la soc. Linn. de Paris. 1827.)

$2167 \div$ — Recueil de plantes cryptogames de l'Agenais, nouvelles, rares et peu connues, omises dans la Flore agénaise (de Suint-Amans) décrites et dessinées. Lithographiées jar Madame Sophie Lamouroux. Suivid'uu supplément ả la Cryptogamie de la Flore agenaise. Agen 1828-1830. 8. Fascicules 1-3: 39 p., 10 tab. ( $7 \mathrm{fr}$.)

2168 Deça, Lopez de. Governo politico de agrieultura, contiene tres prartes prineipales. La primera propone la dignidad, neeessitad y utilidad de la agricultura etc. Madrid, por la vidua d'Alonso Mlartin. 16 18.4. s.

2169* Decaisne, Joseph. Ilerbarii Timorensis descriptio. Parisiis 1833. 4. 173 p., ind., 6 tah.

(Annales du Muséum. 183k. tom. 111.)

2170* Recherches anatomiques et physiologiques sur la Garance, sur le developpement de la matière colorante dans cette plante, sur sa culture et sa préparation, suivies de l'examen botanique du genre Rubia et de ses espèces. Bruxelles 1837. 4. 77 p., 10 tab. col.

2171* - Recherches sur l'analyse et la composition climi(jur. de la betterare a suere par $E$. Péligot; et sur l'organisation anatomique de cette racine par J.Decaisne. Paris 1839.8 . vur, $50 \mathrm{p} ., \mathrm{t}$ tal.

2172* __ Mémoire sur le développement du pollen, de l'ovule et sur la structure des liges de gui (Viscum album). Bruxelles 1840. 4. 63 p., 3 tab

(Mém. de l'Acad. the Bruxelles, tom. Nilt.)

$2173^{*}$ Essai sur une classification des algues el des polypiers ealciferes. Paris 1842.8 . 120 p., 4 tab.

217.; - Enumeration des plantes recueillies par M. Bove dans les deux Arabies, la Palestine, la Syrie et l'Egypte. Paris 1843. \& 67 p., 1 tah.

Eatrait des Amales des se. nat. sér. IJI. tome II.)

Libellus altero insecribitur titulo. Florula sinaica.

2173* _- llistoire de la maladie des pommes de terie en $1845^{\circ}$ Paris 1846.8 . vI, 126 p. et tahle des matières. ( 2 fr. $50 \mathrm{c}$.)

2176* DeCandolle, Alphonse. Monographie des Campanulees. Paris 4830. 4. var. 384 p., 20 tal. $(25 \mathrm{fr}$.) 
$2177^{\circ}$ DeCandolle, Alphonse. Mémoire sur la famille des Anonacées, et en particulier sur les espèees du pays des Birmans. Genève 1832. $4.45 \mathrm{p}, \mathrm{s}$ tah.

$2178^{*}$ - Introduction a l'étude de lit lrotanique on traité élémentaire de cette science. l'aris, Roret. 1835 . Il voll. 8. - I : xvi, 534 p. - Il: vit , 460,16 p., 8 tal). ( $16 \mathrm{fr}$.) - impressio fraudusa: "Bruselles, Mleline, Cans et Co. 1837. gr. 8. xil, 462 1., 8 tal, trossic:e: vertento J. Schychowski. Mosifuae 1837. 8. xxill, 5ill p. 7 tob. el clligie's 1. P. DeCandollia.

germanice: Anleitung zum slutium der Botanik nder Grundriss dieser Wissenschaft, chthallent die Organugraphice, Physiologie, Mce thodologie, din l'llanzengengraphic, vine Uehersieht der fossilen fiewáche, der platmaceutischen Botanik und der Gesilhichts der Botinih. Nach dem franzosischen bearbuitet roul br. Alexander von Bunge. \%neite selur vermehrte Aullige. Leipzig 18"ts. 8. Xxil, 792 p.,

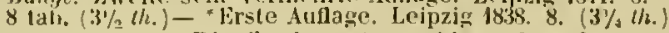

$2179 \div-$ Distribution gcographlique des plantes alimentaires. Genteve 1836. $8.63 \mathrm{p}$.

(Tiré de th Biblintheque unirerselle de Genève Avril el Mai 1836 .

$2180^{\circ}$ - Notice sur le jardin botanique de Geneve; publiese par ordre de l'administration de cet établissement. Genève 184.5 .8 $\$ 7$ p. $(50 \mathrm{c}$.

2181 DeCandolle, Augustin Pyramus. Notice sur le Reticularia rosea (Bull. soc. phil. de Paris, 1798. p.105. I tah.)

$2182 \div-$ Prenier essai sur la nutrition des Lichens. Paris 1798. 4. $11 \mathrm{p}$.

(Jourual de physique 1798. vol. ALvill. p. 107.)

2183 - Oliservation sur une espice de gomme, qui surt des buches du hêtre. (Journal de physique, 1799. vol. XLVIII. p. 447.

218 ' Observations sur les plantes marines. (Extrait: Buli. soc. phil. de Paris 1799. p. 171. 1 tals.)

$2185^{*}$ - Plantarum historia steculentarum. llistoire des plantes grasses, arec leurs figures en coulours, dessinèes par $P$. J. Redoulé. Paris 1799-1829. AXX1 fasciculi. folio. (185tab. col., 159 foll.) Opus rere semper incompletun! Fasciculi $f-x \boldsymbol{X}: 120$ tah. enl. intidempue folia textus praeter titulum, praefatioriem of indicem sismunt volumen prinum. Tunc sequuntur dascieuli XXi-XIVIII, in quibus tabulae et lestus 131- 159 insunt usque ind Mesembryanthemum viridiltorum, sine titula et indice. Uttimos fasciculos XXXX-IXXI annis 1828 - 1529 imprimi curavit bihliopola Garnery Parisisiensis, vix vero redidit, yuum ne in antoris quidem bihliolleea adsint. llis ritian beatus Guittemin operam navavit. Exstant in hibliotheca Delessertinna et Goettingensi Sectuentes insunt tabulae: Stapelin hirsula Cactus Roveni, Timbilicus pendulinus.

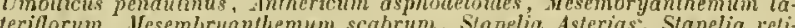
teriflorum, Mesembrynnthemum scabrum, s/npelia Asterias, Stapelia reli culata, Cotyledon mugulatis, Mesembryenthemum albidum, Mesembryan themum tuberculatum, Mesembrysnthemum radicans. - Duac operis sunt impressiones, altora forma folio dictal, cujus ithterdum folia 139-142 cum tabulis desiderantur, sulbditis ális e minori editione; pretilum
fasciculi $30 \mathrm{fr}$. = $930 \mathrm{fr}$; altera quarta torma, pretio fasciculi $12 \mathrm{fr}$.

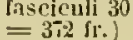

2186

- Notice sur quelques genres de siliculeuses et en particulier sur le nouveau genre Senebicra. (Mém, de ld soc. d'hist nat. de Paris, 1799. vol. I. p. 140. et par extrait: Bull. suc. phil 1799. p. 172.)

2187 - Note sur la monographie des Leggumineuses biloculaires. (Bull. soe. phil. 1800. p. 123.

2188 Expérienees relatives a l'infuence de la lumière sur quelques vécétaux. (Fixtrait: Bull. soc. phil. 1800 . p.138. - Journal) de physique, rol. Lll. p. 124. - et en totalité: Mĺm. des savans étrangers de l'hnstitut, vol. I. (1805.) p. 370.)

2189 Mémoire sur la famille des Joubarbes, Sempervivae Juss. (Extrait: Bull. soc. phil. 180 I. p. 1.)

2190 Mémoire sur les pores de l'écorce de feuilles. (Extrait: Bull. soc. phil. 1801. - Jourual de physique 4801. - et en totalité : Mlém. des savans étrangers Je l'Institut, vol. I.

2191 Némoire sur la régétation du guy. (Extrait: Bult. soc. phil. 1801. - en totalité: Mẻm. des savans étrangers de l'lnstitut vol. 1.)

$2192 \div$ Rapport sur les Conferves, fait à la sociétẻ philomatique. (1802.) 4. 20 p.

Extrait: Bull. soc. phil. 1801. p. 17; et en totalité: Journal de phrsique, 1802 . vol. LIV. D. 121. - Suectat at conmentationes manuscriptas, quas Girod-Chantrans all socjetatent uiserit.

2193 Note sur le Réseda gaude. (Annales des arts, sc. et lit. 1801 .

$2194 \div$ - Sote sur le Cartlame des teinturiers. 1801. S. p. 65 -69.1 tah

Journal fles arts, se. nt lit. II. annèe. 2 ij nivose an $1 \mathrm{~S}$. p. 6̈j-69.)

$219 \ddot{3}$ 4802. p. 68 .
2196 DeCandolle, dugustin Pyramus. Ilescription d'un nouveau genre de plantes numme straphantlus. (Extrait: Bull. soc. phil. I80z. 13. 122. - "Estrait par Oesfonsuines: Ann. du Mluséum dlist. natl. vol. 1. 11. 408-112. ot I tab. - lin totaliti: Mcm. des savans étrangers de l'Institut, rol. I. 1803. p. 406.)

$2197^{*}$ - Les Liliacces pritntes par P. J. Redoute. Paris 1802 -1808 . IV roll. folin. 240 foll. 240 ab. col.

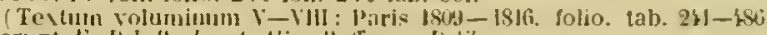

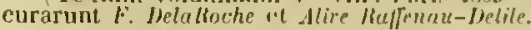

2198* - Recherches botaniro-mérlicales sur les differentes espèers d'tpécacuanho. 4. p. 179-194. I tal,

(Evarait: Bull. soc, phil. 1802. p. 12k; en entier: Ment. de la societe dre irofesseurs de iecole de metecine the paris, vol. I. (incdit? 1812. 1). $178-19 \%$.)

2199 Mémone sur les genres Astragalus, Phat'i, Oxytropis, Colutea et Lessertiit. (Bult. soc. phil. 1802. p. 130.

$2200^{*}$ Astragalogia, nempe Astragali, Bisemulate et Oxytropidis, nec non Phacie, Colutere ot Lessertiae historia iconiluu. illustrata, Parisiis 1802 . folio min. vil, 269 p., 50 til), (60 fr. ${ }^{*}$ Parisiis 1802 . folio max. virı, 218 p., 50 tal). (12 $\mathrm{fr}$.)

22016 Mémoire sur la fertilisation des dunes. P'aris an $\mathrm{Jl}$. 8. 27 p.

(Extrail des Annales de lagriculture françaiso tome .1lli. 1803.

$2202-$ Note sur le genre Rhizomorjula. (liull. sae. phil. 1803. 13. 20 .

2203 Múmoire sur le Viensseuxia, gense de la famille des Iridées. (Extrait: Bull. soc. pliil. 1803. p. 203: en entier: "Ann. du Nuséun d'hist, nat. de Paris, vol. II. p. 136-141. el I tah).

2204 - Note sir deux genres nouveaux de la fimille dris Iridées, le Diasia et le Montbretia. (Bull. soc. phil. 1803. p. 25l.)

2203 Examen d'un sel recueilli sur le Reaumuria; avec II. Frederio Cuvier. (Bull. soc. phil. 1803. p. 251.)

2206 Paquerette, Parisette, Pirnassie, Paronvque, Parthene, Passerage, Pezize. Articles remis à M. Deta.Mturck en 1785, et imprimés sans la participation de l'auteur en 1804 . au rol. T. de la partie botanique de l'incyclopédie métlrodique.

$2207 \div-$ Essai sur les propriétés midicales des plantes comparées arec lenrs formes extérieures et leur classification naturelle. D. Paris 1S04. 4. 148 p. $-{ }^{*}$ Ed. II : Paris 1816. 8. xll, 397 p. $(5 \mathrm{fr} .50 \mathrm{c}$.)

(Editionent fraudosam : Bambers 1803. 8. non villi.)

* germanice: Versuch uber die Arzneikrafle der Ptlanzen, verglichen mit den ausseren Formen und der naturlichen klasseneintheilung derselben. Nach der zueiten franzosischirn Aullage mit Zusitzen unt Anmerkungen son harl Julius Perleb. Aarau 1818.8 . xiv, $\$ 50 \mathrm{p}$. (2 $2 \mathrm{~h}$.

2208* — el Jean Baptiste DelaMarck. Flore française ou descriptions succinctes de toutes les plantes qui croissent naturellement en France, disposées selon une nourelle míliode d'analyse et précédées par un exposé des principes élementaires de la hotanique. Troisième édilion. Paris 1805. IV tomes. 8. - I: xrr, 224,388 p. 11 tab. - If: 111,600 p. avec une carte botanigue de la France. - 111: 731 p. - 1V: 944 p. - "Nìme édition augnentec du tome $\mathrm{V}$ ou volume V1; contenant 1300 especes nou décriles dans les $\mathrm{V}$ preniers volumes. Paris $1813.8 .662 \mathrm{p}$. (48 fr. - La carte sépariment: 6 fr.)

$2209 \div$ - Princjpes élémentaires de botanique et de physique végétale. Paris $180 \%$. $8.164 \mathrm{p}$.

(Evtrait de la troisieme edition do la Flore française.)

2210 Note sur la mausse de Corse. (Bull. soc. phil. 1805. p. 363.$)$

$2211 *$ Synopsis plantarum in Flora gallica descriptarum. Parisiis 1806. 8. (7 fr.) - Ed. 1l. vide: Duby.

$2212 \div$ Sur les champignons parasites. Extrail d'un memoire Iu à l'Institut le 26 octobre $1806.4 .19 \mathrm{p}$.

(Annales du Muséum d'hist. nat. de Paris, vol. IX. 1807. p. 56-7\}.)

$2213+\longrightarrow$ Mimoire sur le Curiera, genre nouveau de la famille des Rubiacées. (Paris 1807.) 4.7 p., 1 lab.

("Annales du Yusium ('hist. nat. de Paris, rol. KX. 1807. p. 216222. et $($ tab.)

2214* - Icones plantarum falliae rariorum nempe incertirum aut nondum delineatarum. Fasciculus I. Parisiis 1808. 4. vit, $16 \mathrm{p} ., 50$ tab.

$2213 \div \div$ Mémoire sur le Drusa, genre noureau de la famille des Ombelliferes. (1508.) 4.8 p., I tab.

(Extrait: Bull soc. phil, 180s, p. 8k; en entier: "Annales du .Muséum d'hist. nat. de paris, vol. X. is07. $\mathrm{r}$. $260-57$. et I tab.) 
2216 DeCandolle, Augustin Pyramus. Note de quelques plantes nouvelles trouvées en France. (Bull. soc. phil. 1808. p) 117.)

2217t Rapports sur les voyages botaniques et agronomiques faits dans les dejpartemens de lempjire d'après les ordres de S. E. le Ministre de l'interieur. Paris 1813, 8.140, 111, $110 \mathrm{p}$. (Singulae jam antea hisce titulis prodierunt:

+ Rapports sur deux voyages botaniques et agronomiques dans les departemens de l'ouest et du sud-ouest. Paris 1808. 8 . $140 \mathrm{p}$.

Mém. de la soc. d'agric. de Paris, X. p. 228. - Xl. p. 1.)

Rapports sur deux royages bolaniques el agronomiques dans les départemens du sud-est ot de l'est. Paris 1810.8. 111 p. (Mem. de la soc. d'agric. de Paris, Xil. p. 210. - Xull. p. 203.)

Rapports sur deux voyages lotaniques et agronomiques daus tes dejpartemens de nord-est et du centre. Paris 1813.8. 119 p. (Mém. de la soc. d'agric. de Paris, XIV. p. 213. - Xv. p. 200.) veau cours complet d'agriculture théorique et pratique, ou dictionnaire raisonne et universel d'agriculture, vol. V1. 1809. p. 355. Ed. ll : ib. val. VIl. 4822. p. 303.)

2219 Note sur la canse de la dircetion des tiges vers la lumière. (Mén, de la soc. d'Arcueil, vol.11. 1809. p. 104.)

$2220+$ Note sur les Georgina. (Montpollier) 4809. 8. $14 \mathrm{p}$. (Bulletin de la soc. libre des sc. el belles lettres de Montpellier tome 1\%: Nr. 48. P. 18̈-198, - *Atmales du Muscum d'hist. uat. de Paris, vol. Xit. 1810 . p. $307-316$.)

222." - Eloge historique de M. Auguste Broussonet. Montpellier $1809.4 .33 \mathrm{p}$.

2222 - Observations sur les plantes Composćes ou Syngenèses. Trois memoires: Compusées, Cynarocephales, Labiatiflores. ( ${ }^{*}$ Annales du Mluseum d'hist. nat. de Paris, rol. XV]. 1810. p. $135-158$. el 1 tab. - *ol. XV. 1810. p. 181-208. et 10 tab. - *ol. XIX. 18 12. 1). 59-72. et 5 tab. - Extrait: Bull. soc. phil. 1811. p. $223 .-1811$. p. $240 .-1812$. p. 166.)

2223 Description du Chailletia. ("Annales du Mustum d'hist. nat. de Paris, vol. XVH. 1811. 1. $153-159$. et 1 tab. (Extrait: Bull. soc. phil. vol. H. 1814. p. 205.)

222: ___ Mémoire sur les Ochnacécs et Simaroubóes. ( ${ }^{*}$ Annales du Muséum d'hist. nat. de Paris, vol. XVll. 1811. p. 398425. et 21 tab. (Extrait: Bull. soc. plsil. vol. 11. 1811. p. 206.)

$222 !)$ Monographie des Biscutelles ou Lunetières. ( ${ }^{*}$ Annales du Muséum d'hist. nat. de Paris, vol. XT11]. 1811 p. 292-301. et $G$ (a).)

$2226^{*} \longrightarrow$ Recueil des mémoires sur la botanique, contenant: Observations sur les plantes Composces, la descriptinn de Chaillelia, monograplie des Oclnacées, Simaroubees et Biscutelles. Paris $1813.4 .52,14,7,28,10$ p. (t 48 lab. ( 24 fr.)

(Insunt qualuor commentationes praecedentes. Ipse Candollius 54 tabulas indicat.)

222:* Catalogus plantarum lıorti botanici Mlonspeliensis addito obserrationum circa species novas aut non satis cognitas fasciculo. Monspelii 4813.8 .455 p., praef.

$2228^{*}$ — Thèrie élémentaire de la bolanique, ou exposition des princijues de la classification naturelle et de l'art de rlécrire et d'étudier les régítaux. Paris 1813 . 8. vili, 500 p., ind. - ${ }^{*}$ Ed.11. revue et augmentée. Paris 1819. 8. vII, 566 1). (6 fr.) - * Ed. Ill. publipe par Alphonse DeCandolle d'après les notes et les manuscrits de l'auteur. Paris 4844. 8. x11. $468 \mathrm{p}$.

* germanice: Theoretische Anfangsgründ. der Botanik, oder Firklarung der Grundsătze der naturlichen klasseneintheilung und der

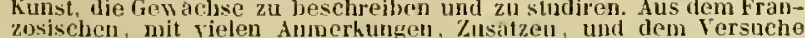
zosischen, mit rielen Anmerkungen, Znstizen, und dem tersucho

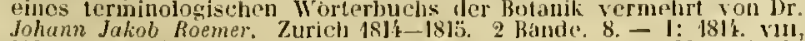

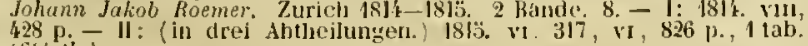
$(6 . / 6$ th. $)$

Némoire sur les Rhizoctones, nouveau genro des champignons, qui attaque les racines des plantes et en particulier celle de la lucerno cultivée. (1815.) 4. p. 209-216., 1 tab, col.

(*.Mèn. du Muséum a'hist. nat. de Piris, vol. JI. 18|ว̈. p. 209-216. et 1 tab.)

$2230^{\circ}$

Mémoire sur le genre Sclerotium el ell part
sur l'ergot des Ceréales. (1815.) 4. p. $401-420.41$ tal, col.

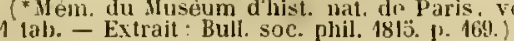

2231- DeCandolle, Augustin Pyramus. Mémoire sur la gèographic des plantes de France, consillerée dans les rapports avec la hauteur absolue. (Paris 1817 .) 8. 1). 262-322.

(Mém. de physique et de chimie de la soc. d'Arcuei., vnl. III. 18IT.) $2232 \div-$ Considérations générales sur les fleurs doubles et en particulier sur celles de la famille des Renonculacées. (Paris 1817.) S. 1.. $385-404$.

(Mén. de physique et de chimie de la soc. d'Arcueit, vol. III. 181\%.

2233 - Troisieme et quatrième mémoire sur les chan:pirgnons parasites. Genres: Xyloma, Asteroma, Polystigma et Stilbosjora. 1817.4. p. 312-340., 2 tab. col.

("Mém. du Museum d'hist. nat. de Paris, vol. MIl. 1817. p. 312-3ł0. et 2 tat.)

2231:- _ Conjectures sur le nomlire total des especes, qui végètent sur le globe. Lues a la société helvétique des sc. nat. a Zurich. (Genève 1817.) 8. p.119-124.

(Bibliotlèque univ. de Geneve, vol. V1. 1817. p. 119-12k.)

$2235 \div-$ Rapport sur un livre du Prince de Solm-Dyck: "Catalogue raisonnó des espèces et variétés d'Aloes décrites par HM Willdenow, Haworth, De Cundolle et Jacquin, et de celles now décrites existautes dans les jardins. 1817.8., 8. 7 p.

$2236^{*}$ - Regni vegetabilis systema naturale, sire ordines genera el species plantarum secundum methodi naturalis uormas digestarum et deseriptarum. Parisiis 1818-1821. Il voll. 8. - I 1818. sistens Prolegomena et ordines quinque, nempe Ranunculatceas, Dilleniaceas, Magnoliaceas, Anonaceas et Mlenispermeas 564 p. - II: 1821 . sistens ordinss sex, nempe Berberideas, Podophylleas, Nymphaeaceas, Pajaveraceas, Fumariaceas et Cruciferas 745 p. $(27 \mathrm{fr}$.)

$2237+-$ Remarks on two genera of plauts to be referred to the family of the Rosaceae, (Kerria and Purshia.) In a letter to Sir J. E. Smith. (London 1818.) 4. 7 p.

(From the Transactions of the Limnean Society, yol. Xil. 2. 1815 p. 152-159. Commentatio practer titulum in lingua gallica scripta est.

$2238+$ Note botanique sur le Gingho biloba L. (Geneve 1818.) 8. p. $130-133$

(Bibliotheque univ. de Genève, vol. I11. 1818. p. 130-133.

$2239 \div-$ (Sur la) Monographie des Céréales et l'Herhariun céréale de la Suisse par $N$. C. Seringe. Bern 4818. s. l. et a. $8.11 \mathrm{p}$

$2240^{*}-$ (Premier) Rapport sur la Jondation du jardin de botanique de Gencre. Genève 1819.8 .42 p. $(75 \mathrm{c}$.)

$2241^{*}$ Catalogue des arbres fruitiers et des vignes du jardin botanique de Genève. Février 1820. Genève 1820. 8. vi, $42 \mathrm{p}$. (1 fr. $25 \mathrm{cs}$ )

$2242 \div$ Instruction pratique sur les collectious botaniques a l'usage des voyageurs, qui sans aroir étudié l'histoire naturelle des plantes, désirent être utiles ả cette science. (Genéve 1820.) 8. $16 \mathrm{p}$.

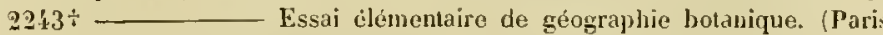
1820.) $8.64 \mathrm{p}$.

(Article: "Gégographie botaniquen du dictionnaire tes sciencre uaturelles, vol. IVill. 1820. J1339-122. - Evtrail: Bibl. univ, de Genève, vol.' XII. 1821. p. 220-233.

224:* - Second rapport sur la fondation du jardin de botanique de Genève. Genère 1821.8.46 p. (75 c.)

$2245 t-$ Mémoire sur les affinités naturelles de la famille de: Nymphaeacées. (Genève 1821.) 4. 36 p., 2 tab.

(Ném. de la soc. de phy's. et d'hist. nat. do Genève, rol. I. 18:1. p. 209. - Extrait: Bull. sc. nat. 1]ll. p. 66.)

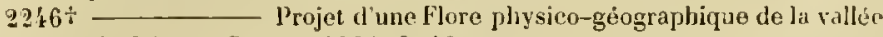
du Léman. Genève 1821. 8. 16 p.

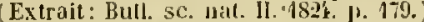

$2247 t$ Hémoiro sur la famille des Cruciferes. (Paris 1821.) 4.84 p., 2 tad.

(*.) Iém. đu Nuséun d'hist. nât. de Paris, vol. Yll. 1821. p. 169202. et 2 tab.

2248t 2 Notice abrégée de l'histoire el l'administration de. jardins botaniques. (Paris 1822.$) 8,19 \mathrm{p}$.

(Dictionnaire des sc. uat. vol. .ivir. 1822. p. 16j-181.)

$2249^{*}-$ Hémoire sur la tribu des Cuspariées.

$2250 \div 3$ tab.: Prenier rapport sur les pommes de terre. Étude comparative du produit des varietes. (Genève 1822.) 8. p. $275-$ $311 .(1 \mathrm{fr} .50 \mathrm{c}$.)

(Bibl. universelle. Agriculture. vul. VIl. 1822. p. 27̈-288.) 
22i1" DeCandolle, Auquslin Pyramus. Mémoire sur les différentes especes, races el varictés de cloux et de raiforts cn Europe. Paris 1822. $8.35 \mathrm{f.}(1 \mathrm{fr} .25 \mathrm{c}$ )

Annalus d digriculturn francaise. 1822. ser. II. vol, xIX. p. 273. Bibl. univ. Aqricullure. Vill. D. 19$\}-226$.

t anglice: Nemoir on the ditterent species, racess and rarietics of

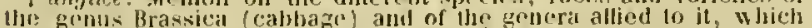
are colltivaled in Lurope. (Londen 1821.$)$ t. 73 l)

(Trallsidetions of the Iforticultural society of J.ondon, rol. 4.1822.

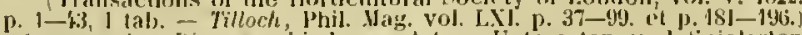
"grmerence: Die verseljiedenen Arten, Unterarten und Spielarlen

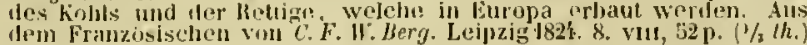

$2252^{*}$ Múnoire sur la famille des Ternstroemideces et en particudir sur le genre Saurauja. fienère 1823.4 .38 p., 8 tab.

(Ném. de la soce de physjque ot d'hist. nat. de Geneve, vol. I. 2

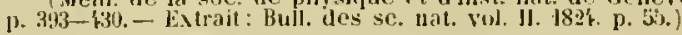

220336 Mémoire sur queljues genres nouveaux de la famille des Butturiaceies. (Paris) 1823.4. 19 1., 5 tah.

("Mém. du Museum d'hisl, nat. de I'iris, fol. X. 1823. p. 97-11. ot 3 tah. - E.rtrit : Rull. de Ferussac, I. J. 53.)

223 t - Discours de cloture d'un cours de bolanique agricole. Geusve 1823. 8. (Bull. de la classe d'agric. avril 1823. Nr. 8 et 9. - Bil). univ. Agriculture, vol. Vill. p. I19-136.)

22:3:" - et Alphonse DeCandolle. Rapports (ou Notices) sur les plantes rares, yui ont fleuri dins le jardin de Genève, Nr. I $-1 \mathrm{X}$. Geneve 1824-1845.4.- I: 33 j. - II: $23 \mathrm{p} .-111: 32 \mathrm{p}$ - IV: 38 p., 5 tals. - V: 28 p., 5 tab. - V]: 24 p., 3 tah. - VII: 55 J., 8 tol. - VIII: 34 p. -1 X: 20 j., 2 tal. col.

Extraits des Mém. de la soc. de plyysique et d'hist. nitt. de Geneve. - Contimuabuntur ab Alphonso Decindolle.)

yeqetabilis, sive enumeratio co rumgue plantarum hucusque cognitarun, juxla methodi naturalis normas digesta. Parisiis $1824-1846$. X partes. 8.1126 fr. -42 th.

(Pars 1- 1ll: $117 \mathrm{fr}$; prix reduit: $7 \mathrm{~S}$ fr. $-26 \mathrm{th}$.)

Pars 1: 1824. Thalamiflorarum ordines $1 \mathrm{JV}$ : v1, $747 \mathrm{p} .(13 \mathrm{fr}$ $4 \frac{1}{3}(h$.

Pars II: 1825. Calycillorarum ordines $X: 644 \mathrm{p} .(13 \mathrm{fr} .-41 / 3 / \mathrm{h}$.

Pars III: 1828. Calycillorarum ordines XXY1: 494 p. (13 fr. $4 \frac{1}{3}(\mathrm{th}$.)

Pars IV: 1830. Calyeillorarum ordines $\mathrm{X}: 683 \mathrm{p}$. (43 fr. $-4 \frac{1}{3}(\mathrm{~h}$.)

l'ars V: 1836. Calycereae el Compositorum trilus priores: $706 \mathrm{p}$. $\left(13 \mathrm{fr} .-4 \frac{1}{3}\right.$ th. $)$

Pars V'l: 1837. Compositarum continuatio: $687 \mathrm{p} .(43 \mathrm{fr},-4 \mathrm{t} / \mathrm{th}$.

Pars V'll. sectio I et II: 1838 - 1839. Compositarum tibus ultimae, ordinis mantissa el ultimi Calyciflorarum ordines: $804 \mathrm{p}$. ( $13 \mathrm{fr}$. $-4 \frac{1}{3}(h \cdot)$

Pars VIII: 1844, editore Alphonso DeCardolle. Corollillorarum ordines XIII: 684 p. $\left(16 \mathrm{fr} .-5^{1 / 3} / \mathrm{h}.\right)$

Pars IX: 4845. editore el pro parle autore Atphonso De Candolle. Corolliflorarum ordises $\mathrm{IX}: 573 \mathrm{\mu}$. ( $16 \mathrm{fr} .-5 \frac{1}{3} \mathrm{th}$.)

Par's X: $184 \mathrm{C}$. clitore el pro parte autore $A$ tphonso DeCandolle. Borragineae proprie dictae et Scrophulariaceae; cum indice nominum el synonymorum voluminum I-X: $679 \mathrm{p} .(16 \mathrm{fr},-5 \mathrm{~s} / \mathrm{h}$.) (Opus insigne lapte continual jtur. Dunal Solanaceas, Bentham La-
hiatas, schauer Verbenacena, Nees ab Esenbeck Acanthaceas, Deraime Plantagiueas, Moquin-Tandon Anaranthaceas et Chrnopodeas, Jeisner Polygoneas, Proleaceas et Beguniaceas recensebit. - Illusirationes iconographicas Benjamin Delesser, indices specierum roluminnm septem priorum Buek, supplenconta in liepertorio suo Hïhelm fierhard Ifalpers curayerunt. - Translationem germanicim generis Pelargonii Weodit Philipp Marimilian Opiz.

De eilandis I'rudromi autoribus Aiph. DeCandalle nuper haec momuit: Botanici nonnulli omissis adnotatjonibus in vol. 1-PIt initio guorut: Botanicinom ordinum vel generum appositis omnia praceipur auctori rundam ordinum vel fenerum appositis omnia praceipuo auctori Prodromi trihuunt, quad mro meritis scripti injustum aut erga patrom aut erga alctores.

itenm Yocare: $-366,33:-422$ elaborayit Seringe.

Cistinear, p. 2133-286 Durial.

Violarieac, $287-316$ Decringins.

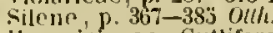

ilypericincae, Gutliferae et Marcyrafiaceac p. 4t-566. Choisy. vol. Vil. Medicago, Trigonella, Melibotus, Trifolium, Lolus, Tetrànomolobus, p. 171-215; Faha, Yicio, Ervm, Pisum, Latisyrus, Orobus

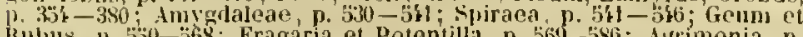
kubus, ]. Fio- 68 ; Fragaria et Potentilla, p. 569-556; Atrimonia, p. $587-788:$ Rosa R. 597-625: Seringe.

rol. III. Epilobium, Gaura, Uenothera, p. 10-52; Seringe. Cucurbitaceae, p. $297-320$; Seringe. Grosentariaceae, p. $\$ 77-483$ Berlandicr.
Yol. 11. Weinmannia, p. 8-11: llyorangea, 11. 13-15; Saxifraga.

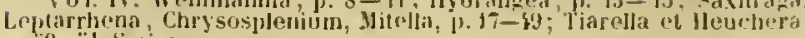

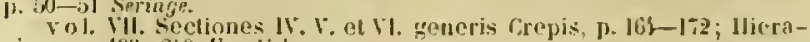
cium, J, $1(x)-26$ Froelich.

$78\}-793$ slphonse decéandoll lincénieae, p. 3is:-

Ericeae, p. 1ijiz-712 Benthain.

Cactera omnia vol. I-ijl. als dugusta l'yramo Derandolle.

In vil. villi et se(j. nomina auctorum titulo cujustis paginae se(tulo apyosita surt.)

22:57 DeCandolle, Augustin Pyramus. Note sur te fenillage des Cliffortia. (Inuales des se. nat. vol. 1. 1824. p. 447. - Extrail: Bull. sc. nat. III. p. 213.)

2238 Note sur la place de la famille des Cucurbitacées dans la série des familles naturelles. (Ném. de lit sue. d'hist. nat. de Geneve, vol. III. 1825. p. $33-37$.

$22: 39$ Notice sur queliques genres el especes nourelles it légumineuses. (Annales des sc. nat. vol. N. 1825. p. 90.)

2260*- Mimoires sur la famille des Legunineuses. $1 \mathrm{Kr}$. 1 XV.) Paris 4825.4 .525 p., 70 tah. et 2 tableaux sur la distribution géographique. ( $72 \mathrm{fr}$. - sur graul raisin vêlin : $160 \mathrm{fr}$.)

2261 Extrait d'un mémoire sur Je noureau genre nonme Pictetia, et sur ceux, qui, comme celui-ci, ávaient élé confondus dans le Rolinia. (Bibl, univ. de Genéve, vol. XXIX. 1823. p.40-47. Extrait: [Bull. sc. nat. VI. p. 60.)

2262 Note sur lo Trifolium magellanicum. (Annales des sc. 1tat. vol. N. 1825. p. 61. - Extrait: Bull. sc. nat. V1. 1. 379.)

$2263^{\circ}-$ Notice sur la culture de l'Olivier. (Extrait de la Statistique agricole de la France, ourrage ineilit.) $8.22 \mathrm{p}$

(Bibl. univ, de Genere. Agriculture, vol. X. 1823. p. 3-22.)

$2264 \div$ Premier mémoire sur les lenticelles des arbres et le dereloppement des racines, qui en sortent. (Paris. I\$26.) 8. 96 p., 2 tab. col.

(Annales des se, nat. Janrier 1823 ; il ter'so: Juin 1927.)

$2265 \%$ - Memoire sur les genres Connarus el Omphalobium ou sur les Connaracées Sarcolobées; présenté i la sociúté d'histoire naturelle de Paris le 19 aoul 1823 . (Paris 1826.) 4.18 j.. 2 lab.

(Mém. de la soc. d'hist. nat. de Paris, tome II. 15:36. p. 379.)

$2266^{*}$ Note sur les Myrlacées. Paris 1826.8.8 p.

Articlo: "Myrtacees" du Dict. classique d hist. nat. vol. XI. p. 399.) 2267 Examen de la matiere organique, qui a colveś en rouge les eaux du lac de Morat. (Mém. de la soc. de pluys. el d'hist. nat. de Geneve, vol. I1l. 1826. part Il. p. 29. et I tab. col.)

$2268^{*}$ - Revue de la famille des Lythraires. Genise 1826.4 32 piém. 3 lab. pe la soc. de phys. et d hist mat. de Gonive, rol. III. 1826 part. 11. p. 65-96. - Evtrait: Bull. se. nat. vol. Nit. 1828. p. $35 \%$.

Organographie végétale ou description raisonné de organes des plantes, pour servir de suite el de developpenent à la theorie élémentaire de la bolanique el d"introduction a la physiologie végétale el à la description des familles. Paris $\$ 827$. II voll. 8 . - J: xx, 558 p. $-11: 304$ p., 60 tab. (18 fr.)

* germanice: Urganographie der Gewächse, oder kritische Beschreibung (ler Pilanzenorgane. Eine Fortselzung und Entwicklunt der Aung der Planzenorgane. Eine Fortselzung und Entwicklung der Anfangs grime der Botanik, und Einleitung zur Planzenphysiologie und zur Beschreibung der Familien. Aus dem Franzosisehen mit Anmerhmgen vo! Karl Friedrich Meisner, Stut

anglice: Vegttable organography, or an analytical description of the orgills of plants. Translated by 13. Kingdon. Ed. II. New Yorh, Wiley and Putnam. 18:0. S. (3 Dollar $30 \mathrm{cts}$.)

$2270 \div-$ Notice sur la botanique du Brésil. (Geneve 18z7.) 8. $11 \mathrm{p}$.

(Bibj, unir. te Geneve, vol. xixit. 1827. p. 20r-2l4.)

$22716+$ Revue de la famille des Portulacces. (Paris 1828.) 4. 20 p., 2 tab.

(Ment de la soe, rlohist, nat. de Paris, rou. IV. 1828. p. 17t-194. Exlrait: lubll. sc. nat. XVl. p. 530 .)

$2272+$ Memoire sur to Fatioa, genre noureau de la famille des Ly'luraires. (Zurich 1828. ) 4. 3 p., 1 tab.

(Mem. de la soc helvélique des sc. nat. vol. I. 1829. p. 97. - Extrail: Bull. sc. nat. Xivil. p. 2ứ.)

2273

- Programme el rapport sur les péninieres du canton de Geneve. (Bull. de la classe dagriculture de Genere, 1822 et 1828. 8.)

$2274 t$

Considérations sur la plyytologie ou botanique generale, son histoire et les moyens de la perfectionner. Paris 1828.8 . $16 \mathrm{p}$. p. $\{-5$. 
2270* DeCandolle, Augustin Pyramus. Memoire sur la famille des Combretaceses. Genève 1928. 4. 42 p., 5 tab.

(Ném. de la soe, de physilue et d hist. nat. de Geneve, vol. IV. p. 1-46. - Extrait: Bull. sc. nat. XX. 1829. p. 435.)

2276* - Notes sur quelques plantes olıserveses en fleurs au mois de Janvier 1828 , dans la serre de $\mathbf{1 l}$. Saludin a Pregny. Genève 1825. $4.8 \mathrm{p}$.

(Mém. de la soc. de physiutue et dhist. nat. de Gencre, vol. ir. p. s5-90. - Extrait: Bull. sc. nat. XWil. p. 26̈̈.)

\section{Collection de dix memoires}

$2277^{2}$ I: Mémoire sur la famille des Mélastomacécs. Paris 1828. $4.84 \mathrm{p}, 10$ tab.

2278* - II: Mèmoiro sur la famille des Crassulacées. Paris 1828. 4.47 p., 13 tab.

2279* 1829.4. 16 p., 3 (a)\}.

$2280^{*}$ IV: Némoire sur la famillo des Paronychies. Paris 1829.4. $16 \mathrm{p}, 6$ tal.

2281* 1 : Alemoire sur la familic des Ombellifères. Paris 1899. 4.84 p., 19 lab.

2282* - V1: Memoire sur la famille des Loranthacées. Paris $1830.4 .31 \mathrm{p} ., 12 \mathrm{tab}$.

2283* … Vll: Memoire sur la famille des Valerianées. Paris 1\$32. 4.24 P., 5 tah.

228:* - VIII: Mémoire sur quelques espèces de Cactées nouvelles ou peu connues. Paris 1834, 4. 27 p., 12 tab.

$228 \ddot{0}^{*}-1 \mathrm{X}$ : Ohservations sur la structure et la elassification le la famille des Composécs. Paris 1838.4.44 p., 19 tab.

$2286^{*}$ X: Statistique de la famille des Composécs. Paris 1838.4 .22 p., 4 tableaux.

Excerpta harum decen commentationum sunt in: Bull. sc. nat. vol. XIV-XIX. - Ann. sc. nat. vol. Xli1.)

$2287 \div$ Plantes rares du jardin de Genève. Genère 1829. 4. 92 p., pracf., ind., 24 tal., col. (60 fr.) (Collectin perpulchra prodiit if fisciculis; I et II: 1825 . $111 \mathrm{et} \mathrm{WV}$ : 1826. - Extrait: Bull. sc. nett. 11. p. 36'; ill. p. 220 ; IX. p. 50.)

2285: — De l'ètat actuel de la botanique genenerale. A Jlonsicul l'éditeur de la Revue française. (Paris 1829 .) 8. p. 33-56.

(Rerue française vol. VIII, avril 1829. p. 33-iki.)

$2289 \div-$ Notice sur l'Arracacha et quelques autres racines légumieres de la famille des Ombelliferes. (Geneve 1829.) 8. 11 p. (Bibl. uais de Geneve, vol. XL. 1829. p. 7f-82. el vol. XLIS. 1832. 1.. $27-32$.

Notice sur les differents yenres et espèces, dont les écorces ont eté confonducs sous le nom de Quinquina. (Bibl. univ. de Genève, ral. Xll. 1829. p. 144-162. - Extrait: Flora 1829. p. 539. - Bull, sc. nat. vol. XXI. 1830. p. 437.

2291 Notice sur la racine de Cainca, nouveau médicanent reçu du Bresil. (Bibl. univ. de Genèe, vol. XLII. 1829. p. $243-250$.)

$2292 \div$ - Notice sur la lotanique de l'Inde orientale et les encouragements que la Compagnie anglaise lui a accordés. (Genève 1829.) 8.12 p.

(Bibl. univ. de Genève, vol. XLII. 1829. p.312-320.)

$3993 \div$ Rerue de la famille des Cactees avec des observations sur leur végétation el leur culture, ainsi que sur celles des autres plantes grasses. Paris 1829.4 . 119 p., 21 tah. col. (Mem. do Moseum dlhist. nat. de Paris, vel. XY1l. p. 1-119. rersiones itt hanc commentationem scripsit Antonio Bertoloni. Bologna $1830.8 .50 \mathrm{p.})$

$2291 \div-$ Résumé de quelques travaux récents sur le Maïs. (Geneye 1830. ) 8. p. 80-92.

(Bibl. unis. de Geneve, vol. XLIII. 1830. p. 80-92.)

$2395^{*}$ Histoire de la hotanique Genevoise. Discours prononcé à la cérémonie académique des promotions, le 14 juin 1830. Genève et Paris 1830.4.61 p.

(Nim. de la soc. de physique et dhist. nat. de Geneve, vol. $V$. $2396 \div$ part 1.1

Notice sur la régétation des plantes pardsites el en particulier des Loranthacées. (Geuève 1830.) 8. 16 p.

(Bibl. univ. de Genève, vol. XLIII. 1830 . p. $303-316$.)

2297 De quelques ourrages récemment publiés sur la botanique de la Lorraine. (Bibl. univ. de Genc̀ve, vol. XLIV. 1830. p. $260-270$.

2298 Notice necrologiqne sur Giuseppe Bulbis. (Bibl. nniv. de Geneve, vel. XLV1. 1831.p. 21:-217.)
2299 DeCandolle, Augustin Pyramus. De quelques arbres très-anciennesures au Mesique. (Bibl. unit. de Geneve, vol. NLV1. 4831 p. $387-394$.)

$2300+2$ Notice sur la lougérité des arhres et los movens de la constater. (Genève 1831.) 8 . $27 \mathrm{p}$.

Hibl. unis. de Genere, vol. XLVIl. 1831. p. 49-73.)

$2301 \div$ D D D C l'influence de la température atmospljérique sur le developpement des arbres au printems. (Genere 1831 .) s. 11 p. Bibl. univ, de Genere, vol. XLVIII. 1831. p. 382-392. - Redit in. "Phỵsiologie végélalu.,.

$2302^{*}$ - Essai sur la théorie des assolemens. Genève 1839 x. 24 p., 1 tab.

(Bull. de la clisse ('azriculture de Geneve, fevrier 183i.)

2303* _... Physiologie vigetale ou exposition des forces et des fonctions vitales des végetaus, pour servir de suite a l'organograthie vegetale et d'introduction a la hotanipue giographique et agricole. laris 1832 . Ill voll. 8. xixu, 1579 p. $\left(6 \frac{2}{3}\right.$ (h.)

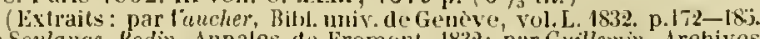
par Soulaugc-Rodin, Anoales de Fromont, 1832; par Guillemin, Archives de botallique, janvier 1833 ; par Henslow Roget, Jonthly Review, mar 1833; par Madame Marcet, Fureign Review.)

germanice: Ptlanzenplyysiologie oder harstelung der Lebonskrafte

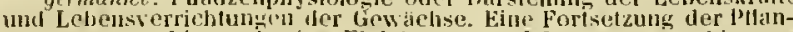
zenoryanographic und eine Einleitung zor ptlanzenzeographie uni thonomischen Botanih. Aus dem Franzosischen ubersetzl unt mit Anmerhunzen verseluril voll, fokannes August ikristion Roeper. Stutt-

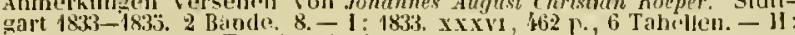
Tist3. vil, 902 p., I Tabelle. $\left(3 i h_{.}\right)$

$$
\text { (Folumen t(rium numquam prodiit.) }
$$

* germanice: (e praecedentis operis rolumine primo seorsim impressum: Tahellarisehe (ebersicht der Zusammensetzong aller einIachen Pflanzemverhindungen, so wie mehrerer in physiologischer pharmeculiseher und technologiseher Beziehung wichtigen Produkit des Gewichsreichs. Nach dem franzosischen Original bearheitet, unc mit vielen Zusätzen und einer Anweisung zum, Gebrauche sermeht dureh Johames August Christian Roeper. Stutgart 1833. 8. 20 D. unt 2 Tahellen in royal-folio. $(\% / \mathrm{s} t h$.

230t Vie de Limé. Extrait de l'ouvrage de $\mathrm{Al}$. Fee, avec des notes. (Bibl. univ. de Genève, vol. Ll. 1832. p. 133-149. anglice: Jameson, Journal. Edinhurgh is33.;

$230 \ddot{3}$ - Rerue de quelques ourrages récemment publiés sur le genre Saule (Salix.) (Bibl. univ. de Geneve, vol. XLLX. 1839. p. 15-27.)

2306 Notices sur la vie et les ecrits de Frangois Huber. (Bibl. univ. de Geneve, vol. XLA. 1832. p. 187-207.)

2307 Hort de Cuvier. (Bibl. univ. de Generv, vol. XLIX 1832. p. $442-448$.

$2308 \div-$ Genres nouveaux appartenant a la famille des Composées ou Synanthérées. II Décades. (Paris 1833.) 8. 6 p.

(Guillemin, Archives de botanique 1833. p. 51t.)

$2309 \div$ - Note sur la division du régne végétal en quatre grandes classes ou embranchemens. (Geneve 1833.) 8.10 p.

(Bibl. univ. de Geneve, vol. LJV. 1833. p. 2i9-268." germanice: volt v. Schlechtendul in Linnaea 1835. p. 270.)

$2310^{*}$ Notice sur les prostès de la botanique pendant l'année 1832 . Genève 1833.8. $53 \mathrm{p}$.

(Bibl. univ: de Geneve, vol. Li1. 1833. p. 112-192. - Archives de botanque, vol. 11. 1833 . p. 22.)

2311 Note sur l'huile de Ramtilla et la plante, qui la pruduit; Ine à la société d'hist. nat. et a la societé médico-chir. Déc. 1833.

$2312 \div-$ Notice historique snr la vie et les trayaux de $M$. Desfontaines. (Geneve 1834.) S. 32 p. - $\div$ (Paris 1834.) 8.22 p. et 1 tab. Facsimile.

(Bibl. univ, de Genève, vol. LV. 153'. p. 130-159. - Amairs des sc. nat. ser. II. Botanirgue. vol. I. 1834. p. ixy.

$2313+\div$ Instruetion pratique sur les collections botaniques. (Genève 1834.) 8.25 p.

$2314 \div 2$ Notice sur les graines de linanas. (Geneve 1834.) 4. 7 p., 2 tah.

(Mem. de la soc. de phrsique el d'hist. nal. de Gentro, tome vil. 183k. - Extrait: Bibl. unir. de Genere. vol. LVIlt. 1\$30. P. 370-376.)

2315\%- Botanique. (Paris 1834.) 8. 14 p.

p. 737 sqle extrait de I'Encyclopédie des gens du monde, tome 111.

$2316^{*}$ Compositac Wightianae; exstant in: Robert Wight, Contributions to the botany of India. Lomilon 1834 . S.

$2317 \div$ - Réponse à une lettre de Jeuri stephens sur les maladies des mélèzes (Larix europaea) dans la Grande-Brétagne. (Geneve 1835.$)$ 8. 15 p.

(Bill. univ, de Genive, rol. LrHII. 1835. p. 119-127.) 
2:318+ DeCandolle, Augustin Pyramus. Notice sur la géographic boIanione de l'Italie. (Geneve 1835. .) 8. 11 J.

(Bibl. univ, do Gemasa, vol. L.IX. 1830. 13. 193-201. - Agitur praeprinis do Bertolonii lifora italicen.)

$23195^{\circ}$ Revue sommaire de la fanille des Pignoniacées. (Gencre 1838.) 8.24 p.

(Bibl. univ. de Ginere, sér. 11. vol XYll. 1838. p. 11-136- Annales des sc. nat. sér. 11. voil. N1. 1839. p. 279.)

$2320 t-$ Nolice sur M. Jean Frederic de Chaillet. (Neufehatel 1839.) 4. $8 \mathrm{p}$.

(Mén. de la soc. dess sc. Mat. de Nuufchátel.)

$2321 \div-$ Deseription d'un nouvelle esprece de figuier (Ficus Saussureana). (Geneve 1840.) 4. 9 p., I tab, col.

(Hém. de la soce de plyys. et thist. nat. de Genère, vol. IX.)

$23224-$ et Alphonse DeCandolle. Mlonstruositis végétales. Premier fascicule. Neufchatel 1841, 4, 29 p., 7 tal). pro parte col.

(Kinveans mémoires do la soc. helvétique des sc. nat. vol. v.

$2323^{\circ}-$ Mimoire sur la famille des Ifyuacées, Ouvrage posthume, publice par les soins du fils de l'auteur (Alphonse De Candolle). Geneve 1842.4 .61 p., 22 tab.

Mein. de la soe. de phys. et dhist. nat. de Genève, vol. IX. (Inedita ab illustrissimo viro derelinta:

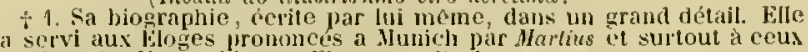
a servi aux bioges prontmces a .lunich par

+2 . Journaux de voyages botaniques et agronomiques dans l'ancien

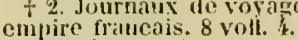

empire fratucais. 8 volt. 4. biet des noms de gemres, sections, tribus, familles et classes du rigne végétal. II voll. folio.

t 4. Galliae plantarum nonina trivialia ordine alphabetico digesta; depuis 1806 . I vol. ?

t 3 . Statistipie végetale de la France. Fragment.

2324. Dechenaux, A. Clé d'analogic en botanique. Genèse des plantes, ou classification des famille's sclon l'ordre des périodes sociales. Paris 1845. 8. Premiere livraison de trois quarts de fenilles.

$2325+$ DeChesnel, Adolphe. La Rose cluez los différens peuples anciens et modernes; description, culture et propricté des roses. Toulouse 1820.8. 174 1). - +Ell.11: Paris $1838.12 .315 \mathrm{p}$.

2326 Botanique des poètes, des arlistes et des gens du moude; avec planches. Paris (avant 1838). 11 voll. 12.

2327t (DeClairville.) Manuel d'herborisation en Suisse et en Valais, redigé selon le systène de Linné, corrigé par ses propres principes. Avec l'indication d'un nouveau système derivé également des principes de ce grand maitre. Par l'auteur de l'entomologie helvétique.

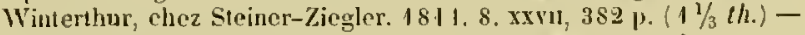
tGeneve et Paris, Paschoud. 1819.8 . est ealem impressio.

2328+ DeCommerell, Abbé. Mémoire et instruction sur la culture, l'usage et les avantages de la racine d'abondance ou de disette. Lausanue 1786. $8.56 \mathrm{p}$.

hollandice: Verhaud. door de Maatsch. ler bevord. van den Landbouw te Amsterdam, 7 beel, p. $1-80$.

2329 —_ Mémoire sur la eulture, lusage et les avantages du Chou-d-faucher. Paris (1789). 8.23 p. B.

9330t Dedu. De l'ame des plantes, de leur naissance, de leur nourriture et de leurs pregrez. Essay de physique. Paris, Michallet. 1682. 12. 60 p., pracf. - *impr. avec l'Anatomic des plantes par Grev. Leide 1685. 12. p. 249-310.

latine: in Nicolai de Blegny Zodiaco gallico.

$2331+$ Defrance. Tableau des curps organisés fossiles, précéde de remarques sur leur petrification. Paris 1824.8 . xvi, $136 \mathrm{p}$. (3 fr. $50 \mathrm{c}$.) (t Rapport verbial sur cet ouvrage par $A$ de II tumboldt. 1825. 8 . 4 p.)

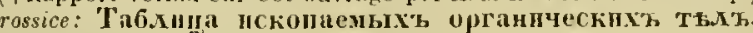

C. Ilereg6. 1830. T.

2332* Degland, J. V. I'. Examen de cette puestion : La sève circule-1-ello dans les plantes à l'instar du sang dans certaines classes d'animaux? 4. $27 \mathrm{p}$.

(A la suite du Disconrs sur tes causes de mourement de la sère (lans les plantes, pir Gouan. an Vill. 4 .)

2333† - De Caricibus Galliae indigonis tentamen. Parisiis 1828, 8. 33, 4 1., 2 tab.

(Extrait de Loiseleur-Deslongchamps, Flora gallica, Ed. H.)

233'. DeGrace. Le jardinier portatif, angmenté de la botanique élémentaire par Rossignol. Paris 1784. 12. - Liège 1798. 12. DC.

$2335+\mathbf{D e}^{\prime}$ grandi, D.F. Istruzione sulla coltivazione del rafano oleifero cinesc. Piacenza 1807.8. $\vee$; $55 \mathrm{p}$.

2336* Dehne, Johann Friedrich Anton. Spaziergang von Leipzig nach dem llarze und den umliegenden Gegenden vorzuglich in botani- seher und mineralogischer Hinsicht. Quedlinburg und Leipzig 1819. 8. $136 \mathrm{p} .(1 / 2$ th.

2337 Dehn-Rothfelser, Ernst Abraham. Ein schon Weinbauluch, wic man dic Weingerge ertanen soll, somberlich nach dieser lande: Art Geburgen, als von Meissen und Dressden biss nach l'irna. Leipzirr, Mintzel. I 629.8. s.

2338* Dehnhardt, Friedrich. Catalogus plantarum horti Camalluleusis. (Neapoli 1829.) 4. 28 p. - "Ed.11. auctior. Neipoli 1832.4.2' p., Itab.

$2339^{*}$ - Replica ad una lettera fubblicata sotto il nome def Dottor D. Quirino Amoruai intorno aul un opucrulo mesce a stampa (in Napoli dal signor Federigo Delunhardt). col titolo di risposta alle osservazioni dell articolo lontanica del terzo fascicolo dellit rivista Napolitana. Parigi $1841,8.48$ p.

23\%0 Dejean, Ferdinand. Dissertatio inauguralis, fuil myonitur histnIn, analysis chemica, orign et usus veconomicus sodae hispanicae. Lugiluni Batatorum 1773.4.42 p. B. (Schlegel, Thes. prat. med. I. 1). 83-122.)

$234 \div$ Deiman, J. R. e'l A. Paets van Troostwyk. Verhandeling over het nut ran den groej der boomen en planten, tot zujsering der lucht. Amsterdam 1780.8. $133 \mathrm{p} .$, praef.

231.* Deininger, Karl Friedrich Heinrich. De Atropa Belladonna. 1). Berolini 1833. 8. 41 P.

231.3 - DeJonghe, J. Monographie du genre Gyclanelı. de sa culture et de sa multiplication. Bruxelles 1844.12 .35 p.

$231 ; \div-$ Traité méthodique de la culture du Pelargenium, [precédé d'une introduction historique, d'une petite bibliographie spéciale el diun description des serres propres a cette culture. Bruxelles 1844.8.144 p.

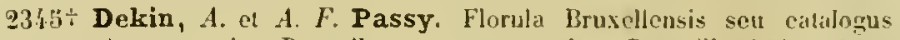
plantarum cirea Bruxellas sponte nascentiun. Bruxellis 1814 . 8. $72 \mathrm{p}$.

2316 $\div$ DelaBaïsse. Dissertation sul la circulation te la seve dans les plantes. Qui a remporté le prix etc. Bordeaux, Brun. 1733. 12. $79 \mathrm{p}$. (Autor est Pater sarrabat, e societate Jesis, (qui in hoc liliro cognomen gentis suae a(loptavit.)

231.7* DelaBillardière, Jacques Julien Houton. Relation du voyage a la recherche de La Pérouse, fait par ordre de l'Assemblee constituante pendant les années 1791 et $1792 \mathrm{et}$ pendant la prenière et la seconde année de la république française. Paris. Jansen. an Vill. (1799.) Il voll. S. et Atlas in folio de 44 planches, dont 14 sont de hotanique. - I: xvI 440 p. - II: 332, 109 j. (tLontres, Deloffe. 1800. 11 vill. 8. est eadem impressio.)

$231.8 * 2$ Novie Hollandice plantarum specimen. Parisis 1804 -1806 . Il voll. 4. - 1: 1804. 11 p. - I1: 1806.130 p., $265 \mathrm{tab}$. (212 fr.)

(Prodiit amnis 1803-1807. fasciculis 26 et dimidio; quisque 10 tabularum il 8 fr.)

$2319^{*}$ Icones plantarum Srriac rariorum, descriptionibus et olservationibus illustratae. Parisiis $1791-1812$. V Vecades. 4. let II: $1791.22,18$ p., 20 tab. - III: 1809.16 p., 10 tab. - IVet T. 1812. 16,16 p., 20 tab. ( $45 \mathrm{fr}$.

$2330^{*}-$ Sertum austro-caledonicum. Parisiis $1824-1825$. II paries. 4.83 p., 80 tab). $(64 \mathrm{fr}$. )

2331* DelaBorde, Alexandre Louis Joseph, Comle. Description des nouveaux jardins de la France el de ses anciens cliateaux, mélee d'observations sur la vie do la eampagne et la composition des jardins. Paris, de l'imprimerie de Delange. 180s. folio max. 226 p., 122 tah. praeter icones $\mathrm{A}-\mathrm{I}$.

("Les dessins soul de Cl. Bourgeois: le texte en fraucais, allemand

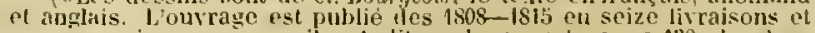
130 on quinze, comme if est dit quelque parl, avec 130 plinches. $200-300$ fr. Q.) Bibl. Caes. Vindob.

2352: DelaBretonnerie. L'école dı jarclin fruiticr, qui comprenal l'origine des arbres fruitiers etc. Paris 1784. II voll. 12. - 1: Lxxil 546 1. - 11: vili, 658 p. - Nouvelle édition revue el augmentéc par Mordont de Launay. Paris 1808 . II voll. 12. ( $7 \mathrm{fr}$.) a.

2353 DelaBrosse, Guy. lcones plantarum horti regii. Parisiis s, a. et titulo. folio.

(Sunt $\$ 8$ tabulae acnear. rariores horli plantas illustrantes atosque ulla explicitione, nunquam editae; praemissa est duplex borti ichnoMraphia. Toste $D C$, cui a Jussieuo datum est exemplar, viginti quingue specimina exstant. De ritrissimo libro cf. Mllll. Bibt. bot. 1. 4t. Jitulis Cat. III. 106. - Cat, Bibl. d linard. p. 80, Jir. 94.)

235:" - De la nature, vertu et utilité des plantes. divisé en cinq livres. Paris, Baragues. 1628.8 .680 p., praef. 
2335* DelaBrosse, Guy. Dessein d'un jardin royal pour la culturo des plantes médicales a Paris. inipr. cum priori. ib. 1628. 8. p. 68 !-849. et ind.

$2356 \div$ Advis pour le jardin roval des plantes medecinales, que le roy veut establir it Paris. (Paris 1634.) 4. $40 \mathrm{p}$.

(Adharent: Ordre du dessein du jardin royal des plantes, p. 41 -46 . et Menoire des plante's usageres, p. 47-38.)

$2357^{*}$ Description du jardin royal des plantes melecinales estably par le Roy louis le Juste a Paris. Contenant le catalogue des plantes, qui y sont de present cultivées, ensemble le plan du jardin. Paris 1636.4, 107 p. et prospectus horti.

(Catalogus plantarum omissa deseriptione horti adest in Simonis Paulli Viridariis variis p. $81-201$.)

$2358+-$ L'ouverture du jarrlin royal de Paris, pour la demonstration des plantes medecinales. Paris, par Jacques Dugast. 1610.8 .38 p. Bibl. Juss.

$2339 \div \div$ Catalogue des plantes cultivécs ă présent au jardin royal des plantes medecinales, estably par Louis le Juste i Paris. Ensemble le Plan de ce jardin en perspective orisontale. Paris, chez Jacques Dugast. 1641. 4. (6) $101 \mathrm{p}$.

$2360 \div$ DelaBrousse. Traité de la culture du figuier. Amsterdam et Paris $1774.8 .83 \mathrm{p}$.

2361 Mélanges d'igriculture. Nismes 1789. II roll. 8. 1: 216 p., 5 tab. - 11: 143 p., 2 tab. B.

2362* DelaChenal, Hermer. Observationes botanico-medicae. D. Basileae 1776. 4. $16 \mathrm{p} ., 1 \mathrm{tab}$. (Acuilegia.)

(Redit in Listeri Delectus Opusc. bot. I. p. 59-80.)

2363 - Delachénaye, $B$. Abécédaire de Flore ou langage des fleurs, méthorle nouvelle de figurer avee des fleurs les lettres, les syllabes et les mots etc. Paris 1811.8 .160 p., prael., 4 tab. uigr., 8 tab. col. (30 fr.)

$2361 \div$ DelaChesnee-Monstereul. Le Floriste francois, traitant de l'origine des tulipes etc. avee un Catalogue des noms de Tulipes et distinctions de leurs couleurs. Seconde édition. Rouen, chez Louys de Mesnil. 1658.8 .250 p., (24 foll.), 1 tab. - Ed. I: 1655.8.

$2365^{*}$ DelaCondamine, Charles Marie. Relation abrégée d'un voyage fait dans l'intérieur de l'Amerrique méridionale, depuis la côte de la mer du sud jusques aux eotes du Bresil et de la Guiane, en descendant la riviere des Amazones. Paris 4745. 8. xv1, $246 \mathrm{p}$. et une carte. (Mem. de l'Acad. des sc. de Paris, 1745. p. 391 - 492.) - *Nonvelle edition augmentie: Maestricht 1778, 8. 379 p., 2 tab.

cuglice: A succinct al)ridgnient of a vovage mate within the inland parts of Somith-America. London $17 \%$. S. 108 p. B.

germanice: llamburger Nagazin, 6. Band p. $3-70$. et p. 227-288. B.

236i, (DelaCourt, Pieler.) Aenmerkingen over het aenleggen valu landhuizen, lusthoven, plantagien, enz. enz. Leiden 1737.4.412 p., If (a). B

* gallice: (anonym) Les agremens de la campayme. etc. Leyde et

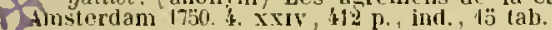

* germanice: (anowym), Anmuthigheiten des Lanllebens. etc. Gottingen und Leipzig 1738.4 . $32 \mathrm{k}$ p., ind., 16 tab.

$2367 \div$ DelaCroix, Demetrius (hibernico suo nomine Mac Encroe) Connubia florum latino carmine demonstrata. Cum interpretatione gallica $\mathrm{D}^{* * * * * * *}$. Parisiis 4725.8 . vir, 39 p., 1 tab. - + Edl. ll: notas et observationes adjecit Richard Clayton. Bathoniae 1791. 8. J 38 p., 1 tab.

+ gallice: Le mariage des lours ent vers latins, arec la traduction française el des notres. Quatrieme édition. Parjs 1798. 8. $108 \mathrm{p}$. germanice: Dir Yermáhlung der Pllanzen. Psysikal. Belustignngen 3. Band, p. 1331-1338.

(llaee fratris ad fratrem de connubiis florum epistola, quae laudes eanit laillantii. exstat primum in Botanico Parisiensi, Leyde 1727. folio. post praefationem.)

2368 $\div$ DelaDoucette, Baron. Notice biographique sur M. Villars. Paris 1818.8. 16 p. et Portrait.

$2369^{*}$ Delafons, Alexandre, Baron de Mélicoq. Prodrome de la Flore des arrondissements do Laon, Vervins, Rocroy et des environs de Noynn. Noyon 4839.8.68 p., ind.

(llaec Florula inpressa est cum ejusdem autoris: Recherches historiques sur Noyou et le Noyonnais.)

$2370 \div$ DelaFontaine. Poeme du Quinquina et autres ourrages en vers. Paris, Thierry. 1682.12.242 p.

237) Delafosse, $G$. Précis élémentaire d'histoire naturelle. Deuxième partie: Bolanique et Zoologic. Paris 1836. 12. (4 fr, $50 \mathrm{c}$.)
$2372 \div$ Delafosse, $G$. Notions élémentaires d'histoire naturelle. Deuxième parlie: Botanique. Ed. II: Paris 1843.12 .176 p., 8 tab.

$2373 \div$ Dela Harpe, Jean. Essai d'une monographie des vraies Joncées, comprenant les genres Juncus, Luzula et Abama. (Paris, typ. Tastu. 1825.) $4.93 \mathrm{p}$.

Extrail du tome lll. des Jemoires de la soc. d'hist. nat. de Paris.)

2374* DelaLlave, Paulus, et Juan Lexarza. Novorum vegetabilium descriptiones. Mexici, apud Mlartinum Riveram. 1824-1825. II lasc. 8. - 1: 1824. (6) $32 \mathrm{p}$. -11 : 1825. (6) $43 \mathrm{p}$.

2375* DelaMarck, Jean Baptiste Pierve Anloine de Monnet, Cheralier. La Floce francaise ou description succinete de toutes les plantes, qui croissent naturellement en France. Paris, cle l'imprimerie royale. 1778. Ill roll. 8. - 1: cxix, 223, 132, xxix p., 8 tab. - ll : Iv, $684 \mathrm{p}$ - III: $654, \mathrm{xx}_{\mathrm{p}}$ - - Ed. II: Paris 1793. III voll. 8. Dc. (Ed. Ill. vide DeCandolle.)

$2376^{*}$ Extrail de la Flore francaise. Deux parties. Paris 1792. 8. xxiv 184,318 p.

$2377^{*}$ Encyclopédie méthodique. Botanique. Paris 17831817. Nill voll. 4. - 1: 1783. 1 -Clio, Xulv, 752 p. - II: 1786. Cic-Gor. 774 p. - 111: 1789. Gor-Mau. vur, 759 p. - IV: 1797. Nau - Pan. VII, 764 p. - Y: 1804 . Pan - Pyx. viI, 748 p. - V1: 1804. Qua-Sci. $786 \mathrm{p}$ - - VlI: 1806. Sei-Tra. $731 \mathrm{p}$ - Vlll: Tre-Zue. 879 p. - Supplensent. LX: 1810. A-Byt. xviı, 761 p.X: 1811. Caa-Gyr. 876 p. - XI: 1813.11ab-Mor. 780 p. - XII: 1816. Hor - Ryn. 731 p. - Xlll: 1817. Sa - Z. et Addenda. vill, 780 p. avec un Atlas gr. in 4:900 tab.

(DelaMarck est autor voluminum $\mathrm{I}-\mathrm{l}$; ; Poiret continuavit opus a vol. V-illi.)

2378* —_ Tableau encyclopédicrue et méthodique des trois regnes de la nature. Botanique. 1llustration des genres. Paris $1791-$ 1823. Ill voll. 4. - 1: 1791 . xvi, 496 p. - JI: 1793. 551 p. - III et Supplénent: $1823.728 \mathrm{p}$

(Dela.Nurck est autor toluminum I et II ; Poiret absolvit opus.

$2379^{*}$ __ Histoire naturelle des vẻgétaux classés par familles, avec la citation de la classe et de lordre de Linnc el l'indication do l'usage qu'on peut faire des plantes daus les arts, le commerce, l'agriculture, le jardinage, la médecine ete. Paris, Deterville. 1802. XV roll. 12. - ${ }^{*}$ Paris, Roret. 1830. XV voll. 12. cum 120 tab.

(Oplus pertinet ad "Sutes de Buffon"; Dela.llarek est autor voluminum 1 et ll; volumina III-IV scripta sunt a Brisseau-Mirbel.)

$2380^{*} \longrightarrow$ et Augustin Pyramus Decandolle. Synopsis plantarum in Flora gallica deseriptarum. Parisiis 1806. 8. xxıv, $432 \mathrm{p}$.

2381 DelaMarre, Louis Gervais. Traité pratique de la culture des pins a grandes dimensions, de leur aménagement, de leur exploitation et des divers emplois de leurs bois. Seconde edition, angmentee d'un appendice sur les cèdres du Liban, les mélèzes et les sapins. Paris 1826.8. 8, vil, 365 p. - Ed. 1. ib. 1821 . s.

2382 DelaMétherie, Jean Claude. Vues physiologiques sur l'organisation animale et végétale. Ansterdam et Paris 1781. 12. 407 p. a.

$2383^{\circ}-$ Considèrations sur les etres organisés. Paris 1804. II voll. $8,-1: x_{1}, 428$ p., 3 tab. (Végétaux: p. 120-283.) - II: 512 p. $(12$ [r.)

$2381 \%$ Delanoye. Traité des productions nalurelles indigènes ot cxotiques ou description des principales marchandises lu commerce français; a l'usage des négocians; redigée par une réunion des commerçans et de courtiers près la bourse de paris, sur les matériau recueillis el fournis par M. Delanoye, courticr de commerce. Paris 1831.8. viI, $560 \mathrm{p}$.

2383 Delany, Mistriss. A catalogue of plants copyed from nature in paper mosaick, finished in the year 1778. 8.47 foll. B.

2386* DelaPeyrouse, Philippe Picot, Baron. Figures de la Flore des Pyrénées, avec des descriptions, des notes critiques et eles observations. Tom. I. (livraisons $1-4$.) Paris $1795-180$ \%. Colio. vil, 68 p., 43 tab. col

(Icones elegantissimae qquarum 33 ad Sasifrayas spectant, a Redoute pietar suit. Ducentas in fucem edere autoris fuit voluntas. (qui jain arino 1775 nommulas pyrenacorum muntiun plantas adunbraverat: ts. 1. 4. 16 p. et 6 tab. sign. 15-20.)

$2387^{*}$ L Ilistoire abrégé des plantes des Pyrénées et ltinéraire des butanistes dans ces montagnes. Toulouse 1813. 8. Lxxxil, $700 \mathrm{p}$, 1 tab. (12 fr.) - *Supplément. ib. 1818. 8. xil, 159 p. 
2388t DeLapeyrouse, Ziphirin. Essai sur les fleurs a cnvelorpe unique. These. I'aris 1830 . 4. 4 " p.

$2389 \div$ DelaPylaie, Bachelot. Élules eryptugami(pues ou Monographies de thivers genres de monses, precedees d'une notice sur les environs do fougires, et l'un essai sur la classilication des mousses, dami loguel se trourant tous les nouvenux genres qui nont pas anscore eté pullies dins les ousrages yui traitent exclusivement de

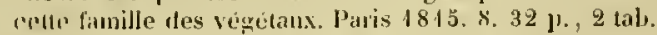

$2390 \div$ - Hore dr l'ile de Terre-neuve et des iles Saint-Pierre et Micloo. (1)arjs 1829.) 4. 128 p.

(D)uk non anjplins prodiit; in hac prima particula Algae alumIranitur.)

2394 * DelaQuintinye, Jean. Instruction pour les jardins fruitiers ef potagess. nvee un traité des orangers. Paris 1690. II voll. 4. - ils. 1695. II voll. 4. - Edl. 11]: Ansterdam 1697. II voll. 4. - 1: 276 1) - II: $344,140 \mathrm{~J}$. cun taluulis. B. - Paris 1715. 1730.1740.1746. 1756. 1760. (eulitioues vahle inferiores.)

auglace: by John Evelyn. Londun 1693.1701 .8$.
otulice: Bassano 1697.8 . Venetiis 170\%. foljo.

$2392+$ Delarbre, Antoine. Flore d'Auvergne ou Recueil les plantes de celte ci-devant province. Clemnont-Ferrand 1795. 8. xt. 220,24 et 11 1. - Paris el Clermont-Ferrand 1797. 8. (uon diflert.) (4 fr.) - $\div$ Seronde édition augmentéc. Riom et Clemont 1800. H roll. 8 . xxw, $891 \mathrm{p}$.

2393t - -.._ Scance jublique pour l'ouverture du jardin royal de Lotanique, tenue le 9 aoùt 1781 par la société ruyale des sciences de Clemont-Ferrand. Clermoot-Ferand $1782.8,66 \mathrm{p}$.

(1. 1-37: Inernin, Discours sur la bolaniapue; p. 39-66: Delarbre, Discours sur l'utilite el la nécessitc dl an jardin ace botaniuge.)

$2394 \div$ DelaRiviere et DuMoulin. Wethote pour hien cultiver les arlires a fruil it pour elever des treilles. Paris 1738 . 8. 319 p., praef. ['reclut 1739. 8. 232 p. B.

$2393^{*}$ DelaRoche, Daniel. Descriptiones plantarum alijuot novarum. I. Lugiluni Batavormm 1766.4.35 j., 5 tah.

(sunt exemplarin quilus eaedem quinque tabulae coloribus jictae arlditie sunt.

$2396^{-}$DeJaRoche, Wancois. Eryngiorum nee non generis wovi Asclepideae historia. Parisiis 1808. fulio. 70 p., 32 tal.

(Iden auter testum voll. $V$-yi. Liliacearum a Redoute pietarum composuit.

2397 t De Las. Phytographie universelle, ou nouveau systeme de botanique, fondé sur une methoto deseriptive die toutes les parties de la lieur; aree une nouvelle laugue antho-phyllograplique. Stockiolm ct Lyou 1783.8 . vill, $182 \mathrm{p}$.

2398 t Delasteyrie, Charles Philibert. Du cotomier et de sa culture etc. Paris 1808 . 8. v111, 446 p., 3 tal.

- latine. Tractatus de cultura gossypii in compoudium redactus et notis illusiratus ab Alyate Ludovico Milterpacher. Budae 1810. 8 . 43 p. 1 tab.

germmine: Aluanullung vom Bau her Banmwollpflanze, hurz ge-

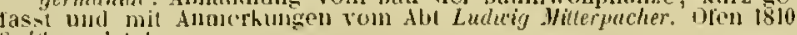
8. Ho p., I lith

slonarice: O Wirobeñu Bawlni od Opata L. Mitlerpacher. ib. 1810. 8 . 37 p., 1 tal.

$2399 t$ - Du pastel, de l'indigotier et des autres végétaux clont on peut extraire une couletur bleue. Paris 1811. 8. vil, 280 p.

$24.00 \div$ Delastre, $C . J$. $L$. Ajerçu statislique de la vógétation du département de la Vicune. Poitiers 1835. 8. 16 p., I tah.

$24.01 \div$ Flore analytique el descriptive du Departenent de la Vienne, avec planches et vocalulaire. Paris et l'oitiers 1842. 8. xxu, 546 p., 4 lal). (i fr. 50 c.)

(† Supplement dans les Annales tles sc. nat. Sept. 18\%2. p. 148-13̈2.)

2402 DelaTaille des Essarts. Nimoire sur le safran. Orleans 1766. 8. 100 p. B.

2:03* DelaTour, Charlotte. Le language des fleurs. Stuttgart 1840. 12. xiv, $155 \mathrm{p} .(5 / 6$ th. $)$

290:" DelaVigne, Gislenus Frangais. De Gratiola officinali L. ojusque usu praecipue in morljis cutaneis. D. Erlangae 1799. $8.46 \mathrm{p} .(1 / 8 / h$.

2:03* Flore germanique, ou histoire des plantes indigènes de l'Allenagne et en grande partie de la France; enrichie des figures colorices de la Flore germanique de J. Sturm. Erlangen $1801-$ 1502. 4 cahiers. 12. xxil, 128 p. et 64 tal). col. $\left(5 \frac{5}{12}\right.$ th. - in charta alba: $6^{11}, 2,(h$.
$2406 \div$ De I'Ecluse, Charles (latine Clusius). Petit recueil, antqued est contemue la description d'aucunes gonmes et liquiurs, provenans faut des iltbres, que des berbes: anomble de qurlques bois, fruicts at racines aromatidues, dreqquelles on se sert des loutiques: retire en partio hors de l'herbier aleman, et assemble en partie laors des rscrits de divers autheurs tant anciens gue noolemrs, lesijuchz ont traiti de ceste matière. Par coluy gui a trarluat l'herhier de bao aleman on françois. Auvers, de l'imprimerie de Jean Lor. 155\%. folio. 1. 54 J) 584 . (impressum cum Cinsi traluctione Doulonaei. Autwerp. 1557.4.)

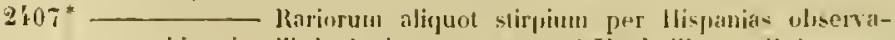
tasun historia, libris dunlus expressil, at Xlasinilianum II. Impera-

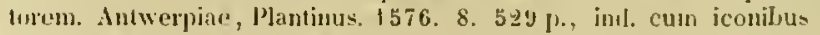
liguo incisis i. 1 ( 8 [1. A. Meilhac. 1845.)

$2108^{*}$ - Sliquot notae in Gurciae Aromatum listorian. Antwerpiae, Plantinus. $1582.8,23$ p. praeter Descrijtiones peregrinarum noumularum stirpiun "t aliarum exoticarum rerum. p. $24-43$. (Medeunt in rlusii Evoliris.)

$2: 09^{*}$ - Rariorum alijuot stirpium jer Pamoniam, . Iustrian et vicinas quastam provincias olsservalarun histuria, yuatuor libris expressa. Antwerpiae, Plantinus, 1583. 8.766 p. el ic. ligno inc. i.t. (Aillaeret Beihii stirpiun nosnenclator pamnonicus. il. 1584, \& (s foll.) ( $7 \mathrm{fr}$, A. Aleilhac. $184 \mathrm{3}$.)

$260^{*}$ - Rariorum plantarum historia. Antwerpiae, ex officina Plantiniana apud Joanuem Moretum. 1601 . Tolio. 364 , cccxurut p. incl. cum ( 1116 ) ic. ligmo ine. i. 1.

Acceseruot Funtorum in Pannonijs observatorum historia : epi-

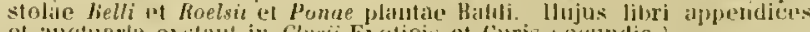
"l anctuarla esstant in Clusii Eanticis et Curis secundis.)

$2411^{*}$ Eisoticorum libri decem, quilus animaliun, plantarum, aromatum, aliorumule peregrinorum fructuun historiae descriluntur: item Petri Belloni olsservationes, (Garcia ab Horto. Christom rul Acosla, Ifonardes), eodem Curlo Clusio interprete. Antwerpiae. Ilastinus. 1605 . folio. $378 \mathrm{~J}$. inul. 52 p. et app. et 242 p.

$2122^{*}-$ Curae posteriores seu jlurimarum non ante cognitarum aut descriptarun stirpium peregrinosumque aliquot animalium novae descriptiones, quibus et omia ipsius opera aliaque ab eu versa augentur et illustrantur. Acessit seorsim Eterarti Forsh de Clusii vita el obitu oratio. Antwerpiae, 1'lantinus. 1611. folio. 71. 24 p. cum ic. ligno ine. i. t. - "ib. 1611.4 .434 el 39 p. cum ic. i. t.

2.13* Caroli Clusii et Conradi Gesneri Epistolac ineditae. Ex archelypis edidit, admotatiunculas arlspersit nec non praefatus est $L$. Chr. Treriramus. Lipsiae $1830.8 .11,69 \mathrm{~m} .(3 / \mathrm{s} / \mathrm{h}$.

Lef. = II. H. de lriese, Over eene verzamelins ejgenhandige bricven an Carolus clusius, vordranden op de bilsibilsech der Leidschr lloogeschool. Leiden 18'3. 8 . 1 if p.

2414* DeLessert, Brnjamin. Icones selectae plantarum, quas in systemate universali ex herhariis Parisiensibus, praesertim ex Lessertiano descripsit Augustiu Pyramus De Cundolle, ex arehetypis speciminilus a P. I. F. Turpin. (Riocreux, Heyland, Decaisne) delineatae. Paris 1820-1846. V voll. folis. - 1: 1820. YI, 26 p., 100 tab. - Il: 1823.

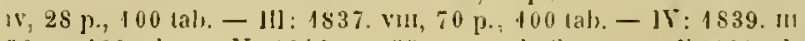
$52 \mathrm{p}, 100 \mathrm{tab} .-\mathrm{V}: 1546.1 \mathrm{~N}, 55 \mathrm{p}$. cum inctice generali; $101 \mathrm{tab}$. (175 fr.)

2413* DeJeuze, Joseph P'ierre. Ueber das Lelsen und die Werke Gurtner's und Hedvig's. Aus den Iranz. Annalen des Museums der Naturgeschiclite uhersetzl. Suttgart $1805,8,109 \mathrm{j})(3 / 5$ th.

$2146^{*}$ Histoire et deseription du Muséum d'histoire naturelle. l'aris 1823 . Il voll. $8.41,720 \mathrm{p}, 3$ plans et 14 vues ( 12 fr.) ( $\mathrm{Avec}$ un rapport, extrail tes Moniteurs de 3 et 30 Juillet is23. 8 . 18 $\mathrm{f}$.

anglice : by A. A. Hoyer. Paris 1823. It voll \&.
(Autoris nomen apul Querard Juseph Phitippe Frangois legiur.

2417 Delicado, Francisco. El modo de adoprare il legno de lndia occidentale, salutifero remedio ad ugni piaga e mal incurabile. Venetiis. sumtibus autoris, 15z9. 4. s.

(In Ximodochin 5. Jacobi Romae autor, clericus lhapans, Jue venerea infectus diu jacuerat, ligni judici decocto salutem recuperavit. Charitatis impulsu novm innc tenporis remediuon alis inpar'iivit.)

2!18* Delise, Dominic Francois. llistoire des Lichens. Genre sticta. Caen, Chalopin. 1823. (in pagina inferiore: 1822.) 8. $171 \mathrm{p}$ avec Atlas: il. 1825. folio min. oblin. 19 tah. col. et un cercle methodigur. des genres. (Mémuires de la soc Lan do Calvados. 1. p) 1-167. If. p. 13 e? [. Uis.) 
$2+1 ! *$ Delius, Heinrich Friedrich, pr. De Peucedano germanico. D. Erlangae 1753.4. $37 \mathrm{\mu}$.

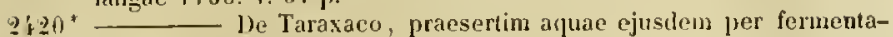
tionem jaratae exinio usu. D. Erlangae 1754. 4. $28 \mathrm{p}$.

w'21* De Aethiope vegetalini cum analectis nonuullis de salibus. D. Erlangae 1774.4 .72 ].

2422* Delle Chiaje, Stefano. Memoria sul Ciclanino Poliano. Napoli 1824. 4. 12 J., 1 tab.

$2423^{*}$ - Iconourafia ed uso delle piante medicinali ossia trattato di farmacologia veretabile. Napoli, typ. Crapart. Il voll. 8. et A vol. 4. - I: 1824. xuiv, 372 p. - I1: 1823.264 j. - I11: 1824. 119 tal. cul, in 4. ( 30 fr. A. Paris, Baillière. 1845 .)

212'* Hyelrophytologiae regni Neapolitani icones. Neapoli, 1yju. Cataneos. 1829 . Folio. $16,12 \mathrm{j}$., $100 \mathrm{kab}$. col. (200 fr. A. Paris, Bailliere. 1845.)

(Opus alias duas gerit inscriptiones: Algarmm regni Neapolis descriptiones ef jeones; nee non: llydroplin tormu siciliae citerioris Prodromus.)

- Flora medica, ossia descrizione delle pianie piu usitate nella Farmacopea napolitana. Napoli 1836 . II voll. $8.140 \mathrm{p}$. et 130 lab. in 4. w.

2426* De l' Obel, Mallhias (Jatine Lobelius). Plantarum seu slirpium historia. Cui arlnexum est Adversariorum volumen. Antwerpiae, Plantiuus. 1576 . folio. $671,471,15,24$ p., ind. el (1495) ic. xylogr. i.t. * belgice: hruydtboeck of Beschryvinghe van allorleye Ginwassen. Kruyderen, Ilsisteren ende Gheboomten. Antwerpen, Plantin. IJ̈si. folio. - I: 99' p. - 11: 312 p. et ic. xylogr. i. t. prateter libellum do succedanis.s.

158. Plantarum seu stirpium icones. Antwerpiae, Plantious. cisae. plerumque binae in unaquaque pagina. - "lcones ligno inseu plautarum tam exoticarum quam indigenarum in gratians rei herbariae studiosorum in duas partes digestae. Cum septem linguarum indicilus ad divcrsarum nationum usum. Antwerpiac, Plantinus. $1591.4 \mathrm{obl}$.

Llaee allera eflitio pdginas iconesque continet totidem, el ego cum Trewio consentio qui editiones inter sese hand dillerre asserit; lene scio, quod alteri accesserit index multilinguis nee non iconum mutalae interdun inscriptiones; sed Dryander Bibl. B. III. 63: vel e minima, inquit, utriusque comparatione eas vere diversas esse apparet.)

$2\{\geq 2$ * Balsami, Opobalsami, Carpobalsami et Xylobalsami cum suo cortice explanatio. Londini 1598.4.40 p.

(Redil in ejus Adversariorum altera parte. Londini, typ. Purfoot. $160 \%$. folio. p. $316-329$.)

25.29* In G. Rondelletii methodicam plarmaceuticam officinam animadversiones, quibus depravata et nutilata ex autoris mente corriguntur et restaurantur. Londini, 19p. Purfool. 1605 . folio. $156 \mathrm{p}$. cum figuris paucis ligno incisis praeter Penae el Lobelii Adversaria.

$2\left\{30^{*}\right.$ Stirpiun illustrationes. Plurimas elaborantes inauditas plantas, subreptitiis Joannis Parkinsoni rhapsodiis e codice manuseripto insalutato sparsin gravaiac. Ejusdem adjecta sunt ad calcem Theatri botanici Amarlemata, accuranic Guilelmo llow, Anglo. Londini, typ. Warren. 165\%.4.170 p., prael, ind.

$2431+$ (DeMailly, Chevalier.) Principales merveilles de la nature. Rouen, Machuel. 1723. 8. xixvi, 330 p. cum tabulis.

(Insunt descriptiones et icones complurium arhorum mirabilium.)

$2: 32 t$ Dematra. Essai dune monographie des rosiers indigènes du canton de Fribourg. Fribourg eı Suisse 1818. 8.8 p.

$2433^{*}$ Demel, Joseph Euslachius. Analysis planlarum. D. Viemae 1782. $8.59 \mathrm{p}$.

$2431+$ Demerson, $L$. La Bolanique enscignée en 22 leçons. Paris 1825 12. svı, 462 p. $-\div$ Ed. Ill. augmentée. Paris 1827 . 12. 498 p. 11 tab. col. $(7 \mathrm{fr}, 50 \mathrm{c}$ )

$2\} 33$ - llistoire nalurelle de la vigne et du vin. Paris 1826. 12. a.

$3436 \div$ Demidoff, Anatole de. Foyage dans la Russie néridionale el la Crimée, par la Hongrie, la Valachie el la Mloldavie, exécuic en 1837 , sous la dircetion de M. Anatole de Demidoff par MM. de Sainson, Le Play, Huot, Leveille, Raflet, Rousseau, de Nordmann et du Ponceau. Paris, Bourdin. 1842. N voll. gr. 8. et un Atlas in folio: 95 tab. ( 300 fr.)

(Vol. II. p. 3k-2ł2: Otservations médicales et Énumeration des plantes recueillit's en Tauride par le Dr. J. H. Liveille avec 6 planche col. des champignours; et une planche des algues fossiles par Adolphe Brongniart, siun. 1-7.)

Pritzel, Thes. lis. bot.
$2437 \div$ (Denidow, Procopius a.) Enumeratio plantarum ordiue alphabetico undique collectarum ex guatuor plagis mundi; adjecta botanicolum characterum descriptione, quae in horto Procojii a Demidou Consiliarii status actualis Mosquae vigent. Mosquac $1786.8,469 \mathrm{l}$. praef. (rossice et latine.)

(Plautas in endem horto cultas recensuil Lepechin, Reise durch Russland, HI. P. 83; el P. S. Pallas in enumeratione T781 edit. llortus $i$ jse, 1756 conditus, it incendio urbis 1812 periat.

2438 DeMoucheron, L. Principes élèmentaires de botanique et de physitpe, milangés de faljes recreatives et morales. paris $182 \mathrm{~s}$. 12. $(4 \mathrm{fr}$.

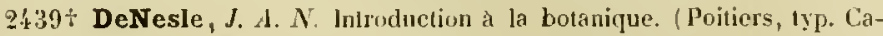
lineau. an T1.) 8.56 j. Bibl. Juss.

2:40* Denham, Dixon, and IIugh Clapperton. Narrative of travels and discureries in muthern and central Africa in the years 1822-1826. Loudon 1826. 4. XLvil , 335, 269 p. cum multis tabulis. (Bulanical appendix by Robert Broucn p. 208-246.) (4l.14s.6d. - 18s. A.

2:41 Denhardt, C. L. Taschenbuch fur Gartenfreunde und Blumenlielhaber. Leipzig $1808,12 .(3 / \mathrm{t}$ h. $)$

$2442 \div$ Denis. Notice sur la culture du Houblon, et de l'emploi des fils dir fer sulsstitues aux perclses. Toul 1828. $8.55 \mathrm{p}$.

2413 3 - Denisse, Elienne. Flore d'Amerique, dessinée d'après nature su les lieux. Riche collection de plantes les plus remarquables, fleur: et fruits de grosseur el de grandeur naturelle. Paris 1843-1846 folio. 12 livraisons a 6 tab. col. sign. $1-72$. el une feuille de tente. (120 fr.)

(Continuatur. Opus hotanicis prorsus inutile.)

2444 Dennstedt, Auyusl Wilhelm. Weimars Flora. Erste Abtheilung (Phanerogamen.) Jena $1800.8 . \mathrm{vi}, 362 \mathrm{p} .(3 / \mathrm{t} / \mathrm{h}$.

$2445^{*}-$ Das Gewáchsreich, oder charakterisirende Beschreibung aller zur Zeil behamten Gewaichse, als Commentar zu den Bertuchschen Tafeln der allgemeinen Naturgeschichte. Ersles lleft. Weinar 1807. gr. 8.248 ]., 6 tab. $\left(1 \frac{1}{2} / h\right.$.)

$2446^{*}$ Nomenclator botanicus seu enumeratio omnium lucusque cugnilorum regetabilium arljectis praecipuis synonymis. Eisenbergae 1840 . 11 voll. 8 . - I: vit, 524 p. - II: y111, 215 p. ( 2 /h.)

$2447^{*}$ Schlussel zum Hortus inlicus malabaricus, oder dreifaches Register zu diesem Werke. Weinar $1818.4 .40 \mathrm{j} .(1 / 2 \mathrm{~h}$. $)$

2448* Hortus Belvedereanus oter Verzeichniss der hestimuten Pflanzen, welche in dem Garten zu Belvedere bei Weimar lislue. gezogen worlen, und zu finden sind, bis weitere Fortsetzungen folgen. Weimar 1820-1821. Zwei Lieferungen. 8. - 1: 1820. vı, 120 p. $-11: 1821.28$ p. $(1 \mathrm{lh}$.

2449* De Notaris, Giuseppe. Specimen de Tortulis italicis. Taurini (1836). 4. $50 \mathrm{p}$.

$2450^{*}-$ Musculogiae italicae spicilegium. Mediolani 1837 $4.26 \mathrm{p}$

$2451^{*}$ - Syjlabus muscorum in Talia et in insulis circunstantibus lucusque cognitorum. Taurini 4838.8 . xx, $33 / \mathrm{p} .\left(2 \frac{1}{3} t h\right.$.)

2452* Prinitiae Hepaticologiae italicae. (Taurini 1838.) 4 74 p., 1 tab.

*Memorie d. R. Accad. di Torino, ser. H. vol. I. p. 287-3\%̈.

$2453^{*}-$ Nicromycetes italici novi vel minus cogniti. Jerrax I-IV. (Taurini $1841-1844.) 4.30,30$ p., 12 tab.

( ${ }^{*}$ Memorie d. R. Accad. di Torino, ser. II. vol. III. N. 5.i-52. at vol. VII. p. $1-30$.)

$2454^{*}-$ Algologiae maris ligustici specimen. (Taurini is42.) 4. 45 p., 7 tab.

( ${ }^{\circ}$ Menorie I. R. Accad. di Torino, ser. II. vol. IV. p. 273-313.

$9255^{*}-$ Inclex seminum, quae hortus botanicus R. Archigymnasii Genuensis pro mutua commutatione olfert anuis $1840-$ $1845.8 .16,14,22,31,27,23 \mathrm{p}$

2:56* - Jsias, norum Orehidearum genus. (Torino 1844.) 4 . 2 p., 1 tab.

("Memorie d. R. Accad. di Torino, ser. II. vol. VI. p. 413-il't.

$2457^{*}-$ Cenno sulla tribil de' pirenoniceti sferiaci e descriziome di alcuni nuovi generi. Firenze 1844.4.10 $\mathrm{j}$.

$2108^{*}$ - Osservazioni su alcuni generi e specie della trilu dei pirenomiceti sferiaci. liresze $1845.8 .20 \mathrm{p}$.

(Estratto del Giornale bot. ilal, amo I.

(Ejusdem autoris Prospectum Florae ligusticie ef Conmuntarios. lichenographicos nondum vidli) 
24:39\% Denyau, Alexander Michael. Oratio panegyrica do plantis. Parisiis, typ. Langlois. 1693.4 .12 p. Bibl. Juss.

2160 * DePré, Joham Friedrich, pr. De regno vegetalsili, morhorum curauslorum principe. D. Eirfordiate 1717.4.23 \%)

$246]^{*}-$ De arundine sacelarina. Fom Zucherrohr. D. Erfordiac 1719.4.16 p.

2462 De Balsano evangelico Samaritano. D. Firfordiac 1733. 4. S.

2163* Dercks, Theodor.' De pignento indico cjusiue effectibus in organismo. D. Dorpati 4836 . \$. 47 p.

2ifí Dercum, Lorenz Anton, pr. Fundamenta rei herbariac. D. Wircehurgi 1742.4 . H.

$2463 t$ - De Rosa. D. Wircelulw 1751.4.27 p., praef.

2'66* Derczen, Johann Dereseny von. leher Tokays Weinbau, dessen Fexung und Gâhung. Nhit geognostischen Beilagen. Wien 1796.8. $x, 1 / 1$ l.

$2160 \%$ De Rennes. Les merveilles et miracles tant naturels que sumaturels de la terre, arbres, plantes, pierres etc. Siunnu, typ. Godean. 1622. 8. 123 p., praef.

lisunt mulla de plantis poemala.)

21.68* Derer, Ignatius. Poetica exhibitio arcis et horti Kismartoniensis. Ex volo ememlate ac locupletate reedita. Sopronii 1828. 8 . '94 1'. Bibt. Caes. Vindob.

2469 Derham, William. Plyysico-theology. Ed. Ill. London 1714. S. $4\{7$ )., ( tal). B.

Libur in twewicam, gallicam, germanicam et suecjean linguan rersus est.)

2170 Miscellanea curiosa. London 1723-1727. IB voll. S. DC.

$2471 \div$ Derive, Théodore. Flore rénéneuse de la province de Liege, ou deseription des plantes muisibles ou suspectes qui croissent spontaniment dans celte partie du royaume. Tervers 1839.12 .128 p., 12 tab. Bibl. Leod.

$2172 \div$ Deroches, Johannes Jacob. De Jlumuli Lupuli viribus meilicis. D. Edinluripi is03. \$. 39 p.

26.73 De Saillet, Alexandre. Une journe au jardin des plantes, précélée d'une introkluction et dles considerations générales sur l'bistoire naturelle. Paris 1840.18. (4 fr.)

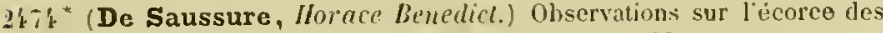
feuilles ot des pétales. Genive 1769 . S. xxul, 102 p.

$21: 0^{*}$ _. Voyages daus les Alpes, pricérles diun essai sur l'histoire naturelle des environs de Geneve. Seufehatel 1779-1796. 17 voll. 4. - I: 1779.540 p., S tab. - II: 1786.641 p., 6 tab. - Ill 1796. 532 p., 2 tab. - IY: 1796.594 p., 5 tab. germanice: Leipzig 1781-1788. 1. Bände. S. $\left(k^{2} / 3 \mathrm{th}\right.$.

$2\left\{76^{*}\right.$ De Saussure, Thédore. Recherehes chimiques sur la végétation. Paris 1804. 8. vill, 327 p., 16 schemata, I lal, " germanice. von Friedrich siegmund loint, mit Anhang und Zusatzen.

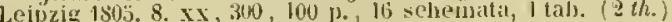

$2677 \div$ De l'influruce du dessechoment sur la germination de plusieurs graines alimentaires. Geneve 1828 . 4. 28 p.

2.78* DeSauvages, François Botssier. Hethodus foliorum, seu plantao Florae Monspeliensis, juxta foliorum originem, ad juvaudam specierun cognitionem digestae. A la llave 1751. 8. xLIV, 343 p., I tal.

21796 - De la rulture des muriers. Nismes 1763.8 . 12S p.

2480 DesBlos. Traité de la garance ou tout ce qui a rapport à celte plante. Paris 1768. 8, H.

21.81 Descemet. Catalogue des arbres, arbrisseau, arbustes, plantes, oignons le fleurs, graines de fleurs et potageres, qui se trouvent dans les jardins et pépinieres du Sicur Descemet. Paris 1782. 12.2813. B.

2482 Descemet, J. Catalogue des plantes du jarlin de MIA. les apothicaires de Paris, suivant la methode de Toumefort. Paris 1759.8. 4.

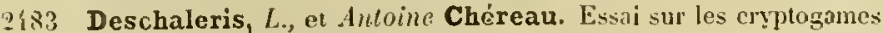
utiles. Paris 1826. 8. 28 p. a.

248 - Deschisaux, Pierre. Némoire pour servir a l'instruction de l'histoire uaturelle des plantes te Russie, et á l'ètablissement d'un jardiu de botanique á St. Petershourg 1725. $8.53 \mathrm{p}$. B.

218\%" Descourtilz, Michel Eliemne. Yoyages d'un naturaliste, et ses (b)servations failes sur les trois regnes de la nature, dans plusieurs ports tlo mer français, en Espagne, au Continent de l'Amérique septentrionale, a Saint-Yago tle Cuba et a St. Domingue ete. Parı 1809. 11 voll. 8. - J: Lxir, 365 j., 16 tal, $-11: 470$ p., 16 tab. III : 476 1). $45 \mathrm{tab}$. (multae desiderantur.)

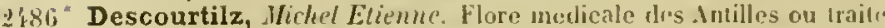
des plantros usuelles des colonirs françaises, anglaises, espagncles in fortugaises; peinte par $J$. Th. Descourtil- Paris $1821-1829$. Vill voll. 8. - 1: 1821. 992 p., tal, col. 1-6.5. - II: 1822. 346 p., 1ah. eol $69-152-111: 1827.370$ p. tah. (ool. 153-212. - I0 : 1827. 339 p., lah. col. $233-304 .-V^{\circ}:$ IS27. 292 p. tah. col. $305-380$ - V : $18 \pm 8.308$ j., tab. col. $381-452 .-111$ : 1829. 344 1.. tab col. $453-331 .-$ V111: 1829.400 1\%. 72 p. ind.. tal. col. $531-600$

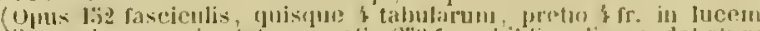

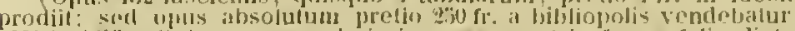

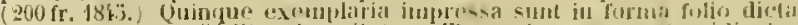

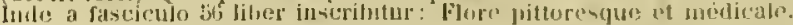

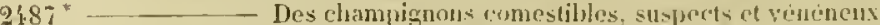
arec lindication des noyens a muloger four neutraliser los elfots des esjeces unisibles; uurage utilo aux persmner pui Iahitent la campague et mis a la portée du public accumpagné de slix planelıede desins faits daprès nature colorices avec soin el representant 200 especes groupées sur le terrain, qui les nourrit. Parik I\$2 i. \$. et Atlas: 10 tals. col. ( $40 \mathrm{fr}$.) a.

(lulem outur addlidil editioni Curmerianac: "Pouli el lirginise Florim iusulae Francogalliae et Inclicte.)

218. Des Etangs, Stamislas. Notes sur yueljues plantes alservetes dans le Dero de l'tube. Truves (1841). S, 리 p.

Extrait tles. Mén. de la soc d'agriculture, sciences. arts et belleslettres de l'sule.

$2189 \div-$ Hémoire sur les hois employés dints les charpente. eles anciens edlifiees et sur les charactères distintifs des bois de. chene et de chataignier. Trojes (1844). S. 27,4 [) $(60 \mathrm{c:})$

Q.490t Liste des nous populaires des plantes de l"Aube eq des environs de Provins, contenant l'indieation des lieur uú jls sont usités, celle de la station des espèces qu'ils concernent, les nom: botaniques, français et latius ‘ui s'y rapportent, eufin les observations ausqu'elles ils ont dume lien. Paris 1815.8 .1101 s.

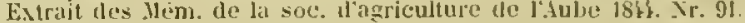

2:91 Desfontaines, Réné Louiche, rlit. Deseription d'un souveau genre de plante: Spaeudoncea. (Paris 1795.) 8. 7 p., I tab. B.

$21.92^{*}$ Flora atlantica sive historia plautarum, fuan in Atlante, agro Tunetano et Algeriensi creseunt. Parisiis, annis VT-VIII reipublicae. (1798-1800.) H voll. 4. - 1: $x x$, \{14 1)., tab.1-116.11: 458 j., tab. $117-261$. (263 fr.-pap.reclin: $526 \mathrm{fr}-70 \mathrm{fr} .1 .1843$. $2493^{*}$ - Tableau de l'école de botaniupe du Iluséum d'histoire naturelle. Paris 1804. \&. vit, 23s p. $-{ }^{\star}$ Edl. 11. ib. 1813. 8. x. 274 p. - "Catalogus plantarum borti regii Parisiensis. Ed. 111. Paris 1829.8. xvir, 446 p. - "Additanjentum: ib. 1832. 8. p. $417-$ $484 .(7 \mathrm{fr}$.

919\%:* Choix des plantes du corollaire des instituts de Tournefort, publiées d'apres son herbier et gravies sur les dessins originaux d'Aubriet. Paris 180 s. 4. 92 p., 70 tab. col.

$2490^{*}$ llistoire des arhres et arbrisseaux, qui peuvent ètre cultives en pleine terre sur le sol de la France. Paris 1809 . Jl vall. S. $-\mathrm{I}: \mathrm{xxx}, 493 \mathrm{p}-\mathrm{II}: 633 \mathrm{p}$.

$2496 \div$ - Voyage dans les régences de Tunis et al'Alger (17\$3 - 1786), publieje par M. Dureau de la Malle. J'aris 1838. \&. LII. 385 p., cum tabulis.

24.97 Deshayes, $C$. A. Notice sur un chẻne extraottinaire appelé lit Cuve, situé tlans le foret royale de Brothonce (Eure). Ronen 1826. S. 8 p., 1 tals.

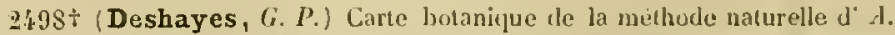
L. de Jussieu. Paris an N. (IS01.) 8. 92 p., ind.

$2.399 \div$ (-) Le Vademecum du botaniste rayagrour aux eurirons te Paris, a l'usage etc. Paris, Bauduuin. 1803 . 8. x11, 426 p. et 1 mappa zeogr.

$2500^{*}$ (— Le botaniste voyageur aux environs te Paris, a l"usage des personnes, qui ont la Flore par J. L. Thuillier. Paris, Villot. 1807. 8. xil, 426 p. et I mappa geogr.

(1laud duhie itlem liber ac praccedens.)

2501* Desjardins, Julien. Sixiène rapport annuel sur les travaux de la société d'histoire naturelle de l'ile Mlaurice. Port Louis, ile Maurice. 1835. 4 min. 33 p. - Septième rapport. ib. 1836.4 min. 67 p. †lluitieme rapport. ib. 1837.4 min. 43 p. - $\div$ Senvieme rapjort. Paris 18 10. 8. 6.S p. (vide Boutun.) 
L2:020 DeSilvestre, A. F. Yotico biographlique sur M. Antome Augustin I'armentier. Paris $1815.8 .22 \mathrm{p}$.

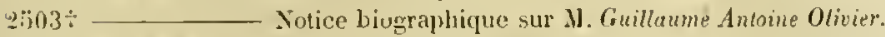
Paris 1815.8 .23 p.

Q504t - Notice biographirjue sur M. Simon Louis Pierre Marquis de Cubieres. Paris 1829. S. 26 j.

$250: 5 \div$ - Notice Jiographique sur M. Louis Auguslin Cuillaume Bose. Paris 1829. S. 28 p.

$2006+$ Notice biographicque sut M. Jean-Jugustin-l゙ictor Yvart. Paris $1832.8 .18 \mathrm{p}$.

yojt - Notice biographipue sur M. C. E. Baron Coquebert de Montluet. Paris 1832.8. $24 \mathrm{p}$.

$2008 \div$ - Notice hiographique sur M. Jacques Joseph Baudrillert. Paris $1832.8,13 \mathrm{j}$,

250!4 Desmazières, J. B. I.J. Agrostograplie des départemens du Trurd de la France, ou aualyse et description de toutes les Graminées yui croissent naturellement ou cjue l'on cultive généralement daus ees départemeus. Lille $1812.8 . x, 179$ p. (3 fr.)

$2310^{*}$ C.Catalogue des planles onises dans la botanographie lrelgique et dans les Flores du Nord de la lrance, etc. Lille 1823. 8. xแ1, 107 p. (2 fr. 50 c.)

2011 Notice sur les Lycoperdons de Linue et sur une nouvclle espece des Corpolées de Mich, a ajouter a la "Flore francaise. " Arras 1823. 8. a.

$2: 312 \div-\ldots$ Plantes cryptogames du uord tle la France. Fasc. 1 Lille 1825 . 4. 23 p. ( 8 fr.) - tPlantes cryptogames de France Ed. II. Lille $1836-1843$. 29 livraisons. 4. 1450 exemplaria sicea cum descriptionibus. (290 fr.) Herb. Montagne.

Prioris editionis IVI fasciculi, quistge 50 specierum, editi sunt.

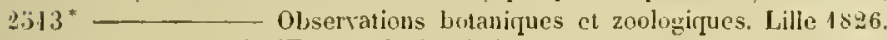
8. 52 p., 3 tab. (Tractat de fungis.)

2:314. Wowographie du genre Naemaspora rles auteurs modernes et du genre Libertella. Lille $1831.8 .11,7,45$ p., 3 tab.

201 fit DesMoulins, Charles. Notice sur des qraines trouvers dans des tombeaux romains, et qui out conserve lour faculté germinative. Bordeaux 1835. 8, 16 p.

$2016 \%$ Catalogue raisonué des plantes qui croissent spontanément dans le tépartement de la Dordogne. Premitre partic. Phanéroganes. Bordeaux $\$ 840$. 8. 165 p. - †Supplément. Prenier fascicule. Renonculacées - Caryophyllies. Bordeaux 1846. 8.69 p.

$2: 37 \div-$ État de la végétation sur le Pie du Midi de Bigorre au 17 0ct. 1840. Bordeaux 1844. 8. 112 p., 1 tab. col.

g.j8: - Note sur le Sisymbrium bursifolium de Lapeyrouse Flor. Pyr. non Lim. (Sept. i 945 .) Borleaux 1843 . 8. 24 p.

(Extrait des Actes de l'Academie royale de Bordeaux. Negligentia autoris in titulo ipso legitur annus 18 '́3.

ä:3!1 De Smyttère, Philippe Joseph Fmmanuel. Tableaux syuoptịucs d'histoire naturelle médlicale. Paris (1829). Neuf feuilles papier grand-aiglé satine avec près de 600 figures graves en taille-douce, representant les caracteres tles familles naturelles botaniques et zoologiques. ( $18 \mathrm{fr}$.)

$2820 \div$ Phytologie pharmaceutique et médicale ou végétaux envisagés sous les rapjorts anatomique, physiologique et therapentique. Paris 1829. gr. $8.122,148$ p., praef, ind. et ic. xylogr. i. t.

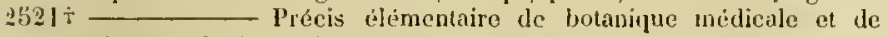
pharmacelogie, Paris $1837.8 .111,980 \mathrm{f}$.

$2322 \div$ Desportes, Eugene Ilenri. De la noix vomique; description de l'arbre et de la plaute qui la preduisent etc. These. Paris 1810. 4. $36 \mathrm{p}$.

$2323 \div$ Desportes, Jean Baptiste Réne Pouppé. Jistnire des maladies de St. Doningue. Paris 1770. 11 voll. 12. - 1: $330 \mathrm{p} .-11: 344 \mathrm{p} .-$ 111: $454 \mathrm{p}$.

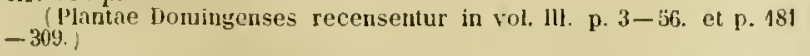

2:32' Desportes, $N$. Rosetum gallieum, ou énumération méthodique des espèces et variétés du genre Rosier iudigines en France ou cultivées daus les jardins avec la synourmie française et latine. Lellans et Paris 1828. 8. xr11, $124 \mathrm{p}$.

(ldem liber realit anno scyuenti is29 now titulu: $\div$ Roses cultivées en l'rance, an nombre de 2062 espices ou varicitis.)
$2323+$ Desportes, $N$. Flore de la Surthe et de la Hayenue (Naine), disposee dlapres ta methole naturelle ave l'iudication des proprictes medicales des plantes et leur usage dons les arts. Lellans 1838.8 Lx, $328 \mathrm{p}$. $(6 \mathrm{fr} .25 \mathrm{c.})$

$2326 \div$ Desrousseaux, Louis Augneste Joseph. An ut in plantis, sic in innimantibus, perspirationi moderandae inserviat epilermis? D. (Paris 1789.) 4. 8 p.

2527 Dessenius, Bernhardus. De compasitione medicanentorum librix. Francofurti a/M1., typ. Egenolf. 1555 . folio. - Lugduni, typ, Rovillius. 1556.8 . Bum.

2628* Destremx, J. J. Elenchus plantarum horti hotanici $J . J$. Destremx, anno 1805 . Nismes $1806.8 .69 \mathrm{p}$ - - - Alais $1821.8 .48 \mathrm{p}$.

2629* (Desvaux, A. A.) Journal de botanique rédigé par une société de hotanistes. Puris 1808-1809. Il voll. 8. - I: 1808.384 p., 11 tab - 11: 1509. 383 P., 13 tab.

$20300(-)$ Journal de botanique applirquéc à lagriculture, a la pharmacie, a la medecine et aux arts. laris $1813-1814$. IV voll. 8 . $-1: 1813.292$ p., tab. 1-11. - II: 1813.272 ].. tab. 12-20.Ill: 192 p., tab, $21-30,-W: 288$ p., tab. $31-41$.

(Sistit alteram seriem diarii praccedentis, immo ejus volumina III- i. . )

2531 Notico su' un mouveau genre des plantes de la fanille des Cypéracies. s. I. 1808 , s. a.

$2332+$ Phyllographie ou histoire naturelle des fenilles, peintes par Bonnet pire et fils. Paris 1809.8 .80 1)., 22 tal,

2533t — Programme du cours de botanique, professc au jurdin des plantes d'ligers pour 1817. Angers 1817.8 .27 p. - Ed. Il. il. 1832.8 .34 p. (2 fr. $50 \mathrm{c.})$

$2534 t$ Nomologie botanique ou essai sur l'ensemble des lois d'organisation végetale. Angers 1817. 8. 28 p. - Ed.11. ib. 1832. 8. $36 \mathrm{p}$.

(Alhaerel semper tibello uraecerleuti.)

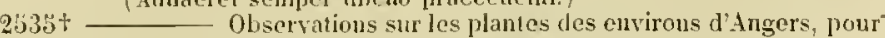
servir de supplément à la Flore de Haine et Loire, et de suite a l'histoire naturelle el critique des plantes de France. Angers et Paris 1848, 19. 188 p.

$2636 \div-$ Recherches sur los appareils secrétoires du nectar ou du nectaire dans les fleurs. Paris 1826.8 .80 p. (9 fr. $50 \mathrm{c.}$ ) (Mémolies de la soc. Limn. de l'aris, vol. $r$.)

2337*_ Flore de I'Anjon, on exposition méthodique des plantes du tlépartement de llainc et Joire et de l'ancien Anjou, d'après. l'ordre des familles naturefles, avec des observations botaniques ot critiques. Angers 1827.8 . xxxvm, 369 p. ( 6 fr.)

$2338 \div-0$ - Opuscules sur les sciences plyysiques et naturelles arec figures. Angers 1831.8 .218 p., 7 tab."

$2339^{\circ}-$ Statisti(pue naturelle de Maine et Loire. Angers 1834. \&. xil, 582 p. (Botaningue: p. $406-589$. )

$2510 t \longrightarrow$ Traite général de botanique. Tome premier, premiere et ileuxieme partic. Paris $1838-1839$. S. xxxi, $950 \mathrm{p}$.

2̈̈4t DeTarade, Alfred. Culture des rosiers écussonnés sur églantiers Paris 1828 . \&. 31 p. $(1 \mathrm{fr} .50 \mathrm{c}$.)

2542* Detharding, Georg Christoph, pr. De Seneca. D. Rostockii 1749 4. $30 \mathrm{p}$.

$2043^{*}$ (Detharding, Georg Gustav.) Verzeichniss ciner Sammlung von getrockueton mechlenhurgischen Gewächsen. Erste Abtheilung. [laanerogamen. Kostock 1809. 8. $32 \mathrm{p}$.

$2544^{*}$ Conspectus plantorum magniducatum Megalepolitanorum phanerogantarum. Rostochi 1828.8 . virt, 84 p. 2 tab. foliu. $\left(2 / 3, h_{0}-5 \%\right.$ th. $)$

2345 Dethicke, Henricus. Gardeners labyrinth. s. 1. et a. (1586?) 4 . Sloane ex $\mathrm{s}$.

25:6* (De Thou, Jacques Augustin, latine Thuanus.) Crambe. Viola Lilium. Phlogis. Terpsinoe. Prrisiis 1611.4.47 p.

(Carminum editor Puulus Renealmus ex praclatione intelligitur.)

25:7 Detlef, Peter. Ossium calli generatio et natura per fracta in animalibus Rubiae radice pastis ossa demonstrata. D. Goettingae 1753.4. H.

25'r8t (D'Etreillis et Adolphe Dammien.) Sur les plantes marines du genre Zostere (Zostera) proposees comme hase d'un nouveau systeme de coucliage incontestablement plus sain, tout aussi commode et beaucoup plus economiquo que celui dont les substances animales fournissent les inatériaux. Paris $1835.8 .24 \mathrm{p}$. 
2ij': Deusing, Anton. Dissertationes de Manna et Saccharo. Groningae 1659. 12.170 1\%. B.

2030 De Mandramorae pomis po Dondain Genes. XXX. Labitis et de Jautragortie mangoniis. 1). Groningae 1659. 12. $34 \mathrm{p}$. praeter alia. B.

2:3:31" (Deville, Nicolas.) llistoire des plantes de l'liurope et des plus usitées rui viement d'Asie, d'Afrique et d'Amérique. Lyon, Niculits Deville. 1719. JI voll. 8.866 p., praef., intl. et ic. i. t. - tl,yon, rhez Duplain. 1737. Il voll. 8.866 J., prace, ind. et ic. i. L. (non dillert.)

$20: i 2$ Deville, I'. I'r. Alhéric. I a botanique de Jean Jacques Rousseau, contonant tout ce qu'il a ecrit sur cette science; augnontce rle l'oxpusition de la méthode de Tournefort, de celle du systeme de linné etc. Seconde udition. Paris 1823.12 .8 1al), el texte. (4 [i:) a.

2.;.5: $\div$ (Dewey, Chester.) keport on the herhaceous flowering plants of Hlassichusetts, arranged according to the natural orders of Lindley, and illustraled chielly by popular descriptions of their character properties ant uses. Published agreealıly to an ortur of the legislature by the conmisioners on the zoological and botanical survey of the state. (amliridge, typ. Folsom. 4840. 8. vir, 277 p). Bibt. borti Paris.

23.j\%. Dexhach, Johann Georg. De Cassia cimamomea el Malabathro. D. Narpurgi 1700.4 . s.

(Y'alentini, Historia simplicium p. $397-609$.)

2:33:3 Dewora, $J$. $V$. Nonatiche Verriclutungen in der Obsthaumzuclut. Hadamar 1815.8 .112 p. $(1 / 3$ th. $)$

$25366^{*}$ D'Hombres (Firmas), Baron L. A. Netes sur quelques vigètaux qui croissent spontanement dans le département du Garl, et qui méritaient une culturo particulière par leurs vertus médicales ou leurs usages dlans les arts. Nismes $1834.8 .22 \mathrm{~J}$. Bibl. Turic.

2587 t Dickie, Georye. Flora thredenensis: compreheuding a list of the llowering plants and ferms found in the neighlourhood of Aberdeen; with remarks on the climate, the features of the vegetation. AberJeen 1838. 8, v, 70 p. $(2 \mathrm{~s} .6 \mathrm{~d}$.

23ijs Dicks, John. The new gardener's dictionary, Loudon 1771. folio. 3 .lphab. 14 jlag., 13 tab. B. germanice: von Zeiher. Vollstindige Gartenhunst. Leipzigr $177 \mathrm{k}$ 2 Binde. 8

2:30) Dickson, Adam. De lagriculture des anciens. Trarluit de l'anglais Paris 1802. Il voll. 8. - I: xiv, 470 p. $-11: 478 \mathrm{j}$. , I tal.

2360 * Dickson, James. Fascieuli (1V) plantarum eryjtoganicarum Britanniae. London $1785-1801$. 4. $28,31,24,28$ j. et 12 tals. partim col. (18s. Lendon, Pamplin. 1846 .)

(Archetypa jconmm a James Soccerby pictarun servantur in Britisu Museum. - Ob summau jn Germania raritatem Turici recudi curaruut Roemer ef Usteri: nec vero, (puatum scio, vltra fasciculun alterum quidquam prodiit.)

$2361^{*}$ Dickson, $\boldsymbol{K}$. IV. Practical angriculture; or a complete system of modern lusbandry: with the best methods of planting, and the improved management of live stock. A urwedition. London 1807. Il rol]. 4. $-1: x L 1 v, 650$ p., 53 (ab) $-11: x x i v, 767$ p., 34 tab. - Appendix: $62 \mathrm{p}$.

2:362+ Dickson, Robert. A lecture on the Dry Rot, and on the most elfectual meants of preventing it; delivered before the institute of british arehiteets. Loulon $1 \$ 37,8.50 \mathrm{p}$.

2563* Diebl, Franz. Die Feldhaumwirthschaft, cin Nittel gegen Ilolzmangel und Theurung. Brunn 1834 . $8.72 \mathrm{pe}(1 / \mathrm{t}$ th. $)$

256't Diecker, Il. R. Der Obstgirtuer in Zimmer. Passau i \$26. 12.(2/3/h.)

$2335+$ Diel, Angust Friedrich Atrian. Ueber die Anlegung einer Obstorangerie in Scherben und die Vegetation der Gewielsse. Dritte vermelsrle Auflage. Frankfurt a/A. 1803. 2 Theile. 8. - I: viII, 405 p. - II: 426 p., 7 tab. nebst einen Olstverzeichniss. $\left(2 \frac{2}{3}\right.$ th.

$2366^{\circ}$ Versucls ciner systematischen Beschreibung der in Deutschland verhandenen hernolistsorten. Franhfurt a/MI. 17991819. 21 Bändchen. $8 .(17 \%$ th. $)$

$2367^{*}$ Systematische Beschreibung der vorzüglichsten in Deutschlanil vorhandenen Keruobstsorten. Stultgart und Tubingen 1821-1832. 6 Báulchen. 8. 245, 242, $325,231,224$ et 241 p., 6 tab. col. $(6 \% / 12(h)$.

(Fistit continuationem, quasi fasciculos $22-27$ operis praecoilentis. Indicen generatem onnium 27 fasciculorum edidit $H$. Meyer Braunschwejg $1 \times 3 \%$. $8 \%, \frac{2}{2}$.)
2568* Diel, August Frichrich Ifrian. Systematisches Verzeichnins der

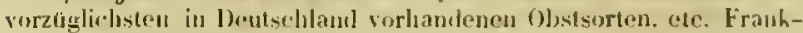

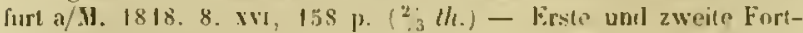
setzing. ib) $1829-1833.8$. (11/12 /h.)

2:369" Dierbach, Juham Heinvich. Ilandluch der mediciniscli-phamatceutisclsell Botanih, oder systematisclie lleschreibung simmticlser oflizineller Gewatise, zum Goloriusehe fur Aerzte, tpotheher, Droguisten unl als Leitfaten fur aharlemische Vurlesungen. Ilejilelloer. 1819. 8. VHI, 492 p. (3 th. $)$

$2570^{*}$ - Wora lleidelhergensis plantas sistuns in pravfectura lletdellergensi et in regione arlini sponte nascantes secumlum systema sexuale Jimeanum digestas. Ileiflelhergac $1819-z 0$. II partes. 12 . su, 406 p. cum mappla groggr. $2 \frac{1}{4}$ th.

$2.371^{*}$ Inleitung zum Studium der Botanih. Fur Vuleumuen und zum Selbstunterrichte. Heidelherg 1820.8. vin, 2801$)$ p.. 13 tal, $(2 / h$.

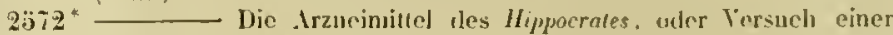
systematischen Aufzálhlung drr in allen Jlippocratiselien Selirifen vorkommenden Medikamente lleidelber 1824. S. xwy, $270 \mathrm{p}$. $\left(1 \frac{1}{2} t h.\right)$

$2: 373^{*}$ Beitrige zu Deutschlands Flora, gesammelt aus den VIerhen dir altenten deutschen Pflanzenforscher. Heidelherg $1893-$ 1833. 4 Tlıeile. 8. - I: 1825 . xvi, 86 p., efligies Trugi. - 11: 182. 80 j.; effigies Fuchsii. - 111 : 1830.64 P. 8 lat., efligies Chusii. JV: 1833. Iv $164 \mathrm{p}$, effigies Conradi liesneri. (3 (h.)

$2577^{*}$ __ Systematische Uebersicht der um Jleidelbers widw achsenden und haufig zum okenonischen Geloraucle cultivirton Growachse. Firstes Heft. Karlsrulı $1827.8 .178 \mathrm{p} .(1 / 2(\mathrm{~h})$.

Extraabdruck aus Geiger's Milgazin fur Phirmacie.

$2575^{*}-$ Dic neuesten Luttleckungen in der materia molica. Heidelberg 1828. Zwei Abtheilungen. s. $\mathrm{xx}, 782 \mathrm{p} .(3 \mathrm{~h}$ ) - Zweite, durchaus neue und his auf die jungsten Zeiten fortgesetzte dusgabe. 13and I-III. 1. Heidelherg 1837- $1845.8 .(9 \mathrm{~h}$.)

$2576^{*}$ - Repertorium botanicun, oder Versuch einer systemalischen Darstellung der neusten Leislungen im ganzen Lmfange der Pflanzenkunde. Jemgo $1831,8, x, 266 \mathrm{j}) .\left(1 \frac{5}{12} / \mathrm{h}.\right)$

$907_{7}$ * Abhandlung ulier die Arzneihráfe der Pflanen, berglichen mit ihrer Structur und ihren chemischen Bestandtheilen. Lengo $1831.8 .1 \mathrm{v}, 392 \mathrm{p}$. $(1 \mathrm{t} / 3 \mathrm{th}$.)

2578* Flora Apiciana. Ein Beitrag zur udheren Kenntniss der Nahrungsmitte] der alten kömer, mit besunderer Rucksicht auf die Bucher des Caelius Apicius de opsoniis et condimentis sive arte coquinaria. Heidelloerg 1831.8 . vin, $75 \mathrm{p} .(1 / 2 \mathrm{th}$.

3279* - Flora nythologica, oder Pflanzenkunde in Bezug auf Mythologic und Symlsolik der Griechen und Römer. Ein Beilrag zur altesten Geschichte der Botanit, Agricultur und Medicin. Frankfurt a/11. $1833.8, x, 218 \mathrm{p} .(11 / 3 \mathrm{th}$.

$2580^{*}$ Grundriss der allgemeinen okonomisch teclnischen Botanik oder systematische Beschreihung der nutzharsten Gew dichse alfer Ilinmelsstriche. Heidelberg 1836-1839. 2 Bünde. 8. - 1: 1836. xy, 263 p. - Il: 1839. xxxiv, 572 p. (4 /h.)

2.381 * Synopsis materiae medieae oller Versuch ciner systematischen Aufzäl.lung der gebräuch]ichsten Arzneinuittel. Heidelberg 1841-1842. Zwei Altheilungen. 8, xvi, $1302 \mathrm{p}$. (6 th.)

2582* Diesing, Karl Morilz. De Nucis romicae principio efficaci. D. Vindobonae 1896. 8. $21 \mathrm{p}$.

2583 Dieskau, Christian Johann Friedrich von. Das regelmassige Versetzen der Bäume in Wáldern und Gárten. Meiningen 1776. 8. 167 p. B.

258 ' - Vortheile in der Gärtherei. Vemehrte Ausgabe. Coburg 179\%. 2 Bande. 8

2585* Dieterich, Karl Friedrich. Pflanzenreich nach dem neusten Natursysteme des k. S. Ritters Carl von Limne. Erfurt 1770. 2 Theile. \& 1332 p., praef, ind. - ${ }^{*}$ Zweite vermelirte Iusgabe von Christion Friedrich Luduig. Leipzig $1798-99$. 3 Bände. 8. xi, 628, 54h, 462 ]. $\left(4 \frac{1}{3}\right.$ th.

$20386 *$ Aufangsgründe der Pflanzeuhenntuiss, Leipzig 1775. \& 362 p., 12 tab. - Zweite verhesserte unt vermehrte Auflage. Leipzig 1785, 8. 323 l., 12 tab. ( I th.)

20̈87* Dietrich, Albert. Flara rer Gegend um Berlin oder .Iufzahlung und Beschreibung der in der Jittelmark wild waclssenden und angebanten 
Pflanzen. Nit einer Vorrede won H. F. Link. Erster Theil. Phanerogamen. Berlin 1824. 8. xit, 9:4 ]). (2 $t / h$.)

2588* Dietrich, Albert. Terminologie der phanerogamischen Pflanzen lurch melor als 600 Figuren erlauterl und besonders zum Luterricht fur Senunarien und Realgymnasieu bestimnt: nobst einer Anleitung fur den Lehrer, wie er in der Botanik mit Nutzen an unterrichten hat. Berlin 1829. folio obl. 26 p., $s$ tab. ( $/ / h$.) $-{ }^{*}$ Zweite durchaus umgearbeitete Auflage. Berlin 1838. gr. 8. vill, $127 \mathrm{p}$. I i lab. $\left(1 \frac{1}{3}\right.$ th. $)$

hollundice: kunstwoordienleer der plithen. Amsterdan 183'. plano. (2 [i: $10 \mathrm{c}$ C.)

Z389* Veber alic europáaschen Arten der Gatung Giadiolus. (Programm.) Berlin 1832.4.13 p. I tab, col.

Z:990* - Flora regni Borussici. Flora des Konigreichs Preussen oder Abbildung und Brschreibung der in Preussen wildwachsenden Pflanzen. Berlin 1833- is í Xll voll. 8 max. 86 i 1ab. col., totidemque foll. text. $(96 \mathrm{th}$. $)$

Fortasse coutimahitur. Cuivis volumini insunt 7e tab. col., pretio $8 h_{0}$ - Fungos esposuit illnsir. Friedrich Filotzsch.

$209 I^{*}$ - Handbuch der phirmacentischen Belanik. Ein Leitfaden zu Vorlesungen und zum Selbststulium. Berlin 1837. 8. xxtx, $414 \mathrm{p}$. (2 th.)

2:392* - Botanik fur Garther unl Gartenfreunde. Berlin 18371839. 3 Theile. 8. - I: 1837. Allgemeine Botanih: 479 p. - H und III: 1839. Besondre oder praktisclie Botanik, 544,844 p. $\left(5^{7} / 12 t h.\right)$ (Nistit sectionem priorem collectionis inseriptae: Handlibliothek fur Gariner.

?393* 2 Flora marehica oder Besehreibung tler in der Nark Brandenburg wildwachsenden Pflanzen. Berlin 1841. 8. XL1V, $8 \pm 0 \mathrm{p}$. $\left(2 \frac{1}{2}(h)\right.$.

$2394 \div$ Dietrich, David Nalhanael Friedrich. Dentschlands Giftpflanzen, nach naturlichen Familien aufgestellt mit Abbildungen. Jena 1826 . S. viu, 64 p., 24 tab. col. $\left(1 / \frac{1}{3} / h\right.$. $)$

$2.93^{*}$ Hlora Jenensis oder Beschreibung ler Pllanzen, welche in der Ungegend ron Jena wachsen. Erster Band wer 2 Theile. Jena $1896.8 . \mathrm{r}, 716 \mathrm{~F}$. ( $(2$ (h.)

(Desinit feliciter in singenesia ; sed e bibliopolac epistolis certio cum factus, alteram cryptoramicam adesse partem 166 pasinarum.

$2096 \div-$ llaudbuch icr Botanik oder systematische Beschreibung aller deutschen pflanzen, so wie tor wichtigen auslandischen. Jena 1S28. S. Erster Theil, arste Abtheilung: v1, 342 p. ( $1 \frac{1 / 4}{t h}$.) (Desinit feticiler in Pentandria.)

2597 - liorstliora oder Abbildung und Beschreibung der fur den Forstmann wichtigen Banme und Stráucher, welche in Deutschland will wachsen, so wie der auslandischen, daselbst im Freien ausdauerndeu. Jena 1828-1833. 23 liefte. gr. 8. 92 tab. $11 \frac{1}{2}$ Bogen Text. (11 $1 / 2$ th.) - Zweitr verbesserte Aullage. Jena $1838-1840$. 29 Hefte. gr. 4. 255 tab. col. 172 Blátter Text. ( 29 /h.)

$2398 \div$ _ Flora medica oder Abbildung der wichtigsten officinellen Pflanzen. Mit Berucksichtigung der preussiselsen und andrer neuer Pharmacopoen herausgegeben. Jena 183 I. 18 Jefte. 4. 4 p., 180 tal. col. ( 12 th. - herabjesetzt: 9 th. $)$

$2: 399$ Das Wichtigste aus dem Pflanzenreiche, fur Landwirthe Fabrikanten, Forst- und Schulmänuer. Jena 1831 - I838. 22 Hefle. gr. 4. 11 Bogen, 88 tal). col. ( $7 \frac{1}{3}$ th.) - Zweite ganz umgearbeitete Aullage. il). 1840. 3 Hefte. ar. 4. 1 1/2 Bogen, 30 tal. col. (2 th.)

$2600 \div-$ Flora universalis in holorirten Alhuldungen. Ein Kupferwerk zu den Schriften Linne's, Willdenow's, Decandollo's, Sprengel's, livemer's und Scluultes' u. A. Jena 1831-1846. 284 Hefte à 10 tab. col. a $2 \frac{1}{3}$ th. $=2840$ tab. col. und Erklärung. $\left(662 \frac{2}{3}\right.$ th. Bibt. Deless.

Erste Abtheilung. Heft 1-63. Zweite Abth. Heft 1-113. Dritte Abth. Ileft $i-108$.)

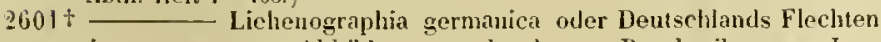
in naturgetreuen Abbildungen nebst kurzen Beschreibungen. Jena 1832-1837. 9 Ilefte. 4.46 p., 225 tab. col. (27 th.)

$2602+$ Deutschlands Flora. Nach naturlichen Familien beschrieben und durch Abbildungen erlautert. Ein Handbuch fur Botaniher uberlsaupt: so wie fur Aerzte, Apotheker, Forstmänner, Ockonomen und Gártner insbesondre. Jena 1833-1842. 3 Bảnde, gr. 8.57 Bogen, 71 tab. col. ( 71 th. - herabgesetzt: 43 th.)

2603 Taschenbuch der Arzneigewachse Deutschlands. Jena 1838. 8. $17 \frac{1}{4}$ Bogen, 50 tab. col. $\left(3 \frac{1}{2}(h)\right.$.

$260 \div \div$ Taschenbuch der auslandisehen Arzneigewdelise. Jena 1839. 8. IV , $39 / 4$ p., 69 tab. cul. ( $51 / 4$ th. $)$
260:3 ${ }^{*}$ Dietrich, David Wathanael Fredrich. Synopsis plantarum seu Enumeratio systematica plantarun plerumque adhuc cognitarum cun differentiis specificis of synonymis selects at uurlum Persoonii elaborata. Vimariae 1839-1847. Wroll. 8. - J: Classis $\mathrm{I}-\mathrm{V}$. 1839. xx, 879 p. - IJ: Classis VI-X. 1840, p. $817-1647$ - IU Classis XI-XV. $1843, x, 730$ \%. - IV: Classis XVT-XIX. 1847 p. $731-1692 .\left(26 \frac{1}{2}\right.$ th.) (Continuabitur.)

2606־ — Dentschlands okonomische Flora oder Beschreibung und Abbildung aller fur Land- und Ilanswirthe wishtigen Pllanzen. Jena 1841-1843. 3 Bande. 8. - I: Die Futterkräuter. Xiv, Xvi, 203 p., 50 tab. col., I tab. nigr. - I1: Die Unhrauter. 8 Bogen, 50 1ab. col. - HI: Getraidearlen, Oelgewüchse u. s. w. 9\% Bogen, 46 tals. col. $\left(9 \frac{1}{6}\right.$, th. $)$

2605 Taschenluch der pharmaceutisch vegetabilisclien Rohwarenhunde fur Acrzte, Apotheker und Droguisten. Jena 184218:6. 6 llefte. 8 . 28 Bogen. 60 tah. col. $\left(4 \frac{1}{2}\right.$ th. $)$

2608 Zeitsehrift fur Gártner, Botaniker und Blumenfreutıde, oler Repertorium hotanicae evoticae systematicae, sistens diagnoses generum et specierum novarum. Jena 1840-1846. 3 Bände. gr. 4. - 1: 12 Hefte. 30 Bogen, 48 tab. col. - It: 12 Hefte. 18 Bogen, 36 tah. col. - III: 12 Ilefte. 6 Bogen, 79 tab. col. - IV: 1 Heft $3 / 2$ Bogen, 6 tab. col. ( $221 / 2$ th.) (Continuatur.)

$2609-$ Encyclopadie der Pflanzen. Enthaltend die Beschreibung aller bis jetzt bekaunten Pflanzen, nach dem Linue'schen Systeme geordnet. Jona 1841-1846. 2 Bande. gr.4. - I: 19 llefie. $82^{3 / 4}$ Bogen, 73 tah. col. - Il: 11 Hefte. $43 \frac{1}{4}$ Bogen, 70 tal. col. $\left(44 \frac{1}{6}\right.$ th. - nigr. $24 \% / 12$ h.) (Continuatur.)

2610 - Abbitdungen von mehr als 30,000 Pflanzenarten, nach dem Lime'schen Systeme geordnet, mit Angabe ter naturlicheu $\mathrm{Fa}$ milien. Als besondrer Abrlruck aus der Encyclopadie der Pflanzen. unl durch viele neue Pllanzen erlautert. Jena 1846. 4. Erstes Heft 2 Bogen, 30 tab. col. $\left(5^{1 / 3}\right.$ th. $)$

(Continuatur. In una tabula $30-50$ plantae alsunt!)

$2611+$ Deutschlands kryptogamische Gewàchse, orler Deutschlands Flora sechster und siebenter Band: Kryptogamip. Jena 1843 - 1846.2 Bande. 8. - V1: 12 Ilefte. Farnkrauter, Laubmoose, Leliermoose. 16 Bogen, 300 tah. col. - VTI: 6 Hefte. Flecbten, Algen und Schwânme. 3 Bogen, 150 tab. col. ( 45 th.)

Conlinuntur: Davites noster infaustus, Germaniae Buchozius, editorem operum miserrimorum, quorum pretiun mille eirciter est thalerorum, Augustum Sclmid habet Jenensem. Par nobile fratrum!)

$2612+$ Dietrich, Friedrich Gotllicb. Die Weimarsche Flora otler Verzeichniss der im llerzoglichen Parh in Weinar befindlichen Baume, Straucher und Stauden. Eisenach 1800.8 . xvi, 244 p. $(3 / 4 / h$.

2613 - Der Apothekergarten, oder Anweisung in Apotheken brauchbare Gewachse zu erzichen. Berlin 1802.8. (1 $1 / 3$ th.)

$2614 \div$ - Dic Limneiscben Geranien fur Botaniker und Blumenliebhaber, durchaus neu und nach ter Natur abgebildet nnd nach sorgfiltigen Beobaclitungen beschrieben. Ersten Bandes $1-3$. lleft. Weimar $1802.4 .50 \mathrm{p}$., 12 tab. col. ( $3 \mathrm{th}$.)

9613* — Vollständiges Lexicon der Gärtnerei und Botanik. Berlin 1802-1810. 10 Bande. 8. - Generalregister: ib. 1811. 8. - Naehtrag: ib. 1815-1821. 10 Bande. $8 .(62$ th.)

$2616^{*}$ - Neu entdeckte Pflanzen, ihre Charahteristik. Benutzum und Behandlung, linsichilich der Standorter, Fortpflanzung umd Vermehrung. Berlin 1825-1835. 7 Batude. 8. Abelicea-Rytiploca. $(2 \mid$ th. $)$

(Sistit continuationem libri pracedentis.)

$2617^{*}$ __. Beschreibung der vorzuglichen Gärten in und bei Eisenach, nebst Verzeichniss der im Carthausgarten vorrathgen Pflanzen. Dritte stark vermehrte Auflage. Eisenach 1811 . 8. Vi, 364 p. 1 (al). $\left(1 \frac{1}{t}\right.$ th. $)$ - Ed. Il: Eisenach I 808.8 .

2618* - Iesthetische Pflanzenhunde oder Auswahl der schonsten Zierpflanzen nach den Bedurfuissen $1 \mathrm{ler}$ Blamenfreunde in Klassen eingetheilt. Berlin 18 12. S. xu, 300 p. $(1 \%$ th. $)$

(Nihil porro prodijt.)

$2619 \div-$ Nachtrar zu Borchbausens botanischem Worterbuche nder Versuch einer Erklarung der vornehmsten Begriffe und Kunstworter in der Botanik. Nit einer geurängten Geschichte der Botanik. Giessen is 16.8 . vi, $111 \mathrm{j}$. $(1 / 2 \mathrm{th})$

$2620^{*}$ - Handluch der botanischen Lustgartnerei etc. Hamburg 1826-1828. 2 Bánde. 8. - 1: xvi. 460 p. - \}1: $31 \frac{1 / 2}{2}$ Bogen. ( 3 th. 
2021 Dietrich, Friedrich Golllieb. Ilandlexicon der Gärtaprei und Botanih oder alpluabetische Beschreilung von Bau, Wartung und Sutzen der vorzuglichsten in - und auslindischen, ohonomischen, ufliziullen und zur Zierde dienenden Gewähse, nach dem neusten Stande der Wissenschaft bearluitet. Berlin 1829-1830. 2 Bande. 8. - I: 1899. Albana-Claryanthemum. vI, 608 p. - Jl: 1830. Chrysiphiala-lleretiera. 11,610 H. $(6$ th.

262? - Der Somıneratruner, oder Beschreibung der Zierpflanzen. Welche in unsern Giaten unter freiem Himmel gedeihen. IIm Is4 1. gr'. 12. 19 12 Bogen. ( $11 / 12 / h$.)

$2623 t^{\circ}$ - Die: Wunler der Pllanzenwelt oder Beschreibung der wunderbaren Jischeinungen im vegetabilischen Reiche. I'lm 18'4. S. W. 231 p., 2 (ab) $(1 / h$.)

262\% - bie Herbst - und Winterflora in Gewachshatusern, Zinmern und salen. Clm $1543,12.8 \%$ Bogen. ( $1 / 12$ th.)

2023: Dietrich, L. L. Die Vermehrungsarten der Zirrgewächse. Nordliausen $1844.8 . \mathrm{vt}, 118 \mathrm{p} .(2 / 3, h$. $)$

2626 - Handbuch des Gártners, in alphabetischer Ordnung. Nordhausen 1844. $8 .\left(1^{5 / 12}\right.$ th.

llic alia multa de horticulura scripsit, quae praetereo, aeque ac sextum alium hujus nominis serijtorem.')

192:- Dietz, Johann Heinrich. Moschoharpologia, i. e. brevis ae succincta de nuce moschata disserlatio. El. II. auctior et emendatior. Giessae llassorum 1681.4.63 ll, I tals.

$2628 *$ Diez, H. Fr, von. Vom TuJpen - unl Sarzissenbau in der Türkei. Aus dem Turhischen des Scheich Muhammed Lalezari uhersetzt. Ilalle 1813.8 .40 p. $(1 / 8$ th. $)$

g629 Digby, hene/me, latine Dygbaeus. A discourse concerning the weretation of plants. London 1661 . $19.100 \mathrm{p}$. - printed with his look on Budies. ils. 1669 . 1. 13. 207-231. B.

- latine: Dissertatio de plantarum rosetatione, habita in collegio Greshanumensi ad diem 23. Jan. I6601: sertente Olfredn Dapper. Anistelo-

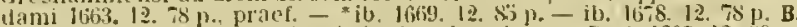
- gallice: Discours sur la vegetation des plantes. Paris 1667. 12. $89 \mathrm{p}$. prief.

$2630^{\circ}$ Dijk, C. I. ran, und A. van Beek. Onderzoekingen aangaande het zwart in de Jelisbrooden. Austerdam 1829. 8.55 p., 2 tab.

2631* Dillenius, Johann Baplista Joseph. De Lichene pyxidato (fimJriato et coccifero). D. Mloguntine 1785. 8.48 \%. I tab.

(Redit in Schlegel, Thes. mat. med. 1. p. $307-326$.)

2632* Dillenius, Joham Jakob. Catalogus plantarum sponte circa Gissam Hascentium. Cum appendice, çua plantae post cditum edalogum circa of cutra Gissam olsservatae recensentur, specierum novarum vel dubiarum descriptiones traduntur, et genera plantarum nova figuris aeneis illustrata, describuntur: pro supplendis institutionibus rei herbariae Josephi Pitton Tournefortii. Francofurti a/M. 1719. S. 240 p., ind. Appendix: 174 p., 16 tab.

Accedit: Evamen Responsinnis Augusi Quirmi Rivmi: 20 p. Jiann lindolonae vidi editionem anni lis is.

$2633^{\circ}$ Hortus Elthamensis, scu plantarum rariormm quas in horto suo Elthami in Cantio coluit vir ornatissimus Jacobus Sherard, delineationes el descriptiones, quarum historia vel plane non, rel imperfecte a rei herbariae scriptorilsus tradita fuit. Londini, sumtibus auctoris. 1732 . IJ voll. folio. vill, $437 \mathrm{~J} ., 324 \mathrm{tab}$

2631: * Horti Elihamensis plantarum rariorum icones et nomina a Johanne Jacoba Dillenio M. D. descriptarum Elthami in Cantio, in horto viri ornatissimi atque praestantissimi Jacobi Sherard, adclitis denominationibus Linneanis. Lugduni Batavorum, apud Cornelium IJaak. 1774. Il voll folio. (12 1.), 324 tals. Nora cst iconum editio absquo textu.

v63̈̈* Listoria muscorum, in qua circiter sexcentae species reteres et norae ad sua genera relatae descrilountur, et iconibus genuinis illustrantur: cum appendice et indice synonymorum. Oxonii e theatro Sheldoniano. 1741, 4. xre, $576 \mathrm{p}, 85$ tab. - " Edinburgi c prelo academico. $\$ 811$. 4, xvi, 576, 8 [3. 85 tab. (A. $4 l .4 \mathrm{~s} .-90$ fr - 8 A. C.Il. Wien, Parrerss. 1846.1

2636* Historia muscorum; a general history of Land and Water etc. Mosses and corals. Containing all the known species, exhibiter by about 1000 figures, or 85 large royal 4. Copperplates, dranil and engraved in the best manner from the originals Their names, places of growth and seasons in english. Their names in latin referring to each ligure. London, Millan, 1763. 4. 13, 10 p.. 85 tals. (1l.5s.) - "ib. 1768 4. (In his editionibus textus desideratur.
2637- Dillwyn, Letcis $17^{*}$ eston. British Confervae; or colored ficures and descriptions of the britisls plants referred hy botaniss to the genus Conferva. Lunilon 1809.4.87, (296) p.. 113 tals. cul.

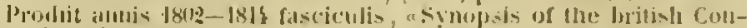
fervace iuscriptis.

" germanice: Givosabritanniens Conlerver Yach Dillw un fur deutsche

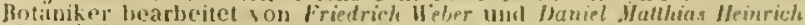

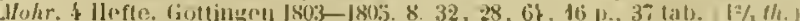

$2638^{\circ}$ (- 1 A Rewiew of the references to the flortu Malibaricu. uf Henry "an Rheede vun Drakenstein. Fot jublished. Swansea. printed at the Cambrian-1)ffice, by Jlurray and lices. 1839, \$, vils $6.9 \mathrm{p}$

Autor fommentarios flamithoni, bibliohrecas et cullueliones Loddigesianas Londiunenses in claborando libella prerdujivis.

$2639 \div$ Dinegro, Giovanni Carlo. lilenchus plantarum horti hotanici, ol,servationilus quoad novas vel rariores species passim interjeclin Genuae $1802.4 \mathrm{~min} .36 \mathrm{p} ., 1 \mathrm{ab}$

sub) unefamiur numen sisnavit Damenico livinni.)

26:10* Dingler, J. G. und $\Pi^{*}$. H. v. Kurrer, Ceher die Nimphaea alla L. Weisce Seerose und deren Inwendung in fler Druck- und Farbokunst. Nebst einer chemischen Analyso des Ilofr. Dr. Foget in Munchen. Wien 1820.8. 16 p.

261 Dionis-du-Séjour. De la maniere promple et facile de multiplier le inurier blane, jar le meven de la grefle, meme dans les climats les plus contraires a sa culture. Paris 1812, $8.16 \mathrm{p}$.

Dioscoridem cum commentatoribus in calce alphabeti recencebo.

261:2* Ditrich, Lurlwig. Planlac officinales inligenac, linguis in Ifungaria vernaculis deductae. D. Budac 1835. \$. 31 p.

2613* Dittrich, Johann Georg. Syslematisches Ilandbuch der Olssthumle nebst Inleitung zur Obstbaumzueht und zweckmássigen Benutzuny des Olswes. Jena 1837-1841. 3 Bünde. 8. - 1: 1837. y2 Bogen. 2 tab. - II: 1\$37.42 Bogem, $6 \mathrm{lab}_{;}$- III: Nit Dr. Liegel's l'ortrait. 18+1. Lxul. 711, 7 p. $\left(\delta^{1 / 2}(\mathrm{~h}\right.$.$) - Zweite termelurte duflage. Jena$ 1839- 1841 . 3 Bunde, 8 , in 22 Lieferungen: $126 \%$ Bugen, Q Tabellen, 9 tah. $(5 \mathrm{~d} / \mathrm{h}$.

(De tabulis, (juilus liber illustratur, ef. rocem: Obstcabinel.)

Q61:4* Dittweiler, Wilhelm. Lehrluch der Belanik fur Thierarzte, Landwirthe und l'harmaceuten und die lielreffenden Lchranstalten, zum Gebrauch bei Vorlesungen und zun Selhstunterricht. Stutgart $1 \$ 47$.

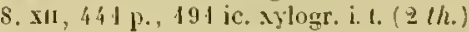

$2613 \div$ Dobel, Karl Friedrich. Smonymisches Wurterbuch der in der Arzneikunde und in llandel rorkommenden Gewaclise. etc. Xach Sprengel's Ausgabe des Lime'schen Systems zusammengestellt. hempten 1830 . 8. xit, 510 p. (2 th.)

$2640^{*}$ - Yeuer Pflauzenhalender, oder Anweisung, wclche in Deutscliand wachsenden Pflanzen man in jedem Monate bluheud finden home, und an welchem Standorte. Vach dem jetzigen Stande

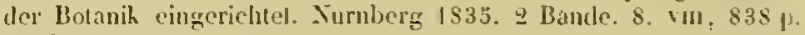
(2) th.

2617* (Dobrowsky, Joseph.) Entwurf eines Planzensystems nach Zalilen und Terhaltnissen. Der Schlijssel zur Vereinigung fler kunstlichen Pfanzensysteme mil der naturlichen Methode. Prag 1809.8. 9 s p., 1 tab. $(7 / 2$, th. $)$

Q6's* Dodart, Dinmys. Memoires pour servir a l'histoire des plantes Paris, te l'imprimerie royale. 1676 . folio. $131 \mathrm{p}, 3 \mathrm{~s}$ tals. in tevtu et 64 tab. absque deseriptione. - "Ed. ll. revue et corrigin. Paris, du l'imprimerie royale $1679.12 .329,(10)$ p. - TEd. Ill: avec les descriptions de quelques arbres et de quelques plantes de Malaque. par le P're de Beze. Amsterdam et Leipzig. Arkste et Merkus. 1758 4. 94 p. et p. $553-644,38$ tab.

Mem. de lifad des se de Paris, 1666-1699. lome IV. 13. 12I-323. (1) corsunetis curis sociorum Acadeniae Parisiensis editum. Icones eaeden stunt. yuam illae a Nicolao Robert. A. Bosse et Ludovico de chastillon editae. In elitione altera solus discursus praelimirico de Chastillon editae. In etitione altera solus discursus
naris adest. Spreng. Ilist. rei herb. Il. p. $23-23$ et p. 1li.)

2649* Dodoens, Remberl, latine Dodonaeus. De frugum historia lilser unus. Fijusdem epistolae duae, una de Farre, Chondro. Trago. Ptisana, Crimno et Alica; altera de Zytho et Cerevisia. Antwerpine. ex officina J. Loci. 1559. S. et ic. xylogr. j. t. Bibl. Caes. Viodob.

Cet opuscule est devenu trís-rare. Les fizures sunt les mêmes que cellus dans le to line du consdehoech, auquel il correspond earctenient, $\mathrm{V}$ Van Meerbeck!)

$2630^{*}$ - Trium priorum de stirpium historia commentariorum imagines ad rivum expressae. Cna cum indicibus graeca, latina. 
ufficinarnm, germanica, brabantica, gallicaque nomina complectentibus. Antwerpiae, ex officina J. Loei. 1533.8 .439 p., prael., ind. (438 icones ligno incisae.) Bibl. Caes. Vindob.

2651 * Dodoens, Rembert, latine Dodonaeus. Posteriorum trium de stirpium listoria commentarionm imagines arl vivum artificiosissime expressae; una cum marginalibus annotationibus. Item ejustem annetationes in aliquot prioris tomi imagines, yui triun priorun liIrorum figuras complectitur. Autrerpine, ex olticina J. Loęi. 1554. 8. 302 p., ind. (275 icenes ligno incisae.) Bibl. Caes. Vindob. tomos digestae, supra prierem editionen multarum nerarum figurarum accessione locupletatne ae postremo recognitae. Acceswere succinctae ac breses in utriusque tomi inigines adnotationes. Antverpiac, ex olficina Loèi. 15ั39. Il vall. 8. cum ic. xylogr. i. t.

Tomus I. 439 paginarum eadem est editio eum priori, prima tantum plagula dento impressa. Tomus If. piginas hahet this, quarum 272 priores ejusdem onnune editionis sulut, reliqua vero vel diversae, vel de novo adhitac indicestgue cum titulo detuo impressic.)

$263.3 \div$ dat es tgheslacht, tatsoen, naem, natuere, cracht ende werckinghe van den cruylen, niet alleen hier te lande wassende, maer eoch van den anderen vremden in der medecijnen oorhoorlijek, met grooter neersticlseyt begrepen ende rerclant es, met derselver cruyden natuerlich naer dat leven conterfeytsel daerby ghesteh. Dner D. Rembert Dodoens, medecijn van der start van Mechelen. (In ealce legitnr:) Ghedrucht Tantwerpen by Jan van der Loe in onser Trouwen pandt, int jaer 1554 . folio. ( 20 loll.) 818 p., ic. xylogr. i. t. (9 foll) Bibl. Reg. Brux.

(Editio prineeps rarissima a Seguierio, Trewio. Inllero, Limnaeo, Pacquotio, Bunksio desiderata, al Hulthemio per viginti tuinque innos frustra quaesita, servatur Brucellis in regia thibliethecil. Provilegiun imperateris datum est Bruvellis die X.Fili. Maji 10̈31. - Post praefationem sequitur eftipies Dodondei. aetatis $3 \%$. - Lilder in sex partes divellitur; sunt 818 paginae; praceedlunt 20 folia absque signatura clauduut 9 folia absque sjgnatura. Prima icon est Abrotanum foemina et mas, ultima Petrosclinum.)

Warpen 458 Cruydeboeck. Antwerpen 1563 . folio. Bibl. Brux. - ${ }^{*}$ Ant- ${ }^{*}$ Cruydt-Baeck; volgens sijne lactste Verbeteringe; met biivoeghtsels achter elck eapittel, uut verscheyden cruydtbeschrijvers; item, een beschrijvinghe vande hadiacnsclse ghewassm, meestighctrocken uyt de sebriften vàn Car. Clusins. Leyden, Fr. van Ravelingen. 1618 Folio. 1493 p., ind., ic. xylogr. i. t. Bibl. Berol. - j Autwerpen, B. Mloretus. 16 亿 f folio. 1492 p., ind., ic. $x y \log r$. i. $t$.

* gallice: IJistoire des plantes, en laquelle est contento la description entierre cles herbes, c'est à dire leurs especes, forme moms, temperanust, vertus et operation: nul seulement de celles qui croissout en ce pays, majs anssi des autres etrangires, qui viennent en usage de medecine. Nouvellement traduite de bas itleman en framcois pall Charles de l"Echuse. Anvers. de l'impromerie de Jean Loé.

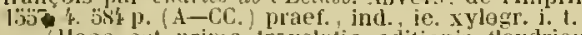

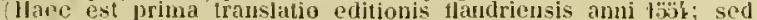
simul quasi editio secunda considerari potest. Dicit enim Doclonaeus in epistula decticatoria anni 105\%: Sccunda liac aeditione severa animadiersione adhibita omnia recosnovinus, plerique mutavimus, nonnulla transtulimus, totum opus non exicua ace'essione locupletavinus et ausinus, multarum stirpium nemini quad seiam adhue depictarem inagines adjecimus, - A p. 5k9-38s sequitur Caroli Clusii Petit recuril d'aueunes etc.

miglice: A niewe herbail or histeri of plants; first sel forth in the loutclie tongur, and now first iranslated unt of french into english by Henry Laje Est. London (imprinted at Antwerpe) 1578. folio. $79 \mathrm{p}$

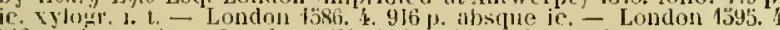
916 p. allitjue ic. - Londen 1619. Tolio. 916 p. ahssue ic. B.

anglice: Dorleon's briefe Epitome of the new lerbal of history of Plints, wherein is eontained the disposition and trute declaralion of the Plisiche belpes of all sorts of horbes and platits, under their Hatnes ald operdious not only of those here in this cur countrey of England urowing, but all other Reillues Cnumtreys anul Yation rollected out of the most exquisite mew llerhall, lirst set forth in the Butch or Almayrie Tongue, by the worthy and learned man of fanous menory, D. Reinbert Dodeon, translated by IJenry Lype. Esquire, atid

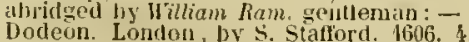

$2630^{*}$ Frumentorum, legunimum, palustrium et aquatilium herbarum ae eorum, quae eo pertinent, historia. Addiae sunt imagines virae, exactissimae, jam recens non absque haud vulgari diligentia et fide artificiesissime expressae, quarum pleraeque novie et hactenus non editae. Antverpiae, ex officina Christophori Plantini. 1566. 8.271 p., int. - ib. 1569.8 .293 p., ic. xylogr. i. 1 .

$2636^{\star}$ - Florum et coronariarum oderatarumpue nomullarum lıerbarum historia. Antverpiac 4568.307 p., ind., ic. xylegr. i. t. / "ib. 1569.8 .309 p., ic. xylogr. i.t.
2657* Dodoens, kembert, latine Dodonaeus. Purgantium ahiarumgue eo facientium, tum et radicum, convolvulorum et deleteriarun herharun ljistoriae, libri $\mathbb{V}$. Aceedit appendix variarum et quidem rarissimarum nomullarum stirpium, ae florum quorundam peregrinorum elegantissimerumıue icones onnino novas nec antea editas, singulorumgue breves descriptiones contiuens, cujus iltera parte umbelliferae exlsibentur non paucae. Antwerpiac, ex oflicina Chr. Plantini. 1574. 8. 505 p., ind., ic. sylogr. i.t.

$2658^{*}$ Llistoria vitis vinique et stirpium nenuularum aliarum; item medicinalium observationum exempla. Colonine, apud Jaternum Cholinum. 1580.8. 168 p., pracl, incl.

(Stirpium alipuot historiat jan recens conscriptae. il p. 17-96.

$2639^{*}$ Stirpium historiac pemptades sex, sive libri XXX. Aut werpiac, ex officina Clristophori Plantini 1583. folio. 860 p., ind. ic. xylogr. i. 1. - *Tarie ab auctore, paullo aute mortem dueti et emendati. Antwerpiae 4616 . folio. 872 p., ind., ic. xylogr. i. t.

(Cif. Richard Courtnis. Commentarius in Bemberti Dodonaci Pempladles il Nov. Act. Acarl. Nit. Curios. IS33̈, vol. N111, pars 11 - lle Dodonueo ipso, summo Helgirum botanieo, vide: J. $P$. vizm Meprbeecli: Recherches historitues ef eriticues sur la vie et les ouvrages die nembert Dodocns. Malines 18\%.1. 8.

2660* Döll, J. Ch. Rheinische Flera. Beschreibung der wildwachsenden und kultivirten Pllanzen des Rheingebiets von Bodensee bis zu Hosel und Lahn, mit besondrer Bericksichtigung des frosslierzogthums Baden. Franklurt a/M. IS43. 8. XL, $832 \mathrm{p} .(3 \mathrm{1} / \mathrm{th}$.)

266 * Doellinger, Ignaz. Nachricht von einen verbesserten aplanatischen Mikroscope aus dem optischen Institute Utzschneider und Fraunholer zu Munchen. (Munchen) 1829. 4. 18 p., 1 tab. $(1 / 3$ th.

2662 Doering, G. Karl. A catalogue of plants naturally growing anc commonly cultivated in divers parts of England, especially about Nottingham. Nottingham 1738.8.231, 24 p. B.

2663 Scaree plants which are met with hereabout, mere frequently than elsewhere. In his Historical account of the town of Nottingham. Nottinghan 1751. 4. p. 89-90. B.

(Autor est Saxo e gentro Doering; sed in Anglia nomen germanicum in Chavles Deering mutitit.

2661.* Döring, Michael. Mithridateiotechnia, h. e. de Mithrirtatii legitina constructione Nicolai Mutoni eollectanea. etc. Jenae 1620. 8. $390 \mathrm{f}$. prael., ind.

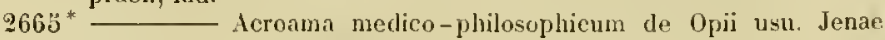
1620. 8. 164 j., Juraef., ind.

$2666^{*} \longrightarrow$ Diatribe de Opolalsamo syriaco juclaico, aegyptic, peruviane, tolutano et europaeo, ls. e. oleo succini. Jenae 1620. 8. 102 p., praef, ind.

$2667^{*}$ Doering, I'ilhelm Ludwig. Die Königin der Blumen, orler die höhere Bedeutung der Rose an sich nnd in Bezichung aul ris. Gemutliswelt, nach Naturanschavung. Poesie und Geschichte. Ein Beitrag zur tiefern Anffassung und Erkenntniss der Natur uberhaupt. Elberfelel 1835.8 . xxx, $748 \mathrm{l} \cdot(3 \mathrm{~d} / 3$ (h.)

2668* Dörrien, Catharina IIelena. Verzeichniss und Beschreibung der sammtlichen in den Fürstlich Oranien-Nassauisehen Landen wildwachsenden Gewachse. Lulseck 1779. 8. 496 p., pracl. ( $\mathrm{t}$ h.

(Editio: *llerborn 1777. 8. non ditfert.

2669 Doisy, C. Essai sur l'histoire naturelle du departement de la Heuse. Partie 1: Flore. Verdun et Paris 4835 . Il voll. 16. $\$ 160$ p., I tah. ( 7 [r.)

2670 t Doleschall, Gabriel. Physiologia plantarum. (hungarice.) D. Pestini 1840. $8.40 \mathrm{p}$

2674* Dollfuss, Johann Georg. Cerasologia medica. D. Basileae 1717. $4.24 \mathrm{p}$.

2672 * Dollfuss, Joham Georg. Specimen botanico-medicum. (Teronica, Caucalis.) D. Basileae 1781.4. $19 \mathrm{p}$.

(Autorem a praeedenti diversun puto.)

2673* Dolliner, Georg. Ėnumeratio plantarum phanerogamiearum in Austria inferiori, erescentiun. Vindobonae 1842 . 8 . Iv $160 \mathrm{l} .(\mathrm{T} / \mathrm{s}$ th. $)$

2674* Domitzer, Johann. Fin newes Pflantzbüchlin von mancherley artiger propfung und beltzung der beyn. Getruekt zu Augapurg durch H. Starner. 1334.8 . (54 p) $-{ }^{*}$ s. l. et a. 8. $-{ }^{*}$ s. l. 1531. 8. ваbы. Caes. Vindob.

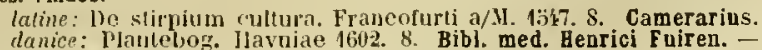
Ilamiac 163:i. 8. Briunich.

(1) autore nihil constat, quum nemo post Camerarium et Fuirenium hos libellos viderit. A guibusdan habetur iden esse cum Loni- 


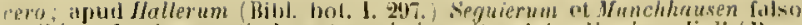

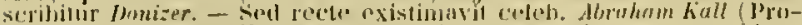

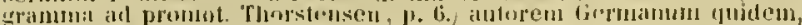
sint a Lonicero diversmu fuisur. ?

267\%" Don, Macid. Prodromus Florae Nopalemsis sive enumceratio vegrtabiliun quae in itinte" pes Nupalian freprie dietan el regiones

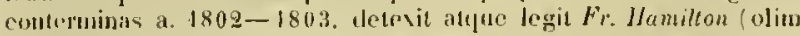
Burhunan). Acemdunt plantae a Hallichio nuperjus missae. Londini 1825. 8. xis, 256 \%. (3s. 6il. - 4s. 6d. A. Pamplin.)

2676 " Don, lieoryu. A general Ilistory of the dichlamydeous plants conurising complete duscriptions of the dilferent orders; lotreller with tho characters of the genera and species, and an enumeration of the cultivaterl rarioties; their places of gruwth, time of llovering; mode of culture, and uses it medicine and tomestic eenumy; the seienlifie names areculuated, their etymologies explainesl, and the classes and orderm illistrated by engravings, and preceded hy introductions li the Limean and hatural systems, and a glossary of the terms used; the whole arrangod accorling to the matural system. (rel altero tifule:) A general systom of gardening aut botany: contaising a complete enumeration aml description of all plants hitherto kuown; with their generic and speeific characters, places of growth, lime of llowering, mode of eulture and theil uses in medicine and domestie econony. J'ereded by introductims to the Linnran and natural systems, and a glossary of the terus used. Foumled upou Miller's Garleners Dictionary. aul arrungeal aeending to the natural system. London $1834-1838$. IV voll. 4. - 1: 1831 . xxvur, 518 p. -

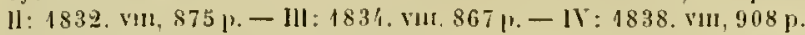

267 t (Donarelli, Carlo.) Ennmeratio seminum ex collectione and 183 h horti Ronani. (Romae 1834 .) folio. 8 p.

2678* Donatb, 11 ilhelm Friedrich. De ligitali purpurea. I). Berolini 1826. 8. $29 \%$.

2679 i Donati, Antonio. Trattato de semplici, pietre e pesce marini, che naseono nel lito di Venetia, la juaggior parte non conosciuti da Trofrasto, Diosconde, Plinio, Galeno e altri serillori, diviso in due libri. Venctia, appresso pietro Maria Berlano. 1631. 4. 120 p., praef., 33 1als, aen. i. 1. Bibl. Cand. Webb. et Deless.

(Rajus iu sylfoge stirpium curopacirun harum plantarum catalogum descripisit.)

g6806 Donati, Marcello. De radice purgante, yuam Mechioacan (i. e. Jalapa) rocaıt. Mantuae $\$ 569.4 .24$ j, Bibl. Juss.

2681 ? Donati, Tilaliuno. Della storia naturale marina dell' aclriatieo. Sargio. Giuntavi una lettera del Signor Lionardo Sesler intorno all un uuovo genere di piante terestri. Venezia, ipplresso Fr. Storti. 1750 4. $81 \mathrm{j}$, prace, 10 tals.

yermanice: Auszug seiner Naturgeschichte des Atriatiscluen Meers len Borlen dis Heers zu untersichen, nehst Justrunenten in suleber: Tiefe zu tixchen; von Classen Jer Jecrpllanzen, der Polyparen, der

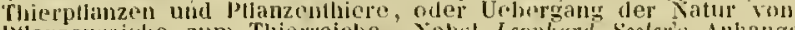
Pilanzenrejore zum Thirreiche, Nobst Lemhard Sesters Anhange ininer Josondern Re
1753. 4.

t gallice: Essai siu lhisloire naturelle de la mer adriatique: avec une lettre du br. Leonard sester sur une nouvelle espece de plante terrestre. Traduit de I'italion. A la llaye, ehez P. le llondt. 1758. 4. 111, 73 p., 11 tab.

2682 Donato d'Eremita. Vera effgie della granadiglia, detla fior della passione. All ill. el ece. Signor Giovan Fabri Linceo. Di Yapoli a 20 (li Decemb. 1649. (Tabula nenea col. Jong. 13 unc. lat. g unc.) B.

$2683 \longrightarrow$ Granaliglia overo fior della passione. All' ill. Sign. Fabio Colonna Linceo. I)i Napoli a 30 di (othobre 1629. (Tabula aenea long. 14 unc. Iat. 10 unc.) B.

(llilec est tabula, eujus menlionem facit Fabin Colonna in annotationibus ad Jernandez historian plantarum mexicanarum, p. 890, sed primam in lialia ditan esse ienuem passiljorac perperam itssein litist. plant. hort. 13. '121.

268:* Donatus ab Altomari, Antonius. De Manuae differentis ac virilous, depue eas cognuseendi via ac ralione. Vonetiis 1562.4. Bibl Caes. Vindob.

$2685 \div-$ De vinacenrum faeultate ac ust. Tencliis 1563,4. 10 foll. Bibl. Reg. Paris.

2686* Donn, James. Ilortus Cantalorigiensis: or a eatalogue of plants indigenous and foreign, cultivated in the Walkerian botanie garden Cambrilge. Cambridge 1796.8. 117 p. - Fil. II. Cambridge 1800 S. - †Ed. III. Cambridge 1804. 8. - Ed. IV. Cambridge 1807. 8. "Ed. I Cambridge 1809 . 8. 266 p. (7s.) - Ed VI. Camaridge
1811.8. 292 p. (9s.) - Fil. VIl. Cambridge 1812. 8. v1, 308 II

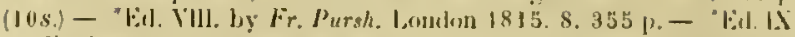
loy Fr. Pursh. Lomilen 1819.8. 355 j. - "Jid. X. lig John Lindley

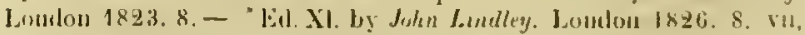
$415 \mathrm{j}$. (10s. 6ol.) - ${ }^{2}$ F.d. Xll. will munerous alditions anl conrectims by George Siaclair. Londen 1831. 8. v11, 543 1) (19s.) -

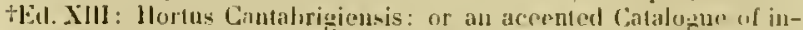
digenous and eantic plants enltivated in llor Combridgo botanie gatren. With tha alditiuns and implovements of the sucersive editors: Fr. Jursh, John Linrley and Ceorge sinclair. The thirtentl edition, now further enlarged, inprosed and lirouglit dow a to the present time, by P. N. Hon. Londun, Lomprman and Co. 1845. 8. M 772 p. $(11.4 \mathrm{~s}$.

2687 Donovan, Edward O. Essay ou the minute pats ol flant- in gencral. Xr. 1-IV. London 1789-1790.) 4. 22 ]., I2 1ab. eol. B.

2688 The lutanical review, or the heautics of lilora. Nr. 1Vil. London (1790).8. 27 p., Jã 1al. col. B.

2689* Donzelli, Giuseppe. Lettera familiare snjua l'opnlal-amo orienlale, adoperato in Roma dalli sienori Autenio Manfreali a Vinrenzo Panuzzi in far la loro teriache. Padoa, jer Paolo Franlotti. 16 \$3. 4 (10 foll.) Bibl. Goett.

2690* D'Orbigny, Alcide. Voyage dans I'Amerijü méridionale, I Io Bresil, la republique oriontale de l'Truguay, Ja repulblique Argentine, la Patagonie, la rejublique de Boliva, la respublique du Perusu, exicute jendant les ansécs $1826-1833$. Tome septieme: Botanirpue. Pựis 1839. yr. 4. Bibl. Link. et Univ. Lips.

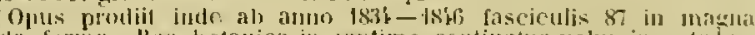

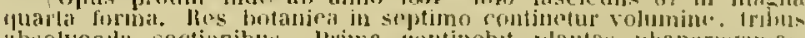

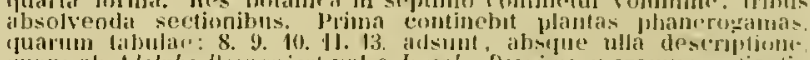

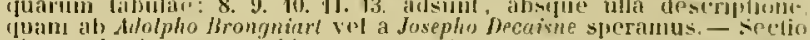

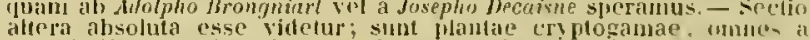

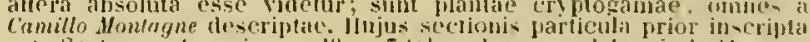

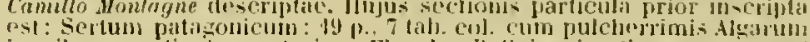

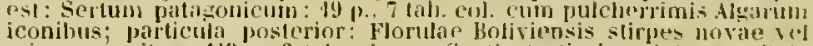

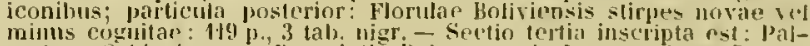

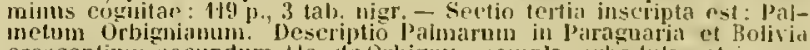

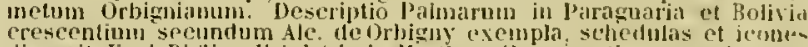
digessil Karl Philipp Fripdrich de Marlus. Hate sectio areue inconplela "st; idsin! $28 \mathrm{p}$. 4 L 19 lab. pulcherrime col. signatae: 2. 11. I3.

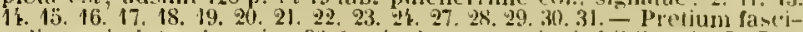
culi uperis integri, cujus 90 rasciculos anmulidvit bibliopola $P$. Beptrand, est $12 \mathrm{fr}$. in c. - pars eryptoganica cum lij sie!) tahulis seorsim prostat pretio 40 [r. - Palmarum icones simsulae col. : I fr. 50 ". et tealus plagulat singulae: 1 fr. )

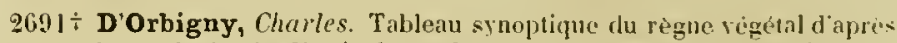
la methode de M. A. L. de Jussieu, molifiede par Achille Rachard. l'aris 1834 . Cue gramle feuille. (3 fro) - Eil. Il: 1835. (4 fr. col. $5 \mathrm{fr}$.)

$2692 \div$ Doria, Laigi. Lettera agromomica sulia ruggrine del ginno. Ronna $1801.8 .34 \mathrm{j}$.

2693* Dorn, J.F. Anleitung und Aufnunterung zum Inglocibau. Leipzig $1505.8 .(1 / 8$ lh.)

269:" Dorstenius, Johann Damiel, pr. Rei herhinise commentatis. D). Marlurui Cattorum 1675. 4. 14 p.

269:" Disputatio de tabaco. D. Marburgi Cattorum I $6 \& 2$. 4. $18 \mathrm{p}$

2696* Dorstenius, Theodericus. Bolanicon eontinens licibarum aliorumque simplicium quorum usus in nedieinis est, descriptines ct icones ad. virum dffoiatas: en praecipuis tam sraecis quasu latiois autoribus jam recens eoncinnatum. Id ditis etiam, yuae neotericonm olservationes et experientiae vel cumprobarunt demuo, vel muper invenerunt. Francofurti, Christianus ligemolplus eseudebat. 1540. folio. $306(10)$ foll., pract., ind., ic. sylogrs. i.t.

2697 Dorthes. Eloge historitue de Pirre Richer de Bellezul. Montpellier 1785. 4. 60 p. eum ienographia horti Mompliensis. acri incisa. E. (Assmuble publ. de la soc. de Youtpellier 1788. 1). 93-132.

2698+ Douglas, David. An account of the species uf Calochortus, a gemus of ameriean plants. Frum the Hurticultural Transactions. Londen 1828. 4. s p., I tal). col. I I al). nigy:

2690 " Douglas, James. Lilium Saruiense of a deseription of the GuernsasLilly. To which is adked the botanical disnection of the Colfecberry. London, typ. Straham. 1723. folin. i 35.22 p. 2 tab. - London 1737. Colio. 76 j.. 3 เah. B. 
groot Douy, J. Nowveau manuel de botanique et de plysique végélale. Paris 1836. 8. 246 p., 7 tab.

2701* Dove, $H$. 11. Ueber den Zusammenlang der Warmeverinderungen der Atmosplsaire mit rer Entwicklung der Pflanzen. Berlin 1846. gr. 4. $132 \mathrm{p}$, , 1 ab. ( $1 \frac{1 / 2}{2}$ th.)

2702* Downing, A.J. A treatise on the theory and practice of Landseape gardening, adlapted to Sorth-America; with a view to the improvement of country resillences. ete. New York anıl Lounlon, Wiley and Putnan. 1841. 8. 451 p., 1 tab., ic. xylogr. i. t. Bibl. Fr. Otto.

2703* Dozy, $F$, et $J$. II. Molkenboer. Huscorum frondosorum novae species ex Archipelago indico et Japonia. Lugduni Batavorum, Hazenherg et soc. 1844 . 8. 22 p., praet. $(1 / 2 / h$.

$2704^{*}$ Musci frondosi inedili archipelagi indici Borneo, Sumatra, Celebes, Amboina, nec non in Japoma nuper detectorum minusve cognitorum. (Fase. 1 et II.) Lugduni Batavorum, llazenberg et soc. $1845-1846.4$. 24,28 p., 20 Lab. ( $7 \mathrm{lh}$.)

$705^{*}$ - Novae fungorum species in Belgio septentrionali muper detectae, quas iconibus et descriptionibus illustrarunt. Lugduni Batarorum, Luchtmans. 1846. 8. 18 p., 2 tals. col. $\left(1 \frac{1}{2}\right.$ th. $)$ (Seorsim impr. ex Hoeven un l'riese Tijdschrilt yol. Xil.)

2706* Draeger, harl Bermhard. De vi et usu Nicotianae Talbaci. D. Halae 1838. 8. 32 p.

2507 Drais, $F$. ron, und $F$. von WaItershausen. Ablandlungen vom Lercbenbaume. Mit Zusátzen herausgegeben von Christoph Wilhelm Jakob Gatterer. Llm 1801. 8. $(3 / 8$ th.)

2708t Dralet. Description des Pyrénées. etc. Paris 1813. 11 voll. 8. I: $x_{x y}, 262$ p., 3 tab. - H: 292 , xi p., I tableas.

(In yol. Il inest: Liste des principaux arbres, arbrissean et arbustes des Pỵénées frimçaises: Xl $\mathrm{p}$.)

9709t - Traité des forets d'arbres résineux et des terreins adjacents sur les montagnes de la France. Toulouse 1820. 8. xil, $271 \mathrm{p}$.

a $70 t$ ___ Traite du hêtre (Fagus sylvatica) et de son aménagement comparé à celui du chêne et des arbres résineux. Toulouse 1824. $8.156 \mathrm{p}$.

"I11 Draparnaud, Jaques Philippe Raymonel. Discours relatifs a l'histoire naturelle. Montpellier an $1 \mathrm{X} .8 .41 \mathrm{p}$.

(Insunt duae orationes: Discours kur les avantages de l'histoire naturelle. p. 3-29, et discours sur les mocurs et lit maniere de vivre des jlantes, p. 30 - 4 .

- Dissertation sur l'utilité de l'histoire naturelle dans Ia médecine, prèsentée à l'école de médecine à Hontpellier. D. Montpellier an XI. 8. $61 \mathrm{p}$.

2713 Draper, Joh Irilliam. A treatise on the forces which produce the organization of plants; with an appendix, containing several memoirs on capillary attraction, electricity and the chimical action of light. New York, llarper and brotbers. 1844.4 .216 p., 4 tab.

271 t Drapiez. Notice sur le Nhandirobe (Fevillea L.) et sur les proprietés alexiteres du fruit de l'ume des espieces de ce genre. Bruxelles $(1819) .8 .15 \mathrm{p}$.

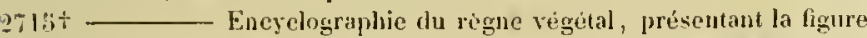
la clescription et l'histoire des juantes le plus récemment déconvertes sur tous les points du globe ou introduites daus les serres des jardins de l'Angleterre, de la Belgique et des autres parties de l'Europe, accompagnée de monographies de genres destinées à former progressivenent une Flore universelle. Ouvrage publié sous la direction de M. Drapiez. Bruxelles, a l'établissement encyclographique. $1833-1838$. Vl voll. (62 fasciculi.) folio min. $372 \mathrm{tab}$. col. et text. (39/ [r.) Bibl. Leod.

$2716 \div-$ Dietionnaire classique des sciences naturelles, répresentant la définition, l'analy̧se et l'histoire de tous les êtres, qui composent les trois règnes etc. Bruxelles $1838-1845$. X roll. 8 max. A-Z. Bibl. Brux.

2717 * Drège, J.F. Zwei phanzengeographische Dohumente, nebst einer Eiuleitung von Erust Meyer. (Besondre Beigabe zus Flora 1843. Band 11.) (Leipzig 1844.) 8. 230 p. und Ilithowr. Karte von Sudafrika. $(2 / 3$ th. $)$

$: 18^{*}$ Catalogus plantarum exsiccatarum Africae australioris, quas emturis offert. 8. Nr. 1. (20 Mart. 1837.) 11 p. - Nr. 2. (20 Mart. 1838.) p. $13-32 .-$ Nr. 3. (24 Apr, 1840.) 16 1).

Pritzel, Thes. lit. bot.
2719* Drejer, Salomon Thomas Nicolai. Flora excursoria Hafuieusis. llafuiae 1838. 12. Lxv, 339 p. (1/6 th.

2720 Lacrebog $i$ del botaniske Temmologi og systemlaere. líolnnlayn 1839. 8. ( 3 Rel. 32 Schili.)

2721 Compendium i den medicinske Botanik. hiobnhavn 4840. 8. viu, 100 p. $(64$ Schill. $)$

$2722 \div \frac{}{(1 / 3 t h .)}$ Elementa pliyllologiae. D. llafniae 1840. 8. $75 \mathrm{l}$.

$2723^{*}$ - Revisio eritica Caricum borealium in terris sub imperiu Danico jacentibus inveutarum. Ilafniae 1841.8 .62 p. (40 Schill.)

2724* Symbolae Caricologiae atl synonymiam Caricum extricandam stabiliendamove et affinitates naturales eruendas. Opus justhumum ab academia seientiarum dauica $\left(\boldsymbol{J} . \mathbf{l}^{\top} a h l\right)$ editum. (Hafniac) 1844. folio. 37 l., 3 schemata, 17 tab. (5 th.) Bibl. Scblecbtend.

2725* Dresig, Siegmund Fiedrich, pr. De Cicuta Atheniensium poena publica. D. Lipsine 1734. 4. 38 p.

2726* Dresky, Wilhelm. De Valeriana officinali Limnaci. D. Erlangae 1776. 4. 30 p.

2727* Dreves, Fr. Botanisches Bilderbuch fur die Jugend und Frounde der Pllanzenhunde. 5 Binde oder 28 Jlefte. Leipzig 1794-1801. 4 $154,176,188,186,124$ p., 152 tab. col. $\left(18 \% \frac{1}{3}\right.$ th. $)$

Inde a volumine III hoc altero inscribitur titulo: Getrene Abbilclungen und Zergliederungen deutsclier Gewachse, von Fr. Ireves und Friedrich Gollob Hayne.)

$2728+-$ et Friedrich Gottlob Bayne. Choix de plantes d'Europe, décrites et dessinées d'après nature. Leipzig 1809 . V voll. 4 - I: XII, 40 j., tab. col. 1-25. - I1: xII, 44 p., tab. col. 26-50. 11l: xII, 44 p., tab. col. $51-75 .-1 V: x 11,40$ p., tab. col. $76-140$. - $V$ : (non vidi) lab. col. $101-125$. (25 th.)

2729 Dreysig, A. F. Practische Behandlung der llortensia mutabilis nebst ilıren Varietáten. Erfurt 1812. 8. $(1 / 3 \mathrm{lh}$.)

2730 Der Levkiengürner. Leipzig 1823. 8. (5/12 th.)

2731 Driessche, Jan van den, latine Drusius. Tractatus, an per 1)udaim Nandragorae significentur? s. l. et a. 12. Bibl. Maz.

2732* (Driessen, $P$.) Index plantarnm quae in horto ac. Groningano coluntur. Groningae 1820.8.57 p.

2733 Driver, $A$. and $W$. Tho Pomona britannica, or fruitgarden displayed. London 1788. 4. 8 p., 8 tab. col. (incompl.) DC.

2734 DrümpeImann, Ernst Wilhelm. Flora livonica, oder Abbildung und Beschreibung der in Livland wildwachsenden PlIanzen. Miga 1809-1810. 10 llefte. folio. Trautv.

(E. Meyer noven vidit fasciculos, quemque 5 tabularum, totidem. que foll. text.

2735 Drummond, J. L. First steps to botany. Ed. 11l. London 1834 . \&. (9s.)

2736* (Dryander, Jonas.) Desiderata pro Bibliotheca Banksiana. (Londou) 1790. 8. 27 p. Bibl. Mus. bot. Vindob.

(Recensentur 43'3 "nera "X historia naturali, quale ill. Banlis pr" Jibliotheca desiderabat, ville rara pleraque, e Seguero potissimum sumta; quorum maxima par's jam mihi innotuit.)

$2737^{*}$ —_ Catalogus bibliothecae historico-naturalis Josephi Bonhs. Londini, typ. Gut. Bulmer et soc. 1796-1800. V voll. 8. - I: Scriptores generales. 1798. vil, 309 p., ind. - Il: Zoologi. 1796. Xx, 578 p., ind - III : Botanici. 4797. xxm, 656 p., ind. - IV: Nineralogi. 1799. $\mathrm{x}, 390 \mathrm{p}$, ind. - V: Supplementum et index avetormm. 1800.531 j. (3l. 3s. A. Panplin.)

2738t Dubois. Héthode éprouvé, avec laquelle on peut parvenir facilement et sans maitre à connatre les plantes de l'intérieur de lis France et en particulier celles des cavirons d’Orléans. etc. Orléans, typ. Darnault-Maurant. an Xl. (1803.) 8. xy, 592 p. - tNovyelle édition: Paris, Cretté. (typ) Ecron.) 1825. 8. xv, 592 p. - Ed. 11 : Paris, typ. Plassan. 1833. 8 . ( $6 \mathrm{fr}, 50 \mathrm{c}$.) - Méthode éprouvée avec laquclle on parvient facilement et sans maitre a connaitre les plantes de la France. Troisième édition entièrenent refondue et augnentés par M. Boilard. l'aris, Cotelle. (typ. Gratiot.) 1840. 8 . ( 8 fr.)

2739t Dubois de Montpéreux, Frédéric. Voyage autour du Cavcase, chez ies Telierkesses et les Abkbases, en Colcbide, en Géorgie, en Armenic et en Criméc; avec un Atlas géographirgue, pittoresque, archeologique, géologique etc. Paris $1836-1839$. V'l voll. 8. * germonice: Varmsladt $18^{\prime} 2-1846.3$ Bande. 8. (vol. II. p. $180-493$ lersuch einer litori des Beschtau, von Charles Godel. 
$2740 \div$ Dubois, Lowis. Du pommier, du poirier et du cormier, considérés dans leur histoire, leur pliysiologio et les diver's usages de leurs fruits, de leurs cidres, de leurs eaux-de-vic, de leurs vinaigres etc. Paris 1804 . Il voll. 8 . - I: xv, 222 p. - II: 176 p., 3 tab.

274 t Dubreuil, $1 t$. Histoire naturelle et médicalo de quelques végétaux de la famille des Euphorbiacées. Thése. Paris 1835, 4. 28 p.

$2742 \div$ Dubuc. Ilemoire sur le I'hytolacea decandra de Limé ou Phytolacjuc. (Extrait du l'récis analytique des travaux de l'Académio de Rouen.) Rouen 1831. 8. 28 p.

$27: 3 \div$ Dubuisson. Némoiro sur les acides natifs du Verjus, de l'orange el du citron. L'aris $1783,8,30 \mathrm{p}$.

274: Dubuisson, $J$. Plantes usuelles indigenes et exotiques. Paris, 1)uprat-Duverger. 1809 . Il voll. 8,102 tab). col. (120 fr.) - l'aris, Demonville. 1812.8. (non (lillert; inmo cadem est impressio novis titulis.) (opus sislit simul editionem octavam Jibri jam in Nr. 18 f recensiti, antore Chomel: Abrégè de llistoire des plautes usuclles.)

$2745+$ Dubuisson, J. R. Jacquelin. Essai sur les proprietés de la forec vitale dans les végétaux. Paris 1808. 8. 66 p.

$2716 \div$ Duburgua. Mémoire théorique et pratique sur la culture du Tabac dans les départemens du midi de la Franco et principalement dans celui de Lot et Garonne. etc. Agen 1805 . 8. xv1, 136 p.

27:7\%" Duby, Jern Etienne. A. P. DcCandolle Botanicon gallicum sive Synopsis plantarum in Flora gallica descriptarum. Editio II. Ex herbariis el schedis Canullianis propriisque digestum. Paris 18281830. Il voll. 8. - I: 1828. Plantac vasculares. xir, p. 1-544.Il: 1830. Plantae cellulares. p. 545-1068.

$2748^{*}$ Essai d'application a un tribu d'Algues, de quelques principes de taxonomie ou Mémoire sur le groupe des Céraminiécs. Genere 1832.4.26 p., 2 tab. - * Second mémoire. Geneve 1832. 4. 25 p., 5 tals. col. - "Troisième mémoire (Genève 1836. ) 4. 16 p., 2 tab.

$2749^{*}-$ Mémoire sur la famille des Primulacées. Genève 1844. 4. 46 p., 4 tab. $\left(1^{3 / 4}(h)\right.$.

2ร50" Duchartre, Nierre Elienne. Revuo botaniquo; recucil mensuel renfermant l'analy'se des travaux publiés en France et à l'étranger sur la botanique el sur les applications à l'horticulturc, l'agriculture, la médecine ctc. Rédigé par $P$. Duchartre, Dr. ès sciences. Paris 1845-1846. 18 fasc. 8 . (Une annéc 12 Ir. $-3 l h$. Leipzig.) (Contimuatur.)

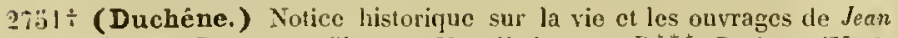
Boptiste Portu, gentilhomuc Napolitain; par $D^{k * *}$. Paris an IX. 8 . $383 \mathrm{p}$.

3752* (Duchesne, Antoine Nicolas, fils.) Manuel de botanique, contenant les propriétés des plantes utiles pour la nourriture, d'usage en módicine, employées dans les arts, d'ornement pour les jardins et que l'on trouve a la campagne aux environs de Paris. Paris 1764. S. xxiv, $44,76,92,94,75$ p. (2 fr. 40 c.)

$2733^{*}$ Histoire naturelle des Fraisiers, contenant les vues d'économie réunies a la botanique ete. Paris 1766,8 , x11, 324, $118 \mathrm{p}$. ( 2 fr. 40 c.)

$2754 \div-$ Essai sur l'histoire naturelle des Courges. (Extrait de I'Encyclopédie méthodique par Delu.l(arck.) s. I. et a. $8.46 \mathrm{p}$.

2735* - Essai sur l'histoire naturelle des Fraisiers. (Extrait de l'Encyclopédie méthodique par Dela.March.) s. 1. el a. 8.46 p. (Ejusdem antoris manuscriptum ineditum: Description de deux champignons observes ans curirons de Paris. (1772.) 4. 8 foll., 2 tab. libi ohservationes suls de myceliis fungorun exponit, servatur in Bibl. Iladrioni de Jussieu. ('. A. L. de Jussieu, Gen. płant. p. 5.)

2736t Duchesne, E. A. Traité du Naís ou blé du Turquic, contenant son histoire, sa culturc et ses emplois en économic domestique et en médecine. Onvrage couronné. Paris 1835.8 .366 p., 2 tab. nigr., 1 tab. col.

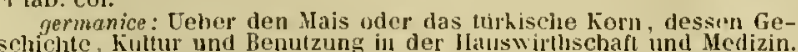
Nach der getirönten Preisschrift des E. A. Duchésne und melureren anderen Haterialien bearbeitet von Christian Heinrich Schmidt. Inmenau und Weimar 1833. 8. $11 \frac{1}{2}$ Bogen, 5 tab. sigr., 1 tab. col. ( 1 th. 23037 Repertoire des plantes utiles et des plantes vénénenses augmentée. Bruxelles 1846 . gr. 8 . xLv, 505 p. - Atlas: 128 tab. cum rxplicatione. ( $16 \mathrm{fr}$.)
2758\% Duchesne, J. B. Guide de la culture des bois ou herbier forestier Paris 1825. \& livraisons. $8, x, 144$ p., 60 tab. in folio. ( 80 ir.)

2759* Duchesne, Leger, latine Leodegarius a Quercu. In Ruellium de stirpibus cpitome. Cui accesserunt volatilium, gressibilium, piscium et placentarum magis frecjuentium apul Gallias uomina. I'or Leadegarım a Quercu. Parisiis, apud Tiletanun. 1539. 8. (8 foll.) pranter apendicen. Bibl. Reg. Dresd. - De stirpilus vel plantis urdine alphahetico digestis cpitome, longo quam antelıac, per Jounnem Brohon lucupletiur emendatiorque edita. Cadoni, ex officina Nichaelis Augier. 1341 . 8. (32 foll.) B. - "Omnia muho quarn antea locupletiora. Parisiis, apud Tiletanum. 1544. 8 . 75 [r. (I!antae: ). 3-66.)

2760* DuChoul, Jean. De varia Quereus historia. Accessit Jylati monlis descriptio. Jugduni, apud Rovillium. 1558. 8.109 p., ind., cum ic. ligno incisis. Bibl. Berol.

(tExemplisia anni $155 \% 3$ laud difforunt.)

2761" Ducluzeau, J. A. I. Essai sur l'histoire naturelle des Conferves des envirous de Mompellier. 1). Mtontprllier (1805\% 4. $89 \%$.

(In calce libri logitur: "sंept planclues, "uji doivent accompagner cette dissertation, suivront. Xon vero secutae sumt.

$2762+$ Duben, Magnus W. von. Conspcclus regetationis Scaniac. D. Lundae 1837. $8.42 \mathrm{\mu}$.

"germanice: Auszug in llikstrom, Jahres], von Beilschnich, 1837. p. $321-326$.

$2763^{*}$ - Ilandbok i Vextrikets naturliga familjer, fleras forrandtskaper, geographiska ubredning, egenskaper och vigtigaste anvandande i medicinskt, ccunomiskt och technisht afseende. Stockholn 181. 8. xLIII, 350 p. (2 Rdr. 16 sk.)

276:- Dufour. Catalogue généra! de sa pepinière c1c. à Montbrillant près Genève. Geneve 1828. 8. 36, 4 p.

$2765 \div$ Dufour, Léon. Revision des genres Cladonia. Scyphoplıorus, llelopodium et Bacomyces de la Flore françaice. Bruxelles s. a. 8 . 32 p.

(Exitrait du 8. tome des Ann. gén. des sc. physs.)

9766 t Lettre a M. le Dr. Gratcloup sur les excursions au Pic d'Anie et au P'ic Amovlat dans les Pýrénées. Bordeaux 1836. \&. $50 \mathrm{p}$.

9767- - Nolice hotanique et culinaire sur les champignons $\mathrm{cn}-$ mestibles du Dép. des Landes. Mont-de-Marsan 1840. S. $14 \mathrm{p}$.

(Extrait des Ann. de la soc. d'agriculture des Landes.)

9768 Dufour, Philippe Sylvestre. De lusage du caplse, du the et du chocolate. Lyon 1671. 12. 488 1. B.

anglice: The manner of making Coffen, Tea and Chocolate translated liy John Chamberlayn.) London 1683.12 . $116 \mathrm{p}$. B.

2769\% - Traitez nouveaux et curieux du cafe, du the et du chocolate. Ouvrage igalement necessaire atr medecins et a tous ceux qui aiment leur santé. Lyon, Girin et Rivierc. 1685.12 .445 p., prael. ind. - + I la Haye, chez Mloetjens. 1685. 12.403 p., ind., i 1ab. tLyon, Deville. 16S8. 12. 444 p., praef, ind. - - A la llaye 1693. 12. 404 p., 4 tiob.

lalime: Novi tractatus de potu Caphi, de rhinensium The et dr Chocolata, a $D$. $M$. notis illustrati. Genesáe 1694 . 12. is p., tab. B.

2750 Libellus primus sub titulo: Jacobi Sponii Beranda asjatica, hoc est physiologia potus Café, a $D . D$. Munget notis et a Constantinopoli plantae iconismis recens jllustrata. (Lugduni) 1705. 4 56 p., 5 tab. (cx libello Comitis IIarsigli.) B.

$2777^{*}$ Dufresne, Pieme. Histoire naturelle ct médicale de la famille des Valerianées. D. Montpellier 1811.4 .61 1,, 3 tal .

$2772 \div$ Du Fresnoy. Des propriétés te la plante appelèe Rhus radicans. ctc. l.cipzig et Paris 1788. 8.48 p.

$2773 \div$ Dugnani, Giulio. Saggio di botanica. Nilano, typ. Marclli. 1775. 4. 28 p., 2 tab. Bibl. Webb.

$2774 \div$ (DuHamel du Monceau, Henri Louis.) Avis pour le transport par mer des arbres, des plantes viraces, des semences et de diverses autres curiosités d'histoire naturelle. Seconde édition considerablement augmentée. Paris, de l'imprimerie royalc. 1753. $s$ vı, 90 p. - "cun Turgot, Démoirc instructif elc. Lyon 175s. S. p. $147-235$.

germonice: Vorschláge. nach welchen der transport der baume, Iandigcwachse, saamen viul verschicdener auderer naturalien uber dio see zu veraustalten ist; (ron Georg Christun Ueder.) Kopenhagen 1756. 8. 133 p. B. - Nordlische Beitrage, I. 2. p. 70 - 102. Caput solummodo primun!

danice: Underretuing om. hrorledes traen. peremerende urter, frón og adshillige andre naturalier, hest hand forsendes til sües; (per N. II. Tyrholm. Kiobnhavn 1760. \&. $93 \mathrm{p}$. в. 
27:35t DuHamel du Monceau, Henri Louis. Traite do la culture des terres, suivant les prineipes de M. Tull, Anglois. Touvelle édition avee planches. Paris $4753-1761$. V voll. 8.

$9756^{*}$ — Ellémens d'agriculture. Paris 1762. Il voll. 8. - I: xxiv, 499 J., \& taJ. - II: vir, 410 p., 10 tal germanice: Stuttgart 176r. II voll. 8

$3737^{*}$ - Traité des arbres et arbustes, qui se cultivent en France en pleine terre. Paris 1755. Il woll. 4. - 1: t.xII. $368 \mathrm{p}$., 139 tah. - 11:387 p., 111 tab. - *il. 1785. nullo mordo differt. ("Arditions pour le traité des arbres et arbustes, impr. arec son "Traité des semis et plantations des arbres.n ib. 1760.4 . $27 \mathrm{p}$., 1 tab. * germanice: Abhamilung von Bäumen, Stauten und Sträuchen, welche in Frankreich in freier Luft gezogen werden. Aus dem Franzusischen voll Karl Christoph Oelhafen von Schoellenbach. Nurnbers 1763. 2 Theile. 4. - 1: 258 p., praef, 3 tab. - Il: 281 p., ind., 7 tab. $(51 / 3 t h$.)

$9778 \div$ - Némoires sur la garance et sa culture. Paris, de l'imprimerie royale. $1757.4 .80 \mathrm{p}, \mathrm{S}$ tab. - Traité de la garance et de sa culture. Nouvelle édition. Paris 1765.8 . vi, $134 \mathrm{~J} ., 4 \mathrm{tab}$. hispanice: Memorias sobre la Granza óRubia, y su cultivo. Madrid 1763. 4. $126 \mathrm{p}, 5$ tab. B.

$2779^{\circ}-$ La pliysique des arbres; ou il est traitú de J'anatomie des plantes et de l'économie végétale; pour servir d'introduction au traite cemplet des bois et des forests; avec une dissertation sur l'utilité des méthodes de hotanique. Paris, Guerin et Delatour. 1758. Il voll. 4. - 1: Lxvm, 307 j., 35 tab. - II: 432 p., 22 tab. tParis, chez la veuve Desaint. 178s. II voll. 4. - I: Lxvar, 307 j., 28 tab. - Il: 438 ]., 22 tab.

"germanice: Nanurgeschichte der Búumo; von der Zeroliederung

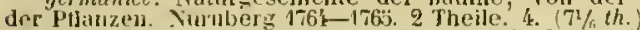

thispanice: Disertacion acerca de los mútodos botanicos: escrita en fralces por el cétebre Mr. Duhanel du Alonceas, y traducila é ilustrada con varias notas por Canimir de Orteya. Nadrid 1772. 4. (4) 33 p.

vigne. Paris 1759. II voll. 12. DC.

germanice: Beschreibung der Weinstocke. Nuruberg 178k. 4

$781 \div-$ Némoire sur le Safran. s. I. et a. 8. virr, 100 p.

낙 782

ture; ou méthodes pour multiplier et élever les arbres, les planter en massifs et en avenues; etc. Paris 1760 . 4. Lxxx, 383 p., 16 tab. Adhaerent: Additions pour le traité des arjores el arbustes: 27p. et 1 tab. - Additions et corrections pnur le traite de la physique des arbres: $40 \mathrm{j}$.

* germanice: Von der Holzsaat und Pflanzung dler Waldbáume, von K. Chr. Oelhafen von Schoellenbach. Nuinberg 1763. 4. 273 p., praef. 16 tah. $\left(2 \frac{2}{3}\right.$ tho $)$ parli avantageux des taillis etc. Paris 1764. Deux parties. 4. xLvu XIV, 708 p. 36 tab.

* germanice: Von der Fallung der Wálder. Numberu 1766-1767 Q Theile. 8 . $\left(6^{2} / 2\right.$ th.

2785 Erklarung der Kunstwörter aus der Botanik und lem Landhaue. Nurnberg 1766.4

278: Dir transport, de la conservation et de la force des bois. Paris 1767. 4.556 p., 27 tab. B.

$2786^{*}$ - Abhandlung von der Erhaltung des Getraides und besonders des Weizens, Aus dem Franzos, von Titius. Leipzig 1755. S $\mathbf{x L}, 220$ p. 13 tab. - Ergúinzung: Leipzig 1768, 8. 132 p., 4 tab.

$2787 \div$ - …… Traité des arbres fruitiers, contenant leur figure, leur description, leur culture etc. Paris 1768 . 11 voll. 4. - 1: $\operatorname{xxix} 337 \mathrm{p}$. (62 Lah.) - II: 280 H. (118 Lab.) - +Paris 1782 . III voll. 8. - I: 320 p. - Il: 338 p. - III: 260 p. cum tabulis plurimis.

germunice: Pomona galliea oder von Obsthaumen. Nurnberg 177 -1783.3 Bande. $4 .(16 \% 3,3$.

\# germanice: Naturgeschichte oder ausfulacliche Beschreilunn: der Erdheerplianzen, aus dessen Abhandlung von den Olsstbaumen beErdbeerpilanzen, aus dessen Abhandinng von den olstbaumen befraisiers vermebrt. Nimnerg 1773 . 4. 42 p., 9 tab.

$2788^{*}-$ Traité des arbres et arbustes que l'on cultive en France en pleine terre. Séconde édition. ("Noureau Duhamel") considérablement augnentée, redigéo par J. L. A. Laiseleur-Delongchamps at Etienne Michel. Avec les figures d'après les dessins de Mil. P. J. Redouté et P. Bessa. Paris 1801-1819. VII voll. foljo. 1: 264 p., 60 tal, col. $-11: 284$ p., 71 tab. col. $-111: 234$ p., 58 tab. col. - IV: 240 p., 63 tab. col. - V: 330 p., 84 tab.col. - VI: $266 \mathrm{p} .$, So tab. col. - VIl : 252 p., 72 tab. col. Bibl. Caes. Vindob. et Deless.

9) $189^{\circ}$ - Traité des arbres fruitiers. Nouvelle édition par $A$. Poitear et P. J.F. Turpin. Paris (1808-)1835. VI foll. folio. 329 tab. col. ex siguatura (sed plures, quum multi numeri bis terve adsint) cum textu absque signatura. Bibl. Caes. Vindob. et Deless. 9790t (Dujardin.) Flore complete d'Indre et Loire publite par la société d'agriculture, sciences, arts et belles-iettres et hédiéo à II. D Entraigness, préfet du Département. Précédec d'une introduction a l'étude do la botanique. Tours 1833.8. (38) $472 \mathrm{~J}$., 2 tab.

$2791 \div$ Dujardin, $F$. Noureau manuel complet de l'observateur au microscope. Paris 1843. 12. 330 p. avec un Atlas. il. 1842. gr. 8 44 p. 30 tab. gravées sur acier.

2792* Dulk, Fiedrich Philipp. De materiis plantarum extractis dictis 1) Regiomonti 1833.8.28 p.

2793ث Dumas, J. Némoire sur les substances régétales qui se rapprochent du camphre et sur quelques luiles essentielles. Thise Paris $1832.8 .22 \mathrm{p}$.

6796- Lecon sur la statique chimique des ètres organises. paris 1841.8 .48 p. - tDenxieme édition, augmentie de documen. numeriques (iutituléo: "Fssai»). ib. 1842.8 .88 p., praef, ( $Q \mathrm{fr}, 50 \mathrm{c}$.)

$2795 \div$ Dumas, Isidore. Quelques mots sur la structure de IHeliéfore fétide el sur l'évolution de ses organes floranx. Thèse. Montpellier 1844.4. 18 p., 6 tab.

2796 t Duméril, A. Augusle. Des odeurs, de leur nature et de leur action physiologigue. lissertation sur quelques points de la physiologio des vègétaux. Thèses. Paris $1843.8 .96,40 \mathrm{p}$

2797t Duméril, A. M. Conslant. Traité élémentaire d'histoire naturelle Ouvrage composé par ordre du gouvernement pour servir à lenseimnement dans les Lycées. Paris 1804. 8. - Ed. 11: Paris 1807 If voll. 8. - I: $\mathbf{x v}, 265$ p. (p. 56-265: Botanique.) - II: XII, 360 p. (Zoologie.) - Ed. III : "Élémens des seiences naturelles." il). 1825 8. - 1: xxvIII, 351 p. (p. $433-351$. el tab. 1-8: llotanique.) tEd. W : Paris 1830 . Il voll. $8 .-1: x v i, 364$ p., 8 tab. (Botanique p. $149-364$.

2798* DuMont de Courset, George Louis Harie. Le botaniste cultivateur, ou Description, culture et usages de la plus grande partic des plantes etrangères, uaturalisées et indigènes, cultivées en France, en Autriche, en ltalie, et en Angleterre, rangées suivant la méthode de Jussieu. Paris 1802. V voll. 8. - ${ }^{*}$ Ed. II. eutièrement refondue et considerablement augmentée. Paris $4811-4814$. V7l voll. $s .-1$ 1811. vIII, $562 \mathrm{j}$. et tableaux - II: $1811.638 \mathrm{p} .-1 \mathrm{II}: 1811.551 \mathrm{p}$ $-\mathrm{N}: 1811.631$ p. $-\mathrm{V}: 1811.567$ p. $-\mathrm{V}: 1811.631$ p. $-\mathrm{VH}$ Suppément. 4814. $370,45 \mathrm{p}$.

germanice: Die botanische Pflanzkunst nach Dumont-Caurset von Christian Gottlieb Lerger. Leipzig 180' 1805 . 2 Theile. 8. (4 th.

* ilalice: Il hotanico coltivatore; opera di G. L. M. Dumoni de Courset. recata in italiano dall' Ab. Girolamo Romano. Padova ' $1819-1820$. Xli voll. 8.

2799* Dumont a'Urville, Julien Sebastien Cèsar. Enumeratio plantarum, quas in insulis Archipelagi aut littoribus Ponti Euxini annis 1819 et 1820 collegit atque detexit. Parisiis 1822. 8. VIII, $135 \mathrm{p}$

(Exirail des Mémoires de la soc. Linn. de Paris, vol. l.)

$2800^{*}$ - Flore des isles Malouines. Paris 1825. 8.56 p.

$2801^{*}$ - Expédition au pole austral et dans l'Océanie des corvettes de sa majesté $L$ 'Astrolube et La Zélèe. Paris 1839. 8. 37 p. 1 carte.

2802* Voyage au Pole Sud et dans l'Océanie sur les corvettes $L$ Astrolabe et $L a$ Zélée, exécuté pendant les années 1837 -1840 sous le commandement de II. J. Dumont dUruille. Paris. Gide. 1841-1847. 8. et Atlas in folio.

(Pars botaniea ilineris nondum ad finem producta est; in antumno $184 k$ ridi in Bibliotheca Linkiana octo priores fasciculos. It prospectu 15 promittuntur. Plantas cryptogamas in so suscepit ill. Camillus Montugne, phanerogamas Ilombran et Jacquinat. Duo prodibunt volumina fornzi octava, et Atlas 80 Labularum, a Barramee e fiacreux delineatarum; plantae eryptogamae in tabulis coloratis.

$2803^{*}$ Dumortier, Barthelemy Charles. Commentationes botanicae. (O),servations botaniques.) Tournay 1822 . (1823.) $8.116 \mathrm{p}$

2804* Observations sur les Gramines de la Flore belgique Tournay 1823.8, $153 \mathrm{\mu}, 46$ tab. col.

$2803^{*}$ Notice sur un nouvean genre de plantes: Hulthemia: précédec d'un aperçu sur la elassification des Roses. Tournay 1824. $8.14 \mathrm{p}$.

$2800^{*}-$ Verhandeling over het geslaclit der Wilgen (Salix) en de natuurlijhe Familic der Anentaceac. (Bijdragen tot de Nat. Wetensch. te Ansterdam.) 4825. 8. 20 p.

$2807^{*}$ Flerula Belgica, operis majoris Prodremus. Staminacia. Tornaci Nerviorum 1827.8.172 p. 
2808* Dumortier, Barthilemy Charies. Analyse des fanilles des plantes avec l'undication des principaux genres, qui s'y rattaclient. Tournay 1829. 8 maj. $104 \mathrm{p}$.

$2809^{*}$ Recherches sur la motilité des végétaux. Gand 1829. 8. $16 \mathrm{p}$

(Extrait du Nussager des sciences et des arts.)

$2810^{*}$ (Eotice sur le genre Dionaea. s. I. et a. $8.8 \mathrm{p}$.

(Evrait du t. IV. des Bull, do P'Ac. de Bruselles.)

$2811^{*} \longrightarrow$ Sylloge Jungermannidearum Europae indigenarum, earum genera et species systematice complectens. Tomaci Nerviorum 1831.8 .100 p., 2 tab. col.

$2812^{*}$ Recherches sur la structure comparée et le développrement des aninaux et des régétaux. Bruxelles 1832. 4. Iv, 143 p., 2 tals.

$2813^{*}$ - Notice sur le genre Maelenia de la famille des Orelidées. Bruxelles 1834. 4. 18 p., 1 tab. cul.

2814* - Essai carpographique présentant une nouvelle classiffcation des fruits. Bruxelles $\$ \$ 35.4$. $\$ 36$ p., 3 tab.

$2815^{*}$ - Notice sur la cluque de la pomme de terre. Bruxelles 1845.8. $20 \mathrm{p}$.

(Extrait lles Bulletins de l'Académie royale de Bruxeltes, tone X11. .ir.9.)

$2816^{*}$ Dunal, Michel Félix. Ilistoire naturello, médicale et économique des Solanum, et des genres, qui ont eté confondus avec eux. D. Montpellier 1813.4. 248 p., ind., 26 tab.

2817* - Solanorum generumpue affinium Synopsis seu Solanorum historiac editionis secundae Summarium, ad cliaracteres differentiales redactum, seriem naturalem, habitationes stationesque specierum breviter indicans. Monspelii 1816.8 .51 p., praef.

$2818^{*}$ Monographie de la famille des Anonacées. Paris 1817 4. 144 p., 35 tab.

$2819+-$ Considérations sur la nalure et les rapporls de quelques-uns des organes de la fleur. Montpellier 1829.4. 148 p., 3tab.

$2820+$ Considérations sur les fonctions des organes floraux colorés et glanduleux. Paris et Montpellier 1829.4.40 p.

$2821+(\longrightarrow$ Némoire sur la structure, le développement et les organes géucrateurs d'une espèce de Marsilea (M. Fabri) trouvé par M. Esprit Fabre dans les environs d'Agde. Orléans, typ. DanicourtHuet. 1837, 8. 19 p., 3 tab.

$2822^{*}$ - Eloge historique de Augusin Pyramus DeCandolle. Montpellier $1842.4 .59 \mathrm{p}$, effigies Candollii.

2823+ — Description du Planera Richardi Miclı, et indication de la cause qui l'empeche de donner des graines dans nos climats. Nontpellier 1843.8 .12 p., 2 tab.

282 $r$ * Duncan, Andrew. An account of the life, writings and character of the late Dr. John Hope. Edinburgin 1789. 8. 31 p.

$2825^{*} \longrightarrow$ Tentamen inaugurale de Swietenia Soymida. Edinburgi 1794. $8.53 \mathrm{p}$

In manuscriptis nosthunis Candolleanis lego, autoren esse $F$ Meyer, $\mathrm{M} . \mathrm{D}$.

$2826^{*}$ Meyer, M. D. A short account of the life of the right honourable Sir Joseph Banks. Ediuburgh 1821. 8.24 p. Bibl. Goett.

$2827+(-)$ Catalogue of medical plants according to their natural orders. Edinburgh 1826. 8. Iv, 27 p.

2828 Duncan, J. S. Botanical theology, or evidences of the existence and attributes of the deity. Oxford 4826.8 .

$2829+$ Dunker, Johann Heinrich August. Turze Besclureibung der gefalırlichsten Giftphanzen fur Kinder und Ungelehrte. Brandenburg 1796-1797. 2 Ilefte. 12. IS tah. col, und Texi.

2830 Pflanzenbelustigung oder Anwcisung, wie man getrocknete Pflanzen auf eine leichte unl geswwiule Art sauber abdruchen kann. Brandenburg 1798. 8. Sch.

$2831^{*}$ Dunker, Wrilhelm. Palaeontographica. Beitrage zur Naturgeschiclıte der Vorwelt, herausgegeben von Dr. Hithelm Dunker und Hermann von Meyer. Erster Band, erste Licferung. Cassel 1846. 4. 44 p. 6 tab. $(12 / 3$ th.) (Continuatur.)

$2832^{*}$ — Monographie der nordileutschen Wealdeubildung. Ein Beitrag zur Geognosie und Naturgeschichte der Vorwelt. Nebst einer Abhandlung uber die in dieser Gebirgsbildung bis jetzt gefundnen Reptilien von Hermann von Meyer. Braunschweig 1846, royal 4. xir, 86 f., 2 I tab. $\left(8^{2} / 3\right.$ th. $)$

(Plantae fossiles in boc libro descriptac recensentur: Bot. Zeitun 18:7. p. 31 .)
283:3 Dunstall, John. I booke of flowers, fruicts, Jeistes, hirds and flies, exactly drawue, and are to liee sold by l?. Stent, at the white hors in Guiltspur street, without Sewgate. 20 tab. aen. Jong. 5 unc. lat. 7 unc. - The second booke of Howers .... exactly drawne newly printed with additious ly Joh Dunstult anno 1661. sould by peter Stent. 20 tab. - The theral burke of flowers, drawne, witl

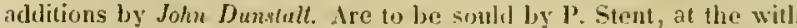
horse in Guiltspur street, lyetwivt leweate and l'ye-comer. 1661 20 tals. B.

Duperrey Voyage vide Bory Mr. 1149-1150 et Bronynur Nr. 1324.

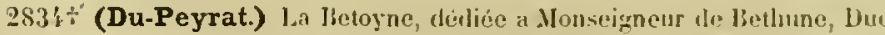
do Sully, Pair do France, Grantuaistre de lartillerie. s. a. al I. s. 8 foll. Bibl. Reg. Paris.

2830* (Du Pinet, Antoine, latine Pinaeus.) Ilistoria plantarum. liarum inagiues, nomenclatura, qualitates et natale solum. (Iuilsus aecesser simplicium medicamentorum facultates secundum lucos et genera ex Dioscoride. Lugduni, apud Gabrielem Coterium. 1561. 12. 6:0 229 p., ind., ic. xylogr. i. t. $-{ }^{2}$ Ed. If: ib. 1567.12 . (non diffist.)

(Est Multhiolus in compendium redactus, ut elncet a prapf. p. 3 "Feriauti mihi incidit in manus anno superiore Mathiolus in Dissooriden, quem uhi gallice reddidiosem, flacuit etian nune namtalen ipsum lacere.s)

2836* Duplessy, $F . S$. Des végétaux résineux tant dindigenes qu'cuntiques ou description confplete des arbres, arbrisseaux, arbustes el plantes qui produisent des résines etc. Paris 1802 . JV roll. $8,-1$ xxxvı, 438 p. - II : XV1, 435 p. - III: XI, 440 p. - IV: XIv, 586 I.

$2837 \div$ Dupont et Carro. Catalogue d'arbres fruiticrs ct autres, arbustes et arbrissenux, légumes et fleurs composant la pépinière lorméc sous les auspices du gouvernement à fichinof en Bessarabie. 1Sz. 8. $13 \mathrm{p}$.

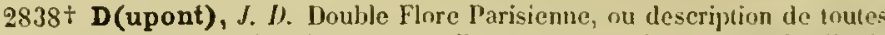
les plantes qui croissent naturellement aux environs de Paris, distribuées suivant la méthode naturelle d'une part et stivant le srsteme de Linnée d'un autre. etc. augmentéc d'un supplement contenant toutes les plantes nouvelles. par A. D.... II. Paris, Gabon. $18 \mathrm{I} 3.8$ xvi, $217,175 \mathrm{p}$.

Est editio prima anni 1803 mutato titujo et addito supplemento a p. $143-175$.

2839- Duppa, Richard. Illustrations of the Lotus of the ancients and Tamara of India. London, typ. Bensley and sou. (Only 25 copies printed.) 1816. folio. 36 p., 12 tab. col. Bibl. Deless.

(In ojore pulcherrimo, quod ob esiniam raritatem nutlibi citatum oflendi, nmmes eaeque diversissimae recensentur plantae, quare apud veteres Lotos nomine ferebantur. Lego in catalogo bibliothecile Regiae societatis Londinensis: " $k$. Duppa, Illustrations of the Lotus of nutiquity. London 1813. b., Eundem esse suspicor librum, negligenter falso titulo, anno ac forma indicatum.)

$28 ! 0^{*}$ Durand, Jean Baptiste Lionard. Voyage au Sénegal. Parik 1802. II voll. S. LVI $, 359,383$ p. arec un Allas en 4 : vIII, 67 p. 43 tab (tab. 22. 37. 38, 39.40, 41. 42, sunt plantarum.) germanice: Weimar 1808. 8.

2841* Durand, Philipp. De quibustam Clloridis speciebus. D. botanica. Monspelii $1808.4 .23 \mathrm{p}$.

$2842+$ (Durande, J. Fr.) Notions élémentaires de botanique, avec l'explication diune carte comprosice pour servir aux cours publics de 1'Acadénie de Dijon. Dijon 1781. 8. 368 , scu p. arec une grande carte, pour illustrer le systeme de Linné en 4 feuilles. Bibt. Juss.

$2843^{*}$ _ Flore de Bourgogne ou Catalogue des plantes naturelles a celle province et de celles, qu'on y culive le plus conumunenent ete. Ourrage rédigé pour servir aux cours publics de l'Académic de Dijon. Dijon 1782. 11 voll. 8. - 1: vil, 520 , Lxxwu p. - 11: xıs. $290, \operatorname{Lxx} \mathrm{p}$.

284t+ Durante, Castare. Ilerbario nuovo, con figure, che rappresentano le vive piante, cho nascoun in tutta Europa, e nell' lndie orientali e occidentali. Con versi latini, che comprehendono le facolta te i semplici medicamenti. Con discorsi, che dimonstrano i nomi, le spetie, la forma, il loco, il tempo, la qualita e le virtu mirabili dell herbe, insieme col peso, o ordine da usarle, seoprendosi rari secreti e singolari rimedii da sanar le piu difficili infirnita del corpo human. Con due tavale copiosissime, l'una dell' lerbe e l'altra tell' infirmità e di tutto quello che nell' opera si contienc. In Roma, appresso Bartholomeo Bonfadino e Tito Diaui. 1583. folio. (12 foll.) 
492 p., ic. parv. xylogr. i. t. (If foll. indices), effigies Jacobi Antoni Cortusi et Castoris Durante; accedunt: Figure aggiunte senza discorsi et alcune trasposte come nclli errati si vede 5 foll. cun 60 ic. Bibl. Cand. - "Venezia 1602. folio. 492 p., ic. $x y \log r$. i. t. et: "Figure aggiunte.» B. - Venezia 1619 . folio. Bibl. Bodl. - Trevigia 1617 folio. Bibl. Reg. Par. - ${ }^{*}$ Yenezia, appresso i Giunti. 1636. 4. (4 foll. praef.), 515 p. cum ic. xy.logr. i. t. (19 p. "Figure aggiunte senza discorsin, 24 p. ind.) - * con aggionta de $\mathrm{i}$ discorsi à quelle figure, che erano nell' appendice, fatti cla Giovanni IIariu Ferra, et hora in questa novissima impressione, vi si è prosto in fine l'herbe Thè, Caffe, Ribes de gli Arabi, e Cioccolata. Yenelia, pressu Giov. Giac. Hertz. 1684. folio. 480 p., ind., ic. xylogr. i. t.

germanice: Ilortutus sanitatis, das ist, ejn heykam und nutzliches gahrtlin der gesunctheit. ins teutsclue versezt durch Peter Lffenbach. Frankfurt a/M. 1609. k. 1081 1., ic. $x \log r$. i. t

(Seguierus laudat editionem prineipem : uTenezia, apud Jo. Jacob. llertz. 13̈8\}. folio. 12 quam adoptare dubilo. Praefatio enim meae editionis e Candalleana bibliolleca data est Romac die Xivill Martii 10̈8" uec meninit autor, librum jam prius impressum fuisse.)

$28150 \div$ (Durazzo, Ippolito.) Il giardino botanico dello Zerbine ossia catalogo delle piante ivi coltivate. Genova 1804. 8.28 p.

$2846 \div$ Durazzo. Calalogue des plantes cultivées dans le jardin de Madame Durazzo de Grimuldi à Pegli, Dèp. de Genès. Genès 1806. 8. 19 p. - ib. 1812.8 .22 p.

$2817 \div$ Duret, Claude. Histoire admirable des jlantes el lierbes esmerveillables et miraculeuses en nature: mesmes d'aucunes qui sont vrays zoophy̧tes ou plantanimales, plantes et animaux tout ensemble pour avoir vie vegetative, sensitive et animale etc. Paris, Buon. 1605.8. 341 p., ic. xylogr. i. t., praef.

Durieu de Maisonneuve vide Exploration scientifique de I'Algerie in parte systenatica.

281.8 * DuRoi, Johann Philipp. Dissertatio inauguralis, Observationes botanicas (de arboribus Americate septentrionalis) sistens. Ilelmstadii 1771. 4.62 p.

$28 \div 9 *$ D De Harbkesche wilke Baumzucht theils nordamerikanischer und andrer fremder theils einheimischer Baume, Strâucher und strauchartigen Pflanzen, nach den Keunzeichen, der Anzucht, fen Eigensehaften und der Benutzung beschrieben. Braunschweig 1771 - 1772. Il voll. 8. - I: 177 1. Lxxx, 447 p., 3 tab. - II : 1772. 512 p., ind., 3 tab. - "llerausgegeben mit Vermehrungen und Veranderungen von Johann Friedrich Pott. Braunschweig $1793-1800$. III voll. 8. - I: 1795 . xLvill, 659 P., 3 tab. -11 : $1800.606 \mathrm{p}$. Ill: 1800.276 p., 3 tab.

2830 DuRondeau. Xlémoire sur la quesrion: Quelles sont les plantes les plus utiles des Pays-Bas, et quel ést leur usage dans la medecine et dans les arts? Bruvelles 1772, 4, 18 p. B.

\851 * DuTertre, Jean Baptiste. llistoire génẻrale des Antilles liabitées par les Français. Paris $1667-1671$. IV voll. 4. 593, 539, 317, $362 \mathrm{p}$.

(Primum prodiit Parisiis annn 16ijk. Antor monachus Dominicanus fuit, non neglesit rem herbarian ; ne iamen characteres plantarum a viro botanices imperito exspectes. Ex hoc tamen fonta Rochefort, Labat, pomet et atii potissimun hauserunt. Hall. Bibl, bot. I. p. 33 i-335. - Revue de Paris, vol. L\%. p. 232.)

2802 * Dutrochet, II. Joachim. Recherehes anatomiques et physiologiques sur la structure intime des animaux et des vẻgétaux et sur leur motilité. Paris 1824.8233 p., 2 tab. (4 fr.)

$28033^{*}$. L'agent immédiat du mouvement vital dévoilé clans la nature et tans son mode d'action chez les vẻgétaux et chez les animaux. Paris 1826.8 . vin, $226 \mathrm{p}$. (4 fr.)

28:4* - Nouvelles recherehes sur l'endosmose et l'exosmose, suivies do l'application expérimentale de ces actions physiques à la solution du problème de l'irritabilité végétale et à la determination de la cause de l'ascension des tiges et do la descente des racines. Paris 1828.8 . Ir, 106 p., 2 tab. (2 fr. 50 c.)

2855* Mémoircs pour servir à l'histoire anatomique et physiolngique des végétaux et des animaux. Paris 1837 . 8. If roll. et Atlas. - I: xuxi, 576 p. - II: 573 p. - Atlas: 36 p., 30 tab.

28 Dú6 Dutróne La Couture, Jacques François. Précis sur la canne, et sur les moyens d'en extraire le sel essentiel. Paris 1790. 8. 382 p., 6 tab. B.

2837 Duttenhofer, Karl Friedrich. Von dem Pflanzenleben, in Beziehung auf dell Ackerbau. Stuttgart 1779.4. 48 p. в. 28ä8 Duval, Charles Jeunet. Systematisches Verzeichuiss derjenigen Farrenkrăuter, Afterfarrenkräutes und Laubmooso, so bei Rogensbury wachsen. Nürnberg $1806.8 .(5 / 2+t h$.)

$2839^{*}$ - Systemalisches Verzeichniss derjenigen Flechten (Lichenes) welche un Regeusburg wild wachsen, nebst Angabe der Wohnorte und Bemerkungen uber die vorzuglichstem Arten. Numberg und Altdorf $1808.8 .56 \mathrm{p}$.

2860 Flora von Irlbach. Regensburg, typ. Montag. 1823. s. Comes de Bray.

2861t DuVal, Guillaume. In phytologian sive doctrinam de plantis praefatio paraenetica. Parisiis, ex typis Joannis Libert. 1614.4 min. 44 p. Bibl. Reg. Par.

2862* ${ }^{*}$ Phytologia sive Philosopbia plantarum. Opus posthumum. Parisiis, apul Casparum Meturas. 1647.8.472 p., dedic, ind Bibl. Goett.

(A p. 3t-32: Commentarius ad libros duos $\pi \varepsilon p t$ ourడ̃v inter Aristotelis opera vulgo quidtem, sed falso.

2863 Duval, IIenri Auguste. Demonstrations botaniques, ou analyse du fruit, consideré en genéral. (Extrait des Leçons de Claude Louis Richard.) Paris 1808.12 . a.

(Ejusdem autoris est parrum supptementum anenymum ad Dupont, Double Flore Parisieune. Paris 1813. 8.

286!* DuvaI, Karl Felix Constans Prosper. De Digitali purpurea. D. Leedii 1824. 4. $31 \mathrm{p}$.

2865t Duvaure, Antoine. Mémoire sur les avantages oł les inconvéniens de la culture du nurier blanc greffé. etc. Paris 1790. 8. - Ed. II Valence 1817. 8. IV , $67 \mathrm{p}$.

$2866^{*}$ Duve, Jordan. De aceeleranda per artem plantarum vegetatione. D. Lipsiae 1717 . 4. 20 p.

2867* (Duverger, $J$.) Notsce biographique sur M. le Barnn (Alexandre, de Théis. Deuxiłme édition. Paris 4843. 8. 14 p. Bibl. Kunz.

(Extrait de P'ascalleh Revue générale biographique, Juin 18

2868+ Duvernin. Discours sur la liotanique, dans la séance publique pour l'ouverture du jardin royal de betanique, tenue le 9 août 1781 par la socicté royale de Clermont-Ferrand. Clermont-Ferrand 1782. \& p. 7-37. (vide: Delarbre, Mr. 2393.)

$2869+$ Duverney, Emanuel Maurice. An largiorem semper exigit Kinakina cilum? D. Paris 1717. 4. 7 p.

$2870^{*}$ Duvernoy, Georg David. De Lathyri quadam renenata specie ju comitatu Nontbelgardensi culta. Basileac $1770.4 .19 \mathrm{p}$.

$281^{\circ} \div$ Duvernoy, Georg Ludwig. Discours prononcé le 22 Dec. 1827 à l'ouverture du cours d'histoire naturelle de la faculté des sciences de Strasbourg. Strasbourg 1828. $8.42 \mathrm{p}$.

2872* Duvernoy, Georg Luducig, filius. De Salvinia natante, cum aliquibus aliis plantis cryptogamis comparata. D. (praeside Gustav Schubler.) Tubingae 1825. 4. 15 p., 1 tab.

$2873^{*}$ Lntersuchungen uber keimung, Bau und Wachsthum der Monokolyledonen. Stuttgart 1834.8. 57, (4) p., 2 tab. (1/3 th.)

2871* Duvernoy, Johann Georg. Designatio plantarum circa Tulyingensem arcem florentium etc. Tubingae $1722.8 .154 \mathrm{p}$.

287ä Dwigubsky, Wwan A. Prodromus Florae Mosquensis. D. Mnsquar 1802.8 .

2876 - Натальнғя основанія 6отапнки i. с. Fundamenta botanica Linnaei. Mosquae 4805.8 .

2877 -_алальия основанія еспесшвенной истоpin растеній. Часть I. і. e. Elementa bistoriae naturalis vegetabilium. Pars 1. Mlosquac 1811. 8. - ib. 1\$23.8.

2878 .Іегкій способт распознавть дикораступія на похяхт Московскихт растенін і. е. Mcthotus facicilis recognescendi plantarum, quae sua sponte circa Nosquan encscuntur, in usum alunnorum universitatis Mosquensis. Mlosquae 1827. 8. - Ell. II. 1838. 8 .

2879 Московская (1.xора, і. є. Flora Mosquensis, sive descriptin plantarum, quae in provincia Nosquensi sua proveniunt spnnte. Mosquae 1828. 12.

Нзобрағіенія растеній, і. е. Icones plantarum medicinalium rossicarum, ordine alpluabetico. Nosquae 1828-1834. IV voll. 4 . 
2881 Dziarkowskj, J. Wybór reslin krajowych alla ekazania skuthow lekarskich, hu wzythowi domowenn. Warszawic 1808. \$. - Ed. II ib. 18 13. S. - Ed. III : i], 1821, 8. Adamski.

(selecta plantarum indigenarum, causa demonstrandae earuin surtutis inedicao scripta.

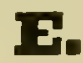

2882t Eaton, Amos. Ilanual of botany for Nortlı America: containing generic and specitic descriptions of the indigenous plants and common cultivated exotics, growing north of the gulf of Mexico. Albany, Webster and Skinners. 1847. 12. 164 p. - Ed. II: ib. 1818.Ld.III : ib. 1822. - Ed.V: ib. 1829. - Ed.VI: ib. 1833. - tEd. VII with an improved and modernized grammar and dictionary; and about 500 new species, chiefly from the Oregon and aretic regions. Albany, Oliver Steele. 1836, \$.672 p., praeter Botanical Grammar aud Dictionary. - Ed. VIII: with John IIright. 1841. (Wiley and Putnam. 5 Dollars 50 ets.)

$2883 \div-$ Botanical grammar and dictionary, modernized down to 1836: published for a Companion of Steele's seventlı edition of the Mlanual of botany. Fourth edition. Albany, Steele. 1836. 8. $125 \mathrm{p}$. (impr. cum ejusdem autoris Manual of botany for North-America, Ed. VII.)

9884 Hotanical exercices; including directions, rules and descriptions to ajd pupils. Albany 1820. 8. Cat. Bibl. New York.

2885 and Dr. Wright, North American botany. Published by E. Gates. 1840. 8. 625 p. w.

(Est forlasse editio Vill. libri inscripti: Manual of botany for North America.)

2886 Eaton, II H. Deseription of a few species of plants from the vicinity of Troy, NY. Lexingten, Ky. 1832. 8. Cat. Bibl. Acad. Pbllad.

2887 Ebbinge, J. De Pluellandrio aquatico. D. Groningae 1802. 4.

2888* Ebel, llithelm. De Irmeriae genere. Prodromus PJumbaginearum familiae. 1). Regiononti Prussorum 1840, 4, iv, 44, (6) p., 1 tab. $(2 / 3$ (h.)

$2889 * \frac{13}{2}$ Zwolf Tage auf Montenegro. Künigsberg 1842-1844 Q Hefte. 8. - I: 1842. Reisebericht. IF, 135 p. - II: 1844. Botanische Bemerkungen. Iv, 176, xxxix p., 4 tab. $\left(2 \frac{1}{6}\right.$ th. $)$

$2890^{*}$ Ebeling, Johann Theodor Philipp Christian. De Quassia et Liclsene islandico. D. Glasguae 1779.8.58 p. (Schleg. Thes. mat. ured. 11. p. $233-273$. )

2891" Ebermaier, Johann Christoph. Vergleichende Besclireibung derjenigen Pflanzen, welelse in den Apotheken leicht mit einander verwechselt werden. Braunsehweig 1794.8.211 p.

2892* —_ Ueber die nothwendige Verbindung der systematischen Pflanzenhunde mit der Pharnacie, und uber die Bekanntmachung der giftartig wirkenden Pflanzen. (Regensburger Preissclıriften.) Hannover 1796. S. $117 p$.

2893" - Von den Standortern der Pflauzen in Allgemeinen und denen der Arzweigewảclıse besouders. Munster 1802. 8. $232 \mathrm{p}$. $(2 / 3$ th. $)$

289: "Ebermaier, Karl Heinrich. Plantarum papilionacearum monographia nedica. D. Berolini 1824. 8. $108 \mathrm{p}$.

2895* Eble, Burkard. Die Lelire von den Jaaren in der gesanmen organischen Natur. Wien 1831.2 Bânde. 8. - 1: Haare der Pflanzen und Thiere. xvil, 224 p., 11 tab. (p. 1-60: Pilanzenhaare.)

2896* Echterling, Johann B. If. Verzeichuiss der im Furstenthum Lippe wildwaclssenden und uberall angebaut werdeuten plsanerogamischen Pflanzen. Detmold 1846. $8.60 \mathrm{p}$.

(E Rudolphi Brandes: "Die Nlineralquellen zu Mleinberg "seorsim impressus.)

2897* Eckard, Eduard Ludwiy Albert Valerius. De radice Ratanhiae. D. Berolini 1822.8. $28 \mathrm{p}$.

2898 Eckard, Gottfried, pr. De Nardo pistica ex Marc. XIN, 3. et Joann. Xill, 3. D. Wittebergae, typ. Ziegenbein. 1681. 4. (16 p.)

9899 Eckerberg, Johann Gustaf. De reformationibus classium plantarum Caroti a Linne. D. Londini Gothorum 1804.4.19 p. w.
2900 Ecklon, Christan Friedrich. Topograpluisches Verzeichuiss ales Pflanzensammlung von Christian Friedrich Eckton. Erste Liefenumg Oder: Standorte und Blutezeit derjenigen Arten aus der Familic der Coronarien und Ensaten, welche bis jetzt auf dem Vorgebirge der guren Ilolfnumg beohaclitet unt gesammelt worden sind. Esslingen 1847.8. $x$, if p., 1 Tabelle. $(1 / 4$ th. $)$

9901* — et Karl Zeyber. Binumeratio plantarum Africae australis extratropicae, quae collectac determinatae et expositie ah Ecklow et Zeyher. Pars I-III. Hamburgi $1834-1837.8 .400$ p. $(21 / 4$ th.

2902 Eckman, I'. J. De l'apavere somnifero. 1). I. Cpsalae 1834. 8. $16 \mathrm{p.}$ w.

2903 Écorchard, J. M. Cours de botanique au jardin des plantes de Nantes. Nantes 1836.8. w.

$290 \% \div$ Spécimen dlune Flore. projet d'embellisicment du jardin des plantes de Nantes. Nantes 1841 . 8 . 39 p.

39036 Derniere répouse aux altaques de $\mathbf{1 1}$. Desurax. Nantes 1841. $8.15 \mathrm{p}$

2906 Eddy, Caspar IFistar. Plantao Plandoneuses, or catalngue isf plants near Plandome. New York. s. a. Cat. Bibl. New York.

$2907 t$ (Edgeworth, Maria.) Dialogues on Botany for the use of young persons explaining the structure of plants and the progress of vegetation. Londons 1819.8 . $11,467 \mathrm{p}$.

2908* Edwards, Bryan. The listory civil and commercial of the british colonies in the West Indies. London 1793. 11 roll. 4.- El. 11 : Loudon 1807. 111 voll. 8 .

gallice: Eul. II. Paris 180k. 8

In vol. 111. p. 367-607 inest: Hortus Eastensis, or a cutalogue of exolic plants in the garden of llinton East ksq. in the motutails of Liguaned in the island of Jamaica, at the tinte of his deceilse: by Arthur Broughton, II. D.)

9909 Edwards, John. The British lierbal, containing 100 plates of the most beautiful mediciual plants, which blow in the open air at Grent Britain, with their botanical claracters, and a slsort account of their cultiration. London 1770. folio. 50 p., 100 tab. cul. B.

$2910^{*}$ A select collection of one hundred plates; consisting of the most beautiful exotic and british flowers, etc. London 4775 . folir. 50 p., 100 tab. col. Bibl. Reg. Dresd.

(Fortasse idem liber ac praecedens.)

2911* Edwards, Sydenham, (and John Lindley.) The botanical Register: cousistiog of coloured figures of exotic plants, cultirated it british gardens, with their listory and mode of treatnent. London 1815-1846. XXXll voll. 8. 2632 tab. col, tolidemque foll. tex.

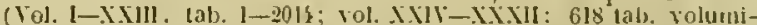
natim signatae. - Ser. II. euris Lindley, incipit cum volumine .VIT 1823. De appendicibus nperis vide: Limlley. Inden generalis volumi num I-X.Xil! prodiit 1S39.)

$2912+$ Edwards, 1 . Fréderic, et Coliu. De l'infuence de la température sur la germination. Paris 1834.8. $11 \mathrm{p}$.

$2913 \div-$ Némoire de physiulogie agricole sur la végétation des céréales sous de hautes temperatures. Yersailles 1835 . 8 . 28 p.

991: Egede, Hans. Det gamle Gronlands nỵe perlustration eller naturelhistorie. Kiöbenhavn 1741.4 .131 p., tab. B.

anglice: A deseription of Greenland. Lenden 17 k. 8.220 p. 2 tab. B. hollandice: Delphis Battavorum 1766. $\mathrm{S}$.

germanice: Besclireibung und Xalurigesclichte von Grumand. Berlin 1763. 8

gollice: Paris 1763. 8. B.

2918* Egenclphus, Christianus. Jlerbarum imagines vivae. der kreuter leblicbe conterfeytunge. Francoforti Christianus Egenolplus excudebat. ("1536.) ("1538.) 4. 40 foll. icones, 4 foll. ind. - "Imaginum herbarum pars ll, Andertheyl der hrentter Conterfertungen. Francaforti, Christianus Egenolphus Hadamarins excudebat. ("1536.) 4. 20 foll. icones, 2 foll. ind.

(sunt fcones prinum, ni fallor, cunı Euchari Rhodii editione llorti

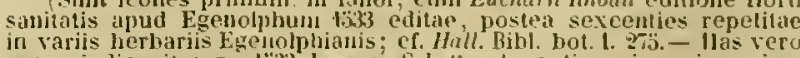
sllat vindicavit anno läi3 Joannes Schottus Argentinensis, qui eas jan antea nescio in quo libro dirulgaverat.)

2916 Adversus illiberales Leonharti Fuchsii calumnias responsio. Francofurti 1544, 4. F.

2917* Eggert, Johann Dietrich. Geoffraeae surinamensis virtus anthelmintica. D. Marburgi 1791. 8.59 p.

2918 Eglinger, Christian Theses anatomicae et uotanicae. Basileae 1711. 1721. 4. H. 
2919* Eglinger, Nicolaus. Positionum botanico-anatomicarum centuria. D. resp. Joanue Casparo Buthin. Basileac, Iyp. Werenfels. 1685. 4 (16 p.)

2920* Egnatius, Johannes Baptista. In loe volumine haec continentur: Joannis Baptistue Egnatii Veneti in Diascaridem ab Hermalao Barbaro tralatum annotamenta, quibus morborum ot remediorum vocabula olsscuriora explicantur etc. et Hermatai Barbari Corollarium. Venetiis, in officina Gregoriorum fratrum. 1516. folio. (33) cxrxiv foll. et Hermolai Burbari Corollarium: 106 foll.

2921* Ehrenberg, Christian Gottried. Sylrae mycologicae Berolinenses. D. Berolini 1818. 4. 32 p., 1 tab. ( $7 / 12$ th.)

$3922^{*}$ - Srzygites, eine neue Schimmelgattung, nobst Beobachtungen uber sichtbare Bewegung in Schimmeln. s.l. et a. 4. 13 p. 2 tab.

$2923^{*}$ Bcitıag zur Charakteristik der Nordafrikanischen Wüsten. Berlin 4827.4.20 p.

292:* Ueber das Pollen der Asclepiadeen. Ein Beitrag zur Aufojsung der Anomalion iu der Pflanzenbefruchtung. Berlin 1831 4. 21 p., 2 tab. col. ( $7 / 12$ th. $)$

$2925^{*}$ - Mikroscopische Analyse des curlündischen Meteorpapiers von 1686 und Erläuterungen desselben als ein Product jetzt lebender Conferveu und Infusorien. Berliu 1839. folio. 14 p., 2 tab. col. $\left(1 \frac{2 / 3}{3}\right.$ th. $)$

$2926^{*}$ - De Myrrhae et Opocalpasi ab Hemprichio et Ehrenbergio in itinere per Arabiam et Ilabessiniam detectis plantis particulam primam offert. Berolini 1841 . folio. 6 p.

2927 Ehret, Georg Dionysius. Plantae et papiliones rariores depictae et aeri incisae. (London 1748-1759.) folio. $15 \mathrm{tab}$. col., long. 17 uuc. lat. 11 unc. B.

(Practerea fuit in Bibliotheca Ranksiana volumen continens ico-

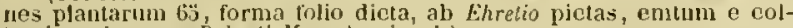
iectione iconum Roberti Hare Armigeri.)

2928 Ehrhart, Balthasar. Botanologiae juvenilis mantissa, in qua de necessitate herharia, quae rocant riva, bono publico tradendi, deque ea conficiendi methodo, dilucide agitur. Ilmae $1732.8 .86 \mathrm{p}$. B.

2939 Continuatio syllabi plantarum, quarum specimina sicca botanophilis offeruntur. MIemmiugae 1746. fulio. H.

9930 - Interricht von einer zu verfasseuden Historie der nutzlichsten Kräuter, Pflanzen und Baume. Memmingen 1752.4 . 20 p. B

2931* Oeconomische Pflanzenhistorie nehst dem Kern der Landwirthschaft, Garten und Arzneikunst. Utm und Memmingen 1733-1762. 12 Bände. 8. - I: 304 p., praef. - II: 268 p. - III $194 \mathrm{p}$. , ind $-\mathrm{Ir}: 184 \mathrm{p} .-\mathrm{V}: 227 \mathrm{p} .-\mathrm{V}]: 369 \mathrm{p}$, ind. $-\mathrm{V} l l$ 400 p. - VIII: 220 p. - IX: 204 p. $-\mathrm{X}: 196$ p. $-\mathrm{Xl}: 153$ p. XIl: Register uber das ganze Werk: $202 \mathrm{p}$.

Octo posteriorum partium. mortuo Ehrharto, auctorem esse Philippum Fridericum Gmelin, refert Beckman, Gesch. der Erfindungon, II. p. 5 ' 2 .

2932* Ehrhart, Friedrich. Beiträige zur Naturkunde und den damit verwandten Wissenschaften, besonders der Botanik, Chemie, Hausund Laudwirthschaft, Arzneigelehrheit und Apothekerkunst. Hannover und Osnabruck 1787-1792. 8. - - 1: 1787. 192 p. - 11: 1788 182 p. $-111: 1788.183$ p. - IV: 1789.18' p. - V: 1790. 184 p. - VI: 1791. 184 p. - ViT: 1792.184 p.

$2933 \div$ Ehrhart, Projectus Joseph. De Cicuta. D. Argentorati 1763.4. 72 p., $f$ tab.

293!* Ehrmann, C. H. Discours prononcé sur la tombe de XI. Christian Goufried Nestler, décédé at Strasbourg le 2 Oet. 1832. Strasbourg 1832.8.7 p

2933 Ehrmann, Johann Christian. De Foenicuto. D. Argentorati 1732 4. 0 .

$2936^{*} \longrightarrow$ De Cumino. D. Argentorati 1733. 4. (12) $36 \mathrm{p}$.

2937× Ehrmann, Johann Christian, filius. De Colchico autumnali. D. Basileae 1772. $421 \mathrm{p}$.

2938* Ehrmann, Martin S. Lehrbuch der Pharmacie. Zweite ungearbeitete Auflage. Zweiter Band: Pharnaceutische Botanik. Wien 1832.8 . vi, $660 \mathrm{p}$.

$2939^{*}$ Eichelberg, J. F. A. Methodischer Leitfaden zum grundlichen Unterricht in der Naturgeschichte fur hohere Lelıranstalten. Zweiter Tbeil. Pflanzenkunde. Zurich 1840 . 8. $155 \mathrm{p} .(1 / 2 \mathrm{th}$.)
29'0 † Eichelberg, J. F. A. Naturgetreue Abbildungen und ausfuhrliche Beschreibungen aller in- und auslándischen Gewachse, welche die wichtigsten Produkte für llandel und Industric liefern, als naturgeselichtliche Bogründung der merkantilischen Waarenkunde. Zurich 1845. roy. 8. $1 \mathrm{v}, 295$ p., 72 tals. col. $(81 / 6 \mathrm{th}$.)

29.1* Eichner, Johann Anton Fr. De tela cellulosa regctabili et animali. D. Monachii $1834.8 .27 \mathrm{p}$.

2942 Eichstad, Lorenz. De theriaca et mitlıridatio. Stettin 1614 et 1624 4. H.

2943 De plantis in genere. D. Gedani 1648 . 4. H.

$2944 \div$ - pr. An camphora Hippocrati, Aristoteli, Theophrasto et aliis priscis philosophis et medicis fueril incognita, et quid de ejus ortu, uatura, qualitate, facultatibus el usu recentiores medici prodiderint? D. Dantisci, typ. Rihel. 1650.4.

2915* Eichwald, Eduard. Naturhistorische Skizze ron Litthauen, Volhynien und Porlolien in geognostisch-mineralogischer, botaniseher und zoologischer llinsicht entworfen. Wilna, typ. Zawadski. 4830. 4. 256 p., 3 tab. $\left(3 \frac{1 / 2}{t h}\right.$.)

$2946^{*}$ —_ Plantarum novarum vel minus cognitarum, quas in itinere Caspio-caucasico observavit, fasciculi duo. Vilnae $1831-$ 1833. folio. 42 p., 40 tab. ( 8 th.)

2947* —_ Reise auf dem Kaspischen Meero und in den Kankasus, unternommen in den Jahren 1525-1526. Erstor Band in zwei $\mathrm{Ab}-$ theilungen. Stuttgat $1834-1837.8$. xxil, $472, \mathrm{x}, 894 \mathrm{p} ., 1 \mathrm{ab} .(6 \mathrm{th}$ )

294.* Eimbcke, G. Flora Jamburgensis pharmaceutica, oder Verzeichniss und Beschrejlung der um Hamburg und in den angränzenden Ländern wildwachsenden Arzneipflanzen. Hamburg 1822. 8. 168 p., ind. $(1$ th. $)$

$29: 4 \div$ Eisen, Johann Georg. Unterricht von der allgemeinen hrauterund Wurzeltrockuung. etc. Riga 1774.8. $116 \mathrm{p}$, praef

2930 * Eisengrein, $G$. A. Die Familic der Schmetterlingsblüthigen oder llüsengewachse, mit besondrer Hinsicht auf Pflanzen-Physiologie und nach den Grundsátzen der physiologisch-systematischen Anordnung ihres Gattungen bearbeitet. Ein Beitrag zur comparativen Botanik. Stuttgart und Tubingen 1836.8 . vill, 462 p. $(12 / 3$ th. $)$

$29: 1^{*}$ Einleitung in das Studium der Pflanzenklasse der Akotyledonen oder des Vegetationskreises der Wurzelherrschaft Freiburg 1842-1844.3 Ilefte. 8. - I : Allgemeiner Theil. 1842. $56 \mathrm{p}$. - Il: Die Ordnung der Susswasseralgen. 1843.108 p. - 11 : Die Ordhung der Flechten. $1844.105 \mathrm{p} .\left(1 \frac{1}{6} \mathrm{th}.\right)$

29:2 $2^{*}$ Ekart, Tobias Ihilipp. Frankens und Thuringens Flora in naturgetreuen Abbildungen. Erstes Heft. Mlit einem Theile der Kleearten. Bamberg und Aschaflenburg 1828.4.6 p., 2 tab. $(1 / 3$ th. $)$

$2953 *$ Synopsis Jungermanniarum in Germania vicinisque terris hucuspue cognitarum, figuris CXVI microscopico-analyticis illustrata. Coburgi 1832. 4. xvr, 72 p., 13 tab. (5 th.)

99:' — Betrachtung üher bildende Landschaftsgartenkunst, in einer Beschreibung des fürstichen Parkes zu Sondershausen. Potsdam 1840 . imp. 4. $4 \frac{1 / 2}{}$ Bogen, 1 tab. folio. $\left(1 \frac{1}{3} \mathrm{th}\right.$.)

29 घ̈j Ekström, Carl Ulrich. Beskrifning ofver Mörkö Socken i Sodermanland. Stockholm 1828. 8. 287, 27 p., tab.

(Norkó Sochens Váxter, p. $116-137$.)

2936 Elfwing, Peter, pr. De Trifolin aquatico. D. Aboae 1724. 8. 29 p. B.

2957* Elias, Karl Philipp Friedrich. Analecta ad Sabinac historiam medico-physicam. D. Marburgi 4816. 8.28 p.

2958 Elie de Beaumont, $L$. Notice sur um gisement de végétaux fossiles et des Bélemuites. Paris 1828. 8. $15 \mathrm{p}$.

2959* Elkan, Ludwig. Tentamen monographiae generis Paparer. D Regiomonti Borussorum 4839. 4. 36 p., 1 tab. ( $1 / 2$ th.)

2960* Elliott, Stephen. A sketch of the botany of South-Carolina and Georgia in two rolumes. Charleston, Schenck. 1821-1824. II vol. 8. - I: 1821. x, 14,606 p., 12 tab. - I1: 1824. vili, 743 p.

(Opus fasciculis singulis jam ab anno 1816 editum est.)

$2961^{*}$ Ellis, John. In essay towards a natural history of the Corallines and other marine productions of the like hind conmonly found on the coasts of Great Britain and Jreland. London 1755. 4. xVII, $103 \mathrm{p}$. ind. , $37 \mathrm{tab}$

" gullice: Essai sur lhistoire uaturello des corallines et autres productions marines du mome genre. A lallave 1756.4 . xv, $123 \mathrm{p} .34 \mathrm{tab}$.

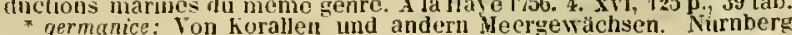
$176 \% .4$ 
$2962^{*}$ Ellis, John. Directions for bringing over seeds and pints from the East-Indies and other distant countries in a state of vegetation etc. to which is added the figure and botanical description of Jionaea muscipula. London 1770. 4. 41 \%., 2 tab. nigy., 1 tál, col. - London 1771. 4. B. (paruin dillert.)

(Jam antea panth suceinctins autor Diontean descripserat in vov. Act. snc. Ups. I. $98-101$.)

-germanice: De bjonaea muscipula, plauta irriahili nuper eletecta

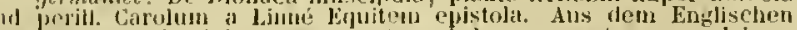
deutseld und lateinisch ubersttzt und herausenereben von Johemn Christian Inniel Schreber. Erlaugen 1771. 4. 18 j., t tab. col. - "germanice tintum: Lriangen 1780. "t. (mit Beschreibung der Sasifraga sallincutosa ) 28 p. 3 tab. col. ( 1 th.

- gallice: Lelle sur la Dionece, attrape-mouche. (Journ. de phys. X. p. $13-21$.

2963 Copies of two letters to Dr. Limuens and to Mr. Wr. Aiton. Lomelou 1771.4. 16 p., 2 tal., B. siambit.

Sum descriptiones et icones llicil Iloridani et Gordonine Li-

- An historical account of Coffere, witl an engraving and botanical description of the tree. London 1774.4 . 14 , 71 ., A tab.col. (Pars imjus opusculi italice adest in Scefta di opusc. interess. (rill. p. 3-30.)

$9960^{*}$ - A description of the Mangostan amel the Bread-fruit, with directions for voyagers, for bringing over these and other vegetalble productions. London 4775. 4. Iv, 47 p., 4 tal,

$2966+$ Ellis, Irilliam. The timbertree jnprovel; or the best practical methods of improving dillerent lands with proper timber. elc. London, Fox. 1738. 8. vi, 110 p. (2s.)

2967* Ellrodt, Theodor Christian. Schwanm-Pomona, oder Beschreibunc der essharen und giftigen Schwamme Deutsclilands, fur Aerzte und Koche. Baireutl 1800, 12. 302 p., 1 Tabelle, 13 tab. col. $\left(2 \frac{2}{3}\right.$ th. $)$

2968 Elmiger, Joseph. Ilistoire naturelle et merlicale des Digitales. D. Montpellier $1812.4,46$ p., 2 tab.

2969* Elsholz, Johann Siegesmund. Flora marchica, sive catalogus plantarum, yuac partim in hortis electoralibus Marchiae Branderlurgicae primariis Berolinensi, Aurangiburgico ("t Potstamensi excoluntur, partim sua sponte passim proveniunt. Berolini, ex officina Rungiana. 1663. 8. 223 p., ind. Bibl. Reg. Berol. Deless. et Univ. Lips. (In bibliotheca revia Berolinensi vidi esemplir cum epistola dedicatoria manoseripta antoris. In eadem bibliotlueca (Libri pieturati A. 53.) exstat ejusdem *Theatrun Tuliparum ad maudatum Seren.

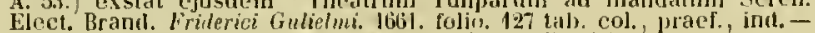
De alijs ejus manuscriptis ef. Joelsen, Epist 11. 21.)

$2970^{*}$ - Neuangelegter Garteubau, oder Unterricht von der Gârınerei auf das Klima der Kurmark Brandenburg, wie auch der benacbirarten deutschen Lánder gerichtet. Colln a. d. Spree, Georg Scluultze. 1666. 4. - "Ell. II: Cölln a. d. Spree 1672. 4. - " Ed. III: Berlin 1684. 4. 395 p., 1ab. - *Vierter Druck. Leipzig, Fritsch. 1715. folio. 258 p., ind., tab. (Adhaeret: Ejusdem Diaeteticon, d. i. Neues Tischluch. 1). $259-520$. et ind.)

2971 — Artznei-Garten und Tischlunch oder Fortsetzung des Gartenlsaues, wie man die von Gott erzeigte Erdgewtichse, Krauter, Blumen und Wurzeln zur Erhaltung guter Gesundheit wohl gebrauchen und anwenden könne etc, etc. Frankfurt und Leipzig, Voeleker. 1690. 4. 466 p.. praef., ind.. lal). Bibl. Deless.

Est reimpressio ejusdem autoris libri: Jiacteticon. Colln a. d. spree 1682.4.$)$

2972* Elsner, Christian Ludwig Kiarl. De plantarum nutrimento als aqua proficiscenti. D. Regiomonti 4798. $8,16 \mathrm{p}$

2973* Elsner, Morilz. Flora von Ilirschuerg und dem angranzenden Riesengebirge. Breslau 1837 . 8. vis, $210 \mathrm{p} .(3 / 4 / \mathrm{h}$.)

2974* Synopsis Flowe Corvinontanae. Praemissa est de sjecici definitionibus quaestiuncula critica. D. Tratislaviae 1839. 8 $43 \mathrm{p} .(1 / \mathrm{t} t h$.

2975 Elvebemes (nomen fictum, teste Limaco). Crrundvahl till plantekienningen. Upsala 1730. 12. Linn.

9976* Elwert, Johann Kaspar Philipp. Fasciculus plantarum e Flora Marggraviatus Baruthini. D. Erlangae 1786. 4. 28 p.

2977* Emerich, Gustav Wilhelm Benno. De Coffeae facullatibus et effectibus. D. Berolini 1839. 8. 25 p

2978 Emmerich, A. The culture of forests. London $1759.8 .129,21$ ]). B. 2979 Emmerich, Georg Theeologia, cjusque infusum. D. Regiomonti 1698.4 s. 9y80t Encontre, Daniel. Additions a la filore biblipue de sprenget (Aontpellier 1811.) 8. $15 \mathrm{p}$.

Evtrajt des Bulletins de la soc. des sc. feltres in arts de Montpellier.)

2081 - Recherches sur Ja botanique des anciens. (Memoire sur Jaennit des anciens.) (Moutpellier 1813.) $8.34 \mathrm{p}$.

lixtrait des Bulledius de la soe, des se. Jettres at arts de .Hont-

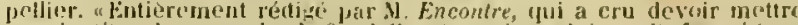
sur le titre le nom de becandolle, lerguel lis' lui inait fourni kque

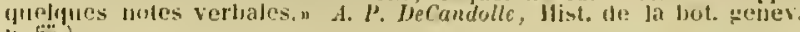
1).

2982* Endlicher, Stephan Ladislaus. Flora Posoniensis, phlihens plantas circa l'osonium sponte crescentes aut frequentius cultis methodo

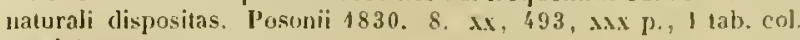
$(2$ th. $)$

2983* — Ceratotheca, eine noue Pflanzengattung aus der Ordnun: fler Sesameae. Berlin 18:32. 8. 42 p., 3 tab.

(Linnica, yol. Vil. p. 1-i2

998: * _ _ Stipium pernjtas iconibus el descriptionibus illustratá. s. I. et a. 8,15 pi, 5 tab.

$298 \ddot{*}^{*}$ Diesingia, novun genus plantarum. s. I. et a. S. $6 \mathrm{f.}$ 1 tal). (Flora 1832. p. 117. .

$2986^{*}$ Prodromus Florne Norfolkicae sive catalogus stirpiun quae in insula Norfolh annis 1804 ot 1805 a Ferdinondo Bauer collectae ef depictae nunc in Museo Caesareo Palatino rerum naturalium Vindobonae servantur. Vindolonae 1833.8 . vin. $100 \mathrm{p}$. ( $1 \mathrm{th}$.

2987" - Nacta Jotanica. Nova genera et species plantarum deseripta et iconjbus illustrata. Vindobonac 4833. folio. $26 \mathrm{p} .40$ tab $(14$ th.

(Tabulae 1-9. 11-23. 2\%. 99-36. 30-0.)

2988* - et Eluard Fenzl. Sertum Calulicum. Enumeratio plantarum quas in itinere inter Dera-Ghazee-Kian et Caluul, mensibus Majo et Junio 1833. col!egit Dr. Martin Honnglerger. Accelun novarum vel minus cognitarum stirpium jcones et descriptiones. Fasc. J. Vindolonae 1836.4 .8 p., 4 tab

2989* Genera jlantarum secundum ordines uaturales disposita. Accedit supplementum pimum. Vindobonac $1836-1840.4$ min LX, 1483 p. (18 th. ) - "Nantissa botanica sistens generun plantarum supplenentum secundum. ib. $1812.114 \mathrm{p} .\left(1 \frac{1}{2}\right.$ th. $)$ - Mantissa botanica altera, sistens generum plantarum supplementum tertiunn. ih. 1843.111 p. $\left(1 \frac{1 / 2}{2}\right.$ h. $)$

$2990^{*}$ — Ieonographia gencrum plantarun. V̈̈nelobonae 9838.4 xrt p., 425 tab. $(151 / 2$ th. $)$

Prodiit annis $1837-1860$ decem Fisciculis.)

2991* Grundzuge einer neuen Theorie der Pllanzenzengun: llien 1838. 8. 29 p. $(5 / 12$ th. $)$

2992* (- Geory Bentham, Eduard Fenzl, Heinrich Schott Enumeratio plantatum yuas ju Novae Ilollandiae ora austro-occidentali ad fluvium Cyguosun et in sinu Regis Georgii collegit $K u$ r

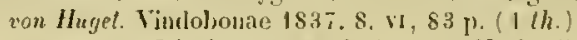

$2993^{*}$ Stirpium Australasicarum JJerbarii JJugediani decades tres. Vindobon: $1838,4,23 \mathrm{p}$.

(Annilen des Wiener Jlus. der Naturgescb. vol. 1. p. 18?-?11.)

299:. (— et Eduard Fenzl.) Novarum stirpium Decades. Eali tae a Museo Caesareo Palatino Vintuhonensi. l. Vindohonae 1839 8. Decas I-X: 90 p. $\left(1 \frac{1}{t}\right.$ th. $)$

$2993^{*}$ et Karl Friedrich l'hilipp von Martius. Flora brasiliensis, sive enuneratio plantarum in Brasilia hactenus detectarum. quas cura Musei Caesaroi liegii Palatini Vindobonensis suis aliorunque botanicorum studiis descriptas et methodo naturali digestas sul auspiciis .... elliderunt. Viadobonae et Lipsiae $1840-1846$. V fasciculi. folio. Lxivi, 136, 64, $226,48,228$ p. XXI, 77 tals. (5) th.)

1: 1\$40. Musci. exposuit Christian Friedrich Hornschuch. Lyenpodiaccae, exposuit snton Fr. Spring. 136 p. 8 tab. - Tabula physognomicae I-Y. earumque explicatio: p. $1-1-111$. ( $\pi$ th.

11: 1841. Anonaceao, aut. Karl Friedrich Philipp von Jlartus

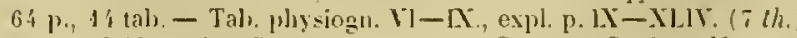

III. W. V: 1842. Cyperaceare, aut. Christum Gottried Nees von Esenbeck 226 p.; 30 tab. - Snilaceae et Diuscoreac au Heinreh Rudolph August Grisebach. 48 j., 6 tab. - Tab. physiogn X-XYll . expl. p. XLT-LXXll. $21 \frac{1}{2}$ (h.)

V1: 1846. Solanacene el Costrineae; exposuil Otto Sendener.

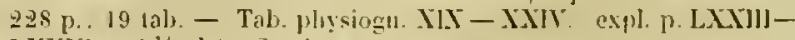
L.XX1 ( $121 / 2$ (h.) (Comtinuatur.) 
2996* Endlicher, Stephan Ladislaus. Enchiridion botanicum exlibens clisses et ordines plantarum; aceedit nomenclator generum et officinalium rel usualium indicatio. Lipsiue 1841.8 . xiv, 763 p. $\left(4 \frac{1}{2}\right.$ th. $)$

$2997^{*}$ Lie Meslizinalpflanzen der östreiclı'selıen Pharmacopoe. Ein Ilandbuch fur Aerzte und Apotheker. Wien 1849. 8. xur, $608 \mathrm{p}$. $\left(3 \frac{1}{3}(h)\right.$.

$\$ 998^{*}$ - Catalogus horti aeademici Vindobonensis. Vindobonae 1842-1843. II voll. 8. - I: 1842. IF, $492 \mathrm{l}$ ) - II: $1843.542 \mathrm{p}$. ( 3 th. $)$

$2999^{*}$ und Franz Unger. Grunlzüge der Botanih. Wien 1843. 8. XL, 494 p., 1 mappa. (4 th.)

$3000^{*}$ Endter, Heinrich Christian Goltlieb. De Astragalo exscapo Limn. D. Gueltingae 1789.8.25 p.

$3001^{*}$ Engel, Karl Gustav. De Digitalis purpurene in delirio potatorum effectu. D. Lipsiae 1835.4. 23 p.

3002 Engel, Samuel. Abhandlung vom Roste im Getraide. Zurich 1758. 8. H.

$3003^{*}$ Engelhardt, $P$. J. P. Die teutschen Arzneigewáchse oder alphabetisch georducte Beschreibungen sammtlicher in Teutschland wildwaelısenden Arzneigewächse, mit Angahe ilıres Standorts, der Zeit ihres Einsanmlung und ilsrer medizinisclien Benutzung. Northausen 1846.8 . vui, 183 p. $(1 / 2$ th. $)$

300; Engelhart, $C$. De Datura Strammonio, ejusque usu medicinali in rheumatismis cluronicis. Trajecti ad Rhenum 1829. 4

$3005^{*}$ Engelmann, Christoph Wilhelm. Generil plantarum oder the Pflanzengattungen der in den russisehen Ostsecprovinzen Esth- Livund hurland wildwachsenden Pflunen. Mitau und Leipzig 1844.8. x, 128 p., 4 tah. $(2 / 3$ th. $)$

3006 * Engelmann, Georg. De antholysi prodromus; eum 93 iconibus in tabulis $\mathrm{V}$ lithograptis. D. Francofurti a/N. 1832. 8.68, vi Ji., 5 tab. $(7 / 12$ th.

3007 - 2 aud $4 s a$ Gray. Plantae Lindheimerianae; an enumeration of $F$. Lindheimer's collection of Texan plants, with remarks and descriptions of new species ete. Boston, typ. Freeman and Bolles. 1845.8.56 p.

(From the Boston Journal of Natural history vol. v.)

$3008^{*}$ Engelmann, ITilhelm. Bibliotheca historieo-naturalis. Yerzeichniss der Bucber uber Naturgeschichte: welche in Deutsclıland, Scandinavien, Ilolland, England, Frankreieh, Italien und Spanien in den Jahren $1700-1846$ erschienen sind. Erster Band. Bucherkunde. Hulfsmittel. Allgemeine Scbriften. Vergleichende Anatomie und Physiologie. Zoologie. Paláontologie. Mlit cinem Namen und Sachregister. Leipzig 1846. 8. vir, $786 \mathrm{p} .\left(3^{2} / 3\right.$ th. $)$

3009 Engeström, Johan, pr. De Quercu, Hebraeis D. I et II. Londini Gothorum 1737-1738.4.34,68 p., praef. $\quad$ в.

$3010^{*}$ Enslin, Johann Christoph. De Boleto suaveolente Linn. D. Erlangac, Palm. 1784.4.32 p., 1 tab. - Manuhemii, Lolller. 1785.4. (nou differt.)

(Schlegel, Thesiurus mat. med. 11. p. 1-32.)

* germanice: Ahhandlung uber die Eigenschiften und den Gebrauch des wohlriechenden Weidenschwammes. Zwcite Aullitge. Marburg 1809. 8. $88 \mathrm{p}, 1$ tab. col. (1/3 th.

$3014^{*}$ Eppel, Friedrich Heinrich. De Belladonnae efficacia contra searlatinam prophylactiea. D. Berolini 4824.8.34 p.

$3012^{*}$ Erdelyi, Michael von. Anleitung zur Pflanzenkenntniss oder Botanik. TVien 4835.2 Theile. 8. - I: vII, 338 p., 2 tab. - II: vi, 336 p. $\left(3 \frac{1}{2}\right.$ th

$3013^{*}$ Erdmann, Johann Friedrich Julius. De virtute et vi medica extracti Filicis maris resinosi ad taenias expellendas. D. Dorpati 1833. 8. $39 \mathrm{p}$.

3014* Erdmann, Karl Gottfried. Sammlung und Beschreibung der Giftplanzen, die in Sachsen wild wachsen. 9 Hefte, jedes mit 10 getruckneten Pllanzen. Dresden 1797. folio. $\left(4 \frac{1 / 2}{t h}\right.$.)

3015 Tabclarisehe Uebersicht der theoretischen und practischen Botanik nach ihrem ganzen Unfange. Dresden 1802 . 4. 30 p., praef. $(1 / 3$ th.

$3046^{*}$ Erhard, Ernst. De Gratiola officinali ejusque praesertim in mania usu. D. Lipsiae 1818. 4. 24 p.

Paitzel, Thes. lit. bot.
3017* Erhardt, H. Der Tahack, mit besondrer Rücksiclıt auf die fur Kultur und llandel wichtigen Anten nebst deren Varietates, botanisch und landwirthschaftlich dargestellt. Heidelberg $1841.8 .67 \mathrm{p} .(1 / 1 \mathrm{th}$.

3018 Ericus, Johannes. 1)e plantis. D. Dorpati 1647. 4. Desid. B.

3019 Erikson, Gustaf. Dissertatio oeconomica, sistens ruflexiones nonnullas eirea nutritionem vegetabilium, quatenus e natura soli liaec imprimis pendeat. D. I-111. Lpsaliae 1815.4.38 p. w.

$3020^{*}$ Erman, Adolf. Reise un die Erde durch Nordasien und die beiden Oceane in den Jahren $1828-1830$ ausgefuhrt. In einer listorischen und einer physik. Abtheilung dargestell und mit einem Atlas begleitet. Erste Abtheilung: Historiseher Bericht. Berlin 1833-1838 2 Theile 8. - 1. 1833. xxIr, 747 p., 6 tais. $-11:$ 1838. 413 J $\left(6 \frac{2}{3}\right.$ th.

$3021^{*}$ Verzeichuiss vou Thieren und Pflanzen, welche auf einer Reise un die Erde gesammelt wurlen. (Naturbistoriscler Allas zur Reise.) Berlin 1835 . folio. 64 p., 17 tab. $\left(4 \frac{1}{3}\right.$ th.)

Plantats itiperis plerumque Kamtschatkenses eum una tabula recensentur j. 53-6k.

$3022+$ Erndl, Christian Ileinrich, latine Erndelius et Erndtelius. De Flora japanica, corlice bibliothecae regiae Berolinensis ralssiuno epistola ad Jobannem Philippum Breynium. Drestae, Iyp. Riedel. (1716.) 4. 14 p. Bibl. Juss.

(Agit de variis eodieifus Bibliothecae Regiae Berolinensis, tiguras animalium et plantarum continentibus.

$3023^{*}$ Varsavia physice illustrata, sive de aére, aquis, Jocis et ineolis Varsaviar eorundenque moribus et morbis tractatus. Cui arnexum est Yirilarium vel eatalogus plantarum eirea Varsavian nascentium. Dresdae, Zimmermanu, 1730, 4. 7, 247 p., praeter Viridarium: $132 \mathrm{p}$.

302.t "Ernsting, Arlhur Konrad. Phellandrologid physico-medicat. I) Brunsvigae 1739, 4. 39 p., 1 tab.

$3023^{*}$ Prima principia botanica, in quibus omnia ad lame scientiam spectantia in usum discentium ordine alphabetico traduntur. (Anfangsgrunde der hráuterwissenschaft.) Wolfenbuttel 1748.8 482 p., prael, ind., 6 tab.

$3026^{*}$ Historisehe und physikalisehe Beselyreibung der (iesehlechter der Planzen, welcher Herm Linnaeus systematisehes Verzeichniss yon den Geschlechtern der Pflanzen beigefügt wordeu Mit Kupfern und Registern. Lemgo 1762. 2 Theile. 4. 748 p., praef., ind., 10 tab.

$302 \tau^{*}$ Ernsts, A. Nizza und Hyères in medizinisch-topograpliselıer Hinsicht. Bonn 1\$39. gr. 12. X11, 410 p., 9 tab. ( $11 / 2$ th.)

3028 * Esche, Julius. De Teratriae effectibus in corpus animale. D. Lipsiat 1836. 4. 1v, 43 p.

3029* Eschenbach, Johann Friedrich. Diatribe epistolaris nectariorun usum exhibens. Lipsiae 1776. 4. $11 \mathrm{p}$.

$3030^{*}$ —_ Diatrilse de plysiologia seminum. Lipsiae 1777. 4. $12 \mathrm{p}$.

$3031^{*}$ — Disputatio physica, observationum botanicarum speecimen continens. Lipsiae 1784.4.40 p.

(Usteri, Delectus opusc. Lot. II. p. 79-120.)

3032* Eschweiler, Franz Gerhurd. De fruetificatione generis Rhizımorphae conmentatio. Accedit novum genus Hyphomycetum. Elberfeldiae 1892.4 .35 p., 1 tab. $(1 / 2, t h$.

$3033^{*}$ - Systema Lichenum, genera exhibens rite distineta. pluribus novis adaueta. Norimbergae 1824.4 .26 p., 4 tab. $(2 / 3$ (h.)

3034* Esmarch, II. P. C. Anfang (und erste und zweite Fortsetzung einer Schleswiggschen Flora. Schleswig 1789. 1790. 1791. 8. 24 , 32, 20 p. (Class. Linn. 1-VIHI.)

(Suspicor, terliam, quartam, quintam et selam continuationem annorum $1792-1793$ adesse. Lego eliam: II. $P$. C: Esmarch, Kurze Beschreinung der Pranzen in der Schleswighschen Gegend. Erste bis funfe Fortsetzung. Schleswig $1810-1812,8$.)

$3035 \div \div$ Besclıreibung der Gräser, rietartigen Gewàchso Schafulinge und hanneukrater, welche in den Herzogthumern Schleswig und Ifolstein wild wachsen. Schleswig und Leipzig 179\%. 8. 111 p., praef.

$3036^{*}$ Esper, Eugen Johann Christoph. Icones fucorum cum characteribus systematicis, synonymis auetorun el descriptionibus novarum speeierum. (Abbildungen dor Tange, mit beigefugten systematischen Kennzcichen, Aufulirungen der Schriftsteller und Beschreibungen 
der neuen Gattungen. Nurnberg 1797-1802. II voll. 4. - 1: fase. I -IV. 1800.217 p., tab. col. 1-111. - II: fase. V-VII. 1808. 13z, iv, III p., tab. col. $112-184 .(361 / 6$ th.

(Fasciculus vif ultimus in multis bihliotheris desideratur. Tabnthe sightiantur $i-169$, sed 15 adsint extra seriem.)

3037 Esteve, Juan Jago, latine Stevius. Dictionario de las yervas y plantas medicibales, fue se hallas en el regno de Valencia.

(I.iber it fap. the lill. primum landatus, vidotor cirea annum 4.532 prodifsse. Glom Mastar, nedicus Valcutians, qui Bumaldo Petrus Jacobus aurdit in Xicandri Colophonis Theriacim interpretationes ef enarcations livit doctissimas, qui liber impressus fuit valentiae per Jo. jestlintlrum. thöz. 8 .

3038 Estienne, Charles, latine Carolus Stephanus. De re hortensi libellus, vulgaria lierbarum, florum ac fruticum, qui in hortis conseri solent, nomina latinis vocibus efforre docens. Lugduni 1536.8 . $88 \mathrm{p}$. - Adlditus est libellus de cultu et satione hortorun, ex antiyuorum sententia. Lutetiae 1545. S, 141 j). B.

$3039^{*}$ - Sylya, Frutetum, Collis. Parisis, apud Fr. Stephanum. 1538. 8.56 foll., ind.

$3050^{*}$ - Arbustum, Fonticulus, Spinetum. l'arisüs, apud Fr. Stephanum. 1538.8. 37 foll., ind. - ib. 1542.8 .42 p. B.

$30 \%$ Pratum, Lacus, Arundinetum. Parisiis, apud Fr. Stepha1.um, 4543.8. 36 foll., ind

$30 \% 2$ Seminarium et plantarium fructiferarum praesertim arborum quae post hortos conseri solent. Parisiis $1540.8 .193 \mathrm{p}$. B. "Denuo auctum et locupletatum. Iluic accessit alter libellus tle conserendis arboribus in seminario: defue is in plantarium transferenclis at (que inserendis. Parisiis, ex officina Roberti Stephani. 1548. $8.180 \mathrm{p} .,(10$ foll. $)$ ind.

$3013 \div-$ Praedium rusticum, in (pro eujusvis soli vel enlti vel inculti plantarum rocabula ac descriptiones, earumque conserendarum atıue excolendarum instrumenta suo ordine deseribuntur. In adolescentulorum, bonarum literarum stuliosorum gratiam. Lotetiae, apud Carolum Stephanum. 1554. 8. 648 p., ind. - il. 1629.8 . 599 p. B.

(In hoc libro libelli quinque pracedientes, una cum Vineto et Aqro, junctim impressi sunt.

t gallire: L'agriculture et maison rustique de M. Charles Esticnne, Docleur en medeeine. cle, Lyon, par Jan llartin. 1563. 12. (2\%) 587 p. ind - Roue! 1625 . 4. $672 \mathrm{p}$. B.

tialice: Agricoliura et casa di villa di carolo Stefann. Nnovamente tradotta dal Cavalier Hereole Calo. Torino, per G. D. Tarino, 1609. 4 (38) itt p.

30 ' - Do nutrimentis libri tres. Parisiis 1550. 8. 156 J. B.

$304 \ddot{H}^{*}$ Estius, Franciscus. Laus rei herbariac. Lustat in principio Historiae stirpium pemptadum Dodonaei. Autwerpiae 1583. folio.

$3016^{*}$ Etlinger, Andreas Emst. De Salvia. D. Lrlangae 1777. 4.63 p.

3047 Ettmüller, Michacl. De virtute opii diaphoretica. D. Lipsiae 1679. $4.48 \mathrm{p}$.

304.8* Etzrodt, Ericin. Das Jutterkorn. D. Würzlourg 4838.8 .38 p.

$3019^{*}$ Euphrasén, Bengt Anders. Reise wach der schwedischen westindischen Insel St. Barthelemy und den Inseln St. Eustache und St. Clnristoph. Aus dem Schwelischen von Blumhof. Göttingen 1798. 8. 308 p., ind., I tab.

$30.00^{*}$ Evelyn, John. Silva: or a discourse of forest trees and the propagation of timber in his Majesty's fluminions. London 1664. folio. 120 p. praeter Pomonam et Calendarium hortense. - ib. 1706. folio. - El. Y: il. 1729 . folio. 329 p. praeter Terram, Pomonam, Acelaria el Calentarium hortense. - Ed. with notes by Alexander Ifunter.

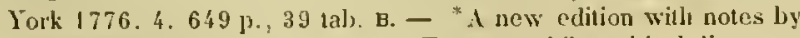
A. Hunter, to which is added the Terra, a philosophical discourse of earth. Fork 1786. Il voll. 4. - 1: $311 \mathrm{p}$, ind. (23 foll.), $28 \mathrm{tab}$, col. et effigies Evelyni. - 11:343 p., ind., 13 tab. col. Bibl. Imp. Ferd.

3031 * _ Yomona, concerning fruit-1rees, in relation to cider; printed with Evelyn's Silva. London 1664. folio, 52 p. - London 1729. folio. app. p. $47-110$. B.

Calendarium hortense, or the gardener's almanac; printed will Evelyn's Silva. London IC64. folio. app. p. $33-83$. - ib. 1729 folio. app. p. 183-234. - Ed. VJll. seorsin : London 1691. 8. $175 \mathrm{p}$. - Ed.X. seorsim: Lomelon 1706. 8. 170 p. B

3033 * - Acetarid, a discourse of salleks. Eil. 1l. London 1706.8 192 p., ind. - printed will Evelyn's silva. London 1729. folio. p. 11$]-481$
303' Evelyn, Jolu. Terra, a philosuphieal discourse of earth; relating (1) the culture and insprovement of it for vegetation and the propagation of plants, with notes la A. llenter. York 1786.4.74 p., ind., 1 tal, (Edita pst una cum Luelyni Silva; el jam antea in editionibus annorum 1729 ot 17\%

30:3 Everartus, Aegidins. De llerlaa Panacea, rfuam alii tabacum, alii letum ant Nicotianau vocau, brevis commentariolus. Antwerpiae, apui Brllerum. 1583. 12. - ib. 1587. 14. - † Ed. 1]l: Lltrajecti. lloogenluysen. 1644. 12.58 p.

$30: 36$ " Everhard, Johamn 11 "̈lhelm. Elaterium magnis mortalium usibus jarari. D. Altdorfii $1722.4 .32 \mathrm{p}$.

3037 Ewer, S. Compendium bolanices. Jondon 1808. 8.

30:88 Eysel, Johann Philipp, latine Eyselius, pr. De Cerevisia Erfurtensi. 1). Erfordiae 1689. 4. H. - iterum: "Erfnrdiae 1727. 4. 16 p. B. 3039 De chocolatac usu et alusu. D. Erfordiae 1694. 4. S.

3060 Die wundernsw urclige Weidenrose. D. Erfordiae 1711.4.s.

$3061^{\text {* }}$ De Agallocho, Paradiesholtz. I) Erfordiae 1712.4. (24 p.) (Ialentini, Historia simplicium n. $591-397$.)

$3062^{*}$ (1) Bellidorraphia sive Bellidis descriptio. D). Erfordiae 1714 4. $(32$ ).

$3063^{*}$ De Fuga Daemonum. D. Erfordiae 1714.4.24 p

306. * - De Bonolrminico oder Guten Ileinricl. In universitate llierana. (Erfordiae) 1714.4.24 p.

$3065^{*}-$ Filius ante patrem (i. e. Tussilago Farfara), phisicorum asylum. D. Erfordiao 1744. 4. 24 p.

3066 De Rore solis. D. Ërordiae 1715. 4. s

$3067^{*}$ De Aquilegia seorbuticorum asylo. D. Erfordiae 1716. 4. $27 \mathrm{p}$

$3068^{*}$ Trifolium fibrinum. 1). Erfordian 1746.4 .20 p.

$3069^{*}$ De Betoujica. D. Erfordiae 1716. 4. 20 ].

$3070^{*}$ - De Veronica, Grundtheil, Ehrenpreis. D. Erfordiae 1717. 4. 24 1).

3071 * Do medicamentis ex malo Cydoniato paratis. D. Erfordiac 1717.4. s.

$3072^{*}$ Eysenhardt, hirl Wilhelm. De accurata plantarum comparatione, adoexis olsservationilus in Floram Prussicam. D. Reyiomonti 1823.4. $22 \mathrm{p} .(1 / 3$ th. $)$

$3073^{*}$ Eysfarth, Christian Siegesmund. De morbis plantarum. D. Lipsiae 1723.4. $48 \mathrm{p}$.

3074 Eysson, Rudo/ph. Sylvac Virgiliancle prodromus, sive specimina philologico-botanica de arboribus glandiferis proprie dictis, earumquo praecipuis additamentis. Groningac 1695.12 .264 p. B.

3073 Disputatio philologico-botanica de Fago, quae Sylvulae Virgilianae prima. D. Groningae 1700. 12. s.

3076 Dispulatio de Castaneis. D. Groningae 1703. 12. $\$ 9$ p. B

\section{$\mathbf{F}$.}

3077 (Fabbroni, Adamo.) Della coltivazione del gelso e dell' exlucazione dee] filugello, o rerme da seta, secondo che si pratica dai Clinesi. Perugia 1784. 16. 80 p. B.

3078 Dell' arte di fare i vino. Firenze 1787.8.264 p. 1 lab. B.

3079 Faber, Ilonoratus. Tractatus duo: quorum prior (p.1-145) cat de plantis et de generatione animalium, posterior de bomine. Parisiis, a]bud Franciscum Iluguet. 1666. 4.440, 142 p., pracf., ind. Norimbergae 1677.4.582 p. B.

3080 Faber, Johann. De Nardo et Ejpiliymo adversus Josephum Scaligerum disputatio. Romae 1007. 4. 34 J). B. - cun libro Caspuris Scioppii et Scaligeri Jlypobolinaeo. Moguntiae 1607. 4. S.

3081* Faber, Johamn Matthaeus. Strychnomania, explicans Strychni manici altiguorum vel Solani furiosi recentiorum historiae monumentum, indolis nocumentum, antidoti docunentum. Augustae Vinclelicorum, Goebel. 1677.4.107 p., 13 tab., appendix.

3082* Fabregou, Mallhieu. Description des plantes qui najssent ou sr renouvelleut aux environs de l'aris, avee leurs usages dins la médicine et dans les arts etc. Paris 1740. WI voll. 8. xxIV, 354, 358, $248,319,304$ et $471 \mathrm{p}$.

Columini ultimo accedit: Dissertation sur forigine et le progress de la botanique, p. $317-471$. 
3083 Fabriani, Giovanni. Index plantarum in Lorto botanico Mlutinensi. Mutinae 1811 . 8. DC.

3081. "Fahricius, Johann Christian. Kultur der Gewàchso zum Gebraucb des Landmannes. Leipzig 1784. 8.207 p.

$3085^{*}$ Fabricius, Philipp Kourad. Prinitiae Florae Butisbacensis, sive sex decades plantarum rariorum inter alias circa Butisbacuru sponte nascentium cum observationibus methudos plantarum Tournefortianam, Rivinianam, Rajanam, Knautianam el Linneanam potissimum concernentibus. Wetzlariae $1743.8 .64 \mathrm{p}$.

3086 Oratio de Gernuanorum in rem herbarian meritis. Helmstadii 1751.4.

$3087^{*}$ Enumeratio methodica plantarum horti medici Ilemstadiensis, subjuncta stirpium rariorum vel nondum satis extricatarum descriptione. Ilelmstadii, typ. Drimborn. $4759.8 .239 \mathrm{p} .$, praef ${ }^{*}$ Ed. 11. auctior. Ilelmstadlii, typ. Drimborn. 1763. 8. 448 p., praef. ind. - ${ }^{*}$ Ed. Ill, auctior posthuma. Ilelmstadii, typ. Drimbert. 4776. 8. (est impressio altera, novo praefixo titulo; sed additum est ad calcem supplementum 24 paginarum. Bibl. Mus. Senckenb.

3088 Fabricius, IFolfyang Ambrosinus. 'A turis plantarum. Norimbergae 1653.4. s.

3089 (Facio de Duillier, Nicolas.) Fruitwalls improved, by inclining them to the horizon. By a member of the royal society, N.F.D. London 1699. 4. 128 p., 2 tal.. B.

3090 Fagerborg, Andreas. De primordiis botanices. D. historico-literaria. Upsaliae 1807.4 .20 p. w.

309. Fagon, Guy Crescent. Les qualités du quinquina confirmées par plusieurs esperiences. Paris 1703.12. a.

3092 An ex tabaci usu frequenti vitae summa lorevior? D. Parisiis 1699. 4. S.

3093 Fairchild, Thomas. Tbe city gardener, éonlaining the method of cultivating such plants as will be ornamental, and thrive best in the London gardens. London 1722. 8. 70 p. B.

309. Fairfax, Blacklerry. Oratio in laudem botanices. London 1747. 4. Desid. B.

309: Oratio apologetica pro re herbaria. 1718. Desid. B.

$3096^{*}$ Falco, Friedrich Christian Ernst. De Ratanhia. D. Wireeburgi 1820. 8. 52 p.

3097 Falimierz, Stefanek (latine Phalimirus). Herbarium polonicum. 1534. folio min.

(Arnold, de monum. hist. nat. Polon. p. 26. - Alamski, llist. rei herb. in Dolonia 1 . 2 2 -20 .)

3098 Fallén, Carl Fredric. De Beta pabulari. D. Lundae 1792. 4. 29 p. B.

$3099-$ De irritabilitate motus caussa in plantis. D. Lundae 1798. $4.28 \mathrm{p}$.

3100 Fallenstein, $F$. Tasehenbucb der ökonomisehen PIlanzenkunde (oder Taschenbuch der Forstbutanik). Erste (und einzige) Altheilung. Erfurt 4809. folio obl. $(T / 12 t h$.)

$3101^{*}$ Fallou, Friedrich Albert. Die Gebirgsformationen zwischen Mittweida und Rochlitz, der Zschopau und leiden Mulden und jhr Einfluss auf die Vegetation. Versuch einer von der Furstl. Jablonowskischen Gesellsclraft der Wissenschaften aufgegebnen geognostisch agron. Beschreilung. Leipzig 1845. 4. $96 \mathrm{p} .(2 / 3$ th.

(Commentatio in certamine literario attero praemio ornata, sistit Actorum societatis Jablonovianae novorum tomum IX.)

3102 Falugi, Tirgilius. Prusopopeiae botanicae, ad methodum Rivini pars l. sive nomenclator botanicus. Florentiae, typ. Mariae de Albizzinis. 1697 , 12, 130 p. B. - Pars secunda de plantis umbelliferis. ib. $1699,12.120$ p. B.

$3103+$ Prosopopeiae botanic ae, Tournefortiana methodo dispositae. Florentiae, typ. Caesaris de Bindis. 1705.12 .341 p., praef, ind.

310\%* Fanzago, Francesco. Sulle virtu della Digitale Memoria. Padova 1810.8.(6) $60 \mathrm{p}$.

$3105^{*}$ Faraday. On the practical prevention of Dry rot in Timber; being the substance of a lecture. With observations etc. London 1836. 8. $30 \mathrm{p}$.

3106 t Farin. Calalogue des plantes du jardin de botanique de Caen. Caen 1781.8. 48 p., 1 tab.
3107 Fasch, Augustin Leimich, pr. De Myrrlia, D. Jenae 1676. 4 (18 foll.) B.

$3108+$ Fauchon, L. J. Dissertation sur lo café. Paris 1815.4 .24 p

3109† Faudel, Friedrich Withelm. De viticultura Richovillana. D. Argentorati $1780.4 .30 \mathrm{p}$.

$3110+$ Faujas-de-Saint-Fond, Barthélemy. Mémoire sur le Phormiun Ienax, inprovement appelé lin de la Nouvelle-Zélande. Paris 1813 4. 30 p., 1 tab.

3111 Féburier. Olsservations sur la végétation de la tulipe. s. I. 1809 s. a.

$3112^{*}$. Essai sur les phénomènes de la végétation, expliqué par les mouvemens des sèves aseendante el descendante. Ouvragre principalement destiné aux cultivateurs. Paris 1812. 8. IV , 188 , ( $2 \mathrm{fr} .30 \mathrm{c}$.)

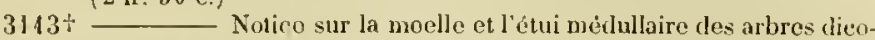
tylédones, sur les eauses de leur forme, de leur dévelojppement at de la reduction de leur diametre. Paris 1812. 8.34 ].

(Extrail des Aunales de l'agrieulture française, 1. LI.)

$3114 t-$ Rapport sur les moyens proposés jusçu’a ce jour pour préserver les blés de la carie. s. l. (1821.) 8. $64 \mathrm{p}$.

$31.135-$ Observations sur la phivsiologie véxétale el sur le systime physiologique de N. Aubert DuPetit-Thouurs. (Versailles 1821.) \&. $79 \mathrm{p}$.

$3116+-$ Précis d'anatomie végétale. Versailles et Paris 4824. 8 II, 71 p. $(2 \mathrm{fr} .50 \mathrm{c}$. $)$

$3117^{*}$ Fechner, Gustav Theodor. Resultate der bis jetzt unternommeneu Pllanzenanalysen, nelyst ausfulurlich chemisch-physikalischer Beschreibung des Holzes, fler Kohle, der Pflanzensafte und einiger andern wichtigen Pllanzenkurper. Leipzig 1829 . S. vilı, 351 p $\left(1 \frac{2}{3}\right.$ th. $)$

3118 Fechner, $\boldsymbol{k}$. A. Allgemeine Botanik fur Schuler in hoheren Burgerschulen, Realschulen und Gynnasien. Görlitz $1 \$ 41$. \$. 64 p. $(1 / 4$ th.

3119* Fée, Antoine Laurent Apollinaire. Eloge de Pline le naturaliste, lu à la socicté de pharmacie dans la séance du 13 mars $1 \times 21$ Paris, typ. Dondey-Dupré. 1\$2 1. 8. 32 p. - Ed. 11. Lille, tỵ. Danel 1827.8.27 r.

$3120^{\circ} \longrightarrow$ Wore de Virgile ou nomenclature métbodique ct critipue des plantes, fruits et procluits végétaus mentionés daus les ouvrages du prince des prëtes latins; travail inséré dans le tome VIll. (p. 429 -460.) de Virgile de la collection des classiques dédiée au roi. Paris 1822.8 .252 p. I tab.

$3121^{*}$ - Sur les Lotos des anciens, extrait de la Flore de Virgile compusée pour les classirues latins. Paris 1822.8 .24 p.

$3122+$ Méthode lichénographique et genera; ornée de quatre planches, dont trois coloriées donnant les caracteres des genres qui composent la famille des Lichens avec leurs détails grossis Paris 1824 (errore: 1825). 4. 100 ]., 4 tab. col. (12 fr.)

(Redit in libro: "Essai sur les Gryplogames des écorces exotiques.")

$3123 \div-$ Note sur les sénés et notamment sur le sẻnè Moka. Paris s. a. 8.8 p., 1 tab.

(Journal de chimie médicale tome $\mathrm{r}$.

3124 Mémoire sur les plantes connues sous le nom des Monocotylédones. 1. Il. s. I. 1826.8

$3125+$ Cours d'histoire naturelle pharmaceutique ou histoin des substances, uxitées dans la thérapeutique, les arts et l'économic domestique. Paris 1828. Il yoll. 8. - 1: xxxv, 659 p. - II: vil. $822 \mathrm{p} .(18 \mathrm{fr}$.

(Végétaus: vol. I. p. 127 - vol. 11. p. 68. .)

$31266^{\circ}-$ Essai historique et eritique sur la phytonymie ou nomenclature régétale. (Lille 1827; imprimé 1828 à Gand.) 8. 24 p.

$3127^{*}-$ Nonographie du genre Cbiodecton. (Paris 4829.) 8. 3 I p., 3 tab. col.

(Extrait des Annales des sc. nat. 1829.)

$3128^{*}$ Monographie du genre Trypethelium. (Paris 1831.) 8 . 50 p., 6 tab. col.

(Exirait des Annales des sc. nat. 1831.)

$3129+\longrightarrow$ Flore de Théocrite et des autres buceliques grees. Paris 1832. 8. XVI, $118^{2} \mathrm{p}$.

$3130^{*}$ Discours prononcé sur la tombe de MI. Christian Goltfried Nestler, décédie a Strasbourg le 2 octobre 1\$32. Strashourg $1832.8 .6 \mathrm{p}$. 
$3131^{*}$ Fèe, Antnate Laurent Ipollinaire. Vio de Lune, rérligée sur les locumens autugraples laisses par er graud lommo of suivie de: l"anilyse de sa correspondaner avere les principaux naturalistes de son éfoulue. Paris 1832.8 . xi, $379 \mathrm{p}$., 6 tab.

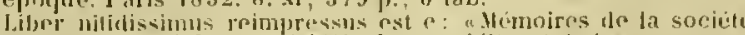

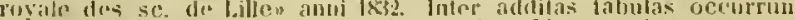

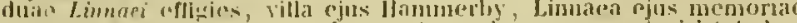

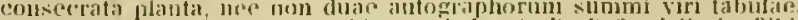

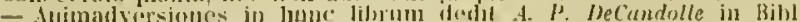

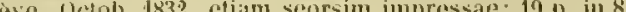

$3132^{*}$ De la reproduction des vegétaux. Strasbourg 1833. $46 \mathrm{p}$.

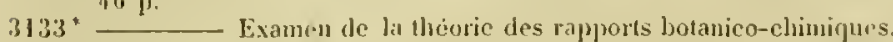
D. Strasbourg 1833. 4. 64 ]3.

$3134 \div$ - Commentaires sur la hotanique et la matierc medieale do Pline composis pour le Pline de la collection Panchouckr. Paris, imprimerie Panchouche. 1833. 111 voll. 8. - 1: w: $423 \mathrm{p} .-11: 468 \mathrm{p}$. - 1]J: $509 \mathrm{p}$.

("Cetle edition a rifi tiréc al io esemplaires seulement; chacun d'eur est unncroté de la main de l'auteur et porte son paraphe.n Fée.

$3133 \%$ (-) Discours botani(ue prononed dans la) Séance publique te la facultè de médecine de Strashourg, 26 Dec. 1833. Strashourg 1834. 4. $55 \mathrm{p}$

$3136^{*}$ Momoire sur le groupe dis ['hyllériées et notamment sur le ganre Erineum. Paris 1834 . 8. 74 p. $11 \mathrm{tab}$

$3137^{*}$ ﹎. Maitre Pierre, ou le savant de village. Entretiens sur la botanique. Paris 1835.12 .191 P., 2 tah.

$3138^{*}$ Catalugue méthodicjue des plantes du jardin botanique de Strasbourg. Strasbourg 1 \$36.8. xv1, 138 p.

$3139^{*}$ Histoire du jardin botanirpue de Strasbourg. Strashourg 1836.8 .27 j).

(Diserours douverture du cours de hotagigue extrait de ta Rinume d'tlsice.

$3140^{*}$ Les Jussieu et la méthode naturelle. Strasbourg 1837

Discours douverture elc. extrait de Ja Revue d'Alsace.)

31 i. Monographlio du genre Paulia. (Linnaea vol. X.) 8.7 p. 1 (a), col.

$3142^{*}$ - Yonographie du genre Gassicuurtia. (Linnaca vol. XI) 8. 11 p., 2 tab. col.

$314,3^{*}$ Essai sur lo.; Cryptogames des écorces exotiques ofticinales, précedé diune methode lichénographique et d'un genera avec des considérations sur la reproduction des agames. Paris 1824 -1837 . Il voll. \&. - 1: 1824. CI, 167 p., tab. col. 1-34. (42 fr.) 11: Supplément et révision. 1837. 178 1), tab. col. 35043

$314^{\circ} \div$ Jemoires lichénographiques. (Ourrage lire à part de l'Acad. imp. des Cur. de la nat. vol. X'lll. Suppl.) 1 S38. 4. 80 p. 6 tab. col.

$3143^{*}$ - Mémoire sur l'ergot du seigle el sur quelques agames qui vivent parasites sur les épis de cette céréale. Premier mémoire. Strasbourg $1843.4 .46 \mathrm{p} .2 \mathrm{tal}$.

$3146^{*}$ Wimoires sur la finilte des fougères. Premier mémoire Examen des bases adoptées tans la classilication des fougeres e rn particulier de la nerration. - Deuxième minoire: Jlistoire des Acrostichees. (Strashourg, 15p. Berger-Levrault.) I 844 (et 1845). folio. 14 ]., 2 tab., 114 1., 64 tab. (76 fr.) Bibl. Kunz. et Deless. (Ilujus operis ios tantum exemplaria impressa sunt.)

31 ' $^{*}$ Fehr, Johaun _Wichnel. Ancliora sacra, vel Scorzonera, arl normam et furmam Academiae Taturae Curiusorum elaborata. Jenac, typ. Bauhofer. 1666 8. 167 p., 4 tab.

$3148^{*}$ Hiera picra, vel de Absinthio analecta. Lipsiae, Trescher 1668. 8. 180 p., pracf., 3 tab. acn., I lab. xỵlogr.

$31,29^{*}$ Feldmann, Bernhard. Comparatio plautarum et animalium. D. Lugduni Batayorum 1732.4.63 p.- "Dissertatio de comparatione plantarum et animalium, ab erud. D. Fetdmanno olim Lugduni evlita, sed novis accessionibus ex ipsis defuncti scbedis nanuseriptis aucta recusa curk J. A. Llerck. Berolini $1780.8 .111 \mathrm{p}$.

$3130 *$ Feldmann, Franz. Do decacto Zittmanni. D. Berolini 4842.8 . $44 \mathrm{j}$.

3Іӟ!" Fellner, Maximilian Joham Nepomuk. Prodromus ad bistoriam fungorum agri Vindobonensis. D. Vienuac 1775. 8.104 p., praef.

3152 Felton, $S$. Gleanings on gardens, chicfly respecting those of the aucient style in England. London 1829. 8. (3s.)
3153 Felton, $S$. On the portraits of english authors of gardenitus, with liographical wotices. Jidl. Il. J.oulon 1830. 8. (7s.)

315 f $^{*}$ Fenzl, Eluard. Versurh ciner barstellung der geographischen Verdurejtungs - und V'ertheilungsirerhalınisse der naturlichen Familin ver Alineen in dur Polarregion und wines Theils der gendssigten Zone der alten Welt. Wion $1833,8.70$ p., 3 Tahellen. $(3 / \mathrm{t}$ th. $)$

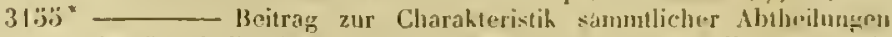
der Cnaphalien IrCandolle's nebst riner synopsis aller zur restiujirten Gattung lfloga Cassini's gelıorigen .Arten. s. I. et a. 8, 36 p.

$3186^{*}$ - Pugillus plantarum novarum Syriae et Tauri accidentalis prinus. Vindohonae $1842,8.18 \mathrm{p}$. (1/, th.

$315 \%$ Linbelliferarum genera neva et species. Abrimek aus Flora 1843. Nr. 28.) 8. 8 p.

31808 " Darstellung und lirlanterung vier minder brhannter, ilurer Strllung in naturlichen Srstenur nacb hisher zweifollaft grblieloner l'llanzengattungen; gefolgt ven einer dl,handlung uher die l'acentation der achten und einer Kritih der zweifulhaften Bignoniacecul. s. I. et a. $4.118 \mathrm{~J}$., 5 tah.

$31099^{*}$ Leber die Stellung Ire Gattung Oxera im naturlichen Systeme. s. J. et a. 4. (10 p.), 2 tab.

$3160^{\circ}$ Pemptas stirpium novarum capensium. IIulis a/s. 184.3. 8. I's p. (Linnaea vol. XVII.)

$3|6|^{*}$ - Ilustrationes et deseriptiones plantarum novarum Syriap et Tauri oceidentalis. Stuttgart 1843. 8. viu, 84 [1., 20 tal. folio.

(Seorsin impressae ex Russeyger, Reisc, Band 1. Theil 2. p.853-970.)

$316 z^{*}$ Ferber, Johan Eberhard. Hortus Agerumensis, exhibens plantals saltem rariores esoticas et officinales, quas horto proprio intulit, secundum methorlum Linnaej sexualen uligestus. Ilolmiac, typ. Lyström. 1739. 8. 76 p., ind.

3163 Feruelius, Johannes. Therapia. s. I. 1567. folio. H.

(In libris $11-111$ occurrunt herbae secundum classes suarum virium dlspositac.)

316' Ferrand. Cours élémentaire de botanique genérale d’ajrès M. Achille Richard, revu par Cambessedes. Prenière partic. Paris 1836. 12.

$3160 ̈ t$ Ferrant, Louis. Traicté du talvac en sternutatoire. Bourges. Toubeau. $1655.4 .30 \mathrm{l}$.

$3166^{*}$ Ferrari, Giovami Batlista. Flora seu de florun cultura libri 11 . Romac, apucl Steplanum Paulinum. 1633.4.522 p., tal). - " accurante Bernhardo Rottendorfio. Anrstelodami, apurl Janssonium. 1646. 4. 522 p., tab. - "accurante Bernhardo Roltendorfio. ib. 1664.4. 552 p., pracf, ind., $45 \mathrm{tab}$

- ilalice: Flora, osero coltura di liori, dislinta in quattro libri e trasportata dalla lingna latina nell' italiana da Lodorico Aureli Perugino. Roma, Facciotti. 163s. 4. 320 p., praef., ind., is tab.

$3167^{*}$ Hesperides sive de malorum aureorum cultura el usu libri quatuor. Romae, sumtibus Hermanni Scheus. 16\$6. folio. (10) 480 p., ind., lab.

3168 Fessenden, $F$. G. New American Gardener, comaining practical directions on the culture of fruits, regetables ctc. Boston 182S. 8 .

3169 Festa, M. Malpighius. Sermo. Bononiae 1810. 4. DC.

$3170^{*}$ Feueregger, Karl. De Yaleriancis Hungariae, Croatiar, Transsylvaniae, Dalmatiae ef litoralis Hungarici. D. Pestini 1837. 8. 30 ].

3 Iil Feuereisen, C.B. Praktische Abhandlungen über einige Gegenstände der feinen Gärtnerei. llannover 1780.8.

$3172^{*}$ Feuereusen, harl Golllob. Pflanzenorganologie order Etwas aus dem Pllanzenreiche, insonderheit die sonderbaren Wirkungen des Nahrungssaftes in den Gewachsen. 11annover 1780. 8.30 p.

$3173^{*}$ Feuillée, Louis. Jonrnal des observations physiques, mathenitiques et hotaniques, faites par lordre du roi sur les cótes orientales de l'Amérique méridionale et dans les lndes occidentales depuis 1707-1712. Paris Griffart. 1714. 111 voll. 4. - 1 et ll: 767 p., 50 tab. (plantas illustrantes). - ilJ: ib. $1725 . x \mathrm{~L}, 426 \mathrm{p}$ - Accedit: Histoire des plantes meddicales de Perou et Chili: 7 I p., 50 talı. in germanice: Beschreibung zur Arznei dienlicher Pllanzen, welche: in den Reichen des mitlagigen Ameriha, in l' ru nod Chile vorzigghich

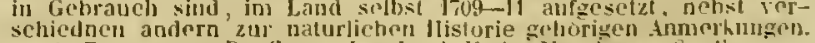
schiednen andern zul naturlichen Ilistorie gohorigen Anmerkningon.

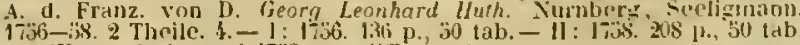
'Exempleria anni 1733 non differunt.

$3174:$ Fibig, Johann. Einleitung in die Naturgeschichte des Pflanzenreichs nach den neusten Entlechungen. Mainz 1791. 8. xis, $446 \mathrm{p}$. 
31 ï" Ficinus, Heimrich. Flora der Gegend um Dresden. Dresden 18071S08. 8 min. Phanerogamie. xxxum, 430 p., 1 tah. col. $\left(1 \frac{1 / 2}{l}(\mathrm{~h})-\right.$. "Zweite wermehre und verbesscrte Aullage. Uresden 1821-1823. Q Theile. 8.- I: 1821. Phanerogamie. xit, 542 p. - ll: 1823. hiryptoganie, von Karl Schubert. xxyul. 466 p., 3 tab. $\left(4 \frac{1 / 2}{2}\right.$ h. $)$ - "Dritte verbesserte. Iuflage, von Ficinus und Gustav Heynhold. Dresden 1838. S. Erster Theil: Plancrogamie. XIIY, $300 \mathrm{r}$. und eine greognostische liarte der [imgegend rou Dresden. ( $2 \frac{1}{2} / \mathrm{h}$.)

$3176 \div$ Fick, Johann Jakob, pr. De plantarum extra terram vegetalione. D. Jesae 1688 , 4. 28 p.

$317 \% \div$ Rosmarinum. D. Jenae 1725. $4.23 \mathrm{p}$.

31 i8 Fieber, Franziaver. Symbolische Pllanzen, Blumen und Fruchte, grusstentheils nach der Natur gezeiclnet und gemalt. Mit erläuterndem Text zu "Selau oder die Sprache der Blumen". Funf Hefte. Prag 1826-1830. $\left\{2.53,51,60,47,48\right.$ p., 100 tab. $\left(1 \frac{2}{3}\right.$ th. col. $4 \frac{1}{5}(h)$.

$31: 9^{*}$ Die Potamogeta Bohmens. Annographisch licarbeitet in ökon. techn. Hinsicht son Friedrich Grafen von Berchtold, in hotanischer von Frunz Kaver Fieber. Prag 1838. 8. 51 p., 4 tab.

$3180=$ Die Eelien Buhmens. (Prag 1841.) 8. 16 p.

(Itrague montstaphia seorsin impressal est ex: Oekonomisch(mintische Flora Bohnens.)

$3181^{*}$ Fiedler, Karl Friedrich Bermhard. Synopsis Ilypnearum Mlegapolitanarum. D. Rostochii, typ. Adler. 1844.8.32 p (Redit in libelfos sequeati.)

$3182^{\circ}$ Srnopsis der Laubmoose Mlechleuburgs. Schwerin I\$44. 8. x. $138 \mathrm{p} .(5 / 8, h$.

$3183^{*}$ Fiedler, Kurl Gistav. Reise durch alle Theile des Kònigreiehs friechenland. Leipzig 1840-1841. 2 Theile. 8. - I: 1840. xvul, S5S p., 6 tab. - 11 : 1841 . vi, 618 p., 5 tals., I mappa geogn. col. ( 9 ih.)

In volumine 1. p. 50 - -838 recensentur vegetabilia Graeciae, quae pars seorsim evitat, inseripta: Tehersicht der few achse des konigreichs Griechentand. Dresden 1810.8. p. 507-8\%, additis appendice ac itulice.)

31s4 Field, Henry. Hemoirs historical and illustrative of the botanick garden at Clieksea, belunging to the society of apothecaries of Londou. London 1820.8 . Bibl. Reg. soc. Lond.

$318 i^{*}$ Fielding, M. B., and Georye Gardener. Sertum plantarum, or drawings and descriptions of rare and undeseribed plants frem the author's (Fielding) herbarium. London 1844. 8. (75 foll.), incl., i5 (a). (21s.)

Continuatio libri nondum prodiit. Quae edita subt, sistunt volumen primum sise particulas $\mathbf{1}-111$.

3186 "Fiera, Baplista. Coena de herbarun virtutibus el ea medicae artis parte, quae in victus ratione consistit. Columella de cultu horturum. De generilus morlsorum, ex imprecaturia satyra Petri Montani. Argenturati, apud Christianum Aegenolphum. s. a. 8.27 (13) p. nutis illustrata a Carolo Avantio, Rhodigino. Patavii, typ. Sardi. 1649. 4. ( 8 foll.) 208 p., ind., efligies autoris.

3187 "Figueiredo, Jeronymo Jonquim de. Flora pharmacentiea e alimentar portugueza ou Tractato daquelles vegetaes indigenas de Portúgal, e outros nelle cultivados, cujos productos são isados, on susceptiveis de se usar come remedios e alimentos, distribuidos segundo "systema Linneanu em Classes, ordens, generos e especies com os seus caracteres genericos e especificos. Offereda a Academia real das sciencias de Lisboa. Lisboa $1825 \%$. S. 604 p. Bibt. Reg. Berol.

$3185 \div$ Figulus, Carolus. Dialogus, qui inseribitur hotanomethodus sive herbarum methodus. Coloniae, apud Johamem Schoenstenium. 13 40. 4. (23 foll.) Bibl. St. Gall.

(Liber hic rarus, quem in billiotheca monasterii st. Golli offendi, facile primam at authuissimam sistit methodum cognosendii herhas: est dialogus inte: autorem Figulum et juvenen Coloniensem Zyluardum, in qua Gisbertus Longolius, medicus Coloniensis, princeps Germanorum botanicus, cui ipse Euricus Cordus cederet, pracedicatur.

3189\% Fillassier, Jean Jacques. Dictiomnaire du jardinier francois. etc. Paris 1789. II voll. 8. - I: xu, 690 p. - Il: 729 p. (10 fr.)

La culture de la grosse asperge, dite de Hollande, la plus hative, la plus féconde et la plus durable que l'on connaisse. Paris 1783. 12. - Ed. II: Paris 1809 . 12. (1 fr. 50 c.) a.

3191" Filter, Franz Ernst. De curtice Angusturae ejusqque usu medico. D. Jenae 1791. 4. 27 p.
3192* Finckh, Friedrech Ludwig. Die Cactus, ibre Beschreibung, Cultur und Vermelırung. Ein llandbuch fur Cactusfreunde. Slnttgart $1 \$ 32$. 8. 120 p., 7 tah. $(1 /$ h. $)$

3193 Fjneschi, Antonio ,Iaria. Disscrtazione sopra la maniera di coltivare i mori gelsi. Siena 1783.8 . Dc.

319: Fingerhuth, Karl Anlon. Tentamen Florulae Lichenum Eifliacae, sive enumeratio lichenum in Eiffla provenientiun. Norimbergac 1829. 8. 100 p. $(1 / 2$, h. $)$

$3193^{*}$ _... Monographia generis Capsici. Dusseltorpii 1832. 4 IV, 32 p., 10 tah. col. ( 2 th. $)$

3196 Fintelmann, $G$. 4 . Die Willbaumzucht. Die Zucht und Pllege der in Deutschland im freien Lande zu erzielsenden und zu uberwinteruden Ilolzyjlanzen, sowobl der harten als zarten. Berlin 1841. 8. $\left(2, h_{-}\right)$

(Est sectio quinta collectionis inscriptae; llandbibliotheh fur Gärtner.

$3197^{*}$ Fintelmann, Karl J. Practische Anleitung zur Fruchttreiberei. Nach 20 jähriger Erfalorung fur Lehrer und Zoglinge der Gartnerei und Gartenfreunde bearheitet. Putsdam 4837. 8. ru, $175 \mathrm{p} .2$ tal. $(2 / 3(t)$.

3198 Die Obstbaumzuclst. Eine praktische Anleitung zur Frziehung und Wartung der Obstbitume. Berlin 1839. 2 Bàude. 8 $\left(3 \frac{3}{4}\right.$ th.) ner.

Est sectio tertia cullectionis inseriptae: Itandbibliothek fur Girlt-

$3199 \div$ Fiorini-Mazzanti, Elisabelta, Contesa. Specinen bryologiae romanae. (El. Il.) Ronac, typ. Puccinelli. 1841. S. 56 ]., praef. Ed. 1. Romae, typ. Boulzaler. 1831. \&. 26 p., 1 tab.

$3200 \div$ - tppendice ad Prodromo della Flora romana (aut. Selastiani et Mauri).s. l. et a. 8.24 p.

$3201^{*}$ Fischer, Hexander. De interna plastarum fabrica. D. Mlosquat 1820. S. 71 1).

$3202 \div$ Fischer, Christian August. Description de Valence ou Tablean de cette province, de ses preductions, de ses habitans, de leurs moeurs, de leurs usages. etc. Pour faire suite anx voyage en Espagne du meme auteur. Traduit par Chr. Fr. Crumer. Paris 1804.8.423 1.

(Inest: Essai ilune Flore de Valence: p. 393-\{18.)

3203* Fischer, Friedrich Frnst Ladwig. Specimen de vegetahilium imprimis filicum propagatione. D. Halae $1804.8 .40 \mathrm{p}$., $4 \mathrm{tab} .(1 / 3 / \mathrm{h}$.

3204* — Beitrag zur botanisehen Systematik, die Existenz der Ionohotyledoneen und der Polyhotyledoneen betreflend, Zurich 1812. 4. 32 p., 3 tab. (1 th.)

$3203^{*}$ (_. Catalugue du jarclin des plautes du Conte Alexis do Ruzoumoffshy à Gorenhi près de Moscou. s. I. 1808. 8. $143 \mathrm{p}$. (3 RuLel.) - †lloseon, typ. Yserulojshy. 1812. S. v111, 76 p., I tab.

$3206^{*}$ (- Index platuarun anno 1824 in hortu imperiali butanicu Petropolitano vigentium. Petropuli $1824.8 .74 \mathrm{p}$.

$3207^{*}$ —. et Karl Anton Meyer. Index seminum, quac hortu. hotanicus imperialis Petropolitanus pro mutua commutatione offert. Accedunt animadversiones botanicae nonullae. Nr. I-LX. Petropoli 1835-1842. S. 42, 54, 48, 52, 43,67,59,74,97 p. - supplementum. $1843.25 \mathrm{p}$.

$3208^{*}(-$ Bericht uher die Getreidearien, welche im Jahr 1836 im Kaiserl botanischen Garten zu St. Petershur: gebaut wurden. (St. Petersburg 1837.) 4. 11 p.

$3209^{*}$ (— — Enumeratio (prina et altera) flantarum novarum a clarissino Schrenk lectarum. Petropoli $1841-1 \$ 42 . \&$. -1 : 1541. vil, 113 p., 2 tab $-11: 1842.111,77$ p.

(t) Vidi in Bibliotheca Candolleana exemplar prioris enumerationis, praenissa intranctione $F$. E. L. Fischeri et $C$. A. Heyeri fert semper desiderata, in qua cell. viri libellum agnosenint, et de schrenkit itinere pauca charrant; sunt \& foll., sign. I-VII.)

3210 Fischer, Gabriel. Freye Gedaoken ron der Natur. Danzig 1743. 8. H.

$3211^{*}$ Fischer von Waldheim, Gotthelf. Das Nationalmuseun der Naturgeschichte zu Paris. Von seinem ersten [rsprunge bis zu seinem jetzigen Glanze. Franhfurt a/M. 1802-1803. 2 Theile. 8. - I: 1802. 12,547 p. 2 tab. $-11: 1803.422$ p., 5 tab. $\left(4 \frac{2}{3}\right.$ th. $)$

3212 - Nolice sur les vígetanx fossiles du gouvernement de Moscou. Moscou 1826.4.

$3213^{*}$ Cóte séculaire de Charles de Limne, célélirée par la snciété impériale les naturalistes de Mlascon. MIoscou 1835.8. 32 1). 
3214" Fischer, Ileinrich. Vermeltrung, Verellung und Behabullung der Camellia japonica. Fur IBlumenliebliaber und (tirtner Sasslich dargestellt. Freilsurg i/B. 1836.8 .24 p., 4 tals. $(1 / \mathrm{s}(\mathrm{h})$.

321:3" Fischer, Johann Andre'as, pr. De Japavere erratico. D. Erfordiac $1718.4 .28 \mathrm{p}$.

$3246^{*}$ De Dirdar Jonsinae Ulmo arbore. D. Erfordiae 1748. 4. $30 \mathrm{p}$.

$3217^{*}$ De kicino americano. D. Erfordias 1719.4.24 p.

:218 Fischer, Johann Beruhard. Vierzehnjihrige Erfahrungen uber deu Aubau auskindischer Getraidearten in Deutschland. Nurnberg $1810.8 .\left(3 / \frac{1}{4}(h)\right.$.

3219* Fischer, J. G. Beschreibung fast aller Gift-und Jer vorzuglichsten Irznei- und Futtergewaclise Deutsclılands, nit besondrer Berücksichtigung der Mark Brandenburg. Neuzelle 1827. 8. vi, 385 p. ind.

$3220^{\circ}$ Fischer, J. G. Das Pflanzenreich oder Beschreibung aller naturhistorischen Gegenstande, Welche auf der 4. und 5. neuen Waodtafel zur Naturgeselichte aljgelpildet sind. Breslau 4835. 8. x, $733 \mathrm{j}$. ( $7 / 8$ /h.) - Zweiter Theil: Dio natürliche Anordnung des Gewáchsreiches. Breslau $1840.8 .(1 / /)-.{ }^{*}$ Dritter Theil : Die schádlichsten Giftpflanzen Deutschlaorls. Nach der Natur auf eine Wandtafel (in 6 Bhatt) gezeichnet von $K$. H\%. Heinrich; und zum Gebrauch in Elementarschulen beschriel)en. Breslau 1836. 8. iv, $103 \mathrm{p} .(1 / \mathrm{t} / \mathrm{h}$.)

32.21" Fischer, Levin. Methotus nova herbaria, plantarum ad septen summa gesera redactarum synonyma, regulas prineipatas, experimentaque eurativa preponens. Brunopoli (i. e. Brunsvigae 1646?) 8. 160 p. Bibl. Reg. Dresd.

3222 Fischer von Atzendorf, Salomon. Unterrichteter Hausvater und kluger Gărtuer. llannover 1705. 12. - ib. 1737. 12. H.

$3223^{*}$ Fischer, Sieqmund kaspar. Lehrbuch der Naturgesehichte für die llauptsehulen in den k. k. Orstreich'schen Provinzen. Wien 1842. 8. xiv, 258 p. (p. 105-202: Botanik.) und Atlas in folio: 12 tal). col. $\left(1 \frac{1}{2}\right.$ th.

3224* Fischer, Traugolt Friedrich. De Phellandrii aquatici usu. D. Wittenbergae 1799. 4. 36 J., A tab.

$3225+$ Fischer, V. F. S. Anleitung zur Truffeljagd oder Trüffelsuche. Ein Beitrag zur Forst und Jagdwissenschaft. Karlsrube 1814. 8. 48 p. 1 tab. $(1 / 3$ th.) Bibl. Léveillé.

3226 Fischerström, Johan. Ltkast till Beskrifning an Mălaren. Stockholm $1785.8 .449 \mathrm{p}$. ind. w.

(Yaxter omkring Halaren och på dess Öar. p. 2h-292.)

$3227+$ (Fitton, Elizabelh, and Sarah Mary Fitton.) Conversations on botany. Ed. VIll : Loudon 4834. 8. (71/2s. - col. 12s.) - † Ed. IX London 1840. 8. xvi, $2 \times 5$ p., 22 tab. col.

3228 Flachs, Siegesmund Andreas. Exercitatio pro loco, sistens vestitum e Papyro is Fallia unper introductum, e scriniis antiquitatis erutum. Lipsiae 1718. 4.(28 foll.) B.

$3229 \div$ Flacourt, Elienne de. llistoire de la grande isle Madagascar. Troyes et Paris, Clouzier. 1661.4.47.1 p., praef., tab.

3230 Fleck, Fr. LeSueur. De Antonii Leurenhoeckii meritis in quasdan partes anatomiae microscopicae. Lugduni Batav. 1843.8 .44 p., Itab.

3231 " Fleckles, Leopold. Karlsbad, seine Gesundbrunen und Mineralbäder in geschichtlicher, topographiseher, naturhistorischer und medizinischer lliusicht dargestellt. Stuttgart 4838. 8. xvul, $374 \mathrm{p}$, 1 tab. $\left(1^{3} / 4 / 1 /\right)$

(Iuest Flora Carlshadensis, autore A. Ortmann.)

3232 Fleischer, Esaias. Underviisoing i det danske og norske skorvaesen (i. e. Institutio de eultura sylvarum Daniae et Norvegiae). Havniac 1779. 8. Brannich.

3233 Forsög til en dansk havebog (i. e. Tentamen herticulturae danicac). llavniae 4782.8. Brannich.

3234 Fleischer, Georg Christian. Lilia Rubenis, sive Dissertatio philologiea-critica de

3233* Fleischer, Johann Gottlieb. Systematisches Verzeichniss der in den Ostsecprovinzen bis jetzt bekannt gewordnen Flanerogamen, nit Angabe der gebránchlichsten deutschen, lettischen und esthnischen Benennungen. Den Freunden der vaterlandischen Pflanzen- kunde zur Prufung udd Erganzung vorgelegt. (lithographist.) Ititau 1830.4. 120 1).

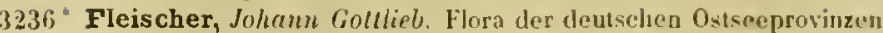
Listh - liv - Und liurland, herausgegreben vou Emonuel Lindemunin. Mit dem Bilduisse des Verfassers. Nitan und lecipzig 1839. 8. "', $390 \mathrm{p}$., effigies Fleischeri. $(13 / \mathrm{th}$.)

$3 \geq 37$ Fleischmann, Andreas. Lebersiclit der Flora liraios ader Verzeiclnniss der in Herzogthume Krain wildwachsenden unrl allgemein kultivirten sichthar hluhenden Gewachse. Laybach, Lercher. 1844. 8. $(2 / 3 t h$.

(1pse autor dedit supplementum in Flora Ratisb. 1\$\%?. p. 239-2\%.)

$3238 \div$ Fleming, John. A catalogue of Inclian tnedicinal plants and drüs, with their names in the hiodustani and sunserit languages. Calcutia, printed at the llindustani press by J. II. IIubluard. 1810.8 .7211 , (V p.) ind. Bibl. Horti Paris.

("This catalogue forms an article in the Ittl yolune of the asiatick resertrehes, but is now printed separate with emendatinus and some addituons, is)

$3239 \div$ (Fleury, J. F.) Orchiclées des environs de Renues. Renues, tyj. Cousin-1)anelle. $1819.8 .32 \mathrm{p}$.

3210 * Flinders, Hatthew. A veyage to Terra australis; undertaken for the purpose of completing the discovery of that vast country and prosecuted in the years 1801,1802 and 1803 in his majesty sh ship? the Investigator and etc. by Matheio Flinders, commander of the Investigator. In two volumes with an Atlas. London 1814.11 roll. 4 1: CCov, 269 \%., 4 tab. - II : 613 p., 5 tab. et Atlas in folio: 18 tab. geogre, 10 ab. bot. a Bauer delin.

(A p. $333-613$ : (ieneral remerks, geographical and systematical. on the Botany of Terra australis, by fobert Brouen, naturalist to the voyage.)

32.1* Floerke, Ileinrich Gustav. De Cladoniis, difficillimo Lichenum genere commentatio nova. Rostockii $1828.8 .186 \mathrm{p} .(2 / 3(h$. $)$

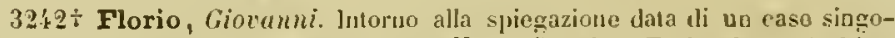
lare d'innesto Lettera al Sign. IJutteo Bunafous. Torino 1832. 8. 2 i p.

$3243+\ldots$ Ricerehe sperimentali sugl' ionesti, sulla eolorazione dei vegetabili e sulla fosforenza del ligno infracidito ragguaglio. Vigevano $1836.8 .26 \mathrm{p}$.

324: $\div$ Flotow, Julus von, Jleinrich liobert Göppert und Christian Gollfried Nees von Esenbeck briugen Il,n. Dr. Ernst II ithetm Martius zur feier sciner goldnen Iochzeit am \$3. Febr. 1849 Gruss und (iluckwunsch. Nit einem Anhange uber die Rinde Páo Pereira und die darauf rorkommenden Lebermoose und Flechten. Breslau ( 1842 ). 8.18 p. Bibl. Juss.

$32405+$ Flourens, I'. Lloges historiques de Rene Louiche Desfontaines et de Jucques Julien DelaBillardiere. Paris 1\$37,4,31 p.

$3216 *$ Jiloge historique d'Antoine Laurent de Jussieu. Paris 1838. 4. $60 \mathrm{p}$.

$32: 7^{*}$ 4. Kloge historique de Pyramus DeCandolle, lu à la seance jublique (de l'institut royal de France) du 19 Decemlore 1842. Paris 1849.4. $48 \mathrm{p}$.

$3248^{*}$ Wloge historique d'Aubert Auber Du Pelit-Thonars; lu a la séance publique anouelle (de l'Institut royal te France) du 10 Mlars 1845. Paris 1845.4. $31 \mathrm{p}$.

$3249^{*}$ Flügge, Johann. Graminum Monographiae. Pars I. Paspalus. Beimaria. Hamburgi $1810.8 .224 \mathrm{p} .\left(1 \frac{1}{3} \mathrm{th}\right.$.)

$32 \ddot{30 *}$ Flume, Irilhelm. De Chiniodino. D. Berolini $1832.8 .32 \mathrm{p}$.

$3251^{*}$ Focke, Gustav Woldemar. De respiratione regctabilium. D. Heidelbergae 1833.4 . vil, 26 ]., I tab. (1/2 th.

3252* — Die Krankheit der Kartolfeln inı Jahr 1845. Fur Botaniker und Landwirthe bearbeitet. Bremen 1846. gr. 4.76 p., 2 tab. col. $(1 \%$ th.

$3233{ }^{*}$ Foehr, Johann. Wichael. De vini Mesellani vi medicatrice in morbo scorbutico olservatio. D. Berolini 1835. 8.32 p.

325: Földi, Jauos. Rövid lritika és rajzolat a Nayyar luvésztudomanyról. (i. e. Brevis critica et delineatio lotanicae hungaricae.) Bétsbeu (Viennae) 1793. 8.60 p. B.

3255 Foerster, Christian Gollieb. Geschichto von der Erfondung und Einfulirung des Cichorienkaffee. Bremen 1773. 8, sı p. B.

3236 * Foerster, liarl Friedrich. Ilandbuch der Cacleenkunde in ihrem ganzen Imfange, oder die erfolareichisten aur die neuesten Erfah- 
rungen gegrundeten Culturangaben, sowic ausfuhrliche und genauc Beschreibung und berichtigte Synonymik sammllicher bis jetzt bekannt geworduer Cacteen. Leipzig 1846.8. XI, 548 j). (2 th.)

$3207^{*}$ Fogel, Warlin, latine Fogelius vel $\mathbf{F o g e l i u s . ~ I l i s t o r i a ~ v i t a o ~ e t ~}$ mortis Jouchimi Jungii, mathematici summi, ceteratue incomparabilis philosophi. Praenittitur editioni huic multo anctiori moumentum el epicedium supremo ejusdem honorj dicata a Kichaele Kirstenio. Argentorati, Bockenhoff. 1658.4. 27 p. Bibl. Caes. Vindob.

3258 Folchi, G. Descrizione degli exemplari delle Chine-chine vere e false conservati nel gabinctto di materia medica lell' università di Roma. etc. Roma I830. 8 .

(Annali di storia natur. tomo IV. p. 13\%.)

3239 Folli, Francesco. Dialogo intorno alla cultura delle vite. Firenze 1670.8. 79 p. B.

$3260^{*}$ Fonseca Benevides, Antonio Albino da. Diccionario rle Glossologia botanica ou Descripçào dos termos technicos cle Organographia, taxonomia, physiologia e pathologia regetal, com a exposiçào succinta clas familias uaturaes o suas tribus actualmente adoptarlas, redigido a'rista dos melhores diccionarios hotanicos em que se acha refundido especialmente o do Dr. Brotero. Pelo aullor do compendio de botanica, o Dr. Antonio Albino da Fonseca Benevides. Lisboa, typ. da Academia. $1841.4 \mathrm{~min}$. Iv, 487 j. Bibl. Reg. Berol.

$3261^{*}$ Fontana, Felice. Osservazioni sopra la rugrine del grano. Lueca 1767. 8.114 p., 1 tab. col.

$3262^{*}$ Saggio di esservazioni solura il falso ergot, e Tremella. Firenze 1775. 4. $29 \mathrm{p}$.

3263* (Forbes, James.) Jourual of a horlicultural Tour through some parts of Flanders, llolland and the north of France, in the autumn of 1817; with engravings. By a deputation of the Calcelonian lorticultural society. Edinburgh $1823.8 . \mathrm{xv}, 574 \mathrm{p}$. ( $16 \mathrm{~s}$.)

326 ' (-) Journal of a horticultural Tour in Germany. London 1837. S. Cat. Lambert.

$3263^{*}$ (- ) Hortus ericaceus IVolumensis, or a catalogue of lieaths in the collection of the Duke of Bedford, at Wohurn Abbey Alphabetically and systematically arranged. (Loudon) 1825. 4. xıv, 42 p., 6 tab. col., 4 tab. nigr. Bibl. Friedr. Otto.

$3266^{*}$ (-) Salicetum Wuburnense: or, a catalogue of willows indigeneus and foreign in the collection of the Duke of Bedford, at Wohurn Abluey; systematically arranged. (London) 1829 . 4. XVI, 294 p. 140 tah. col. (6 Frd'or. A.) Bibl. Reg. Berol. et Mus. Viodob. (Centum inpressa sunt exemplaria, nunquam veualia.)

$3267^{*}$ (__ Hortus Moburnensis, a descriptive catalogue of upwards of six thousand ornamental plants, cultivated at Woburn Ahbey. TVith mumerous illustrative plans for lise erection of fureing houses, green houses and an account of thejr management throughout the year. London 1833. S. Xxiv, 440 p., ind., 27 tab. pro parto col. (2l. 12.s. $6(d$.)

$3268^{*}$ (-) Pinctum Woburnense: or a catalogue of coniferous plants, in the collection of the Duke of Bedford, at Woburn Abbey; systematically arranged. Londini 1839. 8 max. XVI, 226 p., 67 tab. col., 1 tals. nigr. Bibl. Link. et Mus. Vindob.

(Centum ciemplaria typis expressa sunt Loudini apud Janes Moyes, muguam venalia. - Quis antor sit hujus et aliorum de horto IIoburiensi librorum, ambigitur, licet Forbesii nomen sub praefatione legatur. - llortus gramineus Woburnensis in voce Sinclair quacrenclus est.

3269 Forer, Laurentius. Disputatio physica de plantis, propugnata ab Andrea Burchardo in Academia Dilingana. Dilingae, apud vid. Juannis Mlaycr. 1615. 4. Bibl. Reg. Paris.

3270 Forget, Jean. Artis signatae designata fallacia. Nancei, apucl Ant. Charlot. 1633. 12. s.

$3271 \div$ Formi, Pierre. Traité do l'adianton ou cheveu de Venus, conterant la description, les utilitez et les diverses preparations galeniques et spagyriques de cette plante. Pour l'usage familier de toute sorte de personnes, en la guerison de quelle indisposition que ce soit. Mantpeltier, Buisson. 1644.8.80 p., praef, 4 tal,

(Redit in Bbuchoz, Traités très rares. Paris 1780. 12. p. 93-157.)

$3272 \div$ Fornaini, Louis. Dissertation sur la cullure des sapins, traduit de l'italien. Paris 1813.8. 48 p., 1 tab.
$3273^{*}$ Forrest, Thomas. A voyage to New Guinea and the Aloluccas from Balambaugan, during the years 1774-1776. London 1779. 4. 388,13 p., 27 tals.

" gallice: L'aris 1780. 4.

germanice: llamburg 1782-4793. 2 Theile. 8.4

$3274+$ Forsander, Johan. De vegetatione Scaniac. D. Lundac 1820.4 16 I.

$3275^{*}$ Forsberg, Carl Pehr. De Campanulis suecanis. D. Upsaliac 1829 4. 9 p.

3276 Forselles, Jacob IJenrik af. Trenne nya raxter fundne i Sverige ocl beskrifne. Lpsaliae, typ. Ldman. 1807.8 . 16 p. w.

(Dissertatio haece perrara ad Iestum saeculare nativitatis Linnaci anno 180\%. "psaliac disiribula fuit una cum moneta in memoriam Linnari excusit; continet descripliones Poae remotae Fors. ef Artemisiae coarctatic Furs.)

3277 Forshäll, Johan Ilenrik. Larolook i Pluarmacien. Norrköping 1836 8. $\mathrm{xv}, 394, \mathrm{XX1}, 6$ p. (Pharm. Batanik j. $87-394$.$) w.$

$3278^{*}$ Forskâl, Pehr. Flora aegyptiaco-arabica, sive descriptiones plantarum, quas per Aegyptum inferiorem et Arabiam felicem detrsit illustravit Petrus Forskil. Post mortem anctoris [periit peste in loco Jerim Arabiae felicis anno 1763] ediulit Cursten Niebuhr. Accedit Iabula Arabiac felicis geograplico-botanica. llavniae 1775. 4. 32 cxxvi, 219 p., 1 mappa lrot. geogr. $\left(2 \frac{1}{2} t h\right.$.)

tmsunt praeteroa: Finmla litoris Galliae ad Estac prope Massilian, Florula Melitensis, Flora Constantinopolitana, Flora aegrytiaca, sive catalogus plantajum sy stematicus Aegypti inferioris.)

$3279^{*}$ Icones rerum naturalium, quas in ilinere orientali depingi curavit. Post mortem auctoris ad regis mandatum aeri incisas edidit Carsten Niebuhr. Ilavniac 1776.4 . 15 j., 43 tab. ( 5 th.)

$3280^{*}$ Forsten, E. A. De Cedrela febrifuga. D. Lugduni Batavoruu 1836. 4. $34 \mathrm{p}$., I tab.

3281 (Forster, Benjamin Meggot.) Peziza cuticulosa. (London 1792.) 16. 1 fol. cum tabula aen. col. B.

3282* Forster, Georg. Gescliclite und Beschreibung des Brodhaums. Programm. Cassel 1784.4.47 p., 2 tab.

Ilossische Beitrage, vol. I. ]). $208-232$ ct p. 38 t- 400 .)

$3283^{*}$ Florulae insularum australium prodromus. Goettingae 1786. 8. 8, $103 \mathrm{p} .(1 / 3 \mathrm{th}$.

$3284^{*}$ De plantis esculentis insulasum oceani australis commentatio botanica. Beroliui 1786.8.80 p. $(5 / 2+t h$.

3985 - Fasciculus plastarum magellanicarum, et plantac atlanticae, ex insulis Madeira, St. Jacobi, Adscensionis, St. Hclena it Fayal reportatae. (1787.) 4.64 p. B. -7$.

Seorsim adfuit in Billl. B. e Comment. soc. Goctt. vol. 1x. p. 1:?

$3286^{*}$ — Ilerbarium australe, seu catalogus plantarum exsiccatarum quas iı Florulac insularum australium prodromo in commenatione de plantis esculentis insularum uceanj australis, in fasciculo plantarum magellanicarum descripsit et delineavit; nec non earum quas ex insulis Madeira, St. Jacolvi, Adscensionis, St. llelenae et Fayal reportavit. Goetlingae 1797. $8.24 \mathrm{p}$.

3287 Forster, Joham. Reinhold. Florae Americae septentrionalis or it catalogue of the plants of North-America. London 1771. \$. 51 p. printerl with his translation of the Travels of Bossu, ib. 1771.8 . vol. 11. p. $17-67$. B.

3288 Liber singularis de Bysso antiquorum. Londinı 1776.8 133 \%, в.

$3289^{*}$ — et Georg Forster. Characteres generum plantarum quas in itinere ad insulas maris australis collegerunt descripserunt delinearunt annis $1772-1775$. Londini 1776. 4. x. vul, $150 \mathrm{p}$. 75 tab. (9 th.) - Ejusdom editionis impressio in folio: Londini 1776. folio. $76 \mathrm{p} .75 \mathrm{tals}$ p. 3is.)

De huc opero Sprengelï sententia legitur in Gesch. der Bot. II. * germanice: Beschreibungen der Gatmngen vou Pflanzen. aul einer Reise nach den luseln der sudsee acsimmelt, beschrioben und abaczeichned, Wurend den Jahren $172-1773$. Ans dem Latciuschen

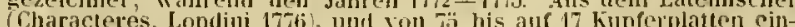
geschriukt durch Johan Siman kerner. Stuttwart $1779.9 .1601 \%$ uraes ind. 18 tab. $\left(1 \frac{2 / 3}{2}\right)$,

$3290^{*}$

Olsservations made during a vayage round the world on physical geograplyy, natural ljistory and ethic philosophy. London 1778. 4. $649 \mathrm{\rho}$.

gallice: Ulsnrvations faites pendant le second royayc de MI. Cook dans l'hemisphero austral el autour du monde sur la seosraphice, 
Ihstoire naturelle el lat philosophie morale. (Tome $\mathrm{V}$. all voyace do Couk. l'aris 1778. 4. 5ilo 11. B.

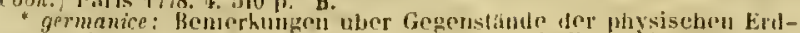

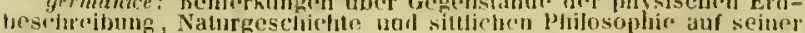

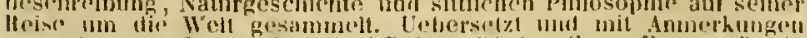

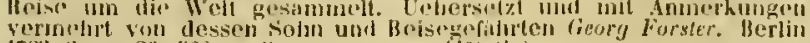
1783. 8. v1, 20, 560 p., it malp. geogr. $(1 \% / 4$. $)$

$1291^{*}$ Forster, Johann Reinholrl. Enchiridion historiac aaturali inser-

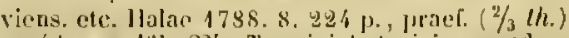

(A paz $\mid(6)-22 \%$ : Tormini botanici secundum methodum Linnaei ex varis ejus operihus congesti.

329? (Forster, Thomas Farleigh s. Fuly.) Aillitions to II arner's Plantae Woodfordienses. s. I. 1784. 8. p. $243-255$. B.

3293 - list of the rare plants found in the neighbourlood of Tunbridge Wells. Lontion 180 1. 12. DC.

it29h Hora Tonbrigensis or a calalogue of plants growing will in the neighbourhood of Tonbridge Wells, arranged according to the Linneau system, from Sir James Edward Smith's Flora britannica. London 4816. S. vit, 216 p., 3 tah. col. $(8 s .6 \mathrm{~d}$.) Bibl. Leod. Fortasse eritio nova libri praceedentis.)

$3298 \%$ Forsyth, J. S. The first lines of botany, or primer to the Limnacan system. ele. London 1827, 12. 18, 184 p., 3 tab. col.

1296 Forsyth, William. Obsesvations on tho diseuses, defects and injuries in all kinds of fruit and forest trees, with an account of a particular method of cure. London 1791.8. 71 j. B.

germanice: Veber die Krankheiterly unt schaden der Ohst- und Forstbinne; whersetzt von Geory Forster. Main\% 1792. 8. (1/f $(h)$ Mit Anmerkingen won J. C. Christ. Frankluth a/M. 1801. 8. (1/s th.)

t gellice. Ohoervations sur los miladies les hlessures et les autres inperfiections des arbres fruilier's ef forestier's de toute espece. Paris 1791. $8.84 \mathrm{p}$

gallice: Observations relatives aux maladies, defauts el acridens te toute espece d'arbres fruitiers; tratuites pitr de Borch. Dorpat 1792. 8.

$3297+$ A treatise on the eulture and management of fiut-trees. etc. Lomilon $1802.4,374$ J., 13 tah.

gallice: Traité de la culture des arbres fruitiers, fraduit de l'anglais par J. P. l'ictel-Mallet. Paris 1803. 8. xxx, 38't 1., 13 Lab. - +Ed. II: il). 1803. 8. Hon differt

germanice: Untser dic Kulfur Ind Behandlung der Obsthiume; ubersetze von Adolf Meinecke. Berlin 180'. 8. (2 th.)

1298 Forsyth, William, filius. A botanical nomenelator, containing a systematical arrangement of the classes, orders, genera and species of plants, as tescribed in the new edition of Limnacus Systema odturae by Dr. Gmelin. London 1794. S. 550 coll. $\boldsymbol{B}$.

$3299^{*}$ Fortemps, Joseph Karl von. Vita plantarum illustrata. Vindolsonac $1780.8 .44 \mathrm{p}$.

3300 Fossa, C. Catalogus plantarum horti botaniei Regiensis. Regii 1811. 8. Cat. Bibl. Radcl. Oxon.

3301 (Fothergill, John.) Some account of the late Peter Collinson. London 1770.4 .18 p. B.

$3302+$ Fournel et Haro. Talbleau des champignons observes dans les enviroos de Netz, préećdé de quelques considérations sur leur nature, leur emploi domestifjue, les aceitlens qüils produisent dans certains cas et les moyens de les prévenir ou d'y remédier etc. Prenier mémoire. Metz $4838.8 .47 \mathrm{p}$. (1 fr. $50 \mathrm{c.}$ )

"Cietle brochure est la meme, que celle publiéc sous le méme titre par M. Haro seut.m) Leveillé.

3303 Fowler, Thomas. Melieal rapports on the effects of Tubacco (Nicotiana Talateum L.) London 1785. S. 84 p. M.

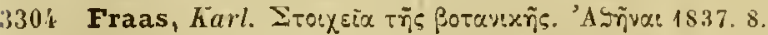

$3303^{*}$ - Synopsis jlantarum florac elassicae oder Vebersichtliche Darstellung der in ten klassischen Sehriften der Grieehen und Romer vorkommenden Pflaızea, nach autnptischer Untersuchung im Florengebicte eutworfen uorl nach Synonymen geordnet. Munchen $1845.8 . x \times x x, 320$ ). $\left(1 \frac{1}{s}(h)\right.$.

3306 Fragoso, Juan. Catalogus singliciun medicanentorum, quae in usitatis hujus temproris compasitionilus aliorum penuria invicem supponuntur, antihalIomena (iraecis dlicuntur et nostrae actatis medicis Quid pro quo. Compluti 1566.8. 126 foll. B.

3307 Discursos de las cosas aromaticas, arboles y frutales y ale otras muchns mediciuns simples, yue se traen de la India oriental y sirven al uso de medicina. Madrid, Francisco Sanchez. 1572. 8. 211 Toll. B.

- latine: Aromatum, fructuum el simplicium aliquor medicamentorum ex India utractue ef orientali el occidentali, in Europam delatorun, quorunt jam est usus plurimus, historia brevis, utilis et ju- cunda. Conseriplat primuro hispanice a Joanne Fragenn, Mulippi 11

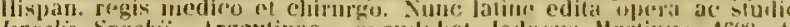

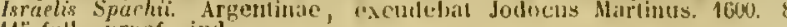
13 foll., praef., ind

$$
\text { (Batiksiamin "t Goettingense exemplar sunt auni 1603.) }
$$

3308 Francis, George W. A catalogue of british howering plants and ferns (ineluded in Dr. Jooker lsritish Flora, EAl. III.) 10 Tacilitate butanical correspondence and reference, as an index to herbariuns.

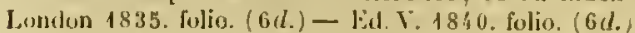

$3309 \div-$ An andysis of the britislt ferus and their allies. Wiil copper-plate engravings of every species and variety. London 1837 8. III, 68 p., incl., 7 tul. (4s.) - Eil. II : Lonton 1843. 8. (5s.)

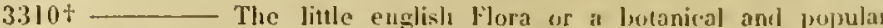
account of all our common field tlowers with engravings on stent o

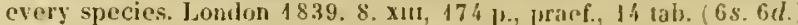

$3311+$ The grammar of botany; will engravings. Ionden 1841) 8. (4) $160 p$

$3312+$ Francis, John II. A diseourse: delivered upots the upening of the new laall of the New lork Lyerum of natural history. New York, typ. Ludwig. 1841.8.93 j.

3313 Francius, Petrus. In lauclem Thiae sinensis anacreontica lluo gracce. Anstelodani 1685.4. 1 plag. B.

331: (Francoeur, Louis Benjamin.) Flore Parisienne ou dencription de earactires de tontes les plantes qui eroissent naturellement aux environs de Paris, distribuées snivant la métlude du jardin de plantes de celte ville par L. B. $F^{* * *}$. Paris an $\mathrm{IX}$. (1801.) 1Z. I 296 l.

$3318+$ François de Neufchateau, Nicolas Li, Comle de. Lettre sur le rolyinicr, connu sous le nom injpropre do faux Acacia, avec plusicurs pieces relatives a la culture ot aux usayes de cet arlore. Paris 1803 12. 314 j), 1 tab. $\{2$ fr. $50 \mathrm{c}$.

$3346+$ Franeau, Jean. Jardin d'hyver ou calinet des fleurs, contenau en XXVl clegies les plus rares ot signalez fleurons de plus lleurissans parterres. Illustré d'execlleotes fignures representantes au naturel les plus belles lleurs des jardins domestiques. A bovay, de l'imprimerie de Pierre Borremaus. 1616. 4. (14) 198, $22 \mathrm{p}$. el tab artı, Bibl. Leod.

$3317^{*}$ Frank, Joseph C. Rastatts Flora. Heidelberg 1830. 8. xxxu $171 \mathrm{p} .(3 / 4$ th. $)$

3318t Frank, Louis. Collection d'opuscules de medecine pratique, ayec un mémoire sur le commeree des nègres au Kaire. Paris 1812. 8 VIII, 238 [?.

Inest: Sur l'efficacite de la senenen de Chichm dans l'ophtalmic (Cassia absus l. ) n. 3\$- 49. Sur Prefticacite du fruit de Baobab (Adan-

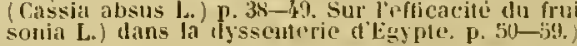

$3319^{*}$ Franke, Geory, latine Francus de Franckenau. Lexicon vegetabilium usualinm, in guo plantarum, quarum usus usipue inootuit nomen cun synonymis latinis, graecis, germanicis et interdun arabicis, temperanentum, rires et usus ganeralis et specialis atque praeparata ex optimis quibusque autoribus lireviter proponuntur. Argentorati, typ. Josiac Staedel. 1679. 12. 142 p., praef. Bibl. Vindob. - Ed. Il: Flora Francica, li. e. Lexicon plantarum hactenus usualium etc. ib. 1685. 12. 165 p., praef. - Ed. IIl: Lipsiae 1698. 12 299 p., prace. el varia programmata $(90$ p.) mox recrusencla. - "Eul. novissina (posthuma) eura Georgii Friderici Frunci, filii autoris annexis geogr. phil. bot. eun indice autorum el rerum. Argentorati typ. Staedel. 1705. 12. 240 p., praef., int. el Programnata: 122 I nell der vornehmsten kraule untersehiedliche Namen, Temperanen der vornehmsten krauter untersethiediche Namen, menta, Krifte, Nutzen, Wirhtingen und Praparati grundlich beschritben werten. Formals vou flerru Geory Franken von Frankenuu hiteinisch ediret und nun ins lientsche uberselzet yod um zwei Theile vermeliret von Christophllellwig. Leilzig, Marlini. 1713. 8. A0h p.. prael

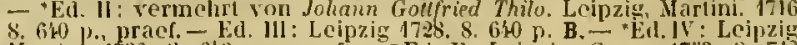
Martin. 136. 8. 610 p. praef. - Ed, $V$ : Leipzig, Gross. 1733. 8. 72 $136 \mathrm{pe}$, praef. - "Ed. VI: Zullichau, Frommann. 176t. 8. $(\% / \mathrm{th}$ ) (non (iitie'?it.) bergac 1674.4. H.

Selianella. D. respondente J. II. Soldan. Heidel- Programmata hotanica Florae Genioque naturae sacra ad herbationes amorum $1677 \mathrm{et} 1678$. Heidelbergae 1677.1678.4

3322 Programma ad berbationes anni 1679. Floralia terrac Palatinae. Heidelbergae $1679 \quad 4 \quad 12 p$. 
3323 Franke, Geory, latine Francus de Franckenau. Programma all herhationes anni 1680 : ad agri lleidelbergis, (po vix praestantior alter, viridaria etc. herbariae rei acstimatores el cultores amicissime invitat. Heidelbergae 1650.4. 23 p. B. - "El. II: De Palingenesia, sive resuscitatione artificiali plantarum, hominum et animalium e suis cineribus liber singularis, commentario illustratus a Jocnne Christiano Nehring. Halae 1717. 4, 40, 48, 296 ]).

332:- Programma ad herhationes anni 1681: Chloris Palatina. lleidelbergae 1681. 4. \& p. B.

3325 Programma ad herbaliones anni 1683: 'Avระopópta Palatina. Ileidelbergac 1683.4.

3326 Programma ad herbationes ammi 1687: Ad Ambarvalia lleidelbergensia; hoe est, ad herbas ac plantas versicolores vculis animisque perlustrandas, et in multiferis montibus atque campis herbosis circa lleidelhergam nohilem, antequam permaturuere adinveniendas subinvitat. Heidelhergae 1687.4.24 \%. B.

(Redenut hace programmata in Flora Francica, 168\%. [). 1-90. 1698. ए. 3-81. 1703. p. 3-122.)

3327 jr. De Malo citrou. D. Ileidelbergae 1686.4 .54 p. B.

$3328^{*}$ Cintalogus variorum tractatıum, programmatun el disputationum. Dresdie 1692. 4. $24 \mathrm{p}$.

3329 Franke, Joham, latine Francus. Ilortus Lusatiae, das ist: Iateinische, deutscho und etzliche wendische nahmen derer gewechse, welehe in Ober- und Nider-Lansitz, entweder in gerten werden gezeuget oder sonsten in wälden, autf den bergen, echern, wiesen und in wassern von sich selber wachsen. Budissinae, apul Michael Wolrab. 1594. 4. 12 plagg. B.

Libellus perrarus apmi exteros et ubique in pattria, Berolini, Vindobonate, Goettingao, Lipsiae, Dresdae el in ipsa forlicensinn bibliotheca frustra quaesitus, a neminc hiblingraphonum germanicorum visus, nunc cum Bibliothmea Ranksiana in Mlusen britannico esslat. Ilaller aliam anni 1619 editionem affert, absulue vila puto ratimne; apul eundem legitur, autorem fuisse inter casparis bauhin imicos. $)$

$3330^{*}$ Franke, Johann, Iatine Franckenius. Signatur, das is1, Grundiliche und Walurhaftige Beschreibung der von forlt und der Natur gebildeten unnd gezeichucten gewichsen, als kreutern, wurtzcln, blettern, blumen, samen, fruchien, sállen, boumen, frestáuden, gunmaton, harlzien, steinen, edelgesteinen und specialerien, sam], ihren tugenden, krifften und wirekungen, in \%weien Theilen unterschiedlichen abgetheilel, dabey auch kurizlich am Eiste von einer Wunderbaren, Mechtigen und lireftigen Wurtzel, so iller andren Wirtzel ein Brunquelle, dass Lebendt, Matrix und Quintum esse ist, gehamtelt wird. etc. elc. Rostock 1618. (1619. B.) 4. 36 (6) foll.

3331 De praeclaris herbae Nicotianae virtutibus. D. Upsaliae $1633.4 . \quad$ h. mom herbarum, arborum, fruticum el sulfruticum nomenclaturac sive applellationes tam in suecica quam latina lingua ad Iustranilum proponumbr: in gratian studiosorum medicinte aliorumque philoholanicurum concimatum, antoris upera ef impensis pullici juris factum. Ljesaliae, excurle) at Aescillns Matthiae. 1638. 4. (25 full.) B. w. - Speculurn botanicum rennvatum, demo revisum, pluribus plantarum speciebus auctun. Upsiliae, escudebat Johan Piuli. 1654. 4. (20 fill.) B. W.

(Antor, Paracelsicus homo. tota signaturae insimia captus, fuit anatomiac a honates in Acadernia Upsaliensi professor, natus

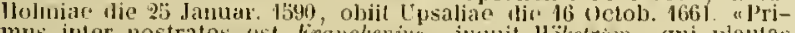
mus inter nostrates est franckenins, inmuit lïlistrom, qui plantas sueciae indigenas adnotavit el lune alphabetice urdine "numeravit intronistis cero exolicis., )

3:333* Franke, Johann, latine Francus, Uluensis. Polycresta herba Veronica ad botanices philosophicae juxta el medicae cynosuram claburata. Ulmae, typ. Gassenmayer. 1690. 12. 272 p., ind.

$333 i^{*}$ - Veronica theezans i. e. collatio Veronicae europacac cum Thee chinitico. Accedit mantissae loco conjectura de Alysso Dioscoridis. Ed. II. auctior el correctior. Lipsiae el Cohurgi, apur I'fotenhauer. 1700.12 .158 p., pracf, ind., 3 tab. - Ed. I: Suabaci 1693. 12. S. - "Lipsiac. typ.Jlagen. s. a. 12.172 p., praef., ind., 3 tab. tyallice: Le The de reurope ou les proprietez de la Veronique Traduction. Paris, Bondot. 1707. 12. 5i. 1., 2 (ally.

$3333^{*}$ - Trifolium fibrini listoria selectis observationilus et perspicuis exemplis illustrata. Francofurti, apud lironiger. 1701. $8.64 \mathrm{p}$ 3336 Lerba Alleluja botanice consilerata. ex veterum el recentiorum decretis, imprimis propria praxi in nujera 1703 el 1704

Prutze.t. Tlies. lit. Jyot. febre epidemica Ulinae observali. Ulmae, lyp. Gassenmager 1709. 12. 390 p., int., I tab. - De vera herba antiquorum Acetosella (.lleluja) ojusilemgue virtute conlra febres malignas, pelechiales et pestem insam áxpó\%u\% listorico-medicum. Angustae Vindelicosun, apul freiger. 1717.12. $390 \mathrm{p}$, ind., A tais

(Est eadem editio novo titilo ef plagula prima denuo inpressa.)

3337 * Franke, Johann, Iatine Francus, Ilmensis. Spicilegium de Euphragia lierba, medicina polycrestra, verumque oculorum solamen. etc. Francofurti et Lipsiae, Sclumacher. 1717. 8. so p., prace.

3338 — Das verschmachle und wicler erholute Flachsseilenhraut oder Berich von dem heylsamen uncl vielen mensclien verborgenen nuzen dieses gewachses. IIm 1718. 8. 32 p. в.

$3339^{*}$ Thapmith Jeruschalmi sen Momordicat descriptio medico-chirurgicu-pharmaceutica etc. Aceessit schelliasma de Scordio vero Johannis Jacobi Kleinknecht. Ulmae, Bartholomaei. 1720.8.761. pracf., 1 talb.

$3340^{*}$ Tractatus singularis de Urtica urente, te qua Gracei at Latini pauea, pancissima Arabes conscripserunt. ele. Dilingae, typ. Schwertlen. 1723. 8. 175 j). Bibl. Reg. Dresd.

3341 Arumbliche untorsuchung der unvergleichlichen Sonnenblume oder sonenannten ILeliotropii magni von Peru. Ulm 1725. \&. 34 p. B.

3342 Franke, $P$. Luterricht zur Erzeugung der Blumen im Wint" Leipzig 1781. \&. $(1 / 2 / h$.)

33\%3* Franz, Johamn Geory Friedrich. De Asparago ex scriptis medi corum vetcrum. J). Lipsiae 1778. 4. 42 p.

334*" Franzoja, Giovanni. Disceptitio academica de analysi Smilacin Clinae et Arundinis 1)onacis. 1). Patavii 1895. 8. 26 p.

$33 \mathrm{rs}^{*}$ Fraser, John. A shot history of the $A$ grostis Cornucopiae or the new american grass, and a botanical deseription of the plant etc. Lonton t789. folio. 8 1., 1 tab. col. (3s. 6 d.)

$3346-$ Thalia? dealbata, discovered growing in a lake of Nortl.America, in the year 1790. I tab. aen. col a J. Sowerby delineata. edita 1 Aug. 179'.

$3347+$ Fray, J. B. Nouvelles experiences extraites d'uu manuscrit qui a pour litre: Essii sur l'origine des substances organisees el inorganistes. Berlin, impr. Quien. 1807. 8. xv111, $112 \mathrm{p}$.

3348 Freeman, Miss Charlotte, and Miss Juliana Sabina Strictland-.) Select specimens of British plants. 1: London 1797. folio. 4 foll., 5 tab. col. B. - II: London 1809. folio. Sch.

$3349^{*}$ Frege, Christian August. Anleitung zur Kenutuiss der schallichen und gifligen l'flanzen fur Stadt- und Landschulen. Kopenhagen und Leipzig 1796.8 . xxu, $156 \mathrm{p}$., ind. $(3 / 8 \mathrm{th}$.)

$3360^{*}$ Versuch ainer kilassification der Weinsorten nach ihren Beeren. Meissen 1804. 8. xul, 171 p. $(5 / 12$ th.

$3351^{*}$ _ Versuch einus allgemeinen botanischen Ilandworlerluchs, lateinisch-deutsch nnul deutsch-lateinisch. Zeitz 1808. \& xvili, 382,160 l., 4 lab. cul.

$3352^{*}$ Gartenlhra. Beschreibung ter Gartengewachse und Blumen. Zeitz 18148 . xvil1, 560,838 p. $(3 \% / \mathrm{h}$. $)$

3333 Freige, Johmmes Thomas, latine Freigius. Quaestiomm melicarum libri XXXV1. Basileae, apul Ilenriem Petrum. 1558. \&. Bum.

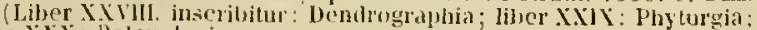
liber XXX: Bolanologia.

3354 Freitag, Johannes. De Opii natura et merlicamentis opiatis liber singularis. Groningae 1632. 8 . $\mathrm{s}$.

3353 Frémont, L. C. I Note sur l'Arrachide. Poiton 1806.8.

3356 t - Nute sur l'Orobanche de Dioscorisle, contenant sa descriplion, ses proprictes, les avantages, yu'on peut retirer de sa culture, la freure, que cette plaute n'est joint parasile, des conjectures sur lOrnhanche de Theophraste. etc. Cherbourg et Paris $1807.8 .32 \mathrm{p}$.

$5357^{*}$ Frentrop, Emanuel. De nuce vomica. D. Berolini $4832.8 .32 \mathrm{p}$.

$3358^{*}$ Frenzel, Franz Justus. Pliysiologische Beobachtungen uber den Umlauf des Safts in dey Pflanzen und Bammen und der Eiststeliung der Eirlschwamme. Preisschrift. Aus dem Lateinischen. Weinar $1804.8 .438 \mathrm{p} .(12 / 3$ th. 
:3,i:) Frenzel, Johann Samuel Traugotl. Verzeichniss wildwaclismuler

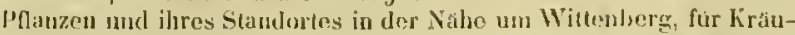
tersammler. Wiltuberg. 1yp Tzschiedrich. 1799.8. 32 p. - Wittenherg, kuhur. 1802.8.(1/sth.)

33130 - Yerzeicluiss willwachsender, angebauter und untorhaltener IIolzarten in der Gegent wol Wittenberg. Wittenberg, iyp. Tzschientrich. 1501.8 .64 3.

33(i) Frenzel, Simon Friedrich, pr. Suavissimum Fragariae fructum, fraga onimo delilsanda proponit Caspar Sehoen. 1). Wittebergae 1662 4. 2 plaer. B.

331;2* Fresenius, Johamn Baptist Georg 11 olfgang. Syllabus ohservalionum de Mentluis, Pulegio et Preslia. Francofurti a/M., typ. Wonnep. 1829. $8.23 \mathrm{H}(1 / \mathrm{s}$ (h.)

Esemplaria: Prancofurti, apud Cioilhauman. 1830. 8. praeter tituhmm non dilfirrunt.

$3.363^{4}$ - Taschenbuch zum Gehrauche auf botanischen Exeursionen in der l'mgrend von Frankfurt a/Al. eutbaltend eipe Auf-

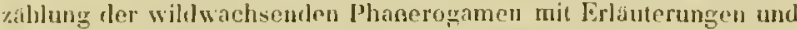
hitisclicn l3emerkungen in Anlange. Zwei Abtheilungen. Frankliurt.a/AL. $1531-1832$. S. vi, 621 li. $\left(1^{3} /\right.$ th. $)$

(Liemplaria cum annis 1832 et I\$33 non ditlerunt.)

336ik" - Grumbriss der Bolanik zum Gobrauclıe bei seinen Vorlesungen. Franhfurt a/M. 1840.8 .78 p. $(3 / 87 h$.$) - Z$ weite verbeswerte und vermehrte Aunage. Frankfurt a/ MI. 1843. 8. IV 90 p. $(1 / 2$ th.

3.36.3t FresneI, . Iuyuste Jean. Rapport sur le mieroscope achromatique ve M. Selligur. Paris 1824 . 8. 23 p. . 1 tah.

Extrait ilos Amm, des sc. nat. Nor. 1824.)

$3366^{*}$ Freudenstein, Georg. Do Cannabis sativae usu ac viribus nar('oticis. 1). Marburgi Cattorum 18 \$1 $8.35 \mathrm{p}$.

$3369^{*}$ Freund, Jeinrich Daniel. Die Cultur der Gartennelke. Nach eignen vieljahrigen Erfalırungen. Quedlinburg und Leipzig 1840. 8. 34 p., 1 lab. col. $(5 / \%$ th.

$3368+$ Freycinet, Casimir. Catalogue raisonné des arbres, arbrisseaux et sous-arbrisscaux, cultivés en plein air dans sa pépinière a Luriol Dép. de la Drome. Valence s. a. S. 134 p.

3369 Freycinet, Louis de, vide Gaudichaud.

3370* Freyer, Johamu Gotlried. De Lythro Salicaria L. D. Goetlingae 1802. 8. 70 p., 1 tab. col.

$3371 \div$ Freylin, L. de. Catalogue des plantes cultivées dans le jardin de Buttiglièra (Harengo). Turin 1810,8.32 p. Supplément: Asti Is 12 8. 7 p. Bibl. Webb.

$3: 12^{*}$ Frezier, Amadé Francois. Relation du royage de la mer du sud aux cotes du Chily et du Pereu, fait pendant les anneses 17121714. Paris 1716.4.- ib. 1732.4.297 D., 37 tab. B. anglice: London IiT i. B. germanice: Hamburg 17 i. 8 . 8 .

$3373^{*}$ Friderici, Johann Arnold, Jr. Guajacan. D. Jenae 1665. 4. ( 16 foll.)

337 - De Tabaco. D. Jenae 1667.4. S.

$3370^{*}$ De Aloe. D. Jenae 1670.4. ( 14 foll.)

$3376^{*}$ De Paeonia. D. Jenae 1670.4. ( 14 foll.)

$3377^{*}$ Friebe, Ilithelm Christian. Oehonomisch-technisehe Flora für Lielland, Esthland umi hurland. Riga 1805 . 8. xxvin, 392 p. $\left(1 \frac{2}{3}\right.$ th.

3378 Friedrich, J. P. Der Kijchengarten. Sehwerin $1802.8 .\left(5 / 2_{2}\right.$ (h.)

337." Friedrichsthal, E. R. Reise in den sudlichen Theilen von Neugriechenland. Nit einem botanischen Auhange (p, 261-311.) von Vincenza Cesati und Eduard Fenzt. Leipzig 1838. 8. vis, 311 p. $\left(1 \frac{1}{2}\right.$ th.

$3380 *$ Fries, Elias Maguus. Novitiae Florae suecieae. Lundae $1814-$ 1823. 4. 192 p. - * El. altera auctior et in formam commentarii in II aldenbergii Floram suecicam redacta. Londini frothorum 1\$28. 8 . xul, $306 \mathrm{p} .(11 / 2$ th.) - "Contimuatio, sistens mantissam I, II, Ill uno volumine cumpreliensas. Accedunt de stirpibus in Torvegia reeentius fleteclis praenntationes e maxima parte communicatae a Math. N. Blytl. Lundae et Upsaliae 1832-1842. 8. 84, 64, x, 204 p.

sursin prodierunt: Mantissa l. Aecenlit enmmontatio de salicjbus. Lundac 1832. 8. 8\% p. $(2 / 3$ th. - Mantissa II. Additis plantis in Norregia recentius detectis. Upsaliac 1839. s. tip p. - Mantissi lli.

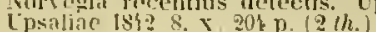

3381" Fries, Elias Ifagnus. Observationes myeologicae, praecipue aul illustrondin Floram suecicam. Ilarniae 1815-1818. Il soll. 8. -

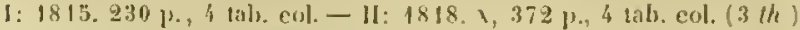
- Eil. nova. Histriae 1824. 8. 368 p., \& tal). eol. ( $3 \frac{1}{2}$ th.)

$8 \mathrm{p}$ Lichenum Jianome nova. I) Lundae $\{817,4,10 \mathrm{p}$ Specinen systematis mycologici. U. Lundae 1817. thoete nascentium, additis lucis natalihus ef uhservalionilus selectis, Pars prior, Monanlrid-Dioecia, Lundae 1817 et 1818 8. 159 1). ( $11 / 12$ th.

Padita est liac pagina tituliri recusa, omissis decem paginis tituarilus acadinicis.)

$3383^{*}$ - symbolac Gasteromycorum at illustrandan Floram succicarn. D. I-III. Lundae 1817-1818. 4. $25 \mathrm{p}$

3386 * - On Itrand och liost pầ wäster, jemte follstánlig uncerrattelse om deras honnetechen. orsaker, skada sant medel till diess forekommande. Lund $1821,8.54 \mathrm{p}$.

3387 Beskrifuing på nya Lafalagten. Stoekholn is 22.8 .46 \} (Crr kongl. Wet. Aead. Handl. IS21. st. II.)

$3388^{*}$ — - Systema mycologicum sistens fungorum ordines, generat et species lucusque cognitas, quas ad normam mothorli niluralis detorminavit, disposuit atque descripsit. Gryphiswaldiae, $1821-$ 1829. III voll. 8. - I: 182 I. LVII, 520 3. $-11: 1823.620$ p. - III: 1829. vin, 524 p. index: 202 p. $\left(9 \frac{1}{\mathrm{t}}\right.$ th. $)$ - + Supplementum voluminis prini ib. $1830.8 .154 \mathrm{p}$.

$3389^{*}$ - Schedulae eriticar de Lichenibus exsiccatis Succiae I-XIV. J.ondini Gothorum (Lincopian et Norcopiae) 18z4- IS33. 4. $24,14,4,34,22,22,17 \mathrm{p}$.

(Non absque tacdio has selicdalas tandem in variis bibliothecis

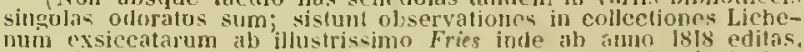
mum exsiccatarum ab illustrissimo Fries inde ah stmo 1818 editas, quas in enumeratione herhariorum, Tenalium aceuratius inlicabe, recensere jemper

Selsedulae eriticae I- W. Species 1-120. Lundini Gothorum 192\%. $2 k$ in

Schedulae criticae V-11. (speeies 121-180.) curavit Christian Stenhammar. Lincopiac 1825 . It p.

Schedulae eritiene Vil. speejes 181-210.) curavit Gustaf Phristian Ljungstedt. Lundae 1826. \& $p$.

Novile scliedulae crilicac (VIII-NIL) (species 211-360.) Lundae 1826 1827. $3 k^{2}, 22 \mathrm{p}$.

Friticae XIII. (species 361 - 390.) Norcopiae 1833.

22 p. Slenhammar?') Xorcopiae $1833.17 \mathrm{p}$.

- Systema urbis regetahilis. Primas lineas novae constructionis periclitatur Elias Fries. Pars I. Plantae homonemeae. Lundae 1825.8 . vil, 374 p. (2 th.)

(Adest etjam pasina titularis specialis: Plantae homonemene. Revisit et disposuit Elias fries.

$3391^{*}$ - Stirpium agri Femsoniensis inder, observationibus illustrata. Lundae 1825- $1826 . \$$. $100 \mathrm{p}$.

Operi completo septem dissertationibus academicis edito hic novus datus est litulus.

$3392^{*}$ - Elenchus fungorum, sistens commentarium in systema mycologicum. Gryphiae 1828. II voll. 8. - I:238 p. - II: vI, $154 \mathrm{p}$ ( 2 th. $)$

$3393^{*}$ - Synopsis Agaricorum europacorum. D. I. Lundae 1830 8. $16 \mathrm{p}$

339: - Primitiae geegraphiae Lichenum. D. Londini Gothorum $1831.8 .18 \mathrm{p}$

$3395^{*}$ — - Lichenographia europaea reformata. Praemittuntur Lichenologiac fundamenta. Compendium in theoreticum et practicum Lichenum studium. Lundae et Gryphiae 1831 . 8. Cxs, $486 \mathrm{p} .\left(3 \frac{1}{3} / \mathrm{h}\right.$. $)$

$3396^{*}$ — Mappa botanica $\mathrm{ex}$ affinitate et analogia, sive clavis artificialis in familias plantarum phanerogamarum indigenas e partibus foris conspicuis. (Manuscr. cum autoris amicis communicatum.) Upsola, Polmblad. 1835 . folio. 2 [3.

Eliam in Flora seanica mutito titulo impressil est: aClinis in familias plantarum indixenas sceundum iffuititem et anilogiam."

$3397^{*}$ - Boleli, lungorum generis, illustratio. D. Ipsaliae $1 \$ 33$ 8. $14,2 \mathrm{p}$

$3398^{*}$ - Flora scanica. Ipsaliae IS35. S. xxIY, $394 \mathrm{p}$.

(0)pus c dissortationilus acalemieis seorsim editis compositum. sistit volumen primum seriei nondmu quantum srin (ontinuatae. quae inseripta est: "Corpus Florarum protincialium Suecitie.n) 
3399" Fries, Elias Magnus. Botaniskit-Antiguarishe Lixcursiouer af livilka der: forsta of er Greliernes Nympheaceer. 1). I-111. (psala 1836. 4. 28 p. - Om Sádeslagens Stamland. D. Upsala 1836. 4. p. 29-36.

$3400 *$ — Nuteckningar ofver de in Sverige véxande atliga Svampar. D. I-Vifl. Upsala 1836.4.68 p.

$3401^{*}$ Genera Hyncuonycetum; nova expositio. D. Upsaliae 1836.8. 17 p.

$3: 422^{*}$ - Synopsis generis Lentinorum. D. Ipsaliae 4836. 8. 15 p. $3403^{*}$ Epicrisis systematis mycologici, seu Synopsis Ilymenomycotum. Upsaliac et Lundae $1836-1838.8$. xil, $610 \mathrm{p} .\left(4 \frac{1}{2} \mathrm{th}.\right)$

34.0 " - Fungi guineenses Adami Afzelii ad schedulas el specimina inventoris descripti. D. I. Upsaliae $\$ \$ 37.4 .8$ p.

$303^{*}-$ Spicilegium plantarum neglectarum. Decas I. Agaricos hyperrhodios sistens. D. Upsalize 1837.4.8 p.

$3406^{*}$ Oofver Váxternes Namn. D. I-IV. Upsala 1842. 8. $64 \mathrm{p}$ (Redit in autoris: Botanisha Uttlygter. Upsalat 1st3. 8. p. 113-178 et germantice a Beilschmied translatum in Mornschuch Archiv shandinavisclier Beitrage 1. p. 41--98.)

3407 terär Stridsfrảga. D. I-III. Upsala $4842.8 .40 \mathrm{p}$

germanice: Sind die Naturwissenschaften ein Rillungsmiltel? Einc literarische Sitreitfrage, der offentlichen Beurtheilung vorcetegt. Aus dem sehwedischen von Prof. Hornschuch. Dresden und Leipzig 18't. gr. 8 . 1111,13 p. $(1 / 3$ th. $)$

3408 - Varen. En botanisk betraktelse. D. I-III. I'psala 1842. 8. $48 \mathrm{p}$.

Redit in: Botaniska Ctflygter. Upsala 1813. 8. p. $211-2: 36$, et germanice a Beilschmied translatum in Uarnschuch Alclsiv skandin. Beitráge 1. p. $181-220$.

$3409^{\circ}$ Grunddragen af Aristotelis Vaxtlara. D. I-III. Ipsala 1842. $8.48 \mathrm{p}$.

(Redit in autoris: Botaniska Utnygter. Upsala 1843. 8. p. 43-82, et germanice a Creplin translatum in Hornschuch: Archiv skandinavischer Beitrage 1. p. $6-40$.)

3410 Botaniska Liflygter. Upsala 1843. 8. 328 p.

$3414^{*}$ Summa vegetabilium Scandinaviae, sive enumeratio systematica el critica plantarum qqum cotyledoncarum tum nemearum, inter mare occidentale et album, inter Eidoram et Nordkap liactenus lectarum indieata simul distributione geograplice. Sectio prior. Accedunt expositio systematis plantarum morphologici, comparatio vegelationis adjacentium regionum, definitiones specierum in Kochii Synopsi Florae germanicae et nemearum monograpliis haud obviarum et aliter expositarum. Holmiae et Lipsiae, Bomier. (1846.) 8. vill, 258 p. (1 1/2 th.) (Continuatur.)

3412 Fries, Lovenz. Synonyma und gerechte Pflegung der Wurter, so man in der Aryney allen Kräutern, Wurzeln, Blumen, Samen, Gesteinen, Saften und andern Dingen zuschreibu, in lateiniseher, hebraischer, arabischer, griechischer und mancherley tudschen Zunge zusammenbracht. Strassburg 1514. 4. Hebenstreit. - Neu corrigirt Strassburg 1535. 4. H.

latine: Synonyma materiae medieae sive de simplicium pharmacorum latinis, graecis, arabibus barbarisque vocalulis. Argentinac, apud Gruningerum. 1333 . folio. Merklin.

gallice: Les synonymes latins, hebreux et grees de differente neurs, plantes, pierres et mineraux de phrysius. 1574. H.

$3 \$ 13$ - Spiegel der Arzney, durch den Lutoren Laurentium Fries und II. Othonem Brunfels wiederun gebessert. Strasslonrg 1526. folio. - 1532. foliu. H.

3ht' Friese, J. R. Grundriss der Phytoguosie. Innspruck 1836. 8. xu 267 p. $(1 / h$.)

3415 Frignet, E. Essai sur l'histaire de la blastogenie foliaire ou de la production des bourgeons par les feuilles. Strasbourg 1846.

3416 Frisch, $J$. De Colchicacearum virtute mediea. D. Pragae 1835.8 . $39 \mathrm{p}$.

$3: 17^{*}$ Fritzsche, Karl Julius. Beiträge zur Kenntniss des Pollen. Erstes Heft. Berlin 1s32. 4. 48 1., 2 tab. eol. $(5 / 6 t h$.

$3418^{*}$ De plantarum polline. D. Berolini $1833.8 .40 \mathrm{p}$.

$3419^{*}$ Veber den Pollen. St. Petersburg 1837.4. 122 p., 13 tab. col. $\left(4 \frac{1}{2}\right.$ th .

(Memoires de rteademie imp. des sc. de Petersbourg, tome 111.)

3 1.20* Frölich, Joseph Aloys. De Gentiana libellus, sistens specierum cognitarum descriptiones cum observationibus. Erlangae, Walther. 1796. 8. 141 p., 11ab.

(Alius adest titulus: Erlangae. typ. Kunstmann. 1796. quo libelius dissertationis loco prodiit; eadem vero est impressio et nullo mudo
differt.)
$3121 \div$ Forst, Jolm. An oration, delivered before the medico-hotanical socicty of Londun at the commencement of its sixtl session. Lundon 1825. 4. $16 \mathrm{p}$

$3422+$ - Some accoum of the science of hotany, heing the suhstance of an illtroductory lecture to a course on hotany, deliverefi in the theatre of the royal institution of Great Britain. London 1827 4. 17 p.

3423 - Remarks on the mustard tree mentioned in the Nin Testament. London 4827,8 .

$342 \mathbf{k}^{*}$ An oration, delivered before the medico-botanical society of London at the commencement of its ninth session. London 1828. 4. 34 l?.

$3\left\{23^{*}\right.$ Fuchs, Karl. Andreas Caesalpinus, de cujus viri ingenio, lloctrina et virtute. D. Narburgi in Caltis 1798. 4. 25 p.

$3: 26^{*}$ Fuchs, Leonhard. Annotationes aliquot herbarum et simplicium a medicis hactenus non recte intellectorum. Impr. cum Brunfelsii llerbario vol. Il. editionis 1531. p. 129-155, editionis 1536. p. $247-271$.

3427* De historia stirpium commentarii insignes maximis inpensis ef vigiliis elaborati, arjectis earundem vivis plusquam (juingentis inaginihus, munquan antea ad naturac imitationem arteficiosius effictis et expressis. Basileae, in officina Isingriniana. 1542. folio. $896 \mathrm{p}$., praef. ( 512 ) ic xylogs. pulcherr. i. t.

$3428 \div \ldots$ We historia stirpium commentarii insignes, maximis impensis el vigiliis elalorati, Leonharto Fuchsio medico elarissimo allthore, multo quam antea castigatiores. Scholiis in singula frope capita longe utilissimis a viro quodam medicinae doctissimo adjectis et plantarum voces gallicas jassim exprimentihus, etc. Parisiis, apuil Mathurinum Dupuys. 1546 . 12. 304 foll. praecedit dedicatio of index; secpuitur vocum difficilium explicatio. - (Parisis 1547. 12. eadem cum priori impressio, diverso titulo. B.) — " Parisiis, apud Rogardum. $1546.12 .492 \mathrm{p}$., praef., ind.

$3429 \div-$ De historia stirpium commentarii insignes, Leonharto Fuchsia medicu autore. Accessit iis succincta vocun obscurarum in Joc oprere occurentium explicatio, una cum triplici indice, groecas. latinas et herbaris seu officinis usitatas nomenclaturas continente. Adjecimus praeterea indicem vulgarium seu gallicarum dictionum ıunçuam antehac excusum. Lugduni, apud Gulielnum Gazellum (excudebat Balthazar Arnonllet). 1347. 12. $957 \mathrm{p}$. et vocum dliffcilium explicatio: ( $16 \mathrm{p}$.) Praecedunt praefatio anni 1542 et inlices: ( 18 foll.) - " Lugduni, apud Artolletum. 4549. 8. 851 p., praef., ind. ic. $x y \log r$, i.t.

$3430^{*}$ De historia stirpium commentarii insignes. Adjectis earundem vivis et ad naturae imitationem arteficiose expressis imaginibus, Leonharda Fuchsio medico, hac nostra aetate clarissimo, auture. Accessil vocum subuscurarum explanatio et triplex index. Lugduni, apud Balthazar Armolletum. 1551. 8. 851 p., praef., ind., ic. xylogr. i.1

$3431 \div$ De listoria stirpium commentarii insignes, Leonharto Fuchsio medico autore. Aceessit iis succincta rocum ubscurarum in loc opere occurrentim explicatio, una cum quintuplici indice, graccas, latinas herbariis seu offeinis usitatas, gallicas et italicas nomenclaturas continente. Lugduni, apud Joann. Tornaesium et Gul. Gazcium. 1555. 12. 976 p. et $(15 \mathrm{p}$.) vocum difficilium explicatio Praecedunt praefatio anni 1542 ; et (20 foll.) ind., absque iconibus * germanice: New kireuterbuch, in welehem uit allein dic gantz histori, tas ist, namon, gestatt, statt und zeit der wachsung, hitur hraft und wirchung des meysten theyls der hrenter so in teutschen und andern lanten wachson, mit dem besten vleiss beschriben, sumder nuch aller derselben wurtzel, stengel, bletter, hlumen, samen frucht und in summa die gantze gestalt allso artlich und kulstlich atgehiltel und kontrafayt ist, das dessgleichen vormals nie gesehen noch an tag hummen. Dirch den hochgelerten Leanhart Fuchsen, des' arzney loctorn unt derselbigen zu Tubingeu Lesern. ete. fietrucht zu Basell, durch Michael Isingrin. 15\%3. tolio. Alphab. 2 et triertuiones 2 ; ic. magn. ligno inc. i. t. Bibl. Reg. Berol.

* beloice: Don nieuwen herbarius, dat is, dboeck van den eruvten, int welche hescreven is niet alfeen die gantse historie van te cruyden, maer oock gefigureert ende geconterfeyt. Basel, lsingrin. s. a folio. Alphab. 1. et trierniones 20, ic. minor. ligno inc. i. t. Bibl. Caes. Vindob.

* gallice: Commentaires tris excelleus de linystoire des plantes, conposez premierement en latin par Leonhart Fousch, medecin tres, composez premierement ent latin par Leonhart rousch, medecin tres renomme et depuis en françois par un homme sarant et bien expert
en ta nratiere. l'aris. Fazeau. 15\%. folio. 3ł' capita cum ic. xylogr. i. t., ind.

1. T. Indlice: L histoire des plantes mis en commentaires plar Leonort Fuschs medecin tres-renomme, et nourellement traduict de latiu en françois avec vraye observation de l'auteur en telle difigence que pourra tesmoigner ceste oeurre presente. Lion, choz f Rouille. $15.5 \%$ \%. 607 p., praef, ind., ic. xylogr. min. i. i. 


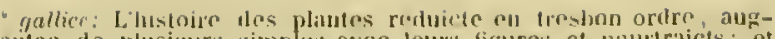

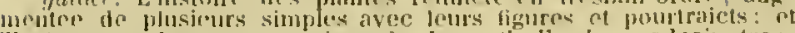
illualree par Jes conmonenaires de Leonarth Fusch, medecin ires-

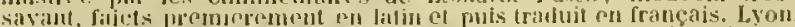

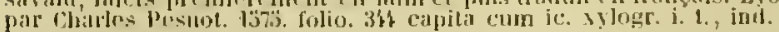

31.32 * Fuchs, Leanhard. Lábliche Albildung und Contrafaytung aller

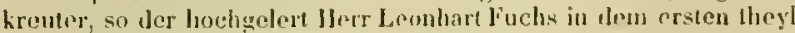
seins neuwen lireuterbuch lat beurillen, in ein kleinere Form auf das allerantlichest gr\%ogen, damit sie fuglich von allen mogen hin

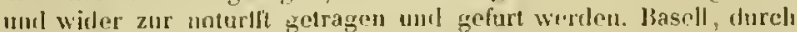
Miclus Isingrin. 1545 . 8. 516 tab., ind.

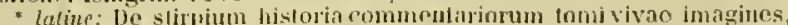

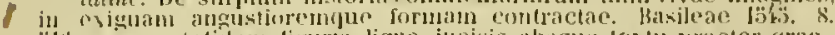

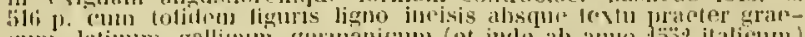

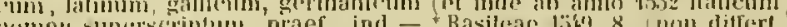

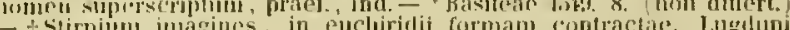

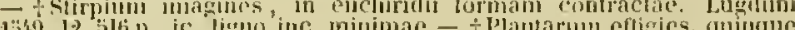

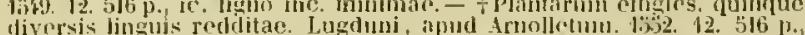

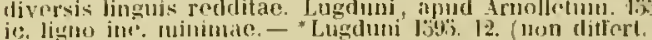

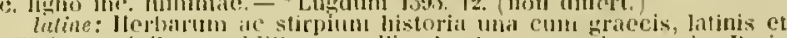
pallicis mominibus, additis nommullis, haclenus non improssis. Paris liit?. 819 p. B.

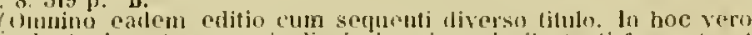

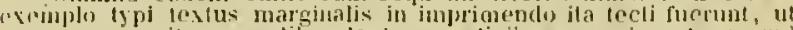
margo purus sil, manetitibus tantum restigits o prossinne typomum. gallice: Histoire des plantes avec lrs noms irre's, latins et franays, ingmentecs de plusiours porlraictz. avec ung estraict et leurs

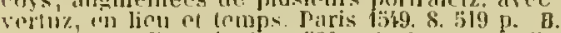

(Fifurar ligun incisite 520; nlurima proribus similes, non eaeJem: quaedan novac; fuaclam printum omissie.

trallice: Histoire generale thes plantes avee lino propriefe pas

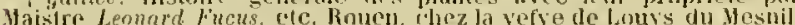

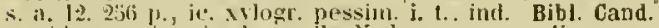

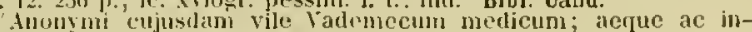
seculuels.)

t gallice: llistoire generale des plintes el herbes, aves leurs pruprimiz. Jar II. Leonurd Fucus. Avn. Ji Vortu du Pelim ou Nicotiane, vulgaimement appelleo herbe a la roy no. Plus un houveau preserva-

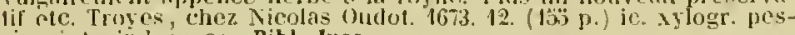
sint. i. t., int. inser. Bibl. Juss.

* hispanice: Ilistojia le las y'rvas, y plantas, sacada de Dioscorido Anazabee y otrus insignes autores, con los nombres griogos, latinos y rifiñoles. Traducida nuevamente ell rspañol por Juan Jarava incodicu y jihilosopho. En Anvers, cul la gallina gorual por los hrore-

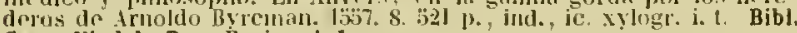
Caes. Vindob. Reg. Paris. et Juss.

$31333^{*}$ - Apologia, qua refellit malitiosas Guatheri Ruff, veteratoris pessimi, reprehensiones. quas ille Dioscoridi nuper ex Egenolphi officina problembi allesuit: olsiterque quim multas, ino propemodum ommes herbarum imagines e suis de slirpium listoria inscriptis commenlaris idem sulluratus sil, ostundit. Basileae, apud Michaelem Jsingrin. 1544 .8. (3) foll.) Bibl. Reg. Dresd.

(Pracfatio dinta est Tubingae die 12 Febr, liib.

31.31* Comarmius furens. Basileac ( 1545$) .8$ lit. (24 foll.) Babl.

Caes. Vindob.

Unicum exmplar libelli rarissimi, quod vidi iu Bibl. Caes, VunIohonensi, in timt mutilum est; sulut 2 f folici, latissima nctava forma, custodihus a-b siguata, quormu ultimum desinit in verbo: "Stultitia, " Est responsio Fuchsii post Cornarï Vulpeculan excoriatim; non rero ut Seguicrus vult, in Nila ac bralsyla.)

$333 \mathrm{i}^{*}$ - Adrersus memtates et christiann homine indiguas Christiani Egenolyhi typographi Franofurtani suigue architecti calumnias Leanharli Fuehsii medici responsio denuo in Jucem edita. Basileae, ex officina Erasmi Xylotecti, 1345, mense Augusto. 8. (26 foll.) Bibl. Caes, Vindob.

Eutio frinceps vix usfuam exstal; hanc Fuchsius I7rico Morharto, typographo Tubingessi, tratiderat iu nundinjs paschalibus

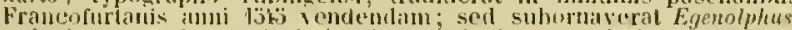
fui citi rersutia ommia lmjus impressinnis exemplaria coemerent,

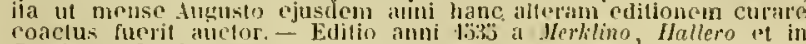
Desideratis Banlsianis laudata. tictitia est.

$3436^{*}-$ Apologiac tres enm alicpun paradoxom explicationilus. Basileae, in officima Roberti M̈iucr. 1539.4 .222 p., praef. ind. - ib. 1540.4 . Desid. B. - ${ }^{*}$ ib. 1544. 4. Bibl. Caes. Vindob.

$3\{37 \div$ De componendorum miscendorumque medicamentorum ratione libri quatuor, jam recens recoguiti. lugduni, apud Frellonium. 1561 . 12. 910 1., ind. Bibl. Juss.

(Elitionent principem, Basileae 10̈̈.j. folio. habet Trewius.

3 1.38* Fürnrohr, August Emmanuel. Gedachtnisstede zur 100 jährigen Jubelfeier der Doctorpromotion Linne's. (Regensburg 1835 .) S. $19 \mathrm{p}$. $(1 / 8$ th.

$3139^{*}$ Grundzuge der Naturgeschichle fui den ersten Uuterricht. Regensburg $1836.8 . \mathrm{vi}, 468 \mathrm{p} .(5 / 8 \mathrm{th}$.$) - Hunfte verbesserte$ Aunlage. Augulurg 1846.8 . $36 \%$ Bogen. $(\% / t h$. $310^{\circ}$ Fünrohr, Auyust Fmmanuel. Flora Ratisbonensis wler loblursivlıt der un Rigenslurg willwaclisenden Gewachse. Kegensburg 1839. 8. xxxı, 274 p., 2 rals., 1 mappla sengn. col. (1/3 th.)

sistit volumen alterutn operis iflscrijut: Naturbistorische Topmgraphir vun kegrousburk.

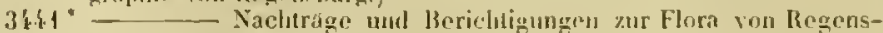
lurg. ln cinem Gratulationsprngrumm zur Hopp'schen DuclorjulselJeier, 5. Mai 1845 . Regenslumig i 8 亿5. 4. 1). 21-31.

3.1.2* Fublrott, Karl. Jussieu's und loc Candollo's naturliclic PllanzenSystome, nach ihres firundsatzen nutwichelt und unit don l’flanzenfamilien von Agardh, lBatsch und linmé, su wie mit dom linneisclıen Sexualsystem verglirlyon. Fur Forlesumgen und zum Sellystunterricht. Hit riner Vorrede von Christum Gotfried Vees run Esenbect. Bunn 1829.8. $v 1,2: 2$ p. $(1 \%, t h$.

$3: 43^{*}$ Las Pnanzeuroich und sciuc Mntamorpluose. Programm der Kealschule zu lilberfeld. Elberfelel 1838. 8.31 j.

34t: Fuiren, feorg. Index plantarum indigenarum, quas in itisere sun olsservavit, guae cilea Nidrosiam reperiuntur. Impr. cusn Thomat Burholini Cista medica Jlafniensi. Jafniae 1669 . 8. p. $278-293$

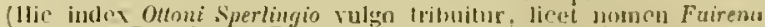
pracferat; cf. Beilschmed, Bot. Jahiesberichle, 18:38. 12. \{01.

34t' Fuiren, Thomas. J3bliotheca nedica Henrici l'uiren, H. U., quan patriae academiae legavit, cum prachalione Thomate Furen. Ilalinar 1659.4. Brennich.

Rariora cjus iemporis el praccelentis aevi scripta $\mathrm{m}$ npria quar ad scientias naturales pertinent, complectitur iste libromu cattalogus.)

Rariora Mlusei Henriri Fuiren. II. D., quace acadcmiac llafnienxi legavit. Hafniae 1663.4. (14 Joll.) B.

(An in eo libro agatur de plantis ignorn: fifes sit penes Linnaeum, (pui jllum retulit in Bîbliothecan bntaticam.

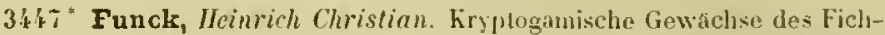
telgeluirges. Zweite Ausgabe. Leipzig 1806-1838. 42 llefe. 4. $\left(31 \frac{5}{8}\right.$ th. $)$

Collectio plautarum siccarum, $\mathrm{Nr}$. 1-86.3. additis textu variisqut olservationibus, Ouscule fasciculus continet 20 slirpes, uretio $3 / \mathrm{th}$ - Post editoris mortem [ $\div$ 12. Apr. 1839.] nihil porro prodiit.

$3.4 .8 *$ Deutschlands Hoose. Ein Taschenlserbarium zum Gebrauch auf bolanischen Excursionen. Baireuth 1820. 8. 70 \{. und 60 13lätler getrockneto Mloose in Eitui. ( 18 th.)

3.49 Furber, Robert. A calalogue of such trees and slirulis, hoth exotich and domestick, as will prosper in our climate, in the open ground, as hath been several years experienced by Mlr. Robert Furber, gardener, over-against Jidle Park gate, at hensington! where auy gentlemen may be furuislied witl any of the following trees and shrubs, at reasonable rates. Impr. cum Milteri Gardeuer's dictinary. London 1724 . 8. vol. 11. sign. $11 h^{3}-111^{8}$. B.

3450 Catalogue of trees, which will thrive in the natural ground in England. 1727. 8. Desid. B.

3131 Furerius, $N$. De radice Chinae. Tolosac 1554.8. s.

31.2 Fusch, hemaclus, latine Fuscus. Plantarum omnium, quarum hndie apurl pharmacopolas usus est magis frequens nomenclaturae, juxta Grecorum, Lalinorum, Gallurum, ltalorum, llispanorum et Germanorum sententiam. Parisiis 1541 . 8. (28 frll.) B.

34333 De plantis antea ignotis. nunc studiosurum aliquot nentericorum summa diligentia inventis libellos, una cum triplici nomenclatura. Venctiis 15/2. 12. Bibl. Reg. Paris.

3 ij: De berbarum notilia, natura atque viribus dialogus. Jor simplicium medicaneutorum clectionc tabella. Antwerpiac $15 \%$. $\mathrm{A}$. 48 foll. B.

\section{G.}

34 Ga Gadd, Pehv Adrian. Lipmuntran och underratlelse til nytliga plantagers vidtagande i Finland. Treolje stycket. Abo 1763. 4. 16 p. Sjette stychet. Abo 1768. 4. is p. B.

3456 Om sadesarternas sjukdomar och deras brimuedol. 1). Ábo 1766.4 .26 p. B.

3457 On akta Saftran, och dess plantoing. 1). Alus 1769.6 10 p. B. 
3 H:j8 Gadd, Pehr Adrian. Försök och anmärkningar on utlindske sädesarter i Finska climatel. I Delelı. D. Abo 1770. 4. 18 p. B.

$3459-$ Om Shidfrukts-wàxter och legumer. D. A bo 1772. 4. 16 p. B.

$3160-0 \mathrm{~m}$ Solidago canadensis, dess ans och nytta i fargerier. 1). Abo 1772.4.8 p. B.

3461 Anmảrkningar om forgiftiga vảster i gemen. D. Âbo 1773.4 .26 p. B.

3362 Afhandling om Asclepias syriaca. D. Åho 1778. 4. 16 p. B

$3163^{*}$ Chemiske och botaniske Anmarkningar nm Lin-och llampe Vaxterne, sant deras Bereining. D. Aho 1786.4. $18 \mathrm{p}$.

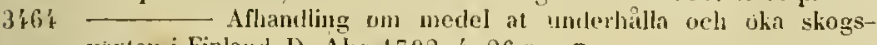
raxien i Finland. D. Abo 1792.4.26 p. B.

$3465+$ (Gaede, $I$. JI.) Index plantarum horti botanici Leodiensis. Lendii 1828. 8. 1v, 99 j.

3466* Gaertner, Joseph. De fructilus et seminibus plantarum. Stuttgartiac et Lipsiae 1788-1507. III roll. 4. $(32 \mathrm{th}$.)

3: Stuttgardiae 1788. Accedunt seminum centuriae quinque priores. cLxrxu, 384 p., ind., tah. $1-79$.

11: Tuchingae 1791. Continens seminum centurias quincpue posteriores. L11, $520 \mathrm{l}$., tab. $80-180 .\left(1-11: 21 \frac{1 / 3}{3}(\mathrm{~h}\right.$.)

111: Lipsiae 1805-1807. Supplementum carpologiae, seu continuati operis Josephi Guertner de fructibus et seminibus plantarum voluminis tertii centuria I et $\mathrm{II}$, auctore Karl Friedrich Gaertner. 256 p., tab. 181-225. $(10 \% / 3, t)$

(Voluminis jrimi editio nova. Lipsiae, lichter. 1801. est fraus bibliopolie.)

$3467^{*}$ Gaertner, Karl Friedrich. Reitráge zur Kenntniss der Befruchtung. Erster Theil. Versuche und Benbachtungen uber die Befruchtungsorgane der vollkomneneren Gew telise, und uber die naturliche unt kinstliche Befruchtung durcl den eignen Pollen. Stutgart 1844. 8. x, $644 \mathrm{p} .\left(3^{3} / \mathrm{t}\right.$ th. $)$

3468* Gaertner, Philipp Gollfried, Bcrnhard Meyer und Johannes Scherbius. Oekonomisch-technische Flora der Wetteran. Frankfurt a/M1. 1799-1802. 3 Bände. 8. - I: 1799. xu1, 531 1., 4 nıappa geugr. - II: $1800,512,52$ p. - III: $1801-1802.438,30,388$, 32 p. $\left(6 \frac{1}{4}\right.$ th. $)$

3h69t Gaillon, Benjamin. Essai sur l'étude des Thalassioplyytes ou plantes marines. Rouen 1820 . 8. 12 p.

3 1706 - Aperçu nicroscopique et physiologique de la fructification des Thalassiophytes symphysistées. Rouen 1841. 8. $14 \mathrm{p}$

3471 Essai sur les causes de la couleur verte, qui prenneut les huitres des pares a certaines épuques rle l'année. Rouen 1821. 8. 16 p. a.

$3472 \div-$ Experiences microscopiques et physiolngiques sur une espece de conferve mariue, production animalisée et réflexions sur plusieurs autres espèces de produetions filamenteuses analogues, consilérées juseju'alors comme végétales. Rouen 1823.8. 16 p.

$343^{*}$ Résuné méthodịue des classifications des Thalassioplytes, arec un tableau synoptique. Strasbourg $1828.8 .59 \mathrm{p}$.

(Exirait du vol. LIII. du Djecionuaire des sc. nat.)

$3 i^{\prime} k^{\prime}+$ Aperçu dhistoire naturelle el observations sur les limiles qui séparent le règne végétal du règue animal. Boulogne $1833.8 .35 \mathrm{p}$.

$3373^{*}$ Gakenholz, Alexander Christoph. Progymnasma de vegetabilium praestantia et intole cognoscenda et exploranda. Ilelmstadii 1706. 4. (24 p.)

3 Sift $^{\circ}$ Calama, S.J. Verhandeling over het moederkoarn, deszelfs hoedanigheden, oorzaken, waren aard, uitwerkselen op dieren en op loet meusehelijk liglhaam in den gezondeu toestand, alsmede deszelfs werkingen als geneesmiddel. Groningen, Oumkens. 1834. 8. vir, 219 p. Bibl. Léveillé.

$3477+$ Galenus. (Operum) quinta classis, eam medicinac partem, quae all pharmaciam spectat, exponens, simplieium medicamentorum, substitutorum, purgantinn, antidslorum, componendorum tan per locos 'quam per genera medicamentorum, ponderum denique ac mensurarum doctrinan comprehendit. Basileac, Froben. 456 \% folio. $558 \mathrm{p}$. (Continet noven af materiam medlicam gemuina vel spuria Ga. teni scripta; primo: De simplicinm nedicamentornm facultatibus litri XI, Theodorico Gerardo Gandono interyrele, p. 3- 170 ; sequitur: p. 111-120. - Spreng. Ilist. rei herb. I. 1. 206-210.)
3478* Gallais, A. Monographie du Cacao an Manuel fle l'amateur de chocolat; ouvrage contenant la tescrijtion, l'histoire et la culture du Cacaoyer, l'analyse et les characteres commerciaux du Cacar, etc. Paris 1827. 8. viII, 216 [3., 2 tal), et 1 carte.

$3479 t$ (Galland, Antoime.) De l'origine ef du progrez du cafe. sur un manuscrit arabe de la Bihliohlieque du Roy. Caen, typ. Cavelier. 1699. 8, 79 P. Bibl. Juss.

3480 * Gallesio, Giorgio, Conte. Traité du Citrus. Paris, Fautin. 1811. 8 xvin, 363 p. et I tableau synoptique du genre Citrus.

"Reproduit mII 1829 avec un nowveau titre amoncant une seconder dition, gui ne diflere de la preniere, que par ce caractere., Huzarl.

$3 \mathbf{1 8 1}$ * Teoria della riproduzione vegetale. Pisa, presso Capurro. IS.16, S. VIII, 136 ].

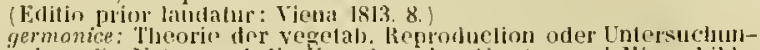
gen uber die Nalur und die Frsachin der Abarten und Missgebijde. Jeutsclı nit Zusatzen yon Georg Jan. Wien, Stuchbolzer. T81'. 8. 14011

$3482^{*}$ Pomona italiana, ussia trattato tegli alberi fruttiferi. Pisa, presso N. Capurro. 1817-1834. IIl voll. folio. - 1: 1817.$11: 1819 .-111:(1834$.

(Opus splendidum, quod vidi iu Bibliotheca Imperatoris Austriae, prodiit fasciculis XLI; heque texus nc"ute talmbe numeris insericol.)

3 ŁS3* (_ _ _ - Pomona italiana; parle scientifica; fasciculo primo contenente il trattato del fico. Pisa 1820 . 8 . xut , $123 \mathrm{p}$. et quadro simottico. (5 paoli.)

$3484 \longrightarrow$ Memoria sulla canapa. Torino 4829. S. 41 1.

$3483^{*}$ Gli agrumi dei giardini botanico-agrarii di Firenze, distribuiti metodicanente in un quadro simntico, coi principii della uuova teoria della riproduzione vegetale. Firenze, 1yp. Fumagalli. 1839. folio. 12 p., | tab.: Tablean synoptique du genre Citrus.

$3186^{*}$ Gallisch, Friedrich Andreas. De Aristotete, rei naturalis scriptore Epistola gratulatoria. Lipsiae 1776.4. 16 p.

3487 * Gallizioli, Filippo. Elementi butonico-agrari. Firenze, 1yp. Ognissanti. 1809-1812. IV voll. 8. - 1: 1809. xI1, 492 p. - II: 1810. 470 p. $-111: 1810.528$ p. - TV: 1812 . vI, $371 \mathrm{p}$.

(Tomus quartus inscribitur: Dizionario botanico che comprende i nome delle piante nelle principali lingue d'Europa, oltre tuelth ti primo secondo e terzo volume degli elementi hotanico-agrari.)

$3.48+$ Galpine, John. A synoptical compend of british botany, arranget after the Linuenn system; and containing the essential eharacters of the ganera, the specific characters, english names, places of growti, soil and situation ete. Second edition with corrections and considerable additions. London 1820. 8. xII, 138 p., ind. (10s. 6d.) Ed. I: Louldon 1806. 12. - London 1813. 8. DC.

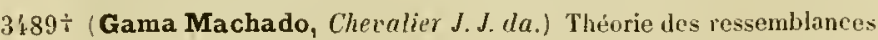
ou essai philusophrique sur les moyens de cleterminer les disposition. plyssiques el morales des animaux, d'après les analogies de formes, de rolycs et de couleurs. Paris 1831. 4. 133 1)., 20 tab. cul. Suites: 1 p.. 6 tab. col. Bibt. cand.

(Nonmila ad plyssiognomian plantarum spectant. Vol. II. III. il, 1836. 18k k. non vidi.)

3190 Gamez, Juan. Ensayo sobre las aguas medicinales de Aranjuez. Mladrid 1771. 4.

$3191^{*}$ Gandoger de Foigny, $P$. Louis. Traiti des vertus des plantes. Ouvrage posthume de Mr. Antoine de Jussieu, edité et augmenté pas Gandoger de Foigny. Nancy, Leclere. 1771. 8. xxxvi, 412 1. - Paris. chez Merlin. 1772. 8. (est eadem impressiu.)

$3492+$ Gandy, Charles $L$. Essai botanitue ot medical sur les plantes ombelliferes. D. Strashourg 1812.4. 30 j.

3493 Gans, Jacobus. Nieuwe vermeenle catalogus van hoomen, heesters en plantagie-gewassen, te bekomen by Jacobus Gutns. Bloemist en Boomqueeker te llillegom by llaarlem. $1780.8 .36 \mathrm{p}$. B.

$3494+$ Ganser, Benno, pr. Obserrationes botanicae circa nutritionem et anatomiam plantarum. D. Salisburgi, typ. Mayr. s. a. 4.14 p.

349: Ganzel, Karl Ludwig. De Lactuca satisa et Lactucario. D. Berolini $1819.8 .32 \mathrm{p}$.

$3496 \div$ Garçon, J. B. Iteponse à une question de medecilıe, lans laquelie on examine, si la théorie de la botanique ou la connaissance des 
Wantes est neciessaire a un nedecin? Narbonme, typ. Besse. 1740. i. 28 1).

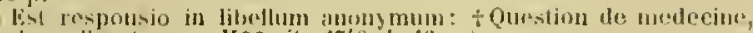

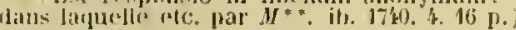

3497 Gardener, Georye. Nusci Jritanuiei, or I'ochet llerlarimu of lritish mossrs, named and arranged according to Hooker's British J'lori, Glasqua 1836.8

$3198 \longrightarrow$ Travels in the interior of Brazil, principally through the unthern provinces and the Gold and Diamonel distriets, during the years 1836 - IS41. Londun, Reve. 1846. Il voll. 8. (1l. 4s.)

de his itmeribus botanicis ef. Hooker, London Jommat of hotany, 18\%. 2. S' S5. )

319!* Gardini, Francesco Guiseppe. Je influxu electricitutis atmosphaericae in vegetantia. D. anno 4782. jraemio clonata. Augustao Taurinorum, excudehat Briolus. 1784. 8 . xvıl, $157 \mathrm{p}$.

:Hol0* GarideI, Pierre Joseph. Ilistoire des plantes, qui naissent aux "Ivirous d'Aix ot dans plusieurs autres endroits ile la Provence (aver wne explication des noms des auteurs lotanistes, avec ifuelques remar(ques historiques sur leurs ouvrages). Aix, chez Ioseph David. 1715 . folio. xxxiv. xLIf. 522 j., ind., $100 \mathrm{tab}$.

Crimt novi tituli: * paris, chez Charles osmont. 1719. et *apud entem 1723; sed impressio ipsa est princeps Aquitana anni 1715.)

3ij)! Garner, $R$. Natural listory of the county of Staftord, comprising its geology, zoology, botany, its antiquities, topograplıy etc. with plates. London 1844.8. (1/. Is.)

jijo2' Garnett, Theodor. Observations on a tour throug the highlands and part of the western isles of Seotland. ete. London 1800 . II voll. 4. + germanice: von losegnten. Luhech u. Luipzig 1802. 2 Bde. 8. (21/2th.)

$3003 \div$ Garnier, Antoine. An Parisinis frequens potus Tle frequenti potu Caffú salulurior? D. Paris 1749.4.4 P.

33̈04. Garofalo, Biagio, latine Blasius Caryophilus. Dissertationes

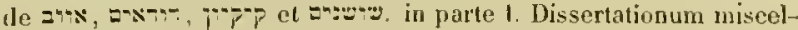
Javearum p. $177-330$. Romae 1718.4. B.

(Exhitent Ribliorum Origanm, Ricinum, Lilium, Mandragaram et llysopum.)

$350 \$$ * Garovaglio, Santo. Catalogo di alcune critlogame raceolte nella provineia di Conn e nella Valtellina. Parte I: Muschi frondusi. Como, presso Ostinclli. 1837.8. 35 j. - Parte II: Licheni. Milano, presso Carpano. $4838.5 .56 \mathrm{j}$. - t Parte III, clo comprente le specie trovate hegli anni 1840-1843. Pdvia, presso Bizzoni. 1543.8.46 p.

$3: 06^{*}$ 1)electus specienum novarum vel minus cognitarum quas in colJectionibus suis cryptogamicis evulgavit. Sectio II: Lichenes illustrans. Ticiui 1838. $8.35 \mathrm{p}$.

(Sectionem primam, museos frondosos sistentem, ibi eodem editan anmo, non vidi. ?

$3507^{*}$ Enumeratio museorum omninm in Austria inferiore lucusque Jectormm, adjecta indicatione loci eorum natalis, et temporis, quo fructum ferunt. Viemae 4840 . 8. vur, 48 p. ( J/2 th.)

$3608^{*}$ Bryologia austriaca excursoria tamejuan Clavis anaJyen al umnas in imperio anstriaco Jueusque inventos muscos facile et lutu feteminandos, Vindobonae 1840 . 8.88 p., praef., ind. $(5 / 6, t h$.

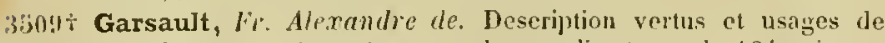
719 plantes taut étrangires qque rle nos climats; et do 134 animax en 730 planches, gravies on taille-douce sur les desseins d'après nature ele. Paris 1767 . IV voll. 8. xiv, 372 r. 643 tals.

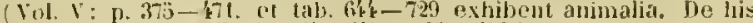
tabulis vide (juerard, France liti. III. p. 26!-270.)

$3:$ lot Gasc, J. P. Jiseours sur les avantages de l'etude des seiences, surtaut de celle de la nature et sur la botanique, considérée en elle-meme et daus ses rapports avec la medecine. Paris 1810.8. $\mathrm{xIt}, \mathrm{s}+\mathrm{p}$.

$3: 1_{1}+\longrightarrow$ Mémaire sur lïnfluence de I'electrieité dans la fécondation des plantes et des animaux et cousidératious générales (in ed. 11: rapides) sur la pretendue génération spontanée. Mayence, э5p. Zabern. $1811.8 .37 \mathrm{j} .-\div$ Paris, tyj. Tastu. 1823.8.63 p.

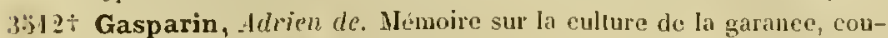
ronuc. Toulouse 1824. 8. $91 \mathrm{j}$.

$3313^{t}$ - Des effets des climats sur les assolemens, considerés dans la région des oliviers. Paris 4896 . 8 . $98 \mathrm{p}$.

$3014 \div$ Gasparrini, Guglielmo. Osservazioni intorno ad alcune piante coltivate nel real orto botanieu di Boceodifalco jresso Palermo. (Articolo inserito ne] fase. IV degli Annali civili.) s. I. et a. 8.24 ].

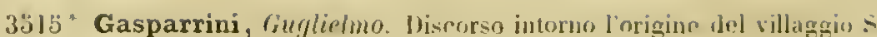

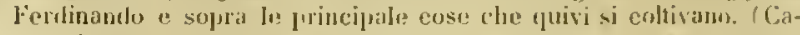
valo dall opere periodico: le utili conosinec.) s. J. लl a. 8.113 p.: 1 tal).

$3: 316^{*}$ Osservazioni intorno la durata et il germuglianento

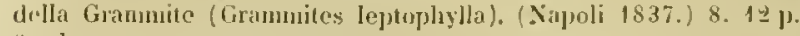
2 talo

$3517^{\circ}$ Deserizione di un nuove genrern di piante della lamiglia telle legmmuose. (Napoli 4838.) 8. 10 p., I tal). (J'aruesia (irlora Gasp.)

$3318^{*}$ — Riecrche sulla natura della pivtra fungaja i" sul fungu vi suprannasee (i. e. Myedium Polypori Tuberastri Fr.) Xapuli 18 i 4. $48 \mathrm{p}, 5$ tab.

$3319^{*} \longrightarrow$ Ricerche sulla struttura degli stomi. Napuli 1849. 4. 9 j., 1 tab

$3520^{*}-$ Nuove ricerelie sulla struttura dei cistomi. Capoli 1844. 4.7 j., 8 tals.

$3521^{\circ}$ Nova genera, guae super nonuulis Fici specichu. struebat. Neapoli $1844.4 .11 \mathrm{p}$.

$3522+\longrightarrow$ Ricerche sulla natura del caprifico, e del fico; e sulla caprificazione. Napoli, lip. dell' acpuila di $V$. P'uzziello. 1845.4 96 J., 8 tals. Bibl. Jac. Gay.

3:323* Gataker, Thomas. Observations on the internal use of the Solanum or nighishade. Londou 1757.8.34 $\mathrm{p}$

$3324 \div$ Gaterau. Deseription des plantes qui croissent anx environs de Montauban ou qu'on cultive dans les jarlios, rangées d'aprés l. méthode sexuelle, avec l’indication du lieu oil elles viennont at les vertus prineijuales des usuelles. Montaulan, Grosilhes. 1789. \& $216 \mathrm{p}$.

$3: 323^{*}$ Gattenhof, Georg Malthias. Stirpes :Igri et horti Heidelbergensis ordine Ludwigii, cum characteribus Lineanis, Mallerianis aliorumque. Heidelbergae 1782.8 .352 p. praef, ind.

$3526^{*}$ Gatterer, Christoph Jilhelm Jahob. Literalur des Wreinbanos aller Nationen, von den altesten bis auf die neuesten Zeiten. nubst Kritiken nud den wichtigsten literariselıen Xaclıweisungen. IJejdellıerg 1832. S. vi, 63 ]. $(3 / 8$ th. $)$

$3527^{*}$ Gaudichaud-Beaupré, Charles. Botanique du voyage antour du inonde, fait par ordre du roi sur les correttes l' Crunie et La Physzcieme pendant les années $1817-1820$ par N. Louis de Freycuel. J'aris 1826. 4. YIt, 522 j. - Atlas: il. 1826. folio: 22 1., $1 \geq 0$ tal, delin. et sculpt. aly A Poiret, filio.

(Voyage de In Bonite vicle laillant.)

$3328 *$ Recherches géuirales sur l'organographie, la plıysiologie et J'orquanogrenie des végetaux. Mémoire çui a partagé, en 1835, le jurix de jhysiologie experimentale fontic par feu de liontyon. Paris $1841.4 .130 \mathrm{~J}$. I $18 \mathrm{tal}$. col.

$3329 *$ Gaudin, Jean Frangois Gottleb Ihilippe. Eiremnes de Flore Nr. 1. puur l'an 4804. Lansanne 1804. $16.206 \mathrm{j}$.

(Insunt praeprimis observitiones do earicibus.)

$3330^{*} \longrightarrow$ Agrostologin helvetien. Jefintionem deserijutionemque graminum et plantarum eis affinium in flelvetia sponte nascentium complectens. Parisiis et Geocvae 1811 . II voll. 8. - 1: xxI: 361 ]) - Il: $326 \mathrm{p}$. (19 fr. $-4 \mathrm{lh}$.)

3331 - Flora lielvetica sive historia stirpium hueusque cognilarum in llelvetia $\mathrm{et}$ iu (ractibus conterminis nut sponte nascentium aut in hominis animaliumquc usus vulgo cultarum continuata. Turiei 182S- 183:3. VJl voll. \&. - 1: 1828. xixu, 504 j., 4 tab. col. - II $1828.626 \mathrm{p.}: 15$ lab. col. $-111:$ is 18.590 p. $-\mathrm{J}: 1829.663 \mathrm{p}$. s tab. col. - V: 1829. 544 p., I tab. col. $-\mathrm{VI}: 1830.400$ J., 3 tab. col. - V'll: 1833. Iilser manulis helvelico-botanicus in usun viatoris botanophili lhelvelian peragrantis, tojpograpliam botanican cumplectens $667 \mathrm{p}$. ( $231 / 2$ th. - heraligeselzt: $16 \% / 3 \mathrm{~h}$.

33.32* —_ Symopsis Florae holveticae. Opus jostbumun continua-

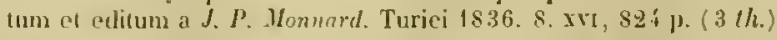

$3833 \div$ Gaultier de Claubry, Memi-Francois. Recherches sur lexistance de J' Jode dins l'eau de la mer et dans les plantes yui prolnisent la soude ale Virecks, et analyse de plusieurs plantes de la famille des algues. The'se. Paris is $15.4 .40 \mathrm{j}$.

$353 \% \div$ Gauthier, Ilugues. Introduction a la connaissance des plantes uu Catalogue des plantes usuelles de la france avee les caraeteres 
distinctifs etc. Aviguon et Poris, Lottin et Robinot. 1760. 8. xxiy, 268 p. - tParis, Santus. 1785 . S. (titulo paulto mutato est earlem impressio.)

$3535+$ Gautier, A. Manuel des plantes médicinales on description, usage et culture des régétaux indigènes employés en médecine. etc. Paris 1322. 8. xvi, 1122 p. $(10 \mathrm{fr}$.)

3536 Herbier médical ou collection des figures représentant les plantes midicinales indigenes. Paris 1822. 10 livraisons. 12. 214 tab. col. $(40 \mathrm{fr}$.) 0 .

3637 Le jardinier fruitier, rédigé d'après los notes de M. Noiselle. Paris 1821 \$q. Ill voll. 4. 90 tal. col. (225 fr.) $a$.

$3538 \div$ Gautieri, Giuseppe. Della ruggine del frumento Pensieri. Milano 1807. S. 3 i p. (sign. 1-27.), I tab).

$3339^{*}$ - Dell' inllinsso de' boschi sullo stato fisico de' paesi e sulla prosperita delle nazioni. Nilano 1814 . S. 32 p.

3340 Gavelli, Niccolo. Storia distinta e curiosa del tabacco, concernento la sua scoperta, la introduzione in Europa, e la maniera di coltivarlo, conservarlo e mrepararlo. Pesaro 1758.8 .84 p. B.

$331.1^{\circ} \mathbf{G a y}$, Claude. Ilistoria fisica y politica de Chile, segun documentos adquiridos en esta republica lurante doce años de residencia en ella $\mathrm{y}$ publicada bajo los auspicios del supremo gobicrno. Botanica. Tomo primero, fasc. 1- IV: Paris, en casa del autor. Chile, eu cl musco de historia natural de Santiage. 1845.8 .512$]$.

Opns admuc sub manu anctoris; simulcum celitur Allas universalis magna quarta forma; cuivis insunt fasciculo yuatuor tabulae pictie, geographiam. elhnographiam, zoologian, botanicam illustrantes: pretium tasciculi $12 \mathrm{fr}$. $30 \mathrm{c}$.)

$331.2 *$ Gay, Jacques. Honographie des cing genres de plantes que comprend la tribu des Lasiopétalèes daus la famille des Buettuériacées. Paris 1821.4 .38 p., 8 tab

$3543^{*}$ - Fragment d'une monographie des vraies Buetneriacées. Paris 1823.4. 24 p., 4 tab.

$334^{*}$ - Histoire de l'Srenaria tetraquetra L. (E.strait des Annales des sc. nat. Sept, 1524.) Paris 1824, 8. $21 \mathrm{p}$.

3345 - Obscrrations sur deux mémoires de botanique rècenment publiés en Italie. Paris 1827. 8 licis.)

Est commentarius in libellos Berlolonii et Tenorit de Crocis ita-

35 r6t - Nonographie des genres Xoranthemum ot Chardinia, apparienant a la tribu rles Carlinées, dans la fanille des Synanthérées. (Lue à la société d'histoire naturelle de Paris le 9 mars 1827.) Paris 1827.4.47 j., 2 lab.

(Extrait du tome III. des Mém. de la suc. d’hist. nat. cle Paris.)

$357^{*}$ __ Notice sur Phalippe Antoine Christophe Endress. Paris 1832.8.66 p

(Extrait des Amnales des sc. nat. Mars 1832.)

$33: 8+$ Erysimorum quorundam noverum thagnoses simulque Erysini muralis clescriptionem praemittit, monographiam generis editurus. Parisiis, Béthune et Plon. 1842, $5,16 \mathrm{p}$

(Liber rarissimus , 60 cremplaribus evulgalus.)

$3519^{*}$ Holostei, Caryophyllearum Alsinearum generis monographia. Parisiis 1845,8, p. 23-44

(Extrait des Annales des se. nat. Juilliet 18 k.5.

3̋̈̈0* Geer, Johamn Lurhwig Wilhelm van. Plantarum Belgii confoederati indigenarum spicilegium alterum, quo Gorteri Flora VII provinciarum amplificatur et illustratur. Trajecti ad Rhenum 1814.8. 59 p. Bibl. E. Meyer.

(Est primum irloue unicum. qund edidit de Geer, alterum post illurl, quod 1788 ediderat Stepheni Johemn van Geuns.)

3351 * Gebhard, Johamn Nepomuk. Verzeichniss der van dem Jahre 1804 bis 1819 auf meinen botanischen Reisen durch und in der Steyermark selbst beobachteten, gesammelten und, bis auf wenige, hereits in meinen Centurien getrocknet gelieferten Pflanzen; nit der Angabe ihrer Standorte, Blutezeil, etc. Gratz 1821. 12. xx, 307 p. $\left(\frac{2}{3}\right.$ (h.)

$3552 *$ Gehler, Johann Karl. De usu macerationis seminum in plantarum vegetatione. Programma. Lipsiae 1763.4.20 p.

3633 - Oratio de nexu studii botanici enm occonomico. lipside 1763.4

35i)' Geiger, Franz Taver. Unterricht in der liunst, die Obsthume durclı Propfen zu veredeln. Esslingen 4811. 8. $(5 / 2+t h$.)
$3556^{*}$ Geiger, Karl Auton. De Secalis cornuti viribus medicatricibus D. Nonachii $1820.8 .15 \mathrm{p}$

3557 Geiger, Philipp Lorenz. De Calendula officinali. D. Jlculclbergat 1818.8. $(1 / 2(h)$

$3558 *$ Pharmaceutische Botanik. Zweite Auflage, neu bearbeitet von Theodor Friedrich Ludwig Nees von Esenleck und Johann Heinrich Dierbach. Zwei llalften. Hejdelberg 1839-1S40. 8. VI. 2023 p. (9 th. $)$ - Ergánzungslieft: Heidelberg 1843. 8. I.vi, 347 p. $\left(1 \frac{2}{3}\right.$ th. $)$

$3389^{*}$ Geilfusius, Bernhard IIZlhelm. De Moxa. D. Marpurgi Cattorum. Schadewitz. 1676.4 .28 p.

$3300^{*}$ Geiseler, Eduard Ferdinand. Crotonis monographia. U. IIalat 1807. 8. $x, 83$ ]. $(1 / 3$ th. $)$

356. Gellerstedt, Johan Danied. Nerikes Flora, eller hort beskrifninแ af Nerikes vilula Vexters kümetecken och nytta, till den Studerande Ungtomens tjenst i Üreloro. Örebro, tryckt hos N. Ml. Lindh. 1831 12. $126,9 \mathrm{p} ., 1$ tab. W.

3562* Gemeinhardt, Johann Laspar. Catalogus plantarum circa Lallbam nascentium tam indigenarum tuam exoticarum culturae mangonio ibidem prognatirum. Budissae, Richter. (Laubae, typ. Scchillii.) 1724.8 .198 p., jract, incl.

$3363^{*}$ Genersich, Samuel. Florae Scepusiensis elenchus sive enumer:1tio plantarum in comitatu llungariae Scepusiensi eumque perenrrentibus montibus carpathicis sponte crescentium. Leutschovian. typ. Podhoránszhi. 1798.8. 76 p.

336:* Genlis, Stephanie Felicite Ducrest de Saint-Aubin, Comtesse de La botanique historique et litéraire, contenant tous les traits, toutes les aneedotes ef les superstitions relatives aux fleurs, dont il est fait mention dans l'histoire sainte el profane, et des détails sur quolques plantes singulieres, ou qui portent les noms des personnages cálèbres el sur celles, qui servent aux cultes religieus of dans les cérémonies civiles des diverses peuples et des sauvages; avec les devises, les proverbes etc. auxquels les veggetaux ont donne lieu; suivie l'une nouvelle intitulée: Les fleurs et les artistes. Paric 1810.8 . vil, 359 p. (5 fr.)

* ilatice: Milano 1813. If voll. 12 Geschichte und Literatur, odter die * germanice: Die Botanik der Geschichte und Literatur, otter the
Pflanzen in ibren mythologischen, religiosen, birgerlichen, siunbild-

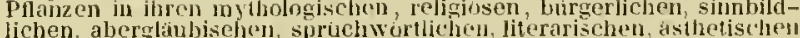
lichen, aberglanhiseh(en, spruchwortlichen, literarischen, dsihetischent

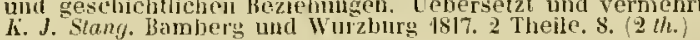

3363 Gennari, Giuscppe. Lettera intorno la vita del fu Pontedera. Venezia 1758.8 .

$3566^{*}$ Genth, C. F. F . Flora des Herzogthum Nassan und der obern, su wie untern Rheingegenden von Speier bis Coln. Erster Theil. Kryptogamie. Erste Abtheilung. Mainz 1836. 8. xII, 439 p. $\left(1 \frac{1}{3}\right.$ th. $)$

unfelicis Genthii bospitem, J. II?. P. Ifuebenerum nonnulli auiorem hujus Florae perhibelt.)

3567 Gentil, André Antoine. Essai tlangronomie ou diètétique gènérale des végétaux, et application de la chimie a l'agriculture. Dijon 1777.8. a.

$3068+-$ Dissertation sur le caffée etc. Paris1787.8. $177 \mathrm{p}, 1 \mathrm{tab}$.

$3569^{*}$ Geoffroy, Etienne François. Tractatus de materia medica. Parisiis, Saillant. 1741. III voll. S. - I: De mineralibus, - Il : De vegetabilibus exoticis. 794 p., ind. - Ill: De vegetabilibus indigenis. 836 p. (desinit in Neliloto.) - Venetiis 1749 . II voll. 4. DC.

+ gallice: Traité de la mitlière métlicale, ou de l'histoire tles vertus, du choix et de lusage des remedes simples. Traduit en français tus, du choix et de lisage des remetes simples. Traduit en irançais par Dr. (Antoine Reryier.) Nouvelle editiou. Paris 1757 . Xrl woll. 12. (vol. II-N ; Plantes exotigues. - vol. l- Yll Plantes indigene Abrotanum-Me

(t Les figures des plantes (et animanx) d'usage "nl medecinc. décrits dans la matiere merticate de Geoflroy. dessioes d'après natur. par Mr. de Garsaull. s. a. Plantes. IV voll. 8. tab. 1-6'3.

$3570+$ Geoffroy, Etienne Louis. An omne esculentum vegetabile cul. turi salubrius? D. Paris, typ. Quillau. 1747. 4. 4 p.

$3571^{*}$ 'Georgi, Johann Gottlieb. Bemerkungen einer Reise im russischen Reiclse im Jahue 1772 . St. Petersburw 1773 . Jl voll. 4. 920 p., 6 tal geogr. $(3 \%$ th. $)$

$3572^{*}$ Geographiseh pliysikalische und naturhistorische Beselireibung tes russischen Reiches. Drei Theile und Nachtrag in dreizchu Abtheilungen. lionigsberg $1797-1802.8 .(1 / \mathrm{th}$. 
$3573^{\circ}$ Georgy, Carsten Friedrich. I). Iucis aste oblectamenti causa instrultis. 1). (ioottingae 1780,4.16 p.

:J674" Gera, Francesco. Della fecondezione dello plimte. Nemoria. Seconda edizime, notaliluentc ineresciula, o corredata di molli utili applicazioni relative alla collura de' campi degli orti e dei giardini. Nilino 1830. S. 14 4). (2 Lire.)

33 int Gérard. Nolice sur le froment ronsidéré sous le rapport botinispe, agricole of economique. Paris 1845.8.16 p.

(Estratt du I)iet. Iunis, l'hist. nat.)

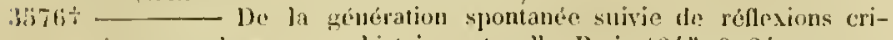
tipues sur le genre en histoire naturelle. Paris 1845.8 .24 p.

(Estrat du nict. univ. d'hist. nat.)

$3377^{*}$ Gerard, Lomis. Flora Galloprovincialis. Parisiis, apud Bauche. 1761.8 . xivil, 585 [1., 19 1ab.

3:i78:- Nimoire lu a l'institut national le 6 Thermidor an VIII, "uncernant deux plantes dont la fructilication s'exceute dans l'intérieur et a l'extérienr de ha terre. (Paris 1800.) 8. 30 p., 1 tab.

$3: 39$ Gerarde, John. Catalogus arlsorum, fruticum ac plantarum tam indigenarum yuam exulicarum in lorto Gerurdi nascentium. Londini, a uflirina Roherti Rohinson. \$596. 4. Sloane. - Ed. II: London 1599. 4. Bibl. Bodl.

$3: 180^{*}$ The Herlall, or generall historie of plantes. London, imprinted by Joln Nortum. 1597. folio. (17) 1392 p., ind. effigies antoris, ic. lizno ine, elegantissime col. i. 1. Bibl. Goett. - " Ed. II: Vers much enlarged at amented by Thomas Johnson. London, printed by Norton, 1633. folio, 1630 p., praef., ind., ic. ligno inc. i.t. (12s. 6d. - 2l. 2s. A. Pany) )in 4846.)

Livemplaria anni "Ifi36 nou differtunt. De libro ipso ef. Sipreng.

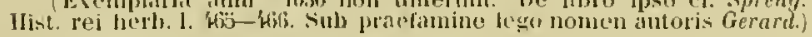

His1" Gérardin, Sehustien (de Mirrcourl.) Tablean élémentaire de botaniqur, dians lequel toutes les parties qui constituent les végétaus sont explifpeces et mises a la prorte de fuut le inonde ete. Piris 1805.8 . xL: 425 j3., 8 tal). ( 7 fr. 50 e.)

$3682+$ Mémoire sur la propriété quont certaines especes de graines de conserver long-temps leur vertu germinative. (Paris 1809.) s. $14 \mathrm{ll}$.

$3383^{*}$ - Lissai ale physiologie végétale, ourrage dans lequel sont espliquées toutes les parties des véugétanx: aecompagné des planches at de tableaux methodiques, representint les trois systèmes de Tuurnefort, de Linne et de Jussien. Paris 1810. Il voll. 8 . - 1: .. 456 p., 32 tal. -11 : xxxvr, 460 p., 22 tab. (25fr. - col. $60 \mathrm{fr}$.)

$3584 \div$ Dictionmaire raisonné de botanique contenant tous les ternes techuiques tant anciens que morlornes, consideres sous le rapport de la hotanique, de l'agriculture, de la nudecine, des arts, des eaux ol forets. Public, revu et augmente de plus de trois mille anticles par N. A. Desvaux. Paris $1817.8, x v 1,746 \mathrm{p}$. et le portrait Ile Gerardm. - Erl. Il. ils. 1823.8 . (10 fr.)

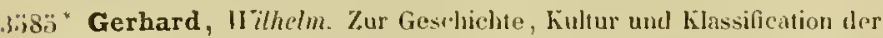
fieorginen ofler Dahlien. Zweits, durch pin verbessertes tirup'pirutyssystem, durch beschleibung 136 neuer Spjelarten und NachIrägliches nlwr dic Kultur der Plianze vormehrte Auflage. Leipzig 1836. \&. x, 16 4 P., 2 1aL. col. (1 th.

3586, Gerike, I'cter, pr. He usu medico Camphorae. D. IIclenstadii 1748. 4. 17 J. B

3087 Germann, Gollfried Albert. Verzeichuiss der l'flanzen des botanischen Gartens der haiserl. Iniversilat zu Dorpat im Jahr 1807. Dorpat 1807. S. T.

$3088^{*}$ Germar, Ernst Frislrirh. Div Versteinerungen des Steinhuhlengelirges von Wettin und Lobejun int Saahheise, libdlich dar'gestellt und beschrichen. Ileft 1-Ill. IJalle 1844-1845. folio. I I Bogen, 15 (al). ( 6 (h).

3ik9t Gerstenberg, Karl. Der Gasteubeohachtur. Fine Zeilscluift. Fister Jis sechsler (Ietzter) Jahrgang. Nuruberg 1837-1842.6 Bunde. 8. 144 tab. col. (17\%, /h.) Bibl. Deless.

3390 Gervasius, Nicolaus. Bizar ie botanihe al'aleuni semplicisti di Sicilia. Napoli, apul Novellum de Bonis 1673.4. s.

3ï91 Gesner, Comrad. Ilistoria plantarum "L vires ex Dioscoride, Paulo legineta. Theophrasto: Plinio el recentioribus Graecis juxta elementurum ordinem. Lna cum resum et rerborum locupletissino indice. Basileae. inusl Robertum Winter. 1541. 8. 281 p.. ind. et epistolit ad Henricum Billingum.
$3392 \div$ Gesner, Comad. Llistoria plantarum el vires ex Dirscoride. Paulo Aegineta, Theophrasto, I'linio et recentiorilus (iraceis juxta elementorum ordinem. Ailjecta ad marginem nomenclitura, qua singulas herbas officinae, herharii of volgus gallicum cotferre solent. Parisiis, apmul Carolan Guillard subs sule aureo. 1541 . 5 min. 261 p. prael., jud. (In calce: Parisiis, excudebat Joanurs Lodoicus Tilutanus. 15/1. Praefatio ad Henricum Bullingum, Janusannac d. 9 Augusia 1541 ; praeceduut indices: 8 foll.

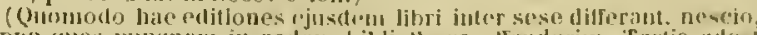
quippe quas mungum in eadern bibliotherea offenderim. Tertia adke-

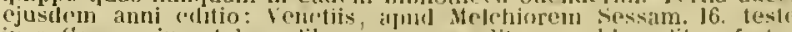

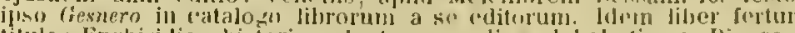
tilulo: Enchiridion hisforiar plimtarum ordlin" alphaturtico ex bioscoride sumptis doscriptimutus.)

$3393^{*}$ - Apparatus ot delectus simplicium modicimentorum. De conpositione medicanenturum socundum genera ex l'aulo Aconeta. De cmprositione medicanentorum ex Galeno. I.ugiluni, apud F rellonios fralres. 1542.8 . (20) 275 p. Bibl. Reg. Dresd.

$3894 \div$ Catalogus plantarm latine, graece, germanice et gallice 1J menbuch allor Erdgewaclsen, lateinisch, griechisch. fculsch und franzosisch. Rogestre do toutes plantes en yuatre langues, latin, grec, ileman ef francoys. Una cum vulgarilous pharmacopolarum nominilus. Aljectae sunt etiam herbarum nomenclaturae variarum gentlium, Dioscoridi adscriptae secuntum literarum uddinem espositae. Tiguri, apud Christophorum Froschoverum. 1542. 4. 162 foll. ot Ejpistola urneupatoria : 3 foll. Bibl. Cand. et Juss. - cum Dioscorid Ryffii. Francofurti 1543. Solio.

$3390 ̈ \div-$ De stirpium callectione talbnlar tum generales lum per duodecim unenses cum germanicis nominilus of aliis hactenus a neniue Irarlitis, olim per Conrudum Gesnerum conscriptae ac editae nunc autoris opera locuplotalac et de novo in usum pharmacopularum luei datae per Casyarum II olphium, Tigurinum nedieum Accossernut de stirpibus et de earum partilus labulae ex Theophrast. praecipue libris, eoden Gesnero autore. Tiguri. ex officina Froschoveri. 1587. S. $1: 6(8)$ foll. Bibl. St. Gallen.

("Prius jan morndierant cun Davidis Kyberi Lexico. Argentinau 1303. 8. p. 467- 48 .

$3396^{*}$ De raris et admirandis herbis, quae sive quod noctu Juceant, siye alias ob causas lunariae nominantur, eommentariolus. (t ohiter de aliis ciam rebus, yuae in tenchris lucent. Joseruntur "t icones quacdam herlarum novae. Lijuslem descrijtio montis fract sive montis Pilati juxta Lucernam in Helvetia. His accedunt Jo, du Choul Lngdunensis Pilati montis in Gallia descriptio; Jo. Rhellican stoch hornius, yua Stockhornus mous altis-imus in Bernensium IJe]vetiolum agro versibus heroicis describitur. Tiguri. apud Andrem et Jacobum Gesnerum. 1555. 4. 86 p. ind., ie 1 logr. i. I. (Evemplis ('um autugrapho Convedi Gesueri. Lonlini apud Pamplin 1546:10s 6(t.) - "Editime hac secunda enendatior, curante Thoma Bartholino. Jafniac ty]. Godicchenii. 1669.8 . 82 p. (1 0 foll. ind.), ic. sylogr. i. 1.

$3597^{*}$ Evonymi Philituri (i. e. Conradi Gesneri) Thesaurus de remediis secretis. Lugduni 1553.46 .498 p. ic. plantarum sylogr. i. 1. - Liber II. a Casparo Holphio ellitus. Tiguri 1565 . 8. н.

tanglice: The Treasure of Evonymus, containinge the wouderfull hid secretes of nallure, tsuchinge the most ipte forntes to prepare ind dostyl medecines etr. Transtated out of litim lis Peter llorwyng. Lonkon, is p. John Daie. (1539.) \&. 20 / 408 p., ic. plantarum xylogr. i.1 - London tibö. $k$. (110n differt.

$3898^{*}$ De stirpium alipuol nominibus velustis ac noyis: quae multis jam saeculis vel ignorarun medici, vel de cis dubitarunt: "ut

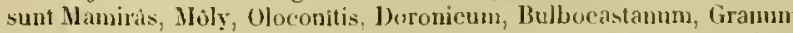
alzelin et habbaziz et alia complura epistolae Il, una Melchioris GuiInndini Burussi, altera Conradi Gesneri. Basileae, apud Epsscopium juniorem. 1557.8 .45 p., ic. ligno inc. i. t. Bibl. Reg. Dresd.

$3599^{*}$ - De stirpilus aliqunt epistolar 1 . Melchiors Guilandini R. IN. Conrudi Gesneri Tigurini I MA. Patavii, aj)ul toratiosum PerChacinum. 1358, 4. 48 foll. Bibl. Reg. Dresd.

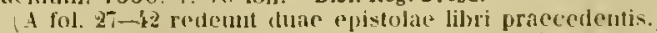

$3600^{*}$ - Itorti Germanice. Esstat in I alerii Cordi Amnotationibus in Dioscoridem. Argentomati 1561. folio. foll. $236-300$.

$3601^{*} \longrightarrow$ Epistola ad Cersparem Collinum de Tulipa Turcarum Fistat in Jalerii Cordi Annetationilus in Diuscoridem. Argentorati 1361 . fulio, foll. 213

$3602 *$ De libris a se editis epistola ad Willam Tumer. Tiguri 156‥8. (16 foll) 
3603+ Gesner, Conrad. Vita clarissini philosophi at medici Conrudi Gesneri Tigurini conseripta a Josia Simlero Tizurino. Item Epistolae Gesneri de libris a s" etlitis et carmina complura in obitum ejus conscripla. His accessit Caspari IVolphii Ilypochesis s. de Conradi Gesueri stirpium historia ad Johannem Crutonem pollicitatio. Tiguri, excrudebat Froschoverus, 1566, 4. 52 foll., ic. ligno inc. i.t. Bıbl. Horti Paris.

360 ' * Lpistolarum medicinalium libri III. IIis arcesserunt Aconiti primi Diascoridis asscveratio, et de oxymellitis elleborati utriusque descriptione et usu libellus. Omnia edita per Casparum Wolphium. Ti,yuri, apud Froschoverum. 1577. 4. 160 foll.

3603 Epistolarum medicinalium liber IV, (ad Joannem Kentmannunı; edidit Simon Gronenberg.) Wittebergae 1584. 4. (26 foll.) B.

$3606^{*}$ Epistolae (plurinae ad Jaannem Bauhinum) a Casp. Buuhino nune prinum editae. Impr. cum Joannis Bauhini de plantis a divis nomen habentibus. Basileae 1591, 8. p. 91-163.

$3607^{*}$ Opera botanica per dus saccula desiderata, vitam autoris et operis historiam, Cardi libruns quintum cum adnotationibus Gesneri in totum opus etc. Nunc primum in lucem edidit et praefatus est Casimir Christoph Schmiedel. Norinbergae 1751-1771. Il voll. folio. - I: 1754. Lvı, 130 p., 22 tab. ligno inc., 21 tab. aen., quarum ultima col. - 11: 1759. 1770. xı, 43,65 p., 31 tab. col.

$3608^{*}$ Gesner, Johamn. Dissertationes de partiun vegetationis et fructificationis structura, dillerentia et usu. Injpr. cum Linnaei Oratione de peregrinationibus intra patrian. Lugduni latavorum 1743. 8. p. 35 -108. - *impr. cum Linnaei Fundamentis hotanicis. Halae 1747. 8. p. 33-78. - impr. cum Giliberti editione Fundam. bot. Il. p. 551 -600 .

$3609^{*}$ De Ranunculo bellidifloro et plantis degeneribus. D. Tiguri 1753.4. 24 p., 1 tab. col.

$3610 t-$ De thermoscopio botanico. D. Tiguri 1755. 4. 9 p. Bibl. Turic.

+ gallice: Dissertation sur le thermometre botanique, traduite du latir. Basle s. a. 4. It p. Bibl. Turic.

* germanice: Von Gebrauche des Thermoseops hei Wartung der Ptlanzen. (Ilamburger Masazin, Band XVl. 1. 288-303.)

$3611^{*}$ _... Phytographia sacra generalis (et specialis). D. 1-VII. et I-II. Tiguri, ex officina Gessneriana. $1759-1773$. 4. - Phytographia sacra generalis: 1759.28 p. - Phytographiae sacrae generalis pars practica 1: 1760.56 p. - II: 1762.54 p. $-111: 1763$. 30 p. - IV: 1764.31 p. - V: 1765. 35 p. - VI: 1766.34 p. VII: 1767. 33 p. - Phytographiae sacrae specialis $1: 1768.27$ p. II: $1769.25 \mathrm{p} .-\mathrm{III}: 1773.32 \mathrm{p}$.

$3612+$ (— Joan. Guil. Weinmanni Thesaurus rei herbariae locupletissimus indice systematico illustratus el emendatus, in quo aliquot plantarum millia secundum classes, ordines, genera, species et varietates methodo Linneana recensentur et passim adnotationibus illustrantur. Augustae Vindelicurum 1787. 8. xxı, 184 p., ind. (Adnotatiunculas aliquot addidit Christian Ludwig Becker.)

$3613^{*}$ Tabulae phytographicae analysin generum plantarum exhibentes. Cum commentatione edidit Christian Salomon Schinz. furici $1795-1826$. Il voll. folio. $-1: 1795$. xul, 225 p., tab. col. 1-28. - Il: 1804. 118 p., tab. cul. $29-64$.

(Anno 184 opus conipletum, 79 plagulae textus el 82 tab. uigr., ad annum 1826 continuatum a libraria emturis pretio $381 / 3$ thalerorun commendabatur. Fasciculus Xixl diciur ultimus.)

3614* Gesner, Johann Albert. De Zingihere. D. Alturfii 1723. 4.32 p.

$3615^{*}$ Geubel, Heinrich Karl. Die physiologische Chemie der Pflanzen, mit Rücksicht auf Agricultur. Zugleich eine wissenschaftliche Widerlegung der Ansichten Liebig's und Schleiden's. Frankfurt a/M. 1845. 8. xil, 312 F. (1 $\frac{1}{2}$ th. $)$

3616 * Geuns, Sleven Jan van. Plantarum Belgii confoederati indigenarum spicilegiun, quo Davides Gorteri, viri clarissimi; Flora VII provinciarum locupletatur. Hardervici 1788. $8.77 \mathrm{p}$.

$3617^{*}$ Verlıandeling over de inlandsche plantgewassen, omtrent welker nuttige eigenschappen men met grond verwagten hau, dat, ten nutte van het vaderland, verdere nasporingen kunuen worden gedaau. Ilaarlem 1789.8.86 p.

$3618^{*}$ Oratio de instaurando inter Batavos studio botanico publice habita. Trajecti ad Rhenum 1791.4.58 p.

3619 Plantarum indigenarum in usum sive medicum sive oeconomicum selectarum index systematicus. Trajecti ad Rhen. 1816. 8 .

Pritzel, Thes. lit. bot.
$3620+$ Gevers Deynoot, P. M. E. Flora Rheno-Trajectina, seu enumeratio plantarum Trajecti ad Rhenum sponte crescentium. Pars I et ll plan. et crypt. continens. (Flera van Utrecht, of Optelling en aanwijzing etc.) Utrecht, N. van der Munde. 1843, 8. x11, 180 p.

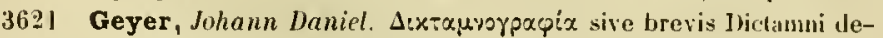
scriptie. D. Francofurti et Lipsiae 1687.4. 38 p., 1 tab. B.

3622* Giacomelli, Anyelo. Cataloge delle Cacteae coltivate da Angele Giacomelli in Treviso. Treviso 1842.4.23 p.

3623 t Gianella, Carln. De admirabili radicis Ipecacuanlac virtute. D Patavii 1754. 4. 13 \%

3624 Gibbes, Leveis $M$. A calalogue of the plraenogamous plants of Columbia, S. C., and its vicinity. Colunbia 1835. 8. Bibl. Acad. Pbilad.

3625* Giboin, N. J. B. Fragmens de plysiologie végétale. Montpellier an VII. (1799). $4.57 \mathrm{p}$

Autor libri est lacques Phitippe Raymond Droparnaud, teste Candolle syst. uat. 1. p. 50.

* germanice: Fragmente aus der Physiologie der Pllanzen. Aus dem Franzosischeu (vou J. Franz Schweighaeuser). Strasburg 1803. 8. IN 87 p. $(1 / 3, h$. $)$

3626* Gil, Felipe Luis, e Gaspar Zuarez. Osservazioni fitologiche sopra alcune piante esotiche introdotte in Roma. Ronta, stamperia Casaletti. 1789-1792. Ill fasc. 4. 64, 70,99 p., 30 tab. Bibt. Reg. Berol. et Deiess.

3627 Gilbert, Samuel. The florists Vademecum. London 1683. 12. 252 p. B.

3628 - The gardeners almanack for fives years 1683 - 1687 printed with his florists Vademecum. London 1683. 12. (18 foll.) B.

$3629+$ Gilby, William Ilall. De mutationibus quas ea, quac e terra gignuntur, aéri inferunt. D. Edinhurgi 1815. $8.36 \mathrm{p}$.

$3630^{*}$ Gilibert, Jean Emmanuel. Flora lithuanica inchoata, seu enuneratio plantarum, quas circa Groduan collegit el determinavit. Grodnae 1781. (el Vilnae 1782). 8. xviti, (22), 243, $294 \mathrm{p}$.

(Post praefationem dilli foliorum sequitur "Chloris Grodnensis seu conspectus plantarum agri Groduensis ordine Limuleano n, 22 foll. absque slunatura; tunc collectio 1: Momopetalae non figuratae; 660. - 11: Labiatie et kingentes; p. 70-164. - 111: Monopetalae compositae: p. 163-213. - IV: Unbelliferae, Cruciatae, Papilionaceae; 1. 1117. - V: Polypetalae pauci-et multistamineae; $1.121-24\}^{\prime}$ - Supplementum primae et secundae collectionis: $0.2 \%$ - 308 - Chloris frodmentum promae et seciores Lithunlae redeuut in. - Chloris trodnensis et plantae rariores Lithanae redeunt in volumine prims $86 \mathrm{p}$., nec nou in Usteri Delect. opust. hot. II. p. 25ik- 330 .)

3631 Indagatores naturae in Lithuania. Wiluae 1781. 8. a.

3632 - Exercitium botanicum in schola principe universitatis Wilnensis peractum. Wilnate 1782.8. a.

$3633^{*} \longrightarrow$ Caroli Linuoei Systema plantarum Europae exhihens characteres naturales generum etc. Coloniac Allobrogum, Piestre. 1785-1787. VII voll. 8. - I: Lxxxvili, 47, 86, 42 et 127 p. (Inest: Flora lithuanica; Chloris lugdunensis; et Flora Delphinalis, opera Villarsii.) - 11: xxiv, 183,221 p. - III: xxxu, 616 p. - IV: 752, 15, 38 p. - V: Lxxy, Lxxvi, 604 p., lab. - Vl: 732,52 p. - Vll: xxxu, 594 p., 13 tab.

(In vol. $Y$-Vil: Fundanenta botanica Linnuei.)

3634 Methodi Linneanae botanicae delineatio. Lugduni 1790. 8. a.

$3635^{*}$ _.... Exercitia phytologica, quibus omnes plantae europaeae, quas vivas invelit in variis herbationibus seu in Litthuania, Gallia, alpibus, analysi nova proponuntur, ex typo naturae describuntur, novisque olsservationibus aut figuris raris illustrantur; additis stationibus, tempore llorendi, usilus nedicis aut oecouomicis, propria auctoris experientia natis. Lugduni Gallorum, Delamollière. 1792. Il voll. 8. - I: Plantae lithuanicae cum lugduneusibus comparatae: Lxxx p. ct p. 1-388. - II: Caeterae plantae lithuauicae cum lugdunensibus comparatae: p. $391-655$.

Liber quasi supplementum systematis plantarum Luropae considerari potest. Mullae intercurrumt tabulae absque signatura, quarum plurimae sunt Inedirae Richeri de lielleval, aliae c Loeselio et Vaillantio sumtae.)

$3636+$ Methodi Linncanac botanicae delineatio, exhibens characteres essentiales generum nec non specierum etc. apus herbationibus acconodatum. Lugduni, typ. Bruyset. s. a. 8. xxiv, 482 p.i 3 tab. sign. $\mathbf{L}-\mathbf{X l}$.

$3637 \div$ - Histoire des plantes d Europe et etrangères les plus conmunes, les plus utiles el les plus curieuses; ou èlémens de botanique praticuse. Seconde edition revue corrigée, considerablement 
augmentée et ornè de plus de 800 figures gravées sur bois et de 50 (al). en taille-douce. Lyon, Lerey, 1806. III voll. 8. - I: xxxu,

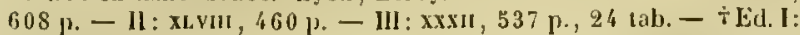
i). 1798.11 voll. 8 .

3638† (Gilibert, Jean Emmanuel.) Tableau des plantes à démontrer dans le jardin botanique do Lyon. (Lyon) 1801.8 .71 p.

$3639^{*}$ Le Calendrier de Flore pour l'année 1778 autour de Grodno et ponr l'anncic 1808 autour de Lyon. Lyon 1809. 8. vili $88 \mathrm{p.},+\mathrm{tab}$.

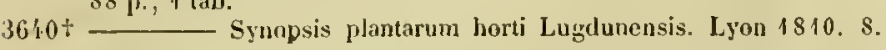
$36 \mathrm{p}$.

36 Gille, Arnold, latine Gillenius. Hortus. Cassellis 1627.4. H. 1632. 4. S.

(Catalogus brevissimus, solorum nominum, abstque synonynis ct induntalionibus.)

$3612+$ Gillet de Laumont, François Pierre Nicolas. Sur la fructification du Phornium tenax ou lin de la nouvelle Zélande à Cherlourg et a Toulon: sur la germination particulière de ces graines et laur culture. (Paris) 1824.8. 8 p.

3643 t Ginanni, Francesco, Conte. Delle malatie del grano in erba Irattato storico-fisieo, con note perpetue ad esso trattato e con altre osservazioni di storia naturale del medesimo autore. Pesaro 1759. 4. xviu, 426 1., 8 tab.

36.4 . Istoria civile e naturale delle Pinete Ravennati elc. opera postuma. lioma 1774.4.478 p., jraef., 18 rab.

$3615^{*}$ Ginanni, Giuscppe, Conte. Opere postume (tomo 1.) nel quale si contengoulo 114 piante (Algao et Zoopliyta) che vegetano nel mare adriatico. Veneria 1755 , folio, (10), xIx, 63 J., 55 tab.

(Volumen 11. omnino zoologici est argumenti.)

3646* Gingins de Lassaraz, Frédéric Charles Jean, Baron. Mèmoire sur liı famille des Violacées. Genève $4823,4.28$ p., 2 tab.

$3647^{*}$ Ilistoire naturello des Lavandes. Genève 1826. (in calce: 1827.$) 8$. vil , $188 \mathrm{p} ., 11 \mathrm{tab}$. in $4 .(7 \mathrm{fr} .50 \mathrm{c.})$

$3643^{*}$ Giobert, Giovanni Antonio. Trattato di agricoltura, fisic a chimica etc. Opera corenata. Torino 1790 . II voll. 8. - I: $347 \mathrm{p} .-$ II: $216 \mathrm{p}$.

$36497 \longrightarrow$ Traité sur lo Pastel (Isatis tinctoria) et l'extraction de son Indigo. Paris, de l'imprimerie impériale. $1813.8 . \times x, 411 \mathrm{p}$., 4 tab.

$3650 t-$ Del sovescio e nuovo sistema di cultura fertilizzante senza dispendio di concio. Torino, typ. Balbino. 4819. 8. 84 p., ind. - ${ }^{*}$ Seconda edizione. Milano, typ. Silvestri. 1819 . 8. Iv, $94 \mathrm{p}$.

$3651^{*}$ Del sovescio di segale. Lettere dilucidative e comenti. I-VI. Torino $\$ \$ 19.8,37,37,60,60,20,44$ et $66 \mathrm{p}$.

(Adharet: Risposta rlel Conte Curlo l'erri alle letlere dilucidative sul sovescio di segale (i $G$. A. Giobert. Milano $1819.8,50 \mathrm{p}$.

$3632+$ Giordano, Antonio. Cenno fisiologico-chimico sulla decolorazione delle foglie in autumuo e della loro caluta. Torino, typ. Varcelotti. 1835. S. 56 p., 1 schema. Bibl. Horti Paris.

$36: 33$ * Giordano, Ferdinando. Memoria su di una nuova specie d'Jbisco. (Hubiscus hakeaefolius Giord.) Napoli 1833.4. 8 p., 1 tab.

365\%* Osservazioni sopra una nuova specie di Emhothrio. Napoli 1837. 4. 10 p., 1 tab.

3603 ijt Girardi, Michele. Do uva ursina ejusque et aquae calcis vi lithonthryptica novae animadversiones, experimenta, observationes. $\mathrm{Pa}-$ Lavii, 1yp. Coozatti. 1764. 8. 173 P., 2 sab. Bibl. Webb.

$36566^{t}$ Girardin, $J$. et Jules Juillet. Nourrau Nanuel de botanique, ov principes élémentaires de physique végétale. Paris 1827. 12. v1, 610 p., 12 tab. ( 5 fr. 50 c. - col. 6 fr. 50 c.)

$30.57 \div-$ Sur le Madia oleifere (Malia sativa) documents recueillis sur la culture et les avantages de cette plante. Rouen 1841.8. $48 \mathrm{p}$.

$3638 \div-$ et $A$. DuBreuil. Deuxiène mémoiro sur la pomme de terre, détermination des meilleures variétés à cultiver dans chaque espèce de sol. Rouen $1841,8.51$ 1\%, 1 tableau.

$36.59+$ (Girin, Jean.) De l'usage du caphe, du the et du chocolate. Lyon, cliez Jeao Girin. 1671. 12, 188 p., praef.

$3660^{*}$ Girod-Chantrans. Recherches chimiques et microscopiques sur les Conferves, Bisses, Tremelles ctc. Paris 1802. 4. viI, 154 p., 36 tab. col. ( 18 fr.)
3661 t Girod-Chantrans. Essai sur la géograplue physique, le climát et I'histoire naturelle du departement du Joubs, ouvrage atpproure par la classi des sciences physicjues et mathematiques de l'Institut, "t dans lecpurl on tronve une cryptogamie enrichie de la deseription d'un grand nombre d'espeeces inédites. Paris 1840 . II voll. 8. - I: xxv1, 303 p. - II: xiv, 432 p. ( 10 fr.)

$3662 \div$ Girou de Buzareinges, Charles. Nimoire sur l'évolution des plantos et sur l'accroisscment en grosseur des exogènes. Paris 1833. 8.31 p., 4 tiib.

(Extrait des Annales des sc. nat. tome Xxi.)

$3663^{*}$ Giseke, Paul Dielerich. Systemata plantarum recentiora. I). Goeltingae $1767.4 .54 \mathrm{p}$.

$3664^{*}$ - Index Limeanus in Leonhardi Plukenetii Opera botanica. Accessere viriac in ritum et opera Plulenetii observationes partim ex ipsius manuscriptis. Index Liuneanus in Jnannis Jucobi Dilleni historiam muscorum. Hamburgi, typ. Mleyn. 1779. folio. $x, 46 \mathrm{p},-$ * Manburgi, typ. Megn. 1779. 4. x, 39 p.

$3663^{*}$ — Tabula genealnico-geographica affuitatum plantarum secundum ordines naturales Linnaci delineat it. 1789. I tal. folio max. $3666^{*}$ Theses botanicae in usum auditorum typis exscriptac. llamlurgae 1790.8.51 p.

(In bibliollecta Bauksiana 111. 68. Jegitur: Jconum plaotarum a P. D. Giselie, Joh. Dominico Schulee, A. A. Atendroth of J. No Buek cidi. tirum adest fosciculis primus, ectypa coutinens $20 \%$, absque litul\%. llamburai 1777. folio.)

$3667^{*}$ Glaser, Friedrich Reinhold von. De virtute et vi medica Lepidii ruderalis $\mathrm{L}$. in morbis tum internis tum extonis adhibiti. D. Dorpati 1816. 8. xv, 64 p.

3668 Gleditsch, Johann Golllieb. Catalogus plantarum, quae tum in horto Domini de Zieten Trebnizii coluntur, tum et in vicinis locis sponte nascuntur. Lipsiae 1737. 8. $152 \mathrm{p}$. B.

$3669^{*}$ Consideratio epicriseos Siegesbechianae in Linnaei ststema plantarum sexuale et methodum botinicam liuic superstnictam. Berolini $1740.8 .36, \operatorname{ccxx}$ p. $(1 / 3 / h$.

$3670^{*}$ Dissertatio inauguralis de methorlo botanica, dubio et fallaci virtutum in plantis indice. Francofurti a/ $T$., typ. Schwartz. 1742. 4.48 p. $-{ }^{*}$ E(l. II. Lipsiae, typ. Langenhem. 1749. 4. (4 foll.) 48 .

$3671^{*}$ Lucubratiuncula de fuco subgloboso, sessili et molli; in Narchia electorali viadrina el ejus viciniis reperiundo. Berolini 1743. 4. $28 \mathrm{p}$.

* germanice: Von der Kugelpflanze, oder der sogenannien Seepflaume in der Mark Brandenburg. In Gleditsch, Physik. bol. okon. Alhandilungen, 111. [., 1-16.

$3672^{*}$ Methodus l'ungorum, exhilens genera, species et varietates cum charactere, differentia sprecifica, synonymis, solo, loco et observationibus. Berolini 1753.8 .162 p., ind., 6 tab. $(1 / 4 / h$.

$3673^{*}$ - Systema plantarum a staminum situ. Berolini 1764. S. CIV, $323 \mathrm{p} .(1 / \mathrm{h}$.

$3674^{*}$ Vermischte physikalisch-botanisch-okonomische AbJandlungren. Halle 1765- 1767. 3 Bande. 8. - I: 1765. 318 p., 2 tab. - II: 1766.440 p., 2 tab. - III: 1767.397 p., 1 tah. (3 th.) $3673^{*}-$ Vermischte Bemerkungen aus ter Arzneiwissenschaft, Kräuterlchre und Oekononie. Erster Theil. Leipzig 1768. 8. 230 p., 1 tab. $(2 / 3 \ell h$.)

3676 Anleiung zu einer Erkenntniss roher Arzneimittel. Berlin 1768. $8 .\left(1 / \frac{1}{3} / \mathrm{h}.\right)$

$3677^{*}$ Nphabetisches Verzeichniss der gewolnlichsten Arzneigewichse, ihrer Theile und rohen Produkte, welche in den grössten deutschen Apothehen gefunclen werden. Berlin 4769. S. x, 480 p., praef., iod. $\left(1 \frac{1}{6}\right.$ th. $)$

$3678^{*}$ - Phanzenverzeichniss zum Nutzen und Vergnugen der Lust - und Baumgartner, nebst Amuerkungen, die deren Pfiege, Vermelirung, Pflanz- und Blutezeit betreffen. Berlin 1773.8.370 p. (1 lh.)

$3679^{*}$ Systematische Einleitung in die neuere Forstwissenschaft. Berlin 1775.2 Hande 8. - 1:544 p. - 11:677 p. (3 th.)

$3680^{*}$ Vollstandig theoretisch-praktische Geschichte aller in der Arznei und Haushaltung nutzlich befundnen Pflanzen. Erster Band. Berlin 4777. 8. x.x.I, 623 P. (1 $/ 2$ th.)

$3681^{*}$ - Einleitung in die Wissenscluaf der rolıen und cinfaclien Arzneimittel. Berlin und Leipzig 1778-1787. 4 voll. 8. - I: 1778. $568 \mathrm{~J} .-$ II: 1. 2. $4779-1781.618,46:$ p. $(51 / 3 \mathrm{th})$ 
3682 Gleditsch, Johann Golllieb. Physikalisch okonomische Betrachtung uber den Haideboden in Jer Mark Brandenlurg, dessen Erzeugung, Zerstorung und Entblössung des daruater stehe日den Flugsandes, nebst einigen darauf gegründeten Gedanken, einen dergheichen Flugsand durch Wiederherstellung seiner naturlichen Erd- und Rasendecke fest und stehent zu machen. Berlin und Leipzig 1789.8 .78 p. B. $(1 / 2 / h$.

$3683^{*}$ —_- Bntanica mediea, oder die Lehre von den vorzüglich wirksamen einheimischen Arzoeigewachsen, zu ollentlichen Vorlesungen fur angebende Aerzte bestimmt. Herausgegehen von $F$. II: A. Luders. Berlin 1788-1789. 2 Theile. 8. - I: 1788, xII, $460 \mathrm{p}$. - II: 1789.420 p., incl. $(12 / 3$ th. $)$

368 * $^{*}$ _- Vier lointerlassene Abhandlungen, das prahlische Forstwesen betreffend. Herausgegehen nit Forrede von Kart Abrahan Gerhard. Berlin 17SS. S. $\$ 1,144$ p., I tab. (Alous quercifolia Gled.) $(1 / 2$ th. $)$

$3683^{*}$ Vermischte botanische Abhandhngen, herausgegeben und mit einer Vorrede versehen von Kart Abraham Gerhard. Berlin 1789. IV voll. 8. - I: 258 p., 2 tab. - II: 296 p., I tab. - III: 248 p., 2 tab. - IV: 1790. 162 p. (2 (h.)

$3686^{*}$ Gleichen, genannt Russwurm, Wilhelm Friedrich, Freiherr von. Das Neuste aus dem Reiche der Pflanzen oder Mlikroskopische Untersuchungen uod Beobachtungen der geheimen Zeugungstheile der Pflanzen etc. Nit Kupfern von Johann Christoph Keller. Numberg 1764. folio. $72,40,26$ p. 45 tab. col. $(162 /, t h$.

$\div$ gallice: Decourertes les plus nouvelles dans le regne végetal ou Ohservations microseopiugues sur les parties de la generation des pluntes renfermens dans lenrs fleurs. etc. Traduit de Tallemand pa J. F. Isenflamm. (Nomberg et Paris) 1770. folio. 76, 48,2 k., praef. e tab. col. $1-\ddot{0}, A-E, 1-30$. et $1-10$.

$3687^{*}$ Auserlesene mikroskopische Entdeckungen hei dee Planzen, Blumen uod Bluten, Insecten und andern Alerkwordigkeiten. Nurnberg 1777-1781, 6 Hefte. gr. 4. 160 p., 83 tab. col. effigies autoris. $(142 / 3$ th. $)$

t.gallice: Ohservations microsconiques sur los parties de la génération des plantes, renfermées daus les fleurs etc. Traduit de iallemand par J. F. Lsenflamm. Nürnbers 1790 . folio. 48,24 p., praef. 51 tal,. col.

$3688^{*}$ Glocke, Georg Johann. De Secali cornuto ejusque viribus medicinalibus. D. Dorpati 1837. $8.60 \mathrm{p}$.

$3689^{*}$ Glocker, Ernst Friedrich. Versuch üher die Wirkungen des Lichtes auf die Gewachse. Breslau 1520. 8. vill, 207 p., ind. $(2 / 3 / h$.

$3690^{*}$ Gloxin, Benjamin Peter. Observationes botanicae. D. Argentorati 1785.4. 26 p., 3 tab.

$3691^{*}$ Glumm, Joseph Anton. De Chelidenie majori. D. Duishurgi 4786. 4. $18 \mathrm{p}$.

3692 Gluthorst, Erdmann von. Die Kultur der Georginen, Nelken und Hortensien in ilirem ganzen Linfange. Nach Paxlan, Piralle, van Reider, Gerhurd, Rüssig, Basse etc. Nordhausen 1842. 8. $9 \frac{1}{2}$ Bogen. $(5 / 12$ th.

$3693 \div$ Gmelin, Christian Golllob, pr. Chenische Untersuchung der Seidelbastrinde. D. (F. L. Baer.) Túbingen 1822.8 .37 p.

$3691 \div$ Gmelin, Ferdinand Golllob, pr. De plantarum exhalationilsus. D. (auctor Johann Lulwig Palmer.) Tuebingae 1817. 8. $45 \mathrm{p}$.

$369 a^{*}-$ Veher das Winden der Pflanzen. Eine hotanisch plysiologische Abhaodluag und 1826 gehronte Preisschrift (autor Ludwig Heinrich Patm.) Tubingen 1827.8. 101 p., 3 tab. ( $/ / 12$ th.)

$3696^{*}$ Gmelin, Georg Friedrich. De consenic日tia plantarum in fructificatione et viribus. D. Tucbingae 1699. 4. $16 \mathrm{p}$.

(Dissertatio inauguralis praeside Rudolpha Jacabo Camerario proposita est.

3697* Gmelin, Johann Friedrich. Irritabilitas vegetabilium in singulis plantarum partibus explorata, ulterioribusque experimentis confirinata. D. Tuebingae $1768.4 .30 \mathrm{p}$.

(Dissertatio inauguralis praeside Ferdinando Christophoro Octinger proposita, reimpressa est in Ludwig, Delect. opusc. Vol. 1. 1).272- - (twy )

$3698^{*}$ - Enumeratio stirpium agro Tubingensi indigenarum. Tuelingae (1772). 8. $16,334 \mathrm{p}$, ind.

$36 ! 9 *$ (- Onomatologia botanica completa, oder vollstandiges botanisches Wörterluuch. Frankfurt u. Leipzig 1772-1778. 10 Bde. 8. 1044, 1120,1080,1108,1034,1004,974. $836.672,1147 \mathrm{p}$. $\left(13^{5} / 5, h\right.$.
$3700^{*}$ Gmelin, Johann Friedrich. Abhandlung von den gifligen Gewachsen, welche in Teutschland und vornehmlich in Scluwaben wile wachsen. Ulm 1755. 8. $228 \mathrm{p}$. - I'Im 1805. 8. ( $1 / 2$ th.)

$3701^{*} \longrightarrow$ Allgeneino Geschichte der Pfanzengifte. Nurnherg 1777. 8.525 p., praef. - ${ }^{*}$ Zweite vermelırte Auflage. Nurnberg 1803 . 8 . $\mathrm{x} 11,852 \mathrm{P} \cdot\left(2^{5} \%\right.$ th. $)$

3702 Ahhandlungen von den Arten des Unkrants auf den Aeckern in Schwaben, und von dessen Benutzung. Nebst einer Zugabe von der Ausrottung desselben, und von einigen Werkzeugen zur Reiuigung des Saathorns, yon J J. II A, D. Lubeck 1779 \&. 405 p. B.

Libellus Gmelini: p. 1-160. - Appendix: p. 161-108.

3703* Gmelin, Johann Geory. Flora silsirica, sive historia plantarum Siliriae. Petropoli 1747-1769. IV voll. 4. - I: 1747. cxxx, 221 p. incl., 50 tab. - II : 1749. xxiv, 240 p., ind., 98 tab, - III: 1768 276 p., ind., 84 tab. $-15: 1769.214$ p., 84 tab. $\left(11 \frac{1}{4}\right.$ th. $)$

(Jolumen tertium et quartum, Joanne Geargio anno 1733 martue prodiernnt o recensione samuelis Gollieb Gmelin. athtoris e fratr. ilii. Folunen (juintum eperis, plantas complectens cryptogimas, nuncluam prodiif.)

$3702^{*}$ - Sermo acndemicus de novorum vegetabilium post creationem divinam exortu. Accedit Rudalphi Jacabi Camerarii de sexu plantarum epistola. Tuebingae $4749.8 .148 \mathrm{p}$

Programma continens vitam Grnelini: p. $1-39$; scrmo ipse: 1 . 40 -82 ; Camerarii epistola: p. $83-148$.)

$3703^{*}$ —_ Reise durch Sibirien von dem Jahre 1733-1743. Goltingen $1751-1752.4$ Theile. $8.467,652,584,692$ p., 4 chartif geogr.

3706 pr. Rhabarbarum officinarum. D. Tuebingae 1752.4. 32 p. B.

3707 pr. De Coffee. D. Tuebingae 1752. 4. 16 p. B.

3708* Gmelin, Karl Christian. Consideratio generalis Filicun. D. Ellangae $4784.4 .63 \mathrm{p}$

$3709^{*}$ lilora Badensis alsatica et confinium regionum cis el transrheoana plantas a lacu bodamico usquo ad confluentem Mosellae et Rheni sponte nascentes exhibens, secuudum systema sexuale cum iconibus ad naturam delineatis. Carlsruhae 1805-1826. IV roll. 8 . - I: 1805. xxxir, 768 p., 5 tab. - H: 4806.747 p., 5 tab. - III 4808. 795 p., 4 tab. - IV: Supplementa cum indicibus. 1826. $507 \mathrm{p}$. 10 tab. $(12 \%$ th. $)$

$3710^{*}$ (—— Hortus Magni Ducis Badensis Carlsruhanus. Carlsrubae 181 1. $8 . x, 285 \mathrm{p}$.

3711 Nothlulfe gegen Mangel aus Misswachs, oder Beschreibung wildwachsender Pflauzen, welche bei Mangel der angebauten als ergiebige und gesunde Nahrung gebraucht werden können Carlsruhe $1817.8 .\left(1 \frac{1}{3}(\mathrm{~h})\right.$.

$3712^{*}(\longrightarrow$ Beschreibung der Mlilchblatterschwamme in Baden und Jessen nächsten Umgebungen. Carlsruhe 1825. 8. 29 p., 1 tal. col $(3 / 8$ (h.)

$3713^{*}$ Gmelin, Philipp Friedrich. Otia botanica, quibus in usum praelectionum academicarum definitingibus et observationibus illustratum reddidit Prodromum Florae Leydensis Adriani vun Rayen, qui plantas terra marique crescenies methodo naturali digessit. Tubingae 1760.4 .200 p., ind.

$3714^{*}$ _ jr. Botanica et chemia ad medicam applicata praxin per illustria quaedam exempla. D. Tubingae 1755.4.30 p.

$3715^{*} \longrightarrow$ pr. Fasciculus plantarue patriae urbi (Reutlingae) vicinarum, sponte crescentium cultnrarumque, cum usu omni earunden plebejo. D. Tubingae 1764. 4. $32 \mathrm{p}$.

$3716^{*}$ - pr. De materia toxicorum hominis vegetabilium simplicium in medicamentum convertenda. D. Tubiagae 1765.4. $32 \mathrm{p}$.

$3717^{*}$ Gmelin, Samuel Golllieb. Historia Fncornm. Petropoli 1768. 4. 6,239 p., 35 tab. sign. I-XXXIII. (5 $3 / 2$ th.)

$3718^{*}$ Reise durch Russland zur Untersuchung der drei Naturreiche. Petersburg 1774. 3 Theile. 4. - I: 182 p., 40 tab. - II 260 p. 46 tab. -111 : 508 p., 57 tal.

$3719^{*}$ Gochnat, Fr. Karl. Tentamen medico-botanicum de Cichoraceis Argentorati 1808.4 .24 p., 3 tab.

$3790 \div$ Godefroy, $F, F$. Lissai sur la formation des substances vẻgétales. These. Strasbourg $1818.4 .20 \mathrm{p}$

3721 Godin, Leopold. De Cumphora. D. Leodii 4823, 8. 28 11. 
3722* Godron, D. A. Essai sur les Renoncules à fruits ridés transversalement. Nancy $1840.8,36$ p., 2 tal,.

Extrait des Némoires de ta soc. royale des seiences, lettres et arts de Xancy, pour $18: 19$.

3723 " Quelques olsservations sur la famille des Alsinées. Naney 1842.8. 21 J. (1 fr. $25 \mathrm{c.}$ )

372 f $^{*}$ - Nonographin des Rubus, qui croissent naturellement aux environs de Nancy. Nancy 1843.8 .45 p. ( 1 fr. 50 c.)

$3725+$ Flore de Lorraine (Meurthe, Muselle, Meuse, Vosges). Nancy 1843-1844. III voll. 8. - I: 1843, xxiv, 330 p. - II : 1843. 305 p. $-111: 1844.274,81$ p. $(12$ fr. $)$ - Tremier supplément. 1845. $31 \mathrm{p}$.

$3726+$ Catalogue des plantes cellulaires du Département de la Meurthe. Namey 1843.8.40 p.

(Extrait de la statistique du bej. de la Meur(he, publiée par Ilenri Lepage.

$3727 *$ Denr l'hybridité dlans les végétaux. Tlıèse. Nancy 1844. 4. $22 \mathrm{p}$.

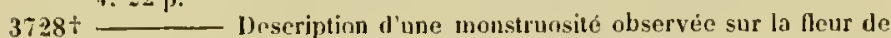
plusienrs Crueiferes. Naucy 1845, 8, 14 p., 1 tab.

$3729^{*}$ ___ Note sur le Dianthus virgineus de Linne. Naney 1846. 8. $17 \mathrm{p}$

(Wiratil des Mén. de la sac. royale dies sciences, lettres et arts

$3730^{*}$ de Xamey.) De l'existence aux environs de Sarrebourg (Meurthe) d'une plante propre aux terrains saliferes. Naney $4846.8 .12 \mathrm{p}$.

$3731^{*}$ Goebel, harl Christian Traugott Friedemann und Gustav Kunze. Pliarmaceutische Waarenkunde, mit illuminirten Kupfern nach der Natur gezeicbnet von Ernst Srhenk. Eisenacb 1827-1834. 2 I3inde, 4. - I: 1827-1829. I Ieft 1-6: Die Rinden und ihre Parasiten aus der Ordnung der Flechten. vII, 240 p., 31 tab. col. - Il: $1830-183 i$. Ileft $7-14$. Die Wurzeln. vilr, 300 p., 40 tab. col. $(18 \%$ th.

Fasciculum I-V Friedemann Goebel, 17-XIN Gustav Kunze curavit.)

- Reise in die Steppen des sudlichen Russlands, in Begleitung der ILerren Dr. Karl Claus und A. Bergmann. Dorpat 1837 -1838. 2 Theile. 4. - I: 1837. xiv, 325 p., 12 tab. topogr. - II : 1838. vit, 372 p., 6 tab. botanicae. ( 15 th.)

Ifae duodeviginti tabular el mappil geographica in fasciculo segingato magna quarta formil continentur.

3733* Goebel, Gustau Otto. De Colehico autumnali. D. Lipsiae 1843. 4. $27 \mathrm{P}$

373!* Goebel, Severinus. De succino libri duo. Ilorum prior liber continet piam commonefactionem, de passione, resurrectione ac beneficiis Christi, quae in historia succini depinguntur. Posterior veram de origine succiui addit sententian. (Francofordiae a/M. 1558.) 8. 37 foll, sign. $\mathrm{e}^{4}-\mathrm{i}^{5}$. Bibl. Univ. Lips.

373̈̈ Goelicke, Andreas Ottomar. De balsamo eacao. D. Francofurli a/V. 1723.4. H. - ib. 1736. 4. Desid. B.

$3736^{*}$ — De Onnpordu carcinomalis averrunco. D. Francolurtia/V 1739. 4. $32 \mathrm{p}$.

3737 Goeller, Christoph Ludwiy. De Cinnamomn. D. Trajecti a/R. 1709. 4. 32 p. B.

$3738^{*}$ Goeppert, lleinrich Jioberl. Nomulla de plantarum nutritione. D. Berolini 1825. 8. $35 \mathrm{p}$.

$3739^{*}$ De acidi hydrocyanici vi in plantas commentatio. Vralislaviae 1827. $9.111,58$ p. $(1 / t$ th. $)$

37:0* Beschreibung dis botanischen Gartens der Königl. Universitait Breslaı. Mit dem Plane dos Gartens. Breslau 1830. 8. vut, 90 p., 4 tab. $(1 / 2$ th. $)$

$3741^{*}$ - Ueber die Warme-Entwickelung in den Pflanzen, deren Gefrieren und die Sehutzmittrl genen dasselbe. Breslau 1830. 8. xIv, 272 p. $\left(1 \frac{2 / 3}{3}\right.$ th. $)$

$37\left\{2^{*} \longrightarrow\right.$ Ueber den sogenanuten Getraide- und Schwefelregen. Breslau 1831, 8, $32 \mathrm{p} ., 1$ lab.

(Aus den Schlesischen Provinzialhlattern, Jan. und Febr. 18:31.

$3743^{*}$ Ueber Warmeentwichlung in der lebenden Pflanze. Eün Vortrag, gelialten zu Wien am 18 . Sept 1832 in der Versammlung deutscher Naturforscher und Aerzle. Wien 1832.8. 26 p. $(1 /+t h$.

$3744^{*}$ Ueber die Bestrehungen der Schlesier, die Flora der Vorwelt zu erláutern. Breslau 4834.8. $26 \mathrm{p}$.

(dus den schles. Provinzialhlältern, Aug. und Sepl. 183k.)
3746" Goeppert, Heinrich llobert. Die in Schlesien wildwachsenden uffizinellen P'llanzen. Eiuladungsprogramn. Ireslau 1835.8 .49 p.

$3746^{*}$ ( Dank und Bjitte an die Schlesier. (Breslau 1835.) 4.6 p. (Aus den Verhandlungen der Schle's. Gesellschart fur 1835.)

$377^{*}$ — Systema Filicun fossilium. Dia fossilen Farrenkráuter lireslau und Houn 1836. gr. 6. xxyII, 486 p. 44 tab. $(8 \%$ th.

(Sistit simul supplementum voluminis XVII. Nove, Act. Acall. Caes Leop. Nat. Cur.

$3748^{*}$ L Ueber den Zustand, in welchen sich die fossilen Pllanzen befinden, und uber den Versteinerumgsprozess inslesondre. Lemgn 1837. 8. 17 j.

(ilisondrer Abdruck aus dem Arehiv Jer Pluarmacic II. Heihe IX. Bandes il. lirift.)

$3749^{*}$ - Uebersicht der bis jetzt behannten fiattungen der fossilen Pflanzen. (Ifalle 1837.) 8. $30 \mathrm{p}$.

Aus Germar's Lalurhuch der gesanmtin Nincralogio

$3750^{*}$ De lloribus in statu fossili. Commentatio botanicis. Iralislaviae 1837. 4. 28 p., 2 tab.

$3731^{*} \longrightarrow$ De Coniferarum structura antonica, Vratislaviae 1841 4. v1, $36 \mathrm{p}, 2$ tals. $(2 / 3$ th.

$3752^{*}$ Ueber die fossile Flora des Quadersandsteins von Schlesien und der Ungegend von Aachen; als erster und zw eiter lisilray zur Flora der Tertiärgebilde. Breslau 1341.4. 38,26 p., 9 lab.

(Nov, Act. Acatl Caes. Leop. Nat. Cur, Vil. MII. 2.

$3753^{*}$ Ucber die fossile Flora der Gsusformation zu llirselecl in Oberschlesien, als dritter Beitrag zur Flora der Tertiargebilde. Breslau 1842, 4. 12 p., 2 tab.

(Xov. Act. Aead. Caes. Leop. Nal, Cur, vol. XII. 2.

3754" Die Gattungen der fossilen Pflanzen, verglichen mil denen der Jetzlwelt wnd durch Abbildungen erláutert. Les genres les jlantes fossiles comparés avee ceux du monde moderne expliqués par des figures. Boun 1841 - 1845. Fasc. I-VI. 4 obl. $(1 \geq 0$ p., 55 tab.) (8 th. $)$

$3750^{*}$ - Beobachungen uber das sogenanute Ueberwallen der Tannenstocke lür Botaniker und Forstmánner. Bonn 1842. 4. vi, 26 p., 3 lab. $(1$ th. $)$

3756 * Zur Erláuterung eines Vortrags uber den Bau und das Wachsthum der Baume, gehalleu den 10. Juni 1843. in selılesischen Forstvereine zu Carlsruhe. (Breslau 1843.) 4. I fol., I lab.

$3757^{*}$ U Uebersicht der fossilen Flora Schlesiens. (Breslau 1844.) 8 .

(Aus Vilimmers Flora von Schlesien 181'. 8. p. 139-22\%.)

$3758^{*}$ — und Georg Karl Berendt. Der Rernstein und die in ihun belindliehen PRanzenreste der Vorwelt. Berlin 1845. folio. IN, 125 p., 7 tal, pro parte col. $\left(4 \frac{2}{3}\right.$ th. $)$

Haec est sectio prima mominis prioris operis universalis de succino, quod inseribitur: "Dje im Bernstein belindlichen organischen Reste der Forwelt, gesammelt und in Verhindung mit Mehrerell bearheitet und herausgegeben von Dr. Georg Karl kerendt. " In hac nostra sectione cuntinentur: "Das Bernsteinland, der Berustein, tie organiseben Bernstein-Einschlusse im Altgemeinen, von Berendt? der Bernsteinbaum, und Cebersicht der his jetzt behannten in und mil dem Rernstein vorkommenden vegetabilischen heste, und Erhlärung der Tafelu, volt Goeppert.)

$3759^{*}$ Goethals, Franz Joseph. De Digitali purpurea. D. Gandavi 1829. 4. $25 \mathrm{p}$.

$3760^{*}$ Goethe, Johann Wolfgang von. Versuch die Metamorphose der Pllanzen zu crklären. Gotba, bei Carl Willelm Ettinger. 1790. gr. 8. ( 3 foll.) 86 p. $(3 / 8$ th. $)$

(llauc haheo editionem prineipem, eujus ipse possiden exemplar cm autngrapho Goethii. Alia enim adest editio, quam vidi in hibliothrea Hndriuni de Inssieu, el quam in bibliopaliis venalen offendi minori duoteceme rorma zy pasinarum, minori claractere escusus, cuare eundem zerit amum it frente. cujusis bibliopolac frandé puan rest gart $x$. 1. p. T-60, in soretiana editione germanieo-galliea,

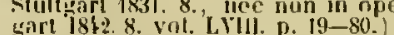

t gallice: Essai sur la méthamorphose des plantes par J. II: de lineihe, traduit de l'allemand sur l'edition originale de Gothil (1790\% par M.' Frederic de Gingins-Lassaraz. Genève 1829. 8. 87 p. ginsii.)

Iluic tradietioni praecedit introdnetio historico-literaria fin-

- gallice et gernanice: Essai sur la métanorphose des plantes. Traduit par Frederic soret. ol suivi de notes historiques. stultgart I831. 8. 239 p. $11 / 6(h$.)

*ifalice: Saggio sulla melamorfosi delle pianle di $G$. ll: Goethe, tra-

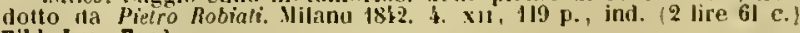
Bibl. Imp. Ferd.

$\div$ epilome anglica: All sssay on the development and modifieations of the evernal organs of plants. Campiled chiclly from the writings of John Woulfang ton Goethe, for a public lecture to the elass of the 
Chester county cabinet of natural seience. WestChester, Pennsylvania. 1839. 8. 38 p. Bibt. Cand.

376.1* Goethe, Johann IVolfgang von. Znr Naturwissenschaft uberhaupt, besonders zur Norploologie. Erfahrung, Betrachtung, Folgerung dureh Lebensereignisse verbunden. Stuttgard und Tübingen 1817-1824. 2 Bande oder 6 Hefte. 8. - J: Ileft 1-4. 1817-1822. xxxu, 368,384 p., 3 tab. - Il: Heft I-2. 1823-1824. 160, 220 p., 6 tab. $\left(6^{1 / 3}(h)\right.$.

(Insmnt: Zur Morphologie 1. 1. p. I-xrxu: Bas Unternehmen wird nutschuldigi; die Absicht eimgeleitet; der Inhalt hevortt ortet; Gesehichte meines batanischen sturtiums; Entstehen des Anfsatzes uber die Metamorphose der Ptlanzen; $p .1-60$ : Versuch die Metamorphose der Ptlanzen zu erklaren; p.61-9it: Schicksal der IJandsehrift; Sehiek. sal der J/ruchschrift; Entdeekung eines treffliehen Vorarbeiters; glnekliches Ereigniss. - I. 2. 1. 177-14: Drei gunstige Recensionen; andre Freundichkeiten; Nacharbeiten und Sammlungen. - I. 3. p. $28 \%$ -304: Verstáubung, Verdunstung, Vertropfung. - - 1. t. p. 355-328.

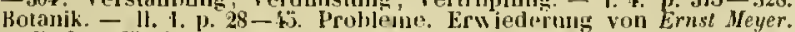
- II. 2. p. 63-83. Jrrwege eines morphologisirenden Botanikers; inber

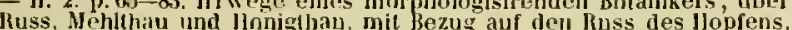
von chr. Goltried Nees von Escribeck. - 11.2. p. 156-160. Ueber Martius Genera el speeies Palmarum, voll Goethe.

"gallice: Geuvres d'histoire naturelle de Guethe, comprenant divers mémnires d'anatomie comparie, de hotanique el de géologie, traduits et annotes par Charles Fr. Martins. Avee un Atlas in folio, eontenaut les planches nriginales de f'auteur et enrichi de trois dessins et d'un tevte pelicatif sur la métanorphose des plantes par $P . j . F$ Turpin. Paris 1837. 8. vil1, $468 \mathrm{p}$. et Atlas in folio: 79 p. 7 tab. (20 fr.) (Rapport sur cel onvrage pir Augusle de Saint-Hilaire: Comptes remkis de l'Acad. des se. 20 aoùt 1838.)

(Cf. Charles Fr. Ifartins: "La Melamorphose des plantes de Goethe at la loi de symétrie d'Aug. Pyramus de rantolle, n Revue indépendante tome Vil. p. 38-60. - Erust Meyer: "Die Metamorplinse der plauzen und inre widersacher, " limaca ill. 1832. p. 401-60.)

$3762^{*}$ Goetz, Georg Heinrich. De eruditis hortorum eultoribus, von gelehrten Gärtnern. Lubeccae 't Lipsiae, Haase, 1726. 4. 24 p.

(Libellus primum Luheecae 1706. 4. impressns est.)

3763* Goetz, Georg Max Theodor. Abbildıngen der vorzïglichsten in Deutschland einheimischen und einheimiseh gew ordenen Giftplanzen. Weimar $1817,8,34$ p., 4 tah. eol. $(1 / 3$ th. $)$

3764* Goetz, Joseph Wichael. Systematica descriptin plantarum exolicarum offieinalium et obsoletarum. D. Viennae 1818. 8. vir, $69 \mathrm{p}$.

$3760^{*}$ Goez, Johann Christian. De Glyeyrrhiza. D. Altdorfii (1715.) 4. $35 \mathrm{p}$.

$3766+$ (Gohori, Jaques.) Instruction sur l'herbe Petum, ditte en France l'herbe de la koyne nu Mldieée: "W sur la raeine Meehiocalu. (Traduit de l'espagnol de Monardes.) Paris, Galiot dn Prẻ. 1572. 12. 31, 46 p., ic. ligno ine. i. L. Bibl. Juss. - eum versione gallica Aemitii Mucri. Rouen, Mallard. 1588. 8. Bibl. Maz.

3767* Gohren, $\mathrm{Fr}$. Ludwiy August Ilermann von. Medicorum priscorun de signatura imprimis plantarum doetrina. Commentationis de necessitudine quae inter morphologiam et plarmacologiam regni vegetabilis intercedit, pars prina. D. Jenae 1840.8 . 101 p. $(11 / 2$, th. $)$

$3768^{*}$ Gok, Karl Friedrich von. Die Weiurebe und ihre Früchte, oder Beschreibung der für den Weinhau wichtigeren Weinrebenarten nebst einem naturgemássen Classificationssystem. Ein Beitrag zur Naturkunde des Weinstoeks. Nit 30 nach der Natur gemalten $\mathrm{Ab}$ bildungen von Friedrich Seubert. Stuttgart $1836(-1839)$. folio. 18 106 p., 30 tab. col. sign. J. B. 1-XXVllI. $(251 / 2$ th. $)$

$3769^{*}$ Golberry, Silv. Meinrad Tavier. Fragmens d'un voyage en Afrique, fait pendant les années $1785-1787$ dans les contrées oceidentales de ce coutinent etc. Paris 1802. Il voll. 8. - I: 512 p. 2 tab. - Il: 522 p., 4 tab.

"germanice: Reisen dureh das westliche Afrika. Leipzig 1803. 2 Rde. 8. $\left(2^{2} / 3\right.$ th. $)$

3770* Goldbach, Karl Ludwig. Dissertatio Croci historiarn botanicomedican sistens. Mosquae 1816. 8. 54 p.

(Fjusdem "Inonographiac g'pneris Groci tentamen" in Ném. de la sne. des nat. de lloscou V. p. 1.2-Ifi.)

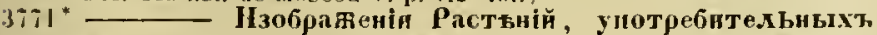
вт, медицин, сехьскомт хозяйствъ, художестваг\% и

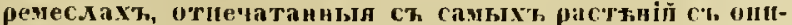
ганіелћ нх' вида И нользы. Москва 1823. II faseiculi. 4. - I: v1, 36 p., 10 tab. - II: 40 p., 12 tab. Bibl. Kunz.

fOpus de plantis officinalihus Rossiae morte autoris [t Moscuae 13 .Hart. 1821] inlerruptum.

3772* Goldenberg. Grundzuge der geoguostischen Verháltnisse und der vorweltlichen Fìna in der năchsten Umgebung von Saarbrüeken. (Scluulprogramm.) Saarbrucken 1835.4.32 p.
3773* Goldmann, J. Grundriss der Botanik. Ein Leitfaden finr den Unterricht auf höheren Schulanstalten. Berlin 1841, 8. vı, 98 p. $(1 / 3 / h$.)

3774* Gomes, Bernardino Anlonio. Observationes botanico-medicae de nonnullis Brasiliae plantis, quas patrio latinoque sermone exaratas regiae seientiarum Aeademiae offert. (Olsservaeōes hotanico-medieas sobrr algumas plantas do Brazil ete) Olisipone. typ. Acarlemiae seientiarum. 1803. II faseiculi. 4. - I: Iv, $46 \mathrm{p} ., 5 \mathrm{tab},-11: 55 \mathrm{p}$, 6 tal,. Bibl. caes. Vindob.

$3775 *$ (-) Nemoria sobre a Canella do Rio de Janeiro. Rin de Janeiro, na impr. regia. 1509. 8. 51 p. Bibl. Reg. Berol.

3776 * (- Modo de cultivar a Canelleira, extrahir e preparar a sua casca oleos, canfora ele. Rin de Janeiro, na impr. regia. 1809.8. 16 p. Bibl. Reg. Berol.

$3777 \div$ Gondinet. Dissertation eouronnée sur les questious suivantes ... et conme on doil étallir pour une des eauses des maladies (des betes) les plantes nuisibles qui infestent nos ditléreutes variétés de prairies et paturages, indiquer ees plantes par lenrs uoms hotaniques el vulgaires, et présenter les moyens les plus promls, les plus sủrs et les mains dispendieux de les détruire. Limoges 1808. 8. $256,4 \mathrm{p}$.

3778 Gore, Charles. The book of Roses. London 1837. 8.

3779 The Rose Faneiers Mannal. London 1838.8

3780 Gorham, G. C. Nemoirs of Jahn and of Thomas Martyn, Professors of botany in the university of Cambridge. London 4830.8 . ( $7 \mathrm{~s}$.)

3784 Gorter, David de. Florae Gelro-Zutphanica. Harderoviei 1745. 8. 204 p. - Florae Gelro-Zutghanicae appendix. ib. 1757. 8. p. 203 -254. B.

(Damorlier anuum editi appendieis 1747 iudlieat.)

3782 t - Elementa botanica methorlo el. Linnaei aceomnodata atque in usum anditorum evulgata. Harderviei 1749. 8.90 p., praef., 11 tal.

$3783^{*}$ Flora ingriea ex sehedis Stephani Krascheninnikow ennfecta el propriis observationibus aueta. Petropoli 1761 . 8. v111, $190 \mathrm{p}$. - Appendix ad Floram ingrieam, ih. 1764. 8. p. 191-204.

3784 - Flora belgica. Trajeeti 1767.8.418 p. B.

3785 - Florao belgieae supplementum primum (et alterun:). Trajecti 1768 et 1777.8 .20 p. B.

$3786 t-$ Flora septem provinctarum Belgii foederati indigena. Harleni 1781. 8. x, 378 p., effigies Gorteri

3787 Flora Zutplianiea. Zutphaniae 1781, 8. Dumortier.

3788 - Léer der Plantkunde. Eerste Deel. Amsterdam 1789. 8. (10) 362 p., 1 lab. Bibl. Reg. Brux.

(Compendium superveniente antoris morte $[t 1783]$ incomplemn.)

3789 Gorter, Jan van. Exarcitationes medieae quatuor. Anstelodami 1737. 4 .

(Spreng. IIist. rei herb. II. p. 413 .)

3790 t Gory, Charles Alexandre. Essai sur le tabac, consideré comme eause de maladies et principalement comme moyen thérapeutique. These. Paris $1820.4 .26 \mathrm{p}$.

3791 Gosse, Philipp Henry. The Canadian naturalist; a series of conversations on the natural history of Lower Canada. London 1840. 8. (12s:)

$3792 \div$ Gossin. Notice sur M. Ilenri de Cassmi, Pair de France. Paris, tỵ. Poussielgue. $1832,8,30 \mathrm{p}$.

3793* Gottschalck, Jakob. Catalogus plantarum lorti aeademici Lugduni Batavorum, eui aceedit nm solum index plantarum indizenarum, sed etiam appendix var. colorum aliarumgue rerum, d. i. Verzeichniss derjenigen Gewàchse ete. Plöen 1697. 8, 173 p.- 'zum zwejtell mal verbessert durch Jakab Gotschalken. Ploen 1704. 8. 179, 34 p. (latine et germanice.)

3794 Gottschalck, Zacharias. Flora hortensis, nder verzeigniss der garten-gewánse, so in deu berühmsten gátlen, zu Pariss, Londen, Leyden, Amsterdam, Cöthen, Leipzig, Gottortl und andern ortern iziger zeit sich befinden. latine et germanice. Cotluen 1703. \&. 329 p. B.

Gottsche, C. M. vide Chr. Gollfried Nees ron Esenbeck.

3795* Gouan, Auloine. Ilortus regius Monspeliensis, sistens plantas tum indigenas Ium exoticas Nr. 2200, ad genera relatas, cum etc. secundum sexualem methodum digestas. In gratiam philiatrorun Mouspeliensium. Lugduni 1762 . 8.548 p., ind., 7 tab. 
3796" Gouan, Autoine. Flora Monspeliaca, sistens plantas Nr. 1850 ad sua genera relatas et hybrida methodo dizestas; adjectis noninibus specilicis trivialibusque, synonymis selectis, hahtationibus jurium in agro Monspeliensi nuper detectarum, et earum quae in usis medicus veniunt uominibus pharnaceuticis virtutibusque probatissimis. Lugduni 1765.8 . xvi, 543 p., 3 tab.

$3797^{\circ}$ Jllustrationes et olservationes botanicae, ad specierum listorian facientes, sen rariorum plantarum indigenarum, pyrenaicarum, exoticarum idumbrationes, synonymorum reformationes, deseriptionum castigationes, varietatum ad species genuinas redactarun determinatimes. Cum icouibus ex naturne tyjo el magnitudine naturali ah anctore delineatis. Tiguri 1773. Folio. 83 p., 26 tab.

$3798+$ — Explication du systême hotanique du Chevalier von Linné; pour servir d'introduetious à l'étude de la botanique. ete. Montpellier 1787. 8, 72 p., 4 tab. - Ed. nova, inseripta: Nomenclature de hotanique, ou explication ete. Paris 1795.8. a.

$1799^{\circ}$ - Herborisations des environs de Montpellier ou guide botanique à l'usage des élèves de l'école tle santé. Ouvrage destiné a servir de supplément an Flora Monspeliaca. Monjpellier an IV. 1796. 8. xil, 174 P., I tab. geogr.

$1800^{*}$ Diseours sur les eauses du mouvement de la sève dans les plantes, Montpellier an VIII. (1802.) 4. $48 \mathrm{p}$.

$3801 \div-$ Traité de botanique et de matiere médieale, précédice d'une nouvelle édition de l'explication du systeme de Linné ou Nomenelateur botanique. Montpellicr 1804. 8. vı, 73, 146, 430 p. et effigies Gouani.

$3802 *$ Lettre a Mr. Deteuze en réponse à l'article "Botanique " insere dans le Monitour du $27 \mathrm{Oet}$. 1811. (Montpellier 1811.) 8. $15 \mathrm{p}$.

$3803^{*}$ Description du Ginkgo biloba dit Noyer de Japon. MIontpellier 1812.8. 11 p., 1 tab.

(Vidi exemplaria ufuarta forma impressa.)

3804 + Goube, J. J. C. Traité de la plysique végétale des bois. Paris 1801 . 8. xil, 326 p., 3 tableaux. (3 fr.)

$3803 \div \div$ Traité de la vie el de l'organisation des plantes. Rouen $1810.8 .1 \mathrm{v}, 308 \mathrm{p}$.

$3806 \div$ Gouffé de la Cour. Mémoire sur les régétaux exotiques qui peuvent étre uaturalisés dans les départemeus méridlionaux de la France, suivi de la liste des plantes rares qui ont fleuri el de celles qui ont fruetifie dans divers jardins de Marseille, principalemeut dans le jardin de hotanique ef de naturalisation de eette vilte. (Extrait des Mém. de l'Aeademie de Marseille.) 1813.8. $111 \mathrm{p}$.

3807 Gouffé de Troisvilles, Chevalier. Mémoire sur l'olivier. Marseille 1823.5 .64 p. a.

3808 Gough, Richard. An account of the Cedar of Libanus, now growing in the garden of Queen Elizabeth's Palace at Enfield. (London) 1788. folio. 4 p. B.

$3809^{*}$ Grabacher, Anton. De venenis nareatieis venefieiisque eorum usu induetis. D. Vindobonae $1840.8 .24 \mathrm{p}$.

$3810^{*}$ Grabowski, Heinrich Emmanuel. Flora von Oberschlesien und dem Gesenke mit Berüchsichtigung der geognostischen, Bodenund Hohen-Yerhältnisse. Breslau 1843. 8. x, 451 p. $\left(1 \frac{1}{2}\right.$ (h.)

$3811^{*}$ Graef, Johann Friedrich. De cortiee nueis Juglanulis regiae. D. Erlangae 1803.8 .31 1.

3812 Graefer, John. A descriptive eatalogue of upwards of 1100 species and varieties of herbaceous or pereunial plants, to which is adiled a list of hardy ferns and the most arnamental annuals. London (1701.) 8. 139 P. B.

$3813^{*}$ Graeger, Johann Nicolaus. We Asaro europaeo. D. physico-chemica. Goettingae $1830.8 .31 \mathrm{p}$.

$3814^{*}$ Graf, Siegmund. De cortice Peruviano. D. Vindobonac 1824. S. $114 \mathrm{p}$.

$3815^{*}$ - Versuch einer gerlrangten Zusammenstellung der Vegetationsverhältnisse des Herzogllums Kraiu. Laibach, Iyp. Blasnik. 1837. 8. 24 ).

(Est reimpressio immutata e Linnaea vol. XI. p. \$7-277.)

$3816 \div$ Graff, Ebcrhard Goltlieb. Preussens Flora odler systematisches Verzeichniss der in Preussen wildwachsenden Pllanzen, mit jeder Pfanze heigefunten Bemerkungen in okonomischer, technologiseber und mediziniseher llinsich1, nach einer das Aufsuchen der Pllanzen erleichternden und sicher leitenten Mothode. Elling und hunigsberg 1809. 8. vill, 239 p. (I th. $)$

3817 * Graffen, Fr. Geory vou. Der prahlisclıe Gurtuer. Jlannover 1 Szz 8. $1 \mathrm{~W}, 258$ [. $(1 \mathrm{~h}$. $)$

$3818^{+}$Graffenauer, Johann Ihilipp). Traite sur le camplire, consideré dans ses rapports arec l'histoire naturelle, la ply'sique, la chimie et la médecine. Strasbourg 1803. 8. 122 p., 1 tab. (Iaurus Camphora L.) $(7 / 8$ th. -3 fr. $)$

3819- Graham, John. A catalogue of the plants growing in Bombay and its vicinity; spontaneous, enltivated or introduced. as far as they lave been aseertained. Published under the auspices and for the use of the agri-horticultural society of Western lndia. To be continued and completed. Bombay, printed at the government press. 1839. 8. IV 254 , IX p. Bibl. Horti Paris.

(Recensentur inethodo Candollowna 7939 species phanerogamarum atque filicum, nova elaboratione earum, quae anno $1 \times 37$ in o.Madras

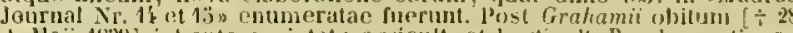
11. Maji 1839] jubente sorjetate arricult. el hurticult. Bomlh. continuavit atque edidit Nimmo: ef. Hook. Journal of botany, III. D. 300 .

$3820^{*}$ GrahI, Johann Friedrich. Melicamenta quaedan Rossorum domestica. D. Jenae 1790.4. $18 \mathrm{p}$

3821 t Grandi, D. Francesco do'. Istruzione sulla coltivazione del rafano oleifeiro einese. Piacenza 1807.8 . v, $55 \mathrm{p}$.

* germanice: Vollstindiger Lnterricht duer den fur Deutsehland wiehtigen Aubau cies chinesisehen Oelrettins und uher die Rerritum des Oeles aus demselhen Aus dem Italienischen des Frunciscus de Grandi utsersetzt und mit Anmerhungen versehen. veue Auflage. Leipziy 180h. 8. $106 \mathrm{p}, 1 \mathrm{tab}$. (13/2s $t h$.

3822 Grapajdus, Franciscus Maria. De partibus aedium. Parmac apul Octavianum Salortum. 1516.4. Bum.

(Aliae editiones lemuntur ilyud Hall. Bibl. bot. I. 257.)

3823* Grape, Eduard. De Opio el do illis, quibus constat, partibus. I). llerolini 1822. 8. $80 \mathrm{p}$.

$3824 \div$ Gras, Albin. Statistique betanique du Departenent de l'Jsere uu guide du botaniste dans ce Départenent. Grenoble 1844. \$. 192 p.

3823 Grassi. Sur l'Isatis tinetoria. Genève 1811. S. DC.

3826* Gratarolo, Gugliclmo. Praelationes duae publice halitae anur 1562 , quarum eontenta sequens pagina indicabit. Hem Oratio lueulenta, in (qua sum laudes agriculturae ete. etc. Argentorati $1563 . \mathrm{S}$ 434 D. Bibl. Senckenb. Francof.

(Pracfatio secunda p. $26-\$ 9$ est de medicinae ac rei plantariae origine, progressu et utiditate.

3827 De vini natura. energia, temperatione, atque de ommi re patabili. Basileae 1565,8 . s.

$3828+$ Grateloup, J. P.A.S. Observations sur la constitution de l'été de 1806 et sur les maladies yui se sont prisentees pendant ce trimestre, précérlées ete. D. Montpellier 1806.4 .90 J., 1 tab.

In ullina pacina: Deseriptiones alifporum ( $k$, ecramiorum noyorum cum iconum explicationibus.)

$3829+$ Cryplogamic Tarbellienne ou description suecincte de plantes cryptogames, qui croissent aux environs de Dax (Aquae auuustae Tarbellicae) dans le Dép. de Landes (in agro syrtico) el dans les lieux circonvoisins. (Bordeaux 1\$35.) \$.68 p)

Extr. lles Actes de la soc. Lian. de Bordeaux t. Vil. 1830̈.

3830 Grau, Johann, laline Gravius. De plantis. D. (octava). Cassellis 1601. 4. H.

$3831 \div$ Graullau. Essai sur cette question: Comment les engraisagis sentils en général? ou l'on trouve le dévelonpement des lois de la végètation et de l'agriculture. Bordeaux 1807. 8. xil, $67 \mathrm{p}$.

3832* GraumüIler, Johann Christian Friedrich. Systematisches Verzeiehniss wilder Pflanzen, die in der Nahe und unliegenden Gegend vou Jena widwachsen nebst Bemerkung ihres Wolworts, ilurer Blutezeit, Fruchtreife und ibres Nutzens. Jena 1\$03. S. xvi, Lxu. $430 \mathrm{p} .\left(1 \frac{1 / 2}{2}\right.$. $)$

$3833^{*}$ Characteristik der um Jena wildwachsenden Planzenarten in tabellarischer Form zun Gebrauch fur Exieursionen als ein Nachtrag zum systematisclien Verzeicluniss wilder Pllanzen etc. Jena $1803.8 .1 \mathrm{~N}, 240 \mathrm{k} .15 \% \mathrm{th}$.

$383 \% \div-$ Neue Methode von naturlichen P!lanzenabdrucken in- und auslandischer Gewachse elc. Erstes Ileft. Jena 1809. 4. vu 36 p., 12 tab. $(1 / 2(h)$ 
3833* Graumüller, Johaun Christian Fricdrich. Tabellarische Uebersicht des alten Linuéischen Pflanzensystems und rles verbesserten von Thunberg, so wie auch der naturlichen Systeme von Jussieu und Batsch. Fur seine Vorlesungen entworfen. Eiseuherg 1811. 4 . sII, $19 \mathrm{p} .(3 / 8$ th. $)$

$3836+$ Diagnose der bekamtesten, besonders europäischen Pflanzengattungen wach dem verbesserten Linnéschen Systeme. Mit Vorrede von Gruner. Eisenberg 18 11. S. vil, 435 p. (21/4th.)

3837 Flora pharmaceutica Jenensis oder Verzeichniss der um Jena wildwachsenden nnd in Gárten und auf Felıleru gezognen in älteren und neueren Zeiten gebräuchlichen Arzneipllanzen. Jena $1815.4 .(1 / 4$ th. $)$

$3838^{*}$ - Handbuch der pharmaceutischi-medizinischen Botanik für Aerzte, Apotheker und zum Selbstunterricht. Fisenberg 1813 -1819.6 Bande. $8 .-1$ : 1813 . xxiv, 496 p. - II: 1814. xiv, 466 p. - III: 1815. xII, 542 p. - IV: 1817. $x, 469$ p. - V: 1818. xIV, 464 p. -11 : (Register.) 1819.170 p, $\left(12 \frac{2}{3}\right.$ th.)

$3839^{*}$ Flora Jenensis oder Beschreibung (ler in der Náne von Jena, (Saclisen-Weimar-Eisenach und Allenburg) ete. wildwachsenden Pfanzen ele. Erster Band. (Classis I-V.) Eisenberg 1824. 8. xxII, 450 p. $(11 / 2$ th. $)$

(Desinit haec Flora in pentandria, morte autoris $\left[\frac{1}{6}\right.$ die 3 Sept. $1821]$ interrupti.

38 :0* Grav, Georg. Panacaea vegetabilis calicla sive Majorana nostra igne rationis examinata. Jenae $1689.12 .204 \mathrm{f}$.

381.1 Gravander, Pehr Olaf. Nleditationes circa alimenta Sueciae succedanea e regno vegetabili. D. Upsaliae $1805.4 .14 \mathrm{~J}$. w.

38 2\% Gravenhorst, Johannes Andreas Christoph. De Cinchonae corticibus. D. Goettingae 4791.4.42 p.

$38+3$ Graves, George. $\Lambda$ monograph of the British grasses. Nr. I- $\mathrm{Y}$ London 1822. roy. 8.42 tab. col. (1l. 1s.)

$38 \mathrm{H}$ - Itortus medicus. London 1833.4.(16s. - col. 1l.5s.)

3813 Hortus regius. London 1834.4. $44 \mathrm{Lab}$.

38:6 Gray, Asa. Elements of botany. New York, Carwille and Co. 1836 12. $428 \mathrm{p.}$ w.

$3817^{*}$ Melanthacearum Americae septentrionalis revisio. NoviEboraci, G. P. Scott. 1837 . 8. p. $105-140$.

(Annals of the Lyceum of NewYork, tom. IV. p. 105-1'0.)

$3848^{*}$ Remarks on the structure and affinities of the order Ceratophyllaceae. New York, typ. Scott. 1837. 8. p. 41-60. (Amals of the Lyceum of Nerrork, vol. iv. p. $11-60$.)

$3819^{*}$ Notes of a botanical excursion to the monntains of North-Carolina. s. l. et a. 8.49 p.

(Amer. Journal of seience and arts, vol. NLII. Nir. 1.)

3830 * Notice of the botanical writings of the late C. S. Rafinesque.s. I. et a. $8.21 \mathrm{p}$.

(Amer. Jouruat of science and arts, vol. NLII. Ni. 2.)

$383 l^{*}$ - The botanical Text-book for colleges, schools and private students: comprising Part I. an introduction to structural and pliysiological botany. Part II. the principles of systematic botany; etc. illustrated with numerous engravings on wook. New-iork Wiley and Putnam. 1842. 8. 443 p. - + Second edition, illustrated with more than a thousand engravings on wood. ib. $1845.8 .509 \mathrm{p}$ ( 1 Dollar 50 cents.)

$3852^{*}(\longrightarrow$ The clremistry of vegetation. From the North Anerican Review. (Newlork) 1845.8.42 p.

(Simt animadversiones in libros te chemia vegetabili a J. Dumas, J. IF. Boussingnaull, Jolinston et Draper editos.)

38:3 Gray, Christopher. A calalogue of trees, sliruls, plants and flowers. which are propagated for sale by Christopher Gray, Nurseryman at Fullam in Middlesex. London $1755.8 .56 \mathrm{p}$. в.

$3834+$ Gray, Samuel Frederick. A supplement to the pharmacopoeas. etc. London 1818.8 . xv, 377 p., ind. (10s. $6(t)$.

$3835^{*}+$ A natural arrangement of british plants according to their relations to each other, as pointed out hy Jussieu, DeCandolle, Brown etc. including those eultivated for use; with an introduetion to botany, in which the terms newly introduced are explained; illustrated by figures. London 1821 . II voll. S. - I: Xxvil, 824 p., 2 | tab. col. - II: viII, 757 p. (21. 2s.)

3836 * Grebe, Kart Friedrich August. De condilionibus ad arborum nostrarum saltuensium ritam necessariis. D. Marburgi Cattorum 1841. S. 31 p.
3857 Greff, Michet. Les pommes de terre régénérées ou recherches sur les causes des maladies des pommes de terre et sur les moyens de régénérer ce végétal. Mletz $1846.8 .61 / 4$ plag.

$3858 \div$ (Gregoire, Jacolus.) Hortus pharmaceuticus Lutetianus. (Paris) typ. Petri Targa. 1638. 12. 84 ]. Bibl. Juss.

$3859^{*}$ Gregorius de Regio. De varietate capsicorum commentarius, latino per Carolun Clusium. In Clusii Curis posterioribus. Antwerpiae 1611. folio. p. $51-57 .-$ ib. 1611.4. p. 96-108.

$3860^{*}$ Grenier, Charles. Souvenirs botaniques des environs des Eauxbonues. (Bordeaux) 1837. $8.16 \mathrm{p}$.

(Extrait des detes de la Societé Linnéenne de Bordeaus.)

3861 t Observations botaniques. Besançon 1838.8.36 p., 2 tab. (Agit de quitusdam plantis phanerogamis Gálliae.)

$3862^{*}$ Obscrvations sur les genres Moenchia el Malachium. (Besançon 1839.) 8. 8 j.

$3863^{*}$ Frarment d'une monographie des Cerastium. (Besançon 1540.) $8.24 \mathrm{p}$.

386." - Monographia de Cerastio. Vesontione, typ. OutheninChalandre. 1841.8 max. 95 p., 9 tab.

$3865 \div$ - Extrait des Mémoires et Comptes rendus de la société d'émulation du Doubs pour Decembre 1841. Partie botaniq̨ue (AJsine). Besánçon 1841.4. p. 31-38, 1 tab.

$3866 \div$ Catalogue des plantes phanérogames du Département du Doubs. (Besançon 1843.) 8. 72 p.

$3867^{*}$ _... Thèse de géographie botanique du Département du Doubs, présentée à la faculté des sciences à Strasbourg. Strasbourg 4844. 8. 29 p., i tab. geogr.

(Injus eximii botanici, quo in gallicarum plantarum eognitione riv eallidior alius, in dies "Synopsin Florae gallicae" ad modum Synopseos Horae germanicae hochianae elaboratam exspectamus.)

3868 Gretscher, Jakob. De plantis ex Aristotele potissimum collecta. D. Ingolstadii, typ. Eder. 1591.4. н.

$3869^{*}$ Greville, Robert Kaye. Scottish eryptogamic Flora or coloured ligures and descriptions of eryptogamic plants belonging chiefly to the order Fungi, and intended to serve as a continuation of English Botany. Ediuburgh 1823-1829. 11 voll. 8.360 foll, ind., 360 tab.col. ( $15 l .6 s$.) (Vidi opus in sex volumina distributum, quoctque 60 tabularum.)

$3870+\ldots$ Flora Erlinensis : or a description of plants growing near Edinburgh, arranged according to the Limnean System. With a concise introduction to the watural orders of the class Cryptogamia an! illustrative plates. Edinlurgls 4824 . 8. Lxxxı, 478 p.. 4 tab.

$3871+$ and $G$. A. Walker-Arnott. A new arrangement of the genera of mosses wilh characters and observations on their distribution, history and strueture. Menoirs 1-3. (Edinburgh 1825.) 8 . 127 p., 4 tab. sign. 7. 2. 3. 13.

(Etian inscribitur. Tentamen methodi muscolum.)

$3872^{*}$ - A]gac britannicae, or descriptions of the marine and other inartieulated plants of the British islands, belonging to the order AJgae; with plates illustrative of the genera. Edinburgh 1830. 8. Lxxxvil, 218 p., 19 tab. col. (2/. 2s.)

3873 Grevin, Jacques. Deux livres des venins. Anvers 1568.4.333 ]) ic. xylogr. i.t. $B$.

(Adjecta sunt Nicandri opera a Grevino gallice facta.)

* latine: be venenis libri duo, gallice primum ab eo scripti et a multis hactemus latine desiderati ef nunc tandem opera et lahor Hieremiae Martii in latinum sermonem summa fide ef diligentia conyersi. Antwerpiae, ex officina Chr. Plantini. 13̈i. folio min. (10 foll. 332 p.. ind, ic. xylogr. i. $t$.

(A p. $276-332$ sequuntur: Nicandri Theriaca in latinum carmen redacta.)

3874: Grew, Nehemiah. The anatomy of regetables begnn. With a general account of vegetation founded thereon. London. Hickman. 1672. 8. (30) 198 (17) p, 3 tab. - " Impr. cum ejus: The anatomy of plants. London 1682. folio. p. 1-49.

* Iatine: Anatomiae vegetahilium primordia, cum generali theoria regetationis eidern superstructio, Ephem. Acad. Nit. Cur. bec. I. Ann. 8. Ар. р. $287^{*}-399$.

$\div$ gallice: Anatomic des plantes, qui contint une description exacte de leurs parties of de leurs usaces. "t tui fait voir comment ellos se forment et eomment elles croissent. Traduite de langhis de $\mathrm{Mr}$. Grew (par Le lasseur. Paris, hez Lambert Houlland, 1675. 12. (26) Grew (par Le Vasseur.) Paris, chez Lamberl Houlland. This. 12 (2) 215 (12) p. cum figur 1679. 12. (non differt.)

* gallice: Anatomie des plantes. Leide 1683. 12. 246 p., 1 tab., praeter Dedu: De l'ame des plantes, el experimenta Grewii el Boylei: 108 p. - ${ }^{2}$ Yourelle edition revue el corrigée. Leide 1691. 12. (non differre puto.) 
3873 Grew, Nehemiah. An idea of a pliytological history propounded, Ingether with a continuation of the anatomy of vegetalshes, particularly prosecuted upon rools. London 1673. 8. 144 p., 7 tah. B. "Impre, cum ejus: The anatony of plants. Londm 1682. folio. p. 51 $-96$.

- latine: ddea historiae phytologieare, cum contimualiene anatomiae vegelahilum, speciatim in radicilus. (Ephem. Ac. Nat. Cur. 1)ec. I. A.II. 9 it 10. App. p. y9-218.

$38 \div 6^{\circ}$ The comparative anatomy of trunks, together with an accunt of their vegetation grounded thereupon; in two parts. The former read before the royal society Febr. 25. 1674/5; the latter June 17. 1675. The whole explicated ly several figures in nineteen copperplates, presented to the royal society in the years 1673 and 1674. London, Kettilby. 1675. 8. 81 (44) p., 19 tab. - *Impr. cum rjus: The anatomy of plants. London 1682. folio, p. 97-140.

* latine: Comparativa auatomia truncerum, una thm throria vegetitionis porum eidem superstructa. Ephem. At: Nat. Cur. Dec. 1. IIn. 9 et 10. App. p. 219-293.)

$3877^{*}$ The anatony of plants, with an idea of a philosophical history of plants, and several other lectures, reat before the royal society. London, printed by Rawlins. 1682 . folio. 304 p., praef., ind., 83 tab.

Practer tres priores libellos hic primum occurrit: The anatomy of leaves, flowers, fruits and seeds finde a p. 213 usque ad tineril of leaves, hower, hits and atjhingur Leelo Grew aus, oe Malpightana suss antyhora habeantur; sed quo srewas partem priorem operis sorietati Neglas tradiclerat die (17 bec. I67f), conten Malpighr cum iconibus codicem aceepit societas ita ut nonnssi hoe num certum evadat, Malpighium si noo prins, tamen absque uljo conanioun Grewianorum adjuvamento sua praestitisse.) $-15.1$

Hall. Biht. bot. 1. p. $562-366$ - spreng. Hist. rei herh. 11. p. 12

$3878^{*}$

- Musaeum Regalis Societatis, or a catalogue and description of the natural and artiticial rarities belonging to the Royal Society, and preserved at Gresham College. London, printed by Rawlins. 1681 . folio. 386,42 p., praef., ind., 34 tab.

(In parte altera agitur de regno vegetahili. - Praefixi sunt novi tituli cum annis $168 \mathrm{k}$. $16 \times 5$. $169 \%$.

$3879^{*}$ Grienwaldt, Franz Jeseph. De vita plaotaruot. D. Altdorfii 1732. 4. $16 \mathrm{p}$.

$3880^{*}$ Griesselich, Luduig. Kleine botanische Schriften. Erster (und einziger) Theil. Karlsrulie 1836.8 . vı, 392 p. $\left(1 \frac{1 / 3}{t} / \mathrm{l}\right.$.

$3881+$ Griffen, Augustus R. An essay on the botanical, chemical and medical properties of the Fucus edulis of Linnaeus. D. NewYork, typ. van Winkle and Wiley. 1816.8. 36 p., t tab, cel.

$3882+$ Grifin, William. A treatise on the culture of the pine apple. lid. Il. Newark, Ridge. 1808. 8. x, 84 p.

$3883+$ Griffith, William. Report on the Tea plant of Upper Assam. (Calcutta 1838.) 8. 85 p., 2 tah. structuram plantae illustr., 4 tal,. gengr. bet.

Extra from the Transactions of the Agriculture and florticulture siociely of india, vol. V.)

$3884 \div-$ Some account of the botanical cellection, brouglit from the Eastward by Dr. Cantor, s. I. et a. 4. 33 p.

$3883^{*}$ - - Om sonie remarkable plants in the II. C. botanic gardens, Calcotla. (Calcutta 1843.) 8.

(Commentationes e Calcutta Jourual of natural history seorsim impressae.

$3886^{*}$ On Azolla aud Salvinia. (Calcutta 1844.) 8. 47 j., 6 tab. sign. $15-20$

$3887^{*}$ The Palms of British East lndia. (Calculta 1845.) 8 146 p. (incompl)

$3888^{*}$ Grigolati, Gaetano. Della natura, coltivazione ed usi della arachide ipegea. Rovigo $1836.8,15 \mathrm{p}$.

3889 Grigor, James. The Eastern Arboretum; or, Register of remarkable Trees, Seats, Gardens ete. in the County of Norfolk. Witls popular delineations of the British Sylva. Illustrated by 50 drawings of trees, etched on cepper by H. Ninhum. London 1841. 8. (17s. 6d.)

$3890+$ Grimaldi, Demenico. Istruzioni sulla nuova manufattura del l'elio, iotrudotta nel regno di Napoli. Ed. II. Nipoli 1777. 8. 130 p., praef. ind., 3 lab

3891 - Nemoria sull' economia olearia antica e moderna. Napoli 1783.8. DC.

$3892+$ Grimwood, Daniel. A catalogue of greenhouse plants, hardy trees and slirubs etc. L.ondon 17838.160 p. (Qs.)
$3893^{*}$ Grindel, David Hieronymus. I'larmaceutische Botunik zum Selbstunterrichte, insbesondre fur angohende Apothoker und Aerzte. liga 1802. 8. - "Ed. II: Higa 1805. 8. xvi, 416 p., \& tal. ( $1 \frac{1}{2}$ lh.)

$389 \mathrm{i}^{*}$ - Hotanisches Taschenluch fur Liv - Kur - und Esthland. Kiga $1803.8 . x, 373$ p., 4 tab. col. $(12 / 3$ th. $)$

$3893^{\circ} \div$ - Fasslich dargestellte Auleitung zur Pflanzenhenniniss. Riga $1804,8.239$ p., 4 tah. $(1 \%$ th.)

$3896^{*}$ - Ideen uber die Vegetation und einige Worte uber den Dunger. Riga 1809.8.88 p. (1/2 th.)

3897 Dic organischen Korper elienisch lsetrachtet. Riga 1811 2 Bande. $8 .(3 / 4$ th. $)$ - Riga 1818. Z Handro. 8. $\left(1 \frac{1 / 3}{3}\right.$ h.

(Volumen primum sistit chrmiam ingrolahilem.

3898t Gris, liusèbe. De l'action des composés ferruginenx solulyles sur la végétation et de leur application au traitement de diverses alterations malatives ile la plante. Ed. II. augnentée. Paris 1843. 8. 10 p p

$3899^{\circ}$ - Nouvelles expériences sur l'action des composés firrugineux solubles appliqués a la végetation et spécialenuent an traitement de la chlorose et de la débiliti des plantes. Chatillou sur Scine 1844. $8.23 \mathrm{u}$.

$3900^{*}$ Grischow, harl Christian. Physikalisch-chemische Lntersuchunngell uber die Athmungen der Gewachse und deren Einfluss auf die gemeine Luft. Leipzig 1819. 8. xuv, 225 p. (11/6 th.)

Etiam joscriptus: Beitráge zur chemischen Kenutniss dr:s Pllanzenjebens, lirstes stuch.

3901* Griscom, John Henry. Olsservations on the Apocyum cannalunum. Philatelphia, typ. Sherrett. 1833. 8. 19 1,

(From the Americ. Jouru. of the med. seience for May 1833.)

3902* Grisebach, August lleinrich Rudolf. Observationes quaedarn de Gentianearum fansiliae cliaracteribus. D. Burolini 1836. 8. $37 \mathrm{p}$.

$3903^{*}$ C Genera et species Gentianearum adjectis observatienibus quilusslan phytogeographicis. Stuttgartiae et Tubingae 1839. 8. vilt, 364 p. (2 th.)

390:* Reise durch Runselien und nach Trussa in Jahre 1839. Göttingen 1841, 2 Băude. $8,-1: v 1,361$ p., 2 talı, -11 : 373 p. $\left(3^{3} / 4\right.$ ih. $)$

$3905^{*} \longrightarrow$ Spicilegium Florae rumelicae et bithyicae, exhibens synopsin plantarum quas aest. 1839 legit. Accedunt species, quas 10 iisden terris lectas cenmunicarunt Friedrichsthal, Frivaldzki, Peslulazza, vel plene descriptas reliquerunt Buxbaum, Forskil Sibtharp, Sestini, alii. Brunsvigae 1843-1845. Il voll. 8. - I: 1843, xil, 407 1) $-11: 1844.548 \mathrm{p})(8 t h$.

$3906^{*}$ …_. Bericht uber die Leistungen in der P'lanzengeographie wahrend des Jahres 1843 . Berlin $1845.8 .78 \mathrm{p} .(2 / 3(\mathrm{~h})$.

$3907^{*}$ - liericlt uber die Leistungen in der Pllanzengeographie wáhrend des Jabres 1844 . Berlin 1846.8 .88 p. $(5 / 6$ th.)

(Uterque e: lliegmann's Archiv fur Niturgeschichte annorun 18 th et 18: reimpressus. In iisdrin collectionihus leguntur: Bericl uber 1840. 1841. 1\$42, (qui seorsim non impressi sunt.)

$3908^{*}$ - Ucher die 13ildung des Turfs in den Eunsnueren aus deren unveránderter Pflanzendecke. Nebst Bemerhungen uber die Kulturfahigheit des Bourtanger Hochmoor's. Gättingen 1846. 8. 118 . $(5 / 12$ th. $)$

(In: Gottinger Studien. 18 i). 8 p. $25 \% 5-370$.

3909 Griselini, Francesco. Nueva maniera di seminare e coltivare il frunento. Venezia 1765 .4. н.

$3910+$ Istruzione per la celtura de' mori bianchi secondo i metodo de' Veronesi. Venezia 1768.4. 44 p., 13 tab.

3911 Della celtura del napo silvatico detto ravizzone. Venezia 1771. 4. DC.

3912 Il setificio ovvero Memerie dodici sopra i diversi rami georgici e d'industria, che lo constiluisceno. Verona 1783. II voll. 4 -1 : vitı, 168 p., 12 tab. dimid. -11 : vit, 284 p., 16 tal. Bibt. Goett. (In volumine primo historia naturatis Mori exponitur.)

$3913+$ Grisley, Gabriel. Viridarium lusitanum, in quo arborum, fruticum et herbarum Allerentiae ononasti insertae, quas ager Ulyssiponensis ultra citraque Tagum ad trigesinum usque lapidem profert. Collectae per Gabrielem Gristey, ehymiatrum et botanicum. Ulyssipone, ex prelo Antenii Craesbeeck, anmusas stIrpes pan Chrest Lege MeDetVr. (166 l.) 12/10 21. 12. (40 foll.) Bibl. Cand. - "Viridarium lusitanun. Aecessere Jahannis Raji de auctore et opere judiciun. Veronae, juxta editionem quat prodiit Ulyssipene ex prelo A. Craesbeeck. 1749. \&. 110 p. - "Viridariun Grisley Lusitanicum Linneanis nomiubus illustratum, jussu Academiae in lucem editum 
¿ Domunico landell. Olisipone, typ. Acarl. reg. scient. 1789. S. xx, $134 \mathrm{p}$.

(Praeterea ab Hallero et Dryandro latulatur impressio sine toco et inno. 8. $76 \mathrm{p}$., quae fortasse eadem est cum illa, quam ex GronoTin habet Scguierus: altagae Comitum, :mmptibus Beaumontianis. 171\%. 12." his additis verbis: "Haec secunda editio cum prima, ordine, forma, characteribus omnno consenit, anniyue $|66|$ notam mraefert, lices inno 17ik typis mandata fuerit, - Imuressio Veronensis anni 1799 cusante seguiero 12.3 tantum exemplarihus excusa est. - Rajus librum inserut in stirpium europatearum syllogen. Lon(lini 169k. 8. P. 370.)

$3914^{\circ}$ Groebenschütz, Anton Felix. De Strychnii in neurosibus vi atque usu. D. Berolini 1833 . 8.40 p.

3915 Groen, Jan van der. Den nederlandzen hovenier. Amsterdam 1668. 4. H.

(Variae adsunt gallicae et germanicae editiones; c. Hall. Bib] bot. I. p. Sil.)

$3916^{*}$ Groening, Kaspar Gabriel. Nomenclator Linnaeauus in Elisabethae Blackwell Herbarium selectum emendatum et auctum. Lipsiae 1794. 8. xv1, $120 \mathrm{p}$.

3917 Grohmann, Johann Christian August. Neue Theorie der schönen Gartenkunst. Leipzig 1797. 2 Theile. 8.

3918 * Gronovius, Johann Friedrich. Camphorae historia. D. Lugduni Batarorum 1715. 4. 38 p.

$3919^{*}$ Flora virginica, exhibens plantas, quas nobilissimus vir D. Johannes Claytonius in Virginia crescentes observavit atque collegit; easdem methodo sexuali disposuit, ad genera propria retulit, nominibus specificis insignivit et miuus cognitas descripsit Joh. Frid. Gronolius. Lugduni Batavornm 1739-1743. II voll. 8. 206 p., ind. - "Flora virginica, exbibens plantas quas nobilissimus vir D.D. Johannes Claytonius in Virginia crescentes observavit, collegit et obiulit D. Joh. Fred. Gronovio, cujus studio et opera descriptae et in ordinem sexualem systematicum redactae sistuntur. Lugduni Batavorum 1762. 4. 476 p., praef., ind. et 1 mappa geogr.

(IIaec est editio secunda, curis Laurentii Theodori Gronovii filii publici juris facti, varisque Claytonii, Coldenii, Mitchellii, Kalnii, aliorum observationibus adaucta.)

$3920^{*} \longrightarrow$ Flora orientalis, sive recensio plantarum, quas botanicorum coryphaeus Leonhardus Rauvolf annis $1573-1575$ in Syria, Arabia, Mlesopotamia, Babylonia, Assyria, Armenia et Judaea crescentes observavit et collegit, earumdem ducenta specimina, quae in bibliotheca publica Lugduno-Batava asservantur, nitidissime exsiccata et chartae adglutiuata in volumen retulit. Has methodo sexuali disposuit, synonymis illustravit, nominibus specificis insignivit. Lugduni Batavorum, typ. de Groot, 1755.8 . 150 p., praef.

$3921^{\text {* Gronovius, Loren }}$ Theodor. Auctuarium in bibliothecam botanicam, antehac a elarissimo viro, botanico eximio D.D. Jounne Francisco Seguierio conscriptam et editam. Lugduni Batavorum, apud Cornelium Haak. 1760.4.65 p., praef, ind.

(Adnexum est fere semper exemplaribus Bibtiothecae botanicate Seguieri.)

3922 Grosgebauer, Philipp. Programma de agnis tartaricis el regetabilibus. Von den Lămmern, so aus der Ërden waclısen. Vinariae 1690.4. Riv.

$3923^{*}$ Gross, Heimamn. De Secali cornuto. D. Vratislaviae 4844.8 .49 p.

392.1* Grosse, Karl. Leitfaden der Bolanik fur deı Unterriclut auf dem Gymnasium zu Stendal. Erster Theil: Allgemeine Pflanzenkunde. Stenral $4835.8 .47 \mathrm{p}$

3!2:- Grossmann, L. Elementarbuch fur den Unterricht in der Botanik. Nit besondrer Beruchsichtigung der Flora von Schwábisch-Hall. Stuttgart $1843.8 . \mathrm{vI}, 224 \mathrm{p} .(3 /$ th. $)$

3926 Grotjan, Johann August. Physikalische Winterbelustigung mit Hyacinthen, Jonquilen, Tazzetten, Tulipanen, Nelken und Leucojen. Nordhausen $1750.8 .120 \mathrm{p}$. B.

$3927^{*}$ Grube, Hermann. De vita et sanitate plantarum. D. Jenae 1664. 4. $(8$ foll. $)$

$3928 *$ Analysis mali citrei compendiosa au botanices, plitosophicae juxta ac medicae, cynosuram redacta. Hafniae 1668.8 . $72 \mathrm{l}$.

3929 Commentarius de modo simplicium medicamentorum facultates cognoscendi, cui praefixa 7'honae Burtholini epistola de simplicibus medicamentis inquilinis cognoscendis. Ilafniae et Francofurti 1669.8 . s.

Pritzel. Thes. lit bot.
3930 GrubeI, Christian. Kñòoyis sive consideratio horti. Jenae 1670. 4. S.

$3931^{*}$ Gruber, Ignaz. Veber den Zustand der neueren organischen Chemie in ilhrer Anwendung auf Agricultur vor dem Jalire 1840. Wien $1841.8 .31 \mathrm{p}$.

$3932^{*}$ Gruelmann, Johann Kourad. Observationes de usu Cicutae, camphorae et corticis peruviani in quiluusdan morbis D. Goettingae 1789. 4. 30 p.

3933 Gruenenberg, Fiedrich. Exercitatio physica de succino. Regiom monti 1660.4 . Desid. B

393.' Grueno, Joseph. De camphora ex aliis stirpibus quam Lauro Camphora elicienda. D. Goettingae 1780.4 .

$3930^{*}$ Grublmann, Johann Gottfied. De novo contra oculorum caliginem remedio tanjuam specifico, /lerniaria se. ocularia. Jenne 1706 $4.12 \mathrm{p}$.

3936 * Gruner, Christian Goltfried. De virtutibus Agarici muscarii, vulgo Fliegenschwamm. Jenae 1778. 4. 22 p.

$3937^{*}$ Gudrius von Tours, Johann. Anatomia el physiognomia simplicium, das ist: Zween Tractatus von der Signatura aller Erdgewaicl_sen. Was namlich aus ihren Geruch, Gescbmack und andrer ilırer Form und Gestalt zu juliciren sei. Stuttgart, bei Johann Weyrich Russlin. 1659.8 .129 p., ind. Bibl. Reg. Dresd.

$3938^{*}$ Gueldenstaedt, Joharn Anton. Reisen durch Russland und in Kaukasischen Gebirge, herausgegeben von Peler Simon Pallas. St Petersburg 1787-1791. 2 Theile. 4. - I: 1787. 511 j., 13 tab. col. et nigr., 1 majpa geogr. $-11: 1791.552$ p., 14 tab.

(C) hurzzisammengezogener Beitrag aus etlichen fremolschaftlichen Briefen zur lieisegeschichte des verstorbenen Herm 1 r. vou Gueldenstuedt hach den kaukasischen Gebirgen und Georgieul gohurig. Schriften der Berliner Gesellsch. naturf. Freunde, Band 3 . $178^{\circ}$ p. $466-579.1$

3939 Beschreibung der kaukasischen Länder. Aus seinen Papieren ganzlich umgearbeitet und herausgegeben ron Jutius Klaproth. Berlin 1834.8. $161 / 4$ Bogen. (1 $1 / 1$ th.)

3940 Guènard, Barome de Méré, Madame. Les enfans royageur. ou les petits botanistes. Paris 1849. IV voll. 18 . ( $8 \mathrm{fr},-$ col. $12 \mathrm{fr}$.)

3941 Guenderrode, Friedrich Jistinian, Freiherr von, und Morit: Balthasar Borkhausen. Vorschlagge zur Verbreitung des Gemüse- und Obstbanes auf dem Lande. Darmstadt 1804.8 .

3942* - Die Pllaumen. Heft 1-6. Darmstadt, im Verlage der Herausgeber. 1804-1808. 8. 186 p., 36 tal, optime col. ( 12 fl. rli.)

39 '.3* Guenther, Johamn, und Friedrich Bertuch. Pinakothek der deutscben Giftgewachse fur Botaniker, Pharmaceuten und Droguisten, so wie zum Schulgebrauch. In naturgetreuen, colorirten Abbildungen berausgegejen. Jena 4840.6 Lieferungen. 4 . 16 p., 36 tal. col. $(3 t h$.

3944* (Guenther, Karl Christian, Heinrich Grabowski und Friedrich Wimmer.) Enumeratio slirpium phanerogamarum quae in Silesia sponte proveniunt. Vratislaviae $1 \$ 24.8$. vilt, $168 \mathrm{p} .\left(2 / 3 t h_{0}\right)$

3945* Guenz, Justus IVilhelm. De cortice Salicis cortiei Peruviano substituendo. D. I-Il. Lipsiae 1772. 4. 28,32 p. $-{ }^{*}$ Ed. nova. Lipsiae 1787. $8.110 \mathrm{p}$

$3946 \div$ Guépin, J. $P$. Flore de Maine et Loire. Tome premier. (Phanérugames.) Augers 1830 . 12. LII, 360 p. - †Ed. J]. ib. 1838 . LXII, 409 p. (7 fi.) - tSupplénent. 1842. 8. แI, 63 p. - $\div$ Ed. III. revue avel. soin et considérablement augmentée. Angers 4845.8 . xcIx, $440 \mathrm{p}$.

$3947 \div$ Guérin-Méneville, Félix Edouard, eı G. Samuel Perrottet. Mémoire sur un insecte et un champignon qui ravagent les cafiers anx Antilles. Paris 1842.8 .40 p., 2 tab.

$3948 \div$ Guérin, Jean. Description de la fontaine de Vaucluse. Avignon 1804. 12. 439 p. - + Ed. Il: Arignon 1813. $42.312 \mathrm{p}$. (2 fr.) Bibl. Jac. Gay.

$3949 \div$ - Fragmens d'une topograplie pliysique et médicale du département do Vaucluse. D. Dlontpellier (1807.) 4. 56 p. Bibl. Jac. Gay.

(La Flore du département: p. 13-21.

3930 Guerrapain, $\mathrm{Cl}$. Th. Notice sur la culture du Sophora, du Platane et de l'Aune. Paris 1809.8. (60 c.) 
3951 Guerrapain, $\mathrm{Cl}$. Th. Aimanach des roses. Paris et Troyes. 1811. 8.64 p. ( $1 \mathrm{fr} .50 \mathrm{c}$.)

$3952 \%$ Guersent, L. B. Qurls sont les caractères des propriétés vitales dans les végètaux? Question présentée et soutenue à l'écale de médecine le Prairial an XI. Paris 1803. 8. 84 [t.

$39: 33^{*}$ Guettard, Jean Elienne. Observations sur les plantes. Paris 1747. II voll, 8. - I: XLvir, 302 p., ind., \& tab. - Il : 464 p., ind.

(liujus oprsis halut parvam occupat partem euregia stampanae ditionis in Aurelianensium agro Flora, e codice manuscripto posthumo patrui (ni fallor) Francisci Descurain $[\mathrm{n} .1658,+1760]$ editis. Je!liqgua to plantis rariotilus australioris Galliae, potissimum viero do pilis glantulis(jue plantarun agunt.

$393 \mathrm{f}+$ Memoires sur differentes parties des sciences ot arts. Paris 1768-1783. V voll. 4. - 1: 1768. cxxvi, 439 p., 18 tab. II: 1770 . Lxxx , LxiI, 330 p. - III: 1770.544 p., 71 tab. - IV: 1783. 687 p., 113 tab. $-\mathrm{V}: 1783.446 \mathrm{p} ., 54$ tab.

(Contenta in parte systematica operis indicabuntur.)

393: Guglielmi, Giuseppe. Osservazioni sulla China-china officinale, e sopra quattro altre specie della stessa. Parma 1811. 8. Dc.

$3930^{*}$ Guhrauer, G. E. De Joachino Jungio commentatio historico-literaria. Vratislaviae $\$ 846,8,40 \mathrm{p} .(1 / 3 \mathrm{lh}$.

C. Jnachinz Jungius, der Baco der Deutschen. Nach G. E. Guhrauer von J'rof. Henschel. Janus 1816. p. 812-822.)

3957 t Gouiart, D. L. Classification végétale et exposé d'une nouvelle méthorle calqquée sur celle de Tournefort, d'après laquelle sont rangées Ies plantes du jardin spéciale de phamacic de Paris. Paris 1807. 1z. 410 p. Bibl. Webb.

$3958 \%$ - Nouvelle méthode calque sur celle de Tournefort, d'après laquelle sont rangées les plantes de l'Ecole de pharmacic de Paris. Paris 1823.8 .48 p.

$3959+$ Guibourt, N. J. B. G. Histoire abrègèe des drogues simples. Paris 1822. II voll. 8. - Ed. lli. augmentée. Paris 1836. II voll. 8. - I: $652 \mathrm{p})-$ II : $820 \mathrm{p} .(17 \mathrm{fr}$.)

* italice: 'rratlato delle droghe semplici. Tratuzione dal francese (ed. II.) di Angelo Buscati. Mifano 1825-1826. IV voll. 8. 237, 315, 479, lit p., 2 tab.

$3960^{*}$ L Notice sur la mousse de Jafua on de Ceylan et sur les nidls de Salangane. Paris s. a. 8.5 p.

3961 - Hémoire sur les résines connues sous les noms de Dammar, de Colıal et d'Animé. Paris s. a. 8. p. 177-209.

(Extrait de la keve scientitique et industriclle.)

$3962+(-)$ Notice sur Félix Louis LII I rminier, suivie de la nomenclature syıonymique créole et botanique des arbres et bois indigènes et exotiques observés à la Guadeloupe. Paris 1834.8. 48 p.

3963 t - Némoire sur l'arigine et les charactères distinctifs des Térébinthines; lua la sociélé de plarmacie a Paris. Paris 1839. 8. $27 \mathrm{p}$.

3964 " Guilandinus, Melchior. De stirpium aliquot nominibus vetustis ac novis, quae multis jam saeenlis vel ignorarunt medici, vel de eis dubitarunt: ut sunt Mamirás, Moly, Oloconitis, Doronicum, Bulbocastanum, Gramen Alzelin vel Habbaziz et alia complura, epistolae duac, una Melchioris Guilandini Borussi, a]tera Conradi Gesneri Tigurini. Adduntur et icones novac tres. Basileae, apud Episcopum juniorem. $1557.8,45$ p., 1 tals., ic. xylogr. i. 2 .

$3965^{*}$ * De stirpibus aliquot epistolae V, Melchioris Guilandini R. IV, Conradi Gesneri Tigurini I. cum Manuco Diattae, boe est aviculae Dei descriptione. Patavii, apud Gratiosum Perchacinum. 1558. 4.48 foll.

(A fol 27-42 redenut duae epistolae libri pracedentis. Epistola Guilandini ruarta cum responsoria Gesneri adsunt in Epistolis Mattholi. Pragac 156 . folio. 1.1 . $13-158$. .

$3966^{t} \longrightarrow$ Apologiac adversus Petrum Andream Matthiolum liber primus, qui inscribitur Theon. Patavii, apud Gratiosum Perchacinum. 1558. 4. 19 foll. Bibl. Hadr. de Juss.

$3967 \div$ Papyrus, hoc est, commentarius in tria Caji Plinii Hajoris do Papyro capita. Venetiis, apud Antonium Ulmum. 1572. 4. 280 p., praef. - †Ed. Il. hoc titulo: In C. Plinii Majoris capita ali„funt ut difficillima ita pulcherrima et utilissima commentarius, varia et non vulgari eruditione refertus: ubi Matheoli errores non panci deteguntur, Lausannac, excudebat Franciscus le Preux. 1576. 4. (6) 151 p. - Ed. III : Papyrus; hoc est commentarius in tria Caji Plinii majoris de Papyro capita; recensente et angente Ilenrico Salmuth. Ambergae, typ. Schönfeld. 1613. 8. 423 p., prael., ind. Bibl. Reg. Berol.

(Guilandini et Mercurialis Eristica de ungucnto acgyptio, in altera et lestia milione omissa, sunt in Veneta, p. 227-280.)
$3968+$ Guilandinus, Melchior. Conjectanea synonymica plantarum, sive index botanicus, erulitissinus Patavii oretenus dietatus. Impr. cum IIorto Patavino, publicanto Johann Georg Schenck von Grafenberg. Francofurti 1600.8. p. 27-93.- "Francofurti 1608. 8. 1).27-93.

3969 Guilding, A. An account of the botanic garden in the island of St. Vincent. Glasgow 1825. 4. \& tab. col. Cat. Lambert.

$3970 \div$ Guillard (frères). Sur la formation et le développement des organes floraux. Paris 1835.4 .16 p., 3 tal).

3971 " Guillemeau, Jean Louis Marie. Ilistoire naturelle de la Rose, ou l'on décrit ses dilférentes espèces, sa culture, ses vertus et ses proprićtés. etc. Paris 1800 . $12 . \mathrm{tx}, 340 \mathrm{p}$, \& ta\}. ( $3 \mathrm{fr}$.)

$3972 t-$ Calendrier de Flore des environs de .Niort. etc. Niort 4801.8 .276 p. ( $3 \mathrm{fr}$.)

$3973^{*}$ Guillemin, Antoine. Icones lithographicae plantarum Australasiae rariorum. Decades duac, quas botanicis oflert. P’arisiis 1827. folio min. II, 14 p., 20 tab.

3974* - Samuel Perrottet et Achille Richard. Florae Senegambiae tentamen, sive listoria plantarum in diversis Senegambiac regionibus a peregrinatoribus $P_{\text {erroltet }}$ ot Leprieur detcetarum. Volumen 1. Parisiis $1830-1833.4$ max. $x I, 316$ p., ind., $72 \mathrm{tab} .(96 \mathrm{fr}$. $)$

$3975+$ Considérations sur l'amertume des régétaux, suivies de l'examen des familles naturelles ou cette qualité pluysique et dominante. Thèse. Paris 1832.4 .59 p.

3976 * Archives de botanique on recucil mensuel de némoires originaux, d'extraits et analyses bibliographiques, d'anjonces et d'avis divers concernant cette science. Rédigées par une societe de botanistes français et étrangers sous la direction de Guillemı. Paris 1833. II voll. 8. - I: 580 p., tab. 1-10. - II: 608 p., tab. $11-20 .(20 \mathrm{fr}$.

$3977^{*}$ — Enumoration des plantes découvertes par les voyageurs dans les iles do la société principalement dans celle de Taiti. Paris $1837.8 .84 \mathrm{p}$.

$3978+\longrightarrow$ Synthèses de pharmacie et de chimie. Paris 1838. 4. $8 \mathrm{p}$.

In vita autoris a Laségne conscripla de cjus nomine hare lego Antoine Guillemin, et non Jean-Baptiste-Antoine, comme il se désignait lui-meme par erreur.")

3979* Guimpel, Friedrich, Friedrich Otto und Friedrich Golllob Hayne. Abbildung der fremden in Deutschland ausdauernden Holzarten für Forstmänner, Gartenbesitzer und Freunde der Botanik. Berlin 1819-1830. 24 llefte. 4. 170 p., 144 tab. col. ( 36 h. )

$3980^{*}$ - Abbildung und Beschreibung aller in der Pharnacopoca borussica aufgeführten Gewachsc. Ilerausgegeben von Friedrich Guimpel. Text von D. F. L. von Schlechtendal. Borlin 1830-4837. 3 Bande oder 53 Hefte. 4. - I: 1\$30. 191 p., tab. col. 1-100. Il : 1833. 123 p., tab. col. $101-200 .-$ III : 1837.120 p., tab. col $201-308$. (a fasc. $1 / 2$ lh. $=26 \frac{1}{2}$ lh. - A. $17 \frac{1}{2}(h$.)

3981* Pflanzenabbildungen und Beschreibungen zur Erkenntniss offizineller Gewächse. Herausgegehen von Friedrich Gruimpel. Text von Johann Friedrich Klotisch. Erster (und einziger) Band. Berlin 1838. 4. IV , 51 p., 24 tab. col. (4 th.)

$3982+$ Guisan. Ohservations sur la culture du giroflicr et du cannellier a l'usage de MIN. les habitans de la Guiane française. Cayenne, de l'imprimerie de roi. 1788. 4. $21 \mathrm{p}$.

3983* Gunner, Johann Ernst. Flora norvegica, observationibus praesertim oeconomicis Panosque norvegici locupletata. Nidrosiae et Hafniae $1766-1779$. Il partes. folio. - I: 1766. 96 p., ind., 3 tab. - II 1772. $148 \mathrm{p.}$, ind., 9 tab.

(Additamenta in hanc Floram: Om nogle Norske planter. Norske

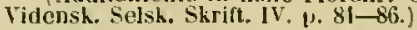

398: Gunner, Niels Dorph. Tentamen oeconomico-botanicum de usu plantarum indigenarum in arte tinctoria, methodo Linneana conscriptum, una cum diseursu de botanices utilitate. Ilafniae 1773.8 . xxvill, 47 p. B.

3985 Samlinger til lluusholdnings villenskaberne. I Bind, 1 luefte: Om Dannemarks og Norges naturlige fordeele til föde for mennesket af planteriget. Kíobenharn 1774.8. 128 p. в.

Tractatus oeconomicus de divitiis Florae dano-norregicae. Hafniae 1774. 8. Brunnich. 
3987" (Gussone, Giovanni.) Catalogus plantarum, quae asservantur in regio horto ser. $F_{r}$. Borbonii Principis Juventutis in Boceadifateo prope Panormun. Adduntur nonnullae adnotationes ac descriptiones novarum aliquot specierum. Neapoli, typ. Trani. 1821. 8. $\mathbf{~ I ~ , ~} 84$ p.

$3988^{*}$ Adnotationes ad catalogum plantarum, quae asservantur in regio herto ser. Francisci Borborii Principis Jucentutis in Boceadifaleo prope Panormum. Neapnli 1821. 8. $16 \mathrm{p}$.

$3989 \div(\longrightarrow)$ Index seminum anni 1825 quae ab horto regio in Boccadifalco pro mutua commutatione exhilsentur. (1825.) 4. 12 p.

3990 * Plantae rariores, quas ni itinere per oras Jonii et Adriatici maris et per regiones Samnii et Apruttii collegit. Neapeli, ex regia typographia. $1826.4 .401,14$ p., praef., 66 tab.

$3991^{*}$ Florae siculae prodromus, sive plantarum in Sicilia ulteriori nascentium enumeratio secundum systema Limneanum disposila. Neapoli, ex regia typographia. $1 \$ 27-1828$. If voll. $8 .-1$ 1827. Classis I-XII. vi11, 592, 11 p. - I1: 1828. Classis X]II-XVII $586 \mathrm{p}$.

$3992^{*}$ (Liber continuatione non gravisus est.) specimen Florae insularum Siciliae ulteriori adjacentium. Fasc. I et II Classis I-XVII. Neapoli, ex regia typographia. $1832-1834.8$. viI, 242 p. Bibl. Griseb.

$3993^{*}$ - Flora sicula sive descriptiones et ieenes plantarum rariorum Siciliae ulterioris, Francisci 1 . Borbonii regis utriusque Siciliae regni jussu edita. Vol. I. Neapoli, ex regia typographia. 4829. folio fasc. 1: 16 p. 5 tab, col. ( 28 ir. 50 c.) Bibl. Imp. Franc. et Bibl. Goett.

(Operis hujus splendidi praeter has quinque tabulas, Salicorniae species illustrantes, nihil porro prodtiit.

$3991^{*}$. Tre articoli inseriti nell' Omnibus e nel Lucifero risguardanti le peregrinazioni fatte in alcune luoghi del regno di Napoli dai Sigiteri Gussone e Tenore nella state del 1838. Napoli, Fibrene. 1838, 8. $36 \mathrm{p}$.

$3995^{*}$ - Florae siculae synopsis exhibens plantas vasculares in Sicilia insulisque adjacentibus hucusque detectas, secundum systema Limeanum dispositas. Neapoli, typ. Tramater. 1842-1845. II voll. 8. - I: 1842. Classis I-XII. v, 582 p. - 11: 1944. Classis XIIXXIV. $920 p$.

Fiorae siculae synopsis, 2892 species complectens, ejusdem autoris interruptum Florae siculae prodromum excepit. Impressiu libr ineepit mense Januario 1842, absoluta est mense Septombri 1815 volumen alterum duabus prodiit partibus, quarum pror Junio 18k (dita 529 paginis classes Linnaei Xill-SIX complectitur; pars posterior, mense Octebri 18,4 absoluta habet a p. $327-668$ Gynantriam usyue ad Filices. Sequitur: Conspectus generum et index generatis, autore M. A. Ziccardi, p. 669-774. Addeuda ot Emendanda, p. 775-890. Synonyma Cupaniana et icones, p. 891-902. Errnces typographici et ind. p. 903-920. - Foluminis II. paginis 123 et 207 viliosus impressis aliae correctiores sinul adduntur substituendae.

$3996^{*}$ Gutbier, August von. Abdrucke und Versteinerungen des Zwickauer Schwarzhohlengebirges und seiner Umgebungen. Zwickau 1335. 8.80 p., 41 tab. $\left(2 \frac{1}{3}\right.$ th. $)$

$3997^{*}$ Ueber einen fossilen Farrenstamm, Caulepteris Freieslebeni aus dem Zwickauer Sclıwarzkohlengebirge. Zwickau 1842 8. $16 \mathrm{p} ., 4$ tab. $(1 / 3$ th: $)$

$3998^{*}$ Gutheil, Hermann E. Beschreibung der Wesergegend um Hoxter und Holzminden. Nebst Auzáhlung der daselbst wildwachsenden phanerogamischen Pilanzen. Holzminden 1837. 8. vi, $76 \mathrm{pl}(\mathrm{H} / \mathrm{t}$ th.

$3999^{*}$ Grundzuge zu einer Flora von Kreuznach. (Regensburs 1839.) $8.68 \mathrm{p}$

(Beiblatter zur Flora 1839. II. p. 1-68.)

4000 t Guyétant, fils. Catalogue des plantes a fleurs visibles, qui croissent dans les montagnes tu Jura el dans les plaines qui s'étendent depuis ces montagnes jusqu'á la Saône. Besançon 4809. 8. 56 p.

$4001^{*}$ Gyllenstålpe, Michael, pr. De regno vegetabili in genere. Abeae 1656. 4. 6 foll

\section{H.}

$40022^{*}$ Haan, Willem van. Conmentatio pretio ornata: Quinam sunt limites inter vitam animalium et vegetabilium? (Leyden) 1821.4.43 p.

4003* Haase, Augustinus. Viola tricolor. D. Erlangae 1782.4.34 p.

$4004^{*}$ Haase, Johann Gottlob, pr. De usu epii salubri et nexio in merbis inflammatoriis. D. I et II. Lipsiae $1757-1758.4$. 30, 31 p.
$4005^{*}$ Haase, Withelm Andreas. De Digitali purpurea. D. Lipsiae 1819 4. 32 p.

$4006^{*}(\longrightarrow)$ Commentatio de faba St. Ignatii Pars 1 et ll. Programma academieum. Lipsiae 1822. 4

4007* HaberJe, Karl Konstantin. Beobachtungen ulser das Entstehen der Sphaeria lagenaria Pers. so wie des Merulius destruens Pers. und uher die verschiednen Gestalten dieser beiden Schwammarten in den verschiednen Perioden ihrer Entwickelung. Erfurt 1806. 8 $64 \mathrm{p}$.

4008 Das Gewächsreich, ofler chakterisirende Beschreilun aller zur Zeit bekaumten Gewáchse, als Cemmentar zu den Bertuch'sclıen Tafeln der allgemeinen Naturgeschichte. Erste Abtheilung Erste Familie. Pilze. Weimar 1806.8 . $\left(1 \frac{1}{2} t h\right.$.)

$4009^{*}$ Succincta rei herbariae hungaricae et transsylvanica historia. Budae 1830.8.66 p. hiana.)

Vidi exenplar jam auctum et emendatum in bibliotheca Lin-

4010 Habizl, Karl Ladwig. Физпчскоё описаніе Таврнтеской области, по ел мвсГоподоженію и но всъмт Тремъ парствамт природия. С. Петер6. 1785. 8. т.

gallice: Destription physique de la contrée de la Tauride relativenient aux trnis regnes de la nature, traduite du russe. La Haye 1788. 8. 298 p. B. - Eadem impressio nevo titulo: Paris an X. (1802.) 8. anglice: From the freneh Iransiation by II: Hadcliffe. London 1789. \&. * germanice: Pinysikalische Beschreibung der Taurischen Stathathalterschaft nach ihrer Laye und allen drei Naturreichen. Aus dem Russischen von Ludolph Guckenberger. Itannover und Osnabruck 1789. 8. $1 \mathrm{~V}, 386 \mathrm{p} .(1 \mathrm{1} / \mathrm{th}$. $)$

4014* Hacquet, Balthasar. Plantae alpinae carniolicae. Viennae, Kraus. 1782. 4. 31 p., 5 lab. - "Idem liber: Viennae, typ. Wappler. 1782 4. 16 p., 5 tals.

$4012^{*}$ Mineralogisch-botanische Lustreise, von dem Berge Terglou in Krain, zu dem Berg Glockner in Tyrol, im Jahr 1779 und 1781. Zwote veranderte und vermehrte Auflage. Wien 1783.8 149 p., 4 lab.

Specimina anni 1784 non differunt. Prodiit primum in: Schriften dor Berliner Gesellschaft naturf. Freunde, vol. 1. p. 119-201.)

$4013^{*}$ Physikalisch politische Reise aus den Dinarischen durch die Julischen, Carnischen, Rhatischen in die Norischen Alpen, im Jahre 1781 und 1783 unternommen. Leipzig 1785. 2 Theile. 8. xvilı, 156,220 p., 12 tab.

4014 Reise durch die Norischen Alpen, physikalischen und andern Inhalts, unternommen in den Jahren $1784-1786$. Nurnberg 1791. 2 Theile. 8.263 p., 4 tab.

4015 - Neneste physikaliseh-politisehe Reisen in den Jahren 1788-1795 durch die Dacischen und Sarmatischen oder nordlichen Karpathen. Nürnberg 1790-1796. 4 Theile. 8. - I: 1790. $206 \mathrm{p}$., 7 tab. col. - II: 1791.249 p., 6 tab. - III: 1794. 247 p., 7 tab. IV: 1796. 254 p., 6 tab. B.

4016* Hadelich, Siegesmund Lebrecht. De Gossipio, quod in terris no stris nascitur, ad usus civium accommodari potest. Programma academicum. Erfordiae (1768). 4. 24 p.

$4017^{*}$ Hadley, Henricus. De Balsamo peruviano. D. Lugduni Batavorum 1718.4.13 p.

$4018^{*}$ HaeberIin, Georg Heinrich. Dissertatio theologica, in qua sententia de generatione plantarum a recentioribus quibusdam philosophis probabiliter asserta ex sacris literis clare ostenditur. Addita est tractatio de generatione animalium. Tuebingae, J. G. Cotta. 1693. 12. $106 \mathrm{p}$, ind.

4019* Haecker, G. R. Luibeckische Flora. Lübeck 4\$44. 8. xx, 376 $\left(1 \frac{1}{2} t h.\right)$

4020* Haemmerlen, David Albert. De Fuco helminthochorto. D. Erlangae $4792.8 .53 \mathrm{p}$. I tab.

4021* Haen, Anton de. Epistola de Cicula. (Vindobonae) 1765. 8.63 p

4022* - Alethophilorum querundam Viennensium elueidatio necessaria epistolae de Cicuta. Vindobonae 1766.8. $111 \mathrm{p}$.

4023* Haenel, Christian Heinrich. De Camphora. D. Lugduni Batavorum 1739.4.32 p. anglice: A medieal )issertation on Camphire. (Acta germanica. p. $289-306$.

402: Haenfler, Johann. Uwvorgreifliche Gedancken, wegen der il Steınwitz auf dem Scheunlluhr den 20 July 1697 angetroffenen mildiglich bluttrieflenden Kornähren. Cuestrin s. a. 4. 32 p. 
$\{023+$ Haenseler, Fetix. Ensayo para una imalysis de las aguas de Carratraca. Malaga, en la olicina de D. Luis de Carreras. $1817.4 .45 \mathrm{p}$. Bibl. Webb.

(Listat de las plantas de Carratraca p. 19-23.)

$1026^{*}$ Haertl, Lorenz. De Quassia in specis et aliis rentedis amaris in genere. D. Landishuti 1826.4 .16 1.

1.027* Haese, Karl Sammel. De Secali cormuso rjustue vi in corpus humanum salubri et inimica. D. Berolini 1829, 8. $32 \mathrm{p}$.

4028 Haeussler, $C . F$. Dis forstliche Verhalten der wichtigsten deutschen Waldbaume in gedrangter Küze. Ein Vadenecum fur Forstleute und lireundo der' spezicllen Forsthotanik. Zweite vermehrte und verinderte Auflage. Stuttgart 1841. 8. 11 Bogen. (4 th.)

\{029 Hagelgans, Johamn Ileinrich. Rosa loquens, hoc est, de primariis Rosae mysteriis ad studiosan juventutem oratio paraenetica. Colurgi $1652.12 .102 \mathrm{p}$

5030 Hagen, Johamn //emrich. Betrachtungen uber den Torf in Preussen. Kurrigsberg 1761. 4.

:031* Physikalisch-botanische Betraclıtungen ulber die Weidenrosen und die in Preussen befindlichen secliszehn nutzharen Weidenaten. Konigsberg 1769, 4, 20 p.

1.032* Hagen, liarl Golffried. Tentamen historiae Lichenum et praesertim jususicorum. Regiomonti 1782. 8. 142 p., 2 lab. col

$4033^{*}$ - Commentatio botanica de Ranunculis prussicis. Regiomonti (1783.) $1784.4 .41 \mathrm{p}$

(Ludwig Delect. opusc. 1. 1. \$33-\$90.)

1.03\%* 2 De Carclamine pratensi. D. Regiomonti $1785.4 .16 \mathrm{p}$. (Dissertationis hujus inauguralis sub pricsidio llagenii propositan autur fortasse est Respondens Ileinrich harl Erust Grohnert.)

$1033^{*}-$ Veronicarum prussicarum recensio. Regiomonti 1790. 4 8 p. Bibl. E. M.

$4036^{*}$ De plantis in Prussia cultis. Programma I. (MonandriaTriandria.) Regiomonti 1791.8 .30 p.

$1037^{*}$ Preussens Pflanzen, beschricben. Königsberg 1818. 2 Bande. 8. - I: xn, 436 p., I tab. - II 438 p., 1 tab. (4 th.)

$1.038^{*} \longrightarrow$ Chloris Borussicn. Regiomenti $1819.12 .446 \mathrm{p} .(12 / 3 \mathrm{th}$.

$1039^{*}$ Hagenbach, C. F. Tentameu Florae Basileensis exhibens plantas phanerogamas sponte nascentes secundum systemil sexuale digestas, adjectis Caspari Bauhini synonymis ope horti ejus sicci comprobatis. Basileae 1821-1834. Il roll. 8, - I: 182 I. xvill, 450 ]. effigies Bauhini, 2 tah. col. - I1: 1834, vut, 537 p. $\left(4 \frac{1}{3}(h)\right.$ † Supplementum: ils. 4843.8 .220 p., i tab. col. ( $5 / 6(h$.

:0.10* Hagendorn, Ehrenfried. Tractatus physico-medicus de Catechu sive terra japonica. Jenae, Biclke. 1679. 8. 81 p., pratef.

$403.1^{*} \longrightarrow$ Cynosbatologia, ad norman Acarlemiae Naturae Curiosorum adornata. Jenae, Bielke. 1681.8 .191 p., pratef, ind., Stab.

$40+2$ Hager, Abraham Ichates. De Aloe aculeata americana (Chorae Solitiana), quac Chorae, Misniae oppido, in horto Conradi Loeseri anno 1663 lloruit. Altenburyi, ty]). Baversinch. 1663. 4. 1\% play. B.

40 '3 Haggren, Lars Christopher. De oeconomico Jistoriac naturalis usu. D. I. Upsaliae 1780.4. $14 \mathrm{p}$.

40.t' Hagstroem, Johan Otto. Jimulauds oeconomiska Beskrifuing eller kämuing $\mathrm{i}$ akt tagen på en Resa om Sommaren år 1749. Stockholm 1731.8 .208 p. B.

10.: Hahn, Johann Dacil. Serno academicus de chemiae cum hotanica conjunctione utili et pulchra. Trajecti ad Rhenum 1759. 4. 34 p. B.

1046 Hahn, Petrus, $p r$. De Platano. D. Aboac 1695. 8. 20 p. B.

$4047-\Delta \varepsilon v 8$ pororia. D. Abaae 1698.4 .40 p. B.

1048* Hahnemann, Samuel. Der Kalfee in seinen Wirkungen. Nach eignen Beobachtungen. Leipzig $1803.8 .56 \mathrm{p} .(3 / 4 / h$.

gallice: Iraduit par Ernst ficorg von Brunnow. Dresdo 182k. 8. (I fi.)

$10 \mathrm{k}^{\circ}$ - Dissertatio historico-medica de llelleborismo veterum. Lipsiae 1812.8 .86 p. $(1 / 4$ th. $)$

20:30* Haidinger, II ilhetm. Veber das Vorkommen von Pllanzeuresten in den Braunkohlen - und Sandisteingelvilden des Elhogner Kreises in Bulmen, nobst eingen danit zusammenhängenden Bemerkungen. Prag 1839. 4. 12 p. (3/th.

(Aus dem Abhandlungen der kon. bohmischen Geselschaft der Wissinschaften. Funfe Folge, Bant I.
40:51" Halbertsma, 11. De Antonu Leeurentoechu meritis in quasdam jar-

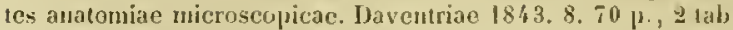

4052 Halden, Johamn Baptista. Plantarium philosoplicum, seu problethata phytologica the plantis. Jillingat 1686. 8. Desid. B.

1.0:3.3* Hales, Stephrn. Statical essars. Volumen 1: Vegetable statichs, or an account of some statieal experinents un the sap in vegetables: being an essay towards is natural history of vegetation: of use to those who are eurious in the culture and improvement of gardening etc. also a specinen of an attempt to analyse the air, by a greas rariety of cliymio-statical experiments, which are read at several meetings lefore the Royal Society. London 1727.8 , Ix, $376 \mathrm{p}$. 19 tab. - "Ed. Il. with anendments. London 173 !. 8, x, 376, (2) p. 19 tals. - "El. Ill. Jonulon 1738. 8. x, 376, (2) p., 19 tals.

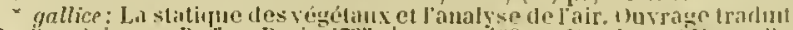

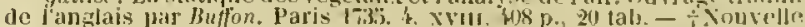

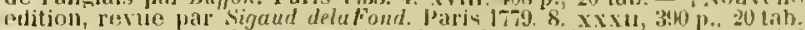

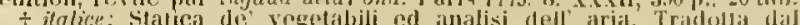
inglese, con varic anuotazioni di Michel Angelo Ardinghelli. Napoli 1776. 8 . 376 j. 20 tall. Bibl. Cand.

770. 8. 376 j. 20 tals. Bibl. Cand.

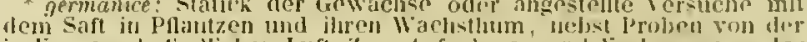

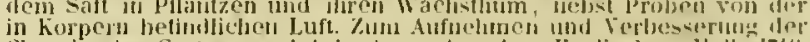

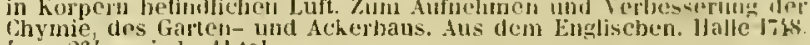
Chymie, des Garten- und

10:3\%" Haliczky, Andreas. Memoria viri immortali lande digni e sepulero in lucem revocata. Budac 1826.4 . (6 p.) (Celebrat Paulum Kitaibel, n. IIl. Non. Felns. 17ist. $\div$ lath. Dece. Hall, agnes $C$. Elements of Jotany. London $1802.8 .219 \mathrm{p}$. 2 (ab). (3s.)

$4056+$ Hall, Hermamn Christian ran. Commentatio de systematibus botanicis cum aliorum tum ipsius Linnaci. Trajecti ad Rhenum 1821. $8.104 \mathrm{p}$.

$4037^{*} \longrightarrow$ Specimen botanicum, exhibens synopsin graminum indigenorum Belgii "partis septentrionalis olim V'll provinciarum, una cum appendice, qua nonnullae indigenae novae indicantur. D. (praeside Jano kops.) Trajecti ad Rhenun 182I.8. 167 p., 1 tab.

$4038 \div-$ Flora Belgii septentrionalis sire index plantarum indigenarum, quae bucusque in septem jrovinciis focderatis repertae sunt. Volumen I. plantas phanerogamas continens. (Flora ran NoordNederland etc.) Amsterdam 4825. 8. xx, 748 p. (6 fl. 70 c.)

$4.059^{*}$ Flora Belgii septentrionalis, sive Florac Batavae Compeudium. Volumen II. plantas cryptogamas contirens. Pars I. Equisetaceae, Filices, Marsiliaceac, Lycopodiaceac, Musci et llepaticae. Elaboratae studio F. A. G. Mliquel et M. Dassen. Edidit, emendavit et praefatus est II. C. van Hall. (Flora van Noord-Nederland etc.) Ansterdam 1832. 8. xvi, 227 p., ind. - Pars 11. Lichenes el Algae. Amsterdam 1836. 8. (5 11.)

(Opus latina simul ac bitava lingula conscripta est. Particulam alter'un voluminis ll. nullibi vidi.)

$4060^{*}$ - Elementa botanices in usum lectionum acadenicarum conscripta. Groningae 1834.8 . x11, 244 p., ind. ( $211.25 \mathrm{c.}$ )

4061 Redevocringen over het Plantenrijk en zijne natuurlijke afbeeldingen en in verband met het Dierenrijk beschouwd. Ten vervolge op de Redevoeringen van $J$. A. Litkens over de volmaaktheclen van den Sclsepper in zijne schepselen beschouwd, tot verheerlijking van Good en tot bevordering van nuttige natuurkennis. (roningen 4838.8 . (2 fl. 80 c.)

1062 $\div$ Hall, T. B. A Flora of Liverpool with an engraved map; and an appeudix, containing meteorological tables and observations for the year 1S38, by Wilson Armistend. London (1839.) 12. xru, is6 p., 1 cliarta geogr. (6s.)

4063 Halldórsson, Biörn. Gras-ny tiar, eda gagn pat, seın hvorr buandi madr getr loaft af peim isanum villijurtum, sem vaxa $\mathrm{i}$ landeign hanus. Kaupmanuahờn 1783. S. 238 p. B.

406'* Halle, Johann Samuel. Die deutsche Giftpflanzen, zur Verhutung der tragischen Yorfalle in den llaushaltungen, nach ihren botanischen Kennzeichen, nebst den Heilungsmitteln. Berlin 1784-1793. 2 Theile. 8. - 1: 1784. vu, 1191,16 tah. col. $-11: 1793.126 \mathrm{p}$. 8 tab. col. - * Dritte Auflage. Berlin 1794. S. 15, 138 p., 16 tab. Berlin 180 1-1805. 2 Theile. 8.24 tab. ( 3 th. $)$

406.; Haller, Albert von. De methodico studio botanices absupe praeceptore. D. Goctlingae 1736. 4. 32 p., 1 tab.

(liedit in cjus Opusculis botanicis p. $3: j-i$ - $)$ 
4066 " Haller, Alberl von. De Veronicis quihusdam aIpinis observationum specimen I et Il. Programmata. Goettingae 1737.4. 18 j.

$4067^{*}$ Dissertatio de Perlicularibus, quae specimen est historiae stirpium in Ilelvetia sponte naseentium. Goettinะae 1737.4.44 p.

$4.068^{*}$ Ex itinere in sylvam Jlereyniam hac aestate suscepto ohservationes botanicae. D. Goettingae $1738.4 .70 \mathrm{~J} ., 4 \mathrm{tah}$.

(Redit in ejus Opusculis hotanicis p. 75-1.32.)

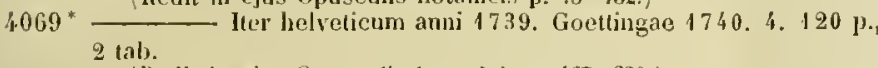

(Hedit in ejus Opusculis botanicis p. 167-320.)

$4070^{*} \longrightarrow$ Enumeratio methodica stirpium llelvetiae indigenarum qua omnium lrevis descriptio el synonymia, compendium virium medicarun, dubiarum declaralio, novarum et rariorum uberior historia et icones continentur. Goettingae 1742. II voll. folio. $36,794 \mathrm{~J}$., 24 tals.

(Auetuaria ef emendationes in parte systematica indicantur.)

407 * (Auctuaria et emendationes in parte systematica indicantur.) flunt aninadversiones aliquae et novarum descriptiones. Goettingae 1743. 8,94 p., 1 tals.

$4072 *$ De Allii genere naturali libellus. Goettingae (1745). 4. 56 p., 2 tab.

Redit in ejus Opusenlis hotanicis p. 32\}-396.)

$4.073^{*}$ - Opuscula sua butaniea prius edita recensuit, retractavit, auxil, conjuncta edliclit. Goettingae 1749.8.396 P., 5 tab. $(1 / \mathrm{h}$.

1.07\%" $\longrightarrow \mathrm{pr}$. De praestantia remediorum vegetabilium. D. Goettingae 1752. 4. 24 p.

$1075^{*}$ Enumeratio plantarum horti regii et agri Gottingensis aucta et emendata, Goltingae 1753. 8. Lxxx, 424 p., ind.

$1076 \div-$ Fmendationes et auctuaria ad stirpium helvetiearum listoriam. (Bernac) 1759.4 .47 p. Bibl. Juss.

1077 Enumeratio stirpium, quao in Helvetia rariores proveniunt. s. J. 1760.8 .56 p. B.

$1078^{*}$ - Ilistoria stirpium indigenarum Ilelvetiae inclioata. Bernae 1768. Ill voll. folio. - J: $444 \mathrm{j}$, tals. 1-20. - II : LXIv, $323 \mathrm{p}$. tab. $21-44 .-111: 204$ p., tah. $45-48$. (15 th.)

$4079^{*}$ Nomenclator ex historia plantarum indigenarum IIelvetiae exeerptus. Bernae 1769. 8. Iv, $216 \mathrm{p}$.

$4080^{*} \longrightarrow$ Praefatio ad Pharmacopoeam Irelveticam. Basileae 1771 folio. 13 1\%.

$4081^{*}$ Bibliotheca botanica, qua scripta ad rem herbariam facientia a rerum initiis recensentur. Tiguri $1771-1772$. II voll. 4. 1: 1774. Tempora ante Tournefortium. xvi, 654 p. - II: $1772 . \AA$ Tournefortio ad nostra tempora. 785 p. $(7 \mathrm{l} / 2$ th.

$4082^{*}$ Appendices in Johannis Scheuchzeri Agrustographiam Tiguri $1775.4 .92 \mathrm{p}$.

$4083^{*}$ Histoire des plantes vénéneuses de la Suisse, contenaut leur description, leurs mauvais effets sur les hommes et sur les animaux, avec leurs antidotes; rédigée d'après ce qu'on a de mienx sur cette matière et surtout d'après I'llistoire des plantes helvétiques de II. Je Baron de Haller; mise à la portée de tout le monde par Philippe Rodolphe l'icat. Yverdun 1776. 8. xxIx, 392, 112 p., 3 tab.

$408 \div \div-$ Matiere medieale, tirée de Lalleri "Historia stirpium indigenarum Ilelvetiae, Bernae 1768 . folio n avec beancoup d'additions par Philippe Rodolphe I'irut. Bern 1776. II voll. S. - †il. II: Ilistoire des plantes suisses ou Mlatière médicale et de l'usage économique des plantes. Berne 1791. II roll. S. vi, $368,360 \mathrm{p}$

*germanice: Albrecht von Haller's Arzueimittellehre der vaterlandischen l'tlanzen, nebst ihrem okonomisclien und technischen Nutzen. Aus den frumzosischen ubersetzt von Samuel Hahnemann. Leipzig 1806. $8.11,42 \% \mathrm{p} .\left(1 \frac{11 / 3}{3} h_{0}\right)$

$4083^{2}$

helveticarum denuo recusae cum descriptionibus clarissimi autoris, ejustem praefatione etc. Bernae 1795. folio. xxxvis, 68 p., 52 tab. $(10$ th. - - Editio denuo enendata et renovata. Bernae 18 13 . folio. (eadem est impressio.)

$4086^{*}$ Haller, Gottlieb Emanuel von. Epistola qua patri Alberto de Haller de natalibus gratulaturus dubia quaedam ex clarissimi linnaei fundamentis hausta offert. Goettingae, 1yp. Schultz. 1750. 4. (6 [ p.)

$1.087^{*}$ Dubia ex linnaei fundamentis hotanicis Lausta tradere pergit. Programma gratulatorium. Goeltingae, typ. Scliultz. $\$ 751$. 4. 24 p.
4088* Haller, Goltlieb Emanuel von. Nuper proposita Iubia contra ill Carolum Limaeum illustraturus etc. adgratulatur. Guettingae, schmidt. $1752.4 .15 \mathrm{p}$.

$4089^{*}$ Dubiarum contra sectionem septimam fundanentorum ill. Linnaei manipulus primus et secundus. Programmata gratulatoria. Goettingae, Bossiegel. 1753. 4. 11 fasc. 19 et $15 \mathrm{p}$.

$4090^{*}$ Halliday, Andrew. The West Indies; the natural aut physical history of the windward and leeward colonies; ete. London 1837.8 vill, 408 l., 3 tal,

(A p. 389-408: Appendix II. Catalogue of plants indigenous, nalturalized and cultivatiod in the British livest India Colonies by the late Jumes Dottin .Maycock, ,H. D.)

4091 Halling, Magmus. Theses Iotanicac Hafniae 1733. 4. Brunnich.

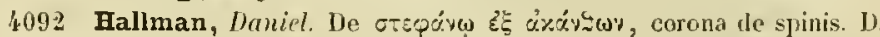
Rostochii 1757.4.88 J., t tab. B.

4093 t Hamberger, Georg Erhard. Praefatio ad Johanus Wolfgange Wedelii Temamen botanieum, gua difficultates in methorlo plantarum ocrurrentes, una cum mediis guibus eacdem removeri possunt

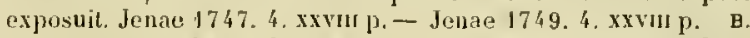

$4094 \div$ Sendsehreiben an T. T. Herru Hofrath Haller in Gottingen, wegen einer in denen Guttingisclien gelehrten Zeitungen rom 11. Martii a. c. im 27. Stuck befindlichen Recension der Hamherger'schen Vorrede zu den Wedel'schen Tentamine botanieo. Jena $1748.4 .8 \mathrm{p}$.

$4093^{*}$ - wr. De Opio. D Jenae 1749.4.32p.

4096* Hamburger, Emanuel. Symbolae quaodam arl doctrinam de plintarum metamorphosi. Commentatio botanico-morphologies. Vratislaviae 1842.4 .52 1., 2 tab. ( $1 / 2$ th.)

4097 Hamilton, Arlhur. Esquisse dune monographie du genre Seutellaria ou Tocjue, suivie du rétablissement du genre Scorodonia de Hoench et d'un némoire sur le fruit et l'embryon des Labiées prar N. C. Seringe. Lyun 1832.8.67 p., 2 tals.

$4.098 \div$ Hamilton, Francis. Some notices concerning the plants of variou. parts of India, and concerning the Sanscrita names of those regions (From tho Transactions of the royal Society of Edinbrrght.) Edinlourgh 1823.4. $16 \mathrm{p}$.

4099 Hamilton, $F$. A. Commentary of the fourth part of the llortus malabaricus. 1826.4. $106 \mathrm{p}$.

4100 Hamilton, Joseph. Treatise on cultivation of the Pine Apple. London 18.. 12. (6s.)

$101^{*}$ Hamilton, Iilliam. Prodronus plautarum Indiae occidentalis hucusque cognitarum tam in oris Americae meridionalis quam in insılis antillicis sponte crescentium aut ibi diuturne hospitantium; nota genera el species hactenus ignotas complectens. Londini 1825.8 . xvi, 67 p., 1 tal. col. $\left(1 \frac{1}{3}\right.$ (h.)

4102 Hammer, Christopher. Samling af botaniske afhandlinger. Christiania 1769. 8. Desid. B.

4103 - — - Florae Norvegicae Prorlromus. Forlober al norshe Flora eller Planterige. Udi systematisk og Linnaeisk Dragt efter Sexualsystemet. Kiobenhavn, trykt hos P. Ilorrebow's Enke. 1794.8 .164 1. (1 0 foll.)

404 Hammer, Friedrich Ludwig. Némoire sur les arbres, qui peuvent former les plantations le long des routes. (Verzeichniss der Baume. welche zu Pllanzungen langs der Landstrassen dienen homnen. Strasboury $1802.8 .46 \mathrm{p} ., 1$ tableau. $(75 \mathrm{c}$ )

405 Hamnerin, Pehr. Vires medicac plantarum quarundan indigenarum. D. Upsaliae 1737.4.16 p. B.

4106* Hampe, Ernst. Prodromus Florae Hereynicae oder Telzeichnis: der in dem Ilarzgebiet wildwachsenden Pflanzen. Ilalle 1836.8 90 p. - *Nachtragge: (Nordhausen) 1842. 8. \& p. - Neueste Nachträge: Linuaea 4844 p. $671-674$.

\$107* - Icolles muscorum novorum vel minus cogruitorum. Der cas 1-IIl. Bonnac 1844.8.37 foll., 30 tab. ( 2 th.)

$4108^{*}$ Klima, Vegetation und Flora des Harzes, uach Mithejlungen von Ernst IIampe in: Brederlow, der Harz. Braunschweis. 1845. 8. p. $86-111$.

\$109* Hanbury, William. I complete hody of Ilanting and gardening. containing the natura] luistory, culture and management of rleciduous. and evergreen forest-trees, with practical directions for raising and improving woods, nurseries, seminaries and plantations. etc. Iondon. 
Dilly. 1770-4771. II voll. folio. $-1: x_{x}, 885$ p., 43 tab. - II: 1774. 832 p., ind., 9 lab.

110 Hancock, John. Observations on the climate, soil and productions of British Guiana. London 1835. 8.

411" Handschuch, Karl Friedrich Gottried Albert. De plantis fumariaceis systematis naturalis earumque viribus et usu, adjectis deseriptionibus specierum, quae in Germania crescunt. D. Erlangae 1832. 8.44 p. $(1 / 6$ th.

\$12* Handtwig, Gustav Christian, pr. De Orclide. D. Roslockii 1747. 4. $29 \mathrm{p}$. \{113* $\frac{4.29 \mathrm{p}}{4.32 \mathrm{p} .}$ De Bryonia, van der heiligeu Rube. Rostockii 4758

41, Hanham, Frederick. Natural illustrations of the british grasses, accompanied by 62 real specimens. London 1846. (3l.)

4115* Hanhart, Johannes. Conrad Gesner. Ein Beitrag zur Geschichte des wissenschaftlichen Strebens und der Glaubensverbesserung in 16. Jahrhundert. Aus den Quellen geschöpt. Winterthur 1824.8 $\mathrm{xx}, 355 \mathrm{p} .\left(1 \frac{1}{2}\right.$ th. $)$

il6 Hanin, $L$. Enumeratio plantarum circa IIetas sponle nascentium quas in continuis fere itineribus collegit et summo studio cum celeberrimorum auctorum deseriptionibus et iconibus rite redegit ad usum Lyeaei Metensis alumnorum. Metis, typ. Collignon. 1806.4 . 28 1. a.

Libellum eundem esso puto, a Godron citatum: Hanin, Calalogue des plantes des environs de Mciz. 1806. \&.

414t Cours do botanique et de plirsiologie vérétale, auquel on a joint une deseription des principaux genres, dont les especes sont cultivées en France, ou qui y sont indigènes. Paris 1811. 8 xxvit, 759 p., 1 tab. col. ( 9 fr.)

$1118^{*}$ Hanmann, Christian. De plantis in genere. D. Lipsiae, Iyp. Ritzsch. 1635. 4. ( 16 p.)

$4119^{*}$ Hannemanp, Johann Ludwig. Nova et accurata methodus cognoscendi simplicia regetabilia juxta triplicem cognitionem grammaticam, philasophicam, medicam. Kilonii 1677, 4. $148 \mathrm{p}$.

$4120^{*} \longrightarrow$ Phoenix botanicus seu diatriba ploysica curiosa de plantarum ex suis cineribus resuscitatione. (Kiliae 1678.) 4. (15 foll.)

4121 * Happe, Andreas Friedrich. Hlora cryptogamica depicla scu muscorum el lichenum isque affinium plantarum icones. Berolini 1783. 4. 50 tab. col., text.

$4122^{*}$ Flora depicta aut plantarum selectarum icones ad naturam delineatac. Berolini 1791 . Folio. ( 8 foll.), 317 tals. col. $\left(63^{1 / 3}\right.$ th $)$

Prodiit annis 1788-1792 viginti sex fasciculis; icon prima: Dracocephalum austriacum; ultima Plumeria alba.)

41 2.3 * - Abbildungen okonomischer Pflanzen. Drei Hefte. Berolini 1792-1794. folio. $\left(5^{3} / 4\right.$ th. $)$

424* - Botaniea pharmaceutica, cxhibens plantas officinales, quarum nomina in dispensatoriis recensentur, cum iconibus al auctore aere incisis et vivo colore expressis, adjectis nominibus tam pharmaceuticis, quam e systemate Linnaei deprontis. Berolini 1788 . folio. 204 p., 595 tab. col. (sign. 1-595.) (140th.)

(Icones, etiam temporis respectu habito, satis mediocres 78 fasciculis aunis 1788-1806 prodierunt.

4123 Harasti, Gaetano. Della piu utile coltivazione del lino. Vicenza 1783.8. DC.

$4126^{*}$ Della piir utile coltivazione del frumento memoria. Vicenza 1784. 8. 252 p., 3 tab.

1 $127^{*}$ Dissertazione. (Netodo per accrescere gli ingrassi.) Milano 1787.4.42 p.

$\$ 128$ Della coltivazione del maiz. Vicenza 1788. 8. DC.

$\$ 129+$ Harchius, Jodocus. Enchiridion medicum, simplicium pharmacorum, quae in usu sunt, nomenclaturam, historiam, facultates et administrationem brevi, elegante fidoque poemate comprehendens. Basileac, excudebat Petrus Perna. 1573. 8. 277 p., praef., ind. (Accedit: Enchiridium medicinae: 46 p.)

430 Hardcassle, Lucy. An introduction to the elements of the Linnean system, with 120 woodcuts. London $1830.4 .154 \mathrm{p}$.

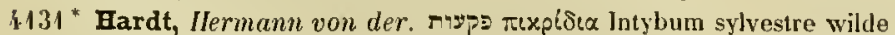
Endivic in Elisae nensa mors in olla 2 Reg. IV. nec non a"שNב a'yptooraలúkıe Bryonia in Esaiae vinea Teufolkürbis Esaia $\mathrm{V}$ pro illustrando Jona. Helmstadii, typ. llanm. 1719.4. $16 \mathrm{p}$
$4432+($ Hardy, A.) Catalogue des végétaux cultivés à la pépinière centrale du gouvernement a Alger. (llamma près Alger, le 31 mai 1844.) 4. 8 p. Bibl. Webs.

4133 Harlequin, $\boldsymbol{N}$. Nouveau jardin des vertus et proprielés des herbes connues. Aix 4624.8. S.

1.131* Harles, Christian Friedrich. Ucber die Belıandlung der llundswuth und insbesondre uber die Wirksamkeit der Datura Stramonium gegen dieselbe. Frankfurt a/Al. 1809.4. $84 \mathrm{p} .(3 / 1 \mathrm{th}$.)

4137) Harlin, C. B. F. Vie Naturkunde des Obstbaues, nebst der Naturbeschreibung des Obsthaumes und Naturgeschichte der darauf einwirkenden nutzlichen und schadlichen Thiere. Stungart 1841.8. $10 \frac{1}{8}$ plag., 1 fol. cmend. ( $1 / 2$ th. $)$

$\$ 136+$ Harmand de Montgarny, J. B. Lettre sur los projriétés medicinales de la racine de Bryone ou de l'lpécacuanlıa européen. Verdun, typ. Christophe. (1783.) 8.16 j).

4137 Harmens, Gustaf, pr. De sinilitudine vitae phrsicac in animalibus et plantis. D. Londini Gothorum 1752.4.24 p. w.

$4138-$ De transpiratione plantarun. D. Londini Gothorum 1756 4. $22 \mathrm{p} . \mathrm{w}$.

4139 De differentia humorum in animalibus et plantis. D Londini Gothorum 1771. 4.24 p. w.

$4140^{*}$ Harnier, Adolph. De vi Cynanchi Vincetoxici pharmacodynamica. Programma gratulatorium. Marburgi 1844.4.11 p.

411 Harnisch, Joham Andreas. Neditationes botanico-medicac de planta quadam Marchiac propria Pimpinella nigra, quibus demonstratur, illan in multis morhis insignem possidere virtutem et efficacian, pertractatae el editae. Lijsiae 1757. 4. 48 p. - "Lipsiae $1758.4 .40 \mathrm{p}$

4142t Haro. Tableau des champignons observés dans les environs de Metz. etc. Prenier mémoire. Metz 1 $\$ 38.8 .47$ p. (1 fr. 50 c.)

(Celte hrochure est la mente, une colle publiéc sous le mème titre avec M. Fournel.) Leveille.

4143* Harpestreng, Ienrik. Danske Lagebog fra det trettende Aarhundrede forste Gang udgivet efter et Pergamentshaandskrift i det store Kongelige Bibliothck, med Inledning, Anmárkniuger og Glossarium af Christian Nlolbech. Kiobcnhavn, Thieje. 1826. 8. vitI, $206 \mathrm{p}$ Bibl. Ernesti Meyer, Dresd. Goett.

(a Eine prosaische, rom foteinischen Original of abweichende dänische Bearbcitung des Macer Floridus, fur Pllanzengeschichte micht unwichtig. Es sollen nur werige Excmplare gedrucht sein. ln den Buchhandel scheint das Werk nicht gehommen zu sefit. o) E. M.

414* Harrington, Robert. A plitosophical and experimental enquiry into the first and general principles of animal and vegetable life: likewise into atmospherical air; with a refutation of Dr. Priestiey: doetrine of air. London 1781 . S. VII, 402 p.

4t tij Harris, Thad. Mason. The natural history of the Bible. Boston (Massachusetts) 1820. 8. - Ed. 11: London 1824. 8.

4.146 Harrison, Charles. A treatise on the eulture and meoagement of fruit-irees, with iustructions of pruning, illustrated with 56 cuts. London 1825. 8. (12s.)

$4147^{*}$ Harrwitz, Julius. De Cladosporio herbarım. D. Berolini 4845 . S. $42 \mathrm{~J}$., $1 \mathrm{tab}$.

$4118^{*}$ Harsleben, Karl Friedrich. De cortice Winterano (et Canella alba). D. Francofurti a/V. 1760.4.36 j).

4149 Hartenfels, Arnold Friedrich von. Neuer Garten-Saal, oder vollständige Beschreibung aller einheimischen und ausländischen Stauden, Knollen, Zwiebeln und Blumengewachse, wodurch deren Anwachs auf leichte Art erhlärt und den Gartenliebhabern zuverlassige Nachricht gegeben wird, wie man allerhand Arten schöner Blumenmuster ordentlich gross und gefullt machen, auch denen Nelken, Aurikeln, Levkoyen u. s. w. verschiedenartige Farben beibringen konne. Frankfurt 1745. S. - Frankfurt 1733. S.

( Nomen fictum! auctor Heiligenstadii vixit, eique nomen fui Kaesersberg, amans hortorum." Hall.)

4.150* Hartjens, Isacus IIesterceen. De cortice Pcruviano. D. Trajecti ad Rhenum 1762.4.45 p.

4151 Hartig, Georg Ludwig. Auweisung zur Holzzuelı für Forster. Marburg 1804. 8. $(1 / /$.

t gallice: Instruction sur la culture du bois a l'usage tes forestiers. Ouvrage traduit de l'allemand par J. J. Baudrillart. Ed. Il. Paris $180{ }^{\circ}$ 12. $\mathrm{xxiv}, 160 \mathrm{p}$ 
4152 Hartig, Georg Ludwig. Versuch über das Verhaltuiss der Brennbarkeit der meisten deutsehen Waldbaumhölzer. Herborn 1807. 8 . $(3 / 12$ th. $)$

$4153^{*} \longrightarrow$ und Theodor Hartig. Forstliches und forstnaturwissenschaftliches Conversations-Lexicen. Ein llandbuch fur Jeden, der sich fur das Forstwesen und die dazu gehorigen Naturwissenschaften interessirt. Berlin 1834. 8, xıv, 1034 p., effigies Hartigii patris. (5th.) - Zweite revidirte Auflage. Stuttgart 1836. 8. (5 th.)

$\$ 154^{*}$ - Erfahrungen uber die Dauer der Ilolzer und uber die Viltel, die Dauer des llolzes zn verlăngern. Berlin 1836. 8. $24 \mathrm{p}$. $\left(1 \%, h_{0}\right)$

4130 Kurze Belehrung uher die Behandlung und Kultur des Waldes. Berlin 1837. 8. 11 plag. $13 \%$ th.)

4156* Hartig, Theodor. Abhandlung uber die Verwandlung der polykotyledonischen Pflanzenzelle in Pilz - und Schwammgehilde, und ler daraus hervorgehenden sogenannten Fáulniss des llokes. Berlin 1833. 8. vit, 46 p., 2 tab. ( $1 / 2$ /h.)

$4157^{*}$ - Jahresberichte uber die Fortsehritte der Forstwissenschaft und forstlichen Naturkunde im Jahre 1836 und 1837 nebst Originalabhandlungen. Erster Jahrgang, Heft I-IV. Berlin 18371839. 8. $\left(4 \frac{1}{2}(h)\right.$.

$\$ 138^{*}-$ Lehrbueh der Pflanzenkunde in ihrer Anwendung auf Forstwissenschaft. Erste Abtheilung. Yollstándige Naturgeschichte der forstlichen Kutturpllanzen Deutschlands. Berlin 1840 - 1846. 10 Hefte. 4. 196 p., 86 tab. col. $\left(16 \frac{2}{3} t h\right.$. $)$

(Opus omnium de botanica saltuaria iconographiarum longe praestantissimum! Continuabitur.)

\$ $169^{*}$ Neue Theoric der Belruchtung der Pflanzen. Gegrundet aul vergleichende Untersuchung der wescntlichsten Verschicdenheiten im Baue der weiblichen Geschlechtstheile. Braunselsweig 1842. 4.44 p., 1 tab. $\left(1 \frac{1}{3} t h\right.$. $)$

$4160^{*}$ - Beiträge zur Entwicklungsgeschichte der Pflanzen. Mlit besondrer Bezichung auf die vom Prol. Dr. M. S. Schteiden in dessen: Grundzüge der wiss. Bot. Bd. II, 1843 gegen meine neueren physiologisehen Arbeiten erhobenen Einwürfe. (Als Beilage zu des Verf. Lehrbuch der Planzenkunde, so wie zur Befruchtungstheorie desselben.) Berlin 1843.4 .28 p., app., 1 tab. $(1 / 2$ th.

$4161^{*}$ —— Das Leben der Planzenzelle, deren Entstehung, Vermehrung, Ausbildung unil Auflosung. Berlin 1844. 4, 52 p., 2 tab. $\left(1 \frac{1}{2} t h.\right)$

$4162^{*} \longrightarrow$ Vergleichende Untersuchungen über den Ertrag der Rothluche in lloch - und Pflanzwalde, im Nlittol - und Vierlerwald-Betriebe, nebst Anleitung zu vergleichenden Ertragserlorschungen. Im Anhange: Ertragstafelı von $J$. C. Pautsen und Georg Ludwig Hartig; Kreishächen-, Secanten-, Tangenton und Reductionstabellen. Nit lllustratiouen in Jlolzschnitten. Berlin 4847 . gr. 4. $176 \mathrm{p}$. $\left\{2 \frac{1}{2}(h\right.$.)

$4163 \div$ Harting, $P$. Bijdrage tot de Anatomie der Cacteen. s. l. et a. 8. 64 p., 2 tab. Bibl. Juss.

$416\}$ Mlikrochemische onderzoekingen over den aard en de ontwikkeling van den plantaardigen celwand. s. l. et a. 8 tab.

(Analysin hujus commentationis dedit Ilugo von Nohl in Botanische Zeitung 186. n. $64-69$.)

$4163^{*}$ - Mikrometrische Untersuchungen uber die Entwickelung der Elementartheile des jáhrlichen Stammes der Dikotylen. Aus dem Franzusischen ubersetzt von Karl Mueller. Aus dem 19. Bande der Linnaea hesenters abgedruckt. Halle 1847.8.102 p.

(Commentatio ill. $P$. Harlingi, olin in Francherana, nune in Trajectina academia professoris, cujus in titulo praefationis nomen errore puto a MI. G. IIarting p scribitur, exstat primum hollantice in Tydschrift voor Haturlijke geschiedenis en physiologie, 18 't. $10 \mathrm{~m}$. XI. fasc. 111 et 15. p. $22 y-335$. - tunc ab autore ipso emendatiur gallice in Ann. des se. nat. 18 hi. tom. W. $\mathrm{p}$. 210-275.)

4166 Recherches sur la nature et les causes de la maladie des pommes de terre en 1845. Amsterdam 1846.8.

$4167^{*}$ Hartinger, Anton. Paradisus Vindobonensis, Auswahl seltner und schonbluhender Pflanzen der Wiener Gárten in naturgetreuen $\mathrm{Ab}$ Lildungen. Erláutert von Stephan Endlicher. Wien $1844-1847$. Fase. I-XV. folie. 60 tab. col., totidemque foll. (col. 120 fl. C.II. $82 \frac{1}{2}$ th. - nigr. 30 fl. C.Ml.) Bibl. Mus. bot. vindob. (Continuatur.) (Descriptiones practer sex nondum editae sunt.)

$4.168^{*}$ Hartman, Carl Johan. Genera graminum in Scandiıavia indigenorum recognita. D. Upsaliae 1819.4.10 p.

(Dissertatio sub pracsidio Caroli Petri Thunberg proposita est.)
$4169^{*}$ Hartman, Carl Johan. Ilandbok i Skandinaviens Flora, innefattande Sveriges och Norriges Vexter, till och med Mlossorna. Stockholu 1820. 8. 32, LxiI, 488 p., 2 tab. - Ed. II. Stockholm 1832. 8 . - Ed. Ill : rättad och förokad. Stockholn 1838. Il voll. gr. 8. - Forra Delen: Botanologien. 1v, 180 p., 2 tab. - Sednare Delen: Floran. xuxı, 305 p., 2 tab. (eaedem!) (4 Rdr.) w.

4170 Utkast till populár Naturkuunighet. Stockholm 4836.8. xvt, 340 p. (2Rdr.) w.

$4 \pi^{*} \longrightarrow$ Svensk och Norsk Excursions-Flora. Plıanerogamer och Ornıbunkar. Stocklıolm 1846. 12. xvi, 191 p. (1 Rdr.)

4172* Hartmann, Franz Sacer. Primae lineae institutionum botanicarum Crantzii. D. Vindobonae 1766.8 .60 p., 4 tab. $-{ }^{*}$ Ed. II. cum Crantii Idditamento generum novorum, cum eorundem speciebus cognitis et specielus novis. Lipsiae 1767. 8.94 p., 4 tab.

$4173^{*}$ Hartmann, Friedrich. Systematische Uebersicht der Versteinerungen Wurteml,ergs, mit vorzuglicher Rüeksicht der in den Ungebungen von Boll sich findenden. Tubingen $1830.8 .(1 / 4$ th.)

4.174 Hartmann, Johann. Tractatus physico-medicus de Opio, publice Mlarburgi praclectus, editus a Johann Georg Pelshofer. Wittenbergae 1635. 8. 173 p. B. - †Opiologia, i. c. Discursus ruidam de opio. Wittenbergae, Berger. 1658. 12. 173 p., praef, ind.

4173 Hartmann, Melchior Philipp. De succine et ejus usu in medicina. D. Lugduni Batavorum 1710.4. B.

4176* Hartmann, Peter Immanuel, pr. Plantarum prope Francofurtun ad Viadrum sponte naseentium fasciculus primus. D. Francolurti $\mathrm{a} / \mathrm{V}$. 1767. $4.46 \mathrm{p}$.

$4177^{*}-$ De Salice laurea oderata, Linnaei pentandra. D. Trajecti a/V. 1769.4.40 p.

$4178^{*}$ Insignem Cicutae Stoerkianae efficacitatem medicam singulari quadam observatione comprobat. D. Trajecti a/V. 1772 4. $40 \mathrm{p}$.

$4179^{*}$ L. Exercitatio litteraria de Joannis Langii studis hotanicis D. Trajecti a/V. $1774.4 .16 \mathrm{p}$

Usteri Delect. opulsc, bot. 11. p. 121-140.)

$4180^{*}-1$ listoria Gentianae naturalis et medica. D. Trajecti a/ $\mathrm{V}$ 1777. $4.48 \mathrm{p}$.

$4181^{*}$ - Antinephritica Uvae ursinae virtus merito suspecta. D Trajecti a/V. $1778.4 .55 \mathrm{p}$.

4182* — Super Daphnes Gnidii usu epispastico pauca quaedam. D. Trajecti a/V. $1780.4 .19 \mathrm{p}$.

$4183^{*} \longrightarrow$ Iconum botanicarum Gesnerio-Camerarianurum minorum nomenclator Linneanus. D. Trajecti a/V. 1781.4.52 p.

418:* De Gratiola. D. Trajecti a/V. 1784.4.28 p., 1 tab.

Respondens fuit Jakob Friedrich Hoffmann, idem ni fallor, qui deinde apud Varsavienses botanicus inlotuit.

$418 a^{*}$ - De Sedo acri Liunaeano ejusque virtute in caucro aperto et exulcerato. D. Trajecti a/V. 1784.4.28 p.

$4186^{*}$ — Virtutem Ilellebori nigri hidrogogam nuperis aliquot exemplis confirmat. D. Trajecti a/V. 1786.4.23 p.

$4.187^{*}-$ Circumspectus Camphorae in morbis inflammatoriis usus internus. D. Trajecti a/V. 1788.4.24 p.

1 $188^{*}$ Usus corticis peruviani in febribus biliosis. D. Trajecti a/V. $1790.4 .17 \mathrm{p}$.

$4189^{*}$ De Nonarda. D. Trajecti a/V. 1791.4. $19 \mathrm{p}$

$4190^{*}$ Hartmann, Philipp Jakob. Succincta succini prussici listoria et demonstratio. Berolini, Rüdiger. 1699. 4. (4 foll.) 48 p.

4191 Succini prussici physiea et civilis historia. D. Francelurti a/V. 1677. 8. B.

4192* Hartmann, Plilipp Karl. Pharmacologia dynamica nsui academico accommodata. Eil. Il. emendata. Vindobonae 1829. Il voll. 8 . - 1: viI, 510 p. - II: 323 p. $(6$ th. $)$

4193* Hartmann, Samuel Adolf Friedrich. De Pechuri. D. Franeofurti a/V. 1792. $8.28 \mathrm{p}$.

4194 Hartmann, Wilhelm. Observationes botanicae de discrimine generico Betulae et Alni. D. Stuttgardiae 1794. 4. 38 p. B.

$4190^{*}$ Hartrodt, $A$. Die Alkaloide; oder Darstellung der Bereitungsarten. der physischen, chemischen und medizinischen Ejgenschaften der bis jetzt bekannten Pllanzenalkatien in alphabetisch-tabellarlscher Form. Leipzig 1832.4. 49 p. $(2 / 3$ th. $)$ 
11!6t Hartung, C. A. F. A. Heimrich. De Cinchonae specielsus alque melicamentis Clinan supplentibus. D. Arenturati 1812.4.39 p.

$1.197^{\circ}$ Hartweg. IIortus Carlsruhanus, oder Verzeiclmiss sámmtlicber (iewachise, welche in dem Grossherzoglich botanischen Garton zu Cartsruhe cultivirt worden, nebst den lieschichtlichen der botani-chen und Lustgarten von $1530-1825$, und vinem Situationsplan vern samntlichen Gewhehshausern. Gallsruhe 1825. 8. xLVI, 307, Tj., 1 tals. $(2 / h$. $)$

$4198^{*}$ Harvey, William Ilenry. The genera of South Afriean plants arranged accorling to the natural system. Cape Town, Rohertson 1838. 8. LxY, 429 1. (12s. Pamplin.) Bibl. Schlechtend., Vindob., Cand.

\$.199. - A Manual of the british Algne: containing generic and specilic descriptions of alt tho known british species of sea-weeds, and of Conlervac both marine and fresh-water. With reforences to the figures in Mrs I'yalt's "Agae Danmonienses" and other works. Lonilon 184 1. 8. LVI, 229 p. (9s.)

$4: 300^{\circ}$ Plycologia britannica : or a Jistory of british sea-weerls, containing coloured figures, generic and specific cliaracters, synonymes and descriptions of all the species of algae inhabiting the shores of the british islands. In three volumes. Yol. 1. fasc. 1-X. Lonrlon 4846. 4. vill p., 60 foll, 60 tab. col. (2l. 10s.)

(Editio minor in octava forma : at fasc. 2s. Ged.)

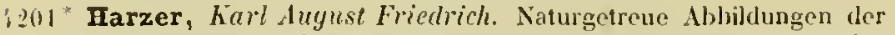
vorzuglichsten essbaren, giftigen und verdichtigen Pilze. Nach eignen Beohachtungen gezeichuet und beschrieben. Bevorwortet von Luduig Keichenbach. Dresden 4842. gr. 4. x, 136 p., ind., 80 tab. col. I tah, nigu. $\left(24 \frac{1}{2}\right.$ th. $)$

(Prodiit annis $18 \% 2-18$ i⿱ sedecim fasciculis.)

1202 Hasaeus, Theodorus. Dissertationum ef observationum philologicarum sylloge. Bremae 1734.8. 630 p., tab. B.

(Insunt dissertatio de liguo Sittim, p. 170-9.2, et dissertatio de Rubo Mosis iser dicto.)

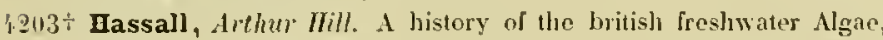
including descriptions of the Desnidede and Diatomacene. With upwards of oue lundred plates illustrating the various species. In Iwo volumes. London $1845.8 .-1$ : vi1, 462 p. $-11: 24$ p., 103 tal. col. (2l. 5.s.)

1204 Hasse, Johemn Goltried. Der aufgefundne Erilanus oder neue Anfsclilusse uber den Ursprung, die Zeit der Entstehung ete. und (iesclichte des Bernsteins. Riga 1796. 8. $(2 / 3 / h$.)

1208 - Preusseus Anspruch, als Bernsteinland, das Paradies der .Iten und [r]and der Mensehheit gewesen zu sein. Königsherg 1799. 8. $(1 /$, th. $)$

\{206 Hasselbom, Nicolaus, pr. Aphorismi de morhis plantarum. D. Nhoae 1748.4 .8 p. B.

1207* Hasselquist, Fredric. lter palaestinum, eller Resa til lleliga Lanclet, forrahttad ifràn à 1749 til 1752, utgivnen af Carl Linnaeus. stuckholm, trp. Salvii. 1757. 8.619 p., praef.

germanice: Reise mach Palistina in den Jahren 1749-1752. Herausuegehen von Carl Limnaeus. Aus dem Schwedischen von Gadebusch Bostoch 1762. 8. $606 \mathrm{p} .(12 / 3 \mathrm{ih}$.)

t anglice: royages and travels in the Levant. London 1766. S. vul Lili 1\%. I mappa geogr.

Hallice: Yuvages thans le Levant. Paris 1769. 11 voll. 12.260 , $201 \mathrm{p}$. Literac Hasselquistii all Limnaeum, priores quac in itiocre a p. 5 .

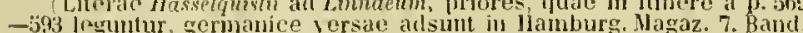
1. $160-201$.

1208† Hasskarl, Justus Larl. Over de Ontwihkeling van Warmte in Planten. Eene physiologisclıe Bydrage. Batavia 4\$3\$. 8 .

(Verhandelingen van het Bat. Gen. van Kunsten en Wetenschappen, Deel XVII. 1. 139-158.)

1209' Catalogus plantarum in horto botanico Bogoriensi culfarum alter. (Tweede Catalogus Iler ins Lands Plantentuin te Buitenzorg gekweekte gewassen.) Batavia, typ. oflicinae publicac. 1844 s. $391 \%(t / h)$

1210* - Aantecheningen over het nut, door de Bewoners von dava ath eenige planten van dat Eiland togeschreven, uit berigten der inlanders zamengestedd. Amsterdam is4:3. 8. vin, $436 \mathrm{p}$. et emend. Bibl. Schlechtend.

1.211 Hastings, Charles. Illustrations of the natural history of Worcestershire, with information on the county; incl. also at short account on the mineral waters. Loudon $1 \$ 34.8$. 1 \$ 11
4212 Hatchett, Charles. On the spihenard of the ancients. London 1836.4.

4213 Hauck, Johannes. Catalogirs plantarum horti academici LugrtunoBatavi, cum indice plantarum indigenarum, quae proje Lugdunum in liatavis nascuntur. Darmstadt 1679.12. 139 p. B.

421:* Hauptmann, Augnst. Insignes aliquot viticulurae crrores d. i. leburaus grosse Weinhaws lrrthumbe. ctc. Nurnberg, Findter. 1642. 8. 151 p., praef.

421: Hauser, Johann Jakob. Theses botancae et anatrmicne. Basileae $1711.4 . \mathrm{H}$.

(Meminit spica Zeae, in tua granun Avenae fuerit.

4.216* Hauser, Joham Käspar. De Colchico autunnali. D. Turici 1835. $8.13 \mathrm{\mu}$.

4217* Hausmann, Frans. Gagea und Lloydia. bine Monographie. Wien 1841. 8. vi, $58 \mathrm{r}$.

4.218* Haworth, Adrian Hardy. Olservations on the grmus Jesenbryanthenum in two parts, containing scientific descriptions of above one hundred and thirty species. Loudon 1794. $8.480 \mathrm{p}$.

$4219^{*}$ Miscellanea naturalia sive dissertationes variae al listoriam naturalem spectantes. Loodini 1803.8. $204 \mathrm{p}$.

Agitur praesertim de Mesembryanthemi, Tetragoniale PortuJaccae et suisifragae generibus.)

$4220^{*}$ - Synopsis plantarum succulentarum cum descriptionilus, synonymis, locis; observationilus anglicanis, culturaque. Londini 1812. S. vili, 334 p. (10s. 6d.) - "Eilitio usui hortorum Germaniae accommolata. (curavit Franz ron Paula Schrunk.) Norimberzae 1819. 8. vill, 372 J. $\left(2 \frac{1}{2}(h)\right)$

4221* - Supplementum plantarum succulentarum, sisten- plantas novas rel nuper introductas sive omissas in synopsi plantarum succulentarum cum olsservationibus sariis anglicanis. Adjumgitur Narcissearum revisio. Loudini $4819.8 . x x, 158$ p. (5s.)

(Autoris "Plantae rarae succulentae" sunt in Philosuphical Magnzine annorum 1823 et $182 i$.)

$4222^{*}$ - Saxifragearum enmeratio. Aecedunt revisiones plantarum sucenlentarum. Londini 4821. 8. xx, 207 p. $(40$ s. 6 d. $)$

4223* - A monograph on the Subordo $V$ of Anaryllideae, containing the Narcisseae. Jontlon 1834. 8. (From Sucet, British Flotser Garden.) - *Narcissearum Monographia. The second edition with adelitions and improvements. London $\{831.8 .22 \mathrm{p}$.

422:* Hayne, Fiedrich Gotllob. Termini botanici iconibus illustrati oder botanisclse Kuostsprache durch Ablildungen erlutert. Berlit 1807. Il voll. 4. 182 p., 69 tal). col. $\left(20^{l / 2}\right.$ th. $)$

(Prodiit annis $1799-1812$ in I's fasciculis.)

122: $3^{*}$ De coloribus corporum natoralium praecipue animalium vegetaliliumrue determinandis commentatio physiographica. (Programma.) Berolini $1814.4 .26 \mathrm{p.}, 2$ tab. $(1 / 3 / \mathrm{h}$.

$4226^{*}$ Dendrologische Flora der Lmgegend und der Garten Berlin's. Berlin $1822.8, x_{0}, 245 \mathrm{j}$., 1 taly. $\left(1 \frac{1 / 3}{t h}\right.$.)

4.227* - Getreue Darstellung und Besclireibung der in der Arzneikunde gebrauchlichen Gewachse, wie auch soliher, welche mit ihnen verwechselt werden könmen. Berlin $1805-1846$. XIV voll. 4. 648 fol]., $648 \mathrm{tab}$. col. (I-Xill: 120 th. $-\mathrm{X} 1 \mathrm{H} .1-2: 8 \mathrm{~h}$.)

(Volumen XII et xill ediclerunt Brandt et Ratzeburg: inde a volu-

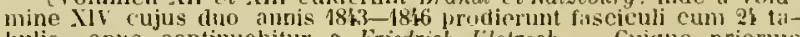
bulis, opus continuabitur a Friedrich klotsch. - Cuique priorun roluminum insunt \&s tabulae.)

1.228* Darstelkng und Beschreibung der Arzneigewàchse, welche in die neue Preussische Pharmacopoc aufgenommen siul. nach naturlichen Familien geordnet und erläutert von Johann Friedrich Brandt und J. Theodor Christian Ratseburg. Berlin 1829-1841. $1 V$ voll. 4. - 1: 1829. p. 1-86, 55 tab. col., effigies Ifuyne. - II: 1830. p. $\$ 7-466,55$ (ab. col. $-111:$ 1834. 77 J., 50 tab. col. IV: 1844.92 p., 70 ab. col. $\left(29 \frac{1}{3}\right.$ /h.

(Repeluntur misera franule tabulae libri praccedentis: num descriptiones de nove elaboratae sint, igumo. Protiit liber anui< is? $-18,1$ fasciculis X.XIl a $60 \mathrm{Lab} .=1 \frac{1}{3}(\mathrm{~h}$.)

4229* Hayne, Joseph. Gemeinmuziger linterricht uber dic schadlichen und nutzlichen Schwamme. Wien $4830.8 .76 \mathrm{p}$. ( $1 / \mathrm{t}$ th.

(Fjustem autoris liber manuscripus: asystematisches Verzeichniss der Arter und Abarten essbarer Fasolen. Welche grtusstentheils schon auf den Markten der ostreichschen Monarchie vorkommen. und im $\mathrm{h}$. $\mathrm{h}$. Universitatsgarten 1823 cultivirt worden sind, "servatur in bibliotheca Musei botanici Vintobonetsis. Recensentur q-9 variptates. addita latina descriptione.) 
4230 Haynes, $J$. An accurate survey of the botanic garden at Chelsea. Lonilon 1754 . fulio. $\mathrm{H}$.

$4231+$ Haynes, Thomas. A treatise on the improved culture of the strawberry, raspberry and gooseberry. London 1812. S. VII, $101 \mathrm{p}$. (1s. 6d.)

4232 Interesting discoveries in horticulture. London 1811. 8.

4233 Hayward, Josiph. The science of horticulture. London 1818. 8.

423\}. Bazen, I'illem van. Naamlyst van Bloem-zaaden, te bekomen by Willem van Hazen, Bloemist te Leyden. s. a. folio. 2 p. B.

4233 Catalogue tant des arbres et plantes errangeres, que rles racines et oignons à fleurs, qu'on vend chez Willem van Hazen, H. Jalkenburgh et Comp., fleuristes a Leyden. Ed. Il. s. a. 8. 109 , 30 J., 4 tab. B.

4236 * Eebenstreit, Ernst Benjamin Gottlieb. Diatribe do vegetatione hyemali. Lipsiae 1777.4.16 p.

$4237^{*}$ Causas humorum motum in plantis commutantes recenset. Lipsiae 1779. 4.12 p.

$4238^{*}$ Momenta quaedam comparationis regni animalis cum vegetabili. D. Lipsiae 1798.4. 47 p.

4239* Eebenstreit, Johann Ernst, pr. De sensu externo facultatum in plantis judice. D. Lijsiae 1730. 4. 44 p. (Res]rondens: Christian Goltlieb Ludvoig.)

4240 — Definitiones plantarum. D. Lipsiae $1731.4 .44 \mathrm{p}$.

$4241^{*}$ _. Programma de methotlo plantarum ex fructu optima. Lipsiae 1740. 4. 16 p.

$4242^{*}$ - Programma de foetu regetabili. Lipsiae 1747.4. $24 \mathrm{p}$.

$1243^{*}$ Hécart, Gabriel Antoine Joseph. Essai sur les qualités et propriétés des arbres, arbrisseaux, arbustes et plantes liyneuses, qui eroissent naturellement dans le département du Nord, ou que l'on peut y naturaliser. Valenciennes, an III. (1795.) 4. $132 \mathrm{p}$., ind.

421:4 Némoires sur les haies. Valenciennes 1812.8. a.

2215 Sur la eulture de l'oreillo d'ours. Bruxelles, Weissenbruck. $1820.8 .7 \mathrm{p}$

( "Tiro à 6 exemplaires." Querard.)

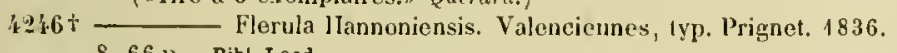
8. 66 1). Bibl. Leod.

42:7 Hechenberger, $W$. Salzburgische Giffplanzen, mit 24 getrockneten Exemplaren. Salzburg 1804-1806. 4 llefte. folio. (2 th.)

$4.248^{*}$ Hecker, Johann Julius. Einleitung in die Botanik, worinnen die nothigsten Stucke dieser Wisseuschaft kürzlich abgehantelt wertlen. Mlit Vorrede von Friedrich Hoffmann. Hallo 1734.8.547 p., praef.

$4249 \ldots$ Specimen Florae Berolinensis. Berolini, typ. Henuing. 1742. fulio. $\mathrm{H}$.

$1250 *$ (- Flora Berolinensis: d. i. Abdruck der Krauter und Blumen uach der besten Abzeichnung der Natur, zur beforderung und Frkenutniss des Pllanzemreichs veranstaltet von der Realschule in Berlin. Centuria I-1II. Berlin $1757-1758$. folio. 8 p., 300 tah. (Sunt icones fuliginis ope de plantis ipsis expressae, ut fut mos
aevo.)

$\{25\}^{*}$ Hedenstroem, Johan. De usu listoriae naturalis oeconomico. D Gryphiae 1796. 4. 12 p.

4252 * Heder, Chistoph Audreas. Hedera teorestris. D. Altuorfii 1736. 4. $24 \mathrm{p}$.

4.253* Hedin, Sveno Andreas. Quid Linnaeo patri debeat medicina? D. Upsaliae 1784. 4. $26 \mathrm{p}$.

(Redil cum Epistolis Linnaeanis, editis a D. II. Stoever, p. 173-19\%.)

\{254 Hedrén, Andreas. Sokn-Beskrifuing ofver Wisnum och Kil i Wermlands Lán. Carlstad 1814. 8. 44 j. w.

4 ․․․ * Hedwig, Johann. Fumlamentum historiae naturalis muscorum frondosurum, conccrnens corun flores, fructus, seminalem propagationem, adjecta generum dispositione methodica, iconibus illustratis. Jipsiae 1782. II voll. 4. - I: xxuI , 112 p., 10 tab. - II: xI, 107 p. 10 tab. $\left(4 \frac{1}{2}\right.$ th. - col. 7 th. $)$

$4236^{*}-$ Theoria generatiunis et fructificationis plantarum cryptoganicarum. Petropoli 1784. 4. 164 p., 37 tab. col. $(1 \% / 8$ th. $)-$ ${ }^{*}$ Theoria generationis et fructificationis plantarun cryptogamicarum Limnaei retractata et aucta, Lipsiae 1798. 4. xи, 268 1., 42 lab. col. $(20$ th. $)$

(Editio princeps Petropolitana Lipsiensi valde est inferior.)

Pritzec, Thes. lit. bot.
$4257^{*}$ Hedwig, Johann. Descriptio el atumbratio microseopico-analytica muscorun froudosorum nec non aliorum vegetantium e classe cryptogamica Linnaei novorum dubiisque vexatorum. (Mikroscopisehanalytische Besehreibungen etc.) Lipsiae 1787-1797. I voll. folio - l: 1787. 109 p., praef, 40 ab. col. - I1: 1789. 119 p.; 40 (al). cul. - IIs: 1792. 100 p., jracf., 40 tab. col. - IV: 1797. 106 j., 40 tab. col (col. 64 th. - nigr. 32 (h.)

$42: 38^{*}$ De fibrae vegetabilis et animalis ortu. Programma academicum. Lipsiae 1789. 4. 32 P. (5/2, th.)

\section{(Esemplaria inni 1790 praeter titulum non differunt.}

$4259^{*}$ Sammlung seiner zerstreuten Abhandlungen und Beolsachtungen uber botanisch okonomische Gegenstande. Leipzig 1793 - 1797. 2 Bändclien. 8. - I: 1793. 208 p., 5 tab. col. - Il: 1797 $175 \mathrm{p}, 1$ tab. cul. $\left(2 \frac{1 / 3}{3}\right.$. $)$

$4260^{*}$ Beleliruug die Pflanzen zu trockinen usd zu orduen. Fur junge Botaniker. Gotha 1797. 8. 206 p. - TEd. II. Gotha 4801. s. vili, $206 \mathrm{p} .(\mathrm{7} / \mathrm{12}$ th. $)$

$4261^{*}$ L_Lilicum genera et species recentiori methodo accomodatae analytico leseriptae. leonibus at naturan pictis illustratac a Romuno Adolpho, filio. Lipsiae 1799-4803. IV fase. folio. 69 p., 24 (al). col.) (12 th.

$4262^{*}$ - Species muscorum frondosorum descriptae et tabulis aeneis coloratis illustrata. Opus posthumum, editum a Friedrich Schwaegrichen. Lipsiae 1801. 4. vi, 352 p., 77 tab. col. - Supplementum 1, vol. 1. 1814. xvi, 196 j., tab. I-XLA. vol. 2. 1816 . vi, 373 p.. lab. L-C. - Sujplementum II, vol. 1. 1823-24. vI, 186 p., tab. CI-CL. vol. 2. $1826-27.210$ p., tab. CLI - CC. - Supplementum IJI, vol. 1. $1827-28$. (180 p.) tab. CCI-CCL. vol. 2.1829 $-30 .(168$ p) tab. CCLI-CCC - Supplementum IV, vol.1. sect.1. 1842. (100 p.) tab. CCCI - CCCAXV. (100 th. - in charta velina : $133 \frac{1}{3}$ th.)

4.263* Hedwig, Romanus Ado/ph. Trenella Nostoch. Commentatio. Lipsiae $1798.4 .71 \mathrm{\mu} ., 1$ tab. col. $(2 / 3 t h$.

4264* Sporarum catalogum offert. Lipsiae 1799.8.16 ].

$4265^{*}$ - Aphorismen uber die Gewachskunde. Zum Gebraneh meiner Vorlesungen mit besondrer Rücksicht auf dio Lehrsátze meines Vaters entworfen. Leipzig 1800.8 . xxiv, $102 \mathrm{p} .(1 / 2 \mathrm{th}$.

$4266^{*}-$ Observationum botanicarum fasciculus I. Lipsiae, Schaifer. 1802.4 . $20 \mathrm{p}, 11$ tab. col. $(3 \mathrm{~h} / \mathrm{h}$.

Eodem titulo prodiit Programma invitatorium Lipsiae, typ. Ilirschfeld. $1802.4 .16 \mathrm{p}$.)

4267* Ciencra plantarunı secundum characteres differentiales acl Mirbelii editionem revisa et aucta edenda curavit. Lipsiae 1806. 8. ve, 378 p. $\left(2 \frac{1}{6}\right.$ th. $)$

(Continet classes Linn. $1-\mathrm{X}$.

4268t Heer, Oszald. Beitrage zur Pflanzengeographie. Mlit einen Gemálde der Vegetationsverhátnisse des Cantons Glarus. Zürich 1833 8. $190 \mathrm{p}$.

(Besondrer Abdruck aus Frobel's und Heer's Mitheilungen aus tem Gebiet der theoretischen Erdkunde. 1. 3.)

1269* Analytische Tabellen zur Bestimunng der planerogamischen Pilanzengattungeo der Sclsweiz. Zurich 1840. gr. 12. p. 1009 $-1135 .(7 / 12$ th. $)$

(Sistit supplementum ad Johannis Hegetschueiler "Flora der Sehweiz.

$4270^{*}-$ Ueber dio obersten Grenzen des thierischen und pllanzlichen Lebens ii den Selweizeralpen. Zürich 4845. 4. 19 p., 1 lah. $(3 / 10$ th.

$4271^{*}$ __ und J. J. Blumer-Beer. Der Canton Glarus, historiselgeographisch-statistisch gesehildert. St. Gallen und Bern 1846.8 . xiv, 665 p., 2 tab.

(Ptlanzenwett: p. 121-138.)

4272* Heering, Albert. De Iride. D. Altdorfii $1710.4 .20 \mathrm{p}$.

4273* Hegetschweiler, Johann. Commentatio botanica sistens descriptionem Seitaminum $\mathbf{L}$. nonnullorum nee non Glycines heterocarjure. Turici 1813.4 .12 p., 7 tab. $(1 / 2$ th. $)$

4274* - Reisen in den Gebirgsstock zwischen Glarus vnd Graubunden in den Jahren 1819-1822. Nebst einem botanisclien Anhang und mehren lithographirten Zeichnungen. Zurich 1825. 8. 193 p., 11 tab. $\left(1 \frac{1 / 3}{3}\right.$ th.

(Inest: Versuch einer theilweisen Monographie von Aretia, Cerastum, Aconitum, Potentilla, Saxifraga, Lleracium.) 
$427 i j+$ Hegetschweiler, Johann, und $J$. D. Labram. Sammlung von Selweizerpllanzen. Basel $1826-1834.80$ Ilefte. 8 . 480 tab. Jith. col., totirlenque folia text. dextrrat solum pagina inpressa. $\left(33 \frac{1}{3} t h\right.$.) (Intereedunt Aualveses collectioni aliis ejusmodi praeferendae.)

$42766 \longrightarrow$ Ihe Giftplanzen der Schweiz (beschrieben von Johnm Ilegetschwevler) gezcichnet von J. D. Labram, lithograjhirt von $C . J$. Brodlmann. Zurich s. a. 3 Jlefte. 4. Xxv, 46 p., 18 tab. col.

(Fusciculi tres posteriores, tabulas sistentes 19-36, quantum scio, uon protiertunt.

\$277" - Beitrage zu ciner kritischen Aufzallılung der Scliwejzerpflanzen und einer Ableitung der helvetischen Pilinzenformen von den binftussen der Aussenwelt. Zurich 1831. 8. 382 p., ind., I tab. gcogr. loot. $(12 / 3$ th. $)$

$4278^{*}$ Flora der Schweiz. Fortgosetzt und herausgegehen von Oswald Ifeer. Zürich 1840 . gr. 12. xxvut, $1135 \mathrm{p} ., 8$ tah. $(3 \mathrm{1} / 8$ lh.) - "Supplenentum: Oswald Ifeer, Analytische Tabellen zur Bestimmung der fluanerogamisclıen Ptlanzengattungen der Schweiz. 1840. p. $1009-1135 .(7 / 12 \mathrm{th}$.

4279 Heidecke, Heinrich. De usu Pethi in catarhis. Duisburgi 1693. 4. 18 p. B.

4280 Heidegger, Johann Meinrich. De Ficu a Christo maledicla. D. Amstelodani 1657.4. S.

4281* Heidler, Larl Joseph. Pllanzen und Gebirgsarten von Alarienbad, gesammelt unl beschrielsen vom P'rinzen Friedrich, Mitregenten von Sachsen $(1834-1835)$, und Johum ll'olfgang von Goethe (182118231, ereatuzt, und mit einem Anhange uber dhe andern naturJistorisehen Verhaltnisse des kurorts herausgegeben. Prag 1837.8. $x, 203$ p., 5 tab. $\left(1 \frac{1 / 2}{2}\right.$ h. $)$

1.282* Heigel, Ambrosius. Opii natura et usus. 1. Altdorfii 468 1. 43 p.

$4283+$ Heim, Friedrich Timolheus. Systematisclie Classifieation und Beschreilunng der Kirschensurten von Christian Freiherrn Truchsess van IVetzausen zu Betterburg. Stuttgart 1819.8. xx山, 692 p., ind.

$4284 \div$ Heim, Geory Christoph. Deutsclie Flora. Aus neueren botanisehen Scbriften zusammengetragen und herausgegelien. Ilalle 1799. 2 Thle. 8. - I: (C.lass. Lim. I-XIII.) - II: (Class. Linn. XIV-XXIIJ.) xiv, $876 \mathrm{pe}\left(2 \frac{1}{2} \mathrm{hl}\right.$. $)$

(Aus dom liotaniker, Heft $1-18$.)

12S:* Heimreich, Ernst Friedrich Justinus. De Pimpinella alba. D. Altorfii 1723. 4. $20 \mathrm{p}$.

$12 S 6^{*}$ Heine, Johann Friedrich Ernst. Do medicamentis vegetabilibus adstringentibus. D. Goettingae $1785.4 .33 \mathrm{p}$.

$4287^{*}$ Heinrich, Johann. Baptisla. Abhandlung uber die Kultur des Waids und die Indig-Bereitung aus demselben. Wien $1812.4 .58 \mathrm{p}$. 4 tab.

$\{288$ Heinricus, Chrislian. De anima vegetante, Lipsiae 1630. 4. Rivin

1289* Heinze, Johann Geory. De muscorum notis et sahubritate. D. Goettingae 1747.4 .51 p., praef.

$\$ 290-$ Commentatio de incremontis botanicae contemplationis muscormm. Grettingae 1747. 4. н.

1.291* Heinzel, Gustav. De Macrozamia Preissii. D. Vratislaviae 4844. 4. 38 p., 4 lal.

1.292* Heister, Elias Friedrich. Oratio de hortorum academicorum utilitate. Ilelmstadii 1739.4.32 J).

4293* Heister, Lorenz. 'Programma de studio rei lierbariac emendando. Ilehstadii 1730.4.46 p.

209k" Index plantarum sariorum, quas anno 1730 in hortum academiae Juliae intult. (IJelmstadii 1730.) 8.40 p.

Libellum salutat autor: "Editio attera correctior." Antiquior vero mihi nullibi ìmotuit.)

$4293^{*} \longrightarrow$ Designatio plantarum, quibus anmo 1731 hortum academiac Jutide auxit. (Jelmstudii 1731 .) 8. 32 1 1 .

$\$ 296^{*}$ Catalogus plantarum, quibus anno 1732 hortum academiae Juliae auxit. (1/elnstadii 1732.) 8.24 p.

1.99: - Enumeratio plantarum, quibus anno 1733 hortum academiac Juliac auxit. (Helmstarlii 1733.) S. 16 tr.

$2298^{*}$ Systema plantarum generale ex fructifieatione, cui annectuntur regulae ejusdem de nominibus jlantarum a cel. Linnaei longe diversae. Jlelmstadii 1748, 8.48 p.
4299* Heister, Lorenz. Designatio librorum, disseriationum aliarumøue exercitatiomum academicarum, quas ab auno 1708 ad annum 1750 ediclit Laurentius Ileisterus. Ilelinstadii 1750. 4. 24 p.

$4300^{*}$ - Deseriptio novi generis plantae ex bulbosarum classc, eui Brunsvigiae nomen impasuit. Brunsvigae 1733. folio. 28 y., 3 tals. col. $\left(1^{2} / 3\right.$ th. $)$

*yermanice: Bresehreihung rines uenen fosehlechts von einer selur raren und uberaus schonen ifrikanischen Polluze ans der fumilic

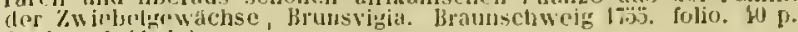
3 tab. col. $(1, h$. $)$

Jraeside Ieistero disserlationes:

4301* - De collectione simulicium. D. Ilelmstadii 1722. 4. 24 1). (Respondens: Christian Friedrich Pabe.)

1.302* — De Manna et speciatim de secnro ae proficuo ejus usu in variolis eonfluentibus. D. IJehmstadii 1725. 4 44 1). (Respundens: Julius Bielitz.)

$4303^{*}$ De foliorum utilitato in constituendis flantarum generibus, iisdemque faeile cognoscendis. 1). llelmstadii $173 z$. 4. $56 \mathrm{j}$. (Respundens: Elias Friedrich Heister.)

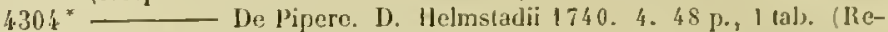
spondens: Georg Konrad P'feffer.)

$4305^{*}$ Neditationes et animadversiones in novum systema botanieum sexuale Linnaei. D. Helmstadii 1741.4.62 p. (Respondens: Philipp Kaspar Goeckel.)

$4306^{*}$ - De nomimum planlarum mutatione utili ac noxia; curn appendiec de floribns Pipserodendri (Sehini mollis.) D. Helmstadii 1741.4.62 p., 1 tah. (Respoudens: Jodocus Edmund Sandhagen.)

$4307^{*}$ _ De Aurantiis eorumgue eximio usu medico. D. Ilelmstadii 1741. 4. 70 p., 1 tab. (Respondens: Johann Hernann Anton IIilberding.)

4308* - De Cydoniis eorumgue exinnio usu medico. D. Helmstadii 1744.4.64 p. (Respondens: Johann Adum Bauer.)

$4: 309^{*}-$ De nuee Been. D. Ilelmstadii 1750 . 4. 28 p. (Respondens: Urban Friedrich Benedict Brückmann.)

$4.310^{*}$ De generibus plantarum medicinae causa polius augendis guam minuendis. D. Ifelmstadii 1751. 4. 47 p. (Respondens: Johann Georg Magnus Woellner.)

4311* Helbach, Friedrich. Oenographia, Weinkeller oder Kunstbuch vom Wein. etc. Frankfurt a/M., typ. Al. Becker. 1604 . 4. 328 p., praef, , ind.

4312 Held, Alexander. Demoustrative Naturgeschielute ader Erfahrungen und Belolırungen uber das Sammeln, Prapariren, Klassifiziren, Aufstellen, Verwalıren un! Demonstriren der Naturkorper aller drei liciche. Bevorwortet von Gothelf IJeinrich Schubert. Stuttgart 1845. Lex. 8. 35 Bogen, 7 tah., 1 Portrait. $\left(3 \frac{1}{2}\right.$ th. $)$

4313* Held, Christian August. De tempestivo corticis peruviani usu in febribus inflammatoriis. D. Goettingae $1775.4 .30 \mathrm{p}$.

4314." Heldmann, C. Oberhessisehe Flora. Taschenluch zum Gebrauche auf botanischen Excursionen in der Umgebung ron Marburg und Giessen. Jarburg 1837. 8. x, $4 / 5$ p. ( $1 \frac{1 / 3}{3} / h$.)

43.15* Helg, Franz Joseph. De botanices systematicae in medicina utilitate. 1). Argentorati 1770.4.29 p. (Aurfor est: Johmin Hermann; ex Meusel, Gelebrtes Deutsclland. El. V. vol. III. p. 2tí.)

\$316 Helie. Sisteme de MI. Limnaeus sur la generation des plantes et Ieur fructifieation. Montpellier 4750.12 .53 , xwIt, 45 p. B.

4.317 Hellbach, Johamn Christian. Ilandbuch uber den Kucliengartenbau fur dic grössere Volkshlasse, nach den hewährtesten Erfahrungen und neusten Benlachtungen, mit zwechmassiger Literatur versehen. Erfurt 1809.8 .250 p. $(3 / 4$ th. $)$

4318 Hellenius, Carl Niclas, pr. Förtekning på Fünska medicinal-vãxter. I. Abo 1773. 4. 22 p. (Respondens: Gustaf Levin.) B.

4319 Hortus aeademiau Ahoensis. D. Hboae 1779. 4. $30 \mathrm{p}$. (Respondens: Joseph Mollin.)

4320 On Finska allmogens nodbrod. D. Âbo 1782. 4. $38 \mathrm{p}$. (Respondens: Johnn Fredrir II'allenius.)

$4321^{*}$ - De Calla, U. Ahoae 1782.4. 14 p. (Respondens: Johnn Fredris Sacklen.)

4322* - Do llippuride. D. Shoae 1786.4 .21 p.. 1 tal). (Respondens: Carl Reginald Brander.)

(C'steri Delect, opusc. Dot. I. p. 1-2?.) 
$4323{ }^{*}$ Hellenius, Carl Niclas, pr. De Evonymo. D. Aboae 1786.4.25 p., 1 rab. (Respondens: Carl Ascholin.) (Usteri Delect. opusc. bot. I. p. $81-10$ r.

$4324^{*}$ - Specimen calendarii Florae et Faunae Aboëusis. D. Aboae 1756. 4. 20 ). (liespondeus: Johan Gustaf Jusiander.)

$4323^{\circ}-$ De Asparago el quibustam hujis suecelancis. D. Aboae 1785.4.22 p. (Respondens: Ulricus Pryss.)

$4326^{*}$ Anmärhningar ròrande ograsen uti Orihvesi Socken af Tavastland. D. Åbo 1789. 4. 18 p. (Respondens : Anders Salovius.) 4327* $\frac{}{\text { Petrus Stenberg.) De Hippophae. D. Aboae 1789. 4. } 11 \text { p. (Respondens: }}$

$4328^{*} \longrightarrow$ De Tropaeolo. D. Aboae 1789.4. 26 p., 1 Iab. (Respondens: Axel Fredric Laurell.)

4329 Strödlle anmärkningar rörande fruktträns shötsel i Finland. D. Äbo 1789.4.13 p. (Respondens: Eric Johan von Pfuler.) B.

$4330-$ Anmärkningar vid fruktbarande buskars skotsel. D. Aho 1789. 4. 10 1. (Respondens: Johan Forsbom.) B.

$4331^{*} \longrightarrow$ De Cichorlo. D. Abore 1792. 4. 18 p. (Respondens: Henricus Nelly.)

4332* Heller, Franz Naver. Organa plantarum functioni sexuali inservientia. D. Wirceburgi 1800 . 8. $74 \mathrm{p}$.

$4333^{*}-$ Graminum in Mlagno Dncatu Wirceburgensi tam sponte crescentium quam cnltorum enumeratio systematica. Tirceburgi 1809. 8.54 p., ind. (1/4 th. $)$

4334. * Flora Wirceburgensis seu plantarum in Magno-Ducatu Wirceburgensi indigeuarum enumeratio systematica etc. Wirceburgi 1810-1815. II voll. 8. - I: 1810. xLvII, 586 p., ind. - II : 1811. v, $450 \mathrm{p}$., int. - Supplementum: $1845.86 \mathrm{p}$., ind. $(5 \mathrm{l} / \mathrm{2} \mathrm{hh}$.

$4333^{*}$ \#llimuth, Leonhard Chrisloph. De radice Senega. D. Erlangae 1782. $4.42 \mathrm{p}$

(Schleg. Thes mat. med. It. p. 423-402.)

4336 Hellrung, Karl Ludwig. Atlas der Weinlüder in Europa, entbaltend in einer Auswalıl von Specialkarten alle beruhmten Weinberge mit ihren Gewhelısen, geograpbisch, statistiseh, ohonomisch und merkantilisch dargestellt; mit heigedruchten Notizen. Magdeburg 1837.3 Hefte. folio. ( 5 h. $)$

4337 Karte des Weingelviets in den Zollvereinsstaaten, nebst eineru Blatte Text. Augshurg 1846. gr. folio. ( $21 / 4 t h$.)

4338* Eelm, Theodor. Quaestiones botanieae de methodo physicolistorica. D. Viennae 1835 . 8.9 I p.

$4339^{*}$ Eelvetius, Johann Friedrich. Iystus lıerbarum. Lustiger Spatzierweg der Kräuter. Worinnen wird verhandelt, wie die Gewachse durch ihre Zeichen, mit dess Menschen inner- und eusserlichen. Leibestheilen eine vergleichung haben, und zu deroselben Gebrechen mit Nutzen konnen gebrauchet werden. Heydelberg, typ. Samuel Broun. 1661. 12. 89 p., praef. Bibl. univ. Lips.

$4310^{*} \longrightarrow$ Berillus tuedicus, ein Edelgestein der Artzney, sehr nutzlich und anmuthig fur alle Liebhaber der Gewächse, nămlich dass sie, wann sie in dem ȟrater-Feld lerumb spatziren, wissen mögen zu jeder Zeit, was in einem jeden Monath aus der Erden herfur lomme, und wie man selhige hann lemen erhennen, und von andern, so an Gestalt und Farben einige Gleichheit mit ihnen haben, unterscheiden, und was bei der Einsammulung in Acht zu nelmen. Heydelberg, typ. Samuel Broun. 1661. 12. 89 p. Bibl. univ. Lips.

43 Helvigius, Chrisloph, pater. De studii botanici uobilitate oratio. Lipsiae 1666. 4. 10 foll. B.

4342* Helvigius, Christoph, filins. Programma de ortu, initio et progressu scientiae botanicae cjusdemque seriptoribus. Gryphiswaldiac 1707. 4. (16 p.)

$4313^{*}$ Specimen plarmacologiae sacrae, de antimonio, Cicuta et pisce magno Tobiae sive Siluro. Gryphiswaldiae 1708.4.34 p.

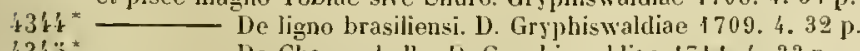

$43 \% 3^{*}-$ De Chaerophyllo. V. Gryphiswaldiae $1711.4 .33 \mathrm{p}$.

$1346 *$ - De Quinquina Europacorum (sc. Fraxino excelsiori). Gryphiswaldiae 1712 . 4. 48 p.

$4347^{*}$ Helwing, Georg Andreas. Flora quasimodogenita, sive enumeratio aliquot plantarum indigenarum in Prussia, quarum in herbariis hactenus editis borussicis aut nulla aut superficiaria facta est mentio, additis nonnullis iconibus, deseriptionibus et observationibus, nec non annexo florilegio ad clima Prussiae accommodato; cum pracfatione Johunnis Philippi Breynii. Gedani 1712. 4. 74 p., 3 tab.
4.348* Helwing, Georg Andreas. Flurac campana seu Pulsatilla cum suis specielus et varietatihus methodice consilerata et interspersis variis olsservationibus oculis curiosorum exposita. Lipsiae (1719.) 4. 100 p., praef., 12 tab.

$4359^{*} \_$Supplementum Florae prussicae, sive enumeratio plantarum indigenarum post editam floram quasimodogenitam additis synonymiis, appellationilus latinis, germanicis, polonicis, nec non observationibus euriosis ultra numerum quadringentesimum aucta. Gedaui (1726.) 4.66 p.. praef, ind., 3 tab).

(Ejusdim autoris liber mannscriptus "Tournefortius prussicus" servatur in Bibliolleca Litiv. Regioniontalae; of. $L$. Ko von Werner. 1766. p. 10 s.14.

$4350^{*}$ Hempel, Joham Collfried. Pharmaceutiseh-chemische Abhandlung uber die Natur ler Pllanzensiuren und die Modificationen, de. nen sie unterworfen sind, nebst einer chemischen Untersuchung der Winter - und Sommereiche. Berlin 1794.8. $176 \mathrm{p} .(5 / 12 \mathrm{~h}$.

4351* Henckel, Johann Friedrich. Flora saturnizans, die Verwandschaft der Pflanzen - nit dem Mineralreich, nach der Naturalhistorie und Chynie aus vielen Anmerkungen und Proben. Nelst einem Anlang vom Kali geniculato Germanorum oder gegliederten Salzhraut, insonderheit von einer hieraus neuerfondenen dem schünsten Ultramarin gleichenden blauen Farbe. Leipzig, Martini. 1722. 8. (10), 671 p., 10 tab. - Neve verbesserte Aulage. Leipzig, Gross. 1755. 8. 608 p., ind., 10 tab.

gallice: tans la traduction de ses oeurres par le Baron d'Holbach et Cheras, revin par Rour, yui a ajoute un tableau de l'analyse végélate, extrait ktes leçons de louelle. Paris in60. Il voll. 4 . Q

4.352* Henckel von Donnersmarck, Leo Felix Viclor, Graf. Nomenclator botanicus sistens plantas omnes in Caroli a Linne Speciebus plantarum ab ill. Kurl Luderig I'illdenow enumeratas. Jlalae 1803.8 IY, 677 p. - Index generum ils. 1806.58 p. - ${ }^{*}$ Ed. II. Halae 182. 8. VI, 828 p. $(2 t h$.

$4383^{*}$ Ahumbrationes plantarum nounullarum horli IJalensis academici selectarum. Halae 1806.4 .24 p., praef., 1 tab.

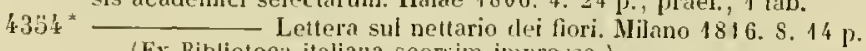

(Ex Biblioteca italiana seorsim impressa.)

Enumeratio plantarum circa Regionontum Borussorum sponte crescentium. Regiomonti 18:7. S. VIt, $240 \mathrm{p}$. (Liber, jam ammo 1812 ad hibliopolarn Hortung missus, incompletus e prelo prodiit. Explieit in Honoecia classe cum Carice panicea.)

4336* Hendel, Christian. Lobrede duf Herrn Jakab Theodor Klein, welche in zahlicicher und ansehnlicher Versanmlung der naturforschenden Geselischaft gehalten worden. Danzig 1759.4. 42 p.

$430 \%$ * Hendel, Johann Christian. Index generum ad Caroli a Linne species plantarum ab Ifilldenoucio editarum. Halae, typ. Hendel. 1806. 8. $52 \mathrm{p}$.

$4388^{*}$ (Henderson, Alexander.) The history of ancient and modern wines. London is24. 4. xvr, 408 p.

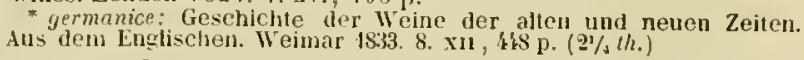

$4359^{*}$ Henkel, Nikolaus. De radice Ipecacuanhae. D. Monachii 1835. 8. $16 \mathrm{p}$.

4360 Henne, David Samuel Ludwig. Anweisung, wie man eine Baumschule in Grossen anlegen und gehorig unterhalten solle. Halle 1769. 8. - Ed. V: llalle 1796. 8.

4361 Neikenkalender oder monatliche Ferrichtung mit deu Grasblumen. Halle 1785. 8.

4362* Henninger, Johamn Siegmund, pr. De Aniso. D. Argentorati 1704 4. 57 p. (Respondens: Johann Baecler.)

4363* - De Viola martia purpurea. D. Argentorati 1718. 4. 36 p. (Respondens: Johann Ballhasar 11 uestenfeld.)

$4364-$ De Millefolio. D. Argentorati 1718.4. S.

$4365 \div$ Eénon, J. L. Notice sur J'Oxalide de Deppe (Oxalis Deppei Lodd Bot. Cal. Nr. 1500 ). Lyon 1838.8. 13 p., 3 tab. Bibl. Webb.

4366 Eenrici, Roberl Stephan. Animadversiones te laude et praestantia vegetabilium. D. Ilavniae 1740.4. I 2 p. (Respondens: Christian Ludwig. Mossin.) B.

4367* Henry, 4. Die Giftpllanzen Deutschlands zum Schujgebrauch und Selbstunterricht durch Abbildungen und Bescireibungen erlautert. Nit einem Vorworte von Theodor Friedrich Ludwig Nees von Esenbeck. Bunn 1836. 8.48 p., 32 tab. col. $\left(2 \frac{5}{12}\right.$ th. $)$ 
4368* Henschel, August Wilhelm Eduard Theodor. Fon der Sexualitat der P'lanzen. Nebst einem historischen Anhange von Franz Joseph Schelver. Breslau 1820.8.644 p. (2 $1 / 2$ th.)

Cf rjustem: "Verzeichuiss eines Systeus yon V'ersuchen uher die Bestaubung der Pllanzen, augestellt in den Jahren 1821-1828. folio. $1 / 2$ plikg.)

- Commentatio de Aristutete botanico philosopho. Vratislaviar 1824.4 .58 f. $(1 / 2 t h$.

$3.370^{*}$ Clavis Rumphiana botanica et zonlogica. Accedunt Vita Geargii Eberhardi Rumphii, Plinii indici, specinenque materiae medicae amboinensis. Vratislaviae 1833.8 . XIY $215 \mathrm{l}$. 4 (ab) $\left(1 \frac{1}{3}\right.$ th.

(Prodiit primum dissertationis academicre loco vic V11. Aug, 1833 mutato tituln: Yita G. E. Rumphii, Ptitui indicl. Accedunt specimen materiae Rumphianae menlicate clavisque herbarii et thesauri anboinensis.

$4371^{*}$ Zur Geschichte der botanisclien Gürten und der Botanik uherhaupt in Sclılesien, in 13. und 16. Jalurbundert. Ein Vortrag. Berlin 4837 . 8. 42 p. ol. $\mathrm{v}, \mathrm{p}, \mathrm{bi}$.)

$4372^{*}-$ Jutrologiae Silesiae specimen primum, exhibens brevissimam medicorum Silesiacorum saeculi XIll ad XVI notitiam, cui catilogus medicorum Silesiae recentiorum eorumque celebriorum adjectus est Prodromus. Tratislaviae 1837. 4. vill, 32 p. $(2 / 3$ th.

$1.373+$ Henshall, John. A practical treatise on the cultivation of orchidaceous plants, witl] remarks on their geographical distribution and a select eatalogue of the best kinds in cultivation. London 1845. 8 viII, 124 p., 1 tab. col. shall dargestell. Wit einer Einleitung und einem alphahetischen Verzeichnisse fast aller exotischen Orclideen. welche in England, Belgien und Deutschland cultivirt werden, von $J$. $F$. $1 \%$. Bosse. Ilannover 18,6 . 8. $435 \mathrm{k},(2 / 3 \mathrm{~h}$.

4374t Henslow, J. S. A catalogue of British plants, arranged according to the natural system with the synonyms of DeCandolle, Smith and Lindley. Cambridge 1829.8.40 p.

$4375^{*}$ - On the examination of a hybrid Digitalis. Cambridge 1834.4. 22 p., 4 tab

(Transactions of the Cambridge Philosophical Society, vol. IF.)

$4.376^{*}$ On a monstrosity of the common Mlignionette (Reseda odorata L.). Cambridge 1833.4. 8 p., 2 tab.

(Transactions of the Cambridge Philosophical Sociely, vol $Y$ )

$4.377^{\circ}$ The principles of descriptive and physiological botany. London 1835. 8. vit , 322 p., ic. xylogr. i.t. (6s.)

Forming Yol. 75 of Dr. Lardner's Cabinet Cyclopaedia.

4378* Hentschel, Karl. Chemie, Alchemie und Botanik. Lehr- und Lobgedicht in vier Ahtheilungen. Ilof und Wunsiedel 1840. 8. 109 p. $(1 / 2$ th.

1.379* Hepp, Philipp. Lichenenflora vol Würzhurg, oder Autzahlung und Beschreibung der un Würzburg wachsenden Flechten. Mainz 1824. 8. 105 p., 1 tab. $(5 / 12$ th.)

$4380^{*}$ Herbert, Heinrich Nicolaus. De Cassarae amarae surinamensis radice. D. Marburgi 1753.4. $24 \mathrm{P}$.

1.381* Herbert, William. An appendix (to the Botanical Register), containing a Treatiso on Bulbous roots, Amaryllis, Brussvigia, Ammocharis, Boophane, Imhofia, Nerine, Lycoris, Griffinia, Crinum, I'rceolaria, Cyrtanthus, Vallota, Monella, Gastronema, Hippeastrum, Coburgia, Sprekelia etc. London 1821. gr. 8. 52 p., 2 tab. nigr., 2 tab. col.

$4382^{*}$ - Amaryllidaceae; preceded by an attempt to arrange the monocotyledonous orders, and followed by a Treatise on Cross-Bred Vegetahles, and supplement. London 4837. 8 max. vi, 428 p., $48 \mathrm{tab}$. col. (3l. $8 s$. - nigr. 1 l. $5 s$.

4383* Herbich, Franz. Additamentum ad Floram Galiciae. Leopoli, Stanislavoniae et Tarnoviae 1831 I. 8.46 p., 1 tah.

438:* Selectus plantarum rariorum Galiciae et Bucovinae. Czernovicii 1836.4. 19 p., praef. ( $1 / 3 \mathrm{th}$.

$\$ 380^{*}$ Heresbach, kourad. Rei rusticae libri quatuor, universam rusticam disciplinam complectentes, una cum appendice oraculorum rusticorum coronidis vice adjecta; item de venatione, aucupio atque piscatione compendium, in usum heroum patrumque familias ruri argentium concinuati. Coloniae, apud Joannem Birchnannum. 1570. 8. 391 foll. praef., ind. $-{ }^{*}$ ih. 1571. 8. (non dilfert.) - Coloniae, apud viduam Joannis Birckmanni. 1573. 8. Bibl. Reg. Paris. - ${ }^{*}$ Re rusticao libri quatuor, universam agriculturae disciplinam continen- tes, a clarissino viro I). Conrado Heresbach in Jurisconsulto olim conscripti: nuuc ab innumeris mendis repurgati et cuin anctuario editi. Spirae Nemetum, typ. Smesmann. 1594.8. 889 p., praef., ind. Spirate Nemetum, typ. Smesinamn. 1595. 8. (non differt) - Spirac Nenietum, typ. Commelin. 1603. 8. Bum.

anglice: Tho whole art of husbandry contained in foure bookes.

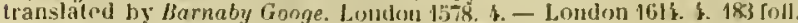
B. - † Loudon, Richard Mioure, 16.31. \&. $380^{\circ}$ p., ind.

4.386 * Hergt, J. L. Versuch einer Flora von Hadanar. llarlamar 1822. 8. xvi, 416 p. $(1 \%$ th. $)$

$4.387^{*}$ Héricart de Thury, L. L. F., V'icomte. Notice historique sur la plantation de la montagne de Saint-Marliu-le-Pauvre entre Thurg et Boulard, Dép. de l'Oise. Paris 1829.4. 39 p.

4388* Hering, Johann Erust, pr. De wa. D. Wittebergac typ. Wends 1666. 4. (24 p.)

4389t Hérissant, Louis Antoine Prosper. Bibliothèque phrsique de la France, ou liste de tous les ourrages, tant imprimes que manuscrits. qui traitent de l'histoire naturelle de ce royaume: arec des notes critiques et historiques. Paris, Jean Thomas Hérissant. 1771. \&. 496 p. (Botanique: p. $261-300$ et $454-463$.)

(Est reimpressio aucta et curis medici Coquereau emendata sectionis "bibliothecae historicae Galliae" ab Herissant elaburallat.)

4.390 Herkt, $C$. Vorlegeblátter fü den Unterricht im Zeichnen. Drittes Heft: P(lanzen. Bunzlau 1846.4. 20 tah. $(2 / 3$ th.

4391 Hermann, Daniel. De rana et lacerta succino insitis. Cracoviae 1580.8. - Riga 1600.4 . Des. B.

4392* Hermann, Paul. Horti academici Lugduno Batavi catalogus, exhibens plantarum omnium nomina, quibus ab anno 1681 ad 1686 hortus fuit instructus, ut et plurimarum in eodem cultarum et a nenine hucustue editarum deseriptiones el icones. Lugduni Batavorum 1687. 8.699 p., ic. aen. i.t.

$4393^{*}$ Paradisi batavi prodromus, sive plantarum exoticarum in Batavorum hortis observatarum index. Edidlit Simon 11 arton in ejus Schola botanica. Amstelacdami 1689. 12. p. 301-386.

439:* — Florae Lugduno-Batavae flores sive enumeratio stirpium horti Lugduno-Batavi methodo naturae vestigiis insistente dispositarum et auno 1689 in lectionibus expositarum a Paulo Hermanno, nunc vero primum in lucem editarum opera Lotharii Zumbach. Lugduni Batavorum 1690. 8. 267 p., praef., ind.

4395* — Paradisus batavus, inummeris exoticis curiosis herbis et rarioribus plautis magno sumtu et cura ex variis terrarum orbis regionibus tam oriente quan occidente collectis, acquisitis, illustratus. Ingeniosissima et dexterrima artificum manu elaboratis iconibus ad vivum aeri incisis; cui accessit catalogus plantarum, quas pro tomis nontlum editis delineandas curaverat. Opns posthumun edidit $1{ }^{*} i t t i a m$ Sherard. Lugduni Batavorum 1698. 4. 247, 15 p., 111 tab. - "ib. 1705. 4. (non differt, praeter titulun.)

4396 Musaci indici catalogus. Lugduni Batavorum 1711. 8. s.

4.397 - Husaeum zeylanicum, sive catalogus plantarun in ZeyIana sponte nascentium observatarum et descriptarum. Lugduni Batavorum 1717.8.71 p. - + Ed. 11: ib. 1726.8. 71 p.

(Hortus siccus, cujus catalogum hic liher exhibet, et quo postea usus est Linnaeus in adornanda Flora ejus zevlanica. in bihtiothecam transierat Banlisii post mortem Comitis Aldami Golll. Moltke, cui defunclo Guenthero, cesserat.

$4398^{*}$ Cynosura matęriae medicae ante sedecin annos in lucem emissa brevibusque annotatis exoruata a Johanue Sigismundo Itenninger, nunc diffusius explanata et compositorum medicamentornm recensione aucta, curante Johanne Boecter. Argentorati 1726. 4.728, 154 p., pracf., ind. - "Continuatio I. ib. 1729.4.891 p. - "Continuatio ll. ib. $1731.4 .894 \mathrm{p}$.

4399* Hermannides, Rutger. Ilortulus velavicus s. orationes aliquot de hortis a studiosa juventute in illustri velavicá, quae est llardervici, schola diversis publicis in actibus recitatae. Hardervici, apud P. yan den Houte. 1665. 8. 279 p., praef, ind. Bibl. Goett.

4400 Hermans, Jan. Recensio plantarun in horto Jounmis Hermanni. pharmacopoei Bruxellensis excultaruin. Bruxellae 1652.4.6 4 p. Appendix plantarum auni 1653.4.8 p. B.

\{401* Hermolaus Barbarus, Castigationes Plinianae. Romae 1492. folio. Quaterniones 10, triemiones 7, duennio 1. - "Secuntae castigationes. Romae 1493. folio. Quaterniones 3 , ternio 1, duernio 1. a-cc. 
- Basileae, apud Joannem Valderum. 153\%. 4. 523 p.. praef., ind Bibl. Caes. Vindob.

$4402^{*}$ Hermolaus Barbarus. Corollarii in Dioscoridem libri quinque non ante impressi. Impr. cum Johunnis Baptistae Egnatii in Diascoridem annotamentis. Venetiis 1516. fotio. 106 foll. - " ln Dioscoridem Corollariorum libri quinque. Adjectus est index eorum, quae hisce libris explicantur, quem post Dioscoridis indices consulto locavimus. Impr. cum Dioscoride, interprete Alarcello l'ergitio. Coloniae, apud Joannem Soterem. 1530 . mense Februario. folio. 78 foll.

4103 * Hernandez, Francisco. Quatro libros de la naturaleza y virtutes de las plantas y aninales que estan recevirlos en el uso de medicina en la nueva España y el metodo y correccion y preparacion, que para administrallas se requiere, con lo que el Docter Francisco Hernandez escrivio en lengua latina. Muy util para todo genero de gente que vive en estacias : pueblos, de no ay medices ni bolica. $\mathrm{Tr}$ ducido y aumentados muchos simples y compuestos y ochos muchos secretos curativos per $F_{l}$. Francisco limenez, hijo del convento de S. Domingo de Mexico, natural de la villa de luna del Reywo de Aragon. En Mexico, en casa de la viuda de Diego Lopez Davalos. 1615.4 .203 foll., praef, ind. Bibl. caes. vindob.

Y0:" " Rerum medicarum Novae Ilispaniae thesaurus, seu plantarum, animalium, mincralium mexicanorum listoria ex Francisci Hernandez, novi orbis medici primarii, relationibus in ipsa mexicana urbe conseriptis a Nardo Antonio Reccho collecta ac in ordinem digesta: a Joanne Terrentio, Joanne Faluro et Fabio Columna Lynceis notis et additionibus illustrata. Cui accessere aliquat ex Principis Federici Caesii frentispiciis theatri naturalis phytosophicae tabulae una cum quan plurimis iconibus. Rumae, typ. Vitalis Mascardi. 1651. folin. 950,90 p., ind., ic. valde mediocres i. t. (Alicr adest titulus anni 1648 .)

(Federici Caesii Phytosophicarum tabularum pars I., quam jam supra Nr. 161 ' indieavi, adjuneta est a p. 901-930.

Opera quem edita tum inedita ad antographi fidem mexsa, impensu et jussu regio. (De historia plantarum Novac llispaniae.) Matriti, typ. Ibarra. 1790. Ill voll. 4. 1: xviII, 452 p. - II : 562 y. - III: 571 p. (A. Barcelona: 80 fr.) Bibl, Reg. Berol.

( Haec est editin perrara lihrorum quinque manuseriptorum Hernandezii ex incendio Excurialis superstitum, yuos vergente saeculo duedevicesimo Juan Bantista Muñaz Casimira Ortegae eclendos tradiderat; cf. Cavanilles, Anal. de cienc. nat. 171. p. 123. - Falso ergo Sprengelit monitum: "Diese Herausgabe ist aber nicht zu Stande gehommen." Gesch. der Bol. Il. p. 61.)

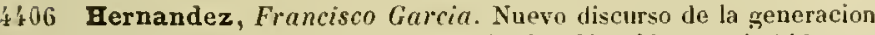
de plantas, insectos, hombres y animales. Madrid 4767. 4. 143 p. B.

\$07 Hernquist, Pehr. Dissertatio (prima et unica), genera Touruefortii stilo reformate et botanico sistens. Londini Gothorum 177 I. 4 . $\geq 4 \mathrm{p}$. B.

Desiluil in classis III. sectione quarta, genere Euplurasiae.)

408 Kort Genwäg til Naturatiers liannedom, $i$ ordning upstald och efter de storsta Kannares handledning for 20 år sedan forfattad. Skara, typ. Lewerentz. 1795. 8.534 p. w.

(Inledning til Waxt-Riket: p. 9--21k.)

$4409^{*}$ Herold, Professor Dr. Taschenbuch der tentschen Flora. Ein Hulfsbuch auf butanischen Excursionen zur moglichst schnellen und sichern Bestimmung der aufgefunduen Pllanzen. Nordhausen, Furst 1845. 8,460 p. $\left(1^{2} / 3\right.$ th.

(Sub) hoe uomine delituit miser quidam librorum consarcinator Schuepfer vel Schraepfer dictus, qui tam insolentes hachii Synopsin exscripsit, ut redemptoro sympeos postulante, hanc fraudosam libr repetitionem omplins divendi lege prohiberetur.)

\$ $10^{*}$ Herr, A. Kurze Anleitung zur Botanik und vortuglich zur Kenntnis der wildwaclisenden phanerogamischen Pflanzen Deutschlands. Giessen 1827. 8. xv1, 304 p. $(5 / 6$ th.

$\$ 11$ Herrera, Gabriel Alonso de. Obra de agricultura, compilada de diversos auctores, de mandado del muy ilustre y reverendisimo Señor el Cardenal de España Arzobispo (Franciseo Ximenez) de Toledo. Con privilegio Real. (al fin dice asi:) Esta obra de agricultura à labranza del campo fue inprimida en la villa de Alcalá de Henares por el honrado y muy industrioso varon en el arte de imprimir Arnuo Guilten de Brocar, cibdadano de Logroño. Leahose de imprimir a 8 dias del mes de Junio, año de nascimiento de nuestro Salvador Jesu Christe. 1513. folio. (Editio princeps!) - Toledo 1520. folio - Alcala de IIcnares 1524 fulio. - Toledo 1524. folio.
- Logroño 1528, folio. - Alcala de Heuares 1539. folio - Toledo 1546. folio. - Toledo 1551. folio. - Valladolid 1563. - Medina 1569. folio. - Medina 1584. folio. - Madrid, typ. Sanchez. 1598. 4. - Madrid, typ. Martinez. 1598. 4. - Pamplona 160 3. folio. Madrid 1620. folio. - Madrid 1643. folio. - Madrid, typ. Sanchez. 1645. folio. - Madrid, typ. Sanchez. 1645. 4. - Madrid 1646. folio. - Madrid 1677. folio. - Madrid 1768. VIl voll. 8. - Madrid 1777. folio. - Madrid 1790. 4. Lagasca. - $\div$ Agricultura general de Gabriel Atonso de Herrera, corregida segun el testo original de la primera edicion publicada en 1513 por el mismo autor, y adicionada por la real sociedacl economica matritense. Mladrid, en la imprenta real. 4818-1819. IV voll. 4 mill - I: 1818. xxiv, 544 p. - I1: 1818. VIII, 466 p. -11 : 1819 . vII, 655 p. - IV: 1819 . VII, $361 \mathrm{p}$

(llaec est editio novissima de llispanorum agricultura longe celeberrimi operis curis virorum illustr. Bautelou. Bo:cas Clemente et Lagasca publici juris faeta; vidi librum in bibliotheea Candolleana. Onnes priores editiones diligentissime ex Lagascae eatalogo apposui, praeter italicam versionem Venetam anni 1577, cujus non menuinit.)

latine: Venetiis 15075 ,

* italice: Agricollura irattada diversi antichi et moderni scrittore dal Sign Gabriello Alfonso d.Herrera of tradolta di linguil snagnuota in volgare ilaliano dit Mambrino Raseo da Fabrionn. Con le tigure de gli albcri e delle herbe, delle quali si tratta nel Libro. Venetia, per nezia 1377. k. - Venezia 1542. 4. - Venezia 1633. 4. Lagasca.

$1412^{*}$ Herrichen, Johann Gollfied. De Thea herba doricum melydrion; graece. Impr. cum Petri Francii Anacreonticis duobus in laudem Thiae sinensis, Amstelodami 1685. 4. et cum Tollii Epistolis itinerariis. Amstelacdami 1700 . 4. p. $79-84$.

$4413 \div$ Herrmann, G. Fr. Kleines aher doeh vollständiges Lelırbnch der Botanik. (Auch: Botaniseher Kinderfreund.) Hamburg und Altona. Vollmer. s. a. 8. xxiv, 172 p., 2 tab. col.

4. 14* Herrmann, Johann. De Rosa. D. Argentorati 1762. 4. 36 p. Idem noster, Professor holanices Argentinensis [n. 31. Dec. 1738, $\div 4$ Oct. 1800 ], sub praesidio Jacabi Reinbaldi Spielmann eodem anno dissertatjonem Cardanomi historiam et vindicias sistentem proposuit, atqu" revera est itutor dissertationis inauguralis "De botaniees systematicae in medicina utilitate, quam supra $\mathrm{N}$. 4315 . sub nomine Franz Joseph IJelg indicavi.)

$4415^{*}$ Berrmann, Johann Friedrich. Calendarium seu index plantarum in Narchia media cirea Beroliuum sponte totum per annum nascentium et in eel. Prof. Willdenovii Prodromo Florae Berolinensis descriptarum. Berolini $1810.12 . x I x, 156 \mathrm{p} .(3 / 4 t h$.

4.16* Eerrmann, Karl Robert. Oekonomische Planzenkunde der landwirthschafticlıen Kulturgewactse. Colberg 1846.8 . vH, $496 \mathrm{p}$. (2th.)

$4.17^{*}$ Herschel, John $F$. IY. On the action of the rays of the solar spectrum on vegetable colours and on new photographic process. London 1842. 4. ( tab.)

From the Philosophical Transactions, 1Sk2. Part II. p. 18I-21\}.,

4' 18* Hert, Johann Kasimir, pr. De Pimpinella Saxifraga. D. Giessae 1726. 4. $32 \mathrm{p}$

44.19 Hertel. Kurze Geschichte der Nelken nebst einem Verzeichniss von denen, die zu Schwerin bei ihm zu bekommen sind. Schwerin 1812. 8. $(1 / 1, t h$.

$4120^{*}$ Hertel, Johann Gottlob, pr. De plantarum transpiratione. D. Lipsiae 1735. 4. 24 p. (Respondens: Traugotl Gerber.)

4. $21^{*}$ Hertodt, Johaun Ferdinand. Crocologia, seu curiosa Croci. regis vegetabilium, enucleatio, continens illius elynologiam, differentias, tempus quo viret et floret, culturam, collectionem, elc. additis diversis observationibus el quaestionibus Crocum concernentibus, ad normam Academiae Naturae Curiosorum congestง. Jenae 1670. S. 283 p., praef., ind., I tab.

4422 Hervey, John. Reflexions on a flower-garden. London 4836. 8. (šs. $6 d$.)

4.423- Hervy, Wichel Christophe. Catalogue méthodique et classique de tous les arbres, arbustes fruitiers of des rignes formant la collection de l'école impériale ctablie près de Luxembourz. Paris, de l'imprimerie inpériale. 1809. 4. 63 p. Bibl. Webb.

42.t Herwech, Olof. Te praestantia studii historici naturae. D. Holmiae 1752. 4.48 p. w.

425* Herzer, Farl Heimich Ludwig Eugen. De Fuco crispo L. sive de Alga Carragéen. D. Turici 1836.8 .26 p. 
4.426 Herzog, Friedrich Wilhelm. De Jpecuanda. D. Lipsiac 1826. 4. $31 \%$

$1427^{\circ}$ Hess, C. Pflanzenkunde, mit einer vollstandigen Flora des germanischen Tieflandes. Berlin 1846. 2 Theile. 8. - I: Mllgemeine Planzenhumle. viı, 627 l?, I f Iab. - 11: Speziclle Pllanzentunde, xiv, 705 1., 1 (al), $(27 / 12 / h$.

'128* Hess, Johannes. Uubersichı ter phanerogamisehen natiorlichen Fumilien, mit riner hurzon Clatathteristik derselben. Darmstalt und J.eipzie $1832.8 . \mathrm{x}, 133 \mathrm{p.}(3 / \mathrm{t} / \mathrm{h}$.

fi.29 Eess, Johamn hudolf. Theses anatomico-botanicie. Basileac 4751 4. 8 .

4.30 Observationes merlicac, Basileac 1753.4.8 p. B.

4.31 Hesse, Meinrich. Neue Gartenlust. Leipzig 1690. 4. Rivin. - Leipzig 1744.4 .389 p., tab. B.

4.32 Teutscher Gartner, (l. i. Grundliche Vorstellung, wie nacls nothwendiger Zubereitung des Erelreichs unter unsern? teutschen Climate ein Lust- Kuchen- und Baungarten fuglich anzurichIon. Lejpzig 4710. fulio. tib. Rivin.

\$.133 Hesselius, Samuel. Beshrifning om Tobaksplanteriug och skiölsel uti America. Stochluolm 1733.4. 1 plag. B.

4.13i Hesslén, Niels. Do usu botanices morali. D. Londini Gotborum 1755. 4. 52 \%. B.

$435^{\circ}$ Hessler, liar. De Timmia, muscorum frondosorun genere. D. Goettiugac $1822.4 .22 \mathrm{p}, 1 \mathrm{tab})(1 / 6 / \mathrm{h}$.

4.36 t Hessus, Paulus. Defensio viginti problematum Melchioris Cruilandini, adversus quac Petrus Jndreas .llutheolus ex contum scripsit. Adjecta est Petri Audreae Mathaenli adversus viginti problemata Melchioris Guiltandini disputatio. Patavii, apud N. Antonium Llmum. 1562. 8. (14) 151 p. Bibl. Juss.

1437* Heucher, Johamn Jeimrich, pr. De regetabilibus ragicis. D. Wittenbergae, typ. Hakc. 1700.4. (9 foll.)

$4438^{*}$ - Jndex plantarum horti melici Acadeniac Wittenhergensis. Wittenbergae, Gerdes. 1711. 4. 54 p., praef., ind., 1 tab.

$4.439^{*}$ Novi proventus horti medici Academiae Wittenlerengensis. Wittenbergao, Gerdes. 1711.4.87 p., pracf, ind., 1 tab, *Vittenbergac, Meisel. 1713.4.90 p., pracf, ind., 1 tab.

$440^{*} \longrightarrow$, pr. Plantarum historia fahularis. D. Wittenbergae, typ. Kreusig. 1713.4.62 p.

$4.41^{*}$ Heuffel, Johann. De distributione plantarum geographica per comitatum Jlungariae Pestiensem. D. Pestini 1827. 8. 40 u.

4142* Heufler, Ladwig, Ritter von. Bericht uber den tiroliseben Pflanzengarten des Ferdinandeums. Innspruck 1840 . $8.12 \mathrm{p}$.

14.43* Die Ursachen des Pllanzenreichthums in Tirol. Ein Vortrag, gelralten im Tiroler Nationaluuscum an 10 . Dezenber 184 . Innspruck $1842,8.38$ 1).

144. - Die Golazberge in der Tsehitscherei. Ein Beitrag zur botanischen Erdhunde. Mit einer liarte. Triest 1845.4, 36 p., I lab. gengr: $(2 / 3(h)$.

44 Heurlin, Samuel. De Syngenesia. D. Lonelini Gothorum 1771. 4. 18 p. B.

$4446^{*}$ Heusinger, Heimrich. Observata quaedam circa Rhoa Toxicodendron el radicantem. 1). llelmstalii 4809.4. 36 p., 2 tab.

1.4.7* Heutzfeld, Hermann. De Nicotiana. D. Berolini 1828. 8. 29 p.

$\$ 48 *$ Heyland, Johann August Hermam. Analysis cliemica radicis Caincac. D. Kiliae 1827. 4. 20 p.

\$4.9* (Heyne, Chrislian Golllieb.) Historiae naturalis fragmenta ex ostentis, prodigiis et monstris. Programmata 1 et lI. Goctingae 784 -1785 . folio. $8,8 \mathrm{p}$.

$4.50 *$ Heyne, $\boldsymbol{F}$. Adolf. Pllauzen-lialender ader Versuch einer Anweisung: welche Pllanzen man in joden Monat in ihrer Blute finden konne und auf welchem Stantarte. Leipzig 1804. 2 llefte. 8. xxir, 403 p., I tals, - * Zweite vermehrte Lullage mit ciner Anleitungr zum Sludium der Botanik von Friedrich Schwagrichen. Leipzig 1806. 2 IIefte. 8. L11, $403 \mathrm{p}$. $\left(1 \frac{1}{2} / \mathrm{h}\right.$. $)$

$4001^{*}$ Heynhold, Gusiac. Das naturliche Planzensystem. Ein Versuch. die gegenseitigen Verwandschatten der Pflanzen aufzutinden, durch Andeutung ilırer liildungsstufen, Uebergange, Ausnalımen. mit Be- rücksichtigung der arzneiliclon und ubrorlaupt anwendlsaren Gewachse, nebst einer Jistorisclien Eialeitung. Gemeinfasslich darrestell und zunachsi fur angrhende Apotheker, Aerzle u. s. w. brarbeitet. Nit einer Porrede von Ilciurich Ficinus. Dresden und Leiprig 1840.8 . vill, 481 p. ( $1 /$ h. $)$

14:32* Heynhold, Guslav. Clavis generum zur Hora von Saclisen von Friedrich Iloll und Gustav lleynhold. lïne synoptische liarstellung der zul diesem Florengebiet gehorigen Gattungen der ersten Alstheilung (der Phaneroganu'n) zun erleichterten Bestimmen, nebst einen deutselien Register derselfen. Bresden 1843.8.70 p. $(1 / t / h$.

$1.933^{*}$ - Nomenclator hotanieus hortensis, oder alplaluetische und synonymische Aufzallang der in den Garten Europa's hultivirten Gewachse nelsst Angabe ilures Autors, ilires Vaterlandes, ihrer l)auer und ihrer Kisltur. Nebst Vorrede von Ludecig Reichenbach. Dresden und Lripzig 1840 . Lexic.-S. xx, $\$ 88$ p. (4/h.)

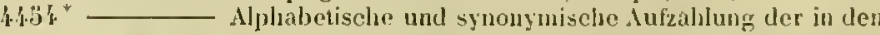
Jahren 1840-1846 in den europáischen Gárten ringefuhrten Gewachse, nebst Angabe ilires Autors, ibres Vaterlantes, ilurer Dauer unal liultur. Dresden und leeipzig 1846.2 llefte. Lexic-8. rul, $320 \mathrm{p}$. $\left(1^{3 / 5}, \mathrm{l}\right.$. $)$

(Continuatur; sistit simul volumen alturum libri praccelentis.)

4433* Hjaltalin, O.J. Islenzk Grasafracti. ['tgefin at tilluhtun hins islenzka Bòmenta félags. Faupmannahofu, prentud af Kivist. 1830. 8. $379 \mathrm{p}$. ( $(\mathrm{lidr}$.)

44006 Eiebner, Johann Chrisloph. Ilorticultura, d. i. Furtz- und verstátliche Anleitung, wie cin Lust - Obst - und Kuchengarten auzulegen, nehat einem ordentlichen Catalogo aller Simplicien, weiche heutiges tages lyekandt und guten theils allhicr $2 u$ befindeo. 13rieg. bei Christoph Tschorn. 1664.8.- *Leipzig, Itahn.1671.8. (32 foll.) - Leijzie, Haluı. 1675.8. Rivin.

4137 * Hieronymus Brunsthwygk von Salern. llie anfahen ist das büclı genanut liber de arte distillandi, vou der kunst der distillierung, zusimmen colligiert uni gesetzt von Hieranymo Brunsthu'ygk, so dan von vilen erfabrenden llevstern der ertzny er erfaliren und ouch durch sin teglicls lantwirchung erhundet und gelernt hatt. (In calce:) Hiemit volendt das buch genant lyber de arte distillandi de simplicibus von Jeronimo Brunschuyg vundtArtzot der keiserlichen freyen statt Sirassburg, und getruckt durch den rvolgeachten Johaunen Grueninger zu Strassluurg in dem achten tag des meyen 1500. folio. 212 foll. ( 238 ) ic. plant. xylogr. i.t.

(Iu praelatione auctor de so ipso haec seribit: "Ich Hieronymus brunscheyg. dos geschlechts Salern, Jurtig von Strasshurgh.n De viti antoris, qui Brunschwick, Jirunswinius, Brmnsvicensis, Brunscheig, Brunactoryg, Mreunschweig viriis vario audit literatoribus, nibil certi conschoyg, Braunschweig varis vario audit literatoribus, nibil crrti constat. Ejus liber imumeris redit impressus vicibus, praesertim cum dert und zelien jar rnwiglieluen gelebet hat" strisshurs. Gruninger.

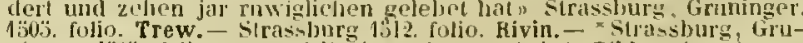

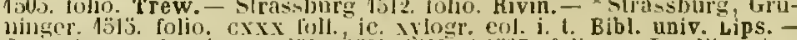
Strassbur\%, Gruninger. 1519) 1521. 1332. - 1337. folio. - Prodiit etiam cum Eucharii khodionis entinnilus Horti sanilatis, Francofurti a/.II

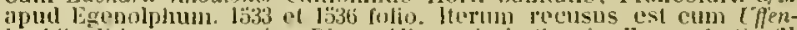
bachit iditione germánica Dioscorillis, onissis tiguris. Francofurti a/, 1610. folio.)

anglice: The vertuose bohe of distyllacyon of the waters of all maner of herbes, translate out of rluvebe. London 1327. folio. Duerniones vel trierniores 27; cum liguris jlantarum rudihus ligno incisis B. - southwark 1320 . foliu. H.

4.458* Hildegardis de Pinguia. Pliysica S. Hildegardis. Elementorum Fluminum aliquot Germaniae, Netallorum, Leguminum, Fructuun et Herbarum: Arborum et Arbustorum: Piscium denique, Volatilium et Animantium terrac naturas et ojerationes $1 \mathrm{~V}$ libris mirabili experientia posterilati tradens. Oribasii medici de simplicibus libri ruinque. Theodori Plyysici Dicta. Aescnlapii de morborum causis. Ounium capitum indice copjosissimo. Argentorati, apud Johannen Sclrottum. 1533, folio. 287,79 p., ind. Bibl. Mus. bot. Vindob.

(Pracoedunt 4 foltia non signata; Hitdegardis p. 1-121; Oribasu et Theotorus p. 1:2-2.26: Aesculapites p. 1-LXXIX; 3 follia ind. non signata. Liber iterum prodiit vis mutatus, practixis Trotulae et Octasiant llureliuni libris. sequenti titulo:

$4409-$ Experinentarius melicinae, continens Trotulue etc librum unicum, Octarimi lloratiuni ete. libri quatuor, libri iten quatuor Ilildegardis de kilementorum, Flumium aliquot Germaniae etc. operationilus. Argentorati, apul Johannem Schottum. 1544. folio Bibl. Ernesti Meyer.

"Voran Trotula p. 1-35, dann JJoratianus p. 1-11k, daraus Jilidegardis p. 1-121: alles fulgende, wie in der vorigen Alusgabe, so das es schem, als habe der lurucker der ursten Ausgabe mir noch einige 
Sehriften zugegejen, um jene hessej abzusetzen. Haller's Angabo in Bibl. bot. 1. p. 218 "Georgius Kraul proprium lihrum in hoc Hillegardis

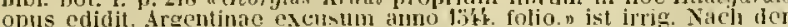
vorrede des Druchers in der zweiten Aisqabe hat Georg fircut 111 den Abdruch der Trotula aus einer llandschrift besorgt. Zu vergleichen ist $F$. A. Reuss De lihris physicis $S$. Hildegardis commentatio historico-nicdica. Vircehurgi 1830. 8. xx, 71 p., worin auch sammtliche bei der heiligen thildegardis vorkommende polnzennameu erlautert verilen. $n$ ) E. M.

$460^{*}$ Hildt, Johamn Adolph. Beschreibung in-und ausländischer llolzarten zur technologischen Kenntniss und Waarenkunde, Charakteristik und Synonymik aller Kunst- Farbe- und Apothekerlober. Weimar 1798-1799. 2 Theile. 8. - I: xII, 164 p. - II: p. 165$251 .(1 \%$ th. $)$

4.61* Hill, John. A general natural history, or new and accurato descriptions of the aninals, vegetables and minerals of the different parts of the world. Vol. II: I history of plants. London 1751 . folio. xivi, 642 p., ind., 16 tab.

$462^{*} \longrightarrow$ A listory of the materia medica. London $1751.4 .895 \mathrm{p}$

$463^{*}$ Essays in natural history and philosophy. Containing a series of discoveries by the assistance of mieroscopes. London 1752. $8.415 \mathrm{j}$. ciner Folmo von Eutdeckungen darch flulfe des Verarosisungsglases. llamburger Marazin, vol. Mll-ix.

$4: 6$ 8 tal. B.

$1460 \%$ The Initish herlal: an history of plants aul trees, natives of Bribin, cultivated for use, or raised for beauty. London 1756. folio. 533 p., ind., 75 tab. col.

\$66 Eden, or a compleat hody of gardening. London 1757 folio. 712 p., 60 tab. col. B.

$467^{*}$ The sleep of plants and cause of motion in the sensitive plants explain'd. In a letter to C. Linnaeus. London 1757. 12. $57 \mathrm{p}$ pracf., ind. - ${ }^{*}$ Ed. Il: London 1762. 8. 35 p.

- grllice: Le sommeil des plantes et la canse du mouvement de la sensitife. Tradtuit te langlitis. Frneve el l'aris 1773. 8. xil, 31 p. Journal de phrsioue, lome 1. 0. $377-39 \%$.)

* germanice. Der schaf der Pllauzen uul die Ursacho der Besve gur an clem Euhtkraul in ciuem Briefe an Linne dus dem Englischem. furtherg 1768 . s. 8

(Duae aliae adsunt translationes germanicac, Francofurtaua ann 1776 of Carlsrubensis anni 1778 .

italice: II souno delle piante. (Scelta di opuse, interess. vol. XVIV. 1. 17-\$7.)

$468^{*}$ The gardener's new lialendar. London 1758.8. $428 \mathrm{p}$. tab. B.

$4.69+$ The vitues of will Valerian in nervous clesorders, will directions for gathering and preserving the root and for chusing the right kind when it is hought dry. London 1758.8 . 24 p., 2 tals. Eil. 111: Lourlon 1758. 8. 24 p., 2 tal). B.

germanice: Valejina, oder von lenen Tugenden der Baldrianwurzel in denen krankheiten und zufillen der Nerven, nehst denen kennzeichen, wodurch die wahre von der unichlon hann unterselieden werden. Aus den Englischen. Nirnberg 17603.8 .31 p., 2 tab. col.

$1470^{*}$ _ Outlines of a system of vegetable generation. London 1758.8 .46 p., 6 1ab.

* germanice: Entw urf eines Lohrgehaiudes von Erzeugung der Pflanzen. Alls dou Englisehen von Genry Leahthan 1huth. Nulubers 1761. 8. 47 T., 6 tab.

$4+i l t-$ An account of a stone, which on being watered produces mushrooms. Loulon 1758, 8.38 p., 2 (al).

$4.42 \div-$ The usefulness of a knowledge of plants: illustrated in varions instances, relating to medecine, lusbandry, arts and conmerce, witl easy means of information. London $1759.8 .18 \mathrm{p}$.

$1+73 \div$ The origin and production of proliferous flowers, with the culture at large for raising duuble from single and proliferous from the double. London 1759.8.38 1., 7 tab. - Ed. Il : I metlod of producing double flowers from single, ly a regular course of culture. London 1759. 8. 40 p., 7 tals. B.

* germanice: Ablandilung von dem Crsprunge und der Erzeuguno prohferirender Blumen nebst einer ausfuhrlichen. Anweisun, wio pronferirenter Blumen nebs einer ausfuhrlichen Anweisum, hurcli die kuftur aus eintachen gefulte: und proliferireme atus gofillen gevogn werden honen. Aus dem Englischen. Nurnherg 1768 .

Hit Hill. London 1759.8 .54 p. B

4 4 $^{3 *}$ —_ Flora britannica, sive synopsis nethodica stirpium britannicarum. Londini 1760. S.672 [., tal.

(Est Synopsis Raji ad methodum Lintaeanam redacti.)
4.76 Hill, John. Botanical tracts viz usefulness of a hnowledge of plants outlines of a sytem of vegretable generation etc. published at various limes, now first collected together. London 1762. S. B.

Titulus practixus opusculis quibusiam, diversis temporibus impressis.)

$4577^{*} \longrightarrow$ Ilorhus liewensis, sistens herlas exolicas indigenasuge rariores in area lotanica loortorum aug. I'r. Cambriae Dotissao apud liew in contitatu Surreiano cultas, methodo lorali nova dispositas. Londini 1768 . 8.458 p., ind, 20 tab. - - Edtio secunda aucta. ib. 1769. 8.458 13., ind., 90 tals. (minimo differt!)

$4.48+$ The fanily praclice of physic. London $1769.8,96 \mathrm{p}$. 9 tab.

$479 \div$ - Herbarium britannicum, exhibens plantas Britanuide indigenas, secundum methodun floralem novan digestas. Cun historia, descriptione, characteribus specificis, viribus et usis. Tahulis aeneis illustrafum. Volumen primum (et alterum). Londini, sumtibus auctoris. $1769.8 .296 \mathrm{p}$. , ind., $195 \mathrm{tal}$.

(Mcthodo propria, eadem ac in systemate ejus, sed adsunt tantum in his voluminibus decem priores classes, "t tribus prima untlecimae.

$480 \div-$ The construction of timber, from its early growth; explaiued by the microscope and proved from experiments in a great variety of kinuls. In fire books. Lomelun, Baldw in, 1770. folio. 62 p. ind., 43 als, - * London, Baldwin. 1770.8 .170 p., ind., 43 lals. tEd. II , corrected and enlared. Lonclon, White. 1774. folio. 62 p. ind. , 44 tab. Bibl. Deless.

4.81* L Exotic botany illustrated, in 35 figures of chinese and american shubs and plants. London 1772. foljo. 35 p., $35 \mathrm{tah}$.

$4.82 \div$ Virtues of british herls, with their history and figures Nr. I-llI. London 1779.8, $106,50 \mathrm{l}, 3.3 \mathrm{tal}$

(Tabulae aeneae eacdem ac in ejus tlerbario britanico, sed heic tantum adsunt Classes 1. 11. et pars lertiae systematis ejus.)

$4.83^{*}$ The vegetable system; or, the intcrual structure and the life of plants; their parts and nourislment explained; their classes orders, genera and species, ascertained and described; in a method altogeher new; comprehenting an artificial intex and a natural system. With figures of ail the plants designed and engraved by the author. The Whole from nature only. London 1761-75. XXV1 voll folio. - ]: (ed. I1.) 1770. 150 p., 21 lal. - II: (cd. II.) $1771.121 \mathrm{p}$, \$ 7 tab. - Ill: 1761. 13. 121-172, tab.88-137.- IV: 1779.49 [. 46 tab. - V: 1763.68 p., 53 tab. - VI: 1764.64 p., 62 tab. V'll: 176 4. 63 p., 60 tab. - VIII: 1765.60 p., 51 tab. - LX: 1765 60 p., 60 tab. - X: 1765.59 1). 59 tab, - Xl: 1767.60 p., $60 \mathrm{tab}$ - XIl: 1767.64 p. 70 tab. - Xlll: 1768.64 [?. 71 tab. - XIV: 1769.60 p.60 tab. - XY: 1769.61 p.61 tab. - XYI: $1770.57 \mathrm{p}$ 61 tab. - XVII: 1770.60 p., 60 tab. - XIIII: 1771.60 p., 61 tab. - XIX: 1771.60 p., 60 tals. - XX: 1772.60 p., 60 tib. - XXI 1779. 60 p., 60 tab. - XXII: 1773.61 p., 6I tab, - XXIII: 1773 60 p., 60 tab. - XXIV: 1774.60 p., 60 lab. 一 XIV: 1774.60 p. 60 tab. $-\mathrm{XXVl}$ et ultimus: 1775. 60 , xx $\mathrm{x}$., index generalis, 60 (ab) (250 (h.) Bibl. Reg. Berol.

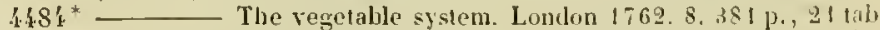

(Idem liber ac tomus primus pracecontis op(ris, continels institutioues botanicas.

$483^{*}$ A Decade of curious and clerant trees and plants: drawn after specimens recrived from the East Indies aml Anerict in the year 1772, and accurately engraved; with thrir history and characters in english and latin. Lonclon 1773. folio nax. 20 1\%. inch., 10 tal. col. (18 th. $)$

1.186 The power of Water-ilock (i. ( Rumex aquaticus) against the scurvy. London 1777. 8. 46 p., A tab. B.

$4.87^{*}$ Dio Kanfto der Salbei zur Verlangerung des menschliclsen Lebens. Aus dem Englischen. Altenhurg 177S, S, Sup.

$4488^{*}$ Beschreibung der anserlichen Theile der PAanzen oder allgencine kinleitung in die Botanik. Jus deu Englischen. Lejuzigr 1781 . 8. vill, 74 p., 49 tab.

Facile plures fertilissimi autoris $\div \div 17 \%$ ibellos praclerii; in-

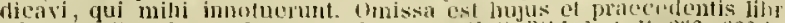
editio anglica. PJuri de antore leguntur Mrill. Bibl. bot. II. 336-36?

4.489t Hill, Thomas. The profitals]e arte of gardening, now the thirde time sett forth, etc. London, typ. Thon ís Mar-lie. Ij6s. 4. (1l. Is. A. Pamplin.) - Lumdon 1574. 4. 134.87 p. B. - Lomdon 1579. 4. 152,92 р. B. - t London, typ. Robert Waldegrave. 1586. 4. 152. 92 p. Bibl. Deless. - Loliclon 1608. 4. Pamplin.

(Autoris nomen persaepe legilur Thmas Hyll., 
$1490^{*}$ Hille, Karl Friedrich. De actione plantarum in partes solidas corporis humani. D. Gottingae 1755. 4. 31 p.

451" Hiller, Johann Karl Gottlieb De Colocynthide ejusque praesertim in hydrope usu. D. Ijpsiae 1821.8.32 p.

$4.92^{*}$ Hiller, Matthaeus, pr. De plantis in scriptura sacra memoratis Decas 1 et ll. Tulungae, Iyj. Reis. 1746. 4.40 p.

$493 \%$ - Nierophyticon, sive commentarius in loca scripturae sacrae quae plantarum facim mantionem, distinctus in duas partes, quarum prior do arhoribus, posterior de herbis dicta complectitur. thi accolit praefatin Salumonis Pfsteri, continests beati autoris vitara, meritu et lituos tam editos quam mannscriptos. Trajecti ad Rhenum, Brocdelet. 1795. 4. 488,287 p., praef., ind.

1491t IIIllhouse, Augustus $L$. Description of the European Olive Tree. (Paris 1818 ) $443 \mathrm{p}, 4$ tal. col.

4. $4: 3^{*}$ Hilscher, Simon Paul. De natura et origine roris mellei vulgo licti et robiginis vegetabilium. Von der Natur und Ursprung des sogenannten Honigthaus und Braud der Erdgewáchse. Jenae 1736. $4.8 \mathrm{p}$.

$4.196^{\circ}$ Proluso de gramine dactylo latiore folio ejusque semine, Germanis Schwaden vel Manna dicto. Jenae 1747. 4. 8 p.

4197 HiItebrandt, $F$. Generis Dracocephali monographia. Geettingae $1805.8 .(1 / 2$ th. $)$ Tr.

$498 *$ Himly, Friedrich Karl. De Caoutsehouk ejusque destillationis siccae prorlnctis et ex his de Caoutsehino, novo corpore ex hydrogenio et carboneo coniposite. Goeltingae 1835.8 . xiv, 108 p., 1 tab.

i $4.99^{*}$ Himly, Karl. De la paralysie de l'iris, occasionée par une application de la Belladomna, et de son utilite dans le traitement de diverses maladies des yeux. Traduit par Ehlers. Paris $1802.8 .30 \mathrm{p}$.

$4: 00$ * Hinderer, Georg Konrad. De Geranio Roluertiano. D. Gissae 1774. 4. $20 \mathrm{p}$.

1.001* Hinds, Richard Brinsley. The regions of vegetation; being an analysis of the distribution of vegetable forms over the surface of the globe in connexion with climate and physical agents. London, typ. Palmer. $1843.8 .140 \mathrm{p}$.

4002 Hinkert, F.W. Systematisch geordnetes llandbuch der Pomologie, mit Inbegriff der in der Königl. baierischen Central-Baumschule zo Weyhenstephan bei Freising aufgestellten und culivirten Kcrn- und Steinohstsarten, und besondrer Berncksichtigung sowohl des Bodens unt Klimas, als der Anwendung und Nutzbarkeit. Nebst einer Einleitung uber Behandlung und Pflege der Obstbaume. Nuuchen 1836. 3 Bábde. 8. $\left(4 \frac{1}{2}\right.$ th. $)$

t503 Hippocrates. Opera omnia quae exstant: in octo sectiones ex Erotiani mente distributa; nune denuo latina interpretatione et annotationilus illustrata, Anutio Foesio mediomatrico medico autore. etc. graece et latiue. Genevae, typ. et sumtibus Samuelis Chovet. 1657. folio. 134 4 p., praef., ind., effigies llippocratis.

(llaec est unica Bibliothecae Banhsianae editio: aljas consulto praetereo.)

450. HirschfeId, Chrislian Cajus Lorenz. Theorie der Gartenkunst. Leipzig $1775-1780.5$ Bande. 4. (181/3 th.)

t gallice: Theorie de l'art des jardins. Traduit de l'altemand. Leipzig $1770-1785$. Y voll. \&

4503 Nene Theorie der Gartenkunst. Leipzig 1775. \&. $(2 / 3$ th. $)$

4506 Gartenkalender von 1782-1786. Hamburg 17821785. 5 Jahrgange. $16 .\left(3 \frac{1}{2}\right.$ th. $)$

4507 llandbuch der Fruchtbaumzucht. Braunscbweig 1788 -1789.2 Theile. $8 .(5 / 6(h$. $)$

danice: Kiobnhavn 1790.8

4508 Kleine Gartenbibliothek. Ërster Theil. Kiel 1791. 8 $(3 / 4 t h$.

$4509^{*}$ HirschfeId, Heimrich. De Lactuca virosa et Scariola. D. Berolini 1833. $8.62 \mathrm{p}$.

$4510^{*}$ HirschfeId, Wilhelm. Die Ernallırung und das Wachsthum der Pflanzen nach den neuesteu clienischen und plysikalischen Beobachtungen erklart nud angewendet anf die Landwirthschaft. Kiel 1844. 8. Xvill, 287 p. (1 $1 / 2$ th. $)$

$45^{\circ}$ —_ Versuch einer Materialrevision der wahren Pflauzennahrung. Nit einem Vorwort von Dr. Christian Heinrich Pfaff. Hamburg 1846. gr. 8. xLIV, 138 p. (1 th. $)$
$4012+$ (His, Charles.) Notice sur les orangers. Paris, Didot. 1829. 4 25 P., 1 tab.

(Centun exemplaribus impressa, Academiae scientiarum p'arisicusj dicata.

4513* Hisinger, Wilhelm. Anteckningar i Plyysich och Geognosi under resnr uti Sverige och Norige. Haftet 1-VI. (Upsala) Stockholm $1819-1837.8 .112,90,103, x, 258,174,7,168$ p., 29 tab. (Atulta spectant ad doctrinam de geongaphia plantarum.)

ijlit Profiler och taleller ofver de fornamsta Beryshojder Sjoars och Strömmars hojıl ofver llafsylan i Sverige oclı Norrige, jente gránsorna for några Trádslags uppstigande och snogränsen Stockholm 1927.4. 32 p. - Eil. Il. Stockholin 1899. 8.55 j. W.

$4515 \div$ - Tabeller ofver llojdmatningar i swerige och Norrige. Stockholm 1829.8.53 p., 1 tab.

(Est idem liber ac editio altera libri praecedentis novo titulo ot addita tabula.)

$4316^{*}$ —_ Esquisse d'un taljeau des pétrifications de la Suède Stockholm, Bredberg. 1829. 8. 27 p. - "Nouvolle édition. StochJolin, typ. Norstedt. 1831. 8.43 p. et un tableau. Bibl. Goett.

$4517 \div$ Catalogue des fossiles de la Suède. Stochholın 1831 $8.23 \mathrm{p}$.

4518 (-) Forteckning på Wáxterna i Skinskattebergs Socken i Westmanland. Stockholm 1832.8.45 p.

$\$ 319^{*}$ Lethaea suecica, seu petrificata Sueciae iconibus et characteribus illustrata. Holmiae $1837,4.124$ p., 37 tab., sign. $A-C$., 1-XXXIY. ( $12 \mathrm{th}$.)

lnest supplementum prinum a p. 113-120.)

$4320=$ Lethacac suecicae supplementum secundum. Holmiae 1840. 4. 11 p., tah. XXXY-XXXCY - Continuatio supplementi secundi. Holmiae 1841.4.6 p., tal. XL-XLll. $\left(2 \frac{2}{3}\right.$ th.

(Plantae fossiles illustrantur in tab. 31. 32. 33. 34. 38. 42.)

401 - Tableau de la végetation du Sneehátten sur le Dorrefjeld et de ses environs. s. l. trycht hos Gjothstrom \& Magnusson. 1841 .

(Cr. Beilschmied, Jabresberichte 1839-1842. p. 481-483.)

$4: 52 \div$ Hitchcock, Edward. A catalogue of plants growing without cultivation in the vicinity of Amherst College. Amherst, typ. Adams and Co. 1829.8 .64 p. Bibl. Webb.

4:323 Hitt, Thomas. A treatise of fruit-trees. London 1755. 8. - Ed. 11 London 1757. 8. I'II, $392 \mathrm{p}$., ind.

452: Hitzer, A. Die Lchensdauer der Pllanzen in ihrem Zusammenhange mit der Fortpflanznng dureh Fruchte und Gemmen dargestellt. Berlin 1844. $8 . \mathrm{vi}, 57 \mathrm{p} .(1 / 3 \mathrm{th}$.

4.523 Hizler, Georg. Oratio de vita et morte Leonhari Fuchsii. Tubingae 1566. 4. 40 p. (sed deest finis.) B.

4326 Hlubek, Franz Iaves. Vie Runkelrube, ihr Anbau, und die Gewinnung des Zuchers aus derselben. Laibach 1839 . 8. (1 th.)

4327 Versuch einer nenen Charakteristik und Klassifitation der Rebensorten, mit besondrer Rucksicht auf die im IJerzogthum steyermark vorkommenden. Ilerausgegeben von der k. k. Landwirthschaftsgeselischaft. Gratz 1 \& $4.8 .(3 / 1 / h$.

$4328^{*}$ Die Ernahrung der Pllanzen und die Statik des Landbaues. Preisschrift. Prag 1841 . 8 . xxx 476 p., 10 Tabellen. (4 th.

4529 - Beantwortung der wichtigsten Fragen des Ackerbaus, als Nachtrag zn meiner Belenchtung der organischen Chemie des Herrn Dr. Justus Liebig. Graetz 1842.8 . x, 132 p. ( $1 \frac{1}{6}$ th. $)$

1:330t Hobius van der Vorm. Atriplex salsum vulge dictum soutenelle, essentia, viribus et operationibus suis primo descriptum. Amsterdam, typ. a Waesberge. 1661.12 .94 p., praef.

15331* Hochstetter, Christian Friedrich. Populäre Botanik, oder fassliche Anleitung zur Kenutniss der Gewächse, besonders der in beutschland und in der Schweiz am hăufigsten wildwachsenden Arten, wie auch der dentschen hulturpflanzen und der merkwirdigsten Gewáchse der wámeren Länder. Stuttgart 1831. S. SW 910 p., 25 tab. col., 3 tab. nigr. $\left(4 \frac{1}{2}\right.$ th. $)$ - "Ed. II: Reutlingen 18.37. 2 Bande. 8 . xu, 846,73 p., 19 tab. col, 3 tab. uigr., efligies Linnaei. (4 th.)

$4532^{*}$ - Nova genera plantarum Africae tum australis tum tropicae bnrealis. Regensburg 1842.8 . 32 p.

(Seorsim impressa e Flora Ratisb. annornn 18:1-18ł2.)

4533* —_. Die Giftgewachse Deutschlands und der Schweiz in lithographirten und colorirten Abbildungen mit erlauterndem Texi. 
Zum Gebrauch in Volksschulen. Realanstalten und Gymnasien. Essliugen 1844.8. II, 56, IV p. und Atlas in 4. mit 24 colorirten Doppelkupfern. $\left(1 \frac{1}{s}, t h\right.$.

\$ö3!* Hocke, Johann llenzel. Bohmens Jopfenbau mit besondrer Wiurdigung der Forzuglichkeit scines Produktes. Wien 1843. 4. 63 p., 1 tab.

4.j3:j Hocquart, $E$. Le jardinier pratique, un traité usuel des plantes utiles, des plantes, arbres etc. revil par $L$. Noisette. Paris 1846.18. $12^{3} / 4$ plag., 8 tab.

$4336 \div$ Hocquart, Léopold. Flore tu Departement de Jemappe, ou définitions des plantes qui y croissent spontanément, faites d'aprés le systime de Limnée a l'usage des éleves en botanique. Mons, Monjot. 1814.8 . vil, 303 p. ( 3 fr.)

$4337^{*}$ Hoefft, $F . M . S . ~ V$. Catalorue des plantes, qui croissent spontanément dans le district de Dmitrieff sur la Svapa dans le grouvornement de Koursk. Noscou, typ. Semen. 1826. 8. xxIII, $66 \mathrm{p}$

1:i38* Hoefle, M. A. Die Pflanzensysteme von Linné, Jussieu, DeCandolle, nebst tabellarischer Uebersicht der Arzuei- Gift- und Nalurungspflanzen nach DeCandolle's System, unter Hinweisung auf tlas System von Linné und Angabo der Merkmale der wichtigsten Pflanzenfamilien so wie der einfachen Arzneistoffe. (Als Rahmen zu meinen Vorlesungen uber medicinische Botanik.) lLeidelberg 1845. 4. $31 \mathrm{p} .(1 / 3, \mathrm{~h}$.

1.339 Hoegström, Pehr. Tal on orsakena, lyvarfore sáden mera skadas af köld på somliga orter i NorJand, «n pả andra. Stocklol m 1755. 8. $16 \mathrm{p}$. B.

$43 ̈ 40^{*}$ Hoelbling, Johann. Lebej das Versetzen der Getreidepllanzen. (Allg. Oestr. Zeitschrift fur Landwintıe.) Wien s. a. 8.8 p.

YS. 1* Hoeller, Ferdinand. Der Konig und die Koniyia der Löhrbảume. Eine Darstellung in Versen, sammt physikalisch-topographischer Beschreibung dieser Naturmerkwurdigheit Schlesiens. Brünn 1820. 4. ( 6 foll.), 1 tab.

(Describitur arbor Larix ingentis magnitudinis in sylva Milkendorfiensi auf den Fullenberge) prope oppidun Troppau; altitudine 171 ped. Vindob., diametro $3 \frac{1}{2}$ ped., circuitu 11 per. Vindob.)

$404.2 *$ Hoeninghaus, Friedrich 11 ilhelm. Ueber fossile Blatter in Susswasserkalk vou Mlembach. Crefeld, 1. Sept. 1840. 4. 1 foll., I tab.

\{:3'3 Hoepfner, Nikolaus. Das verkehrle Jahr, da der Winter im Sommer, und der Sonmer im Winter war, benelsenst vielen andern labey mit furgelauffenen Geschichten von unsres lleilandes Geburth an bis auf das itzige $1696 \mathrm{Jahr}$. Jena (1696). 4. 90 1. B.

kït Hoerter, $J$. Die besten Setzreben, oder Deutschlanuls Weinbau in scinen nöthigen Reformen. Koblenz 1832-1833. 2 Bănule. 12. 11 Bogen, 7 tah. $\left(1 \frac{1}{8}\right.$ th. $)$

\$ $515^{*}$ Hoess, Franz. Gemeinfassliche Anleitung die Btiune und Strauche Uestreichs aus den Blätern zu erkemen. Wien 1830. 12. Lxxvu, 390 p., 10 tab. $\left(2^{3 / 8}\right.$ th. $)$

$456^{*}$ Das Nothigste uber den innern Ban der Organe und deren wichtigere Verrichtungen in Holzgefvachsen. Wien 1833. 8. \$2 p. $(1 / 3$ th. $)$

$4537^{\circ}$ Monographic der Schwarzfulure (Pius anstriaca) in botanischer und forstlicher Bezichung. Wien, typ. Strauss. 1831. folio. 20 , (12) p., 2 tab. col. ( 8 fl C.MI. Gerold.)

455.8† Hoeven, Janus van der. Commentatio de foliorum plantarum ortu, situ, falyrica et functione, victrici (autore Suringar) proxima declarata. Lugduni Batavorun 1821.4.22 p.

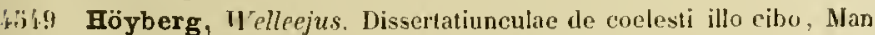
dicto, e Exod. XVI Particula 1. Hafuise 1743. 16 j. B.

16:j0 Hofer, Franz Joseph. Abhaudlung vom Kallee. Frankfurt und Leipzig $1781.8 .150 \mathrm{p}$. B

if:i1 Hoffberg, Carl Fredric. Anwisning til Naturens kamedom. Fursta delen: On Wáxt-Riket. Stockholm 1768.8.81 p., ind., 10 tab. B.

4502

Anwisning til Waxt-Rikets Kännedom. Andra uplagan. Stocklıoln $1784,8.267$ p., 10 tal, B. - Tredge uplagan. Stockholm 1790.8. 460 p., 10 tab. w.

เü̋3* Boffmann, Christian, pr. Ficus arbor plibologice considcrata. D. Jenae, typ. Bauhofer. 1670.4. (20 foll.) Bibl. Reg. Dresd.

PrITzel, Thes lit. bot.
Hoffmann, Franz. De plantis et generatins et iu particulari d.. quibusdan rarioribus regni Bohemiae vegetabilibus. D. Praga. 1748. Scb.

4.33 Hoffmann, Friedrich. Fivercitationes de homonymis. Trajecti ind Rhenum 1689 . folio. DC

\section{Praside Friderico Hoffmann dissertationes:}

$4556^{*}-$ Exercitatio de infusi teronicae efficacia pracferestela lierbae Thée. D. Halae 1694.4 .24 j. - recusa: Ilalae 1705 . 4.

4557 - De Chilla Chinae nodo operandi, usu et abusu. I) llalae 1694.4. Rivin.

4058 De Terebinthina. D. Halae 1699.4. Rivin.

$4559^{*}$ Sacchari historia naturalis et medica. D. llalae 1701

4. $32 \mathrm{p}$

$4560^{*}$ De Garvojhyllis aromaticis. D. IJalae 1701.4.39p

4561 De Opii correctione genuina et usu. D. Ilalae 1702

1. Rivin.

4562 De natura et praestantia riui rhenani in medicina D. llalae 1703. 4. Rivin.

$4663^{*}$ De Balsamo Peruviano ejusque viribus et usu. Halat 1703.4.28 p. - "Halae 1706.4.31 p.

$4564^{*} \longrightarrow$ De usu interuo Camphorae securissimo et pratestantissimo. D. Halae 1714. 4. $36 \mathrm{p}$.

$40 ̈ 65^{*} \longrightarrow$ De Millefolio, germanice Schaf-Garben. 1). Malae 1719.4. $29 \mathrm{p}$.

4566 De vini lungarici excellente natura, virtute et usu. D. Halae 1721. 4. H

$4567^{*}$ De Nanna ejusque praestantissimo in neelicina usu D. Ilalae $1725.4 .34 \mathrm{p}$

$458^{*}$ De recto corticis Chinac usu in febribus. $\mathrm{D}$. Halae $1728.4 .36 \mathrm{p}$.

$4569^{*}$ De cortice Cascarillae, cjusque insignibus in meticina viribus. D. Halie 1738.4.60 p. (Respondens: Philipp Adotph Boehmer.)

$4570^{*}$ Hoffmann, Friedrich. We valliun in Germania boreali principaliun directione memorabili congrua. D. Halae 1823. 8. vi, $19 \mathrm{p}$.

$4671^{*} \longrightarrow$ Physikalische Geograplic. Vorlesungen. Berlin 1837 S. $\mathrm{xL}, 620 \mathrm{p}$. ( $3 \mathrm{lh}$.)

4572 * Hoffmann, Georg Frans. Enumeratio Lichenun iconibus et descriptionibus illustrata. Erlangae 1784. 4. 102 p., 22 tab. (9 th.)

(Prodiit 3 fasciculis annis 178 ' - 1786. Errant, qui 16 Labulas iurlicaverunt.)

$4573^{*}$ Historia Salicum iconibus illustrata. Lipsiae 1785 1791. Il voll. folio. - 1: 1787. 78 1\%, tab. col. 1-24. - Jl: Fase. I 1791. 12 p., tals. $25-31 .\left(10\right.$ th. - nigr. $5 \frac{1}{3}$ th.)

(Post fasciculum quntum, qui est secuudi voluminis primus, nihil anplius prodiit.

4 ZIt $^{*}$ De vario Lichenum usu. Sectio I. D. ErJangae 1786 4. 35 p. $(5 / 2+t h$.

$45 \pi 5^{*}+$ Pierre Joseph Amoreux, et Pierre Remy Willemet. Mémoires couronnés sur l'utilité des Lichens dans la usédicin et dans les arts. Lyon 1787. 8. xxxv1, 48, 103, 68 p., 8 tab. col $(2 \mathrm{l} / \mathrm{s}$ th.

Inest: Willemet, Lichénographie écononjique; Amoreux, Rechriches et experiences sur les divers lichens dusage; Hofmann. (0)mnentatio de vario Lichenum usu.)

$4576^{*}$ Obscrvationes botanicae. Erlaugae 1787. 4, 17 11 $(1 / 12$ th. $)$

$4577^{*}$ Tegetabilia cryptogama. Ellangae $1787-1790$ Il fasc. 4. - I: 1787. vill, 42 1., 8 tab. - Il: 1790. 34 p., 8 tab. (4 th.)

$4578^{*}$ (-) Nunenclator fungorum. Pars I. Agarici. Berlin 1789 8. vıı, 256 p., 6 tal. - "Continuatio. Berlin 1790. 8. 85 p.

$4579^{*}$ - Plautae lichenosac. Descriptio et adunbratio plantarum e classe cryptogamica Linnaei, quae Lichenes dicuntur. Lipsiae $1789-180$ 1. Ill voll. folio. - I: 1790. IV, 104 p., tab. col 1-24. - II: 1794.78 p., tab. col. $25-48 .-111: 1801.62$ p. tab. col. $49-72 .(42 \mathrm{th}$. $)$

(Prodiit integruun opus 12 fasciculis, quisque 6 tabularum pict. pretio $3 \frac{1}{2}$ th.

$40380^{*} \ldots$ Deutschlands Flora oder botanisches Taschenbuch fur das Jajır 1791. Erlangen 1791.12. 360 p., 12 tab. col. - *Neue vermehrte u. verbesserte Auflage. Erlangen 1800. 1804. 2 Baudchen. 
12. 40,273, 40,308 p., 24 tab. col. - " Zweiter Theil fur das Jahr 1795. Kirypugamie. $100,200 \mathrm{H.}, 14 \mathrm{tab}$. col. $\left(9 \frac{1}{8}\right.$ th. - vigr. $61 / \mathrm{th}$.) (Adest ctiam titulus gilliens (et anglicus?): La flore de l'Allemagne ou Etrennes botaunues. )

i.j81" Hoffmann, Georg Franz. IJortus Gottingensis, yuen proponit simulque orationen inchoandae professioni saeran indicit. Goettingae et Lipsiae 1793. Folio 14 j., 4 tab. cul. $\left(1 \frac{2 / 3}{t h}\right.$.)

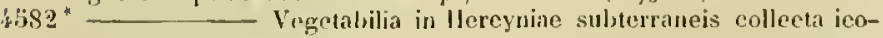
nibus deseriptionilus et observationibus illustrata. Norimbergan 1811. folio. 34 p., jraef., 18 tab. col.

Opus jam anme 1797 inchoituon, anno 1811 demum alssolutum est. Pretinim a bibliopola schrag diminutuon $6 \mathrm{th}$. ante:i $18 \mathrm{th}$.

1583* - Syllabus plantarum officinalium. Systematisches Yerzeichniss der einfachen Arzneimittel des Gewachsreiches. Zum Gebrauch dep medizinisch-betauischen Vorlesungen. Guttingen 1802. 8. 78 p.

1.581. * Phytographisclie Blatter. Verfasst von einer Gesellschaft Gelelirten. Eirster Jahrgang. Gottingen 1803. 8. x, 124 p., 8 tal. col.

40800 - Oratio in universitate Mosquensi habita de lortis botanico-medicis. Mosquae 1807.4. Trautw.

$4: 586^{*}(\longrightarrow$ ) Hortus Mosquensis. Mosquae (1808). 8. 12, (24) p., 1 tab.

i.587* Syllahus plantarum Limbelliferarum denuo dispouendarum, exhibens enumerationem onnium specierum ete. Nosquae $1814.8 .20 \mathrm{p} .(1 / 3 \mathrm{th}$.

i:s88* Cienera plantarum Umbelliferarum eorumque characteres naturales secundum numerun, figuram, situm el proportionem amuium fruetificationis partiun. Mosquae 1814. S. xxtx, 182 1., 3 tab. - *Ed. Jl. aucta el revisa. Mosquae 1816. S. xxxiv, 222 p., alpp., 6 tab. $(31 / 3$ th. $)$

4.j89 Compendium pharmacologiao juxta pharmacopocam castrensem ruthenicam, in usum praelectionum acadenicarum. Mosiquac 1821. 8. Trautv.

1..j90 Oratio de fatis et progressihus rei herhariae, imprimis in imperio rutheno. Nosquae 1824, 4. Trautv.

4.591 Hoffmann, Ilermann. Schilderung dor deutschen Pflanzenfamilien vom botanisch-deseriptiven und physiologisch-chemisehen Standpunkte Giessen $1846.8 . x x, 280$ P., 12 tab. $\left(1 \frac{2}{\mathrm{~s}} \mathrm{th}.\right)$

i.j92 Hoffmann, J. Die Angaben schinesischer und japanischer Naturgeschichten von dem llieinu religiosum (dem Nangthsao der Sehinesen, Sikiminoki der dapaner) und dem davon verschiednen Sternanis des llandels. Leiden 4837.8 max. 46 p., jraef.

4.j93 " Hoffmann, J. F. Bijllrage tot oplossing der vraag : Is Lenna arrhiza auct. cene standvastige onderscheidene Soort, dan wol cen ontwikkelingsvorm van eenige andere van hetzelfde Geslacht? Leiden 1838. 8.52 p., 2 tal.

(Uit het Tydschrift van Nat. Geselt. on Physiol. afzonderlyk afgedruckt.)

$4594^{*}$ Hoffmann, Jakob Friedrich. Zasady natui o Roslinach dla Nauezniących i Ueząeych się podlug 1). Karola Ludwiku H'ildenowa. w Warszawie $1815.8 .332 \mathrm{p} ., 12$ tal,

$459: 3^{*}$ - Drei plysiulogisch-botanische Abhanrlungen. Warschau $1828.8 .58 \mathrm{p} .(1 / 2$, th. $)$

Insunt: Refruchtungsprozess der Pflanzen und Reifung des Samens. Der Rau des Sancus, hesondeps die Lage, Richtung und Restimmung des funjeuli umbiliealis mot des duetus spertuatici. Die Entwicklung des samens, dis Lrsaehe der herumtersteigenden Richtung des rostelli eoreuli, und der aufsteigenden der plumuli.)

$\$ 396 *$ Hoffmann, Johann Moritz. Florae Altdorfinae deliciae hortenses locupletiores factac, sive appendix catalogi horti Altdorfini plantarum novarum aceessione aucta. Altulerfii 1703.4. $49 \mathrm{p}$.

$1.397^{*}$ Hoffmann, Moritz. Florae Altdorfinae dclieine hortenses, sive catalogns plantarum horti medici, quilus auctior crat A. C. 1660. Altdorlii (1660). 4. (30 folt.), 1 tab. ichnographiam horti sistens.

fij98* Florae Altalorfurae deliciae hortenses, sive catalogus plantarum horti medici, quilus A. C. 1650 usque ad annum 1677 auctior est factus. Altdorfii (1677). 4, 6't p. eum eaden Labula.

.:599* Appendix plantarum, quae herte medieo Altclerfino post eatalogi editionem accessere. Altorfii 1691 . 4. (4 foll.)

$\therefore 600^{*}-$ Botanotheca Laurembergiana, lioc est methodus conficiondi herbarium vivum. Altdorfii 1662 . 4. (1' foll.)
$4601^{*}$ Hoffmann, Moritz. Florae Alidorfinae deliciae sylvestres, sive catalogus plantarum in agro Altdorfino locisque vicinis sponte nascentium, cum synouymis auclorum, designatione locorum atque meosium, quibus vigent, lapidumgue ac fungorum observatorun bistoria anctior editus. Altdorfii, typ. Hagen. 1662. 4. (52 foll.), I tab. Mlıderfii, typ. Mrayer. 1677. 4 .

(Est eadem reflitio, novo tautum titulo of addita dedicatione.)

1602 " Florilegium Althorfinun sive tabulae, loca et menses "xhibentes, quibus plintac exoticae et indigenae sub coelo norica vigere et florere solent. Alturlii 1676. 4. 16p.

$1.603^{*}$ - Nontis Mauritiani in agro Leimburgensium, merlio inter Norimbergan et Jirsbruecum, itemque inter Altdorffum et Lauffam loco, eminentis, ejnsçue vieiniae deseriptio medien-botanica, sive catalogus fulantarum in excursionibus herbilegis se offerentium. Altdorfii 1694.4.24 p.

1500: * Hoffmann, Peter. Sammiung merkwirdiger Gegenstande aus dom: Pflanzenreich. sine titulo, folio. 30 tah. evl. (sign. $21-50$. , 4 p. explic. russico idlionate. Bibl. Goett.

$4603^{*}-$ Jeones duarum plantaum rariorun, quae a clarissime Linnaeo inter miraeula naturae numerantur. s. l. et a. folio max. 2 tah. manu pictae, Baronique Asch dientae: Ifrdysarum gyrans et Dionaea muscipula. Bibl. Goett.

4.606" Hoffmannsegg, Johann Centurius firaf von, und Ileimrich Friedrich Link. Flore portugaise, ou description te toutes Ins plantes qui croisseat naturellement en Portugal, avee figures colorièes, cinq planches de terminologie et uıe carte. Berlio 18091840. H voll. folio. - J: $4809.458 \mathrm{j}$., 78 tah. col. - II: $1820.436 \mathrm{p.,}$ 36 tab. col. sign. $79-109$. (253 th. $)$

Operis splendidi longe interrupti anno $18 \% 0$ demum fasciculus vigesinus tortius prodiit.

$4607^{*}$ Catalogus seminum in hortis Comitis de Hofmannsegg annis 1823,1824 et 1825 collectorum, quae offer hortorum praefectus J. G. Jannack. (Dresdac 1823-1823.) 4. 4, 4, 4 p.

$4608^{*}$ Preisverzeichniss der Pl]anzen in seinen Gárten. Aclite Ausgabe. Dresden 1836. 8. 78 p.

$4609^{*}-$ Verzeichniss der Planzenkulturen in den Gräflich Hoffmannseggischen Gärt’n zu Dresden und Rammenau, nebst einigen kritischen Bemerkungen, einer verhessernden Anzeige der hauptsticlılichsten Druckfehler in Ilerru Prof. Link's Enumeratio. Dresden 1824. 8. 310 p., 1 tal, - " Zweiter und dritter Nachtrag. ib. 1926. 8. 240,96 p., i tab. $\left(3 \frac{1}{3}(h\right.$.) - * Nachtrag zu 1841, ih. 1842. 8. $31 \mathrm{p}$.

$4610^{*} \ldots \ldots$ Verzeichniss der Orehideen im Graflich Hofmunn:egg'seheu Garten zu Dresden ucbst ihren Werthen, den Beselureibungen der darunter befindlichen neuen Arton und eioigen allgemeinen Bemerkungen iber ihre sowoht praktische als theoretische Behaudlung. Dresden 1842.8.25 p. - * Ed. ll. ih. $4843.8 .64 \mathrm{p}$. - ${ }^{*}$ Ed. JH. ib. 1844.8 .68 p. $(1 / 2$ th.

4611 Hoffwenius, Pehr, pr. De Nanna. D. Upsaliae 1684.8 .56 p. B.

4.612+ Hofman, $\boldsymbol{N}$. Shrivelse til $\mathrm{lir}$. Professor $S_{\text {chouv angaaende de paa }}$ det indthemmede ved Ilofmansgave frenkomne planter. Kiobenhavn, typ. Seidelin. 1822.8 .8 p.

4613 * Hofman-Bang. De usu Confervarum in oeconomia naturae. Hafniae 1818.8 .27 p., 1 tab. col.

461:" Hofmann, Franz llihlelm. Die Kultur der Handelsgewächse. Prag 1845. 8. (10) $334 \mathrm{p}$.

1.61:; Hofmann, Joseph Vincenz. Ceher die tirolisclıen Arten der Gattung Verluascum. Innspruck 1841, 8. 18 p.

$4616^{*}$ Hofmann, L. Inweisung zum geregelten Anbau, der Frnte und Auflewalurung des liurbis (Cucurhita) als nothwendige Voraus setzung zur Darstellung des kiristallzuckers aus demselben. Wien 1837. 8.20 13., I tab. (1/3 th.)

4617* Hofmann von Elofmannsthal, Ignaz. Die Caruba di Giudea gegen Lungendampf und andre Brusthranklieiten, naturhistorisch und medizinisch bearbeitet. Wien $1 \$ 42,8,2411 ., 1$ tab.

$4.618^{*}$ Hofsteter, Johann Adam. Epistola gratulatoria, in qua de papavere et opio esculeutis agitur. insinulque virtus ipsorum medica expenditur. Ilalae 1704.4 . (5 foll.) 
4619 t Hogg, John. Observations on some of the classical plants of Sicily. (London) 1824,8.

(Extracted from Hooker's Botanical Journal.)

$46 \geq 0^{*}$ Hohenacker, $k . F r$. Eaumeratio plantarum quas in itinere per provinciam Talysch collegit. s. 1. et a. 8.178 p. , 4 tab.

4621* - Hohıenprofil und Kärtchen des sudwestlichen Theiles von Persien mit Rucksicht auf die dortigen Vegetationsverháltnisse nach den Skizzen und Angaben von Theodor Kotschy entworfen. Esslingen 1846. folio. (1/t th.

4622 * Holandre, Jean Joseph Jacques. Flore de la Moselle, ou manuel d'herborisation précédé d'un aperçu géologiıjue sur le département, et d'émens abrégés de botaaique. Mletz 1829. Il roll. 8. LxxviI, 712 p. ( 6 fr. $)$ - Supplément. Metz 1836.8. $62 / 3$ plag. - Nouvelle edition. Metz 1842 . II voll. 8 . Godron.

$4623^{*}$ Holl, Friedrich. Handbuch der Petrefaktenkunde. Mit einer Einleitung über die Vorwalt der organischen Wesen auf der Erde, von Ludwig Choulant. Dresden 1829-1830. 5 Bandchen. 8. 90, vat, $489 \mathrm{p} .(17 / 8$ th. - lierabg. $2 / 3$ th. $)$

462!* Worterbuch deutscher Pflanzennamen oder Verzeichniss sammlicher in der Plarmacio, Ockonomic, Gártnerei, Furstkultur und Technik vorkommeaden Pflanzen und l'flanzentheile nach ihren Provinzial- und systematischen Namen, nebst Angabe der lateinischen, wie auch der Stellung im kunstlichen und naturlichen Systeme. Erfurt 1833. Lexic. 8. Iv, 434 p. (2/h.)

$4625^{\circ}$

und Gustav Heynhold. Flora von Sachsen. Breschreibung der im Konigreiche Sachsen, dem llerzogthume Sachsen preuss. Antlicils, den Grossherz. und Herz. Sticlss. Janden Emestinjscher Linie, den Ilerz. Anhaltischen, Furstl. Scliwarzburgschen und Fürtl. Reussischen Raubstaaten wildwachsenden uod allgemein angebauten Pilanzen, mil besondrer Berucksichtigung ihrer Verwendung. Erster Band. (Phanerogamen.) Dresden 1842. S. x, $862 \mathrm{p}$ $(2 \%$ tll.

4626 t Hollstein, Chrislian Heinrich. Rhabarbari historia. D. Lugduni Batavorum 1718. 4. 21 P., 1 tal.

4627 HoIm, nobilis Holmskjold, Theodor. Aflandling on Anagallis og dens kraft mod yandskrack. Kiobenhavn 1761 . 8. 30 p., 1 tab. col. B.

$1628 *$ Beatia ruris otia fungis danicis impensa. Havniae (1790 -1799.) II voll. folio. - - I: xxiv, 148, 38 p., (33) tab. col. - Il : 70 p., 49 tal. col. $\left(160\right.$ (h. - nigr. $53 \frac{1}{3}$ th. $)$

(Liber danice ac latine scriphus; textus latinus absquo figuris redit in Usteri Anaten der Bot. 17. p. 30-149 nec non in editione in sequente Persooniano. Volunen alterum post obitum autoris $\left[\div 179 y^{\prime}\right]$ curavit Ericus Liborg. - Divenditur hodie Havniae col, $60 \mathrm{Rdr}$., nigr. 13 Rir.)

$4629^{*}$ Coriphaei Clavarias Ramariasrue complectenles cum brevi structurac interioris expositione. Denuo cum adnotationibus editi nec non conmentatione de fungis clavaeformibus aucti a Christiano IJenrico Persoon. Lipsiae 1797. \&. Iv, 239 p., 4 tab. col. ( $1 \frac{1}{2} / \mathrm{h}$. $)$

4630 Holtzachius, Joannes Cosma. Annotationes in Dioscoridem. Lugduni, typ. Frellonii. 1556, 12. Bum.

4631 Holtzbom, Andreas. De Mandragora. D. Trajecti ad Rhenum 1704. 4. $15 \mathrm{p}$. B.

(Dissertatio hecce ommino congruit cum Olai Rudbech disputione de Mandragora, llomiae altuo 1702 proposita.

4632* Homann, G. G. J. Flora von Ponmern oder Beschreibung der in Vor- und Hinterpommern sowolıl einheimischen als auch unter freien Himmel leicht fortkommenden frewtichse. Cösliı 1828-1835. 3 l3ande, 8. - I: 1828, xvı, 348 p. - II: 1830. xxxu, 287 p. - III: 1835. xxxıv, 453 p. (5 th.)

4633 Home, Francis. Principles of agriculture and vegatalion. London 1759. 8. H.

gollice: Les principes de ragriculture et de la régétation. Paris, Prault. 1761. 8. 1. $17 \mathrm{k} \mathrm{p.} \mathrm{-} \mathrm{tBerne,} \mathrm{société} \mathrm{typogriphirpue.} \mathrm{1791.} 8$. vi, 17 k. $\mathrm{p}$.

germanice: Grundsátze des Folibaus und Wachssthums der Pfanzen. Aus dem Englischen von Hioellner. Berlin 1763. 8. - Brrlin 1792. 8. ilalice: Veueza 1764. 4. H.

46.3'* (Honckeny, Gerhard August.) Vollstándiges systematisches Verzeichniss aller Gewachse Teutschlandes zur Beforderung ihrer plyysikalischen und okonomischen Geschichte von einem Mlitglicde del Gesellschaft naturforschender Freunde, und von letztrer zum Druck gefördert. Erster Band. Leipzig 1782. 8. Lvi, $716 \mathrm{p}$. $4630^{\circ}$ " Honckeny, Girhard Auyust. Synopsis plantar'un Germaniac, contineus plantas in Germania sua sponte provenientes arljectis omnilus anctorum synonymis, curante Kart Laduig Willdenow. Berolini 1792

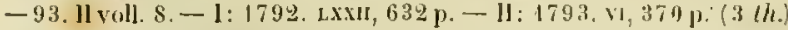

4636 Honuphriis, Franciscus de. Stirpiun nomina in phamaleopelio Minimorum in monte P'incio reperiundarum. Romac 1682. 4. Falc.

$4637^{*}$ Hooke, liobert. Nicrographia, or some physiulogical tescriptions of minute bodies made by magnifying glasses. Witl observationk and incluiries thereupon. London, for J. Allestry. 1667 . folio. (18 foll.) 246 ) , ( 5 folls.), 38 tals.

(Evmplaria Halleri cl Bankiä habent annum 166i. - Compendium splendidi operts, teste Hallero Londini 17 k̈. folio. prodiit, conservatis labulis, sermune contracto, rejectis raticciniis Hookii.)

$4638^{*}$ Hooker, Josepl. Dalton. The Botany of the Antarclic Voyage of H. MI. Jiscovery Ships Erebus and Terror in the years 1839-1843 unler the command of Capt. Sir Jumes Clark Ross, Part I-XIV Lonton $1844-1845.4$. xแ1, 272 p., tab. col. 1-1l2. (5l. 16s. nigr. $3 l .14 s$.)

(Continuationem operis splendidi, cui etiam cst momen aflora antarctica" jam editan nondun coram haber.

46397 The cryptogamic Botany of the Antaretic Voyage of 1]. M. Discovery Ships Erebus ant Terror in the years 1839-1843, under the comnand of Cajt. Sir Jumes Clurle Ross. Jart I-lll: (Anchland and Camplell islands.) London 4845.4. 88 p., tab. col. 5i -80 . (1l. 8s. - nigr. 19s.) Bibl. Montagne.

(Kst particula cryptogamica proris oneris seorsim ndita.

(1)e meritis autris tilii illustr. Il illiam Jackson thooker. in ire herlharia, if. $\div$ Testimonials in favour of Joseph Dallon Mooker, as it candidate for the vacam chair of hotany in the university of Edinburgh. In four series. Edinhurgh $1815.58 .9,36,47,20$ p.)

461.0 Hooker, William. Pomona Londinensis. Fasc. I-V'lll. London $1843 \mathrm{sgq} .4$. DC.

$4641^{*}$ Hooker, William Dawson. Notes on Norway; or a brief jonrnal of a tour made to the northern parts of Norway, in the sumnier of 1836. (Unjublished.) Second edition. Glasgow, Richardson. 1834. 8. $123 \mathrm{j} ., 4$ tab. Bibl. Link.

$4642+-\frac{1}{-}$ Inaugural dissertation upon the Cinchonas, their history, uses and effects. Glasgow 1839,8 , 29 1). Bibl. Gay.

4643 Hooker, IVilliam Jackson. Jotinal of a tour in Jceland. Yarmontl 1811. 8. (6s.) - Ed. II : Londou 1813. II voll. 8. Dc.

$4.644 \div(\longrightarrow$ Orhotrichum; tabula, specierum affinitatem illustrans. s. l. ct a. Bibl. Cand.

$4643^{*}$ Plantae eryptogamicae, quas in plaga orbis novi acquinoctiali collegerunt Alexander von Ilumboldt et Aimé Bonpland. Arljectis tabulis species quastam novas minusve cognitas (Muscorun frondosorum et lıepaticorum) exhibentibus nec non Atexondri dh Humbold notationibus quilusdam plantarum geographiam spectantibus. Nr. I. Londini 1816 . 4. ( 8 foll.), 4 tals, col. (19s.) Bibl. Mus. bot. Viodob.

$466^{*}$ - British Jungermanniae: being a history aud description with coloured figures of each species of the genus and microscopical analyses of the parts. London 1816. folio. 88 tab. col. sign. I84 , suppl. 1-4; textus absque signatura.

ilense Juoio 1839 bihompola Liphiensis Veigel pretium operis indiravit $36 t h$, quod antea fuit $581 / \mathrm{s} t h$.)

$1647^{*}-$ and Thomas Taylor. Musculogia britannica, containing the mosses of Great Britain and Jreland, systematically arrangen and described. London 4818, 8. xxxy, 152 p., 31 tab. (45s. Pamplin

$4648^{*}$ - Mnsci exotici, containing figures and descriptions of neN or little huown foreign mosses and other cryptogamic suljects. London 1818-1820. Il voll. 8. - J 48 I8, tab. 1-96. - II : 1820 . tab.97-176. cum textu absque signatura. (col. 4l.4s. - nigr. 2l.2s.) $4619^{*} \longrightarrow$ Flora scotica, or a description of Scottish plants, it ranged both according to the arteficial and natural methods. In two volumes. Iondon 1821. 8. x, 292, 297 p., ind, 3 lab.; effigies Hooker. (5l.6s. - 12s. A. Panplin.)

$4650^{*}$ Botanical illustrations : being a series of figures designed to illustrate the terms employed in a course of lectures on botany with descriptions. Edinluurgh 1822. folio obliqun. 21 1ab. col., (42) p

$4631^{*}$ - Exotic Flora, containing figures and descriptions of new rare or otherwise interesting exotic plants, especially of such as are deserving of heing cultivated in our gardens. Edinburgh 182.3 -1827. III voll. gr. 8. 232 tals. col., textus alssque signatura.

(In fiscieulo primo crrore typothetae legitur annus 1812. 
4hï2* Hooker, llilliam Jaclison. Some account of a collection of aretic plants formed by Edward Sabine, during a voyage in the polar seas in the year 4823 . Londrum $1824,4.35 \mathrm{p}$.

(Froms the Transactions of the linnean snciety vol. XIT.

1.683. (-) A catalogue of plants contained in the royal botanic granden of rilasgow in the year 1825. aljhabetically arranged. Accompanied by a plan of the garden. Glasgow 1825. 8. 67 p., I tab.

$46: 34^{*}$ and Thomas Taylor. Muscologia britamica; coutaining the mosses of Great-Britain and Ireland, systematically arranged and described: with plates illustrative of the eluaracters of the genera and species. Secourl edition corrected and enlarged. London 1897.

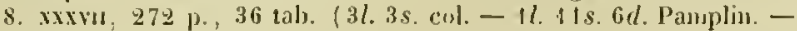
$12 \frac{1}{2}$ th.

(Bluic editioni adjectae sunt hescriptiones, hand simul icones nepaticarun.)

16i3i: - - and Roberl kaye Greville. lcones l'ilicum : ad eas potissimum species illustrandas destimate, quae hactenus vel in herhariis delituerunt prorsus incognitae. vel saltem nondun per icones botanicis innoluerunt. (Figures and descriptions of Ferns ele.) Londmi 1\$29-1831. II voll. folio. - 1: 1829. tab. 1-120, 120 foll. - 11: 1831 . tab. $121-240,120$ foll., 9 1). ind.

$1656^{*}$ — Bolanical Miscellany; containing figures and descriptions of such plants as reconmend themselves liy their novelty, rarity or history ete. London $1830-1833$. III vull. $8 .-1: 1830.356 \mathrm{p}$. , tab. $1-75 .-11$ : 1831.421 13., tab. $76-93$., lab. suppl. col. 1- 19. - III: 1833.390 p., tab. $96-112$. tab. suppl. col. $20-41 .(15 / .15 s$.

4607 " _ The Joumal of Bolany, being a second series of the Lotanical Miscellany; containing figures ant descriptions of such plants as recommend themselves by their novelty, rarity or history, or lyy the uses to which they are applied in the arts, in medicine and in domestic oeconomy; together witl occasional botanical notices and information. London 1834- 1842 . IN voll. 8. - I: 1834. 390 p., 28 tab. pro parte col. sign. 113-140. - 11: 1840.442 p., 16 tah., effigies Otof Swartz. - III: 1841. $446 \mathrm{p}$, $13 \mathrm{tab}$, effigies Jussieu, - NV: $4842.433 \mathrm{p} ., 21$ tab.

$168^{\circ}-$ The London Journal of Botany: ecmtaining figures and descriptions of such plants as l'ecomment themselves by their novelty, rarity, history or uses; together with botanical untices and information and occasional portraits and memoirs of eminent botanists. London 1842-1846. V roll. 8. - 1: 1832. 678 p., 23 tab. - Il: 1843.678 p., 24 tab. - III: 1844.666 p., 24 tab. - I : 1845. 666 p., $24 \mathrm{lab} .-\mathrm{V}: 1846.666 \mathrm{p} ., 24 \mathrm{tal} .(9 /$.$) (Contiuuatur.)$

inif $9^{*}$ The British Flora; in two volumes. Volumen I. comprising the phaenoganous or flowering plants and llie ferns. London $1830.8 . x, 450$ p. (12.s.) - E.t. Il. Lon.lon 1831. S. - Ed. III. London 1835.8 . - ${ }^{*}$ Ed. 15 , with arditions and corrections and numerous figures illustrative of the grasses and umbelliferous plants.

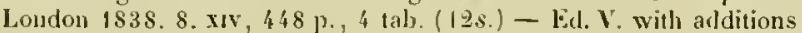
and corrections and numerous figures, illustrative of the umbelliferous and composite plants, grissies and lis ferus. London 1842. 8. $38,464,12$ p. - "Volumen ll. comprising the Cryptogamia. London 1833-1836. I1 parts. S. (11. 4.s.) - 1: 1833. Musci frondosi et hepatici, Liclienes, Charac et Algac. $x, 4.432 \mathrm{p} .(12 \mathrm{~s}$.) II: 1836. Fungi, by the Rev. II. J. Berkeley. 32, 386, XV p. (12s.) (Volumen alterum Hoolieri British Fora ctiam inscribitur: The

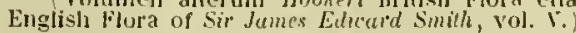

$1660 t=$ Characters of genera extracted from the Brilislı Flora of Willium Jacksan Hooker. Edinhurgh 1830. 8.64 p.

$4661^{*}$ Companion to the Bolanical Magazine: being a Journal, containing such interesting bolanical information, as does not come within the prescribed linits of the Jagazine; wilh occasional figures. London 1835-1836. Il voll. $s_{-}-1: 1835,384$ p., 19 tab., effigies David Douglas. - II: 1836. 381 p., 32 tab), effigies John Fraser et Richard Cunningham.)

ititi: - Flora boreali-amerieana, or the Butany of the northern parts of British America: compiled principally from the plants collected by Dr. Richordson and Mr. Drummond on the late northern expeditions, under command of Captain Sir John Franklin, to which are added those of Mr. Douglos, from North-West-dmerica and of other naturalisis. Illustrated by numerous plates. Londou is334840. Il voll. 4. $-1: 1833$. vi, 335 p. $-11: 1840.351$ p., 238 tab. 1 mappa geogr. (12l.12s. $-84 \mathrm{lh}$.)
4663* Hooker, Irilliam Jackson. Jenues plantarum; or figures. with lurief descriptive cluaracters aml remarks of new or rare plant;, selerted from the authors liertharium. Loudon 1837-1845. Vill voll. (XY parts). 8. tals. $1-750 .(10 l .10 \mathrm{~s})$

Prodliit quinulecim fascreulis parts quorum duo volunoinatim

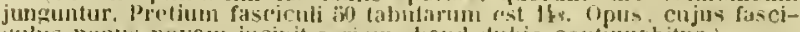
c'ulus nomus novan incipit sirien, hand dulsie contumabitur.

466." (- Copy of a letter atddressed to Dutrson Turner Esy. on the oceasion of the diath of the late Dule of Bedford: particularly in refereure to the sinviess lentered by lis Grace to Butany and Horticulture. Printed ouly for private distrilution Gasgow 1840. 4. $25 \mathrm{p}, \mathrm{i}$ tab. col.

$4663^{*}-$ and G. A. Walker-Arnott. The Botany of Ciajtain Beechey's loyage, comprising an account of the plants collected by Messrs Lay and Collie and other officers of the copedition, during the voyage to the pacific and Bering Strait, perfurned in his Majesty's Ship Blossom, under the ronmand of Captain F. H'. Beechey in the years $1825-1828$. London $1841.4 .485 \mathrm{j} ., 94 \mathrm{lab}$.

$4666^{*}$ Genera Filicum, or illustrations of the Feros and other allied genera; from the original coloured drawings of Francis Bauer Esq., with descriplive letterpress. The plates coloured ty G. Fruces. London 1842. royal S. (120) p., 120 tais. col. ( $7 l .4$ s.)

$4667^{\circ}$ Notes on the botany of the antarctic voy age, condueted loy Capt. Jumes Clark Ross in her Majesty"s discovery shijs Erebus and Terror; with observations on the Tussac grass of the Folkland islands. Loudon $1843,8,83$ p., 2 tab. cul.

$4668^{*}$ Species Filieum; being descriptions of the hown ferne particularly of such as exist in the authorx herharium, or are with sufficient accuracy described in works to which he has had access: accompanied with momerous figures. Volunen 1. containing fileichendia-Dictyoxyplium. London ( $846.8 . x \mathrm{v}, 245$ p., tals. $1-70$.

(Contmuatur; yolmen primum prodit ah amo isi quatuor fasci-

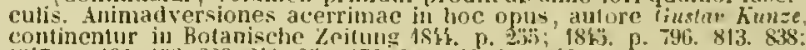
18'7. 13. 183. 198. 223. 241. 238. $276,300,319.325 .349 .1$

$4669 \div \frac{1}{1}$ century of orchilaceous plants selocted from Curtis Botanical Magazine, consisting of a huudred of those most worthy of cultivation, systematically arranged and illustrated with colnured figures and dissections chiefly executed by Mr. Fith; accompanied by an introduction on the culture and general managenust of Orchidaceous plants, and with copious remarhs on the treatment of each species by Joln Charles Lyons. London 1846. 4. Part I: 12 p., tal. col. 1-S. (10s.6d. - nigr. 7s.) (Continuatur.)

$4670 \div$ Hooper, Roberl. Olsservations on the structure and economy of plants: to which is added the analogy between the aninal and the vegetablo Kingdom. Oxford 1797. 8. 11, 129 1). ef conspectus.

$4671 \div$ Hoorebeke, Charles Joseph. Mémoire sur les Orobanches (en Thinis) honger, sneer-kruyd, brem-raep, prienen, pour servir d"instruction da la culture du trèlle dans les conmunes oủ l'Orobanche muit it sa culture, Gand i $\$ 18,8,22$ p. Bibl. Brux.

4672 Hope, Thomas Charles. Tentamen inaugurale, quaciam de plantarum motibus et vita complectens. Edinburgi 1757.8 .37 p. B.

4.673 Hopkirk, Thomas. Flora Glottiana, being a catalogue of the indigemous plants on the banks of the river Clyde, and in the neightbourlumd of the city of Glasgow. Glasgow 1813.8 .170 p. $(7 \mathrm{~s} .6 \mathrm{~d}$.

467\%* Horat anomala. A general view of the annmalies in the vegetable lingdom. Glasgow and London 1817. 8. 198 p., 11 tab. $(10 \mathrm{~s} .6 \mathrm{l}$.

46:3* Hoppe, David Ileimrich. Ectypa plantarum Ratisbonensium, oder Abdruche derjenigen Pflanzen, welche um Regensburg wild wachsen. Lörstes lhis Achtes Hundert. Verfertigt und verlegt von Johann IIay, Scluiftsteclier und Kupferdrucher in Regensburg. Regensburg $1787-1793$. VIll voll. folio. $(52 \mathrm{p})$.800 tab. (32 $/ \mathrm{h}$.

(Texlum voluminum lill et lill non vidi.)

$4676^{*}$ —_ Botauisches Taschenbuch fur die Anfänger dieser Wisscuschaft uid der Apothekerkunst. Nit Abbildungen. Regensburg $1790-1811$. 29 Jahrgange $8.182,205,248,260$, 2958, 268, 252, $232,236,232,252,252,952,252,252,266,251,252,251,243$, 232 et 236 p., (ab. $\left(18 \frac{1}{2}\right.$ (h.)

(inscribitur inde ab anno 1803: "Noues botanisches Taschenbuch."

$4677^{\circ}$ und Jakol Sturm. Die Klecarten Deutschlands in Abbildungen; und Beschreibungen vou Johunn Christian Dumel Sclireber 
und Daved Heimrich Hoppe. Numberg 1804. 12. 32 foll., 32 tab. col $\left(1 \frac{1}{3} t h\right.$.)

(Sistit particulam Florae germanicae a Jukab Surm delineatae.

$4678^{*}$ Hoppe, David Heinrich und Friedrich Hornschuch. Tagebnch riner Reise nach den liusten des adriatischen Neeres und den tiebirgen von Kirain, Kärntben, Tirol, Salzburg, Baiern und Böhmen, vorziglich in botanischer und entomologischer Hinsicht. Regensburg 1818. 8. xul, 283 p., t tab. col. $\left(1 \frac{1 / 2}{t} / \mathrm{h}\right.$.

$4679^{*}-$ Anleilung, Gráser und grasartige Gewäctuse nach einer neuen Nethote fur Ilerbarien zuzubereiten. etc. Regensburg und Nurnberg 18 19. 4. vall, 35 p., 2 tab. $\left(1 \frac{1}{8}\right.$ th. $)$

$4680^{*}$ Caricologia germanica oder Aufzáhlung der in Deutschland wildwachsenden Riedgraser. Zum lsequemen fiebrauch auf botanischon Excursionen, zur erlejelsterten Bestimmung der Arten und zur systentatischen Anordnung derselben in Ilerbarien. Leipzig 1826. 8 . vil, $104 \mathrm{p} .(7 / 12$ (h.)

$4681^{*}$ - unul Jatiob Sturm. Caricologia germanica oder Beschreibungen und Abluildungen alier in Deutschland wildwachsenden Seggen. Nurnberg 1835. 12. 112 foll., 112 tab. col.

(Sinit particulam Flurate germanicac a Jakob Simm delineatae.)

4682 Hoppe, wiedrich ITilhelm. De Balsamo Copayba. D. (Talentini, llisloria simplicium p. 617-624.) B.

$4.683^{*}$ Hoppe, Joham Goltried. De Morjhio et acido meconico. 1). Lipsiae 1820.4. $25 \mathrm{p}$.

1.684 Hoppe, Tobias Konrad. Rericht von denen Eradapfeln; (und von hier zu Lante wachsenden geringen Gewachsen, welehe doch gleichwohl in der llaushaltung brauchbar sindl.) Wolifenbütted 1747. 4. 32 \%. B.

468:; Einige Nachricht von den sogenannten t:ichın- Weilenund Dornrosen, welche in dem vorigen Jahre in der Lausiz und an andern Orten sind gefunden worden, ingleichen von den Libellen oder Wasser-Jungfern, welche in cben dem Jahre in obgedachten Gegenden sich haufig lıaben seheı Jassen. Leipzig 1748. 4.20 p. B.

$4686^{*}$ - Abhandlung von der Begattung der Prlanzen. Nebst ciner Vorrele von Georg Heinrinh Koenigsdoerfer. Altenburg 1773. 8. xvi, 62 j.

$4687^{*}$ Geraische Flora. Nit einer Vorrede von Johann Ernst Immunuel W'ulch. Jena 1774. 8. $224 \mathrm{p}$.

4688* Horaninow, Рaul. Шачахьныя основанія ботаник. Рrimac lineae botanices. Petropoli 1827. 8. 338 p., 12 tab. (rossice.)

4689 - Systema pharmacodynamicum. Petropoli 1829. gr. 12. $\left(1 \frac{1}{8}\right.$ th. $)$

$4690^{*}$ Primae lineae systemalis naturae, nexui naturali omnium evolutionique progressivae per nixus reascendentes supersiructi. Petropoli 1834. 8. xıI, 142, xxi p., 1 tab. $\left(1 \frac{1 / 3}{\mathrm{th}}\right.$.)

$4691^{*}$ _ Tetractys nalurae seu sy'stema quadrimembre omnium naturalium, quod primis lineis systentatis naturae a se editis adjunxit. Petropoli 1843.8 . vi, $62 \mathrm{p} .(3 / \mathrm{t}$ th. $)$

1692* Horbius, Christian Johamn. De fobrifuga Chinae-Chinto virtute. D. Altorfii $1693.4 .24 \mathrm{p}$.

4.693* Horn, Ernst. De Opii abusu. D. Vitebergae $4804.4 .24 \mathrm{p}$.

4.694* Hornemann, Jens Willen. Fors'g til en Dansk oeconomisk Plantelaere. Kjobenhavn 1795. 8. - Ed. Il : il. 4806. 8. - * Ed. III: ib. 1821-1837. II voll. 8. - I: 1821. xu, 1042 p., 2 iab. $-11: 1837$. 990 p. ( 8 Rdr.)

$4693^{*}$ Enumeratio plantarum horti botanici Hahnieusis. IJafniae $4807.8,44 \mathrm{p}$.

$4696 \div-0 \mathrm{~m}$ den svenske naturforsker Daniel Rotander og manuscript af hans reise til Surinam. Kiobenhavn, typ. Seidelin. 1812.8.38 p. Bibl. Webb.

$4697^{*}$ _ - Hortus regius botanicus Hafniensis, in usum tironum et botanophilorum. Hafniae $1813-1815$. Il voll. 8. xiv, $995 \mathrm{p}$.

$4698^{*}$ Snpplementum horti botanici Hafuiensis in usum tironum et botanopliilorum (I-III.) Hafniae 1819.8. 172, 14, 11 p.

$4699^{*}$ havn 1816.8. $32 \mathrm{~m}$ B. (16 Schill.)

(Aftrykt af nye oeconom. Ammaler. 2. Bind.)

$4700^{*}$ De indole plantarum guineensium observationes. Programma academicum. Hafniae 1819.4. $27 \mathrm{p}$.
$4701+$ Hornemann, Jens Wilken. On Martin Vahls Fortjenester af naturkyndigheden som. Videnskabsmand oglacrer. Kiobenhavn $18 \pm 1$. 4. $56 \mathrm{p}$.

Saershildt aftrykt af det h. Dansk Vet. Selsh. Skit.

$4502^{*}$ Nomenclatura Florae danicae emendata, cum indice systematico ef alphabntico. Hafniae 1827.8. xxviI, 214 l. (2 Rbd.)

$4703^{*} \longrightarrow$ Om Fucus buccinalis L. Kiobenhava 1828. i. I tal,

$470 \% \div$ - Om he tydske Naturforskeres og Laegers Forsanling i Berlin i September 1828 , isaer med hensyn til Botanikernes Deeliagelse deri. Kiobenhan 1899. 8.28 p.

$4705+$ Om de indenlandske planter anvendte som zurplanter. (Saerskilt aftryht af lavetidenden.) Kiobenharn $1836.8 .29 \mathrm{p}$.

$4506^{*}$ Hornschuch, Christian Friedrich. De Voitia et Systylio, novis muscorum fronlosorum generibus. Commentatio. Erlangae 1818 4. 22 p., 2 tab). col. $(1 / t$ th. $)$

$4.707^{*}$ … Archiv skandinavischer Beil'áge zur Naturgoschichte. Herausgegeben von Christiun Friedrich Hornschuch. Erster Theil foder drei Hefte). Greifswald 1845.8 . xII, $462,14 \mathrm{p} ., 4$ tab. $\left(2 \frac{1}{2}\right.$ (h.)

4.708* Horsfield, Thomas. An experimental Dissertation on the Rhus Vernix, Rhus radicans and Rhus glabrum. Pbilisdelphia, typ. Cist. 1798. 8. vi, $85 \mathrm{p}$.

4709 Horst, Christoph. Hortulus medicus. Cassellis 1610.4. H

4710 Horst, Gisbert. De Turpeto et Thapsia. Romae, apud Antonium Bladum. 4544. 4. Bum.

4711 Horst, Gregor. De plantis in genere. D. I'Imae 1659, 4. Desid. Banks.

4712* Horst, Jakob. Opusculum de vite vinifera ejusque partibus. ote. IIelmstadii, excudehat Jacolus Lucius. 1587, 8, 60 foll., praef. Reimpressum est cum Ilerbario Horstiano. Marpurgi 1630.8 p. $283-38^{\prime}$

$4713^{*}$ Lerharium Ilorstianum, seu do selectis plantis et radicibus libri duo, olin medicinae candidatis in Academia Julia a. 1587 a celeherrimo medico 1). Iacobo IIorstio propositi; in compendium redacti plurilusque simplicibus enumeratis ac decharatis aucti, suisque auditoribus ante mustos annos in academia communicati per Gregorium Ilorstium. Accessit Jacobi Ilorstii opusculum de vite vinifera. Mirpurgi, typ. Chemlin. 1630.8. (8) $414 \mathrm{p}$.

(1lerbarium llorstianum, p. 1-282; onusculum de vite vinifer: p. 283-38\%. A p. 38\% C/usii cpistola ad Friedericum III. Electorem Pafatimum, yuae purimarum plantarum jtalieartum catalogum continet. lum etian ejusiem Appendix cultori plantarum ntilis. - Fotum opus redit in Horstii Operibus, Norimbergae, apul Joantuem Aulrean Wolfgang. 1600 . folio.

471: Horst, Johann Daniel. Malva arborescens lutea. Adulita est Replica at Thoneri quaerimonium. Gissae Hessorum, typ. Ilampel. 1654.4. (16 p.)

47: (Horvatovszky, S.) Florae Tyrnaviensis ineligenae pars prina. D. Tyrnavii $1774.8 .46 \mathrm{p}$.

4716* Hosack, Dacid. Hortus Elginensis: or a Catalogue of plants indigenous and exotic cultivated in the Elgin botanic garden in the vicinity of New York, established in 1801. New York, Swords. 1806. 8. 29 1\% - * Ed. Il. enlarged. ib. 1811.8. x, 63 p.

$4717^{*}-$ A statement of facts relative to the elablishesnent am the progress of the Elgin botanic garden. New York $1811.8 .56 \mathrm{p}$.

$478+-$ An inaugural discourse dolivered before the Now York Horticultural Society'. New York, typ. Seymour. 1824. 8. $46 \%$

$4719^{*}$ Hosang, Abondius. Vegetatio. D. Argentorati 1773.4.38 p. (Dissertatio sub priesidio Jacobi Reinboldi Spietmam proposita est.)

4720* Hose, Johamn Albert. Herbarium vivum muscorum frontosorum cum descriptionibus analyticis ad normam Iledwigii. Lijısiac 1799 - 1800. II fasciculi. 5. - 1: 1799.93 p., 12 species exsiccatae. II: 1800.89 p., I2 species exsiccalae. ( 1 th. - Liber absque speciminibus musc. $2 / 3$ (h.)

472. * Host, Nicolaus Thomas. Synopsis plantarum in Austria provincisque adjacentibus sponte crescentium. Vindobonae $1797.8 .666 \mathrm{p}$. $\left(2 \frac{1}{2}\right.$ th. $)$

$4722^{*}$ Icones of descriptiones gramiuum anstriacorum. Vindobonae $1801-1809.17^{\circ}$ roll. folio. - I: 1801.74 p., praef., 100 tab. col. - Il: 1802. 72 1), 100 lab. col. - III: 1805.66 p., 100 fab. col. - IV: 1809.58 p., ind., 100 tab. col. $(306$ th. - herabgesetzt: $180 \mathrm{th}$.) 
$423^{\circ}$ Host, Nieolaus Thomas. Flora anstriaca. Yiennae $1827-1831$. II voll. 8. - I: 1827.576 p. - II: 1831.768 p. $(7 / 3 / h$.

$474^{*}$ Salix. Vulumen primum. Vindobonae, typ. Strauss. $1828 \mathrm{l}$ folis. 34 \%., praef, 105 tab. col. (herabgesetzt: 7 th.)

43:35 Hotton, Petrus. Sermo acadenicus, quo rei herbariae historia of fati adumbrantur. P'ublico habitus VIl ld. Maji 1695, quum inauguraretur ad medicinas et botanices professionem in academia LugJuın-Batava iteratò calpessenlam. Lugduni Batavorum, apud Abraluanum E.lzevier. 1695 . 4. 65 p.

Redit in Tsteri, Delectus opuse bot. 1. p. 193-2h. De ejusdem antoris Sy'utas herbaria iuedita ef. Boerhave locl. plant. in prael. p. fi.

\$26 Houghton, John. Collection of letters for the improvement of husbandry and trade. London 1681 . Il voll. 4. S.

$4727^{\circ}$ Houssaye, J. G. Monographie th thé, description botanique, torréfaction, composition chimique, propriétés hygiéniques de cette feuille urné de 18 gravures. Paris 1843, gr. $8.160 \mathrm{p}$, tal. ( $6 \mathrm{fr}$.)

* germanice: Der Thee. Vinc Monoiraphie, enthaltend die Geschichte des Thees und die statistik seines Gohrauchs, seit Einfuhruog dessellen in kuropa bis jetzt; die lontanische Beschreibung des ilin lieferndern strauches; Belehrungen inber den Anbau etc. Quedlinburg und Leipzig 181't. 8. 111 p., 5 ial). $(2 / 3$ th.

7.72 Houstoun, William. Reliquiae Houstounianae: seu plantarum in America meridionali a Guil. Ioustoun collectarun icones manu propria aere incisae: cun descriptionilus o schedis ejusdem in bibliotheca Josephi Bunks asservatis. Londini 1781. 4. 12 p., 26 tab. *Ed. in Germania prima, juxta exemplar Londinense. Norimbergae, Raspe. 1794.8 .24 p., 15 tab. ( $1 / h_{\text {. }}$ )

$4729^{*}$ (Houttuyn, Martin.) Houtkumlo; Verzameling van in- en uitlandsche houten, en derzelver benamingen in het hollandsch, boogduitsch, engelsch, fransch en latijo. Jcones lignorum exoticorum et nostratium, ex arboribus, arbusculis et fruticibus varii generis collectorum, aeri incisae et coloribus nativos imitantibus inductae. Addita sunt eorundem lignorum numina belgica, germanica, anglica, gallica et latina typis inpressa. Amsteliedami, Sepp. 1773. 4. 100, Lvil p., 101 tab. col. (latine et hollandice.) ( 8111.$)$

(Praefatio Houthynii data ost anno 1791.)

- germanice: Scones lignorum exoticorum et nostratium germanicorum ex arthoribus, arbusculis ef fruticibus varii generis collectomon. Abhildung in- uad ausland ischer llolzer. etc. Numberg Seeligmann. \& Hefte. 1773. 177k. 177i. 1778. 4. $\$ 0$ p., 48 tab. col. Qlatine et germanice.

llujus repetitionis illegitimae vix plures prodierunt fasciculi.

4730 - Naturlyke historie oft uitroerige beschryving ter Dieren, Planten en Alinernalen, volgeos het samenstel van Linnaeus. Deel II. Planten. 14 Stuk. Ansterlam 1774-1783, S. 438,616,658, $564,576,468,832,784,760,828,456,558,616,698$ p., tab. 1 $-105 . \quad B$

$4731^{\circ}$ (How, William.) Phytologia britannica, natales exhibens indigenarum stirpium sponte emergentium. Londini, typ. Cates. 1650.8 133 p., praef. Bibl. Juss.

473. Howel, James. Wenlrologia or Dorlona's grove. London 1640. 8. H - gallice: Dentrologie ou la for'st de Dodomne; (par Bandouin.) Paris lits) 4. (16) 322 p. \& tab

(Liber a Hallero in libliothecan botanicam receptus, politici prorsus est ar'mumenti; civitates Europae symlolice arborum nomina gerunt.

4733* Hoyer, Kanl A. II. liurzer aber deutlicher und vollständiger inbegriff der Olistbaumzucht, der Beliandlung des WVeinstocks, des verbesserten Wiesenbaues und des Talsacksbaues. Minden 1837.8. 56 p. 2 tab. $(1 / 6$ th. $)$

$4734^{*}$ - Flora der Grafschift Schaumburg und der Ungegend, mit hesondrer Rücksicht auf Arzneihursle, den Haushalt, die Landwirthschaft und die Gewerbe bearbeitet. Rinteln 1838. 8. IV, 512 , XXXiv p. $\left(1 \frac{1}{3}\right.$ th. $)$

$4733^{*}$ Hruschauer, Franz. Elemente der medizinischen Chemie und Botanik, zum Gelırauche fur Candidaten der metizinisch-chirurgischen Studien. Gratz $1839.8 . x x y, 454$ p. $\left(2 \frac{2}{3}\right.$ th. $)$

4.336t Huard, Alexandre. Propositions et observations sur les effets therapeutiques du seigle ergoto. These. Paris 1830.4. $18 \mathrm{p}$.

4737 Euard du Plessis, $E$. Traité de la culture du noyer dans les départemens du centre. Paris 1847.8 . $36 \mathrm{p}$.

$\$ 738$ Huber, Candidus. Naturgeschichte der verschiechen IIolzarten in Tabellen. Erstes lieft. Landshut $1504.4 .(3 / 8 / h$.
4739 Huber, Candidus. Vollstandige Vaturgeschichte aller in Deutschlind einheimischen und nationalisirten Bau- und Baumholzer. Munclıell 1808.11 voll. 4 . $(3 / /$. $)$

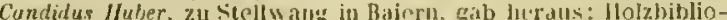
thuk von 112 stuchen." Sichulles (ininulriss 11.319.)

$\left\{70^{*}\right.$ Huber, François et Jean Senebier, Jlémoires sur linfluence de l'air et de diverses substances gazeuses dinns lis germination des

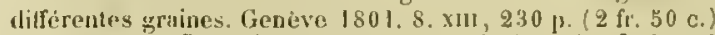

yermanice: Bemprhingen bber den Eintluss der Luft und einiges

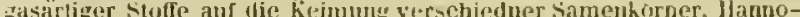
Fer $180.5 .8 .(1 \%, t / 2)$

474) Huber, Johamn Christian. De auro vegetalsili Pannoniae. D. Ilalae $1733.4 .64 \mathrm{p}$.

$1742{ }^{*}$ Huber, Johann Jatob. Positiones anatomico-botanicae. Basileao $1733.4 .8 \mathrm{p}$.

$473^{*}$ Programma de Cicuta. Cassellis $1764.4 .47 \mathrm{p}$

$4.7 k^{*}$ Hudson, IVilliam. Flora anglica; exhibens plantas per regnum Britaniae sponte crescentes, distributas secundum systema sexuale, 'um diflerentiis specierun, synonymis auctorum, nomiubus incolarum, sulo locolum, tempore florendi, officinalibus pharmacopoeorum. London 1762. 8. vit, 506 p., ind. - "Es. II. emendata el aucta. Londini 1778. 8, xxxvit, 690 p.- " London 1798. S. IF, xxxut, 688 p. $(10 \mathrm{~s} .6 \mathrm{~d}$.

47ł" Huebener, J. H. P. Muscologia germanica, oder Beschreibung der deutschen Laubmoose. In erweiterten Linfange nach dem jetzigen Stande der Wissenschaft, nelsst Erörterung der Standorter und ithrer Entdecker, der Synonyme seit lloffmann und Roth, mit erláuternden Anrnerkungen. Leipzig 1833. 8. xvm, $722 \mathrm{p} .\left(3 \frac{1}{2}\right.$ th.

$476^{*}$ - Hepaticolugia germanica, oder Beschreibung der dentschen Lebermoose. In erweiterten Lmfange nach dem jetzigen Stande der Wissenschaft, nebst Erörterung der Stantörter und ilırer Entdecker, hritisclı untl mit erláuternden Ammerhungen. Mannhein 1834. 8. LxIy, 314 p. $\left(1^{2} / 3\right.$ th. $)$

1.7 $17^{*}$ - Einleitung in das Studiun der Pflanzenkunde. kinthaltend die hunstsprache, die Grundzuge zum Eingehen in die Wissenschaft, eine kurze Vebersicht vom Baue der frewachse, Systemkunde, nebst der Anleitung, Pllanzen zu bestimmen, zu zerlegen, und liur das Ilerbarium zu bereiten. Mannheim 1834. gr. 12. VI, $246 \mathrm{p}$. $(1 / 2$ h. $)-{ }^{*}$ Ed. 1l. Nambeim 1836. gr. 12. vi, 246 p. - Ed. Ill. Vannheim $1841 . \mathrm{gr} .12 . \mathrm{vt}, 246 \mathrm{p} .(1 / 2(\mathrm{~h})$. (Editiones vix inter se dillerunt.)

471.8 Theoretische Anfangsgrundeder wisseuschanlichen Pflanzenkunde. Als Anleitung zum Selhststudium fur Anfanger. Erstes 13äntedın: Ilandluuch der Terminologie und Organographie des Pflanzenreichs. Mlainz 1835 . gr. $12.163 / \mathrm{plag} .(1 \mathrm{~h}$.)

4.74. $9^{*}$ Beitrage zur A gronomie. Euthaltend tas Forkommen meirerer dem Landbase nachtheiligen l'llanzen, ihre Naturgeschichte, nebst Jlittel, die man anwendet, ihrer Vermebrung entgegen zu wirken, hesonters uber den Duwock oder Schachtehahn (Equisetum L. Hamburg 1841 . 8 . 58 p. $(1 / 3$ (h.)

$4700^{*}$ Flora der Limgegend von Hamburg, sládtisclien Gebietes, Ildstrin-Lanenburwischen und Lüneburgischen Antheils, entlratend die Gewachse: welehe in diesem Bezirke wild wachsen orler zu okonomischem und technischem Bedarf gehaut worden. llamburg 1846. gr. $8 . \mathrm{sLIV}, 523$ p. $\left(2 \frac{2 / 3}{3} / \mathrm{h}\right.$. - in charta script. $\left.3 \frac{1}{3} / \mathrm{h}.\right)$

4731* Huebner, Geory Friedrich. De llyoscyamo niyro. I). Beroliai 1826. 8. $31 \mathrm{p}$.

4752* Huegel, Karl, Freiherr von. Botanisches Archiv der Gartenbaugesellsclraft des österreichischen Kaiserstaates. Abbildungen und Beschreibungen neuer olter seltener Pflanzen, welche in den Gárten der Monarchie blïhen. Wien 1837. 2 Hefte. 4, 11 foll., 10 tab. col. $(32 / 3$ th.

$4753^{*}$ - Orchideensammlung in Fruhjalar 1845. (Wien 1845.) S. $34 \mathrm{p}$

Recensentur ordine alphabetico 1080 species ex 136 generibus, anditis patria ac synonymis.)

$475 k^{*}$ HuehnefeId, $O$. Die Indigofabrikation oder vollstándige Angabe aller in- und auslandischen Pflanzen, w clche lndigo enthalten, nebst Anleitung zu ihrem Anlrau. Quedlinburg $1846.8 .(1 / 3 \mathrm{~h}$.)

4735 Huelle, Gerhard. Namenverzeichniss und genaue Beschreibung fler auserlesenen Sammlung von Nelken und Grasblumen. Bremen $1790.8 .51 \mathrm{p}$. 
4756" Huenefeld, Friedrich Ludwig. Anweisung durch eine neue Hethode die Gewăchse nalurgetreu, mit Beihelaltung ihrer Stellungen, Ausdelinungen und Farben auf eine leichte Weise zu trocknen und aufzubewahren. Leipzig 1831. 8. 33 p. $(1 / t h$.)

Besondrer Aldruch ans Erdmann's Journal fur technische und okonomische Cliemie, 10. Band, 1. Hefl. )

4737 " Huenerwolf, Jaliob Augustin. Anatomia Paeoniae, in qua natales et qualitates Paeoniae, itemque praeparaliones et medicamenta ex ea varia cum virtutibus el usa ad plurimos humani corporis aflectus exhibenlur. Arnsteti, typ. Ileurer. $1680.8,110$ p., ind.

4738t Euerto, Garcia del, latine ab Borto. Cologuios dos simples, e drogas he cousas mediçinais da India, a assi dalgūas frutas aehadas nella onde se tratam alguas cousas loeantes amediçina, pratica e outras cousas boas, pera saber compostos pello Doutor Garcia Dorta. Impresso em Goa por Joanues de endem as $\mathrm{X}$ dias de Abril de 1563 annos. 4. (7) 217 foll. Bibl. Deless.

"latine: Aromatum et simplicium aliquot nedicamentorum aput Indos nascentum historia: primum quitem lusitaniea lingua per dialogos conseripla a D. Garcia ab Horto, Proregis Indiae medico; deinde latim sermone in epitomen contracta et jconibus ad vivum expressis Incupletioribusine adnotatjunculis illustrata a Carolo Clusio. Antwerpiae, Plantinus. 1567. 8. 250 p., ind. - ${ }^{-E d . ~} 11$ : Antwerpiae, Plantinus 1574. '8. 227 p., jnd. - Ed. liil: Antwerpiae, Plamtinus. 1579. 8. 217 p. ind. - Etl. $r$, castigatior ol aliquot locis anctior. Antwerpiae ex oti Plantiniana apnd vid. Aforeti. 1593. 8. 217 p., ind. - "Efl. 1. eom Clusit

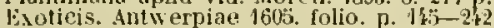

anglice: Londini I5T. 4. Bibl. Bodl.

$\div$ talice: Due libri dell' historia dei sempliei, aromati, et altre eose che vengono portate dall Indje orientali pertinenti all uso slella me reeina, di Don Garcia dall Honto; et due altri libri parimente di quelle che si portano dall Indie occidenrali di Nicolo Honardes. Tradotti nella lingua italiana da $\mathrm{M}$. Amibale Briganti. Venetia 1582. 8. 3' 7 , 249 p., praef., jnd. - Venetia 10̈8. 8. 236 p. prater Monarlen. B.

$\div$ yallice: Ilistoire des drogues, espisceries et de certains medicanens simples, qui naissent es Indes et en l'amérique. Ceste matiere comprise en sil livses: dont il y en a cing tires do latin de charles de lEcluse. etc. transiate par dutoine colin seconde edition charles de Echuse etc. Iransiate par Antoine Colm. Seconde edition

revuc et augmentee. Lyol, Pillehote. 16, praeter Alpinum de Ralsamo, Honarden et Acostam.

Autor in titulo editionis principis troae impressae audit Garcio Dorta; IJallero vero Garcia ab Orta; Dryandro (iarcia del Iluerlo scu ab Horto; Sprengelio Garcias ab Orto; Miltitzio denique lluerto del Garcias.)

4759* Hueser, Friellich. De Carice arenaria. D. Goettingae 1802. 8. 28 p., 1 tab.

$4760^{*}$ Huettenschmid, Gustav Friedrich. Analysis ehemica eorticis Geofroyae jamaicensis nee non Geoflroyae surinamensis. D. lleidelhergae $1824.8 .35 \mathrm{p}$.

(761* Bughes, Griffith. The natural history of Barbados. In ten hooks. London, printed for the author. 1750 , folio. vil, 314 1., adtl, ind., 29 tab.

1762* Zughes, Itilliam. The compleal vineyard, or an excellent way for the planting of wines, aecording to the german and french manner, and long practised in England; wherein in set fortl the ways and all the circumstances necessary for the planting a vinevard, witls the election of the soyl. cte. London, by J. C. Sor WV. Crook. 1670. 8. 92 P., 1 tab.

$4763 \div$ The american physician, or a trealise of the roots, plants, trees, shrubs, fruit, herbs, ete. growing in the english plantations in Ameriea, describing the place, times, names, kinds, temperature, vertues and uses of them, either for dict physick etc. whereunto is amnexed a discourse of the cacao-nut-tree and the use of its fruit, with all the ways of making ehoeolate, the like never extant before. London, by J. C. for W. Crook. 1672. 12. 159 p. Bibl. Reg. Par.

476 ' increase all sorts of flowers. London 1677. 12. Sloane.

47637 Eugo, August Johannes. De variis plantarum melhodis. D. Lugduni Batavorum 1711. $4.24 \mathrm{p}$.

4766+ Eull, John. The British Flora, or a Linnean arrangement of lritish plants; with their generic and specific eharacters, select synonyms, english names, places of growth, duration, times of flowering and references to figures. Manchester, typ. Dean. 1799. Il parts. 8. vir, 449 p., ind. - Ed. II. Manchester IS 08 . \&. Dc.

$476 \div-$ Elenents of botany; illustrated by sixleen engravings. In two volumes. Manchester, Iyp. Dean. 1800.8. - 1: $\mathbf{x x x I y , ~ L X , ~}$ 302 p., 12 tal., - 11: I1, 409 p., 4 tab.
4768\% Hulthem, Charles Joseph Emmanuel van. Diseours sur l'etat ancien et moderne de l'agrieulture et de la botanique dans les ParsBas. Gand, typ. de Goesin-Verhaeghe. 1817. $8.70 \mathrm{p}$.

$4769^{*}$ Bumble, Adolf Henric. De Laetueario. D. Lpsaliae 182 $\bar{\imath}$, 4

(Dissertatio suh pracsidio Caroli Petri Thunberg (lefensa est.)

$4770^{*}$ Aumboldt, Friedrich Heinrich Alexander von. Florae Fribergensis specimen plantas eryptogamicas praesertim subterraneas exhibens. Accelunt Aphorismi ex doctrina physiologiae chemicae plantarum. Berolini 1793. 4. xıv, 189 p., 4 tab. $\left(2 \frac{1}{2}\right.$ th. $)$

(Florae Friberkensis specimen: p. 1-132; Aphorismi ex doctrina physinlogiace chemicae plintarum: f1. 133-182; Synonymia Lichenun castigata. Talnula aflinitatum phytologicarum: p. 183-18"5.'

Cr. ejustem Plantae subterraneac (Frinurgenses) descriptae in Usteri Annalen, III. p.

germanice: Aphorismen aus tler chemischen Physiologie der Pflan zen. Aus dem Latcinischen nbersetzt von Gothelf Fischer. Nebst pinigen Zusatzen yon Johann Hedurig und Worrede von Christian Friedrich Ludwig. Leipzig 17\%. 8. xx, $206 \mathrm{p}$. $(\%$ th. $)$

$4771^{*}$ - Versuehe uber die gereizte Muskel- und Nervenfaser nebst Vermuthumaru nber den chenischen Prozess des Lebens in der Thier-und Pllanzenwelt. Posen und Berlin 1797. Il voll. S. 1: 495 p., 8 tah. $-11: 468$ p. $\left(4 \frac{2}{3}\right.$ th. - in charta velina: $81 / 2$ th.

$4772^{*}$ el Aime Bonpland. Essai sur la géographie des plantes accompagnè d'un tableau physique des régions équinoviales, fonde sur des mesures exécutees depuis le dixicme degre de latitude boréale jusqu'au dixiène degré de latitude australe pendant les années 1799-4803. Paris, an Xill. 1805.4 maj. $135 \mathrm{p}$.

germanice: Ideen zu piner Geographie der Pflanzen nebst einem Naturgemalde dir Tropenlander auf Reohachtungen und Yessungen

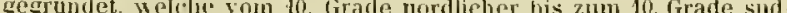
ilcher Breite in den Jaluren $1799-1803$ angestelt worden sind. Bearbeilet und herausgegeben yon dem Erstern. Tubingen 1807. 4. XII, $182 \mathrm{p}$. 1 tab. $\left(9 \frac{1}{3} t h\right.$. col. $13 \mathrm{th}$.

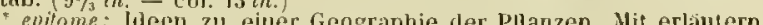
den Zusatzen und Anmerkungen. Wien 1811.8 . 67 p.

Aus den Arehir fur Weit - Erd - und Staatenkinde 1. Band dritles Ileft besonders ihgedruckt.

* epilome: Ansichten der l'llanzengeographie des Herrn A. von Humboldt, in Auszuge herausgegeben von surbes. Berlin 1827. 12. 117 p $(1 / 2, h$.

$4773^{*}$ - Jeen zu einer Physiognomik der Gewachse. Tülingen 1806. S. 28 F. (1/, th.

4774* - Plantae aequinoctiales, per regnum Mexiei in provincijs Caracarum et Novae Andalusiae, in Peruvianorum, Quitensium, Novae Granatae Audiłous, ad Orenoci, Fluvii nigri, fluminis Amazonum ripas nascentes. In ordinem tigessit Amatus Bonpland. Parisiis 1805-1818. Il voll. $=17$ fasciculi. folio. $-1: 1808$. vil, $234 \mathrm{p}$. 68 tab. sign. 1-65; effigies Jose Celestno Mutis. - H: 1809. 191 p. 75 tab. sign. $1-140$. (510 fr.)

(Altera adest gallica inscriptio: Plantes équinoetiales.)

$4770^{*}$ - Monographia Melastomacearum continens plantas hujus ordinis hucusque collectas, praesertim per regnum Mexici, in provineiis Caracarum el Novae Andalusiae, in Peruvianorum, Quitensinm, Novae Granatae Andiluss, ad Oronoci, Fluvii nigri, fluminis Amazonum ripas naseentes. In ordinem digessit Amatus Bonpland. Lutetiae Parisiorum 1806-1823. Il voll. $=24$ fascieuli. folio. 1: Nelastomae. 1816 . vi, 142 p., ind., 60 tab. eol. - H: Rhexiae. 1823. 11,158 p., ind., 60 tab. eol. $(864$ fr. $)$

(Attera adest gillica inscriptio: Mnnographie des Melastomacén: tandem fortius titulus: Monographia Melastomarum, iuctore Amalu Bonpland.

$4756^{*}$ Nova genera et species plantarum guas in peregrinatione orbis novi collegerunt, deseripserunt, partim atumbraverunt Amutus Bonpland et Alexander de Humbotlt. Ex schedis autographis Amati Bonplund in ordinem digessit Carolus Sieyesmund Kunth. Aecedunt Alexundri de Ilumboldt notationes ad geographian plantarum spectantes. Lutetiae Parisiorum $1815-182 \%$. Vll voll. $=36$ fasciculi. folio. - 1: 1815 . xLvi, 302 p., tab. col. 1-96. - II: 1817. 323 p., tal. col. $97-192$. - 111: 1818.456 p., tab. col. $193-300$. -IV: 1820.312 P., Iab. col. $301-402$. V: 1821.432 p., Iab. col. $413-512 .-$ V1: 1823.541 p., 1al., col. sै।3-610. - VII: 1825. 506 p., 1a). col. $611-700$. (6480 fr. - nigr. 1800 fr. - nigr. magna quarta forma : $1206 \mathrm{fr}$.)

(II esmplari Bihliohecae Candolleande volumini alteri adjectae erant decem tahulate uno signatae genus Salviam illuslrantes sub erant decerm jeclae.) 
$137 \gamma^{\prime}$ Humboldt, Fricdrich Heinrich Alexander von. Nimoses et autres plantes Legumineuses du Nouveau Contineut, iccueillies par MII. de Htmboldt et Bonplend, dicrites of jublices jur Kart Sirgesmund Kinth. Paris 1819. folio. $223 \mathrm{p}, 60$ tah, col. (679 fr.)

(1'roulit anuis 1819-18:' if fasciculis.

FiR — Distribution netholigue de la fanille des Ciraminies, jar Karl Siegesmund Kinth. Ouvrage accompagné de deus ceut vingt planclies representant autant d'especes nouvelles ou pen connues, dessinces par Malame Eulalie Delile. Paris 1835. II voli. folio. - 1: (ienera. p. 1- 175, xLv 1) - 11: p. 177-579, Errati, $2 \geq 0$ tals. ( $528 \mathrm{fi}$.)

$4779^{\circ}-$ Ansichten der Natur. Stutlgart 1808. 12. - "Ed. II. Silutgart 1827.2 Bande. 12. $\left(1 \frac{2 / 3}{\mathrm{lh}}\right.$.)

tgollice: Tableau de la nature, ou considerations sul les tléserts,

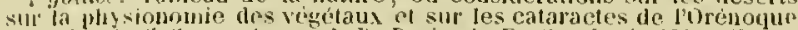
Tradnits de l'allemand par J. Bb. Benjamin Eyries, paris 1808. It voll.

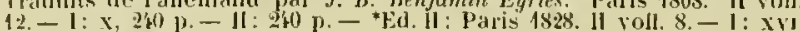
$\pm 70,-11: 250 \%$ 1836.8

itolice: Quadri delli natura; tratloti di Marmacchi. Siena 1834-

Siso —und Aimc Bonpland. Reise in die Acquinoctialgegenden des neuen Contineuts in den Jahren 1799-1804. Stuttgar 1815-1839.6 Theile. $8 .-1: 1815.554 \mathrm{p} .-11: 1818.495 \mathrm{p}$. III: 1820.496 p. - IV: 1823. 755 (3) p. - V: $1826.774 \mathrm{p.}-$ VI: $1829-1832.314,226 \mathrm{p} .(16 \% \mathrm{~m}$ (h)

$4.781^{*}$ - Sur les lois ine l'en olsserve dans la distribution des formes végétales. Paris, Feugueray. 1816. $8.15 \mathrm{p}$.

$4782^{*}$ Nouvelles rechercbes sur les lois que lon olserve dans la distribution des formes végétales. (Paris.) 8. 26 p., it tablean.

(Extrait du 18. vol. de Dict. de's sc. nat. - Eel particula secundlae elahorationis inedicalo geographiae flantarum.

$4.783^{*}$ - We distributione geographica plantarum secundum coeli tenjeriem el altitudinem montium, prolesgomena. Lutetiae Parisiorum, 1y]. Gratiot. 1817. 8. 249 p., ind., I tab. col. (7 fr.)

gernanice: Pflanzengengraphie nach Alexander von Ilumboldt's Werke uber die geouraplinche Fertheilung der Gewachse, mit Anmerkungen

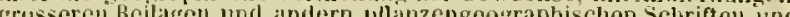
cressure chungen nothigen theksichten von hart Theodor beilschmied. Breslan 1831. 8. xill, 201 p., 1 mappa isogeotherm. $(11 / 2, h$. $)$

$483^{*}$ — Rapport verbal fait a l 1catlémic des sciences, sur un ouvrage de Mr. Auguste de St. Hilaire, intitulé: Plantes usuelles des Brasiliens. Paris 1824, 8. 8 p.

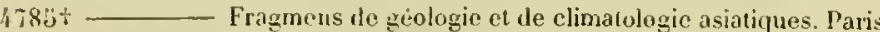
1831. II voll. $8 .-1: x, 309$ p., 1 tab. - Il: p. 309-640. (14 fr.)

germonirp: Fragmente einer Geologie und klimatologic Asiens. Aus dem Franzosicchen mil Aumerhungen von Julius Loeventerg. Berlin 1832. 8. $\left(2 \frac{1}{4} / 1 /.\right)$

rosice: llутешествіс Њирона $\Lambda$ дександра Гумболдта, эренберга и Розе, в' 1829 roду, по Сибнои и кт Каспійскиу морю. Іlерев. С', подлин. Н. Нсроновч. С. Негер0. 1837

$1786^{*}$ - Asie centrale. Recherches sur les chaines de montannes et la climatologie comparéc. Paris 1843 . Ill voll. 8. - 1: Lvil, 5701 . - 11: 558 P. - III: 614 P., 5 cartes.

- germanice: Centrat-Asien. Lutersuchungen uher die Gebirgsketten und die vergleichronde klinatolosie. Aus dem Franzosischeit uther-

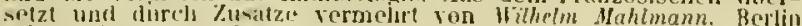
1863-18\%. 2 Bande. 8. $6^{2} / 3$ th.

$4787^{*}$ Kosmos. Entwurf einer physischen Weltbeschreibuns. Erster Band Stuttgart 4845 . 8. xit, 493 p. $\left(2 \frac{2}{3}\right.$ th. $)$ gallice: Cosmos, essai thune rescription physique du monde. Fraduit par' $H$. Faye. Preniere partic. Paris 18 'f6. 8. $371 / 2$ feuilles. (10 fi.) anglice: kosmos: a seneral surver of lie physical phenomena of the universe. Vol. 1 . London isti. 8 . 500 p. (10.s.

anglice: Cosmus: shetch of a physical deseription of the Luiverse.

Iol. 1. translated undes the superititendence of Lieut. Col. Ederard

Sabine. Landon 1846. 8. 497 p. (12.)

italire: Cosmos, ossia tescrizinne fisiea ded mondo di Alles. di Humboldt; prinsa versione ital. ti Giulio falini. Venezia 18'ti. 8.

hollondice: Kosmos. Ontwerp eener natuukknnige Wereldsbesclirijving. Niar het liongduitsch van Alex. v. Hhmboldt door E. M. Beima. 1. Direl. Leirlesi 18\%. gr. 8 .

danice: Kosmos. Lulkast til en physish Verdensbeshrivelso af $A t$.

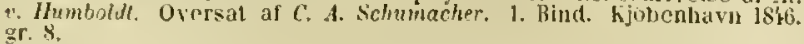

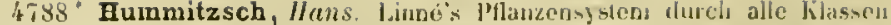
unu Ordnungen hildlich dargestellt zum llesten der .ufonger in der Botanik, J)resdell s. a. 8.6 tab.

$4789 \div$ Hunault, Fansois Joseph. Discours physigue sur les proprietes de la sange et sur le reste des plantes aromatigues, dans lecjuel par occasion l'on traite de la dissulution des corps et de la digestion des alimens dans l'estomac. Paris, Osmunt. 1689. 12. 106 jp., jraef. ind. - Paris 1698. 12. (non ditfert.)

4790* Bundeshagen, Johann Christian. LehrJuch der forst- und landwirthschaftlichen Naturkunde. Erste Abtheiluner: Enkyklopadie der Naturhume, ader Versuch einer alloemeinen kinleitung in die Nalurwissensthaft, besonders in die vier Naturreiche. Tubingen 4827. 8. $15 \frac{1}{2}$ plag. $(3 / 4$ th. $)$ Zweite Abthrilung: I)ic Anatomie, der Chemisnus und die Plıysiologie der Pllanzen. Tubingen 1829. 8. vir, 372 p. $\left(\left\{\frac{1}{2}, h\right.\right.$. $)$ - Dritte Abthutilung: Dic Bodentiunde. Tubingen $1830.8 . \mathrm{N}, 280 \mathrm{p} .\left(1 \frac{1}{3}\right.$ (h.)

4791 Eungerbyhler. De oleo Ricini. Friburgi Brisgoviac $1750.8 .43 \mathrm{p}$ $1 \mathrm{lab}$. B.

4792 Hunter, Alexander. An illusiration of the analogy between vegetable and animal parturition. London (1799). 8. 4 p., 1 tab. B.

1.793* Hunziker, Mudolph. De Sassaprarillae radice. D. Turici 1835.8. 21 j.

479:* Huperz, Johann Peter. De filicun propagatione. D. Goettingae, (3). Grape. 1798.8. 35 p., 1 tab.

(F.jusilem anni alia exstat libelli inpressio, cum Iraralli De vera dorum existentia in plantis dorsiferis endita.)

$4793 \div$ Húry, Ilpolyte. Mémoire sur la culture des carouliers, dans l'ancien royaume de Valence. Paris 1844. $8,16 \mathrm{p}$.

$4796 *$ Huss, Magnus. De IIypericis Succiae indigenis. D. Cpsaliac 1830. 4. $10 \mathrm{p}$.

(1)issertatio sub praesidio Nicalui Jacobi Sillén defensa est.

$4797^{*}$ Hussenot. Chardons Nanceiens ou prodrome d'un catalogue des plantes de la Lorraine; par to Docteur Ifussenot, yui n'est rien, pas mene médecin, membre d'aueune aeademie, corresp. d'aucune soc. savante; qui n'est ni de la sue. royale des sciences lettres el arts de Nancy, ni de la sociéte centr. d'agriculture de la méme ville; pas plus de la socicite d'émulation des Tosges que de celle pbilomathique de Verdun ou d'aucune de celles de Iletz; directeur daucun jarlin public ou particulier; conservaleur daucune colleclion autre que la sienne, qui se mange des betes: redacteur de rien du tont; enfin simple citoyen comme tout le monde hors qui? n'est pas decoré. Premier fascicule. Nancy, țp. Dard. 1835. 8. $213 \mathrm{\mu}$.

Post pisinam $3 \ddot{3}$ seguitur titulus allers: Premier fascicule; denvieme édition. 1836. Liber juctundissini salporis varias contined lépores.)

4798* Huth, Joham Christoph. Nachrieht ron dem Entstehen des Schwamms in denen Gelräuden. Hahersiadt 1776.8 .161 .

4799* Hutten, Llrich von. De Gnajaci medicina ot morbo gallico liler unus. Bononiae, per Hicronymum de Benedictis. 1521. 4. - Mogunliae, in aedibus Joannis Sclioeffer. 1519.4. s. - Noguntiae 152. 4. H. - "Noguntiae (in aediluns Joannis schoeffer). 1531.8. 126 ]. Bibl. Reg. Dresd. - redit in tomo primo Aloysii Luisini De morho gallico omnia, quae exstant. Venctiis 1566 . Folio. Rivin.

anglice: On the wood called Guajacum, that healeth the french pocke's, translated by Thomas Paynel. Lonton 1340 . 4. 58 foll. B.

gallice: Experimee et ayprobation di. lit medecine tu bois dit Guijacum; Traduit par Jean Cheradame. Lyoll s. a. 4. H.

Imprimis practici est argumenti, et cautelas deseriluit, quas in Guajaci usu auhibere necesse est, quo quitem medicamento ipse vir immortalis curatus fuerat.)

4800 Hyde, Thomas. De herbae Cha collectiene eun epistola de mensuris Chinensium. Oxoniae, et theatro Scheldoniano. 4688. 8. Sloane.

(Ejustem autoris, viri cruditissi et rermun orientalium peritissini liber: De religionis vefertm lersarum historia. Oxonii 700 toejusinu noninibus, Syris linpasto, (unde Fsparsette), de Been utroque. cun iconibus.) 


\section{J.}

\$\$ก1 Jablonski, Paul Ernsl. De conditionihus vegetatioui necessariis quaedam. D. Berolini 1839. \$. 32 p.

4802 * Jack, William. Descriptions of Nalayan plants. (Calcutta 1843.) 8. $230,16.7 \mathrm{p}$.

Seorsim impr. una cum llilliam friffilt: nom some remarkable plants in the H. C. botanic gardens to Calcutta, ex Calculta Journal of Yatural Ifistory. Vol. IV. Nr. 13.)

\$S03† Jackson, Miss. The Pictorial Flora; or british botany delineated, in 1500 lithographic drawings of all the species of flowering plants indigenous to Great Britain, illustrating the descriptive works on english botany by Sir J. E. Smith, Lindley, Hooker, Itithering and other authors. London $1 \$ 40.8 .15,42$ p., (131) tab. (15s.)

(Insunt $1500 \mathrm{et} 5 \mathrm{~T} 7$ miserae pusillae icones.)

$\{80\}$ * Jacob, Edward. Plantae Favershamienses. A catalogue of the more perfect plants growing spontaneously about Favershan in the county of Fent. etc. London 177 7. 8. 146, LuI p., effigies autoris.

$\$ 803 \div \div$ Jacobaeus, Johann Adolph. De plantarum structura et vegretatione schedion. Hawniae $17 z 7.8$. 27 p., praef. Bibl. Juss.

$\$ \$ 06^{*}$ Jacobaeus, Oliger. Nuseum regium, seu catalogus rerum tam naturalium, quam artificialium, quae in basilica bibliothecae Christiani V. Hafniae asservantur. Ilafniae 1696. folio. 201 p., 37 tab. *Auctuarium rariorum. ib. 1699 . folio. 97 p., tab. $38-41$. (De plantis tractat in partis primae seclione sexta.)

\$807" Jacobi, Viclor Friedrich Leopold. De rebus rusticis reterum Germanorun Particula I. D. Lipsiae $1 \$ 33.8 .43$ p.

4S08* Jacobovics, Anton. Elenchus plantarum officinalium llungariae indigenarum phanerogamarum. D. Pestini 1835.8.70 p.

4809 Jacobs, Heymann. Den cleynen Herbarius ofte Cruyt Boecrken, inhoudende de Cracht ende Operatie van alle de ghemeene Kruyderen ende bekende Vruchton, die nen dagelycx gebruycht, etc. van nieus oversien en op veel plactsen verbetert en vermerdert. Ansterdam 1627.8. Rivin.

is I0 Jacobus I., Magnae Brilanniae Rex. Misocapnus, sive de abusu Tobacci lusus regius. London 1619. fulio. - "impr. cum Everarbo. Itrajecti $16 \% 4$. 12. p. $199-223$. anglice: Counter biast of tubacco. London 16:2. 4. 0sb.

$4811 \div$ Jacquemart. De la peinture dhistoire naturelle. Paris 1839.8 $26 \mathrm{p}$ $-18 \%$.

$481 \geqslant \div$ Jacquemart, $A$. Flore des Dames. Nouveau langage des lleurs Souvelle edition. Paris s. a. 17. 314 p. I 12 tab. col.

$4813 \div-$ Flore des Dames. Botanique a l'usage des Dames et des jeunes personnes. Faris 1840 . 12. 338 J., 12 tab. col., 9 tab. nigr. (Libellus nitidissimus!)

481;* Jacquemont, Victor. Vuyage dans l'Fnde pendant les annees 1898 -1832. Paris typ. Firmin-Didot. 18:1-1844. IT voll. 4. de Texte et Il roll. 4. Atlas. - Vol. 1-Jll: IS41. Journal. II, 526, 490,644 p. arec un Atlas contenant: Carte de l'lude, Carte de l'llimalaya, Carte de Cachemir, ltinéraire dans le Penjeab. et tab. $1-\$ 3$. (choses générales.) - Vul.1V. Descriptions des collections par MM. Isidore Geoffray Si. Hilaire; Milne Edicurds; Enile Blanchard; Vialenciennes, Cambessedes: J. Decaisne. 1844. Mammiferes et oiseaux: 90 p. et ind. - Crustacees et Insectes. 31 p. - Botanique: Plantac rariores quas in India orientali collegit Victor Jacquemont, auctore $J$. Cambesseder, $183 \mathrm{p}$., avec un Allas, contenant : Zoologie: 28 tab. maxima ex parte col. sign. 1-18, 16-18, 1, 20, 21, 1. 2, 3. Botaniuge 180 lab. sign. $1-180$

"Tab. 29. Periandra cacspitosa devra etre substituec a celle pré cedemment livree sous le nom Flourensia caespitosa; on peut détruire cette derniere.,

\{815: Jacques, A. A. Catalogue glossologique des arbres, arbustes plantes vivaces el annuelles cultivées ou croissant naturellement aux domaines privés du roi (Neuilly, Le Raincy et Mlonceaux) rangees suivant le systeme sexuel de Linnte. Paris 1833. 12. 116 p.

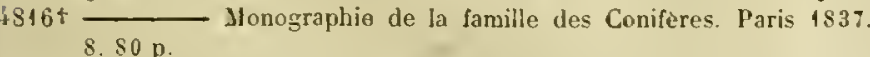

Extrait des Annates de Flore et de Pomone.

Pritzel, Thes. lit. bot
$4817^{*}$ Jacques, A. A. Manuel genéral des plantes, arbies et arbrisseaux ou Flore des jardius de l'Europe, orignines, descrijtions, culture; application a l'agriculture, aux forèts, aux Lesuins lomestigues, aux arts. à l'industrie et aux jardins d'agrement; classés selon la méthode de Decandolle. Ouvrage contenant toutes les especes de Vumant de Courset, auxiuelles ont été ajoutees plus de 13,000 especes. Paris 1845. 8

Virii tres priores fasciculos, in Geraniaceis desinentes: IF , 3N $288 \mathrm{p}$.; sed viginti bihliopola annuntiaverat, quemgue pretio $\mathrm{f}$ fr. $30 \mathrm{c}$.

$4818^{\circ}$ Jacquin. Essai sur la culture, la nonenclature et la classification des Dahlia (Georgina). Paris 1\$2\$. \$. $51 \mu$.

$4819 \div$ - Monographie complete du Nlelon, contenant la culture la description et le classement de toutes les variétes de celle espece, suivies de celles de la pastèque a chair fondante, avec la ligure de chacune dessinee et coloriee daprès nature. Paris 1832 . \& W, 199 p., 33 tab. col.

4820* Jacquin, Joseph Franz con. Eclogae plantarum raviorum aut minus cognitarum, quas ad virum deseripsit et iconibus coloratis illustravit. Vindohonde $1811-1844$. II roll. folio - 1: $1811-1516$ v111, $155 \mathrm{p}$., tab. col. 1-101. - 11: Post obitum Jacquini ah anctori: filia Isabella a Schreibers evulgatum. Synopsin specierum cum indice adjecit Eduard Fenzl. 1844. I1 p., ind., tab. col. 101-169.

(Tabula 107 semper rlesideratur.

\$821" - Eclogae graminum ratiorum aut minus cognitorum, quae ad vivum descripsit et iconilous coloratis illustravit Joseph Franz de Jacquin. I'ost obitum Jacquni ad fiden auctoris manuscripti absolvit, litulo ac indice instruxit Eduard Fen=l. Vindohonae $1813-18,4$ folio. 65 p., prefef, add., ind., 40 tab. cul.

In bibliotheca Candolleana vidi extmplar octo tabulis coloratis ditius quan omnia alia; fortisse DeCaudolle pater anno 1828 , $113 \mathrm{~m}$ Viennae esset eas ab ipso Jacquinio tijio accenit destinatae aran quinto fasciculo Eclogarum Graninun: quia db ipso Fenzlio editore nou laudantur tabulat, eas nominatim recensere jubabut: 1 . Milium vernale. t. 52. Panicum prostratum. t3. Panicum lace. t. 1 . Pent

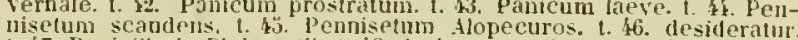
t. 5. Penicillaria PJuhenelii. 1. 48. Andropogon Jaxum. t. 49. Pancum clatjus.

$4822^{*}$ - Synopsis Stapeliarum in quatuor fasciculis prioribus Monographiae Jaçuinianae descrij)tarum. (Wien) IS16. \$. 12 [.

$4823^{*}$ - Eeber Jen Ginkgo. Wien 1819.8. \& p., I tab. col.

$4824^{*}$ Lebersich der neusten Erfahrungen, welche uber den Vorgang bei der geistigen Gálırung der starkmehlhaltigen stolle bekannt sind. Vorgetragen in der k. k. Landwirthschaftsgesellschaft zu Wien, an 14. Febr. 1834 . (Wien 1834.) 8.8 p.

$4820^{*}$ Jacquin, Nicolaus Joseph von. Enumeratio systematica plantarum, quas in insulis Caribaeis vicinaque Americes Continente detesit novas, aut jam cognitas emendavit. Lugduni Batavorum, Haak. 1760. \$. 41 p., praef. - Arl exemplar Lugduni Batavorum apud Th. Haak 1761 excusum Norimbergae, stamo Chr. de Launoy recusum. 1762. 8. $41 \mathrm{p}$.

$4826^{*}$ Enumeratio stirnium plerarumque quae sponte crescun in agro Timdobouensi, montibusque confinibus. Accedunt observa. tionum centuria et appendix de paucis exoticis. Vindobonae 1762. \&. 315 p., ind., 9 tah.

(Plantae addendae et corrigendac sunt in autoris Observat. not p. $41-15$.

4827 " Selectarum stirpium americanarum listoria in qua ad Linneanum systema determinatae descriptaeque sisłuntur plantae illae, quas in insulis Martinica, Janaica, Domingo aliisque et in vicinae Continentis parte observavit rariores, adjectis iconibus in solo natali delineatas. Vindobonae, in off. lirausiana. 1763 . folio. vil, $284 \mathrm{fr}$, 183 tab. aen. (13\% $\left./ h_{.}\right)$- Editio ad exemplar majoris operis recusa. Manhemii $1788.8 .5 ! v, 3631$.

jlujus libri tria tamun sum exemplaria labulis coloratis umnia Vientae.

$48: 8^{*}$ - Selectarum stirpium americanarum historia in qua ad Linneanum systema deterninatae descriptaeque sistuntur plantae illae, quas in insulis Martinica, Jamaica, Domingo aliisque et in vicince Continentis parte observavit rariores; adjectis iconibus ad autoris archetypa pictis (arri haud incisis). (Tindobonae, circa annum 1780$.$) folio max. 137$ p., ind., 964 tal. manu pictae. Bibl. Mus. bot. VIndob., Goett., Dresd., Mus. Brit.

(Opus rarissium auctam praecedentis libri sistit editionem cujus vix ultra is exemplaria typis expressae et pictae sunt, ut ipse saepius affirmaverat Jocuminus. Fuenplar Dresdense, teste Eberio anno 1818 pretio 500 thalerorun entum est. ) 
$4829^{*}$ Jacquin, Nicolaus Joseph von. Observationum botanicarum iconiJus ab anctore delineatis illustratarum Pars 1-IV. Vindobonae, ex officina Krausiana. $1764-1771$. folio. $48,32,22,14$ p., 100 tab. (10 th.)

1830" Hortus botanicus Vindobonensis, seu plantarum rariorum, quas in horto bolanico Vindobonensi etc. coluntur, icones coloratae et succinctao descriptiones. Vindobonao, typ. L. J. Kaliwoda. $1770-1776$. III voll. folio. - I: 1770, p. I-44., tab. col 1-100.- II: 1779. p. 45-93., ind., tab. col. 101-200.- III: typ. Gerolel. 1776.52 p., ind., 100 tab. col. $(250$ h. $)$

(lfujus operis 162 exemplaria mumeris inscripta exstant.)

$4 \$ 31^{*}(\longrightarrow$ Index regni vogetabilis qui continet plantas omnes, quae habentur in liunaeani systematis editione novissima duodecima. Viennae, krauss. 1770.4. $128 \mathrm{p} .-{ }^{*}$ Index editionis XIV. il. 1785. 8. (1th.)

$4832^{*}$ Florae austriacae sive plantarum selcctarum in Austriac Archiducatu sponte crescenturn icones ad vivum eoloratao et descriptionibus ac synonymis illustratae. Viennac, typ. Kaliwoda. 1773 -1778. V voll. folio. - I: 1773.61 p. tab. col. 1-100. - II: 1774. 60 p. tab. col. $101-200 .-111$ : 1775.55 p., tab. col. $201-300 .-$ IV: 1776.53 p., tab. col. $301-400,-$ r: 1778. 60 p., tab. col. $401-450$; cum appendiec stirpium ex aliis provinciis Anstriao adjacentibus: 50 tah. col.

$4833^{*}$ Niscollinea austriaca ad botanicam, elıemiam et historiam naturalem spectantia, cum figuris partim coloratis. Vindobonac, ex officina Krausiana. 1778- 17 1. 11 voll. 4. $-1: 1778.212 p$. 21 tab. - II: 1781.423 p., 23 tab. (13 1/3 th.)

4834" leones plantarum rariorum, Vindobonac, Wappler. 1781 -1793. 111 voll. folio. - 1: 178 I-1786. 20 P., tab. col. 1-200. Il: $1786-1793.22$ p., tab. col. $201-454 .-$ III: $1786-1793$. 24 p., tab. col. $455-648$. (270 (h.)

4830* - Anleitung zur Pflanzenkenntniss nach Linne's Methode. Zum Gelırauche seiner theoretischen Vorlesungen. Wien 1785. 8. 174 p., 14 tab. - Ed. II: Wion 1800. 8. - "Drittc Auflage, umgearheitet und vermeht von Joseph Franz von Jacruin. Mit cinem Atlas von 14 Tafelin. Wien 1840.8 .224 p. 11 tab. $(13 / 8$ th. $)$

*italice: Introduzione allo studio dei vegetahili di Nic. Gius. de Jacquin, tradotta, illnstrata ril aceresciuta da Raberto de lisini. Padova 182\%. gr. 8. xv, 222 p., 10 tab.

$1836^{*}$ Collectanea al botanicam, chemiam et historiam naturalem spectantia, cum figuris. Vindobonac, Wappler. 1786-1796. V voll. 4. - I: 1786.386 p., 22 tab. col. - II: 1788. 374 p., 18 tab. col. - 11l: 1789. 306 p., 23 tab. col. - IV: 1790. 359 p., 27 tab. col. - V: Supplementum. 1796.171 p., 16 tab. col. ( $53 \frac{1}{3} / / \mathrm{h}$.)

4\$ $37^{*}-$ Oxalis. Monographia iconilus illustrata. Vicnnae, Wappler, $1794.4 .119 \mathrm{l})$, S I tib. (quarum 75$)$ eol. $(40 \mathrm{~h}$. $)$

$4838^{*} \longrightarrow$ Plantarum rariorum horli eacsarei Schönbrunnensis descriptiones et icones. Viennac, Wappler. 1797-4804. N voll. folio. - 1: 1797. xur: 70 p., tab. col. 1-129.-11: 1797.68 p., tab. col. 130-250.- III: 1798.80 p., tal). col. $251-400 .-$ IV: $1804.56 \mathrm{p}$. , tab. col. $401-500 .(280 / \mathrm{h}$.

$839^{\circ}$ - Stapeliarum in hortis Vindobonensibus cultaruın descriptiones figuris coloratis illustratae. Vindobonac 1806. folio. ( 64 foll.), praef, ind., 64 tab. col.

(Opus anno 1819 a filio Joseplo Francisco ron Jacquin absolutum est.)

$4840^{\circ}-$ Stapeliac silvestres. Carmen e Stapeliarum descriptione, scorsim impressum. (Vicmnae) s. a. 8. 8 p. latino el germanice.) Blbl. Mus. bot. Vindob.

484 * Fragmenta botanica figuris coloratis illustrata, ab anno 1800 ad annum 1809 per sex fasciculos edita. Viennae, typ. Sclımidt. 1809. folio. 86 p., incl., 138 tab. col. (120 th.)

48 2. $^{*}$ - Genitalia Asclepiadearun controversa. Viennae 1811. 8. 140 p., 1 tab. col. ( $11 / 8$ th.)

(Codices antoris manuscripti "Adversaria in Dioscoridem " volumen unum quarta forma, et "Genera ex Cryptogamia Linnaei figmris ad vivum expressis illusirata faseiculus ia folio, $5 \mathrm{p}$. et 17 tab. col. exsiant in Biblioheca Musei botanici Vindobonensis.)

(Klang. bihliopola Vindobonensis, anno 18 š̉ onnia opera Jacruiniana praeter stirpium americanarum historiam eum tabulis 26 pictis non sculptis, pretio 500 numorum aureorum (ostreichsche species(lucalen) ohtulit; cf. Augsburger Allgemeine Zcitung 15t5. Nr. 3.7.)

4Si 3* Jaeger, B. Lectures sur thistoire naturelle d'llaiti, appliquec a l'économic rurale et domestique. Tom. l. contenant la botanique. Premiere livraison. Port-an-Prince, de l'imprimerio du gouvernement. $1830.4 .11,75$ p. Bibl. Scblecbtend.
484, Jaeger, Christian Friedrich, pr. Iusta et vina neccarina examine potissimum liydrostatico explorata. I). Tulingae 1773.4.54 p.

$4843^{*}$ De Combogiae quttae suce sive Gummi guttae nfficinali. D. Tubingae 1777.4 .32 p.

(Schlegel, Thesaurus mat. med. 11. [1. 276-290.)

4846* De Corticis peruviani in pluthisi pulmonali histeria et usus. D. Tulbingae 1779. 4. $56 \mathrm{p}$.

48:7* Jaeger, Geory Friedrich. Ueber die Nissluildungen der (iewachse. Ein Beitrag zur Geschichte und Theoric der Missentwicklungen organischer Kiurper. Stuttgart 1814. 8. x11, 320 P., 2 tab. $\left(1 \frac{11}{2}\right.$ th. $)$

48:8* Oloservationes quaedam de elfectibus variarum aeris specicrum in plantas. Programma. Stuttgartiae 1823.4.12 p.

$4849^{*}$ Ueler die Pllanzenversteinerungen, welcho in dem Bausandstein von Sluttgart vorkommen. Stntgart 1827.4.40 p., 1 tab. $\left(1 \frac{2}{3}(h)\right.$

1850 * Observationes de (quil)ustam Pini silvestris monstris. Programma festalc. Stuttgartiae, typ. Mánter. 1828. 4. 8 p., 1 tals.

4851* Jachnel, Johann Gotllob. De Gummi ammoniaco. D. Lipsiae 1837. $8.35 \mathrm{p}$.

4852* Jahn, August Friedrich IVilhelm Ernst. Plantas circa Lipsiam nuper inventas describit. Prolusio academica. Lipsiac 1774. 4. 12 p.

48:3* Jakovesich, Anton Paul. Literatura doctrinac de fungis venenatis, suspectis et edulihus, accedento synopsi specierum luugaricarum Amanitac. D. Pestini 1838.8.23 p., 1 tab.

485:" (Jakubowski, Jozef Kalixt.) Gpis Roślin i Bedlek Jadowitycl. (i. e. Beschreilung der giftigen Gewáchso und Pilze.) Poznàn 1835. 8. $15 \mathrm{p}$.

4833* Jampert, Christian Friedrich. Specimen physiologiae plantarum (I et II), quo dubia contra vasorum in plantis probalilitatem proponuntur. D. Halac 1755. $4.44 \mathrm{p}$.

4856* Jan, Georg. Elenclus plantarnm, quae in horto D. botanico Parmensi anno 1826 coluntur, et quac exsiccatae pro mutua offeruntur commutatione. Amalsilis scicutiae Lotanices cultoribus. (Parma 1826 .) folio. $37 \mathrm{p}$.

$4837^{*}\left(\frac{1}{-}\right)$ Catulogus in $N$ sectiones divisus rerum naturalium in Musaco exstantium Jusephi de Christofori et Geargii Jan, complectens adumbrationem oryetognosiac et geognosiac atcque Prodromum Faunao et Florae Italiae superioris. Sectio 1. Botanica. Pars I. Conspectus methodicus plantarum. Parmac 1832. folio. $37 \mathrm{p}$.

4858 * ( ) Ai cultori delle scienze naturali ed a chiunque brama avere nozione esatte concernenti la competenza del Prof. Giorgio Jan sopra il Museo di storit naturale, gia di comune indivisa propricta fra esso ed il nobile defunto Griuseppe de Christofori. Parma 1838. 8. 32 p., app.

480̈9* Janka, Lorenz. De Strychneis. D. Pragae 1\$34. 8. 39 p.

4.860 t Janson. Etablissement d'un cabinet et bureau cle plantes medicinales à Paris. Paris, typ. Millet. 1790.4.32 p. Bibl. Juss.

4861 * Janus, Lnthuig. Observationes aliquot criticae in Caji Plinii Secundi naturalis historiae libros. D. Monachii $1830.4 .32 \mathrm{p} .(1 / 1 / \mathrm{h}$.

4862* Lectiones Plinianae. Particula I. Inedita quaedam ad Coji Plinü Secundi Noturalis historiae finem in supplementum adlenda continens. (Sceundum Codicem Bibliolhecae Bambergensis manuscriptum Catal. Ar. 1007.) (Norimbergac), typ. Frid. Campe. 1934. $4.14 \mathrm{p}$.

4863* Jaroscz, Franz Eduard Felix. Plantac nove capenses. D. Berolini $1821.8 .24 \mathrm{p}$.

4864* Jaskiewicz, Johann. Pharmaca regni vegetabilis. D. Vindobonat 1775. 8.954 p., praef., ind.

4.860* Jaubert, Comle, et Eluarl Spach. Illustrationes plantarum orientalium, ou Choix de plantes nourelles on peu connues de l'Asir. occiclentale. Paris 1842-4846. II voll. 4. - 1: 1842-1843. rl, $176 \mathrm{p}$., 100 tah. et I charta geogr. - 11: 1844-1846. $123 \mathrm{p}$., 100 tab. ( 300 fr.)

(Operis egregit tertium, fuartum, quintum volumen esspectamux. Divulgitur a litraria Roret per fascicnlos; quisque 10 tabulierum, pretio $15 \mathrm{fr}$.

4866* Jauffret, Louis François. Yoyage au jardin des plantes, contenant la description des galerics dhistoire naturelle, des serres ou sont renfermés les arbrisseaux étrangers; de la partio dn jardin appelée l'école de botanique. Paris, au V'I. 1798.18 .244 p., 2 tab. (5 fr.) 
4867* Jaume Saint Hilaire, Jean IIenri. Exposition des familles naturelles et de la germination des plantes; contenant la deseription de 2337 genres et d'environ 4000 espèces les plus utiles et les plus intéressantes; 117 planches, dont les figures ont été dessinées par l'auteur, représentant les caractères des familles et les différents modes de germination des plantes monocotyledunes et dicotyledenes. Paris an XIII. 1805, 11 voll. 8. - 1: 7, LXuI, 512 p., tah. 1- 70 et A-E. - I1: 473 j., tab. $71-112$. (36 [r.) - (edit. in 4.96 lr. pap. vélin: 192 fr.)

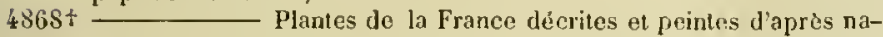
ture. Paris, chez l'auteur, de l'impr. rle Didot le jeune. (18051822. X rell. petil 4. $x$, xxxvit1, 45 p., 1000 foll., 12,1000 tab. $(370 \mathrm{fr}$. in $8,-600 \mathrm{fr}$. in 4.)

(Chaque volume contient 100 planches colorices, rangées en ordre aiphabétique et accompagısées du meme jombre de feuilles de texte plantes sauvazes et cultivées. Les planehes sont numérotées 1-1000. Au frontispice du chacun volume le portrait d'un hotaniste: Tournefort, Vaillant, Barrelier, Adanson, DuHlomel, Desfontaines, Thoun Lamarck, LaBillardiere, Jaume St. Ililaire. - Le premier volume conlient aussi Preface $x \mathrm{p}$. Elemens de botanique: xxxvil p. et tab. $1-$ 12; le dernier index general: $13 \%$ p.)

$4869+\longrightarrow$ Recueil de mémoires sur l'administration des foréts, sur les arbres furestiers et l'éconemie rurale. Paris $1814.8,30 \mathrm{p}$. (1 [r.) - tEd. ll: Paris 4832.8.86 p.

$4870 t$ Mémeire sur les indigoferes du Bengale et de la Chine, ou histeire et description de quelques végélaux peu commus et dont les feuilles donnent un très-bel indigo. Ouvrage erue de figures de grandeur naturelle en noir el en couleur. (Paris 1826.) folio. 12 p., 5 1 ab. col. $(20$ [r.)

4871 - Wémoire sur la culture du Poivrier noir, prẻcédé de quelques observatiens critiques sur l'administration du royaume et orne de figures en noir et en couleur. (Paris 1827.) folio. 8 p., 2 tab. col. ( 10 [r.)

4872* - La Flore et la Pomone françaises ou histoire et figures en ceuleur des fleurs el des fruits de France ou naturalisés sur le sol français. Paris 1828 - 1833. VI vell. folio. 544 tab. col. et texte.

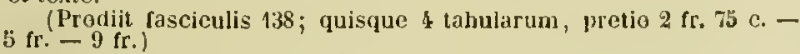

$4873+$ Flore Parisienne, ou Description des plantes qui croissent aux envirens de Paris et dans les départemens voisins, avec l'indication de leurs usages en agriculture, en médecine et dans les arts, accompagnée de la figure d'une ou de phisieurs espèces de chaque genre, avec l'analyse des parties de la lleur', du fruil et de la graine, dessinées de grandeur naturelle el grossies. Paris 1 \$35. 4. 112 p., ic. plur, xylogr. i. t. nigr. el col, I carte. (Continuationem nor vidi.)

487k* Catalogue raisonné des plantes inutiles ou nuisibles aux terres cultivées et aux prairies naturelles, ou vẻuéneuses pour les bestiaux, avec l'indication des ineillieurs moyens de les détruire. Paris $1843.4 .51 \mathrm{p}$.

$4875^{\circ}$ Les Dahlia, ou histoire, description el culture des plus belles espèces ou variétés de Dahlid. Ouvrage orné de figures peintes d'après nature par Mlle Nanine Guillon. Premiere livraison. Paris, 1yp. Didot. s. a. folio. $4 \mathrm{tab}$. col. Bibl. Goett.

("Cette collection paraltra en 10 livraisus de 4 planches a $10 \mathrm{fr} . n$ )

4876* Ideler, G. F. Der Gartenfreund. Alit Vorrede von Karl Ludwig IVilldenow. Berlin 4795-1805. 5 Bánde. 8. $\left(13 \frac{1}{2}\right.$ th. $)$

$4877+$ Jeanjean, Pierve Gillert. Aperçu sur la nature et les propriétés de l'Araica montana. D. Nontpellier 1817, 4. 12 1).

4878 Jefferson, Thomas. An decount of the sugar mapple tree. Philadelplia 1792. 8. DC.

4879* Jelenffy, Karl. De Niceriana. D). Budae 1838. 9. 52 p.

$4880^{*}$ Jenichen, Gotllob August. De Tabaco. D. Ed. 11. Giessae 1756. 4. $19 \mathrm{p}$.

i481 * Jenisch. Katalog der Orchideen-Sammlung des Senator Jertisch zu Flottbeck. Hamburg 1845.8.13 p. (Kecensentur 428 species.)

4882 Jenkinson, James. A generic and specific description of british plants, translated Irom the Genera et species plautarum of Linuaeus. Kendal 1775. 8.258 p., 5 tab. B.

$4883^{*}$ Jeppe, C. F. IV. Herbarium vivum der verzüglichsten, su wio einiger schádlichen Futterkräuter und Gräser nebsı deren reifen
Samen etc. Dritte vermelirte Aullage. Rostack 1835. 4. xiI, 68 p $(5 / 6 l h$,

Editio prima anmo 1826 Ilamburgi prodiit. Libro adjungitur collectio 52 specicrun siccartm una cinn earum sentinibus: $31 / 3$ th.

488' Jesse, Edward. Gleanings in natural history. Ed. N': London 1840. 11 voll. 8. (12s.)

$4880^{*}$ Jessen, $P . W$. Intreductio in commentationem de Digitalis purpureae viribus usurque medico. 11, Kiliae $1820,4.72 \mathrm{p}$.

4886 Jessenius a Jessen, Johann. De plantis dispulalio prior. Wittenbergae 1601.4 .10 foll. B.

4887 * Jester, Friedrich Ernsl. Anleitung zur Kenuniss und zweckmassigen Zugutemachung der Nutzholzer. Konigsberg 1815-18 J6. 3 Bde 4. - 1: 1815. xiv, 137 p., 1 tals. cul. - 11: 1816. vi, 286 p., 2 tab. - $111: 1816.156 \mathrm{p} ., 6$ tab. $(5 \mathrm{~h}$.)

4.888* Jirasek, Johann. Beobachtungen aul Reisen nach dem Riesengetiirge, von Johann Jiraseh, Thaddaeus Ituenke, Abbe Gruber, Franz Gerstner. Veranstaltet und lierausgegeben von der Kouiglichen Bolmischen Gesellsclsaft der Wissenschaften. Dresden 1794. 4. Ivin, $309 \mathrm{p} ., 2$ tal.

4889 Ikenius, Konrad. Dissertatio de Lilio saronitico, emblemate sponsae, ad illustrationem loci Cant. II. 1. Bremae 1728. 8. 38 p. B.

4890 Illiger, Johann firl II ilhelm. Versuch einer vollstandigen systematischen Terminelogie für das Thier- und Pflanzenreicl, nebst Gedanken über die Begriffe Art und Gattung in der Naturgeschichte. Helinstedt 1800 . 8. $\left(1 \frac{1 / 2}{2}\right.$. $)$

suecice: Forsok till..en fullstadig systematisk Terminoloci fur Djur- och Waxt-Riket. Ofversatt och tilloht af Gabriel Marklin. Upsati

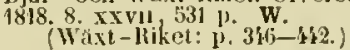

4891* Ilmer, Georp, [1r. De Tilia. D. Lipsiae, typ. Nichaelis. 1669. 4 (16 p.) Bibl. Reg. Dresd. (Respondens: Daniel Lindner.)

(Meminit ingentis longievae tiliae, jam a Caspare Scholto descriptae prope Neustadi an der grossen Linden, ad tluvium Koclier in agro (leibronnensi.)

4892* Ilmoni, Immanuel, pr. Enuneratio plantarum efficinalium Fenniam sponte jnhabitantium. I). Helsing forsiae 1837.8 .90 p.

4893* - Om Aritian och Senegau, sàsom hvarannan pharmakodynamisk motsatta lákenedel. D. Helsingfors 1839. 8. 41 p.

4894* Imhof, Franz Jakol. Tea Maydis morhus ad ustilaginem vulge relatus. D. Argentorati $1784,4.34$ p., 1 tab.

$4.893^{*}$ Imlay, G. A topographical description of the western territory of North America. London 1792. 8. 247 p.

* germanice: Nachrichten yon llem westlichen Lande der Nord amerik. Freistaaten, von dem Klima, den Naturjuroducten u. s. w Aus dem Englischen von Zimmermann. Berlin 1793. 8. xv, 168 p.

4896* Imlin, Philipp Jaliob. De Soda et inde obtinendo peculiari sale D. Argentorati $1760.4 .32 \mathrm{p}$.

4897 Imperato, Ferrante. Dell' historia naturale libri XXV'll. Najeli 1599. [olio. 79 1 p., ic. xylogr. i. 1. B. - Ed. 11: Historia naturale di Ferrante Imperato Napelitano. Nella quale ordinatamente si tratta della diversa condition di minere, pietre pretiose, e altre curiosita cen varie histerie et animali, sin' hora non date in luce. In questa seconda impressione aggiontoni da Giobanni Maria Ferro alcune annetationi alle piante nel libro XXVill. Venetia, presso Combi. 1672. folie. 696 p., prael., ind, ic. xylogr. i. ?.

* latine: Ferrandi Imperali Neapolitani llistoriae naturalis libri XXIlx. Accesserunt nounulld Joannis Muriue Ferro adnotationes ad librum vigesimum octayun, sc. de plantis; nune primum ox italica in linguam conversa latinam cum indice locupletissimo. Culoniae (in alii: exemplaribus: Lipsiae), saumann. $1690^{\circ}$. 4. 928 p., praer., ind., ic xylogr. i. 1 .

Verum auctorem fuisse Nicolaum Antonium Stelliolam pretie re-

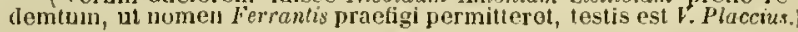

4898* Ingenhousz, Johan. Experiments upen Vegetables, discovering their great power of purifying the commun air in the sunshine, and of injuring it in the shade and at aight. Londen, Elmsly. 1779. 8 . L.xviI, 302 p., ind., 1 tal.

* germanice: Leipzig, Weygaul. 1780. 8. $176 \mathrm{p}$., ind., 1 tab. ( $3 / 12$ th. $)$ schâf, welche sie in einem hoben Grade besitzen, die Luft im Sonnenlichte zu reinigen, uad it der Nacht und im Sehaten zu verderhennenlichte zu reinigen, und it der Nacht und im Schaten zu verderhen; nelsst einer neuen Methode, den Grad der Relnheit und Heilsamkeif
der atmosphírisehen I.nt zu prufon. Aus dem Franzosisehen vun der almosphirisehen Lntt zu prufen. Aus dem Fralnzosischen von

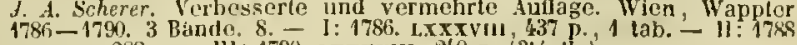
LXxvII, 288 p. - III: 1790. LxxxvII, 240 p. $\left(3 \frac{1}{2}\right.$ h. $)$ 
- hollandice: Proeven of Plantgewassnn, ontlekkende derzelver

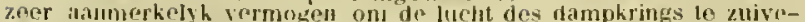

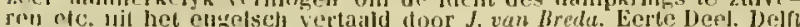

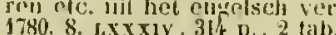

"grellice: Exjeriences sur les viogetiux, sprécialement sur la pro-

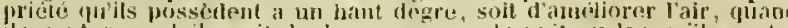
ils sont an soldal, soit de le colromple la muit on lorsgu ils somt

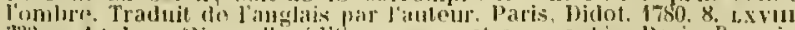
:333 (b., I lab. - Nomvelle edition, pevue et angmentco paris, Barrots 1787-1789. II voll. 8. - I: Cxil, 38t p.- II: LV1, 509 p., I tal).

3.8997 Ingenhousz, Johan. Procte over het Voedzel der l'lanten, en de vrugilsaarnaking van Landeryen. Uit het engelsch vertauld door J. van Breda. Jelft, liy Roelıfswart. 1796. 8. vin, 71 j. Bib!. Leod. lidilio anglica mili non immotuit.)

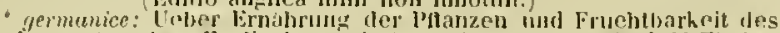
Bodens. Aus den Englischen mil Ammerhum:an vou Gollhelf Fischer

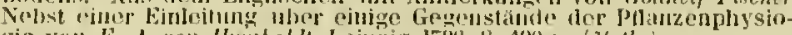

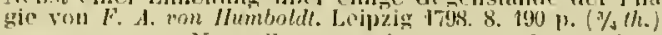

$1900^{*}$ - Nonvelles expériences at ohservations sur divers oljets to physigue. Traduit te l'anglais par l'auteur. Paris 1785.8 xxxvis, 498 p., 4 tals.

(Elitio anglica inibi non immotuit.)

1901 * Vermischte Schriften pliysisel -medicinischen Inlualts Uebersetzl und herausfegeben von Molitor. Zweite Aulage. Wien 1784. 2 liám(le. 8. - 1: xx, 452 p., 2 tab. - I1: vili, 553 p., 3 tab. $(3 \mathrm{th}$.

(Insunf: Bemerkungen uber die Oehomonie der Pliazen; liber die Prisstley'sele grume Waterie; Lell'e de Wr. Senebier.)

$302^{*}$ Miscellanea physieo-medica. Edidit Johann Andreas sicherer. Vicunae 1795.8. 209 p., praef, 1 tal).

1.903 Joblot, Lowis. Descriptions et usages de plusieurs noureaux mi'roscopes, avec de nouvelles observations sur les insectes et autres animaux qui naissent daus les liquenrs. Paris 1718. II voll. 4.I: 78 p., 22 (a). - I1: 96 p., 12 lab. B.

490\%" - Observations d'histoire uaturelle faites avee le microscope. Paris, Briasson. $1754-1755$. II voll. 4. $-1: x_{1}, 38,124 \mathrm{p.}$ 29 1al. - 11 : vi, 78,27 p., 94 tal.

(Practer alia multa redit textus libri praecedentis.)

$190 \ddot{3}^{*}$ Jörlin, Engelbert. Specimen botanico-veconomicum de usu quarundan plantarum indigenarum prae exoticis. D. Loudini Gothorum 1769.4.12 p.

$1906^{*}$ Partes fructificationis sen principia lotanices illustrata. D. Londini Gollorum 1771. 4. 26 p.,6 tab. - tEd. Il. emendata: Prineipia butanices illustrata, seu partes fructificationis, characteribus, terminis teclunicis, figuris illustratite, ad systema botanices Linneanum intelligendum, Iractaudum adaptatae in usum praelectionum. Luntao 1786.8 .32 p., pracf., 6 tab.

$4907^{*}-$, j. Specinen botanico-oeconomicum sistens Trifolium bybridum. D. Lumdae $1780,4.14 \mathrm{j}$.

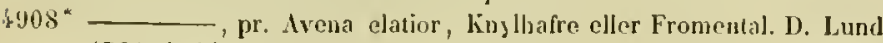
1781.4 .24 p., 1 tab.

$\$ 909$ Underrattelse on Ilislagen Avena clatior, Kuylhafre eller Fromental, och Trifolium hybridum, ett uyt Klöwerslag. Andra upplagan. Lund 1783. 4. $29 \mathrm{p}$., 1 tab.

(Est recusio opuseulorum (jurum juecelentium.)

\$910* Johann, Erzherzog von Oestreich. lcones plantarum austriacarum incelitae. (Vindobonae) s. a. folio. 92 tab. aeri inc.

(Servantur in Musco botanico Viulobunensi.)

49!1* John, Joham Friedrich. Clomische Tabellen der Phanzenanalysen oder Versuch eines systematischen Verzeichnisses der bis jetzl zerlegten Vegetabilien maeh den vorwaltenden naheren Bestandtheilen geordnet und mit Anmerkungen versehen. Nurnberg 18/4. foliu, $x$, 94 p. $\left(2 \frac{3}{8}\right.$ th. $)$

4912* Ueloer die Ernálirung der Pfanzen im Allgemeinen uni den Ursprung der Potlasche und andrer Salze in ihnen insbesonelre. Preisschrift. Berlin 1819. 8. xvut, 299 ]. (1 1/2 th.)

4913 Naturgesehichte des Succin's oder des sogenannten Bernsteius, nebst Theorie der Bildung aller fassilen Jituminosen Infammabilien des organisehen Reiebs und den Aualysen derselben. Cöln 1816. 2 Theile. 8. $\left(2 \frac{1}{3}(h)\right.$.

491' Johns, William. Practical bolany; an improved arrangement of the generic caracters of british plauts; with a familiar introduction to the Linnean system. Iondon 1826.8 .156 p. (9s.)

491:" Johnson, Cuthbert IFilliam. Abhandlung uber die Anwendung des kiochsalzes auf den Feld-umd Gartenbau. etc. Aus dem Engli- sehen der zweiten Ausgabe uberseazt. Leipzig 1825. 8. Ixxvua, $24 \delta$ ) $(1 \%, h$, $)$

(Edjtio anglica mihi nou innotuit.)

$4916^{*}$ Johnson, George William. A history of englisl gardening, clironological, liograpluical, literary and critical. London 18z9. 8. (9s.)

4917* Johnson, Jakob. Von der Nahrumg der Kulturjollanzen. D. St. P'elershur: $1844.8 .56 \mathrm{l}$.

4918 Johnson, Thomas. lier plantarum invesligalionis crun susceptum in agrum Cantianum aumo 1629 Julii 13. - Ericesum Hanstediamun, sive plantarun ihi erescentiun olssurvatio lrabita endem anno. 1 Augusti. (London 1629.) 4.8 full. Bibt. Mus. Brit.

4919 Deseriptio itineris plantarum investigatioris ergo suscepti in agrum Caulianum anno Hom. 1632 , 1.1 coumeratio plantarum is Eriecto Ilampstediano locisque vicinis crescentun. (Londini) 1632. $8.39 \mathrm{\mu} ., 5$ ic. ligno inc. $B$.

Icones redmut in Johnsoni editione llerbarii Gerardi. Lomdon 1633. folin. p. 61' et 1570.$)$

$4920 \div$ ( ) Mereurius botanicus sive plantarum gratia suscepti itineris anno 1634 descriptio. Cum carun nominilsus latinis et anglieis ete. Iluic accessit de Tliermis Bathonicis tractatus. Londoni, excudeluat Thomas Cotes. 1634. (4) 78 p. practer Tlımas Batlonicas: 19 p. Bibl. Juss.

4.921 Mercurii botanici pars altera, sive plaularum gratia suscopti itineris in Cambriam deserijtio, exlibens reliquarum stirpium nostratium (quae in priore parte non enumerabantur) ealalogum. Londini 1641.8. 37 p. B.

Coram habeo prospectum a biblinpolit Londineusi Pamplin paucis abhine annis divulgatum, quo rarissima haec Johnsoni itinera

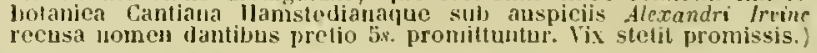

4922* Johnston, George. A Flora of Berwick-upon-Tweed. Euluburgh 4829-1831. Il voll. 8. - I : Phacnogamia. 1829. xxiv, 242 p.. 2 tab. col. - 11: Cryplogamia el Adklenda. 1834.335 p., 8 tab. ( 1 ǰs.)

$4923^{*}$ A History of the Britisb Zoopbytes. Edinburgh 1838. 8. xII, 341 p., 44 tab.

$4924 \%$ Johnston, James $F$. Lectures on agricultural cliemistry and geology. Second edition. Part 1 and II. Edinburgh and London 1842. 8. 434,32 p. $(10 s .6 d$.

$4923 \%$ Elements of agricultural Chemistry and Geology. Second edition. Edinburgh and London $1842.8 . x I, 250$ p. (5s.)

$4926^{*}$ Johren, Martin Daniel. Vademecum botanicum seu bodegus botanicus, non solum hotanophilis sed aliis etc. utilis, secundum methodun Tournefortianam. Colbergac, apud Jeremiam Harmann. (1710).8. 248 l., praef.

$4927+\mathrm{Joly}, N$. Observations generales sur les plantes qui peuvent fournir des conleurs bleues a la teinture, suivies de rechercbes anatomiques, physiologiques el eliniques sur le Polygonum tinetoriun et spécialement sur le Chrozophora tinctoria (Croton tiuctorium J..). Montpellier, typ. Bochm, 1839.4. 99 \%., s tab. col.

4.928 - Etudes sur les plantes indigoferes en géneral el particulièrcment sur le Polygonum tinctorium. Nontpellice, Pieot. 1839. 8. 64 p., 1 tab. col.

(E.Irait du Bull. de la soc. d'agric. do Lllérault.)

4929 Jolyclerc, Nieolas. Cours complet et suivi de lolanique, rédigé sous les formes et dans les termes les plus clairs, d'apres les diverses métlıodes et les principes adoptés par Tournefort, I.innè, Jean Jacques Rousseau, Lamarck, Durand, Villars el antres. Tome I (et unirue). Lyon 1795. 8. a.

4930 Principes kementaires de botanique, rédigés d'après les méthodes do Tournefort, Linné, Jussicu et autres. 1795. 8. a.

$4931+$ Principes de la philosoplie du botaniste, ou Diclionnaire interprète et raisonué des principaux préceptes et des temes, jue la hotanique, la médecine etc. out consacrés a l'ètude et à ls connaissance des plantes. Paris, Rouvaux. an VJ. (J79S). 8. xvi, 462 p. ( 5 fr.) - tParis, Bertramel. 1803.8. (non differt.)

$4932 \div-$ Plytologie universelle ou llistoire naturelle et méthodique des plantes, de leur's proprićtés, de leurs vertus el de leur culture. Paris an V'll. (1799). V voll. 8. Xvi, 496, 551, 525, 534, 504 p. (2s fr.)

(Ail hume Jibrum pertinet, teste Qucrard: Allas pbytologique dn plus de 700 pl. in folio. $72 \mathrm{fr}_{\mathrm{r}}$ ) 
4933 Jolyclerc, Nicolas. Cryptogamio complète ou description des plantes, dont les ciamines sont peu apparentes; suivant les ordres ou fanilles, les gemres, les espèces, avec les caractères et les différences; par Charles Linné. Première édition française, calquée sur celle de Gmelin, augmentèe et enrichic de notions élémentaires, etc. Paris, an VII. (1799). S. 242 ).

1934.t Jomard, Edme Fr. Notice historique sur la vie el les voyages de René Caillie. accompagnéc d'un portrait. Paris 1839 . 8. 70 p., elfigies Caillie.

4.93:* Joncquet, Dionys. Hortus, sive lulex onomasticus plantarum, quas excolebat Parisiis annis 1658 et 1659 . Accessil al calcem stirjuium aliquot paulo obscurius ofticinis, Arabibus alisque denominatarum per Casparem Rauhinum explicalio. Parisits, apud Franciscum Clouzier. 1659.4. 140, 47 p., praef, 2 tab.

$4936^{*}$ (_ - IJortus regius. Pars prior. Parisiis, apuel Dionysium Langlois. 1665 . folio, 188, (22) p

(Sunt exemplaria anni thibi, yuac practer titulum non differunt. Exemplaria Jussieni et Bunksĭ numerint tantum $188 \mathrm{p}$. et 2 foll.)

$4937^{*}$ Jones, J. . . and J. F. Kingston. Flora Devoniensis, or a descriptive catalogue of plants growing wild in the county of Deven etc. Londou 1 S99. 8. xLVII, 162, LxVII, 217 p. (16s.)

4.938 Jones, Ililliam. The religious use of botanical philosophy. A sermon. London 1784, 4. 18 p. B.

:039: Jonghe, Hadrianus, Jatine Junius. Plaalli, ex fungorum genere in Ilollandiae salruletis passin crescentis deseriptio et ad vivun expressa pictura. Res nova et prioribus sacculis incognita. Delphis, apud Ilermamum Schinckelium. 1564. 4. (13 foll.) ic, xylogr. i. t Bibl. Reg. Par. - Deljhis 1569. 4. Burmann. - Lugduni Batavorum apud Christ. Guyotum. 1601. 4. 8 foll. ic. sylogr. i. t. B. - Exstat etiam cum ejus literis, sine icone. Dordraci, apud Vincent. Caimax. 1562. 12. s.

$\$ 910^{*}$ Jonston, Johannes. Thaumatographia naluralis in classes decem divisa : in quibus admiranda coeli, clementorum, metcororum, fossilium, plantarum, avium, quadrupedum, exsanguium, piscium, hominis. Amslelodami, apud Joannem Janssonium. 1632. 12.501 p.${ }^{*}$ Ed. II. priori auclior. ib. 1633. 12. 580 p., praef. (Plantarum admiranda: p. $201-270)$.- tib. 1661.12 .495 p., pracf. $-{ }^{*}$ ib. 1665. 12.495 p.

anglice: A history of the wonderful things of nature. London 1637. folio. 33 p. $\mathrm{B}$.

4941 De Theriaca Andromachi. Lugduni Batavorum 1634. 4. Adamski.

$4942-$ Syntagmatis dendrologici specimen. Lesnaè Polonorum 1645. 4. Adamski.

19.3* - Notitia regni vegetabilis seu plantarum a veleribus observatarum, cum synonymis graceis et latinis obscurioribusque differentiis in suas classes redacta series. Lipsiae, Trescher. 1661. 12. 331 p., praet.

49 1.: * - Dendrograjblias sive historiae naturalis de arboribus et fruticibus tam nostri quam peregrini orbis libri decem, figuris aeneis adornati. Francofurti a/M., Iyp. Polich. 1662. Solio. 477 p., praef. iud., $137 \mathrm{tab}$ - Ed. 11 : llistoriae naturalis de arboribus et planlis libri X., quos ob rarıtatem denoo imprimendos suseejuit F. J. Eckebrecht, bibliojrola Heilbrunnensis. 1768. Il voll. folio. $-1: 214$ foll. 58 tab. - II: 265 foll., 79 tab. a Matthia Merian sculpiae. $\left(13 \frac{1}{6}\right.$ th.)

$\$ 945^{*}$ Jordan, Alexis. Observations sur plusieurs plantes nouvelles, rares ou eritiques de la France. Premier - quatrième fragment. Lyon et Leipzic 1846. 8. - 1: 45 p., 5 tab. - 11: 39 p., 2 tab. - Jll: 254 p., 12 tab. - IV: 37 p., 2 tab. $(6 \%$ oth. $)$

(Extrait des Annales de lat soc. limn. te Lyon, 18\%.)

4946" Jordan, Gerhard Gotllieb. De Amygdalo communi var. amaro. D. Goetlingae 1834. 8. $60 \mathrm{p}$.

$4947^{*}$ Jordan, Johann Ludwig. Disquisitio chemica evictorum regni animalis el vegetabilis elcmentorum. Praemio oruata. Goellingae 1799. 4. $88 \mathrm{p}$.

$4948 \div$ Jori, $B$. Scoperla di due nuovi alcaloidi nella China gialla filosa $e$ del vero componimento organico amaro della medesima. Opusculo chimico. Reggio, Iyp. Davolio. 1\$43. 8. 68 p.

1949 Josselyn, John. New Englands rareties discovered. etc. London, Widclowes. 1672.12 .114 p., ic. xylogr. i. t.
4930 Josselyn, John. An account of two voyages to New England. London 1674. 8. 279 P. B.

$4951 \div$ Joubert, $P . C h$. La séminologie générique ou nouvelle méthod. pour arrêter la formation des syunonymies botaniques. Discours préliminaire. Paris $1840,8.16 \mathrm{p}$.

4952* - Nouveau manuel complet du Sabricant et de l'amatcus de tabac, contchant lihisloire, la culture et la fabrication du tabac. etc. Paris 18:4. $964 \mathrm{p}$.

4933 " Jourdan, Antoine Jacques L. Plarmicopéc universelle, ou Conspectus des Pllimacouées ete, Paris 1828. Il voll. 8. - "Seconde dedition, entiercment refondue et considerablenent augmentée. Parls 1840. II voll. S. - I: xII, 804 p. - II: 647 p. (25 fr)

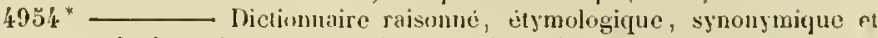
polyglotte des termes usités dans les sciences naturelles, comprenant l'anatomie, lhistoire naturelle, la hotanique ete. Paris 1834 11 voll. gr. $8 .-1: \Lambda-$ K. 674 J. $-11: \mathrm{L}-Z .628 \mathrm{p}$. (18 Ir.)

$4963{ }^{*}$ Irmisch, Thilo. Der Anorganismus. Die Pflanze. Das Thier. Ein Versuch zu deren Bestimmung. Sondershausen 1843. 8. 16 it $(1 / 6, t h$.

$4956^{*}$ Systematisches Verzeichniss der in dem unterlersschaftliclsen Theile der Schwarzburgischen Furstenthumer wildwaclsenden phranerogamischen Pllanzen mit Angabe der wichtigsten Kulturgewachse. Sondershausen 1846. S. xis, $76 \mathrm{p} .(1 / 5$ th.

$4957+$ Irvine, Alexander. The London Flora; containing a coneise deseription of the phacuogamous lirisis fulants, which grow spon taneously in the vicinity of the metropolis, with their localities. arranged in conformity to the natural system: also a Limean arrangement of all the indigenums britisly species. etc. London 1838 gr. 12. XII, 340 p. (10s.)

(Indicatur tilulo paullo mutato.)

4938* Isenflamm, Jakob Friedrich, pr. Methodus plantarum medicinae clinicae alminiculum. D. Erlingae $1764.4 .42 \mathrm{p}$.

4959* Isensee, Emil. Elcmenta nova geographiac et statistices medicınalis. D. Berolini $1833.8 .162 \mathrm{p}$. (1 th.)

(Insunt vitria ad distributionem plantaium medicinalium geographicann spectantia.

$4960^{*}$ Iser, $F . S$. llissertatio circa Plytotoxicologiam e plantis renenatis Bohemiae indigenis, Papaveraceas exhibens. Pragae 1834. S. 69 1

496। Isaacus, Jan. De Rorelia tractatus, in quo de arcanis alchimistarum. L.

4962* Isert, I'aul Erdmann. Reise nach Guinea und den Caribaisehen Inseln in Columbicn. Kopentagen 1788. 8. 376, Lxx p., I tah. Nurnherg 1789.8. (1 th.)

4963 Isidorus, Ilispalensis episcopus. Elymologiarum libri XX. Editic princeps: Argentorati, Joh. Mentelin. s. a. folio. Hain Nr. 9270. Augustae Vindelicorun, per Gintlerum Zainer. 1472. 19 Nov, foliu Huin Nr. 9273. - Origium lihri XX variis lectionibus et scholiiillustrati opera Bonav. Vulcani. Basileae, apud Petrum Peruan. (1577). folio. coll. 496 praeter veteres grammaticos. B. - "Corpus grammaticorum batinorum vetorum. Collegit, auxit, recensuit at potiorem lectionis varietatem adjecit Friedrich Lindemann. Tomus III Isidori llispalensis Episcopi Elymologiarum libros XX continens: edidit Friedrich Wilhetm Olla. Lipsiae 4833. 4, xи, $702 \mathrm{p}$.

(llanc optinam edition'm perlibent. Liber Xin ad historiam botanices ejus aevi, sare. Vil monenti est.

4964 Isink, Adam Menson, pr. Disputatio philologica de falis. Groningae 1712.4 .10 foll. B.

4963 Ismailow, Wladimir. Руссовы иисма 0 ботаникћ, перев. Mockвa 1810 . Trauty.

$4966+$ Itier, Jean. Oratio medica de utilitate atque jucunditate botanicae D. Aonspelii, lyp. l'icot. 1778. 4. is j. Bibl. Juss.

4967 Ittigius, Johamn. We anima regetante. D. Lipsiac 163̈6. 4. Rivin.

$4968^{*}$ Juch, Hermann J'aul, pr. Ho Coron'po, optino coeliacosum acetario. D. Erfordiae 1739. 4. 20 p.

$4969^{*}$ - pr. De libulo ejusque usu medico. D. Erfordiac 1745 4. $25 \mathrm{p}$.

4970* , jr. De ratice Clinae ejusque limitandis laudibus. D. Erlorliae $1753.4 .30 \mathrm{j}$.

4971 Juch, karl Irilhelm. Anleitung zur Pfanzenkenntniss Baierns. IIunchell 1806. 8 . ( $\mathrm{th}$.) 
4972" Juch, Karl Wilhelm. Die Giftpflanzen. Zur Belehrung fur Jedermann. Zwolf llefte. Augshurg 1817. folio min. 48 loull., 48 tals. col. (8 th.)

4973 Das Ganze des liartoffelbaus, uter Geschichte, vortheilhafter Anbau und Bentitzung der Karloffeh. 1/m 1818. 8. ( $1 / 2$ th.)

4974" Jüngst, $L$. $V$. Flara der nächsten U'mgebungen Bielefeld's. Programm. lisielefeld $1833.8 .104 \mathrm{p}$.

$4975^{*}$ - Liurzer Alriss der Pflanzenkunde zum Unterricht an böheren Lehranstalteu. Bielefeld 4833. 8. xw11, $416 \mathrm{p} .(5 / 12$ th.)

$4976^{*}$ —_ l'lora von Biclefeld, zugleich dio Standorte der seltneren Pllanzen in uhrigen Westphalen enthaltend. Bielefeld und Herford 1837. 8. xxเy, 358 p. (1 $1 / 6$ th.

4977 t Juge de Saint Martin, Jacques Joseph. Traité de la culture do chene. ele. Paris 1788.8 . xxxu, $311 \mathrm{p}$. (4 fr.)

49785 Notice des arlures et arbustos, qui eroissent naturollement ou qui peuvent être élevés en pleine terre clans le Limousill. Limoges 1790. S. xv, 309 p. ( $3 \mathrm{fr}$.

$4979+$ Juglar, ainé. Le triomphe de l'Acacia. etc. Paris 4808 . 8. $85 \mathrm{p}$., I tal. ( 1 fr. so c.)

4981 Juhász vel Ihász, graece dictus Melius, Petrus. Herbarium az fáknak, füveknek nevekról, termeszetekról, és hasznokról, GalénusLol, Pliniusból et Alamus Lonicerusból szeclettettek ki. Kolosvàrott (Klausenhurg) 1578. 4. 188 foll. eum indice latino, hungarico et germanico. Haberle.

(Tractat de arbolum et herbarum nominibus, natura et utilitate e Gateno, Jinio, Loulcero Editionem anni 1562 , 4 . Debrecini editam notat Horanyi in Nemorabilibus liungariae.)

\&981 Julia de Fontenelle, J. S. E., et Ilenri Tollard. Mantel de l'herboriste, de l'ópicier-droguiste et da grainier-pépiniériste-horticulteur. Paris 1828. 11 voll. 18. ( $7 \mathrm{fr}$.) 0 .

4982 Juliaans, Arnold. De resina elastica Cajennensi. D. Trajecti ad Rhenum 1780.4.74 p. B.

(Schleg. Thes, mai. med. I. D. 1-56. - Excerpta germanica in Sammluugen znr Jhysik, Il. p. 680-733.

4983 Julian. Rapport sur la plantation d'Anil ou ludigo français. Paris 1804.8. DC.

4984t Julien, Aìnan Stanislas. Résumé des principaux traités chinois sur la culture des muriers et l'education des vers à soie. Traduction. Paris, imprimerie ruyale. 1837.8 xxu, 224 \%., 10 tab.

$4985 t$ Jullien, $A$. Topographie de tous les vignobles connus etc. snivic d'une classification générale des vins. Paris 4846. 8. Xxxu, 566 p. - Ed. Il. ib. 1822. 8. - Ed. Il1. ib. 1832. 8. germanice: Toposraphie aller hekannten Weinherge und Wieinpflanzungen. Quedininne 1833-1833. 2 Bánde. 8 . ( $3 \mathrm{th}$.

4986 Jundzill, X. Bonifaciusz Stanislatw. Opisanio roślin litewskich wedlug ukladu Linneusza. w Wilnie, w drukarni X. X. Pijarów, 1791. 8.374 1. - * Eisl. 11 : il). 181 J. 8.333 p., praef., ind. Bibl. E. Meyer. (Synopsis plantar'um Magni Ducatus Lithuaniae sponte crescentium, secundun systema Linnaei.)

4987 Poczatki Hotaniki, fyzyologia roślin, nauka wyrazów. W Warszawie 1804 . II voll. $8.113,112$ 1.- Ell Il: W Wilnie 4818.8. (Elementa hotanices, physiologia et terminnlogia plantarum.)

4988 Index plantarum horti botanici universitatis Vilnensis. Vilna 4814.8. - Appendix: Villae 1845.8 .6 p. Scb.

4989* Jung, Georg Sebastian. Kovoounitoy seu malum aureum, h. e. Cydonii collectio, decorticatio, enucleatio et praeparatio physicomedica. Vindobonae $1673.8 .268 \mathrm{p}$.

4950 * Jung, Joachim, latine Jungius. Doxoscopiae plyysicae minores, sive Isagoge phy'sica doxoscopica: in qua praecipuae opiniones, in physica passim receptae, breviter quidem, sed accuratissime examinantur. Ex recensione el distinctiono $\mathbf{L}$. F. II. (i. e. Martini Forgetii Hamburgensis), cujus annotationes quaedam accedunt. Hamburgi, typ. Pfuilfer. 1669. 4. Alphab. 3. playg. 12 et 16

In sectione tertia partis seculdate agit de plantis; ad calcem operis notas in llane sectionem fecit edtor. Doxoscopias autem minores editor vneavit, "quia opiniones plysicae in hoc opere breviter, in exercitationibus vero, partim in oymasio ad disputandum propositis, partim nou propusitis, cepte noit impressis, prolixius ab pretore considepatae fuerint, o Has post Fogelii mortem Jo. V'agetius titule Doxoscopiarmm physicarum mojormm edero constituerat, seil titulo Doxoscopiarnm physicarnm mojormm edero constituerat, sel

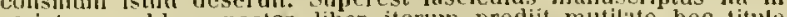
scriptis. - Idem naster liber irerum prodito moto "uitioni duo Jungii seripta hucusque inedita, ilarmonica scilicet et Jsagoge pliytoscripica.
4991" Jung, Joachim, latine Junius. Jsagoge phytoscopica, ut ab ipso privatis in collegiis auditoribus solita fuit tradi. Ad exempla, yuae ipse auctor summa diligentia deprehendebatur revidisse ("1 multis locis sua manu locupletasse, accurate expressa. Jecensente Jo. l'itgetio. Ilamburgi, sumtibus Testamenti Jungiani. (1678). 4. (39 foll.) Bibl. E. Meyer.

4992* — Opuscula hotanico-physica (nempe Isagoge ply.tuseojica et de plantis doxoscopiae physicae minores) ex receusiune of distinctione Martini Fogetu et Jannis I"agetii. Accedit Josepui de Aromutariis Epistola de generatione plantarum e seminibus. Coburgi, Otto. 1747.4. 183 p.,praef.

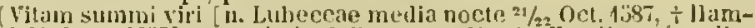
burgi 23 Sept. 1637$\}$ prieprimis delinearnnt Martin Fogelius, ijus discipnlus, in lihro Nr. 3266 a me laudato, cujus editio princeps prodit Hlanburgi jpso Jungii mortis anno. - $J$. II. vun seelen in libru: Athe-

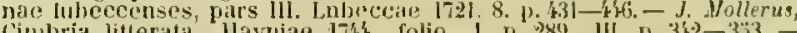
Cimbria litterata, llavniae 17k folio. 1. p. 284 . III. D. 362-3.33. Boehmer in Vitis Prof. llelmstarliensium p. 3s. - Strieder, Grundlage zu eincr llessischen Golelnten - und schriftsteller-Geschichte Yi. p. $399^{\circ}$ - Fo:3. - Paul Dielerich Giseke, De meritis Jlamburgensium in historiam Haturalem. D. llamburgi 1791. 4. - G. E. Guhruner, De Joachimo Jungto commentatio historieo-literaria. Tratislaviac 18'45, 8. - Ilenschel, Joctchim Jungius, der Baco der Deutschen, im Janns 18k7. 13. 812-822. Inter schedas Jungit ineditas, quare in bibliotheca publica llamburgensi asservantur fasciculus cliria de vita Jungün inscriptus laue quae-

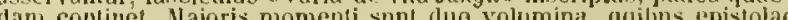

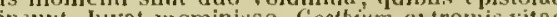
(n)

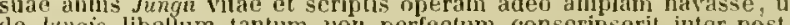

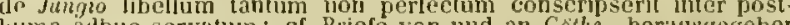

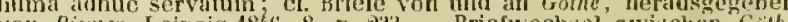
vint Riemer. Leipzig 184ti. 8. p. 233. Friefwechsel zwischen Güthe

$4993^{*}$ Jung, IV. Flora des Harzogthums Nassau oder Verzeichniss der im Herzogthum Nassau wiklwachsenden Gewächse, zugleichı ein Leitfaden beim Unterricht auf Gymnasien. Hadanar und Weilburg 1832. 8. $x \times 1 v, 524$ p. $(21 / 3$ th. $)$

499:' * Jungck, Christian Ludwig. Observationes botanicas in Floram Halensem. 1). Halis Saxonum 1807.8.26 p.

4996* Jungermann, Ludwig. Catalogus plantarum quae cirea Altorfium norieum et vicinis quihusdam locis, recensitus a Casp. Hofmanno. Altorfi, apud Conradum Agricolam. 1615.4. (64 p.)

4996 Cornucupitite Florae Giessensis proventu spontanearum stirpium cum Flora Alinrfiensi amice et amoene conspirantis, nti Lipsiensium, Wittebergensium, Jenensium quoque deliciis herbarum abundantis. Giessae, apud Nicolaum Hampclimm. 1623. 4. S.

$4.997 \div-$ Catalogus plantarum, quae in horto medico Altdorphino reperiuntur. Alldorphii, typ. Scherff. 1635.4 (20 p.) Bibl. Juss.

4998* Catalogus plantarum, quae in horto medico et agro Altdorphino reperiuntur. Auctns et denuo recensitus. Attorphii, typ. Scherff, 1646. S. (80 p.) Bibl. Mus. Senckenb.

$4999^{*}$ Junghannss, Karl Wilhelm. De Opio, analecta quaedam listorica proponens. D. Lipsiae $1815.4 .25 \mathrm{p}$.

6000* (Junghanns, Philipp Kaspar.) Index plantarum horti botanici Ilalensis. Halae 1771.8. (32 p.)

$5001^{*}-$ lcones plantarum raviorum ad vitam impressae. CenIuria l. Halae 1787. folio. tab. col. 1 (Bulbocodium vernum) -68 .

5002* Jeones plantarum officinalium ad vitam impressae. Centuria J. Halae 178 7 . folio. tals. cul. 1 (Daphne Nlezereum) -37.

5003 * Junghuhn, Frant. Praenissa in Floram cryptogamicam Javae insulae. Fasc. J. continet coumerationem fungorum, quos in excursionilus per diversas Javae regiones hucusque observavil. (Batavia 1838.) 8. 86 p., 15 tab. col.

(Verh. ran het Batav. Gen. van hunsten en Wetenschappen. (Ivil Deel. Ill stuh.)

$3004^{*}$ Nova genera et species plantarum Florae javanicae. Jeiden $4840.8,35$ p., 1 lab.

("Tydsehrift voor mat. geschied. Deel VH.)

$5003^{*}$ _ Topographische und naturwissenschafliche Reisen durch Java. Für die liaiserl. Leopoldinische Akademie der Naturforscher zum Druck befördert und bevorwortet von Christion Goufried Nees qon Esenbeck. Nagdeburg 1845.8. vi, 518 p. und Allas in querfolio: is tab., 2 llöhenkarten. ( 6 th.)

$5006^{*}$ _ Die Battalánder auf Sumatra. Aus dem bollăndischen Original ubersetzt vom Verfasser. Berlin 1847. 2 Theile. 8. - I: Chorographie. vil, 300 p., 40 tab. - II: Volkerkunde. $x, 388$ p., 9 tab.

$500 \%$ Jussieu, Adrien de. Description d'un genre nouveau nommé lcacina (Mem. de la soc. d'hist. nat. de paris 1821. 4. p. 17t-178, I tab.) 
5008* Jussieu, Adrien de. Considérations sur la famille des Euphorbiacúes.

(Mémoires du Muséum d'hist. nal. tome X. 1823. 4. 39 p.)

$5009+-$ Revue des genres et tes especes de la famille des Ternstroemiacies, d'aprís les ouvrages les plus recents.

(Extrait cles Aunales des sc. nat. tone 11. 1824. 8. p. 270-281.)

$5010 t-$ Noto sur le genre Francoa.

(Extrait des Ann. des sc. nat. tome 111. 182't. 8. p. 192-199, 1 tab.)

$5011^{*}$ De Euphorbiacearum generibus medicisque earumdem virilus tentamen. Parisiis 1824. 4. 118 p., 18 tab).

$5012^{*}$ Monographie du genre Phebalium. (Paris 1825.) 4. 13 p., 3 tab.

(Extrail du tome ll. des Memoires to la soc. d'bist. nat. de Paris.)

$5013^{*}$ - Mémoires sur les Rutacées ou considérations sur ce groupe de plantes, suivies de l'exposition des genres qui les cumposent. Paris 1825. 4, 160 p. 16 tal. (sign. 14-29.) (15 fr.)

(Extrait des Mém. du Muséum d'hist. nat. tome Xil.)

5014 - Nèmoires sur la groupe des Méliacúes. (Paris 1830.) 4. 152 p., 12 tàb., 1 plan sur la distriluution géographligue.)

(Exirait des Mém. du Musén d'hist. nat. tome XIX. p. $133-30 \%$.)

$5015 \%+$ Note sur l'Oncostemum, nouveau genre do la fanille des Ardisiaces (Paris 1830.) 4. 5 p., 1 tab.

(Extrait des Mémoires du Musceun d'histoire naturelle, tome XIX. p. $133-137$. $5016+\frac{}{8.26 \mathrm{p.}, 2}$ tabservations sur quelques plantes du Chili. (Paris 4831. )

$5017^{*} \quad$ (Extrail des dnnales des se. nat. 1831.)

1839.) 4. $19 \mathrm{j}$., 1 tab.

(Evtr. des Comptes rendus des Séances de l'Aeadémie des sciences, it Juillet Is39.)

$3018+\longrightarrow$ Malpighiacearum synopsis, monographiae mox edendae Prodromus. (Paris 1840.) $8.63 \mathrm{p}$.

(Evirait des Annales des sciences nat. avril 18'

$3019+\ldots$ Note sur les fleurs monstrueuses d'une espece dEr b le (Acer laciniosum.) (Paris 4844.) 8. 4 3., 1 tab.

(Extrait tes Annales des se. nat. Juin 18't.)

$5020^{*}$ _ Monographie des Malpighiaces ou exposition des caractères de cette famille des plantes, des genres et espèces qui la composent. Paris 1843. 4. 151,368 p, 23 tab, pro parte col.

$5021^{*}-$ Butanique. (Cuurs élémentaire d'bistoire naturelle à l'usage des collìges et des maisons d'éducation, rédigé conformément au Programme de l'université du 44 Sept. 1840 , par A. de Jussieu, Hilne-Edwoards et Beudant.) Paris (1844). 8. Deux parties: 728 p., c. icon. xylogr. i. t. ( $6 \mathrm{fr}$.)

(C'est la seconde edition un pen changé de la premiere partie, qui parut deja em 1813 , et qui contenait $276 \mathrm{p}$.; el la premjerr de la seconde partic. Une troisieme édition est impriméc en 18's; ; elle est en peu abregie et contient ru, 562 p. et 688 figures on bois.n) Adr. de Jussieu.

* germanice: Elementarkurs der Botanik, ahgefasst nach dem Programm der Loiversitat yon Paris vom 1k. Sepi. 1810. Aus den Franzosischen (fer ersten Ausgabe) mit Aomerkungen und Zusátzen ron 11. NI. Schmidt - Goebel und Jokann I'fund. J'ras 18't. 8. 239 p., 4 tab. $(11 / \mathrm{s}, \mathrm{h}$.

* germanice: Beudant, Milne-Edwards und A. von Jussieu, Naturgeschichte der drei Reiche. Dritte Antheilung: Botanik, ubersetzt ron G. Kissling. Stuttgart 18t5. Qr. 8. Tht p. (11/\% $\left.h_{\text {. }}\right)$ - Kleine Ausgabe: ib.

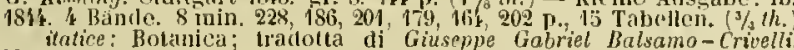
Milano 18i6. 8.

$5022+\div$ Note sur le genre Napoleona Pal. Beauv.

(Amnales des se. nat. Oet. 184' 4. p. 202-229., 1 tab.)

Fitrit Gégraphie botanique. Paris 1845.8. $32 \mathrm{p}$.

(Extrait du Dictionnaire universel d'histoire naturelle.)

$5024 \div$ Jussieu, Antoine de. Discours sur le progrès de la butanique an jardin royal de Paris, suivi d'une introduclion a la connaissance des plantes, prononcéz à l'ouverture des demonstrations publiques le 31 Nay 1718. Paris, Ganeau. 1718.4.24 p.

5023 Dissertatio de analogia inter plantas el animalia. Londini 1721. 4. 0

$5026 *$ Traité des vertus des plantes. Ouvrago posthume do Mr. Antoine de Jussieu, édité et augmeoté par Gandoger de Foigny. Nancy, Leclerc. 1771. 8. xxxvi, 412 p. - Paris, chez Merlin. 1772. 8 . (est eadem impressio.)

5027 Eloge do M. Fagon, avec l'histoire du jardin royal de Paris, et une intruduction à la botanique. Paris 1718.4. a.

$5028 \div$ Jussieu, Antoine Laurent de, pr. An inveteratis alvi fluxibus Simarouba? D. ( 30 Jan. 1772.) Parisiis, typ. Quillau. 1772. 4. 4 p.
$5029^{*}$ Jussieu, Antoine Latrent de. Genera plantarum secundum ordsnes naturales disjosita, juxta methodum in horto regio Parisiensi exaratam anno 1774. Parisiis, apud Ilerissant et IBarrois. 1789. 8. 24, Lxxil, 495 p. - * Reimpressiu: Genera plantarum secundum orlioes naturales disposita, juxta metlsodum in horto regio Parisiensi exaratam anno 1774. Excudi curavit notisque auxit l'aulus Usters. Turici, Ziegler. 1791 . 8. Lxxix, $526 \mathrm{p}$.

$5030 \div$ Principes de la méthode naturelle des végétaux. Paris 1824.8.51 p. (1 fr. 75 c.)

(Extrait du vol. III. du Dicl, des sc. nat.)

$5031+-$ Introductio in historiam plantarum. Introductioois olin. generibus platıtarum praemissac editio altera posthuma, aucta et maxima parte nova, (edidit Adrien de Jussieu.) (Paris, typ. Renonard.) s. a. s. $111 \mathrm{p}$.

\section{Mémoires de botanique de Antoine Laurent de Jussien:}

("Tous ces mémoires, dont seulement ceux sur les Rubiacees of les Paronychiées sont tires it part, sont axtraits do la collection des Mémoires el des Annales du Musenos, dont ils portent la pagination. ils sont rangés ici non par ordre de publieation, mais par ordse de matière, savoir: d'ahortl les mémoires géntéraux, "fui tratent de plusieurs fanilles a la fois; puis les meinoires particuliers sur certains familles ou certains genriss, clisposés d'apres la série publiée par 11. Je Jussien dans jo blémens do hotanique de M. Mirbel; cufin de notes sur certilins points de syllonymic etc:s) Adrien de Jussieut.

$5032+$ Exposition ('nu nouvel ordre des plantes, adopté dans les démonstrations du jardin royal. (Mém, de l'Acad. des sc. 1774. p. $175-197$.

3033t - Némoires sur les caracteres généraux de familles tirés de graines et confirmés ou rectifiés par les observations de Gactuer.

Premier mémoire: Aristolochiées-Plumbaginées. (Ann. V. 1904.)

Supplément. (Ann. VIl, 1806.)

Second mémoire: Monopétales hypogynes. (Ann. V. 1804.)

Troisieme mémoire: Mosopétales perigynes. (Ann. V. 1804.)

Quatrieme menoire: Nonopetales epigynes à antheres reunies.

Première paric. (Ann. VI. 1805 .)

Cincuieme mimoire: - 1)cuxieme partie. (Ann. Vll. 4806.)

Sixième mémoire: - Troisjème partic. (Ann. VHul. 1806.)

Septieme mémoire: Monopétales epigynes à anthères distinctes.

(Ann. $\mathbf{X}, 1807$. )

Huitième mémoire: Caprifoliées - Loranthées. (Ann. Xll. 1808.)

Neuviène mémoire: Araliacées - Ombelliferes. (Ann. XVI. 1810.)

bixième mémoire: Renonculacées - Malpighiacées. (Ann. XVIII.

1811.)

Onziùne mémoirn: llypericées - Guttiferes. (Ann. XX. 1830.)

Douzieme mémoire: Aurantiacées - Théacẻes. (Mim. 1l. 1815.)

Treizième múmoire: Première partie: Hcliacées - Geraniacees

(Ném. III. 1817.)

Treiziène mémoire: Deuxiène partie: Meliacées - Tiliacées. (Ním. V. 1819. )

503 t trancher à diverses familles comules:

Prenier: Primulacées - Rhinanthées - Acanthées - Jasminés: - Verbenacées - Labiées - Personées. (AnI. XIV. 1809.)

Deuxiéme: Solanées - Borraginées - Convolvulacées - Polemoniacées - Bignoniées - Gentianées - Apocinées - Sapotécs Ardisiacées. (Ann. XV. 1810.)

$5035 \%$ - Némoire sur la réunion de plusieurs genres de plantes en un seul dans la famille des Laurinées. (Ann. Vl. 1805.)

$5036+\longrightarrow$ Observations sur la famille des Amarantacées. (Ano. 11. 1803$.

ร037† Observations sur la famille des Nyctaginées. (Anu. Il. 1803.)

$5038+$ Mémoire sur le Dicliptera et le Blechum, genres nouveaux de plantes composés de plusieurs espèces auparavant reunies de Justicia. (Ann. IX. 1807.)

$5039 \div$ Observations sur la famille des Verbenacées. (Ann. VII. 1806.)

3040t- Sur le Curanga, geure nouvean de plantes de la famille des Personées. (Ann. IX. 1S07.)

$50.1 \%$ Mémoire sur le genre Phelipaca de Thunberg et sur d'autres plantes qui portent le mème nom. (Ano. Xil. I80s.)

5042 - Mimoire sur le Cantua, genre de plantes de la famille des Pulemonices. (Aun. LIJ. IS04.) 
:0437 Jussieu, Antoine Lamrent de. Sur le Solanum cornutum du Meaique. (Aill. III. 1804.)

$3019 \div$ - Sur le Petunia, genro noureau de la famille des Solanees. (Ann. Il. 1803.)

"jofi" - Sur la plante nomme par les botanistes Erica Dahoecia et sur la nicessité de la rapperter a mu antre genre el a une ante fanille. (Anu. I 1802.)

$: 30466^{*}$ Mémnire sur los Lobeliacees er les Stylidiees, nouvelles familles de planles. (Amn. X'lJu. 1811.)

:04.7t Mémoire sur l'Acicarpha et Je Boopis, denx neures nouveanx de plantes de la famile des Cinaroceplasles. (Ann. II. 1803.)

$3048 \div$ - Nimoire sur le hileinia et l'Actinea, deux genres nouveaux de jlantes de la famille des Corymbifires. (Anm. Il. 1803.)

$3049 \div-$ Sur Je Gymnostyles, genre nouveau de la famille des Corymbiferes. (Amm. 1Y. 1804.)

$3050 t$ - Memoire sur l'Opercularia, geure de plantes voisin de la fauille des Dipsacées. (Ann. IV. 1804.)

$\mathrm{j03}$ t - Sur la famille des plantes Rubincées. (Hím. VI. 1820. )

$30: 526$ Memoire sur quelques nouvelles especes d'Anémones. (An1. III. 1804.)

3053 t - Némoire sur le Paullinia, grenre de plantes de la familfe des Sapindacces. (Ann. IV. 1804.)

0031 - Memoire sur le Helicocca el quelques especes nouvelles the ce genre des plantes. (Mém. III. 1817.)

j0:3it - Sur quelques especes da genre Hyperienm. (Ann. HII. 1804.)

5056t - Mémuire sur une nouvelle espece Jo Marceravia et sur Ies aflinités botanirues de ce genre. (Inn. XlY. 1809.)

:057\% - Memoire sur to Grewia, genre de plantes de la famille des Tiliacées. (Ann. IV. 1804.)

:058\% - Némoire sur la famille nouvelle des Polygakes. (Mém. I 1815.)

$3059 t$ Examen de la famille des Renoneules. (Mém. de J'Acad. (les sc. 1773. 1). 214-240.)

\%060\%- Note sur le genre Hydropityon de Gaertner fils et sur ses affinites avef d'autres genfes. (Amn. X. 1807.)

6.061t- Sur la nouvelle fanille des Paronychiées (Mém. Il. 1S 15.)

$3062+$ Mémoire sur le Loasa, genre de planles qui devra constitner avec le Mentzeli: une nouvelle famille. (Am. V. 1804.)

$3063 \div-$ OJserrations sur la famille des plantes Onagraires. (ADII. III. 1\$04.)

$3064 t$ Mémoires sur les Passillories:

P'remier menoire: Snr quelques nouvelles espèces du genre Passillore, et sur la necessite d'établir une fumille des l'nssiforces. (Ан1. T1. 1805.)

Secoul mémoire: Sur la famille des Passillorees et particulièrement sur quelques usjeces nouvelles du genre Taesonia. (Anu. VI. 1803.)

$3065 \div$ Mimoire sur les Monimiées, nouvel ordre des plantes. (Ann. XIV. 1809.)

$3060^{\circ}-$ Sny quelipues genres de la Flore de Cochinchina de Lonreiro.

Premiere note: Lubletia. Aglaia. Citta. Knema. (Ann. X]. 1808.)

Deuxicme note: Tetrarlium. Gonus. Limacia. (Anu. XI. JS08.)

Troisieme note: Adenoulus. Reflexions sur l'klaeocarpus. Gemella.

(Ann. X). 1808.)

Quatrième note: Snoma. (Ann. XI. 1808.)

Cinpuiène note: Nephroia. Pselium. Thilachium. (Ann.XII. 1808)

sixieme note: Nelodornm lesmos. Note sur les genres de la famille des Anonaces. (Ann, XVI. 1810.)

Sejtième note: Pliyshinm. (Amm. IX. 1807.)

.067t - Note sur le calice el la corolle. (Ann. XIX, 1812.)

"3068t- Extrait diun Mémoire de Ml. Cusson sur les plantes ombellifères. (Histoire de la société royale de médecine. 1782-1753.)

$3069 \%$ Jussieu, Bernard de, pr. Quaestio medica, au compar animantium et vegetantium perspiratio? l'arisiis, tyj). Quillau. 1777. 4.7 p.

(Proponelat Christophe Nicolas de Jussieu.)
(Bernard de Jassiea de arboribus, palmis, Loto rubra et cocrulea ete. divinationem adeldit insigni operi Joannis Jacobi liarthetemy, iuud inseribitur: Explication de la mosaique de Palestrme. Paris. Guérin at Litlour. ir60 is. cun tabuld.)
50706 Jussieu, Christophle de. Nonveau trate de la theriantue. Trevour chez liticnus Ganeau. 1708. 12. (16) $174 \mathrm{j}$., ind. Brbl. Juss.

5071 "Justander, Johan Gustaf. Olsservationes historian jfantarum fenuicarum illustrantes. D. Aboae 1791.4. 16 p.

5072 " Justi, Karl Wilhelm. De Thymelaea Alezereo. ejus viriluss. nsurue medico. 1). Narburgi 1798. 8.64 1.

:073) Justice, James. The British gardener's director. Eduburald 1764 8.443 j. B.

\section{$\mathbf{z}$}

507: Kaasböl, Wilarius Christoph. J)arhoril,as sodomacis 1). (llafuiae) 1705. 1. $12 \mathrm{j}$. B.

$5075^{*}$ Kabath, Mermann. Flara der L'mgegend ron Cleiwitz, mit Berncksichtigung der geognostischen, Bodrn - und Ilohenverhalunisse. Gleiwitz $1846.8 .210 \mathrm{j}$. (1 th.)

6070 "Kachler, Johann. Encyclopadtisches Pfanzenwörterbuch aller einheimischen und fremulen Vegetatsilien, welche sich dareh Nutzen, Schonheit, Seltenheit oder sonstige Gigenthümlichkeiten Jesonders auszcichnen etc. Wien 1829. II voll. gr. 8. $-1: A-1$.. 296 p. Il: $\mathrm{N}-\mathrm{Z} . \mathrm{v}[\mathrm{ll}, 336 \mathrm{p}$. ( $5 \mathrm{th}$. - heral)gesetzt $2 \mathrm{lh}$.)

$5077^{\circ}$ - Grondriss der Pllanzenhande, in Gestalt eines Wurterbuchis der Jotanischen Sprache. Wien 1830, gr. S. xu, $302 \mathrm{p}$., Titbeflen. $\left(2 \frac{1}{2}\right.$ th. - Jerabgesetzt $2 / 3$ th.

$5078 *$ Aj,hal,etis ch-tabellariselt-scientifisches Sanenverzeicltniss. Wien 1839.8 . I , $205 \mathrm{j}$.

$5079^{*}$ Kaehnlein, Ulrich. Verzeichniss cingger nm Wïtenberg befindlichen lirauter. Wittenberg 1763. 8. (16 J.)

5080 Kaempfer, Engelbert. Decas miscellanearum observationum. D. Lngduoi Batavorum 1694. 4. H.

(Redit in fasciculis amoenitatum exoticarum.)

$5081^{*}$ - Amoenitatum exoticarum politico-physico-medicarum fasciculi $\mathrm{V}$, quibus continentur variae jelationes, observationes et (lescriptiones rerum persicarum et ultorioris Asiae, multa attentione in peregrinationilus per universum Orientem collectae. Lemgoviac, typ. et imp. H. WT. Meyer. 1712. 4. 912 p., Jraef., ind, tal.

(Fascieulus Vl: Herbarii transgangetici specimen cum 500 iconibus interiit: maxima certe at in plegeque ris unquall reparaulis

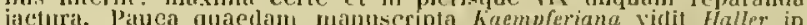
billiotheca (ineltingensi; majoris momatiti snut, quae in Mnseo britannico servantur, recensíta ajud AJurr, Annot. [1. 6-11.)

$5082^{*}$ —._. Geschichte und Besclrreilung von Japan, aus den Originalhandschriften des Verfassers herausgegeben von Chrstian Hrithetm Dohm. Lemgo 4777-1779. 2 Bande. 4. 310, 475 p. 45 tab. $(10 \mathrm{th}$.

anglice: The history of Janan, translated from the original manuscript by Joham kospar scheuchzer. Lonton 1728. II voll. fotio. 612, $7 \mathrm{~T}_{*}, 4 \mathrm{~s}$ tah. B.

"hollandice Be Resuldrying van Japan etc. nyt het Engelsch an

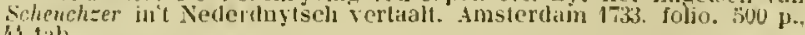
4 tath.

tyallice: llistoire niturelle, cisile ot ecelesiastique du Japon. A la

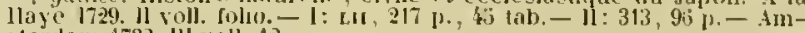
stertain 1732. III voll. 12.

$5083^{*}$ - Icones selectae plantarum, quas in Japonia collegit et Jelineavit Engelbertus Kaempfer; ex archetypis in Museo Lritannico asservatis (edidit Juseph Banks). Londini 1791. folio. 3 ]), 59 tah.

308: Kahler, lligand. Vita Euricii Cordi exposita. Rintelii 1744, 4 74 p. B.

5085* Kahleyss, Jatioh Gollfried Benjamin. De regetahiliun et animalium dilferentiis. D). IIalae $1802.8 .30 \mathrm{p}$.

$3086^{*}$ Kalchberg, Albert, Riller ron. Uelver die Natur, Entwickelungsund Eintheilungsweise der J'llanzenauswuchse. D. Wien 4898. 8. 39 p., 1 schiema.

5087 Kall, Abraham. Programma invitatorium ad promotionem P. Thorstensen. IJafniae 1775.8 .21 p. B.

(Contiset additiones at Halleri Bibliothecam botanicam.)

5088

Kall, Nicolaus Christoph. De duplici plantarum sexu Arabibus cognito Progranna I et II. Ilafniae 1789-1783. folio. Brannich. 
$5089^{*}$ Kalm, Matthias. Sciagraplia studii botanici. D. Aboae 1821. 4 . $20 \mathrm{r}$

$5090^{*}$ Kalm, Pehr. Wastgutha och Bahuslándsha Resi forrätad är 1742. Stockholm 1746. 8. 304 j., praef., ind., ic. xylogr. $5091-$ En Resa til Norra Ameriea. Stockluolin 1753-1761. 538 p. B.

- germanice: Beselireibung der Reise nach dem nordlichen Anerika. Uebersetzt von Johann Andreas Murray. Goltugen 1736-176'. 3 'Theite. 8. $\left(3^{1} / 2, h_{0}\right)$

gallice: Histoire naturelle et poltique de la Penștvanie. Traduit de lallemand (par de Surgy). Paris 1768. 12. a.

anglice: Travels into Forth America, transtated by J. R. Forster Farrington and London $1770-1771$. 111 voli. 8. $400,332,310$ p., lab. B. ('Tomus primus et paginae 101 priores tomi secundi editionis sueeallite omissae sunt in hac versione. ?

3092 En hort berattelse om nattirliga stallet nyttan samt skotsel af några wäxter hembragt frän Norra America. Stockiılın 1751 S. H.

\section{Pracside halmio dissertationes:}

зั093

- Om Amerihanska nafwerbatar. D. Abo 1753, 4. H. (Tractat de arte, qua harbari e cortice Betulie levissimas conficiunt naviculas, tquibus per rapiclissimns torrentes vehuntur.)

509 D. Åbo 1753. 4. 10 p. B.

3093

- Allmănna anmarkiningar wid en krydd-och tra-gårds anlaggande. D. $\Lambda$ bo $1754.4 .8 \mathrm{p}$. B.

5096

5097 anlagggande i Finland. D. Äbo 1754. 4. 12 p. B.

5098

- Possibilitas varia vegetahilia exotica fabricis nostris utilia in Finlandia colendi. D. Aloae 1754.4.11 p. B.

5099

$\$ 100$ 20 p. B. Adumbratio Florae. D. Aboae 1754.4. 28 p. B.

Om Caffé och de inhemska växter, som pläga brukas i des stalle. D. Åbo 1755.4.18 \%. B.

$5 \mathfrak{1 0 1}$ De praerogativis Finlandiae praecipue quoad plantas spontaneas in bellariis adhibitas. D. Aboae $1756.4 .22 \mathrm{p}$. B.

5102 Trän til háckar eller lefvande gúrdes-goardar beskrefne. D. Abo 1756. 4. 21 p. B.

5103 Anmarkuingar vidfrukt-träs planterande i Finland. D. Abo 1757. 4. 12 p. B.

necessariun. D. Aboae 1757. 4. $12 \mathrm{p}$. B.

nytta. D. A bo 1757.4 . $15 \%$. B.

$\$ 110$

i Orihvesi Sokn. D. Alo 1757. 4.23 p. B.

5111

.112

: 113

Omaspens egenskaper och nytta $i$ elen alimámna hushållningen. D. Abo 1759.4. 18 p. B.

5114 och nỵtta $\mathrm{i}$ den allmána lusbillningen. D. Abo 1759.4.53 p. B. Abo 1759. 4. 20 p. B. $1760.4 .23 \mathrm{p}$. B.

- $0 \mathrm{~m}_{\mathrm{b}}$ pyttan och nodvăndigheten af våra inhemska vaxter hanuande. D. Abo $1760.4 .15 \mathrm{p}$. B.

:1147 Praestantia plantarum indigenarum prac exoticis. D. Abo 1762.4 .43 P. B.

$5418 \longrightarrow$ Norra Anericauska fárge-ortes. D. Ảbo 4763. 4. 8 p. B.

5119 - Florae fennicae pars prior. D. Aboae 1765.4.10 p. B.

5120 Uthast til en blomstergàd af inliemska vaister. D. A 1766. 4. $15 \mathrm{p}$. B.

5121 Apple-trans aus och shotsel i Finland. D. 1-11. Âbo 1769. 4. 10, 14 p. B.

Pritzel, Thes. lit bot.
$5122 K_{1}$ Kalm Pehr. Beskrifning ufrer Eenens egenshaper och uylta. O. I -11. Abo 1770.4.34 p. B.

5123 Genera compendiosa plantarum fennicarum. D. Aboae 1771.8.32 p. B.

(Characteres essentiales ex editione decima Systematis naturae.

$5124 \longrightarrow$ Onı neconomistia nytlan af Manna-grás. D. Alıo 1772 4. 8 p. B

$5125^{\circ}$ - Beskifining ofver Swarta Winbärsbushars nỵtla i hushollongen. D. Abo $1772.4 .10 \mathrm{p}$. B.

3126 Om trán tjenliga til lefvande läehar uti hryddgărar $\mathrm{i}$ Fiuland. D. Abo 1775.4 .10 p. B.

3127 Om nyttan af llallon $\mathrm{i}$ hushålningen. D. Abo 1778. 4. 13 p. B.

อั128* Kaltschmied, Kuri Friedrich. Programma de Cieuta. Jenae 1768 4. $12 \%$.

๖199† Kamel, Georg Joseph, latine Camellus. Ilerbarum aliarumque stirpinm in insula Luzone Philippinatum primariâ nascentium icones ab auctore delineatae meditae, quarum syllabus in Joannis Raji llistorize plantarum tomo tertio. folio. 260 tab.

Plures praeterea descriptiones Kameli nondun editae inveniuntur in 1 luseo britannico, Manuser. Sloan. 1078 ef to81.) Bibl. Juss. et Deless.

$5130^{*}$ Kampen, Nicolas van, et fils. Traité des fleurs a oignons. ete. Harlem $1760.8,117$ j., 1 1ab.

$5431 \div$ - The dutel fiorist; or true method of managing all sorts of flowers with bullous roots. Ed. 11: London 1764. 8. 104 p., praef.

5132 Kannegiesser, $\boldsymbol{F} . \boldsymbol{A}$. Aurikelflora, nach der Natur gemalt. Acht Hefte. Dresden 1800-1802. gr. S. 192 tab. col. $(51 / 3$ th. $)$

5133 Die Arten der Rosen. Erstes lleft. Dresden 1805 . 4 $\left(1 \frac{1 / 3}{3}(h)\right.$

3134 Abbillungen der Levkoyen. Dresden 1807. 4. (1 th. 3135 den $1807.4 .(12 \%$ th.

Kaplinski, Jakob Joseph. De Digitali purpurea. D. Berolini 1820. $8.31 \mathrm{p}$.

$5137^{*}$ Kapp, Christian Erhard. Hotum humorum in plantis cum motu humorum in animalibus comparat. Lipsiae $1763.4 .24 \mathrm{p}$.

5138* Kappe, Ernst. Der kleine Botaniker, oder Anleitung, die vornelımsten Gattungen und Arten der nord- unt mitteldeutselien Flora nach eigner Anschanung selbst zu bestimmen. Meurs 1839. 19. viu. $51 \mathrm{p} .(1 / 6, t h)$

5139* Karcher, Johannes Eaptista. De Anetho. D. Argentorati 1734. 4. 22 p.

$5140^{*}$ Karelin, Geory, ot Johann Kirilow. Essumeratio plantarum it desertis Soncroriae orientalis et in jugo summarum alpium Alalan anno 1841 collectarum. (Mlosquae 1842.) 8.223 p.

(Ex scriptis eaes. soc. nat. scrut. Mose. seorsim impressa.

$5141^{*}$ Index plantarum anuo 1840 a cel. Karelin et Kirilow in regionibus altaicis et confinibus collectarum, quas societas imperialis naturae curiosorum Mosquensis pro mutua commutatione offer! Nosquae 1842.4. 8 p.

5142 Karpinskij, $A$. Краткая исторія изсльдованія изконас-

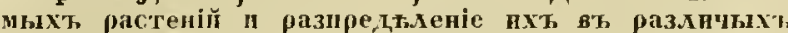
с.хояхт, зечной коры (А,. Броньяра). С. Петер6. 1829. Trautv.

5143 - Два письма Кассини о предметь ботанки и нользы нознапія ея. С. Ileтерб. 1836. Trautv.

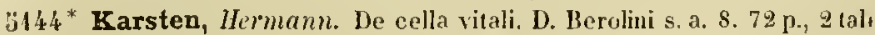

$5145 \div$ Kasthofer, Karl. Der Lehrerin Walde. Bern 1S2S - 1829. 2 Thle. 8. - 1: 1828. vir, 158 p., 17 tab. col. - II: 1829. 158 p., 7 tah. + gullice: Le guide dans les forets; par l'auteur me et $F$. L. Honney. Vevey 1830. 11 volt. 8. - 1: $\mathbf{x}, 256 \mathrm{p}$, is tab. $-11: 328 \mathrm{p}$. 7 tab.

$3146^{*}$ Katzer, Joseph. Systematische Uebersieht der officinellen Planzen, welche in der Oestreich'sehen Pharmacopoe enthalten sind. D Wien $1840.8 .1 \mathrm{v}, 94 \mathrm{p} .(2 / 3$ th. $)$

3147 Kaulfuss, Georg Friedrich. Enumeratio filicum, quas in itiner. eirea terram legii clar. Adulbertus de Chamisso adjectis in ommia harum plantarum genera permultasque species non satis cognitas vel novas animadversionibus. ljpsiae 1824 . 8. I, 300 p., 12 tah. $(13 / 4(h)$. 
\$148* Kaulfuss, Georg Friedrich. Erfalırungen aber das fieimen der Cliaren, nelıst andern lieiträgen zur Konntniss dieser Pflanzengattuug. Leipzig 1825. 8.92 p., i tals. ( $7 / 12$ h.

$5149^{*}$ - Das Wesen dor Farronkráuter, bosonders ihrer Frucluttheile, zugleich mit Rticksicht auf systematische Anordnung betrachtet, und nit einer Darstellung der Entwickelung der Pteris serrulata aus dem Simen begleitet. Erstellälfte. Leipzig 1827. 4. xxiv, $117 \mathrm{p}$. 1 tab. $\left(1 \frac{2}{3}\right.$ (h.)

$5150 *$ Kechelen, Georg Samuel. De genesi Camphorac ejusque rafiuatione. D. Alyentarati 1748.4. 30 p.

5151 Kecht, J. S. Versuch einer durels Erfalırung erprobten Methode, den Weinbau in Gárten und Weinbergen zu verbessern. Berlin 1814 8. $(3 / 8(h$.$) - Sechste Aullage, nach dem Todo des Verfassers her-$ ausgegeben von S. II. Kecht. Berlin 1838.8. 7 plag., 2 tab. $(5 / 6$ th.

31.32 Kehrer. Leitfaten fur den Untericist in der Botanik. Gymnasialprogramm. Heilloronis 1844.4 .28 p.

¿3133* Keibel, Johann Georg Ludwig. De corticis J'eruviani usu medico. D. Ilalae 1805.4. $28 \mathrm{p}$.

blš" Keilhorn, Georg Simon. De radicibus Seneya et Salab. D. Francofurti a/ V. $1765.4 .34 \mathrm{p}$.

3̈l3̈ * Eeith, Patrik. A system of pliysiological hotany; illustrated by nine engravings. London 1816 . II voll. $8 .-1: x_{2}, 478 \mathrm{p} ., 8$ tab. II : $526 \mathrm{p} .$, tab. $(1 \mathrm{l} .6 \mathrm{~s}$.

路6 - I botanical lexicon. London 1838. 8. (10s.6d.)

3157* Kelaart, Edward Frederik. l'Inra Calpensis. Contributions to the botany and topography of Gibraltar and its neighbourhood: with plan and views of the rock. London 1846. 8. xvII, 219 p., it tah. Bibl. Reg. Sax.

3158 Kelch, Wilhelm Golllieb. Flora modica borussica, sistens plantas officinales sponte vigentes. Regionsonti $1805.8 . x, 78 \mathrm{p}$.

$b 139^{*}$ Kellander, Daniel Pelerson. De seminibus. D. Lugduni Batavorum $1720.4 .14 \mathrm{p}$.

5160* Keller, Engelhardt. Der Wein uberhaupt und der Frankenwein insbesondre als Heilmitlel betrachtet. D. Würzburg $1838.8 .24 \mathrm{p}$.

5161 Kempe, Anders Pehrson. Den anatomerade Granen (suecice) Jamburg 1671. (1672.) 12. $122 \mathrm{p}$. Linn. germanice: Hamburg 1688. 12 . Afoeller.

(De libello rarissimo ef. Mlall. Bibl. bot. I. p. 50...)

3162* Kemper, Theodulos. De succino. D. Jenae 1682. 4. (22 foll.)

$5163+$ (Kent, Miss.) Sylvan sketches; or a compaojon to the Park and the shrubbery: with illustratinus from the works of the poets. Isy the author of the Flora domestica. London 1825. S. XLIv, $408 \mathrm{p}$ $(10 s .6 \mathrm{~d}$.

316 " Kentish, Richard. Experiments and observations, an a new species of bark, also a comparative view of the powers of the red and quilled hark, being an attempt towards a general analysis and compendious history of the genus of Cinchona. London 1784. 8. $123 \mathrm{p}$.

$3163 t$ (Kentmann, Theophilus.) Tahula locum et tempus quibus uberius plantae potissimum sfontaneae vigent et proveniunt, exprimons. Wittobergae, apud haoredes Samuelis Seelfisch. 1629. 4. (10 p.) Bibl. Reg. Par. - Lipsiae, 1yp. Bauer. 1659. 4. Rivin. - "impr. cum Joh. Duniet Mlajor Programmate ad rei herbariae cupidos. Kilonii 1667. 12. - "aucta a C. B. Valentini, et jinpr. cum ejus Tournefortio contracto. Francofurti a/AI. 1715. folio. 1 plag.

5166 K'Eogh, John. Botanologia universalis hibernica; or a general Irish herbal. Corke 1735.4 .1430 . B.

bl6it Ker, John Bellenden. On the genus Pancratium. London 1817. S. $22 \mathrm{p} ., 1 \mathrm{tab}$.

$5168+\longrightarrow$ On the genus Crinum. London 1817. 8. $16 \mathrm{p}$.

$5169 \div-$ A review of the genus Amaryllis. Losdon $1817.8 .29 \mathrm{p}$. 1 tab.

(Omues seorsim impressae ex Journal of science and the arts.)

5170 Strelitzia depieta, or eoloured figures of all the known species of the genus Strelitzia, from the drawings, by Francis Bauer, in the Banksian library. London 1818. folio. Fasc. I et II: tab. col. 1-8. Cat. Bibl. Radcliffe 0xon.

(lpse ego nihil praeter quatuar tabulas 1. 2. 3. 5. in biblintheca Musei botanici Vindobonensis vidi, supra jam $\mathrm{Nr}$. 275 recensitas. Texlus olnnino deerat.)
$517 I^{\circ}$ Ker, John Bellenden. Iridearunı gonera, cum ordinis charactere naturali, specierum enumeratione synonymisque. Bruxellis 1827. $8.158 \mathrm{p}$.

(Idem nnster, cui natale revera est nonien Gavler, autor eyt rmmium nescriptintum plantarum in Bo!anical Kegister annorum 1815 -182k, quae sigumm in calce nou gerunt, Gravi mentis perturhationo contactus, studiis botanicis alsdicavit.

alitt Kéralio, Louis Félix Guinement, Chevalier de. Collection do différens morceaux sur l'histoire, naturelle el civile des pays du nord et sur l'histoire naturelle en général. Paris 1763 . Il voll. 14. -1 : 431 p. $-11: 512$ p.

3̈173* Kerner, Joharn Simon. Ilandlungsproduhte aus dem Pflanzenreich. Sechs Hefte. Stuttgart 1781-1786. folio, 49 tah, col. text. $(13$ th. $)$

$3174 \div \div$ Beschreihung und Abbildung der Baume und Gestrâuche, welche in dem Ilerzoghthum Wirtemberg wild waclisen. Kirster Band. Heft 1-6. Stultgart 17S8. 4. 30,106 p., 47 tah. col. Bibl. Deless.

(Tomus primus prodiit sคy fasciculis inde ab anno $1 ; \times 3-17 \times 8$. Lego apud Heinsiun, Allg. Buclierlesicnn. II. p. 57s: a Neun llefle. $1780-1792 .(23,(h)$,

$51733^{*}-\ldots$ kleepflanze, Hedysarum gyrasıs. Programm. Stutgart 1784 4. 32 p., 1 tah.

$5176^{*}$ Giftige und essbare Schwamme, wolche sawohl im Herzogthum Wirtemberg als auch im ubrigen Teutscbland wild wachsen. Stuttgart 1786.8. vit, 68 p., 16 tab. col. (11/3 th.

3177 (-) Flora Stuttgardiensis, oder Verzeicluniss der um Stuttgardt wildwachsenden Pllanzen. Stuttgart 1786.8 .402 p. B.

$317 S^{*}$ Abbildung aller okonomischen Pflanzen. Figures dea plantes economiques. Stutgart 1786-1796. VIll voll. 4. 156, 44, 134 p., 800 tab. col. (240 ih.) Bibl. Jmp. Franc. et Deless.

Descriptiones tantum lingua germanica adsunt.]

$5179-$ Darstellung ausländischer Baume und Gesträuche, welche in Deutschland in Freicn ausdauern. Leipzig, Benj. Fleischer. 1796. Erster Band. Heft 1-4. 4. 60 tab. col. (20 th.)

$3180 \longrightarrow$ Deutschlauds Giftplanzen in Abbildungen mit Erklärungen. Erstes Heft. Hannover 1798. 4. ( $1 / 3$ (h.)

ä181 Beiträge zur Keuntniss der Waaren, welche in den deutschen Handel kommen. Zweillefte. Mannheim $1804.4 .(6 \% / 3$ th. Neue Auflage. Erstes und zweites Stück. Erfurt 1805. 4. 9 tab. col. (4 th.)

$5182^{*}$ - Hortus sempervirens, exllihens iconos plantarum solectiorum ruotquot ad vivorum exemplorum normam reddere licuit. Stuttgardiae, typ. Academiae Carolinae. (typ. Ilenrici Maentler in ultimo vol.). $1795-1830$. LXXi voll. folio eleph. 851 tab. col. manu pictao, 851 foll. Bibl. Imp. Franc. et Deless.

(Uiicum, quod vidi, completum evemplar tJorti sempervirentis, est in bibliotheca Delessertiatla, pretio $32,000 \mathrm{fr}$. gall. emtum. Volumon primum, in quo, ut umnibus insequentihus. duodecim insunt tabulae, a libraria Cottie pretin 1 s 812 th. divendebatur; pretium intogri operis $10,5131 / 2$ th. Quare "senupervorantem" haud insalso appellabat hortum meritissimus hibliothecarius fniperatoris Austriae. qui, guum anno 1826 tabulite voluminis L.N1Y taediosi operis fraudose it autore px prioribus repeterentur, fausta bac nixus occasione, has, Imperatore annuente noll solumt remisit, sed ctiam insequentes accipere omnino tepudiavit. Adsunt tantum 63 volumina cum 756 tabulis pietis. De ipso opere inutili cf. Gottinger Gelehrle Anzeigen 1798. I. \&4.

$5183 \div \div-$ Jcones plantarum selectiorum. Fasc. I. Stuitgartiae 180 . folio. Il foll., 4 lab. col. $\left(3 \frac{1}{2}\right.$ th. $)$ Bibl.cand.

Insunt: Erica ampullacea, Pasaillora perfoliala . Stapelia sororia. Butea frondosa, quase plantae ac tabulae jam in llorto sempervirente nccurrunt, cujus editionem inferiorem edere hoc fasciculo infaustum

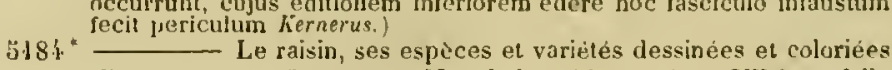
d'apress nature. Stuttgart et Mannheim $1803-1815$. Xil fasc. folio latiss. 144 tab. col., 12 foll. Bibl. Imp. Franc. et Deless.

(In exemplari Vindobonensi desideratur fasciculus ultimus.)

$5185^{*}-$ Les Melons. Stutgart 1810 . folio latiss. 4 foll. text, 3 foll tir. et dedic. scripta ot picta, 34 tab. splendide pictac. Bibl. Imp. Franc. et Detess.

$\$ 186^{*}$ - Genera plantarum selectarum specierum iconibus illustrata. Stuttgartiae et Nanuhemii is $11-1828$. XI voll. folio. 220 tab. col., 220 foll. Bibt. Imp. Franc.

$5187^{*}$ Kerstens, Johann Christian, pr. Primitiae Florae holsaticac. D. Kúliac 1780.8 . $112 \mathrm{p}$.

(Neque praeses, neque respondens Friedrich Heinrich lliggers hanc scripserunt dissertationem: autorem enim se prolitolut $\mathrm{dl}$. Georg Ifeinrich lieber.) 
$5188^{*}$ Kesselmeyer, Johann. De quorundam vegetabilium principio nutriente. D. Argentorati 1759.4. 3. p.

"italice: Dissertazinne sul trincipio nutritivo di alcuni vegetabili. Opuscoli scelti, Ii. 313 -33i.

$5189^{*}$ Kessler, Franz Anton. De Viola. D. Viudobonae 1763.8.55 p.

$5190^{*}$ KeyI, Benjamin Gollhilf Julius. De Secali cornuto ejusque vi in corpus humanum salubri et noxia. 1. Berolini $1823.8 .43 \mathrm{p}$.

$5491^{*}$ Keyser, Georg Adam. Ueber die Veredlung des Obsles und tie Veranderung der Olssthernstamme. Erfurt 1800 . \&. xxxu, $126 \mathrm{p}$. $(1 / 3$ th. $)$

$5192 \div$ Kickx, Jean. Flora Bruxellensis, exhioens eliaracteres generum el specierum plantarum circum Bruxellas crescentium, soeundum Limneum disposita cum synonymis auctorum; eui arditur Lexicon botanicon, in quo termini artis breviter exponuntur. Bruxellis 1812 . gr. $8 . \mathrm{m}, 348$ p. ( 7 fr.)

5193 et Quetelet. Relation d'un voyage, fait à la grotte de Ian. Bruxelles 1823, 4. Dumortier.

5195 Résumé du cours de minéralogie ot de botanique donné au Musée des sciences et lettres de Bruxelles. Bruxelles 1828 . 18 ( 2 fr. 50 e.) a

(Jean Kickx, Morrenio teste, obiit anno 1831.

5193 t Kickx, Jean, filius. Commentatio ad quaestionem botanicam: Detur accurata descriptio plantarum officinalium et venenatarum tum phanerogamarum tum cryptogamarum in agro lavaniensi sponto crescentium, addila earum historia etc. praenio ornata. Lovanii 1827. 4. xvi, $348 \mathrm{p}$.

$5196^{*}$ - Flore cryptogamique des environs de Louvain, on description des plantes eryptogames et agames yui croissent dans le Brabant et dans une partie de la jrovince d'Anvers. Bruxelles $1 \$ 35$. 8. $x \mathrm{~V}, 263,24 \mathrm{p}$.

$5197^{*}$ Notice sur quelques espèces peu connues de la Flore belge. Bruxelles 1833 . 8.10 p., 3 tab. col. (Tungi.)

$5198^{*}$ Netice sur quelques cliampignons du Nexique. Bruxelles 1841.8 .12 p., 2 tab. col.

$5199^{*}$ Recherches pour servir à la Flore crptogamique des Flandres. Trois centuries. Bruxelles $1840-1 \$ 46.4$. - ]: 1840. $46 \mathrm{p} .-$ II: $4843.46 \mathrm{p} .-11 \mathrm{I}: 4846.51 \mathrm{p}$.

$5200+$ Kielmeyer, Karl Friedrich von, pr. Observata quacdam de vegetatinne in regionibus alpinis. I. Tuebingae $1804,8,30 \mathrm{p}$. (Auctor: Karl Albert Kielmann.)

$5201 \div$ Observata quacdam de materierum quarundam oxyJatarum in germinationen efficientia pro diversa seminum rerumque externarum indole. D. Tuebingae 1805,4 . 32 p. (Auetor: Friedrick Schnurrer.

$5202 \div-$ Observationes quaedam chemicae de acredine nonnullorum vegetabilium. D. Tuebingae is05. 8.36 p. (Auctor: Ernst Gottlieb Steudel.)

$5203 \div$ De effectibus arsenici in varios organismos nec non de iudiciis quibusdam venefieii ab arsenico illati. D. Tuebingae 1808. 8. 78 p. (Auetor: Georg Friedrich Jaeger.)

520 * - Animadversiones de materiis nareoticis regui vegetabilis earumque ratione botaniea. D. Tuebingae $1808.8 .76 \mathrm{p}$ (Auetor: Jahann Heinrich Koestlin.)

$5203 \div$ Dissertatio inaunuralis hotanica, sistens cbaractcristicen et descriptiones deeadis rariorum plautarum horti academici Tubiugensis, in systematibus $\mathrm{L}$. vegetabiliun vel non consignatarum vel minus rite definitarum. D. Tuebingae 1814. 4. $18 \mathrm{p}$. (Auctor: Johann Kuspar Straub.)

Omnes has dissertationes, pro more in Academia Tubingensi antiquitus recepto, a Praeside conseriptas esse inter onnes constat.

$3206^{*}$ Kieser, Dielricl Georg. Aphorismen aus der Plysiologie der Pllanzen. Göttingen $1808.8 .150 \mathrm{p} .(2 / 3 \mathrm{lh}$.)

$3207^{*}$ Mémoire sur l'organisation des plantes, qui a remporté Io prix en 1812. Harlem (1812).4. xxi, 345 p., 22 tab.

ร208* Grundzüge der Anatomie der Pflanzen. Zum Gebrauch bei seinen Vorlesungen. Jena 1815. 8, xLIv, $264 \mathrm{p}, 6$ tab. $11 \frac{12 / 3}{l}(\mathrm{~h}$.)

5209 Kieseritzky, Gollfricd Wilhelm. De ratione, quae inter systema plantarum naturale earumque vires medicinales obtinet. D. Rigae 1826. Trautv.
$5210^{*}$ Kiesling, Christian Gollhilf. De succis plantarum. D. Lipsiae 1752. 4. $40 \mathrm{P}$

* germanice: Von den Saften der Pflanzell, in Boerner's Sammlungen aus der Naturgeseluichte 1. 238-306.

5211\% (Kiggelaer, Franciscus.) Horti Beaumontiani exoticarum plantarum eatalogus, exhibens plantarum minus cognitarum et rariorum nomina, quibus idem hortus a. d. 1690 instructus fuit. Hagae Comitis 4690. 8. 42 p., praef.

5212 Kihlmann, J. II. Kiffe. Stocklıolm 1828. 8.20 p. w

5243 Chinesiska Théet. Stockholm 1830. $8.30 \mathrm{p.} \mathrm{w}$

$52 \mathrm{I} / \mathrm{k}$ Kinderling, Andveas. De corpore animato vegetalili. D. IJelmstadii 1622. 4. H.

521:" Kindermann, Karl Gustar. De usu vini therapeutico. D. Lipsiae $1837.8 .52 \mathrm{p}$.

5216 * Kindscher, Friedrich Leopold Esluard. De Morphio. D. Berolini 1828. $8.23 \mathrm{l}$.

32 17* King, lhilipp I'. Narrative of a survey of the intertropieal and western coasts of Australia, performed between the vears 1818 and 1822; with an alpendix, containing various subjects relating to bydrograplyy and natural history. In two volunes, illustrated by plates, carts and woodeuts. London 4827. 8. - 1: xxxix, 454 P., 8 tab. - Il: vil, 637 p., 7 tab.

(Bo

5218* Kircher, Alhanasius. China monumentis qua sacris qua profanis nee non variis naturae et artis spectaculis illustrata. Amstelodami 1667. folio. 237 p., tab. aen. et fig. aeri inc gallice: ib. 1670. folin. B.

5219 Magires, sive de arte magnetica opus tripartitum. Romat 1641. Trew. - "Ed. Il: Coloniae Agrippinae 1643. 4. $797 \mathrm{p.}$, ic xylogr. i.t.

5220* Kirchmaier, Georg Kaspai, pr. De raris atque admirandis arberibus quibusdam. I. Wittenbergae 1660.4. (12 p.)

$5221^{*}$ De Coralio, J3alsamo et Saccharo. J). Wittenbergae 166 1. 4. (16 p)

5222 De Papyro veterum. D. Wittenbergae 1666.4.

$5223^{*}$ De Tribulis potissinum aquaticis ad Theophrastum Eresium, Dioscoridem et C. Plinium Secundum. D. Wittenbergae 1692. 4. $(16$ p.)

5224 - De cornnis. D. Wittenbergae 1693. 4. H.

5295 Coorg Ilolyh verneneries und vermelirtes dreifaches Gartenbuchlein, mit einer Vorrede und Appendice Georg Kaspar Kirchmaier's yon Seriptoribus hortorum und agrieulturae. Wittenberg 1693. S. Rivin.

$5226^{*}$ —— De veterum Celtarum Celia, Oelia et Zstho. Wittenbergae 1695. 4. ( 16 p.)

5227 De arte propagandi vites apud Francos usitata. 1) Vittenbergae 1697, 4. Rivin.

5228* Kirchmaier, Theodor. De virgula divinatrice. D. Wittebergae 1669 4. (24 p.)

5229* Kirchner, Ernst. Vebersicht der wissenschaftlichen Pllanzenkunde, nebst einem Ortsanzeiger der um Neustadt-Eberswalde wildwachsenden bemerkenswerthen Pflanzen. Berlin 1830. 8.66 p. (Fragment.) $(2 / 4 t h$. $)$

$5230^{*}$ Sehulbotanik oder kurze Naturgeschichte der Pflanzen überhaupt. Berlin 1831 . 8 . xu, 630 p., 2 tab. (1 $1 / 2$ lh.

$5231 \div$ Kirkpatrik, H. An aceount of the manner in which Potatoes are cultivated and preserved, ... with a description of a new variety of the Patatoe. Warrington $1796.8 .46 \mathrm{p}$.

$\$ 232$ Kirschleger, Friedrich. Liste des plantes les plus rares d'Alsace et des Vosges; impr. eum Aufschlaeger Description historirue et topographique des deux départemens du Rhin. Strasbourg 1896.8. Supplément.

$5233 \div$ Statistique de la Flore d'Alsace et des Vosges qui font partie de ectte province. Nublbausen 1831. 4. 118 (2) p $\left(2 \frac{2}{3}\right.$ lh. $)$

Prodiit annis 1831 el 1832 duobus faseiculis; incipit alter in p. 37. 5234* - Prodrome de la Flore d'Alsace. Strasbourg 1836. 8 svill, 252 p. (3 fr.)

$5235 \div-$ Appendice au Prodrome de la Flore d'Alsace. Strasbourg $1838.12 .30 \mathrm{p} .(75 \mathrm{c}$. 
6236t Kirschleger, Friedrich. Notice sur les violelles de la Vallée du Rhin, depuis Bale justu'a Mayence, des Vosges et de la Foréb noire. (Strassloourg 1840.) 4. 19 p., 3 lah

Extrait des Mém. de lil soc. du Muscium d'hist. nat. de Strasbourg IIt. 1 .

$3237 t$ Essai historique de triratologie végétale. Thèse. Straslourg 1845.4.7111.

5238 Notices botaniques. Strastjourg 1845. 4.

$3239^{*}$ - Essai sur les folioles carpiques ou carpidies dans les plantes angiespermes. These. Strasbourg $1846.8 .92 \mathrm{p}$.

$3240^{*}$ Kirsten, Andreas Jakob. De Areca Indorum. D. Altorfii 1739. 4. 38 p., $t$ tab.

is'il Kirsten, Georg. Exercitationum phytophilologicarum ex sacris, quarum secunda de Colochyntide prophetica et Coceo. Stetini 1654. 4. $s$.

:32t: Kirsten, Johann Jakob, pr. Exercilalio de Styrace. D. Altorfii 1736. 4. $32 \mathrm{p}$.

\$24:3" In Virgilii versum: "Alla ligustra cadunt, vaccinia nigra loguntur.m D. Altorfii 1764.4.

32.4t (Kitaibel, Paul.) Plantae horti botanici regiae universitatis Hungaricac. (Pesthini) 1809.8. - ib. 1812.8.26 p

421.5 Kite, Charles. An account of the medicinal effects of the resin of Acoroides resinifera, of yellow resin, from Bolany bay. In his Essays and olsservations, physiological and medical. London 1795.8 . p. 141 $-210 . \quad$ B.

$5216+$ Kittel, Marlin Balduin. Rapport sur la nouvelle disposition des mousses présentce par N. Walker-Arnoul, suivi de notes eritiques et d'additions qui completent ce travail et le mettent a la hauteur des comaissances actuelles. Paris 1826. 8. $144 \mathrm{p}$.

(Extrait du V. vol. des Jlém. de lit Société Linn. de Paris.)

$3247^{*}$ Taschenbuch der Flora Deutschlands zum hequemen Gebrauche auf bolanischen Excursionen. Nuruberg 1837. 12. CIV 74 p. $\left(1 \frac{2 / 3}{3}\right.$ th. $-{ }^{*} Z$ weite vermehrte und verbesserte Auflage. Numberg $1844.8 . \mathrm{cxx}, 1221$ p. (2 $/$. $)$

i2'48* Kittlitz, F. II. von. Vier und zwanzig Vegetationsausichten von Küstenlandern und Inseln des stillen Oceans. Aufgenommen in den Jahren 1827-1829 auf der Entdeckungsreise der Kais. Russischen Corvette Senjawin unter Capt. Lutke. (ln zwei Mappen.) Siegen und Wiesbaden $1844-1845.4 .70$ p., 2 f lab. $(2 / \mathrm{th}$.

3219 Kitto, John. Patestine. The plysical geography and natural history of the Holy Land. London 4841.8.

ij2:0 Klapmeier, Friedrich Johann. Voun hleebau und von der Verbindung desselben mir dem Getraidelau, mit Rucksicht auf die Landwirthschaft in kur- und Liefland. Rigat 1797. 2 Theile. 8. $\left(1 \frac{1 / 3}{3}\right.$ th.

$\because 2: 31$ " Klein, Dr. vou. Abhandlungen und Versuche uber die Ratanhia. Hit Beitragen von Renard, Juch, won Flacho, Karpe, Vogel und Christian Gmetin. Stuttgart 1819. 8. xxxvir, 170 p., 1 tab. col. (Krameria triandra.) ( 1 th.

32:52* KIein, Jakob Theodor. Fasciculus plantarun rariorum el exoticarum ex horto. Dantisci 1722. folio. ( 8 p.) Bibl. Reg. Berol.

$5253^{*}$ An Tithymaloides; frutescens; foliis Nerii Plum. nec Cacalia nee Gacaliastrum. Gedani 1730. 4.8 p., I tal.

$5235 \div$ - Fasciculus plantarum rariorum et exoticarum priori auctior 1724 ex herto Kleiniano, cum appendice 1726. 8. (32 p.) (Amus 172 false inscriptus est; laudantur libri ammorum $1739 \mathrm{et}$ $77 k 2$. fasciculus I. aune 1747 et 1768 . Gedani 1748. $8.28 \mathrm{p}$.

$52366^{*}$ - Dubia circa plantarum marinarum fabricam vermiculosam cum tribus tabulis. Accessit IItlii enucleata observatio microscopica decina el sexta. Petropoli 1760.4. 31 p., 3 tab.

:32:37* Kleiner, Johann. De medicamentis usitatis contra Ascarides, praecipue de semine cinde ejusque pracparatis. D. Turici $1843.8 .24 \mathrm{p}$.

52:38* Kleinknecht, Johann Jakob. De Scordio herlsa sehediasma posthumum, nunc antiquorum medicorum munumentis auctum et in lacem primum editum a Joanne Franco; impurssum cum hujus Momordicae descriptione. Ulmae, Bartholomaei. 1720, S, p. 41-76., prace, 1 tab.

5259 Klement, E. De Bignonia Catalpa. D. medico-ophhalmiatrica, adnexis listoriis morhorum. Pragae 1834, 8. 28 p.
$5260^{*}$ Klemm, Johann honrad. De Olea. 1). physico-philologica. Tuehingae 1679. 4. $16 \mathrm{p}$.

\$3261* Klett, Ciustav Theodor, und Hermamn Eberhard Friedrich Richter. Flora der phaneroganischen Gewache der ['mgegent von leipzig. Mit einem Forworte von Ludwig Reichenbach. Leipzin 1830. 2 Theile. 8. xsiv, 816 P., I naappá topogr. $\left(2 \frac{2}{3} / \mathrm{h}\right.$.)

$\$ 262$ Klier, Jakob. Anleitung zur hultur der Pelurgonien. Wien 1826 12. $(1 / 3 t h$.)

$5263^{*}$ - Anlcituny zur Kultur und Vermelirung der Rosa reclinata (Pyranidalrose), walche als Spalier-orler lleckenrose verwendet wird. etc. Wien $1843.8 .60 \mathrm{p} .(1 / 3 / \mathrm{h}$.)

5265 - Die hultur der Páonien, ilıre Vermelırung und Verviclfáltigung durch Samenban und Theilung ihrer kinollwurzehn. Wien 1845. 8. $7 \frac{1}{2}$ plag. $(1 / 2$ th. $)$

526:* Klingsohr, Johann Georg W'ihelm. De Geollroea inemi rjusque cortiec, medieanento anthelinintico. D. Erlangae 1788. 4. $311 \mathrm{p}$.

$3266^{*}$ Klink, August. Lactucae virosae et sative analysis cheniea. U. Kiliae $1820.4 .27 \mathrm{p}$.

3267* Klinkhardt, C. II. Betrachtung des Pflanzenreichs odar Èrhlärung des Wachsthums und der Ausbildung der Pflanzen. Telsst einem Auhange tiber die ursprüngliche Entstehung der Gewäclse. Berlin 1828. 8. vili, 257 p. $\left(1 \frac{1 / 3}{\text { th. }}\right)$

3268* Klinsmann, E. F. De Emetino et Ceplueli Ipecacuanlıa, Psychotria emetica, Richardsonia brasiliensi. D. Berolini 1823 . 8. $54 \mathrm{p}$.

$3269^{*}$ Klipstein, Johann Christian Golllob. De neclariis plantarun. D. Jenae 1784. 4. $18 \mathrm{p}$.

$5270^{*}$ (Klug, Friedrich.) Verzeichniss der Bucher der Gesellscliafe naturforschender Freunde in Berlin. Berlin 1828. 8, iv, 102 p.

5271 Kluk, Chrisloph. Roślin potrzebnycl, wygodnych osobliwie hrajowych, albo które w kraju użyteczne bydż ınoga, utrzłmanie, rozmuozenie i nígcie. w Warszawie, w elrukarni Xięzy Pijarow. $177 \%$ -1780 . HI voll. 8. Adamski. tura.)

(Plantarum necessariarum et utilium praccipne indigenarum cul-

6272 Dykeyonarz roślinny, w którym podlug uhladu Linneusza etc. (Lexicon botanieum sẹcundum Limaei systema concinnatum, ubi non solum indigenae, sylvestres, utiles vel noxiae verum etiam exoticae plantae, quae in patria cultura propagari possinl, describuntur. w Warszawie, w drukarni $\mathrm{X}$. Pijarow. 1786. III roll. 8. Adamski.

3273* Klupsch, J.S. De effectibus Opii analecla historica. D. Ilalae 1804. 4. $43 \mathrm{p}$

327. Knabe, Nichael. Ilorliponolegium, d. i. ein selır liebreich und auserlesen Obstgarten - und Peltzbucl, in drei Theilen. Nurnberg 1621. 4. Rivin.

5275 Knapp, $F . / I$. The botanical chart of british flowering plants and ferus: sliewing at one view their chief characteristics, generic and specific names, with the derivations, their localities, properties etc. Bath 1846.8 .192 p. $(6 s .6 \mathrm{~d}$. $)$

$5276^{*}$ Knapp, John Leonard. Gramina britamica, or representations of the British grasses, with remarks and oceasional descriptions. London 1804. 4. 119 tab. col., 148 foll, praef, ind. (8l. 8 s.) - Ed. Il: London 1840.4 . 118 tab. ( $3 l$. $16 . s$.)

(Autor obiit in oppido Alveston, Gloncestershire, die XXIX. April.

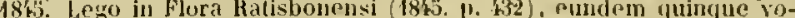
lumina liungorum britanuicorum edidisse, et diarium inscriptum: A Journal of a nituralist.)

$5277^{*}$ Knaut, Christian. Dissertatio praeliminaris, qua de variis doctrinam plautarum tradendi variorum methodis disseritur, veraque ac genuina methodus indigitatur. Halae 1705 . 4. 1 plag.

$3278^{*}$ Methodus plantarum genuina, qua notae characteristicae seu differentiae genericae tam summae quam subalternae ordine digeruntur et per tabulas quas vocant synopticas perspicue delineantur; in gratiam studiosae juventutis adornata atque edita. Lipsiae et llalae 1716. 8.267 p., iud.

5279* Knauth, Christoph. Enumeratio plantarum eirca Halam Saxnnum et in ejus vicinia ad trium fere milliariun spatium provenientium, cum carum synonymis, locis natalibus, ubi proveniunt, et tempore. quo Jorent, additis characteribus generum summormm atque sub-1ternorum, et indice copioso. Lipsiae, Lanchisch. 1687. $8.187 \mathrm{p}$, ind. 
$5280^{*}$ Knieriem, Johann Melchior. Spicilegium observationum de Arniea montana. D. Dorpati 1823.8.67 p.

5281* Knigge, Thomas. De Mentla Piperitide commentatio botanicomedica. Erlangae 1780.4 .40 p., 1 tals. $(1 / \mathrm{lh}$.

$5282 *$ Knight, Joseph. On the cultivation of the plants belonging to the natural order of Proteaceae, with their generic as well as specific characters and places, where they grow wild. London 1809.4 six 128 p., 1 tab. col.

$5283 \div$ Knight, Thomas fudrew. A treatise on the culture of the apple and pear, and on the manufacture of cider and perry, with an appendix. Ludlow 1797. 8. 162, xxul p. - †Ed. V: London 1818. 8. $177 \mathrm{p}$. , ind.

328' - Some doubts relative to the eflicacy of Mr. Forsyth's plaister in renovaling trees. London 1802. 4

628.3 - Pomona Herefordiensis; or a rlescriptive aecount of the cyder and perry fruits of Herfordshire. London 1814. 4. DC.

$3286^{\circ}$ Das Ganze der Ananaszueht, oder die verschiedenen Arten, wie man Ananas gezogen hat und noch zieht. Ilmenau 1825 8. 1 tab. $(2 / 3(h$.)

(Editio anglica milzi non innotnit.)

$5287 \%$ - A selection from the physiological and horticultural papers, published in the Transactions of the Royal and Horticultural Societies by the late Thomas Andrew Knight. Esq. President of the Horticultural Society of London. To which is prefixed (p. 1-77) a sketch of his life. London 1841 . 8. xiI, 379 1., 7 tal., effigies autoris. (15s.) Bibl. Juss.

(Editores sunt George Bertham et John Lindley.)

$3288 \div$ Knight, William. Outlines of botany, intended to accompany a series of practical demonstrations in that science, given in Marischal college and university. Aberdeen 4828.8.100 p

Ђ289* Kniphof, Johann Hieronymus. Lebendig Officinal ǩräuterbuch. Erfurt, Johann Hunke. Centuria I et I1. $1733-1734$. IV voll. folio.

6290 Examen suceedaneorum quorundam corticis peruviani felrrifugi. D. Eirfordiae 1747.4. H.

3291* — De gramine levidensi et praeeellentissimo. D. Erfordiae 1747. 4. 20 p.

¿292* Physikalische Untersuchung des Peltzes, welchen die Natur durch Fáulniss auf einigen Wiesen im Jahre 1752 horvorgebracht hat. Ėrlurt $1753.4 .24 \mathrm{p}$.

5293 Abhandlung vom Salat. Erfurt 1737, 4. H.

$329 \mathbf{k}^{*}$ Botanica in originali, seu Herbarium vivum in quo plantarum tan indigenarum quam exoticarum peculiari quadam onerosacpue enchiresi atramento impressorio olshuctarum nominibus suis ad methodum Linnaei et Ludwigii insignitarum elegantissima ectypa exhibentur opera et studio Joh. Godofr. Trampe, typographi, Halensis. Halae 1757-1764. folio. Xll Centuriae vel Il voll. 1254 tab. fuligine impr. pict. - Accedil : Index universalis, Halae, Tramıe. 1767. folio. $1 / \mathrm{p} .(36 \mathrm{th}$.

$329 \%$ KnobJoch, Tolias. Dissertatio physica de plantis. Wittebergae 1603.4. Desid. B.

5296 Kurlze Besclıreibung des Burekbernheimer Wildt-Bades, nebst einem kurtzen Verzeichniss derer Kriuter, so in und un den Wald gefunden werden, aufs neue revidirt und verhessert. Onoltzbach 1620. 12. Rivin.

i297* Knohll, Johann Paul. Klein Vitikulturbuchlein, d. i. Kurtzer Innbalt u. Unterricht des Weinbaues, wie solcher im Ober-Sáchsischen und meistens im Meissnischen Creysse, nach hiesiger Landes-Art geplleget und jedesnal bestellet werden soll, nach Anleitung der Clurfurstl. Sächsischen hierbei befindlichen Weingelutrģs-Constitution. Dresdeu, Melchior Berg. 1663.8.

$5298^{*}$ Knolle, Friedrich August Golllieb. Plantas venenatas umbelliferas indicat. Lipsiae 1771. 4. $19 \mathrm{p}$.

$5299 \div$ Knoop, Johann Hermann. Pomologia, dat is Besclurijuing en Afbeekdingen van de beste soorten van $A$ ppelen en Peereu. etc. Mlet eene voorreden van Jfartinet. Leeuwardeu $1758-1763$. 11 voll. folio. - J: 1758. 86 p., 20 tab. - Il: (Fructologie, Beschryving der Vrugtboomen.) 1763. 132 p.: 19 tab. - Amsterdam en Dordrecht 1790. folio. - 1: vill, 36 p., 20 tab. col. - Il: (Beschryving vau Vruch(boomen en Vruebten.) 70 p., 19 tab. col.

* germanice: Polnologia, d. i. Beschreilmngen und Abbildungen der heslen Sorteil der depfel und Birnen, welche in Holland, beutsch- land, Frankreich, England und anderwà'ts in Acthtung stolen, mol deswegen gehaut werden. Beschriehen, nach dem Lehen ahgebildet und mit ihren naturlichen Farhen erlenchtet. Ans dem Ilollandischen yon Creorg Leonhart Huth. Nurnberg 1760-1765. II volt. folio. - 1: 1760. 36 p., praef, ind., 8 tab. col. - 11 : 1766. 42 P., praef., ind., 12 tab. eol

gallice: Poinologie ou description des meilleures sortes de pommes et poires que lon estime el enllive leplus, soit aus Pais Bás, soi en Allemagne, en Franco, (nn Angleterre ete. explinuées et gravée Il'apres nature. Ansterdam 4768. Il voll. folio. - 1: 139 p., 20 tah. Il: (Fructologie,) $20 \%$ p., 19 tab.

5300 t Knoop, Johann Hermam. Dendrologia, of Beschryving van Plantagie-Gewassen, die men in ten tuinen cultiveert. Leeuwarden 1763 falio. 168 p. - $\div$ Amsterdam en Dordrecht 1790. folio. 87 p., ind.

$5301^{*}$ Khorr, Georg II'olfgang. Thesanrus rei herbariae hortensisque universalis exlibens figuras florum, herbarum, arborum, linticun aliarumgue plantarum prorsus novas et ad ipsos delineatas depictasque arehetypos nativis eoloribus etc. Nurnterg, bei G. W. Knorr's Erben. 1770-1772. 1l voll. folio, $-1: 1770,30,26,236,24,54$ 34 p. incl., (304) tal). col. - 11: 1772.130 p., ind., (102) tab. eol Eiann inscribilur: Algemeines Blumen - hrauter - Frucht- und Gartenbuch etc. Textum scripserunt Philipp Friedrich Gmelin u. Geors kudolph Boehmer. - Smb exemplaria tomi primi, in quorum titulo aunus 1760 legitur.

$5302^{*}$ Knowles, G. B., and Frederic Westcott. The Floral Cabinei and Magizine of exotic Botany. London 1537-1840. I1I voll. 4. -1 1837. vII, 94 p., tab. col. I-45. - Il: 1838.188 p., tab. col. 46-90. - III : 1840. 488 P., tab. col. 9I-137. (5l.8s.) Bibl. Reg. Berol.

$5303^{*}$ Knowles, Gilbert. Materia medica botanica; in qua symptomati variorum morborum describuntur, herbaeque iisdem depellendis aptissimae apponuntur; carminibus latinis hexametris. Londini, ty], Bowyer. 1723. 4. (14) 256 p., ind.

330': Knox, Richard. An historical relation of the island Ceylon. London 1684. Iolio. $189 \mathrm{p}$., lab. B.

(Fructus et plantas utiles describit, in partis primae capite IV et $v$, etiam aliguas nimus notas.

germanice: Cevlanische Reisebeschreibung, aus dem Englischet ins betutsche viberselzt. Leipzig 1689.4 . Hivin.

gallice: Relation du voyiog de lisle de Ceylan. Amsterdam 1602 Il voll. 8. Rivin.

5303 Knyf, Irillem Jan. Goylandiae libri duo, seu vera ejusdem regionis descriptio historica, nec non herbarum omnium in eadem region sponte nascentium cum earum viribus brevis enarratio. Ansteledami 1621.4 . s.

$3306^{*}$ Koch, Johann Friedrich Wilhelm. Botanisches Ilandbuch zuı Selbstunterricht lü deutsche Lieblaber der Pflanzenkunde uberhaupt, und für Gartenfreunde, Apotheher, Oehonomen und Forstmänner insbesondere. Magdeburg 1797-1798. 2 Bảnde. 8. ${ }^{*}$ Ed. 1l. ib. 180 S, 3 Bde. 8. - ${ }^{*}$ Dritte ganz umgearbeitete Auflage. Magdeburg 1824-1826. 3 Bande. 8. - J: 1824. svi, 125, vu, 535 p. - II: 1826.189 p. - III: 1824.211 p., 2 tab. (47/12 th.)

$5307^{*}$ Koch, Karl. Monographia generis Veronicae. D. Wirceburgi 183 : $8.36 \mathrm{p}$.

5308* Koch, Karl Heinrich Emanuel. Das naturliche System des Pllanzenreichs nachgewiesen in der flora von Jena. Erste und zweite Ahtheilung. Jena 1839.8. iv, 179 p. $\left(1 \frac{1}{6}\right.$ th. $)$

$5309^{*}$ Reise durch Russland nach dem kaukasischen Jshlimu in den Jahren 1836,1837 und 1838. Stuttgart und Tubingen 1842 -1843. 2 Bande. 8. - I: 1842. xu, 542 p. - II : 1843. xu, 339 1. $(51 / 6 t h$.)

$5310^{*} \longrightarrow$ Wanderungen im Oriente waltrend der Jahre 1843 und 1544. Erster Band: Reise langs der Donau nach Konstantinopel und nach Trebisond. Weimar 4846. gr. 8. $x, 450 \mathrm{p}$. ( 2 th. $)-$ Zweiter Band: Reise im pontischen Gebirge und in turkischen Armenien. Weimar 1846. gr. 8. iv, $480 \mathrm{p}$. $(2 \%$ th. $)$

5311* Koch, Wilhelm Daniel Joseph, et J. B. Ziz. Catalogus plantarum, yuas in ditione Florae Palatinalus legerumt, in amicorum usum conscriptus. Mlanerogamia. Moguntiae is 14. 8.24 p.

$5312^{*}$ —De Salicibus europaeis commentatio. Erlangae 1828. 8. $64 \mathrm{p} .$, ind. $(1 / 3 / h$.

$5313^{*}$ - De plantis labiatis. Programma. Erlangae 1833.4. 15 p. $5314^{*} \longrightarrow$ Synopsis Florae gemanicae et helvelicae, exhibens stirpes planerogamas rite cognitas, quae in Germania, IIelvetia, Borussia et Istria sponte crescunt atque in hominum usum copiosius coluntur, secundum systema Candolleanum digestas, praemissa ge- 
norum dispositione, secundum classes et ordines systematis Linneani conscripta, Francofurti a/MI. 1837, 8, Lx, \$44 p. (Index generum, specierum et synanymorun 4838 . 8. 102 p.) (5 th.) "Ell. Il: Leipzig 1843-1845. 8. 1.x, 1164 p.

(In hac novit editione contineutur etian Acotyledoneae vasculares, et a Dispositio specicrun generis Cirsii," autore Karl Nuegeti.) *germanice: Syopsis ler dentschen und Schweizer flora, enthalfead die genaner behannen pllanzen, wejche in beutschiand, der schweiz, in Prenssen und Istrien wild wachsen und zimm Gebranch fer Menschen in grossrer Menge gebaut werden, nach $11 \mathrm{~cm}$ beCandolle'schen systente geordnet, mit einer vorangehenden Uebersich der frattungen nach den Klassen und Ordnungen des Lime'schen systems. Zwei Abtheiluzgen. Frankfurt a/M. 1837-1838. 8. VH1, 810 g. Hosister der Gillungen, Arten und synonyme: 101 p. (5/h.) - Eal. II

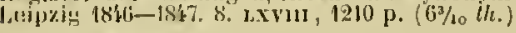

\$31" Koch, Wilhelin Daniel Joseph. Taschenbuch der leutschen und schweizer Flora, enthaltend die genauer bekannten Pflanzen, welche m Deutschland, der Schweiz, in Preussen und Jstrien wild waclssen und zum Gebrauche der Menschen in grossrer Menge gelsaut werden, nach dem Decandolle'schen Systeme geordnet, mit einer vorangehenden Uebersicht der Gattungen nach den Klassen und Ordnungen des Linne'schen Systems. Leipzig 1844. 8. Lxxxir, 604 1). (2 th.)

$3316^{*}$ Koeber, Johann Fr. Schediasma in landem Violae purpureo-coeruleao. Programma. Gcrae, typ. küchler. (1667.) 4. (8 p.)

$5317 *$ Koeck, Wenceslaus Thaddaeus. De Assa foetida. D. Vindobonae 1840.8.32 p.

$3318^{*}$ Koelbing, F. W. Flora der Obcrlausitz, oder Nachweisung der daselbst wildwachsenden phaneroganisehen Pflanzen mil Einsehluss der Farnkránter. Görlitz 1828. 8. xvi, xvi, 118 p. $(3 / 8$ th. $)$

$3319^{*}$ Koelderer, Johann Cieorg. Visctím plerarumque arborum planta parasitica. D. Argentorati 1747.4.32 p. Bibl. Juss. et univ. Lips.

$5320^{*}$ Koeler, Geory Ludwig. Descriptio graminum in Gallia el Germania tam sponte nascentium quam lumana industria copiosius provenientiun. Francofurti o/M. 1802.12 . xiv, 384 p., 10 schenata. ( 9 h. $)$

$3321^{*}$ Lettre à Mr. Ventenal sur les boutons et ramifications des plantes, la naissance de ces erganes et les rapports organiques existant entre le tronc et les branches. Mayence 1805. 4. $28 \mathrm{p} ., 1$ tab.

53 2. " Koelle, Johann Ludwig Christian. Spicilegium observationum de Aconito. Erlangae 1788. S. G0 p., 1 tab. (Sunt exenjplaria anni 1787 .

$5323 \div$ - Flora des Furstenthums Bayreuth. Gesammelt von koelle, bearbeitet und herausgegeben von Theodor Christian Ellrodl. Bayreuth 1798. 8. xiv, 354 p. $(1 \mathrm{th}$. $)$

3324t Koelliker, Albert. Verzeichniss der phanerogamischen Gewaichse des Kantons Zurich. Zurich 1839.8, xxv, 154 p. $(\% / 12 t h$.)

$3323^{*}$ Koelpin, Alexander Bernhard. Commentatio botanico-physica de stylo, ejusque dilferemiis externis. Gryphisivaluide 1764. 4. 51 1.

3326 * Oratio auspicalis de historiac naturalis et speciatim lootanices praestantia ac dignitate. Gryphiswaldiae 1766. 4. $24 \mathrm{p}$.

$3327^{*}$ - Hlarae Gryphicac supplementum herbationibus accommodatum. Gryphiao 1769.8. 128 p., praef., ind.

$3328^{*}$ De cultura historiae naturalis in Pomerania. Programma. Stettini 1773. folio. $12 \mathrm{p}$.

5329* _ Praktische Bemerkungen uber len Gebrauch der sibirischen Schneerose (Rhododendron chrysanthum) in Gichtkrankheiten. Berlin und Stettin 1779, 8, $115 \mathrm{p}, \mathrm{f}$ tab.

$5330^{*}$ Koelreuter, Joseph Gotllieb. De insectis coleopteris, nec non de plantis quibusdam rarioribus. 1). Tucbingae $1755.4 .48 \mathrm{p} ., 1 \mathrm{tab}$. (Schinus molle.)

(Dissertatio praeside Genrg Friedrich Sigwart proposita est.)

$5331^{*}$ Vorlaufige Nachricht vou einigen das Geschlecht der Pflanzen betreffenden Versuchen und Beobaclutungen. Leipzig 1761. 8. 50 p. - * Erste Fortsetzang. ib. 1763.8 .72 p. - * Zweite Fortselzung. ib. $1764.8 .128 \mathrm{p} .-{ }^{*}$ Dritte Fortsetzung. ib. 1766. 8. $156 \mathrm{p}$.

$5332^{*}$ Das entdeckte Geheimniss der Kryptegamie. Karlsruhe $1777.8 .155 \mathrm{p}$.

$5333^{*}$ Koene, Dr. Abhandlung uber Form und Bedeutung der Pflanzennamen in der deutschen Sprache. Mijnster 1840.4,44 p.

(Im 21. Jahreshericht uber das Gymnasium zu Munster.)

533 st Koenig, ainé. Notice sur la meleze et les avantages de sa culture. Colmar $1840,8.19 \mathrm{p}$
$5333 \div$ Koenig, Emanuel, pater. Disputatio physico-medica, generalia regni vegetabilis enucleans. D. Basilcae, typ. Koenig. 1680, 4. 84 \}., praef. Bibl. Juss.

$3336^{*}$ - Regnum vegetabile physice, modice, anatonice, chymice, theoretice, practice enucleatum, vegetabilium ninirum naturam, ortum, propagandi modum, differentias, jartes varias, collectionis et pracparationis modum, saporem, odorem, culorem, figuram, siguaturam, usus multiplices atque curiosa proponens. llasileae 1680. 4. 84 1. - Accessit selectus remediorum e triplici regno juxta norman et Juctum pharmaciae Ludoricianae. Basileate Rauracorum 1685. 4. 186, 271 p., ind. - Pars ll: ib. 1696. 4. - "ib. 1708. 4. 1112 p., ind., efligiı's autoris.

- Spicilegiun botanicum ct anatomicum. Basileae 1703. 1. Rivin.

(Agit de methodis botanicis.)

33338 Koenig, Emanuel, filius. Theses medicae, botanicae el anatomicac. Basileac 1721, 4. - ib. 1724. 4. H.

5339* Adversaria quaedam botaniea et anatomica. D. Basileae 1731. $4.8 \mathrm{p}$

33.40 Koenig, Johann Gerhard. De remediorum indigenorum ad morLos cuivis regioni endenicos expugnandos eflicacia. D. Ilafniac 1773. S. 80 p. B.

Dissertatio inauguralis clarissimi peregrinatoris, praeside $\mathrm{Chr}$. Fr. kollbüll defensa, continet etiam ohservaliones circa plantas in itiuerisus factas. )

531.1* Koenig, Karl. Der botanische Fulurer durch die Rlueinpfalz, uder Vebersicht aller bisher in der Bheinpfalz aufyefunduen phanerogamen Pflanzen, mit Angabe der Prosudie und Etymologie ihrer Namen, derStaudorte und geographischen Verbreitumg, nebst einem I3luthenkalender und einigen Regeln uber das Einsammeln, Trocknen und Aufbewahren der l'llanzen. Mannheim 1841.8 . vi, 243 p. ( $2 / 3$ th.

534.* Koenig, Samuel Friedrich. Do Lamio Plinii. D. Argentorati 1742. 4. 20 p., I tab.

53.13 * Koerber, Gustav II'ilhelm. De gouidiis Lichenum. D. Berolini I $839.8 .75 \mathrm{p}$

$5344^{*}$ Lichenographiae germanicae specimon, Parmeliacearum familiam continens. Commentatio pro obtinenda legendi venia die 23. Naji 1846 publice defensa. Vratislaviae 1846.4. 24 p.

53 H5t Kohlhaas, Johann Jakob. Einleitung in die Naturgeschichte überhaupt und in die Káuterkunde besonders. Nürnberg 1793. \$. $189 \mathrm{p}$. praef., 22 tab. - ib. $1804.8 .\left(1 \frac{1}{3}\right.$ th. $)$

$534.6^{*}$ Giftpllanzen auf Stein abgedruckt mil Beschreibungen Erstes Heft. Regensburg 1805. 4. xxxiv, 22 p, , 10 tab. col. (Sedecin inticantur fasciculi $\mathrm{cum} 160 \mathrm{tab}$, col.)

5347* Kolker, Aegidius ran. Plantarum nsualium horti medici Harlemensis catalogus. Ilarlemi, apul Willeın van liessel.1702. 8. $154 \mathrm{p}$

3348* Kolb, J. N. Bromatologie, oder Uebersicht der bekanntesten Nalırumgsmittel. Zweiter Theil, welcher die eigentlich nahrhafen Vegetabilien enthalt. Hadamar 1829.8 . vu, 524 p. $\left(2 \frac{1}{3}\right.$ th. $)$

5349 Kolb, Valentin. Landhetrachtung rom Wachsthum, Planzen und Forthommen des Getraides. Frankfurt 1764. 8. B.

$3350^{*}$ KoJbani, Paul. Ungarisclıe Giftplanzen zur Verlutung tragischer Vorfalle in den Haushaltungen, nach ihren botanischen kennzeichen, nebst den Jleilungsmitteh. Pressburg 1791. 8. xt, $132 \mathrm{p.}, 8$ tab. col. (1 th.)

5351 Kolbe, Peter. Beschrcibung des Vorgebirgs der guten Iloffnung und der Ilottentetten. Nürnberg 1719 . Jolio. tab. $\left(3 \frac{1}{3} t h\right.$. $)$

hollandice: Naaukeurige en uityoerige beschryving van de Kaap de Goede Hoop. Amsterdiam 1727 . II voll. folio. 529,469 p., tab. B.

Cataloges plantarum indigenarum et descriptiones ab Harlogio. oldenlandio et aliunde sumtas in hoc opere contulit. - Compentia itineris exstant anglice: London 1731. 8. - gallice: Amsterdam 17.41 III voll. 12. - jermanice: Nurnberg $17 \mathrm{~h}$. 4 .)

5352 Komaromy, Johann Peter. De vino hungarico Soproniensi. Basileae 1715. 4. Rivin.

5333 Komma, O. Toxicologia Solaninarun indigenarum. D. Pragae 1834. 8. $64 \mathrm{p}$.

535. Kondratowitsch, hiriak. Дикиіоперт пхн Реченіярт о разикут, пронзраненіяхь, со есть древахт, травахт, etc. C. Ileтен6. 1780. Trautv. 
$5353^{*}$ Konig, Charles, and John Sims. Anuals of Botany. London 1803 -1806 . II voll. 8. - 1: 1805 . VIII, 592 p., 12 tab. - Il : 1806. VIII, $600 \mathrm{p}, 18 \mathrm{lab}$

$5356 \div(-$ Tracts rejative to betany. Translated from different languages. London 1805.8 .277 p., 9 tab.

¿3357 Koning, Peter. De cortice Salicis albae. D. Ilarderovici 1778. 4.

$3358^{*}$ Kops, Jan, en Hermnn Christian van Hall. Flora batava, of Afbeolding en Beschrijwing van Nederlandsche Gewassen. Afyeboold onder opzigt van J. C. Sepp on Zoont. Amsterdam, hij J. C. Sepp on Zoon. $1800-1847$. IX voll. 4. 730 tab. col., totidemque foll. - 1: 1800 - II: 1807. - III: 1814. - IV: 1822 - V: 1828 - VI: 1832. - VIJ: 1836 - VIII: 1844 - IX: 1846. (Continuatur.) (Prodiit hucusque the fasciculis, quoque 5 tats. col. totidomque foll. textus; volumini octavu atciblit: Allgemeen Register of the thans uitgegeven 8 becelen mot entig" Aannerkingen divor Jun Eber-

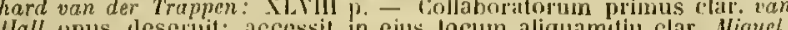
Ilall upus deseruit; accessit in ejus locum aliquametiu clar. Biquel

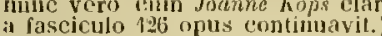

$3339+\left(\frac{1}{(}\right)$ tudex plantarun, (juae in horto Rhenn-Trajectino coluntur anus 1822. Trajecti ad Rhenum 1823.8.76 p., praef.

"360* Korthals, I'eter IVllem. Observationes de Naucleis iudicis. Bonnae 1839. $8.20 \mathrm{p}$.

$336 \mathrm{I}^{*}$ - Vertandelingon wer de natuurlijke (ieselviodenis der Noderlandsche overzeosche Bozittingen, door do Leden der Natuurkundige Commissio in Indie en andere Schrijvers. Uitgegeven op last van den Kouing door $C$. J. Tememinck. Botanie door $P$. W W Korthals. Leiden $1839-18$ 亿2. folio. 259 p., praef, int., 70 tab. col. (63 i.) Bibl. Reg. Berol.

(Insunt: Nepenthes. Bipterocarpeac. Bauhinia. Terrstroentiaceac.

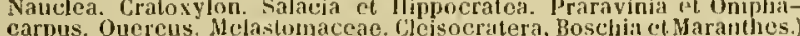

$8362^{*}$ Verhandeling over de op Java, Sumatra en Borneo verzanelde Loranthaceae. s. 1. et a. 8. 92 p., 2 tah.

$\$ 363^{*}-$ Over liet geslacht Tupeia. s. 1. et a. 8.12 p., 1 tab.

3364* Kosegarten, David August Josua Friedrich. Do camplora of partibus quae eam constituunt. D. Goettingae $1785.4 .69 \mathrm{p}$.

(Excerpta gernanica ill: Sammluugen zur Physik, 111. 433-467.)

5363 Kospoth, Karl, Freiher von. Beschreibung und Abbildung aller in Deutschland wilfwachseulen Báume und Strúncher, nehst einigen boi uns in lireien forkommendeu ausländischen Holzarten. Erstes Ileft. Erfurt 1802. 4. $51 / 2$ plag., 1 tab. $(1 / 2$ th.

$\$ 366$ * Kosteletzky, Vincenz Franz. Clavis analytica in Floram Bohemiae phanerogamicam; sive conspectus plantarum phanerogamarum in Bohemia sponte nascentium secundum methodum analyticam. Pray 1824. 8. vill, 1/30 p. $(2 / \mathrm{s} t h$.

$5367^{*} \longrightarrow$ Allgemeine mediziniseh-plarmaceutisclıe Flora, enthaltend die systemalischo Aufzahlung und Boschreibung stimmtliclier bis jetzt bokannt gewordner Gewácluse allor Welttheile, in ihrer Bozielıung auf Diatetik, Therapio und Plsarmacis, wach den natürlichen Familien georduet. Prag $4831-1836$. 6 Bánde. 8. I: 1831, xxvi 312 p. - Il: 1833. p. 313-750. - Ill: 1834. p. $75 \mathrm{I}$ $-1118 .-1 V: 1835$. p. 1119-1556. - V: 1836. 13. 1557-2006. $-\mathrm{Vl}:$ 1836. (Register.) p. $2007-2237$. (9 th. - herah)gestetzt: $43 / 2(h$.

gensis. Verzeichniss der im k. k. botanischen Garten zu Prag kultivirten Pllanzen. Prag 1844. 8. 144 J.

$5369^{*}$ Kostin, Emanuel von. Ueber das essigsaure Morphium, dessen Wirkung und Anwendung an Krantienbette und seino Bereitungsart. D. Muinchon $1838.8 .20 \mathrm{p}$

5370 " Kostrzewski, Jakab. De Gratiola. D. Viennae 1775. 8. 64 p., 1 tab.

3371" Kotschy, Theodor. Abbildungen und Beschreibungon neuer und seltuer Thiere und Pflanzen, in Syrien und im westlichen Taurus von ihm gesammolt. Herausgegeben von Eiluard Fenzt, Ilecket und Redtenbacher. Stultgart 1843.8. vil, 109 p. - Atlas in gr. 4., 14 tab. bot., 6 tals. ichthyol. $\left(3 \frac{1}{3}\right.$ th. $)$

ธ372 " Kotz, Jonathan Valerius. De generibus plantarum. D. Tyrnavide 1776. $8.30 \mathrm{p}$.

5373 * Kozal a Prachien, Johaunes Sophronius. Seplimanae horologii macrocosmi liber ujuartus do vegetabilium speciebus, partibus ef vignaturis. Vesaliae, excudebat Henricus Wolphardt. 1640.4.8i p. Bibl. Goett.

(Pracfatio data ast Borckenii in Epise. Monasteriensi 1638. - Nedicus Pragensis dicitur autor esse.)

537 k Kraeutermann, Valentin. Conpendioses toutselses und lateinisches Blumen und $\mathbf{K r}$ (iuterbuch, nelst einem Unterricht von J)estilliren, aus den besten Juloribus in alphabetischer Ordung zusammengetragen. Frankfurt uut Leipzig 1716. 8. Rivin. - "il). 1726.8. 496 p., pracf, iud. - il. 1733. 8. 592 ر. B. - "Zum viertenmal zum Druok befordert. Arnstad, Beumelburg. $1751.8 .592 \mathrm{~J}$. praef. $(1 / 2(h)$. treibung derer vornehmsten ausländischen ost- und wostindianischon Naterialien und Vegetabilien, ingleichen derer Fossilien unl Metallen, wie auch aller auslándischen Thiere, Fische und Vogrel. Arustadt 1730.8 .552 p. B.

Autor, th polygraphias igwominian facilins subterfugerot, in libri suis luoc minen tictitium adoptavit. Est r'hristophorus de Hellivig, medicus in Teunstaedt Thuringormu, n. 1663. + 1721.

3376 Kraft, Johmen. Pomoua ausiriaca oder Al\}jidung von 576 Obstenatturgen, wio sio in soiner Baumschule zu Wahringon und Weinhaus wachsen. Wien $1791-1794.18$ llefte. 4. tab. col. $\left(43 \frac{1}{3}\right.$ lh.

5377 Pomona austriaca oder Abhandlung von Obstbatumen. worinucn ihre Gestalt, Errzicbung und 1'flego angezeigt und beschricben wird. Wien 1790-1796. $20 \mathrm{Ilefte}=$ II voll. folin. $200 \mathrm{tab}$. col. $(120 \mathrm{th}$.)

Editio minori forma pretio $90 \mathrm{th}$; nee non adsunt editionss, in (quihus textus gallice ost seriptus.)

5378 (Kralitz, Meinrich.) Catalogus plantarum horti academici Lugluno-Batavi, quilrus is instructus orat anno 1635 , praefecto ejusdem Lorti Adolpho Vorstio. Accessit Index plantarum indigenarum, quae prope Lugdunum in Batavis nascuntur. Juggluni Batavorum 1636 g/4. 66 p. S. et B.

Misnicum salutat antorem Segujerus; Ilallero et Dumortiero kira. lix audit. "Forte fuerit, 0 inquit Ilullerus, is kratix, qui cum Pisone Brasiliam adiit, ibique mortem oppretiit. )

6379* Ir ramer, Johann Georg Heinrich. Tentamen Jotanicum sive methodus Rivino-Tournefortiana herbas, fructices, arhores ornnes facillime cognoscendi. Dresdac, Iyp. Ilarpeter. 1728. 8. 31, 151 p. -

"Ei.ll: Tentanen botanicum enendatum et auctum, sive mothodus Rivino-fouruefortiana emendata et aucta cognoscendi omnes plantas facilline. Vientac, Kaliworka 1744 . folio. 60,150 p., 3 tab. (2 (li.)

8380* Kramer, Wilhelm Heinrich. Elenclus vegetabilium et animalium per Austrian inferiorem observatorum. Sistens ea in classes ot ordines, genera et species redacta. Vienuae 4756.8 . $400 \mathrm{p}$., ind. ( $1 \mathrm{th}$. (Vegetabilia: p. 1-307.)

3381* Krapf, Karl von. Experimenta de nonnullorum Ranunculorun venenata qualitate. Viennae $1766.8 .107 \mathrm{p} .(1 / 3 \mathrm{th}$.

$\$ 332^{*}$ Ausfühliche Beschreibung der in Unterosterreich, snnderlich un Wien herum wachsenden erlaubten und unerlaubton Solıwamme elc. 2 Ilefte. Wien 1782. gr. 4. 27,22 1., 17 tah. con! $\left(6 \frac{2}{3}(h)\right.$.

5383 Krascheninnikow, Stephan. Ouncanie 3ersu Kins'rarku. C. IIereg6. 1755. II voll. 4. - I: $\{38$ p. - II: 319 p., Lab. B. Ed. I] : ib. 1786. 4. Trautv.

germanice. Beschreibun!e des Landes Kamtsehatha; ubersetzt won Johann Tobias finehler. Lomgo 1766.4 . - ib. 1789 . 4 . (11/, th

grallice: par Eidous. Lyou 1767. II voll. 12. - par de Sainl-Pré. Amsterdam 177. 11 volt. 8 . Q.

anglice: The history of Kamtschatha and the Kurilshi [slands, with Hhe countries adjacent; trantstaled by James Grieve. Glocester 176t. 280 p., tab). (non integra versio!) B.

3381." Krasper, K. L. E. liurzer Grundriss der fur die Sclıle notbwendigsten bolanischen Ansdrüche. Zweile verbesserte Autlage. Nagdeburg 1845.8 .29 p. $(2 / 15$ th. $)$

(Editio prima milni uon innotuit.)

\$383* Krassow, C. K. A. Freikerr von, und Eduard Leyde. Lehrbuch der' Botanik fur Gymnasien und höhere Bürgerschuloı. Jerlin 1836. 8. vili, 198 p. $(5 / 8(h$.$) - Zweite umgearbeitete Ausgabe. Berlin$ 1816. 8. 14 plag. $(\% / h$. $)$

(III editione novissima autoris nomen mutatum est in: $C . R$. A Graf von Krassow-Diwils.)

$5386^{*}$ Kratochvill, Karl. De radice Colchici autumnalis. D. Francofurti a) $\mathrm{V} .1764 .8 .50 \mathrm{p}$. 
\$387 Kratzenstein, Christian Gotllieb. I'rogramma de Theophrasti hist. plant. Lene merenda sulisidia. (sic!) Havniae 1772. 8. Desid. B. (Commentatio a Bruennichio non laudiald!)

3388 , pr. Je ligni Quassiae usu medico. D. Ilafuiae 1775. 8. 52 1. B.

:3383 Kratzmann, E. I. Le Coniferis usitatis. D. Pragae 1835.8 .50 p.

$5390^{*}$ Kratzmann, Emil. Wio Lelue vom Samen der Pllanzen. Prag 1839. 8. 98 P., 4 tal $)(3 / 4$ th. $)$

$3.391^{*}$ Krauer, Johann Grorg. Prodromus lilonae Lucernensis, sive stirpium phanerogamarum in agro luecrnensi el prosimis ejus confiniis spuntr mascentium catalogus. Lucernae 1824.12 x. $105 \mathrm{p}$.

:39!2* Krause, Christian Ludwig. Catalogus arborum, fruticum et herbarum r.soticarum et indigenarum, quarum semina venduntur Berolini apud ('hr. Lud. Kratise. Berolini 1753, 8.40 p.

:393. Krause, Johann II ithe/m. Abbildungen und Besehreibung aller his jetzt bekanuten Getreidearton mit Angabe ilrer liultur und Nutzen; iu acht Heften. Mit Origiualzeichnungen von Erust Schenk. Leipzig $1835-1837$. folio. $48 \mathrm{tal}$. col., Text. ( $16 \mathrm{th}$.)

(Av operis calcem arldia est: llinblick auf das zur Vervollstandigung dieses Werhes noch Erforderliche und Uebersicht der in den acht ileften abgebildeten und beschriebenen Getraidearten: $3^{1 / 2}$ plag.

339.: * Das Getraidebuch oder neuste Wanderungen durch das wissenselıaftliche Gebiet rer Getraide. Leipzig 4840.8. x, $294 \mathrm{p}$. $\left(1 \frac{1}{2} t h.\right)$

8395 Krause, Rudolf Withelin, latine Crausius. De Rosa. D. Jenae 1674. 4. Desid. B.

7.396 - Ve stndio botanico el chemico. Jenae 1681. 4. Desid. B.

;397" De signaturis vegetabilium. D. Jenae 1697.4.23 p.

$3398^{*}$ De Cardamomis. D. Jenae 4704. 4. 44 p., 1 lab.

\$399" De naturae in regno vegetabili lusilsus. Propenticum inaugurale. Jenae 1706. 4. (s j.)

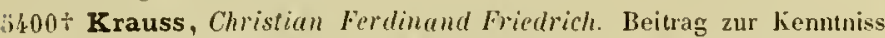
der Corallineen und Zoophyten iler Sudsee nebst Albildungen der neuen Arten. Stuttgart $1837,4,38 \mathrm{p} ., \mathrm{t}$ tah. $(1 / 2 / h$. $)$

$31.01 \%$ (Krauss, G.) Verzeichniss von iu- und ausländischen Pflanzen, wolche im Grossherzogl. Residenzgarten in Wurzburg zu liaben sind. Wurzburg 1\$12. 4. ( 18 foll.)

$312^{*}$ (Krauss, $J . C$.) Afbeeldingen der Artsseny-Gewassen met derzelver nederduitsche en latynsche Beschryvingen. (Ieones plantarum medicindium.) Amsterdam, by J. C. Sepp en Zoon. $1796-1800$. †1 woll. \$. 600 tab. col., totidenque foll. text, ind.

Textum composut Theodericus Leanardus Oskamp.

$\$ 403$ ( ) Afberldingen der fraaiste, meest uithcemsche Boomen anl Heesters, die tot verejering van engelselse Bosschen en Tuinen hunnen geplant en gehweeht werten. Amsterdan $1803-1808$. XX1 faseiculi. $4 .(100$ ก. $80 \mathrm{c}$ )

:30 ** Krebs, F.L. Vollstandige Beselureibung und Abbildung der sanmtlichen Holzarten, welche im mittleren und nordlichen Deutschland wild wachsen. Fur Gutsbesitzer, Forsimanner, Oehonomen und Freunde der Natur. Nách den besten Hulismitteln bearbeijet. Braunsehweig $1827-183525$ Hefte. folio. $1123 \%$ plag., 150 tab. col. $\left(37 \frac{1}{2}\right.$ th. - nigr. $205 / 6$ th. $)$

(Fasciculum .XYF Iion vidi. Oehme et Mueller, hibliepolae Brunsvieenses, librun anno $18 \mathrm{~h}$ novis titulis ediderunt: col. $16 \% / \mathrm{s}$ th.

340.3 “ Krebs, Philipp Melfricus. Tractatus politico-jurilicus de ligno et lapide, quo praecipuam juris forestalis partem, materiam arberum planationis cte. nte. Augustae Vindelicorum, apud I aur. hroniyer. 1700. 11 voll. $4 .-1: 502$ p., praef. $-11: 222$ p. (de lapide) ind. gener, - Ed. aucta: Coloniac, Francofurti et Bonnae, Noethen. $1756.4,366,256$ \%., append, ind.

$53.06^{\circ}$ - Fasciculus quaestionum miscellanearum in theeria et praxi maxime utilium, praecipue in majorem editi de ligno et lapide tractatus elucidationem. ib. 1700.4 .156 p., praef, ind.

(Quaestio $r$ : de dominie herharum sponte e terra nascentium.)

34.07\% Krémer, J. P. Monegraplie des Ileppatiques de la Moselle, suivie d'unc méthode analytique des genres et des especes. Metz 1837. 8 . 1V, 14 \}. Bibl, Lèveille.

$5108^{*}$ Kretzschmar, Samuel. Beschreilung der in Drestien ohnlangst erzeugten Martyniae annuae villosae; nebst einer. Abhandlung von Chrstian Fredrich Schulze vous dem Nutzen, den ein botanischer (rarten in Betrachtung versehiedner wirthschafticher Gewerbe ver- sehaffen konnte. Friedrichstadt (i.e. I) esten) (1764.) 440 p., 2 tab $(\% / 1, t h$.

:3409* Kreutzer, Karl Joseph. Oestreichs Giftgew achse. Wien 1838. \& 177 p. $(2 / 3$ (h.)

$5: 10^{*}$ Beschreibung und Abbildung sammilicher essbaren Schwamme, deren Verhauf auf don niederosterreicliselien Markiten grsetzlieh gestattel ist. Wien 1839. 8. vur, $57 \mathrm{p}$, 8 tah, col. ( $1 / 2$ th.)

:3:11* Lroulromus Florae Vindobonensis, oder Verzeichniss der in den Lngelungen Wien's wild waclssenden Pllanzen. Wien 1840. 8. $1 \mathrm{v}, 103 \mathrm{p} .(1 / 2$ th. $)$

"512* - Anthochronologion plantarum Europae mediae. Blutenhalender der Pflanzen des mittleren Europa. Wien 1840. 12. vus. 236 p. $(3 / 4$ th. $)$

$5133^{*}$ Bluthen-Kalender und systematisch georinete Aufzullung der Pflanzes in den lmgcbungen Wiens. Wien 1840 . 12. W $2 / 7$ p. (1 th. $)$

5414* Kreutzwa]d, Marlin Joseph. De utilitate foliorum Juglandis regiae ad sauandam serophulosin. D. Bonnae 1842.8.22 p.

3 3.15* Kreysig, Friedrich Ludwig. Momenta yuaedam vilac vegelabilis cum animali convenientiam illustrantia exponuntur. Programma I et ll Wittenbergae 1796. 4. 12, 8 p.

\$\$16* Kreyssig, IH". A. Die Menge- und Zwisehensaten der Feldgewatise, mit den Nittelı und Wegen ihrer vortheilhaften Anwentung im deutsclien Feldbau, als ein wesentliches, tief eingreifendes Mittol zur nachhaltigen Erhohung des Feldertrages. Nach naturw iss'ntschaftlichen und laudwirthschaftlichen Versuchen und Erfiturungen. Branselwweig 1844. 8. xvt, $160 \mathrm{l}$. (1 th.)

$5177^{*}$ Krocker, Anton. Ile plantarum epidermide. Cum praefatione Curtu Sprengel. D. Ilalate 1800.8 . Iv, 68 P., 3 tab.

34. $18^{*}$ Krocker, Anlon Johann. Flera silesiaca renovata, emendata, continens plaustas Silesiae indigenas de novo descriptas ultra nongentas, cirea mille auctas; nee in Flora silesiaca pristina, nec in enumeratione stirpium silesiacarum reperiundas. Secundum systema sexuale Linnaci digestas rariores tabulis acneis illuminatis illustratas, in operibus Linnaei non inventas ex aliis cl. autoribus determinatas vel determinandas. Vratislaviae $7787-1823$. Tomi $J-l \mid$ vel 5 partes. - J: 17S7. xxxw, 639 p. - 11: 1790. xx11, 406,529 p. III: 1\$14. LII, 374 p. - JV: 1823 . xL. 3430,334 p., 110 tab. (nigr. 13 (h. - col. 20 th.

$5419^{*}$ Krocker, Hermam. De plantarum epidermide observationes. U. Vratislaviae 1833.4 .27 p., 3 tal $).(1 / 2$ th. $)$

3320 * Kroeber, Heimrich. Ueber die liuta graveolens L. und die mit derselben zunachst verwandten Arten. D. Wurzbuig 1830.8. 321,

3\%21* Kröyer, Christian Car\%. De sexualitate plantarum ante Linnacum cognita. D. Jlafniae 1761.4. 12 p.

5122* Krombholz, Julius Jincenz ron. Conspeetus fungorun esculentorum, qui per rlecursum anni 1820 Pragae publice vendebantur. (Lehersicht der essbareu Schwamme etc.) Programm. Prag 1821. 8. $40 \mathrm{p})(1 / \mathrm{t}(\mathrm{h})$.

$35.23^{*}$ - Naturgetreve Albildungen und Beschreibungen der essharen, sehdidlichen und verdachtigen Schwamme. Prag $1831-$ 1\&47, 10 Jlefte. folio. $x, 85,30,36,32,17,30,24,31,28,28 p$, (5) J) ind., 78 tab. col. $(62 \%$ (h.)

542.* Krueger, Johain Friedrich. Lateinisch - deutsches Handworterbuch der botanischen Kunstsprache und Pflanzennamen Quedlinburg und Leipzig 1833.8 . vi, 133 1., g tab. (1 $1 / 2$ th.)

31.2:** Krueger, Johann Golllob. Gedanchen vom halfee, Thee und Tobach. Ilalle $1743.8 .60 \mathrm{p}$.

gallice: Traité du Callé du Thé et usu Tabac. Ilalle t'ł3. S. As p. B.

$5426^{*}$ Krueger, M. S. Bibliotheca botanica. Handbuch der botanischen Literalur in systematischer Orduung nebst kurzen hiographischen Notizen uber die botanischen Scliriftsteller. Zum Gebrauche fir Freunde und Lehrer der Pflanzenhunde. Berlin 1841. S. \$1, $464 \mathrm{p}$. (2 th.)

3427" Die Botanik in drei Lehrstufen methodisch hearbeitet ZumGebrauch fur Realschulen und Gymnasien. Berlin 1\$44-1847. 8. - Erster Kursus: Pflanzenbeschreibungen. 1844. \& xrı, 10 \&. 64 p. I tab. - Zweiter hursus: Die naturlichen Pflanzenfamilien 
Deutschlands. 1845. 8. xt1, 278 p. $\left(1 \frac{1 / 2}{2} /\right.$. $)$ - Dritter Kursus : (nondum prodiit.)

51.28 Krueger von Kriegsheim, Christoph. Forstwissenscliafliche Bemerkungen etc.; mit Anmerkungen des Bar, von Vietinghelf uber die Kultur der mutzliclisten Holzarten in verschiedenen Gegenden des russischen Reiclss. Dorpat 1806. 8. Trauty.

5 เ29* Krusenstern, Adam Johann von. Reise um die Welt in ten Jalıren 1803-1806 auf Befehl Alexander des Ersten auf den Schiffen Nadeshda und Nevia. St. Petersburg, auf Kosten des Verfassers gedruckt in der Schnoer'schen Buchdruckerei. 1810-1812.3 Thle. 4. -1 : $1810, \mathrm{xx}_{3}, 353$ p. $-11: 1811.436 \mathrm{p} .-\mathrm{III}: 1812.376 \mathrm{p} .-$ Atlas in folio: 1814.106 tab. (102 th. $-{ }^{*}$ Ed. miver: Berlin 1811 -1812. 3 Bände. $8 .\left(5 \frac{1}{3} t h.\right)$

* ilalce: Milane 1818. 8 .

gallice: par Eyriés. Paris 1821. 11 vell. 8. 33 tab. in folio. (30 fr.) hallandice: Ilarlem 1811-1815. II voll. anglice: London 1813. II voll.

5 ' 30 * Kuechelbecker, Georg Gotllob. De spinis plantarum. D. Lipsiae 1756. $4.36 \mathrm{p}$.

"̈ł31* Kuechenmeister, Gottlob Friedrich Heinrich. De Secali corunto. D. Lipsiae 1845.8 .28 p.

$5432^{*}$ Kuehn, Karl Gottlob. De extractis vegetabilium Garayauis. D. Lipsiae 1799.4.32 P.

$5433^{*}$ - Febrifuga remedia, quae cortici peruviano vicaria succedunt, considerantur. Programma. Lipsiae 1810.4.14 p.

5434: K.uetzing, Friedrich Traugott. Synopsis Diatomacearum. Halle 1834.8.92 p., 7 tab. ( 1 th. $)$

(Seorsim impressa ex Linnaea, vol. vill. p. 529-620.)

$5433^{*}$ Algarum aquae dulcis Germaniae Decades I-XVI. Halle 1833-4836. 8. (Herbarium mit Text.) $(10 \% / 3$.)

5436* Ueber die Polypiers calciferes des Lamauroux. Programm. Nordhausen und Leipzi.s 1841. 4. 33 p. ( $5 / 8$ th.)

$5 \mathbf{5 3 7 ^ { * }}$ Die Lmwandlung niedrer Algenformen in liohere, so wie auch in Gattungen ganz verschiedner Familien und Klassen hoherer kryptogamen mit zelligem Bau. Haarlem 1841.4. 131 p. 16 tab.

(Natuurk. Verh. van de Holl. Maatseh. der Wetensch. te Haarlem. II verz. I. Deel.

51:38* - Ply Systemkunde der Tange. Leipzig, F. A. Brochlhaus. 1843. 4. xxxn, $45 \&$ p., so tab. col. ( 40 th. $)$

$5439^{*}$ Ueber die Verwandlung der Infusorien in niedre Algenformen. Nordlausen 1844. 4. vil, 24 p., 1 tab. col. $(2 / 3$ th.

$5440^{*}$ Die kieselsclıaligen Bacillarien oder Diatemeen. Nordhausen 1844.4 .152 p., 30 tab. $(15$ th. $)$

$541^{*}$ Die Sophisten und Dialektiker, die gefahrlichsten Feinde der wissenscliaftichen Betanik. (Streitschrift gegen Schleiden.) Nordhausen 1844.8 .21 p. $(1 / 4 t h$.

$0442^{*}$ Phyeologia germanica, d. i. Deutschlands Algen in bündigen Beschreibungen. Nebst einer Anleiturg zum Untersuchen und Bestimmen dieser Gewachse fur Anfanger. Nordhausen 1845. 8. $x$, 340 p. $\left(3 \frac{1}{2}\right.$ th. $)$

$54: 3^{*}$ Tabulae phycologicae od. Abbildungen der Tange. Nordhausen 1846. gr. 8. Fase. I-II: 16 l ., 20 tal). cel. (4th.) (Continuatur.)

544:* Kuinneth, Georg Friedrich. De faba St. Ignatii. D. Erlangae 1802. 8. 3 I p.

$54433^{*}$ Kullberg, Daniel. De affinitate generum plantarum in classibus systematis sexualis Linnaei obvia. D. Lundao $1796.4 .20 \mathrm{p}$.

34.6 Kulm, Johann Adam. De succino. D. Gedani 1728. 4.

5447 De plantis earumque nutritione. D. Gedani 1728. 4. H.

$3448^{*}$ De literis in ligno Fagi repertis. D. Gedani $1730.4 .29 \mathrm{p}$ 1 lab.

if': 9 * Kunitsch, Michael. Biographie des Franz Iaver, Frhrn. von Wulfen. Wien, Gassler. 1810. 4. 35 p., 1 tah., effigies Wulfenii.

:ji 30 * Kunth, Karl Sigismund. Flora Rerolinensis sive enumeratio plantarum circa Berolinum sponte crescentium, secundum familias naturales dispasita. Berolini $1813.8 . x, 282$ p. $\left(1 \frac{1 / 3}{t h}.\right)-{ }^{*}$ Ed. II: Berolini 1838. Il voll. 8. - I: exhibens polypetalas et monopetalas epigynas ac perigynas. vir, $407 \mathrm{p}$. - II: exhibens monopetalas liypogynas, apetalas, diclines, monocotyledones et cryptogamas filicoideas. $438 \mathrm{p} .\left(3 \frac{3}{\mathrm{~s}}, \mathrm{th}.\right)$

(Adnotationes quaedam ad Floram Berolinensem C. S. Kunthii, auctore Adalberl de Chamissa. $8.13 \mathrm{p}$.)

Pritzel, Thes lit bot
5431* Kunth, Karl Sigismund. Malraceae, Buttneriaceae, Tiliaceae, familicie denuo ad examen revocatae elıaracteribusque magis exactis distinctae, addita familia nova Bixinarum. Paris 1822. 8. 20 p.

34.02* - Synepsis plantarum quas in itinere ad placyam aequinoctialem orbis nevi collegerunt Alexander de Humboldh et Amatu. Banplund. Parisiis 1822-1825. IV voll. 8. - I: 1822. IV 491 p. II: 1823.526 j). - IIl : 4824.496 p. - IV: 1825.528 p. (40 fr.)

$3453^{*}$ Terebinthacearum genera denuo ad examen revocare cliaracteribus magis accuratis distinguere, inque septem familias distribuere conatus est. Paris 1824.8.36 p.

Glält — Nutice sur Louis Cluude Marie Richard, menbro de l'lustitut, professeur à la faculté de medecine de Paris. Paris 1824 $8.23 \mathrm{p}$.

$34533 t-$ Notice sur la Badsamine des jardius (Impratiens Balsamina L.) Paris $1827,4.8 \mathrm{p}$

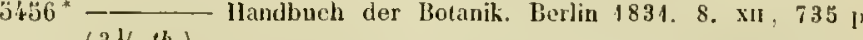
$\left(3 \frac{1}{2}\right.$ th. $)$

hallandice: $\operatorname{loor}$ N. B. Millard. Amsterdam 1836. II rell. 8 . (6 fl.)

5.4077* Vier botanische Ablandlungen. Gelesen in der Akademie der Wissenscliaften den 24. Marz 483 \%. Veher die Verwanlschaft der Gattung Stilbe. - Ueber eine neue Gattung der Nyctagineen. - Veber die Gattung Sympieza Lichtenst. - Ueber die Willdenow'sche Gattung Omplialococea. Berlin 4832. 4. 16 p. (1/6 th.)

5458* Zwei betanische Abhandhngen. Gelesen in der Akademie der Wissenseliaften den 19. Jułi 1832. Ueber die Bliten- uni Fruclutbildung der Cruciferen. - Ueber einige Aublet'sche Pflanzengattungen. Berlin 1833, 4, 24 p., 3 tab.

$54.59^{*}$ Auleitung zur Kenntniss sämmticlser in der Pharnacopoea borussica aufgeführten officinellen Gewächse, uach naturlichen Familien. Berlin 1834. 8. vir, 496 p. $\left(2 \frac{2}{3}\right.$ th. $)$

$5460^{*}$ Bemerkungen ubes die Familie der Piperaceen. Jalle 1840.8. $166 \mathrm{p}$.

(Seersim impr. e Linnaea vol. XIIJ. fasc. V]. p. 561-726.)

$546 \mathrm{f}^{*}$ Eichheruia, genus novum e familia Pontederiacearuı. Berolini 1842.8. 7 p.

$5\left\{62^{*}\right.$ - Einige Bemerkungen uber Blattstellung der Dicetyledunen. Gelesen in der Akademie der Wissenschaften, den 30. October 1843. Berlin 1843. 8. $12 \mathrm{p}$.

5.163* _ Lehrbuch der Botanik. Erster Theil. Allgemeine Botanik: Organographie, Plyysiologie, Systemkunde, Pflanzengeographie. Berlin 1847 . 8. xil, $588 \mathrm{p}$. ( $3 \mathrm{th}$.) (Alterum exspectamus tomum.)

$5464^{*}$ Enumeratio plantarum omnium hueusque cegnitarunı, secundum familias naturales disposita, adjectis characteribus, differentiis et synonymis. Stutgardiae et Tubingae 1833-1843. IV roll. 8. $(16 \%$ th.) (Continuatur.)

Tomes 1: Agrostographia syneptica, sive enumesatio Graminearunı omnium hucusque cognitarum, adjectis characteribus, differentiis et synonymis. $1833.606 \mathrm{p} .(3 \mathrm{th}$.

Supplementum tomi primi, exhibens descriptiones specierum novarum et minus cognitarum. $1833.436(40)$ p., 40 tah. $(31 / 3$ th.

Tomus 11: Cyperographia synoptica, sive enumeratio Cyperacearum omuium hucusque cognitarum, adjectis characteribus, differentiis et synenymis. 1837.591 p. $(3 t h$.

Tomus II] : Enumeratio Aroidearum, Typhinearum, Pandanearum, Fluvialium, Juncaginearum, Alismacearum, Butomearum, Palmarum, Juncacearum, Phylidrearum, Restiacearum, Centrelepidearum el Eriocaulearum omnium hucusque cognitarım, adjectis characteriLus, differentits et synonymis. $1841.644 \mathrm{p} .\left(3 \frac{1}{3} t h.\right)$.

Tomus IV: Enumeratio Xyridearum, Mayacearum, Commelynearum, Pontederiacearum, Melanthacearum, Liliacearum et Asplodelearum omnium hucusque cognitarum, arljectis cltaracteribus, differentiis et synonymis. 1843.752 p. $\left(33_{4}\right.$ th. $)$

5465* Kunze, C. S. II. Deutschlands kryptogamische Gewachse, oder botanisches Taschenbucb auf das Jahr 1793. Hanburg 1795. 8. vi, $102 \mathrm{p} .(1 / 3$ th. $)$

34 $46{ }^{*}$ Kunze, Gustav, und Joharn Karl Schmidt. Nykulogische Hefte, nebst einem allgemein-botanischen Anzeiger. Leipzi: 1817-1823. 2 Hefte. 8. - 1: 1817. xvi, 109 p., 2 tab. - II: 1823. xII, 176 p. 2 tab. (2 $1 / 3$ th. $)$

$3467^{*}$ - Plantarum steotyledonearum Africae australieris recensio nova e Drégei, Ecklani et Zeyheri alierumque peregrinatorum cel- 
lectionibus aucta el ementata. Particula prima, Filices L. compleetens. D. Lipsiae 1836. $8.77 \mathrm{p}$.

(Alia exemplaria alio titulo (nalae) paginis 90 ; ex Linnaeae vol. $\mathrm{X}$. seorsim typis expressi.

\$il 8* Kunze, Gustav. Analecla pteridographica, sive descriptio el illustratio Filicum aut novarmu aut ninus cognitarum. Lipsiae 1837. fulio. vili, 50 p., 30 tab. ( 8 th. $)$

$5 \$ 69^{\circ}-1$ ie Farrukrauter in kolorirten Abbildungen naturgetren erlautert und boschrieben. (Schkuhr's Farnkráuter, Supplenent.) Leipzig 1840-1845. 9 Jefte. 4. 222 p., 90 tal. col. $\left(22 \frac{1}{2}\right.$ th.)

i $470^{*}$ _ Contimuantur.) Supplemente der Riedgráser (Carices) zu Christian Schkuhr's Monographie in Abbildung $\mathrm{u}$. Beschreibung oder Schliuhr's Riodgräser. Neue Folge, Leipzig 1841-1844. \& Hefte. 8. 162 p. 40 tab. col. ( $8 \mathrm{th}$.) (Continuantur.)

$3 \mathrm{r71}^{*}$-...__ Chloris austro-lispanica. E collectionibus IVillkommiunis a mense Majo 1844 ad finen mensis Maji 1845 factis composuit. Ratisbonae 4846.8 .92 p. $(2 / 3$ th. $)$

(Seorsim impressa e Flora Ralisbumensi 1846.)

$5472^{*}$ Kurr, Johann Gotllob. Untorsuchungen uljer die Bedeutung der Nehtarieu in den Blumen, auf eigne Beobachtungen und Versuche gegründet. Stuttgart 1833.8 . vilı, $150 \mathrm{p} .(7 / 12 \mathrm{th}$.)

$5173^{*}$ Beiträge zur fossilen Flura der Juraformation Wuriembergs. Stutgart 1845.4 .21 p., 3 tals. $(8 / 35 t h$.)

(Programma ad concelebranda natalitia Regis Würtembergiae.)

5747k* Kurtze, G. Arlolph. De petrefactis, quae in sclisto bituminoso Mansfeldensi reperiuntur. D. Halae 1839. 4. 38 p., praef, , 3 tab. $(2 / 3$ th. $)$

5475 Kutorga, Stephan. Beitrag zur Geognosie und Paláontologic Dorpats und sciner nächsten Uingebungen. St. Petersburg 1833. Trautv.

$\$ 476$ Kuyper, J. A. B. Eerste naamlyst van zigtbaarbloyende plaanten, welcke in de omstreken ran Breda gevonden. Breda 1826. 8. Dumortier.

$3777^{*}$ Kviakowska, J. von. Erste Anfangsgrüde der Botanik in Briefen; als Anleilung zum Selbststudium dieser Wissenschaft zu gebrauchen. Wien 1823. 8. 87 p., 4 tab. col.

$0.78^{*}$ Kyberus, David. Lexicon rei herbariae trilingue ex variis et optimis qui de stirpium historia scripserunt, authoribus concinnatun. Item Tabulac collectionum in genere et particulatim per XII menses in usum Pharmacopolarum conscriptae per Conradum Gesnerum. Argentinae, apud Wendelinum Rihelium. 1553.8.548 p., praef.

Edidit incle a p. 161 post mortem Davidis Kyberi, medici Argentoratensis († 1553, aet. 28.] Conrad Gesnerus.)

3 h79 K Kylling, Peter. Viridarium danicum, sive catalogus trilinguis latinodanico-germanicus plantarum indigenarum in Dania observatarum, quarum cuique suus est additus locus, quo imprimis nascatur, nec non cuivis sum assignatum est tempus, quando quaevis floreat Ilafniae 1688.4 .174 p., praef., ind.

\section{L.}

3380 * Labat, Jean Baptiste. Nouveau voyage aux isles de l'Amerique, contenant l'histoire naturelle de ces pays etc. Paris, Giffart. 1722. Vl voll. 12. - Ed. II: Paris 1712. VIII voll. 12.

"La partio bolanique de ce voyage a été critiquéc dans los Mémoires de Trevoux, Juiltet 172, p. $1303-1318$, sous te titre dobservalions dun botanisto habitant des fles occidentales de tamérique sur les plantes, dont parle le pere Labat dans son vovage aux iles sur les plantes, don
de ramerique.

$3481 *$ Nouvelle relation de l'Afrique occidentale. Paris, le Gras.

1728. $Y$ voll. 12

$3182+$ Labat, Léon. De l'irritabilité des plantes, de l'analogie qu'elle présente avec la sensibilité organiquo des animaux, et du role important, qu'elle joue dans les diverses maladies des tissus végétaux. Paris 1834. 8. 188 P., 1 tab. $(3$ fr. $50 \mathrm{c.}$ )

(Aulor postea fult archiater aulicus in Persia, et nomen Mirza Labat Kihan adoptavit.)

b.83 Labram, J. David. Sammlung der Zierpflanzen nach der Natur. Basel 1835. 16 Hefte. 8. 96 tab. absque textu.
548. Labram, J. David. Vorlegeblatter zum Pflanzen- und IBlumenzeichnen. llasel 1845.8. 16 tal. cul., 1 foll. $(3 / 4 t h$.

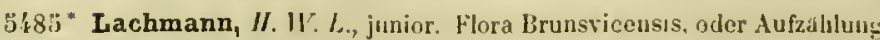
und lieschreiliung der in der Umgrgend von liraunscliweig wildwachsenden I'llanzen naclı Linné's Sexualsỵstem. Irraunschweig 1827-1834. 2 Bande. 8. - I: Chorograplie, Geognosie, Meteorologie, Allgemeino Vegetation. 1827. XLvi, 324 p., I mappa geogr., 5 tab. - II: Plsanerogamen. 1828. 1831 , xiv, 496,352 ). $(61 \%$ th.

$5486^{*}$ Laestadius, Lars Levi. Ilotaniska Anmarkningar, gjorda i Lappmarken och tillgrănsande Landsorter. Stocklıolm 1823.8. $18 \mathrm{p}$

5.187t Laet, Jean de. L'histoire du nouveau monde ou description des Indes occidentales, contenant dix-luuict livres; enrichi de usouvelles tables geographiques et figures des animaux, plantes et fruicts. A Leyde, chez Bonaventuro et Abraham Elseviers. 1640. folio. 63z p.. praef., ind., ic. i. $t$

3488t Lafitau, Joseph François. Némoire presenté a Sun A. R. IJS. Ie Due d'Orlians, concernant la précieuse plante du Gin seng de Tartario, decouverte en Canada. l'aris, clıcz J. Monge. 1718. 8. 88 p. it tab.

(Redit apud Breynium Icon. pl. rar. Ed. II.)

5489+ Lagasca, Mariano. Amenidades naturales de la Españis: o bien disertaciones varias sobre las producciones naturales espontancas n conaturalizadas en los dominios españoles. Tomo I. (num.1.) Orihuela, ell la imprenta de la muy illustre Junta. 1811. 4. XI, 44 P.

(Contenta: Sobre el cencro espigado, Cenchrus spicatus L. p. 1 -18. - Lista de plantas de la China, del Japon, Amboyna, Malabar y Filipinas conaturalizadas en España. p. 19-25. - Disertacion sobre un urden nuevo de plantas de la clase des las Compuestas. p. 26-43.

$3.190 \dagger$ - Instruccion sobre el modo con que pueden dirigir sus remesas y noticias al real jardin tuolanico de Jadrid los que gusten concurrir à la perfeccion de La Ceres Española, ó tratado completo de todas las plantas, especialmente de las cultivadas en Espaia, cujas semillas pueden convertirse en pan. (Madrid 1816.) 4. 3 p.

$5.191^{*}(-$ Elenchus plantarum, quae in horto regio botanico Matritensi colebantur amo 1813 , cum novarum aut uinus cognitarum stirpium diagnosi, nonnullarum descriptionibus contractis. Matriti 1816. 4. 20 p., praef.

$3192 *$ - Genera et species plantarum, quac aut norae sunt aut nondum recte cognoscuntur. Matriti 1816.4 . 35 p., 2 tal. col.

(Una cun Elencho plantarum edita sunt.)

$3493^{*}$ Memoria sobre lds plantas Barrilleras de España, Madricl 4817. 4.84 p., praef, ind.

$549: 1^{*}$ - Amenidades naturales de las Españas. Tom. I. numero segundo. Madrid 1821. 4. p. 47-111.

(Disertacion sohre la familia natural de lits plantas aparasoladas: por su discipulo Sebastian Eugenio l'ela, p. 61-86. - Dispositio Umbelliferarum carpologica, autore Mariano Lagasca. p. 87-111.)

$3495^{*}$ Observaciones solbre la familia natural de las plantas aparasoladas, (Umbelliferae). Londres 1826.8.43 p.

(En el Periodico español que sale en Londres coll el ululo de Ocios de Españoles Emigradas, en la imprenta de A. Jlacintosh, 20 Great New Stroel.

$5496+$ Lagrèze-Fossat, $A$. Notice géologico-botanique sur l'arrondissement de Moissac. Montauban (1838). 8. 22 p. vidi.)

(Idem autor est Florae circuli Tarn et Garonne, quam nondum

$5.197 \div$ Laguna, Andres de. Annotationes in Dioscoridem Anazarbeum per Andream Lacunam, Segobiensem, medicum Julii III. P. M. juxta vetustissimnrum fidem elaboratae. Lugduni, apud Rovillium. 1554. 12. 340 p. Bibl. Juss.

$5498 \div$ Pedazia Diascorides Anazarbea Acerca de la nateria medicinal y de los venenos mortiferos. Traducido de lengua griega en la vulgar castellana y illustrado con claras y substantiales annotaciones y con las figuras de innumeras plantas exquisitas y raras por el Doctor Andres de Laguna. En Anvers, en casa de Juan Latio. 1555. 4. 616 p., praef., ind., ic. i. t. Bibl. Reg. Brux. - TValencia, por .liguel Sorolla. 1636. folio. (20) 616 p., incl., ic. i. t. Bibl. Juss.

$5499+$ Lagusi, Vincenzo. Erbuario italo-siciliano in cui si contiene una raccolta di moltissime piante col nome italiano, latino e siciliano, il tempo di coglierle, dove sogliono nascere, e le loro specifiche virtu, con due indici l'uno latinu, e l'altro sicilimo. Palermo. tỵ. Valenza. 1743. 4. 302 p., praef., ind. Bibl. Webb. et Juss. 
$3: 300^{*}$ Laicharding, Johann Nepomul. Vegetabilia europaea in cemmoJum botanicorun per Europam peregrinantium ex systemate plautarum C. a Linne collecta et novis plantis ac descriptionibus adaucta. Oeniponte $1770-1771$. Il voll. $8 .-1: 1790.541$ p., praef, ind. II: $1791 . \mathrm{LVl}, 782$ p., ind.

$5301^{*}$ Manuale botanicum, sistens plantarum eoropaearum characteres generum, specierum differentias nec non earum loca natalia. Sectio I et II. Lipsiae, Bartl. 1794. 8.631 p., ind. - *Idem liber, sect. I: Oeniponti et Lipsiae, Wayner 1794. 8. 202 p. (non differt.)

3502 (Lainé.) Encore la maladie des pommes de terre, ou suite de mes écrits, 18 sept. 20 mars et 18 mai derniers, avec moyeus d'empecher cette maladie. Paris $1846.4 .4 \mathrm{p}$.

$5303+$ Lair, Pierre Aimé. Description des jardins de Courset, silués aux environs de Bouloque-sur-Mer. Paris 1814. 8.20 p.

(Extrait d'un voyago en France.)

$504^{*}$ Iraisney, Louis. Dissertation sur quelques plantes vénéneuses. D. Montpellier an XIV. $4.31 \mathrm{p}$.

5305 Lambergen, Tiberius. Oratio inauguralis de amico historiae naturalis cun medicina connubio. Franequerae 1751 . folio. 79 p. $\mathbf{B}$.

3306 Oratio inauguralis, exhibens encomia botanices, ejusque in re medica utilitatem singularem. Groningao $1754.4,72 \mathrm{p} . \mathrm{B}$.

5307* (Lambert, Aylmer Bourke.) A description of the genus Cincliona, comprelıending the various species of vegetables, from which the Peruvian and other barks of a similar quality are taken. Illustrated by figures of all the species hitherto discovered. To which is prefixed Prof. Vahl's Dissertation on this genus etc. London, White. 1797. 4. Ix, 54 p., 13 tab.

$5508+-$ An illustration of the genus Cinchona; comprising descriptions of all the officinal peruvian barks, including several new species: Baron de Humboldts account of the Cinclona forests of South America: and Lamberts memoir on the diflerent species of Quinquina. To which are added several dissertations of Don Itippolito Ruiz oll various medicinal plants of South America. With several plates: and a short account of the spikenard of the ancients, with a plate. London, Searle. 1821. 4. IX, 184 p., 5 tab.

$3509^{*}$ - A description of the genus Pinus, illustrated with figures, directions relative to the cultivation and remarks on the uses of the several species. London, printed for J. White by T. Bensley. 1803. folio max. 94 p., (5 foll.), 44 tab. col. (tab. 10, 12. 33 et $34^{\text {b }}$ sunt nigrae). - vol. ll. (to which is added an appendix containing an account of the Lambertian Herbarium by Mr. Ilavid Man.) LonJon, Joln Gale. 1824. folio. vi, 42, (3) p., tab. col. 1. 2. 3. 4. 5. 6. 8. 9. 11. 12, B1bl. Imp. Franc.

$5310 \div+$ A description of the genus Pinus, illustrated with figures; directions relative to the cultivation, and remarks on the uses of the several species; also descriptions of many other trees of the family of Coniferae. To which is added an Appendix containiug descriptions and figures of some other remarkable plants, and an account of the Lambertiau Herbarium, by Mr. David Don. Second edition. In two volumes. London, Weddelf. 1828, folio max. - vol. I: $\mathrm{vt}, 62 \mathrm{p}$ 39 tab. omnes col., effig. Lambert. - vol. I] : p.63-124. et Appendix p. 1-24, (2) p. ind., 25 tab. col., 2 tab. nigr. - vol. III: (Editio prima.) 1837. 32 foll., (31) tab. omues col. (78l. 15s.) Bibl. Deless. (of this magnificent work only 23 copies were taken off. The description to the second and third volumes are by Prof. Don, under whose immediate direction the engravings were coloured in imitation of the originals and have quite the appearance of original drawings. The copy for the conveniellce of the Purchaser has been put into thim boarls and so sewn that it may imniediatly be boond

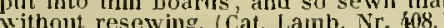

(Exemplar bititiothecae regiae Berolinensis, ni fallor, incompletum est. [uo adsunt volumina minoris editionis magna octava forma, anno 1832 inscripta: vin, 183 p., 81 tab. col. - Pretium hujos editionis 1832 inscripta vil, 83 p. 81 ab. col. - Premam josta exemplar Delessertianum:

Vol. I. Ed. II.

- Effigies Lambert.

$: 9-10$. P. Pinaster
$\therefore$ 13-13. P. Pinea.

1. P. silvestris. 2 . 2 .).

1. P. Pumilio.

-3. P. Banksiana

4. P. Laricio

t. p. Paltasiana.

6. P. maritima. (sign, $\mathrm{X}$.

7. P. halepensis.

1 14. P. inops. 2 rol $/ 4=$

17.. P. resinosa.

-16. P. variahilis

17-18. P. Titeda.

19-20. p. rigida.

21. P palustris.

-22. P. lonzifolia.

- 23-2i. P. Cembr

, 25. P. sirobus.
26. P. excelsa. (sign. 3.)

27. P. Abies.

28. Plba.

30. P. nigra

31. P. orientalis

32. P. Picea.

33. P. balsamea.

34. P. spectabilis. (sign. 2

36. Canaden

637. P. lanceolat

-37. P. lance

$\checkmark$

39. P. pendoli

- 40. P. microcarpa.

iti. P. Cerirus.

4. P. Deodara. $2 p$

43. Dammara orientalis.

i Daminara australis.

45. Araucaria imbricata.

46. A. imbricata. (n, s.)

7. A. brasiliensis. (11. s.)

49. A brasillons. (sign.

50. A. excelsa. (sign. 47.)

b1. A, excelsa. (sign. 4]

52. Taxodium semperv

(Is)

54. Cupressus lusitanical.

56. Thuja pendula. (n. s.

57. Dacrydiam cupressinum. \{sigu. bi)

- I. Thuja Appendix:

- II. Onercis grandifolia.

il. Quercis grandifolia.

- III. Maclora aurantiac

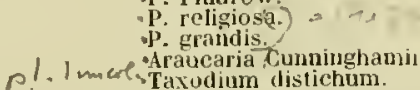

- V. Llex Martiniana.

vi. llex Gongonha.

VIl. NepeotluesRaftlesiana. (nigra o.s.

vili. Nepenthes ampullaria. (nigra II. s.)

Yol. III. Ei. 1

Frontispice (Pints sylvestris.

P. brutia.

P. sinensis

pungells

P. muncata.

ip radiata.

P. radiala.

P. Sabiniana.

P. Coulteri.

l'. patula.

P. Temote

P. Jeiophylli.

P. Montezumae

P. canariensis.

P. Gerardiaui.

p. monticola.

-P. Lambertiana.

P. Lambertiana (cone.

P. Smithiana.

t, Menziesii.

p. Mouglasii.

p. Traglasi.

P. Fraseri.

p. nohitis.

P. bracteata.

$3511^{*}$ Catalogue of the valuable botanical library ( 689 numbers) of the late Aylmer Bourke Lambert, which by order of the executors will be sold by auction at 26 , lower Grosvenor Street, (the residence of the late Mr. Lambert) by Mr. Leigh Sotheby; on Monday; April 48th $1842.8 .42 \mathrm{p}$.

$5512^{*}$ Catalogue of the highly valuable botanical Museum (321 numbers) of the late Aylmer Baurke Lambert, Esq., which will be sold by auction by Mr. Leigh Sotheby, at his house 3, Wellington street Strand; on Monday, June 27th $1842.8 .16 \mathrm{p}$.

5543 Lambertye, Léonce, Comte de. Catalogue raisonné des plantes vasculaires, qui croissent spontanément dans le département de la Marne, avec une carte lotaniquo, indiquant les principales formations géologiques, Paris 1846. 8, $14 \frac{1}{2}$ plag., 1 mappa bot. geol. ( 3 fr.)

53̈l Lambry. Exposé dun noyen mis en pratique pour empecher la vigne de couler, et later lit maturité du raisin. Paris $1517.8,32 \mathrm{p}$., 1 tab. (2 fr.)

S̋̈l5* Lammersdorff, Johann Anton. Plantarum cryptogamicarum fruetificationis historiae Prodromus, de Filicum fructificatione. D. Goettingae $1781.8 .35 \mathrm{p}$.

5546+ Lamoureux, J. B. Justin. Notice biographique sur Pierre Remy Willemet, professeur de botanique a Nancy. Bruxelles 4808. 8. 20 p.

$5517^{*}$ Lamouroux, Jean Vincent F. Dissertations sur plusieurs espèces de Fucus, peu connues ou nouvelles, avec leur description en latin el en francais. Premier fascicule. Agen, an XJII. (1805.) 4, xxiv, 83 p., 36 tab. (15 fr. - papier vélin: $25 \mathrm{fr}$ )

$6518+$ Essai sur les genres de la famille des Thalassiophytes non articulécs. Présenté à l'Institut dans la séance du 3 février 1812. Paris 1813.4.84 B., 7 tab. (6 fr.)

(Extrait des Annales do Muséom dhist. nat. tome $\mathrm{xx}$.

$5549 \div$ Rapport surr le blé Lammas. Caen 1813.8.28 j.

$3000^{*}$ - Jistoire des polypiers coralligènes flexibles, vulgairement nommées Zoophytes. Caen 4816. S. Lxxxiv, 559 p., 19 tab. (20 fr. - papier vélin : $40 \mathrm{fr}$.)

(Icones originariae servantor in Bibliotheea Delessertiana.

$3321+$ Iamouroux, Justin P. Resumé complet de botanique. Paris 1826. Il vell, $12 .-\mathrm{I}$ : vill, 275 p., 3 tab. - Il: IV, 280 p., 2 tab. $(7 \mathrm{fr}$.) * germanice: von $F$. A. Wiese: Abriss der Botanik. Leipzig 1828 2 Bändelien. $12,402,46$ p., 3 tab. $\left(11 / 2, h_{2}\right)$

B322* 2 Resumé de phytographie oa d'histoire naturelle des plautes, contenant les caracteres distinctifs et la description des lamilles et des genres du rìgne végétal, avec l'histoire, la patric et les usages remarquables; accompagnée d'une I conographie de 
108 planches. Paris, Baclselier. 1828. Il voll. 12. - I: XIr, 220 p.

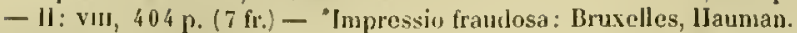
1838. 12. xu, $413 \mathrm{p}$.

3.: 23* Lamouroux, Justin P. Iconographie des familles vigitales ou rollection de figures représentant le: port, les formes et les caractères des plantes, qui peuvent servir de type pour charpue famille, avec des détails anatoniques; dessinées sur pierre par lladame $\mathbf{S}$. Lamouroux; accompagnè d'une explication des planches par Justin P. Lamouroux. Paris, Bachelier. 1828 . 12. 82 p., $108 \mathrm{tab} .47 \mathrm{fr}$. eol. 14 fr.) - " Impressio fraudusa: Bruxelles, Jlauman el Co. 1939. 8 obl. 10 p., 108 tab.

1392 ' $\longrightarrow$ Notice biographique sur Jean I'incent F. Lamouroux. Paris $1829.8 .28 \mathrm{p}$. a.

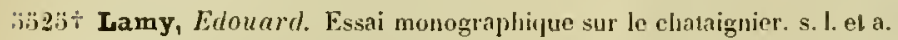
8. $69 \mathrm{p}$.

3326* Lancisi, Giocanni Maria. Dissertatio epistolaris de ortu, vegetatione et testura fungorum ad eximium et nohilissimum virum Coniten Ludovicum Ferdinandum llarsilium. Romae 1714. folie. XVIHI p. praeter Animadversiones in Plinianan Villan. p. XIX-XLVII. el ind. et tals.

(Impressa rst una cum L. F. Marsitii Dissertalione; ad calcem Aninadversionum sequitur: "De herbis of fructibus in recens aggesto iitore "liberis suborientibus.")

30327 * Landsberg, H. Pharmacograplia Euphorhiacearusu. D. Berolini 1831. $8.100 \mathrm{p} .(1 / 2 / h$.

$3.328 \div$ Lang, Adolph Franz. Enumeratio plantarum in Hungaria sponte nascentium, quas in usum botanicorum legit. Pestini $1822.8 .12 \mathrm{p}$.

5329 Lange, Beatus Frans, latine Langius. Catalogus plantarum circa Lucernam Helvetiorum sponte nascentium et a Beato Francisco Langio sul, directione paterno aliquibus ab hic annis ommi industria collectarum, exsiccatarum ac nethodo Tournefortiana descriptarum, cun nomenclatura vulgari, praecipuisque virtutum specificarum notis, nec non locis propriis in quibus crescere et invenire solent: cui aceedit brevis itineris alpini lioc anno per summas montis Pilati radices septentrionem potissinum spectantes instituti, plerarumgue plantarum narratio. Lucernac, apud Wysing. 1724. s.

(Librum not vidi; Lucernae frustra quaesivi, de quo haec monet Hallerus: "Cital editum Seguierus et passim Diaria eitant; sed certo didici, non prosliisse,

3.330 Lange, Daniel. Catalogus der Gewachse, so in dem Lastropischen Garten zu Eimslı̈ttel gewachsen. llambura 1707. 8

(Laudatur als Erndielio.)

:3̈3 I Lange, Johann, latine Langius. Epistolarun medicinalium volumen tripartitum. Basileae 1544. 4. S. - Francofurti 1589.8.1131 p. - Hanoviac 1605.8 .1020 p. B.

(De contentis botanicis epistolirum ef. Hall. Bibl. bot. I. 315.)

äs32 Lange, Johann Heinrich. Dubia Cicutae vexata. Helmstadii 1764. 4. H.

3533 Tentamen nedico-pliysicum de remediis Brunsvicensium domesticis. Brunsvigae 1765.8 . $\mathrm{H}$.

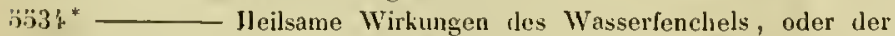
sogenannten Peersaat. Franhfurt und Leipzig 1771. 8. - ih. 1775. $8.48 \mathrm{p}$.

5.33:3* Lange, Joham Michael, pr., latine Langius. Dissertatio botanicotheologica de herba Borith, cujus Jeremias cap. II. vers 22. et Malachias cap. III. versu 2. mentionen faciunt. Altderfi 1705. 4. $40 \mathrm{p.}$, 1 tab.

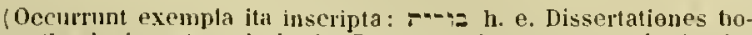
tauico-theologicae tres de herba Borith, serl altera et tertia theologici sunt argumenti. Eruditus vir contra Rudbeclium filium oslendit, Borith esse Kali species Rauwolfianas of ex iis paratum saponem.)

¡j)36 Lange, Karl Nicolaus. Beschreibung des schädlichen Genusses der Kormzapfen. Luzeru 1717. 8. н.

:i:3 $37^{*}$ Langethal, Christian Eduard. Lehrbuch der landwirthschaftlichen Pflanzenkunde fur practische Landwirtle und Frounde des Pflanzenreiches. Jena 1841-1845. 3 Theile. 8. - I: 1841. Süssgräser. vil, 119 p., 10 tab. - II: 1843. Klee-u. Wickpflanzen. $156 \mathrm{p} ., 10$ tat. - III: 1845 . Hack fruchte, Handelsgewaichse und Küchenkráuter. $x, 258$ p., 1 t tab. col. ( 4 (h, - nigr. $3 \frac{1}{2}$ th. $)$ Die Gewtichse des nördlichen Deutsclılauls nach ihren natürlichen Jamilien, Standortern und Stoffen. Nit einem nach neuen Grundsätzen bearbeiteten Blutenkalender. Jena 1843. S. v. $498 \mathrm{l} \cdot\left(z^{2} / \mathrm{s}, h_{\text {. }}\right)$

5is39* Langethal, Christian Eduard. Terminologie der beschreibendeı Botanik. Yehst einem lateinisch-deutseben und deutsch-lateinischen Worterbuche. Mit den dazu notligen Abbildungen von $\boldsymbol{E}$. Schenk. Jena 1846. 8. 334 p., 56 tah. pro parte col. ( 3 th.)

$33: 0$ Langford, $T$. Instructious to raise all sorts of fruit-trees that prosper in England. London, by J. N. for Richard Chiswel. 1681. 8. s. - Ed. II: London 1696. 8. s. - I.oudon 4699. 8. 220 p. 2 tab. B.

35.1. * Langguth, Gcorg August. Antịuitates plintarun feralium apurl Graecos et Remanos. D. Jipsiae 1738. 4. 92 \%.

$5312^{*}$ De immoderatiore Talsaci alsusu. Lipsiae $1750.4 .22 \mathrm{~J}$

$354^{*}$ —_ De cortice peruviano. D. Lipsian 1758. 4. xvi, 28 n.

635." Pregranuma de plantarum venenatarum arcendo scelere. Wittebergae 1770.4.12 p.

3.3\% Langham, Hilliam. The garden of health, conteyning the vertues and properties of all kinds of simples and plants. London 1579. 4. 702 p. - London 1633.4.702 p. B.

33:4 Langhanss, Goltfried. Pregramm von einem verstcinerten Baum Landsluut 1736. 4. Desid. B.

\$347* Langheinrich, Georg Nicolaus, pr. De sensu plantarum. D. I.jpsiae, typ. Wittigau. 1672. 4. (16 p.)

$3348+$ Langlès, Louis Mathieu. Recherches sur la diconverte de l'essence de rose. Paris 1804.12 .47 p. $(1 \mathrm{fr} .50 \mathrm{c}$.) Bibl. Cand. Deless.

63.3.97 Langley, Batly. New principles of gardening ctc. London, Bettesworth. 1728. 4. xvi, 207, 191 p., 1ab. Bibl. Deless.

3350 - A sure methord of impreving estates by plantations of oak, elm, ash, beech and other timber trees. London $1798.8 .274 \mathrm{p}$, I tab. B.

3ij31 Pomona, or the fruitogarden illustrated. Londen $17 \geq 9$. folio, $150 \mathrm{p}$., 79 tab. $\mathrm{B}$.

$3532 \div$ I'Anglois. Livre de fleurs ou sent representées touttes sortes de Tulippes, Nareisses, Iris et plusieurs autres fleurs, avee diversitis d'oiseaux etc. Paris, par Jean le Clerc. 1620. folio.

(Est colfectio tabularum aencarum incerti numeri in bibliotheca Iladriani de Jussieu.)

6533* Langmann, Johann Friedrich. Flora der beiden Grossherzogthuner Mecklenburg für Schulen und zum Selbstunterricht, nebst einer Anleitung zum Selbstbestimmen der phanerogamen Pflanzen. Anlıan: Entwurf ciner PJlanzengeographie Meklenburgs von $G$ Bruckner. Neustrelitz $1841.8 . \mathbf{x}, 414, \mathrm{x}, 22 \mathrm{p} .(12 / 3(h)$.

5335i* Langsdorff, Georg Heinrich, et Friedrich Ernst Luduig Fischer. Plantes recueillies pendant le voyage des Russes autour du monde, expédition dirigée par M. de Ḱrusenstern. Parties I et II: Icones filieum. Tubingen $1810-18$ is. folio. $26 \mathrm{p} ., 30$ tab. ( 5 th.)

435:) Langstedt, Friedrich Ludwig. Thee, Kaffee und Zucher, in historischer, chemischer!, diátetischer. ükenomischer und botanisches Hinsicht. Numberg $1800.8 .\left(1 / h_{.}\right)$

$66566^{*}$ — Allgemeines botanisches Repertoriun zum gemeinnutzigen Gebrauch fur jeden Kenuer und Liebhaber dieser interessanten Wissenschaft. Nürnberg 1801-1805. IJ voll. 8. - I: 1801. A-F. 768 p. - II: 1805. G-Z. VIII, 822 p. $\left(4^{2} / 3\right.$ th. $)$

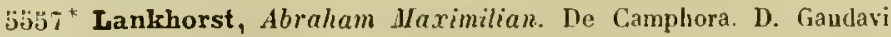
1829. $4.40 \mathrm{p}$.

3338 * Lantzius-Béninga, Bojung Scalo Georg. De evolutione sporidiorum in capsulis muscerum. 1 . Geettingae 1844 . 4 . 94 p., 2 tab $(1 / 3, t h$.

¿3339 Lanzoni, Giuseppe. Citrologia, seu curiesa Citri descriptio. J'errariae 1690.12 .107 p. B. - ib. 1703 . 12. s.

3360 Lapham, J. A. Catalogue of plants found near Milvaukie, W. S. (Wikstrom, Jahresber. 1839-1842. p. 152.)

$5561^{*}$ Larber, Giovanni. Sui funghi saggio generale. Con tavole in rame ed una descrizione e lavola sinotica de' funghi mangerecei piu communi d'Italia. Bassano 1899. II voll. 4. - I: 173 p., 10 tab. col. 11: 324 p., 11 tab. col. sign. 11-20. et suppl. Bibl. Imp. Franc.

$8362+$ (Lardy.) Mémoire sur les dévastatious dles forèts dans les hautes alpes ef les moyens d'y remédier. Zurich 1842.4 .85 . 
3303 t La Rochefaucaut. Le Safran. Poitiers, par Enguilbert de Maruef. 1568. 4. ( 22 foll.) Bibl. Juss.

556 t Ia Roque, Jean de. Yoyage dans I'Arabie heureuse, fait de $170 \mathrm{~s}$ a 1710 , par l'océan oriental et le détroit de la ner rouge, avec la relation d'un yoyage fait du port de Moka a la cour du roi dle d'Yemen de 1711 a 1713. Amsterdam 1716.42 .343 p. B.

Inest: Némoire concernant l'arbre et le fruit du café; traité historique de l'origine et du progris du cafe, 1. 23'-3'3.)

onglice: A royage to Arahia the happy. London 1726. 12. $306 \mathrm{p}$. B. Inest: An account of the collee-tree and its fruit; an historical treatise of the tirst use of Coffea, 17. 217-306.

* epitome germanica: Grindliche ind sichre Nacliricht rom kafee ind Kafecbaum, welche Nonsienl la Roque aus den Bricfen und Jach dem franzosischen Exemplar ubersetzt. Leipzlg 1717. $4.69 \mathrm{p}$.,

epilome germanira: Alshandlung rom Caffe, ubersetzt und mit Anmerkungen erliutert von Friedrich Gerhard Constuntini. Hamover 1771. 8. $138 \mathrm{p}$. B.

6.565* Iarréategui, Joseph Denis. Descriptiom hotanique du Chiranthodendron, arbre du Mexique, nouvellement connu et remaryuable par son aspect et sa beauté. Traduit de l'espagnul par Lescullier. Paris 1805 . 4. 28 p., 2 tal, col.

$3566^{*}$ Lasègue, $A$. Notice sur la vie et les travaux de Antoine Guillemin. Avec portrait et facsimile. Paris 1842.8.14 \%., 2 tah.

Eilrait des Anniles des sc. Hat. tome Xill.)

$3567 *$ - Muséo botanique de Mr. Berijamin Delesserl. Notices sur les collections de plantes et la bibliotheque, qui le composent; conleuant cul outre des documens sur les principaux herliers d'lurope, et l'exposé des voyages entrepris dans l'interet de la botanicjue. Paris 1845. 8. (5), 588 p. ( $7 \mathrm{fr}$.)

$3368 *$ (— Notice sur le Musée botanique de M. Benjamin Delessert. Paris $1845.8 .55 \mathrm{p}$.

(Est particula libri pracedentis scorsim impressa. De eoden Museo disseruit autor in: France literaire, année $V$. tome I. et Alphonsus Defandolle in: Bibliotheque universello de Geneve, Mai 18 '.5.)

5569 Lassobe. Guide du teinturier moderne, contenant une notice sur le bablah. Bordeaux 1826. $8.52 \mathrm{p}$. o.

$3 \% 70 \div-$ Notice sur le bablah, on la gousse du Mimosa, dite galle de l'lade; suivie de divers procédés pour son emploi dans la teinture et pour la fabrication des lndiennes. Bordeaux (1827.) 8. $42 \mathrm{p}$.

3571 Låstbom, Johan, pr. De oleis seminum expressis. D. Upsaliae 1788. 4. 16 p. B.

$5372^{*}$ Lastri, Marco. Biblioteca georgica, ossia catalogo ragionato degli scrittori di agricoltura etc. Firenze 1787, 4, xI, $152 \mathrm{p}$.

ij373* Corso di agricoltura pratica. Milano 1834. 8: vill, 24 i p. 1 tab.

$3371^{*}-$ Calendarj pei contadini. Milano 1834.8.248 p.

$3075 \div$ Latapie, François de Paule A. Ilortus Burdigalensis, seu catalogus omnigenarum plantarum, praesertim officinalium, quae in horto botanico Academiae scientiarum Burdigalensis juxta Linneanum systema demonstrabuntur anno 1784. Burdigalae, apud Mlichael Racle. 1784. 8.83 p. Bib!. Cand.

ö376* Laterrade, Jean François. Flore Bordelaise, ou tableau des plantes, qui croissent naturellement aux environs de Bordeaux, dans un cercle d'un myriametre et demi de rayon, classees d'après le système de Linné etc. Bordeaux, typ. Noreau. 1811. 12. 364 1). tSeconde édition, entièrement refondue et augmentée d'un essai de la Flore de la Gironde. Bordeaux, typ. Brossier. 1821. 12. 5 16 (2) p - Ed. 111: Bordeaux, typ. Laguillottiere. 1829. 12. 2 tab. a. -'Flore Bordelaise et de la Gironde. Quatrieme édition, par $J . E$. Laterrade. Bordeaux, typ. Lafargue. 1846.12 .26 plag. ( 6 fr.)

$3377^{*}$ (Latourrette, Marc Anloine Louis Claret de, et Rozier.) Démonstrations élémentaires de botanique, à l'usage de l'école royale veterinaire. Lyon 1766 . II voll. 8. - I: Introduction a la botanique. xvi, 272 p., 8 tab. - II: Description des plantes usuelles. viII, 652, xı. p. - ${ }^{*}$ Ed. III. augmelltée par Jean Emmanuel Gilibert. Lyon 1787 111 voll. 8 . - I: LII, 176, xxIv, 482 p., 11 tab. - II : LxxxvII, 580 p. - III: 720 p., 2 tab. - ${ }^{*}$ Ed. IV. augmentée par Jean Emmanuel Gilibert. Lyon 1796. IV voll. 8. - I: cxv, 515 p., 8 tab. - II: 752 p. - III : 776 p. - IV: 752 p. 4 tab. - Partie de figures. Lyon 1796 II voll. 4. - I: 15 p., 14 tab., xvi, 104 p., tab. 1-166. - II: tab. 167-282. (Jcones Richerii de Belleval hactenus ineditae.) $24 \mathrm{p}$. 16 tab. (c Leersii Flora Ilerbornensi.) 31 p., 16 tab. (c Vaillantii

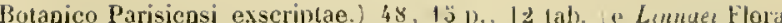
lapponica repetitae.)

$5578^{*}$ (Latourrette, Marc Antoine Louis Claret de, et Rozier.) Voyage au Mont-Pilat dans la province du Lyoumois, contenant des observations sur l'histoire naturelle de cette montagne et des lieu. circonvoisios. Avigno!n 1770.8.223 p.

(A p. 109-223 inest: Botinicon Pilatense, ou catalogue des plantes, qui Croissent au Mnnt-Pilat.

$5379^{*}$ Chloris Lugdunensis. Impr. cum Linnaei Systemate plantarum Europite a Gilibert edito. Lugduni 1785. 8. vili, $43 \mathrm{p}$.

5580 t Laubert, Charles Jean. Recherches botaniques, chimiques, pharmaceutiques sur le Quinquina. Paris $1816.8 .157 \mathrm{p}$.

$5581^{*}$ Laue, Gollhelf Morilz. De radice Caincae ejusque in hydropu efficacia et usu. D. Lipsiae 4827. 4. 32 p.

$5582^{*}$ Lauremberg, Pelrus. Hlorticultura libris 11 comprehensa, huie nostro coelo el solo accomodata; regulis, observationibus, experimentis et figuris novis instructa: in qua quicquid ad hortum proficue colendum el eleganter instruendum facit, explicatur. Francofurti

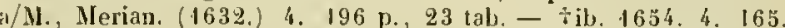
43 p., tab.

$5383^{*}$ - Apparatus plantarius prinus, tributus in duos libros: I. de plantis bulbosis. II. de plantis tuberosis. etc. Adjunctae sunt plautarum quarundam novarum novae ichnographiae et descriptiones. Francofurti a/M., Meran. (1632.) 4. 168 p.. ic. col. i. t., 24 tab. - †ib. 1654. 4. paginae totidem; revera tamen diversa impressio. * germanice: Dir edle Gartenwissenschait, durch (Wolfgang Abraham Stiomer von Reichentiach aus Petri Laurembergii llorticulura et Apparatu plantarum zusammengelesen. Nuruberg, Endier. J682. 3 Theile. s. 336,36 , 703 p., praef., iod., tah.

558: ' Lauremberg, Wilhelm. Botanotheca, hoc est modus conficiendi herbarium, vivun, in gratiam et usum studiosorum medicinae conscripta. Rostochii, typ. Pedani. 1626. 12. (48 foll.)

(Redit pluries chris Mauritï Hoffnanni. Altdorlii 1662. p. - ib. 1693. 4. - Cum Smonis Poulti Viritlariis. Hafuiae 46.33. 12. p. 731-799. . - Erancolurti a/M. 1708. 4. p. $668-690$.

5383 Laurence, John. The clergy-man's recreation, shewing the pleasure and profit of the art of gardening. Ed. IV. London 17 If. \& 84 p. B.

5386 The gentleman's recreation, or the second part of the att of gardening improved. London $1716.8 .115 \mathrm{p} .3$ 1ab. B.

$5587^{*}$ The fruityarden Kalendar. etc. London 1718 . S. v, $149 \mathrm{l}$. I tab

5588 A new system of agriculture, heing a complete body of lusbandry aud gardening. London 1726 . Folio. 456 p. 1 tab. B.

(A p. 38-400: A particular account of the silphium of the ancients.)

$5389^{*}$ Lauth, Thomas. De Acere. D. Argentorati 1781. 4. 40 p.

5590 Vita Johannis ILermann, Prof. med. et historiae naturalis. Argentorati $1 \$ 02.8$; 0 .

$539 . \div$ Lauvergne, Ihubert. Géographie botanique du port de Toulon el Ies iles de llyèrcs. Motifs qui nous font prósager l'entière acclimatation des végétaux exotiques, uriles à l'industrie, à la pharmacie, a l'art uaval. D. Hontpellier 1829.4.41 p.

$5392 \div$ Lavy, Jean. Stationes plantarum Pedemontio indigenarum. Taurini, anno LX. 180 1. 8.103 p. et errata.

$33593 \div-$ Genera plantarum subaljunan regionem exornantium earumque characteres naturales secundun numerum, liguram, situm et proportionem onnium fructificationis partium. Taurini, ann $\mathrm{X}$ (1802.) 8. xxxv, $305 \mathrm{p}$.

$5591^{*}$ Phyllographic pièmontaise, ou nouvelle méthode de coninâitre les plantes d'après les caractères particuliers des feuilles, lisposés en ordre de systeme par un des docteurs agrégés an collège de médecine etc. auteur du lirre imprimé en 1800 avec Ir titre: Johannis Lovy, Genera plantarun subalpinam regionem exornantium. (Turin 1816.) III voll. 8 . - I: xxv, $47 \mathrm{I}$. $-11: 474 \mathrm{p}$. 111: $367 \mathrm{p}$.

$5596 \div-$ État général des vègètaux originaires, on moyen pour juger meme de son cabinet de la salubrité de l'atmosphère, de li fertilité du sol et de la proprièté des luabitans dans toutes les localites de l'univers. Paris 1830.8 .409 p. ( 7 fr. 50 c.) Bibl. Cand. 
"3596, Lawrance, Miss Mary. A collection of roses from nature. London, publislied by Hiss Lawrance, teacher of botanical drawing. 1799. Solio min. 90 tal. col., Froutispice col., 2 foll. ind. (12l. $19 s . \Lambda$ London 1842.) Bibl. Goett.

(Alio luco anni edifimis 1790-1810 indicantur. Opus smmmae rarilit is paucis exemplaribus cum anicis dominae Lawrance corumunicatuni est.

5097 Six numbers of coloured figures of passion-flowers. London s. a. folio. DC.

3598 Lawson, Jolm. A new voyage to Carolina, containiog the cxact description and natural history of that country. Jondon 1709 . \& 258 p., tab. B.

gfrmanice: Allerneueste Beschreibung von harolina und Westi) dien. Jlamburg 1722. 8. H.

"3599\% Lawson, l'ter. The agriculturists manual, being a familiar dcscription of the agricultural plants cultivated in Eurepe. Edinburgh 1836. 8 . xv, 430 p. (9.).)

¿600 Lawson, William. A new Orcliard and garden. Impr. cum Markham Way to get wealth. London 1660.4 .112 p., ic. xylogr. i. t. B.

$5601^{*}$ Laxmann, Erich. Sibirische Briefe, Herausgegeben von August Ludwig Schloezer. Göttingen und Gotha 1769. 8.104 p., ind.

"3602* Leber, Ferdinand. Al)handlung von der Nutzbarkeit des Schicrlings in der Wundarzneikunst. Wien 1762. 8. $79 \mathrm{p}$.

:3603\% (Le Berryais, Louis René.) Traité des jardius, on le nouveau Dela Quintinye. Paris 1775, 8. - Troisième édition par $L . B^{* * *}$ Paris 1789. IV voll. 8. - 1: xxiv, 401 p., 11 tab. - II: 443 p. III: 518 p. - IV: 523 p., 14 tab. (21 fr.)

:360.' - Abrégé du traité des jardins, contenant les arlores fruitiers, les plantes potagères, les arlures, arbrisseaux, Jlenrs et plantes d'ornements, d'orangerie et de scrre-chaude. Avranches 1794. 18. - Jaris 1793. Il voll. 12. (4 fr.) a.

(Idem meritissimus autor Duhamelio adscriptuth librum aTraité sur les arhres fruitiors" (Thes. Nr. yi87) fere totum solus conıposuit. posthumas relicuit descriptiones Phaseolor'um manuscriptas, 49 titbulis coloratis exornatas.

"6003* Lebert, Hermann. De Gestianis in Helvetia sponte nascentibus. J. Turici 1834. 8.49 p'

:506 Leblond, Alexandre. La thèric et la pratique du jardinage, ou I'on traite a fond des beaux jardins etc. Paris 1709. 4. - AmsterJan 1711. 4. - Paris 1722.4 - La llaye 1740.4. s. anglice: The theery and practice of gardening, translated by Joln Ganses. Losidon 1712 . L - London 1728. 4 .

- germanice: Die fiártnerei in iturer Theorie und Prasis, von Franz Anton Dentreiller. Augshurre, Pfeffel. 1731. 8. (12) 368 13. tab. - Neueroffucte Gartuer-Ahallinie. Aus dem Franzosischen von Franz Anton Danreitter. Augsburg 176\%. 8 .

ij607t Ieblond, Charles, et Victor Rendu. Butanique, ou notions élementaires et pratiques sur l'histoire unatuclle des plantes, a l'usage des institutions normales primaires et des écoles. Paris 1834. 8. vis, 142 p. (2 fr. 50 c.) - Impressio fraudosa : Bruxelles 1837.8 .

:608 Leblond, Jean Baptiste. Essai sur l'art de l'indigotier, pour servir à uı ouvrage plus ótendu, lu el approuvé par l'académie des sciences. (Paris) 1791. S. a

\$609 Observations sur lc canelier de la Guyane française. Imjrimécs et publièes par ordre du gouvernement. Cayenne, de l'imprimeric de la républiqque. 1795.8. a.

5610 Mémoire sur la culture du cotonier dans les terres basses, dites Palétuviers à la Guyane française. Impr. par ordre du citosen Victor Hugues, agent du goüvernement français. Cayenue, de l'imprimerie de la république, an IX. 1801.4. a.

$1611 \div$ Description abrégée de la Guyane françaisc, ou tableau des productions naturclles ef comuerciales de cette colonie, expliqué au moyen duno carte śéologico-topographicjue dressée par Poirson. Paris 1814. 8. 91 p., 1 carte. (2 fr.) - Ed. ll. augmentée d'une notice biograplique et scientifique sur M. Leblond. Paris, A. Eymery. 1825. 8. a.

(Esi eadem impressio, additit vita; sect plagulac 13-16 de novo impressia sunt.)

5612* Lebouidre-Delalande, L. Joseph. Leçons á ma fille sur la botanique ou traité élémentaire de physiolugie végétale en six leçons. Paris, Bréauté. 1834-1837. I] voll. 12. - 1: 1834. $319 \mathrm{p} .-$ II: 4837. 323 p., 2 tableaux. ( 5 fr.)

:3613 Traité élémeutaire de physiologie végétale. Paris 1843. 8.25 plag. ( 7 Sr.)
5614 Lebret, Isidore. Mémoiro sur la Trapa natans ou chátaignes d"eau. Rouen, typ. Périaux. 1\$21.8.8 \}. 0 .

5615 Notico sur l'Hlippoulac rhamnoides, lue a la séance publique de la société libre d'émulation de Reuen, le 9 juin 1821. Rouen, Iyp. Baudry. 1821.8 .8 p. 0.

$5616+$ Lebreton, $F$. Manuel de botanique à l"usage des anateurs et des voyageurs; contenant les principes de hotanique, l'explication du système de Linné, un calalogue des différens végétaux étrangers, les moyens de trausporter les arbres et les sernences: la manière de former un herbier, etc. Paris, Prault. 1787. 8, xxis, 328 p., 8 tal). col.

5617 Traite sur les proprietés et les effets du sucre. Paris 1789. 12. 192 ]., \& tab. B. - Nouvelle édition, suivie de l'extrait d'un mémoire de Barry sur les fournis de cannes à sucre. Paris 1790, 12 , a.

5618 Le Brocq, Philip. A description of certain methods of planting, training and managing all hinds of fruit-trees, vines ctc. London 1786. $8.43 \mathrm{p}$, B.

36197 Leche, Johan, pr. Primitiae Florae scanicae. D. Lundae, typ. Decreaux. 1744.4 .54 p., praef., ind.

(Antoris Flora suecica manuscripta inedita servatur in Bibliotheca Bergiana llolmiensi.)

$5620^{*}$ Lechler, 117ilibald. Supplement zur Flora von Wurtemberg. Stuttgart, Schweizerbart. $1844.8 .72 \mathrm{p} .(1 / 3 \mathrm{th}$.)

5621 LeClerc. Cataloguc particulier des drogues. Paris 1701. 19. a.

$3022 \div$ Leclerc, Eugen Alexandre. De l'influence des végétaux sur I'honme. Thesc. Paris, typ. Didot. 1829.4.23 p.

3623 Leconte, Emile. Collection de jolics petites fleurs, chuisies juarmi les plus gracieuses productions en ce genre, tant en Europe que dans les autres parties du mondc. D'aurès les dessios et gravés sous la direction de P. J. Redoute. Fasc. 1-VIl. Paris, tỵ. Pillet. 1836. 4. $28 \mathrm{tab} .(35 \mathrm{fr}$.)

(Duodecim fasciculi quaternis tabulis indicantur.)

362:* Le Conteur, John. Yeber die Varietaten, Eigenthumlichkeiten und Ḱlassification des Weizens. Aus dern Euglischen vou F. A. Ruider. Leipzig, Hiuriclss. $1843.8 .71 \mathrm{p} ., 1$ als. $(1 / 2 / h$. (Editio anglica mibi non imotuit.)

$5620 \div \div$ Iecoq, Henri. Recherches sur la reproduction des végétaux. These. Clermont, typ. Thibaud-Landriot. 1827. 4. 30 p., I tab. cul.

$5626^{\circ}$ Précis élémentaire de hotanique, contenant l'bistoire complète de toutes les parties des plantes et l'exposé des régles it suivre pour décrire et classer les végétaux. Paris, Maire-Nyon. 1828. 8. xuv, $472 \mathrm{p} .(6 \mathrm{fr}$. $)$

5627 - De la préparation des herliers pour l'étude de la botanique ou recucil des moyens employés pour récolter les végétaux, les dessécher et les conserver duus les collections. Avec des exemples de plantes entières et dorganes séparés conservés par les procédés inligués. Paris, Lcvrault. 1829 . 8. $60 \mathrm{p}$. et épreuves. (4 fr.)

5628 Recherches sur Randan. Paris 1830.8.

(linest descriptio et icon pezizae randanensis $u$. sp.

$56295-$ et J. B. Bouillet. Ltinéraire du Départenent du Puyde-1)ome. etc. Paris, Levrault. 1831. 8. xvi, 178 p. 1 carte. (6 fr.)

$5630 \%-$ el $\mathrm{J}$. Juillet. Dictinmaire raisonné des termes de botanique et des Jamilles naturelles, coutenant J'étymologie et la description détaillée de tous les orģanes, leur synony̧mie et la définition des adjectifs, qui servent à les décrire; suivi d un vocabulaire des termes grecs et latius les plus généralement employés dans la glossologie botanique. Paris, J. B. Baillièrc. 1831. 8. xis, 719 p. (9 fr.)

$3631 \div-$ Recherches sur l'emploi des engrais salins en agriculture. Hémoire courouné par l'académie royale du Gard. ClermontFerrand 1832. $8.98 \mathrm{p}$.

$5632 \div$ Traite des plantes fourrageres, ou Flore des prairies naturelles et artificielles de la France, eic. Paris 1844. 8. xur $620 \mathrm{p}$.

$5633^{\circ}$ - De la fécendation naturelle et artificielle des végétau et de l'hybridation, considérée dans les rapporis avec l'horticulture. 1 agriculture et la sylviculture, ou Etudes sur les croisements des plantes des principaux genres cultivés dans les jardins d'ornements 
fruitjers el maraichers, sur les végétaux économiques el de grande culture, les arbres forestiers etc. eontenant les moyens pratiques d'opérer l'hybridation ot de créer facilement des variétés nouvelles. Paris 1845. 8. xx, $287 \mathrm{p}$.

5631. Lecoq, Henri. De la toilette el de la coquetlerie des vigetaux. Clermont-Ferrand, typ. Pérol. 1847. 8. 20 p.

$3635^{*}$ LeCourt, Benoî, latine Curtius. Hortorum libri triginta, auctore Benedicto Curtio Symphariano, equile in ecclesia Lugdunensi. In quilus continetur arborum historia, partim ex probatissimis quibusque autoribus, partim ex ipsius autoris observationo collecta. Lugduni, excudebat Johannes Tornaesius. 4560. folio. 683 p., praef., ind. Bibl. Reg. Berol.

$3636^{*}$ Ledebour, Farl Friedrich von, ot Johann Patricius Adlerstam. Dissertatio botanica sistens plantarum domingensium decadem. Gryphiae $1805.4 .27 \mathrm{p}$.

$6637^{*}(\longleftarrow)$ Enumeratio plantarum horti botanici Gryphici; cun III supplementis. Gryphiae 1806-1810.8.40 p.

$5638+$ Index seninum horti academici Dorpatensis. Dorpati 1822. 8. 20 p. - Suppl. ]: 1823. 8. 7 p. - Suppl. 11: 1824.8. 7 p.

$3639^{*}$ Monographia generis Paridum, qua ad scholas audiendas invitat. Dorpati 1827. folio. 10 j., 1 tah. $(2 / 3$ (h.)

$3630^{*} \longrightarrow$ Reise durch das Altaigehirge und dio soongorische Kirgisensteppe. Berlin 1829-1830.2 Theile. 8. - 1: 1829. vII, $427 \mathrm{p}$, 18 Tabcllen. - II: $1830.1 \mathrm{v}, 522,228 \mathrm{p}$ - Atlas in fol. obliquo: $12 \mathrm{tab} .(9 \mathrm{th}$. - in charta velina: $12 \mathrm{~d} / \mathrm{t} / \mathrm{l}$.

364 *. Flora altaica. Scripsit Kurt Friedrich von Ledelour, adjutoribus Kart Anton Meyer et Alexander von Bunge. Berolini, Reimer. 1829-1834. IV voll. 8. - I: 1829. xxiv, 440 p. - II: 1830. xvi, 464 p. - III: 1831. vill, 368 p. - IV: 1833. xIv, 336, xcvi ]). $(711 / 12$ ll.)

$3642^{*}$ lcones planlarum novarun vel imperfecte cognitarum Floram rossicam, imprimis altaicam, illustrantes. Rigae 1829-1834. V voll. folio. - 1: 1829. 26 \%., tab. col. 1-100. - II: $1830.30 \mathrm{p}$, tab. col. 101-200. - JlI: 4831. 30 p., tab. col. $201-300 .-$ IV: 1833. 28 p., tab. col. $301-400 .-V: 1834.36$ p., tab. col. $401-$ 500. (col. 375 th. - nigr. 215 th.)

56 1.3* - Commentarius in J. G. Gmelini Floram Sibirican. (Regensburg 1841.) 4. 96 p.

(Bes. Abdruck aus den Regensburger Denkschriften, Band 111. 564. p. $^{\text {p } 43-138 .)}$ Flora rossica, sive enuneratio plantarum in totius imperii rossici provinciis europaeis, asiaticis et americanis lucusque observatarum. Stuttgartiae, Schweizerbart. 1842-1846. Il voll. 8 . - I: 1842. xvi, 790 p., mappa geogr. - Il: 1844-1846. v1, 13, 937 j. (14 th.) (Continuatur.)

$5645^{*}$ Ledel, Johann Samuel. Succincta Mannae excorticatio, oder plilologisch-physikalisch-medizinische Betrachtung des Schwadens. Sorau 1733. 8. 74 p., 1 tab.

564.6 Ledelius, Samuel. Centauriun minus, auro tamen majus. Francofurti a/A. (694. 8. 308 ]), B.

$5647^{*}$ Ledermueller, Martin Frobenius. Mikroskopische Gematlss- und Augenergötzungen, bestehend in hundert nach der Natur gezeichneten und illuminirten Kupferlafeln, nebst Nachlese in 5 SammJungen, enthaltend funfzig illuminirte Kupfertafeln. Nurnberg 1759 -1762. gr. 4.204 .94 p., ind., 150 tal). col. $(16 \% / 3$ th. les yeux. Nuremberg $1766^{\prime}-1768$. $4.126,438,118$ p., 100, 30 lab. col. B.

$5648^{*}$ - Physikalisch-mikroskopiselie Zergliederung des liorns oder Rokens nebst der Beobachtung seines Wachsthums. Nürnber. 1764. folio. 12 p., 4 tab. col. $\left(1 \frac{1 / 12}{1}\left(h_{\text {. }}\right)\right.$

š6.9* ${ }^{*}$ Physikalisch-mikroskopische Zergliederung und Vorstellung einer selur kleinen Winterknospe des Hippocastani seu Esculi oder des wilden Rosskastanienbaums. Nurnberg 1764. folio. 8 p., 3 tab. col. $(5 / 6$ th. $)$

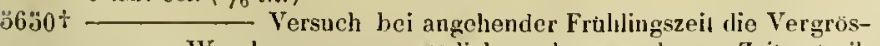
serungs Werckzeuge zum nutzlich und angenebmen Zeitvertreib) anzuweuden. Von dem Verfasser der mikroskopischen Genuthsund Augenergótzung. Essai d'employer etc. Nürnberg 1764. folio. 48 p., 12 tab. col. ( 6 (h.)

56 ä1 ㄴ.. Physikalisch - mikroskopische Vorstellung einer angeblichen Ruckenpflanze, das Stauden-Stock- oder Gerstenkorn genannt. Nürnberg 1765 . folio. $\left(1 \frac{1 / 3}{\mathrm{th}}\right.$.) $\mathrm{H}$.
3652 Ledermueller, Martin Frobenius. Reponse a quelgues ohjection: a lui faites par M. Lo Baron de Gleichen, laguelle servira de supplement aux amusemens microscopiçues; avec une acldition. Noremherg 1768.4.23 p., 2 tab. col. B.

5633 Letzte Beobachtungen seiner mihroskopischen fremuths - und Augenergötzungen. Nurnberg 1776. gr. 4. ( $17 / 12 t h$. (De contentis cf. Hall. Binl. bot. 11.483 .)

56 ' $^{*}$ LeDru, André Pierre. Voyage aux iles de Ténériffe, la Trinité St. Thomas, St. Croix et Porto-Ricce. etc. Paris, Arthus-Bertrand 18 10. II voll. $8 .-$ I: xLvil, $315 \mathrm{p} .-\mathrm{II}: 324 \mathrm{p}$., I carte. $110 \mathrm{fr}$. * germanice: Reise nach den lnselu Tenerilfa Trinidad, St. Thomas

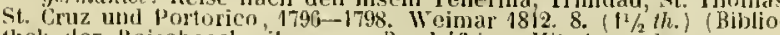
thek (ler Reisebeschreibungen, Band 46.) - Mit Anmerkungen vor Sonini. Elberfeld 1812: 2 Bände. $8 .\left(3 \frac{1}{3} / h\right.$.

5655 Lee, Arthur. De cortice peruviano. D. Edinburgi 1764.8. 47 p. B.

8636 t Lee, James. An introduction to botany, containing an explanation of the theory of that science, and an interpretation of its technical terms, extracted from the works of Linnaeus. London 1760.8 .320 p. 12 tab. - tEll. III : Lonlon 1776. 8. xurv, 432 p., 12 tab. - +Ed. V. London 1794. 8. xxuv, 434 p., 42 tab. - ${ }^{*}$ New edition corrected and revised l,y $C$. Stewurt. Edinburgh 1806.8 , xıI, 379 p., 12 tab. 5657 Catalogue of plauts and seeds, sold by kennedy and Lee. nurserymen at the vinegard, Hammersmith. London 1774. 8. 76 p. B.

$5658^{*}$ Leers, Johamn Daniel. Florallerbornensis, exhibens plantas cirea Herbornan Nassuviorum crescentes, secundum systema sexuale Linneanum distributas, cum descriptionibus rariorum imprimis graminum, propriisque observationibus et nomenclatore. Accesserun graminum omnium indigenorum corumque adfinium icones CIV anctoris manu ad vivum delineatae. Herbornae Nassoviorum 1775 . 8. LIx, 288 p., praef., ind., 16 tab. (Heyer in Giessen: $1 \frac{1}{4}$ th.) * Ed. altera : Berolini, impensis C. F. llimburgi. 1789, 8. LxxvıI 289 p., imol., 46 tab. ( $21 / 2$ th.)

(Iii editione allera, quam a llildenovio curatam esse lego, exstat meritissini autoris vita a filio Henrico Paulo Leers conscripla, p. Nill -XXil, iterum vitam entarravit lluebener in Flora, Ratisbonensi diario, $\left.1839 . \mathrm{P}, 4 \mathrm{~S}^{\prime}-\mathrm{k} \times 8.\right\}$

$\$ 659$ Lees, Edwin. The affinities of planks with man. London 1834. s. $122 \mathrm{p}$.

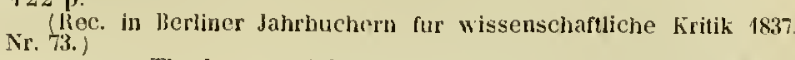

$5660^{*}$ The botany of the Malvern llills in the counties of Worcester, Hereford and Gloucester; will the precise stations of the rarer plants etc. London (1843.) 8. vill, $64 \mathrm{p}$.

5661 Leeuwenhoek, Antonivan. Ontledingen en ontdechingen, vervat in verscheyde brieven, geschreven aan de Koninglijke Societeit tut Londen. Leyden 1686 . 4. B.

(Titutus hic, in Ranksiano exemplo, praefixus opusculis, diversis temporibus editis, quihus continentur epistolac 28-02 ejus ad Regianı Societatem Londinensen inissie. Compactae sunt secuudum ordinen praescriptum in praefatione ad Vervolg der Brieven; hine ita se habent paginae: $10,8,32,33,21,24,19,24,26,2,3-94,76,78,109$.

5662 Vervolg der brieven, gesclureven aan de Koninglijke Societeit in Londen. (Epistolac 53-60.) Leyden 1704. 4. 155 1. B. 5663 Tweede vervolg der brieven. (Epistolae 61-67.) Delft 1697.4. p. $157-350$. B.

3664 Derde vervolg der brieven. (E)istolae 6s-73. Delft 1693. 4. p. 354-531. B

5665 Vierde vervolg der brieven. (Epistolac $76-83$. ) 1694. 4. p. $533-730$. B.

5666 Register van alle de werken van de Heer A. van Leeuwenhock, verdceld in twce deelen, daar van het eene de stoffe, die in do tion eerste tractaten begrepen is, en het andere die van de vior vervolgen der brieven aanwijst; door een bominnanr der natuurlijke wetenschappen t'samen gesteld. Leiden 1695.4 . 34, 29 p. в.

¿667 Vijfde vervolg der brieven, geschreven aan verscheide hoge standspersonen en geleerde hiijden. (Epistolac 8496.) Welft 1696.4.172 p. B.

3668 Sesde vervolg der brieven. (Epistolac $97-107$. Delf 1697. 4. 1. $173-342$.

5669 Sevende vervolg der brieven. (Epistolac 108-146.) Delft 1702.4. 452 P.

(Epistolac hae, latine versae, diversn tamen ordine et diversa 7670 divisione partiun, redent in tomis tribus prioribus Operum omnium. Anatomia seu interiora rerum cum animatarum tum inanimarum (sic!), ope et nebeficio (sic!) ex(puisitissimorum mi- 
roscopiorum detecta, variisque experimentis demonstrata una cum discursu ol ulteriere dilucidationo epistolis quilusdan ad celoberrimun, guod... Lendini lloret, philosophorum collegium datis :onpurehesse. Lugduni lhatavorum, (g). Boutesteyn. J687. 4. 58, $258 \mathrm{fr}$. cum praef. ct tabulis.

(Opera omnia, tomus 1. pars 1.)

$361^{\circ}$ Leeuwenhoek, Anloni van. Continuatio epistelarum datarum ad Ionge celeberrimam regian societaten Londinensem. Lugduni Bataverum, apud Conelium loutestein. 1689. 4. $124 \mathrm{p}$. cum indice rerum el talulis. - thugduni Batavorum, apud J. du Vivie, Tl. Haak of J. A. Langerack. 1715. 4. 124 \%. cum indice rerum et talullis. (non ditlert, sed alia impressie.)

(Operat umnia, lomus J. pars 2.)

$3672^{\circ}$ - Areana naturae, ope et beneficio exquisitissimorum mieroscojvorun detecta, variisque experimentis demonstrata, una "un ..... comprehensa. Delphis 1695. 4. 568 p., praef., ind. Lugduni Batavorum 1722. 4. 515 p. - Editio tertia: Lugduni Batavorum, apud Cornelium Beutestein. CID 15C. CCVIII. (sic!) 4. $64,258 \%$.

(Oplera ommia, tomus II. pars 1.

$8673^{\circ}-$ Continuatio areanor'um naturae detectorun, qua continctur quicquid hactenus ab anclore lingua vernacula editum et in linguam Jatinam transfusnm non fuit. Delphis Batavorum, apud Ilenricun a liroenerelt. 1697. 4. $192 \mathrm{p}$. cum indice el tabulis.

Sunt rpistolae 93-107; redit eadem impressio in operibus omuihus i1. 2.)

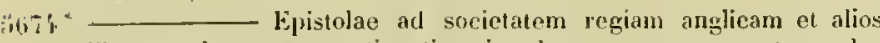
illustres viros, seu continuatio mirandorum artanorm naturae detectorum. (Ejpistolae 108-146.) Lugduni l3atavurmo 1749.4.429 p. Opera omnia, tomus III. 366. $\mathrm{B}$.

germanire: Epistola 13h. in Berine Samulumg, Band I.X. p. 3ili1itis

de Koninkls he Socieleit to Lonten, ins aan andere ansienclyke en geteerde lieden, over verscheyde verborgentheden ter natuure. i)elf( 1718.4 .460 p. B.

latine: Epistolae physiologiene super compluribus naturae areanis: ubi variorun animalium atrue plantarum fabrica, conformatio, proprietates atcue operationes novis el hactenus inobservatis expropretates ilustrantur ot oculis whibentur ete. hactenus nunquam edilas. Delphis, apud A. Benatu. 1719. 4.446 p., ind., tah.

(Opera onnia, tomus IV.)

$566^{\circ}{ }^{\circ}$ - Opera omnia, seu Areana naturae epe exactissimorum microscopiorum detecta, experimemts variis comprobata, epistolis all varios illustres virus, ut et ad integram, quae Londini floret, sapientem societatem, cujus membrum est, datis, comprehensa et quatuor tomis distincta. Editio novissima, prioribus emendatior, cum indicilus cuique tomo accommodatis. Lugiluni Batavorum, арuе Langerah, 1715-1722. IV voll. 4. - I: 1722. $449 \mathrm{p}$., ind. - 11 $1715.515 \mathrm{~J}$, ind $-111: 1722.192 \mathrm{p}$, ind. $-\mathrm{N}: 1719.429 \mathrm{j}$. ind. Ommia cum multis tabulis aeneis.

Enter diesem Titel hat der lerleger Arnold Langerak dir meist schon truher eimzern ersehienenen llerke des tertassers, olue sie umzudruch'll, vernuthlieh mor zusammen gufasst. Der erste Rand enthalt noch l's seiten Dedication us. S. W., wovon mu die 8 ersten parinir siud, drei Briefsammlungen, die erste p. 1- bik, die zweite patimir sind che

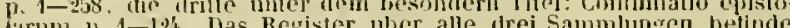
lirum 1) 1-12\%. Das Registrer uher alle trei sammlungen betinde sich ren fortlinfenten signaturen lach $\mathrm{am}$ schluss der zweitc Silnmlung, hal aber heine Paymo - Der zweite theil fuhrt wur den Titel Arcana naturae retecta. Edit. moviss. anctior ef correctior. ilicic rod. Yelu If $\mathrm{f}$. Inhaltsanzeige ohne Pagina Dann Test, p. 1-51: danu Index mit furtlanfender signatur ohne Pagina, Dam nuter he sonderm Tilel: Contimuatio ireanorum diturae detectorun, bid. rou $10 \mathrm{p}$. luhaltsanzeige obne Pagina, daun Text $\mathrm{n}, 1-192$ und index mi fertlaufender Signatur olme Pagina. - Der drittr Band: Epistolae ad societatem regian anglican of alios illustres viros scu contimatio miranderum arcanorum uaturae tetectorum, quae ex Befgico in Latinam linguam tıanslatae sunt; ihilı 1719. 429 paginirte seitel, volal luhallsanzejoe, hinten lnim ohne Pagina, - Der viorte band: livistolac physiologicie super rompluribis naturae arcanis etc. llic tenus nunguam editae. Delphis. apud Adriamum Beman. 1719. 426 Text. voran Inhaltsanzeige, hinten Index ohne pagina. - Die zahlrejehen Abbildungen sind ohuse fortlaufendes Nummer nur mit der Pagina hezeichnet, zu der sic gehoren." E. M.

"Leewwenhock giebt nur isolirte thersuchungen, aber peiche, his jetzt (1815] oft rerhanute Beil'śge zur hohern phanzenunatenie. Kieser.

The select works of $A$. van Leenuenhoek, containing his microscopical discoveries in many of the works of nature, translated frem lle dutch and latin editions published by the author; by samuel Hoole. Londen 1798. 4. Part 1: 88 p., 4 tab. B.
5678" Lefébure, E.A. Expériences sur la germination des plantes. Straslourg, typ. Louis Eck, an IX. (1801.) 8. 139 p. (1 fr. 80 c.)

5679 Lefébure, Louis F. II. J)iscours sur le principe essenticl de liurdre en listoire naturelte et particulièrement en hotanicgue. Paris, typ. D'llautel. 1812.8 .24 p. a.

$5680 \div$ Méthede signalementaire pour servir à l'ílude du nom des plantes, ou nouvelle mavière dapprendre a connailre le uom tes plantes a leur premiere inspection, sans qu'il soit hesoin d'avoir éludié aucun systeme, et par un procédé qui exige a peine une heure d'étude. Arec des tablettes mobiles. Paris, Desoêr. 1814 1815. 8. Nr. $1-3: 96,16,80$ p. (14 fr. 50 c.)

3681 - Concordance des trois systimes de Tournefort, linnaeus et Jussieu, par lo systome foliaire aplylique aux genres des plantes, qui croissent spentanéoment dans le rayon de dix lieues autour de Paris; au moyen dujuel on conoaitra sur-le-champ t.t simultaniment le nom génitique de ces plantes et leurs earacteres classiyues dans ces systimes. Deuxieme idition. Paris, Deseer. 1816. $8.75 \mathrm{p}$. et un poime. ( $3 \mathrm{fr}$.)

$5682 \div-$ Clef du jardin de l'univers d'apres les principes de Tournefort et Linné. J'rospectus. Paris, I!p. Richomme. s. a. 8.4 p., 1 [al). col

5683 - Atlas hotanique ou clef du jardin de l'univers, d'après les prineipes de Tournefort et de Linne réunis. Paris, Treuttel et Wúriz, $18: 7,8,1$ tal). (3 fr. 50 c.) $a$.

568'. Le vrai systeme des fleurs. Paris, Guitel. 18 17. 8.24 \%. $(60 \mathrm{c.}) \quad 0$.

8683 - Reflexiens importantes atressées a Ml. de Jussient sur lo vice radical de l'enseignement mutuel adopté pour la botanique au jardin du roi; lues a la société linneienne de Paris, le 28 Juin 1891. Paris, typ. Richomine. 1821.8.8 p. $(50 \mathrm{c.})$ a.

5686 t Système floral. Flore française, 750 genres. Paris, $1 \mathrm{yp}$ Curnitlon. 1821.8.52 tab. col, 32 tab. nigr.

5087 Cours de promenades champetres aux environs de Paris. en forme de bulletin, dit de Flore, au noyen duquel, on apjrend soi-meme a signaler, reconnatre et classer les plantes d'après la théorie facile et la pratigue sur nature du nouveau système floral. Paris, Lefebure. 1826.8 oll. 2 tal. $a$.

("iouvrage periodique, qui devait paraitre chaque mois par cathiers d'une feuille avec 2 planches; il n'en a été publié qu'un $\mathrm{N}_{\mathrm{r}}$ ? ell 1826 et un Nr. \& ell 1827 . $\mathrm{Q}$.)

tharles Leforestier. Album floral des plantes indigrènes de France, ou botanique élémentaire à l'usage des jeunes personnes. Paris, Lefébure. 1829.8 obl. 5 tab. a.

$5689 \div(-$ Flore de Paris, Genera el species, ou preniere application faite du nouvean systime floral aux plantes vivantes. Paris, Cassin. $1835.8 .1 \mathrm{~V}, 124 \mathrm{j}$. (4 fr.)

("N.. Lefebure met dans ce momnut-ci (i. P. 1833) la dernière

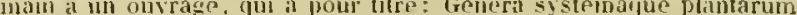
thoriferitum: il se profose d'y eyposer une nourelle methode de classilication qui reponde mieux, selon lui, au hesolns de la seienee que celies dout on se sert aujourd'hui,. Q.)

$\$ 690$ Legati, Lorenzo. Agriomeleis aut in silyestro pornum genus nelamorploses. Bononiat, typ. haer. Victorii Benatii. 1667. 4. S.

3691 - Chrysomeleida, sive auratiorum malorum histeria mythice descripta. Bononiae, tyj. haer. Victorii Benatii. 1667.4. S.

5692 In praeclarissimum Ulyssem Aldrorandum ac ejustem de arborihus historiam ab excellentissimo Ovidio Montulbuno congeslam et elahoratan Et'os. Benoniae, typ. Ferroni. 1668. 4. S.

5693 Nea Casta, sive mythicus de Castanea excursus. Beneniue 1767. 4. Joecher.

$5691 \%$ Le Gendre, cure d"Ilcnoncille. La manière de cultiver les arbres fruitiers, ou il est traití de's pépinières, des espaliers, Jes contre espaliers, des arbres en buisson et a haute lige. Neurelle edition. A lParis, par Ja compagnie des libraires du Palais $1665.12 .332 \mathrm{n}$. Anteriores editiones sunt annorum 1652 et l65\%. - Altctor serus est Antoine Le Naistre, incly tus orator et adrocatus Parisiensis, al thonneur "t la langue du parlement, " [n. 2 .Maji 1608 , + 16383] teste Legrand d'tussy, Vin privee des fransias, vol. I. [). 169 et dronmerque in Tullem. Hist. II. p. 318.

$5695 \%$ Le Grand, Anton. Historia naturae, varis experimentis el ratociniis elucidata. Secundum principia stabilita in institutione philosophine edita ah podem authore. Editio secunda priori auctior. Lendini, Martin. $\{680,4,\{10\} \$ 31\}$, ind 
¿i696" Lehmann, Christian. Historischer Schauplatz derer naturlichen Merkwurdigkeiten in dem Meissnischen Obererzgehirge. Leipzig 1699. 4. 1005 j., tab. aell., ic. $x y \log r$.

Multa ad rem terbariam pertineut. ut totus nonus liber cum catalogo stirpium in sylvis saxonicis reperiundarum anno 1667 a Ilolfoang Patschlie seripto.

5697 * Iehmann, Johann Christian. De Balsamo peruviano nigro. D Lipsiae 1707. 4. 40 p.

¡698 Vollkommner Blumengarton im Winter. Leipzig 1750. 4 71 p. 1 tab. B.

(Editionem anteriorem anni 1718 adesse ex Ilallero probahile est. Johann Christian Lehmam, l'rofessor physices Lipsiensis, obiit anno iา39.

hollandice: Nieuno volmaakte plantagie in den winter. Amsterdam 1718. 8. H.

$5699^{*}$ Lehmann, Johann Friedrich. Primae lineae Florae Herbipolensis 1). Herbipoli 1809.8 .66 p., praef.

$5700^{*}$ Lehmann, Johann Georg Christian. Nonographíi generis Primularum. Lipsiac, Barth. 1817.4. 95 p. 9 tab. (4 th. in charta velina: $5 \frac{1}{3}(h$.)

$5701^{*}$ - Beschreibung einiger neuen und wenig bekannten Pllanzen. (Asperifoliae.) Halle 1847.8. 26 p., 2 tab.

(Seorsim impr. ex: Neue Schriften der naturf. Gesellsch. zu Jlalle, Band III.)

$5702 *$ L Plantae e familia Asperifoliarum nuciferae. Pars I et II. Berolini, Dummler. 1818.4 .478 , Ix p. $\left(4 \frac{2}{3}\right.$ th. - in charta scriptoria: $6(h$.)

6703* - Generis Nicotianarum historia. Pars botanica. (IIamlurgi) 1818.4 .52 p., 4 tab. (1 th.)

5704" Nonographia generis Potentillarum. Hamburgi, Hoffmann et Campe. 1820.4.201 p., 20 tab. (3th.)

$6700^{*}$ Icones et descriptiones novarum et minus cognitarum stirpiun. Pars l. leones rarioruu plantarum e fanilia Asperifoliarum. llamburgi, Perthes et Besser. 1821. folio. 28 p., 50 tal. (13 th. (Prodiit annis 1821-182' quinque fasciculis.)

: $7066^{*}$ Novarum et minus cognitarum stirpium jugilli. Jlanburgi (Perthes et Besser.) 1828-1844. VIIl fasciculi. 4. - I: 1828. 39 p. - II: 1830.30 p. - III: 1834. 58 ر. - IV: 1832.64 p. V: 1833. 28 p. - VI: 1834. 72 p., 5 tab. - Vll: 1838.41 p. Vill $: 1844.56$ p. $\left(9 \frac{1}{2}\right.$ th. $)$

$5707^{*}$ De plantis Cycadeis praesertim Africae australis. Hamburgi, typ. Meissner. 1834. folio, $16 \mathrm{p}, 5$ tab. col. Bibl. Imp. Austriae. (Eaedem sunt tabulae, quae in auturis Pugillo sexto occurrunt.)

$5 \% 08^{*}$ Entgegnung auf die letzte Schrift der llerm Gebrüder Buoth. (Hamburg, typ. Aleissner. Marz 1834.) 8.28 p.

$5709^{*}$ Monograpliae generis Potentillarum supplementum. Fasciculus 1. Hamburgi, Perthes et Besser. 1835. 4 22 p., 10 tab. $\left(1 \frac{1 / 3}{3}(h)\right.$.

$7710^{*}(\longrightarrow$ ) Plantae Preissianae, sive enumeratio plantarum, quas in Australasia oceidentali et meridionali-occidentali annis $1830-$ 1841 collegit Ludwig Preiss. Partim ad, aliis, partim a se ipso determinatas, descriptas, illustratas edidit Christian Lehmunn. Ilamburcyi, Meissner. 1844-4847. Il voll. 8. - 1: (Dicotyledones onnes.) 1844 -1845 . vIII, $647 \mathrm{p}$. (4 th. - in charta velina : $6 \mathrm{k}$.) - Il: (Mlonocotyledones et Acotyledones.) Fasc. I: 1846.160 p. (Continuatur.)

$5714^{*}$ Lehmann, Karl Heinrich. De convenientia plantarum in habitu et viribus. D). Yratislaviae $1834.8 .8,46 \mathrm{p}$.

5712 * Lehmann, M. C. G. Graestangs Brug til Udstopning af Puder og Madratser. Kiobenhavn, tyl. Popp. 1812.8. 24 p., 1 tab.

* germanice: Der entdechte Nutzen des Seegrases zum Fullen der Kissen und Polster. Kopenhager, Schubotlue. 1814. 8.23 p., I tab.

$5713^{*}$ Lehr, Friedrich Augusl. De carbone vegetabili. D. Marburgi Cattorum 1794. 8. $115 \mathrm{p}$

6714* Lehr, Georg Philipp. De Olea europaea. 1), botanico-medica. Goettingae, Dicterich. 1779.4. 70 p., 1 tab.

:575 Leibitzer, Johann. Vollst'ndiges Handbuch der Obstbaumzucht. Wien 1798. 8. $(1 \% / 3, h$.

5716 Praktisches Ilandbuch der Obsthaunzucht. Leutschau 1804. 8. (1 th.)

$5717 \ldots$ Handbuch der Zwergbaumzucht. Wien 1804. 8. (1 th.)

B $718 \div$ Vollstándige Abhandlung von der Runkelrube ihrem Anbau, Nutzen und Gelirauch. Leutschan $4804.8 .53 \mathrm{p} .(1 / \mathrm{s}$ th.

8719 Vollstandiger Gartenkalender. Wien 1808. 8. $(2 \mathrm{l} / \mathrm{s} / \mathrm{h}$.

Pritzf., Thes. lit. bot.
$\$ 720$ Leibitzer, Johamn. Der Gartenbau nach den ueusten Ansichten und Bedurfnissen. Ein Taschenbuch fur Gartenfreunde, wehche Nutzen und Vergnügen suclsen. Nach viejjährigen Beobaclitunzel rerfasst und mil Gartenanlagen erlatuert. Zwrite, wollfeile Ausgabe. Pestl, Hechentast. 1836.4 Bande. 12. 56 plag., 9 tals. (3 $\mathrm{th}$.)

(Tomi singuli inseribuntur: Blumengartnerei, llandolsgartnerei Landsehaftsgartnerei, Obstbaunzuclat.)

5721 Leibnitz, Gollfried Wilhelm von. Relatio de novo antid sentericu americano magnis sumtibus conprobalo. Hannoverae et Wolfonbüttel 1696. 8. H.

57.22* - Ejistola G. G. Leibnitii ad A. C. Gackenholtzium de nutthodo hotanica. J. De optima ratione plantas digerendi. 11 De optima dividendi methodo generatim. III. De dividendi methodo recentioIun botanicorum. IV. We usu plantarum. V. De diversa plantas dividendi methorlo. VI. De methodo Jouchimi Jungii. V'll. De plantarum comparationibus non ex floribus tantum instiluendis. VHJ $-\mathbf{X}$. De diversis plantas diseriminandi capitibus. XI. De re unedica in meliu. provelheuda, atque Ramazzini et IIoffmami in eam useritis. Exstat in Operibus omnibus Leibnitzii, stulio Ludorici Dutens. Genevae 1768. 4. vol. II. p. $169-174$.

3723 Ieidenfrost, Johann Golllob. De succis herbarum recentium recenter expressis. Duishurgi 1751 . 4.

$3721 \div$ Lejeune, A. I. S. Flore des environs de Spa, ou distribution, selon le systime de Linnaeus, des plantes qui croissent spontanement lans le département de l'Ourte et dans les départomens cireonvoisins pour servir de suite á la Floro du Nord de la France de $\mathrm{Mr}$. Roucel. Linge, Duvivier. 1811-1813. Whex parties. 8. - I: 1811 254 p. $-11: 1813.350$ p. $(3$ fr. 50 c. $)$

$5 \% 25 \div-$ De quarumdam indigenarum plantarum virtulibus cummentarii. D. Leodii, typ. Collardin. 1820. 4. 24 p

$3726^{*}$ Revue de la Flore des environs de Sya. Liege, Dusivier. 1824. 8. viII, 264 p. ( 5 fr.)

5727 - et Richard Courtois. Choix de plantes de la Belginue Liège 1826. folio. tab. a.

("Les deux promiers fascicules de cet ouvrage, rui n'a dté tire qu'ì 20 exemplarres seulement, ont été publiés eu 18:6: nous ignorons, si depuis cette époique d'autres ont vu le jour, i a.)

$5728^{*}$ - Compendium Florae belgicae. Leodii, Collardin. 1828-1836. HII voll. 8. - I: 1828. xx, $264 \mathrm{p},-\mathrm{H}$ : 1831 viI, 320 p. $\left(2 \frac{1}{2}\right.$ th. $)$ - 11I: (post obitum Richardi Courtois editum ab A. L. S. Lejeune.) Verviac, Remagie. $1836 . \mathrm{v1}, 423 \mathrm{p.}(2 \mathrm{l} / \mathrm{th}$.)

3729 Leigh, Charles. The natural history of Lancashire, Cheshire and the Pcak, in Derbyshire, with an account of the antiquities in those parts. Oxford 1700 . follio. $196,97,112$ p., tah. B.

(Editio anni 1630 , bene monente Hallero, lietitia est.)

$5730+$ Leighton, W. A. A Flora of Shrepshire. Lundon, John van Voorst. 1841. 8. xIl, 573 p., tab. (1l. 4 s.) Bibl. Webb.

(Prodit istde ab anno 1838 tribus particnlis.)

5731 Leincker, Johann Sigismund. Horti medici Ilelmstadiensis praestantia e plantis rarioribus, superiori anno ibidem florentibus. Helmstadii $1746.4 .23 \mathrm{p}$. B.

3732+ Le Lectier. Catalogue des arbres cultivéz dans le verger el plan du Sieur Le Lectier, procureur du Roy a Orleans. 1628, 8. $35 \mathrm{p}$. Bibl. Reg. Par.

6733 t Lelieur, Comte. Essais sur la culture du Mais et de la Patite douce. Paris, typ. Didot. 1807.8 .80 p. (1 fr. 20 c.)

573 ' — De là culture du Rosier, avec quelques vues sur d’autres arbres et arbustes. Paris, Didot l'ainé. 1811. 12.84 p. 0.

8735 Mémoires sur les maladies des arbres fruitiers. Paris typ. Didot. 1812.12. (1 fr. 50 c.) 0.

5736 La Pemone française, ou traite de la culture et de la taille des arbres fruitiers. Paris, Didot l'aute 1817. 8.8 tab. (10 fr. $50 \mathrm{c.})$ a.

5737 Mémoire sur le Dahlia, et sur sà culture. Paris, lloudaille. 1829. 8. ( $3 \mathrm{fr}$.) a

$5738^{*}$ Lemaire, Charles. Cactearum aliquot novarum ac insuetarum in horto Monvilliano cultarum accurata descriptio. Fasc. I. Paris, Lcvrault. 1838.4 . xiv , $40 \mathrm{p}$., ind., 4 tab. $(3 \mathrm{fr}, 50 \mathrm{c}$.)

$3739 \div-$ Cactearun genera nova speciesque wovae et omnium in horto Monvilliano cultarum ex affinitatibus naturalibus ordinatio nova, indexque methodicus. Lutetiis Parisiorum, Loss, 1839. 8. xvil, 115 p. 
$5740+$ Lcmaire, Charles. L'herticulteur universel; Journal général des jardiniers el amateurs, ródigé par Chartes Lemaire. Paris, Cousin 1839-1844. VI voll. 8. cun tabulis coloratis.

(Inde al) anno 184:5 incipit nova series.)

$5741^{*}$ leonograplie deseriptive des Cactées, ou essajs systématiques et raisonnés sur l'histoire naturelle, la elassification et la eulture des plantes de cetto fimille. Paris, Cousin. Première livraison. 1841. folio. 4 p., 2 tab. col. ( $5 \mathrm{fr}$. souscription.)

(Dueentas libulas edere in volis fuit Lemairii; vix vero $111 \mathrm{tra}$ primum fascieulum progressus est.

5742 " Essais sur l'histuire et la culture des plantes bulbeuses, vulgairement appelées oignens a fleurs, comprenant los caractères diagnustiques, la synonymie, l'étymologio des noms générípuos, la liste des ospeces cultivées, la dato d'introduction, la ceuleur des fleurs de ces plantes etc. Paris, Cousin. 1843.8.392 p.

$5743+\longrightarrow$ Des geures Camellia, Rhododendron, Azalea, Acacia, Épacris, Erica et des plantes de serre froide en général, histoire et culture. Avec la collaboration pour les articles Camellia, Rhododendron el Azalea de N. Paillet. Paris, Audot. 1844. 8. 174 p.

574 — Manuel de l'amateur de Cactus, ou histoire et culture des plantes de la famille des Caclacèes. Premiere partie. Paris 1845. 12. 5 plag

$5745+\longrightarrow$ Scheidweiller, et Louis van Houtte. Flore des serres et jardins de l'Europe, ou descriptions of figures des plantes les plus rares et les plus méritantes nouvellement introduites sur le continent ou on Angleterre, et extrates notammeut des Butanical Magazine etc. Edition française enrichie de notiees historiques ete. Tome 1. Livr. 1-12. Paris; Cousin. 1845-1846. 8. (25 fr.)

(Opera Lemairii conıplura mibi non innolterunt.)

$57 \$ 6$ t Lemaire-Lisancourt. Notiens générales et remarqques partieulières sur la physique végétale. Paris, typ. Celas. 1813. 8. 20 p. Bibl. Juss.

(Lege apud Querard: aParis, Colas. 1814.48 .45 p. (50 c.)n)

Lemaistre, Anloine, vide Le Gendre.

5747* Le Maout, Emmanuel. Leçons élémentaires de betanique fondées sur l'analyse de 50 plantes vulgaires et formant un traité complet d'organographie et de physielogie végétale, à l'usage des étudiants ot des gens du mende. Paris, ehez Langlois et Leclerq. 1844 . Il voll. 8. $x \mathrm{v}, 888 \mathrm{p}$. - Atlas: 50 tab. ( $15 \mathrm{fr}$. - cel. $25 \mathrm{fr}$.)

$5718^{*}$ - Atlas élémentaire de botanique avee le texte en regard, comprenant l'organographie, l'auatomie et l'iconegraphie des familles d'Eurepe, à l'usàge des étudians et des gens du monde. Ouvrage contenant 2340 figures dessinées par MIM. L. Steinheil et Joseph Decaisne. Paris. Fortin, Masson et Co. 1846. gr. 4. vit, 227 p. (15 fr.)

(Idem noster scripsit parten botanicam elegantissimi libri de Horto Parisiensi, supra Nr. 783 eitati.)

$5749^{*}$ Lemcke, $G$. W. Ueber den Lerehenbaum. Hannover, Helwing. 1829. 8. $72 \mathrm{p.}(3 / \mathrm{s}$ th. $)$

5750 t Lémery, Louis. Traité des alimens, eú l'on treuve par ordre et séparément la ditrérence et le choir quon dnit faire de chacuu d'eux en partieulier, les bens et los mauvais effets qu'ils peuvent produire, les principes en quoi ils abondent, le temps, l'áge et le tempérament ou ils conviennent, avec des remarques à la suite de chaque clıapitre, eù l'on explique leur nature et leurs usages suivant les principes chimiques et mócaniques. Paris, Cussun et White. 1702. 12. 541 p., praef. - Ed. Il. Paris 1705. 12. - Ed. Ill. augmentée par Bruhier d'Ablaincourt. Paris 1755. 12. 0.

$5731 \div$ Lémery, Nicolas. Dictionnaire ou traité universel des drogues simples, mis en ordre alphabétique. I aris 1698. 4. - Ed. ll. revue, corrigée et augmentée. Paris, L. D'Houry. 1714. 4. - Amsterdam 1716. 4. 590 p., 25 tab. B. - tRotterdam, Hofhout. 1727. 4. $590 \mathrm{p}$., praef, ind., 25 tab. - Paris, L. D'lloury. 1732. 4. 922 p., 25 tab. B. — Nouvelle édition. Paris, D'Heury. 1759. 4. xxiv, 1015 p., 25 tab., offigies autoris.

(Tabulae praeter ultimam omnes ad botanicam spectunt.)

i752† - Nouveau dietionnaire général des drogues simples ot composées de Lemery; revu, corrigé et considérablement augmenté par Simon Morelot. Paris, Remont. 1807. Il voll. 8. - I: xu, 788 p. - II: 681 p., 20 tab. (15 fr. 50 c.)

germanice: Vollständiges Materialien -Lexicen, verdeutscht dureh Christian Friedrich Richter. Leipzig 1721. folio.

ilalice: Venetiis 1751. folio.
5753 Lemke, Johann. Specimen inauguralc de Anagallidis viribus, inprimis contra hydrophobiam. Rostochii $1790.4 .50 \mathrm{p}$. B.

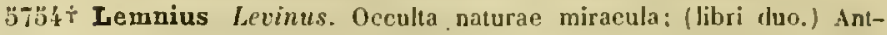
werpiae, Simon. 1561.8.164 foll., praef. - Occulla naturae miracula; (libri quatuor.) Antwerpiae 1567.8.473 p. - Lugduni Batavorum $4666.16 .638 \mathrm{p}$. B.

anglice: The stecret miracles of nature. Lond nn 16 iss. folio. $398 \mathrm{p}$. B. Gohori.

llice: Les occultes merveilles ou secrets do hature, par Jaques

germanice: Oeculta naturar miracula. Wunderharliche Geheimnisse der Natur in des Nensehen Leib und scelo, auch in vielen andern naturlichen Dingen, als steinen, Ertzt, Gewaclis und Thieren. Aus den Latein in tentsche sprich gehracti, zum dritten Mal vermehrt, und eines trossen Theils von Neven selhst geschrieben durch Jacobum llorsium. Leipzis 1593. II voll. \&. Rivin - Leipzig 1572 . 8. H.

57 $33 t+$ Similitudinum ae paraholarum, quae in Biluliis ex herhis atque arhoribus desumuntur, dilueida explicatio: in qua narratione singula loca explanantur, quibus prophetae, observata stirpium natura, conciones suas illustrant, divinacjue oracula fulciunt. Antwerpiae, apud Guilelmum Simenem, 1563. 8. H. - ib. 1569. 8. Rivin. - Erpherdiae, excudebat Esaias Mechlerus. 1581. \&. 137 foll. Rivin. B. - ib. 1584. 8. Rivin. - (Impr. cum Francisci Jallesii Sacra philosuphia.) Lugduni 1588. 8. 194 p. - l.ugduni, apud Ant. Soubren. 1622 et 1652 . S. S.

anglice: An berbal for the Bible, drawen into enylish (with alterations) by Thomas Newton. Lenden'1587, 8.227 p. B.

3756 LeMonnier, Louis Guillaume. Observations d'histoire naturelle. fajtes dans les provinces meridionales de la France pendant l'année 1739. Impr. avec La Mleridienne de I'Observateire de Paris, par Cassini de Thury. Paris 1744.4. p. cIx-ccxxrv. B.

3757 Lettre sur la eulture du café. Amsterdam et Paris, Lehreton. 1773. 12 . a.

5758 Lemprière, $W$. Popular lectures on the study of natural history and the seiences, vegetable physiology etc. Londen 1827. 8 .

$3759^{*}$ Lengefeld, Karl von. Anmerkungen von denen auf dem Tbüringer Walde bekannlesten drei Arten Nadelholzern, Tanne, Fichte und Kionbaum. ete. Mlit col. Kupfern von N. F. Eisenberger. Nürnberg, typ. de Launoy. 1762. 4. 27 p., 7 tab. col.

5760 Lenoir, $B . A$. Traité de la culture de la vigne el de la vinification. Paris 1828. 8.618 p., 8 tab. ( $13 \mathrm{fr}$.)

5761* Ienz, A. F. Die Wild-Baumzucht oder Anzucht, kultur und benutzung der in-und auslandischen Holzpflanzen des freien Laudes. Stuttgart und Tubingen, Cotta. 1843.8 . vilt, 508 p. (15/6 th.)

$57622^{*}$ Lenz, Harald Othmar. Die nüzlichen und schadlichen Schwämme nebst einem Anhange uber die islandische Flechte. Gotha, Becker. 1831. S. v1, 130 p., t tab. - Atlas in 4. Is tab. col. $\left(3 \frac{3}{3}\right.$ th. $)$ ${ }^{*} Z$ weite sehr vertinderte Ausgabe. ib. 1840.8 . vi, 170 p., 16 tab. col. $\left(1^{5} / 6\right.$ th. $)$

5763 - Gemeinnützige Naturgeschichte. Vierter Band. Pflanzenreich und Mineralreich. Getha, Becker. $1838-1839.5 .64^{3} / \mathrm{t}$ plag., 21 tab. $\left(2 \frac{2}{3} t h.\right)$

3764 Leo, Johannes, Afrieanus. De tolius Africae descriptiene libri IX, ab auctore primum arabice seripti, nune latine sersi per Joannem Florianum. Antwerpiae 1556. 8. 302 foll. B. - Tiguri 1559. S. Lugduni, Elzevir, 1632.16. H. italice: Della descrittione dell Afriea, e delle cose notabili, che quivi sono. riaggi raceofte da Ramusio vol. I. foll. 1-90̈. B.

gallice: Ilistoricale deseriptien de l'Afrique, ... escrite $\Gamma$ ar Jean Leon, Africain, en langue arabesque et traduite en françis. Anvers 1556. 8 . anglice: Geographical histerie of Africa, translated by J. Pory. Lendoil 1600. 4

germanice: Beschreihung von Afrika, aus dem ltalienischen übersetzt und mit Anmerhungen versehen von $G$. H: Lorsbach. Erster Band. Ilerbern 1805. 8. (2 ih.)

(In libro VIII plures parum notae plantae Africae indigenae dicuntur.)

$5763^{*}$ Leo, Julius. Taschenbuch der Arzneipflanzen, oder Beschrcibung und Abhildung sammntlicher offininellen Gewăchse. Nebst Anleitung zur systematischen Kenntniss derselben. Mit einer Vorrede von Heinrich Friedrich Link. Berlin, Laue. 1\$26-1\$27. \& Bande oder 40 Hefte. 8.280 tab col, totidemquo foll. text. (cel. $18 \frac{2}{3}$ th., nigr. $9 \frac{1}{3}$ th., semicel. $13 \frac{1 / 3}{t h}$.)

$5766^{*} \frac{1}{(1 / 2 \text { th. })}$ Botanische Kunstspracbe. Berlin. Laue. 1526. 8. 118 p. (Est appendix operis praecedentis.) 
$5767^{*}$ Leonhard, Philipp Konrad. De nova aquae salsae fonte detecto. D. Goettingae 1753.4. $16 \mathrm{p}$.

(De plantis prope satinas crescentibus, p. $11-16$.

5768* Leonhardi, Friedrich Gotllob. Symbolae ad historian agriculturae veterum Germanorum. Specimen 1. Lipsiae, typ. Klaubart. 1790. 4. $28 \mathrm{p}$.

$5769 \div-$ Ueber die Erziehung und Pflauzung der Pappeln uberhaupt, und der Carolinischen und Canadischen insbesondre Leipzig, Baungärtuer. 1798. 4. 14 p., 2 tab.

$5770^{*}$ Leonicenus, Nicolaus. De Plinii et aliorun medicorum erroribus. Impressi Ferrarie per magistrū Laurentium de valentia et Andream de castronovo socios. die. .VIll. Decembris anno domini 1492. 4. ( 18 foll.) Bibl. univ. Lips. - ${ }^{*}$ De Plinii et aliorum snedicorum erroribus liber. Cui addita sunt quaedam ejusdem autoris de herbis et fruticibus, animalibus, metallis, serpentibus, tiro seu vipera. Basileae, excudebat Henricus Petrus, mense Junio 1529. 4. (16) 318 p.

(Excerpta hujus libri sub titulo "De falsa quarundam herbarum inscriptione a Plinion exstant in Brunfelsit llerharii tomo JI. ed. 1531 appendix p. 4 i -89 . - ed. 1536. p. 140-205.)

$5771^{*}$ Nicolai Leoniceni Vicentini, pliilosophi et medic clarissimi, opuscula : quorum catalogum versa pagina indicabit. Per D. Andream Leennium Medicum, a multis quibus scatebant vitiis repurgata, atque annotatiunculis illustrata. Basileae (apud And. Cratandrun.) 1332 . folio. (4) 175 foll. Bibl. univ. Lips.

(Inest: De Plinii et aliorum in medicina erroribus ad doctissimum virum Angetum Politianum libri 1V. foll. 1-61.)

5772* Leopold, Johann Dietrich. Deliciae silvestres Florae Ulmensis, oder Verzeichniss derer Gewáchse, welche in des Heil. Böm. Reichs freye Stadt Ulm in Aeckern, Wiesen, Felsen. Wálderı, Wassern u. s. w. ungephanzt zu wachsen pilegen. etc. Ulm, Wohler. 1728. 8 . $180 \mathrm{p}$., praef., ind.

Idem fuit Respondens dissertationis pracside Elin Camerario propositae: Inpoioyex, seu de Betula. Tubingae 1727.4.)

5773 Lepechin, lwan. Диевыя заниски Ювац Лепехниа по разнылт провниціязъ Россійскаго Государства. 3 част. C. Петер6. 1795. - Vol. IV: IIутенествін Анадеnнка. ib. 1805. Trautv. - J: 1771. 537 p., 23 tab. - 11: 1772. 338 p. 11 tab. - Ill: $1780.376,28$ p., 18 tab. B.

* germanice: Tagebuch der Reise dureh verschiedne Provinzen des Russischen Heiches ubersetzt van Christian Heinrich Hase. Altenburg 1774-1783. 3 Theile. k. - 1: 1774. 331 p., 23 tab. - 11: 1775. 211 p., 11 tab. - III: 1783. 23 ' p., 17 tab.

$5774 \div$ LePlay, $F$. Observatious sur l'histoire naturelle et sur la richesse minérale de l'Espagne. Paris, Carilian-Goeury, 1334, 8. 243 p., 4 tah.

(Liber in geologicis versatur, et leviter tantum botanicen tangit.)

5775* Leporin, Christian Polycarpus. Ausfuhrlicher Bericht vom Leben und Schriften des durch gaoz Europan berühnten Herrn D. Laurentii Heisteri, allen, dje von wahrer Gelehrsamkeit Profession machen, sonderlicl, denen Herm Medicis zum Dienst publiciret. Quedlinburg, typ. Sievert. 1795. 4. 70 p.

$5776+$ LeRouge, Dom. Principes du cultivateur, ou essais sur la culture des champs, des vignes, des arbres, des plantes les plus communes et les plus ordinaires à l'honme, avec un traité des maladies des cultivateurs. Fontenay, Poirier. 1773 . 11 voll. $8.204,232$ p., ind.

$3777+$ Leroy, Alphonse Vincent Louis Antoine. Memoire sur le Kinkina français. Paris, Méquignon. 1808. 8. 16,4 p.

5778 Lery, Jean, latine Lerius. Histoire d'un voyage, fait dans la terre de Brésil. Paris, Antoine Chuppin. 1578. 8. s. latine: llistoria navigationis in Brasilian, quae ot America diciIur, gallice seripta, nuic latinitate donata. Ed. Il. Genevae 159k. 8 340 p. ic. xjlogr. i. t. - in tomo tertio Americae de Bry. p. 13528\%. B.

(De contentis hotanicis ef. Hall. Bibl. Lot. 1. p. 358-359.)

$3779+$ Leschenault de la Tour, Louis Théodore. Notice sur le cannellier de l'ile de Ceylan, sur sa culture et ses produits. A St. Denis, ile Bourbon, de l'imprimerie du gouvernement. 1821. 4. $14 \mathrm{p}$. Bibt. Cand.

Notice sur la végétation de la Nouvelle-llollande et de la terre de Diémen. (Voyage de déconvertes aux terres australe pendant les années 1800-1804 rédigé par (François) Péron. continué par Louis de Freycinet. Ed. II. Paris, Bertrand. 1824. S. vol. IV. p. $327-353$.)
5781 t Leschevin, C. L. Physiodogie végétale. Paris, typ. Feugueray. 1825 8.128 p. ( 2 fr. 50 c.)

̋ี782 LeSeurre de la Bellerie. Description du vignoble de Garaubaud, et discours sur la erapule. Lyon 1669.8. H.

5783* Leske, Nathanael Gollfried. De generatione vegetabilium. D. Lipsiae, typ. Breitkopf. 1773. 4. 32 p. (Commentatio de vegetabilihus semsibilitate destitutis. Lipsiae 1775. 4. in Desideratis Banksianis Leskeo falso adseribitur.)

ö78 ${ }^{+}+$Lespès, J. Max. Louis. Essai sur le mais ou blé de Turquic, considéré sous ses rapports hy'giénique et médical. Paris, typ. Didat. 1825. $4.44 \mathrm{p}$

$5785^{\circ} \div$ Lespiault, Maurice. Notice sur les champignons comestibles du Département de Lot et Garonne et des Landes d'Albret. Agen, typ. Noubel. $4845,8.46 \mathrm{p}$., ind.

$3786^{*}$ Lesquereux, Léo. Quelques recherches sur les narais tourbeux cil général. Neuchatel 1844.4. Iv $140 \mathrm{p}$. (Tiré des Mém. de la société de Neuchátel, tome III. 1845.)

$5787^{*}$ (Tiré des Catalogue des mousses de la Suisse. 4. vi, $54 \mathrm{p}$.

5788 - Directions pour l'exploitation des tourbières dans la principauté de Neuclıatel et Valangin. Imprimées et publiées par ordre du gouvernement. Neuchâtel 1844.8

5789 Lesser, Friedrich Chrislian. Leben des Johannes Thalius. Nordhausen 1747. 4. H.

5790* Lessing, Christian Friedrich. Reise durch Norwegen nach den Loffoden durch Lappland und Schweden. Nebst einem botanischgeographischen Anlıange und einer Karte. Berlin, Mylius. 1831. 8. vi, 302 p., 1 tab. $(12 / 3$ th. $)$

$5791^{*}$ De generibus Cynarocephalarum atque de speciebus generis Arctotidis. D. Berolini, typ. Trowitzsch. 1832. 8. Iv, $30 \mathrm{p}$.

$5792^{*}$ - Synopsis generum Compositarum earunıque dispositionis novae lentamen, monographiis multarum eapensium interjectis. Berolini, Duncker et llumblot. 1832. 8. $x_{1}, 473$ p., 1 tab. (21/2 th.)

5793† Lesson, René Primevère. Flore Rochefortine on description des plantes qui croissent spontanément ou qui sont naturalisćes aux environs de la ville de Rochefort. Ouvrage principalement destine aux élèves de l'école spéciale de médecine de la Marine. Rochefort chez l'éditeur. 1835.8.634 p.

(ldem de geographia plantarum insulae Malouinarum Soledad egregie disseruit in: Observations générales sur l'histoire naturell des diverses contrées visitées par la Corvette La Coguille. Duperrey. Voyage; Zoologie. Paris 1826 . 4. vol. ]. p.187-360.)

579:* Lestiboudois, François Joseph. Botanographie belgique, ou méthode pour connattre facilement toutes les plantes, qui croissent naturellement dans les provinces septentrionales de la France. Lille, typ. Henri. 1781. 8. 8, xuviII, 33 4 p., Jab. - ${ }^{*}$ Seconde édition, corrigée, augmentée et divisée en trois parties. Lille, Vanackère. an VI de la république. (1799.) III voll. 8. - 1: xxIII, 226 p. - II: xIv 344 p. - III : xIv, 335,444 p., 23 tah. ( 18 fr.) - tEd. lll. ib. an Xll 1804. 8. (eadem impressio!)

$5795 \div \longrightarrow$ De viribus plantarum. D. Duaci, typ. Derbaix. 1783 4. 18 p. Bibl. Gay.

$5796+$ (Lestiboudois, Jean Baptiste.) Abrégé élémentaire de batanique, à l'usage de l'école de botanique de Lille. Lille 1774. 8. iv, 49 p.

$5797 \div$ Carte de botanique disposée d'une manière foute nouvelle. Lille 1,774. folio.

("Cette carte appartient a l'Alurégé élémentaire de botanique. $a$.

5798* Lestiboudois, Thémistocle. Essai sur la famille des Cypéracées. Paris, typ. Didot. 1819.4. 46 p. ( 3 fr.)

37996 Notice sur la plus interne des enveloppes florales des Graminées. (Lille, typ. Leleux. 1823.) 8. 7 p.

$5800 t$ Mémoire sur la structure des monocotylédonés. Lille, typ. Leleux. 1823.8.40 p.

घ80 $\mathrm{l}+$ Mémoire sur les fruits siliqueux. Lille, typ. Leleux 1823. $8.16 \mathrm{p}$

$3802+\div$ Mémoire sur le fruit des Papavéracées. Lille, typ Leleux. 1823, 8. $16 \mathrm{p}$

$5803 \div-$ Observations phytologiques. (Sur l'insertion des étamines des Crucifères.) Lille, typ. Leleux. 4826.8 .7 p.

$5804+$ Botanographie démentaire, ou principes de botanique, d'anatomie et de physiologie végétale, contenant la description des organes des plantes, la définition des termes usités en bo$20 *$ 
tanique, une théorie nouvelle sur l'anatomie ot la plysiologie végetale, l'art do d'écrire les plantes, l'exposé des múhodes les pluts employées en hotanique et la description des familles naturelles. Lille, Vanachere. (Paris, Roret.) 1826.8. $\mathrm{xx}, 559 \mathrm{j}$. (7 fr.)

¿̈80̈̈t Lestiboudois, Thémistocle. Isolanographic belgique, on Flor du nord de la France el de la Belgitjue proprenoent dite; ouvrage disjosé sclon la métlode naturelle, contrinant les tableaux analytiques de Frencrois Joseph Lestiboudois, prar Themistocte Lestiboudois. Lille Vanackère. (Paris, Roret.) 4827. Il voll. 8. - 1: Cryptogamie. xxxty 314 p., 22 tahleaux. - 11 : Phanéroganie. 498 p. (14 fr.)

$58066^{-}$Notice sur le genre fledychium de la famille de Musacées. Lille, tyl. Dabel. 18:9.8. 27 \% , 1 tab.

$\$ 807^{\circ}$ - C litudes sur l'anatomie et la plyysiologie des végétaux. Paris, Treuttel et Würtz. 1840.8. 292 j), 21 tab.

"3808+ Letellier, Jean Buptiste Louis. Dissertation sur les propriétes alimentaires, nuedicales et véméneuses des chanpignous, qui eroissen aux environs de Paris, avee une planche lithographice. 1). Paris, tyj). J)idot. 1826. 4. 32 13., I tab. col.

$3809 \div$ - Ilistoire et description des Champignous alimentaires et vénéneux rgui croissent aux environs de paris, precédées des princijes de lotanique indispeusables a leur étude et suivies de planches represemant plus de cent especes, lithographiees et colorifes d'apris nature. Paris, Crevot. 1826.8 . 143 p., I2 tah. 6 fr. - col. $8 \mathrm{fr} .50 \mathrm{c.})$

$.810+$ Figures des champignons servant de supplement au planches de Bultiurd, peiotes d'apres nature a lithographices. Paris Neilhace 1899-1842. Livraisons 1-18.4 . Lab. col. 603-710 sine testu. (Pretiun fasciculi $6 \mathrm{tab}$. col. $=2 \mathrm{fr} .55 \mathrm{c}$. - nigr. $=1 \mathrm{fr}$.)

$3811 \div$ Avis au peuple sur les grandes ressemblances et les petites differrences gui existent enre les champigoons vénéneux et alimentaires, avec 16 figures peintes d'apres nature et Jithographiées. Paris, Delloye. 1841 . 4. 4 p., 2 tab. col. (1 fr. 60 c.)

is12\% Letourneux, $I I$. Leltres a Nanine sur la botanique. Paris, palais royal Nr. 263-64. (Rennes, Duchesne.) 1827. 12. 281 p., t tab ( $3 \mathrm{fi} .50 \mathrm{c.}$ )

$: 3813 \div$ Le Turquier Delongchamp. Flore des environs te Rouel. Deux parties. Rouen, Renauł. 1816.12 . xxxu, 583 p. (7 fr.) - Sujulément: Rouen, typ. Périaus. 1825. 42.84 p.

;814t" __ et Levieux. Concorlance des figures de plantes eryptogames de Dillen, Nicheli, Tounefort, Vaillant et Bulliard arec la nomenclature de DeCandolle, Snith, tcharius et Pcrsoon. Rouen, typ. Périaux. 1820.8.62 p. Bibl. Webb.

$3813 \%$ - Concordances de Persoen (Synopsis methodica fungorum) arec Decandolle (Flore française, vol. ll et VI) et avec Fries (Syst. oyyeol. vol. I et II) et de DeCandolle (Floje francajse vol. Il et II) et des figures des champignous de France de Bulliard avec la nomenclature de Fries. Rouen, lyp. Nicetas Périaux. 1826. 8. (3) 94 p.

"\$816* Leuchs, Johanh farl. Anleitung zur Eingewohnung und zum Anbaue ausläulischer Pilanzen. Preisschrift. Nurnberg 1821. 8. vur, 208 p., I tah. - Jill. 11 : Nurnberg, Leuchs. 1836.8 . I4 plag. $(1 / 8 / h$.

$3817 \%$ - Vollstándige Weinhunde, uder der enropiische kellermeister. Ëin ausfulurliches llandbuel zur Bereitung, Wartung, Pliego und lienutuiss ter naturlichen und kunstlichen Weine. Nurnberg, Leuebs. 1829.8 . vill, 368 p., 1 tab. ( 2 th.

$.3818^{*}$ Leuckart, Friedrich Siegmund. Ueber die Verbreilung der ubriggebliebnen Reste einer vorweltlichen organisehen Schopfung, insbesondre die geographische Verbreitung derselben in Vergleich mil den noch jetzt existirenden organischen Wesen. Freiburg im Breisgau, 1835. 4. xı, 82 j. ( $1 / \mathrm{h}$.)

$\$ 819^{*}$ LeVaillant, Français. Voyge dan. l'intérieur de l'Afrique par lo cap de Bonne-Espérance dans les anmes $1780-1783$. Paris, Leroy. 1790. J vell. 8. - 1: xx11, 274 p., 6 tal, - Il: 292 p., 6 tab. Ed. 11. consilérablement augmentée. Paris, Desray. an $\mathbf{~} 1$. (1798.) Il voll. 8,20 tab. (15 fr.) a.

$8820 \longrightarrow$ Second yoyage dans lintérieur de l'Afrique dans les années :783-85. Paris, Jansen. an 111. (1795.) HI voli. 8. - 1: 304 p., tal. $1-5 .-11$ : 426 p., tab. $5^{\text {bis }}-11 .-111: 525$ p., tab.11 $1^{\text {bi }}-18$. B. "germanice: Reiso in das Inure vou Afriha, vom Vorgehirge der gutol llollnung aus, in den Jahren 1780-178:. Frankfurt a $M$., Fleiceher. 1790. 2 Theile. 8 . - I: 317 p., 6 tat). - II: 336 p..6 6 เat. cinglice $A$ Travels into the interior parts of Africa by the way of

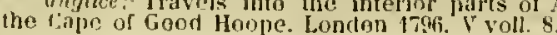

$3821 \div$ Léveillé, J. II. Description d'une nouvelle espece d'Agaric th d'une nouvelle Agaricoidée. Mém. de la soc. Linn. de Paris, rol. JV. 1825. 11. 1-9, 1 tah.

[582\%- Inlluence du froirl sur quelques Igaricoidées et description de deux esperes nouvelles. (Nlem. de la soc. Lirn. dr Paris 1893. vol. I1. 11. 11-18, 1 1al\%.)

68236 Observations sur drux champignons de la famille des Iredinées. (Mèn. de la soc. Lim. de Paris vol. 11. 1825. p. 19-30 1 tab.)

$5824 \div-$ Description du Plouropus aleutherophsllus. (Mem. de la soe. Limn, vol. 1V. 1825. p. 31-35, 1 tah.)

$5825 \div-\ldots$ Sur le gaenre Pilobolus. (Mém. de la soc. Linn. val. IV 1825. p. $36-46$, i tab.)

$5826 \div$ Note sur le genre Dictyophora daus la famile des chanpignons et deserijtion d'une nonvelle espèce prowrnant de l'ile de Jáva. (Mém. de la soc. Linn. vol. V. 1826. 11. 47-55, I tab.)

$382 \% \div$ Menoire sur l'ergot ou nourelles recherches sur la cause et les effets de l'ergot, considére sous le triple rapport botanique, agricole et unédical. ( $\mathbf{N} \in \mathrm{m}$. le la soc. Lim. de Paris, vol. V. (826. 1 . $56-70$.)

(Quate septenn ronjunctae sunt commentation's in libelin inseripo: Recherches sur la famille des Agarics. Paris, typ. Leliel. $182 \% .8 .1$

$5828 \div-$ Recherches sur J'Hymenium des ehampignous. Hiatrat des Amales des se. nat. Déc. 1837.) 8.25 j., 5 tab.

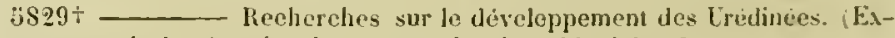
Irait des Annales des sc, nat. Janvier 1839.) 8. 12 p.

$15830^{*}$ Notice sur le genre Agaric, considéré sous les rapports fotanique, économique, médical et toxicologique. Paris 1840 . \$. $20 \mathrm{p}$.

(Extrait du biel. univ. (lhistoire naturelle.

5831 - Destription de quelques espèces nouvelles de cluampignons. (Extrait des Aunales des sc. nat. Octobre 1841.) $8.8 \mathrm{p}$. 2 tab.col.

$5832 t-$ Mémoire sur le genre Sclerotium. (Evirait des Inı. des sc. nat. Oclobre 1843.) 8. 31 p., 2 tah. col.

$5833 \div$ Observations sur ifuelques champignons de la Flore des environs de Paris. (Extrait des Annales des se. nat. Arril 1843.) 8. 1). $213-231$, I [a],

$9831 \div$ Champiznons exotiques. (Extrait des Lunales des sc. 11at. Sept.-Oct. 1844.) 8. p. 167-221. - Suite: (ib. Janvier 1845.) p. $38-71$

Idem noster fungos itineris clarissimi Gaudichaud descripsit. "Deseription des clampignons recueillss par. M. Gaulichand durant In royage de la corvelte do roi La Bonite. Paris, typ. Nidot. S. a. 8.

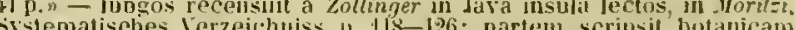
yslematisches Verzeichuiss 1). 118-126; Martem scripsit botanicam itineris Irincipis Anolole de Demidoff supra Nr. 2436 recensiti ; parlem mycologicam exponet in magno opere mox edendo: "Exploration selentiliçue de l'Algéric." )

$5833^{*}$ Levi, M. G. Della maniera di formare e conservare gli erbari botanici capitoli quattro. Venezia, typ. Orlandelli. 1819. 8.65 p.

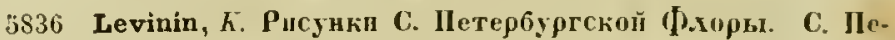
re 66. 1836. Trautv.

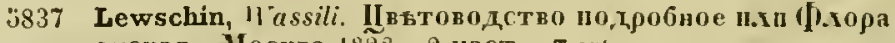
руская. Москва 18.8. 2 част. Trautv.

з838 Новый совершенный садовннк\%, цвътоводецт и огородншкт. Москва 1828.2 गаст. Trautv.

$5839^{*}$ Leydolt, Franz. Die Plantagineen in Bezug anf die naturlistorische Species. Wien, typ. Wallislıausser. (1836.) \&. 34 p., praef., l tab. ( $11 / 12$ th.)

3840 * Leysser, Fiedrich Wilhelm von. Flora Halensis, exhibens plantas circa Halam Salicam crescentes secundum systema sexuale Jimneanum dis(ributas. Halae 1761. 8. 224 p., praef., ind. - * Editio alteri aucta et reformata. Halae Salicae, sumtibus auctoris, typ. C. G. Taeubel. 1783. 8.305 p., indl, i tab.

(Nomen autoris in titulo editionis primae scribitur Leyser.)

3811 " L'héritier de Brutelle, Charles Louis. Stirpes norae aut minus cognitae, quas descriptionibus et iconibus illustravit. Parisiis, typ. P. D. Pierres. $1784-1783$. VI fasciculi. fulio. $\mathrm{VI}, 184 \mathrm{p} ., 84$ tab.

In bibliolheca Caudolleana asservantur juacterea labulae 28 ineditae fasciculotum VII et rill. 
:38.2* L'héritier de Brutel]e, Charles Louis. Geraniologia, seu Erodii, Pelargonii, Geranii, Monsoniae et Grieli historia iconibus illustrata. Parisiis, Iyp. Petri Franeisei Didot. 1787-1788. folio. 44 tab.

(Textus ineditus servatur in bihliotheca Caudolleana, quice onues possidet cottices manuscriptos postlumos L'heritieri inter quo 2000 Dombeyanarum praeprun s.s plantarum at vivum descriptiones I11 Bibl. Banks. 111. 301. citatur praeterea prima phoula Gerantologiae hrevioris octaya forma, in qua continentur differentiae slecificale synonyma et loei natales 26 specierum Erodii, cum observationibus quibusdam.)

$\$ 813^{*}$ et icones specierum Corni minus cognitarum. Parisiis, Iyp. Petri Franeisei Didot. 1788. folio. 15 p., 6 tab.

Suut exemplaria pauca membranacea, forma masina, tabulis coloratis.

$5817^{*}$ Sertum anglicum, sen plantae rariores, quae in hortis juxta Londinum inprimis in horto regio kewensi excoluntur, ab anno $1786-1787$ observatae. Paris, typ. Didot. 1788. folio. $36 \mathrm{p}$., praef., $34 \mathrm{tab}$

Inferdum cxempldria incompleta 20 paginarum ut in ipsa Candolleana bibliotheed offendi. Opus quatuor prodiit laseiculis.?

$5845+(-)$ Kakile, cum animadversionibus in Buniadem, Myagrum et Cramberw. 1788, folio. 11 p. (6 foll.) Bibl. Cand.

Hace dissertatio typis unidem exeusa, nunguam vero evulgata, servatur in bibliothere caudolleana

$5846 \div-$ Buchozia. s. l. el a. folio. 2 foll. 1 lab.

$3847+$ Ilymenopappus. s. l. et a. folin. 2 foll. I tab.

Louicheir. s. I. et a. folio. 2 foll., 1 tab. (Stipes novae, p. $135-136$. .

$5849^{*}-$ Michauxia, s. I. et a. bolio. 2 foll., 2 tab.

$3850^{*} \longrightarrow$ Virgilia s l. et a. folio. 2 foll., 2 tab.

$38301 \div-0 x y b a p h u s .8$. I. et a. It tab. sine textu

$3852 \div-$ Tricratus. s. I. et a. I tab, sine textu.

$38.33^{\circ}-$ Cadia, noureau geme de plante. s. I. el a. 8,14 p.

1 tab.

Extrait du Magazin euç elopédique, tom. .. p. 20.)

3838 Libert, Marie Anne. Notice sur un genre nowreau dllépatiques, Lejeunia. Bruxelles 1820 . 8. Dumortier.

$5853^{*}$ - Mémoires sur des cryptogames observées aux envirous de Malmedy. Paris, typ. Decourchant, 1\$26.8.7 p., i tab.

38.56* Liboschitz, Joseph, et harl Bermhard Trinius. Flore des envirans de St. Petersbourg et de Moscou. Tome prenier. St. Petershourg, Pluehart. 1811.4 .121 p., 40 tab. eol. (36 /h. Vogler.)

58.57 aux environs de $\mathrm{St}$ Pelersbourg 1811. 8 .

$38388^{*}$ Beschreibung eines neuentdeckten Pilzes, in einer an Joseph von Jacquin gerichteten Zuschrift. (Description d'un noweau champignon.) Wien, Camesina. 1814. folio. (8 p.) 1 tah. col. (germanice el gallice.) ( 1 (h.)

0030 Tableau botanique des genres observés cu Russie et disposés selon la methode naturelle. Wien, Camesiua. 1814. folio.

¿860* Lichtenstein, A. G. G. Index alplabeticus generum botinicorum quotquot a llilldenowio in speciebus plantarum et a Persoonio in Synopsi plantarum recensentur, eoneinnatus. Helmstadii, typ. Leuelart. 1814. 8. virr, 88 p. $(1 / 2(h,-2 / 3$ th. $)$

$3861^{*}$ Lichtenstein, Georg hudolph. Anleitung zur medicinischen líráuterkunde 〔ür Aerzte und Apotheker. Erster Theil. Dio Theorie, Linne's Systen und die Kunstsprache. Helmstelt, Kühnlin. 1782.8 . xiv 208 p., 8 tab. (3 Theile. $1782-1756.8 .3 \% 12$ th.

(Partes $\mathrm{i}-\mathrm{lll}$ nolı vidi.)

3862 " Ioidbeck, Anders, pr. De limitibus inter regna traturae. D. Lundae, typ. Berling. 1790.4. 46 p.

$\ddot{8} 863$

, pr. Observationes eirea horticulturam aeademicam et speciatim Luudensem. D. Lundae, typ. Berling. 179I. 4. 28 p.

$5861^{*}$ - pr. De plantis in Suecorum memorian nominatis. D. I.undae, $\{\mathrm{y}]$. Berling. 1792.4. $15 \mathrm{p}$.

386.j Lidbeck, Eric Gustaf. Do silvieultura Seaniae. D. Lundae 1757 4. H.

3866 De arena volatili seanensi, ejusque colsibitione. D. Lundae 1760.4 . nia. Londini Gothorum 1768.4. H.
3869: Lidbeck, Eric Gustaf, pr. Dissertatio, Fungos regno vegetahili vindicans. Londini Gothorum, typ. Berling. 1776, i. 16 p.

Jonus Dryander nou est antos, ut in titulo legitur. sod respondens f. Dryander, Bithl. Banks. IIt. 4k3.

6870 , pr. De Noro alba. D. Lundae 1777. 4. 16 p. в.

$5871 \div$ - J1. De Betula Alno. D. Lundae, typ. Berling 1779. 4

$14 \mathrm{l}$

5872 Liddel, Dincan. De facultate vegetante, ejisque functionibus Helmstadiae 1592..4. Rivin.

$5873{ }^{*}$ Lieb, Johann IIlhelm Friedrich. Die Eispflanze (Mesenlurianthemum crystallinum L.) als e in fast specifisclies Arzneymittel empfohlen. llof, Vierling. 1785. 8. 16 p.

(ldem autor sub prieside Gustav Christian Handwiy dissertutunem de Bryouia proposuit.)

$5874^{*}$ Liebentantz, Michael. De Rachelis deliciis Dutain ad Genesit XXX. comma 14. 1). Wittebergae, t!p. Wendt. 4660.4. (16 p.) Ed. IV: il. 1678. 4. 3 plag. B. - recusa: 1719 , 4. H. Opiniones aliorum refutat, neque quidquam definit.

3873 - De magia baeulorum. Wittenbergae 1661. 4. Rivin.

$5876^{*}$ Liebig, Justus (Freiherr ron.) Die organische Clsemie in ihrer Auwendung auf Agrieultur und Plysiologie. Braunschweig, Vieweg und Sohn. 1840. 8. 351 p. (2 $/ \mathrm{h}).-{ }^{*} Z$ weiter und dritter inverinderter Abdruck. ih, 1841. 8. - Ed. IV: il, 1842. 8. - Funfle ungearbeitete und schr vermehte Auflage. ib. 1843.8 . (2 $1 / 2 \mathrm{lh}$. *Seeliste Juflage. ib. 1846.8 . xvI, 468 p. $\left(2 \frac{1}{2}\right.$ (h.)

gallice: Chimie oryanique ipplicutee a la physiologie vegetale et a l'agriculture, suivie d'un essai rle toxicologie. Tradtiction faite su les manuserits de J'auteur par Chorles Gerhardt. Parjs, Fortin, Massol et Co. 1841. 8. 3:2 p., praef. (7 fr. 50 ().

italice: La chnnica applicata all' agricolura ed alla fiviologit. rersione sulla Yuinta edizimne originale tedesea di D. Guiuseppe Netwald. Vienua, Volke. 18\%. 8. 23 plag. (1t/m th.

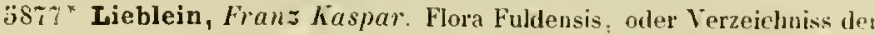
in dem Furstenthume Fuld wildwachsenden Baume, Sträuche un Pflanzen, zum Gebrauch der hiesigen akademischen Vorlesungen. Frankfurt a/MI. Andreac. 1784. $8 . \mathrm{xVr}, 482 \mathrm{p}$., ind. ( $\mathrm{th}$.)

$5878^{*}$ Liegel, $G$. Systematische Anleitung zur Kenntuiss der Pflaunen, oder: das Geschlecht der Pflaumen in seinen Irten und Abarten. Erstes lleft. Passau, Wirkler. 1839.8 . x, 103 p., 2 tab. ( $7 / 12$ th. $)-$ Zweites lleft. Limz, Eurielı und Sohu. 1841, 8, xı, 320 p., 1 tab. effigies J. F. Dittrich. $\left(1 \frac{1}{3}\right.$ th. $)$

5879 Liegelsteiner, Georg. Wohlversuchter Zwerghaum, oder Unterricht, wie derselhe beschnitlen, dessen Fruchte vermeltr, verwrössert und verbessert werden honnen. Frankfurt a/M. 1702.8. 124 J., tab. B.

(Liber pluries reimpressus potissimum ex Jean DelnQuintinge ltau

¿880 Liger, Louis. Écononje générale de la campagne, ou Nouvello Maison rustique. Paris, Serey. 1700. Il voll. 4. a.

(Est nova editio persaepe recusa operis Curoli Stephani Esticune el Jean Liebaull supra Na. 30 in recensiti.)

$5881 \div$ - Dictionnaire général des termes propres a l'agriculiure Paris, Beugnié. 1703.8. 377 p., praef.

$3882 \div-$ Le jardinier floriste, ou la eulture universelle des lleurs, arbres, arbustes, arbrisseaux servant à l'embellissement des jardins. ete. Paris, Beugnié. 1703. 12. - †Nouvelle édition. Paris. Savoye. 1764. S, xxIv, $504 \mathrm{p}$, tab. $(3 \mathrm{fr}$. $)$ - Nouvelle oditinu revur et augmentée. Arignon, Joly. 1821.8 . (3 fr.) a.

$3883 \div-$ Le nnureau theatre d'agriculture et menage dles clatups. Paris, Beugnié. 1712.8. - ib. 1723. Il voll. 4 .

388: * Lightfoot, John. Flora seotiea : or a systematic arrangenent in the Limean method of the native plants of Scothand and the Ilehrides. London, White. 1777 . /l voll. 8 . XLII, 1151 p., ind, 35 tab.

(Evemplaria anni 1792 practer titulum nou differre puto.)

5883 Ligon, Richard. A true and exact history of the island of Barbados, illustrated with a mapp of the islands, as also the prineipal trees and plants there set forth in their due proportions and shapes. drawne out by their several and respective scales. London, for Humphrey Masely. 1657, folio. cum ieonibus. s. gallice: Paris 167 .

(Jlll. Bibl. bot. 1. p. 490.)

¿̈886 Lilja, $\boldsymbol{N}$. Skåues Flora, innefattande oskånes Fanerogamer weh ett Bihang Skånes Ormbunkar, de pả Akren odlade Vext - och Sädesslagen och de i ofriga Sverige forekommandeFanerogamer utom fjallvexterna, med Karahterer, vextställen och nytta, jemte ett ven- 
geografifkt namnregister m. m. Lund, Gleerup. Köpenhamn, Gyldendal. Cliristiania, J. Dahl. 1838. 8. (3 Rdr.) w.

5887 Lilja, $N$. Flora ofver Sveriges odlade Voxter, innefattande de flesta på frik Land odlado Vexter i Sverige, jemte de dlmánnare och vackrare fonster vexterna, med Kannetecken och Kort Anvisning om deras Odlingssatt. Stockholm, Z. Hăggstrom. 1839. 8. xx, 176 p. (1 Rdr. $16 s k$.) w.

\$885 — Flora ofver Sveriges odlade Vexter. Första Supplementet. Stackholm, Z. Jlaeggstrom. 1840.8. 36, 84 p. ( 40 sk.) w.

j889 _ Wandbak i de odlade Vaxternas Flora och deras Kultur, Till ledning for Akerbruhare, Trádgårds-odlare och Blomstervămer efter Endlicher's Naturliga Faniljer, utarbetad af N. Lilja. Första Ilaftet. Örebro, typ. Lindh. 1842.8. 131, $(6,4)$ p. w.

5890 - Tidning för Trägårds-Skótsel och ellmân Vúxt-Koultur, utgifven af $N$. Lilja. Lund, typ. Berling. 1840-1842. Jll voll. 8. w. (De hoc diario cf. breven notitiam in II ikstroem, Jahresberichte 1839-1812. p. 4 ' 18 .)

3891 Liljeblad, Samuel. De historia naturali ordini ecclesiastico necessaria. D. I-Il. Upsaliae, typ. Edman. 1788-1789. 4. 32 p.

(Pars prior hujus dissertationis p. 1-16 sub praesidio Johannes Losibom proposita est.)

:3892* (- Svenska Oert-slagen, eller kort afhandling om sattet at efter botaniske grunder urskilja svenska vaxterna, ti] classer, ordningar och slagter, af $S . L$. Upsala, typ. Edman. (1792.) 8. (4) $88 \mathrm{p}$., I tab. Bibl. Goett.

$5893^{*}$ Utkast til en Svensk Flora, eller Afhandling om Svenska Waxternas văsendteliga känuetekn ooh nytta. Lppala, trycht Edmans Enka. 1792. 8. 358 p., praef., ind., 2 tab. - "Ed. ll. ib. 1798. 8. xxxir, 508 p., 2 tab. - Tredge uplagan, med Norska Waxter lillökt, efter Författarens dod [ +1 Apr. 1815] vigifven. Upsala, tryckt hos Zeipel et Palmblad. 1816. 8. Lvur, 763 p., praef., 2 tab. w.

(Editionem tertiam teste Schultessio ab undecima plagula pos mortem autoris curavit et redegit Johannes Hacquinus Wallman Liucopensis.)

$5894^{*} \longrightarrow$ Ratio plantas in sedecim classes disponendi. D. Upsaliae, typ. Edman. 1796. 4. 8 p. Bibt. Goett.

$3895-$ Coloniae plantarum in Suecia. Pars I-II. Upsaliac 1809. 4.16 p. (incompl.) Bibl. E. Meyer.

5896 Liljemark, Lars. Berettelse om blomman och des åtskilliga delars verkan och gagn, försvenskat til prof utur Pitton Tournefort. s. I. 1735. 4. 4 p., ic. ligno inc. $B$.

5897 Lilienfeld, Fr. Dissertatio circa Plıytotoxicologian cechicam, plantas venenatas Cechiae indigenas Umbelliferas exhibens. Pragae 1834.8.108 p.

3898 Liljenroth, Franz. Anmärkningar om Växternas fodande amnen luilka med Philosoplsiska Facultetens Samtycke, till allmain onpröfning framstallas af Hagister Franz Liljenrolh uch Johun Rix. Lund, typ. Berling. $1797.4 .30 \mathrm{p}$. w.

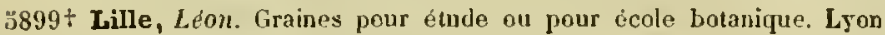
1846. 8.20 p. - ib. 1847.8 .

Catalogi seminum plantarum spontanearum rariorum Galliae venalium. Etablissement horticole de Lean Lille et Ca., Cours Morand, 6 aux Brotleaux près Lyon; chaque paquet $1 / 2 \mathrm{fr}$.)

$\$ 500$ Limbourg, Robert. Dissertation sur cette question: Quelle est l'influence de l'air sur les végćtaux? qui a remporté le prix à Bordeaux en 1757. Rordeanx, veuve de P. Brun. 1758. 4. a

(Iall. Bihl. hot. HI. p. 470 indicat autorem Jean Philippe Limbaurg qui frater fuit Roberti.)

5901 Limmer, Konrad Philipp, pr. De plantis in genere. D. Servestae 1691. 4. 4 plag. (Respondens: Melchior Ernst Wagenit.) B.

3902 , pr. De cerevisia Servestana. D. Servestae 1693. 4. recusa: Servestae 1745.4.54 p. (Respondens: Metchior Erast Wagenilz.) B.

$3903^{*}$ Lincke, Johann Rudolf. Deutschlands Flora in kolorirten Abbildungen. Herausgegeben von Dr. J. R. Lincke Leipzig, Polet. (1840 -1847.) 79 Lieferungen. 8. 320 p., $(346)$ tab. col. $(19 \% / t h$.)

(luter tot vilez librns hotanicos facile hic vilissimus! Editoris nomen fictitium esse e hibliopolae verbis compertun habeo, neque erubuit clarus quidam botanicus Lipsiensis nobili ad opus continuandum accedere manu. - "Oestreichs Flora " el "Preussens Flora" nuandum accedere manu. - "Oestreichs Fibra differunt.)

5904* Lincke, Paul Christian. De Hellebori uigri atque praesertim riridis usu medico. D. Halae 1774.4.23 p.
5905* Lincke, Paul Christian. De Hellebori viridis in fluare albo venereo usu medico. Epistola gratulatoria. Servestae 1775. 4. 18 p.

$3906^{*}$ Lincoln, Almira $H$. Familiar lectures on Botany. Including practical and elementary botany, with generic and specilio descriptions of the most common native and foreign plants and a vocabulary of botanical terms. For the use of ligher schools and academics. Hlartford, Huntington. 1829. 8. 333 3̈ 4 p., 13 lab. - Ed. IV. ib. 1835. 12. (1s. $50 \mathrm{~d}$.)

5907" Lindblom, Alexis Eduard. Stirpes agri Rotnoviensis. D. 1-V. Lundae, typ. Berling. 1826-1829.8.84 p. Bibl. Goett.

(Desinit in Decandria. Partem primam harum dissertationum, p. 1-2i, pro laurea, praeside $C, A$. Aygardh, proposuit Lindblom.)

$5908-$ Bidrag till Blekings Flora. Stockholm, Norstedt. 1831 $8.28 \mathrm{p}$.

(Seorsim impr. ex Actis Acad. Reg. Scient. IJolm. atunl 1830.)

$5909^{*} \longrightarrow$ In geographiam plantarum intra Succiam distributionem adnotata proponit. Lundae, Gleerup. $1835.8,100$ p., 5 tab. (1 th.)

5910 Botaniska Upsater. Lund 1838. 8. w.

(Sarskildt aftryek ur Phys. Sältsk. Tidskr.)

$5911^{*}$ Ridrag lill hånnedomen af de Skandinaviska arterna af slightet Draba. (Stockholm, typ. Norstedt. 1840.) 8.94 p.

$5912^{*}$ Botaniska Notiser forr år 1839-1845. Lund, typ. Perling. (Gleerup.) 1841-1845. vis voll. 8. (11 Rdr:) Bibl. Griseb.

De his diariis, in (puibus praeter editoris continentur commentatione's botanicorum o Fries, Areschoug, Arrhenius, Blylt, Duben, Ilartman, Lilja, Hallman, Angström, Borgström, Lindgren. Holmgren, Drejer. Hamnstrom, Hofberg, Kalen, aliorum, cf. Vilistrom, Jahresberichte 1839 -18 k. p. 400.$)$

5913* Linden, J. Établissement de botanique et d'horticulture de J.Linden a Luxembourg. Prix-cuurant pour priutemps 1847. Luxembourg (1847.) 8. 7 (4) p.

5914* Lindenberg, Johann Bernhard Wilhelm. Synopsis Hepaticarum europaearum adnex is observationibus el adnolationibus criticis illustrata. Bonnae, Weber. 1829.4.133 p., 2 tab. $\left(1 \frac{1 / 3}{t h}\right.$. $)$

(Nov. Act. Acad. Leop. vol. XIY. Supplemestum.)

$59.5^{*} \longrightarrow$ Species Hepathicarum. Recensuit, partim descripsit, iconibusque illustravit J. B. G. Lindenberg. Ronuae, Henry et Cohen. (1839-1847.) Vll fasc. 4. - Fasc. I-V: Monographia Hepaticarum generis Plagiochilae. 1844. v1, xxix, 164, 33 lab. pro parte cul. - Fasc. VI-VII: Species llepaticarum. Recensuerunt, descripserunt, iconibusque illustraverunt J. B. G. Lindenberg et $C . M$. Gattsche. Jungermanuieae. Trichomanoideae. Lepidozia. 1846. 78 p., 12 tab. pro parte col. ( $13 \frac{2}{3}$ th.) (Coutinuatur.)

5916 Linder, nobilis Lindestolpe, Johan. Flora Wiksbergensis, eller et Register uppå the Trad, Buskar, Örter och Grás, som intom en fjerdingsvảg kring Surbrunnen Wiksberg, antingen på åkrar sås, eller wildt waxa, med theras brukeligaste Namu på Latin och på Svenska. Stockholm 1716.8.42 p. - Andra Uplagau. Stockholm, typ. Hurn. 1728. 8. (4) 42 p. w.

5917 Srenska fargakonst med inlandske orter. Stockholm 1720.8. H.

5918 Linderholm, Magnus Guslaf. De Geo urbano. D. botanico-medica, quam praeside C.P. Thunberg pro gradu medico publicae censurae vifert auctor $M$. $G$. Linderholm. Upsaliae, typ. Palmblad. 1827. 4.8 p. W.

$5919^{*}$ Lindern, Franz Balthasar von. Tournefortius alsaticus cis el trans Rhenanus, sive opusculum botanicum, ope cujus plantarum species ete. cirea Argentoratum tiro dignoscere possit. Argentorati, Sleiu. 1728. 8. 160 p., prael., ind., 5 tab.

$5920^{*}$ Hortus alsaticus, plantas in Alsatia nobili inprimis circa Argentinam sponte provenientes menstruo, quo singulae florent, ordine designans. Argentarati, Beck. 1747. 8. 302 p., praef., ind, 12 tab.

5921 Lindley, George. Guide to the orchard and kitchen garden. Editerl with an introduction by John Lindley. London, Longman. 1831. 8. (16s.)

$5922^{*}$ Lindley, John. Rosarum monographia; or a botanical history of Roses. To which is added an appendix for the use of cultivators. London, Rilgway. 1820. 8. $\operatorname{xxxIx}, 156$ p., 19 tab. col. (1l. 1 s.) * gallice. Monographie du genre Rosier, traduite de l'anglais de $\mathbf{M}$ $S$. Lindley, avec des notes de M. $L$. Jofrin et des changemens importans suivie d'un appendice sur les Roses cultivées dans les jardins 
de Paris el environs par M. de Pronville. Paris, Audot. 182\%. 8. vili, 182 p. ( 3 ir. 50 c.)

$5923^{*}$ Lindley, John. Digitalium munographia: sisterts historiam botanicam generis, tabulis omnium specierum hactenus cognitarum illustratam, ut plurimum confectis ad icones Ferdinandi Bauer penes Guilielmum Cattley, Arm. Cura Johannis Lindley. Londini, prostant. venales apud J. H. Bohte. 1821. folio. II, 27 p., 28 tab. col. (nigr. 4l. 4s. - A. 1l. 14s.6d. - col. 6l. 6s. - A. 3l. $3 s$.

5924 * Collectanea botanica: or figures and botanical illustrations of rare and curious exotic plants. (1-VIll.) London, Arch. 1821. folio. 41 foll., 41 tab. col.

$5925^{*}$ Report upon the new or rare plants which have flowered in the garden of tho Horticultural Society at Chiswick, from jts first formation to march 1824. London, Nicol. 1825.4. 41 p., 1 tab. col. (Marica Sabini.) - Continuationes: London, Nicol. 1826. 4. p. 261 -299. - London, Nicol. 1827.4.32 p.

(From the llurticultural Transactions of London.)

$5926+\longrightarrow$ Observations upon the natural laws which govern the production of double flowers arising out of a remarkable ease of praeternatural formation in the flowers of an Amaryllis. London, typ. Nicol. 1826.4.8 p.

(From the Horticultural Transactions of London.)

$5927^{*}-$ Orchidearum sceletos. Commisit Jahannes Lindley. Londini, typ. R. Taylor. 1826.8 .27 p., ic.

$3928+\ldots$ A synopsis of the British Flora; arranged according to the natural orders: contaiuing vasculares, or flowering plants. London, Lougman, Rees etc. 1899. gr. 12. xit, 360 p. - tThe second edition, with numerous additions, corrections and improvements. ib. 1835 . gr. 12. vill, 376 p. $(10 s .6 d$.) - Ed. Ill: ib. 1841. gr. 12. (10s.6d.)

$5929^{*}$ Illustrations of urchidaceous plants; with notes and prefatory remarks by John Lindley; the drawings by Francis Bauer. London 1830-1835. folio. 14, 20 foll., xiv p., praef., 14, 20 tab. col. (6l. - nigr. 3l.)

(Idem opus, quod jam supra Nr. 575 indicavi.)

$5930^{*}$ The genera and species of orchidaceous plants. (IIlustrated by drawings from the sketches of Francis Bauer.) London, Ridgway. $1830-1840$. VIl parts. 8. xvit, Ix, 553 p. - 1: 1830. Malaxideae. p. 1-94. - II: 1831. Epidendreae. p. 95-134. - I1I: 1833. Vandeae. p. 135-255. - 1V-V: 1835. 1839. Ophrydeae. p. 257-379. - VI: 1840. Arethuseae. p. 381-440. - V1l: Neottieae et Cypripedieae; Addenda, ind., p. 441-553.

(llinc inde oceurrunt fascieuli singuli majoris editionis in folio minori cun tabulis coloratis: Part l et 11 in Bihl. Schlechtendalii, Part IIl in Bibliotheca Linkiana, Part l et 111 in Bihl. Mus. bot. Vind.

$3931^{*}$ An autline of the first principles of botany. Londun, Longman. 1830. 12. vili, 106 p., 4 tab. (3s.) - Ed. II. with corrections. ib. 1831 . 12. viIt, 106 p., 4 tab. (3s.)

* germanice: Grundzuge der Anfangsgrunde der Botanik. Weimar Industrie-Cumtoir. 1831. 8. vill, $116 \mathrm{p} .1$ \& tab. $(3 / \mathrm{t}$,

+ gallice: Prineipes de botanique, traduits par P. A. Masson-Faur. Paris, lluzard. 1832. 8. $76 \mathrm{p.}$. 4 tab. (I $\mathrm{fr} .50$ c.)

(Extrait des tomes flil et $1 \mathrm{X}$ des Annales de l'agriculture francaise.)

rossice: vertente Iwan A. Dwigubshy. Nosquae 1839. 8.

$3932^{*}$

- Elements of botany, structural, physiological, systematical and medical; being a fourth edition of the outline of the first principles of botany. London, Taylor and Walton. 1841. 8. Iv, 292 p. ic. ligno inc. i. t. - Ed. V. London 4847.8.

$3933^{*}$ An introduction to the natural system of botany; or a systematic view of the organisation, natural affinities and geographical distribution of the whole vegetable kingdom. London, Longman. 1830.8 . xuvit, 374 p. (12s.) - + Ed. 1l. with eorreetions and numerons additions. London 1835.8 . $x v, 5880$ p., 6 tab. (18s.) - Ed. Ill. with corrections and numerous additions. London 1839.8. (18s.) First american edition: with an appendix by John Torrey. Newlork $1831,8$.

* germanice: Einleitung in das natürliche System der Botanik, oder systematische Uebersieht der Organisalion, naturlichen Verwandschaften und geographischen Verbreituug des ganzen Ptlanzenreichs nebst Angabe des Nutzens der Wichtigsten Arten in der lleilkunde, den kunsten und der Haus- u. Feldwirthschaft. Aus dem Englischen Weimar, Landes-Industrie-Comptoir. 1833. 8. $611,324 \mathrm{p}$. (3 th.)

* germanice: Characteres distinctivi oder llauptkennzeichen der naturlichen Pflanzenfamilien. Aus Lindley's Introduclion to the natural system of botany, London 1830; geordnet nacl der von Kunth in seinem llandbuch der Botanik, Berlin 1831, geváhlten Folge; aus dem Englischen ubersetat von Karl Theodor Beilschmied. Regensburg 1833. 8 . $6 \mathrm{~kg}$.
$5934+$ Lindley, John. Some considerations upon the cultivation of fruit trees. London 1831 . 8.24 p.

$5935^{*}$ _ and William Hutton. The fossil Flora of Great-Britain or figures and descriptions of the vegetable remains found in a fossi] state in this country. London, Ridgway, $1831-1837$. III voll. $8 .-$ I: 1S31-1\$32. LIx, 218 p., tab. 1-79, - II: 1833-1835. xxxvII, 208 p., tab. $80-456 .-$ III: 1837. 204 p., tab. 157-230.

$5936+\ldots$ An outline of the first principles of horticulture. London Longman, Rees, Orme ete. 1832.12 .72 p. $(2 s$.

germanice: llauptgrundsátzo des Gartenhaus, auf einfache Gesetze zurickgefuhrt. Aus dem Englischen von IJilhelm Herts. Stutgart Metzler. $1833.12 .(1 / \mathrm{s}$ th.)

Metzler $18.33 .12 .(1 / 1$ th. $)$ premieres principes dhorticulture par Jahn Lindley; ouvrage traduit de l'angl pris et augmenté de notes explicaLindley; ouvrage traduit de l'anglais et augmenté de notes explica$\mathrm{x}$ tives $\mathrm{et}$ addition
$\mathrm{x}$

$5937+\ldots$ On the principal questions at present debated in the philosophy of botany. From the Report of the British association for the avancement of science for 1833 . London, iyp. Taylor. 1833. 8 . is $p$.

อั938* Nixus plantarum. Lundini, apud Ridgway et filios. 1833. 8. 28 p.

* germanice: Nixus plantarum. Die Stämme des Gewàchsreiches Verdeutscht dureh karl Theodor Beilschmied; mit ciner Vorerinneruus von Cliristian Gattfried Nees van Esenbeck. Nürnberg, Schrag. 183k. \&. its p. $(1 / 2, h$.

59397 Ladies' botany: or a familiar introduction to the study of the natural system of botany. Ed. II: London, Ridgway. s. a. 8 . XIII, 302 p.. 25 tab. (16s.) - Ed. III: London 1837. 8.

* germanice: Rotanik fur Damen, oder fassliche Einleitung in das Studiurn des naturlichen Syslems der Pflanzenkunde. Naeh der zweiten Auflage ans dem Englischen uluersetzt. Bonn, lleary und Colien 1838. 8. xiv, 280 p., 25 tab. col. ( 3 th.

$39: 40^{*}$ — A hey to strnctural, physiulogical and systematical botany, for the use of elasses. Loudon, Longman. 1835.8 .80 p. (5s.) * hungarice: A' Filvészet elveinek vazolatai. D. Lindley Janos nyomán Brassai Śrmuel attal. Kolozsvártl (Klausenburg), Tilsch és lia. 1836. 12. Xvil, 162 p., 9 tab.

t gallice: Aphorismes de physiologie vérétale et de botanique suivis du tableau des altiances des plantes et de l'analyse artiticielle suivis du tableau des alliances des plantes et de l'analyse artiticielle
des ordres. Traduits de langlais et préédes d'une introduction par Paul Antoine Cap. Paris, Colas. 1838. 8.180 p.

$39: 1^{*} \ldots$ A natural system of botany; or a systematic view of the organization, natural affinities and geographieal distribution of the whole vegetable hingdom; together with the uses of the most impurtant species in medicine, the arts aud rural and domestic economy. Second editiou, with numerous additions and corrections and a complete list of genera, with their synouyms. London, Longman. 1836. 8. xvi, 526 p. (18s.)

$5942 *$ Victoria regia. (London, Octaber 16. 1837.) folio eleph. 4 foll., 1 tab. col. Bibl. Mus. bot. Vind.

(Privately printed by W. Nicol at the Shakspeare-Press; 20 copies.)

$5943^{*}$ - Sertum orchidaceum: a wreath of the most beautiful orchidaceous flowers, selected by John Lindley. London, James Ridgway and Sons. 1838. folio max. 49,1 tab. col., (124 p.) (12/ 10s.)

(Prodit annis 1837-1842 decem fasciculis, sinzuli $14.5 s$. )

5944* - Flora medica; a Intanical account of all the more important plants used in medicine, in different parts of the world. London, Looginan. 1838. 8. xill, 656 p. (18s.)

$59456-$ School botany; or an explanation of the characters and differences of the principal natural classes and orders of plants belonging to the Flora of Europa, in the botanieal classification of DeCandolle. London, Longman. 1839. S. vin, 218 p., $(160)$ ic. xy$\log r .(6 s$.

$59.66^{*}$ Miscellaneous notices and miscellaneous matler. (Appendices of Botanical Register, vol, XXIV-XXXI. London 1838 -1846 . 8.) 95. 95, 90,92?, $86,85,92,86 \mathrm{p}$.

$3947^{*}$ - Swan River. Sketch of the vegetation of this colony. Londun, Ridgway. 1840.8 .58 p., 9 tab. col. (10s. 6d.)

(Libellus jam anuo 1839 appendicis luco yoluminum xxll priorum operis iconographici "Botanicai Registern editus fuit.)

The theury of horticulture, or an attempt to explain the principal operations of gardening upon physiological principles. London, Longman. 1840, 8. xvi, 387 p., ic. ligno inc. (12s.) * germanice: Theorie der Gärtnerei, oder Versuch, die vorzüglichsten Verrichluugen in der Gartnerei nach phvsiologischen Grund- 
gilzen zu erklaren. Aus tem Einglischen ubersedzl von $C$. G. Mit

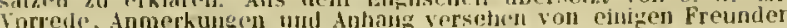

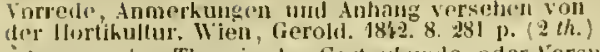

- germanice: Theorie der Gartonhuule, nder Versuch, din vornehmsteii Operationen beim Garleabau uach physiologischen irundsatzen zul crharen. Lebersetzt mit Anmerkun:an vou Ludwig Christian Tre7.t erhlaren.

(7) $19 \%$ Lindley, John. The vegntablo kingrlom; or the structure, classification and uses of plants, illustrated upon the natural system. With upwards of five lumiled illustrations. Jondon, 1yp. Bradbury and livans. 1846. 8. Lxvil, 908 f., 1 tal. (2l. 10s.)

Hustrissint landley novissimum libellum "Orehideae Lichenia-

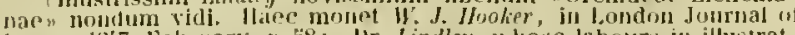
hotan, 18'7. Fehruary, p. 58: "Dr. Lindley. whose lahours in illusiratitu the orehidaceus plauls, hoth by splendid higures and descriptions ire beyond all praise , has here agan favoured the hotanical world with a brochure of twenty-right pages, describing 133 species of plants of this family, from the dined specimens colfected by $\mathrm{Mr}$. linden in Columbia and Guba; no fewer llan 77 are wliolly new to acience, irfeluding 3 new genc'ra. i)

:3:30 Lindsay, Archibald. De plantarum inerementi causis. D. Edinburgi $1781.8 .43 \mathrm{p}$. B.

:9,3]* Ininguet, Simon Nicolas Ilenri, und Tissot. leber das Getreil und Brodt. Aus den Franzosischen. Nebst der Geschichte einer giftigen Art Erbsen (Lathyrus sativus) rom den Uebersetzer (Dr. Hirzel.) Zurich. Fussli. 1780. \$. 150 p., praef., tab.

Easdem ofservationes fecit Georg Marid Duvernoy Diss. te Lathyti ipadam venenata specie. Basileae 17T0. 4.)

:39:32* Iink, Heinrich Friedrich. Florae Goettingensis specimen, sistens vegetabilia saxo ealeareo propria. D). inauguralis botanico-medica, 26 Aug. 1789. Groettingae, ty]). Grape. $1759.8 .43 \mathrm{p} .(1 / 6$ th.)

Redit in Isteri Delect. opusc. bol. 1. p. 299-336. Supplenentum:

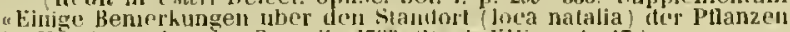

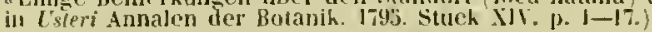

\$9.937 - Annalen der Naturgeschichte. Erstes (und rinziges) Stuck. Götingen, Dieterich. 1791 . 8. 126 1) ( $/ 2, t h$.

(Totus fasciculus an ipso editore seriptus; [. 27-38 "Botanisehe Bemerkungen" ad Floram foettiugensem.

ij9:j* Dissertationes botanicae, quibus accedunt Primiliae horti hotanici et Florae Rostockiensis. (D.1. de terminis botanicis p. 1-31. - D. J. de generum in botanica constituendorum ratione p. $31-35 .-$ D. Il]. de differentiis specificis plantarum. 1. 35-81. Suerin, Bareusprung. $1795.4 . \mathrm{vI}, 81 \mathrm{p} .(2 / 3 \mathrm{th}$.

:95:; * Philosophiae botanicae novae seu institulionum phytographicarum prodromus. Goettingae, Dieterich. 1798. S. 192 p. $(\% / 12$ th.

isöf* - Bemerkungen auf einer Reise durch Frankreich, Spanien und vorzuglich Portugal. Kiel, akademische Buchhandlung. 1799 -1804.3 Theils. $8 .\left(4 \frac{3}{3}\right.$ th.)

yallice: Voyage en Porlugal, drpuis 1797 jusqu'en 17\%) suivi d'un issai sur fe commerce de portugal, traduit de l'allemand. Paris, l.evrault. 1su3. 11 roll. 8. (\$) 15 .)

$\div$ gallice: losage en Portugal, par le Conte de llofmonnsegg, rédige par M. Link, et faisant suite a son voyage daus le neme pays. Paris, I.rvrault. $180 \% 3.8$. vil, $337 \mathrm{p}$

Sistit translationem tomi terti itineris linkiani. Translatio anglica adest, sed mini non innotuit.

79:i" ${ }^{*}$ Grundlelsen der Anatomie und Pliysiologie der Pflanzen. Gottingen, Danchwerts. 1807. 8.305 ]), 6 tab. $\left(1 \frac{2 / 3}{t h}\right.$.)

$5938 *$ Nachräge zu den Grundlehren der Anatomie und Pliysiologie der Pflanzen. Gottingen, 1)anckwerts. 1809. 8.83 p. (1/3th.) - Zweites Jleft. ib. $1812.42 \mathrm{p} .(1 / \mathrm{th})$

is:9!!* - hiritische Bencrkungen und Zusätze zu Lurt Sprengel's Werk: Ueber den Bau mol die Natur ler Gen achse. llalle, Kummel. 1812. $8.59 \mathrm{p} .(1 / \mathrm{t}$ th. $)$

5 560* - Die Unwelt und das Alterthum, Lrlatutert dureh die Naturkunde. Berlin, Dummler. $1820-1822$. 2 Theile. $8 .\left(2 \frac{2}{3}\right.$ th. $)-$ "Zweite ganz umgearbeitete Ausgabe. Erstor Theil. Berlin, Dunmler. 1834.8 . vi, 462 p. (2 th.)

:i!61 - Enumeratio plantarum hotti regii botanici Berolinensis altera. Berolini, G. Reimer. 1821-1822. II voll. 8. - I: 1821. vแH $158 \mathrm{p} .-\mathrm{I}): 1822 . \mathrm{V}, 478 \mathrm{p} .\left(4 \frac{2}{3}\right.$ th. $)$

\$969" - et Friedrich Otto. leones plantarum selectarum horti regii botanici Berolinensis cum descriptionibus et colendi ratione.
Abbildungen auserlesner Gewälise des homiglichen bolanischel Gartens zu lBerlin. Ne)st Beschrejhung und Anleiturng, sic zu er-

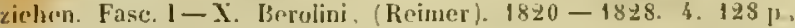
(jo tal), col. $\{20(h)$.

¿963" Link, Heinrich Friedrich, ef Friedrich Otto. Icones jlantarum rariorum lorli regii butanici Berolinensis cum alescriptionibus et colembi ratione. Ahbilatungen neuer und seltener liewáclisto des Koniglichen botanischen Cartens zu Berlin urbst Besclureihungen, uui) Aulritung, sir zu zichen. Pars I, fanc. I-VIll. Bcrolini, Oelımighe. $1828(-1831$ ) 4. 90 p., 48 tal). col. $(10 \%$ th.

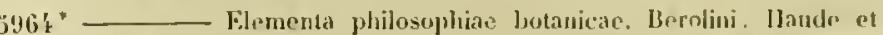
Spones. $1824.8 .486 \mathrm{p} .\left(1^{3} / 4\right.$ th. $)$ - Elenumb philusophiae botanieae. Grundlelıren der hututertundr. (latine el germanice.) Ëd. Il. licrolini, llaule et Spener. 4837. H voll. 8. - 1: 311,501 1\%, 4 tab. - Il: xv. 377 p. (4th.)

396.; ${ }^{*}$ und Frichrich Otto. Veber die Gattungen Melocactus unt Echinocactus, nelost Beschreibung und Ablildung der iu kouiglielien lotanischen Garten bei Berlin befindlichen Arten. Berlin $1827.4,2:$ p., tab. $11-3 i$

(Aus den Verhandunren des Preuss. Gartenhanvereins.

$3966^{*}$ Lortus regius botanicus Berolinensis, descrijutus. Beralini, Reiner. 1827-1833. II voll. 8. - I: 1827. vil, 384 ]. - II: 18:33. $11,376 \mathrm{~J} .(3 \mathrm{th}$.

(Contimualio non prodiit.)

$3967^{*}$ - llandbuch zur Erhennumg der nutzbarsten uul am haufigsten vorkommenden Gewáclise. Berlin, Haude und Spener. 1829 - 1833. 3 Theile. s. - 1: 1829. vit, 864 p. - H: 1831.533 p.[H] : 1833. xvt11 536 p. $(71 / 2$ (h. $)$

(Etian inseribitur: Willenou Grundriss der Krauterhunde. Hach dessen T'odi' nou Jerausgegeben mil Zusatzen von Iemrich liriedeich Link. Theil $11-11.1$

$5963^{*}$ - Leler Pflanzenthiere uberhaupt und die dazu gereelneten Gewachse besonders. Berlin, (Dummier.) 1831.4. 15 1 tab. col. ( $11 / 12$ th.)

$5969 \div$ - Guiletmo Josepho Projessori Rostocliensi .... gratulatur simulque de antiquitatibus botanicis Rostoclsiensibus disputat. Berolini, typ. Feister, die XIV Martii 1835. 4.8 p. Bibl. Juss.

$: 970^{*}$ Jeones anatomico-botanicae ad illustramla clementa pliblosopluae botanicae. Anatomisch-botanische Abbildungen zur Eräuterung der Grundluhren der Kratuterkunde. Berolini, Haude ot Spener. 1\$37-1842. Fase. 1-IV. folio. IV p., 32 tab. (19th.)

$3971^{*}$ __ Jcones selectae anatomico-botanicae. Ausgewalılte anatomiscli-botanische Abbildungen. Berolini, Ilaude et Spener. (Luderitz.) $1539-1842$. Fase. 1-IV. Solio. 15 plag., 32 tab. (12 th.)

$5972^{*}$ - Friedrich Klotzsch und Friedrich Otto. leones plantarum rarionum horti regii botanici Berolinensis. Abluildungen s.ntener Pfinzen des Koniglichen botanischen Gartens in Berlin. Berliu. Veit et Co. (vol. II. Niculai.) 1841-1844. II vnll. 4. - I: 1841. 1. 1-61, tal, col. 1-24. - If: 1842-18:4. 1. 63-126. tal,. col. s5-18. (col. 1 2 th. - nisr. 8 th.)

(1'rndijt octo fasciculis; siuguli 2 plag. . 6 tab.)

$5973^{*}$ Filicum species in horto regio botanico Berolinensi cul1ae. Berolini, Veit. 1841.8.179 p. (1 th.

$694^{*}$ - Nhiotinae horli regii botanici Berolinensis cultae. Halic $1841.8 .65 \mathrm{p}$ Seorsim impr. c Linnaea 48 \$. p. 481-3̈H.

$597 \ddot{Z}^{*}$ Jahresberichte uber die Arbeiten fur physiologische Botanik in den Jahren $1840.1841 .1842-1843.1844-1845$. Ber lin, Nicolai. $1842-1 \$ 46.4$ Bandchen. $8 .\left(3 \frac{1}{2}\right.$ th. $)$

Scorsin impr. e lliegmamis Arelis, vol. 11 squ.

$5976^{*}$ Vorlesungen uber die Krauterkunde fur Freunde der Wisseuschaft, der Natur und der Garten. Ersten Bamdes erste (umb zweite) Abtheilung. Berlin, l.uderitz. 1843-1845. 3. 15. 349 1.. 3 tals. (2\%,th.) (Continuatur.)

$39 \div *$ - Anatomia plantarum iconibus illustrata. Fase. I - Ill. Anatomie der Pflanzen in Alubildungen. Berlin. Luderitz. $1843-$ 1847.4. - 1: 1843. 11 p., tab. 1-12. - Il: 1845. 15 p., 1ab. 1314. -111 : 1847.10 p. tab. $25-36,(6$ th.) (Continuatur.) 
$5978^{*}$ Linnaeus, nobilis von Linné, Carl. Caroli Linnaei, Sueci, Doctoris medicinde, Systema naturae, sive regria tria naturae systematice proposita per classes, ordiues, genera el species. O Jehova! quam ampla sunt opera Tua! quam ea omnia sapienter fecisti! quam plena est terra possessione tua! Psaln CN. 24. Lngduni Batavorum, apud Theodorum Haak. MDCCXXXV. Ex typographia Joannis Willıelmi de Groot. folio max. ( 7 foll.) Bibl. Kunz. et Juss. - ${ }^{*}$ Reimpressio: Systema naturae, sive regna tria naturae systematice proposita per classes, ordines, genera el species. Editio prima reedita, curinte Antaine Laurent Apollinaire Fee. Parisiis, Levidult. 1830.8 , vi, 81 p. ( $5 \mathrm{fr}$.$) - "Systema naturae, in quo naturae regna tia, sccundum$ classes, ordines, genera, species systematice proponuntur. Ėlitio II. auctior. Stockholmiae, apud Gottfr. Kiesewetter. 1740.8. $80 \mathrm{p}$. "latine et germanice per Johan Jouchin Lange. Halle, [y]. Gebaner. 1740. 4 ols. (s), 70 p. - +Ed. IV. ab auctore emeudata et aucla. Iccesserunt nonina gallica. Parisis, David.1744.8.108 p. - Editio eaden, cura Wichael Gotlieb Agnethler. 1lallo 1747. 8. H. - ${ }^{*}$ Ell. VI: Systema natnrae, sistens regna tria naturae, in classes et ordines, generd et species redacta, tabulisque aeneis illnstrata. Editio sexta, emendata el aucta. Stockllolmiae, impensis Gotlofr. Kiesewetter. 1748. 8. 224 p., 18 p. ind., 8 tab., effigies Linnaei. - "Secundum sextam Ilolmiensem editionem. Lipsiae, Kiesewetter. 1748. 8. 224 ]., 48 p. ind., 8 tab., effigies Limnaei. - Lugduni Batavorum 1756.8. 227 p., 8 tab. B. - †Carali Linnati legnum vegetabile juxta systema naturae in classes, urdines el genera als eodem constitutum, socictatis physico-botanicae Florentinae usui accomodatum ac recusum curante Faverio Muretti. Florentiae, typ. Viviani. 1756. gr. 8.123 p., 2 tal. - "inter ejus Opera varia. Lucae, typ. Juntini. 1758. 8. p. 147 -376. - "Systema naturae per regna tria naturao, secundum classes, ordines, genera, species, cum characteribus, dillerentiis, synonymis, locis. Ed.X. reformata. Iolmiae, impensis Laurentii Salvii. 4758 - 1759. Il voll. 8. 1384 p. - Nomenclator extemporaneus rerum naturalium: plantarmm, insectornm, conchyliorum, secundun Systema naturae Linnacanum (editionis decimae) editus a Carl Clerck. Stockholmiae, typ. Grefingii. 1759. 8. 67, (12) p. B. tunlex plantarum in Linnaei Systematis naturae editione decinua receusitarum. Ilafniae, apud fratres Philibert. 1761. 12.54 1.- ${ }^{*} \mathrm{Al}$ editioneu decimam reformatam Ifolmiensem (recusa cura Joh. Jouch. Lange). Ilalac Magdeburgicae, Curt. 1760. Il voll. 8. - I: Animalia. 823 p. - II : Vegetabilia. p. $825-1380$. - Lijsiae 1762. 8. H. Vindobonae 1767. S. H. - ${ }^{*}$ El. Xll. reformata. Ilolmiae, Salvius. 1766-1768. III voll. S. - I: 1766. Animalia. 1327 p., 36 p. ind. 11: 1767. Vegelabilia. 736 p. -111 : 1768. Mlineralia; appendix animalinm el vegetabilium. 236 p., 20 p. ind., 3 tab. - Ex edilione duodecima in epitomen redactum a Johann Beckmann. Goettingae 1772. II voll. 8. - I : Animalia. $240 \mathrm{p}$. - II: Vegetabilia. $356 \mathrm{p}$. B. - (Batavia) 1783. 8. 103 p. (Sola nomina generica, additis nounibus belgicis.) B. - " Ed. XIII. ancta, reformata, cura Johann Friedrich Gmelin. Lipsiac, Beer. 1788-1793. III tomi. 8. - 1: Pars 1-7. 1788. Animalia. 4120 p. - II: Pars 1-2. 1791. Vegetabilia. $\mathbf{x L}_{r}$ 1661 p. - III: 1793. Mineralia. 476 p. (17\% th. - herabgesetzt: 10 th.

germanice: Des Ritters C. won Linne vollstandiges Natursyslem nach der zwolfien lateinischen Ansgahe und nach Anlejting des lmi-

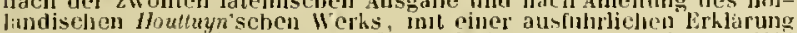
ausoerertigt von Philipp Ludug Siutius Muller. Numberg, IRaspe. 1773

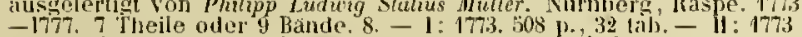

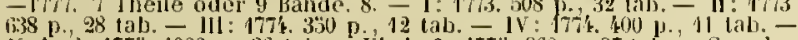

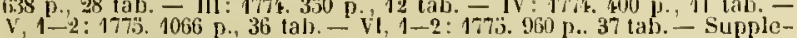
went- nnd Registerband: $1776.38 \%, 536$ p., 3 lib. $B$.

anglice : General systen of nature, translated amented et enlarged by hilliam Turton. London 1806 , Ytl voll, 8. (5l. 5.s. - col.6\%.6s.) suecice: Carali Linnaei luledning i Örl-Riket, clier Systema naturae, pả svenska cofversall af Johan J. Haartman. stochinolm, trycht

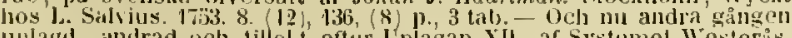
Iuplagd, andrad och tilloki efter Uplagan Xil. af Systemel Westerás. 'Tryent J. L. 11orn. 1777. 8. 158, (8) p., 3 tah. W.

(Versio haece systematis Linnaeani facta fuit suasu Comitissac Tessin. quae sistema hocce cornuscere cupjebat.

gallice: srsteme de la nature, traduit par l'melerstegen de Putle, N'apres la treszieme edition latine de Gmelin. Bruxelles 1793. IV voll. s. Q.

(Editiones 1. I1. 11. . . XII. sunt originariae, ab ipso Linnaeo auctue et reformatie.

(Editio prima systematis naturae valde rara est, ita ut ipse lliks:roem nonnisi in Additamentis eximii sui operis accurate eam (2) fropria inspectione indicare posset: Juo equ vidj exemplaria, paginalibns non inscripta numeris, ila disposita: p. 1: titulus. P. 2: alba.

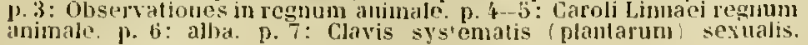
Pritzfi, Thes. lit. bot. p. 8-9: Carali Limaei regnum vegelabile. p. 10: Otservationes in regnum vegetabile. $p .11$ : Observationes nlt regna lil naturae. (in calce

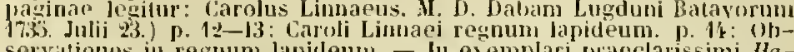
servationes in regunn lapilentm. - Jn esemplari praeclarissimi Hadrinu de Jussiru aljecta est talula colorata cum pagina impressa ita inscrinta: Caroli Limaei, Sueci, Methodus, justit quam pliysiologus aceurate et feliciter concinuare potest bistoriam cujnscunine natupalis subjecti, sedpentibus hisece paragraphis comprehensil. Lugduni Ralavorum, apud Angelnm Sylvium. MDCCXXXT. - "lch saly dinse selthe mur auss wenigen Blattern besteliende Ausgahe an der Thero-
sianischen Bihliotheh zu Wien, und an Naturalienkabinet zu luns-

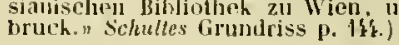

8979 Linnaeus, uobilis von Linné, Carl. Fundamenta botanica, quae majorum ojernn prodromi instar theorian scientiae botanices per breves aphorismos tradunt. Amstelodami, apud Sal. Schouten. 1736. $8.36 \mathrm{p}$ - Fumlamenta bolanica, in quibus theoria botanices aphoristice traditur. Ed. Il. Stochholmiae, apud Gotlfr. Kiesewetter. 1740. 8. 87 p. - "Ed. III. Anstelodami, apud Sal. Schouten. 1741. 8. 51 p. - impr. cum Charles Alston, Index plantarum praecipue officinalium, t]uae in horto medico Edinburgensi demonstrantur. Edinburgi 1740.8. 22 1. B. - timpr. cum Linnaei systemate naturae. Parisiis, David. 1744. 8. xxvi p. - " Enndamenla botanica, in quibus theoria botanices aphoristice traditnr. Accedunt Johannis Gesneri Dissertationes pliysicae, in quibus cel. Linnaei Elementa botanica dilucide explicantur. Ilalao, Bierwirth. 1747.8. 78 p. - + impr. cum Charles Alstan Tirocinio botanico. Edinburgi 1753. 8. p. 83-109. - *impr. cum Linnaci Operibus variis. Lucae, typ. Juntini. 1758. 8. p. 1-61. - "Fondamenta botanica, curante Jean Emmanuel Gilibert. Coloniao Allobrogum 1786. 8. tom. 1. p. 1-45. - latine et lispanice: Matriti 1788.5 .97 p. B.

$5980^{*}$ __ Bibliotheca botanica, recensens lihros plus mille de plantis hucusque editos secundum systema auctorum naturale in classes, ordines, genera et species dispositos, additis editionis loco, tempore, forma, lingua etc. cum explicatione fundamentorm botanicorum pars I. Ansstelodami, apud Sal. Schouten. $736.8 .153 \mathrm{p.}$ praef, clavis el series classinm et ind.: 29 p. $-{ }^{*}$ Editio nova mulıo correctior. Llalae Salicae, Bierwirth. 1747. 8. (12), 124, (8) p. $(1 / 3$ lh. $)$ - Amstelodami 1751. 8. 220 1). B.

$5981^{*}$ _. Musa Clitrortiana, florens Hartecampi 1736 prope llarlemum. Lugduni Balavorum 1736. 4. 46 p., 2 tab.

$5982^{*}$ —_L Ilortus Cliffortianus, plantas exhibens, quas in hortis tam vivis quam siccis llartecampi in Hollandia coluit vir nobilissimus et generosissimus Georgius Clifford, J. U. D., rerluctis varietatibus ad species, specielus ad genera, generilus ad classes, adjectis locis plantarum natalibus differentiisque specierum. Cum tabulis aeneis (nitidissimis). Amstelaedami 1737. folio, $x, 1 v, 504$ p. (i. e. p. 1231 et $301-501$ ), 1 p. atdenda, (16) p. ind., 36 et 1 tab.

(ln pag. 231 dicit Linnarus: aObservet lector, hane paginam excipi a pagina 301. nullo tamen liatu admisso, praeter numierum paGintarum nolis ol typum necessarium. - In Stoever, Leben de fitters von Linne 1. p. T77 de hoc opere hace legninim: "ber bruck Wurde in Quartornat ingefangen, wie noch einge logen bezeugen die der IJr. Dr. Smuth zu Lonton aus den gelehrten Nachlasse Linne s hesitzt. Nan fand aber bald das Unscluchliche und Unbequeme, und Clifford sparte krine hosten, das Repertorium seiner Schálze auf das eleganteste erscheinen zoll lassen. Die Abbildnngen der seltensten Jilanzen wurden won dem Englander Ehret (der treffliche Georg Dionysins Ehret ist, nebenbei gesagt, hein Englander, sonderu ein Deutsehtr. und in Monat Januar 170' im Marggrafenthum Baden geboren\} aul 32 Kupfern gezcichnet. Diese machten das Werk zu dem thenersten, welches Linne jemals bearbejtete. Clifford machte damit lireunden und den vornehmsten Botanikern ein Geschenk. Jie Wenigen Exemptare, die in den Buchbandel kamen, wurden cinzeln nit 23 Thalerm liezahlt." - lu loc libro simul impressa est Caroli Linnaei Bibliolleca hotanica Clitortiana $\mathrm{f}^{1 / 2} \mathrm{p}$ plagularum.

5983 - Virislarium Cliffortianum, in quo eshibentur plantae, quas vivas aluit hortus IIartecampensis annis $1735-1737$ indicatae numinibus ex horto Cliffortiano depromtis. Amstelitedami 1737. 8. 104 j. B.

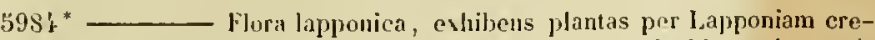
scentes, secundum systema sexuale, collectas in itinere impensis soc. reg. lit. el scient. Sueciac anno 1732 instituto. Additis synonymis el locis natalibus onnium, descriptionibus et figuris rariorum, virilus medicatis et oeconomicis plurimarum. Amslelaedami, apud Salononem Schouten. 1737, 8, 372, (48) p., 12 taly, - *Editio allera, aucla et emendata, studio et curá James Edioard Smith. Londini, impensis B. White. 1792 . S. L, 390 p., $(14)$ p. ind., 12 tab.

(Prolromus immortalis operis "Florula lapponica exstat in Act. liter, et scient. Sueciae 173 ? p. $46-38$. 173\%. p. $12-23$.) 21 
5986 Linnaeus, nobilis von Linné, Carl. fenera plantarum, eorumqque characteres naturales sceubdum numerum, figuram, situm el jropurlionem omnium fructificationis partiun. Lugduni Batavorum, apusl Conrad. Wishelr. 1737.8. 38 4 p., prerof., clavis classium, ind. - "Ed.Il. aucta ef emendata. Lugil. Batav., Wisloll. 1749. 8. 597 p., ind. tEo. 11. (III.) numinibus plantarum gallicis lncuplolita. Parisiis, Darid. $1743.8 . x x x u 1,413$ p., ind., cum framentis methodi naturalis. 2 tab. - "Geurra plantarun, quae novis septuaginta auctoris genesolus sparsim editis lucuplrlita, recuclenda curavit Christoph Karl Strump/f. Ilalae Nagtleburgicac, Kunmel. 1752. 8. xxxu, 44 I p., ind. - ${ }^{*}$ El. V. al) auciore reformata et anch. Ilulmiar, impensis Lau-

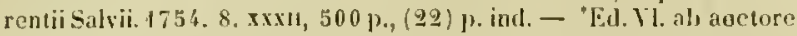
reformata ('t aucta. Ilolmiae, impensis Laurentii Salvii. $1764.8 . \mathrm{xs}$, 580 p., (42) p. ind. et ordines naturales, - Viennae, Tralluer. 1767. 8. - Eil. novissima (Yll.) novis generilus ac ementationilus al, jpso perillustri auctore sparsim evulgatis adaucta, curante Johann

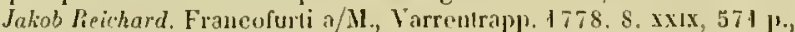
ind. - ${ }^{*}$ Ed. VII, post Reichardianam secunda, prioribus longe auctior atque emendatior, curaute Johamn Christicn Duniel (vou) Schreber. Francofurti a/M., Varrentrapp. 4759-1791. II voll. 8. xxxu, 872 p. - ${ }^{*}$ El. Vill (LX.) praecedente longe auctior, corante Thaddueo Haenke. Vindobonae, ex officina Wappleriana. I791. Il roll. 8. xxı, 811 p. - *Editio nosa, curante Curtio siprengel. Geetlingae, Dieterich. 1830-1831. Il voll. \&. vi, $870 \mathrm{p}$. (4 /h.) *ach der sechsten fusqabe lunt dler erste-11 unt zueiten Mantisse

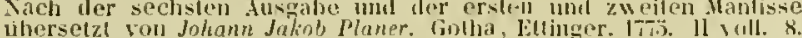

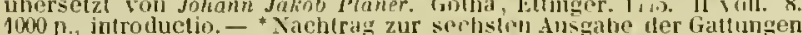

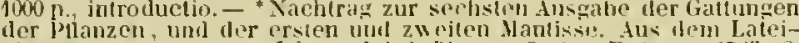
nischen ubersetzt von Joliann Jakob Planer. Gotha, Ellinger. 178\%. \& $10^{\prime} \mathrm{p}$., ind.

$5986 \div-$ Corollarium generum plantarum, exhibens genera plantarum sexaginta, addenda prioribus characteribus expositis in Generibus plantarum. Accedit Mlethoclus senualis. Lugduni Batavorum, apud Conradom Wishoff. $1737.8 .25 \mathrm{p}$.

(Libelus una cum insequenti editus est nua com editione principe Generum.

$5987 \div$ Nethodus sexualis, sistens genera plantarom secundum mares of feminas in classes et ordines rerlacta. Lugduni Batavorum apud Conradum Wishofl. $1737,8.23$ p., I tah.

(Sola nomina, impr. cum libello praecedenti una cum editiono principe Generum.

Classes plantarum, seu Srstemata plantarum omnia a fructificatione desumta, quorum XVi universalia et Xill partialia compendiose proposita secunclum classes, ordines et nomina generica cum clavi cnjusvis melloxti et synonynis genericis. londanentorum botanicorum Pars II. Lngduni Bataporum, apud Conradum Wishofr. 1738. 8. 656 p. - llalae, himmel. $1747.8 .636 \mathrm{p}$.

6989 * Critica botanica, in qua nomine plantarum generica, specifica el rariantia eximini subjiciuntur, selectiora confirmantur, indigna rejiciuntur, simulque doctrina cirea denominationem plantarum traditur. Seu Fundamentorum botanicoron Pars IV. Iccedit Johannis Brokallii de necessitate historiae naturalis discursus. Lugduni Batavorun, apud Couradum Wjshoff. 1737. 8. 270 p., pracf., ind., et Bracallii discursus: 24 p. - "Fundamenta botanica, curante Gilibert, III. p. $363-594$

$5990^{*}$ Flora succica, exlibens plantas per regnum Sueciae crescentes, systematice cum dilferentiis specierum, synonymis autorum, nominibus incolarum, solo locorum, usu pharmacopoeorum. Stochholmiae, sumtu et literis Laurentii Salvii. 1745. 8. xı, 419 p. 1 tal). - ${ }^{*}$ Ed. Il. aucta el emenclata. Stockholmiae, sumstu et literis Laurentii Salvii. 1755. 8. xเx, 464 p., ind., 1 tal,

5991* - Öländska och Gollulandska Resa pả Riksens Jluglonlige Standers befallning forrultad ăhr 1741. Mled Ammirkningar vil 0econamien, Vatural-llistarien, Intiquiteter etc. med âtshillige Figurer. Stochlrolm och Lpsala, hos Gottfried hiesewetter. 1745 . 8. (8), 344, (30) p., 2 chart. geogr., I lab.

" germanice: Herin furls von Limé Reisen rhrch Oeland und Gottland w wethe auf Befeht der hochlublichen Reichsstinde des honig-

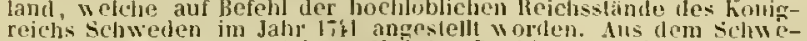
dischen ubersetzt (von Johann Christitu Daniel (won) Schreber.) llalle,

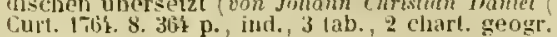

¿3992* Wästgüa-Resa, pâ Riksens Hoglonlige Standers Befallning forrattad år 1746. Med Anmaskuingar uti Oeconomien. Naturkunnogheten, Antiquiteter, Inwảnarues Seder och Lefnadssatl, med tillhorige Figurer. Stochholm, uplagd pả Lars Salvii kostnad. 17 . 8. 244 p., jraef., incl., 5 tab.

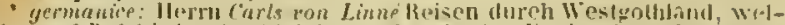

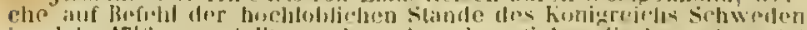

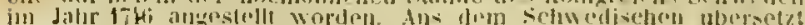

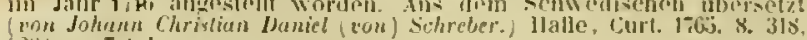
2010) 10., 7 1ils.

4993 Linnaeus, nolsilis von Linné, Curl. Flora zevlanica, si-tens planlas indiens Zeylunae insulae, juac olim $1670-1677$ lectae fuere a P'ablo Llermanna, Prof. Lot. Leydiensi, demum jost 70 annos al, Augusto Guenthero, Plarmacopola llavniensi, orbi redditae: Loc veru opere revisao, esaminatae, determinatae el illuatratae generilus certis, differentiis specificis, syuonynis propriis, descriptionilus: compendiosis, iconilous paucis. Holniar, sumtu of literis Lauruntii Salvii. 1747. 8, 240 p., ind., 4 tab. - "Anstelaedani, apud Wetstenium. 1798. 8. (non differt.)

5995. - Hortus Lpsaliensis, exhibens plintas exalicas lurto Lipsalicusis Icademiae a sese illatas ab anno 1742 in aunum 1748. additis dillereutiis, synongmis, habitationitus, hoxpiliis, rariorumage Jescriptionilus in gratian studiosae juventutis. Vulumen 1. Stockholniae, sumtu et literis Laurentii Salvii. 17:8. 8. 306 j., ind. 3 lab.

$3990^{*}$ —_ Nateria medica, liber 1. de plantis. Ilolmiae, Salvins 1749. 8. 252 p., jrolegomena, 1 lab. - curante J. C. V. Snhreber. Viulobonae 1773. 8. (Regnum vegetalile: p. $31-236,1$ tals.) Ed 1V. ancior, curante J.C. D. Schreber. Lipsine el Filangae 1783. s. (Regum vegetaljile: p. 33-272.) - "Mantissa melitioui quartae Nateriae medicae B. Eq. a Linnẻ auljecta a J. C. D. Sohreber. Frlangae 1782.8 .16 p. - "Ed. V. auctior, curant: J. C. D. Sehreber Lipsiae et Erlangac, Walther. 1787. 8. 3 is p., prolegomena, ind.

$5996^{*}$ - Huenitates acadenicae, seu dissertatinnes variae physicae, medicae, botanicae, antehac scorsin edilae nune collectae et anctae cum tabulis aeneis. Ilolmiae et Lipsiae, apuil Godofiedum Kiesewetter. (inde a volumine II: Holmiae, a mul L. Salvium.) 174! - 1769. V11 vall. 8. - ${ }^{*}$ Ed. H1. curante Joham Christian J)aniel (ton. Schreber. lislangae, Palm. 1787-1790. X voll. 8 . (18 $\mathrm{lh}$.)

Vol. 1: Ilolmiae et Lipsiae, Kiesewetter. 1749. 363 J., 17 tai). (edidii P. Cumper.) - Lugduni Batavorum, apud Cormelium Ilaak. 616 (13) p., 15 tab. - Ed. 111. curante Schreber. Lirlangae 1787. S. $371 \mathrm{p} ., 17 \mathrm{tah}$.

Vol. Il: Ilolmiae, Salvius. 1751. S. (Anstelodami 1752.$) 478 \mathrm{p.}$ 4 lal. - Eil. II. aueta. Holmiae 1762.444 J., 4 tab. - Ell. Ill. curante Scheber. Erlangae 1787.472 p., f tah.

Tol. III: IIolmiae, Salvius. 1756. (Amstelaedami 1764.) $464 \mathrm{p}$ 4 tals. - Ed.H. (IIl.) curante Schreber, Erlangae 1787.46, p., 4 tal).

Vol. $\mathbb{N}^{\circ}$ : Holniae, Salvius. 1739. (Lugduni Batarorum 1760 .) 600 p., 4 tal). - Ed. Il. curante Schrel,er. Eilangale $\{788.600$ p., 4 tals.

Vol. I: IIolmiae, Salrius. (Lugd. Bat.) 1760, 483 p., 3 tah. Ed. II. curante Schreber. Erlangae 1789. 483 p. . 3 tal.

Fol. V1: Ilalmiae, Salvius. 1763. (Lugd Bat, 1764.) 486 p., 5 lab. - Ell. 1l. curante Schreber. Erdangae 1789. 486 J., 6 tah. (Sexta pertinet ad vol. V.)

Vul. VIl: Ilolmiae, Salvius. (Lugd. Bat.) 1769.506 p., 7 \{ab. Eol. Il. curante Sohreber. Erlangae 1789. 306 p. 7 tal.

Vol. V'll: edlidit Schreber. Erlangae 1785.332 p., 8 tab.

Vol. 1.X: colidit Schreher. Erlangae 1783. 331 1).

Vol. X: accedunt Curoli a Liuné filii Dissertationes botanicae cullectae, curante Schreber. Erlangae 1790. 148, 131 j). 6 tab.

(Singula volumina selnel vel bis tantummodo, singula autem lertin vice impressa sunt, iutercedente editione nova Amoenitatum Amsteh)danchsi. Quilre etiam singulorum volunimum editiones, Dryandro duce, approsui.

$399^{-*}$ __ Selectae ex Imoenitatibus academicis disscrationes an universam naturalem historiam pertinentes, yuas eolidil et additamentis auxit L. B. e. S. J. (i. e. Leopold Biucald, Plıysices Professor Graecensis, e societate Jesu.) Graeciae, țp. Widmanstad. 1764. 4.

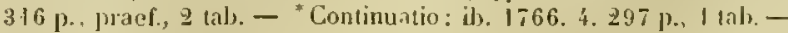
"Continuatio altera: ib. 1769.4. 277 p., 4 tab. - Ed. 11: Graeciae. apud Zaunrieth. 1786. 8 . 285 p., 3 tab. w.

3998 Miscellaneous tracts relating to natural history, husbandry and plysich, translated from the latin, with notes ly Benjamin Stillingfleet. Londen 1759 . 8. 230 p. B. - - Ed. Il. to which is 
added the Calendar of Flora. London, Dadsley, 1762. 8. xxru, 391 p. 11 lab.

5999 Linnaeus, nolyilis von Linné, Carl. Select Dissertations from the Amocnitates academicae, a supplement to Mr. Stillungleet's Tracts reliting to natural history; translated by the liev. $F$. J. Brund. Vol. I. London 1781.8 .480 p. B.

$6000^{*}$ Opera varia, in upuibus continentur Fundamenta butanica, Sponsalia plantarum et Systema naturac. Lueac, lyp. Juntini. 1758. 8. 376 p., praef., I tab.

6001 des Ritters Kurl van Lime auscrlesene AJhandlungen aus der Naturgeschichte, P'hysik und Arznew issenschaft. Nit Kupferu und Aunerkungen. Leipzig, Lolıme. 1776-1778. 3 Theile. 8.

$6002^{*}$ Plilosophia hotanica, in qua explicantur Fundanenta botanica cum definitionibus partium, exemplis terminormm, observationibus rariorum, arjectis figuris aeneis. Stockholmiae, apud Godofi. Kiesewetter. 1751.8. 362 p., 9 lab., 2 tab. xylogs. - Eal. Il: Vienuae Austriac 1755.8 .364 p. 9 tab., 2 tab. xylogr. B. - +Ed. II: Vienuac, $\left.t^{\prime}\right]$. Johann Thomas Tratner. 1763. 8. 368 p., jraef, 9 tab., 2 tab. xylogr. Bibl. Cand. - Ed. Il: jb. 1770. 8. (non dilfert.) - Ed. Il: iJ. 1783. 8. 360 p., 11 tah. - Ed. 11: curante Johun Golllieb Gleditsch. Bcrolini 1750.8.362 1., 11 tab. - * Fundamenta botanica, curante Jean Emmanuel Gilibert, 11l. p. 1-362, 13 tal. ${ }^{*}$ Eul. Ill. ancta cura Kurl Ludicig II illdenow. Berolini 1790. 8. 364 f.., 11 tab. - "El. IV. studio Curtio Sprengpl. Halae, Kummel. 1809.8 362 p., I tals. ( $2 \frac{1}{3}$ lh.) - "Caroli Linnaei Philusophia botanica, in qua explicantur botanices fundamenta, studio Curtit Sprengel; edilio aucta el emendatd. Tornaci Nerviorum, 19p. Caroli Casterman-Dieu. 1834 . 8. xxy , 471 p., 9 tab, et clay is systematis. (Praefatus est editor typogianinus.)

$\div$ anglace: vide ll ug h kose

germanice: Pllanzenphilosophic im Auszuge. Augsoburg, Wolf. 1787. 8 - Yispanice: Explicarion de la filosolia y fundanentos botanicon de

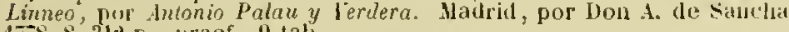
78. 8. 312 p., praef, 9 tals.

hispanice: anuotationibus, explanationibus, supplenentis ancla opera Cusimiro Gomez Ortegu. Matruti 17!), "4. 426 p., 10 lab. B. t gullice: Plibosophie botanique de charles Linue, dans lirguelle sont explicuees les fondements de la bolanique, avec les délinition:de ses parties, les exemples des termes, des observations sur le plus rares. Traduite du latlin par Fr. Alex. Qnesne. Pars, Cailteau. fiss. s. 15, ioti p., 11 lab. ( $7 \mathrm{fr}$.)

6003 âr 1749. Iled lion och tnmärkuiugar uti Oeconomien, Naturalier, Antipuileter, Seder, Lefnatk-satt. Iled tillsorige Figurer. StockJıolm, uplangl pả Lars Salvii hustnad. 1751. S. xis, 434 p., prac ind., 1 mapra geogr., 6 tah. w.

* germanice: Versuche einer Natur-Kunst- und Oekonomiehistoric ron eingen selwwedischen Provinzen, nach eigner Culersuchung zum

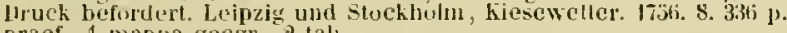
praef. I mappla gengr., 2 tals.

("Versio linjus itineris scanensis facta est a Farl Erust Klein, qu olservaliones valias in priefationc aldidlit," W.

6005 - Species plantarum, exlibentes plantas rite cognitas, ad genera relatas, cum differentiis specificis, nominilus trivialijus, synony̧nis selectis, locis natalibus secundom systema sexuale digestas. Iloiniac, impensis Lanrentii Salvii. 1753 . II voll. 8.1200 p. pracf., ind. Bibl. Cand. (vidi exemplar cum nolis manuscriptis Boissieri de Siarrages.) - "Editio secunda, aucta. Jolmiae, impensis Laurentii Salvii. T762- $\{763$. II roll. 8. - 1: 1762. Monandria-Polyandria. (14), 1-784 p. - Il: 1763. Didynamia - Cryptogamia. p. 7851684, (64) p. ind. - ${ }^{*}$ Ed. IIl : Vindobonac, J. Th. de Trattner. 1764. Il voll. 8. 168 2. p., jud. - * Species plantarum, cxhibentes plantas rite cognilas ad genera relalas, cum differentiis specificis, nominihus trivialibus. synunymis selectis, locis natalibus, secundum systcma sexuale tligestas. Eutitio quarta, post Reichhardianam quinta, adjectis regetabilibus lucusque cosnitis, curante Carolu Ludorico Ifilldenow. Berolini. impensis G. C. Nauck. 1797-1830. VI voll. S. - I: 1797. xxx1, 1568 p. - II: 1799.823 p. - III: 1800.2409 p. - IV: 1805. 1457 p. - V, pars I: 1S10. L, 542 p. $(182 / 3$ lh. charta scriptoria: $23 \%$ \% $(h)-.{ }^{*}$ Tomus $V$, pars ll, sectio prima: Species muscorum frondusorum, pars I, editae a Friedrich Schuuegrichen.

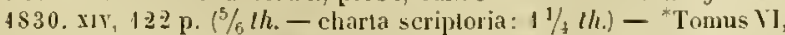
pars I et II : Ilyphomycetes et Gymnonyectes, edidit Heinrich Friedrich Link. $1824-1825 . \mathrm{xv}, 162$, VI, 128 , $\mathbf{x i x}$ p. $\left(1 \frac{1}{3} \mathrm{lh}\right.$. - charla scriptoria : 2 (h.) - "Intex alphabeticus Filicum in Curoli a Linné Specierum plantarum editione quinta cura 17 illdenowii enumerala- rum, adjectis rarietatibus nominumyuc gencricorum el trivialium syonymic. Berolini, Nauch. 1821 . 8.60 p. (1/4t/. - charta scriptoria: $1 / 3(h)-.{ }^{*}$ Species plantarum, exhibentes plautas rile cognitas ad genera relatas, cun differentiis specificis, nominibus trivialibus, synouymis selectis, locis natalibus, secundum systema sexuale digestas. Olim curante Carolo Ludorico It illdenow. Editio sexta. Tomus I pars 1. Sectio 1-2. autore Albert Dietrich. Berolini, Nauch. $1831-$ 1833. 8. - I: 1831. Monandria el Liandria. x, 735 J. - II: 1833 . Triandriac Monogyuia. 747 p. (6 /h. - charta serijtoria: 8 lh. $)$

$600 \ddot{~ L i n n a e u s, ~ n o b i l i s ~ v o n ~ L i n n e ́, ~ C a r l . ~ E l e m e n t a ~ b o l a n i c a . ~(E d i d i t ~}$ Danrel Solander.) Lpsaliae 1756.8.4 p. B.

Redemt in praefatione Systematis vegetabilium, in edilionibus postea inpressis

6006 Delinealio plantae in usum auditorum. Lpsaliae, apud Christianum Steinert. 1758. 8, 8 p. B.

Redit in editionibus systernatis vegetabilimm Xill. of sequenti-

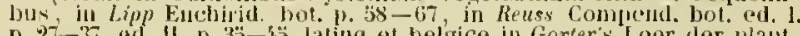
p. $27-37$, ell. II. p. 33 - is, latine et belgice in Gorters Leer der planttables, Iranslated by a hotanical society at Lichield, yol. 1. p. 13-21.) $6007^{*}$ - Disquisitio de quaestione al Academia imperiali scientiarum Petropolitana in anum MIDCCLIS pro pracmio proposita: «Sexum plantarum argumentis et experimentis novis, praeter adhuc jam cognita, vel corroborare vel impugnare, praemissa expositione historica et pliysica omniun plantac partium, quate aliquid ad foecundationem et perfectionem seminis el fructus conferre creduntur, ab eadem Academia die VI. Septembris IIDCCLX in conventu publico pracmio ornata. Petropoli, typ. academiac scientiarum. 1760 . 4. $30 \mathrm{~N}$.

* anglice: A dissertation on the sexes of plants. Translated from the litu of Linnaeus. By James Edreard Smith. Lonton, Nicol. 1786. 8 . $\mathrm{xv}, 62 \mathrm{p}$.

$6008^{*}$ Mantissa plantarum. Generum editionis Vl et Specierum editionis II. Ilolmiae, inpensis Laurentii Salvii. 1767. S. p. 1-142, ind. - "Nantissa plantarmu altera Gencrum editionis Vl et Specierum edilionis 11. Ilolmiae, impensis Laurentii Salvii. 1771. 8. p. 143 -588 , ind.

$6009^{*}$ Systcma vegrtaljilium, secundom classes, orlines, genera, species, cum cbarackribus el differentiis. Editio decima tertia accessionibus et emendationibus novissinis manu perillustris auctoris scriptis adornata a Johanu Andreas. Iurray. Goellingae, Dieterich. 1774. 8. vi, 844 1. - * Supplementum plantarum Systematis regetalsilium editionis Xllı, Gonerum plantarum editionis VI, el Specierum plantarum editionis II. (editum a Curolo Linnaeo. fili\%.) Brunsvigae, inprensis Orphanotropluaei. 1781. \$. 467 p., praef. - *d. XIV, edili a Johan Andreus Mhrray. Goettingae, Diclerich. 1784. 8. xx, 887 p., ind. - +Ed. XV, praecedente longe correctior, curante Johann Andreas Murray. P'arisiis, typ. Didot. 1798. 8. xvI, 821 p.*Editio decima quinta, quae jpsa cst recognitionis a beato Johanne Andrea Hurray institulae teria, procurota a Christan Ifeinrich Persoon. Gocttingae, Dieterich. 1797. 8. xvi, 1026 p., ind. - "Curoli a Lime Equitis Systema regetahilinm secundum classes, ordines, gencra, species. Cum characteribus differentiis et synonymiis. Editio nova, specielus inde ab cditioue $\mathrm{XT}$ detectis aucla et locupletata. Curantibus Joham Jakob Roemer et Joseph August Schultes. Stultgardiae, Cotta. 1817 - 1830. Vil vall. vel Vlll partes. 8. - 1: 1817. xxvim, 642 p. - 11: 1817. vin, 964 p. - III: is 18. v1, 584 p. IV: 1819.

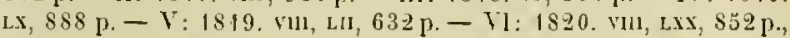
effigies J. J. Roemer. - VII, pars I et 11: curarunt Josejh August Schultes el Julins Hermann Schultes, filius. 1829- $\$ \$ 30$. XLIII, Cvir, is 1 ว p. $\left(33 \frac{1}{2}\right.$ th. $)$ - Systema regetaliliun secuudum classes, ordines et genera. Editio nova, generibus inde ab editione $\mathrm{XV}$ detectis aucta et locupletata. Volumen I. Sectio prima, inceptum a J. J. Roemer et J. A. Schultes, stuttgardide, Cotta. 1\$20. 8.323 p. $\left(1 \frac{1}{2}\right.$ th. $)-{ }^{*}$ Mantissac in rolumina I - III. curarum Joseph August Schultes el Julius Hermann Schulles, filins. Stuttgardiae, Cotta. 1822 -1827 . Ill voll. $8 .-1: 1822$. vi, 386 p. $-11: 1824.388$ p. -111 : 4827. 747 p. $\left(9\right.$ th.) $-{ }^{*}$ Caroli Linnaei Systema vegetabilium. Ed. XVl, curante Kurt sprengel. Goctliugac Djeterich, 1825-1828.

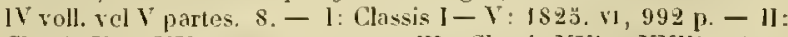
Classis V1-XV. 182 3. 939 p. - III : Classis XT1-XXIli. 1826. 936 p. $-\mathrm{IT}$, pars I: Classis IXIV. 1827.592 p. - IV, pars II: Curac posteriores. $1 \$ 27.410 \mathrm{p}$ - - "Tentamen supplementi ad syㅁ * 
stematis vegelabilium linuaeani erlitionem decinam sextam, aucloro Anton Spreagel. 1828. 35 1). (19 11/12 h.

Systematis vegetalilium editiones idciren a llecima tertia mu-

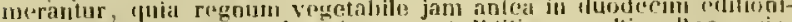
bus systemeitis naturae descrip!un erat. Viditio paenultima Roemerio-

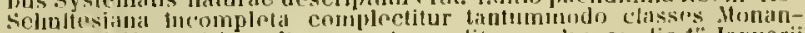

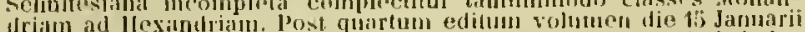
Alriam ad llexintirim,

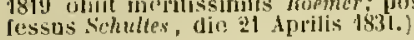

$6010^{*}$ Linnaeus, nobilis von Linné, Carl. Caroli Linnaei Systema plantarum. Liditio novissima, novis plautis ac ememlationibus al auctore sparsion evulgatis adaucta, curante Johann Jakob Reichurl. Francofurti a/AI., Varrentrapp. 1779-1780. IV voll. 8. - l: 1779.778 p. - 11: 1779.674 p. - I11: $1780.972 \mathrm{p}-$ IV: $1780.662 \mathrm{p}$, iul. (Systema plintarum curante Rricharel sislit Systema verotahilium et Spicips plantarum eum utrayue Mdntixsa in unum redactas. germanice: loes Rilters Carl won Lime Vollstandiges Ptlanzensystem, nach der dreizehoten litleinische'n Ausgabo und utath Anlo itung tes bollandischen lloultuyn schen Werkes (vidte Thesaur. Nr. ti30) ulwarsetzt und mit einer ausfulirlichen Erhlarung auswerfertivt < von Golllieb

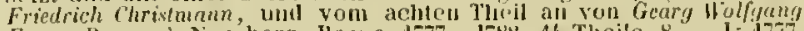
Franz Panzer.) Nuruberg, haspe. 1777-1785. 1" Theile. 8. - 1: 1777.

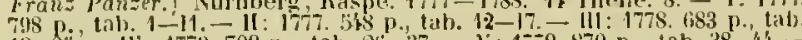

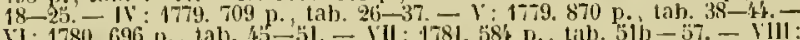

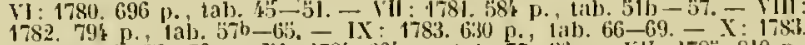

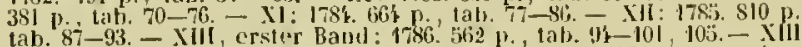
z.weiter Band: 1787.063 b., 1 ab. 102-10\%. - XlV: 1785. Allgemeine Registrer. 6t't p. $(30 \mathrm{l}$.

Volumen primum ot alterum nova immulata editione annis 1794 el 1801 prostierunt. - Epitome ajusdem celifionis in quingue tomos contracta cum iconibus ab eaden bibliopola amis 1791- 179' enrata est.)

germanice: Nach der vierzehnion Alsuahe, mit Znsatzen von Gearg Anton Weizenbeck. Erster Band. Munchen, strubl. 1786. 8.

(Dillerre puto "Linne's voltstandiges deutsehes Pllanzensystem in tabellarische form gebracht von Georg Anton Heizenbeck. lirsies (und

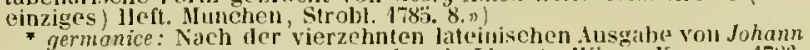
Andreas Jurray uhersutzt voll Joseph Lippert. Wien, hrauss. 1786. 2 Bande. 8.

gernanice: Karl von Linnés Yollstindiges Pllanzeusystem, im Auszuge neu bearbritet, und mit ten neueren Fortschritten thieser Wis senschaft bezeichnet von Blusius Merrent. Marmirg, hrieger. 1811

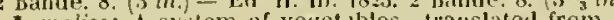

anglice: A system of restables, translated from the 13th edition (as published by Dr. Murray) of the Systema vegetabilium of the hito

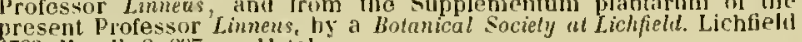
1783. 11 voll. 8. 897 p., 11 tab.

† gallice: Systeme sevuel des végétaux, suivant les classes, les ordres, les genres et les especes, avec les caracteres et les différences, par charles Limee. Preniere édition franeaise, calquée sur cello de Marray et de Persoon, augnentie et enrichie de notons élemsytaires, de notex diverses, dune concordance avee ha méthode do Tournefort et les familles naturelles de Jussieu, par Nicolus Jolycler. Paris, Ronvans, an VI. (1798.) 8.789 p. (9 fr. $2.5 \mathrm{cos}$ - Ed. A. Bertrand. 1810 . 11 voll. 8 . (12 fr.

gallice: Systime des plantes, contenant les classes, ordres, genres thes genres; les phrases earactiristinues des espoces: la citalion des meilleures tigures lo climat at lo lieu uatal des plantes; lepoque de leur thoraison, leurs proprietés et leurs isages dans les arts, feconomic

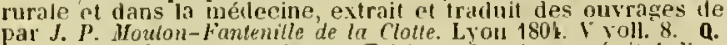
par g. P. Houlon- Limne ratuçois, ou Talleau du règue végétal d'après les principes ot le texte de cet illustre naturaliste, contenant les classes, ordres, genres et especes re. Auquel on a joint leigge historigue

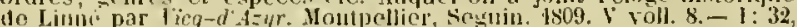

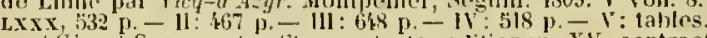

(biosue Scannagata, stoevero teste, entitionem XV. contractam Systematis vegetahilinm edidit, Ticini 7789 . 8 . 288 p., quae mihi prorsus innela est. Tariter jgnoro editionem lusitanicam anni $379 t$.

$6011^{*}$ Coroli Linnaei Systema, Genera, Species plantarum uno rolumine. Editio eritica adstricta, conferta, sive Codex hotanicus Linnacanus, textum Linnaeamum integrum ex onnibus Systematis, Generum, Specierum plantarum editionibus, mantissis, additamentis, selectumque ex cetcris ejus botanicis libris digestum, collatum, conttractum, cum plena editionum discrepantia exlsibens. In usum botanicorum practicum edidit brevique adnotatione explicavit Ilermann Eberhard Richter. Lipsiae, suntum fecit Otto Wigand. 1835. 4. xxru,

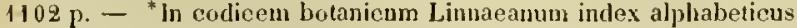
generum, specierum et synonymorum omniun completissimus. Composuil atque edidit ITilhelm Ludwig Petermann. Lipsiae, sumtum fecit Otto Wigand. $1840 . \mathrm{IV}, 202$ p. (16/h. - herabgesetzt : 4/h.)

\section{Orationes Limnaeanae:} $6012^{*}$ Oratio, qua peregrinationum intra patriam asseritur no- quun medicinae professionem resiam et ordinariam susciperet Upsaliar 1741. 8. 48 p. - "Recusio: Caroli Linnaei Oratio de necessitate peregrinationum intra patriam, ejustue lilenchus animalium per Sueciam observatorum. Accedunt Johannis Brateallii Exanen Epicriseos Siegesbechianae in Systena plantarum si"vale et Johanus Gesneri Jissertationes de partiun vegt tationis et fruetificationis structura, differentia et usu, in quuibus elementa hotanica dilucide explicantur. Lugcluni Batavorum, apud Cornclium llaak. 1743. 8. 94, $108 \mathrm{p}$

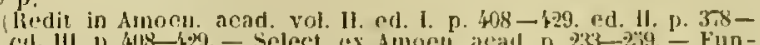

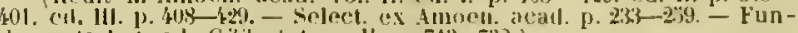
damenta hol. ed. Giliberl. tom. II. P. 7li3-732.

anglice: All uration esncertuing the necessity of travelting in ones own country, trandated hy stiltingleet, in lis Hiscellincous tracts, cl. 1. D. 1-30. ed. 11. p. 1-3.3.

$6013^{*}$ Linnaeus, nolilis von Linné, Carl. Oratio de Telluris habitabilis incremento, habita cum modicinae licentiatum Juhannem W'estmannum merlicinae Doctoren in acadenia regia Ljsaliens ansm MUCCXLIII. April. Xll. more majorum renuntiaret. Et Andrece Celsu Astron. Prof. Oratio de mutationibus generalioribus, quae in superficie corporum coelestium contingunt. Lugduni Batavorum, apul Cornelium IIaak. 1744.8.104 p.

(Editio prineeps Cpsaliensis anni 17\%3. 4. mihi noll innotuit. Recusa est oritio in Amoen. acati. vol. 11. r.d. 1. p. \$.30-i-is. "d. 11. p. for

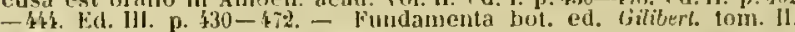
1. $671-711$.

germanice: Leipziger Allg. Magazin ller Valur, Kunst und Wissen-

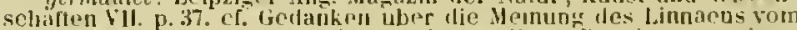
Anwucha der bewohuten Erda. W'ochentliche banziger Anzejugen. 1767. $2 \mathrm{r} .18$.

anglice: On the increase of the hahitable earth, translated in english by F.J. Braad; in his Select Disserlations p. $71-127$.

601: — Tal vid deras Kongl. Najesteters höga nárvaro, lållit uti Upsala den 25 Sept. 1759. Upsala (1759.) folio. 2 plag. $B$. lulime: Oratio coram Rege et Rogina Sueciac. Amoen. acad. vol. $x$. p. $53-63$.

60150 Deliciae naturae. Tal hållit uti Upsala Domkyrka âr 1779 den 14 Decemb. vill Reetoratets nedlággande af Curl von Lime. Efter de Studorandes àstundau, på Svenska ofversatt och, utgifset. Stockholm, tryekt hos Joh. Georg Lango. 1773. 8.39 p. - Anyo Cplagıl. Stockholm, hos P. Sohm. 1816.8.42 p. w.

latine: Amoen. acal edente Schreber, vol. X. P. 66-99.

Edilio originaria latina, a stoever Leben Linne's II. 11. 208. ritutia ex sententia Wilistroemii rix impressa fuit. Oratio liaecece habita fuit. funm anno 172 rectoratum academicum deponeret Limnaeus. Curatures niltiounu acatemicarum tone rogaverunt, ut orationem in publicum ederet, eui petioni etran amıuit.)

$6016 \longrightarrow$ Tal on Jordenes Tillvaxt, hâllit i Kongl. Academien Upsala vil tillfalle af en Promotions-Act. Då Medic. Licunliateu IIr. Johan Westman 1743 cmottog Doctors-Hatten af Curl ron Linne. Forsvánstiadt. Stockholm, tryekt hos Lars Kumblins Enkia. 1776. 8. $32 \mathrm{p}$. W.

\section{Disserlaliones academicae: $1743-1776$}

601 - Dissertatio botanica de Betula nana, quam pracside D.D Carolo Linnaeo publicn bonorum examini modeste suljicit Laurentius Magnus Klase. Stockholniae, typ. I listoriographi Regni. 1743. 4. 20 , (4) P., 1 tab. B.

Amoen. acad. vol. I. ed, Ilolu. p. 1-22. ed. Lugd. p. 333-33i. ed. Eriang. 1. 1-22.)

6018 Disputatio: Ficus. Respondons: Cormelias IIegardu. Lpsaliae 1744.4.28 P., 1 tab. B.

(Anoen. acad. vol. I. ed. Ilolm. p. 23-5i. ed. Lugd. p. 213-2k3. ed. Erlang. P. $23-5 \mathbf{k}$. $)$

6019 Dissertatio botanica de Peloria, quam praeside Dom. Dact. Carolo Linnaeo, curiosorum aculis modoste suljicit Daniel Rudberg. Upsaliae 1744. 4. 18, (10) p., 1 tab. B.

$6020^{*}$ Dissertatio, qua plantae Martino-Burserianae explicantur. Respondons: Roland Martin. Upsaliae 1745.4.32 p.

(Amoen, acad. vol. 1. ed. liolm. p. 161-171. - esl. Lugd, Bat. p. 294 -322 . ed. Erlang. p. $|i|-171$.

$6021^{*}$ Hortus Ujsaliensis. D. Respondens: Samuel Noucler. Upsaliae, typ. Euman. 1745. 4.45 p., 4 tab.

(Amoen. acad. vol. 1. ed. Itolm. p. 172-210. ed. Lugil. Bat. p. 20 -60 . ed. Erlong. p. $172-210$.)

6022 Passiflora. D. Respondens: Johon Gustaf Hollman. Holmiac 1745. 4.37 p., 1 tab. B.

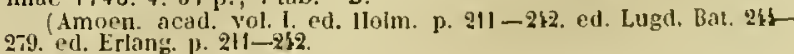


6023 Linnacus, nobilis von Linne, Carl. Anandria. D. Respondens Erland Zacharias Tursen. Upsaliae 1745. 4. 15 p., 1 tab. B.

(Ampen. acarl. vol. 1. ril. Ilolm. p. 2'3-259. ed. Lngd. Bal. p. 16 I -176 . ed. Erlang. p. $2+3-2 * 9$.

$602\}$ Dissertatio botanica, in qua Acrostichum, pracside Dom Doct. Curolo Linnaeo curiosorum oculis modeste subjicit Johan Benjamen Ileiligtaq. Ipsaliae 1745.4.17, (4) 1., A tah. B.

Amoen. acad, rol. I. ed. Ilolm. p. 200-276. ed. Lugit. Bat. J) 15'160. ed. Erlang. p. $260-276$.)

6025" - Sponsalia plantarum, qune sub praesidio Dom. Doct. Caroli Linnaei, spreciminis academici locn, publico honorum exanini submittit Johun Gustaf Wahlbom. Stocklıoln, typ. Laurentii Salvii. 1746. 4. 60, (8) p. I tab.

(Amoen. acad. vol. I eal. Ilolm. p. 327-380. ed. Lugd. Bat. p. 61 -109. ed. Ertang. p. $328-380$.)

suecice: Sponisalia plantarum, eller Rlomstrens biliger. Med Medicinska Facultetens bifall, under kougl. Arehisteros, fierr Doct. Car Limnaei inseente, litgifvit uti elt Aeademisht Snilleprof pi Latin vid Kongl. Academien i Úpsala år 1746 den XI Junii, och nu på Svenska ofversalt af Johan Gustef llahllom. Stockholut, tryekt hos Lar's Salvilis. 1750. 8. 68, (8) p., 1 tab. W.

$6026^{*}$ Vires plantarum, dissertatione acatemica sub praesidio Dom. Doct. Caroli Linnuei examiui publico subjecta a Friedrich IIasselquist. Epsaliae 1747, 4. 37, (3) p.

(Amoen acad. vol. 1. ed. Ilolm. p. \{18-4333. el. Lugd. Bat. p. 389 一228. ed. Erlang. p. $418-$ - 3 3.)

$6027^{*}-$ Nova plautaruni genera. D. Carl Magnus Dassow. Holmiae $1747.4 .32 \mathrm{p}$

Amoen. acad. vol. 1. ed. IJolm. p. 381-117. ed. Lugu. Bat. p. 110 -143. ed. ErJans. p. $381-417$. .

$6028^{*}$ Flora oeconomica, quam praeside Dom. Doct. Carolo Linareo, speciniuis academici locu placidae disquisitioni modeste submittit Elius Aspelin. D. Upsaliae 1749. 4. 30, (8) p.

(Amoen. acad. vol. I. ed. Ilolm. 11. 509-3i39. eol. Lugrl. Bat. p. 392 -385. ed. Erlang. p. 509-5\%0. - Fumd loot. col Gilibert. vol. II. p. 35 -61. - cum alditamicnto editoris: Select. diss. ex dmoen acad. p. 9 - 10.3

suecice: Flora oeconomica, eller Ilnshills-Nyttan af de i Sverige willt wixande Orter, mod Medicinsha foncultetens hifall vid kongl Academien i Upsala, under kougl. Archiaterns Meul. och Bot. Prófessorens, Herr Doct. Carl Limaei insecustle, uti ett Acallemiskt prof,

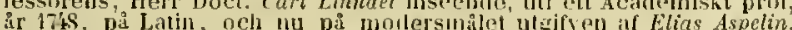
Stochnolm, trycki pi Lars salvii egert Kostuild. 1749. 8.83 p. B. et W.

6029 Specimen academicum de curiositato naturali, quod sub praesidio Dom. Doct. Caroli Linnuei publicae curiosorum censurae moteste sulmittit Olof Soderberg. Ilolmiac, typ. Laurentii Salvii. 1748. $4.25:(7)$ p. B.

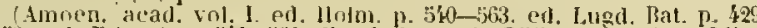

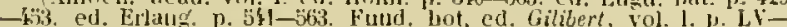
L.Xivi.)

6030 - Specimen acadenicuu de occonomia naturac, quod praeside Dom. Doct. Carolo Linnaro publico examini modesle submittil Isuc J. Biberg. Lpsaliae 1749.4.48, (8) p. B.

(Amoen. acad vol. Il ed. Holn. p. I-58. exl. Lugd. Bat. p. 1-52 ed. Erlang. p. I-59. Sclect. diss. ex Amoen. acad. l. $260-316$

suecice : beconomia naturae, eller shaparens allvisa iuratuing pa våt jord, jagtlagen vid de skapade tingens betraktande i tle Tre Naturens Riken. till deras foriplantning, vidmagthällande och undergang. Med Medicinska Facultetens bifall, under Kougl. Archiatern Herr Doct. Carl Limnaei praesidio, utgiften uti etl Academiskt Snilleprof på Latin vid kongl. Acarlemien f L psale ar 1769 d. 4. Martii. Och IIU thed nignll tillokning pa srenska ufversalt af Isuc J liberg. (Stockholm) 1750. 8. $88 \mathrm{p}$. B. et W.

6031 Lignum colubrinum leviter delinealum. D. Respondens: Johan Anders Darelius. Upsaliac 1749.4.22 p. в.

Amoen. acad. vol. Il. ed. Ilolm. p. 100-125, ed. Lugd. Bat. p. 89 -111 . ed. Erlang. p. 100- 225 .

$6032-$ Radix Senega. D. Respoudens: Janas Kiernunder. Ilolmiae 1749. 4. 32 p., 1 tab. B.

(Amoen, acal. Vol. 11. ed. Ilolm. p. 126-153, ed. Lugd. Bat. p. 112 -136. ed. Erlang. p. 126-153. cum additamento editoris: Select. diss. ex Amoen. acad, p. $903-232$.

$6033^{*}$ Gemmae arborum, quas sub praesidio Dom. Doct. Caroli Linnaei specininis academici loco naturac curiosis examinandas sistil Pehr Lofling. D. Upsaliae 1749.4.32, (4) p.

(Amoen acad. vol. Il. ed. 1101 m. p. $182-22$. ed. Lugd. Bat. p. 163 -202. ed. Erlang. p. 182-22't. Fund. hot. cul. Gilibert, vol. I. p. 363-398.

603 ' examini modeste submili $38,(4)$ p. B.

Amben. acad. vol. Il. ed. Holm. p. 22̈-262. cd. Lugd. Bat. p. 203 -2k1. ed. Erlang. 1. 22\%-262. - Fund. bot, cd. Gilibert, vol. II. p. 63 -9i. - Pan Suecus, emendalus el auctus a Pelir Gustaf Tengmalm. Amoen. acad. vol. X. P. 132-172.

germanice Schwedischer Pan oder thanullung uher die Fut tcrung der cinheimischen Thiers in Sclıweden. dus den Latcinischen $\operatorname{mil}_{17 \mathrm{ij}}$

$$
\text { gallice: Paris } 1801.8 \text {. Q. }
$$

6030 Linnaeus, nobilis von Iinné, Carl. Dissertatio botanica, sistens Splachum, quam praeside Corolo Linnaeo publicae censurae modeste subjicit Lars Jtontin. Stockluolniac, typ. Laurentii Salvii. 1750. 4. 15, (5) p., A tah. col. B.

Amnen. acad. vol. Il. ed. Holm. p. 263-283. ed. Lugrt. Rat. p. 26: -260. ed. Erlang. p. 263-283.

Semina muscorum tetecta. D. Respomelens: Pehr Jona. Bergins. Upsaliae 1750, 4. 18, (6) p., 1 tah. в p. $261-280$. ed. Erlatig. p. 28 ? suppl. p. 13-3i.

$6037^{*}$ Plantae raviores Camtschateenses. D. Respondens: Jona Inlenius. Upsaliae 1750.4.30 p., I tab.

(Amoen. acad. vol. Il rd. llolin. p. 332-36r. ed. Lil:d. Bat. 1. 3ik -33k. ed. Evlang. (1. $332-36 \%$.)

6038 Dissertatio sistens Saporem medicamentorum. Respondens: Jacob Rudberg. Holmae 1751.4.20 p. в.

(Amoen. acall vol. 11. ed. Ilolm. p. 365-387. ed. Lugd. Bat. p, 34 -33i. ed. Erlang. p. 36̈-387. - Fund, bot. cd. Gilibert, vol. II. p. 22 -2 it.

- Nova plantarum genera. D. Respondens: Leonharsl Johar. Chenon. Upsaliae 1751.4. 47 p.

Amoen. acarl. vol. 111 . D. 1-27. cxclusis characteribus gencrun

$6040^{*}$ - Plantae hyloridae, quas sub pracsidio Dom. Doct. Curol Linnari speciminis loco publicae lonorum disquisitioni sistil Joha? Haartman. D. Lpsaliae 175 I. 4. 30, (4) p., 1 tab.

Amonl. acad. vol. Ill. p. 28-62. Fund. bot. ed. Gilibert, vol. I p. $499-492$

60.1 Plantac esculentae patriae, quas praeside Dom. Dor Carolo Limaeo speciminis academici loco publicae ventilationi wuhmittit Johan Iljorth. 1). Upsaliae, trp. Laur. Ml. Hojer. 1752. 4. 28 (6) P. B.

Amoell acal, vol. III. D. 7. 99 . Selecl diss ex Amocn. acar p. 13-43. Finst. loot. en. Gillibert, vol. II. p. $431-45$.

suerce: Pantale esculentae patriae, eller våra iulandska atelis. Wivter, med Metecinshil Facultetens hifall vid Kongl. Academieu. Cpsala, under komer Archiaterms, Med. ord) Rot. Professorens, Met

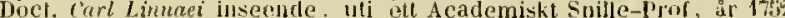

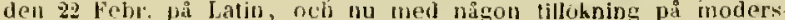
malet franstallute af Jokan HJorth. Stockholm tryckt pa Lars Salvi Kostnad. 17i2. 8. ' 4 , ('t) p. W.

6042 Specimen acndemicum, quo Euphorbia ejusque historia naluralis et medica exluibelar, furaesile Dom. Doct. Carolo Lumue puhlice reutilandum sistit Johan Jl'iman. Upsaliae, escudit l. M Hojer. 1752. 4. $33,(3)$ p. B

Amoen, acad. vol. III. p. 100-131.

6043 Dissertatio, odores medicamentorum exhibens: liespoudens: Auders II ählin. Stockholniae 1752.4.16 p. B.

(Amoen. acall. rol. III. p. 183-201. Contin. Select. dis.s ex Anoen. acad. p. 4t-6i. liund bot. ed. Gilibert, rol. II. p. 207-22i.)

60\%: Dissertatio, sistens Rhabarbarum. Respontens: Samw Ziervogel. Upsaliae 1752.4. 24 p., 1 tab. в.

(Amoen. acad. vol. III. p. $211-230$.)

$60 \% 3$ Quaestio historica-naturalis: Cui bono? quam breviter solutam pracsile Ilom. Doct. Carolo Linnaeo publicae ventilation modeste ollert Christoph Elias Geduer. D. Upsaliac, excudit L. M llöjer. 1752.4.29, (9) p. B.

Amoen. acad. vol. III. p. 23I-20̈. Fund. bot. ed. Gilibert, vol. I p. AXXI-LIII.

suecice: in frảga, som allid furestálles de Naturhumniga, dît de heler: Ilvartill duger thet? \{cui bono ?) Forst framstald och besvarad en Disputation pá Latin. under Kongl. Maj. Archiater, Med, och Bol. Professorens llr. Doct. Curl Limnaei olvervaro, dell 21 oct. år 1762

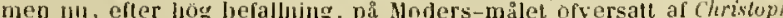
Elias Geduer Stochloolm, tryekt pia Lars Salvii kosthad 1753 \& $32 \mathrm{p}$. 11 .

6046 Hospita insectorum Flora, quam praeside Dom. Doct Carolo Linnaeo publicae disquisitioni subjicit Jonas Gustaf Forsskight. D. Upsaliac, excondebat L. MI. Ilojer. 1752. 4. 40, (4) p. в.

(Amnen. acad. vol. III. p. $271-312$. Fund. bot. ed. Gilibert, vol. II p. 99-136. - Flora ipsa, additis insectorum nominibus trivialibue redit in dissertatione Linnaeano: Pandora insectorum, p. $11-31$.

6047 Vernatio arborun, quan sub praesidio Dom. Doct. Caroli Linnaei jublico examini submillit Harald Burck. Upsaliae, mcudebat M. N. IIöjer. 1753, 4. 20 13. B.

(Amoen. acad vol. III. p. 363-376. Fund hot. ed. Gilibert, vol. I. p. $399-112$.

6048 Incrementa botanices proxime praeterlapsi semisacculi, quae sub pracsidio Carol Linnaer publicac censurae submilti 
Jacob, Bjaur. D. Holmiae, ty]. Laus. Lusl. Grefing. 1733. 4. 20 , (4) P. B.

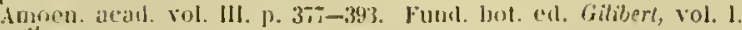
1. $19-1 i$.

foly Linnaeus, nobilis von Linné, Carl. Jemonstrationes plantarum in Lorto Lpsilienai 1753. D. Resprondens: Johan Christian Hojer. Ipsalian 1753.4.27 ]. B.

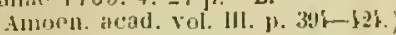

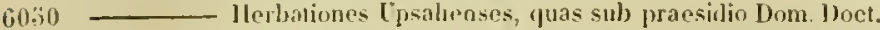
Camli Linnuei publico esamini sulumittit Anders X. Fornunder. 1). lipsaliate, 1. Al. Hojer. 1753.4 .20 p. B. tmoel. acald. 1 ol. III. 1) 12:j-lh.)

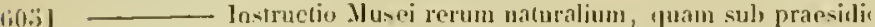
Don. Doct. Caroli Linnati plicilae bonorum censurae sulsjicit Dirvid Ihuman. 1). Lisaliae, excudebat I. H. Ilojer. 1733.4. 19, (3) p. B. (Anoen. acid. vol. III. 1. Shi-i6i.)

uemanire: thanallum von Vaturalien-Cabinetten oder tnlei1um, wio Xahurilienhabinetre riugerichtel, und naturlichn liorpes.

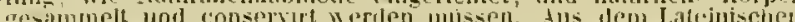

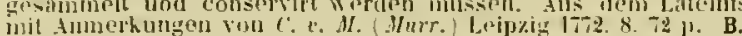

$60: 32$ Dissertatio medicu-botanica, exhiliens Platas officinales, quam sub jraesidio Dom. Doed, Caroli Linnaci placidae bonorum censurae suljicit Nils (sahn. D. Ljesaliae, excudelsat L. Al. Ilojer. 1753.4.31, (3) P. B.

Ammen. acad. vol. IN. 1. 1-23. Fund. bot. ed. Gitibert, vol. II p. $|(x)-|(\mid) \mid$

$60 \ddot{3} \longrightarrow$ Censura medicamentorum simpliciun regetahilium. I). lispontens: Gustaf Jacub Carlbohm. [psaliae 1753. 4. 24 1). B.

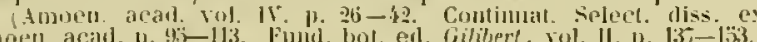

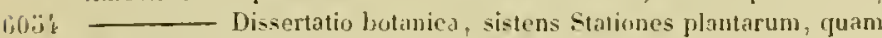
sub praesidio Dom. Inect. Caroli Limnasi publice rentilandam sisti Anders lledenbery. D. Lpsaliae, excudebai L. Il. llojer. 175\%. 4. 23 (i) B. B.

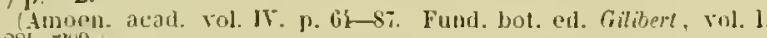
1). $28 \div \rightarrow 309$

$60800^{*}$ - Flora anglica. D. Respondens: Lauc Olai Grufberg Cpsaliae 1734.4.29

(tmoen. acarl. vol. IT. D. 8 S- III.)

100̈6 Jerbarium amboinense. 1). Respondens: Olof Stickman

Lpsaliae 1754.4. 28 j. B.

thoen. acal. vol. 1T. p. 112-143.

6037 - Jissertatio de methodo iurestigandi vires melienmentorum chemica. Respondens: Lars Hortzbery. [jusaliae 1734. 4. $16 \mathrm{j}$. B.

Amonen. acad. vol. IX. ค. 23-3r

Goiss - Dissertatio de hortucultura academica. Respondens

dukun Gusenf II ollrath. Cpsaliae 173̈4.4.21 1). B.

tmoen. acarl. vol. 11. 1. 210-229.)

6039 Ceuturia I. plantar'um, yuam sul, praesillio Dom. Doct Caroli Lunnei orbi botanico esaminandaun sistit Abraham D. Juslenius. 1). Lpsaliae, escudehat L. Al. Hojer. 173ั3. 4. 33 , (วั) ]) B.

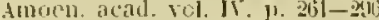

6060 - Dissertatio botanica, Netumorploses plantarum sistens, quam sub prasidio Dom. Doct. Caroli Limnei haturae curiosorum ('msurae suljicit Nils E. Dalller'y. Ilolniae, e typographia regia. 1755. 4. 26 p. B

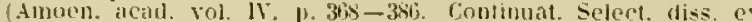

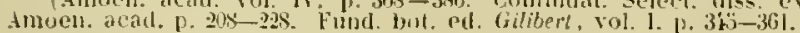

(506) - Somous plantarum in diswertatione acalemica propositus, prapside Dem. Doct. Curolo Linneo, a Petro Bremer. D. Lusaliae 1753.4 . 220 p. I tab. B.

(Amoen. acad. wh. IV. p. 333-33it. Comtinuat, select. diss ex

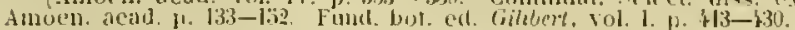

biti? - Fungus melitensis. I. Respondens: Juhann Pferffer. Lpsaliae 1735.4 .16 1.. I tab. B.

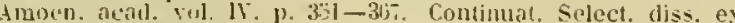
Amorll. acad. 1\% 1.j3-1I.

$6063^{*}-$ Centurial 11. plantarum, yuatu praeside Dom. Doct. Caroln Limnaen, specininis acadenici loce ad pulblicam veutilationem defert

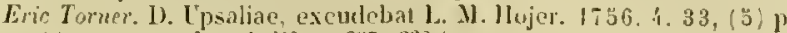
tmocn. acad. vol 11 . 1. $997-33$ :

606i - Fluta palnestina. 1). liespondens: Bengi Johton Strand. Tpsaliae 1756.4. 32 ]. B. Alloen. acal, vol. M. [1. \$13-16:.

6063 - Flora alpina, tuan praeside Doms. Doct. Carmb Lonnaro speciminis academici loco jublicae rentilationi subjicit Ki/s
N. Aman. D. Cpsaliae, excudelsat J. II. Hojer. 1756. 4. 27 , (3) 1. B. B.

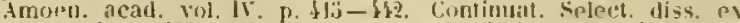

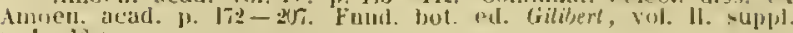
$1-12$

6066 " Linnaeus, nrulilis von Linné, Carl. Calendarium l"lorae (lipsali(nsis), tjuol praeside Dom. Joct. Carolo Linnucu pulplicae ventilationi suljjicit Alexander. Hal. Berger. D. Lpsaliae, exrudebat L. II Ilojer. 1756. 4. 96, (6) p.

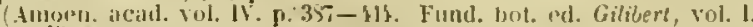
1. . 1.31-6is:

anglice: The Calendar of Flora, translated by l’. stillingpeet. Lon-

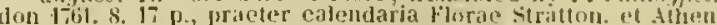

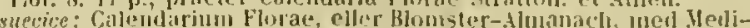

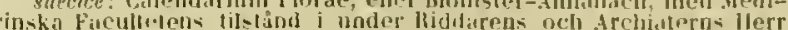

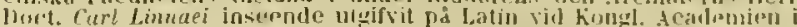

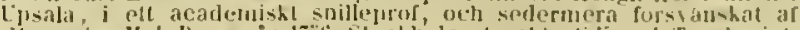

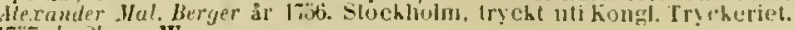
17.07. i. 2h p. w.

$606 \pi^{*}$ - Vilorit Monspeliensis. I). Respondens: Then hilus Erdmann Nathhurst. lipsaliae 1756.4.30 p.

(Amen. acall. vol. 15. p. Stis- $19 ;$

6068

Johum von Coelln. Scarae 1756.4. 28 J. B.

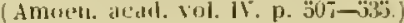

6069 De acetariis. D. Respondens: Hieronymus von der Burg.

[psa]iac $1756.4,16$ ]. B.

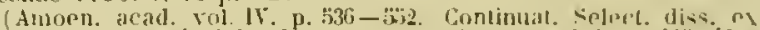
Amoen. acatl. p. lik-132. Fund bot. ed. Gilibert, vol. 11. 1\%. \$1j-i2y.

6070 Prodromus Florae danicae. D. Respondens: Geary Tychu

Holm. Cpsaliae $1757.4 .26 \mathrm{p}$. B.

Amuell. acad. vol. i. p. $30-49$.)

6071 Dissertatio de pane diaetetico. Respondens: Isaue Stensson. [jusaliae 1757.4.20 p. B.

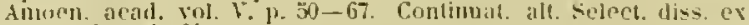
thoc!l. acasi. 1). I-2I.

6072

Satura pelagi. D. Respondens: Johan lienrik Huger.

Lpsaliac $1757.4 .15 \mathrm{j}$. B.

(Amoen. acall vol. V. p. $68-7$. )

6073 Buxhaumia, quan sub praesidio Dom. Doct. Carnli Lmnaei pnblicae ventilationi submittit Anton Rolundi M/nrtin. D. Cpsaliae, excudeliat L. M. Ilojer. 1757.4 . 16 p., 1 1al, titulo adglutinata. B. (Ameen. acad. vol. V. p. $38-9)$.)

- Jlissertatio de transmutatione frumeniorum. Respondens: Bogislaus Hornborg. Lpsaliae $1757.4 .16 \mathrm{l}$. B.

Amoen. atinl. rol. Y. D. 106-119. Comtimat. alt. Select. diss. es Amoen. acal. p. 2.1-37. Fund. bot. ed. (silibert, vol. II. 1). $457-499$.

6073 Culina nutata. D. Respondens: Mugnus G. Osterman. [psaliac 1737.4.1913. B. (Amben. acal. vol. 1. p. 120-132.)

6070 Dissertatio de Spigelia Anthelmia. Respondens: Juhan Geory Collinuler. l'psaliae 1758.4. 16 p., 1 tab. B.

(Amoen. acad. rol. V. p. 133-15i.)

607 - Dissertatio de cortice peruviano. Pars prier. lRespandens: Johan Christim Pehr Petersen. [Psaliae 1738. 4.38 p. B. (Amoen. acall. vol. IX. P. bi-10̈.)

6078 Frutetum suecicum, quod prieside Dom. Doct. Carolu Linnapo jublico eruditorun examini modeste subjicil Datid Magnus Virgander. I). Ipsaliae, excudeluat L. M. Ilojer. 1758 . 4. 26, (2) p. B.

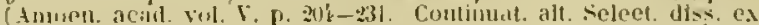

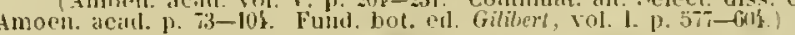
6079 Dissertatio sistens Iledieamenta graveolentia. Respondeus: Jonas Theodor Fragrueus. Lipsaliae 1738. 4. 24 p. B.

Amorn. aciad. vol. V. p. 1's-173. Fund. bot. ed. Gilibert, vol. Il p. $1 \mathrm{si1-200.)}$

6080 Iuctores botanici, in dissertatione propositi, quam sul, praesidio 1)om. Doct. Caroli Linuei at publicum examen defert Aurustin Lon. D. T psaliae 1739. 4. 90, (2) p. B.

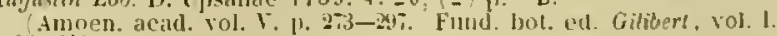
D. $8,-112$.

6081 Instructio peregrinatoris. quam sub pracsidio Iom. Doct. Caroli Limaei pullicae censurae submittit Eric Anders Nordblad

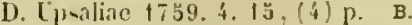

(Amoest. actu. vol. V. P. $215-313$

6082 Plontie linchoriae; de quibus sjecimen botanico-oecunomicun praeside Dom. Doct. Carolo Limneo publico bonurum examini modeste submittit Engelbert Jurlin. D. Lpsiliae 1759. 4. $30 \mathrm{p}$. B.

Amuren. acad. vol. V. p. 31't-3t2. Fund. bot. ed. Gilibert. vol. II. p. $273-2(y)$ 
6083 Linnaeus, nobilis von Linné, Carl. Flora capensis. D. Respondens: Carl Henrik II amman. Cpsaliac 1759.4. 19 p. w. (Amoen. acad. rol. v. p. $333-330$.)

$608 z^{*}$ Arboretum suecieum, quod praesile Don. Doct. Carolo Linnaeo publico examini submittit Datid D. Puntin. D. Ipsaliae 1759. 4. $30 \mathrm{p}$.

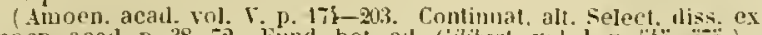
Amoen. acad. p. 3s-i2. Fund. bot. edl. (iilibert, vol. i. p. Sh-jis.)

6085 × Plantarum jamaicensium pugillus. 1). Respondens: Gut briel Elmgren. Ipsaliae 1759.4 .31 1.

(Amoen. acad. vol. Y. p. 359-413.)

$608 \mathrm{C}^{*}$ - Flora jamaicensis. D. Respondens: Carl Gastaf Sandmark. Upsaliae 1759.4.27 p.

(Amoen. acad. vol. i. p. 371-388.)

6087 Dissertatio academica, sistons Nomenclatorem botanicum, ıuam sub praesilio Dom. Noet. Caroli Linnaei pulilico eruditorun exanini subjicit Bengt Brrelius. 1lolmiae, typ. Laurentii Salvii. 1759.4.19 P. B.

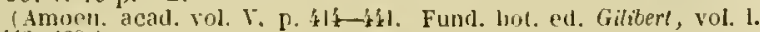
p. $113-139$.

6088 Dissertatio academica de politia naturae, quam praeside Dom. Doct. Carolo Linnueo Jublico esamini submittit Heinrich Christian Daniel Hilcke. Lpsaliae 1760.4.22, (2) p. B. (Amoen. acad. vol. V1. p. 17-39.)

$6089^{*}$ Flora belgica, D. Respondens: Chrastian Fredrik Rosenthul. L psaliae 1760.4. $23 \mathrm{p}$. (Amoen. acad. vol. VI. p. qi-6.)

$6090^{*} \longrightarrow$ Macellum olitorium. D. Respondens: Pehr Jerlin. Ilolmiae, IYp. Laureutii Salvii. 1760.4. 23 p.

thioen. acad. vol. 11. p. 116-131. Fund. hol. ed, Giliber, vol. II. p. $31 \div-330$.

6091 Prolepsis plantaruu, , puan praesile Dom. Doct. Carolo Linnazo publico examini submittit llenrik Cllmork. D. Upsaliae 4760. 4. $22,(2)$ p. B.

(Anom. acad rol Y1. p. 32k-31. Continuat. alt. Select. diss. ex Amoen. acad. p. 14-i66, lund, Jot. ed. Gilibert, rol. 1. p. 311-326.

6092 Plantae rariores africanae. D. Respondens: Jacob Priutz. Ilolmiae 1760. 4. $28 \mathrm{p}$. B.

(Anoell. acad. vol. P. p. $7-11.3$. )

6093 - Dissertatio, in qua potus Coffeae leviter adumbratur. Respondens: Heinrich Sparsehuch. Upsaliae 1761.4. 18 p., 1 1ab. B. iAmen. acad. vo]. II. [1. 160-179. Fund. bol. ed. Gilibert, vol. Il p. $371-3+3$.)

609: Inebriantia. D. Respondens: Olof Henrik Alunder. Upsaliae $1762.4 .26 \mathrm{p}$. B.

(Amurn. acial. vol. 11. p. 180-196. Find. bot. el. Giliberl, vol. II. j). $39 y-\$ 1$.)

$6093^{*}-$ Tenuini botanici, quos preeside Dom. Doct. Carolo Linneeo examinandos sistit Johun Elmgren. D. Ipsalize 1762.4.32 p. (Amoen. acad. vol. 11. $p_{3} 217-246$. Fund hot. cel Gilibert. vol. I. P. 161-lis. - Ed. aucta a Schreler. Lipsiae 1767. 8. W. - Erlangae fis9. \&. W. - Termini hotanici definilionibus pluribus anci a John Rolheram. Sovi Cantri 179. 8. 7 p. B. - impro cum Iludson Flora :melica, ed. II. p. V-X.1.: B.)

6096 Planta Alstrumeria. D. Respondens: Johana Peter Falck. lpsaliae 1762.4.16 p., 4 tab. B.

(Amoen. acarl. vol. V1. p. 2' $7-262$ )

$6097^{*}$ Dissertatio botanica, sisleus Noctaria florum, quam sub, praesialio Dom. Doct. Caroli Limnaei publico examini ollert Birger IHärten Hall. Cpsaliac 1762.4.16, (2) p.

(Amoen. acad. Vol. 11. p. 203-278. Euncl. nol. ed. Gilibert, vol. ]. p. $265-253$, ,

emisk dfhanding ow Bioustrens lliningshus, under framlidue Kongl. Archiat. och Ridd. af den kongl. Nordstjerne-Orden, 131. m. Valb. llerr Farl von Linnés inseende, utgifven af Birger Mồrten Hall. d. 2̈j Juni 1762. Fursvenshid. Stochholin, irycht i for detta llolmerisha Trycheriet. 178. 8. $24 \mathrm{j}$. W.

6098 Fundamentum fructificationis, quod sub praesidio Dom. Doct. Caroli Lianaei publico eruditorum examini submittit Johan Warlen Griberg. 1). Lpsaliae 1762.4. 24 , (4) p. B. Amoen. acad. vol. V1. p. $279-30$ i. Fund. bot. c.l. Giliberl, rol. 1. 11. $169-192.3$

$6099^{\circ} \longrightarrow$ Reformatio botanices, ruam pracsicle Dom. Doct. Carolo Linnoeo pulstico examini nodeste submittit Johan Jlärten Reftelius. D. Lpsaliae 1762.4.21, (6) p.

(Amnell. acad. vol. VI. P. 30a-323. Fund. bot. ed. Gilibert, rol. I.

6100 p. $6 j-8$. $)$ De Raphania dissertatio medica, quam praeside Dom. Docl. Carolo von Limé pro sunumis in medicina howoribus pulblicae disquisitioni oflert Georg Rothman. Lpsaliae 1763. 4. 21, (3) p., 1 tab. B.

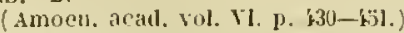

6101 Linnaeus, nobilis von Linné, Carl. Fruclus esculenti, guos dissertatione diaetetica moderatute Doms. Doct. Carolo von Limue publico scrutinio suhjicit Johon Salberg. D. Cpsaliae 1763.4.22. (2) p. B.

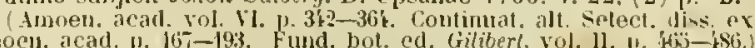
6102 Lignum Quassiae. D. Respondens: Carl Ilagnus Blom. lepsaliac 1763.4. $13 \mathrm{p} ., 1$ tals. B. Amven. acad. vol. H. 13. $416-\$ 29$.

6103 Disquisitio de prolepsi plantarum, quam praeside Dom. Doct. Curolo a Limé publico exanini subnittit Johann Jakob Ferber. D: [psaliale 1763,4.18, (2) D. B.

(Amom, acad yol. V'1. p. 3is-383. Continuat. alt. Select dise ox Amoen. acal. p. 19k-216. Fund. bot. ed. Giliber, vol. 1. p. $32-31$.)

610 - Jortus culinaris. D. Respondens: Jonas Tengborg. 1lolmiae $1764.4 .26 \mathrm{p} . \mathrm{B}$. p. 331 Ampen. acad. vul. VII. p. 18 - fl. Fund. bot. ed. Gitibert, vol. Il. p. $33.3 \mid-3.3 .3$.

6105 - Spiritus frumenti. D. Respondens: Pehr Bergius. Lpsaliae 1764. 4. 20 P. B.

(Amoen. acad. vol. VII. p. $26 k-281$.

6106 Opohalsamum declaratum. D. Respondens : Guilloume Le.lloine. Cusaliae 1764. 4. 48 p. B.

(Amoen. acad. vol. TIl. 1. Ḧ-i3.)

6107 - Dissertatio de potu Chocolatae. Respondens: Anton Ilofmann. Holmiae 1765. 4. 10 p. B.

(Amnell. acad. vol. Vhl. p. 25 -263. Fund. bot. ed. Gilibert, vol. il p. $359-398$.)

6108 Potus Theae. D. Respontens: Pehr Tillaeus. L'psaliae 1765.4. 16 P., 1 tab. B.

(Amoers, acid. vol. vil. p. 236-233. Fund. bol. ed. Gilibert, vol. 11. p. $3 . j-370$.

6109 Purgantia intigena. D. Respondens: Pehr Strandman. Epsaliae 1766. 4. 17 p. B.

(Amnen. acall vol. V11. p. 293-310. Fund. bot. ed. Giliberl. vol. Il. D. $2 k+260$.

6110 Dissertatio, demonstrans necessiatem promovendae historiae naturalis in Rossia. Ruspondens: Alexander de Karamyscheu. Upsaliae 1766.4 .34 p., 1 tab. B.

3h Amoen. acad. vol. VII. p. 438-ibio. In hac dissertatione 1). 3k est Flora siltiric'a.)

6111 Dissertatio academica, demonstrans usum historiae naIuralis in vila communi, quan praeside Dom. Doct. Carolo von Linné publice canindndam subniltit Auctor et Respondens Hatheus A phonin. Ipsaliae 1766. 4. $30,(8)$ P., I tab. B.

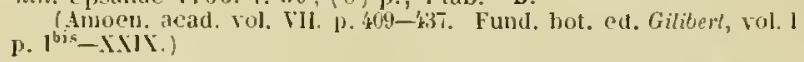

6112 Dissertatio academiea, usum Muscorum breviler delineatura, quam morlerante Dom. Doet. Curolo von Linue curiosorun submittit censurae Andreas Henrici Ber/h. [psaliae 1766. 4. 14 (6) P. B.

(Amoril. acad. vol. VIl. p. 370-35i. Fund. bot. ed. Gilibert, vol. I P. $\{43-307$.

6113 Dissertatio, munlum imvisibilem breviler alineatura. Respontens: Johan Carl Roos. Fpsaliae 1767.4.23 p. B.

tunoen, acad. vol. ril. p. $3 \times j-408$.)

611 - Fundaneuta agrostographiae, praeside Dom. Doct. Carolu a Limé, auctore defendente Henrico Gahn. D. Lpsaliao, typ. Job. Echan. 1767, 4, 38 p., 2 lab. B.

(Amopre. acad. vol. Vll. p. 160-195. Fund. bot. ed. Gilibert, rol. I.

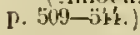

6113 Disserlatio de Mentlae usu. Respondens: Curl Gustuf Laurin. Epsaliae 1767.4.11 p. B.

(Amoen. acad. vol. Vil. p. 282-2y2. Fund. bot. ed. Giliber, vol. II. p. $261-271$.)

Dissertatio, sistens Rariora Norvegiae. Respondens: Henrik Tonning. Upsaliae 1768.4.19 p. B.

(Amocir. acal. vol. Vll. p. 166-196i)

$61.17 \longrightarrow$ Dissertatio de Colouis plantarum, quam praeside Dom. Doct. Carolo a Liane publico examini tradit Johun Flygare. Cpsaliae. apud Joh. Edman. 1768. 4. 13 \%. B.

(Amoen. acad. Yol. Vill. 1) 1-12. Fund. hol. ed. Gilibert, vol. 11. Supplen. p. 1-1:.)

fil18 Dissertatio, sistens Iter in Chinam. Respondens: Anders Sporman. Lpsaliae 1768.4.16 P. B.

(Amoen. acid. vol. Vill. p. $497-306$.) 
(119* Linnaeus, nobilis von Linné, Carl. Flora Aheroensis, guam sub praesidio Jom. Joct. Caroli a Linné publicae ceusune sulijicit Carl Johom Luut. D. Tpsaliae, apud doh. lidman. 1760. 4. 20 J. (Amoen. acad. vol. Vill. p. $24-45$.

(i) 20 - Jissertationem botmican de Firica molerante fom. 1)oct. Carolo Lime pullicae ventilationi offert Juhan ddulf Duhlgren. lesalian $1770,4.15$, (5) p., 1 lab. B. (Antoen. incad. bol. rill. p. 46-62.)

6121 Dissertationem uedicam do Dulcamara moderante Dom Doct. Carolo a Linné exaunandam sistit Georg Hallenberg. Upsaliac, ex preto Edmanuiano. 1771. 4. 14 1. B. imoen. acal. vol. Vill. p. 63-7t.

6122 Pandora el Flura liybyensis, quam dissertatime acadeunica praeside Don. Doct. Carolo a Linné pullicae ventilationi offert Janiel Jenrik Suderberg. D. Lpsaliae, apud Joh. Edman. 1771. 4. 93, (1) p. B.

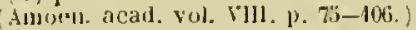

0123 - Fraga vesea dissertatione botanicá fraenide bum. Ioot. C'urolo a Linné jublicae ventilationi proposita a Sveno Anders Jledin. D. Upsiliae, Iyp. Edman. 1779. 4. $13,(5)$ p. B. Amoen. acad. rol. Vlll. p. 169-181.)

(j) 2'. Olsservationes in materiam medicam. I). Hespondens: Johen Lindwall. Upsaliae 1772.4.8 p. B. Amuen. acad. vol. VIl]. [?. 182-192.

6):15 Planta Cinucifuga. 1). liespondens: Johum Jornborg Lipsaliae 1774.4. 10 p., 1 lal. B. (tmoen. acad. vol. vill. p. 193-20k.)

(1) 26 D Dissertatio de Maro. Respondens: Johan . Adolf Duhlgren. Cpsaliae 1774.4.18 $\mathrm{j}$. B. (Amoen. acad. vol. Vill. p. 22)-237.

6127 Dissertatio de Viola lpecacuanha. Respondens: Daniel IVickman. Upsaliae 1774.4.12 \%. B. (Amoen. acad. vol. vill. p. $238-2$ is.)

(198* - Plantae surinamenses. D. Respondens: Jucob Alm. Upsaliae 1775. 4. $18 \mathrm{p}, 1$ tab. col.

Amoen. acad. vol, 1111. p. 219-267.

(129) Dissertatio medica de Ledo palustri, quan praesille Dom. Doct. Curola a Linne publicac bonorum censurac sulmmittit Auctor et kesponclens Johan Pehr Westring. Upsaliae, Iyp. Edman. 1775. 4. 18, (2) p. B.

(Amnes. acad. vol. VIll. p. 268-288.)

b130 Opium. D. Respondens: Geory Eberhard Georgii. Lpsaliae 4775.4 .17 p. B.

Amoun. acall. vol. Vulı. p. $289-302$,

ij131 Dedicamenta purgantia. D. Respondens: John Rotheram.

Lipsaliae 1775.4, 24 p. B.

Amoen. acad, vol. 1X, 1) 2h-207. Fund. bot. ed. Gilibert, vol. II. supplen. p. 33- 2 .)

$6132^{*}$ Planta Aphyteja. D. Respondens: Erik Acharius. l'psaliae, typ. Edman, 1776. 4. 12 p., 1 tab. Amoen. acad. vol. vili. p. $310-317$.

$6133^{\circ}$ - Mypericum, quod dissertatione botanico-medica pracsille Don. Hoct. Carolo a Linne pro gradu Doctoris exhibet Ciml Nits Hellenius. Lipsaliae, typ. Edman. 1776. 4. 14 p., 1 tal. tmoen. acal. vnl. Vill. p. $318-332$

\section{Opera posihuma Linneana.}

613:- Caroli a Linne Ternini botanici, classimm methodi sexualis generumque characteres compendiosi; recndi curavit primos cum suis definitionibus interpretatione germanica donatos Pul Dieterich Grisele. llamburgi 1784.8. 219 p. B. - * Caroli a Linne Termini bolanici, classium methouli sexualis generumque plantarum "haracteres compendiosi. Reculi cum interpretatione germanica definitionum terminorun curavit Punl Dieterich Giseke. Editioni huic alteri accesserunt Fragmenta Ordimu naturalium Linnaei, nomina cremanica Planeri Generum, gallica ef anglica Terminorum; et indices. Ilamburgi, sumtibus B. Chr. Heruldi viluac, excurdit C. W. J]evi. 1787. 8. 396 p., praef.

(1) 30 — Reflexions on the sludy of nature. Transated from the latin of the celelirated Linnaeus (Praefatio operis: Nuseum Regis Adolphi Friderici. Holmiae 1754. folio.) by Jumes Eduard Smith. London $1785.8 .40 \mathrm{p}$. B.

(Redil in Snith's Tracts, p. 1-i6.)

6136* - Caroli a Linne Praelectiones in orlines naturales plantarum. E properio el Jo. Christ. Fabricii, Prof. Kiil. MSto edidit Paul
Hieterch Giselic. Accessit uberior Palmarum et Scitaninum expositio, praeter plurium novorum generum reductiones cum mappa geographico-gencalogica affinilatum ordinum, et aliquot fructumu l'almarum figurae. Ilatulbargi, impensis B. G. Holfmann, typ. G. F. Scluicles. $179 \%$. 8, L. 662 \%., s tal.

0137 Linnaeus, Ioblis von Linné, Carl. Archiateru oclı Jidldaren Carl von Linne"s Termiui botanici eller botarisha Ord, somlade och med anmarkiningar päsvenski Ufversalta af Bengt Anders Euphrasen. Gotheborg, Irycht lios Lars Wahlstrom. 1792.8.74 p. w.

$6138^{\wedge}$ Lachesis lapponica, or a Tour in Lapland, now first pulblished from the origual manuseript Journal of the celehrated Linnaeus; by James Edward Smith. lu two volumes. london, Whise and Cochrate, 1yp. Richard Taylor. 1511, 8. - 1: xvi, $366 \mathrm{p.}-$ II: $306 \mathrm{p}$.

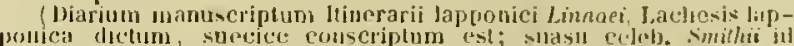

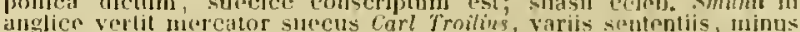

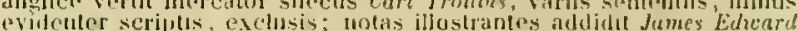

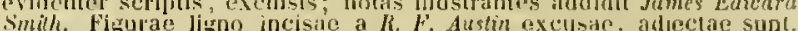
Smith. Figurae ligno incisite a $R$. F. Austin excuside, adjectae sunt. le hoe ilinerario ipse dicit Limnaeus "Flora ma idsoluta, Lachesin

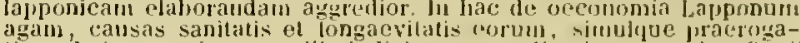
livas hujus gentis prae aliis indigitaturus, leving germantea Curti Sprengel, de ina verba facit Schulles Grundriss p. l'th. nuntuan tyjus excusa est.

$6139 *$ urimae pars prima, continens Anecdoton Linnaeanum. Dissertatin, quam pro graciu philosop,hico, praeside Erik Gustal Geijer. Hist. l'vof., edidit Johan Arvid Afzelius. Lissaliae 1827. 8. 16 p.

(Est partienla Evereitations botanien-physiene fle nuptiis et sexu plantarum, quam anno insequenti integram edidit s/zetius.)

$6140^{*}$ Exercitatio botanico-physica de Iuptiis et sexu plantarum, in qua recentiorum botanicorum placita ol olservationes recensentur. Aullore C. Linnaco. Edidit et latine rertit Johan Artul Afzelius. Ipsaliae, typ. acaremiae. $1828.8 .49 \mathrm{l} .(1 / 3 \mathrm{lh}$.

(Latine el surecice. Rudbechio libellutu evhituit relsins, quo adj-

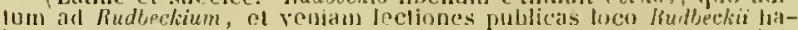

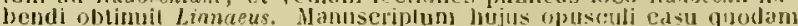

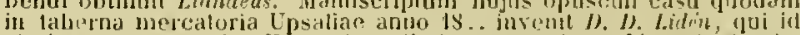

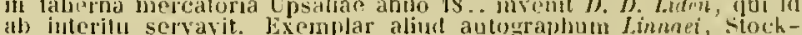
a) interitu servavit. Lxemplar alsint autographum hininet, stockprofessoren. Jlitensom missum, fuil iu possessione Noeveri, qui

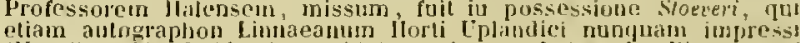

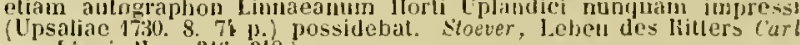
con Linne, 11. p. 316-3is.

\section{Epistolae et vita Linnaei.}

61.1t (-) Orbis erudti judicium de Caroli Linnaes seriptis. (llolniae 1741.) 8. (16 p.) Bibl. Cand.

We hoe rarissmo libello, in colfactione epistolarum Stocverian: p. 159-172 recuso, cf. Buron Desgenettes, Notice sur un opuscule rare p.latif a lime relatif a timne. Extrati du nime cafier, lome xix, du Junrnal com-

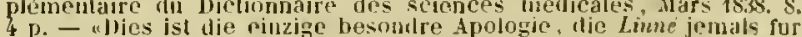
4 p. - "Jies ist die rilizige besondre Apologic, nie Lime jemals fus

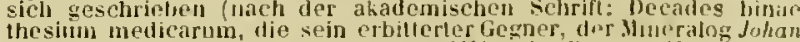
Gottschalk llallerius, an 23. Februar 17h) offentich 241 lpsala verihejoligt hatte) so wie die einzige selurift, die (") anonymiseh lieraus-

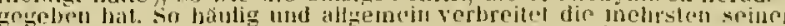
ubrigen Werke sind, so tusserst selten ist diese pjece, selhst in schweden. Weder Huller noch andre Literituren scheinen sie gehasnt zu daben. loer Tilel enthall den Wahlypech Linne's aus deu Virgil: Faman evollere factis - loc virtulis olniy; and and der Ruch seile lie Inschrift Gronow auf Limne: Ne succumb malis; Te

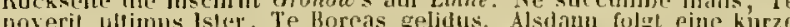
novert nimus lster, Uelorsicht der vorzughichsten Labensmerk w urdighniten Limne's, utu ein rerzeichniss seiner bis dabin erschienenen scliriftell. mil ibres verschiednel Ausgaben zusammen 21 . Hebst eller Algalue der Man-

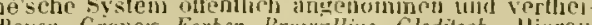
colliue, Gilditsch llierau

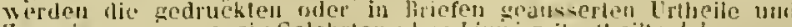
Zeugnisse von zwanzig Gelehrten uber Linte migecheilt: Johunn ean Gorter, Joerhunve usiccula taurlabunt, boni initabuntur, omsnibus proderitn). "an Rayen, (ironon", Burmann; Irms stane, Dillenius, Lamson, Jonell Jacob: DeSaurages, Antoine de Jassipu, Bnorere, Gracel: Albrecht won Inaller, Johmm Gesner; Gleditsch. Breyne, Johann Joachim Longe, Friedrich Ollo Menken, $F$. Thomas Kohl.o Sloeter, Leben des littlers Carl von Linne, l. p. 2h0-25i.

$6142^{*}$ ¿ Animuelse-Tal, ofver Kongl. Vetenskaps Lcademiens framledne Ledamot, Archiatern, Mtedicinae ach Bolanjees Profeswaren i Lpsala, samt Riddaren af Nordstjerne Orden Vilborne ller Carl ron Linue, hållet, i hungl. Naj. Hoga Ofvervaro, for Kinng] Vetenskips Acalemien, den 5 December 1778 af Kougl. Academiens Ledamot Abrahum Buck. Stockholn, tryckt hos Johan Geory Lange. 1779.8 .84 p. 
" gallice: Memoires biograpliques sur Linne, lladuits de langlois de B. Coxe, par M. Hill, medecin a Nanci. s. i. et a. 8 . $17 \mathrm{p}$. (O) ratio baeckï primum creminice versa, lusc in fore itineribus per Polonian, Suecian el fossium anno 178' anglice facta, denique ex anglica in gallicanı traducta est linguam.)

(j) +3 Linnaeus, Jobilis von Linné, Carl. A general view of the writings of Linnaeus, by Richard Pulteney. London 1781. S. 425 p. B.*A general view of the writings of Linnaeus, by Richard Pulleney. The second edition, with corrections, considerable additions and menzoirs of the author by IVillium George Maton. To which is annexed the diary of Linraeus, written by himself, and now translated in to english from the swedish manuscript in the possession of the editor. London, printed for J. Mawman, by Richard Taylor. 1805.4. $\mathrm{xv}, 595$ 1). 4 tab., effigies Linne, Pulleney; medails; facsimile. (17. $1 \mid s .6 \mathrm{~d}$.

* gallice: Revue aénérale des ecrits de Limié; ouvrage dans lequel on trouve les anecdotes les julus ituteressantes do sa vio privée, un abrége de ses systemes ot de ses ourrages, un extrail de ses améatoése de ses systemes rta ses ourages, un extrail de ses amedes notes et diditions par $L$. A. Jillin de Grandmaison. Londres et des notes et adilitions par $L$. A. Millin le Grandmaison.
Paris, Buisson. 1789. II roll. 8. - I: v1, 356 p. $-11: 400 \mathrm{p}$.

61.4

Quid Limoeo patri debeat medicina? dissertatione acadenica praeside Sveno Andreas Hedin adumbratum. Respondens: Chrisioph Carlander. Upsaliae 1784. 4. 26 p. -196 .)

lledit cum Epistolis Linnaeanis, editis a D. H. Stoever, p. 173

$6145 t$ de Saint-Anans. Agen, Noubel. 1791. S. 32 p.

$616^{*}$ Leben des Ritters Carl von Linne. Nebst den biographischen Mterkwurdigkeiten seines Sohnes, des Professors Carl von Linne, und einem volJstäudigen Verzeichnisse seiner Schriften, deren Ausgaben, Ueberselzungen, Auszuge und Commentare, von Dielrich Heinrich Stoener. Hamburg, Holfmann. 1792. 2 Theile. 8. 1: $8 \mathrm{~L}, 392$, (2) p., 1 tab.: effigies Linne. - I : IV , 341 p. - NachIrag: Llamburg 1793.8. $16 \mathrm{p}$.

t anglice: The life of Sir Charles Linnaeus, to which is added a copious list of his works and a biographical sketch of the life of his son by $D . H$. Stoever. Translated from the original german by Joseph Trupp. London, White. $179 \%$. 4 . Xxxv11, 435 p., i tab.: efligies Linne.

$6147^{*}$ Collectio epistolarum, quas at viros illustres et clarissimos scripsit Carolus a Linne. Accerlunt. Opuscula pro et contra virum immortalem scripta, extra Sueciam rarissima. Edidit Dietrich Heinrich Stoever. Hamburgi, Hotfmann. 1792. 8. xıv, $194 \mathrm{p}$

(Ad Albert von Haller epistolie 26 , ad Pemant 1 , ad Academian scientiarum Parisiensem ad Thunberg 8, an Gisetie 8, ad $E$. $C$ schultz 1. Praelerea in laac collectione contiontur rempressiones thecadum binarum thesium medicarum, autore llallerio: Orbis eruditi judicium fle f'arali Linnaei seriptis; e:t dissortatio Hediniana: Oujt Limaeo patri debeat nedicina?)

$6148^{*}$

A selection of the correspondence of Linnaeus and other uaturalists, from the original manuscripts. By Sir James Edward Swith. In two volumes. London, printed by J. Nichols and son, for Longnan, Hurst, Rees etc. 1821.8.- I: XIV, 605 p.- II: IV, 580 , 25 p. $(1 l .10 .5$.

In volumine prinso continentur epistolae Linnaci ad John Ellis: Petri Collinson, Johannis Ellis et Alexandri Grarden epistolae ad Linnaeum, nue non epistolae Inutuae Johannis Ellis et Alexanlri Garden: dein epistola a Banks ad $S m i t h$, et uniea a Francisco Garden ar Johi Ellis data, ac denique biographiae Collinsanit. Ellisii et Alexandri GarEllis data, ac denigue biographiae Collinsonti, Ellisii et Alexandri Garven a Smith conscriptae. In volumine altero plurimae intunt epistolae tuubus in locis publicatae, una cum Halleri ad Linnaeum; Limnaeana ad Grimaldi, Junes Lind, E. Mendes da Costa, Grorg, Edwards, Tulbagh at Cussan; ejustolae ad Linnaeum a billen, Amman, Boerhaave, Antoin et Bernard de Jussieu, Calesby. Mitchell, Colden, Raibaud, D'Ayen, Adansan, de Réaumur, Ascanio, Mulis. Drury, Jean Jaques Rousseau, Ramsay Nanboddy. Caroline Luise von Baden, Masson et Gisele; ad Linnoeum tiliun a Mutis, Masson. Condorcet, DuRoi, Banks eum responsioulius et perplures aliae Anglorum epistolae.

$6149^{*}$ Egenhandiga Anteckniugar af Carl Linnueus om sig sjelf. Med Anmárkningar och Tillägg. Stockholm 1823. 4. xxiv, $248 \mathrm{p}$. 6 tab.

(Autoliographiam Linnaei edidit Adam Afzelius, qui práefationem, commentaria et additamena conscripsit. Maluscriptum originale servatur in bibliotheca univ. reg. Upsaliensis.)

* gernianice: Lime's eigenhandige Anzeichmungen uher sich selhst mit Ammerkungen und Zusalzen voil (Adram) Afzelius. Aus dem Schwedisclien ubersetzt von Karl Lappe. Hit einer Voriede von Karl Asmund Rudalphi. Nehst Linne's Bildniss und llandschrift. Berlin, Reimer. 18?6. 8. Xx, 260 p., 2 tab. $(11 / 4 \mathrm{~h}$. $)$

6150 1894. $\mathrm{w}$

Pritzel, Thes. lit. bot.
6151 t Linnaeus, nobilis von Linné, Carl. Celebration at flushing of the birll-day of Linnueus by the New York Branch of the Linnean Society of Paris; as reported for the New-Iork Statesman. Office of the Statesman. May 1\$24. gr. 8. 16 p. Bibl. Cand.

$6152+$ - Antiquitates Linnaeanae. Programma, quo ad solemnon inaugurationem jhilosophiae Doctorum crastina luce celebrandan magnos hospites ... invitat legitime constitutus promotor Carl Adolf Agardh. Lundae, typ. Berling. 1826. folio. ( 18 p.) Bibl. Juss.

(T) bis Epistolis Limuaeanis ef. Hilkström, Jahrusberichte $1826-$ 1827. 1. 21 ' 216.$)$

$6133 \div-$ Carolo Linnaeo statuam jurentus academica Upsaliensis decrevit anno 1822, posuit anuo 1829. Upsaliae, Palmhlad et Co. 1829. 4. $(8$ p.) Bibl. Cand.

(Est poena lestivm Professoris d'Abriel.)

6.15:* Caroli Linnaei literas XI ad Alexandrum Gardenium Doctorem medicinae Caroliniensem, datas needum promulgatas edidit A. F. Lueders. Kiliae, typ. Mohr. 1829.4. 16 p.

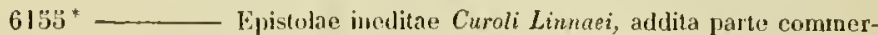
cii literarii inediti, inprimis circa rem botanicam, J. Burmanni, N.L Burmanni, Dillenii, Hallerı, Schmidelii, Johannis Gesneri, Oederi, Pallasii, I'andellii et Thunbergii, amnis 1736-1793. Ex literis autographis edidit Hermann Christian van Hall. Groningae, van Boekeren. 1830.8 .268 p., praef., ind. (17/h.)

(Epistolae Linnueanac ad Iandelli datae exstant in : Vandelli Florae lusitanicae et brasiliensis specimen. Conimhricae 1788. \&.

$6156^{*}$ - Vie do Linne, rédigèe sur les documens autographes laissés par ce grand homme, et suivie de l'analyse de sa correspondance avec les principaux naturalistes de son epoque, par Antoine Laurent Apollinaire Fee. Paris 1832.8, xı, 379 p., 6 tab

Liber nitidissimus est reinpressus e: Memoires de la societe rovale des sciences de Lille" anni 1832 . Inter additas tabulas occurrunt duae Limnaei effigies, villa ejus Hammerby, Linnaed ejus mo moriae consecrata plinta, nec non duat autographorum summi vir tabulae. Animadversiones in lunc Jibrum dedit dugnstin pyramus DeCandolle in Bibliohtegue universelle de Geneve, Ocłobre 1832, etiam seorsim impressue: 19 p. in 8 .)

$6157^{*}$ Fete séculairn de Churles de Linné, célébrúe par la société impériale des naturalistes de Moscou le $11 / 22$ juin 1835, publieic par Gothelf Fischer von If uldheim. Moseon, typ. Semen. 1835.8. 32 p.

$6158+\longrightarrow$ Lettere inedite di Carlo Limeo, publicate dal Cav. Antonio Berloloni, estratte dal fasc. HI. dei nuovi annali delle scienze naturali. Bologna, Iy'). Alarsigli. 1838.8.8 p.

$6159^{*}$ Linne und der Zweiffer. Ein Vortrag von harl Friedrıch Philipy von Martius. (Munchen 1838.) 4. $17 \mathrm{p}$.

(Seorsim ex: "Deutscho Blatler". Munctser 1838. p. 22:-241.)

$6160^{*}$ Caroli Linuei Epistolae ad Nicolaum Josephum Jacyuin ex autographis edidit Karl Nikolaus Joseph von Schreibers. Praefatus est notasque adjecit Stephan Endlicher. Vindobonae, Gerold. 1841 S. vill, $167 \mathrm{p} .(1 \mathrm{~J} / \mathrm{th}$. $)$

6161* — Rede zum Iinmaeusfeste in Ebenhausen bei Munchen von Karl Friedrich Plilipp von Martius. (Regensburg 1842.) 8. 16 p

(Seorsim impr. e Flora Ratisbonensi. Juc faciunt etiam Martius, Reden und Vortrage; cf. infra Nr. 660\%.)

$6162+$ Discorso per l'inaugurazione del busto di Carlo Linneo nell' orto botanico di Modena il giorno 24 Maggio del 1843 da Giovumi de Brignoli de Brunnhoff. Modena, tip. della Camera. 1843. 8. $30 \mathrm{p}$.

$6163^{*}$ Linné, Carl von, filius. Decas prima (et secunda) plantarum rariorum horti Upsaliensis, sistens descriptiones et figuras plantarum minus cognitarum. Stochhohniae, Salvius. 1762-1763. folio. 40 p., 20 tab.

616:* Plantarum rariorum horti Upsaliensis fasciculus primus, sistens descriptiones et figuras plantarum minus cognitarun. Lipsiae, Crusius. 1767. folio. 20 p., 10 tab.

$616 \mathrm{j}^{*}$ - Dissertatio botanica, illustrans nova Graminum genera quam praeside Carolo a Linné filio publico exanini subjicit Daniei Eril Naezen. Upsaliae, typ. Elman. 1779. 4. 37 p., 1 lab.

(Amoen. acad. ed. Schreber, vol. X. Appendix, p. 1-40.)

$6166^{*}$ Dissertatio de Lavandula, quam praeside Carolo a Linne filio publico examini subjicit Johann Daniel Lundmark. Upsaliae, typ. Edman. 1780.4. 22 p., 2 tab.

(Amoen. acad. ed. Schreber, vol. x. Appendix, p. 41-68.) 
6167" Linné, Carl von, filius. Mcthodus Muscorum illustrata. Dissertatio, quam praeside Carolo von Linné filio proponit Olof Swarlz. IJpsaliae, typ. Eriman. 1781.4 .38 p., 2 tah.

(Amoen. acal. ed. Schreber, vol. X. Appendix, p. 69-12\%. Ludicig, Delectus opusc. vol. i. p. 3 k0-381.

\section{Vila Limnari flii.}

6168 Grifte-tal ofver Carl von Linnè (Sonen), lıâllet i Ipsala Domkyrka, den 30 Nov. 1783 , då den å Svărds-sidan utgåugna von Linnéiska attens sholdemárke sönderslogs, af David Schulz von Schulzenheim. Upsala 1784.8.42 p. B.

* germanice: Gedaclituisrole aur den Iloclwwohlgelsorneu llerrn, llerrn farl non Lime, gehallen in der Domkirche zn Lpsal den 30. November 1783, als das adeliche Familieowappers des auf der máonlichen seite erloschonen youl Linneiseheu Stánmes zerschlagen ward ron Datil schulz von Schulsenheim. Aus dem schwedischen vou 'kristim Heinrich Reichel. Leipzig, Muller. 178'. 8. 38 p.

6169 Linocier, Geofroy. Lhistoire des plantes, traduicte de latin. L'histoire des plaotes aromatiques, qui croissent dans l'Inde tant oceidentale qu'orientale. Paris, Charles Macé. 1584. 12. 704 p., ic. xylogr. i. t., praeter appendices. B. - tL'histoire des plantes, traruiete de latin en français: avec leurs pourtraicts, noms, qualitez et lieux, ou elles crojssent, à laquelle sont adjoustées celles de simples aromatiques, unimaux à guatre pieds .... ensemble les destillations. Seconde édition. Paris, ehez Guillanme Mlacé. 1619 12. 704 p., ic. xylogr. i. t., practer appendices, ind.

(Est translatio libri, fquem supra Nr. 2833 recensui.)

$6170 \div(\longrightarrow$ Enticr diseours et manière de distiller les eaux de toutes sortes de plantes, el la vertu qui en provient. Reveu et corrigé par les Ioctes de nostre tems. Seconde édition. Paris, chez Guillaume Macé. 1619. 12. p. 223-239.

\section{(Impr. curm Linocier, L'histoire des plantes.)}

6171 llistoire des plantes aromatiques etc. augmentée de plusieurs plantes venues des Indes, lesquelles ont été prises et cultivées an jardin de Ml. Robin, arboriste dı roy. L'aris, ehez Guillaume Macé. 1619.12. S.

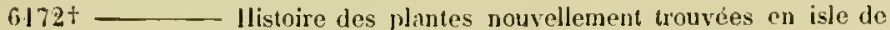
Virginie el autres lieux, lesquelles ont été prises nt cultivèes au jardin dudit Robin. Paris, chez Guillaume Maeé, 1619. 12.

(Impr. cum Linocier, L'histuire des plantes.

6173 Linschotten, Jan Iluyghen van. Itinerarium, ofte Schipvaert naer Oost ofte Pormgaels Imlien, iuhoudende ........ als oock van de Boomen, Vruchten, Kruyden, Speceryen, ende dierghelycke Materialen van die Lauden. Amsterdam 1596. folio. - Imsterdam 1644. folio. Rivin.

anglice: Discours of voyages into the Easte and West Indies. London 4598. folio. $462 \mathrm{p}$, rum mappis geographicis plurimis. B. (Ulistoria maturalis: cap.

(Redit tatine in India orientali de Bry; gallice ot germanice pluribus, ui fallor, vicihus. Peregrinator, e Halleri sententia, melioris bus, ui fallor, vicihus, peregrinator, e Halleri sententia, melioris maticas depietas fledit et descriptas cum Paludani notis.)

6174t Lintz, Louis. Dissertations forestières. Trèves 1808. 8. 64 p., 1 tab., 3 tableaux.

6175* Lipp, Franz Joseph. Enchiridiun botanıcum, sistens delineationen plantae C. von Lime definitam, exemplis et figuris illustratam. Specinsen inaugurale. Vindolonae, typ. de Traltnern. 1765. 8. 74 p., ind., 11 tab. - Ed. II. ib. 1779.8

$6170^{*}$ Lippay, Janos. Posoni Kiert. ete. Nagy Szombatha (Tymaviae), Cosmerovius. 1664. 4. 108, 224 p., praef. - ${ }^{*}$ Pars Il: Niomtattol Beezben (Tiennae) 1667.4.302 p., 4 tab. Bibl. Mus. bot. Vindob.

(Lippay Janos. Posoniensis e socictate Jesu, in hoc Ilorto Posoniemsi animadversiones dedit de hortis Primatis de Gran. Lego apud seguierum, eundem seripsisse hunzarica lingua: "De insitionihus et seminatione. Posonii 1663. o e1: "De fruetilus diversissimis producendis. Posonii fatio." qui libelli facile singulas partes libij modo laudati designant.

$6177+$ Lippi, Auguste. Deseription des plantes observées an Egypte par 11. Lipjy en 1704. Codex manuseriptus (manu Isnardi). 4. 206 p. Bibt. Hadriani de Jussieu.

"Fato infelici sueculuut, a quo praeclara quacque exspectabaniur, Angustinus Lippi, Parisiis (tlie 29 Aprilis) 1678 nitus. Terbarum in dissitis regionibus collizendarum desiderio llagrans, Fagonio commendatus, abiit anno 1703 in Acthiopian, titulo medici legationis, quam Lulovicus X7l: eo missurus reat. Aegyptum feliciler percueurrit, sed in Ahrssinia a sicariis 1704 interlectus est. Do Cynomorio (Mim. 1705. 0. 86. observatio restat; reliqua mamuscripta Rernard de Jussieu servabat. (Mtem. 1761. p. 16\%.)" Spreng. Ilist. rei herb. 11. 2̈3.)
$6178^{*}$ Lisa, Domenico. Elenco doi muscli raceolti nei contorni di Torino. Torino, stamperia reale. $1837.8 .61 \mathrm{p}$.

$6179^{*}$ Lischwitz, Johann Christoph. Veterum in re herbaria diligentiam et ad nostruin uscue aevum hotaniees incrementa lorevissimn evolvit. Progranma. Lipsiae, ty|. Schede. 1724.4. (12 p.)

6180 Oratio panegyrica funebris in obitum Augusti Quirin Rivini. Lipsiae 1724, 4.

6181* Pronramma de variis naturae lusilus ac anomaliis circa plantas. Kilonii 1733.4 . (12 p.)

6182 Orationes duae, I. De plantis dolorosan Domini Jesu passionem, miro naturae lusu et artilicio, quoad unnia passionis instrumenta, depingcutilus. II. De plantis gloriosam resurrectionem Christi nostramque in illa fuadatam a mortuis resuscitationem referentibus. kilonii 1739.4 . H.

\section{Praeside Johann Chrisloph Lischwilz disserlaliones:}

$6183^{*}$ _... De continuanda Rivinorum industria in eruendo plantarum characiere. D. Lipsiae, 1yp. Zunkel. 1726. 4. 25 p. (Respondens: Johaun Ernst Jebenstreit.)

6181." De ordinandis rectius Virgis aureis. D. Lipsiae 1731. 4. 80 p., praef. (Respondens: Johann Goutried Teltelbach.)

$618: 3^{*}$ De plantis diaphoreticis el sudoriferis, cun babitu externo, cun quorjue charactere botanico diversis, charactere autem pharmaceutico ac usu fere congeneribus. D. Kilonii 1734. 4. $63 \mathrm{p}$. (Respondens: Burtholomaeus Ludwig Hill.)

$6186^{*}$ Plantae diureticae cum liabitu externo tum quogue charactere botanico diversae, charactere autem pharnaceuticn congeneres usuque eaedem. D. Kilonii, typ. Bartseh. 1739. 4. 46 p.

$6187^{*}-$ Dissertatio, sistens plantas anthelninticas et habitu externe et tuto genere botanico diversas, charactere autem pharmaceutico usuque medicinali congeneres; cum praecipuis cautelis in administratione observandis. Kilonii 1742.4. $108 \mathrm{p}$. (Respondeas: Johann Christiun Friedrich Tzscheppius.)

6188 Lissander, Anders. Anmärkningar vid Svenska trágårds-skütseln. Stockholm 4768 . 8. 351 p., 4 tab. B.

$6189^{*}$ List, Fr. Ludwig. Spieilegium hotanicun, continens stirpes nuperrime in Lithuania detectas et observationes criticas ad el. Jagentu Chloridem prussican. (Prugramma Gymnasii Tilseusis.) Tilsae, typ. Post. $1825.4 .10 \mathrm{p}$.

$6190^{*}$ Plantae lithuanicae, quae Chlorili burussicae cl. Hageni inserendae sunt. II. Salicum, quae prope Tilsam sponte creseunt, adumbrationes. (Progranma Gymnasii Tilsensis.) Tilsao 1837. 4. $12 \mathrm{p}$.

6191 Lungberg, Nils Johan. De plantis venenatis. D. pro gradı medico praeside Carl Pehr Thunberg. Upsaliae, typ. academiac. 1822. 4. 8 p. w.

6I92t Lloyd, $G . N$. Botanical terminology or dictionary, explaining the terms most generally employed in systematic botany. Ediuburgh, Bell and Bradfute. 1826. 8. vi, 298 p.

$6193 \div$ Lloyd, James. Flore de la Loire-inférieure. Nantes, Prosper Seljire. (Paris, Bailliere.) $1844.12 .335 \mathrm{p}$.

Lobelius, vide De l'Obel.

619' Lobkowitz, Ludug ron. Praktisclıe Anweisung zur Forstwissenschaft in zehn Tabellen, enthaltend die Naturgeschichte der deutschen wilden Holzpflanzen und die kubische Vermessung der Holzkurper. Frankfurt 1802.8. $(3 /$ ih. $)$

$6193^{\circ}$ Locatelli, Michelangelo. Sulla corrente ualattia de' gelsi. D. Verona 1773. 4. DC.

6196* Locher-Balber, IIans. Nekrolog auf Paul Usteri. Ml. D. L'urgermeister des Kantons Zürich. Zurich, Orell, Fussli et Co. 183ఖ. \&. $56 \mathrm{p} .(1 / \mathrm{t} / \mathrm{h}$.)

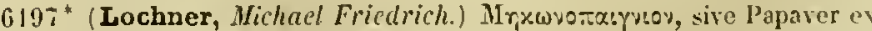
omni antiquitate erutum, gemmis, nummis, statuis et marmoribus aeri incisis illustratum. Normmbergac, typ. Hein. 17i3. 4. (\$), $182 \mathrm{p}$., 30 tab. - *ib. 1719. 4. (non cliffert.)

(Praefatio libnlli cruditi anonymi nomen fert *Periander n; do antore ef. Bibl. mumor. Bunduri 213.) 
6198* Lochner, Michael Friedrich. Mungos animalculum et radix descripta, Nurimbergae, Nichahelles. $1715.4 .32 \mathrm{p}$.

6199* - Nerium, sive Rhododaphne veterum et recentiorum, qua Nerei et Nereidum mythologia, Amyci Laurus, saccharum Alhaschar et ventus ac planta Badsamur aliague explicantur ac diversis sacrae scripturae locis lux affundilur. Accedit Daphne ConstauLiniana. Norimbergae, Hoffmann. 1746.4.112 p., 8 tab.

$6200^{*}$ C Commentatio de Ananasa, sive nuce pinea indica, vulgo Pinlas. Norimbergae, typ. Endter. (1716.) 4. 76 p., 5 tal).

6201 De noxis et exoticis Thee et Cafe succedaneis. (Norimbergae 1717.) $4.16 \mathrm{p}, 1$ tals. B.

6202 Do Acriviola ejusque novis specielous flore pleno el peruviana foliis quinquefidis. (Norimbergae 1717.) 4. 32 p., 4 lab. B

$6203^{*}$ Schediasma de Purreira brava, novo americano alisisuc recentioribus calculi remediis. Editio secunda auctior. Norimbergae apud Petrum Conradum Monath. 17 19. 4. 86 p., 6 lab.

Prodierat jam antea in Ephem. Acal. Nai. Cur. Cent. I. et II. append. p. $241-30$. et cent. 11l. $1 Y$. p. $161-168$.

6201 Locke, John. Outlines of botany. Boston 1825. 8.

6205 Loddiges, Conrad. A catalogue of plants and seeds, which are sold by Courad Loddiges, Nurseryman at llackney. In english and geman. London $1777.8 .54 \mathrm{p}$. B.

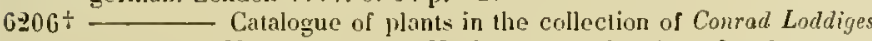
and Sons, Nurserymen, at Ilachuey near London. London, Iyp. Wilson. 1814. 8.40 p. - +Ed. Xll : ib. 1818.8 .51 p. - tEd. . II : ib. $1820,8.55 \mathrm{p},-\rightarrow E d$. Xll : ib. $1823.8 .48 \mathrm{p} .-+\mathrm{Ed}$. XIV : ib. 1826. 8. 78 p. - t Ed. XV: ib. 1830.8 .79 p. - tEd. XVI: ib. 1836. $8.85 \mathrm{p}$.

$6207^{\circ}$ The hotanical Calsinel, consisting of coloured delineations of plants from all countries, with a short account of each tireclions for menagement etc. by Courad Loddiges and Sons. The plates by George Cooke. London, Arch. 1818-1824. A voll. 4. tah. col. $1-1000$, totidem foll. text., ind. - vol. $\mathbf{X l}-\mathbf{X X}$ : ib. $1825-$ 1833. S. Lab. col. 1001-2000. totidem foll. texi, ind. Bibl. Reg. Berol.

$6208^{*}$ Orchideae in the collection of Conrad Loddiges and Suns, Hachney near London, arranged according $10 \mathrm{Dr}$. Lindley's Genera and species: with their native conntries and years of introduction. London, typ. Wilson. (1842.) 12. $40 \mathrm{p}$.

Ditissima collectio 1603 specierum; coram habeo anteriorem edilionem ejusdem catalogi sine anno duodecina forma: $25 \mathrm{p}$, in qua lv't species recensentur.)

$6209^{\circ}$ Loebe, Irilliam. Naturgeschichte fur Landwirlie, Gurtner und Tecluniker. Leipzig, Brochhaus. 1842. Lex. 8. vilr, 407 p., 20 lab col. ( 2 th.

(Pilanzenrcich : p. 16r-3's.)

6210 Die Krankheiten der Kartoffeln, ilıre Kennzeichen un Ursachen, ilıre Verhutung und Folgen. Leipzig, Reichenbach. 1842. $8.8^{3} / 4$ plag. $\left(1 / 2 / h_{0}\right)$

62l1 Loebenstein-Loebel, Eduard. Die Anwendung und Wirkung der Weine in lebensgefalirlidien linutheiten, und wiber deren Wirkungen, nach ejgnen Ansiclsten und Erfahrungen. Leipzig, Brockliaus. $4816.8 .(5 / 6$ th.)

+ gallice: Traite sur l'usage et les effets des vins dans les malaties dangerenses et mortelles, et sur la falsitication de cetle buissun. Traduit de lallemand par Joniel Lobstein. Strasbuurw, ty'p. Levrault 1817. $8 . \mathrm{xll}, 192 \mathrm{p} .(3 \mathrm{fr}, 50 \mathrm{c}$.

fi21? Loechstoer, Ienrik. Dissertatio de Nicotiana vera, ejusque praeparatione et usu medico. Jlafuiae 1738, 4.12 p. B.

$6213^{*}$ Loefling, Pehr. Iter hispanicum, eller Resa till Spanska landerna uti Europa och America, förrättal ifrän år 1751 til ar 1756 , utgifven efter dess fränfalle af Carl Linnueus. Slockholn, Salvius. 1758. 8. 3161 1., praef., 2 tab.

* germinice: Peter Loflings: Reise nach den Spanischen Ländern in Europa und Amerika in den Jahren 1751-1736. Nehst Deobacoutungen und Anmorkingen uber flie merhwurdign friwalise, herausqegeben un Limne. Aus dem Schwedischen uhersetzl wit Alexamer Bernhard foelpin. Berlin und Stralsund, Lange. 1766. 8. 16ik p., praef, 2 lah. noetpin. Berlin und stralsund, Lange. 1760 . Wh useful and necessary texcerpla anglica: AIs abstract of the most useful and necessary articles mentioned jn his travels through spain, and that part or Soutl-America, called Cumana. Printed with the Travels of Bossu, translated hy Johann Reinhold Forster, vol. il. p. 69-132.

6214. Loefwenhjelm, Süren, pr. De cultura et usu Trifolii pratensis neconomico. D. Ujsaliae, typ. Edman. 1805. 8. (Respontlens: S. U. sundelius.) W.
6215* Loehr, Mallhias Joseph. Flora yon Coblenz, oder systematische Zusammenstellung und Beschreibung der in jener Gegend des Alttelrheins wildwachsenden und gelauten phanerogamen Pflan2en, nach dem naturlichen Systeme. Coln, Dumont-Schauherg. 1838. 8. xxw, 320 p. $\left(1 \frac{1}{6}\right.$ th. $)$

$6216^{\circ}$ - Taselsenbuch der Flora von Trier unul Luxemburg, mit Beruchsichtigung der Nahe - und Glangegenden. Trier, Troschel. 1544. S. LSYI, $319 \mathrm{p} .\left(1 \frac{1 / 2}{2} \mathrm{t}\right.$. $)$

6217* Loesche, Gustav Eduard. De causis naturae chenicae et efficaciae plantarum. D. Lipsiae, Iyp. Stariz. 1843. 4. 31 p.

$6218^{*}$ Das vegetaljilische Lehen und die chemische Affinitat in ilıren gegenscitigen Bezichungen dargeslellt. Leipzig, Voss. 1844. S. Iv, $132 \mathrm{p} .(1 / 3$ th. $)$

6219 Loescher, Martin Gothelf, pr. Balsamum de Hecea. D. Vitembergae 1726. 4. 24 p. (Respondens: Johann Gottfried Nicolai.) B.

$6220^{*}$ Loeselius, Johannes. Plantas in Borussia sponte nascentes e manuscrijtis parentis mei divulgo, Johannes Loesetius, Johannis filius. Regiomonti borussorum, tyj. P. Mensenii. 1634. 4. 83 p., prael., ind. Bibl. Reg. Berol. et Deless.

(Exem),ar ill. Ernesti Meyer habet in titulo annum 153\%. Quae ipse vidli, anmun $16 \%$ ferunt; tabulas quoc[ue iis inesse crediderim, sed fortasse eas begligenter in schedulis meis false indicavi. Editionem "rincofurli f67.3. 4,." a Seyuier, Willdenow, Schultes laudatan non vidi. Fictitiam puton.)

6221* — Theriacam Andromachi a Christophoro Meyer plarmacopeco $\mathrm{XX}$ Jan. 1654 confectam recensuit. Regiomonti, typ. Paschalii Mensenii. $1654.4 .66 \mathrm{p}$.

6222* - Flora prussica, sive plantae in regno Prussiae sponte nascentes. Quajum catalogum el nomina Johunnes Loeselius olim disseruit, nunc additis nitidissimis iconibus rariorum, partim ab aliis nondum delineatarum plerarumpue Prussiae propriarum et inquilinarum plantarum, earundemque accurata descriptione, nec non adjectis synony miis veterum botanicorum, interspersisque abservationibus historico-philologico-criticis et medico-practicis noviter efllorescentes, curanto Johann Gattsched. Regiomonti, sumtibus typom graphiae Georgianae. 1703.4 .294 p., pracf., ind., 85 tah.

"Gotlsched erinelt aus Loesel's Nachlass $[+16 \% 5]$ dessen llandschriften und Kupferplatten. Wie viel Eigenes er hinzugetban, ist ungewiss.") E. M.

$6223+$ Loeuillart-D'Avrigni, A. E. C. Principes de hotanique medrcale, contenant l'abrégé de l'anatomie et te la physiologie végétales, l'enumération et la descriplion des plantes médicamenteuses etc. Paris, Payen. 1821. 12. xill, $371 \mathrm{p}$.

622\}* Loew, Heinrich. Botanica clemico-physiographica priucipalium pharmacorum. D. Vindobunae, lyp. Uelserreiler. 1840. 8. 39 j.

622.5 Loew, Karl Friedrich. Epistola ad botanicos, qua de Flora pannonica conscribenda consilium cum ipsis comnunicat. Sempronii 1739. 4. H

(Redit in Acl. Acad. Nat. Cur. vol. V. afpendix, p. 1i5-15k.

6226 Loewe, Johamn harl Christian. Handbuch der theoretisclien und praktisclien lirảterkunde, zun Gebrauche fü Jedermanı. Breslau 4787. 8.509 p. B.

6227* Loewenstein, Albcrt Samucl. De radice Caincae ejusque pracsertim in morl,is loydropicis virtute. D. Berolini, typ. Feister. 1828. 8. 36 p. - * Kerolini, Logier. 4825.8 .44 p. $(1 / 4$ th. $)$

(Paginae 3"j-"í afl priorem impressionem recens sunt additie.)

$6228^{*}$ Loewig, Karl. Ueber Bildung und Zusammensetzung der organischen Verbindungen. Programm, Zurich, typ. Orell. 1843.4.32 P.

6229 Loewis, Andreas von. Anleitung zur Forstwirthschaft in Liefland. Riga, Ileinshausen. 1814.8.(1 th.)

$6230^{*}$ - Leber die ehemalige Verbreitung ter Eichen in Livund Esthland. Ein Beitrag zur Geschichte des Aubaus dieses Lan-

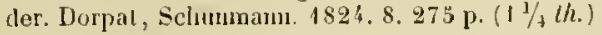

$6231+$ Logan, James. Experimenta et meletemata de plantarum grencratione, nec non eanonum pro inveniendis refractionum tum simplicium tum in lenlibus duplicium focis demonstrationes geometricae. Lugluni Batavorum, Haak. 1739. 8. 32 p., 1 tab.

* anglice et Intine: Exprerimenta et uneletemata de plantarum generatione. Experiments and considerations on the gencration of plants. Translated from the original latin. London, Davis. 177. 8. III, 3y p. * germanice: Versuche und Gedanken volt der Erzeugung der Pilanzen. Plivsikil. Belustigungen, vol. III. [1, 1088-1102 
6232 Lohenschiold, Otlo Chrislian von, pr. De florilus Lygiis vulgo lilia vocatis regni Galliae insignibus. D. Turbingar 1756 . 4. (Respondens: B. H. Bultersack.)

6233 Loisel. Traité complet de In culture des melons, on nouvelle mithode de cultiver ces plantes sous cloches, sur buttes et sur cuuches. Paris, Cousin. $1841.12 .5 \%$ plag. (2 fr.)

* germanice. Loisel's .Helonenlatu in Freien, mit erlüuternten Zeichnumbro. Fur drutscho Gartenfreunde beardseitet. Breslau. Hirl. 18'2. nungren. Fur drutschn Gartentreunde heardeitet. Breslau. Hirl. 18r2.

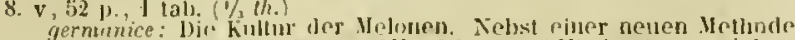

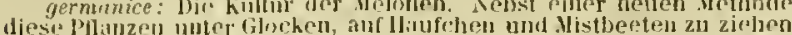

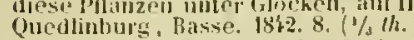

623.4 Traité complet de la culture naturelle el artificielle de l'asperge, ou expose pratique et raisonné de tout ce qu'il est utile Je savoir dans ce genre de culture. Paris, Cousin. 1846 . 8 . $31 / 2$ plag.

623\%* Loiseleur Deslongchamps, Jean Louis Augusle. Flora gallica seu enumeratıo plautarum in Gallia sponte nascentium secundun Linuaeanum systena digest.rum; addita fumiliarum naturalium synopsi. Lutetiae, typ. Migueret. IS06-1807. II voll. 8. vit, $742 \mathrm{p}$., 21 tab. (10 fr.) - ${ }^{\pi} E d$. Il. aucla et emendata. Paris, Baillière. 1828. I1 voll 8. - I: xxxiv, 407 p., 46 tab. $-11: 394$ j), 15 tab. (16 fr.)

$6236^{*}$ Notice sur les plantes à ajouter il la Flore le France (Flora gallica), arec quelques correctinns et observations. Paris, typ. Sajev. 1840.8 .469 p., ind., 6 talt. (2 fr. 50 c.)

$6237 \div$ Recherches historifues, botaniques et medicales sur les narcisses iudigènes, pour servir à l'histoire des plantes de France. Paris, 1yp. Baudouin. 1810.4.42 p.

(Extraites du vol. 11. des Mémoires de I'Institul; savants étrangers, 1811 .)

C238t - Herbier general de l'amateur, contenaul la description, l'histojre, les propriétés et la culture dles vigétaux utiles ef agréables, dédié au Roi par fét Iordnnt DeLuunay: continué (depuis la douzième livraison) par Jean Louis Auguste Loiseleur-Deslongchamps; avec figures peintes d'après nature par $P$. Bessa, peintre d'histoire naturelle. Paris, Audot. 1816-1\$27. VIII voll. = livraisoll 1-96. 4. 570 tab. col. el text. (2016 fr.) Bibl. Deless.

("Cel ouvrage a éle public en 96 lirraisons de 6 planches, arec texte. Prix de souscription pur chache livatson: in 8. papier Jesus ordinaire: 9 fr. - gr. in-\$. papier nom de Jésus, vélin satine: lo fo. _- Nourel herbier de l'amateur, contenant la description, la culture, l'histoire el les proprictés des plantes rares et nouvelles cultivées dans les jardins de l'aris. Par J. L. A. Loiseleur-Deslongchamps, avec figures peintes d'ayrès nature par Madause Deville, éleve de M. Bessa. Paris, Levrault. 1830. 8. et 4. a.

("Ce nouvet lierbier devait paraitre tous les mnis, par livraisons de 6 planches gravees el culoriees avec te plus grand soin, accompagnees alin levte imprimes sur les memes formats el characteres du precedent. Prix de chaque livraison sur papier gr. Jesus velit. vraisons seulement paraissaicut at hat fo is32; toutes nont pas vraisons seulement
six planches.v) Q.

$6210 \div-$ Herbier général de l'amateur. Deuxième série par J. L. A. Loiseleur-Deslongchamys et Charles Lemaire. Paris, Cousin. 1839-1843. 12, liviaisons. 4. 248 tab. col. et tev. Bibl. Deless.

Facile plura prodierunt ; equidem vidi l2 fasciculos $=\mathrm{Vnl}$. l- -ll

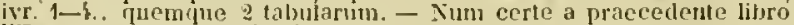
dilferat hace comlinuatio, ignoro.

$621^{t}+$ Nouveau voyage dans lempire de Flare, ou Principes élémentaires de botanique. Paris, Méquignon l'ainé. 1817. II voll. S. - I: xII, 214 p. - II: 377 p. (7 fr. 50 c.)

$6212+$ Manuei des plantes usuelles indigènes, ou histoire abrègée des plantes de France, distribuces d'après une nouvelle mèthede; contenant leurs propriétés et leurs usages en médecine, dans la pharmacie el dans I'économie domestique. Paris, Méquignon I'ainé, 1819. II voll. 8. - I: xxvi, 672 p. - II: 1\%, 170 p., 6 tableaux. (12 fr.)

(Volumen alterum etian inscrititur: a Recherches et observations sur l'emploj de plusieurs plantes de France.o)

6. $243^{*}$ __ Essai sur l'histoire des mùriers el des vers-à-saje, el sur les moyens de faire chaque année plusieurs récoltes. Paris Levrault. 1824. 8.92 p. (3 fr.)

$0294 \div$ - Neuvelle notice sur les plantes à ajouter a la Flore de France (Flora gallica). Paris, secrétariat de la société linnèeone. 1827.8. $40 \mathrm{p}$.

6240 Flore géuérale de la France, ou Iconographie, description et histoire de toutes les plantes phancrogames, crypto- games et agames, ‘ui croissent dans ce royaumn, disposece suivant less familles uaturilles par M.II. Loiseleur-Deslongchamps, Persoon, Gaillon, Boisdurul el DeBrebisson. Thanérnıamie, par Loiseleur-Deslongchamps.s. Paris, Ferra jeune. 1828, 8. a.

tun arait promis, toutes les trojs semainms, nase lisraison de

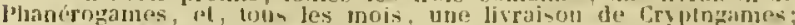

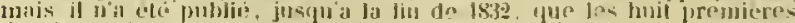

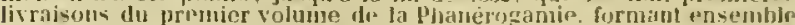
is finilles de tente, ivec is planehes. Prì do lio lis raison de 12 planches avec tevte in-8: 6 fr., $\mathrm{cl} g \mathrm{r}$. in $\$: 12$ fr.v $\mathrm{Q}$.

6216 Loiseleur-Deslongchamps, Jean Louis Augusle. Ilistoire médicale des succédanées, de lipécacuanha, du siné, du jalap, de l'opiun etc. on Recherches el observations sur quarlejuess pnints do matière ınedicale indigène. Paris, Baillière. $1 \$ 30.8$. (3 fr.) a.

6217 Muriers et vers a soie, leur culure et leur education dans le climat de Paris. Paris, typ. Huzard. 1832.8 . 72 p. (1fr. $25 \mathrm{c}$. (Extrait du "Cultivateur."

62 48 - Rappert sur la culture du múrier. (1'aris 1837.) 8 . $96 \mathrm{p}$.

PExtrait des Memoires de la societé d'agricullure.

$6249 \div-$ Histoire du cèdre du Liban. Paris. Huzard. 1837.8 66 p., 2 (a).

$6230 \div$ Considéralions sur les Céreales et principalemen: sur les froments (partie historique), lues à la nociete royale el centrale d'agriculture. Paris, Rouchard-Huzard. 1842.8. 108 p.(Partie pratique ex exirimentale. ib. $1843.8 .248 \mathrm{p.}$

(Cf. Lompte rendu par fillerme. Paris Guiltaumin. IS63. \$. 12 p.

$62 a 1+$ R__ Réfexions sur la formation du bois dans les arbres dicotylédones et sur la circulatien de leur sève. Paris. Iluzard. 1843 8. $16 \mathrm{j}$.

$62: 32$ Roseraies et promenades borticulturales. Paris 1846. 8. $3 \frac{1}{2}$ plag.

6233 Considérations sur les boutures des arbres foresticrs. ou sur le parti, quion pourrait en tirer pour le reboisement. Paris 1846. $8.41 / 4$ plag.

$6 \nexists 3 ̈$ L Londerseel, Assuwerus van. (Icones animalium ef plantarum. Assuxerus vun Londerseel fecit, Clas Janss. I"isscher excudebat anno 1625. 12 tab. aen., lengit. $3 \frac{1}{2}$ unc., latit. 5 unc. B.

6253* Londes, Friedrich Wilhelm. De Chaerophyllo bulloso ejusiun usu cum medico tum hotanico. D. Goettingae, tsp. Grap. 1801. 4. 25 p., 1 tals.

$6236^{*}$ Grundriss zu Yorlesungen uber Foral - und okonomische Botanik. Goutingen. Schroeder. I 02 . \&. 13 p

$6237^{*} \longrightarrow$ Ilandbuclı der Botanik. Zu Vorlesunien fur lerzte un] Apotheker entworfen. Götingen, Rower. I80f. S. $x, 339 \mathrm{p.}$, ind. $(1 / / 2 h$.)

$623 \mathrm{~S}^{*}$ - Verzeichniss der um Götingen wildwachsenden Pfanzen, nebst Bestimmung des Standertes. Als Einleitung zu der Flora von Gottingen. Guttingen, Dieterich. 1805 . 8 . viu, \&s p. $(1 / 3$ th. $)$

$6259 \div$ Long, II L. Some enquiry concerning the Quercus and Fagus of (he ancients. (Iondon) 1838.8. $15 \mathrm{p}$.

From the Gardener's Magazine, vol. Ir. 1.9.

$6260^{*}$ Lonitzer, Adam, latine Lonicerus. Naturalis historiae ojns nosum, in quo tractatur de natura et viribus arberum, fruticum, herbarum, animantiunque torrestrium, volatilimn et acpatilium, item genmarum, metallerum, succorumque concretorum, adeoque de vera cogntitione, delectu et usu omnium simpliciun medicamentorum, quorum el medicis et officinis usus esse drbet, una cum eorundam ad virum effigiatis effigiebus. Ex utriusque linguae summorum virorum penetralibus, summe labere et studio conscripla per Adamum Lonicerum. Francofurti, apud Christianum Egenolphum. 1551. folio. (18), 353 foll., ic. xylogr. i. 1. - "Tom. Il: Naturalihisloriac tomus 11 , de plantarum earumque potissimum, quae locis nostris rariores sunt, descriptione, natura et viribus. Jam recens summo studio et diligentia congestus. Accessit Onomasticon continens varias plantarum uomenclaturas, utpote graecas, latinas, italicas, gallicas, germanicas: vocumique, quarum in plantarum descriptionitus frequens est usus, explicationem, cum indice multiplici. Francofurti, apuil Christianum Egenolphum. (1535.) folio. 85 foll., ic. xylugr. i. I. - + Botanicon. Plantarum historiae cum earundem ad vivun arteficiese expressis iconibus tomi duo. Addita sunt animantium tertestrium, volatilium et aquatilium brevis de- 
seriptio elc. postremo Onomasticon, quo variae plantarum nomenclaturae ex diversis linguis, item roces quarum frequens in descriptionibus usus est, explicantur. Onmia de novo recognita, indice arljecto quintaplici. Francofurti, apud haeredes Christiani Egenolphi. 1565. folio. Bibt. Cand. (Jraeter titulum ne Jevissima quidem nota dillert ab editione $1551-1553$.)

6?61" Lonitzer, Adam, latine Lonicerus. Kreuterbuch, neu zuggericht Kunstliche Conterfeytunge der Baune, Stauden, IJecken, Kíreuter, Getreyde, frewirtze. Item von furnembsten Gelbien der Erden, Vogeln und Fischen; auch ron Metallen, Gummi und gestandnen Safteu. Frankfurt a/M., Egenolph. 1557. Folio. 342 Joll., ind., ic. xylogr. i. t. - Jetzo gantz von newem lurchseher, gebesser, und mit mehren Kreutern und Figuren erstreckt. Frankfurt a/MI. Eqenolph. 1564. Folio. 343 foll., ind., ic. xylogr. i. t. - Frankfurt a/M. 1569. folio. S. - Zum funften Mlal Jurcliselies, gebessert und gemeluret. Frankfurt a/M., Martin Lecl.]er. 1573. folio. ic. xylogr. i. t. Rivin. tFrankfurt a/X. 1577. Colio. Bibl. Reg. Par. - ${ }^{*}$ Frankfurt a/A]. 1587. Jolio. - Frankfurt a/A]., bei Christian Egenolpli's Erben. 1593. Iolio ic. xylogr. i. t. Rivin. - Frankfurt a/MI. 1598. Iolio. Linn. - Frankfurt a/M., getruckt durch Siegismunduta I,atomun, in Verlegung Vincentii Steinmeyers, 1609. Folio. 308 p, ic. xylogr. i. 1. — "Frankfurt a/MI. 1616. folio. ic. xylogr. i. t. - "durch Peter U/Fenbach ubersehen, vesbessert, an riclen Orten vermelurt und in acht sonterbahre Theil unterscheiden. Frankfurt a/Al., Matthias Kempffer. 1630. folio. 750 p., ind., ic. xylogr. i. 1. - ib. 1650 . folio. s. - Llm 1679 folio. 750 p., ind., ic. xylogr. i. t. B. - * Auf das fleissigste uberschen durcb Peter Effenbach. Ulm, Bartıolomae. 1713. Ioliv. 750 p., ind., ic. xylogr. i. 1. - Nit einer Zugabe von Balthasur Ehrhart. Uru 1737. folio. 750 p., ind., ic. xylogr. i. 1. Zugabe: 136 p. B. - * Ulm 1765. folio. 750 p., ind., ic. xylogr. i. t. - ${ }^{*} \mathrm{~L} / \mathrm{m} 1770$. folio. 750 p., ind. ;c. $x y \log$ r. i. t. Bibl. Mus. bot. Vind. - Augsluarg, Wolf. 1783 folio. $\left(3 \frac{2}{3}\right.$ th.

(E. Johannis Culae (i. e. Johann Ifonnecke ex oppido raub) opere Ilorto sanitatis, Adam Lonitzer. Egenolphi uener, pirysicus Francofurtensis. [n. $1528,+1386$ ] reformavit summ el anvit, ut ommino nosus sit liber, latino in universum similis, sed plenior mulno et capitibus, et tiguris, el plantis, et earum viribus ulerius allatis.

6262* Lonitzer, Johann, latine Lonicerus. In Diosroridae Inazurbei de re medica libros a Marcello I imilio rersos scholia nova. Jonmne Lonicero autore. Marpurgi, Clıristian Egenolpluus excudelıat. 1543. folio. 87 foll. : praef, ind.

$6263+$ Loosjes, Arrian. Flora Harlemica, of Lyst der planten rondom llaalen in het wild groeijende. Ilaarlem, Jy Jacoh Tydgaat. 1779. 8. vill, 53 ]. Bibl. Reg. Brux.

626 ; Iorek, $C$. G. Flora prussica. Abbildungen simmtlicher his jetat aufigefundener Pllanzen Preusseus. Konigsherg, Unzer. 1826-1830. 12 ] Jefte. 4. 51 , 4 p., praef., tal. col. 1-210. (25 /h.) * Nachtrag: ib. 1837. tab. col. $211-226$. - Nachtrag: tab. col. $227-230$. "Dritte verbesserte Ausgabe. Königsberg, Universitatsbuclıhandlung. 1846 sqq. 24 Helte. yr. 8 . ( 12 th.)

llace afertian editio a priori vix levera differt, immo novam ejus fepetitionem sistil. De duobus, (gni athuc froclierunt, fasciculis

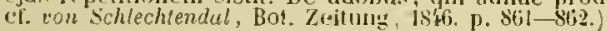

626.5 * Lorente, Vicente Alfonso. Nova generum Polygamiae classificatio. Valentiae, e prelo J. Estevan et Cervera. (1796.) 4. 29 p., praef.

$6266^{*}$ Carta (I-II) solore Jas observaciones hotanicas, que ha publicado D. Antomio Jose Cavanilles. Valencia, por J. Estevan y Cervera. 1797-1793.4. - 1: 1797. 27 p. - 11: 1798. 25 p.

$6 \% 67 \div$ Systema botanicum Linnaeano-anomalisticum, seu do anomaliis plantarum, quae in systenuate Linnaeano observantur. Valentiae, typ. Mlonfort. 1799.4.31 p. Bibl. Juss.

Q268: Iorenz, $J$. $\boldsymbol{B}$. Manue] du Forestier, ou Iraité complet de tout ce qui a rapport á l'listoire naturelle des arbres. Sarrebourg, typ. Jarreis. an $\mathbf{X}$ de la république. (1803.) Il voll. $8 .-\mathbf{I}: \mathbf{x x}, 324 \mathbf{p}_{1}$ ind. - II: xty, 264 p. (6 fr.)

$6269^{*}$ Lorenz, Johamn Friedrich. Grundriss der theoretischen und praktisclıen Botanik Jar Schulen zur Bildung junger Landwirthe und Kameralisten. Leipzig, Weygand. 1781. 8. 128 p.

6270 " Lorey et Duret. Catalogue des plantes, qui croissent naturellement dans le départenent de la Cóte dor, et des espèces le plus gémeralement cultivées observèe jusqu' aujourd'lui. Dijou, 'y]p. Frantiı. $1825.8 .47 \mathrm{p}$.
$6271+$ Lorey et Duret. FJore de la Cute d Or, ou description des plantes indigèues et tes cspèces le plus généralement cultivées et acclimatees, observees jusqu'a ce jour dans ce département, rlisposées sclon la méthode waturelle de Jussiea, suivie d'une table analytic|ue arec figures. Dijon, Douillier. $1 \$ 3$ I. II voll. 8. CLis, 113 I p., 7 tab.

6272* Lorinser, C.J. Versuche und Beohaclutungen uber die Wirkung des Nutterkorues auf den mensclilichien und thieriseben horper etc. Berlin, Scluuppel. $1824.8 . x, 129 \mathrm{p} .(2 / \mathrm{s} / \mathrm{h}$.

6273 Lorinser, Guslat. Couspectus Staclıopteridum in Bohemia spoute maseentium. D. Jragae 1837.8 .

6274* , und Friedrich Lorinser. Taschenbuch ter Flor" Deutschlands und ter Sclwweiz. Zur sichern und leicliten Bestimmungr des wildwaclssenden und allgemein kultivirten phancrogamischen und kryptogamischen Gefásspflanzen. Nach der analytischen Metlıde bearbeitet. Wien, Tendler uud Co. 1847.8 viII, 488 ?. $\left(1 \frac{1}{2}(h\right.$.)

$6273+$ Losana, Malleo. Delle malattie del grano in erba non curate, " hen conosciute. Carmagnola, typ. Barbiè. 1811.8 .350 p., 1 talı.

$6276 \div-$ Saggio sojura il carbone del Mais. Torino, Iyp. Bianco. 1828. 8. 32 p., 1 (a).

6277 Lossius, Jeremias, pr. Disputatio de Nuce vomica. Vittenbergate 1682. 4. (10 foll.) (Respondens: Andreas Kaspar Georgii.) B.

6278\% Loudon, John Claudius. Observations on the formation and management of usefu] antl ornamental plantations; un the theory and practice of landscape gardening. Edinburgh, Constable. ISo 4 . \& 342 p., ind., 10 tab.

$6279+\div$ short treatise on several improvements recently made in hot-høuses. etc. Edinburgh, Constable et Co. $1805.8 .271 \mathrm{p}$. 9 tab.

$6280^{*} \ldots \ldots$ An Encyclojaedia of gardening, conjprising the theor and practicc of horticulture, floriculture, arboriculture and landscape-gardening, including all the batest improvemens; a general history of garleumg in al] countries and a statistical view of its present state; with suggestions for its future progress in the british isles. Jllustrated with many luundred engrarings on wood. Louslon Longman. 1822. 8. xvir, 1469 p., ic. xylogr. i. 1. - tEd. I: London, Longman. 1828. 8. - " A new edition, consiclerably improved and enlarged. London, Longman. 1835.8 . xL, 1270 p. - A new edition. considerably improved and en]arged. Lomdon, Longuan. 1841. 8 (2l. $10 s .-15^{3} /$ th.

germanice: Euktopalie des Gartenwesens. Weimar 182' -1826 2 Binde. 1. $13 \mathrm{i} / \mathrm{h}$.)

$6281 \div$ Tlıe Gardeners Magazine. London, printed for the conductor. London, (Longman.) 1826-1843. NJX voll. S. Bibl. Cand. et Deless.

(Series I: rol.1-XI. Series II : vol. Xli-XW. Serjes III : vol.XWI-XIX.

6282 - Illustrations of landscape-gardening and sarden-arcljitecture. l.ondon 1831 . Il voll. Iolio.

anglice, gallice et germatice: Erster Theil. Strasshurg, Treuttel und

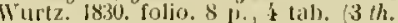

$6283^{*}$ - An Eucyclopamelia of plants; comprising the description the specific character, culture, luistory, application in the arts, and every otlıer desirable particular, respecting all the plants indigenous to, cultivated in, or introduced into Britain; combining all the advantages of a Linnacan and Jussieuan Species plantarum, an Ilistoria plantaum, a Grammar of Botany and a Dictionary of Botauy and vegelable culture. The whole in english, with the synonymes of the commoner plants in the dilierent european and other languages; the scientific names accentuated, their efymology explained; the classes, orders and hotanic terms illustrated by engravings; and witl fisures of nearly 10,000 species, exemplifying several Individuals lwenging to every geuus included in the work. Edited by J. C. Loudon: the specific cllaracters by Professor Lindley; the drawings by J. D. C. Souerby; the engraviugs by R. Branston. London, Longman. 1829. 8. xx, 1159 p., ic. xylogr. i. t. (41. 14s. 6d.)"First additional supplement. ib. 1841. 8. $1 \mathrm{v}, 1143-1329$ p. (15s.) - Ed. Il. corrected, witl supplement. London, Longman. 1841. 8. (3l. 13s. $6 \mathrm{~d}$.)

germanice: Eukyktopidie der Planzen. Enthaltend die Beschreibung aller bis jelist behannten Ptanzen, welclye durch mehr als

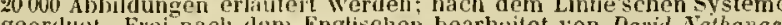
geordinet. Fuei nach alem Englischen bearbeitet von David Nathanael
Friedrich Dietrich. In vier Abtheifungen. Jena, Schmid. 1836- 1816. 


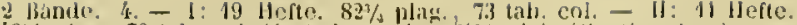

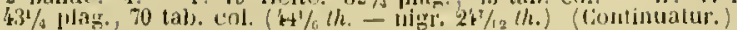

6281. Ioudon, Joln Claudius. Ilortus luritunicus: a catalogue of all the plants juligenous cultivated in, or introduced into Britain. part I. The Linnean arrangment, in which nealy 30,000 species are enumerated. P'art II. The Jussieuan arrangement of nealy 4000 genera. Lundon, Longmat. $1830.8 . x \times 1 v, 576 \mathrm{p} .(1 \mathrm{l} . \mathrm{s}$.$) - "First$ additional supplement: ih. 1832. 8. D. 579-602. - * Ed. Il: London, longman. 1832. 8. xxıv, 602 p. (1l. 3s. 6d.) (mon ditfert.) * Sucond additional supplement: i]), 1839 . 8. p. $602-745 .(8 s)-$. "Ed. 111: with supplenents. London, Longman. 1839. 8. xxiv, 745 p. (11. $11 s .6 d$.

$628 \%$ ligneous plants, indigenous and foreigu, luardy and laal-hardy, cultivated in the gardens and grounds in the neighlourhood of London; with all their synonymes, scientific and popular, including their french, gemman and italian manes; and with their native country, bahitation in lhe sarden ete. To which are added the prices of hardy trees and sluubs in the principal nurseries of LonJon and Ediuburgh, and of Bollwyller in France and in Hamburgh. l.ondon, Longman. 1838. 8. $(7 \mathrm{~s} .6 \mathrm{~d}$. $)$

6386 The Suburban Garlenes and Villa Companion: comprising the cloice of a suburban or villa-residence, or of a situation, on which to form one: the arangement and furnisling of the house; and the laying on, planting and general management of the garden and grounds from one pereh to hifty acres upwards in extent; and intendend for the instruction of those, who know litte of gardening and lural affairs, and more particularly for the use of Ladies. Lonlon, Longman. 1838. 8. ( 1 .)

$6287^{\circ}-$ Arboretum et Fruticetum Jritaunicum: or the trees and shrubs of Britain, wative and foreign, harly and half-hardy, pictorially and botanically delineated, and seientifically and popularly deseribed; with their jropagation, eulure, manarement and uses in the arts, in useful and onumental plantations, and in landscapye-gardeuing. Preceded by a listorical and geographical outline of the trees aud slirubs of temperate climates throughout the wordd. London, lougman. 1838. VIII voll. 8. - vol. I-IV: CCxx, 2694 p., (2546) ic. xylogr. i.t. - vol. V-VIIl: 412 (ab. (10l. - col. London, Ridgway, $25 l .5 \mathrm{s.})$

$6288^{*}$ In Encyclopaedia of trees aud shrubs; being the Arboretuns et Fruticetum britannicum abridged: containing the hardy trees and slurubs of Britain native and foreign, scientifieally and popularly described, with theit propagation, culture and uses in the arts; and nith engravings of nearly ail the species. Abriclged from the large edition, and adapled for the use of uurserynen, seedsmen, gardeners and foresters. Londou, Longnuau. 1842. 8. Lxxı, I162 p. $(2200)$ ic. sylogr. i. 1. (2l. $10 \mathrm{s.})$

$6289^{*}-$ The Derby Arborelum; containing a catalogue of the trees and shruhs included in it; a deserijxtion of the grounds, and directions for their inanagement; a copy of the adrlress delivered when it was presentel to the town council of Derdy by its founder Joseph Sirull Esq., and an account of the eeremonies which took place when it mas opened to the public on Sept. 16. 1840. London, Longnan. 1840.8 .97 p., I tab. (1s.)

(i)g0 The Submrban Ilorticulturist; or an attempt to teach the science and practice of the culture and management of the llower- fruit-kitchen - and forcing-garden, with engravings on wood. London 1842.8 .

(i20) Males of eultivating the Pine-apple in Europe. London, Longmat. 184 ... 8. (9s.)

$6292 \div-$ Self-instruction for young gardeners, foresters etc. With a nemoir of the auhor $[+141) \mathrm{ec}$. is 43.] Lonlon, Longman 1845.8 . LIf, 240 p., effigies autoris $(78.6(l)$.

$6293+$ Loudon, Mistriss J. IV. Instruetions in gardening for Ladies. London, Jolın Murray. 1840.8. xil, 406 J. (6s.)

$699 \% \div$ The Ladies Flower-garton of ormamental annuals. In is heautifully coloured plates, containing upwards of 300 figures of the unost slowy and interesting annual fowers, will full direclious for their culture. London, William Smith. 1840. 4. $8 \%$, 272 p., 48 tab. col. (2l. 2s.) Bibl. Deless.

$15295^{\circ}-$ The Ladies' Flower-garden of ornanental bulhous plants. In 58 beautifully coloured plates, containing abovo 300 figut- res of the most desirable bulbous fowers, with deseriptions and directions for cultivation. Londou, Willian Smith. 1841. 4. x, 270 p., \$8 tab. col. ( $2 l$. 12s.) Bibt. Deless.

6296 Loudon, Mistriss J. I1: The Ladies" Jiluwer-garden of ornamental perenuials. I.ondon, Willian Sinith. 184 .. II voll. 4. (4l. 4s.)

6297 The lirst book of botany. Loudon 1841. 12. (2s.)

$6298^{*}$ __ Botany for Ladies; or a pojular introduction to the natural system of plants, according to the classification of DeCandolle. Loudun, Murray. 1942.8. xvi, 493 J., ic. vylogr. i. t. (8s.)

6299 Ladies Companion to the Flowergarden, being an alphahetical arrangement of al] the ornamental plants usually grown in gardens and slırubberies: with full directins for their culture. London, Willian Snith. 1841. 12. - Ed. 1V. with considerable additions and corrections. London, Wrilian Smitl. 1846. 12. $352 \mathrm{l}$. (6s. 6d.)

6300 Tales abont plants. London, Tegg. 1946. 12. (7s. 6rl.)

6301 Mritish wild flowers. London, Hillian Snith. 1846. 4. (2l. 12s. 6d.)

$6302^{*}$ Loureirn, Joũo de. Flora cochinchinensis, sistens plantas in rerrno Cochincluina nascentes, quibus accedunt aliae observatae in sineusi imperio, Africa orientali, Indiaeque locis variis. Llyssijone, typ. aeademiae. 1790.11 voll. 4, xx, 744 p. - Denuo in Germania edita cum notis a Kurl Luduig Milldenow, Berolini, Ilaude et Spener. 1793. 11 vall. 8 . xxiv, 882 p. ( 3 th.)

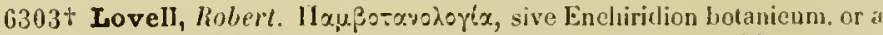
compleat herball, containing the summe of what hath hitherto Jues published either by ancient or moderne authors both galenicall and cliymicall, touching trees, shrubs, plants, fruits, nowers ete. in an aljuabeticall order. Wherein al] that are net in the plysick garden in Oxford ure noted with asterisks, sleeving their place, time, names, kinds, lemperature, vertues, use, dose, daugir and antidotes, together with an introduction to herbarisme etc. Applendis of exoticks; universal index of plants, sheewing what grow wilel in Eugland. Oxford, printed by W. Hall for Richard Davis. 16309. 671 p. et lsagoge: 84 p. Bíbl. Reg. Paris. - $\div$ Ed. 11 : ib. 1665.8. $672 \mathrm{p}$. et Isagoge: $84 \mathrm{p}$. Bibl. Juss.

("Juvenis, neque medici, animosum lentamen. Collectitia omnia.s) H.

630.* Lovén, Nils Ilimrik, pr. Om Geléers, sảrdeles Perl-Tangens (Sphaeroeoccus crispus $\mathrm{Ag}$.) anvandande $\mathrm{i}$ medieinen. D. Lund 1841.8 .20 p.

6305 Lovicz, Simon de. Enchiridion medicinae. Cracoviae, ex officina Ungleriana, 1537.8 .

"Arcedit operi nomenclatura polonica herbarum nostratium et nonumblum exoticarum, secundum seriem alphabeti, el editio de milii Macri de herbarun virlutibus. o) Alumski, llistoria rei herb. jı Polonia, p. $22-2 k$.

$6306^{*}$ Lowe, Richard Thomas. Primitiae Faunae et Florae Maderae et Portus Saneli, sive species quaedam novae vel hactenus minus rite cognitae aumalium et plantarum in his insulis degentium breviter descriptae. Camlirilge, tyj. Snith. 1831 . 4. 70 p., 6 tals. col. ( 9 tal). Helices, \& tab. Plantae.)

(From the Transactious of the Camurioge Philosophical Snciety vol. IF. part I.)

$6307^{*}$ Novitiae Florae Maderensis: or notes and gleanings of Maderan Botany. Cambridge, Parker. 1838. 4. $29 \mathrm{~J}$.

(From the Transactions of the Cambridge Plilosophical Society, vol. 1. part III.)

6308 Loyer, Godefroy. Relation du voyage du royame d'lsṣny, cỏle d'or, pays de Guinée. Paris 1714. 12. 298 p. cum tabulis aeneis. $B$ ("Nonachus, plantas etiam notiores deseribit.n)

$6309^{*}$ Lozano, Pedro. Deseripcion chorografica del terreno, rius, arboles y animales de las dilatadissimas provincias del gran Chaco. GuaJamlı. etc. En Cordoba, por Joseph Santos Balluas. 1733. 4. (20), 485, (5) p., I mapura geugr. Bibl. Goett. (39 6r. A. Barcelona.) (Arboles y planias: p. $26-37$.

G310 Iubeex, Michael. De Opio. D. Lugduni Batavorum. 1699. 4. 5 play. B.

6311 Iucas, Charles. An essay on waters. Lomdon 1756 . III voll. 8. (In inmo III. aliquac plantae Anjisgraneuses reperiuntus. Dumorvier ila intur fontes Forae belgicae citat: oLucas, Essai sur les eau. minérales de Borcoue et Aix-(a-Cltapelle. $)$ 
6312* Lucas, Ewald. Do Solano tuberoso ejusque principio narcutico. D. medico-tovologica. Ilirschberg, typ. Landoldt. 1846. $8.32 \mathrm{p}$.

6313* Luce, Johann Wilhelm Ludwig (von). Topograplusehe Beschreibung von der Insel Oesel in medizinischer und otonomischer Hinsicht. Riga 1823. 8. xvi, $462 \mathrm{p}$. $(1 / 2 / 2$. $)$ Bibt. E. M.

Est Flora insulae secundum Limacanum sistema disposita, interspersis medicis et oeconomicis annotationibus. Fertur quoque sub titulo "Prodromus Florate osiliensis"s: supplrmentum et index prodierunt, leste Trautvelter, Rigae anno 1819 " 1829 ?)

6314 Lucot, Alexis. Ėnblèmes de Flore et des végétaux. Paris 1819. 8.

$6315 *$ Ludolf, llieronymus, pr. Dissertatio de Tabaci noxa post pastum. ErJordiae, typ. Grosch. 1723. 4. 24 p.

6316* - pr. De Jabis Coffee. D. Errfordiae 1724.4. 20 p.

$6317^{*} \longrightarrow$ pr. Saponariam ejusque virtutes specificas examinat. D. Erfordiae, Iyp. IIering. $1756.4 .39 \mathrm{p}$.

6318 Ludolff, Micha'l Mallhias. Anfangsgründe der Arzneiwissenschaft, zum Grunde seiner Lektionen uber dio Materiam medieam und hotanicam. Berlin 1734, 8. н.

$6319^{*}$ Catalogus plantarum, favente, quam lectiones, quae in collegio medico-chirurgico publice habentur, suppeditant, oceasiono Berolini demonstratarum vel demonstrabilium ete. Berolini, Schitz. 1746. $8.232 \mathrm{p}$.

(A p. 223 - 232 sequitur: Synopsis dissertationum duarum perfectiones mellsodi botanicao concernentium; ef. Mem. de l'Academic de Bertin 17k5.)

6320* Ludwig, Christian Friedrich. De plantarun munimentis. Programma. Lipsiae, typ. Langenheim. 1776. 4.20 p.

$6321^{*}$ Epistola ad Friedrich Andreas Gallisch de sexu Muscorum detecto. Lipsiae, typ. BreitkopI. (1777.) 8. (4 Ioll.)

(Redit in ejus Delect. opuse. vol. I. p. 382-388.)

6323* De pulvere antlierarum. D. Lipsiae, typ. Breitkopf. 1778. 4. 33 p. (Kespondens: Peter Gniditsch.)

6323 Die neuere wilde Baunzucht in cinem alphabetischen und systematischen Verzeichmisse aufyestellt. Leipzig 1783.8.70 1. B. - Leipzig, Joachim. 1802. 8. ( $5 / 12$ th. $)$

6324* Delectus opusculorum acl scientiam naturalem spectantium. Ediclit Christian F'riedrich Ludwig. Volumen primum (el uni cum). Lipsiae, Crusius. 1790, 8. v1, 560 p., 7 tab. (15/6 th. $)$

(Insunt: Georg Rudolph Roeltmer, De plantis is memoriam Culterum nominatis: Christoph Detinger t Johann Friedrich Gmelin, Irritabilitas vegetabilium; Ernst findfried Raldinger et Johann Philipp I'olff De Filicum seminilus; Carl von Limne filizs ot Olof Swartz, Methodus M1nseorum illustrata; Christian Friedrich Ludwig, Epistola de sexu Muscorum detecto; Reinhold lierens, le Dracone arbore Clusii ; Karl (iollfripd Ilagen, Do Ranunenlis prussieis.)

$6325^{*}$ - Handbuch der Botanik. Zu Forlesungen Iür Aerzte und Dekonomen. Leipzig, Fritsch. 1800.8 . xiv, 578 p., 4 tah. ( 2 th.)

$6326(-)$ Studien fur den neueren Gartenkünstler. Leipzig 1802. $8 .(1$ th. $)$

$6327^{*}$ Iudwig, Christian Golllieb, pr. Do vegetatione plantarum marinarum. 1. Lipsiac 1736.4.32 p., 1 tab. (Respondens : Michael Morgenbesser.)

$6328^{*}$ — pr. De sexu plantarum. D. Lipsiae 1737.4. 36 p. (Respondens: Christoph Friedrich Jlause.

Retit in Reichard, Sylloge onuse. bot. p. 1-30.

6329" Definitiones plantarum in usum auditorum. Lipsiae, Gleditsch. 1737. 8. 144, (32) p. - "Definitiones generum plantarum olim in usum auditorum collectae, nune auetao el emendatae. Lipsiae, Gleditsch. 1747. 8. 346 p., praef., ind. $(3 / 4$ th. $)$ " Definitiones generum plantarum olim in usum auditorum collectas, nune anctas et emendatas edidit Georg Rudolph Boelmer. Lipsiae, Gleditseh. 1760. 8. xLvm, 516 p., ind. $\left(1 \frac{1 / 6}{\mathrm{th}}\right)$

$6330^{*}$ Aphorismi botanici in usum auditorum conseripti. Lipsiae, typ. Langenheim. 1738.8.80 p.

$6331^{*}$ Institutiones historico-plysicae regni vegetabilis praelectionibus academicis accommodatae. Lipsiae 1742. 8. 224 p. *El. Il. aucta et emendata. Lipsiae, Gleditsch. 1757. 8. 264 p., praef., inl

$6332^{*}$ - Ectypa vegetabiliun usihus medicis praecipue destinatorum, et virium et culturae brevis descriptio. Nach der Natur verfertigte Alsdrucke der Gewälıse unter der Aufsicht Christian Gottlieb Luduig's. IIalae, typ. Trampe. 1760 . Iolio, 100 tab. col., 48 1. Iatine el germanice.

\section{Programmala academica}

$6333^{*}$ Ludwig, Christian Gottlicl. De minuendis plantarum generibus. Lipsiae 1737.4. 16 p.

633' $\mathrm{f}^{*} \longrightarrow$ Observationes in methodum plantarum sexualem celeb. Linnaei. Lipsiae 1739.4. 16 p.

$6333^{*}$ De minuendis plantarum speciebus. Lipsiae 1740.4. $16 \mathrm{p}$.

$6336^{*}$ - Specimen primum, quo radicum officinalium bonitatem ex vegetationis historia dijudicandam esse generatim demonstrat. Lipsiae $1743.4 .16 \mathrm{p}$

$6337^{*}$ - Specimen alterum, quo ratlieun officinalium bonitaten ex vegetationis historia dijudicandam esse speciatim demonstrat Lipsiae 1743. 4. 16 p.

$6338^{*}$ De colore plantarum quaedam observata. Lipsiae 1756. 4. $16 \mathrm{p}$.

$6339^{*}$ - De colore florum mutabili observata proponit. Lipsiac $1758.4 .16 \mathrm{p}$.

$6340^{*}-$ De colore plantarum species distinguente. Lipsine 1758 4. 12 p.

$6341^{*}$ De rei herbariae studio et usu. Lipsiae 1768. 4. 16 p.

$6342^{*}$ De elaboratione succorum plantarum in universum disserit. Pars J-IIl. Lipsiae 1768-1772. 4. - I: 1768. Radis, cau(lex, folium. 16 p. - II : 177 I. Flos, fruetus, germen. 19 1. - III 1772. Medulla. $16 \mathrm{p}$.

$6343^{*}$ - De plantarum viribus medicis in universun. Lipsia 1772.4.16 p. $6344^{*} \frac{}{1722.4 .8}$ p.

$6345^{*}$ - De viritus plantarum cultura mutalis. Lipsiar 1772. 4. $46 \mathrm{p}$.

6316 Ludwig, Johanm Adam Jakob. Ahhandlung von den Erdapfelı. Bern 1770.8. H.

$6347^{*}$ Lueben, August. Anweisung zu einem methodischen Interricht in fler Pflanzenkunde. Fur Burgerschulen, Realschulen, Sclublehrerseminarien und Gymnasien. Mit einem Briefo als Vorwert yon $\mathrm{W}_{\mathrm{a}} \mathrm{-}$ helm Ilarnisch. Halle, Anton. 1832. 8. xxxiv, 556 p. $\left(1 \frac{1 / 2}{t h}\right.$.) "Zweite ganz umgearbeitete und vermehrte Auflage. Halle, Anton. $1841.8 . \times x x, 504$ p. $(1 / 2$ (h.)

$6348^{*}$ - Die Ilaujtformen der aussern Pflanzenorgane in stark vergrosserten Abbildungen auf schwarzem Grunle. Ful den Interricht dargestelt. Leipzig, Barth. 1846, 8. 16 p., 14 tal, cuu 78 ic. in folio. $(13 / 5$ th. $)$

$6349^{*}$ Lueder, Wanz Hermann Heinrich. Briefe über die Bestellung eines kuchengartens in Niedersachsen, besonters zwischen Ilannover, Ilameln und Eimbeck. Ilannover, Helwing. 4768. 8. ${ }^{*}$ Erl. IIl. ib. $1778-1783.3$ Theile. 8. (21/th. - Auszug: ib. 1798. 2 Theile. 8. (1 th. $)$ - Tabelle: Dresden, 1lilscher. 1805. 4. (1/t th.

$6330^{*}$ Briefe uher die Anlogung und Wartung eines Blumengartens. Ilannover, llelwing. 1777.8. - ib. $1786.8 .(3 / 2 / h$.

6351 Voltstintige Anleitung zur Wartung aller in Europa bekannten kuchengartongewächse. Aus dem Englischen neu uhersetzt und mil botanischen und praktischen Anmerkungen erläutert. Lubeck, Donatius, 1780. 8. $\left(2 \frac{5}{6} t h.\right)$

$6352 \div-$ Botanisclt-praktisclıe Lustgårtnerei, uach Anleitung der besten, neuesten brittisehen Gartenschriftsteller, mit nothigen Anmerkungen fur das Kklima in Deutschland. Leijzig, Weirlmann's Frben und Reich. 1783-1786. 4 Bánde. 4. - 1: 1783. L, 430 p. 14 tab. - II: 1784.628 p. - III: 1785.456 p. - IV: 1786. XIr, 494 p., ind. $(15 \%$ th. $)$ Bibl. Deless.

6333* Lueders, Friedrich Wilhelm Anton. Nomenclator hotanicus stirpiun Marchiae brandenlsurgicae, secundum systema Gleditselianum a staninum situ digestus. Berolini, Hesse. 1786. 8. Iv, $107 \mathrm{p}$.

$635 \xi^{*}$ Luedersdorff, $F$. Las Auftrocknen der P'lanzen füs Herbarium und die Aufhewalirung der Pilze, nach einer Methode, wodurch jenen ilure Farbe, diesen ausserdem auch ihre Gestatt erhalten wird. Berlin, Haude und Spener. 4827. 8. xvr, 150 p., 1 tab. $(1 / h$.

635:; Luedgers, Maximilian Slanislaus Joseph. De medicamentu nov-antique Tebaschir dicto. D. Goettingae 1791. $8.46 \mathrm{p}$.

6356* Luehe, F. Karl, Freiherr von der. Hymnus an Flora. Wien 1797 4. $16 \mathrm{p}$. 


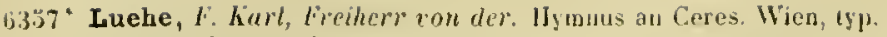
Sinzemelorf, 1800 . 4. $24 \mathrm{p}$

Poculatil conjuncta reimperssi sunt: "Wien, Degen, 1903. 8.)

63.:8* Luetke, Wredrich. Fosage antour du inondo fail par urdre de Sa Najesté I enprererar Vicolus I, sur la corvette Lé Siniaune, pendant les anuces 1826-1829 sous le commandement de Frederic Luethe. Parlie bistorique. Traduite tin rosse par $G$. Boye. Paris, typ. Didot. 1835-1836 III vull. S. - Ailas, litlographic d'ajures les dessins. uriginaux d'Alexandre Postels et du Baron (F.H. von) Kitlliz. Paris, lithographit: de Engelmann et Co. folio. 38 p., 3 mappate geogr. 51 tals.

Talublae 2. 5. 8. 4. 11. 15. 16. 19. 90. 21. 33. 34. 37. 38. 40. 41. 42. 50. physingnomiam vegetationis egregie adumbrant; repetumbur nontullae tiblulae in libro supra Nr. 32 is indicato.

(j3.;9) Luker aud Smith. Catalogue of hardy trees and slıubs, greenhouse and stove plants, herlaceons plants and fruil trees, seeds and buthous roots, sold by Lker and smith, in the City Raid, and at their nursery at Dalston. London 4783. 8.73 p. B.

$6360^{*}$ Lumnitzer, Stephan. Flora Posoniensis, exhibens plantas cirea Posonium sponte crescentes secundum systema sexuale Linnaeanum digestas. Lipsiae, Crusius. 1791. 8. vit, 557 p., 1 tal. (1 1/2 th.)

(j361" Lunan, John. Hortus Jamaicensis, or a Jotanical description (accorling to the Linnacan system) and an account of the virtues etc. of its imligenous plants hitherto known, as also of the most usefull exotics. Compiled from the best authorities, and alphabetically arranged in two volumes. Jamajea, printed at the office of the San Jago de la vega gazette. 1811. 亿. - J: vin, 538 p. - Il: $402 \mathrm{j}$. 21. 12s. 6d.) Bibl. Mus. bot. Vind. et Deless.

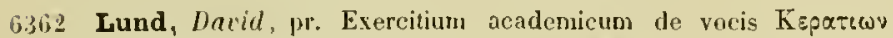
significalu, Evang. Lucae XV, 16. D. Aloano 1697. 8. 44 p. (Respondens: Niculaus Gezelius.) B.

$6363^{*}$ Lund, Johann Jakal Georg. We oleo Crotonis. I). Halae, typ. Gebauer. 1831 . 8. 39 p.

636\% Lund, Nils. Reise igjennem Nordlandene og Vestfinmarken i Sommeren 1841. Christiania, Guldberg et Dzwonkowski. 1842. 8. vi, $118 \mathrm{p}$. w.

Pirs botanica hujus itineris germabice exstat in Hornschuch, Archiv shant. Beiträge, vol. I. p. 99-133.)

$6365^{*}$ Conspectus Hymenomycetum circa Holmiam crescentium, quem supplementum Epicriseos Eliae Fries scrijsit. Christianiae, typ. Mallitg. (Dahıl.) 1845.8 . \& 118 p., praef. $(1 / 5$ (h.)

$6.36 G+$ Lund, $P$. IV. Bemarkninger over Vegetationen paa de indre horsletter al Brasilien, isaer i plantelistorisk hensecnde. Kjöbenlavn,

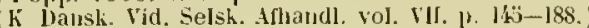

6367 Lundman, Pehr. Disputatio medica inauguralis de Junipero, quam pra gradn doctoratus summistue in medicina honorilyus et privilegiis rite et legitiose consenuendis eruditorum exanini subonittit Petrus Lundman, Wex. Suecus. Ad diem X Oet. 1727 hora locorue solitis. Ilarelerovici, apud viluam Alb. Sas et A. Olofs. 1727. 4. $16 \mathrm{p}$. w.

"Dissertatio baece a Linnaco sub operilus Murtini citatur in Flora suecica, ed. 11. p. XI, unde concludere fas est, Martioum anctorem verunj esse hujus oposculi. a) W.

(368 Lundmark, Johan Danicl. Lissertatio do usu Linnaeae medico, quam praeside $J$. G. Acrel pro gradu medico pulsico suljicil examini Johan Daniel Lundmurk. L'psaliae: 1yp. Edman. 1788.4 .10 p. w.

(3.369 Lundström, Auders. Ilandbok i Trälgàrds-Shotseln. Forrasednare Delen. Stockholm 1831. S. xIV, 253,150 , vit p. 4 tal. Ed.11: Stockholm 1833, s. xvit, 261 : 152 , xxxvi, vu p., 4 lab. Ed. III: Stockholm, tryekt hos P A. Narstedt et soner. 184t. 8. xxIIs, 490 )., I tab. ( 3 Rdr.)

6370 - Seskrifning om Frukt-Trads upprlragning af harnor, plantering föradling och varrl. Stockholm $\$ 833.8$. 1 tal). ( 16 sk.)

637 Lupin, Friedrich Freiherr von. Die Garten. Ein Wort zn seiner Zeit, mit einem Gartenroman, und einem Verzeichnisse der in 1llerfeld vorhaurdenen Pflanzen. Jlunchen, Lentner, 1820, 8. $236 \mathrm{p}$. $(13 / t$ th. $)$

6372* Lursenius, Philipp Syleester. De cortice peruviano. D. Lugluni Batavorum 1751.4.53 p., I tab. (e figura Condumim exseripta.)

6.373* Luther, Johann Melchior. De praestantia ligni Quassiae observatio. Programma. Erfordiae 1779.4.8 P.
$6375+$ Luxford, George. A Flora of the neighlyourhood of lieigate, Surrey, containing the flowering plants and ferns. Jondon, Jolun van

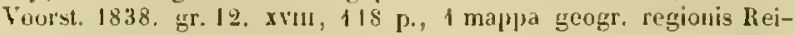
gate. $(5 s$.)

(athe Phytologist," eorlem moderante autore editus, iufra inter cliaria recensetur.

637ä* Luyken, Joham Alberl. Tentamen historiae Lichenum in genere, cui acedunt prinae lineae distributionis nuyac. W. Goettingao, typ. Dicterich. $1809.8 .102 \mathrm{~J} .(1 / 3 / \mathrm{h}$.

$6370^{*}$ Lyman Spalding. Gesclichte der Einfulırung und des Gelurauchs der Scutellaria laterillora (Scullcap) als eines Varbamings - and Heilnittels aer Wasserscheu, die durch den Biss toller Thierc erzeugt wirl, nebst Krankheitsfulleu und einer Abbildung der P'flanze. Aus den: Englischen ubersetzt nud gedrucht fur die DrugueriehandJung Dietz und Richter in Leipzig. Leipzig 1822. 8. 31 j., 1 tal, col. $(1 / 3$ th.

(Editio anglica milaj non innotuil.)

6377* Lyngbye, Ilansen Christian. Tentamen llydraphytologiae danicae, continens omnia hydrophyta cryptogama Daniae, Ilolsatiae, Faeroae, Islandiae, Groenlandiae hucusque cognita, systematice disposita, descripta et iconibus illustrata, adjectis simul speciebus norvegicis. Opus praenio ab universitate regia llavniensi ornatum, sumtu regio editum. Havniae, Gyldendal. 1819. 4. xxxll, $248 \mathrm{p.}$ 70 tal. ( 16 Relr. - Lipsiae: nigr. $16 \frac{1}{3}$ th. - col. $29 \frac{1}{3}$ th.)

$6378+$ Lyons, J. C. A practical treatise on the managenent of Orclitdoceous plants, with a monthly calendar of work to lie done, ant an alplabetical descriptive catalogue of upwards of one thrusand species; with directions for their growth and thowering. Second edition greatly enlarged. London, J. Ridgway. Dublin, llodges and Smith. 1845. 8. xv, 234 p. (10s.) Bibl. Cand.

6379 t Lyons, Israel. Fasciculus planturum circa Cantabrigiam nascentium, quae post hrijum abservatae fuere. Londini, Millar. 1763.8. Xvi, 56 p. Bibl. Webb.

\section{IM.}

$6380 \div$ Macaire-Princeps, Isaac. Nlémoire sur la coloration automnale des feuilles. Genève, Barbezat ef Delarue. 1828. 4. I5 p.

Extr. des Mum. de la soc. Je physirque et d hist. nat. te Genère, rol. IV. p. $43-53$ et Alinales de chimie et phỵsique, 15:8 p. $4100-120.3$

$6381^{\circ}$ Maccary, Ange. Sur la maladic forficulaire do murier. Paris Gabon. 1810.8 . 12 p. $(30$ c. $)$

6382 Mac Clelland, John. Report on llie plysical condition of the Assam Tea plant, with reference to geological structure, soils and climate. (Calculta 1838.) 8.

(From the Transactions of the ayric. and hortic. society of India, vol. v.)

$6383(\longrightarrow$ Papers relating to the measures adopted for introducing the cultivation of the Tea plant in India. Calculta $\$ \$ 39$. folio.

638.t Mac Donald, Alexander. A cumplete ilictionary of practical gardening, containing all the modern improvements in the art etc. A-Z. London, Kearsley. 1807. Il voll. 4. 24 tab.

6383 Macer Floridus. De viribus herbarum. Editio priuceps: Neapoli impressus per Arnoldum de Bruxellu, anno millesimo ifuadringentissimo (sic!) septuagesimo septimo (1487) die vero pona mensis Ilaji. folio minor. sine titulo, signaturis, custodibus et paginarum numeris. 45 foll. Iriginta linearun, literis rotundis. Choulant. Hain Nr. 10420. - Mediolani, Antonius Zarotus Parmensis impressi MCCCCLXXXIl die NIX Novembris. 4. Choulant. Hein Nr. 10421. tEd. s. I. et a. 4. 52 foll. (gothico charactere, cum figuris plantarum xylographicis et signatura a $-q$, sine custodibus el paginarum numeris; pagina plena habet $33-34$ lineas. Folia adsunt 52 ; folium $1^{\text {a }}$ habet inscriptionem Uacer floridus, infra hane posita est icon xylographica meuachum scribentem referens, infra quam legitur: De viribus herlsarum; folium $1^{\mathrm{b}}$ eadem icon; folium $2^{\text {is }}$ legitur: Incipit liber Macri de viribus herbarum. Et primo de Arthemisia; sequitur icon Artemisiae, et tunc: Ilerbarum quasdam dicturus ete.; folium $51^{6}$ : Una diagridii sic apta solutio fiet. Finis. folium $52^{a}$. Herbarum varias qui vis cognescere vires Hacer adest disçe: quo 
duce doctus eris. Infra icon xylographica eadem, quae in titulo; folium 52" album. Bibl. Cand. (Cardollio librum anno 1810 dono dedit bibliotherea Trevirensis; ad amussin congruit cum editione a Choulant p. 16 descripla.) - s. 1. et a. 4. Chaulant. - s. 1. et a. 4. Choulant. - Venetiis, impressus per Bernardinum V'enetum de Fitalibns. 1506. 4. 12 plag. B. et Choulant. - Veneliis 1508. 4. 12 plag. (Diversa editio a priori, licet maxime similis.) B. - Caclomi, ere et impensis $\mathbf{H}$ ich. Angier et Jo. Mace, opera rero Laur. Hostingue. 1509. 8. Choulant. - TParisiis 1511 die 29 Nlart. 8. 56 foll. - Cadomi s. a. 8. cum interpreiationibus Guillermi Gueroaldi. Rivin. Nr. 6389. † Parisiis 1522. 8. cum interpretationibus Guill, Gueroaldi. 159 foll. B. Ejusmodi editiones plures exstant, a Choultent p. Is descriptae. Bibl. Deless. et Cand. - In Banksiani exempli pagina penultima legitur: "Hacer floridus deo duce hic suan capit periodum Parisius quidem exaratus pro Nagistro Petro Baquelier Gratianopolitano anno Christi 1522.n) - * Aemilius Macer de herbarum virtutibus jan primum emaculatior, tersiorque in lucem aeditus. Praeterea Strabi Galli, poetae et theologi clarissimi, Jlorlulus vernantissimus, uterque scholiis Joannis Atrociani illustratus. Basileae (apud Joannem Fabrum Enmeum Juliacensem. MDXXYll.) \&. (8), 73 foll. absque iconibus. Bibl. univ. Lips. - *Aemilius Macer de herbarnm virtutibus, cum Joannis Atrociani commentariis longe utilissimis, et nunquam anlea impressis. Ad liaec. Strubi Galli, poetae et theologi clarissimi, Mortulus vernantissimus. Apud Friburgum Brisgoicum. (Friburgi, apud Joannem Fabrum Enmmeum Juliacensem. 1530.) 8. (4), 108 foll. Bihl. univ. Lips. - Aemilius Macer de herbarum virtutibus, cum veris figuris herbarum, graduationibus simplicium, nomenclatura el interfiretatione polonica herlarum et morborum secunclum seriem alphabeti, et expositione terminorum obscurorum contentorum in loc opere, per Simon de Lovicz. Cracoviae, ex officina Lngleriana. 1537. 8. cum ic. xylogr. i. t. Rivin. - * Macri de materia medica libri $V$. versibus conscripti. Per Janum Cornarium medicum pliysicum emendati et annotati, et nunquan antea ex toto editi. Contenta singulis libris. l et 1l. De herlyis et plantis vulgaribus. 11I. De plantis peregrinis. 111l. (I@noti) de quibusdam plantis, itemque animalium partibns, ac terrae speciebus. V. (Marbodaei de lapidilus el gemmis. Francofurti, Cliristian Egenolph. (1540.) 8. (11), 132 foll. absque iconibus. Bibl. univ. Lips. - "De herLarum virtutibus slenilii Mucri Veroneasis elegantissima poesis cum succincta admodum difficilium et obse'urorum locurum D. Geargii Pictori, Villingani Doctoris medici et apud Caes. Curiam Ensishemii archiatrum, expositione antea nunquam in lucem edita. Adhaerentilus graduum compendiosa tabula omuiumque hic contentorum fructuoso indice, et in fine eleacho, ut quiscue facile ex eo percipiat omnium morborum a summo vertice ad inos pedes medicinalem curan. Cum carmine de herba quadam exotica, cujus nomen mulier est rixosa, eodem D. Georgio Pictorio Villingano autore. Basileae, impr. per Henricum Petri. (mense Jartio 1559.) \&. (12) [oll. 199 p., ic. xylogr. i. ı. "De herbarum virutibus Atmilii Macri Veroneusis elegantissima poesis cum succincla adnodum difficilium et obscusorum locorum, D. Georgii Pictorii Villangani doctoris Nedici, et apud Caesaream curiam Ensishemii olin archiatrum, expositione, jam demum summa diligentia castigata, et in lucem edita. Adhaerentibus gracluum .. curam. Cum carmine de herba quadam exotica, cujus nomen mulier est rixosa, eodem D. Georgio Pictorio Villingano autore. Basileae (per Sebastianum Henricpetri, anno a Cluristo nato CJO $12 \mathrm{XXCI}$. 8. (8) foll., 206 p., ic. xylogr. i. t., 1 folium cum indicatione impressionis. Bibl. univ. Lips. - Hentrici Ranzovii editio duorum librorum Macri de virtutibus herbarum, de quibusdam animaliun partibus ac terrae speciebus. Itemque de medicamentis totius corporis lumani. Jan recenter ex bibliotheca sua Bredenbergensi depromptorum, quorum prior antelac non tam emendate estitit, posterior (i. o Sereni Sumonici carmen jam antea saepius impressum) vero antea ty]jis nunquam fuit expressus elc. Accessit incerti autoris Speculum medicorum, ex eadem bibliolleca iu lucem elitum. Hamburgi, exculebal Jacobus Wolfius. 1590 . 8. - Integra editio recusa: Lipsiae, apud haeredes Joannis Steinnanni. 1590. 8. Chnulant. - * Macer Flaridus de viribus herbarum una cum $11^{\top}$ alafridi Strabonis, Othonis Cremonensis et Jounnis Folcz carminibus similis argumenti, quae secundum codices manuscriplos et reteres editiones recensuit, supplevit, et adnotatioue critica instruxit Ludmg Choulant. Accedit Anonymi carmen graecum de lserbis, quod e codice Viudobonensi

Pritzel, Thes lit. bot. auxit et cum Godofredi Hermanni suisque emcndationibus edidi Julius Sillig. Lipsiae, Yoss. 1832. 8. xII, 220 p. $\left(1^{3 / 4} / h.\right)$

(Praterea mest Macri Floridi carmen in collectione medica Aldina Venetiis $15 \% 7$. folio. et particula carminis in Nicolai Murscalci Enchiridio puetarum claissimorum. Erfordiae 1502 4. - a Friderici Hoerner le demilio Macro ejusque rariore hodie opusculo de virtutibus herbarum dialrihe. Lipsiae 17át. 4. 20 p. " jam supra Xr. 104t recensui. Accuratioren Macrí editionum et codicnn manuseriptorum descriptionem cf. in novissima Chouluntiona p. $15-27$.

anglice: Hacer's Ilerlyal practysyd by Doctor Lynacro. Translated out Latin into Englishe. London, excudehat Robert Wyer. s. it. (post annum l635. 12. Farre mscr. in Bibl. Cand.

gullice: Les lieurs du livre des vertus des herbes, composé jadis en ver's latins par Macer Floride, et illustré des commentaires de $\mathrm{M}$ Guillaume Gueruult, inedecin a Caell, traduit en vers francais $M$. Lucas Tremblay, Parisien Professeur es bonnes sciences mathenaLucas Tremblay, Parisien, Professpur ès bonnes sciences ma tiques. Romen. Martin el Ilonore Mallard. 1588. 8. Bibl. Maz. wlit, eaceteris neglectis. Ad libri calcem remedium ophthalmicum cum Nicotianae descriptione et virtutibus reperitur.)

danice: cf. Ilenrik llarpestreng. Nr. 41 is.

$6386^{*}$ Macfadyen, James. The Flura of Jamaica; a description of the plants of that lsland, arranged according to the natural orders. With all appendix containing an enumeration of the genera according to the Linnean system, and an essiy on the geographical distribution of the species. Volumen 1: Ramunculaceae-Leguminosae. London, Longman. 1837. 8. x11, 351 p. ( 15 s.)

6387 Macgillivray, William. A Naund of botany: comprising vegetalole anatomy and physiology; or an account of the structure and functions of plants; with an outline of the Linnaean and natural systems, and a glossary of terms and index; with wood-cuts and 214 engraved figures. London 1840. 8. (4s.6d.)

liem autor compendia a Hilliam Withering el Jomes Edward Smith seripta novis editionibus curarit, et Achillis Richard "Nouveaux elèmens de botanúue anglice rirtit.

6388* Machacka, Larl Borromaeus. Conspectus geognostico-botanicus circuli Boleslaviensis in Buhemia. D. Vindobonae, typ. Ueberreuter. 1843. $8.43 \mathrm{p}$.

6389 Mac Intosh, E. The new and improved practical gardener and modern horticulturist. Lonelon 1841.8 . (1) is.

$6390+$ Mackay, Jomes Tounsend. A calalogue of the plants found in lreland, with descriptions of some of the rarer sorls. Part I. Dublin, R. Graisherry. 1825. 4. $98 \mathrm{p}$.

$6391^{*}$ Flora hibernica, comprising the flowering plants, ferns, Characeae, Iusci, Hepaticae, Jichenes and Algae of Ireland, arranged according to the natural system, with a Synopsis of the genera accordiug to the Linnaean system. Dublin, Willian Curry, Inn and Co. 1836.8 . xxxiv, 354,279 p. (16s.)

6392* Mackenzie, George Stevarl. Travels in the island of lceland fluring the summer of the year 1810 . Ed. II. Edinburgh, Constable et Co. 1812. 4. xv, $491 \mathrm{p} ., 15$ lab. (3l. $3 s$.)

6393+ Mac Mahon, Bernard. A catalogue of american seeds sold by B. M Makon, seedsman. Philadel] hlia, typ. Graves. 1806. S. 30 p.

639.* Mac Nah, Hilliam. A treatise on the propagation, cultivation and general treaiment of Capeheaths, in a climate where they require protection during the wintermonths. Edinlsurgh, Thomas Clark. 1832.8. 43 p., I lab. col

$6393+$ Macreight, D. C. Manual of british botany; in which the orders and genera are arranged and described according to the natural srstem of DeCandolle; with a series of andrical tables for the assistance of the sludent in the examination of the plants indigenous to, or commonly cultivated in Great Brilain. London, Churchill. 1837. 8. xvil, 296 p. (7s. 6d.) - London 18.44. 8.

$6396+$ Macvicar, John. Observations on the germination of the Filices. Edinburgh, typ. Neill. 1824. 4.8 j., 1 tab. col.

(Fron the Transactions of the Royal society of Edinhurgh.

$6397+$ Maddock, James. The florist's directory; a treatise on the culture of flowers; 10 which is added a supplementary dissertation on soils, manures etc. A new edition, improved with notes and an appendix on the culture of the Dahlia, Chrysanthemum etc. London, llarding. 1822. 8. xxxII, 260 p., 9 tal). col. (nigr. 12s. - col. 1l.)

germanice: Anleitung fur Blumenfreunde, oder Alhaudlung von der hultur der vorzuglichsten Blumen. Ans dem Englischen von August Withelm Manteuffel. Berlin, llimburg. 1798. 8.6 tab. col (3th.)

6398 Madiot. De la culture du mùrier, reduite aux moyens les plus simples el les plus surs. Lyon et Paris, Périsse. 1826. 8. 32 p., 1 lab. 
6399 Madiot. Etule, culure el propagation du múricr en France. Iyon Targo. 1827.8 .75 [. $(2$ fr. $50 \mathrm{c}$.)

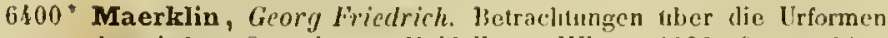
der niederu Organisuen. Ileidelberg, Winter. 1823. 8. sis, $83 \mathrm{p}$. $(1 / 2$ th. $)$

6401' Maerter, Franz Joseph. Verzciclıniss der östrrichiscben Gewáclıso mil kurz gefasste'ı Ammerkungen aus der Natur- und okonomischen fieschichte derselben. Erstes Stuck. Wien, Ilartl. 1780. 8. $115 \mathrm{p}$.

6402* Verzeichniss der ostreichischen Báume, Stauden und Buschgewtichse, mil Anmerkungen aus der Natur-und okonomischen Geschichte derselben. Wien, Gerold. 1781. 8. $212 \mathrm{p} .-$ "Dritte (vermelirte) Aullage: Wien, Staliel et Co. $1796.8 .466 \mathrm{p}$. pracf., ind. $(12 / 3, h$.

6403*- Vorstellung eines okonomiselıen Gartens nach den Grundsâtzen der angewandten Botanik. Wien; lirauss. 1782. 8. $114 \mathrm{p} .$, pract. $(1 / 4, h$. $)$

$6404^{*}$. lundamenta et termini holanici, congesta secundum methodum it al ducturn Linnaei in usum praelectionum theoreticarum. Bruxellis, typ. Lemaire. 1789.8. 130 p., 1 tah. $(2 / 3 / h$.

$0403^{*}$ Naturgeschichte der Batateu, süssen orler spanischen Kartofeln. Nebst Bemerkungen uut Versuchen irber die Kultur dersclben. Wien, Schaumburg. 1797. 8. 52 p., 1 tab. col. $(5 / 12$ lh. $)$

6406 Verzeichniss der in dor grossen Baumschule zu llerrenals bei Wien vorhanduen Tafelobstsorten. Wien, Sclaumburg. 1805. S. $(1 / h$.

$6 f_{0} 7^{*}$ Charakteristik und Kultur des Mahaleb-oder ParfümirKirschenbaums. Wien und Triest, Geistinger. 1813. 8 . xxtv, $226 p$. $\left(1 \frac{1}{3} / h.\right)$

6408t Magaud de Beaufort, Mademoiselle. Cours de botanique pour les Danes, fait à l'Athéuée par Mlademoiselle llagutd de Beatifort. (Paris, ty]). Béthune et I'lou. 1844.) $8.8 \mathrm{p}$.

$6409+$ Elémens des sciences physiques ot naturelles a l'usage des écoles primaires et des pensionats. Botanique. Paris, Tresse. 1846. 8. Iv, 187 p. Bibl. Juss.

6410* Magnenus, Johannes Chrysostomus. Exercitationes de Tabaco. Ticini regii, apud Mlagrium. 1648, 4. 192 p., praef. - +(Papiae) 1658. 12.222 p., praef. - ${ }^{*}$ Ed. ultima repurgata. Jagae Comitis, typ. Vlacq. 165S. 12. 264 p. - TAnstelodami, Boom. 1669. 12 (non differt.)

6411* —_ De Manna lilser singularis. Ticini regii, apud Magrium. 1648. S. s. - † (Papiae) 1658. 12. 100 p., praef. - ${ }^{*}$ Ed ullima repurgata. Hagae Comitis, typ. Vlacq. 1658. 12. $116 \mathrm{p}$. praef, int.

6412* Magnien et Deu. Dictionnaire des productions de la nature et de l'art, qui font l'objet du commerce de la France. ete. Paris, Bailleul. 4809 . Il voll. 8. - I: A-G. xxtr, 434 p. - Il: 1. 2. II-Z. $867 \mathrm{p}$.

6413 Magnol, Pierre. Bolanicun Monspeliense, sive plantarum circa

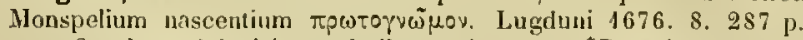
cum figuris aeri incisis et tabulis aeneis. B. - "Botanicum MIonspeliense, sive plantarum circa Honspelium nascentium index, in quo plantarum nomiua meliora seliguntur; loca, in quibus plantae sponte adolescunt, tum a prioribus botanicis, tum ab autore observata indicantur et praecipue facultates traduutur. Adduntur variarum plantarum descriptiones et icones. Cum appendice, quae plantas de novo repertas contiuet et errata emendat. Monspelii, Mlarret. (ex officina Danielis Pech.) 1686. 8. 309 p., praef., tab. Bibl. Mus. bot. Vind.

(Haec est, teste Dryandro, eadem rditio ac originaria Luydunensis, Linnaeo, Seguiero, Hallero, Fandollio ignota, mihi nullibi obvia; novus praefixus est titulus et addita appendix a p. $289-308$.)

$6414^{*}$ - Prodromus historiae generalis plantarum, in quo familiae plantarum per tabulas disponuntur. Monspelii, typ. Peclı. $\mathbf{1 6 8 9}$. 8. 79 p., praef., ind. Bibl. Mus. bot. vind.

$6415^{*} \longrightarrow$ Hortus regius Monspeliensis, sive catalogus plantarum, quae in horto regio Monspeliensi demonstrantur. Accesserunt novae plurimarum plantarum cum suis iconibus descriptiones. Virtutes etiam juxta neotericorum principia breviter explicantur. Monspelii, apud Honoratum Pech. 1697. 8. 209 n., praef., (.21) tab.
6416* Magnol, Pierre. Novus cbaracter plantarum, in duos tractatus divisus. 1. De berbis el sultruticibus, in tres libros divisus. II. Do fruticibus et arboribus, in tres etiam libros divisus. Opus rosthumum ab) autoris filio (Antoine Magnol), in acadrmia Monspeliensi Professore regio, in lucen editum. Monspelii, apuel viduam llonorati Pecli. 1720. 4.340 p., praef.

6417 Mahieu, J. $N$. Élémens de phytologie, explipués au collège do Châlons-sur-Narue et au cours public rle cetle ville. Châlons-surMarne, Bonicz-Lambert. 1833 . 8. 15\% $3 /$ plag., 2 tab.

6it8 Maier, Michael. Tractatus de volucri irborea absque patre el matre, in insulis Orcadum, forma anserculorum proveniente, seu de ortu miraculoso potius quam naturali vegetabilium, animalium, lıomisum el supranalusalium quorundam. Francofurti 1619,8 180 p. B.

6419" Majewski, Erazm. O Grzybach Jadowitych Krajowych. D. Kráków 1\$39. $8.56 \mathrm{p}$.

6420" Main, James. Illustrations of vegetable physiology, practically applied to the cultivation of the garden, the field and the forest, consisting of original obscrvations collected during an experience of fiftly years. London, W. Orr. 1833.8. MII!, 328 p., ic. xỵlogr. i. 1 - Ed. II: ib. 1835. 8. (non differt.)

6421 Popular botany; explanatory of the structure and habits of plants, wilh a familiar explanation of their arrangement. Loudon Orr and Co. 1836.8 .27 tab., ic. xylogr. i. t. (4s. 6d. - col. 7 s.)

6422 Fruit trees: a lsand-book for cultivators. London 1844 18. (2s.)

6423 The kitchen garden: a land-book for cultivators. London 18:1. 18. (2s.)

642' - Flowers: a lrand-book for cuitivitors. London 1844 18. (2s.)

6425 The planter's and pruner's assistant; giving every possible instruction for the planing, rearing, pruning and gencral management of every kind of forest trees; with practical hints on the choice of soil, situition etc. illustrated with numcrous explana1ory plates. London 1839. 12.

6426 Hortus diaetetica; or brief popular descriptions and practical directions for the cultivation of all plants useful as food to man, native as well as exotic. London, Longman. 1845. 18. 180 p. $(3 s$.

6127* Major, Johann Daniel. Dissertatio botanica de planta monstrosa Gottorpiensi mensis Junii anni 1665 , ubi quacdam de coalescentia stirpium et circulatione succi nutritii per easdem proferuntur, cum figuris aeri incisis et additamentis de simili materia. D. Scbleswigae, apud Jobannem Iholwein. 1665. 4. (16) foll., 2 tab.

6428 Programma ad rei lucrbariae cupillos. Accesserunt Theophili Kentmanni tabulae, locum et tempus colligendarum stirpium exprimentes, cum indice alphabetico Johunnis Danielis.Ifujoris Kilonii 1667. $12 \mathrm{obl}$. Rivin.

G12 29* Amerikanische bei deı Schlosse Gottorf im Monat August und Septemher 1668 blubende Aloc, (Schleswig 1668.) 4. 30 p. - "impr. cum 1 aldschmiedt Gründliche Bcschreibung der Aloe insgemein, Kiel $1705.4 .36 \mathrm{p}$

6430 , pr. Dissertatio de Mlyrrha, Locustis, jejunio Christi, Christo medico, lunaticis, paralyticis et sale. Kïlonii $1668.4 .40 \mathrm{p}$ (Respondens: Johann Friedrich Moller.) B.

6431 Memoria initiati horti medici. Kilonii 1669. folio. н.

6432 Catalogus plantarum, quarum mentio fit in Werner Rolfink libro sccundo de vegetabilibus in gratiam praelectionum. Kolonii 1673.4. H.

6\$33 Maironi da Ponte, Giovanni. Osservazioni sul dipartimento del Seno. Bergamo 4803.8. DC.

6434 Maistre, Mallhieu le. Le procès du Melon, a Mr. du Laurens, conseiller et premier médecin du Roy. Paris, Matthieu le Maistre.1607 4. Bibl, Reg. Paris. et $\mathbf{S}$.

$6435^{*}$ Majus, Heinrich. De plantis et arboribus. D. Marpurgi Cattorum. typ. Kürsner. 1691. 4. 16 p.

6436 Majus, Johann Heinrich. Dissertatio inauguralis de Manıa, duplici ex scripturae et naturae libro occasione. Giessae 1706. 4. S. 
5'37 Malacarne, Clerc. Giuseppe. Catalogo delle specie vegetabili, che si coltivano nel giardiıo della scuola botanica del Liceo del dhartimento della Mella. Brescia 1810.4. DC.

6ł38* Malacarne, Vincenzo. Di un lungo della classe de' licoperdi formato a guisa di tempietto clie nasce particolarmente nel territorio Pavese a San Zenone nou descritto fin ora ta verun botanico italiano nè franzese Lezione academica. Verona, typ. Mainardi. 1814. 4. 15 p., Itab.

(Inserito nel tomo Nitl. della societd italiana delle scienze.)

6/39 MaIcolm, William. A catalogue of hot-house and green-house plants, fruit and forest trees, llowering shrubs, herbaceous plants, tree and kitchen garden seeds, jerennial and annual llower seeds, by Hilliam LIJalcolm, Nurseryman near Kennington turnpike, Surry. Londen 1774. 8.71 p. B.

614.0* Malherbe, Alfred. Notice sur juelques especes de clienes et spécialement sur le chene liège (Quercus Suber). Metz, Verronnais. 1839. 8.40 p.

$61.1^{*}$ —— Notice sur le Papyrus. Netz, Lamort. $4840.8 .7 \mathrm{p}$.

6\$4.2 Mallet, Rolierl Yavier. Beauté do la nature, ou fleurimanie raisonnée, concernant l'art de cultiver les oeillets, ainsi quo les fleurs du premier et second ordre, servant dornemens pour les parterres, avec une dissertation sur les arbrisseaux. Paris 1775.12 .274 p. B.

$61\{3+$ Malo, Charles. Guirlande des fleurs, ou origine et histuire des plas jolies fleurs, qu'on cultive en France. Paris 18 15. 8. 16 tal. col. ( 6 fr.)

644 - Ilistoire des tulipes. Paris 1821. 8. (6 $\mathrm{fr}$.)

$6145+$ Histoire des roses, ornée de 19 planches en couleur, dessinees par P. Bessu. Paris, Janet. s. a. 12. Iv, 240 p., 12 tab. col.

6446 Malouin, Paul Jacques. Chynie médicinile, contenant la manière de préprarer les remèdes les plus usités. Paris 1734. 12. - Traité de chymie médicinale. Paris 1750.11 voll. $12 . \mathrm{H}$. germanice: Altenburg, Richtes: $176 \mathrm{~s}$. 2 Theile. 8.

(Toni primi pars tertia tota de plintis est.)

$647^{\circ}$ Malpighi, Marcello. Murcelli Mulpighii, philosophi et medici Bononiensis, e regia sncietate, Anatome plantarum. Cui subjungitur appendix, iteratas et auctas ejusdem auloris de ovo incubato observationes continens. Regiae societati Londini ad scientian vaturalem promovendam institutae dicata. Londini, impensis Johannis Martyn. 1675 . folio. 15, 82, 20 p., 54, 7 tals. - * Anatomes plantarum pars altera. ib. 1679 . folio. 93 p., 39 tal.

$64^{4} 8^{*}$ - Opera onmia, seu thesaurus locupletissimas botanicomedico-anatomicus, 24 tractatas complectens et in doos tomos distributus. Edlitio novissina. Lugdoni Batavorum, apud Petrum van Jer Aa. 1687. II roll. 4. - I: Anatome plantarum. 170 p., ind, 142 icones, - Il: Medico-anatomica continens. 379 p., ind., icones. - TOpera unnia. Londini, apul Kobertum Schot. 1686. 11 voll. folio. cum tabulis aeneis. I: 78,35 p. - II: $72,44,20,144 \mathrm{p}$

$649+\longrightarrow$ Opera posthuma, figuris aeneis illustrata, quilus praefixa est ejusden vita a seipso scripta. Londini, Churehill. 4697. folio. $110,187,10$ p. , 19 tab., efligies Malpighi. — * Opera postbuna. In quibus excellentissimi autoris vita continetur, ac pleraque, quae al ipso priss seripta aut inventa sunt confirmantur et ab adversariorum objectionibus vindicantur. Supplententa necessaria et praefationem addiclit, innumerisque in locis emendavit Petrus Regis Jonspeliensis. Editio ultima figuris aeneis illustrata, priori louge praeferenda. Anstelodami, apud Georgium Gallet. 1698. 4. 387 p., 20 tab. - *Amstelodami, apud Donatum Donali. 1700. 4. (non differt.) - Opera posthuma, cura Fauslini Gavinelli cdita, in quibus continentur: De muscorum seminibus observationes; responsiones objectionibus circa plantas Johannis Baptstae Triumfelli; responsio objectionibus auctoris anonyni circa folia seminalia; alia responsio at impugnationes Johannis Borelli. Veneliis, Andreas Poletıs. 1698. folio. S. - *ib. 1743. folio (non difiert.) - Amsterdam 1755. 4. H. (c)n rient de retrouver dans une maison de Grevaleore une grande quantité de manuscrite de Malmighi. Mr. Gueluno Atui les al remis en lumiere. Ces manuscrits forment lib gros volumes; ils sont relatifs a l'anatumie et physiologie de 1 homme et a celle des plantes; toute cotte partie est iliédite. on y a trouvé aussi les manuscrils de ses ouvrages. Ce tout a élé acquis par le Pape Gregoire $11 \%$ et deposé daus la bibliotherrue de bologne.n Reparateur da par le Temps du 40 Juin 483 .)

64.30* Malthè, Golllieb Friedrich. De generatione mascorum. D. Goettingae, typ. Grape. 1787. $8.32 \mathrm{p}$
6451* Maly, Joseph Karl. De analogis plantarum affinium viribus. D. Pragae, typ. Sommer. 1823.8.50 p., praef.

$6452^{*}$ - Systematische Beschreibang der gebranchlichsten in Jeutsehland willwachsendeı oder kultivirten Arzneigewächse, zum Gebranche liur studirende Aerzte, Wundarzte und Apotheker. Gratz, Ludewiy. $1837.8 . x, 134,8$ p. $(5 / 6$ th. $)$

$6453^{*}$ - Hora styriaca, ader nach natörlichen Familien georlnete Uebersicht der in Ilerzogthum Steyermark wildwachsenden und allgemein gebauten sichthar blahenden Gewáchse and Farreo, mit Angabo der Standorte, der Bluteceit und der Dauer. Gratz, Ludowig. $183 \mathrm{~S}$. gr. $12 . \mathrm{xVI}, 159 \mathrm{p},(2 / 3 \mathrm{lh}$. $)$

64.54* - Anleitung zar Bestimmung der Gattongen der in Deutschland wildwachsenten und allgemein kultivirten PHlanzen, nach der sehr leichten und sichern aualytischen Methorle. Zum Geliraucho för die Besitzer von Koch's und Kitlel's Taschenbüchern der deutschen Flora bearbeitet. Wion, Braunuller und Seidel. 1846. gr. 12. x], $164 \mathrm{p} .(2 / 3, t h$.

6455* Mammatt, Edward. A collection of geological facts and practical observations intended to elucidate the formation of the Ashby-Coalfield. Ashby-de-la-Zouch, Luruley. 1836. 4. max. xII, 101 p., 133 tab. col. (2l.)

(Tabulae 102 sistunt vegetabilia petrificata.)

6.\$56 Manardus, Johannes. Epistolarom medicinaliun libri $\mathrm{XX}$, ad autographum collati et editi. Ejusdem in Mesue simplicia et composita amnotationes et censurao. Busileae, apud Wichael Isingrin. 1540. folio. (10) foll., 603 p. - ib. 4549. folio. Rivin. - Venetiis 1542. folio, 407 p. praeter annotationes in Mesue. B.

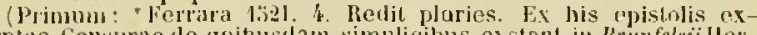
cerptie Censurae dle quitubram simplicibus exstant in lirunfelsiillerharii tono secundo, ed. 1531 . append. p. 32-13. ed. 1336. p. 128-139.

6457 Mander, Carolus van. Lauwerkrantz voor allo Lielhebers des Snuftolsaks. (Laurea corona, omnibus julveris Nicotiani auatorilus propria.) Ilafniae 6665.4 . Bruennich.

6458* Mandirola, Agostino. Il giarlino de' fiori diviso in tre libri. ete Ferrara, typ. Gironi. 4650 . 12. $142 \mathrm{j}$., pract.

6159 Manuale de' giardinieri diviso in tre libri, nel l. il morlo di conoscere e collivare li fiori di bulhi piu rari; nel ll. la cognizione e coltara delli fiori di radiche; nel Ill. il modo di moltiplicare, coltivare e conservare gli agrumi. Vicenza, per Christoforo Rosio. 1652. 12. Rivin. (Redit pluries.)

* germanice: Ber neuaufgesetzte Blamengarten. (Erste deulsche Uebersetzung.) Nurnberg, Typ. Miltenberger. 1670. 12. 2'f6 p.; praef. - ${ }^{*}$ Ed. II : lialianischer Milumen - Imul Pomerantzen-Garten, furgewesen in cincu Gencral-Vorberich und drei untersehiedenen special-Buchern, zum anderumal deutsch aafgelegt und mit Anmerhangen unt schonen Figuren ausgezierce. Nurnberg, typ. Kinorz. 1679

12. 410 p., Mrdef., tab. Paris, chez Sangruin. 1765.8 . LX,

6460 Mandruzzato, Salvalor. Del facolta febbrifuga e delle altro virtu medicinali del Santonicu, Artemisia coerulescens L. Venezia 1800.8

6161* (Manetti, Ciuseppe.) Catalogus plantarum cacsarei regii liorti prope Mlodiciam atl ammu 1842 . Mediolani, typis regiis. 1842. $\mathrm{s}$. x, 107 p. - +5upplementum prinum ad annum 4844. ib. 1844. 8. $36 \mathrm{p}$.

6462* Manetti, Savcrio. Viridarium llorentinum, sive conspectus plantarum, quace floruerunt et semina dederunt hoc anno 1750 in horto caesareo Florentino, societatis Lotanicae custodiae commisso, cum constitutione trium novorum generun. Florentiae, Paperini. 1751. 8. $\mathrm{xy}, 109 \mathrm{p}$.

(Adjocta est appendic 32 paginarum: Spicilegium plantas con-

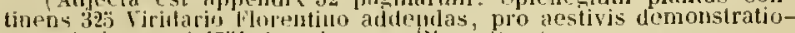
nibus hujus anni 1731 descriptas et dispositas.

$6463+$ Caroli Limaei Regnum regetabile juxta systema naturae in classes, orlines et genera ah corlem constitutum, societalis physico-botanicae Florentinae usui accommodatum ac recusum curante Xaverio $\mathbf{l l}$ ancti. Florentiac, typ. Viviani. 1756. 8. 123 p., 2 tal..

$6164^{*}$ D Delle specie diverse di frumento di pane siccome della panizzazione Memoria. Firenze, typ. Moucke. 1765. 4. 237 p. Bibl. Cand. et univ. Lips.

64.63 Manger, II. L. Vollständige Anleitung zu einer syslematischen Pomologie, wodureh die genaueste Kenntniss von der Nator, Beschalfenheit und den unterschiedenen Merkmalen aller Obstarten $23=$ 
rrlatten werden kann. I,eiprig, $1780-1783.2$ Thrile. folio. I: 1780. Aeplel. 112 p., 1 tab. - 11: 1783. Bunen. 192 p., 1 tab. B.

6 \&66 Manget, Jean Jacques. Bibliotheca pharmacentico-medica, seu thesaurus refertissimus malerío medican. Gencvae 1703. II voll. fulio, $\mathrm{H}$.

$6: 67 *$ Mangles, James. The floral calendar, monthly and daily. With miscellaneous details relative to plants and flowers, gardens and greenhouses, horticulture and hotany, aviaries ele. Iondon, printed by Calder for private distribution. 1839. 8. xx, 156 p., tab. col. (Cibellus nitirlissimus!)

6468 MangoId, Johann haspar. Praeliminaria de conciliandis methodis Tournefortii, Riviui, Ilermanni et Raji. Basileae 1716.4. H.

6.69 MangoId, Justus Jeinrich. De Marma. Riuteln 1725. \&. н.

$6+70^{*}$ Manitius, Samuel Gotthilf. De actatibus Zeduariae relatio, in qua Zcdoariae fructificatio, praeparata ac vires traduntur, caque quac ad plantarum cognitionem requirantur, una cum simplicium qualitatibus, variisque curiosis breviler exponuntur. Dresdae, Kettner. 1691. $1216 \mathrm{~s}$.

6:71* Mann, Johann Golllieb. Deutschlands gefalurlichste Giftpfianzen mil erlauterndem Texte, worin ihre Wirkungsart und die wirksamsten llulfsmittel bei Vergifungen angegrben sind, nebst einer leichtfasslichen Anleitung zur Pfanzenkunde. Nach der Natur gezeichnet. Stuttgart, Brodhag. 1529. folio. 30 p., 92 tab. col., 2 tab. nigr. $(4 \%$ th.

$6972-$ Die ausländischen Arzneipflanen. Lieferung $1-16$ Stuttgart, Brodhag $1830-1833$. Solio. 96 foll., 96 tab. col. (21 $1 / 3$ th.

$6173^{*}$ Mann, Wenseslaus. Lichenum in Bohemia dispositio succinctaque descriptio. D. Praczae, typ. Sommer. (Euders.) 1820. 8. 110 p. $(\% / 3, h$.

$6471^{*}$ Mannhardt, Johannes. Jobariae parietinae seu Lichenis parietini Linn. analysis chemica denuo instiluta. D. Kiliae 1818 . 4. $24 \mathrm{p}$.

$6+7 a ̈$ Mansky, Gothelf Sebastian. Der Feld- Wiesen- Mnl Gartenbau, so wie auch die Frucht- und Forstbaumzuclat Sudpreussens, oder uber die Kultur und Nutzung aller in dieser Provinz forkommenden Gewảchse. Posen, Kühn. 1805. 8.279 p. $(5 / 6 t h$.

6ł76 Mânsson, Arwoidh. En mycket nyttig Örtabouk om the lierlige Örter, som uthi thella höshberömda honunga lijke vărt kàra Fäderueslandh Sverige åhrligen wảxa, såsom ock om någhra uthlandska Örter, huruledes the emot sjukdomar brukas skola, alf Latinska och Tyska Bocker pả Svenska afsatt, med Petri Jonae Wexionensis företal. Calmar 162S. 8. 352 p. - Stocklıoln 1642. 8. 268 p. - Upsala 1643. 8. 298 p. - Linkoping 1650.5 .352 p.Stockholm 1654.8. 268 p. B. et w.

("Arvidi IIanssonii kydaholmensis Örlaboh vires tantum herharum aftert: libellum heic enumeravi, quoliam in catalogis librorum butanicorum citatur' (ab Hallero et Sequiero autoris nemine in "lvilus

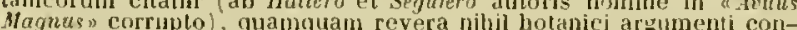

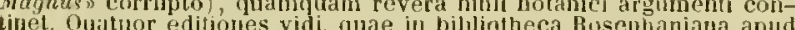
tinet. Quatuor editones vidi, quae in billiotheca Rosenhaniana apud regram academiam scientiarum Jolmiensem adsunt. Editionihus an-

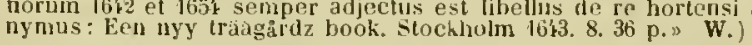

$6.177^{*}$ Mantell, Gideon Algernon. The fossils of the south downs; or illustrations of the geology of Sussex. London, Lupton Relfe, 13, Cornhill. 1822. 4. xv, 327 p., 12 tab. (3l. 3s. - col. 6l. 6s.)

6475 - Hlustrations of the geulogy of Sussex. London IS27. 4. $21 \mathrm{tab},(2 l, 15 \mathrm{~s}$.

6479 The medals of creation, or first lessons in geology and in the study of organic remains, with coloured plates and woodcuts. London, H. Boln. 1844 . Il voll, S. (1/. Is.)

germanice: Die Denkmunzen der Schopfung, oder erster Unterricht in der Geologie und in dem Studium der organischen Reste. Deutsch bearbeitet yon Karl Friedrich Alexander Harlmann. Freiberg, Engelhardt. $18 \%$ - 1816 . 2 Bände. $8.58 \%$ plag., 79 tab. $(\$ 1 / \mathrm{s}$ ih.)

6480 Manteuffel, August Wilhelm. Dsr deutsche Obst-und Fruchtgartner. Berlin, Maurer. 1813.8 .168 p., 3 taly. $(3 / 4$ th.

6 181 Manteuffel, IIans Ernst Freiherr von. Anwoisung zum Hugelpflanzen der Nadelhölzer. Leipzig, Arnold. 1846.8.6\% plag., 1 tab. $(3 / 5$ th.

64.82 Maplet, Johu. A greene forest, or a naturall lustorie. London 1567. 8. $111 \mathrm{p}$. B.

$6483^{*}$ Mappes, J. M. Festreden gelialten im naturgeschichtichen Museum zu Frankfurt a/Al. (Beitrag zur Feier der 95jahrigen Stiftung der Senckenbergschen naturforschenden Gesellschaft am 22. Noventıre 1842.) l'rankfurt a/M., Sauerlánder. 1842. S. VII, 186 p. $(2 / 3$ lh. $)$

648:" Mappus, Marcus. Catalıgus plantarum horti acadenici Aryentinetsis in usum rei herbariae studiosorum. Irgentorati, typ. Spoor 1691. 12. 150 p., praef.

6 i8:" - De potu Thée. D. Argentorati 1691.4.52 p. (Respondens: Johunn Iechieler.)

$6: 86^{*} \longrightarrow$ De potu Café. D. Argentorali 1693. 4. 66 p. (Respondeus: Daniel 11 'encker.)

$6187^{*}-1$ )e potu Chocolatav. D. Argentorati 1695. 4. 62 p (Respondens: Johaun Christoph Juth.)

(llac rissertationes necurrut eliain ho titulo generali practixn: Dissertationes mplicae tres, de receptis hodie etian in Europa potus calidi generibus Thée, Cale, Chocolata. Argentorati 169:3. \&)

$6.58 *$ De Rosa de .lericho vulgo dicta. 1). Aryenturati, týp Spoor. 1700. 4. 16 p. (Respondens: August Friedrich Mergiletas.)

$6489^{*}$ Historia plantarum alsaticarum posthuma, opera el studio Johonnis Christimi Ehrmann. Argentorati, Dulsccker. (Amstelodami, Mortier.) 1742.4. 335 p., praef., ind., 7 tab.

6.90* Marabelli, Francesco. De Zea Mlays planta analytica clispuisitio. Papiae, Comini. 1793. S. 71 1) - Lipsiae, Müller. 1794. S. (1/t th.)

6491 * Maranta, Bartolommeo. Methodi cognoserndorum simplicium libri Ill. Cum indice copioso. Venetiis, ex offeina Erasn. Vincent. Valgrisii. 1559. 4. (18) foll. . 296 p. Bibl, E. M., Goett., Cand.

$6492+$ (-) Novum herbarium, sive metlodus enguosenndorum omnium simplicium non solum purgantium sed quoque adstringenlium et variantium. Opus exactum ab auctoribus omnilus quos in re hembaria ad lıune usque diem scripserunt et in unum volumen redactum ad sturliosorum commoditatem. Venetiis 1571. 4. (18) foll., 296 p. Bibl. Juss.

(Iloc titulo anonymo iterum praeclarmm Barantae opus a Mothodi cognoscendorum simpliciom libri lll." proditt; eadm psse vidotur impressio, sed utriusque exemplaria ub videre non fuit ocrasio. Paginarum numesus stricte idem est.)

$6493^{*}$ Della theriaca e del mithridato. Vinegia 1572. 4.

* Intine: Bartholomaei Marantae libri li. de theriaca et mithridatio. ex italica sermone latinae civilati donati a Jonchim ramerarius. Francofurti a/M., apud haterades Christiani Egenolphi. 1576. 8.

(De Haranta egregium judicium Sprengelii. llist. rei herb. I. p. $3.5-316$.

$6494^{*}$ Maratti, Giovanni Francesco. Descriptio de vera florun existentia, vegetatione et forma in plantis dorsiferis sive epiplyyllospermis, vulgo Capillaribus. Romae, Salvioni. 1760. 8. 19 p., 1 tab. -Josephi Francisci Muratti Liber rarissimus de vera flurun existentia in plantis dorsiferis. Recudi curavil, commentatione auxit de filicum propagatione Joham Peter IIuperz. Goeltingae, Seliroeder. 1798. 8. 23,26 p., 1 tals.

(Ad curiosi lihelli (Spreng. IJist. I. 361.) historiam couferenda est: " Bolanophili Romani ad Clar. Virum joannem Christophorum Amadutium Ariminensen lepistola, qua clarissimum rirum Joannem Franciscan Marallium ab Adansonii Galli censuris vindicat. Rumac, ex arllibus meis, Kalend. Ocl. Iibs. 12. Esslat in Jaralli florie Romanae pracfatione.)

$6190^{*}$ Plantarum Romuleae et Saturnjae in agro Romano existentium specificas notas describit inventor. Romae, typ. Archangeli Casaletti. $1779.8,22$ p., 2 tab.

$6496 \div$ Flora Romana. Opus postlıumum nunc primum in lucem editum (ediclit Hauritius Benedictus Otiveri). Ronac, typ. Joscpl Salviucci. 1892. If voll. S. - I: Classis I-Xill. xxxit, 415 p. 11: Classis XIV-XTJY. 543 p. (Scudi 2. 55.)

6497* Maravigna, Carmelo. Saggio di una Flora medica catanese, ossia catalogo delle principale piante medicinali che spontaneamente crescono in Calania e ne' suoi contorni con la indicazione delle loro mediche azioni. Catania, typ. Pappalardo. $1829.4 .104 \mathrm{p} ., 4$ tab. (Estratto degli Atti della Accademia Gioenia.)

6 198 Marcandier. Traité du chanve. Paris, Nyon. 1758. 12. - Ed. II: Paris, André. 1795. 12. a.

anglice: A treatise ou Hemp, translated from the french. Londor 1766. 8.87 p. B.

* germanice: Abhandlung vom Hanfe. llamburger Magazin XXII $563-637.8$. - Freistadt 1763.8 . H.

6:99 Marcellus, Arilus, alias Angelus. Hortus plantarum l'atavinus. Patavii 1660. 8. Linn.

$6500+$ (Marcet, Mistriss Jane.) Conversations on vegetable physiologr: compreheurling the elements of botany, with their application to 
agriculture. By the author of Conversation on Chemistry, Natural philusophy etc. In two volumes. London, Longman. 1829. Il voll. 8. - I: xII, 286 p. - II: xII, 304 p. - Ed. II : ib. 1834.8.(12s.) tEd. Ill: London, Longman. 1839 . \&. xxvili, 4 \$9 p. 4 tab. * gallice: Conversations sur la physiologio végetale, comprenant les èlémens de la hotinique et leur application a lagriculure, par lauteur des conversations sur la chimie etc. Traduit do l'anglais par

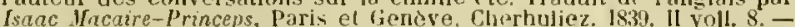

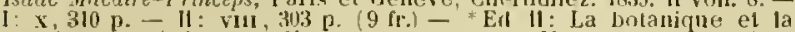
physiologie vécétale en 2 k conversationss; nar Madame Varcet Traduit de Panglais par Isaac Jacaire. Paris, Cherbuliez. 183'. II vuli. 8 . (9 fr.)

* germanice: Unterhaltungen uber die Physiolngie dor Pllanzenwelt. Enthaltend die Elemrnte der Botanik, unil din Anwendung dersethen

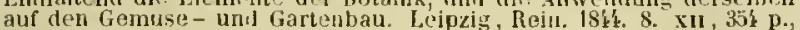
itab. $\left(11 \frac{2}{2} t h\right.$.)

6ว̈0l Maxchand, Eugène. Faits pour servir à l'histoire chimique do la Gratiole. Paris, typ. Bailly. 18: 5 5. 8. 8 p.

$6302+$ Marchand, $L$. Do radicibus el vasis plantarum, ou considérations anatomico-physiologiques sur tes plantes, ot principalement sur leurs raciues et leu's vaisseaux. Utreclat, van Paddenbury et Co. 1830. 8. vi, 138 p., I tah. Bibl. Léveillé.

60303 Marcquis, Iillem. Alne morbifuga in sanitatis conservatione concinnata. Antverpiae, apud Guil. a Tongris. 1663. 12. S.

600." Marcus, Karl Julius. De Cofea. D. Lipsiae 1837. 4. 29 p.

6500̈* Marggravius, Christian. Materia medica contracta, exhiben. simplicia et composita medicamenta officinalia. etc. Lugtuni Batarorum, apud Doude. 1674.4.252 p. - "Amstelaedami, apud WVetstenium. 1682.4. 280 p., prael., ind.

6006 * Margot, II., et Francois George Reuter. Essai d'une Flore de l'ile de Zante. Lu a la société de physique et d'histoire naturelle de Genève, en mars 1838. Genève, Kossmann. 1841.4. p. 1-104. et $81-96,6$ tab. $(3 / 4$ th. $)$

(Seorsim sine vitulo in bibliopoliis divenditur: in catalogo nund. librar. indicantur : 12 plagulae, 7 tah. "Prodiit haec Flora in: Neemoires de la sociéte de physique or d histoire naturelle de Geneve, lome VIII. 2. (1839) p. 2ky-31\%, tas. 1 - 1 et 6 , at ihid. tome IX. 1 (18'1.) p. 1-36, tah. 5.)

6507 * Marincovich, Peter. De succo Tilhymalorum ejusque analisi. D. Yenetiis, Parolari. $1823.8 .24 \mathrm{p}$.

6208 Marino, Andrea. Joh. Mesvae Opera, quae exstant, omnia, ex duplici translatiune: altera antiqua, altera nova Jac. Sylvii; cum Joh. Mancirdi et Jas. Sylvii annotationibus. Adjectae sunt etian recens Andreue Marini Annotationes in Simplicia cum imaginibus desideratis etc. Omnia a Jarino o vetustissimis exemplaribus castigata. Venetiis, apud Vincentium Valgrisium. 1561. folio, ic. xylogr. i. 1 Rivin.

6.009 - Mariotte, Edme. Prenier essay de la végétation des plantes, contenu dans une lettre écrite à Mr. Lontin, conseiller au Parlement de Bourgogne. Paris, chez Estienne Michallet. 1679. 12. 179 p. Bibl. Cand. et Deless.

6510 Mariti, Giovami. Viaggi per l'isola tli Cipro, e per la Soria e Palestina dall' anuo $1760-1768$. Torino $1769-1770$. V voll. 8. Spr. (Exstat quoque in ejusclem Operibus, Lugduni Batavorum 1717. - Ed. emendatior. Hagae Comitis 1740. 4 .)

$6511^{*} \longrightarrow$ Del vino di Cipro ragionamento. Firenze, typ. Cambiagi1772. S. xv1, 127 p. Bibl. Goett.

6512 Della Rol,hia. sua coltivazione, e suoi usi. Firenze 1776. 8. 294 p., 5 tab. B.

6öl3 Marnock. Floricultural Magazine. London (1838?) II voll. 8 (vol. II: $7 s .6 d$. .) w.

63̈l:" Marogna, Nicoló, latine Maronea. Commentarius in tractatus Dioscoridis et Plinii de Amomo. Impr. cum Ponce descriptione Baldi montis. Basileae, sumtibus Lazari Zetzner. 1608.4.75 p.

* italice. Commentario ne' trattati di Dioscoride e di Plinio dell' Amomo. Impr. cum "Monte Baldo deseritto da Giovanni Pona." Venezia, appresso Rob. Noietti. 1617. 4. 132 p.

$6515 *$ Marquart, Friedrich. Beschreibung der in Măhren und Schlesien am haufigsten vorkommendeu essharen und schädlichen Schwámme. Zusammengestellı zum Gebrauche fưr Polizeibeamte, Wundárzle und Alarktbeschauer. Brüm, 1yp. Rohrer. 4842. \$. 72 p.

6316 Marquart, Ludwig Clamor. Die Farben der Bluten. Eine chemischphysiologiscbe Abhandlung. Bom, Habicht. 1835.8 .92 p. ( $1 / 2$ th. $)$
6517* Marquart, Ludwig Clamor, und Julius Rudolph Theodor VogeI. Beitráge zur Geschichte der Hèrba Origani cretici. (Numberg 1840. ) S. $24 \mathrm{p}$.

(Seorsim impr. ex Buchner, Repertorjum der Pharmacie, XNII. 3. p. $289-310$; cf. Fogel in Limmaea Xf. p. 7 -82.

6518 Lehrbuch der praktischen und theuretischen Pharmacie. Erster Band. Pharmaceutische Naturgeschichte. Hainz, Kunze. $1841-1849.8 .291 / 2$ plag. $(1 \% / 8$ th. $)$

$6519+$ Marquet. Venimecum de butanique, contenant la description eb les propriétés des plantes usuelles, la maniere de les employer utilement en médecine, avec différentes formules, oú peuvent entrer leur préparation. Paris, Dufour. 1773. II vall. 12. xxms, 776 p. ( 5 fr.) (Vix crederem hunc libnum pertinere ad François Nicolas Marquet, n. $1657,+29$ die $M$ aji it 759

$6320 \div$ Marquis, Alexandre Louis. Essai sur I'histoire naturello et médicale des Gentianes. Thèse. Paris, 1yp. Didot. 1810, 4. 22 p.

$6321 \longrightarrow$ Recherches historiques sur le chene. Mémoire lu a la séance publique de la sucièté démulation de Rouen, le 9 juin $181 \%$. Rouen, typ. Baudry. 1812.8.20 p. a.

$6522^{*}$ - Plan raisonné d'un cours de hotanique spéciale et médicale, on de la meilleure manière d'étudier et d'enseigner cette seience. Discours prononcé al l'ouverture du cours de l'auteur. Rouen, typ. Baudry. 1815.8 .24 p.

6323 Reflexions sur le Nepenthes dllomère, fragment de l'article Pavot d'une llistoiro générale des plantes de France. Rouen. typ. Baudry. 1815.8. 46 p. 0.

632' - Eloge de Linne. Rouen 1817.8. a.

6523 Les Solanées, ou les plantes vénéneusos. leylle. Rouen 1817.8. 0.

$6326+$ Esquisse du règne végétal ou tahleau charactéristique des familles dles plantes avec l'intication des propriétẻs générales de chaque famille, et des principaux médicamens qu'elle fournit; suivant la classification adoptée pour le cours de botanique spéciale et médicale du jarlin des plantes de la ville de Rouen; précédé d'un aperçu de physiologie végétale, suivi de la classification des médicanısıs exposée dans le même cours. Rouen, Baudry et Renault. 1820. 8. vII, $128 \mathrm{p}$.

$6527+$ Fragmens te philusophie hotanique, ou de la manière la plus convenable de voir et de travailler en histoire naturelle et particulièrement en botanique; et des moyens de rendre cette science plus simple et plus facilo. Paris, Méquignon-Marris et Béchet. 1821.8 . vif, 207 p. ( 2 fr. 50 c.)

$6328-$ Notice nécrologịue sur A. E. M. Havet, naturaliste, voyageur du gouvernement fransais; mort a Madagascar le premier juillet 1820. Paris, Giraudet et Gally. 1823. \$. 20 p. a.

$6529 \div$ Marquis, $F$. Du thé, ou noweau traité sur sa culture, sa récolte, sa préparation et ses usages; orne de gravures culuriées faites d'après nature el d'après des peintures originales de la Chine. Paris Nepreu. 1820, 8. 68 p., tab. ( 5 fr ) - TEd. II. resue et corrigée. Paris, Yepreu. 1\$34.8.99 p., 9 tah, nigr., + tah. col.

6330* Marschall von Bieberstein, Fiedrich Augusl, Freiherr von Tableau des provinces situées sur la cóte occidentale de la mer Caspienne. St. Petersburg (Leipzig, Voss.) 1798. gr. 4. (7/12 th.)

$6531^{*}$ __ _ Beschreibung der Länder zwischen den Flussen Terek und liur am haspischen Neere. Mit einem botanischen Anhange. Frankfurt a/M., Esslinger. $1800.8 .211 \mathrm{p} .(5 / \mathrm{th}$.)

$6832^{*}$ - Flora taurico-caucasica, exhiljens stirpes phaenogamas in Chersoneso taurica et regionibus caurasicis sponte crescentes. Charkoviae, typis academicis. (Lipsiae, Woygand.) IS081819. III voll. $8 .-$ I: 1808 . vi, 428 p. - II : 1808. 477 p. - III: Supplementum, continens plantas phanerugamas per Tauriam atque Caucasun post edita priora volumina detectas et in pristinas animadversiones. 1819. iv, 654 p. (7th.)

$6533^{*}$ Centuria plantarum rariorum Rossiae meridionalis praesertim Tauriae et Caucasi iconibus descriptionibusque illustrata Pors 1. Charkuviae, 1ypis acatenicis. 1810 . folio. 50 foll., tab. col 1-50. - *Tars II. Decas I-III. Petropoli, typ acatemiae. (Lipsiae, Voss.) 1832-1843. folio. 30 foll., tab. col. $51-80$. (Pars 1I. 1-3: 18 th.)

6534* Marshall, Henry. Contribution to a natural and economical histury of the Coco-nut tree. Edinburgh, Carltae and Son. 1832. 8. 30 p. - ${ }^{*}$ Ed. II: Edinburgh, trp. Stark. 1836. \$. 32 p. 
6535 Marshall, llumphry. Arbustum americanum, the american grove or an alphabetical ataloguc of forest trees and slurubs, patives of the american United States. Philadelphia 1785. 8. 174 1'. B.

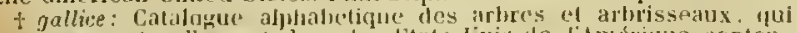

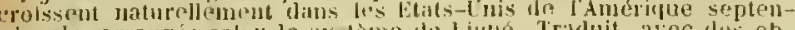
trionale, arrangés splen le systime do lime. Tritult, avec des onsiprvations sur la cullure par (Lezermes.) Jaris, Cuch\%1. 1788. 8. vi, xxIr, $278 \mathrm{p}$.

- germanice: Beschurabung dir wildwachsenden Báume und staudengewachse in den Vercinigtest Station von Sordameriea. Aus dem Engischen abersetzt, mit Aumerkungen von i"hristan Friedrich Ilolfmann. Leipeig, Crusius. 17ss. S. xit, 3h't li., ind. (3/sth.)

6.336* Marsigli, Luigi Ferdinando, Conte, latine Marsilius. Bevanda asiatica, lorindata all' eminentissimu, Bonvisi; elso narra l'historia medica del eave. Vienua d'Lustria, appresso Giovanni van Ghelen. 1685.8. 47 p. Bibl. Imp. Ferd.

6337 Notizie di Constantinopoli sojıra la pianta del Caffé. s. I. 1703. folio. 5 foll., 5 tah. B.

60338 - Brieve ristretta klel sagrio fisico intorno alla storia del mare, ed alla grana dêtıa liermos. Venezia, Audrea Poletti. 1711.4. 72 f. 3 tab. col. $\quad$ B.

tallice: listoire physique de la mel (trintule en francais par

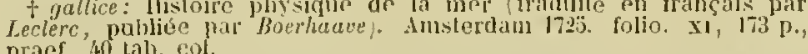

$6339^{*}$ pract., 40 Dissertatio le generatione fungorum, el Johannis Jlariae Lancisii responsio una eam dissertatione ele Plinianae villae ruderibus atque Ostiensis litoris incremento. Romae, typ. Gonzaga. 1714. folio. 40 , xwil p., ind. 31 tah, sign. $1-28$.

(Lancisii libellum supra N. 5.320 aduotavi.)

$6540 *$ - Danubius pannonico-mysicus, observationibus geographicis, astronomicis, liydrographicis, histuricis, physicis perlustratus et in sex tomos digestus. Magae Comitum et Imstelodami 1726. II roll. folio max. - 1: 96 p., 46 lab. -11 : 149 p., 66 tab. -111 : 137 p., 35 tah. -1 W: 92 p., 33 tub. - V: 154 p., 74 lab. - Vl: $12 S$ p., 28 tab. Bibl. univ, Lips.

Splemilidum opus 330 exemplaribus, leste Querard. exeasum est. Translatio gallica, 230 exemplaritus excusa, prodiit llagae Comitum anno 17k kl voll. foliu max. lit tamo sexto rontisetur catalogus plintarum circa Danubium nascentium non uberimus, neque ut respondeal exspectationi folieissimac r'rgionis.)

63\$1 "Marsili, Giovammi, Jatine Marsilius. lungi Carrariensis historia. (Palavii, typ. Penada.) 1766.4.40 p., 1 lab.

$6312+\div$ Notizie inedite seritle da Growann Harsili, gia Professore di botanica nella J. R. Univer'sita di Padova. Padova, typ. Cartallier e Sicca. 1840 . S. 23 p. Hibl. Cand.

Edidit Cesare Sacerdoli.

$6543 \div-$ Notizie del pubblico giarclino de' semplici di Padova compilate intorno l'anno 1771 , la Giovanni llarsili, Professore di botanica e Prefetto dell orto medesimo. Parlova, coi tipi del seminatio. 1840.8 .30 p. Bibl. Cand.

(Edidit, nonnullas animatrersiones atljecit Roberto de Viviani.)

63̊k Marsili, Giuseppe. Di Pier Anlonio Micheli botanico insigne del seculo XVI e di una sua opera manuscritla. Venezia, Marlo. 1845. 4. $24 \mathrm{p}$.

63437 Martelli, Niccola. Brascliae plantae novi generis descriptio, nomini majestatique Pii T $^{\prime}$. P. M. dicata. Rumae, typ. Zempel. 1791. 4. 20 p., I tab. Bibl. Cand.

(Libellus rarissimas latina ae ilalica lingua exhibet descriptiones ac icones duarum ex agro Romano plantarum, quap vis a sedi genere segregari yossunt. Idem antor voluminitus ll-Vil Horti Romani, caem supra Nr. 10us indicilvi, operan navavit.)

6546* Martens, Friderich. Spilzbergische oder Gronlandische ReiseBeschreibung, gethan in Jalıre 1671. Aus eigner Erfalırunge beschrieben, die dazu erforkerte Figuren nach dem Leben selbst abgerissen, (so hierbey in kuplfer zu sehen) und jetzo durch den jruck mitgetheilet. IJamhurg 1675 . 4. ( 5 foll.) 132 p., tab. A-Q.

(Opusculam ut ederet, fecit Jartinus Fogelius, qui varis quaestionibus memorian anctoris refrieubat. All rem berbariam pertinet partis primae eaput primum, in s[u" plantio spitzbergicae reecnsenlur, cum tabulis F. G. H. I. Ilarum planlirum calalogum Rajus it tomo lll. IJistoriac plantarum inseruit.

italice: Tradotto in lingua italiana da Jacobo Rautenfets, gentiluomo Curlandese. Bologna, Giacomo Monti. 1683. 12. S.

belgice: De noordsche weereld, verloond in twee nieuwe derwaerls gedaene roysen, deenc, vin do lleer Martinière, d'andere van de Hamburger Fred. Jfartens vertacld, en net toe-doeningen verrijekt door: $S$, de Iries. Ansteldam 1685 , 33 . 33 p., 4 tab. et $A-O$. B. anglice: Voyage into spitzbergen and freenland, printed in an
account of several late voyages to the south and north. London $169 \%$. 8. $175 \mathrm{p}$, tab. A-0. B.

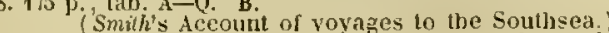

- gallice: In Bernard, Recueil rles voyages du nord, tome 1.
$637^{-2}$ Martens, Georg von. Reise nacl Venedig. L'Jm, Stettu. 1824. 2 Theile. 8. - 1: xiv, 462 p., 2 tub. - II: vi, 664 p., 9 tab. $(6 \mathrm{th}$.) (In volumine il. p. 53y-6is: Flora reneta.

63:4* Martens, all., et llenri Galeotti. Mémoire sur les fougèes du Mexiquo et considérations sar la géograplnje hotanique de cetto contrée. (Bruxelles 18 :2.) 4. 99 p., 23 tal.

(Mémoires de l'Academie rogale do Bruselles, tome xr.)

$65: 9^{*}-$ Sur la malalie des ponmes de terre. (Bruxilles 1846.) 8. 49 p.

(Bulletins de l Acadénic rovale de Bruxplles, tome Xil. Nir. 10.)

$6330+$ Martersteck, Johann Clemens. Bumuischer Flora Erster Theil, oder Verzeicbniss aller hier wild und frei wachsenden Arzneipllanzen, nelsst einer vollstandigen Beschreibung ilırer Eigenschafen ibres Nutzens und Gebrauches. Bonn, Iyp. Alsshoven. (Duishurg, Dinzer.) 1792.8. $475 \mathrm{pe}$, praef. $\left(1 \frac{1}{4}\right.$ th.

$6351+$ Marthe, François. Catalogue des plantes du jardin médical do Paris, dispasies selan le système de Limé, avee l'explication ale quelques ehangements laits à ce systeme. Paris, Gabon. an $\mathbb{X}$. 1801.8. $1441 \%$.

6552* Marti, Antonio de. Lixperimentus y observaciones sobre los sexus y fecundacion de las plimtas, presentades a la real acadenia do Barcelona. Barcelona, por la viuda Piferrer. (1791.j S. 86 p.

6353 Martin, Alexandre. Nanuel de lamateur de melons, ou l'ar! de recounaltre el d'acheter de bans mejons, precéde d'une histoire de ee fruit, avec un traite sur sa culture, et une nomenclature de ses diverses especes el varietes, arec 4 figures. Paris, Udron. 1827. 18. (2 fir. $50 \mathrm{e}$.)

$6534 \div$ - Nanuel de l'amatear de truffes, ou l'art d'olstenir des tralles, au moyen de plants artificiels dans les parcs, bosquets, jardins elc., précédé d'une histoire de la trufle el d'anecdutes gourmandes, et suivi d'un traite sur la culture des champignons. Paris, Leroi. 18 18 . 18. XII, 143 p., 1 tab. col. (2 fr.)

65330 . Martin, François. Instruetion sur la culture diu coton dans la partie méridionale du Déprartement du Yar. Toulon, Aurel. 1808. $8.25 \mathrm{p}$.

$6336+$ Martin Solon, $F$. Alcalia tquadam vegetabilia novissine inventa, seu pura seu carn acilis composita. D. Paris, typ. Lacbevardiere. 1824.4. $4: p$

63037 Martin, William. Petrificata Derbiensia; or figures and descriptions of protrifications collected in Derbyshire. Wigan, typ. Lyon. 1809. 4. 52 tab. col. (2l. 2s.)

6558 Martinel, Joseph Marie François de. Tableau (1-V) sur la cullure de la Solanéc-Parmentière. Lyon 1\$21-1824. folio. a.

$63059+$ Tableaux usuels destines aux agriculteurs, qui recherchont dans la pomme de terre une qualite particuliere. Jls sont le résultat d'observations faites sur cent variétés cultivies en 1821 . et ont été extraits du tableau gévèral de ladite année. Lyon, typ Perrin. 1824. 4. 4 p.

6360 Martinelli, Francesco. Raggionamenti sopra l'Anomo e Calamo aromatico novamente l'anno 1604 avuto di Dlalacea, eittá d'lodia. Venezia, Grazioso Percacino. 1604. 4. S.

Incertus quidem autor contra hunc alium rescripsit librum cui titulus: Giudizio solva i ragiondmenti di Cecchina Martinelli sopra id nuoso tmono e Calimo aromatico, alli speciali della citta di Nantova. Mintova, Franc. Ozanıa. 1603̈. k. Bibl. Maz.

6361 Martinez y Leache, Miguel. Disputatio de vera et legitima Aloes electione jasta .Mesces textum in duas sectiones divisa. Pompeiojoli, Marlinus a Labayen. 1644. 12. s.

6562 Pharmacopales donde se explien las preparaciones y elecciones de Mesues. Pompejopoli 1550.4. s.

6363 (Martini.) Dissertatio epistolaris do oleo Wittnebiano seu Kajuput, ab homine Wrolfenbuttelano in lndia orientali iovento, in terras Brunsvicenses feliciter revocato ejusque saluberrimis effectis. (Wol[cnbuttel) 1731.4.31 p. B.

In titulo libelli anonymi leguntur jiterae D. M. C. M. A. Autoris nomen licquet ex Comment. med. Lips. vol. 1. p. 728.)

656女 Martini, Emmanuel. Dissertacion sopra la theriaca magna. Valentiue 1727. 4. H.

6565 Martini, Georg Ileinrich. De thuris ill reterum Christianorum sacris usu. Lipsiae 1752.4. 
6566* (Martini, Jakob.) Die fruchthare Boriza oder das heilsame Mondkraut (Bolrychium Lunaria), mit vieleu chymischen und lunarischen Fruchten abgebildet. Brieg, typ. Jacob. 1681. \$. 127 p. Bibl. univ. Lips.

(Autoris nomen Jakab Jfortini lego in Bibliotheca Riviniana X.r. 6883.)

6567* Martini, Johann Nepomuk von. De Arnica. I. Yiennac, typ. Schmidt. 1779. 8. 63 p., prace, 1 tab. col.

6 6̈68 Martini, Withelm August. Neneste Erfahrungen uber Anzuch und Wartung der Levkojen. Quedlinturg, Basse. 1842 . \&. ( $1 / 3$ th.)

$6369+$ Martinis, Bartolommeo de. Catalogins plantarum a me in itinere montis Baldi inventarum et juxta methodum aliorom botanicorum descriptarum, illustrissimo Domino Antonio J'allisnerio dicatus. Veronae, typ. Jo. Berni. 1707.4.24 p. Bibl. Juss.

6570 - Nuovo invento, cioé aggiunta al genere delle Anagallidi acquatiche di due non jiiu date in luce, con espiegazione dell' esser sue iddentico. Verona, Merti. 1717. S. cum icone. S.

6571 Martinow, hoan. Tехно-6отанитескій сховарь на хатинскоит, и россійскій языкъ. С. Ifстерб. 1820. Trautv.

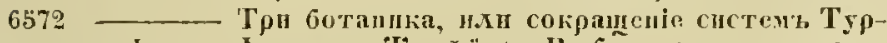

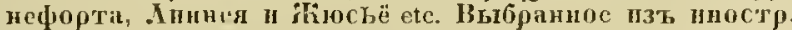
инсате., С. IIстерб. 1821 . Trautv.

$6373+$ Martins, Charles $\mathbf{F r}$. Essai sur la topograplyie botanique du mont Ventoux en Provence. Paris, typ. Renouard. 1838 . 8. 44 p., 1 tab. (Annales des seiences naturelles, tome X. ]. 129-150. 228-249.)

$6574 *$ Du microscupe et de son application à l'étucle des etres orcanisces et en particulier à celle de l'utricule régétale et des globules du sang. Paris, Rignoux. 1839.4. $42 \mathrm{p}$.

$6573^{*}$ - De la délimitation des régions végétales sur les montagnes du continent européen. Paris, Rignoux. 1840. 8. 14 p.

$6576+-.$. Essai sur la mejéorologic et la géographic hotanique de la France. Paris, Dubrochet. (1845.) 8. p. 177-492.

(Exirait du : Patria. la France ancienne el moderue.

(Ab ill. Martins et $J$. Fahl expectanus partem botanicam in: "Foyages de la commission scientitique du nord, en Seandinavic, en Laponic, an Spitzberg et aux Feroe, pendant les annees 1838 1810 sur la correlte La kecherche, commandee par w. Fabure publes par ordre du rol par la librairio Arthus Bertrand sols la durection sextum magui operis, noudum, ipuantum seio, impressum.)

6577* Martius, Erust ITilhelm. Auweisıng, Pnanzen nach dem Leben abzudruchen. Wetzlar, Winkler. 1785.8.80 p., 1 tab.

$6573^{*}$ Gesamnirlte Nachrichten uber den Mlacassarischen Giftbaum. Erlangen, Walther. 4792.8 .43 p., 1 tab. col.

$6579^{*}$ —_ Erinnerungen aus meinem neunzigjährigen Leben. Leipzig, Leopold Yass. 1847. 8. xvi, 327 p. (1//2 th.)

$6580^{*}$ Martius, Meinrich von. Prodromus Florae Mosquensis. Mosquae, ex officina F. Luby. 1812. 8. 202 p. Bibl. Reg. Berol. - "Ed. II: Lipsiae, in comm. industriae. 1817. 8 . xv1, $28 \mathrm{~s} \mathrm{p.}\left(1 \frac{1 / 3}{3}\right.$ th. $)$

Editione mincipe hujus florae vix rarior ullus invenjur liber; duo tantum servata sunt ex magno urlois incendio exemplaria, querum alterum, ev quo reimpressio facta est Lipsicnsis, in regia vidi rum alterum, ex quo re

6381* Martius, Karl Friedrich Philipp von. Plantarum horti academici Erlangensis enumeratio adjectis specierum novarum vel minus cognitarum iescriptionibus atque illustrationibus. D: Erlangae, typ Hilpert. 1814. S. 209 p. (1/2 th.)

$6582^{*} \longrightarrow$ Flora cryptogamica Erlangensis, sistens vegetahilia e classe ultima Linn. in agro Erlangensi hucusque detecta. Norimbergae, Schrag. 1817. 8 , Lxxvir, 505 p., 6 tab. pro parte col. $\left(2 \frac{2}{3}\right.$ th.)

$6583^{*}$ - De plantis nonnuliis antediluvianis ope specierum intra tropicos viventium illustrandis. Ratisbonae, typ. Brenck. 1821. 4. 28 p., 2 tab.

(Regerisburger Denkschriften, vol. 11. p. 121-1k7.

6584 * Johann Baptist von Spix, und Karl Friedrich Phitipp von Martius. Reise in Brasilien, auf Befehl Sr. Najestát Königs Maximilian Joseph von Bayern gemacht in den Jahren 1817-1820. Nüuclıen (und Leipzig: Voss.) 1824-1831. 3 Bände. 4. und Atlas. folio. - I: 1823. X, 412 p. - II: viI, 413-884 p. - III: 1831. vIII, $885-1388$ p. - Geographischer Anhang: 40 p., 1 eharta geogr. - Atlas: 53 tab. $\left(23\right.$ th. - sine atlante: $13 \frac{1}{3}\left(h_{\text {. }}\right)$

$6585^{*}$ Geoera.cl species Palmarum, quas in itinere per Brasiliam annis $1817-1820$ collegit, descrifpsit el iconibus illustravit. Monachi, typ. Lentuer. (Lipsiae, Fr. Fleischer.) Fasc. I-VIII.
1\$23-1845. folio max. xcvi, 304 p., 219 tab. col. (sign. tab geologicae $1-3$, tab. mon inologicae I-LVIl. talı. systematicae 1170.) (nigr. $147^{3} / \mathrm{t}$ th. - col. 269 th. - col. $1164 \mathrm{ft}$.)

Praeclarum hoc opus tribus componitur partibus. Introductio generalia de Palmis olfert, et quiden caput 1 , autore Mohl, de structura, cap. 11 antore Lnger, de Palmis fossilibus agit; in tertio Martius morphologian et historiam evolutionis anple tradit. Quartum erit de Palnarum geographia, addito omnium specierum elencho et novarum charactesibus. Pars secunda Palmarum brasiliensium descriptiones characteribus, Pars secunda palmarum brasiliensium descriptiones
radit, tertia systematicam ordinis, tribuum, generum, specierum se-

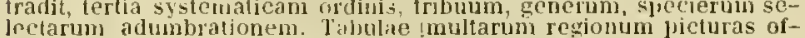
fectarum adumbrationem. Tibuline tmultarum regionum licturas of-

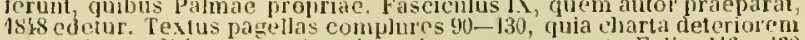
18 is edetur. Texlus page?las complures 90-130, quia clarta deteriorem probavit conditionem, reimprimendas auctor curat. Folia $116-130$

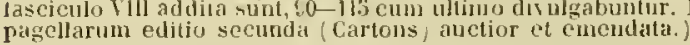

6586* Martius, hacl Friedrieh Philipp von. Nova genera et species plantarum, quas in itinere per Brasilian annis $1817-1820$ suscepto collegit et descripsit. Monachii, 1yp. Lindauer et Wolf. \$824-1832. II] voll. folio. - 1: Pingendas curavit et secundum autoris sclıedulas digessit Joseph Gerhard Zuccarini. 1824, 158 p., tab. col. 1-100. - Il: 1826. 148 p., tab. col. $101-200 .-111=1899-1832.198 \mathrm{p} .$, tab. col. $201-300$. (247\% th. - nigr. $158 \%$ th. -798 fr.)

$6587^{*}$ _..... Die Physiognomie des Phanzenreiclıes in Brasilien. Fine Rede, gelesen in der am 14. Februar $\$ \$ 24$ gehaltnen Sizung der Konigl. Bayerischen tkademic der Wissenschaften. Munchen, IyP. Lindauer. (1824.) 4. $36 \mathrm{p} .(2 / 3 \mathrm{th}$.)

$6588^{*}$ _ Specimen materiae medieae brasiliensis, extribens plantas medicinales, puas in itinere per Brasiliam observavit. (Monachii 1824. 4. 20 p., 9 tab. $(15 / 12$ th. $)$

(Ex Actis Monacensibus seorsim impressum.)

$6589^{*}$ Palmarum familia ejusque genera denuo illustrata. Programma. Mouachii, typ. Lindauer. 4824.4.24 p.

$6590^{*}$ IIortus botanicus Regiae Academiae Manacensis, sive horti bolanici, qui Honachii floret, historia breviter enarrata et praesens conditio descripta. Progranma. Monachii, die 1 Nlaji 1825. 4. 28 p., 2 tab.

$6591^{*}$ __ Beitrag zur henntuiss der natürlichen Familie der Amarantaccen. (Bonnae 1825.) 4. 114 p., 2 tab. (Amarantacearum per orbem terrarum distributionen illustrantes.)

(Acta Acad. Caes. Leop. Carol. Nit, Cur. vol. Xill. p. 209-322.)

$6592^{*}$ Ordinum plantarum charncteres stenographice exponere conatur. (Berolini 1828.) 4. 4 p.

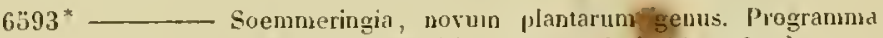
gratulatorium. Monachii, typ. Lindaner. 1828. 4.31 p., 2 tab.

$6594^{*}$ lcones plantarum eryploganicarum, quas in itinere annis 1817-1820 per Brasiliam instituto eollegit et descripsit. Monachiii, impensis autoris. $1828-1834$. Foliu minor. 138 p., 76 tab. col. ( 73 th. $-249 \mathrm{fr}$.)

6593* (— et Franz von Paula Schrank.) liortus regius Monacensis. Verzeichniss der im Küniglichen botanischen Garten zu Munchen wachsenden Pflanzen, naeh der naturlichen Methode geordnet. Munchen und Leipzig, Fr. Fleischer, 1829. 8. хII, 240 p. ( 1 th.)

$6396^{*}$ Amoenitates botanicac Monacenses. Auswahl merkwurdiger Pflanzen des Koniglichen botanischen Cartens zu Aluncben, in Abbildungen und Beschreibungen, nebst Anleitung rücksichtlich ihrer liultur. Frankfurt a/1., Bronner. (Schmerber.) 1829-1831. fase. I-IY. 4.26 p., 16 tab. col. $(5 \% / 3$ th. $-22 \mathrm{fr} .50 \mathrm{c}$.)

(Choix des plintes remarquables du jardin botanique royal de Vuuich figurées et déerites avee des observations sur leur culture " a Querard citatus, jdem est liber, in latina simul et gallica et ger-

$6597 *$ manica lingua scriptus.) Flora brasiliensis, seu enumeratio plantarum in Brasilia tam sua sponte quam accedente cultura provenientium, quas in itinere auspiciis Mluxiniliani Jasephi $I$. Bavariae regis annis 1817'1820 peracto collegit, partim descripsit; alias a Muximiliano Principe 11 iedensi, Sellovio aliisque advectas addidit, communibus amicorum propriisque studiis secundum methodum naturalem dispositas et illustratas edidit Kart Friedrich Philipp von Murtius. Stuttgardiae et Tubingae, Cotta. 1829-1833. Voluminis i. pars prima, et voluminis II. pars prima. 8. $-1,1: 1833$. Algae, Lichenes, Hepaticae. Exposuerunt: Karl Friedrich Philipp von Martius, Franz Gerhard Eschweiter et Christian Goltfried Nees von Esentork. Ir, 390 p. (2 th. ) II, 1: 1829. Gramineac. Etian inscribitur: Agrostologia brasiliensis. 


\section{MARTIUS}

seu descriptio Graminum in inperio brasiliensi hucusque detectorum, auctore Christian Gotfried Necs von Esenbech. II, 608 p. (3 th.)

6598 * Martius, Larl Friedrich Ihilipp von. Whe l'llanzen und Thiere des tropischen Amerika. Lin Naturemalde. Munchen, bei dem Verfasser. (Lripzig, Fr. Fleiselher.) $1831,4.48 \mathrm{p} ., 4 \mathrm{tah},(2 \% / 3 \mathrm{th}$.) seorsm impr. ex editinne majori ltineris lirasiliensis, yol. ll!.

$6599^{*}-$ Die Eriocanleen, als selloststundige Plianzenfamilie aufgestellt und erlautert. (Bonnae 1833.) 4. $72 \mathrm{p}$., 5 tab.

(Acta Acad. Caes. Leop. Carol. Nat. Cur. vol. Nill. p. 1-72.)

$6600^{*}$ Conspectus regni vegetabilis secundum characteres morphologicos praesertim carpicos in classes, ordines et familias digesti, adjectis exemplis nominibusque plantarum usui medico technico et eeconomico inservientiun. Uebersiclıt der Klassen, Ordnungen und Familien des Gewächsrejches nach morphologischen Grundsátzen, unter besondrer kucksicht anf den Fruchibau, mit Angalse von Beispielen und ven den in der Medizin, Technik und Oehonomie besonders wicltigen Pllanzen, zunachst als Leitfaden bei seinen akademischen Vorlesungen entworfen. Nurnberg, Schrag. 1835. 8. xvit1, 72 p., $(1 / 2$ th. $)$

$6001^{*}-$ Akademische Denkrede auf Franz Gubriel, Grafen von Bray. Regensburg 1835. $8.39 \mathrm{p}$.

(Seorsim impr. ex Flora Ratisb. 1833. I. Beiblätter p. 33-71.)

$6602^{*}$ Denkrede auf Franz von Paula won Schrank. Gelesen in der Akademie der Wissenschaften den ys. Márz 1836. München, typ. Wolf. 1836, 4. 3। ].

$6603^{*}$ Herharium Florar Irasiliensis. Plantae brasilienses exsiccatae, guas clenominatas partin diagnosi aut observationibus instructas botanophilis ollert. Monachii $1837(-1840) .8 .352 \mathrm{P}$ (Continuatur.)

(Scorsim impr. ex "Beiblatler zur liegensburger Flora. D Paginae $1-72$ faciunt ai historiam literarian Forac brasiliensis.)

$6604^{*}$ - Reden und Vortráge wber Gegenstande aus den Gebiete der Naturforschung. Stuttgart und Tubingen, Cotta. 1838. S. vi, 308 p. $(11 / 2$ th. $)$

(Insunt: Zum Anienken Linnè an seinem Gehurlstage. Der philosophische Gedanke ill Limne's Werhen. Auszug aus linne's Rede hei einem Besuche Kunig Aduph Friedrich's. Die verschiednen Alter des menschlichen Lebens, nach Linne"s Metamorphosis humana. Ueber den magischen Einlluss der Natur auf die Meuschen. Des Naturforsebers Lejden und Freuden. Irrej Lieder zur leier von Linnés Gehuristag inn Frejen zu singer. Limeische Litanei, ausgefubrt in

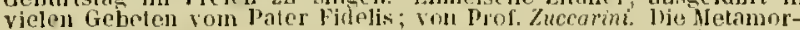
phose der Pllanzen, dargestellt in vier Vorlesungen. Die Seele der

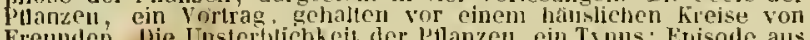

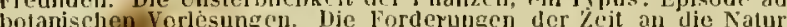
forscler

dunice. Planternes Metaunorphose; fire lorelaesninger, oversat af Salomon Thonas Nicolai Drejer. Kjobenhavi, Reitzel. 1810.' 8. $84 \mathrm{p}$. (8) Skill.)

$6605 *$ (8t Skill.) Linne und der Zweifler. Yortrag. (Atunclien 1S38.) 4. $17 \mathrm{p}$ (Seorsin impr. ex: "Deutsche Blatter. 1838. p. 22\%-2\%1.)

$6606^{*}$ Die Verbreitung der Palmen in der alten Welt, mit besondrer Rücksicht auf die Florenrujche. Erste Ablandlung. Mtunchen 1839. 4. $94,36 \mathrm{p}$.

Seorsin impr. ex a Munchner Gelebrt" Anzeigen 1839. Nr. 105 $\left.6607^{*}-118.1\right)$

chen 1840.) 4, 130 p., ind., 10 tab.

(Konigl. Bayrische Akademie der Wissenschaften, vol. III. 2.

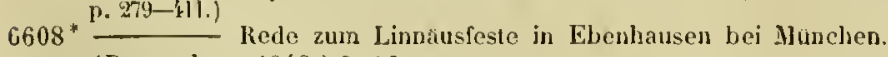

(Regensburg 1842.) 8. $16 \mathrm{p}$

(Seorsim impr. o Finra Ratisbonensi inni 1842.

$6609^{*}$ Die Kartutfel-Epidemie der letzten Jahre, oder die Stuckfaule und Ráude der Kartoflelı, geschildert vud in ihren ursachlichen Verháltnissen erörtert. Munchen, Verlag der Akademie der Wissenschaften. 1842.4 .70 p., 3 tals. col. ( 1 th.

hollandice: De Aardappel der laitste jaareu, enz. litgegeven voor rekening van het genootschap vonr landtouw cu hruidhunde. Te Utrecht, bij D. Scbeltema. 18 it. gr. 4. ( $2 \mathrm{fr}, 50 \mathrm{c}$ )

$6610^{*}$ Systema materiao nedicae vegetabilis brasiliensis. Lipsiae, Friedrich Fleischer. 1\$43. 8 . xxvi, $155 \mathrm{p} .(\mathrm{5} / \mathrm{t} / \mathrm{h}$.

$6611^{*}$ Das Naturell, die Krankilieiten, das Arztllum und die 1leitmittel der Urbewohner Brasiliens. Munchen, typ. Wolf. (1843.) 8. $192 \mathrm{P}$.

(Ex a Bucloner, Repertorium fur Pharmacie, ser. ll. vol. Xxxlll. p. 289. - Editio lusitanica praeparatur, studio Ave Lallemant, in. D. Sebastianopoli.)

$6612^{*}$ Davidi Henrico Hoppe de quinquaginta anuis post summos in medicina honores rite captos gratulatur die V Mlaji anni
MDCCCXLY. Insunt quaedam de priscorum Lotanicorum epistolis in Bjhliotheca Cniversitatis Erlangensis asservatis. Inipr. cum Darid Heinvich Hoppe's Jubelfeier. Neqensburg, Manz. 1845. 4. p. 11-20.

6613 " Martius, Karl Fiedrich Ihilipp ton. Deshrede auf Karl Friednch von Kielmeyer, gehalten in der offentlichens sitzung der honiglich Bayerisehen Akademie der Wissenschaften an 8. Marz 1845. (Munehen 1845.) 4. $28 \mathrm{I}^{1}$. $-109.12)$

661 * $^{*}$ Sendschreiben uber die Kartulledkrankheit. Mit einer Vorrede yon P'rof. Cornelis Adrian Bergsme in Itrecht. Vitrecht und

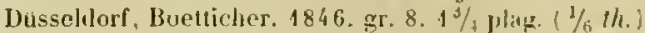

(Scorsin impr. ex: uCentrablatt des landwirhachaftlichen Vereins in Bayern 18,5. p. $362-379,0$ )

$6615^{*}$ Palmetum Orbignianum. Descriptio Palmarum in Paraguaria el holivia crescentium secundum Alcide de Orbigny exempla, schedulas el icones digessit Kurl Philipp Friedrich de Murlius. Impr. cum Alcide DOrbigny, Voyage dans l'Amérique méridionale, vol. VII. sectio IIl. Paris $1843-4846 . \mathrm{gr}$. 4. (vidi incompletas $128 \mathrm{f}$ \%, $29 \mathrm{tab}$. col. sign. 1-24. $27-34$.)

6616* Martius, Theodor llihelm Christian. Grundriss der l'harmakognosie des Pllanzenrciches zum Gelirauche bei akademischen Vorlesungen, so wie fur Aerzte, Apotheher und broguisten. Erlangen, Palm unil Enke. 1832. 8. xx, 459 p. $\left(2 \frac{1}{3} t / 6.\right)$

$6617+$ (Martyn, John.) Tabulac synopticae plantarum officinalium ad methodum lhajanam dispositae. Lumdini, Stratıan. 1726. fulio. Iv, 20 p. Bibl. Juss.

6618 Methoelus plantarum circa Cantahrigian nascentium. Londini 1727 8. 132 p. B.

(Nove editionis emendatae 2 paginae tantum fnrma octava impressae sunt. B.

$6619^{*}$ - Ilistoria plantarum rariorum. Centuriae primae decas l-V. Londini, typ. Reily. 1728 . folio max. Iv, 52 p., 50 tab. col.

(leunes plantarum es horto Chelseano of Cantabrigiensi, ab lluysum pictac et a kirlall aeri ineisae, eleyantissimae certe sunt, pleracrue novile, ita ut splendidissimo operi practer Cateshacum sinile ea aetas non haberet; sed lulla synemyma deljecta sunt, nulli cha-
racteres expressi. Iscaci Rand, socjelatis Lonelinensis socii. sermo de bocee libro hahitus coram societale anglica reperitur in philos. Transact. Nr. 407 . )

* germanice el latine: listoria plantarum rariorum ob praestantiam denuo edilat studio atque opera Johannis Daniel Meyer, pictoris. Bedenuo edita studio atque opera Johanmis Daniel Meyer, pichoris. Be-

sehreibung seltner l'tlanz
$2 \%$ p., pran., 50 lab. col.

* germanice et latine: Abbildung und Beschreihung seltner Gentachse, neu ubersetzt, systematisch bestimmt und mit Anmerhungen begleitet von Genry ilalfgang Franz Panzer. Nurnberg, Frauenholz. $179 \%$ folio. viu, 72 p., 50 tah. col. ( $12 t h$.)

$6620+\longrightarrow$ The first lecture of a course of hotany; heing an introJuction to the rest. London, typ. Rejly. (Strahau.) 1729. \&. vu, 23 p., 14 tab. (1s. $6 d$.) B.bl. Deless. et Juss.

6621 (-) A short explanation of the technical words made use of in botany. s. a. 4. 1/2 plag. B.

$6622+$ Tournefort's History of plants growing about Parjs, with their uses in physick; and a mechanical account of the operation of medicines. Translated into english with many additions and accomodated to the plants growing in Great Britain, by John Martyn. London, Rivington. 1732. 11 voll. $8 .-1$ : Lxvi, $311 \mathrm{\mu}-11: 362 \mathrm{p.}$ incl.

(Docti Martynii in Tirgilium daronem scholia infra sub voce lïrgillius indicabo.)

6623 Martyn, Thomas. Plantae Cantabrigienses, or a calalogue of the plants, which grow wild in the county of Cambridge, disposed accorling to the system of Limacus. Hetbationes Cantabrigieuses, or directions to the places, where they may be found, comprehended in 13 botanical excursions. List of the more rare plants, growing in many parts of England and Wales. London 1763. 8. 114 p. B.

662. - Catalegus horti botanici Cantabrigiensis. Cantabrigiae 1771. \$. 193 p., 1 tab. iconogr. horti. B.

6625 Mantissa plantarum horti botanici Cantabrigiensis. Cantabrigiac $1772,8.31$ p. B.

6626 Horti hotanici Cantabrigiensis catalogus. Cantabrigiae 1794.8 .66 p. B.

$6627+$ Letters on the elements of botany, addressed to a Iady by the celebrated Jean Jacques Roussean. Translated into english with notes and twenty-four additional letters, fully explaining the system of Linnaeus. By Thomas Martyn. London, White and Son. 
1785. 8. xxm1, $503 \mathrm{~J}$.., ind. - + lid. II wilt corrections and improvements. London, White and Son. 1787. 8. xxy, 500 p., ind.

6628t Martyn, Thomas. Thirty-eight plates witl explanations; intended to illustrate Linncens System of vegetables, and particularly adapted to the Letters on the elements of botany. Lombun, White. 1788. 8 . vi, 72 \%., 38 tah. col.

6629 - Flora rustica, exhiliting accurate figures of sucl plants as are either useful or injurious in husbandry, with scicutific character's, popular descriptions and useful ohservations. London 1792 - 1794. IV voll, 8, - 1: 1792. foll. et tab. col. 1-36. - 11: 1792. foll. et tab. col. 37-72. - III : 1792. foll. et tal. col. 73-108. $\mathbb{N}:$ 1794. foll. et tab. col. $109-14$. B.

$6630^{*}$ - The language of botany : heing a dictionary of the terms Inarle use of in that science, principally by linnaeus; with familiar explanations and an altempt to estal,lish signifieant english termes. The whole interspersed wilh critical renarks. London, White. 1793. 8.

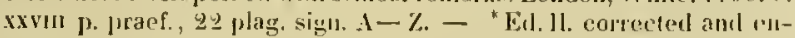
larged. Londou, White. 1796. 8. xxxu p. praef., sine pinginis. *El. 111. corrected aud eniarged. London 1807. 8. xxxill p. praet., sise paginis: $28 \%$ plag. Bibl. E. M.

lijusden "obirivations on the language of botany sunt in

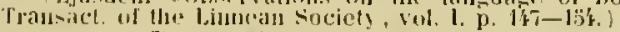

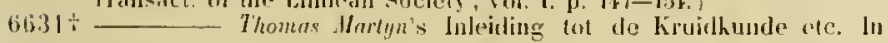
liet fransch en hollaulselı door J. wu Voorden. London, Feruor en llood. (Rotterdan, Benuet.) 4798. 8. Yolumen I: xix, y52, 32 p., 12 tal. col. (Plura non adsunt.) Bibl, Cand.

Aceurate non didici, ad quem liblum hane translationen reforeodam esse. Antor's utiardener's dlictionars " cl. inter' editiones Philippi Miller.)

6632* Marum, Martin van. Dissertatio philosophica insuguralis de motu fluidorum in plantis, experineutis et observationibus indagato. 11 . Grouingae, apud II Spandaw. 1773. 4. 56 p.

$6633^{*}$ - Dissertatio botanico-medica inauguralis, qua disquiritur, quo usque motus fluidorum, et caetera quacdam animalium ("t plinntarum functiones consentiunt. D. Groningae, apud 11. Spandaw, 1773. 4. $32 \mathrm{p}$.

$663 \mathbf{k}^{\circ}+$ Catalogue des plantes rultivées an printens 1810 dans son jardin a Harlem. (Ilarlem 1810.) 8. viI, 64 1).

1;635t (Marzari-Pencati, Giuseppe, Conte.) Elence delle piante spontanee fino ad ora osscrvate nel territorio di Vicenza. Milano, typ. Tosi e Nolile. $1802.8,58 \mathrm{p}$.

$6636^{*}$ Nenoria sull' introduzione del Lichene islandese come alimento in Itatia ete. Venezia, typ. Fracasso. 1815. 4. $100 \mathrm{p}$.

6637 Mascall, Leonard. A beoke of the arte and maner, bowe to plant and gralfo all sortes of trees, howe to set stones, and sowe prepines to make wylde trees to gralle on, by one of the albbey of Saint Vincent in Fraunce, practised will his owne handes; with an addition in the ende of this Jooke, of eertaine Dutch practises, set forth and englished by Leonard Mtescall. London (1572.) 4. 90 p., 1 tah. ligno incisa. B.

6638 The country mans new ort of planting and grafting directing the hest way to make any grrturl good for a rich orelard with the manucl how to plant and grallo all sorts of thees to sel and sow curnels. As also the remedies and medecines concerning the sane, with divers others new experineuts. London, Jane Bell. 1652 4. Sloane.

$6639^{*}$ Maschin, Johanh. Ihissertatio sistens plantas medicinales Bohemiac. Vindobonae, 19p. Veberreiter. $1843.8 .57 \mathrm{p}$.

166 0 (Masius, Geory /leinrich.) Tentamen plasmacopoeae pauperum una cum catalogo plantarum medicinaliom in terris Megalopolitanis indigenarum. D. quam ...... submittit Curolus Fridericus 11'ennmohs. P'raefatus est ...... Georgius Hemricus Masius. Rustochii, 1yp. Adles' 1820.8.64 p.

(Dissertatio integra, indicante ill. Roeper, a pracfatore scripta esi.)

66.1 Mason, George. An essay on designing gardening, first pullislied in 1768; augnented with several publications on the same subject. Londan 1795. 8.

6612* Maspero, Paolo. Sulla segale cornuta opuscolo. Venezia, tgp Bunvechiato. 1835. 8.77 p.

6043 * Massara, Giuseppe Filippo. Prodromo della Flora Valtellinese, ussia catalogo delle priante rinvenutc in varie escursioni botaniche nella provincia di Sourlrio in cui si distingwono con brevi ragiona-

Pritzel, Thes, lit. bot. meuli le specie piu' rare, i noni volgari di molte piante a principali prubluti del suolo e le propricta' che a varie specic si attribuiscono Sondrio, typ. Cagnoletta. 1834. 8. xx, 219 p., i tah. col.

66 H. Masson, Francis. Stajoliae novac; or a collection of several new species of that genus; discovered in the interior parts of Africa. Losulon. Nicol. 1796. folis. 2 i p., 41 tab. col.

(Textus decem priorun specierum redit in Lsteri annaden der

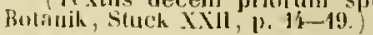

661.5 Massonio, Salvatore. Archidipno, overo dell' insalata, e dell uso di essa tratlato unovo. Venezia, Mareantonio Brogiollo. 1627. 4 426 1. B.

661.6+ Matani, Antonio. Deile produzione naturali del teritorio Pistojese razione isterica e tilosolica. Pistaja, typ. Bracali. 1762. 4. vur, 204 1., 1 mappla geogr.

665.7 Matheron, Philippe. Catalogue méthodique et deseriptif des corps organises fussiles du departement des Butuches-du-Rlıone. Marseille 1819. 8. 95 j., 13 tal.

6648 Mathieu de Dombasle, Christophe Joseph flexrundre. Du modo de untrition des plantes aux diverses épopues de leur croissance. Paris, lluzard. 1821.8. 0.

664 - Notier sur le trefle incarnat ou faronch. (Triolium incarnatum). Paris, lluzarl. 1823. 8.12 1. $(30 \mathrm{c.}) \quad 0$.

bilfait des Anuales d'Agriculture.)

$6630 t$ Des forets considerées relativenent a l'existence des sources. (Nancy, 1yp. Paulet.) Norembre 1839. 8.24 p.

66äl* Matthaeus Sylvaticus. Liber pandectarum melicinae. Editio

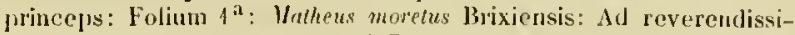
mum in christo patre ac dominu Dominum Franciscū de gonzagat Cardiualem Nantuanum ac Bononic legatu. Folium $1^{\mathrm{b}}-5^{\mathrm{a}}$ : index. Folium $6^{\mathrm{a}}$ : ${ }^{*}$ Liber pandectarum medicine omnia medicine simplicia contines: quem ex ommilus antipuorum libris aggregavit eximins artium at medicine doctor Matheus silvaticus ad serenissinun sicilie rege Rubertum s. l. (Argentorati.) et a. folio max. 367 foll. Bibl. E. M IIain Nr. 15192. (Ex conjectura Paizeri, Ann. typogr. I. p. 79 . Nrot 29 impressio Manteliana.) - "Venetiis 1480. fólio. Bibl. Goett. IIan Nr. 15498. - ${ }^{*}$ Liber pandectarum medicine: omnia medicine simplicia continens: quem ex omnibus antiquorum libris aggregavit eximins artium et medicine doctor Matheus Silsaticus: ad screnissimum Sicilie regem Robertum. Impressum Venetiis arte et ingenio Marini Saraceni anno donini $1488^{\circ}$. NIV Goll. Junii. Jolio. (4), 202 foll. Bibl. St. Gall. Ilain Nr. $15200 .-$ Opus jalluleclaruu, quod aggregavit eximius artium of inedicinae doctor Mallums silvaticus ad serenissimum Sicilie regem kobertum. qui fuerunt anno mundi $65 \$ 6$. anno vero spi 43.17 coaevi Petro de Abano. Nino de garho. Gentili Bonaventure. Francisco mayroni et Nicolan de lira. Impressum venctis (Yenetiis) per Philippum pinzium Nātuauum auno clomini 1492. Folio. (3), 193 foll. 69-71 linearum. Bibl. E. M. Hain Nr. 15201. - Opus pandectarum IItulei Silvatici cum Simone Januense et cum añotationihus auctoritatun Plinii, Galieni ef aliorum auctorum in locis suis. Impressum Venetiis mandate et impensis nobilis viri

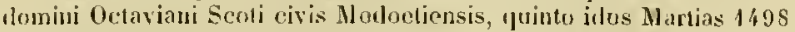
jer Bonetum Locatellum Bergommisem. folio. 181 foll., ind. Bibl. St. Gall. Iltin Nr. 15202. - "Venetiis, per Simonem de Livere. XXVI Martii 1507. folio. Bibl. univ. Lips. et Goett. - "Tourini 1526. folio. Bibl. Goett. - "In hoc volumino habentur haec: Opus pandectatum medicinae Nattlaei Sylvatici cum quotrationilus ommiom authorum in locis propriis. Cui accedit Simon Januensis. Adtlilis nonnullis capitibus simplicium medicinarum etc. Yenetiis, apud haeredes Lucae Antonii Juntae Florentini. 1540. folio, (4) , 188, (3) foll. Bibl. Е. м.

(lmpressionam apud Ilain Repert. loililiogr. Il. Nis. $15192 \div 15202$ recensilarum non vidi Nr. $15193-19197$ et Nr. 13199.

6632* Matthei, Christian Ileinrich. De tincturae Sabinae in morbis quiInstlam genitalinu virilium eflicacia olsservata quaedim. D. Marburgi 1819.4.14 p.

66:33* Matthei, Karl Anlon. In vegetabilihus arl diactam spectantilus. D. Marlourgi Catlorum 1794. 8.48 p.

660.' Matthews, Joln. A voyago to the river Sirra Leone on the coast of Africa. London 4788. \&. $183 \mathrm{p}, 2$ tals. B.

* germanice: Reise mach Sirrra bfone auf der wesllichen kuste von Alriha. loipzig, Weidmam, 17st, 8

gallice: loyage a la riviere de sterra-Leone, sur la cote d'Afriuuo traduit de l'anglais par Bellart. P'atis, llatuboul. 1796. 8. Q. 
66ij:j" Mattioli, I'ietro Andrea, latine. Matthaeolus vol Matthiolus. Apologia adversus Imutun Lusitumum cum consura in ejusdern enallrationes. Venetiis, ex officina Erasmiana Vinecutii Valgrisii. 1558. 8. - " ${ }^{*}$ impr. cun Commentariis in Diuseoridem: ib. 1559. folio. 46 p. - *impr. cum editione Operum. (Basilene) Prancolurti a/M., Iyp. Bassan. 1598 . Solio. 40 p. - "iupr. eum editione Operum. Basileare, typ. Genath. 1674. foliu. 40 's.

$6656^{*}$ _ - Jipistola de Bulbocastaneo, Oloconitide, Mamire, Traso, Moly, Doronico etc. Pragae, apul Johannem Cautorem. 1538.12. (35) 1. Bibl. Reg. Ber.

6657 Epistolarum medicinalium libri (quiugue. Pragae, ex officina Geors Melantrich ab Aientino. 1561. folin. 395 p., ic. xylogr. i. 1. в. - Lugduni, apul Caesarnu Farinam. 1564. 8. 652 p., ic. yologr. min. i. 1. B. - "impr. cum editiono Opermm. (Basileac) Francofurti a/M., 1yp. Bassaci 4598 . folio. p. 41-218. - *impr. cun editione Operum. Basileac, 1yp. Genath. 1674. folio. 11.41-218.

$6638+-$ Adversus viginti problemata Metchoris Guilendini disputatio. Imjer. cum Pauli Hessi lefeusiono (vislo supra Nr. 4436). Patavii, apud N. Antonium Ulmum. 1569. 8. p. | $121-151$. Bibl. Juss. - Disputatio adversus XX problemata Melchioris Guilandini. Venetiis, apul Vincentium Valgrisium. 1563. 4. s.

6639 De cura morbi gallici opusculum. Impr. cum Aloysius Luisinus be morbo gallico omnia, quae exstant. Venetiis, apul Jordanum Zilettum. $1566-1567$. Il voll. folio. Rrvin. - *impr. cum editione Operum. (Basileae) Francofurti a/M., 1yp. Bassaci. 1598. folio. 1. 219-236. - ${ }^{*}$ impr. cum editione Operum. Basileae, typ. Genatl. 1674. folio. p. 219-236.

$6660^{\circ}$ - Opusculum de simplicium medicamentorum facultatilus secundum locos et genera. Venetiis, aput Vincentium Valgrisium. 1569. 12. 329 foll. - TLugduni, apued Guilehum Rovillium. 157\%. 12. $668 \mathrm{p}$. Bibl. Juss.

$6661^{*}$ - Compendium de plantis omnilus : una cum earum iconibus, de quibus scripsit suis in Commentariis in Diascoridem editis. - Accedit Francisci Calceolarii Opusculum de itinere e Verona in Baldum montem. Venetiis, ex officiua Valgrisiana. 1571. 4. 921 p. ic. xylogr. i. 1

Mrathiolum praeterea in compesutium reciegit Antoine buPinet vel pinceus, quem librum supra Yr. 2835 indicavi.

$6662^{*}$ Dé plantis epitomo utilissima novis plane ad vivum expressis ieonihus descriptionibusque longe et pluribus el accuratioribus, nu primum diligenter aucta et Jocupletata a $D$. Joachimo Camerario y essit praeter indicem exactissimum liber singularis de itinere ab urbe Verona ad Baldum montem, auctorn Frmcisco Calceolario, pharmacopoeo Veronensi. Francofurti a/N., 1586. 4. 1003 p., praeter Calceotorium: (17) p., praef., ind, , (1003) ic. xylogr. i. 1.

(leones maxima ex parte sunt Conradi Gesneri; de is conferatur liber supra Nr. $\$ 183$ indicatus : *Peler fmmemuel flarmam, Iconum botanicarum Gresnotio-Camerariaturum
nacanus. D. Trajecti a/V. $1781.4 .52 \mathrm{p}$.)

$6663^{*}-$ Opera, quac exstant, omnia; hoc est: Commentarii in sex liluros Pedacii Dioscoridis Inazarlsei de metica materia, adjectis in margine variis graeci textus lectionibus ex antiquissimis codicibus desumtis, qui Dioscoridis dejravatan lectionem restitumt: nunc a Casparo Bauhino post diversarum editionum collationem infinitis locis aucti. Accedunt de ratione distillandi aquas ex ounibus plantis. Apologia in Amatum Lusitanum. Epistolarum medicinalium libri quinque. Dialogus de morbo gallico. Basileae, typ. Nicolai Bassaei. 1598. folio. 1027 p., praef., ind., 236 p), ic. (330) xylogr. i. t. - ${ }^{*}$ Basileac, Johannes Koenig. 1674 . folio. (non differt.)

(Afallioli eommentarii in Dioscoridem una cum Dioscoride in calce alphateti leguntur.)

666?* Mattuschka, Heinvich Gottfried, Graf ron. Flera silesiaca, oder Verzeichniss der in Schlesien wildwachsenden Pflauzen, nebst einer unstindlichen Beschreibung derselben, inres Nutzens und Gebraucles in Arznei und Haushaltung. Breslau und Leipzig, Korn. 1776 -1777. 2 Theile. $8 .-1: 1776.538 \mathrm{p}$, pracf. -11 : $1777.8,468 \mathrm{p}$. - ${ }^{*}$ Geschlechts - und Nameure yister zur Flora silesiaca. ih. 1789. S. 102 p. $\left(2^{5} / 6\right.$ (h.)

$6663^{*}$ Entmeratio stirpium in Silesia sponte crescentium in usum herborisantium. Vratislaviae, Korn. 1779. 8.348 p., praef., ind. $(5 / 6$ llh. $)$
6666* Mauchart, B. I). Schonhrumn's hotanischior Heiehthum. bin nutzliches Tuschentbueh fur Alle, welelse diesen merkwurdigen Gimbn brosuchen umel schatzen. Wien und Triest, Geistinges, 1805. 12. Iv. 161 p. $\left(1 \frac{1}{t}\right.$ th. $)$ - Narblese zu Schimbrums h hotanischen Reichthune, von J. St. Schmidt. Tiven 4808. 8. 92 p. $(1 /+$ th. $)$

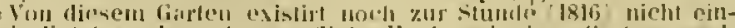

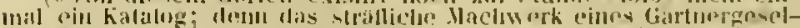

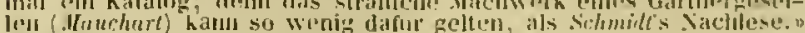
Sehultes.

6667* Mauchart, Burchard David, pr. Butyrum Cacan, novim atıue commendalissimun medicamentum. D. Tulgingac 1733. 4. 24 p. (Respromlens: Gotlieb Ho/fmann.)

6668 (Maude, Thomas.) An accuunt of the oak at Cowthorp, near Wealherloy, Yorkstire. s. J. 1774. 4. 11 p. B.

6669t (Maugin, Luguste.) Question lu Sesame. Petition aldresice aus chanlres législatives par la societe royaln et enntrale l'agriculture, sciences et arts du Departement du Noril. Douai, Mp. INubers. l)écenulure 1843.8. 13 p. Bibl. Webb.

6650* Mauke, Joham Gotllob. Grashüchlein, oller Anwrisung, die sehátlichsten und mutzlichsteu inlandischen Graser henueu .... zu Jernen, fur Landwirhe, Landschullehrer uml liaursteute. J rijuzigr und Meissen, Jacubaer. 180 1. 4. xx, 88 p., 16 Lah. - El. Il. Leipzig, Nuller. 18.18. 4. 16 tab. $\left(1 \frac{1}{3}\right.$ th. $)$

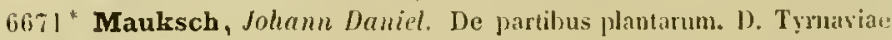
1776. 8.34 p.

$6072 \div$ Maulny. Plantes olsservées aux environs de la ville Ju llans. Avignun 1786.8 . 242 p. Bibl. cand.

Cuicum vidi exemplar libelli rarissimi, 'furm healus condollins pater it) ipso autore acceperat; desunt in eq tilulus ef folimm ultimum; manu Cantollif inscriptum est: Flore dh .Mtens. Titulun o (uerard depromsi.)

$6673^{*}$ Maund, B. The Botanic Garden: consisting of highly linished representations of hardy ornansental flowering plants, cultivated in Great Britain, wilh their classification, history, culture and other iuteresting information. By $B$. Maund. London, Baldwin, Simphin and Marshall. 4825-4842. JX voll. 4 minor. 216 tab, col, text. ( 1 ll. s.s.) Bibl. Reg. Ber.

Majorem vidi editionen lata quarta forma, rol. 1-YI, singula 11. 16.s. $=101$. 16.s. - In quoque volumine 2 't tabulite coloralae; ill (likturo labula $i$ icones.)

$66 \% \%^{*}$ - The Botanist, containing accurately coloured figures of tender and liardy ormamental plants with descriptions scientific and popular; intended to convey both moral and intellectual gralification. Cunducted by B. Meund, assisterl by J. s. Henslor. London. Groomluridge. ( 1839 sqq.) Y roll. 4. 250 tab. col., text. ( 81. - ed. minor: $5 l$.) Bibl. Mus. bot. vind.

$6673 \div$ Maupied, François Louis Wichel. Considerations génirales sur le caractìre de la végétabilité et la forme régétale estérieure dam. leurs rapports avec l'organisation intérieure o' de la série végétale. These. Paris 1841.4 . p. $41-48$.

$6676^{*}$ Maupoil, Carlo. Catalogo generale ledi alleri e piante coltirati nei vivaj di Carto Haupoil al dolo provincia di Venezia. Vinezia, (y]. Felice. $1827,8,37 \mathrm{p}$.

$6677^{*}$ Mauri, Ennesto. Romanarum plantarum centuria decima tertia. Romac, ty]. tle Romanis. 1820.858 p., 2 tal.

Centurias duodecim priores vel lifurac liomanae Prodromun jan an1o 1818 cunn Antonio Sebastiani ediderat, sul, cujns numine infra librum indicabo.)

$6675 \div-$ Antonio Orsini et Lichele Tenore. Enumeratio plantarum, yuas in itinere per Aprutiun vel per pontificiae ditionis finitimas provincias aestate anni 1829 collegerunt. Nealjoli $1830.4 .90 \mathrm{p}$.

(Alli dell Accallenia P'ontaniana, vol. 1: Xiapoli 1832. 4. p. 150-36ti.)

$6679+$ Maurille de Saint Michel, Père. Phytologie sacrée, ou atiscours moral sur les plantes de la Saint Ecriture: symboles des mysteres de la foy et des verites clirestienues; divisée en six parterres. Angers, clez P. Yvain. 1664. 4.7\$7 P., praef, ind. Bibl. Juss.

$6680^{*}$ Mauz, Eberhard Friedrich. Versuche und Beobachtungen uber das Geschlecht der Pflanzen, und die Veranderumgen Jersellieı durch kusst'e Einflusse. Mit Anwendung dieser Beobathtungen auf Ilie Verbesserung des Hanfbanes und einiger andern whonomischen Gewíclise. (Tübingen 1822.) 8. $15 \mathrm{p}$.

$6681^{*}$ Versuche und Beohachtumgen uber den kartoffelbau

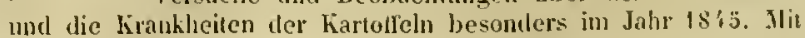


einem Anhange uber kinstlichon erzeugten Guano. Stutgart, Steinhopf. 1845.8 . vi, 58 p. $(1 / 4$ th. $)$

6682 Mauz, Ebcrhard Friedrich. Archiv fur Naturheilkunde unt Agrihultur. IIeft 1-2. Stutgart, Neff. 1845.8 . $19 \frac{1}{2} \mathrm{plag}$. $\left(1 \frac{1}{4}\right.$ th. $)$

6683 - Erörterungen iber die Kartoffelkrankheit, und Rathschlage zu teren Verhütung in Jalı 1847. Stuttgart, Stcinliopf. 1847.8.56 p. (1/th.)

668 : 1 Mavor, Ifilliam. The Lady and Gentlenan's botanical pochet bouk; adapted to IT'ithering's Arrangement of british plants. Lundon, Ternor. (1800.) 19. x, 485 p., ind., 2 lah. (3s.)

6683 Mawe, Jolm. Travels into the interior parts of Brazil, particularly in the gold and dianond districls. Londun, Longman. 1813 . 4. (18s.) * germanice: John Jhuce's Rejsen in das hnere von Brasilien. Rantberg und Leipzig, Kunz. $1817.8 .656 \%$. $\left(11 / 2, h_{0}\right)$

6686 Mawe, Thomas, and John Abercrombie. Every mau is owu gardener; being a complete gardener's calendar and general directory for evers month. Lunton 1776. 8. - Ed. XXIY, with great improvements and the whole brought down to the present state of horticultural knowledge; by James . Hain. London 1839. 12.

6687 Maximovitsch, Michail. O chcтewax, pactiтc.nbaco yajocrua. Mockea 1897. Trautv.

$6688^{*}$ - Оспованія 6отаник. Частт I. Hoсква 1S2S. S. Xv!, 142 J., 2 tab. Bibl. Link.

6689 Систематика растеній. Оспованія бөтіJикі книга вторая. Juckва 1\$31. Trautv.

$6690^{*}$ Maycock, James Dottin. Flora Barbadensis: nr a eatalogue of plants indigenous, naturalized and cultivated in Barbatos. To which is prefixed a geological descrijtion of the island. London, Kidgway. 1\$30. S. xx, 446 p., ind., 2 tab. geol. (18s.)

$6691^{*}$ Mayer, A. F.J. C. Supplemente zur Lelore vom Kreislaufe. Erstes Heft: Supplemente zur Biologie des Blutes und des Pllanzensaftes.

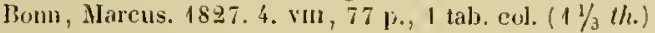

6692* Mayer, Johamn. Pomona franconica, oder naturliche Ahtjilhung und Bcschreilung der besten und vorzughlichsten europaisehen Gattungen der Obsthaune und Fuchte, welche in dem hochfurstlichen Ilofgarten zu Wurzburg gezogen werden. Nebst den hauptsachlichsten Anmerkungen uber deren Erzieluung, Propfing und l'llege. Descrijtion des arbres fruitiers etc. Numberg, Winterschmilt. 1776 -1804. 3 Bámde. 4. - I: 1776. cIr, 152 p., THI, ViII, XYll tab. col. - Il: 1779.364 p. LXXYIl tab. col. - III: 1804.350 p. CLY tab. col. $\left(\$ 72 / 3 t h .-\right.$ in charta meliori: $\left.145 \frac{1}{6} t h.\right)$

6693* Mayer, Joham. Sammlung physikalischer Aufsätze, besonders die bolumische Naturgeschichte betrelfend, von einer Gesellschaft bohmischer Naturforseher. Herausgegeben von Joham Hayer. Dresilen, Walther. 179.1-1798. 5 Bande. 8. - 1: 1791. 270 j., 4 tab. 11: 1792. 364 p., 3 tab. - Ill: 1793. 408 j., 3 \{ab. - IV: 1794. 409 p., 2 lab. - V: 1798.484 p. $(51 / 3$ th. $)$

669:* Mayer, Johann Christoph Andreas. Abhandlung ron dem Nutzen der systematischen Butanik in der Arznei- und Haushaltungstunst. Greifswald, Rose. 1772.4. $48 \mathrm{p}$.

6693 Mein Garten. Frankfurt 1778, 8. (1 th.)

$6696^{*}$ _ Einheimische Giftgewachse, welche fur Mlenschen am schádlichsten sind. Zwei IJefte. Berlin, typ. Decker. $1798-1800$. folio. - 1: 1798. $18 \mathrm{p} ., 5$ tab. col. - II: 1800 . (non vidi.) (3 th.

$6697^{*}$ Yorzugliche einheimische rssluare Schwamme. Anhang der Beschreibung der schädlichen einheimischen Giflgewächse. Berlin, Iyp. Decker, 1804. folio. 20 p., 3 tab, col.

6698 Mayer, Karl Ermst. Neuestes allgemeines deutsches Gartenbuch mit Ruchsicht auf Boden und Klima, oder aljgemeines Handbuch des Garlenhaues etc. Wien, Jlorschner. $1827.8,46$ plag., 4 (ab. ( $21 / 3$ th.)

$6699^{*}$ Mayr, Anton. De venenata Ranuuculorum indole. D. Viennae, ig]. Schmicit. 1783. 8. 28 p.

6700 Mayr, Johann. Deutschlands Flora in schwarzen Abdrucken von den Phanzen sellsst. Regensburg 179 -1799 . Zehn Hefte. folin. Scb.

670.1* Mayrhofer, Karl. De Orchileis in territorio Vindubanensi crescentilus. D. Vindolonae, typ. Sollinger. 1832. 8. vu, 56 p.

6702 Mazzucato, Giovanni. Sopra alcune specie di frumento. Padova 1807. S. DC.
6703 Mazzucato, Giovanni. Sullo zucchero ed altri prodntti economici (lei Diospyros. s.l. et a. 8 . DC.

670.4 - Viaggio botanico all alpi giulie. Lettera al Prof. Arduino, Vidine, typ. Yeudrame, 1811, 8, 28 p. Bibl. Cand. Inest : Páradisea Mazz. novm Litiacearum genus,=Czackia Andrz.) $6703^{*}$ - Triticorum definitiones atłue synonyma. Utini, ex Ispographia Peciliana. $1812.8 .30 \mathrm{p}$.

$6706^{*}$ Mead, Richard. A mechanical account of poisons, in several essays. Fol. IV. London, Brindley. 1747. 8. xhrin, 320 p., 4 tab. latine (Ine faciunt endili operis p. 227-210. latime: Herlanica expositio venenorum. Goettingae 1769. 8. Francufurti a/M; 1763. 8. H.

6707 Meader, James. The planters guide, or pleasure gardencr's companion. London 1779.4 obl. s play., 2 tals. $B$

6708 Meager, Leonard. The english gardener, or a sure guide to young planters and gardeners, in three parts. London, Peter Parker. 1679. S. s.

6709 The new art of grardening, with the gardeners almanach, containiug the true art of gardening in all its particular. London, Peter Parker. 1713. 12. s.

6710 Mecum, Friedrich. Von den kitutern und ihrer liraft. Wittenbergae 1539. 4. H.

671 Meder, Johamn Mrinrich. Medicamenta quaedam simplicia, quibus offieinae nostrae pharmaceuticae facile carere possunt. Guettingae 1760. 4. H.

$6712^{*}$ Medicus vel Medikus, Fricdrich hasimir. Index plantarum horti electoralis Manhemiensis. Maulnenii 4771. 24.70 p., 1 tab. $(5 / 24 t h$.

$6713^{*}$ IBcitrigge zur schösen Gartenhunst. Nanuheim, akactemische Buchbandlung. 1782. $8.378 \mathrm{p}$., praef, ind. $(5 / \mathrm{th}$.)

6714* — Botanische Beobachtungen des Jahres 1782. Vier Hefte. Mannheim, akatemische Buchbandlung. 1783.8 .419 P., 1 tal).

$6715 \div$ - W - Veber den merkwurdigen Ban Iler Zeugungsglieder einiger Geschlechter aus der Familie der Contorten. (Nerium, Periploca, lioelreuteria, Cynanchum, Asclepias.) Mannheim, akadenische Buchhandlung. 1782.8.88 p.

(Sistit particulam libri praecedentis.)

6716 †_ Botanische Beohachtungen des Jahres 17 \$3. Mannheim, akadenische Buchhandlung. 1784 . 8. (30), 312 p., ind. (1. 11: $31 / 3$ th.)

$6717^{*}$ - Theodora speciosa, eim neues Pflanzengeschlecht; nebst einem Entwurfe, die kmstliche und naturliche Jlethode in Ordnung des Pftamzenreiches zugleich anzuwenden, als fler sichersten, cin Phanzenkenner zu werden. Manuheim, (Schwan.) 1786. 8. 116 p. 4 tali. $(5 / 12$ th. $)$

$6718^{*}$-.. Veber einige künstliche Geschlechter aus der Nalvenfamilie, der Klasse der Monadelphien, mit beigefugtom Irtheil über Linneische Geschlechter und deren Klassification, uher llerbarien und Terminologie, dann Empfehlung einer Sammlung von Fruchtgehtiusen und teren Samen, vorzuglich ciner genauen Zerglielerung sänmtlicher Fruktifikationstheile jeder Pllanze. Jannhein 1787. 8. $158 \mathrm{p} .(2 / 3(h)$.

$6719^{*}$ —... Philosophisehe Botanik mit kritischen Bemerkungen. Zwei Ifefte. Jannheim, akademische Buchlrandlung. 1789-1791. 8. - 1: 1789. Von den mamigfaltigen Umbullnngen der Samen. 266 p. - Il: 1791. Veber die zur Iildung einer Planzengattung erforderlichen Eigenschaften. 112 p., int. ( $1 / 6$ th.)

6720 - . P Planzengattungen nach dem lnbegriff simmtlicher Fruhtifikationstheile gebildet und nach dem Sexual-Pllanzenregister geordnet; mit hritischen Bemerhungen. Erstes Ileft. Mlannlieim, Schwan und Goetz. 1792.8. 127 p., 2 lals. $(3 / 1$ th.)

(Versatur in Cruciferarum fanilia.)

$6721^{*}$ —_ Geschichte Jer Botanih unsrer Zeiten. Nannhein, Schwan und Goetz. 1793. $8.96 \mathrm{p} .(3 / 8 t h$.

$6722^{*}$ líritisehe Bemerhungen uher Gegenstinde aus dem Pflanzenreiche. Ersten Bandes erstes und zweites Stuck. Manubeim, Sclowan und Gotz. 4793.8 .303 p. $(5 \%$ th. $)$

$6723^{*}$ Unachter Akazienbaum. Zur Ermunterung des allgemeinen Anbaues dieser in ibrer Art einzigen IIolzart. Eime Zeitschrift. Leipzig, Gralf. 1794-1803. 5 Bancle. 8. - 1:608, 94 p., 1 tab. Il: $606 \mathrm{j} .-11 \mathrm{l}: 432 \mathrm{p} .-\mathrm{NV}: 508 \mathrm{p}, 1 \mathrm{lab},-\mathrm{V}: 368 \mathrm{p} .(71 / 12$ th. $)$

672 \& Auszug aus dem Inachten Akazienbaum, mit Anmerkungen. Drei Stüche. Dusseltorf, Schreiner. $1798-1802.8 .(3 /$ th. t gallice: Lettre sur le robinier. Mannheim 1803. 8. 31 p. 
6720 Medicus vel Medikus, Friedrich liasimir. Hericht uber die in Ien Jahren $1800-1802$ gefulirten Schlage in der kurfurstlichen Akazienanlage zu Mannheim. Leiprag, (araff. 1802. 8. $(1 / 4 h$.

$6726^{*}$ — Beitráge zur P'lanzenanatomie, Pflanzenphysiglogie, und einer neuen Charahterislik der Bume um Straucher. Sieben llefte. Leipzig, Graft. 1799-1801.8.521 p. $(17 / 12$ th. $)$

$6727^{*}$ - Pllanzenplyssiologische Abhandlungen. Leipzig, Graff, 1803. 3 Bäudehen, 12. x11, $287,244,215$ p., ind. (21/4 th.)

6728 - Beitrige zur Kultur esotischer Gewachse. Manhein, Loenllex. $1806.12 .(5 / 6,(h)$.

(in thoc libello costinetur omniun autoris scriptorum catalogns.)

6729 Medley, Johannes. Disputanio inanguralis de natura et virilus Ojui. Lngluni Batavorum 1716. 4. 8 p. B.

6730 Meen, Margaret. Exntic plants from the royal gardens at Kew. Nir. 1. 1790. 4 tab. aen. col., long. 19 unc., lat. 13 unc.

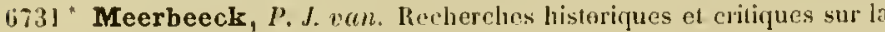
vic et les ouvrages de Rembert Dodoens (Dodonaeus). Halines, Ihanicr. 1841.8. XIY, 340 p., effigies Dodonari.

6732 Meerburgh, Nicolaas. Afbeeldingen van zeldsaame gewassen. Leyten 1775 . folie. 7 plag., 50 tab. col. B.

6733 Namlyst der hoem en heestergewassen, dienstig tot het aanleggen van lustboschjes of zogenaande hermitagien. Leyden 1782.8.41 p. B.

$6734^{*}$ L Plantae (el papiliones) rariores vivis coloribus depictae. Lugduni Batavorum, apud Jacobum Meerburg. 1789. folio. (26) p., 55 tab. col.

$6730^{*}$ — Plantarum selectarum icones pictae. Lugduni Batavorum, apud Jacebun Meerburg. 1798. folio. (10) p., is tab. col.

$6736^{*}$ Meerfels, C. G. Naturhistorisch-botanisch-pharmazeutisches Lehrbuch, zum Selbststudium fur angehende Aerzte und Apotheker, und zum Gehrauche für Gewerhsschulen. Magdeburg, Creutz. 1839. 8 VIII, 686 p. $\left(2^{3 /} / t h.\right)$

(Autor pseudonymus vilissimi compendii aulit Farl Gollfied Quarizius.)

$6737^{*}$ Meese, Dacid. Flora Frisicn, of Lyst der Planten, welke in de Provintie Friestand in liet Wilde gevonden worden. Franeker, typ Brouwer. 1760.8 .87 p., praef., 2 tab.

$6738^{*}$ — Ilet XIX Classe van de Genera plantarum Linn. (Syngenesia) opgeheldert en vermeerdert. Accellit: Beschryving van een zenderlinge Zee-plant. Leeuwarden, Chalnot. 1761. S. Iv, 152 p. 8 tab.

$6739^{*}$ _ Plantarum rudimenta, sivo illarum methodus, ducta ex diflerentia carum seminum, cotyledonum aliarumgue partiun, quae brevi tempore post earum propullulationem ac ulterius incrementum in is conspiesuntur; quorum omnium utilitatem pracfatio satis sujerque lectorem docebit. Investigata, effecta et composita a David Meese. (Pars prima Nr. 1 et 2.) Leovardiae, 1yp. Coulon. 1763.4. 82 p. praef, ind., 7 tab, col. Bibl. Mus. bot. vind.

Fertutur etiam hoc titulo: "Eerste beginseling der Planten, of Lecrwyze derzetve etc. $n$ el liber jpse simul latina et belgica lingua conscriptus est. In plarimis bihliothecis, quac ultra paritis primae numerum 1: "23 P., (32 foll.), 2 tah. col." prodierunt, desiderantur; semel equidem primam alteramulue sectionen vidi: " $82 \mathrm{l}$., (32 foll.),
7 tal., col.")

$6740^{*}$ Megerle von Mühlfeld, Johann Georg. Oestreichs Färbepflanzen, oder Darstellung aller in dem Oestreichschen Kaiserstaate wildwachsenden und im Freien cultivirten, einen brauchlsaren Färbestoff enthaltenden Pilanzen. Wien, typ. Ueberreuter. 1813. 8. xvı, 121 p., ind.

674.1 Meibom, Brandanus. Botanica generalia. Programma lectionibus botanicis praemissum. Helmstadii 1718,4. H.

6742 Meibomius, Johann Heinrich. De cerevisiis potibusque et ebriauinibus extra vinun aliis commentarius. Accessit Adriani Tumebi libellus de vino. Helmstadii, Iyp. lleitmüller. 1668. 4. s. - ib. 1671. 4. 1 aljhab. B.

6743 Meier, Georg, latine Marius. Paralipomena et marginalia hortulasica, d. i. Gartenkunst zum Feldbau angehorig. Strassburg 1568. 8. H.

674:* Meier, Karl Goltlob. De Carice arenaria. D. Francofurti a/V. 1772. 4. 40 p., 1 tah.

67':5* Meigen, Johamn Wilhelm, und II. L. Weniger. Systematisches Verzeichniss der an den Ufern des Rheins, der Roer, der Mas, der
Ourte und in ten angrtuzenden Grgenten withwachenten und unhant werdenden phaneroganischen phanzen. Koln, Romnershirchen. $1819.8 \mathrm{ob}]$. v111, $108 \mathrm{f} .(2 / 3$ th. $)$

$6716^{*}$ (Meigen, Johann IIilhelm.) Versuch einur Flora der l'fer de. Xiederrluius, der Hoer, der Mans, der Ourte und der angrimzenden Gegenden. Nach Anleitung von Heigen's und Il'eniger's Systematischem V'erzeichnisse. Kuln, Rommershirchen. 1823. 12. sxxil, 518 p. ( th. - charta vel. $1 \frac{1}{2}$ th.

$6747^{*}$ Leutschlands Flora, oder systenatische Heschreilung ter in Jeutschland wildwachsenden und im Freien angebauten l'llanzen. Fissen, Badeher. $1836-184$. 3 Bande. 8. - 1: 1836. (ci. J-5.) $x \times, 478$ b., 1ab, $1-49 .-11: 1837$. (Cl. $5-12$.$) vi.$ 500 p., tal. $50-97 .-$ II]: 1842. (C). $13-20)$.620 p., tab. $98-$ 144. $\left(7 \frac{1}{2} \mathrm{th}\right.$.

$6748 *$ Meilhac. Catalogue des livres dhistoire naturello, yui se trouvent chez Jleilhac, libraire, Cluitre St. Beneit Nir. 14 i Paris, Paris, Aull 1845.8.64 p.

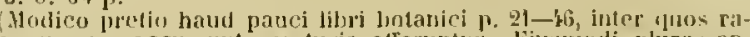
risres unowue occurrunt, enturis offeruntur. Ejusmodi plures an-

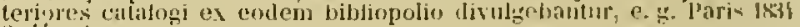
8. it p.i

6749 Meinardus, Franciscus. De visco Druidarum orationes, Dictevii 161i.8. Falc.

$6730^{*}$ Meinecke, Johann Ludwig Georg. Ceher das Zolılenyerhaluis: in den Fruhtilikationsorganen der Pflanzen und Beiträge zur Pflanzenplyswologic. Halle, Hendel. 1809.8 .50 p. $(1 / t / h$.

(Neue schriften der naturf, Ges, zu llalle. 1. Ileft.

$6731+$ Der Botaniker ohne Lelurer. Eine Anweisung zur Pflanzenkunde in Briefen an cine Freundin der Natur nach dean Jucques Rousseau und H.v. C. bearbeitet und mit Anmerkungen begleitet von J. L. G. Ileinecke. Halle, Hendel. 1809. \&. 1III, 361 1). 4 tal). col. $\left(1 \frac{1 / 3}{3}\right.$ th. $)$

$6752^{*}$ Meinicke, $C, E$. Das Festland Australien, eine reographische Hu- $_{1,}$ negraphic. Prenzlau 1837. 2 Theile. $8.131,354,316 \mathrm{p},(3 \mathrm{3} / \mathrm{t} / \mathrm{h}$.

(Pluriena insunt ad geographiam plantarum spectantia.)

$67033^{*}$ Meisner, Karl Friedrich. Monograpiniae geueris Polygoni P'rodromus. Genevae, 1yp. Lador. 1826.4 . Iv 117 j., 7 tab. $(12 / 3$ th.

6754: * Plantarum vascularium genera secumdum ordines naturales digesta eorumque differentiae et affinitates taluulis diagnesticis expositae. Lipsiac, libraria Weilmannia. 1\$36-1843. folio. Par prior. Tabulae diagnosticac. 442 p. Pars altern. Commentarius, exhibens practer adnotationes et explicationes varias, generum srnonyma librorumque indicationem, quibus descrijutiones fusiores et icones nec non specierum novarum diagnoses supjeditantur. 401 l\%. (19 h.)

673̈̈* Meisner, Leonhard Ferdinand. De Catse, Choccolata, lierha 'Thee ac Nicotianae natura, usu et alusu anacrisis medico-historicodiactetica. I'ragae 1720.4. - *Norimbergae, liudiger. 1721. 8. 124 p., 4 tab.

$6756^{*}$ - Panacea lapsorum, sive de herba Arnix. J), Pragne 1736. 4. $47 \mathrm{p}$.

6737 De Camphora. D. Pragae 1737.4.

$6758+$ Meissas, $N$. Résumés dhistoire naturelle. Botanique. Paris et Lyon, Perisse. 1839.8, vo, $304 \mathrm{p}$.

$67597 \longrightarrow$ Petite botanique. Paris et Lyon, l'erisse. 1\$42. 12, $143 \mathrm{p}$.

$6760^{*}$ Meister, George. Der orientalisch-indianische hunst-und Lustgârtuer, wie auch Annerkungen, was bey des Auturis zweinahliger Reise nach Japan, von Jara major, làgst der Kusten Sina, Siam und ruckwarts uber Malacca observiret worden. Dresden, typ. Riedel 1692. 4. 310 p., ind., tab. - Dresden und Leipzig 1731. 4. (eadent editio nevo titulo.) B.

$6761 \div$ Melandri, Girolamo e Giuseppe Moretti. Analisi chiurica delle radici di Carisfilata e di colchice autumnale con alcune ricerche analitiche sull' uva Orsina. Pavia, ty]. Capelli. $1803.8 .1 \times, 131 \mathrm{p}$

6762 Melén, Evik Gustaf. De Erythracis suecanis. Dissertatio botanicomedica, quam praeside Curl Pehr Thunberg pro gradu melico conscripsit et publicae censurae oflert. Upsaliae, typ. Palmblaıl. 18:6 4. 8 p. w.

$6763^{*}$ Mellesinus, Johamn Siegfried. Carmen heroicum de virtutibus et proprielatibus Scordii herbae, nuper in Germania a laterio Cordo 
iwentae. Scriptum a Johanne Sigfrida Mellesino, artis med. studioso, anno 3. Olympiatlis 787. 4. (Augustae Vindelicorun, typ. Hath. Francus.) 7 foll., i tab. col. Bibt. caes. Vindob.

6764t (Melleville.) Les amours des plantes. Poéme, accompagné de nombreuses notes sur la botanique et la physiologie régétale. Paris, Corbet. 1835. 8. vil, 340 p.

6765 Memmert, $J F$. Kurze Beschreibung von 150 in - und auslandischen ökonomischen Samereien, nebst so nach dem leben abgedruckten und illuminirten Abbildungen der Aelren, Pflanzen oder Blatter davon, als Erläuterung des Samendemons!rir-Kabiuettes. 1802. s.l. gr. 4. (12 th.) Vogler.

(Dio Samereien oder Demollstrir habinet sind in Glashästchen.)

$6766^{*}$ Meneghini, Giuseppe. Ricerche sulla struttura del caule nelle piante monocotiledoni. Patova, coi tipi della Minerva. 1836.4 max. 110 p., 10 tats.

$6767^{*}$ Conspectus Apologiae Euganeae, germanicis naturalium rerum scrutatoribus Pragae anno 1837 convenientibus oblatus. Palavii, typ. Minervae. 1837. \$. 37 p.

(Seorsin impr. ex Comment. di medicina del Dr. Spongia, fase. Sept. 1537.)

$6768^{*}$ Comni sulla organografia e fisiologia Jelle Alghe. Padosa, coi tipi della Minerva. 1838 . folio min. $64 \mathrm{p}$.

$6769^{*}$ _ Synopsis Desmiliearum hucusque cugnitarum. Halae ad Salan, typ. Gebaucr. $1840.8 .40 \mathrm{p}$.

(Seorsin impr. ex Linnaea, vol. Xly.)

fijiot - Quattru nuove specie di alghe trovato dal Dr. Jacob Corinaldi ai bagni di S. Giuliano di Pisa. s. I. et a. 12. Bibl. Montagne. (Quatuor species exsiccalae adglutinatae cum nominibus.)

$6771^{*}-$ Lettera al Dr. Jacob Corinaldi. s. I. et a. 8.4 p.

(Seorsim impr. ex Giornale loscana di scienze mediche, fisiche c naturali 18\%1. tom. 1. No. 2.

$6772 \div$ - Sunto di una memoria diretta a mostrare i rapporti di organizzazione tra le alghe propriamente dette of Ficeo o le $A$ lghe terrestri o Licheni, letta nell' adunanza del di 16 settembre 1841 della sezione di botanica del terzo congresso scientifico italiano adunato in Firence. (Firenze) 1841.4. 45 p. Bibl. Juss.

(Estratto degli Atti del congresso.)

$6773^{*}$ — Nonographia Nostochinearum italicarum adrlito specimine de Rivulariis. Augustae Taurinorum, ex officina regia. 1842. 4. $143 \mathrm{p}, 17 \mathrm{tab}$ (pulcherrime) pictis.

(Estratto del vol. V. serie II. delle Memorie delle R. Accarlemia delie Scienzo di Torino.)

$6774+(-)$ Sulla teoria de' meritalli di Gaudichaud. Firenze, per la società tipografica. $4844,8,12 \mathrm{p}$. Bibl. Juss.

$6773 \div(-)$ Sulla metamorfosi delle priante. s. I. et a. 4. 6 p.

(Dal Giornale Eugarseo, anno i. No. 6.)

$676^{*}$ Alghe italiane e dalmatiche illustrate dal Professore Giuseppe Meneghini. Fascic. 1- V. Padora, lipografia di Augelo Sicca. 1842-4846.8. 384 p., 5 tab.

$67 i 7$ Sulla animalità delle Diatomee, e revisione organografica dei generi di Diatomee stabiliti dal Kuetzing. Venezia, Naralovich. 1845, 4, $496 \mathrm{p}$.

6778 Menegoti, Vicenzo. Postille ad alcuni capi della sturia botanica del Sig. Giacoma Zunani. Padova, Frambotti. 1676. 12.63 p. B.

(Vicenza Afeneguti est nomen fictitium. "Giumballista Scarella quandoque nomen suum colavit sub noune Jfenegali." seguier, Bibl. bot. auctuar. p. 35.

$6779^{*}$ Menge, A. Catalogus plantarum planerogamicarum regionis Grudentinensis et Gedanensis. Grudentiae, typ. C. G. Röthe. (Gedani, Homam.) 1839.12 .442 p. (1 th.)

$6780^{*}$ Menke, Karl Theodor. De leguminibus veterum, particula prima. D. Goettingae, Dieterich. 1814.4.32 p.

6781 Menier, Pierre. Le blason des fleurs, ou sont contenus plusieurs secrets de médecine. Paris s. a. 16. $\mathrm{s}$.

6782 Mennander, Carl Fredrik, pr. De nutrimento plantarum. D. Aroae 1747.4.20 P. (Respondens: Gabriel Arenius.) B.

6783 , pr. De foliis plantarum. D. Above 1747. 4. $19 \mathrm{p}$. (Respondens: Isuac Fortelius.) B.

$6784 \longrightarrow$ рт. De radicibus plantarum. D. Aboae 1748.4. 15 p. (Respondens: Abraham Falander.) B.

$6783 \longrightarrow$, pr. De seminibus plantarum. D. Nhoae 1752. 4. 22 p. (Respondens: Petrus Salitander.) B.
6786 Mennesson, Jean Baptiste Augustin Prosper. Lobservateur rural de la Marne, ou tableau historique el topographique des vignobles de ce département. Epernay, Warin-Thierry. 1906. 12.

$6787^{*}$ Mentz, Friedrich. De plantis quas ad rem magican facere crediderunt reteres. D. prior. Lipsiae, typ. Brandenburger. 1705.4. 16 foll.)

(Dissertatio haud contimuta est.)

6788 MentzeI, Christian. Centuria plantarum circa nobile tiedanum sponte nascentium. Dantisei 1650.4 . H.

(Addit auctor, quem filso Seguierus hahet Albertum Menzelium.

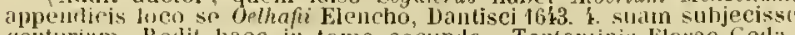
centuriam. Redit haec in tomo secundo "Tentaminis Forae Getlitneusis, autore (rottried Heyger. Dantisci 766. 8. 1). 201-22k.)

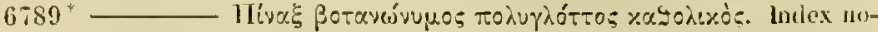
mium plantarum universalis multilinguis, Latinorum, Graecorum et Germanorum literis per Europam usitatis conseriptus et sic constrictus, ut plantarum genera, species, colorum et aliarum partium differentiae, quolquot hactenus innotuere, urdine sub se collocarentur, citatis classicorum autorum locis genuinis ab ipsollippoeralto ad novissimos usque sareculi nostri botanicos tiesumtis. Adjectus est pugillus plantarum rariorum elc. opera Christumi Mentzelia l). Berolini, rx officina Rungiana. 1682 . folio. 331 p., (18) foll., 11 tai.

Reimpressiones hujus libri sunt Berolini 4696. folio et 1713 . folio. Practer ticufum mulatum a Lexicon plantarum polyglotton universale v nulla nota differunt; sed his editionibus accedi: "Al indicent untab. $12-13$, in tho plantae in promontorio bonae spei a Jahann priedrich Ricker collectae recensentur cum figuris quarumblam.

6790 Mentzer, Magmus. Svenska ákermannen otc. i. e. le jraedioruın nusticorum per Sueciam indole et constitutione varia , corundenupu" cultura. Stockholmiae, Werner. 1727. 8. s.

6791 Utforlig beshrifuing om hollandska tabak ortens ans och skutsel lämpate after wort Climate. Stockholm 1747. 8. H.

6792* (Menzel, Albert, et Philipp Menzel.) Synonyma plantarum, seir simplicium, ut vwant, cirea Ingolstadjum sponte nascentium, cum designatione locorum et temporum, quibus vigent et florent: in ustm scholae medicae Ingolstadiensis collecta. Ingolstadii, Iypis Ederianis. 1618. 8. 141 p., praef, - Ingolstadii, typis Ederianis. 1654. 8. 141 p., prae? (eadem impressio!)

Albert. Menzel (el ejus pater Philipp Henzel ab editore Wilhelu Eder autores praedicantur.)

6793* Mérat, Fransois Victor. Nouvelle Flore des environs de Pari. suivant le systeme sexuel de Linné, avec l'indication des vertus des plantes usitées en médecine, des détails sur leur enploi pharmaceutique etc. Paris, typ. Clapelet. I8 12. 8. xxxvit, 420 p. - "Ed. II : Paris 1824. 8. - tEd. 111: Paris $1831-1834$. 11 voll. 12. Ed. IV: corrigée et augmentée. Paris, Mléquignon-Maryis. 1836 Il voll. 42. - I: Cryplogamie, vil, $489 \mathrm{p}$. - Il: Phanérogamie. $\mathbf{x x}$, 662 p. ( 13 fr.) - ${ }^{*}$ Ed. T. corrigée el augmentée. Bruxelles, Ilauman et Co. 1837-1838. Il roll. 12. - J: 1837. Cryptogamie. viı. 388 j. - 11: 1838. Phanérogamie. xuI, 496 p. (4th.)

(Ci. tObservations de M. Auguste de Saint-Hitaire sur ha nouvelle Flore des environs de Paris par M. Francois l'ictor Meral. s. il. 8 . 27 p.)

$6794 \div-$ Élémens de botanique à l'usage des personnes qui suivent les cours du jardin du roi et de la faculté de médecine de Paris. etc. - Ed. IV. Paris, Crochard. 1817. 12. xxII, 386 1. tEd. V. revue, corrigéo el augmentee. Paris, Grocharl. 1822. 12. I 418 p. - Ed. VI. Paris, Crochard. 4829. 12. (4 fr.) a.

(Editiones i-lil. non villi.)

$6793 \div-$ et $A . J$. De Lens. Dictionnaire universel de matière médicale et de thérapeutique générale, contenant l'indication, la description et l'emploi de tous les médicamens connus dans les diverses parties du globe. Paris, Baillièro. $1829-4834.1-Z$. VI voll. 8. $x 11,706,704,742,746,658,4027$ p. (48 fr.)

6796 Examen des genres Apargia et Thrincia, asec la description abrégéc des espèces á feuilles lispides, placées dans ces deux genres. Paris 1834.8 . 10 p. $(75 \mathrm{c})$

6797 - Symopsis de la nouvelle Flore des enviruns le paris suivant la méthode naturelle. Paris, Méquignon-Marvis. 1837. 12. $315 \mathrm{pe}$, pract. $(4 \mathrm{fr} .50 \mathrm{c}$.)

$6798 \div-$ Totice sur une hejpatique, regardée comme lindivitu male du Marchautia conica L. Paris, Bouchard-Huzard. 1840. 8 . 12 p., 1 tab. (Nernoursia tubereulata Mérat.) (75 c.)

(Extrail des Annaies de l'agriculture française, Juillet 1860. 
(i79yt Mérat, Frangois Victor. Revue de la flore l'arisionne, suivie du lexte du Jotanicon Parisiense de laallent avec los noms Linnéons en regarl. Ourrage servant do complement anx quatre cilitions (et au syuopsis) de la nouvelle flore des euvirons do j'aris (du meme: anteur) el á tuules celles poblices jasqüici. Paris, Baillicre. 1843. 8. 15,492 p. ( $5 \mathrm{fr} .50 \mathrm{c.}) \rightarrow+$ Appendix: ils. Janvier 1846 . p. 193 $-496$.

$6800 \div$ Notice sur la alestruction des roses uaissintes par lat larve d'une manche il seie. Paris, tyj. Bethune at Plan. 1844. 8. $16 \mathrm{l}$.

$6801+$ Memoire sur la possibilité do cultiver le thé en pleine torre et eu grand es lrance avec dos observalions sur la preparam tiun de ses feuilles, lear usage elc. Paris, bouchard-Jluzard. 1844. 8. $51 \mathrm{p}$.

6802* Mercklin, Karl Eugen ron. Zur Linwichlungsgeschichte der Jilitlegestalten. Jena 1846.8 . 92 p., 2 tab. ( $1 / 5, / h$.)

epitome gullica: Amn. des se, nat. 18'ti, p. 21:j-2'6.

¿\$03 Mercurialis, Mieronymus. Variarun lectionum lilıri quatuor, in quilus compluriun maximeque medicinae scriplorum infinita paene loea vel corrupta jestiluunlur, yel olscura declarantur. Venetiis 1571.4. 122 foll. B. - Venetiis 1598.4 . н.

(w) Spetant ad philolocritm hotanicam el concilianda loca vetermu

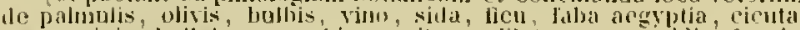
uva taminia, hellehoro, cyphi, aconilo, meliloto, srano caldio, fungis mentha, smytut. $)$ H.

680'. Meriale, Frangois. L'ami des jirdins d'utilite et d'ornement, ou rrecueil des nouvelles plantes polagires et d'agrément, des nouvenux arbres fruiliers, plantes bulbeuses el ojgnons a fleurs; des arbres arloustes et arbrisseaux nouveaux propres a decurer les jardins et les paysages. Liegre, Iemaric. 1805 . 12. ( $1 \mathrm{fr}$.)

fsö Merian, Maria Sibilla. Missertatio de generatione el metamorphosilus insectorum Surinanensium: in qua, praeter vermes et erucas Suranamenses earumque admirandam melamorphosin, plantae, flores et fructus, quibus vescuvtur, el in quilus fuerunt inventae, exhibentur. His adjunguntur bufones, lacerti, serpentes, aranea, aliaque istius regionis animalcula. Dissertation sur la génération et In métamorphose rles insectes de Surisan. Amstelodani, apud Geraldum Walk. 1705. Colio. 60 tab. s. - Amstelotami 1719. folio. 72 tah. - * Hagae Comilum, apud Petrum Gosse, 1796. folio. (6) 72 j., 72 tal. Editio princeps anni 1703 , licet duodecim tabulis pauperinr,
tamen ob pulchrilidinem tabulanm cetoris pracfertur. Maria sibille IIerian, lilia inclyti senptoris Hulhaei Hevian, lsor Johannis Andrene Grall, II. 16'7. + 1717. Surinamum adierat cum filis J. Helena et Grafl, "I
Dorothea Maria, ut novis insectis ditesceret. Opus jost reditum editum Norothea Maria, ut novis insectis ditesceret. Opus jost redilum editum liaclenus huc pejtinet, quod planlas, il quibus insecta nidulantur, simul delineatas hahed; nomina lalina aljecil Caspar fommelyn. Nulta

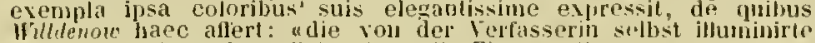
Ausgabe ist daran kenntlich, dass alle Figuren die entgegengesetzle Lage, als in den nicht illuminiten Ausgaben haben." )

$68067-$ Recueil des plantes des Indes. Paris, chez Desnos. 1768. folic. 72 tab., 5 p. Bibl. Deless.

Tabulae hujus collectionis e variis aliis Merinnae operibus deprontat sunt.

6807t Merlet de Ia Boulaye, Gabriel Elionor. Herlsorisations dans le Drpartement de Maine et Loire el aux environs de Thouars, Departement des Deux-Sevtes. Publices par plusieurs de ses élèves (Divy de La Roche.) Angers, Fourier-Mame. 1809. 12. 226 ). (2 fl.)

6808 Merlet, Jean. L'Abrégé des bons fruits, avec la maniere de les comnoistre et de cultiver les arbres. Paris, Charles le serey. 1667. 12. s. - Ed. II: Paris 1675. 12. s. - Ed. II revelle, eorlige et augmentede de plusieurs experiences sur le lail du jardinage, et de f fuantite de nouveaux et excellents fruits. Paris 1690. 12. Rivin.

(i809 Merrem, Blasius. Index plautarum horti academici Marhurgensis. Marburg 1507 . S. $(1 / 4 t h$.

$6810^{*}$ - Ilandbuch der Pfanzenkundr nach dem linne schen Srstem. Marburg, Neue akademische Buchhandlung. 1809 . 2 Theile. S. - ]: xu, 618 p. - II: 140 p. (31/2 th.)

6811 Carl von Linne's Vollstandiges Pllauzensystem, im Iuszugo neu bearbeitel und mil den neueren Fortsehritten dieser Wrissenschaft hereichert von Blasius Merrem. Marburg, Krieger. 1811. 2 Bande. 8. (3/h.) - Ed. If : ib. 1823.2 Bande. \&. $\left(3 \frac{1}{3}\right.$ th.

6812* Merrem, Daniel harl Theodor. Ueber den Cortex adstringens Jrasiliensis. Koln, Bachem. 1828.8. W, 106 j., 1 tab. col. ( $1 / \frac{1}{3}$ th.)
6813+ Merrett, Christophorus. Pinax rerum naturalium Iritannicarum, continens veructabilia, animalia et fossilia, in hac insula reperta inchoatus. Londini, typ. Roycroft. 1667 . S. 223 p., joraef.

681' Frands and alyuses commilted by apothecaries. London 1667. S. H.

681:; Mertens, lirrl /rinrich. Notices (botaniognes) sur les iles Carolines. Impr. cum: Friedrich Luethe, Toyage autour du monde, vol. III p. 1:32-14\%. (c. supra Nr.6358.)

(Meritisini autolis vita exstat in enflem voluminc, p. 337-3j2.)

6816 Mertz, Nicolaus Balthasar. Oenopoliun polypharnacum, in qua succus llarim selectior at evitandam (fuamvis morborum et symutomatum illuviem, jatricae botanicaeque virtulis imbre jracurnans. indigentibus large depromitur, liheraliter elfunditur, sitientilus exlibelur. Ilrrlipoli, Iyp. I1. Pigrini. 163̈2. 4. Rivin.

6817* Merz, Christoph Friedrich. De Caricilus quilusslam medicinalibus Sarsaparillae succedaneis. D. Erlangac 1784. folio. $30 \mathrm{p}$.

$6818^{*}$ Merz, Johamn Jakob. De Digitali jurpurea, ejusyue usu in serofulis metico. D. Jewae 1790. 4. 16 1).

$6819^{*}$ Merz, Luduiy. Die neueren Verbesscrungen an Mihroskope. nebst den sie begleitenden Aenderungen in der Dioptrik. Munelien, Paln. $1843.8 .71 \mathrm{j}$. ( $1 / 2, \mathrm{~h}$.

6S:0 Mesnil, Nicolas. J'art d'enter, planter et cultiver jardins. Paris, Gilles Corroset. 1560.8. Falc.

632. $\div$ Metsch, J.C. Flora Jennebergica, enthaltend die wildwaclssenden und angebauten Gefassplanzen, so wie dic Armleuchtergewachse (Characeen) der Grafschaft Henneberg, Koniwl. Preuss. Antheils. Ein Buitrag zur l'lora des Thuringer. Walcles. Schleusingen, Glaser. 1845. S. xil, 390 p. $(1 \mathrm{th}$.

6822 Mettenius, Georg IIeinrich. De Salvinia. D. Jeidelbergae 1545.4. $6823^{*}$ Beilrtue zor Kenntniss der Rhizocarpeen. Franhfurt a/1I. Schmerber. (Keller.) $1846.4 .65 \mathrm{p}$., praef, 3 lab. ( $1 / 1 / 2_{2}(h$.

682' Metzger, Eduard. Ornamente aus deutsehen Gewiclsen, zum Gebriuche fur Plastik und Malerei entworlen; zur Anwendung auf Architectur md Gewerbe bearbeitet. Munchen, literarisch-artistische Anstalt. 1841-1842.5 Hefte. royal-folio. 5 foll., 25 tah. nigr. 11 tab. col. $\left(17 \frac{3 / 2}{2}\right.$ h.)

682 * $^{*}$ Metzger, Joham. Europàische Cerealien. In botanischer und landwirhsehaftlicher llinsicht bearbeitet. Heidelberg, Winter. 1894 . folio. vut, 74 p), 20 tab. $\left(6 \frac{2}{3}\right.$ th. $)$

$6826^{*}-$ Del Rheinische Weinhau in theoretischer und praklischer Bezichung bearbeitet. Heidelberg, Osswald. 1827. 8. xvi $254 \mathrm{pl}, 17 \mathrm{1al}) .(1 \%, \mathrm{~h}$.

6827 (iartenbuch fur Gartenliebhaber, Gutsbesitzer und angehende Gärther. Als Anloitung zur Erziehung und Behandlung der sammtlichen Kuclsengewächse, Obstbaume und Zierpflanzen. Ileidellserg, Wintes. 1829. 8. 25 plag., 2 tab. $\left(1 / \frac{1}{4}\right.$ h. $)-$ El. Il. ib. 1836.8. 23 plag., 2 tah. ( $1 / \%$.

$6828^{*}$ - Systematische Beschreibung der hullivirten Kollarten mit ihen zahlreichen Spielarten, ihser fultur und okonomischen Benutznug nach mehrjaligen Anbaungsversuchen beabeitet. lleiclelberg, Osswalk. $1833.8 .65 \mathrm{p} ., 1 \mathrm{tab} .(1 / 3 / \mathrm{h}$.

$6829^{*}$ - Gesetze der Pl]anzen - und Mineralienlildung angewenlet auf altdetischen Baustil. Stutgart, Schweizerbart. 1835. gr. 8 vil, 94 p., 9 tab. $(1 / 2$ h. $)$

$6830 \%$ Die Getraidearten und Wiesengraser in botanisclier und ukouomischer Hinsicht bearbeitet. Heidelberg, Winter. I\$ 4 I. S. (IV), $256 \mathrm{p} .(1 / \mathrm{h}$.

$6831^{*}$ L__ Landwirthschaftiche Pflanzenkunde, oder praktische Anleitung zur Kenntiss und zum Anbau Jer fur Oekonomic und llandel wichtigen Gewdichse. Zwei Abtheilungen (oder zwolf Lie-

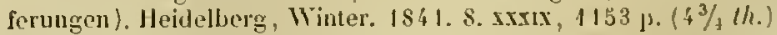

$6832 \div$ Meursius, Johannes, filius. Arboretum sacrum, sive de arlmrum, fruticum ef herbarum consecratione, proprietate, usu ac qualitate librı l'es. Lugduni Batavorum, ex officina Elzesiriana. 1642, 8. 140 p., praef., ind.

(Rodit eum editione Ilortorm Rapini. Ultrajecti 1672. 8. 127 p.)

6833 Meyden, Theodorus de. Trattato della natura del vino, e del ber caldo e freddo. Parma, Mascardi. 1608.8. s. 
6835* Meyen, Franz Julius Ferdinand. De primis vitae plaenomenis in fluidis formativis et de circulationo sanguinis in parenchymate. D. Berolini, typ. Brisehke. (Hirschwald.) 1826.4. 29 p. $(5 / 2, t h$.

$6833^{*}$ _ Anatomisch-physiologische Untersuchungen uber den Inlaalt der Pflanzeuzellen. Berlin, Hirselswalel. $1828.8 .92 \mathrm{p} .(1 / 2(h)$

$6836^{*}$ Phytotomie. (Mit 14 Kupfertafeln a Mikroskopisehe Abbildungen zur Pliytotomies in 4.) Berlin, Haude und Spener. 1830. 8. xxil, 356 p., 14 tab. $(3$ th. $)$

$6837^{*}$ Ueber die llochehene im südliclıen Peru. Gelesen am 7. Dec. 1832 in der geographischen Gesellschaft zu Berliu. (Berlin 1832.) 8.22 p.

$6838^{*}$ - Reiso un die Ërle, ansgefülut auf dem Kon. Preuss. Seehandlungsschiffe Prinzess Louise, Capt. W. Wendt, in den Jahren 1830-1832. (1listorischer Bericht.) Berlin, Sander. 1834-1835. 2 Theile. 4. - 1: vin, 493 p., 2 tab. - Il: vi, 411 p., 1 Plan vou Canton, 2 tal), 2 Tabellen. ( 10 th.

$6839^{*}$ —_ Ueber die Bewegung der Safte in den Pflanzen. Ein Selıreilien an die Ahademie der Wissensehaften zu Paris. Deutseh bearbeitet und mit Anmerhungen versehen. Berlin, Sander. 1834. 8. 20 p. $(1 / 6$ th. $)$

$6840^{*}-$ Velier die neusten Fortschritte der Anatonic und Pliysiologic der Gewathse. Eine von der Teylerseben Gesellsehaft zu IJaarlem in Jahr 1835 gekronte Preisschrift. IJaarien, Boln. (Ansterdam, Müller.) 1836. gr. 4. vm, 319 p., 21 tab. (sign. 1-11.) $\left(10 \frac{1}{4}\right.$ th.

68.1* - Grundriss der Pflanzengeographie nit ausfibrlichen Untersuchungen uber das Vaterland, den Anbitu und den Nutzen der vorzuglichsten Kulturpllanzen, welehe den Wolıstand der Völker begrunden. Berlin, llaude und Spener. 1836.8 . x, 478 p., t tab. $\left(2 \frac{1}{2}\right.$ th.

suecice: Utkast till Vaxt-fiengraphien, jemte utforliga undersohningar ofver de vighigasto Cultur - Vaxternas Faclernesland, .. odling ocl nytta, af $F . J . F$. Meyen. Öfrersittuing of $G$. Torssell. Orebro,

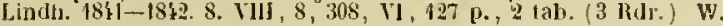

$681.2^{*}$ Ueber die Sekretionsorgane der Pflanzen. Eine von der Königl. Societăt der Wissenschaften zu Göttingen im Dezember 1836 gekrönte Preissclurift. Berlin, Morin. 1837. 4. 99 ]., 9 lab. (3 th.)

$6813^{*}$ Neues System der Pflanzenphysiologie. Berlin, Haude und Spener. 1837-1839.3 Bande. 8. - I: 1837. 440 |3., 6 Lab. Il : 1838. Iv, 562 p., 3 tab., ic. xylogr. $-111: 4839 . x, 697$ p., 6 tab. (s th.)

6844* - Jahresbericht uber die Resultate der Arbeiten im Felde der physiologischen Botanik von den Jalıre 1836. Berlin, Nicolai. $1837.8 .125 \mathrm{p}$.

$6810^{*}$ — Jahresbericht uber die Resultate der Arbeiten im Felde der pliysiologiselıen Botanik von dem Jahre 1837. Berlin, Nicolai. 4838. 8. $\mathrm{VI}, 186 \mathrm{j})(11 / 3$ th. $)$

* anglice: A Report ou the progress of vegetable physiolngy during the year 1837. Translated fron the german by Hillam Franeis. London, Taylor 1839.8 . II, is8 p. (7s. 6u.)

$6846^{*}-$ Jahresbericht uber die Resultate der Arbeiten in Felde der physiologischen Botanik von dem Jahre 1838. Berlin, Nicolai. 1839. 8. IV 153 p. (11\% th.

$6847^{*}$ Jahreslericht uber die Resultate der Arbeiten im Felde der plyysiologischen Botanik von dem Jalıre 1839. Berlin, Nicolai. 1840. 8. viII, 184 p. $\left(1 \frac{1}{3}\right.$ th. $)$

(Contimationes dedit ill. Heinrich Friedrich Link; cf. Nr. 5973 .)

$68 \div 8^{*}$ Noch eimige Worte über den Befruchungsact und die Polyemlsryonie bei den hỏheren Pflanzen. Berlis, Haude u. Speues. 1840.8 .50 p., 2 tals, in $4 .(3 / 8$ (h.)

$681.9^{*}$ - Pllauzenpathologie. Lehre von dem kranken Leben und Bilden derPflanzen. Nach des Verlassers Tode $[t$ niedia nocte $1 / 2$ Sept. 1840] besorgt vou Christian Gott fried Nees von Esentech. Berlin, Haude u. Spener'sehe Buchhaudlung, S. J. Josephi. $1844.8 . x 1,330$ p. $(2 / h$.)

(Etiam inscribitur: "Hanibuch der Pllanzenpathologie und Pllanzesteratologie. Ilerausgexeben von Christian Gottfried Nees von Esenbeck. Erster Band.")

6830 Meyen, Johann Jakob. Aufösung der Preisfrage: Wie komm es, dass die Oekonomie bisher so wenir Vortheile von der l'lirsik und Mathematik gewonnen hat? Berlin 1770,4. H.

683 l Physikalisch ökonomische Baumschule. Ed. II. Stettin, Leiels. 1795. 2 Theile. $8 .(3 / 4$ th. $)$

(Pars ll, seorsin inscripta est: Anweisung zur wildeu Baumzucht.)
$68.22^{*}$ Meyenberg, Heinrich Julius. Flora Einbecceusis sive enumeratio plantarum eirea Einbecean undique ad duo milliaria sponte nascentium cum auctorum synonymis, locis natalibus et tempore yuo florent ordine alpluabetico conscripta. Goettingae, typ. Woyken. 1712.8 .103 p. Bibl. Goett.

$6833{ }^{*}$ Meyendorff, Georges Baron de. Voyage d"Orenbourg a Bouklara fait en 1820 à trarer's les steppes, qui s'étemient à l'est de la mer c'Aral et au-delia de l'ancien Jaxartes. Revu par M. Le clievalier

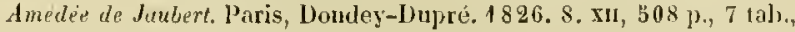
1 mappa geogr. ( $10 \mathrm{fr}$.

(Bolanicue: [3. 372-389). Pander collegit plantas in hue intinere. unas possitet ill, von Fischer Petropolitanus.

* germanice: Reise vol Grenburg nach Buchara in Jahre 1820. Nach dem franzosischen oriugal hearbeitel von liurl Hermam scheidler. Jena, Brall. 1826. gr. 8. (1 th.)

685 ' Meyer von Knonau. Eutwurf, wie die Stadt Zurich mit genugsamen Ilolze versehen werden kounte. Zürich 1763.8 . н.

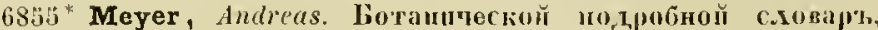
ихи Травникъ i. e. liurzes botanisehes Worterbuch oder Kráaterbuch. Tom. l et Il: Literae A-C. Mloskan 1781-17\$3.4.650, $607,16 \mathrm{p}$. Bibl. Goett.

(Trautuetler Grundriss p. 122 tria inclicat volumina.)

68.66 (Meyer, Bernhard.) Doetor Meypr in llanau bietet dip hierinnen verzeichneten Saamen gegen audere im lireien ausdauernde ron Baumen, Sträuchern und perennirenden Gewcichsen, au. Jlanoviao 1795. 8.26 p. B.

(Hune juto esse Bernhardum Meyer, qui est inter autores Florae Wetteraviae; obiit in oppiclo offenbach die 1. Januarii 1836, aet. circiter 70.

6857 * Meyer, Ernst IIeinrich Friedrich. Junci greneris Monographian specimen. D. Goettingae, typ. Baier. 1819.8.48 p.

$6838 *$ Synopsis Juncorum rite cognitorum. Ad inaugurandan ejustem plantarum generis monographiam. Goettingae, Vandenhoeck. $1822,8.66 \mathrm{p} .(1 / 3$, th. $)$

$6839^{*}$ Synopsis Luzularum rite cognitarum cum arlditamentis (quilousdan ad Juncorum Synopsin prins editan. Goettingae, Vandenloeck. 1823.8 . vin, $40 \mathrm{p}$. (1/6th.)

$6860^{*}$ De Ilouttuynia atque Saurureis. Regiomonti, Unzer. (Lipsiae, Yoss.) 1827.8.62 p., I tab. ( $1 / 2$ th.)

$6861^{*}$ - De plantis labradoricis libri tres. Lipsiae, sumtilus Leopoldi Vossii. 1830.8 . xxu, 218 p. (1\%th.)

(Triginta priores operis paginae seorsirn quoque dissertationis loco anno 1830 editae sunt.

$6862^{*}$ ( monti cirea anum 1835 .) $8.32 \mathrm{p}$.

$6863^{*}$ Commenlariornm de plantis Africae australioris, unas per octo annos collegit olservationibusque manuscriptis illustravit Joanies Franciscus Drige. Vol. I. Iasciculus I el II. Lipsiae, Voss. $1835-1837.8 .4 x x, 326$ j) $(32 / 3$ th.

686 * $^{*}$ —_ Vergleichende Erkläruug eines bisher noch ungedruchten Planzenglossars. Königsberg, Harlung. 4837.4. $25 \mathrm{p}$.

Im "zweiten Bericht uber das naturivissenschaftiche Seminar an der Lniversität zu honigsterg." )

$6863^{*} \ldots$ Preussens Pllanzengatlungen nach Familien georlnet. Konigsberg, Grafe und Unzer. 1839. 12. x, 278 p. $(5 / 6 t h$.

$6866^{*}$ Nicolai Damasceni de plantis lihri duo Aristoteli rulgo adscripti. ExIsuaci Ben Honain versione arabica latine vertit Alfredus. Ad codd. inss. fidem addito apparatu eritico recensuit Ernesh Meyer. Lipsiae, Voss. 184 1. 8. xxvit, 138 p. $\left(1 \frac{1}{2} / h\right.$. $)$

$6867^{*} \longrightarrow$ Ueber das Amylum. Gelesen in der physikaliseh-okonomisehen Gesellscluaft in Konigsberg, den 48. Septemulser 1839.8. p. $385-411$

(Preussische Proviuzialhlitter X.rll. 1839. 1), 380̈-4ll.

$6868^{*}$ Ueber die Coniferen. Vorgelesen in ler l'hysikalisehökonomischen Gesellschaft in Königsberg, den 19. Fehnuar 1841. 8. p. $385-413$.

$6869^{*}$ Ueber Seidenflachs, besonders den neuseelandschen. Vorgelesen in der physikalisch-okonomischen Gesellschaft in Kónigsberg, den 18. Februar 1842; darauf melırfach berichtigt und erweitert. (Konigsberg 1842.) 8. 24 p.

$6870^{*}$ Das Leberwallen abgelzavener Baumstumpfe. VorgeJesen in der physikalislt-okonomisehen Gesellschaft zu Kinigsberg, den 2. Decenber 1849.8.18 p.

(Preussisehe Provinzialblátler, Januarheft 18ł3.) 
1j8il Meyer, Enost Ileimich Friedrich. Die Fntwichlung der Botanik in ihren Haupunomenten. Gelesen in dor plyysikalisch-ohonomischen Gescllschaft zu Konigsberg, den 7. December 1843. Konigsberg, Borntráger. 1844.8.24 p. (1/, th. $)$

68:2* Neneste Nachichten uber einige vergetabilische Eroberer in Sudamerika. Golesen in der plysihaliscth-okonomischen Gesellselıaft in Königsberg. (lionigsberg 1846.) 8.

(konigsberwer nalurwissenschafliche Lnterbaltungen, erster Band, writes lieft, 13. 17-18's.

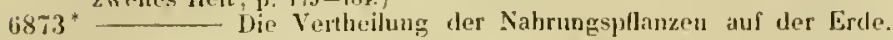
Gelesen in eler physilialisch-ohoneniscluen Graellschaft in Konigsberg. (Konigsberg 1s46.) 8 .

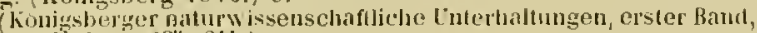
жweites lleft, j. 18:-211.)

6ช:я" Meyer, Friedrich Albrecht Anton. Dissertatio inanguralis de cortico lugusturae. Goettingae 1790. $8.53 \mathrm{p}$.

68:3* Meyer, Geory Fricdrich Wilhelm. Primitiae Florae Essequebocnsis adjectis descriptionibus centum circiter stirpium novarum ulservatimilunspue criticis. (ioettingac, Jieterich. 48 \$ 4 . 4. x, $316 \mathrm{p}$, 2 tab. $\left(4 \frac{1}{2}, h\right.$. $)$

$6876^{*}$ _ Beitrage zur chorographischen Kenntniss des Flussgebiets der lnuerste in den Furstenthumem Gruhenhagen und llileleshein. Mit besonterer Ruchsicht auf die Veranterungen, die durch diesen Strem in der Beschallenheit des Bodens und in der Vegetation bewirkt worden sint. Vine Anlage zur Flora des Kionizreichs llannover. Gottingen, Vandenloeck und Ruprecht. 1822. y Theile. 8. - 1: xxix, 368 p. - II: x, 368 p., I tab. nigr., 1 tab. col. $(3 \%$, h. $)$

$687^{*}$ ㄴ. Nebenstunden meiner Beschaftigungen im Gebiete der Pllanzenkunde. Erster Theil: dic Entwicklung, Metamorphese und Felpflanzung der Flechten, in Anwendung auf ihre systematische Inorelnung, und zur Nachweismug des allgemeinen Ganges der formbildung in den unteren Orelnungen der kryptogamischen Gewachse. Goettingen, Vandenhoeck und Ruprecht. 1825.8 . x1, 372 p., 1 tals. col. ( $2 \frac{2 / 3}{3}$ th.

$6878^{*}$ Chloris Hanoverana, oder nach deu naturlichen Familien geordnete Uebersicht der im Konigreiche Hannover wildwachsenden sichthar biuhenden Gewachse und Farru, nebst einer Zusammenstellung derselben nacli jhrer Benutzung im Haushalte, in den landwirthschaftichen Gewerben und in den Künsten. Gottingen,

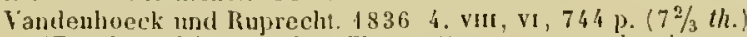

(Tahulae ad illustrandam florim llanoveranam. longis ex amnis, magna civium pecunia inutiliter eftusa, paratae, jacent ineditae, nec mujuam prodibunt, quum delegati a populo auctores sumtus pratestandi liutius fieri noldent.

6879* Meyer, Gottlob Andreas, pr. De Sycomero, guam Zachaeus Publicanorum magister ascenterat. 1) plilelogica. (Luc. XLX, 1-4.) Lipsiae, typ. Goeze. 1694.4. (20 11.) (Respentens: Goulfried Kresse.)

$6880^{\circ}$ Meyer, II. E. L. De Opii uso in inflammationibus. D. Goettingae $1500.4 .18 \mathrm{j} .(\% \mathrm{th}$.

6ss1* Meyer, Johann Christian Friedrich. Nisturgetreue Darstellung der Fntwicklung, Ausbilduug und des Vachstiums der Planzen, und der Bewegung und Funetionen ihrer Stifte, nit vorzuglicher llinsicht auf Holzgewachse. Ein auf Yersuche und Beohachtung gegrundeter Beitrag zu den neuesten Ansichten hieruber. Leipzigs? Sommer. 1808 . 8. xvi, 322 l., 2 tab. $(2 \% / h$.

6882* Meyer, Joham Karl. De fumi Nicotianae suctu. J). Lipsiae 1803. 4. $35 \mathrm{p}$.

6883 Meyer, Israel Joseph. De Salicis fragilis usu medico. Butzow 1770. 4. H.

688:* Meyer, Karl Anton. Ferzeichniss elar Pflanzen, wrlehe waluend fler 1899-1830 unternommen Reise im Caucasus und in den Provinzen am westlichen Ufer des haspischen Meeres gefunden und gesammelt warden sind. Bericht, abgestattet an die Kaiserliche Akademie der Wissenschaften in St. Petershurg in ihrer Silzung vom 11. April $\mid 831$. St. Petersburg, Akademie der Wissensch. (Leipzig, Voss.) 1831.4. $2+1$ 1). (1// th.)

$6885^{\circ} \div$ Bemerkungen uber einje Hymenobrychisarten. Peterslourg. Iruckelei der Akademie der Wissenschaften. 1837.4. 11 p. Memoires de l'Academie imp. de sciences de st. Petershourg I. série, sc. nat. 1. III.)

$6880^{*}$ - Das IJssum minutum unel die zundiclist remandten Arten. menographisch bearbeitet und dusch Abbildungen erläutert.
Arlist riner l ebersicht Ier Arten der Gattung Psilenema. St. Pon tershurg, Druchrrei der Akademie der Wissenseh. (Lejpzig, Voss.) $1840,4,22$ l\%, 2 tab. $(1 / 3$ th.

( Hémoines le licademie inn. des sciences de St. Pelersbourn. II. sério, ac. nat. I. IY. D. 1-22.)

6887* Meyer, Kat Anton. Einige Bemerkungen uber die naturliche Fanilie rfre Polygonaceat. Erster Artikel. Versuch einer uatur"rotreuen Amorduung der Gatungen lieser Fanilie. Si. l'etersbut: Uruckerei der Akarlemie der Wissensehaften. (Lcipzig, Voss.) 1840 4. 17 l., I tab. $(\% / 2$, th.)

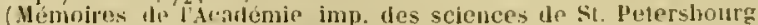

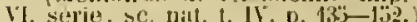

$6888^{*}$ (- Beiträge zur Pflatzenkunde des Russisclıen Roiclıes Herausgegeluen von eler Kaiserliclıen Akademic der Wisseusclaten. Erste Lieferung: Florula provinciae Tambew, oder Verzejcliniss der in Gouvernemmont Tambow heobachtelen Pllanzen, ron C. A. Meyer. St. Petershurg, Akatemie der Wissensclaften. (Leipzig, Voss.) I 84 8. xvu, 30 j. (ressice et germanice.) $(1 / 15 t h$.)

(Fuscienlus sequentes $\|-1 V$, claboravit $\boldsymbol{b}^{2} J$. Ruprerh.)

$6889^{*}$ _ - - Ieber einige Cornusarten aus uler Abtheilung Thely cronia. St. Potersbur. (Jeipzig, Voss.) is45. 4.33 j. $(2 / 1$ th.)

Memoires de l'Academite imp. des sciences do St. Petersboury. sc. natur. t. I

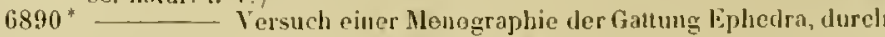
Ablvildungen erlantert. St. Petersburg. (Leipzig. Voss.) 1846. gr. 4. 76 p.. 8 (al), in folio. (1 th.)

Ménurires do l'Acalímic inp. des seiences de St. Petershour: st: nilur. I. Y, 1). $3: j-108$.)

$6891^{*}$ - Ueber die Zimmirosen, insbesondre uber die in Russland wildwachsenden Arten derselben. Ein Beitrag zu der l'lora Russlands. St. Petersburg. (Lejpzis, Voss.) is $47.4 .39 \mathrm{\mu} .(1 / 2$ th.)

Hémoires de l'Académie imp. de sciences de St. petershourg VI. serie, sc, nat. t. VI.)

6892 Meyer, livl lleinrich Gotlich. Gründliche und treue Anweisung zur Ulstluammucht für Gärten und das freie Feld. Vier Hefte. Hof Grau. $1826-4829.8 .\left(1 \frac{1}{2}\right.$ th. $)$

6893 _... Die Obstrüchte. In vergleichender Zusammenstellurng und in ihren charahteristischen Unterschieden beschriebn. Frste Abıheilung. Das Steinolsst. Jlef, Grau. (Nürnberg, Riegel und Wiessner.) $1830-1834.3$ Jlefte. gr. 8. 36 tah. col. $(2 / 4$ th. $)$

6894* Meyer, Leopold. De Fuco vesiculose atque de Jodo quaedam. ıuod continet. D. Kiliae $1830.4 .15 \mathrm{p}$.

6895* Meyer, Ludwig. De Fuco crispo, seu Licliono Carrageno. Џ. Berolini, tyj. Nietack, $1835.8,29$ p.

6896* Meyrick, IVilliam. The new fanily herlsal, or domestic physician etc. Birmingliam, typ. Pearson. 1790.8. xxiv, 498 p., 14 tab. col.

6897 Miscellaneous botany. Birmingham 1794. folio. No. I: 6 p., 3 tab. col. B

6898* Mezger, Geory Balthasar, pr. Helleborus niger medice rlelineatus. Tubingae 1684 . 4. 28 p. (Respondens: Rudotph Jakob Cumerarius.) 6899 Michael, (Hexionius.) De regno vegetabili. D. Aboae 1656.4 Desid. B.

6900 Michaelis, Johamn Darid. Fragen an eme Geselischaft gelehrter Manner, die auf Befelıl des Königes von Dánnemark nach Arabieı reisen. Frankfurt a/M., Bronner. 1762.8.397 j. B. yallice: Refueil des questions, proposees a une socicte de sarants, qui par ordre do Sa Majesté Danoise font le vayage de l'Arabie. Frane(i) rt sur le Main 7763 . 8. 482 p. B.

(Alias gallicas editiones habei Querard, France literair., H. p. 10\%.)

6901 Michalowsky, Johann Jakob. De principio plantarum odoro. D. Regiomonti 1785.8 .16 p. E. M.

6902 MichauIt, Jean Baptiste. Letre sur la situalion de la Bourgogne par rapport a la botanique. s. I. 1738. 8. a.

(Scriptiuucula perrara videtur; est in Desideratis pro bibl. Batuksiana: Parisitis frustra eam yuaesivi.)

6903 Disscrtation historique sur le rent de Galerne. Basle (Dijon) 1741. 12.0 .

("Celle brochure, a l"occasion l'un vent funeste aux vins de la Bourgune, est fublice sous le pseudonime de Jurean de Cherval. Boingono, est lublice sols le pseudonyme de Jureau de cherval

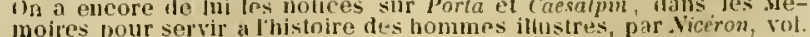
moires lour servir a lihithire des hommes illustres, par. Niceron, pol.

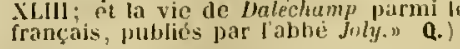

690': Michaux, André. Histeire des chenes de l'Amérique, ou clescriptiens et figures de tontes les especes et variétés dí chênes de l'Amerique septentrionale, considérées sous les rapports te la 
bolanique, de leur culture et de Icur usage. (Publićc par François Andre Mtichanx. Paris, typ. Crapelcl. an IX. 180 \% folio. (30) foll, 36 tab. a Redoute delin. ( $30 \mathrm{fr}$. - papier gr. raisin fin : $60 \mathrm{fr}$.) * germanice: Geschichte der amerikanischen Eichen. Leberselzt uud mit illuminirten Abbildungen hegleitet von Prof. Jokamn Simon fierner. stuttgart, beim Verfasser (Lothund), unt Hanuorer, Jlalu, $1802-180$ ' 2 Hefte. i. 28 p., 1 t tah. coll (6 th. - nigr. 5 th. (Plura non prodierunt.)

690:3* Michaux, André. Mémoire sur le Zelkona, l'lanera crenata, Paris, Iluzard. 1831. 8.20 p. 1 tab. (1 fr. 50 e.) François Audre vel Andreae cuiclam Mhchaux recentiori An potius filio

(9906* Michaux, Francois André, fils, (el Claude Louis Richard) liora borcali-americana, sistens cliaracteres plantarum, quas in America septentrionali collegit et detesit fudreas Llichaux. Parisiis et Argentorati, Levrault. anno Xl. 1803 . Il voll. 8. - I : x, $330 \mathrm{p}$., tal.. 1-29. - Il: 340 1., tal. $30-51 .-{ }^{*}$ lid. 11 : Parisiis, Jouannux 1820. 11 voll. 8. (eadom impressio Jovis titulis!) (Papier grand raisin d'Auvergne: $24 \mathrm{fr}$; papier vẻlin superfin: $4 \mathrm{~S} \mathrm{fr}$; édition in $4: 60 \mathrm{fr}$.)

$6907^{*}$ _ Voyage a l'ouest des monts Alléghanys dans les états dOhio, du kentuchy et du Tennessee, el retour it Charleston par les hautes Carolines; contenant des détails sur l'état actucl de l'agri"ulture et des productions nalurelles de ces contreses etc. entrepris on l'an X. seus les auspices de Il Chaptul, ministre de l'intérieur. Paris, Levraule. 1804 . S. vi, 312 p., 1 earte. $(6$ fr. $)$

Cf. + Ripport sur les royages le u. Mithuar pour Ia naturalisation des arhres furestiers rles Elats-lois, flar Allaire, Bosc, DuP'eli-Thuuar "t Correa de serra. Paris, Huzard. isos. 8.11 l1. anglice: Lonton 1803. 8.

germanice: Reise in das Innere der Nordamarihanischen Freistaagen. Aus dem Franzosischen mit Amorh ungent nud Zusalzen von

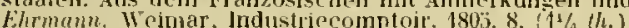
(Bihliothek der Reisen, Band . Xlli.) gourernement avail fait pour arriver à ce but, et les moyeus gu'il 'onviendroit d'employer pour y parvenir; suivi d'un talyeau raisunne des arbres tle ce pays, comparés avec ceux, que jưuluit la France. Paris, Levrault. $1805.8 .36 \mathrm{p}$

$15909+$ Notice sur les iles Bermudes, et particulierement sur l'ile Saint-Georges, adresséc à M.M. les professcurs du Muséun d'histoire naturelle. (Paris) $1806.4 .9 \mathrm{P}$.

(Extrait des Annales du Musetum ilhist. mat. vol. Vill.)

$6910^{*}$ Histoire des arbres foresticrs de l'Amérique septentrionale, considerées principalement sous les rajports te leur emploi dans les arts et de leur introduction dans le commeree, ainsi que d'après les avantages, qu'ils peuvent offriy aux gouvernements en Furope, et aux personnes, qui reulent former le grandes plantations. Paris, typ. Hausmann. 1810-1813. Ill voll. 4. - 1: 1810 222 p., 24 tab. col. (14 tabulae Coniferae et 10 tahulae Juglandes.) - 11: I810. 280 p., 50 tab. col. (26 tabulae Quercus.) - 111 : 1813. 408 p., 74 tab. cul. (complet!)

(Prodiit 2's fasciculis pretio $32^{\prime} \mathrm{fr}$.

- putome anglica: Oahs of the Luited Slates and of Canada. Phila-

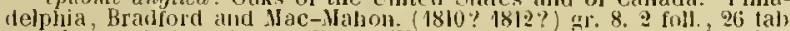
sunt tabulae, in vol. Il. de l'Jistoire des arbies forestiers jam coitac licet uige,

* epilome germanica: Die Eichen der Vereinigten Stitaten von Nordameriha unil Canada, nach Andreas Michanx. Sechs und zu inzig 'lafelt

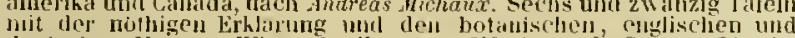

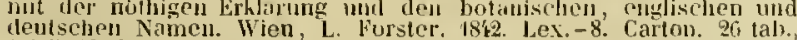
cleutschen

foll. ( 2 th.

anylice: Tlu North-American sylva or a rlescription of the forest trees of the United Slates, Canada and Nova Scotia : considered parficularly with respect to their use in the arts, and their introduction into commeree; 10 which is added a description of the most useffit of the european forest trees; translatel frum whe french, and illustrated w. IN voll. 8 . (216 fr.) - bil. II. New ifarmony, Indiana. $18 \%$. III voll imp. 8 . löi tab. col

(áa preniere édition, faite a paris pour Philadtelphie, a éte jubliée en huil livraisons de clemi-volume." Q. De editionjs secundae supjolementis vide infra: Thmos Nuttail.

$6941 \div$ Michel, Etieme. Traité du citronicr. Paris, Bertrand (typ. Ballard.) 1816. folie. 82 p., 21 tab. col. Bibl. Deless.

fi9!2 Michel, Rudolph G. Tentanen medicu-botanicum de Artemisiis usitatis. D. Pragae $1834.8 .98 \mathrm{p}$.

6913* Michelazzi, Auguslinus. Compendium regui vegelabilis, quod in usum suorum auditorum elucubratus est. (Goritii), typ. Valerii de Valeriis. s. a. 8. IV, 294 p., 1 tab. Bibl. Goett.

Pritzel, Thes. Jit. bot.
691:4* (Micheli, Pierantonio.) Relazione dell' erba detla da' butanici Urob:unclic, e volgasmente succiamele, famma e mal d'occhio: che di molti anni in quá si è soprammodo propagata quasi per tutta la Toscand; nella quale si dimostra qual sia la vera origine di delta erha, perchè danneggi i leguni, e il modo di estirparla. Firenze, 1yp. Tartini. $1723,8.47 \mathrm{p}$. $-\div$ Cumpendio della relazione del celebre hotanico Pierentonio Micheti intorno all erba Orolsanche rletta volgartnente succiancle contenente l'unico e vero modo di estirparla. In Firenze, typ. Bonducci. 1754. 8.34 p. Bibl. webb.

$69.13^{*}$ Lova jlantarum senera justa Tournefortii methodum disposita, quilus plantae IIDCCCC recensentur, scilicet fere NCCCC nonlum observatac, reliquae suis sedibus restitutae; quarum vero fignran exlubere visum fuit, eae ad DL acneis tabulis CVIll graphice expressac sunt; adnotationibus atgue observationibus pracecipue fungorum, mucorum, affiniumque plantarun sationem, ortum et nutrimestum spectantilus, interdum adjectis. Florentiac, typ. Bernasti Paperini. 1729. gr. 4. (11) foll., 234 p., 108 tab. (A. 1846 : 10 th. Scliwan und Get\%; 30 fr. Baillière.)

Icones plantarmn sulmarinarum, tabulae aeneac sexaginta inPeliace, in folio, tomo sermule hujus operis destinatac servantur in Justo britanujeo cum Killiotheca Banksiana. De continuando opere Guidemus piatti, bibliopola l'lorentimss, alano $182 \%$ botanices coullurilous baec anmintiavit: "Celeberrimi Botanici petri dntonii Micheli pars altera Novorum (ienerum Plantarum a botanicis jamdiu exspectalis, quae de plantis acuaticis ot submatinis agere debebat morte pracmatura ipsins Micheli $[-1$ Jan. 1737] interrupta fuit. Posted alt Johame Turgioni Tozzelli ejus discipulo, et herbisii atyue manuscriptornm Miheli possessore absolutum opus fuit sub titulo Descriflio Plantarum marinarun Mlusei sui : quod nune Oetarianus Targioni

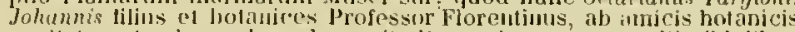
excitatus, tandem eflere decrevit. llaque hoc opus, multis tidedibus

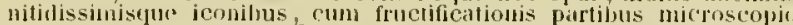

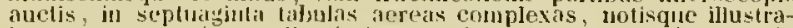
tum et syonymis excellentissiniorum botanicorum nostri temporic latine editum in virios fasciculos botanicis olfert, typis Guillelm Pialti iu folin parro juxlil editionem Novorum Generum Plantarun Michcli, secundam ineditam partem efliciens. Fasciculi incessanter prosimn anno $1 \$ 26$ subscrijtorilus tradentur ; cujus pretium erit seequins: Pro omni folio injuressionis. mezzo Paolo. Pro onni tabula incisi, Paoli 2., Vifii ill Museo bolaniro Iindobonensi (ce. infra sul Taryioni-Tozzetti) (asciculum nrimun: Florentiac, typ. Tofanis. 1826

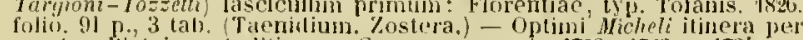

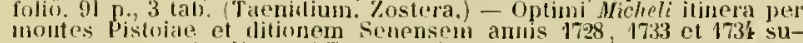
scepta, exstant in Grovanni Targioni-Toszelti: Relazioni d'alcuni viaggi. scepta, cxstallt ill will vol. IX-X.n

$6916^{*}$ Calalogus plantarum horti caesarei Florentini. Opus posthumum, jussu socictatis hotanicae editum, continuatum et ipsius horti historia Jucupletilum ah Joanne Targionio - Tozzelli. Florentiac, 1yp. Bernardi Paperini. 1748. folio. Lxxxvis, 185 p., 7 tah., ichnegraphisa lorti.

(Appendix Targionii-Tozzetti: p. 103-183; ejusque Ilistoria horti Lxxiy p.)

6917 Michetus, Eugenius. Lexicon botanicum, complectens nomina synonyma, qualitates ac celebratiores doles simpliciun exposilorum in publico corundem apparatu Jahsito in festo nativitatis B. Nariae Virginis. Romae, typ. Tinassii. 1675. 12. S.

6918+ Michot. Tableau botanique de la methode naturelle de Jussieu. rédigé par l'Abbé Michot, sur Je plan de l'ouvrage de l'entenal. Mons, Capront. 1842. 1 très graml talleau folio plano. Bibl. Lend.

$6919^{*}$ Mieg, Achilles. Syrecinen olservationum anatonicarum atque botanicarum. (Basileae) typ. Imhof. (Itllero 1754.) 1753.4.(8) p.

$6920^{*}$ Specimen ll. olsservationum botanicarum, anatomicarum atgue pliysiologicarum. D. Basileae, typ. Imhof. 1776. 4. $16 \mathrm{p}$.

6921 * Miehe, Adolph Ferdinand. Nomnulla de Strychninii applicatione endermatica. D. (Goetlingensis.) Halae s. a. (1837 ?) 8, 27 p.

6922 Tiers, John. Travels in Chile and La Plata. London, Baldwin. IS26. Il voll. 8. Bibl. Deless.

(List of plints: vol. II. p, 520-5332.)

6923 _._ Illustrations of South American plants. Part J-II. LonAon, Bailliere. 1\$46-1847.4. 16 tab. (14s.) (Continuatur.)

692:* Mikan, Johann Christian. Die Zuchererzeugung aus Alırnsaft. Prag, typ. IJaase. 1811.4.75 p., 2 lab.

$6923^{*}$ - Celser Galläpfel und knoppern, nelsst einer kurzgefassten Naturgeschichte der lnsecten, durch welche sie entstehen. (Prag 18 16.) 4. (12 p.), 4 talb. col.

(Wijthschaftshalender der h. h. patr. ohon. Gesellschaft in Bohmen 1816.$)$

$6926^{*}$ Delectus Florac el Faunae Jrasiliensis. Vindobonae, typ. Strauss. 1820 . folio. $42 \mathrm{p} .,(24)$ tab. $(72$ th. - herabgesetzt: 54 th. 
6927* (Mikan, Joseph.) Catalogus plantarum omnium juxta systematis vogetabilium Caroli Linnuei editionem novissiman decimam terliam in usum liorti botanici Pragensis. Pragae, Gerle. 1776. 8. VIII, 403 s, ind.

(a) Hikan hinterliess im Ms, ein Verzeichniss you niclut weniger als 1700 Schreib-und bruchfellern mu falschen citaten, die aus dier Reichard'schen Ausgabe der Limescicen Species plantar

6928 Milhau. Dissertation sur le Calfeyer. Montpellier 1746. 8. 29 p. B. 6929 Uissertation sur le Cacaoyer. Nontpellier 1746. \&. 32 p. B.

6930 Milhau, Johann Ludwig. Dissertatio inauguralis de Carvi. Argentorati $1740,4,26 \mathrm{p}$. B.

6931 Milius, Josephus, Voltolinas. De hortorun cultura libri tres. Brisiac, apud Vincentium Salbium. 1574. 8. Bum.

6932 Millar, John. Obscrvations on the astlıma and the hooping congh. landon 1769.8 . H. 1769. 8 .

6933 Miller, Jnhn Frederick. (lcones animalium et plantarum.) painted, engraved and puhlished by John Frederck Hiller. 1776-1794. 60 tals. acn. col., longit. 18 unc., lat. 12 unc. Nonina et loci natales : 10 P.

693: Miller, Joseph. Botanicum officinale, or a compendious hertbal giving an account of all such plants as are now used in the practice of pliysick, with their description and virtues. London, printed for E. Bell. 1722. 8. 466 p. B.

6933 Miller, Philip. The Gardeners and Florists dictionary. London 424. 11 voll. 8. - 1: 1 alphab., 10 plag. - 11: 1 alphab., 9 plag. $B$.

- The Garteners Dictionary: containing the methods of cultivating and improving the kitchen, fruit and flower garden, as also, the physick garden, wilderness, conservatory and vineyard, according to the practice of the most experienc'd gatdeners of the present age; interspers'd with the history of the plants, the characters of each genus, and the names of all particular species in latin and english; and an explanation of all the tems used in botany and gardening. Together with accounts of the nature and use of harometers, thermometers and hygrometers; and of the origin and nature of meteors, and the particular influences of air, earth, fire and water upon vegetation, according to the best natural philosophers: adorn'd with copper plates. Edl. I: London, C. Rivington. 173 J. folio. 7 alphab., 4 plag., 2 alphab. B. - "Ed. II. correctel. London, C. Rivington. 1733. folio, XV1 p., 9 alphah., ind. - ${ }^{*}$ An ajpendix to the Gardeners Dictionary, enntaining several articles, which were omitted in the editions of the work. London, C. Mivington. 1735. folio. 5 plag, - Ed. Ill: London 1737 , folio. 9 alphal., 13 plag. vol. 11: London 1739. folio. 4 alphab., 13 plag. B. - Ed. 1V: London (Dublin) 1741. folio. - Ed. V: London 1747, folio. - Ed. VI: London 1752. folio. - *Ed. Vl1: London 1759. folio. 14 alphab., 16 plag. - tEd. VIII: London 1768 . 11 voll. folio. 14 alphab., 12 plag. Ed. IX. posthuma [Philip Ifller +1751 ], to which are now added a complete enumeration and description of all plants hitherto hnown the whole corrected and nowly arranged by Thamas Martyn. London 1797-1804.11 voll. foljo. - j: 1797. A-i. 16 ajphab., 3 1/2 plag. B. - II: 1804 .

(Alitri editionem novissimam judicant: London 1803-1807. IV roll. folio.)

* hollandice: Leiden $174 \mathrm{kH} .11$ voll. folin.

- germanice: Das englische Gartenhuch oller Philipp Miller's Gärtner-Lexieon, nach der funften Ausgabe des Originals in das Deutsche ubersetze von Georg leanlart Huth. Nurnbery, Lochner. 1730- 1738.

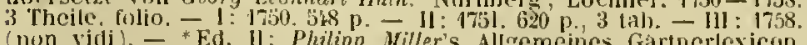
(non vidi) - *Ed. 11: Philipp Miller's Aligemeines Gártnerlexicon, d. i. ausfuhrliche Beschreilung der Geschlechter und (atthugen aller und jeder Pflanzell, nach dem neusten Lehrgelunule des Bitler Linne eingerichtet. etc. Mit verschiednen kupfern, wacts der achten Ausgabe ans dem Englischell uberselz. Nirnbers, Lochner und Folssecker. 1769-1776. Bande 4. - 1: 1769.966 p. - 11: 1772.890 p. - 111: 176. 919 p. $-i v: 1776.960 \mu$, tah. $(10 \% / 3$.

* gallice: Dictionnaire (et calendrier) des jardiniers, contenant les méthodes les plus sures et les plus modernes pour cultiver et ameliorer les jarrlins potagers, á fruits, à fleurs of les pepinieres, ainsi que pour reformer les anciennes pratiques de l'agriculnre de. Ouvrage traduit de l'anglais sur la huitieme edilion, par une societé de gens le lettres (par Laurent Warip de ('hazelles nt autres), avec des rotrs (par lloilandre). Paris, Guillot. 178;-178s. VII voll. 4. - * plement au Dictionnaire des jardinjers, yui conmerend tous les genres et toutes les especes de plantes non detaillées dans le Dictionnaje de Miller, par Laurent Marie de Chazelles. Metz, Claude Lanort. 1-89 -1790 . II voll. t. - 1: 1789. A-K. val1, 731 p., \& tat. - 11: 1790. L-\%. 7 iss p., 5 tah. $(48-60$ or $)$

Eilitio gallica Bruxellensis, 1786. VIll voll. 8. non habel supplementum.)

p.xcerpla germanica: Anleitung zur Pflauzum und Wartung der kinchengewachse. Bern (1766.) 8. $\{1 / 4$ th.

texcerpta yallica: Trailé du plantage at de la culure des prineipales plantes potageres, recupilli du Dictionnaire anglois dle $\mathrm{Mr}$ Init de liller, pirr less soins de la socicté économint

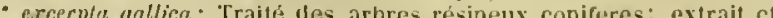
traduit de l'anglais de Plhilip Miller, par lo tharon de Tschude. Netz.

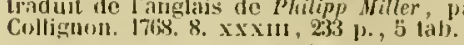

excerptu qallica: Traitis complet sur la maniere de cultiver ta visne. Yverilun 1768. 12. Q.

pxcerpla gallica: Essai sur les arbr's dornement, les arbrisscaux et arbustes de pleioe terre: extrait du Dictionnaire de Viller edilili (par to chevalies de Turgot). Ansterdam et laris, Grange. 178. 8 . Q.

$6937+$ Miller, Philip. Catalogus plantarum officinaliun, yuae in linrec botanico Chelseyano aluntur. Londini 1730 . 8. viu, $152 \mathrm{p}$.

The Gardeners Kalendar; with a slort introduction to the seience of botany. El. XV. London 1769 . S. Lxvi, $382 \mathrm{p}$., 5 tab. B.

Eitilio prima, teste Hallero, Londion 9732. s.

grmance: Gartuerkitlender, uhed'selzt wh buetther. Gerdling(r) Valnelenhock. 17730.8. $\left(5 / 12, h_{4}\right)$

*hollendice: Korte Inleiding tot de krudkunde vals Philipp. Hiller. uit liet Enselsch virtaald etc. door Job fiaster. Tweede Druk. me platen, vermeerderd en verbeterd. Ilaarlem, by Jan Busch. 17iz. 8 5 p. p. 7 tab.

6939 The Gardeners Dictionary abrilg d from the folio edition by the author. (First edition.) London 1733 . 11 woll. 8. - I: 1 alphah., 8 plag. - II: 1 alphab., 12 plag. B. - The abrilgement of the Gardeners Dictionary. Ed. VI. London 1771, 4. 5 alphat. $B$. "germanice: In getreuen Auszuge nach der letzten englisedien Aus-

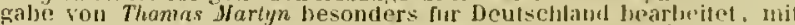
Anmerhungen, Znsátzen und einer Einleitung in tas Liunè sche Pilanzensystem von Franz Johannot. Frankfurt a/M. I Iullliaman. 190?1803. 2 Biude. 8 . (21/\% th.

6940

The method of cultivating Madder. Londion 1758.4.

38 P., 1 tab. col., 6 tab. nigr. B.

(Hedit sul voce Rubia in Dictionarii extitionious Nlf-1...

* germanice: Phitipp. driller's Abhandlung von der Firberrotbe, worinnen sowohl vou dem Bat als von der zubereitung derselben atusfuhrliche Anweisung gegeben wird. Aos dem Englischen ulutsetzt

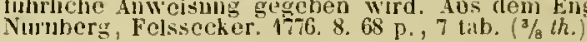

$6941^{*}$ _... Figures of the most beautiful, uscfol and uncommon plants described in the Gardener's Dictionary; to which are added their descriptions. London, Rivington. 1760. Il soll. folio. $200 \mathrm{p}$. praef., incl., 300 tab. col.

"germanice: Abbildungen der niutzlichsten, schonstinl und seltensten Pllanzen, welche in seinem Gártnerlevicon borkinmen. Aus

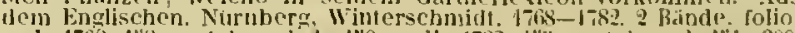

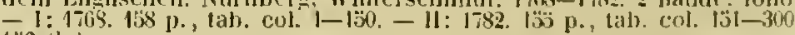
$(30 \mathrm{ih}$.)

6952t Millet d'Aubenton, $C$. Notice sur la culture des oseraies dans lo Déparlement de l'Aisnc. Lyon, typ. Barret. 1837. 8. 19 p.

69 '3t Millin (de Grandmaison), Aubin Louis. Extrait d'un ouvrage le M. hurt Sprengel sur l'histoire de la botanique. Paris, ty]. Sajou. 1809. 8. $28 \%$.

(Autnr nomen summ saepe mutavit; primum . Hillin de firandmatsan, dein inter terrorem Eleutherophile Millin, postremo tubin loous Millin audiclsat.)

694.4 Millot. IIstoire pharmacentique du cemphre. Strasbourg 1837. 4.

69:5 Mills, George. On the culture of cucumbers, melons, sea-cale and asparagus. Lomlon 4841. 8. (10s.)

6946 Milne, Colin. A botanical dictionary. London 1770. 8. as plag. B. - Eil. II : London 1778. 8. - - A butanical dictionary: or elements of systematic and philosopluical botany, - Ed. lll. revised, corrected and very considerably enlarsed, illustrated with 25 new plates. Loudon, Symonds. 1805 . 8. sign. A-Z., ind., 25 tab. col.

$6947^{*}$ - Institutes of botany; containing accurate, compleat am casy descriptions of all the known genera of plarsts: translated from the latin of the celebrated Charles zon Linne. Londen. Griffin. 1771 4. 4, 134 p. - †Part II: ib. 1772.4 . p. $135-302$.

Opus incompletum remansit. Paginae 1-227 culluent a A yiew of the ancient and present state of botany, including a particular illostration of every plan of arrangement, which has appeared since the origin of the science, " Reliquae chatracteres continent rompendiosos et secundarios generum triun priorum elasium ef partis. quartac.) 
69:8 (Milne, Colin.) A descriptive catalogue of rare and curious plants, the seeds of which were lately received from the East-lndies. London 1773. 4. 66 j. B.

69:5 - - and Alexander Gordon, Indigenous botany, or habitations of english plants, containing the result of several botanical excursions, ehiefly in Kent, Middlesex and the adjacent eousties in 1790, 1791, and 1792. Volumen I. London 1793. S. 476 p. B.

6930 * Miltitz, Friedrich von. Ilandbuch der botanischen Literatur für liotaniker, Bibliothekare, Buchhandler und Auctionatoren mit Angabe der Preise und Recensionen. Hit einer Vorrede von Luduin Reichenbach. Bibliotheca bolanica secundum botanices jartes, locos, clironologiam, formam, auctores, volumen, titulos, pretium et recensiones, concinnata auctore Friederico a Millitz. Berlin, Rucker. 1829. 8. vil, $544 \mathrm{p} .(12 / 3, h$.

6951 t Minderer, Raimund. Aloedarium marecestinum. Augustae Vindelicorum, apud Christoph Matıium, I6l6. 8, 235 p., praef, ind. - ${ }^{*}$ Ed. ll. cun annexis conjpositionibus aliquot magistralibus medicis auctoris. Augustae Vindelicorum, typ. Andreae Aperger. 1622. 12. (17) foll., 308 p., ind., 53 p. - Ed. 11l. Augustae Vindelicorum, typ. Joh. Praetorii. 1626. 12. Rivin.

6952* Minding, Julius. Das Leben der Pnanze. Ein Gedicht. Leipzig, Leopold Yoss. 1837. 8. 86 p. $(1 / 2$ th. $)$

6953 Minettus, Ilieronymus. Quacstio non minus pulchra quam utilis de Sarzaeparillae et Ligni sancti viribus, habita in Academia Senensi. Senis, apud Lucam Bonetum. 1593. 4. Bibl. Maz.

69i.) Mini, Paolo. Discorso della natura del vino, delle sue differenze, e del suo uso retto. Firenze, Giorgio Mlarescotti. 1596. folio. 370 p. $\mathbf{3 .}$

69:33* (Miniscalchi, Luigi, Conte.) Nororum libri tres. Carminum liber. Veronae, apud baeredes A. Carattoni. 4769.4.186 p., praef. * italice: La coltivazione de' gelsi, poema latino del Conte Luigi Mrimiscalchi Veronese trasportato in versi italiani dal suo tiglinolo il Conte Leonardo Miniscalchi. Verona, apud haeredes Caralloni. 1792. 8 max. $143 \mathrm{p}$.

6956 Mink, W. Aufzâhlung der wilden Phaneregamen um Crefeld, nebst láufig kultivirten, mit Standörtern; nebst einem Verworte dizu vom Rector Dr, Anton Rein. Jn: Dreizelınte Forlsetzung jälırlicher Nachrichten von der mit den Scheuten'schen Stiftungen verbundnen holieren Stadtschule zu Crefeld. Crefeld 1\$39.4.26 p.

$6957+$ Minuart, Juan. Cerviana, sub auspiciis illustrissimi viri D. Josephi Cervi, archiatri regii, feliciter edita. s. l, et a. 4.2 p. Bibl. Juss.

$6958 \div-$ Cotyledon hispanica. s. l. el a. 4. 2 p. Bibl. Juss.

(Son probabjemente las misinas memorias, que so hallau en los Desiderados de Banks, con el titulo: J. Minuarl, Dos plantas nuevas, que descubrio ell el circuito de Madrid. 1739. 4.)

6959 Miquel, Antoine. Éloge de Parmentier. Paris, au bureau de la gazette de santé. 1822. 8. a.

$6960^{*}$ Miquel, Friedrich Anton Wilhelm. Commentatio (pracmio ornata) de organorum in vegetabilibus ortu et metamorphosi. Lugduni Batavorum, Luchtmans. (Lipsiae, Weidmann.) 1833. 4. 104 p., 2 tab. ( 2 th.)

$6961^{*}$ - Hemerische Flora. Aus dem Ilolländischen uhersetzı von Dr. J. C. II. Laurent. Altona, Hammerich. 1836. 8. v1I, 70 p. $(1 / 3$ th. $)$

(Originale hollandicum exstat in Tijdschrift voor natuurlijke Geschiedenis, Deel II. Stuk 3.)

6962 De nord-neederlandsche vergiftige Gewassen. Fasc. IIV. Amsterdam 1836. folio. 36 tab. col.

$69633^{*}$ Disquisitio geograplico-botanica de plantarum regni batavi distributione. Lugduni Balavorum, van den lleuvell. (Lipsiae, Weidmann.) 4837. 8. xxxII, $88 \mathrm{p} .\left(1^{1 / 3}\right.$ th. $)$

696 - Leerboek tot de kennis der Artsenijgewassen, krachten, gebruik, en pharmaceutische bereidingen. Amsterdam 1838. 8. XLIP, $406 \mathrm{p}$.

$6965^{*}$ - Commentarii phytographici, quibus varia rei herbariae eapita illustrantur. Lugduni Batarorum, Luclıtmans. $1838-1840$ folio. vII, $146 \mathrm{p}$., $14 \mathrm{tab}$.

1. Commentatio de vero pipere Cubeba, deque speciebus cogıatis ae cum eo commutatis, eui praemissa est disputatio taxonomica et geographica de Piperaceis. Lugduni Batavorum, Luchtmans. 1839. folio. p. $1-29$, tab. $1-3$. $(3 \% / 12$ th. $)$

11. *Observationes de Piperaceis el Melastomaceis. ib. 1840. folio. p. $30-92$, lab. $4-11$.
III. *Sylloge plantaruın novarum vel minus cognitarum ex orlinibus Araliacearum, Cactearum, Hypoxidearum, Cycadearum et Urtieacearum. ib. 1840. folio. p. 93-146, tab. 12-14.

6966* Miquel, Friedrich Anton Wilhclm. Genera Cactearum descripta et ordinata, guibus praemissi sunt characteres totius ordinis et affinitatum adumbratio. Rotererlami, Baedeker. 1839.8 .32 p. $(1 / 3 t h$. (Bull. des sc. phys, et nat. en Néerl. année 1839. p. 87-119.)

$6967^{*}$ Monographia generis Nelocacti. Vratislaviae et Bonnae, Weber. 1841 . gr. 4. $15 \%$ plag., 11 tab. (4 th.)

Acta Acall. Caes. Leop. Carol, Nat. Cur. vol. XVIll. Supplementum I. 11. 83-202C.

$6968^{*}$ - Sertum exolicum, contenant des figures et descriptions de plantes nouvelles ou peu connues. Première livraison. Roterdam, Lramers. (Leipzig, Dyk.) 1842, royal 4. 8 p., 5 tab. (1 1/3 th.) (Continuatio milii non innotuit.)

$6969^{*}$ - Nonographia Cycarlearum. Trajecti ad Rhenum, apud Robertum Natan. 1849 . Folio. 82 p., 8 tab. $\left(4 \frac{1}{3}\right.$ th. $)$

(Cf. Lijnsdem de Cycidleis Lorldigesianis epistola ad virum clarissinum C. II. de Vriese. $18^{\prime} 2.8$. 8 . 0 .)

$6970 \div \ldots$ Lijst der planten, welke in de Kolonie Suriname gehweeht worden. s. l. el a. 8.13 p.

$69 \pi$ * Oloservationes botanicae de quiłusdam plantis, quas in colonia Surinamensi legit vir gravissimus $H$. C. Focke. s. I. (1843.) 8. 21 1?., 3 tab.

(E diario lnstituti regii scient. Nederl. anni 18 ł seorsinz impressae.)

$6972 *$ - Systena Piperacearum. Fascic. J-11. (complet.) Roterodami, apud 11. A. Kramers. (Lipsiae, Dyk.) is $43-1844.8$. IV, 575 p. $(5 t h$.

$6973^{*}$ - Oratio de regno vegetabili in telluris superficie mutanda efficaci, quam publice habuit die JI. m. Nartii 1846, quum in Alhenaeo illustri Amstelaedamensi medicinae et botanices professionem ordinariam auspicaretur. Amstelaedani, typ. civ. publ. 1846. 4. $43 \mathrm{p}$.

6974* Mischlovicsew, M. N. De Conio maculato. D. Budae, typ. universitatis. $1834.8 .54 \mathrm{p}$.

6973* Mitchell, Jo/hn. Dissertatio brevis de principiis botanicorum et zoologorum deque novo stabiliendo naturae rerun congruo, cum Appendice aliquot generum plintarum recens conditerum et in Virginia observatorum. Norimbergae, impensis Wolfgangi Schwarzkopfii. $1769.4 .46 \mathrm{p}$.

(Praefatio: "ex aedibus meis Viryiniae 1711/341." Libellus, jam in Actis Acall. Nat. Cur, vol. Vllt. p. 187-22t typis excusus, continet additiones ad Linnaei Generum plantarum editionem primam.

6976 Mitchell, John. Dendrologia, or a treatise on forest trees, with Evelyn's Sylva revised, corrected and abridged. London, Balıwin. 1828. 8. (15s.)

6977 Treatise on the ergot of rye. London s. a. Underwood. 8. $(6 s$.

6978* Mitchell, T. L. Three expeditions into the interior parts of eastern Australia; with descriptions of the recently explored recion of Australia felix, and of the present colony of New South Wales. London 1838. 8. - ${ }^{*}$ Ed. H. carefully revised. London, Boone. 1839. II voll. 8. - I: xx1, 355 p., tab. 1-21. - H: 1x, 415 p., tab. $22-$ 51. (2l.) Bibl. Goett.

(In variis operis locis a John Lindley septuaginta septem novae plantarum species describuntur. Redeunt, had descriptiones in Antlales des se. nat vol. $X V$. Janvier 18 . De recentioribus lineribus cf. Sir T. L. Mitchell's discovelies in the interior of New South Wales; by $R$. Heward, Esq., in Hooker, London Journal of botany, July $18 \% 7$.
p. $363-372$. .

6979+ Mittler, Ludwig. Taselsenbuch far Cactusliebhaber. Aur neue Erfahrungen gestitzte Kultur und Uebersieht der im teutschen Handel rorkommenden Cactuspflanzen. Leipzig, Schreck. 1841-4844. 2 Bände. gr. 16. - 1: $1841, x, 98$ j., 1 tab. col. (Pilocereus senilis). - II: $1844 . \mathrm{vi}, 124$ p., 2 tab. col. $(1 / 12$ th.

6980 Mizauld, Antoine, latine Mizaldus. Secretorum agri enchiridion prinum, lortorum curam, auxilia, secreta, et medica praesidia, inventu promta ae paratu facilia, libris HI pulcherrimis eomplectens. Lutetiae, apud Federicum Morellum. 1560. 8. 180 foll. B. - ib. 1575. 8. s.

6981 De hortensium arborum insitione opusculum. Ejusdem Dendranatome, hoc est, partium corporis arborei explieatio brevis, ubi de earundem nutritione. Lutetiae, apud Federicum Mlerellum. 1560. 8. S. - ib. 1575. 8. Bum. 
6982 Mizauld, Antoine, latine Mizaldus. Alexikepus seu auxiliaris lortus, extemporanea morlutum remerlia ex singulorum virilariis facile compranda pacis proponens. Accessit Dioctis Carystii epistola ad Antigonum do tuendit valetudine per hortensia. Lutetian, apud Federicum Morellum. 1564. 8. S. - "Lutetiac, apul Federicum Morellum. 1563 . \&. (8) foll., 267 p.. iml. - ib. 1574.8 .107 foll. B. - t Alexikepus seu auxiliaris et medicus hortus, rerum variarum $\mathrm{r}$ secretorum remediorum accussione locupletatus. Coloniac, apurl Joannem Gymnicum. 1576. 8. (24) 200 p.

$6983^{*}$ __ Nova et mira arteficia comparandorum fructuum, olerun, radicum, uvarum et aliorum hortensium, quac corpus blande et abstque noxa purgent. Ael haee llethodus perpolehra componendorum vinorum, quae diversis morlis elementer succurrant: cum juisco et recenti catalogo fuorumelam. Lutetiae, apud Federicun Morellum. 1565. 8. (8) foll., 79 p., (4) foll. - tArteficiosa methodus comparandorum hortessium fructuum, olerum, radicun, uvarum, vinorum, earnium et jusculorım, (que corpus clementer purgent, et variis norbis absque: ulla noxa et nausea blanele suecurrant. Coloniae Agrippinae 1577.8 . (16) $76 \mathrm{p}$. 12. g.

germance: per Georg Stenisch. Basilene, apull Lud. Regem. 1616.

698; - Nemorabilium, utilium ac jucuntorum centuriae novem, in aphorismos arcanorum omnis generis locupletes perpulelire digestae. Lutetiae, apud Ferlericum Morellum. 1567. S. S.

6983 - Opusculum de Sena, planta inter omnes quotquot suut hominibus beneficentissima et saluberrima. Lutetiae, apud Federicum Morellum. 1572. S. - ib. 1574.8. s.

$6986 \div$ - Historia hortensium guatuor opusculis methodicis contexla, quorum prinum hortorum curam, ornatum et secreta quamplurima ostentit; secundum insitionum artes proponit; tertium auxiliares et merlicas hortensium utilitates percurrit; quartom jucunda et benefica medicandorum hortensium olerum, raflicum, fructuun, uvarum, vinorum et carnium arteficia esplicat. Accesserunt alia quaedam. Coloniae Agri]pinae, apud Joannem Gymuicum. 1577. 8. 296 p., praef, ind.

gallice: Traduction des livres de Mizauld, par André de la faille; sgavoir te Jardinage, contenant da mantore dembelije les jarelins item, comme jt faut enter les arbres el les rendre medecinaux. Epitre item, comme it faut enter les arbres et les rendre modecinaux. Epitre
de carystius. Du symaisme, ot nanjere do purger par to vomisse-

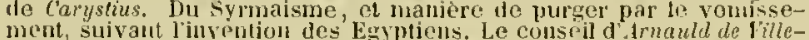
newe. Traité dus sent. Receptes de diyers seerets. Jarilin medicinal.

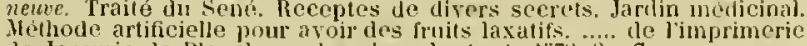
ile Jeremie de Planches, chez Jean lertout. 14is. 8 . S.

gallice: Epitome de la llaison rustique, emtenant ic Jirdin médecinal et le Jardinage d'Antoine Mizauld. Item Ja maniere d'embetlir les jardins: plus la façon denter les arbres. Tillefrauche, Jean Arnaut. 1605.8 . $\mathrm{s}$.

$6987^{*}$ Mlady, Fr. R. Dissertatio inauguralis medico-myeographica, sistens Synopsin Amanitarum in agro Pragensi sponte nascentium. Pragae, typ. llaase. $1838.8 .33 \mathrm{p}$.

6988 Modéer, Adolph. Tal, on några ámnen, som uti de tree Naturens Riken Törunderligen lihna hvarandra, sa till utseemle som ock merendels till bruk och nytta; laallit Jor Kongl. Vet. Acat. 4788. Stochholm, Zetterberg. 179 i. $8.18 \mathrm{p}$. в.

germanice: Von gewissen Dingen in den drei Naturreichen, welche sowohl dem ausseren Ansehen, als auch mehrentheits dem Gebrauch und Nutzen nach, eine bewundrungswiurdige Achulichkeit unit einander haliell. Aus dem schwedischen ubersetzt von kaspar cinbriel Groening. Leipzig, (iritt. 17\%t. 8. 16 p.

6989 Model, Johann Georg. Untersucluung des Nutterkorns. Wittenlerg, Boehme. 1771. 8. ( $1 / 8$ th.)

$6990^{*}$ Moebius, Goufried. Anatomia camphorne, ejus originem, qualitates, praeparationes chymicas ac vires exhibens. Jenae, typ. Sengenwald. 1660.4.104 p., praef.

6991* Moeckel, Heinrich August. De Diosma crenata, oleo Crotonis Tiglii et carbone animali. D. Lipsiae $1820,4,28$ \}).

6992 Moegling, Johan Ludwiy. Praeludia rei herbariac. Tubingac 1612,4 . H.

6993 at resurrectionem corporum nostrorum futuram ipplicatio. D. Tubingile 1683.4 .20 p. (Respondens: Johann Adem Dassdorff.) B.

6994 Moegling, Theodor. Anleitung zur Maulheerpllanzung und Scidenzucht. In Auftrage der Kon. Wurtemberg'schent Regierung verfasst. Tubingen, Fues. $1841.8 .51 / 2$ plig., 2 tab. (1/2 th.)
$6993 \div$ Moehring, Paul Ileinrich Gerhard. Primae lincae horli privati ill proprium et amiconum usun per triennium exstructi. Oldenlsurgi, typ. J. C. Gótjen. 1736. 8. 111 p. Bibł. Cand.

6996* Moehsen, Johann Karl II ilhetm. Disserlatio epistolica prima de manuseriptis nedicis, quac inter codices bibliothecae regine Berolinensis servantur. Berolini, apud Anbrosium llaude. 1746. 4. (8), $30 \mathrm{p}$.

$6997^{*}$ - Dissertatio epistolica secuncla te manuscriptis merlicis, quae inter codices bibliothecae regiae Berolinensis servantur. Berolini, impensis Jol. Adam Rueliger. 1747. 4. p. $31-82$.

6998* Moellenbrock, Valentin Andreas. Cuchlearia curiosa, cum inclice rerum et verborum lacupletissimo. Lipsiae, Gross. 1674. \$. 140 p., praef., ind, 4 lab. - Lipsine 1746.8 . H.

t unglice: Cochlenria curiosa, or the curinsities of scurvegrass onte englished by Thomas Sherley. London, Cade. 1676. 8. 1!5 p., Jrawe, incl., $t$ (it)

6999 Moeller, Georg Friedrich. Bescbreibung der besten Arten von Kermobst. Berlin, Realschulbuchhandlung. $1759.8 .(1 / 8$ /h.

(1) "jusdem experimentis cirea foccundationem plantarum on in eal anthatversionilus Profossoris Abroham Gothelf huestner cf. spreng. 1list. rei tierh. II. p. 393-396.)

7000 Moeller, Joham Anton Amold. Leber die syrische Seilenpflanze (.Iselepias syriaca). Jamm 1793. S.

7001 Emplelılung zum Aubau der Akazie. Dortmund, Nallinhrodt. $1796.8 .(1 / 2+t h$.

7002 Versuche den englisclien Senf als Oelpflanze mit Vortheil zu bauen; nebst zwei andern Gewachsen zu noch feinerem Oele. Dortmund, Mallinhroelt. 1796. $8 .(1 / 2$, th. $)$

$7003^{*}$ Moeller, Johann Christoph. Specimen inaugurale medicum de lpecacuanha. Firfordiae, typ. Goerling. 1795. 4. $12 \mathrm{~g}$.

700:* Moench, konrad. Enumeratio plantarum incligenarum Ilassine praescrtim inferioris secundum methodum sexualeur dispositirum. Pars prior cum (V'1) tabulis aeri incisis. Cassellis, sumtibus auctoris. (Goettingae, Vardenhoeck.) 1777. 8. 268 p. (1 th.)

(J)esinit in Jcosandria. Pars áltera nunquam prorlitit.)

$7000^{*}$ _ _ _ Verzeichuiss auslándischer Bäume und Staurien de. Lustsclilosses Weissenstein bei Cassel. Frankfurt und Leipzig, Fleisclier. 1785 . S. xuv, 144 p., 8 tab. $(2 / 3$ th. $)$

$7006^{*}$ - Netholus plantas horti botaniej et agri Marburgensis a staminum situ deseribendi. Harburgi Cattorum, in libraria academica. 1794. S. vir, $780 \mathrm{~F}$, ind. - "Supplementum ib. $1802.8 . \cdots$, $328 \mathrm{p} \cdot\left(3 \frac{2}{3}(h)\right.$

$7007^{*}$ - Einleitung zur Pflanzenkunde. Marburg, akademisclie Buclitanellung. $1798.8 .274 \mathrm{p} .(5 \% \mathrm{th})$

7008* Moerch, O.J. N. Catalogus plantarum horti botanici Hafuicnsis. Jauniae, typ. Scliultz. 4839 . 8. 102 p. - Supjlementum. il. 1840 8. $12 \mathrm{p}$.

7009 Moessler, Johann Christian. Botanische Bläter zur Beforderunn der Pflanzenkunde. Herausgegeben von A, F. H. Ilayer. Hamburg. Wettach. $1806,8 .(1 / h$. $)$

7010t — Taschenbuch der Botanik zur Selhstbelelorung, welches die botanische Sprache, die Erlauterung des Linnéschen Syslem. der dreinulzwanzig ersten Klassen, und die dalin gehorigen wilken Gewachse Teutschlinds enthalt. Hamburg, Hofmann. 1805. 8. vir, 287 p., 6 tab. col. $\left(2 \frac{1}{2}\right.$ th. $)$

$70.14^{*}$ Gemeinnutziges Handbuch ter Gewachskunde, nelst einer Einleitung in die Botanik. Atona, Hanmericls. 1815.2 Bănde

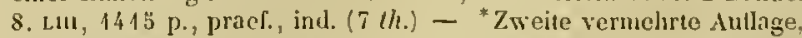
herausgrgeben von IIeinrich Grotlieb Ludwig Reichenbach. Atona llammerich. 1827-1829.3 Bande. 8. $\left(5 \frac{1}{3}\right.$ th. $)$ - Handluch der Gewăchshunde, enthaltend eine Flora von Deutschland, mil Hinzufigung der wiclıtigsten auslandischen Kulturpflanzen. Dritte Auflage. gänzlich umarearbeitet und lurch die neusten Eutdeckungen vermelsrt von Ileinrich Groltieb Ludwig Reichenbach. Altona, Itammerich 1833-1834. 3 Bánde. 8. Cxir, 1994 p. $\left(6^{3} / \mathrm{th}\right.$. $)$

7012* Mohl, Hugo von. Ueber den Ban und das Winclen eler Ranhen und Schlingphlanzen. Eine gehroute Preisschrift. Tühingen, Laup],

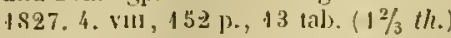

$7013^{*}$ Leber dic Poren des Pnanzenzellgewebes. Tubingen, Laupp. 1828. 4. 36 p., 4 tab. $(2 / 3$ th.j 
7014

MohI, Huyo von. De Palmarum structura. Ex. Murtii opere: "Ge16 tab.

(Lebersetzt in: Vermischte Scluriften p. 129-183, 1 tab.)

$705^{\circ}$ _. Ueber den Bau des Crealcenstammes und sein Verlualtniss zu dem Stamme der Coniferen unel Baumfarn. (Besondrer Abdruck der Denkschriften der Muncluner Akatemie der Wissenschaften, Band X.) Nunchen 1832.4.46 p., 3 tab.

(Ungearleitet in: Vermisehte Schriften p. 19;--211.

$7016^{*}$ De structura caudicis filicum arborearum. Seorsim expressum e Hartii opere: a Icones selectae plantarum cryptogamicarum Brasiliae, N Jonaclsii 1833. folin. 23 p., 6 tab. col.

(1m) Auszuge übersetzt ohne Tufelu ilt: Fernischte sehriften p. $108-121$.

$7017^{*}$ L_Einge Benerkungen wher die Eutwickelung und den Bau der Sporen der kryptogamischen Gewachse. Erste Abtheilung Regensburg 4833.8 . 43 p., 2 lah. (Aus der Flora.)

(Vermischte Schriften p. 67-83.

$7018^{*}$ Beitrage zur Anatomie und Pliysiologie der Gewächso. Erstes Heft: Ueber den Bau und die Formen der Pollenkörner. Beru Fischer, 1834.4 . Iv , 130 p., 6 tal). $\left(3 \frac{1}{8}\right.$ th. $)$

7019* _... Ueber die Vermohrung der Pflanzenzellen durel Theilung. D. Tuhingen, Fues. $1835.4 .20 \mathrm{~J}$., I tal,

(Ganzlich umgearbeitet in Vermischte schurften p. 362-371.)

$7020^{*}$ Leluer die Verbindung der Pflanzenzellen unter einander D. Tuhingen, Fues. 1835. 4. 24 j., 2 tab

$7021^{*}$-_L Lntersuchungen ulsel die Entwichlung des Korkes un der Borke auf der Rinde der baumartigen Dicotyledonen. D. Tübingen Fues. $1836.4 .26 \mathrm{p}$.

(Vermischte Schriften p. 212-228.)

7022* Untersuchungen uber den Mittelstock von Tamus Elephantipes L. D. Tübingen, Fues. 1836.4.16 p. (Vermischte Schriften j. 186-19\%.)

- Beobachitungen uber dic Umwantlung von Antheren in Carpelle. D. Tubingen, Bähr. 1836.8 .37 p. (Vermisclite Schrifien p. 28-14.)

7021." __ Erläuterung und Vertheidigung neiner Ansicht rout der Atructur der Pllanzonsubstanz. Thibingen, Fues. 1836. 4. Iv, $39 \mathrm{p}$. 2 tab. ( 1 th. $)$

$7023^{*}$ Untersuchung ler Frage: Welcho Autoriat soll den Galtungsnamen der Pllanzen beigezehen werden? D. Tubingen, lues. 1836. 8.24 p. (Vermischite Schriften p. 1-12.)

$7026^{*}$ _ Ueher die Symmetrie der Ptlanzen. D. Tubingen, Fues. $1836.8 .49 \mathrm{p}$.

(Lingearbeitet in: Vermischte Seluriften p. 13-27.

$7027^{*}-$ Ueber die Functionen der Blatter. D. Tubingen, Fues. 1836. 8. $25 \mathrm{p}$.

$7028^{*}$ __ Untersuchungen wher die Lenticellen. I. Tubingen, Fues. 1836. 4. $19 \mathrm{p}$

(Vernisclite Schriften p. 233-2ri.)

$7029^{*}$ Culersuchungen uber die winterliche Fárbnng der Blăt-

ter. D. Tubingen, Bäır. $1837.8 .36 \mathrm{p}$.

(Mit Zusatizen : Vermisehte Sehriften p. 37j-392.)

$7030^{*}$ - Untersuehungen uber" die anatomischen Verhalnisse des Chloropliylls. D. Tubingen, Buhr. 1\$37, 8, 26 p. (Vermischite Schriften p. $319-361$.)

$7031^{*}$ - Anatomische Untersuchungen uber die purosen Zellen von Splagnum. D. Tübingen, Bahr. $1837.8 .43 \mathrm{p}$ (Vermischte schriften p. $291-313$.)

$7032^{*}$ - Ueber don Bau der vegetabilischen Zellenmembran. D. Tulbingen 4837.8.44 p.

(vermischte Schriften p. 31 k-33k.)

7033* —— Ueber die mânnlichen Bliten der Coniferen. D. Tubingelt, Bahr. 1837.8.36 p.

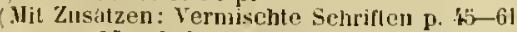

$703 \mathrm{r}^{*}$ - Morphologische Betrachtungen ulser das Sporangium der nit Gefíssen versehenen Kryplogameı. D. Tubingen, Balır. 1837. $8.40 \mathrm{p}$.

(Vermischte Schriften p. 9'-107.)

$703.5^{*}$ Untersueluugen uber die Wurzelausscheidung. D. Ein Auszuy aus einer ron der medizinisclien Facultät in Tubingen im Jahr 1836 gekröuten Preisschrift. Als Juauguraldissertation unter dem Prasidiun von Hugo Moht der ollentlichen Pruinng vorgelegt von Eduard Wulser von UIn. Tulsingen 1838. \$. 48 p.
Mohl, Uuyo ron. Veher den Einfluss des Bodens auf die Verbriptung der Ajpenpflanzen. D. Tubingen I838. $8.68 \mathrm{p}$

(Fimischte Schriften p. 393-i28.

$7037^{*}$ Untersuchungen uber die Frage: In welchem systen des Holzes wird der rohe Nahrungssaft zu den Organen geleitel. J). Tulingen $1843,8.28 \mathrm{p}$

$7038 *$ Dr. Justus Liebig's Verhăluiss zur Pflanzenphysiologie. Tubingen, Fues. 1843.8 .59 p. $(3 / 8$ th. $)$

$7039^{*}$ Termischte Schriften botanischen Inlialts. Tubingen, L. F. Fues. 1845. 4. vir, 442 p. 13 tab. $\left(3 \frac{1}{3}\right.$ th. $)$

Practer jan indicatis dissortationes in hac collectione continentur "Ueber dir filyosen Zellen der. Antheren. Flora 1830. 11. 1.697. Inrm. Schr. 1). 62-66, - Uelser die Entwichelung der sporen von Anthoceros laevis. Linmaea 1839. Verm. Schr, p. 8r-98. - Leber den Ban des stammes ron lsortes lacustris. Linnaea 18\%. Verm. Sehr. p. 122-128 - Sind dic Lenticullen als Wurzelknospen zu betrachten. Jora 1832. Verm schr. p. 229-232, - Teher dio Spaltotinungen atuf den Blattern der Protenceen. Act. Leop. AVI. 1I. 1833. Verm. Selar. p.

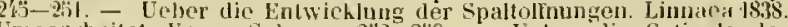
Umgearbestot Verm. Schr. p. 252-259. - Ueber die Cuticula der Gewachse. Linnitea 18'2. Verm. Schr. P. 260-267. - Velier den Ban der yrossen getupfelten Rohren von Epherira. Jimnaca 1s31. Verm. Sichr. b. 268-271. - linige Bemerhungen uber den Bau der getupfelten Gefisse. Linuana is'2. Yerm. Schr. p. 272-283, 1 bas. - Teber den liau der Ringrefasse. Flora 1834. Verm. Sehr. p. $26-293$. - Einge Beobuchtungen uber die blaue Farbung der vegetabiliselien zollenmenbrat durch Jocl. Flora $18 \% 0$ : Verm. Schr. p. 335-3ks. - Leber

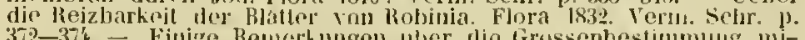
372-37\%, - Einige Benterhngem uber dic Grossenbestimmung mihroscopincher Olijecte. Linnaea 1822. Mit Zusäzen: Fermischteseluriften p. $429-42, \ldots\}$

$50.0^{*}$ - Mikroyraphie, oder Anleitung zur Kenntuiss und zum

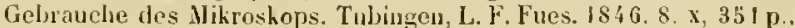
6 tab. $(23 / 5$ th. $)$

701. Mohr, Daniel Malthias Ileinrich. Observationes botanicae, tuibus plintarum eryptogamarum ordines, genera et species illustrar. conatus est. D. Kiliae typ. Nolır. $1803.8 .45 \mathrm{p}$.

(Caletera sua sicripta cum Friedrich ileber edidit.)

70\%. Mohrbegk, G. t.J. Dissertatio de Rhabarbaro et ejus luern in Pomerania, suecia, similibusque regionibus. Gryphiswaldiae 1788.4.

7043 Moisand, Charles Auguste. Flore Nantaise, ou tableau analytique d'aprés la méllonde de H. Delanarck des plantes naturelles au département du la Loire-inférieure et de celles qui sont cultivées le plus généralenent, elassées selon Jussieu, avec une concordanç linuéenne et lindication de leurs usages dans la médecine el dams les arts. Nanir's, 1yp. Mellinet. 1839.8.50 plag.

(Liber mihi nullibi Parjsiis olvius fuit.)

70 ... * Moldenhawer, Johann Heinrich Daniel. Dissertatio anatomicit de vasis plantarum spreciatim radicen Jerbamono adeuntibus. I) Trajecli ad Viadrurn, typ. Winter. 1779. $4.85 \mathrm{p} .(1 / 3$ th.

70 :5* Moldenhawer, Johann Jakob Paul. Beiträge zur Anatomie Jer Pflanzen. Kiel, typ. Waser. (llamburg, Perthes und Besser.) 1812 4. x11, 335 p., 6 tab. $(8 \mathrm{th}$.)

$7046^{*}$ Tentamen in Hlistoriam plantarum Theophrasti. Hamburgi, lloflmants. 1791.8 .151 p. $(2 / 3$ th. $)$

70 itt Molina, Giovami lgnasio. Sagaio sulla storia naturale del Chile. Bologna, typ. Tommaso d'Aquino. 1782.8.367 p., 1 mappa geogr' - Eil. Il: Bologna 1\$10. 4.

* germantice: Yersuth einer Naturgeschichte ron Chili. Aus tent Italienjschen von J. D. Brandis. Lecipzig, Jacobdier. 1786. 8. 328 p., praef. 1 tab. gengr. (1 th.)

(iu p. 99-170 agitur de plantis.)

t gallice: Essai sur l'histolre naturelte du Chili. Traduil de l'italien et enrichi de noles par Giruel. Paris, Née de la Rochelle. 1789. 8. $\mathrm{Arl}, 331 \mathrm{p}$.

(Livre III, p. 93-168: Horhes, arluustes et arbres du Chili.)

7048 Molinariis, Simon de. Ambrosia asiatica, seu de virlute el usu herbae The seu Cia, nec non de modo adbibendae et praeparandae ejus potionis. Genuae, Georg Tranchellius. 1672. 12. S.

7019 * Molkenboer, J. H., et C. Kerbert. Flora Leidensis, sire elenchns: plantarum sponlanearum phanerogamicarum, quae hucusque prope Luglunum latavorum repertae sunt, secundum ordiues naturales digestus. Accedit clavis generum secundum systema sexuale Linneanum. Lugduni hatavorum, suntibus J. W. van Leeuwen. 1840. 8. xxxu1, 389 p. $(5 \mathrm{fl} .-4 \mathrm{~h}$. $)$

Caetera sua scripta cum $F$. Dozy edidit.

$70300+$ Mollet, Andre. Le jardin de plaisir, contenant plusieurs desseins de jardinage, tant parterres en broderie, compartimens de gazon 
Ifue bosquels el autres; avoc un abrége d'agriculture touchan ce qui peut ctre le plus utile et necessaire a la constrnction et accompaynement dudil jardin de plaisir. Stockholm, chez Kayser. 1651. folio. 47 p., 30 lab. delineationes hort. gall.

mglice: The garden of pleasure, containing several daughts of gardens. London, T. Xi. for John Martyn. 1670. fislio. lal). S.

70\$1 Mollet, Andri. La maniere pour eslever des melons. s. I. 1659. 4. Rivin.

7052 Mollet, Claude. Théatre des plaus el jardinages, coutenant des secrets el des inventions inconuues a tous ceus qui jusqu'a jrésent se sout melez d'écrire sur cette matière; avec un traite d'astrologic pour la culture des jardins. Paris, Clıarles de Sercy, 1632 . 4. 1als. s.

7063 Théalre des jardinages, contenıul une méthode facile pour faire des pépintères, planter, élever, enler, greffer el cultiver toute sorte d'arbres fruitiers, avec les fleurs qu'il faut mettre dans les parterres qui servent á l'embellissineut des jardins. Paris, Charles de Serey, 1660, 12. - ib, 1678, 12. s.

705\%. Monardes, Nicolas. De Rosa et partilus ejus. De succi Rosarum temperatura. De Rosis persicis seu alexandrinis. De Malis Citriis, Aurautiis el Linoniis. Impr. cum Ejus Do secanda vena in plearilide. Antwerpiac 1534. 16. sign. $\mathrm{e}^{7}-\mathrm{i}^{8}$. B. $-{ }^{*}$ cum eodem Jibro. Antwerpiae, apud Martini Nulii viduan. 1564. 8. foll. 22-35. - "In Clusii Exoticis. Antwerpiae 1605. folio. II, J, 43-50.

705i - De dos medicinas excellentissimas contra todo veneno lia piedra Bezear y la Yerva Escorzonera. Sevilla 1569. 8. H. lutine: In Clusii Exoticis, Autwerpiae 160's. folio.

7056 Tratado del efecto de varias iervas. Ifispali 1571. 8. s.

7037 De tabaco, lispanice. (Titulum nullili indicatum imeni.)

tyallice: Instruction sur l'herbe Petum, ditte en France liherbe de lit Buyne ou Mledicée: el sur la racine Mechiocan. (Traduit de l'espingnol de Monardes par Jaques Gohori.) Paris, Galiot dn Pré. 1572 12. 31, 16 p., ic. xylogr. $\mathrm{j}$. t. bibl. Juss. - cum versione gallica demili Macri, lioven, Mallard. 1588 , 8 . Bibl. Maz.

italice: Herba Tabaco d'lndia. Genova 4578. s. s.

italice: Ilerba Tabaco dindia. Genova 4578 . 8 . S.
ilatice: Della virlu del tobacco, colle sue operazioni. Venezia, Doninico Lovisa. S. a. 12. s.

- Historia mediciual de las cosas que se traen de nuestras Indias occidentales, que sirven en medicina. Duas partidas. Sevilla 1569.4 . - Ed. II. con lo tratado de la grandeza de Hierru e de la Neve. Sevilla 1574. 4. - tEd. III: Prima y segunda y tercera partes de la historia medicinal: de las cosas que se traen de nuestras Indias occidentales, que sirven en medicina. etc. En Sevilla, els casa de Fernando Diaz. 1580. 4. (7), 162 foll. Bibl. Deless.

(Liber tertius hac posthuma editione, Monarde eirca annum 1578 mortto, primum prodiit. Praefatio addita est anni $157 \mathrm{k}$.

- latine: De simplicibus medicamentis ex occidentali India delatis quorun in medicina usus est. Auctore D. Nicolno Monardis Hispalensi

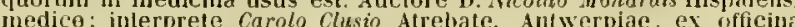
Ciristophori PJantini. 1574.8 .88 \%., ind., ic, xylogr. i. 1 .

latine: Simplicium medicamentorum ex novo orbe delatorum, quorum in medicina usus est, historia, hispanieo sermone descripta a 1). Nicolan Monardis Hispalensi medico Latio deinde donata el adnotalionibus jeonibusque aftabre depictis illustrata a Ca roloClusio Alrebate. Alle ra editio. Antwerpiae, ex officina Plantini. 4579.8 . 8' p., ind., jc. 1 ylogr. i. 1 .

IIae duae editiones partem I et 11 Monardis tantum continent, mutato ordine a Clusio in unum volumen contractas.

* latine: Simplicium medicamentorum es nova orbe delatorum, quoruto in medicina usus est, historias liber tertius: inispanico serquoruta in medicina usus est, historiac liber tertius: hispanico ser-
mone muper lescriptus a D. Nicolao Nonardes, Hispalensi medico: mone muper lescriptus a D. Nicolao Monardes" Hispalensi medico: Antwerpiae, ex offieina Conistophori l'lantini. 1582. 8. 47 1).

Allwerpae, ex oftelina christophorim editionem hispanicam ami 1580 clusius ex Anglia in Belgiun properans, adverso ventu Gravesendate et in ipso alto aequore alliquandiu detentus, ut islius morac lardium falleret inter nauticos clinurr's latinum fecit. ;

latine: Simplicium medicamentorum ex novo orbe delatorum, quorum in medacina usus est, historia ; hispanicu sermone duobus linris descripta, Latio deinde innata et in unum, volunen eontracta, insuper annotationibus illustrata a rarolo Clusio. Tertia editio. (Libri ili illera.) Impr. cum Garciae ab Horto Aromatum historia, Antwerpiae

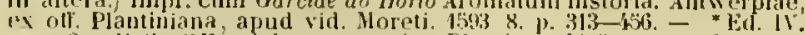
cum Carolic'lusii Exoticis. Antwerpiae, Plantinus. 160\%. folio. p. 29\%-305. (In hac editione tres libri in unum contraci sunt.)

anglice: Joyfult newes out of the newe founde worlde, wherein is declared the vertues of hearbes, trees, oyles, plantes and slones, englished by Jhon Framplon, Marchant. London 1577 . \&. 109 foll. B. Loudon listo. 4. 109 foll. praeter reliquos tractatus Monardis. B. London 1596. 4. 109 foll. praeter reliquos tractatns . Monardis B.

(In bac ultima versione etiam liber lertius continetur.)

$\div$ ilulire: Delle cose, che yengono portate dall" Indie occidentali perlinenli all uso della medicina. Novamente recala dalla syagnola nilla nostra lingua jtaliaud (da Annibali ligiganti). Parte prima "t se-

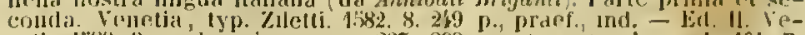
netia lis9. 8. parte primera, p. 235-2099. paste seconda, p. 1-101. B. netia lis9. 8. parte primera p pe $237-2,9$, parte seconda, p. $1-101$. b. Horto; liber tertius italice non esstat.)

- gallice: Histoire des simples medicanulls apportés de l'Amerique. desinets ont se sert en la medecine. Escrite premierement en Espagno par II. Vicolas Monard, nuedicin de siville. Ju despuis mise en lalin "il illustrie de plusieurs annolations pir Charles de l'Ecluse d'Arras. Ei nouvellement traduicte en francais par dntoine Colin. Edition seconde aumenlie. lyon, Pillehotte. 1619. 8 . $262 \mathrm{p}$, ind.. ic. Xyluar. i. L

7059 Monchy, Salomon de. Dissertatio inauguralis de Opio. Lugduni Batavorum 1739.4.52 p. B.

7060 Monconys, Ballhazar de. Juurnal de ses voygages, publié par le Sieur de Liergues, son fils. Lyon 1665-1666. III voll. 4. B. (J) contentis cf. IIall. Bibl. bot. f. p. 525.)

7061 Monginot, lirangois de. De la guérisen des fievres par Je Quinquina. Paris 1679.12 . H. latine: in Blegny Zodiaco medico. Generae 1681 . Feloris China expugnata. Ferrara 1697. 4 . H.

7062 Monheim, Johann. Elementurun physiologiae, seu philosaphiae naturalis libri V'II. Coloniae 1542-1544. II voll. 8.

(In vol. Il. Seguiero teslis, salis abunde de plantis traclavit.

7063* Monkewitz, Joham Meinrich. Clıenisch medizinische Lintersuchung uher dic Wandflechte (Lichen parietiuus) und uber dic gehráuchliclısten Clinarinden. D. Derpal 4817. $8.38 \mathrm{p}$.

706. Monnard, J. $I$. Observations sur quelques Cruciferes décrites par I. DeCandolle dans le seconl volume de son Systema; avec des notes de M. Jacques Gay. Paris 1826. 8. a.

(Idem continavit el edidil Gaudini Synopsin Florae helvelicae. Turiej 1836 . \&.)

$7065 \div$ Monnereau, Elie. Le parfait indigotier, ou description de l'Indigo, avec un trailé sur la culture du café. NuuvelJe édition. Amsterdam et Narseille, Mossy. 1765. 12.238 p., 1 tab.

(IIall. Bibl. but. II. p. 50̈3-ijs.)

$7066^{*}$ Monnier, Augusle. Essai monegraphique sur les llieracium et quelques genres voisins. Nancy, typ. Hissetle. 1829.8 .92 p., 5 tab.

7067 Monrad, Jeremias IIolfyang. De Verbena ejusque usu in sacris el incanlationihus velerum. D. Jiteraria. Ilafina 1751.4. н.

7068 Mons, Jean Baptiste van. Erfahrungen üher die heilsame Anwendung des wurzelnden Sumaclıs, der gelben Narcisse, und iles Pfefferschwammes, nebst einer Abhandlung üjer den wurzelnden Sumaelı. Aus dem Franzosischen von C.F. Nasse. Halle 1801.8.238 p.

$7069+$ Montagne, Jean François Camille. Memoire sur le genre Pilobole et sur une nouvelle espèce. (Extrait des Annales de la société Limneenne de Lyon.) Lyon 1826. 8. 7 p., 1 (ał), col.

$7070 \div$ Matcriaux pour servir à la Flore de Barbarie. Deuxieme article: Notice sur les Cryptoganes recueillies aux environs de Bonc, par Adotphe Steinheil. (Extrait des Aum. des sc. nat. Mai 1834.) 8.8 p., t tab.

(uToul ce Iravail, á partir du genre Lyeopodium, doit ctre regarde comme ctant entieremeat de Camille Montagne.")

7071 - _ Descriplion de plusieurs nouvelles espèces de cryptoganes découvertes par MI. Guudichaud dans l'Amérique miridiunale (Extrail des Ann. des se. nat. Decembre 1834.) 8. 7, I 2 p., 2 lab. col.

$7072+$ Enumération des mousses et des hépatiques recueillies par M. Leprieur dans la Guiane centrale, el description de plusieurs nouvelles espices de ces deux familles. (Extrait des Ann. (les sc, nat. Avril 183 s.) 8.27 p., 2 tal.

$7073 \div$ - Prodromus Florae Fernandesianae. Pars prima, sislens enuneratiunem plantarum cellularium, quas in insula Juan Fernandez a clarissimo Bertero collectas describi edicue curavit. (Exlrait des Aun. des sc. nat. Juin 1835.) 8.24 p.

$7074 \div$ - Notice sur les plantes cryptogames a ajouter a la Flore française. Paris : typ. Renouard. 1835-1836. S. (No. 1-5.) $34,38,26,32,19$ p., 9 tals. pro parte col.

$7075 \div$ Jungernanniearum Ilerbarii Montagneani species exposuerunt Christian Gollfried Nees ron Esenbeck et Cumille. Ifonagne. (Extrait des Ann. des sc. nat. Janv. 1836. ) 8. 21 p., 2 tab.

$7076+$ Monographie du genre Conomitrium de la famille des mousses. (Extrait des Ann. des sc. nat. Octobre \$\$37.) S. 16 p. 1 tab.

$7077+$ Des organes males du genre Targionia découverts sur une espece nouvelle du Chili. (Extrait des Ann. des se. nat. Fivrier 1838.) 8. 15 p., 1 tab. 
$7078 \div$ Montagne, Jean Frangois Camille. De I'organisation et du morle de reproduction des Caulerpées et en particulier du Caulerpa Webbiand, espèce nouvelle des iles Canaries. (Estrait des Ann. des sc. nat. Mars (838.) 8. 22 p., 1 tal.

$7079 \div$ Cryptogames algériennes ou plantes celiulaires recueillies par M. Roussel aux environs d'Alger. (Extrail des Anu. des se. nat. Novembre el Decembre 1838.) 8. 23 1., 2 tab. 'col.

$7080 \div-$ Centuries $(\mathrm{I}-\mathrm{V})$ des plantes cellulaires exotiques nouvelles. (Paris, IYp. Renouarl.) 1835-1845. 8. 45, 107, 85, 72, 102 p., 11 tab.

(Exirait des Annales des scicnces naturelles.)

$7081+$ Cryptogamae brasilienses seu plantae celiulares, quas in itinere per Brasiliam a eel. Auguste de Suint-Hilaire collectas recensuit observationibusque nonnullis illustravit. (Extrait des Aun. des sc. nat. Juillet 1839.) 8. 14 p., 1 tab.

$7032 \div$ - Remarques sur le Callithamnion clavalum et sa synonymie. (Extrail des Inn. des sc. nat. Septemhre i839.) 8. 4 p.

$7083^{*}$ Sertum patagonicum. Cryptogames de la Patagonie Paris 1839. 4. 19 p., 7 tab. col.: Algae.

(Pertinet ad sectionem alteram partis botanicne operis: Alcide Dorbigny, Voyage daus l'Amerique meritionale; cf. $\mathrm{Nr}$. 2(900.)

708 '. $^{*}$ - Flonula Boliviensis. Cryptogames do la Bolivia, recueillies par Alcide DO Orbigmy. Paris 1839. 4. 119 1\%, 3 tab.

Perine ad sectionem intrean partis botanicae oporis: Alcide Dorbigny, Voyago dans l'Amérique méridionale; cf. Ni. 2690 .

7083 - Considérations suceinctes sur la tribu des Laminariees, de la sous-famille des Fucaceies et caracteres sur lesquels est établi le nouveau genre Capea, appartenant a lit uème trilus. (Extrait des Aun. des se. uat. Juillet 1840.) 8. 7 p.

$7086^{*}$ __ Esquisse organographique $\mathrm{et}$ f plysiologique sur la classe des champignons. Paris, Bertrand. $1841.8 .56 \mathrm{p}$.

(Liher sistit particutam operis: "Blistoire physique, politique et maturelle rlo lite de Cuha par Ramon de la Sagra." Interdum accedunt adnotationes quaedan manuseriptae.

" germanice: Skizzen zur Organographio und Physiologie der klasse der Schwamme. Uebersetzt und nat einigen Anmerkuigen versehen vor Johumes $D$. C. Pfund. Prag, Calve. $18 \%$. 8. X, 67 p. $(1 / 2 t h$. $)$

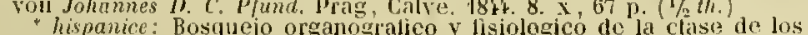
hongos. (Traducido por P. Jutian Furvion.) impreso en la listoria lisira politica y natural de la isla de Cuba que publica D. Ramon de

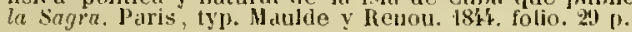

$7087+$ - Recherches sur la structure du Nuclèus des genres Sphnerophoron de la famille des Lichens, et Lichina de eelle des Byssacees. (E.trait des Ann. des se. nat. Mars 1841.) 8. 11 p., 1 tab.

$7088+\longrightarrow$ Cryplogamae Nilgherienses, seu plantarum cellularium in montibus jeninsulae indicae Neil-Gherries dictis a cl. Porroltet colfectarum enumeratio. (Extrait des Ann. des sc. nat. AvrilJuillet 4842.) 8. 26 p.

$7089 \div$ Du genre Xiphophora, et, a sou occasion, Recherches sur cette question: Tronve-t-on dans les Fucacćes des deux modes de propagation, qu'on observe ehez les Floridées? (Extrait des Ann. des sc. nat. Octobre 1842.) 8.7 p.

$7090^{*}$ Prodromus generum, speciesumque Pliyeearum novarum, in itinere ad polum antareticum ab illustri Dumont d'Urville preacto collectarum, notis diaznosticis tantum lac evulgatarum, descriptionibus vero fusioribus nee non iconibus analyticis jam jamque illustrandarum. Parisiis, (iide, 1842, 8, $16 \mathrm{p}$.

$7091+\ldots$ Considérations générales sur la tribu des Podaxinées, et fondation du nouveau genre Gyropluragmium, appartenant à celto tribu. (Extrait des Anuales des sc. nat. Aoùt 4843.) 8. $14 \mathrm{p}$.

$7092^{*}$ - Cryptogamie. Exposition sommaire de la morphologie des plantes cellulaires. (Extrait du Dietionnaire universel dhistoire naturelle.) Paris, ty]. Bourgogne et Martinet. 1843. 8. $16 \mathrm{p}$.

$7093^{\circ}$ - Quelques observations touchant la structure et la fructification des genres Ctenodus, Delisea el Lenormandia, de la fanille des Floridées. (Extrait des Ann. des se. nat. Mars 1844.) 8. 14 j., 2 tab.

$7094+\longrightarrow$ Sur un nouveau genre de la famille des Hépatiques (Duriaea) par Bory de St. Vincent et C. Montagne. (Extrait tes Ann. des sc. nat. Avril $1844.18 .13 \mathrm{p}$.

$7093 \%$ Ménoire sur le phénomòne de la coloration des eaux de la mer rouge; lu á l'Académic des sciences, le 15 Juillet 1844. (Paris 1844.) 8. 31 p., A tab. (Trichodesmium erythraeum Elirenb. ) $70960^{\circ}$ Montagne, Jean François Camille. Plantae cellulares, quas in insulis Philippiucnsibus a cl. Cuming collectac receusuit, observationibus nonnullis deseriptionibus illustravit. (Hooker Londou Journ. of botany, Dee. 1844.) $12 \mathrm{p}$.

$7097^{*}$ - Voyage au Pole Sud et dans l'Océanie sur les corvettes l'Astrolabe el La Zelee, sous le commandement de Monsienr J/ulien Sebastien César) Dumont d'Urville, 1837-1840. Botanique, par Ilombron et Jucquinot. Tome prentier: Plantes cellulaires par Cumille Honlugue. Paris, Gide. 1845 . 8 . xiv, 349 p. et Atlas: 20 tab. col. a Borromee et Piocreux delineatae.

(Ci. supra Ni. 2799.

$7098^{*}$ _ Essai d'organographie de la famille des llépatiques. (Extrait du Dietionnaire universel d'historre naturelle.) Paris, tỵ. Bourgogne et Martiuet. 1845.8 . 15 p.

$7099^{*}$ Aperçu morphologique de la famille des Lichens. (Extrait du Dietionnaire universel d'histoire naturelie. Paris, typ. Bourgogne mt Nlartinet. 1846.8 .12 p.

7100 Tote sur un nouveau fait do coloration des eaux de la mer par une algue microscopique. Paris 1847.8 .

(litusirissimus autor practer haee allata scripta aliis permullts the re herharia majoribus operibus, itineribus priesertim, doeta stla manu in exponesda cryptogania succueurit. Cryptoganiam Canariensem in llebbianu perpulchra Canariensium insuiarun Histuria fractavit; chilensom inceditam servat ad exornandun librum: rlaud Gay, llistoria tistea y nolitica de Chile; Algas exposuit in magno opere: "Exploration scientifigne de l'Algerie;" provinciam sibi retinnit illistrandace cryptoginnine in "Voyage autour diu monde execute pendant les anners $1836-1837$ sur la corvelte la Bonite, commandée par Jaillent, Nostri sunt quae iu altera ill. Webbii (Hiorum hispinicorum Decade eryptogimica contincmur, omuesque praeter aCham-

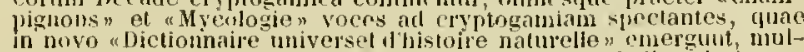
taque alia in parte systemitica mei libri distinctius indicaista.

ilol Montalbanus, Ovidius. Index plantarum ombium a se collectarum, exsiccatarum et chartis agglutinatarum, ex quibus yuatuor magua volumina botanoscopica consorcinavit. Bononiae, ex officina Theodori Mascheronii et Clementis Ferronii. 1624, 4. Bum.

7102 - Geoscopia ampelite, overo speculazione terristro circa le viti. Bologna, typ. Ferroni. 1635.4. s.

$7103-$ Geoseopia cereale, overo speculazione terrestre circa le hiade. Bologna, typ. Ferroni. 1636. 4. s.

710 ' Kiposcopia, overo speculazione de gli orti Discorsu insieme colle predizioni do' tempi ed affari dell' anno 1638. Bologna, typ. Clementis Ferroni. 1638. 4. s.

$7105^{*}$ Enfiteoseopia overo speculazione dell' insetamento delle pianto Diseorso etc. Ilologna, typ. Ferroni. 1639. 4. 20 p.

7106 Charagmaposcopia, overo speculazione dell' interna proprieta dell' erbe, mediante gl' oggetti de' sensi. Bologna 1640. 4. s.

7107 1654.4 .5 .

(Continet vegetalilia, quae diflicilis annotsae tempore pauperibus subsidio esse possent. Nomen praetixum est Johannes Antonius Bumaldus.)

7lost - Johannis Antomii Bumaldi (i. e. Ovidius Montalbanus) Bibliotheca botaniea, seu herbaristarum seriptorum promota synodia; cui accessit individualis graminum omnium ab auctoribus lucusque observatorum mumerosissima nomenclatura. Bononiae, typ. her. Benatii. 1657. 12 min. 188 p. (Biblioheca: p. 1-110. Gramina : p. $111-488$.$) -$ Primum Bononiae, typis lieredum Benatii anno 1657 impressa, nunc iterum (una cum Seguieri Bibliotheca botanica) edita llagae Comitum, apud Joamen Neaulme. 1740. 4 66 p. (Bibliotheca : p. 5-40. Species graminum individuales: p. 41 -62 . Index autorum: p. $63-66$.)

$7109^{*}$ Hertus botanographieus, herbarum ideas et facies supra bis mille av́tóratas, perpetuam et facillimam immensae cognitionis botanicarum differentiarum ad memoriam in parvo trium tomorum oetavi folio coneludens spatio, quem sibi genioque suo construxit, coluit el perennavit auctor; cui singularum plantarum sequens praecessit index. Bononiac, typ. Jacohi Montii. 1660. 8. 110 p. cum figuris xylographicis.

(Indo a pagina $100-110$ sequitur appendix: Monstrosarum alirpuo! observationum indicatio, de quibus in Addrovandaea Dendrologia mox edenda suis locis diftusa dabitur historia. - De hoe opero hat apud ipsum Honlulbanum in rjus Bibtiotheea botanica landes leguntur: "Tres tandern tomos Bolanographiae in octava folii forma, inole 
quidem parvos, sed virtute guam maximos nee num admirahilissinus, ald manus habet (anno $16 ; j 7)$, in quibus intumerae plantae quanlumis procorae et incentes a natura ef arte simul jubctis artiliciosissime tot facilline refigiatar visuntur iu arternitatom, ubi el campi, prata, sylvac, montes, valles, ibj(l+m abloreviari el veluti ad nutum conspicientis inambulari persentiuntur." )

7llo Montalbanus, Ovidius. Nova ant"fracludialis dendranatomes, arborene scilicet resolutionis adumbratio. Bonomae, typ. Ferroni. 1660. folio, Bibl. Reg. Paris, et $\mathrm{S}$.

(Puerile opus esse (estatur Malphighi opp. posth. p. 161.)

I11 Arboreac monstrositates aligutst nuperrime oloservatae. Bononiae, typ. Ferroni. s. a. folio. 1 pling. Bibl. Reg. Paris. et s.

$112^{*}$ _ Ulyssis Aldrovandi Dendrolograc naturalis scilicet ndorum historiae libri duo. Sylva gylundaria acinosunque pomarium. Ubi eluditiones omuium generum una cum botanicis ductrinis ingenia ruaceunque non parum juvant el oblectant. Ovidius Jontalbunus opus summo labore collegit, ligessit, concinnavil. Bononiae, tyj. Ferroni. 1668. (in tergo: 1667.) folio. 660 p., ind., ic. xylogr i. t. - Francolurtia/ M., typ. Hster. 1671. folio. 480 p., praef., ind.

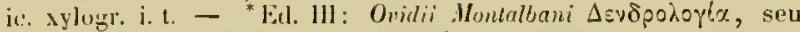
Irboretun libris 11 de Sylva glandaria, acinosoque Pomario conprehensum ad methodum Ulyssis Aldrovandi, cum indice copioso, el praefatione Georgii Frunci. Francofurti a/M., sumtibus Albeti ()thonis Jabri. 1690. folio. ic. Iylogr. i. t.

(Opus al Clysse Altrovando $[+15$. Non. Maji 160; $]$ derelictum a Montalbrno binis vicibus editum, tandem post ejus fala $[\div 1672]$ sub ipsius Montalbani nomine prodiit.

7113 - Catalogus alphabcticus plantarum officinalium. Exstat in libro: L'Onore de $\mathrm{i}$ Collegi dell' arti della citta di Bologna. Bologra 1670 . folio. p. $2 s-39$. s.

714 - Dell' Issopo di Salomone Discorso. Exstat in libro: Prose de Signori Acead. Gelati di Bologna 1671.4. s.

i15 La falurica del pane soventizio dichiarata. Bologua 1674. 4. s.

$7116 \%$ M(ontbrison), L. Bernard de. Lottres à $M^{m e}$ de $C^{* *}$ sur la butanique et sur quelques sujets de physique et d'histoire naturelle suivies d'une méthode élémentaire de hotanique. Paris, Levrault. 1809. Il roll. 12. $-1: 273$ p., ind., 3 tab, - 11: 316 p., ind.g 1 tab. (7 fi.)

I17 Monteiro, Joseph de Carvalho. Diccionario portuguez das plantas, arbustos, matas, arvores etc. Lisboa 1765. S. Vogler.

T118 Montelatici, Ubaldo. Raggionamento sopra i mezi piu necessari per far rifiorice l'agricolura. Firenze 1752.8 . н.

I119 Estratti de piu celebri autori che hanuo trattato della coltivazione ed usi varj delle patate. Finenze 1767. 4. H.

7120 Monte Pigati, Giovanni Anlonio de. Nova ad praxin medicam precipue utilissima, universae botanices rullimenta. Patavii 1757. 4. 1 11. B.

7121 * Monti, Gileseppe. Catalogi stirpium agri Bononiensis Prodromus, gramilia ac hujusmarli affinia complecteus, in (juo ipsorum etymologian, notae characteristicae, peculiares usus nedici, synonyma selectiora summatim exhibentur; ac insuper propriis observationibus 'xoticisquo graminibus eademque disperse locuplefantur. Bononiae, Pisarri. 1719.4 . 66 [)., ind., 3 tab.

$7122 \%$ Plantarum varii indices ad usum demonstrationum. 13ononiae, apud Const. Pisarri. 1724. 4. sx p., 1 tals.

('fulia sunt exemplaria incompleta litri insequentis, in quibus solummolo Dissertatio rei horbaride nec non horti publici Bononiansis historiam praceipue complcetens una cum iconographia lorti continetur.)

7133 Plantarum vari indices ad usum demonstrationum, yuae in Bononiensis archigymuasii publico horto quotannis habenfur, nempe: I. Plantarum genera a botanicis instituta, juxta Tournefortii methodum ad proprias classes relata. H. Plantarun generum index alphabelicus. 111. Index plantarum, quac in medicum usum recipi solent. $1 \mathrm{~V}$. Plantarum elenchi in classes dipartiti, juxta facultaces, quibus in re medica pollent. lis pracefixa est Dissertatio ilidem habita anno 1723 ad easdem demonstrationes auspicandas, horti pulslici Bononiensis historiam Iraccipue complectens. Iononiae, apud Const. Pisarri. 1724. 4. xx, 78 p., I tab. s. et B. - ("Ed. 11. curante Gapluno _Monti, filio.) Indices botanici et materiae medicae (1)ilus plantarum genera hactenus instituta: simplicium quoque tam vulgarium quam exoticorum nomina el facultates summation recen- sentur. Accedit horti publici Bononionsis lorevis listoria. Bononiae, typ. Laclii a Vulpe. $1753.4 . x x, 160$ p., 2 tab.

$7124+$ Monti, Giuseppe. Exnticorun simplicium medicamentorum varii iudices ad usum exercitationum, quac in Bononiensi instituto singolis hebdomadis hahentur. Bononiae, 1yp. Laelii a Vulpe. 1724. 4. 39 p. - " kid. 11. impr. cutn Indicibus botanicis et materiae medicae, curante Gratano Afonti. ib. 1753.4. p. 129-160.

712:3* Monti, Lorenzo. Dizionario butanico Veronese, che comprendre i nomi volgari Veronesi delle piante da giardino col corrisjondente latino Linncano, cui aggiungonsi altre specie indigne e i nomi ilaliani. (Parts prima.) Verona, typ. Mainardi. $181 \overline{7} .8 .159 \mathrm{p} .(\mathrm{A}-\%$. (2 Lire $25 c^{\circ}$ )

7126 Montif, Lucian. Neue Gartenlust, d. i. Nenes Baum-Kuchengarten- und Ilumenhuchlein, mit Figuren; mit sonderbarem Fleiss zusammengetragen durch Lociun. Montif. Fi. Min. Capuc. L'In 1698. 12. Rivin. - Ulm 1723.8. H.

727 Montpellier, $A$. Wo la cultivation des arbres a fruit. Castelnaudary, typ. Labadic. 1815.8 .56 p. (1 fr. 50 c.)

$7128+$ (Mont-Sainct, Thomas.) Le jardin Senounis cultive naturellement d'environ six cents plantes diverses, qui croissent a moins d'une lirue de la ville et eité de Sens. Sens, chez (ieorge Xiverd. 1604 19. 26 p., praef., 4 p. appendix. Bibl. cand.

IAd calcem addita est: "Lettre missive escrite par .I. Thomas Montsanct, maitre chiruruien a Sens a un sien Any do cette ville do Paris sur le sujet du fait prodigieox alvenu le jour de resteDien dornier (1617) cul ladite ville de Sens, on il est tombe grand Dieu dernier 1617 , chl ladite ville de Sens, on il est tombe grand qoimtite de pluye rouge conme sing oly po Libelus rarissmus, cujns duo exemplaria in biblotheca Candolleana seryimtur, reinpressus ist ad editionem originalem curis Theodori Tarbe, inipres-
soris et hibliopolate senonensis; possidet reimpressionem ill. C'umille Montagne. Vidi.)

-129t Moon, flextnder. A catalogue of the indigenous and exolic plants growing in Ceylon, distinguishing the several esculent vegetables, fruits, roots and grains, trgetber with a sketch of the divisions of genera and species in use amongst the singhhlese. Nlso an outline of the Linnean System of Botany; in the english and singhalese languages, for the use of the Singhalese. Colomlo, printed at the Wesleyan mission press. 1824. 4. 9, 77, 41, (40) p. Bibl. Deless. (Liber perrarus!)

$7130^{*}$ Moorcroft, William, and George Trebeck. Travels in the Himalayan provinces of Jlindustan and the Panjab; in Ladakil and Kaslımir'; in Peslıawar, Kabul, Kunduz and Bokbara; Ly Mr. W'illiam Moorcroft and Alr. George Trebeck from 1819 to 1825. Prepared for the press by Horace Hayman Hilson. In two volumes. London, Nurray, 1841. 8. - I: LVI, 459 p., 2 tab. - II: vil, 508 p., 1 tab. (Praefatio est anni 1837. Pauea insumt botanici argumesti; ef. Wilstrum, Jahresherichte 1839-18'2. p. 1't2. 238.)

II31* Moquin-Tandon, Alfred. Essai sur les dédoublemens ou multiplications d'organes dans les végétaux. Montpellier, typ. Martel. 1826. 4.24 p., 2 lab. $(2$ fr. 50 c.)

$7132^{*}$ Chenopodearum monographica enumeralio. l'arisiis, P. J. Loss. 1840.8 . x1, 182 p. (3 fr. 50 c.)

$7133^{*}$ _ Elémens de tératologie végétale, ou llistoire abrégée des anomalies de l'organisation dans les végctaux. Paris, Luss. 1841. S. $x 11,403$ \%.

* germanice: Pllanzen-Teratoluzie. Lehre von den regelwidrigen Wachsen und Bilden der Planzen. dus dom limanzosischen, mit ZuWarken von Johumb homrad Schauer. Berlin. llaude und Spener'sche

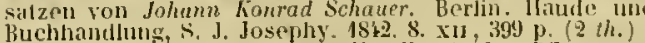

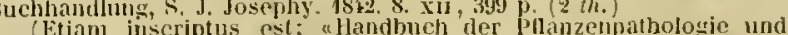

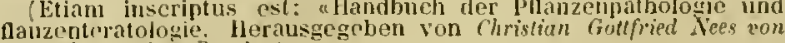
Esenbeck. Zweiter Band."

7134 (Morand.) Heimuire sur la maladie des pommes de terre, remedes et autres instructions aussi uties que curieuses. Gap 1846. S. $20 \mathrm{p}$.

7133̈ Morandi, Giamballista. Osservazioni intorno al sinonimo alfabetico dell' erhe pii usuali, che si leyge nell' antidotario Mlianese. Mlilano, stamperia Malatesta. 1743.4.8 p., 1 tab.

$7136^{*}$ - Risposta alle osservazioni apologetiche fatte d. Cesare Carini, ordinata a confermare le sue usservazioni intorno al sinonimo alfahelieo dell' erlı. Mlilano, stamperia Malatesta.1743.4. $24 \mathrm{p}$. (De his litihus ef. Hall. Bibl. bot. 1l. p. 337.)

$7137^{*}$ _. Historia botanica practica, seu plantarum, quae ad usum medicinae pertinent, nomenclatura, descriptio ct virtutes. Mectiolani, 
typ. Malateslae. 1744. folio max. $32,164 \mathrm{p}, 68 \mathrm{tab}$. col. (25 lire imp.) - *Mediolani, apud Galeatum. 1761. folio. 32, 16 ' p., pracf., 68 tab.

il38 - Mordant DeLaunay, J. Cl. Mient. Le hou jardinier. Almanach pour les annees 1804-1815. Paris, chez Onfroy. (Audot.) 18041815.8

[Continuationes post obitum editoris $[\div 13$.Mart. 1816] curaverum Loiseleur-Deslongchamps, Vilmorin et Noiselle. Jordant DeLaunay edictit praeterea volumen primum collectionis supra Mr. 6238 recensitae: "llerbjer genera! de l'amateur."

7139 More, Thomas. A flower-garden for Gentleman and Ladies, or the art of raising llowers to blow in the depth of winter, also the method of raising salleting, cucumbers ete. at any time in the year. Impr. cum Anonymi Flowergarden display'd. London 1734. 4. p. $125-$ 139. B.

71.0" Moreau de Jonnès, Alexandre. Histoire physique des Antilles françaises; savoir la Martinigue et les iles de la Guadeloupe contenant la géologie, leur llore cte. Tome premier. Paris, ty]p. Migneret. 1822.8 .560 p., A tal,

(Volumen $\mathrm{ll}$-IV hujus uperis nunquam prodierunt; in primo botanicen levissime tangit aulor. Querard, France dit. V1. 296. Laudat ejusdem "Carte orographique et butanique din volean du Piton-rluCarbet a la Martinique, pour servir a la connassance de l'zalotation des plantes de la Fiore ite cette ile.n)

ilł1 Mémoire sur le déboiscment des furêts, pour lequel l'académie royale de Bruxelles à decerné nute médaille d'or. Bruxelles, P. J. Demat. 1823. 4. 207 p. a.

germanice: Lutersuchungen uher di. Peranderungen, die durch die Ausrottung der Watder in dem physischen Zustande der Linder entstehen. Aus dem Franzosiscbon von 11 . $\|$ idenman. Tubingen, Osiander. $1828.8 . x, 212 \mathrm{p} .(\%, t h$.

$7142 \div$ Morel de Vindé. Notice sommaire sur les assolemens, adoptés dans son expluitation a la Celle-Saint-Cloud, pres Versailles. Paris Huzard. 1816. 8. 54 p.

$71^{\prime} 36$ - Quclques observations pratiques sur la theorie des assolemens. Paris, Huzard. 1822 . 8. 48 p. - Appentlice: ib. 1823 8. $12 \mathrm{p}$.

ilkt Morel, J. F. Nicolas. Catalogue des plantes du jardin botanique établi a Besançon, Département du Douhs. Besançon, typ. Daclin. an Xill. 1805.8 . vili, $112 \mathrm{p}$.

I145 Morel, J. M. L'art de distribuer les jardins suivant l'usage des Chinois. Londres 1757.8 . Q.

7146 Theorie des jardins, ou l'art des jarilins de la nature. Paris, Pissot. 1776. 8. - Nouvelle édition revue et enrichie des notes, et suivie d'un tableau dendrologique. Paris, Panckoucke.1802. 11 voll. 8 . ( $9 \mathrm{fr}$.) a

Edilio prima est absque nomine autoris.]

Ilift Tableau dendrologique contenant la liste des plantes ligneuses indigènes et exoliques acclimatées. J you, typ. Bruyset. 1800. 4 obl. vill, 52 foll.

If $\mathbf{8}$ Morelot, Simon. Cours élémentaire dhistoirc naturelle pharmaceutique. Paris, Giguet et Co. 1800.11 voll. 8 . (9 fr.) a.

$71.9 \div-$ Histoire naturelle appliquee a li chimie, aux arts etc Paris, Schoell et Nicolle. 1809 . Il voll. 8 . ( 9 fr.)

(Vol. 1. p. 131-3ł3: des végetaux.

$7150 \div$ Moretti, Giuseppe. Notizia sopra diverse piante da aggiungersi alla Flora Vicentina. (Inserita nell' ottavo tomo del giornale di fisica, chimica etc. del Sign. Brugnutelli.) Pavia, typ. Galeazzi.1813.4. 16 p. 1.tab. - t Continuazione: ib), $1820,4.8 \mathrm{p}$.

$7151^{*}$ Lettera all' autore delle osservazioni intorno all viaggio al lago di Garda e al monte Baldo del Dottor Ciro Pollini. Pavia, typ. Bizzoni. $1817.8 .15 \mathrm{p}$.

$732^{*}$ - Sulla coltivazione gli usi ed i principi costituenti rella Batata dolce Lettera I. al Signor Giuseppe dcerbi. Milano, typ. Mlaspero. 1818.8. $16 \mathrm{p}$.

$7153^{*}$ - Osservazioni sopra diverse specie di piante indigene dell Italia. Lettera al Direttore della biblioteca italiana. Milano. Iyp. imp. reg. 1818 . 8 . $12 \mathrm{p}$.

(Estratto dalla Biblioteca italiana.)

$713 k^{\circ} \div-$ Nemorie ed osservazioni intorno a diversi oggenti riseuardanti le scienze naturali. Vol. 1. Pavia. typ. Bizzoni. 1820. 8. MII, 307 p.. 1 tab.

(A P. 239-305: Notizia sopra diverse piante da aggiungersi alla Flora Ticentiuá.

PrITZEL, Thes. lit bot.
TI:3ï Moretti, Giuseppe. Jntorno alla Flora Veronensis del Signor Prof. Pollini osservazioui. Nilano, typ. imp. reg. $1822.8 .36 \mathrm{p}$. (Estratto dalla Riblioteca italiana.)

7136 - Tentativo diretto ad illustrare la sinonimia delle specie del genere Saxifraga indigene del suolo italiano. Pavia, tyj. Fusi et Co. $1823.4 .36 \mathrm{p}$, ind.

$7137^{*} \longrightarrow 11$ botanico italiano, ussia Diseussioni sulla Flora italica del Prof. Ginseppe Morelti. Nr. J-IIl. Pavia, typ. Fusi et Co. 1826.4. 44 p., 3 tab.

il58* - Bibliotheca agraria, ossia Raccolta di scelte istruzioni economico-rurali. Milano, typ. Stella. 1826. 8. 11 p. (Prospetto.) $(10 \mathrm{c.})$

$7159^{*}$ - Biblioteca agraria ossia Raceolta di scelti istruzzioni cconomico-rurali, diretta da Gruseppe Morelli. Milano, typ. Stella. 1896-1839. XXll voll. 8 .

(Tom. XIl sui gelsi; tom XX: Alberi fruttiferi; tom, VIII, IX, X: Orti ; toll. XXIl : Compendio di nosologia vegetabile. )

$7160^{*} \longrightarrow$ e Carlo Chiolini. Sui gelsi e sui bachi da seta istruzione compilata. Nilano, typ. Stella. 1829.8. xv1r, $356 \mathrm{p} ., 4$ tab. ( 4 lire 54 c.)

(Biblioteca agraria vol. Xll.)

$7161^{*}$ - Sopra alcuni erluarj del Padre Boccone cumservati nell imperiale hiblioteca di Vienna. Lettera al Sign. 1)r. Carlo J"ittadini. Pavia, typ. Bizzoni. 1830. 8. 16 p.

(Estraltic dalla Minerva Ticinese.

$7162^{*}$ Guida allo studio della fisiulogia vegetabile e della botanica. Pavia, Fusi. 1835. II fasc. 8. 160 p. (3 lire.)

(Vi) plura prodiernut; Beroliui, Vindobonae, Genevae librum vidi incompletun 160 paginarusn.)

$7163^{*}$ — Prodromo di una monografia delle specie del genere Norus. Milano, typ. G. B. di Gio. 1842.8.22 p

7164 ( Andrea Matlioli, botanico del XVl. secolo. (Milano 1844.) 8. $59 \mathrm{p}$.

(Seorsim impr. e Giornale del Istit. Lomb. e Bibl. italiana, vol. IX.

Dissertationes Ticinenses praeside Giuseppe Morelli:

$71603 t-$ Francesca Mfrtignon, De epidermidis plantarum struetura et evolutione. D. Ticini regii, typ. Bizzoni. 1823. 8. 29 p. G. Moretti in litt. ad $D C$.)

$7166 \div-$ Francesco Agostino Gera, Della fecondazione delle piante D. Aliano, typ. editor. ann. univ. $1830.8 .45 \mathrm{p}$.

(Editionem alteran supra Nr. 357 ' sub nonine antoris indicavi.)

$7167 \%$ Giacinto Guicciardi, De nomullis plrysiologico-botanicis animadversionibus quas retrogradum lymphae vegetabilis motum respiciunt. D. Ticini regii, typ. Fusi. 1831, 8.22 p.

$7168 \div$ - Alessandro Lattuda, De Primulis italicis. D. Ticini regii typ. Fusi et suc. 1831. 8. 22 1.

$7169^{*}-$ A. Zani, Nounulla de Crocis italicis. D. Pavia 1834. 8. $28 \mathrm{p}$.

$1770^{\circ}$ Pietro Motlini, Srmopsis Veronicarum, quae in Italia sponte nascuntur, nomullis additis ad virtutes medicas et usum therapeuticum ipsarum pertinentibus. D. Ticini regii, typ. Fusi et soc. 1834.8. $35 \mathrm{p}$.

$7171^{*}$ Augusto Trinchinetli, Osservaziomi ed esperienze supra alcuni punti di fissologia vegetabile norr per anco studiati dai botanici. D. Pavia, typ. Bizzoni. 1835.8 .21 p., 1 tab.

$7172^{*} \longrightarrow$ Joseph Culasunz Schlosser, De Papilionaceis in Germania sponte crescentibus. D. Ticini regii, typ. Fusi et soc. $1836.8 .52 \mathrm{p}$.

$7173 t-$ Bernardo Andreoli, De radicis vegetabilium officiis. D. Ticini regii, Iyp. Fusi et soc. 1837, 8,24 p.

$7174 \div$ - Giuseppe Bergonzoli, De plantarum morphologid. D. Ticini regii, typ. Bizzoni. $4838.8 .39 \mathrm{p}$.

7173 Stefano Castiglioni, Do vegetabilibus sponte crescentihus in caevadio almi collegii Borromaei. D. Tieini regii 1838. 8.

7176 Giulio Galeti, De regetabilibus phanerogamicis quae sponte erescunt in variis cavaediis Archigymnasii Ticinensis. D Ticini regii 1838.8 .32 l.

7177 Giovanni Niccolo Zunolini, De Cedru Libani. D. Paviae 1838.8. $39 \mathrm{p}$.

7178 M. Leoni, Sul influsso della luna nella vegetazione. Parma (?) $1838.8 .16 \mathrm{p}$. 
7179 Moretti, Giusepne, Giusppe Anell, De vegetabilium rhachitide. D. Ticini regii 1839. $8.20 \mathrm{l}$.

(Jarum dissertationum aliae a praeside, aliar a proponentibus conscriptae sunt, quas equidem certe secerifere nequeo.)

$7180^{*}$ Moricand, Stefano. Flora Veneta, sen enumeratio plantarum circa Venetian nascentium secundum methodum Linnaeauam sisposita. Volumen 1: Phanerogamia. Genevae, J'asclioul. 1820. 8. x, $439 \mathrm{p}$. $\left(6\right.$ fr. $-2 \frac{1}{2}$ th.

(Volumen alterum cryplogamicum munpuam prouit; confrras de hac liara: Giuseppe Morelli, Intorno alla Flora Peneta del Sinnore Moricand osservazioni. s. a. 8 . 48 p., e Biblioteca italiana.)

$781^{*}$ Plantao anericanao rariores descriptae et iconiluus illustratae, autore Stepheno Moricand. Geneve, librairie de J. Barbezat ot Co., edifeurs, rue du klsone 177. 1830. folio. 8 p., tab. 1-10: Brougniartia intermedia, Laplacea bardinervis, Ternstroemia Ruiziana, Ternstroemia Pavoniana, Itibiscus tampicensis, H. BerJandierianus, H. Lavateroides, Sila filiformis, Sila anomala, var. mexicana, Platanus mexicanus. Bibl. Kunz.

Fasciculus casn infolici ineditus, quo jam anno 1830 autor opus insequens inchoaverat; ef. Schlechtendal, Rot. Zeilung, 1817. p. 475-477.)

7482 - Plantes nonvelles d'Amérique. Genève, imprimerie do Jules Guillaume Fick. 1\$33-1846. gr. 4. Iv, $776 \mathrm{p}, 100$ tab. (Prodiit decem fasciculis.

7183* Morier, James. A journey through Persia. Armenia and Asia minor to Constantinople in the years $1808-1809$. with engravings ant maps. London, Longman. 1812.4 . (cum sequenti: $7 l .7 \mathrm{~s}$.)

gallice: Paris Nepveu. 181 k. III voll. 8.

germanice: Bibliotheh der Reisen, vol. II. Weimar 181\%. 8.

$7184^{*}$ - A second journey through Persia, Armenia and Asia minor to Constautinople between the gears 1810 and 1816 . with engravings and maps. London, Longmatı. 1818. 4. (cum praecedenti: $7 l .7 s$.

ilalice: Raccolta nuova de viaggi, tom. XXxy-xxivi

gallice: Paris Gide fils. 1818 . il voll. 8 . (15 $\mathrm{fr}$.

germanice: Bibl. der Reisen, Vol. XXili. Weimar 1820.8

$7185^{\circ}$ Morin, Pierre. Catalogues de quelques plantes à fleurs, qui sont de present au jardin de Pierre Horin le jeune, dit troisième, fleuriste. Paris, typ. Francois le Cointe 1651.4. 48 p. - ih. 1655.4. - TImpr. cum Jibro insequenti. Paris, chez Charles de Sercy. 1638. 12. p. 149-222. Bibl. Juss.

$7186^{6}$ - Remarques necessaires pour la culture des fleurs, diligeument observées par Pierre Morin. Avec un catalogue des plantes rares. Paris, chez Charles de Sercy. 1658 , 4. 222 p., jracf., ind. Bibl. Juss. - Rouen 1665. 8. s. - Lugmentées d'un traité des veilJets, et de quelle facon il faut les cultiver. Paris, chez Charles de Sercy. 1674. 12. s. - il. 1698.12 . s.

7187 Instruction facile, pour connoistre toutes sortes d'orangers et citronniers, qui enseigne aussi la manière de les cultiver, semer, planter, greffer, transplanter, tailler et gouverner, selon les climats, les mois et saisons de l'année. Arec un traite de la taille des arbres, composé par le Sir Pierre Vorin. Paris 1674. 12. Rivin. - Paris 1680. 12. Rivin.

i188+ Morin, René. Catalogus plantarum horti Renali Morini inseriptarum ordine alphabeticn, cun quatuor anni temporibus, quibus florent. (Parisiis) 1621. 12. 26 p. Bibl. Juss.

7189+ Moris, Giuseppe Giacinto. Stirpium sardoarum elenchus. Fasciculus 1-111. Caruli, ex typis regiis. 1827-1829. 4. 55, 12, 4, 26 p.

$7190^{*}$ (_- Enumeratio seminum regii horti botanici Taurinensis. Taurini 1831-1846.8. - 1831:36 p. - 4832:34 p. - 1833: 34 p. $-1835: 25$ j. $-1836: 29$ p. $-1837: 31$ p. $-1838: 38 \mathrm{p}$. - 1839:37 p. - 1840:40 p. - 1841:44 p. (Ridolfia, novum genus Umbelliferarum.) - 1842: 42 p. $-1843: 31$ p. $-1844:$ 32 p. $-1845: 32$ p. (Buglossites n. g.) - $4846: 32$ p.

11917 Illustrationes rariorum stirpium horti botanici univ. Taurinensis. (Taurini 1833.) 4. 26 p., 6 tal.

Mem. della Realo Accad. «elle scienze di Torino, Iom. Xxxil. p. $177-200$.

$7192^{*}$ __ et Giuseppe De Notaris. Florula Caprariae, sive enumeratio plantarum in insula Capraria vel sponto nascentium vel ad utilitatem latius excultarum. Taurini, ex regio typografeo. 1839. 4. 244 D., 6 tab.

Mem. della Reale Accad. di Torino. Ser. II. tom. Il p. 59. .

$7193^{*}$ Stirpes sardoae novae aut minus notae. (Taurini 1839. ) 4. (6) p.

(Nem, della Reale Accad. delle scienze di Torino, Ser. II. tom. II p. $301-30 \%$.)
7191" Moris, Giuseppe Giacinto. Hora sardoa, seu historia plantarum in Sardinia et adjacentibus insulis vel sponte nascentium rel at] utilitatem Jatius excultarum. Taurini, ex regio typographen. (vendesi fresso Guiseppe Bocea.) 1837-1843. JI voll. 4. - I: 1837. Ranunculacuae-L.eruminosae. xu, 606 p., tab. ! -72 . (60 lire $-23 \frac{2}{3}$ th.) - II: $1840-1843$. Rinsaceae - Ericaceae. 5C2 p., tab. $73-93$, 4 mappa geogr. regni Sardiniae. (Continuatur.)

7193 Morison, hobert. Hortus regius Blesensis. Parisiis 1633. folin. S $7196^{*}$ Pracludia hotanica. Pars 1: Ilortus regius Blesensis auctus, cun notulis durationis, et characterismis plantarum tam additarum, quam non serij)tarum. Item plantarum in eodem horto regio Blesensi aucto contentarum, nemini hucusque scriptarum brevis et succincla descriptio; quibus accessere Observationes generaliores botanicae ex eodem horto collectae, rei herbariae studiosis value necessariae; p. 1-347. - Pars II: Hallucinationes Caspari Bauhini in Pinace, tam in digerendis quam denominandis plantis; p. $349-$ 425. Animadversiones in tres tomos universalis historide plantarum Johennis Batuhi; p. 427-459. Dialogus inter socium enllegii regii Londinensis Gresham dicti et botanographum regium de nethodo autorum in rem botanicam bucusque scribentium et de plantis imperfectis; j). 460-499. In calce: Epistola ad Abel Brunyer et $N_{i-}$ coleum Murchunt. Londini, typ. Royeroft. 1669 . 12. 499 p., praef.

$7197^{*}$ — Plantarum L'mbelliferarum distributio nova, per tabulas cognationis et affinitatis ex libro naturae observata et detecta. Osonii, e theatro Scheldoniano. 1672. folio. 91 p., 3 foll., 12 tab. iconum. $\$$ tab. affinitatum, explicationibus arersa pagina impressis.

Liber considerari potest quasi tomus primus operis insequentis. cujus initiun al) altera parte sumitur. Reimpressn vel nova potin editio immutata renovatis titulis, quam eniserunt anno 17lö Paulus ef Isaacus l'aullant, bibliopolae Londinenses, salutatur harre ob rem: plantarum historiae universalıs Oxoniensis tomus primus. Sed revera tomus primus operis, in quo arbores contineri debehant, munguan prodiit.)

$7198^{*}$ — Plantarum bistoriae universalis Oxoniensis Pars secunda, sen Herbarum distributio nova, per tabulas cognationis et affinitati. ex libro naturao observata ef detecta. Oxonii, e theatro Scheldoniann. 1680. folio. 617 p. $8,25,95,31,29=118$ tals. - * Plantarum historiae universalis Oxoniensis Pars tertia, post auctoris mortem $[+1683]$ expleta el absoluta a Jacobo Bobartio. Cum vita Ilorisonii Oxonii, e theatro Scheldoniano. 1699. folio. 637 p., ind., $15,37,18$, $22,3,31,48,7,5,10=166$ tab.

llae cluae partes una cum lihro praecedenti occurrunt nova immutata editione sub hoc titulo: Plantarum historia universalis 0:0niensis, pars !-III. Oxonii, et prostat Londini, apud Paulunı el Isaacun Vaillant. 1715 . folio.)

千199* Moritz, Wilhelm. De Lini cathartici vi purgante observationes. D. Dorpati $1835.8 .32 \mathrm{p}$.

$7200^{*}$ Moritzi, Alexander. Die Pflanzen der Schweiz, ihrem wesentlichen Charakter nach beschrieben, und nit Angaben uber iliren Standort, Nutzen u. s. w. versehen. (Die Cotyledonalpflanzen.) Chur, Benedict. (Zurich, Schulthess.) 1832.8 . vIIr, $462 \mathrm{p}$., $1 \mathrm{tab} .(21 / 12$ th.)

$7201 \div$ Die Pllanzen Graubundens. Fin Verzeichniss der bisher in Graubiuden gefundenen Pflanzen mit besondrer Berucksichtigung ihres Vorkommens. (Die Gefasspllanzen.) Neucbatel, ty]). J'etitpierre. 1839. 4. 158 P., 6 tab.

(Neue Denkschriften der schweizerischen naturf. Gesellschaft, Band [II.

$7202 \div$ Réflexions sur J'éspèce en histoire naturelle. Soleure. typ. Vogelsang-Gralt. 1842.8. 109 p.

$7203^{*}$ - Die Flora der Schweiz mit besondrer Berucksichtigung ibrer Vertheilung nach allgemeinen physischen und geologischen Iomenten: Zurich und Winterthur, Literarisches Comtoir. 1844.8 xxu, 640 p., 1 inappa geologica. $(2 \% / 3$ th. $)$ - Leipzig. Verlagsbureau. 1847. 8. (1 $1 / 2$ th.) (eadem impressio novo titulo!)

Conferantur animadiersiones in hanc Floram antore Oswald lleer in : Veue llelvetia. Zweiter lahrgang. 184k. p. 350-362 et 422-453.

7201: - Prospectus du Lexicon botanicum, ou Dictionnaire des noms vulgaires des plantes rapportés à Jeurs noms scientifiques, par A. Morilzi. Professeur, d'après Jes directions de Augustin Pyramus DeCundolle, et arec le secours de sa bibliotheque et le ses notes manuscrits. Origine de l'ourrage, et Specimen. s. J. et a. (1845.) 4. $(4 \mathrm{p}$.

$7203^{*}$ Srstematisches Verzeichniss der von $H$. Zothinger in den Jahren 1842-1844 auf Java gesammelten Pflanzen, nebst einer kurzen Beschreibung der neuen Gattungen und Arten. Solothurn, 
typ. Zepfel. (Verlag des Verfassers.) $1845-1846.8$. x11, $144 \mathrm{p}$ $(1$ th. $)$

(Fungi, autore Leveille, p. $118-196$; Lichenes, antore Schaerer, p $126-124 ;$; Wusci, autore Duby, p. 130-133.)

7206 Moro, Giovanni. Dissertazione intorno la generazione degli animali e vegetabili. Bassann 1753.4. 46 p. B.

$7207+$ Morogues, Pierre Marie Sébastien, Bigot, Baron de. De l'influence des récoltes intercalaires sur les blès, qui leur succèdent. Orlearus, typ. Juet-Perdoux. 1824.8.23 p.

(Extrait des Annales de la societé royale arjeans.)

7208* Morren, Auguste, el Charle's F. A. Morren. Recherches sur la rubéfaction des eaux et leur oxygénation par les animalcules et les algues. Bruxelles, typ. Hayez. 184 1. 4. x11, 130 p., 5 tab. col, (16 fr.)

$7209^{*}$ Morren, Charles $F$. A. Responsio ad quaestionem ab Academia Gandaviensi anno 1826 propositam: Quneritur Orchidis latifoliac descriptio botanica et anatomica, guae pracmiun reportavit dic VIII Octobris 1827. s. 1. 4. 92 p., 6 tab.

7210 Notice sur J. Kickx. Paris 1832. 12.

$7211 \div-$ Notice sur un lis du Japon. Gand, Iyp. Vanderhaeghen. 1833. 8. 4 p., 2 tab. col.

$7212 \div(-)$ Cataloguc de la collection des graines recoltées en 1835 au jardin botanique et l'universite de Liege. (Liege is35. 8. $19 \mathrm{p}$.

7213 Notice sur Rouçel. Jiruselles 1835. 12

$7214 \div-$ Quelques mols sur l'histoire de Ihorticulture suivis du rapport sur la première période décemnale de la société d'lorticulture de Liège. Liège, typ. Jeunehomme. 1836. gr. 8. 16 p.

7215* —_— et Joseph Decaisne. Observations sur quelques plantes du Japon. Bruxelles, typ. Ilayez. 1836. 8. 10 p.

(Exirait du Bulletin Nr. 5.)

$7216^{*} \longrightarrow$ Les siècles et les legumes, ou quelques mots sur lihistoire des jardins potagers. Discours. Liege, Dessain. 1837.8.14 p.

¿217* - Adrien Spiegel. (Extrait d'une histoire inédite de la botanique belge depuis les temps les plus reculés jusqu'a nos jours.) Bruxelles 1838, 8. $32 \mathrm{p}$.

$7218^{*}$ Notice sur la vie et travaux de Richord Courtuis, présentée a l'Académie royale des sciences et belles-lettres de Bruxelles, séance du 2 Décembre 4837. (Bruxelles 1838.) 12. 24 p

(Extrait de l'Annuaire de l'Académie pour 1838.

$7219^{*}$ Recherches physiologiques sur les llydrophytes de la Belgique. Premier mémoire: Histoire d'un genre nouveau de la tribu des Confervées, nommé Aphanizomène. Bruxelles, typ. Hlayez. 1838. 4. 20 p., 1 tab. col.

(Acad. royale des sciences et belles-lettres de Bruvelles.)

$722^{*}$ Recherches sur le mouvement et l'anatomie du Stylidium graminifolium. Bruxelles, Hayez. 1838. 4. 22 p., 1 tab. col.

7221 Considérations sur le mouvement de la séve des Dicotylédones. s. i. et a. (1838?) 8. 45 p.

7222 IIorticulture et philosophio. Liège 1838. 8.

7223 De la spécialité des cultures propres aux établissements horticoles de Liège. Liège 1838. 8.

72 ? . $^{*}$ Nemoire sur la formation de l'Indigo dans les feuilles du Polygenum tinctorium ou Renouée tinctoriale. Bruxelles, Hayez. 1839. 4. 32 p., 1 tab. col.

$7225^{*}$ Recherches sur le mouvement et l'anatomie du style du Goldlussia anisophylla. Bruxelles, Hayez. 1839.4. 34 p., 2 tab.

$7296^{*}-$ Rapport sur le Némoire de Mr. Auguste Trinchineuti de Monza, iutitulé: De odoribus florum observationes et experimeuta. Bruxelles, Hayez. 1839.8.29 p.

$7227^{*}$ Prémices (Études) d'anatonic et de pliysiologie végétales, ou collection d'opuscules sur ces sciences. Bruxelles et Leipzig, C. Muquardit. 1341. 8. (96) p., 5 tab.

(Est collectio 21 commentariolorum e "Bulletins de l'Academie royile de Bruyelles" seorsim impressorum. Singuli colligati hic absque ullo paginarum ordine in uno comprehenduntur voluninc.

$7228^{*}$ - lémoires pour servir aux éloges biographiques des savants de la Belgique et a l'histoire des sciences dans ce pays. (Notice sur la vie el les travaux d'Auguste Pyrame De Candolle, lue a la séance publique de cette académie, le 14 décembre 1842.) Bruxelles, typ. Hayez. 1843.12.57 p.

(Extrait de l'Annuaire de l'Académie royale de Bruxelles pour 18'3.)
7229 Morren, Charles F. A. Dodonaea, ou Recueil d'observations de botanique. Bruxelles 1847 . 11 voll. 8 . 10 tab. ( 2 th.)

¿230 Morris, John. A catalogue of British Fossils. Comprising all the genera and species hitherto described; with references to their geological distrilution and to the localities in which they have been fount. London, Joln van Voorst. 1S43. S. x, 222 p. (10s.)

7231* Morris, Richard. The Botanists lianual: a catalogue of hardy, exotic and indigenous plants, arranged according to their respective months of Ilowering. London, Sherwood. 1824. 8. $189 \mathrm{p} .(7 \mathrm{~s} .6 \mathrm{~d}$.

7232 Filora conspicua: a selection of the most ornamental howering, liardy, exotic and indigenons trees, shrubs and herbaceous plants etc. London, Whitacker. 1825. 8 . 28 tab. col. (2l. 2s.)

$7233^{*}$ Morscher, Jakob. De Secali cornuto. D. Viudobonac, typ. Ueherreuter. $1840.8 .23 \mathrm{p}$.

733: Morton, George. A memoir of William Maclure Escl., late President of the academy of natural sciences of Philadelphic. Pliladelphia 1841. 8. - tEd. Il: Philadelphia, typ. Merrichew and Thompson. 1844. $8.34 \mathrm{p}$

7233 Morton, John. The natural history of Northamptonshire, with some account of the antiquities. London, R. Kuaplock. 1712. folio. 551 , $46 \mathrm{p}, 14$ tah. $\mathrm{B}$.

(De plantis illius comitatus in capite sesto tractavit. 1. De plantis nondum obscrvatıs. II. Je quibusdim it liajo omissis in Synops flantarunt Angliae. III. De raroribus. IV. De illis, quae propter earum ufuaditailes masinse observandae sunt.)

7236 Morton, Samuel George. Synopsis of the organic remains of the cretaceous groupe of the linited States. Pliladelphia 1834. 8

7237 Moscardo, Lodovico, Conte. Note, overo Memorio del Museo di Lodovico Hoscardo. Padova, Paolo Frambotti. 1656. folio. 306 p., tab. aen. B.

(De plantis in Museo suo asservatis egit lib. III. p. 25i.)

7238* (Moscati, Pietro.) Dissertazioni sopra una gramigna che nella Lombardia infesta la Secale. Milano, typ. Marelli. 1772. 4. 366 p. praef, 2 tab.

(insunt commentationes anctoribus: Pietro Moscati, Michele Rosa, Giovanni Videmor, Francesco Franchelli, Giannambrogio Sangiorgio.]

7239 Moschettini, Cosimo. Della brusca malattia degli olivi. Napoli 1777. 12. DC.

$7240^{*}-$ Lettera della coltivazione degli ulivi. Napoli $1794-$ 1796. 11 voll. 8

72 il (Moser, Heinrich Christoph.) Ueber Feld- und Gartenproducto mit Ruchisicht auf das Klima von l)eutschland. Leipzig, Vogel. 1791 -1794. 2 Bande. 8. (1 1/12 th.)

(Nomen autoris legitur in tomo secundo.)

7212 - The wesentlichen liennzeichen der deutschen und nordamerikanischen Holzarten und Forstkräuter. Leipzig, Graff. 1794. 8. $(7 / 8$ th. $)$

$7213^{*}-$ Deutschlands ökonomisclıe Flora. Ein Tascbenbueh zum Gebrauche fur Landwirthe und Freunde der Gärtwerci fur das Jahr 1796. Leipzig, ḱleefelt. (Bauer.) 1796. 12. vin, 199 p., 2 tab. $(2 / 3$ th.

724' Mossin, Christian Ludwig. De Centaurio minore et Chelidonio minore. D. Havniae 1742. 4. Brünich.

7243 Most, N. Ml. O. Das Karluffolbuch, oder die liuns, die Kartoffeln auf die vortheilhafteste Weise zu bauen, und zu melr als liundert haushalterischen und technischen Zwecken zu benutzen. Quedlinburg, Basse. 1842. 8. $101 / 2$ plag. $(5 / 12$ th. $)$ - Ed. Il: ib. 1846.8 . 10 plag. $(5 / 12$ th.

$72 ! 6+$ Mottard. Jardin expérimental de Saint-Jean-de Maurienne, établi par M. le Chevalier Bonafous et dirigé par II. Je Docteur Mollard. Tusin, typ. Chirio et Nina. 1844. 8.30 p.

(Extrait des Mèmoires de l'Académie 18:t.)

72:7* (Motty, J. B.) Leitfaden der Botanik etc. Nebst einem Pllanzenverzeichnisse nach $\mathrm{dem}$ Linneischen System mit polnischer Terminologie; von $J . B . M$. Posen, Scherk. $1836.8 .90 \mathrm{p}$, 4 tab. $(1 / 3 t h$.)

$7218 \div$ Mougeot, $J . B$. Index alplabeticus generum, specierum et synonymorum in J. B. Ilougeot. C. Nestler et W. P. Schimper stirpibus eryptoganis Vogeso-Rhenanis a fusciculo prino ad duodecimum usque enumeratorum. Bruyerii Vogesorum $1843.4 .25 \mathrm{p}$.

$26 *$ 
2219* Mougeot, J. B. Extrait de la Statistıque du Dép. des Fesges par MIN. II. Lepage et Churles Churton. lirgne végétal. Considerations générales sur la végétation spontanće du Dép. des Vasges. Epinal, INp. Glay. 1845. 8. 386 p.

7230 Mountaine, Dydymus. The gardeners labyriuh, containing a discourse of the gardeners life, in the yearly travels to be bestowed on his plot of earth, for the use of a garden. Lowton 1577. 4. 79, 180 p., ic. xylogr. i. $t$. B.

i2ijl Mousinus, Jean. Discours de l'yrresse el yrognerie, auquel les eauses, nature, et effects de l'yresse sont amplenent deduits, avec la guterison et préservation d'icelle. Toul, Selrastien Philippe. 1612. 8. s.

latime: Pandora Bacchical furcus, medicis armis oppugnala etc.

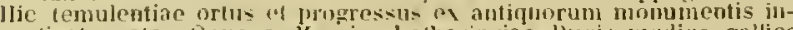
vestigatur ete. Opus a Mausino lootharingiae bucis murdico galliec primum conseriptum, hatis. a Chishophoro Cachetio redulum et auctum. Tulli. Seluastian Philiplus. 16\%. 12. Falc. $\mathrm{S}$.

$7252 \div$ - llortus iatrophysicus, ex guo immensam exoljcorum florum sylvam euivis decerpere liret. Opus delectabili novitate jueundum pariter ae sturliosa lectione utile. Nanceii, apud Arthonium Charlot. 1639. 8. (14) 44 1 p. Bibl. Reg. Paris.

singuier et Haller titulum hujus libri ita indicant: "Jlortus iatrojhysieus, seu de floribus in slvis smunte nascentilms, Eisi huc spectare putes hoe el titulo librum, non tamen bolaniei est argomenti. Paradoxa sunt omnino.)

$7233 \div$ Mouton-Pontenille (de la Clotte), J. P. Talleau des systèmes de botanique generau et particuliers. etc. Lyon, chez l'auteur et Reymann. 1798.8.212,95 p., 100 tableaux synoptizues; et deux memoires: 55 ]. ( $5 \mathrm{fr}$.) - Lyol, Frernath, an IX. 1801.8 . a.

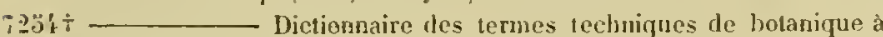
l'usage des élèes et des amateurs. Lyon, Bruyset. 1803. S. xxvi, 444 p. ( 5 fr. $30 \mathrm{c}$.)

izä3̈t Coup doeil sur la hotanique. Discours prononce le mereredi 9 mai 1810 , jour de l'ouverture du cours d'histoire naturelle a l'Academie de Lyon. Lyon, Yvernault et Cahin. 1810. 8 . xxxy, $79 \mathrm{l}$.

$7256 \div$ Éloge de Joseph Dombey, médecin, botaniste du roi. Bourg, typ, Bottier. (1813.) 12.57 p.

72376 - Tableaux de concordance des genres d'un Pinax des plantes Européennes. Paris, Deterville. (Lyon, Cabin.) (18141816.) 8. xx, $95 \mathrm{p}$.

(Adhaerent: Pinas des plantes Europienes; Prospectus: \& p. Nouveat Pina:; Prospectus: 4.8 p.

$7258 \div$ Moynier. De la Trulfe, traité complet de la tubercule, contenant sa description et son histoire naturelle la plus détaillèe, son exploitation commerciale et sa position dans l'art culinaire. Paris, Barba 1S36. 8.404 p. $(7$ fr. 50 c.) Bibt. Lèv.

(" Manvais ouvrage. dans Inquel il n'est question que du commeree des truftes, et re la maniere te les accommoder.n heveillè.)

氵239* Mudie, Robert. The botanic anuual, or familiar illustrations of the structure, habits, economy, geograplyy, classification and principal uses of plants, with notices of the way in which ther are affected by climate and seasens: and a short sketch of Coniferae. London, Coclurane. 1832. 8, xv, 446 p., 2 tah. (1 $3 . s$.

$7260+$ Muehlenbeck, Heinrich Guslar. Notice nécrologique sur Menri Gustave .Huehtenbeck, Docteur en médecine à Nulliouse, décédé le 31 Novembre 1845 a l'age de 47 ans et demi. Mullouse, ty]. Baret. 1845.8.19 p.

$7261^{\circ}$ Muehlenberg, Henry. Catalogus plantarum Americae septentrionalis hucusque cognitarum indigenarum et cicurum, or a Catalogus of the hitherto known native and naturalized plants of Yorth-America arranged according to the sexual system of Linnaeus. Lancaster, typ. Ifinmilton. 1813 . S. Iv, 119 p. - " lid.11. aucta et correcta. Philadelphia, Conrad. 1818.8. Iv, 192 p.

$7262^{*}$ - Descriptio uberior graminum et plantarum calamariarum Americae septentrionalis. Pliladelphia, Conrad. 1817. 8. II $295 \mathrm{p}$.

Ejusdem autoris opus posthunum: "Descriptio uberinr Florae

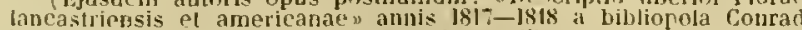
I'siladelphiae amuntiatum, vis e prelo prodliit.

7263 Muehlpfort, Heinrich, latine Mylphortus. Grundiche Erklarung, was des Breslischen Bieres oder Schopsenbieres Eigenschaften seien. Brieg 1624. 4. H.
726 , Muehlpfort, Heinrich, latine Mylphortus. Medizinisches Spaziergánglein, darinne der mit leiligen Sanen bekanten krauter Irt und ligigenschaft angedmutet wirl. Scbleusiugen 1627.8 . (Antoris poemata prodierunt Vratislaviar lGsti. \&. Rivin.

726; Muelertz, P. C. Forsog med og Nytten af adshillige norshe vilde lfaer. Kjoblenhavn, Gyldendal. 1 b04. 8. (10 Shill.)

7266 Mueller, Bernhard. Be plantaram cugnitione medicu necessaria 1). Basileae 1616.4. Rivin.

2267 (Mueller, Elias.) Inhalt einer Abhandlung von Furtremiclikeit der Gewaichse (res naturales) in Dänemark und Norwegen, samt jer dazu behorigen Lúnder. Hamburg s. a. 8. 6 / p. B.

$7268^{*}$ Mueller, F. A. H. J. Tahellarisclse Lehersicht dles Pflanzenreich. nach lime sclien und naturlichera system. Siutgart, Rieger. 1836 5 Tabellen. folio max. $\left(1^{3 / 8} / \mathrm{th}\right.$.)

7269 Mueller, Gerhard Audreas. De oleis nssentialibus seu aethereis vegetabilium alssque destillatione parandss, D, Giessae 1750. 4. н

7270 Mueller, J. C. F. Anweisung zur zwechmássigen Behnutlung tes Obst-und Genusegartens, nebst einem Anhang von HIumen. Frank-

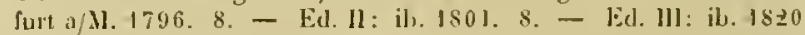
2 Theile. $s .\left(1 \frac{1}{2}\right.$ th. $)$

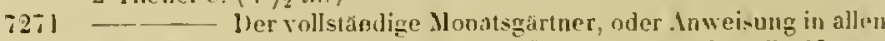
Geschaften im Boum- Kuclsen-unil Blunengarten fir alle Nonate les Jaltres Frankfurt a/MI., Guilhaunan. 4797. 8. - Eal. V: il. $1820.8 .12 / 3$ th.

7272 - - - Die wiehtigsten Lehren des Gartenbaues. Leipzig, G. Fleischer. Is 00. S. $(2 / 3$ th.

7273 Deutschlasds Weinbau. Leipzig, Fleischer jun. 1803. 8 $\left(1 \frac{1}{6}\right.$ th.

727! * Mueller, J. J. Fon den Aubau und Nutzen der Asclepias syriaca L. Zweite vermelsrte Aullage. Frankfurt a/Al., Behrens. Is0 09.8 . 8 p. 2 tab. col. $(1 / 3, h$.)

7273 - Inwejsung zum einträglichen Anbau der Eromandelu und deren Benutzung. Frankfurt a/Mi., Jaeger. 1809 . 8.2 tab. $(1 / 4 t h$.

$7276^{*}$ Mueller, Jean Baptiste. Botanisch prosodisches Worterbuch, nehst einer Charakteristik der wichtigsten natürlichen Pllanzenfanilien, fur angehenle Aerzte, Apotheker, Forsmänner und Dilettanten der lotanik. Brilon, Iy]. Lechner. (Paderbora, Wesener.) Zwei LieSermogen. $1840-1841.4 . \mathrm{v}, 504$ p. $\left(3 \frac{1}{\mathrm{~s}} \mathrm{th}.\right)$

$7277^{*}$ Flora Waldecensis et ltterensis, oder Aufzahlung und Beschreibung der in dem Fürstenthum Waldeck und der llessischen Herrschaft Iter wildwachsenden und allgemein angebauten pllanzen. Planerogamen. Brilon, Lechner. (Paderbom, Wesener.) $1841.8 .5 \mathrm{C}, 45.3 \mathrm{p} .(1 \% 3 \mathrm{~h}$. $)$

727s Mueller, Johann. De rirtute herbarum medicamentosa. Witlehergae 1676. 4. Rivin.

7279* Mueller, Johann Abraham Theodor. De Clematide Vitalba L. ejusque usu medico. D. Erlangae, Iyp. Kunstmann. 1786. 4. 2S p.

7280 Mueller, Johann Georg. Deliciae hortenses, d. i. Blumen- Arzneim küehen- und Baumgartenlust. in zwei ahsonderliche Thuile verfasset, aufs neve wieder uberselien und vermehret. Stuthgart, Plitipp Jak ob Laidig. 1676 . 12. Rivin. - Cum additionibus Christimni Anthophili. Suntyart und Ulm 1710. 12. S. - Stutgart 1717. 12. S. Stuttgart 1745. 8. н.

Prodiit primum, teste Hallero, sub titulo: hurzer Entwurf eines (treifachen Gartenhaues. Stutgart $16 \%$ \%ö. 12.)

2081* Mueller, Johgmn Gothilf. Species plantarum secundun vegetationis et fructificationis partes ad virum clelineatae ef latina ac germanica dictione determinata descriptac. Decas I: (Dic Planzengattungen mach ihren Belaubungs- und Befruchtungstheilen in ihrer naturlichen Gestalt abgebildet.) Berlin, hunst. 1757. folio. 10 tab.col. $\left(2 \frac{3}{3} \mathrm{th}\right.$.

(P)ura non prodierunt.)

728? Mueller, Johann Heinrich. Catalogus plantarun. Ulu 1745. 8. H.

7'S3 * Mueller, Johann Sebastian, anglice John Miller. Illustratio systematis sexualis Linnaei. Londini 177\%. folio. 104,4 tab. col., 104 foll., 5 p. (21).) Bibl. Caes. Vind. - tLondini, typ. Faulder. 1794. folio. (vix dilfert.) Bibl. Deless.

De pulcherriun opere. latine et angliec conscripto, ef. Yurr Annotationes in Bibl. bot. Lall. p. 19- $\div 0$, Guttinger litehrte duzeigen, 17-13. p. $3-11$. 
- grmanice et latine: Illustratio systematis sevmalis Linnaei denuo edita, revisa ac Iranslatione gemanica locullutita per Marit Rallhasar linrthausen, adjectis labulis 108 ad origunale Nilleriannm aeri incisis el coloratis (per Konrad Felsing, Darmstarlinum). Darmstadti Nerk. 1792. folio. (Vis a sequenti differt!) - "Francofurti a/M. apud Varrentrapp of ileaner. 180k. folio. (18 plag. $=120$ p.), 108 tab. col. $(76 \mathrm{th}$.

¿28; Mueller, Johann Sebastian, anglice John Miller. An illustration of the sexual system of Linnaeus, London 1779-1789. Il voll. 8 . - 1: 1779. $106 \mathrm{p} ., 104,1$ tah. - 11: 1789. An ilhtstration of the termini botanici of Linnaeus. 86 p., 86 lab. B.

(Tabula ultima voluminis primi numerum fert 106 , sed nulla tabula lot nee $10 k$ adest. Tabola aenea sine mmero praefixa est inioductioni.

troductioni. inustratio systematis sexualis Limneani qaam e textu anglico etlitionis minoris translatinn munc ementatam additamentis varis projeris praecipue terminorum buanicormu notioni inservientibus atque indicihus necessarix Joenpletatam aceuravit 7 . Fridericu Guilielmus lleiss. Francofurti a/.l., anul Varrentrapp ef Wenner. 1789 II voll. 8. - 1: xxiv, $493 \mathrm{p}-11: 10 \mathrm{k}, 1$ lai). col. (sculptore Carolo epperto.) $\left(12^{3} / 4\right.$ th. - nigr. $6^{3} / 4$ th

(Volumen alterum etian inscribitur: Tabular iconum etc.)

$7285^{*}-$ (lcones plantarum. Loudini $7 \mathrm{~T} 80$. ) gr. folıo, tab. col. 1-7., explicatiu latina el anglica: 1 foll. Bibl. Mus. bot. Vind.

(Tabulae posthumae; [Johann Sebastian Mueller, n. Norimbergae $1715_{1}+$ Londini 1780 ] phimes non prodierunt; titulus semper desicteratur. Hur, Adnot. in Bibl. bot. Hull. p. 20.)

¿286* Mueller, Johannes. Der Taback in zeschichtlicher, botanischer, chemischer medicinischer und diatetischer llinsicht. Emmerich, Daams. 1842.8 . $11.151 \mathrm{p}$. $(2 / 3$ (h.)

7287 * Mueller, Joseph. Systemutisches Verzeichuiss der in der Umgegend Aachens wildwachsenden phanerogamen Planzen. Aachen, Schulbuchhandlang. 1832. 4. 28 p. $(5 / 2$ th. $)$

$7288^{*}$ Prodromas der phanerogamischen Flora von Aachen. (Systematisches Terzeichniss etc.) Zweile Aullage. Aachen und Leipzig, Mayer. 1836. 8. xII, I82 p. ( //12 th.)

:289* Mueller, harl August. Tentamen accuratioris cryplogamoram et eryplogamiae definitionis. Goettingae $180 \mathrm{5} .8 .22 \mathrm{p}$.

$7290^{*}$ Mueller, Klothar Moritz. De Juglandis regiae viribus. D. Lipsiae 1S43. $5.31 \mathrm{p}$

7291 Mueller, Martin. Grundlicher Bericht vom Torf von Tabenried. Ulm 1752. 8. н.

$7292^{*}$ Mueller, Otto Friedrich. Efterretuing og erfaring om Svampe, isaer Ror-Swampens velsmagende Pilse (Boletus bovinus). KiolvenJavn, 1yp. Moller. (Schubothe.) 1763.4.70 p., 2 tal. (4S Skill.) * germanice: Von Schwammen, ilsonderheit von dem essluaren Bilz. In ejis kleine sehriften I. p. $31-98$

$\because 293^{*}$ (_- Flora Fridrichsdalina, sive methodica deseriptio plantarum in agro Fridrichselalensi simalque per regnum Daniae crescentium cum characteribus genericis et specificis, nominibus trivialibus, vernacalis, pharmaceuticis, locis natalilus specialissinis, iconibus optimis allegatis, ac speciebus pluribus in Dania nuper detectis. Argentorati, in officina libraria Joa. God. Baueri. 1767. 8. xvill, 238 p., ind., 2 tab.

(Cf. $Y-g$. Schreiben an len IIerrn $H^{* * *}$ dic Beurtheilung der Flora Fridrichsdalina in dem Danischen Jomrnal betgeftend, nebst einer Vermebrung dej danischen Furen. 1769. 8. 19 p.)

$729 !^{*}$ Kleine Scbriften aus der Naturhistorie, herausgegeben von Johann August Ephraim Gaeze. Erster Band. Dessau 1782. 8. 132 p., 18 tab. $(5 / 6$ (h.)

(FJoram danicau annis $1773-1782$ continuavit a fisciculo $\mathrm{X}-\mathrm{Ir}$ )

¡295 Mueller, Philipp. De plantis in genere capita disputationis publicae instituendae, permissu collegii physici Lipsiensis. Lipsiae, Lantzenberger. 1607.4. Rivin.

7296 Mueller, Philipp Hieronymus, dictas Wohlhermer. De aqua traumatica, eau d'arquelsusade. Heidelberg 1722. 4. н.

(Tractat de plantis, ex quibus componitur.)

7297* Mueller, Samuel. Vademecum botanicum, oder beytrigliches Krauterbuchlein, darinnen der vornelımsten and in der Arzneikunst gehräuchlichsten Kráuterund Gewáchse Abbildungen und Beschreibung. Frankfort und Leipzis 1687. 8.869 p., praef., ind., jc. xy̆logr. i. t. Bibl. Link. - ib. 1694.8. s.

7298 Curioser Botanicus, oder sonderluares Ḱráuterhuch, nebst dem curjosen Chymico, Medico und Chirurgo. Dressden und Leipzig 1706. 8. tab. Rivin.

7299 Mueller, Sebald. Vom Brodibacken, Mahl- und Back-Proben. Leipzig, typ. llemig. 1616.4 .
Mueller, Hilhelm Johann. Die afrikanische Landschaft Felu. llamburg 1673.8. H.

De plantis cultis tractat: hahet testimonium pro sexu plautatum.

730I* Muench, Burchard Friedrich. De Belladouna efficaci in rabie canina remedio. D. Goetlingae, \{yp. Rosenbusch. 17S1.8.47 p.

$7302^{*}$ _ Prahlische Abhaudlung von der Belladonna und ilurer Anwendung besonders zur Vorbauung und Heilung der Wuth nach dem Bisse von tollen llunden. Gottingen, Dieterich. 1785. \&. xv1, $40 s$ p., 2 lab. col.

$7303^{*}$ Muench, Johann Heinrich, filius. Observationes practicae circa usum Belladonnae in melancholia, mania et epilepsia. D. Goetlingae. 19p. Dieterich. $1783.4 .32 \mathrm{p}$.

730:* Muench, Johann Heiurich, pater. Beobachtungen bei angewendeter Belladonna hei den Menschen. Stïck 2-4. Stendal, Franzen und Grosse. $1790-1795.8$. xxxII, 150, 142, xxxiv, $226 \mathrm{p})\left(1 \frac{1}{2}(h)\right.$. (Stuck I. annj 1789 non vili.)

7303 Muenchhausen, Otto ron. Neues varlaufiges Verzeichniss derer in seinem farten zu Schwabbern in Jahr 1748 vorhanden gewesenen Jaume, stauden und Kírater. Goltingen 1748. folio. H.

7306 Der Hausvater. Eine okonomische Schrift. Hannover, Helwing. 1765-1774. VI voll. 8. (11//. - in clsarta meliori: $14 \%$ th.)

[Permulta in crudilo opere ad rem botanicam spectant; ef. llatl. Bibl. bol. II. 37' 37 . 702 . Urdo operis completi: 1. II. 1.2. 1I. i. 2. 3. IV. I. 3. V. 1. 2. Zngabe. V1. 1. - Conlinuatio morte nobilissimi ediinris $[+177\}$ interrupla est.)

7307 * Muenster, Georg, Graf zu. Beiträge zur Petrefaktenkunde vou ITermunu van Mejer, Ernst Friedrich Germar, Gaeppert, Althus und Graf Muenster. C'nter Mitwirkung des Professor Franz Unger herausgegeben von Georg, Graf zu Muesster. Bayreuth, Buchner. $1839-$ 1846. Vil Hefte. 4. (herahgeselzt: 24 ih.)

Ad regum vegretabilo perpanca lantum pertinent.

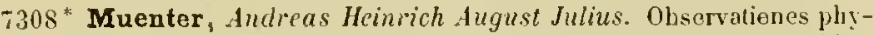
tophysiologicae. (De cadis incremento.) D. Berolini 1841.8. 34 p.

$7309^{*}-$ Die lirankheiten der Kartofleln, insbesondre die im Jahre 1845 pandemisch hersehende nasse Faule. Berlin 1846. 8. x, 168 p., $1 \mathrm{tal} .(4 / 5 \mathrm{~h}$.

$3310^{*}$ Muenz, Martin, et Ferdinand Raab. De cortice Peruviano et radice Ipecacuanhae eorumque surrogatis. D. Landishuti, 1yp. Thomalun. $1812.8 .233 \mathrm{p}$, pracf. (1 th.)

¿311 Muenzel, $F$, und $C$. A. L. von Behr. Das Ganze der Nelkenzucht uder System der Nelhe nach der Natur aufgestellt. Leijziç, Magazin fur Industrie. 1810 . 2 Theile. gr. 8 . 3 tab. nigr., 24 tah. col. $(3 \% 2(h)$.

$7312^{*}$ Muhl, Servatius. Das Pflanzenreich nach naturlichen Familien. Ein Lejtaden beim pflanzenkandlichen Unterricht auf Schullehrerseminarien, hoheren und niederen Bargersclulen. Trier, Gall. 1828. 8. xxxil, $183 \mathrm{p} .(1 / 2$ th. $)$

$7313+$ Mulder, Claas. Elenchus plantarum, quae prope urbem Leidam Jascuntur, ex sententia Academiae Lugduno-Batavae praemio ornatus. Lugduni Batavorum, apud Luchtmans. 1818. 4. 127 p.

731\% Mule, Johannes. De Ficu arefacta meditationes. D. Ilavniae 1739. 4. 1 plag. (Respondens: Nic. Zeuthen.) B.

7310̈ Mulsant, $E$. Note sur une nouvelle espece du genre Sphaeria Haller. Lyon, typ. Damoulin. 1847.8.4 p.

7316 Munby, $G$. Flore de l'Algérie, ou catalogue des plantes indigènes du royaume d'Alger, accompagné des descriptions de quelques especes nouvelles ou peu connoes. Paris, Bailliere. 1847.8.6 tah. (4 fr:)

$7317 \div$ Mund, S. G. F. Tom Unhraute. Leipzig, Crusius. 1787. 8. 105 p. $(1 /$ th. $)$

i318 Mundella, Aloysius. Epistolae medicinales variarum quaestionum et locorum difficilium Gaieni expositioncyn continentes, ab jpso auctore auctae et recognitae. Ejuxdem Annotationes in Antonii Musue Brasavalat Simplicium medicamentorum examen. Basileae, apud Miclacl lsingrin. 1538, 8. - ib. 1543,4. Rivin.

7319 Mundelstrup, Janus Nicolai. De pomis sodomiticis. D. Havniae 1683. 4. 2 plag. (Respendens: Jan Schroeder.) B.

$7320^{*}$ Munting, Alraham. Waare Oeflening der Planten, waas in de reclite aart, naluire en verborgene eigenschappen der boomen, heesteren, kruiden ende bloemen door een veeljaarige ondersockinge 
z. IIs gevonden, als meede op wat maniere $2 y$, in onze Neder en Jloog Duitsche landen, gezaait, geplant, bewaan, ende door het geheele jaar, geregeert moeten zyn, heubaar gemaakt worten. Met io Kupere Plaaten van de raarste Plauten verzient. Ansterdam, Jan Rieuwertsz. 1072. 4. 652 p., ind., 40 tals. - Ed. JI: Amsterdam 1682. 4. 656 3., 40 tals, B.

(Textus parum differt ab ejus "Naauwhenrige Beschryving der Aarigewassen", jisi fluod in illa etiam usus plantarum medieus consiteretur.)

7321 * Munting, Abraham. De vera antipuorum herba Britannica, ejusdem efficacia contra Stomacaccen seu Scelotyrben, lirisiis et Batavis de Seheurbuych. Amstelodami, apud Hieronyntum Sweerts. 1681. 4. 231 p., 24 2ab.

$7322 *$ Aluidarium, sive Aloes mucronato folio americanae majoris aliarumyue ejusdem speciei historia, in qua Floridi illius temporis, loci, naturae, culturae nec non qualitatum ratio paucis enarratur. $1 \mathrm{mpr}$. cum libro praecedeuti, ib. $1680.4 .33 \mathrm{p}$, ind, $8 \mathrm{tab}$.

(Ebilio sic dicta alteril "Anstelodami, apud Wolters. 1695. 4." praeter yenovatos titulos 110 differt. Ilenrici cammegieter Notas atque observationes in Muntingii librum de herha Britannica vide supra Nr. 1670.)

$7323^{*}$ Nasuwkeurige Besclırying der Aardgewasseu, waar in de veelerley Aart en bijzondere Eigenschappen der Boomen, Ifeesters, Kruyden, Bloemen, met laare Vrugten, Zaden, Wortelen en Bollen, neevens derzelver waare Toortleeling, geluckige Aan winning en heylzaame Genees-Krachten, na een veel-jarige Oeffening en eigen Ondervinding in drie onderscheide Bocken, naaukeuriglijk beschreeven worden; door den Heer Abruham Munting, in zijn leeven Hoogleerarar der Genees- en hruydkunde in de vermaarde Akademie te Groeningen. Nu eerst nieuvelijhs uitgegeeven en met meer dan 250 Afbeeldingen, alle naer't leeven geteekend en koustiglyk in't Koper gesneeden vereiert. Leyden en Utrecht, P. van der Aa. 1696. Polio. 929 p., praef, ind., 243 p.

732: — Phytographia curiosa, exhibens arborum, fruticum, helbarum et florum icones, 245 tabulis ad vivum delineatis ac artifrciosissime aeri incisis. Varias earun denominationes latinas, gallicas, italicas, germanicas, belgicas aliasque ex probatissimis autoribus desumtas collegit et adjecit Franciscus Kiggelaer. Lugduni Batavorum et Amstelodami, apud Petrum van der Aa et Fr. Ilalmam. 1702. 11 voll. folio. $47 \mathrm{p}$., praef, oratio funebris in obitum Afuntingii $[+1683]$ a Joanne Mensingu habita, ind., $245 \mathrm{tab}$. Amstelodami 1711. Folio. (non differt.) - Amstelodami, apud Wetstenios. 1713. Solio. (non differt.) - tAmstelodami, apud Petrum de Coup. 1727. folio. (non diflert.)

(Sunt eaeden tabulae, ac in libro praecedenti.)

$7325^{*}$ Munting, Henrich. Hortus et universae materiae medicae gazophylacium, in quo plantas tum usitatiores ac vulgatiores et in agro Omlandico ac Drentico, caeterisque cunterminis, jassim per campos, pascua, viridaria, nemora, saltus, stagna, lacus, flumina et loca palustria ac maritima ubertim provenientes, tum etiam minus usitatas ac rariores ex diversis mudi plagis periculose ac difficulter conquisitas atque huc translatas ordine alpbabetico descripsit. Groeningae, ex officina Augusti Eissens. 1646.12.53\% plag.

Ejusdem Catalogus plantarum horti Groeningeusis unno 176 est in simonis Paull viridaris variis, p. 593-706.)

7326 Muralt, Johann von. Physicae specialis pars quarta, Botanologia sive Helvetiae Paradisus. Tiguri 1740, 8. н.

* germanice: Evdgnossischer Lustgarle, d. i. grundliche Beschreibung aller in den Eydgnossischen Landen und Gebirgen frey auswachsender und in den Gärten geptlanzter Krauter und Gewächse tarimnen der mutzbaren Gestalt an kraut, Biutl, Staudeu und Saamen, Kraft und Wirkung, sammt dem orth; vordem in latin, nut aber in der Muttersprache' mit sebonen Holzsehniten vorgestelli. Zurich, Lindimer. 1715. 8. 48 p., praef., int., cum tig. ligno incisis, bibi. Turio.

7327 Murillo y Velarde, Thomus de. Tratado de raras y peregrinas yervas, y la diferencia que ay entre el antiguo Abrotano, y la natural y legitima planta Buplithalmo; y umas anotaciones a las yerbas Mandragoras, Nacho y Hembra. Madrid 4674. 4. 50 foll. B.

$7328 \div$ Murith. Je guide de bolaniste, qui voyage dans le Valais, aree un catalogue des plantes de ce paly's et de ses envirous, auquel on a joint les lieux de naissance el l'époque de la fleuraison nour chaque espèce. Lausanne, Vincent. 1810. 4. vil, $108 \mathrm{p}$.

Murithii Flora valesiaca numquam inupressa fuit; ef. Eschasseriaux, Lettres sur le Valais. Paris 1806. 8.)

7329 Murphy, E Treatise on agricultural grasses London, Longman. 18 . $8 .(2 s .6 d$.)
$7330^{*}$ Murr, Christoph Golllieb von. Adnutationes ad bibliothecas /lalleriunas botinicam, anatomican, chirurgicam et nedicinae jracticae, cum variis all scripta. Michuelis Serveti pertinentilus. L̈rlangae, Palm. $1505.4 .67 \mathrm{p}$.

(Ad bubliothream botanicam spectant 20 priores paginac, accuratissime a me ante Halleri collationem comparatae.

7331 Murray, Alexander. The nertlem (Scotland) Flora. Eilinburgh and Londun 1836.8.

7332 (Murray, Ladly Charlolle.) The british garden: a deseriptive catalogue of liardy plants, indigenous or cultivated in the climate of Great-Britain. Battı 1799. II voll. 8. - J: xxxı, 380 p. - II: J. 381 -767 . B.

$7333 \div$ Murray, John. Experimental researches on the painted Corolla of the Flower, in relation to its physiology: with remarhs on the luninosity of the sea. Lumlon, Longman, llurst etc. 18\%4. 8. $19 \mathrm{p}$.

733: - Tho phrsielegy of plants. London 1833. 12.

$7333^{2}+A$ descriptive aecount of the Palo de Vaca or Cow-Tree of the Caracas. With a chemical analysis of the milk and hark. London, Lifingham Wilson. 1837.8 max. 24 p., I Lab.

$7336^{*}$ Murray, Johan Anders. Jinumeratio vocabulorum quortindam. quibus antigui linguae latinae auctores in re herbaria usi sunt. Viro summo veneralsili, parenti optimu Andreas M/urray pio anino dedieata a filio Johanne Indrea Murray. Holmiae, tỵ. Nystrom 4756. 4. 11 p. Bibl. E. M.

$7337^{*}$ Commentatio de Arbuto uva ursi, exhilsens descriptionem ejus botanicam, analysin chemicam, ejusque in medicina et oeconomia varium usum. Programma academicum. Guettingae, typ. Pochwitz. 1764.4.66 p.

(Redit ill autoris opuseulis, vol. I. p. 1-101.)

7338 De amico insectorum scrucinii cum re herbaria connulio. Guettingae 1764.4. Desid. B.

$7339^{*}$ Prodromus designationis stirpium Gottingensium, cum figuris aeneis. Gottingae, Dietericlı. 1770 . 8. 259 p., praef, @ tab. $(1 / 2$ (h.)

$630^{*}-$ Apparatus medicaminum tam simplicium quam praeparatorum et compositorum in praxeos adjumentum consileratus. Goettingae, Dieterich. 1776-1792. V1 voll. 8. - I: 1776.627 p. Jl: 1779.465 p. $-11 \mathrm{~J}: 1784.572$ p. $-1 \mathrm{~V}: 1787.665 \mathrm{p.}-\mathrm{V}:$ 1790. 604 p. - VI: post mortem auctoris $[\div 22$ Naji 1791$]$ edidit Ludwig Christoph Althof. 1792. 243 p. - + Editio altera auctior, curante Ludwig Christoph Althof. ib. 1793-1794. VIvoll. 8. - J: 1793. xxxun, 964 p., ind. - Jl: 1794.628 p., ind. - III-VI sunt prioris editionis, $1784-1792: 572,665,604: 243 \mathrm{p}$, ind.

$7341^{*}$, pr. Dissertatio, Dulcium naturam el vires expendens. Goettingae 1779. 4.39 p.

Redil in autoris Opusculis vol. If. p. 139-190.)

$7342^{*}$ Vindiciae nominum trivialium stirpibus a Linneo impertitorum. D. Sectio ] et I]. Goettingae, typ. Dietericl. 1782. 4. 28 , $23 \mathrm{p}$.

(Redit in autoris Opusculis vol. II. p. 293-332 et in Linnaei Fund. bot. ed. Gilibert, i. p. ALVit-L.X.YV.

$7343^{*}$ - Succi Aloes amari inilia. Programma academicun. Goettillgae $1785.4 .24 \mathrm{p}$

(Redit in anteris Opusculis vol. 11. p. 47-500.)

$7344^{*}$ (Redit in apuscula in quibus commentationes varias tam medicas quam ad rem naturalem spectantes retractavit, emendavit, auxit. Goettingae, Dieterich. $1785-4786$. Il voll. 8. - I: $1785 . x \times 11,392 \mathrm{p}$. 2 tab. - 11: 1786. vi, 500 p., 3 tab.

7343* - Memorial fur den Herrn D. Puul Usteri in Zurich. Gottingen, Dieterich. 1790.8.13 p. Bibl. Goett.

$7356+$ (Murray, S.) Consanion to the Glasgow botanic garden, or pupular notices of some of the mure renarkable plants cuntained in it; with plan. Glasgow, smith. (18 19.) \&. 116 p., I tab. ("To be continued.") $(3 s .6(l)$

(Autoren esse puto S. Jurruy, horti euratorem.)

$73: 7^{*}$ Mussche, Jean Henri. Catalogue des plantes du jardin botanique de la ville te Gand. Gand, Iyp. Goesin-Verhaeghe. (I\$10.) s. 49 p. (Conditor horti fuit Bernard Coppens anno 1797.)

73 ' $8 \div-1$ L L L L C Ganduvensis, ou tableau général de toutes les plantes exotiques et indigenes, cultivees dans le jardin botanique de la ville de Gand etc. Gand, Goesin-Yerlaeghe.1S 17. 8. 14, 164 p., 1 tab. (Hoorebekia : Haplopappus Cass. novum genus Compos.) 
7349 Mustel. Mémoire sur les pommes de terre el sur le pain écononomique. Rouen et Paris 1768. 8. a.

7350 _ Mémoire sur la culture des pommes de terre, faisant suite au Mémoire précédent. Rouen et Paris 1770. 8. 0.

7351 * _._. Traité théorique el pratique de la végétation contenant plusieurs cxperiences nuuvelles et démonstratives sur l'écononie végétale et sur la culture des arlıres. Paris et Roncn, Leboucher. 1781-1784. IV voll. 8. - I: 1781. xv1, $502 \mathrm{p} .-11: 1781.482 \mathrm{p}$. - III: 1784. IV, 496 j., 4 tab. - N : 1784. vir, 524 p. (20 fr.)

7352* Mutel, A. Flore du Dauphine, ou description succincte des plantes croissant naturellement en Dauphiné ou cultiveses pour l'usage de l'homme el des animaux, précédée d'un précis de botanique, de lanalyse des genres el de leur tableau d'aurès le systeme de Limné. Grenoble et Paris, Prudhonme et Trouttel et Wuitz. 1830. Il voll. 8. - I: XI, 148 p., 4 tab. - II: 544 p. (10 fr.)

$7353^{*}$ - - Flore francaise destinée aux berborisations, ou rescription des plantes croissant naturellement rn France ou cultivées pour l'usage do l'bumme et des animaux, arec l'analyse des genres et leur tableau d'après le systeme de Linné, ornée de planches représcntant les caractires de 550 especes critiques. Paris, Levrault. 1934-1838. V voll. 8. et I Atlas en 4 obl. - I: $1934 . x, 594$ j. - II: $1835.452 \mathrm{p} .-111$ : $1836.410 \mathrm{p} .-$ IV: $1837.218,81,81 \mathrm{p}$. - V: Table génerale et sujplément final. 1838 . $189 \mathrm{p}$. - Allas: 1834. (1837.) 92 1ab., 3 tab. suppl

$735.1 \div$ Premier mémoire sur les Orchidées. Paris, Bailliere. $183 \mathrm{~s}, 8,16 \mathrm{p} ., 4 \mathrm{tab}(3 \mathrm{fr}$.)

$7355 \div$ - Mémuire sur plusieurs Orchidées nouvelles on peu connues, avec les observations sur les earactères génériques. Paris, Bailliere. 4842.4 .61 p., 5 tab.

Elements de botanique, enrichis do cing planches, renfermant le détail de divers organes des végétaux, par A. Mlutel. Ed. 11: Grenob]c, Prudhomme. 1847. 16.81/ plag., 5 tab. (Ifr. $25 \mathrm{c}$.)

7357 * Muth, Ferdinand. De Digitali purpurea. D. Kiliae $1839.8 .27 \mathrm{p}$.

7358 (Mutis, Joseph Celestino.) Instruceion formada por un facultativo existente por muchos añus en el Peru, relativa do las especies y virtudes de la Quina. Cadiz 1792.4.19 p. B.

(Cf. Notizia sopra la Chinologia del Mutis, dc. Professore Antonio Bertoloni: Annali di storia naturai, tom. III. p. 411-i12.)

7359 - Monographia de Caryocar Almendron. Madrid s. a. 4. DC.

(C. Caryncar amygdalifolium $M u t$ in Car. Ic. vol. IY. p. 37-42.) (Mutis multas observationes botanicas publici fecit juris in sliartio quodam mili jgnoto urbis Santa Fé de Bogoti, ul,i inde ab anno 1760 sedem fixprat. Alias multas cum Limnaeo conmunicavil, in Supplementum plantarum amni $\$ 781$ a Linnaen filio receutas. Pretiosa collectio iconum, ad Floram de Sanla Fé de Bogota illustraudam destiuatarum una cum ditissimo herbario jacet inedita in horto Hatritensi. Colmeiro, Ensayo historico p. 36 .)

$7360^{*}$ Mylius, Golllob Friedrich. Nemorabilia Saxoniac subterraneae d. i. des unterirdischen Sachsens seltsame Wunder der Natur ete. Leipzig, Weidmanu. 1720.4.80, 89 p., ind., tab.

$7361^{*}$ Mylius, Martin. llortus philosophicus in XIY areas distributus. Gorlicii, excudebat Johannes Rhanba. 1597. 12.630 p., praef., ind. Bibl, Reg. Berol.

germanice: Aus dem Lateinischen ins Teutsche übersetzet und darliebcu vermehret und gehessert ilurch Lycasthenem I'sellionoros, darnebcul rermehret und gehessert dirch Lycasthenem I'sel
Andropediacum. Strassburg, bei Johann Carolo. 1621. 8. Rivin.

7362 Myrin, Claes Gustav. Anmärkningar om Wermlands och Dalslands vegetation. Stockholm 1832.8. w.

(Seorsim impr. ex Kongl. Vet. Acad. Jlandl.)

7363 - Historia rei herbariae in Suecia. D. I. Upsala 1833. 4. $8 \mathrm{p} . \quad \mathrm{w}$.

7364* Corollarium Florae Upsaliensis, dissertationibus academicis annorum $1833-1834$ edilum. Upsaliac, typ. Palmblad (Grypliae, apud Mauritium.) 1834. $.123 \mathrm{p}$.

Minnes-Tal ofver Fil. Mag. och Bot. Doc. Claes Gustuv Myrin, hållet på Wermländska nationens i Upsala allmänna sammankomst d. 12 Dec. 1835 . Upsala, Palmblad el Co. 1836. 12.34 p. w. 1835.)
$7366^{*}$ Naccari, Fortunato Luigi. Flora Veneta, o descrizione delle piante cho nascono uella provincia de Venezia disposto secondo il sistema Linneano c colla indicazione al metodo di Jussieu modificato dal beCaudolle, arrichita di osservazioni medico-econoniche. Venezia, Bonvechiato. 1826-1828. VI voll. 4. 127, 135, 170,150, 142,133 p., 1 tab.

$7367^{*} \ldots$ Algologia adriatica. Bologna, typ. Cardinali e Frulli. 1828. 4. $97 \mathrm{p}$.

7368 Naegeli, Johann Jakol. Unterricht von Pflanzung und Nutzung (ler Eirdaipfel. Zurich 1771 . 8. н.

$7369^{*}$ Naegeli, Karl. Die Cirsien der Schweiz. (Newchatel 1841.) 4. vir, 166 p., $8 \mathrm{tab}$

(Neue Denhschriften der schweizerischen Gesellschaft fur Nuturw. Band Y.:

7370* Zur Entwichlungsgeschichte des Pollens bei den l'hanerogamen. Zurich, Orell, Füssli et Co. 1842.8 .36 p., 3 tal. $(5 / 12$ th.

$7377^{*}$ Die neuen Algensysteme, und Versucl zur Begrundung cines eignen Systems der Algen und Florideen. Zurich, in kommission bei Friedrich Schulthess. 1847,4, 275 p., 10 tab. (311/15 th.)

7372 Naezén, Daniel Erik. Index plantarum rariorum, quas in itinere anno 1780 in urhis Ulricaehamn Vestrogothiae confinis detexit. Impr. cum $F$ antii dissertatione de Ulricaehamu, Vestrogothiae urbe. Upsaliae, typ. Edman. 1782. 4. p. 29-32.

7373 Nagel, Heinrich von. Vollstandige Uebersicht der monatlichen Verrichungen im Obst-Küchen - und Bienengarten. Nach eigner Erfalırung ete. Niunchen, Füsterlin. 1823. 8. 264 p. ( $1 \mathrm{th}$.

7374. _ _ Praktischer Unterricht zum. Saflorbau in Baicrn. Munchen, Finsterlin. 1827.8. $(1 / 8 t h$.

7375 - Praktischer Unterricht zum Mohnbau in Baiern. Minnchen, Finsterlin. 1828. 8. $(1 / 8 / h$.)

7376 _ Praklischer Unteryicht zum Leinbau in Baiern. Mtinchen, Firsterlin. 1834. 8. (1/ th.)

7377 NageI, Leopold Anton. Cardamine pratessis characterem botanicum et usum medicum publice defendet. D. Trajecti a/V. 1793. 4 . $16 \mathrm{P} . \mathrm{B}$.

$7378^{*}$ Nahuys, Alexander Peter. Oratio innuguralis de religiusa plantarum contemplatione, acerrimo ad divini numinis amorem et cultuis stimulo. Trajecti ad Rhenum 1775. 4.56 p.

$7379^{*}$ Naironi, Antonius Faustus. De saluberrima potione Cahve seu Cafe nuncupata discursus Fusti Nuironi Banesii, Maronitae, linguac chaldaicae seu syriacae in alno urbis archigymnasio lectoris. Ad eminentissimum et reverendissimum principem D. Jo. Nicolaum S. R. E. Card. de Comilibus. Romae, apud Mich. Hereulem. 1671 $12.57 \mathrm{p}$.

(Nimis negligenter Segnierum et Rivinum secutus, librum jan supra Ni. libi sub voce Banesius enumeravi, quod est cognomen alutoris ex urbe Bant oriundi.)

$7380^{*}$ Nardo, Giovanni Domenico. Considerazioni generali sulle alghe. loru carattere, classificazione, composizione climica e applicazioni alla medicina, all' arti, all' agricoltura etc. segnitc da brevi cesni storici sui progressi doll' algologia e dá due articoli riguardanti la formazione degli algari vivi e secchi, e da' un appendice sulle. Alighe. Venezia, typ. Antonelli. 1835.4.46 p.

7381* Nardo, Luigi. Su alcuni usi ed applicazioni econoniche del Pinus maritima e della sua corteggia Mlomoria chimico-lechnica. Venczia, typ. Lampato. 1834. 8. 20 p.

7382 Nast, Johann Konrad. Vollstandige Abhandlung des ganzen Weinbaues. Frankfurt und Leipzig 1766-1767. 2 Bande. S. H.

$7383^{\dagger}$ Nati, Pietro. Florentina plrytologica observatio de malo Limonia citrata - aurantia Florentiae vulgo La Bizarria. Florentiac, typ. Il. de Nave. 1674.4 .18 p., 1 tab. Bibl. Juss.

anglice: A phytological obscrvation concerning Oranges and Limons, both separatily and in one picec produced on one and the mons, both sepitatily and in one piece produced on ont
same trec. Plijos. Triusict. vol. X. Nr. 114. p. 313-314. B. il caltivo uso del ber fresco con la neve. Insicme: Trattato delle Vi- 
nace di Antonio Donato d".llomare, tradotto dal latino in volgare Priorenza, Giorgio Marescotti. 1676. 12. Bibl. Reg. Parıs.

Orsus erit enltectionem Iconum hortonm liturenlinorum: Targioni ichorografia prat'. p. b). - In Desilderatis pro Bibliotheca Banksiana citantur: alcones plantivum " in folio.

738:5 Nau, Bernhard Sebastian. Praktisehe Anteitung uber den WeinLau, nach Erfahrungén am Zurcher- und Bodensse. Frankfurt a/M. Andreae. $1804.8 .(3 / 8 t h$.

1386 Pilanzenabdruche und Verstrinerungen aus dem Kohlenwerke St. Inghert in bairischen Rhoiuhroise. Munchen, Franz. 1821.4. 4 tab. $(1 / 5$ th.

(Denhschriflen der Konigl. bairischen Ahirdemic der W"issenscharten, Birnd Vil.)

738 t Naudin, Charles. Thèse pour le Doctorat des sciences naturelles litudes sur la végétation des Solances, la disposition de leurs feuilles (.t leurs infloreseences. Paris, typ. Laudouin. 1849.4 . 46 p., app., I tak).

$7388^{*}$ Naumann, Karl Friedrich. Ueber den Quincuux als Grundgesetz Ifr. Blattstellung vieler Pflanzen. Dresden und Leipzis, Arnold. 18 is. 8. vi, 80 p., t tab. $(2 / 3$ th. $)$

7384 * Naumburg, Johann Samuel. Jolineationrs Veronicae Chamaedryos, Dianthi Carthusianorum, Lanii maculati et purpurei, Arabis alpinae, Violae grandiflora, Zanichelliae palustris et Polymorphi tremelloides. D. Erfordiae $1792.8 .35 \mathrm{p}$.

(Ujssertatio inauguralis pracside Johum Frictrich lleissenborn proposita.)

Lelırbuch der reiuen Botanik nach auf Erfahrungswissenselıaft angewandten Prineipien ler kritischen Philusophie, mit Vorrole von Friedrich Kasimir Medicus. Llamburg und Altona, Volluner. 1798. S. xi1, 655 p. $(13 / 4$ th. $)$

73:1 * Navarro, Joseph Alberto. Instruccion o memoria sobre la siembra, cultivo, cosecha y eonservacion de la nueva planta llamada la raiz de la miseria o de la abundancia y sobre sus usos, uilidades y ventajas. Bareelona, typ. Surici y Burgada. (178s.) 4. 29 p. Bibl. Reg. Dresd.

73y2t (Navier, Pierre Toussaint.) Observations sur le Cacao et sur le Chocolat, ou l'un examine les avantages et les inconvénients qui peuvent résulter de l'usage de ces substances nuurricières. Paris, Didot. 1772. 12. $144 \mathrm{p}$.

7393 Neal, Adam. A catalogue of the plants in the garden of John Blackburne Esq., at Oxford, Lancashive. Warrington 1779 . 8. 72 p. B.

739 \% Neander, Johann. Tabacologia h. e. Tabaci seu Nicotianae descriptio medico-chirurgico-phamaceutica. etc. Lugduni Batavorum, ex officina Elzeviri. 1622.4.256 p., praef., tab. - "ib. 1626. 4. (non dillert. - Hmpr. cum Everhurti Herha Panacea. Lltrajedi, Hoogenhuysen. 1644. 12. p. 59-139.

(In hae editione onissa sunt, quae de virtutihus Tabaci seripsi a p. 7 t - 203 in editione priori; nee arlsint tatulite

gallice: Traiete du tabac, nis en françois par J. I: Lyon. Barth. Vincent. 1625.8 . 3 L2 13. 9 tab. B.

739:" - Sassafrasologia: hoe est: Tecmarsis nobile Sassafra lignum dextre ac feliciter in onnibus ferme corporis humani incommoelis in usum ducendi. Bremae, typ. Wessel. 1627.4 . 102 p., prael. ind. Bibl, Reg. Drcsd.

7396 Nebel, Christoph Ludwig. Dissertatio de Secali cornoto ejusque moxis. Giessae 1771, 4, 40 p. B.

* germanice: Abhandluns von der schtidlichteit des Mutterhorns. Jena 172. 8

$7397^{*}$ Dissertationem suam de Secali cornuto a temerariis et contumeliosis objectionilus $D$. D. Schlegeri vindicat. Programma. Girssae 1772, 4. $16 \mathrm{p}$.

7398 Nebel, Daniel. De novis hujus saeculi incentis butanicis. Marburgi 1694.4.

$7399^{*}$ L pr. De plantis vermo tempore efforescentibus, et unualibus plerisque. Marburgi 1706. 4. (liespondens: Johann Borellus.

$7400^{*} \longrightarrow$ pr. De plantis incipiente aestate rfflorescentibus, usualibus plerisque. D. Narburgi Catterum, typ. Kursner. 170-. $4.16 \mathrm{p}$. (Rrspontens: M. Obermann.)

7101 Wr. De Roremarino, D. Heidelhergae 1710. 4. S. (Respondens: Ludwig Limberger.)

7402 , Jr. De Balsame Copayba. D. Heidelbriza 1710. 4. н. (Redit in Talentini llistoria simplicium p $617-62 \xi$. Auetorem se dicil Resp mulens Friedrich Hithelm Hoppe.
$7403 \div$ Nebel, Wilhelm Bermhard, pr. De Aemella palatina D. Ileide!luchace, typ. llaener, 1739. 4. 24 p., 1 tals. (Hespondens: Johrmn Blunkenhorn.)

7404" Necker, Noel Joseph de. Deliciar gallo-bronirar sylustres, seu tractatus grneralis plantarum gallo-lyalıgicarua ad genera relata

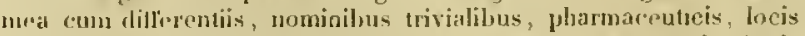
natalibus, proprictatibus, virtutibus, ex observatione, chonatae lagiJus. auctoribus praeclaris, cum animadversionilus seeundum principia Limneana. Aryentorati, Leroux. 1768 . II voll. 8. xxI\%, $568 \mathrm{l} \%$ ind., 2 tab. - "Argentorati, Stein. 1773. II roll. 8. (nen differt.)

$7103^{*}$ __ Melhodus museorum per classes, ordines, genera et spreies, eun stuonymis etc. Mannhum, (Loeller.) 1771. 8. xir, 296 p., I tab. $(5 / 6$ (h.)

$7406^{*}$ __ Physologia muscorum per examon analyticum de corporibus variis naturalibus inter se collatis continuibatrm proximanve aninalis cum vegetabrili concatendtioncm indicantilus. Nanhremii, Scliwan. $1774.8 .343 \mathrm{p} .,+$ tab. $(1 \mathrm{th}$.)

t gullice: Plyssologie des corjus or"ganisos, nu examen andylique

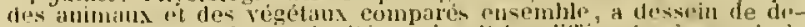
montrel li chaine de continuité. qui unit le's ditlerents règnes de la natture. Traduit du latin (par Coste.) Bouillon, (Paris, Barrojs. 17ï. 8. 3 'to p., 1 tab.

7407 Eelaireissements sur la propagation des Filicées en général. Mannheim 1775. 4. a.

7.08 llistoire naturelle du tussilage et du petasite, pour servir a la phytologie du palatinat du Rhin et des duches de Juliers el de Berg. Mambeim 1779.4. 0.

$7409^{*} \longrightarrow$ Traitc sur la Mycitologie, ou diseours historicue sur les clamplgnons "n génict cte. Mannhein, Fontaine. 1783.8. $133 \mathrm{p}$, 1 till.

$7410^{*}$ Blemrnta botanica, genera genuina, species naturales omnium vegelalilium detectorum, eorunque characters dianosticos ae peculiares exhibentia, secundun systema omologicum seu naturale rvulgata. Tribus voluminibus alivisa, eum 63 talmlis aeri incisis, volumine separato collectis. Aecedit Corollarium ad philosophiam botanicam Linnuei speetans; cum phytozoologia philosophica lingua galliea conscripta. Neowedae ad Rhenum, apud societatem typographicam. 1790 et Argentorati, apud Koniu. 1791. 8. I: xxxul, 389 p. $-11: 460$ p. - III: $456,99,78$ j., 54 tab. $(7 / 2 / \mathrm{h}$. - Moguntii, liupferberg. 1808. 1ll voll. 8. (vix diflert.)

$7 \mathrm{H}^{*}$ Phytozoclogie philosuphique, dans lanuelle on dimontre, cemment le nombre des genres et des espees, coneernant les animaux et les régétaux, a été limité el fixé par la mature. cote. Yeuwied sur le Rhin, el Strasbourg, Kunig. 1790. S. is p., efligies Neckeri.

74. 2* Corollarium ad philosephian botanieam Linnae spectans, generis, specici naturalis etc. vegetabilium omnium deloctorum: fructum diversorem aliarumque fructificationis partiun definitiones expletas, continens. Neow rdae ad Rhomum, apud societaten typographicam. 1790. S. $29,(2)$ p.

$\$ 1.3^{*}$ Nectoux, Hipolyle. Voyage dans la hate Erypte au dessus de. cataractes, avee des olsservations sur les diverses espèces de Séne, jui sont repantues dans le commerce. Paris, Garnery. 180s. folio. xit, 22 p. 4 tab. col. ad Cassiam genus spectantes.

7tif Needham, Jean Turberville. An account of some new microscopical discoveries. London 1745 . \$. 126 p., 6 tab. B.

vallice. Nouvelles decouvertes faites avee le microseone. Leide 17k7. 12. $136 \mathrm{p}$.. T tal

germanice: Introductio et cap. 1-17. NI. vestente Goeze, in Berlin. Sanuml. VII. $271-2 \times 4 ; 341-362 ; 43-13 ; 363-382$. B.

ijlit Observations upon the generation, eomprosition and decomposition of amimal and regetable substances. London, frinted in the year $1749.4 .52 \mathrm{p}$., 1 tab.

- gallice: Fouvelles observations microscopiques, arec des decouvertos intiressantes sur la composilion et lit decompositiun des

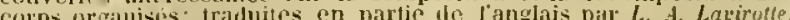

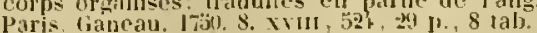

(sur la pussiere, qui feconde les plantes, p. $71-102$.)

$7116^{*}$ Nees von Esenbeck, Christian Gottried. Die Algen des sussen Wassers naelt iliren lentwichlungsstufen dargestelt. Bamberg, C. F. Kunz. $1814.8 . \mathrm{N}, 4 \mathrm{~S}$ p. $(3 / \mathrm{s}$ th.

$7417^{*}$ Das System der Pilze und Sehwamme. Fin Versuch. Wüzburg, Stahel, 1816.4 xxxvi1, 329 p. 44 tab. ad uat, col. $(25 / /$. 
$7418^{*}$ Nees von Esembeck, Christian Goltfried. Synopsis specierum generis Asterum lerbacearum, praemissis nonullis de Asteribus in senere, eorum strictura el evolutione naturali. Exercitatio qua praelectiones suas, die 1V. Calendas Maji inchoandas, indicit et simul monographian Asterum herLaceorum mox edemlan commendat. Erlangae $1818.4 .32 \mathrm{p}$.

$7.19^{*}$ Leber die Jartmundigen Enzianarten. (Erlangae 1818.) 438 p.

(Nov. Act. Acad. Caes. Leop. Carol. Nat. Cur. vol. IX. p. 141-178.)

$7120^{*} \longrightarrow$ C. Gustav Bischof, und Heimich August Rothe. Die Entwickelung der Pflamzensubstanz physiologisch, chemisch und unathematisch dargestelıt mit combinatorischen Tafełı der möglichen l'llanzenstoffe und den Gesetzen ihrer stochiometrischen Zusanmensetzung. Erlanwen, Palm unt linke. 1819. 4. 232 p. $(2 / 3$ th.

$71.21^{*}$

Ilorac physicae Berolinemses collectae ex symbolis virorum doctorum Heinrich Friedrich Link, Kart Asmund Rudolphi, Friedrich Kluq. Christim frollfried Nees von Esenbeck, Friedrich Olto, Adelbert vou Chomisso, Christion Friedrich IIornschuch, Diederich Fripdrich Ludwig won Schlechlendul, Christian Golfried Ehrenberg. Euli curavit Christian Gottfried Nees von Esenberk. (Limk: Epistola de Algis a!puaticis in genera disponendis; Oto: Plantae rariores, quae in horto Irgio Berolincusi a mense Jaunario all ultimum Majum anni 1819 floruere; Nees von Esenbeck: Sylloze observationum botanicarum; Hornschuch: Musci frondosi exotici herbarii Willdenowiani, Ium capenses a Bergius lecti, tun alii quidam ox Australasiae aliisque orbis terrarum plagis it Chamisso relati; Chamisso: Ex plantis in expelitione Romanzoffiana detectis, genera iria novi. Ehrenherg: Enumeralio fungorum a Chamisso in itinere circa terrarum globum collectorum; von Schtechtendul: Geuus Gymbaria, revisum et emendatum; Nees von Esenbeck: Plantarum Canariensium a Smithio in itinere suo detectarum, species quatuor novae, descriptionibus, iconibus et adnotationibus Leopold von Buch de locis carum natalibus illustratae; Ehrenberg: de Coenogonio, novo Lichenum genere ex peut viri clarissini (hamisso desumto.) Bonuae, sumtihus Adolpli Marcus. 1820. folio. 123 p., 27 tab. $(62 / 3(h)$.

7422 - Jandbuch der Botanik. (Etiam inscriptus: Ilandbuch del Naturgeschichto zum Gebrauch hei Vorlesungen. Vou Gothelf Heinrich Schuber. Vierter Theil.) Nurnberg, Schrag. 1820-1821. 2 Binde. $8 .-1$ : $1820 . \mathrm{xxx}, 725 \mathrm{p} .-\mathrm{II}: 1821$. vI, $690 \mathrm{p} .(57 / 8 \mathrm{~h})$

$7\left\{23^{*} \longrightarrow\right.$ et Theodor Friedrich Ludivig Nees von Esenbeck. De Cimnamono dispuratio, qua lrortum medicum Bonneusem feliciter instructum rite inauguraturi res ejus viris rei herbariae studiosis commendant. (Amoenitates botanicae Bonneuses. Fasciculus I.)

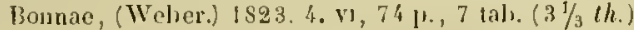
(1) Manipulus 1 . 13 p., 6 tab. col. $\left(2 \frac{1}{3}\right.$ th. $)$

7. $23^{*}$ — Christian Friedrich Hornschuch, et Jakol Sturm. Bryologia germanica, oder Bcschreibung der in Deutschland und in der Schweiz wachsenten Laubmoose. Nurnberg, Sturm. 1823-1831. 11 voll. 8. - I: 1823. cLi!, 206 p., tab. col. I-XII. - 11: 1 et 2. 1827 et $1831,182,208$ p., tab. col. XIII - XLII]. (11 th. - nigr. $31 / 2$ th.

If $266^{*}$ Fridericia et Zollernia, ad socios literae. (Bonnae) 1827. 4. 18 p., 4 tals Sor. Act. Acald. Ciles. Leop. Carol. Nat. Cur. vol. Xill.

$7127^{\circ}-$ Agrostologia brasiliensis, seu descriptio graminum in imperio brasiliensi hucusque detectorum, auctore C. G. Nees ab Esenbeck. Stuttardine et Tubingae, Cotta, $1829,8,11,608 \mathrm{p} .(3 \mathrm{th}$.) Est volumen alterum Florae brasiliensis a Martius edituo.)

7 $1.28^{*}$ Enumeratio plantarum cryptoganicarum Javae et insularum adjacentium, quas a Blumio ef Remmardtio collectas describi erlique curavit. Fasciculus prior, Hepaticas complectens. Vratislaviae, Grass, Barth et soc. $1 \$ 30.8$. Yul, 86 p. ( $1 / 2$ th.)

$7429^{\circ}$ Genera el species Asterearum. Recensuit, descriptiunibus et animadrersionibus illustravit, synonyma emendavit. Vratislavize, Gruson. 1832.8 . sw , 309 p. $\left(1 \frac{3}{1}(h\right.$. $)$

$7 k 30^{*}$ - Ilufelandiae Illustratio. (Programma gratulatorium.) Vratislaviae 1833.4 . 25 p., 2 tal,

Pritzel, Thes. Jit. hot.
$71.31^{*}$ Nees von Esenbeck, Christian Gollfried. Naturgesehichte der europäischen Lebermoose. Mit besondrer Bezjclung auf Schlesien und dio Oertlichkeiten des Riesengebirgs. (Etian inscriptus: Erinnorungell aus dem Riesengebirge.) Berlin und lireslau 1833-1838. IV voll. 8. - 1: Rerlin, Rucker. 1833. xx, 347 p., I tab. - II: Berlin, Rucker.1836. xII, 499 p. - III : Breslau, Gross, Bartlı et Co. 1838. 593 p. - IV: Breslau, Grass, Barth et Co. 1838 , Lxxil, 539 p. $\left(7 \frac{1}{2}\right.$ th.)

$7332^{*}$ Systema Laurinarum. Berolini, Teit. 1836. 8. 1x, 720 p., cum charta, distribulionem geographicam exhibens. $\left(3 \frac{1}{2}\right.$ th. $)$ $7433^{*}$ Theodor Friedrich Ludwig Nees von Esenbeck [11. 26 Juli 1787, $\div$ 12 Dee. 1837.] Den Freunden des Verstorbnen gewillmet. (Als Nanuscript gedrucht.) Breslau, 12 Dec. 1838. 8.40 P.

743\%* Kamptzia, novum arhorum Myrtacearum genus. (Programnı gratulatorium.) Vratislaviąe ad Viadrum, typ. Grass, Barth et soc. 1840. folio. 12 p., 2 tab.

$7133^{*}$ - Florae Africae australioris illustrationes monograplucae. 1. Gramineac. Glogaviae, Prausnitz. 1841. 8. xx, 490 I. (2 /h.)

$7436^{*}$ — Ad socios literae etc. Adjecta ost Lepidagathidis, generis ex Acanthaceapm ordine, illustratio monographica. Vratislaviae 4l Viadrum, typ. Grass, Barth et soc. 1841. 4. 40 1\%.

$7137^{*}$ Synopsis Ilepaticarum. Conjunctis studiis scripserunt et edi curaverunt C. M. Goltsche, Johann Bernhard Withelm Lindenberg et Christian Gottried Nees von Esenbeck. Hamburgi, Meissner. 1844. 8. xiv, 768 p. (ultimas paginas nondum vidi.) (5 th. - charta velina: $71 / 2 t h$.)

(Prodiit liber nume absolutus quinque fasciculis annis 18\% $k-18 \% 7$.) Vita optimi yiri cum uberioro scriptorum decensione legitur in Nowack, Schles. Schrifistelter-Lexicon, J. 49.)

7ł38* Nees von Esenbeck, Theodor Friedrich Ludwig. De muscorun propagatione. Commentatio. Erlangae (Bonnae, Marcus.) 1818. 4. 26 p., I tab. col. $(1 / 2$ th.

$7439^{*}$ Radix plantarum mycetoidearum. Commentatio botanica. Bonnae, (Marcus.) 1819.4. 19 p., 4 tab. $(3 / \mathrm{t}$ th. $)$

$7+10^{*}$ Plantae officinales, oder Sammlung offizineller Pflanzen. Nit lithographirten Abbildungen von A. Henry, und Beschreibungen von M.F. W'eihe, J. Wr. W'olter und $P$. Wr. Funke. Fortgesetzt von Theador Friedrich Ludwig Nees von Esenbeck. Dusselelori, in ter lithographischen Anstalt Arnz et Co. 1821-1833. 18 Hefte und 5 Supplementhefte. folio. (822) p., 552 (ab. col. (92th.) - (A. 30 th.) 20 (h.)

$7\{1$ M. F. Weihe, J. IV. Wolter und P. W. Funke. Beschreibung offizineller P'llanzen. Mit besondrer Berücksichtigung der Kon. Preuss. Plarmakopoe. Dusseldorf, Arnz et Co. 1829. gr. folio. $\left(202 \frac{1}{2}\right)$ foll. $(6$ th. $)$

(Est toxtus operis praecedentis seorsin ellitus.)

$7142-$ Ueber ein neues Arzneimillel: Cortex Alyxiae aromaticae. Schmalkalden, Varnhagen. 1824. 8. ( $1 / 6 t h$.)

(Seorsin impr, ex "Brandes Archiv des Apothehervereins" vol. IV.

$7943^{*} \longrightarrow$ und Hilhelm Sinning. Sammlumg schönbluhender Gewachse in lithographirten Abbildungen fur Blumen- und Gartenfreunde. Mit Beschreibungen und vollstandiger Angabe der Kultur Dusseldorf, Aruz et Co. 1825. 4. $222(3)$ j, 100 tab. roy. foliu. $(15 \mathrm{th} .-\mathrm{col} .25 \mathrm{th}$.) Bibl. Mus. Senckenb.

\section{Prodiit decem fasciculis anuis $18203-1831$.}

$744^{*}{ }^{-}$und Karl Heinrich Ebermaier. Handbuch der medizinisch-pharmacentischen Botanik. Nach den naturlicben Familien des Gewáchsreiches bearbeitet. Dusseldorf, Arnz et Co. 1830-1832. 3 Theile. 8. - I: 1830. vIII, 391 p. - II: 1831 . p. $392-894 .-$ III: 1832 . vili, $602 \mathrm{p} .\left(6^{3} / \mathrm{th}\right.$. $)$

$7945^{*}$ Genera plantarum Florae germanicae, iconibus et descriptionibus illustrata. Bonnae, sumtibus llenry et Cohen. 1833 -1845 . Fasciculus I-XXIV. 8. (480) (ab., totidem foll. text. $(24 \mathrm{th}$.

I. Plantarum monocotyledonearum Volunien I. Gramineae, auctore Theodor Friedrich Ludwig Nees von Esenbech. Post auctoris mortem absolverunt Aloys Putterlick et Stephan Endticher. 1843. 94 tab., 2, 94 foll.)

I1. Plantarum monocotyledonearum Volnmen II. Cyperaceae, HeIobieac, Coronariae, auctore Theodor Friedrich Ludwig Nees von Escnbeck. 1843. (64 tab., 2, 64 foll.)

III. Plantarum monocotyledonearum Volunen III. (nondum absolutum est.) 
IV. Plantarum dicotyledenearum subclassis !nima: Monnchlamydeae. 1835 . ( 80 tab., 3,80 foll.)

V. Plantarum dicotyledonearum subclassis secuuda: (aimoprialine. Volumen 1. (Plantagineae, Plumbagiueae, Prinulaceac, Lentibulurieac, Acanthaceac, Scrophularineae, Orolsancheac, Sulanaccae, Convolvulacene, Cuscuteae.) Poxt anctoris murtem absolverunt Aloys l'uttertick et Stephan Endlicher. 1845.78 1ab., 2.78 foll.)

VI. Plantaym dicotyledonearum subclassis secunda: Gamopetalae. Volumen II. (Labiatae, Verbenicene, Borragincae.) auctore Friedrich hart Lenpold Spenner; post ejus morten absolverunt dloys Putterlick et Stephian Endlicher. 1843.67 (a)s., 2, 67 foll.)

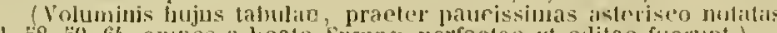
5). So. 59. 64. onters a beato spenner perfectar "t editar fuedunt.)

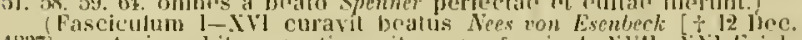

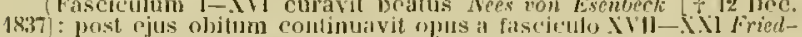

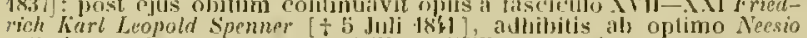
relietis tabulis fasejeculorum xill ot avill post ejus mortem ent-

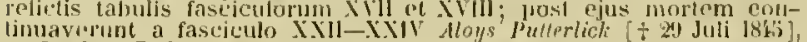
ot Stephan Endlicher, solus ex omnihus operis autoribus felis superstes, cujus cum Theophili Gritelmi Bischof conjunclis curis ad lactum [inem perductum iri librum speranus.)

$71\} 6^{*}$ Nees von Esenbeck, Theodor Friedrich Ludwig und A. Eenry. Das System der Pilze. Durch Beschreibungen und Abbilhungen erlautert. Erste Ahtheilung. Boņn, Ilenry und Colien. 1837. grr. 8. v", 74 p., 12 tab. col. (2 th.)

Fir Negrier, G. Sur la traitement ete. Archives de médecine de Paris, Avril et liai 1841.

germanice: Die Behandlung der scrofeln mit Wallnussblittern. Vach dem Franzosischen mit Beifugung eiguer Beohachtungen von 11. J. Kreutavald. Bom, Mareus. 1353.8 . $4^{3} / \mathrm{s}$ plag. $(1 / 2$ th. germanice: Behandlung der Scrofeln mit Wallnussblattern. dus

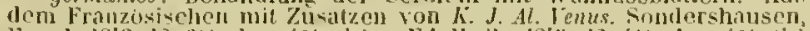

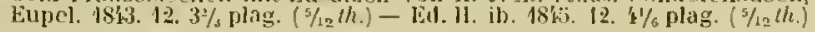

ifts Neill, Patrik. The fruit-flower-and kitchengarden. (Forming the article "Ilorticulture" of the Encyelopedia britannica.) Edinburgh 1840. gr. S. ic. xylogr. i. 1. (6s.)

71.9 * Neilreich, -August. Flora von Wien. Fine Sufzahlung der in ten Uingelsungen Wiens wildwachsenden oder im Grossen gebauten Gefässpflanzen, nebst einer pflanzengeographischen Uebersicht Wien, Beck. 1846. gr. 8. xc11, 706 p. (4 $1 / 2 \mathrm{~h}$.)

74.:0* Nemnich, Philipp Andreas. Allgemeines Polyglotten-Lexicon der Naturgeschichte. Leipzig, Bölume. 4 Bande oder S Lieferungen. $(1793-1798)$.4 . - J: 1793. 1684 p., praet - 11: 1795. 1592 ). - $111: 1036$ p. $-1 \mathrm{~V}: 1798.1 \%$ 1057-2108. (20 (h.)

ik:31 Beiträge zur Cigarrenkunde. Leipzig, (Brockhaus.) 1808. 8. $(1 / \%$ th. $)$

73:22 Nenci, Giuseppe. Riflessi sopra to pin frequenti c neessarie operazione della collivazione. Siena 1713.12 . S.

i $\{13$ * Nendtvich, C. M. Dissertatio, exhilons enumerationem planlarum in territorio Quinque-ecclesinsi sponte crescentium, praemisso tractatu generali de natura geognostica montiun etc. Buclae, typ. universitatis. $1836.8 .38 \mathrm{p}$, , 2 tab.

i1:34" Nestler, Christian Gollficed. Ilonographia de Potentilla, praemissis nounullis observationilus cirea familiam Rosacearum. Parisiis et Argentorati, Treuttel et Würtz. 1816. 4. 80 p., int., 12 tab. (2 (h.)

(Tahulim priman analyses sistentem curavit Louis Claude Richord.

$793 \%$ * (- Indcx plantarum quae in horto acalemico Argentinensi anno 18.17 viguerunt. Aryentorati, Levrault. 1818. 8. 23 \%. tSupplementum: $1819.8 .8 \mathrm{p}$.

$7136^{*}-$ Discours prononce le 11 Dec. 1828. Strashourg, typ. Levrault. 1829. 4. 16 p.

ifä $7^{*}$ Neubert, $3 V$. Die Mndepflnzen unsrer Zeit. Stultgart u. Tubingen, Cotta. 1839-1842. 2 Bádichen. 8. - 1: \$839. Camellien und Cactus, (1rach Scheelhase.) v11, 1111 . - I1: 1842 . Rosen. vi, $102 \mathrm{p}$. $\left(1 / \frac{1}{3}(h)\right.$.

ij:j8 Neufchateau, Fransois, Comte de. Lettres sur le Robinier, connu sous le nom impropre de Faux-Acacia, arec plusicurs pièces rélatiyes a la culture et aux usages de cet arbre. l'aris 1802.12.

$7159^{*}$ - Supplément au Mémoire de M. Parmentier sur to Mas (ou plutót Maiz). Paris, Huzard. 1817. S. 420 p.

$7460^{*}$ Neugebauer, Luduig Allolf. De calore plantarum. D. Vratislaviae, typ. klein. $1845.8 .55 \mathrm{p}$
Th61 Neumann, lierdinand. Die Kultur der Georginen in Deutschlimal, tnit hosondrer Ruchsicht auf Erfurt. Weissensee, Grossmann. 18:1. 8. $13 / 4$ jlaw., I tal. $(1 / 2, \mathrm{~h}$.)

if $62^{*}$ - Die liamilie der Amaryllideen mit den synonymen dor einzelnen Sprecies. Weissensee, Grossmann. 1844.8 . $180 \mathrm{~J} .63 \%$ th.

7r.63* Neumann, Karl licorg. Hie lelendige Natur. Berlin, Llerbis. 1835.8. $278 \mathrm{p} .\left(1 \frac{2}{3}\right.$ th. $)$

7tfir Neumann, Kaspar. Lectio clymica von Cauphora Impr. cum rjus Lectione chinnica de salibus alcalino-fisis. Berlin 17z7. 4. 1. $93-164$

F $60 \%$ " Lectiones publicae von vier Suljectis plarmaceulicis, nelunlich vou succino, Opic, Caryophyllis arumaticis und Castorce. Berlin 1730. 4. $226 \mathrm{p}$.

7160 Lectiones publicae von vier Subjectis dineteticis, nebntlich von viererley tietrünken, rum Thee, Kalfee, Biı̀ und Wein l,cipzig 1735. 4. 468 p. B.

(Inde a mortr ameloris prodicrunt ejus Opera collecta, mditors

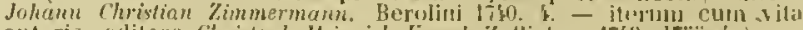

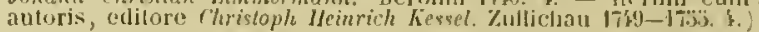

7 h67" Neunes, Christ. E. A. De cortice peruvianu. D. Jenar 1789. I $30 \mathrm{p}$.

$74.65^{*}$ Neves Mello, Anlonio Joseph das: Cirea Stipac arenariae aristam (hygrometri loeo adhibendam j atque Cinchonap brasiliensem et aliss, observationes. Rio de Janeiro, na impr. regia. Y 811 . S. t ip.

$769 \div$ Nevianus, Marcus. Marci Neviani Gerardimonani de plantarun viribus poematium. Lovanii, apud Hieronymum Welleum. 1563. \& 106 foll., praef., ind. Bibl. Juss.

7t70 Newman, Edward. Notes on Irish Natural llistory, mure espu cially lems. Reprinted with additions from the a Hagazine of Natural History.p Lonclon and Bublin 1840.8. (3s.)

74il" - A history of british ferus and allied plants. London, John van Voorst. 1840 . 8. xxxiv, 104 p., (87) ic. xylogr. i. 1. (10s.) ib. 1844. 8. xxxn 424 p., ic. xylogr. i. t. (1/. 5 s.)

7172 Newton, James. Enchiridion universale plantarum, or an universal and compleat history of plants, with their icons, in a manual, comprebending all hitherto exstant, with additions. s. 1. et a. 8. B.

("0)pus ineompletum, rujus tantum initim impressum, viz. Liber primus te arhoriths pomiteris: 34 j., practer tabulan, auctorum foll, cum 13 labulis aeneis. Nillus adest titulus, sed eirea annum
1689 impressum videtur, quum Historia plantartm Raji tiss hopressae mentio fiat, nec syriopsis stirpium $169 y$ edita. " Dryander.

7. $73^{*}$ A compleat herbal, containing the prints and the english names of several thousand trees, plants, shrubs. flowers, exotics ete. All couriously engraved on copper-plates. London, printed by Gave. 1752. 8. (20) P., $176 \mathrm{tab}$. - $\div$ Ed. II: London, Bachington, Illen et Co. 1798. 8. (20) P., 176 tab., effigies James Neutur. (non differt.) (10s. 6d.)

(Nerie sunt icones parrac el subtiles, numerosissinne, ex Par-

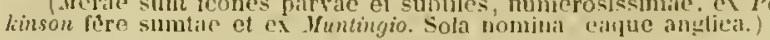

75.7." Neygenfind, Friclrich 11 ithelm. Enchiridium botanicum, conliuens plantas Silesiae indigenas, cui adjungitur in fine Colendariun botanicum. Botanisches Taschenbuch, welches die in Schlesien einheimischen J'flanzen enthrilt. Nebst einem Pflanzenkalender, une! einer Ansicht des Riesengebirges. Misenac, Goedsche. 1821. \$. x 332 ]., 1 tais. ( $21 / 6$ th.)

$7475^{*}$ Kalender der schlesischen Flora. Aus dem Enchiridio botanico besonders alggefrucht. Moissen, Goctsche. 1822. 8. $(1 / t$ th. $)$

740 Niaudet, Fictor. Des pepinieres, semis of plantations. Phris 1839. 12. 7 plag. ( 2 fr.)

747 Niblaeus, Johan Erik. Dissertatio de Brunica. Lpsaliac 1804. 4. $s$ p.

7.78* Nicander. Alexipharmaca et TherT̃ca. Ed. princeps; cum Dioscoride. Tenetiis, apud dldum. 1499. Solio. - ${ }^{*}$ Nicandri, veteris poetae et medici Theriaca et Alexipharmaca, cum scholiis, interprete $J_{0-}$ hanne Lonicero. Golonia opera Johan. Soteris. 1531 . 4. (8), 109 p. - "Nicandri Colophonii. poetae et medici antiquissimi clarissimique, Alexiphannaca. $J_{i}$, Gorrueo Parisiensi medico interprete. Ljusden interpretis in Alexipharmae praefatio, omnem de venenis disputationem summatim eomplectens et annotationes. Parisiis, apul Vaseosanum via Jacobaca, at insigne Fontis. 1549. 8. io foll. - Theriaca. 
gracee el latine, interprete Jo. Gorraeo. Parisiis 1557. 4. 106 p. B. Alexipharmaca el Theriaca, in latimum caruen redicta. Impr. cum Frevino de venenis. Antverpiac 1571. 4. 1) $276-332$. B. - I.cs Therianues et Jes Contrepoisons, traduictes eu vers françois, par Jacques Grevin. Anvers 1568 . 4. 90 p. - "Nicundri-Theriaca Nevipharmaca. Joannes Gorrhaeus latinis versibus reddidit, italicis vero qui nunc primum in lucem prodeunt Ant. Mar. Satrinius. Accedunt variantes codicum lectiones, selectic adnotationes, et graeca Eutecni Soplaistae Metaphrasis ex codicibus Mlediceae et Vindolsonensis bibliothecae descripta et nondun calita, curante Angelo Maria Bandini. Florentiae, ex officina Nouchiana. 1764. 8. (6), 376 p. "Alexipharmaca, cum scholiis graecis et Eutecnii sophistae Mletaphrasi graeca. Ex libris seriptis emendavit, animadrersionibusque et paraphrasi latina illustravit Johann Golllob Schneider. Ilalac, in orphanotropheo. 1792. 8. 346 p. (1\% /h.) - " Theriaca, cum scholis graceis auctioribus; Eutecnii Metaphrasi gracca, editoris latina et caminum deperditorum fragmentis. Ad librorum seriptorum fiden recensuit, emendavit et illustravit Johomn Guttob Schneider. Lipsiae, Fleischer. $1816.8 .^{\prime}\left(3 \frac{1}{3}\right.$ th. $)$

(Hoffmann, Levicon bit)liogr. Fd. II. Ynl. I]. p. 611-619. - Spreng.

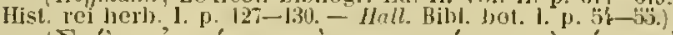

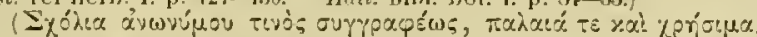

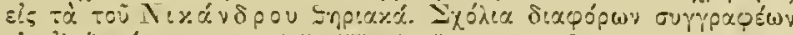

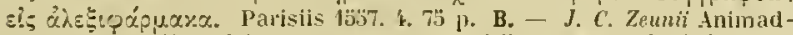
rersiones ad Nicandri carmen utrunue. Wittenhergae 1776. 4.

7.179* Nicandri Theriaca et Alexipharmaca recognovit $F$. S. Lehrs. Jnupr. cum Poctis bucolicis el didacticis. Parisiis, Ambros. Firmin Didot. (Lipsiae, llermaun.) 1846. Lex.-8. [1. 127-156. Accedit Anonỵmi Carmen de herhis. p. $168-174$.

Fisot Nichols, T. Obserrations on the propagation and management of oak trees in general. etc. Southampton, iyp. Baker. (1791.) 8.77 p. Bibl. Webb.

i.881 Nicholson, Henry. Methodus plantarum, in horto medico collegii 1)ublinensis, jamjam disponendarum. Dublini 1712. 4. 35 p. B.

7 fr8 ${ }^{*}$ Nickels, C. Kultur, Benennung und Beschreihung der Rosen. Pressburg, 1yp. Sclomid. 1836-1837. 3 Ilefte. 8. - 1: 1836. Xvi 64 p. - II: 4836.80 p., ind., I tab. col. - $111: 1837.61$ p., ind 2 th.) - Zwcite Auflage. Pressburg, Jancles Wittwe. 1846.5 Ilefte. gr. $8.26 \frac{1}{2}$ plag., I tab. col. $(1 \mathrm{~h}$.)

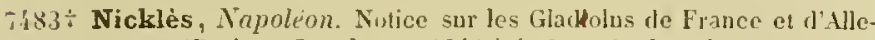
magne. (Paris et Strasbourg 1840.) 4.6 P., 1 tab. col. Bibl. Webb. Memoires de la societe du .Juseum d'histoire maturelle de Siraslourg, torl. iil.

Tis' Kicol, Walther. Der prahtische Pflanzer, orler uber die Aupflanzung der Waldhaume. Aus dem Euglischen mit Inmerhungen von hart August .Voeldechen. Berlin, Niculai. $1800.8 .(3 / \mathrm{t}$ th.)

Th:i; Nicol, Irilliam. The gardeners halendar. l.onden 1812.8 .

79.86 * Nicolai, Frnst Anton. Programma JJ de viribus medicamentorum explorandis. Jenae $1770.4 .8 \mathrm{p}$.

$7: 87^{*}-$, pr. We Nucis vomicae virilous et usin. D. Jenae 1784.4 35 p. (Respondens: Anton Friedrich Cappel.)

I's8 * Nicolai, Ernst August. Verzeichniss der Pflanzen, die in der Ĺmgebung von Arnstadt wild wachsen, nebst Angabe ibres Standorts und Bhutezeit. Arustadt 1836. gr. 12.1v, 74 p. $(1 / \mathrm{t}$ th. $)$

7is9 Nicolai, $J$. De phyllobolia. Francofurti 1698 . 8 . H.

J4!0 Nicolai, J. D. Was ist fur und wider den eindudischen Zuckerbau in detr Preussischen Staaten zu sagen? Berlin 1799.8 67 p. $\quad$ B.

$7491^{*}$ Nicolai Damasceni de plantis libri duo Aristoteli vulgo glscripti. Ex Isaaci Ben Honain versione arabica latine vertit Alfredus. Ad codd. mss. fidem alddito apparatu critico recensuit Ernestus. Yleyer. Lipsiae, Voss. 1841 . 8. xivun, 38 p. (1 $\frac{1}{2}$ th.

$792 \div$ Nicolle, H. C. Histoire de la Digitale pourprée. Paris, 1yp. Didot. 4824. 4. $46 \mathrm{p}$.

$79.93 \div$ (Nicolson.) Essai sur l'listoir naturelle de liste de Saint-Domingue. Paris, Gobreau. 1776. 8. $x \times x 1,374$ p., 10 lab.

(Autor est Pater Nicolson, ordinis Dominicanorum; of. Adansoni approbationen p. 37t. Tabulae quatuor priores sunt hotanicat

- i?:" Nicolucci, $J$. De quibusdam al gis aquae dulcis. Neapoli, ty. Sebeti. $4 \$ 13 . \& 22 p$
I49:3" Nicosia, Filippo, Barone di S. Giaime e del rozzo. Il podere fruttifero e dilcttevole diviso in tre pati. etc. I’alermo, typ. Felicella. 1735. 4. xu, 583 p. Bibl. Mus. Senckenb.

$7196 *$ Niebuhr, Carsten. Reiseheschreibung nach Arahien und andern umliegenden Lăndern. Kopenhagen $1774-1778$. 2 Bände. 4. 1. 1774.505 ]., 79 tab. $-11: 1778.479$ p., 52 tal). $(16 \mathrm{lh}$.

gollice: Yoyage en Arabie et en d'autres pays circonvoisins; tra dinit de l'allemand. Amsterdam et Utrecht, Baalde ef Schoonhoven 176- 1780. II 、 oll. \&. - 1: 1776. $\$ 09$ p., 72 tab. - II: 1780.359 p., 52 tab,

ił97 Niemann, August. Inbegriff der Forstwissenschaft. Esster Theil, enthaltenl die allyemeine Waldbaumhunde. Altona; Hammerich. 1814. $8 .(2 \%$.

7498 Taterländische Waldberichte, nebst Blicken in die allgemeine Wálderkunde und in die Geschichte und Literatur de Forstwissensehaft. Aitona, Ilammerich. 1820 - 1829. 2 Bände. \& $(31 / 3$ th. $)$

$7199 *$ Niemann, Karl Gottried. De corticis peruviani virtute propria atque specificae. D. Lipsiae $1783.4 .32 \mathrm{p}$.

(Praeses: Allum Michael Birkholz.)

7,300 Niemecsky, Daniel. Pertractatio de plantis parasiticis aliisque segeti olstantibus; cum pluribus iconibus aeneis. Francofurti a. dJ. 1795. II voll. 8 .

$7301^{*}-$ Einleitung in die Pflanzenkur, nebst neuer Eintheilung des Pllanzenreichs, Wien 1796. 4. 8 p. - Ed. 1l. Leipzig Kummer. $1800.4 \cdot(2 / 3$ th. $)$

$7502^{*}$ Niemeyer, Johann Heimrich Andreas. De Violae caninae in medicína usu. D. Goettingae, typ. Grape. 1785.4 .27 p.

$7303^{*}$ Nieremberg, Johann Eusebius. Ilistoria naturae maxime peregrinae libris $\mathbf{X l 1}$ distincta. Antwerpiac, ex officina Plantiniana. 1635. tolio. 502 p., jracf., ind., ic. xylogr. i. 1.

Plantae . 1. 20k-372 lihri XI et XV. Primum hispanice prodii hoe titulo: Filosolia eurinsa y tesoro de maraviglias de la naturalesa.
Nadril 1637. Il voll. 8.)

T30't Nietner, Theodor Eduard. Die Kuchengartnerei. Eine praktische Anleitung zur Erzichung und Pllege aller im Gebiete dieses Theiles der Gartnerei vortomuenden Gewăchse. Berlin, llerbig. 1840 2 Bande. $8.501 / 3$ plag., 2 Lab. ( $31 / 2$ th.

llatubibliothek fur furtner, zweite Abtheilung.)

$7303^{*}$ Das Gonze der Erdbeerzucht, sowohl in Freien als in verschlossinen Ritumen jeder Art und zu jeder Zeit des Jahres, und monograplische Beschreihnng der meisten kultivirten Sorten. Berlin, Nauck. $1842.8 . x, 205$ p. $(3 / \mathrm{f}$ th. $)$

$7506^{*}$ Nietzlki, Adam. Dissertatio epistolaris de studii botanici ratione ad medici clinici acumen in ohservando. Halde Salanae, aere Curtianu. 175s. 4.8 p.

7507 Nieuhof, Jkm. Het gezantschap der Neerlandtsche Oost-Indische Compagnie etc. Ansterdam, Jacob Neurs. 1665. folio, tab. - il). 1673. 4. - ib. 1681.4. s.

In capite $\mathrm{XY}$ de plantis chinensibus tractavit.

* germanice: Die Gesandschaft der Ostindischen Gesellschaft in den iereinigten Niederlandern an den Tatarischen Cham, und unmeh auch Sinisclien lieiser, verrichtet durch die Herrn Peler de Gojern und

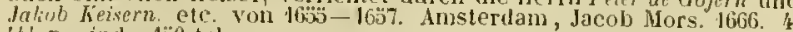
4 t' p., ind., 130 tab.

latine: Legatio batavica ar magum Tartariae Chamum Sungteium. modernum sinale imperatnrem, 1630-1657; latinitate dotlata per Georgium Hornim. Amslelodami 1668. folio. 184,172 p., tab. B. anglice: An enhassy from the East-lndia company of the finter Provinces to the Granl Tartar ('ham Emperor of China, with in alypendix of sereral remarks taken ont of Father Athanasius hircher, englissied by John Ogilby. London 1673 . folio. 431 p., tab. B.

G0S Nieuwkerk, cun. Grand catalogue hollandais de le plus exquisses et superbes sortes des oignons a fleurs, comme Jacinthes, Tulipes. Renoncules, Ancmones, Narcisses, Fritillaries, Iris et autres oignons. llarlem 1789. folio.

$7309^{*}$ Nightingale, Thomas. Oceanic sketches. With a botanical appendix by Dr. Hoaker of Glasgow. London, Cochrane. 1835 . gr. 12. $x, 132$ 1). 6 tab. $(7 s .6 \ell$.)

(A 1. 127-132: Ililliam Jackson Hooker, List of the ferns in the botanical collection made by Mr. Nightingale in the pacific isles.)

73t0 Nigrisoli, Francesco Maria. Febris Chinachind expugnata, Ferrariae $1687,4 .-\mathrm{il}, 1700.4 \mathrm{~s}$.

(Ejustem aL'anatomia delle piante di Neemia Grew, tradntta dal francese in itatiano, e di molte osservazioni accresciuta, n a Seguiero allata milii sson intotuit. 
751 . Nitzsch, Christian Ludwig. Beitrag zur Infusorienkunde oder Naturbesehreibung der Zerkarien und Bacillarien. IIalles, Ilendel. 1817. 8. VIII, 128 p., 6 tab. col. $\left(1 \frac{1}{4}\right.$ th. $)$

(Sehriften der naturforseh(ondon Ges(allschaft z.u Halle, III. 1.)

7312 Niven, Nivian. Praktisclse Auweisung zu einer verbesserten kultur des Spargels. Aus dem linglischen. Quedliuburg, Basse. 1841. 8. $1 \frac{1 / 2}{2}$ lag. $(1 / 3$ (h.)

iij3 Nobili, Pietro de. Erbario che in 32 tavole coutiene la figura di 128 piante con la dichiarazione delle virti o proprieta di ciascuna. s. l. et ๙. 4.32 tab. aen. long. 6 unc., lat. 4 unc. B.

(Libellus Bibliothese Banksiande titulo manuseripto emtus fuit Patavii anno 178i ex libris Jacobi Soranzo.)

ïl'." Nocca, Domenico. In botanices commendationem oratio. Turici 1793. 8. $32 \mathrm{p}$.

73) $\ddot{B}^{*}$ Observationes botanicae. (Turici 1793.) 8.23 p. (Ex Usteri Annalen der Botanik, Stuck V. p. 1-23.)

7516 — Nomina quarundam plantarum italica et corrupta Lombardiae. (Turici 1793.) 8. 14 p.

(Ex Usteri Annaten iler Botanik, Sluck V. p. 4:3-3̈3.)

$7317^{*}-$ Horti botanici Mantuani historia, deseriptio, týpus. (Turici 1793.) 8. 31 p., 1 tab.

(Ex Usteri Annalen tier Botanik, Stuck VI. p. 1-29.)

$7318^{*}$ IHustrationes nonuullarum plantarum horti botanici MlanLuani. (Turici 1793.) $8.5 \mathrm{p}$

(Ex Usteri Annalen der Botanih, Stuck VI. p. 60-64.)

$7519^{*}$ - Italieum D.D. Aloysii Gelmethii in Diario medicinae Veneto de radice Caliguala ojusculum, latine redditum. (Turici 1793.) S. 18 p.

(Ex Esteri Anualen der Botanik, Stuck VI. p. 63-82.)

$7320^{*}$ De itineribus ad varia Juca, Alexandriam praesertim Statiellorum, Augustam Taurinorum ae Geunam, coumentarius epistolaris. (Turici 1794.) 8.34 p.

(Ex Usteri Annalen der Botaulk, Stuck X. p. I-33.)

$7321^{*} \longrightarrow$ Scenographia horli hotanici Mantuani. (Turici 1796.) 8 . $19 \mathrm{p},{ }_{1} 1 \mathrm{tab}$

Ex Usteri Aunalon der Botanik, Stuek XVlit. p. 67-83.)

$7322^{*} \longrightarrow$ Nonitum eorum gratia editum, qui ad botanicam introduci volunt. (Turici 1800. ) 8. $48 \mathrm{p}$.

(Ex Esteri Aunalen der Botanih, Stuck xxil. p. 1-18. Redit in libro sequenti.

$7023^{*}$ Ticinensis horti acadenici plantae selectae, quas descriptionibus illustravit, observationibus auxit, colorilus ad naturam prope reddidit. Fasciculus I. Tieini, typ. Galeazzi. 1800. folio. 52 p., 6 tab. col. (Winterthur, Steiner: $8 \mathrm{th}$.)

7329.* ___ Elementi di botanica. Con varie tavole, che illustrano i sistema Linneano, disegnate dall' autore. Pavia, Galeazzi. 1801. 8 . 489 p., 4 tab. - $\div$ Ed. Il : ib. 1805.8 .473 p., 5 tab.

$7033^{*}$ Istituzioni di hotanica pratica a conmodo di quelli, che se applicano alle scienze meliche. Pavia, Galeazzi. $1801.8 .372 \mathrm{p}$.

$7326+(-)$ Svnopsis plantarum lorti botanici Ticinensis anno 1803. Papiae, typ. Bolzani. (1503.) 8. 43 p. - Appendix: 16 1.

$7327 \div$ Synonymia plantarum horti botanici Ticineusis. Papiae, Galeazzi. 1804. 8. $115 \mathrm{p}$.

$7528+-$ Epistalae ad nultos viros doctos datae. Aecedunt ejusdem inscriptiones variae. Ticini, 1yp. Galeazzi. $4805.8 .123 \mathrm{p}$.

$7329 \div$ - Il sonno delle forlie dello priante espresso colle figure ed illustrato con nuove osservazioni. (Prefazione.) Pavia, ty]. Galeazi. $1805.4 .4 \mathrm{p}$.

7530 Nomenclatura stirpium horti botanici Ticinensis, juxta Speeies plantarum a $\mathrm{cl}$. Willdenow hueusque erulgatas. Papiae 1807.8 .

$7531^{*}$ Instituzioni di botanica pratica applicabili alla medicina, alla fisiologia, all' economia ed alle arti. Pavia, Capelli. 1808-1809. Ill voll. $8 .-1: x, 407$ p. - II: IV, 420 p. - III: Iv, 343 j.

$7032 \div$ - Illustratio usus et nominis plantarum, quae in Jutii Caesaris commentaris indigitantur. Tieini, tรp. Bolzani. 1512.4. 28 p.

$7533^{*}$ _ Storia ragionata delle piante nostrati ed esotiche, dalle unali si puo estrare dlello zucelsero. l'avia, 1yj. Bolzani. (IS 12.) 4. $29 \mathrm{p}$.

$7534+-{ }^{29} \mathrm{p}$ Lettera al Signore Brugnatelli sull' origine dello zuechero e su la caltivazione antica del camameli in Calabria. Payia. Lyp. Bolzani. 1812.4.11 p.
75335: Nocca, Domenico. Lettera al signore Cavaliere Luigs Ros». in cunferma dell uppinime, elie if cannanele norn fu mai coltivato iu Calaluria. Pavia, typ. Bolzani. 1813.4 . 13 p.

$7536+1$ - Onomatologia seu nomenclatura plantarum, quae in lorro medico Ticinensi coluntur anno 1813; alditur synonymia nommullariun stirpiun at errores qua in commutationibus, qua in coentionihus dischenelos accommodata. P'ajiam, 1Yj. Bolzani. (1813.) 8. $76,(7)$ ).

$7337^{\circ}$ Termini botanico-cryjtoganici all normam recentionu deliniti nec non esmplis e classe XVIl systematis Linneani desumtis iconitusque 218 illustrati. Papiae, 19p. Capelli. 181\%. \$. xxIII, $188, x \times$ p., 4 tilb.

$7338^{*}$ et Giovanni Batlista Balbis. Flora Ticinunsis, seu ("numeratio plantarum quas in peregrinationiJus multiplicibus jolures per antos solertissime in Papiunsi aygro peractis olseryarunt et collegerunt. Adrluntur regionis ichnograplia plantarums wol notarum vel minus cognitarum icones, stationes, indloresceuliate temprar, unmullarum stirpiun officinalium virtutes merlicae recentiorum esperientia natae. Ticini, typ. Capelli, $\mid 816-1821$. II roll. 4. - I: 1816. (Cl. 1-14.) 17, Cxxxix, 409 p., tab.1-10. 1 malpa geogr. - II: 1821. (C. 15-24.) xw, 393, 39 )., tab. 11-27.

$75390^{\circ}(-1$ Signor Luigi Arduni l' anonimo del Polierafu Ar. 9 Nee talia passus l'isses. s. I. et a. 4. $8 \mathrm{p}$.

$7340^{\circ}$ (— II eriticu eriticato, ossia risposta all' estensore dell articolo sulla Flora Ticinensis, inserito nella Biblioteca italiana . Xll. Dec. 1816 . j. 492. Pavia, presso Fusi e Co. 1817.4. 25 j.

$751^{*}$ - Ilistoria atque iclunograplua horti botanici Ticinemsis. Tieini regii, tỵp. Fusi el Galeazzi. 1818. 4. 114 p., 1 tah. nį̣r. flal. col.

$73 \mathbf{2}^{*}$ - Sce lirgilio ha veramente descritto il limuno o Citrus medica de' bolanici nel libro segondo delle georgiche coi versi: Icdia fert tristes succos. D. s. I, I 19 . folio min. 20 p.

$75.33^{*}(-)$ Clavis ren herbariam addiscendi alssque praeceptore, seu Enchirielion ad exeursiones Jotanicas in agı Ticinensi. Pars l et ll. Tieini regii, typ. Fusi et socii. $1823.8 .157,272 \mathrm{p}$.

$75 \mathrm{k}^{*}$ (- Flora farmacentica, o deserizioni delle piante indigene ed esotiche, cho sono preseritte in medicina, seguendo la farmacopea austriaca e l'Apparatus medicaninum del Sign. Murruy etc. Pitvia, Ig]s. Bizzoni, 1826. II voll. 8. - 1: vili, 317 p., 5 tals. II : IV, $192 \mathrm{p}$

ïł5 Nocito, Gerardo. Lucidarium medicinae, seu notilia omuinm simplicium medicinalium, in quo tempora collectionis plantarum determinantur. Neajoli, impressum per Antonium de Caneto Pipiensem. 1511. 4. Bum.

$73: 4{ }^{*}$ Noeggerath, Jahob. Ceber aufreeht in Gebirgsgestein ringesclulossene fossile Baunstämme und andre Vegetabilien. Ilistoriselıe: und Beobachtung. Boum, Weber. 1819. 8.65 p., praef, 2 tab. $(1 / 2 t h$.

ij $_{\mathrm{r}^{*}}^{*}$ Fortgesetzte Bemerhungen uher fossile Banmstamme und andre Vegetabilien. Bonn, Weluer. $1821.8 .68 \mathrm{p.}(1 / 3 \mathrm{th}$.)

$754^{*}$ Noehden, Heimrich Adolph. De argumentis contra Ilederigii theoriam de generatione muscorum. D. Goettingae, typ. Rosenbusch. 1797. 4. $36 \mathrm{p}$.

$7519^{*}$ Entwurf 24 Vorlesungen uher die pharmacologiselie Botanik. Gottingen, Schrocder. 1802. 8. 16 p.

$73300 \div$ Noel (de la Morinière), Simon Barlhelemy Joseph. Premies essai sur le Département de la Seine inferieure, ete. Rouen, te l'imprimerie des arts. 1793 . II voll. 8. - I: xvi, $230 \mathrm{p} .-11: 292 \mathrm{~J}$. ind. - Second essail. ib. 1797.8

(Rem nostram vis tingit.)

73032 Noeldechen, liarl .Luyust. Leber den Aubau der sogenannten Rumkelruben, und die mit denselben angestellten Zuekerversuche Berlin, Xicolai. 1799-1800. 3 Ilefte. $8.70,139, x$ p. $\left(1 \frac{1}{t} t h ..\right)$

¡j̈̈ * NoeII, lhilipp. Leber die Wirksamkeit des Colehicum autumnale. D. Wurzlung $1826.8,46$ p., 1 tab.

75ă3 Nörager, Christiern. Observationes de potu Thee. 1). Ilafniae 1740. 4. 16 p. (Respondens: Peler Schore.) B.

$733\}^{*}$ Nogueira da Gama, Manoel Jacinto. Nemoria sobre w Loureirn Cinnamomo vulgo Cancleira de Ceylão. Lishoa, un off. patriarcal. 1797. S. 3s p., I tah. col. 
$7303 i 5 t$ Noirot. Traite de la culture des forcts ou de l'application des sciences agricoles et industrielles à l'èconomic forestiere, avec des recherchex sur la valeur progressive des biens-funds et des bois depuis le 13 me siecle jusrua nos jours. Paris, lluzard.1832. 8. 373 j. ( $6 \mathrm{fr}$.)

$7556+$ Noisette, Louts. Le jardin fruitier, contenant l'historre, la descriplion, la culture et les usages des arbres Iruitiers, des fraisiers et iles meilleures especes de vignes qui se trouvent en Europe; les usages des fruits sous le rapport de l'économie domestique et de la médicine etc. rédigés par L. A. Guutier. Ouvrage orné de 90 planches représentant 220 espèces de fruits coloriés d'après nature. Paris, Andot. $1821.4 .95,1760,90$ tals. col. ( $180 \mathrm{fr},-1 \mathrm{nigr} .37 \mathrm{fr} .50 \mathrm{c.}$ ) (Prodiit inde ab antuo 1813 quindecim fasciculis.

737 Le jardin frutier. llistoire et culture des arbres fruitiers, des Ananas, Melons et Fraisiers ete. gravés sur de nouveaux dessims faits d'aprês nature par P. Bessa. Ed. II. augmentée. Paris, Audot. 1832- I\$39. Fase. 1-XXVl. 8. 216 tab. (130 fr.) à 3 ir.)

(Prodiit usque id anum 18:39 fasciculis 26; singulus 6 tabularum, nières a l3runoy, par Noisette, pere et fils. (Paris, iyp. Panckoucke.)

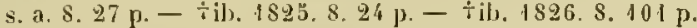

7389 - Hanuel complet du jardinier maraicher, pépiniériste, botaniste flcuriste el paysagiste (rédigé par Pierre Boiturd.) Paris, Rousselon. 1825-1827. (V ioll. 8. tab. (40 fr.) - Supplément. ib. 1828,8 . (2 $\mathrm{fr}$.)

* germanice: Vollstandiges Handbuch der Gartenhunst, enthaltend die Gemuse - Baum - Pilanzen - Blumen - und Landsclaftsgirtuerei. tus dem Franzosischen iberselzt von $G$. C. L. Siguart. Stultgart, Hetzler. 1820 - 1830.9 Theile. 8 . $\left(10^{1 / 2}\right.$ th.

1. Anweisung zum Jfropfert Beschneiden und Zichen der Obstbaume.

11. Der Kuchen - und Olstgarten.

III. Fon den Garten und ifrer Anlegun?

15. Die Erlattumg und Vermenirueg der Pllanzen.

$\because$-IX. Die Erzielung del Gartenptlanzen, nobst Beschreibuıg derselben uach den naturlichen lamilien.

7560 Manuel du jardinier des primeurs, ou l'art de forcer les plantes à donner leurs fruits et leurs fleurs dans toutes les saisons, par Louis Noisette et Pierre Boitard. Paris, Roret. 1832. 18. (3 $\mathrm{rr}$.)

(Liber autorem alium non habet praeter Pierre Boilard.

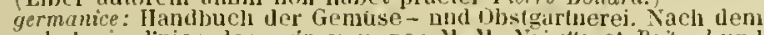
Manued du jardinier des prinieurs par M. M. Noisette et Boilarh und nach eignen krrahrungen herausgeseben von L. Hout. Eul. IIl. Mannlreim. 18.. gr. 12. 121/2 plag, 3 tals. $(1 / 3(h$. $)$

7361 Nolin et Blavet. Essai sur l'agricultore moderne, dans lequel il est traiti des arbres, arbrisseaux, oignons de fleurs et arbres fruiliers. Paris 1755.12 . (1 fr. $50 \mathrm{c.}$ ) Q.

$7662 *$ Nolte, Ernst Ferdinand. Botanische Bemerkungen über Stratiotes und Sagittaria. Kopenhagen, typ. Popp. (Hamburg, Perthes und Besser.) 1823.4 .44 p., 2 tab. $(11 / 3 / h$. $)$

$7.363^{*}$ Novitiae Florae holsaticac, sive supplementum alterum Primitiarum Florae lıolsaticae G. II. Weberi. Kilonii, Libraria aceademica 1826. (Ilamburg, Perthes und Besser. 1828.) 8. xxıy, 82 p. $(3 / 4 \mathrm{lh}$.

T56t: Nonne, Johann Philipp. Flora in tertitorio Erfordensi indigena. Erfordiae, typ. Nonne. $1763.8 .336, \mathrm{sxx} p$.

7363 _ De botanices usu, et ratione, qua studium hoc rite illgrediendun. Erfordiae 1763.4.

$7566^{*}$ - De plantis nothis, occasione spicar Tritici, cui Avenae fatuae aliquot semina innata erant. Progranma. Erfordiae, ty]. Nonne (1765.) 4. $11 \mathrm{p}$

(Usteri, Delectus opuse. bot. vol. I. p. 2',

$7367+$ Nonnius, Ludovicas. Diaeteticon, sive de re cibaria libri IV. Nune primum lucem vidit. thtwerpiac, ex officina Petri Beller. 1646. 4. 12 Ioll.), $526 \mathrm{p}$

(Liber 1. p. 1-lï; De nutrimentis e regno vegetabili. Dryander habet editionem alteram anni $16^{6} \mathrm{k}^{\circ}$.)

7368 Nordmeyer, Karl Heinrich Christoph. Commentatio, calendarium Aegypti oeeonomicum sistens. Goctlingae 1792.4. 119 p. B.

7569 Nordstedt, Carl Pehr Udalricus. De Barlana dissertatio pluarmacologica, quam praeside Carl Pehr Thunberg proponit. Upsaliae, typ. Palmblad et Co. 1823.4.13 p. w.

7370 North, Richard. An account of the different kinds of grasses propagated in England, for the improvement of corn and pasture lands. Londall s. a. 8.23 ․ B.
$75 \pi 1^{*}$ Noulet, J. B. Flore du bassin sous-pyrénece, ou description des plantes, qui croissent naturellement dans cette circonseription géologiøue, avec l'indication spéciale des espèces qui se trouvent aux environs de Toulouse. Toulouse, Paya. 4837 . 8. Lxvil, 753 p. ( 8 fr.)

$7572 \div$ et $A$. Dassier. Traité des champignons comestibles suspectes et vénéneux, qui croissent dans le bassin sous-pyrénéen, orné de figures coloriées de crandeur naturelle. Toulouse et Paris, Paya. $1838,8 . x x x, 260$ p., 42 tab. col. (24 fr.)

7073 - Additions et corrections à la Flore du bassin sous-pyré1séen. Toulouse, typ. Bonnal. 1846.8.44 [).

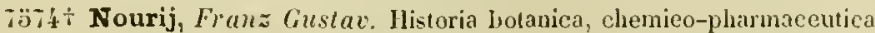
et medica foliorum Diosmae serratifoliae (vulgo foliorum Buchu). I). froningac, Romelingh. 1827.8.64 p.

7570 Nourse, Timothy. Campania felix, or a cliscourse of the benelits and inprovements of husbandry, eontaining directious for all manner of tillage, pasturage and plantations: as also for the making of cyder and perry etc. London, Ior Thomas Bennet. 1700.12. $\mathbf{s}$.

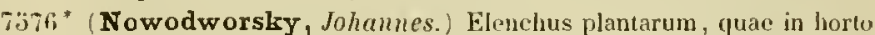
illustrissimi Conitis Josephi Mulabaila de Canal studio et diligentia coluntur ac in herbario vivo asservantur. Pragae, typ. llaase. 1804. 8. $\mathrm{x}, 70 \mathrm{p}$.

7077 - Noyer. Forets vierges de la Guiane française, considérées sous le rapport des produits 'ju'on peut en retirer pour les chantiers maritimes de la France, les constructions civiles et les arts. Paris, Iluzard. 1827. 8. xil, $104 \mathrm{p}$.

$7578^{*}$ Numan, A., et L. Marchand. Sur les proprietés uuisibles, que les fourrages peuvent acquérir pour différens animaux domestiques par des produetinus cryptogamiqnes. Traduit du Hollandais. Groningue, Schierbeck. $1830.8 .115 \mathrm{p}$., pracf., 5 tab.

7579 Nutius, Michael. Faseiculus, sive elenchus herbarum. Venetiis 1678. 12. s.

$7580^{*}$ Nuttall, Thomas. The genera of North-Imerican plants, and a catalogue of the species to the year 1847. Philadelplia, 1yp. Heartt. 1818. II roll, $8,-1$ : vili, $312 \mathrm{p} .-11: 234,14 \mathrm{p}$.

$7 i 381$ Notice of an introduction to systematic and pliysiological botany. Cambriclge, North America. 1827. 8

$7382^{*}$ —_Collections towards a Flora of the territory of Arkansas. (s. t.) 1834 . 4. p. $139-203$.

$7883^{*}$ Descriptions of new species and genera of plants in the uatural order of the Compositao, coliceded in a tour aeross the continent to the pacific, a residence in Oregon, and a visit to the Sandwich islands and upper California during the years 1834 and 1835. (s. t.) 1840.4 . p. $283-453$. $-(33$.

Transactions of the American Plilosophial Socjety 1841, p. 283

738t - The North-American Sylva, or a deseription of the forest trees of the Lnited States, Canada and Nova Scotia, not described in the work of Fransois Andre Michaux, and containing all the forest trees discovered in the Rocky Mountains, the territory of Oregon down to the shores of the Pacifie and into the confines of Cahifornia, as well as in various parts of the L'nited States, illustrated by 122 finely coloured plates. Pbiladelphia, J. Dobson. $1842 \mathrm{sgq}$. Ill roll. imp. 8. (nigr. 41. $40 s .-$ col. 61.6s.)

(Sistit supplementum editionis novan anglicae operis: "Michaux Histoire des arbres forestiers de l'Amerique septentrionale ". quod supra Mr. 6910 indieavi. Certo non scio an omnes tres tomi cum iconibus hucusque jam prodierint.)

$7383^{*}$ Nylander, Fredrik. Spicileginm plantarum fennicarum. D. Centuria 1 et ll. Helsingforsiae, typ. Frenchc!. 1843-1844. 8. - I: 1843. 31 p. - 【: $1844.38 \mathrm{p}$.

(Haec spicilegia sub praeside Joluane Magno a Tengstrom proposita sunt.)

7:386t Nylandt, Pelrus. Der Nederlandsche llerbarius ol Krurdt-Bueck, beschryvende de geslachten, gedaente, plaetse, tijt, oclfening, aert, krachten en medieinacl gebruyck van alderhande boomen, heesteren, boon-gewassen, kruyden en planten, die in de Nederlanden in wilde gevonder, en in de hoven anderhonden werden, als mede de uytlandisen of veemde droogens, die gemeenlyck in do Apotheker winckels gebruyckt worden, uyt rerscheyde kruydt-bescliryvers tot nut van alle natuurkunders, geneesmeesters, Apothekers, Chirurgyns, en lieflebbers van kruzilen en planten by een vergadert en beschreven. T' Amsterdam, Mareus Doornich, 1670. 4. $342 \mathrm{p}$. 
NYHAN

(130) it, syloger. i. 1. - - Amsterdam, Narcus Hoornich, 1673. 8. $820 \mathrm{p}$, gracef., ind., ie, xyloerr. i. 1.

(fhmortier citat iditionem: Ansterdam 16\$2. 4.)

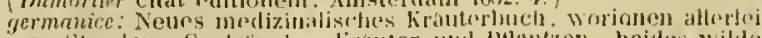

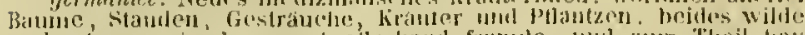

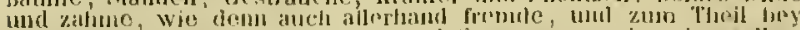

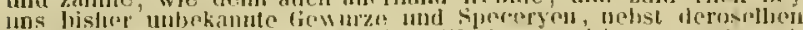

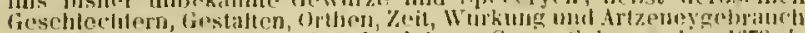

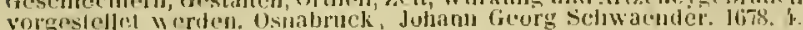
$39 \%$ D. ic. Ayloser. i. i. B.

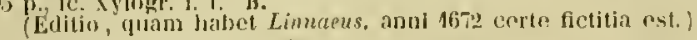

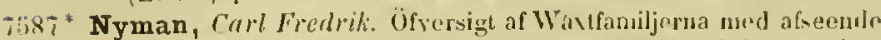
pai teras anvandande vid waxternas undersöhning och bestanniug, enligt Prof. Fries system. Stockholn 1843. 8. x, 1.18 p. (1 Rdh.)

7688 Nyst, $P$. Catalogue linnéen des plantes du plateinu de Sit. Pierru a Macstricht. Impr'. 'un Bory de Saint J incent. Voyage souterrain. Paris 1821. S. Dumortier.

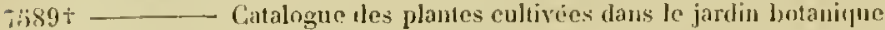
de Ja ville do Bruxclles. Bruxelles, typ. Bols-Willouck. 1826. S. W, $91 \mathrm{j}$.

$7: i 90 \div$ Nysten, $I$. II. Reeluerches sur les maladies des vers a soie et les moyens de les prévenir. Paris, iuprimeric injúriale. 1805. 5.1881 . Bibl. Léveilté.

(ODservavit atuidem morlum Muscardine nune diclum, nou vero intelexit ijus naturan icgetalsilem autor'?

\section{O.}

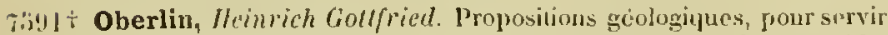
d'introduction à un ourrage sur les élémens ule la churographlue, arec l'exposé do leur plan el leur application a la ilescription géognostique du ban do la Roche. Strasbourg, typ. Levrault. 1806. S. xiv, 261 p., 5 tah. (Pyrola unbellata.) ( 4 fr.) (Botanique: p. 89-153.)

7ig9 Oberlin, fiarl Ileinrich. De Opio liberius in medicina adhibendo. Argentorati 1752.4. 4.

7393 Oberndorffer, Johann. Horti medici, qui Ratishonae est, descriptio, in qua arborum, frutieum et plantarum tum indigenarum, quam exoticarum nomina ceu in catalogo lesignantur. Katisbonae, 1v11. Nathliae Nylii. 1621.8. Rivin.

(Est condilor horti, de cujus fatis muntii desilcrantur.)

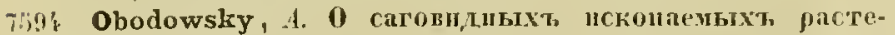

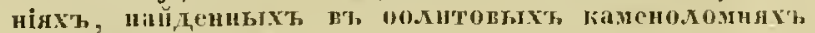
сстрова Портханда. Соי. Бокианда. Нерев. Сһ Аига. C. II exep6. 1834. Trautv.

7.:1:;* Ocyorus va Oxyorius rel Oxyotus, germanice Schnellenberg, Targuinius. Experiucuta von zwentzig l'estileulz Wurtzeln, und kreutern, wie sie alle, und ein jegliches besnnder, fur Gift und Pestilentz gebraucht mugen werden, dem Menschen irn und ausswendig, sanut viel andern heilsamen tugenden unnd wirchungen, Teutsche kecepta, Auch der Kreuter gestalt uml eigenschallt, auss langwiriger uñ gewisser erfahrung, dusch Tarquinium Oeyorum alias Schnellenbergium, der freyen Kunste unud Artzney Doctorn, zu Dortmünde an den tag gegeden. Frankfurdt a/M., gedrucht durch WTeygand. (1546.) S. (48) foll. - " Frankfurt a/N. 1552. S. - lionigsberg, Johtann Lauhmann. 1555. 4. Rivin. - *Fratkfurt a/M. (dureh Georg Raben und Weygand Hanen Erben.) 1566. 8. (64) foll., (21) lon. ic. xylogr. i. t. - Argenturati, Riholius. 1589. S. S. - Jrankfurt a/0, bei Friedrich Ilarmanı. 1613. 8. Rivin. - Strassburg, Mulbe. 1654. 8. Rivin. - Amblserg, bei David Nicolai 1680.8. Rivin. - Sirassburg 1700.8 . Rivin.

:i96 Oczko, lloyciech, i. e. Adaberlus. Descriptio herbarum medicarum. Cracoviac 1581.4.

7is97 Odhelius, Johan Lorentz. Aminuelse-tal ofver Pehr Kalm. Stockholm 1780. S. 32 p, B.

iagst Odonus, Caesar. Theophrasti sparse (ac) de plantis sententiae in continuatam sericm al propria capita revocatie, noninaque secundun literasum ordinen disposita, per Cuesarem Odonum F'silusophums ac Medicum Bononiae practicam medicinae ordinariam profitenten.
Acensserunt disputationes duae, adtrum an Kheubarbarma ctc. Bononiae, apud Mlesandrum Benacimu. 1561. 4. 142 foll.

7i,99 Oeder, Georg ('hristian (ton). Index plantarum in Systentate na-

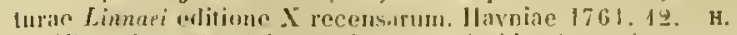

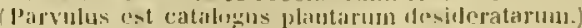

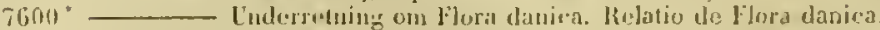
llafuiac 176 \%. folio. 7 p., 1 tah. col.

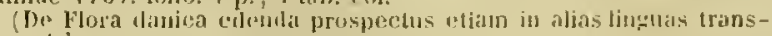
lata est.)

$760 \mathrm{r}^{*}$ - bones flantarum sponte nascentium in requis Daniace o Norvegiae, in ducatilus Slesvici et Ilskatiac, et in comitatibus Oddenburei tet Dedmealuorstiae, aif illustrandum upus de ijodem plantis regio jussu exarandum, Florae dasicat umuine inseriptum; editac a Georgio Christiano Order. Allihdungen der P'flanzen. welche in den Konizreiclsen Dituemark und Formegen, in den Jlerzogthümeru Schlesswig umd Jolstein, und iu den Grafochafen Oldenburg und Delmeulıorst wild waclisen: zu ierläutromes des tunter (lom Titel flora dunica anf fionigliclien befehl verancialte-

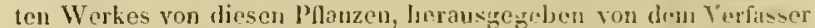
des herusdden Werhes Georg Christiun Oeder. Kopenhagen, wadruch bei s. Kon. Najestat Hofluchdrucker Niculaus Noller. 1761-1843. ITV voll. $=41$ fasciculi. folio, 2460 tals, col. (a fasc. cul. 18 lies. $=13 \frac{1}{2}$ th. - nigr. $6 \mathrm{lidr} .=4 \frac{1}{2}(\mathrm{~h}$.

Vol. 1: Fasc. 1-3.1766.(1761.1763. 1764.) (al). col. $1-180$, 34 l., ind.

Vol. II: Fasc. 4-6. 1766. (1763. 1766. 1767.) tab. col. $181-$ $360,30 \mathrm{p}$., ind.

Vol. III: Fasc. 7-9. 1770. (1768. 1709. 1770, 1ab. col. 36 $5: 0,28$ p. ind.

(Pasciculos 1-9 coldut Georg Chrivtian Oeder: munnere rolicto

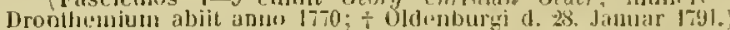

Fol. IV: Fasc. 10-14. 1777. (1771. 1775. 1777.) tah. col. 56 I $-720,24 \mathrm{p}$, ind.

Vol. V: Fasc. 13-15.4782. (1775. 1780.1782.j 4als, cul. 72i900,22 l),

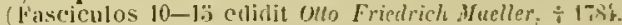

Vol. Vi: Fasc. 16-18. 1792. (1787. 1790. 1792.) 1ab. col. 9(1)

$-1080 ., 261$.

Vol. V1]: Fase. 19-21. 1799. (1794. 1797. 1799.) lab. col 1081 $-1260 ., 2411$

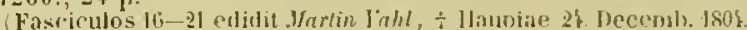

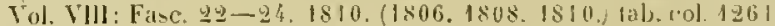

$-1440,26 \mathrm{p}$.

Vol. II: Fasc. $2: j-2 i, 1820,(1823: 1816,1818$.$) tab. col, 1441$

$-1620 ., 31 \mathrm{j}$.

Fol. X: Fasc, $2 S-30,1823 .(1819.182$ 1, IS⒊) lab. col. 1621

$-1800 ., 38 p^{2}$

Vou, XI: Fasc, $31-33.182 S$ (1823. 18年7. 1829.) (ab. cul, 1801

$-1980,41 \mathrm{p}$

Vol. Dil: Fase. 34-36. 1834. 1830. 1832. 1834.) tab. col. Ios $2160 ., 38 \mathrm{p}$

Vol. Xl11: Fase. 37-39. 1810. (1\$36. $\{\$ 39,1840$.$) tab. (col. 2161$ $-2340 ., 41\}$,

(Fasciculos 22-31 cedidit Jens Hitken Hornemann, t llivrniac d 30. Julii 1s'1.

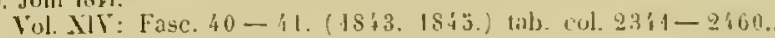

$18,17 \mathrm{p}$.

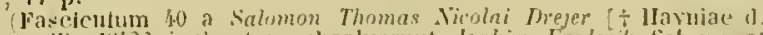

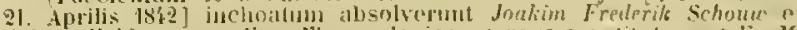

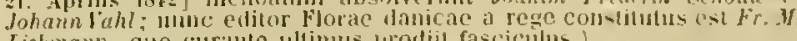
Liebmann. quo curante ultimus jurbliil fasciculus.

(Tituli sulgulis veluminitus praclixi varie dofferunt; in prioribus voluminibus germanica hugua, in posterioribus latima evprimuntur

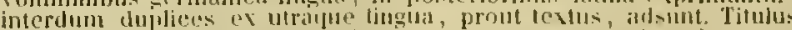
ultimi tomi hic est: a lennes plantirum sponte nascontium in regne

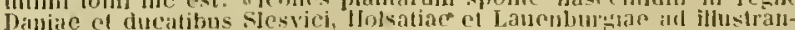

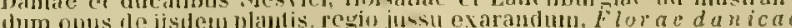
nomine inseriptum, Hinmiac, tglo. Bianco Luno,

$7602^{*}$ - Elementa botanicac. Ilavniae, Mumme. (Sclubothe.) $1764-1766,11$ voll. 8. 11, 382 1., 14 lab. (2 Rbd. 64 shill.) * yermanice linteitum zu der krauterhemutniss. Koponlagen, Nunme.

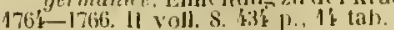

$7603^{*}$ ㄴ. Nomenclator botanicus inserviens Florae danicae. Havniae, 1yp. Pluilibert. (Selubothe.) 1769. 8. 231 p. ( / kdr.) - "Jdem liber titulo el jracfamiac germanico: Nomenclator botanicus, entlıalterul dio Namen der in den dünischen Staateu wild wachsenden Kratuler in franzusischer, englischer, deutscher, schwedischer und danischer Sprache, nelsit tenen auf den syotheken grebratdilichen 
lateinischen Kismen, und einigen Synonymen unsystematischer Scluriftsteller. il). 1769. \$. 231 j. (non iliffert.)

$760 \mathrm{\prime}^{*}$ Oeder, Geory Clristian ( $\mathrm{cm}$ ). Enumeratio plantarum Florac danicae, i. e. sponte nascentiun in reguis Daniae ct Korvegiae, ducatibus Slesvigi of flolsaliae, conitalibus Oldenburas et Delmenlorstine. Ilayniae, typ. Philibert. (Schulyothe.) 1770. S. (Cryplan(herar.) 112 ]. (48 skill.)

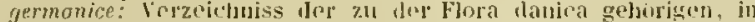
dern Kungreiche Dannentrek w ildw achsenden Jplanzen. Kopenhagen 1770. $\mathrm{S}$.

$760 \%$ Oedmann, Samuel Lars. Äminnelse-Tal ofier Clas Bjerliandev. Stochlolnı 1798.8.29 J. B.

$7606 t^{\circ}$ Antunelse-Tal ufver framlidne theologiae loctorn, prosten ach kythoherden Pehr Osbeck. Stockholm, typ. Lindh. 1815. 8. 16 1).

7607 " Oelhafen von Schoellenbach, Karl Christoph. Hbildung des wilıen Bäume, Stauden- untl luschgewachse, welche nicht nur nit Farben nach der Natur vorgestellt, sumdern auch nach ilırer wahren beschaffenheit, uach dem stand ifrer Blatter, nach iluen mamulichen und weiblichen Bluthen, Früclsen und Samen, naclı ihrem Waclssthum und Alter, das sio gewuhulich erreichon, nach ilıres likiehung und l'flege, die sie erfordrrn, kurz und grundlich boschritben werlen. Herausgegenen, verlegt, und nit den in Kupfer gestochenen und illuminirten Abbildungen versehen von Adam II olfgong IVinterschnidt. Nurnberg, Wiuterschunidt. 1767-1S04. III voll. 4. - 1: 1773. Tangel - oder immergrute Bátume. 82 p., 34 tab. col. (6 th.) - II: Laub - oder Blatterbaume. 72 p., 43 tab. col. (incompiet:) (15th.) - III: Stauden. (9th.)

(Vidi somper exemplatria incompleta in medio altero volumint

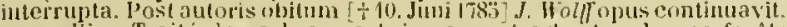
gallice: Traité des arbres, arlorisseaus et arbustes sle nos fords traduit de l'allemand pilr God. Benistant. Nurentherg 17730 . 111 cahiers. 4. (\$s fr.) Q.

(Ifaen trouslatio vix continuata est.)

7608* Oelhafius, Nicolaus. Eilenchus plantarum cirea nobile Borussorum Dantiscum sua sponte nascentium, earuntem synonyma latina et germanica, loca natalitia, florum tempora et vires exhibens. Dautisci, Iypis et inpensis G. Rheti. 1643. 4. 20 foll. sign. 1-S0., praef, ind. - ${ }^{*}$ Ed. recensita ae locupletata a successore Laurentio Eichstadio. ib. 1656.8 . 256 p., praef., 3 tab.

Fi09 Oelreich, Nils, pr. Wissertatio philosophica, generationem aequivocan ul alssonam demonstrans. Resjondens: Ammund Gabriel Myrsted. Landini Gothorum, tyj. Decreaux. 1739. 4. 15, (7) p. w.

itilo orstedt, A. S. Plauterigets Naturhistorie, en almeenfattelig Fremstilling af de vigtigste Planter $i$ deres Forhold till Menueskene og Jorden, naermest udarb. for Realskoler og til Selistudium. lijobenlava, kilein. 1839. 8. xvi, 384 J., 34 tah. (2 Rbd. 40 Skill.)

$7611^{*}$ De regionibus marinis. Elementa topographiae historiconaturalis freti Öresund. Dissertalio inauguralis, quam ad honorem magistri artium rite capessendum seripsit el publice defentere studehit. Haunine 1844. 8 . (2), 88 )., 2 Lab. (1/2th.)

(ci. Schlechtendalii de boc opuseulo relationem in Bot. \%eitumg, ग813. $1.38 j-359$.)

T612 Oestberg, Charlolle. Om Onling af Mullbärs-Trad och SilkesMaskar i Srerige. Stockholm, typ. Elmén och Granberg. 1824. 8. 23 j. w.

j013 Vabledning for dem son vilja odla Mullbärs-Träd och uppfuda Silkes-Maskar. Stockholm, Oberg. 1831. 8.33 p. w.

7613 " Oesterreicher, Elias. Generalia de fungris renenatis. J). Pestini, 1yp. Trattner-lsirolyi. s. a. 8.16 j.

561:;* Oetinger, Ferdinand Christoph, pr. Irritabilitas vegetabilium in singulis plantarum partibus explorata, uterioribusigue experimentis confirmata. D. Tuebingae 1763 . 4. $30 \mathrm{p}$.

(Respondens et fortasse antor est Johann Friedrich Gmelin; redit in (isteri Delectus opuse. 1. $272-309$.)

$7616^{*}$ Oettel, Karl Christian. Systematisches Verzeichniss der in der Oberlausiz wildwachsenden Pilanzen. Görlitz, Auton. 1799. 8.88 p. $(3 / 2$, th. $)$

$7617+$ Oken, Lorenz. Esquisse du systeme d'anatomic et physiologie et d'histoire naturelle. Paris, chez Béchet jeune. 1821. 8.62 j.

$7618^{*}$ Lehrbuch der Naturgeschichte. Zweiter Theil. Botanik Jeve, Schmid. 1825-1826.8. sv, 1077 p. (6 th. $)$
7619* Oken, Larenz. Allgemeine Naturgeschichte fur alle stande. Band 4 und 3 oder B ot anik, Band 1 uud 2. Stuttgart, Ilofmann. $1839-$ 1841.8. - I: 1839. iv, 386 p. - 11: 1841. $2135, \mathrm{xxx}, 44$ p. (21/2 th.) Allas in 4: 8 tab. col. eum explicatione.

(III Bibliotheca Linhiana est fasciculus absque loco, anno et uominc autoris, ita inscriptus: „Eulwurf von Oliens philusophischem Planzensysteme." 8. 110 p. Neutiquan summi viri stilus.

7620 Olafsen, Eggert, og Biarne Povelsen. Reise igiennem Island, lieskreven af Eggerl Olafsen. Soroe 1772. Il voll. 4. 1042 p., 50 Lab. B. (In'st: Johumn Zoega, Fora islandica ex ohscrvationibus et Jerbariis Johumis Gerhardi Koenig collecela et dispositi. 20 p.)

* germanice: Eggert Olafsen nud Biarne Porelsen, Revise: durch Island, veranstalte" vou der Kungulichen Societat der IV issenschaften in fopenhagen, und beschricben ton bemeldten Eggert Olufsen. Aus detn bitniscden. hopendagen und Leipzig, Jleineche und baber. liti-17is.

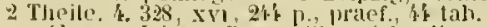

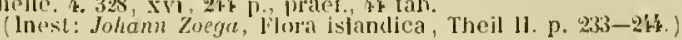

T621 Olafsyn sive Olavius, Olaf. Islendsk urtagards bok. (islandice. i. e. Horticultura Islandurum.) Kaujmannahöfn 1770.8 . 88 p., 5 tah. ligno incisae. $\mathrm{B}$.

$7622-$ - Termini botanici, som grunle til plantelaeren. Kiobenhavn 1772 . S. 72 p. B.

( Ljis explicatio nominum plantarum Islandiae fernaculorun est in Act. Soc. Sc. island. vol. I. J. 1-19.)

7623 Olagnier, F. Le guide de l'amateur hotaniste, ou choix, description ef culturo des plantes étrangères, de serre et naturalisees, les plus interessantes par leur feuillage, leurs fleurs et leur odeur. Paris, Raynal. 1826.12. (3 fr.) o.

i621: (Olcese, Francois Jules Marie.) Istruzione sul siroppo e zncehero d'uva, el sul sireppo di fichi. Genova, typ. Gravies. 1810. 8. 11. if p., inl.

76237 ( - Memoria sulla coltivaziene delle biete rape. Genowa 1y]. Gravier. IS11. S. 15 1).

$7626^{*}$ Olearius, Joham Christoph. Aloedarium historicum, i. e. Ilistorische Beschreibung derjenigen Aloen, welche in europäischen Landen, sonderlich in Teutsehland, nach und nach bisher gebhlıt und bekannt worden. ete. Arnstadt, typ. Neurer. 1713. 8. 48 p., praef. 2 tab. Bibl. Goett.

7627 " Olearius, Johkm Gollfried. Ilyacinth-Betrachtung, darimn die annuthige und niberaus schöne Ilyacinthblume zu leiblieher Ergetzung und geistlicher Erhauung allen rechtschatinen gottseligen (rartenliebhabern zu cinem Exempel der christlichen fartenlusl furgestellt wird. Leijzig, Witligau, I665. 12.100 p., prace., ind., I tal).

$7628^{*}(\longrightarrow)$ Specimen Florae Jlallensis, sive designatio plantarum hortuli M. J. G. O. quibus instructus fuit anno $1666,1667.1668$. certis de causis, amicis maxime sic volentibus exhibita atque publicata. IIalae Saxonum, Iyp. Salfeld. 1668. 12. (30) foll. Bibl. Reg. Dresd.

$7629 \div$ Olin, Johan Henrik. Plantae suecanae, annonae imprimis difficultale urgente, victui humimo inservientes. f). 1 et Il. Upsaliae, typ. Eiliman. $1797-1798.4 .30 \mathrm{p}$.

$7630 \div-$ De Arnica. D. Upsaliae, typ. Eumau. 1799. 4. $34 \mathrm{p}$

$7631^{*}$ Olivi, Giovanni Battista. Ine reconditis et praccipuis collectaneis a Francisco Culceolario Yeronensi in Musaeo adversatis Joannis baytstue Olivi testificatio. Venetiis, Paulus Zamfretus, 1584. 4. 54 p. Veronae, apud Hieronymum Discijulum. 1593.4.84 p.

$7632^{*}$ Olivi, Giuseppe. Dell' Ulya atropurpurea, specie nuova e tinturta delle Lagune Venete Memoria botanica. (Padova) 1793. 4. 13 p. (Seorsim impr. e Saggi dell tecad. “i Padova, lom. 11i. T. p. 1ik-15k.)

$7633 \div$ Olivier, Guillaume Antoine. Vuygge daus l'empire Ohomau, ['Egypte et la Perse, fait par urdre du gouvemement pendant les six premieres amées de la république. Deux rolumes el Atlas. Paris an JX-XII. 1801-1804.4. - I: 1801. xu, 432 p. - I1: 4804. I1. 466 p. - Allas en trois liveaisons an?. 4.: 50 tab. - ${ }^{*}$ Ed. minor. ił. $1801-1807.8$

(TaJ). 12. 13. 4k. 13. 32. 43. 4k. 43. 46. 47. taugunt rem herbariam.

763\%" Olorinus, Johannes. Centuria arborum mirabilinm, d. i. Iluntert W'underbciume auf dem Grund und Boden tes grossen Weltengilltens unsres Herrn Gottes gewaclisen. Aus dem grossen Weltgarten in diess kleine papieren Gártlein versetzet. Durch Fleiss, Arbeit und IIand Johonnis Olorini Varisci. Magdeburghk, hey Lewin Brannss 1616. $12.122 \mathrm{p}$, praef. 
$7633^{\circ}$ Olorinus, Johannes. Centuria herbarmm mirabilium I. i. Ilunder Wunderhituter, so da theils in der Newen Welt, theils in Jorutseltland wachsen. Allen Liebhabern der Wundergeschöpfe Ciottes zur Lust, Lelire und Trost. Aus vielen lieglaubten Autoribus mit grosser Muhe und Fleiss zusammengetragen durch Johannem Olorinum lariscum. Nagdeburgk, bey Jevin Braunss. 1616. 12.139 p.

7636 Oosten, Henry ran. Niederländischer Blumen-Olsst-und Orangeriegarten, nebst denen neuen nisderlándisehen llesperidibus isler Pflegung der Limonien - und Orangunbáum etc. lurelı langw ierige Erfalnung nach den ('limate dieser Lande eingerichtet, tiberselien nut fast ein Drithell mit neuen Anmerkungen vermehret durch Henr. von Osten. Aus dem Ilollandischen ins Hocluteutsche ubersetzet. Ilannover utud Wolfenbuttel 1706. $8.79,30,44,84,68 \mathrm{p}$. st tals. B.

anglice: 7'be rluteh gardener, transhated from the dutch. El. II. Lonton 17i1. 8. 269 $\mathrm{p}=2$ iah. B

gallice: Le jartin be Jlollande, plinte el garni de flours, to fruils

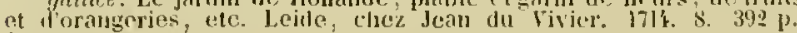
5 tah. B. 1. 5 ;.3.)

7637* Opatowski, Meinrich. De Meneeyeleis ordine naturali a Decandolle constituto. D. Berolini, typ. Nietack. 1838. 8.28 p.

$7638^{*}$ Opatowski, Wilhelm. Conmentatio historico-naturalis de familia Fungorum Boletoideoman. D. Berolini, typ. Seharle, 1836. 8. 34 p. 4 tab. col

$7639^{*}$ Opitz, F. G. Das Wahre der Kartoffelkrankheit neuster Zeit. Charakteristisch systematisch dargestellt nach ihrem Eintstehen, Verlaufen und Erloschen. Schneeberg und Leipzig, liein. 1846. gr. 8 $28 \mathrm{p} .(1 / 2 t h$.

7610* Opiz, Philipp Haximilian. Deutselılands hryptogamische Gewachse nach ihren naturlichen Standorten geordnet. Anlang zur Flora Deutschlands von Roehling. Prag, typ. Scholl. 1816. S. $166 \mathrm{p}$. $(1 / h$.

$7641^{*} \longrightarrow$ Böheims phanerogamische und kryptoganische Gewáchse. Nebst Angabe ihres gebrauchliehsten J'rovinzialnamens ilures Vorkommens, ihrer Verbreitung, Anfuhrung rler Fundorte de seltneren nebst iluen Finderu, und Andeutung des landesublichen Gelırauchs, ihres Nutzens und ilırer Schadliehkeit. Prag, Enders. 1823. $8.168 \mathrm{p})(2 / 3 \mathrm{~h}$.

$76 \mathbf{2}^{\prime 2}$ - Die Pelargonien. Eiı unentbehrlicher Leilfaden zu ilırer richtigen Bestimmung fur Botaniker, Gärtner, Gartenlesitzer und BJumenliebhaber. Als Auszug aus DeCandolle's Prodromus systenatis naturalis ins Deutsehe ubertragen. Prag, Euders. $4820.8 \mathrm{~min}$ is 5 p., praef. $(1 / 2$ th. $)$

$7613^{*}$ - Inf welchen Wege wire die Wahrheil, das hochste Ziel der reinen Bolanik zu erreichen? Ein Wort zur Beherzigung eines jeden Botanikers. Prag, Enders. 1829. 8. 29 p. ( $1 / 6$ lh.

$76 \%^{\circ}=$ Die Rulsaceen Boheims. Nit Einschluss der Furberrothe (Rubia tinctorum.) Mlonographisel, bearbeited in okonomisch teehniseher Hinsicht von Friedrich Grafen von. Berchtold, in botanischer von Philipp Ltuximiliun Opiz. Prag 1838.8 .99 p. (1/3 th.)

(Jonographia seorsim impressil est a Oehonomisch-techniache Flora Behmens; vido supra Nr. T28.)

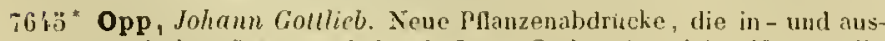
Jändischen Griser enthattend. Jena, Croker. (1814.) 2 Ilefte, folio. 50 lab. $(2 \%,(h$. $)$

7616 * Oppenheim, Elias. De Phytochemia pharmacologiae lucem focnerante. D. Ilalis, typ. Dietlein. 1803.8.48 p.

$7617 *$ Oppler, Salomon. De Strychniui nitrici inteme adhibiti usu et efficacia. D. Berolini $1834.8,32 \mathrm{p}$.

76 :8* Ordoyno, Thomas. Flora Nottinghamiensis, or a systematic arrangement of the plants, growing naturally in the county of Notlingham; with their Linnean and english names, generie and specific cliaracters in latin and english, places of growth and time of flowering. Newark, typ. Ridge. 1807. 8. 7, v, 344 p. (6s.)

$7649^{\circ}$ Orfila, $P$. Traité des poisons tirés des règues minéral, régétal et animal, ou Toxicologie générale, considérée sous les rapports de la physiologie, de la pathologic et de la médicine légale. Paris 18 13 - is 15. 8. - "Troisieme édition, revue. corrige el augmente
Pari. Crochard. 1826. II voll. S, - I xiv. 758 1). - II xim, 720 p. ( $16 \mathrm{fr}$.)

"grmanire: Orfula altgencine Toxikologie onter fifthmde. worin die

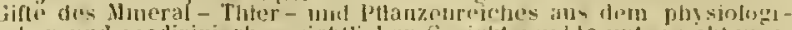

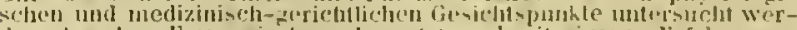
den. Aus dem Franzusischen ubersilzt, und nit risonen Erfidhrmazen

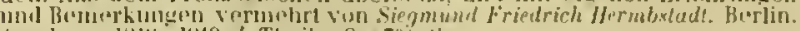
Amelang. $1818-1819$, \& T twile. 8 , $7 \%$ th

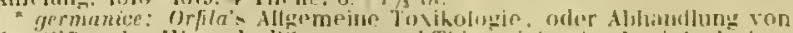

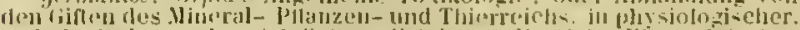

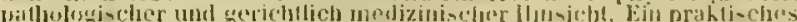

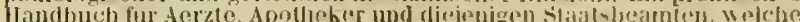

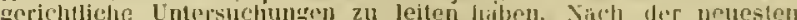
Q

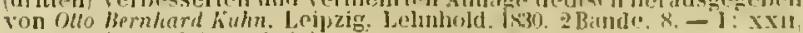
$621 \mathrm{p} .-11: \mathrm{x}, 622 \mathrm{p} .(6 \mathrm{~h} / \mathrm{h}$.

$76: 300^{*}$ Oribasius, Pergamenus. Oribasii medici Jo simplicibus libri quinque. Impr. cum Sianclae Hildegardis Plysicis. Irenntorali, ajıd Scholtum. 1533. fulio. p. 122-233. - "impr. cum sinnctae Ifildequrdis Plysseis in Experimentario medicinar. Argentorati, apue Joannem Schottum. 1544. folis. p. 122-233. ' (ratlem inpresio?') Holl. Bibl. bot. I. I's-10̈0.

$7631+$ Ormea, Carlo. Sagyo sul Riso Bertone e mazzi jor preveniro la malatia del Jrusone. Torino, typ. lieyeent. 1\$33. \&. 19 p. tIppendice: ib. $1834.8,37$ p. (1 Lire 40 r.)

$7632+$ Ortega, Casimiro Gomez (de) De Cicula commentarus. Matriti. 1yn. Jharra. 1763. 4. (8), 45 p.. I tah. Bibl. Hortj Paris.

hisponice: Tratado de lis naluralezil y virtudes de la rienta, llamado rulsarmente Cañacja. Madrid, Ibarri. 1563. 6. 52 p., prace., I tab.

76.33:- De nova quadam stirpe, seu Cotyledonis . Ilucizuniae et Pistoriniac descriptio. Jitriti, Ibarra. 1772.4 .6 p. I tab. Bibl. Juss.

760:" (- Indice de las plantas, que si han smmljrado en el real jarlin botanico (rle Madrid) en este ano de 1772 , arreglado d las denominaciones de los mas acereditados botanicos. (Manrit 17T. 4. 1513 .

$7633^{*}$ - Tabulae hotanicae, in quibus elasses. secliones el genera plantarum in Institutionibus Tonrunfortianis tradita synoplice exhibentur in usun praclectionum botanicarum. Matriti, apud Jnach.

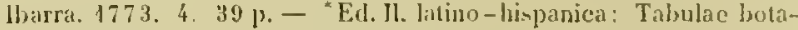
nieae, in quibus syoptice exhiluntur classes, sectiones et genera plantarum in institutionilus Tournefortianis tradita: snlsjectis plurium specierum nominilus hispanicis el guarundan vecun lechnicirum explicatione. la usum praclectimun u juregrinationum hm tanicarum. Mlatriti, typogr. regia. $17 \$ 3 . \& .16 \%$, ( $\$ 6)$ )

Etiam hisnanice inseribitur: "Tablas botanicas v ele.

7636 Tratado de las aguas temales de Trillo: (ompreliende de sus plantas y minerales; la anulisis le las aguas: las curaciones y casos adversos etc. Madrid 1778 . 8 .

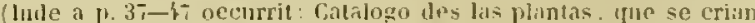
en el sitio de los Bañus de Trillo y sll inmediacion. Redit illem. ni fallor catalogus ut list of sucll plants its be fumple in the environs of Trilto " in John Talbol Dillon, Travels throuph spain. London. 1780. \{. p. $97-107$.)

$7637^{*}$ _ Instruecion sobre el modo mas seguro y econonico do transportar plantas vivas por mar y tiejra a los paises mas distantes Madrid, Jbarra. 1779. 4. T0 p., 1 ab.

$7655^{*}$ Listoria natural de la Mlolagueta, o pimienta de Tavasco. etc. Madrid, lbarra. 1780.4. 34 p., 1 tab.

$6639^{*}$ _. y Antonio Palau g Verdera. Curso elemental de intanima dispuesto para la enschanza dlel real jardin rle tladrius.

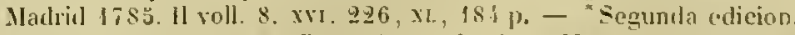
corregida, aumentade e illustrada eou latuinas. Sladrill, imprenta de Marin. 1795. II voll. gr. 8. - J'arte teoriea: xw, $256 \mathrm{f}$, prolegomena, 9 talı. - Parte praclica: $x \mathrm{~L} 1 \mathrm{y}, 240 \mathrm{p}$. 1 tab.

Pisterior pars continet characteres ansentiales generum Limant hispallice versas.)

itahce: Corso elmentare teorico di botaniea ed introduzione alla narte pratica per l'ammaestramento che si fa nel R. giardino di sla-

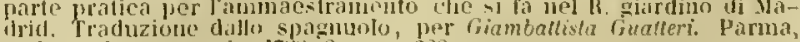
dalla reale stanperia. liss.8. $8 \times x, 32 S$, xix p.

i660* _ Novarum ant rariorum plintarum horti regii botanic Matritensis descriptionum decades $(\mathbf{l}-\mathbf{X})$, cum nomullarum iconibus. II itriti, typ. lhorra, 1797-1800.4. $138 \mathrm{p}$.. praef., Is tab Bibl. Mus. bot. Vind., Cand., Deless.

Quite decem decades in Candolleana bibliotheca hoc generali

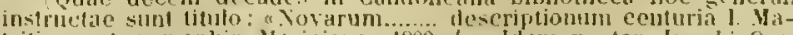
triti, el typographia Mariniana. isoö. 4. "Idem noster Josephi Quer

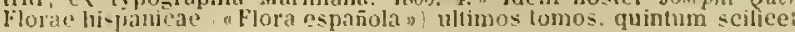


atque sextum redegit, supplevit et anno Tis edidit, quos infra recenseho. Sed de alin verba facit ill. Miguel Colmeirn (Ensayo historico p. 32.) opere botanico Orlegae, quod jworsus iznoro: "Consagró dos escelentes obras á las plantas nas notables, raras, o descouocidas indigenas de España algunas, $y$ ta mayor pirte de sus dominios: la una con el tilulo de Flora hispanicde delectus, sive insigniornm plantarun per hispaniense juperums onte signiormm plantarum per his aniense iluperium spont nascentium icones el descriptiones, en latin castelano, y la otra elc.w - Lepidum de autore aftert judicium ill. Limk, Reise in vintien und Portugal 1. 112: "Casimir Gomez Orlega, erster Anfseher des Madrider' Gartens, ein entsetzlich dieker, gesclw wtziger, gefiilliger Mann, der vielleicht viele Keuntusse haben nag, nur Pllanzen kenut er nicht. Seine Descriptiones novarum plantarum horti Matritensis soll sein Schwiegersohu Ruiz schreben. Ein Mann, "ia Orlega, der unwisselıd in scinen Facl ist, und doch einen grossen Ruf daris im Lande hat. ist immer gefahrlich; er unterdrickt wabre kemntnisse. " Paulo post, anmo 1804 , Urtega a munere silo abdicate el inimico Cavanilles professionem et bortum cedere coactus est.

766I\% Orth, Joham Martin Anastasius, pr. Flora doliciosa foecundae germinantis copiae cornu superba, contemplationi botanophilorum exposita a Matthia Eustachio Schmidt. D. Herbijoli, typ. Kleyer.1723. S. 120 p., praef.

T662* OrtIob, Joham Friedrich, pr. Analogia nutritionis plautarum et animalium. D. Lipsiae 1683.4.2 plag. (Respondens: Chr. Schmeer.)

i663 Ortolff von Bayrlandt, alias Megtenberger. Artzieibuch. Fulium $1^{\mathrm{a}}$ : Hie hebt sich an das Register des ] nachrolgenden artzneibuchs. Folium $4^{b}$ : Ein ende hat das Regrister des artzneibuchs in | welchem begriffen wirt was guts diss buch in helt | uñ an welchem blat man yegklichs vinden solle. Folium $5^{\text {a }}$ : Die vorrede diss buchs | Der hochst hat geschallë die entznei | vou dem ertrich und der weis man | wirdt sy nicht verschmahen ete. stct | geschribe ecclesiastici an de $\mathbf{X X T}$ TII | capitel. Das ertzuci edler sey dann andre kunst. dz sicht man wol wirt / eyn meyster sicch das in sein kunst | nit gehelffen mag | Darumb begeret er ertzney das | er seinen gesunt behab. Darumb will ich Orfolf vō Beypland doctor der ertznei eyn artztbuch machen | zo teutsch aus allen artztbüchern die jeh in latein ye / vernan. ctc. Exylicit: Folium $104^{6}$ : unsynnig. Nit dem habent die kreutter ein ende. s. I. et a. (Angustae Vindelicorum, Guuher Zainer.) folio. (4), 104 foll, 35 linearum cun literis inilialibus xylographicis. II ain $\mathrm{Nl}$. 12,111. - "Ed. 11: 1477. Fo-

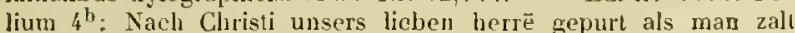
Tau | sent vierhundert und siben und silentzig Jar am Montag | nach Mittervasten. In des heiligē Ruemischē Reichs Stat | Nurenher Ist diss Artzneipuch nit sundern lleis durch | Amonij $\mathbf{K}$ aburger Burger daseltss gedrucht worde. folio. (5), 89 foll. (Von den kreuttern in einer gemeine: foll. 65-82.) Bibl. Goett. - ${ }^{*}$ Ed. III: 1479. Folium $104^{15}$. Las artzneibuch hat getruckt und vollenndet | Anthonius Sorg zu Augfourg An mitwochē | nacls Altre. In dem LXXIX. jare. folio. (4), 100 foll. (Von den kreutern in einer gemayn: foll. $74-$ 100.) Bibl. univ. Lips. - ${ }^{*} \mathrm{Ed}$. $1 \mathrm{~T}$ : 1482 . Folium 105: Das ercznerbucl hat getrucket und vollendel | Anthonius Sorg czu Augfpurg Am montag | nach Gregory. In dem LXXXII. Jare. folio. 105 foll. Bibl. Sangall. - "Ed. T: 1484. Hyr hevel syk an en bock der arstedien van allen hrankhejden un shebreken des menschē. (In calce:) Hoc opus arte mei (sic!) impressum Bartholomei Chatun, degentis et in urbe Lubeck residentis. 1484. 4. 146 foll. (Tan den liruderen in dat ghemene: foll. 105-146.) Bibl. Goett. - * Ed. V1: 1488. Folium $1^{\mathrm{a}}$ : Ein arczneybuch von allen I geprafalen der menschen nye ] man den hellfen sol zu irer ge I sunthert und stercke. Folinm 194a Das erczneybuch bat getruckt uñ | vollendet Anthonits Sorg in der heiser | lichen stat Augfpurg an montag nach / Erasui. Do man zalt von der gepurt eri | sti M. CCCC. und ju. LXXXVIı. jar. 4. (S), 186 foll. 23 linearum. Bibl. Ernesti Meyer. - Ed. V11: 1490. Gedruckt und volendet in der heyserlichen stat $\mathbf{L u g f p u r g}$ von Hansen Schopsser als man zalt IICCCC und in dem LXIXX. jar. 4. Hain Nr. 12115

Nomen Ortolf von Bayrland praeterquam in inilio libri etiam foll 102 legitur. In exemplari. quod olim possicturat Trew, ignota eaque 102 legitur. In exemplari. quod olim possittuat Trew, ignota eaque ver artznev usz Barrland o ubi equidem in nowine Heidenberger errorem der artzney usz Bayrland o ubi equidem in nowine leidenberger errorem incsse supicor. Aperte enim verum nomen autoris adest in editione III.
foll. 97 : alcl M egtenberger wane, das die wurtz merreltichy elc.)

766t* Osbeck, Pehr. Dagbok ofwer en Ostindisk Resa âreu 1750-1752. ctc. Stockholm, typ. Grefing. 1757. 8. 376 p., praef., ind., 12 tab. * anglice: A royage to China and the East Indies, translated from the gerntan by Jahann Reinhold Forster. London, White. 1771. 8. xx, $396,128 \mathrm{p}$, арp.

* germanice: Peler Osbeck's Reise nach Ostindien und China. Nebst o. Toreens Heise nach Suratte, und $C$. G. Ekeberg's Nachricht von

Pritzel, Thes. lit. bot. ler Landwirthschaft der Chineser. Aus dem Seliwedischen ron Jaham Gollicb Geurgi. Rostock, Koppe. 776.3 .8 . xxır, 552 p., ind. , 13 tab.

$7663^{*}$ Oschatz, Adolf. De Phalli impudici germinatione. D. Vratislaviae, typ. Grass, Barth et soc. $1842.4 .16 \mathrm{p} ., 1$ tah.

$7666^{*}$ Osgood, Francis $S$. The floral offering : a token of friendship. Edited lyy Francis S. Osgaod, author of "Poetry of flowers, and Flowers of poetry. Illustrated with ten beautiful bouquets of flowers elegantly colored after nature by J. Ackerman. Philadelphia, Carey and Ilart. 1847.4. (64) foll., 10 tab. col. (71/2 th.)

$7667+$ Oskamp, Didericus (Theodoricus) Leonardus. Specimen botanico-physicum inaugurale, exhibens nonnulla, plantarum fabricam el oeconomiam spectantia. Trajecti ad Rhenum, typ. Paddenburg. 1789. 4. $70 \mathrm{p}$.

$7668^{*}$ Tabulae plantarum terminologicae, adjecta systematis Linnaei explicatione, nec nou praecipuos vegetabilium characteres eruendi metlodo brevissina. Lugduni Batarorum, Honkoop. 1793. fulio. 8 p., (6) foll.

$7669^{*}$ (- ) Afbeeldingen der Artsenygewassen met derzelver nederduitsche en latyusche Beschryvingen. (Icones plantarun medicinalium.) Ansterdam, by J. C. Sepp en Zoon. 1796-1800. VI voll. 8. 600 tab. col., totidemque foll. text, ind.

(lcones delineavit $J$. C. Krauss; ef. supra Nr. $5 \$ 02$ et $2 \% 1$. )

7670 Ostendorf, Johamnes. Traité de l'usage du tabac. Bordeaux 1636. s. S.

7671* Otho Cremonensis. De electione meliorum simplicium ac specierum medicinalium rythmi. Inpr. cum Macro ox recensione Choulant. Lipsiae, Toss. 1832. 8. p. 157-177.

7672 Ott, Johann Jahob. Dendrologia Europae mediae. Von der Saatpflanzung lud Gobrauch des Holzes, nach den Grundsátzen des IJersn Dullamel. Zurich 1763. S. н.

7673 Kurzer Berich fur den Landmann, von den vornehmsten Futterkrauteru, und vom welschen Korn. Zürich 1764.8. $\mathrm{H}$.

767\%* Otto, Bullhasar, pr. De Nardo Pistica, ex historia passionis dominicae exercitatio plilologica. Lipsiae, e cassiterographia Coleri. 1673.4. (16) foll.

\section{Praeside Bermhard Christian Otto dissertationes:}

$7675^{*}$ Otto, Bermhard Christian. Theses aliquot botanicac medicaeque. D. Trajecti a/V. 1789. 4. 8 p. (Respondens: Christian Andreas Cothenius.)

$7676^{*}$ - De Fumaria. D. Trajecti a/V. 1789.4. 23 p. (Respondens: Daniel Gollfried Ililler.)

$7677^{*}$ — De Phytolacea. D. Trajecti a/ V. 1792. 4. 19 p. (Respondens: Johann Friedrich Hilhelm Kuehn.)

$7678^{*}$ We Pbellandrii aquatici charactere botanico et usu medico. D. Trajecti a/V. 1793.4. 28 p. (Respondens: Johanu Philipp Schwan.)

$7679^{*}$ Otto, Eduard. Reisecrimerungen an Cuba, Nord- und Südanierica 1838-1841. Berlin, Nauck. 1843.8. vil, 326 p., 2 tab. (11/3 th.)

$7680^{*}(-)$ Terzeichniss einer Auswahl von in Freien ausdauernden Btumen, Gesträuchen und Staudengewảchsen, so wie von Hauspllanzen, wèlche im llamburgisehen botanischen Garten abgegeheu werden konnen. Ilamburg, typ. Meissuer. 1845.8 .72 p.

$7681^{*}$ Otto, Friedrich, und Fricdrich Schramm. Kurze Anleitung zum Bau der Gewáhishauser, mil Angabe der innern Einrichtung derselben und der Construction ilurer einzelnen Theile. (A. d. Verliandl. des Vereins zur Beford. des Gartenbaus in d. K. Prenss. Staaten besonders abgerlruckt.) Berliı 1S26. 4.98 p., 6 tab.

7682* - Allgemeine Gartenzeitung. Eine Zeitschrift für Gartnerei und alle damit in Bezieliung stehende Wissenschaften. In Terbindunğ mit den tuebtigsten Gärtnerı und Botanikern des In - und Auslands herausgegeben von Friedrich Otto und Albert Dielrich. Funfzehn Jahrgánge. Herlin, Nauck. 1833-1847. XV voll. gr. 4. $(60$ th. $)$

(Singulae plagulae per licbdomades eduntur. Pretium anni sive voluminis: $4 h$. Accedunt bisce de re hortensi Germaniae longe praestantissinis Annalibus variae icones.)

$7683^{*}$ Otto, Georg Christian. De Carduo benedicto. D. Argentorati, typ. Kursner. 1738.4 .241 . 
itis:" Otto, $J, G$. Versuch ciner auf die Ordnung und den Stand der Lamellen gegründeten Anorduung und J3eselıreibung der Igaricorum. Leipzig, Gerhard Fleischer, I8 16.8 xv, 106 p., ind. (1/2/h.)

j68:3* Otto, Karl. Die vorzaglichsteu in Thuringen wilulwachsenden Giftphanzen, unit besondrer Ruchsicht auf iluron Standpunht in Furstenthum Schwarzburg-Redolstadt. Zur Selbstbelelirung der Jugend und zum Scluulgobrauche dargestell. Rudolstadt, Renovanz. 1834 8. 28 p., 15 tab. ( $7 / 12$ th. $)$ - Lid. Il. jl. $1842.8 .(1 / 1 / h .-$ col. $1 / 3 / h$.

$76.86^{*}$ Der Schlussel zur Botanih, oder hurze und deulliche Anleitung zum Studinn don Gewallskinde ete. Rudolstadt 1835. 12. xvi, 430 p., 19 tah. $\left(4^{3 / 4}\right.$ th. $)$

7687 Naturgeschichte fur Kinder. Saalfold, Niese, 1\$391843. 14 Liclerungen. ar. 8 . $\left(3 \frac{1}{2}\right.$ th. $)$

7688 Outhov, Gerard. Exercitatio de Manma Jsraelitarum. Groningae 1694, 4. H.

7ib99 Oviedo y Valdes, Goncalo Fernandez de. Sumario de la natural y general istoria de las Lndias. Toledo 4526 . Folio. 52 foll. 8.

7690 Primera varte de la historia natural $\mathrm{y}$ general de las Indias, yslas y tierra firme del mas oceano. Sevilla 1535 . folio. CXCIII foll, , ic. sudos xylonr, i. t. B.

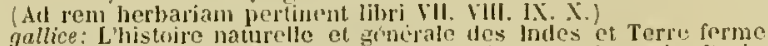
le la grand mer oceane. Trabluicto de castillan en francais, paris,

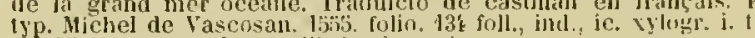
(Sunt tantum decent libri priores.)

7691 Ovington, John. Essay upon the niture and gualities of Tea London 1699. 12. H.

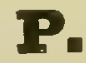

$7692{ }^{*}$ Paarmann, Peter Hichael. Ligni Quassiae examen. D. Argentorati Iyp. Loreuz. 1772. 4. 40 p.

$7693+$ Paaw, Peter, latine Pawius. Ifortus publicus academiae LugdungBatavae, ejus ichnographia, descriptio, usus. Adelito, quas luabet stirpium, numero et nominibus, Lngeluni, typ. Patii. 1603.8. $176 \mathrm{l}$. prael, ind. $-{ }^{*}$ i]. 1629.8 .179 1 , pracf., incl.

(Aliae sunt ellitiones ammorum 1641,1601 ot 1617 . Paginae 176 inseribendis nominibus plantarum inserviturae, qum practer lineas transversas et numeros in margine nolatos nihil contineant. Sequitur Index horti academiae Lumumo-liatavae, chlibens reas, quibus is instructus fuit, stirpes (ad oetingentas) singullis indicatis annis, cum icnographia horti aeri incisa.)

i69: Pabst, II. W. Der landwirthschaftiche Plonzenbau. (Lehrluch der Landwirtluschaft. Erster Rand, zweite Abtheilung: Speziclle Pflauzenprodukitionslehre.) Darmstadt 1839. 8.24 plas. $\left(1 \frac{1}{3} \mathrm{th}.\right)$

(In prima sectione voluminjs printi continelur: "Pllanzenproduktionslehre, ouler atlongeine Giludsitze de's Ackerbaues."

7693 Pacini, Zenobio. Eetypa plantarum. folio. Bibl. Lib. Bar. Roemer.

(De rarissimo opere thane benevole mecum communicavit clarissimus possessor notam: "Der lederland in lseitem Grossfolio trigt auf dem Rucken die Rezeichnung: Icun, plant, origin. lun Bande sellst kommen zuerst 20 Rlatt Papier, auf deren cinem une Salvia pratensis ectypirt mot colorirt ist. Jas Papier lat eill altes Nurnberger Papierzeichen (stadtugpen und ist heinl Binden erst der Sammlung biut-

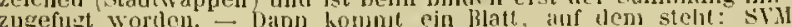
Johannis Oberndorferij Mred. D. dimruter eine giunz hurze lateil. Anweisung zur Fertigung ter Abdrucke voll einer anderu lland. Die llandschrift Oberndorffers deutet auf $1380-1600$. Auf (ler luchseito dieses Blattes ans freier Hand gezeichuet und grmalt ein zweig mit? Acpfeh;

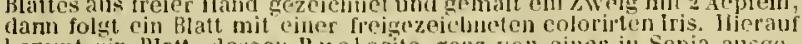
hommt ein RIatt, desseu $\mathrm{R}$ uchseite ganz son ejuct ju sepia alusger-

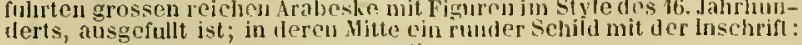
ZENOBITS-PACINVS. FI:S FACIEBAT. Das abhevirte Wort viellejeht Fluminensis andeutend? (1) der Maum uhrigens nur das Blat mut der Arabeshe, oder die ganze Eety pen-Sammbng maclite, bleibt ungewiss. Dann folgen suforl die Blatter mit den coloriten Pflanzenahdrucken, oben in der rechten Lehe jetfes folium beziffert Das letzte Folium ist 159 and jedes tright ant bo id en seiten eine Eotype. Es sind mejst ofticinelle, und der italiet. Flor a augehorige Pdlanzen jede mit dem lateinischen Namen jencr \%eit unterzejehnet. Eimual kommt eiu Blatt yor mit einen atus frejer flaut colorist auscefinltent fratanthus nivalis, wonehers mit hleinerer sclurjt: crescit in horto anno 1605 . Doch seheint dieses Blitt nicht zur ursprunglichen, gewiss siteren Samnlung au gehoren und ist wahrscheiulich durel deo Besitzer Oberudorffer beim Biudenlassen eingeschillet. Ein beigelentes sitzer Oberndorffer beim Biudenlassen eingeschaltet. Em beigelegtes in Nünberg Buchersammlung" stamme, "Nacb inzcige Beckmanns

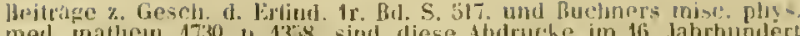
med. Inathon. 1730. p. 135. sind diese Abdrucke im 16. Jahrbunder

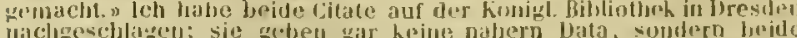
erwiluc'n nur die lisistenz dinses Werkes it Baiers Biblinthek, o)

7695 "Packbusch, Stephan Luduiy. De varia Mlantarnm propagation". D. Lijusian, typ. Reinloldi. 1645. 4. (10) foll. liesprondens: Johnn Jukol, Wonyt.)

7697* Padeira, liuiolph. De Secali comulo. D. Berolini 1834. 8. 45 p.

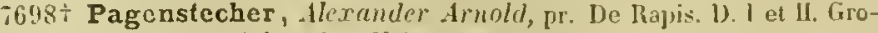
ningar, typ. Johannis a Velsen. 1710 . 12. 40 p. Bibl. Webb.

$7699^{*}$ Pagenstecher, Friedrich. Vel,er Linum catharticuun Liun. 1) Mlunclsen, 1yp. liranz. 1845. S. 24 j.

$7700+$ Pagés. Remartues sur une erreur t]e synonymie relativement au. Lycopodes. Paris, typ. Lebel. 1824. 8.9 p. Bibl. Montagne.

$7501+$ Pajon de Moucets, l'ierre Abraham. In post cibum funus 1abaci? D. Paris, Iyp. (Quillau. 1749.4.4 p.

$7702^{*}$ Palacky, Franz. Dic Grafen Kospar und Franz Sternberg, und ihr Wirken fur Wissenscluaft und Kunst in Bulmen. Vortrag, gelıalten in der Tersammlung der hönigl. bohmischen Gesellschaft der Wissenschaften, am 15. Dezember iS 4. Prag, kronberger und Riwnac. $1843.4 .38 \mathrm{j},(1 / 2, \mathrm{~h}$.

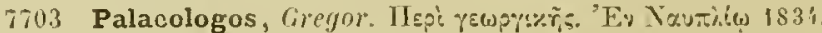
Fraas sinups. plant. II. class. 1. 27.

7701. Palasso. Essai sur la mineralogie des Pyrenées, suivi d'un cat:1logue des plantes. Paris 1781.8.

$7003^{*}$ Palisot-Beauvois, Ambroise liarie Franrois Joseph. Flor d'Oware et de Benin en Arrique. (Latine et gallice.) Paris, de l'inprimerie de Fain joune et Co. $1804-1807$. Il voll, folio. - I: in Xl1. $1804 . x i n, 100$ ]., tals, col. 1-60. - II: 1807.95 p., tab. col. $61-120 .(480 \mathrm{fr},-$ nigr. $240 \mathrm{rr}$.

(Raman jolque puleherrinum opus prodiit 20 fascieulis usque ad

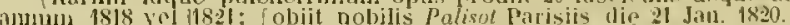
In singulis fasciculis insunt 6 tabulae: pretio 12 fr. nimr.; 24 fr. (ool.)

$7706^{*}$ Prodrume des cinquieme et sixiense familles de J'Actheganuie. Ises Mausses, les lijcopodes. Paris, Fournier lil1805. 8. $11,114 \mathrm{p} .(3 \mathrm{fr}$ )

(Scorsirn impr. ex Mlagasin encyclopédique, an IX. rol. Y.j

7707 Eloge historique de II. Fourcrny, ronseiller thetal a vic. Paris, tyl lain. $1811.4 .38 \mathrm{p}$ a.

$708+$ Nouvelles observalions sur la fructification des Mousses et des Lycopodes. (Paris typ. Courcier. 1 8 I1.) 4. 32 p., 1tah. $5709 \div$ Premier (et second) menuoire et abservations sur l'arrangement et la disposition des feuilles; sur la moelle des régetaux ligneus et sur la conversion des couches conticales en hois. (Paris 1812.) 4. 42 P., 4 tal\%.

$770^{\circ}$ _ Essai d'une nouvelle agrostographic; ou nomveaux genres des Graminées avec figures rejrésentant les caractères de tous les genres. Paris, typ. Fain. 1812. 8. Lxxiv, 182 p., et . Atlas in 4

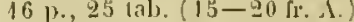

(Sunt ramplaria in uguata forma impressa.)

$\mathrm{ZTil}^{*}$ Muscologie, on traté sur les Mousses. Paris, tỵ. (l'llautel. 1822. S. SS 1), 11 tab.

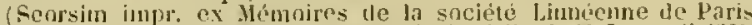

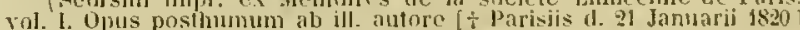
imperfectum derelictum, solummodo gencra continet.

$7712^{*}$ Palladius, Rutilius Taurus Aemilianus. De re rustica libri. (Cum scriptoribus rej rusticao.) Editio prinecps: Venetiis, Nicol Jenson. 1472. folio. a foll. 239-298. - * El. Il. Reurii, Bnz. Bruschus, alias Bottonus, nonis Junii 1482. folio. - "Parisiis 1533. folio. - "Lugduni, Sobastian Gryphius. 1541. 8. - "Parisits, Stephunus. 1543.8. - Lugduni, apud Gryphium. 1549. 8. - " curavit J. M. Gesner. Lipsiae, Fritseh. 1735.4. - "Biponti 1787. 8. - " Ex optimorum scriptorum atque editorum fide et virorum doctorum conjecturis correxit, atque interpretum omuium collectis et excerptis commentlariis suisque illustravit Joham Grollob Schneider. Lipsiae, Fritsch. 1795. S. - ${ }^{*}$ De insitionibus (le re rustica liber $\mathbf{N} 1 \mathrm{~V}^{\circ}$ ) impr. cum Poet. lat, min. ed. N. E. Lemaire, Paris 1824-1826. 8, vol. Vll.) (Ilas pancas ediniones ipse vidi.) sansosinto. Venetia 1500 \& 90 foll. B.

italice: Tratlato di agricoltura, lato alla Juee da $P$. Zanolti. lierona, llamanzini. 1810. 4. Ebert.

anglice: The fourtecen boohs of Palladius Rutilius Taurus Aemiliunus on agriculture, by Th. Oreen. London $180^{-}$, \&. (8s.) Ebert. 
Ebert.

$7713^{*}$ Pallas, Johann Dietrich. De Clirysosplenio. D. Argentorati, Iyp. Jeitz. 1758.4.20 p

771 $4^{*}$ Pallas, Peter Simon. Reise durch verschiedne Provinzen des russischen Reiches. St. Petcrsburg, Drucherei der Akatemie der Wissenschaften. (Leipzig, Voss.) 1771-1776. 3 Theile. 4. - 1 1771. 504 p., tab. sign. $1-11$ et $\Lambda$-L. - ${ }^{*}$ Ed. Il : ib. $1801 .-$ Il 1773. 74 p., tab. sign. 1-14, A - Z. - Ill: 1776.760 p., ind. tah. sign. $1-8, A-N$. $\left(11 \frac{1}{4}(h)\right.$

rassice: II. C. II ал.маса путешествӥе по разныпғ, шровинціямт Россійской Нилсрій. Уастт 1-3. Ed. I et Il. IIere 6 . Trautv.

+ gallice: V'oyages dans plusieurs provinces de l'impire de Russie et dans I'Asie septentrionale, traduits de l'allemand par le C. Gauthier de la Peyronie. Nouvelle érlition. Parjs, Maradau. an II. 1793. vill voll 8 Botanique: vol. IIII. p. 21 - 28 ) avec Atlas in $4^{\circ}$ to8 tab. (tab. 41-108 ad hotanicam spectant.)

- Reise durch rerschiedene Provinzen des russisclien usfulurlichen Auszuge. Frankfurt und Leipzia, Fleischer, 1776-1778. 3 Theile. 8. - 1: $1776.384,52$ p. 4 tab. - II: 1777. 464,51 p. 22 tab. - 111: 1778. 488,80 p., ind. 51 tab.

$7716^{*}$ Ennmeratio plantarum, quae iu horto Procopii a Demidof Moscuae vigent. Petropoli 1784. 8. xxx, 163 p., 3 tał, col

(Editionem alteram auctiorcm anonymam recensui supra Nr. $2 k 37$.)

$7317^{*}$ - Flora rossica, seu stirpium imperii rossiei per Europam et Assain indigenarum descriptinnes et icones. Jussu et auspiciis Cutharinae 1I. augustae edidlit. Petropoli, ex typographia imperiali J. J. Weitbrecht. (Lipsiae, Voss.) Tomi J. pars I el Jl. $1784-1788$. fulio - Tomi l pars I: 1784. vil, so p., 1ab. col 1 - L. - Tomi I pars II : $1788.11 /$ p., aal, col. LI-C. $\left(24^{3} / 8 / /\right.$. $)$

(Jil Bibliotheea herbarii regii Berolinensis rexstat exenplar notis Pallasi manuscriptis.)

$77188^{-}$Flora rossica, seu stirpium imperii rossici per Europan el Asiam indigenarum descriptiones. Tomi I pars I ef ll. Francofurti et Lipsiac, J. G. Fleischer. 1789-1790. 8. - 1: 1789. xxI, $191 \mathrm{l}$. - II: 1790. $229 \mathrm{p}$.

(Est reimpressio textus ex editione originali Florae rossicae, absigue tabulis.)

$7319^{*}$ - Tableau physique el topograplique de la Tauide, tiré du jourual d'un voyage fait en 1794 . St. Petersbourg (Leipzig, Voss.) 179 s. gr. 4. 59 p. $(3 / 8$ lh. $)$

* germanice: Phy sikalisch-topographisches Gemalde von Taurien. In ejus Neve nordische Beitrige VII. p. 371-438. - Physische und topouraphische Scbilderung Tauriens, limelin's Juirnal I. p. 86-13'

$7 j 20^{*}-3$ í) Luaterschaften des russischen Reichs, in den Jahren 1793-1794.

Erster Band. Leipzig, Martini. 1799. 4. xxxil, 516 p., 25 tab. col.

anglice: Travels through the soutluern provinces of the Russian Empire, 1793-179'. London 1502-1503. I1 voll. 4

$7721^{*}$ Specjes Astragalorum descriptae et iconibus colrratis illustratae. Cum appendice. Lipsiae, sumtibus Godofredi Martini. 1800. folio. vit, $12 \%$ J), 91 iab. col. (53 th.)

$7722^{*}$ —_. Illustrationes jlantarum imperfecte vel nondun cognitarum, cum centuria (non alssoluta) icnnum, recensente Petro Simon Pallus. Lipsiae, sumtibus Godofredi Martini. 1 s 03 , folio. 68 p., 59 tab. col. $\left(34^{1 / 2}\right.$ th. $)$

(Prodjit quatuor fasciculis annis 1803-1806. Liber omnino in IIaInphytis versatur. Singularum specicrum recensioni praecedit: De Italophytis set plantis apetalis kalicis getieratim, p. 1-6.

("In catalogo Jibrorum ad nuntinas pischales anni isog impres sorum indicantur: «P.S. Pallas, Jcones plintarum selectarum cum descriptionibus. Fasciculus I. Lipsiae, Tauchnitz in comm. 1809. folio. Quie tabulae a Pallasii in itineribus sucio, Geissler, Lipsiensi, scuiptae, licel a Schultes Grundriss p. 220 , et a vener. Link (Wjlld. Grundriss. erl. Vil. vol. 1. p. 600 ) citatie, certo e pretis Tauchnitzianis, teste virn human. Caralo Tauchnitz, nou prodierunt.)

$7723^{*} \mathbf{P a l m}$, Ludwig Ileinrich. Ueber das Winden der P(lanzen. Preissclurift. Stuttgarl 1827. 8. vi, 101 1), 3 tab. ( $7 / 12$ lh.) (Praeside Ferdinand Gollob Gmelin; ef. Nr. 3695.)

7724 Palmberg, Johan. Serta florea suecana, eller: svenske Örte-Krantz, afr Johanne Palmberg, Medicinae el Physices Lector uthi Strengnáas, sammanflatad. Alır efter Christi Bord 1684. Tryekt af Zach. Asp. 8. $(46), 416 \mathrm{p}$, ind., cum figuris. B. et W. - Serta florea suecana etc. A nyo uplagd och forbăttrad, samt vid slutet forsedd med en vacker tilukining af många hárliga och bálsosamma Orter, af $J$. B. Stenmeyer, Lycei IIolm. teul. Rectore. Stockholm, uplagil med Joh. L. IIorns egen bekostnad. $1738.8 .282,118$ p., (62) p. ind., sine figuris. W. (De npere Palmbergit dixit Linnaeus in Flora suecica ed.11. p. IX: "J)escriptiones imperfectae, figurar rudes, vires compilatae. Stenmeyer $\div$ i 1738] appendicem subject. $)$

772:3* Palmer, Johann Ludwig. De plantarum exhalationibus. D. Tuel)ingae 1817. 8. 45 p. (Pracside Ferdinand Gotllob Gmelin; ef. Nr. 3694.)

$7726+$ Palustre. Éturles de botanque, ou classification des végétaux d'après les méthodes de MII. de Jussieu el de Candolle, avee deux nomenclatures botaniques. Puitiers, 1yp. Saurin. 1840.4. 34 p. (3 fr.)

$7727+$ Botanique. Niort, typ. Robin. 1841. 8. $12 \mathrm{p}$.

$7728^{*}$ Pamplin, IIlliam. $\Lambda$ Catalogue of books, chiefly botanical et horticultural, olfered for sale by IVilliam Pamplin, (successor to the late Hr. John Jlumeman) 9, Gueen Street, Soho Square, London. London, Luxford. 1840. 8. 26 p.

7729* Pampuch, Albert. Flori Tremesnensis, oder systematisclse Aufstellung der in der Umgegend von Trzenessno (Magn. Duc. Posnan.) bis jetzt entdeckten wildwacbsenden Planzen. etc. Trzomessno, Olawski. 1840.8. 70 p.

7730 Panarolns, Dominicus. Polyearponia, seu variorum fructuum labores. Romae 1647. 12. H.

$7731^{*}$ - De necessitate botanices seu de simplicium cognitione medico necessaria Proludium. Impr, cum ejus Medic. observat. pentacust. quinque. Ronae 1652. 4. - "Hanoviae, typ. Aulary. 1654. 4. p. 182-188. Bibl. aul. vind.

Prodiit prius teste Merklin: Romae 1643.4.

7732 " - Pantarum amplitheatralium catalogus. Impr. cum ejus Medic. olsservat. pentacost. quinque. Romae 1652. 4. - "llanoviae, 1yp. Aubry. 1654. 4. p. 189-195.

(Sunt plautae in Aniluilueatro Vespasiani Romae sponte nascentes.)

7733* Panckow, Thomas, latine Pancovius. Ilerbarium portatile, oder behendes lirăuter und Gewachsbuch, darin nicht allein 1363 sowohl einhcimische als auslándische lírauter zierlich und eigentlich abgebildet, sondern auch die meisten hurzlich erklart werden. Nebst Herrn Theophili Kenntmanni angelıảngter Krâutertafel. Berlin, typ. Chr. Runge. (1654 ) 4. 172 p., ind, 1363 ic. xylogr, i. t. - ${ }^{*}$ Herbarium, oder lírater- und Gewáclsbuch, darin sowoll] einheinische als ausländische Krâuter zierlich und eigentliclı alogebilatet zu finden. Auf vielfalliges Begehren mit Fleiss ubcrsehn elc. durch Bartholomueam Zornn. Colln an der Spree, Geors Schultze. 1673.4. 425 p., praef., ind., 4536 ic. xylogr. i. 1. - (Eadem impressio redit Lipsiae 1679. 4. prima tantum plagula denuo impressa.) в.

7734* Panzer, Georg I'olfgany Franz. Observationum botanicarum specimen. Norimbergae et Lipsiae, Schneider, 1781. 8. 56 p., praef. $(1 / 6$ th. $)$

$7733^{*}$ Beitrag zur Geschichte des ustindisches Brotbaums mit einer systematischen Beschreibung desselben aus den álteren sowohl als neueren Nachirichten und Beschreibungen zusammengetragen. Nüruberg, Raspe. 1783.8 .45 p., I tab. (1/t th.

(Redit in Linme's Vollstándiges Prlanzensystem vol. X. Nurnber: 1783. 8. 1). 337-381.)

$7736^{*}$ De Volcamero quaedam, additis duabus Boerhavii et Tournefortii ad illum epistolis antea nondum impressis. Programma gratulatorium. Norimbergae $1802.4 .15 \mathrm{p}$.

$7737^{*}$ - Ideen zu einer kunftigen Revision der Gattungen der Gräser. Munchen, (Frauz.) 1813.4.62 p., 6 tab. ( 1 th.)

(Senrsim impr. ex Jenkschriften der Konigl. Akademie der Wissenschaften zu Munctjeı fur 1813. p. 233-31\%.)

$7738^{*}$ Pappe, Karl Wilhelm Ludwig. Enumerationis plantarum plaenvgamarum Lipsiensium specimen. D. Lipsiae, typ. IIirsch felı. 1827. S. $\mathrm{xx}, 42 \mathrm{p}$.

$7739^{*}$ Synopsis plantarum phaenogamarum agro Lipsiensi indigenarum. Lipsiae, Voss. 1828, \&. xx, $85 \mathrm{p} .(1 / 2 \mathrm{th}$.

7740 Paquet, $V$. Traité complet de la culture ordinaire el forcée des plantes potagères dans les 86 départemens de la France, contenant etc. Paris, Garnier. 1846.12 .17 plag. (3 fr. 75 e.)

774 Paracelsus, Aureolus Ihilippus Theophrastus Bombast von Hohenheim, cognomine Paracelsus. Das llolzbüclılein, darinnen grintlich der recht wuz unnd gelrauch des Franzosenlsolzes reichlich wirt angezaigt. 1565 . S. $2 \frac{1}{2}$ plag. B. 
7712 Paracelsus, Aureolus Philippus Theophrastus Bombast von Hohenheim, cognomine Paracelsus. Bticher und Schriften, jetz aufs new aus den Originalien an Tay gehen durch J. Juserum. Basel, Chr. Waldkirch. 1589-1590. II Bánde. 4. Ebert.

7743 - Operum nedico-chymicorum sive pararloxorum tomi Xll. Francofurti a/AI, apud Palthenios. 1603. IV voll. 4. S.

774k" - Opera emuia medico-clscmico-chirurgica, tribus voluminibus eompreliensa. Editio novissima et emenclatissima ad germaniea "I latina exemplaria aceuratissime collata; variis tractatibus et opusculis summa hine inte diligentia conçuisitis, ut in voluunins primi praefatione indicatur, loeupletata : indicibusque enactissimis instructa. Genevae, sumtibus Joh. Ant. et Samuelis De Tournes. 1658. folio. effigies autoris. Bibl. univ. Lips.

$77150+$ Paris. Mémoire sur la culture comparative de cliverses espèces de cotonniers. Paris, typ. Iuzard. 1810.8.78 p., 2 tableaux.

$7746 t$ Mémoire sur la culture de la soude dans l'arrondissement de Tarascon, Dép. des Bouclıes-du-Rhóne; suivi d'un rapport fait a la saciété par MM. Jauquelin, Tessier et Bosc. Paris, typ. Huzard. $1810.8 .36 \%$.

$777^{*}$ Parkinson, James. Organic remains of a former world. London, typ. Wittingham. 1811. Mll voll. 4. - Vol. l. containing the vegetable kinglom: xil, 461 p., ind., 9 tal). col., 2 tab. nigr. (4l. $4 \mathrm{~s} . \mathrm{A}$.) (Vol. H et III, rem nostram non tangunt.)

77 1 8 t Parkinson, John. Paradisi in sole Paradisus terrestris, or a garden of all serts of pleasant flowers ... with a hitchen garden of all manner of herbes, rootes and fruites, for meate or sause used with cuts, and an orchast of all sorte of fruthearing trees and slurubbes fit for our land together with the right orderinge planting and preserviug of them and their uses and vertues. Louton (printed by Humplirey Lownes and R. Young.) 1629. Jolio. 612 p., pracf., ind., ic. xylogr. i. t., effigies autoris aet. 62. - †The second impression much corrected and enlarged. Lonton, Thrale. 1656. Solio. 612 p., pracf., ind., ic. rylngr. i. t. Bibl. Juss.

(aDans l'édition de 1633 il n'y a autre chose de changé que lo frontispico. $D C$. mss.)

$7799^{k}$ — Theatrum botanicum: the theater of plonls: or an herball of a large extent: containing therein a more ample and exact history and declaration of the physicall herbs and plants that are in other authours, enereased by the accesse of many luurireds of new, rare and strange plants from all the parts of the world. etc. etc. Jondon, printed by Tho. Cotes. 1640. folio. ( 9 foll.), $1755 \mathrm{p}$. cun multis iconibus ligno incisis.

750 Parkinson, Sydney. A journal of a voyage to the South Seas, in his Majesty's slip, the Endeavour. London 1773.4.212 p., 27 tab. B. (Plants of use for foot, medicine ete in Otaheite p. $37-30$; germanice: Die Ptanzen des' insel tutaluitee, mit Annerkungen erliutert, in Naturforseher, viertes Stick, [3. 220-208.)

$7731+$ (Parjasca, Simon.) Il fiore della granadiglia overo della passione di nostro Signore Giesu Clıristo spiegato e loclato con discorsi e vario rime. In Bologna, appresso Bartolomeo Cocehi. 1609. 4. ad iustanza di Simone Parlasca. 22 p. 1 tab. Desid. Banks., Bibl. Reg. Par.

(Adjecta sunt varia latina ac italiea carminit in florem passionis Christi, endem anno per eunden Coechium impressa: $42 \mathrm{p}$.)

$7752+$ Parlatore, Filippo. Breve Cenuo sulla vita e sulle opere del Barone Antonio Bivona-Bernardi. Patermo, tipografia del giornale letterario. $1837.8 .49 \mathrm{p}$.

(Estratto dal Giornale di scienze, Iettere ell arti per la Sicilia Nr. 180.)

7733 t - Rariorum plantarum et haul cognitarum in Sicilia sponte provenientium fasciculus I et II. Panormi, typ. diarii literarii et typ. Oretea. 1838-1840.8. - I: 1838. 16 p., 2 tals. - II: 4840.16 p., tab. (non vidi tabulas.)

7754 - Observations sur quelques plantes d'Italie. (Extrait des Annales des se. nat. Cahier Mai 1841.) Paris, typ. Renouard. 1841. 8. 12 p.

$7755^{*}-$ In nomullas Filaginis Fvacisque species ox naturali Compositarum familia observationes. (Firenze 1841.) 8. 8 p. Nr. 2.)

Giornale Toscano di scienze mediche, tisiche e naturale, 1. I.

$7736^{*}$ Nr. 2.) Sulla botanica in Italia e sulla necessiti di farmare un erbario generale in Firenzc. Discorso. Parigi, Lacombe. 1841. 8. $19 \mathrm{p}$.

(Lo stesso riprodollo in Palermo ISr?.)
7757* Parlatore, Filippo. Come passa cousiderarsi la lutauica uello stato attuale delle scienze naturali. l'rolusione etc. lirenze, Piatti. 18:2. 8. $35 \mathrm{p}$.

$7758^{\circ}$ Plantar novae vel minus notae opusculis diversis olim descriptae generibus quilusdam speciebusijue novis adjectis iterum recunnitae. P'arisiis, Gide. 18 亿 8.87 p.

$7759+$ Sulle impronte de' vegetalrili fussili di M. Mlessi e di M. Bamboli nella Maremma Toscana. Lettera al chiar. Sign. Cav. P'rof. Paolo Savi. (Firenze 1843.) 8. (4) p.

$7760^{\circ}$ Notizia sulla Pachira alba della faniglia delle Bombaceac. Firenze $1843.8 .7 \mathrm{p}$.

$7761^{*}$ Lezioni di botanica comparata. Firenze, societa tipografica. $1843.8 .238 \mathrm{p}$.

$7622^{*}$ — Nonografia delle Funariée, presentata alla Sezione botanica del quarto congresso degli scienziati italíni in Padova, nel settembre del 1842 . Firenze, per la societa tipografica. 1844. 8. x. 110 l., 1 tab. (3 Lire fiorentine.)

$7763^{*}-$ Sullo spirito dello seienze naturali nel secolo passato $r$ nel presente prolusiene. Firenze, societa tipografica. 1844.8. Z1 p.

$\% \boldsymbol{1}^{*}$ - Osservazioni sull anatomia dell Aldrovanda resiculusa, pianta ajuatica della famiglia delle Droseracee. Firenze, sec. lipogr. 1844.8.8 p.

$7763^{*}$ Maria Antonia, novello genere della famiglia delle Leguminese. Firenze, sacieta tipografica. 1844.4 .8 p., 11 ab.

$7566^{*}$ Gionalo butanico italiano, compilato per cura della sezione botanica dei congressi scientifici italiani. Firenze, per lit societa tipografica. $1844-1846.8$.

(Accuralius indicabitur infra inter diaria.)

$7767^{*}$ _ Flora Palermitana, ossia deserizione delle piante che crescono spontanee nella valle di Palerno. Volunse primo. Firenze, per la societa tipografica, 1845. 8. xxu, 218 p. (4 fr. 20 c.) Bibl. Griseb.

(List particula incompleta Flarae quinque voluminibus absolvendae, in qua plantac trium priorum classium Litut. continentur. In Bibliotheca Cantolleana et Delessertiana idem fragmentum adest hoc latino titulo "Flora Panormitana sivo plantarum prope Panomum sjonte nascentium enumeratio. Vol. I. Fase. I-II. Panormi, typ. Pensanto 1839.8.,

$7768 \div-$ Sulla stato attuale dell erbario centrale italiano. Discorso letto il 23 Settembre 1845 nella sezione botanica del settimo congresso degli scienziati italiani in Napeli. s. 1. (1845.) 8.11 j).

(singulos insequentes autoris comnentariolos, qui partim in collectionc Nr. T758 redeunt, non vidi: Su di una prelesa nuova specie di lino. Palermo 1833 . - Nova Serapiadis species ex Orchidearum familia. panormi 1837. eum icone (redit in Linnaca Xil. 3\$7.) - Prospetto dello stato della hotanica in sicilia nel princijio del secula decimonono. Palermo 1838. - Tcones plantarum rarierum et haud cognit. Florae Panormitarae. Panormi 1839. - Gita botanica. Palermo 1834 - Su danni e sull" utitita dei fiori. palermo 1839. - Trignea, novello genero della famiglia delle Liliacte. Palermo 1839. - Yova (Inithogalispecie ox Liticucearum familia. Paoormi 183!) - Nova Silenes spedies (s. Manclralisci) ex Carrophyllacearum fanilia. Panormi 1S39. - Plantie Canarienses Gramineae of I'mbelliferae, in II ebb. ct Berthelot llistoire naturelle des iles Canaries.)

$7769+$ Parley, Peter. Tales about plants; witl engravings. London, Tegg. 1839. S. su, 500 p. $(7 \mathrm{~s} .6 \mathrm{ll}$.

7770 Parmentier, Antoine Augustin. Mémoire qui a renporté le prix de l'Acalimic de Besançon sur cette question: Indiquer les végétaus qui pourraient suppléer, en tempss de disette, à ceux qu'on emploio communement à la nourriture des hommes, et qu'clie en devrait etre la preparation. Paris 1772. 12. Q.

771 Examen chimique des pommes de terre, dans lequel on traite des parties constituantes du bled. Paris, Didet le jeune. 1773. 12. (2 fr. $50 \mathrm{c.}$ ) a.

7772 Ouvrage économique sur les ponmes de terre, le froment et le riz. Paris 1774.12 . Q.

$7773 \div$ Expériences et réflexions relatives à lanalyse du bled et des farines. Paris, Monery. $1776.8 .1 \mathrm{v}, 194$ p. ( 2 fr.)

$777 \%$ Manière do faire le pain de pommes de terre sans mélange de farine. Paris, de l'imprinerie royale. 1779. 8. a.

$7775^{*} \longrightarrow$ Traité de la chataigne. Bastia et Paris. Monory. 1780. 8. xxvil, $160 \mathrm{p}$.

$7576-$ Les pommes de terre considérées relativement à la sonté et a l'économie; ourrage dans lequel on traite aussi du froment et du riz. Paris, Nyon l'ainé. 1781.12. a.

$7775+\longrightarrow$ Recherches sur les végétaux nourrissans, qui dass les temps de disette peurent remplacer les alimens ardinaires, arec 
des nouvelles observations sur la culture des ponmes de terre. Paris, imprimerie royale. 1781.8 . xvi, 599 p., 1 tab.

7778 Parmentier, Antoine Augustin. Mémoire sur cetto question: Quel serait le meilleur procédé nour conserver le plus long-tenus possible, le mais ou blé de 'Turquic; augmenté de tont ce qui regarde l'histoire natnrelle et la culture de ce graill. Bordeaux, Pallandre l'ainé, 1785. 4. a.

Instruction sur la conservation et les usages de la poume de terre, publiée par ordre du gouvernement. Paris, de l'imprimerie royale. 1787.8 . a.

$7780 \div$ Traité sur la culture et les usages des pommes de terre, de la Patate et du Topinambour. Paris, Barrois. 1789. 8. Virr, $386 \mathrm{p}$.

$7781 \div-$ Rozier, Lasteyrie et Delalause. Traité thẻorique et pratique sur la culture des grains. Paris, Delalain. 1802. ll voll. 8. - I: vilt, $472 \mathrm{p}$. $-11: 574$ p., 15 lals.

Instruction sur les noyens de suppléer le sucre etc. paris, Mequiguon l'aine. 1808 . 8. 96 p. - Ed. ll. ib. $4809.8 .-$ Ell. III: Traité sur l'art de fabriquer les sirops et conserves de raisins, destiués à suppléer le sncre des colonies dans les principaux usages de l'économie donestique. il). 1810.8 . (5 fr.)

77837 - Aperçu des resultats ubtenns de la fabrication des sirops et des conserves de rajins. etc. Paris, de l'imprimerio impériale. $1812.8 .452 \mathrm{p}$. ( $5 \mathrm{fr}$.)

$7784^{*}$ Le Mays ou blé de Turquie apprécié sous tous les rapports. Némoire conronne; nouvelle édition. Paris, de l'imprinerie impériale. 1812.8 . vill, 303 p. $(4 \mathrm{fr}$.)

(Editionem priman habes snpra Nr. 7778.)

$785^{*}$ Parmentier, Joseph. Catalogue des arlures et plantes cultivés dans les jardins de Mr. Joseph Parmentier. Bruxelles, Demanet. 1818. $8.82 \mathrm{p}$.

786 Parnell, Richard. The grasses of Britain, containing a scientifie description of each species, remarks on their use in agriculture etc illustrated by figures drawn and engraved by the author. Edinburgh and London, Blackwood and Son. 4845. gr. 8. 360 p., 142 tab. (2l. 2s.)

(Grasses of Scotland: tab. 1-66. Grasses of Britain: tah. 67-1t2. Gramina Scotiae quae in hoe libro redeut, jam amo 48 '2 seorsin prodierant, pretio 1 .)

$7787^{*}$ Parrot, Friedrich. Reise zum Ararat. Berlin, Ilaude und Spener. 1834. 2 Theile. 8. - I: Reisebeschreiluung. 262 p., 5 (ab. - II Wissenschaftliche Abbandlnngen. $498 \mathrm{p}, 3 \mathrm{tab},(5 \mathrm{th}$.)

De hoc itiugere of Trautwetter Grundriss p.

7788 Parskius, Fr: Rosa aurea omnique aevo sacra. s.1.1728.4. 86 p. в.

7789 Parsons, James. The nieroscopial theatre of seeds. Volumen I. London 1745. 4. 348 p., 8 tab. B.

(In Bibliotheca Banksiana adsnut etiam arehetypa iconum al) autore delineata com figuris tabnlite nonae ineditie.)

7790 _... Philosophical observations on the analogy between the propagation of animals and that of vegetables, with an explanation of the manner in which each piece of a divided Polypus beeomes another perfect animal of the same species. London 1752. 8. 276 p. B.

7791 Partington, C.F. Introduction to botany, illustraterl on a new principle. Loudon, llarvey. 1836.8 . $(6 \mathrm{~s}$. - cum 10 tab.: 1l. 1s. cum 14 tab. col.: $2 l .2 s$.)

7792* Partsch, Paul. Bericht uber das Detonationsphanomen auf der Insel Mleleda bei Ragusa. Wien, Heubner. 1826. 8. xı, $241 \mathrm{p}$. 1 charta geogr. $(13 / 4$ th.

(Plantae iisulae Meleda p. 19-22.)

7793 Pasini, Antonio. Annotazioni ed emendazioni mella tradottione di P. A. Mathioli de cinque libri della materia medicinale di Dioscoride. Bergamo, Corvino Ventura. 1592. 4. 252 p. B. - ‘jb. 1600.4. Bibl. Reg. Paris.

779.4* Pasquale, Giuseppe Antonio, e Giulio Avellino. Flora medica della provineia di Napoli, ossia descrizione etc. Napoli, Azzolino. 1841. 8. $200 \mathrm{p}$.

$7793 ̈+$ Pasquier, Victor. Monographie du Madi cultivé, Madia sativa. Liège, tỵp. Oudarı. 1841.8 .135 p., 3 tab.

$7796^{*}$ Passaeus, Crispinus, alias Du Pas. Hortus floridus, in quo rariorum et minus vulgarium florum icones ad vivani veramque formam accuratissime delineatae et sccundun quatuor anni tempora divisae exhibentur, incredibili labore ac diligentia Crispimi Passue junioris delineatae ac suum in ordinem redactae. Aruhemii, apud Janssonium. 1614-(1617.) 4 ohliq. 484 foll. et tab.

Ver: $\$ 1$ tah. aeneac, (Hallera 34.$)$ Aestas: 19 tabulac aeneae. Autunnus: $2 j$ tah, deneae, praeter duas numeris non lotatas. llyems: 12 tab, aeneac. Textus latinus in aversa pagina tabularum inpressus est. Pars altera: Jigurae 1920 in 61 tabnlis absque textu. Bars harum tabularum redit in lconibns Boetii de Boot, quas supra Nr. 1046 reeensui. Tabularnm fartis vernalis duae adsunt editiones, quarum altera figoras variat insectormu habet, altera vero non. Tabularum etiam partis autumnalis of hy'enalis duae adsunt editiones, quarun altera numerum tabularum sculptum non liabet, nec ullum testum, altera prioribus assimilatur. Seguitrus habet partis prinae editionem anteriorem: Aruhemii 1607, 4. et conjunctorun tomorum posteriores: Amstelodami 1631 . tolio. et $163 k^{2} 4$.

anglice: A garden of thwers, wherein is contained a description of all the flowers contained in these fonre followinge hookes, as also the perfect true mamier of colonringe the same with their naturall coloures. Utrecht $161 \%$, folio obliq. B.

( 1 Booke : 5 foll, 4 tat. aenene, ut in priori editione et practerea tabulae 43-5' Tuliparum, quarum vero nulla in textu mentio. 9 Booke : 2 foll., 20 tals. 3 Booke 3 foll., 25 tab. - 4 Booke: 2 foll., prioris editionis, et in hac nit nisi deseriptio colorum.)

$7797 \div$ Passaeus, Crispinus, alias Du Pas. Cognoseite lilia agri quomodo crescant, won laborant neque nent: attamen dico vobis ne Salomonem ruidem in universa gloria sua sic amictum fuisse, ut unun $\mathrm{ex}$ his. Mlatth. 6. cap. Formulis Crispiani Passaei et Joannis Waldnetii. s. a. et 1.4 obliq. is foll. cum titulo. Bibl. Cand.

Continentur in loc libro plantarum figurae aeri incisae 1-99, nominibus latinis, gallicis, anglicis, germanis. Prima icon est Chamaeniolon; ultima Quer('ns.)

7798 Passavant, Claude. Theses anatomico-botanicae. Basileae 1733. 4. H.

7799 Passeratus, Johannes. De Oliva carmen conditum Kal. Jun. anno 1588. s.

$7800^{*}$ Passerini, J. Flora ltaliae superioris methodo analytica. Thalamiflorae, pracmissa synopsi familiarum Pbanerogamiae. Mediolani, apud Sanctum Bravetta. 1844. 8. vIII, 134 p.

7801 Passerini, Valentino. Sogno di I'alent. Passerini nella licenza, ch"ei prende da Monte Baldo. Treato, Giovanni Parone. 1684. 12. S.

(Versibus plantas in munte Baldo ah eo repertas deseribit autor.)

$7802+$ Pasta, Giuscupe. De la vertu de l'opium dans les maladies vénériennes. Opuscule traduit de l'italien par Brion. Lyon, chez le traducteur. $4816.8 . x v 1,22 p$

7803* Paterson, lyilliam. A narrative of four journeys into the country of the IJotentots, and Caffraria, in the years $1777-1779$. London 1789. 4. 171 p., 17 tah. col. I mappa geogr.

(Icones redeunt in Bruce Trasels : + 19 iab. folio ; pleraeque renı tangunt herbarian-

* germanice: Reisen" in das Land der liottentotten und Kaffern. withrend der Jahre 177\%-1779. Aus dem Englischen von Johann Reinhold Forster. Berlin, loss. 1790, 8. 170 p, 13 lab., 1 mappa geogr. depuis yai lot jusqu'en chez Benjamin de Laborde. Paris, Didot. 1790. 8. - Traduits par Mandar. Paris 1791. 8. Q.

780 1 $\div$ Patrick, llilliam. A popular description of the indigenous plants of Lanarkshire, with an introduction to botany and a glossary of botanical terms. Edinburgh, Daniel Lizars. 1831 . 12. xxxiץ, 399 p. (6s.)

7805 Patrin, Eugène Louis Melchior. Relation d'un voyage anx monts d'Altai en sibérie en 1781. St. Petersbourg, Logan. 1783. 8.40 p. a.

$7806^{*}$ Patzelt, Joseph Eduard. Wildwacbsende Thalamifloren der Umgebungen Wiens. Wien, typ. Ueberrenter. $4842.8 .90 \mathrm{p}$.

$7807 \div$ Paulet, Jean Jacques. Tabula plantarum fungosarum. Parisiis, e typographia regia. 1791.4 .31 p., 1 tableau, 1 tab. (2 fr.) (Roemer's Archiv, vol. 1. Stuch 2, p. 59-7i.)

$7808+$ - Traité cles champignons, ouvrage dans lequel on trouve après l'histoire analytique el chronologique des découvertes et des travaux sur ces plantes, suivie de lenr synonymic botanique et des tables nécessaires, la description détaillée, les qualités, les effets, les différens usages non seulement des champignons propremen dits, mais des truffes, des agarics, des morilles el antres productions de cette nature, avec une suite d'expériences tentées sur ies animaux, l'examen cles principes pernicieux de certaines espèces, et les moyens de prévenir leurs effets, ou d'y remédier; le tout enrichi de plus de deux cents planches, ou ils sont représentés avec leurs couleurs et en général leurs grandeurs naturelles, et distribués suivanl une nouvelle méthode. Paris, de l'imprimerie nationale exé- 
custive du Lousve. 1793. (- 1835.) It rull. 4. at Allas in folio min.

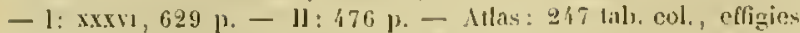
nutoris. (230 fr. Iluzard et llouel J'anlat, rue Chanssee d'Autin Nr. 13. -248 fr. Bailliero.)

Honct Paulet incliant 22.5 tabulas pictis, Bailliere solummodo 217

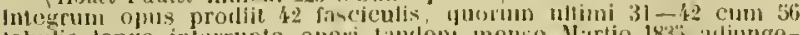
tabulis longe inlerrupto operi tanclem mense Martio 18in alijurgehantur. Pretium singuli fasciculi : G fr. Autor, gumm of dice Augnsti 1826 e vita decederel, relirjuit trintslationem matuscriptam listoriat plantarum Theophrasti,

iticus d' lippocrate.

("Col ouvrage est le résultat d'une infinité d'expérinces sur les

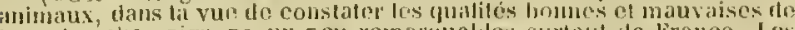
tous los champignons un peu remaryualiles surtout de franee. Les plinches de cet ouvrage enluminers ayes un, soin particulice, To fentent superieur a ce cui a éto pubhó justpu'al ce jour (1835) sur celto maniere. C'est In sert ourram do co genre sur Iculuel on puisso complire pour reconnairo les yualites de ces plantes mome au promier coup d'orit: un signe it? eonvontion is ciste, annoncant leurs qualités et leurs effets sur l'hommo et sur les animanx. „ Q.)

$7809 \div$ Paulet, Jean Jarues. Examen de la fartic botanique de l'essai d'uno l'histuire pragmatipue le la médecine par Kurl Sprenget. Nouvelle édition. 1’aris, 1yp. Baillcul. 1815.8 .25 p. (75 c.)

("Poutet, dans cel lexanen, qui partit pour la premiere fois vers 1809, signales un tres-grand noinloro de meprises de sprengel sur les plantes, dont les anciens ont fast mention," Q.

$7810^{*}(-)$ Examen d'un ouvrage, qui a pour titro: a llustrationes Theophrasti in usum botanicorum praecijue peregrinantium, auctore Johame Sluckhouse. Oxonii 1811.8 . $110 \mathrm{p}$, avec une figure et lo portrait de l'auteur. n Nelun el J'aris, chez lluzarl. 18:6.8.61 p. ( $1 \mathrm{fr} .50 \mathrm{c}$.

$7811^{*}(-)$ Flore et Faune de Virgile, ou listoire naturelle tes plantes et des animaux les jlus interessans a connaitre, et dont ce poeto a fait mention. Paris, lluzard. 1S24. 8. xix, 159 p., 4 (ab). ( $7 \mathrm{fr}$. - col. $15 \mathrm{fr}$.)

7812 Paulet, Maxime. Chimie agricole. Théorie et pratique des engrais, précédées d'anatomie et do pliysiologie végétiles. Saiut-Denis-duPort, typ. Giroux. $1846.5 .19 \%$ plag. (6 fr.)

$7813 \div$ Pauli, Adrian, pr. Decas problematum de plantis. D. (propronit Samuel Makowski.) Danlisci, typ. llincfeld. 16/4. 4. (8) foll. Bibl. Juss.

781 . _ pr. Do succini natura. D. (proponit Gelnilius.) Dantisci 1614. 4. $2 \frac{1}{2}$ plag. Boehmer.

$7815^{*}$ Pauli sive Povelsen, Biamo. Specimen observationum, quas cirea plantarum quarundam maris islandici of sjeciatim algae sacchariferae dictae originem, partes el usus collegit. llavniac, typ Berling. 1749. 4. $28 \mathrm{p}$.

7816 Paulin, llippolyte. Panegyrique orllwdoxe, mysterieux et propliclique sur l'anliquité, noblesse el splendeur des fleurs de Lỵs. Paris 1626. 8. Meusel.

is 17 Paulli, Johan. Dansk oeconomisk urte-bog. Kiblsenliavn 1761, 8 510 ]. B.

7818 Paulli, Simon. Quadripartitum botanicum de simplicium medieamentorum facultatibus. Rostoclii, ex oflicina Hallevordiana. 1639. 4. 80, 484, 19 p. B. - Argentorati 1667.4 .567 p., practer opuscula imedica, et Guilelni Laurembergii Botanothecam, h. e. Methodum confeiendi licrbarium vivum, p. 635-660, - "Ed. III: Quadripartitum botanicum de simpliciun medicamentorum facultatibus, ex veterun et recentiorum decretis of observationihus, cum medicis, tum anatomicis, itemque multis ehinica principia ac lumaniora studia spectantibus; in usus medicinac caudidatorum prasin medicam, Deo benedicente, auspieaturorm, nee non artis pharmacentices studiusorum concinnatum; additis 1. purgantium dosibus; 2. Guilielmi Laurembergii Botanothoca; 3. jam vero recens auctum Josephi l'illon Taurnefort Charactere plantarum; 4. commentario de usu el abusu Tabaci et herbae Thee: atgue multiplicis usus gratia instıuctum 5. quintuplici indice, latino, germanico, danico, syllabo authorum et rerum locupletissimo, curante Juhanne Jucobo Fichio. Francofurti a/M. apud Georgium IIenricum Ochrlingium, 1yp. Jols. Bauer. 1708. 4 (9) foll., sit p., intices.

(Gradripartitum [?. 1-625. Doses purganlium D. 629-667. Laurembergii Botanotheca 1. 665-690. Tiabulac, Oratio de almsu Labaci, be officio medicorum p. 691-798. Vita Simonis Paulli p. 799-811.

$8819^{*}-$ Florn danica, det er: Dausk Irtchog: ete. Kiobeuhavm, 1yp. Melchior Nartzan. 1648. (in tergo 1647.) 4.393 p., pract., ind., 393 tah. xylugr.

(lusunt etiam plantae hortenses.)
7820\% Paulli, Simon. Virillaria varia regia ef acalenuica pullica in usum mignatuni ab oidoßr-x́vav collecta ac recornita. - 1. Catilogus plantarum horti regii Hafniensis. - II Catalogne des plantes cultivées au jardin ru kog a laris depuis deux am ct tlengy qu'il est dressé. 1686. - III. Catalogeus plantarum tam exoticarum quan iusligenarum, ¡uac anno 1601 in lıortis regiis Virsaviae nasci observatac sunt. - $\mathbb{1}$. Catalogus plantarum lonti medici Oxonjensis. - V. Catalogus plantarum horti g! Innasii Patavini, ıuilus auctior erat anno 164\%. - V]. Catalogus plantarum horli academici Lugduno Batavi, quiłus is constructus erat amois 1642 et 1649 . - V'lJ. Judex plantarum indigenarum, quae in locis paludosis, pratensibus etc. proje Lugdunum iu Botavis noscuntur. VIJ]. Apuendix plantarum, quae borto publico aciulemiato J.ugduno Batavac accesserunt anno 1641. - IX'. Cutalogus plantarun lorti Groeningensis, ordine aljhabetico editus anno $1640 .-\mathrm{X}$. Catalowis plantarum seminum exolicorum. - Nl. Guilielmi Luuremberyii l3otanotheca, ed. 11. 1. 731-799. Ilafniae, (y). Lamurecht. 1633. 12. 799 p., praef Bibl. Juss.

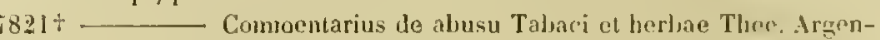
torati, sumtihus filii Simonis Paulli. 1663. 4.61 foll., pract, efligic: autoris, 2 tal. - *impr. cum ejus Quadripartito botanico. Francofurti a/M. 1708.4. p. 69\}-778.

angline: A treatise on tobaceo, tra, coffee and chocolate, translated by Dr. Jimes. London 1746. 8. 171 p., 2 tab. B.

7822 Paullini, Christian Franz. J)issertatio botaniea de Chamaenuro norvegica ubservationibus illustrata. Hanburgi 1676 . 4. H.

-823* - Sacra herba, sive nobilis Salvia, juxta methotum ef leges ill. Acadeniae Nat. Cur. descripta. Augustae Vindelicorum. Kroniger. 1688, 8. 114 1., pracf., ind.

782! * D Dalapa liber singularis, secundum leges "t methodum imp. Acad. J copoldinac Naturae Curiosormm seriptus, variistue ohscrvationilous memorabilibus conspersus, Francoforti a/M., linoch. 1700. 8.417 p., praef., ind.

782:* - De Theriaca coclesti reformata liber singulari<, secundun leges et methodum impcrialis Academiac Leopoldinae Naturac Curiosorum seriptus, multisque observationibus rariorilus jolysicomedicis illustralus et conlirmatus. Francofurti a/A].. Knoclı. 1701. S. 347 p. pritef., ind.

$7826^{*}$ Moбyokxpuoypropis, seu nucis moschatac curinsa droscriptio historico-plyysico-medica, multis rarioribus naturae et altis obscrvationihus, amoenis curiositatibus et selectis memorabilibus illustrata et confirmata. Francofurti et Lipsine, Ftocssel. (Firfordiae, (y\}. Grosch.) 1704.8 .876 p., praef, ind., I tab. e Dietzii libre (Tlıes. lit. bot. Nr. 2627) exscripta.

fire semper adhaeret: rita, studia el gloria Poulliniana lide crena lleseriptal ab Ésaica Dahlborn. ib. 1703. 8. 17) p.)

7827 Paulmier, Julien de, latine Palmarius. De vinu et pomacco libri duo. Parisiis 1589.8 .75 foll. B.

gallice: Traite du vin el du sidre. Caen 1599, 8. si foll. B.

7828t Pauquy, Charles Louis Constart. De la Belatone, consideree sous les rapports hotanique, chinique, pharmaceutique ctc. Thèse. Paris, typ. Diclot. 1825. 4. 60 p.

$7829 \div$ _ Statistique botanique, ou Flore du Departement rle la Somme et des environs do Paris. ele. Amiens, typ. Alachart. is31. 8. $x 1,635$ 1. - tParis, Bailliere. 1834. 8. (8 fr.) (est eadem in(jressio:)

$7830^{*}$ (Pavon, Joseph.) Disertacion botanica sobre lus generos Tovaria, Aetinoplyyllum, Araucaria y Salmia. s. I. ct a. $4.14 \mathrm{p}$.

Einsilem tabulas inedilas ad genus Laurus spectantes recensebu infra cuu Flora peruviana in voce Ruis.)

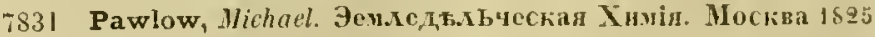
Tautv.

$7832+$ Paxton, Joseph. Magazine of botany, and register of nowering plants. London, Orr and Suntlu. 1834-1843. A voll. 8. 500 tab. col. Bibl. Deless.

(II singulo volumine sive anno insun 30 tab. Col. pretio 11.15. . ) i833 A practical treatise on the cultivation of Dablia. London 1838. 12. (2s.6d.)

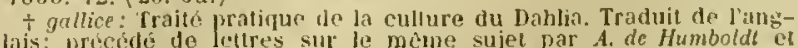
ditrion de Jussieu. Paris, Leleux. 1830. 12. xy, 173...p. (2 fr.)

dhe holm, trycht hos L. J. Hjerta. 1839.8.93 $\mathrm{f}$. W. 
grmanice: Die Kultur der Georginen. Nach dem Englischen mit 7uzirlung des Herrn Fischer in Weimat bearbeitet yon /I. (rauss. Hit zwei des franzosischen Ueberkelzung beigefuston Briefen der

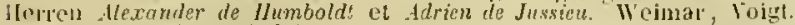
18:39. 8. v1v, 102 \%. (1/2 th.

7831. Paxton, Joseph, et John Lind]ey. Botanical pocket diclionary, comprising the name, history and eulture of all plants known in Britain. London 1840. 12. (15s.)

$7835^{\circ}$ Payen, A. et .1. Chevallier. Némoire sur le houblou, sa culture en France, son analyse etc. suivi d'une notice sur les avantages de substituer en médecine la matière jaune active de boublon aux lleurs de cette mene plante. Seconde edition. Pasis, Bachelier. 1823. \$. 52 p. - t Mlénoire sur le boublou; sa valeur réelle, sa culture, sa récolte et ses usages. Troisieme édition. Paris, Auclin. 1825. 8 . 70 ]). I tab. - Ed. IV: Traité de la culture et des emplois du hou-

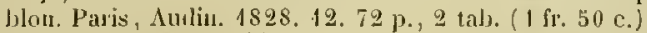

(In hac tortia editione apparet in litulo coilaborator Chappellet. bilitio primit evstat in "Annales de lindustrie.")

seut especes de pommes de terre. Paris, typ. Fau. 1823, 8. 16 p. 0 (Seorsin impr. e a Journal de pharmacie.")

$7837+$ Traité de la pomme de terre, sa culture et sos divers emplois. Parris, Thomine. 1826. 8. vilt, 160 j), 3 tab. ( 3 Ir. $25 \mathrm{c}$.

$7838^{\circ}$ Ménoire sur l'Amidon, consilléré sous les poilts de vue anatomique, chinique et physiologique. Sur les fécules des diverses plantes et lenrs applications. Paris, typ. Renouard. 1839.8 . $147 \mathrm{p}$. 6 tah.

$7839^{*}$ —_ Némoires sur les dévelojpements des végétaux. Paris imprimeric royale. I\$42. 4. $463 \mathrm{p}, 16 \mathrm{tab}$. col.

:8:0 E____ Enqucte sur la majadie des pommes de terre en France pendant les années 1845-1846. Examen et analyses de dirers échantillens de recoltes. Paris 1847.8.

$1811 \div$ Payer, $J$. Des classifications el des métlodes en histoire naturelle. Theso. Paris, typ. Delacour. 1844.4.36 j.

is'.2\% Payer, Jean Baptisle. These pour le Ductorat is sciences naturelles. Dewieme partie: Essai sur la nervation des fenilles dans les plantes dicotylées. Paris, typ. Baudouin. 1840. 4. 12 p., 1 tab.

781.3 Teccana, Alessandro. De' commentarii della scandella libri tre. Terona, ty]. Tamo. \{622.4. 86 p. Bibl. Reg. Paris.

$7814 \div$ - De Chondro et Alica libri duo. Verona, ty]. Tami. 1627. 4. $\$ 0$ p. Bibl. Reg. Paris.

isfï Pechey, John. The campleat herbal of jugsical plants. Lonclon, llenry Bonwiche. 1694. 8. 349 p. B.

is f; * Pechlin, Johamnes Nicolaus. "Theophilus bibaculus, sive de potu Theat dialogus. Kilonii et Francofurti 1684. 4. $103 \mathrm{p}$.

78:7 Pein, Elias. Der Bosensche Garten in Leipzig, oder ein Verzeichnuss derer, so wohl aussländiseher, alss einheimiscler Baume, Staudes nur! Krátuter, so in denselben itzo zu funden. Halle, Christoph Salfeld. 1690. 8. Rivin. - El. 11: Leipzig 1699. 8. S. - ${ }^{*}$ Edl. Ill: IIortus Bosianus, oder Terzeichniss allev sowobl in-als ausländischer Baume, Standen, Krauter und andrer Gewächse, welche in dem Kaspar Bosischen Garten etc. zun drittenınal herausgegeben von Elias Prinen. Jeeipzig, typ. Tietze. $1705.8 .111 \mathrm{p},-{ }^{*}$ zum viertenmal heransegebeu von Elias Pcine. Leipzig, typ. Tietze. 1713. 8. $115 \%$

ists Eigentiche Abbildung der amerikanischen Aloe, so zu Leipzig im Bosischen Garten amno 1700 den 13 Maji den Stengel anfangen zu treiben. Lejpzig, bej Peter Sclienk. 1 tab, aenea, long. 10 unc., lat. 7 une. B.

7849 Wörterbüchlein, in welehem diejenigen Worter entbalten, welche sonderlich bei der Gartnerey ublich sind. Leipzig $1713.8 .96 \mathrm{p}$. B.

$7850+$ Peixoto, Domingos Ribeiro dos Guimaraens. Dissertation sur les médicamens brésiliens que l'on peut sujstitucr aıx medicamens exotiques dans la pratique de la médecine au lBrisil etc. Thèse. Paris, typ. Didot. $1830.4 .152 \mathrm{p}$.

7831 Pelée de Saint Maurice. L'art de cultiver les peupliers d'ltalie. Paris 1762. 8. - Lyon 1767.8. H. $176 \% .8$
7862* Péligot, Eugune. Recherches sur l'aualyse el la composition chiniques de la betterive a sucre; et sur J"organisation anatomique de cette racine par Joseph Decaisne. Paris, Mathias. 1839. S, vut, 50 p., I tal).

$73033 \div$ Pelletan, Ciabriel. Note sur deux especes de Jalaju du commerce. Paris, typ. Locquin. 4\$34. \$. 25 p., 2 tal).

Extrait dil Journal de chimie médicale. Annee 183 k.

$785 \%:$ Pelletier, $J$. Essai sur la nature des substances cunnues sous le nom de gommes résines. These. Paris 1812.4, 321 .

78557 et Caventou. Analyse chimique des Quinuuina, suivio d'ohservations médicales sur l'emploi de la quinine ot de la cinchonine. Paris, Colas. 1821, 8 . vil, $8 \mathrm{~s}$.

7850 Pelouze. Exposé complet de la culture du coton aux Antilles, précédé d'un apercu de cette culture dans les Etats-Unis d'Amérioue ct de considerations préliminaires sur la similitude du rlimat, et sur l'opportunitó des rultures tarridiennes, dans la ci-rlevant régenec d'Alger. Paris 1838. 5.

7857* Pena, Piewe, et Malhias De l'Obel. Stirpium adversaria nova, jerfacilis vestigatio, luculentaque accessio ad priscorum, praesertin Dioscoridis et recentiorum materiam medicam. Quibus prae diem accedit altera pars. Conjectancorum de plantis appendix. De succis medicatis et metallicis sectio. Antiquae et novae medicinae lectiorum remediorum thesaurus. De succedaneis libellus. Londini, Thomas Purfoot. 1570. (in tergo: 1574.) falio. 457 p., ind., (268) ic. xylogr. i. t. - * Antwerpiae, Plantinus. 1576 , folio. $471 \mathrm{p.}$ ic. xylogs. i. 1. - "DiJucidae simplicium medicamentorum explicationes et stirjium adversaria, quilus accessit altera pars cum prioris illustrationibus, castigationibus, aucuariis, rarioribus aliquot plantis, selectioribus remedis, succis medicatis et metallicis medicinae thesauris. opii, opiati et antisloti decantatissimique chymistarum ct fiermanorum Laudani opiati formulis. Imjs. cun Lobelii lı G. Rondelletii methodicam plammecutican officinam animadversiones. Londini, Tlıomas Purfuot. 1605. fulio. 519 p., ind., ic. xylogr. i.t.

Bene jan monet Dryunder: "Tres esse disersas editiones nol crediderim, sed IIstue ad Dilanam 456 vere eanden, mutato tituto (L diversis ad calcem additionibus: of Trew Calalowus prinus libro-

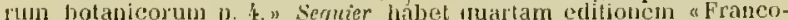
furti igal folio gue furti f6ol. folio. "quae min non inmotuit. In appendice editionis pri-

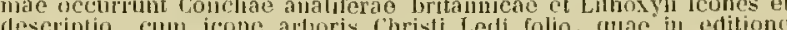
altera

7858 Penfold, Jane 1 Wallas. I selection of Madeira flowers, fruits and ferns; a selection of the botanical productions of that island, foreign and indigenous, drawn and coloured from nature. London, Reevr brothers. 1845 . royal 4. 20 p., 20 tals. col. (1l. Is.)

$7839 \%$ Pennier de Iongchamp, Pierre Barthelemy. Disscrtation physico-modicale sur les trulles et sur les cbampignons. Avignon, Rolserty el Guilhermont. 1766 . 12. 111, 59 p. Bibl. Léveilté.

$7860+$ Pepe, T'incenzo, ed Gaetano Cupido. Analisi del Irutto del Platano orientale con eui è stato preparato il licjuore anticolerico con altri composti attivi a curare i colerici, ete. Napoli, ty]. Farrucciu. 1837. 8. 32 p. (Desunt pancae pagellac.)

$7861 \div$ Pépin. Notes horticulturales. (Extrait des Annalis de Flure et ile Pomone.) Paris, Rousselou. 4837. 8. 25 p. - Deuxiene serie. ib. 1838, 8, 30 1\%.

$7862+$ Note sur la culture et la multiplication du Bignonia grandiflora Tlıunb. Bignonia sinensis Lamk. Bignone a grandes fleurs. Paris, Bonchard-lluzard. 1839. 8. 8 p.

$7863+$ Mémoire sur la culture du Chou Pi-Tsaie IBrassica sinensis L.) Paris, Bouchard-Ilızard. 1840.8. 12 p.

$7864 \%$ Note sur la culture et les avantages que l'on peut tirer des liges de l'Urtica nivea L. Paris, Bouchard-lluzard. 184 .. $8.11 \mathrm{p}$.

7865 Percival, Thomas. Essays on the adstringent and hitters. London 1767. S. H.

$7866^{*}$ Pereboom, Cornelis. Systema characterum plantarum, seu Dictionarium rerum botanicum, filio conseriptum et ab ipso figuris illustratum. Lugduni Batavorum, Luchtmans. 1788. 4. $311 \mathrm{p}$.

$7867^{*}$ Pereboom, Nicolaus Ewoud. Materia vegetabilis, systemati plantarum pracsertim philosophiac botanicae inserviens: characteribus, quoscunque ill. Linnaeus indicavit, delineatis. Lugduni Batavorum, Luchtmans. $1787 \mathrm{et} 17 \mathrm{ss}$. (III Decades.) 4.74 p., 30 tal). 
7868 Pereira, Jonathan. Materia medica. London. Longman. 1842. 11 voll. 8. (2l. $10 \mathrm{~s}$.)

"gprmanice: Handbuch dor Ifeilmittritehre. Nach dem Standpunkte

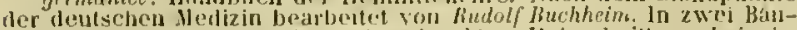
den mit viclen in den Texl eingedruchten Ilolzschnilten. Leipzig. deopoli voss. 18't-18'7. 8 .

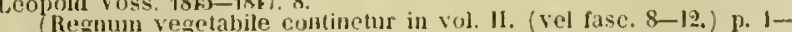
bio, continuatur.)

7869 Pereligin, Peter. Патертаnie иравихт, Аћсово,дства. C. Ileтер6. 1831. 2 "Iact. Trautv.

7870 Perez, Gaspar. De Balsamo, y de sus utilinades para las ebfermedades del cuerpo lumano. Sevilla, Juan Vareta. 1530.4. s

787 Perez, Lorena (vel Lazuro). De la teriaca. Toledo 1575. Cap. de Vill.

- De medicamentorum simplicium el compositorum hodierno acvo apud nostrates pharmacopolas exsiantium deleetu, repositione et actate per generationes duas. Additac integrae et repurgatae eorum nomenclaturae rte. Toleti 1599 . Cap. de Vilt.

7873 Perkins, E. E. The elements of botany. London, llurst. 1837. 8. (10s. 6l. - col. 14s.)

787 t* Perktold, Anton. Erlauterung und Besclureibung der Limbilicarien von Tirol. Innsbruck, Wagner. 1842. 8. 16 p.

7873 Perla, Francesco. De orientali Oprobalsamo uuper in Theriacae confectione adhibito et inter Romanos medicos controverso, dissertatio. Romac 1641. 12. 214 p. B.

$7876^{*}$ Perleb, Karl Julius. Lehrbuch rler Naurgeschichte des Planzenreichs. Freiburg in Breisgau, Wagner. $1826.8, x 11,422 \mathrm{p} .\left(1^{2} / 3(h)\right.$ (* Lehrbuch der Natursesehichte. lirster Band. 1826. p. 193-620.)

$7877^{*}$ — De horto botanico Fuburgensi. Programma academicum Friburgi Brisgoviae, 1צp. Wagner. 1829. 4. xxv11, 38 p., 1 lals. $(1 / 2$ th.

$7878^{*}-$ Claris classium, nrdinum et familiarum atrue index generum regni vegetabilis. Uiagnostische Lehersichtstafeln des naturlichen Planzensystems. Nebst vollstámligem Gattungsregister. Freiburg im Breisgau, Adolph Emmerliıg. 1838. 4. vılı, 94 p. (1 (h.)

7879 Perman, S. Underráttelser om homstervaxter, huilka al frön i Sverige kunna odlas. Orehro, Lindh. 1838. 12. (16 skill.)

$7880^{*}$ Pernitzsch, Heinrich. Flora von Deutschlands Waldern mit besondrer Ruchsicht auf praktische Forstwissenschaft. Leipzig, Baumgartner. $1825.8 . \mathrm{vi}, 332 \mathrm{p} \cdot\left(1 \frac{1 / 2 t h .)}{2}\right.$

7881 Péron, Frangois. Observations sur la dyssenterie des pays chands et sur l'usage du Betel. Paris 1\$04, 8.

$7882+$ Perotti, Carlo. Fisiologia delle piante. ele. (Barge), stamperia Saviglianese. 1840 . Il voll. 8. - 1: v11, $222 \mathrm{p} .-11: 309$ p. Bibl. Cand. et Deless.

7883 Observations plyysiquessur les inconvénients de planter des arbres fruiters dans les prairies et de la meilleure maniere de les tailler et des avantages de cette operation; ourrage rédigé d'après l'etat actuel des connaissances de plysique et de phisiologie végétale. Seconde édition revue et augmentée par lauteur. Carmagnole, P. Barbie. $1812.8 .132 \mathrm{p} .(1 \mathrm{fr}$.) a.

iss t: (Perreymond.) Plantes phanérogames qui croissent aux environs de Fréjus avec leur habitat et l'époque de leur fleuraison. Paris Levrault. (Fréjus, Aragon.) 1833. \$. 90 p., praef. (Requien a part a cel ouvrage.)

$7883^{*}$ Perron. Le guide du consemmateur de chocolat et de thé, suivi de conseils pour préparer du café parfait, par Perron, fabrieant. Paris, chez l'auteur, 14 rue Vivienne. $1845.8 .16 \mathrm{p}$

$7836 \div$ Perrot, Catherine. Les leçous royales, ou la manière de peindre en miniature les fleurs etc. Paris, Nego. 1681 . 12. 231 p., praef, ind.

$7887+$ Perrottet, G. Samuel. Catalogue raisonú des plantes introduites dans les colonies françaises de Bourbon et de Cayenne et de celles rapportées virantes des mers d'Asie et cle la Guyane au jardin du rni i Parjs. Paris, typ. Lebel. 18ะ4. 8.63 1.

7888\% — Observations sur les essais de culture tentés au Sénégal et sur linfluence du climat par rapport á la régétation; précédées d'un examen genéral sur le pays. (Lùrait des Annales maritimes. 1831.) Paris, de l'imprimeric royale. $4834.8 .76 \mathrm{p}$.

$7889 \div$ Hémoire sur la culture des indigofères tinctorianx et sur la fabrication de l'Indigo. Paris, typ. Duverger, 1832. 8. 52 p. 1 tab. $7890^{\circ}$ Perrottet, G. Samuel. Sur la culture du murier etc. l'aris, Mrai $1840.8 .36 \mathrm{p}$.

E. Strait des Amnales maritines et enloniales.)

$7891 \div$-.. Art de l'indigotier on traité des indigofieres tinctoriaux at de la fabrication do I'Intigo, suivi d'une notice sur le Wrightia tinctoria et sur les moyens d'extraire de ses [entilles le prineipe colorant ip'elles contienuent. l'aris, Boucharil-lluzart. 18 19. 8. vilu, $2191 \%$

$7892\}^{\circ}$ - Rapport adressé à M. le ministre de la marine et des colonies sur une mission dans l'Inde, a Hourbon, a Cayenue, a la Martinipge et à la Guadelouje, concernant l'industrie serignene ol la culcure du murier. (Extrait des Annales maritines el coloniales.) l'aris, imprimeric royale. $1942.8 .80 \mathrm{p}$.

(1) indefesso peregrinatore ef. Toliens historiques sur M.M. Samuel Peroltet el Lovis Ayassiz. Lausanine 1831. 8. 20 j). )

7893 Persoon, Christian Ileinrich. Einige Bemerkungen uber dip Flechten, nebst Beschreibungen einiger neuen Arten aus rimer Familic der Aftermnose. (Zürich 1794.) 8. 36 p.,3 tab. col. B.

Usteri, Annalen der Botanik, stuck 111. P. 1-32, 1:30-1:38.

7894: * Ohservationes mycologicae, sou descriptiones tam nororum tuam notabiliun fungorum. Lipsiae, Wolf. 1796-1799. Il partes. 8. - I: 1796. 115 p., E tab. col. - Il: 1799. xil, 106 p., 6 tab. col. $\left(5 \frac{1}{3}\right.$ th.

Pars ll alio insuner titulo inseribitur: \& duimadrersiones et diucidationes circa varias funsorun species a anno 1800

$7890^{\circ}$ * Commentatio de fungis clavaeformibus, sistens specierum hucusque notarum descriptiones curn dilTerentiis specificis nec non aucterum syuonymis. Lipsiac, Wolf. 1797. 8. 124 p., 4 tab. col. $(2$ th. $)$

$7896^{*}$ - Tentamen dispositionis methodicae fungerum in classes, ardines, genera et familias cum supplemento adjecto. lipsiac. Wolf. 1797. 8. 1v, 76 p., 4 tab. $(2 / 3$ lh. $)$

(Paginae prinres 48 redeunt ex Roemer Neues Magazin fur din Bolanik, vol. 1. p. $81-128$; reliquae sistunt supplementum. In hoc libro desilleratur introductio germanice seripla "Neuer Versuch einer ststentatischen Eintheilung der Schwamues in lioemer 1. c. p. $633-80$.)

$7897^{*}$. Icones et descriptiones fungorum minus coguitorum. lipsiae, Breitkopf-Hártel. $(1798-1800$.) basc. 1-11. 4. 60 p., 1 i tal), col. $(6, h$. $)$

$7898^{*}$ Commentarius, D. Jacobi Christiani Sshaefferi Fungorum lSarariae indigenorum icones pictas, differentiis specificis synon:mis et observationibus selectis illustrans. Erlangae, Palm. 1800. 4. $130 \mathrm{p} .$, praef., ind. $(2 / 3 / h$.

$7899^{*}$ Synopsis methodica fungorum, sistell mnumerationem omnium lucusque detectarum specierum cum brevibus descriptionibus nee non synonymis et observationibus sclectis. Goettingac. Dieterich. $180 \mathrm{I}$. II partes. $8 . \mathbf{x x x}, 706 \mathrm{j}$. eum proprio indice specierum, anni 1808. 5 tab. $\left(2 \frac{2}{3} /\right.$ h. $)$

$7900^{*}$ - Icones pictac rariorum fungarum. Fasc. 1-11: Paris $1803-1806 \quad 4.64 \mathrm{p} ., 24 \mathrm{lab} .(12 \% \mathrm{~h}$.

$7901^{*}$ _.__ syopsis plantarum, seu Enchiridjum botanicum. conplectens enmerationem systematicam specierum hucusque rognitarum. Paris, Cramer. Tuebingae, Colta. 1805-1807. II roll. 12. I: 1805. xus, 546 p. $-11: 1807.657$ p. $(3 \% / 6$ th. $)$

$7902^{*}$ _ Traité sur les champignons comestibles contenant l'inlication des espèces nuisibles, précélé diune introduction a l'bistoire des champignons. Paris, Belin-1.epricur. 1818. S. 10. 276 p.: 4 tab. col.

(Sunt eremplaria anni 1819 .

- germanice: Abhandlung uber die essbaren sichw amme. Wit Angabe der sehfullichen Arten und einer Eintritum in ulie Geschichte der der sehatlichrn Arten wnd einer Eintritung in the Geschichto der

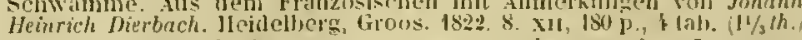

$7903^{*} \longrightarrow$ Mycologia europaea, seu completa omnium fungorum in variis Europrac regionibus detectorum enumeratio, methodo naturali disposita; descriptione suecineta, stonnymia selecta el observationibus criticis additis. Erlangae, Paln. III sectiones. $1892-1828$. s. - 1: 1822. 356 p., tab. col. 1-12. - 11: 1\$25. 214 p., 1ab. col. 13-22. - Jll : (part. 1) 1828. 282 p, tak. col. $23-30 .\left(12 \frac{2}{3}\right.$ th.)

$790 \%$ : Peschier, Jean. De irritabilitate animalium et regetabilinm. D. Ediulurgh, typ. Mudie. 4797. 8.51 p.

(Aulor hanc dissertationen sub praesillio G. Baird proposuit.

$7905 \%$ Pesneau, J. B. Catalogue des plantes recueillies dans le Dejpartement de la Loire inférieure, classé suivant le systeme de Limnée. Nantes, Forest. (Paris, Pesron.) 1837. 12. $\mathrm{r}, 475 \mathrm{p}$. (2 fr. $50 \mathrm{c}$.) 
$7906 \div$ Petagna, lincenzo. Institutiones botanicae. Neajeli, typ. Porcelli. $1785-1787$. Y roll. 8. - J: 1785. De pliilosophia botanica. $\mathbf{x Y}$ 285 p., 10 tab. - Il-V: 1787 . De plantis in speeje. $2142 \mathrm{~J}$, ind. Bibl. Cand.

$9907^{*}$ Petermann, llithelm Ludwig. De llore gramineo, adjectis graminum circa Lipsiam tam sponte nascentium quam io agris cultorum descriptionibus genericis. D. Lipsiae, Barth. 1835 . 8.80 p., 4 schema, i tab. $(1 / 2(h)$.

....- Nandbuch der Gewachshunde zum Gehrauclie bei Vorlesungen, so wie zum Selbststudium. Lejpzig, Barth. 1\$36. \&. xxvs, $690 \mathrm{p}$. $\left(3 \frac{1 / 2}{2}\right.$ th. $)$

7909* Flora Lipsieusis excursoria, exhibens plantas phanerogamas circa Lipsiam tan sponte nascentes, quan in agris cultas, simul cum arboribus et fruticibus pomerii Lipsiensis. Accedunt: Mappa geographica sistens Territorium Florae, et index generum specierumque synonymicus. Lipsiae, Barth. 1838.8 . x, 707 p. (3/h.)

In collicem botanicum Linnaeanum (vide sujra Nr. 6041) index alphabeticus generum, specierun et syonymorum omnium conjpletissimus. Composuit atque ediclit Hithelm Ludwiy Petermann. Lipsiae, Otto Wigand. 1840.4. 1V, 202 j).

$7911^{*}$ - Flora des Bienitz und seiner Imgebungen. Nit einer kiarte. Lei]zzig, Friedrich Fleischer. 1841. 16. xvi1, 171 p., 1 mappa geogr. $(2 / 3$ th. $)$

$7912^{*}$ Taschentuch der Botanik. Leipzig, Volckmar. 1842. 8.484 p. 12 tab. (2th.)

$7913^{*}$ - Das Pflanzenreich in vollstiuligen J3eschreibungen aller wichtigen Gewachse dargestellt und dureh naturgetreue Abbilduagen erlautert. Nit 282 Tafeln, die Abbilumgen von 4600 Pflanzen usel der vichtigsten Theile jeder derselhen, so wie 426 erlauternde liguren auf den Einleitungstafeln $\left(N_{r}, 1-10\right)$ entha]tend. Leijzig, Eisenach. 1845 . gr. 8. 1v, 1010 j., 282 tab. col. (col. $33 \frac{1}{3}$ th. - nigr. $14^{1 / 2}$ th. - sine tab. 10 (h.)

(Prodiit ab anno $1838-18$ is quinquaginta fasciculis.)

7944" Analytischer Pllanzenschlussel fur hotanische Excursionen in der Umgegend von Leipzig. Leipzig, C. I1. Reclam sen. 1846. 8. CLXVt, $592 \mathrm{p}$. $\left(4^{1 / 2}\right.$ th. $)$

$7915^{*}$ - Deutschlands Flara. Mit Abbilklungen summtlicher Gattungen und Untergattungen. Lieferung $1-5$. Leipzig, G. Wigand. 1846-1847.4. p. 1-248., tab. $1-40 .\left(a \frac{2}{3}\right.$ th.) (Continuatur.)

$7916^{*}$ Petersen, Clairaut. Ueber den Einfluss der Waldungen auf die Wïterungscerháltnisse und das hlima. Altona, in comm. Schlüter. is $46.8 .24 \mathrm{p} \cdot(1 / 6 / h$.

7917 Petershagen, C. G. Th. Vollstandige Anweisung zur Kultur des Weinstocks, dessen Fortpflanzung, Veredlung, hranklıeiten, Feinde etc. Quedlinburg, Basse. 1843. $8.12 \%$ plag. $(2 / 3(h)$.

$7918+$ Petif, C. Enumeratio plantarum in ditione Florae Palatinatus spronte crescentium. Post Pollichiun, Kochium et Zizium denuo recensuit auxitque. Pars pluaneragamica. Biponti, typ. Ritter, 1830.8. Y'n, $96 \mathrm{p}$.

79196 (Petit, François Pourfour du.) Lettres d'un médecin des hôpitaux dı roy à un autre médecin de ses amis. Namur, chez Albert. $1710.4 .50 \mathrm{p} ., 8$ tab. Bibl. Juss.

(uLa troisieme lettre contient une criticue sur les trois especes de chrrsosplenium iles lnstituts da Tourtefort, frojs nouveaux genes te plaites et quelifues nourelles espèces. p. $39-50$ et 7 (al). " $\mathbf{B}$.

7920 Petit, $P . H$. II imoire sur le pavot d'orient ou de Tournefort et analyse chimique de cetle plante. Paris, L. Colas. 1827. 8. 20 p. a. (Extrait du "Journal de pharmacie.")

7921 Petit, Pierve. Thea, sive de sinensi herba Thee earmen, cui adjectae Johamis Nicolai Pechlini de eadem herba epigraplate (ex libro supra $\mathrm{Nr} .7846$ allato) et descriptiones aliae. Lipsiae 1685.4 . 6 plag., 1 tals. B.

7922 IJomeri Nepenthes, sive de Helenae mecicamento luctum, animique omnem aegritudinem abolente et alis quilusdam eadem facultate praeditis Dissertatio. Trajecti a/R., typ. Kudolph Zyll. 1689. S. Hivin.

7923 Petitmaitre, Sigismund. Dissertatio inauguralis de usu et abusu Nicotianae. Basileae 1756. 4. 18 p. B.

792. Petit-Radel, Philippe. De amoribus Pancharitis et Zuroae poema erotico-didacticon; seu umbratica lucubratio de cultu Veneris Hileto

Pritzel, Thes. lit bot olim peracto, ut amathunteo sacello mysta subduxit et variis de generatione fuum vegetantium, tum aninantium exemplis auctum vulgavit Alhenis. Parisïs, Molini. 1798. 8. (1 fr.) - Ed. II. plane reformata ef talulis aeneis illustrata; cui accedit vila autoris. Parisiis, Didot jeune, atl IX. IS01.8. effigies autoris, 1 carte, 2 gravures. $(6 \mathrm{fr}) \quad$.$a .$

+gallice: Le mariage des plantes, traduil de louvrage du D. PetitRadel, intitute: De innoribus Pancharitis et Zoroae. Jaris, Fuchs. III VIII. 1795.12 .23 n.

tgallice: Les amours de Zoroas ct de Pancharis. ete. Ouvrage Iraduit sur la seconde edilion de lorignal latin par un amateur de "antigutiti (Dr. Petit-Radel). Paris, typ. Patris. 1802. 111 voll. 8. - 1: cr.

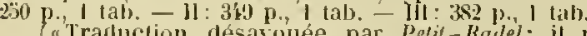
partie de cet onvrage en français, sous le titre de Mariage des mantes," $\mathbf{Q}$.

tgallice: Les Mysteres de Flore, on couj l'oeil sur la naissance les amours, le mariage et la mort rles plantes. Extrait de louvrage du D. Pelit-Radel, intifule: De amoribus Pancharitis et \%orode. Seconde édition resue et augmentée de la traduetion fjançaise arec des notes, Paris, 1yp. Chansoll. 1813. 8. $56 \mathrm{p}$. (1 fi, $50 \mathrm{c}$ )

792:" Petiver, James. Iusei Petiveriuni centuria $\mathbf{I}(-\mathrm{X})$, rariora naturae continens, viz. animalia, fossilia, plantas, ex variis mundi plagis advecta, ordine digesta, et noninibus propriis signata. Londini, typ Smith and Walford. 1695. (1692-1703.) 8. 93 p., 2 tab.

Nille sunt rariorum species, quae inter multie plantae sunt undiłue contuisiline cum syonymis et nonnulis iconibus. Rari etiam et novi eo invo Husei intercerliut.

7926 - Gazophylacii naturae el artis decalles $\mathbf{X}$, in quibus animalia, quaclrupedes, aves, pisces, rejtilia, insecta, vegetibilia, item fossilia, corpora marina et stirpes minerales e terra erutae, lapides figura insignes, descriptionilus brevibus et iconibus illustrantur. Ilisce annexa suppellex antiquaria. Londini, Chrisophorus Bateman. $1702-1709$. II voll. - I: Decas I $-\mathrm{V} .1702-1704.78 \mathrm{p}$. in $\mathrm{S}$. tal), in folie $1-50$. A classical and topical catalogue of all the things figured in the 5 Decades, or first volume of the frazopluylacium naturae et artis. 1706, 8. j. 84-94. - II : Decas VI-X. 1709. folio 12 p. tab. $51-100$. B

Inter animalia aljasuue non nostri seopi icones intercedunt plurimar plantarum exoticarum eapensium et $\mathrm{px}$ utraque Indiat allatarum; alpinae etian eaedem, quae apud scheuch zerum, fisurae. Redeunt hate tabulate et textus in folio in operum ejus vatumiue primo, tabulis auctie $101-1066$, cun 10 p. textus, nbi vero nulla meniio tabulate 130 .

7927 Catalogus classicus et topicus amnium rerum figuratarum in quinque Decadibus, seu primo volumine Gazophylacii naturae et artis. Londini 1709. folio. 4 p. B.

Redit in l'alentini isuseo Nuseorim II. app. p. 43-52.)

7928 Catalogus classicus et tepicus omnium rerum figuratarum in quinque Decadilsus, seu secundo volumine Gazophylacii naturae et artis. Londini 1711 . foliu. 4 p. B.

7929 - I catalogue of plants folnd on the mountains about Geneva, as mont Jura, and la Dole, Saleve, and la Bisile, witl several others growing in the fields, woods, hills and mearlours about that City, olserved there by those most celebrated botanists of their time, viz. Cuspar and John Bauhin, Chubraeus, Gesner, and Ray's memoirs fort curious. 1709 . s.

(Exscribo titulum a Seguiero, gui eum thabet e Scheuchzeri Bibl. hist. nit. Ejusmodi liner vis adest.

7930 Pterigraplia americana, icones eontinens Filicum, nec uou Muscos, Lichenes, Fungos, Corallia, Spongias aliaque submarina; eui adjiciuntur Crustacea, Testacea, aliaque animalia fere omnia ex insulis nostris Charibbaeis riz. Antego, larbados, S. Christophers, Newis, Jamaica etc. (Londini 1712.) folio, 3 (al), aen. catalogi, 20 tals. aen. iconum. B.

Redit in ejus Operun tomo secundo: figurae maximam partem e Plumieri Filicibus desumtae, valde dimimtae.)

7931 - W Lerbarii britannici Raji catalogus cum iconilus. A catalogue of Mr. Rinjs English Herbal, illustrated with figures on folia copperplates, on which are engraven their names to each, as also the places where growing colvur of their llowers, and time of flourisling if amual of perennial common or rare the flower, seed, vessel etc. fignred from the life, and added to eachl dilferent kind. (Loudon 1713.) folio. 4 catalogi latini, 4 catalogi ing lici, 50 tab. aen. (cuu 600 figuris plantarum.) B. - English berbal continu'd witl] the fourth leaved foncrs. (London 1715.) folio, tab, aen. 51-72. s. (Redeunt bae labulae 72 cum sex catalogis latinis et quatuor eatalogis anglicis in operum ejus tomo secundo; residerantur Crrptogamae, (iramina, Arhores et Frutices. Seguierus eitat insuper editionen alteram Cura 1), Mans Sloane. Londini 1732. folio., elijus perpauca exemplaria sub prelo submissa fuere.) 
7932 Petiver, James. Plantarum Etruriae rariorum calalogus e Caesalpiza, Boccone, Mentatio, Rujo. Londini 1715 . folio, 1 plag. S.

7933 Plantarum Italiae marinarum (sc. zooplyytorum) el graminum icones, nomina ete. I, ndini 1715 . folio. 1 plag., 5 tab. S. et B. (Rodeunt in (pertun volumine secundo.)

793 — Lortus P'eruvianus meliciualis, or the Southea herbal, containing the names, use etc. of tivers medieinal plants lately diseovered by Father Fraillee one of the hing of France's herbalists. To which are ardled the figures ete. of rlivers anerican gum trees, dying wooks drugs, as the Jesuit's lark trees, and other much desired and very necessary to bo know by all such as now traffik to the Soutlisea, or reside in those parts. I.ondon 1715 . folio. 5 tal. Sloane.

(Redil in Operuro volumine seeunder, ubi tabula sivita addita est, sistents Aromata ludiar, raltice; et gumusi, figuris nuvenu.)

5935 — Plants alreaty engraved in Mr. Petiner linglish lierbal. London, Christopluer Baleman. s. a. folio. 1 plag. Sloane.

7936 —_ Graminum, Muscorun, Fungorum sulmaninorum el britannicorum concordia. Londini 1716. folio, Sloane.

7937 - Monspelii desideratarum plantarum catalogus e Riajo, Mugnolio, Chabraco, Caspare el Johanne Bauhino, ordine alphabetico. Londini 1746 . folio. 1 plag. $\mathrm{s}$.

7938 Plantae silesiacae rariores ae desideratae a Cuspare Schwenclifeldio excerptae, et methodo Rayana digestac. Londini 17.17 folio. 1 plag. s.

7939 Petiveriana seu naturae collectanea III, lomi forisque auetori communicala. Londini, apud auclorem. 1717. folio. Sloane.

7940 Plantarum aegypliacarum rariorum icones, et aliarum minus vulgarium eatalogi duo, el plantar Aegypti a D. Lippi obser'valae ex Lutetia ad Petiverium transmissae a Sebastiano l'aillant el Ludovico Stoschio. Lonsinj 1717. Pulio. 1 jrag., 2 lab. S.

$79+1$ Hortus siccus pharmaceulicus, sive eollectio curiosissima plantarum officinalium tam exoticarum, quam indigenarum alpluabetico ordine digesta, cum synonymis necessariis; locis natalibus et tompore vigendi: accesserunt cliaı illarum partes ac pracparationes, quae maxime sunt in usu; i. ৎ. Nonima plantarum cum synonymis unicuique plantae horti ejusdem sicci afigenda. $\mathrm{s}$.

(Citantur a Seguiero praeterea "Variae plantirum icones seorsim editac, nempe: Plantarum ancricanarum tab, 6 , plautarum anserjcanarum passitlorarum tab. 2 , planturum americanarum scandentium tas). 2, american plants with ono $3-4$ - or $i$-leaved pine or hollow

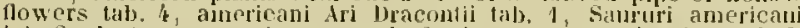
tab. 2, planturum austriacarum tab.-2, plantarum canadensium tab. 2 Aromatum Indiae, radicum of gummi tal, 1 , the rudiments of englist botany tah. 2, Orchidum litruriae tloribus cum ligulis a bruno Tozzin Abbati Vallumbrosino piclarum tal. 1 , rerum naturalium Elmiae ab eorlem tab. 1, phantarum Veroneusium tab. I, plantarum in monto Baldo creseentiun tab. 1, $p$ )

$7942 *$ Opera listoriam naturalem spectantia or Gazophylacium. Containing several 1000 figures of bircls, beasts, reptiles, insects fish, beetles, moths, flies, shells, corals, fossils, minerals, stones, fungusses, mosses, herbs, plants ete. from all nations, on 156 copperplates wilh Jatin anel englislı names. London, Millan. 1764. Il] voll folio et 8. - 1: folio. (10) plag., 180 tab. - 11 : folio. $(231 / 2)$ plag., 126 tab. - 111 : 8. $93,96 \mathrm{p}, 4$ tab.

7943 Petraeus, Aescillus. Suv SÉw Collegii physici Disputatio XVI. De metallis, lapidihus, suecis et terris pretiosis, slirpium natura iu genere, earum corruptionibus, jlantarum partibus et summis generilsus, quam auxiliante altissimo etc. in regia Ubsaliensi aeademia praesile M. Aescillo Petrueo discutiendam proponil Gilius $N$. Pistorius, Upsalice, typ. Acscillus Matthiae. 1625. 4.(10) p. w

794. * Petrelli, Eugenius. Vera narratio fruticis, florum et fructuum novissime in oceilentalilus Indiis nascentium. Impr. cum Antoni Possevini Cultura ingesiorum. Colonide Agrippinae, apud Joannem Gymnicum. 1610.8. p. 189-207, I tab.

Est drscriptio et icon mystiea Passillorae, uli prins Simon Parlasca Bibliopola Bononiae ediderat prelo Cocciano.)

7945* Petrus, Cornelius. Annotaliunculae aliquol Coruelii Petri Leydensis in quatuor libros Dioscoridis Anazarbei. (Antwerpiae, excudebal Joannes Grapheus.) 1533. 8. ( 51 foll.) Bibl. Univ. Lips.

$7946+$ Petri von Hartenfelss, Georg Chrisloph. Asylun languentium seu Carduus sanetus vulgo benedictus, medicina patrumfamilias polyehresta, verusque pauperum thesaurus ad normam et formam Academiae uaturae curiosorum elahoralus. Jenae, Trescher. 1669.
8. 952 [., 2 la], - tSecunda editio correctior. Lipsiae, Klose. 1698. 8. 252 p., ind., 2 lah.

79,7" Pefri, J. G. Der thicriscle . Wagnetismus in seiner Anwendung auf

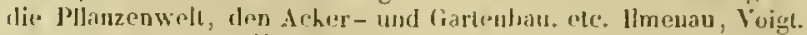
1824. $8 . x I N, 97 \mathrm{p} .(1 / 2$ th. $)$

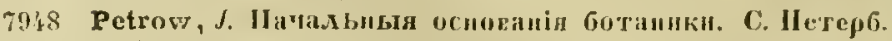
1845. Trautv.

7949* Petrus de Abano, alias Abbano, Apono, Appano, Aponensis. Conciliator differentiarun philosophurum et praccipue medicorun.

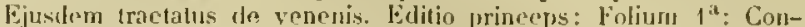
eiliator. differenti | arum. philosophorum, el | precipue. nedicorum: cla | rissimi. viri. petri. de. alsa | no. patavini foeliciter | incipit. prologus. Foliun 364 in fine eonciliatoris: Laus. deo. amen. finit conci | liator. Lodovicus Carmelita primus / loc opus aere iurimi jussit Mīiue. per Thomā | Septécastrésem de civilate Hermeni el Jo

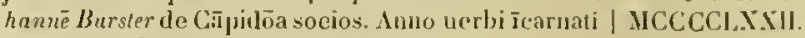
Foliun $365^{a}$ : Traetatus te venenis. a I magistro petro de abha I no editus. In fine: Dro gratias. Manlue hoc phylosoplorum alecus Ith | strissimo principe el domino: domino, Lorlonicho de Gonzagla Mar | chione ihidem feliciter re | guante impressum. An | nis urerli incarnatil. M.C.CCC.LCXIll. folio. (371) fell. binis columnis 56 linearum. Itain Nr. 1. Bibt. Reg. Dresd. - Venetiis, a masistro Gabriele " Tarvisio. 1476. follo. Main Nr. 2. - Papie, per Gabrielem de Grassis. 1490. Folio. Huin Nr. 3. - Vencliis 1496, Jolio. IIoin Nr. 4. Feneliis, apud Oetavianum Seolum. 1499. folio. Main Nr. 5. - Veneliis 1483. folio. I/ain Nr. 6.

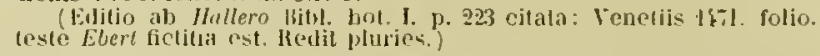

$7950^{*}$ - Tractatus de venenis. Editio princeps. Impr. cun Conciliatore. Mantue 1472. folio. 7 foll. Bibl. Reg. Dresd. - Padue 1473. 4. 29 foll. B. - ${ }^{*}$ De venenis atque eurunten commorlis remediis liluer plane aureus per Joa. Dryandrum medicum pristino suo nitori restitulus. Alarpurgi, ex officina Eucharii Corvic. Agrippinatis. 1537. $8.79 \mathrm{p}$. (licalit pluries, Editiones anteriores ab anno 1300 recensentur
apud lluin Mr. $7-13$. .)

7951 * Petrus de Crescentiis. Opns ruralium commolorum. Elitio princeps. Folium $\left.\right|^{i 2}$ : Petri de crescentijs civis. Bononiensis | ejistola

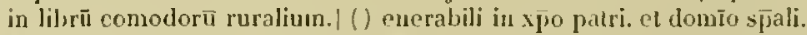
viro / etc. Fulium $109^{\mathrm{a}}$ : Petri de erefeencijs ciuis bonon. ruraliit omorlorun libri tuo decim | finiunt feliciter per iahanne Schuszler ciuem augustensem impressi. | circil xiiij halendas marcias. Anno vero a partu virginis salutife- | ro Millesimo quadringentesimo et septuagesimnprimo $7 \tilde{6}$ (1471.) folio. (209) foll. 35 linearum. Bibl. univ. Lips. Jlain Nr. 5828 .

(apostolo Zeno hat bewiesen, dass das Original lateinisch goschrielonk wurde.n Ebert. Aetas oneris est inter anmm 130k-1309 cf. Tiraboschi, Storia della lett. ital. vol. V. lib. I1. cap. 2 . $\$$. "3s.)

7932 Opus ruralinn commodorun. Impressum per Jøannen dr Wesiplaalia, in alma universilate louaniessi residente. Anno inearuationis dominiee MCCCCLAXNT, mensis becmlsis die nona. folio. 196 foll. binis columnis 42 linearum. Huin Xo. 5829 .

(llace editio incipit cum epistola dedicatoria ald Aynericum Placentinum. - Johannis de liestphalia aliae dude impressiones sine anno exstant, de guilus haec affert Ebert: "Es giebt zwei Ausgahen dieses Iruckers ohne lbalum, weiche selner als die voll lit. aber, weil sie signaturen haben, spater als dieselbe sind. Man unterscheidel

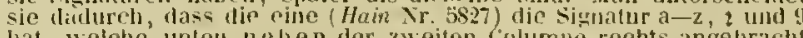
hat, wejche unten to ben der zweiten Columue reehts angehrachit

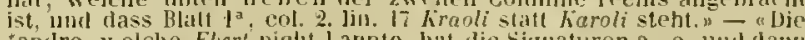
tandre, welche Eberi niclit hannte, hat die signaturen a-o, und dant sofort aa-li, nichinelien, sonderin unter der Columne rechts, und

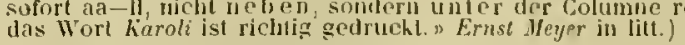

7953 Opus ruralium conmorlorum. s. I. et a. folio. 158 foll. sign. 53 linearum, charaetere gothico. Ebert Mr. 5438 .

( Nor den meisten Kapitein botinteu sich IJolzschnitle, zum Theil you Tllanzen. Einige, z. B. Cicertulit, sind ziendich henntlich, dir? meislen ganz unhemutlich oder erdichtel, mehrere wiederholes sich

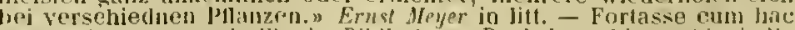
impressione eongruit illa in Bibliotheca Batuksiana his vertin indicalc: "Petri de crescemiis" civis Bononien. in eommodum ruralium cum tisuris lifri duodecim. s. l. et a. folio. CLIII foll. cum figuris ligno incinis", quae certo esl eadem ac prima llaini Mr. :3526.)

$7934^{*}$ - Opus ruralium eommodorum. Argentine, anno domini $14 \$ 6$, finilum quinla leria aute festum Sancii Gregorii. folio. 147 foll. binis columnis 46 linearum. Bibl. univ. Lips. Hain Nr. 5831 .

(a Stimmt in der Form der Lettern und in den Lesarten genau mit der Lowener Ausgabe uberein. " Ernst deyer in litt.) 
7953* Petrus de Crescentiis. De agricullura. ommilusque plantarum et animalium generibus libri XIl. ete. Basileae, per llenticum Petrum. 1538.4.564 (574 E. M.) B., ind

$7936 \div$ De amnibus agriculiurae partibus et de plantarum animaliumque natura et uilitate libri Xll. Basileae, per Henrieum l'etri. (1548.) folio. (5) foll., 383 p., ic. xs logr. i

"Unter diesen verschiednen Ausgaben des lateinischen Textes siud die Augaburger, Low "dier, die oline loruchort mit lolzschnitten, und die Baseler oftenbar nach ganz verselhiednen Hindseluriften aburdrucht, unt in den Lesarten sehr ahweichent. Die beiden ersten scheinen den Vorzu; zu verdienen. Die Baseler, sowols die in folio, als die in 4. die ganz ubereinstimmen, sind wegor virfacher, zum

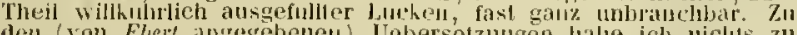
den (van Ebert angegebeneu) Uebersetzungen habe ich nichts zu mit, beibâtig gesart, zismlich unbedeutenden Aumerthungen, und eine deutselo," Errest veyer ill lil

italice: In libra tella agricultura di Pintro Crescentis. Florentic. per me Nicholaum (Laurentii, alenuanum) diocesis uratislusiensis, dis xv mensis julie, Anmo M. GCec. L. Xxvil, in-fol. de gol $\mathrm{f}$. nou chiflés, a 43 lig. par page, sign. a-blh. Brunet.

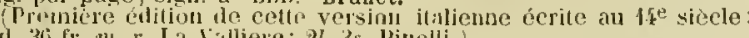
vend. $36 \mathrm{fr}, m, r$. La Valliere; $2 l$. 35 . Pitselli.

(Cette traduct., aprís avirir éte réimpr. a vicence, en 19.90 , in-fol. et plusieur's fois a l'cuise, dans le courant du $16^{\circ}$ siecele, en dufférents formats, fut revue par Bastiano de' Rossi, qui la publia a F'lorence, en 160.3 , sous le tittr Trattuto dell uyricolura di Pietro de Crescenci. Cest dipres colte cillit. in-t, qu'ont de faites celles de Naples,

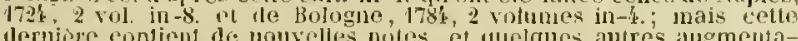

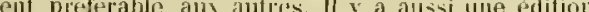
de Milan, is 805,3 vol. in-8.)

- ilatice: Tratolto muovamente yer Francesen Samsopinn. Fenetia

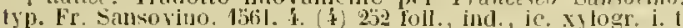

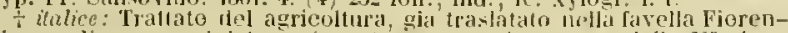
tina e di nuovo liviste e riscontro con testi a penna dallo Nierigno (Bastiano de Rossi), accadentico della Crusca. Firenze, Cosimo Giunti. $1600.4 .576 \mathrm{p}$.

itulice: Nupnli 172k. 11 voll. 8. - 1: 275 p. - 11: 296 1). B.

gallice: Lo liure des prouftits ehamprestres et rurauls, rompile par maistre pierre de Crescences, et translate dipuis on langage

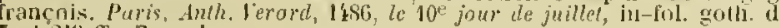
7 el 219 if. Brunet.

(Edition fort rare de celle traducion écrite en 1333 )

gallice: Liure des prouffits champestress. an recto ilu dernier $f$.

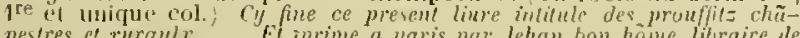
pestres et ruraulx.... El iprme a parts par Jehan bon home huraire th

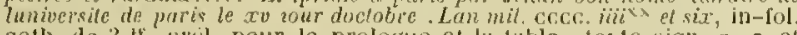

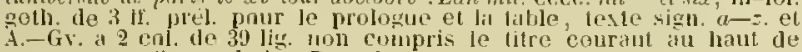
pages; avee tig. en hois. Brunet.

iculte entition nest pas comme nous l'avons dit autrefois, la meme que la precelente. Je prens. f. présente une gravure en bois. au desius de laqueste se lisent les mols le probogue, et le sommaire suivant qui occupe quatre longurs lignes et un bout de ligne: $C y$ silivant qui occupe "fuatre longurs lignes et un bout de ligne: Cy commence le hure tles rurautx proufnts dhe labour des chaps le guel fut at depuis a este trnnstate en francoys a la requeste du roy charles de france le guint de ce nom. Et pancrement sensuyt le prologue de lacteur lu livre.

Peut-itre mantue-t-il dans lexempl. de la Biblioth. du roi (que nous decrivons) quelpues fí. prélim. quil apparticndraiejt a la table.)

gallice: Le line des pronffitz chãpestres lit rurank touchat le labour des champs edifices de maisons puys of cysternes compose rerbes besles ef autres choses mont ntille's ? prouffitables a toutes gens, Et do plusieurs numbe le mesnaiger nothellement corrige et imprime en piris pour Jaques huguetan marchanl libraire de lyon... (a la lin) (y fine ce presút liare.... imprime a paris Par maistre thoma. höne. Jaques huquetan (sie).... int-fol. goth. de 8 if. prél. pour le titre "i la table, churvi if de cexte, à 2 col. de 40 lig., avec tig. en bojs. Brunet.

(Edition imprimée de 1520 at 1530 .)

grallice: Lo bon Nesilagrer. Au present valume des prouffiz champestres et rurauh est traiete du labour des champs, vigues, iardins, arbres de tous especes. De lenr nature of bonte, de la nature vertu des herbes, de la maniere de nourrir toutes hestes, volailles et oyseaulx de prix. Pareillomed la mánicre le prendre tontes liestes saulrtages, joissons ef nystruls: neume moull utile z proufliable Le dit liure rompile par Pintre de Cresecus iadis hourgecys de Boulogne la grasse, nouucllement cortige, veu $?$ amende sur les vieilz originaul auparauat imprimez. On dit liurr est adionste oultre les precedentes improsionp. La manierp de Enter. Planter : nurrir precedmes impresions. La maniere de Enter, Planter " nourir

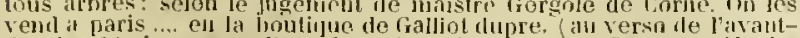
dernier [. Le present liure fut uchene de imprim. a Paris por Nicolas

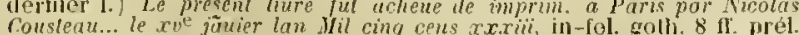

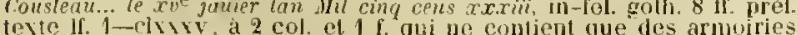

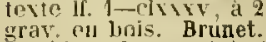
(Ce volume a été réimprimé a Paris, en $13 \%$, in-fol. Les dillérentes
éditions se paient de 18 a 30 fr.)

germanice: Petrus de Crescentljs zu teutsch mit liguren. s. I. et a. folio. $20 \%$, (5) foll. If ain Nir. 5833.

germanice Folium $1^{2}$ : leetrus de crescentiis zil teulsch mil figuren. Folium 229t: Ilie endet sich Pelrus de crescenciis zu dulscho. fiedruck uij rolendet noch der geburt Cristi. Mccccxclit. (1493. Des dinstags noch sant Michels 1ay. s. I. (Strisshurg.) folin. (23h) foll. linis columnis (sign. a-z,
Bibl. univ. Lips.

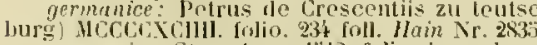

germanice: Strassburg 1312 folio. ic. Xylogr. i. L. Eberl.

yormanice : Von dom Nutz der bing, die in Aeckern gebuwl wer-

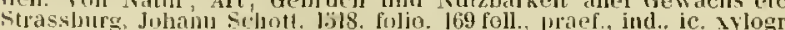
i. t. Bibl. Dresd. et Vind.

grmanice: Ion Ackerbau, Erdwucher und Bawleuten. Yon Natur, Alt, Gebiauch und Nutharkeit aller Gewach, Frueluten, Thicren, samt allen dem, so dem Vensiluen dientiel in spejss unn Artzli31. fôlio. Rivin.

gemranice: New loldt und Acherbaw vermelut uld gebessert Franhfurt a/11., Peter schmidt. 1583. folio. ic. aylogr. i. t. hivin. germanice: 'strasalurg, Zetzner. 1602 folio. ie. Yylogr. i. t. Ebert. polonice: Cracoviar, apud llelentam Unglin. 1349 . folio. - Ed. ll Cracoviae, apud stanislaun scharfoubers. 157i. folio.

7907 Pétsi, alias Peéchi, Lucas. Kereszlény szüzeknek tisztességes koszoruja, avagy lelki füves kert, lelki virảgos kert, h. e. Virginum cliristianarum coroula honesta, sive liorius floridus animarun. Tymaviae 1591 . 8. 20 ic, xylogr. j. 1. Haberle

Deseribit autor monachus, ident yui etian enluil hortulum botimicum privilum, int opusen rarissmo corouam florum e vigint diversis plantis cum nominibus el proprietalibus, pieque admone ad viginti virtutes diversas.

7958* Pettenkofer, Max. Eelser Mlikania Guaco. D. Muschen, typ. Wolf. $1844,8,49$ j.

$7930^{*}$ Petter, Franz. Botanischer Wegweiser in der Gegend von Spalato in Dahnatien. Ein alphabotisclies Verzeichniss tler von den Verfasser in Dalmatien und inshesondre in der Gegent von Spalato gefundnen wildwachsenden Pflauzen nebst Angabe iher Fundörter, Blütezeil elc. In Carton. Zara. Battara. (Wien, Gerold.) $4832.12 \mathrm{obl}$ $32,144$ p. ( $11 / 12$ th. $)$

$7960^{*}$ Petzholdt, Alexander. De Calamitis et Lithanthracibus. Drestac el Lipsiae, Iruold. 1841.8 .42 p., 3 lab. (1 th.)

$7961^{*}$ - Ueber Calamiten und Steinkohlenbildung. Dresden und Leipzig, Arnold. 1841. 8. vi, 68 p., \& tab. $(5 / 6$ th.)

7962* Papuläre Vorlesungen uber Agrikulurchemie. Leipzig, Weher. 1844, 8. x, 363 p., ic, xylogr. i. t. $\left(15 \%\right.$ th.) - ${ }^{*}$ Dic Agrikulturchemie in populuren Vorlesungert. Nit eingedruchten Ilolzschnitten. Zweite ungearheitete Aullage. Leipzig, Lorck. 1846. gr. 8 xvi, 461 p. (2 th.)

7963 - Die sogenannte Kartoffelfuule. Eine auf Veranlassung des (saclisischen) Ilohen Ministeriums des Innern untemonnene Untersuchung dieser lirankleit. Dresden und Leipzig, Amold. 1846.

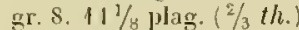

7961. Peucer, haspar. Propositiones de origine el causis succini. Wittebergae 15 š5. 8. 2 plig. B.

$7963^{*}$ - Yocabula rei nummariae ponderum et mensurarum graeca latini chraica, quorm intellectus omnibus necessarius est; collecta ex Budei, Joachmi Camerarii et Philipui Melanchthonis annotationibus. Additae sunt ilpellationes quadrupedum, insectorum, volucrum, piseium, frugun, leguminum, olerum et fructuum communium, collectae a Puulo Ebero " Cusparo Peucero. Recognitae el auctae. Vitehergae, excullebat Johanmes Cralo. 1556. 8. (104 foll. Cust. A-0.). - "Lipsiae 1570.8 . (non differt.)

7966 Peyer, Johann. Pentas juaestionum de planlis. Basileae 1623. 4. $s$.

7967* Peyer, Johann Jakob. De corlice Peruviano. D. Basileae, Iyp. Thurnisius. $1745.4 .24 \mathrm{p}$.

791; $8^{*}$ Peyre, B. L. Nèthode analytique-comparative de botanique, appliquice aux genres de plantes phanirogames qui composent la Foro française. Paris, Ferra jeune. 1823.4 . xvr, 62 p., 1 iableau. (9 $\mathrm{fr}$.)

7969\% Peyrilhe, Bcrnarl. Tableau metholique d'un cours d'histoire naturelle medicale. Paris, Panchoucke. au VIl. 1799. 8. xvi, 575 p. ( $7 \mathrm{fr}$.) - tNouvelle (quatrième) élition revue et augnentée. Paris, Néquignon. 1804 . II voll. $8 . \mathbf{x}, 736$ p. (9 fr.)

7970 Pfau, Ludwig. Eeber Botanik. Nach Claudius. Ulm, Seilz. 1842. 12. $3 \frac{1}{2}$ plag. $(1 / 12$ lh. $)$

(Etian inscribitur: "Wohireilste Sammlung guter Bücher. Lrstes Bandelsen.n! 
7971 Pfau, Philipp. Die Kultur der Rosen, mit lsesondres Racksicht auf das lieberwintern der immerbluhenden in freien Lando. IJeilbronn, (Drechsler.) 1846.8.3 $3 / 8$ plag. $(1 / 15$ (h.)

7972 Pfautz, Johann. Jescriptio grantuis metlici plenior, ex variis haml infinitac notae scriptoribus, to numine, forma, locn, tempore, qualitatibus ac viribus, cum additione descriptionis Anjuelnprasi proliferi. Ulmae, Balthasar Kulune. 1656 . 1. 19 p. B.

7973 Pfeiffer, Christoph Ludury. Lelırgelicht auf ten Knaster. Leipzig IInd Wittenberg 1754. \%. H.

7974* Pfeiffer, Louis. Enumeratio diagnostica Cactearum lucusque cognitarum. Berolini, Oehmigke. 1837. 8. vm, $192 \mathrm{f} .(5 / 6 \mathrm{th}$.

$797 j^{*}$ - Beschreibung und Symonymik der in deutschrn Gärten lebend vorkommenden Kakteen. Nebst einer l'ebersicht der grosseren Sammlungen und einem Aulınge uber dis Kultur der Laktuspllanzen. Berlin, Oehmigke. 1837 . \&, vi, $231 \mathrm{p} .(\mathrm{i} / \mathrm{l}$.

$7976^{*}$ und Friedrich Otto. Abbililung und lesclureibung loluhender Kakteen. (Figures des Cactees en lleur peintes el lithographiées d'après nature.) Kassel, rỉcher. 1843-1847. 11 roll. 4. 1: Fase. 1-6. 1543. 30 tab. pro parte col., totidem foll. texi. 11: Fase. 7-9. 1844-1847. 15 tih. pro parte col., totidemyue foll. lext. $(9$ th. - omnino col. 27 th.)

(Singulus fasciculus liabet 5 tah.; pro parte col. 1 th. - ommino col. 3 th.

$7977^{*}$ C..... Einige Worte uber die subalpine f'lora des Neissners. Dem Herrn Geh. Holrath Dr. Richurd Harnier zu Kassel an Jubilaumstage seiner alen 24. September 1794 mumbiclist erlangten Doctorwürde gewidmel von Dr. Louis Pfeiffer. Kassel, typ. Ilotop. $1844.8 .16 \mathrm{p}$.

$7978^{*}$ - Uebersicht Uer hislier in kurhessen beobachteten wilıwachsenden und eirgeburgerten I'flauzen. Im . Auftrage des V'ereins fur hessische Gesehichte unl Lauleskunde, und unter specieller Mitwirkung des Dr. Jokann Ileinrish Cassebeer zu Bieber hearbeitet von Dr. Lovis Pfeiffer in Kassel. Eirste Abtheiluag. Kassel, Bohné $1844.8, \mathrm{x}, 251 \mathrm{p} .\left(1 \frac{1}{6}(\mathrm{~h})\right.$.

$7979^{*}$ - Flora von Niederhessen und Munden. Beschreibung aller in Gelsiete wildwachsendon und in Grossen angebauten Pllanzen mit Ruckisicht auf Schulgebrauch und Solbststudium bearbeitet. Erster Bamu. Dikotyledonen. Kassel, Fischer. $1847.8 .4,428 \mathrm{p} .(1 \mathrm{th}$.)

$7980^{*}$ Pfund, Johannes. Nonographiac generis Verbasei prodromus. Deutschlands Bärtlinge ouler Wollkrauter (Konigskerzen) mit besondrer Borückichtigung der böhnischen drten. In ökonomischtechnischer und medizinischer llinsicht bearheitet von Friedrich Grafen van Berchtold, in botanischer von Juhannes Pfund. Prag, Iyp. Th. Thabor. 1840.8 , s0 p., I tab.

(llaud dubie seorsim impressum ex libro supra Nir. 728 citato.)

7981 Phelps. Botanical calendar, exhibitiıg at one view the generic and specific name, the elass, order and habitat of all the british plants. London 1810. $8.186 \mathrm{p} ., 5$ tab. $(3 s .6 d$.

7982* Phelsum, Murk ran. Fxplicatio partis IV Plyjtographiae Leonhard 'Pluc' neti. Jlarlingae, typ. van der Plaats. 1769.4. xir, $35 \mathrm{j}$., ind

7983 Philes, Manuel, Ephesios. Carmina graeca. Gracee et latine cum annotationibus, cura Goltlieb Wernsdorfii. Lipsiae 1768.8 .350 p. B. (1lue facit earmen tle plantis p. 9:3-129.)

7984* Philibert, J. C. Introduction a l'étude de la bolanigne. Ourrage orné de dix planches coloriées. Paris, Delalain. an V1l. 1799.111 roll. 8. - 1: 454 p. - 11: 658 p. - 111:524 p., 10 tals. - *ib. 1802. III voll. 8. ( $18 \mathrm{fr}$.) (non) differt.)

$7983^{*}$ Exercices de botanique à l'usige des commençans. Ouvrage élémentaire orné tle 157 planches. Paris, Bossange. 1804. 11 roll. 8.438 p., 153 tab. col. (30 fr. nigr. - col. $42 \mathrm{fr}$.)

$7986 t$ L__ Lecous élénentaires le bolanique, à l'usage des cours publies et perticuliers et des écules ou lycées. Paris 1802. 8. $\div$ Nouvelle édition. Paris, Dentu, 4807. 8. vit, 544 p. (6 fr.)

$7987^{*}$ —_ Dictionnaire abrégé de hotanique, faisant suite aux exercices de botanque a l'usage des commençans. Paris, lyp. Chapelet. 1803. 8. vi, 180 p., 24 tab. col. ( 8 fr.)

7988 - Dictionnaire universel de holaniqur contenant l'explication détaillèe de tous les termes français el laliıs de hotanique et te physirue végétale. Paris, Merlin. 180\%. 11l voll. 8. - J: A-E. 1x, 604 p. $-11:$ F - 0.554 p. - 111: P - Z. p. $551-1134 ., 5$ tab. $(19 \mathrm{fr} .50 \mathrm{c.})$
$7989+$ Philippar, Fr. Vogage agronomique en Angleterre fait en 1829 ; ou essai sur les cultures de ce pays comparées à celles de la France. paris, Rousselon, 1830.8 . vir, 188 p., 20 tah. (6 fr.)

7990 t Traité organographiıue et plıysiologico-agricole sur la Carie, le charbon, l'ergot, la rooille et autres inaladies flu merme geure qui ravagent les cérẻales, avec ligures explicatives. Verstilles, 1yp. Marlin. 1837, 8, 220 p., 9 tab.

$7991 \div-$ Progranme raisonue du cours de culture, professé a l'école normale de Versailles. Versailles, 1)ufaure. 1844 . \$. $252 p$, $16 \mathrm{tah}$.

(Fr. Philipper et F. H. Philippar fortusse nomina discrsa sunt cjusden autoris.)

$7992+$ Philippar, F. II. Cataloguo méthodliłue des vigétanx cultivis dans le jartin des plantes de la ville de Versailles, précéde d'une uotice historiyue sur les jardins royaux et particuliers de Versailles, sur les honmes, qui dans la botanique et dans l'herticulture ont rendu des services a la ville. Aree plan el plusieurs facsimiles. Versailles, typ. Hontalatu-Bougleux. 1843.8 mix. 284 j., 3 tals.

$7993+$ - Notice sur la maladie qui a affectó les prommes de terro. Paris, 1yp. lluzard. 1845. 8. 13 p.

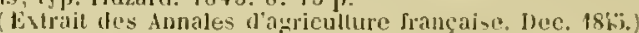

799: Philips, John. Cyder. A poem in two boohs. London. Cor J. T. 1720. 12. $\mathrm{s}$.

7993̈t Phillips, Henry. Pomarium britannicum : an historical ans botanical aceount of fruits, known in Great Britain. London, Alluan. 18:0.

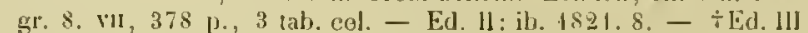
London, Colburn et Co. 1823. s. $1 x, 372$ p., 3 tab.

$7996+\longrightarrow$ History of cultivated regetables ele. Lit. II. London, Colburn. 1822. II voll. 8. - 1: vil, $383 \mathrm{p} .-11: 430 \mathrm{p} .(1 / .1 \mathrm{~s}$.

$7997^{*}$ - Sylva lorifera: the shrubbery historical and botanically" treated; with ohservations on the formation of ormamental plantations and picturestue scenery. la two volumes. Loudon, Longman of $\mathrm{Co}$. 1823. 8. - I: 11, 336 p. - IJ: 333 p. (11. 4 s.)

$7998^{*}$ Flora historica: or the three seasons of the Jritish parterre listorically and botanically treated: with observations on planting ete. London, Lloyd. 1824 . 11 voll. \&. - I: LI, 354 p. - 11: xi, 464 p. (11.4s.) - ${ }^{*}$ The second edition revined. Lotulon, Lloved. 4829. Il roll. 8. - I: xLvi, 333 p. - II: vin, 423 j. (1l. 1s.)

$7999^{*}$ Phoebus, Philipp. Deutschlands kryptogamische Giftgewichse in Abbildungen und Beschreibungen. Berlin, 1lirschwald. 1838. 4. xII, 114 j., 9 lali. col. ( 3 th.

(Esi sectio altera libri supra Nr. 1236 indieati.)

$8000 \div$ Picard, Casimir. Elude sur les Geraniees rjui croissent spontanement dans les départemens de la Somme el du Pas-de-Calais. Boulogne, typ. Le Roy-Nabille. 1938. 8.46 p. ( 1 fr. 50 c.)

$8001+-$ Observations botaniques sur le genre Sonchus. Boulogne, typ. Le Roy-Mlabille. s. a. 8.16 1s., t tab. ( 1 fr.)

$8002 \div$ Piccioli, Autonio. Pomona Tuscana, che contiene una breve deserizione di tulti i frutli che si eoltivano nel suolo toseano jer servire alla collezionr in gesso dei modesimi. Firenze 1920.8 ( (16) foll.

(Describunter it varietates Citri ad colfectionem illustrandan.

$8003^{*}$ - Nuovo e sieuro mezzo di distreggere gl" inselti che dannegriano la pianta dell' Ananasso, senza oftendere coll applicazione di esso la pianta stesso o il suo frutto Ritrovamento. Firenze, typ. Pezzati. 1825. 8. $10 \mathrm{P}$

800 * $^{*}\left(\frac{}{-}\right)$ Catalogus plantarum horti hotanici Florentini. Florenliae, typ. Pezzati. $18 \geq 9.8 .54$ p.

80035 - N Nuovo netodo per la riprotuzione delle piante per margotto ritrovato o proposto. Firenze, 1уp. Pezzati. 1829 . 8. viu p. 1 tab.

8006t Picciuoli, Giuseppe. Ilortus Panciaticus, ossia catalogn delle piante esotiche e dei fiori esistenti nel giardino della villa detta la loggia presso a Firenze, di proprieta del Marchese Niccolu Panciofirhi. Firenze 1783. 4. 32 p, I tab. col. (Panciatica purpurea.)

$8007^{*}$ Picco, Ticlorius, latine Picus. Melethemata inauguralia. Augustae Taurinorum, excudebat Jriolus. $17 \$ \$ . \$ .2 \$ 3$ 1 ., 2 tab. col.

(De fungorum generatione p. 1-103; ex materia medica. de fungis p. $105-167$ : de symptomalibus, quae fungorum vencuatorum estini conserpui solent p. 23i-264.)

$8008+$ Picconi, Giammaria. Saggi sull" economia olearia. etc. Genora, typ. Gioxsi. 1808-1840. 11 soll. 8. - J: 4808, xcu, 298 p., 4 tab. - 11: 1810. xxvil, 452 p. Bibl. Cand. 
S009t Pichon et Broca. Catalogne raisonné ou tableau analytique et descriptif des plantes eultiveses à l'école de botanique de Brest, ete. rédigè par Pichon et Broca. Brest, de l'imprimerie imperiale. 1811. 8. xiv, $571 \mathrm{p}$.

8010 Pickel, G. Die diessjăhrigen Wetterbeohaebtungen in Fruh-und Spatjahre, in Bezug auf Sehutzung der Weimbergo gegen Frost. Bamberg und Wurzburg, Gobhardt. $1804.8 .1 \%$ th.

$8011^{*}$ Die Witterung des Jahres 1805 mit ihrem Einflusse auf die Pllanzenprodulte, besouders des Weinbaus. Bamberg und Wurzburg, Gobliartt. 1806.8 .56 j. $(1 / 4$ th.

8012 - Versuch einer genauen Bestimmung des imeren und wahren Gehaltes der Pflanzenfruehte, inchesondre der Weine und des Getreides. Wurzburg, Stahel. $1823.8 .(5 / 12 / h$.)

$8013+$ Pictet, Charles. Traité des assolemens, ou de l'art d'étalilir les rotations de récoltes. Genéve, Paschoud. 1804.8. 284 p. (5 fr.)

804: Pictorius, Johann Baptist. Der in Jlumen- Kuchen-Arzeneyund Baumgarten gründlich instruirte Gártner. Nurnberg 1729. S.

8015* Fiddington, $I$. An english index to the plants of ludia. Calcutta, Thacker et Co. (printed at the haptist mission press.) 1832. 8. viII, $235 \mathrm{p}$.

S016* Piepenbring, Georg Ileinrich. Lebrjucli rler Fundamental-Botanik bearbeitet fur deu Gebrauch zu Vorlesungen. Gotha, Ettinger. 1805. 8. xiv, $445 \mathrm{p} .\left(1^{1 / 3}\right.$ th. $)$

Altero inseribitur titulo: Erster Unterrieht in der vorbereitenden liriuterhunde. :

8017* Pieper, Philipp Auton. Das weelıselude Farbenverháltniss in den rersehiednen I.ebensperioden des Blattes nach seinen Erscheinungen und Ursachen. Berlin, Enslin. $1834.8 . \mathrm{xv}, 167$ p., 2 tab. (1 th.)

$8018^{*}-$ Nechera Schlechtendali. Programma gratulatorium. Paderbornae 1838.4.10 p., 1 tab.

8019* Pieri, Wichele Triroli. Della Coreirese Flora Centurie prima, seconda e terza, ossid storia di piante treeouto, appartenente al suolo (lell' isola di Corfu. Corfi, nella stamperia del governo. 1814.4 max. (formae folio similis.) 141 p., praef. Bibl. Mus. bot. vind.

$8020^{*}$ - Flora Corcirensis Centuriae I et II, sive enumeratio 200 plantarum, quas in insula Corcirae invenit. Coreirae, typis pulılicis. 1824. 8. IX, $85 \mathrm{p}$.

8021 Pierre. La botanique; par le capitaine Pierre. Seeonde edition enticrement refondue et enrichie du langage de Flore. Laon 1845. 18. 11 plag. ( $4 \mathrm{fr}$-)

8022 Pietsch, Joham Gothold. Abhandlung von Anziehung und Pflege der Kastanienhäume, llauptsachlich der guten, essbaren, und dem Gebrauch ihrer Fruchte. Halle 1776, 8. 68 p)

$8023^{*}$ Pietsch, Valentin. Theriaca Andromachi ex simplicibus selectis omnium obtutui at explorandum expositis aeeuratoque medicae faeultatis examine approbatis. Sub Augusto et Ausjucato Friderici lhegis regimine a I'aleatino Pietsch, pharmacopaen Regio confecta die 26. Junii 1704. Regiomonti, typ. Reusner. (1704.) 4. (4 foll.)

$8024+$ Pignol, A. R. Des rapports sur l'influence du elimat et de l'halitation sur les plantes et les animaux en général. Lyon, typ. Rusand. s. a. $8.20 \mathrm{p}$

$8025^{*}$ Piller, Malhias, et Ludurg Mitterpacher. Iter per Poseganam Slavoniae provinciam, mensibus Junio et Julio 1782 suseeptum. Budao, typ. regiae universitutis, prostat apud Weingand et Kopf. 1783. 4.147 p., 16 lab.

(Tabulae 2-9 in multis exemplarilous sunt coloratae.)

$8026+$ Pilleterius, Caspar. Plantarum lum patriarum quam exoliearum in Walaehria, Zeelandiae insula, nascentium synonymia. Middelburgi, excudebat Riehardus Schilders. 6 10.8.398 p., praef.

$8027 \div$ Pinnock. Catechism of botany; being a pleasing description of the vegetalle kingdom. London, Whittacker. 1822.12 .72 p., effigies Limnei. $(9 d$. $)$

$8028+$ Pio, Gioranni Ballista. De Viola speeimen lotanieo medicum. D. Taurini, typ. Bianco. 1813.4 .52 p., 3 tab. Bibl. Cand.

8029t Pion, Pelrus. Phytologia, sive Theses de plantis quatenus medieis materiam subministrant remediorum, quas in catholica et celelserrima llerbipolensi aeademia sub praesidio elarissini viri domini $A$.
Romani, medicinae practieae Professoris ordinarii jro gradu bacedlaureatus in medicina adipiscendo contra quoscunque oppugnare volenter defendere conabitur. Wirceburgi, exendebat Georgius Fleischmann, die 13 Oct. 1598.4.88 p. Bibl. Cand.

(A p. 8-22: Centum plintarum sponte in Gemania provenientiam

8030 Piper, Wilhelm. Taschenbuelı der norddeutsehen Flora, enthaltend eine Charahteristik der gemeinsten im norddeutsehen Flachlande sowohl wildwatssenden als kultivirten Pflanzen. Aus den besten Quellen nach naturlichen Familien und dem Linne'schen Symem. Nalchin, Piper. $1846.8 .24 \frac{1 / 2}{\text { plag. }}\left(1 \frac{1}{4} \mathrm{th}\right.$.)

8031 * Pirck, Joham Lorens. De Camphora. D. Viennae, ty.j. Schultz. 1767. 8.

$8032 *$ Pirolle. L'horticulteur français, ou le Jardinier amatıur; traité complet théorique et pratique du jardinage, divisé en luvit livres. Paris, Koret. 1824. 12. x, 878 p., 2 tab. (7 fr.) - Suppliment. Paris 1826. 12. (2 fr.) a.

8033 Calendrier du Jarlinier français, contenant le precis de tons les travaux a exicuter dans chacun des mois de l'année, avec la notice des fleurs, fruits et agréments que peuvent se procurer dans ees memes mois les eultivateurs de jardins. Paris, Roret. 1825 18. a.

803i Traite special et elidactique du Dahlia, sous tous les rapports, qui peurent intéresser les cultivateurs, les amateurs, les connajsseurs et les curieux de ce heau geure. Paris, P. J. Loss. 1839. gr. 12 . ( 2 fr. $50 \mathrm{c}$.)

(a) Pirolle a ele aussi te principal redactmar du Bon Jardinier, antues 4820 a 1822 ; il cot tout-a-fait eiranger aux armées anterieure. et posterieures. Comme secretaire de la soeiete clagronomie pratique il est le prineipal rédaeteur des Annales des järdiniers amateurs, recueil rui a commencé a paraitre en janvier 1831. I1 a fait en outre, la description des lioses peintes par Redoute." Q.

8030̈* Pisanski, George Christoph. Naehıicht von dem gelehrten Konigsberger IIelchior Guilandiu. Programm der lionigsberger Cathedralschule vom Rector D. George Christoph Pisanshi. Kionigsberg, typ. Driest. 1785.4. 16 p. Bibl. Mus. Senckenb.

8036* Piso, Willem. Guilielmi Pisonis de medicina brasiliensi libri IV, et Georgii Maregravii historiae rerum naturalium Brasiliae libri VIII. Joannes de Laet in ordinem tligessit et annotationes addidit et varic ab auctore omissa supplevit. Lugduni Batarorum, apul Franeiseum Haehium, et Amstelodami, apud Elzevirios. 1648, folio. 122, 293 p., praef, ind., ie. xylogr. i. t. - ${ }^{*}$ Edl. Il: Gulielmi Pisonis, medici Ansstelaedamensis, de Judiae utriasque re naturali et medica libri quatuordecin, quorum contenta pagina seruens exlibet. Amstelaedami, apud Ludoricum et Daniclem Ekzevirios. 1658. folio. 327 p., prolegomena, ind. - Aeeedit: Georgii Murcgrovii de Liebstad Tractatus topographicus et meteorologicus Brasiliae cum eclipsi solari etc. 39 p. - Jacobi Boutii llistorice naturalis et medicae Indiae orientalis libri sex. 226 p., ind., (185) ic. xylogyr. i. t.

In hae altera editione weedit eliam Guitielmi Pismis Mantissa aromatica seu de iromatibus eardinatibus quatuor el de plantis aliquot indicis in medicintm receplis relatio nova. Ex vetere orbe hic exwat Caneltae historia ot uova icoln, et Nucis moschatae et l'iperis. Arundinis dlambu, Rotang, aliaipue.)

$8037^{*} \longrightarrow$ Gulietmi Pisoris Historia medica Brasiliae. Novam editionem curavit et jraefatus est Josephus Eques de T'ering. Vindobonae. typ. congres. Armenorum. 1817.8.157 p.

8038 Pitorius, l'eregrinus. Opolsalsami Rumani censura. Venetiis 1642. 8. 86 p. B.

8039 Pitzschmann, Georye Gollob. Gottseelig und vernunft-mássign vermuthung von einem gewachse der Erden, welches gleich einer Semmel in einem garten Sclutesiens gefunden worden. Leipzig 1700. 8. 196 p. B.

$80 \% 0^{*}$ Place, Franz. De usu corticis radicis Granati, D. Berolini 1825. 8. $30 \mathrm{p}$.

80.1 Plack, C. $F$. Anweisung, auf einfache und hostenlose Weise die Kartoffeln zu verbessern, und nicht nur viele, gesunde, grosse und wohlschmeckente kartofieln zu erndten, sondern auch mindestens das Doppelte des Ertrags zu erlangen. Breslau, Trewendt. 1846. 8. $3 /+$ plag. $(1 / 15$ th.

$8042+$ Planchon, $J$. E. Némoire sur les développenents et les caraetères des vrais el des faux arilles; suivi do considerations sur les orules 
de quelques Vemniques el de l'Avicemnia. Montpellied, typ. Boehm. 1844.4 .53 p., 3 tab.

so'.3 Planchon, $J$. E. Note sur le gence Godoya et ses analogues, avec des observations sur les limiles des Oelnaceses, el une revue dos genres el espices de ce spoupe. l'aris 1847. 8 .

So': 1. Planer, Johann Jakol. Inulex plantarum, "fuas in agro Erfurtensi sponte provenientes olim D. Juhann Whiliph Somne, Jeinde D. Johann Jakob Planer collogerumt. Gothae, Ettingser. 1788, 8. $28 \%$ j.

so: $:^{*}$ - Indici plantarum lirfurtensiun fungos ef plantas quastan nuper collectas alldit. I'rogramma. Erfordiae, 1ур. Nomne. 178s. 8. 44 j., praef

$80 \% 6$ - Versuch ciner leutschen Fomenhlatur der Linnoischen Gattungen, zur Lebersolzung fer Genera planlatum Linnaei. Erfurt, Muller. 1771.8 .228 p. $(5 / \mathrm{s} / \mathrm{h}$.) Beckmann.

so1.7* Plappart, Joachim Friedrich. De Juglaude nigra. D. Tindobonae, 191. Geruln. $1777.8,27$ 1.. 1 1ab. col.

(Rodil anclil duglande ciucrea in Jacquin Miscellanea austr. vol. Il p. $3-2 \hat{2}$.)

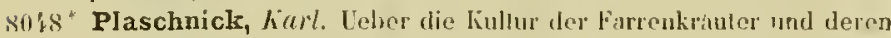
Erziehung aus Sanen in lien. hotanischen Garten zu Berlin. Berlin $1831.4 .19 \%$

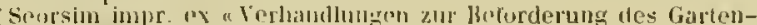
haus in den Kon. Preussiselın stititen.)

sil.9 PIat, Ihugh. The garden of Elen, or a description of all flowers and fruits now growing in lingland, whily rules low to advance their nature and growth. Eal. V. London 1660. S. 175 p. - The second part of the garden of Eden, never before printed. London 1660.8 . 159 p. B.

so:jot Platania, Salcalore. Sopua una essudazione sponlanea della guercia memoria. Catania, typ. Lotıgr. 1823 . 4. 8 p.

so:j * Plato, harl Gottled. Deutschlauds Giftptlauzen, zum Gebrauche fur Suluulen fasslicl bencluriclon. Vier llefte. Leipzir, Magazin fur

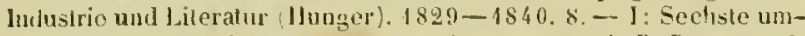
geanderle und verbesserte Auflage, hesorgt von A. B. Reichenbuch. 1840.56 p., 1 tab. col. (2/3 (h.) - II: Tierle verbesserte Auflage, besusot von Eduard 11 ilrenk (i. a. IVinkter.) 18.33. 11, 56 p. 1 tab. col. $(2 / 3$ (h.) - III: Fon Edurud Ifitrenk. 1829. 59 p., I tah. col.

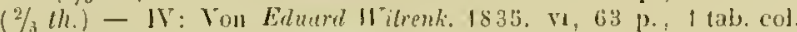
$2 / 3$ (h.)

Editio prima fascleuli frimi jam anno 1813 prodiit.

80"32* Plaz, Anton II ilhelm. Llistoriam radicum exponit. Propramma. lipsiac 1733.4 .20 p.

(liedit in ejus organicarum in plantis partinm historia p.j-21.

$8053^{*}$ De plantarum seminilus. Progrtanna. Lipsiae 1736.4 (8) foll!.

Redit in ejus Organicarum in plantis parlium historia p. 21-33.)

sob.

(Respondens: Johann Andreas ['ngebouer.) Redit in ejus Orgaticarum in plantis partium listoria p. $36 \rightarrow 67$.

$\aleph 0: i^{*}$ Caulis plantarum explicalus. D. Lipsiae 1745 . 4. $42 \mathrm{p}$

(Respondens: Meinrich Otto Bosseck.)

Redit in ejus Organicarun in plantix partiun lustoria p. 67-90.)

$8056^{*}-$ De llore plantarum. D. Lipsiac 1749.4.55 p. (Respon-

dens: Heinrich Otto Bossecl.)

(Checlit in ejus Otganicarum in plantis partium historia p. 90-119.)

$8057^{*}$ Organicarum in plantis parlium historia physiologica antelıc seorsin succincte exposita, nunc curatius revisa el aucta. Lipsiae, ex officina Langenhemia. 1751.4 .119 p., praef., ind. (linsunt in hac collectione libelli quinque academici, modo Nis. $80 \% 2-8050$ recensiti.)

$8038^{*} \longrightarrow$ De plantarum plethora. Programma. Lipsiae 1754.4 $2.3 \mathrm{p}$.

$80 . y^{*}$ De natura plantas munient(. Programnı. Lipsiae 1761. 4. $16 \mathrm{p}$.

$\$ 060^{*}$ - De planlarum virtulbus e. ipsarum charactere haudquaqquam addiscendis. Prolusio $1-111$. Liprsiar 1762-1763.4. 16 $12 p$.

$8061^{*}$ De Saccharo. Programma. Lipsiae 1763.4. $16 \mathrm{p}$

$8062^{*}$ De planlarum sub diverso coelo nascentium cultura. Prograuma. Lipsiac 1764.4. 12 j.

$806.3^{*}$ De molu humorum in plantis vernali tempore vividiore Prugramma. Lipsiae 1764. 4. 8 p.
S064" Plaz, Anton Itilhelm. De Atropa Belladonna. D. Lipsiae 1776.4. १0 p. (Respondens: Peter Johann Andreas Daries.)

806.j- Plée, duyuste, el Fancors PIée. Ilrrborisalions artificielles aux environs de Paris, un liecueil d.e luules las plantes, qui j croissent naturelloment, dessineses et graves d'aprés noture, de grandeur naturelle, avec les details aratumitues en couleur au bas sle chatuo espere elc. Paris, chez les autcurs. Is/1. S. 12 p., 40 tals. col. Bibl. Cand.

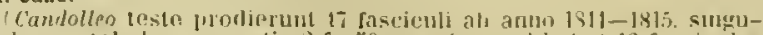

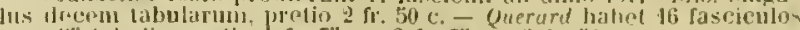

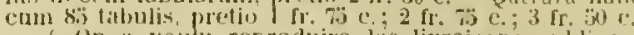

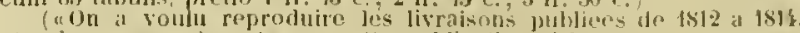
if achever on momo inmes cette publication i long-loups suspen-

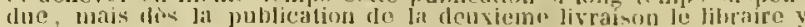
a renunce. la peproduction a part sols ee titer: Horborisalions

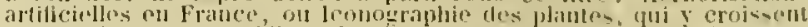

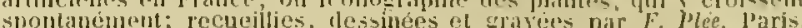
iequien. 1830.)

$8066^{*}$ Le jeune botanisle, au entrelions d"un père avec son fils sur la hotanique el la physiolovie véútale. Paris. l"erra. Is 12.

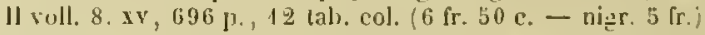

$8067 t$ Plée, $F$. Tspes de chajue famille et des principaux genres ales plantes croissant spontanément en France; exposition délaillée et complite de leurs caractères el de l'embryologio. Paris, chez l'autent, lue nouve sainte Goneviève, 22. (J. B. Bailliore.) $1844-1847$. fusc. 1-XIXYII. 1. 37 lab. col., text. ( $46 \mathrm{fr} .25 \mathrm{c}$ ) (Comlinuatur.)

siugulus fascien]us, pretio 1 fr. $25 \mathrm{c}$. continet unam talmbin splendido piclan eam analysibus, ef explicatione 2- paginarum: in priano fasciculo praeterea introductio: $8 \mathrm{p}$.

8068* PleischI, ddolph. Wer Thee (Thea) in elremischer und diciteliscluet Beziclung. Auwcisung, las Theegeträuk auf ejne einfache und wolılfeile Weise kraftiger wolshclumechender und der Gesundheit zuIräglieber zu bereiten. Wien, 1yp. Strauss. 1844.8. 38 p.

$8069^{*}$ Plenck, Joseph Jakol (vou). Bromatologia, seu docirina de esculentis e potulenlis. Viemne, Graeffer. 1784.8 .498 p., ind., 1 lab. (Pagrinae 19-176 agunt de vegetahilibus eseulentis.)

$8070^{*}$ Toxicologia, seu doctrina de renenis et antidotis. Tiennae, firaeller, 1785.8 .338 p., ind.

$8071^{*}$ L I couns planlarum medicinalium secundum systema Linnaei digestaum cum enumeratione viriun ef usus melici, chirurgici atyue diatetici. Viennae, R. Graeffer. 1788-1s/2. VlI] roll. folio. $75 \mathrm{~N}$ ab). col., lext. latine et germanice. ( 200 (h.)

(Volmuen lill post obilutu [t 1807$]$ atuctoris caldil Jeseph Lorenz liernill.)

8072* - Physiologia et jathologia plantarum. Tiennae, Blumauer. 1794. 8. 184 p., ind.

* germanice: Physiologie und Pathologie der Planzen. Wiel. Wappler. 1795.8 . $1: 37$ 1. pracf. int.

* germanice: Physiologio und Pathologie der Pfanzen. Als dom

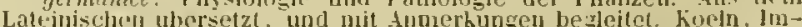
holf. Isis. 8. 215 \%.

t gallire: Plisiologio el pathologio des plantes. Trabluites du latin

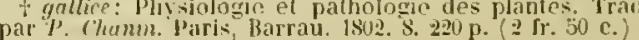

$8073^{\circ}$ Wementa terminologiae bolanicae ac systematis sexualis plantarum. Viennae, Bumauer. 1796 . S. 169 p., ind.

$8074 \div-$ Anfangsgrumle der botanischen Terminologie und des Geschlechtssystems der Planzen. Wien, Waplder. 1798. 4. $168 \mathrm{p}$. $(3 / 4 / h$.)

* hispanice: Elemenlos de la nomenclatura botanjea, y sistema

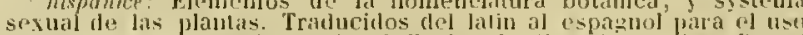

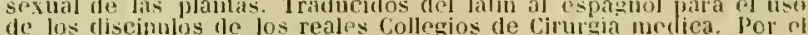

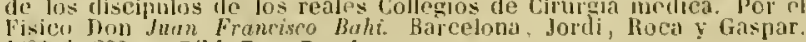
1s02. k. 222 p. Bibl. Reg. Berol.

$8073^{*}$ Pleniger, Andreas. Leber Pflanzenphysiologie. I). Wien, 1yp. Leberreuler. Is41.8.78 p.

$8076^{*}$ Plinius Secundus, Cajus. Historiae naluralis libri XXXIl. Ed. princeps: Venetiis, J. de Spira, 1469 . folio. 35 亿 foll. (Folim prinum libri secundi ef secundum libri udtimi recentioris sunt impressionis.) - Li.l. 11: Romae 1470. folio. 373 foll. (Desielerantur. 2 foliu, ant finem libri 23 el initiun libri 24.) - Ed. 111: Venetiis 1479. folio. 356 foll. - El. IV: Rome 1473. folio. 400 foll. - Parmac Iis 1. folio. $2 i$ quaterniones, 8 trieniones, 1 duernio. - Tenetiis 14S3. folio. 25 quinquerniones. 12 quatcrniones. - Venetiis 1487 . folio. I quinquernio, 3 q quaterniones, 1 triemio. - Teneliis 1491. Solio. 37 yuaterniones, 2 triemiones. - Historiac naturalis libri XVITll, ab Alexandro Benedicto emendatiores redulit. Venetiis 1507 . folio. 280 foll. - Lutecie Parrhis., Nicol. de Pratis. 15 11 . folio. CCLXII foll. - 
Parisiis, per Nicolaum de Pratis. 1516. folio. CCL.Nll foll. (Editio priori sinilis, sed diversa.) - Lutetiae, impensis Ber. et Regin Chalderii. 1516. folio, CCLXXIJII foll. - Venetiis 1525. Folio. CCXIX foll., practer Jo. Camertis indlicem : 9 yutterniones. - Basileae 1530. Solio. 671 p., praeter indicen ad exemplum Jo. Cumertis: 2 quaterniones, 12 triemiones. - Parisiis 1532. folio. 671 p., praeter indicem ad exemplum $J_{0}$. Camertis: 15 trierniones, I duemio. Basileae 1539. Jolio. 671 p., practer \&. Gelenii annotationes: 13 plag., el indicem al exemplum J. Camertis: 2 quaterviones, 12 trierniones. - Basileae 1545. foliu. 671 p., prieter S. Gelenii annotationes: 15 plag., el inticem ut in priori. - IBasileac 155\%. Folio. 663 j. practer Gelenii annetationes: 13 plag , el indic(n) ad exemplum Camertis : 13 trierniones. - Ilistoriae naturalis libri XXXVII, a Punlo Manutio emendati. Venctiis 1559 . folio. 976 coll., praeter Goleni annotationes: 3 trierniones, et inflicem al exrmplum Camertis: 11 trierniones. - Francofurti a/M. 1382 . Folio. 528 j., practer Gelem annotationes: 13 plag., et indicem: 23 dusurnones. - Ed. opera Jucobi Dalechempii. Francofurti a/A. 4509 . Lolio. 204 p., praeter Gelenu annotationes: 3 quaternones, et indicem: 1 quaternio, 11 trierniones. - Aureliae Allobrogum 1606. Folio. 792 P., jraeter Gelenii unnotationes: 4 trierniones, et indicem: 14 trierniones, 1 duernio. - Acceslun Pauli Cigalini praelectiones duae. Iruncofurti 4608 . Il voll. 8. - 1: $752 \mathrm{p},-11:$ 1).753-1688, praeter indicem: 12 plag. - Interpretatione et notis illustravil Joannes Harduinus, in usum Delphini; editio altera enendatior et auctior. Parisiis 1723. II voll. folio. - 1: 790 p. - II: 1289 p. - Historia naturale tradocta di Jingna latina in Fïorentina ner Christophoro Landino. Venesia 1501. folio. 34 triernionss. - L'listoire du monde, enrichie d'annotations, à quoy a esté aljousté un traité des poin et mesures antiques, le tout mis en fralcois par Antoine du Pinet. Lyon 1566. If voll. folio. $-1: 678$ p., jraeter inticem: 13 trierniones, $-11: 745 \mathrm{p}$, index : 8 triemiones, 1 tuernio. - The history of the world, commonly called, the naturall historie of $C$. Plinius, translated into english by Philemon Holland. London 1604. Il voll. foliu. $-1: 614 \mathrm{pe}$, index sign. $\mathrm{Gg} \mathrm{g} \mathrm{ij}-\mathrm{K} \mathrm{hk} \mathrm{iv,}-11: 632 \mathrm{p}$, index sign. 1 i i-D p p vi. - ib. 1635 . folio. (non tliflert.) B.

(Plinit hic Banhsianas solummodo iddlitis quibustam nuperioribus editiones affero; praeterea intaclum eum relinuluo. llall, Bibl.
bot. 1. 1).9!-98. 11. p. 29 . - Spreng. Ilist. rei hert. 1. p. 193-906.

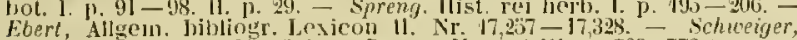
Ebert, Algell, Jibliogr. Lexicot 11 . Nr. 17,207-117,325-769-773.) Coji Plinii Secundi Ilistoriao naturalis libri XXX7II. quos interpretatime et motis illustravit Junmes Hunduinus e societate Jesu, jussu regis clristianissimi Ludovici Mlagni in usum serenissini Del] hini. Editio nova emendatior et anctior. Parisiis, impensis societatis. 1741. II voll. folio, - 1: $7 \mathrm{SS}$ p., pracf, tab. - 11: $1279 \mathrm{p}$ (a p. 835 ad finem indices.)

$8078^{*}$ Caji Plinii Secundi Naturalis historiae libri XXXVII ex editione Gabrielis Brotier cum notis el interpretatione in usum Delthini variis lectionilsus, notis variorum, recensu erlitionum et codicum et indicibus locupletissimis accurate recensiti. Londini, curante et imprimente A. J. Talpy. 1826. NIT voll. 8.

$8079^{*}$ — C Coji Plinii Secundi IJistoriae naturalis libri XXXYll eum selectis commentariis $J$. Harduini ac recentiorum interprelum novisque adnotationibus. Parisiis, colligelat Nicolaus Eligius Lemoire, poeseos latinae Professor. 1827-1831. I voll. 8. (172 fr. $50 \mathrm{c.}$ )

Ilujus editionis volumina $\mathrm{V}$-Vll continent libros Xil-X.Xill vel rem hertburiam, curante $L$. Desfontaines.)

$8080^{*}$ Cuji Plinii Secundi Ilistoriae naturalis Jibri XXXYI. Ad optimorum librorum fidem editi, cum indice rermm. Editio stereotypica. Lijssiae, Tauchnitz. 1830 . Il voll. $16.130 \mathrm{plag}$. (211/2 th. ill charta meliori $4 \%\left(h_{\text {. }}\right)$

$8081^{*}$ Caji Plinii Secundi Naturalis historiae libri XXXYll. Recognovit et varietates lectionis adjecit Julius sillig. Vol. I-Y Aiduntur excerpta cod. Bambergens. cum achotationibus Ludorici

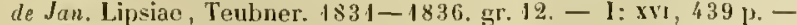
II: 380 p. - III: 488 p. - IV: 448 p. $-V: x x, 507$ p. $(5 \% / 8$ th. in charta anglica: $77 / 8(h$.

$8082^{*}$ quibus accessere novus index anim)alium, mineralium, vegetabilium synonymicus, nomisumque et rerum quo ad cetera enodatio, habita alphabetici ordinis ratione, e notis galicao editionis Ajusson de
Graudsugne Parisiis, Panchouche. (Leipzig, Brochliaus et Avenarius.) is $38.1 \mathrm{~S}$ voll. \&. ( $36 \mathrm{fr}$.)

Oecurrit nuris tilulis: Parisis, excudebant Plon fratres, 18 'b.

$8083^{*}$ Plinius Secundus, Cajus. Coji Plinii Secundi Ilistoriae naturalis libri XXXV'H, cum indicibus rerum locupletissimis ad (sptimorum lilrorum fidem emendatissime ediit, curante Carolo Hermanu II eisio. Elitio slereotypica, une volumine totum opus complexa. Lipsiae Carol. Tauchuitz. $1841.4 .63 \mathrm{ll} \mathrm{ag} .(3 \mathrm{l} / \mathrm{l}$ (h.)

$8081 \div$ Plot, lobert. The natural history of Strafford-Shire. OAford, printed at the Theater. 1686 . Folio, $430 \mathrm{~J} .$, praef, ind., $37 \mathrm{tal}$.

8080 - The natural history of Oxfordshire. The socond edition. Oxford 4705 . Solio, 366 p., 16 Lab. B.

S086* Plukenett, Leonard. (Opera omnia botanica, in sex tomos divisa Londini, aput Innys. 1720 . Vi voll. 4

1: Phytographia, seu slirpinm illustriun et minus coguitarum icones, tabulis aeneis summa cliligentia elaboratae, yturum unajuaeque titulis descriptoriis an untis suis propriis et characteristicis desumptis insignita, al, aliis ejustem sortis facile discriminatur. Pirs l el II Lonflini, sumtilus anctoris. 1691. 1ab. $1-120$

II: Phytographia. Pars Ill. Lourlini, suntibus aucturis. 1692. tab. $121-250$.

11I : Plytograplia. Pars IV. Londini, sumtibus auctoris, 1696. tah, $251-328$

IV: Almagestum botanicum, seu Phytograpliae Pluc'netianac Onumasticon, methodo synthetica digestum, exbibens stirjium exoticarum rariornn novarunque nomina, quae descriptionis locum supplere possunt, cui (acl ampliandum regmun vegetabilium) accessere plantae circiter 500 suis nominibus similiter insignilae, quae nullibi nisi in boc opere (sex fere plantarum chiliades complectento) menoran1 r; adjiciuntur et aliguot novarum plantarum icones. Londin, sumtibus auctoris. $1696.402 \mathrm{p}$.

$\mathrm{V}$ : Nlmagesti botanici Nantissa, filantarum novissime delectarum uftra millenaniun nunerum complectens. Londinj 1700 . 19 \& p., ind. 1ab. $323-350$.

V1: Amaltheum lotanicum, i. e. stirpium indicarum alterum copiae cornu, millenas al nininum et bis centum diversas species uovas el iulictas nominatim comprehendens, quarum sexcentar of insuper selectis iconibus aeneist pue tabulis illustrantur. Londini 1705. 214 D., tals. $351-454$.

Ejusdem impressionis est editio altera, ita inscripta. * Lemardi

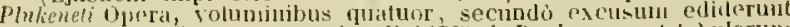

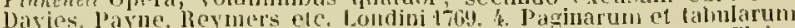
mumerus ail amussim congruit, sed volumini primo addita est efligies Plukeneti.)

$8087^{*}$ Plumier, Charles. Description des plantes de l'Amerique, avee leurs figures. Paris, de l'imprimerie royale. 1693 . Folio. 94 p., praef. ind., 108 tab. (11.7s. 6d. A. Paniplin.)

Talublae 50 proves redeunt in ejus "Traite des fougeres." Yid

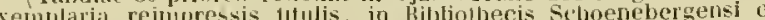
Cindolleana, in quilms anmus 1713 legitur.

$8088^{*}$ — Nova plantarum americanarum zenera. (Accedit Calalogus plantarum ancrjcanarum, quarum genera in Institutionibus rei herbariae jam nota sunt, guastgue deseripsit et delinwavit in insulis americanis.) Parisiis, lioulot. $1703,4,52,21$ p., 40 tab.

$8089 \div$ Filicetum americanum, sen filicum, polypodiorum, adiantorum etc. in America nascentium Icones. Parisis, e typographia regia. 1703. folio. 222 tab. simn. 1-222., ind. mser. Bibl. Deless.

(Tabulae 1-16i sistunt Filicum easdem labulas, quac sunt in litiro serquenti tábulior $16 \%-222$ ededen sunt ac tabmae 51-108 in libro: Drseription des plantus de lanérique, polissimum e pissithorearun et Aroiffearum familia.

$8090^{*}$ Traitć des fougères de l'Amérique. Tractatus de filicilus americanis. Paris, de l'mprimerie royale 1705 . folio. latine el gallice xxrvi, $146 \mathrm{p}$., ind., 170, 2 tab. (2l. $2 s$. $\Lambda$. Pamplin.)

$8091^{*}$ - Pantarum americanarum fasciculus primus (-decimus) continens plantas, quas olin Carolus Plumierus, botanicorum princeps, detexit eruitcue, atque in insulis Antillis ipse depinsit. Has prinum in lucem edidit, concinnis descriptionibus el observationibus, aeneisque tahulis illustravit Johannes Burmannus. Sumtibus auctoris : prostant Amstelodami in horto medico. 1755-1760. folio. $262 \mathrm{p}$, ind., $262 \mathrm{tab}$.

Recensentur yraterea in Bitslotheca Bauhsiana Jll. 187. voluminit quinque, emta e Bibliolheca Johumis Comitis de Bute, in quibus continentur 312 icones Plumeriande, quacdam ex editis in diversis operihus ejus, sed plurimae inoditas; allac coloribus fucatas, altae partin 
809?2 Pluskal, $F$. S. Wie sammtlichen bisher bekannten Kranklieiten der Kartolloln, mit hesontrer Wurligung der belgiselsen Kartolfelseuche in den Jahren 1845 und 1846 . lin okonomisch-phytopatholegiselier Versurll, Brum, (Wintuer, 1847.8 .125 p. $(5 / 12$ th.)

$8093^{\circ}$ Poech, Joseph. Enumeratio plautarum huscusque eognitarum insulao

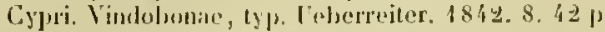

xogh: Poederle, lingene Joseph Charles Gilain Ilubert d Obnen, Baron de. Manuel de l'arboristo et ilu forestier lielgicjues; auvrage extrait des meillsurs aut curs et soutenu d'observations faites dans dilferents pay's, ou l'auteur a voyaré. Bruxelles, l'lon. 1772. 8. - Supplément. ib. 1779. 8. - Ed. II: ib. 1788. 8. - + Ed. IIl: ib. 1792 . II voll. 8. - I: 284 1., int. - Il: 342 ر., ind.

$8093^{*}$ Poehlmann, A. Ch. A. I'hysiologiseh-toxicologische Untersuchungen uber das Coniin. D. Lirlangen, Palm und Enke. 1838. 8. $40 \mathrm{p}$. $\left(y_{6} t h.\right)$

8046* Poeppig, Ethurd. Fragmentum Synopseos Plianeroganarum ab anctore annis $1827-182 y$ in Chile lectarum. D. Lipsiae, typ. Elbert. $1833.8 .30 \mathrm{p}$.

$8097^{*}$ - Reiso in Chile, Peru, und auf dem Amazonenstrome wăhrend der Jahre 18ะ7-18:32. Lejpzig, Friedrich Fleiseher. 1835 -1836 . 2 liande. 4. - 1: 1835. xvil, 466 p. - II: 1836. VIII, 464 p., 1 malyra geogr., 16 lah, in folio. $\left(13 \frac{1}{3}\right.$ th. $)$

$8098^{*}$ - Nova gentra ae species plantarum, quas in regno Chilensi, Peruviano et in terra Amazonica annis 1827-32 legit Eduardus Poeppig et cum Stephano Endlicher teseripsit iconibusque illustravit. Lipsiae, Friedrich Hofmeister. 1835- 1845. HI voll. folio. -

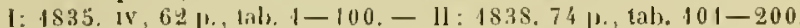
- III: 1845.1v, 91 p., tab. $201-300$. (60 (h. - col. 190 (h.)

8099 Pogankow, h'an, el Alex. Kirejewsk. Pуководство д,х

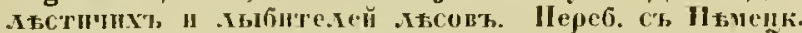
C. IIeTep6. Is10. Trautv.

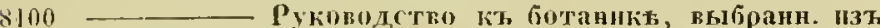
ботаник Ви.дыстова и творенія Сукова Мельхіоромт.

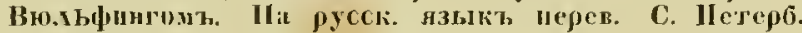
1814. Trautv.

$8101+$ Poggi, $J . J$. Manuel pour extraire le suere du raisin. Traduit de litalien. Paris, lyp. Demonville. 1808 . 8 . v, 34 1).

8102 Pohl, Ilans Friedrich. Botaniselıer Kinderfreunt, oder botanisches Lehr - und Leschueh fur tie Jagend, und fur Pflanzenlicbhaber aus allen Standen. Ersten Handes erste Halfto. Leipzig, Joachim. 1797. 8. $(1$ th. $)$

\$103* Pohl, Johanu Ehrenfried. Animalversiones in strueturan ac figuram foliorum in plantis. D. Lipsiae, typ. Langenlyeim. $1771.4 .32 \mathrm{p}$. Respondens: Nathanael Gollfried Leske.)

$$
\text { Isteri Delect. opuse. bot. 1. 1). 1'tr-19's.) }
$$

8104. - _ De plantis venenatis umbelliferis. D. Lipsiae 1771.4

$8105^{*}$ Do soli dillerentia in cultura plantarum attentenda. D. Lipsiae, typ. Langenlıcim. 4773. 4. 18 p.

8106* Pohl, Johann Emanucl. Tentamen Florae Bohemiae. Tersuch einer Flora Bulmens. Prag, Enders und Co. Zwei Abiheilungen. $1810-1815.8 .-$ I: 1810. xxxit, 302 p., I tab. - II: 1845. v1 234 p. (Class. Linn. $1-13$.) $\left(9^{2} / 3\right.$ th.

$8107^{*}$ Des Freibern von Hochbery botanischer fiarten zu IIlubosch. Prag, typ. Gerzabek. 1812.8.58 p., praef.

$8108^{*}$ _ Plantarum Brasiliae icones et lescriptiones hactenus ineditas. Vinduhonae, (Wallishauser.) 1827-1834. II voll. folio. I: 1827. xv1, 136 p., lah. col. 1-100. - 11: 1831. 152 נ., tab. col 101-200. (nigr. $42 \frac{2}{3}$ th. Ioss. $46 \frac{2}{3}$ th. Heinsius. - col $213 \frac{1}{3}$ th. loss. $150 \frac{2}{3}$ (h. Heinsius.)

S109* _ Reise im lunern ron Brasilien. Wien, (Wallishauser.) 1832-1837. 2 Theile. 4. - 1: 1832. $\times x x, 148 \mathrm{j}$., und Atas mit grossen Ansichten, 1 illuminirte luseclen- und 1 illuminirte geognoslische Tafel. $\left(22^{2} / 3\right.$ th. $)-11: 4837 . x 11,641$ p. 3 tals. $(28 / h$.

$\$ 110$ Pohlmann, E. II. Anweisung zur hemntniss, Wurdigung und Befrandlung der Georgine oder Dalılie. Nebst einem Anlıange zur riebligen Aussprache der englischen Georginenuamen. Fur Freunde und Liebhaber dieser Blume. Magdeburg, Schmilinsky. 1841. 8. 4 plag. $(1 / 4 t h$.
$8111^{*}$ Pohnert, fictor. De plantis medicinalitus. 1). V"indobonae, Iyp Leberreuter. $1841.8 .34 \mathrm{p}$.

8II2 Poinsot, $P$. G. L'ami des jardiniers, wu introduchion méthorlique a la portée des anateurs el dles jarliniers te profession, sur tout ee uni concerne les jardins fruitiers "t potagers, pares, jardins anglais parterres, orangeries at serres chaudes. Paris, Levrault. 18041805. II roll. 8. (12 fr.) a.

$8113^{*}$ Poiret, J. L. Marie. Voyage en Barharie, ou Lallrws icrites de l'ancienne Numidie, pendaut les années 1785 et 1786 a arec un essai sur Ihistoire naturelle to ce pays. Paris. Sie de la Rochelle. 1789. Il voll. 8. - I: Xxiv, 363 p. - II: $395 \mathrm{p}$. (Hegne vegetal: vol. 11. p. $71-315$ )

germanice: Keise in die Barbary oder Briefo aus Alt-Numidien geschrieben in den Jahren $178.1-1786$. Nibst einem Verwebe wher die Naturgeshlhichte dieses Landes. Aus dem Franzusischen. strassburg 1789.2 Theile. 8. - 1: xxiv, 360 p. - $11: 26$ f1. ? tat.

$8144^{*}$ Leeons de Flore. Conrs conuplet de hotanirue, explication de tous les systemes, introduction a l'atude des plantes. Suivi d'une iconographie végetale en 56 planches colurices olirant pres de mille objects par Pierre Jeun Francois Turpin. Ouvrage antierement neuf. Paris, Panchoucke, 1819-1820. III voll. 8. - I: 1819. viII, S, $278,(5)$ p. - II : is20.3, 174 1.., 57 tab. col. - III: 1820. 199 p. $(34 \mathrm{fr}$. $)$

(Prodiit 17 faseiculis. llabet etiam afterum titulum: assui d ane iconographien cte.

81134 - Leçons de Flore. Cours de botanique, explieation des principraux systèmes, introduction á l'étude des plantes. Edition classigue. Paris, Panckouche. 1823.8 . vill, 367 p. (5 fr.)

$8116+$ Ilistoire philosophitue, litteraire, economique des plantes de l'Europe. Paris, chez Ladrange el Verdiere. 1825-1829. Vil voll. 8. - I: 1825. xxiv, 494 p. - II: 1825. $332 \mathrm{p} .-$ III: 1826. $500 \mathrm{p} .-\mathrm{IV}: 1827.500$ p. - I: $1827.516 \mathrm{j}$. $-\mathrm{VI}$ : (non vidi.) - Vll: 1829. 496 p. Bibl. Cand. et Deless.

(Volumen sextum in Candolleana arepue ac in Delessertiana desideratur billiotleea. Ad hoc upus, cujus pretium fuit $10 \mathrm{sir}$. pertiuent 160 tabulae, octo editi fasericulis; pgo solmmmodo 127 tábulas caloratas vidi, seorsim ligatas eum exillicatione. lidi etiam prospectun operis forma ortava impressim : $15,35 \mathrm{po}$.

Poiret partem botanicam operis: "Encrelopédie mühodique" a quinto ad decimum tertium volumen absolvit; vide suprat l'hesaurum lit. Jot. Nr. $2377-2378$.

8117 (Poisle-Desgranges.) Le petil botaniste, on deseription de diverses plantes. Paris, Violel. 1837. 12.

$8118+$ Poiteau, A., et Pierre Jean François Turpin. Flore parisienne, contenant la descriptiou des plantes, qui eroissent naturellement aux environs de Paris. Ouvrage orné de figures, el disposé suivant le systeme sexuel. Paris, Schoell. 1 \$ 13 . folio. 40 p., 45 tab. col.. sign. 1-68. Bibl. Cand.

("II r"a été publie que huit (sept?) tivraisons te cette flor. pendiut les anneses 1808-1813, dont be prix thait in k. papser grand Jesus lin, figures noires: $72 \mathrm{fr}$; in folio, sur mene papier, col. $200 \mathrm{fr}$. et sur trand colunbier vélin, tlont il ti a eté tire que 12 exemplairen. avec dis tigures in couleurs: 38 i $\mathrm{fr}, " \mathrm{Q}$.)

8119 Le jardin botaniqur de l'école de médecine de Paris. ou deseription abregie des plantes pui y sont eultives. Paris Méquignon-Marvis. 1\$ 16. 12. (3 fr.) a.

$8120-$ Notice sur H. Bosc. Poris, 1yp. Fain. 1828.4 .4 p. a.

$8121+$ Memoire tendant a faire admettre au nombre des vérites demontrées la thiorie te Lahire sur lorigine et la direction des fibres ligneuses dans les végétaux. Paris, 1yp. Fain. $1831.8 .44 \mathrm{p}$. 1 1al. ( 1 ir. 25 c.)

8122 - Pomologie francaise. Recueil sles plus leaux fruils cullivés en France. Ouvrage publié en 431 lisraisons in folio, contenant clacune une plancho coloriée avec texto descriptif réligé par 1 . Poitean. Paris et Strasbourg 1838 . cl stiv. folio. 431 1a). col. (singulus fasciculus: $(\mathrm{f} \mathrm{f} .50 \mathrm{c}$.)

8123 Cours d'hortieulture. Tome I. Paris, Bouchard-Huzard. 1847. 8. ( $5 \mathrm{fr}$.)

812\%. Poitevin, Jacques. Notice sur la vie et les ourrages de M. (Jacques Philippe Raymond) Draparnaud. Montpellier, Rennud. an XIII. (1805) 8. a.

SIOSE (Poivre, Pierre.) Voyages d'un philosophe, on observations sur les moeurs et les arts tles peuples de l'Afrique, de l'Asie et de I'Amérique. Yverdun 1768. 12. 142 p. B. - Maestricht 1779. 19. 151 1. B. - Paris 1786. 1797. 1799. S. a. 
$8126 \div$ Poivre, Pierre. Oeuvres eompletes précédées de sa vie (par Dupont), et aecompagnées tle notes (par Lunglis). Paris, Fuchs. $1797.8 .11,310 \mathrm{p}$.

8127: Polack, Moses. De Nucis romicae viribus atque antilutis. D. Goettingae 1840.4 , vil, $48 \mathrm{p}$.

S128 Polisius, Goltried Samuel. Myrrhologia. Impr. cun anno sexto decadis secundae Ephemeridum Acalemiae Naturae Curiosorum. Norimbergae $1688,4.339$ p. B.

(Cf. Buechner. Ilist. Acad. Nat. Cur. p. 285. not. 33̈.)

$8129^{*}$ Pollich, Johann Adam. Ilistoria jlantarum in Palatinatu electorali syonte nascentium incepla, secundum systema sexuale digesta. Mannhemii, C. F. Schwan. (Sehwan u. Goelz.) 1776-1777. lll tomi. 8. - I: 1776. xxx11, 454 p. - II: 1777.664 p. - III: 1777.320 p. ind., 4 tab. ( 1845 herabgesetzt: 2 th.)

8130 Pollini, Ciro. Synonynia botanica moderua. Milano 1804. S. DC.

8131 - Succinto esamerlegli Elernenti di hotanica del Professore Puolo Sangiorgio. Terna 1809.8. DC.

8132 Dell mfluenza thelle scienze naturale sull agricoltura Verona 1809. 4. DC.

$8133^{\circ}$ - Elementi di lrotaniea compilati. Verona, Iyp. Mloroni. $1810-1811.11$ roll. $8 .-1: 1810.399$ p. 11 tab. $-11: 1811$. 526 p., 9 tab.

$8134^{\circ}$ Discorso istarico sulla botanica. Vernna, typ. Moroni 1512. $8.30 \mathrm{p}$.

8133 Catalogus plantarum horti botanici Veronensis. Verona 1812.8. - Ed.11: il. 1814. 8. DC.

$8136^{*}$ - Saggio di osservazioni e di sperienze sulla vegetazione degli alberi. Verona. typ. Bisesti. 1815. 8. $160 \mathrm{j}$.

$8137^{*}$ - - Iorli et provinciae Veronessis plantae novae vel minus cognitae, quas descriptionilus ef olservationilus exornavit. Fasciculus primus. Insert. in tomo $\mathrm{L}$ Diarii physici medici Ticinensis. Ticini, typ. Galeatli, 1816.4 .40 p., 1 lal,.

$8133^{*}$ — Viaggio al Largo di Garda e al monte lialdo, in cui si ragiona delle cose naturali di quei luoghii aggiuntovi un cenno sulle euriosita tel bolea e tlegli altri monti veronesi. Verona, Mainardi. 1816. 8. $1521 \%, 1$ tab.

$8139^{*}$ Osservazioni intorno al Viaggio al lago di Garda, e al Monte Baldo. s. I. 1817.8.56 p.

(t Risposta di Eleuterio Ronacense alls osservazioni di Cenomio Euganeo iutnruo il riaggio al lago di Garila o al Monte Baldn te Detior riro Pollini. Timepoli 1817. $8.76 \mathrm{p}$.)

SI: $0^{\circ}-$ Sulle Alghe viventi nelle terme Euganer, con un indice delle piante rinveute sui colli Euganei, e un' appenlice sopra alcune alshe della provineia Veronese, Lettera. Milano, typ. Pirotta. 1817. 8. 24 1., I tals.

(Bibliotera ifaliana tom. (II.)

$811^{*}$ _ - Sopra alcune malattie degli ulivi e ti alcuni serpente Lettera al Signor Griuseppe Acerbi. Mlilano, Lyp. Naspero. 1848. 8. 10 p.

$8142^{*}$ __ Sopra la teoria della riproduzione vegetale del Signor Gallesio, agginutevi alcune osservazioni fisiologiche, Lettera al Conte Fr. Rizzo Pulurolo. Mlilano, IYp. Maspero. 1818 . 8 . 24 p.

$81.43^{*}(-)$ Osservazioni meteorologiche metiche ed agrarie fatte in Verona uell anuo 4847 . Verona, typ. Rimanzini. 4818. 8. $31 \mathrm{p} \cdot$ 3 sehenati

8141" - Flora Veronensis, quam in Prorlronum Florae llaliae septentrionalis exhibet. Veronae, impensis societatis tylograplicae. 1822-1824. Ill voll. 8. - 1: 1822. xxxv, 535 p., 2 lab. $-11: 1822$ 754 I., 6 tab. - III: 1824.898 I., 4 tab.

$\$ 155^{*}$ Polsterer, Albert Johann. Hyeres in der Provence. Wien, Beck. 1834. $8,46 \mathrm{j} .(3 / 2 / / \mathrm{l})$

(luest a pagina $36-46$ enumeratio 350 pliatarum indigenarum.

S1,6 Polti, A. De Gentianis comensibus. D. Ticui revii 1 \$\$2. 8 .

S1' : Pomet, licrre. IJistoire géntirale des ilrogues simples et compostes, traitant des plantes, des animaux el des minéraux. Ouvrage enrichi de plus de 400 figures en taille-donee, tirées d'après nature, avec un discours, qui explique leurs tilférents noms, les pays d'oi elles viennent, la maniize de connoitre les véritables d'avec les falsifien, el leurs proprielez: ou l'on déeonve l'erreur des anciens et des muderues; le tout Irès-utile au public. Paris, Jean Baptiste Loyson. 1694. folio, 304, $108,116,16$ p., ic. xylogr. i. 1. - *Nouvelle edition augmentée et corrigée par Pomet, fils. Paris, Ganeau.

PRITzE. Thes lit. bot
1735. Il voll. 4. - 1: xwi1, 306 p., ind, cum tabulis aeneis. - II. $406 \mathrm{p}$., ind., eum tabulis aeneis.

anglie: Ilistory of truys, translated in molish, and itlustraten

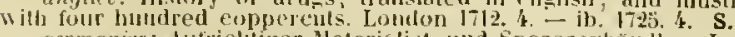

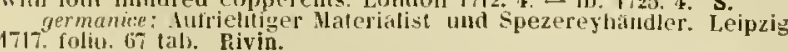

81is Pomet, Pierre. Droguier curieux, on catalogue des drogues simples el eompostes mis par alphahet, utile pour la connoissance et conmerce des drogues. Paris 1695. 8. - Ed. Jl: Paris, Laurent d'lloury. 1709.8. s.

$8149^{*}$ Pompper, Hermann. Die vorzuglichsten Charakterpflanzen, -Sáugethiere, - Vogel und - Amphilsien tler Erdheile besehrieben und zugleich als naturueseltiehtliehes Hulfsbueh zu Korl Vogel's ueuem Selsulatlas bearbeitet. Leipzig, Bolsme. 1842. 8. vin, 428 p. $\left(1^{3} / 4 t h.\right)$

8150 Pona, Francesco. II paratiso de ftori, overo lo archetypo de giardini discorso. Con il eatalogo delle piante che si possono avere del monte 13aldo nel mese di maggio. Yerona, presso Angelo Tamo. 1622.4. S

81 I Pona, Giovanni. Plantae seu simplicia, ut rocant, quae in Baldo monte "t in via ab Veroua al Baldnu reperiuntur; eum iconibus et nominibus quamplurimann quae a nullo ante sunt observatae: nume a Joanne Pona. Pliarmaeopaeo Veronensi repertae, descriptae el ellitae. Verona 4595.4. 16 ieones. s. - t. Antwerpiae, ex officina Plantiniana, apud Joannem Noretum. 1601. folio. Impr. cum Clusii Ilistoria planterum 1\%. CCCXXI - CCCALV'llI. - *Plantae seu simplicia, ut vocaut, yuae in Baldo monte et in via a Verona ad lahalum reperiuntur cum iconibus et nominibus aliarum quan plurimarum, quae a multu aute sumt observatae. Secunda editio. Cui additae sumt nommullar stirpes insignes al IIonorio Bollo Vieetino in Creta observatae. Apposita etian est disceptatio Nicolui Haroneac de amono veterum, cum legitima amomi racemi icone. Basileae, Zetzner. 1608 . 4. 112 p., praef., iul., (38) ic. sylogr. i. t.

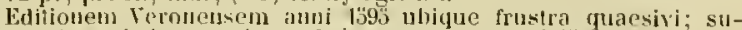
s pectam hane habro; sed praefatio revera est anni 159.)

* italice: Montr Bahlo descritto da Giovami l'ona Veronese. In cui

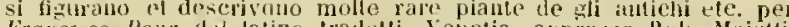

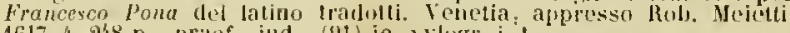

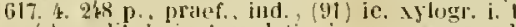

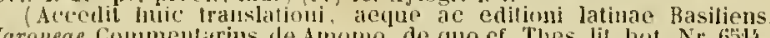
Maronea Commentirius de Amomo, de quo cf. Thes, lit, bot. Nr. 6ist'. 8132 Dol vero Balsamo de sli autichi. Commentario sopra l'istoria di Dioscoride, nel quale si prova, che solo l'opobalsamo arahico è il legitino, e s'esclude ogn' altro licore abbracciato sotto il nome di balsamo. Tenezia, Roberto Mejetti. 1623.4.54 1. B.

$8153+$ Poncelet, Polycarpe. Histoire taturelle du froment, des maladies du blé, etc. Paris, lesprez. 1779. 8. xxxir, 387 p., 10 tab. $(6$ fr.)

815: * Pons, Jacques. Iu historiam generalem plantarum Rovillii duobus tomis el appendice comprehensan breves annotationes et animadversionis compendiosae. Lugduni, apud Joannem Pillehotte. 1600.8 .59 p.

$8155 \%$ Traité des melons, ou il est parlé tle leur nature, de leur culture, de leurs vertus el de leur usage. Nuvellement mis au jour. Lyon, Cellies. 1680.12 .51 p., praef. Bibl. Juss.

8156 Pontanus, Johannes Joidanus. Horli Hesperidum libri duo, quibls agitur de Citrio fructu et arbore. Florentiae, Filippo Junta. 1514. 12. $\mathrm{s}$.

(Exstant etian in rajusdem Operibus Yeneliis, apud Aldum. $13 ̈ 18$ et 1533. et Bisileae, apud Cratantrum. 1536. 8.)

$8157^{*}$ Pontedera, Giulio. Compendium tabularum botanjearum, in quo plantae 272 ab eo in flalia nuper tletectae recenseutur. Accessit ejustom Epistola ad Sherardum. Patavii, typ. semiuarii. 1718. 4. Xvili, 16s, AXiY [?.

Talulae ipsae mumuan prodierum; cf. Lellera del Abhate Ginseppe Genmeri intorno la vita del fu Pontedera. Vemezia 1758. 8. - Vita efiam exstat in dug. Febronii Vitne ltalorum toctrina exeellentinm,

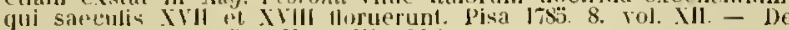
seriptis inedilis ef. liot. Nag. Xli. $18 \%$.

$8138^{*}$ - Anthologia, sive de floris natura libri tres, plurimis inventis observationilusque ac aeneis tabulis orıati. Accedunt ejusdem Dissertationes XI. l'atuvii, tyl. seminarii. 1720. 4. 303, 296 p., ind. 12 tab.

8139 Epistolar dune de lorto Patavino. Impr. eum Nicolui Comneni Papedopoli llistoria gymnasii Patavini. Venetiis 1726. folio. p. 14-23. B.

8160 - Epistolae ae rissertationes. Opus posthumum in duns tomos distributum; praefatione et notis auctun ab Josepho Antonio 
Bonoto. Patavii, typ. seminarii, apud N. Bettimelli. 179 \}. Il voll. 4.I: L, 378 \%. - II: 364 \%., ind.

(Cf. Articolo in Giomale de' letteratti tom. Lxxiry. Pisád 1791. 8. p. $121-1: 10$.

\$ $\$ 61$ Pontoppidan, Erich. Det forsto forsög pal Norges naturlige historie. Kibenhayn 175y-1753.11voll. 4. - I: 1752. 338 p., 16 lab. - $11: 1753.464 \mathrm{p}, 14$ lab.

t unglice: The natural history of Norway: containing a parlienlar and accurate acconth of the immpetithre of the air, the different

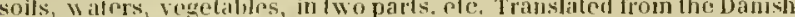

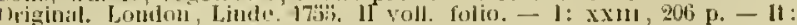
vit, sel p., intl., cuII mullis tabulis,

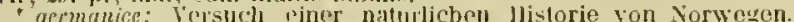
Flenslurg und Leipzig 1769. \%wei Theile, 8

8162 Pontoppidan, Johannes. De Manna Israclitarum. D. I. Havniac 1756. 4. 1 plag. (Respondens: Erasmus Lindegaurd.) B.

8163* (Popowitsch, dohamn Siegmund Valentin.) Intersuchungen vom Meere, dic auf Veranlassung einer Sclirift ele colunnis Herculis, welche der hochberuhmte Professor in Althorf, Herr Christian Grolllieb Sehwarz herausgegebru, nebst anden zu dersebigen gehorigen Annorkungen von einem Licblaher der Naturlelire und der Philologie vorgetragen werden. Frankfurt und Leipzig 1750. 4. 3s, Lxw, $49-432$ p., alpp., prace., iudl.

A p. 3ij-39s agitur de funcis, et merila Limnaei delrectantur.

816:* Poppe, Johamn. Kratuterbuch, darimon dire kiruter des Teutschen Landes, aus dem Licht der Natus, nach reclater Art der Signaturen der himmlischen Einfliessung nicht allein beschrieben, auch darinnen angezeigt wird, unter welchen l'taneten, unter welchem Zcichen Zodiaci, auch in welchen Gradu cin jeles hraut stche, wio man aus den signaturen erhennen hant, wozu ein jedes hraut zu gebrauchen, und wievirl ein jodes Kraut siguaturen in sich habe Leipzig, Zacharias Schurer und Golze. 1625. 8. 676 p., praef., ind.

8165t Porta, Giovanni Ballisla. Suae Viliae Pomarim. Neapoli, apud Itoratium Salvianum el Caesarem Cacsaris. 1583 . (un calco 4584.) 4. 323 p. - +Villae fibri XIl: domms, sylva caedua, sylva glandaria, cultus et insitio, pomarim, olivetum, vinea, arbustum, hortus coronarius, hortus olitorius, soges, pratum. In quibus etc. Francofurti apud Wechelii heredes. 1592. 4. 914 p., prasf., ind.

$8166+\ldots$ Phytognomica acto lihris contenta, in quibus nova facillimaque affertur methodus, qua plantarum, animalium, metallorum rerum denique omnium ex prima extinae facici inspectione quivis abditas vires assegulatur. etc. Neapoli, apurl Jloratium Salvianum 4588. folio. 320 p., ic. xylogr. i. L. - *El. II: Francofurti a/MI, apud Joannem Wechelun. 1591. \&. 552 p., praef. ic. xylogr. i. t. *Ed. III: Francofurti a/Al, apud Nicolaulu Ilothmannum. 1608. 8 539 p., ic. xylogr. i. t. - ${ }^{*}$ Ed. IV : Rothomagi, Bertbelin. 1650 . S 605 p., praef., ic. xylogr. i. 1.

$8167^{*}$ Portal, Salvalor. Catalogus plantarum horti botanici Salvotori Portal Albaevillae in Sicilia, qua nutua commutatione exlibentur Catanae, typ. Longo. 1826.12.69 p.

$8168^{*}$ PortenschJag-Ledermayer, Frans Edlervon. Énumeratio plantarum in Dalmatia lectarun. Zum Andenken des Verewigten von seinen Freunden. Wien, Franz Härter. 1824, S. 16 j\% 12 tab. $(1 / 2(h)$.

(Ii) hibliotheca Candolleana servatur collectio plantarum a Portenschlag in Dalmatia detectarum, curis illustr. von Helden anno 1822 sculptarum.)

8169t Porter, George Richardson. The Iropical agriculturist: a practical treatise on the cultivation and managrment of various productions suited to tropical climates. London, Smith, Elker and Co. 1833.8. xil, 429 p., ic. xylogr. i. 1., 1 talı, col. (1l. 1s.) Bibl. cand.

- Nature and properties of the Sugar Cane. London, Snith Elder and Co. 18 .. 8. (12s.)

8171 Portzius, Johann Doniel. Vini rhenani, in specie Baclaracensis anatomia chymica, ex novis principiis acielo et alcali resoluta, in qua pauca de terra, vite, uva, musto, vino, ejusque spiritu, tartaro tandenque aceto brevibus tractantur, suosque in usus rediguntur Ileydelbergae 1672. 12. Rivin.

$8172^{*}$ Postels, Alexander, el Franz Ruprecht. Illustrationes $\mathrm{Algarum}$ in itinere circa orbem jussu imperatoris Nicolıi $I$. atque auspiciis wavarchi Friderici Lutke annis $1 \$ 26,4827,1828$ et $1 \$ 29$ celoce Senrovin exsecuto in oceano pacifico, inprinis septentrionali ad littura rossica asiatico-americana collectarum. Petropoli, trp. Eduard
I'ralz. (Lipsiae, Voss.) 1840. folio max. rossiec ne latine: v1, 30, iv, 24 p., 41 tab. col. sign. $1-40$. (nigr. $33 \frac{1}{3} / \mathrm{h} .-\mathrm{col} .85 \frac{1}{3} \mathrm{~h}$.) Bibl. Goett., Berol.

('rima tabula non sipnata inseribitur: Fegetatio Algarum ; Lal). 39-4i) Anatomia Alenarnu.

Je sumpunso litiro ef. Berliner Jahrbücher fur w issenschaftliche

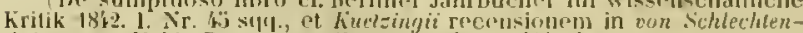

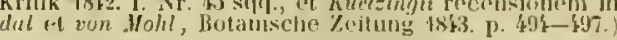

$8173+$ Potiez-Defroom, J. L. F. Catalogue des planles cultixins dans les jardius do la societé royale et centralı d'agriculture, science el arts du Département de Norl, seant a Douai. Dutai, ţ̧. Wagrez. 1835.8 .108 p.

8174* Pott, Johamn Frielrich. Index herbarii mei vivi. (Post fatum posm sessoris auchoritate haeredum imprimi curavit 1/r. J. C. L. Jelluig.) Brunovici, typ. Vieweg. nense Julio 4805. 8. (5z) p.

S173 Potter, $T$. $R$. The history and antiquities of Charnwood Forest. With an appendix on the geology, hotany and ornithology of the district. Iondon 1842. 4. 224 J., 24 tal. ( $21 s$.)

(Sectioncu botanican elaboraverunt A. Bloxam el Charles Babinglon.)

8176t Pouchet, felix A. Essai sur l'histoire naturelle et mérlicale de la fanille des Solnnées. Thèse. Paris, typ. Didot. 1827. 4. 78 p.

$8177^{\circ}$ - Ilistoire naturelle ef médicale de la famille des Solances. Romen, typ. Baudry. 4829.8. 187 p.

8.78 Considerations sur le jardin botanique de Rouen. Rouen 15p. Baudry. 1832, 4. 12 p., avec un plan. $a$.

8179 - Nouvolles considérations scientificjues et eronomirpues sur le jardin botanique do houen. Rouen, typ. Baudry, 1832. 8 32 p. a.

Slsot Florr, an Statistique botanique de la Srine-inferieure, contenant la discriłtion, les propriétés medicales el éconminues et l'histoire abrigie des plantes de ce département. Tome premier Flore dilrérencielle. Rouen, typ. Baudry. 1834. 8. xv1, 10 p. - Tome sccond. Flore descriptive: 84 p. Bibl. Juss. sepi.)

(C'est lil premiere livraison d'un uny'rage, eni en derrait avoir

$8181+$ T Trailé élémentaire de bolanique applizinée, contenant la description do toutes les familles regétales et colle dos genres cultivés, ou offrant des ulantes remarquables par Jours propriétés ou par leur histoirc. Paris, Bailliere. 1835-1836. Il voll. 8. - I: 1835. vis, 396 p. - II: 1836.661 p. (14 fr.)

$8182+$ Pourret, lierre Andre. Extrait de la Chloris Narhonnensis, renferméc dans la relation d'un voyago fail depuis Narbonno juscqu'au Montserrat, par les Pyrénées. (Exirait des llémoires de Tuuluuse, rol. HIl.) 4. 38 p. Bibl. Juss.

81834 - Noticia bistoriea de la familia de Salvador de la ciudad de Barcelona por Don Pedro Audres Pourret. Barcelona, jor Matheo Barceló. 1796.4. (4) 32 p. Bibl. Webb.

S184* Pouzin, N. Fulcrand. Avis au botaniste, qui doil parcourir les alpes. (Nontpellier), typ. Izar et Ricard. Floreal, an Till. $4.62 \mathrm{p}$.

SIS5t Pouzolz, P. M. C. de. Catalogue des plantes qui croissent naturellement dans lo Gard, pour servir à la formation de la Flore de cc Département. Nisnes, typ. Ballivet et Fabre. $1842.4 .46 \mathrm{p}$.

\$186 Praefectus, Jacobus. De diversorum vini generum natura liber. Venetiis 1559.8 .56 foll. B.

$8187^{*}$ Praetorius, Johames. Mcletematun physicorum disputatio XXI De plantis. D. Halae Saxoniae, 1yp. Salfeld. 1677. 4. I plag. (Respondens: Christian Keller.)

8J88t Prahl, J.F. Index plantarum, quac circa Gustroviam sponte nascuntur, phanerogamarum. Gustroviae, Opitz. $1 \$ 37.8$. w, $66 \mathrm{p} .(3 / 8 \mathrm{~h}$.

$8189^{*}$ Praschil, Wenceslaus Wilhelm. Plantac venenatae in territorio Vindobonensi sponte crescentes. D. Viennae, Iyp. Mechitaristarum. 1840.8. 40 p.

$8190 \div$ Pratesi, Pielro. Tavole di botanica elementare. (Pavia 1801. ) 8 lat. 30 p. 45 tab. terminologiam illustrantes. Bibl. Cand.

8191 Prefontaine, de. Maison rustique à l'usage des habitans de Cayenne. Piris 1763.8. B.

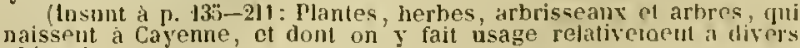
naissetst 
8192 Preibisius, Christoph. De plantarum natura. D. Lipsiae 1620. 4. Desid. Banks.

8193 De anima vegetativa ejusque facultatibus et ellectibus. Lipsiae 1629. 4. Rivin.

819:* Preiss, Balthasar. Mhizographie, oder Versuch einer Beschreibung und Eintheilung tor Wurzeln, Kuollen und Zwiebeln der Pflanzen etc. Prag, lironberger, 1823. $8.256 \mathrm{p}$., ind. $\left(2 \frac{2}{3}\right.$ th.

$819: 5^{\circ}$ - Die Kartofolpllanze, ihre unterirdischen Organe, ihro nutzenbringende Kultur und die sich dieser bisweilen rutgegenstellenden Krankheiten, fur Landwirthe und Freunde dieser Planze. Leipzig, Jackowitz. 1844 . 8. xil, $80 \mathrm{p}$., 1 tab. col. $(1 / 2 / h$.

$8196 \div$ Preisser, $F$. Dissertation sur l'origine et la nature des matieres colorantes organiques et itude spéciale de l'action de l'oxigène sur ces principes imnédiats. Tlı̀se. Rouen, typ. Peron. 4\$43. $8.78 \mathrm{p}$.

$\$ 197^{*}$ Presas, Joseph de. Instruccion pra el cultiro do la plauta Nopal o tuna higuera, y cria de la Cochinilla. Malaya, Martino de Aguilar. 1825. 8 max. 28 1".

8198 * Presl, Jan Suatopluk, el Karel Borinog Pres]. Flora cechica. Indicatis nedicinalibus, necononicis teclnologicispue plantis. l'ragae,

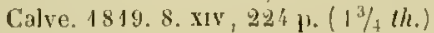

$8199^{*} \longrightarrow$ Deliciae Pragenses, historian naturalem spectantes. Vul. I. Pragar, Gilve. 1822. 8. vir, 244 ). ( $11 / 3$ th. $)$

$8200^{r}$ Wseubecuj́ Rusilinopis, čli popsáni rostlin we wšclikém uhtedu užtečujch a shodlicojch. Prag, Museum's Verlag. (Kronberger.) 1846. Il voll. \&. - I: xxx11, p. 1-1006. - 11: p. 10072079. Bibl. Petri Jordan.

(Est compendiun botanices generalis, prapsertim de plantis nocivis et utilibus, a societatr pragensi ad resuscilaulim linguim et literaturan cechican constitutı editum. Nuseumsschriften Nr. 23. .)

\$201* Presl, Karel Bořinog. Gramincae siculae. D. Pragae, typ. Sommer. 1818.8 .40 p.

$8202^{*}$ Cyperacear et Gramineae siculae. Pragae, Jlartmann. (typ. Sommer.) 1820. 8. xxil, 58 p. $(1 / 3$ th.

$8903^{*}$ - Flora sicula, exlubens plantas vasculosis in Sicilia aut sponte crescentes aut frequentissine cultas, secunlum systema naturale degestas. Tomus I. (Ad Rutaceas usque.) Pragae, Borrosch. 1826. 8. XLY, 216 P. (2) $(h$.)

$890 k^{*} \longrightarrow$ Epistola de Symplysia, novo genere plautarum ad $d_{a-}$ sephum de Jacquir. P'ragae 1897. 4. (4) p., 1 tab.

$8: 05^{*}$ —_ Relinuiae llaenkeanae, seu descriptiones et icones plantarum, quas in Anerica meridionali et boreali, in iusulis Plifippinis et Mari.nis collegit Thaddueus Iftente. Redegit ot in ordinem digessit Kinel Bornivar Prest. Cura Musei bohemici. Pragae, Calve. 1830-1836. Il voll. folio. - I: 1830. xv, 356 J., tab. 1-48. II: Fase. I-11. $1835-1836.152$ ]., tab. $49-72 .\left(34 \frac{2}{3}\right.$ (h.)

$8306^{*}$ - Symbolae botanicae, sive descriptiones et icones plantarum novarum aut minụs cognitarum. Pragae, sumtibus auctoris, typ. J. Spumy. 1832-1833. II voll. vel VIl fasc. Folio. - I: Fasc. 1 -Y. 1832. Il, 76 p., ind., tal. 1-50. - Jl: Fase. VI-V11. 1833. 24 p., tals. $51-70 .(293 / t$ th. $)$

$8207^{\circ}$ - Repertorium bolanicae systematicae. Excerpla e scriptoribus bolanicis, continentia diagnoses generum of specicrum novarum aut melius distinctarun, indicationes iconum, generun et specierum jam connitarum et adnotationes succinctas botanican systematicam spectantes, sistentia supplementun contiuum Prodromi systematis naturalis Cundollei, systematis vegetahilium Schultesii et Sprengetii. Tolunen I Pragao, typ. filiorum Theophili llaase. 1834 s. vili, $385 \mathrm{p}$. ( 2 th. $)$

$8208^{*}$ Yermischte botanische Aufsatze. (Ueber lie Reizbarkeit der Staubfadenrulire bei Medicago; Beobachtung einer seltuen Monstrositat an den Staubbeuteln der gemeinen Tulpe; B]attermetamorphose an Modiengo sativa; theilweise Fullung ter Blunen an Rohinia Pseudoacacia; Metimorphose der Carpelle an Prunus Padus.) s. 1. et a. $8.16 \mathrm{p} ., 1 \mathrm{tab}$

$8209^{*}$ Bemerkungen uber den Bau der Blumen der Balsamineen. Prag, Haase. 1836.8 .54 p., 1 tah. $(1 / 3 / h$.)

(Aus den Abhandlungen der hunigl. Duhmischen Gesellschaft der Missenschaften.).

$8210^{*}-$ Beschreibung zweier neuen bohmischen Arten der Gattung Asplenium. Prag, llase. 1836.8. 11 p., I tah
8211* Presl, harel Bořiwog. Prodromus nonographiae Lobeliacearum. Pragae, Hianse. 1836. $8.52 \mathrm{fr}(1 / \mathrm{t}$ th. $)$

Seorsim inns: ex Actis regiac lwhenicie societ scient.)

8212* — Tentamen pteridugraphiae, seu genera filicacearum praesertim juxta venarum decursum et distributionem exposita. Pragae, llanse. 1336. 8. $290 \mathrm{p}$. srorsin impr. "s Actis regiae hobenicae snciet. scient.)

8.13* - Hymenophylaceac. Eine botanische Abhandlung. Prag. 1laase. $1843.4,70$ p., 12 tals. $(2 / h$.)

(Aus den Ahlamilumen der konigl. bohmischen Gesellschaft der Wissenschalten, funfte Folge, Band III.) 8214: $\frac{}{(13 / 5 t h .)}$ Jiotanische Bemerhungen. Prag, llaase. 1844.4. $154 \mathrm{P}$ Hissensclialter, linfte: Folse, Band lii.

$8215^{*}$ — - Supplementum tentaminis pteritlographiae, continens genera et species ordinum dictorum Marattiaceae, Ophioglossacene, Osmundacear, Schizacaceae el Lygodiaceae. Pragae, llaase. 1845. 4. 1191$)(1+15 t h$.

(Segrsim impr. ex Actis regiac bohemicae societ, scient.)

$8216+$ Presta, Giocamui. Degli ulivi delle ulivo e dilla maniera di cavar l'olio. Napoli, nella stamperia reale. 1794.4.346 1\%, "4 Lab.

8217 Prestele, Joseph. Jie wichtigsteu Gifipflanzen Deutschlands in lebensgrossen $\Lambda$ blsildungen zur $1 \mathrm{~V}$ armung und Jelelırung iber die Gefalır, nach der Natur gemalt; ausgewahlt uni beschrieben vom Lehrer Kurl Soldan. Friedberg, Bindernagel. 1843. 8. 4 platg., 24 tals. gr. folio. ( 2 th. - col. $4 \frac{1 / 3}{3}$ h. $)$

8218 Preston, Cieorye. Calologus omnium jhantarum, quas in seminario medicinac dicato transtulit. Ed, 11. Edinlsurgh 1716. 12.59 p. B.

S219 Preu, Panl Sigismund Farl. Narratio succincta de vita et meritis Joachimi Camerarit. Altorfii 1782.4. 2S p. B.

8220 * Preuschen, ficory August. De Cypero esculento L. D. Erlangae, Hilpert. 1801.8 .43 1\%

8221* Preuss, hirel Ludwig. De Belladonna. 1), Rustochi, typ. Adler. $1831.8 .32 \mathrm{f}$.

8222t Prevost, J'an. Catalogue des plantes, qui croissent en Bearn, Navarre et liegorre et es Costes de la mer des liasques, depuis Bajonne jusfues a Fontarabie et S. Seloastien en Espagne. Pau, par la vefve ile Pierre Desbaralz. 1655.8 .60 p., praef. Bibl. Juss.

8223: Prevost, Jean Lauis. Collection des fleurs et des fruits peints d'après nature el tirés de son porte-feuilln. Avec un discour's d'introduction sur l'usage de cetle cullection dans les arts et les manufacures, suivi d'un précis historique sur l'art de la broderie el d'une vue générale sur toutes les manières de peindre depuis l'antirguité jusqua à nous par $I$. $M$. Gault-de-Saint-Germain, avec une explication des julanches par Antoine Nicolas Duchesne. Paris, Vilquin. 4s05. folio. Iv, 19 (48) p., ind., $4 \mathrm{~s}$ tab. col. (50 fr. Meillıac.)

8224: Prevost, Isaac Bénedict. Mémoire sur la eause imméliate de la carie ou charlion des blés el do plusieurs autres maladies des plantes. Montuban, Fontanel. 1807. 4. 80 p., ind., 3 tab.

8295t Priezac, Salomon de. Ilorti Ruelloni authore Salomone Priezaca in monetarun curia Senatore ad amicum. Jarisiis, typ. Jacobi Lugast. 1640.4. 8 j. Bibl. Cand.

(Aclulatoria inque contorfula effictio poetica hortorum Cardinalis Richelietl.)

8226 Prince, Franciscus. Dissertatio inauguralis de vino Neocomensi. Basileac 1743. 4. 기 p. B.

822\%* Prince, II illiam $A$ treatise on fruit and oruamental trees aut plants cultivated at tho Linnean botanic garden, flushing, LongIsłand, near New-York. New York, lyj. Swords. 1820 . 8. 81 p.Ell. Il: ib. 1822. 8.

$8228+$ Catalogue of american indigenous trees, plants and seeds, cultivated and for sale at the linnean botanic garden, Flushing, Jong-Island, near New York. New York, typ. Swords. $4820.42 .19 \mathrm{p}$.

8229* Pritchard, Stephen F. An alphabetical list of indigenous and exotic plants, growing on the island of St. Ilelena, compiled by Stephen F. Pritchart Esq., and corrected by Mr. James Bowie, botanist, Ludwigslıurg garden. Capetown, printed by G. J. Pike. 1836. 8. 31 p. Bibl. Mus. Senkenb. 
$8230^{\circ}$ Pritzel, Georg August. Anemonarum revicio. Lipsiae, in commissis apul Leopoldun Yoss. I84z. 8. 142 p., 6 lal). $\left(1 \frac{1}{3}\right.$ /h.)

(seorsim impr. addito indice specicrum et synonymorum e binnaea vol. $X V .1,561$.)

$8231^{*}$ - In ordines XII priores Repertorii Imotanices systematicae supplementum, arjectis Resediaceis. Berolini 1843.8.28 $\mathrm{p}$.

(Soorsim impr. e Halpers, Repert. Bot. syst. vol. H. p. 737-76i.)

$8232^{*}$ —_- Specimen bibliographiae betanicae, pund Ernesto Meyer, botanices Professori Regiomontano, nuptias Johcunue Isenburtiae cum Doctore Zaddachio celebranti gratulatmus seripsit. Viennae, tyl. Caroli Gerold. 1845.8. 7 p.

(Insunt vari librorum lituli jocose mutilati, undique collecti. Noveri iuter anicos distribui cxemilaria.

8233* Pritzlow, Ilithelm. He nuce vomica. H. Berolini, typ. Nietack. $1831.8 .45 \mathrm{p}$.

8234* Probst, Johann Ernst. Verzcichniss der in - und auslándischen Baume, Staudeu und Sommergew ticlise des Kuspar Borisclien Gartens in vier Ordumngen, wie solehe sich in Jahre 1737 befurden. Leipzig, typ. Laogenhein. 1. Januar 1738.8 .144 p., 2 tab. - "Leipzig $1747.8 .140 \mathrm{p}$

8233* — Wurterbuch, worionen deren Kisuter Nahmen, Beyworte und sonst gewohnliche Redensarten aus dem Lateinisehen ins teutsche ulertragen sind. Leipzig 1741 . 8. $160 \mathrm{p} .-$ "Leipzig 1747.8. $160 \mathrm{p}$.

(Multa habei e dietionario Eliae Pein, de quo supra Xir. 78.9.)

$8236^{*}$ Proell, Alois. Tenlamen, fungos austriacos esculentos iisque similes virulentos propria investigatione deteminandi. D. Viemnac, Іур. Pichler. 1839. 8. 22 p.

8237 t Pronville, Augusle de. Nomenclature raisounece des espices, variétés et sous-variétés du genre rosier, observées au jardin royal des plantes, dans ceux de Trianon, de Malmaison et dans les pepinières dos envirous de paris. Paris, lluzard. 1818. 8 . $119 \mathrm{p}$. (2 $\mathrm{fr}$. 50 c.)

$8238+$ - Sommaire d'une monographie du grenre rosier. Paris, Iluzard. $1822.8 .52 \mathrm{p}$.

$8239^{*} \longrightarrow$ Monograpluce du genre rosier, traduite de l'anglais de Lindley avec des notes de $L$. Joffrin et des changenens importants, suivie d'un appendice sur les roses cultivées dans les jardins de Paris et envirous. Paris, Audot. 1824. 8. vili, 182 p. ( 3 fr. 50 c.)

$8240+$ Prost, T. C. Notice sur la Flore du departement de la Lozere Mende, cliez lgnon. (1820.) 8. 12 p.

$8241+$ Liste des mousses, hẹpatiques et lichens, observés dans le département de la Lozere. Ilende, Ignon. 1828. 8. 80 p. Bibl. Montagne.

(Extrait des .Mémoires de la soc. d'agriculture ete. de Mende.)

821.2 Provanzale, G. F. Memoria sulla Cannucia palustre, Aruodo Phragmites. Firenze 1809. 8. DC.

8243* Prytz, Lars Johan. Florae fenuicao breviarium, dissertationibus academicis absolvendum. D. I - VI. Ahoae, typ. Frenckel. 18191821. $4.92 \mathrm{p}$

Continuatio, ni fallor, munguam proditt, lusunt 277 species. Dissedlationes 1 et 11 , anno 1819 edilas, in quibus continentur p. 1-28, ipse ego non vidi.

824: * Puccinelli, Benedello. Synopsis plantarum in agro Lurensi sponte nascentium. (Fascieulus 1-III.) Lucae, typ. Bertini. 1841 (-1843.) 8. 326, xxxxix p., (9) tab.

(Insunt classes Linneeanae I-XIV.)

$8243 t$ - Lettera del Dottor Benedetto Puccinelli, Prof. di hotanica in Lucca, al Prof. Pictro Savi sul Pogonostylis squarrosu.s Bertol. s. I. et a. 8.8 p., 1 tab.

(Giomale Toscano di Scienze mediche, fisiche e naturali tom. 1. Nr. 2. ante 18:1.)

8246* Pueckler-Muskau, Ilormann, First von. Andeutungen iber Landsclıaltsgártnerei, verbunden mit der Beschreibung ihrer praktischell Anwendung in Muskau. Stuttgart, Hallherger. 1834. $8.282 \mathrm{p}$. und Atlas in gr. folio mit $44 \mathrm{col}$. Ansichten und 5 Grundplanen. sign. A-D. $\left(30 \frac{2 / 3}{3}\right.$ h. - col. 80 th. $)$

$8247 \div$ Puel, $T$. Catalogue des plantes, qui croissent dans le Département du Lot, classées d'après le système de Linnéc, suivi d'une table analytique pour la determination des genres et des espèces. s. I. et a. 8. $40 \mathrm{p}$.
82?8" Pujade, J. I. J. Dissertation sur l'utilité de la lontanique dans la médicinr. Montpellier, typ. Concourdin. an Xlll. 4. $\$ 35$.

8219 * Puihn, Johann V'eorg. Materin venenaria regni vegetalsilis. Lipsiae, Hilscher. 1785. 8. x4, 196 [).

$82: 30 \div$ Pujoulx, Jean Bapliste. La hotaniquo des jeunes gens. mic. l'aris, Briand. 1810 . 11 voll. 8 . xi1t, $665 \mathrm{\mu}$., 21 tal.

82316 Promenades an marche aux frurs on to hotmiste du secont age. Paris, Lepetit, 1811 . 8. 408 p., 12 till. (3 ft, - col. s $(\mathrm{f}, 50 \mathrm{r}$.)

82:2 Pulteney, Richard. Dinscrtatio inauguralis de Cinchona officinali Limnaci, sive curtice peruviano. Edinhurai 1764. 8.60 p., I tals. \& figura /lankinsii exscri]uta.) B.

82:33* - A general view of the writinge of Limnaeus, London 1781. 8. 425 j. - * The sccond edlition witle eorrections, considerable additions and memoirs of the author ly llilliam George Huan. To which is antuexed the diary of Linnaeus, written l,y him self and now translated into english, from the swedish manuscript in the possession of the editor. Lourlon, Mawman. 1805. ‘. xi, 5930 p. 5 tal). (1l. 11 s. $6 d$.

- gallice: Revue quncrale des cerils de Linné: ouvrage dians loduel on trome les anecdotes fes plus merresiantes de sa vio priver, un

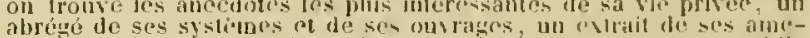

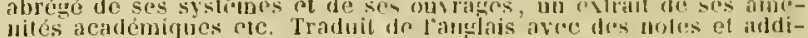

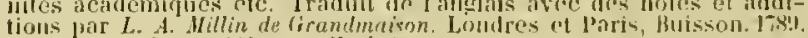
il voll. $8 .-1$ : vi, 386 p. - 11: 400 p.

$823 \%$ " Ilistorical and biograplieal sketches of tho progress of botany in England, from its orimin to the introduction of the Limnesn System. Lontun, Carlell. 1790. II roll. S. - 1: $x$ w, 360 p. - II: $352 \mathrm{p}$, ind.

" germanice: Geschichto der Botauih his anf dip neuerrou Zeiten mit

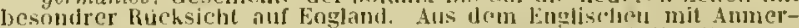

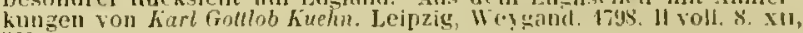
$566 \mathrm{p}$.

$\div$ gallice: Escuuisses historiumes ot bographiques des fungres de la

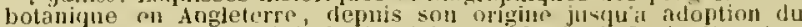
systime te lime. Traluit de l'anglajs (par Boulard. I'uris, Ilaradan. 1809. 11 vell. $8 .-1$ : vil, $31 \mathrm{i}$. -11 : $36 \mathrm{j} \mathrm{n}$.

S2öö * Pundt, Johamnes. 1)issertatio inauguralis de Isa foctida. Goentingae 1778.4.22 p.

$8206^{*}$ Purkinje, Johannes Evangelista. Dr cellulis antherarum fibrosis nec non de granorum pollinarium formis commentatio pliytotomica. Vratislaviae, J. D. Giuson. 1830 . 4. vil, 58 p.: 18 tals. ( $31 / 2$ th.)

8257* Pursch, Friedrich Traugoll, anglice Frederick Pursh. Verzeichniss der im Plauisclien Grumble und den zunticlist angrenzenden Gegenden wildwachsenden Pflanzen. Lupr. eum $11^{*}$. G. Becker, der Plauische Grund bei Dresden. Nürnbers, Frauenholz. 1799. folio. P. $45-94$

$8258^{*}$ - Flora Americae septentrionalis, wr a systematic arrangement and description of the plants of Yorth-America. London, White, Cochrane el Co. 1814. 11 voll. 8. xxxv1, 751 p., 24 tab. col. - *ib. 1816. S. xxxvi, 75 I J., 24 tab, col. (eaden impressio.)

$8259 \div-$ Iortus Orloviensis, or a calalugue of plants cultivated in the island of Orloff near St. Petershurgh by Peter Buek, gardener to his E. Coun Orloff. London, Iyp. Taylor. 1815.8 . '11, 72 p.

8260 Purton, (Thomas?). British plants of the Mldiand counties. Stratford-upon-Avon 1817. Ill voll. 8. - I et II: $795 \mathrm{p}$, tab. col. 1-8. - III : 575 p., tab. col. 9-34. (2/. 10s.)

Fortasse edlitio mova adest, (quar mihi noll innotuit; ef. Loudon. Magazine of natural history 1836 . p). fit(6.)

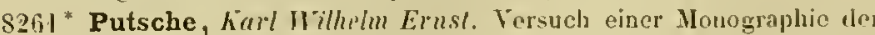
Kartoffeln oder ausfuhrliche Besclureiluung der hartoffeln, nach ihree Geschichte, Charakteristik, Kultu und Anwendung in Teutschland. Herausgegeben von Fr. Just. Rertuch. Weimar, Industrie-Comtoir. 18 19. 4. x, 158 p., 9 tab. col., 4 tals. niys. $\left(3 \frac{1}{2} t h\right.$.)

8262* Putterlick, Aloys. Synopsis Pittosporearum. Vindobondo, Beck. 1839. 8.30 p., ind. $(5 / 12$ th. $)$

$8263^{\circ}$ (Puvis, A.) Observations sur la dégéneration des varjẻtés des végétaux et sur lcur rebouvellement pir les semis el par les croisemens; par M. A. $P^{* * * *}$. Bourg, țp. Bollier. s. a. $8.19 p$.

826 Ł — De la dégénération el de l'exstinction des varietes do végétanx propagés par les grelles, boutures, tubercules etc. et do la erention des variétés nouvelles par les croisemens at les semis. Paris, Huzard. 1837.8.94 p. 
826:) Puvis, A. Notico su la maladio do la pomme de terre. Bourg, typ. Nillict-Bottier. 1846.8 .20 p.

$8266 \div$ Puymaurin, de. Notizia intorno al guado (lsatis tinctorum) della sua coltura e de' mezzi d'estrare l'indaco. Ililano, stamperia reale. 1810.8 .50 p. Bibl. Webb.

t gallice: Notice sur le Pastel (Isatis linctorum), sa cullure ef les moyeus den retirer l'ndigo. Touloose. Douladoure. 1811.8 .501 .

$8267 \%$ Instrution sur l'art d'extraire l'indigo contenu dans les feuilles du Pastel. Paris, imprimerie imperiale. is 13. 8. 42 p.

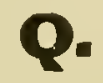

8268* Quadri, Giovamni Battista. Notizie intorno ad una spetecio di fungo velenoso. Milino, ty]. Silvestri. 1807.4.12 [1, I tab. col.

8269 Quarin, Joseph, Giaf won. Tentamina de Cieuta. Vindohonae 1761. 8. 40 p. B.

$8270^{*}$ (Quarizius, fier) Goltried.) Naturhistorisehes botaniseh-pharma-

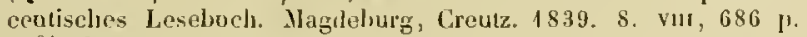
$\left(2^{3} / t_{\text {th }}\right.$ th

(lu tilulo compilationis miserale autor nomen liclitum C. (i. Meerfols affectavit.)

$8271+$ Quatremere d'Isjonval, Jissai sur les caraclères qui distinguent les cotons des diverses parties du monde. etc. Paris, Demonville. 1784. A. 82 ].

$8272^{*}$ Quelmalz, Samuel Theodor. De oleo Palmae, materia injectionibus anatomicis aptissima. Programma academicum. Lipsiae 1750. 4. $15 \mathrm{p}$.

8273 (Quelus, de.) Ilistoire naturelle du Cacao et du Sucre. Paris 1749. 12. 227 \}.: 6 tab. - Ansterdam 1720.8. 228 p., 6 tal). B. anglice: Ihe natural bistory of Chocolate, translated by R. Brookes. Ed. II. London 1730.8.9: p. B.

(lin translationo omissa est historia sacchari.)

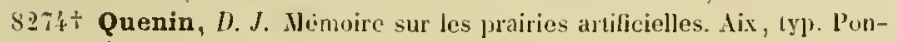
ticr. 1812.8. $111,103 \mathrm{p}$.

$8275^{*}$ Quenstedt, Fr. Iuyust. Petrefaktenkunde Deutschlands. Nit besondrer Rucksicht auf Wurtemberg. Tulbingen, Fues. 1846-1847. Jleft 1-3. 8. Iv, 264 p., tab. 1-48. (a $12 / 3$ th.) (Continuatur.)

$8276^{*}$ Quer y Martinez, Joseph. Flora Española, ó llistoria de las plan1as, que se crian en España. Madrid, por J. Ibarra. 1762-1784. II voll. 4. - 1: 1762. 402 p., praef, Lal,.1-11. - 11: 1762. $303 \mathrm{j}$, praef., 1ab. 12-13. - II]: 1762.436 p., prace, 79 Lab. - I1: 1764. 471 p., 66 tals. - V et V1: 1784. xxxur, 538, 667 p., 34 tab. (1. 200 fr. Barcelona; 100 fr. Jaris, Meillac.)

(Contimuaciou, ordenada, suplicla y publicala par Doull rusimiro Gomez de Ortega.)

(Tormus primus continet versionem Isagoges in ren hertarian Tourneforti, p. Gij-272, el discursum de methodis bolanicis, p. 273379. Tomus secundus continet: Diccionarin en que se critican los terminos y voces mas usuales de la botancea, p. 1-6 , Josephi Mronti

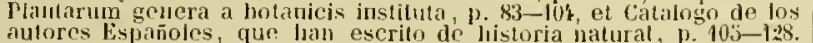
autores Espanoles, que luan escrito de listoria natural, p. 10 0 -1:28.
Incipit Flora ijssa in pagina 129.)

$8277 \div$ Dissertacion physico-lyotanica solıre la passion uephritica, e su vordadero especifico, la liva ursi o garubas. Madrid, lbarra. 1763.4.4,56 p., I lab.

8278 Dissertacion physico-botanica solıre el uso de la Cicuta. Madrid 1764. 4. 43 P., 2 tab. B.

8259t Quetelet, A. Resumé des obscrvations sur la méléorologie, sur le maguctisme, sur les temperatures de la terre, sur la floraison des plantes etc. (Bruxelles) $1 \$ 41.4 .29 \mathrm{p}$.

Extrait des Alem.de l'Academie royale des Bruxelles, tome $\mathrm{XIF}$

$8280^{*}$ Notice historique sur Jean Baptiste van Ifons. Liruxelles, Hayez. 1843. 8. $51 \mathrm{p}$.

8281 Quiqueran, l'ierre. Nouvelle agriculture, ou instruction pour ensemencer les arbres fruitiors, et divers traitis de la vertu des fleurs, du naturel des animaux (contenus dans la Provence de Pierre Quiqueran de Beaujeu) traduit du latin par $\boldsymbol{F}$. Niny de Claret. Tournon, Reignaud. 1616.8 . s.
8282* Quistorp, Johann, jr. Dissertatio philosophico-botanica de serie vegetabilium. Gryphiae, 1yp. Eckharit. 1800. 4. 14 p.

(Antor fortasse est Johan Pehr Ponten, yni dissertationem pro gradu philosophico propusuit.)

\section{R.}

$8283^{*}$ Rabenhorst, Ludwig. Flora lusatica, oler Vorzcichniss und lieschreilhung der in der Ober- und Niederlinsilz wildwaclssenden und haufig cultivirten P'llanzen. Leipzig Kummer. 1839- 1840 . 2 Jande. 8. - 1: Pluancrogamen. 1839. Lxvil, 336 p. - I1: Kryptogausen. $4840 . x x u, 507$ p. $(41 / 12$ th. $)$

828\%" —_ Populär practische Botanih, wier Anleitung, die in Deutschland haufig wilkwachsenden und grezognen Gewachso homen zu lernen, nchst einer lichersiclat des Gewachsreichs nach seiner organogenctischen lintwich elung. Leipzig, Kunmer. 1843. 8. $x, 406 \mathrm{p} ., 1$ Tabelle. $\left(11 \frac{1}{12}\right.$ th.

$8283^{*}$ Deulschlands hryptogamenllora, oder llandbuch zur Bestimmung der hryptogamischen Gewachso Deutschlands, der Schweiz, des Lombardisch-Venetianischen honiornichs und Istriens. I.cipzig, Kunmer. $1844-1847.2$ Bande. $8 .(5 \% / 2$ t.) (Continuatur.) 1: 1844. Pilze, xxu, 613 p. $\left(3 \frac{1}{3}\right.$ th. $)$

11. Erste Abtheilung: 1845 . Lichenen. xu, 129 p. $(5 / 6$ th.

II. Zweite Ablheilung: 1847. Algen. xix, $216 \mathrm{p} .(1 \mathrm{1} / \mathrm{s}$ th.

$8286^{*}$ Botanisches Centralblatt fur beutschland, redigirt von L. Rabenhorst. Ërster (oud eiuziger) Jahrgang. (26 Numun ru.) Leipzig, Kunmer. 1846. 8. vin, 552 p., 1 tah. $(2 \% / 3$ th.

(Pdcicle obiit in runis. Ilave, pia anima!)

$8287^{*}$ Radda, $J . F$. Sintbilder aus der Pflanzenwelt. Wien, Beck, 1826. 12. viI, +12$).(3 / 8$ th. $)$

8288 + Raddi, Giuseppe. Di alcune specie nuove e rase di piante crilloganu: ritrovate nei contorni di Firenze Memoria. s. I. et a. 4. 11 p., 3 tal. sign. 1-4. Bibl. Cand.

(liuic commentationi praemissmm est fulium quarta forma ita inseriplum: "Novae species erypteganatum inventao in florentinis soburbanitatibos et descriptie in actis acarlemiar? Seneusis anno 1808 a Josepho Raddi." Sum diagnoses earuntem specictum. Lego etians a schultesio cilatas: "Nolarum yel rariorum "s eryptogania stitpium decades It. Bonouiace 1s08. ', p)

$8289^{*}$ - Synopsis Filieum lrasiliensium. Bononiae, typ. Nobili. 1819.4. 19 p., 2 \{al).

$8290^{*}$ _- Jungermanningrafia etunsea. (Mcmorie della sociela italiana delle scienze residente in Moslena, tom. XTIII. 1820.) Bonnae, Jenry et Colien. 1841.4. Iv, 28 p., 7 tal. (1 th.)

(lianc novan editionen latinan curavit fhristem follfied Neps von Esenbech.)

8391* _ _ - Di alcone specie nuove di rettili c piante brasiliane Vlemoria, inserita nel tomo XVIll degli atli de la societi italiana delle scienze in Modena. Modlena, societa lipografica. 1820 . 4. 39 p., 4 tal. col.

$8292^{*}$ Quaranta piante mune del Brasile. il. 1820. 4. 35 p. 2 lab.

$8293^{*}-$ Crytlogame Lrasiliane. ib. 1892.4. 33 1.

$8294^{*}$ - Descrizione di una nuova Orchitea brasiliana. ils. 1823 4. 6 [P., I tals.

$8295^{\circ}-$ Breve osservazione sull' lsola di Madera [atta nel tragitto da Livorno a Rio Janciro. Firenze 1821.8. Iy p., I tab.

(Estratta dal fasc. l. dell Antologia.)

$8296^{\circ} \longrightarrow$ Di alcune specie di Pero ivdiano (Psitlimn) Memorid. Bologrua, typ. Noljili. 1821. 4. 7 p.: 1 1ab.

$8297^{\circ}$ Agrostographia brasiliensis, sive Ėuuncratio plantarum arl familias naturales graniıum et cypernidarum spectantium, quas in Brasilia collegit et descrij)sit. Lucca, dalla tipogralia ducale. 1823. 8.58 p., 1 tab.

$8298^{*}$ Plantarnu hrasiliensium nova genera el species novao vel minus cognitae. Pars l. Filices. Florentiac, 19]r. Pezzati. 1825. folio. 104 p., 84 tab. male lith. ( 45 Lirc.)

8299 Radermacher, Jacob Cornelius Jatthaeus. Naamlyst der planten, die gevonden worden op loet eiland Java. Batavia $1780-1782$. 
III Stuk. 4. - 1: 1780.60 13. - 11: 1781. 67, 88, 10 p. - 111: 1782. $402,42,70 \mathrm{p} . \mathrm{B}$.

8300 " Radius, Justus. Dissortatio fon l'yrola et Clinumplila. Specimen

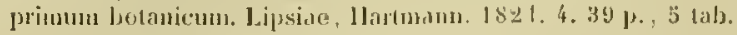

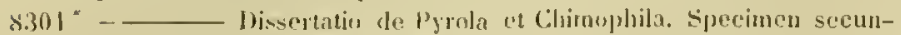
Ilum meslicum. Lipsiae, Voss. 1829. 4. 32 1) (I et 11: / /h.)

83112 Radzibor, Karl II Tadimir. De Nuce vomica. 1). Berolini 1837. 8.30 1.

8303 " Racuschel, Ernsl Adolf. Nonmelator botanicus, omnes plantas ab ill. Curolo von Linne descriptas, aliisplue holanicis tomporis recentioris detectas pnumerans. Liditio tertia. Jipsiae, Feind. 1797.8. xil, $4141 \%$.

Sunt priores folitiones hrjus Nomenelatoris anonymae: "Lipsiae, aptud Junium. 1772. 8. 279 p., int. - Editio tura. Lipsiae, apud Juก11111. 1782. 8. 280 p., ind.

8301t Raffeneau-Delile, Alire. Ibissoration sur les ellets d'un poison Je Java, ajuele Lpas lieuté, et sur la noix monipue, la fero dest. Intace, le strychuos potatorum et la pomme do Vontac, yui sont du mino genre le plantes, que l'lpas liende. D. Paris, typ. Didot. 1809 4. 48 p. Eibl. cand.

(1) XIV Aprilis cjusdem anni ilustrissimus $r$. Jagendie legeral III Academia schentianm conmentationcm "Lsamen do laction de

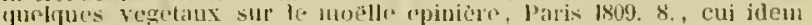
omnino est scopus, et in yuli elaborandit adjutor fuit belite.

$8305 t$ Nemoires botanipues extraits ule la "Description de

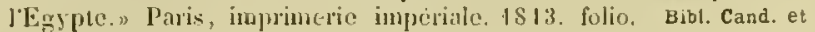
Deless.

1. Description du Palmier Doum de la Ilaute Egypte, ou Cucifera Whelsaica. $1810.6 \mathrm{p}$.

II. Ilistoire des plantes cultivies en liggple. 1813. $14 \mathrm{p}$.

III. Memoire sur les plantes yui ervissent spontanement ell ligypte. $1813.10 \mathrm{p}$.

11. Forac acoyptiacare illustratio. I8 $13.34 \mathrm{p}$ bot.

V. Flore d'Egyte. Explication des planches. $18+3.176 \mathrm{p}, 62 \mathrm{tah}$

$8306^{*}$ Centurie de planles dilfripue du voyane a Néroe recucillies par M. Frederic Cailliaul et décrites par M. RuffeneauDelite. Paris, imprimerie royale. 1826. 8. 112 1., 3 Lab. sign. $62-64$ Extrit du Voyage a Mcroó par Cailliand, vol. 11. 1). $293-102$ vide supra Nr. 1618 .

$8307^{*}$ Fragmens d'une Flore de l'Arahie pétréc. Plantes recueillies par M. Lion de Laborde, nommeus classees et decrites par N. Delile. Paris, Giard. 1833.4. $25 \mathrm{j} ., 1$ ials.

Tiré de De Laborde, Voyage dais l'Arabiu petre.

$830 x^{*}$ L_ Lecon de bolanique a l'ouverture du cours de cette science, a la faculté de médecine do Muntpellier. Nontpellier, Ricard. $1833.8 .35 y$.

8309* Lssais d'acclimations a Montpellier et mejanges d'observations. (Alontpellice 4836.) 8. 42 p.

(Bulletin de lin soeicede dagriculture de l"lterantt.)

$8310 t$ Nomel examen de la plosplorescence do lagaric de l'Olivier. (Montpellier 1837.) 8. 16 p., I tal, col. (Bulletin de la sucieté el'agriculture de l'tlerault.)

$8311^{\circ}$ - Nolice sur un voyage horticole et botanitjue en Belgipue et en Ilollande. Montpellicer, Picot. 4835 s. 8.36 p., 4 tab.

(Bulletin de fa société diagrieniture de liferaull.)

$8.312^{*}$ Index complectens semina in horto botanico regio Monspeliensi anno 1838 collecti, wo mutua commutatione oblata, additis characteribus specificis plantarum upuarunclan y'cl ex toto novarum, rel accuratius nuper ohservatarum. (Nonspelii, typ. Martel. 1839.) S. 14 p., 2 tab. col.

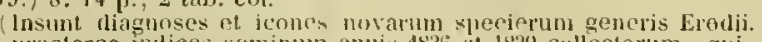
Vitli macterea indices scminum anuis 1833 . 1839 collectorum, qui-

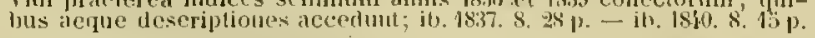

$8313 t$ - Souvenirs lleggpte. Ilerlorisations an Desert. Montpellier, typ. Boehm. 1844.8 . $15 \mathrm{p}$.

[Exirait de la Revue du Midi, Juillet Is'rk.

$8311 \div-$ Eclaircissements sur diverses parties de la butaninue. Lecture faile par le Professeur Alire Raffeneun-Delile, a L'ouverture du cours de botanique du semestre d'ete (avril 4\$45) à la facultó de médecine de Monipellier. Montpellier, typ. Martel. 1845. $8.35 \mathrm{p}$.

8313\% Rafinesque-Schmaltz, Conslanlino Sumuel, el Guiseppe Emmanucle Ortolani. Statistica generale di Sicilia. Parte I. Fisica dellit Siciliu. Palermo, dalla reale stamperia. $1810.8 .49 \mathrm{p}, 2$ tab seogr.

8316* Rafinesque-Schmaltz, Constuntino Samuel. Caratteri di alcuni movi generi o nuove specie di animali e piante della sieilia, con varie osscrvazioni sopra i medesimi. Palermo, ly p. Sanfilipjo. 1810. 4. 105 [1., 20 tah. Bibl. Mus. bot. Vind ob. et Gust. Kunze.

(Tabulae 1-17 ichthyolugiam, tabulie 18-20 trotanican tangunt.

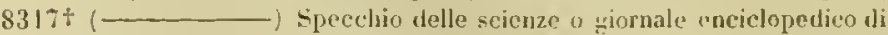
Sicilia deposito letterario delle moderno comaizioni, scoperte ed usservazioni sopra to scienze el arti e particorlarnenle sopra la fisica, lit chiniea, la storia naturale, la bolaniria. l'agricultura, la medicina, il comereio, Ja legislazione, le ducazionu ctc. Tomo primo (e secundo) prima antata. Palerno, 1y. di Francesco .1Jate Qm. Jencnico. 1814. II voll. 8. - tomo 1. Nr. 1-6. Januar-Juni 1814 $216 \mathrm{p} ., 1$ tab. - tome II. Nir. 7-11. Juli-November $1814.160 \mathrm{p}$. 1 tah. Bibl. Cand.

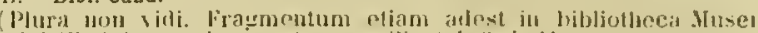
botanici Vintobonensis, sectiones scilicet 1. 3. f. 11.

$8318^{*}$ Précis des décourertes et travaux sumiolegiques entre 1800-1814, on choix raisunné de ses principales deronvertes en zoologie el en lsutauique, pour servir d'introduction a ses ouvrages futurs. Palerme, Iypographie militaire. $151 \%$. 12. $55 \mathrm{p}$. (25 c.)

8319 " Priscipes fondamentaux de sominlogic, ou les lois de la nomenclature el de la clasification de J"ennpiro organipue ou des animans et des végetaux, l'alerme, typ. Aluate. 1814.8 . 50 p. (25 c.)

$8320^{*}$ - Analyse de la nature, ou tablear de linnirers et des corps organisés. Palerme, aux depens de l'auteur. 1815. 8. 224 p., elligies Rafinesque.

$8321+\longrightarrow$ Circular address on botany and zoologr: followed by the Prospectus of two periodical works; Annals of nature and somiology of North-America. Pliladelphia, typ. Nerritt. 18/6. \$. $36 \mathrm{p}$.

$8322^{*}$ Florula Ludoviciana, or a Flora of the state of Louisiana. Translated, revised and improved from the french (Voyage vol. III.) of C. C. Robin. New-Tork, C. Wiley et Co. 1317.8 .178 p. ( 1 Dullar.)

$8323 \div-$ Amils of nature or annual synopsis of new genera and specins of animals, plants ete. discovered in North-America. First anmal number for 1820 . Lexington, typ. Smitl. 1820. 8. $16 \mathrm{p}$.

832f. $(\longrightarrow$ First catalognes and circulars of the bolanical garden of Transsylvania Lniversity at Lexington in Kentucky for the year 4824 . Lexington, typ. Al'Calla, $1824.8 .24 \mathrm{p}$.

$83235+$ Neogenyton, or indication of 66 new genera of plants of Nurtli-America. s. J. 1825 . gr. 8.4 p.

$8326^{*}$ - Merlical Flora, or Manual of the Medlical Botany of the Initerl States of North-Ameriea. Containing a selection of above 100 figures and deseriptions of medical plants, with their names, qualities, properties, Jistury ete. PJiladelplia, Athiuson. $1828-1830$. Il voll. $8 .-1: 4828, x 11,268$ p., 52 tab. col. $-11: 4830.976 \mathrm{p}$, 48 tal. col. (3 Dollar. - A. Paris 16 fr.)

$8327^{*}$ - Amcrican Manual of the grape vines and the art of making wine; ctc. Plhilatelplia 4830.12 .64 p., 2 lab. (20 cents.)

$8328^{*}$ Mllantic Journal, and friend of knowledge in cight numbers. Coutaining about 160 original articles and tracts on natural and listorical scicnces, the tescription of about 150 new plants and 100 new animaix or fossils. Mauy rocalularys of languages, listorical and geological facts. Philadelphia $1832-1833$. 8 . 212 p., 1 tal. ( 2 Dollars.)

8329* - Jerbarium Rafinesquianum. Prodrumus. Pars prima. Rariss. plant. Hot. Herbals; or lootanical collections of $C$. \&. Rufinesque. Nr. 1-11I. PhiladeJphia 1833. S. So p. (I Dollar.)

(Allantic Jourual extra of Xir. 6.)

$8330 \div$ New Flora and Botany of North-smerica. Being a supplemental Flora to the various Floras aud botanical worhs of Michaux, Mhehlenberg, Pursh, Nuttall, Ellioll, Torrey, Beck, Eaton, Bigelow, Rarton, Robin, Ilooker, Riddell, Darlington, Schueinits, Gibus etc. - Besides the great works of Linneus. II illdenow, Vahl. Yil- 
manin, Persaon, Lamurck, De Candotle, Syrenged, Jussiru, Adanson. Necker. Lindley etc. containing nearly 500 additional or revised new genera aıd 1500 additional or correcled new species illustrated by figures in Antikon lotanicou. Philatlelplua, printed for the author and publisher. Third part: New Sylva. 1836. 8. 96 p. Bibl. Cand.

Plura non vidi. Lego in proommo: "This work will contain six smilar parts forming at thick volume of tree 600 pilses. Price for subscribers 8 Dollars, for the others 6 mollirs. The filora Telluriana is a companion to his, same form, size and price.")

$8331^{*}$ Rafn, Carl Gottlob. Danmarks og Holsleens Flora, syslematisk, physisk og okonoonisk bearbeydot. Kiohenlavn, Buclıs. 1796-1800. Ii voll. $8 .-$ I: $1796 . x, 722 \mathrm{p} .-\mathrm{Il}: 1800, \mathrm{x}, 840 \mathrm{p}$. (Desinit in classe" Decondria.)

8332 Udkast till en Plante-Physiologio, grundet jaa de nycro Legreber i Physiologie og (hemie. lijubenlavn 1796. 8. 240 p.

Recusa in Rafn's Dammark och Ilolsteen's Flora I. p. 81-320.)

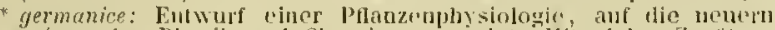
Theorieen der Physik und Chemir? gejtumlot. Mit vielen Zosailzer und feranderungen des Verfassers. Ans dem Danischen ubersetz ron Jaham dmbrosius Harlussen. Kopenhingen und Leijzig, schubothe. $1798.8 . \mathrm{xx}, 346 \mathrm{p}$.

suecice: Itkast till ell Vist-Physiologie. Örversalt på Svenska a

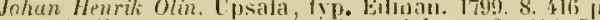

Hii nomen autoris scibunt Johann Gallieb Rafn.)

$8333^{*}$ Ragazzini, Francesco. Analisi dell" Astro montano "particolarmente del sugo espresso di questa jianta. D. Padova, 1yp. Crescini. 1523.8 .21 p

$833 \%$ * Ragonot-Godefroy. Traité sur la cullure des oeillets: suivi d'une neuvelle classification pouvant aussi s'appliquer aux genres Rosier Dajklia, Chrysintheme, et a tous ceux yui sont nombreux en varietés. Paris, Autol. 1842.8 .57 p., 3 tab. col. (I fr.) Brbl. A. W. Bornemann

8335* Raimann, $J$. N. Redo zü Gedac]ıtniss[eier fur Nicolans Jaseph Freiherrn von Jacquin, gehalten am 9. Jumi 1818 . Wien, typ. Strauss. $1818.4 .28 \mathrm{p}$.

(In csemplari hilliothecae Musci botanici rindobonensis addita sunt varia manuscripta ad vitam Jacquini spectintia.)

8336 Rainssant, Pierre. Dissertation sur l'origine de la figure des fleurs de Lys. Paris 1678. 4. Meusel.

$8337+$ Ralfs, Jolu. The britis] phaenogamous plants and ferns; arranged on the Limean system, and analyzed after the methed of Lamarek, with a short comparative analysis of the natural fanilies. Lonton Lollgnan, Orme elc. 1839.8 . XYr, 208 p. ( $8 s$.)

8338 Rambaldi, Angelo. Ambrosia arabica, overo tella saluttare bevanda Café. Bologna 1691. 12.69 p. B.

8339 Rammlow, J.C. Scillenzuchı und Naull,eerlaum. Eine Denkschrif für den Grundlyesitzer und Landwirth, insliesondre fur Preussens

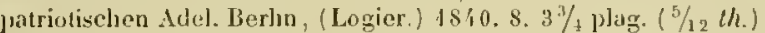

$83: 0^{*}$ Ramon de la Sagra. Informe sobre el eslado actual del jardin y te la catedra de botanica applicata a la agrieultura: Jeido por el Proleser de historia natural D. Rumon de lu Sagma, (') las jumtas generales de la real sociedad patriotica de la llabana, a fines de 1825 impresso per orden de la misma. 4. 23 p. Bibl. Mus. bot. Vindob.

$8341^{*}$ L_ Histoire physique, pelitique el naturelle de l'ile de Cuba. Belanique. Paris, Arthos Bertrand. 1838- I8 42.11 voll. 8. 1: 1838-1842. Plantes cellulaires, par Camille Montagne. $549 \mathrm{p}$. 19 tab. col., in folio. - Il : Plantes vasculaires, par Achille Richard. 336 p. $48 \mathrm{tab}$., in folio.

(Plantae phanerogamae sunt incompletae; desinunt in Uchnacearum familia.)

$8312^{*}$ - llistoire physinue et politigue de lile de Cuba, par M. Ramon de la Sagra. Deux parties. Paris, Arthus Btotrand. 1844 . 8. Lxxi, 771 p., 20 tab. (15 fr.)

Sistit epitomen operis majoris. Capita III ef $\mathrm{V}$ rem nostran tangunt: "Clinats p. 123-232; "dgricultere" p. 331-i31.

$83^{4} 3^{*}$ (Ramond (de Carbonniere), Louis Fransois Elizabeth, Baron.) Observations faites dans les Pyrénées, pour servir le suite à des observations sur les Alpes, iuserées daus une traduction des Lettres de II. Coxe, sur la Suisse. l'aris, Belin. 1789 . 8. vill, $452 \mathrm{j}$. 3 tab.

834. * Voyages au Mont-Perdu et Jans la partie adjacente des IJautes-Pyrenées. Paris, Belin. 180 1. 8. 392 p., 6 tab.
834;" Ramspeck, Jaliob Christoph. Selectarum ebservationum anatomico-physiologicarum atque bolanicarum specimen agonisticum Basileae, typ. l'istor. 1731 . 4. $28 \mathrm{p}$.

$8346^{*}$ - specimen agonisticum secundum, vercyue tunultuarium. Basilene, 15] Pistor. 1752. 4. 17 .

83 \{t Rand, Isaac.) Index plantarum officinalium, quas at materiar medicae scientian promovendam in horto Chelseano ali ac demonstrari curavi socictas planmaceutica Loodinensis. Lonlini, imprimebat J. W. 1730.12. 11, 96 p. Bibl. Juss.

$8348^{*}$ - Horti medici Chelseiani index compendiarius, exhiben nomina plantarum, yuas ad rei leerbariae, jraecipue materiae medicae scientian fromnventam ali curavit societas Plarmacopoeorm Londinensium. Lomdiıi, Whislon. (lyp. Strahan.) 4739. 8. 214 p. pracf.

83 :9* Randich, Fortunalus. De Astro montano, antiloto veneni ani-

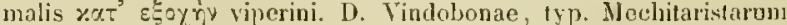
$1810.8 .62 \mathrm{p}$

8330 Ranfftl, Franz Anton. Catalogus horit botanici in universitate Salisburgensi jo anı 178 . a Francisco Antonio Runffl crectus. Salishurgi 178..) 8. 25 1. - Supplementur luorti botanics SilisJurgensis jur anno $1786.8 .16 \mathrm{~N}$. B.

$8331^{*}$ RaouJ, L. Chuix Ies plantes de la Nonrelle-Zélanule, recueillies et décrites par II. $E$. Rhuoul, clinurgien de prenière classe de la marine royale, (corvelte l'Aube) Ouvage publie sons les anspices de M. le baron de Mucku, Pair de France, Vice-Amiral, ministre secretaire délat au départenent de la marine ot des colonies Paris, Furtin, Mlassin el Co. 1 \$6 4 gr. 4.53 p., 30 tab. delineatae al Alfredo Riocreux. sculptac a], Eugenia Taillunt. (36 fr.)

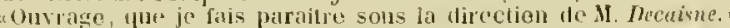
Verba autoris in practatione.

$8332 \div$ Rapin. Estruisse de l'listoire nuturelle les Plantaginées. Paris, au secrétariat do la socicti Linnéenne. 1827.8.55 p.

(Extrait des Amalcs de la societé Linneenue de Paris, fomo li.

8353 t Rapin, Daniel. Le guide du Jotaniste dans le canton rle Taud; coniruenant la deseription lle toutes les plantes vasculaires gui croissent spontancment daus ce canton et lindication do celles gui y soul généralement cultivées pour les usages domestijues. Lansanne chez tous les liluraires, 1849 . 8. xxm11, $488 \mathrm{~J}$.

(Autol furtasse illem est, jui fricerenlentem seripsit libellum

$833{ }^{\prime} \div+$ Rapinus, Renatus. Hortorum librill, tum disputatione de culture horlensi. Parisiis, e typograpluia regia. 1665. 4. (24). 219 p. ${ }^{*}$ Ed. altera, Luscluni Batavorum, ex officina Am. Doude. 1668.12. 100 p., praef., ind. - Cun disputatione de miversa culturae horlensis disciplina. Llirajecti, apud Johannem Ribbium. 1672.8. 116 69 p. B. - †llorterum libri quatuor. Accedit ejusdem Oclarum liber. Ed. MI. Parisiis, ty p. Malure-Cramoisy. 1673. 12. 120 1., praef., int. practer Odas. Bibl. Juss.

Editinni Tllyjertinat aceedust insuper Johannis Meursii Arboretum sacrum, Angeli Politiani Rusticns, Justi Lipsii Leges hurleuses at Lazari Bomamici Cilmen de vila rustica.

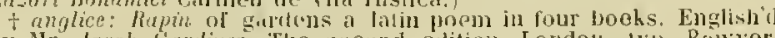
thy Mr. Jatob lardiner. The secund rution. London, typ. Bowyer 170k. 8. 200 p., praet, ind., efligies tradtuctoris. - Hortorun lib. It Nemus, translated in english rerses by Evelyn junior, printed with $J$. Enelyn's Sylrat. London 172y. folion. p. 313-318. B.

t qallice: Les jarlins. Pocune en quatre chanls. Traduction fihre précédee d'uls disconlr's pill Ginzon-Deurxime. Paris, Caillao. 1773. 12 9.37 4., t tab. - Traduction nouvelle par $l^{* * * *}$ et $G^{* *}$. Amslerdam el Patris, cailleatu, 1782. 8. vil, 261 p.

8353* Rapp, Wilhelm ron, pr. Ueber das Santoun. D. Heilloronn. 1838 S. $46 \mathrm{p}$.

$8356^{*}-$, pr. Ueber tie Veralrine. D. Tubıngen $1839.8 .42 \mathrm{~J}$.

$8357^{*}$ Rappolt, fiarl Heinrich. De origine succini in litore Sanbiensi meditatio epistalaris. Acevdit descriptio sudinorum w] essun eaptantium. Regiomuni J'russormu, typ. Reusner. 1737. 4. 16 p. Bibl. Reg. Dṛesd.

Cuji Lerennii Ropidii Pisonis Sermo ad Pisones. Pis. Aestior. 1748. 8. I plar.

Est poema jocosum Professoris physices Regiomentani Caroli Henrici Rappoll in pisa prussica "graue Erbsen.n

8359 Rasciotti, Don. Copia del fiore a frutto clse nasce nelle ladie erientali. Venetia 1609 fulio. DC.

8360 t Raspail, François Vincent. Némoires sur la famille des Graminées, contenant 1. la physiologie, 2. la classification des Graminées 
3. Ianalyso microseopirgue ef le Jërelopjement do la féeulo dans los cerciales. Paris 1845. 8. 48, 28, 32, if, 44, 11 p, 6 lab.

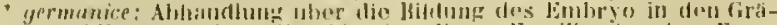

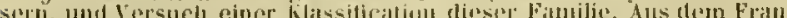

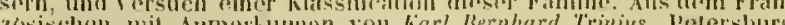

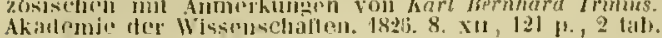

8.361 t Raspail, Francois Fincent. Nouveau systeme de nhimie organique fondé sur des méthodes nom elles d'observation. Paris, Bailliere. 1833.8. $576 \mathrm{p}, 12$ tab. fro parte rol.

8362* - Nouveau système te physiolngie végétale et de botanirgue, fondé sur les méthodes d'ulservation qui ont été développées dans lo nosveau sýstème de chimie organicjue. 1’aris, Baillièro.

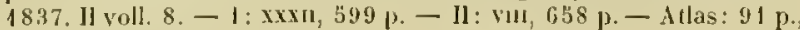
60 tah. (30 fr. - col. $50 \mathrm{fr}$.) - "Bruxelles, Hauman. 1837. 8. VII 655 p. et Allits: 53 p., 60 tals.

8363 Histoire naturelle de la santé ot fo la malarlie ehez les vegétaus et chez les animaux en géneral ot particuliorement chez l'humme. Paris $1 \$ 46$. III voll. \&. 89 plag., tals. (25 fr. - eol. $35 \mathrm{fr}$.) - Ed. Jl. Paris 1846. 111 voll. 8.95 jag , tah. $25 \mathrm{fr}$ - col. $35 \mathrm{fr}$.)

836 h Raspe, Goltried. Disputatio plysica de planlis. lipsiae 1627 4. H.

836jt Rastoin, Edouard. Lettres d'un frère a sa sueur sur la botaninue et la physiologie ales plantes. Paris, lefelure. 1829. $12.273 \mathrm{j}$.

$8366^{*}$ (Rathke, J.) linmeratio plantarum horti hotanici universitatis regiae Fridericianae Christianiensis. Christianiae, 1y.]. Grondalıl. 1823. 8. 59 p., praef.

836\% Rattray, Jamos. A botanical chart or eoneise introduetion to the Linnean system of hotany, cuboulying all the modern additions to the seience. Glasgow, Blackie. 1835. 8. - New anl enlarged edition will 300 engraved illustrations. Glasgow, Blachic. 183s. \$. $33 \mathrm{~s} .6 \mathrm{~d}$.

$8368^{*}$ Ratzeburg, J. T. C. Observationes ad peloriarum indolen definiendan spectantes. Berolini (1825.) 4. 27 l. . 1 tab. $(7 / 12 t / 6)$

$8369^{*}$ Lntersuchungen uber Formen und Zahlenverhaltnisse der Naturliorper. Berlin, ty]. Trowitzselł. 1829. 4. vi, 34 p., 1 lals.

$8370^{*}$ Forstnaturwissenselafiliche Reisen durch resschiedne Gegrulen Deutschlands. Ein Rathgeber und begleiter auf Reisen und bein natur - und forstwissenschaftlichen Unterrichte. Berlin, Nicolai. $1842.8 . x x, 477$ p., 4 tah., ic. xylogr. i. 1.

$8371^{*}$ Rau, Ambrosius. Enumeratio Rosarum circa Wirceburgum et pagas aljacentes sponte creseentium, cum earum defintionilus, deseriptionibos et syonongmis secundum nnvan methodum disposita et speciebus varictatibustoe novis nucta. Norimberyae, Felssecher. 1.816. 8. $17 \mathrm{~s} \mathrm{p.,} 1$ tab. col. ( I /h.)

$8372 \div$ Rauch, $l$. A. Régénèration de la nature vigetale, ou recherclses sur les moyens de réweer dans tous les climats, les anciennes températures et l'ordre primitif des saisons par iles plantations raisonnees. ete. Paris, 1yj. Didot. 1818. II roll. 8. - 1: xxxi, 502 j. II : $398 \mathrm{p} .(10 \mathrm{fr}$.

8373* Fauwolf, Leonhart, Leonharti Ramuolfen, ver Artznei Doctorn und bestallon Medici zu Augsburg Aigentliche Beschreibung der Raiss, so er vor dieser zeit gegen Aullgang in die Morgenlanuer, furmelumlich Syriam, Julacam, Arabiam, Mosopotamiam, Babylonian, Assyrim, Armeniam ete. nicht olne geringe dlule und grosse gefahr selbs volluracht: neben vermcldung etlicher unelır gar sehon fremdeı und ausstandischen Gewaelısen, samt iren mit angelsenekton lebendigen contarfacturen unul auch annderer denchwurdiger sachen, die alle er auf solcher erkundigt, gesehen und observiret lat. Alles in vier unterschilliche Thail mit somteren Fleiss abgethailet und ein jeden weitter in seine sondere Capitel, wie dero innfralt in zu eut gesetztem Rrgister zu finden. (Iaugingen, durch Leonhart Rejumichel.) In costen und verlag Georgen Willers. 1583. 4. $487 \mathrm{p}$, pracf., $\left._{2} 2\right)$ foll., 44 ic. jolantarum xylogr.

(Huic edition primum accessit pars quala botanici omnino argrmenti, ita inseripta: Jer vierte thail, "llichror sehoner aussindischer kronter, so uns noch unhehand, umil deren in seiner rayss in tho morgenlinder gethon, gedacht wird, artliche umb lebendige

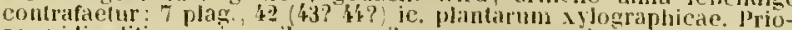
res vidi rditiones in quibus ommibus pars juarla icomosraphica dosidexatur: "Langingen, dureh Leonhart Rejunichel. \&. 4s\% p. - *ib.

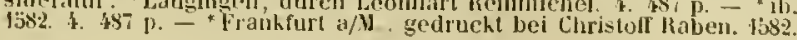

4. $(12,123,161,176,6,0,-$ C. insuper fronosu librum supra जir. 3420 allatum.

hollandice: Versameling der Reiswn tom. XVIl.

anglice: Travels into the liastrm tommtries translined by Nicholase

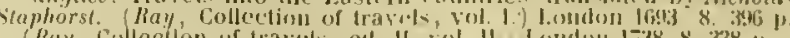

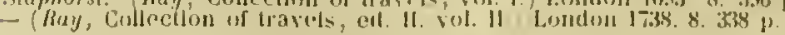

83\%: Ravius, Christian. De Dulaim Kubenis. I. Ipsilil 1656. 8. Desid Banks.

837:" (Ray, John, latine Rajus,) Calalogus plaularum cirra Cantabrigiam nascentium, in tpuo exhibentur fuolquet har.tonus imventae sunt yuae vel sponte proveniunt $v a l$ in ayris seruntur; una cum synonymis selectioribus, locis watalibus et observationibus quibusdam oppido raris. Arljiciuntur in gratiam tironam indes anglico-latuns etc. Cantabrigiae, typ. Fichl. 1660 . S. (30) 182 p. - Mypendix: il. 1663. 8. - tAppendicis editio secunda, ancetit plantis sinaginta. Cantabrigiae, 1yp. llayes, 1685. 8. \{32\} p. Bibt. Juss.

$8376^{\circ}$ (-) Index plantarum agri Cantabrigionsis: in you nonuina anglica latinis pracponumtur ordine alphabelico: in pratian tirumum Cantalurgiae, typ. Field. 1660. S. 103 \%.

8377 Travels through the Low-countries, Germany, ltaly and France witl curious ofservations, natural, lopographical, moral. plysiological etc. also, a catalogue of plants foumd spontaneously growing in those parts and their virtues. etc. 1.onthn 1673. 8. B. t The serond edition. Lonton, IValthue. 1738. II voll. \$. - 1:428, 119 \%. - 11: $459,44 \mathrm{~J}$.

linest: Conlalosus stirpium in exteris rogionibus a nobis obsorvatarmn, quate vel non omnino vil parce adiusdum in Anglia sloute proverniuti.

83787 C_._. Latagus plantarum Angliae of insularum adjacentim: tum indigenas tum in agris pasaim cultas complectens. In quo praeter synonyma necessaria, faculates guorjue smmmatim tratuntur, una cum olsservationilus et experimentis novis medicis et fulsyicis. Londini, impensis Johannis Martyn. 1670.8.358 P., pracf. - "Ejitio secunda, plantis cireiter quadragiuta sex ef ubservationibus aliguam multis auctior. Lotrdiui. Iyp. A. Clark, impensis Julannis Marty. 1677. 8. 311 p., praef., ind., 2 tals.

$8379 \div$ - Melhodas plantarum nova, Jrevitatis el perspicuitatis causa synoptice in tabulis exhibita; cum notis gronerun tum summorum tum subalternorun charaeteristicis, usscrationibus nonnullis Jo seminibus plantarum et indice copiosu. (Londini) Amstelaedami, Jansson-1V aesberg. 1682, 8. 166 jp, praef, ind. - "Nethodus plantarum enendata el aucta ; in qua notac maxime characteristicae exhilıutu, tuibus stirpium genera tum summa tum infina cognoscuntur ef a se nutuo dignoscuntur, non neeessariis omissis. Accedit methodus Graminum, Juncorum et Cyperorum specialis ealem anctore. Londini, Smith et Walford. 1703 . 8. 202 p., ind. - Amstelacdami, apul Wetstenios. 1710 . S. Rivin. - ${ }^{*}$ Londini, apud Clur. A. Myntsing. 1733.8 .196 p., pracf, ind.

$8380^{*}$ _ _ - Mistoria plantarum, species haetenus editas aliascjue insuper multas noviter inventas ef descriplas complectens. In qua agitur primo be plantis in genere, carumuge parti!us, aceidentibus et diljerentiis: deinde genera omnia tum summa tum subalterua au species usfue infimas, notis suis certis et characteristicis definita, methudo naturae resligiis insistente disponuntur; species singulae accurate describuntur, ubscura illustrantur, omissa supplentur, superlha resecintur, symonyma necessaria aeljiciuntur; ires deni(jue el usus recepti compendio traduntur. lomdini, 1y. Nariac Clark. $1686-1704$. 11I voll. folio. - J: 1686. p. 1-983. - JI: 1688. 1.985-1944., indices el nomenclator. - 111: Supjulementun tonj 1 et Il. Accedit: Histuria stirpium insulae Luzonis et Plhilippinarum a Georgio Josegho Camello. item Tourneforti Corollarium institutionum. Londini, apud Smith et Waleford. 1704, Ix, 666, $135,255 \mathrm{p}$. , ind.

(Tomms I et II redemi ex endem futo jumpossione amo 1693 mutatis tilulis.)

8381 Fasciculus stituium britannicarum, yost editum plantarum Ingliae catalogun observatamur, cum synonymis el locis natalibus. Londini, Faithorne. 1688.8 . 2 p. B.

$8382 \div \ldots$ synopsis methodiea stirpium loritanniearum, in qua tum notae generum characteristicae traduntur, tum species singulac breviter describuntur: ducentae yuinguaginta plus minus novae sjuecios partim suis locis inseruntur partim in appendice seorsin exhilsentur: cum indice et virium epritomt. Londini, Sam. Smitl. 1690. \$. 317 p.. praef., 2 tab. - Hid. Il: Londini, Sam. Smith et 
Walfordi 1696.8.346 p. prael., ind., praeter Rivini et Roji epistolas. - ${ }^{*}$ Ed. JIl. emendata el aucta. Londini, Inmys. 1724.8. 482 p. praef., ind., 24 tals.

$8383^{*}$ Ray, John, latine Rajus. Stirpium europaearum calra Britannias nasceulinm Sylloge, quas partin olıservavit ipse, partim ex Coroli C'lusii łhsturia, Casparis Bouhini Prorlromo et Catalogo plantarum circa Basileam, Fabii Columne Eephrasi, Catalogis hollandicarum Commelmi, Altdorfinarum Mauritii Hofmanni, sicularum $P_{n u l i} B a c-$ rani, Monspeliensium Petri Mugnolii collegit. Aeljiciuntur catalogi rariorum alpinarum et pyrenaicaram, baldensium, hispanicarum fatriclis Grisleii, gracearum et orientalium, creticarum, aegypliararum, alïque ab eodem. Lombini, Snith et Wallord. 1694. 8. 400,45 p., effigies John Ray.

$838\}^{*}$ — De variis plantarum nethodis dissertatio brevis, in qua agitur l. de methodi origine et progressu, ll. de notis generum characteristicis, HI. de methodo sua in specie, $\mathbb{N}$. de notis, quas reprobat el rejiciendas censet Tournefort. V. de methodo Tournefortiana. Londini 1696. 8. 48 p.

838: - Philosophical letters between the late learned Mr. John Ray, and several of his ingeninus correspondents, to which are added those of Francis IV illughby Esq., published by II illium Derham. London 1718.8 .376 p. 3.

S386 - Select remains of John Ray, with his life Ly llilliam Derham. published by George Scoll. London 1760. 8.336 j. в.

$\$ 387^{*}$ Razoux, Jean. Dissertatio epistolaris de Cicuta, Stranonio, Hyoscyamo et Acunito. Nemausi, apud Beanme. 1780. $8.46 \mathrm{p}$.

$\$ 388 \mathbf{R e}$, Filippo, Conte. Vingsio al monte V́chtasso ed alla terme di Guara nel Keggiano. Milano (1789.) 8. Dc.

$8389 t$ — Sagcrio di hibliografia georgica, ossia indice ragionato delle principale opere di agricoltura si antiche che moderne. Prima edizione. Venczia, Pezzana. 4\$02. \$. 285 p.

$8390 \div-$ Saggio di nosologia regetabile. Firenze, Tofani. 1807. 8. 63 p. ( $1 \frac{1 / 2}{\text { paoli. })}$

$8394^{*}$ _ _ - Saggio teorico-pratico sulle malattic delle piante. Venezia, typ. Vitarelli. 1807.8.437 p. - "Ed. II : Milano, typ. Silvestri. 1817. 8. 331 p. ( 3 Lire.)

$\$ 392-$ Elementi di agricoltura. Venezia 1806 . III voll. 8. DC. Sinovi elementi di agricoltura. IV voll. 8 . (12 Lire 22 e.)

$\$ 393$ — Annali dell' agricoltura del regno d'Italia, comineiati in gennajo 4809 , e terminati in giugno 4814 . Fascicoli 66 , formanti 22 volumi, con eirca 30 rami e tarole. (100 Lire.)

839\% - Del Cotone, e delle avrertenze per ben coltivarlo. Ed. II. Milann 1811.8. ( 1 Lira $35 \mathrm{c.}$ )

8393 - 11 giardiniere avriato nell' esereizio della sua professione. Ell. HII. Nilano 1812 . II voll. 8. (8 Lire 4 c.)

8390 - Florae Itestinae Prodrumus. Intinae 4816. 8. Dc.

$8397^{*}$ _. Saggio sopra la storia e il coltivamento dell" erba melica. Ed. li. Mrilano, Silvestri. 18 I6. 8. 1v, 103 p. ( 1 Lira 25 e.)

8398* Sagojo sulla coltirazione e su gli usi del pomo di terra e specialmente como valga a migliorare i terreni, con una lettera sulle rape. Mitano, Silrestri. 1817.8 .156 p. (1 lira 50 c.)

$8399 \div$ Lchtera sıa semi del gius(quiamo. (Estratta dal Nr. 22 (lel Repertorio medico chirurgieo di Torino.) Torino 4822. 8. (6) p.

8.00* Re, Giocani Francesco. Flora Segnsiensis, sivo stirpium in cirenitu Segusiensi, nec non in monte Cenisio aliisjuo circumeuntilns montilsus sponte enascentium enumeratio, secundum Linnaeanum systema. Taurui, typ. Barberis. (1805.), 8.93 p.

$8 \% 01+$ Ad Floram Pclenontanam Appendix (prima). Taurini, typagraphia regia. (1521.) $8.62 \mathrm{p}$.

(t) Appendiy altera exstat in Nem. della R. Ace. di Torino, tom. XXxl. 1821. 1. 189-22' 1.)

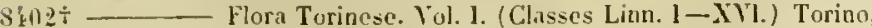
typ. Bianco. 1825. S. 372 p. Bibl. Cand.

840.3* Rea, John. Flora . seu de florum culura; or a complete florilege, furnished with all requisites belonging to a lilorist. (1"lora, Ceres et Pomona.) London, Narriolt. 166 3. Folio. 239 j., praef., ind. "Flora, Ceres el Pomona. Second impression. London, Marriott. 1676. folio. 231 \%., ind., 8 tab. - Third impression. London 1702. folio. (cadem impressio, novo titulo.) B.

Pritzer, Thes. lit. bot.
8:01: Read. Traité dir seigle crģoté, dans lequel on examine les causes de cette excroissance végétale etc. Strasbonrg, 1sp. Le Roux. 1771. S. 93 p.. praci. , I tab.

$8: 03$ * Rebentisch, Johann Friedrich. Prodromus Florae neomarchicae, secundnm systema proprium conseriptus atque figuris $\mathrm{XX}$ coloratis adoruatus, cum praefatione Curoli Ludovici II illdenow, in qua de vegetabilinm eryptoganicorum dispositione iraetator. Berolini, Sehuppel. 1804 . S. Lxil, 406 p., 4 tab. col. $\left(2 \frac{1}{2} / h\right.$.

$8106^{*}$ Fndex plantarnm circa Berolinum sponte nascentium adjectis aliguot fungorum descriptionibus. Berolini, Schappel. 1805 \$. $46 \mathrm{p} \cdot(1 / \mathrm{th}$. $)$

8.407t Reboul, Euyen de. Nomnullarum specierum Tuliparnm in agro Foreutino spronle naseentium propriae notae. (Florentiae, in archi-

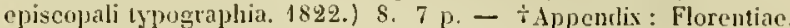
NiI. Kalend. Maji 1823.8 .2 p. Bibl. Cand.

$8408 \div-$ Sclecta specierum Tuliparum in agro Florentino sponte nascentium synonyma. Florentiac, typ. Galilaci. 1838. $8.8 \mathrm{w}$ Bibl. Cand.

8:09* Reche, $E$. $F$. Th. The Amyridis speciehns officinalibus. D. Halae Iyp. RuIf. 1801. 8. 26 p.

$8+10 \div$ Recluz, $C$. Des sues végétanx aqueux en général. Paris, Trouvé 1828. 8.40 , vil p.

Evtrait du Journal de Chimie medicaje, de pharmacie et de tovicologie, année $1 N^{\circ}$, ir. $1-5$ et 7 .)

81.11* Redouté, Pierre Joseph. Les Liliacées, peintes par P. J. Pedoute Paris, de l'imprimeric Didol. I802 - is 16. Vlll voll. folio. 486 foll. infl. 486 tab. eol.

Textum voluminum !- IV seripsit Augustin Pyramus Decundolle,

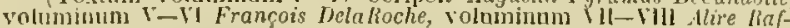
jeneau-Detile.

8 12* - Ia botanique de Jean Jacques Rousseau, ornée de sojsante-cinq planches imprimées en couleurs d'après les peintures de P. J. Redouté. l’aris, Delachaussée et Garnery. an XiV. 1805. Folio. $x, 124$ p., 65 tal. col. ( $350 \mathrm{fr}$. - édition in $4.200 \mathrm{fr}$.) (')rodiit untserim fasciculis.)

$8413^{*}$ - Les tioses peintes par P. J. Redoute, décrites par Cluud Antoine Thory. Paris, de l'imprimerie F. Didat. 1847-1824. IlI voll. Folio minor. - 1: 1847. 156 p., 59 tab, col., effigies $P$. J. Redoute - Il: 1821. 122 p., 59 tal). col. - Hlf: 1824.125 p., 54 tab. col. (750 fr.) - Paris, Panchoucke. 1824. gr. 8.160 foll., 160 tab. col. (140 Fr.)

Edatio minor prodiat 40 fasciculis a $3 \mathrm{fr}$. $50 \mathrm{c}$., quisrue cum \& tabulis. Editie major triginta divulgata es fasciculis, praentisso Prospecu1 nperis; in volunine primo, 10. 139 - 156 reperitur bibliotheca botaniea operum de Rosis.

Silit- Choix des plus helles fleurs, prises dans ditlerentes familles dn règne végétal, et de quelques branches des plus beans fruits groupées quelyuefois et sonvent animées par des insectes et des papillons. irarees, imprimées en coulcur et retouchées at pinceau avec un soin qui doit répondre de leur perfection. Dédié á LL. A.I. Rh. Ies Princesses Louise et Maric d Orleans. Paris, chez l'anteur el les libraires, typ. Panckonche. 1827. Julio. 17 p., praef, (144) tal, col. Bibl. Cand. et Deless.

(Textum anno 1833 addidit heatus Antoine Guillemin.)

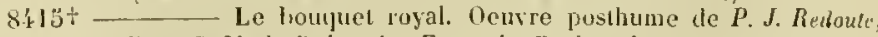
dédie à S. M. La Reine des Français. Paris, chez les marchands de nouveaulés. 1843. folio. 4 tab. col. (Rosae), praef., effigies $I^{2} . J$. Rerloule. Bibl, Deless.

$8416 \div$ (Redowsky, D.) Enumeratio plantarum, quae in horta Comitis Alexii "Razmmousky in parn Hosquensi Gorinka vigent. s. I. 1804. 12. 5211

(Trautrelter alian notat ejustom horli cummerationem eodem Redowestiy autore, ex anno 1803.)

8:17* Redtenbacher, Joseph. De Caricibus territorii Vindobonensis. I Vindobonae, typ. Wallishausser. $1834.8 .40 \mathrm{p}$.

8.18t Rees, Richard van. Disquisitio de decompositione acidi carbonici in regetatione, praemio ornata. Trajecti ad Rhenum, Paddenbure. 1818. S. $6 \div$ p.

8419* Regel, Edhard. Dic hultur mol Aufzählung der in deutselicn und englischen Gürten befindlichen Eriken, nebst Synonymie und huzer Charakterisirung und Besclureibung derselben. Ein Leitaden fur Gärtner und Erikenzuchter. (Zuriclı, Orell, Fussli et Co. 1843.) 4 189 p., 3 tab. $\left(1 \frac{1}{2} / \mathrm{h}\right.$. $)$

(seorsin imur. ex Verlandlungen der Gesellschaft zur Beforderung de's Gatculaues in den Preussischen Staaten, Lieferung 33 . 


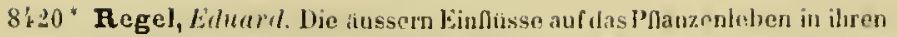

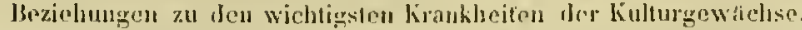

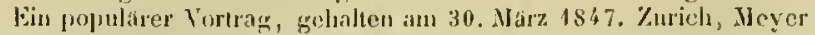

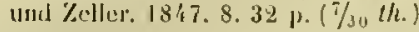

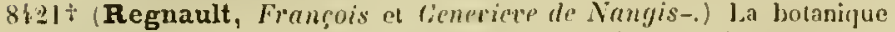
mise a la portéu de lou te monire, ou collection des jlantes d'usaro dinns la médicine, dans les alinens et daus les arts. P'aris, chez l'auteur. 1774 . Jll voll. fulio. 467 foll., 3 schenata explicaltioni partium inservientia, ind, , 467 [a], (col.

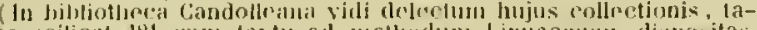

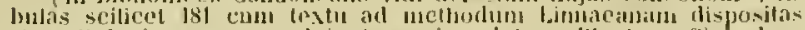
sine titulo impresso sing in tergo inseriptis "Plantac oflicinales.

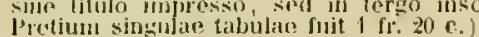

8'22* Rehfeldt, Abraham. llodegus hotanicus menstruts, praemissis rudimentis botanicis, plantas guae jutissinum eirca llalan Saxonum vel spronte proveniunt vel studiose nutrimtur, emumerans, quo loco eaclem invoniantur, ef nuo tenpore juxta serien mensiun floreant, indigitans, plantis officinalibus peculiaritrer motatis. Halae, sumtibus orplianotrophei. $1717.8 .95 \mathrm{p}$.

8:2.3* (Reich, Goltried Christian.) Magazin des Pllanzenreiches. Erster Jand. Fildangen, Walther. 1793. 4. I1, 168 p., 22 tab., (2) tab. Filices.

8'2!' * Reichard, Johann Jakob. l'lora Mocno-Franeofurtand, enumerans stirpes cirea Francofurtum ad Mocoun crescentes, secundum methodum sexualem disposilas. Francofurli a/M., typ. Il. L. Bronner. $1772-1778.13$ voll. S. - 1: 1772. 112 p., ind. $-11: 1778.196$ p., ind., $\{$ tai).

842: * - Sylloge opusculorum botanicorum, cum adjectis annotationibus. Pars I. Francofurti a/M., Varrentrapp. 1782. 8. $182 \mathrm{p}$.

$8: 26$ — Enumeratio stirpium horti hotanici Senkenbergiani, qui Francoforti ad Noenum est. Francofurli a/M., Varrentrapl et Wenner. 1782.8.68 p.

34:27* ReicheI, Christoph Käl. De Tabaco, ejusiue asu medico. D. Vitembergae $1750.4 .34 \mathrm{~J}$.

$8428 *$ _ Diatribe de vegetabilibus polvifactis. Vitombergae, Zimmermanu. 1750.4 .26 p.

81.9* ReicheI, Friedrich Daniel. Standorte der seltneren und ausgezcichneteren Phanzen in der Ungenend vou Dresden. Dresden und Leipzig $1837 . \mathrm{gr} .16 .80 \mathrm{p}$. (1/th.)

$8130^{*}$ ReicheI, George Christian. The vasis plantarun spiralilus. D. Ijpsiae 1758. 4. 41 p., I tab. (Rospondens: Kat Christiun ITayner.)

8 \$31" Reichenbach, Auton Benelikt. Allgemeine Pllanzenkunde. Leipzig, lianke. 1837. 4. vall, LI! p., 8 tal\}. col. ( $1 \frac{1 / 6}{6}$. - nigr. $2 / 3$ th.

$8132 \%$ Naturgeschichte des l'hanzenreichs, oder Ahbildung und Beschreibung dicr wichtigsten in - und auslandischen Pllanzen, nit rorzuglicher Beruchsichtigung ilures Nutzens. Nach dem Linnéschen Systeme weordnet, von einer Aufzihlung der Gattungen uaelı naturticher Anordnung begleitet, und nach ten besten Qoelten bearbeitet. Leipzig, Franhe. 1\$37. 4. vul, L11, 392 p., 72 tah. eol.

$8133^{*}$ _ Naturgeschichte des Pflanzemedelıs für Gymnasien, Real- Ilandels - und Gewerbsehulen, und zum Sielbstunterrichte. Leijzig, Kollnam. 1840.8. $180 \%$.

8434 Die Pflanzenulır, oder Besclueil,ung der Pflanzen, an welchen zu bestimnten Sturden cles Tages eine auffallende Veranderung wahzzuchmen isl. Nebst kurzer Auleilung zur Behandilung

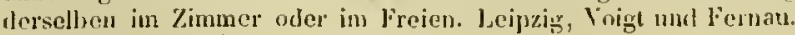
1846. 16.56 p. $(1 / 6 t / \%)$

8. $3.3^{*}$ Reichenbach, Heinrich Gottlieb Ludwig. Flora Lijsiensis pharmaceutica; sistens plautarum agri Lipsieusis nunc et olim officimalium venenalarumque diagnoses, duscriptiones, synonyma, locos natales, qualitates, vires et usum. Lipsiae, Franz. 1817. 8. xu, $260 \mathrm{ps}$ ( (1 th. $)$

8 '36* - Uebersicht der Gattung Aconitum. Grundzige einer Monographic derselben. Regenshurg 1819 . $\$ .84$ p. $(1 / 2$ th. $)$ (seorsiu impr. e Flora, diario botanico Rallsbonensi.)

81.37* Monographia generis Aconiti, iconilus omuium specierum coloralis illustrata, latine ef germanice elaborata. Lipsiac. Vogel. 1820 . II roll. folio. 100 p., 19 tab. col. $\left(11 \frac{1 / 2}{t h}\right.$. $)$
84.38* Reichenbach, Mcinrich fottlieb Lndwig. Anoenitates botanicar Jrestenses. Specinen primum, olservationes in Mỵsotidis gonus continens. D. Jresdar, Arnuld. 1820,8.30 J. $(\% / \mathrm{h}$.)

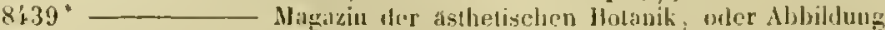
und Beschreilung der fur Gartanhulur empfelilungswerthen Gewachse, nebst Angabe ihrer Frzieluug. leunes et descriptiones

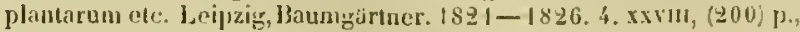
96 tab. col. ( 16 th. $)$

81.40" (- Katechismus der Botanik, als Auleitung zun Selliststudiun dieses Wissenschaft, und als botanisches Wurterbuch zu gebrauchrn. Gestalilehre, nit melor als 600 erláuterulen Figuren. Leipzig, Baumgürtner. 1820. 8. xxxıv, $217 \mathrm{\mu} ., 7$ lah. ( 1 th. $)-$ "\%eite, fast um das Doppelte vermelirte Auliage. liestaltlelır'. il. 1825. 8. xxx, 215 p., 7 tab. (1 1/2 th.) - " Kweites Baudchen: Plis-

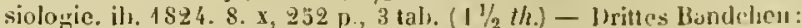
Systematik. ih. 1826.8 . $x$ p., 5 tal. $(13 / 4$ th. $)$

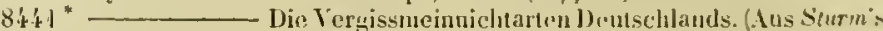
Flora, Jleft 1-42.) Nürnberg, Sturm. 1822.12.17 lab. col, 1est. $(2 / 3 t h$. $8,42^{*}-$ Illustratio specierum Aconiti generis, alditis Delphiniis quilusdam. Neue Bearbeituns der Arten der (Battung Aconitum. Lipsiae, leriedrich Hofmeister. $1823-1827$. folio. (132) 1 . 72 tal. col. $(12 \mathrm{th}$.

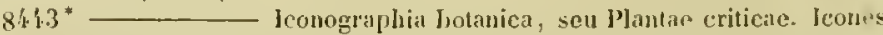
flautarum rariurum et minus rite cognitarum indigenarum exolicarumgue, iconographis et supplenentum, inprimis ad opera II illienowii, Schkuhrii, Perssonii, hoemeri et Schultesii, delineatae et cum commentario succinclo editae a II. G. Ludoricn Reichenbuch. Centuria 1-X. Lipsiae, Friedrich IIofmeister. 1823-1832. X voll. 4. -1 : 1823. 98 1), tab. col. 1-100. - 11: 1824. 96 j., tab. col. $101-200 .-111: 1825.92 \mathrm{n}$, tal), col. $201-300 .-11: 1826$. 88 j), tab. col. $301-400 .-V: 1827.68,90$ J. inul, tals. col. 401 $-500 .-\mathrm{Vl}: 1828.1 \mathrm{v}, 34,28$ j., tab. col. $501-600 .-\mathrm{V} 11$ : 1829 50 ]., tal. col. $601-700$. - VIIJ : 1830. 38 P., tab. col. $701-800$ - IX: 1831.50 p., tab. col. $801-900 .-\mathrm{X}: 1832.42$ p., tah. col. $901-1000$. (nigr. $66 \frac{2}{3}$ th. - col. $133 \frac{1}{3}$ th. $)$

84 t $^{*}$ - lcones Florae gernanicac et Jelvelicae, sinul pedemontanae, istriacae, dalmaticae, hungaricae, transsylsanicae, borussicae, holsaticae, belgicae, hollandicae, ergo mediae europede, exhibens nuperrine detectis novitiis additis, collectionem compendiosam iniginum characteristicarum omnium generum atque specierum, guas in sua Flora germanica excursoria recensuit auctor. Centuria 1-X. Lipsiae, Friedrich 1 lof meister. $1834-1848$. X voll. 4. (col. $149^{1 / 12}$ th. - nigr. 8Q $3 / 5$ th.

Vol. 1: 1834. Agrostograplia germanica. 50 j., tał). col. 1- 110.

Vol. Il : 1837-1838. Cruciferce cum liesedeis. 32 j., tab col. $1-103$.

Vol. Ill: 1838-1839. Papaveraceae eum Fumaricis et Berberideis, Cilpparideae, Violaceac, Cistineae el Hanunculaceae. 16 p., 106 tal. col. sign. $1-19,1-40,1-46$.

Vol. IV: 1840 . Anemoneac, Clematideae, Hellcloreac. vil, 28 p., 82 tal, eol. sigu. $4 i-128$.

Vol. V: 1842. Rutaceaecum Euphorbiaceis, Sapindaceac. Alalvaceae, Oxalicleac, Caryophyllaceac. 38 p., 100 tab. col. sign. $129-230$.

V'ol. VI: 1844. Caryophyllaceae, Theaceae, Tilideeae, cun lineis llypericincae. $84 \mathrm{j} ., 125$ lib. col. sign. $231-332$.

Vol. Vil: 1845. Isoetean, Zosteraceae, Aroidleae, Putanogcloneae, Alismaceae, Ifydrocharideae, Nymphacaceac. $40 \mathrm{p}$, tah. col. $1-82$.

Vol. VIll: 1846. Cyperoideae (et 11 tal). Gramineae). iso p. 126 tab. cul. sign. $193-3.18$.

Vol. IX: 1847. Typhaceae, Iridete, Narcissincae et Juncacene. 24 p., 100 tab. col. sign. $319-418$

Tol. X: 1848. Samentaceac, Coronariac. 28 p., 102 tab. cul. sign. $419-520$

(Altern inscribitur titulo: Iconograpluia botanica, seu Plantae criticae, Centuria Xi-XX.

germanice: Deutschlands Flora, mit hochst naturgetreurn charahlioristischen Abbildungen aller durer l'flanzenarlen in naturlicher

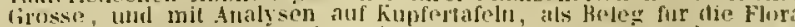
germancea excursorid, und zur Aufualume und Verbreilung der nentesterg linbleckungen innerhalb Deutschlands und der angränzenden iander. Browion und llolland, Holsicin und schleswig, dotpreusscu

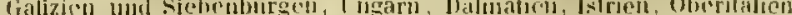

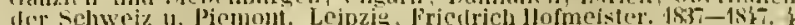

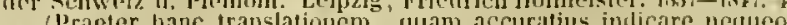
(1)eutitur elian editio minor pretio modico \% 
84t5* Reichenbach, lleinrich Gottlich Ludwig. Taschenbuch fur Gartenfreunde. Eine Erläuterung von 1960 Zierpllanzen, nach natürlichen Familien geordnet, und mit Nachweisungen zu ihrer Kultur begleitet. Dresden, Hilscher. 1827. 8 . xxiv, 481 p. (1 th.

$84.6^{*}$ _ J J Jongraphia botanica exotica, sire IJortus botanicus, imagines plantarum imprimis extra Europam inventarum colligens, cum commentario succincto ceditus. Lipsiae, Friedrich Holmeister. $4827-1830$. III voll. 4 . xx, $72, x, x, x v 1,18$ p., 250 tab. (nigr. $16 \frac{2}{3}$ th. - col. $33 \frac{1}{3}$ (h.)

$84.7^{*}$ - _ Conspectus regni veyctabilis per gradus naturales evoluti. Tentamen. Pars prima. Inest elavis herbariorum loortorumfue, seu dispositio regni vegetabilis secundum classes, ordines, formationes, familias, tribus, generil ef subgenera, adjecto indice locupletissimo generun, subgenernm, synonymorum et nominum franco-gallicorum. Uelersicht de's Gewichsreiches in seinen naturlichen Entwickluugsstufen. Lipsiae, Cnobloch. 1S98. 8. xıv, $294 \mathrm{p}$. $\left(1 \frac{1}{2}\right.$ th.

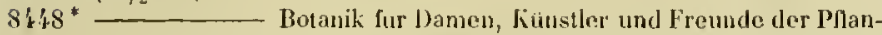
zenwelt uberhaupt, enthaltend eine Darstellung des P'llanzenreicbs in seiner Letamorphose, eine Anleitung zum Studium der Wissonschaft und zum Anlegen von IJerbarien. Leipzig, Crobloch. 1828. 8. $x, 584$ p. $\left(2^{2} / 3(h)\right.$.

$81.99^{*}$ Flora germanica excursoria, ex affinitate regni vegetabilis naturali disposita, sive principia Synopseos plantarum in Germania terrisque in Europa media adjacentibus sponte nascentium cultarumque frequentius. Insunt plantae: Acroblastae et Pbylloblastae. Accerlit: I. Conspectus gencrum it elavis e systemate sexuali Linnaeano. Il. Expositio methodi uaturalis cum tabula. III. Index generum et specierun synonymicus locupletissinus, simul ad sublevandum commercium botanicum adaptatus et seorsin accipiendus. IV. Mappa geograyhica, sistens Territoriun Florae. Y. Nappa orographica, sistens Mpiun tractum. Lipsire, Cnoludoch. 1830-1832. 12. xLVur, 878 p., 2 tal. - ${ }^{*}$ Florae mermanieac Clavis synonynica Lipsiac, Cnoliloclı. 1833, 12. Lxxu, 140 p. $\left(4 \frac{1}{2}\right.$ th. $)$

8fiio* Das Pflanzenrenich in seinen natumlichen Klassen und Familien entwickelt, und durcl mehr als tausend in kupfer gestuchene ibersiehtliche bildliche Jarstellungen fur Anfanger und Freunde der Botanik erláutert. Lei lvig, Verlag der Expedition des Naturfreundes. 1834, 4. iv, 62 1., 1 talb, in folio max. - "Erste Fortsetzung: 1. Gesetze für dic naturliche Verwandtschaft der Pllanzen. 2. Die Entfaltung der Stufen des Phanzenreiclss selbst. 3. Zusitmmenstellung der Entwicklungsstufen. Leipzig, Wagner. 1835. 4. 1). $63-95 .(1 \%$ th.)

(Liber sinul sislit fasciculos primun ch quartum colfectionis, quae uscribitur: "Das Linirersum der Nilur." Tabula seorsim divenditur $11 / 2$ th.

Die Prachiplanzen des Auslandes mit naturgetrewen Abbildungen herausgegeben von ciner Gesellschaft von Garteufreunden in Brussel, mit erlaterndem Text, und Anleitung zur Kultur von H. G. Lurkig Reichenbach. Leipzig, Fricdrich Hofmeister. 1834-1836. V voll. folin. - I: 1834.58 p., 72 tab. col. $-J 1$ : 1834.48 p., 72 tab. col. -11 : 1835.52 p., 72 tab. col. WV. 1835.46 p., 72 tab.col. - T: 1836.48 p., 72 tab.col. (120 th. (Singula evemplaria rolmminis quinti irrore inscripta sunt "Viol. $\mid 1 . "$.

84:32* Kupfersammlung zum prahlischen deutsclien Botanisirbuche. Erste (unrl einzige) Lieferung. Eutbált: Keimumor und knospung, und 294 Gattongers der dentsclson Flora mit ilıren AnitIysell. Leipzig, Wagner. 1836.8.16 p., $12 \mathrm{tab} .(3 / 4 t h$.

$\checkmark 4: 33^{*} \longrightarrow$ Handluach des naturlichen Pllanzensystems, nach allen seinen Klassen, Ordnungen und Familien, nebst naturgemásser Gruppirung der Gattungen, oder Stanm und Verzweigung des Gewaelssteiches, enthaltent eine vollständige Charahteristik und Ausfulırung der naturlichon Verwandtscbaften tler Pllanzen in ihrer Riclutung aus der Metamorphose und geographischen Verbreitung, wie die fortgebildete Zeit deren Anschauung fordert. Dresden und Leipzig, Arnold. 1837.4. $x, 346 \mathrm{p} .\left(3^{3} / 4\right.$ th. $)$

$8\left\{0\right.$ f $^{-} \longrightarrow$ Der deutsche Botaniker. Erster Band: Das Herbarientuuch. Repertoriun herbarii, sive nomenclator generum plantarum systematicus, synonymicus et alphaleticus, in usum practicum accommodatus, quo alfinitas naturalis et locus cujusque generis in herbario citissime explorentur. Drestac et Lipsiae, Amold. 1841.8. Zwei Abtheilungen. $\mathrm{xcr}, 213,236 \mathrm{p} .\left(z^{1 / 2} \mathrm{th}\right)$
S'šö* Reichenbach, Ileinrich Gottlicb Ludwig. Jlerbarien-Etiketten. Schedulae herhariorum. Uebersicht aller naturlichen l'flanzenfanilien, Zunfte und Gruppen Jussien's und aller neueren Autoren, mit fortaufendır Numerirung aller Gattungen. Zur grossten Zeitersparniss fur llerbarienbesitzer zusammenacstelt. Jresden, Arnold. 1841 folio max. 7 plag. $(1 / 3$ th.

(1'ertinent hae schedulae atl librum praecedentem.

$8356^{*} \longrightarrow$ Der deutsche Botaniker. Zweiter Band: Flora saxoníca. Die Flora von Sachsen, ein botanisclies Excursionshuch fur das Konigreich Sochsen, das Grossherzogthum Sachsen-WeimarEisenach, dio Jerzogllumer Saclısen-Altenluurg, Saclisen-CoburgGothat und Sachsen-1lciningen, die Fürstlich Schwarzburgischen und lieussischen lande, die llerzogthumer Anhalt-1)essau, AnhaltBernhurg und Aulatt-liothen, die Preussische Provinz Saclisen und die Preussische lausitz. Nebst Schlussel zum orleichterten Bestimmen der Gattungen nach Linnés Sexualsystem, und deutschem und lateinischem Register. Dresden und Leipzig, Arnold. 1842. 8. xLvII 46.1 p. $\left(1 \frac{1}{2}\right.$ th. $)$ - ${ }^{*}$ Wweite Ausgale mit vollstindigem Register der deutsclien und lateinisclien Namen. ib. 1814. S. XLvin, $503 \mathrm{p}$ (2) (ll.) indice.

Ectitio altera est omnino impressio primaria, audito solumuodo

8.57 Reichnau, Georg Friolrich. De Opio. J). Lugduni Batavorum 1704. 4.18 p. B.

8158* Reicholdt, Christoph, und Jahob Ernst von Reider. Die pharmaceutisclie Waarenkunde unl Waarenbercitnng aus tem Pllanzenreiche efc. Nelıst einer Terminologie der Botanik ron Auton lienediht Reichenbach. Leipzig, Schwickert.1844. 8 . xiv, $393 \mathrm{f})\left(1^{1 / 4} t h\right.$.

$8595+$ Reid, IIugo. Outlines of medical botiny, comprising vegetable analomy and plyysiology, the claracters and properties of the naitural orters of pliuts ete. Edinburgh, Naclachlon et Co. 1832. 8. tSecont edition greatly enlarged. ib. 1839 . 8. xu, 425 p., 1 tal,

8\$60* Reider, Jakol Ernst von. Beschreibung aller bekanten Pelargonien, und Anleitung zur Erkenmung und Kultur derselben. Numberg, Zeh. 1829.8 . vim, 383 p. (2 th.)

81.61* Das Ganze der Blumenzucht. Nürnberg, Zeh. 1831. \& $\left(1 \frac{2 / 3}{3}\right.$ h. $)$ - ${ }^{*}$ Zweite Ausgabo: Nürnberg, Lotzbeck. 1847 . 8. vilt, 390 p. $(5 / 6$ th. $)$

$8462^{*}$ Wer schnell unterrichtete Botaniker und Blumist. Nürnberg 1835. 8. xv1, 696 p. (2 th.) - * Zweite Ausgabe: Nurnberg Lotzbeck. 1847. 8. xvi, $696 \mathrm{p}$. (1 $1 \frac{1}{3}$ th.

$8163^{*} \longrightarrow$ Der gut eingerichtete ohonomische Jlansaarten, oder das Ganze des Genuselnaues, Obstbaues und der Blumengartnerei. Leipzig, Schwickert. 1842 . 8. xiv, 241 p. $(5 / 6 / h$.

Millo consulto plurimos illios fertilissimi seriptoris de re hortensi libellos, quos unllibi vidi.

816\%. Reimarus, Hermamn Diederich. Dissertatio, animatversiones quas(аam de Opii, praceipue in febrilus, usu, exhibens. s. 1. 1784. 4. B. (Schlegel Thes. mat. med. 1. 2t1-262.)

$816: 3^{*}$ Reimers, Martin. Respirationis plantarun explicatio. D. Kiliae 1839.4. $16 \mathrm{p}$.

$81.66^{*}$ Reiner, Joseph, und Sigmund von Hohenwarth. Botanische Rejsen nach einigen Oberkarmtnerischen und Jenacbbarten $\mathrm{N}_{\text {pen }}$ unternommen, und webst einer ausfuhrlichen Alpenflora und entomologischen Beitrigen als ein Jlantlumeb fur reisende Lichaber herausgegeben. Lirste Reise in Jalır 1791. Klagenfurt, Walliser. 1792. 8. xi, 270 p., ind., 6 tab. col. - *Ulm 1793. 8. (uon tliffert.) - ${ }^{*}$ \%weiter Band. Als Furtselzung der ersten licise im Jahr 1794. k]agenfurt, Johann Lcon. 18 12, 8. is, 261 p., 10 lah,

iolumen alterum post Reineri nortem adjurante Lorenz ('hrysanih won l'est claboratum ot editum est; inest Flora aljuita a p. 127 -261. Tabulae 8. 9. 10 sunt pielae.

$8: 67^{*}$ Reinhold, $F$. Garten-Kalender, enthaltend eine deutiche und grundlicho Anweisung zur Bestedlung de's liuehengartens. nebst naturgeschichtichen Eiläuterungen der ausseren kiennzeichen, der Alstammung und des Nutzens der dort angebauten Gewactise. sulzbach, Seidel. $1845.8 . \mathrm{Vt}, 58 \mathrm{p} .(1 / 6 \mathrm{th}$.

8468* Reinhold, samuel Alraham. De Aconito Napello. D. Argentorati, typ. Heitz. 1769.4.42 [?.

$8169+$ Reinwardt, Kaspar Georg Kar\%. Oratio de ardore, quo listoriae naturalis et imprinis botanices cultores in sua studia feruntur. Jlardervici, Tyhoff. $1801.4,56$ p. Bibl. Cand. 
Siro Reinwardt, Kaspar Geory harl. Oratio de angments, guae historiae naturali ex ludise investigatione accesserunt. Hardervici 1823. 4.

$84.74^{*}$ Ueber den Charakter dor Vegetaliou auf den Inseln "les indischen Arehipols. Fin Vortrag. Borlin, Akadrmie der Wisseuschalien. $182 \mathrm{~S}, 4$. is $\mathrm{j} .(1 / 3 / / \mathrm{l}$.

8.72 Reiter, Johann Jakob. De Opio et Opialis. Lipsiar 1623. 4. Rivin.

8: $33^{*}$ Reitter, J. D., und G. F. Abel. Albildung der luudert deutschasu wilden llolzarten, nach dem Nummernvorzeichniss in Forsthandbuche von Fricdrich dugust Ludwig von Burgsdorf. Vier Ilefte. Stuttgart, Druckerei der Karlssehule. 1790.4. 38 p., 100 tals. col.

8:3: - Beschreibung und Abhihlung der in Dentsehland selten wildwachsenden und einiger luereits naturliehen llolzarten, als fortsetzung der huodert dentschen widden llolzarten. Stuttgart, Cutta. $1803,4.25,2$ tals. (cum pratecedenti: $41 \frac{2}{3}$ th.)

8175 * Relhan, hichard. Flora Cantahrigiensis, cxhibens plantas agro Cantalırigiensi indigenas, secunlum systema sexulale digestas, cum claracteribus genericis, cliaguosi specian, synonynis selectis, nominibus trivialibus, loco natali, tempore influrescentiae. CantaIrigiae, lyp. J. Archdeacon, veneunt apud J. Merrill. $1785.8,490$ p., 7 tab.

$8476^{*}$ - Florne Cantabrigiensi supplementum. Cautabrigiae 1786. 8. 39 p.

Sin? Ileads of a courso of lectures on botany, read in the University of Cambridge. Cambriılge 1787. S. 8 p. B.

Si-is Florae Cantabrigiensi supplementun alterum. Cantabrigiae 178s. 8. 36 \%. B.

81.59 - Florie Cantahrigiensi supplenientum tertium. Cantabrigiae 4793.8 .44 p. B.

8's0 Relph, John. An infuiry into the medical eflicacy of a new speeies of Peruvian Bark, lately imported into this country under the name of jellow bark. London 1794. S. 177 p. B.

Sisil Remy, Jules. Analecta Roliviana, seu novil genera et species plantarum in Bolivia errseentium. Pars prima. Paris, typ. Martinet. 1847. S. 358 p., t tah.

8182 Renard, $J$. A. Ilistoire naturelie, chimiqque et médicale du Lichen d'lshande. Paris, Crochard. 4836. 8. 5 plag., 1 tab.

Sis:3* Renard, Joseph Claudius. Die inlandischen Surrogate der Chinarinde, in besnndres Hinsicht auf das Kontinent von Europa, NJainz, liupferherg. $1809.8 . \mathrm{xtI}, 196 \mathrm{p} .(1 \mathrm{t} / \mathrm{h})$

$8484 \div$ (Renault, $D$. A.) Memoire sur la culture les pommirs dans toute l'útendue de la répulliqque française. Rouen, an IH. (1795.) 8 $53 \mathrm{p}$.

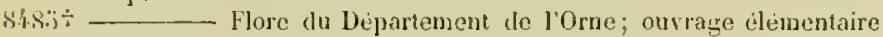
do botanique, compose de la réunion des systemes de Touruefort, !n Liıné el de Jussicu; avec une description exacle les plantes, linclication des lieux, où elles se tronvent et une notjce sur leur usage ef leur utilité dans les arls. Nençon, Lepernay, an XII. (1804.) 8. $x, 222$ p. (3 fr.)

$8186+$ Rendu, Victor. Botanique, on histoire naturelle des plantes, a l'usage tos cultivateurs el des ícoles primaires. Ouvrage adopté par le eonseil royal de linstruction publique. Nouvelle édition. Paris, Angiv. 1838.8 .193 p., praef, 4 tals.

$387+\longrightarrow$ et Ambroise Rendu, fils. Nonvean spectacle de la aature, on Dieu et ses oeuvres. Botanique. Paris, Pitois-Levrault. 1840. 12. 144 p., ic. xylogr. i. t.

81.85* Reneaulme, Paul, latine Renealmus. Specimen listoriae plantarum. Plantae typis aencis expressae. Parisiis, apud llatrianum lyeys. $1611.4 .150 \mathrm{~F} \%$ (5) [oll., 25 tals.

sh9 Rennie, James. Aphabet of medical hotany. Eilinburg 1333. \$. (2s. G $l$.)

8.90 - Handbook of plain hotany. Edinhurgh 1934. \&. (2s.)

81.91 Botany for the uso of beyiners; jevised by Arabell Clark. New York 1833. Is. $130 \mathrm{p}$.

$3192^{*}$ Rennie, $R$. Essays on the hatural history and origin of Peat moss the peculiar qualities of that sulostance; the means of eonverting it into a manure; and the other economical purposes to which it may be made subvervient. Edinburgh, ty13. Ramsay. 4811). 8. xv1, $665 \mathrm{p}$.

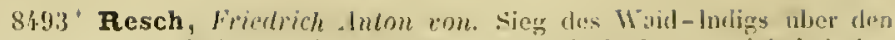

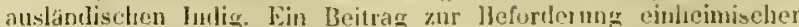
Kultur. Nelıst einer Musterkarto. Weimar, halustrie-Conptoir. 181=2. 4. 31 p., praef., 1 tals. col. $\left[3 / 3\left(h_{0}\right)\right.$

819:* Respinger, Johann Heinrich. Theses anatomico-botimear. Hosileat, (y]. Decker- $1733.4 .8 \mathrm{p}$.

8.295* Retzius, Anders Jahan. Tal, on det, som forbinder oss till Thatural-llistoriens Laraude, samt huru den bü drifwas vill Niya hn-

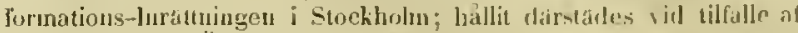
en Disputations-Öning, den 3 Nov. 1770. Af Auders Jaluu Retzites. Stockluolm, typ. Stolpe. 1770. 8. 20 p. w.

$8: 96$ - Pasciculus observationum bolanicarum. I). Lublini, typ. Berling. 1774. 4. 28 p. (Respontens: Magnus Gustuf Sullisled.) B.

$8: 97^{*} \longrightarrow$ Observationes bolanicae, sex fasciculis compreluensate Quibus aceehut Johumis Gerardi Kapnig Descriptiones Monandritrum et Ejvidendrorum in Inclia orientali factac. Lipsine, Crusius. 1779-1791. folio, 35, 2S, $76,30,32,67$ p., 19 1ab. col., effigies Retii. (nigr. 5 th. - col. $8 \frac{2}{3}$ th.)

8.498* Florac Seandinaviae Prodronus, entumerans plintas Sueciae, Lapponiae, Finlandine et Pomeraniae, ac Janiae, Norvegiae, Ilolsatiae, lslandiıe, Groenlandiaeıue. Ilolmine, typ. Petri Hessellyerg. 1779. 8. 257 l., praef., incl. - " lid. Il: Lipsiae, Crusius. 1795. 8. $x \% 1,382 \mathrm{p}$.

8499 Dissertatio, sistens Supplementum "l cuchdationes in editionen secundam Prodromi Florae Seandinasiae. Lumblae, Iyll. Berling. 1\$05. 4. 20 p. (Respondens: Johut (hr. Iskelof.)

$8300^{*}$ Jissertatio, sistens Supplementum Il ef emendationes

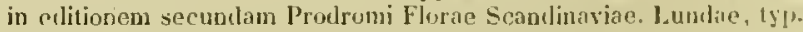
lierling. 1809.4 .14 p. (Respondens: (rulm. Sindmath.)

$8301^{*} \longrightarrow$ Einleitung in die Lelue von den Arzneinn des l'flanzenreichs. Aus dem Lateinischen mit Anmerkungen von Juhum Friedrich WVestrumb. Leipzig, Muller. 17S6. 8.84 p., praet.

8502 Dissertatio sistens moditationes nomnullas de distributione rerum naturalium, providentiao divinae teste. 1). Lmblas, tyly. Berling. 1798. 4. 19 1. (Pespondens: Simon Jlagnus Halmgrehn.) w.

8303 Dissertatio gradualis, sistens monrenta nonnulla de genere in listoria naturali. D. Londini Gothorum, ty\%. Berling. 1799. 4. 16 ر. (Respondens: Magnus Erik Forsscinder.) w.

8.30\% Dissertatio botanicd, sistcus methodun Tournefortianam a cl. Guiart filio reformatam, quam sub pracsidio 1). MI. A. J. Retzi pro laurea moleste exhibet Curolus Adolphus Agardh. Lundie, typ. Berling. 1805. 4. 1f p. w.

$830.3^{*}$ Fursök till en Flora oecomonica sueciac, oller srensha Wáxters Ny̆ta och Shada i Ilushallningen. Lund, typ. Landb]ad. 1806. Il voll. \&. vıt, 792 p., incl. ( 40 Skill.)

8306 - Bihang till Flora oeconomica suecile. 1). Lund, typ. Berling. 18 12. 4. 20 p. (Respondens: Lars Johan Darin.) w.

8007 _ Rotanico oeconomisk Athanding om Perlseris liuskens Nytta och Skalla. I). Lund, ty]. Berling. 1807. 4. 21 p. w.

$8 \ddot{3} 08^{*} \longrightarrow$ De plantis cilariis Romanorum. 1). Lunclae. 1y p. Berling. 4808.4.711\%.

$8309^{*}$ — Flora Virgiliana, oller Fúrsök at utreda de Wäxtce som anforas uti $P$. Jirgilii Jharonis Eclogae, Georgiea och Aeneides, jamte Jihang om Romarues Matwaxtes. Lund, trycht hos Prof. D. Joh. Lundlblad, och på dess behostnad. 1809. \$. 207 p. Bibl. Goett. et E. M. $8310^{*}$ Oliservationum botanicarum Pugillus. U. Lundae, 19̣1 Berling. 1810.4 .23 p.

$8511^{*}$ Observationum in Criticam Lotanican Carole a Linme specimen primum et secundum. 1). Lumbar. typ. licrling. 1s It. is. $47 \mathrm{p}$.

$\$ 312^{*}$ _._. Tankar oin Natural-llistoriens nitta och viurde. D. Lund. typ. Berliug. IS 11.4.31 p.

$8: 313^{*}$ De historia naturali, fundamento theologian niluralis D. Lutulae, lyp. Berling. 181 1. 4. 13 p.

8.31. Retudenjus, Jichat. De novo Gummi purgante epistula aul tohannem ddumum Schucartium, cum ejusdem Apologia arl Philinum Hechsterum, Lughuai Batavorum, apud Joh. Maire. 1625. iz. Rivin. 
sïlï* Reum, Johamn Adam. Onkonomische Rolanik, oder Larstellung ler haus - und landwirthsehaflichen. Pflanzen, zum Interrichte junger Landwirthe. Dresten und Leipzig, Arnold. 1 833. 8. xu, 356 p. ( 2 ih.)

$8316^{*}$ Pllanzenphysiologie, oder das Wachsen, Lehen und Verhalten der Pllanzen, mit Hinsicht auf feren Zucht und l'flege. Dresden und Leipzig, Armold. 1835. 8, xim, 262 p. ( $11 / 2 / h$.

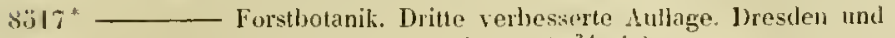
Leipzig, Arnold. 4837 . 8. vill, 468 p. $\left(2 \frac{3}{8}(\mathrm{~h})\right.$.

$\$ 518$ Reusch, Erhard. Programma de Botanicis non Medlicis. Helnaestadii 1739. 4. 1 plag. B.

851!) Reuss, August Em. Die Versieinerungen der bölımischın lírcideformation. Mlit Abbildung der neuen oder weniger hekanten Arten, gezeichet von Joseph Rubesch. Zwei Abtheilungen. Stuttgart, Sehweizerbart. $1845-1846$. royal $4.263 /$ plaz., 51 tal $)$. (15 th. $)$

83i20* Reuss, Christian Friedrich. Conm rendium botanices, systematis linnacani conspectum, ejusdem applicationem ad selectiora plantarum Germanjae indigenarum usu medica ct oeconomico insignnium genera eorumgue speeies continens. Uhnar, stettiu. 1774. 8. 445 j), pracf, ind., 10 tab. - TEd. 11 aucta: Ulmae, Stettin. $1785.8 .589 \mathrm{p}$, jraef, ind., 10 tab.

Sวั21 (- Lenntniss derjenigen Pllanzen, die Maleru unıl Färberu zum Nutzen gerejehen liunnen. Leipzig 1776. $8.812 \mathrm{p}$.

(Nomen atoris liquet o Comment. med. Lips. X.11l. p. 6i3.)

852.2* (- Dictionarium botanicum, oder bolanisches, lateinisehes und deutsehes Handworterluch fur Aorzle, kameralisten ete. nach Ien linueischen Systeme. Leipzig, Jlilselier. 1781. II voll. 8. xvi, $376,485 \mathrm{p}$.

\$323* Reuss, Friedrich Anton. Walafridi Strubi Hortulus. Carmen ad rodd. mss. veterumyue editionum fidem recensitum, lectionis vatietate notisque instructum. Accedunt Analecta ad antiquitates Florae germanicae et capita aliquat Macri nondum edita. Wirceburgi, Stahel. 1834.8 .105 p. $(2 / 3$ th. $)$

$832 \mathrm{r}^{*}$ De libris physicis S. Mitdegardis commentatio historicumedica Wirceburgi, Stalsel. Is $30 \mathrm{~s} .8 . \mathrm{xx}, 71 \mathrm{l} .(\mathrm{H} / \mathrm{s}$ th.)

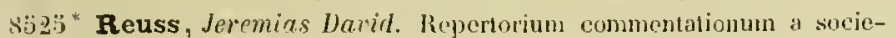
tatibus literariis editarum. Secundum discipdinarum ordinem digessit J. D. Reuss. Scientia naturalis. Tomus I et II. Goettingae, Dielerich. 1801-1802.4. - I: 1804. Jistoria naturalis geueralis et Zuolugia. iv, 574 j. - Il: 1802. Botanica (st Mineralogia. VIll, vill, $604 \mathrm{p}$. $(3 \%)$ th.

83̈ఖ(; Reuss, Jeopoli. Flora des Lnter-Dunaukreises, oder Aufzahlung und kurze lieschreibung der in Lnter-Donaukreise wildwachsendeu Pflanzen. Nit Angabe des Standortes, der Blutezcit, der okonomischen, teclmischen und medizinischen Benutzung. Pasiau, Pustet. $1831.8 .18 \frac{1}{2}$ plag. $\left(1 \frac{1}{3} t h\right.$.)

4327 - Flara van Passau. Passau, Pustet. 1838.12

8.,328* Reuter, A.P. Der Boden und die atmosphäriselie Luft in allseitigen materiellen, gasformigen u. dynamischen Einwirkungen auf Ėrahreu unt Gedeihen der Pflanzen, mit Bezug auf Land-nud Forstwirthschaft, Frankfurt a/M., Sauerlander. 1833.8 . xiv, 325 p. $\left(1 \frac{1}{3}(\mathrm{~h})\right.$.

$8329+$ Reuter, George Francois. Catalozue détaillé des plantes vasenlaires, qui croissent naturellement aux environs de Genève, avec l'indication des localités et do l'ipoque de la fioraison. Genive, Cherbuliez. 1832.8 .138 p.

$8.330^{*}$ - Supplément au Catalogue des plantes vasculaires, qui rroissent naturellement aux environs de Genive. Genteve, fruaz. 1841. 8.51 \%., 1 1ab. (Arabis bybrida Reut.)

$83831 \div-$ Essai sur la vegetation de la Nouvelle Castille. Genève, typ. Fick. 1843.4.34 P., 1 tab. (Colmeiroa buxifolia Reut.)

\$ä32 Revelli, Giuseppe Naria. Istruzione sulla coltura e preparazione della garanza. Torino 1770. S. DC.

$8533^{*}$ Reyger, Gollfied. Tentamen Florac Gedanensis nethodo sexuali accommodatae. Dantisci, Wedel. $1764-1766$. Il voll. 8. - I: 1764 993 J. - II: Accessit Joannis Philippi Breynii vita ot Christiani Menzetii centuria plantarum Gedanensium. 1766. x11.224 p.

(Tomus secundus sistit editionem auctan et reformatam tomi prioris.)
833\%" Reyger, Gottried. J)ie um Danzig wildwachsemden Pllanzen nach ihren Geschlechistheilen georenet und beschrieben. Danzig 1768 . 8. (7) full. 434 p. Bibl. Ernesti Meyer.

"Diess Werk enthilt mus die von Reyger [n. 170h + 1788] sellst hecibachteten Prlanze"l); doch deren einige metr als die zw eite latcinische Ausgabe. Es ist also jencm Werh vorzuzichen, aluer viol belt"Ier." E. M.

$80330^{*}$ _____ Die um Danzig wildwachsenden Pflanzen nach ilaren (ieschlechtstheilen geordnet und beschrieben. Neue ganz ungearheitete und vermelute Auflage voll Johann Gottfried Weiss. Danzig Inluth. 1825-1826. II voll. 8. - 1: 1825. Phanerogamia. vu, $541 \mathrm{p} .-11: 1826$. Cryptrgamia. Lx, $432,10 \mathrm{p}, 3$ tab. $(2 \% / 3$ th. $)$ aus con schlechlendal's riora Berolinensis fast wortlich ubersetzi." E. M.)

83̈36 Reyher, Andreas. De anima in genere, 11 et in specic de vegetaute. Lipsiae 1632. 4. Rivin.

3537 t Reynier, Louis. Némoires pour servir a l'histoire physique et maturelle de Ja Snisse. Tome 1. Lausanne, Hourer..178s. 8. vin, 296 p., 2 tab

(Paginae $3 i-224$ spectant all regnum vegetations.)

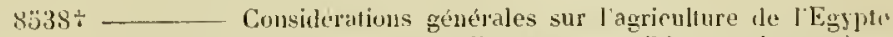

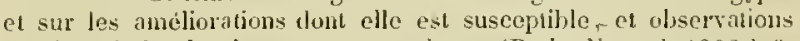
sur le Palmicr-1)attier of sur sa culture. (Paris, Juzard. 1802.) \& $124 \mathrm{p}$

(Seorsim impr. ex Annales de l'agriculture françasse, tome X.)

$80 ̈ 39$ Rhagorius, Danicl. Pllantz-(iart, d. i. Bericlıt, welchergestalt 1. Obst- 2. Kraut- 3. Wein-Gürten mit Lust und Nutz anzustellen. zu hauen und zu erhalten, samt Verteutsehung der zu denselbigen diensilichen lateinischen und franzosischen Worter, anf die Schweizerische Landesart gerichtet. Bern, bey Stephan Schuid. 1639. 8 Rivin. - Pllantz-Gat, vermelirt mit einem nutzlichen Boricht, was des Pflantzens hall, 1 . in gewissen Monaten furzunelımen, 2 . ant etlichen nahmhaften Tazen zu lialten, 3, aus der Witterung zu schliessen sey. Bern, bey Georg Sonnleitner. 1650. 8. Rivin. Pflantz-Gart, zum irittenmal im Druck verfertigt. Mayntz, bey Nicolaus Hoyll. 165\% 8. - t Eineuerter Pllanzengarlen. Basel, kónig. $1669.8 .240,160,140,212$ \%., maef.

$85 \% 0^{*}$ Rheede tot Draakestein, Heinrich Adrian van. Hortus indicus malabarieus, continens regni malaharici apud holos celeberrimi umnis generis plantas rariores, latinis, malabaricis, arabicis ef Bramaumm characteribus expressas etc. Amstelodami, sumtibus Someren et van Dyck. 1678-1703. Xll voll. folio.

1: 1678. Adornavit Henricus van Rheede tot Druakestein et Johannes Caseurius, commentariis illustravit Aruoldus Syen. (De arboribus.) 110 p., 57 lab.

11: 1679. Allomavit $H$, van theede of J. Caseurius, commentariis illustravit Johumes Commelinus. (De fruticibus regni malabarici.) 110 3., 56 tals.

III: 682 . Adomavit II. van Rheede el Johannes Ilunnichs, commentariis illustravit Johannes Commelinks. 87 p., 64 tah.

IV: (errere) $4673 .(1683)$.125 p., 61 tab.

$\mathrm{V}: 1685.120 \mathrm{p}, 60 \mathrm{tab}$.

V1: 1686. Adornavit H, van Rheede el Theodorus Junsomas ab Atmeloveen, commentariis illustravit Johunnes Conmelimus, 109 p., 61 เał.

VIl: 1688. Adomavit 11 . van Rheede, commentariis illustravit dohames Commelinus, in ordinem redegit et latinitate clonavit Abrahum a. Poot. (De varii generis fruticilus scandentibus.) $114 \mathrm{p} ., 59$ tals.

VI1I: 1688. (De varii generis herbis pomiferis et leguminosis.) $97 \mathrm{p}, 51 \mathrm{tab}$.

IX: 1689.170 p. 87 tals.

X: 1690.187 p., 94 tab.

II: 1692.133 p., 65 tab.

XIl: 1703. $151 \mathrm{p}$, ind., 79 tab.

(1)e celeberrimo opere ef. Journal des sav. VIl. 150. Xllı. 9. xill. $6 \%$ 6. - Claves et catatogos Burmanui, Commelini et Dillcynit supra in $\mathrm{Nr} .1382,1937,1938$ el 2638 recensui.

$83 \mathrm{H}$ - Hortus indicus malabaricus; classium, generum el specierum characteres Limaeanas, symonyma autorum atque observationes addidit John Hill. Pars 1. Londini 1774. 4. 110 p., 57 tab. B.

(llujus editionis plures non prodierunt partes.) 
8312 Theede tot Draakestein, Mleinrich Adrian tall. Malalsaarse Liruidhof etc. vertaalt Joor Abraheem van Pont. Amsteldam, van Someren. 1689. Il voll. folio. - J:39 p., 57 tals. - Il: 29 1), 56 tal Bibl. Juss.

8513 Rhind, Ifilliam. A catchism of botany. Fidlinburgh 1833.12.

854: - Exemsions illustrative of the natural history of Evinlurgh. Ed. J1. Eilinburgh 1836. 12. (3s.6d.)

$8560^{*}$ Rhode, J. G. Beitrige zur Pflanzentunde der Vorwelt, nach AbJrucken in Lohlenschiofer und Sandstein aus sehlesischen Stein-

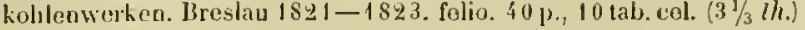

845 if * Rhodius, L. Die Digitalis purpurea in grosseren Gahen und in infange aent-entzundlicher Kranhheiten zu reichen. I). Nergentheim $1837.8 .28 \mathrm{p}$

8:37" Ribbeck, Paulinus. De Ilelleborisme veterum. D. Berolini 1844. 8.38 p.

835.8: Riboud, Thomas. Menoire sur les difforentes espèces de haies et elotures usitées dans le lépartement de l'Ain. Paris, typ. Huzard. 1840.8 .35 \%.

Observationes de variis agrieuturae ejusdem circuli quaestionibus, teste Decandolle, leguntur in Annuaires de lain anni 1806 et sequic ntiunt.

$8: 3,9 \div$ Rich, $O$. A catalogue of ancient ant modern botanical books, comprising part of the libraries of Prof. Syrengel of Ilalle, the late A. II. Hazcarth Esq., Prof. Mertens of Ihremen, Labillartiere, Desfontuines, Ortega etc. oftered for sale at very reduced prices. Nr. 1-451. (Londen, 12, red Lion Sruare.) 1835.8.16 p.

$8550^{*}$ Richard, Achille. Nouveaux élemens de botanique et de physiologie vigétale. Paris, Béchet. 1819.8 . xv, 410 p., 8 tah, - +Ell. II Paris, Béclıet. 1822. 8. xvill, 487 p., 8 tab. - "Edl. III: Paris Bichet. 1825.8 . xxiv, 519 p., 8 tab. - *Quatrieme édition, revue corrigce et augnenté du caractere des familles naturelles du rigne végétal. Paris, Béchet. 1828 . 8 . xxiv, 593 p., 8 tab. col. - † Ed. T Paris, Béchet. 1833.8. xxiv, 436, $256 \mathrm{p},-{ }^{*}$ Nouveaux elémens de hotanique et de physiologio végétale, avec le tableau méthodique Ies familles naturelles. Nouvelle édition, augnentée d'un précis des propriétés médicamenteuses des végétaux ou de leurs produits d'après les meilleurs traités de matière médicale et d'un grand nombre de figures pour aider a lintelligence des caracteres des familles du rèque végétal, par Drapirz. Bruxelles, Ad. Wahlen. 1837 4. 343 p., 46 tab. pro parte col. - "Sixieme édition revue, corrigée ot aurmentie des caractères des familles naturelles du règne végétal; omée de 5 planches nouvelles gravées sur acier, et te 163 wravures intercalces dans le texte, gravies sur bois par dndrewo, Best et Leloir. Paris, Bechet. 1838. 8. xit, 756 p., 4 tah. (Leipzig, Brockhaus of Avenarius: $2 \frac{1}{3} t h$.) $-\div$ Septione édition revue, corrigée et entièrement refondue, ornée de plus de huit cents ligures intercalues dans le texte. Paris, Béchet. 1846. 8. vi, 851 p., ic. xylogi i. t. $(9 \mathrm{Cr}$. $)$

germanice: Neuer Grundriss der Botanik und der PllanzenphysioIoniv, etc. ubersetzt von Martin Balemin hittel. Nurnber's Schys 1828. 8. xxvilt 646 p.. 8 tab. - bil. 11 : Numberg, schrag. 1831. \&. Lil. Ill: Nach der sechsten frimzosischen Urimintlausuabe froj hearbeitet von Jartin Badduin Killel. Nurnberg, Selurag. 1860. 8. 71 plan iti tab. $(21 / 2) t h$.

hollandice: Nienwe Beginselen der Kiruidhnnde etc. door H. L. v'un Allena, met antekeningen van Claas MIulder. Vol. I. Franeher 1830. 8 . $18,300 \mathrm{l}^{3}$, , tah.

anflice: Elements of botony and vegetable physiology. Translated

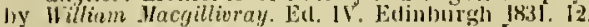

rossice: Основанія 60таники п Физіодогін растсній. Москва 183 s.

S3:31" - Histoire naturelle ot médicale des différentes espèces d'luécacuanha du commeree. Paris, Béchet. 1820.4 . 72 p., 2 tab. $(3 \mathrm{fr} .50 \mathrm{c}$.

$\$ 842^{*}$ Monographie du genre Ilydrocotyle de la famille des Ombelliferes. Bruxelles, typ. Weissenbrueh. 4820.8 .86 p., 16 tab. ( 5 fr.)

(Extrait rles Annales des seiences physiques; tome IV.)

Sis.3* —_ Bolanique médicale, ou llistoire naturelle el médicale Jes mélicamens, des poisons el des alinens, tirés du rẻyne vézedal Paris, Béchet. 1823. Il voll. 8. xiv, 817 p.

- germanice: A. Richartls Medizinische Bolanik. Aus dem Franzosischet], mit Zusatzen und Annerkungen von Gustav Kurte und $(\dot{s} . F$.

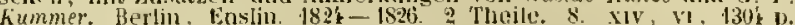
(3 th. 8ijiif" Richard, Achille. Monographic des Orchides des iles de France ct de Beurbon. Fentrsit d'un lissai d'une l'lore des iles do l'rance el do lioulyon. Paris, typ. Tastu. 1828.4 .83 p. 1 i tals.

(listrait des Memoires dhistoires naturelle, tomo il.)

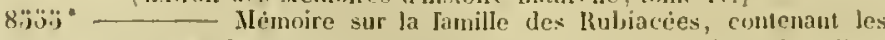
earactires des genres de cette fanille ot d'un grand noubre diuspecess nouvellos. Paris, typ. Tastu. 1829. 4. 224 p., 45 (al).

(bitrit des Memoires dhistoire naturelle, tome $\mathrm{V}$.)

$83056+$ Elemens dhistoire naturelle médicale, cuntenant des notions générales sur l'histoire et les propriétés de tous les alimens. médlicamens ou poisons, tirés des trois rèmues de la nature. I'aris.

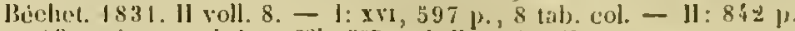

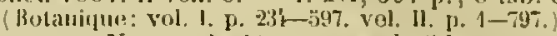

$8.377^{*}-$ Toyage de décomvertes de tharalabe, exécuté par ordr. du roi pentant les années $1826-1829$ sous le commandement do 11. Julien Sebastien César Dunont d'Lrville. Botanique par A. Lessun et Achille Richard. Paris, Tistu. 1832-1834. Il voll. 8. et Lllas in folio. - I: 1832. (Essai d'une Flore de la Nourcelle-Zilande, par Achille Richard.) xvi, 376 p. - II: 1834. (Sertum Istrolabianuso. par Jchille Richard.) Lvi, 167 p. - Allas: 1833. 39, 39 tab, nigr. et col.

8.j68* Monegraphie des Orchidées recueillies dans la chaiur des Nil-Gherries (Indes-orientales) par M. G. Sumuel Perroltet. Paris. typ. Renomaril. 1841. 4.36 p., 12 lab.

(Extrail des Annales des sc. ndt. Jamvier 18't.)

S3̈9 Richard, Heinrich. Die Kartelielkrankheiten im Allgemeinen, besonders aber die jetzt herrschende, ilıro Kennzeichen und L'rsaclien. mit Angabe der Nittel, lie scbúdlichen Folgen der Kranklueit zu vermindern, und derselben fír die Zukuuft vorzubeugen. Hamburs, Kittler. 1845.8 .3 plag. $(1 / 6, h$. $)$

8360* Richard, Louis Claude Marie. Tablean explicatil du systeme sexuel de Linné. I'aris, typ. Ilautbout. s. a. gr. Folio. I plag.

$8 \ddot{6} 61^{*}$ Demonstrations Jotaniques, ou Analyse du Iruit eonsidéré en général. Publices par Henri Auguste Duvul. Paris, Gabon. 1808.8. $111 \mathrm{p}$.

* germanice: Analyse der Frucht und des Samenkorn.. Tach der Daval'sc'len Ausgalie übersetzl, und mit vielen \%usitzon und Uriginazeichnmugen Richard's, so wie andern Beitrasen vernehrt von

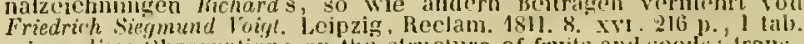
tanglice: ohservistions on the structure of fruits and seeds: IransLated from the Analyse du fruit par .1. Louis Claude Richurd. Comprising the authors latest corrections; and illustrated with plates and original notes by Jolen Lindley. London, John Ilarding. 1819. 8. Ix 100 p., ij tab.

\$56 $2^{*}$ Analyse bolanique des embryons endorlizes ou nonocotylérlonis, et particulièrement de celui des Graminées: suivie d'un examen critique sur quelques mémoires anatomico-physiologico-botaniques par Mirbe!. Paris, Courcier. 1811. 4. 74, it j., 6 tab. $(8 \mathrm{rr}$.

8:363* — De Orclideis europaeis annotationes, praesertim ar genera dilucidanda spectantes. Parisiis, typ. Beliı. 1847.4.39 p. 1 tab. $(3 \mathrm{fr} .50 \mathrm{c}$.)

$8664^{*}$ - _.._ Commentatio hotanica de Conifereis et Cyeadeis, tharacteres genericos singulorum uriusque familiae et liguris analyticis eximie ab autore ipso ad naturam delineatis orrates complectens. Opus posthumum ab Achille Richard, filio, perfectum et in lucem editum. Stuttgardiae, Cotta. 1826 . folio miner. xv, 212 p., 30 tab. (36 fr.)

$8360^{*}$ De Musaceis commontatio Lotanica, sistens characteres hujusce familiae generum. Opus postlumum ab Achille (Richard) lilio terminatum et in Jucem editum. Vratislaviae et Bonnae, Weber 1831. 4. 32 [., 12 tab. (4 $/ h$.)

Act. Acal. Caes. Leop. Nal. Cur. Vol. Mr.)

8:366 Richardson, John. Botanical appendix (10 John Frenklin's Narrative of a journey from the shores of Iluklsons Bay and the Polar Sea.) London, typ. Clowes. (1823.) 4. 55 p., 5 tab. pro jarte col. Bibl. Cand.

\$ن̈67 Richardson, Richarl. Extracts from the litera'y and seientific rorrespondance of Richard Richardson, M. J). F. R. S., of Bierle! Forkshire, [1]. $1663 . \div 1721]$ illustrative of the state and progres: of botany, and interspersed with infornations respecting the sind? of antiquities and general literature in Great Britain, during the first half of the cightepnth century. Yarnouth, printed for Dituson Turner to privale distribution. 1835.8 .

cf. Hinchner Gelehrte Anzeigen $18 \% 0$, .r. 1:6, antore $\Omega$. 
$83 ̈ 68$ Richardson, IIlliam. On Fiorin grass. Lonlon 1814. \&.

8üb9 Riche, Claude Antoine Gaspard. De elıenta vegetabilium. Avenione 1786.8 .

gallice: Considerations sur la elimie des végétaux, pour servir

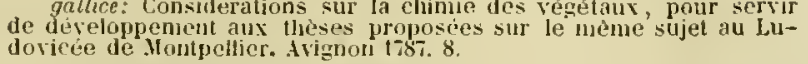

\$570* Richerius Rhodiginus, Caelius Ludovicus. Leetionun antiquaJum libri XXX. Venetiis, Aldus, 1516. folio. - " Basileae, Frobenius. 1542. folio. - ${ }^{*}$ Basileae, Frobenius. 1550 . folio, - ${ }^{*}$ ib. 1566. folio.

$8571^{*}$ Richter, August. Anleitung zur Gewảchskunde, zunáchst fur Seminaristen und Volksschullehrer. Koln, Schuitz. 1836. S. xxvı, 438 p., 2 tab. $\left(1 \frac{1}{4}\right.$ th. $)$

8372* Richter, Auyust Gottlieb. De Agarico. Programma academicum. Goettingae, typ. Dieterich. 1778. 4. 8 p).

$8373^{*} \longrightarrow$ De Junipero Sabina, ejusque virtute salutari. D. Wittenbergae $1803.4 .23 \mathrm{p}$.

8574* Richter, Ernst Heinrich. Abriss der Terminologie der planerogamischen Gewachse, so wie der Sáugethiere uod der Vögel, nelsst Darstellung des Linne'scheu Pflanzensystemes. Franhfurt a/0., 11 oflmann. 4837 . 8.40 p., 7 tab. - Zweite verbesserte Aullage: Frankfurt a/O., lloffmann. $1846.8 .2 \frac{3}{4}$ plag., 7 tab. $(1 / 3 \mathrm{th}$.

\$งั73* Richter, Georg Gottlob, pr. De muscorum notis et salubritate. D. Goettingae 1747.4 .51 p., praef.

(Hallerus pracdicat autor'm Respondenten Joham Georg Heinse.

\$it6* Richter, Karl Samuel August. Tasehenbuels der Botanik. Als Leitfaden fur Sclsuler entworfen von $K$. R. Botanophilos. Zweite, stark rermelırte Auflage. Mlagdeburg, Creutz. 1830. 8. vill, 168 fr., se schemata, it tab. ( $1 / 2$ th.)

$857 i$ * Richter, $k$. Dio Flora von Saalfeld. Programm der Realschule zu Saalfeld. Saalfeld, 1yp. Wiedemann. 1846.4. $16 \mathrm{p}$.

85̈78 Richter, Rudolph. Versuch einer medizinischen Topographie der Gouvernements - und Ilafenstadt Arcliangelsk. Dorpat 1828. Trautv.

8579t Ricord-Madianna, Jean Baptiste. Recherches et experiences sur les poisons d'Amérique, tirés des trois règnes de la nature ete (I. Du Jrinvilliers, Spigelia anthelminthica L. II. I) Mancenillier, Ilippomane Mancinella L.) Bordeaux, Lawalle. 1826. 4. 169 p. 3 tals.

So8 $80 \div$ Riddel, John L. A synopsis of the Flora of the Western States. Cincinnati, Deming. 1835 . $8.116 \mathrm{p}$. Bibl. Juss.

8581 Supplementary catalogue of Ohio plants, Cincinuati 1836. 8 .

\$582 Riddermarck, Auders, pr. De Clmo. D. Londini Scaniae 1692. 8.4 plag. (Respondens: Harald Ulmgrehn.) B.

$8383^{*}$ (Ridol6, C.) Catalogo delle piante coltivate a Bibbiani, e Cenıi su yuelcuna delle medesime. Firenze, 1y]. Galilei. 1843. 4. xvr, 2 ' p.

83̈8' Rieger, Johann Christoph. Introductio in notitiam rerum naturalium et arte factarum, quarum in conmuni vita, sed praecipue is medicina usus est, per alplabeti ordinem digesta. Hagae Conitum 1742. II voll. 4. - 1: A. 1102 p. - II: B. C. 1230 p. B.

83̈8:" Rieger, Joseph Alexander. De Atropa Belladonua, 1. Berolini, typ. Brüschke. 1823,8.39 p.

\$586 * Riemschneider, Friedrich Eduard. De lorbae Nicotianae, inprimis Tabaci ejusque utilitate in arte mediea collectanca quaedam et observata. D. Lijsiae $1840.8 .52 \mathrm{p}$.

$8587 \div$ Riley, $J$. Catalogue of ferns after the arrangement of C. Sprengel, with additions from $C . B$. Presl, and references to the authors by whom the sprecies are described: to which is adderl a synoptical table of $C . B$. Presl's arrangement of genera. London, Danilton, Adams et Co. 1841 . 8. 29 pr.

\$588 * Rinaldi, Giovanni de'. Il mostruosissimo mostro di Giovunni de Rinaldi, diviso in due trattati. Nel primo de' quali si ragiona del siguificato de' colori. Nel secondo si tratta dell' herle e fiori. Di nuovo ristampato et dal medesino riveduto et ampliato. Ferrara, ad instanza di Alfonso Caraffa. 1588.8 . 158 p., (6) foll. Bibl. Caes. Vindob.

(Lihri rariscimi pracfatio data est anno $138 \%$. Sectio altera tractat de significatione symbolica florum es anticuissimis poetis et philosophis.)
\$๕89" Ringel, Friedrich. De natura et viribus herbae Ledi palustris, sive Rosmarini silvestris. D. Halae, 1yp. Grunert. 1824. S. 26 p.

$8590^{*}$ Ringius, Jl. Jenrik. llerbationes luudenses. D. 1. Lundae $183 \mathrm{~s}$. 8. 16 p.

(Ilace dissertatio sub praeside Steno Nilsson defensa est.)

8ï91 Riolan, Jean, fils. Requette au roi pour l'élablissement d"un jardin. Paris 1618. \$. Desid. Banks.

(Deest iu IIorto Parisiensi, in bibliotheca Madriani de Jussieu et u regia Parisimsi bibliotheca.

$8592^{*}$ Ripa, Lodovico $a$. Historiae universalis plantarum scribendae propositum, addito specinine. Patavii, typ. Conzatti. 1718. 4. 195 p. praef, ind.

$8593^{*}$ Risler, Jaliol. De Verisaseo. D. Argentorati, typ. Pauschinger. 1754. 4.76 1), 1 tab.

839:" Risler, Josua. Serenissini Marchionis el Principis Bada-Durlacensis llortus Carlsruhanus, in tres ordines digestus, exlliliens nomina plantarum exoticarun perennium et annuarum, quac ahuntur per Christian Thrun. Accedit Aurantiorum catalogus. Loeraci, typ. Carriere. 4747. 8. 224,14 p., praef.

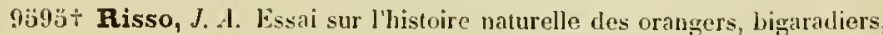
limettiers, cedratiers, limoniers ou citronniers cultives dans le departement des Alpes maritimes. Paris, Dufour. 1813.4. 74 p., 2 tab. sign. $3-4$

$8396^{*}-$ et A. Poiteau. Histoire naturelle des orangers. Paris 1yp. Ilerissant le Doux. $1818-1819$. folio. 280 p., $109 \mathrm{rab}$. col ( 475 fr.) Bıbl. Imp. Austr., Goett., Deless.

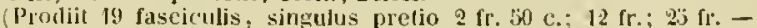
Tabulas splendidas pimsit A. Priteau.

$80 ̈ 97^{*}$ ___ Ilistoire naturelle des priocipales productions de l'kurope méridionale et particulièrement de celles des environs de Nice et des Alpes maritimes. Paris, Levrault. 1826-1828. V voll. $S$. 46 tal., 2 mapp. geogr. (nigr. $67 \mathrm{fr} .50 \mathrm{co}-\mathrm{col} .135 \mathrm{fr}$.)

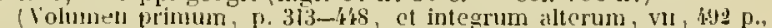
quae anno 1826 prodicruit, continent fistorian regni regetabilis.)

$8398^{\circ} \div$ Memmire sur les etres organises nuisibles au oliviers du département des Alpes maritimes, et de leurs moyens curatifs. s. I. et a. $8.31 \mathrm{p}$.

$8599 \div-$ Flore de Nice, el des principales plantes exotiques naturadisées dans ses environs. Nice, suciété typographique. 1844.8. ¿\$8 p., tab. Bibl, Jacobl Gay.

(Liber niserrimus!)

$8600^{*}$ Ritter, Christian Irilhelm. Versuch einer Beschreibung der in den Herzogthumeru Schleswig und Jolstein etc. Wildwachsendeu kryptogamen, deren Nutzen und Schaden bekanut ist. Ein Anlang zu meiner Schleswig-llolstein'schen Flora. Augustenburg, Timmermann. 1817.8 .68 p., et appendix Florae: $17 \mathrm{p}$.

S601 Ritter von Rittersberg, J. Abbé Joseph Dobroucsiy. Biographische Shizze. Prag, Enders. 1829. gr. 8. $21 \%$ plag. effizies Jusejh Dobrouskly. (11/2+th.

8602* Ritter, Johann Albert. Allgemeines dentselies Gartenluch. Ein vollstảndiges Ilandbuch zum Selbstunterricht in allen Theilen der Gartenkunde, nclst Belehrung uber die systematische Eintheilung der Pflanzen. wher die Anlegung, Erhaltung und Verschonerung vou Lustgårten und Parks, cinem vollständigen Gartenkalender u. a.m. In alphabetischer Ordnung. Zweite, ungearbeitete und verbesserte Aullase. Quedlin]m und Leipzig, Basse. 1832. 8. $39 \frac{1}{2}$ plag., 4 tab. $(15 \%$ th $)$ - $\left.{ }^{*} 1\right)$ ritte vermelirte und verbesserte Auflage. ib. 1835. 8. xxvt , 566 p., 5 tab. $(1 \%$ th. $)$ - Neu bearbeitet ion harl liosse. Funfte vermelite und rerhesserte Aulage, ib. 1842.8 . Iv , 556 p., 4 tab. $(1 \%$ th. $)$ - Neu bearbeitet ron Karl Bosse und Ludwig Krause. Sechste vermelirte und rerbesserte Auflage. ilh. 1846. S. Iv, 556 p., 4 tab. $(15 \%$ th. $)$

8603 Ritter, Johann Jakob. Animadversiones in Floram Riedeseliam. Vratislaviae 1752.4.

(App. Act. med. ply's vol. X. p. 21-11's.)

8604* Ritter, Karl. Naturhistorisehe Reise nach der westindischen insel llayti auf liosten Sr. Majestăt des haisers ron Oesterreich. Stuttgart, Jlallberger. $1836.8 .206 \mathrm{p}, 3 \mathrm{tab}$. in folio. $\left(3 \frac{1 / 2}{\mathrm{th}}\right.$.)

$8603^{*}$ (Ritter, Liarl) Die Verbreilung der Dattcl- und Kokosplalme in Indien. s. 1. el a. 8.35 p. 
$8606^{*}$ (Ritter, Karl.) Die Verinreilung der Pfelferrelıe. Panane und $\mid 8618$ d] ango in Indien. s. I. et a. 8. $32 \mathrm{j}$.

$8607^{*}$ (— ) Der indische l'eigenhanm, Asvattha; die Banjane (l"icus indica) etc. s. I. et a. 8.35 p.

8608 (- Die Opjumhultur und clio Molmpflanze. s. l. el a. 8. $30 \mathrm{p}$.

$8609^{*}$ (-) Die Kultur tes Zuckmrohrs in Asien, und scine geographische Verbreitumg. s. l, et a. $8.64 \mathrm{p}$

(Commentationcs tumues seorsim imyressic sunt ex egregil víri Allemene Erithuade.

8610 - Veher die geagraphiseho Verbreitung ales Zuckerrohrs. Eine in der lionigl. Akatenie der Wissensehaften gelesene $\mathrm{Ab}$ handlung. Lerlin, Druckerei der Akademie. 1840. 4. $108 \mathrm{p}$., 1 mappi but. greogr

$8611^{*}$ Rivinus, Altgustus Quirimes, paterno nomine Bachmann. Introductio generalis iı rem lerharian. Lipsiae, typ Günther. 1690. folio. 39 p., pracf. - * El. 11 : Lipsiae, Ileinrich. 1696. 12. 114 p., praef. - ${ }^{*}$ Ed. III: Introrluctio generalis in rem herbariam. Accedit corollarii loco responsio ad Joannis Jacobi Dillenii objectiones. Lipsiac, Winzer. $1720.12 .157 \mathrm{p}$., praef.

Erlitionis tertias P. 1-106 sistunt Introfluetionem seneralem 1) $107-125$ Dillenii Judichm de methotlo kivini, p. 123- 157 hivi Responsionem ad J. J. Dillenii objectiontes.)

$8612^{*} \longrightarrow$ Orlo plantarum, quae sunt flore irregulari monopetalo. Lipsiae, sumptibus authoris, typ. Fleischer. 1690 . folio. 22 p., ind., 126 tab. (125 tah. B.)

$8613^{*}$ Orlo plastarum, quae sunt llore irregulari tetrapetalo. Lipsiae, typ. Fleischer. 1601 . folio. 20 p., ind., 119 tab. (121 tab. B.)

$8614^{+}-$Orlo plantarum, quae sunt flore irregulari pentapetalo. Lipsiae, typ. Richter. 1699. folio. 28 p., praef., ind., 140 tah. (1 39 lab. B.) Bibl. Cand.

(De Joc opere cf. Johonn Christoph Lischutzit Disserlationem de conlinuanda Rivinorum industria in renendo plautarum elaractere. Lipsiae, typ. Zulukel. 1726. 4. $93 \mathrm{p}$. Fignrarum, quas lithulis his post prinam entitiouem additas esse ille p. yl refert, sequentes in Banksiano exemplari arlsunt: Irreg. monopet, tab. 2. Valeriana tlore exiguo 1ab, 6. Locusta minor; tał. 37. Jlom minum jlore variegato; tab. 42. serpilium montanum hirsutum; tals. G7. Hedera terrestris minur tah. 49. Veronica minima repens; 1 ab. 100. Receabunga minor. Irreg. pentapet tah. 121. Viola tlore coeruleo dongifolia. lietiguae desideranIur. Alij exemplaribus aliae additae sunt digurae.

$8615 \div$ - Icones plantarum, quae sunt flore irregulari hexapetalo. s. I. et a. folio. (17) 1ab. Bibl. Cand.

Ilas a tivino paratas, al Rupṕio saepe cilatas labulas eclidit Christion Gollieb Luluigy dlin ab illustrissini viri morte [n. Lipsiate 9 Dec. stion Golltied Luwhig (lin ab illustrissini riri morte [n. Lipsiite 9 Dec. 5.52. False has Sprengel, Geschichte der Bot. II. 50 . aupelint iureditas. W0. False has sprengel, Geschichte der kot. I1. 60. appellat imeditas.

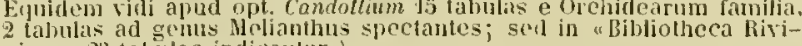
niana" 23 tahulae indicoutur.

$8616^{*}$ — Biblictleca Riviniana, sive Catalogus librorum philologico-phitosophico-historicorum, itherariorum, inprimis autem merlicorum, botanicorum et historiae naturalis seriptorum ete. rariorum, (juam magno studio et sumtu sibi comparavit I). Augustus (uirinus Rivinus, therapeut. et bot. Prof. pulsl., collegii maj. prine. collegiatus, societatis regiae anglicanao socins, acalemiac Decemvir, et fac. med. Decanus, ventenda in vaporario collegii rubri a die XXY11 Octebris MDCCXXVIl, more auctionis consucto. Praenissa est Vita Rivini descripta per M. Georn Sumuel Memann, Mitweida Mlisı. Mecl. C., catalogi autorem. Lipsiae, ty]). Immanuelis Titii. (1727.) 8 . (7) foll., 740 1., infl, effigies Rivini.

(Citalogus copia sua aeculo ac cumia firlo et ermdila librorm dispositione menorahilis, diligentissime a mo' exerptus, plutimos costue rarissimus indlicat libelles botanicos nullibi alias repertos. llisturiae plantarum scriptores recousentur it Nr. 63.31-3132. Inter uosthuma ineilita liviniana in hoe calalogo cnumprantur: i. Tomus sosthuma inementom afl opus hutanicum, constans d12 tabulis aeneis. folio mas. - 2. Orfo plantarum, fuac sumt llope irreguldri bexapefalo constans 23 tabulis aeneis. folio ints. - Jrocinium botanicumb

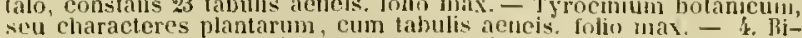
seu characteres plantarum, cum tabulis acucis. folio mas. - - , Bi-

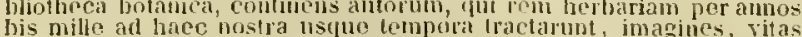
his mille ad haec nostra ustue temporat lractirunt, imagines, ritas rum atque ceensura. gr. 't. cum iconil)us aeri incisis 200 ot nutlis alluc soulpentis. -5 . observalionos botanicae. 4 .)

8617* Rivinus, Quintus Septimius Florens. Quacstio phỹtologion, an plantarum vires ex figura et colore cognosci possint? Lipsiae 1670. 4. 2 plag. (Respomlens: Augustus Quirinus Rivinus.)
(Roberg, Lars.) Aelvebenes. Grundrahl til flintok jacuningu. l.jnaliao 1730. 12. $20 \mathrm{p}$. ie. sylogr. maxime e Tournefortio. B. Librum rarissimim ne liksiron quidem il-pevil.)

8619 (-) Vegelabiliun cum animalilus comparalio discervata coram alumuis regiis. Lpsaliae 1737 . 12.4 [1., 2 ic. sylugr i. t. w

Praeside Laurentio Robery dissertationes:

8620 De Piceae Pinique silvestris resina. 1). Cjusalis 1714.4. 24 p. (Respondeus: Johan Hesselius.)

8621 Dissertatio pliysica, Graesoeam repraesentans. quam pracside Laurentio Roberg publico eruditorum axamini modeste sulsInitlit Adam IVerner. Cpsaliae, typ. Wernor. 1727.4.22 p.. 3 ic. w.

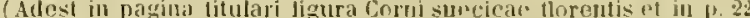
Corni suecicae fruetiterae nec non Corallorrbizat imbatar Br.

$8622^{*}$ De jlanta Sceptrum Carolinum dicta. 1). Upsaliar 1731. 4.17 p. (Respondens: Johan Olof Ruclleck.)

8623 (-) Berettelse on Blomman och dess ätshilliga dolars verkan och gagn, försvenskat till prof utur Pillon Tourneforl och Exper ac Consult Facultati mefl. Lpsaliensi hòrsammast hemstalt af furs Liljemarck. Upsaliae 1733 . 4. 4 1). w.

(loutinet theses pro stipendio editas. Auctor est Rober!y. In patcina printil aldunt ligurae corollae he?apelalat ot partes cjus frucli(icationis.)

8624 De succerlancis Acaciao aegypliacae. II. Tpsaliae 1737 4. Desid. Banks.

8623* - Plantarum generatio leviter adumbrata. 1). Ljusalian 1738. 4. 8 p., t tab. ligno incisa. (Respondens: Bengt Lossberg.)

8626 De Blito. D. Upsaliae 1740. 4. Desid. Banks.

862 it (Robert.) Plantes phanerogames, fui eroissent naturellement auv environs de Toulon. Brignolles, Perreymond-Dufort. $1838.8 .117 \mathrm{p}$., 1 mappa geogr.

8628t Robert de Limbourg. Dissertatinn sur la question: Quelln est l'intluence de l'air sur les végetaux? IBorteaux, ty. 13run. 4758. 4. $48 \mathrm{p}$.

$8629 \div$ Robert, $E$. Observations sur la régélation en lslankle, avec une Liste des plantes yue l'on suppose exister en Islande, dresscie par H. Vahl. Impr. cum ejus Voyage en Jslanele et au Groenland. Paris 1841.8. p. $337-379$.

8630* Robert, Emst Friedrich Ferdinand Karl II IThelm. Commenlittiones in Secalis cornuti listoriam merlico-physicam. D. Marburgi 1825. $8.65 \mathrm{p}$.

$8631+$ Robert, Nicolas. Variae et multiformes florum speeies ad rivum et aencis tabulis ineisae. Paris, F. Poilly excudit. s. a. 4. 30 tab. Bibl. Juss.

8632* _ Abraham Bosse, et Louis de Chastillon. Recueil de plantes, dessineses et gravées par urdre du roi Louis $\mathrm{MI}^{\circ}$. (Paris 170 I.) Ill roll. fulio max. (16 unc. long., 12 unc. lat. (319) tab. ( 0 fr. Brunet.) Bibl. Imp. Austriae, Decand., Deless.

(lu exmplari bibliothecae Sherarlianae. Oxenii astervatac, titul adsunt: "Eslampes four survir a l'histoire des futantes. Partic ] et li.

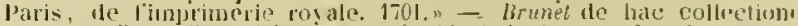
monet: "Recucil parfaitement esécuté et dont on recherehe cucur" III peu les anciennes eprenves. Lourrage parut dabord sins expli-

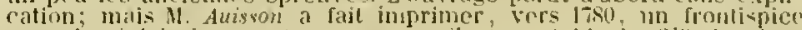
arec des ectaircissoments smr ce recueil, el une lalue des 319 glanches. te tout formint 20 foll.,

$8633^{*}$ Robertson, Archibald. Colloquia te rehus praecipuis plyysiologiae vegetalilium atyuo Jotanices, funestionibus et responsis ad usum stuliosae juventutis accommorlata. Opus recusum. Loviniae 19p. Vanlintlsout. I822. 8.73 [?., 4 tab.

863\%* Robertson, 11: A collection of rarions forms of stores used for forcing fine plants, fruit trees and preserving tender exolics etr. Louton, Ackermanu. 1798. 4. 24 tab. col., text.

yallice: Cutlection dos difitiontes especes de serres chantes etc. Leipzig, Balumgartuer. 1799. folio.

8633 t (Robillard D'Argentelle.) Catalogue des fruits of des plintes

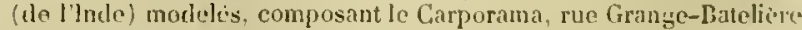
Nंr. 2. l'aris, tyr. Delaguette. (1827? 8.47 p. ( 50 c.) (Museum publice eyrositum Don, de Robillard Didrgenelle.)

$8636^{*}$ Robin, Charles. Les veigetaux, qui croissent sur les animaux vi-

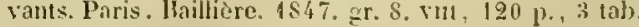

S637* Robin, Jean, latiue Robinus. Catalugus stirpium tam indigenarum, quam exoticarum, quae Lutcliae coluntur. Parisis, typ. Plilippi a Prato. 1604.8.67 p., pracf., carmina gratulatoria. 
8638 + Robin, Jean, latine Robinus. Exoticae quaedam plandae (a Jean Robin, filio) ex Guinea et Ilispania thelatae anno 1603. folio. 2 p. Bibl. Juss.

(Jean Robin, pater, hotanicus regius et horti scholae Parisjensis curator, adudidit has fliutas operi Petri l'allet "Le jardin du Roy tres chrestien Henry ll:w jufra recensendo.

$8639 \div$ - Ilistuire des plantes nouvellement trousées à lisle Vircrine et autres lieux, lescruelles ont esté prises et tultivées au jarulin de Mr. Robin, arboriste du Ray. Non encore veues n'y imprimées par cydevant. (Impr. cum Geofray Linacier, L'histoire des plantes, Ed. II.) Paris, chez Guillsume Macé. $1620,12.16$ p., ic. xylogr. i. t.

86406 Enchiriltion isagosicum al facilem notitian stirpium tan indigenarum quam exoticarum. Ilae coluntur iu horlo D.1). Johannis ef I"espasiani Rubin, hotanicorum regiorum. Parisiis, apud Petrum de Bresche, 1624, s. 71 p., pracf.

861 t Robinet, Stephane. Ohservations sur la salseparoille, en réponse a un article de J. J. Jirey. Paris, typ. Fuurnier. 1823. 8.4 p.

86.2 Robley, Augusta $J$. A selection of Madeira flowers, drawn and coloured from nature, by Auyusta J. Robley. London, Reeve. 1845. folio. $(1 /, 1 s$.

864.3* Robson, Stephen. The British Florn, containing the select names ctc. With the principales of botany. York, I'hilijps. 1777. 8. xx, 330 p., ind., 5 lab.

S61: Rocardus, Claudius. The planlis Mbsinthii tractalus. Tenetiis, apul Robertum Mejetım. 1389. 4. Bum. - *impr. cum Jean Bauhin, De plantis Absynthii nomen habentibus. Nontisbeligardi 1593. 8.

864.5 Rochefort, Cesar de. Histoire niturelle et morale des isles AnLillos d'Amérique. Rotterdam, Aruout Leers. 1639. 4. s. - Ed. II: Rolterdan 1665. 4. 583 j., Lab. B. - Rolterdam, Reinier Leers. 1681.4. S.

hollandice: Xatuurlyke en zedelyke llistorie yan d"Eylanden de Voor-bylanden van America ete. vertaalt en neder-duytsch door H. Dullaur. Rotterdaun 1662. 't. Rivin.

anglice: The history of the Caribby-islands, renderel into english by $J$. Davies. London 16066 . folin. $331 \mathrm{p}$., (al). B.

germanice: Historisclac Benchrelbung der Antullen-luseln in Amerika getegen, ans dem Franzosischen ins Deutsche ubersetzt; mit kupferu. Frankfut trits. 12. Rivin.

86:6- Rochel, Anton. PlJanzenumrisse aus dem südustlichen Karpati des Bannats. Erste Lieferung mit 82 Abbildungen in naturlicher firosse, sanmt den nothigen Zergliederungen iuf 39 Tafeln nach dem Leben gezcichnel, und mil Beschreilungen begleitel. Wien 1520. Colio. I tab. Bibl. Cand.

llujus tilıri, qui fortasse nunquam in lucem prodiit, vidi solummodu titulun in kilbliotheca cindulleatua; rarias foliormm formae in marginc foln arte lithographica reprapsentantur.)

$86: 7^{*}$ Naturhistorische Miscellen uber den nordwestlichen Karpath in Oberungarn. Pestl, typ. Trattner. 1821. 8. xIt, $135 \mathrm{j}$., 1 charta geogr. ( $2 \frac{1}{3}$ th.)

$\$ 6.88^{*}$ Plantae Banatus rariores, iconibus et descriptionibus illustratae. Praemisso tractatu phytogengraphico et subnexis additamentis in terminologian bolanicam. Acceiunt tabulae botanicae $\mathrm{XL}$ et dune majpae lithographicae. Pestini, typ. Fiskiut. (Jlartleben.) 1S29. folio. $1 \mathrm{H}, 84 \mathrm{p}$., ind, 42 tab. $(6 \mathrm{th}$.)

$86.9^{*}$ - Botanische Reise in das Bannat im Jahre $183 \%$, nebst Gelegenheitsbemerhungen und einem Verzeicluniss aller bis zur Stunde daselbst vorgefundenen wiblwaclsenden phanerogamen Pflanzen, sammt topographischen Beitragen uber den sudustlichen Theil des Donaustromes in ostreichsehen Kaiserthum. Mit einer lithograplirten Ansicht. Pesth, Ilechenast. (Leipzig, Otto Wiganu.) 1838.8. 90 p., | tab. $(2 / 3(h)$.

8630 * Rochleder, Friedrich. Beilrage zur Plytochenie. Wien, Staatsduckerei. (Gerold.) 4847.8 .51 p. $(2 / 5$ th.)

$8651^{*}$ ( $\mathbf{F o d a t i}$, Aloys.) Index plantarum, quae exstant in horto publico Bunoniac antu 1802. Accelunt observationes circa duas species Agaves, nee non continuatio historiae horti ejusden. Bononiae, typ. Th. Aquinatis. (1802.) 4. $121 \mathrm{l}$., $5 \mathrm{tab}$.

8632 Catalogue des plantes euitives dans Ie jardin de Mr. de Spin à St. Sebastien, Département dı Po. 1804. 8. - Suppl. I: 1805.8. - Suppl. II: 1806.8. Dc.

(Posteriares hujus horti calaloges vide infra in nomine Spin).

8653 Rodet, $H . J$. A. Leçons de botanique élémentaire. Toulouse 4847. 8. ( $5 \mathrm{fr}$.)

Prirzel, Thes. lit. bot.
S65: Rodon y Bell, Martin. Breve discurso de la bolanica. Cartagena 1788. 4. Bibl. Reg. Soc. Lond.

865:* Rodschied, Ernst Karl. Commentatio de necessitate et utilitate studii botanici. D. Narburgi, Iyp. academiae. 1790, 8. 32 p.

$8636^{*}$ Roeber, Feanz Eduard. Explicatio systematis plantarum naturais pharmacodynamica praecipue alcaloiclum respectu. D. Herbipoli, tȳp. Benilas et Bauer. 1842. S. $126 \mathrm{p}$.

$8657^{*}$ Roederer, Charles Gale. De radice Filicis maris et de extracto es co parato. 1). Jenae 1829, 4. 26 p.

8658* Roehling, Johann Chrisloph. Deutschlauds FJora, zum bequeneu Gebrauclie beim Botanisiren. Nobst einer erklarenden Einleitung in die botanische kimstsprache, zum Besten der Anfanger. Bremen 1796. S. LXIN, 540 p., ind. - ${ }^{*}$ Ed II: Frankfurt a/M. $1812-1813$. III voll. S. - * Ed. III: Deutsehlands Flora. Nach einen veranderten und erweiterten Plane bearbeitet von Franz Karl Mertens und ITilkeln Daniel Joseph Kach. Franhfurt a/M., Friedrich Wilmans. 1823 - I\$39. V roll. 8. - 1: sect. 1. 2. 1823. xxw, 891 p. - II: 1826. Iv, 659 p. - III: 1831. v111, 573 p. - IV: 1833. IV, 744 p. V: sed. 1. $1839.1 \mathrm{r}, 370 \mathrm{p} .(20 \mathrm{th}$.

(operis atlune incompleti, quod inde a volumine quarto solus edidit rever. Koch, continuationen conjunelis optimi senis et Bischoffit Hejdelbergensis curis in dies exspectamus.)

$8639^{*}$ Deutschlands Moose. Naclı der neusten Methode geordnet und beschrieben. (Noasgeschichte 1)eutschlands.) Bremen, Friedrich Wilmans. $1800.8 . \times L 1,436 \mathrm{p} .(15 \%$ th. $)$

$8660^{*}$ (Maritz Balhetsar) Barkhausen's Riugen nach dem schönsten Ziele des Mannes. Ein Denhmal der Freundschaft. Frankfurta/M., Friedrich Wilmans. 1808.8 , xiv, 162 p., 1 tab. col. $(3 / 4$ th.)

8661* RoelI, Cornelis Constantin. Do Veratrine ejusque usu medico observationibus clinicis investigatio. W. Trajecti a/Rh. 1\$37.8.103p.

8662 ${ }^{*}$ Roelsius, Tobias. Epistola de certis quibusdam plantis ad Clusium. Impr. cum Churles De lEckuse, Rariorum plautarum historia. AntWerpiae, ex oflicina Plantiniana. 1601. folio. p. CCCXY-CCCXX.

$8663^{*}$ Roemer, Friedrich Adolph. Die Versteinerungen des Harzgebirges. Hannever, Ilahn. 1843, 4. xx, $40 \mathrm{p}$, 12 tab. (2 th.

$8664^{*}$ — Die Algen Deutschlands. Hannover, Hahn. 1845. 4, II. 72 p., 14 tals. (2 th.)

$8665^{*}$ Foemer, Joham Jakob. Nagazin fur die Botanik, herausgegeben von Joham Jakob Raener und Paulus Usteri. Zürich, Fussli (Ziegler und Solme.) $1787-1790.12$ Stuck $=I V$ voll. S. - I: $1787.167 \mathrm{p}$. 2 tab. - II: 1787. 164 J., 3 tab. - III: 1788.158 p. - IV: 178s 189 p. 4 tab. col. - V: 1789.184 p. - VI: 1789. 194 p., I tab. nigr., 2 tab. col. - VII: 1790. 178 p., \& tab. col. - Vill: 1790. 184 p. $-\mathrm{IX}: 1790.147 \mathrm{p} ., 2$ tab. $-\mathrm{X}: 1790.200 \mathrm{p}-\mathrm{XI}: 1790$. 192 j., 2 tab. col. - Xll: 1790.205 p., 2 lab. col. $(8$ th.

$8666^{*}$ - Neues Magazin fur die Botanik in ihrem ganzen Umfange. Erster Band, Zurich, Ziegler und Sobne. 1794. 8. vir, $336 \mathrm{p}$. 4 tab. $\left(1 \frac{1}{3}(h)\right.$.

$8667^{*}-$ Archiv fur die Betanik. Leipzig, Schaefer. 1796-1805. 9 stuck = III voll. 4. - I: Stück $1-3$. $1796-1798$. vill, 134 , 192, $186 \mathrm{p} .$, ind., $17 \mathrm{tah}$. - II: Stuck 4-6. $1799-1801.450 \mathrm{p}$. ind., 13 tab. - III: Stuch $7-9.1803-1805$. v1, 464 p., 9 tab. (24 th.)

$8668^{*}$ Scriptores de plantis hispanicis, Jusitanicis, brasiliensibus alornavit et recudi curavit Johann Jakab Roemer. Norimbergae, Raspe. 1796. 8. 184 p., 8 tab. (1 th.)

8669 Encyclopádie für Gärtner und Liebbaber der Gärtuerei. Erstes (und einziges) Ileft. Tubingen 1797. S. ( 1 th.)

$8670^{*}$ - Flura europaea inchoata. Fasciculus I-XIV. Torimbergae, Raspe. 1797-1811.8. 112 tab. col., text. (14th.)

(plura non prodierunt. Singulus fasciculus, pretio $1 / t_{\text {., }}$ thabet s tabulas coloritas.)

$8671+(\longrightarrow$ Calalogus horti botaniei societatis physicae Turicensis. (Turiei) $1802.12 .(66) \mathrm{p}$.

$8672^{*}$ Collectanea al omnem rem bolanicam spectantia. Partim e propriis, partim ex amicorum schedis manuscriptis concinnavit et edidit. Turici, Gessner. 1809.4 .314 p., 4 tab. $\left(3 \frac{1}{3}\right.$ th.)

$8673^{*}$ Versuch cines möglichsł vollstandigen Worterbuchs der hotanischen Terminologie. Zurich, Orell, Fussli et Co. 1816. 8. vI, 826 P. $(4 \%$ th. $)$

(Addutur etiam translation Candollii "Théorie élémentaire de la botanique.s) 
8671" Roemer, Johann Jakob. Caroli a Lime Ejutis Systema vegetahilium secundum classes, orlines, genera, spreies. Cum characterilus, differentiis et synonymiis. Fiditio nova, specielous inde ab edilione XV detectis auch of loctujletita. Curantibus Johum Jokat, Roemer et Joseph Alugust Schultes. Stuttgarlias, Cotta. 1817-1830. V'll voll. vel vill partes. 8. - I: 1817. xxvit , 642 p. - 1l: 1817. vIII, 964 p. - III: 1818 . VI, 584 p. - N: 1819. LX, 888 p. - V: 1819. vil, 1.1I, 632 p. - VI: 1820 . vin, txx, 852 p., elligies J.J. Roemer. - VII, pars 1 et 11 : curarunt Joseph August Schultes et Julius Hermunn Schutles, filius. $1829-1830$. xLm, cvu, $1815 \mathrm{p} .\left(33 \frac{1}{2} \mathrm{lh}\right.$.) - * Systema vegetabilium secunlum elasses, orlines et genera. Lilitio nova, generibus inde ab editione XV deteclis aucta et locnpletata. Volumen I. Sectio prina, inceptum ab J. J. Roemer el J. A. Schultes. Stuttgardiae, Cotta. $1820.8 .323 \mathrm{Jr}(1 \mathrm{~J} / 2 \mathrm{~h}$. $)$ - NJantissae in volumina 1 - III curarunt Joseph August Sehulles of Julius Ilermann Schultes, filius. Stutgardiae, Culta. 1822-1827. III voll. 8. - I: 1822. "'], 386 p. - II: 1824. 388 p. - III: 1827. 717 p. (9/h.) (Opus sohummodo usquo ad lleptandriam classem perduchum est. Volumina Y - VII et Mantissae frost Roenter obitum a Schullesio edita sunt.)

$8675^{*}$ Roemer, M. J. Ilandbuch der allgemeinen Botanik, zum Selbststudium auf der Grundlage des naturlichen Systems bearbeitet. Drei Altheilungen. München, Fleiselimann. 1835-1840.8. - J: 1835. $\mathrm{vl}, 426 \mathrm{p} .-11: 1836.562 \mathrm{p} .-111: 1840.716 \mathrm{p} .(6 \%$, lh. $)$ (Prodiil etiam it' fasciculis.)

$8676^{*}$ Geographie und Geschichto der Pflanzen. München, Fleischmann. 1841 . 8. 144 p. $(2 / 3$ (h.)

(Seorsim impr. ex libro pracecdenti.)

$8677^{*}$ - Faniliarum naturalium regni vegetabilis sỵnopses monographicae; seu enumeratio omnium plantarum liucusque detectarum secundum ordines uaturales, genera el species digestarum, additis diaguosibus, synonymis, novarumque rel minus cognitarum descriptionibus. Wimariae, Industrie Comptrir. 1846-4847. Fasc. I -IV. 8. $\left(5 \frac{1}{5}(h)\right.$

Fase. 1: 1846. Hesperides. rm, $151 \mathrm{p}$. (1 $\mathrm{lh}$.)

Fase. II: 1846. Peponiferarun Pars I. x, $222 \mathrm{p} .(1 \mathrm{l} / \mathrm{s} / \mathrm{h}$.

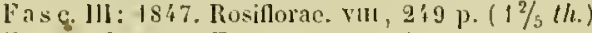

Fasc. 1V: 1847. Ensatac. Pars prima. vi, $314 \mathrm{p} .(13 / 5 / \mathrm{h}$.

8678* Roeper, Johannes August Christian. Enumeratio Euphorbiarnm, quao in Germania et Pannonia gignuntur. Gocttingae, typ. C. E. Rosenbusch. 1824. 4. vill, $65 \mathrm{p} ., 3$ tab. $\left(1 \frac{1}{3} / \mathrm{h}.\right)$

$8679^{*} \longrightarrow$ De organis plantarum. Basileao, typ. A. Wieland. 1828 . 4. 23 p. $(1 / 4$ th. $)$

$8680^{*}$ De florihus el affinitatibus Balsaminearum. Basileae, typ. J. G. Neuhirch. 1830.8 . 11, 70 p.

$8681+-$ Verzeichniss der Griser MeckJenJurgs. Rostock, typ Idler. $1840.4 .15 \mathrm{p}$.

8682* - Zur Flora Mechlenburgs. Erster Theil. (Filices.) Rehtoratsprogramm. Rostock, Iyp. Ailler. (Leopold.) is43. 8. 160 p., 1 tab. $(5 / 8(h)$.

8683* Zur Flora Mecklenburga, Zweiter Theil. (Gramineae.) Rostock, [y]). Adler. 1844. 8. 296 p., 1 tab. (1 $1 / 2$ (h.)

S68: * Roessig, Karl Gollob. Oehonomisch-physikalisehe Ablandlung uber das Mutterkorn (Sclerotium Clavus), dessen Entstehung und Bestandtheile. Leipzig, Schnciler, 1786, 8.76 p.

$8685+$ (- Handbuch fur hiebhaher englischer P(lanzungen und für Gärner. Neue, betráchtlich vermelirte Ausgabe, neJsst einen Anhange uber die Auswalıl ter Gewachse za charahteristischen und einigen audern Anlagen. Leijzig, Sommer. 4 i96.8.300 p., praef.

$8686^{*}$ Ochunomisch-butanis the Beschreihmugder verschiednen und rorziglicheren Arten, Abarten und Spielarten der Rosen. Leipzig, Klecfeld. 1799-1803. Il roll. S. - I; 1799. xu, 24Q p. 11: $1803 . x v 1,247$ p. $(11 / 2$ lh. $)$

$8687^{*}$ — Die Rosen, nach der Natur gezeiclnnet und kolorirt, mit kurzen botanischen Bestimnungen begleitet von ). Roessig (und Karl Friedrich Waitz?) Les Roses dessinées et enluminées d'aprés nature, avee une courte description botani,jue; traduit de Jallemand par 11. de Lahitte. Leipzig, Industric-Conptoir. (1802-1820.) II voll. = $12 \mathrm{Hlefte}$ 4. 60 foll. germanico et gallice, $60 \mathrm{tab} . \mathrm{col}$. (10 th.) Versuch einer holanischen bestimmung der Runkelgen uber die kultur derselben. Leipzig $4800.8,51$ p. B.
$8689 \div$ Rnessig, Karl Gotllob. Die Nelken uach jhron Arten, besonders nach der J. C. Etler's in Selneebery und andern beruluten SammJungen, in Jhattern nach der Natur gezeichet und ausgenalt. ac. Leipzis, Irulustrie-Comptoir. $(1806-1807$.$) 4. 82$ p., 30 tab. (fig. $1-120)$ col. $\left(1 \frac{1}{2}(h\right.$. $)$

$8690 t$ Versucl rines neuen Systems, die Varietaten und Sorten der Tulpen uach ihrer Zeichnung zu ordnen. etc. Nene dudage. I.eipzig, Joaclitm's lit, Magazin. (1807.) 8. 81 p., tah.

(11) pagins $7 \%-78$ literatura de Tulipis suse espouitur.)

8691t Roffavier, Cieorge. Notice sur Madane (Clenence) lortet, (nee Pichurd), membure de la société linntente de Lyun. Lyon, typ. Perrin. 4.835.8. $11 \mathrm{P}$.

8692* Roget, Peler Mark. Aninal and vegetable plysiology, considered witl reference to natural theology. London, William Pichering. 1834. 8. - " Ed. 111: London, William Pickering. 1s\$0. 11 roll. \$. - I: xxxvi, 524 p., ic. xylogr, i. t. - II: vu, $59 \mathrm{~S}$ p., ic, xylogre i. t. The Bridgewater Trioatives, Nir.

germanice: ubersetzt von Dr. Hauf. Stullgart 183;, s.

8693" Rohde, Michael. Monographiae Ginchnnae greucris specimen, sistens historiam ejus critican ad introductionem ill looc gems inservientem. D. Gocttingae, typ. Barmeier. 180\%.8. 56 \%.- "Ed. II. auetior. Goettingae, Vandenhoeck et Ruprecht. IS0 4. $8 . x, 189 \mathrm{p}$. $\left(1 / 2, h_{0}\right)$

S69:* Rohr, Julius Bernhard ron. Ilistoria naturalis arborum el fruticum sylvestrium Germaniae, oder Vaturmássige Geschichte der vou siclı selbst wilde wachsenden Bäume und Siráucher in Teutschland. ete. Leipzigr, Braun. 4732. folio. 248 1\%, jraef, ind. - Leijzig 1753.8 .

$8693^{*}$ Plyysikalisch-okonomischer Trahlat von dem Nutzen der Gewachse, insunderheit der hräuter und Blumen, in beforderung der Gluchseligheit und Bequendichkeit des menschlichen Lebens. Accelit: Auf was fur Art in dem keich dor Gewaclse die sehweren, undeutlichen und ungewissen Benennungen nach und nach aljzuschallen und solche deutlicher uml rernunftmássiger einzurichten. Coburg, Steinmarck. 1736. 8.358 p.

$8696^{*}$ - Phytotheologid, ader yernunft- und scluriftnássiger Versuch, wie ans tem Reiche der Gewächse die Allmacht, Weisheit, Gute und Gerechtigkeil des grossen Schöpfers erhannt werden möge etc. Franhfurt unl Leipzig, Blochberger: 1740. 8. 590 p., praef, ind. - "E \&. Il: ib. 1745.8 .540 p., praef., ind.

8697 Rohr, Julius Philipp Benjamin ron. Anmerkumgen uber den Cattunbau. Altuna uml Leipzig 1791-1793. Il voll. 8. - I: 1791 . 139 1. $-11: 1793.156$ p. B.

t gallice: Dibservations sur la culture du coton. Paris, Jluzard. 1805, 8. $\mathrm{xx}, 231 \mathrm{p}$

8698* Rohrer, Iludolph, und Augusl Mayer. Vorarbeiten zu einer Flora des Maluriselien Gouvernements, ader systematisches Verzeichniss aller in Mlahren und Oesterreuhisch-Sehlesien wildwachsenden PJanerogamen. Brün, Rohrer. 1835.8 . xLW, 217 p., incl. $\left(1 \frac{1}{2} \mathrm{lh}\right.$.)

S699* (Roland, de Fourlou.) Letle du Bostangi-Buchi de Fourtou a Hadame $R$. $B$. sa fille, contenan Jes instructions necessaires jour former, entrefenir les pépinieres et en tirer arantage. Carenssumne. 1уp. Gareng. an XII. $1804.12 .20 \mathrm{p}$.

$8700 t(-)$ Seconcle lettre du Bostangi-Bachi de Fourton a Maulame R. B. sa fille, contenant un abrége du système de Mr. Dillamel sur l'utilite de la racine pivotante. Carcassonne, 1yp. Gareng. an . $\mathbf{l l l}$. $1805.12 .8 \mathrm{p}$.

$8701+(-)$ Lettres du Bastangi-Bachi de Fourtou à ITadame $R^{* * *}$ $B^{* * *}$ sn fille, suivies de sa méthode pour faire un fussé d'asperges. Carcassnmo, 1yp. Gareng. $1807.12 .45 \mathrm{p}$.

Redeunt in hoc libro duae praecedentes epistolice, addlita tertia atque nuchocio culturae Asparagi.

8702* Rollfink, J'erner, Jatine Guernerus Rolfincius. Liber de purgantibus vegetabilibus, sectionibus $\mathrm{XV}$ absolutus. Jenae. tYp. Joh. Werther. 1667.4 .454 p., praef, ind. - Ell. 11: Jenae, Iyp. Jols. Werther. 168\%, 4, Rivin.

$8703^{*}=$ De vegetabilibus, plantis, suffruticihus, fruticibus, arboribus in genere libri duo. Jenae, typ. Joh. Werther. 1670. 4. 2.16 p., praef., ind.

870"* Rolnff, Christian Luduig. Index plantarum tam peregrinarum quam nostro nascentium coelo, quae aluntur Berolini in horto ce- 
lebri Krausiano. Berolini, typ. Kunst. (1746.) 8. 176 p., praef., ind. 4 tah. Ni. (Alium

$8703 \div$ Roman, J. G. Catalogus plantarum usualium, quae in horto aeademico Groningano coluntur, secundum systema Linnaeanum digestus. Groningae, Zuidena. 1802.8. 146 p., praef, ind.

$5706^{*}$ Romano, Antonio. Plantae officinales in Europa sponte crescentes. Viennae, typ. Nochitaristarum. 1837.8. 128 p.

8707\% Romano, Girolamo. Catalugus plantarum italicarum. Patavii, 1Yp. Minerva. $1820.8 .74 \mathrm{p}$.

$8708^{*}-$ Le piante fanerogane Euganee, per le auspieatissime nozze Heneghini-Fabris. Padova 4828. 8. - ${ }^{*}$ Ed. III : Padova 1831.8 .

$8709+$ Ronalds, Jugh. Pyrus Malus Brentfordiensis: or a concise descrijtion of selected apples. With a figure of each sort drawn from nature on stone by his daughter. London, typ. Taylor. 1831. gr. 4. sur, 91 p., 42 tab. pulcherrime col. (5l. 5.s.) Bibl. Deless.

$8710^{*}$ Ronconi, Agoslino. Osservazioni del Duttor Agastıno Ronconi su la Flora napulitana. Lettera prima. Napoli, stamperia Flantina. 1811. 8. $40 \mathrm{p}$.

$8711^{*}$ Analisi delle Osservazioni del Dottor Agostino Rancani su la Flora napolitana del Dottor Giovanni Gussane. Napoli, stamperia Coda. $1811.8 .4 \mathrm{dp}$

$8712+$ Ronconi, Ignazio. Dizionario d'agricoltura, ossia la coltivazione italiana. Venezia 177I. 8. - †Ed. V: Tenezia 1804. V voll. 8. Bibl cand.

$8713^{*}$ Rooke, llayman. Deseriptions and shetches of some remarkable oaks in the Park at Welbech, with observations on the age and durability of that tree, and remarks on the annual growth of the Acorn. London, White. 1790. 4. 23 p., 10 tab.

8714 Rootsey, S. Syllabus of a course of botanical lectures; to which is prefixed a poem upon the importance of the sluty of botany by Mrs. Turner. Bristol 1818. 12. Bibl. Reg. Soc. Lond.

8713 t Roques, Joseph. Plantes usuelles indigènes el exoliques, dessinées et coloriées d'après nature avec la description de leurs caractères distinctifs et de leurs propriétés mélicales. l'aris, Hocquart. 1807-1808. Il voll. 4. - 1: 1807. vill, 266 p., 72 tab. col. - Il: 1808. 278 1., 61 tah. col. (100 fr.)

$8716+$ Pliylographie médicale, ornée de figures colorièes de grandeur maturelle, ou l'on expose l'histoiro des joisons tirés du régue vẻgétal et les moyens de remédier à leurs eftets délétères, avec des observations sur les propriétés et les usages de's plantes héroiques. Paris, chez l'auteur, 15p. Didot. 1821. I1 voll. 4. - ]: xII, 304 p., tab. col. 1-90. - II: 328 p., tah. col. 91-180. - †Phytographie médicale, histoire des substances liéroiques et des poisons tirès ‘lu règne végétal. Nouvelle édition entierement relundue avec un Atlas grand-in-4. Paris, Cormon el Blanc. 1835. Hll voll. 8. I: $x I x, 560$ p. - II: 620 p. $-111: 560$ p. - Allas: 150 tab. col. (60 fr.)

$8717^{*}-$ Ilistoire des cliampignons, comestibles el vénéneux, oủ l'on expose leurs caractères distinctils, leurs propriétés alimentaires et économiques, leurs effets muisibles et les moyens de s'en garantir ou d'y remédier. Paris, Ilocquart. 1832. 8. - ${ }^{*}$ Ed. II. revue et augmentee. Paris, Fortin, Mlasson et Co. 1841. 8. 482 p. - Atlas in $4: 24$ tab. col. ( $27 \mathrm{fr}$.)

8718 - Youveau traité des plantes usucles, spécialement appliqué à la médecine domestique et au régime alimentaire de I'homme sain ou malade. Paris, Dufart. $1837-$ i 838 . IV voll. 8.

8719 Roschmann, Anton. Reguum animale, regetabile et medieum tyrolense. Oeniponti 1738.4. H.

$8720^{*}$ Roscoe, William. Honandrian plants of the order Scitamineae, chiefly drawn from living specimens in the botanic garden at Liverpool. Arranged according to the system of Limnaeus with descriptions ancl observations. Liverpool, typ. George Smith. 1828. folio. (137) foll., 112 tab. col. (15l.15s.) (46 ih. A. Berlin.)

(Cf. Transactions of the Linnaean Sociely, vol. Vill. p. 330.)

8721 $\div$ Roscoe, Mistriss Edward. Floral illustrations of the seasons, consisting of representations drawn Irom uature of some of the most heautiful hardy and rare herbaeeous plants cultivated in the flowergarden, carefully arranged according to their season of flowering, with botanical descriptions, directions for enlture etc. engraved by R. Havell jur. Nr. I. Spring. London, Baldwin and Cradock. 1829.4. vi. 8 p. 8 tab. cul. (9s.) Bibl. Cand.

(Plura non vidi. Mistriss Edward Roscoe est filia autoris praece-

$8722 \div$ Rose, IIugh. The elements of botany: containing the listory of the science: with accurate definitions of all the terms of art etc. being a transtation of the Philosophia botanica of Limaeus, to which is added ais Apuendix, wherein are described some plants lately found in Norfolk and Suffolk, never found before in England, with 3 plates. London, Cadell. 1775. 8. xil, 472 p., 11, 3 tab.

8793 Rosén, nolvilis Rosenblad, Eberhard, pr. De cortice peruviano. D. Lomdini Guthorum 1744. 4. 60 P., 1 tab. e figura Condamini exseripta. (Respoudens: Nils Johan Lönquist.) в.

$872 \xi^{*}$ Ohservationes botanieae circa plantas quasdam Scaniae non ubivis obvias et partin quidem in Suecia luveusque non detectas, quibus accessit brevis disquisilio de strage bovilla, quotannis in pascuis Christianstaclii ohservata. Londinj Gothorun, 1yp. Berling 1749. 4. 89 p., praef.

872"3 Rosenbach, Konrad. Neues Paradiesgärtlein der edelsten Kráuter in Reimen besclurieben. Frankfurt a/N. 1613. 8. H.

8726 Rosenbach, Zacharias. Paradiesgârtlein, darinn die edelsten ḱráuter ahconterfeytet u. beschrieben sind. Frankfurt a/M. 1588. 12. H.

$8727^{*}$ Quatuor indices phrsiei corporum naturalium perfecte mixtorum. Impr. in Joannis Henrici Alstedii Lexico philosoplico. Herbornae 1626. 8. p. 1925-3250.

(Euuneratio stirpium llerbornensium Rosenbachii, cujus meninit Johann Daniel Leers in praefatione llorae llerbornensis, neutiquan pastat. Ortus est eror e loco thale intellecto in Casparis Baulini pinacis reditione allera post praefationem; cf. Flora, diarium bot. Pinacis (2ditione all
Rutisb. $4539 . \mathrm{p} .667$ )

8728* Rosenberg, Joham harl. Rhoulologia, seu phỉosoplico-medica generosae Rosae deseriptio. Flosculis philosophicis, arcanis politicis, chymicis etc. adornata. Argentinae, typ. Marci ab 1leyden. 1628. 2. 316 p., prace. - * Editıo novissina aucta. Francofurti a/M., Fitzer. (ty]. haeredum Palthenii.) 1631.8. 403 p., praef., ind.

8729 Rosenberger, Otto Friedrich. Anleitung, die Fruchtbăume durch

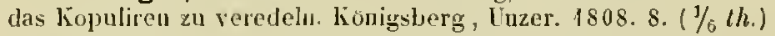

$8730^{*}$ Rosencreutzer, Max Friedrich. Newe Practica des Wurtz- und kinuterkalenders. etc. Nurwherg, Eudter. 1652. 4. (15) foll.

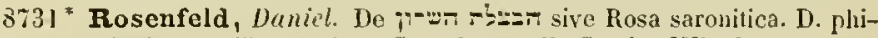
lolugica idl illustrandum Com. I. eap. Il. Cantic. Wittebergae, typ. Gerdes. 1715. 4. 24 p. (Respondens: Christian Albert Reineccius.)

8732* Rosenmueller, Ernst Friedrich Karl. Handbuch der biblischen Altertlumshunde. Vierter Band, erste Abtheilung : Biblische Naturgescliclite. Erster Theil: das biblische Mineral- und Pflanzeureich. Leipzig, Baungartner. 1830. 8.347 p.

(llistoria plintarum bihlicarum: p. 69-3k7.)

$8733^{*}$ Rosenthal, Collfried Erich. Versuche, die zum Wachsthum der Pilanzen benothigte Wäme zu bestimmeu. Erfurt, Keyser. 1784. 4. $24 \mathrm{p}$. (Acta Acad. Nogunt. 1782, 83.)

873:* Ross, James Clark. A voyaye of diseorery and research in the southern and antarctic regions, during the years 1839-1843. By Captain Sir James Clark Ross. With plates, maps and woodcuts. In two volumes. London, John Mlurray. 1847. Il voll. 8. - I: Lit, 366 p., is tab. $-11: x, 447 \mathrm{p}$.

(Nonmulla iusunt capita botanici argumenti, quae suppeditavit itineris clarus botanicus, Jaseph ballon Hooker.

* germanice: übes'setzt von Julius Seybl. Leipzig, Lorck. 18'7. 8. গT, 432 p., 2 tab. (21/2 $h$.)

8735* Ross, John. A voyage of diseovery made under the orders of the Admirality in His Majesty's ships Isubella and Alexander for tho purpose of exploring Baffin's Bay, and inquiring into the probability of a nortli-west passage. London, Murray. 1819.4 . xL, 252 , cxulv p., 7 tab. $\{3 l .13 s .6 d$. $)$

(Botanical appendix : "l.ist of plants collected on the coasts of Baffin's Bay ind at Possessions Bay, by Rabert Brounn, p. 137-14'.)

$8736^{*}$ (Rossi, Giovanni.) Catalogus plantarum horti regii Modoetiensis ad annum 1825 . Mlediolani, typis regiis. 1826. 4. VII1, 83 p., 3 tab. 
$8737^{*}$ Rossi, Leonhard Ileinrich Johamu. Do elfectu Coniini in organismum animalem. D. Marburgi 1844. 8. $49 \mathrm{f}^{\text {r }}$

8738* Rossi, fietro. De noumulis plantis, quac pro renenatis halsentur, observationes ex experimcutil a Petro Rossi liformotie instituta. Pisis, 15p. Giovanelli. $1762.8 .66 \mathrm{p}$.

$8739^{*}$ - Memoria di Pietro lossi extratla dal lomo TIJ (p. $369-$ 430) degli alti della socicti italiana. (Istoria di cir che è stato pensato intoruo alla fecondazione dello piate, dalla scoplerta alel doppro sesso fino a yluesto tempo, coll' agrgiunta di unove sperienze.) Verona, per Diunigi Ramanzini. 1794. 4. 62 1.

$8740 \div$ Rossignol (de Vallouise), Jean Joseph. Botanijue élémertnire, ou l'on apprend a conmalre les plantes sans le secours d'aucun maitre. Turiu, Reycend. 1790. 8. B0, 24 1).

8741* Rossmaessler, Emil Adolph. Bejträge zur Verstcinerungskumle. Erstes Ileft. Dresden und Leipzig, Aruald. 1840. gr. 8. vi, 征 j., 12 tal. ( 2 th.)

$8712^{*}$ — Das Wielutigste vom innern Ban und Leben der fiewhichse, fur ilen [raktischen Landwirlh fasslich dargestellt. Dresten und Leipzig, Aruolu. 1843 . 8. xvi, 220 p., 3 tah. $(1 / / 3 / h$.)

874.3* Rost, II oldemar. He Filicum ectypis ohviis in lithanthracum Wettinensium Lobejumensium fodiuis. D). Halae, Iyp. Ploetz. 1839. \&. $31 \mathrm{p}$.

$873+1+$ Rostan, Casimir. Instruction sur la fabricalion du syrop ou sucre liquide de raisiı. Marseille, ty j. Achard. 1808. 8.15 p.

$873.5^{*}$ Rostkovius, Friedrich Wilhe/m. Golllieh. Dissertatio botanica do Junco. Halae IV Apr. 1801 . 8. 58 p., 2 lal. - * Eil. II: Monograplsia generis Junci. Berolini, Nauch. 180 J. 8. (nou differt.)

$87.6^{*} \longrightarrow$ ot Wilhelm Ludwig Evald Schmidt. Flora Sedinensis, exhibens plantas phanerogamas spontaneas nee non plantas praecipuas agri swinemundii. Sedini, typ. Struck. 1824. S. van, 4.11 p., 2 tab. $\left(1 / \frac{1}{t}\right.$ h. $)$

8747* Rot von Schreckenstein, Friedrich, und J. M. von Engelberg. l'lora der Gegend um den l'rsprung des Donau und des Neckars; daun vom Einlluss der Schussen in den Bodensee bis zum Einfluss der Kinzing in den Bhein. Érstos Bandehen. (AlonandriaTetrandria.) Dondueschingen, Wilibald. 4801. 8. 389 p.

(Plura jon vidi. Tres prodiisse dicurıtı tomuli.)

8718* Rota, Lorenzo. Enumerazione telle piante fanerogame rare della provincia Bergamasca. Pavia, typ. Fusi et Co. 1843.8. $38 \mathrm{p}$.

8719* Roth, Albrecht Wilhelm. Verzeichniss derjenigen Pflanzen, welclie nach der Anzalsl und der Beschaffenheit ihrer Geschlechistheile nicht in den gehorigen Kilassen und Ortnungen des Linneischen Systemes stehen, nelıst ciner Eituleitung in dieses System. Altenburg $1781.8 .216 \mathrm{p}$.

(Additamentum invenilur in cjusdem "Beilrcige zur Botanih vol. 11. p. 101-121.

$8750^{\circ}-$ Beitráge zur Botauik. Bremen, Forster. 1782-1783. II voll. 8. - I: 1782. viI, 132 p. - II: 1783. vIII, 190 p.

$8731^{*}$ Botanische Abhandlungen und Beolachtungen. Nürnherr. Wintersclımidt. 1787. 4. 6s p., 12 tab. col.

8752* (t. III : ib. Gleditsch.) $1788-1800$. Ill voll. 8 , - Tomus I, continens enumerationem plantarum in Germania sponte nascentiun. 1788 xvı, 560 p., ind. - Tomus Il, pars prior, continens synonyma et adversaria ad illustrationem Florae germanicae. 1789 . If, 694 p. Tomus Il, pars secunda, continens symonyma et adversaria ad illustrationem Florae germanicae. 1793.593 p. - Tomus III, pars prior, continens symonyma et adversaria in illustrationem Florae germanieae. 1800 . vill, 578 p. $(6 \% / 2$ th $)$

$5753^{*}$ - Bemerkungen uber das Studium fler kryptogamischen Wassergewachse. Hanover, Ilalm. 1797.8. 109 p. (7/2, (h.)

$8734^{*}$ Catalecta botanica, quibus plantae nevae el minus cognitae describuntur atque illustrantur. Fase. I - III. Lipsiae, Gleditsch. (F. A. Bruckhaus.) 1797-1806. 8. - I: Lipsiae, J. G. Muller 1797. viI, 244 p., ind., 8 tab. col. - II: 1800.258 p., ind., 9 tab.

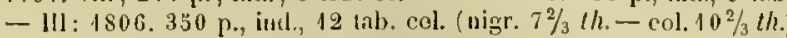

$8755^{*}-$ Neue Beilrige zur Botanik. Erster Theil. Frankfurt a/N. Wilmans. $1802.8 . \mathrm{xu}, 351 \mathrm{p} .(1 \%$ th. $)$

$8736^{*}-$ Anweisung, Pllanzen zum Nutzen und Vergnugen zu samnılu, und nach dem Linneischen Systeme zu bestimmen. Zweite umgearbeitcte Auflage. Gutha, Eittingor. 1803. 8. xvi, 300 p. $(3 /$, th. $)$

8737* Roth, Allurecht II ilhelm. Botanische Benerkungen und Berichti-

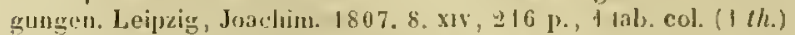

$8738^{*}$ Covae plantarum species presertim luliae orientalis, ex collectione Dr. Benjamin Heyni. Cum alrseripntonilus el ubser-

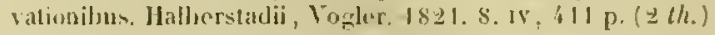

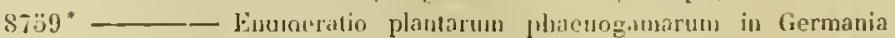
sponte nascentium. Pars primil. Sertio prior. Classis $1-1$. Lipsiae,

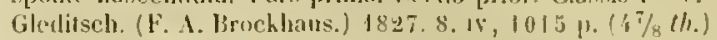

$8760^{\circ}$ Manuale botanicum peregrinalionitus lotanicis accommodalum, sive Prodromus enumeralionis plantarum pluanerogamarum in Germania sponte nascentium. Fasc. I - III. L.jpsiae, Hahn. 1830.8. VI, $1467 \%$ \% ( $/$ h. $)$

$8761^{*}$ Roth, Friedrich Karl. De Inlico, medicanius. D. Berolini 1834. 8. 32 p.

S762* Rotheram, John. The seves of plants vindicated: in a lotter to Mr. ITilliam Smetlie, containing a refutation of his arguments agilust the sexcs of plants, and remarks on certain passingem of his philnsophy of natural philosiplyy. Eilinhurgh, Creech, $1790.8 .43 \mathrm{f}$.

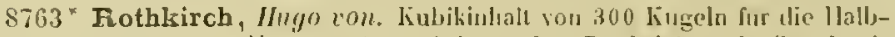
messer, 1, 1 1/2, 2- 150, mil besondrer Rucksiclu auf mihroskopische Messunget, und Viclfache von t/3 $\pi$ vou $1-350$. Breslau, typ. Grass, Barli in Co. 1843.4.12 p.

(Scorsm inpr. ex Nov. Act. Acal. Caes. Lrop. Car. Nut. Cur.)

$8764^{*}$ Rottboell, Christen Frik. Bulanikons udstrakte myte, foredragel $i$ el Indhydelses Skrifl. Kiobenharn, Iyp. Iloller. (Schubothe.) 177. S. 63 p., 1 tab. ( 60 shill.)

(in p. 21-6i3 antur agit de Conlortis.)

876:3 Descriptiones plantarun rariorum icouibus lustrandas programorate indicit. Uavniae 1772. 8. 32 p. B.

Programma hoceo sistit l'prollomum uperis sanuentis.

$8766^{\circ}$ - Descriptionum el iconum rarioles el fro masina parle novas plantas illustrantium liber primus. Ilavniac 1773. Solio. 71 p., $21 \mathrm{tab}$. - ${ }^{*}$ Deseriptiones et icones rarjorum et pro maxima parte novarum plantarum. Eulitio nova. Havuiae, Gyldental. 1786. foliss. 71 p., 21 tals. (I Redr. 48 skill. - 3 (h).) (non dillert.)

8767 Plantas horli universitatis rariores programnate describit. Havuiae 1773.8.32 J. B.

8768 Descriptiunes rariorum plantarum (surinameusium), nec non materiae medicae atque oeconomicae e terra surimamensi fragmentum. D. Haviliae 1776. 4. 34 p., 5 lab. (Respondens: Arnold Nicolaus Aasheim.) B. - Descriptiones plantarum quarundam surinamensium. Cum fragmento materiae medicae et oecrnomicas surinamensis. Editio secunda emendation. Hafniae et Lipsiar, Schubothe. 1798. folio. 22 j., 5 tial). (ss skill. $-3 /, / h$.

(Acta therar. unversitatis Halluiensis 17 is. p. $267-30$.

$8769-$ Anmähinger og oplysninger til IJ. Porcius Ciato de re rustica. Kiöhenhavn 1790.4.72 p. B.

(Dilushe Vidensk. Selsh. Shrift. nye Samling, vol. NV. [1. 228-300.

8770 _ Reslirivelse over Strelitzia reginae. Impr. cum eins Anmárkninger og oplysuinger til. II. Porcius Culo de re rustica. Kiobenhavn 1790. 4.IX p., l ab. col. B.

(Danske Vidensk. Selsk. Shrift. nye Sanling, vol. W. p. 301-309.)

$8771+$ Roubieu, G. d. Opuscules d'anatente of dhistuire naturelle. Première partic, contenatat: 3. une dissertation sur l'Moe pitte (Agave anericana L.) \&. la descriplion du Colocasia (Arum Colocasia L.) 5. un précis sur les chevre-fenilles tes cnvirons de Montpellier. Montpellier, typ. Fournel. 1816.8 .87 p., 2 tal. ( 2 fr.)

(Arlisa est: in apereri sur lit sensibilité des plantes pas J. Rovbieu, $16 \mathrm{p}$, tiro des Anuales cliniques, tone XXill.)

$8772+$ Rouçel, $F$. Traité des plantes les moins fréquentes, qqui croissent natureliement tans les environs des villes de Gand, d'Alust, de Termonde ot Bruxelles, rajportées sous les dénominations des modernes et des anciens, et arrangíes suivant le système le Liunacus, avec une explication etc. Paris, Bossange. (Bruxelles, Lemaire.) 1792. 8. xxix, Jis p.

$8773^{*}$ Flore du Nord de la France, ou description des plantes indigènes el de celles cultivées dans les départemens de la Lys, de I'Escaut, de la Dyle et des Deux-Nèhes, y compris les plantes, upi naissent dans les pays limitrophes de ces départemens. Onvrago 
de près de 30 ans de soins et de recherches, etc. Paris, Richaril. 1803. II voll. 8. - I : xxxy , 465 p. - II: 348 p. (10 fr.)

877. Roulet, Jean Anloine. Recueil de mémoires sur la culture de la vigue, successivenent présentés par Jéan Antoine Roulet, el couronnés par la société d'énulation patriotipue de Nenchatel. Neuchâtel 1803.8 .

s73̈̈* Rousseau, Jean Jacques. Essais élémentaires sur la botanique (écrits en 1771.) (Oeuvres completes: Milanges, tome V.) Londres 1782. 12. 291 ). - Letres sur la hotanique, (et Fragnent d'un dictionnaire.) Paris 1793- 1793. 8. (Geures completes.) - "Paris el Amsterdam, typ. Didot le jeune. an Vl. 4. (Oewres tome IX, Mlanges tume IV, p. I-214.) - ${ }^{*}$ La Botanir|w ile Jeun Jacques Rousseun. cunlenant tout ce ru'il a ecrit sur eette science ete. Paris, Louis, 1802. 8. xav, 319 p. - " Let!res élémentaires sur la bolanique. Bruxelles, Boubers, $1 \mathrm{~s} 02$. IV voll. 8 . $-1: 364$ p. - 11:374 p. - 111:351 1\% - IV: Recueil des plantes colorices: 54 tah. col., texle. - ${ }^{*}$ La Lotanique de Jeun Jacques Rousseau, orncée de soixante-ciny planches imprimées en eouleurs d'après les peintures de $P$. J. Rutoute. Paris, Delachaussce et Garnery. an XIT. 1805 . fulio. $x, 121$ p. 63 a ab. col. (350 fr. - élition in 4: $200 \mathrm{fr}$.) - "Le botaniste sans maitre, ou maniere d'apprendre seul la botanique, au moyen de l'instruction commencée par $J$.J. Rousseou. Continuée el completón lans la méme forme jar 11. do C. (二 Ilonsieur D. Clairville.) Paris, Levrault. 1S05. 12. xxıv, 297 p., 6 tab. - * Lettres sur la botanique et fragrnent d'un diclionnaire. (Uouvres t. XII. p. 317-554.) Paris, Lefevre. 1819. 8. - La Jotanique de J. J. Rousseu, contenant tout ce qu'il a écrit sur rette science; augmenteo de l'exposition do la métlode de Tournefort, de celle du systime de Linne ete. Paris, l. Louis. 1823. 12. 8 tab., texle. (t/fi.) a. - tJeltres sur la botanique par $J . J$. housseau précédées d'un précis elémentaire de cette science pal L. Gruull. Paris, Beaujonan. (1838.) 12. 192 p.

tanglice: Letter's on the elenents of botany, adressed to a Lady by the celebrated J. J. Mousseau. Translated into english "uth notes

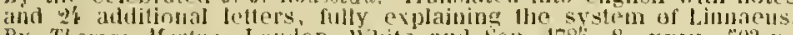
By Thomes Alartyn. Louton, White ant Son. 178.5. 8. Xxut, 503 p. inicl. - t Ed. 11 . with corrections and improvements, ib. 1787. 8. xxy $500 \mathrm{p}$, ind.

rossice: Руссовы инсиа о ботаник, vertente ll'ladimir Ismailow. Mosijuae 1810.8 .

$8776+$ Rousseau, L. F. Limile. De l'effieacití des feuilles du loux (Ilex Aquifolium) tans te traitement des fievres intermittentes. Paris, Baillicre. 183 I. 8.115 p., 2 tableaux, 1 lab. $(3 \mathrm{fr}$.

8777 t Rousseau, Louis, ot Céran Lemonnier. Promenades au jardin des plantes; avec un plan et quatre vues du jardiu. Paris, Bailliere. 1537. 12, xxxi, 519 p., 5 tal. ( 3 fr. )

8778* Roussel, Henri Fransois Anne de. Tablrau des plantes usuelles laugées par ortre, suivant les rapports te leurs principes et do leurs preprićlés. Caen, 19p. Poisson. 1792. 8. 175 1. - "El. 11: Paris, Francart. an V. 8.224 p.

$8779 \div$ - _ L Flore du Calvados et terreins arljacents, composée suivant la méthorle de Jussieu. Caen, typ. Poissun. an IV. (1796.) 8. 268 p. - TEd. Il: Caen, typ. Poisson. 1806. 8. 371 p.

s780* Roussy, Joseph Ludwig. De Fumaria vulgari. D. Argentorati, typ. Pauschinger. 1749.4. $20 \mathrm{p}$.

$5781+$ Roux. Trajte de la culture et fle la plantation des arbres à ouvrer. Paris, Jumlert. 1750.8. $\mathbf{x x}, 357 \mathrm{p}$

8782t Fowden, Frances Arabella. A poetical introduction to the study of botany. London, White and Hooklsam. 4801. 8. Lxx1, $167 \mathrm{p}$.

$8783+$ Roxas Clenente y Rubio, Don Simon de. Ensayo solve las variedades de la vid comun que vegetan en Aulalucia, con un indice etimológico, y tres listas de plautas en que se caracterizan varias especies nuevas. Marlriu, en la imprenta de Villalpando. 1807. 8. xvill, 324, (1) 1\%. Bibl. Cand. et Deless.

* gallice: Essai sur les variétés de ta rigue. qui végétent eú Andalousie; par D. Simon knxas Clemente, hibiothecaire du jardin roya Jolanifue de Madrid. Traduit (de l'espagnol) par $L$. J. C(aumels.) Paris, typ. Poulet. 1si.k. 8 , xv! s.18 1., ibd.

* germanice: Versuch uber die Variotiten des Weinstocks in Andalusien. Aus dem Franzisischen dus Marquis de Caumels ins Deutsche uberselzt dureh A. A. Freiherrn von .Jascon. Gratz, Ferstl. 1821. 8. xil 388 p., 1 tab., 6 schenata. (2 th.)

$8781 .+$ Nemoria solsre el cultivo y cosecha del Algodon (Gossypiun) en general y con aplicacion a España, particular- mente a Motril. Madrid, en la imprentia real. Is 18 s. $43 \mathrm{p}$. Bibl. Webb.

8783 Roxburgh, William. A holanical description of at new species of Swielenia, witl experiments and observations on the bark thereof, in order to determine and compare its powers will those of Peruvian hark, for which it is proposed as a substitute. (Lomtuon 1793.) 4.

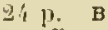

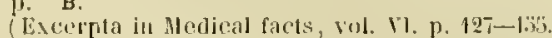

87st;" … Plants of the cuast of Coromandml; selected from drawings and descriptions presented to the Ilon. Court of I birector. of the liast ludia Conpany. Puhlisted, by their nriler, under the direction of Sir Joseph Bunks, Bart. London, printed by W. Buhmer. fur George Nicol, boulsseller. 1795-1813. Ill rull. folio max. 1: 1795. vill, 6s p., tab. col. 1-100. - II: 4798.56 p., \{al). (o) $101-200 .-111: 1819.98$ p. ind., tal), ('ol. $201-300$.

(Volumina I ef II olleruntur antur Iste Lontini pretio 10 Guin.)

$8737+$ An alphabetical list of planls, seen by Dr. Roxburgh growing on the Island of St. Holena ist $1813-1814$. Londen 1816 4. $34 \mathrm{p}$.

(Eustat paucis esemplaribus seorsim impr. ex Alerander Beatson

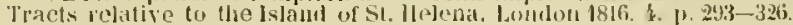

$8788^{*}$ (—— Hortus Bergalousis, or a catatngue of thr plants growing in the honourahle East India Compans's botanjc garden at Cinleutta. Serampore, printed at the mission press. 18/4. 4, V, sts. $76 \mathrm{p}$.

$8789^{*}$ - A catalogne of plants described ly Dr. Roxburgh in his moss. Flora iudica, lut not yet intrortuced inte the lotanical garden. lumpr. cum libro praecedenti. Serampore 4813. 6. p. 77 $-105$.

$8790^{*}$ Flora imlica; or descriptions of Indian plants. Serampore, mission press. $1820-1824$. II voll. 8. $-1: 1820.4931$. - II: 1824.588 p. (26 Rup.)

(Hacere Florace indicae editio prima ultra Pentandrian producta not) est.

$8791^{*}$ - Flora indiea; or tlescriptions of ludian plants. Serampore: printed for W. Thacker and Co., Calcutta, aud for Pirhury, Allen et Co., Londun. 1832 . III voll, grr. 8. - I: Classis I-T $741 \mathrm{l}$. - 11 : Classis V-XIll. v1, 691 p. - 111: Classis XIV-XXII vili, 875 p. (3\% 18s.)

$8792+$ The cryptoganous plants of lir. Roxburgh, formus the fourth and last part of the Flora indica. (l'ublished hy permission of tovernment from Dr. Roxburgh's alss. in the library of the II. C. Jotanic garilens. s. I. et a. 8. 58, II [1. Bibl. Juss.

(Extra from Caleutta Journal.)

8793 Roy, C. И. von. Ansichten uber Entstelumg und Vorkommu tley Bernsteius, so wie pralitische Mittheilungen uber den Werth und die Belaudlung dessellien als Jlautelsware. Danzig (Leipzig, Fort.) 1840. gr. $8.3 \frac{1}{2}$ plag. ( $1 / 3$ th. $)$

879. Roy, Henricus van, latine Regius. Hortus acadenicus Cleritjectimus. Litrajecti 1650.8 .7 plag. B.

$8795+$ Royen, Adrian van. De anatome et oeconomia plintarum. II Lugdumi Batasorum, Samuel Luelttmans. 1728. 4. 46 1\%, practe. poemata gratulatoria.

$87960^{*}$ Oratio cqua jucunda, utilis ac necessaria medicinac cultoribus commendatur doctrina botanica; Jalila LX Maji 1729. qum publicum inslitutioues botanicas praelegendi munus in aeadeni: Lugduno-lBatava inchoaret. Lugdumi Batavorum, Saumel Luchıman. 1799. 4. 26 p., promata.

$8797^{*}$ Carmen elexiacum de amoribus et connubiis plantarum, quum medicinae et botanices professionem in Baltava, tguae est Leidae, academia aspicaretur, dictum. Lugduni Batavorum, Sanuel Luchumans. $1732.4,34,(4) \mathrm{p}$.

$8798^{*}$ Florae Leydensis Prodromus, oxhibens plantas quae in Iorto acaldemico Lugduno-Batavo aluntur. Lugduni Batavorum, Samuel Luchtmans. 1740.8.535 p., praef., ind., I tab,

(Adriuni man Royen codex mantseriptus "Praclectiones"publicac, sive sermo de anatome et neconomia plantarum", volumeul yuarta forma 20 priginatum, servatur in bibliotheca Nusei hotanici Vindobonensis. )

$8799^{*}$ Royen, David van. Oratio de horlis Jublicis, jraestantissimis scientiae botanicae adminiculis. Lugduni batavorun, Luehtmans. 1754. 4. 23 p., poemata. 
8800 Royer. Catalogue des plantes du jardin du Sieur Royer, marchand ipicier, rue du Faubourg St. Martin, a l'aris. Paris 1760. 8. 111 p. B.

$8801^{*}$ Royer, Johann. Bescliribung des ganzen Furstlich Braunschweigischen Gartens zu Ilessem, mit seinen hunstlichen Abtheilunge:1, Guartieren, Geljeghen, fioluaden, Lauberhotten, Wasserkinsten, Brumen und ausgohauenen Hilulern, auch ordentlicher Specificalion iller derer Simpliciun und Kinuter, so von 4607 biss 1658 darinuen gezeuget worlen, nebst nothwendigen Interrich, wie ein feiner Lust-Obsi - und kúchengarten anzulegen, item Anleitung, wie แвan allerley sonderlichn: Garten-Gewätise in der huchen vielfaltig nutzen soll, uml was fur feine Simplicia in den benachbarteı Waklem, Bergen, Grunden, Bruchen, und auf den Iligeln in der see zu finten und aufzulıben seyn. Zum andem Truck vermehret und verbessert. Braunschweig, G. Mluller. 1658, 4. 130 p., praef. s tab. - Ed. 1: Halberstadt, 1648.4. 128 p., 14 tab. B.

Iin prima editione est descriptio horti at p. 1-10; Catalogus aller

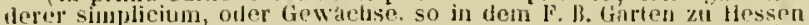

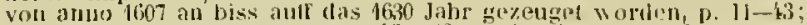

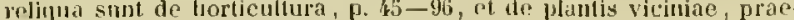
sertiuz moutis Gaterselsjeberisis, p. 112-128.)

$8802+$ Royle, John Forles. An essay on the antiquity of llintoo medicine, including an introduetory lecture to the course of Nateria medien and Therapeuties, delivered at Kings College. London, W'm. 11. Allen el Co. 1837 . S. Iv, 196 p. (6s. 6d.)

$8803^{*}$ Lllustrations of the hotany and other branches of the natural listory of the Ilimalayan mountains and of the Flora of Caslunere. London, Allen et Co. 1839. Il voll. folio. -1 : vit, $472 \mathrm{p}$. - 11: Plales. LxXVIll p., 3, 100 tab. col. (1/l. A s.) Bibl. Link. et univ. Lips.

(De pulchnrrimo opere, annis $18.33-1810$ undecim fascienlis edito, ('. 309 .

$8804^{4}-$ Essay on the productive resources of India. London, Allen al Co. 1 \$ $40.8 . x, 451$ 1.

8803 - A manual of materia medica and therapeutics, including the preparations of the pharmacopoeas of London, Edinburgl and Vublin; with many new medicines. London 1847.12.744 p.

$8806+$ Rozan, Abbe de. Essais sur littérature of d'listoire naturelle, ivec la traduction italienne prar le Père Morealdi. Naples, chez V. Orsino. 1823. 4. x11, 122 p. Bibl. Juss.

(linsunt: Conjectures sur les plantes fossiles du nont Bolea.)

8807 Rozier, Fransois. Mémoire sur la meilleure maniere de faire ct de gouverner les vins de Provence. Lausanne 1772, 8. 350 p., 3 lal. B.

8808 Jlémoire sur la culture et le rouissage du chanre. lyon 1787.8. Dc.

italice: Transunto delta memoria sulla cultura e la macerazione del Canape. Opuseoli seelti XI. $302-31$ s.

8809 Cours complet ou Dictionnaire a'agriculture théorique et pratique. Paris $1781-4805$. Xll voll. 4. - Ed. Il: Paris 1809. Vill voll. $8 .(48$ fr.) DC.

Ultima tria volnmina edilionis furimac, fuum ill. Rozier anno 1793 e vila decessisset, cur'arumt potissimum viri doctissimi dndre Thouin et Antoine Augustin Parmentier; editionem alter'in ediderunt Charles sigisbert Sommini et Tollard.)

$8810+$ Rozin, $A$. Hestier portalif des plantes, qui se trouvent dans les environs de Liège, avec leur description et classification selon le systeme de Linue. l'récété d'un discours sur la botanique. Prémier calicr. (Liège) 1791.8 . vm, 72 p.

(lnsunt specimina plantarum essiceata; continutio non prodiit.)

S811* Rubel, Franz. De Agarico officinali. D. Vindobonae, Gerold. 1778. 8. 42 p., 4 tab.

(Jacquin, Miscellanea austr. vol. 1. p. 104-203.)

8812 Rubens, Ferdinand. Vollstindige Anleitung zur Obstbaumzucht, nelst einer systematisclien lilassifikation und Besclureibung des Obstsorten. Erster Band. Essen, Baedeher. 1843.8 . $26 \%$ plag., 4 tab. $\left(1 \frac{1 / 3}{3} / h.\right)$

8813 - Leichtassliche Anleitung zur Erzielung und Behandlung des Weinstocks. Nannheim, Iloft. 4844.8 . 23 plac., 2 tab. (1 ih.)

881 - Der Obstbaumfreund. Leichtfasslicher Unterricht in der Obstbaumzweln fur Landleute. Stuttgart, Hollmanu. 1846. 8.19 plag., 2 (ab). $(2 / 3 t h$.
881: Rubeus, Hieronymus. Disputatio de Melonibus. Venetiis, apud Joannem Baptistan licrtonum. 1607.4. 11 foll. B.

(Exslat etian inter epistoles lincentiz d/surii Venetiis editas.)

$8816^{*}$ Ruchinger, $G$. Flora dei Lidi Veneli. V'enezia, Iyp. Fuchs. 1818. 8. 304 p., pracef.

S817* Ruchinger, Giusteppe Maria. Centui inturno all' orto botanico del Liceo Convilto di Venezin. Tenezia, typ. Cecehini. 18/2.8.11 p.

(Tres stut liuchingeri, pater cum lithis, quos ad cogromina vix certe secermo. litimu prögensent unihi iluse patter praedicavit autocerte secerno. Fillum plitis

S818 Ruda, J. Plytrotoxicologiae cechicae Imutamen, exlibens plantas senenatus Cechiae indigenas orline naturali. D. J'ragae 1834.8 $82 \mathrm{p}$.

S819 Rudbeck, Olof, pater. Catalogus plantarum, quilus hortum acadenieum Ubsaliensem prinum instruxit anno 1657. L'bsaliae 1658. 4 它. 43 p. B.

8820 , pr. Ilorticultura nova Ipsaliensis. D. Lpsaliae 1664. 4. $2 \%$ plag. (Respondens: Gustaf Lohrmun.) B.

8821 Deliciae V'allis Jacobaeae, sive Jacolusclaal Comitis . Jagn Gubrielis DeluGardie praedii et hortorum prope Stocklıolmian descriptio. Upsaline 1666, 12,36 p.

8822 IJortus Lipaliensis acarlemine, primum instructus anno 1637; accedit ejusdem auctuarium novissimun. Lpsaliae 1666. 12. 43,12 ?. B.

(Est eadem orsuino impressio ac praecedens, novo substituto litulo el addita appentice I' pagmarun.

$8823^{*}$ Hortus botanieus, varis exolicis indigenisque plantis instructus. Upsaliae, Iyp. Ilenr. Curio. 1655.8 . 120, (4) p.

882 * $^{*}$ Canpi Elysii liber secundus, (qui lridum, Nareissorum, Ilyaciuthorum, Tuliparum, Liliorum, Crocorum atque alias ex bulborum genere figuras justa magnitudine expressas habet), opera Olai Rudbecki patris et tilii editus. Then Antre Delen af Glysis Wald, Igenom Olof Rutbuck, Fadren nch Sonen, utlıgangen och tryckit uti Ipsala Ahr 1704. Ipsaliae 170 1. folio. 239 p., (2) foll., ic. .yylogr. i.t. Bibl. aul. Vindob., Reg. Paris.

8823 Campi Elysii liber primus, opera Olai Rudbeckii patris et filii editus. Then Forste Delen al Glysis Wald, Igenom Olof Rudbäck, Fadren och Sonen, uthgängen och trycht uti Lpsala ähr $170 z$. folio. 224 p., ic. xylogr. i. 1. Bibl, Horti bot. 0xon.

$8826^{*}$ Reliquiae Rudbeckianae, sive Camporum Ely siorum libri primi, olim ab Olao Rudbeck patre et filio Lipsaliae anno 1702 editi, quae supersunt, adjectis nominibus Linnaeanis. Accedunt aliae quacdim icones caeteris voluminibus Rudlechianis aut destinatae aut certe haud omnino alienae, hactenus ineditae, cura Jacobi Eduardi Smith. Londini, impensis editoris. 1789 . folio. 35 j., jud., ic.sylogr. i... (Decrevit Olof kulbeck pater ieones ligno incisas plantirum omnium sibi cognirarum una cum synony'mis carum edere; itanjuc partim ex aliis libris, partim et autopsid 11.000 circites plantas maximatn partem ipse delineavit, colorihus oruavit, infque dumbecim volunina digessit, easque dein ligun ineidendas curavit. In hoe opero conseribendo magnan suae vitac partem cousumsit, eique sencscenti filus Olof Kulbeck in his curis operam tulit alssiluan. Taudem anno 1701 tomum secundum operis "Canpri Ely sii o dicti edidermat, enmene propteroa, quod figuras circiler for filintarum Liliacearum, Coronariarum, Ensatarum, Orchidearum et Urabanchearum, quae co continelantur optatiores esise ementibus crediderunt, quan eo conluneliantinr, optatiores este ementibus crediderunt, quam ceteras. Ann 1mo et Jumedrearum, ledu eadem ratione ac in tomo

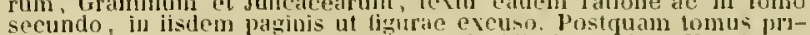
secundo, in isdem paginis ut figrace excus. postquam tomus pra-

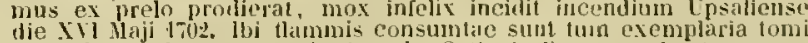
secundi plurima, quat in templo Cathedrali asservabintur, Imm exemplaria tomi primi ommia, ex oflicina typographica mondun emissa, duobus tankummodo exceptis, quorum allerum, quod primum fuit in bibliotheea Benzeliung, tunc ill ciepriana, hodie. teste Hikstrum, ibi nune temporis deest. Énicum, 'fuod hodie superest, cuemplar est in bibliothee sherardiana in hurlo botanico Oxoniensi, enjus

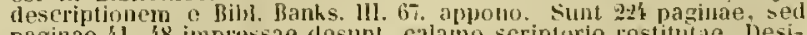
paginae $4 \mathbf{l}-48$ impressae desunt, calamo seripturio restitulde, besideratur eliam tiftlus. Fusiorem operis celcbratissimi et rarissimi historian habes apud llikström, Cons]. lit. bot. in Suecia, p. 220-220.)

$8827^{*}$ Rudbeck, Olof, filius. Propagatio plantarum botanico-pliysica, quam experienlia et rationibus stabilitam, fignuris aeneis exornatam, et huic nostro climati ncenmmodatam evulyat Olarus Rudbeck. Ol. filius. Ipsaliae, exculit Henricus Curio. 1686. 8. 142 p., praef., 5 tab., ic. xylogr. i. t.

Sunt exemplitria cum alia academicat pagina titulari. in qua eliam praesidis $\mathrm{D}$. Andreae prossandri nome'n legitur.) 
8828* Rudbeck, Olof, filius. Disputatio nedica inauguralis de fundamentali plantarum notitia rite acquirenda, quam pro gradu doctoratus publico exanini subjicit ot. Rudleck. Liltrajecti a/Rh., typ. Ilalma. 1690.4. 25 p. - "Dissertatio de fundamentali plantarum notitia rite acquirenda, collatis methorlis, Ilermanniana, Rajana, Riviniana. Augustac Vindelicorum, typ. Schonig. 1691. 12.57 p.

$8829^{*}$ _ Nora Samolad, sive Laponia illustratil, et ites per Uplanliam, Gestriciam, Ilelsingiam, Melelpadian, Angermannian, Rothniam etc. Nora Samolad, eller Uplyste lapland. Hedls Resin genom UpJand, Gestrihland etc. latine et suecice. Upsalac, propriis impensis editum. 1704. 4. 79 p., praef., 2 tab. xylogr., Itab. acu. Bibl. Reg. Dresd.

Opus hoc, teste Linraeo. 12 constabal temis manuscriptis, qunrum primus solm in hoc libello, iter per Lulandian, propmintur perlinet catalozus baccarum eduliun septeutriontialium et icons Sceptri periniet cata

8830 , pr. Disputatio de Ilandragora. Upsaliae 1702. 8. 2 S p. (Respondens: Andreas Hollstom.) $\boldsymbol{B}$.

(Dissertatio hacece omnino congruit cum ea Trajecti a/Rh. 170k. edita, quam supra in nomine Andreas Holtsbom Nr. bisi enumeravi.)

$8831^{*}-$ pr. De Hedera, D. Upsaliae, ty]. Werner. 1707. 4. $45 \mathrm{p}$. (Respondens: Juc. Lundelius.)

$8832^{*} \longrightarrow, \mathrm{pr}$. Rubus hunilis, fragariae folio, fructu rubro, Ackerbä́ frï Norlanden. D. Upsaliae, 1yp. Weruer. 1716.8 .50 p., 2 tab. (Respondens: Doniel Kellander.)

8833 - Ichtlıvologiae biblicae pars seeunda, de Rorith fullonum, quod non herbam aliquam, multo minus smegma vel saponem fuisse, sed purpuram, ex Hierem. 11. 22. at Halich. 111. 2. perplurinis evincitur argumentis. Upsalis, ty]. Werner. 1722. 4. 162 p. B.

8834 - Responsum ad Christiuni Benediti Michaclis, linguarum orientalium Professoris apud llatan objectiones, quo Borith fulloıum, non saponem vel smegmo, ut ijse contendit, sed jurpuram et fucun fuisse, jluribus adhue probatur argumentis. Upsalis, typ. Weruer. $1733,4.38$ p. B.

8833 - Dudaim Rulsenis, quns neutiquam Mindragorae fructus fuisso, aut flores amabiles, lilia, violas, nareissos, leucoía, species molonis, vaccinia, chanachatum, rosan, solanum, halicacabum, certas uras, tubera, maiisch, circaeam, hordeum, philtra amatoria etc. seel fraga, vel mora Rubi idaei spinosi, allatac lic rationes satis videntur evincere. Lpsalis, typ. Werner. 1733.4.18 p. B.

$8836^{*}$ Rudge, Edward. Plantarum Guianae rariorum icones et descriptiones lactenus ineditas. Volumen primum. Londini, sumtilus aucloris, 1yp. Richardi Taylor. 1805 . folio. 32 p., 50 tab. (4l.) Bibl. aul. Vindob. et Deless.

(Pulcherrimi operis nihil amplins prodiit: dun praeparahantur volumina octo fasciculis absolvenda: cubue fascieulo 12 tabulie (lestinatae erant.)

8837* Rudolph, Johamn Heimrich. Florae Jenensis plantac ad Polyandrian IIonogyniam Linuaei pertinentes. D. Jenae, typ. Fickelsclser. $1781.4 .26 \mathrm{p}$.

8838* Rudolphi, Friedrich Karl Ludwig. Systema orbis vegetabilium. D. Grypliae, typ. Kunike. 1830.8 .80 1\% $(5 / 12$ th. $)$

8839 Rudolphi, Johann Christian. Nelkentheorie, oder in systematischer Ordnung nach der Natur gemalte Nelhentalielle. Meissen 1787. 8. - ${ }^{*}$ Zweite verbesserte Auflage: Meissen, Erbstein. 1799. 8.20 p., 1 tab. col. in folio.

88.10* Rudolphi, Karl Asmund. Anatomie der Pflauzen. Götinger Preisschrift. Berlin, Mylius. 1807. 8. xvi, $286 \mathrm{p}, 6$ tab. $(1 \% / 3$ (ht.)

$8841^{*}$ (- Index numismatum in virorum de relous merlicis vel physicis meritorum nemoriam percussorum. (Ad dien semisaecularem Blumenbachii.) Berolini, XIX Sept. 1825. 8. XII, 131 p., I tab.

$8812 *$ Ruecker, Olto Georg. De Campliorae virtutc medica. D. Dorpati 1835. $8.59 \mathrm{p}$.

88 '3* Rueckert, Ernsı Ferdinand. I3esclıreibung der an lıăufigsten wildwachsenden und kultivirten phanerogamen Gewächse, Farnkräuter, so wie einiger offiziuellen Moose und Schwamme Sachsens und der angranzenden Preussischen Provinzen, mit Augabe ilırer nutzlichon und schádichen Eigenschaften. Fur Frcunde der Botanik, Schullehrer und Oekonomen bearbeitet. Leipzig, Crayen. 1840. 2 Theile. 8. -- I: vin, 306 p. -1$]: 302$ p. $\left(2 \frac{1}{2}(h\right.$.)
8851." Rueckert, Ernst Ferlinand. Flora yon Sachsen, ein prakischer und bequemer Wegweiser auf heinatllichen botanischen Excursioneu durch die Pllanzenwelt des Konigreichs Sachsen, der sächsischen Ilerzogthuner n. Grenzprovinzen. Grimma, Verlags-Comptoir. (1844.) 2 Theile. 8. - I: vill, $306 \mathrm{p} .-11: 302 \mathrm{p}$. (1 th.)

Est idem liber ac praecedens, a fraudoso biblinpoli fallaci hoc titulo dle noso enissus.)

88 : ${ }^{*}$ Rueder, $F$. A. Ueber die Emálurung der Pflanzen und die Stalik des Lanthans in Beziehung auf Illubek's Preisschrift. Lejpzig, Peter. $1843.8 .54 \mathrm{p} .(1 / 3, h$.

$8810^{*}$ Rueling, Joham Ihilipp. Commentatio hotanica do ordiubus naturalihus plantarum. Goettingae, typ. Rosenbusch, 1766, 4, 36 p., 1 talunla phytngraphica universalis.

$881.7+$ (Usteri, Dedect. opusc. bot. II. 431-169.) der zum Füstenthum Götingen gelsurigen Stadt Nordheim und ilırer umliegenden Gegend. Gottingen, Vandenhoeck und liuprecht. 1779. S. 340 p., tal). ( $1 / 1 / t_{2}(h$.

$8848^{*}$ Onlines naturales plantarum. Goettingae, Vandeuhocek. 1774.8 .112 p., 1 tab.

(Cf. Erxleben Physik. Bibliounch 1. Yig-160.)

$8819^{*}-$ Verzcichniss der an und auf dem Harz wildwachsenden Batume, Gestriuche und liräuter. Impr. cun Christoph Withelm Jakob Galterer, Anleitung den Harz zu hereisen. Goltingen 1786. \&. vol. Il. p. $186-247$

$88.00+$ Ruelle, Jean, latine Ruellius. De natura stirpium libri trcs. Parisiis, ex officina Simonis Colinaci. 1536. folio, (6) foll., 884 p. (62) p. ind. Bibl. Cand. et Deless. - * De natura stirpium libri teres, Jounne Ruellio autore, medico lac actate lenge clarissimo, cum indice omnium universi operis olsservatione dignorum copjosissimo. Basileae, in officina Frobeniana. 1537. folio. 666 p., intl. - Venetiis, per Bernardum Bindanum. 4538. Il voll. 8. s. - Basileae, in olficina Frobeniana. 1543. folio. Rivin. - ib. 1573. folio. Babl. Maz. ir. 2759 . 2 .)

$8831^{*}$ Rueppell, Ethard. Reise in Nuhien, Korlofan und dem petràischen Aralsien, verzuglich in geographisclt-statistisclier llinsicht. Frankfurt a/Al., Wilmans. 1829.8 . xxvi, 388 p., 12 tab. (5/h.)

$88 \ddot{2} 2^{*}$ Ruesch, Johann Ulrich. Ueber das Secale cornutum als ein die Geburtsthátigkeit erlsuhendes Mittel. D. Trugen (Wurzburg) 1829. 8. $28 \mathrm{p}$

$8853^{*}$ Ruhland, leinhold Ludwig. Dissertatio inauguralis, sistens fragmenta de nutritione plantarum. Landishuti 1809.8 .37 p.

SSöt* Ruiz, Ilipolito. Quinologria, o tratado del arbol de la Quini o Cascarilla, con su descripeion, y la de otras especies de Quinos nuevamente descubiertas en e. Perú; del modo de beneficiarla, de su eleccion, consercio, virtudes, y extracto elaborado con cortezas recientes, $\mathrm{y}$ de la efficacia de este, comprobada con observaciones; à que se ã̃aten algunns experimentos chimicos, y noticias acerca del analisis de todas ellas. Madrid, en la officina de la viuda e hijo de Mlarin. 1792. 4. 103 p., praef, ind. (20 fr. Barcelona.)

germanice: Vou Hen oflizinellen Fielierrindenbaun nud den andern Arter dessellocu. Hie nenerlich Hippolitus Ruiz entdechts: nun beschrieb. Aus dem spanischen ins llatientiscbe, und aus diescm jus beutsche uliersetzt. Goetlingen, Vundenhoeck und Ruprechl. 179\%. 8 . $106 \mathrm{p}$., praet, init.

$88: 5^{*}$ el Josef Pavon. Florae peruvianac et chilensis l'rnJromus, sive novorum generum plantarum peruvianorum et chilensium descriptiones et icones. Descripciones y laninas de los uuevos generos de plantas de la Flora del Perú y Chile. De orden del Rey. Hadriul, en la imprenta de Sancha. 1794. Folio. xxu, $153 \mathrm{p.}$ 37 tab. - "Editio secunda auctior et emendatior. Romae, typ. Palearini. 1797. or. 4. xxvı, 151 p., 37 tab.

(Editio originaria latine et hispanice, editio Romana tantummoto latine conseripta cat. In cemplari Dejessertiano addita est tabula, Beauluanoisian getus illustrills, cum descriptione.

8830 * cion, que lia divulgado prematuramente el Presbitero Don Josef Antonio Cavanilles contra el Prodromo de la Flora del Peru. etc. Madrid, typ. Mlarin. 1796.4 min. $100 \mathrm{p}$.

$8837^{*}$ Je vera Fuci natautis fructificatione commentarius Natriti, typ. Marin. 1798.4 min. 38 p., 1 tab.

8838* - et Josef Pavon. Systema regetabiliun Florae peruvianae el chilensis, characteres Prodromi genericos differentiales, 
specierum omninm differentias, durationem, Joca natalia, tempus llorendi, nomima vernacula, vires et usus nomullis illustralionibus interspersis complectens. lonus primus. s. I. ty p. Gabriclis do Sanclua. 1798. grt, 8. vi, $45.5 \mathrm{p}$ (45 fr. Barcelona.)

(Inde a 1). 303 incipit: Pir's 11 .

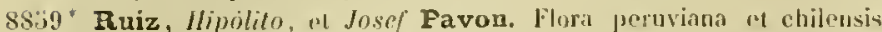
sive rlescriptions el icones plantarum peruvianarum el rhilemsiun, secundum systcua limuannum dignstae, cum characterihus plurium

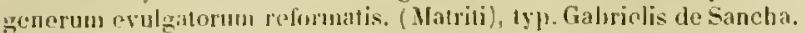
1798-1802. 15 voll. folio. - I: 1798. vi, 78 p., lals. 1-106. 11: 1799. 76 p., เah. 107-222. - III: $1802 . x \times 1 \mathrm{v}, 95$ 1), Lab. 223 -325. - $11:$ : 802 . 1ab. 326-495. Bibl. Reg. Berol, Vindob., Cand. Deless. ( $500 \mathrm{fr}$. Barcelona.)

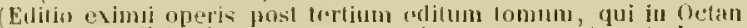

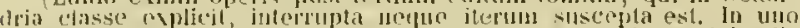

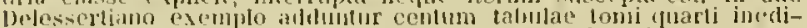

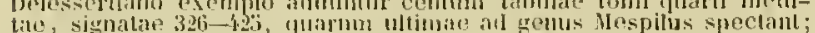

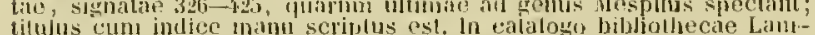

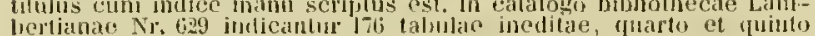

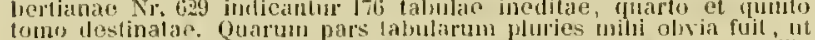
inter Candolleanos, Jussiuni, llebessertianos libros, seguentes scilieet 28 tabulac Lam specierim, aljeclis alis quibuselam, paralae, uf cum Flurae permvidae lonto ijuarto edepentur:

1. Peumo el Lingue.

L. conrulea.

L. relicialata.

1. Hetirantlora

l. ferruginea.

L. sulicordalia

h. purpure

L. Iircata.

L. ovalifolia.

i. sulenta.

i. Perseal

i. nitida.

f. d!sodanthis

1. inimationtoria.

1. halamocarıa.

i. aculifolia

i.. Muci.

L. pinctata.

l. muniglandinlosa.

L. limbnsa.

l. Iongifolia.

1.. Promifolia

L. liacillifolia.

L. lincallifolin.

l. obovala.

1.. cutreifolia.

l'itronia sempervirens. (his.

Gomortega nitida. (bis

Bombarnoisia fruclipendula Laetia serrilita. bis.

Poly jodiun Galasusila.

lirameria triamira.

Nunujua polystachya.

Aristolinlifal fragrantissima.

Unanuea febrifuga.

88606 - Disertacion sobre la raiz de la Ratánhia, especifico singular contra lus fluxos de sungre ele. Malrid. typ. Marin. 1799.4. $(12), 47 \mathrm{p}$.

$8 \times(j)^{*}$ Supplemento a la Quinologia. Mladrid, en la officina de la viuda e lijo de Marin. 1804 . 4. 154 p., praef, 1 lals.

$8862^{*}$ - Ad clarissimum virum A. L. Jussieum Epistola, in qua ejus duhiis circa nova plantarum genera in lilora peruviana el in D. Cavanilles operibus conslitula respondetor. Matriti, 1yp. Mariu. $1801.4 \mathrm{~min}$. p. $121-154$.

s8637 - Memoria sobre las virtudes y usos de la planta Jlamada en el Prú Bejuco de la Éstrella. Marrid, en la imprenta de D. Josi del Collado. 1805. 4. 52 p., praef., I tab. (Aristolochia fragrantissima.) Bibl. Cand.

$8861+$ Memnria de las virludes y usos de la raiz de la planta Llamada Yallhos en el Peru. Madriel, en la juprenta re L. José del Collado. IS0 5. 4. 35 p., 1 rab. (Momnina polystaclıya.) Bibi. Cand.

\$86it —_ Menoria sobre la legitima Calaguala y otrus dos raices que con el mismo nombre nos vienen de la Anjerica meridional Madrid, en la imprenta (le I). Josed tlel Collado. 1805.4 4. 60 p., praef., I lab. (Polypodium Calagguala.) Bibl. Cand.

$8866^{*}$ An histurical Eulugium on Don Kipotito Ruiz Lopez, furst lotanist and chiet of the expedition to Peru and Chile etc. Translated from the spanish. Salisbury, Brodie. $1831.8 .55 \mathrm{p}$.

(Originale hispanteum mili ignotum prodiit Matrin :tuno 181 .

$8867 t$ Fuiz, Selastian Josef Lopez. Defensa y demustracion del verdadero descubridor de las Qumas del reyun de Sama Fé, con varias noticias utiles de este especilico, en rontestacion a la memoria de Don Francisco Antonio Zé. Su autor el mismo descubridor $D$. Sebaslium Josef Lopez Ruiz. Madrid, tỵ. Marin. 1802.4. 24 p. Bibl. Cana.

8868 * Ruland, Joseph. Liber das botanische System des Rivinus. D. Wiirzburg 1832 . S. $19 \mathrm{p}$.

8869 Rullmann, A. Die Gifinflanzen und Gifschwamme Deutsehlands elc. Iritte verb. Antlage. Liassel, Luckhartt. 1837. 8. (1/2 (h.)

$\$ 870 \div$ Rumetius, Ludovicus. Sacrorum bibliorum arborelum marale Parisiis, excudebat Franciscos Julliot. 1606.12. 109 p., praef., ind. Bibl. Juss.
8871 t Rumetius, Ludovicus. Scriplurae sacrae viridarium lismale of mvsticum, in tres libros of mexaginta arluorota digestum. Paristis, apud Joantem Fonet. 1626.8.901 j., prace, ind. Bibl. Juss.

8872t Rumford, Benjamin Thomson, Comle de. Recherches sur lis hois el le charbon. Paris, typ. Deverat. 1812.4 .60 p. $\{1$ r. 50 c. $\}$

8873 Rumpelt, Gory Ludwig. Albandlung von der vortreflichen

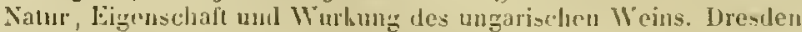
1761.8. H.

887:* Rumpf, Geory Eberhard, latine Rumphius. Itorbarium Amboinonse, plurimas complectens arbores, frulices, herluas, phutas lerrestres et atputicas, yuae in Imboina et atjacentibus rejperiuntur iusulis, alcuratissine descriptas juxta earum formas cum diversis domominalionilus, cultura, usu ac virtulibus. Quod et insuper eshibet varia insectorum animaliumque geneva, plurima cum naluralibus corum liguris drpicha. Ommia magno labore ac sludio nullos jor años collecta el $\mathbf{X l l}$ conserijata libris. Nune primum in lucem edita ef in latinum sermonem versa, cura st sludio Jounnis Burmunni, qui varias adjecil symonyma suasue ubservationes. Amstelodami, apul M Uytwerf. $1750 .(1741-1755$.$) V'] voll. foliu. lation of loollandica$

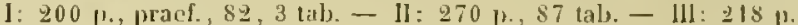
141 tab. - J1: $154 \mathrm{p}, 82$ tab. - V: 1747. 492 p., 154 tals. 11: 256 p., 90 (a).

$88 \%$ " Herbarii Amboinensisaucluarium. Amsterelam 1755 . folio. 7 p., ind. universalis, 30 tah.

$887 f^{*}$ Runge, Fricalieb Ferdinand. Neueste phỵlochemische Findeckungen zur Beyrumdung einer wissenschaflichen Plstochemies. Zwei Lieferumgen. Berlin. Reimer. I820-1821.8. - I: 1820. x4II, yof 1., 3 Lab. - 11: 1821. xxul, 264 p., 4 lab. $\left(2 \frac{2}{3}\right.$ th.

$8877^{*}$ De pigmento indico ejusque commulois cum metallorum nomullis axydis. D. Berolinj, Reimer. $1892.8 .54 \mathrm{j} .(1 / \mathrm{th}$.

$8878^{*}$ Resultate chemiselier Untersuchungen dor Cynaresu. Eupatorinen, Radiaten, Cichoreen, Aggregaten, Valerianeen umul Caprifolien in Auffurlung und Tachweisung eines diesen Pl]anzenfamilien cigenthumlichen Stolles. Breslau, typ. Grass, Barth et Co. 182S. 4. $19 \mathrm{p} .(1 / \mathrm{th}$.

$8879 *$ Ruppius, Ilinrich Bermhard. Flora Jenensis, sive erumeratio plantarum tan sponte circa Jenam en in locis vicinis niscentium quam in homlis obrianm. uethorlo conveniente in classes ristriluta, figurisque rariorum acueis ornata: in ustum botanophilurum Jenensium edita a Johanne Henrico Sihulteo. Ciui aceedit supplementum. l'rancofurti et lipsiac, Bailliar. 4748. 8. 376 p., praef., iul.. 3 tab. - Ed. ememdata et aucta. Francofurli et lipsiae, liaillar. 1726. 8. 311 [\%, praef., ind., 3 tab. - ${ }^{*}$ Ed. III: Flora Jenensis Menrici Bermardi Ruppii, ex postlumis anctoris scluedis el propris olsservationibus ancta ot smeudata al) Aberto Haller. Accesserunt blantarum rarionm novae icones. Jenae, sumsibus C. F. Cunonis, 1745. 8. 416 p., praef., ind., 6 tab.

$8880^{*}$ Rupprecht, Joham Baptist. Leber das Chrysanthemum indicum seine Geschichte, Bestimnung und Pllege. Ein hotanisch-prahtischer Versuch. Mien, Strauss. $1833.8 .211 \mathrm{p}-(1 \%$ th.

$8881^{*}$ Ruprecht, $F . J$. Tentamen Agrostographiac universalis, exhiben: characterns orlinum, generunque dispositionem naturalem cun distributione geographica, adjectis tabulis analyticis. I'ragae, typ. llaase. 1835. $8.48 \mathrm{p}$.

8892* Bambuseae. Petropoli, typ. academiae scientiarum. (Lipsiae, Voss.) 1\$39. 4. 74 p., is tab. (I th.) (Acl. Acal. Pelrop ser. VI, tons. I.)

$8883^{*} \longrightarrow$ P. Hores Samojedorum cisuralensium. Petropoli, typ. acad. sc. (Lipsiac, Vuss.) 1843. 8. 67 p., 6 tab. $(2 / 3$ th.)

888:* Distributio eryptogamarum vascularium in imperio rossico. Petropoli, Iyp. acad. sc. (Lipsiae, Voss.) 1845. \$. 56 p. $(1 / 3$ (h.)

$8880^{*}$ - In bistoriam stirpium Florae pelropolitanae diatribae. Petropmli, typ. acall. sc. (Lipsiae, Vuss.) $\$ \$ 45.8 .93 \mathrm{p} .(1 / 2 t h$.

(Tres ultimi libelli sistunt simul fasciculos II-IV collectionis in-

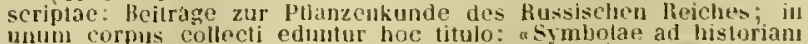
et geograptiam plantarum rossicarum,v petropoli 134 . 8. 232 p., 6 tah. et geograt 
$3886^{*}$ Fussell, Alexander. The natural history of Aleppo and parts adjacent, containing a description of the city and the principal natural productions in its neighbourhood, etc. London, Millar. 1856. (i. e. 4756.) 4. vin, 266 p., ind., 16 tah. - * The second edition, revised, anlarged and illustrated witlı notes by Patrick Rassell. London 1794. II roll. 4. - I: 446, xxuI p., tab. 1-5. - II: 430, xxxiv p., 1ah. $5-46$.

* kollandice: Naaunkeurige en natuurlyke besehrijving ran de Stad Helpo ete. Lyt het Engelsch. Leyden, Pecker. 1762. \$. $29 k$ p., praef., ind.. 8 tab.

"germanice: Naturgesehichte von Aleppo, enthattend eine Bescbreil)ung dex" stadt und der yornehmsten Naturerzeugnisse in ihrer Nachbarschaft. Zwote Ausgabe von Patrick Russell: inherselzl von Joham Friedrich Gmelin. Goettingen l losenbuseh. 1797-1798, il voll. 8. -

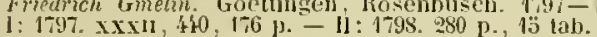

Russell, Duke of Bedford, John, vide Forles et Sinclair.

8887 Russell, Patrick. An account of the Tabasheer. s. 1. et a. 45 p. B. (Philosoph. Transact. vol. 80. (1. 273-283. Medical Facts, vol. 1 . (1. 1 1 1-1-152.)

"S888* Ruthe, Johann Friedrich. Flura der Mark Brandenburg und der Niederlansitz. Erste Abtheilung: Phaneroganien. Berliu, Logier. 1827. R. $x \times r v, 491$ p. $\left(1 \frac{1}{2}\right.$ th. $)$ - ${ }^{2}$ Zweite vermehrte u. verbesserte Auflage. Phanerogamen und Kryptogamen. Berlin, Luderitz. 1834. 8. xxvi, 687 p., 2 tab. ( 2 th.)

sss:! Rutström, Carl Birger. Positiones nonnullae medici et botanici argumenti. D. Harderovici 1793 . W.

88:90 - Spicilegium plantarum cryjtogamarum Sueciae, pro argumento publicae disputationis etc. vindicibus Carl Birger Rutstrom et Johun Gistaf Ilaurman. D. Aboae, typ. Frenchel. 1794. 4. 20 p. w.

s894t (Ryan, J.) Catalogus herharii $J$. Ryani, M. I). Ilavniae, typ. Cohen. 1809. $8.38 \mathrm{j}$.

8842 Rydelius, Anders, pr. Dissertatio de Palua. Londini Gothorum 1790.8. 32 p. (Kespondens: Siman Palmegreen.) B.

x\$:3 Ryder, Thomas. Some account of the Maranta, or Indian Arrow root, in which it is considered and reconmended as a substitute for starch prepared from corn. Loudon 4796.8.32 p. B.

\$894: Ryff, Waller Hermann. Vom Guajaco. Stuasshurg 1544. 8.

$8893^{*}$ Das neue grosse Distillirbuch wolgegrundeter recht kunstlicher Distillation. Frankfurt a/M., typ. Egenolpl. 1545. 4. CC.XX p., praef., incl., ic.xylogr.i.1. - *ib. 1556. folio. - *ib. 1557. folio. Bibl. Goett.

$\$ \$ 406$ Kurtzer Auszug und sumıarischer Bericht der Natur, Figenschaft, wunderbarlichen Wurckung und rechten eigentlichen Gebrauch der fremden neuerfundnen Medicin, der Wurtzel China genandt ete. aus lateinischer und toskanischer Sprach transferiret. Wurzburg, Hans Myller. 1548. 4. Rivin.

צx $17 *$ Rytschkow, Nikolai ( $\%$ n.). Tagebuch uber seine Reise durch verschiedene provinzen des russischen Reichs. Aus dem Russischen uberselzt von Christiun Ileinrich llase. Riga 1774. 8. 424 p., cum mappis geographicis.

$8898^{*}$ Rzacynski, Cabriel. Ilistoria' naturalis curiusa Poloniae, magniducatus Litthuaniae, annexarumque jrovinciarum, in tractatus $X X^{*}$ divisa etc. Sandomiriae, typ. collegii Jesu. 1721.4.456 p., ind.

$8899^{\circ}$ Auetuarium historiae naturalis curiosae regni Poloniae etc. Opus posthumum, Gedani 1745. 4.50k j.

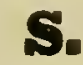

$8 \$ 00$ Saage, . U. J. Catalogus plantarum phanerogamarum circa Brunsbergan sponte crescentium cum clave Limnaeana et systemate naturali in usum discipulorum. Brunsbergae, typ. Jleyne. (1846.) 8 88 p.

8901 Saal, C. Th. B. Die Kultur der Sommerlerkoyen, und das Geheimniss ilres Samenerziehung. Weinar, Voigt. 1843. $8.81 / 2$ plag. $(1 / 2$ th. $)$

Pritzel, Thes. lit. hot.
$8902{ }^{*}$ Sabbati, Liberatus. Synopsis plantarum quae in solo Romano Juxuriantur. etc. Ferrariae, apsud J. Barbieri. 1745. 4. 50 p., 2 tab. et 2 fig. aeri incisae i. t.

8903 Collectio plantarum, quae in solo Romano luxuriantur. liomae 1754.4. B.

(Est jdem tiber ac praccedeus, mutato solum titulo et prima plagula.)

$8904^{*}$ Sabine, Joseph. Sone account of the edible fruits of Sierra Leone. (From the llorticultural Transactions.) London, Nicol. 1824. 4. 30 p). 1 tah. col.

$8905^{*}$ Sacco, Luigi. Sopra un nuovo metodo di preparare il linu e la canapa. Milano, dall' imp, reg, stamperia. $18 \not{4} 3.4$. 15 p., 1 tab.

$8906^{*}$ Sacconj, Agostino. Ristretlo dello piante, con suoi nomi antichi e moderni, della terra, aria e sito, ch' amano. Vienna d'Austria, typ. Jeyinger. 1697. 4. 197 p., praef.

(Etitor est autoris fraler Francesco Persio Sacconi.)

$8907^{*}$ Sach, Johann IIcinrich Farl. Deutschlands wilde Gewachse nach dem Lime'schen Geschleclitssysteme georinet und dureh sorgfältige Znsammenstellung der vou ihnen bekannten Wahrheiten deu Liebhaber muglichst kennhar gemacht. Eirsten Theiles erster Band. Berlin, Kon. Ak. Buchlhandlung. 1804. 8. xx, 383 p. ( $12 / 3 t h$.)

$8908^{*}$ Sachs, Fanz Jakob. De Ulmo. D. Argenturati, typ. Pastor. 1738. 4. $36 \mathrm{p}$.

$8909^{*}$ Sachs von Lewenhaimb, Philipp Jakob. 'A Vitis viniferae ejusque partium consideratio playsico-philologicohistorico-medico-chymica, in qua tum ele Vite in genere, quum in specie de ejus pampinis, flore, lachryma, sarmentis, fruetu, vini multifario usu, de spiritu vini, aceto, vini fece el tartaro, curiosa notata plurima ad normam Coll. Nat. Cur. instituta plurimis jucundis secretis naturae artisque locupletata. Lipsiae, Trescher, 1661. 8. 670 p., praef., 70 p.

$8910^{*}$ Sachse, J. D. IY. Verzeichniss von Bilduissen von Aerzten und Naturforschern, seit den altesten bis auf unsre Zeiten, mit Biograplien. Erstes Heft. Petrus de Abano-Azzogujoi. Schwerin, Kürschner. 1847. 8. vi, 93 p. $(2 / 3$ th. $)$

$89 \mathrm{I}^{*}$ SadIer, Joseph. Verzeiehniss der um Posth uud ofen wildwachsenden phanerogamischen Gewálise mit Angabe ihrer Standorte und Blutezeit. Pesth, Jlartleber. 1815. $8 . \mathrm{v1}, 79 \mathrm{p} .(1 / 3 / h$. $)$

$8942^{*}$ Descriptio plantarum epiphyllospermarum Hungariae et provinciarum adnexarum atque Transsylvaniae indigenarum. D. Pestini, typ. Trattner. 4820.8.33 p.

$8913^{*}$ (-) De Stipae noxa. Pesthini, typ. universitatis. 1825. \& $15 \mathrm{p}$.

* germanice: jlu. 182\%. 8. 16 p.

hungarice. ib. 1825.8 .16 p.

S914* Flora Comitatus Pesthinensis. Pestini 1525-1526.11 voll. 8. 335,398 p. $(3 / h)-.{ }^{*}$ Ed. II : Flora Comitatus Pesthinensis in uno volumine comprehensa. Pestini, Kilian et Co. 4840. 8. $499 \mathrm{p}$. (2 th.)

$8915^{*}$ De Filicibus veris Hungariae, Transsylvaniae, Croatiae et Litoralis hungarici. D. Budae, typ. universitatis. 4830 . $8.70 \mathrm{p}$. $(1 / 2 t h$.

$8916^{*}$ Sadler, Michael. Synopsis Salicum Hungariae, D. Pestini, typ. Trattner-Kiroly. 1831.8.35 p.

$8917^{*}$ Sagar, Michael. De Salicaria, D). Viemae, typ. Kircliherger. 1762. 4. $15 \mathrm{p}$.

$8918^{*}$ Sage, Ballhazar George. Analyse des blés et expériences propres a faire counaitre la qualité du froment et principalement celle du fou de ce grain. Paris, im

$8919+$ Sageret. Mémoire sur le semis de la Solanée parmentière ou pomme de terre, d'après plusieurs expériences faites à diverses époques el récomment en 1813. Faris, typ. lluzard. 1844. 8. $51 \mathrm{f}$.

$8920 \div$ Discussion sur l'existence des deux séves dites do printemps et dAoùt; exposition de quelques idées sur leur nature, leur cause et leurs ellets présumés. Paris, typ. Huzard. 1818. 8 45 p.

8921* - Mémoire sur les Cucurbitacées, principalement sur le Nelon avec des considérations sur la production des liybrides, des variétés etc. Paris, Huzard. 4826.8.60 p. - " Deuvième Némoire. Paris, Jluzard. 1827.8 .418 p. $(2 \mathrm{fr} .50 \mathrm{c}$ ) 
8922 * Sajler, Fianz Seraphin. Die Flora OJjerostreiclss. Linz, Ilaslinger.

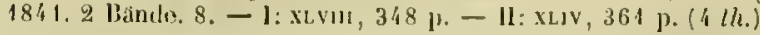

$8923^{*}$ — Wora der linzergecrend und des obern und untern Miulitviertels in Oberostreich, oder Aufzahlung dor dlda wildwachsenden l'llanzen mit kenutlichen Bhithen mittelst Anzalse ilırer deutschen, lateinischen und vulgaren Namen. Lins, bei dem Verfasses. 184,. 8.54 p.

8924 Sailly, Paulus Franciscus de. Dissertatio inmuralis de Manna. Lugduni Batavorum 1740. 1. 38 p. B.

$8923 \div$ Sajnt-Amans, Jean Florimond Boulon de. Fragmens d'un vovage sentimental et pittoresune dans les Pyrénées, ou Lettre écrito de ees montagnes. Metz, Devilly. 1789. 8. iv, $259 \mathrm{p}$.

(Inest a p. 189-259: Lo hourpuet des Pyrénées m calalogue des flantes abservées dans ces montagnes, pendant les mois de Juillet it toût de l'année 1788.)

$8926 \%$ Recherches sur la cause et les remedes de la maladie, qui détruit les arbres des promenades d'Agen. Agen, typ. Noubel. $1789.8 .27 \mathrm{p}$.

$892 i t$ Éloge de Chant's von Linne. Agen, Nunbel. 1791.8. 32 ].

$8928^{*}$ - Flore Agenaise, on description mithodique des plantes observées daus lo département de Lot-et-Garonne et dans quelques parties des déprartemens voisins. Agen, Prosper Noubel. 1821. \$. 632 p., 12 tab. (9 fr.)

8929 * Le boupuet du dipartement de Lot-et-fiaronne ou fascicule de quelques plantes de ce déjrartement nouvelles, rares, point ou mal figurées dans les ouvrages de botanique et décrites dans la Flore Arenaise. Agen, Prosper Noubel. 1821.8 .1 1 12 tab.

(Sul) hoc titulo tabulae libri praecedentis seorsim sunt editae.)

8930 Saint-Estienne, Claude. Nouvelle instruction pour comnoistre les bons fruits, sclon les mois de l'annie, avec une méthode facile pour la connoissance des arbres fruitiers et la facon de les cultiver, 'par Don Cluude S. Estienne. 1'aris, Charles de Serey. 1660. 12. s. Paris 1687.8 . Rivin.

8931 t Saint-Evre, Edouard. Recherehes sur l'huile essenticlle de Sassafras. These. Paris, typ. Bachelier. 1846.4.18 p.

$8932+$ Saint-Germain, J.J. Le. Manuel des vérétaux, ou Catalogue latin et françois do toutes les plantes, arhres et arbrisseaux connus sur le globe jusqu'a ce jour, rangés selon le système de Limné par classes, ordres, genres at esjeces; etc. Paris, Delaguetle. 1754.8. $\mathrm{XL}, 378 \mathrm{p}$.

8933 Suite du Nanuel des végétanx, ou les présens de Pomone. Paris 1786. 12.191 1. B.

89:3: Saint- Hilaire, Auguslin Frangois César Prouvensal, nonmé Augusle de. Réponse aux reproches, que les gens du monde font a létude de la botanique. Lue a la société des sciences pliysiques, médicales el d'agriculture d'Orleans. Paris, tyju. Huet-l'erdoux. 1 s'il. $8.301 \%$

$8933 \div+\ldots$ - Observations sur le genre Hyacinthus, Orleans, tyl. Iluet-Perdoux. s. a. 8, 6 p.

$8936 \div-$ Nolice sur 70 espèces el quelques variétés de plantes phanérogames trouvées dans le Département du Loiret, depuis la publication de lil Flore Orléanaise de M. labbé Dubois. Orléans, typ. Iluet-Perdunx. s. a. $8.47 \mathrm{p}$.

$8937^{\circ}$ Mémoire sur les plantes auxiuelles on attribue un placenta central libre ot sur la nouvelle fimille des Paronychices; suivi d'une note sur la inene famille par MI. Intoine Laurent de Jussieu. Paris, typ. Belin. 1S 16. 4. $109 \mathrm{p}$., 1 tab. ( 5 fr.)

$8938^{*}+\ldots$ Aperçu d'un voyago dans l'intérieur du Brísil, la province Cisplatinc et les missions dites du Paraguay. Paris, Iyp. Belin. 4823.4 .73 1.

(Extrait des Mémoines du Muscum dhistoire nalurelfo, tome IX.)

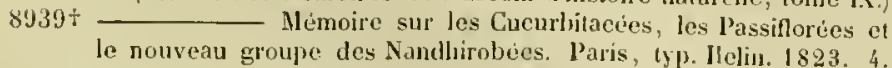
47, 321 .

$8940^{*}$ — Histoire les plantes les plus remarjual) les du Brésil et du Paraguay; comprenant leur description el des dissertations sur leurs rapports, leurs usages ete. Tun. I. Paris, Belin. 1824.4 Lxvis, 355 p., 30 tals. ( $40 \mathrm{lr}$.)

(Comtinuatio hujus operis hucusque mon prodiit.)
894. Saint-Hilaire, dugustin Froncros Cesur Prouvensal, wunmes Auguslin de. Jlantes usuelles des lirasiliens. Paris, Grimbre. I\$Q2: $-1828 .(298)$ ]1., 70 Lab. (70 fr.)

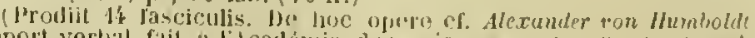

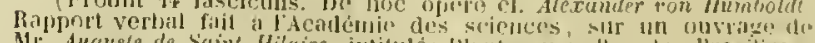

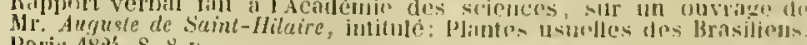
Paris 182'. 8.8 J.

$8942^{*}$ —. Flora Brasiliae merilionalis. Arredunt tabulae delineatae a Turpinio aericue incisae. Paris, Belin. 1825-1833. 111 voll. folio, - 1: 1825. 15, 393 p., ind, tal., col. 1-82. - II: 1829. al1torilous Auguste de Saint-llitaire, Jdrien de Jussien et Jacgues CamLessedes; tabulas delineante Eulutiu Delile. 381 \%., ind., tab. vol. $\mathrm{A3}$ -159. - III: 1832-1833. 160 1), tab. col. 161-192. Bibl. Reg. Berol.

(0)pus non continuabitur. Prodierunt ?t fasciculi, Jute sunt reditioues, altera, easulue vulsatior, in yuarta furma impresid. libulis

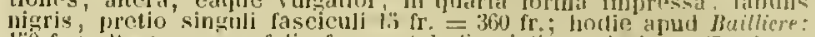
liso fr.; iltera, imagna folio forma, libulis pictis, rarissime olfesultitur:

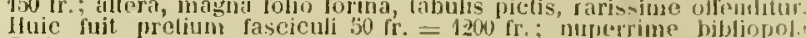

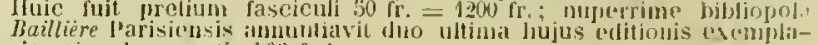
Bailliere Parisicisis immuthat
ria, singulum pretio 500 fr.)

$893^{*}$ Conspectus Polygalararum lirasiliac merilionalis. Orléans, typ. Danicourt-1luet. 1828. 8.18 p.

89:4* - Voyage dans les provinees de Rio de Jineiro et de Minas Geraes. Paris, Grimbert w Horez. 1830. II voll. 8. - I xvi. 45S p. - II: vi, 478 p. ( 15 fr.)

$8945^{*} \longrightarrow$ Voyage dans le distriet des liamans at sur le litoral

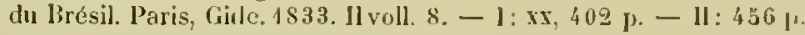

$8946 t-$ Histoire de l'Indigo depuis lorigine les tenups historiques jusqu'á l'anuce 1933 . Orlénns, typ. Danicourt-Huet. 1837. 8. $13 \mathrm{p}$.

(Extrait des Mimoiros de la sucielé male des se, dorteran tomo $\mathrm{I}$.)

$8947^{*}$ - Tableau géographicjue de la virctation primitive dans la province de Minas Geraes. P'aris. P'. Ile la Forest. 1837. ․ $49 \mathrm{p}$.

(In nonmullis exemplaribus legitur in schedulit tutulo idglutinati "Seconte édition leve ch corrigee.)

894. $8^{*}$ Deuxieme Mèmoire sur les Résédicers. Muntıellier, typ. Jean Martel. $4837.4,42$ p.

$894 !^{*}$ Leçons de botanique comjrenant principalement la morphologie végétale, la terminologie, la botanique comparér, l'examen de la valeur des caractères dans les diverses familles naturelles. Paris, Loss. 1840.8 . vin, 930 1), 24 tab.

8930 * _ et Fréderic de Girard. Nonographie des l'rimulacées et des Lentibulariées du liresil méridional et de la république argentine. (Deuxieme edition corrigíc.) Orlians, tsp. Dinicourtlluet. 1840.8 .48 p., 2 tab.

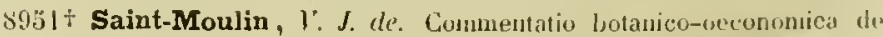
quibusclam arborilsus in lielgio cultis. Trijecti ald Rhenum. Altheer 1827. 8. $116 \mathrm{p}$.

$89322^{*}$ (Saint-Pierre, Jacques Henri Bernardin de.) Voyage al'lsle de France, il l'lsle de Bourbon, au Cap de Bume lisperance enc. par un officier du roi. Amsterdam 1773. 11 voll. $8 .-1: 328$ p., 1ab. 1-4. - II: 978 p., tab. 5-6. - Paris, IItard. 1 \$35. II roll. \&. (1 fr. $30 \mathrm{c}$.

$89533^{*}$ Etudes de la nalure, Paris. Didut. 1784. III voll. 12.

- Ed. IV. Paris 1792- 1799. V voll. 8. - Ell. arer des nutes par

L. Jime Lartin. Paris, Lefévre. 1836 . II voll. 8. (14 fr.)

germanice: Betrachlungen uber die Vatur. Gurlitz (Italle. Auton 1795. a Báude. S. ( $1(h$.)

snecice: Forskningar uti Naturen, G̈fversattning af J. F. Jonsson. stochliolm 1821-1822. III voll. 8. W.

$89: 4^{*}-$ Hamonies de la nature, faisant suite aux Fitudes de la mature. Paris, Marvis. 1815.11 voll. $8 .(22 \mathrm{fr}$.)

$8965^{*}$ (Saint-Simon, Marquis de.) Des Jacintes, de leur anatomie, reproduction et culture. Ansterdam 1768.4. 164 p., ind., 10 tab.

(In exam!lari Banksiano accedult calalogi Ilyaciuthorum: $13 \mathrm{n}$. .)

$89 \ddot{6} 6+$ Sala, Anyclo. Opiologia, ou traicte concernant le naturel, proprielés, vraye préparation et leur usage de l'opium. A la lfaye, chez Jacolss. 1614. 8. 68 p., praef. - Impr. cum Operibus. Rothomang, Bertlielin. 1650.4. S.

anglice: Iranstated by Thomas Bretnor. Lundon 1618. \&. S.

$8957^{*}$ Sala, Antonio. Mermoria sobra la Aruica de los montes. Barcelona, Suria y Burgada. (1786.) 4. 52 p., 4 tab. 


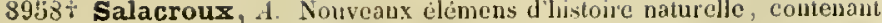
la zoologie, la botanique, la minéralogie et la géologie. Paris $\mathbf{1} 835$. 8. - $\div$ Seconde édition augmentée. Paris, Jaillière. 1839. 12. xII, 1071 p., 48 tab. ( 7 fr.)

(Botanipue: 1. S36-967.)

$8959^{*}$ Salisbury, hichard Anthony. Icones stirpium rariorum descriptionibus illustratae. Londini, typ. Bulmer. 4791. folio max. 20 p., tab. col. $1-40$.

$8960^{*}$ Prodromus stirpium in horto arl Chapel Allerton vigentium. Londini 1796. 8. vin, $422 \mathrm{p}$.

$3961+$ - The generic characters in the English Botany collated with those of Linné. Jondon, Hatchard. 1806. 8. Iv, 34 p.

8963 * - The Paradisus Londinensis: containing plants cultivated in the vicinity of the Metropolis. The deserintions by Richard Anthony Salisbury; the figures by IIIllam Ilooker, pupil of Francis Bauer. London, publisherd by Willian llooker. 1806-1807. Il voll. 4. 117 tal. pulcherr. Col., text. Bibl. Imper. Austr., Deless.

(Opus splendidum prodiit quadraginta fasciculis, tabulis ternis pictis, ant is 1806-1809. Tabulirum explicatio adest usque ad tab. 122; sed ipsac tabulae $118-122$ certo non prodierunt.)

s963+ Salisbury, Hilliam. llortus Padelingtonensis: or a catalogue of plauts cultivated in the garden ofJ. Symmons, Esq. Paddiugtonlouse. London, typ. Conchman, 4797.8.97 p., ind.

196\% The Botanists Companion. London (1822?) II voll. 8.

896:; (Salm-Reifferscheid-Dyck, Joseph, Furst von.) Verzeichniss der verschieduen Arten und Abarten des Geschlechts Aloe, welche von Wilktenow, Jlaworth, DeCandolle und Jacquin beschrieben worden. oder noch unbeschrieben in den Gárten Deulschlands, lirankreichs und ter Niederlande sich befinden. (Dusseldorf) $1 \$ 17$. 8. 8,73 1).

gallice: Cutalogne raisonnè des especes et des rarietés d'Aloos. etc. ib. $1817.8,8,72$ p.

$8966^{*}$ Ohservationes botanicae in horto Dyckensi notatae. Fase. 1-1II. Coloniae, typ. Thiriart. 1820-1822, 12. - J: 1820. p. 1-35. - 11: 1\$21. p. 37-73. - III: 1822. 47 p.

$8967^{*}$ — Plantac succulentae horti Dychensis. s. I. 1821. 12. $42 \mathrm{p}$

$8968^{*}$ — Index plantarum succulentarum in holto Dyckeusi cultarun Aquisarani 4 822. 8 . 60 \%.

(Eaden impressio additionibus calamo seriptorio ancta iterum anto is?'t (divulgata est. )

$3969^{*}$ - Index plantarum succulentarum in lıorto Dyckensi cultarum. Aquisgrani, Beaufort. 1829.8. $71 \mathrm{p}$.

8970* (_ - Hortus Dyckensis, ou catalogue des plantes culivées dans les jardins de Dych. Dusseldorf, Arnz et Co. 1\$34. 8 . vıu, 376 p., 4 tab. $(2$ th. $)$

8971* - Monographia generis Aloes et Nlesenubrianthemi. Dusseldorf. Arnz el Co. 1836-1842. IV roll. 4. (230) foll., 230 tab. $\left(26 \frac{2}{3}\right.$ th. $)$

\$972* … Ueber die Fantilie der Cacteen, und ilsre Eintheilung in Tribus und Genera. (Berlin 1840.) 8. 14 p.

Seorsim inipr. ex Friedrich Otho Gartenzeitung, 1810. Nr. 8.

$8973^{2} \longrightarrow$ Cacteac in Jorto Dychensi cultae anno 1841, additis tribuun generumque claracterilus emendatis. Disseldorjii, typ. Wolf. 1841.8 .48 1.

8975." Cacteae in horto 1)yckensi cultae anno 1844, adulitis tribuun acnerumque characteribus emendatis. Parisiis, typ. Crdprelet. (Dusseldorf, Armz et Co.) 1845 . gr. 8.51 p., 1 tal. $(1 / 3 / h$.)

\$97;, Salmon, Hilliam. Botonologia; the Euglish lierbal or history of plants. Their names, Greek. Latine and English; lleir species, or various kints; their descriptions; their places of growth: their times of hlowering and seeding; qualities or properties; their specifications; their preparations; their virtues and uses; a compleat florileginm of all the choice flowers cultivated by out florists etc. Adorned with icons or figures of the most considerable species. Jondon, J. Dawys. 1710-1711. II voll. folio - l: 1710. p. 1-680, ic. sylogr. i. 1. - 11 : 1711 . p. $681-1296$., ic. xylogr. i. t. B.

8976 Salter, T. B. Short account of the botany of Poole and its neighbourhord. Poole 1839.8

$\$ 977$ Saltzmann, Johann Rurlolph, pr. De Rosa. D. Argentorati 1670. 4. Rivin
8978* Salzmann, F. Z. Pomologia orler Fruchtlehre etc. Potsdam, lyp. Sommer. 1774. 8, x, $182 \mathrm{p}$., ind.

$8979^{*}$ Salzmann, J.G. Allgemeines deutsches Gartenbuch. Dritte Auflage. Munchen, Fleischmann. 1824.8. (1 1/3 th.)

$8980^{*}$ Samson de Himmelstiern, Guido H. De extracto aethereo oleosoresinoso seminum Cinae. D. Dorpati 1834. 8.48 p.

8981 Samzelius, Alraham. Blomster-Kirants af the allnannaste och märkyárdigaste uti Neriket befintliga Váxter, hopflatade och enkannerligeu till undervisning för Scholae-Ungolomen uti Örebro utgifvel. Orelıro, typ. Lindh. 1760.12 .84 p. w.

8982 (-) Beskrifning pả Svenska Fargegräsen huru de af Allmogen och andra hăr i Riket varda nyttjade til Fárgniug; utur flera vittra Mlans Daglsöcker och ingifne berältelser til liongl. WetenskapsAcademien sammandragen år 1763 . Urebro, typ. Lind́lı. 1765. 8. $48 \mathrm{p}$. W.

$8983+$ Sandalio de Arias y Costa, Don Antonio. Lecciones de agricultura explicadas en Ia catedra del real jardin botanico de Madric en año 1815 . Madrid, en la imprenta que fue de fuenteneluro. 1816 Il voll. 4 min. $-1: x \mathrm{~L}, 174$ p. - Il $: 400$ p., ind. Bibl. Cand.

(A [1.32)-372: Catalogi plantarum spontanearum oeconomicarum Ilispaniae.)

8984 Sandeman, Georg. De Rheo palmato. D. Edinburgh 1769. \&. Desid, Banks.

8983 Sanden, Heinrich von, pr. De succino electricorum principe. D Regiomonti $1714,4.4 \frac{1}{2}$ plag. B.

$8986^{*}$ Sandi, A.F. Enumeratio stirpium plantarum phanerogamarum agri Bellunensis, quas hucusque patrio municipio cohortante collegit Beluni, apud F. Deliberali. 1837. 8.32 p.

$\$ 987$ Sangiorgio, Paolo. Delle eproche piu tuminose della botanica erl agricoltura. Mlilano 1807. 8. DC.

$8988+\ldots$ Elementi di botanica compilati ad uso delle universita' e dei Licei del regno d'ltalia. Nlilano, typ. Sonzogno Batt. 1808 8.484 p., 13 tab.

$8989 \overline{\text { IV roll. } 8 . \quad \text { DC }}$

8990 - Sulla coltivazione della Barbetola came pianta da zucchero. Nlilano 1812. \$. DC.

8991* Sanguinetti, Pietro. Centuriae tres Prodromo Florae Romanac addentac. Romae, typ. Contedini. 1\$37. $8.140 \mathrm{p}$.

8992 San Martino, Giambatista da. Menoria sopra la Nebbia dei vegetabili. Vicenza $1785.8 .86 \mathrm{p}$. B.

Excerpta hujus libri in opuscoli scelti Vlll. p. 3\$3-393.)

8993 Sansovino, Francesco. Della materia medicinale Jibri IV. Ne primo e secondo, detti l'Erbolario, si contengono i semplici medicamenti, con le figure dell' erbe elc. da varii autori raccolte. Venezid Giovanni Andrea Valvassori. 1561. (in calce: 1562.) 4. 332 foll ic. xylogr. i. t. $B$.

899: * Santi, Giorgio. Analisi chimica delle accue dei Bagni Pisani, dell acqua acidula di Asciano. Pisa 1789.8.136 p.

In cetpite tertin mineralia et regetabilia vicinitatis recensentur.

$8993^{*}$ - Viazgio al Montamiata e per le due provincie Senesi Pisa, per R. Prosperi. 1795-1806. III voll. 8. - I: 1795. vuI 356 p., 7 tab. - II : 1798. 454 p., 9 tab. - HI: 1806. 433 p. 8 tab.

* gallice: loyage au Montamiata et dans le Siennois, contenant de ol) servations nonvelles sur la formation des volcans, l'histoire géujoginue, misteralogique et hotanique de celte partie de l'talie. Traduit de Bodard. Lyon, Bruyset. 1802. Il roll. 8. - 1: xvi, 33.7 p., 4 tab.

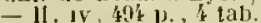

8996 * Sartorelli, Giovanni battista. Degli alberi indigene ai boschi dell' Italia superiore trattato. Milano, typ. Baret. 1816.8. $454 \mathrm{p}$

$8997^{*}$ Mezzi di conservare i boschi. Nilano 1826.8.

\$998t Sartori, Franz. Specimen nomenclatoris plantarum phaenogamarum in Styria sponte crescentium, adjunctis arlnotationibus. Vienuae, Doll. 1808. S. 107 p. $(1 /$ t $h$. $)$ Bibl. Cand.

8999t Saubinet, aine. Notice sur les mousses et les fougeres des environs de Reims. (Reims 1844.) 8.15 P. Bibl. Montagne.

(Extrait des Annales de l'Académie de Reims, annèe 18'3-18\%'.)

$9000 \div$ Saucerotte, Constant. Élémens d'histoire naturelie, présentant dans une suite de tableaux synoptiques accomparnés de figures un précis 
complet de celto scienco. Ouvrage destiuć aux déves des facultós, aux colleges etc. Botani(juo. Paris, Delalain el Roret. 1834. 8. (4 fr.) - +E.l. Hi: ib. 1840. 8. vul, 78 j., 28 tal.

9001 Saumaise, Claude, latime Salmasius. De Hyssopo in cruce Christi epistolae tres al Thomam Barholimum. Lughtuni Batavorum $1616.8 . \mathrm{s}$.

9002 Responsio in quaestionem Reverovicii de Ilyssopo Evoncolii. Impr. cun rjustem lipist. quaest. Roterotami 1654. 12. s.

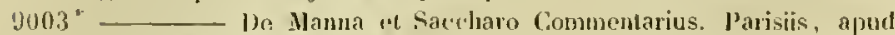
C. du Mesuil. 1663. 8. 95 p.

900: - - Prafatio in librom de llomonymis luyles iatricae, ejusJem de Plinio julicium. Divione, apud viduan P. Chavannac. 1668. folio. 110 p. B.

$90063^{*}$ Plinianan exereitationes in Caji Julii Solini Polyhistora a veteribus libris emendatus. Aecesserunt huic editioni te homonynis hyles iatricao exereitationes antehac inctitae, nec non de Manna ot Saccharo. Trajecti ad Rhonum 4689. Il voll. folio. I: (24) foll., p. 1-625. - II: p. 627-943; 16, 157 p. ind. Ippendix: Exercitationes de homonymis lyyles iatrices, et libelli de Nanna et Saccharo. 259 p., 20 l. ind.

(Mitto editionem priorem - Parisiis 1629 . folio, in mua desidferatur appendis, sine cognitione quidem ipsins haturao scriptus, altancu ifl rei heibariae historiam yravissimi mornenti.)

90106 Saunders, Samucl. A short and casy introduction to scientific aud philosophic botany. London 1792.8.107 p. B.

9007 Saunders, Itilliam. Observations on the superior efficacy of the red Peruvian Lark. London 1782. 8. 176 1\% B.

!0018* Sauter, Anton Eleulherius. Versucl ciner geographisch-botanischen Schilılerung aler Umgebungen Wiens. Dissertatio de territorio Vindobononsi geographico-botanica. Wien, Iyp. Haykul. 1826. 8. 48 p.

$900 y \div$ Sauvanau. Rechurches analyticues sur la composition des terres végútales des Départements tlu hhone ot te l'Ain. Mémoire couround. Lyon, Savy. 1845.8 .47 p.

9010 Sava, R. Lucubrazioni sulla Flora e Fauna dell Étua, e sopra l'origine delle spelonche nelle lave di questo vulcano. Milano 1844 Bibl. Reg. Monac.

$9011 \div$ Savastano, Franresco Eulalio. Francisci Eulalii Satastani, e socictate Jesu, liotanicorum seu institutionum rei herbariae libri IV. Neapoli, ex officina Novelli de Bonis. 1749. 8. $147,(28)$ j. Bibl. Cand.

" ilalice: I rulaltor lituri delle cose holaniche, nolla traduzione in verst sedulto ilalianu dfi Giampietro Bergantint. V'enczia, Bassaglia. 17'9. 8. $x \mathrm{r1}, 311$ p., 2 tah.

9012* Savi, Caclano. Flora Pisana. Pisa, Giacomelli. 1798. Il voll. 8. 1: $x 111,485 \mathrm{p} ., 2$ tals. $-11: 500 \mathrm{p}$.

(0013 - Enumeratio stirpium in horto Pisano. I'isis 1804.8.

y014* _- Trattato Iegli alleri della Toscana. Pisa $1801.8 .250 \mathrm{p}$. - ${ }^{*}$ Ed. II: Firenze, Piatti. 1811.11 voll. $8 .-1: 234$ ]. $-11: 218 \mathrm{p}$.

$9013^{*} \longrightarrow$ Due centurie di piante appartenenti alla lilora etrusca. Pisa, typ. Prosjeri. 1804. 8. VIII, 241 1'.

y(1) $16^{*}$ - Materia medica vegetahile toseanu. Firenze, Molini Lamli et Co. 1805 . folio. 56 p., 60 tal). $(15$ th.

y01 $\nearrow^{*}$ - Botanicon etruscum, sistens plantas in Etruria sponte erescentes. Pisis, 1Yp. R. Prosperi. 1808-1825. IV voll. 8. - I: $1808.200 \mathrm{p} .-11:$ is $15.268 \mathrm{p} .-111: 1818.184 \mathrm{p}-1 \mathrm{~V}: 1825$ 320 l).

yotה* Pugillo di piants da agniungersi al Botanicon etruscum. s. 1. el a. \$. $20 \%$ \%

$9019^{\circ}$ _. Memoria sopra i Trifogli vescicosi e sopura il Trifolium Bocenni. (Pisa 1509.) 8. 13 p (Seorsim impr. ex Giorualu Pisano, tom. X.

$9020^{*}$ Oloservationes in varias Trifoliorum species. Florentiae, [y] ). P’atti, $1510.8,146 \mathrm{p}$, incl., 1 tab.

$9021+-$ Lezioni di botanica. Firenzr, Molini, Landi et Co. 1811 II voll. $8 .-1: 178 \mathrm{p} .-11: 210 \mathrm{j}$.

$0022^{*}$ Osservazioni sopra diverse piante. Pisa, typ. Bracali. 1816.8 .28 P., t tah

$9023^{*}$ - Sopra una pianta cueurbitacea, che pui formare un nuoro genere (Kenincasa). Wilano, Maspero $4518,8,12 \mathrm{p}, 4$ tab.

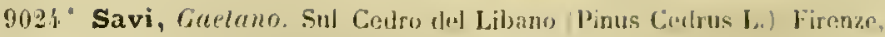
l'ialti. 1818.8. 13 \%).

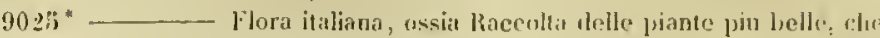
si roltivano nei giardini d"lalia, dirclli e illuslrata dal Professor. Gaptano Savi. Pisa, presso Nicenlo Capurro. 1818-182\%. III voll.

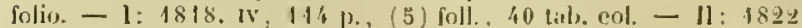
90 p., int., 40 tab, col. - 111 : 1924.86 j2., ind., 40 tal?. col. Bibl. Caes. Vindob.

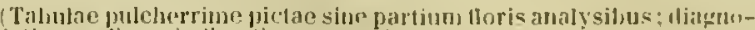
ses latibs, reliqua itulica lituguil exprimuntur.

$9026+-$ Xuov rlementi di botanico. Pisa, 1yp. Nistri. 18208. $\mathrm{xv}, 337 \mathrm{p}$.

$9027^{*}$ Sulla naturalisazione delle piante. (1'isit 4822.) S. 24 1. $9028^{*}$ Osservazioni sopra i generi lliaseolus ct Dolichos. Iro meria I (-N). Pisa, typ. Nistri, 1822.8.20, 25, 22, 10 \%. 4 tab.

$9029+\ldots$ - Sul liscum alloum ed il Loranthus europacus Marourin Pisa, typ. Nistri. 1823.8.23 p.

$9030^{*} \longrightarrow$ Scelta di generi di piante con i loro respettisi analteri disposti il sistena sossuale e il metodo naturale per uso delli studenli di botanica. Pisa, lyp. Nistri. 1826. \&. xu, 302 \%.

9031" - Notizie per servire alla storia del giardino o musen della universita di Pisa. Jisa, typ. Nistri. 1828. $9.35 \mathrm{p}$.

$9032 \div-$ Sepra alcune Acacie egiziane Nemorio, J'ika, typ. Nistri 1830.8.31 p., I \{a\}.

9033* (-) Alla Memoria di Giuseppe Raddi. Firenze, ty p. Chiari 1830.4. 33 J., ind., 2 tah,, efligies et monumentum Josp phi Radd.

(A p. 17-33: Rapporto sulla collezione di piante: raccolte in Eujtt dal naturalisia foiuseppe ladedi.)

$903 \% \div$ Cose botaniche. Pisa, 19p. Nistri. 1832. 8.57 p. 3 tal, !033 Nolizic sul té della China, l'isa 1836.8 .

$9036^{*}$ - Descrizione di una speeie di lilaeagnus " di varie altra piante. (Cornachinia fragiformis.) Modena, typ. tella camera. 1836. 4.32 p., 2 tab.

$9037+\longrightarrow$ - Sul Citrus Ilystrix \& sul Citruk salicifolia. (Firnaze) 1837. \&. 16 p., 1 tab.

(Alti Accul. Georgofili ti Firenze, vol. .lv.)

$9038^{*}$ - Osservazioni sopra alcune specie del genere (Mriganum Memaria. Pisa, 15p. Nistri. 1840.8 . 20 p., 1 tal,

y039t - Sull' Erigeron siculum L. (Jasonia siculiı MC. Proulr.) Nemoria. Nodena, Iyp. della camera. 1844.4. 7 p., 1 tab.

90 i0* Savi, Paolo. Sopra un illusione oltica frequentissima nell' osacrvazioni mieroscopiche IJemoria. Pisa, 1yp. Nistri. 1822. 8. 14 j3.. $1 \mathrm{tab}$.

(Seorsim impr. ex ejus Ilemorie scientiliche, Decate p̀rima.)

90 it Savi, Pielro. Descrizione della Fimbristylis cioniana. Pisa, presso Ranieri Prosperi. 1843 . 8. \& P., I tab).

(Estratta dal vol. lil delle Memorie baldarnesi.

y0:2* - Florula gorwonica. Firenze. con i forchi della soricta lipografica. 1844.8.39 p.

(Estratta dal Giormale bolanico ialiano, Art. 1. fasc. 5.)

9014.3 Scaliger, Josephus Justus. Animatversiones in Melrhiuris Guilundini commentarium in tria C. Plinii de Papyro enpita libri . Null in Scaligeri Opusculis variis, Francofurti 1612.8. P. 1-52. B.

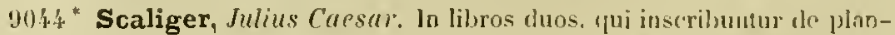
tis, Aristotele autore, libri duo. Luteliae, ex offecha Michaelis Vaseosani. 1556.4.226 foll. $-{ }^{*}$ In libros de plantis, Aristoteli inseriptos. commentarii. Lugduni, apul Gulielmun Rovillium. (Genevae, apud Johannem Crisjinum.) 1566. folin, 143 p., ind. - "In libros dinos.

$I$ qui inserifumtur de plantis, Aristotele autore", libri duo. Denuo nitori suc restituti et in lucem editi. Marpurgi, apul Paulun Egenolphum. 1598. 8. 498 p., praef.

9013 Exotericarum excreitationun liber yuintus decimus de subtilitate al Hieronymum Cardanum. Lutetiae 1557.4, 476 foll. B. - Francofurti a/N. 1582. S. - Hanoviae 1634.8.1076 J. B.

$90 \mathrm{st}$ Commentarii et anmadrersiones in sex liluros do causis plantarum Theophrusti. Lugduni, apud Guli. (sic!) Rovillium. (Genrvan, Iyp. Joannis Crispini ) 1566 . folio. (4) foll., 396 J., (14) foll. ind. Bibl. Juss.

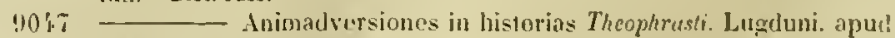
Joannam Jac. Juntae F. 1584.8 .424 p. B.

(lusunt guocure Roberti Constimtini Annotationes in listorias Theo-

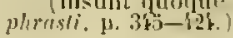


90 i. (Scarella, Giambatlista.) Postille ad alcuni capi della storia betanicil del Sign. Giucomo Zanoni. Palova, Framlıotti. 1676. 12. 63 p. B.

Autor in titulo fictum nomen l'icenso Menegoli affectavit.)

903.9 Lettera apologetica intorno ad una pianta anonima (Isuardia palustris). Paduva 1687. 4. 12 p., 1 lab. B.

90.30 - Breve ragguaglio intorno al finre dell' Aloo americana. Padova, Conzatti. 1710.8 .56 p., 1 tab. B.

90:5) Scazzola, Giovami Antonio. Filosofia dei liori. Mlessandria, typ. Capriola. 1836.8 . 124 p.

$9032{ }^{*}$ Scepin, Constantinus. De acilo vegetabili cum annotationibus botanicis. D. Lugduni Batavonum, Potulict. 1758. 4.44 p.

(monotiones botanicae: p. 2l-'r's.)

$3053^{*}$ Schabel, A. Flora von Ellwangen. Stullgart, Balz. 1837. 8. xu, $100 \mathrm{p} .(1 / 2, h$. $)$

90:5. Schabol, alias Roger-Schabol, Jean. Dictionnaire pour la thenrie et la pratique dn jardinage. Paris 1770.8. DC.

$9033 t \longrightarrow$ La théarie du jardinage. Ouvrage rédigni aprìs la mort de l'auteur par $D^{* * *}$. Paris, Debure 1771 . 8. xvili, $408 \mathrm{p}$. (3f. $60 \mathrm{c}$.)

yosit — La pratique du jardinage. Ouvrage rédige après sa mort $[+9 . A p r .1768]$ sur ses llémoires par 1]. $D^{* * *}$ (i. e. Antoine Nicolas Dezallicr d'drgenville). Nouvelle élition resue et augmentede. P'aris, Debure. 1772. II voll. 19. - I:500 p., 9 tab. - 11: $514 \mathrm{p}$. 7 tal. - +ib. 1774. 12. - I: 504 p., 10 tab. - 11: 492 p., 5 tab. germenice: Prankfurl 1778. 8.

(y): $i^{*}$ Schaefer, $\boldsymbol{H}$. Trierische Flori, eller Kurze Beschreibung der in Regierungsbezirk Trier wildwaclsenden Pllanzen. Trier, Lintz. 1826 is Theile. \&. - 1: Lvir, 252 p., intl. - 11: 254 p.. ind. - Ill : liryptoyamen. 1829. xLvill, 389 p., ind. - Anhang: 37 p. $(3 \% /$ th. $)$

90:3* Schaeffer, Jakoh Christian. Dis eingebildeten Wurmer in Zihnen. Regensburc, tyj. Zunkel. 1757.4.42 p., 1 lals. col.

$91: 34 \div-$ Epistola all illustrem J. R. Academiam Roveredensem re studii botanici faciliori ac tutiori methorlo, cum specimine tabularmm sexualium el universalium in lune finem elaboratarum acrique incisarum. (Rotisbonae), typ. Zunkel. (1758.) 4. 14 p., 2 tah. gallice: Lettre contenant li maniere de remdre létude do la ho tanique plus facile et plus sure. Journal de physique, tom. XY 1.. $260-2 \times 1.1$

yobio * _ Jsagoge in botanicam expeditiorem, iconibus acri incisis et pictis illustrata. Ratisbonae, typ. Zunkel. 1759 . 8. 96 p., prarf. inl., it tab. col.

9061 Vorläufige Beobachtungen der Schwamme um Regenslourg. liegensburg 1759.4.59 p., 4 1ab. col. B.

$9062^{*}$ —— Der Gichtschwamm mit grïnsehleimigen lluto. Regensburs, Montag. 1760. 4. 36 p., praef, 5 tab. col.

$9063^{*}$ - Botanica expeditior. Genera plantarum in tabulis sexualibus et universaliluus aeri incisis exhilsens. Jatishonae, typ. Weiss. 1760. 4. IV, 338 p., ind., I lah. col. - *ib. 1762 . 4. (13on diller.)

$3065^{2}$ - Icones et descriptio fungorum ijuorundam singularium, simul Fungorum Bayariae jeones editioni jam paratae propedien evulgandae denunciantur. Ablildung und Beschreilsung einiger sonderbaren unil merkwurligen Scluwamme. Regensburs. Weiss. 1761 . 4. 16 p., 1 tab. col.

$9063^{*}$ Fungorum qui in Bavaria et Palatinatu circa Ratisbonam mascunfur icones, nativis colorilus expressae. Ratislmae, inpensis suctoris, typ. Zunkel. 1762-1774. IV voll. 4. -1 : 1762. tab. eol. I-100, text. - I1: 1763, tal, col. 101-200, text. - I1I: 1770. tab. col. $201-300$, text. - IV: 1774. tab. col. $301-330$, text. 136 p., (2) foll. $\left(53 \frac{1}{3}\right.$ th.

(Commentarium in hoe opus, autore Chrisian Heinrich Persoon, vide sulira Nr. 7898.)

9066 Schaeffer, Johamn, latine Schefferus. Lapponia, i. e. recionis l,apponum et gentis nova et verissima descriptio. Francofurti, typ. Wolti. 1673. 4. (16), 378 p., ic, xylogr. i. l, w.

C.aput XXVI, p. 337-362 tractat le arboribus ot plantis, Adsun versiones germunicie, gallicac, anglicae et bollaudicac.)

9067 Schaeffer, Johamnes. Dissertatio inauguralis, sistens Anthelmintica regni vegetalilis. Altdorfii 7784.8 .98 p. B.

(Schleget, Thesaur. mat. med. 11. p. 127-186.)

$9068^{*}$ Schaeffer, Karl. Deliciae botanicae Hallenses, sen Catalogus plantarum indigenarum, quae in lacis herlosis, pratensilus, montosis, saxosis clivosis. nmbrosis, arenosis, paludosis. uliqinosis, nemorosis et sylvestribus circa Ifallam Saxonum procrescunt. Hallae Saxonum, typ. Salfeld. 1662. 12. (64) p.

9069* Schaerer, Ludwiy Emmanucl. Lichenes Helveliae exciccati. Fasc. J-X.. (Cantons.) Bernde, Burgdorfer. 1823-4843. 4. $\left(33^{3} /\right.$ th. $)$

tnsunt species 1-500 adtlilis diagnosibus et observationibus.

9070 Schagerström, Johan August. Plantae volyledoneae paroeciae Roslagriaè Bro. D. Upsaliae 1\$39-1840.8. 30 p.

9071 Conspectus vegetationis Uplandiac. J). Upsaliae 1845 8. 83 p.

9072 Lárobek i Skandinaviens Váxt-familjes ofter dot Friesisha systemet. Upsala 1846.8.96 p.

9073* Schaller, Johann Philipp Bonaventura. De Jalappa. 1). Argentorati, 1yp. Hcitz. 1761.4.27 p.

907\%" Schallern, Gottlieb delam Johamn von. Chelidonii majeris vintus modica. D. Erlangae 1790.4.31 p.

$9073^{+}$Schams, Franz. Betrachtungen uber Ungarns Weinbau, oder alu Erfahrung gegrintete Belchrungen zur moglichen Verbesserumy dieses wichtigen Landwirlhschaftszweigs. Prejsschrifı. Pes(h, llartIeben. $1830.8 .81 \mathrm{p} .(1 / 2$ th. *hungarice: ib. 1831. 8

9076 Ungans Woinbau in seinem ganzen Umfange, oder vollstíndige Beschreilung sămmtlicher beruhmen Weingehirge des ungarischen Reiches in statistischer, topographiseher, naturhistorischer und ükonomischer Hinsicht. Jestl, (Heckenast.) 1832- 1833 2 Rande. $8 .\left(2 \frac{2}{3}(h\right.$.)

9077 Scharbau, Heinrich. De plantis al voce tvoñ.s comprehensis et respirantibus, ad illustrationem loci Act. XV'll. 25. Lipsiae, apm liaeredes Lanckisch. 17 17.8. S.

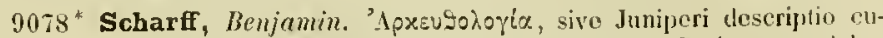
riosa, ad normam et formam Academiae Naturae Curiosorum claborata of varüs medicamentis ac observationibus referta. Francofurti et Lipsiae, Wolfs. 4679.8.380 p., ind., 5 tal).

$9079^{*}$ Schatz, 31 ilhelm. Flora llalberstadensis excursoria, oder lichersicht Iror un Halberstadt wildwachsenden sichthar bluhenden Pflanzen und Farm. IIalberstadt. Lindeguist. 1839. 8. xxin, $119 \mathrm{~J}$. $(1 / 2 t h$.

$9080^{*}$ Schauer, dohann liomad. Die Helaleuhen der dentsedsen Girtan (Berlin 1835.) 8, 16 p

(Seorsim impr. "xi Friedrich otto, Allgemeine Gartenzeitung, 15:3. Nr. 21 .)

9081* - Chamaelaucicae. ]). Vralislaviac, 1yp. Grass et Barth. 1841. 4.2113

$9082^{*}$ — Chamaelaucicae. Commentatio Hotanica. Vratislavile, typ. Grass el Barth. 1841. 4. 120 p., 7 tab

Nov. Actorum tcaul. Lcom Vat Cur. vol XiX. Suppl. If: Monuarapia Myracearum verociunicarum. Sactio I Chamaelaucisarum hucusquo cognitarum gelera et species illustrans.

$9083^{*}$ - Universitati literarum Erlangensi secularia prima a. il. X. Lal. Sept. 1\$43. celebranda gratulatur Acallomia LeopoldinaCarolina Caesarea Naturae Curiosorum. Arljecta est: Johamnis Conradi Schauer do Regelia, Beaufortin et Calothamno dissertatio gratulatoria. Vratislaviae, typ. universitatis. $4.36 \mathrm{p}$., f tab.

1)081: - Der lionigliche Jotanische Garten zu Breslau. Licgnitz Pfingsten. 1843.8.16 p.

(senrsim imps. ex sehlesisclse Garten- 1mu! blumenzeitum!: Ileft $\mathbf{j - 1 1 . )}$

$908 \pi^{*} \longrightarrow$ Die Stockfaule Jer Kartoffeln. Ein Vortrag, gchalten in Fllenaer landwirthschaftlichen Vereine an 15 . Novenber 184. Anclam und Swisemunde, Dietze. 1846.8 .43 p. (1/5/h.)

Extrabistruck aus den Verhandlungen des Baltischen Vereiss. fur $18 \%$. p. $187-2.27$.)

y080 SchedJbauer, J. K. Dissertatio circa Pluytotoxicologian ceclicam. Pragae 1834.8.69 p.

9087* Schefer, Johann Daniel. Ne Chamomilla. D. Argentorati, tyl. Spoor. 1700.4 .30 ].

$9088+$ Scheidweiler, $J$. Cours raisonne et pratipue d'agriculture el de chimie agricole. Bruxelles, llamman et Co. 1841-i\$43. Il voll. \& - J: vI , 604 p. - II: $484 \mathrm{p}$. Schelhammer, Giinther Christoph. Progromma ad rem licrbariam excolendam. s. I. 1681. 4. Desid. Banks. 
9090 * Schelhammer, Gunther Christoph. Calalogus juluntarum masimam partem rariorum, tguas per l,oe bicunim it liortulo domestico aluit, et, paucis exceptis, etian his vernis aestivisque mensibus poterit exhibere. Ilelustarii, typ. Hamm. 1683.4.(19) foll.

9091 Programma, quum rei herbariae prof assionem auspiearotur. Jenao 4690.4 .

$9492^{*}$ De nova plantas in elasses digerendi ratione ad Johannem Rajum et Augustum Quirinum Rivinum epistolica dissertatio. llamburgi, Liebezcit. 1695. 4. 32 p.

y09.3 - Je nova plantas rognoscendi methodo. s. I. 1695.4. Desid. Banks.

1309\% Viae regiae ad artem stadium primum, de studio botanico recte instituendo. Programma. Kilonit 1705. 4. Bibl. E. Meyer.

9095; Schelver, Franz Joseph. Kritik der Lelire von den Geschlechtern lor Pllanze. Hoidelluerg, Braun. 1812. 8. 86 p.- * Fiste Fortsetzung. ib. 1814. 8. 118 p. - * Zweite Fortsetzung. Carlsrulie Braun. 1823. 8. xvi, 270 p. (2/h.)

y0y6 Lehens - und Formgeschichte der Planzenwelt. llandbuch sciner Vorlesungen. Erster Hand. Heirlelberg, Engolmatiı. 1822. 8. xi1, 269 p. (1\%/12 th. $)$

9097 Schelwig, Samuel. Thesos de suceino. Thorunii 1671. 4. 11/2 plag. Boebmer.

9098* Schencl, A. Anleitung zur Bestimnung der im Herzogthum Nassau und dessen U'mgebung wildwachsenden Pllanzengatungen, nelsst pädagogisch-didaktischen Vorerimorungen. (Gymusialprogramm von Dillenburg.) (Wiesbaden, Friedrieh. 1846. ) 4. 112 p. (1/3 th.)

y099t Schenckbecher, Johann Georg. Bericht von den heilsamen Wirkungen der Kinkina oder Peruvianischen Rinde and von der Nichtigkeit dor Forurtheile, welche das Publikum gegen diese Rindo noch hat. ete. Riga und Mictau, Hartknoch. 1769. 8. 174 p.

J100t Schenckius a Grafenberg, Johann Georg. Hortus Patavinus: cui accessere Helchioris Guilundini Conjectanea synonymica plantarum etc. publicante Jo. Georg. Schenckio a Grafenberg. Francofurti, typ. Becker. 1600. 8.93 P., praef. Bibl. Juss. - *ib. 1608. 8. (non differt.)

(Payinae 1-2.2 conveniunt omano eum Cortusii L'horts rei sempliei di Padova, supra Nr. 1999 allato; paginae 23-26: In horto Patalandini Conjectanea synonymica plantarum, et icnographia horti aeri ineist.)

9104 Schenckius, Johann Theodor. Catalogus plantarum horti medici Jemeusis, earumquc quae in vicinia proveniunt; cum figuris aeneis. Jenae 1659. 12. 4 plag. B.

Iraeside Johanne Theodoro Schenchio dissertationes:

(1)112 De le herbaria. D. Jenae 1653.4

1) $103^{*}$ Historia plantarum generalis, in synopsin redacta et al usum medicum coneinnata. D. Jenae, 15p. Nise. 1656. 4. (44) p.

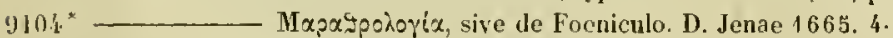
88 p. (Respondens: Friedrich Kaltschmied.)

$4103^{*}-$ De Cinuamomo. D. Jenae, typ. Werthor. 1670. 4 53 p. (Respondens: Johann Phitipp Hoechstelter.)

glof — De succino. 1). Jonno 1671. 4. $4 \frac{1}{2}$ plag. (Respondons: Goltfried Schultz.) B.

9107* Schenk, August. Plantarun spocies, quas in itinere per Aegyptum, Irabiam et Syriam G. H. de Schubert, M. Erdt et J. R. Roth collegerunt, recensuit et ex parte descripsit. Monachii, typ). Wolf. (Wurzburg, Voigt et Mlocker.) 1840. 8. vi, 46 p. (1/3 th.)

y $10 x^{*}$ Schenk, Geory, Edler ron. Der lebendo Woissdorn-Spaliorzaun. 7weite Auflage. Mit 26 Ilolzschniten. Lenberg, Millikowski. 1844. 8. xit, 60 p., ic. xylogr. i. 1. $(2 / 3$ th. $)$

hungarice: vertente Petro Lange. Kromstadt (Numeth.) 18k3. 8.71 p., 5 taJ). $(\% / 1$, th. $)$

$9103^{*}$ Schenkel, J. Das Pflawenreich mit hesoutror Ruchsicht auf Inscetologio, Gewerbskunde und Landwirlhsehaft. Ein naturgoschiehtliches Lehr - und Lesehuch fur Schule und Ilaus. Mit 180 SteinIafeln, gezeichnet von Lehrer Philipp Klier. Mainz, Kunze. 1847.

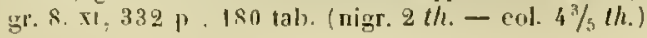

$9110^{\circ}$ Scherbius, Johannes. De lysimachide purpuroae sive Lytlri silicariae L. virtute medicinali non dubia. 1). Jenae 1790. 4. 34 p.. 1 tab.

9111 " Scherbius, Melchior. Do loco et situ plantarun. 1). Basileae, Iyp. Pistor. 1731.4 .32 \%.

9112* Scherer, Johann Andreas. Bonbachitugen und Viisuclin uber lás pllazenalujliche Wesen in den warmen Karlsbader und Toplitzer Wássern in 13olımen. Dresden, Walther. 1787.4. 20 p.

(Est furtasse: Iralkjatio commentationis in Jacquin Collect. vol. I 1750. 1\%. 171-183 insertae: Observationes et "Yjerimenta super ma terii virili Thermarmm Carolinarum et Tneplizensium rengil l3obemilie.)

9113t Scheuchzer, Johannes. Agrostagraphiao luelvaticae Prodiomus sisteus binas graminum alpinorum hactenus non descriptorum et (juorundan ambiguorum decades. (Tiguri), sumtilus auctoris. $170 \mathrm{~s}$ folio. 28 p., 8 tab. Bibl. Juss.

$9114 t \longrightarrow$ Operis agrostograplici idea, seu Graminum, Junco-

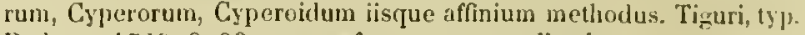
Bodmer. 1719.8 .93 p., praef. et vocum explicatio.

$91.15^{*} \longrightarrow$ Mgrostographia, sive Graminum, Juscorum, Cyperorum, Cyperoitum, iisque affinium historia. Tiguri, Bodmer, 1719.4. 512 1\%, praef., int., 11,8 tab. - Editio nava. Accesserunt Alberl ron Ifaller synonyma nuperiora, graminum 70 species, de generibus graminum epicrisis. Denicpue plantae rhaetici itineris anno 1709 a J. Scheuchzero suscepti. Tiguri, Orell ot soc. 1775. 4. vul, 512 j., praef, ind., 19 tab). - Ajpondix: $92 \mathrm{p}$.

(Talulae uctn ultimae redemit el Agrostographiar helvoticae prodromo. Eititio altera praeter appendicen minime distert.)

$9110^{*}$ Scheuchzer, Johannes, junior. De alimentis farinaceis. D. Luoduni Batavorum, WischolI. 1760.4.38 j., 1 tab.

$9.17 \div$ Scheuchzer, Johannes Jakol. Oupeo:Q̧o:rn; helreticus, sive itinera alpuna tria (annorum 1702-1704.) etc. Londiui, Clements. 1708. 4. - 1:57 p., 10 tab. - II: 72 j, 21 1ab. - 111:22 p. 10 tab:

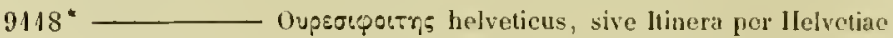
alpinas regiones facta aunis $1702-1711$ plurimis tabulis aeneis illustrata, in quatuor tomos distincta. Lugduni Batavorum, is'p. et suntibus ['etri Van der Aa. 1723.4.635 p., praef., ind., tal, plur. (Tomus primus contluet tria itinera anuorum 1702-170' de novo edita.)

$9.19^{*}$ Herbariun diluvianum. Tiguri 1709. folio. 44 p., 10 tab. - *ilio novissima duplo auetior. Lugduni Batavorum, apud Petrum Van der Aa. 1723. folio. 119 p., pracf, ind., 14 tab.

9120 -_ Physica sacra iconibus illustrata, in qua de variis Scripturae sacrae plautis, procurante Andrea Pfeffel, chaleographo Angustano. Augustae Vindelicorum $1732-1735$. V voll. folio. 650 tal Bibl. S. Germ. ex S.

gallice: Physique sacréc, ou histoire naturelle le lis Bible, traduite clu latiu. Amsterdam 1732-7737. vit voll. folio. 127, 163, 18\%. 160 18i, $248,452,258,85$ p., 730 tau. B.

$9121^{*}$ Schiede, Chr. Julius II ilhelm. De plantis hybridis sponte natis. Cassellis Catturum, Kirieger. 1825. $8.80 \mathrm{p} .(1 / \mathrm{t}$ (h.)

$9122 *$ Schiel, Jcinrich. Grundzige der Pflanzenkunde nach iltren gegenwartigen Zustande mit Rücksiclit auf Medizin und Pharmacir. Guns Reicliard. $1838.8 . x x, 275 \mathrm{j} .\left(1^{3} / \mathrm{t}\right.$ th. $)$

9123 Schiemann, Karl Christian. De Digitali purpurea. ). Goctingae 1786. 4. 63 p. B.

912.* Schiera, Giovami Maria. Dissertationes duao, yuarum una de plantaruu sexu, foecundatione, sistemate sesuali et multiplicatione: altera te naturali et constanti plantarum affectione ad perpendiculum etc. agit. Mediolani, apud Fr. Agnellum. 1750. 8. 76 p., praef.

9125 Schildbach, Karl. Heschreibung einer 11alz-Bibliothek. Cassel 1788.8 .16 p., I foll. B.

9.126 Schilling, Gottried II ilhelm. Heseriptio trium j]antarum in curatione leprac adhiberi solitarum. Inpr. cum cjus Commentationibus de lepra. Lugduni Latavorum 1778. S. p. 196-213, 3 tab. в.

$9197^{*}$ Schilling, Johann Jakob. Phytologiae scu Ijysicos plantarum specimen ] (-Iil). Duishurgi ad Rlıenum, typ. Straub. 1752. 4. $84 \mathrm{p}$. 
9\{ $2 x^{\circ} \div$ Schilling, Samuel. Gemeinnutziges Handbuch der Botanik oder Gewächskunde der in - und auslandischen etc. Breslau, Richter. 1840.8 .476 p., 60 lab. (2 th.)

912!* Schimert, Johann Peter. 1)e systemate sexuali. D. Tyrnaviae 1776. 8. 22 [3.

1) $130^{*}$ Schimper, KarlFriedrich. Beschreibung des Symphytum Zeyheri und seiner zwei deutschen Verwandten S. bublbosum Schimp. et S. tuberosum Jacr. (Aus Geiger's Magazin, Band 28.) Ileidelberg, Winter. 1835.8 .119 p., 6 tab. $(5 / 6$ th. $)$

$4131^{*}$ Schimper, Wilhelm. Reise uach Alyier in den Jahren 1831-1832. Stuttgart, Metzler. 1834.8. $x, 215$ j). (1 th.)

4132* Schimper, Wilhelm Philipp, et A. Mougeot. Monographie des plantes fossiles du grès bigarré de la cluaine des Vosges. Leipzig, Engelmann. 1844.4.83 p., 40 tab. col. (11 th.)

9133* Schinne, J. E. C. van. Catalogus plantarum indigenarum et exoticarum, quae in horto medico Rolterodamensi aluutur, secundun systema Linnaeanum dispositarum. (Roterodami) 1809. 8. 48 p., praef, ind.

913: Schinz, H. Nonegraphie des Kartolfelbaus, oder Anleitung zur Sant, Pllege ete. nebst Schilderung des Wachsthums und der Krankheiten dieser Knollenpflanzen. Aarau, Clsristen. 1846. 8. vi, 88 p. $(1 / 3 t h$.)

9133 * Schinz, Salomon. Primae lineae botanicae ex tabulis playtographicis cl. Dr. Joannis Gessneri ductae. Erster Grundriss etc. latine el germanice. Turiei, J. C. Fussli. 1775. folio. 49 p., 2 Lal. col.

$9136^{*}(-)$ Anleitung zu der Pflanzenkenntniss und derselben nutzlichsten Anwendung. Zurich, Waisenhaus. 1774. (1777. ef. p. 119.) folio. $129,7 \mathrm{p} ., 100 \mathrm{tab}$. col.

$9137^{*}$ Schkuhr, Christian. Botanisches Handbueh ser melirsten theils in Deutschland wildwachsenden theils auslindischen in Deutsehland unter freien Hinmel ausdanernden Gewàchse. Zweite, mit dem Nachtrag der Riedgraser vermehrte Auflage. Leipzig, G. Fleischer. 1808. 4 Bäde. 8. - 1: vm, 408 p. - 11: Iv, 421 p. - 111: 305 p. - IV: xw, 455 j. Cum 400 tals. col. sign. $1-358$. $(80 \mathrm{th}$. -20 (h. A.)

(Prodiit primum Wittenlsergae $1787-1803$ 1riginta fasciculis vel tribus partibus, quae annos $170,1796,1803$ in titulis gerunt.)

9.138* Enchiridion botanicun, seu deseriptiones et icones plantasum in Europa vel sponte crescentium vel in hortis sub Dio perdurantium. Editio latina (curante Friedrich Schwaegrichen.) Lipsiae, G. Fleischer. 1805.8 . - I: xiv, 268 p., 88 tab. col.

$9139^{*} \longrightarrow$ Beschreibung und Abbildung der theils bekannten, theils noch niclit beschriebnen Arten von Riedgr'isern, mach eigenen Beobachtungen, und vergrosserter Darstellung der kleinsten Theile. Wittenberg is01. 8. $128 \mathrm{p} ., 54$ ab. col. - Nachtrag od. die zweile Halfte der Riedgraiser. il, 1806.8 , x11, 94 p., 39 tab. col. (16 th.) + gallice: llistoire des Carex on Laiches, contenant la description et les figures colorićes de toules les especes conmues et diu grand nomhre d'especes nouvelles. Traduite de l'illemand et alugmentée nar Gislenus François Dela Tigne. Leipzig, Voss et Co. 1802. S. Xvi, par Gislenus Frunçois Deld
167 p., $5 k$ tab. col. $(10 \mathrm{th}$.

$9140^{*} \longrightarrow$ Vier und zwanzigsie Klasse des Linnéschen Pllanzensystems oder Kryptogamische Gewáchse. Erster Band mit 219 ausgemalten Liupfertafeln enthalt ausser den sâmmtlichen Farnkiriutern Deutschlands noch eine grosse Anzahl andrer aus allen Welturilen, welche noch nicht oder zum Theil mivollkommen, auch mur in seltnen Werken abgebildet sind. Wittenberg, bei dem Verfasser. 1809. 4. xIv, 212 p., 219 tab. col., effigies autoris. $(45 \mathrm{th}$.)

(Exemplaria titulo gallico cum dedicatione ad imperatricen Jasephinam, Wittenberg, chez l'auteur. 1806. 8. mon differunt.)

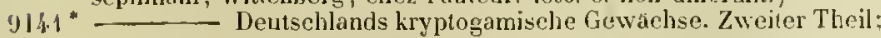
oder vier und zwanzigste Pllanzenklasse. Il. Abtheilung, die deutsehen Moose enthaltend. In 3 Hleften. Leipzig, Ernst Fleischer. 1 \$ 10 -1847.4 . x, 88 p., 42 tab. col. (sign. 1-39.) (10 th.)

y $112^{*} \longrightarrow$ Deutschlands kryptogamische Gewachse. Zweiter Theil. Oder vier und zwanzigste Planzenhlasse. Il. Altheilung, die deutschen IIoose enthalteud. Supplement. Leipzig, Ernst Fleischer. 1847. 4. p. v-s, $83-8$ s., tal. col. $38-39 .(2 / 3$ th. $)$ ducti.)

$91 \% 3^{*}$ Schlauter, E. A. Die Orobanchen Deutschlands in vabeliarischer Uebersicht. Quedlinburg und Leipzig, Basse. 1834.8 . 14 p. (1/6 (h.)
9144" Schlechtendal, Diederich Friedrich Ludwig ron. Inimadversiones botanicae in Ranunculeas Cundollii. Sectio prior. D. Berolini, 1y]. Stareke. 18 19.4.30 13., 4 tab. - " Sectio posterior. Beroliui, tjp. Scharle. 1820. 4. 39 ], 2 tab. (1 th.)

$9145^{*}-$ Erineum Pers. Regensburg 1821.4.31 p.

(Seorsim impr. ex Regensburger Denkschrifter, vol. 11. 1). 73-100.

$9146^{*}$ Flora Berolinensis. Berolini, Dümmler. 1823-1824. Il voll. 8. - I : Phanerogamia, 1823. Lxxit, 535 p. - 11: Cryputgamia. 1824. xiv, 284 p. $\left(3 \frac{2}{3}\right.$ th. $)$

$9147^{*}$ Adumbrationes plantarum. (Filices capenses.) Fasc. I -V. Berolini, Dummler. $1825(-1832) .4.56 \mathrm{p} ., 30 \mathrm{lab} .(4 \% \mathrm{~h}$.

$9148^{*} \longrightarrow$ und P.C. Bouché. Ueher die wilde Kartoffe) (Papa eimarron) von Mexico. Berlin 1833.4 .7 p., 1 tab.

$9149^{*}$ Hortus Halensis tam vivus quam siceus iconibus et descriptionibus illustratus. Fase. 1-1]. Halae Saxomum, Schwetsclihe et fil. $1841.4 .14 \mathrm{j} ., 8$ tab. col. $\left(1^{3} / \mathrm{t}\right.$ th. $)$

$9150^{*} \longrightarrow$ Viro perillustri Jo. Christ. Friderico K'ug tie XXIII Novbr. A. 1847 acceptis inte quinquaginta annos in Academia llalensi summis in medicina honoribus gratulatur D. F. L. de Schtechtendol. Lnest de Aseroës genere dissertatio. Lalae Saxonum (1\$47.) 4. 15 p., 1 tals. col.

9151* Schlegel, Johann Andreas. Tractatus medicus, von naturlichen, umatulichen und wider die Natur laufenden Dingen .... darbey dic Signatur etzlicher Gewachse und zu welchen Krankheiten dieselben zu gebrauchen, angezciget worden. Nurnberg 1686. $8.431 \%$.

9152 * Schleger, Theodor August. Versuche mit dem Mutterkorn. Gassel 1770.4.32 p.

$9153^{*}$ Schleicher, J. C. Catalogus plantarum in Helvetia cis-et transalpina sponte noscentim, quas in continuis fere itineribus in usum botanophiforum collegit et summo sturlio, collatione cum celeberrimorum autorum descriptionibus et iconibus facta, rite redegit. lies Helveliae (1S00.) 8. 76 p. - † EJ. Il: ib. 1807.8 .39 p., et calalogus Salieum: 2 p. - * Ed. Ill. emendata et auctior. il. 1515 . \& 48 p. - tEl. IV. emendata et auctior. Camberii (Chamberry), typ Corrin et Routin. $1824,8.64 \mathrm{p}$.

915:* Schleiden, Matthias J. Beitrage zur Anatumie der Cacteen. Dt. Petershurg (Leipzig, Engelmann. 1842.) 4. 46 1., 10 tab. col. in folin obliquo. ( 4 th.)

Seorsim impr, ex Mèm, de l'acarlémie imp. des se. de st. Pwtershourg, série ri, tome IV.)

$9133^{*}$ Crundzuge der wissensehaftichen Bolanik, nebst einer methodologischen Eiulejtung als Anleitung zum Studium der Planze. Leipzig, Engelman. 1842-1843. 2 Theile. S. - I: 1842. Melhodologisclse Einleitung. Vegetalilische Stofflehre. Die Lehre von ter Pllanzenzelle. xxv1, 289 p. - 11: 1843 . Horphologie, Organologit. xviı, $564 \mathrm{p} .\left(4^{2} / 3\right.$ lh. $)-{ }^{*}$ Zweite gänzlich umgearheitete Aultage (Die Botanik, als inductive Wissenschaft behandelt.) Mit 256 emgedruckien llolzschnitten und a Kupfertafeln. Leipzig, Engelmann 1845-1846. 2 Theile. 8. - ]: 1845. Mlethodologische Grundlaye. Vegetabilische Stofllebre. Die Lehre von der Pllanzenzelle. is 329 p., 4 lab. -11 : is 46 . Mlorphologie. Organologie. xv, $614 \mathrm{l}$. 4 tals. $\left(6 \frac{1}{2}\right.$ th. $)$

$94: 6^{*}-11 \mathrm{err}$ Dr. Justus Liebig in Giessen und die Pllanzenpliysiologie. Leipzig, Engelmann. Is 42.8 .37 p. $(1 / 6 t h$.

$9157^{*}$ Ofhes Sendsctureiben an Hr. Dr. Justus Liebig in Giensen, eine gegen mich gerichtete Anmerkung im Juniheft der Annalen der Chemie und Phamacie betreflend. Nebst einigen Bemerkmgen zu der Schrift: Ueber Licbig's Theorie der Pllanzenernthrung und Schleiden's Einwendungen gegen dieselbe. Fon Karl ITinkelblech, Professor in Kassel. Leipzig, Engelmann. $1842.8 .40 \mathrm{p.}(1 / 6 \mathrm{th}$.

$9138^{*}$ _ Die neuern Einwurfe gegen meine Lehre von der Befruclitung als Antwort auf Dr. Theodor Martig's Beitrage zur Entwicklungsgeschichte ter Pflanzen. Leipzig, Engelmann. 1844. 5. 38 ]. $(1 / 6$ th.)

$9159^{*}-$ und harl Naegeli. Zeitselurift fur wissenscinaftliche Botanik. Heft I-IV. Zurich, Heyer und Zeller. 184h-1846. 8. I: $1844.188 \mathrm{p}, 4 \mathrm{tab} .-\mathrm{HI}: 1845.1 \mathrm{v}, 210 \mathrm{p}, 4$ tab. $-\mathrm{III}-\mathrm{IN}$ 1846. vil, 319 p. 8 tah. $\left(6 \frac{1}{30}\right.$ th. $)$ 
"1t0" Schleiden, Mallhias J. Schelling's und Ileyel's Verhaltniss zur Naturwissenschaft. (Als Antwort auf dio Aneriffe des llern Christian Gollfried Nees von Esenbeck in der Nenen Jenaischen Lit. Zoitung, Nai 1843, inshesondre fur dic: Leser dieser Zeitschrift.) Leipzig, Engelmans. 1844.8 .87 p. $(1 / 3 / h$.

$9161^{*}$ Beitrige zur Botanik. Gesammelte Aufsitze. Erster Band. Leipzig, Engelmann. 1844. 8. v111, 242 p., 9 tah. $(15 / 6$ th. $)$

9 $162^{*}$ Grundriss der Botanik zun Gebrauch hei seinen Vorlesungen. Nit 16 IJolzschnitton. Lejpzig, Eugelmann. 1846. 8. vi, 214 p. (1 th. $)$

$1163^{*}$ - Dir geognestischen Verbaltuisse des Saalthales bei Jena von Dr. E. E. Schmid und Dr. M. J. Schlciden, Professoren in Jena. Leipzig, Engelmann. 1846 . folio. $72,(4)$ p., 5 tib. col. $\left(5 \frac{1}{3}\right.$ (h.)

(lucst a p. 63̈-72: Ueber tie fossilen Pllanzenreste des Jenaischen Musclielkalkos, von M. J. Schleiden.

9) 161* - Ueber Ernalurung der Pflanzen und Saftbewegung in denselben. Leipzig, Engelmanu. 1\$46. 8. 6\% plag. ( $1 / 2 t h$.

(Aus ter zweiten Aullage der' Grundzuse der wissensehaftichen Botanik flir Landwirlle und Gebiddete unt(a' den Laien besonders abgedrucht.)

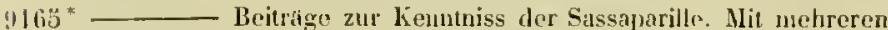
in den Text eingelruchten J Jelzschnitten und zwei illuminirten Steindruchtafeln. Aus den Archiv der Plaarmacie besonders alygedruckt.) Hannover, Hahus. 1847.8. 42 p., 2 Lab. col.

$9166^{*}$ - Die Pflanze und ihr Lehen. Fopuläe Vorträge. Leipzig, Engelunann. $1847.8 .329 \mathrm{p} ., 5$ tab. col. $\left(2^{1 / 4} / / h_{\text {. }}\right)$

!167* Schleifentag, Cabriel. De plantis. D. Lipsiae, tyju. Liger. 1625 4. (8) foll.

4 ltis Schlichtkrull, O. N.C. De officinelle Planter orduede ofter DeCandolle's naturlige Plantesystem, tilligemed de vigtigste characterer paa disse planters fanilier. Kiobuhavn 4831.8. W.

11 69* Schlipf, J.A. Jer Pllanzenhan nach den Bedurfnissen der nenesten Zeit. Reullingen, Macken. 1847. 8.171 p. $(5 / 12$ th.

!170* Schlosser, Joseph Calasanz. Anleitung die im Mahrischen Gourernement wildwachsenden und am laufigsten eultivirten phanerogamen Pflanzen naclı der analytischen Methode durch eigne Untersuchungen zu bestimmen. Brunu, typ. Rolirer. (Wieu, Beck.) 1843. s. 401 , LI j. (3 th. - in charta seriptoria: $3 \frac{1}{2}(h$.)

(Ejus Dissertationem "de Papilionaceis in Grmania sponte erescentibus o vide supla Nr. 7172 .

9171" Schlotheim, Ernst Friedrich ron. Besehreibung merkwürdiger Krtiuterabdrücke und Pflanzenversteinerungen. Ein Jeitrag zur Flora der Vorwelt. Erste Abtheilung. Gotha, Becker, 1504. gr. 4. 68 p., 14 tab. $(5$ th. $)$

$9172^{*}$ Dic Petrefactenkunde auf iluem jetzigen Standpunkte durch die Beschreibung seiner Sammlung versteinerter und fossiler I'eberreste des Thier - und Pflanzenreichs der Forwelt crlautert. Gotha, Becker. 1820 . 8. Lxil, 437 p., 15 tab. sign. $15-29$. (5 th.) (Tubulao 1-l's sunt in libro praecerlenti.)

(1)7: * Naclsträge zur Petrefactenkunde. Nr. J: ib. 1822. \& Ir, 100 p., gl tah. - Nr. 11 : ib. 1823.8 .114 p., 16 tab. $\left(7 \frac{1}{4}\right.$ th. $)$

117 F $^{*}$ Schmalz, Eduard. Dispositio synopuica generum jlantarum circa Dresdam et sponte crescentium of in agris frequentius cultarun adjeetis faniliis maturalibus. Tabellarisehe Uebersiclst ete. Als Awhang zu Leinrich Ficinus Flora von Dresden. Dresden, Arnold. 1822. folio. $37 \mathrm{p} .(1 \mathrm{th}$.

(17:3* Fungurum surecies novis iconibus novisque descriphionibus illustratae. Prospectus. s. I. el a. 4. 7 p., 2 tah. col.

!) $76 *$ Schmalz, Friedrich. Theorie des Pflanzenlsaus mit Beispiclen aus der Erfalırung in Grossen erláutert und bestätiğt. Königsberg, Borntrager. $1840.8 . \mathrm{xis}, 187 \mathrm{p} .\left(1 \frac{1}{4}\right.$ (h. $)$

$9179^{*}$ _ Anleitung zur kionutuiss und Anwendung eines neuen Ackerbausystems. Auf Theorio und Erfalırung gegrundet. Leipzig, Brockliaus. 1842.8. N, 107 p. $(1 / 2 / h$.

$31 \% 8^{*}$ Schmid, Christian. Resurrectio rerum (vegetabiliuns) artificialis. D. Lipsiae, typ. Sporel 1677. 4. 8 foll.

3179* Schmia, Edmund. Dr. Justus Liebig's Zustand der Clsemic in Oestreich und Preussen, nit Ruchsicht auf Dr. Schteiden und Winkelblech. Stutigart, typ. Metzler. 1\$42. 8. 30 [3.

$9180^{*}$ Schmid, lymaz. Je fungis esculentis et reuenatis. D. Vindobonae, typ. Ulrich. 1836.8 . 39 [\%.
9181" Schmidberger, Joseph. Leichtfaschicher Luterricht von der liszielıung der Obstlsámme, gegeben in einer kritischen Wirstellungés des gegenwartigen Zustandes dor Obstháumzucht in (Destreich ol, der Eums. cte. Linz, Haslinger. 182\}.8. 269 \%. (1/h. $)$

$9182^{\circ}$ - Beiträge zur Obstbanuzucht und zur Xaturgeschichte der den (Obstbumen sclsallichen Jusectens. Linz. IJaslinger. 48274836. 4 Hefte. 8. - J: 1827. 195 1. - 11: 1830. 271 p. - III: 1833. 243 j. - N: 1836.297 p. $(3 \% / 32 / h$.

9183* Schmidel, Casimir Christoph. Jeones plantarum al analy'ses partium aeri incisae atpur vivis colorilus insignitae, arljectis indicibus nominum necessariis, fignrarum explicationilus et lorevilus animarl-

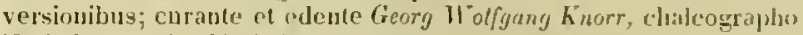
Norimbergensi. (Norimbergae), typ). J. J. l'J (ischmann. 174\%. folio. $\{97$ p., 50 lab. col. - * Curante Juhmn Christoph heller. (Norinbergae), Iyp. Ile Launoy. 1762 . folio. $197 \mathrm{j} ., 50$ tab. col. - ${ }^{*}$ Ed. 11 curante Bischoff. Manijulus I - III. Folangae, Palm. 1793-1797 folio. $280 \mathrm{p}$. 75 tab. col. $(36 \mathrm{H}, \mathrm{th}$. $)$

918:. — De medulla radicis ad flerem pertingente epistula. Impr. cum Specimine bolanico Nicolai Laurentii Burmann rle Geraniis. Lugduni Batavorum 1759. 4. (10) p., 1 tals. (Schmidel, Diss. bot. argum. 1). $113-130$. )

9185* Disscrtationes botanici argumenti revisae of recusar. Erlangae, Walther. 1783.4.130 p., $4 \mathrm{tab}$.

Do Oreoselino p. 1-28, De Buxhaumia ph-62, De [3lasia p. 63 -88 , De Jumgermaniae charactere 1 . $89-11$, , De minulid radic is ad 110ren pertingeute p. $113-130$.)

$9186-$ Descriptio itineris per Helvetiam, Galliam etr. Erlangáse 1794. 4. DC.

Disserlationes praeside Casimir Christoph Schmidel:

$9187^{*}$ De Oreoselino. D. Frlangate, typ. Tetzschner. 1751. 4. $42 \mathrm{p}$. (Respondens : Georg Christian Troelizsch.) (Schmidel, Diss. bot. argum. p. 1-28.)

$9188^{*}$ — De Buxbaunia. 1). Errangae, typ. Tetzsehner. 175. 4 . 46 p., 1 tab. (Respondens: Johunn Georg Hoelzel.)

(Sclimidel, Diss. bot. ar'unu1). 1). $29-62$.)

$9189^{*} \longrightarrow$ Do Blasia. b. Erlangae, 1yp. Tetzsehner. 1759.4. $32 \mathrm{J3.}$ 1 tab. (Respondens: Johann Christoph Zimmermann.)

(Schmidel, Diss. but. argum. p. 63-88.)

$9190^{*} \longrightarrow$ De Jungermanuiae charactere. 1). Erlangae, typ. 'Tetäschner. 1760, 4. 29 P., 1 lab. (Respondens, Christoph Andreas Pauer.) (Schmilel, Diss. bot. argum. 1).89-11k.)

9191* Schmidlin, Eduard. Flora vou Stutgart, oder Beschreibung der in der Ungegend von Stuttgart wildwaehsenden sichtbar bluhenden

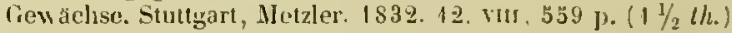

9192 Die bürgerliche Gartenkunst etc. Stuttyart, Ifoffnann. 1843. gr. 8.42 plag., 24 lab. (2 / h. )

$9193^{*}$ Anleitung zum Botasisiren und zur Anlesung von Planzensanmlungen, nebst einer leichtasslichen [nterweisung in Lntersuchen der [flanzen und einem praktisehen Schlussel zum Auffinden der Gattungen und Arten. Fur Anfanger unl Volksschulen. Stultgart, Hofmaniu. 1846.8 . vit, $407 \mathrm{p})(2 / 3$ th. $)$

919: _ Der Wintergarten. Vellstundige und fassliclse Anleitung zur Blumenzucht im Zimmer. Ein Handbuch fur jeden lilumenfreund. Stuttgart, Holmann. 1847. 16.424 p. $(2 / 3 / /$. $)$

$9195^{*}$ Schmidt, C. A. Haudbuch der molizinischen und Farbekrảuter, Bhatter, Bluten, Sanen und Wurzeln wilder un! kultivirter Pflanzen und Bäume Deutsehlands etc. Gotha und Erfurt, Jennings. 1832. \&. $\mathrm{x}, 177 \mathrm{p} .(3 / 4$ th. $)$

$9196^{*}$ - Wilbelms Wanderungen in das Gebiet der Giftpllanzen Deutsehlanls ete. Erfurt, Hennings, 1838. 8. 64 p., 14 tab. col. $(3 / 8$ (h.)

y197* Schmidt, C. P. Neue Nechore, die phanerogamischen Pllanzeu zu trocknen, mit Inbegrilf tler Farrnkrauter fur das Ilerbarium, nacl welcher dieselben in selar kurzer Zeit gut getrochnet und dabei in ilırem natürlichen Farbenschmuche erhalten werden. Gorlitz, Eılwin Sclimidt. 1831.8 .48 p. $(1 / 4$ th.

$9198^{*}$ Schmidt, F.A. Petrefaktenbuch oder allgeneine und besondre Versteinerungskunde. Stuttgart, Holmmann. 1846. 4.174 j., 64 tah. eul. (5 th.) 
9199 Schmidt, David. Taschenbuch der pharmaceutisch-vegetabilischen Rohwaarenkundo für Aerzte, Apotheker und Droguisten. Frster Band, Heft $1-5$. Jena, Schmid. 1847. 8. 360 p., 50 tab. col. $\left(3^{3} / 4\right.$ th. $)$

9200* Schmidt, Franz. Oestreichs allgemeine Baumzucht, oder Abbildungen in- und ausländischer Batume und Strauche, deren Anpflanzung in Oestreich möglich und nutzlich ist. Wien, typ. Alberti. 1792-1522. IV roll. folio. $-1: 1792.57$ p., ind. tab. col. $1-60$. - 11: 1794. $6 \$$ p., ind., tab. col. $61-120 .-111: 1800.51$ p., ind. tab. col. 12I-180. - TV: ih. typ. Strauss. 1822.58 p., ind., tab. col. $181-240 .(118 t h$.

Textum roluminis quarti et utius tandem anno 1839 absolvit Leopold Trattinick, postyuam operis continuatio morto autoris $[\div 183$ k $]$ diu interrupta fnerat.

9201 - Anleitung zur sichern Erziehung und Vermehrung derjenigen Aholnarten, die allgemein vermehrt zu werden verdienen. Wien, Staatsdruckerei. 1812 . 4. vi, 50 p., 10 tab. col.

$9202^{*}$ Schmidt, Franz Uilibald. Neue und seltene Pflanzen nebst einigen andern botanischen Beobachtungen. D. Prag, Calve. 1793. 8. 58 p., 1 tiab. $(5 / 12$ th. $)$

$9203^{*}$ - Flora boénica inchoata, exlnibens plantarum regni Boèmiae indigenarum species. Tomus I. Centuria I-JY. Pragae, Calve 1793-1794. fulio. $86,97,112,96$ p. $\left(1 \frac{1}{3}\right.$ th. $)$

920 ' - Sammlung physikalisch-okonomischer Aufsátze, zur Aufnahme der Nuturkunde und deren damit verwandten Wissenschaften in Böhmen; herausgegeben von Franz llitibald Schmidt. Erster (und einziger) Band. Prag, Calve. 1795. 8. 375 p., 3 tab. ( 1 th. $)$

Insunt: Bemerkungen uber verseliedne in dem Systema natuvae. cura Gmelin, angefuhrte Pllauzen, p. 1800-201: botanische Beobachiungen, p. 22'-2 250 ; uber Limne's Syngenesia, Polygamia aequalis semillosculosi, p. $23 i-286$.

$9203^{*}$ Schmidt, H. H. Preussens Pflanzen nach dem naturlichen Systeme geordnet und beschrieben. (Auch: Grundriss der Naturgeschichte. Zweite Abtheilung: Phytologie.) Danzig, Homann. 1843. 8. Iv, 267 p. $\left(1 \frac{1 / 4}{4} t h.\right)$

9206 Schmidt, J. A. F. IIandledning i Trädgåds-skotseh. Nyköping 1841. 13. 105 p., 1 tab. (40 skill.)

9207 Schmidt, Johann Andreas. De frondibus festivis pentecostalibus. IIclnstadii 1707.4. H.

9208* Schmidt, Johann Andreas, junior. De Glyeyrrhiza. D. Jenae, typ. lirebs. 1717.4

$9209^{*}$ Schmidt, Johann August Friedrich. Der angehende Botaniker oder liurze und leichtfassliche Anleitung die Pflanzen kennen uud bestimmen zu lernen. etc. Ilmenau, Voigt. 1832. 12. - Ed. Il. ib. 1834. 12. - *Dritte verbesserte Aullage. Weimar, Voigt. 1836. 12 xvili, 470 p., 36 tab. $\left(1 \frac{1}{3} \mathrm{th}.\right)$

9210* Schmidt, Joham Christoph. De analogia regni regetabilis cum animali. D. Basileac, typ. Ludii. 1721. 4. 24 p.

9211* Schmidt, Johann Joachim. Aeusserungen uber ein System in der Pflanzenkunde. (Boitzenburg) 1797. 8.39 p. $(1 / 19$ th.)

$9212 \div-$ Botanisches Jahrbuch fur Jedermann, etc. dic Pflanzen des Irrdbodens aller Art, deren System, Geschiclıte und Literatur náher kennen zu lernen. Luneburg, Herold und Wahlstab. 1799. 8. 305 j., pritef. $\left(1 \frac{1}{3} t h.\right)$

$9213 \div$ Schmidt, Johann Karl. Allgemeine akunomiseh-technische Flori, oder Abbildungen und Beselıreibungen aller in Bezug auf 0ekonomie und Techuologie merkwurdigen fewächse. Jena, Schmid. 11 voll. 8. - I: 1827. (Heft 1-10.) 230 p., tab. col. 1-50. - II: 1829. (Heft 11-15.) $x$ p. et tab. col. $51-75 .(10$ th.)

(frodiit annis 1820-1831 quindecim fasciculis.)

921' Schmidt, J. St. Nachlese zu Schönbrunns botanischem Reichthume (von B.D. Maucharl). Wien $4808.8 .92 \mathrm{p} .(1 / \mathrm{t} t h$.

9. $13 *$ Schmidt, Jilhelm Ludwig Ewald. De Erythraea. D. Berolini, typ. Krause. 1828. 4. 30 p., 2 tab.

$9216^{*} \longrightarrow$ Kurze Anweisung für junge Pharmaceuten, das Studium der Botanik zweckentsprechend und selbststandig zu betreiben. Stettin, Bohme. 1830.8 .72 p. $(5 / 12$ th. $)$

$9217^{*}$ - Getreue und systematische Besclireibung der officinellen Planzen der neuesten Preussischen Landespharmacopoe, in ta-

Pritzel, Thes, lit. bot. bellarischer Uebersicht. Berlin, Enslin. 1831. folio obliquo 122 p. (1 th.)

9218* Schnidt, J17lhelm Ludwig Ewald. Botanischer Wegweiser, oder praktische Unterweisung, zweckgemáss das Studium der Botani zu beginnen etc. Stettin, Nicolai. 1837. 8. Iv, 118 p. (1/2 th.)

$9219^{*}$ Flora von Pommern und Rugen. Stettin, Becker und Attendorff. 1840. 8. xxxxvil, 392 p. $\left(1 \frac{1}{2}\right.$ th. $)$

9220 Schninckius, J. II. Dissertatio de cultu religioso arboris Jovis, pracsertim in Ilassia. D. Narburgi 1714. 4. 28 p. (Respondens Johann I'ithetm Schonfeldt.) B.

9221* Schmitz, J. Joseph, et Eduard Regel. Flora Bonnensis. Praemissa est L.C. Trevirani, Prof. Bonn., Comparatio Florae Vratislaviensis et Bonneusis. Bonnac, H. B. König. 1841. 8. xLvu, 512 p. ( 2 th.)

9292* Schmutz, Michael Raphael. Tractatus novus de nymphis CaroloBadensibus admiralibus in regno Bohemiae. $1661.8 .155 \mathrm{p}$.

Nuntumn continet de celebri horto in Schlackenwerth, p. 6 .

9223 Schneeberger, Anton. Catalogus stirpium quarundam latine et polonice conscriptus. Cracoviae, apud Lazarum Andream. 1557. 8 min. (94) foll. Arnold.

$9221^{*}$ __ Catalogus medicamentorum simplicium, sive euporistôn pestilentiae veneno adversantium, et quomodo iis utendum sit, brevis institutio. Tiguri, typ. Jac. Gesner. (1561.) 8.58 foll., praef. - ${ }^{*}$ Impr. cum Cassio Jatrosoph. Tiguri 4562. 8. Bibl. Goett.

9223* Schneevoogt, $G$. Voorhelm. Icones plantarum rariorum; delineavit et in aes incidit $I$. Schwegman; scriptionem inspexit Steven Jan van Geuns. Ilarlem, Plaat. 1793-1794. Fasc. I-XIV. $\Longrightarrow I I$ voll folio. 42 foll., 42 tab. col

(Volumen primum continet fasciculos $1-\mathrm{X} I l$, alterum XIIL-XIV plures nou prodierunt.)

9226 * Schneider, $A$. Die vorzüglichsted Giftpflanzen Deutschlands und der Scbweiz. Alit kolorirten Zeichnungen von J. Schedler. Konstanz 1846. insp. folio. 1 Tabelle. (1 th.)

9227* Schneider, Karl Ernst Christoph. Deseriptio codicis vetustissimi in bibliotheea academica (Vratislaviensi) asservati cum precationibus quibusdam ex eo editis. Impr. cum Indice lectionum in univ Viadrina per hiemen anni 1839 instituendarum. 4.6 p.

9228* Schneider, liarl Friedrich Robert. Die Vertheilung und Verbreitung der schlesischen Pflanzen, nachgewiesen in 14 Gebieten der schlesischen Flora. Nebst einem Anhange uber die Vergleichung der schlesischen mil der britischen Flora. Nebst einer botanisch-geognostischen Karte von Bunzlau. Breslau, Grass, Barth u. Co. 1838. 8. 292 p. $(2 / 3$ th. $)$

(Etian inscribitur: "Beitrage zur schlesischen Pflanzenhunde, Priores 188 paginae praeterea seorsim editae sult, inseriptae: "Flor" von Bunzlau, odler die Pflanzen der Umgegend von Bumzlau nach Vorhommen, Ilaufigheit, stindort und Blutezeit, mit Angabe aller schlesischen Pflanzen nach Vorhommeo und Blutezeit. o)

9229* Schnekker, Johann Daniel. Idea generalis ordinis plantarum verticillatarum. D. Giessae, typ. Braun. 1777.4.32 p.

$9230^{*}$ Schneyder, Johann. Ueber den Wein- und Obstbau der alten Römer. Programm. Rastalt, typ. Mayer. 1846. gr. 8. vi, 58 p.

9231* Schnittspahn, G. F. Flora der phanerogamischen Gewachse de. Grossherzogthums Hessen. Ein Taschenbuch fur botanische Excursionen. Darmstadl, Dichl. 1839 . 8. Lxvin, 304 j., 1 mappa geogr - El. II : Darmstadt, Diehl. 1846. 8. LXXII, 328 p. (1 th.)

$9232 *$ Schnizlein, Adalbert. lconographia familiarum uaturalium regni vegetabilis. Abbildungen aller maturlichen Familien des Gewächsreiches. Fasc. I-V. Bonn, Jlenry und Cohen. $1843-1847.4 . x \mathrm{p}$, 100 tab. col. ( 10 th. $)$

$9233^{*}$ Die naturliche Pflanzenfamilie der Typhaceen, mit besondrer Rückicht auf die deutschen trten bearbeitet. Nordlingen, Beck. 1545.8 . 28 p., 2 tab., explicatio tabularum. ( $2 / 5$ th.

9234* - Die Flora von Bayern, nebst den angränzenden Gegenden von Hessen, Thuringen, Böhmen, Oesterreich und Tyrol, so wie von ganz Wurtemberg und Baden. Erlangen, Heyder. 1\$47. 8. Crt, $373 \mathrm{p} .(1 / 2 \mathrm{th}$.

$9235 \longrightarrow$ u. Albert Frickhinger. Die Vegetationsverhä]tnisse der Jura - und Keuperfornation in den Flussgebieten der $\mathbf{W}$ ornitz und Altmühl. Nehst einer geognostischen Karte. Nordlingen. Bech.

(Libri mox prodituri tituiun debeo cl. allor:.) 
$92.36+$ Schoder, C. F. II. Die Erolaten im Gebiete der Pflanzenregetation, ele. Judwigslourg, Nast. 1825. 8. vit, 97 p. (1/2 (h.)

9237 Schoenfeld, Melchior. 1) plantis in genero. 1). Lipsiae 1619. 4.

$9238^{*}$ Schoepf, Johann Dacid. Materia medica americana, potissimum regni vegetabilis. Limangao, l'alm. 4787. 8. Xvil, 170 j.

9239* Schoepfer, Franz Kaver. lilora Oenipontana, oder Heschreilung der in der Gegend um lumsbruck wildwachsemlen Pflanzen, nubst Angabe ilırer Wohmorte, Hutezeit und Nutzen. Junspruck, Wagner. (Leinzig, l3artlo.) +805. 8. 396 p., praef, ind. (15/6 th.)

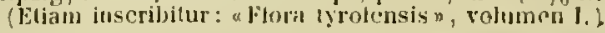

9210 Schoepfius, Johannes. Hortus Ulmensis, Ulmiselier I'aradissGarten, d. i. ein Verzeichnuss und Register der Simplicien, an ter Zahlıl uber 600, welche in Gärten und nechsten lBezirek uml, die stadt Ulm zu finten. (Iatine el germanice.) Ulm, Johann Meder. 1622. 8. Rivin.

921.1* Scholler, Friedrich Adam. Flora Barbiensis. In usum scminarii fratrum. Lipsiae, apud Weidmann haeredes et Reicln in commissis. 1775. 8. 310 p., ind. - "Supplementum Florae Larbiensis, edente J. J. Bossart. Barbii, typ. Sprllenberg. 1787. 8. p. 311-366. 1 tab.

$922^{*}$ Scholtz, Ileinrich. Enumeratio Filicum in Silesin sponte crescentium earumque de usu, additis Lycopodiaceis et Equisctaceis. D. Vratislaviae $1836.8 .58 \mathrm{p}$.

$924.3^{*}$ Flora der Umgegend von Breslau. Breslau, Selıuz el Co. 1843. $8.336 \mathrm{p} .(3 / 4 t h$.

92 fi. Scholz, Lorenz. Ifortus Vratislaviae situs et rarioribus plautis consitus, earminc celebratus, enm ejusdem horti catalogo botanico. Vratislaviae, apud hacredes Scharfenberg. 1587. 4. s.

$9210^{*}-$ Catalogus arlsorum, fruticun ac plantarum tum indigenarum quam exoticarum lonti medici Laurentii Scholzii. Yratislaviae, typ. Georg Baumnnn. 159\%. 4. (12) p. Bibl. Reg. Berol.

(Riviniano exmplari accesserumt Epigrammata amicorum mox Heenda; lalentis Aridalii Janns qualrifrous; leges hortenses et convisiates; Johannis Ferschit sermo de viris in materiam medieam et herlariant bene meritis.?

921.6t - Hortus Lawentii Schalzii, quem ille colit Vratislaviae, situm intra ijsa civitatis moenia, celebratus carmine Andreae Calugii. Vratislaviae, typ. Geurg Baumann. 1592. 4. (10) foll.

$9347 \div-$ In Laurentii Scholzii, mediei Vratislaviensis, Hortum epigrammata amicorum. Tratislaviae, fyp. Georg Baumann. 1594.4. (48) foll.

$9218^{*}$ Schomburgk, Richard. Reisen in Britiselı-Guiana, in den Jahren 1840-1844. Jm Auftrage Sr. Najestat des lionigs von Prenssen ausgefulirt von Richard Schomburgk. Nebst einer Fauna und Florn Fuianas, Mach Vorlagen von Johannes Muller, Ehrenberg, Erichson. Klolssch, Trusckel, Cabanis und Andern. Mit AJbildungen und einer Karto von liritiselı-Guiana aufgenommen von Sir Robert Schomburgk. Zwei liande. Leipzig, Weber. 1847 - 1848. gr. S. - I: 1847. x, vili, 469 p., 9 tal. - II: $1848 . x$ p. $\left(13 \frac{1}{2}\right.$ th. $)$

(In volumine altero continctur enumeratio omnium plantarum in itincre Ieclarum, antorihus klotzsch, von schlechtendal, Barling, frisebach, Steet=, Schulli Bip., aliis. Aldita est mappa botanico-geo-

9239 * Schomburgk, Roberl /lermann. A deserijtion of British Guiana, geographical and statistical: exhibiting its resources and capaljilities, ingether with the present and future condition and prospects of the colony. London, Sinpkin, Marshall and Co. $1840.8 .155 \mathrm{~J}$., 1 majpa geogr. ( $5 s$.

(Vegelable productions: p. 28-37.)

* yermanice: Geographisch-siatislische Beschreilung von RrittischGuilua, elc. Aus lem Englischen von Oto Alfred Schomburgli. Mlagdelurg, sclmiliusky. 18.1. 8. vil, $15 \%$ p., 1 majula geogr, (1 th.

$9230^{*}-$ Reisen in Guiana und am Orinoko wahrend der Jalure 1835-1839; naclı seinen Berichten und Mittheilungen an die geograpluische Gescllschaft in London herausgegehen von Otto Alfred Schomburgk. Hil einem Vorworl von Alexander von IIumboldt. Leipzig, Georg Wigand. 1841. 8. xxiv, 510 p., 6 tab. col., 1 mappa geogr. $(6 \% / 3$ th. $)$

$3251 \div$ Descrijtion of Calycoplyyllum Stanleyanum, a new Rubiacea from Guiana. (Reprinted for private distribution from the London Journal of botauy, vol. III.) (London 1841.) 4. 3 p., 1 lab.

9252* - Die Barbacenia Alexindrinac und Alexandra Imperatricis, entdecht und beschriclsen. Braunselıweig $1845.4 .22 \mathrm{p} ., 1 \mathrm{tal}$.
92:3" Schomburgk, Robert /lermann. Die Rapatea Friderici Augusti und Saxo-J'riderichia regalis, entdeckt und beschrieben. Jlraunsclweig 1845 . 4. 14 p., 2 tal).

92:' Schookius, Martin. Je cerevisia liber, in guo umnia at illam pertinentia discutiuntur. Groningae, tgp. 13ronclıorst, 1661 . 12. s.

923:3 Dissertatio de Tulijus. Franerfurti 1680.4. s.

$92: 36 \div$ Schoon, Theodor. Waare orffening en ontleding der juanten ete. lier nevens weril ter nedergestehl de culture ofle voortupeeking. van de Tabak, etc. In's Gravenluage, ly Meindert L'twerf. 1692. \& 564 p., jraef., isd., 12 (a).

9257 Schosulan, Johann Michael. Dissertatio inauguralis de vinis. Viesnae 1767. 8. 56 p. B.

$9258^{*}$ Schott, Heinrich, el Stephan Endlicher. Meletemata Jotanica Vindobonae, typ. Carol. Gerold. 1832 . folio. 36 p.. 5 tab.

Opus rarissinum, nunquam in tif)liopoliis venale, vix ac ne us quiden sexagina exemplaribus divulgatum est.)

$9239^{*}$ - Rutaceae. Fragmenta Jotanica. Vindobonae, WallisJausser. 1834 . folio. 14 p., 7 ald,

$9260^{*}$ Genera Filicum. Vindobanae, Wallishausser. 1834 4 obliqua. (44) p., 20 lal). ( 8 /h.)

9261 * Schott, Wilhelm. Skizze zu einer Topographie der l'raducte des elinesischen Reichs. Gelesen in rler Akademio der Wissenschaftent am 2. Juni 1842. Berlin, Druckerei der Akiddemir. 1842. 4. 141 1,

9262* Schotte, Hermann Adolph. De Opio indigeno nonnulla. D. Berolini, typ. Nictack. 1833. 8.28 p

$926.3^{*}$ Schottlaender, G. A. E. Die vorzugliclssten in Heutschland wachsenden Giffplanzen und deren Wirkungen auf las Lelsen und dir Gesundlıeil der Vensehen. Nolst Angabe der Jjilfsmiltel bei Vergifungsfallen. 17m, Ebner. 1837.8 .53 p., 2 tab. col. in folio. ( $5 / 8$ th.)

9261* Schousboe, P.K. A. Jagllagelser over Vextriget i Narohto. Forste Styche. Kiolnhavn, typ. Seitlelin. 1800.4 .206 p., $T$ tal.

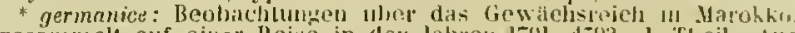
gesnmmelt anf eimer lieise in don Jahren 1791-4793. 1. Theil. tus dem Deinisetsen von J. Ambr. Harliussen. Kopenlangen und Leipzig. Sclubothe. 1801 . S. Xit, $156 \mathrm{D} ., 2$ als. $(5 / \mathrm{s} / \mathrm{h}$.)

926:3* Schouw, Joakim Frederil. Dissertatio de sedibus plantarum originariis. Seetio prima. De pluribus cujusvis speciei individuis originariis statuendis. Jlavniae, 2 yp. Popj. 28 . Scpt. 18।6. S. So p.

$9260 *$ Grundtrack til en almindelig Plantegeographie. Jiobenhavn, Gyldendal. 1822. 8. vil, 463 p., 4 mappae bot geogr. (4 Rbd. 32 sk.)

$9267^{*}$ Plantegeographisk Atlas. Ifenhureude till Sammes Grundtraek til en almindelig Plautegeographie. Kiölsenharu, typ. J. I]. Schultz. 1824 . folio. 1 foll., 22 majp). hot. grengr. ( $7 \mathrm{lBb}$ d.)

Editionem novam lahulis 12 duplicilus ad noros sciruliae progressus reformatam ridi in bibliotheca ill. Jladriani de Jussicu. * germanice: Grundzige viner allgemeinen Pllanzelyzeograplice. AuAcum Dänischen uberseizt vom Verfasser. Berlin, Reimer. 1823. S. Vut 524 p., 4 mappar bot. geogr.: $\left(6^{2} / 3(h\right.$. $)$

germanice: Pllauzengeographiseher Allas zur Erlauterung rou Schoun's Gruidzugen eilier allgemeinen Pllanzengeographic. Berliu, ileimer. 1823. folio. 1 foll., 22 mapp. bot. geogr.

$9268^{*}$ Beitrage zur vergleiclienden Klimatologie. Erstes lleft. Kopenlagen, ty]). Schultz. (Gyldendal.) 1827. S. 136 ). (64 sk. $-1(h$.

92696 - Specimen geograpluae plysicae comjarativac. Ilavniac, Igp. Scluultz. (Gyjdendal.) 1828.4.65 p., 3 a ab. (1 Rbd.)

9250 Europa, en let fattelig Naturskilatring. kijobenhann. Gylelendal. 1832. 8. - Ed. II : ib. 1835.8 . 140 p. Allas: \& tal,. (2 lidr.) (Text: 48 sk., Atlas: 1 Rbd. 48 sk.)

" germanice: Europa. Plyysisch geographische Schuderumg. Koupu-

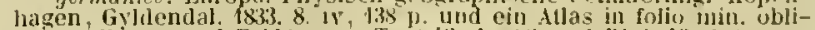
quo: 6 karten und Erhlarung. (Text is' sk. Allas: I Rhd. 48 sk.)

9271 Natur-Skildringer: en Raekke af almeenfaltelige Forelaosninger. Kiobenhavn, Gyldendal, 4837 . 8. vil, 176 p., 2 tah. (1 Rbd. 12 skill.) - EJ. 11: ib. 1839. 8. (non differt.) - Samling ll: ib. 1846 . S. $10 \frac{1}{2}$ plag., 5 tab. nigr. ef eol. $\{23 / 2+$ th. - I et 11 : $11 / 12$ (h.)

* germanire: Naturschildarungen. Eine lieine allgemein fasclielıer

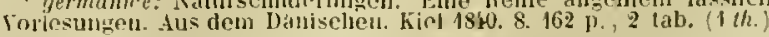

92:2* - Tableat du elimat et de la végćtation de l'ltalie, résultat de deux royiges en ce pays dans les années $1817-1819 \mathrm{et}$ 1829-1830. Vol. 1. Tableau de la femperature et des pluies de 
I'Italie. Avec un Allas de 5 cartes. Copenhague. Gyldendal. 1839. 4. $x, 214,227 . p .(6 t h .-8$ Rbd.)

9273 Schouw, Joakim Frederik. Erindringsord til en Forelaesningen over den almind. Plantelaere. Ny Udg. Kjöbenhavn (Gyldendal.) 1839.8.48 p. (24 sk.)

$927 z^{*}$ - Forelobig Fortegnelse over den Kjobenlavuske botaniske Ilayen Planter. Indeholdende dem, der ere blevne undersegte i Larene 1849-1846. Med et (lith.) Kort over Haven (in 4.) lKjölesthavn, Gyldendal. (1847.) gr. 8.180 p. $(2 / 3$ th. $)$

9273* (Schrader, Christian Friedrich.) Index plantarum horti botanici Paedagogii regii Glauchensis. Halae, typ. Ilessii. 1772. 16. 52 p.

$9276^{*}$ Genera plantarum selecta in usum tironum botanophilorum methodo tabellari adornavit. Halae, 1ур. Orphanotrophei. $1780.8 .54 \mathrm{p}$

9277 Schrader, Friedrich. Dissertatio epistolica de microscopiorum usu in naturali scientia et anatome. Goettingae 1681.8.36 p. B.

$4278^{*}$ Programma quo medicinae in illustri academia Julia studiosi ad exercitia botanica excitantur et de nova plantarum methodo admonentur. Helmstadii, typ. Hamn. 1690. 4. (8) Joll. Bibl. Reg. Dresd.

9279* Schrader, Gotllieb Nathanael. De Anagallide. D. Ilalae, Hendel. $1760.4 .28 \mathrm{p}$.

9280* Schrader, Heinrich Adolph. Spicilegium Florao germanicae. Pars prior. Jlannoverae, Ritscher. 1794.8. 194 p., 4 tab. col.

!281* - Sertum IIannoveranum, seu plantae rariores, quae in hortis regiis Hannoverae vicinis coluntur. Descriptae ab Henrico Adolpho Schrader, delineatae et sculptae a Joham Christian Wendland. Volumen I, Pasc. I-W. Goettingae, Vandenhoek el Ruprecht (fasc. IV: Hahn.) 1793-1798. folio. 28,8 p., ind., 24 tab. col. (5th.) (In tergo tituli faseiculi quarti auctore Ilendland legitur: $0 \mathrm{~b} \mathrm{im}-$ pedimenta quaedan hocce opus cum D. Schrader conjunctim edere non amplius licuit. In posterum prodibit sub titulo: Hortus TlerrenJusanus.)

$9282^{*}$ ___ Srstematische Sammlung kryptogamischer Gewaichse. Zwei Lieferungen. Goettingen, Dieterich. 1796-1797. 8. - I 1796. 20 p. $-11: 1797.16$ p.

$9283^{*}$ - Nova genera plantarum. Pars l. Lipsiae, Crusius. 1797. folio. vir, 30 p., 6 tab. col. $\left(3 \frac{1}{2}\right.$ th. $)$

928.t - Abermablige Revision der Gattung Usnea in des Herrn Prof. IIoffmann Flora Deutschlands zweiten Theile. Als Beleuchtung der in der Jenaer Literaturzeitung 1799. Nr. 240 befindlichen Recension des ersten Stüchs des botanischen Journals. Goettingen, Dieterich. 1799. 8. Lil ]. $(1 / 2 t h$. $)$ Bubl. Léveille.

Cr. Schraderi anteriorem commentationem: «Ueber die Gattung Usnea, nebst einigen rorausgeschicklen Bemerkungen über den zweiten Theil der Hoffmann'schen Flora Deutschlands in in Schrader's Journal, stuck I. D. $42-8 \ddot{3}$. I tab.)

928:* — Journal fur die Botanik. Ilerausgeg. von Nedizinalrath Schrader: Gottingen, Dieterich. 1799-1803. V voll. 8. - I: 1799 viu, 526 p., 6 tab., effigies Thunberg. - II: 1799.502 p., 5 tab., elfigies $N$. J. Jacquin. - Ill: 1801 . LII, 446 p., 9 tab., effigies Vaht. - IV: 1804.487 p., 7 tab., effigies Smith. - V: 1803. vi, 504 p., 6 tab., effigies Swarlz. $\left(6^{2 / 3} t h.\right)$

$9286^{*}$ - Nenes Journal für die Botanik. Erfurt, Knick und Multer. 1806-1810. 4 Bande. 8. - 1: 1806, 184, 204, 200 p., 6 tab., effigies Cavanilles. - II: 1807. 172,376 p., 3 tab., effigies A.L.Jussieu. - III: 1809. 260, 294 p., 3 Iab., effigies Willdenow. - IV: 1810. 288 p., 2 tab. $\left(6^{5} / \mathrm{s}\right.$ th. $)$

$9287^{*}$ Commentatio super Veronicis spicatis Linnaei. Goettingae, Dieterich. 1803.8 .40 p., 2 tab. $(1 / 3 \mathrm{th}$.

$9288^{*}$ - Flora germanica. Tomus I. (et unicus.) Goettingae, Dieterich. $1806.8 .432 \mathrm{p} ., 6 \mathrm{tab} .(12 / 3$ th. $)$

9289 Catalogus horti Goettingensis. (Goetlingae) 1806.8. Schultes.

$9290^{*}$ - Genera nonnulla plantarum ensendata et observationibus illustrata. Goettingae, Dieterich. $1808.4 .20 \mathrm{p} ., 5 \mathrm{tab} .(3 / \mathrm{t} / \mathrm{h}$. $)$

9291* _. Hortus Gottingensis, sive plantae novae et rariores horti regii botanici Gottingensis descriptae et iconibus illustratae. Goettingae, Dieterich. 1809 . Solio. 22 p., 16 tal). col. ( $8 t h$.)

$9292+(\longrightarrow)$ Verzeichniss der Treib- und Glaslıauspflanzen, wie auch der larten Staudengerfachse und Striuclicr, die aus dem bo- tanischen Garten zu Gottingen gegen baare Bezahlung abzustehon sind. (Goettingen) 1810.4.(8) p. - ib. 1812.4. Sckultes.

9293* Schrader, Ileinrich Adolph. De Jlalophytis Pallasii, respectu in primis ad Salsolam et Suaedam habito conmentatio. Goettirgae, Dietcrich. 1810.4 .20 p., 3 tab. $(3 / 8$ th. $)$

929:" * Monographia generis Verbasci. Goetlingae, Dieterich. 1813-1823. Il sectiones. 4. - I: 1813.40 p., 5 tab. - II: 1823 58 p. 3 tab.$(1 \%$ th. $)$

$9293^{*}$ Do Asperifolis Linnei commentatio. Gaettingae, Dieterich. 1820.4 .26 p., 1 tab.

$9296^{*}$ Blumenbachia, novum e Loasearum familia genus, adjectis observationibus super nonnullis aliis rarioribus aut minus cognitis planlis. Goettingae, Dieterich. 1827.4 .54 p., 4 tal). $(2 / 3$ th.

$9297^{*}$-... Analecta ad Floram Capensem. 1. Cyperaceae. Goettingae, Dieterich. 1832.4 .55 p., 4 tab. $(2 / 3 t h$.

$9298^{*}$ - Reliquae Schraderiande. H. A. Schuder's Lebensbeschreibung und hinterlassene unvollendete botanische Ablandlungen. (Aus Linnaea, vol. XIl.) Halle, Gebauer. 1838. 8. 124 ]).

9299* Schrader, Johann Christian Karl. Die norddeutschen Arzueipllanzen für Anfänger der Apothekerkunst. Berlin, Mylius. 1792. 8 . $\mathrm{x}, 644$ p. 4 Tabellen. $(15 \%$ th. $)$

$9300^{*}$ und Johann Samuel Benjamin Neumann. Zwei Preisschriften uber die eigentliche Beschaffenheit und Ėzeugung der erdigen Bestandtheile in den verschiednen inländischen Getraidearten. Herausgegeben von der Kigl. Akademie der Wissenscbaften zu Berlin. Berlin, Fr, Maurer. 1800. S. 120 p.

930 I $^{*}$ Schrader, Johann Eduard Julius. De Monocotyledonearum et Dicotyledonearum circa gemmarum explicationem differentia. 1). Bomnae, typ. Georgii. 1834 . S. 23 p.

9302* Schramm, Johannes Augustin. Die Pflanzen des Leobschutzer Stadtwaldes, ein Unterrichtsmittel der Lehranstalt. Ratibor, typ. Langer. $1833.8 .92 \mathrm{p}$.

$9303^{*}$ Die seltneren Pflanzen der schlesischen Flora in den Umgebungen von Leobschitz, nebst einigen Beobachtungen uber gemeinere. Leobschutz, Schubert. $1840.8 .45 \mathrm{p}$.

9304 Schramm, Karl Traugott. Mitheilungen über Flora, Gesellschaft fur Botanik und Gartenbau in Dresden. Im Auftrage der Gesellschaft. herausgegeben. Erstes bis drittes lleft. Dresden, Arnold. 18411843. gr. 8. (1 $1 / 2$ th. $)$

9305* Schrank, Franz von Paula (von). Beiträge zur Naturgeschichte. Leipzig 1776. 8.137 p., 7 tab. $(7 / 12$ th. $)$ -137.)

Genauere Untersuchung einiger sich "ahnlichen Phanzen, p. 129 Vorlesung. Regenslourg, Montag. 1780.8.39 p. (1/12 th.)

$9307^{*}$ Eine Centurie botanischer Anmerkungen zu des Ritters ron Limé Species plantarum. Erfurt, Keyser. 1781.4 .64 p. $(5 / 2+t h$. (Acta Erfordensia, 1782. vol. III.

$9308^{*}$ Allgemeine Anleitung, die Naturgeschichte zu studiren. Munchen, Strobl. 1783.8.223 p. $(1 / 2$ th. $)$

$9309^{*} \longrightarrow$ und Karl Ehrenbert von Moll. Naturljistolische Briefe uber Oestreicl, Salzburg, Passau und Bercbtesgaden. Salzburg, Mlayr. 1785. 2 Bănde. 8. - I: 332 p., 1 tab. - Il : xxx, 457 p., 2 talı. ( 2 th.

(Inest: Flora Berchtesgadensis, vol. II. p. 160-323.)

$9310^{*}$ - Anfangsgrunde der Botanik. Nünchen, Strobl. 1785. 8. 206 p. $(\% / 2, t h$.

931 ${ }^{*}-$ Baiersche Reise. München, Strobl. 1786. 8. $276 \mathrm{p}$ 3 tal. $(3 / 6$ th. $)$

$9312^{*}-$ Baiersche Flora. München, Strobl. 1799. 2 Brinde. 8. 1: 753 p. $-11: 670 \mathrm{p}$. , ind. $\left(3^{2} / 3 \mathrm{th}.\right)$

$9313^{*}$ Schrank's Baiersche Flora zum berquemeren Gebrauche als Taschenbuch in tabellarische Form gebracbt. Mlit einigen Aenderungen und Verbesserungen. Regensburg, Montag. 1793.8.352 p. $(13 / 3$ th. $)$

(Omiltitur in egregia ac uberrina scriptorum Schrankianorum recensione ap. Martius. "Wenkrede auf Franzvonlaula von schrank. Wunchen, typ. Wolf. 1836. \& 31 \%., quare vix genuinis autoris operibus potest adnumerari.) 
\$31'" Schrank, Franz von Paula (von). Primitiae l'lorae Salisburgensis, eum dissertatione praevia de diserimino plantarum ab animalibus. Francofurti a/Al., Varrentrapp. 1792. 8. xv, 240 p., 2 tab. $\left(1 \frac{1 / 1}{12} / \mathrm{h}\right.$.) (Innet p. 1-16: Dissertatio de charactere plantas ab animalibus (discriminante.)

93.:; — Vom Pflanzenschlafe und von verwandten Eisscheinungen bei den Pllinzen. lugolstadt 1792.8.(1/, th.) v. Martius.

9316 - Akademisclue Reise nach den südichen Gebirgen von Baiern, in dahı 1788. Munchen, Lindauer. 1793. 8. (1 1/6 th.) v. Martius

$9317^{*}$ - Yon den Nebengefissen der l'flanzen und ihrem Nutzen. Halle, Gebauer. 1794. 8. 94 p., 3 tab. (1/2 th. $)$

9318 Naturhistorische und okonomische Briefo uber das Donaumuus. Nannheim 1795. 4. $(17 / 12$ th. $)$ v. Martius.

$9319^{*}$ - Sanumlung naturhistoriselser und physikaliseher Aufsátzo. Nürnberg 1796. 8. 456 p. (1 $1 / 2$ th. $)$

Insunt: Jetracbtungen uber Syngenesia polygamia frustranea und áhuliche Erscheinumgen, p. $381-4 i k$. )

$4320^{*} \longrightarrow$ Briefe naturhistorischen, physikaliselıen und okonomiscben Inlualts an Bernhard Sebastian Nau. Erlangen, Schubart. 1802. 8. 384 p., 4 tab. ( $1 \frac{1 / 2}{2}$ th.)

9321 * Grundriss einer Naturgeschichte der Pflanzen. Erlangen, Sclubart. 1803.8 .452 \%., praef., ind. $\left(1 \frac{13}{3}\right.$ th. $)$

9322 Catalogus plantarum horti acadenici Landeslsutani. Landisbuti 4807. 4. v. Martius.

$9323^{*}$ - Flora Monacensis, seu plantae sponte circa Monachiun nascentes, quas pinxit et in lapide delineavit Johann Nepomnk llayrhoffer. Commentarium perpetuum addidit Franciscus de Paula Schrant. Monachii, in instituto lithographico scholae festivalis. (Fleischmanu.) I8II-1818. IV voll. gr. folio. 400 full., $400 \mathrm{tab}$. col., effigies Schrank et Mayrhoffer. $\left(141^{2 / 3}\right.$ th. - col. 250 th. $)$ Bibl. Imp. Austr., Deless.

932'* ㄴ. Plantae rariores horti academici Nonacensis descriptae et icunibus illustratae. Monachii, in iustituto lithographico scholae festivalis. 1819. II voil. folio. 100 foll., 100 tab. col. (40 th.)

$9323^{*}$ Schreber, Daniel Goltfried. Historische, physische und okonomische Besehreilung des Waidtes, dessen Baues, Bereitung und Gebrauchs zum Färben, auch Handels mit selbigen uberlıaupt, besonders aber in Thuringen. Mit Beilagen und einem Anlıange dreier alten Schriften. IJalle, Waisenhaus. 1752. 4. 157, 120 p., 3 lab. $(1 \%$ th.

(Inest etion Henricus Crolachius, de cultura Isatidis. Tignri 130\%. 12)

9326 Schreber, Johann Christian Daniel (con). Botanisch-okononische Abhandlung vom Grasbaue. Leipzig, Fritsch. 1764.8 . ( $1 / 6$ th.)

$9327^{k}$ - leones et deseriptiones plautarum minus cognitarum. Decas I (unica.) Ilaiae, 1yp. et sumt. J. J. Curt. 1766. folio. 20 p., 10 tab. ( 1 th.

(Plantae ib Andr, de Gundelsheimer, Tournefortii in itinere orientali comite, lectae.)

$9328^{*}$ — Beschreihung der Gräser nebst ihren Abbildungen nach der Natur. Leipzig, Crusius. (Vogel.) 1769-1810. 3 Theile. folio. - I: 1769. 154 p., tab. col. 1-20. - II: 1772. (-1779.) p. 1 -88., tab. col. 21-40. - III: 1810. p. 89-160., tab. col. 41-54. (nigr. $8 \frac{1}{2}$ th. - col. $19 \frac{1}{3}$ th.)

(Librum fere in omnibus bibliothecis incompletum offendi. Tomo tertio interdum praefixus est titulus: tom. II. 1810.)

$9329^{*}$ De Plsasco observationes, quibus hoc genus muscorum vindicatur atque illustratur. Lipsiae, Crusins. (Yogel.) 1770. 4. xxir p., 2 tab. $(1 / t, h$.

$9330^{*}$ - Spicilegium Florae Lipsicae. Lipsiae, Dyk. 1771. 8. 148 p., praef, ind. $(1 / 2(h)$.

$9331^{*}$ - Beschreibung der Quecke nebst ilırer Abbildung nach der Natur. Leipzig, Grusius. (Vogel.) 1772.4.28 p., I tab. (1/t th.)

$9332^{*}$ Plantae verticillatae unilabiatae. D. Erlangac, typ. Walther. Sept. 1773. 4. Lxxv p., 1 tab.

$9333^{*}$ Plantarum verticillatarum unilabiatarum genera et species. Lipsiac, Crusius. (Vogel.) 1774. 4. Lxxv p., I tab. $(2 / 3$ th. Est idem liber ac praecedens.)

$9331^{*}$ — Mantissa edilioni quartae Matcriae medicne Equitis a Linné adjecta a J. C. D. Schreber. Erlangae 1782. 8. 16 p.
933: Schreck, Christoph Jakob. De Cynoglosso. D. Altdorfii 1753. † 32 p. B.

9336* Schreger, Bernhard Nathanael Colltob. De cortiris Fraxini excelsioris uatura et viribus medicis. D. Lipsiac 1791, 4. $35 \mathrm{p}$.

3337* Schreiber, Johann Friedrich. Vernuflige und bescheidene Gegenantwort anf die Antwort des Wohledlen und Wohlufuelumen IIerru Tobias Conrud Iloppens, berulumten Specerey-Ilándlers in Gera, darimnen er ihm scine gentaclsten Zw wifel von W"eiden-Rosen und versteinerten Gryphiten auflusen wollen. Jlerausgegeben und mit Annerkungen begleitet von dem Verfasser des Naturforscbers. Gera 1748.4. $16 \mathrm{p}$

9338* (Schreibers, Karl Nicolaus Joseph von.) Nachrichten von den kais. kön. Naturforschern in Brasilien, und den Resultaten ibrer lietrielssamkeit. Irumn, Trassler. 1820-1822. 2 IJfte. 8. - I: 1820 191 p., 2 tah. $-11: 1822.8 .112 \mathrm{p}$.

(Fasciculo alteri adduntur: Schot's Tagebucher, $11 \mathrm{k}$ p.)

9339* Schréter, Gustav Adolph. De constructione lierbarii. D. Vindobunae, typ. Utrich. 1826.8.30 p. (germanice.)

9340* Schroeder, C. II. A. De seminum Colchici autumnalis virtute of chemica et dynamica. D. Kiliae $1836.4 .15 \mathrm{p}$.

93h * $^{*}$ Schroeder, Heinrich Erust. Gedanken vom Nutzen der Botanik in Ansebung eines jeden frelehrten wegen der damit zu seiner Gesundheit verhundnen Leibesbowegung. Halle, Bayer, 1774. 4. $20 \mathrm{p}$.

931.2* Schroeder, Joham Joachim, pr. De hortis velerun Heinacorum. D. Narburgi 1722. 4. 16 p. (Respondens: Johann Duniel Schramm.)

934.3 Schroeder, Philipp Richard, pr. De jure succini in regnu Borussiae. D. Regiomonti 1722. 4. (Respondens: Julius Aegidsus Negctein.) B.

934: Schroeer, Samuel. Brevis et curjosa ju naturan Opii inquisitio, h. e. Opii intima et accurata examinatio, in qua variis ratiociniis et experimentis demonstratur, Opium non ob frigus, nee particulas sulphutreas aut alcalinas esse narcoticum, sed quod solitirie ob particulas acido-volatiles edat operationes. Lipsiae, 1yp. Kruger. 1696. 8. $80 \mathrm{p}$.

$9343^{*}$ Schroen, Friedrich Ludwig. De Jigitali purjurea. D. Monachii 1829.8. 39 p.

9316* Schroer, Johann Christoph. Curiobe Beschreibung des Eschenbaumes, worinnen dieses Baumes Natur, Eigensehaft und Nutzen sowolsl in der Nedicin als Chirurgie deutlich vorgestellet werden. Frankfurt a/0., Gottschalek. 1700.8. (56) foll. Bibl. Reg. Dresd.

931.7 Scrutinium medicum de natura et viribus Trifolii fibriniGubenae, 1yp. Christoph Gruber. 1700. \&. Rivin.

93 's Schtscheglow, Nicolai. Vkaзатехт открытій nо фнзикт, химін, естественио̆ исторіи п 'Технохогін. С. IІетер6. 1824. Trauty.

9319 Хозяйственнап 6отаника. С. IІетер6.1825. Trautv.

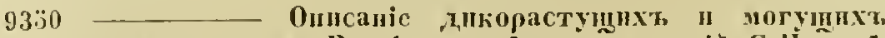
разводиться пт, Россіи прагебныхт растеній. С. ІІетерб. 1828. Trautv.

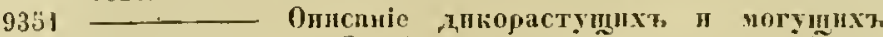
разводиться вт, Россіи хозяйственныхт ристеиій. С. Heтep6. 1828. Trautv

93.32 * Schubert, Anton. De Secali cornuto et murbo cereali. D. Vindobonae, typ. Wallishausser. $1840.8 .18 \mathrm{p}$.

$9353^{*}$ Schubert, Gothilf Heinrich (von). Leinbuch der Naturgeschichte für Sehulen und zum Selbstunterricht. Erlangen, Heyder. 1\$23. 8 . - ${ }^{*}$ Ed. XV: Erlangen, IJeyder. 1846. s. iv, 459 p. $(5 / 12$ th. $)$

93:3. * Die Geschichte der Erde, als zweite, gânzlich umgearbeitete Auflage der allgenicinen Naturgeschichle. Zweiter Band. Zweite Abtheilung: (Botanik.) Eriangen 1836. 8. xvi, 969-59\& p. 12 lab.

$9353^{*}$ —_ Biographien und Erzăhlungen. Erlangen, Ileyder. 1847. 2 Bïnte. 8. - I: xw, 306 p. - II: si, 334 p. (2 th.)

(Insunt vitae ac fata clarissimorum viatorum Jean Boptisle Tanernier, vol. J. p. 62-233 of 'Pierre Nartin Remi Aucher-Eloy, vol. Il p. 13 i- 130.$)$

$9356^{*}$ Schubert, Michal, polonice Michal Szubert. Spis roslin ogrodu botanicznero Kiólewsko-Marszaw skiego Unitersỵtelu. / Catalugus 
plantarum horti universitatis Varsaviensis.) WV Warszawie 1820.8. $\mathrm{xIV}, 156 \mathrm{p}$.

9315 t $\mathbf{S}$ chubert, Michael, polonice Michal Szubert. Spis roślin ogrodu botanieznego Królewskiego-Warszawskiego Uniwersitetu. WV Warszawie, w drukani szkolnéy. 1824. 8. xhıv, 583 p., 2 tab. ad iconogr. horti.

(Est editio nova penitus reformata libri praceedentis.)

9358 - Rosprawa o skladzie nasienia, począlkowém rozrastaniu się zarodka i glównych róźnicach skladu wewnętrznego roślin. (De anatomia et germinatione plantarum.) W Warszawie, w drukarni Xięży Piarów. 1824.8. 179 p., 4 tab.

$93 \ddot{3} 9^{*} \longrightarrow$ Opisanie drzew i krzewów leśnyelı krỏlestwa polskiego. (De arboribus sylvaticis Poloniae.) W Warszawie, typ. Glueksberg. 1827. 8. xxxiv, 357 p., praef., ind.

$9360^{*}$ Schubert, Robert Gustav. De quatuor stadiis, quibus legi cuidam naturae generali eonvenienter lıominum, animalium et plantarum majoris ordinis genesis ac formatio absolvitur. Sebleizae, typ. Meyer. (1841.) 8. Ix, 29 p. (1/3 lh.)

9361 * Schuchard, Rudolph Friedrich. Dissertatio inauguralis sistens nonnulla de Cicuta officinarum. Goettingae 1848.4.38 p.

9362 Schuebler, Gustav. Uebersicht der fur die Vegetation wichtigsten Eigensehaften der obersten Erdschichten und Ackererden. Stuttgart, Metzler. 1821. folio. ( $1 / \mathrm{l} h$.)

$9363^{*}$ _ _ Systematisches Verzeichniss der wildwachsenden phanerogamen Pllanzen um Tübingen. (Beilage zu Dr. Eisenuach's Geselichte von Tubingen.) Tubingen 1822.8.60 p.

$936\}^{*}$ _ Grundsătze der Agrikulturehemie iı năherer Beziehung auf land - und forstwirthschaftiche Gewerbe. (Aus Putsche's Encyclopädie abgedruckit) Leipzig, Baumgärtner. 1831. 8. $\left(1 \frac{2 / 3}{3}\right.$ th.) ${ }^{*}$ Zweite Auflage, durchgeselin und verbessert von $K$. $L$. Krutzsch. Leipzig, Raumgartner. 1838. 2 Theile. 8. - 1: Agriculturchemie. xv, 270 p., 1 tab. - II: Agronomie. 266 p., 1 tab. (2 th.)

936: — und Geory von Martens. Flora von Wurtemberg. Tubingen, Osiander. 1834. 8. 6, xxxı, 695 p., 1 mapp. geogr. (3 lh.)

(Supulementum bujus Florae scripsit Wilibald Lechler, Supplement zinr litora von Wurtenberg. Stutgart, Schweizerlarirt. 18\%. 8. 72 p. $(1 / 3$ th.

\section{Praeside Guslavo Schuebler disserlaliones academicue:}

$9366^{*}$ Characteristica et descriptiones Cerealium in horto acalemico Tuebingensi et in Wurtembergia cultorum annexis observationibus de plantatione et ubertate eorum. D. Tuebingae, typ. Fues. 1818 . 8. 47 p., I schema, 1 tab. (Respondens: Joham Luduig Rade.)

$9367^{*}$ C Chemische Untersuchung der Ilanfblatter. D. Tubingen 1821.8.28 p. (Autor: Ferdinund Tscheppe.)

$9368^{*}$ —_ De distributione geographica plantarun Helvetiae. D. Tuebingae, typ. Selramm. 1823. 8. 34 p., 3 schemata. (Respondens: Victor Abraham Ringier.)

$9369^{*}$ Descriptiones plantarum novarum vel minus cognitarum horti botanici acadenici Tuebingensis. D. Tuebingae, typ. Richter. 1825.8. 31 p. (Autor: Johann Christoph Schuez.)

$9370^{*}$ De Salvinia natante, cum aliquibus aliis plantis cryptogamis eomparata. D. Tuebingae, typ. Eifert. 1825. 4. 15, (2) p. 1 tab. (Autor: Georg Ludwig Duvernoy.)

$933^{*}$ Untersuchumgen uber die Farben der Bluten und einige damit in Beziebung stehende Gegenstande. D. Túbingen, Schunhardt. $1825.8 .38 \mathrm{p}$.

$9372^{*}$ Beobachtungen uber die Temperatur der Vegetalilien und einige damit verwandte Gegenstånde. D. Tủsingen, typ. Schönliardt. 1826. 8. 16 p., 1 schema. (Respondens: Franz Anton Halder.) $9373^{*}$ typ. Scloonhardt. 1826. 8. 32 p. (Respondens: Karl Friedrich Renz.)

937\%* — Untersuchungen uber die Einwirkung verschiedner Steffe des organischen und unerganischen Reichs auf ulas Leben der Pflanzen. D. Tubingen, typ. Schönhardt. 1826. 8. 58 p. (Respondens: Ernst Albert Zeller.)
9375* Schuebler, Gustav. Untersuchungen wher Most- und Weintrauhenarten Würtembergs. D. Tubingen, tỵp. Schönhardt. 1826. 8. 26 p. (Respondens: Friedrich Koehler.)

$8376^{*}$ - Untersuchungen uber die pflanzengeographischen VerJáltnisse Deutsehlands. D. Tubingen, typ. Schönhardt. 1827. 8 40 p., 1 schema. (Respondens: Anton Wiest.)

(Redit in Ifertha, Juli 1827; et auctius in Esehweiler's bot. Literaturblattern, Band III. Iteft 1.)

$9377^{*}$ Untersuchungen uber Obst- und Weintraubenarten Würtembergs. D. Tubingen, typ. Fues. 1827. 8.34 p., 2 sehemata.

$9378^{*}$ Untersuchungen uber 'die fetten Dele Deutselilands in Beziehung anf ihre wichtigeren plysischen Eigenschaften. D. Tubingen, typ. Eifert. 1828. 8. 39 p., 2 schemata. (Respondens Daniel Bentsch.)

$9379^{*}$ _ Untersuchungen über die Temperaturverảnterungen der Vegetabilien und versehiedene damit in Beziehung stehende Gegenstande. D. Tubingen, typ. Hopfer de l'Orme. 1829. S. $41 \mathrm{p}$. (lRespondens: Wilhelm Neuffer.)

$9380^{*}$ — D. sistens olservationes quasdam botanico-physiologieas (de antherarum exeisione ad effieiendos flores plenos, et de cfficacia Natri nuriatici in plautis comparati cum aliis quibusdam salibus, ejusque atl augendam soli fertilitatem usu), adjectis de tumore albo genu thesiluss. Tubingae, typ. Reis, 1830. 8. $27 \mathrm{p}$. (Respondens: Guslav Majer.)

$9381^{*}$ De Sceali cornuto. D. Tuebingae, typ. Fues. 1830.8 43 p. (Autor: Johann Fviedrich Finkh.)

9382* —_ Systematische Uebersicht der Versteinerungen Wurtembergs, mit vorzäglielser Rucksicht der in den Ungebungen von lloll sich findenden. Tulingen, Laupp. 1830. 8. 55 p. (Autor: Friedrich Hartmann.)

9383* - Untersuchungen wher die Vertheilung iler Farben und Geruchsverbaltnisse in der Familie der Rubjaeeen. D. Tubingen. typ. Reiss, 1834, 8. 36 p., 1 lab. (Respondlens : Franz' Taver Mueller.)

9384* — Untersuchungen uber die Vertheilung der Farben und Geruchsverhaltnisse in den wichtigeren Familien des Pflanzenreichs. F). Tubingen, typ. Keiss. 1831.8 .50 p. (Respondens: Franz Joseyh Koehler.)

$9385^{*}$ L Untersuchungen über die Vertheilung der farben und Gernchsverhálınisse iı den Familien der Asperifolien, I'rimulaceen Convolvulaceen, Campanulaceen, Rosaceen, Ranunculaceen, Papareraceen und Nymphaeen. D. Tubingen, typ. Reiss. 1831.8.30 p. (Respondens: Kavl Frederich Feil.)

$9386^{*}$ - Untersuchungen uber die Temperaturverhaltnisse der schwäbischen Alp. D. Tübingen, typ. Reiss. 1831.8. $30 \mathrm{~g} ., 1 \mathrm{tab}$. (Respoudens: Wilhelm Friedrich Kern.)

$9387^{*}$ Untersuchungen uber die mittlere Zeit der Blutenentwicklung mehrerer vorzuglich in der Flora Deutschlands einheimiselier Planzen in der Gegend ron Tubingen. D. Tubingen, typ. Richter. 1831.8.31 p. (Respondens: Fr. Joseph Beck.)

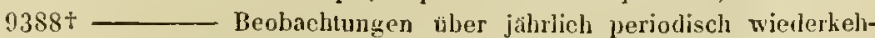
rende Erscheinungen in Thier- whl Pflanzenreicls. D. Tubngen, typ. Reiss. 1831.8. 35 p., 1 tab.

$9389^{*}$ Ueber die Riedgráser Wurtembergs, mit hesondrer Berucksichtigung der in der Flora von Tubingen einheimischen. $\mathbf{D}$. Tübingen, Osiander. 1832.8 .34 p. (Autor: FranzFleischer.) (J/6 lh.)

$9390^{*}$ Utrieulariae vulgaris adunhratio. D. Tubingae, typ. Eifert. 1832.8. 29 p. (Autar: Gustav Hartmann.)

$9391^{*}$ Ueber die geognostischen Verhalnisse der Vmgeburgen ron Tubingen. D. Tubjngen, typ. Reiss. $4832.8 .32 \mathrm{p} ., 1$ tab. (kespondens: Hermann V'ogel.)

$9392^{*}$ Untersuchungen uber die Regenverbajtuisse der schwáJiselien Alp unil des Seliwarzwalds. D. Tubingen, typ. Băbr. 1832. 8.20 p. (Respondens : August IIartmann.)

$9393^{*}$ Seminum Surghi vulgaris analysis, acljectis thesibus medico-chirurgicis. D. Tubingae, typ. Fues. 1832.8 .24 p. (Autor: Georg Werner.)

$9394^{*}$ C Beitrage zur Naturkunde (zur Flora) Oberschwahens. D. Tubingen, typ. Ilopfer de l'Orme. 1832. 8. 32 p. (Respondens: Karl Lingg.) 
$9390^{*}$ " Schuehler, Giustav. Untersuclungen aher die Bedeutung der Nektarien in den Blumen auf eigene Beobachtungen und Versucho gegrundet. 1). Stuttgart, Friedrich Ilenne. 1832. 8. VIu, I52 13. (Autor: Johann Golllob Kurr.) ( $7 / 12$ th.)

(") Postulat officii mei ralion, contirmat schuebler praeses Canditato in ealco operis, ut publico attester, tractalum Tumm de veeta

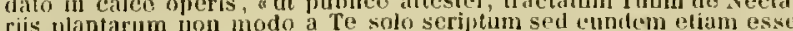
rits plantarum non modom nuper in certanine publico lando dignus (qracdicaluatur, s)

$9396^{*}$ _ Intersuchungen iber die Farbenveránderungen ter Blüten. D. Tubingen, typ. Fues. 1\$33.8. 18 p., I tab. (Kespondens: Johann C. Lachenmeyer.)

$9397^{*}$ Untersuchungen uber die Farbenverlálenisso in den Bluten ter Flora Deutschlands. D. Tübingen, typ. Bahr. 1833. 8. 23 p. (Respondens: Philipp L. I'ternle.)

$9398^{*}$ Untersueliungen uber dic Farlıenverbältnisse in rlen Bluten der Flora Frankreichs. D. Túbingen, typ. Fues. $1833.8 .21 \mathrm{p}$. (Respondens: Isauk Roeder.)

$9399^{*}$ — Beobachtungen und Versucho ulyer die Beziehung der Neetarien zur Befruchtung und Samenbildung der Gewáclise. D. Tübingen, typ. Fues. 1833.8 .40 p. (Autor: Fr. X. Woer:.)

$9400^{*}$ Untersuchungen uber die Bestandheile der Jlirse, Panienm miliaceum L. D. Tübingen, typ. Eifert. 183\%. 8.23 j. (Autor: Christinn Jenisch.)

$91.01^{*}$ Schuephach, Ferdinand Albrecht David. Von dem therapentischen Gebrauche des Bitsenkrautes. D. Wurzlurg 1818. 8.60 p.

9'02* Schuett, Peter Andreas. Specimen inaugurale de viribus Arnicae. D. Goettingae 1774. 4. 34 p.

$9403^{*}$ Schuetz, harl Emil. De Taxo baccata ejusque veneno. Diss. toxicalugieo-medica. Vratislaviae, typ. Fritz. 1 S40.8. 41 p.

940\% Schultens, Albert, pr. Dissertatio de Palma artente. Pars I et II. Franequerae 1725. 4. $190,28 \mathrm{p}$.

9:40 * Oratio academica in memoriam Ilermanni Boerhavii Lugduni Batavorum 1738. 4.83 p.

$9306^{*}$ (Schultes, Joseph August.) Oestreichs Flora. Ein Handbuch au botanischen Lxcursienen. Wien 1794. Il voll. 8. - I: 215 p. II: 244 p. - ${ }^{*}$ Flora austriaca. Viennae 1800. 8. (non dillert.) ${ }^{*} Z$ weite ganz umgearbcilete, vermehrte und verbesserte Auflage. Wien, Sehaumburg. 1814. 2 voll. 8. - I: X1v, 700 p. $-11: 577$ p., ind. $\left(3 \frac{1}{3}\right.$ th. $)$

$9407^{*}$ - Ausflugo nach dem Schneeberge in Unteröstreich. Wien Degen. 1802. $12 \mathrm{obl}$. $x 1,305 \mathrm{p} .(5 / 12 t h)-.{ }^{*}$ Zweite vermehrte verhesserte und mit 7 Kupfern verschonerte Auflage. ib. 1807. 2 Bâncle. $8 .\left(2 \frac{1}{3}\right.$ th. - in charta velina: $5 \frac{1}{3}$ th.)

Aecedit: Kleine Fama nud Flora von der sudwesllichen Gegent un Wien bis anf den Gipfel des Selmeebergs: $127 \mathrm{p} .(1 / \mathrm{s} t h$.

$9408^{*}-$ Catalogus primus plantarum horti botanici C. R. Universitatis Cracoviensis anno 1806. Cracoviae 1807. 12. 47 p.Cat. II : ib. 1808. 12. Sch.

$9409^{*}$ - Observationes botanicae in Linnaei species plantarum ex editione C. L. Wiltdenow. Oeniponti, Wagner. 1809. 8. xu, 220 p. ( 1 th. $)$

$9.10^{*}$ - Keisen durch Oberüstreich (Salzkammergul) in den Jahren $1794,1795,1802,1803,1804$ und is 08 . Tubingen, Cotta. 1809. 2 Bande. 8. - l:244 p., 6 tab. - 11: 200 p., schemata, 15 tab. ( 5 th.)

9.11t - Catalogus horli regii botanici Lanclisluti Bojorum. Landishuti, typ. Thomann. 1810.8 .22 1) - Supplementum 1-IIl. ib. $1811-18 \mid 3.8 .8,7,7 \mathrm{p}$.

$9412^{*} \longrightarrow$ Baierns Flora. Vollstandige Beschreilung der in Königreich Baiern wildwachsenden Plianzen. Erste Centurie. Landshut Krill. 1811.8 . xvi, $(400)$ p. $(15 / 12$ th. $)$

$9 \$ 13^{*}-$ Grundriss einer Geschichte und Literatur der Botanik von Theophrastos Eresios bis auf die neuesten Zeiten; nelsst einer Geschichto der botanischen Gárten. Wien, Schaunlıurg et Co. 1817. S. xve 411 p. $(12 / 3$ th. $)$

(Etiam sub titulo: Anleitung zum gründlichen Studimm der Butanik, zum Gebranche bei Torlesungen und zum Selbshnterrichte.

9: $1 \mathrm{f}^{*}$ Reiso auf den Glockner, an kírnthens, Salzburgs und Tirols Grenze, und durch Salzbury und Berchtesgaden. Wien, Morschner und Jasper. (1824.) 4 Theile. 8. - 1: xxv1, 349 p.II: 366 p. $-11 \mathrm{IJ}: 27$ p. $-\mathrm{Jl}: 270$ p. 11 tab. $\left(2 \frac{2}{3}(h)\right.$.
95.1 ï" Schultz. Franz Johann. Ablildung der in- und auslandischen Binume, Stauden und Sträuche, welelie in Oestreich fortkummen mc. Wien, Sammer. 1792-1S04. 3 Jände und einige Jlefte. folio. 360 tab. cul., (40) tah. col. (ranus aphyllos illustrantes), el 116 , 104,112 \%. Bibl. Imp. Austriae.

$91.16^{*}$ Schultz, Friedrich Wilhelm, nedieus in oppido Bitscls Alsatiae. Beitrag zur kienntniss der deutsehen Drolsanchen. (Fur seine Frrunde in Druck gegeben.) Nunchen 1829. folio. $12 \mathrm{p} ., 1 \mathrm{tah} .(1 / 2 \mathrm{th}$.

$9.17^{*} \longrightarrow$ Flora Galliae et Germaniae exsiceata. Herbier des plantes rares et critiques de ta France et de l'Allenágne, recueillies par la sociéte de la lifore de France et d'Allemagne. Jitche et DeuxPonts, chez l'auteur. $1836-1840$. Solin. Cent. ] - IV. 8, 4, 6 p. * Arelives de la Flore de France el d'Mlemagne. Traités sur les phantes et catalngues. ib. 1841-1847. 8. Centuria V-X. 98 J.

9'18* Flora der Pfalz, enthaltend ein Verzeieluiss aller bis jetzt in der baiersclien Pfalz und den angranzenden Gegenden liadens, Hessens, Oldenburgs, Rheinpreussens und Frankreichs beobachteten Gefasspflanzen, mil Angabe der geognostischen Bescliaffenheit des Bodens etc. Eine von der pfalzischen Gesellsclıaft fül Pharmacie und Technik gekrönte Preisschrift. Speyer, Lanğ 1846. 8. Lxxv1, 575 p. $(21 / 2(h)$.

$9419^{*} \longrightarrow$ Nachtrag zur Flora der Pfalz, enthattend die deutschen Namen der Gattuugen und Arten aller bis jetzt in der bayerisehen Pfalz und den angränzenden Gegenden Badens, llessens, Oldenlurgs, Rheinpreussens und Frankreichs beobachteten Gefusspflanzen, nchst Bemerkungen und Verbesserungen. Speyer (1846.) 8. $35 \mathrm{p} .(\mathrm{J} / \mathrm{t}$ li. $)$

9 \& $20^{*}$ Schultz, Larl Friedrich. Predromus Florae Stargardiensis, continens plantas in Ducatu Megaprolitano-Statgardiensi seu Strelitzeusi spunte provenientes. Jerolini, C. F. E. Spaethen. 1806 . S. x, 530 p. - ${ }^{*}$ Supplementum: Neobrandenburgi is 19.8 . v, 93 p. $(3 \% / h$. $)$

9!2l* Schultz, Karl Ileinrich, Bipontinus. Analysis Cichoriacearum Palatinatus secundum systema articulatum. Landan, typ. Baur. 1841. S. 8 p.

(Seorsim impr. ex Jahrl, fúr practisehe Pharmacie, Bantl. 4.)

$9422^{*}-$ Ueber die Tanaceteen, mit besondrer Beruchsichtigung der deutschen Arteı. (Festgabe zu Koch's Doctorjubiláum.) Neustadt a/d. Haardt, typ. Trautmann. 1844. 4. $69 \mathrm{p}$.

(Fidi in Delessertiana bibliotheca exemplar forma folio dieta excusum.)

$9123^{*}$ Erster Jahresbericht der Pollichia, eines naturwissenselhaftichen Vereins der bayrischen Pfalz. Nebst dem Vortrage von Dr. C. II. Schultz Bip. über Hypecoum pendulum L. Landau, typ. J3aur. 1843.8 .24 p. $-{ }^{*} Z$ weiter: Nenstadt a/d. Haardt, Iyp. Trautmann. 1844. 8. 69 p. - "Dritter: ib. 1845.8 .15 p. - "Vierter: ib. $1846.8 .22 \mathrm{p}$.

9!21* Schultz, Karl Meinrich, Bernlinensis, cognomine Schuitzenstein. Ueber den líreislauf des Saftes im Schollhraute und in melıren andern Pflanzen und uber die Assimilation des rolıen Nahrungsstoffes in den Pllanzen uberhaujt. Mlikroscopische Beobachtungen und Entdeckungen. Nit einer Vorrede Link's. Berlin, Dummler. 1892. 8. xiv, 66 p., tab.col. $(5 / 12$ th. $)$

$9120^{*}-$ Ueber den Kreislauf des Saftes in den Pflanzen. Erläuternde Bemerkungen. Berlin, Reimer. 1824. 8.64 p. $(1 / 4$ th. $)$

$9.226^{*}$ Die Natur der lebendigen Pflanze. Errieiterung und Bereicherung der Entdeckungen des Kreislaufs im Zusammenhauge mit dem ganzen Pllanzenleben nach eiser neuen Methode dargesteltt. 1823-1828. 2 Theile. $8 .-1$ : (etiam inscribitur: Die Pllanze und das Pflanzenreich.) Berlin, Reimer. 1823. L11, 693 p., 4 tab. 11: (etiam inscribitur : Die Fortpllanzung und Ernährung der Pflanzen.) Stuttgart, Cotta. 182S, xv1, 624 p., 3 tab. (6 $11 / 12$ th.)

$9427^{*}$ _ Naturliches System des Pllanzenreichs nach sciner innern Organisation, nebst einer vergleichenden Darstellung der wichtigsten aller frúlıeren kunstlichen und naturlichen Pflanzensysteme. Berlin, Jlirselwwald. I\$32. S. xxvit, $586 \mathrm{~J}$., I tah. $\{9 \%$ th. $)$

9128* - Sur la cireulation el sur les vaisseaux lactiferes dans les plantes. Mémoire qui a remporlé le grand frix pour 1833 . Paris et Berlin, llirschwald. 1839.4 . 110 p., 23 tab. $\left(3 \frac{1}{3} \mathrm{th}\right.$.)

(Scorsim impir. ex llémoires des sarans étmagers, vol. Yll. De proprio opere disseruit autor in Berliner Jahrbuchern fur wissensehartliche kiritik, 18 in. 1. Nr. 17 sqgo.) 
9'29* Schultz, Karl Heimich, Berolinensis, cognomino Schultzenstein. Die Cyklose des Lebenssaftes in den Pllanzen. Herausgegehen von ter Kaiserl. Ieop. Carol. Ahadenio der Naturforscher. Breshu und llonn 1841. 4. xil, 355 p., 3l tab. uigr., 2 tab. col. ( $\$ 1 / 2 / h$.)

(Nov. Acta Acad. caes. Leop. Carol. Nat. Cur. vol. Xrill. Supplementum il.)

$9430^{\circ}$ — Die Anaphytose oder Verjungung der Pflanzen. Ein Schlussel zur Erklarung des Wachsens, Bluliens und Fruclatiragens, mit praktischen Risksichten auf die kintur der Pflanzen. Berlin, Hirsclewald. 1843. 8. xxi1, 214 p. $\left(1 \frac{1 / 4}{t}\right.$. $)$

9431 * siclı zu einer Agriculturphyssiologic. Berlin, Ilirsclıwald. 1844. 8. 142 p. $(2 / 3 t h$.

9432* - Neues System der Morphologie der Pflanzen nach den organischen Bildungsgesetzen, als Grundlage eines wissenschafticlen Studiums der Botanik, besonders auf Universitaten und Schulen. Berlin, Hirschwahl. 1847. S. xxiv, 246 p., 1 tab. (1 th.)

$9\left\{33^{*}\right.$ Schultze, A. G. R. Compendium ter officinellen Gewachse nach naturlichen Familien georlnet. Nebst einer gedrängten Lebersicht der botanischen Terminologie und Systemkunde. Berlin, llirschwalcl. 1840. 8, x, $362 \mathrm{p} .(12 / 3$ th. $)$

91.3. Schultze, Chrislian Friedrich. Kurze Betraclitung der verstejnerten Ilölzer. Dresden, Groll. 1754. 4. 32 p., I taly.

$9: 3: i^{*}$ - Kurtze Betrachtung derer Krauterabdrucke in Steinreiche, worimnen dieselben sowohl in Ausehung ihres Ursprungs, als auch ilıres eigenthumlichen Luterschiedes und ibrirren Eigenscluaften in Erwägung gezogen werden. Dresden und Leipzig, Heckel. 1753.4 . 76 p., 6 tah.

$93.36^{*}$ Schultze, J. C. L. Die Waltlerzielıung in Verbindung mit der Forstbenutzung, soweit diese labei in Betracht kommt. Leipzig, Baumgârtner. 1839. 8. 356 p. $\left(1 \frac{2 / 3}{\text { th. }}\right)$

$9437^{*}$ Schultze, Johannes Dominicus. Veher lie grosse amerikanisclie Aloe, richtiger Agave, bei Gelegenlieit der jetzt isu Raths-ipothekergarten blubenden. llamburg, Ilerold. $1789.8 .64 \mathrm{l}$.

$9138^{*}$ Schultze, Karl August Siegmund. Mikroscopischo Untersuchungen uber des Ilerrn Robert Brown Entdeckung lebenter, selbst im Feuer unzerstöluarer Theilchen in allen körpesı, und uher Erzengung der Monaden. Carlsruho und Freilurg, Herder. 4525. 4. 39 p., i (ab). ( $1 / 2$ th.)

$9 \mathrm{k}^{3} 9^{*}$ Schultze, Nicolaus. De Nuce moscliata. 1). Trajecti a/Rh., typ. van de Water. 1709. 4. 30 p., I tab. (Praeses: Jacobus Tallon.)

910 Schulz von Schulzenheim, David. Grifte-tal ufver Carl von Limne (Sonen), liăllet i Tpsala Domkyrka, den 30 Nov. 1783, då den à Sriruls-sidan utgängua vou Linnéiska attens skuldemuke sunderslogs. Lpsala 1784.8 .42 p. B.

- germanice: Gedachinissrede aur den Hochwohlgeboruen Ilerrn, llerrn Carl von Linne, gehalten in der lyomhircle zu Lpsal de'u 30 . November 1783, als das adelige Familienwappen des aut der mannlichen seite erloschenen von Linneischen stammes zerschligen ward. Aus dem Schwedischen von Christian Ifeinrich Reichel. Leipzig, Alulles, $4781.8 .38 \mathrm{p}$.

$9 \$ 1$ Schulz, J. II. Grundriss der Zoologie u. Botanik. Zum Gebrauche in Gymmasien, Seminarien und loheren Scluulanstalten. Dritte rerhesserte u. vermelırte Auflage. Berlin, Muller. 1846.8 .17 plag. (1/h.)

$9 \nvdash Z^{*}$ Schulz, Johannes. De radice Ginseng rel Ninsi. (Panax quinquefoliun.) D. Derpati $1836.8 .32 \mathrm{p}$

$943^{*}$ Schulz, Karl. Deutschlands Giftplanzen; eine Sammlung kalligraphischer Schulvorscluiften mit kolorinten Bilderu zum Gelsrauche fur Volksschulen. Berlin, Enslin. (s. a.) 4 olll. 32 p)

nith Schujze, Christian Ernst Wilberg. Tanker om planternes dyrishe liighed. Kiobenhavn 1772.8.81 p. B.

94 :0* $^{*}$ Schulze, Franz. Vom Entstehen der Braunkolsle. etc. Halle, Anton. 1826.8 .70 p. $(1 / 3$ (h.)

946 Schulze, Georg Peter. De succino marchico, aliisque naturac donis. Tloruni 1612, 4. Boetmer.

$91: 7^{*}$ Schulze, Joham Ernst Ferdinand. Toxicologia reterum, plantas venenatas exhibens Theophrasti, Galeni, Dioscoridis, Plinii, aliorumque auctoritate ad deleteria venena relatas. Loca ex veterum monimentis eruta perpetuo commentario ornavit, varia exjerimenta et observata adjecit. Halao, typ. Orphimotrophei. 4788 . 4. $78 \mathrm{p}$. (Adest eliam titulus dissertationis inauguralis.)
94 ' $\$^{*}$ Schulze, Joharm Ileinrich, pr. De Aloe. D. Altdorfi, 1yp. Kohles 1723. 4. 20 p. (Respondens: Christian Jacobi.)

$9449^{*}$ De Colocyuthicle. D. Jlalae 4734. 4. 34 p. (Respon(lens: Johann Friedrich Watther.)

9 :ä0 De succino. D. Halae 1734.4.40 p. Boehmer.

$9431^{*}$ _.. De Persicaria acida Jungermanni. D. Halae 1735. 4. 26 p. (Re.pondens: Johann IIcinrich Muecke.)

$9432^{*}$ De fruetibus horneis. D. Jlalae 1737.4.28 p. (Respondens: Ernst Friedrich Redtel.

9.433* - Examen chenicum radicis Scillae marinae. D. Ilalae typ. Ililliger. 1739.4.34 ]1. (Respondens: Johann Gottfried Heder.)

945': - De Chamaemelo. D. Halae 1739.4.34 p. (Respondens Samuel Herog.)

$9150^{*}$ — De Asaro. D. Jalae 1739.4 .22 p. (Bespondens: Johan Christian Heinz.)

81.06" De Melissa. D. Ilalae 1739.4.20 p. (Respondens: Georg Daniel Reuss.)

$9437^{*}-$ De Lilio Convallium. D. Ialae 1742.4. 28 1. (Respondens: Gollfried Christoph Hossdorf.)

$94: 58^{*}$ De Rubo idaco officinarum. D. Ilalac 1744. 4. $26 \mathrm{p}$ (Respondens: Johann August Meyer.)

9 i:j $9^{*} \longrightarrow$ De lpecacuanla americana. D. Ilalae 1744. 4. $27 \mathrm{p.}$ (Respontens: Joham Samuel Hueber.)

$9100^{*}$ Schumacher, Christen Fredric. Enumeratio plantarum in prartihus Saellandine septentrionalis et orientalis. Havuiae, Brummer. (Schubothe.) 1801-1803. Il voll. 8. - I: 1801. vit, 304 1).II: 1803.489 p. $\left(2 \frac{1}{12}\right.$ lh. -1 Rbd. $)$

9461 Den lijobenhavnshe Flora, Planterne med tytelige Befrugtuingstele, overs. og foroget med danske Trivielnavine of Register ved $F, C$. Kielsen, lijubenhavn, Schubothe. 1804.8.308 p. (32 shill.)

94.62 or J. D. Herholdt. De officinelle Laegemidler af Planteriget, som voxe vildt eller kunne dyrkes $\mathrm{i}$ de danshe stater. lijobenlavu, Scluhothe. 1808 . 4. (24 skill.)

9463 Medicinsl Plantelicre for studerende Laegr og Plarmaceuter. Kjobenhavn, Schubothe. 1\$25- 1826 . II voll. 8. (1 lijd. 48 skill.)

$946 \div$ Beskrivelso af Guineiske Planter som ere fundne at daushe hotanikere, isaer af Etatsraad Thonniag. Kiobenlavi, tу1. Popp. $\{827.4 .466$ ].

(Saershit aftryht af det kongl. Dansk. Videnskabers Sclskabs shrifier.)

9i.6:" Schumacher, Geory Ileinrich. De Arnica montana. D. Berolisi, Iyp. Nietack. 1836, 4. 29 p.

9:66* Schummel, T. Emil. Ueber die giftigen Pilze, nit besondrer Rucksicht auf Schlesien. Breslau, Grass, Barth et Co, 1840. 4. 28 p. 2 tab. col. ( $1 / 2$ th.) ( Jan 1838 in programmate prodiit: 40 p.)

9.67* Schuster, J. Terminulogia botanica. Editio altera correctior. Budae, typ. universitatis. 1815.8 .148 p.

9'68 Schuurmans Stekhoven, $I$. Kruidkundig llandboek, bevattende eene sijstematische beschrijving van alle in de Nederlanden, in hed wild groeijende boomen, heesters en kruiden. Ansterdam, Sepl, 1815-1818. I1 voll. 8. - 1: 1813. Planerogamae. - 11: 1818 Cryptogamae, (4 Il. 50 c.) Dumortier.

94.69 linulhundige Kunstwoordenbock. Leyden 1826 . \& Dierb.

$9470^{*}$ Schuyl, Florentius. Catalogus plantarum horti acadenuici Lugiluni llatavi, quibus is instructus erat ammo 1668 . Accedit indes plantarum inligenarum, guae prope Lugdunum in Batavis nascuntur. Lugduni Batavorum, apud haeredes Joh. Elsevirii. 1668. 8. 74 p. †lleidelbergae, Zubrodt. 1672.12.91 p.

9:71* Schwabe, S. II. Flora Anhaltina. Berolini, Reimer. 1838 - 1839 II voll. 8. - I: 1838. (Phanerogamia.) 431 p. - ll : 1839. (Cryplogamia el ludex gonerum.) 425 p., 7 tab. (4 (h.)

$9172 *$ Schwaegrichen, Christian Friedrich. Topographiae botanicar et entomologicae Lipsiensis specimen I. Lipsiae 1799. 4, 36 p. *Topograpliae lotanicae Lipsiensis specimen H. ib. 1799.4 .48 j. * Sprecimen IV, plantas nuper inventas indicans. ib. 1806.4. 20 p. 
$9173^{*}$ Schwaegrichen, Christian Friedrich. Ilistoriae Muscorum liepaticorum Prudromus. Commentatio upa liortum botanicum Iipsiensem feliciter instauratum renuntiat. Lipsiae, liarth. 1814.8 . 39 p., 1 tab. col. $(1 / 3, h$. $)$

947t" Schwalbe, Christian Geory. De Clina offieinarum. D. Lugduni Batavorum, Wisholt 1715.4. $21 \mathrm{P}$.

$9175^{*}$ Schwann, Theodor. Mikroskopische Lutersuclsungen uber die Uebereinstimmung in der Structur und dem Wachsthum der Thiere und Pllanzen. Berlin, Keimer. 1839. 8. xvin, $270 \mathrm{p}$., i lib. (15/\% th.)

$9476^{*}$ Schwartze, Augusl Jakob. Observationes de virtute corticis Geoffraeae surinamensis contra tacniam. D. Goettingae 1792. 4 46 ].

$9177^{\circ}$ Schwartze, Gollhilf Wilhelm. De Belladonna scarlatinae jraesidio. D. Lipsiae 1827.8.24 p.

9478+ Schwediaur, Franz Yavier, anglico Francis Swediaur. Plarmacologia, seu Materia medica, exhihens cognitionem merlicamentorum simplicium analyticam. Edit. 11. Parisiis, Levrault. 1803 . Il voll. 12. $\mathbf{x \times v i}, 510 \mathrm{p}$.

(Editio prima titulo paullo mutato prodit Parisis anno 1800.

91.79* Schweigger, August Friedrich. Specimen Florae Erlangensis. Pars 1: Classis 1-XJII. D. medica inauguralis. Erlangae, typ. llilpert. 1804. 8. 136 p. - *Addenda: p. 137-160. - *Flora Erlangensis. Pars II, autoribus A.F. Schweigger et Franz Koerte. Classis XIV-XXIII. Erlangae, Palm. 1811. 8. vili, 143 1). (1 $1 / 3$ th. $)$

$94.80^{*}(\longrightarrow$ Enumeratio plantarum horti botanici Regiomontani. Regiomonti, typ. acad. $1812.8 . \mathrm{v}, 79 \mathrm{p}$.

4:81* - Nachriclten über den botanischen Garten zu hönigsberg. Konigsberg, akadem. Buclıhandlung. 1819. 8.45 p., 2 tab. $(1 / 2$ th. $)$

$9482^{*}$ Beobachtungen auf naturhistorisclien Reisen. Anatomisch-physiologische Untersuchungen uher Corallen, nebst einem Anhange, Bemerkungen uber den Berustein enthaltend. Berlin Reimer. 1819. 4. v1, 127 p., 12 Tabellen, 8 tab. $(3 \% / / h$. $)$

$91.83^{*}$ - De plantarun elassificatione naturali, lisquisitionilus anatomicis et plysiologicis stabilienda commentatio. Regiomonti, typ. acad. (Lipsiae, Dyk.) 1820. S. 19, 32 p., 3 chart. $(1 / 3$ th.)

9484* Schweinitz, Levis David von. Specimen Florae Americae septentrionalis cryptogamicae, sistens Iluscos hepaticos hucusque in America septentrionali observatos. Raleigh, typ. Gales. $1821.8 .27 \mathrm{p}$.

$9483^{*}$ - Monograph of the North-American species of the genus Carex. Edited by John Torrey. Newlork, typ. Seymour. 1825. 8. p. $283-373,6$ tab.

(Annals of the Lyce of nat. hist. of Newlork vol. I. Part II.)

9186* - Narrative of an expedition to the source of St. Peter's River, lake Winnepech, lake of the woods, performed in the year 1823 , by order of the hon. J. C. Culhoun, under the command of Stephen II. Long. Compiled from the notes of Major Long, Messrs Say, Kealing et Colhoun, by II illium II. Keuting. London, printed for Geo. B. Whittaker. 1825. Il voll. 8. - I: xur, 458 p., 5 tab. II: 248,456 l., 2 tab, nigr., I tab. col. (1l. Ss.)

(Vol. Il. Appendix p. I0̈-123. Section 11. Botany. A catalogue of plants collected in the north-western territory by Mr. Thomas say, in the year 1823 . by Lewois $D$. de Schuceinit.)

9.87 * Schwencke, Martin Wilhelm. Officinalium plantarun catalogus, quae in horto medico, qui llagae Comitum est, aluntur. Jlagae Comitum, P. de Hondt. 1752.8. v1, $86 \mathrm{p}$.

$9488 \div$ - Verhandeling orer de waare gedaante, aart en uytwerking der Cicuta aquatica Gesneri, of groole waterscleerling. etc. Gravenhage, Gaillard. 1756.8 .54 p., 4 tab.

$9189 \div$ - Kruidkundige Beschryving der in - en uitlandsche gewassen, welke lieedendaagsch meest in gebruik zyn. Gravenhage, typ. van Karnebeek. 1766.8 .327 p., praef.

$9190 \div$ Novae plantae Scliwenchia dictae a celeberrimo Linnaeo in Gen. plant. ed. VI. p. 567 ox celeb. Davidis van Rooyen Charact. mss. 1761 communicata brevis descriptio et delineatio cum notis characteristicis. Hagae Comitum, tıp. van Karnebeek. 1766. 8. (6) p., 4 tab. col.

(Exstat hatine et hollandice impressa cum libro praecedenti.)

34.9 * Schwenckfelt, Kaspar. Stirpium et fossilium Silesiae catalogus, in quo praeter etymon, natales, lempus, natura et vires cun variis experimentis assignantur; cum indice remediorum. Lipsiale, Alberti. 1600. 4. $\{07$ p., introluctio, ind.

(Catalogus stirpinm explicit in pagina 3's.)

9492* Schwenckfelt, Kaspar. Jirschbergischen Warmeu Bades, in Sclılesien unter den kiesen (ieburge gelegen, hurtze und einfaltio Beschreilung: was dessen Natur, Arth unt Eigenschalft, liraff und Wirckung sey: ..... Und hurtzem Verzeichniss terer híuter mud lBerg.trthen, welche umb diesen warmen Brunnen hin umel wieder aufu Gebnrgen gefunden werden, gestellet und verfasset dureli Casparum Scherencheldt D. Physicum reij). Gorl. ord. (ionlitz, Joh. Rhanbaw. 1607. S. 236 p., praes., ind. - Ed. ll: llirschberg Georg Opitz. (1619.) 8. 237 p., praef, ind. Bibl. unit. Lips.

(A p. 183-236 et 181-237 insunt: hrăuter, welche umb diese Gegend wachsen.)

$9493^{*}$ Schwendimann, Peler Joseph. Helminthochorti historia, natura atque vires. Argenturati $1780.4 .40 \mathrm{p}$.

$949 \% \div$ Schwerin, Johann Daxid. Nahmregister derjenigen in- und atsJändischen Baume, Pflantzen, Bluhmen, welche dieses Jalır auf einem wollbekandten im llorn vor der Stadt Ilanburg belegencu Garlen sich Jefinden. Jamburg, 1yp. Neumann. 1710. 8. - Erster Anhang. ib. 1711. 8. - Zweiter Auhang. ił. 1712. 8. A-Z. Bibl. Juss.

$9495^{*}$ (Schweyckert, J. IJ.) Catalogus plantarun horti botulici Carolsruhani secundun Systematis regetabilium Linnaci editionem XIV. Carolsrulsae, typ. Macklot. 1791. 8. $60 \mathrm{p}$.

$9496 \div$ Schwilgué, C.J.A. Traité de matière médicale. Paris 1805 . Il voll. 12. - Lid. Il : revue, corrigée et augmentée. laris, Brosson. 1809. Il voll. 8. - 1: xL, 469 p. - 11:590 p. - Ed. III. par P. II. Niysten. Paris, Brosson. 1818.11 voll. 8. (19 [r.)

9497 Schwimmer, Johann Hichael. Qunedam naturae miracula circa vegetabilia. Jenae 1673.8 . H.

9498 Plıysikalische Ergüzlichkeiten: Phrsikalische Gartenlust und physikalische Himmelsbetrachtung und Gartenlust. Erfurt 1701. 8. - Franhfurt und Leipzig 1716. 8. K.

$9499^{*}$ Schychowsky, Lwan. De Digitali purpurea. D. Dorpati 18 $¥ 9.8$. $66 \mathrm{p}$.

(Rossice alirgos scripsit libellos, (pui mihi non imotuerunt.)

$9300^{*}$ —.... De fruclus plantarum phanerogamarum natura. D. Dorpati, typ. Schunmann. $1832.8 .57 \mathrm{p}$.

930। Sckell, $F$. L. von. Beiträge zur bildenden Gartenhunst, fur angeheude Gurtenkunsiler und Gartenlieblnaber. Nunchen, Lindauer. 1818. 8. 8 tab. (2 1/2 h.) - Ell. 11: Nunchen, Lindauer. 1825. \$.

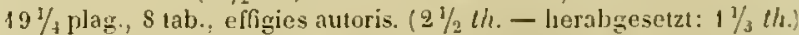

$9502^{*}$ Scopoli, Johann Anton. Nethodus plantarum enumerandis stirjibus aly en hucusque repertis testinata. Viennae Austriae. typ. van Glielen. $1754.4 .26 \mathrm{p}$.

$9303^{*}$ Flora carniolica, exlubens plantas Carnioliae indigenas et distributas in classes, genera, species, varietates, ordine Lianeano. Viennae, Trattner. 1760.8.607 p., prael. - "Editio secuntes aucta ef reformata. Viemnae, Krauss. 1772 . Il voll. $\$ .-1: 448 \mathrm{p}$. praef, ind, tah. 1-32. $-11: 496$ p., ind. tals. $33-65 .\left(5 \frac{1}{3}\right.$ (h.)

$9504^{*}$ Anni listorico-naturales. Lipsiae, Jlilsclıer. 1769-1772. V voll. 8. - 1: 1769.168 p. (Omithologica.) - I1: 1769.118 p. (lter Gorizense; iter Tyrolense; de cucurbita pepose observationes; Lichenis islandici vires medicae.) - 13]: $1769.108 \mathrm{p}$. (Medica et Jineralogica.) - W: 1770. 150 j., 2 lab. (Duhia Jotanica; Fungi in Ilumgaria detecti.j - $\mathrm{V}: 1772.128$ p. (Nineralogica et Zoologica.)

$9303^{*}$ Dissertątiones ad scientiam naturalem pertinentes. Pars I. Pragie 1772. \$. 120 \%., 46 tab.

(Insumt: Plantae subterraneac, p. Si-120, tab. 1- 6 .)

$9 \ddot{306 *}$ Introductio ad listoriam nuturalen; sistens genera lapivlum, plantarum et animalium hactenus detecta, characterihus essentialihus donata, in tribus divisa, subinde ad leges naturae. l'ragae, Gerle. 1777. $8.506 \mathrm{p}$. ind.

$9507+$ Fumdanenta botanica praelectionibus publicis accommodata. Papiae, typ. monasterii Salvatoris. 1783.8 .174 p., 10 tab. "Tiennae Wappler. 1786.8. 180 p. 10 Lab. - Viennae 1802.8.

$9308^{*}$ 1) Deliciae Florae et Faunae insubricae, seu norae aut minus cognitae species plantarum et animalium, quas in Insubria austriaca, tam spontaneas, quan exoticas vidit, descripsit el aeri 
incidi curavit. Pars 1-Ill. Ticini, typ. monasterii S. Salvatoris. 1786 -1788 . folio. $1 x, 85,113$, 87 p., 75 tab.

(Inest: Specinen botanicum de Astragalo, 1I. p. 103-11k.)

$9509^{*}$ Scoresby, Ililliam, junior. Journal of a voyage to the northern Whate-fishery; including researches and discoveries on the eastern coast of West Greenland, made in the summer of 1822 in the slip Baffin of Liverjool. Edinburgh, Constable. 1923. 8. xitil, 472 p., $s$ tab. (16s.)

(Appendi Nr. II: List of plants from the Fast coast of Greenland "ith some remarhs, by Dr. Hooker. p. $10-\$ 13$. - redit in Robert Brown Fermischte Schriften I. $30 \%$ I-5ös.

* germanice: von hries. Hamburg, l'erthes. 1523. 8.

9 s̆l0 Scot, Heynolde. A perfite platforme of a lloppe garden, and necessaric instructions for the making and mantenance thereof London 1574. 4. 56 p., ic. xylogr. i, t. B.

y511 Scribe, $F$. Mémoire sur la résine icica. Paris, typ. Bachelier. 1845 $8.12 \mathrm{p}$.

9อ̆ 1 2* Scribonius Largus. Scribonii Largi de compositionibus medicamentorum liber unus, antehac nusquam excusus: Joanne Ruellio doctore medico castigatore. Impr. cun Celso. l'arisis, apud Christianum Wechel, sub scuto Basiliensi. 1529. folio. (9), 30, (5) foll. Bibl. univ. Lips. - "Scribonii Largi de compositione medicancntorum liber, jampridem Jo. Ruellii opera e tenebris erutus et a situ vindicatus; cum aliis. Basileae, apud Andream Cratandrum. 1 529. 8. 348 3. - Scribonii Largi Compositiones medicac. Joannes Rhodius recensuit, notis illustravit, lexicon Scribonianum adjecit. Patavii, typ. Pauli Frambotti. 1655. 4. (10) foll., 144, 465 p., ind., ic. xylogr. i. t.

(Hall. Bibl. hot, I. p. 76-77. - Spreng. Hist. rei herb. 1. p. 213.)

$9513^{*}$ Scrofani, Iavier. Voyage en Grece, fait en 179: et 1795. Traduit de l'italien par Blanillain. Paris 1801. 14 voll. 8. (. $8 \mathrm{fr}$.)

$9314+$ Scuderi, Saverio. Trattato dei boschi dell' Etna. (Con un quadro sinotico della statistica de' boschi dell' Etna.) (Catanca 1824.) 4. Bibl. Juss.

(Estratto degli Atti acead. di Catanca, vol. I. cupi $1-3$, p. $\$ 1-80$, $2 \$-292,19-i 8$; sara continuato.

9515 " Scultetus, Johannes, germanice Scholz. Plantarum cultura aratione exculta. Noribergae, typ. Felsecker. $1666.12 .72 \mathrm{p}$.

Y516* Scultetus, Kisplar II ilhelm. Gedichte ron Hancke und 11 achtel auf seinen Orangeriegarten in Direslau. Katalogus aller derer Sorten Agrumi und Grundriss des Gartens vom Jahr 1731 . (Breslau 1731.) folio. 6 foll., 2 tah. Bibl. Reg. Dresd.

9817* Seba, Albertus. Locupletissimi rerum naturalium thesauri accurata descriptio et iconibus arteficrosissimis expressio per univerzan physices historiam. Opus cui in hoe rerum genere nullum par exstitit. Amstelaedani, apud Wetstenium. 1734-1765. Wv voll. folio. latine et gallice. - I: 1734. $154 \mathrm{p}$, praef, 111 tab. $-11: 1735.154 \mathrm{p} .1$ 114 tals.

(Intercedunt nonuullae plantac; \&.gr. tabulae 1-29 voluminis primi ; volumida lil et IV nostram rem non tangunt.)

$9318^{*}$ Sebastiani, Antonio. Romanarum plantarum fasciculus primus. Romae, typ. de Romanis. 1813.4 .14 p., 4 tab.

$9519^{*}$ - Ronanarum plantarum fasciculus alter. Accedit Enumeratio plantarum sponte nascentium in ruderibus druphitheatri Flavii. Romae, 1yp. Salriucci. 1815.4 .81 p., 6 tab.

$9220^{*}$ — E Erneslo Mauri. Hlorae Romanae Prodromus, exhibens centurias NIl plantarum circa Roman at in Cisapenninis pontificiae ditionis proviuciis sponte nascentiun sexuali systemate digestas. Romac, Poggioli. 1818. 8. xv, 351 p., 10 tab.

9521 Esposizione del sistema di Linneo, pianti officinali indigine o esotiche domiciliate nell orto botanico. Roma 1819. 8. Bibl. Nov, Ebor.

$93222^{*}$ Sebeòk de Szent-Mikjòs, Alexander. D. medico-Jjotanica le Tataria hungarica. Viennac, typ. Sclmidt. 1779.8. 29 p., 1 tab. (Jacq. Miscellanea austriaca, vol. II. p. 27t-201.)

9.23* Sebisch, Melchior, latine Sebizius. De alimentorum facultatibus Jibri quinupe. Argentinae, impensis Julbii. 1650.4. 1552 p., pracf., ind.

9524* Secondat, Jean Baptisle, Baron de. Observations de physique et d'histoire naturelle. Paris 1750. \&. 205 p.

(Inest descriptio Clvae speciei cujusdan, in aqua fervida vigentis.)

Prttzel, Thes. lit. bot.
952:3* Secondat, Jean Bapliste, Baron de. Memoires sur l'histoire naturelle du chéne sur la résistance des bois à etro rompus par les poid dont ils sont chargés; sur les arlures forestiers de la Guienne: sur des champignons qui paroissent tires leur origine d'une pierre; sur la maladie pestilentielle des boeufs en 1774 ; sur la culture de la vigne, et sur le vin de la Guienue. Paris, chez de Bure. 1785 folio. 31 p., 7 tab. praeter alia adjecta.

$9526 *$ Secretan, Louis. Mycographie Suisse, ou description des champignons qui croissent en Suisse, particulierement dans le canton de Vaud, aux environs de Lausanne. Genève, typ. Bonnant, 1833.11 voll. 8. $-1: \mathrm{Lv}, 522$ p. $-11: 576$ p. - 111: viir, 759,95 p. (30 fr. $-9 \mathrm{th}$.)

9527 Securius, Thomas. D. X. de plantis. Lipsiac 1625. 4. Desid. Banks

$9328 \div$ Sedy. Catalogue alphabétique des plantes, arbres et arbustes etc. cultivés dans ses jardins et pépinieres. Lyon, ț̣p. Kindelem. 1810. 8. vi, $39 \mathrm{p}$.

9529* Seenus, Joseph, Freiherr von. Beschreiluung einer Reise nach lstrien und Dalnatien, vorzuglich in botanischer Hitsicht. Hit Vorretle von David Heinrich Hoppe. (Beilage zum hotanischen Taschenlouch auf 1805.) Nurnberg und Altdorf, Monath und Kussler, 1805 8. 77 p. $(1 / 4$ ih. $)$

$9530^{*}$ Seetzen, Ulrich Jasper. Systenatum generaliorum de morbis plantarum brevis dijudicatio. D. Goettingae, Dieterich. $1789.8 .62 \mathrm{p}$.

9531 Seger, Georg. Synopsis methodica rariorum tam naturalium, quan artificialium, quac Hafniae servantur in Musaeo Olai Hormii. Hafniae 1653.4 .44 p. B.

9532* Segerstedt, Alberl Julius. De pharmacis indigenis observationes aeconomicae. Specimen I. Upsaliae, typ. Edman. 1787. 4. $12 \mathrm{f}$. (Respondens: Gustav Frederik Forssberg.)

9533 Inledning til Kunskapen om de Jordiske Kropparne, med afseende pă derias kannemárken, egenskaper och nytta uti Naturens bushâllning samt det almanna lefiernet. Strengnas 1798. 8. 213 p., praef., ind.

953i* Séguier, Jean François. Bibliotheca botanica, sive Catalogus auctorum et librorun onnium gui de re fotanica, de medicamentis ex vegetabilitus paratis, de 1: rustica, ("l de lorticultura tractant, a Jounne Francisco Seguiero Nenausense digestus. Iccessit bibliotheca botanica Juhanuis Antonii Bumaldi, seu potius Ovidii Montalbani Bononiensis. Hagac Comitum, apud Joanen Neaulme, 1740. 4. 16, 450,66 1. - * Lugghni Batavorum, ipuel Contelium Jaak. 1760. 4 . (eadem est impressio, novis titulis, et addito lihro insequeute:)

$9333^{*}$ - Auctuarium in Bibliothecan botanicam, antehac a clariss. viro, hotanico exinnio J).D. Joanne Fruzcisco Seguipro, conscriptam et editam prolatum a Laur. Theod. Gronorio, J. U. D. et soc. med. phys. Basilaeensis socio. Lugduni Batavorum, ajud Conelium llank. 4760. 4. (9), $65,(7)$ p.

(Oeilli Montalbani bibliothecan, quae utrique accedit edilion, jam supra ...r. 7108 indicavi.)

$9336^{*}$ —_- Bibliotlincae botanicae, quae prodit Hagae Conitum amı 1740 , supplementum. hupr. cum ejus Plant. Veron. vol. 11. Veronae, typ. seminarii 4743 . 8.79 p.

9537 Catalogus plantarum, quae in agro Veronensi reperiuntur. Veronae $174 \mathrm{3}, 8.111 \mathrm{p}$. B

$9338^{*}$ Plantae Veronenses, seu stirpium, quac in agro VeroIn rnsi reperinutur, methodica synopsis. Acecdit ejusdem Hilliothecae botanicae supplementum. Veronae, typ. seminarii. $174 \%$. 11 voll. 8. - 1: Lxxi, 516 p., tab. 1-12. - 11: 480, 79 1., tab. 13-17.

(In rolumine altero praeter supplementum bihliothecae botani-

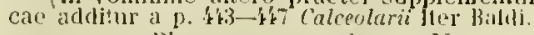

$9539^{*}$ Plantarum, quae in agro Veronensi reperiuntur, volumen tertium seu supplementum. Teronac $1734.8 . \mathrm{NF}, 312 \mathrm{p} ., 8 \mathrm{tab}$.

$9540^{*}$ SeideI, Jaliob, pr. Theses te causis, speciebus, ditferentiis, partibus et facultatibus plantarum. D. Gryphiswaldiae, typ. Ferber. 1640. 4. (24) foll. Bibl. Goett.

9031.1 * Seidel, Johann Heinrich. Verzeichniss der Glas - und Treibhausplanzen, ingleichen der Bamme, Straucher, Stauden und Sommergewáchse. Jresden 1794. 12. 88 p. - "Synonymisches Yerzeichniss aller im Kurftirstlichen Urangengarten zu Dresden befindlichen Gewachse. Dresden, churfurstliche J)rucherei. 4799. 8. x1, $148 \mathrm{p}$. - "Dritte vermelirte Aullage, geordnet yon Friedrich Wilhelm Loeber 
Jresden, Walther, 1806. 8. xı, 216 p., 1 tal\%. (Cobea scaulens.) $(2 / 3 t h$.

$932^{*}$ Sejdel, Traugoll Jalno. Dic Camellien; wie sie bohandelt sein wollen, damit ihre Blumenkoospen nicht var rler Blutuzeit abfallen, sondern gesunde und grosse Hlunen bringen. Wien, typ. Ghelen. 1530. 8.33 p.

$9533^{*}$ —_ Alleitung zur Kultur unl Vermehung der Camellien. Dresden 1837. S. 16 p., \& tab.

1354" - Die Rhodoraceac oler lihodudendreac. Eine Anleitung zur Cultur dieser Pllanzenfamilic. Nelsst einer systematischen Beschreihun der Gattungen und Arten derselben von Gustav Meynhold. Dresten unt Leipzig, Arnokl. 1843. 8. 126 p. $(1 / 2$ (h.) - " Zweite Ausgabe: ib. 1846.8 .126 p. $(1 / 3$ th. $)$

9545* Seidenschnur, Michael Jaliob. De Cannabis vi medica. D. Halae, typ. Bath. 1803.4. 16 p.

$9346^{*}$ Seits, Tobias Anton. Allgemeine okononische Samen- und Fruchtelehre, als Vorlúufer einer europbaischen karpologisehen Flora. Salzburg, Mayr. 1822. 8. ( $19 / 2$, th.)

935. Lie Kosen nach ibren Fruchten. Ein unenthehrlicher Leitfaten zu ihrer riclitigen Bestimmung fur Botaniker, Gärtner uud Blumenliebhaber; oder alle bisher bekannten Rosenarten nach Trattinili's Synodus karpologisch dargestellt. Prag, Enders. 1825. 16. 229 p. $(2 / 3$ th. $)$

$9518^{*}$ Selbstherr, Karl. Die Bosen in 25 Gruppen und 95 Arten. Breslau, gedruckt bei Plilipp's Erben. 1532 . 4. 230 p. $\left(2 \frac{1}{3}\right.$ th. $)$

9319 Selby, Prideaux John. A history of british forest trees, indigenous or introluced. Part I-X. London, Jolun van Voorst. 1\$41-1842. 8. (4/.8s. - in roval-nctavo: $y / .16 s$.

$9350^{\circ}$ Selig, Christoph Wilhelm. De Galii rotundifolii charactere botanico usuque medico. 1). Errlangae, (yp. llilpert. 1802. 8. 40 p.

9301 * Seligmann, Komen. Liber fumlamentorum pharmacolagiae. Anctore Abu Ilansur Howafk Ben dli el Hervi. Epitome codicis manuseripti persici Bibl. caes. reg. Vieun. inediti. Primus Latio donavit Dr. Romeo Seliymunn. Pars 1. D. Vinclobonas, typ. Schmid. 1830. 8.90 p.Par's II. Vindobonae, typ. Sehmid. 1833. 8. $111 \mathrm{p}$.

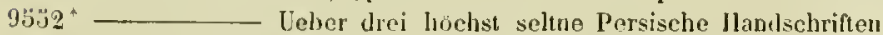
Ein Breitag zır Literatur der orientalisehen Arzmeimittellehre. Wien typ. Sclimill. 1833. 5

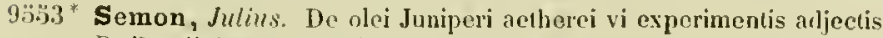
D. Berolini 1844.8. $24 \mathrm{p}$.

953:." Senckenberg, Joham Christian. De Jilii convallium rjusque inprimis baceae viribus. D. Goettingae, typ. Schultz. $+737.4 .40 \mathrm{p}$

955.: Sendel, Nathanael. Electrologiae per varia tentamiua listorica ac physica continuandae Alissus l. de perfectione succinorum aperibus naturae et artis promota, testimoniisfue rativois et experientiae demonstrata. Elbingae, sumtibus ilutoris. 1725 4. 56 p. Boebmer.

9.30 - Electrologiae Missus 11. de mollitie succinorum et inde emeryentibus contentis variis. Ell,ingac, sumtibus autoris. 1726. 4. 64 p. Boebmer.

9.307 - Electrologiate Missus 111. de prosapia succimorum et eorum variis aflectionibus, vi electrica, rolore. etc. Eilbingae, sumtibus autoris. $4728.8 .56 \mathrm{p}$. Boehmer.

$93 \mathrm{~B}^{*}$ __ Historia succinorum corpora aliena imolventium et naturae ofjere pictorum of caclatorum ox regiis sugustorum cimeliis Drestlie contitis aeri inseulptorum couscripta. Lipsiae, Gleditsch. 1742. folio. vutt, 325 p., 13 tilb.

$9 \ddot{3}$ ht Sendtner, Ollo. De Cyphomanlra, novo Solanacearum genere (ropicae Americae. D. (Honachii 1845.) 8. 15 p., I tah.

irorsim impr. E Flora, diario totanico Ratisbonensi anni $18 \mathrm{~h}$. )

9360 Senebjer, Jean. Iissertatio de Polygamia. s. 1. 1765.4. 0.

$9 \$ 61$ - Eloge historigue d'. Llhert de Ituller, avec un catalogue complet de ses oeuvres, (ienère, Barlin. 1778. 8. Q.

9362 - Dictiounaire des for'ts et bois. Tome premier, premièro cl seconde parties. Paris, Agasse. $1790-1815$. 4. (20 fr.) a. Sistil sectionem operis inseripti: Enevelopedir methodinue. Pars phrsiologica a semebiero seriptit est. culitio quasi princeps operis

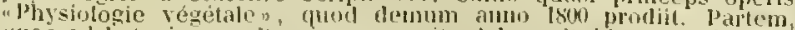

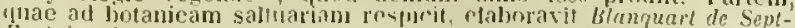
(Fontaines.)
$9563^{*}$ Senebier, Jean. Mémaires physico-chimiques sur l'influence de lil lumiere solaire pour modifier les ètres des trois règnes de la nature, et surtout ceux du régne végetal. Geneve, Chirol. 1782. 111 voll. 8. - I: Xvi, 408 p. -11 : vHI, 411 p. - III: vHI, 419 p., 2 tals.

"germanice: Ihysikalisch-chemische Ahhandlumgen wher den Ein-

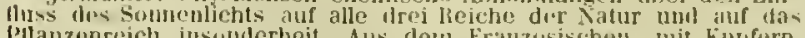
Plianzenreich insonderheit. Aus den Frnzusischen, mit kupfern.

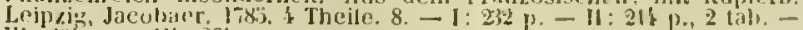
III: $20 \%$ D. -11 : 260 D

$9561+$ Recherches sur linfluence de la lumière solaire, pour métamorphoser l'air fixe en air pur par la végetation. Geneve, ChiIol. 1783. \&. Xxxu, 385 p).

$9363^{*}$ —_ Expériences sur laction de la lumiere sulaire dans in végétation. Genèvo, Barde. 1788. 8. xv1, $446 \mathrm{p}$.

$9366^{*}$ — Plı̣siologie végétale, contenant une descrijution dess organes des plantes el une exposition des plienomènes jroduits pas leur organisation. Geneve, Paschoud. Cint volumes. (1800.) 8. 1: 463 p. $-11: 472$ p. $-111: 420$ p. $-1 V: 435 \mathrm{p}-\mathrm{V}: 351 \mathrm{p}$. (21 fr.)

$9567+$ - Rapports de l'air avec les Atres organisés. ete. Genève, Paschoud. 1807. III voll. 8. (19 fr.)

(Vol. 111: 347 p. contient: Traité sur les rapports tex plantrs avec lair atmospherifgue.

0368 Mémoire histerique sur la vie et les cerits le lloraen Benedict De Saussure, pour servir à lintroduction a la lecture de ses ouvrages. Genete, Paschoud. an LX. (1801.) 8. (2 fr. 50 c.)

0369 Senfftel, Johann Jakol. Seminarium viridum, oder das grunende Feld, begreifend eine Gemuthserfreuende Beselireibung der FeldIruchte, Kuchenkrikter, Wurtzeln, Grass und Blumen; init Kupfero. Augspurg, Johano Koppmayer. 1689. 8. Rivio.

9:50* Senger, Gerhard Anton. Die áteste Urhunde der Papierfabrication in der Natur entdeckt, nelist Vorschlagen zu neuen Papjerstolfen. Dortmuml und Leipzig, Mallinckrorh. 1794. 8. $96 \mathrm{p}$. (1/2 th.

(Libellus impressus est in charta e variis parata eonfervis. Ad jecta est critica dijudieatio ejustem, quae prodit: Essen, Batleher. 1800.8 .31 1.)

9371 Senguerdius, Wolferdus. Disputatio botanien-mediea inauguralis de China officinarum. Lugduni Batavorum 1715. 4. s.

9572 - Disputatio botanico-metlica inauguralis Camphorae listoriam exhibens. Lugduni Batarorum 1715. 4. S.

$9573^{*}$ Seringe, Nicolas Charles. Eissai d'une monographie des saules de la Suisse. Berne, typ. Maurhofer. 1815.8. 100 p., 2 tal. (3 fr.)

(Simul edita sunt specimina sicca Salicum llelveliae ab autore collecti el ileterminati. Tabulam magnam ligno incisam, qquae rum exemplari Meyeriano conjuncta est, non villi.)

9.77:" - Mélanges lotaniques, ou Recueil d'observatious, mumaires el notices sur la Lotanique. Berne, Geneve et Lyon 18181831. II voll. 8. - I: 1318. 244 p., 1 tab. - II: 1826-1831. 156 p., 3 tah.

Fol. 1. Nr. 1: Critique des Roses desúchés. Herne 1818. \$. 1. $1-63$.

Vol. l. Nr. 2: Monographie des Cérćales de la Suisse. ou deseription de blés, seigle, orges, avoines, mais, millets cultivés en Suisse, leurs malidies et leurs usages économirues. Berne el Leipzig, Cnol,loch. 1819. 8. vi, 65-244 p., 11 als.

Vol. 11. Nr. 3 : Feneve, Mai 1524. 8. p. 1-44.

Vol. II. Nr. 4: Observations sur le genre Ranunculus et partirulierement sur le carcteres a tirer des carpelles pour la distinction des especes. Geneve, typ. Bonnant. Mlars 1826. 8. p. 45-70, 1 tab,

Vol. II. Nr. 5: Observations sur la nature des lleurs el des inflorescences, par J. Roeper. Genève, 1yp. Bonnant. Mars 1826. \&. 1. $71-114$.

Vol. 11. Nr. 6: Mémoire sur la culture et l'emploi des Céreales it de quelques autres Graminèes, peur la falırication tes chapeaux "t des tissus de paille, suivi de notes sur les Gramines en general. Eatrair des Mémoires de la socièté royale l'agriculture de Lyon. Lyon, typ. Barret. Octolure 1831.8. p. 115-158., 2 tab.

$9: \pi^{\circ} 0^{\circ}$ - Nusie helvetique dlhistoire naturelte (jartic hotanifue), ou Collection de memuires, monographies, notices botaniques. Tome 1. Museum der Naturgeschichte llelvetiens, botanische $A b-$ theilung. Fister Band, oder sechs Lieferungen. Bern, Burgdorfer.

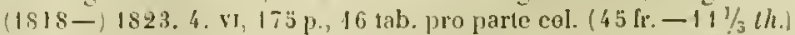

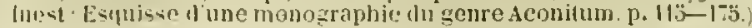


9576 * Seringe, Nicolas Charles. Mlémoire sur la famille des Cucurbitacées. Gencve 1825.4.40 p., 5 tab.

(Extrait des Mémeires de la société de physique et dhistoire naturelle de Geneve, vol. III.)

$9577^{*}$ Mémoire sur la lamille des Mélastomacées. Genève Barbezat. 4830. 4. 28 p., 4 tab.

(Lu en 1827, et extrajt des Mémoires de la société de physique et ('histoire naturelle de Geneve, vol. IV. p. 337-36i.)

$9378^{*}$ Bulletin botanique, ou Collection de notices originales et d'extraits des ouvrages botaniques, souvent accompagnés de gravures représentants des analyses d'organes importants de la ijeur ou du fruit etc. Geneve, Barbezat. 4830.8 .348 p., 9 tab. (12 fr.) (Prodiit duodecim fasciculis, quorum ultimus demum mense Februario $4 \$ 32$ Lugduni edilus est.

$9579^{*}-$ et Guillard. Essai de formules botaniques représentant les caractires des plantes par des signes analytiques qui renplacent les phrases descriptives; suivi d'un vocabulaire organographifue et d'une synonymie des organes. Paris, Mercklein. 4835. 4. $128 \mathrm{p}$. ( $4 \mathrm{fr}$.)

$9: 80+$ Notice sur le Maelure orangé. Lyon, typ. Barret. 1837. 8. 15 p., I tab. col.

9381 t Le jetit agriculteur, ou traité élémentaire d'agriculture. Paris, Ilachette. 4844. 12. Xv1, 426, xCv1 P., 4 tab.

$9582^{\dagger}$ C Élémens de hotanique spécialement destinés aux établissemens d'éducation. Paris et Lyon, Jlachette. 1841. 8. xil, $268 \mathrm{p.}$. 28 tab. avec texte explicatif. - Nouvelle édition. Lyun, Savy. 1845. 8. (6 [r.)

$3583+$ Descriptions et figures des Céréales européennes, telles que orge, scigle, blé, nivièra, avoine, phalaris, riz, millet, mais etc. Seconde édition, avec $30-35$ planclues gravées in 4. Quatre livraisons. Paris, Bouehard-lluzard. (Lyon, Giberton et Brun.) $1841-$ 1847. gr. 8. (18 fr.)

(Vidi anno 48,6 fasciculum primum et alterum $450 \% \mathrm{~J} ., 19$ tals. sign. 1-47.)

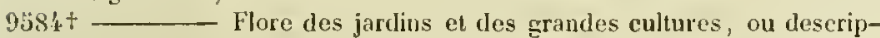
tion des plantes de jardins, dorangeries ct des grandes cultures, leur multiplication, I'époque de leur fleuraison et de leur fruetification et leur emploi. Tone premier. Lyon, Sayy. 1\$45. 8. xxxil, 605 [., 14 tab. (9 fr.)

(Volumen alterum nondum vidli. IItuc operi accedunt fasciculi forma maxima allustration" inscripti, Quatuor prodierant anno 1816 ; unisquo continet liuas taluulas coloratas et textum, pretio $2 \mathrm{fr} .50 \mathrm{e}$.)

$9585+\longrightarrow$ Rapport de la commission nommée daus le seim de la société d'horticulture pratígue du Rhòne, pour s'occuper de la maladie des pommes de terre. Lyon, Savy. $180 \mathrm{ct}$. 1845. 8. 20 p., $1 \mathrm{tab}$.

9586 Flore el Pomone Lyomaises, ou dessins et descriptions des fleurs et des fruils oblenus ou introduits par les hortieulteurs du département du Rhỏne. Publication mensuelle redigée par N. C. Seringe. Première année. Lyon 1847. 4. (10 fr.)

\587 Serpetro, Nicolio. Il mercato delle maraviglie della natura, overo Istoria maturale. Venezia, Tonasini. 1653.4. S.

(A p. 196-2's sive Porticu T/ (le plantis egit.)

9588 Serres, Heclor. Notice sur la culture du pin maritime dans les Landes et sur la fabrication des produits appelés matières résineuses. Bordeaux, typ. Guizonnier: 4837.8 .44 p., 1 tab. a.

\$589t Serres, J.J. Flore abreggée de Toulouse, ou Catalogue méthodique des végétaux phanè ogames qui croissent naturellement aux environs de cette ville, indiquant les stations et les époques de fleuraison de claque plante; suivi d'une clef analytique des genres et des espèces, et d'un dictionnaire des termes. Toulouse, Corne. 1836.8. vili, $237 \mathrm{p}$.

9590 Serres, Olivier de, Seigneur du Iradel. Le théâte d'agriculture et mesnage des champs. Paris 1600. Tolio. - Paris 1641. 8. tGeneve. Chouet. 1699.4.878 p., praef, ind. Bibl. Cand. - Rouen, chez Jean Berthelin. 1646. 4. S. - Genève 1651. 4. S. - Lyon 1675. folio. - Théatre d'agriculture el ménage des champs, ou l'on roit arec clarté et précision l'arı de bien employer et eultiver la terre, en tout ce qui la concerne, suivant ses dillérentes qualités et climats divers, tant d'après la doctrine des aneiens que par l'expérience. Remis en français par A. M. Gisors. Paris, Mleurant. an Xl. (1803.) IV roll. S. - I: xxvi1, 632 p., 1 tab. - Il: 627 p., 1 tab. - Ill: 614 p., I tab. - IV: IV, 639 p., 1 tab. (25 fr.) - †Le théatre d'agriculture et mesnage des clamps d'Olivier de Serres,
Seigneur du Pradel. Nonvolle édition, augmentée de notes et d'un roeabulaire: pullliée par la société d'agrieulture du département de la Seine. Paris, Iluzard. 1804-1805. II voll. 4. - I : 1804. CxCII, 672 p. $-11:$ 1805. xuIV, $94 \mathrm{~S}$ p. ot planehes. ( $30 \mathrm{fr}$.)

(«Magnum opus et bonum, viri experti, simplicium amantis, neque impendiosorum artiliciorum studiosi.n Hall. Bibl. Wot. I. p. 395-396. Non satis distingun ab hoe opere aliud supra $\mathrm{Nr}$. Goss in voce Liger allatum; sed diversa puto, et Ligerii potius Stephani reformatum l'raedium risticum. Plura de nostro autore alciue ultimis dualus editionibus leguntur apud Quérard, France littéraire, vol. IX. p. 79-81.

$9591+$ Serres, Olivier de, Scigneur du Pradel. La cueillete de Ia soye par la nourriture des vers qui la font. Echantillo du théatre d'agriculture d'Olivier de Serres, Seigneur du Pradel. Sódition annotée par M. Matthieu Banafons. Paris, Boucliard-Huzard. 1543. 8. 116 p.

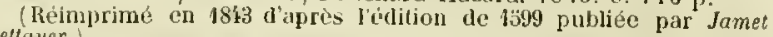
Mellayer.

9592 La seconde richesse dı meurier blane, qui se trouve en son escorce pour en faire des toiles de toutes sontes. Paris 1603 8. s. - "Imprimé avec les opuscules de Richer de lielleval, publiés par Pierre Marie Auguste Broussonet. Paris 1785 . S. 18 p.

anglice: The preparation of the tharke of the white Nulherrie, for to make linnen cloath on, and other workes. Prinled with his lerfect use of Silk-wormes. London, Felix Kyngston. 1607, 4. p. 86-93. B.

$9393+$ (Servais, Gaspar Joseph de.) Korte Verhandeling van de boomen, heesters en liontagtige Kruid-gerassen, welke in de nederlandsche lugtstreck de winterkoude konnen uitstaan. ete. Mechelen. Hanieq. 1789. S. xi1, 237 p., 4 tah. Bibl. Reg. Brux.

(Autoris nomeu indicavi teste van Hulthem.)

959. Sestini, Domenico. Leltere scritte dalla Sieilia e dalla Turchia. Firenze 1779-1784. VII voll. 12. 242, 218, 234, 215, 210, 221, 223 p. B.

gallice: Lettres écrites i ses anis en Toseane, pendant le cours de ses voyages enl llalie, en Sicile el en Turquie, sur thistuire nafurelle, rindustrie et le commerce de ces difterentes contrées; (raduites de litalien et enriclies de notes par Pingeron. laris, Duchesne. 1789. III voll. 8. ( $13 \mathrm{fr}$.) Q.

9505 Lettere odeporiche, ossia viaggio per la penisola di Cizico per Brussa e Nicea. Livorno 4785. 11 voll. S. - I: 163 p. II: 138 p. B. - Ed. Il : Livorno 1789.8. Schultes. idea.)

(luest in editionis primae vol. II. p. 93-138: Florac Olympicae gallice: Yoyage dans la Grèce asialique, a la péninsule de cyzique, a Brus-e et a Nicée. Traduit de litalien par Pingeron. Parjs, Leroy. 1789. 8. $252 \mathrm{p}$. B.

(Flore du mont Olympe, p. .38-252.)

9396 Opuscoli. I: Deserizione del littorale do Canale di Costantinopoli, e della coltura delle Vigne lungo le coste del medesimo. II : Della eoltura di varie cose geoponiche lungo le coste medesime. III : Idea dei giardini turco-bisantini, e coltura dei varj fiori che si fa nei medesini. IV: Della Caecia turca, con una deserizione Jegli animali, e degli uccelli, che si asservano annualmente lungo il Canale di Costautinopoli. Firenze 1785. 12.210 p. B.

$9397^{*}$ Viaggi e opuscoli diversi Berlino, Iyp. Quien. 1807.8 xill, 313 p., 2 tat.

9398 Sethi, Symeon. De eiluariorum facultate syntagma, graece et latine, Lilio Gregorio Gyruldo interprete. Basileae 1538. 8. 199 p. B. Volumen de almentorum facultatibus, graece et latine, per Murtinum Bagdanum. Lutetiae Parisiorum 1658.8.174 p. B.

$9599+$ Sette, Vincenzo. Memoria storico naturale sull' arrossimento straordinario di aleune sostanze alimentose osservato nella provincia di Pudova l'anno 1819. Venezia, typ. Alvisopoli. 1824.8.63 p.

$9600^{*}$ Seubert, Moritz. Flora azorica, quam ex collectionibus schedisque Hochstetteri patris et filii elaboravit et tabulis $\mathrm{XV}$ propria manu aeri ineisis illustravit. Bonnae, Mareus. 1844.4 vi: 49 p., 15 tab. $\left(2 \frac{2}{3} \mathrm{lh}\right.$.)

$9601^{*}$ Seutter, Mallhaeus. Disputatio botanico-medica inauguralis de Nuce vomiea. Lugduni Batavorum, Iур. Abrah. Elzevier. 1691. 4. (13) foll., 2 tab.

9602 Severgin, Wassil. Начахьныя основанія естеетвениой псторін. C. Нетер6. 1794. 3 таст. 4. Trautv.

9603 Опыть нинералогпескато описанія Россійскаго Государства. C. Il стер6. 1S09. Trautv.

9604* Severinus, Marcus Aurelius. Ejpistolae duae: altera de lapide fungifere: altera de lapide fungimappa. Inpr. cum Fierae Coena. Patavii, Yp. Sardi. 1649. 4. p. 167-208. - *Publici juris iterum 
factae a Fronz Ernst Braeckmanu. Guclpherlyti 1728. 4. 44 p., I lal).

"gallice: Jourual de physique, supplement, vol. Xill, p. 1-22, 231

960 t 5 Seward, Inna. Memoirs of the life of 1)r. Erasmus Dorwin, chiefly during his residence at Lichfield, witl anectlotes of his friends and criticisms of his writings. Jomblon, Johnson. 1804. 8. XIV , $430 \mathrm{p}$.

9606 Sharrock, liobert. The history of the propagation and improvement of vergetables liy the concurrence of art and nature. Oxford 4660. 8. 150 J., 4 tab. B. - Ed. Jl. much enlarged. Oxford 1672. x. - Ed. 1II: An improvement to the art of gardening, or an exact listory of plants. London 1694. 8.255 p. B.

9607t Shaw, Thomas. Travels or observations relating to several parts of Barbary and the Levant. Oxford, printed at the theatre. 1738 . folio. $\mathrm{xr}, 442,60$ p., ind., tals. $-A$ suppleme nt to a hook entituled: Travels or observations elc. wherein sume observations lately matle against it, are fully considered and answered. ib. 1746 . folio. $112 \mathrm{p}$. 1 tab. - I further vintication of tho look of travels and the supplement to it. (ib. 1747.) folis. 6 p.

(In altera parte p. 37-77: Specimcu Phytographiae africanat, or it Catalogue of some of the rarer plants of Barbary, Egypt and Arabia, enm ti tabulis.)

* germanice: Reisen, odtr Ammerkungen versehientne Theile der Barharei und Levante hetrelfoud. Nach der zweiten englivehen AusYabe ins Dentsche vibersetat und mit vielen Landkarten und andern kuıfer" erlisutert. Leipzis, Breithopf. 176̈. 4. $421 \mathrm{k}$., prael., ind 32 lab.

(A p. 313-403, til). 1-6: Specimen Phytographiac afrieanae. gallice: Voyages dans li Barbarit: et io Levant. La llitye, Néautme 17t3. Il voll. \&. 0

9608 Catalogus plantarum, quas in variis Africae et $\Lambda$ siae partihus collegit Thomas Shancius. Acerssit appendix de coralliis et rorum affuihus. Oparä J. D. (i. e. Johannis Jacobi Ditlenii.) Oxonii 1738. folio. S.

Est impressin scorsim facta ex opure praecedenti.)

$9609 t$ Shecut, John L. E. II. Flora Carolinatensis; or a historical, medical and neconomical display of the vegetable hingdom; according 16 the Linnean or sexual system of botany. Being a collection or compilation of the various blants hitherto discovered and made hnown hy the several authors on botany etc. In two volumes. Vil. I. Charlestom, typ. John Hotf. 1806.8.579 j., 5 tab. Bibl. Cand. (Volmuen alteruni non virli.)

9610 Sheldrake, Timothy. Botanicum medicinale, an herlal of medicinal plants on the College of Physicians list. London s. a. Colio. 117 tal. aen. eol. eum descriptionilus sculptis in iisdem tabulis. B.

9611 Shiercliff, E. Bristol and llotwell guide. Bristol 1793. 8. B.

(batalugue of the plants, which grow on St. Vincent's Rocks abt nejghbourhood, p. $82-86$, cum tahida aenea, Arabim strjetam "xliibente.)

9612 Short, Thomas. Hodicina Jritannica, or a treatise on such plysical plants as are ginerally to be found in the fields or gardens in Great-Britain. Lonlon 1747. 8. 352, 39 p. B.

9643 A dissertation 11 mon Tea. A discourse on the virtues of Sage and Water. London 1753.4.96 p. B.

3614* Sibbald, Roberlus. Scotia illustrata, sive Prodronus historiae naturalis, in quo regionis natura, incolarum ingenia el mores, morbi iisque medendi metholus et medicina indigena accurate explieantır, et multipliees naturae partus in tripliec ejus remo, vegetahili scilicet, animali et minerali cxponuntur. Edinlsurgi, ex officina Jincolbi Kniblo. 1684, folio

(Partis secunflae tomus I est de plantis. $11 \mathrm{k}$ p., ind

9615 Siber, Urban Gottried. De Maly Hermetis herba. Schneebergae 1699. 4. Desid. Banks.

9616 "Sibthorp, Johr. Flora Oxoniensis, exhibens plantas in agro 0xoniensi spunte crescentes, secundum systema sexuale distributas. Oxonii, Fleteluer. 1794. 8. xxuv, 422 p., ind.

$9617^{*}$ Florae graecale Prodromus: sive plantarum omnium coumeratio, fuas in proviucis aut insulis fraceiae invenit Joh. Sibthorp. ete. Cliaracteres et synonyma omnim cum adnotationibus elalıoravit Jac. Ed. Smith. Londini, typ. Taylor. 1806-1813. Il voll.

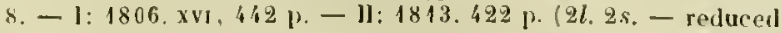
14.s.)

$9618^{*}$ - Flora graeca: sive plantarum rariorum Jjistoria, fuas in frovinciis aut insulis firaeciae legil, iwvestigavit et depingi curavit
Johunnes Sibthorp. Llic illic etiam insertae sunt pauculae species. "was vir idem clarissimus, Graccinm versus navignas, in itiler praesertim aput Italian et Siciliam, invernerit. Claracteres ommiun, descriptiones et synonyma elahurivit Jac. Ed. Smith. Londini, typ. Rich. Taylor. (veneunt apud W"hite, Payne et Foss.) 1806-1840. $\mathrm{X}$ voll. folio. - I: 1806. Classis I-III. vill, 82 [3., tab. col. 1-100. II: 1843. Classis IIJ-V. 83 II, tal). col. $101-200,-$ II]: 1819. Classis V. 93 p., lab. col. $201-300$. $-\mathrm{JV}$ : 1823. Classis V-X.

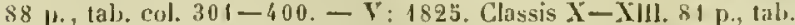
col. 401-500. - Vl: 1827. Classis XIII-XII: 80 fr. tah. col. 501 -600. - VII: 1830. Classis XIV-XVII. 87 p., tah. col. 604-700. - VIII : 1833. Classis XVII-XIX. 75 p., tab. col. 70t-800, IX: 1837. Classis NIX. 77 p. tah. col. $801-900,-\mathrm{X}$ : 1840. Classis XIX-XXIV. 106 p., tah. col. $901-966$. (250l.) Bibl. Imper. Ferd. Austriae, Bibl. Deless.

IVistoriam operis rarissimi, cujus triginta tantum e prinaria impressione exmplaria exslant, Mitran' in Gersidorfi Letpziger Repertorium, 18k7. IJeft 33, p. 2058-261. Volumina Y YII-X jost obitum Smithii [t 17 Mart. 1828] 'didit John Lindley; of. Atmonenda in calce voluminis septimi. Folumen $x$ habet a p. $57-106$ Appendices : 1: Notoina autorum compendiaria in hoe opere cilatorum fusius exposita, p. 59 it: lnumeratio plantarum omnium cmendati, jllis Sithorpius in Graecia imvenit, p. 67-82. - III: Catalogus plantarum grae"drum Dioscoridi notaruni, eum synnnymis botanicis, ad seriptormm uptimorun sententias elahoratus, D. 83-88. - W Index nominum, quac Graecia hodlie in usu labet, cum synonymis bolanicis, p. 91-96. - $r$ : Index nominum turcicorum, eun synonymis hotanicis, p. 97 . - Vi: Index nominum systemiticorum ei svionyma, p. 99-106. Exeniplaria inempleta (vol. 1-V1, vol. 1-Vii) Goettingae, Berolmu, I'tindobonae in Palatina, et Dresdae in Rergiu Bibliotheca servantur. Opu. de noyo typis excusmm prodit curis ili. Charles Daubeny. Professoris

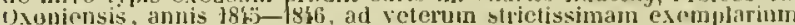
similitudinen atlaptatum Loudioi in libraria Menry G. Bohut pretio 63l venale. Uujuscemodi exenptar possidet ill. Judolphus L.R. de Roemer Dresdensis. LF, eon Schlechlendal's Botanisehe Zesitung, 184. T. $79 y_{1}-796$.

9619 * Sickel, Christoph hented, latine Sicelius. Diatrile intanicomedica de Belladonna, seu Sulano furioso. Jenae 1724. 4. is p.

$9620^{*}$ Sickler, Friedrich Karl Ludu ig. Alfuemeine Geschichte ller Obstkultur von den Zeiten der Urwelt an bis auf die gegenwartigen herah. Erster Band. Geschichte der Olnstkultur vou den \%eiten der L'rwelt his zu Constantin den Grossen. Nebst einer genetiselien Obstkarte und 2 andern Kupfern. Frankfurt a/M., Jäger. 1802. 8. Lxyy, 507 p., 3 tab. $(2 \%$ th. $)$

9621 Sickler, Johann Folkmar. Des Kurfüstan August von Sachsen Kinstliches Obstgartenhuichleit. Von Neuem herausgegeben. Weimar, Industrie-Comptair. 1802. 8. $(1 /+$ th. $)$

9622 _ _ Gartenhandlexikon fur Lnerfalurne in der Gartenkuns und Besizer kleiner Garten. Erfut, Hemninys. 1811. 8. (1 1/3 th.) Iritte Auflagi, neu bearbeitet von J. Chr. G. Il eisp. Fotha, Ilenuings. 1829. $8 .(2$ th.)

9623 Der vollkommene Orangeriegärther, obler vollständige Leselureibung der Limoneu, Citronen und Pomeranzen, oder der torrumi in Italion und ihrer kultur. Weimar, Industrie-Comptoir $1816.4 .\left(2 \frac{1}{2}(h)\right.$

962:" Sickmann, J. $K$. Enumeratio stirnium phanernamarum cirea llamburgum sponte erescentium. Hamburgi, Meissner. 1\$36.8. $80 \mathrm{~J} .(1 / 2, h$.

Illaee seripliuncula non ante meusem . Wartium $1 \$ 39$ a bihliopolis divilgata est.)

962:; Sieber, Franz IIthelm. Lerbarium Florie apgyutiaean, sive collectio stippium rariurum tegyti indigenorum. Yindohosan 1820 folio. 4 foll

$9626^{*}$ - Lerbarium Florae creticae, sive collectio slirpinm rariorum in insula Creta sjonte wascentium. Vindobnnae $18 \geq 0$. folio. \& [oll.

$9627^{*}$ ___ Inkindigung von Herbarien. (1824.) 8. $6,16,14 \mathrm{p}$ $9628^{*}$ _. Rrise naih der Insel Creta im griechischen Irelipela(n) in Jalıre 1817. Jeipzig, Fleischer. 1\$23. 2 Bande. $8 .-$ I 548 p. $-11: 328$ je, 14 lab. $\left(5 \frac{1}{2}\right.$ th.

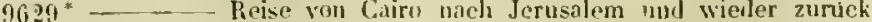
molist Belenchtung einiger leiligen Orte. L'rag, Neureuter. 1893. s. 167 p. 3 tals. $\left(1 \frac{1}{3}\right.$ (h.)

Conferas ats moritissimo collectore: "Fron: Villielm Sirber. Fin biosraphisclier flenkstein von Dr. Legis Gluskselig. Wion, Bech. 1837.

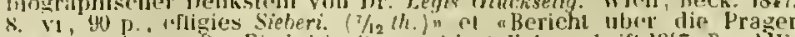

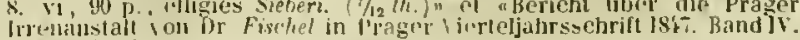
p. $13 x+139)$ 
$9630^{*}$ Siebold, Karl von. De finibus inter regnum animale et vegetabile constituenelis. Programma gratulatorium. Erlangae, typ. Jung. (Blaesing.) 1844. 4. 14 p. $(1 / 4$ th. $)$

$9631+$ Siebold, Philipp Franz von. De historiae naturalis in Japonia statı, nec non de augmento emolumentisque in decursu perscrutationum exspectandis Dissertatio, cui accedunt spicilegia Faunae japonicae. Bataviae 1824. S. 16 p. Bibl. Cand.

Sphatmate typographico nomina auctoris in litulo: (s. T. Jeguntur.)

$9632^{*}$ Tabulae synopticae usus plantarum. In insula Dezima 1827. folio. 4 foll. Bibl. Reg. Berol.

$9633+$ Synopsis plantarum oeconomicarum universi regni japonici. (Dezima, Nov. 1827.) 8. IV, 74 1). Bibl. Reg. Brux.

$9634^{*}$ —_ Flora japonica, sive Plantae, quas in imperio japonico collegit, descripsit, ex parte in ipsis locis pingendas curavit. Sectio prima, contineus plantas ornatui vel usui inservientes. Digessit Jaseph Gerhard Zuccarini. Lugduni Balavertum, apurl atutorem. (Lipsiae, Leopold Voss.) 1835-1844. folio. - Centuria prima. (Fase. 1-AT.) 4835. 193 p., tals. col. 1-100. - Centuria altera. (Fasc. $1-Y$.) $1842-4844.44$ p., tab. col. 101-127, tab. nigr. $124^{\text {bis }}$ et 137. (col. $116^{2} / 3$ th. - nip.p. $58 \frac{1}{3}$ th.

(Contimuabitur [opt. Zuccarini +18 . Febr. 18 18 ) in tasciculis quinque talyularum, simgulus pretio col. $4 \frac{2}{3}$ th., nigr. $21 / \mathrm{s}$ th, $\rightarrow$ hil Centuria altera hueusque solum coniferae continentur.)

$9630^{*}$ _- Erwiederung auf II. II. de Frisse's Abhandlung: Het liezag van Kuempfer, Thunbery, Linnueus en inderen, omtrent den botanischen oorsprong van den Ster-anijs des Handels, gebandhaafd tegen Dr. Ph. Fr, von Siebold all Prof. A. G. Zuecarini. Mli Bozug auf die von $J$. Hoffmann mitgetheilten Awgaluen sehinesiselser unt japanischer Nalurgescluicluten. Leilen, hei dem Verfasser. (Leipzig, Voss und Jir. Fleischer.) 4\$37. 8. 19 $\mathrm{k}$, 식. ( $1 \mathrm{th}$.

9636 * Siegesbeck, Joham Georg. Primitiae Florae l'ornolitanae, sive Catalogus plantarum tam indigenarum yuam exolicarum, quibus instructus fuit bortus medicus Petrilurgensis praesenti anno 1736 Rigae, typ. Froelicl. (1736.) 4. 111 p., praef. -- "Sujplementum: ib. $1737.4 .36 \mathrm{y}$

9637 Propenptienm do Majanthemo, Litium ronvallium offeinis vulgo nuncupato. Petropoli $1736,4,15 \mathrm{p}$. B.

9638 Programıa de Tetragono llippacrutis. Petropeli 1737. 4. 12 p. B

$9639^{*}$ Wolanosophiac verioris Jrevis Sciangraphia in usum discentinm adernata; accedit ob argumenti analogiam lepicrisis in CI. Linnaei nuperrime evulgatum Systema plabtarum sexuale ef huic superstructam methedum botanicam. Petropoli, typ. Academiae. 1737.4 .64 p., praef. $(1 / 4$ th.

(Kipicrisis Systematis Linnaei: p. 40-64t.

$9610^{*}$ _ Vaniloquentiae butanicae specimen, a II. Joham Gollieb Gteditsch in consideratione Epicriseos Siagesbeckianae in scripta hotanica Limaei, pro rite obtinento sexualistae titulo, nuptrs evulgatum, jure rero retorsionis refutatum el elusum. Petropoli $17 \mathrm{l}$. 4. 54 1.. (1/, th. $)$

$961.1 \div$ Siegfried, J. J. Die Pflanzen in ihrer Anwenlung auf Furst-und Landwirtischaft, Garteubau, Gewerbe und llandel. Für ten Unterriclut vorzüglich is schweizerischon Schulen bearbeitel. Zürich, Schulthess. 1840.8 . xu, 264 p. $(1 / 2$ th. $)$

$96 \% 2{ }^{*}$ Siegl, hudolph. De calendario plantarum officinalium. D. Vintobonae, typ. Ludwig. s. a. $8.32 \mathrm{p}$.

96: $3^{*}$ Siehr, Robert. De cortice radicis Granati. 1). Berolini, (y) 1. Brüschke. 1529. $8.55 \mathrm{p}$.

96 it Siemers, C. L. Trädgärulsskutsel i ehononisht afscendo. Örebre, Lindl. 1844. 12. 110 p. (28 shill.)

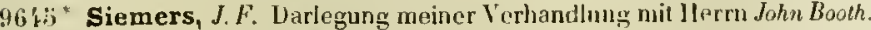
Altona, tyj. Hammerich. 1834.8. 8 1\%.

96 if Siemssen, Alolph Christian. Dissertatio diactico-physica, qua radicum Solani tuberosi innocentia justo vindicatur. Rostockii 1798. 8 .

$9617^{*}$ - Naturgeschichte des Hausschwammes, des Mauersalzes und des Iosaischen IIfiuscraussatzes, (III Mos. XIV, v. $33-54$.) nebst Vorselilagon zu deren gámzlielıer Vertilgung. Lefipzig, stiller. 1809. \& 9 i p. $(1 / 3$ th.
9648 Siennik, Marcin. Ilerharz to iest ziól tuteeznycl postromyelı i zamorskich opisanie, co za moc maią, a jaho ich używać etc. (IIerbarium vel hrobarum indigenarum ef exoticarum descriptio.) Krakowie, w drukarni Mikulaia Szarfenberga, 1568. Lolio min. 628 p.

96.49 Sierstorpf, Kaspar Meimich, Freiherr von. Einige Bemerkungen uber die in dea Winter 1788-17\$9 erfrorenen Bäume. Braunschweig, Schulluch haodlung. $1790 . \mathrm{gr} .8 .(1 / 8$ th.

9630 - Ueber die forstmassige Erziehung, Erhaltung und Bronutzung der vorzuglichsten inlandischen Holzarten. (Erster Theil. 1794. Die Forstbutanik, die Naturkunde der Bảume uberlaupt un die Beschreibung der Eiche. Zweiter Theil. 1813. Die lieschrribung der Fichte.) Mit illuminirten Kupfern. Hannover, Ilahn. $\$ 794$ -1813.2 Theile. yr. $4 .\left(5 \frac{1}{2}\right.$ th. $)$

9654 t Sieuve, Lasare. Mémoire et Journal d'olservations of d'esporiences sur les moyens de garantir" les olives de la piquire des insectes. Nouvelle méthode pour en extraire une buile plus ahon"lante " plus tinn. "uc. Paris, typ. Lambert. 1769.8. 126 1., 3 tal. - + Nouvello edition angmentée. Paris, Iyp. Lambert. 1786. 8 126 [). 3 (a)

9652 Sigmond, $G$., ant $F$. Farre. Essay on the Ceylon Moss. (Spharrococens lichenoides kiutz.) London, Renshaw. 1840. 12. (2s. 6d.)

9653 \% Sigwart, (irory Friellich, pr. De vegetabilium ulterieri indagine ejusdemque necessitate et utilitate. 1). Tuebingae, typ. Fues. 1769 4. 22 1).

965\%* Silfverstrăhle, Gustaf. liestämaing af Blad och Kuopłars divergence. Stockliolm 1839. 8. $11 \mathrm{p}$. -212 .

Srorsim inpr. ed kongl. Velensh-dcat. Hauld. for âr 1838. p. 202

9653 Sillén, Nicolaus Jacolus, pr. Flora Paroeciae Brankyrka, cujus parten I-III jro aradu philusophieo proponmut Nicolaus Guilichnus Lundequist, J. F. Kjellberg el Juhannes Daniel Gellerstedt. I). Upsatiae, typ. acidemiac. $1827.8 .48 \mathrm{p}$. w.

9656 * Siltemann, Johann Rurlolph. De cortico Winteranu, D. Erfordian, 1yp. Groscld. 1711, 4. (24) p.

9637t Silva, Johannes Baplista. An sonibus The? D. Paris, Iyp. Muguel. $1712.4 .4 \mathrm{p}$.

9658 t Silva Lisboa, Balthazar da. Riqueza do Brasil em Madeiras de construçīo e carpintaria. Rio de Jaturiro, na ty pugraphia nacional 1823.8. $67 \mathrm{p}$.

96:5? * Silva Manso, Antonio Luiz Patricio da. Enumeraçào das suhstancias Brazileiras, que podem promover a catarze. Memoria roroada pela imperial academia de medicina do Rio lle Janeiro $\mathrm{rm}$ o anno de 1836 . Rio de Janeiro, na 1ypographia nacienal. 1836. \& 51 p. Bibl. Pal. Vindob.

9660 Simler, Josias. Vita Conradi Gesneri. Tiguri 1566, 8. 20 foll. в.

(Accedunt: Conradi Gesnere Kipistola de libris a se editis, Canminat in whitun Comradi Gesneri, et Caspari llolphii ýróyects sive the 1. Geszeri Stirpium historio pollicitatio, foll. $21-52$.

9661* - Vallesiae Iescriptio libri duo. De alpibus coomentarius. Tiguri, excudobal Frosehoverus. 1574. \$. 151 foll., pract. (A foll. 126 - 132 agitur de plantis alpinis secundun Conradum Gesnerum.)

$9662^{*}$ Simon, Gustav Irilhelm. De sarcina ventriculi. D. Halis 1847.8 v1, $29 \mathrm{p}$., I tab.

$9663^{*}$ Simon Januensis vel Genuensis. Ed. princeps: Synonyma medieinae seu Clavis sanationis. Opus impressun Mediolani per Antunium Zarolum Parnensem, anne Domini MCCCCLXXill die Martis III. Augusti, folio. IIain Nr. 14747. - Ed. H: incipit elavis santationis elaborata pur vonerabi]eol virum magistrum Simonem Januensem domini papae subdyaconum et caprellanum medicum quondam felieis recordationis domini Nicolai papae quarti qui fuit primus de urdine ninorum. In civitate Patavina ger Petrum Maufer. 1474 folie. (174) foll. binis columnis 40 lin. Bibl. univ. Regiom. (Hant Nr. 14748.) - Venetiis, per Guielmum de Tridino ex Monteferato. 1486. folio. Hain Nr. 14749. - " Simmis Januensis opusculum, cui nomen elavis sanationis simplicia medicinalia latina, graeca et arabica ordine alpluabetico mirifice elucidans recognitum ac mendipurgalum: et yuotationibus Plinii maxime: ac aliorum in maryiniIsus ornatus: et quan diligentius ac correctius id frert putuit, in- 
pressum. (Jn ealce:) Finis. Simoms Jannenss adlitis auctoritatilus Plinii locis propriis per Georgium de Ferrariis tle Varolẽgo monttisserati, artium et medicino doctorem. Impressum Venetiis per Gregorium ale Gregnriis Anno domini 1514 die XXll mensis Ilaji. folio. 65 foll. Bibl. Goett. et Cand.

(a) Mit vieler Saclikentniss und ejaener Reobachtung bearbritet, taher fur Geschichte der Botanik wichtï. Die angehliehen spatern Ausuaben gelwen vermuthfiely alte, zun Theil gewiss, gar tuitht tierher sontern zo Inatthaei Syldatici opus pantectarum nedicinae, in dessen spatern Auggabon puiges voll simon Junuensis whergecangen ist, theils ohnr, theils nit Erwilhnung seines Namens auf flen Titel. Eine Ausgabe tler letzten Alt scheint syrengel zu sejuem

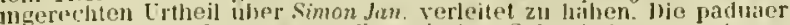
Ausgahe, die zil den grussten literarischen Seltenheiten zu gehoren scheint, befindet sicl auf der Kon. Bibliothek zu kinimsberg. on E. M.)

966:- Simonde (de Sismondi), Jean Charles Léonard. Tableau de l'agriculture toscane. Genève, Paschoud. 1801. 8. xiv, 327 P., 1 tab. (3 fr.)

* germanice: Gemálde der toshanischen Landwirthschaft. Aus $1 \mathrm{frm}$ Franzusischen mit Anmerkungen von J. Burger. Tubingen, Cotta. 180\%. 8. (1 th. )

9665 Sinclair, George. Hortus gramineus Woburnensis. London 1896. folio.

Editio princeps rarissima cum exemplaribus graminum siccis: lescribitur ist Lowndes Biluliographer's Nanual of english literature, vol. II. [1. 1686 .)

$9666+\longrightarrow$ Horlus gramineus Woburnensis, of an account of the results of experiments on the produce and nutritive qualities of different grasses and other plants used as the fonl of the more valuable domestic animals: instituted by John, Dulie of Bedfard. Illustrated eet. etc. lid. IJ: London, Ridgway. 1825. 8. xx, 438 p. with numerous figures. (1l. $10 s)$.- Ed. $1 \mathrm{Y}$ : ib. 1838.8. (1l.10s.) * germanice: Hortus gramincus Wolurnensis, oder Versuche uber den Ertrag und die Nahrungshrifte verschiether Griser und andrer den Erirag und die Nahrungskrifte verschietner Griser und andrer Pllanzen, welelw zim L nterhalt der nutzlicheren llaustbiere rienen,

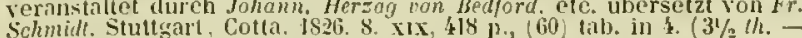
Schmilt. Stuttgart, Cotta. 1826.8 . xix, 418 )., (60) tab. in $4 .\left(3 \frac{1}{2} / h\right.$. col. $4^{3} / \mathrm{s}, \mathrm{h}$.

* germanice: Joham Hlerzog van Bedford's Chemisch-agronomische L'ntersuchnn;en ther den Werth verschieilner Fuftergraser. Zuers heransgegeben von sir llumphry Dary. Xach rem Frauzosiselhen von 1fergt. ) 1821. 8. 1338 p., praef., ind. $(3 / 4$ th. $)$

9667 Sinclair, James. A history aud description of the different varieties of the freorgina or Dahlia, now in cultivation in the british gardens, illustrated with coloured figures of all the choicest sorts. Part L. London, Slierwood. 1835.

9668 Sinclair, Joln. Code of agriculture. London, Sherwood. s. a. 8. (Ill.) " germanice: Grundgesetze des Ackerbaus, nehst Bemerkungeu uber Gartenlau, Obsthaumzueht, Forsteultur und llokzptanzung. Ans dem

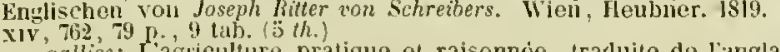

gallice: Lagrieulture pratique et raisonnée, traduite do l'anglai Dombasle. Paris, lluzard. $182 \%$. II voll. \&. 9 tab. (13 fr.) $\mathbf{a}$.

9609 Hints on regetation, the agents necessary for the production of plants and those which are injurious or destructive to them. London 1832 ?

$9670-$ Memoirs of Sir Jahn. Sinclair, by his son. London, B3lackwood. 1837 . Il rell. S. (1l. 1s.)

germanice: Das Lelen und Wirkell des Sir John Sinclair, dargestelit ron seinem Sohne. Nach dem Englisehen bearbeited von Boumann. Braunschweig, Westermanu. 1838. 2 Theile. $8 .\left(3 \frac{1}{2} t h\right.$.

967 I Sinet, J. L.F. Perfectionnement de la culture des grains nommés Céréales. Paris, Delaunay. 1821. 8. 62 p. a

9672 Siricius, Johannes. Ilistorische, physische und medizinische Besehreibung derer im Furstlich Gottorpisehen Garten, das Neue-Werek genannt, dreyen blühenden Aloen (mit Beyfugung einer Beschreibung der gleichfalls bluhenden lueca gloriosa.) Selıeswig 1705. 4. 64 p., 1 lab. B.

9673 - liurze Beantwortung derer von Dr. II. Ir. II. (i. e. Wilhelm Ulrich II aldschmiedl) sohr ungereinten, nichtswürdigen und injurieusen Imputationen, wider seine herausgegebene Beschreilung derer im Ilochfürstlichen Gottorpsehen Garten verwiehenes Jahr 1705 blühenden Aloen, und dessen Persohn, der Wabrheit zu Steuer, und zur Rettung seines ehrlichen Nahmens, allen Verstandigen und Uupassionirten zum Urtheil ubergeben. (Kiel) 1706.4 .68 p. B.

967 it Rajae cimbricae, seu Carmen de Aloe americana. Schleswigae 1709. folio. Desid. Banks.
9675 Skinner, Stephanus. Eivmologicon hotanicum, scu eaplicatio nominım (anglicorum) omnium vegetabilium. Impr. cum ejus litymologico linguae anglieanae. Londini 1671. folio. $\mathbf{B}$.

$96760^{\circ}$ (Slack, Henry, Turrell and Holland.) Improvements in the microseope. London, typ. Moyes. 1833.8.45 j3. 4 tab. Btbt. Juss.

(From the Transictions of the society of arts, manufactures eommeree ete. vol. .LLIX.)

967 Slegelius, Paulus Marquartus. Programma ad hartenses lectiones. Jenae 1639. 4. 1 plag. B.

9678 Slevogt, Johann IIadrian. De Jalapa. D. s. I. 1678. 4. Desid Banks.

\section{Proyrammata academica:}

$9679^{*}$ De Aegilope herba. Jenae, typ. Krehs. 1695. 4. 8 p.

$9680^{\circ}$ Prolusio acallemica, qua ostenditur, nucenn Jlethel Avcennae esse Daturam modernorum. Jenac, typ. Werther. 1695. 4. (8) p.

$9681^{*}$ (1) Polypodio. Jenae 1699. 4. (8) p.

9682* - Ve Acmella ceylanica, novo fluoris albi remedio. Jenie, typ. Gollner. 1703. 4. (8) p.

9683 De cortice Culilaran. Jenac 1705. 4. Desld. Banks.

9684 De Cinnamomo. Jenae 1707.4. Desid. Baoks.

$9683^{*} \longrightarrow$ De Prrethro. Jenae 1709.4.8 p.

$9686^{*}$ Commendatio Centaurii minoris. Jenac, typ. Krebs. 1713 4. (8) p.

$9687^{*}$ De Lino sylvestri eatharetico Anglorum. Jenae, typ. Krelss. $1715.4 .8 \mathrm{p}$

$9688^{*}$ De virtute IIyoscyami catharctica. Jenae, typ. Kirebs. 1795. 4. $8 \mathrm{p}$.

$9689^{*}$ - Nonnulla ad natalem locum, claracterem et vires herbae Seordii pertinentia. Jenae 1716. 4. (8) p.

$9690^{*}-$ Jenense vinum a nocentis ealeis suspicione vindicatur. Jenae $1718.4 .8 \mathrm{p}$.

$9691^{*}$ De Momurdica. Jenae 1719.4. (12) p.

$9692^{*} \longrightarrow$ De Bandura Ceylonensium. Jenae, typ. Werther. 1719 4. (8) p.

$9693^{*}$ __ De Thea romana et lungarica sive silesiaca, aliisqque ejus suceedaneis. Jenae, typ. Ritter. 1721.4.8 p.

9694* - De Astrantiae charactere a Tournefortio minus sufficienter delincato, florisque genitalibus. Jenae $1721.4 .8 \mathrm{p}$.

\section{Disserlationes praeside Johann IJadrian Slerogt}

$9690^{*}$ - Balsamun rerum, quod vulgo Opobalsanum dicutur. D Jenae 1705. 4. 31 p. (Respondens: Johann Friedrich II eissmann.)

$9696^{*} \longrightarrow$ De Lrticis. D. Jenae, typ. Gollner. 1707.4. 30 p., A tab. (Respondens: Jaham Melchior Drechssler.)

$9697^{*}$ - De Ruta. D. Jenae, țp. Gollner. 1715. 4.40 p. (Respondens: Jesaias Curtius.)

$9698^{*}$ De Opohalsamo. 1). Jenae 17 17.4.32 p. (Respondens: Johann Samuel Ileinsius.)

$9699^{*} \longrightarrow$ De Gentiana. D. Jenae, 1yp. Werther 1720.4. $25 \mathrm{p}$. (Respondens: Jahann Andreas Heber.)

$9700^{*} \longrightarrow$ De Seropluularia. D. Jenae, typ. Werlher. 1720.4. $27 \mathrm{p}$ (Respondens: Heinrich Christiun Ehrlich.)

$9701^{*}$ Sloane, Hans. Catalogus jlantarum, tuae in insula Jamaica spronte proveniunt vel rulgo coluntur cum carunden synonymis el locis natalibus; auljectis aliis quibusdam, quae in insulis IIalerae, Barbados, Nieves et St. Lliristophori nascuntur, seu Prodromi historia. naturalis Jamaicae Pars J. Londini, Brown. 1696. 8. 232 p., praef. ind.

$9702^{*}$ A voyage to the Islands Nadera, Barbados, Nieves, 3 Christophers aul Jamaica, with the natural history of the herbs and trees, four-footed beasts, fishes, birds, insects, reptiles ete. of the last of those lslands; etc. In two volumes. Londull. printed by B. I]. for the author. 1707-1725. folio. - 1: 1707. CLIr, $264 \mathrm{j}$. praef. tab. $1-156 .-$ II : 1725. xrit1, 499 \%., tab. 157-274, et x1. (A) 6l. $6 s .-13$ th.) Bibl. Schlechtend.

9703 Smee, A. De la ponme de terre, de ses usages et de ses propriétés: de la cause le la maladie actuelle de cette plante et des moyeus de la prérenir. London 1846. 8 . iom. Arelives dies se. Jliys et nat par De la Rive, Mferignac et Picte? 
9704 Smelowsky, T. Фихософія ботаник . Гинея. Перев C. IIe're 0 6. 1800. Trautv.

9703 Smidth, Jens Hansen. Arboretum scandinavicum. Fasc. 1. Kjöbenliarn (Scluubothe). 1831.12. 160 P. (1 Rbd.)

9706* Smissen, J. P. J. van der. Pflanzen-Oratorium, Kỉel, LuiversitátsBuchlı. 1834.8.65 p. (1/2 th.)

9707* Smith, Gerard Edwards. A catalogue of rare or remarkable phaenogamous plants collected in South Kent: with descriptive notices and observations. I.ondon, Longuan. 1829. 8.'xw, $76 \mathrm{p.}$ 5 tab. col.

9708 Smith, Henrick. Een skön loestig ny urtegaardt. Malmó 4546. 8. CCXill foll. B.

$9709^{*}$ Smith, James Edward. Plantarum icones hactenus ineditac, plerumłue ad plantas in herhario Linneano conservatas delineatae. Fasc. 1-JII. London, White. 1789-1791. folio. 75 foll., tab. 1-75. (3l. $3 s$.

(Textus redit in Magazin fur Botanik, Stuck IX. 1). 33-62; Lsteri Annaicn, Stück 111. p. 73-112, Stick Xil, p. 26-37.

$9710^{*}$ _ Icones pictae plantarum rariorum. Londini, typ. Davis. Fasc. $1-111$. 1790-1793. folio max. 36 foll., 48 tab. col. Jatine et anglice.

Trium fascicnlorun textus btinus redit in Roemer Archiv 1. 1 p. $71-9\}$.)

9711" - English Botany, or coloured figures of british plants, with their essential characters, synonymes and places of growth. To which will be added occasional remarks by Jumes Etecard Smith and James Sowerby. The figures by James Sowerby. London, White. 1790-1814. XXXVI roll. 8. 72, (2592) p., tal). col. 1-2592. "Supplement to the English Botany, by William Jackson Hooker and other eminent botanists; the figures lyy James de Carle Sowerby. Nr. 1-L.TY. London, Longman. 1834 sqq. 8. p. 2593-2905., tal,. col. $2593-2905$. Bibl. Reg. Berol. et Cand.

(Editionem notarn integri operis prodisse lego, hude ab anno 1832, e volnminibus noven colstantem, tabulis circiter 1300. Anno 18 $\div 2$ fasciculi 332 editi erant.)

$972+$ General indexes to the thirty-six volumes of English Botany to which is added a alphabetical index to english fungi making together a catalogue of indigenons british plants. London, Sowerlyy. 1814. 8. vi p., (37) foll.

9713* - Spicilegium botanicum. Fase. I et II. London 1791 1792. folio. 22 p. tab. col. 1-24. Bibl. Reg. Berol.

(Plura non prodierunt. Titulus improssus desideratur.)

$3714^{*}$ - Tentamen botanicum de Filicum generibus dorsiferarum. ('Turin, chez J. M. Briolo. 1793.) 4. 22 p., 1 tab. -422 .

(Seorsim impr. ex Actis Taurinensibus anni 1,90. vol. V. p. 404 $971 \ddot{3}^{\circ}$

specimen of the Botany of New-Holland The figures

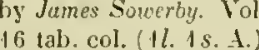

9716 Syllabus of a course of lectures on botany. London 1795. 8. 72 P. B.

$9717+$ Tracts relating to natural history. London, White. 1798. 8. $x \mathrm{Iv}, 312 \mathrm{j})(7 \mathrm{~s}$ )

$9718^{*}$ Compendium Florae britannicae. Londini, White, 1800 8. vill, 122 p., ind. - ${ }^{*}$ Editio ill usum Florke germanicae a Georg Franz Ho/fmann. Erlangae, Palm. 1801. 12. 274 p., ind., effoies

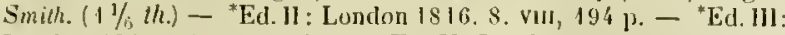
London 1818. 12. vm, 194 p. - Ed. V: London 1828. 19. (7s. 6d.)

$9719^{*}$ - Flora britanuica. Londini, White, $1800-1804$. II] yoll. \$. $1407 \mathrm{p}$., praef., ind. (1l.6s.6(l.) - "Recudi curavit arlditis jussim adnotatiunculis Johann Jakol Roemer. Turici, 1yp. Gessuer. $1804-$ 1805.11 voll. $8.1406 \mathrm{p}$, prief., ind. $\left(5 / / 8 / h_{.}\right)$

9720 * _ Exotic Botany, consisting of coloured figures and scientific descriptions, of such new, beautiful or rare plants as are worthy of cultivation in the garclens of Britain. The figures ls James Soxcerby. london, J. Sowerby. 1804-1805. II voll. gr. 8. vi, IIs, 122 p., 120 tab. col. ( 3 l.

(Élitio alia in 4. non differt.)

9721* —- An introduction to physiological and systematical botany. London, White. 1807. 8. - Ed. J1: Loudon, White 1809. S. $(14 s .-$ col. 1 l. $8 s)-$. Ed. III: ib. 1814.8. xxi1t, 333 p., 15 tab.
- Ed. IV: London, Longman. 18 19. 8. xx, 407 p., 15 tab. *El. V: ib. 1825. 8. xxı, 435 p., 15 1ab. (14s. - col. 11. $8 s)$. "An introrluction to the study of hotany. Ed. Vil. corrected by IIillium Jachson Hooker. London, Longman. 1833. S. xs, 504 p. 36 tab. $(16 s .-$ col. $2 l .19 s .6 d$.$) - New edition, with considerable$ arlditions by 1 Tilliam _llacgillivray. London 1838. 12. (9.s.)

* germanice: Aulcitong zum Studium der physiologischen und svStematischen Botanik. Nach der dritten Originalausgabe aus dem Englischen ubersetzt ron Joseph August Schultes. Wien, Doll. 181\%.8 XL, 400 p., lis tal. $(21 / 3$ th. $)$

$9722 t$ Smith, James Edward. A review of the modern state of Botan\}, with a particular reference to the natural systems of Linnaeus and Jussieu. (From the second volume of the Supplensent to the Encyclopaedia britanuica. London 1817.) 4. 48 p.

$9723^{*} \longrightarrow$ - 1 grammar of botany illustrative of artificial as well as natural classification, with an explanation of Jussieu's system. London, Longman. 4S21. 8. xx, 242 p., 21 tab. col. - ${ }^{*}$ Ed. Il: Lomlon, Longman. 1826. 8. xxil, 240 p., 21 tab. (12s. - col. 1l. 11s. 6u.)

* germanice: Botanische Grammatik zur Erliuterung sownhl der humstlichen, als der naturlichen Classification, nebst einer Darstellung des Jussieu'schen Systens. Aus dem Englischen phersetzt. Wej-

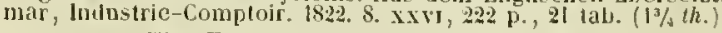

$972 k^{*} \longrightarrow$ The English Flora. London, Longman et Co. $1824-$ 1836. V voll. $8 .(3 l .12 s$.

Vol. I: Phanerogamia. 1824, xly, $371 \mathrm{p}$.

Vol. 11: Plianerogamia. 1824. rin, $470 \mathrm{p}$.

Vol. 111 : Phanerogamia. $1825 . \mathrm{vi}, 512 \mathrm{p}$.

Vol. IV: Plianerogamia et Filices. 1828 . vr, $373 \mathrm{p}$. (I-IV: $21.8 \mathrm{~s}$.

Vol. V, Parl l: 1833. Musci frondosi, Hepaticac, Lichenes, Cluraceae, Algae, hy Hilliam Jackson Ifooker, x, 4, 432 p. (12s.)

Vol. V, Part ll: 1836. Fungi, by the Rev. H. J. Berteley. 32 $386, \mathrm{xV}$ p. $(12 s$.

(Vol. V. Part 1. Il. sistit eliam volumen alterum Hookeri British Flora; cf. Nr. 4639 .

$9725+-\Lambda$ Compendinm of the English Flora. London, Longman 1829. $g r$. 12. v11, $219 \mathrm{p}$. - ${ }^{*}$ Second edition with arlditions and corrections Jy IVilliam Jackson Hooker. London, Longman. 1\$36.8. VII, 230 l). $(7 s, 6 d$.

$9726^{*} \longrightarrow$ Nenuir and correspondence of the late Sir James Edvard Smith. Elited Jy Lafly Smith. Jn two volumes. London, Longman, Rees, Orme elc. 1832. 8. - 1: vill, 610 p., with portrait of the bust of Sir James. - I1: Iv, 610 p. with tahles of autographs.

(James Eduard Smih est autor vocum votanica'um in Abraham Rees New Cyclopedia.)

9727 Smith, John. On the growth of Cucumbers and Nielons, with Aspararagus, Muslirooms, Rhubarb. Ed. IV. London, Simphin, Narshall and Co. $1841.8 .(4 s .6 d$.)

$9728+$ Smith, Thomas. Traité d'anriculture et d'horticulture. Tradnit de l'anglais sur la dixième édition de Smith par A. Bulos. Paris, Urbain Canel. 1825.12 .266 1). (6 fr.)

9729 Sniadecki, Andrens. Théorie des etres organiques. Traduite du polonois par J.J. Bullard of Dessuix. Paris, Gabon el Co. 1825. 8 . ( 4 fr. 50 c.)

9730 Snippendal, Johannes. Catalogus plantarum horti Amstelndanensis. 1646. 4. Desid. Banks.

$9731+$ Sobolewski, Gregor. Flora Petropolitana, sistens plantas in gubernio Petropolitono sponte crescentes, tam eas quae olim in Flora ingrica $K$ ruscheminnikovii a Gortero cnumeratae sunt quam novas post annum 1764 hucusifuc a variis hotanicis Petropoli degentibus detectas, nune vero generice ac specifice descriptas cum additione variarum observationum atque russica plantarum denominatione. Petropoli, typ. Collegii medici. 1799. 8. ril, $355 \mathrm{p}$.

9732 — Сanтnетер6ургская Џора. С. Петер6. 1801-1802. 2 rac'T. Trautv.

9733 Socinus, Abel. Theses anatomico-botanicae. Basileae 1751. 4. 8 p. B.

973!* Soderini, Gioancettorio. Trattato della coltivazione delle viti; e la coltirazione toseana dello vili ed' alcuni arbori del S. Bernardo Davenzati Bostichi. etc. (Davanzati: 45 p., ind. - Lionardo Giachini, Lettera apologetica scritld a Ml. Filippo Jalori l'anno 1527 in difesa et lode del popone. 19 p.) Firenze, per Fil. Giunti. 1600.4. 128 p. praci., ind. - "ib. 1622.4 
973: Soeckeland, B. Einigi: Andentungen nber den Unterricht in der Naturbeschreibung an Gymnasien, init besondrer Bezielıug auf den Unterricht in der Planzenkunde. Programm. Koesfeld 1832.4.

9736 * Soennerberg, Jakob. Dijudicatio emendationum systematis sexualis Linnaci. D. Landae, typ. Berling. 1798. 4. $20 \mathrm{p}$.

$9737^{*}$ Sokolnicki, Franz. DeSucalicoruuto. D). Cracoviae 1839.8.49 p.

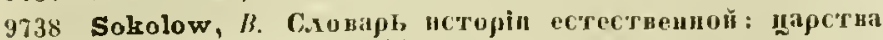

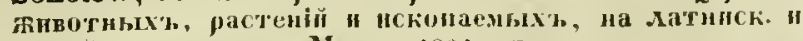
россіиск. дзыках\%. Москн. 1801. Trautv.

9739* Sole, William. Nentluae britannicae; heing a new botanical arrangement of all the british mints hilherto discovered. etc. Batb, 1yp. Cruttwell. 1798, folio osin. vitt, 55 p., 24 tals. (1l. 5s.)

9740 Soliva, Salvador. Dissertacion sobre el Sen de España. Madrid 1774. 8.44 p., 1 tab. B.

$971^{*}$ Solly, Edward. Rural Chemistry: an elementar introduetion to the study of the seience io its relation to agriculture. Lendon, office of (rardeners Chronicle. 1843.8. xix, 169 p. (4s.6d.)

9742* Sommer, Karl Benjamin. De virtute et vi medica Gratiolae officinalis L. D. Rigae 1796. 4. 26 p.

9743* Sommerfelt, Sören Christian. Supplementuru Florae lappenicae, quam edidit Dr. Georgius Wahlenberg. Christianiac, typ. Borgianis. 1826. 8. xu, 334 p., 3 tab. col. ( 3 th.

Bemaerkninger ved Supplementum Forae lapponicae, in Magazin tor Niaturvidenskaherne, 1827. 1. p. 163-166.

974:" —_ Plysisk oekonomisk beskrivelse over Saltdaleus Praestegjeld i Nordlandenc. Udgivet af det kongelige wershe Videnskabers Selskab. Tronditjem 1827. 4. 148 p. Bibl. Goett.

(Um Planteriget: $1,38-81.1$

$9745^{*}$ Sonder, W. Revision der Ileliophilecn. (Hamburg 1846.) 4. 103 p., tab. $17-29$.

(Abhandlungen des nat. Vereins in llamburg. Bd. I. j. 173-279.)

$9746^{*}$ Sonnenburg, Albert. Aritumonomia naturalis seu de numeris in rerum natura tentamen, e mineralogia, botanice et zoologia illustratum. Dresdae et Lipsiae, Arnold. 1838. folio min. vi, 124 p., 1 tab.

$9747+$ Snnnerat, Pierre. Voyage a la nouvelle Guinée, dans lequel on trouve la description des lieux, des observations physiques et morales et des détails relatifs a l'histoire naturelle dans le regne animal et le regne végétal. Paris, Ruault. 1776. 4. xII, 206 p., 120 tab. Tabulae ad botanican et ornithologiam spectant.

9748 Voyage aux Indes oriemales et à la Chine, fait par ordre Ju roi depuis 1774 jusqu'en 1781. Paris 1782 . II voll. 4. $-1: 317 \mathrm{p}$, lab. 1-80. - 11: 298 p., tab. 81-140. B. - Ed. II: ib. 1806. IV voll. 8. et Atlas. DC.

* germanice: lkeise nach Ostindien unt China, anf Befehl des Konig unternomosen you Jahr 175i-1781. Zurich, Orell et Co. 1783. If roil 4. - 1: xu, 268 p., tab. $1-80 .-11: x, 21,1$. tab. $81-160$.

$4749^{*}$ Sonnini (de Manoncour), Charles Sigisbert. Mémoire sur la culture et les avantages dn Cliun-navet de Liponie. Paris 4788. 8. $52 \mathrm{p}$.

$9750 *$ _ - Toyage daus la haute (ot basse Egypte. Paris, an Vil. 1799. Ill voll. 8. $-1: 425$ p. - Il: 417 p. - Ill: 424 p., 38 tab. in 4. * germanice: Leipzig, llejisius, 1800.2 Bánde. 8 unglice: Londou 179y. 111 voli. 8 .

5751" - Voyage en freece el en Turquie. Paris 1801 . Il vell. 8. anglice: London 1801. 4. tyermanice: Vossisches Nagazin, Bant XXW

9732 —— Culure de la Julienne. Paris 1804. 8. DC.

9733 - Trate de l'arachide on pistache de terre. Paris, Colas. 1808. s. a.

973\%* — Traite des Asclepiatlées, particulièrement de Tsclepiade de Syrie, précédé de quelyues observations sur la culture du coton en France. Paris, Buisson. 1810.8 .146 12, 2 tab. col.

$9755 \div-$ Veillard et Chevalier. Voeabulaire portatil d'agricalture, .... le betanique ... etc. Paris, Bnisson. 1810. 8. xIV, 463 p,

9756* Sonntag, Christoph, pr. Paraliponena quilus ligna Siltin explicata et applicata sistumtur. D. Altdorlii, typ. Kohles. $1710.4 .28 \mathrm{p}$.

$9757+$ Sorolla, Ildefonso. Epitome Medices. We dilferentiis herbaran ex historia plantarum Theophrash. Valentiae, typ. Claulii Mace, suantibus Sonzoni. 1642.8. 94 foll., pract. Bibl. Reg. Par.

(In fine lezitur: Valentiae, apul Nichlelem Sorolla, juxta universitaten. 162\%. Yon nisi quatuor pristes folia sunt novae impresslunis.
$9738 \div$ Soulange-Bodin, Etienne. Notree sur une nouvelle espece de Naguslia. Paris, Decourchant et Gallay. 1826. $8.42 p$.

97397 Jiscours sar l'importance de l'borticulture et sor les avantages dr son uniou avec les sciences pliysiques. l'aris. secrétariat de la suciété linnécnne. 1827.8, $20 \mathrm{p}$.

$9760 \div$ 1 Jr la culture des plantes dites de terre de bruyere it de lenr introuluction en grand dans les jardins paysagers. 1'aris, typ. Iluzard. 1828. 8. 32 I1.

9761 Catalogue des Dahlias nains l'origine anglaise, pour l'antue 1832. Paris, typ. Huzard. 1831.8.16 p.

$9762+$ Mémoire sur l'introdontion des arbres foresticrs exotifoes dans les grandes plantations économirques. Paris, I!p. Huzard. 1833.8. 20 p.

$9763 \div$ Courtes considérations sur les ancicus parterres. P'aris, $\{y]$. Jluzard. 1937. gr. 8.12 p.

(Extreites de IEncyciopédio pratique tiu jardinage, lom. IIt.

976!" Soulavie, Jean Louis Giraud.. Histoire natorelle de la France méridionale. seconde partic: Les végétaux. Coutcuant les principes de la géographit physiqque du règoe végétal, avec des eartes pour en exprimer les limites. Paris, J. F. Quillan. 1783 . \$. 394 p., 2 tals. Bibl. Francof. a/M.

9765 Sowerby, C. E. The illustrated catalogue of britisls plants, arranged accordiug to the natural orders with references to Linde? smith, llooker etc. Mr. I. Pbanerogamia. London, Longusan ot C.o. 1841. 12. 8 tab. w.

9766 Sowerhy, James. An easy introduction to drawing flowers according to nature. London s. a. 4 obl. 6 foll., 6 tab. B.

germanice: Botanisches Zeiclinenbuch. mit hopfern. Weimar, l,andes-hntustrie-Compteir. 17yk. yr. k. $(1 / 2+1 /$. $)$

9767 - Flora luxurians, of the Florist's delight. Loudon 1789 -1791.) Nr. 1-Ill. folio. 18 tab. col., 18 foll. 8.

$9768^{*}$ Coloured figures of english Fungi or Muslırooms. Loudon, typ. Davis. Ill voll. and Supplement. 1i97-1809. folio. 440 tals. col., teat, ind. (10l. - A. $7 l$. 15s.)

(Prodiit amus 1797-1815 32 fasciculis.)

$9769+$ Soyer-Willemet, llubert $F$. Némoire sur le neclaire, ‘ui a obtenu en $\$ 325$ la mention lonorable an concours ouvert par la société Linucenue de Paris. Paris. Decourchant et Gallay. 1826. 8. $56 \mathrm{p}$.

$9770^{*} \longrightarrow$ Observations sur quelques plantes de France, suivies du catalogue des plantes vasculaires des environs de Naney. Nancy, Bontoux. 1828. 8.495 p. $(2$ fr. 50 c.)

$977^{*}$ - Euphrasia offeinalis et especes volsines. Eirica vagans et multillora. Ohservations de botanique. Nancy, typ. Itissefte. 1835. 8.49 p.

Chtrait des Mémoires de la soc. royale de sc. leltr. et arta d. Nancy $\{8,33-183$ i.

$9772^{*}$ - Gniphaliun neglectum, neuvelle sopece (u groupe des Filagineses ete. Naner, typ. llisselte. 1836. 8, 11 p., I tah.

$9773^{*}$ Sur le cerastium manticum el quelques especes do ce genre. Erodium chium et lacioiatum, plantes nowelles de la

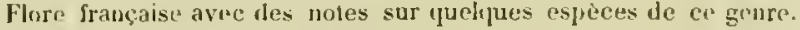
Nancy, Grimblot. $1839.8 .24 \mathrm{p}$.

977i" - Revue des Trènles de la section Chronosemium, prir Mu. Soyer-llillemet et fordron. Nancy, Grimblot et reuse bayboin. $1847.8 .35 \%$

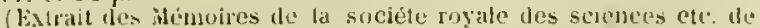
Nancy, ilunée 18'6.)

9775* Spach, Eloucerl. Histoire naturelle des végétaux. I'hantrogames. Paris, Roret. 1834-1848. XTV voll. 8. - I: 1834 . 11I, 490 p. II: $1834.540 \mathrm{p} .-\mathrm{III}: 1834.519 \mathrm{p} .-\mathrm{IV}: 1835.446 \mathrm{p} . \mathrm{N}$ 1×36. 524 p. - VT: $1838.58 \%$ p. - V'll: 1839.538 p. - V'lll 1839.562 p. - IX: 1840.586 p. $-\mathbf{X}: 1841.572$ p. $-\mathbf{X} 1: 1842$ 444 \%. Xll: 1846.458 \%. - Xill: 1846.444 p. - Ill: 1848 Tables. $432 \mathrm{p}$. $(91 \mathrm{fr})$ - * tilas. ib. $1846 . \mathrm{gr} .8$. $71 \mathrm{p.} .15 \geq \mathrm{tal}$ col. (nigr. 45 fr. - col. 90 fr.)

Sistit scetionem operis inveripti : Stuites a Bulfon.p Pars cryplo-

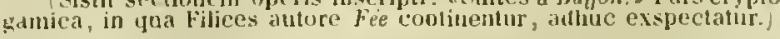

9776t Spadoni, Paolo. Delle siepi vive di spino bianco dissertazione Bologna, typ. Toumasu d'Aquino. 1790. 8. 52 p.

4757 Lettere odeporiche sulla montagna ligustica, Bologna 1793. s. DC. 
978t Spadoni, Paoto. Nuova specie di Lino origitario di Siberia per la prima yolta nomenclato e descritto. Nacerata, typ. Capitani. 1808. 8. 22 p., 1 tal. cal. (Linum Beauharnaisianun.)

9779 * Spaendonck, Gerard vall. Fleurs dessinées d'apres nature par Gerard van Spaendonck. Reeueil utile aux amateurs, au jeunes artistes, aux eleves des eeoles centrales et aux dessinateurs des manufactures. Paris, ebez l'auteur et Bance. s. a. folio. Cahier 1-6. 24 tal). col. (36 fr.) Bibl. Imp. Austr.

(Depuis la mort de cet artisto mo a public: Souvenirs de Yan spaendonck, oul lecueil te fleurs lithographiees dapres les dessins de ce celebre Professeur, accompagne d'un texte rédigé par plusieurs de ses éloves. Jaris, Castel de Courval. is:5. obl. an tab. (20 fi.) a.

9780 Spallanzani, Lazaro. Opuscoli di fisica animale e vecetabile. Nodena 1776. II voll. 8. - I: 304 p., tab. 1-2.- II: 277 p., tab. $3-6$ (lusunt: Osservazioni e sperienze intorno all origine delle piantine delle Mutfe, ral. II. 1.. $230-277$.

qallice: Opuseutes de physique inimale et rónćtale. Traduits de l'italien par Jeun Senebier, Geneve 1777. II voll. 8. - Paris, Duplain.

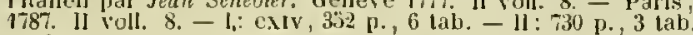

9781 - Fisica animale e regetabile. Venezia 1782. Ill voll. 12. $312,396,488$ p., 2 tab. B.

(nest: Dolla generazione di diverse piante, vol. III. p. 303-461.) anglice: Dissertations relative to the naturad history of animals and regelithes. London 178 '. Il voll. $8.328,3$ in p., 3 lab.

$9782^{*}$ Expérienees pour servir à l'lisioire de la génération des animaux et des plantes. Avec une ébauche de l'histoire des etres organisés avant leur fécondation par Jean Senebier. Genevo, Chirol. 1786. 8. xCvt, 413 p. (5 fr.)

* germanice: Versuche uber die Erzengung der Thiere und Pllanzen. Aus rtem Franzosischen von Michaelis. Erste Abtheilung. Leipzig, Goschell. 1786.8. 462,80 p. 3 tab.

9783* Spalowsky, Joachim Johann Nepomuk, De Cieuta, Flammula Jovis, Acunito, P'ulsatilla, Gratiola, Dictamno, Stramonio, Hyoseyamo et Colchico. D. Vindobouae, 15p. Trattner. 1777. 8.44 p., praef., 9 tals.

978: Sparrman, Anders. Resa til Goda-Hopps Ldden. Vol. I. (unicum!) Stockliolm 1783. 8. 766 p., 10 tab. anglice : London $17 \times 6 \mathrm{j}$. II voll. 4. $368,330 \mathrm{l}$., $11 \mathrm{tab}$

germanice: Reise nach dem Yorgebirge tier guten lloftnung, den südlichen Polarlandern ond um die Welt, hauptsaeblicts aber in den Ladılern der Hottentotten und Kalfern, in den dahren 1772-1776. Aus dem Schwedischen von Groskurd und Forster. Berlin, llaude u. Sue-

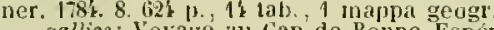
gallice: Voyage au Cap de Bonne-Esperance. Paris, Buisson. 1787 III roll. 8 . vel 11 voll. 4 . Q.

4785* Speck-Sternburg, Max von. Darstellung des IJopfentraus auf seinem Gute zu St. Veit in Oberbaiern. Leipzig, Tauclınitz. 1840. \& $\mathrm{x}, 26$ p., 5 tab. $\left(11 / 24\left(h_{\text {. }}\right)\right.$

9786 Speechly, Irilliam. A treatise on the culture of the Pine Apple. Iork 1779.8. 100 p., t tab. B.

hallandice: Verhandeling over het kweehen der Ananassen. Goneeskund. Jaar')ochen, vol. V. 188-2i0, 273-293.)

9787 A treatise on the eulture of the Vine, with llints on the formation of vines in England. York 1790, 4. 224 1., 5 Lab. B. Ed. Il. London 1789. gr. 8. ( $7 s .6 \mathrm{~d}$.)

9788* Spenner, Fridolin Karl Leopold. Flora Frihurgensis et regionum proxime adjacentium. Friburgi Brisgoviae, typ. Wagner, 18251829. IlI voll. 8. - J: 1825. p. Lxxxvis, 1-233., 2 tal). - II: 1826 . p. xtvill, $255-608 ., 1 \mathrm{tab} .-\mathrm{Ill}$ : 1820. 13. $609-1088$, ind. $\left(3 \frac{3}{4}\right.$, h. $)$

Spenneri introductio chorosraphico-phytographica in Floram Friburgensen redit ancta et reformata in libello professoris Weick: "Freibury und seiste Umgebungen. Freibury 1838. 8." ldem noster disseruit "Ueber die vegetation des Renchthales und der dasselbe Jegranzenden llöben in libro Dnetoris J. Zentner: Jlas Rench!hal und seine Bader. Freiburg, Wagner. 1827. 8. - Ed. 11 : Karlsruhe 1839. 12. $\mathrm{x} r 11,271 \mathrm{p} .(11 / \mathrm{s} / \mathrm{h}$.

$9789^{*}$ Monographia generis Nigellae. Friburgi Brisgoviae, typ Wagner. 1829.4.12 p.

$9790^{*}$ Jandbuch (ler angewandten Botanik, oder prakitische Anleitung zur Kenntniss der medizinisch, techniselı und okonomisch gebrauchlichen Gowachse Deutschlands und der Sclsweiz. Drei Alsheilungen. Freiburg, Groos. 1834-1836. 8. $945, \mathbf{x x}, 325 \mathrm{p}$. ( 5 lh.

$9791+$ Deutsehlands plianerogamiselse Plauzengattungen in analytisehen Bestimmungstabelleu nach dem naturlichen und Linnéschen Systeme. Wit rinem lateinischen und teutschen terminologischen Worlerbuelse. Freilıurg, Groos. 1836 8. xLII, 322 p. $(1 \% /$ th. $)$

Pritzel Thes. lit bot.
9792+ Sperling, Joharines. Carpologia plsysica posthuna. Opusculum utile ac jucundam: nunc secundum prodiens e Iuseo Georgii Caspur Kirchmaier. Wittebergae, typ. Michael Wendt. 1661. 8. $230 \mathrm{p}$., praef. - $\div$ Wittebergae, Berger. 1669.8 .230 p., praef. Bibl. Juss.

\section{Pracside Johanne Sperling dissertationes:}

9793 De uva, musto ac vino. D. Wittebergae 1642. 4. Rivin. $979 \mathrm{t}^{*}$ Exereitatio de traductione formarum in plantis. D. Wittebergae 1648. 4. (8) foll. (Resondens: Christiun Buether.)

9793 Neditationes in Johamis Caesaris Scaligeri Exoticas exercitationes. Wittebergae 1656.8. Desid. Banks.

9796 Sperling, Otho. Ilortus Christianaeus, seu Catalogus plantarum, quibus Christiuni I $\mathrm{F}$. Daniae Regis viridarium llafniense anno 1642 et superiore adornatum erat. Hufniae $1642.12 .2 \frac{1}{2}$ plag. B.

Redit in Simonis Paulli Viridariis variis, p. 1-80.)

9797 Spiczyński, Hieromymus. 0 ziolach tutecznyeh i zamorshich i mocy ich a khetnu Ksįgi lekarskie, wedle rejestru niżéy nowo wypisanego wszem wielni użyteezne. (De berbis indigenis et exotiejs atque de earum vi, nee non libri medieinales valdo utiles.) Cracoviae, apud haeredes Marei Scharfenhergor. 1556. fulio min.

(De rarissino libro ef. Arnold, de monum, hist. nat. Polon. p. 43. - Adamsli, llist, rei herb. in Polonia, j. 13. 23 .

9798* Spiekerkoetter, C. G. II. Die Giftptlanzen Deutselılands, dereı Wirkungen auf das Leben und die Gesundlheit der Nensehen und Thiere; nebst Augabe einiger Antidote bei Vergiftungsfallen dureh Pflanzengifte, einer liurzgefassten Einleitung zur Botanik und dem Linneischen Sexualsysteme. Minden, Essmanu. 1844.8.93 p. (1/4 th.

$9799^{*}$ Anleitung zur Kiesntniss der vorzuglichsten einheimisehen Giftpllanzen. Ein Lols - und Lesebuchlein fur die liebe Jugend in den Elementarschulen. Minden, Essmann. 1844.8.30 p. $(1 / 16, h$.

$9800^{*}$ Spiegel, Adrian, latine Spigelius. lsagoges in rem herbariam libri duo. Patavii, apud Paulum Mejettum. 1606. 4. 138 p., praef., ind. - "Lugduni Batavorum, ex officina Elzeviriana, 1633. 12. 272 p., ind. - ${ }^{*}$ Editio prioribus correctior. Ilelmstadii, lleitmüller. 1667.4. 127 p., praef, ind.

Editioni Lugdunensi aceedit a p. 223-262: Catalogus plantarum horti acatemici Lugduno-Batavi, quisus is instructus erat anno 16633 praefecto ejusdem horti Adolfo torstio. Isagoges tubri duo exstant praeterea in Operum omniun editionibus: Tenetiis, apud Evangefistam Deuchinum. 1627. folio. - Francofurti, apud Mallı. Merjanum. 1632. 4. et in editione Lindeniana: Amstelodami, apud Joanne'in Blaeu. 165. folio. - De iutoris vita ac meritis circa allatomian plantarum ef. Charles Morren: Adrien Spiegel. Extrait d'une instoire inedite de la bolanique belge. Bruxesles 1838. 8.32 p.

9801* Spieler, Alexander Julius Theodor. De plantis venenatis Silesiae. D. toxicologico-mediea. Vralislaviae, 1yp. Richter. 1841. 8. 12 p.

9802* (Spielmann, Jakob Kcinbold.) Prodromus Florae Argentoratensis. Argentorati, Bauer. 1766.8. 154 p., ind.

Autoris nomell compertum habeo ex Crell, Chemisebe Annaten. 178, 1. [. 579.$)$

$9803^{*} \longrightarrow$ Institutiones materiae medicae praelectionibus aeademicis accommadatae. Argentorati, Bauer. 177h. 8.656 1., prael, ind.

* germanice: Anteitung zur henutniss der Arzneimittel. Neuc Auflage. Strassburg, Trenllel et Wurtz. 1785, 8 .

$9804^{*} \ldots \ldots \ldots$ - Pharmacopoea generalis. Argentorati, Treuttel. 1783. 4. 218,372 p., praef., ind., effigies autoris.

\section{Pracside Jacobo Reinboldo Spielmann dissertationes:}

$9805^{*}-$ Cardamomi historia et vindiciae. D. Argentorati, typ. Heitz. 1762.4. 40 p. (Respondens: Johann Herrmann.)

$9806^{*} \ldots \ldots$ De vegetabilibus venenatis Alsatiae. 1). Argentorati, typ. Ileitz. 1766. 4. 76 p. (Respondens: Franz Auton Guerin.)

$9807^{*}$ Acaciae offieinalis historia. D. Aryentorati, typ. Heitz. 1768.4. 16 1). (Respondens: Ignaz Javer Emer. Paul. Lachausse.)

$9808^{*} \longrightarrow$ Olerum Argentoratensium fascienlus. D. Argentorati, typ. Heitz. 1769. 4. 62 p. - Faseiculus alter. ib. 1770.4. $40 \mathrm{p}$. (Respondens: Johann Jakob Spielmann, filius.)

$9809^{*}(\longrightarrow)$ Vegetąio. D. Argentorati, typ. Kursuer. 1773. 4. 38 p. (Respondens Abondius Hosang.)

$9810^{*}(-$ ) Helmintluelıorti historia, nalura atque vires. D. Argentorati, typ. Jleitz. 4780.4 . 40 p. (Respondens: Peser Joseph Sclucendimam.) 
9811" (Spielmann, Jakob Reinbold.) De viticultura Rtehovillana. D. Argentorati, typ. Ileitz. 1780. 4. 30 \%. (Respondens: Friedrich Wilhelm Faudel.)

0812" Spiering, Karl Theorlor Hermann. De Secali cornuto. D. Berolini, typ. Nietack. 1839. 8. 36 p).

9813 Spies, Johann Kart. Programma de Siliquis Convolvuli americani, vulgo Vanigliis. Helmstadii 1724. 4. $1 \frac{1 / 2}{\text { plagg. }}$ B.

\section{Praeside Johanne Carolo Spies dissertationes:}

981 \&t _ Rosmarini coronarii historia medica. Ilelmstadii, typ. Sehnorr. 1718. 4.39 p. Bibl. Juss.

$9815^{*}$ De Avellana mexieana. D. Ilelnıstadii $4721.4 .48 \mathrm{p}$. 2 tab.

(Aular forlasse est Respondens Franz Ernst Brueckmann; ef. supra Nr. 1 1602.)

- De Valeriana. D. Ilelmstadii, typ. Schnorr. 1724. 4. 34 p. (Respondens: Johann Friedrich Bismarck.)

(Vitam enarravit programmate Uermannus von der Jlardl: Mensoria experimentissini medici Domini Jahannis Carali Spies, anno 4729 die Xil Julii pie deftneti [n. 24 Nov, 1663 Wernigerodae ]. Hlelntstadii, typ. Schnorr. (1729.) 4. $16 \mathrm{p}$.)

9817 Spiessenhoff, Karl Eugen Luchini von, pr. Solanum caule inermi, llexuoso, foliis superioribus hastatis, vulgo Julcamara dietum, chenice et medice discussum. 1). Heidelbergae 1742. 4. $28 \mathrm{p}$. (Respondens: Bartholomaeus Schabinger.) B.

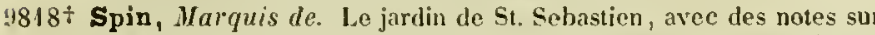
(puelques plantes nouvelles ou peu conuues. Turin, typ. Bianco. 1809. 8. 25 p., 2 tab. - * Turin, typ. Soffietti. 1812. 8. 28 p., 2 tab. - ${ }^{*}$ Turin, Pomba. 1818. 8. 33 p., 2 tab. - †Supplément: Turin, Pomba. 1823.8 .15 p., it tab.

$9819^{*}$ Splitgerber, Friedrich Luduig. Enumeratio Filicum at Lyeopodiacearum, quas in Surinamo legit. Leiden, Luchtmans. 1840. 8. $56 \mathrm{p}$.

Tydschrift voor Nat. Gesch. vol. Vil.)

$9820^{*}-$ Observationes de Yoyria. (Leiden, Luchtmans. 1840.)

8. 11 p., 2 tal).

(Tydschrift yoor Nat. Gesch. vol. Vil.)

98216 Notice sur une nouvelle espece do Vauille. Paris $1841.8 .8 \mathrm{p}$.

(Tiré des Annales des se. nat. vol. Xvi.)

9822* De plantis novis surinamensibus. (Amstelodami 1842 .) 8. 20 ]).

$9823+$ Description du genre Urania non Schreb. nec Kich. (Arusterdam 1843.) 4. 8 p., 2 tab.

9824* Spolverini, Giamballista. La coltivazione del riso. Verona, Carattoni. 1758.4. - TEd. Il. Bergamo, typ. Locatelli. 1764.8 . 1/10 p. praef. - "Verona, typ. Bisesti. 1819.8

Etiam exstat in Raccolta de poem. did. Milano I813.)

982:3 Sponius, Jacolus. 'Tractatus novi de potu Caphé, de Chinensium Thé, et Chocolata. Parisiis, apud Petrum Mluguet. 1685. 12. Rivin.

9826 - Jicabi Spanii Bevanda asiatica, hoc est, physiologia potus Café, a D.D. IJanget notis, et storsim a Constantinopoli plantae iconismis reeens illustrata. Lipsian $1705,4.56$ p., 5 tab. eaedem ac in Marsilii libello. B.

Cf. alia autoris opera, quae suh nomine lietitio Philippe Sylnestre Dufour prodierumt, supra Ar. 2768-2770. - Magasin ency'clop. 1810. tome IV. p. $20 \%$.

9827 Spratt, G. The medieo-botanical bochet-Book. London 1\$36. 8 (10s. 6d.)

9828* Sprecchis, Pompejus. Antabsinthium Clavenae, i. e. quod Absinthium umbelliferum in monte Servae Belluni et aliis ltaliae moutibus ortum sit idem cum Absinllyo alpino umbellifero Curoli Clusii. Venetiis, apud Antonium Turinum. 1611.4.120 p., 1 tab.

(List responsio in lihrum rarissimum Nicolai Clavenae (Chiavena) Rellonensis supra Xir. 1870 citatum, qu'm nune tandem in hiblintheca ilt. Comilis Leanis Henckel a Donnersmarek inspicere con(iyit.)

9829* Sprengel, Anton. Commentatio de Psarolithis, ligni fossilis genere. Halae, Anton. 1828. 8. 42 p. $(1 / 4 h$.

$9830^{*}$ Sprengel, Christian konrad. Das entlechto Geheimniss der Natur in Bau und in der Befruclitung der Blumen. Berlin, Fr. Vieweg sen. 1793.4. 444 p. ind, 25 tab. $\left(3^{2} / 3\right.$ (h.)
9831" Sprengel, Karl. Meine Erfahrungen im Gebjete der allgemeinen und s]ezicllen Pflanzenkultur. Lirster Band. L.eipzıg, Baumgartner. 1847. 8. xil 345 p. $\left(1 \frac{1}{2}\right.$ (h. $)$

9832* Sprengel, Kurl. Anticuitatum botanicarum specimen primum L.ipsiae, Schaefer. 1798.4. vu, 110 p., 2 lab. (1 $1 / \$$ h.)

$9833^{*}$ (_- Der botanische Garten vlur Cniversitat zu Hallo in Jahre 1799. Nit dem Grundrisse des botanisehen Gartens. Ilalle,

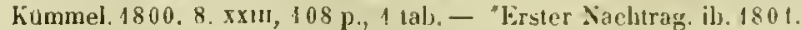
$8.44 \mathrm{p} \cdot(3 / \mathrm{t} / \mathrm{h}$.

983:* —_ Anleitung zur Kenntniss der Gewáchse. In lbriefen. Drei Sammlungen. llalle, Kümmel. 1802-1804.8. - 1: 180z. $4 \mathrm{z} 1 \mathrm{p}$. 4 tab. - II: 1802. 367 p., 4 tab. - 111: Einleitung in das Studium der kryptogamischen Gewáchse. 4804.374 p., 10 tab. - "weite ganz umgearbeitete Ausgabe. 2 Theile ader 3 Jkinde. ils. 18171848. 8. xil, 482, xvin, xu, 992 p., 25 tab. pro parte enl. $(82 / 3$ th. $)$ tanglice: An introduction to the study of cryptopamuss plants, in letters. Translated from the german, london. White. 18(17. 8. vill. thl p., 10 tab. - ib. 1813. 8. DC. - ih. 1819. 8. Bibi. Nov. Ebor.

$9835^{*}$ (-) De graminum fabrica et oeconomia. D. Halac 1804. 4. $31 \mathrm{p}, \mathrm{i}$ tab. col.

libellus prorsus Sprengelii est, lieet nomen autoris August Babel in titulo legatur.

9836 Gartenzeitung, hesausgegeben ron hurt Sprengel. Mil illuminirten kupfern. Halle, Gebauer. 1804-1806. 4 Bdude. 4. $\left(9^{5} / 8\right.$ th. $)$

$9837^{*}$ - Florae Ilalensis tentamen norum. Halac Saxonum, hunmel. 1806.8 . xyr 420 p. $\left(1^{3} / 4, h.\right)$ - Jantissa jrima Florae Halensis, addita novarum plantarum Centuria. il. 1907. 8 . 38 et $31 \mathrm{p}$. - Mantissa altera. il). 1811.8 .31 p. ( $1 / 3$ (h.) - "Flora llalensis. Ed. 1l. aucta el emendata. ib. 1832 . Il tomi. 8.763 p. $\left(2 \frac{1}{3} / \mathrm{ll}\right.$.)

$9838^{*}$ Historia rei herbariae. Amstelodami, sumtibus tabernae librariae et artium. (Leipzig, Brachihaus.) 1807-1808. Il voll. 8. l: 1307. xv, 532 p. $-11: 4808$. xvil, 574 p. (6 /h.)

$9839^{*}$ (_- Index plantarum, quae in horto botanico llalensi amm 1807 viguerunt. Ilalise, 19p. Gebaver. $1807.12 .64 \mathrm{p}$

$98.0 \div$ Index plantarum, quae in borto botanico Halensi anno 1808 viguerunt. Ilalae, iyp. Grunert. $1808.8 .46 \mathrm{p}$.

Indices seminum in horto botanico Halensi collectarum vidi annorum: 1809. $2 \%$ p. -1810.31 p. -1828.7 p. -1829.8 p.)

$9841^{*}$ Gesammelte Nachrieliten von der Arakatscha, deren Anbau und Benutzung. Aus dem Englisehen. Dresden, Gerlacb. 1808. 8. 23 p., 1 tab. eol. $(1 / 4,(h)$.

$981.2^{*}$ Von dem Bau und der Natur der Gewalose. Halle, Kümmel. 1812. 8. Ix, 634 p. 14 tab. $\left(4^{3 / 4}\right.$ th.

(Simul editae sumt lleinrich Friedrich Link kritische Bemerhungen und Zusatze; ef. supra Nr. 5959.

suecice: Om Vaxternas bygunad och Yatur. Af $r$. Sprengel. Öfersattning af H. M. Ronnore mesl Foretal af Professor $C$. A Agardh. "psala, Palmblarl et Co. 1820.8 . viII, 152, (3) p., उ̈ tab. w.

9843 Dissertatio de germanis rei herbariae patriluus. Eüne Abhandlung. München, (G. Franz.) 1813.4. (5/12 (h.)

984: — Plantarum Lmbelliferarum denuo disponendarum Prodromus. Halae, typ. Ilendel. 1813.8 .42 p., $A$ tab. $(5 / 12 l h$.

(Seorsim impr. ex Sehriften des Naturf. Gesellschaft zu llalle Rand 11. lleft J. p. i-42.)

$98\left\{0^{*}\right.$ Plantarum minus cognitarum pugillus primus ef secundus. Ilalae, Kummel.1813-1815. 8. - I: 1813.98 p. - II: 1815. $98 \mathrm{p}$. , ind. $(5 / 6 \mathrm{lh}$.)

$98: 6^{*}$ - De frumentorum, maxine Secales, antiquilatilus. l'rogramna academieum. Halae, typ. Grunert. 1816.4 .8 p.

981.7* Species Umbelliferarum minus eognitae, illustratae. Halae, Renger. $1818.4 . x, 154$ p., 7 tab. $\left(2 \frac{1}{3}\right.$ (h.)

$9848^{*}$ Gesehichte der Botanik. Nen bearbeitet. Altenburg und Leipzig, F. A. Brocklıaus. 1817-1818. 2 Theile. 8. - J : 1817. (4), 424 p., 8 tab. col. - II: 1818 . (4), 396 p. $\left(4^{2} / 3\right.$ (h.)

$98.19^{*}$ Jahrbucher der Gewachskunde, berausgegeben von Kurt Sprengel, Adalph Heinrich Schrader und Jeinrich Friedrich Lunk. Berlin, Nauck. 1818-1820. 3 Ilefte. 8. - J: 1818. vi, 191 p. ll : 1819.197 p., 1 tab. - Ill : 1820.184 p., / tab. $(2 / /$ th. $)$

$9850^{*}$ - Novi proventus hortorum academicorum Jlalensis et lerolinensis. Centuria specierum minus cognitarum, quae vel per annum 1918 in horto JJalensi et Berolinensi floruerunt, vel siccac missae fueruut. Halae, Gebauer. (1819.) $8.48 \mathrm{pe}(1 / \mathrm{th}$. 
$9851+$ Sprengel, Kurt. Narcissorum conspectus. s. I. 1820.8 .32 p.

9852* - A. P. DeCandolle und hurt Sprengel's Grundzüge der wissenschaftlichen Pflanzenkunde. Zn Forlesungen. Leipzig, Cnobloch. 4820. S. vili, 611 p., 8 tab. $\left(2 \frac{1}{2}\right.$ (h.)

(Candollius semper, se aliquid laboris in hoc orus contulisse, negavit. )

$\div$ anglice: Elements of the philosophy of plants: containing the principles of scientific botany; nonenclature, theory of classlfication, phytography; anatomy, chemistry, physiology, geography and diaphytography; anatomy, chemistry, phys siongy, geography and diations. Translated from the german. Ediniburgh, Blackwood. 1821 . tiols. Translated from the
xxxil, 456 p. 8 tah. ( 78.$)$

9853* - Neue Entdeckurgen im ganzen Lmfang der Pflanzenkunde. Leipzig, Fr. Fleisclıer. 1890-1822. III voll. 8. - J: 1820. Iv, 452 p., 3 tab) - II: 1821.363 p., 3 tab, - JII: $1822.409 \mathrm{p}$ $\left(6 \frac{2 / 3}{3}(h-)\right.$

983:* Theophrast's Natnrgeschiclute der Gewácluse, übersetzt und erláutert. Altona, Hammerich. 1822. 2 Theile. 8. - 1: lebersetzung. 358 p. -11 : Ersänternngen. 427 p. $\left(3 \frac{1}{8}\right.$ lh. $)$

9855 * _ Caroli Linnaei Systema regetabilium. Editio XV, curante Kurt Sprengel. Gouttingae, typ. Dieterich. 18z5-1828. IV voll. vel V゙ partes. 8. - J: Classis J- I. 1825. vi, 992 p. - Il: Classis VI - XY. 1825. 939 p. - III: Classis XVI-XXIll. 1826. 936 p. IV. Pars 1: Classis XX14. 1527. 592 ]. - IV. Pars Il: Curae posteriores. $1897.410 \mathrm{p} .-{ }^{*}$ Tentamen supplementi ad Systematis vegetahilium Linnaei editionen decimam sextam, anctore Antun Sprengel. $1828.35 \mathrm{p} \cdot\left(19^{11 / 12}\right.$ th. $)$

$9856 *$ Curtii Sprengelii Opusenla academica collegit, edidit vitanque anctoris breviter enarravit Julius Rosenbaum. Lipsiae, Gebaner. $1844.8 . \mathbf{x r}, 155$ p. $(5 / 6$ th. $)$

9857 * Sprenger, Philipp Stephen. Horti inedici catalogus arborna, fruticum ac plantarum tam indigenarun quam exoticarum. Francofurti a/MI., typ. J. Spiess. 1597 . 4. (44) p.

9858* Spring, Anlon Fr. Ueber die naturhistorischen Begriffe von Gattung, Art und Ahart und uber die Lrsachen der Abartungen in den organischen Reiclıeı. Eine Preisschrift. Leipzig, Fr. Fleischer. 1838. s. vill, 184 p. $\left(1 / h_{1}\right)$

980 Squarcialupus, Marcellus. De Anygdalarum amararum in ebrietaten vi contra Plutarchum opinio. Pesclavii Rlietorum inalpinorum, ex officina fratrum Landulphorum. 15\&6, \&, Rivin.

$9860^{*}$ Stackhouse, John. Nereis Lritannica, continens species onmes Fucorum in insulis britannicis crescentium (descriptione latina et anglica, necnon) iconibus illustrata. Bathoniae, typ. llazard. 1801 fulio. $\mathbf{x L}, 112 \mathrm{p}$., appendix, 24 tab. col. $(21.8 s . \Lambda$.) - Ed. altera: Oxonii, typ. Collingwood. 1816. 4. xII, 68 p., 20 tab.

9\$6 $\div$ - De Libanoto, Smyrna et Balsamo Theophrasti notitiae, addita de Inasio et Sari apud eundem conjectura: ex editione Listoriae plantarum curante Joh. Stackhouse. Oxonii 1814 in usum peregrinantium. 8. 16 p., 3 tab. (graece et latine.) Bibl. Juss.

$9862^{\circ}$ Extracts from Bruce's Travels in Abyssinia, and other moderı authorities respecting the Balsam and Myrrlı Trees, illnstrative of the Natural History of Theoplirustus. Bath, Binns. 1815.8. xxI, 15 p., 3 tab.

9863* Stahl, J'o Johannes, pr. We Pane speciatim triticeo, juxta principia, dilferentias, usum atque abnsum spectato. D. Erfordiae 1727. 4. 44 p. (Respondens: Johan Friedrich Tenzel.)

$986 t^{*}$ De veris herbae Tlsee proprietatibus. D. Erforliae 1734 4. 24 p. (Respondens: Alraham Golllieb Reichel.)

9865 Stalenus, Johan Lars. Disputatio philosophica de plautis, quan sub praesidio Johumms Laurentii Staleni pro magisterio in plilosophia proponit Daniel Kylander. Lpsaliae, isuprimebat Aescillns Intthiae. 1634.4 . (10) p. w.

$9866^{*}$ Stange. Index plantarom phanerogamarum, quae in agro Francofurtano nascuntur. Proggramn des Gynnasiums. Frankfurt a/0., ts], Trowitzsclı. 1839. 4. $x \mathbf{x v}$ p.

$9867^{*}$ Stanhope, Earl. Address of Earl Stunhope, President of the Hedico-botanical Sociely for the anneversary Jeeting, January 16. 1829. London, typ. Wilson. 1829. 8. 22 p. - " id. is 30 . ib. is 30 8. $34 \mathrm{p}$.

9868 Stapell, Johann Friedrich. Tulipanen Geheimniss, oder Geistliche Betrachtung der unbegreiflich schonen Blumen der Tulipen, zur
Erweckung christlicher Audacht vorgestellet. Lubeck, bey Ulrich Wettstein. 1663.12. Rivin.

$9869^{*}$ Starck, Christoph Heinrich. Sertum rutaceum domus saxonica。 insigne. Lipsiae, typ. Hahn. 1664. 4. (14) folJ.

$9870^{*}$ Stechmann, Johannes Paul. De Artemisiis. D. Goettingae, typ. Rosenbusch. 1775. 4.59 p.

9871* Steck, Abraham. De Sagu. D. Argentorati, typ. Heitz. 1757. 4. $44 \mathrm{p}$.

$9872^{*}$ Stedmann, John Gabriel. Narrative of a five years expedition against the revolted negroes of Surinam in Guiana, ete. and the deseription of its prodnctions; with 80 elegant engravings. London, Johnson. 1796 . If voll. 4.

× gallice: Yoyage à Surinam el à Vintéricur de la Guiane, iraduit de langlais par lienry. Paris, Buisson. 1799. III voll. 8. et Allas in $\$$ 4 tab. $28 \mathrm{fr}$.

$9873+$ Steele, Richard. An essay upon gardening, containing a catalogue of exotic plants for the stoves and greenhouses of the british gar'. dens. etc. York, typ. Peacoch. 1793. 4. xxi , 159, 102 p., 3 tab.

98 if Steele, II. E. Handbook of Field-Botany; comprising the flowering plants and ferns indigenous to the british isles, arranged according to the natural system; the orders, genera and species carefnlly analyzed, so as to facilitate their discrimination, with a synoptical table of the genera according to the Linnaean classification, and a glossary of those terms most commonly in use. Dutlin 1847. gr. 8 . 278 p. $(7 s .6(i))$

987 Steenstrup, J.J. S. Untersuchungen uber das Vorkommen des Hermaphroditismus in der Natur. Ein naturhistorischer Versuch. Aus dem Dánischeu ubersetzi von C.F. Ilornschuch. Greifswald, Otte. 1\$46. 4. 2 tab. ( $2(h$.

$9876^{*}$ Steggall, Johtr. The pupil's introduction to botany; containing the description and physiology of plants and explanation of the classification of Limuaeus and Jussieu; and a glossary of botanical terms. London, Highley. 1829. S. vill, 174 p., S tab. col. (6s.)

987 Stehelinus, Benedictus. Observationes anatomico-botanicae. D. Basileae 1731.4.8 p. (Respoudens: Johann Heinrich Rippelius.) в.

9878 Stehelinus, Johannes. Theses miscellaneae medico-anatomicobotanicae. D. Basileae 1751.4. 8 p. (Respondens: Konrud Schindler.)

9879 Stehelinus, Johannes Rodolphus. Specimen observationum anatomicarum et botanicarum. D. Basileae 1751. 4.8 p. B.

9880 _ - Specimen observationum medicarum. D. Basileae 1753. 4. 8 p. (Respondens: Johann Rudolf Buxtorf.) B.

(Pagina 5-8 hotanici sunt argumenti.)

9881 Steige, Joachim, latine Steigius. Beschreilung des Lindenbanms. Wittebergae 1617.4. Desid. Banks.

(Lego apud Joecher anum editionis 16037 .)

9882* Stein, Friedrich. Grundriss der organischen Naturgeschiclute. Zum Gebrauche für lıohere Schulen. Erste Abtheilung: Organographie der Pllanzen. Berlin, Duncker und Humblot. 1845. 8. IV, $152 \mathrm{p}$ $(1 / 2$ l.h. $)$

9883* Stein, Cieorg Anton. De faba St. Ignatii. D. Erlaugae 1793. S. 32 p.

988:* Stein, Johann Ileinrich. Versuche und Beobachtnngen uber Angewohnung auslindischer Pflanzen an den Westphalischen Ilimnelsstrich. Mit Vorrede von Friedrich Kusinir Medikus. Mannheim, Hofbuchbandlung. $1787.8,76 \mathrm{p}$, praef, ind. $(1 / \mathrm{t} / \mathrm{h}$.

$9885^{*}$ _ Geschichte einer knnstlichen Befruchtung der Lerkoyen nehst einer Amweisung, wie dadnrch gefïllte BJumen zo erlaalten. Jlinden, Koerber. 1787.8 .45 p. $(1 / 8 \mathrm{lh}$.

$9886^{*}$ Steinbeck, $A$. Veber die Bernsteingew innung und das Braunkohlenlager bei lirandenburg an der llavel. Braudeuburg, Muller. (1841.) gr. 12.24 p. $(1 / 6$ th. $)$

$9887 \div$ Steinheil, Adolph. De l'individualité considérée dans Je règne végétal. Mémoire présenté a la suciété d'luistoire naturelle de Strasbonrg dans la seance du 19 Janvier 1836. (Strasbourg 1836.) 4. $18 \mathrm{p}$.

9888 — - Quentend on par Eudosmose et Exosmose? (Extrait d'uue thèse soutenue á Paris par Jouanguy. Paris, Mars 1838.) 4. 19 p.

$9889 \div-$ Obserzations sur la régétation des Dunes à Calais. Versailles, ty]. Montalant-Bongleux. s. a. $8.22 \mathrm{p}$.

(Extrait des Memoires sc. nat. de Seine et Oise.) 
9890 t Steininger, Johann. Geognostische Beschreilsung des Landes zwischen der untern Saar und dem Rheine. Ein Bericht an die Gesellschaft nutzlieher Forschungen zn Trier. Nachtrage mit 5 Petrefactenzeichnungen. Trier, Lintz. 1841. $4.49 \mathrm{p} ., 4 \mathrm{tab})(9 \mathrm{~h}$.

9891 Steinmeyer, Geory Friedrich. Dissertatio inauguralis de Ruhia tinetorum. Argentorati 1762.4.32 p. B.

9892 Stelka, J. J. Do Arnica montana. I). Pragae 1835. 8.28 p.

$9893^{*}$ Stella, Benedello. Il tabacco, opera, nella quale si tratta dell' origine, listoria, eoltura, preparazione, qualiti, natura, virti el uso della pianta volgarmente detta Tabacro. etc. Roma, per Filippo Maria Mancini. 1669. 8. (32), 480 p. Bibl. Goett.

989. Stellati, lincente. Istituzioni di filosofia botanica. Napoli 1809. 8. DC.

989:* Steller, Georg Wilhelm. Beschreibung von den Lande Kamtselıtha, dessen Einwolınern, deren Sitten, Namen, Lebensart und verschiodnen Gewohnlieiten, heransgegeben von J. B. Scherer. Frankfurt und Leipzig 1774. S. (4), 394,76 p., 13 tab. (1 $\frac{1}{2}$ (h.)

9896 Stelluti, Francesco. Del legno fossile nnovamente scoperto. B. IV. 175 .

$9897^{*}$ Stemler, Johann Gottlieb. Specimen paralelismi inter systema Linneanum et Jussiouanum. D. Jenae, typ. Etzdorf. 1810.4. 12 p.

9898* Stengelius, Carolus. ITortensius et Dea Flora cum Pomona historiee, tropologice et anagogice deseripti. Augustae Vindelicorum, typ. Apperger. 1647. Il tomi. 12. 384,537 p. Bibl. Mus. bot. Vindob.

$9899^{*}$ llortorum, florum et arlrorum historia in duns tomos distributa. Editio altera anction. Augustae Vindelicorum 1650. II tomi. 12. 384,537 p.

(Iu ealce impressa dicitur anno 16\%7; adcouge novo mutato titule novam mentitur ditionem Jibri praecedentis. ?

$9900^{*}$ Stentzel, Christian Golfried, pr. De Salvia in infuso adlibenda hujusque prae Thea elinensi praestantia. D. Wiltenhergae, ty] Gerdes. 1723. 4. 40 p. (Respondens: Melchior Golllieb Feyerabend.)

$9901^{*}$ De lkuta medicamento et veneno. D. Wittenbergae 1735. 4. 48 p. (Respondens: Johann Christoph Stemberg.)

9902* Stephan, Friedrich. De Pediculari comosa, lectum in societate Linueana. Isipsiae XX| Dec. 1791.8.8 p., $\mid$ tab.

$9903^{*}$ - Enumeratio stirpium agri Mosquensis. Mlosquae 1792. $8.63 \mathrm{p}$.

$990 x^{*}$ _ leones plantarum Mlosquensium ad historian plantarum sponte circa Mosquam erescentium illustrandam pinxit et in aes incidit. Decas 1. Mosquac, apud Rürliger et Clandi. 1795. folio. 2 p. 10 tab.

990:3* Stephanitz, Alexander Luduriy. De Rhaharharo Dissertatio geographico-historica. Berolini, Burmeister et Stange. 1838. 8. $25 \mathrm{p}$. $(1 / t$ th.

9906 Stephenson, John, and J. M. Churchill. Medical botany. Tom. I. Nr. 1-48. London $1827-1830.8$. - New edition by Gilbert $T$. Burnet. London, Churehill. 1837. III voll. 8. (6/.6s.)

$9907^{*}$ Sterbeeck, Franciscus ean. Thentrum fungorum of het toonech der camprornoelien, waer inne vertoont wort de gedaente, kentceckens, natuere, crachten, voetsel, deught ende ondeught; mitsgaders het voorsichtigh schoonmaken ende berevilen van alilerhande fungien; en blijckteeckenon van de gene die vergiftighe gegeten hebben, met de geneesmiddelen tot soodanigli ongeval dienende: beneffens eene naukeurighe beschrijvinge vande derilluylen, Papas, Tarratouffli, Artichiocken onder d'acrde, ende dierchelijeken yhewasschen. Waer by ghevoeght is en cort Tractact vande hinderlijcke eruyden van dit landt, als wilde petereelie, ende andere, met te teghen middelen teghen soodanigh vergif. Alles inut neerstigheyt, lanck-duerige ondervindinghe, ende ijverigh ondersoecken vande schriften der ervarenste cruyt-Kenders vergaedert ende beschreven. T'Antwerpen, by Josepl Jacobs. 1675. 4. (1 8 foll.) 396 p., iml., 36 tab. praeter effigiem Jonnnis van Buyten. - ${ }^{*}$ Den tweeden Druck verbetert. T'Antwerpen, by Franciseus Huyssens. 1712. 4. (Immo eddem est impressio, nullarno omnino nota differt praeter omissam effigiem Buytenii et dedicationem.)

(lluins libri una tantum impressio allest, quae primum prodiit anno 1675 . loditio anni 163 ' a seyuiern laulata bene monente protsit Bibl. bot I. Bso., commentitia cat.
$9908^{*}$ Sterbeeck, Franciscus van. Citricultura, oft regeriughe der uythemsche boomen te weten oranien, citrouten, limoenen, granaten. lanricren en andere. Waer in beschreven is de gedaente ende kentisse der bunmen, met lunne blocmen, bladeren en vruchten: van jeder geslacht in liet besonder. Als ouch van den Ranckappel. oprechten Lanrier vал Ameriea, den Caneelboom, ende besonderlijek van den verboden Adams oft Paradysappel. T'Antwerpen, by Joseph Jacojs. 1682, 4. (20 foll.), 296 p., ind., 14 tab. - "i)en iweeden druck verbetert. T'Antwerpen, by Franciscus lluysens 1712. 4. (Eaclem est impressio ac praceedens, novo titulo.) (Jemes fere omnes sunt e Ferrario repetitac.)

$4909^{*}$ Sterler, Alois. Hortus Nymphenburgensis, seu Finumeratio planLarun in horto regio Nympheulurgensi cultarum. (Der Garten zu Nymphenlurg ete.) Nonachii, (Lind.) 1824. 8 . vit, 119 1). ( $1 / 2$ th.) - +Editio altera. ib. 1826. 8. vi, 164 p.

9910* —_ Europas Nedicinische Flora. Herausgegeben von Alors Sterler und Johann Nepomuck Mayerhoffer. München, 1y. Lentner. 1820. folio. 80 p., 80 tals. col. $\left(26^{19} / 2\right.$, $(h$. $)$

(Prodiit annis 1820-1824 fasciculis 20 a 48 .ir. nigr., $1 \mathrm{fl} .36 \mathrm{Nr}$. col pastea $1 \mathrm{H1} .12 \mathrm{Xr}$. nigr., 2 11. enl.)

$9911^{*}$ Sternberg, Kaspar, Graf con. Botanische Wanderung in den Bolsmer Walcl. Nurnberg, Nonath. 1806.8 .14 p., 4 Tabellen. $(1 / 2$ th.

$9912^{*}$ _ Reise in die Rhetischen Alpen vorzuglich in bolanischer Hinsicht im Sommer 1804. Nurnberg, Monath. (Prag, Calve.) 1806. $8.64 \mathrm{p} .(1 / 2$ th. $)$

9913 Reise Jurch Tirol in die osterreichischen Provinzen Italiens im Fruhjahr 1504 . Regensburg (Prag, Calve.) 1806. folio min. xu, 466 p., 4 tals. $(7 \%$, th. $)$

9914* _ Revisio Saxifragarum iconibus illustrata. Ratisbonae typ. Augustin. 1810. folio. xiv, 60 p., 34 tab. - Supplementum, Decas I: ib. 1822. vi, 16 p., tal). col. I-10. - Supplementum II: Prag, Calve. $183 \mathrm{~J}$. vı, 104 p., tab. col. 11-26. (43//3 th.)

9915* - Ablandlung uher die Planzenkunde in Böhmen. In zwei Abtheilungen. Prag, Calve. 1818. 8. - 1: Ilistorisch-chronologisehe Entwickelung der Fortschritte der Pflanzenkunde in Bohnen. 168 [3. - II: Kritische Beurtheilung der in Böhmen erschienenen Werke, dic ven Pfanzen liandeln. 128, xLvi p. $(1 \% / 12$ th.

$9916^{*}$ Versuch einer geognostisch-botanischen Darstellung der Flora der Vorwelt. Leipzig und Prag, Fr. Fleischer. 1820-1838. Il voll. follio. $-1: 1820,24,33,39$, xu1, 48,79 p., 90 tah. col. - II: 1838. 220, Lxxi, 70 tab. col. $(60$ th. $)$

† gallice: Kssai d'un exposé géognostico-botanirue de la Fluru du mondo primitif. Traduit de l'allenand par le Conte Francois Crabrie de Bray. Livraison I-lV. Lejpzig et Prague, Fr. Fleiseher. Is20 (-1827) folio. $x$ p., 6 i tab. col. (3i th.)

$9917^{*} \longrightarrow$ Catalogus plantarum all septem varias editiones Conmentariorum Malholi in Dioscoridem. Ad Limnacani systematis regulas elaboravit. Pragae, Calve. 1821 . folio, iv, 30 p. $\left(1 \frac{1}{3}\right.$ / h. $)$

9948 Enumeratio plantarum horti et agri Březinensis, secundum Steudelii nomenelatorem botanieum et leeandollii systema vegotabilium, jussu domini Caspari Comilis Sternbery concimata al, Antonio Franz, horti Rrezinensis praefecto. (Pragae 1824.) 8. 37 p.

$9919^{*}$ Bruchstuche aus den Tagebuch einer naturhistorischen Reise von Prag nach Istrien. (Besondrer Alulruck aus Flora 1826.) Regensburg 1826. 8.92 $\mathrm{l}$.

$9920^{*}$ Ueber cinige Eigenthumlich heiten der bohmisehen Flora und die klimatische Verloreitung der Pllanzen der Vor-und Jetztwelt. Zweite Ausgabe. Regensburg (Leipzig, Hofmeister.) 1829.8. 25 p. $(1 / 8(h)$.

9921 Steuchius, Elav'us, pr. Dissertatio de nutritione arborum. Lpsaliae 1722. 8. 19 p. (Respondens: Jakob Manques.) B.

9922* Steudel, Ernst Golllieb. Ist eine Verbindung der Botaniher 21 einer gemeinschaftlichen Bearbeilung cines Systema vegetalsilium nothig und moglich? Regenslsurg 1820.4.22 p.

(Seorsim impr. ex Regenshurger Denksehriften.

9923* — et Christian Friedrich Hochstetter. Enumeratio plintarun Germapiae llelvetiaeque indigenarum, seu Prorlromus, quem symopsin jhantarum Germaniae IJelvetiaeque edituri botanophilisfue adjuvantanı commendantes scripserunt. Stuttgartiae et Tuehingae, Cotta. 1826. S. vill, 352 p. $(12 / 3$ th. $)$ 
992: " Steudel, Ernst Gottlieb. Ueber eil neues Pflanzengenus (Frankia Schimperi), vorgetragen zu Esslingen den 26. Sept. 1836. (Extraabruck aus dem Mediziniscben Correspondenzblatl.) S. 14 p., 2 tab.

$9925^{*}$ - Nomenclator botanicus, seu synonymia plantarum universalis, enumerans ordine alplubetico nomina atgue synonyma lum generica tum specifica, el a Limnaeo et a recentioribus de re botanica scriptoribus plantis phanerogamis imposita. Edilio secunda ex novo elaborata et aucta. Stuttgardiae el Tuebingae, 1 ypis et sumtibus J. G. Cottae. 1840-1841. Il partes. $8 \mathrm{max}$ - I : Litt. A-K. 1840. 852 p. - Il: Litt. L - Z. 1841.810 p. $(8$ th. $)-{ }^{*}$ Ed. I. ib. 1824. 8 max. xvil, 900 p. $\left(8 \frac{1}{3}\right.$ th. $)$

9926* Steven, C. Monographia Pedicularis. (Arl acta soc. eaes. nat. scrutatorum tom. V1.) 1822. 4. 60 p., $17 \mathrm{tab}$.

9927 Stevenson, $H$. The gentlemen gardener. Ed. Vill. London 1769. 12. 293 p. B.

9928 Stewart, Baronet. The Planters Guide. Edinburgh 1 1828. 8. (18s.)

9929 Stewart, R. B. Outlines of botany. Loudon, Ridgway. 1835. \&. (2s.6d.)

9930 Stewart, $S$. Hortus cryptogamicus Edinensis. Erlinburglı 1819. Bibl. Nov. Ebor.

9931* StiebeI, Salomon Friedrich. Die Grundformen der Infusorien in den lleilquellen nehst allgemeinen Pemerkungen uber die Entwickelung derselben. Erstes Heft. Gallionella ferruginea. Conferva filiformis sulphurata. Leber die Keimpunetchen uml deren Bedeutung in der organischen Entwicklungsgeschichte. Frankfurt a/ Ml., Jügel. $1841.4 .22 \mathrm{p}$, itab. $(1 / 2 t h$.)

9932* Stieff, Johann Ernst. De vita nuptiisque plantarum. Lipsiae, typ. Breitkopf. 4741. 4. 24 p.

Redit in Reichard sylloge opuse. botan. p. 40-69.1

$9933^{*}$ Stiehler, August Wilhelm. Ueber die Bildung der Steinkohle nach Lindley und Hutton, nit Rucksicht auf andro daruber aufrestellte Ansichten. Braunschweig, Leibrock. 1843.8 . Iv, 69 p. ( $1 / 2$ th. $)$

993' Stillingfleet, Benjamin. Miscellaneous tracts relating to natural history, husbandry and plyysick. Translated from le latin, with notes. London 1759.28 .230 p. B. - FEd. Il. To which is added the Calendu' of Flora hy Theophrastus. London, Dodsley. 1762. 8. xxxis, 394 p., 11 tab. Bibl. Cand.

9933 L L Literary life and select worhs, with unpublished observations on some of the plants of Theophrastus: by' IF illium Coxe. London, Nichuls. 184. III voll. 8. (2l. 2.s.) Cat. Bibt. Radclifie 0xon.

9936* Stisser, Johann Andreas. Botanica curiosa, oder nutzliche Anmerkungen, wie einige fremde Kratuter und Blumen in seinem 1692 zu Helmstedt angelegten medicinisehen Garten bisher cultivirt und lortgebracbi; nebst einigen Abrissen fremder Gewachse. Ilelmstedt, Hamm. 1697 8. 224 p., praef, append., 12 tab. - ib. (1708.) 8. 224 p., 12 tal). B.

9937 - Horti medici Helmsladiensis eatalogus plantas omues enumerans, quarum culturam al, anno 1692 usque 1699 in horto suo instituit. Helmstadii 4699.8 .42 p. B.

9938 Stockmar. Ueber den verderblichen Misswaclss oder die unfruchtbare Abartung unter den behannten Sprisekartoffeln, clessen Ursachen, Vertilgung dieses Vebels und Ilaassregeln zur Verhütung der Wiederkehr desselben, ingleiclien uber den Kartoffelbau im Grossen. Berlin, Felisch. 1802.8. (1/2 th.)

$9939+$ Stoerck, Anton. Libellus, quo demonstratur, Cicutan non solum usu interno qutissime exhiberi sel ot esse simul remedium valde utile in multis morbis, qui hucusque curatu impossibiles dicebantur. Vindobonae, typ. Trattuer. 1760.8 .348 p. 1 tab.

(In Bibliollueca Ranhsiana indicantur Lihellus I et If et Suppleuentum: Vindohnuae 1761. 8. 63, 147, 38 p., I tah.)

gallice: par Letégue de Presle.'Paris 1762.' 12. Q.

yallice: par Collin. Paris 1763. 12. Q.

$9910^{*}$ L Libellus, quo demonstratur Stramoninm, Hyoscyamum, Aconitum tuto posse exhibori usu interno hominibus. Vindobonae, Tratuner. 1762.8 .118 p., 4 tab.

gallice: Expériences et observations sur lusage interme de la Pomme épineuse, de Ja Jisquiame el de l'teonit. Paris 1763.12 . $139 \mathrm{p}$. 3 tab. B.

$9941^{*}$ __ L L Libellus, quo demonstratur, Colchici antumnalis radicem non sulum tuto posse exhiberi hominibus, sed et ejus usu interno curarı quandoque morbos difficillimos, qui aliis remediis non cedunt Vindebonae, typ. Trattner. 1763. 8. cum Appendice de Cicuta 96 p. 1 tab.

anglice: An essay on the use and effects of the root of Colchicun autumnale, or Meadow-Satfron; with Appendix to the Cicuta or Ilemlock. Lonton 176k. 8. 47 p. B.

gallice: Traduit par Letergue de Presle. Paris 176\%. 12. Q.

99.2* Stoerck, Anton. Libcllus de usu medico Pulsatillae nigricantis. Vindobonae, typ. Trattner. 1771.8.61 p., 1 tab.

$9943^{*}$ —_ Instituta facultatis medicae Vindobonensis. Vintobonal, typ. Trattner. 1775.8 .59 p., 1 tab: typus horti Vindobonensis.

9944 Stohr, Johann Moritz. Poma sodomitica, ad illustrationem Sapienliae $\boldsymbol{X}, 7$. D. Lipsiae 1695. 4. 2 plag. (Respondens: Adam Fricdrich Oeter.) B.

9940* Stokar de Neuforn, G. II. De Hyoseyami nigri virtutibus merlicis. D. Erlangae, typ. Kuustmann. 1797.8. 72 p.

9916 Stokar de Neuforn, Johann Georg. De suceino in gencre et speciation de succino fossili Willolzensi. D. Lugduni Bataverum 1760. 4.

9947 Stokes, Jonathan. A botanical Materia medica, consisting of the generic and specific characters of the plants used in medicine ancl diet will synonyms and references to medical authors. In four volumes. London, Jolusson and Co. 4812.8. - I: ixvil, 503 p.11: 567 p. $-111: 549$ p. - IV: 702 p. (3l.)

$9948^{*}$ - Botanical Commentaries. Yol. I. London, Simpkin and Marshall, Treuttel el Wurtz. 1830. 8. Xxyil, cxxiv, 272 p. (14s.)

Paginae 28 priores sistunt pracfationem; seyuuntur $13 \%$ paginae hotanjeal terms and abbreviations; tune 272 paginae spectant ad systentaticam hotanicam classium Linnean. $1-3$.

99.9* Stolz, Johann Christian. Flore des plantes qui croissent dans les déparlemens du Haut et Bas-Rhin, formés par la cidevant Alsacr. Strashours, Levrault. 1802. 8. vut, 62 p. (1 fr. 50 c.)

$9950^{*}$ Stotter, Michael, und Ludwig, Ritter von Heufler. Geognustisch-botanische Bemerhungen auf einer Reise durch Detztlal und Schnals. Mit einer geognostiseh-botanisehen Karte. Inushruck, My. Wagner. $1840.8 .450 .11 \mathrm{lab}$. col.

(Seorsim impr. ex Neue Zeitsedurift des Ferdinandeums, Band VI.

9951 Strabo, Walafridus. Strabi, Fuldeusis monaclıi, llortulus, apul Helvetios in Sancti falli monasterio repertus, carminis elegantia tum delectabilis, quum doctrinae cognoscentlarum quarundan herbarum varietute utilis. Norimbergae, in officina Joh. Weissenturger 1512. 4. Rivin. - *Impr. cum Macro. Basileae (apul Joannem Fabrum Emmeum Juliaeensem.) 1527. 8. foll. 48-57. - "'mpr. cum Macro. Friburgi 4530. 8. foll. 99-108. - ${ }^{*}$ Walafridi Strabi llortulus. Carmen ad codd. mss. veterumque editionum fldem recensitum, lectionis varietate notisque instructum a Friedrich dnton Reus.s. Aceedunt Analceta ad antiquitates Florae germanicae et eapita aliquol Hacri noudum edita. Wirceburgi, Stahel. 1834. \&. $105 \mathrm{p}$. $(2 / 3$ th. $)$

9952 Strange, Giovanni. Lettera sopra l'origine della Carta naturale di Cortona, corredata rli varic altre osservazioni relative agli usi, prerogative della Conferva Plinii, e di altre piante congeneri. Pisit 1764.4. 107 p. в. - Seconda eritione. 12. LXXY] p. B.

(llujus libelli excerpta per auctoren eum nilterioribus observattionjlous adsunt in Philosoph. Transact. vol. LIX, p. 50-36; itemgut gallice versa in Journal de physique, Introduction tome J, p. 13-46.)

9953 Strasburg, Johann Ceorg. Positiones anatomicae et butanicae. Regiomonti 1663. 4. Desid. Banks.

9934 (Strauss, Lorenz.) F, P. De polu Coffi. Francofurti 1666. 4. $21 /+$ plag. cum figuris ligno incisis. $B$.

(Kadem sille dulio est Dissertatio praeside Laurentio Strauss, respondente Francisco Peters, quan recenset Heflier in Museo Dispul. vol. I. Nr. 7571 . )

germanice: Laurentius Straussius rom Coffi. Impr. cuiu Koschutile Vollstindige Apothehe p. 9k9-9.92. B.

gallice: Impr. cum Dufour (i. E. Jacobus Spon) De l'usage din eaphe, du the of du ehocolate. Lyon, Jean Girin, 16\%. 1: p. 1 -30 . B.

anglice: Impr, in The manner of mahing of Coffe, Tea and Chocolate. London 168.3 .12 . p. 1-1.k. B.

99:5\%* Strehler, $\boldsymbol{L}, \boldsymbol{F}$. Tel,ersicht der un Ingolstadt wildwachsenden phanerogamiselsen Pflanzen. Als Programm zum Jahresberichte fur 1840/1841. Ingolstadt, typ. Attenkover. (1841.) 4. XLVIt p., praef. ind. 
9936 Strehler, L. F. Ueber das Missratlen der Erndten. Straubing 1846. 4 .

9957* StrempeI, Karl Friedrich. Filicum lierolinensium Synopsis. D Berolini, typ. Starck. 1822.8 .48 \%., 1 tab.

19:38* Streubel, A. V. Der Consorvator oder practische Anlettung, Naturalien aller Reiche zu sammeln, zu conserviren und für wissenschaftiche Zwecke, wie anch zum Verguugen aufzustellen. Ein Ililfsbuch zum Selbstunterricht, nach eignen Erfahrungen bearl,eitet und mit Tabellen zur leichtern Bestimmung der Nineralien und Pflanzen verselien. Berlin, Rulsach. 1845. 8. 1v , 396 p. $\left(1^{1 / 2}\right.$ th.

(Yon der Einrichtung der Herbarien p.37-71. - Botunik: p. 73-325.)

9959 Strickland, Agnes. Flural shetclıes. London, Wilson. 1836. 18. (3s. 6d.)

9960 Strobelberger, Johann Stephan. Tractatus novus, in quo de Cocco Baphiea, et quae inde paratur confectionis Alchermes recto usu disseritur, cui insertus est Laurenti Caleleni genuinus ejusdem confectionis apparandae modus, o gallicn in latinum sermenem conversus. Jenac, typ. Beithmann. 1620.4. Rivin.

- Recens nec antea sic visa Galliac politica-medica descriptio, in qua de qualitatibus ejus, acatemiis celelorioribus, urbibus praceipuis, lluviis dignioribus, aquis medicatis, fontibus mirabilibus, plantis el herbis rarioribus, aliisque notatu dignissimis rebus a nemine adhuc publicitus emissis ingenue disseritur. Jenae, typis et sumtibus Johannis Beithmanni. 1620. 12. 271 p. Bibl. univ. Lips.

(Tota sectio quinta, p. 175-271, est de plantis rarioribus, quae per totam Gallian, praecipue in Gallia Narbonensi, Proventiali et Languedocia sponte virent: uhi earum loci uatales, simulque aliae res seitu diguissimae proponumtur.)

9962* - Mastichologia, seu de universa Nastiches natura dissertatio mediea, in gna et arhoris Lentisei et nobilissimi ejus Gummi Resinae, Masticlies, nomenelaturae, descriptiones, loci natales. eulturae, qualitates, varietas, dignitas, electio, probatio, collectio, aestimatio, succedancil, utilitas ac indo parata medicamenta oflicinalia, magistralia el artificialia describuntur. Lipsiae, typ. Jansonii. 1628 . 8. 109 p.

9963* (Ström, Hans.) Underretning om den islandske Moos, Mariegraesset og Gejtnaskoven, deres tilberetlelse til mad. Kiobenbavi, (yp. N. Moller. 1785, 8. 22 p., 4 tal., col.

996 '* Stromeyer, August Adolf Ludwig. De radice Columbo. D. Gocttingae 1829. 4. $19 \mathrm{p}$.

$9963^{*}$ Stromeyer, Friedrich. Conmentatio inauguralis sistens Jlistoriac vegetabilium geographicac specimen. Goettingae, typ. Dieterich. XXXI Dec. 1800. 4. 80 p.

$9360^{*}$ Stromeyer, Johann Friedrich. D. botanico-mediea sistens planlalum solanacearum ordinem. Gocttingae, typ. Rosenbusch. 1772. 4. $36 \mathrm{p}$.

!!67 Stroud, T. B. Elements of botany, physiological and systematical; to which is added a comprehensive dictionary of all terms used in that scicnee. Greenwich 1824.8.257 j., ]receding the dictionary. $(10 s$.

9468 Strunilla, Jozef. O ogroduch pólnocnych. (De lortis septentrionalibus.) Adamski.

1969* (Strumpf, Ferdinand Ludwig.) Die oftizinellen Gewhichse in den naturlichen Pflanzenfamilien ete. Eine tabellarische Uebersicht nach Anorinung von Nees von Escnbeck's und Ebermaier's medicinischpharmaceutischer Jotanik. Berlin, Logier. 1840, 4 Tabellen in grr. folio. $(3 / 4$ th. $)$

1970 Systematisches Handbuch der Arzneimittellehre. Berlin, Th. Enslin. $1845-1848.8$.

(Editur $10-12$ fasciculis a $8 / 15$ the

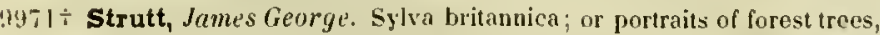
distinguished for their antiłuity, magnitude or beanty. Drawn from nature Jy Jucob George Strutt, auther of "1)eliciae sylvarum." Lonlon, for the author by Longman, Jlees otc. (1831-1836.) 8 max. xvı, $151 \mathrm{pe,}(50)$ tab) ( $3 l .3 \mathrm{~s}$. - imp. folio: $4 \mathrm{l} .10 \mathrm{~s}$. - India praprer: 7l. $17 s .6 d .$, Bibl. Cand.

9!72 * Struve, Friedrich Christian, pr. Dissertatio sistens vires plantarum eryploganicarum nedicas. Kiliae 1773. 4. 32 p. (Respondells: Genrg Itciurich II'eber.) $9973^{\circ}$ Struve, Gustav Adolph. De silicia in plantis nounullis. 1). Berolini, typ. Nietack. 1835. 8. 30 12., 2 tab.

997: Stubbe, 'Henry. The Indian nectar, or a discourse concerning Chocolatit. Lonton 1662. 8. 184 \% B.

9973* Stumpf, Geory, pr. De liobiniae P'seuduacaciat praestantia et cultu. D. I et Il. Gryphiae 1796 . (recusa 1798.) 4. \&i p. (licspondentes: Bernhard Beronius et Magnus Petrus Wetterlund.)

9976* Stupanus, Johannes Rudolph, pr. Sprecimen miscellaneum anatomico-Jntanicum. Hasileac 1751. 4. 8 p. (Respondens: dchilles Mieg.)

9977 Stupper, C. L. Medizinisch-pharmazeutische Bolanik, oder Bescloreiloung und Abbildung sammlicher in der neuesten $k$. $k$. osterreichischen landes-Pharmakopoe vom Jabre 1836 aufgefuhrten Arzueipllanzen; in naturhistorischer, phytugraphischer, pltarmakognostischer unt pharmakodyamischer Bezichung; mit besondrer Rucksicht auf dio botanisch-plarnazeutischen Synonyme, und die Verfálschung oder Verwecliselung der abgehandelten Arzneistolre. Mit ganz getreu gezeichneten und fein holorirten Abbildungen. Wien, (Gerold.) 1841-1843. 2 Bande. gr. 4. - 1: 1841. 16 j]lag., 60 tab. col. - 11: $1843.16 \%$ plag., 60 tab. col. $(20 /$ t. $)$

9978 Sturm, Benjamin Christian Gottlieb. Visci quercini descriptio botanica, analysis chemica et usus medicus. Specimen inaugurale. Jenae 1796. 8. 38 p. в.

$9979^{*}$ Sturm, Jakob. Deutschlands Flora in Abbildungen nach der Natu mit Beschreibungen. Nurnberg, gedrucht auf Kosten des llerausgebers. (Panierstrasse S. Nr. 709.) (Leipzig, Hinrichs und L. Voss.) 1798-1848. 149 Ilefte. 12. 2200 tab. col., totidem foll. text. $\left(111^{3} / \mathrm{th}\right.$. $)$

Erste Alblheilung. Phanerogamen. Heft 1-92. (Bändchen 1-20.) 1798 -1847. 12. 1480 tab. col., 1480 foll., ind.

Uebersicht der in $J . S t u r m$ 's Deutschlands Flora 1. Abth. Ileft 1-75 enthalteneu juanerogamischen Pflanzen. Nach Koch's Synopsis Florae germanicae et helveticae systematisch geordnet, mit lBerichtigung der Nomenclatur und alphabetischem Register. ib. 1839. 12. 79 ).

(leones nitidissimas post patris mortem sculpsit joh. Irilhelm Slurm. - Plura genera monngraphice a variis autoribus cxposita sint, e. $g$. Trifolium, autore Schreber, fasc. $130-16$; Vicia el Ervum, autore Ifoppe fasc. 31-32; Savifraga autore Comite liaspar sternberg. Iasc. 33. 33: Mysotis, autore Luivig Reichenbach, fasc. 42: Cires (Carienlogia gemaniea), autore Hoppe, fase. 47. 50. 53. 53. 57. 61. 69: Cyperacearum et uncaccarun samilia autore lloppe, tasc 9. 10.13

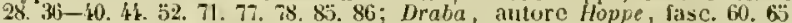
et inde a fascieulo 63 eomplurium generuun optiune illustruloues ct inde a fasciculo ba complurum generum optimac ilustratrones attore venerabili

Zweite Abtheilung. Kryptogamen (mit Ausselsluss der Pilze). lleft 1-31. 1798-1839.12.416 tab, col., test

(Lichenes exposuit ill. Laurer Gryphiensis, Jungermannieas of Algas Corda l'regensis.

J)ritte Abtheilung. Pitse. Heft 1-26. 1813-1848. 12. 304 tab. col. text 17. (Polyciculos 1-1 elaboravit L. P. F. Ditmar: faseiculos is. 10. 16. 21-2k Roletus 'elaburavit Friedrich Wilhelm. Theophilus Rosikows sodinensis: fasciculi 6 . Augusium Josphum b. Corda Pragensem; fasciculos $25-26$ exposint Augusfim Jospphum C. Corda Pra

$9980 \div$ Sturm, Johannes. De Rosa hierochuntina liber unus, in quo de cjus natura, proprietatibus, motibus et eausis pulchre disseritur. Lovanii, typ. Gerardi Rivii. 160 8. S. 96 p., praef. Bibl. Reg. Brux.

9981* Sturm, Johctm Christoph, pr. Extoypopix quaedan diducendi alias uberius argumenti de plantarum animalimmgue generatione. Altdorfii, typ. Schonnerstadt. $1687,4.24$ p. (Respondens: 11 ithetm Bechmann.)

9982* Sturm, Johamn IVilhelm, und Adalhert Schnizlein. Verzeichniss der Phanerogamen uni kryptogamischen Gefassplanzen in der Lmgegentl vol Nurnberg und Erlangen. Erlangen und Leipzig, Hinrichs. $1847.8 .44 \mathrm{p} .(1 / 3$ th. $)$

$9983^{*}$ Styx, II. E. Ueher tie Heilhrafte der Wandflechte als neuentdecktes, inlandisches Substitut der Clunarinde. I). Dorpat is1;. 8. $39 \mathrm{p}$.

(Aus den Yeueren uhonom. Repert. fir Livland, 3. Bd., 3. Stuch.)

9984* (Suardus, P'aulus, aromatarius.) Thesautus aromatariorum. (Inpressum Venetiis]per Albertinum Vereellensem currente I]CCCCCIIII. die .XXVll Junii.) folio. 44 fall. Btbl. univ. Lips. 
998: Suarez de Rivera, Don Francisco. Clave Lotaniea, o medicina hotanica, nueva y novissima. Madrid 1738.4 .280 p., 5 tab. aeneae, pessimae. B.

9986 * Succow, Friedrich Wilhelm Ludwig. Flora Mannhemiensis et vicinarum regionum cis et transrlienarum. Mannhemii, Scliwan et Gotz. 1822. II partes. 8. x, 244, 168 p., I mappa geogr. (2 th.)

$9987 \div$ Succow; Gustav. Commentatio plysica de lucis effectihus chemicis in corpora organica et organis destituta. Jenae, Bran. 1828.4. xv, 92 p., 1 tab.

(De lucis in plantas eftectu chemico: p. $43-62$.)

9988 Suckow, Georg Adolph. Ookonomische Botanik, zum Gebrauch seiner Vorlesungen. Mannlıeim und Lautern, Schwan und Götz. 1777.8. 436 p. (1 th. $)$

rossice: Экономитеская ботаника Хоктора Суккова. Съ ньиецк. нзыка иерев.; vertente Andrea Terjuew. (. IIcтер6. 1804. 4. Trautv.

9989 - Versuche über die Wirkungen verschiedner Luftarten auf die Vegetation, und aber dicjenige Luft, welche die Gervaclise liclern. Inuchen (G. Franz.) 1782. gr. 4. $(1 / 4$ th.)

9990 t Anfangsgrinde der theoretischen und angewandten Botanik. Leipzig, Weidmanı's Erben und Reich. 1786. 2 Theile. S. - 1: xx, 190 p., ind., 16 tab. - II : Band 1-2. xil, 938 p., ind. - ${ }^{*}$ Zweite vermelıte Auflage. Leipzig , Weidmann. 1797. 2 Theile. 8. - I: xxu, 299 p. 47 tals. - 11: Band 1-3. L.1, 738 , LVI, $632, x \cup 1,376$ p. $(7$ th. $)$

9991* Diagnose der Pflanzengatumgen nach der neusten Ausgabe des Linneischen Sexualsystems. Leipzig, Weidmanu. 1792. 8. vill, 423 p. $(11 / 3$ th. $)$

9992* Suckow, Lorenz Johann Daniel. Bezeichnung der vornehmsten Pflanzen und ihrer hultur zum Vortheile der Oekonomie. Vierte vernehrte und verbesserte Aullage. Jena, ahadenische Buchhandlung. $1794.8,110$ p. $(7 / 2+t h$.

9993* (Suffren, de.) Principes de hotanique extraits des ouvrages de Linné et suivi d'un Catalogue des plantes du Frioul et de la Carnia, avec le nom des lieux, oú on les trouve. Venise, chez Antoine Rosa. 1802. 8. 208 p.

(Nicolaus, Comes de Concina hunc a Domino de Suffen scriptum librum edidit.)

9994* Sullivant, William S. Musci Alleglianienses, sive Enumeratio muscorum atque hepaticarum, quos in itinere a Marylandia usque ad Georgiam per traetus montium anno domini 1843 decerpserunt Asn Gray et W. S. Sullivant. (interjectis nomnullis aliumde collectis.) Columbus in Ohione. $1846.8 .87 \mathrm{p}$.

(Huic splendide impressae 292 specierutn enumerationi accedit elegantissima speciminnm oninim exsiccatornm collectio; sunt

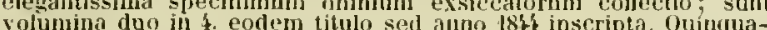
volunina doo in 4. eodem titulo sed anno 18 in inseripta. Quinduauna cum herbario in bibliothecis Delessertii, Monfagnit et Schimperi.)

9095 Contributions to the Bryology and Hepaticology of Nortl-America. Part I. 1847. 4.

(From the Hemoirs of the Anerican dcademy of arts and sciences, nov. ser. vol. III.)

9996 t Suringar, Gerhard Konrad Bernhard. Conmentatio in quaestionem: Quaeritur concinna expositio eorum, quae de foliorum plantarum ortu, situ, fabrica et functione innotuerunt, quae praemium reportavit. (Lugduni Batavorum 1820.) 4.63 p.

$9997^{*}$ Suśrutas. Áyurvédas. Id est medicinae systema a venerabili D'Hanvantare demonstratum a Suśruta discipulo compositum. Nunc primun ex Sanskrita in latinum semonem vertit, introductionem, annotationes et rerum indicem adjecit Dr. Franciscus Hessler. Erlangae, Enke. 1844-1847. Il voll. 8. - I: 1844, vil, 206, (2) p. $-11: 1847$. vill, $248,(3)$ p. $\left(9 \frac{1}{3}\right.$ th. $)$

(Volumen tertinm, in quo clavis continetur omnium plantarum Linnaeanus, nondum prodiit.)

9998 Soutaine, Maximilien. Essai sur I'histoire des vins de le Champagne. Reims, typ. Jacquet. 1846.12 .5 plag.

$9999^{*}$ Suter, Johann Kudolf. Flora helvetica, exhilsens plantas IIelvetiae indigenas Hallerianas et omnes, quae nuper detectae sunt ordite Liuneano. Turici, Orell, Fussli et Co. 1802. II roll. 12. I: LXIII, $345 \mathrm{p}$. - II: 416 p., ind. - ${ }^{*}$ Editionem alteram edidit ef auxit Johunn Hegetscheceiler. ib. 1822. Il voll. 12. - I: cxru, 408 p. - $11: 504 \mathrm{p} .(3$ th. $)$
10000 t Sutherland, James. Inrtus medicus Edinburgensis, or a cataIngue of the plants in the plyssical garden at Edinburgh, containing their most proper latin and english names, with an english alphabetical index. Fulinburgh, typ. Anderson. 1683. 8. $367 \mathrm{p}$., praef., ind. - Edinburgh, by Andrew Anderson. 1692. 8. Rivin.

10001 Svenonius, Johannes. Specimen de usu plantarum in Islandia indigonarum in arte tinctoria. Hafniae $1776.8 .32 \mathrm{p}$. (Respondens. Enarus Biarnesen Thorlacius.) B.

10002 Swammerdam, Johannes. De Filice mare Dodonat dissertatio epistolaris. Impr. cum ejus Bibliis naturae vol. Il. p. 906-910. в. anglice: Un the Felix mas, or male fern of Dodonaeus. Printed with his Book of nature, p. $151-153$. B.

$10003^{*}$ Swartz, Olof. Methodus muscorum illustrata. D. (praeside Carolo von Linne, (ilio.) Upsaliae, typ. Edman. 1781.4.38 p., 2 tab.

(llancce dissertatio, jam supra Nr. 6167 indicata, in llikstrom, Couspect. lit. bot. operibus Surtzit adnumeratur.)

$10004^{*}$ _. Nova genera et species plantarum, seu Prodromus descriptionum vegetalilium maximam partem incognitorum quac sub itinere in Indiam occidentalem annis $1783-1787$ digessit $0 . \$$ Holniae, Lpsaliae et Abuae, in bihliopolio Swederi. 1788. 8. x. $152 \mathrm{p}$. , ind.

10003 — Intrădes tal, innehăllande anmärkningar om Vestindien. Stockholm 1790.8 .27 p. B.

10006 Tal on Natural-Historiens uphof och framsteg i Sverige; hảllit för Kongl. Wetenskaps-Academien vid Praesidii nedlaggande, d. 8 Sept. 1790. Stockholm, typ. Zetterberg. 1794. S. $48 \mathrm{p} . \mathrm{W}$

$10007^{*}-$ Observationes botanicae, quibus plantae Indiae occidentalis aliaeque Systematis vegetabilinm ed. XIV. illustrantur, earumque characteres passim emendantur. Erlangae, Palm. 1791. 8. 424 p., 11 tal., (2 th.)

$10008^{*}$ Icones plantarum incognitarum, quas in India oceidentali detexit atrue delinenvit. Fasciculus 1. Erlangae, Palm. 1794. folio. 8 p., 13 tal. col. $\left(5 \frac{1}{4}\right.$ th. $)$

$10009^{*}$ _. Flora Indiae occidentalis aucta atque illustrata, sive descriptiones plantarum in Prodromo recensitarum. Erlangae, Palm. 1797-1806. III voll. 8. - 1: 1797. vill, 640 p., 15 tab. - II: 1800. p. $641-1230$, tab. $\{6-29$. -11$\}: 1806$. p. $\{231-2018$. index: $x p .\left(7 \frac{2}{3}\right.$ th. $)$

$10010^{*}$ Dispositio systematica muscorum frondosorum Sueciae. Adjectis descriptionibus et iconibus novarum specierum. Erlangae, Palm. 1799. 12, 112 p., 9 tab. col. $\left(1 \frac{1}{3}\right.$ th.

$10011^{*}$ - Genera of sjecies Orchidearum systematice coordinatarum. s. I. 1805.8 .105 p., 1 tab.

(Seorsim impr. ex Schrrderi Neuem Journal, Band 1.$)$

10012* Synopsis Filicum, earum genera et species systematice complectens. Adjectis Lycopodineis et descriptionibus novarum et rariorum specierum. Kiliac, bibliopolium acadenicum. 1806. 8. xvisi, 445 j., 5 tab. ( 3 th.)

$10013^{*}$ Lichenes americani, quos partim in Flora Indiae occidentalis descripsit, partim e regionilsus diversis Americae obtimuit Iconibus coloratis illustravit Jukob Sturm. Fasc. I. Norimbergac, Sturm. 1811.8.25 p., 18 tab. col. $(21 / t$ th. $)$

10044 (-) Grunderna till Läran on Djur och Vaxter. Stockholm. tryckt hos Anders Gadelius. $1813.8 .54 \mathrm{p}$. w.

$10015^{*}$ (-) Summa vegetabilium Scandinaviae systematice coordinatorum. Holmae, typ. Caroli Delén. 1814.8. 71 p.

$10046^{*}$ - Adnotationes botanicae, quas reliquit Olavus Swart-. Post mortem auctoris collectae, examinatae, in ordinen systematicum redactie atque notis et pracfatione instructae a Johann Emanuele II'ilstrum. Accedit Biographia Swartaii, autoribus Curtin Sprengel et Carolo Aelolpho Agurdh. Ilolmiae, typ. Norstedt. 1829. 8. Lxxiv, 188 p., 4 tab. $(21 / 4$ th.)

(Tabulac duae priores sistum effigiem ef sepulcrum Swartzu, duac posteriores Urchidearum varias icones.)

10017 Swayne, G. Gramina pascua: or a collection of specimens of the common pasture grasses, with their Linnaean and english names, descriptions and remarks, with 19 dried specimens. Bristol 1790. folio. 11 foll. ( $16 \mathrm{~s}$.) 
10018* Sweert, Emanuel. Florilegimm, tractans de variis floribus et aliis indieis plantis, ad vivum delineatum, in duabus partibns el quatuor linguis enciunatum. lirancofurti :1/./I., apued Antoninm hempner, subtilus autoris. 1612. folio. - I: (18) foll., 67 tab. 11: 43 tah. - *Amstelodami, apmil Johannem Janssonium. 1620. folio. - ${ }^{*}$ ib. 1631. folio. - *i1. 1641. folio. 67, 43 tab. col. "it) 1647. folio. - "il. 1655. Solio.

(Ellitiones rix inter se ditterunt; interdum ocenrrunt tabulae pictae. Privilerium operis datum est anmo 1609.$)$

10019" Sweet, hoberl. Hortus sulurlbanu. Loudinensis: or a Catalogue of plants cultivated in the neighbourhood of London, arranged to the Limuean systen ete. London, Ridgway, 1818. 8. xt, $242 \mathrm{p}$. $(18 s$.

$101020^{*}-$ Geraniacene. The natural order of Gerania, illustrated by coloured figures and descriptions, comprising the numerous and beautiful mule-varieties cultivated in the gardens of GreatBritain, with directiuns for their treatment. London, Ridgway. $1820-1830$. V voll. 8.500 foll., 500 titb. col. (19l.)

$10021^{*}$ - The british Flower-Garden : containing coloured figure and descriptions of the most ornamental and curious hardy herbaceous plants, including annuals, bienials and perennials, etc. The drawings by E. D. Smith. London, Simpkin and Marshalt. 1823-1829. Ill voll. 8. 300 tab, col. totidem foll. - "Series the second. London, Ridgway. 1831-IS3S. IV voll. 8.412 tab. col., totidem foll. (22l. 16s.)

10022* - The Trial of Robert Sweet, at the Old Bailey, before Mr. Justice Best. Upon a charge alledged against him, for feloniously receiving a hox, containing plants, stolen from the Royal gardens at kew. London, typ. Nichols. 1824. 8.31 p. (1s.)

- Cistineae. The natural order of Cistus, or Rock-Rose illustrated by eoloured figures and deseriptions of all the distinet sprecies and the most proninent rarieties, that could be at present procured in the gardeus of Great-Britain; with the best directions for their cultivation and propagation. London, Ridgway. 18254830. 8. xx, 224 p., 112 tals. col. (2l. 12s.6d.)

1002 - Sweel's Hortus britannicus, or a catalogue of plants cultivated in the gardens of Great-Britain: arranged in natural orders: with the aldition of the Linnoan classes and orders to which they belong etc. Loudon, Ridgway. 1827. 8. 492 p., ind. $(10 s .6 d)-.{ }^{*}$ Seveet's IIortus britanuicus, or a catalogue of plants indizenous or cultivated in the gardens of Greal Britain, arranged according to their natural orders, with references to the Limean class and order, to which eacls genus belongs; the whole brought up to the present time, and contains above 34,000 plants etc. Seeond edition. London, Ridgway. 1830. 8. xv, 623 p. (1l. 4s.) - tThirl edition, greatly enlarged and improved, edited by George Don. London, Ridgway. 1839. 8. xx, 799 p. (1l. 1 s.)

$10023^{*}-$ Flora australasiea, or a selection of handsome or curious plants, natives of New-llolland and the Southsea-islands, containing coloured figures and descriptions etc. Loudon, James Ridgway. 1827-4828. gr. 8.56 foll., ind, 56 tab. col. (1/. 16s.)

$10026^{*}$ _. way. 1831.8 .8 foll., 2 tab. col. ( $2 s .6(l$.

(Hujus operis nontisi fasciculum primum vidi in bibliotheea regia Berolinensi. Duodecim fisciculi, singulus binarum tabuarum comum explent. In quaqua tabula cquatuor platiarum ienses valde minutie repraesentantur.)

10027 Swinden, $N$. The beauties of Flora displayed, or Gentleman and Lady's pocket companion to the flower and kitehen gardell. London 1778, 8. 86 p., 4 tah. B.

10028 Switzer, $S$. A dissertation on the true "Cytisus $n$ of the ancients. Ed. 1l. London 1735. 8. Bibl. Radcliffe 0xon.

10029 Sylvius, Johannes. Oratio de Rosis. IJafniae 1601. 4. $3 \frac{1}{2} \mathrm{plag}$. B.

$10030 \div$ Syme, Patrick. T'emer's nomenclature of colours with additions, arranged so as to reuder it bighly uscful to the arts and seiences, particularly zoology, botany, chemistry etc. with 110 specimens of eolours. Second edition. Edinburgh, twp. Blackwood. 1821. 8. 47 p., 13 tal. col. Bibl. Webb.

10031 Symes, Michael. An account of an cmbassy to the kingdom of Ava, sent by the Governor-General of India, in the rear 1795 . L.ondon 4800.4.503 p., 27 tah. B.

- gallice: traduit par J. Costera. Paris, Buisson, an IL. 1801 IIl voll.

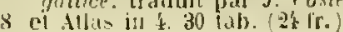

$10032 \div$ Symons, Jelinger. Synopsis plantarun insulis britannicis indigenarum; complectens characteres generieos et specificos secunfum systema soxuale distribntos. Londini, White. 1798. 8. vu, $207 \mathrm{p}$.

$10033^{*}$ Syreniusz Syreński, Szymon, latine Simon Syrennins. Zielnik, Herbarzem który zezyka Laciuskjego zowią etc. etc. i. e. Viridarium, Herbarium latino sermone vocant, hoc est descriptio propria nominum, formae, virtutis el virium singularum herbarum, arborun, frulicum et radieum efc. magna cum cura et consilio lingua polonica collecta et in octo libros divisa etc. Cracosiae, in typographia Basilii Skalski. 1613. folio. 1540 p., ic. xylogr. i. 1.

(A p. 1336-1:39 Appendix ejusden autoris do ty ramille fudaeorum in infantes lihristianos. Sequuntur 12 foll. indices latini, polonici et germaniel; in fronte sint 2 foll. cum dedieatione ef praefatione editoris D. Gabriel Joanticy ad reminam Sueciac frmm be hoc npere, quod vidi in Caesarea vilulohonensi ot in liegia parisiensi hibliothecis, ejusdue autore, summo l'olonorum illius aetatis bolanieu, fuse agit Arnold De monume stis hisl. nat. l'olnniae, p. $79-88$, et Adanisli Prodromns hist. rei herbariae in Polonia, p. $32-3\}$.

1003: Syrucžek, Eugen. Kurzer Alyriss der allgemeinen Forstbotanik zur Belebrung für angolsende Forstmánner und Oekonomen. Nelsst einem Anhange von österreichischen Forstgesetzen. Prag, Creducr. 1846. 8.681 p., 8 tab. col. $\left(2 \frac{1}{6}\right.$ th. $)$

$10033^{*}$ Szarzýnski, Stanislaus ron. De Secali cornuto cjusque virilsus nocentibus et salutaribus. D. Berolini 1844.8.43 p.

\section{T.}

10036* Tabernaemontanus, Jacolus Theodorus, cognomine. Neuw Kreuterbuch mit sehonen, kunstlichen und kehlichen Figuren und Konterfeyten aller Gewachss der hreuter etc. etc. Durch Jacabum Theodorum Tabernaemontonum, der Artznei Doctorem und Kurf. Pfalı best. Medicum zu Neuwhansen. Frankfurt a/M., dureh Nieulaum Basseum. 1588, folio. 818 p., indices, ic. xylogr. i. t. - "Das ander Thesl [Tubernaemontanus $\div$ 1590] durch Nicolaum Braun. il). 1591 . folio, $822 \mathrm{p}$, decem indicus, ic. $x y \log r$ i. 1. - "New vollkomentlich ḱreuterbuch, mit schönen und kuastlıchen Figuren aller Gewachs der Baumen, Stauden und Kráutern, so in Teutschen und Welschen Landeu, auch in Hispanien, Ost und Westinclien oder jo der Newen Welt waelsen, derer uber 3000 eygentlich beschriebea werden, anch deren Inderscheidt und Wurchung sampt ihren Namen in mancherlei Sprachen angezeigt werdent. derengleichen vormals nie in keiner Sprach in Truek tommen: ete. durch Jucobum Theodorum Tabernaemontarum. Jetzl wiederumb, etc. durel, Cusparum Bauhinum. ( 3 Theile.) Frankfurt a/N., durelı Nicolaum llolinam. 1613. folio. 686,844 p., indices, ic. $y$ logr. i. 1. - Franeofurti a/MI., apud Paulum Jacolım. 1625. III voll. folio. - "Tormals dureh Casp. Bouhinum mit sonderem Fleiss gebessert, itzt wiederumb aufs neue ubersehen, mit uutzliehen Alarginalien, Synoymis, Registern und andern vermehrt durch Hieron:mum Buthinum. Basel, Jakob Werenfels. 1664. folio. $x$ p., ic. . ylogr. i. t. - "Neu vollkommen kráuterbueh, darinen uber 3000 Kráter mil sehonen und kunstliehen Figuren, auch deren Lnterscheid und Wurkung, samm ihren Namen in mancheslei Sprachen beselırieben; desgleichen anch. Wie diesellige in allerhand hranchheiten, beyde der Mensehen und des liehs sollen angewendet $u$. geliraucht werden, augezeigt wird. Erstlichen durch Casp. Bouhinun mit sebr nutzlicheu Marginalien, Synonymis, neuen Registern u. anderen vermehrt. Und mun zum drittemal aufs fleissigst ubersehen, an unzahlbaren Orten absonderlich verbessert, an scheinbaren Mlängelı durehaus ergänzt, und endlichen zu hochverlangter Vollkommenheit gebracht. Basel, gedrucht u. verlegt bei Jolınn Ludwig liönig und Johann Jirandmyllern. 1687. Iolio. 1529 p. ind. . ic. $x y \log r$. i. t. - ${ }^{*}$ ib. 1734 . folio. (non dilfert.)

$10037^{*}$ (—_ Eicones plantarum seu stirpium, arborum nempe fruticum, herbarun. fructuun, lignorum, radieum omus generis: tam inquilinorum quam exoticorum, quae partim Germania sponte protucit, partm ab extexis regionibus allata in Germania plantan- 
tar: in gratian medicinae reique lierbariae studiosorum in tres partes digestae. Adjecto indice gemino locupletissimo. Curante Nicoluo Bassaeo, typographo Francofurtensi. Francofurti a/M. 1590. 4 obliquo. $112 \mathrm{~s} \mathrm{p.,} \mathrm{ind.}$

(lcones sunt 2253 , binae in singula pagina, ex opere praecedeut sumtae ac seorsin edilae.)

10038 Tachard, Guy. Second voyage du Père Tachard et des Jesuites au royaume de Siam. Paris, Daniel llortemels. 1689. 4. 416 p., tab. - Ansterdam 1689. 12.369 \%,, tab. B.

10039* Taddei, Gioacchino. Repertorio dei veleni e conlravveleñi. Firenze, typ. Pezzati. 1835.11 voll. 8. - 1: xvil, 333 p. - Il: 384 p. $\left(15 \frac{1}{2}\right.$ paoli.)

100 \% Tagault, $J$. De medicamentis simplicibus purgantibus. Basileae 1537.4.

100 '1 Tagliabue, Alberto Limneo. Saggio sulla coltivazione usi o classazione del garofano. Slilano, per Giovanni Silvestri. 1837.8.80 p. ( 1 Lira 9 c.)

$100: 2 *$ Tagliabue, Giuseppe. Storia e descrizione della Littaca geminiflora. leettera al Sign. Giuseppe Acerbi. (Biblioteca italiana Nr. 1.) Milano, typ. Pirotta. 1816.8 .14 p., 1 tab.

(111. Comes Hencliel v. I). certiorem me fecit, hanc commentationem il (iovanni Brignoli scriptam esse.)

100.3 Taglini, Carlo. Lettere scientifiche sopra varii dilettevoli argomenti di lisica. Firenze 1747.4.304 p.

(Iuc pertinet epistola secunda, p. 37-9k: "Se l'Aglio trapiantate al pie del Rosaio possa conferire alla Rosa una maggiod fragranza " in qua fabulae aliquae botanicae refutantur.)

100\%' Tanaro, Tincenzo. L'Economia del citadilo in villa. Bologna 1644. 4.

$10045^{*}$ Tappe, Jakob, latine Tappius. Oratio de Tabaco ejusque hodierno abusu. Helmestadii 1660.4 .5 plag. - ${ }^{*}$ Tertio edita auctior. Helmstadii, typ. Muller. 1673. 4. (22) foil.

10016t Tardent, Charles. Essai sur l'histoile naturelle de la Bessarabie. Lausanne, Ducloux. I\$4 1. $8.88 \mathrm{p}$

A p. 27- S8: Cataloguo des plantes qui croissent naturellement en Bessarabie et aux environs dodessa.

100.7 Tarelli, Camillo. Ricordo d'agriculıra. Venezia 1567. 8. Trevigi 1601.8.

(Hall. Bibl. bot. 1. 3'0-3'1.)

10048* Targioni-Tozzetti, Anlonio. Sulla Datisca cannalina. (Firenze 1835.) 8.7 p

(Ati della tccad dej Georgofili di Firenze, vol. MIV.)

$100: 9^{*}$ Kapporto delle osservazioni fatte al giardino dell Aecademia dei Georgofili anno 1\$36. (Firenze 1836.) 8. $11 \mathrm{p}$ (Atti della Accadenia dej Georgofili di Firenze, vol. XV.)

10030 Targioni-Tozzetti, Giovanni. De praestanlia et usı plantarum. Pisis 1734 . folio. Desid. Banks.

$10051^{*}-$ Prodrumo della corografia e della topografia fisica della Toscana. Firenze, nella stamperia imperiale. $1754.8 .210 \mathrm{p}$.

10032 Ragiunamenti sull' agricoltura toscana. Lucca 1759. 8. 216 p. B.

10033 Relazioni d'alcuni viaggi fatti in diverse parti della Tuscana. Edizione seconda, con cupiose giunte. Firenze $1768-$ 1779. Xll tomi. 8. - 1: 1768. 464 p., 3 tab. aen. - Il: 1768. 540 p., 2 tab. $-111: 1769.473$ p., 2 tab. $-1 \mathrm{~N}: 1770.478$ p. 2 tab. - V: 1773. 474 p., 2 tab. - V1: 1773.430 p., 2 tab. Vll: 1774. $4 S 5$ p., 1 tab. - VIIl: 1775.528 p., 2 tab. - IX: 1776. 456 p. - X: 1777. 466 p., 8 tab. - XI: 1777. 455 j), 4 tab. - Xil : 1779. 446 p. B.

1003i * Joannis Turgioni-Tozzetti Catalogus vegetabilinn marinorum musei sui, opus posthumum ad secundam partem novolum generum plantarum celeberrimi Petri Antonii Jicheli inserviens, cum notis Octaviani Targioni Tozzetti Johunnis filii. Florentiae, tvy). Tofanis. 1826. folio. (Fase. 1.) 91 p., 3 tab. (18 paoli.)

(Cf. annotationem, guam supra sub Nr. 6915 dedi.)

10055* Targioni-Tozzetti, Ottaviano. Sulle Cicerchie Memoria. Firenze, ty]. Carlieri. 1793. 8. 72 p.

$10056^{*} \longrightarrow$ Istitutioni botaniche. Firenze 1794 . Il Voll. 8. *Ed. 1]: Firenze, Piatti. 1802. Il parte ossia lll tomi. 8. - I: vill, 392 p., 12 tab. - Il: xxu, 440 p. - Ill: 589 p. - † Ed. Ill : Fi-

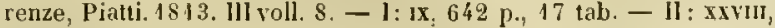
552 p. - III: 684 p.

Pritzel, Thes. Jit. bot.
10057 Targioni-Tozzetti, Otlaviano. Lezioni di agricultura specialmente toscana. Firenze, presso Piatii. 1802-1804. Vivoll. 8. 184, $216,294,190,195,240 \mathrm{p}$.

$10058^{*} \ldots$ Sopra alcuni funglui ritrovati nell' apparecclio di una frattura complicata d'una gamba unana. Modena 1805. 4. 24 p., 1 tab.

(Seorsim impr. ex Act. della societa italiana delle seienze, tom. Xlll.

$10059+\ldots$ Prospetto per la Flora ecunomica fiorentina. Verona, typ. Gambaretti. 1808. 4. 31 p.

(Inserito nel tomo Xlf della società ital. delle scienze.)

$10060^{*}$ Dizionario botanico italiano che comprende $i$ nomi volgari italiani specialmente loscani, e veruacoli delle piante raccolti da diversi autori e dalla gente di campagna col corrispondente latino Linneano. Firenze, presso G. Piatti. 1809. II partes. 8. 1: xvı, 195 p. - 11: 124 p. - Ed. Il: Firenze 1825. Il voll. $\mathrm{s}$.

$10061^{*} \ldots$ ___ Rapporto del Professore di botanica Otlaviano Targioni-Tozzelti. (Firenze 1809.) 4. 15 p.

10062* Ohservationum botanicarum Decas I - V. (Flurentiae 180s-1S10.) 4.55, 103 p., 13 tab.

(Ann. Mus, imp. Florent. vol. I et II.)

$10063^{*}$ Lettera contenente l'istoria d'una malatia prodotia dal Rhus Vernix. (Firenze 1817.) 8. 24 p.

$10064 \div$ - Della necessita di osservare le parti della fruttificazione avanti e dopo la florescenza. Menuria. Nodena, tipografia camerale. $1825.4 .14 \mathrm{p}$.

$10065^{*}$ Tarnow, J. M. Ueber die zur Lohe tauglichen Meklenburgischen Gewaclsse. Rostock, Nuller. 1794.8.40 p.

10066 Tartaglini, Lione. La prima parte dell' Erbolario di Lione Tarlaglini da Fojano di Valdichiane. Fiorenza 1558. 12. s.

$10067^{*}$ Taschenberg, Ernst L. Handbuch der botanischen hunstsprache. Mlit doppelten, alpluabetischen Registern und 2 Kupfertafein verselı. Hallo, Anton. 1843. 8. xvi, 184 p., 2 tab. $(3 / 4 t h$.

$10068^{*}$ Deutschlands Pllazengattungen oder charakteristische Merkmale der in Deutschland wildwachsenden Gattungen der Phanerogamen, einiger Kryptogamen und der uberall angepflanzten auslandischen Büme und Straucher, besonders zum Selıulycbranche zusammengestellt. Merselıırg, Nulaudt. 1845. 8. $\mathrm{x} i \mathrm{t}, 147 \mathrm{p} .(1 / \mathrm{t}$ th. $)$

$10069^{*}$ (-) Botaniscbe Abbildungen zur Erlaiterung des naturlichen Systems der Gewachse, sowie der Charaktere fast aller einheimischen Pflanzengattungen. Berlin, Reimer. 1845. 4. 8 p., 44 tab. $\left(3 \frac{1}{3}(h)\right.$.

(Librum anno 4833 ah ill. Hermann Burmeister inchoalum anno 1845 absolvit Einst $L$. Taschenberg.)

$10070^{*}$ Taschner, Christian Friedrich. De duabus novis Trichomanum speciebus de earum nec non aliarum hujus generis plantarum structura. Jenae 1843.4.35 p., 2 tab.

$10071+$ Tassin, L. F. Rapport sur les Dunes du golfe de Gascogne. Mont de Marsan, typ. Delaroy. an X. (1802.) 8. 54 p

$10073+$ Tatin, $A$. Priucipes raisonnes et pratiques de la culture des arbres, arbrisseaux et arbustes etc. Quatrième édition remplaçant les trois premières connues sous le titre de Catalogue raisonné. Ieux parties. Paris, chez l'auteur. 1811.8. - 1: vis, 273 p. II: 270 p.

10073 Tatti, Giovanni. Della aguicoltura libri V. Venezia 1560. 4

1007' Taube, Johann. Beiträge zur Naturkunde des Herzogthums Zelle (und Luneburg). Zelle 1766-1769. 8. 264 p.

1007 Taunay, $C$., et $L$. Riedel. Manoal do agricultor brasileiro. Rio de Janeiro 1839 . w.

$10076+$ Tausch, Ignaz Friedrich. Index plantarum, quae in horto excellentissimi Conitis Josephi Hulabaila de Canal coluntur (cum adnotationibus). Pragae 1821.4. 12 P.

$10077^{*}$ Hortus Canalius, seu plantarum rariorum, quae in horto betanico illustr. ac excell. Josephi Malabaila Comilis de Canal coluntur, jcones et descriptiones. Touns mimus. Decas I. Pragae, typ. et lithographia Theophili llaase. (Calve.) 1823. folio. $28 \mathrm{p}$, 10 tab. col., effigies Comits Canat. (nigr. 8 th. - col. $11 \frac{1 / 3}{3}$ h.

(Decaden alteran prodisse lego, unllibi vero vidi.) 
$10078+$ Tavanti, Giuseppe. Memoria in risposta al Programma proposto sotto il di' 7 Sett. 1803 dalla 11. Societa economica fiorentina detta do' georgofili premiata trell' adunanza del di' 1 Giugno 1805. Firenze, typ. Giglio. $1805.4,36$ p., (12) foll., tah. 3-6.

$10079+$ Memoria in risposta at Programma proposto sotto il di' 8 Maggio 1805 dalla R. Societa economica Fiorentina detta de' georgofili premiata ucli' arlunanka del di' 6 Maggio 1807. Firenze, typ. Giglio. 1807. 4.62 p.

$10080 \div$ - Trattato teorico-pratico completo sull' ulivo. etc. Fi-

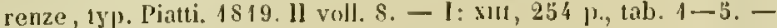
11: 239 p., tab, $6-12$.

10081* Tavernier, Jean Baplisle, Baron de. Sis voyages en Turquie, en Perse, anx Indos. Paris 1676.4

(Redeunt pluries; sunt versiones anglicae, germanicae, italicae. Contenta hotanica recensentrur apud Uall Bibl bot L 596. - I) ejus vita et fatis of Sclubert Bigeraphich und lirzihlungen, Band I. p. $660-233$.

10082* Teichmeyer, Hermann Friedrich. Programma 11. de Caapeba sive Parreira brava. Jenae 1730.4 . (8) p.

$10083^{*}$ Institutiones botanicae, seu brevis in rem herbariam introductio. Jenae, typ. Fickelscherr. 4731 . 3.79 p., praef. — +ib. 1737. 8. 79 p., praef. — " l'rancofurti et Lipsiac 1764.8. 79 p., praef.

10084* Teindl, Johann Ubald. Die Unkrautpflanzen und Ieren Vertilgungsart; nebst einer botanisch-ukonomischen Beschreibung derselben. Wien, Mürschner, 1827. 8. xII, 294 p. $\left(1 \frac{1}{1}\right.$ th. $)$

10083 Templeman, Peter. Curions remarks ant observations in pliysick, anatomy, chemistry and botany. London 1753. 8 . $\mathrm{H}$.

10086 Tench, Watkin. Compleat account of the settement of Port Jackson. London 1788. S

germanice: Reise nach der Botany-Bay. (Neue Geschichte der Sec-und Landreisen, V1. 2.) IIamburg, Hoffmamn. 179'. 8. (1 th.)

$10087^{*}$ Tengström, Johannes Magnus a. 1) fructus in phanerophytis evolutione. D. Helsingforsiac $4841.4 .20 \mathrm{p}$.

10088* Naturhistoriens studium i Finland forre Limnés tid. D. I. Elias Tillandz och hans föregingare. llelsingfors 1843. 8. $32,16 \mathrm{p}$.

$10089^{*}$ Stirpes cotyledoneae paroeciae Pojo. D. Helsingforsiae $4844.8,22$ r.

$10090^{*}$ - In distributionem vegetationis ner Ostrobothniam collectanea, D. Ilelsin 2 forsiae $1846.8 .24 \mathrm{p}$

(Conf. supra Nr. 7085 vocem Nylander.)

$10091 \div$ Tenore, Nichele. Quadro ragionato delle botaniche lezioni. (Napoli 4802.) 4. 39 p. (20 Gr.)

10092* (— Catalogo delle piante del real giandino bolanico di Napoli. Napoli, nella stamperia reale. 1807.16.112 p.

(lndices scminum hurti botanici Neapolitani eun animadversionilus vidi annorum $182 \%-18 \mathrm{k}^{\circ}$.

$10093^{*}$ (—) Corso delle botaniche lezioni. Napoli, typ. Orsini 1806. Il voll. S. - 1: Trattato di fitognosia. Tomo primo: Vocabulario metodico ed alfabetico di botanica tecnologia, xvi, $511 \mathrm{p}$. - TEl. II : Napoli, ty p. Sancriacomo el diarii encyclopaedici. 1816 - 1823. IV voll. 8. - 1-11: Trattalo di fitugnosia. 4816. 300 354 p. $(1$ D. 20 G.) - III: Trattato di fito-fisiologia. $1821.356 \mathrm{p}$. ind. ( $80 \mathrm{Gr}$ ) $-\mathrm{IV}, 1-2$ : Flora medica universale, e Flora particolare della provincia di Napoli. 1823. 8. 620, 178, 44 p., ind (2 D.)

10094* (-) Trattato di fitognosia, ossia esposizione della glossologia, tassonomia e fitogrulia. Terza edizione. Napoli, Tizzano 1833. $8.404 \mathrm{p}$.

(Elian inscribitur: Corso delle botaniche lezioni, vol. I-II.)

$10093^{*}$ _- Saggio sulla quílita medicinali delle piante della Flora Napolitana, et sulla maniera di servirsene per surrogirle alle Jroghe esotiche. Napoli, typ. Coda. 1808. 8. 776 p. - tSeconda erlizione accresciuta di circa 150 nuovi articoli di piante indigene. Napoli, tipografia del giornale enciclopredico. 1820. 8. vi1s, $295 \mathrm{p}$ (60 Gr.)

(Etiam inscrihitur: Corso delle botaniche lezioni, vol. 1T. parte Il.) 10096 - Memoria sull' Arachide americana, Napoli 1807.4.

$10097 \div(-)$ Catalogo delle piante del giardino botanico del Signo Principe de Bisignano. Napoli, typ. Corriere. 1809. 8. vm, 32 p.
10098 Tenore, Michele. Flora Napolitana, ossia descrizione dello piante indigene del regno di Napoli e delle piu raro specie di piante esotiche coltivate ne' giardini, deI Cavalier Michete Tenore, Dottor. in medicina, ete. Napoli, nella stamperia reale. $1811-1838$. Vivoll. folio. - 1: 1811-1815. LxxI1, 324 p. - 11: 1820.398 p. - III: $1824-1829 . x 11,412$ p. - N: 1830.358, xril p. - V: 1835 - 1836. xiv, 379 p. - Jcones in folio maximo: 250 tab. col. (2125 Lire ital.)

10099 * - Laccolta di viaggi fisico-botanici effetuiti nel regno di Napoli dai collaboraturi della Flora Napolitana. Articoli estratti dal gionale enciclopedicu. Vol. I. Napoli, 2yp. Migliaccio. 1812. 8. $477 \mathrm{p}$.

$10100^{*}(\longrightarrow$ Catalogus plantarum horti regii Noapolitani ad anmut 1813. Neapoli, typ. Trani. 1812. 4. vir, 122 p. $(50$ Gr.) - "A1 Catalogum plantarum horti regii Neapolitani anno 1813 editum appendix prima. Neapoli 1815 . 8. v1, 76 p. - " Ed. II. Neapoli. typ. diarii encyclopaedici. 1819.8 . $\$ 9$ p. (60 Gr.)

10104 Catalogo della collezione agraria del real giardino della. piaute. Naproli 1815. 8. (50 Gr.)

$10402+-$ Osservazioni botanico-agrarie intorno la collezione de Cereali del real orto hotanico di Napoli. Napoli, Sangiacomo. 1847 8. $32 \mathrm{p}$.

(Estratto dal Giornale enciclopedicn di Napoli, anno .11, Mr. 1.)

$10103^{*}$ Discorso pronunciato in occasione dell' apertura delli nuova sala destinata per le publiche lezioni, nel real orto botanico di Napoli, il di 7 Maggio 4848. Nopoli 1818 . 4. et 8.30 p., 1 tal. (20 Gr.)

$10104 \div(\longrightarrow$ Ad Florae Neapolitanae Prodromm appendix quarta. Neapoli, typ. diarii encyolopaedici. 1823. 8.36 j.

$10103^{*}(\longrightarrow$ ) Ad lilorae Neapolitanae Prodromum appendix , uinta, exhibens centurias duas plantarum nuperrime detectarum; nec uon specierum novarum vel minus rite cognitarum, characteres et illustrationes. Neapoli, apud R. Marotta et Vanspandoch. 1896. \&. 34 p. $(30 \mathrm{Gr}$.

$10106^{*}$ Memoria sulle specie e varieta di Crocchi delli Flora Napolitona. Napoli, presso R. Narolla e Vauspandocls. 1826. 4. 13 p., 4 tab. col. ( 60 Gr. - in charta velina: 1 D. 20 Gr.)

$10107^{*}(-)$ Osservazioni sulla Flora Virgiliana. Napoli, Zambraja. 1826. 8.18 p. $(20 \mathrm{Gr}$.

$10108^{*}$ Osservazioni sulla Flora di Teocrilo e degli altri lunecolici greci. (Napoli) s. a. 4.7 p.

10109 Viaggio in alcuni luoghi della Basilicata : della CaIabria citeriore. Napoli 1827. 8. (60 Gr.)

10110 Cenno di geografia fisica e botanica del regno di Napoli. Naproli 4827.8. 2 mapl) geogr. (1 1). - in charta velina: (1). 50 Gr.)

$11111^{*}$ Essai sur la gègraphie physique et botanique du joyaume de Naples. Naples, inprimerie française. 1827.8 .130 ). 2 mapp. geogr. ( 5 fr. - in charta velina: 7 fr.)

10112 Memorie lette alla Reale Accademia di scienze di $\mathrm{x}_{\mathrm{i}}$ poli negli anmi $1822-1827$. Napoli 1834 . 4. 7 tab. (1 U. $50 \mathrm{Gr}$ )

(Insunt: Acer Lobelii, Thoya pyramidalis, Dracaena Boerhavii. oxonis Dehnhter(lii , Onnithogalum garganicum, Ivia ranitlora. (Campanulat sarwanica.)

101136 Viaggio per diverse parti d'ltalia, Svizzera, Fancia, Inghiltera e Germania. Napoli, dalla stamperia francese. 1828. IV voll. S. - I: 356 ]. - II: 403 p. - II] : 528 p. - IV: 337 p. (5 D.)

10114:* Memoria sul Pruno Cocuniglia di Calabria. Napoli 1828.4. 9 ]., I lab. (30 Gr.)

10113 - Succinta relaziono del viaggio fatto in Alruzzo ed in "Icune parti dello stato pontificio nell' esta del 1829 . (Letla all" Accademia Pontaniana nella tornata de' 6 settembre dello stesso anno.) Napoli, nella stamperia della societa filomatica. IS30. 4. 90 p. $(60$ Gr. $)$

$10116^{\circ}+$ Relazione del viagrio fatto in alcune luoghi di.Abruzzo citeriore nella state del 1831. Napoli, ty]. Tizzano. 1832. 8 132 p., 1 mappa geogr. (60 Gr-)

$10117 \div-$ Se la voce Ulva denotasse presso gli antichi la generaliti dolle piante arpuatiche zahustri, overo la sola Typha 
latifelia; riflessioni seguite da alcune osservazioni sul papis'v. (Napoli) 1831.4.29 p.

$10118^{*}$ Tenore, Michele. Syllege plantarum vaseularium Florae Neapolitanac hucusque detectarum. Neapoli, typ. Fil)reni. 1831. 8. (Cum appendicibus 1-3.) 639 p. (3 I).) - Appendix quarta: 52 p. *Appendix quinta: (Neapoli, Tizzano. 1842.) 56 p-

1011! - Memeria sul genere Musa, colla descrizione della Nusa speciosa; letta all' Accademia Pontaniana in Agosto 1830. 4. 3 tab. (1 I.)

(Atti della Accademia Pontaniana.)

$10120 \div-$ Memoria sopra diverse specie del genere Musa; letta all' Accademia 28 Marzo 1830. Napoli 1832.4.35 D., 3 tal.

(Atti della decademia l'ontaniana vol. Il. fasc. I.)

$10121^{*}$ Memoria su di una muova felce e su varie altre specic. Napoli, typ. Fernandes. 1832.4 .32 p., 5 tab. (1 D. 20 G.)

10122 Saggio sulla botanica italiana. Napoli 1832. 8. (20 Gr.)

$10123^{\circ}$ Memoria sı di una nuova specie di Angelica. Napoli, typ. Fernandes. 1837 . 4. 9 p., 1 tab. col.

$10124 \div-$ Nuove ricercle su la Caulinia occanica. Memoria letta alla real accadenia delle scienze di 3 Aprile 1838. (Napoli 1838.) 4. 43 p., 1 tals.

$101234 \div$ Memoria sulle diverse specie e varieta di Cotone coltivate nel regno di Napoli, colle istruzzioni pel coltivanento del cotone siamese e le notizie sulle altre specie, di cui puossi provare l'introduzione. Napoli, typ. Tramater. 1839.4 .34 p, 2 tal.

$10196^{*}$ ______ Sopra i due nuovi generi di piante Syncarpia e Donzellia Menoria. Modena 1840.4.13 p., 2 tab. col.

(Mem. della Accad. di Modena, ton. XXIl, p. 226-236.)

$10127 \div$ Ricerche sull' araneio fetifero. Modena, dai tipi della R. D. Camera. 1843.4 .10 p., 1 tah.

(Mem. dellu Accad, di Modéna, tom. Xxil!.)

$10128+(-)$ Catalogo delle piante che si coltivano nel R. orte botanice di Napoli, corredato della pianta del medesime e di annoıazioni. Napoli, lipografia dell' Aquila di V. Puzziello. 1845. 4. xu, 104 p., 1 tals.

10129 * Tenzel, Franz Berhhard Richard. Beschreibung einer besondern Pflauzenkrankheit. Kenpten (Erlangen, Heyder.) 1819. $\mathbf{8}$. 15 p. $(1 / 12$ th.

$10130^{*}$ Nemenclater systematicus in Leonarli Plukenetii plıytographiam. Erlangae, typ. Junge. (Ileyder.) 1820. 8. $106 \mathrm{p} .(1 / 2$ th.) (Erore typographico annus $1830 \mathrm{in}$ fronte libelli indicatur.

$10131^{*}$ Termo, $M$. IF. Schlussel zur Botanik nach Jinués System io Ǩlassen und Ordnungen. Leijuzig 4837 . ar. 12 . v1, $135 \mathrm{p}, 4 \mathrm{tab}$, in folio. $(2 / 3$ th. - col. 1 th. $)$

suecice: lnledning till Botauiken. Stockbolm 1838. 12. 110 p., 1 tab.

10.132* Tesanek, Johunnes. De radice lpecacuanhae. D. Vindobonac, typ. Velserrenter. $1841,8.28 \mathrm{p}$.

$10133 \div$ Tesnière, T. $J$. Essai sur les poisons végétaux les plus cummuns en France et leurs antidotes. D. Montpellier, tyj. Martel. 4809.4 $19 \mathrm{p}$.

1013't Tessier, Heni Alexandre. An similis vegetantiun et animantium generandi modus? D. prieside Felix Iricq d'szyr. Parisiis, typ. Quillau. $1775.4 .8 \mathrm{p}$.

$10133 \% \div$ Traité des maladies des grains, ete. Paris, IJérissant. 1783. 8. vilı, 351 p., 6 tab. cul.

$10136 \div-$ Résultats et expériences faites a Rambouillet sous les yeux du roi, relativement a la maladie du froment, appellée earie ete. Paris, Hérissant. 1785.8 .19 p. $(30$ c.)

$10137 \div-$ Noyens éprouvés pour préserver les fromens de la carie. Avignon, Blery. $1786.8 .15 \mathrm{p}$.

$10138 \div$ - Instruction sur la eulture du eoton en France. Paris Huzard. 1807. 8. 11 p. - + Ed. Il: Paris, Huzard. 1808. 8. 30 p.

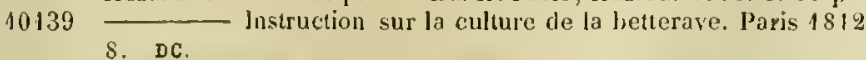

10140 * Tettelbach, Moritz. Ilulfsblatter zum Studium der Botanik, nach der Natur gezeichnet. IHerausgegeben von Traugot und Jakob Seidet. Dresien $1821-1825.8 .45 \mathrm{ial}$. lithogr. (1 th.)

$10141^{*}$ Teubera, Ernst Felix Thcodor von. De herbae Digitalis purpureae vi pluarmacodynanica. D. Jenae, typ. Schlolter, 1\$40. 8. 29 10112t Textor, Benclictus. Stirpium ditferentide ex Dioscoride secundum locos communes, opus ad ipsarum plautarum comnitionem admerlum conducibile. Parisis, Simon Colin. 1534. 12. 103 foll. Bibl. Reip. Paris. - Venetiis, in offeina Divi Bernardini 1537.12. Rivin. - ${ }^{*}$ Impr. cum Hieronymi Tragi De stirpium nomeoclaturis. Argentinae, excudefyat Wendelinus Rihelius. 1552. 4. 1. 1129 -1200 .

$101: 3$ Textor, Vincent. Traité de la nature du vin, et de l'abus, tant d'icelui, que des autres breuvages, par le vice d'yvrognerie. Genève, Gabriel Clartier. 1604 . S. $\mathrm{s}$.

$1014 . *$ Thalius, Johennes. Sylva IJercynia, sive Catalogus plantarum spente nascentium ia montibus et Jocis plerisque Jereyniac Sylvae, quae respicit Saxoniam, conscriptus singulari studio a Joh. Thalio, medico Northusano. Impr. cum Camerarii Horto medico. Francofurti ad Moenum, Joh. Feyerabend. 1588.4. 133 p., 9 tab. ic. xylogr. (Editionem "Nurthusae $167 \%$. 4. " frustra ubi(jue quaesivi.)

$10145^{*}$ Thebesius, Gearg Daniel. Deutliche und ausührliche Nachricht von Rauch- und Schnupfahack. (Halle) 1713.4.56 1). - Halle, Hendol. $1751.4 .84 \mathrm{p}$.

$10146^{*}$ Thedenius, Knut Fredrik. Bidrag till Kánuedomen om Najas marina L. Stockloolm, typ. Norstedt of suner. 1838.8 .13 p., 1 tab. (Kungl. Fetensk. Acad. Handl. 1\$37. p. 2't]-243.) germanice: von Oum. Dotzauer fil Flora 1810.I 1\%. 305-320 cum ta-

$10147^{*}$ Jolm, typ. Norstedt et Sorrer. $1839.8 .53 \mathrm{p}, 1$ tal.

(Kongl. Vet. Acad. Handl. for år 1838. p. 2, 76.)

$1011.8 *$ Theile, Friedrich. De vilibus Daphnes Nezerei nonnulla. D. Lipsiae 1838. 8. $43 \mathrm{p}$.

$10149^{*}$ Theis, Alexandre de. Glossaire do hotauique, ou Dictionnaire etymologique de tous les noms et termes relatifs a cette seienee. Paris, Gabriel Dufour. 1810. 8. xxvi, 542 p.

("Plusieurs hotanistes se sont bornés a expliquer les noms qui viennent des langues grecque et latine, tandis qu'jl en est un grand nombre dérivés de fancien celtique et des langues orientales, qu'ils ont entierement négliges. $M$. de Theis a puisé dans ces sources etc." Jussieu. Hauy ot Desfontaines, commissaires.)

t italice: Spicgazione etimologica de' nomi generici delle piante. tratta dal glossario di botaniea di Alessondro de Theis e da altri tratta dal gossario di hotaniea di Alessondro de Theis

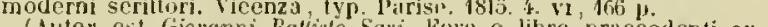
(Autor est Giovanni Batlista Savi.
scriptum traoslatioubus adscribu.)

10130t Theophrastus Eresius. Theophrasti de historia et de causis plantarum libros ut latinos legeremus, Theodorus Gaza. (in calce:) Impressum Tarvisii, per Bartholomaeum Confalonerium de Salodio anno domini 1483 die XX Februari. folio. 155 foll. sign. A-L et a-k. (Hain Repert. Nr. 15,491.) Bibl. Deless.

$10151^{*} \ldots$ Theophrasti Eresii Opera omnia. Theodoro Gaza interprete, graece et latine. Venetiis, Aldus. mense Martio 1504. folio. 273 foll.

(Insunt De historia et de causis plantarum, foll. 10y-20k.)

$10152^{*} \longrightarrow$ Theophrasti de historia plautarum el de causis plantarum. Impr. cum Aristotele. s. I. 1513 . folio.

$10133^{*} \longrightarrow$ Theophrasti de suffuticibus, herbisque ac frugibus libri quatuor (Historiae plantarum libri VI-1X), Theodoro Gaza interprete. Accedunt Planii Natur. listor. lib. XX. capita tria. (In calce:) Argentorati, per Jlenricum Seybold, mense Augusto 1528. 8 .

$101345+$ Theophrasti le historia et calssis plantarum libri quindecim, latine, Theodoro Gaza interprete. Parisiis, alud Aegidium Gonrmonetum. 1529. 8. 354 p., praef, ind. Babl. Juss.

$1015 \%$ " Theophrasti Eresii De historia plantarum et de causis plantarum, latine, Theodoro Gaza interprete. Impr. cum Aristotele. Basileae, Cratander. 1534. Iolio. 264 p.

$10156^{*}$ Theophrasti Opera, quae quidem a to saeculis adhuc restant, omnia: summo studio partim binc iode conquisita, atque in unum veluti corpus utunc primum redacta, partim a multis (puilus etian hactenus scatebant mendis, doctorum virorum industria ac meliorum exemplarium ope repurgata. Iisileae (1544.) folio. $291 \mathrm{p}$

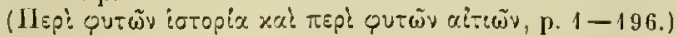

$10137+$ Dell' historia delle piante di Theophrasto libri III tradutti novamente in lingua italiana da Michel Angclo Biondo medico. elc. Vineria, typ. Biondo. 1549. 8. (4) 72 fell. Bibl. Deless. 
10138 I'heophrastus Eresius. Theophrasti de causis plantarum liber primus graece. Parisiis, apud Vascosanum. 1550.4. S.

$10459+$ Theophrasti philosophi clarissini de historia plantarum libri $\mathrm{IX}$ cun decimi principio: et de causis sivo earum generatione lihri Vl, latine, Theodoro Guza interprete. Quantum diligentiae huic editioni Joannes Jordanus athibuerit, docebit te sequens epistola ad lectorem. Lugduni, apud Rovillium. 1552. S. (56), 399 p., ind. Bibl. Juss.

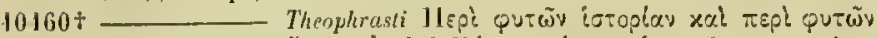

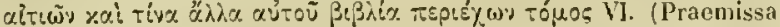
est vita Theophrasti.) Venetiis, Aldus tilius. $1552.8 .652 \mathrm{p}$

10161 Theophrusti de causis plantarum liher sextus, graece et latine. Parisiis, aput Guil. Horelium. 1558. 8. s.

$10162^{*}$ Theophrasti Eresii graece et latinc Opera ommia. Daniel Ileinsius texlum graecum locis infinitis partim ex ingenin partim e libris emendavit: hiulca supplevit; male concepta recersuit: inter|retationem passim interpolavit. Cun indice locupletissimo. Lugrduni Batavorum, typ. Ilenrici al Haestens. 1613 . folio. (8) foll., $508 \mathrm{p}$.

$10163^{*}$ Theophrusti Eresii de listoria plantarum libri alecem, graece et latino, in guibus textum graecum variis lectionibus, emendationibus, hiulcorum supplementis, latinan Gazae versionem nova interpretatine al margines: totum opus absolutissimis cum notis, tum comneutariis: item rariorum plantarum ieonibus illustravit Jounnes Rodueus a Situpel, medicus Amstelodamensis. Accesserunt Julii Caesaris Scaligeri in eosdem librus aninadversiones, et Roberti Consusutini annotationes, cunt indice locuplelissimo. Amstelodami, apual Ilenricum Laurentium. (typ. Judoci Broerssen.) 1644. folio. 1187 p., praef., iud., ic, xylogr. i. t.

10161" —_ Theophrasti Eresii le listoria plantarum libri decem, graece, cum Syllabo gonerum el specierum, glossario, el notis. Curante Joh. Stackhouse. Oxonii, excudebat S. Collingwood. 1813 -1814.11 partes. 8. - 1: 1813, 1-J11, 1-241 p., effigies Sluckhouse, 1 tab. - II: 1814 , LIII-LxxxvII, $243-509$, (2) p.

(llaee editio neque in rebus philologicis nergue in botanicis satisfacit.)

$10163^{*}$ Theophrasti Eresii quae supersunt Opera et excerpta librorum quatuor tomis comprehensa. Ad fidem librorum editorum et scriptorum emendavit historiam et libros VI de causis plantarum conjuncta opera $H . F$. Liakii, excerpta solus explicare conatus est Joh. Gollob Schneider Saxo. Lipsiae, Vogel. $1848-$ 1891. V voll. 8. -1 : 4818. $\mathrm{xL}, 896 \mathrm{p} .-11: 4818.630$ p. - Ill: $1818.843 \mathrm{p},-\mathrm{N}: 1818.873 \mathrm{p} .-\mathrm{V}: 1821$ LXvi, $549 \mathrm{p} .(3 \mathrm{hh}$.

$10166^{*}$ _ Theophrast's Naturgeschichte der Gewachse. Uehersetzt und erlautert von hurt Sprengel. Altona, Hammerich. 1822. 2 Theile. 8. - I: Uebersotzung. 358 p., praef. - 11: Erlouterungen. $427 \mathrm{p} \cdot\left(3 \frac{1}{\mathrm{~s}} \mathrm{th}\right.$.

10167 " Theophrasit Eresii llistoria plautarun. Emendavit, cum adnotatione eritica edidit Frid. Wimmer. (Operum Theophrasti tomus primus.) Vratislaviae, llirt 1842.8 . xLvil, $347 \mathrm{p.}(3 \mathrm{lh}$.) Rec. dedit Christ. Petersen Hamburgensis in Bergk et Caesar Zeitschrift für Alterthumswissenschaft, 18\%7, fase. 1. p. 8i-91.)

\section{Illuslranlia Theophrastum scripla}

- Odonus, Caesar. Theophrasti sparse (a)e) de plantis sententiae in continuatam seriem ad propria capita revocatae, nominaque secundum literarum ordinem disposita, per Caesarem Odonum Plsilosophum ac Medicum Bononiae practicam mediciaae ordisarian profitentem. Accosiserunt disputationes duac, altermn an Rheubarbarum etc. Bononiae, apud Alexandrum Benaccium. 1561, 4. 142 foll.

Scaliger, Julius Caesar. Commentarii et aninadversiones in sex libros de causis plantarum Theophrusti. Lugduni, apud Guli (sic!) Rovilliun. (Generae, typ. Joannis Crispini.) 1566. folio. (4) foll., 396 p., (1/) foll, ind. Bibl. Juss.

- Inimadversiones in listorias Theophrasti. Lugduni apud Joannam Jac. Juntae F. 1584.8424 p. B.

Insunt quoque Roberti Constantini Annotationes in historias Theoplirasti, p. 3 kj- $\{2 k$.

Acorambonus, Felix. Explanatio sententiarum difficilium in Theophrost libris de plantis (i. e. Historia plantarum et de caussis plantarum.) Romae, apud Sanctium et soc. 1590 . folio. - ib. 1603. folio. (Cat. Brit. Ilas. 1. 89.)

* Vigna, Dominicus. Animatversiones sive observationes in lilsros de listuria el de causis plantarun Theophrasti per Dominicum Vignam. etc. Pisis, apud Mlarchettum el Massinun 1625. 4. (12), 117 p. Bibl. Juss.

+ Sorolla, Ildefonso. Epitome IIedices. De differentiis lyerbarum ex listoria plantarum Theophrasti. Valentiae, typ. Claudii Mace, suntibus Sonzoni. 1642.8. 94 foll. prace. (In the legitur: Valentiae, apud Michaelen Sorolla, juxta universitatem. 1627. Non nisi quatuor priores folia sunt novae impressionis.) Bibl. Reip. Par.

" Moldenhawer, Johann Jakol Paul. Tentamen in historiant plantarum Theoplirasti. llamburgi, llolimann. 1791. 8. 151 p. $(2 / 3$ llo. $)$

(Anetor Jibelli praemisit historiam Jitterarian, atque deindu. exhihuit p. 17-36 priora yuatuor capita libri primi historiat plimtarmm, ubi texlui grieco suhjeeit varias lectiones attuı. cersionem latinan Grzoe emendatam. In textu grieco emendamlo usus est codlice msto Ilafniensi atque veteribus crlitionilous; in antmadversionibus coptosissimus p. 37 sıq. adjectis expedimntur et ros criticac et botanicac.

Stackhouse, Jolnt. Illustrationes Theophrasti in usum botanicorum praecipue peregrinantium. Oxonii, 1yp. Clarendon. 1814. 8. vill, 83,94 p. Bibl. Juss.

$\div$ De Libanoto, Smyrna et Balsamo Theophrasti notitiae, addita de Inasio et Sari apud eundem conjectura: ex editioue historiae plantarum curante Joh. Stachhouse. Oxonii 1814 iı usum peregrinantium. $8,16[2,3 \mathrm{tab}$. (graece et latine.) Bibi. Juss.

_- Extracts from Bruce's Travels in Abysinia, ancl nther modern authorities respecting the Balsam aud Ilyrili Trees, illustrative of the Natural History of Theophrastus, Bath. Binus. 1815.8 . xxI, 15 p., 3 tab.

(Paulet de Fontainebleau, Jean Jacques.) Esamen d'un ouvrage qui a pour titre: "lllustratioues Theophrasti in usum botanicorum praecipue peregrinantium. Auctore Joh. Sturkhouse. Oxonii 1811.8. 110 p.n avec une ligure et le portrait de l'auteur. Helun et Paris, Huzard. 1816. 8.61 p. ( 1 fr. $50 \mathrm{c}$. Sturz, Friedrich Wilhelm. Duo loca Theophrasti de caussis plantarum I. 14 el 27. emendantur et explicantur. Impr. cum Chr. Dan. Beckii Commentariis soc. philol. Lips. I. 2. p. 266. Montesanto, Giuseppe. Dei libri de Teofrasto Eresio intorno alle piante, commentati da Gasparo Hoffmann. Nolizio. Padora $1822.8 .54 \mathrm{p}$.

Speranza, Carlo. Teofrasto primo botunico. Discorso. Firenze $1841.8 .32 \mathrm{p} .(84 \mathrm{c}$ )

(llall. Bibl. hot. 1. P. 31-39. - Sprenty. llist. rei herb. I. p. bi 119. - Schultes Grundriss p. $4-\bar{t}$.

10168 Theuss, Theodor. Die Obstbaumzucht nach theoretischen und praktischen Grundsatzen bearbeitet. llalle, Gebaucr. 180 f. \&. $\left(1 \frac{1}{4}, h\right.$.)

10164 Allgemeines Blumeulexicon, oder Beschroibung aller bis jetzt in Teutselıland bekamnten in-und auslandisclıen Gartenblumen und Ziergewachse, nit Anweisung zu ihrer Belıandlung. Weimar, Industrie-Comptoir. 1811. 2 Theile. $8 . A-Z .(31 / 2 / h$.

11170 * Thevenot, Jean de. Relation d'un royage fait an Levant. Paris, Billaine. 1664. 4.

10171 - Suite du meme voyage. Paris, Augot. 1674. 4.

10172 - Relation de l'Indostan. Paris, Barhin. 1684. 4.

(De hoe riatore, cujus itinera pluries etjam anglice ot germanice versa redeunt, cf. Hall. Bihl, bot. 1. p. 322. Cavendum est, ne confundetur, ut llallerus fecit, cum arunculo Ifelchisedech Therenol. confundetur, ut Ilallerus fecil, cum arunculo Melchis
itinerum celebri collectore, nec vero ipso viatore.)

10.173\% Thevet, Andre. Les singularitez de la France antarctique autrement nommé Amerique. Paris, cliez les heritiers de Maurice de la Porte. 1558. 4. 166 foll., praef., ind, ic. xỵlogr. i. t.

1017) Thibaud, Etienne. Disquisitio, utrum in plantis existat principium vitale, principio vitali in animalibus analogum? Jonspelii $1785.4 .22 \mathrm{p}$.

$10173 \div$ (Thibault de Chanvalon.) Voyage a la Martinique, contenant diverses observations sur la pliysique, l'histoire naturelle, l'agriculture, les moeurs et les uxages de celte isle, faites en $1751 \mathrm{et}$ 
dans les annèes suivantes. Paris, Bauche. 1763. 4. vil, $192 \mathrm{p}$. et Observatious météorologiques.

(Botanique: p. 173-178 et 188-192.)

$10176 \div$ Thiébaut-de-Berneaud, Arsenne. Du genet, considèré sous lo rapport de ses différentes espèces, de ses propriétés et des avantages, qu'il offre à l'agriculture et à l'économie tomestique. Paris, Colas. 1810.8 . 11,92 p.

$10177^{\circ}+\ldots \ldots$ Coup d'oeil historique, agricole, botanique et pittoresque sur le Monte Circello. Paris, typ. Poulet. 1814.8. 43 p.

$10.178 \div$ Lloge historique de Ambroise Murie Francois Joseph Palisol, Baron de Beauvois. Paris, typ. d'Hautel, rue de la Harpe Nr. 80. 1821.8. 81 p., effigies Palisol de Beauvois.

$10179 \div \ldots$ Recherches sur les plantes connues des anciens sous le nom do I'lva. Paris, D'Jautel. 1822.8.25 p.

(Extrait des Mémoires de la Société Linućenno de Paris, tome l.)

$10180 t-$ Description du jardin de cultures exotiques établi a Fromont près Paris. Paris, typ. Lebel. 1824. 8. 13 p).

10181 Voyage à Ermenonville, contenant le plan des jardins et la Flore de Ermenonville. Ed. IIJ. Paris, chez l'auteur. 1826. 8 .

(11 y a une liste fautive des ptantes des cnvirons.)

$10182 \div$ Mémoire sur les Dahlias, leur culture, leurs proprićtés économiques et leurs usages comme plantes d'ornement. Denxieme édition. Paris, Roret, 1834.8. 23 p.

$10183^{*} \ldots$ Traité élémentaire de botanique et de physiologie vigétale, ou simples études sur les divers phénomènes que présentent les plantes, appuyées de planches dessinées d'après nature et gravées avec soin. Paris, Veuve le Gras. (1837.) 8. MI, 384 p. et Atlas: 36 tab. col.

1018 ' Thiel, F.J. Theoretisch-praktische Anleitungr zun zweckmássigen Aubau und Benutzung der Weberkarde. Pras 1824. 8. (1/3 th.)

$10.83 \%$ (Thienaeus, Antonius Maria.) Series plantarum quae studio et diligentia in horto hotanice nobilis Comitis Vicentini Autonii Mariue Thienaei modo coluntur. Vicetiae, typ. Paroni. 1802.8. 26 p.

10186 * Thienenann, Fr. August Ludwig, und Gustav Bicdermann Guenther. Reise im Norden Europas, vorzuglich in Island, in den Jalıren 1820-1821. Leipzig, Reclam. 1824-1827. 2 Abtheilungen. 8. vin, 160 , xiv, 410 p. 27 tab. in 4. pro parte cul. $(11 \mathrm{th}$.) (Sparsae intercurrunt animadversiunes hotanicae.)

$10187 \div$ Thiery de Menonville, Nicolas Joscph. Traite de la cullure Iu Nopal et de l'éducation de la cocbenille dans les colonies francaises de l'Amérique. Précédé d'un voyage à Guaxaca. tu Capfrançais, Herbault. (Paris, I)elalaiı.) 1787. s. Gxuı, 436, 94 p., 9 tab. col.

$10188^{*}$ Thiesen, Gottried. Warnung fur die unvorsiclitige und schidliche Geniessung der sowohl im Wasser als auf der Erde waclsenden Schierlingswurzelı. Königsberg, Zeise und Hantung. 1766. 4. (12) p.

10489* Thiesen, Johannes. De plantarum anima. Regiomonti 1758. 4. $22 \mathrm{p}$.

10190 Thile, Johann. Theelogia medica, i. e. de usu et abusu potus calidi cum lierba Thee exercitatio. Wittenbergae 1690. 4. Rivin.

$10191^{*}$ Thilo, Gottfried, pr. De succino. D. Wittebergae 1648. 4. Ed. II: Wittebergae 1668. 4. (Respondens: Kuspar Graeber.)

10192 Thilo, Isaac. De succino Borussorum. J). 1. Lipsiae 1663. 4. $4 \frac{1}{2}$ plag. Rivin.

$10193+$ Thiriart. Catalogue des plantes et arbustes cultives du jardin botanique de Cologne. Cologne, typ. Thiriart. 1806.8.43,64, 21, 34 j., praef., ind.

10.19.t Thoering, Anton von. Erörterte Preisfrage, ob der Bajersche Hopfen dem Böhmiscben an Güte gleich sei. Mlıneben 1769. 8.

10193 Thomae, $C$. Alpluabetisches Verzeichniss der in der Umgegend von Wiesbaden (im Radius von 4 Stunden) wildwachsenden Pflaızen (Phanerogamen), und der wichtigsten Kulıurgewachse fur Freunde der Botanik. Wieslsaden, Selıoltz. 18 11. 8. 10\% plag. $(1 / 3$ th.
10196* Thomas, Emanuel. Catalogue des plantes suisses, qui se ventent cliez Emanuel Thomas a Bex Canton de Vaud en Suisse. I ausanne, typ. Ducloux. 1815.8.38 p. - *il. 1837.8 .49 p. - Strasbourg, typ. Dantbach. 1841.8.4, 8 p. Cryptogames.

$10197^{*}$ (Thomasius, Jaliob.) De laudibus forum. Lipsiac, typ. llen 4652, 4. (8) p.

$10198^{*}$ (—... Disputatio philologica de Mandragora. Voll der Mraun-Wurtzel. In acadenia Lipsiensi 1655 ventilata. Lipsiae, typ. Ritzsch. 1655. 4. (Respondens: Johann Schmidel.) - *Recusi et aucta: Lipsiae, typ. IJahn. 1674.4.(24) p. - "Jalae Magrleburgicae 1739.4.24 p. - ${ }^{*}$ Lipsiae 1769.4. (24) P.

J0199 Thomé. Sur la culture lu Mcurier blanc. Lyon 1763. 8. - 1,yon 1767. 8 .

10200 Thompson, John. Botany lisplayed, being a complete and compenclions elucilation of botany, according to the system of Linnueus, wilh plates serving as examples of the most beautiful, rare and curious plants, designed by $A$. Nunes. London 1798. 4. Nr. 1-4: 10 p., 9 foll., 12 tal. col. B.

(Plura lon prodierunt.)

10201 Thompson, Robert. Englische Stachelbectsotten kurz beschricben. Aus Ilom Engliselien und systematisch geordnet nebst einer Vurrede von Lorenz Pausner. Arnstadt, (Meinhardt.) 1846. \&. 1 plag. $(1 / 6$ th.

10202 Thoms, J. II. F. Anleitung zur Behandlung der Obstbaume und les Weiustochs. Steruberg und Wismar $1835.8 .(1 / 3$ th.)

10203t Thomson, Anthony Todd. Lectures on the elements of botany. Part 1. containing the descrijuive anatomy of those oryans, on which the growth and preservation of the vegetable depend. Vol. I. London, longman, Ilurst etc. 1822. 8. xxxili, 688 j., ind., 10 tab.

$10204 .+$ Botaniıjue du Droguiste et du négociant en substances exoliques. Traduit ilo l'anglais par $E$. Pelouze. Paris, Mallıer et Co. 1827. 12. xII, $380 \mathrm{\mu}$.

10205 Thomson, Georg. Short method of discovering the virtues of plants. London 1734.8 .

$10206^{*}$ Thomson, Thomas. Clienistry of organic bodies. Vogetabjes. Lonilon, J. B. Bailliere. 1838. 8. xvi, 1076 p.

$10207^{*}$ Thore, Jean. Essai d'une Chloris du Département lles Landes. Dax, Seize. an XI. (1803.) XLIV, 516 j.

10208 Thorius, Raphael. Ilymnus Tabaci. (etiam do Pacto.) Lugduni Batavorum, (y). Elzeviri. 1628.4. 44 p., appendix. - timpr. cum Everharti Ilerba Panacen. Ed. 11]. Ultrajecti, Jloogenhuyson. 1644. 12. p. $225-305$.

$10209^{*}$ Thornton, Hoberl John, A new illustration of the sexual system of Limaeus. Volmmen 1. - Tle genera of exotic and indigenous plants that are to bo met with in Great-Britain; arranged accolding to the reformed system. - The plibosophy of botany. Londou (1799-1809.) imp. folie. 184 P., 66 tab. Bibl. Reg. Berol.

(Inter taliulas occurrumt affigies bolanicorum James Edwat Smith, Martyn, Rutherford, Jean Jacutes Rousseau, Darwin, Shaw, Hill, Hales, Bonnet, fulin Milne, Wilhering, Curtis, Ray, Vaillant, Tounefort, aliormm.

$10210^{*} \ldots$ Select plants. The Temple of llie Flora. Picturesque botanical plates of the New illustration of tho sexual system of Linnueus. Loudon, printed fur the publisher. 1799. imp. folio. (30) foll., 31 tal. col. Bibl. Reg. Berol. et Deless.

luter tahulas uccurrunt duae Linnaei eftigies; altera eum depingit pelegrinantem in Lapponia.

$10211 \div \div$ new family berbal: or popular account of the natures and properties of tho various plants used in medicine, diet and the arts. The plants drawn from nature by IIenderson, ant engraved on woud by Thomas Bewick. London, Phillips. 1810. S. xvi, 904 p., (283) ic. xylogr. i. t. (1l. 10s.)

$10212^{*}$ The British Flora; or genera and species of british plants: arranged after the reformed sexualsystem; and illustrated by ummerous tables and dissections. London, typ. Whiting. 1812. $V$ voll. 8. - 1: $x, 120$ p., totid. tab. - 11: 138 p., toticl. tab. III : 126 j., totid. tal). - IV: 100 j., totid. tab. - V: 53 scliemata, 52 p. (10l. 10s.) Bibl. Goett. 
10213 Thornton, Robert John. Elements of botang: Lobdon 1812. II voll. rep. $8 .-1: 90$ \%., 52 tab. $-11: 73 \% ., 84$ (ab. (10l. 6ul)

10214 Practical botany, being a new illustration of the genera of plants. London s. a. 8 , vol. I: 90 [3., 85 tall.

$1021: 3 \longrightarrow$ The greenlsuuse companion. London 1824. 8.

10216 An introduction to the seience of botany. London 4833. 12. (8s. - col. 12s.)

10217 Thorstensen, Pelrus. De Scirpis in Dania sponte nasecntilus. D. Havniae 1770.4.16 p. (Respondens: Nicolaus Mohr.) B.

10218t Thory, Claude Antoine. Rosa Recloutea, seu descriptio novae speciei generis Rosae, dicati Petro Joseptho Redoute, eximio florum pictori. Parisiis, typ. Ilérissant lo Duux. 1817. 8.7 p., 1 tab. col.

$10219 \div$ Rosa Candolleana, seu doscrijtie novae speciei generis Rosae, dicita A. Pyrumo De Candolle; addito catalogo inedito Rosarum quas Andreas DuPont in horto suo studiose colebat anuo 1813. Parisiis, typ. Hérissant le Dous, 4819. 8. 19 p., 1 tab. col.

$10220^{*}$ - Prodrome de la Monographie des especes et variétés connues du genre rosier, diviscés selou leur ordre katurel, avec la synonymie des noms vulgaires, un talileau synoptique et deux planches gravées eu couleur. Paris, Dufart. 1820. 8. 190 p., 2 tah. col. ( 6 fr.)

$10221 \div$ - Monographie ou histoire uaturelle du genre groseillier, contenant la description, l'histoire, la culture et les usages de toutes les groseilles connues, avec 24 planclies coloriées. Paris, Dufart. 1829. 8. xvı, 152 p., 24 tab. col., eftigies autoris. ( $8 \mathrm{fr}$. eol. 10 fr.)

(Claude Antoine Thory composuit lextum operis: Les Roses peintes par Pierre Joseph Redoute; vide supra Nir. 8 't3.

10222* Thoss, Karl Gustar. De radice Senega. D. Lipsiae $1820.4 .40 \mathrm{p}$.

$10223 t$ Thouin, André. Monograplie des greffes, ou deseription technique des diverses sortes de greffes employées pour la multiplication des végétaux. (Paris, typ. Huzard. 1821. ) 4.100 p., 13 tab. (6 fr.) germanice: Monographie des Propfens. Aus dem Franzosisehen

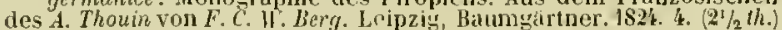

10224* —_ Cours de culture et de naturalisation dles végétaux. Avec un Atlas de 65 planches in 4. publié par Oscar Leclerc, son neveu et aide au jardin du roi. Paris, lluzard et Déterville. 1827. III voll. 8. - I: xxxı, 528 p. (contient la Vie de Thouin.) - II: 614 p. - III: 476 p. - Atlas: 4 obl. 65 tal). $(35 \mathrm{fr}$.)

$10225 \div$ Thouin, Gabriel. Plans raisonnes de toutes les especes de jardins. Paris, chez l'auteur, typ. Lebegue. 1819. folio. 56 p., 56 tab. - Ed. Ill: Paris, Iluzard. 1828. folio. 58 p., 59 tab. (niggr. 50 fi. - col. 100 fr.

10226* Thran, Christian. Index plantarum horti Carolsrulsani tripartilus, autore Christiano Thran. (1733.) S. 132 p. Bibl. Senckenb. Francof. a/M.

$10227 \div$ Threlkeld, Caleb. Synopsis stirpium bibernicarum alphabetice clispositarum, sive commentio de plantis indigenis praesertim Dublinensihus instituta, beiug a short treatise of uative plants, especially such as grow spmutaneously in the vicinity of Dublin; with an appendix of observations male upon plants, by Dr. Thomas) Molyneux. Dublin, typ. Powell. 1727. 8. (114) p. Appeudix: 60 p. Bibl. Juss.

10228* Thuemmig, Ludwig Philipp. Experimestum singulare de arborihus ex folio educatis ad rationes pliysicas revocatum. D. Halae, ıyp. Hilliger. 1791. 4. 56 p. (Respondens: Johann Mayer.)

* germanice: Von den Baumen, weicho ans Blattern auferzogen werden. In libro secuunti, sluch il. p. 110-173; et inter Meletemata varis atgumenti. Brunsviei 1727 . \&.

$10229^{*}$ — Versuch eiser grundlichen Erlauterung der merkwürligsten Begebenlieiten in der Natur. 1-3. Stuck. Ilalle 1723. 8. 270 p. - Mlarburg 1735. 8. H.

(Insunt: Transiatio disserlationis praecedentis, II. p.110-173. De conservationo tlorum per plures annos, III, p. 181-188. - De slece arborum per frigus manante $\mathrm{Nr}$. 10. - De circulis annuis, Nr. 12. - De arborum inversinus, ut rami in terram mergerentur et radices agerent, $\mathrm{Nr}$. 22 - Cur plus olci ex adultis plantis babeatur, quam ex teneris, Nir. 28. - De autore ef. Holl. Bibl. bot. II. p. 171. - Spreng. Ilist. rei lierb. II. p. $311-312$.

10230* Thuillier, Jean Louis. La Flore des environs de Paris, ou DistriIution méthodique des plantes qui $y$ croissent naturellemenl, faite d'après le système de Linne; avec le nom et la description de clacune en latin et en francais: l'indication de leur lieu natal. de leur diree, du tems de leur llorason, de la couleus des fleurs et la citation des auteurs, qui les ont le mieux déserites ou en ont dounc les meilleures figures. Paris, Desaint. 17y0. 12. vil, 359 p. - *Nouvelle édition, revue, corrigée et considérablement angmontée. Paris, chez l'auteur. án VII. (1799.) 8. Xlvin, 550 1). (6 fr.)

("On croit, "que Claude Lovis Richard, de Instiust, a cu part " cet ouvrage.." Q. Titulus reimpressus est amo 182t.)

$10231^{*}$ Thunberg, Carl Pchr. Flora japonica, sistens plantis insularum japonicarum secundum systema scxuale cmendatum redactas arl XX classes, ordines, genera et specirs cum differentiis specifieis. syonymis paucis, descriptionibus concinnis ef 39 iconilous aljectis. Lipsiac, Muller. (F. A. Brochliaus.) 1784. 8. LIt. 418 p. 39 tab. $\left(3 \frac{1}{3}\right.$ th. $)$

(Botanieat observations on the Flora japonicit. Trausact. of the lumean society, vol. 11. p. 326-3kz. - Esteri, Amnalen der Botanik. stuch XVill, 13. $89-105$. .

$10232^{*}$ leones plantarum japonicarum, quas in insulis japrnsicis amtis 1775 et 1776 collegil et deseripsit. Upsaline, Ednan. (Schubothe.) 1794-1805. folio. - (1: 1794. (Orchideae). - II. 4800. - III: 1801. - IY: 1802. - Y: 1805.) (20) 1., 50 tal, $(s / 2 t h$.

$10233^{*}$ _..... Resa uti Europa, Africa, Asia, forrăllad firen 17701779. Lpsala, Edmas. 4788-1793. IV volt. 8. - 1: 1788. 389 1.. 2 lab. - 11: 1789. 384 p., 4 tab. $-111: 1791.414$ 1. $-11: 4793$ 3 亿 p., 4 tab.

"germanice: Reise dureh einen Theil von Europa. Afrika und

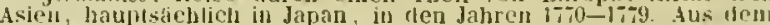
sehwed. von Groskurd. Yit kupfern. Berlin. Ilande ot Spener. 1792

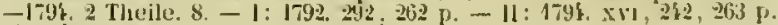
$(1 \% / \mathrm{th}$.

"germanice: Reisen in Afriha und Asien, vorzugliclı in BJapan.

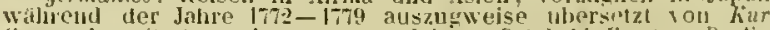
sprenget, nit Anmerkungen von Johann Remhold Forster. Berliu, Voss. 1792, \&. v111, 230 p. $(11 / 12 t h$.

anglice: Travels in Europe, Africa and Asia, London 179! 179; If woll. 8. - 1: 317 11, 2 tab. - 11:316 1., 4 tab. - III: 28:3, 31 1) IV: 293 p., 4 tab.

t gallice: Voyages de C. P. Thunberg au Japon, par to Cap de

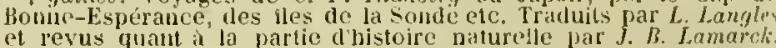
Paris. Jandré. 1796 . IN voll. 8 . os tab., efticies Thunbergï. (12-lï fr.) gallice: Voyause en Afrique et ell Asie, principalement au Japon. pencliut les annees 1770-1779, servant de suite au vovage dr Sparman, traduit du suedois ivec des notes. Paris. Fuchs. 179 t. 8. $16{ }^{6}(1)$

10234* - Prodronus plantarum Capensium, quas in promontorio Bonae Spei Africes anmis 1772-1775 collegit. Pars 1 et II. Lipaliae, Elman. (Schubothe.) 1794-1800. 8.191 p., 3 tab. (2\%/3 $/ \mathrm{h}$.)

$1023 \ddot{3}^{*}$ ___ Flora Capeusis, sistens plantas pronoutorii Bopar Spei Africes, secundum systema sexuale emendatum. redactas ad classes. orlines, genera el species cum differentis specificis synonymis et deseriptionibus. Volumen jrimum. Fasc. [-III. Cpsaliae $1807-1813.8 .578$ p. - "Ilauniae. Bomber. $1818-1820.8$ Fase. I-1.578, 352 p. - - Edidit et pracfatus est Joseph dugus. Schultes. Stuttuarilite, Cotta. IS23. 8. Lxw. 803 p. $(4$ th

Praeside Carolo P'etro Thunbery disserlationes academicae: (Respondentium nomina consultò nnito.)

$10236^{*}$ - De Gardenia. D. Lpsuliae. 15 . Edman. $1780.4 .22 p$ 2 tah.

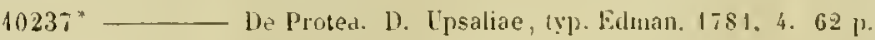
5 til

$10238^{*}-$ Oxalis. D. Ipsaliae, typ. Edmant. 1781.4.32 p., 2 tab. $10239^{\circ}-$ Nova genera plautarum. D. I - XYi. Lpsaliae, typ. Ednaแ. 1781-1801. 4. 194

$10210^{*}-$ His. D. Ljsaliae, typ. Edman. 1782.4 .36 p.. 2 tab.

$1024.1^{*}$ — Ixia. D. Lpsaliae, Iy $]^{2}$ Edman. 1783.4 .24 p., 2 tab.

1021.7 - Gladiolus. D. I psaliae, typ. Edman, 1784. 4. 26 p. 2 tab.

1024. $3^{*}$ De Aloe. I). Lipsaliae, typ. Euman. 1785. $4.14 \mathrm{p}$.

$10244^{*}$ De medicina Africanorum. D. [psaliae, Iy). Edman. $1785.4 .8 \mathrm{p}$.

Magazin Iur rlje Botanik, Stuck 1 . p. 50-66 - schlegel Thesanrus mat. med. I p. 19!-ims 
$10213^{*}$ Thumberg, Carl Pehr. De Eriea. D. Upsaliae, typ. Edman. 1785. 4. 62 p., 6 tab.

(llaec dissertatio recusa est in Lsteri Delect. opusc. Jot. II p. 1-78, omissis tabulis. Editionem alteram, nomine Respondentis Jacobi Rernhardi Struwe inseriptam, curavit Richard Anthony Salisbury. (Privately printed.) Featherstone 1800 , 4. $62 \mathrm{p}$., addita nova tabula. (3s. 6d. Bolun.)

$10216^{*}$ - Ficus genus. D. Upsaliac, typ. Edman. 1786.4 .16 p., 1 tal.

(Uster belect. opusc. hot. I. N. 12\%-15k.)

$1097^{*} \longrightarrow$ Museum naturalium Acadeniae Upsaliensis. Dissertatienibus acadenticis. Pars 1-XXII. Upsaliae, typ. Edman. 17871797. 4. p. 1-191, 93-226. - Appendix I-V1l: 1791-179s. p. $111-150,103-125$.

$10248^{*} \longrightarrow$ De Horaea. D. Upsaliae 1787.4. 20 p., 2 tab.

$10249^{*} \longrightarrow$ Restie. D. Upsalide, 1yp. Edman. 1788. 4. 22 p., I tab. (Usteri Delectus opusc. bot. I. j. 35- 38 .)

$10250^{*}-$ Arbor toxicaria Macassariensis. D. Upsaliae, typ. Lillmant 1788.4 . $11 \mathrm{p}$.

(Usteri Delectus opusc. bot. I. p. 23-34.

$10231^{*}$ De Myristica. D. Upsaliae, typ. Edman. 1788. 4. 10 p. $10252^{*}$ Ne Caryophyllis aromaticis. D. Upsaliae, typ. Edman. 1788. 4.8 p.

$10253^{*} \longrightarrow$ De Noxae atque ignis in medicina rationali usu. 1). Upsaliac, typ. Edman. 1788. 4. $15 \mathrm{j}$.

$10255^{*}$ Flora Strengnesensis. 10. Upsaliae, tฐp. Edman. 1791. 4. $62 \mathrm{p}$. tribuit.)

III. Iikstrom hanc dissertatienem Respondenti Carl Axel Carlson

$10233^{*}$ De Benzoè. D. Upsaliae, typ. Edman. 1793.4. 7 p.

$10256^{*}$ — De Acere. D. Upsaliae, typ. Edman. 1793. 4. 12 p.

$10257^{*} \longrightarrow$ De cortice Angusturae. 1). Upsaliac, typ. Edman. 1793. 4. $7 \mathrm{p}$.

$10258^{*} \longrightarrow$ De scientia botanica utili atrue jueunda. D. Upsaliae, เyp. Edmalı. 1793. 4. 10 p.

$10289^{*} \longrightarrow$ De Hermannia. D. Upsaliae, 15|J. Edman. 1794. 4. $19 \mathrm{p} ., 1$ tab.

$10260^{*} \longrightarrow$ De olco Cajuputi. D. I-II. Upsaliac, typ. Ėman. 1797. 4. $48 \mathrm{p}$.

$10261^{*} \longrightarrow$ De Diosma. D. Upsaliae, typ. Edmant. 1797. 4. 20 p.

$10262^{*}-$ De usu Menyanthidis trifoliatae. D. Upsaliae, typ. Edman. 4797. 4.6 p.

$10263^{*}$ - De Drosera. 1). Upsaliae, typ. Edman. 1797.4.8 p.

1026:* — De Ilydrucotyle. D. Upsaliae, tyj. Edman. 1798. 4. S p., I tal.

$10265^{*} \longrightarrow$ Arctotis. J). Upsaliae, typ. Edman. 1799. 4. 19 1).

$10266^{*} \longrightarrow$ De Arnica. D. Upsaliae, typ. Edman. 1799. 4. 34 p.

$10267^{*}$ Dissertationes academicae Upsaliae Jabitae sul praesidio Caroli Petri Thunberg (edidit Christian Meinrich Persoon). Goettingae, Dieterich. 1799-4804. 111 voll. 3. - I: 1799. vıII, 326 p., "̈ tab. - II: 1800. 436 p., 3 tab. - III: 1801. 272 ]., 12 tab. $\left(3 \frac{1}{2}\right.$ th.

(In voluminibus 1-II continentur \&1 dissertationes botanicae; in volumine III 18 dissertationes zoologici argunenti.

$10268^{*} \longrightarrow$ Juctificationis partium varietates. D. I-1I, 2. Upsaliae, typ. Edmall. 1800-1802.4.32 p.

$10269^{*}$ De Phylica. D. Upsaliae, typ. Edinan. 1804. 4. 10 p.

$10270^{*}-$ De Brunia. D. Upsaliac, typ. Edman. 1804 4. 8 p.

$10277^{*}$ - Thesium. D. Upsaliae, typ. Edman. 1806.4 .13 p.

$10272^{*}$ — Betula. D. Upsaliae, typ. Edman. 4807.4. 18 p., 1 tab.

$10273^{*}$ 1) Dracaena. D. Upsaliae, typ. Eilman. 1808.4. 8̊ p., 1 tal. $10274^{*} \frac{1}{1 \text { tab. }}$ Dc Borbenia. D. Upsaliae, typ. Edman. 1811.4. 7 p.

$10275^{*} \longrightarrow$ De Cinchona. D. Upsaliae, typ. Edman. $1811.4 .10 \mathrm{p}$. $10976 *$ De utilitate plantarum quarundam succicarum. D. Upsaliae, typ. Stenhammar. 1813.4.9 p.

$10277^{*}$ D De Rubo. D. Upsaliae, typ. Stenhammar. 1813.4. 12 p 1 tals.

$10278^{*}$ - De Styrace. D. Upsaliac, typ. Stenlammar. 1813.4
$10279 *$ Thunberg, Canl Pehr. Dissertatio, geographiam plantarum cultarum adunbrans. Upsaliae, typ. Stenhammar. 1813.4.10 p.

10980 Flora Runstcniensis. D. 1-V. Upsaliae, typ. Zeipel et Palmblad. $4815-1817.4 .32$ p. w.

(Clar. Wileström Abrahamo Ahlquist adscripsit hane dissertationem.)

10281* In narcoticis observationes. D. Upsalixe, typ. Zeipel et Palmblad. 1816. 4.8 p.

$10282^{*}$ De Daphne. D. Upsaliae 1817.8.54 p.

(Autor est Joharnes Emanuel Wikstrom.)

10283* Plantarum brasiliensium Decas I - III. Upsaliae, ty [1. Palmblat. $1817-182$ 1. 4.38 p., 3 tals.

1028:* — In genus Echitis obscrvationes. D. Upsaliae, 1yp. acaldemiae. 1819.4.8 p., I tab.

$10285^{*}$ De nutritione plantarum. D. I-III. Upsaliac, 1yp. academiae. $1819.4 .32 \mathrm{p}$.

$10286^{*}$ Cencra graminum in Scandinavia indigenorum recognita. D. Upsaliae, typ. academiae. 1819.4.10 p. (Auter est Carl Johan Hartman.)

$10287^{*} \longrightarrow$ Flora Gothoburgensis. D. I-11, 2. Upsaliae, typ. acidemize. $1820-1824.8 .117 \mathrm{p}$

(Autor est Pehr Fredrik Wahlberg.)

$10288^{*}$ De Krameria. Dissertatio botanico-medica sistens lijstoriam botanicam generis nee non notiones auctorum circa $R$ attanhiam radicem chemicas et medicas. D. Upsaliac, typ. academiae. 1822.4.19 p.

$10289^{*} \longrightarrow$ De Digitali purpurea. D. Upsaliae, typ. academiae. 1822. 4. $16 \mathrm{p}$

Autor est Carl August Thelning.)

$10290^{*}$ De lpeeacuanha. D. 1-11. Upsaliae 18.4.8.38 p

$10294^{*} \ldots$ Examen classis Diandriae in systemate sexuali. D. Lpsaliae, typ. Palmblad. 1824.4. $11 \mathrm{p}$

10292* Wxamen classis Gynandriae. D. Upsaliae, typ. Palnıblad. 1824.4.8 p.

10293* - Examen classis Monoeciac. D. I-11. Upsaliac, tyj. Palmblad. 4825. 4. 22 p.

1029:* — Examen classis IDioeciae. D. I-II. I'psaliac, typ. Palmblad. 1825. 4. 18 p.

$10295^{*}-$ Examen classis Polygamide. D. l-II. Upsaliac, tyu. Palmblad. 1S25. 4. $14 \mathrm{p}$

10296 * - De Palmis. D. I. Upsala, tyly. Palmblad. 1823.4 .8 j.

$10297^{*}$ Florula javanica. D. I - ll. Upsaliae, typ. Palmblad. 1525. 4. 23 1).

$10298^{*} \longrightarrow$ Florula ceilanica. D. Upsaliae, ty]. Palmblad. 1825. 4. 11 p.

10299 Anvisning till rle svenska pluarmaceutiska vảxtemas igenkännande. D. I. Upsala, typ. Palmblad. 1826.8 .20 p. w.

(Autor est Pelir Fredrili Wahlbery.)

$10300^{*} \longrightarrow$ Do Gummi amnoniaco. D. Upsaliate, typ. Palmblad. 1828.4.8 p.

$10301^{*}$ Afhandling on the wixter, sem i Bibelen omtalas. I. I-IX. Upsala, typ. Palmblad. 1828, 8. 128 p.

("Die schwedischen Naturforscher Katl Peter Thunberg und Johan Withelm Dalmar. Aus den Ahbandlungen der Kgl. Akademies der Wissensehaften zu Stockholm tibersetzit von Gotlied Moknike. stralsund, struck. 1831.8 . $111,70 \mathrm{p} .(1 / \mathrm{t} / \mathrm{h}$. $)$

$10302 \div$ (Thurmann, J.) Réunion de la société géologịpe de France à Porrentruy (Suisse, Canton Ue Berne.) Porrentruy, typ. Michel. 1838. 4. 4 p., 1 tab.

(Enumeration des plantes des emvirons de Porrentruy, p. 3-4.)

$10303^{*}$ Thurneisser zum Thurn, Leonhard. Historia, sive descriptio plantarum omnium, tam domosticarum quam exoticarum, earunden cum virtutes influentiales, elementares et naturales, tum subrilitates nec non icones etiam veras ad vivum arteficiose expressas proponens, atque una cum his partium omnium humani corporis externarum et internarum picturas, et instrumentorum extractioni chymicac servientium delineationem usumque ac methodes pharmaceuticos quasvis, ad curam valetudinis dextre tractandam necessarias complectens. Bcrlini, cxcudebat Alichael Hentzske. 1578. folio. cLvi p., praef., ind., ie. xylogr. i. $\mathrm{.} .-\div \mathrm{Co}-$ Joniac Agrippinae, apud Joannem Gymnicum, sub monocerote. 1587. folio. Bibl. Cand.

(llaec altera editio non differt immo eadem est impressio litulo solum novo. Operis liber secundus nunquam prodiit.) 
10301", Thurneisser zum Thurn, Leonhard. Ilistoria und Beschreibung Influentischer, Elementischer und Nidurlicher Wirchunzen aller fremden und heimischen Erdgewechsen, auch irer Subliliteten, sampt walnhaftiger und kunstlicher Conterfeitung derselbigen, aucl, aller thoiler, inuerlicher und ausserlicher glider am mensellichen Köper, nebst Furbildung alter zu der Extraction diensilicher Instrumenten, auch deren Gebrauch, und allen zu erhaltung der gesundheit notwendigen Prozessen, gemeinem Nutz zu gut. I)urch Leonhardt Thurneysser zum Tuhn, Kurf. Brand. Lest. L.eilmedicus. Gedruckt zu Herliu lei Mlichacl Hentzken. 1578. folio. 156 p., praef, ind., ic. xylogr. i. t. (2 th. A.)

A praecedente libro fre nom differ, ab ipso autore germanice simul ac Jatine ediitus. Solac suut l'nubelliferare, cum mirificis sy nonymis lacisque Hatalibus. (Mmnia plena nugarum astrologicarum. tcones paraveral 1921, tesle Bayer lipist. 1\%. Tt. quae ad Pancomium transierunt. Singularis hominis fata enarrabo infra in Vitis Botanicorum.)

10305 Thurneysen, Johann Jakol. Theses medicae. Basileae 1751. 4. $S$ p. B.

(Thesium p. 5-8 hotanici sumt argumnei.)

10306 Thym, Johaun Friedrich. Dic Nutzbarkiejt, fremde Thicre Baume und Pflanzen, sowol\}] zur Nalırung als zu Fabriquen einzufulıren und fortzujllanzen. Berlin und Leipzig 1775. 8. 60 p. B.

$10307^{*}$ Tidemann, Johanu Rudolph. Historia Sambuci vulgaris. D. Groningae, typ. Spandaw. 1733.4. 45 j). Bibl. Goett.

$10308^{*}$ Tidicaeus, Franz. Plyytologia generalis, capitibus aliquot complectens ea quae ad plantarum essentian naturamque universin? explicandam pertinent. D. seripta et in disjutationem vocata pulvlicam in schola plyssica cel. Ac. Lipsiensis die II Cal. Maji a. 82 a M. Francisco Tidicaeo, Gedimensi, inclytae fac. phil. t. 1. Decano. Lipsiae, Georgius Defmerus imprimelyat. 1582. 12. (68) p. Bibl. Reg. Berol.

$10309^{*}$ Tidyman, Philipp. Conımentatio inauguralis de Oryza sativa. Goettingae, Dictericlı. 1800.4 .25 J., 2 tab. ('oul.

$10310^{*}$ Tiemeroth, Joham Ileinrich. Planta ac fructus Ananas loujusque usus medicus. D. Erfordiae, typ. Grosch. 4723. 4. 16 p.

10341 Tilemann, Johannes. Praxis Lotanica, hoc est methodus cognitionis et culturae plantarun. Herbijoli 1657,8. s.

$10312^{*}$ Tilemann, Tolias. De metallis, plantis ac brutis animalibus. D. Wittebergae 1610.4. (8, p.

$10313^{*}$ Tilesjus, 11 illelm Gottlieb. Musar pararlisiacae quae nuper Lipsiac floruit icones quatuor exhibuit. Lij)siae 1792. 8. 14 p. 4 tab. col. $(2 / 3$ th. $)$

J1331 $1 \div$ Til-Landz, Elias. Catalogus plantarum quae prope Aboam tam in escultis quam incultis locis hueusque inventae sunt. Nhoae 1673 8. - $\div$ Ed. IJ: in gratjam philobotanicorum auctior editus. Aboae, typ. Wallius. 1683 . S. ( 36$)$ foll. Bibl. Juss.

$10315 \div-$ leones norae in usum selectae el calalogo plantarum promiscue appensae. Aboae, typ. Wallius, 1683 . 8. 160 1ab. lign. inc. Bibl. Juss.

10316, Tillet, Malkicu. Disserlation sur la canse, yui corrompt et noircit les arains de bled daus les épis, et sur les moyens de prevenir ces accidens. Bordeaux 1755.4.150 p.

Suite des expériences et reflexions relatives a la dissertation sur la cause, fui corrompt et qui unircit les grains de bled dans les épis, et sur les muyens, de prévenir ces accidens. Paris 1755.4. H.

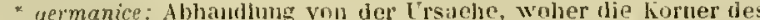
lietrailes in den Aehrers inderben und schwarz werden. Aus dem Franzosisciten. J'reissehrift. Ilamburg und Leipzig, firtnd n. Ilolle. 17.3. 8. 312 1)., 8 Tabelien

10318 Précis des exjériences faites a Trianon sur la corruption des bleds et sur les moyens de la prévenir. Troyes 1756. 12. H.

Hall. Bibl. hot. vol, 11. p. Hï.)

103196 Tilli, Giovanni Lorenzo. Enumeratio stirpium in horto acarlemico Pisono viventium. Pisis, typ. Prosperi. 1806, 8. $38 \%$ \% Auctuarium I. 1807: 9 p. $-1810:$ \& $\mathrm{j}$.

$10320^{*}$ Tilli, Michel Angelo. Catalogus plantarum lurti Pisani. Florentiae, apud Tartimum et Franchium. 1793, folio. x11, 187 p., 50 tal)., iconozraphia horti, effigics Tilli.

Hall. Bibl. hot. vol. 11. p. 187 - Spreing. Jlist rei heri. 11 306.)
10321* Tilling, Mathias, latine Tilingius. Khabarbarologia, seu curiosa klabarl,ari disłuisitio, illius ely mologiam, differentiam, locun natalem, formam, temperamentum, vires detegens. P'raemittitur praefatio, in qua prolixus discursus de mineralibus, aninalilus el plantis admirandis et peregrinis, unae in China reperiuntur. Francofurti a/Ml., seyler. 1679.4.782 1., 2 tals.

10322\% - Lilium curiosum, seu accurata Lilii alhi Jescriptio, in qua ejus uatura et essentia mirabilis, nobilitas et jracstantia singularis, qualitates et vires jneffabiles fere pluilulogice, physice, ther)logice et medice, secundum leges et methodum Acadeniac Naturar Curiosorum explicantur, multaruo arcana quum sjoritualia tun naturalia relevantur. Francofurti a/M., Seyler. 1683. 8. $576 \mathrm{p}$. prace.

10323* Timm, Joachim Christian. Jlorae Megapolitanae Prodromus, exhibens plantas ducalus Megapolitano-Suerinensis spontaneas. Jaxime secundum systema Linneano-Thunbergianum digestas. Lipsiae, J. G. Nuller. 1788. 8. Xv. 284 p., ind., 1 tab. col.

10324* Timmermann, Theodor Gerhard. Belladonna. D. Rintelii, typ. linax. $1765.4 .35 \mathrm{p}$.

$10325 \div$ Tinant, Frangois A. Flore Luxembourgeoise ou description des plantes phanérogames, recueillies et observées lans le grantduclió de Luxembourg, classèes d'ajrès le systime sexuel te Linnce. Luxembourg, Kuborn. 1\$36. 8.512 p.

10326+ Tinelli, Giovanni. Dizionario elementare di botanica. Mantova, tipografia Virgiliana. 1809.8 . v11, $254 \mathrm{p}$.

10327 Tinelli, Luigi. llints on the culivation of the mulberry. New Sork 1\$37. 8.50 J. w.

(Laud dubie e lingua italica translatio est.)

10328* (Tineo, Giuseppe.) Index plantarum lıorti butanici Acadomian regiae Panormilanae una cum nominibus plarmaceulicis alcjuc vernaculis in usum medicae juventulis. (Panormi) $1790.8 .88 \mathrm{p}$.

10329 Synopsis plantarum hooti acndemici Panormitani. Panormi 1802-1807. DC.

$10330^{*}$ Tineo, Fincente. Plantarum rariorum Siciliae pugillus prinus. D. Janormi, typ. regiis. 1817.8 .22 p., ind.

$10331^{*}$ — Catalogus plantarum horti regii Panormitani ad annum 1827. Panormi, typ. regiis. 1527. 5.284 j).

10332 Tirellus, Mauritius. De historia vini et febrium lihri duo. Fenetiis $1630.4 .395 \mathrm{p} . \quad$ B.

10333* Tita, Autonio. Catalogus planfarum, quubus consitus est Patavii amoenissinus hortus Illustrissimi ac exceltentissimi Equitis $J_{0}$. Francisci Maurocen, Veneti Senatoris, ab Antonio Tula confectus. Accedit Antonii Titae iter per alpes Tridentinas in Feltrensi ditione, per vallem Sambucae iuter Bassani nontes, ac per Marcesinae alpestria, quao sejtem communibus accensentur. Patavii. ty]\}. seminarii. 1743. 8. 183 p., (13) foll.

10334 Titford, II: J. Shetehes towards a Ilortus botanicus americanus: or coloured plates (with a catalogue and concise and familiar descriptions of many slecies) of new and valuall]e iplants of the Westindies and North and South America: also of several others. natives of Africa and the East Indies: arranged after the Limnean system. London, typ. Stower. 1811. 4. x11, 132 p., ind., explicatio tabularum, 18 tab. col

(Beitsehmied notat editionesn anni 18?6.)

40335" Titius, Johann Daniel, germanice Tietz. Sistema plantarum sexuali ad naturam compositum. D. Wittenbergae, tyj. Durrii. 1767.4. 19 p. (Respondens: Karl Friedrich Pfotenhauer.) sonders int Absicht auf dis Gesehlecht derselben. In libro sequenti. rol 1 10-142, of in veues llamburger llagazin, siuek XC 11. $483-\mathrm{Bin}$.

(a) Nemo Tilio ineptius doctrinam sesualem aggressus pst. Ratociniun id quale all infante int al, homine expectaveris rationis

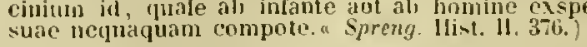

10336 Cremeinnuzige Abliandlungen zur Beforderung der Erkenntuiss und des Giebraucles naturlicher Dinge in Absiclt auf die Wolufahrt des Staates und des menschlichen Geschlechtes uberhaupt, von Johamn Daniel Titius. Erster Theil. Leipzig 1768. S. 528 j., 3 tal. B.

10337* Titius, Miehael. Catalogus plantarum Jurti electoralis Regiomonlani. recensitus a Michaele Titio. Prusso, roi herbariae Liltore. 
Regionenti, typ. Jeh. Reusneri. 1634. 12. (29) foll. Bibl. Reg. Berol. et Bibl. urb. Regiom.

Libelium rarissimum recudi cnravit ill. Ernestus Meyer in von Schlechlendal, Linnaea, vol. X. p. 369 suq.)

10338* Titius, Salomon Constantin. De acido vegetabilium elementari, ejusque varia modificatione. Lipsiae, typ. Sommer. 1788. 4. $16 \mathrm{p}$.

$10339^{*}$ - De cespite ustili vulgo Turfa. D. I - Il. Wittebergae, typ. Tzschiedrich. 1794.4.24, 20 p.

$10340^{*}$ De aere in Coluteae leguminibus contento Prolusio I. Wittebergae, typ. Clıaris. $1800.4 .8 \mathrm{p}$.

$103+1$ Tittmann, Johann August. Darstellung der in Sachsen wildwachsenden Medizinalpflanzen, naclı dem Linneischen Systeme. Ileft. 1. Dresden 1810. gr. 8.12 tab. col. $\left(1 \frac{1}{2}\right.$ th. $)$

10342* Ueber den Embryo des Sanenkorns und seine Entwicklung zur Pflanze. Dresden, Walther. 1817. 8. IV, $100 \mathrm{p}$. $(\% / 12$ th. $)$

$1033^{*}$ Die Keimung der Pflanzen, durelı Beselsreibung und Abbildung einzelner Saameı und Keimpflanzen erläutert. Dresden, Walther. 1821.4 . 11,200 p., 27 tal). col. $\left(8^{2} / 3\right.$ th. $)$

103:t Toase, $W . K$. A series of botanical tables and tables of the Materia medica; with woodeuts and majes. London 1805. (1835.) 4. (4s.)

$10343^{*}$ Tobias, Michael. De llellebori nigri indole chemica et usu medico. D. Berolini 1819.8.28 p.

$10346^{*}$ Tod, George. Plans, elevations and sections of hot-louses, greenlouses and aquarium, conservatories etc. recently built in different parts of England, for various noblemen and gentlemen. etc. Lon(lon, Taylor. 1807. folio. 23 p., 27 tab. col. - *ib. 1812. Solio. (non differt.)

10347t Todaro, Augustino. Orchideae siculae, sive Enumeratio Orelidearum in Sicilia hucusque detectarum. Panormi, ex Eimpedoclea officina. 1842.8 .135 p., 2 tab.

$1033.8^{*} \longrightarrow$ Rarierum plantarum minusve recte cognitarum in Sicilia spente provenientium Decas I. s. I. (1843.) 4. $16 \mathrm{p}$.

103 ig Todd, William. The North-west prospect of Whinfield forest, in the ceunty of Westmorland, with an exact representation of that most wonderful and surprizing large 0 ak tree .... known by the name of the Three brethren trec. ONeate del. Pranker sculps. Tabula aenea long. 9 unc., lat. 12 unc. praeter descriptionem typis impressam. B.

10300 * Tode, Ileinrich Julus. Fungi Mecklenburgenses selecti. Luneburgi, Lemke. 1790-1791. II fascieuli. 8. - 1: 1790. vur, 47 p., tab. I-VII. - II: 1791. vแI, 64 p., tab. VIII-XVII. $\left(2 \frac{1}{2}\right.$ th.)

$10351^{*}$ Toensen, A.C.E. De analysi et usu antisyphilitico Smilacis Sassaparillae. D. Kiliae, typ. Molır. 1826. 4. 18 p.

10332 Togni, Vichele. Raccolta delle singolari qualita del Caffé. Venezia, Giov. Franc. Valvasense. 1675. 12. S.

$10353^{*}$ Tokelem. Beschreibung der Holzer, welche in den nordlichen Gegenden Russlands wachsen. Petersburg 1766.8.373 p., 26 tab. Bibl. Goett.

1030̈4 TolI, Bernhard Leinrich von. Guter Rath fur den Landmann, um seine Aernten ansehnlich zu vermeluren. Reval 1840.8.24 p.

10300 - Zuverlässigne auf dreissigjálırige Erfahrung gegrürdete Anleitung zum sichern Anhau der deutschen Gerste. Reval 1819. 8. $19 \mathrm{p}$.

$10336+$ Tollard, ainé, $C$. Traité des végètaux qui compesent l'agriculture de l'empire français. etc. Paris, Tollard frères. $4805.8 . x v 1,102 \mathrm{p}$. ( 3 fr. 50 c.) - Ed. II: Paris, chez l'auteur; L. Colas. 1838. 19. ( 6 fr.) 0.

10357 Tollard, IIenri. Manuel de l'herboriste, de l'épicier droguiste et du grainier-pépiniériste-horticulteur. Paris, Roret. 1828. II voll. 18. 17 (r.)

10358 Tollat von Vochenberg, Johann. Folium $2^{2}$ : Ain meisterlichs buchlin der | artzney fur manigerley hranck | heit uñ siechtagen $\delta$ menschen. Folium 40". Hye endet sich dz meisterlich buchlin | der krutter gesamlet durch Johanné Tol | lat von vochenberg in der weit berümtē | vniuersitet zu wien by dern aller erfarnistē I mañ der artzney doctor Schrick. Anno domini 1497. 4. 40, (4) foll.

Pritzel, Thes. lit. bet.
IIain Nr. 15.538. - Ed. II : 1498.4. 34, (4) foll. Hain Nr.15,539. * Margarite medicine. ein meysterliches ausserlesenes buchlein der Arznei fur mancherlei Krankheit und Siechtagen der Menselien. Augsl,urg, typ. Froselsauer. 1504. 4. 40 foll. - * Strasburg, typ. Martin Flacl. 1507.4.83 p. - ${ }^{*}$ Strassburg 1508.4. 43 foll. *Augsburg 1514.4.- ${ }^{*}$ Nuirnberg, flurch Friedrich Peypus. 1516 4. 35 foll. - * Strassburg, durch Math. Hupfauf. 1520. 4. - Erffurtt, dureh Melchior Sachssen. 1530. 8. Rivin. - * Arzneybüchlein der Kreutter. Bei dem allererfarnesten der Artzney Doctor Schricken zu Wyen. (Leiptzigk, dureh Michael Blum.) 1532. 4. 47 foll.

10359 Tollius, Jacolus. Epistolae itinerariae, ex auctoris schedis postlumis recensitae, suppletae, digestae; annotationibus et figuris adornatae, studio Henrici Christiani Ilenninii. Amstelaedami 1700. (1744.) 4. 260 p., tal. B.

(Plantao memorabiles recensentur, quae circa Joachimsthal proveniunt, ex Greiselio sumtae. Aurum vegetabile defendit.)

$10360+$ (Tommaselli, Guiseppe.) Antisi dei vegetabili per arrivare alta conoscenza de' generi e delle specie. Verona, typ. Ramanzini. 1794. II voll. 8 . xiv, $112,240 \mathrm{p}$.

$10361 \div$ (- Compendio di fisiologia vegetale, estratto dalle opere piü decenti. Verena, per l'erede Nlerlo. 1800. 8. (8) $276 \mathrm{p}$.

10362* Tommasini, Muzio. Der Berg Slavnik im Kustenlande und seine botanischen Merkwh tigkeiten, insonderheit Pedicularis Friderici Augusti. (Besondrer Abdruck aus Linnaea, vol. XIIl.) IIalle, typ. Gelbauer. 4839. 8. 30 p., 4 tab. col.

10363* Tonning, Ilenrik. Norsk medicinsk och oekonomisk Flora, indeholdende adskillige planter, som fornemmelig ere samlede i Tronliems stift. Forste deel. (Class. Linn.1-15.) Kiobenlavn, typ. Svare. (Schubothe.) 1773. 4. (14) $485 \mathrm{p}$.

(Tomus secundus nunguam proditi.)

1036' Tonnini, Ferdinando. Prospetto cromo-litografice confrontativo, tulto dal vero dei funghi mangerecci coi funghi velenosi e sospeti i più communi. Como 1846. 4 .

10363* Tornabene, Francesco. Sopra alcuni fatti di anatomia e fisiologia vegetale. Catania, typ. Riggio. 1838. 4. 21, 41 p.

$10366^{*}$ Biografia del Padre Emil. Guttadauro. Catania, typ. Scinto. 1839.8.8 p.

10367* Torraca, Gactano. Specimen experinentorum et olservationum, quibus corticis peruviani vis antiseptica comprobari vieletur. llomae, Remondini. 1765. 4. vm, $55 \mathrm{p}$.

$10368^{*}$ (Torrey, John.) A Catalogue of plants growing spontaneously within 30 miles of the city of New-York. Published by the Lyceum of natural history of New-Yerk. Allsany, typ. Websters and Skinners. $4819.8 .100 \mathrm{p}$.

$10369^{*}$ A Flora of the northern and middle sections of the United States; or a systematic arrangement and description of all the plauts hitherto discovered in the United states, north of Virginia. Vol. I: (Classis Limn. I-XII.) New-York, Sworts. 1824. S. xiI, 513 p.

(Volumen at(erum nunquam prodit.)

10370 —_ Account of a collection of plants from the Rocky Mountains ánd adjacent countries. New York, typ. Seymour. 1827. 8 . From the Annals of the Lyceum of Natural history, 1827. p. 161 $-25 \%$, i tab.)

10371 - Catalogue of North-American genera of plants, arranged according to the orders of Lindley's introduction to the natural system of botany: with the number of species belonging to each genus as far as they are at present determined. New York, 1yp. Sleight and Robinson. 4831.8. $22 \mathrm{p}$.

10372* 는 Nonograph of North-American Cyperaceae. To which is appended a Monograplı of the North American species of Rlıynchospora, by Asa Gray. NewYork, typ. Scott. 1836.8.

From the Anuals of the Liceum of Natural Ilistory of NewYork vol. 111. p. $191-238,239-1,4,1$ tab.

10373* — and Asa Gray. A Flora ol North-America, containing abridged descriptions of all the known indigenous and naturalized plants grewing north of Mesico; arranged according to the natural system. NewYork, Wiley and Putnam. (London, Wiley and Putnam; Paris, Bossange el Co.) 1838-1843. Il voll. 8. - I: Comprising the nolypetalous division of the dicetyledonous or exogenous 
plants. $1838-1840$. xiv, 711 1. (16. 10s.) - II, Part 1-3: 1841 -1843.504 p. (12s. $6 d$.)

(Contimuhitur. Desinit in fine Compositarum.)

1037i" Torrey, John. A Flora of the State of Newlork, comprising full descriptions of all the indigenous and saturalized plants hitherto discovered in the stato, with remarks on their economical and medicinal properties. By John Torrey. Volumen l. (Ranunculaceac - Frieacoae.) Albany, Carroll and Cooh, printers to the assembly, 1843. 4. X11, 484 p., (72) tal., cul. Bibl. Link.

(Etiam inscrihitur: Natural llistory of New York, Part 11: Botany lin parte prima, p. 113-197, ejustem uperis, Albany 1839. 8 . continctur Johannis Torrey Beport on the botanical department of the survey in NewYork; cf. Reilschmied Jahresherichte 1839-1812, p. 15.3.)

$10373 t$ leones incditae ad Floram Philidelphiae illustrandam destinatae. s. J. et a. 4. 130 tal). col. Bibl. Horti Paris.

$10326+$ Torrubia, Joseph. Aparato para la historia natural española. etc. Mladrid, Don Ag. de Cordejucla y Sierra. 175\%. 4. 204 p., praef., ind., 14 tah. Bibl. Webb.

("Compilatitium opus, in suo potissimum de corporibus lapidefactis agit., $\mathrm{H}$.

10377 Torssell, $G$. Enumcratio Lichenum et Byssacearum Scandinaviae hucusque cognitorum. Upsaliae 1843. 12. 55 1). (16 skill.)

10378 " Tosetti, Peler Joseph. Animadversiones nomullae de radice Artemisiae vulgaris, renedio amiepileptico. D. Berolini 4827. 8. $32 \mathrm{p}$.

10379 Toso, Alessandro dal. Leltera sopra la coltura delle risaje. Verona 1786.8 . DC.

$10380+$ Toulouze, Guillaume. Live de houcquets de fleurs et oyseaux faictz par Guilloume Toulauze, Maistro brodeur de Montpellier et se vend cliez l'auteur. Montpellier, faiet à l'année 1655. folio. Bibl. Juss.

10381 Tournefort, Joseph Pillon de. Elemens de botanique, ou méthode pour connattre les plantes. Paris, de l'iniprimerie royale. 1694. III voll. gr. $8 .-1: 562$ p., pracf., ind. - II el III: 451 tab. - †ilemens de botanique, ou méthode pour connatre les plantes. Élition augmentée de tous les supplémens donnés par Antoine de Jussieu, enrichie dune concordance etc. par N. Jolyclerc. Lyon, chez Bernuset. 1797. Vl voll. $8 .-\mathrm{I}: \mathrm{xv}, 480 \mathrm{p} .-\mathrm{Il}: 436 \mathrm{p}$. III 452 p. - IV: 416 p. - V: tab. 1-244. - VI: tab. $245-$ 489. ( 30 fr.) Bibl. Juss.

$10382 \div$ (— pour connaitre les plantes, par N. de Tournefort. Avignon, chez Seguin et Joly. 1749.12. 319 p.

$10383^{*}$ - De optima methodo instituenda in re herbaria, al Guilelmum Sherurdum epistola, in qua respondetur dissertationi D. Raji de variis plantarum methodis. (Parisiis 1697.) S.27 p.

$10384^{\circ}$ Histoire des plantes, qui naisseut aux environs de Paris, avec leur usage daus la medecine. Paris, de l'imprimeric royale. 1698. 12. 543 p., praef, ind. - "Seconde édition, revue ę augmentée par Bernard de Jussieu. Paris, Musier. 1725. Il voll. 12. - I: $407 \mathrm{p} .$, prael., ind. - 11: $528 \mathrm{p}$., ind.

$\div$ anglice: History of plants growing ahout paris, with their uses in physich; athd a mechanieal account of the operation of medicines. Translated into english "ilt many additions and accomodateil to the plants growing in Great Britain by John Jfartyn. London, Rivington. 1732. II voll. 8. - - 1: Lxv11, 311 p. - 11:362 p., ind.

$10383^{*}$ Institutiones rei herbariac. Editio altera, gallica longe auctior, quingentis circiter tabulis aencis adornata. Parisiis, e typographia regia. 1700. 111 roll. 4. $-1: 697$ p. - II: tab. 1250. - 111: tab. $251-476$. - "Editio tertia, appendicibus aucta al) Autonio de Jussieu, Lugdunaeo. Lugduni (juxta exemplar Parisiis, e typographia regia.) 1719. III voll. 4. - I: xxxn, 695 p. II: tah. 1-252. - III : tab. $253-489$.

$10386^{*}$ Corollarium Institutionım rei herbariae, in quo plantae 1356 in orientalibus regionibus observatae recensentur et ad genora sua revocantur. Parisiis, ex typographia regia. 1703. 4. 54 p., tab. $477-489$. - *Impr. cum editione tertia listitutionum. Lugduni 1719. 4. 58 p., tab. 477-489. - * In ordinem alphabeticum digestum in Raji Historia plantarum, vol. III, appendix, p. $97-112$.

10387 Traité de la matière médicale, ou l'histoire et l'usage des médicamens et leur analyse chimique. Ouvrage post- hume de M. Tournefort, mis au jour par M. Besuer. Paris, d'IJoury 1717. Il voll. 12. - I: L. 11,539 p. - II: 480 p. B. anglice: Materia medica, or a flescription of simple medicines generally us'd in pliysick. Londun 1708. 8. - Ed. II. London 1716. 8. $406 \mathrm{p}$. B.

(Versio anglica facta est secundum I'raclectiones Tournefortu manuscriptas.)

$10388^{*}$ Tournefort, Joseph Pillon de. Relation l'un voyage du Levant. fait par ordre du roi, contenant lihistoire ancienne ct morlerne de plusieurs lles de l'Archipel, les plans des villes et des lieux les plus considérables, et curichie de deseriptions et do figures dr* plantes, d'animaux et d'observations singulieres touchant l'histoire naturelle. Paris, de l'imprimerie royale. 1717. 11 voll. 4. - 1:554 p., praef, tab. - Il: 526 p., ind, tab. $(40$ fr.) - Lyon, Anisson. 1717. 111 voll. 8 . (24 fr.) a. - Amulerdam 1718.11 roll. 4.188. $208 \mathrm{p}$.

Epistolac sunt ex ipso ilinere latae ad 1), de Pontehartruin.

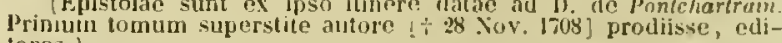
lorres.)

anglice: A voyage into the Levant. London 17t1. III voll. 8. 33i. 390,36 p., lab. B.

germanice: Tournefort's Beschreilung einer auf konisl. Refehl unternormmenen Reise nach der I.evinte. Aus dom franzosisclien Nurnherg Haspe. $1776-1777$. 111 yoll. 8. - 1: 1766.503 p., 41 tab. -

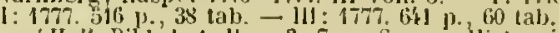

(Ilall. Bibi. bot. II. p. 3-7. - Spreng. Hist. rei herb. II. p. 63-73.

10389 " Tournon, Dominique Jérôme. Flore de Toulouse, ou description des plantes qui croissent aux environs de cette ville, avec l'indication de leur licu natal, l'époque de leur floraison, des observations sur leurs propriétés en inédicine, cn économie rurale, ot les tables de leurs noms français, latins et patois. Toulouse, Bellegarrigue. 181 1. 8. 393 1) - Ed. I1. ib. 1827. 8. (vix differt.)

Vidi Prospectum hujus Florae Tretosagum anno Reipuhlicae quarto Burdigaliae ectitum, in quo autor de suis in agro Tolosaun annis 1783-1788 institutis botanicis lougutur exeursionibus.)

10390 Towers, John. The domestic gardeners manual; being an introduction to practical gardening, or philosoplucal principles: to which are added a naturalists calendar. New edition improverl. London, Parker. 1839.8 . (13s.)

$1039 \mathrm{l}$ Townley, J. The discases, regeneration and culture of the Potato; containing and examioation of the royal agricultural societys prize essays on the blight, a reply to Dr. Lindley on the wearing out of plants etc. London 1847.8. 112 p. (2s.)

$10392^{*}$ Townsend, Benjamin. Der vollkommenc Samenhändler etc. Aus dem Englischen. Leipzig, Martini. 1727. 8. 120 p. - ib. $176 \mathrm{~s}$ 8. H.

10393 Townsend, Joseph. A journey through Spain in the years 1786 and 1787. London 1791. III voll. 8. -1 : 402 p. $-11: 414$ p. 3II : 356 p. cum tab. aen. B.

* germanice: Reise durch Spanien, deutseh mit Anmerhungen von J. J. Sollmann. Leipzig, Weidmans, 1792. 2 Bandes $S$. (3 th.) + gallice: Voyage cli kspagne, traduit en francais par J. P. Piclet. Jaris, Desitu. 1809 . Ill roll. 8 . ct Allas: 22 tab. (30 is.)

10394. Townson, kobert. Travels in llungary, London 1797. 4. 506 p.. 16 tah. B.

gallice: Voyage en lJorngrie fait en 1797 ; précédé dune description de la ville de Vientie et des jardins imperiaux de schoenbrun. Paris, Poignée. 1799. 111 yoll. 8. (15 fr.

Versio germanica, 'juam fecerat Joseph August Schulles, Schueaegrichenio a traductore iradita fuit, ut editorem quacreret; nunquam vero impressa est.)

1039:5 Tozzi, Bruno, monachus Valumbrosanus. Specimina jeonum pro Catalogo plantarum Toscaniae. 1703. 4. 6 tab. aen. sine textu. Bibl. Juss.

(Titulus manu est scriptus.)

10396 Tozzi, Luca. Medicinae theoreticae Pars 1. (dc regetatione.) Jugduni 1681.8 . H.

$10397^{*}$ Tradescant, John, filius. Nusaeum Tradescantianım, or a collection of rarities preserved at South-Lambeth near London. London 1656. 8. $183 \mathrm{p}$.

(lnest: Calalogus plantarum in liorto Johannis Tradescant nascentinn, p. 73-178; ef. William Hatson, Sume account of the remains if John Tradescants garden at Lambcth. Philos. Transact. 1749. "f John Tradescant's garden
vol. XLV1, Nr. $492, \mathrm{p}$. $160-161$.

1039s (Trafvenfelt, Erik Carl.) Anmarkningar om Natural-Historiens lirande vidl Rikets lägre Läroverk, $j$ anledning af Kongl. UptostringsKonnitténs underdåniga Forslag tull en forbattrad Skol-Orduing. Stockholm, typ. Lindh. 1818.8 .33 p. w. 
10399* Trainer, Iilhelm Adolph Bartholomacus. Examen chemicum Mannae. D. Erlangae, typ. Kunstmann. 1793. 8. 32 p.

10400* Trappen, Johann Eberhard van der. Respensio ad quaestionem: Quaeritul historia Solani tuberosi L. liujusque plantae descriptio botanica, culturae modus et varius usus oeconemicus? Trajecti a/Rh., Altheer. $1835.8 .153 \mathrm{p}$.

$10401^{*}$ Specimen historico-medicum de Coffea, quod ex auctoritate Rectoris Mlagnifici Cornelii Adriuni Bergsma pro gradu doctoratus eruditorum examini submittit. D. Trajecti a/Rh., typ. Kemink. 1843. 8. (2) $152 \mathrm{p}$.

10 k02* Trattinick, Leopold. Anleitung zur Kultur der achten Baumwolle in Oestreich. Wien 4797.8. 26 p. (1/12 th. $)$

$10103^{*}$ - Genera plantarum methodo naturali disposita. Vindobonae, impensis aucteris. $4802.8 .88 \mathrm{p}$.

10.10.1 — - Fungi austriaci ad specimina viva cera expressi, doscriptiones ac bistoriam naturalem completam adelidit Leopold Tratunick. Oesterreichs Schwamme uach Jebendigen Originalien in Wachs gearbeitet, mil Beschreibuugen und einer ausführlichen Naturgeschichte. Hanipulus ]-V. Wien, Geistinger 1804-4806. 4. 202 p., 18 tab. cel.

$10.103^{*}$ Fungi austriaci delectu singulari iconibus XL observationibusıue illustrati. Oestreichs Schwamme in einer Auswahl etc. Editio nova. Wien, Gerold. 1830.4 , VI, 210 p., 20 tab. cel. $\left(2 \frac{1}{2} t h.\right)$

$10106^{*} \longrightarrow$ Dic essharen Schwanme des Oestreichschen Kaiserstaates. Wien und Triest, Geistinger.1809. 8. cxxı, 174 p., 30 tab. col. - ${ }^{*}$ Neue Ausgabe. Wien, Gerold. 1830. 8. cxxil, 189 p., 30 tab. col. $\left(1 \frac{2 / 3}{t h}\right.$.)

(Editio nova praeter additamenta p. 175-189 nen differt.)

$10: 407^{*}$ Thesaurus botauicus. (Fasc. I-XX.) Viemae, typ. Strauss. (1805-) 1819. folio. 13 p., 80 tab. col. $(26 \%$ th. - col. $33 \frac{5}{12}$ th.)

10 \%08* Plan zum Archiv der Gewaclıskunde. Wien 1811. 4. $16 \mathrm{p}$.

$10409^{*}$ — Archiv der Gewachskunde. Wien, auf Kosten des Ilerausgebers. (Schaumburg.) 1812-1818, 5 Lieferungen oder 2 Bánde. 4. 296 tab., text. $\left(24 \frac{1}{6}\right.$ th. $)$

$10 \div 10^{*}$ Observationes botanicae tabularum rei herbariae illustrantes. Fasc. 1 - lll. Viennae, sumtibus editoris. 1811-1812. 4. $128 \mathrm{p}$.

(Editac sunt una cum opere praecedenti.)

$10411^{*}$ Ausgemalte Tafeln aus dem Archiv der Gewảchskunde. Wien, auf hosten des lleransgehers. 18.12-1814. JV voll. 4. I: 1812.34 p., appendix, (400) tab. col., effigies Leopold Trattinick. - II: 1813.94 n., appendix, (100) tab. col., effigies Carlvon Linne. - 111: 1814.61 p., appendix, (100) tab. col., effigies George Lou is le Clerc Comte de Buffon. - JV: 1814.42 p., appeudix, (100) tab. col., effigies Friedrich Gollieb Dietrich.

$10112 *$ Flora des Oesterreichischen haiserthumes. Wien, typ. Strauss. (Schaunburg.) 1816-1822. 2 Bande oder 24 Hefte. gr. 4. - J: 1816. xiv, 143 p., 100 tab. col. - 11. $1820, x, 82$ p., $100 \mathrm{tab}$. col. - Heft $23-24: 1829$. 16 p., 21 tal). col. $\left(37 \frac{1}{3}\right.$ lh. - col. 112 (h.)

$10\} 13^{*}$ Oestreichscher Blumenkranz. Wien, typ. Strauss. 1819. 12. XxIV, 240 p.

(Redit almo 18:0 cum titulo: "Calliope und Flora.,)

1014: - Ein Schritt vorwarts in unsern Ansichten der Natur. (Regensburg) 1821.8.30 p.

$10: 13^{*} \longrightarrow$ Botanisches Taschenbuch, oder Conservatorium aller Resultate, Jleen und Ansichten aus dem ganzen Umfange der Gewachskunde. Erster (uod einziger) Jahrgang. Wien, Schaumburg. 1821. 8. X11, 347 p., effigies Leopold Truttinick. $\left(1 \frac{1}{3}\right.$ th. $)$

$10.416^{*}$ Auswahl vorzuglich schöner, seltner, beruhmter und sonst sehr merkwürliger Garteupflanzen in getreuen Abbjldungen, nebst Erlauterungen über ihre Charakteristik, Verwandtschaft, Klassification, Geschichte, Verwendung, Kultur und asthetische Ansichten. Wien, auf Kosten des Herausgebers. (Schaumburg.) 1S21. (Fasc. I-XXIII.) II voll. 4. - 1: xxiv, 148 p., 100 tab. Il: vi, 97 p., 100 tab. $\left(35^{3} / 4\right.$ th. - col. $143 \frac{1}{8}$ th. $)$
104.17* Trattinick, Leopold. Rosacearum Monograplia. (Synodus botanica, emnes familias, genera et species plantarum illustrans.) Vindobonae, Heubner. 1823-1824. JV voll. 8. - 1: xxıI, 86 p., 17 plag. - 11: xxvı p., $301 / 2$ plag. - IJl: xvi p., $21 \frac{1}{2}$ plag. - IV: xxıI p. $20 \frac{1}{2}$ plag. $\left(6 \frac{2}{3}\right.$ th. $)$

$10418^{*}$ Genera nova plantarum iconibus olsservationibusque illustrata. Fasc. 1-Il. Viennae, (Schaumburg.) 1S25. 4. 24 tdb. (24) foll. $\left(2 \frac{1}{3}\right.$ th.)

$10119^{\circ}$ - Neue Arten von Pelargonien deutschen Ursprungs. Als Beitrag zu Robert Sweet's Geraniaccen mit Abbildungen und Beschreibungen. Ilerausgegeben von einigen deutschen Gartenfreunden; der Text vou Leopold Trattinick. Wien, auf Kesten der llerausgeber. (Schaumburg.) 1825-1343. 6 Bánde. 8. 264 tab. col., text. $(54,1 / 6$ th. $)$

(Icones poitissimum secundum plantas flerentes horti Jacobi Klier, hortulani Vindobonensis, factae sunt.)

10.420* Der Kaiserkranz zum 12. Februar 1829. (Aus dem Archiv fur Geschichte, Staatenkunde, Literatur und Kunst besenders abgedruckt.) 4.4 p., 1 tab. col.

(Agitur de Franciscea unillora Pohl.)

$10421^{*}$ (— stige und gemuthliche Unterhaltungen in den Gebicten der bluhenden Natur. Probeheft. Wien, typ. Wallishausser. 1839.4. 24 p.

$10422^{*}$ Calliope und Flora, oder poetische Unterhaltungen in den Gefilden der blülienden Natur. (Neue unveranderte Ausgabe des Oestreichschen Blumenkranzes.) Wien, Beck. 1840. 8. צxiv, 240 p. $(2 / 3$ th. $)$

$104.23^{\circ}$ - Die Schule der bluhenden Natur, oder ästhetischphilosophische Unterhaltungen. Wien, typ. Wallishausser. 1843. $8.88 \mathrm{p}$.

10424* Traunsteiner, Joseph. Monegraphie der Weiden von Tirol und Vorarlberg. Innsbruck, Wagner, 1842.8.40 p.

10425* Trautmann, Friedrich August Moritz. De radice Bryeniae albae ejusque in hemicrania arthritica usu. D. Lipsiae $1825.4 .40 \mathrm{p}$.

10426* Trautner, Johann Karl Friedrich. Wissenschaflliches Verzeichniss der in der Stadtbibliotliek zu Nürnberg enthaltenen Ausgaben, Uehersetzungen und Erläuterungen medicinisch-physikalischer Werke der griechischen und arabischen, danı der álteren lateinischen Literatur bis zum dreizehnten Jahrhundert. Nüruberg, Schrag. $1843.8 .(3 / 10$ th. $)$

J0427 Trautvetter, Ernst Christian (von). Die Quatember. 2 Bände. Nitau 1829-1830.8. Trautv.

$104.28^{*}$ De novo systemate betanico brevem nolitiam dedit. (Mitau, Reyher. 1842.) 8. 20 p., 1 tab. ( $1 / 6$ th.)

10.29 - Das Laubwerk oder der Spross (frons), als eine Blume in Nacheinanderfolge. (Aus eidem handschriftichen Werke: Grundriss der Pflanzenlelire.) (Nlitau, Reyher.) 1844. 8. 1/2 plag. $(1 / 6$ th. $)$

$10 \$ 30$ Trautvetter, Ernst Rudolph (von). Ueber die Nebenblatter. Nlitau 1831.8 .

(Seorsim impr. ex Ernesti Christiani Trautvetter patris Annalibus : Die Quatember.

$10431^{*}$ De Echinope genere Capita 1]. D. Mitaviae, typ. Steffenhagen. 1833.4.32 p., 1 tab.

$10432^{*}$ Salicetum, sive Salicum formae, quae hodie innotuere, descriptae et systematice dispesitae. Fasc. J. continens Salices pleiandras et monandras. Petropoli, Acad. scient, 1836. 4. 30 p., 4 tab.

$104.33^{*}$ Grundriss einer Geschichte der Botanik in Bezug auf Russland. St. Petersburg, Druckerei der Akademie der Wissenschaftels. $1837.8 . v, 145$ p. $(5 / 6$ th. $)$

1043:* ㄴ. De Pentastemone genere Commentatio. (Comment. Acad. tom. IV.) Petropoli, typ. Acad. scient. 1839.4.26 p., ind.

$10435^{*}$ Ueber die Krzemieniecer botanischen Garten. (Aloskau 1844.) 8.14 p.

(Senrsim impr. ex Bulletin der naturf. Gesellschaft zu Moshau, Band Xvill.

$10436^{*}-$ Plantarum imagines et descriptiones Fleram russicam illustrantes. Fasc. 1-VIll. Monachii, impensis auctoris. Stuttgartiae, Schweizerbart. 1844-1846. 4. p. 1-65, tab. 1-40. (6 th.) (Continuatur.) 
$10437^{*}$ (Trautvetter, Ernsl Kudolph (von). Reise in den áussersten Norden und Osten Sibiriens wahrend der Jahre 1843 und 1844 init allerhochster frenehmigumg auf Veranstalung der $\mathrm{K}$. Akademie der Wissenschaften zu St. Peterslurg ausgefulırt, und in Yerbindung mit vielen Gelehrten herausgegeben von Dr. Al. Th. von Middendorff. Erster Band, zweiter Theil: Botanik. 1. AlstheiJung: Pliánogame Pflanzen aus den llochnorden. Bearbeitet von Dr. E. R. von Trautelter. St. l'elershurg (Leijuzig, Voss.) 1847. gr. 4. $1 \mathrm{x}, 190$ p., 8 tah. $\left(6 / h_{\text {. }}\right)$ (Continuatur.)

(Contenta indicantur in Gersdorfii Loipziger Repertorium 1818. 1. 20 ' - 2017.

10438* Trautvetter, Friedrich Wilhelm von. Anleitung zum gedeilslichsten Bau der 70 faltig tragenden Ilimalayagerste (Hordeum coeleste limalayense). Dresden und Leijzzig, Arnoli. 1840.8. vi, 26 P., 1 tab. ( $1 / 4$ th.

$10139^{*}$ Der Schilfroggen (Secale arundinaceum) durch botanische Grunde und okonomische Erfahrungen als die ergielijgste und allerwarts gerleiblichste constante neue Roggenart dargesiell. Dresden und Leipzig, Arnóld. 1810. 8. 27 p., 2 tab. $(3 / \mathrm{s}$ lh. $)$

10440 (Travis, William.) Catalegus plantarum circa Scarborough sponte nascentium. s. a. 4.1 p. B.

10\$1t (Trecco, Giovami Battista.) Collivazione e governo del lino marzuolo. Vicenza, Bardella. 1792. 4. vıı, 80 \%., 12 tab. Bibl. webb.

10442+ Trécul, Auguste. Recherches sur la structure et le développement du Nuphar Jutea. (Paris 1343.) 8.60 p., 4 tab.

(Estrait des Annales des sciences naturelles. Nov,-Dec. 18\%.)

10:43 Trembley, Jean. Mémoire pour servir à l'luistoire de la vie et des ouvrages de Charles Bonnet. Berne 1795. 8. a

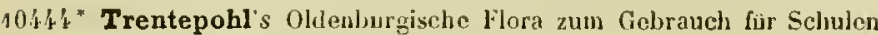
und beim Selbstunterricht, bearbeitet von Kurt Hagena. Oldenburg, Schulze. 1839. 8. xxviu, 298 p. (1 th. $)$

10415* Treu, latine Trew, Christoph Jakoh. Beschreibung der grossen amerikanisehen Aloe, wobei das täglielıe Wachsthum des Stengels der im Jahr 4726 zu Nurnberg verbluheten Aloo erláutert wird. Nünberg, typ. Adelburner. 1727.4 obl. 36 p., 1 tab.

$10446^{*}$ Die Nabrungsgefässe in den Blattlern der Bàme nach ilree unterschiedlichen Austheilung und Zusammenfügung, so wic solclıe die Natur selbst bildet, abgedruckt von Johonn Michael Seligmann. Nebst Christoph Jakal Trew's historischem Bericht von der Anatomic der Pfanzen und der Absich dieses Werks. Nürnber'g, Fleischnann. 1748. folio. 8 p., 32,2 tab).

$10477^{*}-$ Plantae selectae, quarum imagines ad exemplaria naturalia Londini in hortis Curiosorun nutrita manu artificiosa doctaque pinxit Georgius Dionystus Ehret; occasione haud rujgari publici usus ergo collegit et a tab. 1-72 nominibus propriis notisque illustravit Christophorus Jucobus Trew; hinc ad centesimam usque addendo itidem nomina ac uotas produxit D. Benedictus Christianus Vogel; in aes incidit et vivis coloribus repraesentavit primum Johannes Jucolus Ihuid, inde Johunnes Elias Haid, filius. (Norimbergae) per Decades editac $1750-1773$. folio. 56 p., 100 tab. col, et inagines Trewii, Ehretii et Iluidii patris.

thollandice: Uitgezochte Mlanten. etc. Uit het Jatyu vertaalil en met aanteheningen verrykt door Cornetius Pereboom. Amsterdam Sepp. 1771. folio. 11, 72 p., 100 tab. col. et imagines Trewii, Ehreti et Hutdii patris. Bibl. Cand.

$10448+$ Hortus nitidissimis omuem per annum superbiens floribus, sive amenissinorum lforum imagines, quas magnis sumtibus collegit vir clarissimus Christophorus Jucobus Trew, ijuso vero annuente in aes incisas vivisque coloribus pictas in publicum erlidit Johannes Michael Seligmann. Der das ganze Jahr hindurch im schönsten Flor stehende Blumengarten, oder Abbildungen ier lieblichsten Blumen etc. Nürnberg, sumtibus liacredum Seligmann. 1750-1786. 111 voll. folio. latine el germanice. - 1: 1750-1768. (22) plag., tab. col. 1-59. - 11: (edidit Adam Ludwig Wirsing.) 1772. 5 J p., tab. col. $60-120 .-$ HI: (edidit Adam Ludwig Wirsing.) 1786. 58 p., tab. col. $121-180$.

104.49* Librorum botanicorum catalogi duo, quorum prior recentiores quosdam posterior plerosque autiquos ad annum IDL usque excusos'ad ductum propriae collectionis breviter recenset. Norimbergac, stamno Fleischmanniano. 1752. folio. (54) p.
10450 Treu, latine Trew, Chrisloph Jakob. Librorum botanicorum catalogus tertius, in quo recentiores quosdam ad ductum propriae collectionis porro recenset. Norimbergac 155\% folio. p. 55-80. B. IScorsim impressi sunt ex Treviana IIertarit Blach Welliani editione, do fua supre Nr. 920. - Bankins possidebat exemplar auctoris natu correctum, e bibliotheca Philippi Miller.

$104: 1^{*}$ Cedrorum Liljani historia carumque claracter botancus cum illo Laricis, Alietis l'inique comparatus. Accedit brevis disquisitio an liaec arbor sit illa ipsa in sacro codice prae omniljus celebrata et vel aeres vel berosel dicta, itemque an Graecis butanicis fuerit cognita. Cum apologia et mantissa. Norinhergae, Scliwarzkopf. 1757 et $1767.4 .28,50$ p., 7 tals.

(Apolugiam ol Mantissan observationis de Cedro Libanj sen)!sim prodiisse lego: Norimbergac 1767. 't.)

$10452^{*}$ Plantae rarinres, quas maximam partem ipse in hort" domestico coluit secundum notas suas examinavit et breviter $p x-$ plicavit, nec uon depingendas acrique incidentas curavit Christophorus Jacobus Trew, edente Johunn Christoph Keller, pictore Norimbergense. (Norimbergae) ex officina Clir. de Launoy. 1763 folio. 14 p., tab. col. 1-10. - Plantae rariores, quarum primans decaden curavit C.J. Trew, posteriorum curam et illustrationem suscepit Benedikt Christion Fogel, auxiliante arte sua Adum Ludu's Wirsing. Decas 11. ib. 1779. folio. 22 p., tab. col. 11-20.

$104033+$ Trevelyan, IV. C. On the vegetation and temperature of the Faroe lslands. (From the Edinburgh New. Phil. Journ. for January 1835 reprinted with corrections.) Florence, June 1837. 4. $16 \mathrm{p}$.

10 f5; Treveris, $P$. The grete herball; with numerous woodengravings. London 1526 . folio. Cat. Bibl. Radcliffe 0 xon.

$10455 *$ Treviranus, Christian Iudolf. Pom inwendigen Bau der (iowachse, und vou der Saftbewegung in tensellen. ËHe Sclurift, welcher die Konigliche Societat der Wisseuschaften in Gottungen das Accessit zucrkannt. Gottingen, Dieterich. 1 \$ 06.8 . xx, 208 p., 2 tab. ( $1 / h$.)

$10456^{*} \longrightarrow$ Beiträge zur Pllanzenplyysiologie. Gottingeu. Dieterich. $1811.8 . x, 260$ p., 5 tab. $(1 / h$.)

$10457^{*}$ Observationes botanicae, quibus stirpes quaselam germanicas illustrare conatus est. Programma. Rostochii, typ. Adler. 1812.4 .24 p.

10458* —_. Von der Entwichlung des Embryo und seiner Linhuillungen im Pflanzenei. Berlin, Reimer. 1815. 4. v1, 102 p., 6 tab. $(13 / 4$ lh. $)$

$10459^{*}$ De Delphinio et Aquilegia observationes, quas munia professoralia in hoc alma Musarum sede ingressus lierbarum studiosis offert. Vratislaviae, Korn. $1817.4 .28 \mathrm{p}, 2$ tab. $(1 / 3$ th.

$10^{4} 60^{*} \longrightarrow$ und Gollfried Reinhold Treviranus. Vermischte Scliriften anatomischen und physiologischen Inlalts. Band $\mathbb{T}$. Bremen, Heyse. 1821. 4. II, 242 p., 6 tab. $(21 / 2$ th.

$10461^{*}$ ___ Die Lelure rom Geschlechte der Pflanzen in Bezug auf die neusten Angriffe erwogen. Bremen, lleyso. 1922. 8. 146 p., Nachsehrift: (2) p. $(3 / 4$ th. $)$

$10462^{*}$ Alli species quotquot in horto botanico Vratislaviensi coluntur, recensuit, rariores observationibus illustravit, • novas quasdan descripsit. Programma academicun. Vratislaviae, typ. universitatis. $1822.4 .18 \mathrm{p}$.

$10463^{*}$ Ueher gewisse in Westpreussen und Schlesien angeblich mit einem Gew itterregen gefallene Samenkörner. Breslau, Max. $4823.8 .31 \mathrm{p} .(1 / 6 / h$.

1046: $t^{*}$ De ovo vegetabili ejusque mutationibus observationes recentiores. Programma academicum. Vratislaviae, tyy. universitatis. 1828.4 .20 p. $(1 / 6$ (h.)

$10463^{*} \longrightarrow$ Caroli Clusii Atrebatis et Conradi Gesneri Tigurini Epistolae ineditae. Ex archetypis edidit, adnotatiuneulas adspersit, nec non praefatus esi $L$. Chr. Trevirantus. Lipsiae, Toss. 1830. S. v1, $62 \mathrm{p} .(3 / 8$ th. $)$

$10466^{*}$ - Symbelarum phytolegicarun, quibus res herbaria illustratur, fasciculus 1. Goettingae, Dieterich. 1831 . 4. viI, $92 \mathrm{p}$. 3 (a). $(1 \mathrm{~h}$. $)$

10467: — Plysiologie der Gewächse. Bonn, Marcus. 18351838. II voll. 8. - I: is35. xx, 570 p., 3 tal. -11 : 1833. IV, 809 p., 3 tab. $(7 / /$. $)$ 
101.68* Treviranus, Christian Ludolf. De plantis Orientis, unde pharmaca quaedam colliguntur, accuratius determinandis. s. a. et 1.8 . (13) p.

(Seorsim impr. ex Brandes Arehiv, vol. XII.)

101.69* Trevisan, Victore, Conte. Enumeratio stirpiun cryptogamicarum luncusque in provincia Patavina observatarum. Patavii, typ. Cartallier el Sicea, sumtibus auctoris. $1840.8 .39 \mathrm{p}$.

10:7 $70^{*}(-)$ Prospetto della Flora Euganea. Padova, typ. seminarii. $1842.8 .67 \mathrm{p}$.

101.71* Triller, Daniel II Thelm. Moly Homericum detectum, cum reliquis ad fabulam Circaeam pertinentibus. D. Lipsiae, typ. Titii. 1716. 4. (Respondens: Johann Jakob Wagner.)

(Redit auetius in opusculorum medicorum el philologicorusn collectione, Lipsite 1766. 4 .)

10472 De cortieis peruviani usu senibus, gravidis et infantibus salutari. Wittebergae 1758.4 . H.

10473 De morte subita ex nimio violarum odore olorta. Wittebergae 1762.4. H.

Nobilis viruo, quum in cubiculo violarum odore pleno dormisset, mane moribunda reperta, servari non potuit.)

$104.74^{*} \longrightarrow$ De planta quadam venenata ejusque furioso effectu

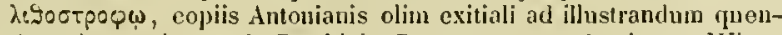
dam Appini locum in Parthicis. Programma academicum. Wittebergae, typ. Eichsfeld. 1765. 4. xvi p.

(Conjecturam facit all Daturam.)

$10.73^{*}$ Trinchinetti, Augusto. Sulla facoltà assorbente delle radici de vegetabili. Memoria premiata. Milano, typ. G. Bernardoni di Gio. $1843.4 .81 \mathrm{p}$.

(Botanische Zeiturg 18ki. p. 111-112.)

$10476^{*}$ Trinius, Karl Bermhard (von). Fundamenta Agrostographiae, sive Theoria constructionis floris graminei; adjecta synopsi generum graninum hueusque eognitorum. Viennae, Heubner. $1820 . \mathrm{s}$. $\mathrm{x}, 244$ p., ind., 3 tab. $(12 / 3$ th. $)$

1067 $77^{2}-$ Clavis Agrostographiac antiquioris. Uelersicht des Zustandes der Agrostograpluie bis auf Linné, und Versuch einer Reduction der alten Synonyme der Gráser auf die heutigen Trivialnamen. Cohurg, Biedermann. 1822. \&. xxiv, 412 p., 4 tab. $\left(2 \frac{1}{4}\right.$ th. $)$

$10478^{*}$ De graminibus unifloris et sesquifluris Dissertatio botanica, sistens Theoriac constructionis floris graminei epicrisin, terminologiae novae rationes, de mellodo disquisitiones, adjecta generum et specierum e tribu Uni- et Sesquiflororum plurium synopsi. Petropoli, Academia scient. (Lipsiae, Voss.) 4824. 8. $314 \mathrm{p}$., ind., 5 tab. $\left(1 \frac{1}{8}\right.$ th. $)$

$10479^{*}$ De graminibus paniceis. Dissertatio botanica altera. Petropoli, Academia scient. (Lipsiae, Voss.) 1826.8 .289 p. $(3 / 4 t h$.

$10480^{*}$ Species graminum iconibus et descriptionibus illustravit. Petropoli, impensis Academiac imper. scientiarum. (Li)siae, Leop. loss.) 1828 (1823) - 1836. III voll. 4. 360 tab., texi. (45 th.)

(Prodiit 30 fasciculis; a 12 tab. $11 / 2$ th.)

$10481^{*}$ Ueher den gegenwartigen wissensehaftlichen Standpunkt der Naturforschung. St. Petersburg (Leipzig, Voss.) 1828. gr. 8.82 p. $(1 / 2, t h$.

$10482+(\longrightarrow$ Genera plantarum ad familias suas redacta. Petropoli, impensis Academiae scientiarum. 1835. 4.399 p.

$10483^{*}$ - Agrostidea. I. Vilfea. Petropoli, typ. Academiac. (Lipsiae, Yoss.) 1840.4.112 3. (1/2 th.)

(Ex Actis Acad. scient. Petrop. ser. VI. tom. V. sc. nat.)

10484* Ayrostidea. II. Callo rotundo. (Agrostea.) Petropoli, typ. Academiae. (Lipsiae, Voss.) 1841. 4. 144 p. $(2 / 5$ th.) (Ex Actis Acad, scient. Petrop. ser. VI. tom. Vi. se. nat.)

$10.8 \ddot{z}^{*} \longrightarrow$ et $F . J$. Ruprecht. Species graminum Stipaceorum. Petropoli, typ. Academiae. (Lipsiae, Voss.) 1842. 4. 189 p. (1 th.) (Ex Actis Aead. seient. Petrop. ser. V. tom. V. se. nat.)

10486 Tristan, Jean, Seigneur de Saint-Amand. Traité du Lys, symbole de l'esperance. Paris 1656. 4.

(Confutat Chifletii sententiam in Auastasi Childerici regis. Antwerpii 1603 . 4 cap. Xll., quae apos regibus Francide pro insignibus inservierint: lilia potius inde a Chlodovaeo $I$, adhibita fuisse, tria
vero jam inde a Philippo VI. Respondit (hi/let anto toss.)

104.87 Tristan, Jean, Comte de. Rapport au nom de la commission nommée pour l'examen d'une nouvelle métliode de greffer les ligneaux, designée sous le nom générique d'écusson-greffe. Nantes typ. Mellinet. $1830.8 .8 \mathrm{p}$. Q.

10488t Tristan, Jules, Comte de. Mémoire sur la situation botanique de l'Orléanais et sur les earactères de la Flore Orléanaise. Orléans. typ. Iluet-Perdoux. $1810.8 .15 \mathrm{p}$.

$10489 \div$ Mémoire sur les aigrettes des fleurs composées et sur les earactères du genre Zinnia. Orléans, typ. Huet Perdoux. 1811 8.13 p.

$10490 \div$ Hémoiro sur les organes caulinaires des asperges. Orléans, typ. Ilıet-Perdoux. 1813.8.46 p.

$10491 \div$ Tableau des eporques de la végétation observées aus environs d'Orléans année 1817 et 1818. (Orléans, typ. HuetPerdoux.) 8. 8, 16 p., 3 tableaux.

$10492 *$ Triumfetti, Giovanni Battista. Observationes de ortu ac vegetatione plantarum cum novarum stirpium listoria jeonibus illustrata, ad illustr. Antonium Feticem Abbatem Marsilium. Ronac. typ. A. Herculis. 1685,4 . (6), 106 p., 17 tab.

$10493 \div$ Syllabus plantarum horto medico Romanae Sapientiae huc re ipsa anno 1688 additarum. Romae, typ. D. Ant. IJerculis. 1688.4 .8 p. Bibl. Juss.

$10494 \div$ Praelusio ad publieas herbarum ostensiones habita in lıorto medico Romanae Sapientiae anno jubilaej 1700 a Johanne Baptista Triumfetti Bononiensi. Cui aecesserunt novarum stirpinm descriptiones et icones. Romae, Iyp. D. Antonii Herculis. (1700.) 4. 64 j., 6 tab. Bibl. Deless.

$10493^{*}$ Yindiciarum veritatis a castigationibus quarundam fropositionum, quae habentur in opusculo de ortn ac vegetatione plantarum, cum auetoris specinine cirea plantarum plsaenomena ae metamorphoses Pars prior, in qua experimenta ac novae observationes de ortu ae vegetatione plantarum eontinentur. Romate typ. A. de Rubeis. 1703.4 .205 p., praef., 4 tab.

$10496^{*}$ Trog, J. G. Taluula analytiea fungorum in Epicrisi vel Synopsi Iymenomycetum Friesiana descriptorum, ad operis usum facilinrem enllata. Bernae, Huber et Co, 1846. gr. 12. viti, 313, (1) p $\left(1 \frac{1}{3}\right.$ th. $)$

(Llem edidit jeones fungorum edulium et venenatorum lielveiac ad naturam delineatis atque pictas ab $J$ hergner. Quatuor prodicrunt fasciculi, forma folio; singulus continet $b^{6}$ tab. col. it textum, pretio $\&$ ih.

10497* Tromsdorf, Joham Samuel. Ros mellis, non ros, nee mellis ros; der ungleich angegebne Ilonigthau ete. D. Erfurti, typ. Muller. 1699. 4. (20) $\mathrm{p}$.

10498 Trommsdorff, Wilhetm Bernhard, pr. De oleis vegetabilihus essentialibus, eorumque partibus eonstitutivis. Erfordiae 1765.4.

$10499^{*}$ De Lichene islandico. D. Erfordiae, ıур. Nonne. 1778. 4. $20 \mathrm{p}$.

$10500+$ Troufflant. Discours sur la botanique, pour l'ourerture du cour's de cette science établi a Nevers. Nevers, typ. Lefebure. on 11 de lin repulblique. $8.76 \mathrm{p}$. Bibl. Juss.

10501 Trotzky, Petrus Kornuch. Разсуж, деніе о семействт крс-

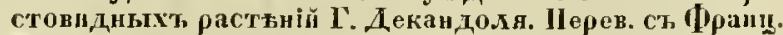
Mockis. 1826. Trautv.

$10502^{*} \longrightarrow$ De plantarum phanerogamarum germinatione. D. Dorpati, typ. Seluunmann. $1832.8 .61 \mathrm{p}$.

10503 Trowel, Samuel. On hosbandry and gardening. London 1739. 8. H.

germanice: Neue Ahhandlung vom Ackerbau, der Cartnerei, vollstandig gemacht yon Ellis. Leipzig 1750.8. B. (Hall. Bibl. bot. II. 304.)

1050\} Trozelius, Clas Blechert. Tankar on en Hushållares upmarksambet vid Váxt-Riket. D. Lund, ty’p. Berling. 1760. 4. 32, (2) p. (Respondens: Is. Sandahl.) w.

10505 Annaarkningar vìl Hvit-ock Rot-kålsls planteringen. D. Lund 1762.4. 26 p. (Respondens: Magnus Lund.) B.

Physico-occonomisk Beskrifning ofver Mistelăhs Socken uti Småland. D. Luul, typ. Berling. 1766. 4. 20 p. (Respontlens: B. N. Hagetberg.) w.

(Calalogus plantarum Paroeciae Mistelåns, D. 19-20.)

10507 De generatione ac uutritione arborum. D. I-II. Londini Gothorum, typ. Berling. 1768.4.27 p. (Respondens: Carl Kevigin.) B. 
l050s Trozelius, Clas Blechert. Tankar om Såcker oclı Siruj, af inliemska vaxter. D. Lund 1771. 4. 16 p. (Respondens: Pehr Giers.) B.

10509 Förslag til nya Brygg-och Briches anmen. D. Lund 1772. 4. 19 p. (Respondens: Pehr Johan Lindstrum.) B.

10310 Specimen graduale de Sacerdole bolanico. D. Londini Gothornm, typ). Berling. 177\%. 4. 13 p. (Respundens: Jucab Bengt Brandstrüm.) B.

$10311-$ Inledning til Gods underverk uti naturen. D. 1-111. Lund, typ. Berling. $1778-1780.4 .64$ p. w.

$10312 \longrightarrow$ Landuanma genvàgolil fruhl-trán. D. Lund 1780. 4. 16 p. (Respondens: Rich. Arr. Ackerman.) B.

10513 — Om trän och Juskar i allmanhel. D. 1-11. Lund, tỵp. Berling. 1781.4. 48 p. (Respondens: Magnus Lars Lödman.) B.

10öl:" Trummer, Franz. Systematische Classilicatiun und Beschreiloung der im Herzoghum Steienmark vorkommenden Rebensorten. Herausgegehen von der $k$. $k$. Landwirthschaftsgesellschaft in Steiermark. Gratz 1041.8. x, $36 z$ p., 4 schemata, a tah. $(15 \%$ th.

IU:jlä Tschiffeli, Daniel. L'ècole des jardiniers. Berne, André llogenot. 1696. 12. Bibl. Eugen.

10316 " Tschudy, Jean Bapliste Louis Theodore, Baron de. Traité des arbres résineux coniferes; extrait et traduil de l'auglais de Philipp Miller. Metz, Collignon. 1763. 8. xxxı1, 233 p., 5 tab.

1031 _ De la transplantation, de la naturalisation el du perfectionnement des regetaux. Londres et l'aris, Lambert. 1778. 8. a.

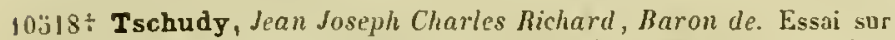
la gretre de l'herbe des plantes el des arbres. Metz, typ. Antoine. 1819.8.60 P. A tab. (1 fr.)

$10: 319^{*}$ Tschudi, J.J. ron. Die Kolkelstörner und das Pikrotoxin. Mit Benutzung van Dr. Ch. K. Vossler's hinterlassenen Versuchen. St. Gallen, Scheillin und Zollikoter. 1847. 8. vur, 130 p.

$10320 \div$ Tuckerman, Edward. A furlher enumeration of some NewEngland Lichenes. (Boston 1840.) 8. 26 p.

(From the Boston Journat of natural history, vol. IIt.

$10521^{*}$ - Enumeratio mellsodica Caricum quarundam. Species recensuit et secondum hahitum pro viribus disponere tentavit. Schenecstadiae, typ. Riggs. 1843. 8. 21 p.

$1082_{2}{ }^{2}$ In enumeration of North American Lichenes, with a preliminary view of the structure and general history of these plants, and of the Fricsian system: to which is prefixed an essay nt the natural sistems of Oken, Fries and Endlicher. Cambridge, John Owell. 1845.8 . vi, 59 p. Bibl. Scblectend.

10i23 * Tuckey, Caplain J. K. Narrative of an expedition to explore the river Zaire usually called the Congo in South-Africa in 1816. To which is added the Journal of Professor Smith; some general obserrations on the country and its inhahitants; and an appendix: containin the natural history of that part of the hingdon of Congo through which the Zaire nows. London, Murray. 1818. 4. Lxxxit, 498 p., 14 tab.

Appendix $r$ : Observations systematical and geographical on profestal Christian smith ' Collection of Plants tron the vicinity of Pre River Congo, by Robert Rrawn. p. 420-\$6.)

1032't Tuerk, Ililhetm ron. Anleitung zur Pflege und Erziehung der Maulbeerbaume. Vierte bedeutend vermehrte Auflage. Leipzis. Heichenbach. $1841.8 .4 \frac{1}{2}$ plag., 1 tab. $(1 / 3 / h$.

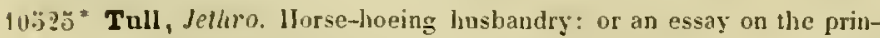
ciples of vegetation and tillage etc. London, by G. Strahan. 1733. folio. - "Third edition. London, Millar. 1751. 8. xvı, 432 p., tab. (De eximio rei agraride scriptore, quem polissimum secutus est ill. DuHamel, ef. Hall. Bibl. bot. II. p. 23\}-23j.)

10is 26 " Tulpe, Nicolaus, latiue Tulpius. Observationes medicae. Amstelodami 1652.8 .403 p., tab.

(Insumt varia botanica, de Plıallo, Thea, aliis.)

10327 Tupper, J. P. An essay on the probability of sensation in regetables; witls additional observations on instinct, sensation, irritability etc. London 1813. 8. - The second edition. London, Longman, Hurst etc. 1817. 8. $1 \mathrm{x}, 142 \mathrm{p}$. (6s.)

10328 Turczaninow, Nicolaus. Flora baicalensi-dahurica seu descriptio plantarum in regionibus cis - et transbaicalensibus atque in
Dahuria sponte nascentium. Pars I. Mosquae, Severin. (Lipsiae, Voss.) 184z-1845. gr. 8.544 p. (3 th.)

$10329+$ (Turgot, Marquis de Cousmon, Etienne Francois.) Mémoire instructif sur la manière de rassembler, de préparer, de conserver et d'envoyer les diverses curiosités d'listoire naturelle. I.yon 1758. 8. $146 \mathrm{p}$., 95 lab.

10330 Essai sur les arbres d'ornement, les arlurisseaux et les arbustes de pleine terre; extlail dı Dictionnaire de Phitipp Ifiller, ed. V1l. Amsterdan et Paris, Grangé. 1778. 8, a

$10331 \div$ Turio, Bernardino. Specimen plantarum, yoas in agro Clavariensi aliisque dipartimenti Appenninorum locis collegit atque $e_{-}$ siccavit. Clavari, typ. Pila. (1806.) 4. 32 p. Bibl. Cand.

$10.332 \div$ Turnbull, 4 . On the medical properties of the natural vrder Ranunculaceae: and more particularly on the uses of Sabadilla secds. Delphinium Slaphisagria and Aconitum Napellus, and their Alcaloids Veratria, Sabadilline, Delphinia and Aconitine. London, Longman. 1835. 8. vill, 171 p. Bibt. Weьt.

10533* Turnebus, Adrianus. De vina libellus. Parisiis, Claude Morcllus. 1600. 8. - " De vino libellus. Cum proemio Jo. Caselii ad Theodorum Farnsbachum. Ejusdem Caselii ad latinan linguam accuratius discendam colırtatio. Helmstadii 1605. 4. - "Hclmsladii, typ. Jacobi Lucii. 16 19. 4. (40) foll. - "inpr. cum Meibomio de cerevisis. Helmestadii 1674. 4. (16) foll.

10534 * Turner, Dawson. A Synopsis of the British Fuci. London, White. (Yarmoulh, typ. F. Bush.) 1802. II voll. 8. xLV, 400 p.

$10533^{*}$ Moscologiae hibernicae spicilegium. Yermuthi et Londini, White. 1804. 8. xI, 200 , sI p., 16 tab. col.

$10336^{*}$ and Lewis Weston Dillwyn. The bolanists guide trough England and Wrales. London, Plilipps and Fardon. 1805. 11 voll. 8. Sv1, 804 p.

$10337^{*}$ — Fuci, sive plantarum Fucorum generi a botanicis adscriptarum icones, descriptiones et historia. (Etiam anglice inscriptus: Fuci, or colored figures and descriptions etc.) London, Arch. 1808-1819. IV voll. gr. 4. - I: 1808.164 p. tab. col. 1-71. - II: 1809. 162 p., tab. col. $72-134 .-111$ : 1811. 148 p., tab. col. 135-196. - 11: 1819. 153, 7 p., tab. col. 197-258.

$10538 \div$ Turner, Robert. Botanologia, the brittish plysician: or the nature and vertues of euglish plants. etc. London, Brook. 1664.8 .663 p., praef., ind., effigies autoris. - London 1687.8 .363 p. B.

10339 Turner, Samuel. An account of an embassy to the court of the Teshoo Lama in Tibet; containing a narrative of a journey tbrouglt Bootan and part of Tibet. London 1800.4 .473 p., 14 tab. B.

* gallice: Ambassade an Tihet et an Boulan, avec des notes par J. Castera. Paris, an 1X. 1800 . II voll. 8 . et 15 tab. in-\$. (12 fr.) germanice: ubersetzi von Sprengel. Weimar 1801. 8.

$103: 0^{\circ}$ Turner, IIIlliam. A new Ilerball, wherin are contevned the names of herbes in greke, latin, englysh, duch, frenche and in the potecaries and herbarieslatio, with the properties, degrees and naturall places of the same, gathered and made by 11 illiam Turner, Physicion uoto the duke of Somersettes Grace. Imprimed at London, by Steven Mierdman. anno 1551. folio. (94) foll. custod. A - p. cum iconibus ligno incisis. - The seconde parte. Collen 1562. folio. 171 foll. - The first and secunde partes of the Herbal of II illiam Turner, Doctor in phisick, lately overseve, corrected and enlarged with the thirde parte, lately gathered etc. Imprinted at Collen, by Arnold Birckmann. 1568. folio. - Part I: 223 p., praef., ic. xylogr. i. 1. - Part II: 171 [oll., ic. xylogr. i. 1. (est eadem impressio, novo titula ac praefatione.) - Part IIl: 81 foll., ic. xylogr, i. t. Bibl. Juss.

(In Germaniam auctor se receperal, saeviente Maria, alque Coloniae cum profogorum colonia viserat, quare ejus regionis plantas spontaneas solus fere onniom auclorum tradit.)

103 i 1 A bew boke of the natures and properties of all wines that are commonlye used here in England. London 1568. 8. $4 \frac{1}{2} \mathrm{plag}$. praeter libellum de theriaca. B.

a Gulielmus Turnerus, Anglus, historiam de naturis herbarum scholiis el notis vallatam edidit'Cotoniae: apud Gymnicum. 15t'. 4.D Bnm. Hunc librum trustra quaesivi.)

10542 Turpin, François Rene. Histoire civile et naturelle du royaume de Siam, sur les manuscrits, qui ont été communiqués parl'éveque de Tabraca, vicaire apostolique de Siam, et autres missionaires de 
ce royaume. Paris, veuve Regnard ot Demonville, 1771. II voll. 12. 450,444 P. B.

Caput xit. de arboribus redit germanice in Berlin. Sammlung vol. Vill. p. 137-167. Lego in Querard. France litt. IX. p. 583: "Ouvrage supprimé par arrêt du conscil.»)

$10513^{*}$ Turpin, Pierre Jean François. Mémoire sur l'inflorescence dos Graminées et des Cyperées comparéo avec celle des autres végétaux sexiferes; suivi de quelques observations sur les disques. (Paris 1819.) 4.67 p., 2 tab.

(Extrait des Annales du Muséum d'histoire naturelle, tome v.)

105.4. —_ Essai d'une iconographie élémentaire et philosophique des végétaux avec un texte explicatif. Paris, Panckoucke. 1820.8. 200 p., 59 tab.

(Sistit simul vol. Vlll operis inscripti: Flore médicale, quod supra Nr. 1811 recensui.)

$103: 3^{*} \longrightarrow$ Organographie végétale; observation sur quelques végétaux microscopiques, et sur le rôle important que Jeurs analogues jouent dans la formation et l'accroissement du tissu cellulaire. Paris, Belin. 1827.4.55 p., 1 tab. col. ( 3 fr. 50 c.)

(Extrait des Mémoires du Muséum, tome Xiv.)

1051.6 Mémoire sur l'organisation intérieure et extérieure des tubercules du Solaumm tuberosum et de l'llelianthus unbcrosus, considérée comme une véritable tige souterraine. Paris 1828. 4. $x$ p., 5 tab. ( 3 fr. 50 c.)

$1051.7+-$ Obscrvations sur la famille des Cactées, suivies de la description d'une espece nunvelle d'Echinocactus et de celle de Rlipsalis parasitica. Paris, typ. Huzard. 1830 . s. 69 p., 3 tab.

(Extrait des Amales de l'Institut horticole de Fromont.)

103187 Examen d'une cliloranthie ou monstruosilé observée sur l'inflorescence du Saule marceau. Paris, lyp. Huzard. 1833.8 . 13 p., 1 tab.

$105.9+$ Mémoire de nosologie végétale. (Paris 1833.) 4. $24 \mathrm{p}$. 1 tab. nigr., I tab. col

Extrait des Mémoires des Savans étrangers, lome VI.)

$10300 \div-$ Flore usuelle; Recueil de plantes enployées dans l'économie domestique, les leaux arts, les arts mécaniques, la médecine, la plarmacie, peinte par $\mathbf{~ l l}^{\text {mig }}$ Ern. Panchoucke et $P . J$. F. Turpin. Fasc. 1-VIIl. Paris, Panckoucke. 1834.8 .8 foll., 8 tab. col. (à 65 c.) Bibl. Deless.

( ${ }^{*}$ Nofice des travaus de M. P. J. F. Turpin. Paris, typ. Fain s. a. $4.12 \mathrm{p}$.)

$10331 \div-$ Observations générales sur l'organogènie et la physiologie des végétaux. Paris, typ. Didut. 1835.4 .50 p., 1 tab. col. (Mémoires de l'Académie, tome Nill.)

$10352 \div-$ Notice sur une maladie qui se développe sur les tiges vivantes des murier's et plus particulierement sur celles du murier multicaule. Paris, lluzard. 1838.8. 8 p., 1 tab. (Accedit: Nlaladie des feuilles du mùrier: 7 p.)

$10533^{*}$ __ Iconographie végétale, on organisation des végètaux illustrée an moyen de figures analytiques. Arec un teste explicatif raisonné et une notice biograpbique sur M. Turpin par M. Achille Richard. Paris, Panckoucke. 1841.4 min. xu, 144 p., 57 tab. col.

(Eximia sua plantas delineandi arte plurimos ornavit ill. Turpin libros botanicos; ef. Brisseau Mirbel $\mathrm{Nr}$ 1293, Chaumeton Nr. 1811 DeCandolle Nr. 221 , DelaBillardiere Nr. 2318 et 2330 , Delesserl Nr. 211 Goethe Nr. 3761, IIumboldt Nr. 4774-4777, Poirel Nr. 8114, Poiteau Nr. 8118, Raffeneau-Delile Nr. 8305, Saint-1tilaire Nr. 87Ł2, Tussac Nr. 10560 , I'entenat Nr. 10702.

1033: Turra, Antonio. Istoria del arbore della China. Livorno 1764. 4.

$10555+$ Farsetia, novum genus. Accedumt animadversiones quaedam botanicae. (Velıetiis 1765.) 4. 14 p., 1 tab. Bibl. Juss.

$10536+(-)$ Florae italicae prodromus. Vicetiae, ex officina Turraeana. $1780.8 .68 \mathrm{p}$. Bibl. Cand.

Desinit quidem in Cryptogamia cum Boleto inclinato tamen incompletum videtur opus, quod $D C$. teste cum catalogo insectorum ahsolvitur.)

10557 Turre, Georgius $\alpha$. Catalogus plantarum horti Patavini novo incremento locupletior. Patavii, ex typographia Camerali. 1660. 8. Rivin. - Patavii, typ. Frambotti. 1662. 12. 132 p., praef. Bibl. Juss.

10558 Junonis et Nestis vires. Opus botanicum. Patavii, typ. Frambotti. 1668.4. S.

10559* —_ Dryadum, Amadryadum, Chloridisque Triumpbus, ubi plantarun universa natura spectatur, affectiones expenduntur, facultates explicantur. Patavii, typ. Frambotti. 1685. folio. $709 \mathrm{p}$ praef., ind.

Gelleralia varia praemittit et fuse vires medicatas plantarum tradit. Ad ipsam naluram vix so demittit. Liber in lextu et in praefixo ante tilutum folio nuncupatur: "Historia plantarmn.

$10560^{*}$ Tussac, F. R. de. Flora Antillarum, seu historia generalis botanica, ruralis, oeconomica vegetabilium in Antillis indigenorum, et exoticorum indigenis cultura adseriptorum; secundun systema sexuale Linnaei et methodum naturalem Jussieui in loco natali elaborata, iconibus accuratissime delineatis et coloratis illustrata. Parisiis, apud auctorem et Fr. Schöll, 1808-1827. IV voll. folio. - I: 4808.198 p., 30 tab. col. - II: $1818: 221$ p., 34 tab. col. - III : 1824.127 j., 37 tab. col. - IV: 1827. 121 p.. 37 tab. col.

Opus sulendidum, cujus tantum 1000 exemplaria sunt impressa prodiit per fasciculos $k-5$ tabularum, siugulus pretio 3 fr. - Numerus tabularan est 138.

10561 Tusser, Thomas. Five liundreth points of good husbandry united to as ntany of good huswiferie, first devised, and nowe lately augmented with diverse approved lessons concerning hopps and gardening. London 1573. 4. 66, 31 foll. B. - * Five lundred points of good husbandry; together witl a book of luswifery'. A new edition by Willinm Mavor. London 1812.4. Bibl. Pal. Vindob.

10562 Twamley, Louisa Amne. The romance of naturn, or the Flower Seasons illustrated. Ed. III. London 1836. 8. 27 1ab. col. (16. $1 \mid s, 6 d$.

10563 Flora's Gems. London 1837.4.12 tab. col. by Andrews. (2l. $2 s$.

1056\% Ou wild fowers familiarly descrihed and illustrated. London 1838.8.12 tab. col. ( $1 / .4 s$.)

$10365 \div$ Twent, A.P. Proeve of eenige aanteckeningen wegens liet planten op Duinen van Raaphorst, aan liefluelubers van planten meede gedeeld, van nut konden zyn. In's Graveulıage, Wynants. 1800.8 . $104 \mathrm{p}$.

10366 " Tylkowski, Adlalbert. Physica curiosa. Cracoviae 4669. 4. Bibl. Reg. Dresd. - ${ }^{*}$ Oliva, typ. Fritsch. 1680-1682. 8

(Pars VIII. p. 453-690 agit de plantis.)

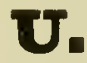

$10567^{*}$ Ucria, Bernardino $a b$. llortus regius Panhormitanus, aere vulgaris anno 1780 noviter exstructus, septoque ex indigenis, exoticisque phurimas complectens plantas. Punorni, typis regiis. 1789 4. v1, 498 p. Bibl. mus. Vind., Bibl. Webb.

(I) J Jaudat erlitionem: Panormi 1819. \&. - Ejusdem autoris "PJantae ad Linnaeanum opus addendae "masime e cupani Pamphyto siculo redeunt in Roemer Archiv, 1.67-70.)

$10568^{*}$ Uechtritz, Max F. S. von. Kleine Reisen eines Naturforschers. Breslau, Korn. $1820.8 . x, 354$ p. $\left(1 \frac{1}{3} t h .-\right.$ herabgesetzt: $2 / 3 t h$.)

10569 Ugla, Petrus. De praefectura Naesgardensis Dalekarlide. D. Upsalis, typ. Werner. 1734.4.150(16) p. w.

(Vegelabilia regionis: p. 26-27.)

$10570^{*}$ Ulitzsch, Karl August. Botanische Schattenrisse, nebst einer kurzen Einleitung in dio systematische Kräuterkunde nach Linné, und einer Beschreibung der Pflanzen nach ihren Kennzejchion und Eigenschaften. Torgau, auf Kosteu des Ilerausgebers. 1796. 2 Hefte. 4. 120 p., 80 tab. $\left(1 \frac{1}{2}\right.$ th. $)$

(Sunt ectypa foliorum fuligine expressa.)

10871 Ullgren, Olof Mathias. De plantis tinctorïs suecanis. D. I - II. Upsaliae, typ. academiae. 1815.4 .14 p. (Respondentes: CariHallberg et $F_{r}$. Segerstedt.) w.

(Non continuata esl; desinit in Tetrandria cum Rubia tinctorum.)

100072 Ulloa, Antonio de. Relacion historica del vjage à la America meridional, hecho de orden de S. Mag. para medir algunos grados de meridiano terrestre. Madrid 1748. II voll. folio. - I: $682 \mathrm{p}$, 21 tab. - Il: 603 , cxc. p., 13 tab. B.

gallice: Voyage historique de l'Amérique méridionale, fait par ordre du roi d'Espagne par Don George Juan et Don Antonio de 
Clloa; Iradnit de lespaznol (par de Ifcucillon), Amsterdan 1752. II volt. 4. (20-2' ir.) Q.

anqlice: A voyago to South-America. Thirt edition, with notes and observations liy John Alams, who losided several years in those parts. Loudon 1722 . Il voll. 8, 479,49 p. 7 tal. B.

$10573^{*}$ Ulloa, Antonio de. Noticias anericanas entretenemientos phisicos-listoricos sobre la América meridional y la septentrionaloriental. etc. Madrid, typ. Mena. 1772.4 .407 [., praef.

* germanice: Physikalische und historische Nachrichten vom sudlichen und nordostlichen America. Aus dem spanischen vou $J$. A Dieze. Mit Zustitzen. Loipzig, Wuidmanns Erben und Iteich. 1781 2 Theile. 8. - I: xxil, 262 p. - II: vil , 431 p. $\left(12 \frac{2}{3} t h\right.$.

gallice: Memoires philosonhiujes, fistoriques et physiques, concernant la découverte de l'Amerique, ses anciess habitants, les produits etc. traduits de l'pspagnol (par Lefebure de l'illebrune). Praris, Buisson. 1787 . II voll. 8 . Q.

1057' Ummius, Johannes Anton. De herla Fumaria. D. Groningae 1723. 4.14 p. B.

10575* Unanue, Joseph IIipólito. Disertacion solure el aspecto, cultivo comercio $y$ virtudes de la famosa planta del Perú nombrada Coca. publicada en el Nercurio Peruano num. 372. Impresa en Lina, en la imprenta real de los niños expositos. 1794. 4. 45 p., pracf., I tab.

40576t (Underwood, John.) Catalogue of plants in the Arboretum, Frulicetum, Herbarium, Gramina vera, Hortus tinctorius, lot et greenhouses of the Dublin Societys botanic garden at Glasvevin. Dublin, typ. Giaisberry. 1802.8.247 p.

$10577^{*}$ A catalogue of plants, indigenous and exotic, cultivated in the botanic garden belonging to the Dublin Society at Glasvenis. Dublin, typ. Graisberry. 1804.8. 134 p. and map.

$10 \ddot{7} 78^{*}$ Ungebauer, Johann Andreas, pr. De cultura plantarum. D. Lipsiae 1741.4.28 p. (Rospondens: Johamn Christian Hebenstreit.)

$10579 *$ Unger, Franz. Dic Exantheme der Pflanzen und einige mil diesen verwandte Krankheiten der Gewdelse, pathogenetisch und nosographisch dargestellt. Wien, Gerold. 1833. 8. xı, 422 p., 7 lah. (nigr. $2 t h$. - col. $2 \frac{1}{2}$ th.)

$10580^{*}$ Ueber den Einfluss des Bodens auf die Vertheilung der Gewächse, nachgewiesen in der Vegetation des nordöstlichen Tirols. Mit 2 Karten und 6 Tabellen. Wien, Rohrmann u. Schweigerd. 1836. gr. 8. xxIv, 367 p., 9 mappac. ( $3 \frac{1}{2}$ th.)

10081 - Ueber das Stulium der Botanik. Ein Vortrag. Grătz, typ. Tanzer. $1836.8 .24 \mathrm{p}$.

1058:* —_ Die Schwicrigkeiten und Anuelimliclikeiten des Studiums der Botanik. Ein Vortrag, gelıalten am 8. Márz 1837. s. I. 8. $11 \mathrm{p}$.

$10583^{*}$ - Aphorismen zur Anatomie und Pliysiologie der Pđanzell. Wien, Beck. 1838 . 8. 20 p. (1/2 th.)

$10584^{*}$ - Ueber den Ban und das Waclisthum des Dicotyledonenstammes. Preisschrift. St. Pelersburg, Akademie der Wissensclsaften. (Leipzig, Voss.) 1840. 4. III, 204 p., 16 tab. ( $2 \frac{1 / 3}{3}$ h.)

$10585^{*}$ —_ Ueber Krystallbildungen in den Planzenzellen. (WVien 1840.) 4. 60 p., 7 tals.

Seorsin impr ex Aunalen des Viener Nuseums der Naturgeschichte, Band ii.)

$10586^{*} \longrightarrow$ Beiträge zur vergleichenden Palhologie. Sendschreiben au Schöntein. Wien, Beck. 1840. 4. vi, 42 p., 1 tab. col. (1 th.)

$10.587^{*}$ Die Pflanze im Momente der Thierwerdung. Wien, Beck. 1843. 8. 99 p., 1 tab. col. (1 th.)

$10588^{*}$ Ueber merismatische Zellenlildung bei dler Entwicklung des Pollens. s. 1. 1844. 4. (7) p., 1 lab. (Unde?)

$10589^{*}$ Synopsis plantarum fossilium. Lipsiac, Voss. 1845.8. xvtri, 330 p. $\left(1 \frac{2 / 3}{3}\right.$ th. $)$

Literatura plantarum fossilium: p. VII-XVIll.

$10590^{*}$ Grundzúge der Anatonic und Plsysiologie der Planzen. Wien, Gerold. 1846. 8. xlv, 131 p., (79) ic. xylogr. i. 1. $(1 / 2$ th. $)$

10501* Chloris protogaea. Beitrage zur Flora der Vorwelt Leipzig, in Commission bei Wilhelm Engelmanu. I847. 4. 1v, cx, 150 p., 50 tah. $\left(33 \frac{1 / 3}{/ h}\right.$. $)$

Prodit annis 181 1-18\$7 tecem fasciculis. Opus, editione L'ngeri frenerum el specierum plantarum fossilium, quae nune ab illustr seientiarum Vindohnensi academia paratur, finita, fortasse ab ill. autote contisuabitur.
10392 * Unger, Franz. „Ueher die fossile Flora ron Parschlug. (Grátz 1847.) gr. 8.39 1\%., ic. xylogr. i. 1

Besonders ahgedricht aus der Stejermárhischen Zuitschrift, nene folge, Jalirsang IX. Ileft I.

$103093^{*}$ Unger, Johann Gollfried. Disscrtatio de -"-*; hoc est, de Papyro frutice ad Jesaian XIX, 7. L. Lipsiae 1731.4 .42 p. (Respondens: Immanuet Errust Hahn.)

1059:* Unger, Michael. Animadversiones circa Jussieui methodum plantarum naturalem. D. Halac, typ. Gebauer. 1806.8 .34 p.

10393 Ungius, Nicolaus Thomas. Encomion historiae plautarum, seu oratio do plantis etc., quam in florentissima Suocorum Academia Upsaliensi jussu et consensu rev. el clar. Lom. Inspectorum die Pliblippi et Jacobi Apostolorum anno 1636 publice recitavit Nicom laus Thomas Ungius. Upsaliac, typ. Wallianis. 1636. 4. (10) 1). W.

10396 * Ungnad, Christian Samuel. De Malo Persica. D. Francofurti a/V. typ. Winter. 1757.4. 34 p.

$10: 97$ Unonius, Olof. Iisputalio plysica de plantis, quam in Regia Upsaliensi Academia pro conseruendls magisterii plilosophici privilegiis etc. Directore M. Otao Unonio publico examisi submittit Mignus Nicotai (Cetsius). Upsaliac, imprimebat Eschillus Mattliac. 1647. 4. (10) 1). w.

$10: 398$ Unverricht, harl. Anleitung zur Pllanzenkenntniss. Ein Handbuch der allgemeinen Botanik uıd Flora von Deutschland. Fur den Sclnul- und Selbstunterricht bearljeitet. Schweidnitz, llecge. 1842. gr. $12.35^{3} / \mathrm{p}$ play. $(1 / 3$ th.

$10399^{*}$ Unzer, Johann August. Sammlung kleiner Schriften. Physikalische. Rinteln und Leipzig (F. A. Brockluaus.) 1766.8. 440 p. Zwote Sammlung. Zur speculativen Philosophic. ib. 1769 . $8.410 \mathrm{p}$. - Dritte Sammlung. ib. 1769.8. $(2 / 3$ th. $)$

(Insunt: Betrachtungen uber einige Besonderheiten aus dem Gewtichsreiclie I 5 ' - Untersuchüng, wie die Băume vor dem Gewtichsreiche. I. 5 fit. Untersuchung, wie die Baume vor dem Erfrieren zu hew
zen 1. $212-255$.

$10600 t$ Ursinus, Johannes Heinrich. Arborctum biblicum, in quo arbores el frutices passim in s. literis occurrentes, nolis philologicis, philosophicis, theologicis exponuntur et illustrantur. Norinbergae, stumtibus Tauberi imprimebat Gerhardus. 1663.8 .621 p., praef. ind., tab. plur. - Ed. Il: Norimberge 1672. \$. 621 p., tab. plur. B. - Ed. 111: Norimbergae, typ. Froberg. 1685. 8.621 p., tab. plur. - Continuatio historiae plantarum biblicae. ib. 1685. \$. 276 p., praeter appendices. - t Arboretum bublicum, in quo arbores et frutices passim in $\mathrm{S}$. Literis occurrentes, ut et plantac, herbac ac aromata, notis philologicis, philosophicis, theologicis exponuntur et illustrantur. Nunc jraecipuis emblematibus et arboribus acre incisis exornatum, a vitis purgatum atque indicibus utilissimis rerum, dictorum praecipuorum biblicorum, nominumque cbracorum et graecorum in hoc libro occurrentium adauctum: adjuncto theologiae symbolica Sylva. Norimbergae, apud J. D. Tauberum. 1699. II voll. 8. - I: 62 I p., praef, ind., tab. plur. - Il: (sive coutinuatio.) 212 p., ind. Bibl. Cand.

10601 Ursinus, Leonhard. Tulipa de Alepo. Programma. Lipsiac 1661 4. $1 / 2$ plag. B.

10602* De Rosa menstrua. Programna. Lipsiae 1661. 4 $1 / 2$ plag.

$10603^{*}$ - Ad demonstrationes botanicas Programma. (Lipsiae) 27 April 1662. 4. 1/2 plag.

1060 ' Lilium album plenun. Programma. Lipsiae 1662. 4. $1 / 2$ plag. B.

$10605^{*}$ Urzedow, Marcin. Herbarz polshi, to iest o przyrodzeniu ziol y drzew roznailych, $y$ in nych rzeczy do lekarzw nalezacych, hisięi dwoie, Doctora Marcina Urzedouca i. e. Herbarium polunicum l. e. de natura herbarum et arborum variarum atque aliarum rerum ad pharmaca pertinentiun libri duo. W Krakowie, w drukárni Lázárzowèy. 1595 . folio. (6), 488 p., ic. xỵlogr. i. t. Bibl. Goett. (Arnold de monum. hist. nat. Poloniac p. 60. - Adamski Prodrounus hist. rei herh. in Polonia p. 29. - Spreng. Hist. rei lierb. 40\%-460. Linnaeus et Hallerus nomen autoris varie mutilaverunt est enim iden noster N. Zedora el Mortin Unzendorf, Ilall. Bibl bot. 1. 389.)

10606 Uschakow, S., et $N$. Ossipowitsch. Всеобщپil̆ са,довивкт. C. IIerep6. 1812-1829. 4 Iac'r. Trautv. 
10607* Dslar, Johann Julius von. Fragmente neurer Planzenkunde. Braunschweig, Schulbuch handlung. 1794.8. 188 p. (7/12 th. $)$

+ anglice: Chemico-plysiological observatious on plants. Trans lated from the German with additions by $G$. Sichmeisser. Edinburgh, Creech. 1795. 8. x11, $171 \mathrm{p}$.

10608* Uslar, Justus Ludwigvon. Die Bodenvergiftung durch die Wurzelausscheidungen der Pflanzon als vorzuglichster Grund fur die Ptlanzen-Wecbselwirthschaft. Altuna, Blatt. $1 \$ 44.8 .161 \mathrm{p} .(1 \mathrm{ht}$.

$10609^{*}$ Usteri, Paulus. Delectus opusculonum botanicorum, edidit notisune illustravit. Argentorati, in bibliopolio acadenuicu. 1790-1793.

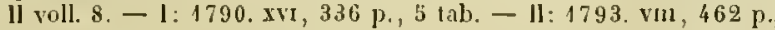
5 tab.

$10610^{*}$ - Annalen der Botanik. Herausgegeben von Paulus Usteri. Zurich, Orell, Gessner, Fussli el Cu. Leipzig, Peter Philip Wolf Vjerundzwanzig Stuck. $1791-1800.8 .\left(17 \frac{1}{2} / h.\right)$

I: 1791.203 p., 1 tab

II: 1794.226 p., 5 tab.

XIII : 1795.429 p.

III: 1792.282 p., + tal.

IV: 1793.205 li. 1 tal.

XIV: $1795.121 \mathrm{p} ., 1$ tab.

XV: 1795.137 p., 3 tab.

XVI: 1795. 153 p., 1 tals.

$V: 1793.170$ p. 7 tab.

XVII : $1796.169 \mathrm{p}$

XVIII: 1796. $137 \mathrm{p}$

Vi: 1793,133 p., 1 tab.

XIX: 1796. $154 \mathrm{p} ., 1$ tab

XX: 1796.437 p. 4 tab.

VIII: $1794,153 \mathrm{p}$.

IX: 1794. 121 p., 4 tab.

$X: 1794.129$ p., 1 tah.

XX1: 1797.137 p. 1 tab

XX1l: 1797.137 p., 2 tab.

XI: 1794. 136 p., 4 tab.

XXIlI: 1799.153 p., 2 tab

NII: 1794.154 p.. 2 tab. XXIV: 1800.153 p., 1 tab tanik,")

$10614^{*}$ Uxkull-Gyllenband, Kuno Otto, Graf von. Kurze Beschreibung der Oestreich'schen Sclswarzkiefer, Pinus nigra austriaca, und ihres grossen Nutzens für die Forst- $u$. Landwirtliscliaft. Frankfurt a/M. Sauerländer. 1845.8 .53 p., $\uparrow$ tab. $(1 / 3 / h$.

10642 - Einige Worte uber die Anlegung von Saat - und Phanzenschuleu, so wie das Neveste uleer das Versetzen von

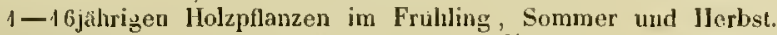
Tubingen, Fues. 1846. 8. 2 plag., 3 tab. $(1 / 1 / t h$.)

\section{V.}

$10613+$ (Vaccari, Gaspare.) Sul richiamo della canna zuccherina in Sicilia e sulle ragioni che lo esiggano di $G$. $V^{\gamma}$ e $P$. Palermo, typ. Solli. 1825-1826. II voll. \&. - I: 1825. 200 p., A tab. - II: 1826. 180 p., 1 tab.

( Autor est Gaspard laccari, Intendant de la province de Girgenti. " DC.

10614* Vahl, Martin. Symbulae botanicae, sive plantarum tam earum, quas in itinere imprimis orjentali collegit Petrus Forstiål, quam aliarum recentius detectarum exactiores descriptiones, nec non observationes cirea quasdam plantas dudum cognitas. Havniae, impensis auctoris. (Schubothe.) 1790-1794. III partes. foliv. I: 1790.85 p., tab. 1-25. - Il: 1791. 105 p., tab. $26-50 .-$ III : 1794.104 p., tab, $51-75 .(142 / 3$, h. $)$

$10613^{*}-$ Eclogae americanae, seu descriptiones plantarum praesertim Americae meridionalis nondum cognitarum. Fasc. 1- III. Havniae, impensis auctoris. (Schubothe.) 1796-1807. folio. 1: 1796. 52 p., tab. 1-10. - II: 1798. 56 p., tab. 11-20. III : 1807.58 p., tab. $21-30 .\left(14 \frac{1}{2}\right.$ th.

$10616^{*}$ __ Icones illustrationi plantarum anericanarum in Eclogis deseriptarum inservientes edidit $\boldsymbol{M}$. $\boldsymbol{V}$. Decas I-Ill. Havniae, impensis auctoris. (Schubothe.) $1798-4799$. folio. 30 tab. ( 6 th.)

1061\%" —_ Enumeratio plantarum vel ab aliis, vel ab jpso observatarum, cum earum differentiis specificis, synonymis selectis et descriptionibus suecinctis. Havniae, typ. Molleri, impensis auctoris. 1804-1806. II voll. 8. - 1: 1\$04. Lx, 384 p. - II: 1806. viI, 423 p. ( 5 Rbdr. $-51 / 3$ th.)

(Est editio minoris pretij, Gocttingae, Vandenhoek el Ruprecltt. 2 th., quae praeter annos $182 \mathrm{t}$ et 1825 in titulis minime differt. Opus in Triandria clisse incompletum remansit.)

Pritze: Thes, lit. bot.
10618* Vaillant. Voyage autour du monde exécuté pendant les années 1836-1837 sur la corvette Ja Bonite, commande par M. I'aillant. Botanique par M. Charles Gaudichaud-Beaupré. Paris, Arthus Bertrand. 1839-1846.8. et Atlas in folio

Opus nondum absolutum est. Prodiit anno 1845 partis botanicae volumen 23 plagulirum, in quo Cryptogamae cellulares et rasculares autorilus Montagne, Léveille et Spring (Lycopotliaceae) continentur. Tabularum pictarum vidi fasciculos 5 . 9. 10.)

$10619^{*}$ Vaillant, Sébastien. Sermo de structura florum, horum differentia usuque partium eos constituentium, habitus in ipsis auspiciis demonstrationis publieae stirpium in horto regio Parisino, d. 10 Junio 4717 et Constitutio trium novorum generum plantarum, Araliastri, Sherardiae, Bocrhaaviae. Cum descriptione duasum plantarum novarum generi postremo inscriptarum. Discours sur la structure des fleurs, leurs différences et l'usage de leurs parties, jrononcé à l'ouverture du jardin royal de Paris le 10 Juin 1717 , et l'établissement de trois nouveaux genres de plantes l'Araliastrum, la Sherardia et la Boerhaavia, avec la description de deux nouvelles espèces rapportées au dernicr genre. Lugduni Batavorum, apud P. van der Aa. 171S. 4.55 p. - *ib. 1727. 4 . 55 p. - tib. 1728. 4. 55 p. (gallice et latine.)

10620 - Etablissement d'nn nouveáu genre de plante nommẻ Araliastrum, du quel le fameux Ninzeı ou Ginseng des Chinois est une espèce. Communiqué par M. Faillant, Demonstrateur des plantes au jardin royal de Paris, a un des ces amis (Hugo) a Hannover ce 3 fevrier. 1748. 4. (4) foll. Bibt. Juss. (Ephem. Acad. Nat. Cur. Cent. VII - Vlil, appendix, p. 189-192;
redit in Sermone de structura llorum.)

$10621+$ Botanicon Parisiense. Operis majoris prodituri Prodromus. Lugduni Batavorum, apud Petrum van der Aa. 1723. 8. 132 p., praef. Boerhaqvii. - +Editio nova emendalior et aucta. Lugduni Batavorum et Parisiis, Briasson. 1743. 8. 134 p., praef. (differt.)

10622* Butanicon Parisiense, ou Dénombrement par ordre alphabetique des plantes, qui se trouvent aux environs de Paris compris dans la carte de la Prevoté el de l'Election do la dite ville par le Sieur Danet Gendre année 1722, avec plusieurs descriptions des plantes, leurs synonymes, le tens de fleurir et de grainer, at une critique des auteurs de botanique. Enrichi de plus de trois cents figures, dessinées par le Sieur Claude Aubriel, peintre du cabinet du Roy. Leide et Amsterdam, chez Verbeek et Lakeman. 1727. fulio, xII, 205 p., ind., XXXIll tab.

Catalogum manuscriptum Herbarii Vaillantiani, quad in Vuseo horti Parieiensis servatur, vidi in Bibl. ill. Hadrianide Jussieu, Il voll. 4. $1550 \mathrm{p}$.

10623 Valcarenghi, Taulus. In Ebenbitar tractatum de Malis Limoniis commentaria. Cremonae 1759.4.232 p. B.

10624* Valente, Anlonio. Recensio plantarum villa atque horto praesertim botanico Francisci Cuetani ducis comprehensarum juxta $C$. Linnaei et A. L. Jussieu systemata dispositarum. Romae, typ. Caetani in Exquiliis, 1803. 8. xvit, 167 p., effigies Principis Caetani. Bibl. Goett.

10623* VaJentin, Johann Christoph. De plantarum succis. D. chemicomedica, Marburgi, typ. acadeniae. 1795.8.84 p.

10626 Valentine. Muscologia Nottinghamiensis. (Hooker Journal of Botany vol. lll. p. 375.)

10627* Valentini, Chrisloph Bernhard. Tuurnefortius contractus, sub forma tabularum sistens institutiones rei herbariae juxta metlodum modernorum cum Jaburatorio Parisiensi ejusdem autoris. Accedit Materia medica a Paulo llermanno in certas classes characteristicas redacta, cum rluplici schematismo, excursionibus botanicis et herbariis vivis conficiendis inserviente. Francofurti a/M., Andreae. 1715. folio. 48 p., ind., 4 tab.

10628 Valentini, Konrad Michael. De Mlacis. Giessae 1719. 4. н.

10629 Valentini, Michael Bernhard. De China Chinae. D. Giessae 1695. 4. (Respondens: P. I'olfart.) н.

10630 De Ipecacuanlia novo Gallorum antidysenterico. D. Giessae 1698. 4. (Respondens: Christoph Friedrich Kueussel.) н.

10631* — Polychresta exotica, accedunt seorsin olim editac, nunc autem conjunctim denuo prodeuntes Disscrtationes epistolicae varii argumenti. Francofurti a/Ml., Zunner. 1704. 4. 293 p.

(lusunt: De fahis st. Ignatii, p. 1-4k. Dissertatio do Ipecacuanlra, p. 10-29. Discursus academicus de China Chinao, p. $65-67$. 
Responsoria ail hudolphi Jacobi Camerarii epistolam de sexu plantarum, p. 272.)

10632* Valentini, Michael Bernhard. Museum museorum oder Vollständige Schaubühne aller Materialien und Spezereien. Frankfurt a/A., Zunuer, 1704-1714. III voll. folio. - 1: 1704. 250 p., tab., et Johrum Daniel Major, Unvorgreillliches Bedencken von kunst- uad Naturalienkammern, $76 \mathrm{p},-1 \mathrm{~J}: 171$ h. $196 \mathrm{p} ., 38 \mathrm{tab}$. et Oast-indianische Sendschreiben, von allerhand raren Gewachsen, Báumen, Juvelen, auch andere Raritaten, durch Cleyern, Rumphen, Ilerbert de Jager, ten Rliyne ctc. gewechseli, und aus deraselben in hallándischer Sprach geschriehenen Originalien ubersetzet von Michael Beruhard Valentini, 119 p., tab.

(Volumen 111 agit de instrumentis physicis.)

10633 Prodromus historiae naturalis Ilassiae, quem anno acaJemiae Juliae Gissenae jubilaro 1707 sub praesidio autoris Jahannes Nicalaus Mueller, Giessa-llassus propasuit. Giessae, apud IJenningium Mullerum. 1707. 4. $\mathrm{s}$.

(In eapite quarto de plantis llassiae agilur.)

$10634^{*}$ Viridarium reformatum, seu Regnum vegetabile, das ist: Neu eingerichtetes und vollstäudiges krtutelunch, worinnen auf noch nicht gesehene Weise derer Vegetabilien als Kráutern, Sträuchen etc. eic. Frankfurt a/M., Heinscheidt. 1719. folio. 584 ]., indices, 384 tab., ic. i. t.

$10635^{*}$ - Historia siuplicium reformata sub Musei Museorum titulo antehac in vernacula edita, jam autem in gratiam exterorum sub directione, emendatione et locupletatione autoris a D. Joh. Conr. Beckero latio restituta. Accedit India literata, e lingua belgica primum in germanicam translata, nunc vero ad desiderium exterorum latinitate donata, longe auctior reddita, novisque figuris aeneis illustrata a Christophara Bernardino Tulentini, M. B. filio. Francofurti a/M., ex officina Zunneriana. 1716. folio. 664 p., praef., ind. 16 tab. - * Offenbaci 1732 . folio. (uon differt.)

(A p. 377 ad tinem est: India literata.)

$10636^{*}$ Valentyn, Frangois. Oud-en nieuw Oost-Indien. Dordrecht et Amsterdan, Jeau Braam. $1724-1726$. V voll. folio. Bibl. palat. Vindob.

(Valuminis tertii alıno 1726 editi magna pars est botanici argumenti. Adjulus est a Van der Stellits. Plantas amboinenses plerumque arboreas unultas describit, depingit in novem tabulis deneis 125. Hall. Bibl. bot. 11. 191.

10637 Valet, $F$. Uebersicht der in der Umgegend von Ulm wildwaclsender phanerogamischen Pflanzen nebst Angabe der Standorte und Blutezeit. Ulm, Nübling. 1847.8. $111 \mathrm{p} .(\% / 15 \mathrm{th}$.

$10638^{*}$ Valla, Gioryio. Georgii Vallae Placentiui de simplicium natura liber uuus. Argentinae, per Henricum Sybold. (1528 mense Augusto.) 8. (104) foll. sign. $\mathrm{A}-\mathrm{N}$.

10639* Valle, Felix. Florula Corsicae, edita a Caralo Alliano. (Misc. Taur. II. p. 204-218, 1 tah. - * Florula Corsicae, aucta ex scriptis Dn. Jaussin a Nic. Laur. Burnunno. Nov. Act. Acad. Nat. Cur. W, Append. p. 205-254.)

10640 t Valle, Roberlus de, Rothomagensis. Plinianorum locarum diffcilium explanatio, cum prologo et finali conclusione; et Compendium memarandorum vires naturales et commoda compreliendens a Plinio data. Impressum Parisii, per Felicem Baligaud, impensa magistri Durandi Gerdier. a. M. v. C. (1500.) 4 min. Bibl. Reip. Paris.

$106 \% 1^{*}$ Vallemont, Pierre Lorrain, Abbe de. Curiosités de la naturc et de l'art sur la végétation ou l'agriculture et le jardinage dans leur perfection ete Paris, Cellier. 1705. 8. 332 p., praef, tab. - *ib. 1708. 8. 472 p. - +Bruxelles, Leonard. 1723 . II voll. 12. 1: 283 p., prael., lab. - 11: 326 p., incl., lab. - * Paris 1734. Il voll. 12. 393,293 p., (a)).

"germanice: Merkwürdigheiten der Natur und Kunst etc. Budissin, Richter. $1733-1749.2$ Bánde. $8 .-1: 1733.217$ p., praef., iud. - It: 1749. 489 p., ind.

$106 \% 2+$ Vallesius, Franciscus. De is, quae scripta sunt physice in libris sacris, sive de sacra philosophia liber singularis. Cui propter argumenti similitudinem adjuncti sunt duo alii, nempe Levini Lemnii de plantis sacris el Francisci Ruei de gemmis, ante quidem editi, sed nunc emendatius expressi. Lugduni, apud Franciscum Le Fevre. 1588. 8. 693,285 p. - " De sacra philosophia, sive de iis, (puae in libris sacris physice scripta sunt, liber singularis. Ed. V1. Iugrluni 1652.8. 1/0 p.
106 13t Vallet, Pierre. Le jardin du roy tres chrestien Henry IV roy de France et de Navarre, dedié à la royne par Pierre Vallet, brodeur ordinaire du roy. 1608 . folio. \& foll., 73 tal), efligies Pierre Vallet et Jean Rabin.

Jean liobin, botasicus rogins ot horti sclıolac parisiensis curator, adetidit exoticas quasdan platutas a Jean kobin, filio, e. Guinea el llispania delatas anno lov3.1

$106 \mathrm{f}$. folio. (3), 12 p., 91 tal). Bibl. Juss.

10613 Vallisneri, Anlonio. Prima raccolta d'Osservazioni e d'Esperienze. Venezia, Albrizzi. 1710. 12. s.

(lusunt: De arcano Lenticulae palustris semino, p. 1: Finre della Lenticula palustris scopertu dall autore, p. 27; Jo Pinu africana, p. 8\%: Index plantarum, quae juxta Lihurnum nascuntur, ah aucióre notalae, et a Tiberio Scalio Liburnensi descriptae, cum notationibus Jo. Bapt. Scarella, p. 112.)

$1064.6^{*} \longrightarrow$ Opere diversi. (Inest: Raccolta di varj trattati.) Venezia, Ertz. 1715.4 .261 p., tab.

$1067^{*}-$ Opere fisico-mediche, raccolte da Antonio ( 1 allisneri), suo figliualo. Venezia, Sebastian Coleti. 1733 . IIl vull. folio. - I: Lxxxii, 469 p., 52 tab. - 11: 551 p., 36 tab. - 111: 676 p., 6 tals. (Insunt: Osservazioni intoruo al fiore dell" Aloe americana, ed al sugo stillante dalla medesima, vol. 11. p. 69-7 t De arcano Lenticulae palustris semuine ac admiranda vegetatione, vol. II. p. 81 - 89.1

$10648 \div$ Vallot, J. $N$. Histoire de la botanique en Baurgogne. Dijon, typ. Frantin. 1828.8. 51 p. (2 fr.) Bibl. Cand.

$10619^{*}$ Valmont de Bomare, Jacques Christophe. Dictionnaire raisonne universel d'histoire naturelle, contenant l'histoire des animaux, des végétaux et des minéraux etc. Paris, Lacombe. 1764. Vl voll. 8. ( $\mathrm{A}-\mathrm{Z}$ et Supplément.) - ${ }^{*}$ Nouvelle édition rerue et augmentée. ib. 1769. VI voll. 8. (A-Z.) - †El. III: Lyon, Bruysel. 1776. IX vol]. S. $(\Lambda-Z$.$) - tEd. IV. Lyon, Bruyset. 1791$. IV roll. 8. (A-Z.) - +Nauvelle édilian. Jyon, Bruyset. 1800. XV voll. 8. $(\mathrm{A}-\mathrm{Z}$. $)$ ilalice: Venpzia 1767. 8. DC. hallandice: Dordrecht 1769. 4. DC

$10650 \div$ Vandamme, Henri. Mémoire sur les maladies des Graninces et sur les moyens de préserver ces végétaux du danger qui les menace. Hazebrouck, typ. Guermouprez. $1838.8 .11 \mathrm{j}$.

110651 Vandelli, Domingos. Dissertatio de arbore Draconis seu Dracaena. Accedit D. re sludio historiae naturalis necessario. Olisipone, apud Galliardum. 1768. 8.39 p., I tab.

(Redit in Römeri Seriptoribus.)

106.32 Memoria sobre a utilidade das jardins batanicas a respecto da agricultura, e principalmente da cultivaçã dos charnecas. Lisloa 1770.8 .23 p. B.

(Redit eum ejus biccionario dos termos tochnicos de historia natural. Coimbra 1788. 2. p. 293-301.

$10653^{*} \longrightarrow$ Fasciculus plantarum, cum novis generibus et specieJus. Olisipone, ex typographia regia. 1771.4 .20 p., 4 tal.

$1063^{\prime}$ Diccionario dos termos technicos de Jistoria natural extrahidos das obras de Linneo, com a sua explicaçaõ. Coimbra 1788.4.301 p., 20 tab.

(Memoria sobre a utilidade dos jardins botanicos, p. 293-301.)

$10633^{*}$ (— Florae Jusitanicae et brasiliensis specimen. Et eprotoJae a Carolo a Linné et $A$. de Haen ad Dorn. Fundelli scriptae. Conimbricae, Barneoud. 1788.4.96 p., 5 tab.

$10636^{*}$ _ Viridarium Grisley Lusitanicum, Linneanis nominiluus illustratum, jussu Academiae in lucem editum a Dominica Fandelli. Olisipone, typ. Acad. Scient. 1789. 8. xx, $134 \mathrm{p}$.

10637 - Vandermonde, Jacob Franciscus. An a tabaco naribus assunipto, peculiaris quaedam cephalalgiae species aliique affectus? D. Paris, typ. Quillau. 1733.4. 4 p.

$10638+\ldots$ An infirmis a morbo viribus Ginseng? D. Paris, typ. Quillau. 1736. 4. $4 \mathrm{p}$

$10659 \div$ VandeWoestyne, $J . X$. Discours (sur la bolanique). Gand, Goesin-Verhaeglie. 1814 . S. S, (2) p. Bibl. Juss.

$10660+$ (VanHoutte, Louis.) Hortus Vanhoutteanus, un description de plantes nouvolles, rares ou peu connues, introduites daus les jardins flc Lauis van Houtte, horticulteur à Gand; avec catalogue descriptif et prix-courant des nouveautes et des multiplications disjonibjes dans cet étalılissement. Bulletin périodique faisant 
suite a la Flore des serres et des jardins de l'Europe. Gand, VanLoutte. Fasc. I. Nov. 1845. 8. 28 p., 4 tab. Bibl. Deless.

(Plura noll vidi.)

10661 Vanière, Jacques de. Carmina. (Vites et vinum.) Parisiis, vid. Sim. Bernard. 1696. 12, a.

$10662^{*}$ Praedium rusticum. Carmen, Jibri X. Tolosae 1706. 12. s. - "Luteliae Parisiorum, apud Joannem LeClerc. 1707. 8. 268 p., praef, ind., 10 tab. - Coloniae 1712. 12. s. - *Amstelaedami 1744. 8. - Tolosae, apud Robertum. 1730. 12. s. *Amstelaedami 1731. 12. - Tolosae 1742. 8. - * Parisiis 1746. 8. - ${ }^{*}$ Coloniae 1750. 8. - ${ }^{*}$ Parisiis, Barbou. 1774. 8. - ${ }^{*}$ Parisiis, Barbou. 1786. 12. - Nova editio, caeteris emendatior, cum indice locupletiori. Accedit vita auctoris nune primum in lucem edita. Parisiis, Delalain. 1817. 12. (5 fr.) - Parisiis, Maire-Nyon. 1829. 12. (4 fr.)

(Privilegium operis fatum est die 21 Aug. 1706. gallice: Economio rurale, tracluite du poeme du P. Tanière, par Berland d'Halouvry. Paris, Estienne. 1766. If voll. 12. Q.

gallice: Traduction en vers francais par Roulhoc de Clusaud; ouvrage couronné par l'Académie des scieucos de Montauban. Limoges 1779. 8 . 0 .

germanice: Vollstandiger Mayerhof, Augsburg 1772.8 .

10663 VanMons, Jean Baptiste. Catalogue des arbres fruitiers de sa collection. Louvain 4823. 8.

$10661 \div$ - Arbres fruitiers. Leur culture en Belgique et leur propagation par la graine, ou Pomouomie belge, expérimentale et raisonnée. On y a joint le catalogue descriptif abrégé des bons fruits nouveaux procréés et cultivés à la pépinière d'expérience de l'auteur a Louvain. Louvain, typ. Dusart et Vaudenbroeck. J] voll. 12. - I: 1835. II, 500 p. - Jl: 1836. (non vidi.)

10663* Varro, Marcus Terentius. De re rustica libri tres. (Cum scriptoribus rei rusticae.) Editio princeps: Venetiis, Nicol Jenson. 1472. folio. - ${ }^{*}$ Ed. II : Regii, Bm. Bruschus, alias Bottonus, nonis Junii 1482. Folio. - ${ }^{\star}$ Parisiis 1533. Soljo. - Separatim a Petro Victorio editi. Parisiis, apud Ludovicum Tiletanum. 1535. 4. s. - ${ }^{*}$ Lugduni, Sebastian Gryphius. 1541.8. - "Parisiis, Stephanus. 1343. 8. - ${ }^{*}$ Lugduni, apud Gryphium. 1549. 8. - Cum notis interris Petri Victorii el Josephi Scaligeri. Parisiis, Stephanus. 4569. 1573. 1581. 1583. 8. S. - Cum commentariis Ausonii Popmae Frisii. Lugduni Batavorum, Plantinus. 1601. 8. S. - Durdraci, Brerewond. 1619 . 8. S. - Anstelodami, Janssonius. 1623. 8. S. "curavil J. M. Gesner. Lipsiae, Fritsch. 1735. 4. - "Biponti 1787. 8. - ${ }^{*}$ Ex optimurum scriptorum atquo editorum fide et virorum doctorum conjecturis correxit, atque interpretum onınium eolleetis et excerptis commentariis suisque illustravit Johann Gottlob Schneider. Lipsiae, Fritsch. 1795. 8.

$10666 \div$ Vassalli, Antonmaria. Spiegazione delle esperienze recate contro l'ioflusso dell' elettricita' nella vegetazione da' Signori Ingenhousz, e Schwankhardt et ulteriori esperienze confermanti tale inllusso. Torino, Briolo. 1788.8.36 p.

10667 - Della fecondazione arteficiale delle piante e dei vanlaggi della medesima. (Extratto di Calendario geurgico di 1802.) 12. p. $7-11$.

$40668 \div-$ Saggio teorico-pratico sopra l'Arachis lyypogaea. Torino, stamperia di dipartimento. 4807. 8.47 p., 3 lab.

Nomen autoris in duobus ultimis libris legitur Antonio Maria Vassali-Eandi.)

10669* Vater, Abraham. Balsami de Mecca natura et usus. Programma. Wittenbergae 1720.4. (4) foll.

$10670^{*}$ Catalogus plantarum imprimis exoticarum horti academici Wittenbergensis in usum auditorum juxia seriem alphabeticau adornatus. Wittenhergae, apud viduam Gerdesiam. 1721. 4. $28 \mathrm{P}$., prael., 1 tab.

$10671^{*}$ Supplementum Catalogi plantarum, sistens accessiones noras, quibus hortus academicus Wittembergensis hucusque anctus est. Wittembergae, Gerdes. 1724. 4. 20 p., praef., 1 tal.

10672* Catalogus variorum exoticorum, quae in Museo suo, brevi luci exponendo, possidet A. Vater. Wittembergae 1726. 4. 16 p., prael.

$10673^{*}$ De Ruta ejusdemque virtutibus. D. Vitembergae 1735. 4. 21 p. (Respondens: Johanu Adolph Kettner.)

10674 De Cereo americano. D. Vitembergae 1735. 4. н.
$10673^{*}$ Vater, Abraham. De Laurocerasi indole venenata exemplis honinum et brutorum ejus aqua necatorum confirnata. D. Wittebergae $1737.4 .32 \mathrm{p}$.

10676 - Syllabus plantarum, potissimum exoticarum, quae in borto academiae Wittenbergensis aluntur. Wittembergae 1738.8 . 72 p. B.

$10677^{*}$ - Anatome trunci Ulmi, cui cornu eervinum inolitum. Programma. Vitembergae 1741.4.8 p. (Fraudem detexit.)

$10678^{*}$ - _ C Coinu cervi monstrosum a trunco arboris Fagi, cui adhaesit, reseetum. Programma. Vitembergae 1744. 4. 8 p.

$10679^{*}$ Vater, Christian. Rei herbariae aestimatoribus et cultoribus s. p.d. eosdemque ad solenues plantaam in agris, sylvis, ripis et muntibus Wittelyergensibus Justrationes humanissime invilat. Wittebergae (1692.) 4. (4) foll.

10680 t Vaucher, Jean Pierre Etienne. Mémoire sur les graines des Conferves. (Paris, typ. Peronneau.) 1800, 4. 16 p., 2 tab.

$10681^{*}$ Jistoire des Conferves d'eau douce, contenant leurs différens modes de reproduetion et la description de leurs principales espèces, suivie de l'histoire des Trémelles et des Ulves d'eau douce. Genive, Paschoud. an XI. 1803. 4. xY, 285 p., $17 \mathrm{tab}$. ( $15 \mathrm{fr}$.)

$10682^{*}$ - Monographie des Prèles. Histoise génerale el plıysiologique du genre. Geneve, Paschoud. 1822. 4. 1v, 63 p., 13 tab.

Extraite des Mémoires de la societo d'histoire naturelle de Geneve, tome 1. p. $329-391$.

$10683^{*}-$ Monographie des Orobanches. Geneve et Paris, $\mathrm{Pa}$ schoud. 1827. 4. 11, 72 p., 16 tab. ( 8 fr. - col. 12 fr.)

$10681 \%$ Mémoire sur la chule des feuilles. Genève, Barbezat et Delarne. $1828.4 .17 \mathrm{p}$.

(Extrait des Ménoires de la sociéte dhist. nat. de Geneve, $10685+$ tom. 1. p. 120-136.)

10685 \% Histoire pliysiologique des plantes d'Europe, ou exposition des phénomènes qu'elles présentent dans les divers périodes de leur dévelopjement. Tome premier. Genève, Barbezat et Co. 1830.8 .503 p. et un Avertissement.

(Plura bujus editunis non prodierunt.)

$10686^{*}-$ Histoire physiologique des plantes d'Europe, ou Exposition des phenomènes qu'elles presentent dans les diverses périudes de leur développement. Paris, Marc Aurel frères. 1841. IV voll. gr. 8. - I: xxxI, 583 p. - Il: 743 p. - IlJ: 786 p. IV: 637 p. (30 fr.)

$10687 \div$ Vauquelin, Nicolas Louis. Expériences sur les sèves des vẻgéLaux. P'aris, Quillau. an VIi. (1799.) 8. $32 \mathrm{p}$

10688 Vaux, Thomas. Outlines of a new plan of tilliug and fertilizing land. Loudon 1840. 8. (6s.6 $\left.\mathrm{d}_{\text {. }}\right)$

$10689 \div$ Vavasseur, $P$., I. L. Cottereau et A. Gillet de Grandmont. Dictionnaire universel de botanique agricole, intustrielle, médicale et usuelle, comprenant toutes les plantes vénéneuses et Jes champignons délétères el comestibles. Tome prenjer. Paris, au bureau, rue du faubuurg Prisonnière Nr. 14. 1836. 4. p. 1-16,97-160, tab. col. $13-16,42-45$.)

(Les trois premiers livraisons du meme ouvraye, dont la pulification est interrompue, était d'abord imprinée sous le titre "Botanique médicale et industrielle.")

10690 Veit, Raimund. Anleitung zum Jeinbau und zur Flachsbereitung nacb dem Verfahren der Niederlander. Augsburg, Rieger. 1841. 8 . 3 plag., 1 iab. ( $1 / 6$ th.)

$10691^{*}$ Veith, Emanuel. Systematisclıe Beselıreibung der vorzüglichsten in Oestreich wildwachsenden oder in Gärten gewobnlichen Arzneigewachse mit besondrer Rucksicht auf die nene ostreichsche Provinzial-Pharmacopoe. Wien und Triest, Geistinger. 1813. 8. 143 j., ind. $(1 / 2$ th.

(Irlem liber jam anno praecedente 1812 latino titulo inscriptus

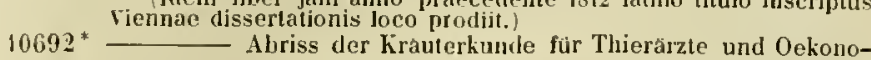
men, nebst einer Uebersicht der gewohnlichsten einlieimischen Gewáchse und ihrer Standörter. Wien und Triest, Geistinger. 1813 8. xvi, 413 p., i tab. col. $\left(1 \frac{2 / 3}{\text { th. }}\right)$

10693* Velley, Thomas. Coloured figures of marine plants, found on the southern coast of England; illustrated with descriptions and observations accompanied witl a figure of the Arabis stricta from St. Vincent Ruck. To which is prefixed an inquiry into the mode $39^{*}$ 
of propagation peculiar to soa plants. Plantarum maritimarum etc. Bathoniae, typ. Hazard. (Lonton, White.) 1795. Jolin. (38) p., s tab. col.

(Disquisitio de plantarum maritimarum propacationo hujns libri, redit ill Roemer Archiv, Band 1 , stuch 111. p. 108-118.

10694 t Velloso, José Marianno da Conceição. Alographia dos alkalis fixos veyetal ou potassa, mineral ou soda e dos seus nitratos, segundo as melhores memorias estrangeiras. Parte primeira: Do Nikali fixo vegetal ou Potassa. Lisbøa, na offic. de Sineñō Thaddeo Ferreira. 1798. 8. xiv, 245 p., 20 tab.

(A p. 191 ad finem sequiur: Floria ilogrophica ejusdem autoris.)

$10693^{*}$ Quinografia portugueza, ou Collecęaú de varias memorias sobre vinte e luas especies de quinas, tendentes ao seu deseobrimento nos vastos doninios do Brasil, copiada de varios authores modernos, enriquecida com cinco estampas de quiuas verdadeiras, quatro de falsas, e einco de balsameiras. Lisboa, na offic. Correa cla Silva. 1799. 8. $191 \mathrm{p}$., praef.

10696" (Vellozo de Miranda, Joaquim.) Petro, nomine ac imperio primo, brasiliensis imperii perpetuo defensore ino fundatore, seientiarum artium literarumpue patrono et eultore juliente, Florue Fluminensis Icones nunc primo eduntur. Edidit Dom. Frat. Antonius da Arrabida, Episcopus de Anemuria, eaesareae majestatis a consiliis nec non confessor, Cappellani maximi coadjutor, studiorum principum ex imperiali stipe moderator et imperialis publicaequo bibliothecac in urbe Fluninensi praefectus. Parisiis, ex officina lith. Senefelder, curante E. Jinecht. 1827. XI voll. folio max. 153, $156,168,189,135,113,164,164,164,143,127$ tab. $=1676$ tab., praefatio: $1 \mathrm{p}$, index alphabeticus: $14 \mathrm{p}$., index methodicus: $21 \mathrm{p}$. Operis fistoriam satis nemorahilem narravit ill. von ifartius in Finra, Beinlatter 1837, vol. I1. p.9-13. Commentariis plantas uryptogamas in undecimo Yalumine occurrentes illustravit Prof. Gusta Kunse in Flor:1 1837. 13. 321-333. Anno 1833 opus in bibliopolio germanico venale factum est, Lipsiac, Leop. Joss. $(60 t h$.$) - Tabula-$ rum nunierum habet ill. von IJartius 1639.

$10697^{*}$ Venetz, Ignaz. Catalogus plantarum in Valesia sponte nascentim. Seduni 1817,8, $17 \mathrm{p}$.

$10698^{*}$ Ventenat, Eticnne Pierre. Tableau du règne végétal selon la methode de Jussieu. Paris, typ. Drissonnier. an VII. 1794. IV voll. 8. - 1: LxxII, 627 p. - 11: 607 p. $-111: 587$ p. - N : 265 p., 24 tal). ( 40 ir.)

$10699+$ Principes de botanique, expliqués an Lycce républicain. Paris, Sallior, an Jll. (1795.) 8. 223 p., 14 tab. (5 fr.) * germanice: Anfangsgrtinde der Botanih. Frei vibersotzt. Durelsans mit Alumerkungen und Zusátzen (von Albrecht von llaller, den sobne.) Zurieli, Orell, Fisssli of Co. 1802. 8. xvi, 378 p., fit tab. $(2 \%, i$ ih.

$10700^{*}$ Description des plantes nouvelles of peu eonnues, cultivées dans le jardin de J.M. Cels. Paris, de l'imprimerie de Chapelet. an VIll. 1800.4. 100 foll., praef., ind., 100 tab. a Redoute delineatae.

(Ouerard indicat 20 fisciculos, singulum decen tabularum, 12 (r. 2 't fr. $=200$ tab. Ego nonnisi centum vidi.

$10701 \div$ Nonographie du genre tilleul. Paris, Baudouin. an X. (1802.) 4. 21 p., 5 tab. Bibl. Cand. 1803.) (Extraite des Mémoires de l'Acadénir des sciences, tome IV

$10702^{*}$

Choix des plantes, dont la plupart sont culivées dans 60 tah. $(250 \mathrm{fr}$.

(Prodiit decem fasciculis.)

$10703^{*}$ Jardin de la Malmaisont. Paris 1803-1804. Il voll. folio. - 1: (y). Chapelet. 1803 . foll. et tab. col. 1-60. - Il: typ. Herhan. 4804 . foll. citab. col. 61-120.(800 fr.)

(Prndiit 20 fasciculis. Continuationem ef. supra Ni. 1109. Talulas egresia arte delineavit "t pinxit $P . J$. Redoute.

1070: - Deeas genermm nnvorum. Parisiis 1808.4. DC.

10 pus ab ill. DeCandolle in Regni veg. syst. nat. I. 109., a Querard in France litt. $x$. 98. "Parisiis 1808. folio." citatun frustra ubifue quacsivi.

$10700^{*}$ (— Catalogue des lives de la bibliotlièque de feu M. $E$. P. I'entenat. Paris, Tilliard. 1808. 8 . xir, 83 p. (75 c.)

Vidi in bibliotheea ill. Hadriani de Jussieu nlapuam forma masima a l'ntenal ad illustrandum systema Jussieuinum editam. )

$10706^{*}$ Venturi, Antonio. Plantae in horto Antonii lenturi prope Eriviam collectae cum illiis permutandae. Brixiae, Iyp. Bettoni. 1835. $8.16 \mathrm{p}$.
$1070 \gamma^{*}$ Venturi, Intonio. Studi micologici. Brescia, lipografia del pin istituto in S. Ilarnaloa, 1842 . 4. $x, 56$ p., 13 tab. eol. (10 Lire 54 c.) Bibl. Mus. bot. Vindob.

$10708-$ I miceti dell' agro llresciano, descritti ed illnstrati cou figure tratte dal veru. Fasc. I. Brescia 18 í5. fulio. $32 \mathrm{p}$.

$10709^{*}$ Verdries, Johann Melchior, jr. De sueci nutritii in plantis circuitu. D. Giessae, typ). Muller. 1707. 4. 33 p., 1 tab. (Respondens: Johann Christoph Francti.)

10710 Vergin, Johan Bernhard. Ron och försòk om en underbar sádesartenes forwandling ifrăn samre til battre slag. Stoekbolm 1757. 8. 38 \%. B.

hollandice: Procfureminge, angaande eene wonderlyke verbetering van Grdun. llaarlem 1758. 8 . B.

(Hollant's Magazyn, Deel ill. .io. 2. p. 18.)

$10 \tau 11$ Vergnaud-Romagnési, C.F. Mémoire sur le Maromier d'lude, sur ses prnduits et partieulierement sur le parti avantageux quion peut tirer de lamidon ou fécule dre son fruit, extrait par un procédó particulier. Paris, Roret. 1825.8 .18 p., I tab. B. léans.)

(Extrait des Amnales de la socicté royale des seienees d'Or-

$10712^{*}$ Vernau, Constantin de. Rudinentum physiographiae Moldaviar Budae, typ. universitatis. 1836.8 . vi, $62 \mathrm{p}$.

10713 Verzascha, Bernhard. Neu vollkommenes krauterbuch, von allerhand Gewáchsen der Bäumen, Stauden und krtiutern, die in Teutschland, Italien, Franhreich und in andern Orten der Welt herfü kommen ete. verbessert, vermelırt und mit iutzlichen Registern verseben. Basel, Johan dakob Decker. 1678 . folio. $792 \mathrm{p}$. ie. xylogr. i. t. B.

(In nuvum ordinem redactun edidit postea Theodor Zuringer, de quo mox infra.

$1071 q^{*}$ Vesalius, Andreas. Radicis Cllynae usus. Lugduni, encudebat Job. Frellonius. 1547. 12. 290 p.

$10715^{*}$ Vesling, Johannes, De plantis Aegrptiis olservationes et nutae ad Prosperum Alpinum, eum additamentis aliarum ejusden regionis. Patavii, apud Paulum Frambottum. 1638. 4. 80 12., ind., ic. xylogr. i. . .

Impressae sunt cum edtlione altera Prosperi Alpini De Mantis Aegypti, el cum ejus listoria nat. Aegypti parte 11. p. 149-2 6.)

10716 Catalogus planturum horti gymnasii Patavini, quilus auctior erat anıo 1642 , praefecto ejusdem horti Joanne l'estingio. Patavii, apud Paulum Frambottum. 1642. 12. Bibl. Maz.

10717 Catalogus plantarum horti gymnasii l'atavini, quibus auctior erat anno 1644. 12. Bibl. Maz.

(Exstat etiam in Historia gymnasii Patavini Jacobi Philippi Thomasini 1. 99, in qua p. 90 exlibetur Catalogus plantarum cretensium guas Ignatius ab Agris, medicus Insulanus, jussu senatus Veneti ab ea insula Patavium advinerat anno 16k0.)

$10718^{\circ}$ - De cognato anatomici et botanici studio Dissertatic (oratio putius). Patavii, typ. Frambotti. 1638.4. (16) 11.

10719 " _ _ Opobalsami veteribus cogniti vindiciac. Aceclunt ejusdem Paraeneses ad rem herbariam, publieis flantarum ostensionilus praemissae. Patavii, typ. Pauli Frambotti. 1644. 4. 108 p. *Impr. cum Prosperi Alpini Operum posthumorum vol. Il. Lugduni Batavorum 1735. 4. p. $85-146,217-306$.

10720 * Vest, Lorenz Chrysanth von. Manuale botanieun, inserviens exeursionibus botanicis, sistens stirpes totius Germaniae phaenogamas, yuarum genera triplici systemate, corollino, carpico et sexuali coordinata, specierum(ne characteres abservationibus illustrati sunt. Klagenfurti, t5p. Leon. 1805 . \&. 818 p., praef. (4th.)

$10721^{*}$ Anleitung zum grundlichen Studium der Botanik. Mit einer Uebersieht über den Bau naturhistorisclıer Klassifieationssysteme, einer Kritik des Jussieu'schen und den Grundzugen eine's neuen naturlichen Systems. Wien, Gerold. 1818. 8. xix, 362 p. $(13 / 4$ th. $)$

$10722^{*}$ Versuch einer systematischen Zusammenstellung der in Steyermark eultivirten Weinreben mit ihren Diagnosen, Besehreibungen und Synonymenindex. Gräı, 1yp. Leyham. 1826.8 . $103 \mathrm{p}$.

10723* Vesti, Justus, pr. De symbolo Pythagorae: Fabis abstineto. D. Erfordiae, typ. Kindleb. 1694. 4. 30 p.

$1072 \mathrm{~s}^{*}-\mathrm{pr}$. Succinum, physice et medice consideratum. D. Erfordiae, typ. Kindleb. 1702. i. $16 p$ 
$1072 ; *$ Vettori, Piero, latine Petrus Victorius. Explieationes suarnm in Catonem, Iarronem, Columellum castigationum. Lugduni, apud Gryphium. 1542, 8. $144 \mathrm{p}$.

10726* - Exercitationes in Scriptores de ro rustica. Parisiis, apud Stoplanum. 15/3. 8.

$10727^{*}$ Delle lodi o della coltivazione degli Ulivi. Firenze 1569. 4. 89 p. - Fironze, Giunti. 1574. 4. - Ed. con la Coltivazione delle Vili di Bernardo Davanzati. Firenze 1600. 4. - Firenze 1622. 4. - Firenze 1700.4. - Ed. di nuovo ristampato colle annotazioni del Dolt. Giuseppe Bianchini. Firenze 1718.4. 80 p. B. Eal. con la Coltivazione delle Viti di Bernardo Davanzati. Firenze, Domenico Manni. 1734. 4. S. - T'Trattato di Piero Veltori dello lodi e della coltivazione degli ulivi, nuova accuratissima edizione. Firenze, typ. Stecchi. 1762 . 4. vH, 112 p.

10728 Viali, Felix. Plantae satae in seminario horti Patavini. Patavii, typ. Frambotti. 1686. 12. s.

$10729 t$ Vibert, $J . P$. Observations sur la nomenclature et le classmont les roses, suivies du cataloguo de colles cultivées. Paris, Huzard. 1824. 8.75 p. ( $1 \mathrm{fr} .50 \mathrm{c}$.)

10730 —_ Essai sur les roses. Paris, Iluzard. 1824.8.83 p.

(Plura non vidi. Querard indical 4 livraisous. $182 \%-1830.8 .8 \mathrm{fr}$.)

10731 Culture exclusive du rosier. Catalogne des roses. Paris, Huzard. 1836.8 .34 p. $(75 \mathrm{c.}) \quad$ a.

$10732^{*}$ Viborg, Erik. Efteretning om Sandvexterne och deres anyendelse (i) at daempe sandflugten paa vesterkanten af Jyland. kïöbenhavn 1788. 4. 7 1 p., 7 lab.

* germanice: Beschreihung Iler Sandgewachse, und ihrer Anwendung zur llemmung des Flingsandes auf der husto vou Jutland. Aus dem Danischen ubersetzt von J. Petersen. kopenhagen, Proft. 1789. 8. x, 70 p., 7 tab. ( 10 Shill.)

$10733^{*}$ - Botanisk ockonomisk Aflandling on Bygget. Priisskrift. Kiobenhavn, Thiole. 1788. 4.62 p., 4 tah. (32 Skill.)

- germanice: Botanisch-ökonomische Abhantlung von der Gerste. Preisschrift. Kopenhagen, Brummer. 1802. 4. 560 p., 3 tab. $(1 / 2 \mathrm{th}$.

10731. * Forsog til systematiske danske navno af indenlandske planter. Kiobenhavn, typ. Moller. 1793. 8.344 p.

10735 B__ Botanisk Bestemmolse of do $\mathrm{i}$ danske Lor omtalte Sandrexter, samt om Sandflugtens Daempning, kjobenhavn, Selubothe. 1795. 8. (40 Skill.)

$10736^{*}$ — Bolanisk oekonomisk beskrivelso over di i Landlluuslıoldningen vigtigste Aspe- og Pilearter. (Populus et Salix.) El uriisskrivt. Kiobenharn, Gyldendal, 1\$00. 8.116 p. (36 Shill.)

$10737^{*}$ Vietz, Ferdinand Bernhard. Icones plantarum medico-oeconomico-technologicarum, oder Abbildungen allor medizinischokonomisch-technologischen Gewáchse, nit der Beschreibung ihres Nutzens und Gelırauches. Wien, Schrämbl. (Rohrmanı ot Schw.) 1800-1820. X voll. 4. 935 (vol 1088) tah. col. cum textu latino et germanico. - Supplementunı: ib. 1822. 4. 116 p., 100 tab. col. $\left(33^{1 / 3}\right.$ th. Klang. A.)

(Ii) voluminihus I et Il continentur plantac ofticinales. $1-Z$. 225 tah. col.)

$10738+$ Vigier, Joaon. Historil das plantas da Europa e das mais uzadas que vem de Asia, de Affrica e da Amorica; onde ve so suas fignras, seus nomes, em quo tempo florecen et o hugar ondle nacem. Dividida en dois volumes et acomotlada na forma do grande Pinax de Gaspar Bauhino. Lion, na officina de Anisson, Posnel et Rigaud 17.18. 11 voll. 8.866 p., praef., ind., ic. ligno inc. i. I. Bibl. Juss.

$10239 t$ Vigna, Dominicus. Animadversiones sive nlsservationes in libros le bistoria et de cansis plantarum Theophrasti per Dominicum Vignam. etc. Pisis, apud Marchettum et Massinum. 1625. 4. (42), 117 p. Bibl. Juss.

$10710^{*}$ Vigneux, A. Flore pitoresque des environs de Paris, contenant la description de loutes les plantes qui crnissent naturellement dans un rayon de dix-huit a vingt liens do cette capitale etc. etc. Paris, chez l'auteus, Migneret et Fantin. 1812. 4. xxv, 214 p. 68 lab. col. (sign. $1-6, J-L X 11$.) et 4 carte col. des environs de Paris. (30 fr.) $-\dagger$ Supplément: ib. 1814. 4. 28 p, 1 tab. col. (3 fr.)

107k1t Vigo, Giovanni Bernardo. Tubera terrac. Carmen. Taurini, ex Iypographia regia. 1776.4 . (4), $47 \mathrm{p}$.

t titalice: I tartufti. Pnemetto tradotto dal latino. ib. 1776. \&. wa p.
10742 'Viguier, L. G. Alexandre. Ilistoire naturelle, médicale ef économique des Pavots et des Argémones. D. Nontpellier, Martel 1814.4.50 p., f tal.

10713 Villa, Fray Eslevan de. Ramillote de plantas. Burgos 1637. 亿. 148 foll. (15 fr. A.) B.

"Liber rarus, tribus absolutus partibus, quarum pruna novem continet capita de vita, generibus et virtutibus plantarum, alteria descriptionem is plantarum alphabutico ortine, (Axesixo-Turbit), tertia variit praccepta pharmaceutica." Tschudi jn lit. all Fenzl.

1071 - Liluro de simples incognitos en la medecina. Burgos Pedro Gomez de Valdiviolsn. 1643.4. S.

10715 t Villa de Montpascal, Philippe, Comte. Lellre a Mr. le Chrvalier Muthieu Bonafous sur l'utilité du murier des Philippincs (Morus cucullata). Turin, typ. Chirio of Mina. $1838.5,20 \mathrm{p}$.

10746t Villars, Dominique. Prospeotus de l'histoire des plantes dr. Dauphinó ol d'une nouvelle méllsode de botanique, suivi d'un c'italonue des mantes qui y sont été nouvollement découvertes et do celles rut sont les phis rares, ou qui sont particulières a cette province. Avoc leurs caractères spécifiques et l'otablissement d'un nowveau genre, appolló Bernardia. Grenoble, imprimerie roy alr. 1779. 8. 49 p. Bibl. Cand.

$1071.7^{*}$ — Ilistniro tes plautes dı Dauphiné, contenant une preface historique, un dictionnaire des termes de botanique; le: classes, les familles, les gonres of les Jerborisations des convirons de Grenoble, do la Grande Chartreuse, de Briançon, de Gap et do Montelimar. Gronoblo, chez l'auteur. 1786-1789. Ill voll. \&. - l: 1786. Lxxx, 467 p., t tab. - Il: 1797 . xxiv, 690 p., tah. 1 $-15 .-111$ : 1789. xxxu, 1091 \%., talı. 16-55. (33 fr.)

Ejus Flora belphinalis impressa est cum vol. I. Gilibertianae editinnts limnaei Systemalis pluntarum Europao; vide Thesaurus: Nr. 3633 .)

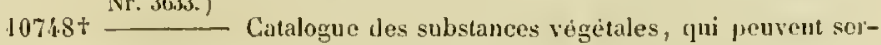
vir a la nourrituro de l'homme, el qui se trouvont dans les dlupartemens lo l'Isère, la I)rôme et les llautes-Alpes. Firenoble, typ. Giroud. (an II de la république.) $8.48 \mathrm{p}$.

In litulo hujus libelli aeque ac in Nr. $1074 \mathrm{k}$ nomen autoris $5 \mathrm{crl}$ hitur villar, a loco sito nalali sumtum. Postea sempor filler's auth

$10749^{*}$ — - Mémoire sur les moyens d'accélérer les progrès de lat botanique. Paris, Villior. an IX. (1801.) 8.31 p. (60 c.)

10750 Némoiro sur la découverte d'une nouvelle espéce dr. llicracium. s. l. et a. 8. Dc.

107316 Mémoires sur la topographie et l'histoire naturelle, extraits du cours do l'école centrale du département de l'isère: suivis d'olsservations stitistiques sur la nature des montagnes; sur les animaux ot les plantes microscopiques etc. Lyon, Reymann (Paris, Brunot.) an xul. (1804.) 8. 172 \%., praef., inel. Bibl. Webo.

$10752 \div(-)$ Tablean pour la plantation et l'ordre du jardin de botanique de l'école de módecine de Strasbourg dlaprès la mithode de Jussicu. Straslonurg, Lovrault. 1806 . 8. 51 p. Bibl. Juss.

$10753^{*}$ Catalogue méthodique des plantes du jardin de Stras bourg , dédié aus professeurs actuels de l'école. Strasbourg, Levrault. 1807. 8. xLvil, 398 p., 6 tab. ( 6 fr.)

1075/* Custav Lauth el A. Nestler. Précis d'un vayage botanique fail ej Suisse, dans los Grisons, aux sources du Rhin an St. Gotharıl ctc. en 1811; précédé de quelques réflexions sur l'utilite des voyages pour les naturalistes. Paris et Strashourg, Lenormant. 1812.8.64 p., 4 tab.

10735 Villemin, Eugene. Le liseron des chamjs (Convolvulus arvensis). Orlćans, typ. Jacoh. 4839.8 .12 p. 0.

$10756 \div-$ Herbior pootique, avec notes par Auguste de SaintHilaire. Paris, I aisné. 1842.8 . III, 349 p. $(3$ fr. 50 c.)

$10757 \div$ Villette. Nouveau Nanuel de botanique démentaire et do botanipue appliquée à l'agriculture, à la médecine des hommes ef les animaux, aux arts industriels et à l'économie domestipqus. Paris, rue du battoir, 3. 1838. IJ voll. $12 .-1: 212$ p., 1 tab. II: 212 p., 2 tab. ( 3 fr.)

$10738 *$ Villifranchi, Giovanni Cosimo. Oenologia toscana, ossia Momoria sopra $i$ vini ed in specio toscani. Firenze, tỵ. Cambiagi. 1773. Il voll. 8. - I: xI, 264 p. - II: 307 p.

$10739+$ Vincens, Jean César, et Baumes. Topographie de la ville de Nismos el de sa banlicuc. Nismes, 1yp. Belle. 1802. 4. xxıv, $588 \mu$. Bib1, Reip. Par.

(Botanique: p. $322-415$. 
$10760^{*}$ Vincentius Bellovacensis. Speculum uaturale. Editio prineeps. s. I. et a. (Argentorati, Johannes Mentelin.) II voll. gr. folio binis columnis linearum 66 , sine sign. et eustod. - I: Lib. IXV'llI. (3|8) foll. - Il: Lib. XIX - XXIII. (327) foll. Bibl. univ. Lips.

(a Deeimus liber incipit agere de sceundo opero diei tercie, hoc est de terre germinatione et agit primo de plantis in genterali postea cle berhis communibus. Uudecimus liber agit de ceteris herbis videlicet que nascuntur in lacis cultis at in ortis et agris. Duodecimus liber agit do his alue procedunt de herlsis scilice seminimus of grauls ac steceis. Tertius decinus liter primo in communi des arboribus et postundum specialiter de arboribus commumun didelicet silvaticis et aurestihus. Ouartus deeimus liber agit de arteribus cultis of frugiferis et preeipue de illis quarum frucin de artoribus eumbur cibos. Ouinus docimus liher agit de arboiII htmanos sumuntur cibos. Quintus docimos ther age de arbolum fructibus et succis a quibusdam earum prolluenlihus." Speculi doctrinalis liber YII est de oecononia.- Anutus impressionis dubius est; Speculum historialo antho 1173 , speculum morale

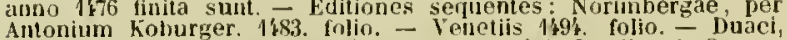

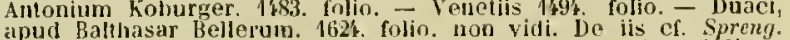

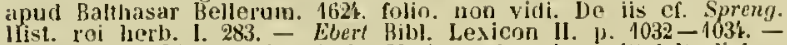

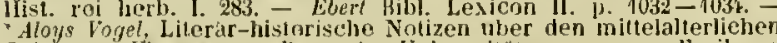
Gelehrten Vincenz von keauvais. Universitätsprugramn. Freiburg, typ. Groos. 18i3. 4. 66 [1.)

10 ibl Virey, Julien Joseph. Des médicaments aphrodisiaques en gènéral et en particulier sur lo Dudaim de la Bible. Paris, typ. Colas. 1813.8 .24 p. ( 1 fr. 25 e.)

10762 Nouvelles considérations sur l'histoire et les effets Jiygiéniques du eafé, et sur le genre Coffea. Paris, Colas. 1816. 12. $36 \mathrm{p}$.

$10763^{*}$ Philosopbie de l'histoire naturelle ou plienomenes de l'organisation des animaux et des végétaux. Paris, Baillière. 1835. 8. xvi, 512 p. ( 7 fr.)

10764 Publius Virgilius Maro. Georgieorum libri $1 V$, with an english translation and noles by John Martyn, Professor of botany at CamJridge. London 1741. 4. - Loudon 1746. 8. н.

"Cum doctis notis, quales a hotanices perito exspectes, eum aliorum Geoponicorum locis analogis, etiam lectionihus variantibus codicum Meadianorum, alliorumque, ex regia bibliotheca Bodleyana et Cautabrigiensi, ot nomultis tharum iconibus. Germanice reddita edilio Martynii prodiil llamburgi 1759. 8. "Hall. Bibl. bot. l. 68 .

10765 - The Bueoliks of Virgit with an english translation and notes, by John Martyn. London 1749. 4. H.

40760 Les Bucoliques de Virgile, traduits en vers français, avec des notes historiques et littéraires et entichies d'une Ftore l'irgilienne par M. G. de Mancy. Paris, Pélicier. 1828. $18 . \quad$ a.

(Nullas praeter has, in quibus botanicae res peritius exponuntur, cito editiones. Virgilianarum explicationum supra conferenda Osservazioni sulla Flora V'irgiliana, Thes. Nir. 10107.

$10767^{*}$ Visiani, Roberto de. Stirpium dalmaticarum specimen. Patavii, typ. Lrescinianis. 1826. 4. xxur, 57 p., praef., 8 tab.

$10768^{*}$ __ Plantae quaedam Aegypti ac Nubiae enumeratae atque illustratae. Patavii, typ. Minervae editorum. 1836. 8.43 p., 8 tab. (6 Lire.)

(Commentarii di Medicina del Dottore G. F. Spongia, Fasc mensis Augusti 1836 . )

$10769^{*}$ Della utilita ed amenita delle piante. Discorso. Padova 1837. 8.48 p.

$10770^{*}$ Della origine ed anzianita dell' orto botanico di Padova Memoria. Yenezia, typ. Mello. 1839.8 .43 p. (1 Lira.)

(Estratto dal vol, I. fase. VII et Vill del Memoriale della Merlicina contemporanea.

$10771^{*}$ - Illustrazione delle piante nuove o rare del' orto botanico di Padova Nemoria 1. Paduva, typ. Sicca, 1840.4.24 p.*Memoria Jl, ib. 1844. 4. 26 p.

$10772^{*}$ - Sopra la Gastonia palmata Roxb. proposta qual tipo di un nuovo genere nella faniglia delle Araliaceae. Torino 1841 4. 12 p., ital). (Trevesia.)

$10773^{*}$ (— L L Orto botanico di Padova nell anno 1842. Padova iyp. Sicca. 1842. 8. 151 p., 1 lab.

107\%': Illustrazione di alcune piante della Grecia e del Asia minore. Venezia, Antonelli. 1842.4. 22 p., 6 tab.

$10775^{*}$ —_ Flora dalmatiea, sive enumeratio stirpium vascularium quas laaetenus in Dalmatia lectas et sibi observatas deseripsit, digessit, rariorunque iconibus illustravit Robertus de l'isiani. Lipsiae, Fr. Ilofmeister, 1842-1847. Il voll. 4. - J: 1842, x1r, 552 p.
Iab. 1-25. - II: 1847. x, 268 p., 28 tab. sign. $26-51,10^{\text {b." }}$, $10^{\text {eer }}$ (nigr. $8 \mathrm{th} .-\mathrm{col} .13 \frac{1}{3} \mathrm{th}$.)

Volunen tertium alliuc desideratur; ef. Gersdorf Leipz. Repert. 185i. [3. $483-488$.

$10776^{*}$ Visiani, Roberto de. Del metodo e delle avrertenze che si usano nell' orto botanico di Padova per la eultura, fecondazione e fruttificazione della vaniglia Memoria. Venezia, typ. Antonelli. 1844. 4. 18 p., 1 tab.

$10777^{*}-$ Osservazioni sopra alcune specie di Matricaria e proposta di un nuovo genere e di una nuova specie fra le medesine. Firenze 1845 . S. 16 p.

(Estratto dal Giornale bot. ital. anno I. fasc. $7-8$.)

$107-8+$ Vitet, Louis, et fils. Matière médicale, ou exposition méthodique des médicamens. Lyon, Leroỵ. 1803. 8. vin, 386 p.

10779 Vitman, Fulgenzio. De medicatis herbarum facultatibus liber. Faventise 1770 . 11 voll. $8.371,364$ p. B.

10780 Saggio dell' istoria erbaria delle Alpi di Pistoja, Modena e Lucea. Bologna 1773.8.51 p. B.

$10781^{*}$ Summa plantarum, quae hactenus innotuerunt, methodo Linneana per genera et species digesta, illustrata, deseripta. Mediolani, typ. Mlon. Ambrosii majoris. 1789-1792. V'I voll. 8.I: 1789. vIII, $497 \mathrm{p} .-11: 1789.459 \mathrm{p} .-\mathrm{III}: 1789.557 \mathrm{p} .-$ JV: 1790.487 p. - V: 1794.458 p. - VI: 1792. 397, sLuI p. t Supplementum: Vol. I. (Classes Linn. J-V.) ib. 1802. 8. vilt, $384 \mathrm{p}$.

10782* Vittadini, Carlo. Tentamen mycologicum, seu Amanitarum illustratio. 1). Mediolani, typ. Rusconi. 1826.4.34 p. 1 tab.

$10783^{*}$ Monographia Tuberacearum. Mediolani, typ. Ruseoni. 1831.4. 88 p.. 5 tab.

$10784 \div-$ Descrizione dei funghi mangerecei piu conuni dell Italia e de' velenosi else possono co' medesimi confondersi. Milano. Rusconi. 183 5. 4. XLVII, 364 p., 44 tab. col. (48 Lire.)

(Prodiit annis 1832-1835 duodecin faseiculis.)

10785 t _ Nonographia Lyeoperdineorum. Augustae Taurinurum, ex offieina regia. 1842.4 .93 p., 3 tab. col.

(Memorie della Accad, di Torino, tomo $\mathrm{V}$.)

10786* Viviani, Domenico. Annali di hotanica. Genova, stamperia nazionale. 1802 . 4. 248 p. - * Annales botanici redacti cura $D_{0 m}$. Viviuni. Vol. I. pars II. Genuae, apud J. Delle-Piani. 1804. 4. 193 p., 5 tab

$10787+$ Voyage dans les Appenins de la ci-devant Ligurie pour servir d'introduetion à l'histoise naturelle de ce pays. Gencs. lyp. Giossi. 1807.4.28 p.

$10788^{*}$ - Florae italicae fragmenta, seu plantae rariores vel nondun cognitae in variis Italiae regionilus detectae. deserijtionibus et figuris illustratae. Fase. I. Genuae, 1yp. Giossi. (180S.) 4 vili, 28 p., 26 tal).

$10789^{*}$ ( - _ Saggio sulla maniera d'impedire la cunfusione, che tien dietro alla innovazione de' nomi, e alle inesatte descrizioni delle piante in botanica. Milano, typ. Zeno. s. a. 4 . 14 p., 2 tab.

$10790^{*}$ - Florae Jybicac specimen, sive plantarum enumeratio Cyrenaicam, Pentapolim, Magnae Syrteos desertum et regionem Tripolitanam ineolentium. quas ex siccis speeiminibus delineavit. descripsit "t aere inseulpi curavit. Genuae, ex t!pographia pagana. 1824. folio, x11, 68 p., 27 tab.

$10791^{*}$ - Florar Corsicae specierum novarum vel ninus cognitarun diagnosis quam in Florae italicae fragmeuti alterius Prodramun exhibet. Genuae, ex typograpbia pagana. 1894.4. $16 \mathrm{p}$. - Appendix ad Florae Corsicae Prodromum. Genuae, (y). Gravier, 1825.4 .8 p., 1 tab. - Appendix altera. ib. 1830.4 . 8 [., 2 tab.

$10799^{*}$ Plantarum aegyptiarum Decades $\mathrm{IV}$. Quas vel primus deseripsit vel observationibus illustravit. Genuae, typ. Gesino. 1830. 8.30 p., 2 tab.

$10793^{*}$ Della struttura degli organi elensentari nelle piante e delle loro funzioni nella vita vegetabili. Genova, typ. Gravier. 1831 $8.362 \mathrm{p},, 8$ tab. in 4 .

$10794^{*}$ - 1 fungli d'ltalia e principalmente le loro specie mangereccie, velenose e sospette, descritte ed illustrate cou tavole 
disegnato e colorite dal vero. Genova, typ. Ponthenier. 1834. folic. $\mathrm{xv}, 64$ p., 50 tab. col.

(Opus, cujus quinque fasciculi a 20 fr. prodierunt, haud absolutum est.

107935 Viviani, Domenico. Del bisso degli antichi. (Milano) 1836. 8. $16 \mathrm{p}$.

(Seorsim impr. e Biblioteca italiana, Narzo 1836.)

$10796^{*}$ Memoria sopra alcuni plagi in botanica, con alcune riflessioni clse ne conseguitano esposte in un' appendice. Milano, typ. Ruseoni. 1838. 8. 40 p.

10797 * Vogel, A. Quaestio de Hesperidum malis. Programma scholae cathedralis Numburgensis. Numburgi, typ. Klaffenbach. 1832. 4. $19 \mathrm{p}$.

10798 Vogel, August. Gartenkalender für Privatgårtner, auf die Jahre 1838-4842, mit besondrer Rucksicht auf Georginen und Dahlien. Vier Jahrgänge. Grimma, Verlags-Comptoir. 183S-1841. gr. 12. (1 th.)

$10799^{*}$ Vogel, Benedict Christian. Programma de generatione plantarum. Altdorfi, typ. Meyer. 1768. 4. (20) p.

$10800 \div$ - Ueber die Amerikanische Agave, und besonders diejenige, welelıe im Sommer 1798 im botanisehen Garten zu Altdorf geblcihet und auch Fruchte angesetzet hat. Altdorf und Nurnberg, Monath und Kussler. 1800 . S. 77 p., 1 tab. col. in folio. $\left(1 \frac{1}{3} t h\right.$. - col. $2(t h$.)

10801* Vogel, Julius. Anleitung zum Gebrauch des Mikroscopes zur zoochemischen Analyse und zur nikroseopisch-chemischen Untersuehung überhaupt. Leipzig, Voss. 1841. 8. xxvur, 599 p., 3 tab. $\left(2 \frac{2}{3}\right.$ th. $)$

$10802^{*}$ Vogel, Rudolph Augustin. Historia materiae medicae ad novissima tempora producta. Editio nova correctior ac emendatior. Francofurti et Lipsiae 1760.8. 410 p., praef., iud.

$10803^{*} \longrightarrow$ De statu plantarum, quo noctu dermire dicuntur. Programma. Goettingae, typ. Hager. 1759.4.16 p.

1080:. — De verioribus Balsani Aleceani noctis. Programma Goettingae 1763.4. $15 \mathrm{p}$.

(Schlogel, Thes. mat. med. 11. p. 33-42.)

1080:3* Vogel, Theodor. Generis Cassiae synopsis. D. Berolini, typ. Nictack. $\mathrm{Y}$ Aug. 1837. 8. 72 p. - ${ }^{*}$ Berolini, Lagier. 1837. 8. 79 p. $(1 / \mathrm{s}$ th. $)$

(Editio altera indice aueta est, ceterum immutata.)

$10806 t$ Vogeli, Félix. Flore fourragère, ou Traité eomplet des alimens du elieval. ete. avee un grand lableau synoptique. Paris, Anselin. 1836. 8. $\mathrm{x}, 324$ p. (6 fr.)

$10807^{*}$ Voget, Albert R. L. Anleitung zur Kenntniss der verzügliehsten Giftpflanzen etc. Ein IIandbuch für Volkssehulen. Crefeld, Schuller. 1829.8. 94 p., 9 tab. - "Dritte Auflage. ib. 1830 . 8.80 p., 9 tab. $(1 / 2$ th. - col. $3 / t$ th. $)$

$1080 * *$ Vogler, $H$. Verzeichuiss seiner auserlesnen Sammlung botanischer Werke, auch solcher, welche den Gartenbau, die Olsstbaumzuclit und Forstwissenschaft betreffen. Braunschweig, Waisenlıausdruckerei. 1818. 8. viI, $144 \mathrm{p}$.

$10809^{*}$ Vogler, Johann Andreas. Dissertatio inauguralis, sistens Polypodii speciem nuperis auctoribus ignotanı, Polypodium montanum vacatam. Gissae, Braun. 1781. 4.16 p.

$10810^{*}$ Vogler, Johann Philipp. Schediasma botanicum de duabus graminum speciebus nondum satis extricatis. Giessae, Krieger. 1776. $8.22 \mathrm{p}$.

(Bromus scaber Linn. suppl. et Avena, quam strigosam dicit.)

$10811^{*}$ Abhandlung vom Sommerspeltz oder Emmer. Wetzlar 1777. 4.12p.

$10812^{*}$ Versuche mit den Scharlachbeeren in Absicht ihres Nutzens in der Fäberei. (Grana Kermes von Quercus llex und Q. coceifera.) Wetzlar, typ. Ungewitter. 1780.4.10 p.

10813* Vogt, Traugott Karl August, pr. De Junipero Sabina ejusque virtute salutari. D. Vitenbergae, typ. Charis. $1803.4 .23 \mathrm{p}$

(Autor est August Gottried Richter, ab August Gotltieb Richter. quem supra Nr. 8573 cum hof confundi, diversus.)

10811:* Voigt, Friedrich Ernst. De Junipero Sabina. D. Berolini 1826. 8. $46 \mathrm{p}$.
10815* Voigt, Friedrich Siegmund. Dissertatio sistens conspectum tractatus de plantis hybridis. Jenae 1802.4. 14 p.

$10816^{*}$ Handworterbuch der botanischen kunstspraclie. Jena, Stahl. 1803. 8. xviti, 269 p. $(2 / 3$ th. $)$ - "Würterbueh der botauisehen Kunstsprache. Zweite, sehr vermehrte und verliesserte Auflage. Jena, Schmid. 1824. 8. xu, 260 p. (1 th.)

$10817^{*}$ Darstellung des naturlichen Pflanzensystens von Jussieu, nach seinen neuesten Verbesserungen. In Tabellen. Leipzig Reclan. 1806 . folio. 24 , xv p., 13 Tabellen. ( 2 th.)

$10818^{*}$ System der Bolanik, Jena, akademische Buchthandlung. 1808. 8. xxix, 384 p., 4 tab. $(1 \%$ th. $)$

$10819^{*}(\longrightarrow)$ Catalogus plantarum, quae in hortis ducalibus botanico Jenensi et Belvederensi coluntur. Jenae, typ. Goepferdt. 1812. $8.78 \mathrm{p}$.

$10820^{*}$ Lehrbuch der Botanik. Zweite umgearbeitete Ausgale. Jena, Schmid. 4827.8. x, $485 \mathrm{p} .\left(2 \frac{1}{2}\right.$ th. $)$

(Als erste Ausgabe muss wohl das "Systen) der Rotanik" rom Jahr 1808 angeseln werden, und nicht der kurze Abschnjt whel das Pflanzenreich im "System der Natur." Jena 1823. 8. p $704-725$.

10821* —_ Gesehichte des Pflanzenreichs. Erste Lieferung. Jena. Dlauke. 1847. 8. 112 p. $(2 / 5$, h. $)$

(Liber in $8-10$ raseiculis absolutus prodibit.)

10822* Voigt, Gottried. Curiositates physicae. Gustrurii, Seeipelius. 1668. 8. 184 p. - Lipsiae 1698. 12. Rivin.

(Inter atia contra resurrectionem plantarum.

10823* Voigt, Johann Karl Wilhelm. Versuch einer Geschichte der Steinkolilen, der Braunkohlen und des Torfes. Gottinger l'reisscbrift. Weimar, Hotfmann. 1802-1805. 2 Theile. 8. - I: 180y. xxt11, 307 p., ind., t tab. - H: 1805.197 p., ind., 2 tab. $(25 / 2$ th.)

1082.* Voigt, J. O. Hortus suburbanus Calcuttensis. A catalogue of th* plants which have been cultivated in the Ilon. East India Company's botanical garden, Caleutta, and in the Serampore botanical garden, generally known as Dr. Curey's garden, from the beginning of both etablishements $(1786$ and 1800$)$ to the end of August 1841; drawn up accerdiug to the Jussieuan arrangement, and mootly in conformity with the second edition (1836) of Lindley s natural system of butany. By the late $J$. O Foigt. Printed under the superintendence of W. Griffit. Calcutta, Bisheps College Press. (Hafniae, Reitzel.) 1845. gr. 8. xxix, 745 , Lxvil p. (97/8 th.)

10825 * Voit, Johann Gottlob IVithelm. Historia muscorum frondosorum in Magno Ducatu Herbipolitano erescentium. Norimbergae, Weigel-Schneider. 1812.8. viı, 231 p., 1 tab. $(2 / 3 t h$. $)$

$10826^{*}$ Volckamer, Johann Christoph. Nürnbergische Ilesperides, odel gründliche Beschreibung der edlen Citronat -, Citronen - und Pomeranzenfrüehte, wie solche in selbiger und benachbarter Gegend recht mögen eingesetzt, gewartet, erhalten und fortgebracht werden, samml ausfuhrlicher Erzáhlung der meisten Sorten, welche theils in Nurnberg wureklich gewachsen, theils von versehiedenen fremden Orten dahin gebracht worden, in vier Theile eingetheilet und mit nützlichen Anmerkungen erkläret. Beneben der Flora, oder curiosen Vorstelluug verschiedener rarer Blumen und etlicher andrer Gewächse, ausfülnrlichem Berieht, wie eine richtig zutreffende Sonnen-Uhr im Garten-Feld von Bux anzulezen, und die Gärten nach den Perspektiv leicht aufzureissen, wie auch einen Bericht von denen in des Autoris Garton stelsenden Columnis miliaribus. Nürnberg, Endter. 1708 . folio. 255 p., ind., $115 \mathrm{tab}$.

- (Inest : Nürnhergische Flora, p. 209-243, 19 lab.) run, fimonum aurantiarnmque cultura et ust libri IV, bene multis iconibus in aes elegantissime incisis ornati: quibus subjuneta est Flora, llores plantasque rariores in agro norico cultas exhibens. Accessit de lorologii etc. Omnia e lingua germanica in latinam nune translata. Norimbergae, Endter. (1713.) folie. 271 p., praef, ind. 113 lab.

(Tabulae sunt eaeden ac in germanica editione. Ftera Norimbergensis, $p .209-243,19$ iatb.)

10827 Conlinuation der Nürnbergischen llesperidum. Nüruberg 1714. folio. 239 p., tab. plurimae. в.

(Inest. Beschreibung etlicher frenden Gewachse, p. 209-236 11 tab.)

10828* Volckamer, Johann Georg, filius. Flora Noribergensis, sive Catalogus plantarum in agro Noribergensi tam sponte nascentium,

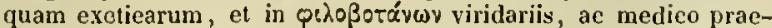
cipue horto aliquot abhinc annis enutritarum, cum denominationi- 
bus locorum, ubj proveniunt, ac mensium, quibus vigent florentque, addita siugularilus exoticis cultura, propagandigue ratione, cum generum et speciertum notis characteristicis, partiu ex Morisono, Ammanno, llermanno, Rajo atque Rivino, partim el ex ipso naturae libro propriis observationibus depromptis, cum iconibus et descriptiouibus rariorum aliejuot plantarum. Norihergae, $\mathrm{Mli}$ chael, typ. Knorz. 1700.4. 407 j., tah. - "Norimbergae, Monath. 1718. 4, 407 p.: tab. (praeter titulum non differt.)

$10829^{*}$ Volckamer, Johann Georg, pater. Opobalsami orientalis in theriaces confectionem Romae revocati examen doctiorumque calculis approbati sinceritas. Norimbergac, typ. Ender. 1644.12 .224 p., praef., ind.

(Nomen gentile Jegitur varie I'olkamer, Volckamer, Volcamerus.)

$10830^{*}$ Volkmann, Georg Aulon. Silesia subtorranea, oder Schlesien mit seinen unterirdisehen Schatzen, Seltsambeiten etc. Leipzig, Weidmanu. 1720.4. 344 p., ind., tal.

108:31 Vollberg, Karl Ulrich Fricdrich. Dissertatio inauguralis medica, pharmaca quaedam indigena pharmacopoeae :ossicae addenda proponeus. Worpati 1816.8 .

$10832^{*}$ Volney, Constantin François, Comie de. Tableau du climat et du sol des états unis d'Amérique. ete. Paris 1803. II voll. $\mathrm{S}$. Xvi, 334 p., 4 tal,. - Ed. II : Paris, Bossange. 1822. II roll. 8. (15 fi.)

$10833+$ Voorhelm, Georye. Traité sur la Jacinte; contenant la manièro de la cultiver suivant l'experiesıce qui en a eté faite par George J"oorhelm, IJeuriste d'llarlem. Harlem 1752. 8. - +Ed. II: Ilarlem, typ. Bebn. 1762.8.13, 127 p., 3 tah., effigies Voorhelm. - tEd. III. revue et augmentée. Jlarlem, typ. Beets. 1773. 8. x, 142 p., 3 tab.

germanice: Abhandung von Hyacinthen, uberselzt von Georg Leonhart Iluth. Nurnberg 1733. 8. H.

10834 - De large catalogue of Dutcli flowers, by Voorhelm and Schneevoogt, Flowrists at Haerlem. (Harlem) 1783.8.48 p. B.

10833 Grand catalogue des oignons et plantes de fleurs et arbrisseaux, de Foorhelm et Schneevoogl. llarlen 1788. 8.55 p. B.

10836 Catalogus of Dutch flower-roots and plants, from Voorhelm et Schneevoogt. Harlem 1792.8.56 p. B.

$10837+$ Vorm, Jobius van der. Atriplex salsum vulgo dıctum soutenelle, essentia, viribus et operationibus suis primo descriptum. Amsterdam, typ. a Waesberge. 1661. 12. 94 [?., praef.

10838 * Vorstius, Adolph. Catalogus plantarum horti academici Lugduni Batavi, quibus is instructus erat anno 1633 , praelecto ejusdem horti Adolfo Iorstio. Jnpr. cum Spiegel Isagoge in rem herbariam. Lugduni Batavorum 1633. 12. P. $223-262$; et index plantarum indigenarum, j. $263-272$. - Calalogus plantarum horti academici 1635 , et index plantarum indigenarum. Lugduni Batavorum 1636. 12.66 p. - Catalogus plantarum horti acadenici Lugduni Batavi, quibus is instructus erat anno 1642. Accedit index plantarum indigenarum, quae prope Lugdunum in Batavis nascuntur. Lugduni Batavorum, ex officina Elseviriana. 1643. 12. 71 p. Catalogus plantarum horti academici 1649 , et index plantarum indigenarum. ib. 1649. 12. 72 p.- * Catalogus jlantarum horti acadenici 1657, et index plantarum indigenarum. ib. 1658. 12. $72 \mathrm{p}$.

$10839^{*}$ Vorstius, Everhardus. Oratio funehris in obitum Caroli Clusii Atrebatis. Accesserunt variorum epicedia. (Antwerpiae), in oflicina Plantiniana Raphelengii. 1611 . 4. 39 p. - *ib. 1611. folio. $24 \mathrm{p}$.

(Impr, cum Clusii Curis posteriorihus, vido supra Nr. 2h12.)

J08 1.0* Voss, Leopold. Bibliotheca physico-medica. Verzeichniss wichtiger altrer sowohl, als sammtlieber seit 1821 in Deutschland gedruchler Bucher aus den Fachern der l'hysik, Chemie, Geognosie, Mineralogie, Botanik, Zoologie. vergleichenden und menschlichen Anatomie, Pliysiologie, Pathologie, Therapie, Materia medica, Chirurgie, Augrenleilkunde, Geburtshulfe, Staatsarzneikmnde, Pharmazie, Thierarzneikundo u.s.w. (Zweiter Abdruch.) Leipzig, Voss. 1S35.8. vi, 189 p. $(2 / 3$ (h.)

108'1 1 riese, Guilielmus Henricus de. Responsio ad quaestionem etc Quid luactenus ex plantarum physiologia de forma, directione, structura et functione radicum innotuerit et quaenam sint phacnomena in acconouna rurali observata. quae ex hac cognitione utili- tes explicari possint? quae praemiun reportavil. Groningae, Iyp. Comheris. 1829.4.93 J.

10812" Vriese, Jillem Itendrik de. Mratio de progressu physiologiae plantarum, prudenti nafuram indagandi rationi triluuendo. Anstelodami, typ. civ. pub]. 1835. 4. 39 p.

$10843^{*}$ —_. Plantonkunde voor Apothekers en Artsen of Besclirijvingen der geneeskrachtige Platen naar de natuurlijke fauilieu van het Plantenrijk. Jeiden, van der Jlack. 1835-1838. II voll. $8.787 \mathrm{p}$.

1081:4 — - Ilortus Spaarn-Bergensis. Enumeratio stirjum, quas in villa Spaarn-Berg prepe Ilarlemum alit Adr. van der Hooj. Amstelodami, Joh. Muller. 1839. 8. xIt, 146, svt p., g tab. col.

$108: 5^{*}$ Herimneringen aan Franz Julius Ferdinand Heyen. (Leiden 1840.) 8. 38 p.

Scorsim impr. ex van der lloeven et de lriese Tijulschrift. vol. VIII, append. p. $3-38.1$

$108: 6^{*}$ ( brengen van levendo Planten uit overzeesche lauden naar Furopa. inzonderheit uit Indie naar Nederland. Amsterdam 30 Juni 1840. 8. $15 \mathrm{p}$.

$108.4 *$ Protrepticus ad commilitones etc. (Historia rei herbariac.) Anstelodami, Muller. 1841.8,35 j.

$10848^{*}-$ Berigt aangaande een' onlangs uit Java ontvangen Cyeas cireinalis I., gekweekt en thans bloeijende in den Kruidtuiu ler Stad Amsterdam. Amsterdam, A. Zweesaardt. 1842.8. 19 p.

$10849^{*}$ Oyer cene Verzameling eigenhandige Brieven an $\mathrm{Ca}-$ rolus Clusius, voorhanden op de Bibliotheck der lueidsche lloogesclrool. Leiden, Luclitmans. 1843. 8. 14 j.

$10800^{*}$ Over de anorganische Bestanddeelen der lanten. Onderzoekingen van Dr. A. Wiegmann en $L$. Polstory/l. Leiden. Luchtmans. 1843. 8.69 p.

$108 \mathrm{I}^{*}$ - Oratio de re herbaria Batavis non minus quam reliquis Europac populis excolenda, quam habuit die XXVIl mensis Septembris 1845 , quum ordinarian botanices in Academia LugdunoBatava professionem solemni ritı auspicaretur, Lugduni Balavorum, typ. Luchtmans. $1 \$ 45.8 .34$ p. $(1 / 4 / h$.

$10852^{*}$-... Plantae novae et minus cognitae Indiae batavae orientalis. Nouvelles recherclies sur la Flore les possessinus neérlandaises aux Indes orientales. Ouvrage orné de planclies dessinées par le Colonel Q. M. R. Jer Huell. Fasc. I. Ansterdam, Elix et Co. (Londres, H. Bailliere. Paris, Fortin, Masson et Co. Leipzig, Steinacker.) 1845. 4 max. 12 p.. praef., 1ah. col. $1-3 .\left(9 \frac{1}{2}\right.$ (h.) (Continuatur.)

$10833^{*}$ Nederlautselı kruidkundig Archief. Uitgegeren door II. de I'riese, F. Dozy en J. II. Molkenbuer. Eerste Deel. Stuk I-III. Leyden, Luchtmans. I $846.8 .(2)$, is 4 p.

1085: Chloris medica. Praecipuarum plantarum medicatarum ad naturam facta illustratio el descriptio. Naar le natuur gemaahte afbeeldingen en besehrijıingen van de vornaamste geneeshrachtige gewassen, met de henmerhen van naturlijke orden, geslachien, soort, en die van derzelver verwisselingen en vervalschingen, bencvens de ontleding der Bloem - en Trucluteleeleu. (Fasc. J.) Amsterdam, Beijerinch. (Amersfoort, Taats.) 1847.4.19 p., 2 tab. $(5 / 12$, $h .-60$ c.) (Continuatur.)

$1085^{*}{ }^{*}$ Descriptions et figures des plantes nouvelles et rares du jardin botanique de l'université de Leide et des principaux jardins du royaume des Pay's-Bảs. (Fasc. I.) Leide, A. Aruz el Co. Jeipzig, Friedrich Fleischer. 1847. gr. folio. (4) foll., (5) tab. col. ( 4 ch.) (Contimuatur.)

10856* Vrolik, Gerurd. Dissertatio sistens observationes de defoliatione regetabilium nec non de viribus plantarum ex principiis botanicis dijudicandis. Lugduni Batavorum, Honkooj), 1796. \$. 66, (6) p.

$10857^{*} \longrightarrow$ Oratio de co, quod Amstelodanenses ad rem botanicam exomandam contulerunt. Amstelodami, P. H. Dronsberg. 1797. 4. $70 \mathrm{p}$.

$10858+\div$ Catalogus plantarum medicinalium in Plıarmacopoea batava menoratarum. Editio altera auctior. Accedit introductio de studio botanico recte instituendo. Amstelodani, Holtrop. 1S05. 8. vill, 165 p., 2 scliemata. - Ed. 111: ib. Is 13.8. 
10859* (Vrolik, Gerard.) Elenchus plautarum, quae in horto Amstelaedamensi coluntur. Amstelaedami 1814. 8. 55 p. - *ib. (1821.) S. 84 p.

$10860^{*}$ Waarnemingen en Proeven over de onlangs geheerseht hebbende ziekte der aardappelen. Amsterdam, Sulpke. 1845. 8. v1, 22 p.

10861 * _ Observations el expériences rélatives á la maladie des pommes de terre. Amsterdam, (Leipzig, T. 0. Weigel.) 1846. gr. $8.2 \frac{1}{2}$ plag., 1 tab. col. $(1 / 3$ th.

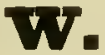

10862 - Wachendorf, Everardus Jacobus van. Oratio botanico-medica de plantis immensitatis intellectus divini testibus locupletissimis. Trajeeti ad Rhenum, typ. Broedelet. 1743.4.55 p.

$10863^{*}$ Horti Ultrajectini index. Trajecti ad Rlıenum, van Vuclut. 1747. 8. $x x x, 394$ p., pracf., ind.

1080.* Wackenroder, H. G.F. De anthelminthicis regni vegetabilis etc. 1). Goettingae, typ. Dieterich. 1826.4.67 p.

10863 Wade, IValter. Catalogus systematicus plantarum indigenarum in Comitatu Dublinensi inventarum. Pars 1. Dublini 1794. 8.275 p. B.

10866 Syllabus of a course of lectures on botany. Dublin 1802. 8.

$10867+-$ Plantae rariores in llibernia inventae; or habitats of some plants, rather searce and valuable fonnd in Ireland; with concise remarks on the properties and uses of many of them. Dublin, typ. Graisberry and Campbell. 1804. 8. xiv, 214 p.

$10868^{*}$ - Salices or an essay towards a general history of sallows, willows and osiers, their uses and best methods of propagating and cultivating them. Dublin, typ. Graisherry and Campbell. 1811.8. xxIt, 406,56 p., 1 tab. col.

$10869^{*}$ Prospectus of lectures on botany, to be delivered in the theatre of the Dnblin Society. First course. 1820 . Dublin, typ. Graisberry. 1820.8.40 p.

$10870^{*}$ Waechter, $J . K$. Ueber die Reproduetionskraft der Gewächse, insbesondre der Ilolzpflanzen. Ein Beitrag zur Pflanzenphysiologie nit Auwendnug auf Forst - und Landwirthschaft und auf Gartenbauknnst. Hannover, Halin. 1840. 8. Iv, $202 \mathrm{p}$. (1 th.)

$10871^{*}$ Wagener, Philipp Chrislian, und Friedrich Gruber d. J. Flora von Hildesheim, oder Besehreibung und Abbildung der im Furstenthum Hildeshein wildwachsenden Pllanzen. Erstes Zehend. llildesheim, typ. Schlegel. 1798. folio. (6 p.), 10 tab. col. Bibl. Goett.

10872 Wagner, Chr. und G. C. Hebig. Botanisches Forsthandbuch zum Selbstunterricht oder Beschreiljung deutscher und ausländiseher IIolzarten nach ilırer Kenutniss, Anpflanzung, Eigenschaften und Benutzung. Giessen, Heyer. 180 1. 8. (1 $1 / 3$ th. - herabgesetzt: $1 / 2$ th.

10873* Wagner, Daniet. Pharmaceutisch-merlizinische Botanik, oder Beschreibung und Abbildung aller in der k. $k$. Oestreich'schen Pliarmacopoe vom Jahre 1820 vorkommenden Arzneipflanzen in botanischer, pharmaceutiseher, medizinischer, historiseher und chemischer Beziebung etc. mit getreven, genau nach der Natur gezeichneten und gemalten Abbildnngen. Wien, typ. F. Ullrich, auf Kosten und in Verlage des Verfassers. 182S. Il voll. gr. folio. 2.16 foll., praef., 249 tab. col.

1087/." Wagner, Georg Friedrich, pr. Diseursus de Balsamo. D. Regiomonti 1683.4. 2 plag. (Respondens: Christaph IVoschkius.)

$10875^{*}$ _. . De natura et virtutibus plantarum in generc. D. Regiomonti 1688. 4. 2 plag. (Respondens: Friedrich Bogislaus Hillius.)

10876 Wagner, Johannes Gerhard. Arboreti sacri perfectioris specimen, sistens Laurum ex omni antiquitate crutan. Ilelmstadii 1732. S. 216 p. B.

Pritzel, Thes. lit. bot.
10877* Wagner, Johannes Jakob. Ilistoria naturalis Helvetiae curiosa. Tiguri $1680.12 .390 \mathrm{p}$

(Hall. Bibl. bot. vol. I. p. 606.)

10878* Wagner, Rudolph Christian, pr. Gyros Convolvulorum evolvere tontabit Jahann Gearg Wilhelm Starcken. Helnstadii, typ. Hamn. 1705. 4. 96 p., 1 tab.

10879* Wablberg, Pehr Fredrik. Flora Gothoburgensis. D. I-11, 2. Upsaliae, typ. academiae. 1820-1824.8. $117 \mathrm{p}$.

(Dissertatio sub praesidio Caroli Petri Thunberg proposita est.)

10880 Anvisning till Svenska Foder-Vaxternas kännedom. Stockholm, 1I. G. Nordström. 1835. 8. 318 p., 4 tab. (2 Rdr.) w. Prodiit primum in honal. Svenskat Landtbruks-Aeadeniens liandfingar, i̊ren 1833-183k. Siochtrolns, typ. HI. G. Nordstrom. 18335. 8. p. 165-282. - år 1630. ib. 1836. 8. 13. 6́-262.

10881 Wahlbom, Carl Adolph. De Oelandia. D. I. Upsaliac, typ. Edman. 1786.4. 44 p., 1 tab. geogr. W.

(Catalogus plantarum oclandicarum valde incompletus: p. f.2

10882* Wahlenberg, Göran. De sedibus materiarum immediatarum in plantis tractatio. Epsaliae, typ. Edman. $1806-1807.4 .74$ p.

Prodiit titulo sic mulato "Trictatio anatomica de sedibus materiarum immediatarum in plantis" in quatnor dissertationilisus vel sectionibus, quarum primam die IV Jnnii 1806 sub praesidio $C . P$. Thunberg pro gradu medico proposuit autor.)

10883 Berattelse om matningar och observationer for att bestänma Lappska Fjällens höjd ocl temperatur vid $67^{\circ}$ Graders Polhöjd, forráttade àr 1807 af Göran Wahlenberg. Med charta och 3 utsigter. Stockholm, typ. Delén. 1808.4.58 p., 4 tab. w.

Fragmentum hujus operis, de regionibus plintarum, anulice translatum a Uryander adest in Limaei Lachesi lapponica a Snithio edita.

* germanice: Bericit über Messungen und Beoljachtungen zur Bestimnung der Hohe und Temperalur der Lapplindischen Alpen stimnung der Hohe und Temperalur der Lapplindischen Alpeu
unter dem 67. Bretengrade; angestelt im Jahre 1807. Aus den Sehwedischen mil Ammerhungen von J. Friedrich Ludwig Hausmann. Gottingen, Dieterich. 1812. 4 . vi, 61 P., \& tab. $(5 / 6 / h$.)

10884* Flora lapponiea, exlubens plantas geosraphice et botanice consideratas in Lapponiis snecicis, scilicet Umensi, Piteusi, Lulensi, Tornensi et Kemensi nee non Lapponiis norvegieis, seilice Norlandia ef Finmarkia utraque indigenas, et itineribus annorum $1800,1802,1807$ et 1810 denuo investigatas. Cun mappa botaniev-geographica, tabula temperaturae et tabulis botanicis XXX. Berolini, in taberna libraria scholae realis. (Reimer.) 1812. 8. LXvi, 550 p., 30 tab. (6 th.)

$10885^{*}$ De vegetatione et climate in Ilelvetia septentrionali inter flumina Rlrenum et Arolam observatis et cum sumni septentrionis comparatis tentamen. Turici, Orell, Füssli et Co. 1813. 8. IIG, 200 p., 3 tab. $\left(3 \frac{1}{3}\right.$ th. $)$

$10886^{*}$ Flora Carpatorum principalium, exlibens plantas in montibus Carpaticis inter flumina Waagum et Dunagetz eorumque ramos Arvam et Popradum crescentes. Cui praemitlitur Tractatus de altitudine, vegetatione, temperatura et meteoris horum montium in genere. Cum mappa physico-geographica, tabula altitudinem montium ostendente et 2 tabulis botanicis. Goettingae, Vandenloeck." 1814. 8. cxvil, 408 p., 4 tab. $\left(2 \frac{2}{3}\right.$ th. $)$

$10887^{*}$ _..... Flora Lpsaliensis, enumerans plantas circa Upsaliam sponte, erescentes. Enchiridion excursionibus studiosorum Upsaliensium aecommotatum. Cum mappa geographico-botanica regionis. Upsaliae, typ. academiae. (Lipsiae, F. A. Brockhaus.) 1820. 8. vul, 495 p., 1 mappa geogr. $\left(2 \frac{1}{2}\right.$ th. $)$

10888:- Ttterligare Anmärkningar om Ölands Natur. Stockholm, typ. Lindhs Eukia. 1822.8 .16 p.

(Ur K. Vet. Acad. Hand. 1821. St. II.)

10889t Anmärkningar vid Cardamine parviflora L. Stockholm, typ. Lindhs Euka. 1823. 8.7 p.

(Ur K. Vet. Acad. llandl. 1822.)

$10890 *$ Flera suecica, enumerans plantas Sueciae indigenas, post Linnaeum edita. Upsaliae, Palmblad. (Lipsiae, F. A. Brochliaus.) 1824 - $\$ 826$. Il partes. S. Lxxrvm, 1117 p. (51/12 th. - Flora suecica, enumerans plantas Sueciae indigenas, cum synopsi elassium ordinumque, characteribus generum, differentiis specierum, synonymis citationibusque selectis, locis regionibusque natalibus, deseriptionibus habitualibus nomina incolarum et qualitates plantarum illnstrantibus, post Linnaeum edita. Auctior et emendatior denuo impressa. Lpsaliae, Palmblad. 1831- 1833. 
II voll. 8. - l: 1831. 443 p. - II: 1833. xcvil, 447-1134 p. (6 Jdr. 20 skill.)

10891t Wahlenberg, Göran. De eamplera ejusque usu therapeutico. D. I - Il. Upsaliae, Iyp. regiis. 1834. 4. 16 p.

10892 Om mogligheten att, enligt vegetabiliernas naturliga analogier, a priori bestámma deras egenskaper och verkningar pä menskliga organismen. D. 1-11. Upsala $1834.8 .31 \mathrm{p}$. w.

10893 De notione antidoti. D. Upsaliae 1837.8. 16 p.

$1089 \mathbf{1}^{*}$ Synepsis Florae gothlandicae. D. I - II. Lpsaliae, typ. ncademicis. $1837.8 .34 \mathrm{p}$.

(Autor est Respondens Carl Sáve.)

$10893^{*}$ - Historisk Undersattelse om Upsala Universitetets Botaniska Trädyård, 1836. (Infordt i Shandia $\mathbf{L}^{*}$. 1.) Upsala, Lefler et Selsell. 1837.8.26 p.

germanice: ubersetzl von Dr. Creplin, in Flora 1838. Beihlatter p. $37-76$.

$10896^{*}$ Waitz, $F$. A. C. Praktische Beolsachtungen uber einige javanische Arzneimittel etc. Aus dem llollăndisclien mit Anmerkungen von Dr. Johann Braptist Fischer. Leipzig, F. A. Brocklıaus. (Brüssel, Frank.) 1829. 8, xvi, 79 p. $(1 / 2$ th. $)$

$10897^{*}$ Waitz, Karl Friedrich. Beschreibung der Gattung und Arten der lleiden nebst einer Anweisung zur zwecknássigen Kultur derselben. Altenburg, link. 1805. 8. xir, 355 p., 2 tab. - * Neue Ausgabe: Leipzig und Altenburg, Ilinrichs, 1809. 8. XII, 355 p., 2 tab. $\left(1 \frac{2 / 3}{3}\right.$ h. $)$ (non differt; eadem impressio.)

$10898+$ Wakefield, Priscilla. An introduction to botany in a series of familiar letters. London 1796. 12. 184 p., 11 tab. - + Ed. 11 : Londen, Newbery, 1798.8. 200 p., 11 tah. $(4 s .-$ col. $\$ s$.) † gallice: Flore des jeunes personues, ou Lettres élémentaires Sur lia botanque, écrites par une Anglaise a son amie at tradoites de Ianglais par Octave Ségur. Paris, Buisson. 1801. 12. 2227 p., 12 tab. - Lid. if: ib. 1802. 12, (3 fr. $60 \mathrm{c}$ - - col. $7 \mathrm{fl}$. $50 \mathrm{cs}$ )

$10899^{*}$ Walberg, Theobald von. Ueber die linltur und Benutzung des inländischen und ausländischen Ahornbaumes, zur Gewinnung des Saftes zum Roluzueker in den Oestroichschen Erbstaaten. Wien, Degen. 1810.8 .40 p. $(1 / 2$ th. $)$

$10900^{*}$ Walch, Georg Friedrich. Calendarium Palaestinae oeconomicum. Goettingae, Vandenhoeck et Ruprecht. (1785.) 4.48 p. $(1 / 3 t h$.

10901 Walchner, Fran- Hermann. Darstellnng der wichtigsten bis jetzt erkaunten Verfálschungen der Arzneimittel und Droguen, uebst einer Zusammenstellung derjenigen Arzneigewachse, welche mit andern Pflanzen aus Betrug oder Unkenntniss verwechselt und in den llandel gebracht werden. Karlsruhe, Macklol. 1842. 8. $14^{3 / 4}$ plag. (1 th.)

$10902^{*} \longrightarrow$ Der practische Naturforscher. Ein unentbelirliches lland- u. Hulfsbueh für Freunde der Naturwissensehaften. Sechste Abtheilung: Der Botaniker. Karlsrulse, Macklot. 1844. 8. p. 1097 $-1198 .(\% / 12$ th. $)$

10903 Walcott, John. Flora britannica indigena, or plates of the indigeneus plants of Great Britain. Bath 1778. 8. 8 p., 168 tab. B.

1090." Waldbrueh], Wilhelm von. Die deutsehen Pllanzennamen, gesammelt uud gesichtet. Berlin, Vereinsbuchlıandlung. 4841. 8. vi, 82 p. $(1 / 3$ (h.)

10905* Waldin, Johann Gottlieb. Die Frankenberger Verstejnerungen, nebst ihrem Ursprung beschrieben. Marburg, Bayrhöfer. 1778.4. 32 p., 2 tab. $(1 / 4$ th. $)$

$10906^{*}$ WaJdschmiedt, Johann Jaliob. Honita medica circa Opii et opiatorum usum, vulgo Schlarl-Tränck. Mlarpurgi 1679.4

10907 De potu Theao. D. Marpurgi 1685. 4. (Respondens: Christiun Kürsner.) s.

10908 De vegetabilium ertu, vita et morte. D. Narpurgi 1788. 4. Desid. Banks.

10909 Waldschmiedt, Wilhelm Ulrich (IIuldreich), pr. De usu et alusu potus Thee in genere, praecipue vere in hydrope. D. Kiliao 1692. 4. (Respendens: Jeremius Muller.)

10910 Programma ad herbationos anni 1696. Kiliae 1696. 4. 1 play. B.

10911 Programma ad herbationes anni 1701. (De jucuuditate studii plantarum.) Kiliae 1701.4. 1 plag. $B$.
10912 Waldschmiedt, Wilhelm Ulrich (Huldreich). Programma ad herbationes anni 1702. Kiliae 1702.4 . 1 plag. B.

$10913^{*}$ De sexu ejustlem plantae gemino. D. Kiliae, typ. Reuilser. 1705.4 .22 p. (Respondens: Jakob P'renzler.)

$1091 k^{*}$ - Kurtze und grandliche lleschreibung derer Aloen insgemein, insunderheit aber derer Amerikanischen, durch Veranlassung zweier in dem Hoclufurstlichen Lust-Garten zu Gottorf bald bluhenden Amerikaniselsen Aloen, nelrst Johann Daniel Mujoris Tractat von eben dieser Naterie, Kiel, Rieclıel. 1705. 4. 36 p., prater opıusculum Mojoris.

$1091 \%$ Amerikanischer 212 Gottorlf bluhender Aloen fernere Beschreibung, worinnen derselten lklulung und Terblukung, vebst andern sonderbahren Ammerkungen kurtzliclı erortert, und einige wieder die herausgegebene Beschreibung gemaclıte Einwurlfe eines guten lireundes boscheidentlich wiederleget werden. hiel, bey Barthold leuthern. 1706. 4. 36 \%. в.

$10916^{*}$ Programma de vegetabilium usu eximjo in medicina. Kiliae 1707.4. 1 plag.

$10917^{*}$ - Programma (de plantarum vegetatione), que ai publicas plantarum demonstıationes invitat. Kiliae 1710.4. 1 plag.

10918* Progranma de industria aevi hodierni, qua propagatio plantarum, veterum circa res liorlenses occupationes joust se relimpuit. líliae 1712.4. 1 plag.

$10919^{*}$ Waldstein, Frans Adol, Graf von, et Paul Kitaib e)l. Descriptiones et icones plantarum rariorum llungariae. Viennae, Iyp. Schmidt. (Schaumburg.) 4802-1812. Ill voll. folio, - I: 1802 . xxxi, 104 p., tab. col. 1-100, - II: 1805. xxxII, 105-221 p. tab. col. $101-200 .-111: 1812.223-310$ p., ind, tab. col. 201 -280.1224 th. Voss. $-311 \frac{1}{8}$ th. Kayser.

$10920 t$ Walker-Arnott, George Arnoll. Disposition méthodique des especes de mousses. Paris, typ. Tastu. 1825. 4. 7z $p$.

$10921+\ldots$ Botany. (Article in Eneyclopaedia britannica, ed. Vll vol. V. p. $30-141,14$ tab.) s. I. et a. 4 . Bibl. Cand.

10922 Walker, John. Experiments on the motion of the sap in trees. s. I. et a. 4.40 p., 1 tab. B.

(Transactions of the Royal Society of Edinburgh, vel. I. p. : -10$.

germanice: Versuche uber die Bewegung des Saftes in den Báumen. Samulungen zur Physih, Banul IT. P. Y toj-\$93.)

$10923^{*}$ Walker, kichard. The Flora of Oxfordshire and its contiguous counties, comprising the flowering plauts only, arranged in eas! and familiar language, according to the Linnean and natural systems; precederl by an introdnction to botany. Oxford, Slatter. 1833. 8. $\mathrm{Cxxxr}, 33 \mathrm{~S}$ p., 42 tal. (14s.)

1092'** Walker, 11 ilhelm. Die Olsstlelıre der Griechen und Römer. Nacl Quellen bearbeitet. Reutlingen, Mácken. 1845. 8. vir, 357 1. $\left(1 \frac{1}{2}\right.$ th.)

10923 Wallace, James. A deseription of the isles of Orkney. Eilinburgh 1693.8.94 p., 2 tals. B. - London 1700.8. 147 p., 2 tals. B. (Continel catalogum plantarum indigenarum Orcadum.)

$10926^{*}$ Wallenius, Johan Fredric. Nova Ammeos species. D. Aboae typ. Frenckel. 1810.4. $13 \mathrm{p}$.

$10927^{*}$ Waller, Karl Alexis. Der Stulsengàntner, oder Anleitung zur hemutniss und liultur der vorzuglichsten auslandischen Gewachse. Nordhusen 1806. 8. - "Vierte Ausgabe. Ilmenau, Voigt. 1831. 8. vill, 190 p. $(2 / 3$ th. $)$

10928 Wallerius, Johan Gotschalk. Elementa agriculturae physicochemica. Lpsaliae 1761.4.

germanice: Chemisehe Grundsätze des Acherhaues. Aus den La einischen mil Anmerkungen yon J G Srunit Berlin, Wever. 176i. 8. $\left(1 / 4, t h_{s}\right)$

tgallice: Eiemens d'agriculture pliysique et chimique. Yrerdon 1766. 8. $\mathrm{Vi}, 226 \mathrm{p}$.

gallice: L'astriculture réduite à ses vrais principes; nuvrage traduit en francais sur la version latine, auquel on a ajouté un trant nombre de notes tirees de la version allemande (par to Raron d'Holbach.) Paris, Lacombe. 177t. 12. Q.

Praeside J. G. Wallerio dissertationes academicae:

$10929^{*} \longrightarrow$ De historiae naturalis usu medico. D. Tpsaliac 1740. 4. 44 p. (Kespronlens: Olof Mulmsten.) 
$10930^{*}$ Wallerius, Johan Gotschalk. Decarles binae thesium nedicarum. D. Upsaliae 1741.4.38 p. (Respondens: Johun Anders Darelius.)

(De injurioso contra Linnaeum lihello, in Stoereriana collectione epistolarum p. 119-\$ä8 recuso, cf. Thes. lit. hot. Nr. 61ł1.)

10931 De principiis vegetationis. D. I. IJolmiae, typ. regiis. 1751.4.21 p. (Respondens: Jac. Stenius.) B.

* germanice: Von den Ursachen, Wejche hei dem Wachsthum der Pflanzen bemerkt werden. Physihalische Belustigungen, Band 111. P. $773-813$.

$10932^{*}$ De artificiosa foecundalione immersiva seminum vegetabilium. D. Holmiac, Іур. Salvii. 1752. 4. 24 p. (Respondens: Jahan Pihlman.)

10933 De prima vinerum origine casuali. D. Holmiae 1760. 4. 12 p. (Respondens: Olof Nordeholm II'esimar.) B.

10934. De vestigiis diluvii universalis. D. Upsaliac 1760. 4. 16 p. (Respondens: Daniel Johan Lagerlof.) B.

10933 t - De origine olcorum in vogetabilitus. D. Upsaliac 1761 4. 12 p. (Respondens: G. Rothman.)

$40936+\longrightarrow$ De vegetatione seminum vegetabilium per mortem. D. Upsaliae 1761.4. 5 p. (Respondeus: Mhchael IIenrik Ottin.)

10937 Indoles historiae naturalis in genere. D. Jlolmiae, typ. Salvii. 1764.4.8 p. (Respondens: Lars Lyth.) B.

10938 De Palingenesia. D. chenico-physica. Lpsaliae 1764. 4. 22 p. (Respondens: Gerhard Reinhald Hoyer.) w.

$10939 \div$ Wallich, Nathanael. Descriptions of some rare Indian plants. (Calcutta 1818.) 4. p. $369-415 .(14)$ tab. (Prinula prolifera Ienispermum Cocculus.)

$10940 \div$ List of Indian woods collected. London, J. Moyes. s. a. $8.43 \mathrm{p}$.

(From the Transactions of the Suciety of arts, vol. XLIIII.)

$10941^{*}-$ Tentamen Florae Napalensis illustratae, consisting of botanical descriptions and lithographic figures of select Nipal plants. Fasc. I-II. Cälculla and Serampore, printed and published at the Asiatic Lithogr. Press. 1821-1826. folio. $64 \mathrm{p}$, 50 tab.

(Titulus in tegumento impressus sirepe dlesideratur. In ex emplari Candolleano legitur: "The tables which have been struck of on India paper will he replaced by olhers on Europe naper, before the first volume is finished, - Opus incompletum, dle cujus conlentis cf. Linnaea 1827. D. 532-5\%10, el Eschweiler Rot. Lit. Rlitter II. p. 286-295, desinit: "The winged seeds nul nectary, at the").

$10942^{*}$. nt numerical List of tried sfjecimens of plants in the East India Companys Museum, collected under the superintendence of Dr. Wallich, of the Companys Botanic garden at Calculta. London, 1 Dec. 1828. folio. 268 p.

(Catalogus arte lithographica exsusus 7683 specicrum e collectione Wallichiana, quas societas Mercatorum ludiae orientalis celebriorihus Europae hotanicis dono dedit; cf. Beilschmied Jahresbericht uher 1832 . p. $82-81$.)

$10943^{*}$ Plantae asiaticae rariores; or tescriptions and figures of a select number of unpublished East Indian plants, by Nathanuel Wallich. London, Treuttel and Wurtz. $1830-1832$. III voll. folio. - 1: 1830.45,84 p., tab. col. 1-100, - II: 1831.86 p., tab. col. 101-200. - III: 1832. vin, 117 p., tab. col. 201-295, et Map of Jndia, sign. $296-300$. (circiter 250 lh. -972 fr.)

$109 \mathrm{k}^{*}$. Upon the preparation and management of plants during a royage from India. London. typ. Nicol. $1 \$ 32.4 .4 \mathrm{p}$.

(Frum the llorticultural Transactions.)

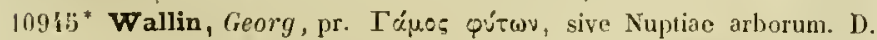
Upsaliae, typ. Winter. 1729. 4. p. 243-290, 1 tab., ic. xylogr. i.t. (Respondens: Pehr Ugla.)

10946 Wallin, Joseph. Hinne af Pehr Hernquist, Professor och Lector. Upplást vid Prăstmotel i Skara d. 26. Sept. 1816 af L. Tiden. Skara, typ. J. Lewerentz. 1818.8 .34 p., effigies Hernquist. w.

10947 Wallis, John. Deudrology; in which are facts, experiments and observations demonstrating that trees and vegetables derive their nutriment independently of the earth. London, Berger, 1833.8 . (4s.)

1094 Wallman, Johan Hacquimus. De systematibus vegetabilium, qua ratione oeconomicae scientiae profuerint. D. I - II. Upsaliac, typ. Zeipel et Palmblad. 1818.4.16 p. w. (De eodem autore ef. supra Nir. 5893 .

10949* Wallroth, C. Friedrich IVilhelm. Gesclichte des Obstes der Alten. Erstes (und einziges) Heft. Ilalle, Hendel. 1812. gr. 8. xviI, $142 \mathrm{p} .(1 / 2$ th. $)$
10930* Wallroth, C. Friedrich IIthelm. Annus bolanicus, sive Supplementum tertium ad $C$. Sprengelii Floram Halensem. Cum tractalu ot iconibus TI Charam genus illustrantibus. Ilalae, Kummel. 1815. 8. $x x x, 200$ p., 6 tab. $\left(1 \frac{1 / 2}{2}\right.$ th. $)$

$10951^{*}$ Schedulae criticae de plantis Florac Halensis selectis. Corollarium novum ad Sprengelii Floram Halensem. Tonus I. Plranerogamid. Ilalae, Kummel. 1822. 8. 516 p., 5 tab. (21/2 th.)

$109022^{*}$ Oruluanches generis Diaskeue. Ad Car. Mertensium epistola. Francofurti a/M., Wilmans. 1825. 8.80 p. $(7 / 12$ th.)

$10933^{*}$ Naturgeschichte der Flechten. Nach neuen Normen und in ihrem Unfange bearbcitet. Ein fasslicher Unterrich zum Selbststudium der Flechtenkunde. Frankfurt a/M., Wilmans. 1825 - 1827. 2 Bánde. 8. - I: 1825. Lvur, 722 p. - Il: 1827. Pliysiologic und Pathologie des Flechtenlagers. Xvi, 548, (1) p. ( 7 th.

1095: - Rosae plantarum generis historia succincta, in qua Rosarum species tum suae terrae proventu tum in horlis natas suppositicias secundum normas naturales ad slirpium besscstres primitivos revocat intue speciminum ratorum fidem rlodologorum et rhodophilorum caplui accommodat. Nordhusae, Kohne. 1828. 8. xII, $3: 1$ p. $(2$ th. $)$

10955* - Naturgesclijchte der SäulchenflecJiten; ader monographischer Abschlușs tiber die Flechtengattung Cenomyce Acharii. Naumburg, in Commission bei Eduard Zimmermann. 1829. 8. vi, $198 \mathrm{p} .\left(1 \frac{1}{3} \mathrm{l} / \mathrm{h}.\right)$

$109 \ddot{3} 6^{*} \longrightarrow$ Flora eryplogamica Germaniae. Norimbergae, Schrag. 1831-1833. II voll. 12. - Pars prior, continens Filices, Liclienastra, Miscos et Lichenes. 1834. XXVI, 654 p. - Pars posterior, continens Algas et Fungos. 1833. Lvi, 923 p. (6 th.)

$10957^{*}$ — Erster Beilrag zur Flora hercjuica. Erste Abtheilung, allgemeine Berichtigungen einiger in Hampe's Prodromus Florae Hercyniae erwảhuten Gewachsarten entbaltend. Halle, typ. Gebauer-Scliwetsclihe. $1840.8 .158 \mathrm{p}$.

(Seorsim impr. ex Limnaea, vol. XIY. 18\%0. p. 1-158. - Continuatio: ib. p. 529-70k. - Titulus in Linnaea sic differt $\Sigma X O \Lambda$ ION zu Hampe's Prodromus Florae Hercyniae.)

$10958^{*}$ —_ Beitrage zur Botanik. Eine Sammlung monographischer Abhandlungen uber besonders schwierige Gewàchsgatlungen der Flora Deutschlands. Ersier Band. Heft 1-2. Leipzig, Hofmeister. 1812-1844. gr. 8. vi, 252 p., 3 tab. col. $(12 / 3$ th. $)$

IJ efi I: 1842. Honographischer Versuch uber Agrimonia Cels.Zur Naturgeschichte der Usnea nigra Dill. - Zur Naturgeschichte der Orchis bifolia Thal. - Naturgeschichte des Senecio paludosus L. - Die Naturgeschichte der Erysibe subterranea Wallr. (des Brandes der Kartoffeln). vi, 1-123 p., tab. coJ. 1-II. (5/6 th.)

Ileft II : 1844. Nonographischer Versuch uber die Gattung Lampsana Dodon. - Zur Kenntniss der Anthemis tinctoria mit schwefelgelben Strablenbluthen. - Naturgesclichte der mykelischen Entomoplayten. - Nonograpbie der Gattung Armeria Willd. - Monograpbie der Gattung Xanthium Diosc. - Zur Kenntniss der Salix liastata L. 125-252 p., tab. col. IJI. (5/6 th.

10959* Walmstedt, Lars Pehr. Nagnos literarum patronos, hospites, palres civesque academicos el urbicos ad audiendam orationem solemnem, qua medicinae et botanices Professoris munus auspicaturus est experientissimus et celeberrimus medicinae Doctor Georgius II ahlenbery, reverenter el officiose invitat regiae academiae Upsaliensis Rector Laurentius l'etrus Walmstedt. Upsaliae, excudehant regiae academiae typographi. (4829.) folio. (4) p.

(Insunt vitae succinctae Professorum Upsaliensium Johannes Frante, 1628-1661; Olof Rudbeck pater, 1660-1690; Olaf Rudbeck filius, $1691-1710$; Carl van imé pater, 17, -178; Carl von Linne lilius, 1777-1783; Carl Pehr Thunbery, 1785-1828.)

$10960^{*}$ Walpers, ITilhelm Gerhard. Animadrersiones criticae in Leguminosas capenses herbarii regii Berolinensis. D. Halae, typ. Gebauer-Sehwetschke. 1839. 8.99 p.

$10961^{*}$ - Reprrtorium botanices systemalicae. Lipsiac, Fr. Hormeister. $1842-1848$. VI voll. $8 .\left(30^{2} / 5\right.$ th. $)$

Tomus I: 1842. (Ranumculaceac-Mimoseae; index generum.) IV, 947 , (4) p. (5 th.

T o m u s II : 1843. (Chrysobalaneae-Nonotropcae; supplemenlum primum ad Repertorii hotanices systematicae tomum primum et secundum: Ranunculaceae - Gesneriaceae; index generum tomi I -II.) vilt, 1029 p. $(6 \mathrm{th}$.)

$40^{*}$ 
Tomus III: 1844-184\$. Synopsis Snlanacearum, Scrophularinarum, Orobanchearum et Labiatarum in botanicorum scriptis ad hunc diem editis deseriptarum. (Addenda et corrigenda; synopsis generum; index generum.) xit, 1002 p. $\left(5 \frac{1}{3}\right.$ th.

Tomus IV: 1844-1848. Synopsis Verbenacearum, Myoporinearum, Selaginearuin, Stilbinearum, Globulariearum et Plantaginearum omnium ad anıum MLCCCXLIV cognitarum. Additus est index ordinum, subordinum, generum, sectionum, specierum et synonymorum ormnium in Repertorii botanices systemalicae fasciculis $1-\mathrm{XXV}$ i obviorum. vir, 821 p. (4th.)

Tomus V: 1845-1846. Synopsis plantarum exogenearum dialypetalarum omnium iude ab anno MDCCCXLIIl detectarum, exhibens supplementun tertium ad ordines XCVl priores vegetabilium in Prodromo Candolleano descriptorum. (Ranunculaceae Loranthaceae; index generum.) vur, 982 p. ( 6 th.)

Tomus VI: 1846-1847. Synopsis plantarun exogenearum gamopetalarum post Prodromi Candolleani tomum decinum et Repertorii botanices systematicae fasciculum decinum sextum editos delectarum. (Losicereae - Plantagineae, additamenta; index generum fasc. I-XXVl.) vil, 834 p. $\left(4 \frac{1}{15}\right.$ th. $)$

Repertorium botanices systematicae his sex tomis absolutum est. Nunc quotannis prodibunt annales botinices s y stemaic ae", in quibus nou uisi recens descriptae species secundum familias naturales digestac colligentur.)

10962* Walpole, Kobert. Memoirs relating to european and asiatic Turkey, and other eountries of the east. The second edition. London Longman. 1818.4 . xxı1, 615 p. with plates. (3l. $3 s$.)

(Plants of Greece from Dr. Silhorp's Papers, p. 233-23k.)

$10963^{*}$ Walser, Franz Laver. De Atropa Belladouna. D. Monachii, typ. Giesser. 1839.8. 24 p.

1096:* (Walter, $F$.) Verzeichniss der auf clen Friedlándischen Gütern cultivirten Gewăclsse, nelsst einem Beitrage zur Flora der Mittelmark. Dritte Auflage. 1815. 8. xit, 60 p.

Accedunt huic tertiac editioni: Adnotationes quaedam ad Floram Berolinensem $C$, S. Kunthii, auctore Adelberlo de Chamisso: $13 \mathrm{p}$. - Editionem primam anno 180 euravit Karl Ludwig Willdenuno. supplementum prodiit anno 1805 , et editio altera anno 1806.

10963\% Walter, Franz. Plantae officinales, ad naturam delincatae. (Argentorati) s. a. 4. 6 tah. col., 6 foll. (germanice et gallice.) Bibl. Cand.

$10966^{*}$ Walter, Thomas. Flora Caroliniana, secundum systema vegetabilium perillustris Linnaei digesta, characteres essentiales, natuturalesve et differentias veras exlibens, cum emendationibus numerosis descriptionum antea evulgatarum, adumbrationes stirpium plus mille continens nec non generibus novis non paucis, speciebus plurimis novisque ornata. London, Fraser. 17SS. S. viII, 263 p., I tab.

$10967^{*}$ Walther, Augustin Friedrich. Plantarum oxoticarum indigenarunque index tripartitus. etc. Lipsiae, typ. Langenheim. 1732. 8. So p. Bibl. Goett.

Est catalogus horti ejus privati.)

$10968^{*} \longrightarrow$ Designatio plantarum, quas hortus Augustini Friderici Waltheri, Path. Prof. Lips., complectitur. Accedunt novae plantarum icones XXIV. Lipsiae, Gleditseh. 1735. 8. 171 p., 94 tab.

10969* Progranma de plantarum structura. Lipsiae 1740. 4. $16 \mathrm{p}$.

Redit in Reichard Sylloge opusc. Mot. p. 69-81.)

$10970^{*} \longrightarrow$ De Silphio in veterum nummis ac diversis plantae speciebus disserit. Programma academicum. (Lipsiae 1746.) 4. 24 p., ic. xylogr. i. t.

10971 Programma de Loto aeryptia in nummis antiquis. Lipsiae 1746. folio. 2 plag.

10979* Walther, Friedrich Ludwig. Flnra von Giessen und der umliegenden Gegend fur Anfanger und junge Freunde dar Gewăchskunde. Nebst einem illuminitten l'lan des neuen okonomiscli-botanisehen Universitatsgartens in Giessen. Giessen und Darmstadt, Heyer. 1802. 8. vin, 704 , svil p., I tab. col. ( $2 \frac{1}{2} t h$. - herabgesetzi: $1 \frac{1 / 3}{3}$ th.

10973 Walther, Ludwig August. Pliarmahognostisch-pharmakologische Tabellen oder systematisch-tabellarische Uebersicht der offizinellen einfachen vegetabilisclsen Arzneinittel der neuesten preussischen Plsarmakopoe. Nebst einer Einleitung und Besclsreibung der
Systeme von Linne, Jussieu und Reıchenbach. Mainz, Kupferberg. 1838. folio obl. xir, 129 p. $(2 \%$ th. $)$

10974 Walt, Joseph. Handhuch der Naturgeschichte. Zweiter Theil. Bolanik. Regensburg, Reitmayr. 1837. 8. 5 plag. (1/, th.)

$10970^{*}$ Waltl, Joseph. Das Amylon und Inulin. Chemiselıe Abhandlung mit steter llinsicht auf Pflanzenphysiologie, Techik und Medicin. Nürnberg, Riegel und Wiesstier. 1829. 8. Iv, 60 p. (1/t th.

$10976^{*}$ Walz, Georg Friedrich. Der Milchsaft des Giftattichs clemisch untersucht. U. lleidelberg 1839.8. 54 p.

10977* Wangenheim, Friedrich Adam Julius ron. Beschreibung einiger Nordamerikanisclıer IJolz- und Buscharten mit Anwendung auf deutsche Forsten; zum Gebrauch fur Holzgerechte Jäger und Anpflanzer fremder Jlolzarten; aus den in den dortigen Provinzen seit den Jalıreı 1777-1780 gemachten Bemerkungen. Götıingen, Dieterich. $1781.8 .151 \mathrm{p}$., ind. $(1 / 3 \mathrm{th}$.

$10978^{*}$ Beitrag zur teutschen holzgerechten forstwissenschaft, die Anjulanzung Nordamerikanischer Holzarten, mit Anwendung auf teutsche Forste, betreffend. Göttingen, Dieterich. 178\%. folio. xLv, 124 p., ind., 31 tab. ( 5 th.

$10979^{*}$ Ward, $N$. B. On the growth of plants in closely glazed cases. londou, J. van Voorst. 1842. 8. II, 95 p. (5s.)

("On the growth of plauts without open exposure to air. Letler to sir UI. J. Hooker. published in the Companion to the Botanical Magazine for llay 1836.8 . 7 p.)

10930 Warner, kichard. Plantae Woodfordienses, a catalogue of the more perfect plants growing spontaneously about Woodford in the county of Essex. London 1771. 8. 238 p. B.

(Index latinus, p. 223-238, post librum editum impressus in paucis tantum exemplis adest.

10981* Wartmann, Jakob. Butanik fur die meibliclıe Jugend. St. Gallen, Scheitlin und Zollikofer. 1841. 8. iv, $192 \mathrm{p} .(3 / \mathrm{t}$ th. $)$

$10982^{*}$ __. Gallische Flor, für Anfanger und Freunde der Botanik bearbeitet. St. Gallen, Scheitlin und Zollikofer. 1847, 8. v1. 268 p. $(\% / 10$ th. $)$

10983* (Warton, Simon.) Schola botanica, sive Catalogus plantarum, quas ab aliquot annis in horto regio Parisiensi studiosis indigitavit vir clarissimus Josewh Pitton Tournefort, ut et Pauli IIermanni Paradisi batavi Prodromus. Ėdente in lucem S. W.A. Amstelaedani. apud Henricum Welstesium. 1689. 12.386 p., praef., ind.

(A p. 301-386 Pauli Hermanni Paradisi batavi Prodroumus.)

1098: Washington, George. Letters to Sir Arthur Sinclair on the rural econony of the United States. Alexandria 1803. 4. Bibl. Nov, Ebor.

10983t Watelet, Claude Henri. Essai sur les jardins. Paris, Prault. 1774. $8.160 \mathrm{p}$.

10986 Waterhouse, Benjamin. The botanist, being the botanical part of a course of lectures delivered in the university of Cambridge (America). ete. Boston 1811. 8. 259 p. (5s.)

10987 Watkins, William. A treatise on forest-trees. London 1753. 8. s.

10988t (Watson, Alexander.) Flora Sta Helenica. St. Ilelena: printed by J. Boyd. 1825. 4. v, 20 p.

Sistit praeter introductinnem anglica scriptam lingua ratalncum plantarum methodn Linneana dispositum, adjcetis nominibus anglicis; autor fertur: Alexander Hatson, militum pracfecus.)

10989: Watson, Hcwelt Cottrell. Outlines of the geographical distribution of britislt plants; belongiug to the division of vasculares or cotylednnes, Edinburgh: printed for private distribution. (1832.) 8. XYI, $334 \mathrm{p}$.

10990 - The new botanist's guide to the localities of the rarer plants of Britain; on the plan of Turnar and Dillwyn's Botanist: guide. London, Longman, Rees, Orme etc. 1835-1837. 11 voll. 8. - I : England and Wales. 1835. v1, 403 p. - 11: 1837. Scotland and adjacent isles. $x x i v, 407-674$ p. (16.s. 6d.)

$10991^{*}$ Rentarks on the geographical distribution of british plauts; chielly in comection with latitude, eleration and climate. London, Iongman, Rees, Orme ete. IS 35 . 8. xw, 285 p. (6s. 6d.) * germanice: Bemerhungen üher die geographische Vertheilun und Perbreitung der Gewachse Grossbritanniens, besonders nacl jhrer Abltugigheit ron der geographischen Breite, der lohe und dem Klima. Cobersetzt und mit Beilagen und Ammerkungen versehen von Karl Traugnt Reilschmied. Breslan, in Connmission bei Jos. Ilax et Co. 183i, s. xx, 201 p. $\left(11 / 3, h_{0}\right)$ 
10992* Watson, Ilewell Coltrell. The geographical distribution of british plants. Third edition. Part J. London, printed for the author. 1843. 8. IV, 259 p. Bibl. Griseb.

(Ranunculaceae, Nymphaeacede, Papaveraceae.)

10993* Cybele britannica; or british plants and their geographical relations. Part I. London 1847.8 .476 p. $(10 s .6 d$.

1099 ' Watson, John. History of the parish of IJalifax. London 1775. 4. B.

(Thest a p. 729-764: A catalogue of plants growing in the parish of Ilatifax, hy James Bollon.)

$1099: \div$ Watson, P. W. Dendrologia britannica, or trees and shrubs that will live in the open air of Britain throughout the year. A work useful to proprietors and possessors of estates etc. London, Arch. 1825. 11 voll. gr. 8.172 foll., ind., Lxxil, 30 p., 172 tab. col.

$10996+$ Wauters, P.E. Dissertatio botanico-medica de quilusslam plantis belgicis in locum exoticarum sufficieudis. Gandavii, van der Schueren. $1785.8 .80 \mathrm{p}$.

$10997^{+}-$Repertorium remediorum indigenorum exoticis in medicina substitnendorum. Responsum coronatum. Gandae, typ. Goesio-Disbecq. 1810.8. VIII, $302 \mathrm{p}$., ind.

10998 Webb, John. A catalogue of seeds and hardy plants, with instructions for sowing and planting, by $J_{0} h n$ II $e b b$, scedsman, at the Acorn, near Westminster bridge, London. 1760.8.28 p. B.

$10999^{*}$ Webb, Philip Barker, et Salin Berthelot. Ilistoire naturelle des iles Canaries. Tome 1ll. (Botanique.) Paris, Béthune. 18361847. 4. et dilas. ib. 1838 . folio.

Première partie, contenant la greographie botanique. 1840 . sv, 210 p., 25 tab. ex Atlante. (90 fr.)

Deuxième partie: Phytugraplia canariensis.

Sectio I-ll : Plantes phanérogames. 220,224 p., 158 tab. ( 80 fr.) (Continuatur.)

Sectio Ill: Plantes cellulaires, par Camilte Montagne, 208 p., 9 (als. (20 fr.)

Atlas: 1838. folio. 34 tab. sign. 1-XIV, 1-9, 1-11, effigies IV ebb et Berthelot.

(Universi operis anno 18,6 prodierunt 81 fasciculi "livraisons" singulus $3-3$ playulas et $3-4$ tabulas contincus, pretio 6 fr. et in editione splendidiori cum tabulis pietis $12 \mathrm{fr}$. Tabulas exinia arto Belinearunt Mme Gry (Compositae), Mle Legendre, Spachii conjux, Heyland, Riocreux. Chazal, Thiolat, alii. Plantarum phateroganarnn sectio altera nondum ad finem perdueta est.)

$11000 *$

- Ler hispaniense, or a synopsis of plants colfected in the southern provinces of Spain and in Porugal, witl geographical remarks, and observations on rare and undescribed species. Paris, Bethune and Plon, and at London, by llenry Coxhead. 1838.8. Iv, so p. ( 1 th. $)$

$11001^{*}$ _ Otia hispanicd, seu Delectus plantarum rariorum per Ilispanias sponte nascentium. Pentas I-II. Parisiis, Brocklaus et Avenarius; London, H. Coxlsead. 1839. folio. 13 p., 6 tab. sign. I $-\mathrm{X}$. (s $(h$.)

$11002 \div-$ Topographie de la Troade ancienne et moderne. Paris, Gide. 1844. 8. III, 196 p., 5 tab.

(Pauca intercedunt botanici argumenti.)

11003 Weber, F. C. Grun lliche Anleitung zum Gartenbau, und insonderheit zur Baumzucht, aus den franzosischen Schriften des Ilerrn Quintinye und des Jardinier solitairo, wie ancl aus dem mündlichen Lnterricht geschickter Gärtner. Hamburg 1725. 4. 199 p., tab. B.

$11004^{*}$ Weber, Friedrich. Botanische Briefe an Hr. Prof. Kurt Sprenget in Halle. Ein Anhang zu seiner Einleitung in das Studium der kryptogamischen Gewächse. Kiel, akademische Buchhandlung. 1804. 8. 111 p. ( $1 / 2$ th. $)$

$11003^{*}$ und Daniel Malthias Heinrich Mohr. Naturhistorische Reise durch einen Theil Schwedens. Götungen, Dieterich. 1804.8 .207 p., 3 tab. $\left(1 \frac{1}{3}(h)\right.$.

$11006^{\star}$ - Archiv für die systematische Naturgeschichte. Ersten Bandes erstes Stuck. Leipzig, Schafer. 1804.8 . $\mathbf{x}, 153$ p., 5 tab. col. ( 1 th.)

$1100 \tau^{*}$ mit ilıren Freunden verfasst und herausgegeben. Kiel, akademische Buchliandlung. $1805-18^{\prime} 10$. 2 Bänle. 8. $-1: 1805$. vill, 356 p., 7 tab. nigr. et col. - Il: 1810 . vi, 400 p., 4 tab. ( $4 \frac{1}{3}$ th. $)$
11008* Weber, Friedrich, und Daniel Matthias Ileinrich Mohr. Botanisches Taschenbuch auf das Jahr 1807. Deutschlands kryptoganische Gewáchse. Erste Abtheilung: Filices, Mlusci frondosi et hepatici. (Jlandbuch der Einleitung etc.) Kiel, akademische Buchhandlung. 1807. 12. xLVI, 509 p., 12 lab. ( 3 th. - col. 41/2 th.)

$11009^{*} \longrightarrow$ Tabula exhibens calyptratarnm operculatarnm sive Iluscorum frondosorum genera. Kiliae, Mohr. is 13 . folio. 3 plag. $(1 / 3$ th.

$11010^{*}$ Historiae Muscorum hepaticornm Prodromus. Kiliae Hesse. 1815.8 .160 p. $(5 / 6$, h. $)$

$11011^{*}$ Ilortus Kiliensis; oder Verzeichniss der Pflanzen, welche im botanischen Garten in Kiel 1822 gezonen werden. Kiel, akademische Buchlhandlung. 1822. 8. x11, $113 \mathrm{p} .(3 / 4$ th. $)$

$11012^{*}$ Weber, Georg IIeinrich. Spicilegium Florae Gottingensis, plantas inprimis cryptogamicas Hercyoiae illustrans. Gothae, Ettinger. 1778. 8. 288 p., praef., ind., 5 tab. col.

$11013^{*}(-)$ Primitiae Florae holsaticae. D. Kiliae, typ. Bartsch. $1780.8 .112 \mathrm{p}$.

(Dissertationem die 29 Martii 1780 sub praesidio Johnnnis Christimni Kerstens proposuit Friedrich Heinrich Wiggers; sed autorem so professus est cl. Gearg Heinrich lleber.)

$11014^{*}-$, pr. Plantarum minus cognitarum decuria. D. Kiloniae 1784.4.20 p. (Respondens: Sebrstian Grnuer.)

11045* Weber, Johann Heinrich. De Daturae Strammonii viribus et usu medico. D. Bonnae, typ. Buschler. 1820.8 .80 p.

11016* Weber, Johann Karl. Alpeupflanzen Deutschlands und der Schweiz in coloritten Abbildungen nach der Natur (?) und in natirlicher Grösse. Alumchen, (bei Christian Kaiser.) 1845. 12.96 tab. col., 10 p. ind. $(6$ th. $)$

11017 Weddell. British lotany: or coloured figures of the plants nacive of Great Britain. London 4831. Nr. I. 8 p., 2 tab. (2s. $6 d$.)

11048 Wedel, Christian. Centuria thesium de theriaca. Jenae 1700. 4. Rivin.

$11019^{*}$ Wedel, Geory Wolfgang. Opiologia. Jenae 1674. 4. 170 p. Jenae 1682.4 . 170 p., ind. B.

(Amno 1667 Jenae dissertationem inauguralem de Opio proposuerat lledelius.

11020 Tabulae synopticae de compositione medicamentorum extemporanea, ad praxin clinicam et usum hodiernum acconımodatae. Jenae, typ. Krelss. 1677. folio. Rivin.

$11021^{*}$ _ Pharmacia in altis formam redacta, experimentis, observationilus et discursu perpetuo illustrata. Jenae, typ. Krebs. 4677. 4. 245 P., praef, iod., effigies Georg Wolfgung Wedet. Ed. II: Jenae 1693. 4, Rivin.

$11022^{*}$ De medicamentorum facultatibus cognoscendis et applicandis libri duo. Jenae 1678. 4.

11023 - De medicamentorum compositione extemporanea a1 praxill clinicam et usum hodiernum accommodata liber, tribus sectionibus distinctus. Jenne, typ. Krebs. 1678. 4. - Ed. Il: Jenae, typ. viluae Krebs. 1693. 4. Rivin.

1102:* _ Experimentum chimicum novum sle sale volatili plantarum, quo demonstratur, posse ex plantis modo peculiari parari sal volatile verum et genuinum. Jenae, typ. Krebs.1682. 42. 96 p., praef., ind.

(Supplementum libeli codem prodiit anno.)

11025 Amoenitates materiae medicae. Jenae 1684.4.512 p. B.

11026 Pharmacia acroantatica. Jenae 1686.4. Rivin.

11027 Centuriae (duae) exercitationom medico-philolugicarum sacrarum et profanarum, varias lectiones, experimenta et commentarios euriosos exhibens. Jenae 1701-1720. 4. Rivin.

(Sunt programmata mox dicenda collecta, arjectis aliis, uumero 130.$)$

$11028^{*}$ Theoria saporum medica. Jenae 1703.4.

$11029^{*}$ Experimentum curiosum de Colchico veneno et alexipharmaco, simpliei et composito. Jenae $1718.4 .20 \mathrm{P}$.

11030 Syllabus materiae medicae selectioris. Jenao 1735. 4. H.

Propemtica s. programmata, autore Georg Holfgang IVedel.

11031* _... De Amello V"irgilii. Jenae 1686. 4. (8) p.

11032 De usu Cucumerum innoxio. Jenae 1686. 4. Rivin. 
$11033^{4}$ Wedel, Georg IVolfyang. De Hyperico mystico. Junae 1686.4. (8) p.

11034. Do unguento nardino. Jenae 1687.4. H.

$11035^{*}$ De Tetragono Ilippacratis. Jenac 1688. 4. (8) p.

$11036^{*}$ (1tme Aril, Indico, Gilasto. Jenae 1689.4. (8) p.

(Indicum et Gilistum ejusdeun esse originis perperan credit.)

$11037^{*}$ We horhis germanis Ovidii. Jenac 1689.4 . (8) p.

$11038^{*}$ - De sinapi seripturac. Jenae 1690.4. (8) 1.

$11039^{*}$ - De morbo et herba solstitiali. Jenae 1690.4. (8) 1).

1104.0 De Nectare et Ambrosia. Jenac 1694. 4. Rivin.

$11041^{*}$ - De Nepenthe Ilomeri. Jenae 1692.4.(8) p.

1104.2* - Je radice amara IIomeri. Jenae 1692.4. (8) p.

$11043-$ De Hyssopo. ]-IIl. Jenae 1692.4. H.

1104 - Do Maza (Zea Mays?) Jenac 1693, 4. н.

11043 - Do ligno Aloes. Jenao 1693.4. H.

$11046^{*}-$ De Faecula Coa. Jenae 1693. 4. (8) p.

$14047^{*}$ Do Corchoro Theopthrasti in senere. Jenae 1695. 4

(8) p.

$11048^{*}$ - De Corchoro Theophrasti in specie. Jenac 1695.4. (8) p.

$11069^{*}$ De corona Christi spinea. 1. Jenae 1696. 4. (8) p.

11050 De ramn aureo l'írgilii. Jenac 1699. 4. Rivin.

11031 De Lilia agri. Jenae 1700.4. H.

$11082^{*}$ De Cirsio Dioscaridis. Jenae 1700.4. (8) p.

$14033^{*}$ — De resina aegyptăa Plauti. Jenae 4700.4 . (8) p.

$11054^{*}$ De bubo veterum. Jente $1701.4 .(8)$ p.

11085 De pane Dyrrhachinn Julii Caesaris. Jenae 1701. 4.

Rivin.

11056 De Theriaca coelesti. Jenae 1703.4. Rivin.

$11057^{*}$ De Purpura et Bysso. Jenae 1706. 4. (8) p.

$11058^{*}$ De lignis thyinis Apocalypseos in genere, Jenac 1707. 4. (8) p.

$11059 *$ De Sahina scriplurae. Jenae 1707.4. (s) p.

$11060^{*}$ De Thyo Homeri. Jenae 1707.4. (8) p.

$11061^{*}$ De mensis citreis. Jenae 1707.4.(8)

$11062^{*}$ - De Rhabarbari origine. Jenae 1708.4 . (8) p

$11063^{*}$ De Rhabarbari genere, differentiis et virlute. Jenae

1708.4.(8) p.

$11054^{*}$ De Theseo Theophrasi Eresii. Jenae 1708.4. 12 1.

$11065^{*}$ De Calamo aromatico. Jenae 1708. 4.

$11066^{*}$ De Oenanthe Theaphrasti Eresii. Jenae 4710.4. (8) p.

$11067^{*}$ — De Lilio convallium Salomonis. Jenae 1710.4.12 p.

$11068^{*}$ De Moly Ilomeri in genere. Jenae 1713.4.(8) p.

$11069^{*}$ - De Mloly Homeri in specie. Jenae 1713.4. (8) p.

$11070^{*}$ De mythologia Noly Homeri. Jenae 1713.4. 8 p.

$11071^{*} \longrightarrow$ De Zvtho scripturae. Jenae 1713.4.12 p.

$11072 *$ De Holoconitide Ilippocrutis. I - Il. Jenae 1715. 4. (16) p.

Disserlaliones praeside Georg IVolfgang Wedel:

$11073^{*}$ — De Gialapa, D. Jenae 1678. 4. 40 p. (Respondens: Jahum Ulrich Schmid.) - Jenae 1715.4. Rivin.

$11071^{*}$-.. De Camphora. D. Jenae 1697.4.36 p. (Respondens: Jahann Adolph Wedel.)

$11073^{*}$ De Terelinthina. D. Jenae 1700.4

$11076^{*}$ De Aro. D. Jenac 1701.4. 36 p. (Respondens: Christophl Elias Schelhass.)

$11077^{*}$ - De Mlusco terrestri clavato. D. Jenae 1702. $4.44 \mathrm{p}$. (Respondens: Meno Nicolans IIannelien.)

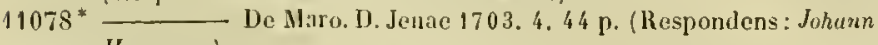
Hermann.)

$11079^{*}-$ De precacuanha americana et germanica. D. Jenae 1705. 4.44 p. (Respondens: Jahann Lorenz Leincker.)

$11080^{*}$ De Cubebis. D. Jenae 1705.4.39 p. (Respondens: Ilermann Friedrich Teichneyer.)

11081* —_ De Sabina. D. Jenac 4707. 4. 36 p. (Respondens: Jahann Friedrich Krausold.)

$11082^{*}-$ Do Cinnanıomo. D. Jenae 1707. 4. 36 p., 1 Lab. (Respondens: Geory Christian Titias.)

11083 De Thea. D. Jenae 1707.4. н

11084 - De Serpentaria virginiana. D. Jenae 1710. 4. 39 p. (Respondens: Chrstaph Ludeig Goechelius.)

(Redit in V'alentini llistoria simplicium p. 579-591.)
Wedel, Geory Wolfgang. De Contrayerva. D. Jenae 1712. 4. 40 p. (Respondens: Joham I'eter Doellinus.)

$11086^{*}$ De Ilantagine. D. Jenac 1712.4.36 p. (Respondens Nicolaus Chiliani.)

$14087^{*}$ Je Centaurio minori. D. Jenae 1713.4. 40 p. (Respondens: Nicolans Chiliani.)

11088* De Salvia. D. Jenae 1715. 4. 40 p. (Respondens: Brojumin II"eissheil.)

$11089^{*}$ We Cuscuta. D. Jenae 1715. 4. 117 1]. (Respondens: Johann Adolph Bilhard.)

$11090^{*}$ De Hyoseyamo. D. Jenae 1715.4.64 p. (Respondeus: Johann Withelm Eclihard.)

$11091^{*}$ De Ilyperico, aliis Fuga Dacmonum. D. Jenae 1716.4. 51 l. (Respondens: Fredrich Houch.)

$11092^{*}$ De Viola martia purpurea. D. Jenae 1717. 4. 36 p. (Respondens: Johann Audreus Benedilit Gratel.)

$11093^{*}$ De Glycyrrliza. D. Jenac 1717.4. 34 [., 4 tab. (Respoudens: Johann Andreess Schmid.)

1109:." DeAllio. I). Jenae 1718, 4.28 p. (Respontens: Sanut Emhard.)

(1)mnia haec programmata atgue dissertationes $n$ lypographia lirebsiana prodierunt.

$1109 \ddot{b}^{*} \longrightarrow$ De Sambuco. J). Jenae, (vp. Ritter. 1720.4. $40 \mathrm{p}$ (Respondens: Friedrich August Treise.)

$11096^{*}$ — De Polypodio. D. Jenae, typ. Ritler. 1721. 4. $22 \mathrm{p}$. (Respondens: Karl Friedrich Laev.)

$11097^{*}$ Wedel, Johann Alolph, pr. De Scordio. D. Jenae, typ. Krebs. 1746. 4. 32 p. (Respondens: 11"alral ll'igand.)

$11098^{*} \longrightarrow$, pr. De Calamo aromatico. D. Jenac, typ. Krelss. 1718 4. 24 p. (Respondens: Larenz Beriken.)

$11099^{*}-\mathrm{pr}$. De Helenio. D. Jenae 1719.4.16 p. (Respondens: Johann Friedrich Beck.)

$11100^{*}-, \mathrm{pr}$. De Vincetoxico. D. Jenae, typ. Ritter. 1720. 4. 20 p. (Respondens: Gearg Christoph Wolff.)

$11101^{*}-$ pr. De Verhena. D. Jenae, typ. Ritter. 1721.4. 18 p. (Respondens: Samuel Arnold.)

$11102^{*}$ - pr. De Fungis. D. Jenae, Iyp. Ritter. 1744. 4. 34 p. (Respondens: Erdmann Christian Seyffert.)

(III libliotheca Banhsiania adest exemplum in folio impressum, cui annexae sunt: lcones Fungorum, quas ad vivum colorihus delineavit Parens noster carissimus lleinricus Christophorus Seyffertus, Med. Lic, el Phys. Poosneccensis. Poesneccae 17th. folio. 133 foll.)

$11103^{*}$ Wedel, Johann IIolfgang. Tentamen botanicum flores plantarum in classes, genera superiora et inferiora per characteres ex ipsis floribus desumtos dividendo, cognitioni nominis generi infimo ad quod planta pertinet competentis inserviens. Praefationem addidit Gearg Ehrhard IInmberger. Jenae, Ritter. 1747. 4. xxvin, 90 p. ind. - ${ }^{*}$ Ed. II. alucta et emendata. Jenac, Ritter. 1749. 4. xxym $116 \mathrm{p} .$, ind.

1110:* - Sendschreiben an seines Ilerra Vellors des Herm llofrath IItler in Gottingen Wolılgeboren wegen der in denen Gottingischen gelehrten Zeitungen vom 11. Martii im 27 . Stuck befindlichen Beurtheilung seines Tentaminis botanici sowohl als der IIamberger'schen Vorrede. Jena, Ritter. 1748. 4. 16 p.

(Cf. vocem llamberger, Thes. lit. bol. Nr. $4093-309 \%$. - Hall. Bibl. bot. 11. p. 371-372.

11103* Wegelin, Theodor. Enumeratio stirpium Florae belveticae secundum ordines naturales disposita. Dissertatio inauguralis. Turici. typ. Orell, Fussli el soc. 4838.8 . vin, $82 \mathrm{p} .(3 / 8 \mathrm{lh}$. $)$

$11106^{*}$ Wehmann, Achalz Friedrich. Ilortus Caspar Bosianus, oder richtiges Verzeichniss aller, sowohl fremder als einheimischer Gewáchse, Biume, Stauten, Krauter und Blumen, welche in Tit. Ilern Caspar Bosens, Vornchmen des Raths und weitheriihmten Ilandelsheren allhier in Leipzig, Garten vor deu Grimmischen Thore bestándig unterhalten werden und zu finden sind. (Leipzig) 1723. 8. (84) J., 4 tal).

$11107^{*}$ Weigel, Chrislian Ehrenfried. Flora Pomerano-Rugica, exhibens plantas per Pomeraniam anteriorem suecicam et Rugiani sponte nascentes, methodo Limneana secundum systema sexuale digestas, cum differentiis specificis, nominibus germanicis, officinalibus pharmacopoeorun, locis natalibus, tempore florendi, obscuriorum deseriptionibus. Berolini. Stralsundiac et Lipsiac, apud 
Gottl. Aug. Lange. 1769. 8. 222 j., praef, ind. - Supplementum : Gryphiae 1773.8. Desid. Banks.

$11108^{*}$ Weigel, Chrislian Ehrenfried. Observationes botanicae. D. Gryphiswaldiae, typ. Rose. 1772. 4. 51, (10) p., 3 tab. (Respondens: Moritz Ulrich W'illich.)

dunice: Bolaniske observationer. Plıysiogr. Sulskap. Ilandt. I. p. $\{2-5 \mathrm{sic}$.

$11109^{*}$ Einladungsschrift vom Nutzen der Botanik. Greifswald 1773. 4. $15 \mathrm{p}$.

$11110^{*}$ (- - Index seminum et plantarum horti Gryplici systomaticus. Gryphiae, typ. Röse. 1773. 8. 20 p.

$11111^{*}$ Dissertatio academiea, sistens hortum Gryphicum. Gryphiae, typ. Röse. 1782 . 4. 36 p. (Respendens: Laur. Timon Grönberg.)

$11112^{*}$ Dissertationem Clus Fredric Itornstedt do fructibus Javac esculentis indicit, sinulgue de oleis Camphorne quaedam disserit. Gryphiae, typ. Böse. 1786. 4. 22, 31 p.

11113 WeigeI, Johann Adam Valenlin. Sehtesischer Planzenkalender, oder Verzeichniss der in Schlesien wildwachsenden Pflanzen, wie sie in jedein Ilonate bhuen. 4791. 8. Wimmer.

1111 : $^{*}$ _ Geographiseh - 11aturhistorische Beschreibung des Herzogthumes Schlesien. Berlin 1800-1806. 10 Bde. 4. (6 /h. $)$

$11113^{*}$ Weihe, Karl. De Umbelliferis officinalibus. D. Lemgoviae, Meyer. $1817.8 .30 \mathrm{p}$.

$11116^{*}$ Weihe, Karl Ernsl August. De nectariis. D. Halae, typ. Bath. $1802.8 .44 \mathrm{p}$.

$11117^{*} \longrightarrow$ et Chrislian Gattried Nees von Esenbeck. Rubi germanici descripti et figuris illustrati. Beschreibung der deutschen Brombee rstráucher. Bonnae, sumtibus autorum. 1822. (Elberfeldae, Schon. 1822-1827.) folio. 116 p., 60 tab. pro parte col. (20 lh.)

(Prodit decem fasciculis. Textus germanicus seorsim: $130 \mathrm{p}$.)

$111.18^{*}$ Weinlig, Albert. Die Pflanzenchemie, ein Handbuclı fur Aerzte und Apotheker. Unter theilweiser Zugrundelegung vou Thamson's Organic ehemistry, unt nit Benutzung der besten Quel]en. Leipzig, Vogel. $1839.8 . x \mathrm{~W}, 833$ p. $(4 \mathrm{th}$. $)$

$11149 \div$ (Weinmann, J. A.) Del botanische Garten der Koiserliclıen Universitát zu Derpat im Jahre 1810. Dorpat, typ. Grenzius. 1810.8 . xvit, $168 \mathrm{p}$.

(Pag. 1- 168 inscrilitur : Enumeratio plantarum ordine alphabetico, quae in horto botanien borpatensi anmo 1810 viguerunt. tsupplementum 1. Enunerationis, auclore Karl Friedrich Ledebaur. isil.8.5 p.)

$11120^{\circ}$ - Elenchus plantarum horti imperialis Pawlowskiensis et agri Petropolitan. Petropoli, typ. orphanotrophei. 1824. 8. $\mathrm{xx}$ VII, $472 \mathrm{p}$.

$1112 i^{*}-$ Hymeno - et Gasteromycetes hucusque in imperin rossico observatos recensuit. Pars prodromi Florae rossicae. Petropoli, Acad scient. 1836.8 .676 , xxxvit p. (3 th. $)$

(Enumeratio Gasteromyeetum genumorum hucossue in imperio ruthenteo obscrvaturum; Linnaer, vol. I. p. 103-46.)

$11122^{*}$ Enumeratio stirpiun in agro Petropolitano sponte erescentium secundum systena sexuale Linneanum compusita. Petropoli $4837.8 .320 \mathrm{p}$

$11123^{*}$ Weinmann, Johamn Georg. Tractatus botanieo-criticus de Chara Cuesaris, cujus libr. Ill. de bello civ. c. XLVIIl meminit. Praenittitur laus Caesaris. Carolsruhae, Machlot. 1769.8.76 p.

(Ejus dissertationem inauguralen de plantis patriae urbis Reutlingen vide supra Nir. 371:3.)

1112 4* Weinmann, Johann llilhelm. Phytauthozaiconographia, sive Conspectus aliquet millium tam indigenarum tan exoticarum ex quatuor mundi partibus longe annorum serie indefessoquo studio a Johanne Guilielma Weinmanna, Dicast. Ratisb. Ass. et Pharmac. sen. collectarum plantarum, arloorun, fruticum, florum, fructuum, fungorun etc. quae'nitidissime aeri incisae et simul diu desiderata ac recens inventa arte vivis coloribus et iconibus naturae aemulis excusae et repraesentatae per Burt. Senterum, Joh. Eliam Ridingerum et Joh. Jac. Huidium, pietores et chalcographos, quorum desoninationes etc. làtino et germanico idiomate sincere explicautur a Johann Georg Nicolaus Dieterichs (tom. I. II.) et Ambrosius Karl Bieler (t. III. IV.) Eigentliche Vorstellung etlicher tausend von
J. W. Weinmann gesammelter Pflanzen, welche in kupfer gesteehen, und durch eine neu erfundne Art ele. Ratisbonae, per H. Lenzium. 1737 - 1745. IV voll. folio. - I: 1737. A-R, 200 p., tab. col. 1-275. - Il: 1739. C-F. 516 p., tals. col. 276-525. - Ill : 1742. G-0.488 p., tab. col.526-775. - IV: $1745.540 \mathrm{p}$., tab. col. $376-1025$, prael. Halleri, ind. (llall. Bils. bot. vol. II. p. 278.)

t hallandice: Tualryk Register der plaat- ofte figulur-beschryvingen der hloemdragende sew asseru, door den lleer Jaham bitlelun Heinmann ete Nu in het nederduitsch door een woornaam

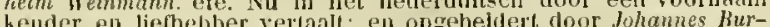

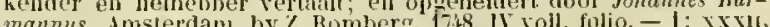
manns. Amsterdam, by 2. Romberg.

11120 Weinmann, Joham Wilhelm. Hodesta excusatio errorum botanicorum. s. a. folio. Desid. Banks.

$11126^{*}$ Weinrich, Georg Alberl. Dissertatio inauguralis de Haematoxylu Campechiano. Erlangae 1780.4.38

(Schlegel Thes. mat. med. 11. p. 157-220.)

$11127^{*}$ Weise, Johann Christoph Golllob. Encyclopädisches Gastenworterbuch. ete. Erfurt und Gotha, Itenuings. 1830 . 8. xxxu, $626 \mathrm{p}$., 12 tab. ( 2 th.

11128 Der vollkommene Melonen-Gurken- und Spargelgätuer. Ilmenaı $4830.8 .\left(1 / 3 l_{l}.\right)$

$11129^{*}$ Deutschlands Pfanzenblutekalender, orler monatliches Verzeichniss aller in Deutschland wildwachsenden bis 1828 hekaunten Phanerogamen, mit Angabe der Standörter und genauen Kennzeiehen. Gutha und Erfurt, Hennings. 1831-1832.2 Bande. 8. $\mathrm{x}, 447,332,7 \mathrm{~s}$ p. $(3 \mathrm{th}$. $)$

$11130^{*}$ Weiss, Friedrich Jilhelm. Plantae cryptogamicae Florae Gottingensis. Gottingae, Vandentoeek. 4770. 8. xu, 333 p., 1 tab. col.

Nomen autors melius seribitur lieiss, licet in fronte liujus libri legatur lieis.)

11131 Betrachtung uber die nutzbare Einrichtung akatemiselıer Vorlesungen in der Botanik, nebst Anzeige seiner Vorlesungen im Winter 1774. Gottingen (1774.) 4. vil 1). B.

11132 Entwurf einer Forstbotanik. Erster Band. Göttingen 1775. 8.358 p., 8 tab. B.

$11133+$ Weiss, Johann Christoph. De Malo Punica. D. Altorfi 1712. 4. 28 p.

(Valentini Hist. simpliciun p. 652-660. - Autor est Praeses Johann Jakab Baier.)

$11134^{*}$ Weiss, Simon. Dissertatio physica de excrescentiis plantarum animatis. Lipsiae, typ. Fleischer. 4694. 4. (24) p.

$11135^{*}$ Weissmantel, Johann Nicolaus, sonst Schneider. Des Blumisten erster Theil, io welchem die Nelke orler Grasblume, 1) ihre Wartung und Behandlung durehs ganze Jalır, 2) die Schönheitsregelı derselben, 3) Beschreibung einiger vorzüglichen Nelken, deutlich und vollständig abgehandelt werden. Leipzig, Bühne. 1779. 8. 468 p., ind. $(5 / 5 t h$.) - Des Blumisten zweiter Theil, enthalt die Aurikel. Ërfurt 1783. $8 .\left(1 \frac{1}{6}\right.$ th. $)$

$11136^{*}$ Weitenweber, Iilhelm Mudolph. Der arabische Kalfee in naturhistorischer, diattetischer und medizinischer Ilinsicht geschildert. Prag, typ. Thabor. $1835.8 .130 \mathrm{p}$.

(Literatura Corfeas, p. 9-1k.)

11137 (Weizenbeck, Georg Anton.) Botanische Unterhaltungen mit jungen lireunden der Kráuterkunde auf Spaziergangen. Zwöl Stück. München (Fleisehmann.) 1784. S. (1 $1 / 3 / h$.)

$11138 \longrightarrow$ Limne's vollstandiges deutsches Pflanzensystem in tabellarische Form gebracht. Erstes (und einzigges) Heft. Junchen, Strobl. $1785.8 .(1 / 3 / h$.

$11139 t$ Anzeige der meisten um München wildwachsenden oder allgemein gebauten Pflanzen, mit ihren kennzeichen in tabellarisclier Form. Ein Anhang zu den botanischen Unterhaltungen des zweiten Jahrganges. München, Surobl. 1786. 8. 159 \%. $(1 / 3$ th. $)$

$11140^{*}$ WeIden, Ludwig, Freiherr von. Der Monte Rosa. Eine topographische und naturhistorische Skizze. Wien, Gerold. 1824. \&. vili, 166 p., 8 tab. $(2 / h$.)

$11141^{*}$ Well, Joharn Jakol von. Kurz verfassete Gründe zur PllanzenJehre, als ein zur Naturgesehichte unumgangliclı nòthiger Theil. Wien, 1yp. Grund. 4785. 8. 236 p., praef., ind. 
$1142^{*}$ (Welling, Christian Friedrieh von.) Allgemeine historisch-physiologische Naturgeschichte der Gowiclse, den Lieblıaberu des l'flanzenbaues gewidmet vou Chr. Fr. v. IV**. Gotha, Ettinger. 1794. 8. 332 p., pracf, ird., 36 tab. col.

$11143^{*}$ Welsch, Christian Ludwiy. Basis botanica, sive brevis ad rem herbarian manuductio, omnes plantirum partes, una cum earundem virtutibus secundum novissimorum batanicorum fundamenta generali quadam methodo demonstrans; cum ooomastico plantarum in climate Lipsiensi crescentium. Lipsiae, IIeybey. 1697. 12. $228 \mathrm{p}$.

11144* Welwitsch, Friedrich. Synopsis Nostochinearum Austriae inferioris. Eine systematische Aufzáblung der Gallert-Tange des Erzherzogthums Oestreich unter der Ens mit nabrer Bezeichnung ihres Vorkommens und ilsrer Fundorte. Wien 1\$36.8. $30 \mathrm{p}$.

(Ejus "Beitráge zur hryptegamischen Flura Unteróstreich's " impressa suat in Beiträge zur Landeskunde Oestreich's, Band iv. impressa suat in

11145 Wenderoth, Georg IVilhclm Frans. Dissertatio inauguralis medica, sistens Materiae pharmaceuticac hassiacae specimen. Marburgi, Krieger. $1802.8 .(1 / \mathrm{t} / \mathrm{h}$.

11146 - Celer das Studium der Botanik. Finige Worte an seine akademischen Mitburger zur Berichtigung seiner angekundigten im Sommer $1805 \mathrm{zu}$ haltendon Vorlesungen uber medizinische Botanik. Mlarburg 1805. S.

11147 - Index plantarum horti Marburgensis. Marburgi 4807.8.

$111: 8^{*}$ Lehrbuch der Botanik zu Vorlesungen und zum Selbststudium. Marburg, Kirieger. 1821 . 8. xv1, 590 p. (3 th.)

$11149 \div-$ Beiträge zur Flora von llessen. Marburg I\$23. S. $39 \mathrm{p}$.

(Seorsim impr. ex Marburger Schriften, Band I. Nr. 6.)

$11150^{*}$ Einige Bemerkungen uber verscliedne neue Pflanzenarten des botanischen Gartens in Marburg, nebst einer Abliildung der Polygala depressa Wender. Narburg u. Cassel, Krieger. 1831.8 .59 p., 1 tab. col. $(1 / 3$ th.

(Seorsim impr. ex Marburger Schriften, Band II, Heft 6. )

$11131^{*}$ Bemerkungen uber wichtige einheimische Arzneipflanzen nebst Vorschlagen in Betrelf derselben. (Akonitarzneien.) Kassel, Krieger. 1837.12 .23 P. $(1 / 6 t /$.

$11152^{*}$ —_ Versuch einer Charakteristik der Vegetation von Kurhessen. Als Einleitung in dic Flora dieses Landes. Nebst 2 Probebogen: einer der Flora hassiaca, und einer der Flora Marburgensis. Kassel, Krieger. 1839. S. xı, 155, 16, 16 p., 3 tab. $\left(1 \frac{1}{4}\right.$ lh. $)$

Schriften der Gesellschaft zur Beforderung der Nalurw. zu Marburg. Band W.')

$11153^{*}$ - Flora hassiaca, ader systematisches Verzeichniss aller bis jetzt in Kurhessen uad (hinsichtlich der selueren) in den nachst angrenzenden Gegenden des Grossherzogthums llessenDarmstadt beobachteten Pflanzen, entlualtend die offen blubenden Gewächse. Cassel, Fischer. 1846. 8. xxvin, 402 p. $\left(1 \frac{1}{2} / /\right.$. $)$

1113 q $^{*}$ Wendland, Ileimrich Ludolph. Commentatio de Acaciis aphyllis. Ilannoverae, Jlahn. 1820.4 . xil, 55 p., 14 tab. (2 $1 / 4$ th.)

$11153^{*}$ Wendland, Johanu Christoph. Jortus Herrenhusanus, seu plantae rariores, quae in horto regio Jlerrenhusano prope Itannoveram coluntur. Fasc. I-IV. Ilannoverae, Hahn. 1789-1801. folio. 16, $8, S$ p., 24 tab. col., et elelinoatio borti col. (10 th. - herabgesetzt: $5(h$.

$11156^{*}$ (welche sich auf dem Königlichen Berggarten zu Herrenhausen bei Ilannover befinden. Hannover, typ. Pockwitz. 1797. S. 79, 38 p.

$11157^{*}-$ Botanisclıe Beobachtungen, nebst einigen neuen Gattungen und Arten. Ilannorer, Jlahn. 1798. folio. 58 p., 4 tab. col. $(3 / 4$ th. $)$

$11138^{*} \longrightarrow$ Ericarum icones et descriptiones. Abbildung und Beschreihung der Heiden. Fase. I-XXVIl. Hannover, Hahn. 1798 -1823.4 . (180), 190, 34 p., 162 tab. col. $\left(37 \frac{5}{6}\right.$ th. $)$

$111599^{*} \longrightarrow$ Collectio plantarum tam exoticarum quam indigenarum cum delineatione, descriptione, culturaque earum. Sammlung ausländischer und einheimischer P'lanzen, mit ihrer Abbildung, Beschreibung und Kultur. IJannover, Hahn. 1808-1819.
Ill voll. 4. vil, 98, 82, 24 [., 84 tal). col. (28 th. - herabgesetzt: $18 \mathrm{th}$.

11160 Wendt, Georg Friedrich hiarl. Deutschlands Haumzuclı, ader Verzeichniss der Holzarten, welche das Klima von Deutschland im Freien aushalten, nelost Ingabe ihrer Gröse, des erforulerlichen llodens, Standes, der Blutezeil, lieife und.Iustauer. Eisenach. Wittekindt. 1804. 4. 72 p. $(1 / 2$ th. $)$

$11161^{*}$ Wendt, Johanu. Dic Thermen zu Warmlsunn in schlesischen liesengebirge. Breslau, Gosohersky, 1540.8, xvı, 320 p., 1 tab. $\left(1 \frac{1}{2}\right.$ th.

(Inest a p. \& k-11: Znr Flora Warmlnetans und seiner Umgebungen, von Christian Gollfried Xees ton Esenbeck, mit rallstadiger

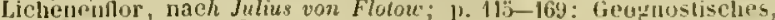
von Heinrich Robert Goepperl.)

$11162 *$ D Die eisenhaltigen Quellen zu Altwasser in Schlesien. Breslau, llirt. 1841. 8. 16 plag., 10 tab. $(1 \mathrm{th}$.

(Plantas rariores ditionis indicavit ill. Goeppert.)

11163 Wennström, Johan Pehr. Ilandbok i blonsterkulturen fur liruntimmer. Stockholm, typ. Norstedt. 1831. 8. vil, 298 p. (2 lidr.)

1116łt Wenzel, T.J. Hémoire présenté a l'assemblèe nationale, en faveur te l'établissement d'une manufacture de régétaux artificiels. (Paris, typ. Jontard.) 1790.4. 16 p. Bibl. Juss.

$11165+$ L'art d'imiter les végétaux, conformément aux modèles exposés dans l'un des portiques du Palais national des sciences et des arts, d'après les nouveaux procédés, inventiuns ct découvertes de $T . J$. Wenzel, fleuriste, bréveté par la reine en 1785 . Cours pratique et complet en vingt-cinq lecons. Paris, typ. Gille. 1802. 8.20 p. Babl. Juss.

$11166^{*}$ Wenzlaff, Franz. De lefoliatione plantarum. D. Berolini, typ. Schlesinger. $1844.8 .49 \mathrm{p}$.

$11167^{*}$ Wepfer, Johann Jakol. Cicutae aquaticae historia et nosae, commentario illustrata. Basileae, Konig. 1679.4 .336 p., praef., ind., 4 tat. - Adjectae sunt Dissertationes de Thee helvetico ac Cymbalaria. curante Theodor Zwinger. Basileae, ex officina Episcopiana. 1716. 4. 336 p., praef, ind., 4 tab. - ${ }^{*}$ Lugduni Batavorun, Potuliet. 1733.8 .422 p., praef, ind., 4 tab.

(Theodori Kungeri Dissertationes de Thee helvetico ac CymbitJaria, 1). 423-i81.)

11168 t Werneck, Ludwig Friedrich Frans, Freiherr von. Anleitung zur gemeimutzlichen Kenntniss der Jjalzpflanzen. Franhfurt a/M Jager. 1791.8. xvI, $316 \mathrm{p} .\left(1 / h_{\text {. }}\right)$

$11169 t-$ Versuch einer Pflanzenpathologie und Therapie. Ein Beitrag zur hobern Forstwissenschaft. Mannheim und Ileidelberı, Schwan und Gotz. 1807.8 .60 p. $(1 / 2$ th. $)$

11170 Anleitung zur Ahornzucht, mit besoudrer Benutzung ihrer Safte auf Zucker, nebst einer Widerlegung der Ahornzuckererzeugung in gemússigten Gegenden des europáischen Continents. Cassel und Marburg, Kirieger. 1814.8. ( $2 / 3$ th.

$11171^{*}$ Wernekinck, Franz. Icones plantarum sponte nascentum in Episcopatu Monasteriensi, additis dillerentiis specificis, synouymis et locis natalibus. Vol. l. continens tab. 1-100. Monasterii, typ. Aschendorf. 1798, follio, 12 p.

(Est explicatio 100 tabularum, qua numpuam prodierunt.)

$11172^{*}$ Werner, Alexamder. De herl,a Rubi Chanaemori. D. Vilnae. typ. Zawadiski. 1815.8.24 p.

$11173^{*}$ Werner, Ludwig Reinhold von. De scriptoribus historiam plantarum borussicarum illustrantibus disserit. etc. Custrini 1756. 4. $16 \mathrm{p}$.

$1117\}^{*}$ Wernischeck, Jatiob. Gencra plantarum ad facilius consequendan earum notitiam secundum numernm laciniarum curollae disposita. Vindobonae, typ. Kaliwoda. 1763.8.430 p., ind. - "Vindobonac, typ. Tratmern. 1764. $8.430 \mathrm{p}$, ind.

11173 Wernsdorf, J. C. Ilemoria J. Laurentii Heisteri. JJelmstadii 1758.4. $11176^{*}$ Wertmueller, Karl Heinrich. De Catechu. D. Goetlingae 1759. $4.52 \mathrm{p}$.

(J. L. Murray Opusc. vol. 11. p. 77-138.)

11177 Wessén, Carl Johan. Plantae cotyledoneae in paroecia Osthogothiae Kámit, quas securdum methodum naturalem celeberr. Friesii disposuit atque congessit. Upsalifé, Lefler et Sebell. (Lipsiae, Voss.) 1838. S. Iv. 62 p., (4) p. index. $(2 / 3$ th.) w. 
11178 West, H. Bidrag til beskrivelse over Ste Croix, med en kort udsigt over St. Thomas, St. Jean, Tortela, Spanishtown og Crabeneiland. Kiobenhavn 1793, 8. 363 p. B.

(Cap. II: Om Landets produeter, p. 259-336, uhi insularum st. Croix et Thomas Flora exponitur. Vidi exemplar notis inanuscriptis ab ill. Puerari auctum in bibliotheca Candolleana.

11179 Westbeck, Gustaf. Underrättelse om tvănne slags Svensk bomull. Andra uplagan Stockholm 1744.4.20 p. B.

11480 Ytterligare underrâttelse om en påfunnen tvănne slags bomull, samt om laf - och tráde-måssa, och dess nytta. Stockholm 1745. 4.44 p. B.

1118. Westenberg, Ernst Wilhelm. Viridarii academiae Ducatus Gelriae et Comitatus Zutphaniae, quod est Harderoviei, herbarum ac usualium plantarum eatalogus. Ilardereviei 1709.12 .65 p. B.

$11182+$ Westmacott, William. Theobotanulugia, sive historia vegetabilium sacra: or, a scripture herbal; wherein all the trees, shrubs, herbs, plants, flowers, fruits etc. London, Salisbury. 1694. 12. 232 p., praef., ind.

11183 Weston, Richard. Botanieus universalis et hortulanus: exhibens descriptiones specierum et varietatum arborum, fruticum, herbarum, florum et fructuum tam indigenorum quam exoticorum, per totum orbem, seu cultiv(at)orum in hortis et viridariis europaeis sive descriptorum botanicis hodiernis. Secundum systema sexuale magni Linnaei digestorum, cum nominibus anglice redditis. (The Universal betanist and Nurseryman ete.) Londini, Bell. 17701777. IV voll. 8. $-1: 1770$. Catalogus arborum et fruticum secundum ordinem alphabeti. $x v, 360$ p. $-11: 1771$. xn11, $384 \mathrm{p}$ - 1II: 1772. Jerbae secundum ordinem alphabeti. p. $385-748$. - IV: 1777. Cryptogamian, 95 p. Catalugue of flowers and their prices p. 51-128. Catalugue of the most esteemed fruits, p. 129 -212. Catalogue of the principal botanical authors, p. XVII LXXX. Clurenulegical table of botanical author's (ex Adansonio), XXX p., 17 tab. ad explicationem systematis Linuaeani.

(Volumina ]-III annis 1777 novis litulis pro editione seeunda instructa sunt.

11184 The English Flora, or a catalogue of trees, shrubs, plants and fruits, natives as well as exoties, cultivated in the English nurseries, greenhouses and stoves. London 1775. 8. 259 p. B.

11185 The Supplement to the English Flora. London 1780. 8. 120 p. B.

$11186^{*}$ A catalogue of stove plants cultivated in England in 1775, and described in the English Flura. s. I. (1775.) gr. folio. 5 foll. Bibl. Goett.

$11187^{*}$ Westring, Johan Peter. Svenska Lafvarnas Farghistoria, eller sáttet att anvânda dem till färgning oel annan hushållsny'tta. Första bandet. (Haftet 1-7.) Stochluelm, Iryekt hes Carl Delén. 1805. 8. xv, 32, 292,23 p., 21 tab. col.

(Prodiit annis $1803-1809$ octo fasciculis, secundum IIikström XV, 339, vil p. et 2 t tab. cot, singulus pretio $2+$ skill. Beo.

* germanice: Schwedens vorzuglichste Farbetlechten treu nach der Natur aboebildet, nehst der chemischen Bearbeitung derselben, besonders iu Ruichsicbt auf Farberei. Aus dem Schwedischen ubersetzt von $F . D$. I). Ulrich. Norkoping u. Leupzig, bei F. D. D. Uirich. 1805. 8. xxI1, 23 p., 3 tab. col.

(Nihil praeter hume fasciculum prodiit.)

11188* Weyda, II. Der chinesische Thee in Bezug auf Naturgeschichto und Diätetik. Nach den neusten Quellen dargestellt. Wien, Kaulfuss Wittwe. 1844. 8. vi, 48 p., 1 tab. $(3 / 8$ th.

$11189^{*}$ (Whately, Thomas.) L'art de former des jardins modernes, ou l'art des jardins anglais; traduit de l'anglais (par Latapie), avec un discours préliminaire du traducteur, des notes, le plan et la deseription des jardins de Stowe. Paris, Jombert. 1771. 8. Lxiv, 404 p. ( 7 fr.)

$11190+$ Whistling, Christian Gottried. Dekonomische Pflanzenkunde fur Land und Ilauswirthe, Gártner, Kunstler etc. Leipzig, Richter und Gleditsch. 1805-1807. 4 Theile. 8. - 1: 1805. xvul, $478 \mathrm{p}$. - II: 1805. xvIII, 420 p. - III: 1806. sx, 619 p. - IV: 1807 . 473 p. $(7 \%$ th. $)$

11191 Whitaker, John. Notice of the Fucus natans. Lewes 1830. 12. 7 p., 1 tab.

11192 Whitaker, Tobias. Tractatus de sanguine uvae, ejusque natura et usu, diaetetice et pharmaceutice. Francofurti, Wolfgang Ifolfmann. 1655. 8. Rivin.

Prutzel, Thes. lit. bot.
11193 White. Essay on the indigenous grasses of Ireland. Dublin 1808. 8. $\mathrm{x} \times 1 \mathrm{x}, 156$ p., 2 tab. col. $\{5 s .6 d$.

11194 White, Francis J. Inaugural dissertation on the geography of plants. Ediuburgh, Maclachlan et Stewart. 1838. 8. x, 62 p.

11195 White, Gilbert. The natural histury and antiquities of Selborne, in the county of Southampton. Lenden 1789. 4.468 p., 9 tab. B. - Londen 1822. II vull. 8. - New edition, by Bennet. London 1836. 8. (18s.)

11196 A naturalists Calendar, and ubservations on various parts of nature. London 1795. 8. 170 p., 1 tab. B.

(Calendarium Florae of Selborne, llampshire: p. 1-53.)

11197 White, William. Observatiuns and experiments on the breadleaved willow bark. (Salix caprea.) Bath 1798. 8. 58 p. B.

$11198+$ Whitley, Brames and Milne. A catalogue of plants, trees etc. Fulham Niursery near London, s. a. 8.38 p.

11199 Wibel, August II ilhelm Eberhard Christoph. Dissertatio inauguralis, P'rimitiarum Florae Werthemensis sistens Prodromum. D. Jenae 1797.8. 40 p. B.

(Redit in libro sequenti p. 1-36.)

$11200^{*} \longrightarrow$ Primitiae Florae Werthemensis. Jenae, Goepferdt. 1799. 8. 372 p. $\left(1 \frac{1}{t}\right.$ th. $)$

$11201^{*}$ —_ Beitrăge zur Beförderung der Pflanzenkunde. Ersten Bandes erste Abtheilung. Frankfurt a/M., Guilhauman. 1800. 8. $x$, 116 p., 2 tab. $(1 / 2$ th. $)$

$11202^{*}$ Wichert. Beitrag zur Culturgeschichte Hispaniens, die Nachrichten der Alten über die physische und technische Cultur dieses Landes umfassend. (Programme des Kneiphofischen Stadt-Gymnasiums von 1845 und 1846.) Königsberg, typ. Dalkowski. 18451846. 4. 32,38 p.

11203 t Wickham, William. Memoranda respecting the culture of fig trees in the open air in England. (Fron the Herticultural Transactions.) London, typ. Bulmer. 1818. 4. 12 p.

1120 Widegren, Pehr David. Försök till en ny beskrifning af Österguthland. Baudet I. Linköping, typ. A. Petre, 1817.8. w.

(IIsunt sallisyntare víxter, vol. I. p. 24-31.)

$11205^{*}$ Widnmann, Friedrich. Catalogus systematicus secundum Linnaei systema vegetabilium adoruatus arborum, fruticum et plantarum celeberrimi horti Eystettensis. Edidit Dr. Widnmann. Norimbergae, ex officina Felsecheriana. 1805. 4.79 p.

t gallice: Catalogue des arbres, arbrisseaux el plantes, qui croissajent dans l'ancien jardin, qu'existait dans le XVI et XVII siècle a l'entour du chateau de l'evéché d'Eystett, rangés suivant te système de Linnaeus. (Dédio à l'jimpératrice Josephine.) Eystett 1806. 4. 80 p.

$11206^{*}$ Wied-Neuwied, Maximilian, Prinz zu. Reise nach Brasilien in den Jahren 1815-1817. Frankfurt a/M., Brömer. 1820-1821. 2 Theile. 8. - I : 1820. 376 p., I mappa geogr. - II : 1821. v1, 345 p. 1 mappa geogr. $\left(1^{3} / 4\right.$ th. $)$

(Est editio major duubus voluminibus quarta forma, cum th tahulis, pretio 39 th.

$11207^{*}$ - Reise in das innere Nord-Amerika in den Jahren 1832-1834 von Naximiliun, Prinz zu Wied. Mit 48 Kupferı 33 Vignetten, vielen Holzschnitten und einer Charte. Coblenz, Hoelscher. $1839-184$ 1. 2 Bäde. 4. - I: 1839. xvi, 653 p. II: $1841, \mathrm{xxIl}, 687$ p. $\left(63 \frac{1}{3}\right.$ th. $)$

(Plantas recensuit Christian Goltfried Nees ab Esenbeck in vol. Il. p. $429-15 i$.)

11208* Wiegmann, A. F. Ueber das Einsaugungsvermögen der Wurzeln. Marburg, Krieger. 1828.8. 18 p. (1/8 th.)

(Extraabdruck aus den Narhurger Schriftell, Band II. Ileft 1.)

$11209^{*}$ - Ueber die Bastarderzeugung im Planzenreiche. Eine von der Königl. Akademie der Wissenschaften zu Berlin gekronte Preisschrift. Braunsclwweig, Vieweg. 1828. 4. xu, 40 p., 1 tab. col. $(2 / 3$ th. $)$

$11210^{*}$ - Ueber die Eutstehung, Bildung und das Wesen des Terfes. Preisschrift. Braunschweig, Vieweg. 1837. gr. 8. vIII, 90 p. $(1 / 2$ th. $)$

$11211^{*}$ Die Krankheiten und krankhaften Missbildungen der Gewachse. Ein Handbuch fur Landwirthe, Gártner und Forstmanner. Brauuschweig, Vieweg. 1839.8. viII, 176 p., 1 tab. $\{3 / 4$ th. danice: Om Planternes Sygdomme, deres Aarsager, Helbredelse og Forebyggelse, og om nogle for Planterne shadelige Dyr og deres Udryddelse. En Haandbeg for Landmaend, Gartnere uch Forst- 
maend; oversat af Salomon Thomas Nicolai Drejer, udg. af lot $\mathrm{kgl}$. Landluusld-Selsk. Kjobenhas u 1839. 8. 20.3 P., 4 tab. (6k Shill.) hollandice: Over vo zlekteu eII enige uisvolmingen der gehollantice: Jver je zlekten en centipe wertaali donr E. C. Entlasr. Zwollo, bij W. E. J. Tjeenh Willink.

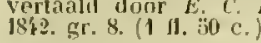

11212* Wiegmann, A. F., und L. Polstorff. Teber dic anorganisehen Bestandtheile der Pllanzen, oller Beantwortung der Frage: Sind dic anorganischen Elemente, welche sich in der Asche der Planzen linden, so wesentliche Restandtheile des vegetahilischen Organismus, flass dieser sie zu seiner nuthigen Ausbildung bedarf, und werden sie den Gewähsen von aussen dargehoron? Gotlinger J'reisschrift. Nebst eilım Anlıange uber die fragliche Assimilation les Humuscxtractes. Braunschweig, Vieweg. 1842. gr. 8. 55 p. ( $1 / 3$ th.

hollandice: II. U. de Friese, Over Je anorgatusche Bestanddeclan der Panten. Onderzoekingen van Dr. A. Hiegmamn en L. PolstorplT. Leiden, Luclituans, 18 33 . 8. 69 p.

$1.1213^{*}$ Wiesend, Otto. De Dulcamara. D. Mouachii 1837.8 .15 p.

11214* Wigand, Albert. liritik und Geschichte der Lehre von der Metamorphose der Pllanze. Jeipzig (Engelmann.) I8/6.8. IV, 131 j., ind. $(7 / 12$ th. $)$

$11215^{*}$ Wigandus, Johannes. Vera historia do succino borussico; de alce borussica, ot de herbis in Borussia nascentibus, etc. studio et npera Johannis Rosini. Jente, tỵ. Stcinmann. 1590. 8. 153 foll., jraef., ind.

(De succinu, foll. 1-37. Catalogus herbarum in Borussia nascentium, cum preefatione 11 igandi auni 1583 , foll. $48-88$.)

$11216^{*}$ Wiggers, Heinrich August t.ulwig. Inguisitio in Secale coruutum, respectu imprimis habito ad ejus ortum, naturam et partes constituentes, nominatim eas, quilus vires medicinales adscribendae sunt. Commentatio praemio ornata. Goettingac, tyj. RosenJusch. 1S31.4.78 p.

11217t Wight, Robert. Ilustrations of Indian Botany; principally of the sonthern parts of the Peninsula. Glasgow, Curll et Bell, printers 1831. 4. 58 p., 32 tah. col. Bibl. Cand.

(Prodiit hucusquo frihus fasciculis, sed incompletum videlur opus. In hibliothecd ill. pon Schlecherdal adsullt 19 tabulace, addito (ituls: "Supplement 1-Il of the Botanical Miscellany of Hooker." In bac libro fritenomen autoris legitur Richard: sed certe aud
Robert llight. Recte ita ponitur in ommibus alis ejus operibns.)

$11218+\div$ Catalogue of plants of East India. s. 1. 28 May $1833 . \mathrm{S}$. $142 \mathrm{p}$.

(Catalogus arle lithographica excusus 237 ) plantarum indicarum.)

11219* _.. - and George Arnoll Walker-Arnott. Prodromus Florae Peninsulae Indiae orientalis, containing abridged descriptions of the plants found in the Peninsula of Britisl India, arranged according to the natural systom. Vol. I. London, Parbury, Allen et Co. 1834. S. xxsvit, 480 p. (16s. - 12 Rupecs, Maciras.)

$11220^{*}$ Contributions to the Bolany of India. London, Parbury 1834. S. 136 p. (7s. 6 d. - 7 Rupees, Madras.)

11221* Illustrations of Indiau Botany; or figures illustrative of each of the natural orders of Indian plants, described in the authors Prodiomus Flnrae Peninsulae Indiae orientalis, with observations on their botanical relations, economical uses and medical propertics; including descriptions of recenty discovored or imperfectly known plants. Madras, published by J. B. Pharoah for the author. Xll parts. 1\$38-4\$41.4. - Vol. I. (Part I-XIl.) (1838-) 1840. xi, II, 218 p., 101 tab. col. sign. 1-95. (London Bailliere: 4l. 17s, 6d.) - Vol. Il. (Part I.) 1841.67 P., 40 taì. col. sign. 96-134. (10 Rup. - London, Baillière: 1/. 5s.)

$14222^{*}$ Icones plantarum Indiae orientalis, or figures of Indian plants. By Robert Wight. Madras, published hy J. B. Pharoah, for the author. (Madras, Franck it Co. Calcutta, Ostell, Lepage et Co. London, Baillière.) 1838-1847. Ill voll. 4. (15\%. $5 \mathrm{s.}$.) - I: (18381840. $x$ foll. , tab. $1-318$. (4l.) - I1: (Part I-IV.) 1842. $x$ foll., tab. 319-736. (5l. 5s.) - III: (Part J-IV.) 1843(-1847.) $x$ foll., ind., tab. $737-1162 .(6 l$.

$11223^{*} \longrightarrow$ Spicilegium Neilgherrense; or, a selection of Neilgherry plants, drawn and coloured from nature, with brief descriptions of each; some general remarks on the geography and affinities of natural families of plants, and oceasional uotices of their economical properties and uses. Madras: printed in the Athenaeum press for the author, and sold by Franck and Co., Madras, and Ostcll, Lepage and Co. Calculta. (Part I : Rauunculaceac - Rhamneae. 1846.) 4. 42 P., 50 tab. col. (1/. 10s. Bailliere.) - (Part Il. 1847.) $x$ [oll., tab. col. $51-100$. (1/. 15s. Bailliere.)

(Plura illustrissimi autoris opuscula impressa sunt in a Madras Joulual of litterature and sciuncep, gluae ituterdun seoraim divulgala sull, Uccurruut it volumine quinto: ollu the homocothermal method of acrimaling eycalropical plants withein the tropies

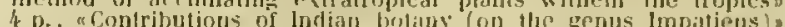

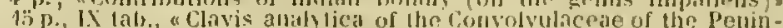
sulit sula of India ") 8 p. . T tab. - In voluminr dundecimo colulinentur "Remarks on the Iruit of the datural order cucurbilaceap o 12 [1. Gambogia lintla L., Stalagmites gumbogioildes .I urr. and on Jaurus Cussia L." 13 p. - Plura seorsion imuressa nou vicli.)

1122 Wikström, Johan Emanucl. Nuscum naturalium acadcmiae Upsaliensis, cujus appendirem X.XI ete. praesirle C. P. Thunberg proponil J. E. Wikstróm. D. Lpsaliae, typ. Stenhammar el Palmblad. $18 \uparrow 3.4 .24 \mathrm{p}$. W.

(Dissertalio haecce historiam Lichenographiao praesertim suecanar rontinel, adjecto califogo lichenum in horbario regiae universitatis [psaliensis asservatorum.)

$1] 223^{*}$ - Dissertatio botanica de Dapluse, quam pracside C.P. Thunberg pro gradu medico proponit auctor Joh. Em. Wikstrum. Ipsaliac 1817.8.5\% p. - Erl, alterit cmendata et auctu. StockJolmiae, typ. Strimholm. 1820.8. $42 \mathrm{p}$

Ii) Aclis Acad. scient. Ilolnt. anni 1818. p. $263-349$ ediderat aurlor: Graushuing af of lill Thymrlaparum vaviordning horaude

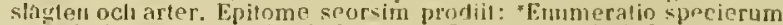
gerieris Daphnes, Stochliolioiae, Ivp. Ortwann. 1820, 8, $16 \mathrm{p}$.)

$11226 \div-$ Ofversigt af Botaniskid Arbeten orh lpptackter, pai Kinugl. Vetenskaps-Academiens befalluing lennad àr $1821-1826$ af Joh. Em. Wikstrom. Slockholm, typ. Lindh (typ. Norstedt.) 1822 -1826.8.84,157,105,119,64,160 p. - Ars-Berattelse om Framstegen uti Botanik (om Botaniska Arbeten och Lpptackter för ãron 1826-1842. Stockholm, 15p. Norstcdt. 1827-184\%. S. (Pretium integrae collectionis: $27 \mathrm{Rdr}$.)

(Verainem germanican curavit Kart Traugolt Beilschmied; rt supra Nir. 666.)

$11227^{*}-$ Några arter af vaxtsligtel Rosa, Stockholm, 1yp Lindhs Euka. 1821 . \&. 14 p., 1 tab.

(Ur Kongl. Vet. Acad. lland1. for är 1820.)

$11228^{*} \longrightarrow$ Trenne arter af vastslägtet Equisetum. Stochiolm, typ. Lindh. $1821,8.7$ p., 1 tah.

(Kongl. Vet. Acad. Jlaudl. for år 182I.)

$14229^{*} \longrightarrow$ Beskrifning af venne nya arter af vaxtsläglet Fritillaria, jemte anmảrkningar om àtskilliga arter af samma slagte. Stockholm, typ. Lindh. 1822.8 .11 p., J tah.

(Kongl. Vet. Acad. Hand!. 1821. St. 11. 13. 3.;0-359.)

$11230^{*}$ - Nindre kanda vaxter. Stockholm, typ. Lindhs Enka. 1\$23.8. 14 p. - Continuatio: ib. 1824.8.10 p.

(ir Kongl. Vet, Acad. Handl, for ir 1522-1523.)

$11231+\div-$ Den Americanska Agaves eller den sả kallade hundrateåriga Aloe'ns natural-historia. Slockholm, typ. Forstedt. 1 S2S. s. $15 \mathrm{p}$.

(Fräll liongl. Vet. Acad. Ârsh. fir âr IS27, p. 29 -308.)

$11232^{*}-$ Biographie uber den professor Olof Suarla, Stockholm, typ. Norstedt. 182S. 8. 32 p., 2 tab. (effigies et sepulcrum Sumartzii.)

(Ex "Anmotationihus botanicis, quas relifuit Olarus Stcartzo p. XXX-LXI. seorsim 0 exemplaribus impressa.)

$11233^{*}$ - Conspectus litteraturae hotanican in Suecia ab anliquissimis temporibus usque ad fuem anni 1831 , notis bibliograplicis et biographiis auctorum adjectis. Holnviac, cxcudebant P. A. Vorstedt et filii. 1831.8 . Xtix, $3+1$ p. $(9 t / t)$

1123 - Öfrersigt af Stockholms-tracteus naturbeskaffenliet Stockliolm $1839.8 . \mathrm{Vi}$, is5 p.

$11233^{*}-$ Stockholms Flora, eller kort Beskrifuing af de vid Stockholm i vilàt tillstånd forekommande vaxicr. Ned en inledning iunehållande en ofversigt af Stockholms-traktens natur-beskaffenhet. Forra Delen. (Class. 1-13.) Stockbolm, Nolstedt. 1840. S. vill, 185, 423 p., Appendix: 27 p., 1 mappa geegr. ( 3 Rdr. 32 skill.)

$11236^{*}$ Wilbrand, Johann Bernhard. Ilandbuch /der Botanik nach Linne's System, enthaitend die in Deutschland und in den angränzenden Gegenden wildwachsenden und merkwürdigen ausländischen Gewáchse. ctc. Giessen, Hejer. 1819. 2 Bănde. 8., \pm 54 , 491 p., 16 tab. (4 $/ 2$ (h.) - Neuo Auflage. Darmstadt, Leske. 1837. 8. Lvi, 703 p. (3 th. - herabgesetzl: 2 th.) 
11237* Wilbrand, Johann Bernhard, und Ferdinand August Ritgen. Gemalde der organischen Natur in ihrer Verbreitung auf der Erde. Giessen, Muller, 1821. 8. 128 p., 4 tab. in gr. folio. $\left(4 \frac{1}{2}\right.$ th. col. $8 \frac{2}{3}(h$.)

* suecice : Ithast till den Orgauiska Vaturens Greographi. Örversat af Hentrik Sandstrom. Stockholm, IJacgstrom. 1828. 8. $87 \mathrm{p}$.

$11238^{*}$ __ Uebersicht der Vegetation Deutschlauds nach ihren naturlichen Familien. (Regensburg 1824.) $8.73 \mathrm{p} .(1 / \mathrm{th}$.)

(Seorsin impr. ex Flora, disrio but. Ratisb. anni 182.)

$11239^{*} \longrightarrow$ Die naturlichen Pflanzenfamilien in ilsren gegen. seitigen Stellungen, Verzweigungen und Gruppirungen zu einem naturlichen Pfanzensysteme. Giessen, Heyer, 1834. 8. Iv, 95 p. $(1 / t h$ the

$11210^{*}$ Allgemeine Physiologie, insbesondre vergleichende Physiologie der Pflanzen und der Thiere. lleidelberg und Leipzig, Groos. 1833. 8. xil, 452 p. $(21 / 2$ th. $)$

$11241+$ Wilcke, Georg Wilhelm Constantin von. Versuch einer Anleitung, die wilden Baume und Sträucher unsrer deutschen Wălder und Geliolze auf ihren blossen Anblick mit Sicherheit erkennen und unterscheiden zu lemen. Halle, Gebauer. 1788. 8. vIII, $326 \mathrm{p}$., 3 tab.

11212 Wilcke, Heinrich Christian Daniel. De usu systematis sexualis in medicina. D. Gryphiswaldiae 1764.4.20 p. (Respondens: Heinrich Alexander Roseuthul.) $\mathbf{B}$.

$112\} 3^{*}$ Wilcke, Samuel Custav. Flora Gryphica, exlibens plantas circa Gryphiam intra milliare sponte nascentes, una cum nominibus et locis natalibus. Gryphiae, Röse. 1763.8 .144 p., ind.

$11244^{*}$ Hurtus Gryphicus, exhibens plantas prima ejus constitutione illatas et altas, una cum hurti historia. Gryphiae, typ. Bose. 1765. 8. 104 p., praef., ind.

1125.5* Wildvogel, Christian, pr. De jure florum, Vom Blumenrechte. D. Jenae, typ. Múller. 169 1. 4. (48) p. (Respoudens: Johann G. Doehter.)

11246 WilheIm, Fr. Flora Herbipolitana. Bamberg, Göbhardı. 1782. gr. $8 .(1 / 2$ th. $)$

1) $21.7^{*}$ (Wilhelm, Gottlieb Tobias.) Unterhaltugen aus der Naturgesclichte, Band XVI-XXV: Las Pflanzenreich. Band 1-X. Augsburs, Engelbrecht. (Sondershausen, Voigt.) 1\$10-1822. $10 \mathrm{Bde}$ 8. $x$ p., 616 tab. col. $\left(63 \frac{1}{6}\right.$ th. $)$

$1121 \mathrm{~S}^{*}$ Wilhelm, Johann Ceorg. Dissertatio inauguralis, tradens Juniperum. Argentorati $1718,4.42 \mathrm{p}$.

1) $249^{*}$ Wilhelmi, Christoph Ludivig. Colchicum auf eine sunderbare Art gebrauchet, als ein von Gott gezeigtes und uffenbartes Mittel wider die Pest vorgestellet. Leipzig 1721. 4. $x$ p.

112000 Wilhem, Hieronymus de. Dissertatio inauguralis de Manna $x \varepsilon-$

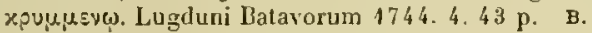

1125. Willan, Robert. Observations on the Sulphur-water at Croft near Darlington. London 1782. s. - ib. 1786 . 8. B.

(Deseribitur p. 9-10 Conterva quaedam in his rquis obvia, nomine Byssi Januginosae.

11252* Willdenow, Karl Ludwig. Florae Berolinensis Prodromus secundum systema Linneanum a Thunbergio emendatum conscriptus. Berolini, W. Vieweg. 4787.8 . xvı, 439 p. 7 tal.

(Vidi exenplar cum numerosis annutationilus manuscriptis autoris in hibliotheca Herbarii Berolinensis.)

11253* - Tractatus botanico-medicus de Achilleis, cui accedit supplementum generis Tanaceti. IIalao, Hendel. 1789. 8. Xı, 59 p., 2 tab.

$11254^{*}$ Historia Amaranuhorum. Turici, Ziegler et fil. 1790. folio. 38 p., 12 tab. col. $(6$ th. $)$

$11255^{*}$ - _ und Paul Usteri. Beiträge zur Biographie des versturbenen Dr. Johann Golllieb Gleditsch. Zurich 1790. 8. 111 p., effigies Gledilsch.

$11256^{*}$ _ Grundriss der Kräuterkunde zu Vorlesungen entworfen. Berlin, Haude und Spener. 1792. S. xiv, 486 p., 9 tab. *Ed. II: Wien 1799. 8. 454 p., ind., 10 tab. - *Ed. IIl. Berlin, Haude und Spener. 1802.8.644 p., 11 tab. - ${ }^{*}$ Ed. IV. ib. 1805. 654 p., 11 tab. - ${ }^{*} E d$. V. ib. 1810.638 p., 11 tab. - *Ed. V: Wien, typ. Bauer. 1808.8. 548 p., 11 tab. $-{ }^{*}$ Nach der funften Auflage mit Anmerkungen und Zusátzen von Joseph August Schulles.
Wien, Doll. 1\$18. 8. 652 p., J I tab. - * Grundriss der Krauterkunde zu Vorlesungen entworfen. Nach dessen Tode neu herausgegeben mit Zusátzen von Heinrich Friedrich Link, Sechste vermebrte und verbesserte Auflage. Erster (heoretiseluer) Theil. Berlin, Ilaude und Spener. 1821.8 .711 p., 11 tab. - * Siebente Auflage: ib. 1831 . 8.694 p., 11 tah. ( $2 \frac{1}{2}$ th.)

(Tomum II-IV vide supra Nr. 5967.

- danice: Uitkast tall ell Laerebog i Botaniken, orersat etc. af Henrik Steffens. Kiobenhavn, Bacli. $179 k .8 .400$ p., 9 tab.

tenglice. The principles of botany and of p.. 3 tah. rrinslited from tho german. Ediuburgh, Blachwood. 1803. 8. iv 608 p., 10 tab.

$11257^{*}$ Willdenow, harl Ludwig. Phytographia, seu descriptio rariorum misus cognitarum plantarum. Fasciculus primus. Erlangae, Walther. 1794 , foliu. 15 p., 10 tab. (2 th.)

$11258^{*}$ - Berlinische Baumzucht, oder Beschreibung der in den Gúrten um Berlin im Freien ausdauernden Baume und Stráucher, fur Gartenliebhaber uud Freunde der Botanik. Berlin, Nauk. 1796. 8. xxxı , 452 p., 7 tab. - ${ }^{*}$ Zweite vermehrte Ausgabe. ib. 1811.8. xxII, 586 p., 7 tab. $\left(3 \frac{1}{4}\right.$ th. $)$

$11259^{*}$ Geraniologia in amicorum usum seorsim impressa. Berulini 1800.8 . $\$ 6$ p.

$11260^{*}$ und A. II. Homeyer. Gekronte pomologische Preisschriften. Erfurt, Beyer und Maring. 1804.8. 159 p. $(1 / 2$ th. $)$

$11261^{*}$ Bemerkungen uber cinige seltene Farrenkrauter. Erfurt, Beyer und Maring. 1802.8 .32 p., 3 tab. ( ${ }^{1 / 2}(h$.

11262* _ Anleitung zum Selbststudium der Botanik, ein Handbuch zu üffentlichen Vorlesungen. Berlin, Oelmmigke. 1804. 12. vi 666, 12 p., 4 tab. col., effigies Willdenow. - Zweite Aullage. Berlin, Oehmigke. 1810. 8. - ${ }^{*}$ Dritte vermelste und verbesserte Auflage, von Ileinrich Friedrich Link. Berlin, Oelımigke. 1822. 8. vir, 537 p., 4 tab. col. - *Vierte vermelirte und verbesserte Auflage von Albert Dietrich. Berlin, Oehmigke. 1832. 8. vIII, 582 ]., 4 tab. col. (2 th.)

hollandice: llandleiding tot de kennis der planten, gevolgd naar het hoogduitsch van C. L. Hilldenow, foor Mr. Hïllewaal. S. I. et a. gr. $8 .(5$ t1. 50 c.)

$11263^{*}$ C__ Caricologia, sive descriptiones omnium specierum Caricis, in usum excursionum botanicarun pro amicis seorsim inpressa. Berolini 1805.8.107 p.

11264* - Enumeratio plantarum horti regii hotanici Berolinensis, continens descriptiones omnium regetabilium in horto dicto cultorum. Berolini, in taherna libraria scholae realis. 1S09. 8. vi, 1099 p. - * Supplementum post mortem autoris editum a vois Schtechtendal (patre.) ib. $1813.8 . x, 70$ p. $(6 \%$ th.)

$11260^{*}$ llortus Berolinensis, sive icones et descriptiones plantarum rariorum vel minus cognitarum, quae in horto regio botanico Berolinensi exculuutur. Berolini, Schüppel. 1816. folio. $x$ p., 140 tab. col. $\left(38 \frac{1}{3}\right.$ th. $-8 \frac{1}{2}$ th. A.)

(Praefatus est IIilldenow anno 1806; epilogum scripsit Link anno 1816.)

11266 t Willemet, Pierre Kemi François de Paule, filius. An vires plantarum ex claracteribus butanicis sunt inferendae? D. Nancy, typ. Bachot. 1782 . 4. 4 p. Bibt. Juss.

$11267^{*}$ Herbarium Mauritianum. Praefatus est Aubin Louis Miltin. Lipsiae, Wolff. 1796. 8. xı1, 64 p.

(Usteri, Annalen der Bintanik, Stuck Jilis, p. 1-66.)

11268 Willemet, Remi, pater. Phytographie économique de la Lorraine, ou Recherches botaniques sur les plantes utiles dans les arts. Nancy 1780.8. 142 p. B.

11269 Willemetia, nouxeau genre de plantes crée par M. de Necker et fragment pour servir à l'listuire naturelle de la Neckeria capnoides de Scopuli. s. l. et a. 7 p., 1 tab. B.

$11270^{*}$ Nonographie puur servir a l'histoire naturelle et botanique de la famille des plantes étoilées. Strasburg, Koenig. 1791. 8. cill p.

11271 Catalogus plantarum horti botanici Nancej'uensis. Nancy 1802.8. a.

11272* Phytographie encyclopédique, ou Flore de l'ancienne Lorraine et des departemens circonvoisins. Nancy, Guivard. 1805. III voll. $8 . x, 1394,94$ p. (15 fr.)

(Post mortem autoris $(+21$ Juni 1807 ) ab editore novis mutatis titulis edita est. Videas supra vocem Coste, Nr. $2011-2012$. 
$11273 \div$ Williams, Charles. The vegetable world. London, Westley and Davis. 1833. 12. iv, $288 \mathrm{l}$., $1 \mathrm{lab}$.

11271* Willich, Christian Ludwig. Observationes quaedam lotanicae et medicae cum novae plantae figura. Goettingae, Vandenloek. (1747.) $4.22 \mathrm{p}$.

(In titulu Jujus tibelli nomen antoris false scribitur Villig.)

$11275^{*} \longrightarrow$ De plantis quilussdam observationes. Goentingae, V'andenhoek. $1762.8,76 \mathrm{p}$

$11276^{*}$ Illustrationes quaedam botanicae. Goettingae, Vandenllock. $1766.8 .55 \mathrm{p}$.

Omnes tres libelli redeunt in Reichard Sylloge opusc. Lot. p. $82-182$.

$11277+$ Willshire, Hughes. The principles of botany; structural, tunetiunal and systematic, condensed and immediately adapted to the use of students of medecine. London, Ilighley, 1839. 8. xi1, $232 \mathrm{p}$. $(6 s$.

11278 Willy. The aggriculture musenm by D. Willy and II'. A. Rind. Georgetown 1811. 8. DC.

11279* Wilmanns, C.A. Commentatio de anthelminthicis regui vegetabilis. Goettingat, typ. Baier. 1826.4 .59 p. $(1 / 3$ th. $)$

11280 Wilson, Alexander Philip. An experimental essay on the mantuer, in which Opium acts on the living animal body. Edinburgh 1795 8. $162 \mathrm{p}$. B.

$11281 \div$ Wilson, John. A synopsis of british plants in Mr. Ray's method; with their characters, descriptions etc. Newcastle upon Tyne, typ. Gooding. 1744. 8.14, 272 p., praef, ind., 2 tab.

$11282 *$ Wimmer, Friedrich, et Heinrich Grabowski. Flora Silesiae Vratislaviae, Korn. 1827-1829. HI vol!. 8. - 1: Classis $3-\mathrm{X}$. 1827. xvi, 446 p., effigies Seliger, - Il: Classis Xl- XV. 1839. xxiv, 282 p., effigies Kurl Christian Cuenther. - Ill: Classis XV1XXII. 1829.400 p. $(4$ th. $)$

$11283^{*} \longrightarrow$ Ueber den Unterricht in der Naturgeschiclte. Programm des Friedrichsgymnasiums zu Breslau. Breslau, typ. Grass, Barth et Co. 1829. 4. $14 \mathrm{p}$.

$11284^{*}$ - Flora von Schlesien. Ilandhuch zur Bestimmung und Kenntniss der phanerogamischen Gewachse dieser Provinz, nelıst einer gedrängten Einjeitung in die Pflanzenkunde. Berlin, Rucker. 1832. gr. 8. Ix, 400 p. $(12 / 3$ th.

$11285^{*}$ - Phytologide Aristotelicae fragmenta edidit Fridericus Irimmer. Vratislaviae, Jos. Max et soc. 1838.8 . xII, 98 p. $(2 / 3$ th.

$11286^{*}$ - Flora von Schlesien preussischen und osterreichischen Antheils ober vom obern Oder- und Weichselquellengebiet, mit besondrer Berucksichtigung der Umgegend ven Breslau. Nach naturlichen Familien mit Hinweisung aut das Limuéselse System. Nebst plytogeograplisclien Angaben und einer Profilkarte des Schlesischen Gebirgszugs. Breslau, Ratibor und Pless, Ferdinand Hirt. 1840. gr. 12. Xuvin, 464,82 p. $\left(9^{2} / 3\right.$ th. $)$ - ${ }^{*}$ weite, neu redigirte und bereicherte Ausgabe. Nebst einer Uebersicht der fossilen Flora Schlesiens von Heinvich Roberl Goeppert. ib. 1844. 2 Bande. 12. -3 : XLviII, 512 p. - II : 225,54 p., I mapp. geul (3 th.)

Editio altera practer additamenta non differt Volumen, in quo haec additamenta continentur, separatim venditur: 1 th,

$11287^{*}$ Wimmer, Martin. De Caincae radice. D. Monachii 1832. 8. $20 \mathrm{p}$.

11288\% Winch, Nathanael John. An essay on the geograpluical distribution of plants through the counties of Northumberland, Cumberland and Durham. Newcastle, typ. Walker. 1819. 8. 52 p. tSecond editiun. Newcastle, typ. llodgson. 1825. 8.54 p. * germanice: Versuch iber die geograptischo Verhreitung der Pllanzen in den englischen Grafschafteil Norttumberlanil, Cumberlanel und Durham; überselzt ron Karl Traugoll Beilschmied. Flora 1837. 1. o. $289-317$.)

$11289 \div$ - Flora of Northumberland and Durham. Neweastle, 1yp. Hadgson. 1831. 4. $149 \mathrm{p}$.

From the Transaclinns of the nalural history of Northumberland, Durham and Neweastle upon 'Tyne. I8:31.

$11290 t-$ Contributions to the Flora of Cumberland, to which are added Remarks on the lists of plants published in IIutchinson's history of that county, and in Turner and Dillwyn Botanists guide through England and Wales. NewCastle, typ. Hodgsen. 1833. 4. $17 \mathrm{p}$.
$11991^{*}$ Winckler, Daniel. De Opio tractatus, in quo simul liber de Opio Johannis Freilagii examinatur. Lipsiae, 15p. Jansonii. 1635. 8.

$11292^{*}$ Winckler, Ciustav Adolf. De Digitali purpurea. D. Berolini 1837. 8. $31 \mathrm{p}$.

$11293+$ Winckler, Vicolaus. Chronica luerbarım, florum, seminum, fructum, ridlicum, succorum, animalium atque eorundem partium, quo nimirum tempore singula corum colligendi atque in usum adfcrenda sunt medicum. Augustae Vindelicorum, typ. Manger. 1571. 4. 91 foll.

yermanice: Ans den Lateiniscisen ins Teutsehe ubersetzet. Augshurg, typ. Manger. 1577. 8. Bivin.

1129 " Winkelblech, Karl. Ueber Liebig's Theorie der Pflanzenernahrung und Schleiden's Einwendungen gegen dieselbe. Kassel, Krieger. 1842.8 .31 p. $(1 / 6$ th. $)$

$11293^{*}$ - Bemerkungen 24 Schleiden's offenem Sendsclureiben an Dr. Justus Liebig. Braunschweig, Viewew. 1842. 8. 23 p. (1/8 th.)

11296* Winleler, Eduard. Sammliche Giftgewachse Deutschlands uaturgetreu dargestellt und allyemein fasslich beschrieben. Mit einer Vorrede von Friedrich Schwaegrichen. Berlin, Natorlf et Co. 1831. 8. 11, xt, 119 p. 96 tals. col, sign. 1-95. (4 th.) - " Zweite Aullage. ib. 1832. (mon differt.) - ${ }^{*} Z$ weite vermehrte u. verbesserte Aullage. Leipzig, Magazin für Industric. 1835. 8. IIV, $120 \mathrm{p}$. 100 tab. col. $\left(6 \frac{2}{3}\right.$ th. - sine tab. $2 / 3$ th. $)$

$11297^{*}$ - Abbildungen sámmtlicher Arzneigewachse Deutschlands, welche in die Plsarmacopoun der grössern deutschen Staaten aufgenommen sind. Nach der Natur gezeichnet rull Eduard II inkler. Leipzig, Magazin für Industrie und Literatur. (Sclıáfer.) (1832 sqq.) 4. 192, 16 tab. col. ( 26 th.)

(llarum iconum textus est ill libro sequenti.)

$11299^{\circ}$ — Iandbuclı der Gewăclıskunde zum Selloststudiım oder Beschreibung sânmtlicher pharmazeutisch-medizinischer Gewichse, welche in den Pharmakopöen der grossern deutschen Staaten aufgenommen sind. (Etiam inscribitur: Sammlliche Arzneigewachse Deutschlands, welche in den Pharmacopoen der grosseren deutschen Staaten aufgenommeu sind, naturgetreu dargestellt u. Sasslich beschrieben.) Leipzig, Magazin für Industrie. (Schäfer.) 1834. gy'. 8. vill, (2). 783 p. (4 th.) - Ergảnzungsheft. ib. 1834 gr. $8.2 \frac{3}{4}$ plag. $(1 / 3$ th. $)$

11299 Anfangsgrinde der Botanik zum Gebrauch für Schulen und zum Selbstunterrichte. Zweite gánzlich umgearbeitete u. vormehrte Aunage, nuit 140 Abbildungen. Leipzig, F. A. Brocklıaus. laas. 1536 . 16. $16 \frac{1}{2}$ plag. $(3 / 4$ th.

$11300^{*}$ — Vollstandiges Real-Lexicon der medicinisch-pharmaceutischen Naturgeschichte und Rohwaarenkunde. Enthaltend: Erklärungen und Nachweisungen uber alle Gegenstunde tler Naturreiche, welche bis auf die neusten Zeiten in medizinisch-pharmaceutischer, toxikologischer und diatetischer Hiusicht bemerkenswerth geworden sind. Leipzig, Brockhaus. 1840- 18 49 . 2 Bande. 8. - I: 1840. A-L. XII, 953 p. - II: 1319. M-Z. xv1, 1914 p. $\left(9 \frac{1}{3}(h)\right.$.

$11301^{*}$ Ausfuhrlicho Beschreibung sánmtlicher Arzneigewaclıse, welche homöopathisch geprüft worden sind und angevendel werlen. Für Hoınöopathiker zur Benutzung beim Einsammeln der Arzneikörper aus dem Pflanzcnreiche. Leipzig, Magazin für Industrie und Literatur. 1\$36. 8. sil, $312 \mathrm{j}) .\left(1 \frac{2}{3} \mathrm{lh}\right.$.

$11302^{*}$ Ausfuhrliche Beschrcibung sammtlicher Arzneigewachse, welche homoopathisch gepruft worden sind und angeweudet werden. Für Homöopatliker zur Benutzung beim Einsammelı der Arzneikörper aus dem Pflanzenreiche. Erklarung der Abbildungen aul 156 Blattern. Leipzig, Magazin für Industrio und Literatur. $1836.8 .61 \mathrm{p}$.

$11303^{*}$ - Ahbildungen der Arzneigewachse, welche homoopathisch geprnft worden sind und angewendet werden. I,eipzig Magazin fur Industrie und Literatur. (Sehafer.) $(1834-1 \$ 36$.$) \&.$ (156) tab. col. (24 th.)

$1130 \mathrm{k}^{*}$ Pharmaccutische Waarenkinde, oder Ilandatlas der Pharmakologie, enthaltend Abbildungen aller wichtigen pharmaceutischen Naturalien und Rohwaaren nclsst genaner Charakteristik und kurzer Beschreihung. Bildersanmlung zu folgenden Werken: zu Ed. Hinkter's vollstandigem Real-Lexikon der nedicinisclı- 
pharmaceutischen Naturgeschichte u. Rohwaarenkunde; zu Dulk's preussischer Pharmacopoe; zu Geiger's llandbuch der Pharmacie und andern. Licferung $1-15$. Leipzig, Schafer. $1844-1848$. $x$ p., (75) tab. col. (10 lh.) (Continuatur.)

("Zweite Auflage" non differt.)

$11303^{*}$ Winkler, Eduard. Getrene Abbildung aller in den Pharmacopóen Deutschlands aufgenommenen officinellen Gewíchse, nebst ausfuhrlicher Beschreibung derselben in medicinischer, pharmaceutischer und botanischer llinsicht. Dritte verhesserte Auflage. Leipzig, C. B. Polet. (1\$46-1847.) 4. Lfg 1-54. 4. (270) tab. col. $\left(13 \frac{1}{2}\right.$ th. $)$

(Est una tantum impressio, quae itdo ab anno $18 \%$ prodiit.)

$11306^{*}-$ Charaktere der Gattungen und Arten sämmtlicher offzinellen Pflanzen. Leipzig, Polet. (1846.) $8.108 \mathrm{p} .(\mathrm{I} / 2 \mathrm{th}$.

(Sistit lextum libri "Getrene Abbildung.")

$1\left\{307^{*} \longrightarrow\right.$ Hanlbuch der nedizinisch-pharmaceutischen Botanik. Nach den neusten Estdeckungen bearbeitet. Leipzig, Polet. (1846.) $8.440 \mathrm{p}$. (Continuatur.)

(Additur operi a Getrene Ahhildung etc. o)

$11308^{*}$ Winkler, Friedrich Ludwig. Die echten Chinarinden. Ein Beitrag zur genaueren Kenntniss dieser wichtigen Arzneimittel. Darnstadt und Leipzig, Leske. 1834. 8. Iv, 83 p., 2 tab. (1/2 th.)

(Abgedrucht aus des Verfassers Lebrbuch der pharmacuntschen (thentie unil Pharmahogunsie.)

$\$ 1309$ Winneken, Christian. Beschrcibung des wahren Opobalsambaumes. Kopenhagen 1745.8 Desis. Banks. I

$11310^{*}$ Winslow, Jacob. Spicilegium anatomico-botanicum generale de machinae plantanimalis oecunomia analogica. Ilavniae, "typ. Bockenhoffer. 1694.4. $20 \mathrm{p}$.

$11311^{*}$ (Winterl, Joseph Jakob.) Index horti botanici universitatis hungaricae, quae Pcstini est. (Pestini) 1788. 8. 7 plag. 26 tab. (In plurimis exemplarihus nomnisi 10 tabulae adsunt; desinunt hujuscemodi exemplaria in Tordylio Anthrisco.)

11312 Winterschmidt, Johann Samuel. Nürnbergische Flora, oder Abbildung und Beschreibung der in Nurnbergs Ungegend ohne Kultur waclssemden Pflanzen. Nurnberg $1818-1821.8$. 1. u. 2. Band und 3. Bandes 1. Ileft. 108 tab. et totidem foll.

(Opus haud continuatum est.)

11313 Winther, $M$. Literaturae scientiac rerun naturalium in Dania, Norvegia et Holsatia usque ad annum 1829 enchiridion in usum physicorum et medicorum. Havnine, Wabl. 1829. 8. xv1, 233, $15 \mathrm{p}$. w.

$11314+$ (Wionius, Georgins.) Botanotrophium seu hortus medicus Petri Rtcarti, pharınacopoei Lillensis celeberrimi, cura Georgii Wionii, artium Doctoris ac Iledici descriptus ac ellitus. Lillao Gallo-FlanIricae, typ. Simonis le Francq. 1644. 12 . (12), 56 p. Bibl. Juss.

$11313^{*}$ Wipacher, David. Flora Lipsiensis bipartita. Pars prior, plantarum indigenarum, quarum curan: in circulo Lipsiensi solus gerit creator benignissimus, historiam exbibens. Kurtzer doch grundlicher Bericht von denenjenigen Krautern und Gewächsen, welche allein durch gottliche Verordnung und Pflege um Leipzig gefunden und erlalten werden. Lipsiae, sumtibus autoris, typ. Bauch. 1726. 8. 80 p., ind. Bibl. univ. Lips.

$11316^{*}$ Wirsing, Adam Ludwig. Eclogac botanicae e dictionario regni vegetabilis Buchoziano collectae, exhibentes plantarum antea ineditarum icones ad prototypa accuratissine expressas, cum descriptioniluus et adnotationibus necessariis. Manjusulus 1. Norimbergae 1778. folio. 2 p., 10 ab.

$11317^{*}$ Wirtgen, Philipp. Leitfaden fur den Unterricht in der Butanik an Gymnasicu und höheren Bürgerschulen. Zugleich als Anleitung zur leichtern Bestimmung der wilı wachsenden phanerogamischen Pflanzen des mittleren und nürdlichen Deutschlands. Coblenz, llolscher. 1839. gr. 12. xI, $318 \mathrm{p} .(1 / 2, t h$.$) - Zweite umgear-$ beitele Auflage. Coblenz, Ilölscher. 1846. gr. 12. Jv, $483 \mathrm{p}$. $(\% / 10 l h$.

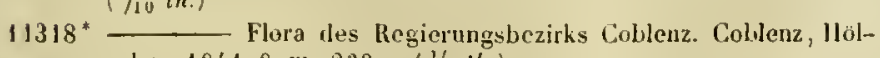
scher. 1841.8. xı, 238 p. $(1 / 2$ th. $)$

$11319^{*}$ Prodromus der Flara der preussisclien Rheinlande. Erste Abthcilung: Phancrogamen. In Auftrage des botanischen Vereins an Hittcl- und Niederrleine, zunáchst fúr dessen Mlitglicder unter besondrer Mitwirkung der IIH. Bach, Bogenhard, Finger- hulh, Flock, Löhr, Sellmeyer und Theodor Vogel bearbcitel und herausgegeben von Philipp Wirtgen. Bouu, in Commission van Henry und Cohen. 1842. 8. xu, 208 p.

$11320^{*}$ Wirzén, Johannes Ernst Adhemar. De geographica plantarun per partem provinciae Casanensis distributione. U. Ilelsing forsiae. typ. Frenkel. 1839. 8. 129 p.

$11321^{*}$ - Scriptores rei herbariae fennicac. Discuisitio botanicocritica. D. I. Helsingforsiac, 19 p. Prenkel. 1843. S. 16 p. (non contimuata est.)

11322* ——— Prodromus Florac fennicae. D. I - II. Ilelsingforsiae, tyl. Frenkel. 18 \&3. 8. 32 l?

(Desinit in Triandria.)

11323 Wissett, Roberl. On the cultivation and preparation of hemp as also of an article produced in India called Sum, which may be introduced as a substitute for many uses to which hemp is applied. London 1804. 4 .

11324* Wilham, Henry, Observations on fossil yegetables, accompanied by representations of their internal structure, is scent througls the microscope. Edinburgh and Loudon, Blackwood and Cadell. 1831. 4. 48 p., 6 tab. $\{$ ll. $\mid$ s. $\}$

$11325^{*}$ A description of a fossil tree discovered in the Quarry at Craigleith near Edinburgh in the month of November 1830 Edinburgh, typ. Neill. 1833. 4. 9, 4 p., 4 tab. col.

$113266^{*}$ The internal structure of fossil vegetables found in the carboniferous and oolitic deposits nf Great-Britain described and illustrated. Edinhurgh, Black. 1833.4 .84 p., 16 tab. col. (1/. Is.

$11327^{*}$ Witman, Ernst. Entwurf einer tabellarischen Darsteling der Terminologie der Phäuagamisten. Wien, Beck. 1812. S. Z4 p. 16 Tabellen in folio. $\left(1 \frac{2}{3}\right.$ ch. $)$

$11328^{*}$ — Rede als Einleitung zur Hy cotheca und Mycographia austriaca. Wien, typ. Mechitarist. 1816. 8. xxil p.

$11329^{*}$ Withering, William. A botanical arrangement of all the vegetables naturally growing in Great Isritain, with descriptions of the genera and species etc. Birmingham, typ. Swinney. 1776. Il voll 8. xcvi, 838 p. 12 tab. - ${ }^{*}$ Ed. 11: A botanical arrangement of british plants, etc. including a new set of references to figures, by Jonathan Stokes. ib. 1787- 1793. IIl voll. S. - I et II : L.xv1, 1151 p., 2 tab. - III: 1792. CLvit, 503 p., tab. $3-19 .-$ +Ed. 111: ib. 1796. IV voll. 8. - I: 402 p.. tab. 1-19. - II: 512 1., tab. 20 $-28 .-111$ : p. $513-920$, tab. $29-30$. - IV: 418 p., tah. 17 , 18.31. - A systematic arrangement of british plants; with an easy introkuction to the study of botany, illastrated by colperplates. The fourth edition, in four volumes, currected and enlarged hy II'illium I'ithering Esq. London, Cadell and Lavies. 1801. IV voll. 8. xII, $402,900,410$ p. 32 tab. - "An arrangement of british plants atccording to the latest inprovements of the Linnean System; with an easy introduction to the study of botany illustrated by copperplates. The seventh edition in four volumes including the most recent discoseries and numerous enlarged annotations illustrative of the regetahle economy; by William Withering. London, typ. Baldwin. 1830. IV voll. 8. - 1: LxIy, 394 p. - II: 590 p. - Il: p. 591-1169. - W: 444 p., 35 tab. (2l. 16s.) - I systematic arrangement of the british plants by II itliam llithering. conlensed and brought down to the present period. Preceded by an introduction to the study of botany accompanied by 155 figures and 1 col. plate; by thillam Hacgillivray. Ediuburgh 1835.8. (10s. 6l.)

11330 An account of tho foxglove, and some uf its medical uses. (Fx Curtis Flora Londinensis.) Birmingham 1785. 8. 207 ). I tab. col. B.

"germanice: thhandiung rom rothen Fingerhut und dessen Anwendung bei der Wassersucht. Aus dem Englischen voll Christian Friedrich Hichaelis. Leipzis, Mutler. 1786. 8. Xxvin, 23\% p., I tab. cul.

11331 N Miscellaneous tracts; with a memoir of his life character and writings. London, Longmall. 1822. II roll. 8 . (1/.7s.) Bibl. Radcl. Oxon.

$11332^{*}$ Witt, Johann Constantin. De legribus quibusdam ad processum vegetationis pertinentibus. D. Ilalae, typ. Batl. 1802. 8. xvı, 47 p.

$11333^{*}$ Wittfeld, Johann Heinrich. De vera Digitalis indicatione. D. Bonnae 1826.8.25 p. 
11334. Witzendorf, August Bruno. De Chinividino. D. Lipsiae 18 \{0. 4. $22 \mathrm{p}$.

113:3: Wodzicki, Stanislaw, Comes. O chorluwaniu, užythu, możenin i poznawaniu Drzew kirzewow Roslin i Ziel celnicyszych: hu ozdobiu Ogroduw przy zastosowaniu du naszoy strefy. Dzielo Milosniknin Ogrodow poswiecone przez Stanislawa IV'odzickiego. (Ueber Kultur, Sitzen, Vermebrung und Ertienuen der vorzuglicheren Baune, Stranchor, Staudengentachse una kranter zur Zierde der (Garten, angewandt auf unser Kilima.) Tum. I. W lirakünie $181 \mathrm{~S}$. S xxiv, 593 p. - il,. 1825. IV voll. 8 .

(1) entegio opere ef. Sprengel Neuc lintflechungen, Band I. D. $408-121$.

$14336^{*}$ Wohlleben, Johann Friedrich. Supplementi all Leysseri Floram llalensem fasciculus primus. Ilalae, Renger. 1796. 8. (2), 44 p., I tab.

$11337^{*}$ Wolf, Elias. De Pyrola umbellata. I). Goettingae 1817. 8.54 p.

$1.338^{*}$ Wolf, Ccorg Armin. De radice Caincae. D. Marburgi 1S31. S. 是 $\mathrm{p}$.

11339 * Wolf, Johann. Deutsclilands Gemüse. Gezcichnet und geatzt von Johum Samuel W'interschmidt dem Jungsten. Mangolelarten. (Beta.) Nurnberg, Winterselmidt. 1 S0 5. 4. Iv, 14 p., 14 tab. col.

$11340^{*} \longrightarrow$ Abljildung und Beschreibung des Wassermegerichs (Alisma Plantago L.) als eines neu emplolenen wirksamen Mittels gegen die Wasserselseu. Nürnberg, Tyroll, 1817. 4. 8 p., 1 tab. col. $(1 /$ th. $)$

113 1* (Wolf, Nathanael Mathacus von.) Genera et species plantarum vocaludis characteristicis defnita. Marienwerder, typ. Kanter, 1781. 8. $454 \mathrm{p}$. (Accedunt: Genera plantarum vocabulis eharacteristicis definita. S. I. 1776. 8. 177 p. - Concordantia botanica: Dantisci, typ. Muller. 1780. 8. 19 plag. dimid.)

143 '2* Wolf, Rudolf. Jahannes Gessner, der Freund und Zeitgenosse von Ilaller und Linné. Nach seinem Leben und Wirken dargestellt. Mit Gessner"s Bildniss (gestochen von II. Meyer). Zürich, Mleyer und Zeller. 1846. 4. 27 p., effigies Gessuer. $(3 / 10 \mathrm{th}$.

113 i.3" wolf, Christian, Freyherr von. Eutdechung der wahren Ursache von der wunderharen Vermelirung des Golreydes, dadurch zugleich der Wachsthum der Baume und Plantzen uberhaupt erlautert wird. als die erste Probe der Latersuehungen ron flem Wachsthume der Pllantzen zum drittenmalıle berausgegeben. Haile, Renger. 1750. 4. 140 \%., prael., 1 tal,

Prodiit primum, nj fallor, anno 1718 . Edilio anni 1725 a tertia ami tzöo non cliftert.

$1134 \mathbf{f}^{*}$ - Erlauterung der Enteckung der wahren Ursache von der wumlerharen femehrung les Getreydes, darinnen auf die Frimerungen, welehe daruber heraus kommen, geantwortet wird. Frankfurt und Leibzig 1730.4.44 p., praef.

(Editinuem [rimam jam anno 1718 prodiisse, docet dedieatio.)

$11343^{*}$ __ Allerhaud nulzliche Versuche zu gemauer Erkenntnis der Natur und liumst. Halle 1721. 3 Theile. 8.

$11346^{*}$ Veruunfige Gedanken von den Whirkungen der Natur llalle 1723. 8.

$1137^{*}-$ Vernunftige Gedanken yon den Absichten der uaturlielsen Dinge. llalle 1794. 8.

$11348^{*}$ Vernunflige Gedanken von dem Gebranche der Theile in Mensehen, Thieren und Pllanzen. Frankfurt u. Leipzig 1725. S (1) omnibus his libellis ef. Hall. Bibl. bot. 11. p. 152-1533.)

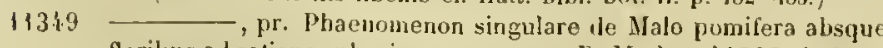
floribus ad rationes physicas revoeatum. D. Marburgi 1727.4.20 p (Respondens: Adum Ixstatt.) B.

(Ejusden de pono ex iruneo arboris enato dissertatio, in qua varia tradnntur ad theoriam vegetalionis plantarum facientia. exslat in Comment. Acad. Petrop. tomo ilil. p. $197-20 \mathrm{~S}^{2}$.)

11350 * Wolf, Emil Th. Die chemischen Forschungen auf dem Gebiete der Agrikultur und Pflanzenphysiologic. Ein Supplementband fur dic Lehrbucher der Agriculturcisemie, physiologischen Chemie und der rationellen Landwirthschaft. Mit sorgfaltiger Benutzumg der Originalabhandlungen und Scbriften ausgearbeitet. Leipzig, Barth. 1847. 8. vir, 549 p. $\left(2 \frac{1}{2}\right.$ th. $)$

$11351^{*}$ Wolff, Johann Friedrich. Commentatio de Lemna. Altdorfii el Norimbergae, Lechner. 1801. 4. 22 p.. 1 tab.
$113 \ddot{2} 2^{*}$ Wolf, Kaspar Friedrich. Theoria generationis. D. Halae 1759. 4. 146 p., 2 ab. - "l'heoria generationis. Editio nova aucta et emendata. Ilalac, Hendel. 1774. 8. Lxiv, 231 p., 2 tab. $(3 / 1$ th. $)$

germanice: Theorie von der Generation. Berlin 176\%. 8. 283 p.

11353 Wolfhart, honrad, graece Lycosthenes. Prodigiorum ae ostentorum chronicon. Basileae (1557.) folio. 670 p., ic. xylogr. i. 1. B.

1133 F $^{*}$ Wollebius, Lucas. Dissertatio medica de melhodo herhas lustrandi, cui annexa sunt corollaria quaedau anatmica. Hasileae 1711.4. 22 p. (Respoudens: Johun Gerhard Hose.)

$113933^{*}$ De llelleboru nigro. D. Basileae, ty]. Thumisius.1721. 4. $24 \mathrm{p}$.

113306 Wolter, Johann Chrisloph. Kurze fassliche und methodische Auleitung zur liestellung eines Kuchengartens. Alitau 1805. 8. 84 p.

$113 \ddot{3} 7^{*}$ Woodforde, James. A catalogue of the indigenous plienogamic plants, growing in the neighbuurhoud of Edinburgh; and of certain species of the class Ciryptogamia: with reference to their Jocalities. Edinburgh, Carfrae. $1821.12 . x 1,86$ p. $(3 s .6 d$.

$11358 \div$ Woodville, Hilliam. Mfedical botany, containing systematic and general descriptions, with plates of all the medical plants comprehended in the catalogues of the Materia medica, as published by the Royal Cullegre of Pliysicians of London and Edinburgh. London, Philipps. 1790-1793. Ill volt. 4. 578 p., praef, ind., 910 tab. tSupplement: il). 1794.4. 169 \%. tab. col. $211-274 .-$ Third $^{-}$ edition, in which 39 new plants have been introduced. The botanical descriptions arranged and corrected by llilliam Jackson Ilooker; the new merlico-botanical portion supplied by G. Sprutt. London. Bohn. 1832 . Voil. 4. $-1-15: 824$ p., appendis, 274 lab. col. - V: 157 p., ind., 39 ab. col. (sl. S.s.)

$11339 *$ Woodward, Samuel. A synoptical table of british organic remains: in which all the edited british fossils are systematically arranged, in accordance wilh the views of the geologists of the present day. etc. London, Longman. 4330 . 8. xit, 50 p., 1 tal. (5s.)

11360 Woolridge, $J$. The art of gardening. Third edition. London 1688. 8.278 p., 3 tab. B.

$11361 \div$ Wrangel, Friedrich Anton. Försok att narmare ulreda och bestamma Cardamine parvillora L. Slockholm, tỵ. Liudlıs Entia 1S23. $8.15 \mathrm{p}$

(Ur Kongl. Vet. Acad. Hani1. 1822; cf. supra in vace llahtenberg Nr. 108s9.)

$\$ 1362$ Wrede, E. Chr. C. Verzeichuiss meiner Rosen nach einer genauen systematischen Bestimmung. Dritle verbesserte Auflage. Braunscliweig 1814 . S. ( $1 / 5, h$.)

11363* Wredow, Johann Christian Ludwig. Tabellarissche Vebersicht der in Melilenburg wildwachsenden phanngamischen Pllanzengesehlechter, nebst einer allgemeinen Einleitung in die Pflanzenhunde. etc. Luneburg, Ilerold. 1807 . S. xı, 308 p. (1 th.)

1136 : $^{*} \longrightarrow$ Oekonunisch-technische Flora Melilenburgs, oder Beschreilung etc. Luneburg, llerold. $1811-1812$ 2 Bande. 8. 1: 1811. (Cl. 1-5.) xit1, 601 p. - I1: 1819 . Ersto Abilexilung. (Cl. 6-13.) vill, 614 J. ( 4 /h.)

11303 - Gartenfreund, ocler vollstandiger, auf Theorie und Erfahrung gegrundeter Unlerricht uber die Belaasdlung des Bodens und Erziehung der Gewachse im Kuchen- Obst- und Blunengarten, in Verbindung mit dem Zimner- und Fenstergarten, nebst einem Anhange uber len Jlopfenbau. Sechste Auflage, verbessert und vermehrt und mit ainer Anweisung zur Behandlung der Pllanzen in Gewáchshauseru versehen von Kurl Ilelm. Berlin, Amelang.

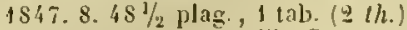

(Editio prima prodiit: Berlin isis. 8 .

$11360^{*}$ Wright, I'illiam. An butanical and medical account of the Quassia Simaruba, or tree which produces the Cortex Simaruba. (Edinburgh 1778.) 4. 9 p., 2 Lab.

(From the Trancactions of the Royal Society of Edinburgh vol. II. p. $73-81$; cr. Londun Medical Journal vol. Xit. p. 91-102.)

$11367^{*}$ Wuensche, Johann Georg. Enumeratio plantarum circa Vitebergam in aquis, loeis paludosis et bumidis praecipuarum nec non officinalium sponte crescentium cum praefamine Traug. Carol. Aug. Vogt. Wittenbergae. Zinmermann. 1804. 8. IVI, 101 p. ( $\%$, th.) 
1368* Wuertemberg, Paul Wilhelm, Herzog von. Erste Reise nach dem nördlichen Amerika in den Jahren 1822 - 1824. Stuttgart und Tubingen, Cotta. 1835 . 8. vi, 394 p., 1 mappa geogr. ( 2 th. $)$

$11369+$ Wuertz, Georg Christoph. Conamen mappae generalis medicamentorum simplicium secundum affinitates virium naturalium nova methodo geographica dispositorum. Argentorati, Bauer et Treuttel. 177 S. 4. 221 p., 1 tab.

$11370^{*}$ Wuestemann, $E . F$. Ueber die liunstgarinerei bei den alten Pömern. Vorlrag in zwei Sitzungen des Tburinger Gattenbauvereins zu Gotha im October und November $1 \$ 45$ gehalten. 1846. S. $32 \mathrm{p}$.

$11371^{*}$ Wuestenfeld, Ferdinand. Geschichte der arabischen Acrzte und Naturfurscher. Nach den Quellen bearbeitet. Gottingen, Vandenhocek et Ruprecht. 1840.8 . xv, 167 p. $(5 \%$ h.

$11372^{*}$ Wulfen, Franz Faver von. Cryplogama aquatica. Lipsiae, Scharfer. 1803. 4. 64 p., 1 tab. $(2 / 3$ (h.)

(Viri egreaii "lcones piclae fungorum (austriacorum) ineditae 113 tab. col. in 4 . servantur in Museo bolanico Vindohonensi.

$11373^{*}$ _ Plantarum rariorum descriptiones. Lipsiae, Schăfer. (Kühr.) 1805.4. 116 p., ind., 6 tab. (1 th.)

1137.* Wulff, Johann Christoph. Specimen inaugurale plantas XXII in Borussia repertas et nondum descriptas comprehendens. Regiomonti (1744.) 4. 20 p. Bibl.E. M.

$11373^{*}$ - Flora borussica denuo efforescens auctior. Cum figuris. Regiomonti et Lipsiae, Hartung et Zeis, 1765. 8. 267 p., praef., ind., I tab. (Struthiopteris germanica.)

$11376^{*}$ Wulf, Julius .Hichael Theodor. Neletemata circa vim propriam Belladounae analytice investigandam. D. Dorpati 1 \$34. 8. 32 p.

$11377^{*}$ Wunschmann, $F$. Deulschlands gefälichste Gifiplanzen naturgetreu dargestellt und aach ihren Wirkungen und Gegenmitteln beschricben. elc. Berlin, Logier. 1833. 8. vi, 58 p., 24 tab. col $(5 / 6$ th.)

11378 Wurfbain, Friedrich Sigismund. De Rubea tinctorum. D. Basileae $1707.4 .3 \frac{1}{2} \mathrm{plag} . \mathbf{B}$.

$11379^{*}$ Wydler, Henri. Essai monographique sur le genre Scrophularia Geneve, Barbazet. 1\$28.4. 50 p., 5 tab.

$11380^{*}$ Ueber dichotome Verzweigung der Bluthenaxen dicotyledonischer Gewächse. Halle, typ. Gebauer. 1843. 8. 40 p. 2 tab.

(Seorsim impr. ex Limuaca, rol. Xill.)

11381 Wynne, ciabriel. De cortice peruviano, usuque ejus in morbis febrilibus. D. Ediaburgi 1779. 8.48 p. B.

\section{X.}

11382 Yannez y Girona, Augustino. Elogio bistorico de Mariano Lagasca y Segura. Madrict 1840.8.

11383* Yates, William. Elemens of natural plifosoplyy and natural Jistery in a series of familiar dialogues, designed for the instruction of indian youth. Galculta 1825. 8. 100 p. (Sanserit.)

1138: Young. Hortus Epsomensis, or a calalogue of plants cultivated in the Epsom uursery. Part I. By Charles, James and Puter Young. uurserymen. London 1S2S. 19. $55 \mathrm{p}$.

$11383^{\circ} \div$ Young, Arthur. Yoyages en France pendant les années 17871790 entrepris plus particulièrement pour s'assurer de l'élat de l'agriculture, des richesses, des ressaurces et cle la prospèrité de cette nation. Traduit de l'anglais. Seconde édiliun, Paris, Buisson. 1794. 111 voll. 8. - 1: 492 p., 1 carte. - IJ : 408 p., 1 carte col. - Ill: $\$ 16 \mathrm{p}$.

$11386 \div$ Voyage en ltalie pendant l'anıée 1789 , traduit de l'anglais par Françoss Soulés. Paris, Fuchs. 1796. 8. v11, 375 p.

$11387 \%$ Yvart, Jean Augustin Victor. Coup d'oeil sur le sol, le olimat. el l'agriculture de la France, comparée avec les contrécs, qui l'aroisinent et particulièrement avec l'Angleterre. Paris, typ. Iluzard. 1807.8. 111 p., 1 carle.

$11388 \div$ Yvart, Jean Augustin Victor. Objet d'interes public, recommandé à l'atlention du gouvernement et de tous les amis de l'agriculture. (Sur l'influence qu'exerce le vinettier ou épine-vinette (Berberis vulgaris) sur la fructification du froment.) Paris, Huard. 1816. S. 92 p. ( 1 fr. 50 c.)

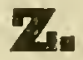

11389 Zachar, Daniel. De corona de spinis Mutthaei. D. Rostockii 1757. 4. H.

$11390^{*}$ Zahn, Johann Heinrich. Dissertatio inauguralis de Rhododendro chrysantho. Jenae 1783,4,24 p.

11391 zallinger, Johann Baplista. De ortu frugum ex mechanismo plantarum. D. Oeniponli 1769. 4 .

* germanice: Abhandlmaz von dem Ursprung der Früchte aus ihrenu bau hergeleitet. Als dem Lateinischen uherselzt yon Joham, Grafen van Auersperg. Augsbury, kilett. 1750. 8.96 p.

11392 - De incremento frugum. D. Oeniponti 1771. 4

* germanice: Allhandlung voil dem Wachsthum der vruclue aus dem Bau der Planzen hergeleitet. Aus dem Lateinjschen nbersetzt voil Johann, Grafen vion Auersperg. Augshurg, Klett. 1781. \$. 131 p.

$11393 \div$ De morbis plantarum cognuscendis el curandis dissertatio ex phacnomeusis deducta. D. Oeniponti, typ. de Trathem. 1773. S. 137 p., appendix. (Respondens: Karl Burger.) Bibl. Sangall.

germanice: Ahhandlung uber die Krankheiten der Pllanzen, ihrer (sic!) Kentuiks und liejlung. Aus dem Lateinisclken ubersetzt von Johann, Grafen von Auersperg. Augshurg, Klell. 1779. 8. w. $143 \mathrm{l}$

11394* — Die Krankheiten der Bäume, derseltjen Kennzeichen, Ursachen und Jleilung. (Aus dem Lalcinischen ubersetzt?) von Johann, Grafen von Suersperg. Brunn, typ. Gastl. 1809. 8. 2i p. $(1 / 6$ th. $)$

113937 Zaluzianslyy à Zaluzian, latine Zaluzanius a Zaluzaniis, Adam. Methodi herbariae libri tres Adami Zaluziansky à Zaluzion, Med. D. Pragae, in officina Georgii Dacziceni anto Dominin MDXCII. 4. (122) foll. et 1 tabula (ad foll. 69 pertinens), Orcheos distributionem sislens, Bibl. Deless., Rivin., Haller., Bibl. univ. Basil. - Adami Zaluzanii a Zaluzaniis Mlethodi herbariae libri tres. Prorlit Francofurti e Collegio Pallheniann. 1604. 4. $(120)$ foll. et 1 tabula, Orcheos distribulionem sistens. Bibl. Berol., Goett., Cand., Vind., Basil., Banks., Haller.

(De hoc opere optime disseruit ill. Roeper in Flora diario thotauieo Ratisbonensi, 1835. p. 225-236. Bene monuit, editiones minime praeter prdefixas praefationes inter se differre, quod ipse ego accurata didici instiluta comparatione. Signum chartae impressum utriusque editionis est equus saltans. Pagina decinat tortit

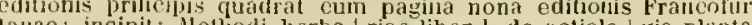
tanae incipit: Mellodi herba riae liber 1 . de aetiolo g gia plantarum. IQuid sit herbaria Cap. l. I Herbariae nomine vulgo comprehenditur | permistil... Exemplar Delessertianum cmtum cst cx libris Sprengelianis, el gerit in fronte propria illustris antoris manu hace verba: "Doctrina et virtute excellentissimo Viro Domino Melchior Zostelin medicinao lonctori et mallsem. Professori publ. in Academia Vitenhergensi, Domino amico suo, in testimonium benevolentiato mutuae ddt autor." In calce achacret, sed nostram rem non tangit: "Oratio pro inatomia et instaurationo totius studii medici in intcly to regno Boheniae. Ad itviclissinum imperatorem Rudolphum Seeunlum. Caesarem Allgustum, Adomi Zaluzanï a Zaluzanis N. Voctoris. Pragae, typ. Venceslai Marini a Genczicz. 1600. \&. (12) foll. Utinall olementissjmus Roeper universam simfli modo peragrarel literaturam botaticam, nobisalue in compeudinso libello ac modico offerret pretio. ul tandem vile melum opus feliciter supprimeretur, in quo oonscribendo oum: juventute qua equae mea erant et esso debebant consumsi!?

11396 Zamboni, Giuseppe. Parnassi botanici fragmenta. Florentiae 1721.4. H.

(Num differant nescio a Seguierio citathe "Iculnes plantarum CCV cum earumdem virtutibus versibus exaratis, in 4.p llarun iconum exemplar unicum numc apud D. Joan. Anton. Targionium medioum Florentinum asservatun edendum curavit Petr. Ant. Hichelius, qui subinde ex illarum aere novas pro opere quod tuno parabat tle Novis plantarum generibus tabulas contlavit. S.) 
11397 (Zamzelius, Abraham.) A. S. H. Blounsterhrants af de allmálinaste och márkvärdigaste uti Neriket befíntliga waxter hopflálader. Örehro 1760.12 .84 p. B.

p. 2 (Fomell autoris habet Dryander e Thunberg Flora Strengnes.

$11398^{*}$ Zanardini, Giovanni. Syuopsis Algarum in mari adriatico hucusque collectarum, cui accedunt Monographia Siplsonearum nec non generales de algarum vita el structura disquisitiones cum tabulis auctoris manu ad vivum dejpictis. Taurini, ex regio typograplan.18. 1841.4 .153 p., 8 tab. col. (Serorim impr. ex Memorie della R. Accad. di Torino, ser. ll. tom. IV. p. 10:-2066.

$11399^{\circ}$ — Saggio di elassificazione naturale delle ficee, aggiunti nuovi studii sopra l'Anlrosace degli antichi, con tavola minjata ed enumerizione di tutte le specie seoperte e raccolte dall' autore in Dalmazia. (Ëlizione di cento sole copie.) Venezia, Iỵ. Girolano Tasso. 1843. 4. 64 p., 1 tab. col.

(Bot. Zeitung $18 \%$. p. 40 10 -108.)

11,00 t - Sulle corallinee (polipaj calciferi di Lumouroux) Rivista. Venezia, typ. Tasso. 1844. gr. 8.38 p.

11 iol Zander, Johannes. Primitiae viridarii medici Steltinensis. Selliui 1672. Desıd. Banks.

11402 Zannichelli, Giovanni (Gian) Girolamo. Gatalogus plantarum terrestrium et marinarum, quitus domus ejus ornatac erant in festo eorporis Christi. Venetiis 1711 . 1712 . S.

$1 / 403^{*}$ De Myriopliyllo pelagico, aliaque marina plautula anonyma ad Christinum Ilartinellium epistola. Venetiis, apud Andrean Poletum. 1714. 8. 17 p., 3 tab.

$1140 \mathbf{k}^{\circ}$ De Rusco, ejusque medicamentosa praeparatione ad Franciscum Mariam Nigrisolum episłola. Venetiis, apud Bunifacium Viezzerum. 1727.8.15 p., I tab.

$11: 05^{*}-$ Opuscula botanica posthuma a Joanne Jacobo filı iu Jucem edita. Veneliis, typ. Dom. Lovisa. 1730. 4.87 p., praef (Insunt quingue ilinera botanica per lstriam of insulas adjacoltes: Montis Caballi; slirpium in Monte Veltarum agri Feltrin sponte nasecntium descriptio; plantarum Montis Summani agr Vicentini descripton; per montes Euganens.)

$11 \mathrm{i}^{\circ} \mathrm{f}^{*}$ Istoria delle piante che nascono ne' lidi intorno a Venezia; opera postuma di Gian Girolamo Zannichelli, accresciula da Gian Jucopo. figliuolo dello stesso. Venezia, A. Bortoli. 1735. folio. 290 p., praef., 78 tab.

(sunt 311 icones, quatuor in singula tabula aenca.)

11 ;07: Zannichelli, Giocami Jacopo. Letlera intorno alle facolta dell' ipjrocastano. Venezia, 1yp. Tommasini. 1733.4. 15 p., 1 tab.

$11,08^{*}$ - Enumeratio rerum naturalium, quae in Nusaeo Zunnichelliano asservantur. Venetiis, Antonius Bortolus. 1736. 4 $126 \mathrm{p}$.

- Osscrvazioni intorno all abuso della Coffea ed alla virtuto di un nuovo The veneziano. Venezia 1755. 4. н.

$19140^{*}$ Zanon, Antonio. Dell agricoltura, dell' arti e del conmercio, in quanto unite contribuiscono alla felicita' degli stati, Lettere. Venezia, typ. Fenzo. 1763-1771. VHll voll. 8. cum effigie autoris. Bibl. Goett.

$1\{1\}$ Delle coltivazione c del uso delle patate e d'altre piante comestibili, Veuezia 1767.8. H.

$11 / 12 *$ Zanon, $B$. Intorno un punto della nuova dottrina del Signor $G$. Pelletier relativamente all influenza elettrochimica delle varie terre sulla vegetazione. Belluno, 1yp. Deliberali. 1840. 8. 10 p.

11413 Zanoni, Giacomo. Indice delle piante portate nell' anno $1652 \mathrm{nel}$ viagrio di Castiglione ed altri monti di Bologna. Bologna, Ferroni. 1652. Folio 1 plag. Bibl. Reip. Paris.

(Hall. Bibl. bot. 1. p. 486 habet titulum latinum "Observationes aliquac circa plantas unvas el non vulgares in Bolloniensi agro thascentes. Bononiae 1652. folio.)

IJ1' Descrizione d'alcune piante nuove trovate da Giacomo Zanoni. s. I. el a. 2 p., 5 fig. s.

$111133^{*}$ _ - Istoria botanica di Giacomo Zunoni, simplicista et sopraintendente all' Horto publico di Bologna, nella quale se descrivono alcunc piante de gl' antichi, da moderni con altri nomi proposte; c molt' altre non piu osservate, e da varie reggioni del mondo venute, con le virtu e qualita della maggior parte diesse, efl in figure al vivo rappresentate. Bologna, per Giosello Longhi. 1675. folie. 211 p., ind., 80 tab.
11:16" Zanoni, Giacomo. Rariorum stirpium listoria ex parte olim edita. Nunc centum plus tabulis ex commentariis auctoris ab ejusdem nepotibus ampliata. Opus universum digessil, latime reddidit, supplevitque Cajetanus Ifontius. Bononiae, Ivp. Laelii a Vulpe. 1742. fulio. 247 p., praef., vita Zunonii, effigies Zunonii, 185 tab.

$11417^{*}$ Zantedeschi, Francesco. Dell' inlluenza dei raggi solari rifratti dai vetri colorati sulla vegetazione delle piante e germinazione de' semi Memoria. Venezia, Antonelli. 1843.4.26 p.

Ejus "Piante rare rinvenute in un vlaggio botanico alle alp! Bresciane e Bergamaschen exstant in 'Commentarj dell' Ateneo di Brescia per 1825.)

114 $18^{*}$ Zawadski, Alexander. Enumeratio plantarum Galiciae et Bucowinae, oder die in Galizien und der Bukowina wildwachsenden Plinuzen mit genauer Angabe ilırer Standorte. Breslau, Forn. 1835. 8. $x \times 1 v, 200 \mathrm{pe}(1$ th. $)$

$11419^{*}$ Flora der Stadt Lemberg, oder Beschreibung der um Lemberg wildwachsemlen Pflanzen nach ihrer Blutezeit geordnet. Lcmberg, Nillikowski. 1836. 8. xis, -338 p. $\left(1 \frac{1 / 3}{3}\right.$ h. $)$

$11120^{*}$ Zeipel, Carl van. Zwei Alusensohme und ein Spassvogel, ader Linneus, Arledi und Rudbeck. Universitátsskizzen. Aus dem Scliwedischen. Berlin, Morin. 1844. 8.224 p. (1 th.)

11'21* Zeitner, Seneca Friedrich. Aualysis chemica atque usus seminunı Crotonis Tiglii. D. Kiliae 1827.4. 24 p.

$14422^{*}$ Zendrini, Bernardo. Trattato della Cluna China. Venezia 1715. 8.

$11423^{*}$ Zenker, Jonathan Karl. Dic Pflanen und ihr wissenschaftliches Studium uberhaupt. Ein botaniscler Grundriss zum Gebraucho academischer Vorträge und zun Sellsststudiun. Eisenach, Bareche. 1830. 8. xIt, $278 \mathrm{p} .(11 / 3 \mathrm{th}$.

11 '21* Merkantilische Waarenhunde, oder Naturgeschichto der vorzuglichsten Handelsartikel. Durch illuminirte Abbildungen theils nach der Natur, theils nach den besten Originalien erlatutert vou Ernst Schenk. Jena, Maukc. (Schmid.) Drei Bănde oder 9 llefte. 1831-1835. 4. - I: Heft 1-4. I831. vi, 136 p., tab. col. I-24. - Il: Heft 5-8. 1832. vi, 155 p., tab. col. $25-48 .-$ ll] : Heft 1 . 1835. 26 p., tab. col. $49-54 .\left(11 \frac{1}{3}\right.$ (h.)

$11423^{*}$ Beitráge zur Naturgeschichte der Urwelt. Organische Reste (Petrefakten) aus der Altenburger Braunkohlen-Formation, dem Blankenburger Quadersaudstein, jenaischen bunten Sandslein und böhmischen Uebergangsgelirge. Jena, Mauke. 1833. 4. vın, 67 p., 6 tab. col. ( 3 th.)

$11\left\{26^{*}\right.$ Plantae indicae, quas in montilus Coimbaturicis coeruleis, Nilagiri sive Neilgherries dictis, collegit Bernhurdus Schmid. Decas I. Jenae, A. Schmid. (Paris, Treuttel et $\left.W^{\prime} u ̈ r z.\right) ~ 1835$. folio. 10 p. 10 tab. col. (4th.)

$11+27^{*}$ Historisch-topographisches Taschenbuch von Jena und seiner Umgebung besouders in naturw issenschaflicher und medicinischer Beziehung; mit einem Plane von Jena und einem geognostischeu Profile. Jena, Frommann. 1836. 8. $x, 338$ p., 2 tab. $(12 / 3$ th. $)$

(Flora Jenensis: p. 238-286.)

$11428^{*} \longrightarrow$ Flora von Thüringen und der angrauzenden Provinzen. Ileft 1-88. Jena (Mauke.) 1836 - 1848. 8. 880 tab. col., text. $\left(29 \frac{1}{3}\right.$ th. $)$

(Tabulas delineavit Ernst Schenk; texlum post Zenkeri ohitum scripsit D. F. L. van Schlechtendul, nunc Christian Eduard Lange-
that.)

11429* Zenneck. Oekonomische Flora, ofler systematisch tabellarische Beschreibung von 1000 fast uberall iu IYeutschland wildwachsenden phanerogamischen Pílanzen. Stuttgart und Prag, Calve. 1822. 4. $x, 55$ p., 1 tab. $(1 / 3$ lh. $)$

11430 Zerapha, Stefano. Florae Melitensis thesaurus. Fasciculus 1. Nelitae 1827.4.

(Cf. Bertoloni Annali di storia naturale, tomo Il. p. 33̈s-365.)

11431 Zerzog, J. F. Funfundzwanzig practische Hauplregeln mit einfachen kurzeı Erlâuterungen uber Ablulfe der berrschenden Kartoffelkrankheiten. Zweite Auflage. Bayreuth, Buchner. 1846. 8 vin, 80 p. $(1 / \mathrm{t} t h$.

11432* Zetl, Joseph. De Nicotianae utilitate el noxis. D. Landishuti s. a. 8. $30 \mathrm{p}$.

11433 Zetterstedt, Johan Wilhelm, pr. De foecundatione plantarum. D. I-III. Lundae, typ. Berling. $1810-1812.4 .42$ p. w. 
11434* Zetterstedt, Johan IIilhelm. Resa genom Sveriges och Norriges Lappmarker, förattad àr 1\$21. Lund, typ. Berling. 1822. Il voll. 8. - I: $\mathbf{x y}, 266$ p., 3 tab. col. $-11: 231 \mathrm{p}$.

(Register ofver vétster, fume under resun i Lappmarken, vol. II. p. $22 i-231$.

$11435^{*}-$ Resa genom Umeå Lappmarker i Vesterbottens Län, år 1832. Örebro 1833. 8.398 p., 4 tab. (3 Rdr.)

$11436^{*}-$ Conspectus plantarum in horto botanico et plantatione universitatis Lundensis praccipue amnis $1834-1837$ obviarum. Lundae, typ. Berling. 1838. 8. 109,2 p.

11:37* Zeyher und Georg Chr. Roemer. Beschireibung der Gartenanlagen zu Sclwwetzingen. Nannbeim, Bender. 4809. 8. vut, 96, 95 p., 8 tab. et iconogr. borti. $(32 / 3$ th. $)$

$14438^{*}$ ___ Verzeielniss der Gewiebse in Grossherzoglichen Garten zu Schwetzingen. Maunheim, Sehwan u. Gutz. 1818. 8. 207 p. $(15 \%$ th. $)$

11439* - und $J$. G. Rieger. Sclswezingen und seine Gartenaulagen. Nanuheim, Schwan und Goetz. (1826.) 8. Vur, 182 p., 8 tab., I Plan. ( 3 th.)

11440 Zieger, Christian Gotllob. De vita inter plantas optimo sanitatis tuendae praesidio. Lipsiae 1757.4.12 p. B.

114 Ziegler, Franz ron. De Jiquore C. C. succinato. D. Rintelii 1743. 4. 3 plag. (Respondens: Kaht.)

$11142^{*}$ Ziegler, Louis. Die officinellen Gew tichse in tabellariseher Uebersicht nach dem hunstlichen und naturlichen Systeme geordnet. Für angehende Vlediciner und Ploarmacenten. Lannover, Kius. 1845. 4. $42 \mathrm{p} .(1 / 2$ th. $)$

$11443^{*}$ Ziegra, Christian Samuel. De morte plantarum. Disputatio physica. Wittebergae, typ. Wilehii. 1680.4. (24) p. (Respondens: Johann Benjumin Reising. I

1144: Zigno, Achille de. Sopra aleuni corpi organici che si osservano nelle infusioni Cenni. Padova, typ. Cartallier e Sicca. 1839.8.25 p.

1 lq43 Zigra, Johann Hermann. Anweisung zur kiultur aller Kuchengewachse und der vorzüglichsten luchenkräuer, geschrieben fur das Klima Kur - Liv - und Esthlands. Riga 1800. S. 144 p. leltice : vertente K. H. Prechl. Riga 1846. 8

11446 Der Raumgartner, odler ausfubrliche Anweisung zur Obstbaumzucbt, gesehrieben für das nortlielie klima. Riga is03. 8. - Neue Ausgabe: Der nordische Baumgartuer. liga 1520. 8. Lellice: vertente Y. Stobbe. Riga 1803.8 . Trautv. rassice: vertente Lysarch, cogmomine hoenigh. ỉetropoli 1803.8. Trautv.

11447 Ausfubrliches Verzeichniss uber 2000 Species der seltenen exotiselsen Pllanzen, die Johann Hermanu Zigra 1804 auf seine Kusten in Russland aus England selbst eingefuhrt hat. Riga 1805.8.40 P.

11448 Der nordische Blumengartner. Riga 1806. $8.204 \mathrm{p}$. rassice: vertente Poul con Schicartz. Mosquar: 1816. 8. Trautv.

$11449 \div$ Oekonomisch-praktisches llandbuch uber Gemuseund llopfenbau, und Kultur der Ananas etc. bearbeitet furs Russische Reich. Riga 1808. 8. - Zweile verbesserte Auflage: Oehonomisch praktisches Handbuch der Gartenkunst. Riga 1816.8. rossice: vertente Paul von Schucurl. Nosfline 1818. 8. Trautv.

11430 Ausfuhrliches Verzeichniss derjenigen Obsthame und Straucher, welche in Riga in dem Garten von J. II. Zigra gezogen werlen. Riga 1817.4 .28 p.

11431 - Ausfuhrliches Verzeichniss derjengen Obsthiume und Straucher, desgleichen der nordamerikanisehen Bäume und Strâucher, perennirenden Blumenpflanzen nnd einer Auswahl der schonsten Pflanzen fur Treib-und Gewtiehshänser, die in Riga im Garten von J. H. Zigra kultivirt werden. Nitau 1819.4.20 p.

11402 - Tordischer Blumenfreund, oder Repertorium des Wissenswurdigsten zur Erziebung der beliebtesten Blumen und exotischen Ziergewächse. Riga 1924.8.417 p., 1 tab.

$11453^{*} \longrightarrow$ Dendrulogisch-ókonomisch-technische Flora Jer in Russischen Kaiserreiche bis jetzt lekannten Baume und Straucher, nebst deren vollstandiger Kultur etc. Dorpat, typ. Lindfors. 1839. 2 Bande. $8.461,393$ p.

$11404^{*}$ Zimmermann, Ferdinand Joseph von. Gundzuge der Phytologie zum Gebrauche seines offentlichen Vortrags entworfen. Wien, Heubner. 1831 . 8 . rxw , 702 p. $(3 \mathrm{l} / 3$ th. $)$

Pritzel, Thes, lit. bot.
11450* Zimmermann, Johann Georg. Das Leben des Herrn von Haller. Zurich, lleidegger et Co. 4755. 8. (36), $430 \mathrm{p}$

114506 Zinker, Georg. Bemerkenswerthe Beobachtungen und Erfahrungen über die Kartotrelkranklıeit. München, Franz. 1847. 8. 16 p. $(1 / 30$ th. $)$

$11457^{*}$ Zinn, Johann Gottfried. Observationes quaedam Lotanicae et anatonicae de vasis subtilioribus oculi et cochlea auris internae. Goettingae, Vandenhoech. 1753.4.41 p. (Wiservationes de caulibus fasciatis et variis monstrosis formis p. $1-13$. ?

$11458^{*}$ Catalogus plintarum horti academici et agri Gottingensis. Gottingae, Vaudenlueck. 1757. 8. 441 p., praef., ind.

11459 zippe, F. X. M. Die Steinkohlen, ihr Werth, ihre Wiclutigkeit in Allgemeinen und ibre Verbreitung in Bohmen. Prag, Borroseh v. André. 1842. gr. $8.31 / 2$ plag., 4 lab. folio. $(5 / 8$ th. $)$

$11: 60$ Zoelner, Basilius. De Succino. D. Lipsiae 1604. 4. Boehmer.

14:61* Zollikofer, C. T. Versuch einer Alpenflora der Schweiz, in Abbildungen auf Stein, nach der Natur gezeichnet und beselırieben. Tentamen Florae alpinae llelyetiae ete. Ileft I. St. Callen, Huber et Cu. 1828. folio. $\langle 20\rangle_{\text {[1., }} 10$ tab. col. $\left\{2 \frac{1}{2}\right.$ th. - nigr. ${ }^{11 / 12}$ th. $\rangle$

$11462+$ Zorn, Bartholomaeus. Botanologia medica, seu dilucida et brevis manuduetio ad plantarum et stirpium tam patriarum ruan exeticarum in officinis pharmaceuticis usitatarum cegnitionem, oder Kurze Anweisung, wie dirojenigen Krăuter und Gewachse, welche in der Artzwey gebrauchlich und in den Apothecken befindlich, zu des Jlensclıen Nutzen und Erhaltung guter Gesundheit honnen angewendet werien. Berlin, Pape. 1714. 4. 740 p., praef, ind., 5 tab.

$11463^{*}$ (Zorn, Johannes.) lcones plantarum medicinalium. Abbiledungen von Arzueigewachsen. Centuria 1-Y. Nurnberg, Raspe. 17591784.8 .336 p., 500 tab. col. (16 th. - col. 48 th.) - " Zweite Auft. Centuria I-VI. Nuruber Raspe. 1784-1790. 8. $x$ p., 600 tab. cul. (Texus est latimus et germanicus a Johanne Zorn scriptus.)

$11461^{*}$ Zosimi Panopolitui de zythorum confectione fragmentum nunc primum graeee ac latine editum. Accedit historia zythorum sive cerevisiarum, quarum apud veteres mentio fit, scripsit Christion Goltfried Gruner. Sulislyaci, typ. Seide]. 1814.8. x, 118 p. (1/2 th.)

$11465^{*}$ Zschocke, Heinich. Jie Alpenwalder. Fur Naturforscher und Forstmänuer. Tubingen, Cotta. 1804 . 8 . xiv, 240 p. $(5 \%$ th. $)$

$11466^{*}$ Zsigray, Farl Ludwig. Enumeratio Centaurearum Hungariae. D. Pestini 1838. 8. 13 p.

$11467^{*}$ Zuccagni, Altilio. Dissertazione concernente l'istoria di una pianta panizzabile dell Abissinia, conoseiuta da guei popoli sotto il nome di Tel. Firenze, typ. Vamni. 1775. 8. vu, 45 p., 1 tab.

$11468^{\circ}-$ De naturali liliorum, quae ante simulacra Deiparae loeantur, fructilicatione, veluti prodigium evulgata. (Floreatiae 1796.) 8. (16) p. Bibl. Webb.

$11469 \div$ Lettera indirizzata al Signor Guiseppe Antonio Cavanilles (sepra i fiori della Lopezia racemosa.) s. I. et a. 8.11 p., 1 tab. col. (Estratto dal Ginruale Pisano tom. V. Nr. 14.)

$1470+$ Centuria prima ohservationum botanicarum, quas in horto regio Florentino ad stirpes ejusdem novas vel rariores illustrandas instituit. (Florentiae 1806 .) 4. (25) foll., 1 tab.

$11571+(\longrightarrow$ Synopsis plantarum, quae vireseunt in horto botanico Nusei R. Florentini hoc anno 1806 . (Florentiae, typ. Didot. 1806.) gr. 8. LXIX p.

$14472^{*}$ Zuccarini, Joseph Gerhard. Monographie der amerikanischen Oxalisarten. Munchen, typ. Seidel. 1825. 4.60 p., 6 tab. - "Nachtrag zu der Monographic ter amerihanischen Oxalisarten. ib. 1831. 4. 100 p., 3 lab.

(Seorsim impr. ex Denhschriften der Munchner Akademie ter Wissensehaften.

$11: 73^{*}$ - Flora Iler Gegend um Munchen. Erster Theil. Phanerogamen. (Class. I-XI.) Munchen, Lindauer. 1829. 8. 418 p. $(11 / 3$ th.

$114\}^{*}$ Characteristik der deutschen Holzgew ichse im hattlosen Zustande. Hit Abbildungeu von Sebastiun Minsinger. Munchen, (Cutta.) $1829-1831,2$ Hefte. 4.32 p., 18 tab. col. $(52 / 3 t h$. $11470^{*}$ Ueber die Vegetationsgruppen in Baiern. Eine Redle, gehalten in der oflentlichen Sitzung der Kgl. baierschen Akademio 
der Wisseuschaften am 24. Aug. 1833. München, typ. Püssenbacher. $1833.4 .26 \mathrm{p} .(1 / 3 / h$.

$11476^{*}$ Zuccarini, Joseph Gerhard. Leichfasslicher Uuterricht in der l'hanzenkunde fur den Burger und Landmann und zum Gebraucle in Gewerbsschulen. München (Landshut, Thumann.) 1834. 8. Iv, $506 \mathrm{p} .(2 / 3 \mathrm{th}$.

$11477^{*}-$ Naturgeschichte des Pflanzenreichs. Kempten, Dannheimer. $1843,8.322$ p., praef. ( 1 th. $)$

(Etiam inscribitur: $J$. $A$. H'agner's llaudbuch der Naturgeschichte, Banil 11.

11478* Zucchini, Andrea. Sopra la Luteola sativa, pianta, che sotto il volgar nome di Hietoli gialla da tempo immemorabile si coltiva, ed $e$ in commercio per la tintura nell' agro Cortonese. s. l. 1779. 8. 49 p., I tab. Bibl. Goett.

$11479^{*}$ Zueckert, Johann Friedrich. Die Naturgeschichte und Bergwerksverfassung des Oberharzes. Berlin, Nicolai. 1762. 8. 300 p.

$11480^{*}$ Die Naturgeschichte einiger Provinzen des Unterharzes. Berlin, Nicolai. 1763.8. 212 p.

$11481^{*}$ - Materia alimentaria in genera, classes et species disposita. Berolini, Mylius. 1769. 8. $427 \mathrm{p}$.

$11482^{*}$ - Von den Speisen aus dem rflanzenreich, oder zwote Fortsetzung seiner Ablandlung von den Nahrungsmitteln. Berlin, Mylius. 1778. 8. $292 \mathrm{p}$.

$11483^{*}$ Zunck, Hermann Leopold. Die natürlichen Pflanzensysteme geschichtlich entwickeit. Eine von der plilosophischen Facultat zu Leipzig gehronte Preisschrift. Leipzig, llinrichs. 1840. 8. vi, $208 \mathrm{p}$ $\left(1 \frac{1}{6}\right.$ th. $)$

1148: Zuppinger, Ferdinand. Die glüchlich entulechte Irsache der Kartolfelkrankheit, und das zuverlassige leiehte Nittel zu sofortiger bleibender Deseitigung dieser allgemeinen Plage der Volher, nebst sehr wichtigen Andeutungen uber Gahrung und Anstechung. Zürich, Orell, Füssli et Co. 1847.8 .29 p. $(8 / 15$ lh. $)$

$11483^{*}$ Zwenger, Konstantir. Nonnulla de Catechino. D. Gissae 1841. $4.18 \mathrm{p}$.

$11486^{*}$ Zwierlein, $K$. A. Deutschlands Eichbaum mit seinen höchst wirksamen Heikraften, vorzuglich in den Früchen durch 48 jährige Erfahrung bestatigt. Leipzig, Boumgartuer. 1824. 8. $\mathrm{x}, 117 \mathrm{p}$ $(1 / 2$ th.

$11487^{*}$ Zwinger, Friedrich. Positiones anatomico-botanicae. Basileac, typ. Decker. 1731. 4. $11 \mathrm{p}$.

$11: 488^{*}$ Theses anatomico-botanicae. D. Basileae, typ. Decher 1733. 4. 8 p. (Respondens: Johann Heinrich Rippelius.)

11489 Zwinger, Johann Jakob. Dissertatio meilica inauguralis de valetudine plantarum secunda et adversa. Hasileae, apud Joh. Jac. Genathium. 1708, 4. Rivin.

Exstat etiam in Theadori Ziringeri Fasciculo dissertationum medicarum selectiorum p. 309-3̈̈8.)

$14: 90^{*}$ Zwinger, Theodor. Theatrum botanicum, das ist, neu vollkommenes Kríuterbuch, erstens an das Tagesliecht gegeben von Bernhurd Verzascha, in eine ganz neue Ordinung gebricht, auch melir als umb die hellite vermehret unl verbessert dureh Theodor Zucinger. Basel, Jakol, Bertsche. 1696. folio. 995 l., ic. xylogr, i. 1. - ${ }^{*}$ Theatrum botanicum, das ist, Vollkommenes Kräuterhuch, worinnen allerhand Erdgewachse elc. Itzo ubersehn und vermehr durch Friedrich Zwinger, des seligen Autors $[+1724]$ Sohn. Basel, Bischoff. 1744. folio. (6) foll., 1216 p., ind., ic. xylngr. i. t.

(Editionem primam Verzoschae vide supra Nr. 10713. Sunt icones, quibus Camerarius in Epitome usus fuerat, of vires mediche, el opus ipsum Mallhinli, per Camerarium et lerzascham correctum. Editionem habet $\mathrm{Zwingerianam} \mathrm{Seguerus:} \mathrm{Basileae,} \mathrm{apul} \mathrm{Joh.} \mathrm{Phil.}$ Richterum, 1690 . folio.

11 \$9 __ Lucubrationes academicae circa plantarum doctrinan in genere, cum continuatione. Basileae 1698. 4. Rivin.

11,92 pr. Dissertatio botanico-medica, Amygdalarum fructus analysin exhibens. Basileae 1703. 4. (Respontens Johaun Uirich Hegner.) Rivin.

(Exstat etiam in Thendori Zmingeri Fasciculo dissertationum medicarum selectiorum p. 112-162.

$11493^{*}$ Fasciculus dissertationnm medicarum selectiorum Theodorus Zwingerus, cujus privata cura, institutione et ausilio, a suis quaeque auctoribus conseriptae, publiceque ventilatae fuerunt, revidit, emendavit, auxit. Basileae, König. 1710.8 .649 p.
1149:"Zwinger, Theodor. Examen plantarum nasturcinarum, quo vegelabilium horum structura naturalis, qualitates, vires at!jue usus in vita lumana salubris breviter ac dilncide explicantur. D). Hasileae, typ. Thurnisiorum. 1714. 4. vur, 92 \%. (Kespondens: Johann Radolpht Hieg.)

$11495^{*}$ - ur. De Cymbalaria. D. Hasileae, typ. Lude. 1715. 4. 20 p., 1 tal), col. (Respondons: Johmm Ileinrich Ilermasu.) - "Impr. cum IVepfer Cicutae aquaticae historia. Hasilea 1716.4. - "Lugduni Batavorum 1733.8. p. $459-481$.

$11496^{*}$, pr. De Thee helvetico. D. Impr. cum IVepfer Cicutae aquaticae historia. Basileae 1716. 4. - "Lugduni Batavorum 1733. 8. p. 423-458.

\section{Dioscorides.}

(Ilall. Bibl. bot. I. p. 77-87. - Spreng. Ilist. rei herb. I. p. 15 I -193. - Ioffmann, Lexicon bihliographieun ser. graec. vol. Il. p. 111-121. (ell. Il. vol. l. p. 599-608.) - Choulant, Ilandluuch der Bucherkunde fur die áltere Medicin. Zweite Auflage. Leipzig 1841. 8. p. $76-83$.)

\section{Editiones graecae:}

$11497^{*}$ Dioscorides. Editio princeps: IIEAAKIOY 1 LIOSKOPIJOY

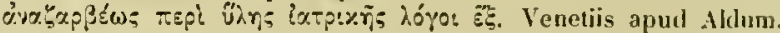
Mense Julio. M.ID. folio. Titulus, 5 foll. ind., 129 foll. textus Dioscoridis, 48 foll. textus et scholia Nicundri. Bibl. univ. Lips. et Goett. (IJuin Repert. Nr. 6257.)

(III foll. it Jabetur epistola inscripta: "Aldus Manutins liomauus Ilieronymo Ilonato patritio Veneto $S$. D. et sienata: "Venetii

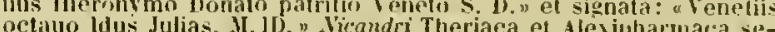
octino ldus Julias. M. ID. "Neandri Theriaca et Alesipharmaca sefiunterantur. Omnia quae tamen monnunguam in exemplarihus desiderantur. Omnia to folia quadrdsinta linearum cum eustolitus et sighaturis implent. Editio princeps jureque maxini aestimali, quae novem tantum Dioscoridis complestitur libros, yuorum sexius es Pónwr (de renenatis animalibus). Libellas, qui inseribilur $\pi: p$ ?

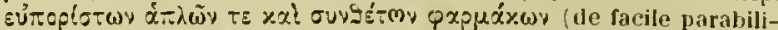
lus tam simplicibus quam compositis medieamentis prorsus deest

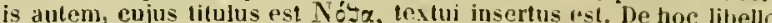
cf. Choulant Bucherhunte. Leipzig 18\}1. 8. p. 77-78. Curtii Sprengel de hac editione judicinm legitur in ejus praefutione p. XI. hiv verbis: - Editionum princeps, quam Aldus Nanutius 1499 Veneliis $\mathrm{cu}-$ ravit, a pancis visa, a nemine consulti, quod, ut fere increclibile, profecto tamen verissimum est. Concinnun est, quod ipse possideo, exemplar et ritidum, paucas hatet mendas, accentus multo scientius collocatos, quam in posterioribus; lectiones plurinas optimas continet, quas saracenus tandem divinavi!

$11498^{*}-\triangle I O E K O P[\Delta H S$. Venetiis, in aedibus Alli et Andreae soceri, mense Junio M.D.XVIll. 4 min. (12), 243 , (1) foll. Bibl. univ. Lips.

(A foll. 223 orto numerorum turbatus est, ideoque folinm ultimum 233 falso numeratum est. Ceterum hic eadem librorum divi-

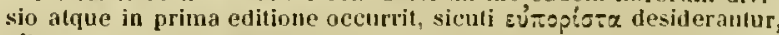
yó $\$ \alpha$ autem a foll. 21 - 230 textu finito habentur. Nicander quouue, yui omissus est, plerumgue ex editione anni 1323 mutic addlilur. yui omissus est, plerumgue ex editione anmi 1323 hinic adilitur. Anonymi carmen de herhis 190 hexametris constans, in guo 13 diversae plantae describuntur, scholits monnulis graects illustritum a folt. 231 -23; legitur. Jane secundam editionen esse correctio-
rem, srol nuth rariorem minusque quaesitam vulgo judicant, sicut rem, sred multo rariorem minusque quaesilam yulgo judicant, sicut eliam Schneciger, aliorum verba repetens, Curtii Sprengelii judicium prolulit: "Provima est quam Aldinam etiam secundam nominare consuesent, quamque Saracenus, "Im ipsi plane ignota esset princeps, Aldinae (quasi unicae) nomine magnivit, Curavit eam Fr. Asulanus, Aldi levir, opem ferente Hi. Roscio, medico Patavino qui eastigasse textum et e codicum collatione recognovisse dicitur. Prodiit lenetiis 1.31S forma subquadrata. Discessit plame a textu lldino, quen uusquam citat, neque fontes commemoravit multa notavit fom visu in appendicente fontes commemorast, multa (nicem amandarit, ubi tamen et plura erant.n? quae incusta aut negligentia in textu imprimendo omissa

11:99*

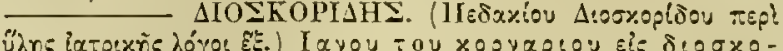

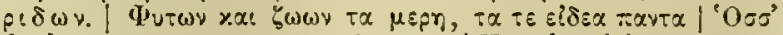

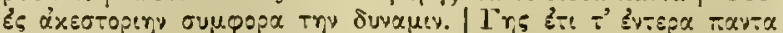

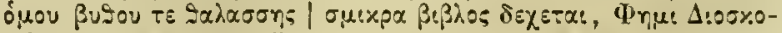

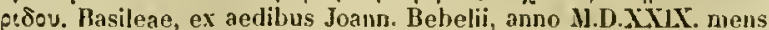
Aug. 4 min. (non 8.) (12), 446 foll. Bibl. univ. Lips.

(Paucis emendatis ex editione anni 1318 repetita est. o Nullum vestigium est, edilorem Janem Cornarium codicibus usum fuisse., Spreng.)

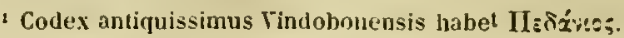


Ediliones graeco-latinae:

$11500^{*}$ Pedacii Dloscoridae Anazarbei de medica materia libri V. de letalibus venenis, eerumgue precautione et curatione etc. liber unus, interprete Marcello Vergitio, Secretario Florentino. Ejusdem Marcelli V'ergilii in hosce Dioscorid is libros commentarii doctissimi, in quibus praeter omuigenam variamque eruditionem collatis aliorum interpretum versionibus, suae tralationis ex utriusque linguae autoribus certissima adferuntur documenta. etc. Coloniae, opera et impensa Joanuis Soteris, MDXXIX. mense Augusto. folio. (12 foll.) 753 p. Bibl, univ. Lips.

(4 Ex enlitione anni 1318 textus est expressus, cui eximiam opposuit l'ergilius interpretationen et castigationes lectu dignissimas. bici paucis nequit, quam laudabilis sit opera ab ipso in exponrndo et castigando froscoridis textu collocata. Conjecturas sagacissimas adjunit, nonnunnuans et doctos eveursus, quibus alii passim auctores illusirantur." Spreng. - Jluje editioni fere semper affixi sumt Itermolai Barbari in Dioscaridem corollariorum libri quinque. Coloniae $1: 30$. fulie.

- Dioscoridis libri octo graece et latine. Castigationes in eosdem libros (auctore Jacobo Gaupylo). Parisiis, apud Petrum Haultinum et impensis viduae Arnoldı Birkmanni. 1549. (Excudehat Benedictus Prevost in vico Frementello, sub siguo stellae aureae, mense Augusto 1549.) 8. (20), 392 foll. Bibl. univ. Lips. et Juss.

(Jiane eflitionem Jac. Goupylus curavil, qui codlicum msstorum Parisiensinm usu, quorum etiam varias lectiones in calce (foll. 382 -391) adjunxit, priorem editionem longe superavit. Versio latina nenalis et vó $\$ \alpha$ in calce adfiua labentur; súropir- $\alpha$ autem desiderantur. Diligenter typis excusa editio el magni habita.)

$11502 *$

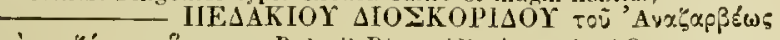

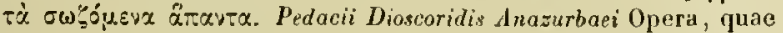
exstant, omnia. Ex nova interpretatione Jani Antonii Suraceni Lugdunaei, medici. Addita sunt ad calcem ejusden interpretis scholia, in quibus variae codicum variorum lectiones examinantur, diversae de medica materia, seu priscorum, seu etiam recentiorum sententiae proponuntur, ac interdum cenciliantur: ipsius denique autoris corruptiora, obscuriora, diffieilioraque loca restituuntur, illustrantur et explicantur. (Lugduni et Francofurti) sumtibus haereduin Andreae Wecheli. 1598. folio. (17) foll., 479, 144, $135 \mathrm{p}$, ind., effigies Diascoridis et Suraceni.

(Verissimum de lac erlitione judicium tnlit Curlius Sprengel in praefatione p. XXI, dicens: "Egregia omnino est, quum, quantum in potestate erat, ad castigantum textun contulerit, quum ipse satis aeute nonmuuguam reras auguratus sit lectiones, studiumigue laudabile collocaverit in comparandis et vetorum monumentis Dioscoriden excipientibus et interpretibus priseis, Cum Euitopir: $\alpha$, 6 foll. praefia, $133 \mathrm{p}$. complectentia, siugularem titulum hateant, relinu opera in uovem limros sunt divisa, quorum quinque priores Nateriamera in hovem limros sunt divisa, quorum quinque priores Nateriam medicam continen, ut froscorides ipse in prarfatione mdieaverat. Photius librum sextum Alp vipharmaea et septimun calce leguutur.)

$11503^{*}$ - Pedanii Dioscoridis Anazarbei de materia medica libri quinque. Ad fiden codicum manuscrijtorum, editionis Aldinae principis usquequaque neglectae, et interpretum priscorum textum recensuit, varias addidit lectiones, interpretationem enendavit, commentario illustravit Curtius Sprengel. (Kuehn, Opera medicorum graecurum tom. XXV-XYV'.) Lipsiae, Cnobloch. 1829 -I830. Il rull. S. - I: 1829. xxvH, 850 p. - II: 1830. IV, $716 \mathrm{p}$. (10 th. $)$

$1130 \mathrm{t}^{*}$ - Eviroglorx $P_{e d}$. Dioseoridis Anazarbei ad Audromachum, hoc est de curationibus morborum per medicamenta paratu facilia, libri II. Nunc primum et graece editi el partin a Joanne Moibano, medico Augustano, partim vero post hujus morten a Conrudo Gesucro in linguam latinam conversi; adjectis ab utroque interprete symphonis Guleni aliorumque graecorum medicorum. Argentorati, excudebat Josias Rihelius. M.LI.LXV. 8. (32) foll, 903 P., (11) foll. Bibl. univ. Lips.

\section{Editiones lalinae:} plex rperit or | dinatio cum eodem tamen uphemio omnino. Una qdë f in quĩque libros cptita: ut testat etiā nō pa ${ }^{4}$ hüc diascoridem recōmendat: In / qua plura otiment capta s. Lreviora ita ut uolumen sit. (Folium $101^{\mathrm{a}}$ ) Explic dyasenrides que petrus | paduanēsis legendo corexit et exponendo ì vtiliora süt íluce; deduxit. I lnıpressus colle $\mathrm{cp}$ magistru; ioh'en I allemanum de medemblick. anno | Xipi millesime. CCCC. Ixxvıij. (1478.) mense / iulij. folio.
(103) foll. 47 lin. Linis columnis, cum signaturis. Hain Repert Nr. 6258.

(De vetustissima Dioscoridis versione, quae fortasse facta est a Petro Aponensi, ef. Dibdin Ribl. Spene. suppl. p. 121. - Colle legitur,
non Coloniae. Folia $101^{b}-103^{2}$ continent tabulam et registrum.

$11506^{*}-\left(\right.$ Folium $1^{\mathrm{a}}$ :) Index librorum in presenti volumine contentorum. | Dyoscoridis exactissimi indagatoris fidelissimiq: scri| ptoris virtutū simplicin̄ medicinarü Liber. ccccccxuvij | continens capitula: cum nönullis arditionibus $P_{e} \mid$ tri paduanesis in margine libri uotatis. Fjusdem Dyoscori / dis de natur is et virtutibus aruarum tractatus vuus. (Folium $120^{\mathrm{b}}$ :) Explicit lilier dyascorid is de 1 natura simpliciū quë Petrus po | duanensis padue legēdo correxit! et exponêdo que vitiliora sunt in | lucē deduxit: imp̄ssus Lugduni per Gilbertū de villiers expēsis | IIonestissimi viri Bartholomei| trot. Anno dōi MI. ccccc. xuj. die / vo. XXIX. mensis Jlartij. I gr. 4. (16), 120 foll., ind. Bibl. univ. Lips., Juss.

(Ilune versionem et sequentem cum Hoffmanno tanum Euporistá continere existinn; ill. Choulant contra eant pro versione librorun $\pi \varepsilon p l$ f́kns latp:xīs ab autiquissima anui 1478 fortasse non diversa habet.)

11307 Dioscoridis Libellus virtulum simplicium medicinarum cum Petri Paduanensss arlditionibus. Ejusdem Dioscoridis de naturis et virtutibus aquarum liber. Venetiis, per Georgium Arrivabenum. MDSIV. die XXIT. Martii, folio. Hoffmann.

$11508^{*}-$ In loc volumine haec continentur: Joannis Baptistae Egnatii Yeneti in Dioscoridem ah Hermoluo Barbaro tralatum annotamenta, quibus morborum et remediorum vacabula ebscuriora in usum etiam mediocriter eruditorum explicantur. Pedacii Dioscoridis Anazarbei de medicinali materia ab eodem Burbaro Jatinitate primum donati libri quinque, etc. Ilermolai Barbari Corollarium libris quinque absolutum. Accedit in Dioscoridem et corollarium indexque copiosissimus. (Excudendos Venetiis liosce Dioscoridis libros octo Aloisius et Franciscus Barbari et Joannes Bartholomeus Astensis curarunt in Gregoriorum fratrum officina Ilermolao Barbaro Patricio Veneto et Aquileiensi Patriarcha interprete Lauredano Principe optino Kal. Februaris MCCCCCXVI restitutae salutis.) folio. (36), Cxxxı1 106 foll. Bjbl. univ. Lips.

(Choulant hanc rersionem Hermolai Barbari non citat, sed aliam s. l. el a. folio, ad guan accuralius cognoscendam revocat Panzerum Annal. VIli. p. 432 . No. 767.)

$11509 t-$ Pedacii Diascaridis Anazarbei de medicinali materia libri quinq; de virulêtis animalibus et venenis cane rabioso, et eorum notis ac remediis libri quatuor, Joanne Ruellio Suessionensi interprete. (Impressum est in jraeclarissino Parrhisiorum Gymnasio hoc celeberrimum Dioscoridis opus in officina Henrici Stephani e regione scholae decretorum absolutumq; octauo Calendas Maias. Anno domini M.D.XVl. folio. (12), 157, (2) foll. Bibl. Juss.

( Erste Ausgabe der gesebatzten Uebersetzung des J. Ruellius (11. $1475+1: 37$ ). Spater erselien sie noch Argentorati 1529 . Lofio.

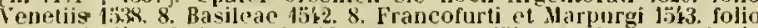

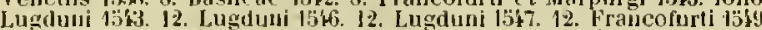

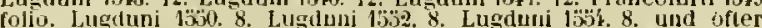
theils mit, theils obne Abibildungen. Auch tindet sich diese Lebrorsetzung ini des Jac. Goupylus gr'iechisch-lateinischer Ausgabe, Paris 43̈9. 8., u. liegt den Lateinischen Mattholus zu Gr'unde." Choulant. lilsri sex, interprete Marcello I'ergilio, secretario Florentino, cum ejusdem annotationibus, nuperque diligentissime excusi. Addito indice eorum, quae digna notatu visa sunt. (Florentiae, per haeredes Philippi Juntae Florentini anno ab incarnatione Domini MDX VIl, Idilus Octobris, Leone decimu christianam rempublicam gerente. folio. 364 foll. Hoffmann.

11511 Pedacii Dioscoridae Anazarbei de medica materia libri sex a Marcello Virgilio (Vergilio), secretario Florentino, latinitate donati, cum ejustem commentationibus, nuper quam diligentissime ex secunda interpretis recognitione excusi. Accedit insuper in Dioscoridem index latine graeceque excusus, alius praeterea in commentationes quam copiosissimus eorum, quae tum graece, tum latine notatu digna visa sunt. (Florentiae, per haeredes Philippi Juntae Florentini. Anue ab incarnatione Domini M.D.XXIll. Idibus Februarii. folio. (10), 352 foll. Hoffmann.

(Panzer in Aunal. typogr. Vil. p. 4b. Nir. 219 habet tertiam eslitionem Florentinam per liaeredes Phitippae Juntae anuo MDXXVin. folio. secundum Catalogue des livres de Bolong. Crev. II. p. tü, et

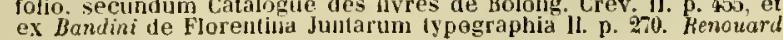
ex Bandini de Florentiba Juntarum lypograph 
antem in sceunda editione libri: Anmalos des Aldes t. 111. p. 387.

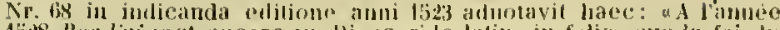
Aists Bandini met eucore un Dioseoride latio, in folio, sur la foi du second catalogne de Crimema. Miju le promier de 1766 en nen-

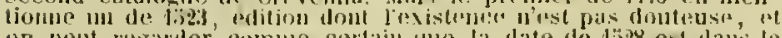

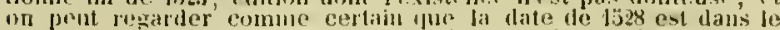

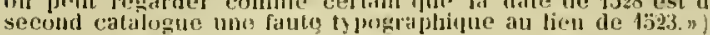

11512 - Peducii Dioscoridis Anuzurbei de medicinali materia libri susem Jonmue Ruello Suessionensi interprete. M.OXXYi. Arul Cynthium Achillinum. (in calce: Hunon. in aedi Cynthii Ichillini; mense Junii M.D.X.IV.) \&. Hofmann.

Pedacii Dioscortis Opura, ex versione Jounnis Ruellii Suessionensis. Venetiis 1527. 8. Hofmann.

$11514^{*} \longrightarrow$ P. Dinscoridne Pharmacorum simplieium reirue medicae libri VIII. Jo. Ruellio interprete. Ena cum Ilerm. Burburi corollariis et Murc. Vergilii in singula capita censuris sive annotationibus. Adjecto indice duplici singulormm simplicium et diflicilium terminorum. In inclyta Argentorato apud Jo. Sehottum. 1529. tolio. (4), $362,(13)$ foll. Bibl. uaiv. Lips.

$11515 \longrightarrow$ Puducii Dioscoridue Anazarbei Simplicium medicamentorum, reigue medicae libri interprote Marcello Virgilio, secretario Florentino, quibus accrssit practer pharmacorum simplicium eatalogum novus omnium fere medelarum seu curationum index. Basileae, per Andrean Cratandrum et Joannem Bebeliun, mense Augusto. M.D.XXXII. 8. Hofimann.

11316 Pedacii Dioscoridis Anazarbei le medica materia libri V, Joa. Ruellio interprete. Parisiis 1537. 8. Cat. Bibl. Lpsal. I. 242 .

$11517^{*} \longrightarrow$ Pedanii Dioscoridis Anaz. le medica nateria libri sex, Jounne Ruellig Suessionensi interprete, postremum ab ipso Ruellia recogniti et suo nitori restituti. Jlis accessit, praeter pharmacorum simplicium catalogum, copiosus ommium fere medelarum sive curationum index. Basileae, apud Mich. Isiug(rin). N.J.XLIJ. 8. Bibl. univ. Lips.

$11518^{*}$ Pedunĩ Dioscoridis Auazarbei de medicinali nateria Jilyri sex, Joanne Ruellio Suessionensi interprete. Singolis cum stirjium, tum animantium historiis, ad naturac aemulationem expressis imaginilsus, seu vivis picturis, ultra millenarium numcrum adjectis; non sine multiplici peregrinatione, sumptu maximo, studio atque diligentia singulari, ex diversis renionibus conruisitis. Additis etiam Amotationibus sive Schuliis brevissimis quidem, quae tamen de medicinali materia ounnem controversiam facile tollant. Per Guultherum II. Ryff, Argentinum. Omnia ex doctissimorum virorum lucubrationibus jamprimum concinnata et in lucem aedita. etc. Accessere in eundem autorem Scholia nova, cum nomenclaturis graecis, latinis, hebraicis et germanicis, Joanne Lonicero autore. Franc(ofurti), apud Chr. Egenolphum. (Excusum Marpurgi jer Cliristianum Aegenolphum, mense Augusto 1543.) folio. (12) foll., 439 p., ic. xylogl. i. t., (10) foll., 87 p.

$110 \mathrm{19} \longrightarrow$ Pedunii Dioscoridis Anaznrbei de melica materia libri VI, Joanne Ruellia interprete. Lugduni, sub seuto Culoniensi 1543. 12. 617 p., ind., nolla. Bibl. Juss. - Lugduni 1546 . 12. Lugduni, apud Frellonium. 1547. 12. - Lugduni, apud Theobaldum Paganum. 1547. 12.

11320 Pedanii Dioscoridis Snuzarbei De melica materia libri sex, cum notis Guulh. Rivii, Valerii Cordi, nomenclaturisque herbarum vario idiomate, per Conradum Gesnerum. Francofurti 1545. folio. Hofimarn.

$1 \mid \not ̈ 2]^{*}-$ Pedanii Dioscaridis Anazarbei de medieinali materia libri sex, Joanne Ruellio Suessionensi interprele. Singulis eun stirpium, tum aninantium historiis, atl naturae aemulationem expressis imaginibus, seu vivis picturis, ultra millenarium numerum aljectis non sine nultiplici peregrination, sumptu masimo, studio atque diligentia singulari, ex diversis regionibus eonguisitis. Adlitis etian Annotationibus sive Sclroliis brevssimis quidem, quae tamen de medicinali materia omnom controversiam facile tollant. Per Gualherum Rinium, Argentimum, Medicum. Acer-sserunt priori editioni Talerii Cordi Simesusii Annotationes doetissimae in Diascorilis de medica materia libros. Eurici Cordi Simesusii Judicium de herbis el simplicibus medicinae: ac eorum quae apud medicos controvertuntur explicatio. Jerbarum nomenclaturae variarum gentium Dioscoridi adscriptae, secundum literarum orlinem expositae, auLore Conradu Gesnero, Medico. Cum indice quintuplici copiosissimo: yuorum primus omnium ferc simplicium, quibus passim uluntur medici, nomenelaturas graecas: alter latinas, officinis, herloaris et Arabum familiae vulgares: tertius gallicas: quartus Germaniau superioris et inferioris, saxonicae item linguac nomina: quintus rurationes at remedia morborum miro ordine complectitur. Franc. Apud CHr. Egenolphum. (iı calce: Francoforti, Apud Chr. Egenolphum Iladamarium. anun 1549. Meuse Ajorili.) foliu. (38), 554 p., je. sylugr. i. t. Bibl. univ. Lips., Juss.

$11322^{\circ}-$ Pedunii Dioscoridis Anazurbei de medicinali materia libri sex, Joanne Ruellio Suessiunensi interuret!. Cuilihet capiti additae annotationes eruditac et compendiariae e selectiori medicorum promptuario. Lugduni, apud labltiazarem Aruolletum. M.D.XXXX. 8. (16) foll., 790 p., ic. sylogr. i. t.

1.1523 Pedacii Dioscorid is de matoria meclica libri $T$, interprete J. Ruellia. Venetiis, excudebat Jominicus Lilius. 1550, 16. Hoffmann.

$11521+$ Pedanii Diascoridis Anazarbei de medicinali materia libri sex, Joumue Ruellio Suessionensi interprete. Cuilibet capiti hujus secundae editionis atditae annotationes eruditae el comjendiariae e selectiori medicorum promptuario: cum triginta iconilus stirjum nonlum delineatarum duas lujusce lilri finis dahit. Jugdumi, apud Balthazarem Arnolletum. (in calce: excudeluat Vienuac Jalthazar Arnonllet.) 1552. 8. (16 foll., 790 p.e ic. $x$ !logr. i. t. sefjuuntur: Icone's numero triginta (Dulechumpii) (S) foll.

11520 - interprete Pet. Andr. Mathiolo, cum ejuaden commentaris. Fonetis, apud Vincentium Valgrisium. 1554. folio. ic. xylogr. min. i. 1.

(urste lateinjeche Ansqabe der brishmten Commentarien des l'ietra Andren Multiali [n. Iow $+13 \%]$ zum Diosenrites, mil denen

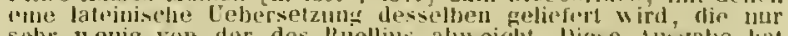

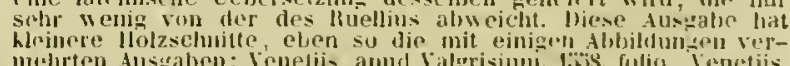

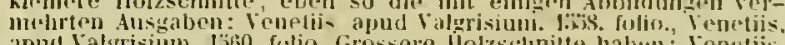

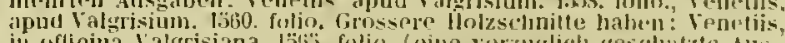

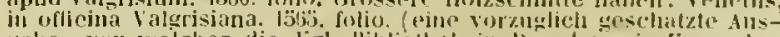

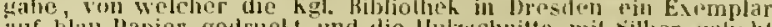

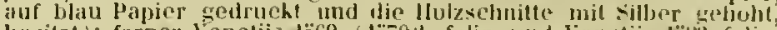

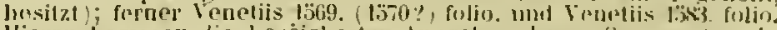
Jierzu hommen die bereicherten Ausgabin despr Commontare in

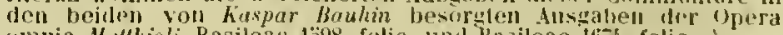

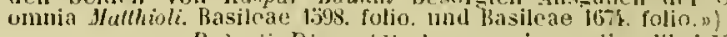

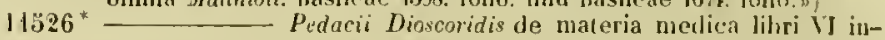
mumeris locis ab Andreu Malthiolo emendati ac restituti. Luguluni, apruil J. Frellonimu. (apud Gul. Rovillium). 1554. 16.564 p., ind.

$11327^{*}-$ Peducii Dioscoridae Anazarbensis de materia medica libri V, Jano Cornario Medico Physico interprete. Ejustlem Juni Cornurii Emblentata singulis capitibus adjecta. Dioscoridue de bestiis veuenum ejaculantibus et letalilous medicamentis liliri Il. rolem Carnaria interprete. Ejusdem Jani Carnarii in eosilen Jibros Fxpositionum libri Il. Adjunetis in fine tribus tabulis lacupletissimis, quibus umnia, quae toto tractantur upere, indicantur. Froben. Basileac M. I. LTil. (in calce: Basileae per Jlioronymum Frobenium. M.L.LVII.) folio. (34), 560, (23) foll. Bibl. univ. Lips.. Juss.

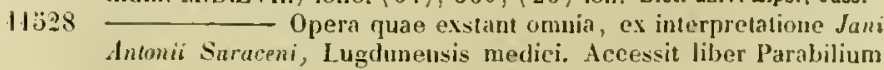
eolem interprete. (Francofurti a/M.), apud haeredes Andreac Wecheli. 1598. 8. cboulant.

(D) Lebersetzun: des Janus Antonius Saracenus unverändert aus dior grimelich-lateinischens Ausgahe (Xr. 11302 ) absedruchl. Die Euporista und sammiliche Scholien feller..)

\section{Ediliones ilalicae:}

(Hoffmann Bibl. Lex. H. I Is habet librum inter italicas Dioscoridis versiones "Herbolario volgare inserijtum, quem lue alferre dubitavi. Invenitur infra in libris anonymis.)

$11329-$ Dioscoride fatto di greco italiano. Al cui fine sone apposte le sue tavole ordinate, con certe avertenze, e trattati uecessarij, per la materia medesima, Per Curtio Trojano di Navó. MDXLII. (in ealce: In Venetia per Giovanni de Farri et fratelli. Nel MDXLII.) 8

(Titulus hujus versionis, quae parum imnotuit, est: a1)i Dinscoride Annzarbea tle la nedicinal materia, libro primo. Interprete a Fausta da hongiuno. "Finito libro sevto exhiturntur: Le certe aver-

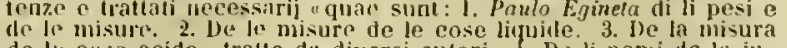
de Io misurto 2. De la misure de le cose liquide. 3. Ie la misura

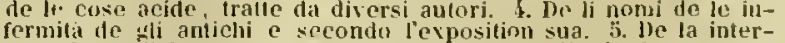
fermita de ali antichi e sceonda l'exposition sua. 5 . le la inter-
urctatione dialcune parole che sono parute di pii importanza. pretatione daleune parole che sono parute di pi
i. Diversita de testi dalcuni hochi d'importanza.,

Listoria et materia medicinale tradotti in lingua rolgare italiana 
da M. Pietro Antrea Muttioli (Molthiolo?) Sanese Medico. Con amplissimi Discorsi, et commenti, et Dotlissime annotationi et censure del medesimo interprete. Ja cui fotra ciascuno facilmente acquistare la vera cognitione de' semplici nou sulamente scritti da Dioscoride, ma da altri antichi et moderni scrittori, et massimamente da Galeno. La cui duttrina intorno à tale facultà tutta fedelmente interpretata si ritrova posta ne' proprii luughi. Con due tavole alphabeticlıe da poter con prestezza ritrovare cio, che vi si cerea. Et con la dichiaratione di molti vocaboli medicinali, che da tulti forse nou sono intesi. Opera veramente uon manco utilo, che necessaria. Con privilegio di N. S. Papa Paolo III. Et dello Illustriss. Senato Veneto per anni X. MI.D.XLIII. (in fine: Stampato in Tenetia per Niculo de Bascarini da Pavone di Brescia. Corretto, et rivisto per il proprio Auttore il mese d Ottobre dell' anno 210 XLIIIl. folio. Hoffmann.

(llare est prima editio varsionis italicae et commentarii Jatthinli. Numerosis has editinnes efpidem accurate indicare nequeo; cf. Difesa e illostrazions delle opere botaniche di l'ielro Andrea Mattioli, botanico del $\mathrm{Xl1}$ secolo (nutore Giuseppe Moretti). (Milano 18't.) 8. 59 p. luntuessa est docta commentatio in Gionale del istit. Lomb. e Bibl. jtaliana, vol. I..)

$11531 \%$ dofto in lingua florentina da M. Murcantonio Montigiamo da S. Gimignano, medico. In Firenze MLSLVII. (in lise: Stampato in Fiorenza, appresso Bernardo de? Giunti: di Genaio MIDXIVI.) 8. 302 foll., (7) foll. ind. Bibl. Deless.

(Allerum volumen in praefatione promissum, quod Limendationes haber's debelbat, non proaliit.)

$11332 \div-11$ Dioscoride dell' eccellente Dottor Medico I1. P. Andrea llatlioli da Siena: co i suoi discorsi, da esso la seconda volta illustrati et diligentemente ampliati: con l'aggiunta del sesto libro de $\mathrm{i}$ rimedi di tuti i veleni da lui uuovamente tradotto, et con dottissimi discorsi per tutto commentato. Cun Privilegio di $\mathrm{N}$. S. Papa Paolo llI. et dell Illustrissimo Senato Vünitiano per anni $\mathbf{X}$. In Vinegia, oppresso Vincenzo Valyrisi, alla bottega d'Erasmo. M. D. XLVIII. 4. (64), 756,128 p. Bibl. Deless.

11333 II Dioscoride ..... conmentato. Con la giunta di tutte le figure delle piante, delle herbe, delle pietre e de gli animali tratle dal vero, et istesso naturale, et non piu stampate. In Mantova, appresso Jacnmo Roffinello. 1549.4. Hoffmann.

(1laec est terlia, non secunda, Lfathioli versionis editio.)

1133 t II Dioscoride ete. con li swoi discorsi per la terza volta illustrati, el copiosamente anpliati : co'l sesto libro de gli Antidoti contra à tutti i veleni da lui tradotto et con dottissimi discorsi per tutto conmentato. Aggiuntevi due amplissime tavole, nell' uni delle quali con somma ficilita si puo ritrovare ció, ehe in tutto il volume si contiene; nell' altra poi turti i Semplici medicamenti, per qual si roglia morbo adumati insieme. Sonovi anchora aggiunte tre tavole poste in fiqura, le quali dichiarano tutti i pesi et le misure delle cose, di cuj fa memoria Dioscoricle; accommodate à $i$ pesi et a le misure che oggidh s'usano nelle speciarie. Vi is ancho aggiunta un' aitra tarola in figura, laqual brevemente dichiara ove si prendano i Semplici Nedieamenti. Vi sono poi molto altre argiunte sparse per lutto 'I volume lue bellissimi discorsi aggiunti sopra i prologtii del primo el del quinto libro; ove si tratla iu uno, cio che si puó clesiderar intorno all' historia delle piante, e nell' altro, quel tutto, che alla generazione, materia, et causa delle cose minerali s'appartiene. Con privilegio del Sonmo Pont. et dell' Illustrissimo Senato Yinitiano per anni dieci, come appare nella sesta carta. In Vinegia, appresso Vincenzo Valgrisi, alla bottega d'Erasmo. MIDLlI 4. Hoffmann.

(Praeterea citat Hoffmann duas ellitiones italicae rorsionis Yinegia, appresso Vincenzn Valgrisi. 1530. 4. et Villegia, appresso mentaria continent, side infra in sectione: "Lllustrantia Dioscoridem scripla.n

\section{Editiones germanicae:} 1 Jj35 Des hochporumpten Pedanii Dioscoridis Anazarbei Bucher verfast, und zun ersten mal aus der Griechischen und Lateinischen Sprachen gründlich verteutsclı durch Johan Dantzert con dst. Fraslifurt am Mayn, bei Ciriaco Jacobizzum Bart. 1546. folio. ic. $x y \log r$. i. t.

$11536^{*}$ Kräuterbuch des uralten und in aller Welt berühmtesten Griechischen Skribenten Pedaci Diuscoridis Anazarbei, Yon allerley wolriechenden hräutern, Gewurtzen, köstlichen Oelen und Sallien, Baumen. Harizen, Gummi, Getrayt, liochlidutern, scharpffschmächenden Kräutern, und audern, so allein zur Artzuey gehorig, Krăuterwein, Metalle, Steinen, allerley Erden, allem und jedem Gill, viel und manchorley Thieren, und derselbigen heylsamen und nutzbaren Stuck. Jı siben sonderbare Bucher unterschieden. Erstlich durch Joannem Danzium von Ast, der Artzney Ductorem, vertentscht, Nun mehr aber von Petro L/fenbach, bestelten Mledico zu Francklurt Aufs newe uberselien, verbessert, in ein richtige Form gebracht, und nicht allein mit Lebhatlten Figuren geziert, soudern auch mit dess wolerfahrnen Wundarztes llieronymi Bravnsschweig zweyen Büchern, als der Kunst zu destillieren, und dann dem beylsamen und vielfaltigen febratach aller und jeden destillierten Wasser, vermelurt. Mit Kays. Jay. Freyheit uit nach zu trucken. Gedruckt zu Frankfurt an Mayn, durch Johann Bringern, in Verlegung Conrad Carthoys. II.J) C. X. folio. (6) foll., 6 I6 p., (16) foll. ind., ie. xylogr. i.t. - *Gedrucht zu Franchfurt am Mayn, durch Erasmum Kempflern, in Vellegung Conrad Carthoys. Anno MIDC.XIV. folio. (proeter recens impressun titulum non dilfert.)

\section{Editiones hispanicae:}

$11337 \div$ Pedacio Dioscorides Anazarbeo Acerca de la materia medicinal y de los venenos mortiferos. Traducido de lengua griega en la vulgar castellana y illustrado cun elaras y substanciales annotationes y con las figuras de imumeras plantas exquisitas y raras por el Doctor Audres de Laguna, Medico de Julio III. Pont. Max. En Auvers, en casa de Joan Latio. 1535 . Sulio min. 616 p., praef, ind., ic. xylogr. i t. Bibl. Reg. Brux. - †Valencia, por Niguel Sorolla. 4636. folio. (20), 616 p., ic. Nylogr. i. t. Bibl. Juss.

(Aliat: indicantur editiones, quae fortasse num dillerunt, quas

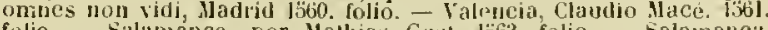
folio. - Salamanea, por Mathias falst 1563. folio. - Salamanca,

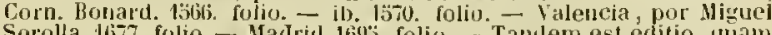
Sorolla. 167\%. folio. - Madrid 169\%. folio. - Tandem est editio, quam vero potius transiationem Commentariorun Malthioli sistere equidem censeo, Madrid 1733. ll voll. foljo. et novis titulis. Madrid 1752. II voll. loslio., in quo Commentarius inest a Lun Francisco Suarez de hivera confectus. quí etiam enendavit monnulla. - Lego insuper apud Colmeiro Ensayo hislórico sobre los progresos de la botiniea, 11. 9: "El celelir" Lebrija hizo imprimir en Alcalia en lisis el Dioscorides iraducido por Huellio, gue corrigio y unio is su Lex icon aris mellicanentariae." Collectionem icomum a Juan Jaram titulo "Historia de las yervas y plautas, sacakla the lioscoride Anazarbeon editam vide supra in (ranslationilus Fuchsii, Nr. 3'32.)

\section{Editiones gallicae:}

$11538+$ Les six livres de Pedacion Dioscoride drAnazarbe de la matière médicale translatez de latin en françois. A chacun chapitre sont adjoustées cerrames anmotations fort docles (par D. Martin Mathen). Lyon, cliez Thibault Payan. 1559. 4. (12), 574 p., jc. xylogr. i. t. Bibl. Juss. - t Lyon, pour Loys Cloyuemiı. 1580. 4. (eadem inpressio, novo titulo.) Bibl. Juss.

(Seguier fudient antifuiorem edilionem, quae forlasse est in bihliotlueca St. Ger'm. Pinlisiensi: "Translaté en frimcois par Martin Matthee Médecin, avec des amotations. Lyon, Balthazar Arnoullet. 13̈3. folio." addens: "In calce adjectae sunt plurimorum simpliciun descriptiones et icones, quae in Dioscoride non continentur.")

\section{Illustruntia Dioscoridem scripta:}

Hermolai Barbari Corollarii in Dioscoridem libri uninque non ante impressi. Jmpr. cum Joonnis Baptistae Egnatic Veneli in Dioscoridem al) Hermolao Barbara tralatum annotamentis. Tenetiis, in Gregoriorum fiatrum officina. 1516. folio. 106 foll. - In Dioseoridem Corollariorum libri quinque. Adjectus est index eorun, quae hisce libris explicantur, quem post Dioscaridlis indices consulto locavimus. Impr. cum Dioscoride, interprele Marcello J'ergilio. Coloniae, apud Joannem Soterem. 1530. mense Februario. folio. 78 foll.

(Sequier loabet e Bibl. Niz. Parisiensi editionem s. l. forsan. Boniae 1692. folio.)

Brunfels, Otlo. Exegesis omnium simplicium Dioscoridis, et quomodo is, quae in olficinis servantur, respondent. Impr. cum Brunfetsii Novi herbarii tomo II. Argentorati, apud Joannem Schollum. 153 \%. folio.

Petrus, Cornelius. Annotatiunculae aliquot Cornelii Petri Leydensis in quatuor libros Dioscorid is Anozorbei. (Antwerpiae, excudebat Joannes Grapheus.) 1533. 8. (51) foll. Bibl. univ. Lips. 
+ Textor, Benediclus. Stirpium differentiae ex Dioscoride secundum locos communes, opus ad ipsarum plantarum cognitionem admodum conducibile. Parisiis, Simon Colin, 1534. 12. 103 foll. Błbl Reip. Paris. - Venetiis, in officiná Divi Bernardini. 1537. 12. Rivin. - " Impr. cum Kieronymi Tragi de stirpiun nomenclaturis. Argentinae, excudebat Wendeluus lailielius. 1359. 4. p. $1129-1200$.

+ Amatus Lusitanus. Iudex Dioscoridis. Ejusdem historiales campi cum axpositione Joannis Roderici Castelli albi Lusitani (Amall Lusiluni). Anwerpiae, apud viduam Ilartiıi Caesaris. 1536. folio. Bibl. Reip.Paris.

Agricola (Paeurle), Johames, cognomine Ammonius. Medicinae herbariae libri duo, quorum primas habet herbas lujus saeculi communes cum veteribus, Dioscoride videlicet, Guleno, Oribasio, Pullo, Aetio; Plnio et horum sinilibus. Secundus fere a recentibus medicis inventas berbas, quae post Gulenum accesserunt. Basileae, apud Bartholomacum W'esthemerum. $1539.8,336$ p., ind.

Lonitzer, Johamnes. In Dioscoridae Anuzarbei de re medica libros a Marcello J'irgilio versos scholia novi, Joanne Lonicera autore. Marpurgi, Clıristian Egenolphus excudebat. 1543. folio. 87 foll., prael., ind.

(Brunfels, Ollo.) In Dioscoridis historiam plantarum certissima adaptatio, cum carundem iconum nomenclaturis graecis, latinis ot germanicis. Der kreuter rechte wahrhalfige contrafactur, erkanntuuss und namen, kryechisch, lateinisch und deutsch, nach der Beschreibung Dioscoridis. Argentorati, Jo Schottus aere perennius derlit. 1543 . folio. 372 p. (p. 108114 , et 244-292 semper omissae), 14 p. index, ic xylogr. i.t. ("Continet hic liber 314 icones, et duibus 27 t eaedem sunt, guats in brunfelsii operibus vel latinis vel girrmanicis apud eundem typographum excusis reperiuntur. Quaniam vero tuic libro mulla praefatio nee alia informatio praetixa est, incertun manet, cujus ope usus sit typorraphus in illis, quae ad correctionem et auctionem ejus portinent. Seguierus falso, a catalogo Ruviniano deceptus, Fuchsii operibus athumerat, in Trew.)

* Fuchs, Leonhard. Apologia, qua refellit malitiosis Gualheri $R y f f$, veteratoris pessimi, reprehensiones, quas illo Dioscoridi nuper ex Egenolphi officina prodeunti attexuit: obiterque quam multas, imo propemodum omnes herbarum imagines e suis de stirpium historia inscriptis commentariis idem suffuratus sit, ostentit. Basileae, apud Michaelem Isingrin. 1544. 8. (31) foll. Bibl. Reg. Dresd.

Mattioli, Jietro Audrea, latine Matthaeolus vel Matthiolus. Di Pedacio Dioscoride Anazarbeo Jibri cinque della bistoria e1 materia medicinale tradotta in lingua volgare italiana da M. PietroAndrea Mutthiolo Sanese medico. Con amplissini Diseorsi et commenti, et doltissime annotatione et censure del medesimo interpuete. etc. Venetia, per Nicolo de Bascarina da Pavone di Brescia. MLXLIII. folio. (cf. Nr. 11530.) - tFirenze MDSLVII. 8. (ef. Nr. 11531.) - tVinegia M.J). SLVHI. 4. (cf. Ni. 11532.) - Mantova 1549.4. (ef. Nr. 11533.) - Vinegia MLLII. 4. (ef. Nr. 11534.)

- 1 discorsi di II. Pietro Audrea Matthioli ne i sei libri della materia medicinale di Pedacio Dioscoride Anazarbeo. Vinegia, typ. Valgrisi. 1555. folio. (86), 741 p., ic. xylogr. i. t. Bibl. Deless.

In italiano, accresciuto dall' autore. Venezia, typ. Valgrisi. 1563 . folio. ic. parv. xylogr. i. t. s.

In italiano, con le figure grandi, ed in fine dell? arte di distillar. Venezia, typ. Valgrisi. 1570 . folio. (957) ic. magn. xylogr. i. t. $s$.

sylogr. i. t. s.

In italiuno. Venezia, Alberli. 1604. folio. ic. magn

\section{Editiones lalinae:}

Pedacii Dioscoridis de materia medica libri sex interprete Petro Andrea Mattiolo, cum ejustem commentariis. Venetiis, in oflicina Lirasmiana, apud Vincentiun Valgrisium. 1554. Solio. ic. xylogr. min. i. t. - Secundo aucti, adjectis plurimis plantarum et animalium inaginibus, quae in priore editione non habentur. Jlis accesserunt Apologia adversus Amalum Lusitanum cum censura in ejusdem ennarrationcs.
Venetiis, ex officiua Erasmiana Vincentii Valgrisii. 1558. folio. ic. xylogr. min. i. t. - ib. 1559 , folio. - ib. 1560. folio. Venetiis 1563.4. s. - "Petri Andreae Matthioli Senensis medici Commentarii in sex librus Pedacii Dioscoridis Anazarben do medica materia, jam denuo ab ipso autore recogniti et locis plus mille aucti. Adjectis magnis ac novis plantarum ac animalium iconibus supra priores editiones delineatis. Accedit De ratione destillandi aquas ex omnibus plantis. Venetiis, ex officina Valgrisiana. 1565 . folio. 1459 p., ind., ic. xylogr. magn. i. t. - ib. 1569. fulio ic. xylogr. magn. i. I. - ib. 1570. folio. 956 p., praef, ind., ic, xylogr. i. t. - "Yenetiis, apud l'elicem Valgrisium. 4583 . Il voll. folio. $583 ; 772$ p., praef., ind., (4) foll., ic. xylogr. magn. i. t. - Venetiis, apud Valgrisium. 1596. folio. ic. xylogr. parv. i. t. - "Petri Andreue Matthioli Opera, quae exstant omnia; hoc est: Commentarii in sex libros Peducii Dioscoridis Anuzarbei de medica materia, adjectis in margine variis gracci textus lectionitus ex antiquissimis codicibus desumtis, qui bioscoridis depravatam lectionem restituunt: nunc a Caspuro Bauhino post diversarum editionum collationem infinitis locis aucti. Accedunt de ratione distillandi aquas ex onnibus plantis. Apologia in Amalum Lusitanum. Epistolarum medicinalium libri quinque. Djalogus de morbo gallico. Basileae, typ. Nicolai Bassaci. 1598. folio. 1027 p., praef., ind., 236 p., ic. (330) sylogr. i. t. - "Opera omıia. Basileae, Johames Koenig. 1674. folio. (non dilfert.) - Matthioli Commeutarii in Dioscoridem. Venetiis, apud Nicolaum Pezzanam. 1744. \{olio. ic. xylogr. minim. i. t. s.

(—_-) Mlistoria plantarum. Earum imagines, nomenclatura, qualitates et natale solum. Quibus accessere simplicium medicamentorum facultates secundum locos et genera ex Dioscoride. Lugduni, apud Gabrielem Coterium. 1561. 12. 640,229 p., ind., ic. xylogr. i. 1. - ${ }^{*}$ Ed. Il: ib. 1567. 12. (non ditfert.)

(Est Mathiolus in compendium redaclus, autore Antonio $\mathrm{P}_{i-}$ naeo potius Antoine Dit Pinet, ut elucet e praefatione p. 3 : " Ferianti mihi ineidit in manus anno superiore Matthiolus in Dinscoridem, quem ubi gallice reddidissem, placuil etian nunc manualem ipsum facere.")

\section{Editiones bohemicae:}

* Herbarz: ginak Bylinar etc. per Thaddeum Ilageh. Wystisstieno w Starém Hiestie Prazshem y Girkijka flelantrycha $z$ Awentynu. Lètha Pánie. 1562. folio. $39 z$ foll., praef., ind., ic. xylogr. i. t. Bibl. Reg. Berol.

(1596.) folio.

(Adamski eirat editionem bohemicam per Hieronymum Spiczyiski Vilıae läbil et löbì ediltun.

\section{Editiones germanicae:}

- New Krauterbuch, verdeutscht durch Georg IJandsch. Prag, typ. Melantrich ab Aventino. 1563 . folio. (30) foll. $\$ 75$ p., ic. sylogr. magn. i. t., effigies Matthioli. Bibl. Reg. Berol., Deless.

(llaec versio secumdum Matllioli versionem latinam facta est. Impressio rarissind pulchra muce er meis libris in bibliothecan Delessertianam migravit. Tilulus loujus exemplaris desideratur. "Novau enlitinuem cum illustrationibus Joachimi Camerarii, additis iconilms I2:3, laudat seguierus: Prashfurt a $M$. Jakoh Fischer. 1626. folio.s quae Parisiis est in Bibliotheca heipublicae. Ton viuli.)

Kreuterbuch des hochgelelirten und weitberahuten Hr. D. Petri Andreae Multhioli, jetzt wiederumb mit vielen schönen newen Figuren, auch nüzlichen Artzneyen und andern guteo Stucken zum audern Mal aus sondren Fleis: gemehrt und gefertigt durch Jouchimun Camerarium, der loblichen Reichsstall Nürnberg Medicum. Sampt dreien wohlgeordneten nutzlichen liegistern etc. Frankfurt a/M., gedruckt bei Johann Feyerabend (in Verlegung Peter Fischers). 1590. folio. 455 foll., ind., ic. xylogr. i.t. - ib. 1598 . 5olio. S. *ib. 1600 . folio. - ${ }^{*}$ ib. 1611 . folio. (non differunt.)

Ediliones gallicae:

Les Commentaires de M. P. Andre Malthiolus sur les six livres de Peducius Diascoride Anazarbeen de la matière medecinale. Traluits de latin en françois par M. Antoine du Pinet. Lyon. Galıriel Cotier. 1561 . folio. ic. xylogr. parr. i. t. 
- ib. 1572 folio. s. - ib. 1580. folio. s - †Les Commentaires de II. $P$. Andre Muthiolus sur les six livres de Pedacius Dioscoride Anazarbeen de lit matiere medecinale. Traduits de latin en françois par M. Antoine $d u$ Pinet: et illustrez de nouveau d'un bon nombre de figures, et augmentez en plus de mille lieux a la terniere érlition de l'auteur, tant de plusieurs remedes a diverses sortes de maladies; que aussi des destillatious: comme pareillement de la connitissance des simples. Lyou, chez Pierre Rigaud. 1605 . folio. 606 p., praef, ind., ie. $x y \log r$. i.t. Bibl. Deless. - ib. 1619, folio. s. - Lyon, Claude Prost. 1656 . folio. - tLes Commentaires de M. P. Aadre Malthiole, medecin sienois, sur les six livres de la matitre medecinale de Pedacitus Dioscoride Anuzarbeen. Traduits de latin en francois par Antoine du Pinet: et enrichis de nouveau d'un nombre consilerable de figures; el augmentez tant de plusieurs remedes a diverses sortes de maladies: comme aussi d'un traité de clyynie en abregé pour l'analyse tant des végétaux que de quelques animaux el mineraux, par un Docteur en medecine. Dermiere edition, reveuè, corrigée et mise dans un meitleur langage avec deu, tabjes latine et françoise. Lyon, chez Jean Baptiste de Ville. 1680 . folio. (3) foll., xcr p., elfigies Mallhioli; ( 7 ) foll., 636 p., (17) foll. ind., ic. xylogr. parv. i. t. Bibl. Cand.

+ — Commentaires de M. Pierre Andre Matthiole medecin senois, sur les six livres ule Ped. Diascoride Anazarbeen de la matiere medecinale. etc. mis en françois sur la derniere édition latine de l'autbeur, par M. Jean des Moulins, Docteur en metlecine. A Lyon, par Guillaume Roville. 1572. folio. 8.19 p., praef., incl.. ic. i. t. - ib. 1579 . folio. s.

(u Des Grafen huspar ron Sternberg Calalogus plantarum ad septem varias taditiones Commentariorum Muthioli in Dioscortdem ad limaeani ststematis regntas elaboratus. Pragae, Calve. 1821. folio. iv, $30 \mathrm{p}$. (11/3/t.) giebt die lateinische Synonyik 1821. folio. Iv, 30 p .

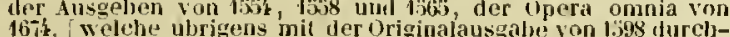
167 , welche ubrigens mit der Originalausgabe von lis9s durchMus uhereinstimmen, zweier hohmischen Uehersetzungen des

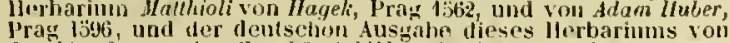
Joachin Canaerarius, Prankfurt 16!l. Folio, [ welche ebenfills von der Originalausgatie con lis90 nicbt atweich1]. Daher sind nur drei Ausgahen der Commenlarien henutzt, die andern vier Werke sind das oft mit den Commentarien verwechselte llerbarium, welches nur die botanischent llolzschuitte mit ibnen gemein hat, aber "waler den Text des Dioscorides noch tlie Erfinterun: zu demselhen euthall; auch handelt das Herbarium nur von pltamzen, die Commentarien auch von Thierun und anderu Arzneikurpern." choulast.)

* Amatus Lusitanus. In Dioscorillis Anusarbei de materia medica libros enarationes eruditissimae Amati Lusituni i. e. Juan Rodriguez de Castellanco). Venetiis, apud Gualterum Scotum. 1553. 4. - * Arcentini, excudebat Rihelius. 1554.4. 536 p., praef., ind. - Venetiis, apur Jordanum Zilettum. 1557. 4.514 p. alısque liguris. B. - ${ }^{*}$ In Dioscoridis Anazarbei de medica materia libros quinque Amati Lusilani enarrationes ernditae. Accedunt praeter correctiones lemmotum etiam aclnotationes Roberti Constantini, nec non simplicium picturae ex Leonhardo Fuchsio, Jucobo Dalechampio atque aliis. Luggluni, apud visluam Arnolleti. 1558. 8. 807 p. ic. xylogr. i. t., praef., ind., praeter plagulam, 30 continentem figuras Dulechampii easdem, quae editioni Dioscoridis Lugduni 1552. 8. annexae sunt.

(Contra hune librum prodiit trallhioli Ápologia adversus Amolum Lusitanum cum censura in ejusitem enarratimes. Venetiis, ex officina Erasmiana Vincentii Valgrisi. 1ajos. 8 .

t Laguna, Andres de. Annotationes in Dioscoridrm Aa azurbeum per Audream Lacunara, Segobiensem, medicum Julii 111. P. H. juxta velustissimorum fidem elaboratae. Lugduni, apud Rovillium. 1554.12.340 p. Bib. Juss.

Holtzachius, Johames Cosma. Annotationes in Dioscoridem. Lugduni, typ. Frellonii. 1556. 12. Bum.

+ Guilandinus, Melchior. Apologiae alversus Petrum Andream Mathiolum liher primus, yui inscribitur Theon. Patavii, apud Gratiosum Perchacinum, 1558. 4. 19 foll. Bibl. Juss.

* Cordus, Valerius. Valerii Cordi Annotationes in Pedacii Diascoridis Anazarbei de medica materia libros $\mathrm{V}$ longe aliae quam antehac sunt evulgatae. Quibus accesserunt etc. etc.
Omnia summo studio atque industria Conrudi Gesneri collecta (adjecto Commentatorum in Dioseoridem inslice). Argentorati, exculebat Josias Rilielius. 1561. folio. 301 foll. cum praefatione ef literis Gesneri, ind., ic. xylogr. i. t.

(Primum prodierum cum versione latima Dioscoridis, Francofurt a/M. 15is. folio. Adduntur etiam Butanulogico Eurici Cordi, Parisiis, apud Guileimum Morelinn. lï̈il. 12.)

Stupanus, Antonius. Simpliciun medicamentorum facnlates ex Dioscoride (secundum Mathroli deserijtiones). Lugduni 1561. 12. Hofimann.

Pasini, Antonio. Amnotazioni ed emendazioni nela tradottione rli P.A. Mathioli de cinque libri della materia medicinale di Dioscoride. Bergamo, Corvino Ventura. 1592. 4. $252 \mathrm{p}$. B. - tib. 1600 . 4. Bibl. Reip. Paris.

Marogna, Nicolo, latine Maronea. Commentarius in tractatus Dioscoridis et Pliaii de Amomu. Impr. cum Ponae Descriptione Baldi montis. Basileae, sumtibus Lazari Zetzner. $1608.4 .75 \mathrm{p}$.

* ilalice: Commentarin ne' trattati di Dioscoride e di Plinio dell Amomo. Inpr. cum ullonte Batdo descritto da Giorani Pona." lenezia, appresso Rob. Meietti. 1617. $4.132 \mathrm{p}$.

+ Contant, Jacques et Paul. Les divers esercices de Jacques el Paul Confunl, pere el fils, maistres apoticaires de la ville de Poictiers, ou sont esclaircis et resiuldz plusienrs doultes qui se rencontrent en quelques chapitres tle Disscoride et qui ont travaille plusieurs interpretes composez par le dit Jacques, et recueillies, reveus, angmentez et mis en bon ordre par le dit Puul, pour servir de commentaire aus simples escriptz daus son poesme intitule: le second Eden. Puictiers, par JuJian Thoreau. 1628. folio. $250 \mathrm{p}$., praef. Bibl. Juss.

(Legilur etiam in exordio operum coltcelorum, quae eodem prodicrunt antıo; ef. Tliesaurus lit. bot. Nir. 1938.)

* Alpliabetum empiricum, sive Divscoridis et Stephani Athenupusis philosophorum et medicorum de remediis exjertis liber, justa alphabetiordinem digestus. Nune primum a Cusparo IVolyhio, Tigurino medico, in latinam linguam conversus, et in licem enlitus. (Tiguri) 1581.8.76 foll. Bibl. univ. Lips.

(Secundum codicem minuscriptum in Conradi Gesneri bi-

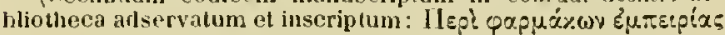
liber (raductus esse dicitur.)

\section{Codices manuscripli:}

Duo prae ceteris codices sunt manuscripti magni habiti in $\mathrm{Pa}-$ latin. Vindobonensi Bibliotheca asservati, guorum alterum Busbecyuius Haximiliano secundo Imperatori Constantinopoli apportavit, cum iconibus pictis pulcherrimis, de quo $\mathrm{cf}$. Mosel, Geschichte der Wiener Hofbibliothek, p. 32, 320-322. Mario Theresia Imperatrice jubente hujus picturae olim ad edendum paratae sunt. Lego in libro manuscripto optimi Cundollii patris haec verba anno 1816 in itinere anglico scripta: "J'ai vu a Norwich chez Mr. James Elward Smith les planches du manuscrit de Dioscaride de Vienne, qu'on dit itre du cinquième siecle; l'imperatrice les avait fait graver, et Jacquin donna le premier exemplaire à Linné, et le second a Sibthorp; le premier se trouve aujourdlıui à Norwich, le second a Oxfort. Après cela les planches ont été perdues ou détruites, et il n'en reste que ces denx exemplaires. Mr. Jacquin le fils demande a l'université d'Oxford, de lui rendre celui, que son père avait, dit-il, pretó à Silthorp." Alter est Neapolitanus saeculi quinti. - De aliis codicibus Dioscoridis cf. de l'illoison, Epist. Wimar. Turici 1785.4. p. 109. - Natthaei, Sammlung griechischer Aerzte, 1808, p. 360. - Iriarte, Corld. Bibl. Madrit. I. 435. - Millin, Magazin encyclopedligue, tome ll. 1796. j. 152. - Weigel in Baldinger's Jedic, phys. Journal, Bd. VII!, Stuck XXXIl. p. 5. - Dietz, Analecta med. Lipsiae 1833. 8. - I. Fynes Clinton, Fasti hellenici. Fol. 11. Oxonii 1830. 4. j. 548. - Hull. Bibl. hot. Il. p. 85-86. - Anticua Dioscoridis versio, quae Cassiodori aetate exstabat, non amplius superest, de qua ille Div. Ject. cap. XXXl. sic loquitur: "Quod si vobis (i. e. monachis infirmorum curam habentibus) non fuerit graecarum linguarum nota facundia, imprimis habetis Ilerbarium Dioscoridis, qui herbas agrorum mirabili proprietate doscrijssit atque depinxit.» 


\section{OPERA ANONYMIA.}

Ablildung vide Guimpel $3979-3980$

Abbildungen und Besclıreilungen vide Kolschy 5371 .

A trooke of flowers vide Dunsiall 2833.

Alregé curieux vide Besnier 845.

Abrégé des élémens vicle Tournefort 10382.

Alrègé élémentaire vide Lestiboudois 5796 .

A catalogue... New York vide Torrey 10368.

A catalogue of plants ... Glasgow vide Hooker 4653.

Additions to Warner's Plantae Woodfordienses vide Forster 3299.

A description . . Cinchona vide Lambert 5507 .

A deseriptive catalogne vide Mlne 6948.

Aeumerkingen vide De la Court 2366.

Afbeeldingen vide Krauss 5402-5403.

Afbeeldingeu vide Oskamp 7669.

Ai eultori vide $J / 2 n 4858$.

Alla Hemoria vide Sav 9033

Allgemeine Gartenzeitung vide Otto 7682 .

Allgemeine historiseh-pliysiolugische vide I"elling 11142.

Al Signor Luigi Arduini vide Nocca 7539 .

All account of the nak vide Haude 6668 .

Analisi dei vegetabili vide Tommaselli 10360.

An historical Eulogium vide Rui= $\mathbf{8 8 6 6 .}$

Anleitung zu der Pllanzenhenutniss vide Schinz 9136.

Aumárkiningar vicle Trafuenfell 10398.

Antralen der Botanik vide Esteri 10610.

Annals of botany vide Konig 5355 .

Archiv fur die Butanik vide Roemer 8667 .

Archives de botanipue vide Guillemin 3976

A Rewiew of ... Hlortus Malabaricus ville Dilluyn 2638 . .

A short explanation vide $\mathbf{Y l a r t y n} 6621$.

Astrolalse vide Richurd 8557 .

Ausflug vide Brunner 1434.

Avis pour le transport vide DuHamel du Monceau 2734 .

Beautés méridionales vide Belleval 687.

Reitráge zur Pflanzenkusde vide Meyer 6888, Ruprech $8883-8885$.

Beobachlungen auf Reisen vide Jirosek 4888 .

Berettelse om Blomman vide Roberg $\$ 623$.

Bericlst vide Brumer 1432.

Bericht uber die Getraidearten vide Fischer 3208 .

Berigten van P'oefnemingen vide I'riese $10 \$ 46$.

Besclureibung vide Bocris 984 .

Beschreilung der Milchblatterschwämine viele Gnelin 3712.

Beshrifning vide Samzelius 8982

Betoyne vide Du-Peyral 2834.

Blomsterkrants vide Zamzelius 11397.

Bonite virle Vuillant 10618 .

Botanical Jagazine vide Curtis 2091.

Botanical Register vide Edwards 2941

Botaniska Notiser vide Lindblom 5912.

Butauische Abhildungen vide Taschenberg 10069.

Botanische Unterbaltungen vide 11 eizenbeck $1113 \%$.

Botanisches Archiv vide Huegel 4759.

Botanisclies Ceutralblatt vide Rabenhorst 8256 .

Botaniste voyageur vide Deshayes 2500.

Potanograplia vide Commelyn 1938.

Botanologiae juvenilis vide Ehrhart 2988 .
Botanophili Romani vide Maralh 6494.

Botanotroplium vide Wionius 11314 .

Calendrier de Flore vide lictorine de Chastenel 1807.

Carte botanique vide Deshayes $949 \mathrm{~S}$.

Catalogo ... Bisignano vide Tenore 10097.

Catalogo ... Napoli vide Tenore 10092, 10128

Catalogo delle piante a Bibhiani vide Rudulf 8583.

Catalogo delle piante vide Cultaneo 1756 .

Catalogo generale vide . Yupoil $66 ; 0$

Catalogue ... a Mger vide llurdy \& 132 .

Catalogue des plantes... de Taud vide Blanchet 998 .

Catalogue ... Glasvenin vide Lnderwood 10576.

Catalogue of medical plants vide Duncan 2827 .

Catalogue ... plauts of Great Britain vide Cuxhead 2034.

Catalogue des fruits vide Robillurd 8635 .

Catalogue ... de Liège vide Morren 7212.

Catalogue du jardin ... a Gorenki vide $F$ ischer $320 \%$.

Catalogus horti Boecadifalco vide Gussone 3987.

Catalogus luorti Amstelodamensis vide Cornelius 1990.

Catalogus horti Carolsruliani vide Schueyckert 9495.

Catalogus horti Coloniensis vide Rerkenkump 776 .

Catalogus horti Florentini vide Piccioli s004.

Catalogus horti Jenensis vide Batsch 559.

Catalngus horti Neapolitani vide Tenore 10100.

Catalogus borti Oxoniensis vide Bobort $96 z$.

Catalogus lıorti Oxoniensis vide Browne 1390.

Catalogus... Scarborough vide Truvis 10440.

Catalogus horti Turicensis vide Roemer $\$ 671$.

Catalıgus horti Lugduno-Batavi vide Kralit= 5378 .

Catalogus horti Modoetiensis vicle Rossi \$736.

Catalogus plantarum ... Judician vide Manetti 6461 .

Catalogus in IV sectiones vide Jan 4857 .

Catalogus plantarum cirea Cantabrigiam vide Ray 8375 .

Catalogus plantarum ounium vide Jikan 6927.

Catalogus rariorum vide Boelin 999.

Catalogus stirpium vide Cupelli 1680.

Clavis rem herbariam vide Nocea $75 \div 3$.

Cognoseite lilia agri vide Passuens 7797.

Coltivazione vide Trecco $104+1$.

Commentatio de faba St. Ignatii vide Haase 4006

Companion to the Glasgow garden vide Ifurray 7346 .

Comparatio nominum vide Arenstor 286 .

Compendio di fisiologia vide Tommaselli 10361 .

Conspectus horti ... Jenensis vide Batsch 558 .

Conversations on butany vide Fillon 3 ż三

Conrersatious on vegelable physiology vide June Murcet 6500.

Copy of a letter vide Hooker 4664 .

Corguille vide Bory de Suint-I'inrent 1149-1150, Bronguiart 1324

Corso delle botanielse lezione vide Tenore 10093.

Crambe. Viola. Lilium vide De Thou 9546

Curiositez de la nature vide Biron 895 .

De laudibus florum vide Thomasius 10197.

Delectus opusculorum visle Ludicig 6324.

Della coltirazione vide Fubbroni 307 .

Della idropisia de' gelsi vide Cattuneo $175 \mathrm{~S}$.

De l'origine du cafe vide Galland $34: 9$. 
De l'usage du caphe vide Girin 3659.

Des Jacintes vide Suint-Siman 8955.

Dérnonstrations élémentaires vide Latourreite 5577

De potu Coffi vide Strauss 9956 .

Der botanische Garten zu Dorpat vide Weinmann 11119.

Der hotanische Garten zu llatle vide Simengel 9833.

De Salicum rosis fictis vide Albrecht 137 .

Desiderata vide Dryander 2736.

Des hurfurston August vide Sickler 9699.

Je Stipae noxa vide Sadler 8913 .

Deutschlands Flora vide Sturm 9979.

Deutschlands liernobstsorten vide Johann Lexa, Freih, von Achrenthal 49.

De viticultura Richovillana vide Spielmunn 9811 .

Dialogues on botany vide Edycuorth 2907.

Dictionarium hotanicum vide Reuss 8529.

Dictionnaire bolaniciue vide Nicolus Alexundre 144.

Dietionnaire classirjue des sciences naturelles vide Drapiez 2716 .

Dictionuaire raisonné universel vile I'ulmont de Bumbre 10649

Dictionnaire universel vide Tavasseur 10689.

Die fruchtbare Boriza vide Martini 6566 .

Die offizinellen Gewaclise vide Strump 9967

Die Rose vide Benemann 707.

Die Tulpe vide Benemann 706.

I ie schwedischen Naturforscher vide Thunberg 10301

Difesa e illustrazione vide Moretti 716 f.

Discorso della irritabilita vide Covola 2027.

Discours botanique vide Fée 3133 .

Disertacion botanica vide $P_{c k}$ on 7830 .

Dispulatio de Mlandragora vide Thamasius 10198

Dissertatio epistolaris vide Martini 6563.

Dissertation... Caclıou vide Amoreux 205.

Dissertation... Hesperides vide Amorux 203.

Dissertation ... plantes religieuses vide Amoreux 906 .

Diasertazioni sopra ride Hoscati 7238 .

Double Flore Parisienne vide Dupont 2838.

Ectypa plantarum vide Hoppe 4675.

Ectypa plantarum viste Pucini 7695.

Ectypa vegetabilium vide Ludwig 6382 .

Eicones planlarum vide Tabernaemontanus 10037

Elenclus plantarum Borussiae vide Heyer 6862 .

Elenchus plantarum horti Amstelaedamensis vide I"rolik 10859

Elenclius plantarum horti Canal vicle Nowodzorsly 7576

Elenchus plantarum horti Luguluno-Batavi vide Brugmans 1416.

Elenchus plantarum Jorti Hadritensis vide Lagasca 3491.

Elenco delle piante ... Vicenza vide Marzari-Pencati 6635

Elémens succincts vide Jubin 344 .

Encore la maladie vide Lainé 5502.

Entier discours vide Linucier 6170.

Encyclographie du règne végétal vide thapiez 2715

Englisl Botany vide Smith 9707.

Entwurf eines Pflanzensystems vide Dobronsky 2647

Enumeratio ... horti Christianiensis vicle Rathke 8366

Enumeratio ... Iorli Gryphici vide Ledebour 5637.

Enumeratio... lorti Regiomontani vide Schweigger 9480

Enumeratio ... horti Romani vicle Donarelli 2677.

Enumeratio ... horli Taurinensis vide Iforis 7190.

Eumeratio plantarum vide Demidaro 2437.

Enumeratio plantarum ... Gorinka vide Redarsky $\$ 416$

Enumeratio plantarum ... von Iluegel vide Endlicher 2992

Enumeratio plantarum ... Schrenkii vide Fischer 3209

Enumeratio plantarum Regiom. vide Henckel ton Donnersmarch 4355

Enumeratio stirpium ... in Silesia vide Guenther 3944.

Essai sur lhistoire vide Nicolson 7493.

Exactissina descriptio vide Castelli 1736

Examen d'un ouvrage vide Paulet 7810

Examell epicriseos vide Browallius 1350

Fxercices d'histoire vaturelle vide Aubry de la Mottrate 346.

Fasciculus plantarun vide Blackstone 917 .

First catalogues vide Rafinesque $\$ 324$.

Flora Antillarum vide Tussac 10560

Flora austriaca vide Schultes 9406.

Flora batava ride Kops 5358 .

Pritzel, Thes. lit. bot.
Flora Berolinensis vide Hecker 4250 .

Flora brasiliensis vide Endlicher 2995.

Flora daniea ride Oeder 7601 .

Flora der Wetterau vide Gacrtner 3468.

Flora farmaceutica vide Nacca 7544 .

Flora Fluminensis vide Tellozo 10696.

Flora Friclrichsdalina vide Maeller 7293.

Flora graeca vide Silthorp 9618.

lilora japonica vile siehald 9634 .

Flora Napolitana vide Tenore 10098.

Flora prussica vide Lopselius 6222

Flora Romana vide Llaralli 6496 .

Flora sicula vide Gussane 3993.

Flora St. llelenica vide Ilatson 10958.

Flora Stuttgardiensis vide Kerner 5177.

Flora von Thuringen vide Zenker 11428

Flora Tyrnaviensis vide Ilorvatouszky 4715.

Florae italicae prodromus vide Turra 10556.

Florae lusitanicae specimen vide Tandelli 10655.

Flore complite d'Indre el Loire vide Dujardin 2790.

Flore de Paris vide Lefébure 5689.

Flore des jeunes personnes vide W'akefield 10898.

Flore des serres et jardius vide Lemaire 5745

Flore économique viøle Buchaz 1488.

Flore et Faune de Virgile vide Paulet 7841.

Flore et Pomone Lyonnaises vide Seringe 9586.

Flore médicale vide Chaumeton 1811.

Flore Parisienne vide Francaeur 3314.

Fortechning vide Hisinger 4518 .

Fruitwalls improved vide Facia de Duillier 3089.

Gartenzeitung vide Siprenyel 9836 .

Gedanken iber... Blumen vide Benemann 705 .

Genera et species vide II olf 11341.

Genera plantarum vide Trinius 10482.

Giomale lıotanico italiano vide Parlatore 7766.

Gpis Roślin vide Jakubaushi 4851 .

Grunderna vide Suartz 10014.

Grundralil vide Elvebemes 2975 , Raberg 86 is

Handbuch fur Liebhaber vide Roessig 8685 .

Jlandbuch fur Naturaliensammler vide Boitard 1066

Helminthochorti bistoria vide Spielmann 9810.

Herbarum inagines vivae vide Egenalphus 2915

Herbier élémentaire vide Benoit 714.

Jlisloire des drogues vide IIuerto 4758 .

Histoice des plantes de l'Europe vide Deville 2551

Hlistoire des plantes vénéneuses vide Ilaller 4083 .

Ilistoire naturelle vide Quelus 8273.

1listoire generalis plantarum vide Dalechamps.s 2121

Ilistoria plantarum vide Boerhuave 1042.

Historia plantarum vide DuPinet $2 \$ 35$.

Ilistoriae naturalis fragaienta vide Heyne 4449

IIorn des Hevls vide Carrichter 1699.

Horti Beaumoutiani catalogus vide Kiggelaer 5211 .

Hortus Bengalensis vide Roxburgh 8788 .

Hortus Canalius vide Tausch 10077.

Hortus Carlsruhanus vide Gmelin 3710.

Hortus Dyckensis vide Salm-Reifferscheid-Dyek 8970

Hortus Eastensis vide Broughton 1344-1345.

Hortus Ellhamensis vide Dillenius 2633-2634.

Iortus ericaceus Wuburnensis vide Furbes 3265.

Hortus Eystettensis vide Besier 840

Hortus Doridus vide Pusvacus 7796 .

Hortus gramineus Woburnensis vide Sinclair 9666 .

Hortus Mosquensis vide IIaffmann 4586.

Hortus pharmaceuticus Lutetianus vide Gregoire 3858 .

Hortus regius vide Joncquet 4936 .

Hortus regius Blesensis vide Brunyer 1438 .

Hortus regius Blesensis vide Morisan 7195 .

Hortus regius Nonacensis vide Martius 6595.

Hortus Romanus vide Ronelli 1098.

Hortus suburbanus Calcullensis vide Ioigt $\mathbf{1 0 8 2 4}$

HIortus Uptoneasis vide Caakley-Lettsom 1883. 
IIortus VanHoutteanus vide I'anlloutte 10660

llortus TVoburnensis vide Forbes $\$ 267$.

Iloutkunde vide Houtuyn 4729.

Jahrbticher der Gewachshunde vide Sprengel 9843.

Jalıresbericlıte vido Beilschmied 666 .

Jahresberichte der Pollichia vide schultz 9423

lcones arborum vide $A$ a 1 .

leones lignorum vide lloutluyn 4729.

Icones plantarmm vide Oeder 7601 .

Icones plantarum virJo Mueller 7285.

Icones plantarum vide Rivinus 8615 .

Jcones plantarum virle Vielz 10737.

lcones plantarum vide Zorn 11463 .

leones selectar plantarum vide Kaempfer 5083.

II critico criticato vide Nocca 7540 .

II fiore della granadiglia vide Parlasca. 7751.

Il giardino botanico vide Durazzo 2845 .

I misteri di Flora vide Bellinelli 854.

Improvements in the microscope vide Slack 9676.

Indox liorti Argentinensis vide Nestler 7455.

Index horti Boccadifalco ville Gussone 3989.

Index horti Glaucheusis vide Schrader 9275 .

Index horti Groningani vide Driessen 2732.

tulex horti Gryphici vide Weigel 11110

Indox lorti JIalonsis vile Junghens 5000

Index horti Halensis vido Sprengel 9839.

Index horti Leodiensis vide Gaede 3465 .

Index horti Panormitani vide Tineo 10328

Index borti Pesthiniensis vide Winterl 11311

Index lorti Petropolitani vide Fischer 3206.

Index horti Pragensis vide Kosteletzky 5368 .

Index borti Rheno-Trajectini vide Kops 5359

Index numismatum vide Rudolphi 8841 .

ludex plantarum agri Cantalırigionsis virle Ruy $\$ 376$.

Inclex plantarum liorti Bononiac vide Roduti 8651 .

Index plantarum officinalium vide Rand 8347 .

Indox regni vegetabilis vide Jacquin $4 \$ 31$.

lndice de las pliatas vide Ortega 7634 .

In Dioscoriulis historiam vide Brunfels $142 \mathrm{~S}$.

lnhalt einer Abhantlung vide Mueller 7267.

Instruceion formada vide Matis 7358 .

Instruction facilo vide Morin 7187.

Instruction sur liherbe Petum vide Gohori 3766

Introduction vide Chavonnes 1813.

Journal de batanique vide Desvaux 2529-2530

Journal fur die Botanik vide Schrader 9285.

Journal of a horticultural tour vide Fortes 3263-3264

Istruzione sul siroppo vide Olcese 7624 .

Kakile vide L'heritier 5845 .

Katechismus dor Botanik vide Reichonbark 8440 .

Keuntuiss derjenigen Planzen vide Reuss 8521.

Korte Verhandeling vide Servais 9593 .

La Betoyne vide Du-Peyral 2834.

La Bonito vide I"aillane $106 \mathbf{1 8 .}$

La botaniquo mise a la portée vile Regnuult 8421.

L'abrégé des hons fruits vide Merlet 6808.

L'agronome vido des Allets 154.

L'art de former vicle Whately 1189.

L'Astrolabe vide Humont d'Urville 2802 . Muntagne 7097. Kichard 8537.

La Zéléo vido Dumont d'Urville $280 \mathrm{2}$, Montugne 7097.

Le lon usage vide Buillurd 418.

Le botaninto cultivateur vido DuMont de Courset 2798.

Le lotaniste sans maitre (par DeClairvillo) vide Rousseau 8773 .

Le botaniste voyageur vide Deshayes 2500.

Le jardin Senonois vide Mont-Suinct 7128.

Leilfaden der Botanik vide Molly 7247.

Le petil botanisto vide Poisle-Desgranges 8117.

Les amours des plantos vide Mellerille 6704 .

Letre sur les arbres à épiceries vide Cossigny 2002.

Lettres a $\mathbf{M}^{\mathrm{me}}$ de $\mathrm{C}^{* *}$ vido Uontbrison 7116 .

I.ettres du Bostangi-Baclii vide Roland 8699-8701.

Lettres d'un médecin vide petit 7919 .
Lettres sur la botanique vide Collel 1920.

Le Vademecum du botaniste vide Deshayes 2499.

L'horticulteur universel vide Lemaire 5740.

L'Orto botanico di l'adova vide I'isiuni 10773.

L'horto tlei simplici di Padova vidle Corlusi 1999.

Lichenographia britannica vide Borrer 1141.

Magazin des Pflanzenreiches vide Reich 8423.

Nagazin fur die Botanik vide Roemer $8665-8666$

Magazine of botany vide Puxton 7832.

Manuel de botanique vide Duchesne 2732.

Manuel d'herborisation vide De Clairville 2327.

Matière médicale vide Haller 4084.

Mrizwyora.tyveoy vide Locher 6197.

Mémoire instructif vide Turgot 10529.

Mémoire sur la culture vide Kenaule 8484.

Mémoire sur la maladie vide Morand 7134 .

Mémoire sur la structure vide Dunal 2821.

Mémoire sur les dévastations vide $\operatorname{Lardy} \mathbf{5 5 6 2 .}$

Mémoires pour . . Languedoe vide Astrnc 326.

Mémoires pour servir vide Dodart 2648.

Memoria sobre a Canella vide Gomes 3775 .

Nemoria sulla coltivazione vide Olcese 7625 .

Mercurius botanicus vide Johnson 4920-4921.

Nisocapnus vide Jacobus I. 4810 .

Mittleilungen uber Flura vide Schramm 9304.

Mollo de cultivar vide Gomes 3776 .

Mororum libri Ires vide Miniscalchi 6955.

Musée helvéticuo dhistuire naturelle vide Seringe 9575.

Nachrichten vide Schreibers 9338.

Naturhistorisches botanisclı vide Quarizius 8270.

Neues Journal für tlic Botanik vide Schruder 9286.

Nonenclator vide Raeuschel 8303.

Nomenclator fungorum vide $/ /$ ofmann 4578.

Notice biographique sur II. de Théis vide Duverger 2567 .

Notice historique... Porta vide Duchèsne 2751.

Notice sur le Nusée vide Lasigue 5568 .

Notice sur les orangers vide Ilis 4512 .

Notice sur l'llerminier vide Guibourt 3962.

Notice topo-plyytographique vide Cordienne 1976.

Notions élémentaires vide Durande 2842.

Novarum stirpium decades vide Endlicher 2994.

Noyum herbariun vide Maranta 6492.

Observations faites dans les Pyrénées vide Ramond 8343.

Observations sur la dégéneration vide $P$ uvis $\$ 263$.

Observations sur le Cacao vide Navier 7392.

Observations sul l'écorce vide DeSuussure 2176.

Oenologie vide Beguillet 653 .

Ockonomisch-techuische Flora Buhmens vide Berchold ias.

Oestreich's Flora vido Schultes 9406.

Onomatologia vide. Nocca 7536 .

Onomatologia botaniea vide Gmelin $369 \%$.

Orbis cruditi judicium vide Lime 6141 .

Orehidóes des environs de Rennes vide Fleury 3239.

Orthotrichum vide Ilooker 4644.

Osservazioni meteorologiclue vide Pollini $\$ 143$.

Osservazioni sulla Flora Virgiliana vide Tenore 10107.

Palacontographica vidle Dunker 2831.

Papers relatimg. ... Tea vide Ifoe Clelland 6383.

Paradisus Vindolonensis vide IIartinger $\$ 167$.

Petro nomine ac imperio vile lellozo 10696.

Peziza culiculosa vide Forster 3281.

Pflanzenalhildungen vide Guimpel 39s 1.

Pflanzen und Gebirgsarten vide Heidler 4281.

Physikalische Arbeiten vide Born 1138.

Plyytologia britannica vide lfow 4731 .

Pinetum Woburnense vide Forbes 3268 .

Plantae horti Pesthiensis vide Kitaibel 5244.

Plantae Lindlucimerianae vide Engelmann 3007.

Plantao Preissianac vide Lehmann 5710.

Plantac rariores vide Treu $10 \$ 52$.

Plantac selectae vile Tiru 104í7.

PJantarum seu stirpium icones vide De lobel 2427 


\section{OPERA ANONYHA}

Plantes phanérogames vide Perreymond 7884 .

Plantes phanérogames vide Robert 8627.

Pomona austriaca vide Kraf $5376-5377$.

Pomona britanniea vide Driver 2733.

Pomona franeoniea vide Muyer 6692.

Pomona italiana vide Gollesio $3482-3383$

Postille ad aleuni eapi vide Scurella 9048.

Praedium rustieum vide Estienne 3043.

Praedium rusticum vide Vunière 10662.

Principales merveilles vide De.llailly 2434.

Prineipes de botanique vide Suffren 9993.

Prodramus Florae Argentoratensis vide Spielmann 9802

Prospetto vide Trevisan 10470.

Question du Sésame vide Mougin 6669

Rapports annuels... Mauriee vide Desjardins 2501, Bouton 1209

Reeherches sur... Richer do Belleval vido Amoureux 200 .

Recueil des plantes vide Robert 8632 .

Reise in den áussersten Norden vide Trautvetter 10437.

Relazione dell' erba vide Micheli 6914 .

Repliea vide Dehnhardl 2339.

Report on the plants of Massachusetts vide Dewry 2553.

Réunion vide Thurmann 10302.

Revue botanique vide Duchortre 2750.

Rheiniselses Magazin vide Borhhausen 1134.

Saggio sul eastagno d'India vide Canzonteri 1675.

Saggio sulla maniera vide Tiviani 10789.

Saliceturn Woburmense vide Furbes 3266 .

Sammlung physihaliseher Aufsatze vide Muyer 6693

Sehedulae critieae vide Fries 3389.

Selıla botanica vide $W^{\top}$ arton 10983.

Seleet specimens vide Freeman 3348.

Series plantarum vide Thienaeus 10185

Sertum plantarum vide Fielding 3185 .

Some account vide Fothergill $\mathbf{3 3 0 1 .}$

Specchio clelle scienze vide Rafinesque 8317

Specimen Florae Hallensis vide Otearius 7628 .

Specimen of a Lichenographia britannica vide Borrer 1141

Spiergazione vide Theis 10149

studien vide Luducig 6326.

Suites a Buffon vide Spach 9775.

Sulla metamorfosi vide Meneghini 6775 .

Sulla teoria ville Meneghini 6774 .

Sulphur vide Benthum 722.

Sul richiamo vide Vaccuri 10613.

Summa vegetabilium vide Swartz 10015.

Sur les plantes marines vide D'Etreillis 2548.

Sveıska Oertslagen vide Liljeblad 5892 .

Sylvan sketelıes vide Kent 5163 .

Symbolae ad historiam vide Linne 6439 .

Synonyma plantarum vide Menzel 6792 .

Synopsis plantarum vide Nocca 7526

Synopsis plantarum horti Florentinj vidi Zuccogn 11471

Synopsis stirpium ... Aragoniae vide Asso 321.

Syntagma herbarum vide Colius 1900.

Systematische Uebersicht vide Jahann Lexa, Freiherr von Aehrenthul 50.

Tableau vide Villars 10751.

Tableau de la Flore du Jura vide Bernard 784.

Tableau des plantes vide Gilibert 3638 .

Tabula loeum vide Kentmann 5165.

Tabulae phytagraphicae vide Gesner 3613 .

\section{OPERA ANONYMA}

Tabulae synoptieae vide Joln Marlyn 6617

Tentamrn pharmacopoeae vide Masius 6640

Terminologie botanique vide Coppens 1967

The Botanieal Cabinet vide Loddiges 6207.

The Botanieal Magazine vide Curtis 2091.

The Botanical Register vide Edwards 2911.

The Botanic Garden vide Darwin 2147.

The Botanic Garden vide Maund 6673.

The Botanist vide Maund 6674 .

The Botany of Captain Beechey's Voyage vide Ilooker 4665

The Botany ... Sulphur vide Bentham 722.

The British Garden vide Murray 7332.

The Floral Cabinet vide Knowles $\$ 302$.

The Gardener's Magazine vide Loudon 6281.

The history of ... wines vide IIenderson 4358 .

The North-Ameriean Sylvan vide Nuttall 7584.

Théorie de ressemblanees vide Grama Machado 3489

Thesaurus aromatariorum vide Suardus 9984.

Toilette de Flore vide Buchoz 1469.

Traets relative to botany vide Konig 5356 .

Trailé de l'olivier vide Amoreux 499.

Traité des jardins viele Le Berryais 5603 .

Traité des vertus vide Gundoyer de Foigny 3491

Trattato di !itognosia vile Tenore 10094.

Ueber das Vermögen vide Crell 2048.

Ueber Feld - und Garteuprodukte vide Moser 7241

Underretning vide DuIIanzel 2774.

Underretning ville Strom 9963.

Unterhaliungen vide $\mathrm{H}_{\text {ilhelm }} 11247$.

Untersuehungen vom Meere vide Popowitsch 8163.

Vademecum du botiniste vide Deshayes 2499.

Vegetabilium eum vide Roberg 8619.

Vegetatio vide Spielmann 9809.

Verhandelingen vide Korthals 5361 .

Versueh einer Flora vide Meigen 6746.

Versueh einer teutsehen vide Planer 8046.

Versuehe vide Trathinick 10421.

Verzeichniss vide Freiherr von Aehrenthal 51

Verzeichniss vide Detharding 2543 .

Verzeielnniss vide Krouss 5401 .

Verzeielniss vide Otto 7680

Verzeichniss vide Sulm-Reifferscheid-Dycls 8965

Verzeichniss vide Schrader 9292.

Verzeichniss vide Wulter 10964.

Verzeicluniss vide Wendland 11156 .

Toeabula rei nummaride vide Peucer 7965.

Vollständiges systematisches Verzeichniss vide Honckeny 4634

Vom Tulpen- und Narzissenbau vide Diez 2628.

Vorschlage, nach welehen vide Dulfomel 2774 .

Voyage à la Nartinique vide Thibaull 10175.

Voyage à I'Isle de France vide Suint-Pierre 8952

Vovage au Mont-Pilat vide Latourrette 5578.

Voyage au Pole Sud vide Dumont d'Urville 2802.

Voyage au Pole Sud vide Montagne 7097.

Voyage dans l'Ámérique mériclionale vide Alcide D'Orbigny 2690.

Voyage dans le Finistère vicle Cambry 1641.

Voyage de découvertes de l'Astrolabe vide Richard 8557 .

Voyages d'un philosophe vide Poivie 8125.

TVeinmauni Thesaurus vide Gesner 3612 .

Zeitschrift fur wissenschaftliche Batanik vide Schleiden 9159. 


\section{Opera anonyma rengliea:}

11539 A boke of the properties of herbes called an lierball, drawen out of an auncyent booke of plisyck by II' C. London, by Wyllyam Goplanci. s. a. 8. 10 plag. B.

$110340 \quad \Lambda$ booke of beast, hirds, llowers, fruits, flies and wormes, exactly drawne with their lively colours truly described. Ar to be sould Jy Thomas. Johnson in Brittaynus Isurse. 1630.20 tab. aen. long. 6 unc., lat. 8 uuc. B.

llijł A catalogne of green house, hot house, herlaccous and hardy plants, which will be sold by auction, at Hackocy, July 1799 by order of the executors of Thomas Sikes, Ess(1. (London 1799.) 8. $50 \mathrm{l}$.

$115122^{*}$ A catalogue of plants in the hotanie gorden at Liverpeol. Liverpool, tyj. J. Smith. 1808 . 8. vr, 298 j. cun iconograplia herti.

11543 A eatalogne of trees and slruls growing in the botanic gatrden at Edinburigh. Edinburgh 1773.8. 17 j. B.

llity $\Lambda$ catilogue of trees, shrubs, plants and flowers, which are prapagated for sale in the gariens near london. London 1730. folio. 30 J., 24 tał. col. B.

$11545 \Lambda$ description of a great varicty of animals and vegetables, heing a supplement to a deseription of 300 animals. Lonclen 1736.12. 137 p., tab. B.

11546 A family-herbal, or the treasure of health, wherein you have an account of the nature of all sorts of meats, flesli, fish, fruits, herbs etc. and also all sorts of clrinks. (Trauslated from the italian by $J$. Chamberluyne.) Second edition. London 1689. 12.232 p. B.

11537 A list of plants and seeds, wanted from China and Japan, to which is atded Directions fur l,ringing then to Europe. London 1789. 8. 22 p., 1 tab. B.

11548 An englisl catalegue of the trees and plants in the ploysiche garden of the university of $0 x$ ford, with the latine names added thereunto. Oxford 1648. 8. 31 p. B.

11549 An English herbal, or a diseovery of the phissical vertues of all herles in this kington. London s, a. 12. 7 9 p. B.

$1 \$ 550$ A short aecount of the late clonation of a lotanic garden to the University of Cambrilge by the Rev. Dr. II"uller, with rules and urders for the gevernment of it. Cimbrirlye 4763.4 .6 p. B.

11551 A slort attempt to recommend the study of hotanical analogy, in investigating the propertics of medicin's from the regetable kingdom. London 1784.8 .101 p. B.

11352 A supplement to the description of the Coffectree lately published by Dr. Douglas. (Thes. lit. bet. Nir. 2699.) London 1727. fulio. 54 1). B.

11383 A true account of the Aloe americana or africana, which is now in blossom in Mr. Cowell's garden at Hoxton, which is upwards of twenty foot ligh, and has already put sorth thitly branches for flowers alt upon one stem, twelve whereof are already fairly oponed and blown out. As also of the Cereus, or great TorehThistle, which have likewise jut forth their blessoms in Mr. Cowell's said garden, the like whereof has never lieen seen in England befere. Loudon, T. Warner. 1729. 8. 44 p., 1 tab. B.

(Tribuitur a Seguiero Richardo Rradley.)

11354. Botanical Labels for the herbarium, adapted to the Floras of Smith Hooker, Lindley and Macreiglt, giving the scientific ant pepular names, synonyms and habitats of each plant, with blank spaces for notes and observations. Edited by a corresponding member of the botanical society of Lendon. Faversham, W. Rateliffe. (London, Pamplin.) 1811. (5s.)

11555 Calalogue for sale of the hot-house and green-heuse plants in Dr. Fothergill's garden at Upton. (Londen) 1781. 8.50 p. B.

11336 * Catalogue of American trees, plants and seeds for sale by Stephen F. Mills et Co., Flushing near NewYork. Newlork, typ. Swords. 1827. 8. p. $129-168$.

$11557+$ Catalogue of British plants. Printed for the Botanical Socicty of Edinburgh. Edinburg, Maclachlan and Stewart. $183 \mathrm{G}, 8.15 \mathrm{p}$. Second edition. ib. 1841. 8. 16 p.

11358 t Catalegue of exolic plants cultivated in the island of Mauritius, at the royal betanic garden Pamplemousses, at bis excellency the governor's garden at reduit, at mon plaisir, hois clieri etc. with an enumeration of the most renarkable indignous plants of that colony. Compiled and published under the auspices and autlırity of lis excellency Sir Robert Tounsend Farquhar, liarourel, Goveruor, Captain-General, lice-Admiral. (Printed by .Malluc brethers, prinlers to governement.) 1822 . 4. 44 p.

$110399+$ Catalogue of fruits cultivated in the garden of the llorticultural Suciety of Londen at Chiswick. Londen, tyj». Nicol. 1826. 8. x, 22 p. - t Eil. II : il. 1831. 8. v, 166 \}).

$11360^{*}$ Catalogue of plants in the Arhoretum, fruticetum, herbariusn, gramina vera, hortus tinctorius, hot et green-houses of the Dublin Society's botanic garden at filasnevin. Dublin, typ. Graisherr?. 1802.8.297\%

11361 Catalogue of the nativo phaenogamous plants and ferus of kintucky: and supplementary catalogue of tlie same. Leviıgton $\mathbf{1 8 3 3 .}$ 8. Bibl. Acad. Philad.

H562 Essay concerning the best methods of pruning fruit-trees, also the method of prutuing timber-trees; with a discourse concernog the improvement of the Potatoc. Loulon 1732. 8. 64 j. B.

11363 Flera anglica, ou Flore angloise, contenant les plantes qui croissent naturellement en Angleterye. Londres 1764. 8. Schultes.

1136 t Florula Columbiensis, or a list of plants found in the district of Calumbra, duriag the years $1817-1818$. Washingten 1819. $\$$. Bibl. Nov. Ebor.

11:603 IJereafter foloweth the knowledge, propertics and the vertues of herbes. London, by liobelt Wyer. s. a. 8.15 plag. dinid. $B$.

11566 Herefordshire Orchards, a pattern for all England, by J. B. locendon 1724.8.36 P. B.

$14567+11$ ortus anglicus, or the modern english garten: containing a faniliar description of all the plants which are eullivated in the climate of Great Britain, either for use or ornament, and of a selection from the established favourites of the stove and greculouse; irranged accorling to the system of Linnaeus; with remarks an the properties of the more valuable species. By the author of "Thr british botanist "ln two volunes. London, Rivingten. 1822. 12. 1: $\mathbf{8 1}, 514 \mathrm{\mu},-11: 589 \mathrm{p}$, , ind.

11368 Memoirs on the Rose. London, Westley. 1524. 19.

113069 New theory of vegetable physiology, based on electricity, ancl substantiated by facts, with its application to agriculure. bidinburgh $1848 . \mathrm{gr} .12 .186 \mathrm{p} .(5 \mathrm{~s}$.

11370 Observations on the Ohecroo, a Palm-1ree. Lonclun 1754. 4. 32 \%., 1 tab. B.

$11371^{*}$ Pecudarium, or Cattle division in the Dublin Society's fotanical garden, at Glasnevin. Dublin, typ. Graisberry and Camplsell. s. a. 4. IV, $11 \mathrm{p}$.

11372 Portable instructions for purchasing the drugs and spices of Asia and the East-Indies, pointing out the distinguishing characteristic: of those that are genuine and the arts practised in their adulteration. Lendon $1779.8 .96 \mathrm{p}$. B.

11573 Remarks on the manufacturing of Maplo Sugar. Philadelpllie 1790 12. 24 p. B.

1167\%. St. Foine improved, a disceurse shewing the utility and benefit which Eugland hath and may receive by the grasse called st. Foine. London 1671. 4. 20 p. B.

11375 Synopsis of the genera of American plants. Georgetown 1814. 12. Bibl. Acad. Philad.

11376t The Lotanieal Society of Edinburgh, instiluted 17. march 1836. Edinburgh, typ. Neill et Co. 1840.8.30 p.

15877 The complete florist. Ed. 11. Lendon s. a. $12.147 \mathrm{j} . \quad$ B.

$11378 *$ The Cyclopacdia; or universal dictionary of arts, sciences and literature, by Atrahum Recs. In 39 volumes. London, Longman. 1819. Axxill voll. text., 11 voll. tab. 4 .

(The Botany by James Edward Smith, Dr. Woodville and Rev. Uuod. Tabulae duodeviginti sunt botanicae.)

11379 * The families of plants, with their natural characters, according to the number, figure, situation aud proportion of all the parts of fructificalion. Translated from the last edition hy Dr. Reichard of the Genera and Hantissae plantarum of Limnaeus. ete. Licblield, Jebnsen. 1787. 11 voll. 8. Lxys, 840 p. 
t1380 The Floral Telegraph, a companion to the language of fowers. London 1836. 18. $(10 \mathrm{~s} .6 \mathrm{~d}$.)

11381 the flower garden display'd, in alove four huntred curions rejresentations of the most beautifu! flowers, regulary clistos il in the respective months of their blossom, curiously engraved on eoppraplates from the designs of Mlr. Furber and olbers and coInured to the life; with the description and history of each plant and the method of their culture. Loudon, llazard, 1732, 4. 108 p., 13 tal. col. - Eil. 1l. ib. 1734. 4. (non ditlert.)

11.382 The grete Jerball. Lendou 1526. folio. 28 trinrniones, ic. xylogr. i. $\mathrm{t}$. B.

Itu Catalngo bibliothecae oxoniensis thic liber adseribitur Jeremiae Triverio (Driver, Triveris) Professolj Lovinionsi [ +1335.$]$. 111 cilce lesilur: "Thus endeth the grete herbill wheh is uansiated out ye frensibe in to Englyssche.")

1 li83 The grete herball. London 4529. folio. 1 duerıio, 28 trieruiones, ic. xylogrr. i. I. B.

1158: The grete herluall. London 1539. folio. A duenio, 26 trierniones, absıpue figuris. B.

1158.3 The grete herball. London 1561. folio. 22 trierniones, 2 quaterniones, absique figuris. B.

11586 The Handbeok of plain botany, or Limmaean lessons for field and garden use. London 1836.8 . (2s.)

1 lïst The Irish lilora, conprising the flowering plants and ferns. Dublin 1847. 12. $220 \mathrm{p} .(5 \mathrm{~s}$.

11:388t The London Catalogue of British plants. Publisled under the direction of the hotanical society of London. London, Pamplin. 1844. S. $16 \mathrm{j}$. $(6 \mathrm{ll}$.

11389 The Lotus, or Faery Flowor of the pocts, Lonton, Simphin. 18. 19. $(4 s$.

11:390 The natural history of Ceffee, Ther, Chocolate, Tolbacen, with a tract of lilder-and Juniper-berries, and also the way of making Mum, witl some remarlis upen that liquor. London 1682 . 4. $36 \mathrm{p} . \quad$ B.

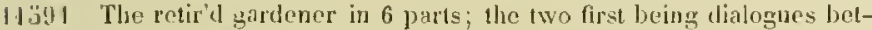
ween a gentleman and a gardeuer, translated from the second edition printed at Paris, the 4 last parts translated from the french of Louis Liger: heretofore published in 2 volumes, witl allerations and additious by George London and IIenry 11 ise. Second edition, pullished in one volume by Joseph Carpenter. London 1717. 8. 432 p., $x$ tal,. B.

(list translitto operis: "Le jardinier solitaje.,

$11: 992$ The Rice manufacture in Cluina, from the originals broughtu from China. Londen s. a. folin obl. 24 tab. Jat. 10 unc., long. 8 unc. B.

11:593. The spirit of the woods. By the anthor of the Moral of flowers. With coluured engravings. London, Longman et Co. 1837. reyal 8. $306 \mathrm{p} .(\mathrm{I} l .46 \mathrm{~s}$.

1159:" Vegetable substances, used in the arts and in domestic economy. Timber trees: fruits: used for the foot of man; materials of manufactures. (Published under the superintendence of the saciety for the diffusion of useful knowledge.) London, Charles linight. is 30 -1833. III voll. 8. - I: 1830.422 p. - II: 1832. 396 p. III : $1833.456 \mathrm{p}$.

\section{Opera anonyma gallica.}

11:59: Mbregé étémentaire des principes de botanique. Par $M . F . L^{* * *}$. Paris 1807.8.

11396 Abregé pour les arbres naius et autres, par J. L. (Laurent), notilire a Jaon. Paris 1675.12 . Barbier.

$11597^{*}$ Almanach de Carlsbad, ou mélanges médicaux, scientifiques et littirajes relatifs a ces therunes et au pays. Anne 1-V. P'rague $1831-1835.12$

(Annorum scquention editiones non vidi. (n) anuis III. p. 1- $\$ 0$, ร. p. 31-42 continetur "Flore de Carlshad" autore Anton Orinann.

11:398t Analyse des plantes vasculaires du Lyonnais el du Mont-Pilat, a l'usage des betanistes en excursion. Lyou, (typ. Perisse) chez l'auteur, place des Mlinimes, 4. 1838. 12. IV, $113 \mathrm{p}$.

$14599 t$ Anuuaire du jardinier et de l'agroneme pour 1826. Paris, Roret. 4826. 48. $212 \mathrm{p}$.
11600 t Annuaire de l'herboriste. Par un medecin bolaniste. Paris, Serviere, $180 \% .8 .499 \mathrm{p}$.

$11601 \div$ Bibliotheque universelle ales Itimes. Botanique. Paris 1786. II voll. 12. - I: $\mathrm{xt}, 180$ p., 8 tab. - II: 335 p.

11602 Biographic do Albert de Ilaller: par l'auteur de l'Essai sur la vie de J. Gr. Lavater. Seconde cdition. Paris, Delay. 1845. 8. $21 \% 1 /$ plag. (4 fr.)

II603 ljotani jue a l"usage de la jeunesse; par $\mathbf{I}^{\text {" e }}$ b $^{*}$ ". Meuxieme editiun. Lille, tyl. Lefort. 1845. 12. 12 plag., 1 tab.

$11604 \div$ l3otanicjue do la jeunesse, uu méthode facile pour connattre les végétaux sans maitre, ete. Edition ornée d'un grand nombre de planches, l'ar un P'rolesseur de botanique. Paris, chez Delarue. (Lille, Castianx.) (1812.) 12. 265 p., effigies Limnaei. Volume des planches: 35 p., 35 tab.

$11605 t$ Botanique des Dames, ou méthode facile pour connaitre les végétaux saus maitre. Par un Professeur de betanique. Paris, Delarue. (Iille, typ. I3Jocquel.) s. a. III voll. 12. - I: 192 p., eftigies Tournefortii, - II: 197 1), ceffigies de Jussieu. - III: 35 p., 85 tab., effiges Linuaei.

11606 t Bolanifue des enfans, on histoire naturelle, gincrale et pirticum lière du règne végétal, contenant 1 . les ledtres démentair's de J. J. Rousseau sur la botanifue; 2. une istroduction ele. Drus parlies. Paris, Batudouin. an Vlll, (1500.) 8. 189, 14, $226 \mathrm{p}$

11607 t Calalogue des intres et arbrisseaux, qui se peuvent elever un pleine terre aux environs de Paris (et yui sont au Tremblay.) Paris, typ. Bullot. 1735. 8.70 p.

11608t Catalogue des lives de botanique qui se trouvent clun J. B. Balliere, libraire de l'Leadénic royale de médecine, sue de l'école de médecine, 17. (Londres, chez II. Bailliere, 919, Regeut-Street.) Paris $1845.8 .16 \mathrm{l}$.

$11609+$ Catalogue des plintes cultivies au jardin botanique de la Marine royale du Port de Tuulon. Arignon, Soguin. 1821.8.50 1.

$11610 \div$ Catalogue das julutes cultivées an jardin de hotaniujue de Toulouse; a l'usaga des ileves de l'école du jardin. Tuulouse, typ. Douladoure. 1827.8.166 p. et eniendanda.

11611 Catulague des planters usuelles, qui se trouvent dans les jardins de botanique de l'Acatemie royale des sciences. Toulouse 1782. \&. 28 p. B.

$11612+$ Catalogue des plantes du jardin de botanique de Gironde. Berdeaux, chez Pinard. s. a. 8. 72 p.

Ifis Catalogue des plintes du jardin te J'Academie de Rourn. s. I. et a. 12. 116 p. B.

11614* Catilogue des plantes du jardin des Messieurs les apolicaires de Paris, suivant leurs genres et les caractores des fleurs, conformement a la métlucte: de Mr. Tournefort dans son Edition française de 1694. (Paris) 1741.8. 100 p. - tib. 1759. 8. xxis, $136 \mathrm{p}$. Autor est J. Descemet.)

11610 Catalogue des plantes dicotylédunes el monocutylédones qui croissent spontancment dans le département de la Mayeune. Par une sociéte de botanistes. Laval 1838. $18.23 / 2$ plag.

11616 Catalogue des piantes usuelles. Amiens 1754.12 .56 p. B.

116.1 it Catalogue des plus excellens fruits, les plus rares et les phis estimés, qui so cultivent dans les pépinières des reverends péres Chartreux de Paris. Arec leurs descriptions et le tems le plus ordinaire de leur maturité. Paris, typ. Coighard. 1798. 4. 4 p.tParis, Delespine. $1736.12 .40 \mathrm{p}$.

$11618^{*}$ Catalogue d'une partie de plantes existant en doulule au jardiu de la sucieté royale d'lorticulture des Pays-Bas, et qui sont a eichanger ou a céder. Brusclles, typ. Wertens. 1830. 8. 19 p., 1 lab.

$11619 \div$ Catalogue général des plantes cultivécs dans l'établissenent de la société royale d'lorticulture de Belgique a Bruxelles. liruxelles, 1yp. Stienon. 1842. S. 32 p.

$11620 \div$ Catalogue provisoire publié pour servir à la Flare de la Charenteinféricure, par la socicté des sciences naturelles de ce département. La Rochelle, Iyp. Maresehal. 1840.4. 159 p. Bibl. borti Paris

$1.1621^{*}$ Catalogue raisonné des (456) livres de botaninue, qui composent la bihliothèque d'un anateu', déposẻe chez Ivornault et Cabin, libraires, rue St. Dominicjue Nr. 64 a Lyen. Lyon 1809. 8. v1, 41 p. 
$11622 t$ Collection choisie de plantes et arlustes (par $C^{* *}$ ) Auswahl von Pflanzen und Gestráuchen. Zurich, liussli. 1796. 4. xxi, 37 p. 9 tal), col.

$110337^{\circ}$ De la culture du sininfoin. (Iledysarum Onobrychis I..) Par ..." nembre dis la société economique de lJerne. Paris, Neurant. 1797. S. $\mathrm{W}, 120 \mathrm{p}$.

1162 \& 7 Descrijtinu abrégée des plantes usuelles avee leurs vertus, leurs usages el lanrs jropriétés. P’ar l'auteur du Januel de's l)anes de clarite of pour servir de suite au meme envrage. Paris, Deburo 17607. 12. xvแ1, 503 ]?. (2 fr. 50 c.)

$1162: j$ Description de yuatre herles, gui ont la propriété de guturir ale la rage, et dle prouver si la prersonne ou l'animal, dui ont elé mortus est véritallement enragé, découvertes en Allemagne et rapportées en lirance par 1 . le Due de Doudeavill. P'remièe edition. Paris typ. Chassaignon. $1846,8,16 \mathrm{p}$.

$116: 2 \mathrm{i}^{*}$ Diclionnaire Iotanique el plitrmaceutique, contenant les prineipales proprietez to minéraux, les vigétatux et des animaux d'usaga, avec les préparations de pharmacie internes et externes les plus usitées en melecine el en chirurgie: le tom tiré des meilleurs autcurs, surtout des modernes par ${ }^{\text {** }}$ (Nicolas flexandie.) l'aris chez Laureut de Conte. 1716. 8.

(Editinues serjuentes er. supra Mr. 1hr.)

$11197^{*}$ Diclinnnaire classique dhistoire nalurelle par Alessieurs Auduin, * Bourdon efc. dirige par Bary de Suint-l'incent. Paris, Rey el Gravier. $1822-1831$. XVll voll. 8 .

(Volumen Irll continet 160 lab. col. el 1 t 1 p. explicationes.)

$11623 \div$ Dietionnaire des plantes alimentaires, qui peuvent servir de nourritur. at de luisson aux dilférens peuples de la terre. etc. I'aris, Samson. 1803.11 voll. 8. - I: II, 398 p. $-11: 412$ p.

11 fig9t Dictionnaire des plantes usuelles, des arbres et arbustes etc. orné l'environ 800 planehes dessineses l'apres nature, pouvant servir de sujplément aux dietionnaires de Bomare et de Lemery. etc. Par une secieté de gens de lettres naturalistes et medécins. Paris, Lany. an II. de la république. (1793.) VIll voll. \&. 764 1ab. col. et text: $1-\%$

(Barbier indicat antores DelaBeyrie et Goulin.)

$41630^{*}$ Ilictionıaire des sciences naturelles, dans lequel ou traite mithodiquement des différens êtres de la nature, considerés soit en eux mémes, d'après l'état actuel des nos conuaissances, soit relıtivement à J'utilité qu'en peuvent retirer la médecine, l'auriculture, le commerce et les arts; suivi d'une Biegraphie des plus célebres naturalistes. Ouvrage destiné aux .... par plusieurs Professeurs du jardin du roi et des principales écoles de Paris. Paris et Strassbourg, Levrault. 1816-1830. LX voll. 8.

(Ad hoc opus pertinent practerea volumen supplenentum et schemata sistens, 60 fasciculi iconcs, 4 volumina higgraphias et ¿ fasciculi effigies naturae serutatorum continentes. Tabulae botanicae coloratae sunt 500. Res bolanicas cxposueruut Brongniart, DeCandolle, Cassini, Desfontaines, St. Hilaire, con Humbolul, de Jussieu, Lesson, Loiseleur-Deslongchamps, Mirtiel, Poirel, alii.)

11631 Dietionnaire du jardinage (par D'Argenville). Paris, De Bure. 1767. 12. - liege, Bassompierre. 1783, 12. Barbier.

116.32 Dictionnaire raisonne du jardinier botaniste, fleuriste elc. Il voll. 8. (Autorem indicat Barbier: Le Bigue de Presle.)

11633 Dietionnaire raisouné universel de la matière médicale (par DelaBeyrie. ou plutot par Goulin, qui l'a refait). Paris, Didot le jeune. 1773 . IV voll. 8

(Teste Barbier llon differt a "Dictionnaire des plantes usuelles" ce. supr'd Nr. 11623 .)

11634. Dictionnaire universol d'agriculture et de jardinage (par La Chenaye-des-Bois). Paris 1751 . II voll. 4. Barbier.

11633 * Dictiounaire nuiversel d'histeire naturelle, résumant et complétant tous les faits présentés par los encyclopédies, les anciens dictionnaires scientifiques, les oeurres complètes de Buffon, et les meilleurs traités spéciaux sur les diverses branches des sciences naturelles; donnant la description des étres et des divers pluénımenes de la nature, l'étymologie el la définition des noms scientifiques, les principales applications des corps organiques et inorganiques, à l'agriculture, a la médecine, aux arts industriels, etc.: ouvrage utile aux médecins, aux pharmaciens, aux agriculteurs, aux industriels, et généralement à tous les hommes désireux de s'initier aux merveilles de la nature; par Messieur's Arugo, Baudement, Becquerel, Bibron, Blanchurd, Boilard, De Brébisson, Ad.
Brongniar, C. Broussais, Brulle, Chevrolat, Curdier, Decaisne, Delafosse, Deshuyes, Desmarest, J. Desnoyers, Alcide et Charles D'Orbigny, Doyere, Duchartre, Dujardin, Dumas, Dupnnchel, Duvernoy, Elie de

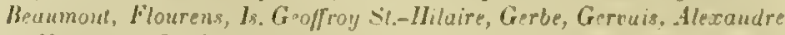
de Ilumboldh, De Jussieu, De Lafresnaye, Luurillard, Lemaire, Levelle. Jucrs, Murlin st.-dnge. Mllne-Edururds, Mondayne, Pelouze, Pellier, C. Prevost, De Quatrefages, .1. Richurd, Riviere, Roulin, Spuch, Vulenciennes, etc. dirige par Il. Charles Dorbigny, et enrichi d'un magnifique Alas de planclus gravees sur acier. l'aris, Renard. .lartinet et Co. 1842-184 S. .II voll. \&. A-S. (Continuatur.)

$116366^{\circ}$ Diseours sur la vegétation des plantes, par le Clievalier Digby. traduit de l'anglais (par D'. De Treitun). Paris, Noette. 1667. Iz $89 \mathrm{p} .$, praed.

11637 Discours sur les trois merveilles arrivens aux trois lleurs de lys (par Petit, substitut du procureur géneral de Vézelai). 1617. 4 16 1. Barbier.

11538 Jiscnurs sur Jes vignes (jar Herberl). Dijon et l'aris, Pissot. 1756. 12. 68 p. Barbier.

11639 Dissertation sur un nouveau remede anti-vénérien végetal (par De l'elnos). Paris 1765. 12. Barbier.

$1] 6.10$ École dn jardin potager (Jiar DeCumbes). Paris, Boudet. 1750. Il voll. 12. Barbier.

$116+1$ * Explaration scientifique de l'Igerie jendant les années 1840, 1841,1542 , pulslice par ardre ilu gouvernement ot arec le concours d'une comnission academique. Sciences physinges. Bolanipue. Pall AII. Bory de St. Iincent el Durieu de Maisonneute. membres de la commission ncientifịue d"Algéric. Livraison I-VI. Paris, injurimerie royale. (Gidle et Co.) $1846-1847 . \mathrm{gr} .4 .280$ ])., tal. col. 1-14, 19-34, $44,51-53,55,58,67,69,74,77.80$ -88. (a livr. 13 fr.) (Continuatur.)

(Contenta indicantur in Gersdurf Leipz. Repertoriun 18'8. II.

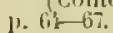

$1164 \geq \div$ Flore Ies serres et jardins du Paris, ou collection des plantes remarquables par leur utilin', leur élégance, leur éclat ou leur nouveaute; consistant en 600 planches soigneusement lithographiees ei colorieses, accompagnees diun texte particulier pour chacpue plante, exprosant son ordre méthodique, ses caracteres génerique et spécifique ainsi que sa synonymie. son listoire, l'épeque de sa découverte, celle de son introduction dans nos contrées el dans nos jardins, ses usages, seil dans les arts soit dans l"économir dumestigue et la médecinc; enfin les dilférens modes de culture qui réuississent le mieux dans nos climats pour lui faire parcourir complètument toutes les puriodes de la vie végétale etc. Par une socicté de Gotanistes. Paris, an dépot general de librairie, rue du Con St. Honore $n^{\circ}$. 4. 1834. 1] voll. 4. $(600)$ tab. col., $(600)$ foll., $10 \mathrm{p}$. ind. Bibl. Deless.

$11643^{\circ}$ Guide de la culture des loois ou llerbier forestier. Allas. Paris typ. Moreau, rue Moutmartre n". 39. 18 20. folio. 15 tab. a Deshuyes delineatac. Bibl. cand.

1164: Jlistoire des plantes de l'Europe et des plus usitées, qui viennent d'Asie, d'Afrique et d'Amérique etc. divisée en deux tomes, et rangée suivant l'ordre du Pinax de Gaspard Bunhin. Lyon, chez Jean Baptiste de Ville. 1683. Il roll. 8. Rivin. - Lyon 1689. Jl voll. 12. 866 p. в. - Lyon, elıez Nicelas de Ville. 1707 . II roll. \&. Rivin. - "Lyon, chez Nicolas de Ville. 1716.11 voll. 8. (non dillert.) - " Lyou, chez Nicolas Deville. 1799. II voll. 8. 866 p., praef., ind., ic. xylogr. i. 1. - *ib. 1726. Il voll. 8 . (non differt.) - "lyon. cliez Duplain. 1737. II voll. 8. (non dillert.)

11643 Instruction du plantage et propriétes des meuriers, et gouvernement des vers a soye (par Benigne Le Roy). Lyon, Jlaignard. 1695. 12. Barbier.

$11646 \div$ Instruction pour les royageurs et pour les employés dans les colonies, sur la manière de recucillir, de conserver el d'envoyer les objets d histoire naturelle. Rédigée... par l'administration du Muséun royal d'histoire naturelle. Paris, typ. Belin. 1818.4.45 p - +Ed. Ill. ib. $1829.8 .61 \mathrm{p}$.

11647 Instruction sur la culture des navets, sur la manière de les conserver et sur les moyens, de les rendre propres à la nourriture des bestiaux (rédigee par Broussonet). Paris 1785.8 . Barbier. 
$116 \% 8$ Instruction sur la culture et les avantages des plantes légumineuses, par MII. Dubois, Cels, Vilmorin, Gilbert, Husard et Purmentier. Ed. Ill. Paris, Madame Huzard. 1896.8

$116: 9 \div$ Instruction sur la maniere de planter et cultiver avec succès les plantes el graines de 'gerofliers et muscardiers. A l'usage de MIM. les habitans des isles de France et de lourbon. A l'Jsle de France, de l'imprimerio royale. $1772.4 .9 \mathrm{p}$

$116.50 \div$ Instruction sur l'ordre ef l'arrangement du jardin botauique, établi dans le jardin de lá ville a Orléans. Oılèans 1793.12 .44 p., ind.

$11631 \%$ Insiructions pour la semence, platutation et culture rles muriers et sur la manière de bien élever les vers a soie, inprimeses a Corte dans l'isle de Corse en 1765 par S. F. Batini, traduites par Joubert de lliberderie. A Imboise Choiseul. 1770. 12. vi, $71 \mathrm{p}$.

$116022^{*}$ Instructions pour les arbres fruictiers par M. R. T.P.D. S. M. (R. Triquet, Picur de Saint-Marc). Paris 1653. 12. - "Eel.ll : A la llaye, chez Adrian Vlacq. 1655. 12. 130 p., ind. - Ed. Jll. Paris 1664. 12. - Paris 1676. 12. s.

$110: 33$ Introduction a la hotanique. Impr. avec le $*$ Catalogue des plantes usuelles." Amiens 1754. 12. 34 [3. B.

$11605+$ La Botanique. (Bibliotleeque populaire, livraison VIll.) Paris, Touiquet et Co. 1826.12.128 p.

$1160 . j \div$ La elef de la botanique. Toulouse, Broulhiet et Meilhac. 1796. 12. Ss p., it tahleau.

1160606 la maniere de semer pepins et faire peprinicres. A Paris, pour la vefre Jean Bonfuns.s. s. a. S. sign. $1-11$. Bibl. Deless.

116.57 Lart de distribuer les jardins suivant l'usage des Chinois (par J. H. Morel). Londres 1757. 8.

$110: 38$ L'art de tailler les arbres fruitiers (par Nicolas lenelle). Paris, Charles de Sercy. 1683. 12. Barbier.

116039 L'art ou la manière de taillor les arbres fruitiers. Amsterdam 1699. 4. 19 p., ic. xylogr. i. t. B.

11660 Le bon jardinier. Almanach pour l'année 1847, par Poiteur, Vilmorin, Louis Vilmorin, Decaisne, Neumanu et Pepin. Quarante-luitiema édilion. Paris, 1)usacq. 1847. $12.58 \%$ plag. ( 7 fr.)

(Prostiit inde ab aluno 180k curantibus Hordant DeLuunay, Loiseleur-Derluxgchanps, Noiselle, aliis; cf. supra .r. T138.

II66i Le ealendrier des jardiniers, traduit de l'anglais de bradley (prar De Puisieux) avec une description des serres. Paris 1750. 12. Barbier.

Illif? L'école du jardinier flenriste. Paris, Pancloucke. 1764. 12. xII; 379 p., 1 tab.

$11663 \div$ Leçons de hotanique faites au jordin royal de Montpellier; par Honsieur Imbert, Professeur et Chancellier en l'universiti de nédecine et recueillies par Mr. Dupuy des Esquiles, maitre Ez arts et incien Etudian en Chirurgie. En Jollande, aux depens des libraires. (Avignon, Simon Tournel.) 1762. 12. 215 p. Bibl. Cand., Deless.

list satyra satis insalsa in Imbertum, qui Monspelii botanices Profesioris inumere fudgebatur autoribus ('usson, Gouan et Commerson.)

$11601 \%$ Le graut herbier en francoys : contenant les qualitez : vertus : et proprietez des herbes : arbres : gommes : semences : hnylles : ot pierres procienses: extraict de plusicurs traicioz de medecine: comno de Avicenne: Rasis : Constantin : Isaac : Plataire : el Yjoras. Solon le commun usaige. Imprime nouvellement a Paris. Par Aluin Lotrian lumprimeur et libraire. s. a. 4. (20), 176 foll. binis columus 41 linearum, ic. parr. xylogr. i. t. (Aloc-Zuccarum.) Bibl. Deless. - tImprine par Denis Janot el Alain Lotriun. s. a. 4. (20), 176 foll. Bibl. Deless. - tImprime nouvellement a Paris par

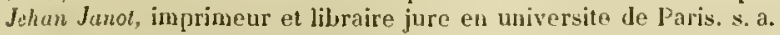
4. (20), 176 foll. binis columnis 39 linearum, ic. parv. xylogr. i. t. Bibi. Juss. - †s.l. et a. 4.108 foll., ind., binis colunuis 46 linearum, ic. xylogr. i. t. (Aloe - Zucearum.) Bibl. Juss.

11603 Le guide du cultivateur et du fleuriste. Annuaje de la socicté linnéenne d'émulation de Bordeaux, pour l'an 1826. Bordeaux, Brossier. $1825.12 .120 \mathrm{p}$.

$11666^{+}$Le guide du naturaliste dans les trois regnes de la nature, ou méthode analytique par laquelle on peut découvrir le nom générique de l'animal, du végétal ou du minéral, que l'on propese de counaitre. Par Mr. I.D.S. de P. Bruxelles, Lemaire.1792. 8. $515 \mathrm{p}$.
11667 " Le jardio de Hollande, planté el garni do flours, fe fruits et d"orangeries, ou l'on enseigne, comment on peut élerer el cultives loutes sortes de fleurs ete. Leide, ebez Jean du Vivier. 1714. s. 392 p., praef.

(Barbier appellat autorem Jean Du fivier.

$11668^{*}$ Le jardin de sante translate de latin en francoys nouvellenen inprime a Paris. (Philippe le noir. 1539.) folio. 246 foll., ind., ic. rud. xylogr. i. t. Bibl. Palat. Vindob.

Aliam habet editionem Ilain Repert. bibliour. Nr. 84:68: Pars,

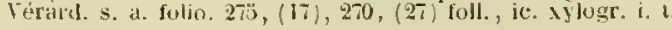

11669 Le jardinage des ocillets par $L . B$. Paris, Louis Bunlanger. 16 亿 12. $s$.

$11670^{*}$ Le jardinier françois, qui enseigne a cultiver les arbres et lierbes potagìres, avee la manicre de conserver les fruits et faire toutes sortes de confitures par R. D. C. I. I'. B. D. N. (Nicolus de Bonnefurs, valet de cluambre du roi). Seconde édition. Paris, clıez Pierre des Hayes, 1651. 12. $-{ }^{*}$ Cinquieme édition. Paris, chez Pierre des Hayes. 1634. 12. 381 p., pracf., 2 tab. - Iluitième édition, augnentéc par l'auteur du tiers cle la prenière partic. Paris, Antoine Cellier. 1666. 12. Bibl. Reip. Paris. - Rouen, Resogne. 1704. 12. - Paris, Michel David. 1711. 12. - Troyes, la venve de Jac. Oudot. 1723.12. s.

11671 Le jardinier royal, qui enseigne la manière de planter, euftiver et dresser toutes sortes d'arbres, avec une breve méthode pour bien grefler tous fruits à noyanx, le moyen de faire pépinières etc. (par labbe Grobelint. Paris, Charles de Sercy, 1661.12. - ib. 1671. 12. - ib. 1677. 12. $\$$.

$11672 \div$ Le jardinier solitaire, on dialogues entre un eurienx et un jardinier solitaire, contenant la méthode de faire et de cultiver un jardin fruilier et potager (par frère François, chartreux). Paris, liggaud. 1704. 12. - Ed. IV. Paris, Rigaud. 1712. 12. - Ed. V. Paris Rigaud. 1723. 12. 440 p., praef.

$11673+$ Le médecin herboriste. Par un médecin botabiste. Paris, Servière. $1802.8 .43 \%$ p.

1167 Les admirables qualités dı Quinquina, et la manière do s'en servir (traduit de l'anglais de Talbol?), avec les réflexions de Eayor. Paris 1705. 12.

(Prodiit jam anno 1689. Autor omnino dubius est; cf. Marlier I. p. 26f.)

$11675^{*}$ Les agrómens de la caupagne, ou remarques particulières sur la construction des maisons de campagne, des jardins de plaisance et des plantages. etc. Leyde, Luclımans. 1750, 4. $\mathbf{x} \times \mathrm{r}^{\circ}, 412 \mathrm{\mu}$, ind., 15 tab. - Paris 1752 . IIl voll. 12.

Est tratuctio a de frool facta operis hollandici Petri Delacourt: ef. Thes. lit. bot. Nr. 2360 .)

11676 Les figures et poutraicts des plantes et herbes, dont on use coustunierement, soit au menger, ou en medecine, arec leur propriets et vertu. Paris 1576. 19. 155 p., ic. xylogr. i. t. 8.

$11677^{\div}$Lettre a Mr. le Monnicr suc la culture du Cafe. Amsterdain ot Paris, le lireton. 1773.8.131 p.

A Okerardo deceptus loune librum supra Nr. 5737 false operibus Lellonieri admuncravi.)

11678 Manière de culliver la navette et le colzat (par Frangois Rozier) Paris 1774. 8. Barbier.

11679 Miscellanea botanica, contenant la description et l'iconograpbice des plantes les plus intéressantes des différentes contrées du globe sous le rapport de l'utilité et cle l'agrément, sous la dirertion du Dr. Meisser. Les planches dessinées et eoloriées par d'habiles artistes, retouchces au pinceau par Nllle G. Fontuine. Tome I Bruxelles, Vandermaelen. (1838?) gr. 8. ( $36 \mathrm{fr}$.)

$11680 \div$ Notice des principaux ubjets d'histoire natnrelle, conserves dans les galeries du Muséun du jardin des plantes de Paris (par N. Jaume de Saiut-Hilaire). Paris, Donnier. an IX. S. 216 p.

11681 Nouveau cours complet, au Dictionnaire raisonné d'agrieulture, par les membres de la section d'agriculture de l'Institul. Paris $\mathbf{1 8 0 9 .}$ Xill roll. 8 , DC.

(Vide supra François Rozier, Nr. 8809.)

$11682 \div$ Nouveau Dictionnaire d'histoire naturelle, appliquee aux arts, it l'agriculture, à l'ćconomie rurale et domestique, à la mcidecine cte. jar une société de naturalistes el d'agriculteurs. Nouvelle édition presque entierement refondue. Paris, Deterville. $1816-1819$. XXXvi voll. $8 . A-Z$. 
$11683+$ Nouveau Iraité des orangers el citronniors, contenant la maniere do les connoitro etc. Paris, Sergy. 1692. 8. $187 \mathrm{p}$, ind.

1168' Nouveau traité pour la culture des fleurs. Paris $1682.12 .160 \mathrm{P}$. B.

If68: Noureau traiti sur l'arlore nomme Acacia. Hordeaux 9762. 12. 45 1). B.

$11686+$ Nouveaux ìmens de botanique à l'usage des élères qui suivent le cours du jardin des plantes ct de l'ceule de midecine de Paris, par \$l. $L^{* * *}$. Paris, Crucluarl. 1809.8. xx, $167,20+\mathrm{p} .-\div \mathrm{Se}-$ cundo édition revuc et corrige par M. C...., Prolesseur de butanicpue. Paris, Crocluard. 1812. 12. Xx, 204,9 p. - Ed. III. Paris 1815. 12. - +Ed. IV. corrigée el aumenteo pilr Francois Victor Merut. Paris 1817. 12. xxii, 386 p. - Ed. Vl. corrigce ol augmentec par Fransois lictor Mtrat. Praris 1829. 19.

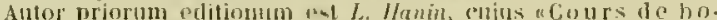
laniguen Thes. Nr. hlli ot "Voyage dills ! tampirede flore Thes. Nr. 11710 als hoc libru is ditlerunt.

$11687+$ Nouvelle Flore des environs do Paris. Preniere livraison. Paris Garutisse. 5. a. 12.36 J., | | tał . Bibl horti Paris.

11688 Nouvelle instruclion pour la culture des figuier's (par Ballon et Gurnier). Paris 1692. 12. Barbier.

11689 Nouvelle mélhode pour cultiver toutes sortes d'arbres fruiticrs (par DuMoulin). Jaris, Sangrain le jenue. 1763. 19. Barbier.

IJ690 Observations physiques sur l'agriculture. les plantes, les mineraux el vegetaus (par Tiphaigne). La Haye el Paris, Delalain. 1763 3. 19. (Teste Barbier non dittelt a libro "Questions relatives a lagriculture" Nr. $116 \%$.

$116 ! 1$ Observations sur la maladie des pommes de terre, sa cause, essais pour la comluattre. Résullats. l'aris, typ. Poullet. 1847.8. 8 p.

11692 t Plantes et arbustes d'aggement, graves et eulumines d'après nature. Ouvage entrepris par quelepes amateurs. Fasc. 1-N Winterthur, Steiner et Co. 1791-1794. 8. 90 p., 20 tab. col.

11693 Précis des experiences faites par ortre du roi a Trianon sur la cause de la corruption des blés et sur les moyens de la prévenir a la suite duquel est une instruction propre à guider les laboureurs dans la manière dont ils doivent préparer le graiu avant de le semer. Paris, de l'imprimerie royale. $1785.4 .22 \mathrm{p}$.

$11694 \div$ Principes élémentaires le botani fuo, rúdigés d'après les diverses méthodes de Tourncfort, Linné, J. J. Rousseau, Jussien, Lamark, IJurande, Villars etc. P'ar un uaturaliste Lyonnais. Lyon, an IV. 8 , xxxII, $534 \mathrm{p}$.

$1169: 5 t$ Questions relatives a l'agriculture et a la nature des plantes (par Tiphaigne). A la Haye, cliez Neaulme. 1759.8. 120 p., praef., ind. Bibl. Juss.

(Idem liber repelitus est tllulo abbervations physiques s ur l'agriculturen Lil lliye et Paris, Delitliin. 1760. 12.)

$11696 \div$ Recueil de mémoires, instructions, olservations, expériences ef assais sur la culture de l'arachitte ou cacalutide. (Irachis hy pogaca L.) Mort-de-Marsan, typ. Delaroy, isoz. 8. 118 p. de (Inoan, Echeondio, Ifeches anlorihus Tessier, Don Francuis Tabarés

11697 t Reflexions sur les differents systemes fle botanique, par un jeune amateur de celte science. Paris, Pichard. 1804.4.16 p., 1 tableau.

$\$ 1698+$ Sertum botanicum. Collection cluvisic des flantes les plus remarquables par leur élégince, leur éclat et leur utilité; dédièe à la Reine par une suciétó des hotanistes, et lirigee par M. P. C. van Geel. Bruxelles (1828-) 1836. Folio nin. Bubl, univ. Leod.

(Est collectio tabularum pictarum forlasse tiun diversa ab alia cFloredes serres" iuscripta.)

I 1699 Solution du probleme éconumico-politipue concernant ba conservation ou la suppression de la culture du Riz en Lombardie et basse Jtalie, avec lindication des moyeus propres a former des Rizieres sans porter attcinte à la salulnite pullique. Turin, de l'imprimerie royale 1819

11700 Symopsis analytique de la Flore du Gard, ou métlode facile pour arriver au nom de toutes les plantes vasculaires de ce département. Ourrage utile pour les herborisalions; par M. l'abbe J. G. Nimes et Paris, Vaton. 1847. 12.16 plag.

11701t Tableau de l'école de botanicjue du jardin ales plantes de Paris, ou catalogue général des plantes qui y' sont cultivées otc. par un botaniste (Moret). Paris, Didel. 1560.8 .107 p. Bibl. Juss.

117027 Terminologie botanique a l'usage des elères de l'écale contrale dı Département de l'Escaut. Gand, Colier. 1797. \$. 56 p., prael.
11703+ Traité compendieux et alırégé des Tulippes et de leurs diserses surtes el espèces etc. Paris, chez Jlelehior Tavernier. 1617. 4 $\$$ l., 11 lab. Bibl. Juss.

1170 t Tiaté complet de la culture, falırication es vente du Taluac daprey les procidés pratigués dans la Pannonie, la Virginie, le Danemarch, I'Ceraine, etc. P'al un ancien cullivateur (de l'illeneure.) Paris, Buisson. 1791. 8. vir, $\mathrm{xv}, 456$ p., 6 tab.

$11703 t$ Trate complet sur le jardin jotager. Par un amatcur. Paris, Narchant. 1808. 12. x14, 322 j., 1 lih.

11706 Trailé de la culture de différentes Deurs (par de Sistn-l'eravo). Paris, Saugrain le jeune. 1765.12. Barbier.

11707 Traito de la culture de l'auricule, on creilfe al'ours. frar un curieux de province (Ingenu, anagramme de Guenin). Bruxelles 1735. 12. Barbier.

11708 t Traité de la culture dins péclıers. Paris 1745. 8. - Eil. Il. Paris 1750. 8. - tTroisieme édition. l'aris. Leprieur. 1759. 8. xv, 198 p. - Nouvelle édition revue, corrigée el augnentée (par DeCombes). Paris, Leprieur. 1770. 12. Barbier.

11709 Traité de la culture des jenoncules, des ucillets, des auricules et des tulijes (par Moet). Paris 1754. 19. Barbier.

$13710 t$ Voyage dans l'empire de Flure, ou démens d'histoire naturello regetale. Ourrage ou l'on trouve lanalyse des leçons du savan anteur de la Flore atlamlique. Par L. II. P. $T^{* *}$, médecin. Paris.

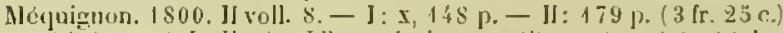
Auleir est $L$. Hanin. Liber plurtes repetitus est mutalo titulu: ecours de butaliguen Thes. Mr. f17 el woureaus ele-

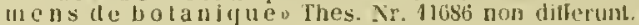

\section{Opera anonyma germanica:}

$11711^{*}$ Abhildung eines Gerstenstochs, welcher in Jahre 1789 im Garten des Kais. Landkadettentorps (zu Petershurg) aus einem Samen 26 Halme nit volstandigen Achren, die 1193 Samenköner enthiclten, hervorgebracht hat. gr, folio, 1 tab. Bibl. Goett.

$11712^{*}$ Abbildung ciuer Llirsenstaule, welche im Jahre 1789 itn Garten des Kais. Landkadettenkorps (zu Petersburg) aus einen einzigen Korne 37 Rispen, welche bler 42,000 liomer enthielten, liervingel,racht hat. gr. folio. I tal,. Bibl. Goett.

117 i3 Abbildung und Beschreibung der gefalirlichsten in Baicrn vorhommenten Giftgewaclise. Nunchen (Bayreuth, Buchuer.) 1842. gr. $4.6 \frac{1}{2}$ plag., 24 tab. col. $\left(1 \frac{1}{3}\right.$ th. $)$

147. Abriss eines wunderbaren Kornstengels mit etlichen zwanzig Achren, welcher allhier in Sachsen olnw eit Mugehn bei desn Dorfe Kroptewitz etc. gefanden warden. Gedrucht im Jahr 1741.4. 2 p. ic. i. t.

$11713^{*}$ Algemeine okonomisch-technische Flora, vder die manuich falligste Benutzung des Gewachseichs etc. Zwei Lieferungen. Breslau. Bartl. 1809. folio. v1, 23, 28 p., und 24 gretruckiete Pllanzen ( 3 th.)

$11716^{*}$ Also hatten die JPlanzen Vorstellungen und Bewosstsein ihrer Existenz? Eine Iliatrilse fur Lieblaber der Naturhunde und Psychologie. Frankfurt, Jager. 1790.8 .60 p.

Thomas Percival scripserat conmentationem "speculations on llie perceptive 1 moner of vegetables Mancliester, vol. II. p. 1l!-t30, quae it hoc libello liberal redit iraductione. Adest eliam germance a Betrathlungens uber las bimptin-

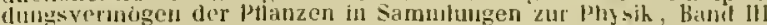
p. $6606-678$.

13717 Auatonia et plysiognomia simplicium: das ist, Zween Tractat von der Signatura aller Erdgewachsen. Nürnberg, Wolfrang Endter. $16 \div 7.12 . \mathrm{s}$.

$11718^{*}$ Anleitung zur Zuchererzeugung aus dem Safte inländischer Ahornbáume. Nebst einem Anhange uber Mannagewinnung aus ciuleimischen Eschen. Wien, Slantsdruckerei. 1812.4.58 $\mathrm{p}$.

$11719^{*}$ Arboretum floridum, ades cine Gemuthserfrischende Beschreibung der Baumen. Augspurg. typ. Koppmayer. 1689 12. (2), 108 p., 3 it till.

11720 Bericlı voù den auf den Blattern der Baume irn Jalır 1680 háufịg gefundenen Schlangengestalten vols J. C. B. (i. e. Johanis Christaph Bectimann.) Franklurt a/0.1680.4. H.

(Varia insunt de plantis serpentiformibus, de floribus multiformibus el fascialis. Figurae sunt vestigia itineris erucae quam ctiam un chartam injprimit. 
11721* Dericht einiger Korm-Aeliren, welche in diesem 1695 sten und vorigem Jahre in Thuringen, Jessen und Vogtland mit Verwunderung geseben worden. Armstad, typ. Nicol. Bachmanu. (1695.) 4. 1/2 plag. 5 ic. $x y \log r$ in titulo. Bibl. Hal. Ponickav.

$11722^{*}$ Beschreibung der Obstsorten in ter Central-Obstbaumschule am standischen Musteriłe zu Grátz. \%wei Lieferungen. Gräz, ıp. Lerkam. 1827-1829. 8. - 1: 1827. Aepfel. xı, 192 p. - IJ: 1829. Biruen. $144 \mathrm{p}$.

$11723^{*}$ Beschreibung einer Methode, aus inlaulischen zun Theile wildwachsenden Pflanzen eine der Baunwolle ahnliche Wolle zu bereiten. (Durch Jakob Angeto veranlassı.) Wien, Hofdruckerci. 1812. 8. $24 \%$.

172', Blumen und Insehtenbuch, darinnen auf das fleissigste die Blumen nit ihren Blattern nach dem Leben vor Augen gestellet, jede Blume nach ilirem eigentlichen Namen genennet, und wie solche mil ibrer annelimlichen Bluhe und Farbe soll nachgemaclu, auch die Farben in einander gemischet, aufgetragen, schattiret und aufgemacht werden. Nit Kupfern. Nuruberg, bei Christian Siegmund Froberg. s. a. folio. Rivin

1172: Botanicus euriasus, oder souderbares Kráuterbuch, darin die vornelumsten und in der Arzneikunde geloruchlichsten Kiauter und Gewachse, Abbildung und Beschreibung nach ihrem Geschlechte ctc. Dresden 1745. 8. vogler.

(Liber fortasse non differt a Samuel Maeller Curioser Botanicus, cf. supra Xr. $7 \pm 98$.

11:26 Bolanische Beselıreibung der Gräser nach ilıren manelserley einzelnen Bestandtheilen. Franhfurt an Xayn 7788.8 . 57 p. 4 tab. B.

$11727^{*}$ Rotanisches Wöterbuch, veranstaltet und herausgegeben von der freien okonomischen Gesellschaft im Jahr 1795. (Deutsch-lateiniseh-russische PRanzennamen.) St. Petersburg (1795.) 4. 157 p.

$11728^{*}$ Catalog wher die in dem k. k. Lustgarten an Renuwege dermalen vorhandnen edlen Olsstbäume. Wien, gedrucht bei den Mechitaristen. 1823. 3 Hefto. 8. - 1: Aepfelsurten: 27 p. -11 : Birnsorten: 14 p. - III : Pllaumensorten: 8 p.

11:29* Catalogus 1. der Nelken sampt ilıren Beynamen, sn in llorto medica zu Leipzigg (bey mir D. Leonhardo Beeren, horti med. praefecto) anzulrellen seyn. 1662.8.4 foll.

$11730^{*}$ Curreuse Nachricht von den schon vor vielen Jahren, anch in diesem 1747. Jahre zum Forschein gehommenen Weyden-Rosen, dem publico, sowohl aus alten, als allerneuesten authentiquen Berichten conmuniciret. Erfurts, typ. Werther. (1747.) 4. 4 foll., 2 ic. sylogr. in titulo.

$11: 31^{*}$ Darstellung der ersten Pllanzenausstellung in Wien. In Mlonat Mlai 1827. Wieu, typ. Strauss. 1827.8.66 p., 1 tab.

117.32 " Das Jobauniskraut, chemisclt-medicinisch abgchandelt von Anthropo-Mago-Botanophilo. Leipzi. Boehme. 1781. 8. 76 p.

$11733^{*}$ Der Botaniker, oder compendiöse Bibliothek alles Wissenswurdigen aus dem Gebiete der Botanik. Heft 1 und 2 . Gotha und Halle, Gebauer. 1793-1794. 8. 84, 108 p.

11734 Der Clurist bei dem Kornhalme. Bresslau 1757. 4. 1 plag., jc. xỵlqugr. i. t. B.

11735 * Der Fruclitbringenden Gesellscluaft Namen, Vorlaben, Gemalde und Worter. Frankfurt a/..l., Merian. 1646. 4. (Das dritte Hundert.) 100 tab.

(Sunt Icones plantarum cum sententiis et allegoriis.)

11736 Der neueste deutsche Stellvertreter des indischen Zuchers, oder der Zucker aus Runkelrüben. Zweite .Juilage. Berlin 1799. 8. 44 p., 1 tab. $B$.

$11737^{*}$ Der Selam des Orients oder die Spraehe der Blumen (von Johum Daniel Symanski.) Berlin, Posen und Bremberg, Mittler. 1841. 3 Theile. 8 . - 1: vm, 232 p. $-11: 225$ p. $-111: 263$ p. (2/h.)

11738 Deutliche Abbildung und Beschreibung der wunderbaren Kornahre, welclse in dem zwischen Poren und Konigstein gelegenen Dorfe Struppen bey dem dasigen Kirchvater Schunen befindlich ist. s. I. 1757. 4. H. จ. D.

$11739^{*}$ Deutschlauds Giftplanzen. Mit 18 illuminirten Abbildungen. Neue Auflage. Nlagdeburg, Rubach. 1829. 8. 16 p., 8 tah. col. $(3 / 8 / h$.)

$11740^{*}$ Die amerikanisehe wunderschone Aloe, welche 1712 zu Copenick mit 7277 Blumen im 44. Lebensjalıre geblubt, von Samuel JakobR. Berlin, typ. Koniy. 1712. 4. 8 p.

Prttzel, Thies. lit. bot.
113 1* Die Benutzung der Stachelljeeren, sowohl des Strauchs als iler Fruchte. Arnstadt, Meiulardt. 1846.8.72 p. ( $1 / 6$ th.)

11742 Die beste Art und Weise Ananas zu pflanzen, aus ciner franzosischen llanlschrift ubersetzt. Stuttgart 1778. 8.26 p., 2 tab. B.

$11743^{*}$ Die duftende Blumenwelt oder die licblichen Kinder der Flora besungen. Ilalberstadt $1823.8 . x x, 202 \mathrm{p}$.

117 k $^{*}$ Die fruchtbare Boriza (Jotryclium Lunaria) oder das lieilsame Mondhraut, init vielen chymischen und lunarischen Fruchten abgebildet. lirieg, typ. Jacul. 1681.8.197 p.

(Nomen antoris Jaliob if artini liquet e Bibl. Bivin. Nir. 6883.)

$117\{0$ Die gefahrlichsten Giflpflanzen Deutselılands. Stutlyart, Bech und Frankel. 1837.8 . ( $1 / 3$ th. $)$

$117\left\{6^{*}\right.$ Die Giftpflanzen des Elsasses. Durch einen hiesigen Lehrerverein zum Druck befordert. Strassburg, typ. Levrault. 1\$25. 8. $46 \mathrm{p}$, $37 \mathrm{tab} .(1 / 2 \mathrm{th})$

11747 Dic jungen Pflanzenforscher, oder totanische Unterhaltungen eines Pfaryers mit seinen Kindern. Aus dem Franzosischen. Nit einem pädagogischen Vurworte vom Prof. Zyro. Bern, Fischer. 1836. 8. xv, 128 1. (1/2 th. - Zweite Ausgabe. ib. 1812.8 . ( $1 / 2$ th. $)$

$11748^{*}$ Dieser Tractat helt yn von Bereytung der wein zu gesundheyt und uutzbarkeyt der menschen. Getrucht zu Strassburgy von Mathis llupfuli als man zalt 1506.4 . 19 foll.

$11749^{*}$ Drrihundert auserlesene Amerikanische Gewähse nach Limüischer Ordnung. (Nach Jucquin's Stirpes amerieanae entworfen.) Nurnberg, Raspe. 1785-1788.8. $x$ foll., 300 tab. col. (24 th.)

11750 Eigendiche Ablildumg des wunderschonen Weitzenstocks von 72 Haimen aus einem eimzigen Wurzlein. Strasburg 1563 . Scheuchz.

117301 Eine Neue beschichte von einem Weintrauben, weleher in Frankenland 18 Traublein aus einem Aug erzeugt Jat anuo 1577. Scheuchz.

1173̈2 Eines Chur-Furstliclien liunst-Gareness Garten-Memorial, samlı einem Catalogo der Gewaichsen. Leipzig 1703. 8. 78 p. B. - Impr. cum Heinrich Hesseri's Neuer Gartenlust. Leipzig 1714. 4. B.

11753 Ein neues Garten- Baum - und Pelz-buchlein. Zum erstenmal also gedrucht. s. 1. et a. 8.112 p. B.

11754 Ein wunderbarliches Gewachs einer Weizen-Aehre, an welcher 73 andre gewachsen sind in Schwaben. Augspurg 1569 . Scheuchz.

11755* Erste Anfangsgrunde der Botanik in Briefen; als Anleitung zum Selbststudium dieser W"issenschaft zu gebratehen, von $J . v . K$. Wien, Sclurambl. 1823.8 .87 p., 1 tab. ( $/ 12$ th. $)$

$11736^{*}$ Etwas uher Standorte und Blutezeit der in den Fürstenthümern Hohenlohe und Verzenthein bis jetzt entdeckten wildwachsenden Pflanzen. Ilerausgegeben von einigen Freunden der Naturgeschiclute zu Hergentheim. Mergentheim, typ. Thomm. 1816.8. 96 p., praef. $(2 / 5$ th. $)$

$11757^{*}$ Flora's Stammbuch. Frankfurt a/M., Krus. 1835.12 .144 p. $(3 / 8 t h$.

11700 Flora universalis, oder naturgetreue Abbildungen aller bekannten, auch der seltensten Gewachse. 6 Ilefte. (complet.) Dresden 1805. folio. 75 tab. col. ( $32 t h$.)

$117599^{*}$ Gedaukeu uber die Rosen und Nelhen, so dermalen die Weiden tragen, von J. F. E. (Nássau, Dietz.) 1750.4.8 p.

$11760^{*}$ Giftpflanzenbuch; oder die scludlichen Giftgewächse und essbaren Schwamme Deutschlands, nach der Natur abgebildet und beschrieben. etc. Zweite viel vermehrte Auflage. Berlin, Franke. 1805. 8. xu, 129 p., 19 tab. col. (1 1/3 th.)

11761 Grundiche Anweisung zur wohleingerichteten Baumschule. llamburg 1702, 8. 120 p., 12 tab. B.

$11762^{*}$ Handatlas sanmulicher medicinisch-pharnaceutischer Gewachse, oder naturgetrene thbildungen und Beschreibung der offizinellen Pflanzen fur Pharmacenten, Mediciner und Droguisten. Llerausgegeben von einem Vereine Gelebrter. Jena, Nauke. 1845-1847. 4 min. xxx, $x$ p., 192 tah. col. (10 th.)

(Prodit in $2 \mathrm{i}$ fisciculis, singuhus 8 tabulas continens, à $3 / 12$ th.)

11763 Historischer und verständiger Blumengartner, und von Anlegung, Wartung und Pllegung eines Baum - und Küchengartens. Leipzig 1715. 4. 783 p., 21 tal. B.

1176 ' Hye nach volget das puch der natur, das Innhaltet. Zn dem ersten von eygensehafft und natur des menschen. Darnach von der natur 44 
und eygenschafn des limels, der tier des gefugels, der kreuter, der steyn und ron vil ander naturlichen dingen Vud an disem puch hat ein hochgelerter man bey funfzehen iaren Colligient und gearbeyt, .... Welches pucls meyster Cumrat von Megenberg von latein in teutsch transferiert und geschrichel hat. Hanns Bcimler zu Augspurg lxxy. (1475.) folio. 292 foll. B.

$11760^{*}$ Katalog Jer in dem hiesigen Schlossgarten und den dazu gehorigen botanisedten _Aulagon enthaltnen Pllanzen. Darmstadt, typ. Will 1832. 8. vi, 47 p.

11766 Kupferatlas der vorzuglichsten Ilandetspflanzen. Acht IJefie. Jona, Matuke. $1839.4 .6 \%$ plag., 48 tab. col. (4 /h.)

$11767^{*}$ Nachricht ron dem lrotanischen Garten der ligl. Unirersitá zu Breslau. s. 1. et a. 8.14 p.

11768 Naturbuch, vonn nutz, eigenschaft, wunderwirckung unnd gebranch aller geschoplf, element unnd creaturu, flem menschen zu gut beschafien, verordnet und verteuschet durch Conradum Mengenberger. liranckenfurt am Mlegn. 1536. folio. LXVI p., ic. Aylogr. i. t. B.

(Sunt excerpta libri supra Nr. 1176k allati.)

11769 Naturgemasse Besclireiburg des Coffee, Thee, Chocolate, Tobacks in vier anterschiedlichen Abtheilungen, mit einem Trahtátlein vom Hollunder und Wachholderbeeren, welches anweiset, wie nutzlich dieselben seyn kounten in unsern Colree-llususen, wic auch den Weg die Mumme zu bereiten, sammt etlichen Anmerkungen uber dirses Getranke. Ans der englischen in die hochdeutsche Sprache übersotzel durch Johunn Langen. Hamburg 1684. 12. Rivin.

11770 t Neue Alshandung von dem Baume Acacia oder dem Schotenderne. Aus dem Frauzosischen üherselzt von Max Wilhelm Reinhard. Carlsruhe, Macklot. 1766.8.70 p.

(Origuate gallicum vide supra Nr. 11683, Nouveau traité etc.)

1177. Neue Unterweisung zu dem lilumenhau. Leipzig 1734. 4.317 §. в.

11772 Nie erhörte wunderbare Blumenlust. llamburg 1710. folio. H.

$11773^{*}$ Ockonomische Abhandlung uber einige zur Nalırung dienende Errigewächse, besonlers uber die Erdapfelplauzung zur unpartheiischen Prüfung vorgetragen. Wien, Kurzbeck. 1781.8.85 p.

11774 " Pflanzen, welche zur Nahrung und Erhohung der Lebenszenisse des Menschen dienen, und zwar sámmtliche Getraide-GemuseGewürzarten u. s. w. Aus dem Englisehen von Dr. F. A. Wiese Zwei Abtheilungen. Leipzig, Baumgùrtner. 1837-1838. S. 474 D. $\left(1 \frac{1}{3} \mathrm{th}.\right)$

11770 Pflanzenetiketten ( 1560 ) fur alle phanerogamischen und kryptogamischen Gewachse der Provinz Braudenburg. Berlin 1839. folio. $(1 / 2$ th. $)$

11776 Pflanzeureich (das) in tabellarischer Uebersicht. Nach Linne's System geordnet. Botanische liarte Nr. 11-11I. Weimar 1837-1838. gr. folio. (1 $\frac{1}{8}$ th.)

$11757^{*}$ Pouniria ot vinaria IJoratiana. Unserm geliehten Schwager, $11 \mathrm{crrn}$ M. Christiun Adolph Pescheck am Tage seiner Amtsjubelfeier glickwinschend zugeeignet von (Mehreien). Zitua, 1yp. Seyfert. 1841 8. $16 \mathrm{p}$

$11778+$ Pomona austriaca, ou arbres fruitiers d'Autriclı, representés en figures, dessinées et peintes d'après nature. Vienne, chez A. Blumauer. 1797. If voll. Colio. 24,20 p., 200 tab. col.

(Sunt eaedem tahulae supra $\mathrm{N} r$. 5377 in voce hraf recensilae.)

11779* Promptuarium nedicinue. (Incipit: Hyr hevet sik an dat. Revister des / ses bokes schone unde suverlik. ( y'ut diji de erste myn ! sche uthe deme eddelē | staet der unschult etc.) s. 1. et a. 4. (7) foll. ind., 112 foll. binis columnis 41 lin. Bibl. Goett.

$11780^{*}$ Rosen. Sammlung der nousten und schönsten aus Frankreich, England, Belgien und Deutschland bezognen, in unserm Garten cultivirten, nach der Natur gezeichneten und colorirten Rosen. Erste Centuric, Lieferung 1-6. Düsselderf, Arnz et Co. 1840. gr. 8.60 tab. col. ( 6 th. $)$

11781 Rossmarin-Búchlein, eder Beschreibung, wie Rossmarin nicht allein zu zeugen, sondern auch mit gressem Profit zu gebrauchen. Halberstadt 1685. 8. Rivin.

11782* Skizze der Noatur, oder Schilderung einheimischer Blumen, dann in - und auslándischer Baume, nach ilhrer Gestalt und Eigenschaft. W'ien, Schaumburg. $1800.8 .74 \mathrm{p}$.
11783 "Tahellarische Uebersiclat der Naturgeschichte der hunilert deutschen wilden Ilolzarten im naturlichen Zustande. Tubingen 1822. folio.

1178:* Tulpen und Staatspapiere. Fin lieitrag zur Geschichte des llandels des 17. und 19. Jahrhunderts. Ilaniburg, Hellmam und Campe. $1830.8 .24 \mathrm{p}$.

(1)ie tieschichte des Tulptusclswindels ist ans Beckmann's Geschichte der Erlindungen 1. p. 223 squ. entlehnt.

11785t Ueber das Studium der lletanik als eine der nuzlichsten und angenehmsteu Bescháfigungen fur alle Stande. Pirna, Pinther. s. a. 12. $76 \mathrm{p}$.

11786 Vebersicht der merkwurdigen Figenschaften der veredelten Wohlverdoihblunc. Wiesbaden $1 \$ 35.8$.

$11787^{*}$ Vebersicht der Planzenfamilien nach verschiednen Sutoren, mit Angabe der brkannten Gattungen, nebst einer kurzen Darstellung des Linnéschen Systems. Berlion, Logier. 1\$29. 4. xvil, 214 ]). $(1 \%+t h$.

$11788^{*}$ Unterricht, wie iu Kärndıcn dic lebrndige Zăune zu pllanzen und zu pflegen. Wien, ty). Trattneru. 1767. \&. (28) p.

11789 Versuch einer poctischen Beschreibung zweier amerikanischen Aloen, welche in dem Konigl. Lustgarlen zu Friedriclsslerg geblubet haben. liopenhagen 1745. 4. 24 p., 4 tah. B.

11790 Verzeichniss der Báume und Stráucher, welche sich auf der Kön. Platage zu llerrenhausen bei llannover hefinden. $1787.8 .30 \mathrm{p}$. B.

1179] Verzeichniss der Glas-und Treihhauspflanzen, welche sich auf dem Konigl. Berggarten zu llerrenhauseu bei llannover befinden. 1787. 8.31 p. B.

11792* Verzeichniss der exolischen Kalt- und Warmhausplanzen, welcho sich in dem von Rothschild'schen Garten befindch. (lirankfurt a/ $\mathbf{M I}$. 1S23.) $8.35 \mathrm{p}$.

11793 t Verzeichniss der im Freien ausdauernden Baune, Gestrátuclie und Staudengewachse, so wie der llausplanzen, welche in llamburg'schen batanischen Garten abgegeben werden honnen. Jlanburg, typ. Meissner. 1830. 8. 92 p.

1179: Verzeichniss sichtbar bluhender Cewichse, welche un den Ursprung der Donau und des Neckars, dana um den untern Theil des Bodensees vorkommen. Winterthur 1799.8 .50 p. B.

$11793^{*}$ Verzeichniss und kurze Beschreibung der meistentheils andandischen Baume und Strâcher, dio in dem botanischen Garten der $\mathrm{Kgl}$. Akademie der Wissenschaften zu Berlin gezogen und abgelassen werden. Bcrlin, typ. Decker. 1773. 8.63 p.

11796 * Vier Verzeichnisse als Beiträge zur Kienntniss der Fauna und Flori des Harzes. Nordhausen, typ. Schmidt. 1842.8.

(liest: Errst llampe, Nachtrage zum Prodromus Florac hercynicae, 8 p.)

$11797^{*}$ Vollstandige Abhandlung von den Nelken und Tulpen. von einem Blumenfreunde aus eigner Erfahrung gezogen, und den fialtenund Blumenfreunden zum Nulzen und Vergnugen gew idmet. Riga, I1artknoch. 1794.8. $202 \mathrm{p}$.

$11798^{*}$ Vorbereitungen znr Naturgeschichte für Liebhaber. Vondem Pflanzemreiche. Berlin, Sclıoene. 1790. 8. vill, 90 p., t tab.

11799 Wahrhaftige neue Zeitung, wie in Maissen bei \%wichau solcho wunderbarliche Gewachs auf deu Eichbaumen sieh erzeigt haben. 1582. Scheuchz.

$11800^{*}$ Wundersame Noe, so zu Schlicben, eine Neile hinter Jena, aufgebluhet, annn $\$ 669$. s. 1. 1669.4 .2 foll.

Opera anonyma ilalica, suecica, danica, hollandica, hispanica, lusiIanica, bohemica, hungarica, armeniaca:

$11801^{*} A^{\prime}$ magyar Tudós Társaság Exkonyrei. Misodik kotet. Budan, Magyar Királyi Egyctem Nyomtatása. $1835.4 .326 \mathrm{p}$.

(Inest: Frivaldsky, Teherstcht der auf dem Bathan gesammelten Gewachse, p. $233-276 .+$ Lab. Col.: Ilaberlea thodopeusis Friv. Lathyrus inermins Rocli., Centaurea napulifera Roch., sculclaria erientalis, pinuatifida Roch.)

11802 Alli della commissione speciale destinata dalla Sautita di N. S. Papa Pio VII. per le Risaje della provincia bolognese, ed altre nell' anno 1816. Roma, Poggioli. 1818. 8. 236 p., 4 tab. 
11803 Berättelse om Svenska Trädgards-foreningen; jemte dess Stadgar. Stockholm 1832.8.30, $15 \mathrm{p}$.

1180k Blomspråk, eller Blommornas betydelso efter Fiuska Runor. Uddevalla 1831.16. ( 8 skill.)

11805 Blomsterspråket, eller Blommornas botydelse efter ósterlándskt sătl. Öfversáttning. Calmar 1827. 8. 27 p. - Ed. J]: Calmar 1830. 8. $27 \mathrm{p}$.

$11806^{*}$ Catalogo degli alberi ed arbusti, delle piante da fiori e delle pii scelte specie di piante di ormamento, de bulbi, tuberi, piante fruttifere o semi che si espongono in vondita dall' appaltatore dol seminario di alberi c deposito de moltiplici del real orto botanico di Napoli. Napoli, typ. Tizzano. 1841. 8. 36 p.

11807 Catalogo delle piante del giardino Ferroni di Firenze. Firenze 1804.8.

11808 t Catalogo delle piante esistenti nel giardino della Signora Marchesa di Priero al Villar-Perosa. Torino, typ. Chirio e Nina. 1832. 8. $73 \mathrm{p}$.

11809+ (P. $B . F$.) Cenni brevissimi supra i boschi e le selve degli stati di terrafernı di S. M. il Re di Sardegua. Edizione seconda. Turino, stamperia reale. $1832.8 .178 \mathrm{p}$.

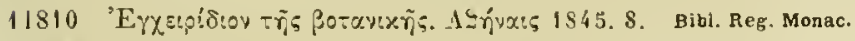

11811 * Flora Ligustica. (Prospetlo.) Geneva, tipografia del R. J. de Sordomuti. (1844.) 4. 2 p., 2 tab.

11812 Ilandbibliothek i Trúdgårds-skotschn, eller systematiskt ordnad llandbuk uti alla si val praktiska som theoretiska delar af Tradgärds-velenskapen. Fersta Afdeluing. Blomsterskotseln. Baudet I-II. Stochholm 1842-1846. 8. - 1: 1842. (auctoribus Sieurin et Thedenius.) 749 p., 4 tab. - 11: 1846. (auctore C.F. Nyman.) 1539 p., 2 lab.

$11813+1$ landboek voor LiefheLbers van vreemde Plantzoenen en tuiniers af aduleuding tot de kennisse van alle in en uitlandsche boomen en heesters, welke bij ons in de opene lucht kunnen gekweekt worden. Naar de nicuwste horigten uit hot hoogduitsch samengesteld door J. B. vun 11 interhoven. Utrecht, van Paddenburg en Zoon. 1795. 8. v11 , 580 p.

1181; Jlandlok i Svenska Tradgårds - och Blomsterskotseln. Öfversedd af Lars Jacob Luurell. Upsala 1841. 8. IV, 4 it p. (2 Rdr.)

(Autor est $N$. 11: Lundequist.)

11815 Ilandbok i Tradgårdskkotseln. Stockholm 1837. 8. 32 p. (12 skill.) (Autor est E. Jr. Uhngren.)

11816 Ilerbarium pharmaceuticum, eller Afbildninger of the officinelle Laegenidler af Planteriget i de Danske Stater. Fasc. 1-Vl. Kiobnhavn 1824.8 .

$11817^{*}$ Historia naturalis edita a congregatione Nechitaristarum sumtibus cujusdam benefactoris. Viennae, typ. Mechitaristarum. 1842-1844. II voll. 8. - 1: 1842. Zoologia. 330 p., 9 tab. - II: 1844. Botanica. 260,37 p., 10 tab.

(Opus idiomate arneniaco conseriptum elegantissime titeris excusmu, honis iconibus instructum, virurum rei perilorum laudiexcusim, bonis

11S18* Il nuovo giarelino. Zara, typ. Demarchi. 1829. 8. (26) p. (Sunt carmina latina italica el germanica in honorem Fr. a Velden, qui Zarae pulchrum condidit hortum.

11819 In difesa delle risaie Lombarde e Piemontesi Lettera. Mlilano, MlaJatesta. 1817.8.

$11820+$ Instruccion sobre el cultivo del Nopal y eria de la cachinilla do America. Publicada para uso de las labradores por la real suciedad economica de amigos del pais de Cádiz. (Cádiz), en la imprenta de don Tomas José Bortleta. 1825.4.28 p.

(In billintheea Delessertiana servatur hujus libri translatio gallica manuscripta autore $\|$ ahu.)

$11821^{*}$ Knieha lekarska hleraz slo- I we herbarz: a neb zelinarz: I zvelmi vziteczna : zmno- | hych knieh latinskych. | yz/kutecznych pra-| czij vybrana : po- I czina se sstia-stnic. (i. e. Arzneibuch, welches heisot Krauterbuch : sebr nutzliches : aus vielen Jateinischen $\mathbf{B u -}$ cherı und aus wirklichen Arbeiten (Praxis) ausgewăhlt : es beginnt glücklich.) s. I. et a. folio. 130 foll., ic. xylogr. i. t. Bibl. Mus. Seockenb. Francor.

In Dagina reclit tituli sunt icones duorum virorum; in pagina versà sub praefamine scutum heraldicum cum literis $N, C_{0}$ )
11822 Kort anvisning att anlaggga tradgårdar i mindre eller storre skata Stockholn 1843. 8. 23 p., 6 tab. ( 32 skill.)

11823 t Lảsning for alimogen i Kronobergs Làn i amnen, som rora Landtlushålluingen. Utgifwen genom Lánets luushăls-sâllshaps forsorg. Nr. 3. Om Brand, Rost $\mathrm{m}$. f. wästernas sjukdomar. Lund, typ. Berding. $1821.8 .54 \mathrm{p}$.

2982 it Nemoria sulse a cultura da oliveira. Coimbra, na imprensa de Trovao et Co. 1827.4. 26 p. Bibl. Webb.

11825 Osservazioni sul elima, sul territorio o sulle acrue della Liguria marillima, di un collivatore di Diano. Genova, Pagano. 1818. Il voll. 8. - I: $187 \mathrm{j} .-\mathrm{JI}: 25 \mathrm{f} \mathrm{j}, \mathrm{I}$ taL.

11826 Svensha Blomsterspråket, med 72 kolorerade blomster, jemte ett Blomster - ur samt en Vaderleks-visare af blommor. Stockholm 1845. 16. $\{24\}, 60, \mathrm{vI}$.

11827* Svensk Bolanik. Stockholm 1802-1838. Xl voll. (Fasc. 1-129.) gr. 8.774 foll., 774 tab, col.

Forst a B andet, utgifven af $J$. W. Palmstruch och C.W.Venus. Stocklolm, trycht hos C. Delin och J. G. Forsgren. 1802. 8. foll. et tab. col. 1-72. - Ed. Jl. utgifven af Johan Wilhelm Pulmstruch, och à nyo upplagil af Gustaf Johan Billberg. Stocklohn, tryckt hos C. Delén. 1815. err. 8 .

Andra Bandet, utgifven af Johan Wilhelm Palmstruch. Stockholm, tryeht hos Carl Delén. 1803. sr. 8. foll. et tab. col. 73-144.

Tredge Bandet; utgifven af J. W. Palmstruch, med text forfattad af C. Quensel. Stockholm, Iryckt hos llenrik A. Nordström. 1804 . gr. 8. foll. et tab. col. 145-216.

Fjerde Bandet, utgifven af $J$. 11 . Palmstruch, med text fórfattad af C. Quensel. Stachlulin, trycht hos Carl Delon. 1805. ggr. 8. [oll. et tab. col. $217-288$.

Femte lbandet, ulgifven al J. W. Palmsiruch, med text författad af 0 . Swartz. Stockholm, tryckt hos Carl Delén. 1807. gr. 8. foll. et tak. col. $289-360$.

Sjette Bandel, utgifven af $J W$. Palmstruch, med text forJattad af $O$. Swartz. Stochholm, tryekt hos Carl Delén. 1809. gr. 8. foll. et tab. col. $361-432$.

Sjunde Bandet, utgifven af $G$. J. Billberg, med text forfattad af 0 . Swartz. Stuckholm, tryekt hos Olof Gralın. 1812. gr. 8. foll. et tab. col. $433-504$.

A $t$ o nde B a n det, utgifven af G. J. Billberg, med tex författad Nr. 1-6 af 0 . Swartz, Nr. 7-12 af Uigifvaren. Stockholm, tryckt hos Carl Delen. 1819. gr. 8. foll. el tab. col. 505-576.

Nionde Bandet, utgifven af liongl. Vutenshaps Academien; inneliallande Nr. 577-648. Jfrản och med Nr. 595 sammanfattadı af Güran Wahlenberg. Ipsala, tryekt hus Palmblad et Cu. 18231825. gr. 8. foll. et tab. col. $577-648$.

Tionde Bandet, ugifven af Kongl. Vetenskaps Academien; innehållaude Nr. 649-720, sammaufattadt af Goran W'ahlenberg. Upsala, tryckt hos Palmblad et Co. 1826 - 1829. gr. 12. foll. el tab. col. $649-720$.

Elfte B a ud et (Haftena 121-129), utgifien af Kongl. Vetenshaps Academien, sammanfalladt af Goran Wahlenberg el Pehr Fredrik II ahlberg. Upsala, tryckı hos Palmblad et Co. Stockholm, tryckt hos Norstedt et Soner. 1830-1839. gr. 8. foll. et tab. col. $721-774$

fOperis Svensk Botanik ex decreto Acadeniale regiae Holmiensis contiunationes non amplius prodibunt. Textum conseripserunt Quensel vol. $1-1 \mathrm{~V}$, anmis 1802-1806; Swart vol. V-Vill et fasciculos $85-90$ tomi octavi, annis 1806-1817; Millberg rasciculos $91-96$ tomi octavi el 97-99 tonii noni, annis 1818-1821; Hahlenberg fasciculos 100-108 tomi noni, tomum tlecinum, et fasciculos $\{21-123$ toni undecimi, annis 1822-1830; Pehr Fredrit liahlberg fasciculos $12 k-1829$ tomi undecimi amis $1 \times 30-18.38$. Figurae pictae sunt a lenus el Palnstruch utruque Centurione equestri, a Professoribus Swarl. Acharius, Itahlberg, darelius, Laeshudius.' Prcliun uriusSwart. Acharius, in ahtberg, Agrelins, Laescudrus. Preliun uninscujusinie fascietili milio valde mit modicum, 76 skill. Bco., dein ad ris fuse tradit ill. Wikstrom in Consp. lit. bot. in Suecia p. $25 !-256$.)

\section{Opera anonyma lalina:}

$11828+$ Catalogus Herbarii J. Ryani, M. D. Havuiae, typ. Cohen. 1809. 8. $38 \mathrm{p}$.

$11829 \div$ Catalogus plantarum horti botanici Divionensis. Divione (Dijon), typ. Bernard-Defay. 1808. 8. 25 p. 
11830 Catalogus plantarum in Lortis regiae villae prope Hodoetiam (Noliza). Nodootiae 1813.8. Amo 1826 cjusdem horti catahgum curasit Giovami lossi; vido supra Nr. 8736 .

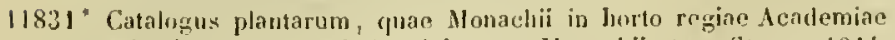
scientiarom anno 1814 colebantux. Monachii, typ. Storno. 1814. 8. $56 \mathrm{p}$.

118324 Catalogus plantarum, fuarum semima anno 1819 in horto regio Pilluitziensi scrvabantur. Dresdae, typ. Meinluold. 1819.8.93 p.

I 1833 t Catalegns plantarum singularum suis arenlis listinctarum scholae botanicae Jorti regii l'arisiensis, ! juibus ea instructa crat anno 1656 . freessit infex plantarum aliarum puar passim in coeteris ejustem horti partibus occurrunt. Cur, at th. AI. A. E. P. P. Parisiis, apul J. Bessin. 1656.12.59 p. - ib. $1660.12 .59 \mathrm{j}$. (dliffert.) Bibl. Juss.

$1183\{$ the latinis of graccis nominilus artorum, fruticum, hertarum, piscium et avium liber: ex Aristolele, Theophrasto, Diuscoride, fialeno. Nicandro, Alhenaco, Opjoiano, Aeliano, Plinio, Jermolao Barbaro et Joanne Ruellio: cun gallica earum nominum appellatione. Luteliae, ex officina Roberti stephani. 1514. $8.85 \mathrm{p}$., incl. - +Lugdmi, apud Theobaldum Pagamum. $1548.8 \mathrm{~min} .155 \mathrm{p.}$ imel. - tib. 1552. 12. 148 p, iml. - tlid. IIl: Piclavii, ex oflicima Maruesiorum et Houchetorum [rotrun. 1559. 4. 77 p., iud. tEוl. IV: Lutetiae, apud Ciarolum Stephanum. 155\%. 8. 102 j., ind.

$1183: ;$ * De Papyro fruetus ac seminis experte commentarioli ad llioh VIII, 12. Particula I-1II. Programmata. Columegi 1772-1779. 4. 29 p.

11836 " De phintis libri duo Arisfoteh falso adscripti. Basileac, apud Robertum Winter. I339. 8. - "Impr. grace cun Operilus Theophrusti. Bisileae (1541.) folio. p. 197-214. - thutetiae 1356. 4. "Irepr. latine cum Operibus Iristotelis. Lugchui 1579. 12. tom W. p. 801-842. - * *netiis 1585. 8. - * Jmpr. graece et latine cum Operilus Arisiotelis ex liblintheca Is. Casauboni. Lugduni, apud Gu. Lacmarium. 1390. folio. tom. 11. p. 5\$2-595. - Graece "1 Jaline, cum interpretatione Jalii Caesaris Scaligeri. Parisiis, Iyp. Reyiis. 16 19. fulio. s.

(Editionem novissimam recensente E. Meyer vido sugra Kr. Tho] in voce Nicolans Dumascenths. Commentarii Scaligen legunlur stura Ni., פo'ri.)

$11837 \div$ Elenchus plantarum horti medici Amsteladamensis. (Imstclodami) 1807,1808 et $1809.8 .56 \mathrm{p}$.

(Vide supra Gerard Srolik Nir. 108:i.)

$11838 \div$ EJenchus plantarum horti regii bolanici Malritensis. 1796. 8. 34 p. Bibl. Juss.

$11839 \div$ Elenchus plantarum Jorti regii Lotanici Parmensis. (Parmac) 1802. 12. $40 \mathrm{p}$.

(Aulor fortasse est Profressor Pascul.

$11840^{*}$ Enumeratio plantarum Sueciae indigenanum secundun cel. Itahlentergii Floram suecicam. Sectio I. (Upsala 1530.) 8. 16 p.

I18'.l E Eumoratio plantarun, quae in horto Lugduno-Bataro colnutur. s. J. $1831.8,87$ 1).

$1185.2^{*}$ Enumeratio seminum lorti Pillnitzicnsis. s. I. 1824. 4. (11) p.

11813 t Epistole et judicia clarissimorum aliyno medicorum de Tabaco. Impr. cum Everhurti Herba Janacea. Llurajecti, Iloogenhuysen. 1644. 12. p. 147-197.

118\%. Jlortus Argentoratensis. (Argentorati) 1781.8 .30 p. - ib. 1782. 8.8 p. B

$11835+$ Hortus regius Academiae Rothomagensis. (Rothonagi) 1778. 12. $\mathrm{xII}, 166 \mathrm{p}$.

118 'b leones plantarum, partes, colorem, magnitulinem of habitun earum ad anussim exhibentes, adjectis nominilus Linnaeanis; ediderunt l'aul Dieterich Giseke, Johaun Dominicus Schenlze, A. A. Abendrath et N. J. Buek. Pasc. I-III. Hamburgi, opera et sumsibus Jacobi von Doelilen. 1777-1778. folio. 75 tab. col.

1181.7 " Jcones plantarum sponte Clind nascentium e Bibliotheca Braamiana excerplae. London, J. II. llohte. 1821. folio. 30 tab, col., praef. (3l. 3s.)

(In Calalogo Bibliothecae Radcliffe Oxoniensis liber autori H. $B$. Ker adseribilur.)

148 's T Index plantarum offeinalium, quae in horto regio Edinensi alunlur. (1738.) $8.16 \mathrm{p}$.
$11819^{*}$ Liber aggregationis sive secretorum de virtutibus locrbarum, falsu Alberta Ilagno adscriftus. Argentine 1493. pridie Id. Mar. 8. (31) foll. - tImprine pour Thomas Laisne libraire demourant a louen. s. a. 8.7 plag. - Impr. per Willı. de Mechlinia in opslentissima civitate Loutliniarum. s. a. 4. Bibl. Mus, brit. - 'Argentorati, Zetzner. 1604.12 . p. $141-155$.

(Libri miserrimi sescenties impressi ndlithones nquidtem colligere meglexi. Sestulo indicantur à viris ill. Choulant et Thierfelder in liensekels Jumos, Banri l.)

$118 \ddot{30} 0^{*}$ Mensa philosoplica. In lioc opusculo tractatur de his, guibus utimur in menso; de naturis rerum videlicet cilsi el protus etc. Imjuressus Colonie apud preclicatores. 1508. 4. (106) p. Bibl. Link.

(Freyiug Aly [ial. liter. 11. p. 81\%.)

11851 t Plantarum index. Parisiis, typ. Lud. de la Fosse. 1661 . 12.60 p.

11832 Scriptores rei ruslicae. (Folium $\left.\right|^{\mathrm{a}}$ :) Lucii Junii Noderati Columellacl rei rusticale capitula libri primi. (Fulium s̈it:) Lutii Juni Aloderan Columellae rei in / sticae liber prinus. Prasfatio. (Folinn 152":) Lucii Junii Moderati Columellae rerum | rusticarum libri opera et imponsa Nicolai | Jenson Galli impressi Venetiis Xicolao | Tluromo Juce invictissino. MICCCC LXXII. (Folitun 15\%") Pulladii Rutili Tauri Aemiliani viri illustris | de re rostica liber primus. (l'olium $213^{\text {at }}$ ) Palladii Rutili Tauri Aemiliani viri illustris / de re rustica liluri impressi Venetiis opera | "t injensa Nerolui Jenson Gallici. M.CCCC.L.XXIl. I Nicolas Throno duce Vencliarnm inclyto. (Fo-

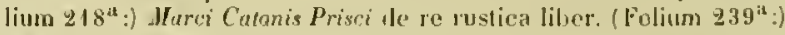
Harci Prisci Calonis qui hominom summos | in omni usu fuil de re rustica liber unus | yuem alsolutum nec imperfectun Plinio | auctore collegimus cura et artificio $\mathrm{N}_{i}$ f ealni Jenson Gallici inpressus Venetiis. | M.CCCC.LXXII. (Folium $24^{n}$ :) Maren Terentii Jorronis rerum rusticarum | ad fundaniam uxorem liber I. J'rolugus. (Folium $283^{\text {h") }}$ Marci Terentii l'atronis yui rem ruat $/$ cam expolivit libri tres. Hos diligen I ter atque venusto inuprescit -licolaus | Jenson Gallicus genere Venctiis. N.CCCCI.XIII, folio. 298 foll. Hain Nr. 1/564.

11853 Scripteres rei rusticae. Impressi Regii opera et inpensis Bartholnmei Ilraschi oi Botoni Regiensis MCCCCLXXXll nonis Junii. folio. 302 full. Ilain Nr. 14565.

1183i' Serijutores agriculturae seu rusticae rei Cato, larro, Columella, Palludius. s. 1. 1488. folio. Hain Nr. 14366.

IIS5ij Rei rusticae scriptores Cate, Furro, Columella et Pallatius. Regii per Donysium Bertochum. 1498. folio. Iluin Nr. 14567.

$118 \ddot{6} 0$ Opera agricolationum : Columellat : Jar | ronis : Calonişue : nec non Pullatii : cu | excriptionibus. D. Mhilipui | Berualdi : et commen | tariis quae in aliis impressioni | fus non | evtut. (in calce:) Impressa bunon. Im | pensis Benedicti hecturis hononiensis. MCCCCLXXXXIIII. XIII.calen. | octub. Joñne bëliuo. Il. reip. bonn. habenas foeliciter moterante. folio. 274 foll. Ilain Nr. I toj6.

11857 Opera agricolationum Calumellue, Farronis, Catanisgue nec non l'alladii cum esscriptionibus Philigni Beronldi ef commentariis. Impressa Regii impensis Dionysii Bertochi Regien. imperante divu llercule lesten. MICCCLXXXITI. Xlll. Kalend. Oelobris. folin. llain $\mathrm{Nr}$. 14569 .

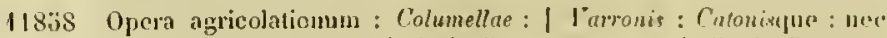
nun Palladii: cum esscriptio | nihus et commêta | riis. J). Philip| pi Beroaldi. (in calce:) Impressa Regii impésis l'rñeisci Ma | zali

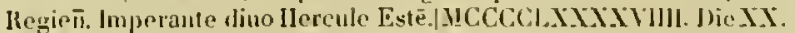
Nouembris. folio. 24 i foll. Ilain Nr. 14570.

11839 " Liluri de re rustiea. M. Cutonis liber I. . K. Terrentii larronis libri III. L. Jun. Hoderali Columellue libri XII. Ejusdem de arboribus liber separatus al aliis. Puladii libri XIV. et indices. Venctiis, . Iluus. 1523. 4. 295 foll. praeter indices in fronte.

$11860^{*}$ Lubri de re rusliea .II. Catonis lilıer 1., II. Terrentii Varronis lilıri III., L. Junii Iaderati Columellae libri Xll. Ejustem de arboribus liber sepraratus al, aliis. Palladii libri XIV. etc. Llasileae, ex officiua Joamis Hervig. 1533.4 .295 foll., (52) foll.) indlices.

11861 " Scriptores rei rusticae veteres Jatini, Cata, larro, Calumella, Pallinlirs, quilsus nune accerdit legetius de Mlule-medicina of Gargitii Martialis fragnentum cum editionibus prope omnibus et mss. pluribus collati, aljectae notale virorum clarissinorum integrae tum 
editae tum ineditae et Lexicon rei rusticae, curante Johonn. Mathius Gessner. Lipsiae, Fritsch, 1735 . Il voll. 4. Lv1, 1316,159 p., 5̆ tab.

$11862^{\circ}$ Scriptores rei rusticae veteres latini e recunsione Jo. Wath. Gesneri, cum ejusdem praefatione et Lexico rustico. Bijonti, Iyp. societatis. 1787-4788. IV voll. 8. - I: Cato el Varro. CLVI, 248 p. - II Columella. 566 p. - III: Palludius et I'egelius. 510 p. - IV: Lexicon rusticum.

$11863^{*}$ Liluri de re rustica. Ex optinorum seriptorum atque editorum file et virorum doctorum conjecturis correxit, atrue interpretumomnim collectis et excerptis commentariis suisque illostravit Johann Gottlob Schneider. Lipsiae 1794-1793. Ill voll. 8. - 1: 1794. Cato et Farro. 358,682 p., 12 tab. - 11: 1794. Columella. 670, 717 p., 3 tab. - 111: 1795. Pulladius. 391,224 p.

1186 f $^{*}$ Sylloge plantarum novarum itemque minus cognitarun a praestantissimis botanicis adhuc viventibus collecta, et a societate regia hotanica Ratisbonensi edita. Ratisbonae, typ. Brenck. 1894 -1828 . II roll. 8. - I: 1824. xII, 244 p., I tab. - II: 1828. vil1, $256 \mathrm{p}, \mathrm{t}$ tab.

$118630 \div$ Theatrum Florae, in quo ex toto orle selecti mirabiles venustiores ac praecipui flores tanquam al, ipsius locae sinu proferuntur. Lutetiae Parisiorum, apud Nicolaum Hathonice. 1622. folio. 69, 2 tab. aen. alssque textu. Bibl. Cand., Deless. - "Iutctiae Parisioram, apud Petrum Firens. 1633. folio. 69, 3 tal, aen. absque textu. Bibl. Reg. Berol. (non differt.)

$11866 \div$ Tractatus de vini conservatione, autore anonymo. Bononiae 1488 impressus. 4. 8 foll. Bibl. Rejp. Par1s.

\section{Herbarius.}

$11867^{*}$ Iferharius. Ma I guntic impressus. I auno 1484. 4. (4), 150, (19) foll., ic. xylogr. i. t. Bibl. Palat. Vind., Bibl. Francof. Senckeub. Itain $\mathrm{Nr} .8444$

(1)pus incipit Rogatu plurimorn in opum numorum rgentium appotecas relutantium ". leones rudissinac; ordo nst speumbur alphaheti spripm ab Absinthen ad tsuran. Subjuncta sunt in late impressione Petri sshoefferi rulus seuta in pagind prima rwcla. A seyuentibus editionibas Patavii (juod teste Hith Pissavium = Passau, non ralavium = Padua sisnilical diflertre non videtur. Altor hujus libri termr Jacobus de Dondis vel Paluanus, etiam Lgregator Palavinus cognominatus lidionum Ionga est series hand

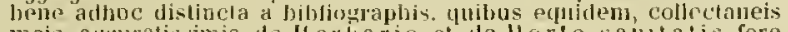
meis acenratissmis de Ifribario of te florto satutatis fere omnibes casu infelici disperditis, fucem vis afferan. Honeo, antiquissimn adesse Brusellis in Mullhemiana bibliotheca editionem cireti annom 1 'k73 inpressam: in hiblintheca regia lierolidensi duas

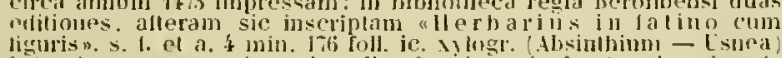

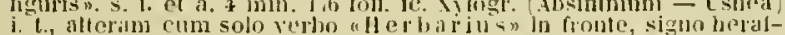

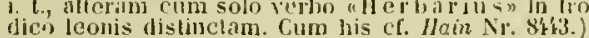

$11868^{*}$ Herbarius Palavie in / pressus anno donī z cete / ra I.XXXY. i. (4), CL, (1) foll., cum CL ic. xylogr. satis rudibus. Bibl. Palat. Vindob., Bibl, Cand, Huin Mr. 8445.

(Incipit folinm $2^{3}$ : Rogatu filurimorum | inopä nömorum egetin appotecas re-1. Ordo iconum : Absintleum-lsnea.)

$11869^{*}$ Herlarius Patavie im | pressus anno donini et ce / tera LXXXY1. 4. (4), CL, (18) foll., cum CL ic. xylogr. siltis rudibus. Bibl. Palat. vindob., Bibl. Francof. Senckenb. Hain Nr. 8446.

(Incipit folium $2^{2}$ : (R) Ogatu plurimorum I inopum muñom

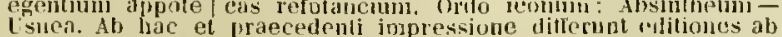

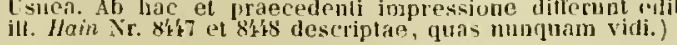

11870 (Herbarius.) Herbolarion seu de virtutilus herbarum. (Foliun CL $^{\mathrm{b}}$ :) Finiunt Liber vocatur herbolarium de virtutibus herbarum. Impressum Vincentiae, per Magistrum Leonurdum de Busilea el Guilielmum de Papia Socios. Anno salutis M.CCCC.LXXXXj. die XXV'll meñ. Octob. Deo Gratias. 4. CL, (18) foll., ic. xylogr. i. t. If tiin Nr. 8451.

Pratecedit Prologus, qui [olium 2a incipit. Pars Injus Folii ligneo includitur ormamento, in cujus superioni parte repracsoutantur irmoldus de rilla Nova et Avicema sedentes deque herbis dispatabtes.)

$119 ; 1 \div$ (Ilerbarios). Incipit tractatus de virtutibus herbarum. I Anoldi de rova rilla Avicenna. Imbressum Venetiis jer christophorum de pensis anno domini nostti Jesu Clıristi I 502 , Julius, die vero 4. 4. A la:b/c-r; omnes quatern; praeter A qui est duernus. ic. sylogr. i. t. Bibl. Webb.

Incipit: Rogatu plarinorum inopī | mummorum egentium d dpote | cas refutautium occedsione illa | |

11872 (Ilerlarins). Venetiis, per Jo. Rubeum et Bernardinum, fratro Tercellenses. 1509 . 4. ic. Iylogr. i. I. Rivio

\section{Edilio belgica}

11873 Fin llerbarins of Kruydhoek. s. I. (19p. Joh. V'eldener Calenburui. 1484. 4. ic. 1ylogr. i. 1. Hain Nr. $\$ 449$.

\section{Ediliones italicae:}

$1187 \mathrm{i}$. IJerbolarin rolgare : nel quale se dimostra a conoser le lerbe : o le sue virtu : $a$ il molo rli operarle : con molti altri smplici : di novo vemute i lnce: e di latino in volgare tradutte. etc. (in calce:) Stampato in Venetia con somma diligentia : per Giovanno Maria l'alanilles. 1539 . a di ultimo Jugio. 8 tat. $x$ foll., $(150)$ ic. $x y \log r$. i. I. (Aaron uvero Serpentaria - Usnea. Bibl. Deless.

11875 : Ilerholario wolgare, nol dual è le vertu telle herbe e molti alti semplici se dechiarano, con alcune belle aggionte novamente de lalino in volgare tralutto. (in calce:) Stipato ne la inclita citta ti Venetia con decoratissima dilizentia per Giovanni Mlaria Palamides nel anno MDXL. 8. (181) foll., $(150)$ ic. 1 logrt. i. 1. Bibt. Reip. Parıs llnuc liarum et prareediontem, qui in Prologo ab timo autori

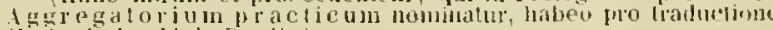
llerbanis Jacobi de Dondiv.

\section{Fortus ${ }^{1}$ sanitatis.}

\section{Editiones latinae:}

$11876^{*}$ - _...._. (Folium $1^{\text {in }}$ tit.:) Ortus sanitatis / De horbis et plantis. | De animalibus 2 reptilibus | De Auibus et volatilibus | De Pilcilus : nalatilibus | De lapilibus 2 in terre venis nafcēêtulus? De Ininis et ea 2 freciebus | Tabula medicinalis Cum directo- rik generali per cimnes tractatus. (Folium $1^{\text {b }}$ ) icon xylogr. (Foliom $2^{\text {it }}$ sign. aij:) to Nripotētis | eternie; dei: tolig natu | re creatoris (1pit mira- | hilia admirandaq; me | cū vieilog iterati crebri | us pecogitioto reuolui. / etc. (Folium 202

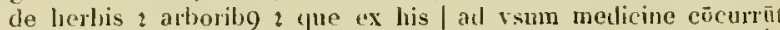
fufficiant. (Foliam $203^{\text {"l }}$ tit. :) Tractatus de Animalibus. (Foliun $203^{\prime \prime}$ ) jc, xylogr. cum inser. : Jomo natus de muliere breni viuens tempore. (Folium $20^{\text {it }}$, sign. Aij:) Prologus in tractatum | De animaliLus. (Qooni in priorilig diuino nobis affiftente /etc. (Folium $245^{\mathrm{b}}$ :) c) Hec iggitur de natura animaliū qua- / drupedum : alijs in terris morantiom | fufficiant. quia fiqua alia sunt facile ex | inteelictis agnosci possumt. ( Polium $246^{\text {a }}$, sign. Giiij:) incipit tract. de avibus.

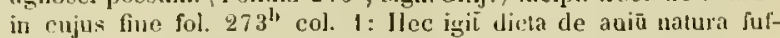
ficiant, Ead. pag. col. 2. incip. tract. de piscilsus. Folium $295^{a}$ sty tracl. de lapidibus. (Folium $332^{b}$ col. 2 :) El hec de lapirlibus jre-

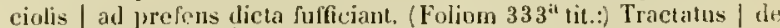
Lrinis. (Folium $333^{b}:$ ic $x$ ylogr. (Folium $334^{\text {* }}$, sign. aaij:) (Jonian unt- / dicus elt artifex fenfitiug | Expl. fol. 3 \& $2^{b}$ col. Il. lin. il : nis dicta fulfeiant. Finis. Foliom $343^{\text {a }}$ sign. ce. Fol. $360^{\mathrm{it}}$ : tabls, in ealee: linis. s. l., a. at lyp. $54-55$ lin. Jinis col. 360 foll. ic. sylogr. i. 1. Huin Nr. 8941 .

$11877^{*}-$ (Folium $\left.\right|^{\text {at }}$ tit.:) Ortus Sanitatis | De herhis : plantis I De Inimalibus ? reptilibus | De Auiluss : rolalilibus | De Pifcibus : nafatilibus | De Lapidibus : in terre venis nafcetibns | De Lrinis z earum fpeciclous | Tabula medicinalis Cum directorio geuerali per ommes tractalus. (Fulium $1^{b}$ :) icon sylogr. (Folium $2^{i}$. sign. aij:) ( Mnipotetis / eterniq; dei : totius natu- re ereatoris opera mira- | bilia admirandaq: mecu | vicibus iteratis crelrius peogitīdo reuolui efe. (Folium $202^{\text {it }}$ col. II. lin. 15 et 16 :) Jlec te herbis et arhorib at que ex his / ad vsum meticine cücurrūt luf-

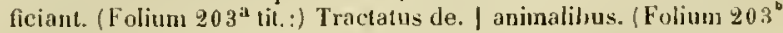
icon xylogr. c. inscr.:) llomo natus de muliere breui viuens tempore. (Folium 204", sign. Aij:) Prologus in tractatum | De aninaiibus. Quonia in prioribus diuino nobis alliftẹ te etc. (Foliom $2\left\{5^{\prime \prime}\right.$ :)

\footnotetext{
1 reclius Orlus sanitatis.
} 
q. Hec igiī de natora animaliū quadrupedum / 2 alijs in terris morautiō fulficiant: quia fifua / alia funt facile ex antedictis agnofci poffunt. (Folium $246^{*}$, sign. Ciiij pro Giiij:) incipjt tract. de avibus, in eujus fine fol. $273^{\mathrm{b}} \mathrm{col}$. I : llee igii dicta le aujü natura fulficraut. Ead. pag. col, 2: incip. trace de jifcilsus. Folium $298^{\text {a }}$ sed. tract. de lapidilus. (Folium $332^{\circ}$ col. 2 :) bi liee de laprabas

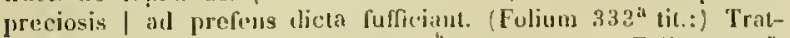
tactus (sic) | de vrius. (Fulium $333^{\text {t }}$ ) ) icon xylogr. (Folinm $334^{\text {at }}$ sign. aaij:) () Uonian me- / licus è arlifex lenliliuus / etc. Lxpl

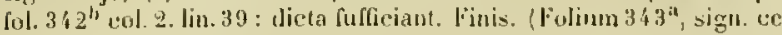

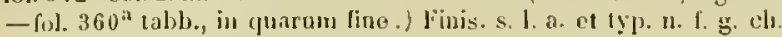
a. f. 54-55 lin. 360 foll., ic. xylugr. i. 1. Ifain Nir. 8949 .

(hx oflicina edtitionis praecedentiq.)

$11878-$ s. 1. a. el typ. In. f. g. c1. sign. 1-1.1.; 50 lin binis col. 360 foll., ic sylogr. i. t. Mrtin Nr. $\$ 943$.

(Verosimiliter ("x eadin ofticina.)

11579 * IJortus smitatis. (Folium $1^{\text {a }}$ tit. :) Ortus fanitatia. (Folium $1^{\text {b }}$ :) icon

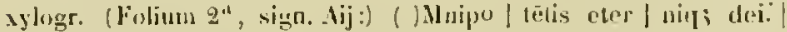
tocisg nature cre / atoris opera ni / rabiia adnirā / danf mecü vici | bas iteralis crebrias peogitando rubl| ui ete. (Folium $248^{\text {it: }}$ ) Hee de horbis ? arloribus ? ī ex lis / ad vium medicine ocurrüt fafliciant. (Folium $2 / 9^{\text {it }}$ (it.:) Tractatus de Animalihus / vitan in terris ducentiun. (sic) (Folium $249^{\text {th }}$ ) icon xylngr. (Folinu $250^{\text {it }}$, sign. nij:) Prologus. | (q) Unnian in prioribus di | uno nobis aflistente ausi / ele. (Finliam $298^{b}$ :) Hece igit de natura animalium qudru / perlums. et alijs in terris morantiū fúlici / ant quisi fiqaa alia cunt ficcile os aй diclis / agnotei pollunt. (Folian $299^{2}$ lit.: Tractatus de Auibus. (Folium $299^{\mathrm{b}}$ :) icon xylogr. (Folium $300^{\mathrm{a}}$,

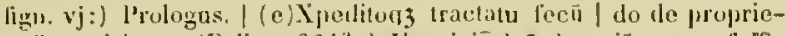

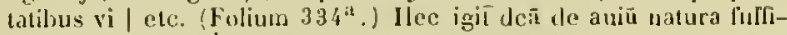

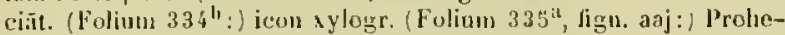
min̄. I (i): Am in prececlenli tra | ctatu lacutū lumuf de | elc. (Folium $364^{\text {it: }}$ ) Hec de Pilcilus ac monRruo 4 a ajua | tilium 2 naturis breuiando tranfcurring. I Sequit tractatus Quintus. Je Lapidi $\mid$ bus vidalicet preciofis eorut; v'tutilus. (Folium $364^{b}$ :) icon xylogr. (Folium $365^{i t}$, tign, ceiij:) Prolemiū. | (C) Eneca i naturalibus queltionilus libro fe ptimo dieit. Sieut in etc. (Folium $40 \mathrm{~s}^{\mathrm{b}}$ :) lit lec de Lapillibus preciofis / ad prelens dicta fufticiant. (Folium $409^{\text {it }}$ tit.:) Tractatus de Urinis. (Folium $409^{\text {ts }}$ :) icon. sylogr. (Foliun $410^{\mathrm{at}}$, fign. ij:) (q) Uoniam medicus elt $/$ artifes fenfitious. 1 p | figna ì egritudinum | elc. Lixpl fol. 429it col. 2, lit. 47 : bee de rrinis dicta lufficiant. (Folium $422^{\prime \prime}$ ) icon xylugr. (Folium) $423^{2}$,

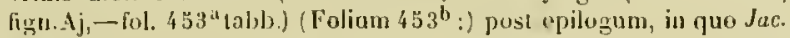
Meydenbach libri impressor nominatur: Injprellum ell attem hoe ipm in inclita / ciuitate Moguntina. gue ab antiquis au I red Maguntia dicta, ac a magis id elt fa I pientilus vt fertur prinitus londata. in | qua nobilifima ciuitate 2 ar's ac leientia | hec fultiliffuma caracterifandi leu impri / inendi fait primi inuenta. Imprefium | elt inquam fub Arehiprefulatu Reueren | diffuni : Dignilfini principis : drii. du / mini Bortuldi archiepifcopi Mogñtin / ac principis eleetoris cuins felicilfimo au | lepicio gratlitur recipitur 2 auetorifatur. Anne lalutis Millefimo Quadringente | fimo Nonagefimo primo. Die vero to uis vicefnua tercia menfis Junij. folio. 453 loll. 47 lin. hinis cal., ic, aylogr. i.t. Bibl. Dresd., Goett., Francof., Webb. I!ain Nr. 8944.

(Orito iconum est: Arona (Calla ralustris), Abrolanum, Absin-

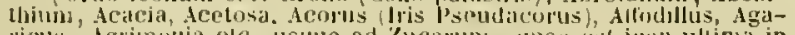
rieus, Agrimonia ele. Issfue ad Zuearum, quat est ienm ultima in eapite DfXX. Nomina germantea plantitrom, gaae sunt ill llerbario, hic it inseriptloubus desjleranlur.)

$11880^{\circ}$ Ortus sanititis. De herbis et plantis. de animalibus ot reptilibus. de avibus el volatilibus. de piseibus el natatilibus. de lapidibus et in terre venis nascentibus. de urinis et earum speciebus. Tabula medicinalis eum directorio generali per umaes tractatus. 1547. 4. 355 foll. hinis columnis 57 lin., ic. xylogr. i. t. Bibl. Mus. bot. Vindob., Bibl. Mus. Senckenb. Francof.

\section{Editiones germanicae}

$11881^{*}-$ (Folium $1^{\mathrm{a}}$, sign. a.ij:) (I)Ch loab oft I vnd vil bey | mir lelhs be | traclstel die | wundersame | werche des | fehopfers $f$ | naturé. etc. In ser. legitur: - a Vud nemen difes buch | zu latein. Ortus fanitatis, aull | leutsch. Ein garten der gefundt- I heit In wölché garten nan fin | det vierbundert vnd xxxv, kreu- / ter, elc. (Folian $3^{2 .}$, lign. aiiij:) incipit opus iplum. Expl. fol. $229^{\mathrm{h}}$ col. 2. lin. 37 :) nitatis. (Folium $230^{\mathrm{it}}$, lign. F.j:) Difes ilt das dritteyl | difes luchs. vnd it ein regiter | zu finden hreuter die do lasieren / dz ill ltulgáng bringen. elc. (Fulium $23 \mathbf{1}^{\text {b }}$ poft icon sylosr.: Difes itt das vierde | tey difes bochs, vid faget vas | von allen farben des harms. (Folinni $234^{\mathrm{h}}$, sub finem col. 1 :) Hyenach voluet das | funift teyl vnnd das leczte dỵes / buclis. ví itt ein regilter bethend | zu linden von allen kranckheite $\mid$ ete. (Folium 253", fignt. Jiiij, cul. 1. lin. 5:) Dyfz find dye capitel f der kreutter nach ordnunge des $\mid$ alphaheis. (l'olium $255^{-b}$ :) a: Eyn ende hat difes regitter. s. I. a. el typ. folio. 257 foll. c. 42 lin. binis

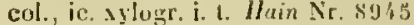

(Videtur impressio Augustac Vindelicorum facta.)

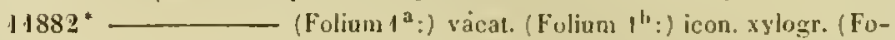
lium $2^{\text {a }}$, sign. aij:) ( )Fft visl | vil habe | ich bey mir fel | bell betracht dye wunder- | fan wercke / des lchoples's | $\delta$ wature ele. In seq. legitur: vñ nennē difs J,ach zu latin Ortus la | nitalis. vir teutch ein gart $\delta$ gefunt- | heit. in welehe garté mī findet. cccc.| vn. xix. krenter ete. (Fulium $3^{\text {a }}$ col. 2 , fign. aiij : incijut opus ipfom.) (Folium 20,b, sub finem col. 2:) Das it das dritteil dic | buchs vnd ilt ein reigitter (sie) za finden | hreuter die da lasierẻ das itt ltulgé | go bringen cte. (Folium 206 ${ }^{\mathrm{i}}$, fign. Dij post icon xylogr. :) Dis ift das vierile teyl / difs lucbs vud faget vns von allen / farwen des harns. (Folium $20 \mathrm{~s}^{\mathrm{t}}$, cul. 2 :) llienach volget dz funft|leyl vul das lelt difs Juelss vin ilt ein regilter behende zu finden von allen| kranckheiten etc. (l'olium $221^{a}$, col. 2:) Dis fint die capite! der kru / ter nach urlenung lles alplabets. Expl. Lol. $323^{b} \mathrm{col}$. lin. 28 . s. I. a. et typ. folio. 223 foll., $42-43$ lin. binis cal., ic. $x y \operatorname{logr}$. i. t. YArgentorati s. Mlogunt.) Hain Xr. 8946.

$11883^{*}-\left(\right.$ Folium $f^{\text {it }}$ :) vacat. (Foliun th: $^{\text {h }}$ ) icon xylogr. (Fo-

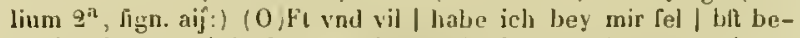
tracht dic wun- | derfam wercke des | fehopfers des natuer | etc. In fequentilous legitur: - Und ne $\mid$ nen difs buch zu latin Ortus Canutalif | auff toutich ein gart der gefuntheit. I In wolchen garten nan lindet. cccc. I vnd. xxxy. kreuter etc. (Folium $3^{3}$, fign. aiij: incipit opus ipsum. Expl. fol. $204^{b}$ cul. 2 . lin. 31 : de ingenio TaniIatis. Deinde: Dis ift dz dirtteil (sic) / difs buchs vn it eyn regitter zu fintē / kreuter tho da laxiren dz ilt ftulgenge / bringen. itc. (Foliun $406^{\text {it }}$ post icon. xylogr.:) Difz ilt das vierde | tey! difs

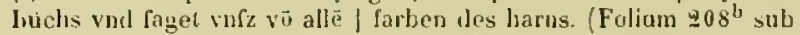
finem col. 1:) lie nach volget / das fuuffe teyl vad dz lent difs buchs I rud it eyu regilter behende zu fynde I ron allen kranck-

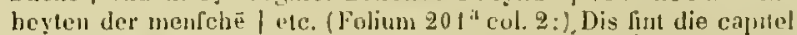
| J kruter uach ordenüg def alphabets. Expl. fol $223^{\text {l }}$ col. 2 lin. 2. s. I. a. et typ. fulio, 223 foll. 43 Jin. binis col., ic sylugr. i. L. Has/ Nir. 8947

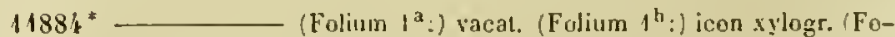
liom $2^{\text {it }}$ ) ( ) m vad vil habe ich by mir felbıt betracht die wüdersam | werck des fehepfer's der natuer wie er am anbeginde dẻ liy. etc. In Sequentibus legitur: - Vul neune difs buch zu Jatin Ortus fanitatis. vtl' teutlicl | ein gart der gefuntheit. In welchem garten

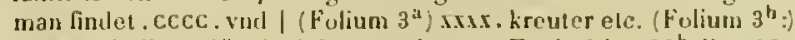
vacat. (liolium $4^{\text {it }}$ ) incipit npus ipsum. Expl. fol. $338^{\text {b }}$ lin. 22 : lienus itt beweren in fynẽ buch de ingenio fanitatis. (Folium $339^{3}$ :) Dirz ilt das dritteyl dilz buchs vnd ilt eyu | regilter za finden kruter die da laxieren das in latugenze brengen / ete. (Folium $341^{\mathrm{a}}$ :) icon xylogr. Infra: Diliz itt das vieve deyl difz buchs vnd ra / get vas von allen farben defz harus. (Folium $344^{\text {b }}$ :) Hie nach volget das funfte leyl und das / left difs buchs. vnd it ein regitter behendet zu finden von allen krang I heyten der menfehen etc. (Folium $354^{\text {a }}$ col. 2:) Difz fynt die capitel ter kru / ter nach ordenūg defs alphabets. (Folium $336^{t}$ litt. missal, rubro:) Diller Herbarius it czu | mencz gedrucht vul geen | det vif dem xxriij dage des ] merez, Anno. Ml.ccc.Jxrxi. Scuta Schoefferi rubra. folio. g. eh. s. f. c. et pp. n. 356 foll., ic illogr. i. t. Bibl. Mus. Senckenb. Francof., Bibl. Goett. IIain Nor. S948.

(llaec editio imsignis est iconibus magnis bene scalplis, quae etian in ordine ab altis differun!. Prima est icon in capite LI. Agaricus, lannenswam; deinde Agnus rastus, Schafmulle; Betonica, Betonien, , Buglessa,
Zucarum, Zocker.) lium $2^{2}{ }^{2}$ fign. aj:) $(0) m$ und vil hab ich bey nir felbs betracht dye 
wü | dersamo werck des fchepfers der natur. wie er an | etc. In fequentibus legitur: - Vad nennen difs buch zu latein Ortus fa|nitatis. aud[ teutich ein gart $\delta$ gefuntheyt. In welchem garlen mī] vindt .CCCC. vod xxxv. kreuter. etc. (Folium $3^{\text {b }}$ :) vacat. (Folium $4^{\text {it }}$, fign. aiij:) incipit opus ipsum. Expl. fol. $338^{\mathrm{b}}$ lin. 22: als galienus itt beweren in seinem buch de ingenio fanitatis. (Folium $339^{\text {at }}$ :) 01 Dyfz ilt dz dritt reyl (sic) dif's buchs vnd in ein reigifteer ( $\mathrm{sic}$ ) ze findē kreu / ter die do laxierent dz ift at geng briugent ete. (Folium $344^{\text {al }}$ post icon xylogr: a d Difs ilt das vierd teyl difs buehs vod fagt | vus vout allen farben des harus. (Folium $344^{b}$ sub finem pag.: Ol Hyenach volget das funllt vud das letzt teyl difs buchs. vnd | ilt ein regilter bejend zeuituden von allen kranchesten der

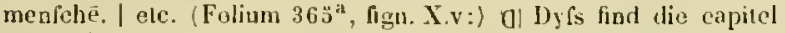
der hrei | ter nach ordnung des alphabets. (Folium $369^{\text {it: }}$ ) al IIye hat ein end der herbarius in der keyferlieben ftatt Augfp/urg Gedruekt vond vollendet an I montag neeht vor Bartholo- | mei nach Critti gepurt Il. CCcc | Jxxxy. folio. 369 foll., ic. xylogr. i. t. (Aut. Sorg.) Bibl. Goett., Bibl. St. Petr. Salisb. II uin Nr. 8919.

$11886^{*}$

Orus fanitatis. anli teutfelo. Ein Garten der GeIlanufon fehoulperger inder Keyferlichen Stalt zu Lugfpurg an der mittwochen nacl dem weyffen luntag. Anno. MI.CCCC vnd in dem Lxixyj. jare. folio. ic. xylogr. i. t. IJuin Nr. 8950

$11887^{\circ}$ (Foliun $f^{a}$ ) vacat. (Folium $f^{b}$;) icon $x y$ logr. (Folium $2^{a}$, lign. a ij:) ()Fft (sic) vad vil hab | ich bey nir felhs | betracht die wī $\mid$ derfamen werck $\mid$ des fehoffers $\delta \mid$ naturen. wye er | etc. In fequentibus Jegitur: - ol V̄n mene | difes buch zu latein Ortus fanitatis auff teutfeh. Fan garten $\precsim$ I gefundtheit In wolchem gartē | man furdet .cccc. vod .xxxy. hreü|ter. etc. (FoJiun $3^{\text {li }}$ ) vacat. (Folium $4^{\text {id }}$, lign. a.diij:) incipit opus ipsum. Expl. fol. $230^{\text {b }}$ col. 2. lin. 41: 1atis. (Folium $231^{\text {az }}$, fign. F.j:) Difz ift das dritteil | difss buchs vod ift ein regifter | zu fibden breuter die do laxieré | daz it itulgenge brimen. elc. (Foliun $232^{\mathrm{b}}$ post icon. xylogr.:) Dytz itt das vierde / teil difss buchs vind laget rns | von allen farben des harms. (Foljum $235^{\mathrm{b}}$ sub finem col, 1: hie nach volget dan (sic) | fünlite teil rnd das leczit difss / buchs. vurd it ein reuilter he- | hende zu finden von allen bran | ghheiten etc.

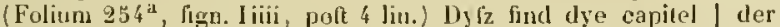
kreüter nach ordenung des $\mid$ alphabets. (Folium $257^{\text {h }}$ ) Ol Gedruckt rnd volendet difer | Herbarius durch IJannfen fch-lonfperser in der keferylichen (sie) | Itatl zu $\mathrm{Aug}$ flourg an fant Bo | nifacius tag Anno. M. CCCC. vil / in dem .Jxxxvj. jare. folio. 257 foll. 42 Jim. binis col., ie. xylogr. i. 1. Ilain Nir. 8951.

(Folium $1^{\text {a }}$ ) vacal. (Folium $4^{\text {th }}$ ) icon. xylogr.

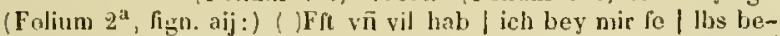
trachtet | die wundersamnen | werek des fehöp(Ters der naturen| etc. In sequentilıus legitur: - al Vind nennen / difes buch zu Intein. Ortus lanila / tis. autr teutfeh. Ain garten der ge / funllait. In weliche garten man / findet. cccc. Ynd xxxy. kreuter, etc, (Fo-

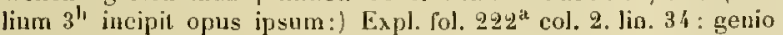
fantatis. (Folium $222^{\mathrm{h}}$ :) vacat. (Foliun $223^{\mathrm{a}}$, figa. $\mathrm{Fj}$ :) Difz ift das dritteil difz | buchs, vn in ain reuiter zefinden / hreuter die do Jaxiren das ilt itul | genge bringen. elc. (Folium 224a col. 2:) Difz ift das vierde teil | difs brichs. vnd fanget vos von al- | len farheu des barms. Icon xylogr. (Folium $226^{\text {h }}$ sub finem col. 2 :) Hie nacl vollget das | funffteil vnd das lelft difs buchs. I vol ift ain regilter behent zefinden I von allen kranchheiten of menfelez | etc. (Folium $243^{\text {b }}$ col. 2 . lin. 9 seq. :) Dilz lyud dio eapitel / der hreutter nach ordungo des al- | phabetes. (Folium 247":) Gelruckt rnd vollendet feligklichen diler | Herbarius, Durel Couraden Dinckmut zu | Ulm. Am famitag vor Judica. Als man zalt | nach Chrift vnulers herren geburt Taufent | vierhundert vul fibenundachtzig Jare. | Gott fey lob. folio. 247 foll., 48 Jin. binis col., ic. xylogr. i. t. Bibl. St. Gall. Jlain Nr. 8952.

11889

- (Folium $1^{a}$ tit.:) llerbarius zu teut $\mid$ feh und von aller | handt kreateren. (Folium $2^{\text {ia }}$ :) Aron an den .xvj. capitel etc. (Folium $4^{\text {b }}$ :) g' Eyn ende trat difes reqifter. (Folium $5^{\text {a }}$ : vacat.) (Folium $5^{\mathbf{b}}$ :) icon $x y \log r$. (Folium $6^{\mathrm{a}}$, fign. a.ji:) (1)Ch lab oft vad vil bey | mir felbs be | trachtet die | wundfamē | wercke des | fchopfers $\delta$ | naturē. etc. In sequentibus Jegitur: al Vod nemen difes bucl | zu latein. Ortus fanitatis. aufl' | teutfch. Ein garten der gefundt- | heit. In wolehē garten man fin | det vierhuntert vad .xxxy. hreü- | ter. etc. (Folium $7^{b}$ :) vacat. (Folium $8^{\mathbf{a}}$ :) incipit opus ipsum. Expl. fol. $234^{\mathrm{b}}$ col. 2. lin. 37 : nitalis. (Folium $235^{\mathrm{i}}$, fign. F.j :) Difes ift das dritteyl | difes Juchs, vnd ilt ein regitter | zu finden hreuter die do laxieren / dz ift itulgaing bringen eft. (Folium $236^{\text {b) }}$ col. I post iconem xylogr. :) Ilifes ilt das vierde | teyl difes buchs. rud faget vus / von allen farlsen des harms. (Folium $239^{\text {b }}$ sub tinem col. I: Ilyenach volget das funllt teyl ynal das leczto diles | buchs. vri ift ein regifter behend | zu linden ron allen kranck-

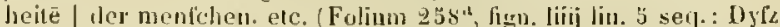
find dye capital | der kreutter nach ordnunge des | alphabets. Folium $261^{15}$ : a! Gedrucht and volentet dycer / heebarius durch Jamnfen fchön | fperger in der lieyferlichen italt | zu Augfpurg an montag vor | lant Thomas tag. Aunn. Ll.ccec | vad in dem. lsxrvitj. jare. folio. 261 foll. 42 lin, binis col., ic. xylogr. i. t. Ilain Ni. 8953.

$11890^{*}-$ (Folium $1^{\text {a }}$ tit. Jitt. nissal.:) Herbarius zu teüt|fche vod von afler l haudt kreuteren. (Folium $2^{\text {at }}$ ) Aron an dem . xv J capitol | etc. (Folium 4" col. 2: G' Ein encle hat difes regifier. (Folium 5:) vacat. (Folium $6^{i}$, fign aij:) (Li)ll vad off / habe ich bey | mir lelbs be / trachtet die | winderfomē / wercke des | fehöpfers $\mathcal{f}$ | naturê. wie | ete. In sequentibus Jegilur: - ol Vod nennen difes buch | zu Jatein. Ortus fanitatis. aulf | teutfeb. Ein garten der gefundt- | heyt. In wolichem garten man | tindet vierlsundert vit funfr vad / dreillig kreuter, etc. (Folium $7^{b}$ :) icon xylogr. (Folinm 8b:) incipit opus ipsum. Expl. fol. $234^{b}$. col. 2 lin. 40 : de ingenio lanitatis. (Folimm $235^{\mathrm{a}}$, lien. F.j:) Difes if das dritteyl difes buchs vnd ift ein regifter | zu Guden krentter die do laxier $\mid$ daz ilt ltulgeng bringen etc. (Folim $236^{\mathrm{h}}$ post icon $x y$ lngr.:) Dyles ift das vicrli / teyl drfes buches vad fagt vns / von allen farben des harmes. (Folium $239^{\text {h }}$ sub finem col. i:) llie nach rolget das | funlit teyl vond das letzl dy fes | buches. vnnd it ein regifter be / hende zu funden von alien kran-|ckheyten etc.

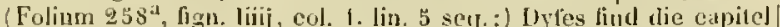
aler kreutter nach ordnunge des alphahets. (Folium 261 ${ }^{b}$ ) o, Gedruckt ynd faligkich vol- lendet dyfer Herbarius durch|Hamien Schönfperger in der / hey lerlichen itat Augfourg an I dem alfiermontag nach Tybur-cij. Nach Crilti geburt taujent | vierhundert. vnad in dem clreu- | und neänezigilten jaro. folio. 261 foll. 42 lin. biois col., ic. xylogr. i. t. Hain Nr. 8954 .

("Vidi exempl., cujus 20 foll. prina fic differum. Folim 1-i et folt. 13-20 ex ell. a th96 sumpta. Folun $5-12$ vero diversac im-

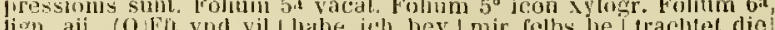
lign. atij. (O Fh vod vil | labe ith bey mir felhs be trachlet dio "undersamp / weerche (sic) des / ete. Poliun gu viteit. Folium $12^{6}$ ult, lin.: lich waller. machel woh harmen. lis ed. suptir descr. pun-
clum post w affer deest." Hain.)

[189. * (Folium $1^{\text {it }}$ tit. Jitt. missal.:) Herbarius zu teutch vund yon allerbaudt / kreäteren. (Foliun $2^{a}$ ) Aron an dem xvj. capitel. (Folium $4^{b}$ col. 2:) ol Ein ende hat difes regifter. (Folium $5:$ ) vacat. (Folium $6^{\text {i }}$, fign. aij :) (V)Ji vind off / habo ich bey / mir felbs be | trachtet dye | wüderlame | werche des | fehopfers $\delta$ | naturē. In fequeutibus legitur: Vin/uenē dy lios buch zu Jatein. Ortus fantatis. aull teulfch. Ein garte / der gofundtheyt. In wölichêe gar | ten man findet vier luudert (sic) vnd | funtfunddreilfig kretr-

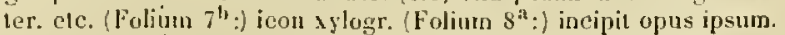

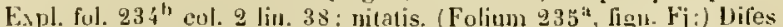
if daz dritteil di | hes buchs vin ilt ein regitter zu fon | den kreutter die do laxieren daz ift / itulgeng bringen. etc. (Folium $236^{\mathrm{th}}$ post icon aylogr.:) Dytes ift das vieril- / teil dyfes buchs vad fogt vus $\checkmark \overline{0}$ | allen farben des harmes. (Folium $239^{\mathrm{h}}$ sub finem col. 1:) llie - nach volget das. I funillt teil vnd dz letr dyfes buch- es vod if ein regifter behendo zu- | finden vou allen hranchhejtè $\delta$ mé | cte. (Folium $258^{\mathrm{a}}$, figm. liiij, lin. 4 seq.) Dyfes find die eapitel / Der Lreuter nach ordunng des al-iphabets. (Folium $261^{\text {h }}$ :) ol Ged/rucht vad faligklich volen | det dyfer Ilerbarius durch Ilann | len Schonfperger in der Keyfer I, lichen ftatt Augfpurg an after- I montag vor vafer's herré aullart | Nach Crifti geturt taufent vier-|hundert. vnd in de fechfs vndneun | zziglten jare. fulio. 26 | foll. 39 lin. binis col. ic. xylogr. i. t. Bibl. St. Gall. Hain Nr. $\$ 955$.

$11892^{*}-$ Ilerbarius zu tenfch. In fine: Gedrucht rnd relighlich volendt diler llerbarius durch Hanfen Schönfperger in der heiferlichen hat Augfuurg am montag nach vnfers herrn Hymelfart 


\section{HORTUS SANITATIS}

nach Chulti gepurt taufentvierhundert rnd in dem neun vnd neunzigilten Jare. folio. ic, xylogr. Hain Nir. 8956.

$11893^{*}$ Augsburg, Schonfperger. 1502. folio, Bibl. Dresd.

$1489 \%$; Getruch und flyliylich belehen dureh Joannem Prufs, Buchtrucher zu Thiergarten, Burger zu Strafslourg. Geendet nll Sant Jolamis lenthauptungstage. 1507. Solio. Bibl. Dresd.

$11893^{\circ}-$ Sirassburg 1509. folio. Bibl. Dresd., Goett.

$11890^{\circ}$ Strasshurg, durch Renatum Bech, 1515. folio. Bibl. univ. Lips

$118917^{*}$ In diefem Buch der Ilewbri: aler líreuterluch: yenannt der Gart der Gefuntleit: mit merern Figuren und Regiliern. Getuckt und flofiglichen solendet (Strasslurer) durch Renatums Bech. 1524. 4. 160 foll., ap\}., ind., ic. xylogr. i. 1. Bibl. Schlechtend

$11898^{\circ}-$ Strassburg 1524. folio. Bibl. Goett.

$11899^{*}-$ Strussburg 152S. folio. Bibl. Goett.

$11400^{\circ} \longrightarrow$ Das Kreuterbuch oder Ifordarius. Das Buch von illen lirrutern. Wurtzeln und andern Dingen, wie mans bruelien loll zu Geliudheit der Menfehen. Yon neuwern corrigirt und gelielfert. Item, wie man verfolun foll die Gradus. Strassburg, Balthasar lieck. 1530. folio. 162 foll., ind., ic. xylogr. i. t.

$11901^{\circ}$ hreutterbuch von allem Erdtgrwähs, anfenglieh Ion Dr. Johan Cuba zusamenlsracht, jetz widerum new corrigirt, und auss den hestherumptsien derztell, auch tiglicher erfarnuss, gemeluri. Mit warer Ahconterfeitung aller kreuter. Distillirbuch Mierommi Bruunschereg von aller hrouter aussgebreinten Wassern, hiemit fuglich ingeleibt. D. Eucharius Rhodion, Stattartzt zu Franckfurt am Meyn. (Getruckt zu Franckfurt am Meyn, hei Christian Egenolff, volendet uf dea 26 tan Mlertzens. Naclı der geburt Christi unsers Selimmachers MDXXXIII jare. Solio min. (8) foll., CCXIJ p. (4) foll., ie. xylogr. i. t. - "Frankfurt a/M., bei Christian Ëgenolph. 1540. folio. (24), CCCCIII, (5) p., ic. xylog! i. 1. - ${ }^{*}$ Frankfurt a/M. bei Cluristian Eqenolph. 1550. folio. Bibl. Reg. Dresd.

Editiones posterines al) Adam Lonilzer, Peler Iffenboch ol Bolthasar Ehrhart mulutac et editae supra Nr. 6261 recensentur. frusius de hoe rpere tractatur in Bolanische \%eitung 18'tb. p. 785790 : a Nejster Johonn lionnecte von Caub. Fon Georg Angust Prituel. et in Janus, von Henschel. 18:7. p. 91-97: a Noch Finges nber den

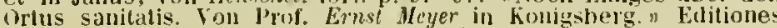
variae toplime describuntur in Trew Librorum botanicorum cala $\log 0.1$
Editiones in idiomate Saxoniate inferioris

$11902^{\circ}$ Hur hellet an de luatighe unde (ge?) nochlighr Gaerde der suntheit. (Ineipit:) Aken unde vele lieble ih by my sulven overdachit de wum I derlihe wurke des scliepuers der nature. wo he in deme an beginne den hëmel helft gheschapen. uti ghetziret mil selıonen luehrende sternè. (In line:) Hỹr endighet sik ditt boek der hrude. der eddelen stem unde dwatere der unyseljē ghenomet (de glurnochlihe gharde d'suntheit) de leetheerto d' mernheit begravē unde verborghen ghewest is. umle nu den mynschen to nutte gheapenbaret unde in dat licht ghebrocht (unde ghedruchet is doreh dat beverel Steffuni Arudes inwaner d'heiserliken stat Lubeck na dor horth unses heren IICCCCXCII. Des got) mit alleme lienelselıen heere glielaret unde gheerel sy nu unde to ewighen tiderı. gr. 4. Bibl Reip. Paris, Blbl. univ, Goett.

Sunt 688 capita, quorum 1622 cun totidem iconibus aqunt do plantis. Icones: Artemisia-Zuearum.

11903. - Dit is de genochlike Garde der funtheyt. to latine Ortulus fanitatis edder Jlerbarius genomet, dar me yne vindet alle arth, nature unde eghenfchop der krudere unde der eddelen ftene ctc. Lubeck in faligen Steffen Arndes nagelaten Drucherye. 1520. folio. Bibl. Goett.

Yit signatur aber obne Pasinirune, die Colımnent nicht ge-

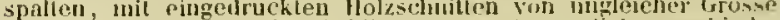
vuwohl dem Tes als den Abbildumen nach comelivh serschieden von dem lateinkeluen Orfus santatis.)

\section{Edilio hollandica:}

119014 Dé mrotè herbarius net al syrn figurè, die Ortu sanitatis ghenaent is. ete. (in calee:) Defen boek is gheprint in die virmeerde Coopstadt van Antwerpen bi mi Claes de Grase. iut jaer ons heeren 1514 den XYll dacla van Junius. 4 ic. $x$ lo i. L. Bibl. Reg. Brux.

(Ellitio alia hollandica sine loco anni $10 ; 32$ est in biblintherit universitatis Gocttingensis.)

\section{Edilio gallica:}

11905

Ortus sanitatis, translaté de latin en francoys. Paris, Verard. s. a. folio. $275,(17), 270,(27)$ foll., ic. sylogr. i. 1. Bibl. Goett. Ilain Nr. 8958

$11906^{\circ}$

Le jardin de santé translate de latin en francoys nouvellement imprime a Paris. (Philippe le noir. 1539.) folin. 246 foll., ind., ie. rud. $\mathbf{x} \log$ r. i. t. Bibl. Palat. Viodob. 


\title{
LITERATURAE BOTANICAE
}

\author{
THESAURI
}

\section{PARS SYSTEMATICA.}





\section{LITERATURAE BOTANICAE THESAURI PARS SYSTEMATICA.}

\section{Historia botanices.}

Slegelius, Pregramma ad lortenses lectiones. Jenae 1639. 4.

Hotton, Sermo quo rei herbariae listorid et fata adumbrantur. Lugd. Bat. 1695. 4 .

Goetz, De eruditis hortorum cultoribus. Lubeccae 1706.4. - Lipsiae 1726.4. Helvigius, De ortu et progressu scientiae botanicae. Gryphiswaldiae 1707.4.

Erndl, De Flora japanica, codice bilhiolhecae berolinensis rarissino. Dresdae (1716.) 4

Lischwitz, Veterum de re herbaria diligentia. Lipsiae 179\%. 4

Monti, Dissertatio rei luesbariae historiam complectens. In ejus: I'lantarum varii indices. Benoniae 1724. 4.

Reusch, De Botanicis non Medicis. Ilelmstadii 1739.4

Fabregau, Dissertation sur l'origine et le progrès de la botanique. In ejus: Description etc. Paris 1740. 8. vol. Vl. p. 347-471.

Mohsen, De manuseriptis medicis inter codices bibliothecae berolinensis. Berolisi 1746-1747.4

Fabricius, Oratio de Gernanorun in rem herbariam meritis. Helmstadii 1751. 4

Linné, Incrementa botanices proxime praeterlapsi semisaeculi. Ilolmiae 1753. 4 .

Werner, De scriptoribus plantarum borussicarum. Custrini 1756. 4

fialm, Fala botanices in Finlandia. Aboae 1758. 4.

Linne, Refornatio botanices. Upsaliae 1762. 4

Leçons de botanique faites au jardin de Montpellier. (Avignun) 1762. 12. (Satyra in Imbertum, autoribus Cusson, Gouan et Commerson.)

Boehmer, De plantis in Cultorum memoriam nominatis. Wittebergae 1770.4 - Ed. nova continuata: Lipsiae 1799.8.

Additamenta ill. Leonis Comitis Henckel von Donnersmarck teguntur in Millin, Magazin encyclupedique, Paris 4810. tome IV, p. 27i-278 tome $\mathrm{V}, \mathrm{p} .46-73,2 \mathrm{il}-26^{\prime}$.

Milne, Institutes of botany. London 1771-1772. 4.

Koelpin, De cultura historiae naturalis in Pomerania. Stettini 1773. folio.

Gilibert, Indagatores naturae in Lithuania. Wiluae 1781. 8.

Kall, De duplici plantarum sexu Arabibus cognito. Hafuiae 1782-1783. folio.

Ducarel, Letter upon the early cultivation of botany in England. (Philos. Transact. LXIII. 79-88.)

Rottböll, An Urtelaereus tilstand i Dannemark. (Kiobenh. Selsk. Skr. X. $393-424,463-468$.)

Pulteney, Historical and biographical sketches of the progress of botany in England. London 1790.8. (germanice, gallice.)

Lidbeck, De plantis in Suecorum memorian uominatis. Lundae 1792. 4. Medicus, Geschichte der Botanik unsrer Zeiten. Mannheim 1793. 8.

Baldinger, Veber Literargeschichte der Botanik. Marburg 1794. 8.

Bondt, De utilitate laborum recentiorun in re botanica. Amsterlam 1794. 4.

Swartz, Tal om Naturalhistoriens uphef i Sverige. Stocklıeln 1794. 8.

Vrolik, Oratio de eo, yuod Ansstelodamenses ad rem botanicam contulerunt. Amstelodami 1797. 4.

Reinwardt, Oratio de ardore, quo botanices cultores in sua studia feruntur. llardervici 1804. 4.

Sickler, Allgemeine Geschichto der Obstkultur. 1: Von den Zeiten der Urwelt bis zu konstantin dem Grossen. Frankfurt a/M. 1802. 8.
Dicksan, De l'agriculture des anciens. Paris 1802.8.

Cambry, Notice sur l'agriculture des Celtes et des Germains. Paris 1806.8.

Sangiorgio, Delle epoche piu luminose della Lotanica. Milano 1807,8.

Fagerbory, De primordits betanices. Upsaliae 1807.4

Sprengel, hlisteria rei herbariae. Amstelodami 1807-1808. 8.

Millin, Extrait de Sprengel, L'histoire de la botanique. Paris 1809.8.

Paulet, Examen de la partie batanique de I'listojre de la médecine par Sprengel. Paris 1809. 8. - ib. 1815.8 .

Cuvier, Rapport historique sur les progres des sciences naturelles. Paris 1810.4 .

Mouton-Fontenille, Coup d'oeil sur la botanique. Lyon 1810.8

Wallroth, Geschichte des Obstes der Alten. Ilalle 1812. gr. 8.

Pollini, Discorso istorico sulla botanica. Verona 1812. 8.

Sprengel, De germanis rei herbariae patribus. Munchen 1813.4.

Ifulthem, Sur l'état ancien el moderne de l'agriculture et de botanique dans les Pays-Bas. Gand 1817. 8 .

Smith, A review of the moderne state of botany. (London 1817.) 4.

Schultes, Gruudriss einer Geschichte und Literatur der Botanik. IVien 1817.8.

Sprengel, Geschichte der Botanik. Altenburg und Leipzig 1817-1818. 8. Sternberg, Ablandlung uber die Pflanzenkumde in Rohmen. Prag 1818. 8 . Arnold, De monmentis bist. nat. Poloniae literariis. Varsaviae 1818.8.

Cuvier, Recueil des éloges historiques. Paris 1819-1827.8.

Wikström, Öfversigl af betaniska arbeten och upptackler. (Års-herattelse etc.) 1821-1844. Stockholm 1822-1849.8.

Beilschmied, Jahresberichte der Kgl. Schwedischen Ahadenie der Wissenschaften uber die Fortselaritte der Botanik. Breslau 1834--1847, 8 .

Aubert du Petit-Thouars, La physiologie végétale et le prix Monthion Paris 4822.8

Reinwardt, Oratio de augmentis historiae naturalis ex Indiae investigatione. llardervici 1823 . 4.

Hoffmann, Oratio de fatis et pregressibus rei herbariae imprimis in inplerio rutheno. Mosquae 1824. 4.

Adamski, Prodromus historiae rei herbariae in Polonia. Vratislaviae 1825. 8 .

(Rudolphi) Index munismatum in medicorum vel physicorum memeriam percussorum. Berolini 1825. 8.

Vallot, llistoire de la botanique en Bourgogue. Dijon 1S28. 8 .

Trinius, Ueber den gegenwärtigen wissenschaftlichen Standpunkı der Naturforschung. St. Petersburg 1828. gr. 8.

De Candolle, De l'état actuel de la botanique générale. (Revue française 1829. vol. VIII, p. $33-56$.)

Hornemann, Om de tydske Naturferskeres Forsamling i Berlin. Kiolnhhavn 1829. 8.

Adress of Earl Stanhope, President of the medico-botanical society. London 1829. 8. - ib. 1830.8.

Johnson, History of english gardening. London 1329. 8.

Felton, On the portraits of english authors of gardening. London 1830.8 .

Haberle, Rei berbariae hungaricae et transsylvanicae historia. Budae 1830.8.

De Candolle, Histoire de la botanique genevoise. Geneve 1830. 4.

Progrès de la botanique en 1832 . Gen̨̧ve 1833. 8 .

Seligmann, Ueber drei böchst seltne persischo Handschriften. Wien 1833. 8 
Myrin, Historia rei herbariae in Suecia. Upsala 1833. 4.

Bongard, Esquisse historique des travaux sur la botanique en liussie Petersbourg 1834.4 .

Link, De antiquitatibus botanicis rostochicosibus. Berolini 1835. 4.

Desjardins et Bouton, Rapports annuels (VI-XIII) sur les travaux de la société l'hist. nat. de lile Slaurice. Port Louis 1835-1843.4.

Meyen, Jahresbericlate uber physiologische Botanik in den Jahren 1836 -1839 . Berlin $1837-1840.8$. (anglice.)

Link, Jahresberichte uber die Arbeiten fur physiologisclıe Botanik in den Jahren 1840-1845. Berlin 1842-1846.8

Cesati, Sugli studii fiso-fisiologiei degli Italiani etc. Nilano 1836. \&

Henschel, Jatrologiae Silesiae specimen. Vratislaviae 1837.4.

Zur Geschichte der botanischen Gárten und der Botanik in Schlesien im 15. und 16. Jahrhundert. Berlin 1837.8.

Trautvetter, Grundriss einer Geschichte Jler Botanik Russlands. St Petersburg 1837.8.

Morren, Les siecles et les legumes. Jiège 1\$37.8

Schneider, Descriptio codicis vetustissimi. Iratislaviae 1839.4

The botanical society of Edinburgh. Ediuburgh 1840.8 .

Wuestenfeld, Geschichte der arabischen Aerzte und Naturforseher. frottingen 1840.8 .

Cuvier, Histoire des sciences naturelles. Paris $1841-1 \leqslant 43.8$.

Grisebach, Bericht uber die Leistungen in der Pflanzengeographie wahremr der Jahre 1840-1846. Berlin 1841-1849. S.

Iriese, Protrepticus ad commilitones. (Historia rei herbariae.) Amstelodami 1841.8.

Parlatore, Come possa considerarsi la botanica etc. Firenze 1842.8 . - Sullo spirito delle scienzi maturali nel secolo passato e presente. Firenze 1844.8.

Philippar, Catalogue methodique etc. Versailles 1843. gr. 8 .

Colmerro, Ensayo histórico sobre los progiesos de la hotanica. Barcelona 1842. 8.

Schultz, Jahresbericbte $\left(I-\mathrm{N}^{\circ}\right)$ der Pollichia. Landau 1843-1846. \&

(Moretti) Difesa e illustrazione delle opere botaniche di Pietro Andrea Muttioli. (Milano 1844.) 8.

Meyer, Die Entwicklung der Botanik in ilıren Hauptmomenten. Konigsberg 1844. 8 .

Borean, Compte-rendu des travaux de la section botanique a Milan en 1844 Angers 1846.8 .

Walker, Die Obstlehre der Griechen und Romer. Reutlingen 1845. 8.

Schreyder, Ueber den Wein- und Obstbau der alten Romer. Rastatt 1846. gr. 8 .

H'uestemann, Leber die hunstgártnerei bei den alten Römern. (Gotha) 1846. 8 .

Sachse, Verzeichniss von Bildnissen von Aerzten und Naturforscherı. Schwerin 1847.8

\section{Vitac botanicorum.}

Eloge de Michel Adanson. (Cuvicr, Recueil.) Paris 1819.8

Nemoria Bernhardi Siegfriedi Albini. (Comment. med. lips. vol. XVIl. p. $543-553$.

Bunina, Reflexions sur les ouvrages et la vie de Charles Allioni. Turin s. a, 8 .

Vita, obitus et scripta Caroli Alston. (Comm, med. lips, vol. XI. p. 556-558.)

Gallisch, De Aristotele rei uaturalis scriptore. Lipsiae 1776. 4

Henschel, Commentatio de Aristotele hotanico philozopho. Vratislaviae 1824. 4 .

Flourens, Éloge historique d'Aubert Aubert Du Petit-Thouars. Paris 1845.4 .

Schubert, Leben und Reisen Aucher-Eloy's. In ejus a Riographien n. Erlangen 1847. 8. vol. 11. 13. 134-155.

De Candolle, Notice nécrologique sur Balbis. (Bib] unix. de Genive |s3। vol. ALV1. $214-217$.)

Colla, Elogio del Pror. Giovami Battista Balbis. (Torino 1832.) 4.
Jurlington, Biographical menoir of William Baldwin. It lictiquiar Malelwinianae. Philadelplia 1843. 8 .

Innean, A short account of the life of the right lenusuralule sil Josiphl Banks. Edinburgh 1821.8.

Eloge de Sir Joseph Banks. (Cueirr, kurueil., Paris $1 \$ \geq خ$. \&

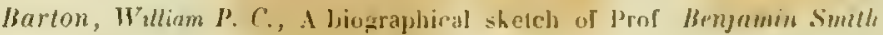

Barton. Philatelplia 1816.8

De Silvestre, Notice biographinue sur Baudrillart. Paris $183 \mathrm{z}$.

Imoreux, Recherches sur l'icre licher de Belleval. Irignon 17\$6. A

llorthes, Eloge historique de Pierre Richer de Belleval. Junlupllier 1788.4

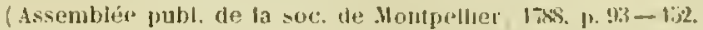

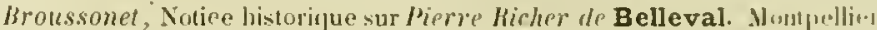
1838.8

Nemoria Caroli Augusti de Bergen. (Coumemt. med. lips. vol. IX pr 5 s. -560 .

Oedmann, Aminuelse-Tal ofver Clas Bjerkander. Sturhholm livs :

Parlatore, Breve cenno sulla vita e sulle npere fol Harone Antomin Bi. vona-Bernardi. Palermo 1837. 8

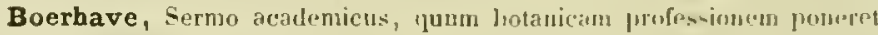
Lugd. Bat. 1729. 4.

Schultens, Oratio in memoriam Ilermanni Boerhavii. Lumsl. Iatav 1738. 4.

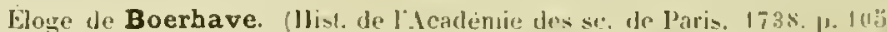
-116 .)

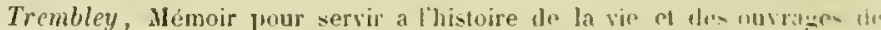
Charles Bonnet. Berue 1795. 8 .

Eirige Lebensumstaude von dem seligen Bonnet. (I rigt s . Magrazun. IS Br. 2. Stuck. p. $180-18 \%$ :

Roehling, Borkhausen's kingen nach dem schunsten Zirle te . Mannes Frankfurt a/JI. 1808.8

Poitean, Notice sur Louis Augustin Guillaume Bosc. Paris 1828. 4

De Silvestre, Notice hiographique sur Bosc. Paris 1829. \&.

Martius, Akademische Denkrede auf Fran: Gabriel, firafme mon Bray. Regensburg 1835.8.

Vita Jacobi Breynii. In ejus "Prodromi „etc. Gedani 1739.4. p. 5-i

Vila Joannis Phulippi Breynii. In Reyger, Tentamen Florae wedaneusio. Dantisci 1766. 8. vol. II. p. 1-24.

Vita Magni von Bromell. (Act. lit. et sc. Sueciae. 1736. p. 1!19-211.

De Candolle, Éloge listorique de Mr. Auguste Broussonet. Montpelliek 1809.4 .

Eloge de Picrve Maric Auguste Broussonet. (Cumer, Recuril, Jari1819.8

Eloge de M. le Comte de Buffon. Wlist, de lacad. des se. de l'aris. 17s p. $50-84$.)

Fuchs, Andreas Caesalpinus, lle cujum viri ingenio, dnetrina at virtule Narburgi 1798. 4

Michault, Notices sur Caesalpin. (Niceron, Memoiren. wol. XiJII.

Jomard, Notice sur la vie et les voyages de Rene Caillié. Parin 1.39. \&.

Preu, Narratio succincta de visa et meritis Joachimi Camerarii. Altrorlii 1782. 4 .

Nemoria Camerariana. (Act. acarl. nat. cur. rol. J. app). p. 163

Gossin, Notice sur llenri de Cassini, Pair de France. Paris Is32. s.

Eloge de Franşois Cels. (Curier, Recueil.) Paris IS19. \&.

Buck, Aminnelsetal of ver Olaf Celsius. Stochholm 1758. \&

Vita Olavi Celsii. (Nov. Act. soc. ups. vol. Il. p. 295-308.)

De Candolle, Notice de Jean Fréderic de Chaillet. (Neufchatel I\$39. 4.

Cap, Mogse Charas. Éloge. Paris $1 \$ 40.8$

The life and remains of the lare Sir Edward Daniel Clarke. Inndon 1824.4 .

(Fothergill) Some account of the late Peter Collinson. London 1750. 4

Nemoria Petri Collinson. (Comment. med. lips. vol. XVl. p. $351-353$

Fabii Columnae vita, Jano Planco autore. In ejus "Phỵtobasanos. Florentiae $1744.4 . \mathrm{p} 1-\mathrm{X}$ 
Éloge de Commerson, par de la Lande. (Journal de physique, Y. S9120. VIII. $357-363$.

1he Silvestre, Notice bio graphique sur le Baron Coquebert de Montbret. Paris 1832. 8.

Lahler, Vita Euricii Cordi exposita. Rintelii 1744. 4.

llieronymi Schreiberi Norimbergensis Episiola de morbo et oljitu Valerii Cordi; ef. Thes. lit. bot. no. 1983.

Casparis Crucigeri Elegia in obitum Valerii Cordi; cf. Thes. lit. bat. no. 1983.

Morren, Notice sur la vie of les travaux de Richard Courtois. Bruxelles 1838.12.

Sprat, De vita et serijtis Abrahami Couleii. Impr. cum Covley, Poemata latina. Loudini 4668.12.

Monımentorum Crellii Sylloge. llelmstadii 1747. folio.

llauks, Vita 11. B. Cromii. Impr. cum Croom, Catalogue of plants of New Bern. New York 1837.8.

De Sillestre, Notice biographique sur le Marquis de Cubières. Pariz 1829. 8 .

Thornton, Shetels of the life and writings of the late Mr. Ililliam Curtis. Impr. eum Curtis, Lectures on botany. Loudon 1805. 8.

We Candolle, Hort de Cuvier. (Bibl. univ, de Genève 1832. vol. Xitx. $442-448$.

Wichault, La vie de Daléchamp, in Joly, Eloges de quelques nuteurs français.

Seward, Mlenoirs of the life of Dr. Erasmus Darwin. London Iso'. S

Eloge de Louis Jean Marie Daubenton. (Cuvier, Recueil.) Paris 1819.8

Flourens, Eloge listorigue d'Augustin l'yramus De Candolle. Paris 1842.4.

Dunal, Éloge historique de A. P. De Candolle. Montpellier 1S42. 4

Morren, Notice sur la vie el les travaux d'Augusle l'yrane De Candolle. Bruxelles 1843. 12.

Flourens, Ėloge historique de Jaerues Julien De la Billardière. Paris 1837. 4 .

Vorstius, Oratio funebris in obitum Caroli Clusii (De l'Ėcluse) lirebatis. (Antwerpiae) 1611.4

Senebier, Mémoire historique sur la vie et les ecrits de Horace Bénedict De Saussure. Genè e (1801.) s.

Eloge de De Saussure. (Cuvier, Recueil.) Paris 1819. 8.

Menoria Francisci Boissierii De Sauvages. (Comm. med. lips. IY $554-560$.

De Candolle, Notice listoripue sur la vie el les travaux de Desfontaines. (Geneve 1834.) 8.

Flourens, Eloge historique le liene' Louiche Desfontaines. Paris 1837.4

Ritler von Riltersberg, Abbé Joseph Dobrowsky. Prag 1829. gr.8.

Éloge de Denis Dodart. (Ilistoire do l'acadl. des se. de Paris. 1707. p 189 - 192.)

Meerbeeck, Recherches sur la vie et les ouvrages de Remberl Dodoens. Malines 1841.8

Mouton-Fontenille, Eloge de Joseph Dombey. Bourg (1813.) 12.

Poitevin, Notice sur la vie et les nuvrages de Ml. Draparnaud. Monlpellier (1805.) 8.

Éloge de Du Hamel de Monteau. (Cuvier, Recueil.) Paris 1827. 8.

Bélanger, Notice nécrologique sur Auguste Duvau. Paris 1832. 8 .

(iay, Nolice sur Philippe Antoine Christophe Endress. Paris 1532.8.

Jussieu, Éloge de Fagon. Paris 1718. 4.

Éloge de Auguste Denis Fougeroux de Bondaroy. (Hist. de l'Acarl. des se. de l'aris. $17 \$ 9$. p. 39-44.)

Palisot-Beaurais, Eloge bistorique de Antoine Frangois Fourcroy. Paris 1 i 11.4

Éloge de Fourcroy. (Cuvier, Recueil.) Paris 1819.8

Vita Johanuis Frank. In Walmstedl "Magnos" ete. Upsaliae 1829. folin. llizler, Oratio de vita et morle Leonharli Fuchsii. Tubingae 1566. \&

belpuze, Ueber das L,eben und die Werke Gaertner's und Hedwig's. Stutgart 1805.8
Gesner, De liluris a se editis epistala ad Hilliam Turner. Tigari 1562. 4 Simler, Vita Conradi Gesneri. Tiguri 1566. s.

Vita Comradi Gesner. In Operum parte 1. ed. Schmiedel. p. I-Xl

Ilanharl, Conrad Gesner. Winterthur 1824. S.

Wolf, Johannes Gessner nach seinem Leben und Wirken. Zurich 1846. 4. Vita Comitis Franeisci Ginanni. (Comment. med. lips. Xlll. $334-353$ Nov. act. acad. nat. cur. 1om. IV. app. 297-298.?

Willdenow et Usteri, Meitrage zur lBographie des Johann Goulich Gle. ditsch. Zurich 1790.8.

Nachricht von den Lebensumatanden des llerrn $J$. G. Gleditsch. (Beab. der Berl. naturf. Frounde, 111. $301-314$. )

Ausz.uy aus der Lebensbeschreibung des Baron llilhelm friedrich von Gleichen, geuannt Russworm. (Scluriften der Berl. uaturf. Freumle. V. $491-496$.)

Vita Johannis Cieorgii Gmelin, in ejus "Sermo academicus" "te. Tubingae 1749. \&. p. $1-39$.

Memoria Johannis Georgii Gmelin. Comment. med. lips. JN. 729- 33 s.

Imoreux, Notice historique sur Antoine Gouan, Paris 1822. s.

Memoria Johannis Friederici Gronovii. (Comment. mecl. lips. XI. p. 721 -726$.

Kurze Lebensgesclichte des llerru ron Gueldenstaedt. (Echriften del Berl. naturf. Freunde, 11. $402-404$.)

Eloge de Jean Etienne Guettard. (Ilist. de l'acall des sc. de Par's. 1786 13. $47-69$.

Pisanski, Nachricht von den gelchrten Kunigsberger Uelchior Guilan. din. Kunigsberg 1785 . 4.

Lasègue, Notice sur la vie et les travaux de Antoine Guillemin. 1'aris: 1842.8.

Tomabene, Biografia de] Padre Emil. Guttadauro. Catania 1839. \$.

Cluge de Stephen Eales. (llist. de l'acad. des se. de Paris. 1762. p. 213 $-230 . j$

Zimmerinam, das Leben des Ilerrn ron Haller. Zurich 1753. s.

Raldinger, Oralio in laudes unrntorum Alberli de Haller. Cinettingat 1778.4 .

Senebier, Eloge historique de Albert de Baller. Geneve 1778. S.

Heyne, Alberti de Haller Elogium. (Nov. comm. sue. gotling. VIII. apl. p. $9-20$.

Eloge de Baller. (Illist. de l'acad. des sc. de Paris, 1777. P. 127-154.)

Ėloge de Haller. (Hist. de la soc. royale de medecine, 1776. 1. $59-93$.

Biographie de Albert de Haller. Paris 1845. 8 .

Baeck, Aminnelsetal ofver Fredric Hasselquist. Stochtoln 1758. s.

Marquis, Notice necrologique sur A. E. M. Havet. Paris 1823. \&.

Menoria Johamnis Ernesti Hebenstreit. (Nov, act. acad, nat. cur. tons. If. app. p. 437-452. - Comment. med. lips. V1. 791-735.)

Designatio librorum el dissertationun, quas annis $1708-1750$ edidil Loren: Heister. Helmstadii 1750.4

Leporin, Ausfuhdicher Bericht rom Lehen D, Laurentii Heisteri. Quedlinburg 1723. 4 .

llernsdorf, Memoria J. Laurentii Heisteri. Helmstadii 1758. \&.

Memoria Laurentii Heisteri. (Comment. med. lips. V1l. 724-741. Nov. act. acatl. nat. cur. tom. 11. apy. p. $453-506$.

Laulh, Vita Johamis Hermann. Argentorati 1802. \&

Bidloo, Oratio in Junere Pauli Hermanni dicta. Lugd. Jatax. 1693. 4.

11 allin, Minne al Pehr Hernquist. Shara 1818. S.

Short account of the live, nritings and character of the lite Sir John Bill. Edinburgh 1779. 8. $21 \mathrm{p}$.

Jfister, Vita Mathaei Billeri. In Hiller, Hierophyticon. Trajecti a/Rh. 1725. 4 .

Duncan, Account of the late Dr. John \#ope. Edinlurght 1789.8.

Testimonials in favour of Joseph Dalton Hooker. Ediuburgh 1843.8.

De Candolle, Notice sur Franrois Huber. (Bibl, unir. de Genère is 32 vol. XLLX. 187-207.)

Raimann, Rede zur Gedachtuissfeier fur Nicolaus Joseph Freiherrn ron Jacquin. Wien 1818. 4. 
Fogel, Historia vitae et mortis Joachimi Jungij. Argentorati 4658.4 Guhrauer, De Joachimo Jungio commentatio. V́ratislaviae 1846.8. Eloge d'Antoine de Jussieu. (Ilist. de l'acad. des se. de Paris, 1758. p. $115-126$.)

Memoria Bernardi de Jussieu. (Hist. de l'acad. des sc. de Paris, 1777. p. 94-117. - Comment. med. lips. XXIll. p. 173-176.)

Elogo Je M. Jussieu, par le Preux. (Journal de physigue XV. 3-16.)

Brongniart, Notice historigue sur Antoine Laurent de Jussieu. Paris 1837. 8.

Flourens, Floge historique d'Antoine Laurent de Jussieu. Paris 1838.4. Odhelius, Aninnelse-Tal ofver Pehr Kalm. Stocklıolm 1780.8.

Morren, Notice sur J. Kickx. Paris 1832. 12.

Marlius, Denkrede auf Kurl Friedrich von KieJmeyer. (Nunchen 1845.) 4 .

Haliczliy, Memoria viri immortali laude digni e sepuleru in lucem revacata. (Paul Kitaibel.) Butae 1826.4.

Uendel, Lobrede auf Ilerrn Jakol Theodor Klein. Danzig 1759.4. (Neue Sammlung der naturf. Gesellschaft in Dauzig, I. 300-316.)

Nemoria Jacobi Theodori Kleinii. (Comm, med. lips. VIII. 36 I-376.)

Shetch of the life of Thomas Andrew Knight; in ejus "A selectionn etc. London 4841.8 .

Bolzano, Dr. Vincenz Julius ron Krombholz. Prag 1845.4.

Yannez y Girona, Elogio Jistorico de Mariano Lagasca y Segura. Madrid 1840.8.

Jamouroux, Justin. Nolice bingraphique sur Jean bincent F. Lamouroux. Paris 1829.8

Hartmamn, Exereitatio de Joanmis Langii studiis botanicis. Trajecti a/V. 1774. 4.

Totice sur Marc Antoine Louis Clarét de Latourrette. (1 ejus a Démonstrationsm. Lyon i796. S. vol. I. p. XLVIl-LVIll.)

Notice biographique el scientilique sur Jcan Baptiste Leblond. In ejus "Deseription de la Guyane française ". Paris 1825.8.

Vita Johannis Danielis Leers. In ejus aFlora herhornensi». Ed. II. Berolini 1789.8 .

Fleck, De Antonii Leeuwenhoeckii meritis. Lugd. Bat. 1843. 8.

Halbertsma, De Antonii Leeuwenhoeckii meritis. Daventriae 1843. 8.

Cap, Nicolas Lémery, chimiste. Floge. Rouen 1838. 8.

Eloge de Louis Guillaume Le Monnier. (Cuvier, Recucil.) Paris 1\$19. 8. Eitwas zur Lebensgeschichte Nathanael Golthied Leskens, von Loeper. (Leipz. Mlagazin, 1786. p. 504-520\%)

liloge de L'Héritier. (Cuier, Recueil.) Paris 1819. s.

(Guibourt) Notice sur Félix Lonis L'Herminier. Puris 1834. 8 .

(Linné) Orbis eruditi judicium de Caroli Linnaei scruptis. (Holmiae 1741.) 8

Bacck, Aminnelse-Tal ofver Carl von Linné. Stockliolm 1779. 8. (gallice.)

Pultency, A general view of the writings of Linnaeus. London 1781, S. - Ed. II: ib. 1805.4 (gattice.)

Bloge de Linnaeus. (1list. de la soc. royale de medecine, 1777-1778. p. 17-44.)

Eloge de Linné. (Ilist. de l'acad. des sc. de Paris, 1778. 66-8'. - Ass. publ. de la soc. de Montpellier, 1779. p. 100-116.)

Vita Caroli a Linné. (Nov. act. soc. ups. V. $335-344$.)

De vila el meritis Linnaei. (Gilibert, Fumlamenta, vol. III. p. Y-XXXII. Démonstratious élémentaires. Lyon 1796. II. ser. V. p. 3-21.)

Medin, Quid Linnaeo patri debeat medicina? Upsaliae 17\$4.4.

Saint-Amans, Ėloge de Charles von Linné. Agen 1791. 8.

Stoever, Leben des Ritlers Carl von Linné. Ilamburg 1799-1793. S. (anglice.)

Marquis, Eloge de Linné. Rouen 1817. 8.

Ifzelius, Egenhándiga anteckningar af Carl Linnaeus om sig sjelf. Stockholm 1823. 4 .

(germanice.)

Beckmann, Minnen af Jediga stunder. Stockholm 1824. 8.
Celelsration at flushing of the birtb-day of Linnaeus. New York 1824.8 Agarlh, Antiquitates Limnaeanae. Lundae 1826. Solio.

Vita Linnaei patris. In Walmstedt "Magnos» etc. Upsaliae 1829. folio.

Carolo Linnaeo statuam juventus academica upsaliensis decrevit. Lipsaliae 1829. 4.

Fée, Vie de Linné. Paris 1832.8. - (DC. in Bibl. univ. de Genève, 1832. vol. IJI. p. $133-149$; et anglice.)

Fuerurohr, Gedaclstnissrede zur Linnéischen Jubelfeier. (Regensburg 1835.) 8.

Fischer (von Waldheim), Fête séculaire de Charles de Linné. Moscou 1835. 8 .

Martius, Linné und der Zweifler. (Nunchen 1838.) 4.

- Kede zum Lintaeusfeste. (Regenshurg $18 \% 9)$.

Brignoli, Discorso per l'inaugurazione del busto di Carlo Linneo. Modena 1843.8.

Zeipel, Zwoi Musensohne und ein Spassiogel, oder Linneus, Artedi und Rudbeck. Berlin 1844.8. (suecice.)

Schulz von Schulzenheim, Grifte-tal öfrer Carl ron Linnè (Sonen). Ipsala 1784.8 . (germanice.

Vita Linnaej flii. In Walmstedl a llagnos » etc. Upsaliae 1829. folio.

Roffavier, Notice sur Madame Lortet. Lyon 1835. 8.

Memoir of John Claudius Loudon. In ejus a Self-instruction». London 1845. 8.

Nemoria Christiani Cotllieb Ludwig. (Comm. med. lips. XX. 153-188.)

Morton, A memoir of William Maclure Esi]. Philadelphia 1841. 8, i.. 1844.8 .

Boerner, De Aemilio Macro, ejusque rariore hodie opusculo de virtutilus herbarum. Lipsiae (1754.) 4.

Éloge de Pierre Magnol, par Gauteron. (Hist. de la soc. de Montpellier, I. $260-268$.)

Vila Marcelli Malpighi a sejpso scrijpla. In ejus "Operibus posthumis". Londini 1697. folio. p. 1-102.

Vie de Malpighi. (Journal de plysique, tom. I. p. 73-78.)

Festa, Malpighius. Sermo. Bononiae 1810.4.

Lebensgrschichte Andreas Sigismund Marggrafs, von Crell. (Creli's Annalen 1786. I. 181-192.)

Monti, De scriptis Comitis Aloysii Ferdinandi Marsilii. (Comment. inst. bonon. t. II. pars II. p. 378-388.

Martius, Eriunerungen aus meinem neunzigjahrigen Leben. Leipzig 1847.8.

Some account of John Martyn and his writings. London 1770.8.

Gorhum, Memoirs of John and of Thomas Martyn. London 1\$30. 8.

Vita Caroli llenrici Mertens. (Luethe, Voyage antour du monde, vol. III. p. $337-352$.)

Vriesc, Herinneringen aan Franz Julius Ferdinand Meyen. (Leiden 1840.) 8.

Cubières, Notice sur F. André Michaux. s. ì. 1807. 8.

Narsili, Di Pier Antonio MicheJi, botanice insigne. Venezia 1845.4.

Vita Roberti Morison. In Plantarum historiae universalis parte IJI. Oxonii 1699. folio.

Nolice necrologique sur McnriGustave MuehJenbeck. Mlulhouse $1845 \mathrm{~s}$.

Mensing, Oratio in olvitum Abrahami Munting. In ejus "Plygtographia curiosav. Lugd. Bat. 1709. folio.

Heyne, Elogium Johannis .Indre'ae Murray. (Comm. soc. gott. X. p. S.)

Ackermann, De Antonio Musa, et libris qui illi adscribuntur. Altdorfi 1786. 4.

Minnes-Tal ofver Claes Gustav Myrin. Upsala 1836. 12.

llillemet, Notice sur Noel Joseph Necker. (Magaz. encyclop. II. annee. tome I. p. 192-199.)

Ehrmann, Discours prononcé sur la tombe de Christian Gottfried Nestler. Strassburg 1832. 8.

Fée, Discours sur la tombe de Nestler. Strassluurg 1832.8. 
Vita Chr. Goltfr. Nees von Esenbeck: Nourack, Schles. Sehriftstellerlexikon I. 99

Nees von Esenbeck sen., Theodor Friedrich Ludwig Nees von Esenbeck. Breslau 1838. 8 .

Vita Casparis Neumann, in Operum editione altera. Zullichau 1749.4.

De Silveslre, Notice biographique sur Guillaume Anloine Olivier. Paris $1815,8$.

Éloge de Olivier. (Cuvier, Recueil.) Paris 1819.8.

Oedmann, Äminuelse-Tal ofver Pehr Osbeck. Stockbolm 1815. 8.

Thiebaul-de-Berneaud, Eloge historique de Ambroise Marie François Joseph Palisot, Baron de Beauvois. Paris 1821. 8 .

Éloge de Palisot de Beauvois. (Cuvier, Recueil.) Paris 1827. 8.

Eloge de Peler Simon Pallas. (Cuvier, Recueil.) Paris 18 19.8.

De Silvestre, Notice biograplique sur Antoine Augustin Parmentier. Paris 1815.8

líloge de Parmentier. (Cuvier, Reeueil.) Paris 1819. 8.

Niquel, Éloge de Parmentier. Paris 1\$22. 8.

Vita Simonis Paulli. In ejus "Quadripartitum botanieumn. lrancofurti a/AI. 1708. 4. p. 799-811.

Dahlborn, Vita, studia et gloria Paulliniana. Lipsiae 1703. 8.

Notiees historiques sur MIM. Samuel Perrottet et Louis Agassiz. Lausane 1831.8 .

Vita Philippi Petit - Radel. In ejus "Dc amoribusn etc. Paris 1801.8

Vita Antonii Guilielmi Plaz. (Comm. med. lips. XXv'. 546-554.)

Fée, Éloge de Pline le naturaliste. Paris 1921. S. - Lille 1827. 8.

Giseke, Variae in vitam et opera Plukenetii observationes. Impr. cum ejus Indice etc. Hamburgi 1779. folio. p. I-X.

Dupont, La vie de Pierro Poivre. In Poivre, Oeuvres complètes. Paris 1797. 8.

Gennari, Lettera intorno la vita del fu Pontedera. Venezia 1758. 8.

Vita Pontederae in Febronii Vitae Italorum doetrina excellentium saec. XVII. et XVIII. Pisa 1785. 8. vol. NII.

(De scriptis ineditis cf. Bot. Mag. Xll. 183.)

Duchéne) Notice historique sur Jean laptiste Porta, gentilhomme napolitain. Paris an IX. 8.

Michaull, Notices sur Porta, in Nicéron, Mlémoires. vol. TLIIl

(Savi) Alla memoria di Giuseppe Raddi. Firenze 1830. 4.

Gray, Notice of the botanieal writings of lue late C. S. Rafinesque. s. 1. et a. 8.

Derham, The life of John $\mathbf{R a y . ~ ( S e l e c t ~ r e m a i n s ~ o f ~ J o h n ~ R a y , ~ b y ~ G . ~ S r o t t . ~}$ London 1760.8. p. 1-100.)

Kunth, Notice sur Louis Claude Marie Richard. Paris 1844. S.

Ėloǵe de Richard. (Cuvier, Recueil.) Paris 1827. 8.

Lischwitz, Oratio panegyrica funebris in obitum Augusti Quirini Rivini. Lipsiae 1724. 4.

Ilermann, Vita A.Q. Rivini. In Bibliotheea Riviniana. Lipsiae (1727.) 8.

Homemann, On den svenske naturforsker Daniel Rolander. liobenliavil 1819.8.

Morren, Notice sur Rouçel. Bruxelles 1835. 12.

Vita Olof Rudbeck patris. In Halmstedt "Magnos" ete. Upsaliae 1829 folio.

Vita Otof Rudbeck filii. (Act. soc. ups. 1740. p. 124-132.)

Vita Olof Rudbeck filii. In Walmstedt "Maguos». etc. Upsaliae 1829 folio.

An historieal eulogium on Don IIpolito Ruiz Lopez. Salisbury 1834. 8 (hispanice.)

Ėloge de Benjamin Thomson, Comte de Rumford. (Cuvier, Reeueil.) Paris 1819.8.

llenschel, Vita G. E. Rumphii, Plinii indici. In ejus "Clavis Rumphiana". Vratislaviae 1833.8 .

Pourret, Noticia listorica de la familia de Salvador de la ciudad de Barcelona. Bareelona 1796. 4.

II. A. Schrader's Lebensbesclireibung. In Reliquiae Sehraderianae. llalle 1838. S.
Marlius, Denkrede auf Frans von Paula ron Schrank. Munelien 1836.4 .

Biographische Nachrichten von J. A. Scopoli. (Roemer, Magazin fur die Botanik, V. $3-1+$.)

Franz Wilhelm Sieber. Ein biographischer Denkstein ron Gluckseliy. Wien 1847.8.

(Bericht uher die Prager lrienanstalt, in der Prager Vierteljahrschrift 18'?, Band IV. p. 13\%-139.

Memoirs of Sir John Sinclair, by his son. London 1837. 8 (germanice.)

Vita Johannis SJoane. (Comm. med. lips. II. 366-368. 727-732.)

Éloge de Sloane. (Hist. de l'acad. des se. de Paris, 1753. 11. 305-320.)

Michactis, Sloanii vita. (Comm. soc, gott. 1T. 503-511.)

Levensheschryving van den Heere Jans Sloane. (Uitgezogte Verlıandelingen, I. p. 1-17.)

Lady Smith, Memoir and correspondence of the late Sir James Edward Smith. Loudon 1832.8

Morren, Adrien Spiegel. Bruxelles 4838. 8.

Wittwer, Lebensgeschichte Jakob Reinbold Spielmann's. (Crell's chem. Anm. 1784. 1. 545-580. - Selurften der Berl. naturf. Freunde, $Y$ $497-506$.

von der Hardt, Memoria Domini Johannis Caroli Spies. Helmstadii (1729.) 4 .

Vita Curtii Sprengel in ejus Opusc. acaden. ed. Rosenbanm. Lijsiae 1844.8.

Vita Johannis Swammerdam. In ejus Bibliis naturae. Leidac 1737. folio.

Wiliström, Biographic uber den Professor Olof Swartz. Stockholm 1828. 8

Sprengel et Agardh, Vita Swartzii. In Swartz, Annotationes botanicae. Ilolmiae 1829.8.

The Trial of Robert Sweet etc. London 1824,8.

Palacky, die Grafen Kaspar und Franz Sternberg. Prag 1843.4.

The literary life and seleet works of Benjamin Stillingfleet; by Hilliam Coxe. Loudon 1814. 8.

Bertoloni, Elogio del Professore Ottaviano Targioni-Tozzetti. Modena 1837. 4.

Sehubert, Leben und Reisen Jeau Baptiste Tavernier's. In ejus "Biographiel ». Erlangen 4847. 8. vol. 1. p. 62-233.

Lesser, Leben des Johannes Thalius. Nordhausen 1747. 4.

(Duverger) Notice biographique sur le Baron (Alexandre) de Théis. Paris 4843.8 .

Eloge de André Thouin. (Cuvier, Recueil.) Paris 1827.8.

La vie de André Thouin. In ejus "Cours de culıure". Paris 1827. 8. vol. J. p. I-XXXנl.

Vita Thunbergii. In Walmstedl "Magnos» ete. Upsaliae 1829. folin.

Die sehwedischen Naturforscher Karl peter Thunberg und J. W. Dalman. Stralsund 1831. 8 .

Billberg, Åminnelse-Tal ofver C. P. Thunberg. Stoekholm 1832. 8.

Tengström, Elias Tillandz ocls hans foregångare. Helsingfors 4843.8.

Éloge de Tournefort. (1list. de l'acad. des sc. de Paris, 1708. p. 143154. - In ejus "Relation d'un voyage". Paris 1717. 4. et in ed. angl. London 174.1. 8.

(Laulhier) The life of Tournefort, in a letter to M. Begon. Noyage into the Levaut. London 7741. 8. p. I-XXXVII.)

Terrasson, Projet de Reneaume sur les manuscrits de Tournefort. (Mem. de l'acad. des se. de Paris, 1709. p. 315-320.)

Ducarel, Some particulars about John Tradescant. (Philos. Transact. LXIll. p. $82-88$.)

liumpel, Monumentum Christophoro Jacobo Trew positum. (Nov. act. aead. nat. eur. IV. app. p. $315-332$.

ILemaria Christophori Jacobi Trew. (Comm. med. lips. XV. p. 712-720.(

Richard, Notice biograplique sur P.J. F. Turpin. In ejus "Ieonographie végétalen. Paris 1841. 4.

Locher-Balber, Nekrolog auf Paul Usteri. Zurich 1832. 8.

IJornemann, Om Marlin Vahl's Fortjenester af naturkyudigheden. Kiobenhavn 1821.4 . 
Configliachi, Discorso intorno agli seriti del Cav. Antomo Vallisneri. Parlova 1836. folio.

Vita Jacobi de Vanière. In ejus "Prnediun rusticum". Jaris 1817. 12. (uetelet, Notico sur Jean Buptiste Van Mons. Bruxelles 1843. 8.

bilore de Elienne !ierre Ventenat. (Cuvier, Recueil.) Paris 1849.8.

De la Houcelle, Notice biographirjue sur M. Villars. Paris 1818. 8 .

Vogel, Ueler den mittelatterlichen Gelehrten Vincenz von Beauvais. Ireiburg 1843.4

Heyne, Flogium Rudolphi Luynstini Vogel. (Nor, comm, soc. nott. V. app. (1. 1-10.)

Panzer, De Volcanero quaedam, additis duabus Boerhavii et Tonrnefortii ad illum epistolis. Norimberane 1802.4.

Lamoureux, Nutice biographique sur lierre Remy Willemet. IBruxelles 1808.8 .

Nemoir of the life, eharacter and writings of Irillium Withering. In ejus "Miscellancous tracts". Landon 1822.8.

Kunitsch, Biographie des Franz Naver, Freiherru von Wulfen. Wien 1810.4.

De Silvestre, Notice biographique sur Yvart. Paris 1832. 8.

Vita Jucoli Zanoni. In ejus "Rariorum stirpiun listoria". Bononicte 1742. folio.

Kurze Lebensgeschichte Johann Friedrich Zueckert's. (Schr. der Berl. naturf. Freunde. 1. $395-408$.

\section{Effigies botanicorum.}

Abercrombie, John. no. 10.

Acharius, Erili. no. 27

Adanson, Nichel. no. 4868

Agricola, Georg Andreas. no. 96.

Alamanni, Luigi. no. 112.

Baldinger, Ernst Cottried. no. 440.

Baldwin, IVilliam. no. 448.

Barrelier, Jacques. no. 4868 .

Barton, Benjamin Smilh. no. 524

Baubin, Gaspard. no. 4039.

Belleval, Pierre Picher de. no. $134 \mathrm{~s}$

Berthelot, Sabin. no. 10999.

Bock, llieronymus. no. 2573

Bonnet, Charles. no. 10209.

Bray, Franz Gabriel, Graf von. 110. 12'5

Breyn, Jakol. no. 1265.

Buffon, George Louis le Clere, Comte de. no. 10411

Buyten, Johamues ran. no. 9907.

Caetani, Francesco, Principe. no. 10624

Caillè, René. no. 4934 .

Calvel, Elienne. no. 1628.

Camerarius, Rudolf Jakob. no. 1662

Canal, Joseph Mlalabaila, Graf von. no. 10077.

Cavanilles, Antonio Jose. no. 9286.

Chamisso, Adalbert von. no. 1796.

Chiavena, Giacomo Amlonio. no. 1879

Clarke, Edward Daniel. no. 1867.

Cortusi, Giacomo Antonio. no. 1999. 2814

Cunningham, Richard, no. 4661

Curtis, William. no. 2092. 10209

Darwin, Erasmus. no. 10209.

De Candolle, Augustin Pyramus. no. 2822.

De la Billardière, Jacques Julien IIouton. no. 4868

De la Marck, Jean Bapliste Pierre Antointe de Monnet, Cilevalier, no. 4868 .

De 1'Écluse, Charles. no. 2573.

Desfontaines, Réné Louiche, dit. no. 4868

Dietrich, Friedrich Golllieb. no. 10411

Dittrich, Johann Geory. no. 5878

Dobrowski, Joseph. no. 8601
Dodoens, Rembert. no, 2653,6731

Douglas, Navid. no. 4661 .

Du Hamel du Monceau, Henri Louis. no, $4 \times 68$.

Durante, Castore. no. 2814.

Ehret, Geory Dionysius. no. 10447

Evelyn, John. no. 3050.

Fiera, Buptista. no. 3186.

Fleischer, Johann Golllieb. no, 3236

Fraser, John. no. $\{661$.

Fuchs, Leonhart. no. 2573

Gerarde, John. no. 3580 .

Gérardin, Sebastien. no. 3584.

Gesner, Konrad. no. 2573.

Gessner, Johamnes. no. 11342.

Gleditsch, Johann Gollliel. no. 11253

Gleichen, geuannt Russwurm, Withelm Fredrich, Freiherr sun no. 3687 .

Gorter, David de. no. 3786

Gouan, Antoine. no. 3804.

Guenther, Larl Christian. no. 11282.

Guillemin, Antoine. no. 5566.

Haid, Johann Jakole. n. 10447.

Hales, Stephen. no. 10209.

Hartig, Georg Ludioig. no. 4153.

Hayne, Friedrich Golllob. no. 4298

Elernquist, Pehr. no. 10946.

Hill, John, no. 10209.

Hippocrates. no. 4503 .

Hooker, William Jackson. no. 4649 .

Jacob, Edward. no. 4804.

Jacquin, Nicolaus Joseph. no. 9285.

Jaume Saint Hilaire, Jean Hewri. no, 4868

Jungius, Joachtm. no. 339.

Jussieu, Antoine Laurent de. no. 1393.4657.9256. 11605

Knight, Thomas Andrew. no. 5287

Koenig, Emanuel, pater. no. 5336 .

Krombholz, Fincenz Julius von. no. 1080.

Kunze, Gustav. 110. 5469 .

Lambert, Aylmer Bourke, no. 5510

Lémery, Nicolas. no. 5754.

Liegel, $G$, no. 2643.

Linné, Carl von. no. $465,4531,6143.6146^{\circ}$. (his!) 6149. (lıs!) 6156. (bis!) 8027.10210 . (bis!) 10411. 11604.11605

Loudon, John Claudius. no. 6292

Malpighi, Marcello. no. 6449

Martyn, John. no. 10209.

Martyn, Thomas. no. 10209

Mayrhoffer, Johann Nepomuk, no. 9323

Milne, Colin. no. 10209.

Mutis, José Celestino. no. 4774

Necker, Noel Joseph de. no. 7411.

Newton, James. no. 7473.

Palisot, Baron de Beauvois, Ambroise Jarie François Joseph. no. 40178 .

Paracelsus, no. 7744.

Parkinson, James, no. 7748.

Paulet, Jean Jacques. no. 7808

Paulli, Simon. no. 7521.

Petit-Radel, Philippe. no. 7924

Plukenett, Leonard. no. \$0\$6

Pulteney, Kichard. no. 6143

Raddi, Giuseppe. 110.9033

Rafinesque-Schmaltz, Constantino Samuel. no. 8320.

Ray, Joln. no. 8383.10209.

Redouté, Pierre Joseph. no. 84138415.

Retzius, Anders Jahan, no. 8497

Rivinus, Augustus Quirinus. no, 8616 .

Robin, Jean. no. 10643.

Rousseau, Jean Jacques. no, 10209

Rutherford. n. 10209.

Schkuhr, Christian. 110. 9140.

Schrank, Franz von Paula. no. 9323. 
Sckell, F. L. vou. 110.9501 .

Seliger. no. 11282.

Shaw, Thomas. 110. 10209.

Sieber, Fronz Ilithelm. no. 9629

Smith, James Eduarl. no. 9285.9718 .9726 .10209

Spielmann, Juliol kivebold. no. 980 i

Stackhouse, Jolit. no. $7 \$ 10$.

Swartz, Olo\% 110. 4657.9285 .10016 .11232

Targioni-Tozzetti, Otlavilno, 110. 829.

Thouin, Aulie' no. 4865 .

Thunberg, Carl Pehl. 110.9285

Tilli, Nichel Angelo. no. 10320.

Tournefort, Joseph l'itlon rle. $10.4868 \quad 10209$. 111505.

Trattinick, Leopold. 110. 10411.10415.

Tren, Christoph Jakuh. no. 10447.

Turner, Bobert. no. 10538.

Vahl, Jarlin. 110.9285.

Vaillant, Sebasticn. Ho. 4868.10209.

Vallet, Hiere'. 10. 10643.

Villars, Dominique. 11\%. 2368 .

Voorhelm, Georye. no. 10833.

Webb, Philin Barler. no. 10999.

Wedel, Georg Ilolfycuy. no. 11021.

Willdenow, Karl Luducig. no. $9286.1+262$

Withering, II illicin. no. 10209.

Wulfen, Franz laver, Freiletr vou. no. 5449

Zanon, Automio. no. 11410.

Zanoni, (iincomo. I16. 11416

\section{Epistolarum collectioncs.}

Maltoli, Epistularum medieinclium libri quinque. Pragae 1561 . folio. Gesner, Epistolarum medicinalium libri tres. Tiguri 1577.4.

- Epistolarum modicinatium liber IV. Wittebergare 1584. A

- Epistolae a Bauhino editac. Basileae 1591.8.

Letters betweres Mr. John Ray and his correspondents. Iandon 17 18. 8 . select remains of Jolun kay with his life by IItliam Irotham. Lindon 1760.8.

Epistolae a Carolo "Limni et A. de IIaen ad Dom. Fandelli veriplae. Conimbricar 1788.4

Pontedera, Epistolie ac dissertalinues, ed. Bomato. Patisci 1791. i.

Linne, Collecto "pistolarum, ed. Stoever. Hamburgi 1792 -

Schrank, Briefe an B. S. Nau. Erhangen $1 \$ 02.8$.

Tocea, Epistolae ad multos viros doctos datie. Ticini 1805.8 .

Sinth, A selection of the correspondener of i.muaeus. London 1821.8.

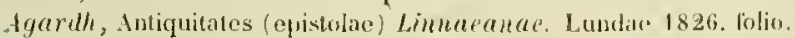

Limue, Literar $\mathrm{Xl}$ arl Alexandrum Gardenimm. ml, Landers. Kilia 1829. 4.

- Epistolie ineditas, ed. van Hall. Groningate 1830 . 8.

Trevionus, Caroli Clusii et Conradi Cesneri epristolae ineditar. Lipsiae $1831 \%$ \&.

Extracts from the literary and scientific correspondance of hicharthichardson. larmouth 1833. 8.

B.imne, Leltere inedite, ed. Bertoloni. Bolugna $183 \mathrm{~s}$. \&

- Epistolae ad Nirol. Jos. Jacquin, ed. Schreibers. Vindobonae 1541.8 .

firay, Selections from tho scientilic correspontence of Calwallader Colden with Gronovins, Limacus, Collinson. New Haven 18.3. 8.

Reliquiae Baldurinianae, hy Iarlington. Pljiladeljua 1843.8.

Vriese, Over eene verzameling eigcuhandige brieven an Carolus Clusius. Leiden 1843.8 .

Vortius, De priscorum hotanicorum ppistolis in bibliotheca erlangensi asservatis. Regenshurg 1845. 4 .

\section{Bibliothecac botanicac.}

Gesiter, He rei herbariae scriptoribus. In Bock, Stirpium historia. Argentratit 1552.4.

Bumaldus (i. e. Montalbanus), Bibliotheca botanica. Bononiae 1657. 12. - Hagae 1740. 4.

Fuiren, Bibliolheca medica Henrici Fuiren. Ilavniae 1659.4.

Bromelius, Catalogus Jilıcorum Jotanicorum ex bibliotheca Bromeliana. Gothoburmi 1694. 8.

Mangel, Biblioheca pharmaceulieo-medica. Genevae 1703. folio.

Garillel, Catalogue historique des auteurs, qui ont écrit sur les plantes Lmpl. cum ejus aHistoire" etc. Ais 1715. folio. p. XIXII.

Hermann, Bibliotheca Ririniana. Lipsiae (1727.) 8.

Linne, Bisliothec:i Lotanica. Amstelodami 1736. 8. - llalae 1747. s. Amstelorlami 1751.8 .

- Bibliotheca hotanica Cliffortiuna. In ejus "Horto Clifortiano". Arosielodami 1737. Solio.

zyuier, Bihliotheca botanica. Hagae Comitum 1740.4.

-_ Bibliothecae botanicae supplementum. Veronae 1745.8.

Cronovius, Auchuariun in Bibliothecam botanicam Skguieri. Lugel. Bat 1760. 4 .

Haller, Forrede zu Weimmann's Phytanthoza-jconographia. (De iconilus plantarum a Germanis paratis.) Regensburg 1745. folio.

Treu, Librorum botanicorun catalogi duo. Norimbergae 1752. folio. Librorum botanicorum catalogus tertius. ib. 1757. folio.

Linnei, Auctores lotanici. Upsaliae 1759. 4.

Catalogo de los autores españoles, que han escrito de historia natural. In Quer, Flera española. Madrid 1762. 4. vol. 11. p. 105-128.

Fabricius, Suppellex mea libraria botanica. In ejus" "Enumeratio horti helmstadiensis $\%, 1763.8 .12$ foll.

Baldinger, Catalogus dissentationnm, 'fuac medicamentorum historiam, fata ef vires expouunt. Altenburgi 1768. 4

Herissam, Billiotheque plyysique de la France. Paris 1771.8. (Botanique, p. $261-300,454-463$.)

Haller, Bibliohera botanica. Tiguri $1771-1772.4$.

Kall, Adlitiones arl IIalleri Bibliothecam hotanieam. Hafnjae 1775. S.

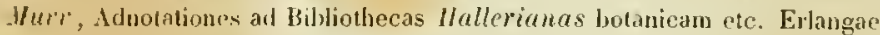
181) 5.4

Cobres, Deliciac Cobresianae. (Augsburg 1782.) 8

Boehmer, Bibliothea seriptorum historiae naturaljs. Lipsiae 1785-1789 s. (Pars 111, 1-2: Pliytologi.)

Lastri, Biblioteca georgica. Firenze 1787. 4.

Ballinger, Litcratura universa materiae medicae elc. Marburgi 1793. 8 .

- Vober Literargeschichte der Botanik. Marburg 1794. 8.

(Uryanter) Desiderata pro bibliotheea Bantisiana. (London) 1790. 8 . - Catalogos bibliotbecac historico-llaturalis Josephi Banlis. Londini $1796-1800.8$.

Reuss, Repertorium commentationum a societatilus literariis editarum. Goctlingae $1801-1802.4$.

Re, Saggio di bibliografia georgica. Venezia 1802. 8.

Burchardl, Pomolowische Bibliothek, berausgegeben vol Buether. Coburg 1806. 8 .

11 inther, Literaturae scientine nat. in Dania, Norvegia et Holsatia enchiridion. Ilavniae 1829.8.

Mlttit, llandhuch der botanischeu Literatur. (Bihliollbera lsotanica.) Berlin 1829.8 .

llierbach, Repertorium hotanicum. Lemgo 1834. 8.

IVikstrim, Conspectus literaturae botanicae in Suecia. liolmiac 4831. 8.

Galterer, Literatur des Weinbaues aller Nationen. Heidelberg 1832 . S.

hrueger, Bibliotleca botanica. Berlin is41.8.

Choulant, Handbueh der Bucherhunde fur die altere Medicin. Leipzig 1828. 8. - ib. 1941.8

Bihliotheca melicu-historica. Lipsiae 1842.8 
Engelmann, Bibliotheca historico-naturalis. Lipsiac 1846.8

(Cataloges minores vide no, 5270, 6748. 7728. 8549. 10426. 10705. $10808.10840 .116,08,11621$.

\section{Plantac sacrorum Bibliorum.}

Lemmins, Similitudinem ac paraloolarnm, yuac in biblits ex herbis des'smuntur, explicatio. Antwerpiar: 1563.8.

(anglico.)

Vallesius, De sacra philosophia liler singularis. Lugduni 1388 . s. - Ed. V1: ib. 1652, 8.

linmetius, Sacrorum hibliorun arboretum morale. Paris 1606. 12.

Scripturae sacrie viridarim literale et unsticum. Paris 1626.8.

Anomocus, Kreuzgarten der heiliyen Schrift. Nuruberg 1609. 8.

Cornarius, Theologiae vitis viniferae libri tres. IIeidelbergae 1614.8.

Barreira, Tractado das significaconus das plantas na sacrada escrijptura. Lisboa 1622. 4 .

Meursius, Arborctum sacrum. Lugut. Bat. 1642. 8.

Saumaise, De Hyssopo in cruce Christi epistolae Ires. Lugd. Lat. 1646. 8.

- Responsio in quaesionem Revernvicii de llyssopn Evangelii. Roterodami 1654. 12

hirsten, Exercitatio de Colochyntide prophetica et Cocco. Stetini 1651 i

Ileidegger, De Ficu a Christo malerlicta. Anstelodami 1657. 4.

Driessche vel trusius, Tractatus, an per Dudaim Jandragorac significentur? s. I. et a. 12.

liavius, De Dudaim Rubenis. Upsala 1656.8.

Deusing, De Mandragorae pomis pro Douditim Genes. XXX. haluitis. Groningae 1659.12

Liebentantz, De Rachelis deliciis 1)udaim ad Genesin XXX, 14. Wiltubergae 1660.4 .

Ursinus, Arboretum biblicum. Norimbergae 1663. 8. - Continuatio: il. 1685. 8.

Maurille de St. Michel, Phỵtologie sacrée. Angers 1664. 4.

Cocquius, Observationes et exercitationes etc. (Plhytologia sacra.) Vlissingae 1664. 4.

Castellus, Via ad clarius enarrandam botanolagicam Scripturae partem. Londini 1667, 4.

Major, De Myrrha, locustis ete. Kilonii 1668. 4.

Jontallanus, Dell' Issopo di Salomone. Bologna 1671. 4

Olto, De Nardo Pistica ex historia passionis dominicae. Lipsiae 1673.4

Beck, Lliva magna cananaea. Jenae 1679. 4.

Eckard, De Nardo pistica ex Jurc. XIV. 3, el Joann. XII. 3. Wiltebergae 1681. 4.

Mundelstrup, De pomis solomiticis. Havniac 1683. 4.

II'edel, De llyperico mystico. Jenac 1686. 4.

De unguento narulino. Jenae 1687.4

Do Sinapi scripturae. Jeñe $1690,4$.

De Hy'ssopo. Jenae 1692. 4

Ilacherlin, De generatione plantarum ex sacris literis. Tuchingae 1693. 12.

Westmacott, Theobotanologia. London 1694. 12.

Outhor, Exercitatio de Manna Israclitarum. Groningae 1694. h.

Ileyer, De Syconoro yuam Zachaeus ascondrat, Luc. XIX, 1-4. Lipsiae 1694. 4.

Stohr, Poma sodonitica all illustrutionem Sapientiae X, 7. Lipsiae 1695. 4.

II'edel, De corona Christi spinea. Jenae 1696.4.

Lund, De vocis Kepattwy signilicatu, Ev. Lucae $\mathrm{XV}$, 16. Mroae 1697. 8.

II'edel, De Lilio agri. Jenae 1700. 4.

Ludorici, Dudaim esse tubera. (Eph. act nat. cur. Dec. I. Ann. 4-5. p. $269-272$.)

Been, Spinae et tribuli ante lapsum producti. Haviae 1702. 4.

relsius, Botanici sacri exercitatio prima. Upsaliae 1702.8.
Flezsher, Lilia liubenis. Havniae 1703.4.

linasboel, De arboribus sodmaeis. (Hafniae) 1705.4.

Lange, Ju herla Borith, cujus Jeremias II. 22. el Malachias III. 2. mentionen faciunt. Altalorfi 1705. \$.

Majus, De Manna, duplici ex scripturae et naturae libro ocensione. (iiessan 1706.4.

IIedel, De Sabina seripturac. Jenac 1707. 4

Je lignis thyinis Apucalypsens, Jenae 1707. 4.

llelvigius, Specinen pharmacologiae sacrae, de Cícuta. Gryphiswaldian 1708. 4.

IVedel, De Lilis convallium Salomonis. Jenae 1710. 4.

Sonntay, Paralipomena, quilus ligna Sittim explicata sistuntur. Altdorfii 1710. 4 .

Celsius, Exercitationis de Palma caput primum. Lipalian 1711 \&

IVedel, De Zytho scripturae. Jenae 1713. 4.

Rosenfeld, W. Rosa saronitica. (Cant. II. 1.) Wittebergae 1715.4

Celsius, De arbort scientiae buni et mali. Upsaliae 1715. 8 .

Hille' $r$, De platis in scriptura sacra memoratis. Tubinga! 1716. 4.

Garofalo, Dissertationes niscellae. (Origanum, Ricinus, Lilium, Mandragora et llyssopus.) Jinuae 17.18. 4.

Ilardt, Intylum sylvestre in Elisae mensa nors in ulla, 2. Rus. IV. 40. In: non Bryonia in Esaiae vinea. Ilelmstadii 1719. 4.

Schroede", De liotis veterum Ilebraeorum. Marburgi 1722. 4.

Rudleck, Do Borih fullonum ex Ilierem. 11. 22. m Malach. III. 2. Ijsali 1722. 4 .

Responsum at Chr. Bened. Ifichaclis ohjectiones. Ipsali1733. 4

Schultens, De Palma ardente. Pars I-ll. Franequerar 1725

Ililler, llierophyticon. Trajecti a/Kh. 1725. 4.

Celsius, Molones aegyptii al Israelitis desiderati, Num. X1. 5. Lugut. Bat. 1726. 8.

Ihenius, Do Lilio saronitico emblemate sponsae all illustr. Cant. II. I Bremae 1728. 8 .

IIrasaeus, Dissertationmm philologicarum sylloge. (De ligno sitlim et if Rubo Mosis.) Bremae 1731. 8

Unger, Do Papyro frutice ad Jesaian XIX, 7. Lipsiae 1731. 4.

Cramer, De Myrto. Tiguri 1731. 4.

Goerit, Hyssopus ratisponensis rrescens e maceria. (Act. acarl. nat eur. 1. $120-122$.)

Tolla, Leltera sul lsopo. (Opuse. scelti V. $397-408$.)

Wrayner, Arboreti sacri specimen sisteus Laurum ox omni antiquitate erutam. Helmstadii 1732. \&.

Scheuchzer, Physica sacra, iconibus illustrata. Aug Viud. 1732-1735. folio.

( gallice.

Rudbeck, Dudaim Ruheais fraga vel mora Rubi idaei spinosi Iuisse. Lpsalis 1733.4 .

De Pré, De Balsamo evangelico Samaritano. Erfordiae 1733. 4.

Bose, De potiouibus mortiferis ad illustr. Harc. Ali, Is. Lipsiae 17361737. 4

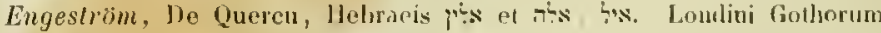
$1737-1738.4$.

Mule, De Ficu arefacta meditationes. Ilavniac 1739.4.

Biel, De lignis ex Lithno ad templum hierosolymitanum acdificandum prlitis. Brunsvigae 1740.4.

Hoyberg, De coelesti cibo Man dicto, a Exod. XV', 15. Ilafuiae 1743. 4.

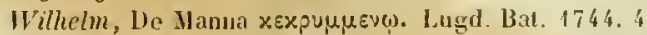

Celsius, Ilierobotanicon. Upsaliae 1745-1747.8.

Pontoppidan, De Manna Israelitarum. Jlarniae 4756.4.

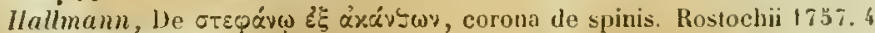
Clewberg, De ari arborc, sub qua Elias profugus recubuisse legitur $1 \mathrm{Reg}$ XIX. 4. 5. Upsaliae 1755. 4.

Treu, Cedrorum Libani historia. Norimbergae 1757-1767.4.

Hadelich, De optimis arborum spreciebus apud Ebracos. (Act. acid. mog II. $631-648$.) 
Gessner, Plhytograpbia sacra geveralis. Tiguri 1759-1767.4.

Pliylographia sacra specialis. Tiguri $1768-1773.4$

Clewberg, he variis frumentorum et leguninum speciebus in Vet. Test. memoratis. L'psaliae 1760. 4 .

Wichaelis, Fragen an eine Gesellschaft gelehter Manner. Frankfurt a/M. 1768. 8 . (gallice.)

Bang, De plantis quibusdam sacrae botanicae. Hivniae 1767. \&.

Bloch, Tentanien phoinicologiae sacrae. 1lavniac 1767.8.

(Boddaerl) Verbandeling over den Palmboom. (Nieuwe geneesk. JaarLoeken $\mathrm{V}, 157-168$.)

- Verhandeling over den Cederboom. (Nieuwe geneeshund. Jaarlocken V. 151-156.)

De Papyro fructus ac seminis experte commentarioli ad lliob VIIJ, 12. Coburgi $1772-1779.4$.

Gorter, hruidkundige verhandeling over Jeren. IVIl, 6. (Tamarischboon.) (Verh. van de Maatsch. te Haarlem XY, 126-86. NTI, 381-382.)

Hofstede. Do ware hleur van den sdelen of byhelschen Sorek-wya aangetoonel. (Verhand, van het Genootsch. te Vlissing. XI, 257-322.)

Andrieux', L'olivier, le figuier etc. Juges IX, \& Paris 1793. 8.

Sprengel, Flora biblica. (IIist. rei herb. Amstelodami 1807. 8. I, 6-19.)

Encontre, Idditions a la Flore bihlique de Sprengel. (Montpellier 1811.8.)

Virey, lles médicaments apluodiasiques et sur to Dudain de la Bible. Paris 1813.8 .

Amoureur, Dissertation philologique sur les plantes réligieuses. Montpellier 1817.8 .

Harris, The natural history of the Bible. Boston 1820. *

Duncan, Botanical theologs. Oxford is26.8.

Frost, Remarks on the mustard tree mentioned in the New Testament. London 4827. 8.

Carpenter, Scripture naturil history. London 1828 . \&

Thumberg, Afhandling om the waxter, som i Bibelen omtalas. Lpsala 1828.8 .

Rosenmueller, Biblische Naturgescbichte. Leipzig 1830. 8. (Historia plantarum hiblirarum: p. $69-34 \%$.

\section{Phytotheologi.}

lioebel, be succino libri duo (I. de passione, resurrectione "t beneficiis Christi). (Francofordiae 1558.) 8.

Petsi, Kereszteny szuzekueh tiszlesseges Koszuruja, l. c. Virginum christianarum curona honesta. Tyrnaviae 1591.8 .

Par/asca) Il fiore della granadiglia. Bolngna 1609.4 .

Pelrelli, Vera narratio fruticis (Passiflorae). Coloniae Agrippinae 1610. 8.

Auslen, The spiritual use of an orchard. Ouford 1653.4. - London 1847.8 .

Olearius, Hyacinth-Betrachtung. Leipzig 1665.12

Stapell, Tulipanen Gelieimniss, zu Erw eckung christlicher Andacht. Lubeck 1663.12

Derham, Physico-Theology. London 1714. \&.

Belgice, gallice, germanice, suecice.

Viencentytt. Ilet regt gebruih der werelt beschouwingeu. Amsterdam 1717.4 .

Lischucilz, De plantis dolorosam Domini Jesu passionem et gloriosam resurrectionem depingentibus. Kilonii 1739.4.

Rohr , Plıytotheologia. Frankfurt und Leipzig 1740.8.

Klingenstierna, De perfectionibus divinis. Upsaliae 1740.4.

(Fischer) Vernunftige Gedanken von der Natur. 1743. 8 .

Wachendorff, Oratio de plantis immensitatis intellectus divini testibus Trajecti a/Bh. 1743. 4.

Limne, De oeconomia naturae. Upsaliae 1749.4. isuecice.
Lesser, Die Orrenbarumg Gottes in der Natur. Nordhansen 1750.4 J) Glaubigon als Baume betrachtet. (Kleine Schriften. Leipzig 1754.8. P. 139-197.)

Hesslen, De usu botanices morali. Londini Goth. 1755, 4.

Mauperluis, Essai de cosmologie. (Oeuvres. Lyon 1756. 8. 1, 1-78.)

Der Christ bei dem Kornhalme. Breslau 1757. 4

fay, The wisdom of God manifested in the works of the creation. Ed. Xll. London 1759. S.

Gesner, Phytographia sacra generalis et specialis. Tiguri 1759-1773. 4.

Limne, be politia naturae. Upsaliae 1760.4.

Inzer, Betrachtungen uber einige Besonderheiten ats dem Gewachsreiche. In ejus "Sammlungn etc. 1. 1766. p. 54-64.

Edwards, Of the wisdom and power of God. (ln ejus "Essays". London 1750. \&. J. 1-40.)

Nahuys, De religiosa plantanum contemplatione. Trajecti a/Rh. 1775. 4.

Schrocter, Ueber den Einfuss der Naturgeschichte in die Kenntniss des Sclıopfers. (In ejus "Abhandlungen». Halle. 1776. 8. I, 1-21.)

Trozelius, Inledning til Guds underverk nti naturen. Lund 1778-1780. 4. Joues, The religious use of bntanical philosophy. London 1784. 4.

Retsius, De historia naturali fundamento theologiae naturalis. Iundae 1814.4 .

Rogel, Animal and regetable physiology. (Bridgewater-Treatises no. V.) London 1834. 8. - ib). 1840 . \&.

Dietrich. Die Wunder der Pflanzenwelt. Ulm 1844.8

\section{Symbola e plantis desumta.}

Rinaldi, II mostruosissimo mostro. Ferrara 1588.8

Camerarius, Symbolorm et emblematum ex re herbaria desuntorum centuriae. Naribergae 1590-1595.4.

Du Peyral La Betoyne dedie a Monseigneur de Bethune, Duc de Sully. s. I. et al. 8 .

Panlin, Sur l'antiquite, nohlesse el splendeur des fleurs de Lys. Paris 1626. $s$.

Hovel, Dendrologia or Dodona's grove. London 1640. 8 . (gallice.)

Der fruchtbringemen Gesellschaft Namen etc. Frankfurt a/M. 1646, 4. Stengelius, llorteusius et Dea Flora cum Pomona. Aug. Vind. 1647. 12. Tristan. Traite du Lys, sỵmble de l'esperance. Paris 1656. 4.

Starch, Sertum rutaceum domus saxonicae insigne. Lipsiae 1664. 4.

Rainssant, Sur l'origine de la figure des lleurs de Lys. Paris 1675. 4.

parskites, Rosa aurea omni aevo sacra. s. 1. 1728.4.

Cramer, De Myrto. Tiguri 1731. 4.

Lohenschiold, De floribus Lygiis vulgo lilia vocatis. Tubingae 1756. 4.

Genlis, La botanique historique et litéraire. Paris 1810. 8. (tiatice, gormanice.)

De la Chénage, Abécédaire de Flore. Paris 1811. 8.

Jacquemart, Flore des Dames. Paris s. a. 12.

Lucot, Enblêmes de Flore et des végétaux. Paris 1819.8.

( lient) Sylvan shetches. London 1825.8.

The Lotus. or faery flower of the poets. London $18-12$.

Fieber, Symbolische Pflanzen, Blumen und Fruchte. Prag 1926-1830. 12.

Blomsterprảhet. Calmar 1827.8 .

Blomspråket. Lddevalla 1831.16.

Svensha Blomsterprảket. Stochholm 1845. 16.

(Gama Yachado) Theorie des ressemblences. Paris 1831. 4.

Lees, The affinities of plants with man. London 1834. 8 .

Döring, Die Künigin der Blumen. Elberfeld 1835. 8.

Scazzola, Filosofia dei fiori. Allessandria 1836. 8 .

Stricliand, Floral sketches. London 1836. 18.

The floral telegraph. London 1836.18. 
The spririt of the waods. London 1837. 8.

(Trattinick) Versuclue in der contemplativen Bolanik. Wien 1839.4. Die Schule der bluhenden Natur. Wirn 4843.8.

De la Tour, Lo languge des fleurs. Stutlgart 1840. 12.

(Symanski) Der Solan des Orieuls. Berlin 18/1.8.

Osgood, The lloral offering, a token of friendship. Pluladelphia 1847. 4.

Lecoq, De la toiletie et de la corpuetterie des végitaux. Clermont-Ferrand 1847.8

\section{Pocmata de plantis.}

Virgilius, Georgicorum libri $1 \mathrm{~V}$, by John Martyn. London 1741. 4 Bucolica, by John Martyn. Loudon 17:9.4.

Bucolica, en vers francuis, avec une Flore Virgilienne par de Moncy. Praris 1828. 8 .

Philes, Carmioa graeca cil. I'ernsdorf. Lijosiac 176s. 8. (Carmen de plantis, 1. 93-123.)

Andromachus, Antiquissimum de Theriaca carmen. Norimbergae 1754. 4.

Otho Cremonensis De electione melierun simplicium rluythmi. Impr. eum Macro ex rec. Choulant. Lijisiae 1832. 8. 1. 157-177.

Macer Floridus, De viribus herbarun. Neapoli 1477. folio. - Ed. Choulant. Lipsiae 1\$32.8.

(anglice, gallice, danice.)

Nicander, Alexipliarmaca et Thoriaca, Venetiis 1499. folio. - Paris 1846, gr. 8 .

IValafridus Strabo, Hortulus. Norimbergae 1512. 4. - ex ree. Renss. Wirceburgi 1834.8 .

Atrociani Scholia, impr. cum priori. Basileae 1527.8

Bigoutier (Bigotherius), Rapina seu Raporum encomium. Lugrluni 1341.8

Nevianus, De plantarum viribus pocmatium. Lovanii 1563.8 .

Ilarchius, Enchiridien medicum simplicia pharmaca elegante fidorjue poemate compreheudens. Basileae 1573.8.

Le facolta dei semplici. In Castore Durante Ilerbario nuovo. Roma 1585. folio.

Passeratus, De Oliva. 1588. Seg.

Cyrilli Alcxandrini De plantarum et animalium proprictate. Ronae 1590.8 .

Hortus Laurentii Scholzii celebratus carmine Andrcae Calagii. Vratislaviae 1592. 4

In Laurentii Scholsii Jortum epigrammata anicorum. Vratislaviae 1594, 4.

Chiocchius, De Balsami natura carnen. Verenae 1596.4.

Alamanni, La coltivazione. Parigi 1546. 4. - ib. 1832. 12.

(Parlasca) II fiore della granadiglia. Bologna 1609. 4.

(De Thou vel Thuanus) Crambe, Viola. Lilium. Parisiis 1611.4.

Bosenbach, Neues Pararliesgarárlein. Frankfurı a/Ml. 1613, 8.

Franeau, Jardin dhyver. Devay 1616.4.

Jacobus 1, Magnae Britanuiae Rex, Nisocapuus, sive de abusu Tobacci lusus regius. London 1619 . folio. (anglice.)

De Rennes, Les merveilles et miracles. (Poemata Je plantis.) Saumur 1622. 8 .

Mellesinus, Carmen heroicum de virtutibus Scordii lwrbae. (Aug. Vindel. Olymp. 787. anno 3.) 4 .

Thorius, Hymus Tabaci. Lugd. Bat. 1628. 4.

Contant, Le second Eden. Poiticrs 1628. folio.

Priezac, llorii Buellani. Parisiis 1640.4.

Raldus, Satyra contra abusum tabaci. Monachii 1657. 12.

Lapinus, Hortorum libri $\mathrm{N}$. Parisijs 1665 . 4. (anglice, gallice.)

Coneley, Poemata latina. Londini 1668. 19

P'lantarum liuri sex. Basilene 1793,8.

De la Fontaine, Poene du Quinquina. Paris 1682. 12.
Passerimi, sogno uella licenza, chei prende da Ilonte Baldo. Trento $1684,12$.

Herrichen, De Thea herba doricum melydrion. granes lupr. eum Francii Aracrenticis. Anstelorlami $1685,4$.

Francius, lu laudem Thiar sinensis anacreontica dao: equere. Instelodami 1685. 4.

Petil, Thea, sive de sinensi herla Thee carmen. Ijusiae 1685 \&

Muehlpfort, Puemata. Tratislaviap 16866.8.

Vaniire, Carmina. (Vites el vinum.) Parisiis 1696. 12

Falugi, Prosopepociae bolanicae, sive nomenclator holanicus. Flerentian 1697.12.

- Prosopeproeiae hotanicae pars secunda de planlis umbelliferis Fiorentiac 1699. 12

- Prosopopocias hotanicae Tournefortiana tucthork dispositae. Florentiae 1705.12 .

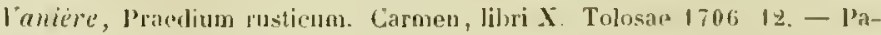
risiis 1829.12

(gallice, germanice.

Siricius, Bajae cimbricae, sea carmm de .loe antericand, fichleswigan 1709. folio.

Savastano, Botanicorum seu institutionum rei herbarian libri II Trapoli 1712.8

(ilalice.)

Baruffaldi, la tabachcile. Ferrara 1714.4

Commelyn, Oratio metrica in laudem rej herlarian. Amstelodimi 1715. १.

Thilips, Cyder. A poem in two boohs. Lombon 1720. 12.

Zamboni, Parnassi botanici frarmenta. Florentiae 1721 4.

Brolies, Irdisches Vergnugen in Gotl. Ilamburg 1721.8

Knowles, Materia medica bolinica. Londim $1723,4$.

De la Croix vel Hac Encroe, Connubia florum latino cartaine drmonstrata. Paris $172 \%$. 8

(sallice, germanice.)

Gedichte auf Scultetus Orangeriegarten in Breslau. (Breslau 1731.) folio.

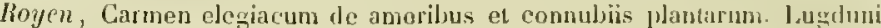
Bat. 1732. 4

Baruffaldi, Jl canapajo. Jologna 1741. 4.

Berti, Coltivazione dellit Canape. lmpr. cum Baruffaldi, Il cantipajo. Bologna 1741.4

Versuch einer poetischen lieschreibung zweier Aloen. lioprenliagen 17 i.j.

Caji Herenii Rapidii Pisonis (i. e. Karl Heinrich Rappoll) Sermo all Pisones. Pis. Acstior. 1748. 8

Cuno, Ode uber sciuew Garten. Imsterlan 1750. 8 .

Denso, Beweis der Gotheit aus den Grase. lmpr. cum Cuno. Imsterdam 1750.8

Ifeiffer, Lehrgedicht auf den Knaster. Leipzig 1754. 4.

Spolverini, La coltivazione del riso. Verona 1758.4

Miniscalchi) Mororum lilni ires. Carminum liber. Verona $176 \%$. (italice.)

Vigo, Tubera terrate. Taurini 1776.4. (tralice.)

(Marvin) The botanic garden. (1. The [conomy of vegetation: 11. The loves of the plints.) Lichfield 1789.4 (gatliee, italice.)

C'astel, Jes plantes. Poème. Paris 1797. 12. - Ed. V. Paris 1832. 12 (atiun.)

Luche, IIymus an Flora. Wien 1797. 4.

- Hyonus an Ceres. Winn 1800.4

Petil-Radrl, De amoribus Pancharitis et Zoroae poena erotiro-didactiın Paris 1798. 8. - ib. 1801.8

(Epitome gallica: Le mariage des plantes. Paris 1798. 12. - 1.64 Mysteres de Flore. Paris 1813 . 3 .

Bowden, A poetical introduction to the study of botany. London 1801 . \& (Bellinelli) I misteri di Flora. s. J, 1806. 12

Jacquin, Stajneliae sylvestres; latine et germanice. (Viennac 1806 .) 8

Marquis, Los Solanées. Idỵlle. Rouen 1817. 8.

Arici, La coltivazione degli ulivi. Brescia 1818 . 8 . 
Turner, Poem upon the study of hotany. In Roolsey, syllabus ete. Bristol 1818.12.

Trallinick, Oestreiehischer Bumentranz. Wien 1819. 12. (Calliope und Flora. Wien 1840. 12.)

Itoeller, Der Konig und die Königin Ier Lolırbaume. Brumı 1820. 4.

Die duftende Blumenwelt. Ilalberstadt 1828. 8 .

Radda, Sinnbilder aus der Pllinzenwelt. Wien 1824. I2.

Derer, Poptica eshibitio arcis of horti Kismartunionsis. Sopronii 1828 . 8

Amaralii Brisiliensis Carmen de sncchari opificio. In Marlius, Flora brasiliensis, vol. 11. Stultgardiate $1 \$ 29.8$.

Il nuovo giardino (se: Ludovici de Heden). Zara 1529. s.

Smissen, Pflazen-Oratorium. Kiel 1834, 8

(Wellowille) lees anours dles plantes. Paris 1835 . s.

Minding, Das Leben der Pflanze. Loipzig 1837. 8.

rillemin, Le liseron des elamps. (Comblvulus arvensis.) Orleans 1839.8 .

Hentschel, Clsemie, Alehenie uncl Hotanik. L,ebr- und Lolggedicht. Hof 1840.8 .

Tillemin, Herbier puetique. Paris 1842.8 .

Buternsrhmilt, Die Pflanzenwelt. Sulzhach 1846 . *

\section{De plantis Veterum Critici.}

Mercurialis, Variarum lectunum libri qualuor. Vonetiis 1571. 4

Saumaise, Praefatio in librum de homonymis liyles intricar. Divione 1668. folio.

Plinianale asercitationes in C.J. Solini Polyhistora ete. Trajeeti a/Rh. 1689. folio.

Sprengel, Antifuitatum botanicarun specimen. Lipsiae 1798. 4.

Billerbecl, Flora elassica. Lipsiae 1824. 8.

Fraus, synopusis plantarum Florae classicas. Munchen 1845. s.

Ifoyy, Ohservations on some of the classical plants of sicily. (London) 18 24. 8.

Fé, Flora de Theocrite. Paris 1832.8.

Tenore, Osservazioni sulla Flora di Teocritu "deghi buecolici greci. Napoli s. a. 4.

Hiquel, Homerische Flora. Altuna 1836. 8. (botlandire.)

Eysson, Sylvae lirgilianae prodromus. Cironingae 1695. 12.

Martyn, lirgilii Georgiea, cun commentario. Loudon 1741. 4.

- The Bucolihs of Virgile. London 1749.4.

J)issertations upon the Aeneids of Virgil. London 1770.

Retzius, Flosa Virgiliana. Lund 1809.8.

Fe'e, lilore de Virylle. Paris 1822.8.

('aulet) Flore et Faune de Virgile. P'aris 1824. s.

(Tenore) Osservazioni sulla Flora Virgiliana. Napoli 1826. \$.

Mancy, Flore Virgilienne. In ejus: Les Bueolinues de Virgile. Paris 1828. 18 .

Wedel, De herbis germanis Ocidii. Jenae 1689.4

Nocca, Illustratio plantarum, quae in Julie Cat'saris commentariis indigitantur. Ticini 1812.4 .

Retzius, l)e plantis cibariis Romanorum. Lundae 1808. h.

Menlie, be leguminibus veterum. Goettingae 1814. 4.

Morren, Les siecles et les legumes. Liege 1837. 8 .

Dierbach, Flora Apiciana. Heidelberg 1831, 8.

Schulze, Toxieologia velerum, plantas venenatas exhibens Theophrasti, Galeni, Dioscoridis, Plinii etc. Ilalae 1788.4

Dierbach, Die Arzneimittel des Ilippocrates. Ileidelberg 1824.8.
Encombe, Recherebes sur la botanique (sur l'Aeonit) eles anciens. (Montpellier 1813.$)$ s.

Slerogl, De degilope lierbat. Jenae 1695 . 4

Gleditsch, Eelaireissemints sur le veritahle legolethron de Iline. (Ilst. de l'acad. de Berliu, 1759. D. 45-\$6.)

- Untersuchnng des Aegulothri des Plinius. (Plyys. bot. ok Ahh. III, 144-199.)

Tiedel, the Anello Tirgilit. Jenate 1686 . 4

Marogna, Commentarius in tractatus flioscorielis et Minii de Anomo. Basileae 1608.4 (italice.)

liamel, De Tugus seu Amono legitimo. (Philos. Transact. XXI. mo. 248. p. 2-4. - Ray, Ilist. [)!. III, 89-90.)

Zanardini, Nuovi studii sopra ]'Androsnee degli antichi. In ejus : Saggio elr. Vonezia 1843.4

Franz, De Asparago ex seriptis medicorum veterum lipsiac 1778. 4.

IIedel, De Bubu veterum. Jenae 1701. 4.

- De Puipura et Bysso. Jenae 1706. 4 .

Forster, liber singularis te Bysso antiquorum. Londini 1776 . \&

Rertoloni, Dissertatio de Bysso antiquorum. Bononiae 1835. 4.

Fiviani, Dell Bisso degli antichi. (Nilano) 1836.8.

Eichstad, An Camphora Ilippocrali, Aristoleli, Theophrasto fuerit ucognila? Dantisi'i 1650.4 .

Eysson, be Castaneis. Groningae 1703. 12

Hedel, De pane dyrrhachino Julii Caesaris. Jenae 1701.4

Il eimmam, Tractatus de Chara Caesaris, eujus lib. III. de hollo civili, cap. L meminit. Cinulsruhae 1769. S.

Peccama, De Chumbo el Alica libri duo. Verona 162\%. 4.

Dresig, De Cicuta Aheniensinun poena puhliea. Lipsiae 1734.4

Campi, Dialogo, nel qualo si manifesta lu seonosciuto Cimnamomo delli anlichi. Lurca $165 \%$. 4 .

Conraliuus, spicilegiun botanienm. Lucae 1654.4.

Nees von Esenbech, the Cimnmomo disputatio. Bonnae 1823.

Hiedel, De Cirsio Dioscoridis. Jellae 1700.4.

De mensis eitreis. Jenae 1707. \&

Nocca, se Virgilio ha veranente descritto il limone o Cirus medica. \&. I. 1819. folio min.

Iredel, De Colchoro Theophrasti in genere et specie. Jenale 1695. 4.

Baldini, Tractatus de Cucumeribus. Florentiae 1586. 4

Suitzer, A dissertition on the true "Cytisusn of the ancients. Eu. II. Lundon 1735 . 8 .

Amoréur, Sur le Cytise dlus anciens. (Mém. de la soe. d'agriculture de Paris, 1787. Trinn, d'ete, 1). 68-86.)

Slevogt, Nucem Methel Avicennue esse Daturam moderuorum. Jenac 1695. 4.

Trilles, De planta qualam venenita copiis Antonianis exitiali ad illustr. Ippiami locum in Parllieis. Wittebergat 1765.4.

Julius Alexamdrinus, Epistola apologetiea (rle Fabis veterum). Francofurti 1554.8 .

Yesti, De symbolo Iythayorae: Fabis abstineto. Erfordiae 1694. 4.

Isink, Disjutatio plilologica de Fahis. Groningae 1712. 4

Eysson, lhe Fayo. Aroningae 1700.12.

IVedel, De Feeula coa. Jenae 1693. 4.

IIo/fmann, Fieus arbor philologice eonsilerata. Jenae 1670. 4.

Wedel, De Iloloconitid. Mippocralis. Jenae 1715.4

hoeniy, De Lamio IVlinii. Argentorati 1742. 4.

hirsten, In Virgilit versum " Mlba Ligustra cadunt, Vaceinia nigra leguntur". Altorfii 1764.4.

11 allher, De Loto aegyptia in nummis antiquis. Lipsiae $\$ 746$. Tolio.

Jussieu, Divinatio de arboribus, palmis, Loto rubra et cocrulea, in Rarthelemy: Explieation de la Mosanue de Palestrine. Paris 1760.4.

liay, Von dem agyplisehen Lotus. (Hanb. Magazin XXIII, 201-209.)

Desfonlaines, Rucluerebes sur le Lotos de Lybie. (Mém. da l'acau. des se. de Paris, 1788. 413-453. - Journal de pliysique, XXXIIJ 28 i -292$. 
Duppa, Illustrations of the lotus of the ancients and Tamara of India. London 1816. folio.

Fie, Sur les lotos dios anciens. Paris 1822. 8

Fries, Botanisht-anticuarishe excursioncr. Upsala 1836. 4. (Ofver Grehernes Nympheaceer, p. 1-28; on studeslagens Stamland, p. 29-36.)

Deusing, Do Manna et Sacchtro. Groningite 1659. 14.

Saumaise, De Manta of Sacharo commentarius. Jarisiis 1663.8 .

De Saccluaro. In ejus: Fxercitationes etc. Divinne 166s: folio. 1). $255-25 i$

Llannemanu et Stoilerfoht, De Saccharo Salmasiano. (Nov. literar. Mar. Bald1. 1701. 11. 209-213.)

Ifzelius, De origine Myrrhare controversa. Upsilliae 1825-1829.4.

licher, De Nardo et Epithymo, adversus Josephum Scaligerum. Romac 1607.4 .

Blanc. Account of the Nardus indiea or spikenard. (1hil. Transact. LXXX, $284-299$.

Jones, On the spikenard of the ancients. (Transact. of the sue. of Bengal II, $405-417$.

Hatchett, On the spikenard of the atcients. Lomalon 1836.4.

Lochner, Nerium sive Rlododaphne veterum et reentiorun. Norimbergat $1716 \quad 4$

Amoreux ( flls), Eelaireissemens sur l'esprece de fourrage, que les anciens nommaient Oeynum. (Mentr. de lit sue. digrie. de Paris. 1789. Printempis, p. 62-70.)

Wedel, De Oenanthe Theophrasti. donce 1710,4

Fremont, Note sur l'Orohanche de Dioscoride et de Theophraste. Cherhourg 1807.8

(Lochner) Vnzovoratyrov sive Papaver en onmi antiguitute erulum. Norimlergae 1713. 4.

Gililandinus, Papyrus h. a. commentarius in tria Caji Mlini Majoris de Piepyro capita. Venetiis 1572.4.

Scaliger, Animatversiones in Guilandine commentarium in tria C. Plinii de Papyrn eapita. In Scaligeri (Opusculis variis. Francofurti 1612.8. p. $1-52$.

kinchmaies, lle Papyro veterum. Wittelvergac 1666. 4

Flachs, Vestitus e Papyro in Gallia muper introduclus $r$ scriniis antiquitatis erutus. Lipsiae 1718.4.

Caylus, Dissertation sur le Papyrus. (Paris) 1758. 4.

Cirillo, Cyperus Papyrus. Parma 1796. folio.

Malherbe, Notice sur le Papyrus. Metz 1840.8.

Schreber, Programmata de Persea Aeggptiorum. (Nag. fur Bot. IV, 4652. 1. 14-23. - Usteri, Annajen. IV, $71-76$.)

Forster, Literae ad Schreberum de Prorsear. (Mag. fur lios. 1. 23.)

Slevoyt, De Pyrethro. Jenae 17094

Long, Some enquiry concerning the guercus and fagus of the ancients. (Lonilon) 1838.8.

Wedel, De Radice amara Homeri Jalla 1692. 4.

De Resina aegyptia Mauti. Jenae 1700.4

Bose, Otia wittebergensia. (Antipuitates Succhari.) Wittebergae 1739. 4.

Sprengel, De frumentorum manime Secales anti(juitutilus. Halae 1816.4.

l'eccana, De' commentarii della Scandella libri tre. Yerona 1622. 4

Conti, It vero Silfio. Venczia 1673.4

Letlera sopra la detta seoperta. Venezlal $1674 \quad 4$

Risposta a çuesta lettera. Venezia 1674. 4

Laurence, A partieular account of the Silplium of the ancients. In ejus New System etc. London 1726. Folin.

Walthe, De Silphio in veterum numnis. (Lipside 1746.) 4

Viedel, De morbo el herha solstitiali. Jenae 1690.4

De Tetragono Ifippocratis. Jenie 1688. 4.

Siegesbeck, De Tetragono Hippocratis. Petropoli 1737.

Wedel, De Thesen Theophrasti. Jenae 1708.4.

De Thyo Homeri. Jenas 1707.4.

Fougeroux, sur le Thuya de Theophraste. (Joumal de physique. XVIII, $354-356$. - Nieuwe geneesk. Jaarb. I. 216-219.)
Cornelissen, Sur les Tulsera des inciens (Suelonius). s. I. et a. 8.

Thichaul-de-Bernoaul, Rrecherches sur les plantes connues des ancirun sous le nom de l'lva. Parin 1822.8.

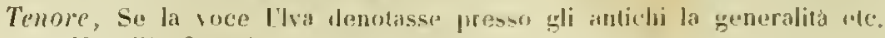
(Nipoli) 1831 . h

\section{Plantarum mythicarum et magicarum historia.}

Wolfhart, Prodigiorum ac ostentorum chronicon. Basileae (1557.) folio. Lemnius, Oeculta naturae miracula. Antwerpiae 4561. 8. (anglice, gallice, germanice.)

Wahrhalrige neue Zeitung ete. 1582.

Isacacus, De Rorella traetatus, in guo de arcanis alchinistarum. Linne!

Meinardus, De Viseo Druidarum orationes. Pietavii 1614. 8.

Olorimus, Centuria arborum mirabilium. Magdeburuk 1616. 12.

Centuria Jerlnarum mirabilium. Magdeburgh 1616. Iz.

Jaier, Tractatus de volucri arloorea. Francofurij 1619.8.

the Rennes, Les merreilles et miracles. Saumur 1622.8 .

Coclenius, Mirabilium naturae liber. Francofurti 1625.8

Jonston, Thaumatographiat naturalis. Anstolodami 1632.12 (anglice.)

Ilagelgans, Rosa lorjurns h e. lle primariis Rosar musteriis. Colurga 1652. 12.

(Thomasius) Disputatio de Mandragora. Von der Araut-Wurtzel. Lipsian 1655. 4 .

Deusing, De Mandragorae pomis (et mangonis . Groningae $1659,1 z$. (Uiss. select. p. $586-598$.)

Liebentonts, be magia baculorum. Wittebergae 1661. 4.

Kirchmaier, De virgula divinatrice. Wittebergae 1669. 4.

Legati, Clirysomeleida sive aurantiorum malorum historia mythica. Bononiae 1667.4 .

- Agriomeleis aut in silvestre pomum genus metatnorphoses. Bononiae 1667.4 .

- Nra Cista, sive mythicus de Castanea excursus. Bumoniac 1667.4. Schwimmer, Natura niracula érea vegetabilia. Jonae 1673. 8.

IBericht von den Schlangengestalten auf den Blâtern der Ibanuse. Frankfurt a/0. 1680.4 .

Grosgebauer, Programma te aguis tartaricis et vegetabilibus. Fon den Lammern, so aus der Erden wachsen. Vinariae 1690. 4.

Huentler, Unvorgreinliche fiedanchen wegen der mildiglich bluttrieflemt on Romahren. Custrin (1697.) 4

Petit, Homeri Nepenthes. Trajecti a/Rl. 1689.8

11 edel, De Nepenthe Jomeri. Jenae 1692. 4.

Marquis, Rillexinus sur le Nepentbes d Homere. Rouen is 15 . \&

Siber, De Moly llermetis hérba. Schneebergae 1699. 4

Iledel, De Moly Llomeri I-II. Jenae 1713.4

_- Ve nythologia Moly Ilomeri. Jenae 17134.

Triller, Moly Ilomericun detectum. Lipsiae 1716.4 .

IV'edel, De Nectare et Ambrosia. Jenae 1691. 4.

- De ramo aureo Virgilii. Jenae 1699. 4

litzschmann, Gotseligo Vermuthung von einem Gewaclise der Firden gleich einer Semmel. Leipzig 1700. s.

Heucher, De regetabilibus magicis. Wittebergae 1700.4.

Went: De plantis, quas an rem magicam facere erediderunt veleres. Lipsiae 1705.4.

llauser, Theses botanicae. (Sprica Zeae. in gua granum Avenae fuerit.) Basileac 1711. 4

Ileucher, Plantarum historia falbularis. Wittebergae 1713. 4.

Schminchius, De cultu religiosu arhoris Jovis praesertim in Hassia. Marburgi 1714.4. 
(De Vailly) Principales merveilles de la nature. Rouen 1723.8

Parshius, Rosa aurea omni aevo sacra. s. 1. 1728. 4.

Lanyguth, Antiquitates plintarum feralium apud Graecos et Romanos. Lipsiae 1738.4.

Trewo, De Serpentaria mirabili nontana Huntingui. (Commere. liter. norimlı. 1738. p. $377-379$.

Lentilius, J)e radice effractoria vel apertoria, Sprengwurzel. (Ephem. acad. nat. cur, dec. III. Ann. VII-V'III. p. 144-152.)

Monrad, De Verbena ejusijue usn in satris et incantationibns veterum. Hafniae 1751. 4.

Gesner, De Ranunculo belliclilloro el plantis degenerilsus. Tiguri 4753. 4 Baldinger, Alexiteria et alesipharmacd contra diabolum. Goettingae 1778.4 .

Foersch, Naturliche Geschichte des Bohon-Lpas auf der Insel Java. (Leipz. Nagazin $1784.373-391$.

Jeber den Gifthanm Johoon Upas, der auf Java wachsen soll. (Sammlungen zur Plyssik NY. 439-453. (Usteri, Anualen. I11. 262-275.)

(Heyne) llisteriae naturalis fragmenta ix ostentis, prodigiis et monstris. Gopltingae 1784-1785. folio.

Zuccagni, De naturali lilisum ante simulacra Deiparae fruetificatione. (F'lorentiae 1796.) s.

Boehmer, Plantas fabulosas imprimis my thologicas recenset. J-XV. Witteberirae $1800-1803.4$.

(Amorenr) 1)issertation sur les ponunes dor des llespérides. Muntpellier 1809. 8 .

logel, Quaestio de llesperidum malis. Numburgi 1832.4.

Treviramus, Ueber gew isse angelylich mil einem Gewilterregen gefallne Samenkomer. Breslau 1823. 8 .

Goeppert, L'eber den Getraide-und Schwefelregen. Breslau 1831. 8.

Dierbach, Flora mythologica. Frankfurt a/3]. 1833. 8.

\section{Collectanca. Miscellanca. Diaria.}

Norison, Praeludia botanica. Londini 1669. 12.

Blegny, Zodiacus nedico-gallicus. Genevae $1680-1686.4$.

Vallisneri, Prima raccolta d'Osservazioni e d'Esperienze. Venezia 1701. 19.

_-_ Opere diversi. Venezia 1715. 4.

- Opere fisico-mediche. Venezia 1733. folio.

Wedel, Centuriae (duae) excrcitationum. Jenae 1701-1720. 4.

Zuinger", Fasciculus dissertationum. Basileae 1710. 8 .

Blair, Niscellaneous observations. London 1718. 8.

Pontedera, Dissertationes botanicae XI. Patavii 1720. 4.

Epistolae ac dissertationes. Opus posthumum ed. Bonato.

Palavii 1791. 4.

Thuemmig, Versuch einer grundlichen Erlauterung ec. Ilalle 1723. 8.

Derham, Miscellanea curiosa. Lundon 1723-1727. 8 .

Monti, Plantarum varii indices. Bononiae 1724. 4. - ils. 1753.4.

Alpimus, Opera postluma. Jugduni Batavorum 1735. 4.

Haller, Opuscnla botanica. Goellingae 1749. 8 .

Linne, Amoenitates academicae. Hulmiae 1749-1769. 8. - Lid. III Ërlangae $1787-1790.8$.

Opera varia. Lucae 1758. s.

Auserlesene Abhandlumgen. Leipzig 1776-1778. 8.

Selectae ex Amoenilatilus academicis dissertationes. Graeciae 1764

-1769.4 .

- Miscellaneous tracts by Stillingfeet. London 1759. 8. - ib. 1762.8 .

- Select dissertations, by Brand. London 1781. 8.

Secondat, Observations de physique et d'histoire naturelle. Paris 1750.8. Gesneri Opera botanica per duo saecula desiderata, edid. Schmiedel. Norimbergae $1751-1771$. folio.

Alston, Tirocinium botanicum edinburgense. Edinburgi 1753. 12.
Templeman, Curious remarhs and ubservations. London 1753. s. Albinus, Academicarum annolationum libri Vill. Leidae 1754-176s, 4.

Berryat, Recueil de Júmuires, ou Collection de pièces academijues Dijon $1754-1779.4$.

Hill, Botanical tracts. London 1762.8.

Kéralio, Collection de clifferrens morceaus etc. Paris 1763. 19

Alleon du Lac, Mélanges d'histoire naturelle. Lyon 1763-1765. \&

Gleditsch, Vermischte physihalisch-botanisch-öonomische Abhanl]ungen. Halle $1765-1767.8$.

- Turmischte Bemerknngen aus der Arzneiwissenschatt. Kraulerlehre und Oekonomie. Lejpzig 1768.8 .

- Vermischte botanische thatudlungen. Berlin $1789 \mathrm{~s}$.

Muenchhausen, Der Ilausvater. Hannover $1765-1774$. s

Unzer, Sammlung hleinel Schriften. Kinteln und Leipzig 1766-1769. 8.

Barbeu-Dubourg, Le botaniste français. Paris 1767. 8.

Titius, Gemeinnutzige Aly handlungen. Leipzig 1768 . \&.

Guettard, Memoires sur differmtes parties des sciences al arts. Paris $1768-1783.4$.

Hammer, Samling af botaniske aflıandlinger. Christania $1769 . \wedge$.

Scopoli, Anni historico-naturales. Lipsiae 1769-1772. 8.

- Dissertationes all scientiam naturalem pertinentes, l'rog:te 1772.8.

Bechmann, Pluysthaliselı-ohonomische Bibliotheh. Gottingen 1770-1805. \&.

(Moscali) Dissertazioni sopra nna gramigna. Mlano 1772. 4

Schrank, Beiträge zur Naturgesehichte. Leipzig 1776. s.

Jacquin, Mliscellanea austriaca ad botanicam, chemian et historiam naturalem spectantia. Vindobonae $1778-1781.4$.

- Collectanea ad hotanicam, chemiam et historiam naturalem spectantia. Vindobonae 1786-1796. 4 .

Beclmann, Beitrige zur Geschichte der Ertindungen. Juipzo 17801786. 8.

Mueller, Kleine Scluriften. Dessan 1782.8.

Roth, lieiträge zur Botanik. Bremen 1782-1783. 8.

Reichard, Sylloge opnseulorum hotanicorum. Francofnrti a/s]. 1789. \$. . Schmidel, Dissertationes botanici argumenti revisae rt recusae. Erlangae 1783.4 .

Born, Physikalische Arbeitea der eintrachtigen. Freunde in Wien. Wien 1783-1788. 4.

Jngenhousz, Vermischte Schriften. Wien 1784.8.

Miscellanea physico-medica. Viermae 1795. \&

Belleval, Opuscules. Paris 1785.8 .

Secondat, Némoires sur l'histoire naturelle. Paris 1785. Voliu.

Vurray, Opuscula. Goettingae 1785-1786. 8.

Sestimi, Opuscoli. Firenze 1785. 12. - Berlino 1807. \$.

Linné, Systema plantarum Europae, curante Gilibert. Coloniae Allobrogum $1785-1787.8$.

Bernard, Némoires à l'histoire naturelle de la Provence. Paris $1787-$ 1788. 12.

Ehrhart, Beitrige zur Naturkunde. Hannover 1787-1792. 8.

I'icco, Nelethemata inauguralia. Augustie Taurinornm $1788 . \&$.

Roenter, Magazin fur die Botanik. Zurich 1787-1790.8.

- Nenes Nagazin fur die Botanik. Zuriclt 1794.8.

_ Archis fur die Botanik. Leipzig 1796-4805. 4.

Usteri, Annalen der Botanik. Zorich und Leipzig 1791-1800. s.

IIoppe, Botanisches Taschenbuch. Regensburg 1790-4811. \&.

Usteri, Delectus opusculorum botanicorum. Argentarati 1790-1793.8.

Ludwig, Delectus op)usculorum ad scientiam uaturalem speetantium. Lipsiae 1790. 8 .

Baumann, Niscellanea medico-hotanica. Nlarjurgi 1791. 8.

Link, Annaleu der Naturgeschiclite. Gottingen 1791. 8.

Nayer, Sammlung physihalischer Aufsatze. Dresden 1791-1798,.

Schriften der regensburgischen betanischen Gesellschaft. Regensburg 1792. 8 .

( Reich) Magazin des P'llanzenrejches. Erlangeu 4793. 4. 
Comparetti, Riscontri lisiro-lutanici. Padova 1793.8.

Borlihausen, Kheinisclies Magazin. Giessen 1793. 8

Virdhoig, Sammlung zerstrenter Abandlungen uher hotanisch-ohonomischo Ciegenstánde. Leipzig 17y3-1797. 8.

Link, Lissertationes botanicae. Snerini 1795. 4.

ichmidt, Sammlung plysihalisch-ohonomischer Aafsatze. I'rag 1795. . .

Schrank, Sammlung naturhistorisclier Aafsátze. Narnberg 1796.8.

Roemer, seriptares de plantis Jispanicis, lusitanicis, brasilinnsibus. Norimbergae 1796.8 .

Cavanilles, Coleccion de papeles solure controversias butanicas. Madrid 1796. 8

Poirre, Oenvres cumpletes. Paris 1797.8.

Camerarius, Opuscula buanica, ed. Milian. Iragate 1797. $\mathrm{x}$.

Smith, Tracts relating to natoral history. Lonton 1798.8.

Thunbery, Lissertationrs academicae Lpsaliate habitae, edid. Persoon (ioctlingae $1799-1801.8$.

schrader, Journal fur die Botanih. Gotlingen 17y9-1803. \&.

Neues Journal for die Bolanih. Erfurt 1806-1810,8.

Wibel, Beitráge zur Beförlerung der Pllanzenkunde. Frankfurt a/M. 1800.8 .

Viviani, Annali di botanica. (Annali botanici.) Genova 1802-1804.4

Hoffmann, Plyytograplische I3latter. liuttingen 1803. \&

Ilaworth, Miscellanea naturalia. Londini 1803. 8.

Villars, llémoires etc. (Paris 1804.) 8.

Weber und Molr, Arelsiv fur die Naturgeschichte. Leipzin iso4. 8.

Beirage zar Naturkunde. Kiel 1805-1810. \&.

(Koniy) Tracts relative to hotany. London 1805. 8 .

Koniy et sims, Annals of botany. London $1805-1806.8$.

Hocsster, Botanische Blatter, herausgegeben ron Maycr. Ilamburg 1806.8 .

(Descaux) Juurnal de bolanique. Paris $1808-1814$. VI voll. 8 .

Roemer, Collectanea ad ommem rem botanicam spectantia. Turici 1809. 4

Re, Annali dell agricoltura del regno d'Italia, 1809-1814.0.

Auberl du pelit-Thouars, Mélanges de botanicjue. Paris 1811.8.

Lagasca, Anenidades naturales de las Españas. 1: Orihuela 1811.4. 11: Madrid 1821. 4.

(Rafinesque) Specchio delle scienze. Palemo 1814.8.

Roubieu, Opuscules l'anatomie et d'histoire naturelle. Montpellier 1816.8 .

sprengel, Schrader und Link, Jahrbucher Jer Gewachskunde. Inrlin $1818-1820.8$.

sprengel, Neue Entdechungen. Leipzig 1820-152z. s

Bertoloni, Amoenitates italicac. Bononiae 1819. 4.

Seringe, Musce helvetịoe d'histoire naturelle, partie botaniggue. Museum elc. Bern (1818-) 1823.4.

- Milanges hotaniques. Berne, Geneve et Lyon 1818-1831. \$.

Hoppe unl Furnrohr, Flora oder allgemeine botanische Zeitung. Jahrg. 1-33. Regensburg 1818-1850. S.

Nees von Eseubeck, Ilorae playsicae berolinenses. Bonnac 1820. folio

Trallinick, Botanisches Taschenbuch. Wien 1821.8

Treviranus, Vermischte Sibriften. Bremen 1821.4.

Presl, Deliciae pragenses. Pragae 1822.8

Withering, Miscellaneous tracts. Lundon 4822.8

Schlscheylow. (Thes no. 9348.)

Bronon, Vermischte botanische Schriften, herausgegeben von Nees von Esenbeck. Nurnberg 1825-1834. \&

Cassini, Opuscules phytologiques. I’aris 1826-1834, \&.

Horelli, Biblioteci agravia. Nilano 1526-1839. XXill boll. 8 .

Schlechtendal, Linnaca. Lin Journal fur die Botanih. Band I-XXIV. Halle $1826-1850.8$.

Trauletter, Dic Quatember. Mitau 1829-1830. 8.

Seringu, Bullelin botanique. Genève $1830(-1832)$. s

Deserax, Opuscules sur les sciences naturelles. Angers 1831. 8

Rafinesqúe, Atlantic Joumal. Philadelphia 1832-1833. 8

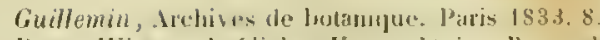

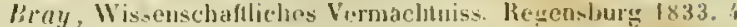

Hooker, Compranion to the lsotanical Nagazine. I.ondun 1835-1836, 8

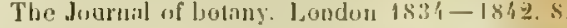

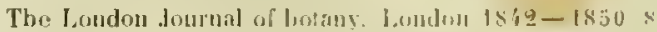

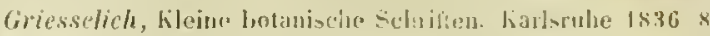

Jartius, keden und lintige. Suttwast 1838. s. (ditnice.)

Lindbhom, Botanisha opsater' Luml 1838 . \&

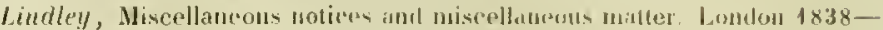
1840. 8 .

Knight, A selection fron his physiological and lorticultural paper's. London 1841.8.

Horren, Prénices (Études) d'anatomie el de plyysiologie végrétales. Bruxelles 1841.8

Schramm, Mittheilungen ulser Flora. Dresten 1841-1843. gr. K

Lindblom, Botanisha notiser. Lund $1841-18146.8$

Wrallrolh, Beitrage zur Botanih. Loipzig 1842-1\$44. Hr. K.

Fries, Botaniska Utllygter. Epsala 1843. 8.

Mohl und Schlechtendul, Bolanische Zeitung. Jahrgang I-VIll Berlin $1843-1850.4$.

Luxford, The Phytologist. London 1843. 8.

Schleiden, Beilráge zur Botanik Gesamnelte dufsátze. Leipzig 1444.8.

Parlatore, Giomale botanico italiano. Firenze 1844-1846. s

Schleiden und Taegeli, Zeitschrift fur wissenschaftiche l'otanih Zurich $1844-18 i 6.8$

Mohl, Vermischte Schriften botanischen Juhalts. Tubingen 1845.

Duchartre, Revue botanique. Paris $1845-1846.8$.

Mornschuch, Archiv shandinavisclıer Beitrage zur Naturgescluichte. Mreifswald $1845-1850.8$.

Rabenhorst, Botanisches Contralblatt fur Dẹtschlaud. Leipzig 1846. \$.

Iriese, Dozy en Molkenboer, Nederlandsch kruilhundign archief. Leyden 1846.8 .

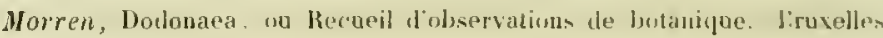
$18 \div 7.8$

\section{Lexica varia botanica.}

Duchesne (Leodegarius a Quercu), In linellium de surpibus epitone. Paris 1539. 8. - Cadomi 1541.8.

Fusch, Plantarum unniun nomenclaturae. Parisiis 1541.8 .

Gesner, Catalogus plantarum latine, graece, germanice w gallice. Tiquri 1542.4 .

_ Herbarum nomenclaturae Dioscoridi adscrigtae. In ejus a Catalogiss etc. Tiguri 15:2. 8. p. 146-158.

hyberus, Lexicon rei herbariae trilingue. Argentinae 1553. .

linitandinus, Conjectanea synonymica plintarum. Impr. cum Srhent ron Grafenberg Horto patavino. Francofurti 1600.8. P. $27-93$.

Franke, Speculum botanicum. Lpsaliae 1638. 4.

Lambertus Vossius, Lexicon novum plantarum tripartitum. Impr. cum Boetio de Boot. Bragis 1640. 4 .

Joncquet, Stirpium obscurius denominatarum mplicatio. Parisiis 1659.4. Ambrosiuns, Phytologia. Bononiae 1666. folio.

Franke de Franckenau, Lexicon vegetabilium usoalium. Argentorati 1679. 12.

germanice.)

Leimery, Dictionnaire iles drogues simples. Paris 1698.4. - il). 1759.4

Peine, Worterbuchlein oler Gartncrey. Leipzig 1713. s.

(Alexande $)$ Dictionnaire botanique ef jharmaceutique. Paris 1716. s ib. 1817 s.

Bradley, Dictionarium holanicum. London 1728. 8.

Burggrate, Lexicon undicum universale. A-B. Francofurti 1733. Folio, 
Miller The gardeners and florists dictionary. London 1724, 8.

The garteners dictionary. London 1731. folio. - Ed. IX. by Thomas Vartyu. London 1797-1804, folio.

(hollandice, germanice, gallice.

The gardener's dietionary abridged. London 1735. \&. - London 17714. Herinanice.

Probst, Wurterbuch. Leipzin 1741, s

Monti, Plantarum gemera. In ejus "Indicess elc. Bonsmiae 1753. 4. 1) $1-76$

Dictionnaire universel d'agrieulture el de jardinawe. Laris 1751.4

Limbe, Nomenclator botanicus. Holmiae 1759.4

Valmont de Bomare, Dictionnaire raisonne universed d'histoire naturelle. Paris 1764. S. - Ed. V. Paris 1800.8.

(ilatice, hollandice.)

Monteiro, Diccionario portuguez dis plantas. Lisboa $1765 \mathrm{.}$.

Dictionnaire du jardinage. Paris 1767.12.

Oeder, Nomenclator botanicus. Copenhagen 1769. 8.

Mitne, A isutanical dietionary. Louton 1770. 8. - Ed. 111: ib. 1805. \&.

bicks, The new gardeners alictionary. London 1771. folio germanice.

Dietionnaire de la matiere medicale, Paris 1773. $\mathrm{x}$.

( (imelin) Onomatologia botanica completa. Frankfurt 177z-1778. s.

(Reuss) Dictionarium hotanicum. Leipzig 1781. 8.

Meyer, Lesicun botanicun. (rossice.) Moskau 1781-1783. 4

Je la March (et Poirel) Eucyclopedie méthodique. Botanique. Paris 1783 $-1817.4$

1823.4.

Kluk, l)yheyonarz roślinny (Lexicon botanicum). w Warszawie 1786. \$. (Senebier) Jietionnaire des forets et bois. Paris 1790-1815.4.

Bryant, A dictionary of the ornamental trees and plants. Norwich (9790.) 8 . Graefer, A descriptive catalogue of plants. London (1791.) 8.

Dictionnaire des plantes usuelles. Paris 1793, 8.

Raemer, Encyclopadie fur Gártuer. Tuhingen 1797.8

Langstedt, Allgemeines botanisches Repertorium. Nüruberg $1801-1805.8$.

Dietrich, Vollständiges Lexienn der Gartnerei und Botanik. Berlin 1802 1835. 28 Bande. 8 .

- Handlexicon der Gárınerei und Botanik. Berlin 1824-4830, 8.

1)ictionnaire des plantes alimentaires. Paris 1803. 8 .

Nouveau cours complet ou Dictionnaire raisonné d'ayriculture. Paris 1809.8 .

Sonnimi, Veillard et Cheralier, Vocabulaire d'agriculture. do lntanique etc. Paris $1810 . \$$

Jemistedt, Nomenclator botadicus. Eisenhergae 1810.8

Soureau dictionmaire d'histoire naturelle. Paris $1816-1819$. *

Dictionnaire des sciences naturelles. Paris $1816-1830.8$.

Bertani, Nuovo Dizionario di botanjea. Mantova $1817-181 \%$.

The Cyclopraedia; by Rees. London 1819.4

J)ictionnaire classį̣ue d'histoire naturelle, dirigé par Bory de st. Tincent. Paris 1822-1831.8.

Kachler, Fucyclopadisches Pflanzenworterbuch. Wien 18ะ9. 8.

Wérat et lle Lens, Dictionnaire universel de matiere médicale. Paris 1829 $-1834.8$

- Inhon, llandworterbuch der pharmaceutisclien Nonenklaturen. Nurnberg $1 \times 33,8$.

lavassen, Dictionnaire universel de botanique agricole, medicale ot industrielle. Paris 1836. 4.

Keith, A botanical lesicon. London is38. 8

Drapiez, Dictionnaire classique des sciences naturelles. Bruxelles 18381845.8 .

Kachler, Aphabetisch-scientifisches Samenverzeichniss. Wien 1839.8

Paxton and Lindley, Botanical pocket-dictinnary. London 1840. 19.

Steudel, Nonenclator hotanicns. Ed. Il. Stuttgardiae $1840-1841$, gr. 8 .

Pritzel, Thes lit. bot
Heymhold, Nomenclator botanicus hortensis. Dresden 1840-1848. gr.8. II inkler, Real-J,exicon der medizinisch-pharmaceutischen Naturgeschichte un! Rohwaarenhunde. Leijrig 1840-1842.8.

Dictionaire uniyersel d'histoire naturelle. Paris 1842-1850.8.

\section{Encomia botanices.}

Estius, laus rei herbariae. Imjer. cum Iodoens Hist. stirp. Pempt. Antwerpiae 15\$3. folio.

Gratarolo, Pracfatio de rew plantariae origine, progressu et utilitate. Argentorati 1563,8 .

Alberti, Tres orationes. (1. De cogutitiono herbarum.) Norimbergae 4585.8 . Ballus, Oratio prima hotanologiea. Regiomonti 1601. 4.

(Colius) Syntagma herbarum encomiasticnm. Lugduni Batav, 1606.4.

Du Val, In pliytologiam praefatio paraenetica. Paris 1614.4.

Hueller", De plantarum cogritione medico necessaria. Basileae 1616.4.

I'ngins, Encomion historiate plantarum seu oratio te plantis. Upsaliae 1636. 4 .

Vesling, De cognato anatomico et Dotanico studio. Patavii 1638. 4.

Punarolus, De uecessitate hotanices. Romae 1643.4.

lesling, Paraeneses ad ren lierbarian. Ju ejus: Opobalsami vindiciae. Patavii 1644. 4. p. 61-108. - Alpini Hist. natur. Aegypti Il, p. 85 -146 .

Ursimns, Programma ad denonstuationes botanicas. Lipside 1662.4.

Melvigius, De studii botsuici nobilitate. Lipsiae 1666. 4.

Borrich, Oratio de experimentis lotanicis, habita anno 1675. In ejus: Dissertatiunes ete. Havniac 1715.8.1, p. 6-62.

Dorstenius, Rei herhariao commendatio. Narpurgi 1675.4 .

Franke, Programmata ad herbationes annorum 4677-1687. Heidellergar $1677-\$ 687.4$.

Redunt in ejus: Fora francica 1685. p. 1-90.)

hirause, De studio botanico et chenico. Jenae 1681.4

Schelhammes, Programma ad rem herhariam excolendam. s. 1. 1681. 4.

Ten Rhyne, Iiscursus de chymiae et botanicae antiquitate et dignitate. In ejus: De Arthritide, Lomlini 1683. 8. p. $225-269$.

Schrader, Progranma quo studiosi an exercitia botanica excitantur. Helmstadii 1690 .

Vater, Programint invitatorium ad herbationes. Wittebergae (1692.) 4

Denyau, Oratio panegyrica de plantis. Paris 1695.4.

II aldschmiedl, Progranmata al herbationes. Kiliae 1696-1702. 4.

Triumfelli, Praelusio ad publicas herbarum astensiones. Ronae (1700.) 4.

Gakenhols, De vegetabilium praestantia et indole cognoscenda. Helmistarlii 1706.4 .

Commelym, Oratio metrica in laudem rei herbariae. Amstelaedami 1715.4.

Fairfax, Oratio in laudem botanices. London 1717.4.

- Oratio apologetica pro re herbaria. ib. 1718. 4.

Crell, Oratiuncula de studii botanici praestantia. Lipsiae 1723. ?

Loyen, Oratio qua jucunda et necessaria commendatur doctriua botanica. Lugduni Batavorum 1729.4.

Alherti, De erroritus in pharmacopoliis ex neglecto studio botanico. Ilalae 1733.4

browallius, the introducenda in scholas historiac naturalis lectione. In: Limie, Critica. Lugiluni Batavorum 1737. 8 .

Gurçon, Reponse a une question, si ia théorie de la botanique est nẻcessaire a un médecin. Narbonne 1740. 4.

Barrère, La connaissance des plantes est-elle nécessaire à un médecin? Narbonne 1740.4

Ilallerius, De historiae naturalis usu medico. Upsaliae 1740.4.

llenrici, Animadversiones de laude et praestantia vegetabilium. Havniae 1740.4. 
Limué, Oratio qua peregrinationum intra patriam asseritur ancessitas. Ipsatiac 1741.8

(anglice.

De curiositate naturali. IIolmiae 1748.4.

Haller, Oratio de botanices utilitate. In rjus: Opuscula. Gorttingue 1749 8. p. $153-166$.

Cointrel, Oratio in Judem botanires. Insulis 1749.4

Discours sur la botanique. I.ille 1750. 19.

Stehelimus, Theses miscellaneae. Basileac 1751. 4.

lambergen, De amico historiae naturalis cum medicina conubljo. Franequerae 175 \% folio.

Encomia botanices. Groningae 1754. 4.

Ilerwech, De praestantia studii historici naturae. Iolmiae 1759. 4.

Limne, Quaestio historico-naturalis: Cui bono? Cpsaliae 1752.4. (suecice.)

Alston, Dinsertatio de re herbaria. In ejus: Tirocinium. Edinhurgi 1753. 12. (anglice.)

Ilesslén, De usu botanices morali. Lond. Goth. 1755. 4.

Zieger, De vita inter plantas optimo sanitatis tuendae praesilio. Lipsiac 1757. 4 .

Kalm, Studlium historiae naturalis informatori necessarium. Aboae 1757.4.

Nietzki, De studii botanici ratione etc. Halae 1758. 4

Hill; Usefulness of a knowledge of plants. London 1759.8.

Limne, Tal vid teras Kongl. Majesteters hoga nárvaro. Ypsala (1759), folio (latine.

Nonne, De botanices usu. Erfordiae 1763. 4.

Kretzschmar, Abhandlung vom Nutzen der Krăuterlehre. In ejus: Beschreibung der Mlartynia. Friedrichstadt (1764.) 4. p. 1-9.

Murray, De amico insectorum scrutinii cum re herbaria connulio. Goellingae :764. 4 .

Koelpin, De botanices praestantia et dignitate. Gryphiswaldiae 1766.4

Linné, Necessitas promoveodae historiac naturalis in Rossia. Ipsaliac 1766.4.

Usus historiae naturalis in vita communi. Upsaliae 1766.4.

Iandelli, De studio historiae naturalis necessario. Olisipone 1768.8.

Ludwig, De rei herhariae studio et usu. Lipsiae 1768.4.

Ilelg (potius IIermann), De botanices systematicae in medicina utilitate. Argrentoráti 1770. 4.

Hottboell, Botanikens utstrakte nytte. Kiobenhavil 1771. 8.

Peirson, on the connection between botany and agriculture. In Hunter, Georgical essays. London 1772. S, voll. HI. 7-24.

Vayer, lom Nutzen der Botanik. Greifswald 1772. 4.

Trozeluus, De sacerdote botanico. Lond. Gotl. 1772. 4

Weigel, Vom Nutzen der Botanik. Greifswald 1773.4

Cinnner, Discursus de botanices utilitate. In ejus: Tentamen etc. Hafniac 1773.8 .

Linne, Deliciue naturae. Tal hållit etc. Stockholm 1773. 8. - ib. 1816.8. (latine.)

Weiss, Veber die nutzbare Eiarichtung ahatemiseher Vorlesungen in der Botanik. Gottingen (1774.) 4 .

Schrofler, Gedanhen rom Nutzen der Botanik in Anschung der Leibesbewegung. Halle 1774. 4

Murande, Discours prononce le 29 Mai 1774. (Journal de physique, IV. $190-204.1$

Iticr, Oratio de utilitate atque jucunditate botanicac. Monspelii 1778. 4.

Ilaggren, De oeconomico historiae naturalis usu. Lpsaliae 1780.4.

Durruin, Discours sur la hotanique. In Delarbre, séance publique. Clermont-Ferrand 1782. 8, p. 7-37.

Roth, Widerlegung einiger Vorurtheile wider das Studium der Betanik In ejus: Beitrăge. Bremen 1783. 8. If , 1-13.

Brugmans, Orationes de accuratiori plantarum indigenarum notitia etc. Lugd. Pat. 1787.4

Liljeblad, De historia naturali ordini ecclesiastico necessaria. Upsaliae $1788-1789.4$.

Chiarelli, Discorso. Palermo 1759. 4.
Bodschied, Wre necessitate et utilitate studii hotaniri. Marpurgi 1790.8 Geuns, Oratio de instanrando inter Batavos studio lotanico. Trajecti a/ 1 hh. 1791.4

Baumann, De utili ac honesto botanices studio ex monumentis reterum In ejus: Miscellanea. Narburgi 1791, 8, p.1-16.

Kohlhaas, Rede an 1. Sitzungstage der regensburgischen hot. liesellschaft. (Schriften der regensb. Ges. 1, 1-is.)

Martius, Celser den lVerth riner systematischen Pflanzenhonntuiss. (Schrifton der regronsh. Ges. I, 23s $35-253$ )

Thumbery, De seientia botanica utili atjue juennda. Ljpsaliae 1793. \&

Nocca, In botanices commendationem oratiu. Turici 1793.8.

Tronffant, Discours sur lit botanique. Severs. an ll. \&.

Heknstroem, De usu historiac naturalis ocenomico. Gryphiac 1796.4

Draparnaul, hiscours sus les avantages de l'histoire niturenle. Inontpellier, IX. 8

_. Sur l'utilité de l'histoire naturelle. Hontpelliar, XI. 8.

Brisseru-Mirbel, De linlluence de l'histrige nuturelle sur la civilisation. Paris, an L. (1801.) 8 .

Nocca, Monitum eorum gratid editum qui al botanicam introluci volunt (Turici 1800.)8.

Prujade, Sor l'utilite de la botanique dans la medecinr. Monpeltier, an XIII. 4 .

II"enderoth, Ueber das Studium der Botanik. Narlure 1805.8

Gasc, Discours sur les avantages de l'étude de la hetanique. P'aris I\&10. 8 Saint-llilaire, Répronse aux reproches, que les gens du morele font a l'étude de la botanique. Paris 1811 . $\$$.

Retzıs, Tankar om uatural-listoriens nytta och varde. Lumd 1814. \&

Van de Woestyne, Diseours (sur la Iıotaniqque). Gand IR14. 8

Witmann, Rede als Einteitung zur Mycotheca austriaca. Wien 1816.8.

Breda, Oratio de historiae naturalis studio. Leovardiae 1818.4.

Frost, Orations before the medico-botanical society. Lombon 18251828. 4 .

Duvernoy, Discours. Strasshurg 1828. 8.

Daudirac, Jtilité de la batanique en médecine. Paris 1828 . 4.

(Fèe) Discours butanigue. Strassburg 1834. 4.

Daubeny, Inaugural lecture on the study ef botany. Oxford 1834. 8 .

Ecorchard, Cours de botanique au jardin des plantes le Nantes. Nantes 1836. \&.

Unger, Ueber das Studium der Botanik. Grátz $1 \$ 36.8$.

- Die Schwierigkeiten und Lnannehmlichkeiten des Studiums der Botanik. (Gritz) 1837.8

Visiani, Della utilita ed amenit delle piante. Padova $1837 . \mathrm{s}$.

Francis, I discourse. New York 1841.8

Fries, Äro Naturietenskaperna någol Buldningsmedel? Lpsala 1842 \& germanice.

Vriese, Oratio de re hertaria excolenda. Lugduni Bataverum $1 \$ 45.8$. .

\section{Nomina plantarum.}

Peucer, Vocabula ... frugun, leguminum, alerum et fructum communium. Vitebergte 1556.8 .

Rosenbach, Quatuor indices physici. In Alstedii Lexico philosophico. Her-bornae 1626. 8. p. $1925-3250$

Shimner, Etymologicon botanicum, sell explicatio nominum (anglicurum) omnium vegetahilium. Londini $16 \bar{i}$. folia.

Cleyer, Herbarium parvum sinieis vocabulis inlicis insestis constans. Francofurti 1680.4

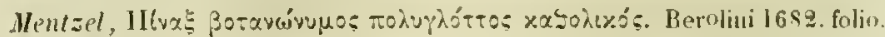

Hoffmann, Exercitationes de Lomonymis. Trajecti a/Rlı. 1689. folio.

Rohr, Auf was fur Art in dem Reich der Gewachse die schweren und undeutlichen Benennungen abzuschaffen? In ejus "Tractat" etc. Coburg 1736. S. P. 157-342 
Limne, Critica botanica. Lugd. Bat. 1737. 8. (Funtamenta botanica, ed. Gilibert. vol. IJI, p. 363-594.)

Heister, Ve nomisum plantarum mutatione utili et noxia. Helmstadii 1741.4. - Regular de nominibus plantarum a cel. limnaei longe diversae In ejus "Systema" etc. Melmstadii 1748. \$. p. 23-48.

Boehmer, De plantis in Cultorum memoriam nominatis. Wittebergae 1770. 4. - Lipsiae 1799. 8. (Millin, Nag. encycl. IV, 271-278. V, 46$73,241-264$.

I'laner Tersuch einer teutschen Nomenklatur der Limeischen Gattungen. Erfurt 1771. 8.

Murray, Vindiciae nominum trivialium stirpibus a Limneo inpertitorum. Grottingae 1782. 4 (Opuscula JJ, 293-332.)

Bergeret, Phytonomatotechie universelle. Paris 1783-1784. folio.

Lidbeck, De plantis in Suecorum memoriam umminatis. Lundac 1799. 4.

Noccu, Nomina plantarum italica et corrupta Lombardiae. (Turici 1793.) S.

Vibory. Forsog til systematiske danshe navne af indenlandske planter. Kiwlienhavn 1793. S.

Nemnich, Allgemeines Polyglottendexition der Naturgeschichte. Leipzig $(1793-1798)$.

Olafsyn. Explicatio nominum plantarum Islandiae vernaculorum in Act. soc. sc. Islankl. vol. I, p. $1-19$.

Imbodik, Norum dictionarium botanicum rosso-Jatino-germanicum. Petrotropoli 1789. 4. - ib. 1808.4 .

Botanisches Worterbuch. St. Peterslurg 1797. 4.

Beckmum, Lexicon botanieum. Goettingen 1801. 8.

Boehmer, Lexicon rei herbariae tripartitum. Lipsiae 1809.8.

Berger. Anweisung zur richtigen Aussprache der Pflanzennamen. Leipzig 1804.8 .

Jirasek, Beiträge zu einer botanischen Provinzial-Nomenklatur von Salzburg, Baden und Tirol. Salzburg 1806. 4.

Targioni-Tozzetli, Dizionario botanico italiano. Firenze 1809. 8. - Ed. II: ib. 1825.8 .

Theis, Glossaire de Jotanique. Paris 1810.8. (ilalice.)

Relzilts, Observationes in Criticam botanican Limnaet. Lundae $18 \$ 1.4$

Gallizioli. Jizionario botanico. Firenze 1812.8.

Monli, Dizionario botanico veronese. Verona 1817.8 .

Homilton, Notices concerning plants of India and their Sanserita nanes. Edinburgh 1823. 4.

Fre, Essai historique et critique sur la phytonymic ou nonenclature végétale. Gand 1825.8.

IIoll, Worterbuch deutscher Pllawzennamen. Erfurt 1833. gr. 8

Guibourt) Nomenclature synonșmicjue créole et botaniøue des arbres de la Gualeloupe. Paris 1834.8 .

Unhl. Welche Intorital soll den Gatlungsaamen der Pllanzen beigegeben werden? Tühingen $1 \$ 36.8$.

Mener, Vergleichenule ErkJarung eines Pflanzenglussars. Konigsherg 1837.4.

- Preussens Pllanzengattungen. Könissherg 183912

foenc, Veher Furm und Bedeutung der Pllanzennamen in der deutschen Sirache. Munster 1840.4 .

Ineller. Botanisch-prosodisches Worterhuch. Brilon 1840-1841.4

Wuldbruehl, Die deutsclien Pflanzennamen. Lerlin 1841.8.

Fries, Ofver Vasternes Namn. Ipsala 1842. \&.

les Elanys, Liste des noms populaires des plantes de l'Auhe. Paris 1845.8

Brossard, Phỵtonomie genérale. (Manuscript! of Thr's. lit. bot. p. 34.)

Morit: $i$, Dictionnaire des noms vulgaires te plantes. (Manuscript! cf. Thes. lit. bot p. 202.)

\section{Mcthodus studii botanici.}

Rulleck, De fundamentali planarum notitia rite acquirenda. Ultrajecti a/Rls. 1690.4.

Schelhammer, De nova plantas cognoscendi nuethodo. s. I. 1698. 4.
Schethammer, De studio botanico recte instituendo. Kilonii 1705.4.

IIollebins. De methodo herbas Justrandi. Basileae 1711.4.

I!eister. De studio rei herbariate emendando. Ilelmstadii 1730.4.

Haller, be mediodico studio botanices absque praeceptore. Goettingar. 1736. 4 .

Schaeffer, Epistola des studii botanici faciliori ac tutiori methodo. (Batisbonae 1758.) 4. (gallice.)

falm, Om saltet at ratt tracktera historia naturalis. Åbo 1760. 4

Ludwiy, De rei herbariae studio. Lipsiae 1768. 4.

Baldinger, Ueher das Sudium der Botanik. Jena 1770.4.

I'eiss, Unber die nutzbare Finrichtung ahademischer Vorlesungen in der Bolanik. Guttingen 1774. 4

Schrank, Ueber die Weise, Naturgeschichte zu studiren. Regensburg 1780.8.

- Anleitung die Naturgeschichte zu studiren. Munchen 1783.8.

- Cogitata dle mothodo botanicam docendi. (Roemer, Magazin XIJ. $3-13$.

Suctow, Neber das Studium der angewandten Botanik. (Vorles. der hurprälzischen pliys. okon. Ges. II, 125-156.)

Usteri, Ueber Vortrag und Lehrmethode der Botanik. (Roemer, Magazin II, 3-15.)

Ebermaier. Ueber die nothwendige Verbindung der systematischen Pflanzenkunde mit der Pharmacie. Hannover 1796. 8

Tiltmamn) Ueber das Studium der Botanik. Pirna s. a. 12.

Villars, Noyens daccélérer les progrès de la botanique. Paris (1804.) 8

Lefébure. Méthorle signalementaire. Paris 1814-1815. 8.

(Trafienfelt) Ammarkningar on Natural-llistoriens larande. Stockholm 1818.8 .

Kalm, Sciagraphia studii butanici. Aboae 1821. 4.

IVimmer, Veber den Interrich in der Naturgeschichte. Breslau 1829. 4.

Sopclelund, Veher den Unterriclat in der Pflanzenkunde. Koesfeld 18324.

Helm. Quaestiones botanicac de methodo physicohistorica Viennae 18358

\section{Termini botanici.}

Marlyn, The first lecture of a course of botany. London 1729. 8

(_._-) A short explanation of the technical words. s. J. et a. 4.

IIilson, Botanical dictionary. In ejus "Synopsis" etc. Newcastle 1744.8.

Murray, Enumeratio rocalulorum quorundam, quibus antiqni linguae la-

tinae auctores in re herbaria usi sumt. Holmiae 1756. 4.

Limé, Velineatio plantac. Upsaliae 1758. 8.

Lipp, Enchiridion botanicum. Vindubonae 1765. 8.

Quer, Diccionario en que se explican los terminos. In ejus "Flora españolas. Madrid 1762. 4. vol ll. p. 1-64.

Limé, Termini lotánici. Upsaliae 1762. 4.

Berlienhout, Clavis anglica linguae botanicae. London 1764.8.

Dil Ilamel, Erklarung der Kunstworter aus der Botanik. Nürnberg 1766. 4.

Termini botanici. Elinburgi 1770. 8 .

Joerlim, Partes fructificationis. Lunlae 1771. 4. - ib. 1786. s.

Olafsyn. Temini botanici. Kiobenhavn 1772.8.

Leprs, Nomenclator Linnaeanus. In ejus aFlora Jerbornensis ». Ilerbornae 1775. 8.

Linne. Termini botanici. Hamburgi 4781. 8. - ib. 1787. 8. (suecice.)

Ortega, Explicatio quarundam vocum. In ejus "Tabulacn etc. Matriti 1783.8

Bulliard, Dietionnaire élementaire de botanique. Paris 1783. Folio. Eulition resu" et refondue par Kichurd. Paris 1812. folio.

lillars, Dictionnaire des termes de botanique. In ejus "Histoire des planles du Daupliué. Grenoble 1786. 8. vol. I, p. 1-111. 


\section{TERMINI BOTANICI}

Pereboom, Materia vegetabilis. Lugd. Bat. 1i87-1788.

Forster, Enchiridion. Ualae 1788. \&.

(Tormini botanici : p. 161-22' )

Perebnom, Systema chiracterum plantaruns. Iuggd. Bat. 1788. 4

Vandelli, Diecionario dos termos teclunicos. Comulra 1788.4.

Hiller, Hlenstration of the termini botanici of Linnacus. London 1789. 8 .

Necker, Coroliarium at Linnaei Mlilosophian holanicam. Neowedan 1790. 8.

Ehhart, Erhlarung der kuostworter in II achendorf's l'llanzensysten. (Beitrage Vl, 1-13.)

Hartyu, Thr languane of botany. Loodon 1793. 8. - Ed. III: London 1807. 8. (ct. Transact. of the Linn. soc. 1, 147-154.)

(Coppens) Terninologie botanicjue. Gand 1797. 8 .

llliger. Versuch einer vollstandigen Terminologie fur Thier- und Pllanzenreich. Helmstedt 1800.8.

(snecice.)

Borkhausen, Botanisches Worterbuch. Giessen 1797.8.

bietrich, Nachtrag zu Borkhausen's botanischem Worterhuche. Giessen 1816. s.

Houton-Fontenille. Dictionnaire des temes de botanique. Lyon 1803.8.

Philibert, Dictionnaire abrégé de botanique. Paris 1503.8.

Dictionnaire universel de botanique. I'aris 1804.8 .

Voigt, Handworterbuch der botanischen Kunstsprache. Jesı 1803. \&. ib. 4824.8 .

Hayne, Termini botanici. Berlin 1807. (1799-1812.) 4 .

Frege. Versuch eines allgencinen botanischen Ildndworterluchs. Zeitz 1808.8 .

Timelli, Jizionario elementare di botanica. Mantova 1809. 8.

Bertani, Osservazioni intorno al Dizionario dell' Tinelli. Nantova 1809. 8.

"Yitmann; Entwurf einer tabollarischen Darstellung der Teminologie. Wien 18128.

Nocca, Termini botanico-cryptogamici. Papiae 1814. 8.

IIayne, De coloribus corporum naturalium determinandis. Bornlini 1S14.4.

Schuster. Terminologia bolanica, Budae 1815. 8

Roemer, Versuch cines Worterbuchs der Terminologie. Zurich 1816. 8. Gérardin, Dictionnaire raisonné de botanique. Paris 1817. \&.

Syme, IVerner's nomenclature of colours with additions. 1821. 8 .

Bischoff, Die botanische Kunstsprache. Numberg 4822. folio

Leo, Botanisclse Kunstsprache. Berlin 1\$26. 8 .

Lloyd, Botanical terminology. Edinburgh 1826. s.

Schuu'mans stekhoren, Kruidkundig Kunstwoordenboek. Leyden 1826.8.

Dietrich, Terminologie der phanerogamischen Pflanzen. Berlin 1829. folio. - ih. 1838. gr. 8 .

(hollandice.)

Lecoq et Juillet, Dictinnnaire raisonoé des termes de botanique. Paris $1 \$ 31.8$.

Krueger, IIandworterbuch der botanischen Kunstsprache. Quedlinburg 1833. 8

Jourdan, Dictiomaire des termes usités dans les sciences naturelles. Paris 1834.8 .

Bischoff, Handluch der hotanischen Terminologie und Systemkunde. Nurnberg 1833-1844. 4 .

W_ Worterbuch der beschreibenden Botanik. Stultgart 1839. 8.

Fonseca, Diccionario de glossolngia botanica. Lisbaa 1\$41, 4.

Arrhenius, Utkast till vástrikets terninolugie. Ijsala 1842.8.

Taschenberg, llandbuch der botanischen kunstsprache. llalle 1843. 8

Krasper, Kurzer Grundriss der botanischen Ausdriche. Magdehurg 1845. 8 .

Langethal, Terminologie der beschrwhenden Botanik. Jena 1846. 8 .

\section{Artes botanicac.}

\author{
1. Germanicap.
}

Figulus. Dialogus, qui inscribitur lootinomedhodus. Colomite 1540.4

Tidicarus, Plytologia generalis. lipsiae 1582. 12

Gesner. De partilus et differentiis plantarun. In ejus a Talsulie collectizmumw. Tiguri 1587. 8. foll. 1-40.

Zalusiansli a Zaluzian. Methodi herbariae lihn tres. Jragar 159z 4

Moegling, Pracludia rei horbariae. Tubingae 1612. 4.

Fischer, Melbodus nova herharia. Brumopoli 1646.8.

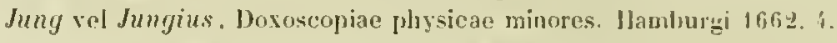

lsagoge phytoscopica. Hamlburgi (1678.) 4.

(Conjunction: Opuseula bolanico-plysica. Coburgi 1747. 4.)

Rollfinl, De vegetilbilibus in genere libri duo. Jonae 1670.4.

Mannemann. Methorlus enguoscendi simplicia vegelabilia. Kilonii 16774

foenig, Regnum vegetabile. Basileae 1680. 4. - ib. 1708. 4

11 elsch, Basis botanica. Lipsiae 1697. 12.

11ollebius, De mellsodo herbas lustranli. Basileae 1711.4

Falentini, Tournefortius contraclus. Francofurti a/M. 1715. folio

Camerarius, De botanica. Tuebingae 1717.4.

Relifeldt, Rudimenta botanica. In ejus "Hodegus " llalae 1717. . . . 4-17.

Meibom, Botanica generalia. Hehustiulii 1718.4.

Teichmeyer, Institutiones botanicac. Jenar 1731.8

Hecker. Einleitung in die Botanik. Halle 1734. 8.

Lulwig, Aphorismi totanici. Lipsiae 1738. 8.

Dercum, Fundamenta rei hesbariae. Wirceburgi 1742. 1.

Ludwig, Institutiones regni vegetabilis. Lipsiae 1749. 8. - ib. 1757. 8.

Ernsting, Prina principia hotanica. (Anfangsgrumle der Krétuterwissenschaft.) Wollenbuttel 1748. 8.

Bergen, De studio botanices methodice addiscendae. In ejus "Flora francofurtanas. Francofurti a/T. 1750 . 8. p. 1-38.

Ifaller, Dubia quaeditm ex Linnaei fundamentis hausta. I-V. Croettingae 1750-1753. 4. (Loefling, Literae ad Jlullerum. 1, p. 9- 17.)

Schacfer. De studii botanici faciliori ac tutiori methodo. Ratisironat (1758.) 4 .

- Isagoge in botanicam expeditiorem. Ratisbonac 1759. 8

Cranlz, Inslitutiones rei herbariae. Viennae 1766.8

Ifartmanu, Primae lineae institutionum botanjearum C'rautzii. Vindobonae 1766. 8 .

Astheimer, Plıytologia generalis. Neoburgi 1773.4.

Reuss, Compendium bolanices. Ulmae 1774. s. - ils. 1785. s.

(Schinz) Anleitung zu der Planzenkenntniss. Zurich 1774 . folio.

__ Primae lineae botanicae. Erster Grundriss etc. Turici 1775. folio.

Dieterich, Anfangsgrunde der Pflanzenkenutniss. Leipzig 1775. \&

Scopoli, Introductio ad historiam naturalem. Pragae 1777.8.

Augustin, Prolegomena in systena sexuale hotanicorum. Viennae 177. s.

IIill, Allgemeine Einleitung in die Botanik. Leipzig $1781 . \mathrm{K}$. (anglice.)

Lorenz. Grundriss der Botanik. Leipzig 1781. \&.

Scopoli, Fundamenta botanica. Papiace 1783.s.

Schkuhr, Botanisclses llandluch. Willenberg 1783-1803. 8. - Ed. II: Leipzig 1808.8 .

- Eochiridion hotanicum, ed. Schwaegrichen. Lipsiae 1s05. \&.

(1)

Well, Grunde zur Phanzenlehre. Wien 1785. 8.

Schrank, Anfangsgrunde der Botanik. Munchen 1785. S.

Jacquir, Anleitung zur Pllanzeukentuiss. Wien 1785.8. - ib. 1800. \& - ib. 1840.8

(italice.)

Suekow, Anfangsgrunde der Botanik. Leipzig 1786. S. - ib. 1797. \&.

Loewe, IJamlbuch der Krauterkunde. Breslau 1787. 8 
Batsch, Versuch einer Anleitung zur Kenntniss der Pflanzen. Ilalle 1787 -1788.8 .

Bochmer, Dispositionem plantarum in tabulis symopticis illustrat. Wittebergae 1789.4

- Tahularum synopticarum exem]la proponit. Wittebrgae 1790.4. Vecker, Corollarium ad philosophiam hotanicam Linnaei spectans. Neowedae 1790. 8 .

Gisefir, Theses botanicae in usum auditorum. Ilamburgae 1790. $\mathrm{s}$.

Vorbereitungen zur Naturgeschichte. Berlin 1790. 8 .

Fibig, Einleitung in die Naturgeschichtn des Pllanzenreiches. Mainz 1791. 8.

(W'elling) Naturgeschichte der Gouachse, Gotha 1791. \&

Hildenow, Grundriss der lirauterhunde. Berlin 1792. 8. - Ed. VH: ib. $183 \mathrm{~A} .8$.

(anglice, dianice.

Lohlhars, Eiuleitung in tie Krauterkunde. Nurnbers 1793. 8.

Der Botaniher. Jlatla 1793-1794. s.

Plenck. Physiologis et pathologia plantarmm. Viennae 1794. 8. Gormanice, gatlice, italicele.

Batsch. Botanih fur Fravenzimmer. Weimar 1795. \& (sallice, danice, succice.

Menck. Elementa terminologiae hotanicae et systematis sexualis. Viennae 1796. 8 . mermanice, Jispanice.

Bechstein. Naturgesehichte der Gewachse. Leipzin 1796. \&.

I'ohl, Botanischer linderfreund. Leinzig 1797.8.

Koch, Botanisches llandluch zum Selbstunterricht. Haghlolurg 17971798.8. - Ed. Il]: ib. 1824-1826.8.

Link, Philosophliae botanicac novae prodromus. Gorttingae 1798. \&.

Moench, Einleitung in die Pflanzenkunde. Marburg 1798. 8.

Naumburg, Lehthuch aler reinen Botanik, Hamburg 1798. 8.

Schmidt, Botanisches Jahrbuch fur Jedermann. Lunolurg 1799.8

Lurlwig, Hantbuch eler Botanik. Leipzig $\$$ \$ 00.8.

Medwig. Aphorismen aber die Gewächskundr. Leįzig 1800. \&

Ilerrmann, kleines Lehrbuch der Botanik. Ilamburg s. a. \&.

Ilummitzsch, Linne's Pflanzensystem. Dresclen s. a. 8.

Jichela $z$ zi, Compendiun regni vegelabilis. (froritii) s. a. \&.

Berger, Handbuch der Pflanzenkenntniss. Leipzig $180 \mathrm{I} .8$

Batsch. Grundzuge der Naturgeschichte des Gewichsreiches. Wrimar 1801.8

- Beiträge mul Lintwurfe zur pragmatischen Gesehichte des Gewachsreichs Weinar 1804.4.

Erdmam, Tabellarische Vebersicht der Botanik. Dresden 1802.4.

Sprengel. Inleitung zur Kienntniss der Gewàchse. Ilalle 1502-1804.8. (anglice.)

Einleitung in das Studium der kryplogamischen Gewächse.

Jalle 1804. 8 . (angfice.

UTeber, Anhang zu Sprengel's Einleitung in das Studium der kryptogamischen Gewachse. Kicl 1804.8.

Schrank, Grundriss einer Naturgesehichte der Pllnnzen. Erlangon 1803.8.

koth, Arweisung Pllanzen zu sammeln und zu bestimmen. Gotha 1803.8

Gindel, Anleitung zur Pflanzenkenntniss. Rira 1804. 8.

Beruhardi, Anleitung zur Kentniss der Pflanzen. (Handluach der Botanik.) Firfuirt 1904.8

Londes, llandbuch der Botanik. Gottingen 1804. S

Hilldenow, Anleitung zum Selhststudium der Butanik. Berlin 1804. 12. Ed. W: il. 1832.8 .

(hollandice.)

Moessler, Taschenbuch der Botanik. Hamburg 1805. 8.

Piepenbring, Lebrbuch der Fundamentalbotanik. Gotha 1805.8.

V'est, Mamule botanienm. Klagenfurti 1805.8

Juch, Anleitung zur Pflanzenkenntniss. Nunchen 1806.8.

Schwaegrichen, Anleitung zum Studium der Botanik. In IJeyne, Pllanzenkalender. Leipzig 1806.8 .
Voint, Darstellung des Jussien'schen Systems in Taliellen. Leipzig 1806. Jolio.

Dennstedl. Das Gewáchsreich. Weimar $180 \bar{t}$ gr. s

Crome, Botanischer kinhlerfreund, Gottingen $180 \bar{\tau}-180 \mathrm{~s}, 12$.

Voigt, System der Bolanik. Jena 180 s. 8.

Meinecke, Der Botaniker obue Lehrer. Halle 1809. 8.

Nerrem, llandluch der Pllanzenkunde. Marburg 1809.8

(Wilhelm) Unterhaltungen aus iler Naturgeschichte: Das Pflunzenreich. Augsburg 1810-1822. 8 .

Graumiller, Tabellarische Cehersicht der Pflanzensysteme von limne. Thuuberg, Jussieu und Batsith. Eisenberg 1811. 4.

-.._ biagnose der bekanntesten Pflanzengattungen Eisenbers 1811. 8 .

Ackermann, Ueber die Natur des Gewachses. Mannheim 1812.4.

Moessler, Jlandluuch der Gewächskunde. Altona 1\$15.8. - Ed. Ill. von Reichenbach. il. $1833-1834.8$.

Cassel, Lelirbuch der naturlichen Pflanzenordnung. Frankfurt 1817. 8

Sprengel, Anleitung zur Kenntniss der Gewachse. Zweite ganz umogrbeitete Aullage. Ilalle 1817-1818.8. (anglice.

Test, Anleitung zum Stulium der Botanik. Wien 1818.8.

I1 ilbrand, llandbuch der Botanik. Giessen 1819. 8. - Darmstadt 1837. 8. Sprengel, Grundzuge der wissenschaftichen Pflanzenhunde. Leipzig 1820.8 (anglier.)

Dierbach, Anleitung zum Studium der Butanik. Heidelberg 1820. \&

(Reichenbach) Katchismus der Botanil. Leipziy 1820. s. - Eel. II it $1824-1826.8$

Nees von Esenbeck, Haulluach ter Botanik. Nuruberg 1820-1821.8.

I'enderoth, Lebrbuch der Botanik. Marburg 1821. 8.

Tettelbach, Hulfsblatter zum Studium der Botanik. Dresden 1821-1825. 8 .

Schelver, Lebens - und Formgeschichte der Pflanzenwelt. Ileidelberg 1822. 8 .

Hergt, Anleitung zur Pflanzenkenntniss. In ejus "Flora von Hadamar". Hatamar 1822.8.

Kviakouska, Erste Anfangsgrunde der Botanik. Wien 18238

Schubert, Lehrbuch der Naturgeschichte. Erlangen 1823. 8. - ib. 1846.8. Schultz. Die Natur der lebendigen Pllanze. Borlin und Stuttgart 1823 1\$28. \&.

Cuerie, Anleitung zum Bestimmen der Pflanzen des mittlern und sudlichen Deutschlands. Gorlitz 1824. 8. - Ed. V1]: Kittlitz 1849. 8.

Link, Elementa philosophiac botanicae. Grundlehren der Kráuterkunde. Berolini 1824.8. - ib. 1837.8.

- leones anatonico-botanicie ad illustr. Elementa plilosophiae botanicae. Berolini 1837-1842. folio.

Oken, Lehrbuch ter Naturgeschichte. II: Botanik. Jena 1825-1826. 8.

Perleb, Lchrbuch der Naturgeschichte des Planzenreichs. Freiburg i/Mr. 1826. 8

/ler., Anleitung zur Botanik. Giessen 1827. 8.

Voigt, Lehrbuch der Botanih. Jena 1827.8.

Keichenbach. Botanik fur Damen. Leipzig 4828.8.

Muhl, Das Pflanzenrcich nach natürlichen Familien. Trier 1828. 8.

Dietrich, Handhuch der Botanik. Jena 1828. 8

Bischoff. Uelsersicht des Linnéischen Sexualsystems. Heidelherg 1829. folio.

Fuhlrott. Jussieus und De Candolle's naturliche Pflanzensysteme. Bonn 1829. 8

Link, Ilandbuch zur Erkennung der Gewächse. Berlin 1829-1833. 8.

Kachler, Grundriss der Pllanzenkundo. Wien 1830.8.

Richter, Taschenbuch der Botanik. Nagdehurg 1830. 8.

Schmialt, Kurze Anweisung zur Botanik. Stettin 1830. 8.

Zenker, die Pllatzen und ihr Studium. Eisenach 1830.8

Kirchner, Uebersicht der Pflanzenkunde. Berlin 1830.8 Schulbotanik. Berlin 1831.8. 
drendt, Tabellarische Teluersicht der Flord Deutschlands.

Osnabruck 1831. folio.

k̈unth, Ilandisuch der Botanik. Berlin 4831. 8. (hollindices.

Hochsteller, Pupulare Butanik. Situltgart 1831. 8. - ib. 1837.8.

Zimmermann, Grundzuge der Phytologie. Wien 1831. 8.

lless, Uebersicht der phanerogamischen naturlichen Familien. Darmstadt 1832. 8 .

Schmidl, Der ango|snute Botaniker. Insenau 1832. 12. - Weimar 1836.12.

Lueben. Auwrisung zum Unterricht in der Pllauzenhunde. IIalle 1832.8. - ii). 1844.8.

Juenyst, liurzer AJriss der Pflanzenhunde. Birlefold 1833.8.

Anthon, 'Tabello uber die Pflanzenfamilien Deutschlands. Nurubery 1833. foliu.

Bischoff, Handluted, der botanischen Terminologio und Systemkunde. Nurnlery 18.3.3-1844.4

Comle, Jas P'llauzenreich nach .1. L. de Jussien in methodischer Uebersicht. Woimar 1834 . imp,-folio

Keichenbach, bas Pllanzenreich in seinen naturlichen Klassen und Fannilion. (Universum der Natur, I et IV.) Leiprig 1834-1835. 4.

Bischoff, Lehrluch der allgerneinen Botanik. Stutcgart 1834-1839. 8.

Zuccarini, Untericlut in der Pflanzenhunde. Munchen 1834.8

Wildrand, Lic unturlichen Pflanzenfanilien. Giessen 1834. s

Huebener, Einleitung in das Studium der Pilanzenhunde. Manuheim 1834. gr. 12. gr. 12.

Cirosse, Leitfaden der Butanik. Stendal 1835. S.

Erdelyi, Anleitung zur Pllanzenkenntniss. Wien 1835. 8.

Otto. Der Schlussel zur Botanik. Rurlolstadt 1835. 12.

Fischer. Das Pllanzenreich. Bueslau 1835-1840.8.

Hoemer, Handbuch der allgenseisen lBotanik. Munchen 1835-1840.8.

(Burmeister und Tuschenberg) Botanische Abbildungen. Berlin (1835-) 1845. 4 .

Die jungen P'llamenforscher. Bern |836. 8.

Friese, Grunlriss der Phy'tognosie. Innspruck 1836. 8.

Fuernirohr, Grundzuge der Naturgeschichte. Regensluurg 1836. 8. Angshurg 1846.8.

Krassow et Leyde, Lehrbuch der Botanik. Berlin 1836. 8. - ib. 1846.8

(Mouly) Leitfaden der Botanik. Posen 1836. s

Mueller, Tabellarische Vehersicht des Pflanzenreichs. Stuttgart 1836. folie max.

Petermann, Ilandbuch der Gewächshunde. Leipzig 1836.8 .

Reichenbach, kupfersanunlung zum deutschen Botanisirluche. Leipzis 1836. 8 .

Kichter, Anleitung zur Gewachskunde. Koln 48.36. \&

Schubert, Geschichte der Erde. 11, 2: Botanik. Erlangen 1836. 8.

Spenner, Deutschlands phanerogamische Pllanzengattungen in analytischen Bestimunngstatellen. Freihurg 1836. 8.

Winkler, Anfangsgrunde der Botanik Leipzig 1836. 16.

Reichenbach, Handbuch des naturlichen Pflanzensystems. Dresden 1837.4.

Reichenbach, Allgemeine Pflanzenkunde. Leipzig 1837. 4.

- Naturgeschiclte des Pflanzenreiclss. Leipzig 1837.4

Schmidt, Botanisclier Wegweiser. Stetlin 1837.8.

Termo, Schlussel zur Botanik. Leipzig 1837. gr. 12. (suecice.)

Wall, Botanik. Regensburg 1837. 8.

Pflanzenreich in tabellariseher Vebersicht. Weinar 1837-1838. gr. folio Dietrich, Botanik fur Gártner. Berlin 1837-1839.8.

Fuhlroll, Das Pflanzeureich und seine Mtamorplose. Elherfeld 1838. 8. Schiel, Grundzuge der Pflanzenkunde. Guns 1838. 8.

Lenz, Naturgeschichte: Pllanzenreich Gotha 1838-1839. 8.

Petermam, Das Planzenreich. Leipzig (1838-) 1845. gr. S

Otto, Naturgeschichte fur Kinder. Saalfeld 1839-1843. gr. 8
Kappe, Der hleine Botaniher. Muls 1839. 12. - ib. 1843, 12 koch, Jas naturliche System des Pflanzenreiches. Jena 1839.8 Meyer, l'reusseas \{llanzengattungen. Konigsberg 1839. 1z.

Ifirlgen, Leitfaden fir deu l'nterricht in der Botanik. LoJslenz 1839. gar. 12. - i\}. 1846. gr. 12

Oken, Allgemeine Naturgeschichta. II - III: Botanih, Stuttgar1 18391841. 8. und . Wlas.

Eichelberg, Ptlanzenkunde. Zurich 1840.8 .

Fresenius, Grumlriss der lolanik. Frankfunt a/M. 1840.8 - ih 1843. 8.

Heer, Analytische Tabellon zur Bestimmune dor Gallmugin. \%urich 1840. gr. 12.

Heynhold, Jas naturliche IJlanzensystem. Dresten 18408

Reichenbach, Naturgeschichte des Pflanzenreichs. Leeipzig 1840. 8.

schilling, Handluch der Botanik. Breslau 4840. 8

delbury, Entwicklung einer analytisch-levikalischen Methode. W'ien 1841.8 .

Fechner, Allgemeine Botanik. Gorlitz 1841.8.

Endlicher, Enchiridion botanicum. Lipsiae 1841. 8.

Gollntam, Grundriss der Botanik. Berlin 1841.8.

If artmann, Botanik fur die weibliche Jugeml. St Gallen 1841.8.

Corla, Anleituny zum Studium der Nykolagie. Prag 1842.8.

Fischer, Lehrfuch der Naturgeschichte. Wien 1842.8

Petermann, Taschenbuch der Botanik. Larifrair 1849.8.

Ifau, Uisher Botanik. Ulm 1842. 12.

lompper, lle vorzuglichsten Charakterpllanzen etc. Leipzin $1842 \mathrm{x}$

Unervichl, Anleitung zur Pflanzenhenntniss. Schweidnitz 1842. gr 12

Schlriden, Grundzuge der wissenschaftlichen Botanih. Leijzig 1\$4Z1843.8 .

Endlicher und Unger, Grundzuge der Botanik. Wien 1843. \&

Grossmann, Elementarbuch in der Botanik. Stuttgart 1843. s

Lanyethal, Die Gewachse des nordliehen Deutschlands. Jena 18438

Rabenhorst, Populár praktische Botanik. Leipzig 1843. 8.

llossmaessler, Das Wiclutigste vom inneru Bau und Leben dor Gewachse. Dresten 1843.8 .

Schlosser, Anleitung die Pllanzen Mábrens zu bestimnen. Brunn 1843. 8. Schmidl, Preussens Pllanzen. (Plyylologie.) Danzig 1843. s

Zuccarini, Naturgeschichte des Pllanzenreich.s. Kimpten 1843.8

Link, Vorlesungen uber die hratulerkunde. Berlin 1843-1845. s.

hilher, Leitfaden in die Botanih. Jeilluronn 1844.4.

IValchner, Der prahtische Naturforscher. VI: Mes Botaniher. Karlsrular 1844.8.

Engelmamu, Genera planarum. Mitan 1844.8

Krueger, Die Botanik in drei Lehrstufen. Borlin 1844-1547. s

Bruellow, Systematische Eintheilung des Pllanzenreichs nach nitturlicin." Familien fur Schulen. Posen 1845. 8.

Burmeister, Grundriss der Naturgeschichte. Berlin 1845. 8.

Hoefle, Die Pllanzensysteme von Linné, Jussieu, De Canlolle. Heidelhery is 45.4 .

Tuschentury, Deutschlands Pflanzenzattumgen. Merseburg 1845.8

Stein, Oryanegraphie der Pflanzeı. Berlin 1845.8

Schleiden, Grundzuge der wissenschaftlichen Botanik. Zweile vauzliclı ungearbeitete Auflage. Leipzig $1845-1846$. S

—_ Frundriss der Bolanik. Leipzig 1846.8

Die Pflanze und ihr Leben. Leipzig 1847.8

(allylice.)

Hess, Pflanzenkunde. Berlin 1846, 8.

Iloffmann, sclilderung der deutschen Pllauzenfamilien. Giessen 1846, s

Lucben, Die Hauptformen der ausseru Pllanzenorgane. Leipzig 1846. \$.

Maly, Anleitung zum Bestimmen der deutschen Pllawengattungen. Wien 1846. $\mathrm{gr} .12$

Petermann, Analytischer Pllinzenschlussel. Leipzig 1846. 8.

Deutschlands Flora. Leipziz 1846-18\$9.4.

Piper, Tascheubuch der nertldeutschen Flora. Malchin 1846. 8 


\section{ARTES BOTANICAI:}

schenct, duleitung zur Bestimmung der in Nassau wilelwaebsenden Pflanzengattungen. (Wiesbaden 1846.) 4 .

Schmillin, Anleitung zum Jotanisiren. Stuttgart 1846.8

Schula, Grundriss der Zoologie und Botanik. Berlin 1846.8.

Unger, Grumlzuge der Anatomie und Physiologie der Pीanzen. 1846. 8 .

Muttweiler, Lehrbueb der Botanik. Stutgart 1847.8.

Kunth, Lehrhucls der Botanih. 1. Theil. Berlin 1847.8.

Schentiel, Das Pflauzenreich. Mainz 1847. gr. 8.

Voigl, Gesclijchte des Planzenreichs. Jena 1847 sq̨ॄ. 8.

\section{B. Gallicue.}

The la Brosse, the la nature, vertu et utilité des plantes. Paris 1628. 8.

Vaber, Traetatus de plantis. Paris 1666. 4.

Tournefort, Élémens de hotanicjue. Paris 1694 \&.

Institutiones rei berbariae. Paris 1700. 4. - Corollarium: ib. 1703. 4. - E.1. 111 : il. 1719.4.

(—) Abrégé des èlèmens de bolanique. Avignon 1749.12.

Helie, Systeme de Linnaeus sur la genération des plantis. Montpellier 1750.12

Introduction a la botanique. Amiens 1754. 12.

Adansort, Fumilles des plantes. Première pratte. Paris 1763.8.

Latourrelle et Rozier) Démonstrations élénentaires de botanique. Lyon 1766. S. - Ed. IV: ih. 1796.8.

Burbeu-lhuboury, Nourelle méthode de botanique. In ejus "Botaniste françaisn. Paris 1767. 12, vol. I, p. 1-154.

$$
\text { Manuel de botanique. l'aris 1768. } 12 .
$$

Bucquet, Introduction à l'étude des corps du rìgne végétal. Paris 1773.8. Lestiboutois) Alrégé élémentaire de Lotanique (et carte). Lille 1774. 8 Bulliarel, Introduction a la Flore des environs de Paris. Paris 1776.8

(Durande) Notions ilémentaires de hotanique. Dijon 1781. 8 .

Rousseru, Lissils elémentaires sur la lotanique, irrits en 1771. Londres 1782. 12.

Lettres sur la botanique. Paris 1793-1795. 8. - ilı. 1838. 12. anglice, rusicice.

Blanc, Fssai do botanique pratique. Embrun 1784. 12

Billiothicque des Dames. Botanique. Paris 1786.12.

Lebreton, Manuel de botanique. Paris 1787. 8

Gouan, Explication du svsteme botanique du Chevalier ron Limme. Montpellier 17\$7. 9 .

Ilyon, Cours de botanique. Paris 1787-1788. folio

Cotte, Manuel d'histoire naturelle. Paris 1787.8

Leçons élémentaires d'histoire naturelle. Paris 1787. 8.

Rossignal, Butanique élémentaire. Turin 1790.8.

Gilibert, Methodi Linneanae betanicae delineatio. Lugduni 1790. 8.

Ventenal, Tableau du règne végétal. Paris 1794.8

Prineipes de botanique. Paris (1795.) 8

(germanice.)

Jolyclere, Cours complet de botanique. Lyon $1795^{\circ} .8$

Desfontaines. Cours de hotanique élémentair'. (Usteri. Annalen. XVI, $27-87$.

La clef de la Irotanique. Toulouse 1796. 12.

Principes élémentaires de botaníjue. Lyon an IV. 8.

De Nesle, Introduction à la botanique. (Poitiers an V1.) 8 .

Philibert, Introduction à l'élude de la botanique. Paris 1799.8.

Jolyclerc, Principes de la philosophie du botaniste. Paris 1798. 8

Youton-Fontenille, Tableau des systemes de hotanique. Lyon 1798, S.

Botanique les enfans. Paris (1800.) 8.

Voyage dans l'empire de Flore. Paris 1800.8 .

(Deshayes) Carte botanique de la méthorle Jussieu. Paris 1801. 8.

(Gilibert) Tableau des plantes à démontrer. (1.you) 1801.8.

Philibert, Exercices de botanique. Paris 18018
IRTES BOTANICAE

Philitert, Leçons chenentaires de Lotanigue. Paris 1802 . \&

Behere, Tableau methodique du systeme de Tournefort. Paris $\$ 802$. gr. folio.

Brisscau-dhirbel, Traité d'anatonie et de physiologis vẹgetales. Paris, an X. (1902.) 8

M(onllrison), Letires a $\mathbf{A I}^{\text {me }}$ de $C^{* *}$ sur la botanique. Paris 1802 . I

(Suffren) Principes do botanirge. Venise 1802. 8.

(Aubin) Elemens succincts le botanique. Paris 1803.8 .

(Deshayes) Le Vademecum du botaniste voyageur. Paris 1803.8.

(Le hotaniste voyageur. ib. 1807, 8. non differt.)

Gouan, Traité de hotanique et de matiere médicale. Montpellier 1804. \&.

Dumeril, Traité élémentaire dhistoire naturelle. Paris 1804.8. - Ed. W. Paris 1830.8 .

Do Candolle, Principes élémentaires do botanique. Paris 1805.8 .

Gérardin, Talleau élémentaire de botanique. Paris 1805.8 .

Jaume St. lliluire, Exprosition des fanilles naturelles et de la germination des plantes. Paris 1805.8 .

Redoulé, La totanique de Jean Jacques Rousseau. Paris 1805. folio.

Abrégé ècémentaire des princọpes de botanique. Paris 1807. 8.

Nouveaux elemens de hotanique. Paris 1809. 8. - ib. 1829. 12.

Hanin, Cours de botanique et de physiologie végétale. Paris 1811.8

(Benoit) Herbier élémentaire. Paris 1811. folio.

Botanique de la jeunesse. Paris 1812.12.

Plee, Le jeune botaniste. Paris 1812. 8 .

De Candolle, Théorie élémentaire de la botanique. Paris 1813. - Paris 1819.8. - Paris 1844.8

(germanice.)

Rafinesque, Principes fondintentaux de somiologie. Palerme 1814. $\mathrm{s}$.

Marquis, Plan raisonué d’un cours de botanique. Rouen 1815.8.

Méral, Elémens da botanique. El. IV. Paris 1817. 12. - Ed. Vl: it, 1829. 12.

Loiseleur, Nonveau voyago clans l'empire de Flore. Paris 1817.8.

Desuaux, Progranme du cours de botanique. Angers 1817. 8. - il. 1832. 8 .

Nomologie botanque. Angers 1817, 8. - ib. 1832. s.

Richard, Nonveau élemens de botanique. Paris 1819. 8. - Eıl. vil: ih. 1846.8 .

(germanice, bollandiee, angliee, rossice.)

Tablean explicatif du słstème de Linné. Paris s. a. gr. folio.

Poiret, Leçons de Flore. Paris 1819-1820. 8. - ib. 1823. 8.

Guenard, Les enfans voyageurs. Paris 1819.8

Aubert du Petit-Thouars, Cours te phytologie. Paris 1819 - $\mathbf{8 2 0} 0 . \delta$.

Marquis, Esquisse du régne régetal. Ronen 1820.8.

Turpin, Essai d'une iconograplie élémentaire. Paris 1820.8.

Baitard, Botanique des Dames. Paris 1821. 12.

Flore de la hotanique des Dames. Paris 4821. 12.

Murquis, Fragmens de philosophie bótanique. Paris 1821. 8.

Caffin, Exposition méthodique du règne végétal. Paris 1822. 8

Peyre, Méthode analytique-comparative de botanique. Paris 1823. 4.

Brierre et Pollier, litmens de botanique. Paris 1825. 12.

Demerson, La holanique enseiguee en 22 leçons. Paris 1825. 12.

Lescherin, Physiologie végétale. Paris 1825. 8.

Anquetin, Manuel de botani(gue. Paris 1826. 8.

Boitarl, Manuel complet de botanique. Paris 1826. 12.

(germatuce.)

L a bolanique. Paris 1826. 12.

Lestiboudois, Botanographie élémentaire. Lille 1826. 8.

Lamouroux, Resumé complet de botanique. Paris 1826.12. (germanice.)

De Candolle, Organographie végétale. Paris 1827.8. (germanice, angtiee.)

Girarlin et Juillet, Nouvean manuel de botanique. Paris 1827. 12.

Lelourneux, Lettres a Nanine sur la botanique. Paris 1827. 12.

Dargassies, Lettres a Nanine sur la botanique. Toulouse 1828. 12. 
De doucheron, Princijes élementaires du botanigue. Jaris 18:8. 12.

Lamouroux, Rosumé do plı̨tographie. Paris 1828. 12.

lcomograpuic des familles vécutales. Paris 1828.12

Lecor, Precis élémentaire de botanique. Puris 1828. S.

Boitard, Plsysiologie vegótale. P'aris 1829.12.

Lefebure et Leforeslier, Album lloral alcs plantes de France. Paris 1829. 8. obl.

Rastoin, lettres sur la botanique. Paris 1829.12.

De Chesnet, Botanique des poetes. Paris s. a. 8.

De Candolle, Plısiologie végétale. Paris 1832.8. (germanice.)

Lafleneau-Delile, Leçon de botaniquo. Montjellier 4833.8.

b'Orbigmy, Tableau symoptique du régne végétal d'après dussieo. Paris 1834. gr' folio.

Loblond et Rendu, Botanique. Paris 4834.5 .

Saucerotte, Jimens l'histoire naturelle: Botanicue Paris 1834. $8 .-$ il. 1840.8 .

Lebovidre-Delalande, Leçons sur la hotanipue. Paris 1834-1837. 12.

Boitard, Herhjer des Demoiselles. Paris 1832. 4.

Botanique des Demoiselles. Paris 1835.8 .

Clerc, Manuel classique et étémentaire de botanique. Paris 1835. 朱.

Fée, Mastre Pierre. Entreliens sur la botanique. Paris 1835. 12.

Matieu, Élémens de phỵtologie. Châlons-sur-Marue 1835. 8.

Salacroux, Elémens l'histoire naturelle. 'Jaris 1835. 8. - if. 1839. 8.

Pouchet, Traité élémentaire de botanique appliquée. Paris $1835-1836.8$.

De Candolle, Introduction a l'élude de hotanique. Paris 1835. 8. (germanice, rossice.)

Delafosse, Precis (Notions) d histoire naturelle. Botanique. Paris 1836. 12. - ib. 1843.12 .

Douy, Nouveau manuel le botanique. Paris 1836. 8.

Ferrand, Cours élémentaira de botanique génèrale d'après hichard. $\mathrm{Pa}$ ris 1836.12.

Thiebaut-de-Berneaud, Traité élementaire de botanique. Paris (1837.)8.

(Poisle-Desgranges) Le petit botaniste. Paris 1837. 12.

Villelle, Nouveau manuel de botanique. Paris 1838.12.

Hendu, Botanique. Paris 1838. 8. - il. 1840.12.

Desvaux, Traité général de botaniłue. Paris $1838-1839.8$.

Meissas, Rotanique. Paris 1839, 8.

Jacyuemart, Flore des Dames. Paris 1840. 12.

Sainl-llilaire, Lecons de botanique. Paris 1840.8

Brisseau-Mirbcl, Aualyses de plantes. S. a. folio.

Palustre, Etudes de botanique. Poiliers 1540. 4

Botanique. Niort 4841. S.

Pujoulx, La botanique des jeunes gens. Paris 1840. 8.

Promenades au marché des fleurs. Paris 1841.8.

Chiral, Étude tes fleurs. Lyon 18/ 12.

Seringe, Elémens de botanique. Lyon 1841.8. - ib. 1845. \$

Michol, Tableau botanique de la métlode de Jussieu. Mons 1842 . folio max.

Meissas, Petite botanique. Paris 1842. 12.

Jussieu, Botanique. Jaris 1843.8. - ib. 1844. 8. - ib. 1845.8. (sermanico, italice.)

De Candolle, Théoria elémenaire de botaoique. Fu. III, publiée prar Alphonse De Candolle. Paris 1844.8.

Le Maout, Leçons élémcntaires de botanique. Paris 1844. 8. Atlas élementaire de botanique. Paris 1846. gr. 4.

Magaud de Beaufort, Cours re hotaniuge. Paris 1844. S. - Botanique. ib. 1846.8 .

Botanique à l'usage de la jeunesse. Lille 184512.

Comte, Botanique. Paris 4845.8.

Dechenaux, Glé d'analogie en botanique. Paris 1845. 8.

Lebouidre-Delalande, Traité élémentaire de physiologye végêtale. Paris 1845.8 .

Pierre, La botanique. Laon 1845. Is

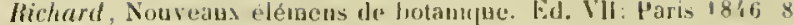
(go ruamee. hollamblice, ancrlice, rossice.)

Mutel, Élémeus de botaninue. Gramoble 18:7. If

Rodet, Leçons de botaniune. Toulouse 1847.8

\section{Anglicae.}

Coles, The art of sinupling. London 1656. 12

Biair, Botanih assays. Jomilon 1720.8 .

Alston, Dissertatio de re herbaria. Je ejus "Tirocinum. Eilinluargi 175: 8. 1. $1-82$.

$$
\text { (anglice.) }
$$

Lee, An introduction to holany. Lonton 1760 . \&. - Edinburgh $1 \times 06$.

IIill, The vegetable systrm. London 1762.8 .

Mueller vel Miller, Short introduction to the science of botany. In ejus a Gardene's kalendar". London 1769. 8. j\%. XVII-LXVI.

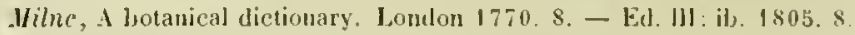

Rose, The elements of botany, London 1775.8 .

Kobson, The principles of hotany. In ejus "British floran. York 1777.8. p. $1-53$.

Curlis, linnaeus system of bolany. London 1777.4.

Hurller vel Miller, Jllustratio systematis sexualis Limmar. Iundini 1777 folio.

(anglice-latup, germanice-latine.

Marlyn, Letters on the elements of hotany, by Rousseau; translatrod will notes and 24 adolitional letters. London 1785 . 8 .

- Thity-eight plates with explanations. London 1788. 8.

R. W. D., Principia hotanica. Newark 1787. s.

Relhan, Heads of a course on botany. Cambridge 1787..

Curtis, Companion to the Botanical Magazine. Iomon $1788 . \$$.

Saunders, Introduction to bolany. Londoo 1792. \&.

Smilh, Syllabus of a course of lectures on botany. Lomdon 1795 . S.

Wakefield, Jutroduction to botany. London $1796 \quad 12$.

(gallice.)

Thompson, lkotany disjlayed. London 1798. 4

Martyn, Inleiding tot de kirnidkunde. London 1798. \& (auglice.)

Thornton, A new illustration of llie sexual system of. Linnaun. 1.ondon (1799-1809.) imp. folio.

IIull, Elements of bolany. Nanchester 1800.8 .

Mavor, Botanical poeket book. London (1800.) iz

Ilall, Elemeats of holany. Louton 1802 . \&

11 ade, Sylabus of a course on hotany. Duldin 1802.8.

Curlis, Lectures on botany. I.ondon 1805. 8 .

Toase, A series of botanical tabels. London 1805. 4.

Smith, Introduction to hotany. Lomelon 1807. 8. - Ed. V111: i], 1834. 12. (germanice.)

Eucr, Compendiun botanices. London Isos. 8.

Thornton, A new family berbal. London 1810.8 . - Elements of hotany. London 1812 . 8

Practical botany. London s. a. 8 .

heith, A system of physiological botany. Lomilon I \& 16.8.

Allman, syllabus of hotanical lectures. Dullin 1917.8 .

Rootsey, Syllabus of a course of hotanical lectures. Bristol 1818.12.

(Edgeworth) Dialogues on botany, London 1819.8.

IVale, Prospectus of lectures on botany. Dublin $1 \$ 20.8$

Gray, A natural arragement of tritish junts. London 1821. 8.

Smilh, Grammar of botany. London 1821. 8. - ih. 1826. 8. (germanice.)

Stroud, Elements of botany. Greenwich 1821 .

Pinnoch, Catcelism of butany. London 182z. 12

Thonson, ldectures on hotan!. London 1822. 8

Johns, Practical holany. I.ondon 1826.8 .

Butt, The botanical primer. London 1827. 12 
Forsyth, The first lines of botany. Londoo 1827. 12

Frost, Some account of the science of botany. London 1827.4.

Lempriere, Popular lectures on regetable physiology etc. London 1827.8.

Allman, Analysis per differentias constanes viginti. London 1828. 4.

kinigh, Outlines of botany. Aberdeen 1828.8 .

Castle, An introduction to botany. London 1829. 12.

Lineoln, Familiar lectures on botany. Ilartford 1829. 8. - il. 1835. 12.

(Mareet) Conversations on vegetable physiology. Lundon 1829. 8. - il. 1839.8. (gallice, germanice.)

Steggall, The pupil's introduction to botany. Lonton 1829.8 .

Hardcastle, Introduction to the elements of the Linuacitn systen. London 1830.4 .

lindley, An outline of the first principles of botany. London 1830.8 . (germanice, gallice, rossice.)

An introduction to the natural system of botany. London $\$ 830.8$.

- ib. 1839.8 . (germanice.)

II alker-Amolt, Botany. s. I. el a. 4.

Patrick, A popular description etc. Filinburgh 1831. 19.

Banks, Introduction to the study of english botany. London 1832.8 .

Mudie, The botanic annual. London 1832.8 .

Reil, Outlines of medical botany. Edinburgh 1832. 8. - il». 1839. 8.

Castle, Synopsis of systematic botany. London $1 \$ 33.8$.

Lindley, Nixus plantarum. Londini 1833. 8. (germanice.)

Rhind, A catechism of botany. Ediuburght 1833.12.

Thornton, lutroduction to botany. London 1833. 12.

Williams, The vegetable world. London 1833. 8.

Drummond, First steps to botany. London 1834.8

(Fitton) Conversations ou hotany. Ed. YIII. London 1834. 8. - Ed. IX ib. 1840.8 .

logel, Animal and regelable plysiology. (Bridgewater-Treatises no. V.) London $1834,8 .-$ ih. 1840.8. (germanice.)

Burnell, Outlines of hotany. London 1835.8 .

IIcnslow, Principles of botany. London 1835.8.

Rallray, A hotanical chart. Glasgow 1833 . S.

Stewart, Dutlines of Lotany. Londun 1835. 8

Lindley, A key to structural, phrssiological and systomatical botany: London 1835.8 hungarier, gallice.

Ladies botany, London 183x. \&. - il. 1837.s (remaluice.)

A natural system of botany. Lomdon 1836.8

Yain, Popular hotans. London 1836. 8 .

Partington, Introduction to lotany. London 1836. \&

The Ilantlyook of plain hotany. Lonton 1836.8 .

('astle, The Limean artificial system of hotany. London 1837. 4.

Harereight, Manual of british botany. London 1837. 8. - ib. 1844 \&

l'erkins, The elements of botany. Jondon 1837.8.

Renoit, Botanist's Companion. London 1838. 32

Baskerville, Affinities of plants. Lomlon 4839. \&.

lindley. Schnol botany. London 1839. \&.

Parley, Tales about plants. London 1939. 8

IVillshire, The principles of botany. London 4 \$39. \&

Franeis, Grammar of botany. Loudon 1840.8

Je'se, frleanings in natural history. London 1840.8

Macgillicray, A manual of botany. London 1840.8

Loudon. The first book of botany. London 1841.8.

L Botany for Ladies. London 1549 . 8 .

Lindley, Elements of botany. Londun 1841. 5. - 11. 1847. \&

—_ The vegetable kingdom. London 1846.8.

Loudon, Tales about plants. London $1 \$ 16.12$

Stecle, Hamdluock of field-lontany. Dublin is 47.8

Pritzer, Thes. lit bot.

\section{Suecicae. Danicae.}

Limné, Fundamenta hotanica. Amstelodami 1736. s.

- Philosoplria hotanica. Stockhomiae 1751. 8. - Ed. IV Ilahif 1809.8.

(anglice, germanice, gallice, hispanice.)

Elementa hotanica. (ed. Solander.) Upsaliae 1756.8.

Oeder. Elementa hotanicae. Havniae 1764-1766.8. (sermanice.)

Buchlare, Grunden til Plantelaeren. Soroe 1768.8.

Iloffberg, Anwisning til Wäxt-Rikets kannedom. Stockholm 1768. 8. Ed. III: ib. 1790.8.

Joerlin, Partes fructificationis seu principia botanices illustrata. Lune n 1771. 8. - ib. 1786.8.

Brander, Kort Begrepp af Natural-Historien. Westerås 1785.8.

Limne, Praelectiones in orlines naturales plantarum. Hamburgi 179\%. 8 .

Hernquist, Kort Genwäg til Naturaliers kánnedon. Skara 1795. 8.

(Swartz) Grundirna till Láran om Djur ochı Växter. Stochholm 1813. \&

Agardh, Lárobok i Botanik. Malmo 1830-1832.8. (germanicen, danice.)

Hartman, Uthast till populàr naturkunnighet. Stockholm 1836. 8.

-_ - Botanologien. Stockbolm 1838.8.

Drejer, Laerebog. Kiolmhisn 1839.8

Orstedt, Planterigets naturhistorie. Kjobenbasn 1839. 8.

Dueben, Handboh i vextrikets naturliga familjer. Stockholm 1841. 8.

Arrhenius, Vthast till vistrihets terminologic. Upsala 1842. 8 .

Nyman, Ofversigt af wálfamiljerna. Stockholm 1843. 8.

Arrhenius, Elementar-kurs i hotamiken. Upsala 4845.8.

Schayerstrim, Larolıok i Skandinaviens växtfamiljes. Upsala $1846 \mathrm{~s}$

\section{Belgicae.}

Bidloo. Missertatio de re herharia. Ansterdam 1683.8 .

Corter. Elementa Jotanica. Ilardervici 1749. 8.

Baster, Yerhandeling over de voortlelling der dieren 'n planten. Harlem 1768.8.

Gorter, Leer der plantkunde. Ansterdam 1782.8.

Maerter, Fuodamenta et termini botanici. Bruxellis 1789. 8.

Oskamp, Plantarum fabrica et oeconomia. Trajecti a/Rh. 1789.4.

Le guide du naturaliste. Bruxelles 1792. 8 .

Oskamp, Tabulae plantarum terminologicae. Lugd. Bat. 1793. folio.

hultix, Resume dn cours de mineralogie et de botanique. Bruvillo 1828.8 .

IIall, Elementa botanices. Groningae 1834. S.

-_- Redevoringen nver het plantenrijk. Groningen 1838.8 .

\section{F. Hispanicue. Lusitanicae.}

Barnades, Principios de hotanica. Madrid 1767. 4.

Ortega, Tabulae botanicae. (Tablas botalicas etc.) Matriti 1773.4. ib. 1783.8 .

Ortega et Palau y Verdera. Curso elenental de botanica. Madrid 1785. s. - ib. 1795.8 . (italice.)

Rodon y Bell. Breve discurso di botanica. Cartagena 1788. 4.

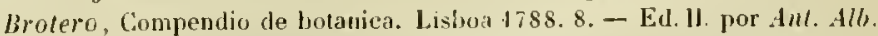
da Fonseca Benevides. Lishoa 1837-1839.8. Principios de agricultura philosophica. (Livro l: Anatomia e physiologia dos regetaes.) Coimbra 1793. 4.

Lorente, Carta (I-II) solsre las ofiservaciones botanicas de Cacanilles. Valencia $1797-1798.4$

Cavanilles, Descripeion de las planlas ete. Marlrid 1802. 8 . (italice.)

Blanco. Tratado elemental de botanica. Valencia 1834-1835. 4. 


\section{G. Italicue.}

Costapus, De universali stirpium natura libri dun. Aug. Taur. 1578. 4.

Spiegel, Isagoges in rem herharian libri duo. Patavii 1606.4.

Caessius, Pliytosoplicarum talnlarun pars l. Impr. cum Hernandez, Ilistoria plantarun mexicanarum. Romae $165 \mathrm{f}$. folio.

Danielli, Quistioni intorno a cose di hotanica. Jhologna 1723.8.

Bianchi, Vademecum botanico. Firenze 1763.8

Cirillo, dd botanicas institutiones introductio. Neapoli 1766.4.

Mugnaui, Sargio di botanica. Milano 1775.4.

Petagna, lnstitutiones botanicae. Neapoli 1785-1737.8.

Cirillo, Fundamenta botanica. Neapoli 1785-1787. 8 .

—_ Tabulae hotanicae elementares. Neapoli 1790. folio.

(Tommaselli) Analisi dei vegetihili. Verona 1794. 8.

Taryioni-Tozzetli. Institutioni botaniche. Firenze 1794. 8. - Ell. Ill : il). 1813. 8 .

Botton, Esane critico 'puanto alla parte botaniea degli Elementi di storia naturale del cittadino Millin. Torimo 1799. 8.

(Tommaselli) Compendio di fisiologia vegetale. Verona 1800.8.

pratesi. Tavole di hotanica elementare. (J'avia 1801.) 8.

Nocca, Elementi di botanica. Pavia 1801.8. - ib. 1805.8

Tenore Quadro delle botaniche lezioni. (Napuli 1802.) 4.

Bayle-Barelle, Tavole analittco-elenentari di botanica. Hilano I804. 8 .

Briganti, Clavis systematis sexualis Linmei. Neanoli 1804. folio.

Cosentino, Saggio di botanica. Catanea 1805.8.

(Tenore) Corso delle botaniche lezioni. Napoli 1806. 8. - ib. $1816-$ 1823. 8. - il. 1833. 8.

Sangiorgio, Elementi di hotanica. Milano 1808.8.

Pollini, Succinto esame dergli Elementi di hotanica del Prol. Paolo Sangiorgio. Verona 1809 . 8 .

Stellati, Istituzioni di filosofia botanica. Napoli 1809. 8

Pollini, Elementi di botanica. Verona $1840-1814.8$.

Savi, Lezioni di bntaniea. Firenze 1811. 8.

Sebastiami, Esjosizione del sistema di Linneu. Roma 1819. 8.

Savi, Nuovi elementi di lotanica. Pisa 1820.8.

(Nocca) Clavis rem herbariam aldiscendi absque praeceptore: Ticini 1823 . S.

Sari, Scelta di generi di piante. Pisa 1826. 8.

Berloloni, Praelectiones rei herbariae. Bononiae 1827.8.

Morelli, Guida allo sturlio della fisiologia vegetabile e della botaniea. Pavia 1835.8

Parlalore, Lezinni di bolanica comparata. Firenze 1843.8.

\section{Americanae.}

Barton, Elemeuts of botany. Jhiladelphia 1803.8 .

Shecul, l"lora carolinaeensis. Charleston 1806.8

Bingley, Usoful huowledge: Vol. Il. Vegetables. Philadelphia Is08. s.

IVaterhouse, The Lotanist. Boston 1S 1 1.8.

Eaton, Botanical exercices. Albany 1820.8.

Locke, Outlines of hotany. Bostun 1895. 8.

Nultall, Notice of an infroduction to bolany. Cambrislge 1827.8.

Beck, A shetch of the rudiments of botany. In ejus "Botany". Alhany 1833. 8 .

lieunie, Butany for the use of beginners. New lorh 1833.8 .

Handbook of plain holans. Edinburgls 1 \$34. 8 .

Gray, Elements of botany. Sew York 1836. 12.

Eaton, Botanical grammar and dictiounary. Allany 1836.8 .

Narby, Manual of botany. New York is 1.12.

Gray, The botanical text-book for colleges, schouls and privale students. New Jork 1842.8. - ib. 1845.8.

\section{Polonicae. Rossicue.}

Czenpinski, Bolanica dlà szhúl Naradowych. Warszawie 1785.8

Jundzill, Elementa botanices (polonice). W Warszawio 1804.8. - w Wilnic 1818,8 .

Ambodik, Botanicac elementaris fundamenta (rossico). Petropoli 1796. S.

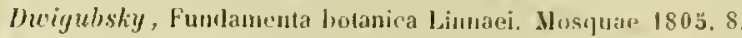

- Elementa listoriac waturalis vegetabilium. Mlosquae 1811.8. Ilethodus facilis recognoscendi plantarum. Mosquae 1827.8. - Ed. 11: ih. 1838.8.

floraninow, Primae lineae hotanices (rossice). Pelropoli 1827.8.

Alios de hotaniees elementis libros rossicos conferan in parto

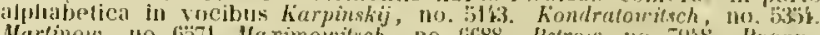

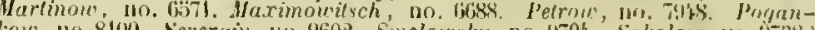

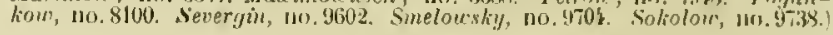

\section{K. Irariae.}

Presl, Wseobecny rosilinopis. Prag 1846.8.

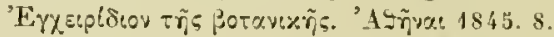

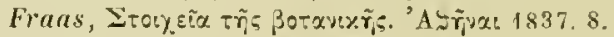

Ilistoria naturalis armeniaca Hechitaristarum. 11: Botanica. Viennac 1844.8. Moon, Outline of the Jionean system of hotany for the use of the Singlialese. In ejus a Cataloguen. Colombo 1824. 4.

Vates, Elemens of natural philosophy. (Sanserit.) Calcutta 18ะ5. \&.

Jaeger, Lectures sur l'histoire naturelle d'llaiti. Tome I: Botani(jue. Portau-Prince 1830.4 .

\section{Collectio herbariorum.}

Lauremberg. Botanotheca. Rostochii 1626. 12. - Altdorfii 1662.4. Francofurti a/M. 1708.4.

Bolnest. Rational way of preparing vegetables. London 1672. 12.

Valentini. Tabula excursionibus botanicis inserviens. In ejus a Tourneforlius contractus». Francofurti a/M. 1713 . folio.

Thuemmig, Von Verwalırung der Blumest. In ejus a Versuch einer Erläuteruig" etc. Halle 1723. 8. p. $181-188$. (c.f. Alh. der naturf. Ges. in Danzig, 1. $76-90$.

Monti, De florum pulchritudine conservanda. (Comn. inst. honton. IJ. 2. 229-237. - Journat de physique. Il. 623-628.)

Jlarmann, Versuch ele. (Ilamb. Magazin XX14. 375-384. XXV1. 583 -592$.

(Ehrhart) Botanologiae juvenilis mantissa. Ulmae 1732. 8.

Linne. Instructio muse rerum naturalium. Ljealiae 1753. 4. (girmatice.)

(Du Ilamel du Monceau) Avis pour le transport par uer des arbres, des plartes vivaces et des semences. Paris 1753.8 . (germanice, danice.)

(Turgol) Mémoire instructif sur la maniète de rassembler et conserier les euriosités d'listoire naturelle. Lyon 1758. 8.

Limne, Instructio peregrinatoris. Ljssaliae 1759.4

Petiver, loirections for the gathering of plants. In cjus "Opera p. vol. I. London 1764. folio.

Fllis, Directions for bringiug over seeds and plants. London 1770.4.

Coaliley-Lellsom, Le voyageur naturaliste. Amsterdan 1775. 8.

Ortega, Instruccion sobre el modo de transportar plantas vivas etc. Madrid 1779. 8 .

hoth, Lebor Pflanzensammlungen. (Beiträge zur Botanik, 1. 110-119. II. $42-69$. II. $83-86$.)

Haiuy, Observations sur la manière de faire les herbiers. (Mćm. de l'acad. des sc. de Jaris, 1785. p. $210-212$.) 
Batsch. Ueber Biumenprapparate. (Roemer, Magazin X, 3-13.)

llithering, I new method of preserving fungi. (Transact. Linu. soe. Il, $263-266$.)

Hedwig. Belehrung die Pllanzen zu trocknen und zu ordnen. Gotha 1797. 8

Pouzin, Avis an botanisle, qui doit parcourir les alpes. (Montpellier) an Vili. 4.

Roth, Anweisung Pflanzen zu sammeln. Gotha 1803.8.

lloppe, Anleitung Graser fur llerbarien zuzubereiten. Regensbury $1 \$ 19.4$

Levi. Della maniera di formare e conservare gli erhari botanici. Venezia 1819.8 .

De Candolle, Instruction pratipue sur les collections botaniques a l'usage des voyageurs. (Geneve 1820.) 8.

Bauhardl, Grundliche Anleitung zum Eiulogen ded Pllanzen. Weimar 1823.8.

Boitard, Manuel du naturaliste. P’aris 1825. 18. (germanice.)

Schreter, Je constructione Lerbarii. Vindobonae 1826.8 .

Luedersiorff, Das Aufirochen der Planzen furs Herbariun und die Aufbewalurung der Pilze. Rerlin 1827.8.

Instruction pour les voyageurs el les employés dans les colonies. Paris 1818. 4. - ib. 1829. 8.

Lecon, 1)e la préparation des herbiers pour l'étude de li botanique. Paris 1 s:9. 8 .

Scltmidt, Nene Methode Pflanzen zu trocknen. Gurlitz 1831.8.

Iluenefeld, Anweisung die Gewachse zu trochnen. Leipzig 1831. 8

$1 /$ "allich, Upon the preparation and managenent of plants during a vuyage from India. London 1832.4.

De Candolle, fustruetion pratique sur les eollections botaniques. (Geneve 1834.) 8 .

Bronn, Anleitung zum Sammeln, Zubereiten und Verpachen von Thieren, Pflanzen und Mineralien. Ileidelberg 1838. 12.

Berlholdi, Der Pflanzensanmler. Berlin 1840. 12.

(Vriese Het overbrengen van levende planten uit Indie naar Nederland. Amsterdam 1840.8

Reichenbach, Der deutsche Botaniker. 1: Das Merbarienbuch. Repertoriun lierbarii. Drestae 4844.8 . folio max

Streubel, Des Conservator. Berlin 1845.8.

Ileld, Demoustrative Naturgeschichte. Stuttgart 1845. yr. 8 .

Schmillin, Anleitung zum Rotanisiren und zum Anlegen von Sanmlungen Stultgart $1 \$ 46.8$

\section{Ectypa plantarum.}

Percini, Ectyja plastarum. s. a. (1517? folis.

Brueclimann, Die Art, Krauter nach dem Lebon abzudrueken. Wolfenluttel 1733.4

(Buechner, Nis, phys. med. 1730. 1. 13'b-1360.)

hiniploof, Offizinal firaterbuch. Eirfurt 1733-\$734. folio.

- Botanica in originali. Halae 1757-1767. folio.

Ulecker, specimen Florae berolinensis. Berolini 1742. foliu.

$(-)$ Hora berolinensis. Berlin $1737-1758$. folio.

Jurlwiy, Ectypa vegetabilium. Ilalae 1760. folio.

Biber, Blatterskelete. Gotha 1774.

Reckmann. Pllazenabulrucke. In ejus "Beitrage zur Gesehichto der Erfindungenn. Leipzig 1780. 8. vol. 1, p. $514-523$.

Martius, Anweisung Pllanzen abzudrucken. Wetzlar 1785. S.

Jun, harms. Icones plantarum rariorum. Il:slae 1787. folio.

L Icones plantarum offieinalium. Halae 1787. folio.

Hoppe, Eetypa plantarum ratisboneusium. Regensburg 1787-1793. folio.

Ectypa plantarum selectarum. Regensburg 1796. folio.
Ulitzsch, Botanische Schatlenrisse. Torgau 1796.4.

Dunker. Pflanzenbelustigung. Brandenburg 1798. 8.

iluyi, Doutschlands Flora, Regensburg 1798-1799. folio.

Hrmmert, Kurze Beschreilung von 150 okonomischen Samereien. (Mit Fabinet in Glaskastehen.) s. 1. 1802. gr. 4.

Graumiller, Neue Methode von naturlichen Pflanzenabdrucken. Jena 1809.4 .

Bomel, Facies plantarum. Carcassonne 1810. folio.

Opp. Neue Pllanzenabelluche. (Graser.) Jena (1814.) folio.

Aiguebelle, Homographie. Paris 1828. folio.

(Bulletil des sc. nat. Avril 1829. p. 103.)

\section{Horti botanici.}

Gesner, Horti Germaniae. Iupr. cum Valerii Cordi Aunotationilous in Ljoscoridem. Argentorati 4561 . folio.

Frednanuus, Hortorum viridariorunuque icones ichnographieae. Colonise 1615.4.

Palli, Viridaria varia. Jlafniae $\$ 653$. 12.

Hermannides, llortulus velavieus seu orationes aliquot de hortis. Ilardervici 1665.8 .

Gollschalch, Flora hortensis. Cothen 1703.8.

11 aldschmimlt, De imlustria acvi lodierni circa propagationem plantarum. kiliale 1712.4.

Baier. He hortis fieruaniae botanico-medicis eelebrioribus prolusio. In llist. horti alturfieusis. Mlturfi 1727.4.

Ileister, De hortorum acadenicorum utilitate. Helmstadii 1739. 4.

Reuschins, De hortmum acalenicorum utilitate. Helmstadii 1739. 4.

Linne, De horticulura academica. Ujosaliae 1754. 4.

Royen, Oratio do hortis publicis pracstantissimis hotanicae adminiculis Lughaui liat. 175 个. 4 .

Schulze. Von dem Nitzen aines botanischen Gartens. In Krelaschmar. Beschreibung Wer Matyua, Frichichstadt (1764.) 4.

Tandelli, Memoria sobre a utilidade dos jardius butanieos. Lishoa 1770.8 . Delarhe, Discours sur l'utilice d’un jarlin botanique. In ejus "Séance v ete. Cletmoat-Ferrdad 178. s. 1. 39-66.

Giseke, Ueber dea Nutzen botanischer Garten fur eine Stadt. (Hamburger Adress-Combirnachrichtem, 1782. Stuck 76. 77.)

Strumilla, or ogruluch pojlnocnych. (1)e hortis septentrionalibus.)

llelenze. Mémoire sur les planus domement el sur Jeur introduction daus nos jardins. (Annales du Miséum $\mathbf{X}, 149$. )

Armano, Sull utilitu regli orti bolanici. (Poligrafo, Ann. III, p. 73.)

Hoffuann, Oratio de houtis botanieo-medicis. Mosquae 1807. 4.

De Cantolle. Fotice abrégrea do l'histoire et l'administration des jardius botaniques. (Paris 1822.$) \mathrm{s}$.

Menschel, Zur Geschiehte der Jotanischen Gärten in Schiesien in 15. und 16. Jihrhuvart. Berlin 1837.8.

\section{Horti publici Italiac.}

\section{Horlus bononiensis.}

Ambrosinus, Hortas stadiosorum Bononiae conditas. Bononiae 1637.4.

Monli, Horli bononiensis historia. In ejus "Plantarum varij indiees». Bumoniae 1734.4. - ils. 1753 . 4

(Rolali) Index plantarum londi lomoniemsis (et continuatio historiae hort). bononiae (1802.) '.

Bertolimi. Rapporto sullo statu ricll orto agrario di Bologna. Milaun 1812.8.

Bertoloni, Elenehus plantarun horti botanici bononiensis. Bononiae 1820.4. 
Berloloni, Viridarii hononiensis vegetabilia commutanda. I'ononiae 1824.4 . Ilorti hotaniei hononiensis plantae commutandae. Bononiae 1826. 4 .

Continuatio historiate horti botaniei hononiensis. Bononiae 1827.4 . Sylloge plantarum borti botintici Jomoniensis. Bononiac 1827.4. 1839. 4 Horti botanici bononiensis flantac novae. Bononiae 1838(Inclices seminum : $1833-1819$. follo.)

\section{Hortus brixiensis.}

Malacu'ne, Catalogo del giardino del Liceo del dij). della Mella. Brescia 1810.4

\section{IIorlus camaldulensis.}

Dehnhardt, Catalogus horti camaldulensis. (Neapoli 1829.) 4. - ib. 1832. 4 .

\section{Iortus ferraviensis.}

Campanu, Catalogus horti ferrariensis. Ferrariae 1812.8

\section{Horlus florentinus.}

Manetti, Catalogus plantarum horti aearlemiae florentinae. Forentiae 1747. folio.

Micheli, Catalogus plantarum horti llorentini. Florentiae 1748. folio.

Targioni-Tozzetti, Ilistoria horti florentini. In Micheti. Catalogus ete. Florentiae 1748 . folio.

Manelli, Viridarium florentinun. Floreutiae 1751.8.

(Zucagni) Synopsis plantarum lorti florentini et auetuariom. $1782-$ 1795. folio, 8, et 4 .

(…… Synopsis plantarum horti hotanici florentini. (Florentiae 1806.) gr. 8

Centuria prima olsservationum in horto regio florentino. (Florentiae 1506.$) 4$.

(Piccioli) Catalogus plantarum horti florentini. Florentiae 1829. 8. (Catilogus senimum : 1836-1849. 4.)

Targioni-Tozzelli, Osservazioni fatte al giardino dei Georgofili. (Firenze 1836.) 8 .

\section{Hortus genuensis.}

Dinegro, Elenchus plantarum horti botanici. Genuae 1802.4.

(Durazzo) Il giardino butanieo dello Zerbino. Genova 1804.8

De Nolaris, hulea seminam horti genuensis. Genuae 1840-1849.8.

\section{Hortus mantuanus.}

Catalogus plantarum. Mantova 1785.8.

Nocea, Horti hotanici mantuani historia, descriptio, typus. (Turici 1793.) 8. Illustrationes plantarum herti mantuani. (Turici 1793.) S.

Scenographia horti botanici mantuani. (Turici 1796.) 8 . (Visteri, Aunalen V1. 1-29,60-6h. XVill, 67-83.)

\section{Mortus mediolanensis (braydensis).}

Amana, Catalogus horti regii botaniei braydensis (Brera). Merliolani 1812,8 . Sugli orti hotanici di Milano. (Poligrufo. Anu. 1812. p. 71. )

\section{Ilortus messanensis}

I'asfelli, Ilortus messanensis. Messanae 1640.4

\section{Ifortus mutinensis.}

Fabriani, Index plantarum in horto mutinensi. Mutiuse 1811.8 .

Brignoli a Brumnhoff, Catalogus horti hotanici mutiuensis. Mutinae 1917. 8. - ils. 1836 . 8

$-1848.8$

Elenchus seminum. Nutinae 1818.8. - ih. 1843

Horti botanici mutunensis histuria. Mlutinae 1842.4.

11. Hortus modoetiensis.

(Satalogus plantarum in hortis regiac villae prope Modoetiam. Modoetiae 1813.8.
(Rossi) Catalogus plantarum horti moloetiensis. Mediolani 1826.4

Catalogo delle piante vendilili. Monza 1832. 8.

(Manctii) Catalonus plantarutn horti prope Modician. Nediolani 1842 1844.8 .

(Iudices seminum: 1832-1819. \&

12. Inorus neapolilanus.

(Tenore) Catalogo defle piante del giardino botanico di Napoli Naproli 1807.16.

- Catalogus plantarum horti regii neaprolitani. Nestpoli 1812, 4. Appendia : ils. 1815. 8, - Ed. Il: il). 1819.8. (Indices seminum cam adnotationibus vidi annorum 18:2 - $18 \mathrm{kij}$ Catalogo della collezione agraria. Napoli $1815 \% .8$.

Osservazione butanicu-agrarie. Napoli 1817.8

Catalogo degli alberi ele. in venditı. Napoli 1841.8.

- Catalogo delle piante nel orto botanico di Napoli. Napoli 1845.4.

\section{Hortus novariensis.}

Biroli, Catalogus jlantarum horti uovariensis. Sovariac 181 11. S.

\section{Hortus panormilanus.}

Veria, Hortus regius panhormitanus. Panormi 1789. 4.

(Tineo) Index plantarum horti panormitani. Panormi 1790. 8. Synopsis plantarum horti panormitani. Panorni is0z-1807. 8 . Calalogus plantarum herti panormitani. P'anormi 1827.8.

15. Horlus patacinus.

(cf. Tiraboschi, Storia della lit. ital. t. VIl. (2) Facciolati, Fasti gṣnn. patas. (Cortusi) Lhorto dei simplici di Padova. Venezia 1594. 8.

Schenckius a Grafenberg, Hortus pratavinus. Francofurti 1600.8 .

Vesling, Catalogus platutarun horti gymnasii patavini. Patavii $1642-$ 1644.12.

Marccllus, Hortus plantarum patavinus. Patavii 1660. S.

Turre, Catalogus plantarum horti patavini. Patavii 1660. 8. - ib. 1662. 12.

Viali, Plantae satae in seminario horti patavini. Patavii 1686, 12.

Pontedera, Epistolae duae de horto patavino. Impr. cum Nieolai Commeni Papadopoli Historia gymnasii patavini. Venetiis 1726. folio. p. $14-23$.

Arduino, Catalogo primo delle piante nel real orto di agricoltura di $\mathrm{Pa}$ dova. Padova 1807.8.

Bonato, Catalogus plaotarum horti patavini. Parlova 1811 .. ludices seminum: $182 k-18 \%$.

Fisiani, Pianto nuova o rare dell' orto hotanico di Padova. Padova 1840 $-1 \$ 44.4$

- Della origine ed anzianità dell' orto hotanico di padova. Venezia 1839.8.

Marsili, Notizie del pubblico giardino de' semulici di Padova, ed. Visiani. Padova 1840.8 .

(Visiani) L'orto botanico di Padova. Padova 1842. 8.

16. Hortus licinensis.

Brusati, Catalogrus horti ticineusis. Paptac 1793.8.

Scanagata, Catalogus 1797.

Nocca, Ticinensis horti academici plantae selectae. Ticini 1800 , folio. (ef. V'wiani, Saggio sulla manieril d'impedire ete. Milano 1800. el Colombano potius . Yocca, Collezione ragionata ete. 1800.8.)

(-) Synopsis plantarum horti botanici ticinensis. Papiae (1803.) 8 . Synonymia plantarum horti botanici ticinensis. Papiae 1804.8 . Nomenclatura stirpium lıort ticinensis. Papiae 1507. 8.

(-) Onomatologia plantarum horti ticinensis. Papiac (1813.) $\mathrm{S}$.

Ilistoria atque iclnographia hont botanici ticinensis. Ticini $4 \$ 18.4$ (fudices seminum: 182i-18ki)

\section{Hortus parmensis.}

Elenchus plantarum parmensis. (Parmae) 1802 IZ.

Jan, Elenchus plantarum horti botaniei parmeusis. (Parma 1826.) folio (Indices semiunm: 1827-1833.) 


\section{Horlus pisanus.}

Bellucei, Plantarum index horti pisani. Florentiao 1662. 12

Vellia, Catalogo di piante nel giardino de' semplici di Pisa l'anno 1635. (Targioni-Tozzelti. Dei progressi etc. IIJ, 243-250.)

Tilli, Catalogus plantarum horti pisani. Florentiae 1723. folio.

Calvius, Comnentarium ad historian vireti pisani. Pisis 1777. 4

Savi, Enumeratio stirpiom horti pisani. Pisis 1804.8.

Tilli, Eisumeratio stirpium horti pisani. Pisis $1806-1810.8$.

- Index seminum. 1817.

Savi, Notizie alla storia del giardino e museo di Pisa. Pisa 1828. 8 . (Indices seminum: $183 \mathrm{r}-18 \mathrm{r} 8$.)

\section{Hortus regiensis.}

Foss $\alpha$, Catalogus horti hotanici regiensis. Regii 1811.8.

\section{Hortus romanus.}

Triumfelli, Syllabus plantaram horto medico ronanae Sapientiae additarum. Romae 168\$. 4

Cavallini, Brevis enumeratio plantarum etc. Romae 1689. 12.

Triumfetti, l'raelusio ad pablicas herbarum ostensiones. Romae 1700. 4. Cocchi, Oratio in aperitione horti botanici supra Janiculum. Romae 1796. 4. Bonelli et Sabbati, Hortus romanus. Rumae 1779-1793. folio.

(Donarelli) Euameratio seminum horti romani. (Romae 183\%.) folio.

\section{Hortus senensis.}

(Giuli) Selectio seminum ex horto uıiversitatis Senarum. 1843-1844.

\section{Hortus laurinensis.}

Allione, Synopsis methodica stirpium horti taurinensis. Aug. Taur. 1760. 4. Balbis, Miscellanea botanica. Taurini 1804-1806.4.

- Enumeratio lorti botanici taurinensis. Taurini 1805. 4.

Catalogus stirpium horti taurinensis. Taurini 1807-1814. 8.

- Horti taurinensis stirpium icones et descriptiones. Taurini 1810.4 . Biroli, Catalogas plantarum horti taorinensis. Augustae Taur. 1815.8 . (Capelli) Catalogus horti taurinensis. Aug. Taor. 1821. 8.

Moris, Jllusirationes rariorom stirpium horli taariuensis. (Taurini 1833.) 4. (—) Enomeratio semiuum horti taurinensis. Taurini 1831-1846.8.

\section{Hortus venetus.}

Aluchinger, Cenni intorno all' orto botanico del Liceo Convito di Venezia. Venezia 1842.8.

\section{Ilortus veronensis.}

Pollini, Gatalogus plantarum borti botanici veronensis. Verona 1812.8. ib. 1814.8 .

- Horti et provinciae veronensis plantae novae vel minus cognitae. Ticini 1816,4

\section{Horti privati Italiac.}

1. Hortus in villa Bibbirni prope Florentiam.

(Ridolfi) Catalogo delle piante coltivate a Bil,biani. Firenze 1843. 4.

\section{Hortus Principis de Bisignano, Neapoli.}

(Tenore) Catalogo delle piante del giardino botanico del Signor Principe de Bisignena. Napoli 1809.8.

\section{Hortus Pauli Boccune, Calaneae.}

Boccone, Elegantissimarum plantarun semind. Catanene 1668 . folio.

\section{Iorlus Johannis Bochm, Venetiis.}

Catulogus rariorum plantarum hortuli Johannis Boehm. Tenetiis 1689. 8.

\section{Hortus Equitis Bonafous.}

Mottard, Jardin expérimental de Saint-Jean-de-Nlaurienne. Turin 1844. 8.
6. Hortus Fr. Borlonii, Principis Jucentulis in Boceadifaleo. (Gussone) Catalogus plantarum horti in Boceadifalco prope Panormum. Neapoli 1821.8 .

- Index seminum horti in Boccadifalco. (1823.) 4

Gasparrini, Piante coltivate nel real orto di Boccodifalco. s. I. et a. S. et a 8 . Discorso intorno l'origine del villaggio S. Ferdinando. s. 1 .

\section{Hortus Bultiglierae.}

Freglin, Catalogue du jardin de Buttigliera (Marengo). Turin et Asti 1810 -1812.8 .

\section{Hortus Francisci Caetani Ducis, Romae.}

Valente, Recensio plantarum villa atrue horto botanico Francisci Caetani Docis comprohensarum. Romae 1803. 8.

9. Horms Josephi, Principis Catholicae, Panormi.

Cupani, Jortus Catholicus. Neapoli $1696-1697.4$

10. Horfus Domini Callaneo, Novarae.

Cattaneo) Jortus Cattaneus. Novara 1807.

Catalogo delle piante del giardino Cattaneo. Novara 1812.8

11. Horlus Antonii Pis. de Ciancio, Cataneae.

Ciancio, Catalogo delle piante del giardino suo a Cattanea. 1816. 8 .

12. IIortus Lulovici Colla, Ripulis.

Colla, Hortus ripulensis. Aug. Taur. 1824-1828. 4.

15. Mortus Comitissae Cloeliae Durazzo de Grimaldi in villa Pegli mope Genuam.

Catalogue des plantes dans le jardin de Nadame Durazza de Grimaldi a Pegli, Dép. de Genes. Gènes 1806. 8.

\section{Hortus Cardinalis Odoardi Farnesii, Romae.}

(Castelli) Exactissima descriptio rariorum plantarom in borto Farnesiano. Romae 1625. folio. 1692. folio.

cf. Sandrart, Giardini di Roma oder romische Gărten. Nurnberg

\section{Hortus Ferronianus, Florentiae.}

Catalogo del giardino Ferroni di Firenze. Firenze 1504. 8

16. Hortus Caroli Maupoil, in provincia veneta.

Maupoil, Catalogo degli alleri e piante. Venezia 1827. 8.

17. Hortus J. F. Mauroceni, Patavii.

Tita, Catalogus plantarum horti Equitis Maurocem. Patavii 1713.8

18. Hortus Marchionis Panciatichi, prope Florentiam. Picciuoli, Hortus Panciaticus. Firenze 1783.4.

\section{Horlus Alberti Parolini, Bassani.}

Indices semium horti Paraliniani. Bassano 1834-1848.

20. Horlus Salvatoris Portal, Albaevillae.

Catalogus plantarun horti botanici Sultatoris Portal Albaevillae in Sicilia. Catanae 1826. 12 .

\section{Hortus Marchionis di Priero in Fillar-Perosa.}

Catalogo del giardino della Marcheso di Priero al Villar-Perosa. Torino 1832.8 .

\section{Hortus Gerardi Sagredo.}

Ienographia borti Gerurdi Suyredo. in Clorici, Istoria etc. Venezia 1726.4 25. Horlus Marchionis de Spin, St. Sebastiani ad Padum.

Kodati, Catalogue du jardin de Mr. de Spin a St. Sebastien, dep. du Po. s. I. $1804-1806.8$.

Spin, Le jardin de St. Sebastien. Turiu 1809. 8. - ib. 1812.8. - ih. $1818-1823.8$ 
HORTI PUBLICI BRITANNIAE
(Thenaeus) Series plantarum in horto hotanico Comitis Antonil Mariae Thiennei. Vicetiols 1802.8 .

2.5. Hortus Antoniz lenturi propre Brixiam.

lenturi, Jantate in lorto Antonii l'mturi prope Brixiam. Brixiae 1835.8.

\section{Horti publici Britanniac.}

\section{Horlus cantairigiensis.}

Account of the donation of a botanic garden of Cambridge. Cambridge 1763. 4 .

Martyn, Catalogus torti botaniei cantahrigiensis. Cantebrigiae 1771. 8. Mantissu: ib. 1772.8.

__ Jorti botanici cantabrigiensis catalogos. Cantabrigiac 1794. S.

Down, Hortus cantabrigiensis. Camlniulge 1796.8. - Eıl. Xlll: London 1845.8

\section{Hortus rhelseanus soc. pharm. londinensis.}

Pelieer, Botanicum hortense. (Philos. Transactions, vol. XXVl]-XXIX.)

A catalogue of fifty plants presented to the Royal Sociely, by the Company of apothecaries of London, pursuan to the direction of Sir llans Sloane. For the years 1722-1773. (1)ilos. Transactions, vol. AXXIl - I.XIV.)

Niller, Catalogus plantarum officinalium in horto chelseyano. Conclini 1730.8 .

(Rand) Index plantarum officinalium horti clselseani. Londini 1730, 12. Horti nedici chelseiani index compendiarius. Londini 1739. 8.

Ilaymes, An accurate survey of the botanic garden at Chelsed. London 1751. folio.

Field, Memoirs on the botanick garden at Chelsea. London 1820.8.

5. Hortus soc. hortic. lond. in Chiswick.

Cintulugue of the Morticultural Society's of London garden at Cliswick J London 1826. 8. - ib. 1831. s

Lindley, Report upon the new or rare plitnts in the garden at Chiswick. London $1825-1827.4$

Bentham, Report ( 1 and 11 ) on some of the wore remirkable plants raised in the Horticultural Society's garden. Lonclon 1834. 4 .

\section{Hortus dublinensis.}

Nicholson. Methodus plantarum horti dublinensis. Mublini 1712.4.

\section{Horlus societatis dublinensis in Glaseenin}

(Undermood) Catalogue of plants of the Dublin Socielys botanic garden it Glasvenin. Dublin 1802.8 - ib. 1804.8.

\section{Hortus edinburgensis.}

Sulherland, IIortus medicus edinlurgensis, Edinburgh 1683. 8. - il). 1692. 8 .

Preston, Catalogus plantarum seminarii medicinae. Edinhurgh 1716. 19. Inlex plintarum officinalim horti edinensis. (1738.) 8 .

Alston, Index plantarum horti edinhurgensis. Finubrgi 1740. 8. - ib. 1753.8.

Catalogur of the hotanic garden at Ediuluugh. Ehimburgh 4775.8

Bury, A selection of Ilesaudrian plants. Lomon (1831-1834.) folio max.

\section{T. Hortus glollianus.}

(Murray) Companion to the Glasgow Intanic garden. Glasgow (1819.) S.

(Hooker) A catalogue of plants in the royal hotanic gardeu of Glasgow. (i)asow 1845. \&.

8. Horlus regius liewensis.

IIIll, Hortus hewensis. Londini 1768. 8.

Lihitier, Sertum anglicum. Paris 1788. folio.

\section{IIORTI PRIVATI BRITANNLE}

Aiton, llortus kewensis. I.ondon 1789. 8.

Meen, Exulic plants from the royal gardens at kew. s. I. 1790. foluo.

Bater, Deliueations of exolich plants cultivated in the royal garden at Kew. London 1796. folio.

Allon, Jlortus hewensis. E.1. 11. cur. Jon. Dryander "hob. Brown. Lonlon $1810-1813.8$.

- Epitume of the llortus hawensis. Lomlun 1814.8 .

\section{Hortus botanicus urbis Licerponl.}

Calalogut of plants in the hotanic girden at Liverpool. Liverpool 1808.8. Roscoe, Monandrian plants from living specimens in the hotanic garden at Liverjonl. Liverpool 1828 . folio.

\section{Hortus axoniensis.}

Au english catalogye of the physicke garden at 1)xford. Oxford 1648.8.

(Bobarl) Catalogus planlarum horti oxoniensis. Oxonii 1648 . 8. (Paull. Viridaria varia. jr. $325-394$.

Catalogus horti oxoniensis, eura Philippi Stephani et fillelmi Brounei. O.nonii 1658 . s.

\section{Horti privati Britanniac.}

11 estan, linglish Flora. London 1775-1750. S.

(Murray) The liritish garden. Bath 1799. 8.

Salishury, The Paralisus londinensis. London $1806-1807.4$

Swet, Jlortus sulmrbanus londinensis. London 1 is 18.8

_- The britisls flowergarden. London 1823-1829.8.

- Hortus britannicus. London 1827. 8. - ih. 1830. 8. - ih. 1\$39. 8. Graves, Hortus regius. London 1834. 4.

Loudon, llortus britannicus. London 4832. 8. - il. 1839.8.

Hortus hignosus londinensis. London 1838.8.

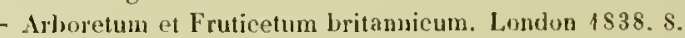

The Derby Arboretum. London 1840. \&.

I. Hortus Johannis Blackburne Armig., Orfordiae.

Neal, Catalogue of the rarden of John Blackburne Esq. at Orford, Lancashire. Warrington 1779.8.

\section{Horlus Philippi Broun, prope Mancestriam.}

A catalogue of very curious plants collected ly the lato Philipp Brown Manchester 1779. \&.

5. Hortus Episcopi londinensis Henrici Comptom, in Fulham.

Ray, Arlores ef [rutices rari et exotici in horto 1). Klenrici Compton, ejpcopi londinensis. (Kay, llist. p1. 11. 16\$6.? p. 1798.)

IItatson, Hilliam. An account of the Bishop of London's garilen at Fulham. (Plil. Transact. vol. XLVIl. p. 241-2:7.)

\section{Hortus Doctoris Coyle, Gippovici.}

Coyte, llortus botanicus gippovicensis. Ipswich 1796. 8.

3. Hortus Guilielmi Curtis, in Lambeth Marsh, posteu in Brompton.

Curlis, Catalogne of plants in the London hotanical garden. London 1783.8 .

Caltalogue of the Brompton botanic garden. 1790-1799. 8 .

6. Horlus Johannis Fothergill, in Upton.

Catalogne of Dr. Fohergills garden at lpton. (London) 1781. 8.

(Coaktey-l.ellsom) Hortus uptonensis. (1783.) 8.

7. Horlus Johannis Gerarde, Londini.

Gerarde, Catalogus arberun, frutieun ac plantarum in hortoGerurdi. Londini 1596.4. - its. 1599.4. 
S. Hortus Johannis Russell, Ducis Bedfordiae, in Hoburn Abbey.

sinclair, Ilortas gramineas woburneusis. London 1816. folio. - ib. 1895. 8. - ib. 1838. 8 . (gallice, germanice.)

(Forbes) Ilortus ericaceas wobarnensis. (London) 1823.4. Salicctum woburnense. (London) 1829.4.

- Hortus wohumensis. London 1833. 8.

Pinetum woburnense. Londini 1839. gr. 8.

\section{Hortus ad Chapel Allerton.}

Salisbury, Prodromus stippiom in hortu ad Chupel Allerton vigentium. Londini 1796. 8.

\section{Hortus Jacobi Sherard, Ellhami.}

Dillenius, Ilortus elthamensis. Londini 1732. folio.

11. Horlus J. Symmons, Armigeri, in Paddinglonleouse.

Salisbury, llortus paddingtonensis. London 1797. \&.

\section{Hortus Johannis Tradescant, in Lambeth.}

Tradescanl, Catalogus plantarum ete. (Hasaeum Tradescantianum. London $1656.8, p, 73-178$.)

II alson, Some aceount of the remains of John Tradescant s garden at Lanbeth. (Plii). Transact. vol. XLVI, 1. 160-161.)

\section{Horlus in insula St. Iincentii.}

Guilding, Aceount of the botanic sarden in the islind of St. Vincent. Glasgow 1825. 4.

\section{Forti publici Germaniac.}

\section{Hortus aldorfiensis.}

Jungermann, Citalogus plantarum iu horto altdorphino. Altdorphii $1633^{*}$. 4. - ib. 1646.8 .

Hoffmann, Florae altdorfinae deliciae liortenses, Altrorfii 1660. 1677 1691. 1703.4 .

Baier, Ilorti altolorfensis historia. Altdorfi 1727.4.

logel, ludex plantarum medicinalium horti altdorfini. Altelorfi 1790. 4.

\section{Hortus berulinensis.}

Elsholz, Flori marehica. (Ilorti regii Berlin, Oranienbury, Polsdam.) Berolini 1663.8 .

Ludotf, Catalogiss plantarum demonstratarum vel demonstrabilium. Berolini 1746.8 .

Verzeichniss ete. (Thes. no. 11795.) Berlin 1773.8

Hilldenow, Berlinische IBamzueht. Berlin 1796. 8. - Eid. II: ib. 1811. S.

Hayne, Dendrologische Flora der Gar:en Berlius. Berlin 1822. 8.

IVilldenow, Enumeratio plautarum hont herolinensis. Berolini 1809. 8. Suppleasentum: ib. 1813.8.

_- Ilortus berolinensis. Berolini (1806-) is16. folio.

sprengel, Novi proventus hortorum balensis et berolinensis. Ilalac (1819.) 8 .

Oto, Plantae rariores horti berolinensis. In Ilor. pliys. ber. Boun 1820 . folio.

Link, Enuneratio plantarum horti berolinensis alterb. Berolini 1821 1822.8.

- Ilortus regios botanicus berolinensis. J3orolini $1827-1833.8$

Link et Otlo, Icones plantarum selectarum horli herolinensis. Berolini 1820 -1828.4 .

_... Kones plantarum rarioruo horti lecolinensis. Berulini $182 \mathrm{~S}$ $(-1831)$.4 .

Link, Klotssch et Otto, lcones plantarum rariorum lorti berolinensis Berolini $1841-1844.4$.

Link, Filicum species horti berolinensis. Berolini 1841.8.

- Abietinae horti berolinensis. Beroliui 1841.8 lndices seminum: 181\%. 1518. 1836-18'9.)

\section{i. Hortus bonnensis.}

Nees con Esenbecti el Sinning, Plantarum in lurto bonnensi metritarum icones selectae. Bonnie 1824. 4 .

(Indices semimtm: $18: 31-18 \% 9$.)

\section{Hortus carlsruthanus.}

Thran, Iadex ltorti carolssahini. (1733.) 8.

Risler, Horlus carhruhaums. Loeraci 1747. 8.

Catclogas etc. Ilerausgegeben von A. W. Sievert. s. l. et a.

Schweycter () Catalogus plantarum horti botanici carolsrulani. Carolsruhae 1791.8 .

(Gmelin) Hortus carlsruhanus. Carlsruliae 1811. 8.

IIarkeeg, llortus earlsruhanus. Karlsiuhe 1825. 8.

(Indices sensinum: 1836-1819.)

5. Hortus cotoniensis.

Thiriart, Catalogue du jardin botanique de Culogoe. Cologne 1806.8 .

(Bertentamp) Catalogus plantarum horti coloniensis. Coloniae Agrippinte 1816.8

\section{Ifortus erfurtensis.}

Beruhardi, Catalogus plantarum horti erfurtensis. Erfurti 1799-1808. 8.

\section{Horlus erlangensis.}

Marlins, Plantarum horti erlangensis enuneratio. Erlangac 1814.8

\section{S. Hortus francofurtanus $a / M$.}

Reichart, Lummeratio stirpium lorti Jotanici Senckenbergiani. Francofurti a/Al. 1782.s

Indices seminum: 183 ; $-18 t^{\prime}$.)

9. Hortus francofurlanus $a / V$.

Beryen, Catalogus stipium horti academine viadrinae. Franeolurti a/V. 1742. 8

\section{Hortus friburgensis.}

Perleb, De horlo botanico friburgensi. Friburgi Brisgoviac 1829.4.

\section{Horlus gissensis.}

Heiland, Catalogus plantarum. (I'alentini, Prodromus bist. nat. Ilassiae, p. $27-33$.)

(Illuminirler Plan des bolan. Gartens in Giessen. In II ather, Flora. Giessen 1802. 8.)

\section{IJortus paedagugii glauchensis prope IIalam.}

(Schrader) lndex horti pitedagogii glauchensis. 11alae 1772. 16.

\section{Hortus gollingensis.}

Ilaller, Brevis enumeratio slimpium horti gottiogensis. Gottingae 1743.8.

- Enumeratio plantirum horti gollingensis aucta et emendata. Gotlingae 1753. 8.

Zim, Catalogus horti el agri gottingensis. Gottingae 1757. 8.

Murray, Prodronus designationis stirpium gottiugensium. Gottingae 1770.8 .

(1lorti historia, p. $833-13 \mathrm{k}$ Platae ljorleases 1769, p. 133-23t.

Observationes super stirpilins in horto alcademico institutae.

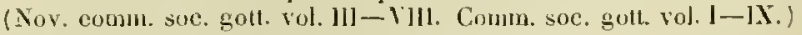

Hoffmann, Hortus gottingensis. Gottingae 1793. foliu.

Schrader, Catalogus horli gottingensis. (1yottingae) 1806.8 .

- llortus gottingensis. Gotlingae 1809. folio.

(Golt. Gel. Aaz. 1809. 10.37-38. 1810. 1. 641. 1512. 1. 129.

) Verzeichniss hathicher Pflanzen des Gottinger Gartens. Gottingen 1810.4. - ils. 1812.4.

(Indices seminimun: 181'r. 1821, 182j-18\%9.)

barlling, Der botanisehe Garten zu Gottingen. Gollingen 1837. 4.

\section{Hortus yryphicus.}

Hilcke, Ilortus gryphicus. Gryphiae 1765. 8.

(I'eigel) Incles horti gryphici. Guyphiae 1773. S. 
Weigel, Hortus gryphicus. Gryphian 1789. 4.

(Ledebour) Emuneratio plantarum horti gryplici. Gryphiae 1806-1810.8.

\section{3). Hortus halensis.}

(Junghanns) ludes flantarum horti halensis. 1!alae 1771.8.

(Sprengel) Der botanische Girten zu llille. Ilalle 1800-1801.8. (cr. Hatl. Allg. Lit. Zeitg. 180t. I. p. 1. - 180'. Hutcll. Rt. p. 168\% 1810. Dec. 1). $833-836.1$

Ifenckel von Dounersmarek, Adumbrationes plantarum nonnullarum liorti halensis. Ilalae 1806.4 .

siprengel, Index plantarum borti halensis. Ilalac 1807. 12. - ib. 1808. 8. Indter seminum anmorum 1809. 1810. 1814. 1818. 1819. 1828. 1829. $183 i-1869$.

- Plintarum miuss cognitarum pugillus I - II. Ilalae 18131.\$5. 8.

_- Novi proventus hortorum halensis et berolinensis. IIalae (1819.) 8 . Schechtentol, Hortus hirlensis. Fasc. I-II. IJalae Saxonum 1841.4.

\section{Horlus hamburgensis.}

Verzeichniss alozugehender Pflanzen. Hamburg 1830.8 .

(Ot10) Verzeichniss abzugebender Pflanzen. Ilamburg 1845.. (Indices seminum: 1823-184!.)

\section{Hortus heidelhergensis.}

sprenyer, llurti medici catalogus. lrancofurti a/M. 1597. 4.

Caus, llortus palatinus. Francofurti a/M. 1620. folio.

Franke, Anbarvalia heilelbergensia. Ilridellsergae 1687.4.

Augusta llygeiac palatinae corona etc. lleidelbergae 1751. 4.

fiallenhof, stirpes agri et horti heidelbergensis. Heidelhergar 1782, 8.

\section{Hortus helmstadiensis.}

Heister, Index plantarum rariorum, quilus hortum academiae Inliae auxit. Helmstirlii $1730-1733.4$.

Leincker. IIorti helmstadiensis praestantia. Helmstadii 1746. 4.

Fabricius, Emuneratio plantarum horti helmstadiensis. Ilelmstadii 1759. 8. - ib. 1763.8 . - ib. 1776.8

\section{Horius herbijolensis.}

Beringer et llereum, Plantarum quarundam exoticarum in horto herbijolensi catalogus. Ilerbipoli 1722. folio.

(Krouss) Verzeichniss von Pllanzen in Resilenzyarten in Wurzburg. Wurzburg 1812.4 .

(ef. Afayer, Pomona franconica. Nurnherg 1776-1801. \&)

(Leiblein) Selectus senuinum: $1841-1849$.

\section{Hortus ingolstadiensis.}

Historia horti botanici ete. Ingolstadii 4723. 4.

\section{Hortus jenensis.}

Negelius, Programma ad hortenses lectiones. Jenae 1639.4

Schenckius, Catalogus plantarum horti medici jenensis. Jenae 1659. 12.

schelhammer, Programma quum rei herbariae professionem auspicaretur. Jenac 1690. \&

Boldinger, Index plantarum horti ef agri jenensis. Goettingae 1773.8 .

(Batsch) Conspectus horti botanici jenensis. Jenae 1795. 4.

(—) Catalogus plantarum horti Jenac 1794 fundati. Jenac 1797. folio.

(Voigt) Catalogus plantarum hottorum jenensis et belvederensis. Jenae 1812.8 .

\section{Hortus kilimsis}

Major, Memoria initiati horti medici. Kilonii 1669. folio.

I'eber, Hortus kiliensis. Kiel 1529 . \&

\subsection{Hortus landeshulamu..}

Schrank, Catalogus horti latideshutani. Landeshuti 1807.4.

schultes, Catalogus horti botanici landeshuti Bojorum. Landeshuti 1810 $-18138$

\section{HORTI PUBIICI GERMANIA:}

21. Horms lipsiensis.

Ammenu, Caralogus seminum. Lipsiae 1664.4.

Suppelles botanica. lipsiac 1675.8.

Baumgarten, Sertum lipsicum. Lipsiae 1790.8.

Heduig, Sporarum catalogus. Lipsiae 1799.8.

Schewegrichen, Ilortun botanicum lipsiensem foliciter iustauratum remuntiat. In e ajus "llist. Musc. liep prodromus w. Lipsian 1814. \$.

(Loipz. Jit. Zeitg. 1809. Intell.-Blatt no. 31.

(Kunze) Indices sominum ex burlo lipsirusi. 1837 - 1849.

\section{2̈. Homlus manhemensis.}

Medicus, Indes horti manheniensis. Hanhenii 1771. 12.

26. Ilorlus murburgensis.

Moench, Methoulus plantas horti marburgensis describendi. Marburgi 1794 -1802.8 .

Henderoth (Merrem?), Index plantarum horti marburgensis. Harlurgi 1807.8 .

11 enderoth, Bemerkungen über newe Pflanzenarten des Marburger Gartens. Marburg 1831.8.

\section{Ilorlus monacensis.}

Catalogus etc. Monachii 1814.8.

Schrank, Plantae rariores horti academici monacensis. Monachii $1 \$ 19$. folio.

Murtius, Jortus Jotanicus monacensis. Monachii 1825. 4.

(Martius et Schrank) Hortus regius monacensis. Verzeichniss atc. Munchen unt Leipzis 1829. 8.

Martius, Amoenitates botanicae monacenses. Franhfurt a/MI 18џ91831. 4 .

$$
\text { Indices semisum: 183;;-1818.) }
$$

\section{IIorli noribergenses.}

lolckamer, lilora noribergensis. Noribergae 1700.4.

Brueckmam, Notae in Volcknmeri Floram noribergensem. Fipist. itin. LIII. Cent. 3, p. 678-705.)

Volckamer, Numbergische Flora. In cjus "Numb. Ilesperides". Number" 1708. Solio. p. 209-243.

__ Fiora norimbergensis. In ejus "Hesperides norimbergenses". Numberg (1713.) folio. p. $209-243$.

Beschreilung ethcher fremden frewachse. (Continuation des Tumbery. IIesp. 1744. folio. p. $209-236$. .)

\section{Ilortus oenipontanus.}

Heufler. Berich uber den Pllanzengarten des Frrlinandeums. lumsprmith 1840.8

\section{Horlus pragensis.}

(Kostelelzky) lukes plantarum horti pragensis. Prag $1844 . \$$ (Indices semimum: 1821. 18:33-1865.

\section{Iortus ratishonensis.}

Oberndorffer, Horti medici, qui Ratislonae est descriphu. Latishonae 1621. 8 .

\section{Horlus regiomontamus.}

Titiue, Catalogus plantarun horti electoralis regiomontani. Lieqionumti 1634.12.

Sichuecigger linumeratio plantarum horti botanici regiomontani. Regiomonti 1812.8 .

___ Nachrichten nber den botanischen farten zu kenigswers. Konigsberg 1819.8 .

(Hortus regiomontamu seminifor: $1826-1868$.)

5.5. Lortus rostockiensis.

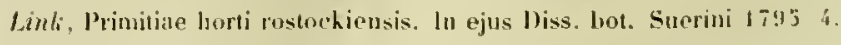

51. Ilortus salishurgensis.

Ranffl, (Gatalogus horti botanici salishurgensis. (Salisburgi $178 \mathrm{x}-17 \mathrm{is6}$.) R. 
j5. Horths stellinensis.

Zander, Primitiae viridarii medici stellinensis. Sedini 1672

j6. Hortus tergestinus

(Biasoletto) Selectus seminum: 1835-1847

\section{j7. Hortus tulingensis}

Kielmeyer, Decas rariorum plantarum horti tuluingensis. Tubingae 1814.4. Srhmebler, l)escriptiones plantarum novarum horti ublingensis. Tubingae 1895.8 .

Delectll 4rmisum: 1K25, 1\$29.)

58. Hortus ulmensis.

Schoepfius, Ilortus ulmensis, Ulmischer Paradissgirten. IIm 1622.8.

59. Horkus vindobouensis.

Jacquin, Hortus botanicus vindobonensis. Vindobona 1770-1776. folio. Stoerck, Instituta fienltatis medicar vindohonensis. Vindobonac 1775. 8. Mappam horti ediutit Anton Liber Baro won Guldenslein.)

Endlicher, Catalogus horti acadenici vindoboneusis. Tindolnnae 18 亿 1843.8 .

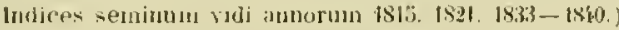

\section{Ilortus matislaviensis.}

Coeppert, Beschreibung des Breslauer Gartens. Breslan $1830 \mathrm{~s}$ Schaner, Der lintanische Garten zu Breslan. liegnitz 1843. 8

Nachricht von dem botanischen Garten. s. l. pl a. S Indices seminum: 183 ' -1819 .

\section{Horms wittonbergensis.}

Ieucher, lndes horti wittenbergensis. Wittenbergae 1711.4. Novi 1713.

Bruecham, Notae et observationes in Keucheri Seripta botanica. (lipist. itin. I.I. Cellt. 13], p. $583-6,27$.

l'uler, Catalogus plantarum horti wiltenlergensis. Wittenbergace 1792. 4. - Supplementum: ib. 1724. 4.

- Syllabus flantarmm horli wittenhergensis. Wittenhergar 1738.8

\section{Horti privati Germaniac.}

1. Horms Dirpctoris Franz Larl tchard, in pagn FransosischBuchols mope Berolinum.

Achard, Virzeichniss einer Sammlung etc. Jierlin 1796. \&

\section{Hortas schoenbrunnensis, Inperatoris Alustruce.}

Jacruin, Plantarun rariorum horli schoenturumensis foseriptiones et icom nes. Vimnae $1797-1804$. folio.

Manchart, Schonbrunn's butanisched Reichthum. Wien 1805.12. Schmill, Nachlesi zu Schonbrunn's botanischem Reichthum. Wien 480 s. 8. Boos, Schonbrunn's Flora. Wien 1816.8 .

Hartinger. Paradisus vindobonensis. Wien 184i-184i. folio.

־. Hortus Magni Ducis badensis. in Schwetzingen.

Zeyher und Roemer, Besclureibung der Gartenanlagen zu Scluwetzingen. Jannitein 1809.8

Zeyher und hieger, Schwetzingen und seine Gatenaulagen. Mannheim (1826.) 8

Zeyhr, Verzeichniss der Gewachse zu schnetzingen. Manuheim 1818. 8.

4. Hortus Regis Racariae, in Nymphenlury.

stevler, llortus nytuphenburgensis. Monachij 1821. 8. - ib. 1826. 8

\section{Hortus Golllob Boerner, Diesdae.}

Boerner, Alpbahelisclıes Verzeıchniss Dresdeı 1786. 8 - ib. 1787.8.

Pritzel, Thes. lit. lwL

\section{HORTI PKIVATI GERDINIAE}

\section{Horfus mercatoris haspuris Bose, Lipsiue.}

tmmun, Ilorus Bosianus. Lipsiae 1686.4

Pein. Der Bosensche Garten in Leijzig. Jlalle 1690. 8. - Lejpzig 1699 ४. - ils.1705.8. - ils.1713.8.

II chmann, Ilorlus Caspar Bosionus. Leipzig 1723.8

Prolsst, lerzeichniss des Kaspur Bose'schen Gartens. Leipzig 1738. 8. ib. 1747.8 .

7. Hortus Cousulis ron Bostel, Hornae prope Ilamburgum.

Scheerin, Nahmenregister eines wohlbekandten Gartens in Horn vor Jer Stadt Hamburg. Hamburg $1710-1712.8$.

$$
\text { S. Ilurms Chr. Ang. Breiler, Lipsine. }
$$

Breiter, Hortus Breiterianus. Leipzig 1817.8

9. Hortus hessensis, Ducis bmensweensis

hoyer. Beschreibung des Gattens zu llessem. Ifalberstadl 1648.4 Ed. 1]: Braunschweig 1658. 4.

\section{Hortus J. N. Buek, Francofurti a/ $\mathrm{I}$}

Buek, Hortus francofurtanus. P'ranhfurt a/d. 0. 1824 s.

11. Hortus Comitis Josephi Malabaila de Canal, Prayae.

Nowodworsky Elenchus plantarum horti Comitis Josephi Ualubaila de Cancl. Pragae iso4. 8

Tausch, Index plantarum liorti Comitis Josephi Malabnila de Canal. Pragae 1891,4

- Dlortus Catulius. Pragae 1823, folio.

\section{Ilorti friedlandiani.}

Willdenow) Verzejehniss der auf den friedlandisehen Gutern kultivinten frewachse. Berlin) 180 $-1805.8 .-$ Ed. I1: ib. 1806. 8. - Ed. I1 voll $F$. I' alter): il. 1815.8

1.5. Hortus ,Whonnis honradi con Gemmingen, Episcopi eystetlensis in monte St. Iritibalsi.

Besler, Ilortus eyslellensis, 1613, 1640, 1713. folio mas

II idumum, Catalogus systentaticus horti eystettensis. Norimbergae 1803.4 gallıce.)

1'. Itortus 0r. Arnoldi Gille, Cassellis.

cille. llortus, (aissellis 1627, 9. - ih. 1632.

\section{Ij. Ilorti Regis Ilannoverae.}

Ehrheml Terzrichniss der lilum und Stracher zu Herrenhausen. 1787. s.

Ehrhml Verzichnics der. 1787. $\$$.

11 endlam Verzeichniss der (ilas- Imıl Treilhauspllanzen zu Herrenhausen. Hamover 1797. S.

Schroder el II"pndlant, Sertum hannoveranum. froettingae 1795-1798. folio.

Wendland, Hortus berenhusinus. Hannoverae 1798-1801. folio

16. Hortus Electoris IIassiute, Cassellis.

Boellyer, Besclureilung Iles hotanisehen Gartens zu Cassel. Cassel 1777. 4.

17 Horlus Electoris Ilassiae, in arce Weissenstein.

Boeltyer, Verzeichniss der Baume in Park zu Weissenstein. Cassel 1777.4

Moench, Verzeichniss der Bitume und Standen des Lustschlosses Weissenstein hei Cassel. Frankfurt 1785.8

\section{S. Hortus Magni Duris Ilassiae, Darmsladii.}

katalog des Schlossgartemkz zu Harmstadt. Darmstadt 1832. 8.

(Indircou semilum : 1826. 183'-1849.)

19. IIorhs L. B. ron Hochbery, in pago Illubosch.

Pohl. Des Freiherrn vou Jlochberg lotanischer Garten zu llluboscl. Prag 1812.5 
20. Hortus Comitis von IIo/fmannsegg, Dresdae.

Catalogus seminum ex horlis Comitis de Ho/fmannsegy. Dresiala $1823-$ 1825. 4 .

Preisverzeicluniss der Pilanzen in seinen fítrtell. Ed. Vlll. Wresden 1836.8.

Verzeichniss der Pflanzenhulturmin in Graflich Hoffmannsegg'schen Ciarlen. Dresden 1824-1842. S.

Verzeichniss der Orchideen im Grallich Hofmannsegg'suls Garten z.1 Dresden. Dresden 1842-1844.8.

\section{Hortus illerfeldiensis.}

Verzeichniss der Pflanzen zu Illerfuld. In Lupin, Die Garten. Munchen 1820.8

\section{Uorlus Jac. Theod. Kilein, Dantisci}

K'lein, Fasciculus (I-II1) plantarum rariorum ex horto Kileiniano. Dintisci 1722. folio. - ib. 1724.1726.1748, s.

\section{Hortus C. L. Lrause, hortulani, Berolini.}

Roloff, Index plantarum horti Krausiani. Berolini (1746.) 8.

Krause, Catalogus arborum etc. Berolini 1753. 8.

\section{IIortus Lastropianus in Eimsbuellel.}

Lange, Catalogus der Gewáchso im lastropischen Garten zu Eimstuttel. Hamburg 1707.8.

\section{0̈. Horti Lissatiac.}

Franke. Iortus Lusatiae. Budissinae 1594. 4

26. Horlus Joh. Chr. Andr. Maypr.

Mayer, Mein Garten. Frankfurt 1778. 8.

27. Hortus Bernhardi Aleyer. Hanoviae.

Meyer, Samenkatalog. Janoviae 1795. \&.

25. Hortus P. II. G. Hoehring, Jeverae.

Moehring, Primae lineae lorti privati. Oldenlurgi 1736. 8.

29. Horlus Julii IJerculis Mueller, Ulmae.

Catalogus plantarum horti sui. Ulmae 1745.8

50. Hortus Otlonis von Muenchhausen in Schwobbern.

Muenchhausen, Verzeichniss seines Gartens zu Schwobbern. Göttingen 1748. folio

31. Horlus Pastoris J. G. Oelschlaeger, Halae.

(Otearius) Specimen Florae hallensis. Halae 1668, 12.

32. Paradisus Principis Hermann von Puecter ad oppidulam Husken Lusatiae.

Pueckler-Muskau, Andeutungen uber Landschaftsgärtnerei ete. Stuttgart 1834. 8. und Allas in folio.

5.5. Ilortus Rothschildianus, Franeofurti a/د.

Verzeichniss. Frankfurt a/M. 1823.8.

54. Hortus Principis Joseph Salm-Reifferscheid-Dyck in pago Dyck $a / R /$.

Salm-Reifferscheid-Dyck, Observationes botanicae in horto dyckensi notatae. Coloniae 1820-1822.12.

$12-1822.8 .-1829.8$

Plantae succulentae horti dyckensis. $1 \$ 21$.

Hortus dychnusis. Musseldorf 1834.8

Duesseldnrpii is í. 8 .

Paris 1845.8 .

Cacteae in Jonrto dyckensi cultae anno 1844.

50. Hortus Electoris Saxoniae, Dresdae.

Sidel, Verzeichniss. Dresden 1794.12. - ib. 1799. 8. - ib. 1806.8.
56. Horius Regis Saxoniae, l'illnitzii.

Catalogus. Dresdae 1819.8, - Linuneratio seminum: 1824.4.

57. Hortus G. C. Schelhammer, Itelmstadii.

Schelhammer, Catalogus plantarum rariorum lortuli donestici. Ilelmstadii 1683. 4 .

5S. Hortus in payo Schlackenwerth, Bohemiae.

Schmulz, Tractatus de nymphis earolo-hadensibus, 1661.8

59. Horlus Laurentii Schol, M. D., I ratislaviae.

Scholz, Itortus Vratislaviao silus. Vratislaviae 1587.4.

Catalogus borti Laurentii Scholaii. Vratislaviae 1596. \&.

(Calagii camen. Vratislaviae 1592. 4. - Epigrammata anicosum: it 1594.4 .

10. Hortus hasp. Guil. Sculteti, I'ratisluviue.

Sculletus, Catalogus aller Sorten Agrumi, und firundriss spines liartens: nelssi Gedichten. (Breslau 1731.) folin.

11. Horhes Principis Schmarzbury in Sondershansen.

Ekart, Beselireibung des Parkes zu Sondershausen. Potsdam I8 0 . inp. 4.

12. Horlus Comilis haspar won Sternberg, Brezinae.

Stemberg, Enumeratio plantarum horti brezinensis. (Pragae 1824.) S.

43. Hortus J. A. Stisser, IJelmstadii.

Stisser, Botanica curiosa. Helmstedt 1697. \$.

Horti nedici helmstadiensis cataJogus. Helmstadii 1699.8

44. Hortus Domini von Veltheim in payo Llarblie.

Du Roi, Die Harbliesche wilde Baunzucht. Braunselıwejg 1771-1772.8.

- Ed. Il. von Polt. ib. 1795-1800.8.

15. Hortus A. F. Walther, Lipsiae.

Walther, Plantarum index tripartitus. Lipsiae 1732. 8.

Hesignatio plantarum horli ejus. Lipsiae 1735. 8.

46. Horti Magni Ducis Wimariue.

Dietrich, Weinarsche Flora. (Park zu Weimar.) Eisenach 1800, 8 .

Besclireibung der Gáten in und bei Eisenach. Eisenach 1808.

8. - ib. 1811.8 .

Dennstedt. Ilortus Belvedereanus. Weimar $1820-1521.8$

47. Hortus Domini de Zieten, Trebniziz in agro lebusano. Gleditsch, Catalogus horti Domini de Zieten Trebnizii. Lipsiae 1737. 8

\section{Horti publici Galliac.}

\section{Horlus angeriensis (juliomagensis).}

Bastard, Végétaux du jardin des plantes d'Angers. Angers 1810. 12. Boreau, Catalogue du jardin botanique d'Angers. Angers 1842-1844. 4.

\section{Hortus argentoratensis.}

Mappus, Catalogus horti argentinensis. Argentorati 1691. 12

(Spielmam?) Hortus argentoratensis. 1781. 8. - 1782..

(Villars) Tableau pour la plantation du jardin de strassburg. Strassburg 1806.8.

fillars, Catalogue nethodique du jardin de Strassburg. Strassburg 1807.8

(Nestler) ludex plantarum horti argentinensis. Argentorati 1818-1819.8.

Fée, Histoire du jardin botanique de Strassburg. Strassburg 1836.8

_ Catalogue du jardin de Strassburg. Strassburg 1836. \&. (Indices seninum : $183 \hat{k}-18 \mathrm{k}$.)

5. Horlus aurelianensis.

Instruction sur J'ordre du jardin botanique d'Orléans. Orléans 1783.49 


\section{Ilortus brevalensis.}

Pichon et Broca, Catalogue raisonné des plantes cultivées i l'école de botanique de Brest. Brest 1811. 8 .

\section{Hortus burdigalensis.}

Latupic, Hortus burdigalensis. Burdigalas 1784.8.

Catalogue du jarlin botanique de Gironde. Bordeaux s. a. 8.

$$
\text { 6. Llortus cadomensis. }
$$

Furin, Catalogue da jardin de Caen. Caen 1781. 8.

\section{Hortus divionensis.}

Catalogus horti divionensis. Divione $180 \mathrm{~s}$. 8.

(Fleurot) Catalognes des graines: $1833-1847$.

\section{S. Hortus dovacensis.}

Potiez-Defroom, Catalogue des plantes cultiveses dins les jardins de la sociéte d'agriculture à Douai. Douai 1835.8.

\section{Hortus in Fromunt prope Parisios.}

Thiebaut-de-Berneaud, Description du jardin établi a l'romont près Paris. Paris 1824,8

\section{Hortus insulanus.}

Cointrel, Catalogue du jardin botanique de lille. Lille 1731.8 .

\section{Hortus lugdunensis.}

Gilibert, Synopsis plantarum lorti luggdunensis. Lyon 1810.8.

(Scringe) Catalogues des graines: $1833-1847$

\section{Hortus massiliensis.}

Gouffe de la Cour, Liste des plantes raras du jardin de Marseille, In ejus "Hémoire" etc. Marseille 1813.8.

\section{Horfus monspeliensis.}

Belleral, Onomatologia stirpium in horto monspeliensi. Monspelii 1598. 12. - Dessein toucliant la recherche des plantes. Montpellier 1605.8. Remontrance et supplication au Roy Itenry $/ \mathrm{F}^{*}$. s. at 4 Opuscules. Paris 1785.8

Magnol. Hortus regius monspeliensis. Hontpelii 1697. S.

Gouan, Hortus regins monspeliensis. Lugduni 1762.8.

icunographia horti monspelieusis. In: Dorthes, Eloge de Belleval. Montpellier 1788. 4.

Broussonel, Eleuchus plantarum horti butanici monspeliensis. Monspelii 1805.8 .

De. Candolle, Catalogus plantarum horti botanici monspelinnsis. Mouspelii 1813.8

Baffeneau-Delile. Index seminum horti momspeliensis. (Monspelii 1837 -1844)$.8 .

\section{Hortus nanceymensis.}

II illemel, Catalogus plantarum horti nanceyensis. Nancy 1809. S.

\section{Hortus nannetensis}

Ecorchard. Spècimen d'une Flore. Nantes 1841.8

\section{Hortus parisiensis.}

Vallet. Le jardin du Roy tres chrestien Ilenry IV. (Paris) 1608, folio. - Le jarilin du Roy tres chrestien Louis NIII. Paris 1623. folio. Violan, Requette au roi pour l'étalılissement d'un jardin. Paris 1618. 8 . De la Brosse. Dessein d'un jardin royal à Paris. Paris 1628. 8.

Advis pour le jardin royal des plantes medecinales, 'pue le roy veut establir a Paris. Paris 1631. 4.

- Description du jardin royal des plantes metlecinales estably par le Roy Louis le Juste à Paris. P'iris 1636.4

1641. 4 .
L'ouverture du jardin royal de Paris. Paris 1640.8.

Catalogue des plantes cultivées au jardin royal Paris
Catalogus plantarum singularum etc. Parisïs 1656 . 12.

(Joncquet) Hortus regius. Parisiis 1661. folio.

(IV arton) Schola botanica. Amstelnedami 1689. 12.

Jussieu. Discours sur le progres de la botanique au jardin royal de Paris. Paris 1718. 4.

Buchoz, Le jardiu du Roi. I'aris 1792. folio.

Jauffrel. Voyage au jardin des plantes. Paris 1798. 8.

Tahleau de l'école de botaniujue du jardin des plantes. Paris 1800.8.

Notice des principam oljjets etc. Paris, an IX. 8.

Fischer von Il'alilhim. Das Nationalmuseum der Naturgeschichte zu Paris. Froukfurt il/1I. Is02-1803. 8.

Desfontaines, Tabieau de l'écolo de botanique du Muséun dhistoire náfurelle. Paris 180 4. 8. - Ell II: ib. 1815.8. - Ed. III: Ciatalogus plantarum horti regii parisiousis. ib. 1829.8. - Additamentum: ib. 1832.8 .

Deleuze. Histoire et deseription du Muséum d'histoire naturelie. Paris 1823.8.

(angtice.e.)

Perrottel, Catalogue des plantes ete. Paris 1824.8 .

Ronsseau et Lemonnier, Promenades au jardin des plantes. Paris 1837.19. De Saillet. Une journée an jartin des plantes. Paris 1840.8.

Boilard. Le jardin des plantes. Paris 1842. 8.

Bernard et Lemaout, La jarlin des plantes. Paris 1842. gr. 8.

Brongniarl, Enumeration des genres de plantes cultivées an Nuscum d'histoire naturelie de l'aris. Paris 1843.8.

Catalugues des graines: $1828-1847$.

\section{Horths pharmacopoeorum. Parisies.}

(Gregoire) Hortus phanailceuticus lutetianus. (['aris) 1638. 12.

(Descemel) Catalogue du jardin des apoticaires de Paris. Paris 1741.8. ib. 1759.8

Buisson, Classes el noms des plautes. Paris 1779. 12.

Guiart. Classification rigatale ... plantes du jardin de pharmacie de Paris. P'aris 1507. 12. - ih. 1823. s.

18. Ilorlus scholae medicae parisiensis.

Marlhe, Catalogur du jardin médical de Paris. Paris 180\% 8.

I'oiteru. Le jarliu hotanigue do l'école de medecine de Paris. Pam 1816. 12

\section{Arboretum Luxembourg, Parisiis.}

Her:y. Catalogue de l'ecole impériale près de luxembourg. Paris 1809.4. Bosc. Vignt's 'ultivées daus les pépinières du Luxembourg. Pariss. a. 8.

\section{Ilortus rothomagensis.}

Catalogue du jardin de Rouen. s. I. et il. (17xx.) 12.

Hortus regius rotlomagensis. (Rothomagi) 1778. 19.

Pouthet, Considerations sur le jarlin botanique de Ronen. Rouen 1834. 4 . Nonyelles considérations sur le jardin botanique de Rouen. Rouen 1839.8

\section{Arborelum regium Roule.}

Aubert du l'etil-Thouars, Notice listorique sur la pépinière du roi au lioule. Paris 1825.8.

\section{Horius tolosanus}

Catalogue du jardin botanique de Toulotise. Toulouse 1789. 8 .

Catalogue du jardin hotanique de Toulouse. Toulouse 1827.8.

\section{2.j. Horlus telonensis}

Catalogue du jardin botanique du port de Toulon. Avignon 1824. 8 .

\subsection{IIorlus versaliensis.}

Philippar. Catalogue du jarlin de la ville de Versailles. Versailles 1843. gr. 8.

\section{Hontus vesontionensis.}

Morel, Catalogue du jardin botanịue établi a Besauçon. Besançen 1 \$ 05.8 . 


\section{Horti privati Galliac.}

1. Hortus viryinis Aglae Adanson, in Buleine.

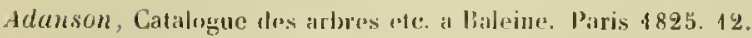

2. Hortus blesensis, Ducis Aurelianensium.

(Brunyer) IInrlus regins blesrosis. Parisiis 1653.4. - bel. Il: Parisiis 1655. folio.

Morison. Hortus regius b) lesensis auctus. (Praeludlia botanica. Londini 1669. 5 .

\section{Horlus Barbeu-Dubourg.}

Rarbeu-Juboury, Gatalogue d"un jarlin de plantes usuelles. (Botaniste français, 1. 1-72.)

\section{Ilortus Celsiamus, l'arisiis.}

Ventenat. Description des plantes nouvelles ou peu connues du jardin de J. M. Cels. Paris 1800.4.

Choix des plantes du jardin de Cels. Paris 1803 . fnlio.

Catalogues de l'établissement de Frunçois C\%ls. Paris 1817-1845. \&.

\section{.). Hortus .. J. Destremu.}

Destremx, Elenchus plantarum horti ejus. Nismes 1806.8. - Alais 1821.8.

6. Hortus Dionysii Joncquel, Parisiis.

Jonequet, llortus. Parisiis 4659.4.

\section{Horhes Imperalricis Josephinae, in Mulmaison.}

Ventenat. Jardiu de la Malmaison. Paris 1803-1804. folio.

Bonptand, Description des plantes rares cultivẻes a Malmaison et a Navarre, Paris 1813 . folio.

\section{S. Hortus Domini Le Lectier, Aureliani.}

Le Lecher, Catalogue des arbres. Orleans 1628.8.

\section{Ludovici Philippi horti Nerilly, Le Raincy et Honceaux.}

Jacques, Catalogue des arbres et plantes cultivèes aux demaines privés du Roi. Paris 1833. 12.

\section{Hortus Petri Morin, Parisiis.}

Morin, Catalogues de quelques plantes à fleurs. Paris 1651.4. - ib. 1658, 12.

\section{Hortus Ronali Morin, Parisiis.}

Catalogus plantarum berti Renati Mormi. Paris 1621.12

\section{Hortus Pelri Ricarti, Lillae.}

(IVionius) Botanotrophinm sen hortus medicus Petri Ricarti. Lillae 1644, 12.

\section{Ilorti Cardinalis Richelieu.}

Priezac, llorti Ruelani. Parisiis 1640. 4

\section{Hortus Joh. el Jesp. Robin, Parisis.}

Robin, Catalogus stirpium, quae Luteliae coluntur. Parisiis 160 \%. s.

Linocier, Histoire des plantes trouvées en islo de Virginie cultivées au jardin de MI. Robin. Paris 1619. 12.

Robin, Histoire des plantes de l'isle Virgine cultivées an jardin de M. Robin. Paris 1620.12.

Enchiridion isagogicum. Paris 1624.8.

\section{Hortus mercatoris Royer, Parisiis}

Royer, Catalogue de son jardin. Paris 1760.8

16. Hortus Laurentii Thomae Walliser, Argentorati, 1618. (cf. de Rry, Florilegium. Thes. 110. 14tï-1466.

\section{Horti publici Belgii.}

Ilermann, Paradisi batavi predromus. In Ilarton, Schola butanica. Amstelodami 1689. 12. p. $301-386$.

\section{Hortus amstelodamensis.}

Snippendul, Catalogus plantarum lorti anstelodinnensis. S. 1. 1646. 6 (Cornelius) Catalogus horti ansteloxlamensis. Austolodinni 1661.8.

Commelyn, Catalogus plautarun horli medici anustelaedanensis. Imstelodami 1689.8.

- Herti medici anstelonamrnsis variorum plantarum descriptio et iconfs. Amsteledami 1697-1701. folio.

Plantarun usualium horti amstelodamensis catalogus. Amstelodami (1698.) 8. - E.d. III: ih. (1724.j8.

I'racludia botanica. Lugd. Bat. 1703. "

II rrti medici amstelaedamensis plantar rartores "s exoticae. Lugd. Bal. 1706.4 .

Elenclius plautarum horti anstelodamensis. Amstelodimi 180 (Irolik) Elenclus plantarum lıorti anstelaedamensis. Instelacdami 1814 8. - ib. $(1821) 8$.

\section{IIortus tredensis.}

Brosterhusius, Catalogus horti medici bredensis. Bredae $16: 7,12$

\section{Hortus bruxellensis.}

Nyst, Catalogue des plantes du jardin botanique te Bruxelles. IBruxelles 1826. 8 .

\section{Jardin de la socicte d'horticulture de Relgique.}

Catalogue. Bruxelles 1830. 8. - ı. 1842.8.

\section{Hortus gandavensis.}

Couret-Villeneuve, Hortus gandavensis. Gandavii, an X.. 12.

Mussche, Catalogue du jarlin botanique de Gand. Fand (1810.) 8. - Hortus gandavensis. Gand 1817.8.

\section{Horlus groninganus.}

Roman, Catalogus plantarum horti greníngaıi. Greningae 1\$02.8.

(Driessen) Index plantarum in horto groningano. Groningae 1820.8

\section{Hortus harderovicensis.}

Westenberg, Viridarii academiae IJarderovici catalogus. Ilarderevici 1709. 12.

\section{Hortus harlemensis.}

Koker, Plantarum usualium horti harlemensis catalogus. Harlemi 1702. 8

\section{Hortus leorliensis.}

(Gaede) Index plantarum horti leorliensis. Leodii 1898.8

Morren) Catalegue des graines du jardin de Liège. (Liège 1835-1844.) 8.

\section{Horlus lugduno-batatus}

Paano, Hortus publicus academiae lugduno-batavae. Lugduni 1591.8. ib. 160 1. S. - ib. 1603.8. - ib. 1629.8

Vorstius, Catalogus plantarum horti lugdunn-batavi. Lugd. Bat. 1633, 12 - ib. 9636.12. - ib. 1643.19. - ib. 1649.12. - ib. 1658.12

Schuyl. Catalogus plantarum horti Jugduni batavi. Lugil. Bal. 1668. S. lleidelhergae 1672.12.

Hauck, Catalogus plantarum horti lugduno-batavi. Darmstadt 1679. 12

Hermann, Horti Jugduni-batavi catalngus. Lugd. Bat. 1687.8.

Florae lugduno-batavae fiores. Lugd. Bat. 1690. S.

Gollschalck, Catalogus plantarum horti academici Lugduui Bataverum. Plóen 1697. 8. - ib. 1704.8.

Boerhaave. Index plantarum in lıorto academico lugduno-batavo. Lugd. Bat. 1710.8 .

Index alter plantarum, quae in horto academico lugdunobatavo aluntur. Lugduni Batav., apud Petrum van der Aa. 1720. ^. 
Roerhaave, Historia plantarum. Romae 1727.8.

Royen, Florae leydensis prodrouus. Lugd. Bat. 1740. 8.

Gmelin, Otia Lotanica. Tubingae 1760. 4.

(Brugmans) Elenchus plantarum in horto Iugduni-lataso. Lugd. Batav. 1818. 8 .

Enumeratio plantarum horti lugduno-batavi. 1831. 8.

liriese. Descriptions el figures des plantes nouvelles du jardin botanique de Leide. Leide 1847 sqq. gr. folio.

10. Hortus roterodamensis.

Schimne, Latalogus plantarum horti roterodamensis. Roterorlami 1809.8.

\section{Hortus ultrajectinus.}

Roy vel Regius, Hortus academicus ultrajectinus. Ultrajecti 1650. 8.

Wachendorf, Horti ultrajectini index. Trajecti a/Rh. 1747. 8.

(Kops) Index plantarum in horto rheno-trajectinn. Trajecti a/Rh: 1823. S. Index seminum: 1819. 1836-1838.)

\section{Horti privati Bclgii.}

1. Hortus Simonis Beaumont, IIagae Comitum.

(Kiggelaer) Ilorti Beaumontiani catalogus. Ilagae Comitis 1690. 8.

2. Hortus Beeldsnijderianus in Rupelmonde.

Beeldsuijder, Catalogue des plantes à Rupelmonle, province d'Utrecht. 1823. 8.

\section{Hortus Georgai Clifford, IIarlecampi.}

Limné, Hortus Cliffortianus. Amstelaedami 1737. folio. Viridarium Cliffortianum. Amstelaedani 1737. s.

1. Iortus Johannis Hermanni, Bruxellis.

Recensio plantarusu in horto Joannis llermanni. Bruxellae 1652-1653.4.

\section{j. Hortus honselaprdigensis.}

Brandon, Hortus regius houselaerdigensis. folio.

6. Hortus Adriani van der Hoop, in villa Spuarn-Berg prope IIarlemum.

Iriese, Ilortus spaarn-lyergensis. Amstelodani 1839. 8.

7. Hortus Martini van Marum, Harlemi.

Marum, Catalogue de son jardin a Jarlem. (Jarlem 1840.) 8.

8. Hortus Henrici Hunting, Groningae.

Munting, Hortus. Groningie 1646.12.

Catalogus plantarum horti groningensis anno 1646 . In Simon Paulli Viridariis p. $593-706$.

9. IIorti Josephi Parmentier, Bruxellis.

(Parmentier) Catalogue des jardius de Mr. Joseph Parmentier. Bruxelles 1818.8.

10. Hortus M. IT. Schwencke, Hagae Comilum.

Scheencke Officinalium plantarum lorti Hagae Comitum catalogus. Hagae Comitum 1752. 4.

11. Horti Ludoxici Tan Houte, Gandavii.

(Tan IIoulle) IJortus Vanhoutteanus. Gant 1845.8 .

\section{Horti Helvetiac.}

1. IIorlus basileensis.

(Meissner) Indices seninun. Basileae 1837-1847.
(IVydler) Index semmun: 1844.

\section{Horlus bernensis.}

\section{Hortus generensis.}

De Candolle, Rapport sur la fundation du jardin de botaniçue de Genéve. Genève 1819.8.

Catalogue des arbres et vignes du jardin de Gielıève. Genève 1820.8.

Second rapport sur la fondation du jardin de botanique de Geneve. Genèvo 1824.8.

Notices sur les plantes rares cultivées dans le jardin de tienève. Genève 1823-1847.4.

Plantes rares du jardin de Geneve. Genève 1829.4.

Notice sur le jardin botanique de Genève. Genève 1845. 8. (Choix de graines: 1833-18k7.)

De Candolle, Programme el rapport sur les pépinières du canton de Genève. (Genève 1822. 3828.) 8.

a Pregny. Geneve 1825. 4.

Dufour, Catalogue de sa pépinière à Montbrillant près Genève. Genòve 1828. 8.

Dailledouze, Catalogue des pépinieres au Petit Sacconex. Gonère $182 \mathrm{~S}$. 1831.8 .

\section{Hortus turicensis.}

(Schinz) Catalogus horti botanici societatis physicae turicensis. Turici 1772. 8. - 1776.8. - 1784.8. - 1788. S.

(Roemer) Catalogus horti botaniei turicensis. (Turici) 1802. 12. (Indices seminum: 1826. 1835. 1839-18:8.)

5. Hortulus Remigii Fescliii J. C. Basileae 1644. (cf. de Bry, Florilegium. Thes. no. 14tio.)

\section{Horti Hispaniac.}

\author{
1. Hortus barcinonensis.
}

Colmciro, Caralogus horti barcinonensis. Barcinone 1844. 8.

\section{Hortus matritensis.}

(Orlega) Indice de las plantas en el real jardin botanico (de Madrid). Madrid 1772. 4 .

(-) Elenchus plantarum horti matritensis. 1796.8

(cf. Colmeiro, Ensayo historico, p. 41.)

Novarum aut rariorum plantarum horti matritensis descriptionum decades 1-X. Matriti $1797-1800.4$.

(Lagasca) Elenchus plantarum horti matritensis. Matriti 1816.4.

\section{Horti Hungariae.}

\section{Hortus pestinensis.}

(Winterl) Index horti botanici pestini. (Pestini) 1788.8.

(Kilaibel) Plantae horti univérsitatis hungaricae. (Pestini) 1809. 8. - ib. 1812. 8 .

\section{Jortus lismarloniertsis.}

Derer, Poetica exhibitio arcis et horti hismartoniensis. Sopronii 1828. 8

5. Hortus Primatis de Gran, Posonii.

Lippay, Posoni Kert. Nagy-Szombatba et Béczben 1664-1667. 4 . 


\section{Horti Poloniac.}

\section{Hortus cracoviensis.}

Schultes, Gatalogi loorti universitatis eracoviensis. Cracoviae $1807-$ 1808. 12.

\section{Hontus framieniecensis.}

Besser, Catalogue des plantes du jardin botanique á Krzemieniec. Krzemicniec 1810. 8. - ib. 1811.8. - Supplément 1-111: ib. 18121814. 8 .

Catalogus plantarum in liorto botanico Cremeneci cultarum. Cremeneci 1816 . S.

Trautvelter. Uelier den Krzenieniecer hotanischen Garten. (Moskau 1844.) 8

\section{Hortus varsamiensis,}

Bernhard, Catalogus plantarum in hortis rengis Varsaviae. Dantisci 1652. 12.

(Paulli, Viridaria p. 203-287.)

Schubert, Spis roślin i. e. Catalogus plantarum horti varsaviensis. w Warszawie 1820.8. - Ed. auctior: ib. 1824. S.

\section{Hortus viluensis}

Jundzill, Index horti vilnensis. Vilnae $1814-1815.8$

\section{Horti Rossiac.}

1. Ilorius aboënsis.

Hetlenius. Hortus academiae aboensis. Aboae 1779. 4.

\section{Hortus dorpatensis.}

Germamn, Ferzeichniss der Pflanzen im botanischen Garten zu Dorpat Dorpat 1807. 8.

(Weinmann) Der botanische Garten zu Dorpat. Dorpat 1810. 8. - Supplementum: ib. 1811.8.

Ledebour, Index seminum horti dorpatensis. Dorpati 1822-1824. 8

Bunge, Delectus seminum ex horto botanico dorpatensi. Dorpati 1836 1848.8

\section{II rrtus kichinovensis.}

Duponl ot Carro, Catalogue de la pépinière à Kichinoft en Bessarabie $182 x, 8$

\section{Hortus kiovensis.}

(Trautvetter) Delectus seminum in horto kiovensi collectorum. $1840-$ 1849.8

\section{Hortus mosquensis.}

(Hoffmann) Horlus mosqnensis. Mosquae (1808.) 8.

\section{Hortus pawolowskiensis.}

Weinmann, Elenclous plantarum horti pawlowskiensis. Petropoli 1824, 8.

\section{Horlus petropolitanus.}

Deschisaux, Némoire sur l'établissement d'un jardin de botanique à St. Peterslyourg. 1725. 8 .

Siegesbeck, Primitiae Florae petropolitanae. Rigae 1736-1737.4.

(Fischer) Index liorti petropolitani. Petropoli 1824. 8.

Fischer et Meyer, Indices semuinum luorti petropolitani. Petropoli 18351848. 8 .

1837.) 4 .

\section{Horlus Procopii a Demidof, Mosquae.}

Pallas. Enumeratio plantarum in horto Procopi a Demidof. Petropoli 1781. 8 .

Enumeratio plantarum in liorto Procopii a Demidow. Mosquac 1786. 8

\section{IIORTI DANIAE - HORTI SUECIAE}

9. Hortus Demidovianus, Solkamskiac.

Lepechin, Catalugus horti Demidoviani. (In ejus Dnevuyia zapisky, $17 i 1$ p. 136-189. Tagebuch etc. 111, 83-117.)

10. Jortus Comitis Orloff in insula Orloviana.

Buek, Nomina plantarum in horto Comitis $f_{x} 11$ : Orlovi cultarum. \&. 1. 1811.4

Pursch, llortus ONos iensis. Londen 1815. 8.

\section{Hortus Comitis Alexii a lianmousliy in Gorinla.}

(Redowsky) Enumeratin plantarum horti Conitis Atexri a Razumowsky in payo mostuenci Gorinka. s. I. 1804. 12.

(Fischer) Catalogue du jarlin a Gorenhi. s. 1. 1808. 8. - Noscou 1812.8.

\section{Horti Daniac.}

1. Hortus cronenburgensis.

Bloeh, Descriptio vireti ad arcem Cronenburg prope Ilelsingoram. Cum ejus Horticultura danica. Havniae 1647. 4.

\section{Hortus hafniensis.}

Sperling, Hortus Coristianaeus. Havniae 1642. 12.

(Paulli, Viridaria varia, n. 1-80.)

1645.8

Catalogus stirpiun indigenarum, quas in horto aluit. Havnia

foltboell, Pantae lorti universitatis rariores. Havniae 1773.8 .

Bache, Et par ord i anledning af IIr. Riegels usandfaerdige beretning etc. Havniae 1787. 4 .

___ Kammerraad Lund's angreb. Havniae 1788. 4.

Hornemann, Enumeratio horti botanici hafniensis. Hafniae 1807.8. - Hortus regius botanicus hafniensis. Hafniae 1813-1819.8

Moerch, Catalogus plantarum horti hafniensis. Hauniac 1839-1840.8. (Indices seminun: $1812-1818$.)

Schouro, Over den Kjobenhavnske Lotanishe haven planter. Kjobenhavn (1847.) gr. 8

\section{Hortus gyldenlundensis}

Kylling, Gyldenlund seu Catalogus plantarum 404, quilus Clıristiani $V$. lucus aureus exurnatus est. Havisiae 1684 . 4 .

\section{Horti nidrosienses.}

Baade, Tronlaiemske have-planter. (Norsk. vidensk. selsk. skrifter, $\mathbf{I V}$. $372-416$.

\section{Horti Sueciae.}

\section{Hortus christianensis.}

(Rathke) Enumeratio plantarum horti butanici christianiensis. Christianiae 1823.8

(Semina horti: 1837.8 )

\section{IJorius lundensis.}

Lidbeck, Horticultura academica lundensis. Lundae 1791. 4

Zetterstedt, Conspectus plantarum in horto botanico lundensi. Lundac 1838. 8 .

\section{j. Hortus upsaliensis.}

Kudbeck, Catalogus plantarum horti uhsaliersis. Ubsaliao 1658, 12. Auctuarium: il. 1666.12.

- Horticultura nova upsaliensis. Upsaliae 1664.4

- Hortus botanicus. Upsaliae 1685.8.

Linné, Hortus upsaliensis. Upsaliae 1745. 4. 
Limme: Ilortus upsaliensis. Stockholmiae 1748. 8.

Demonstrationes plantarum in horto upsaliensi. Upsaliae 1753. 4.

fil. Decas (1 - II) plantarum rariorum horti upsaliensis. Stockbolmiar $1762-1763$. folio.

folio.

(ef. Murray in Roemer und Usteri, Magazin. II. Sllok. 1788.)

IVakleuberg, Om Cpsala lniversiletets botaniska tradgard. Upsala 1837. 8. igermanice.)

4. Horlus Comilis De la Gardie in Jacobsdal, hodic Ulricsdal.

Rudleck, Deliciae vallis Jacolacae. Cpsaliae 1666, 12.

5. Horius J. E. Ferber in Agerum prope Carlscronam.

Ferber, Hortus agerumensis. Holniae 1739. 8.

\section{Horti extra Europam.}

Dancer, Catalogue of plants in the botanical garden of Jamaica. Sl. Jago de la Vega 1792. 4

Broughton, Ilortus Eastensis. Kingston 1792. 4.

Hortus Easteusis. St. Jago de la Vega 1794. 4.

A catalogue of plants in the public garden in the mountains of Liguanea. (St. Jago de la Vega) 1794.4.

I list of plants delivered by $C$. Bligh at the lotanical garden at St. Vincent, Jamaica. (Transactions of the soc. for encour. of arts, vol. Xll $303-313$.

Auderson, State of some of tho most valuable plants in the royal hotanical gardens in the istant of St. Vincent. (Transactions of the soc. for encour. of arts, rol. XVI.)

Lunan, Uortus jamaicensis. Jamaica 1814. 4

Guilding, Account of the botanic garden in the island of st. Vincent. Glasgow 1823.4

llosack, Hortus Eiginensis. New York 1806. ^. - ib. 1814. 8.

A statement of facts relative to the Elgin botanic garden. New Tork 1811.8

Prince, $A$ treatise on trees and plants cultivated at the botanic garden, Flushing, Loug Island, near New York. New York 1820. 8. - ib. 1822.8.

- Catalogue of american indigenous trees and plants cultivated at Flushing. New Iork 1820. 12.

(liafinesque) First catalogues and circular's of the botanical garden of Lexington. Lexington 1894.8 .

Blme, Catalogus van gewassen iu's lands plantentuin Io Builenzerg. Batavia (1823.) 8.

llasstarl, Catalogus plantarum in horto butanco longoriensi cultarum a]ter. Batavia 1844,8 .

Ramon de la Sagra, Informe sobre el estado actual del jardin do la Har bana. Jahana 1825.4.

breen, Catalogne des plantes cultivées au jardins butaniope et de naturalisation de J'île Bourbon. Saint-Denis $1820-1825.4$.

Jortus Jauberti in monte Tafelberg ad Caput Bonae Spei, vile Erkilon, Topographisches Verzeichniss. Esslingen 1827. 8.

Gatalogue of plants culllvated in the island of Maurilius. (Mauritius) 1522.4. Bojer, IJorus manritianus. Maurice 1837.8 .

Graham. A calalogue of the plants growny in Bombay and its vicinily. Bombay 1839.8 .
(Boxburgh) Hortus hengalensis. Serampore 1814.4.

Griffith, Remarkable plants in the II. C. hotanic gardens, Cakcuta. (Calculla 1843.$) 8$.

Voigt, Ilortus suburhanus calcuttensis. Calcutta 1845. gr. 8

(Hardy) Catalogue des vegétaux cultivées a la pépinière centrale du gouvernement à Alger. (Hanma près Alger 1844.) 4

\section{Catalogi hortulanorum.}

Alfroy, Catalogue de la pépinière de Lieursaint. Paris 1821.8 .

Alix, Catalogue do ses jardins. Lyon 1819.8.

Andrierex, Catalogue raisonne des plantes. Paris 1774. 8 .

Audibert, Catalogues de ses jardins à Tonnelle près Tarascon. Ivignon $1810-1838.8$.

Barraud, Catalogue des rosiers etc. Lausanne 1822. 8

Brinton, John et Co. A catalogue of plants cultivated at their nursery, Perryhill. Birmingham 1777.8.

Ruek. Verzeichniss seines Ilandelsgartens in Hamburg. Bremen 1779. 8. Hillesheim 1790.8.

Cels, Catalogues de l'étalulissement de Frangois Cets. Paris 1817-1845.8.

Descemet, Calalogute de ses jardins. Paris 1782. 12.

Freycinet, Catalogue raisonné de sa pépinière à Lorial (Drôme). Valence s. a. 8 .

Furber, Catalogue of trees and shrubs at Kensington. London 1794. 8. ib. 1727.8

Gans, Jacobus. Jloemist te Hillegom by Haarlem, Catalogus van boomen, heesters en plantagie-gewassen. 1780.8 .

Gray, Christopher, nurseryman at Fullam in Middlesex, Catalogue. London 1755.8 .

Grimwood, A catalogue of greenhouse plants etc. London 1783.8.

IIazen, II illem van. Bloemist te Leyden, Naanlyst vau Bloemzaaden. s. a. folio.

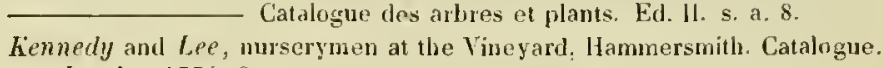
London 1774.8.

Lair, Deseription des jardins de Courset. Paris 1\$14.8

Linden, Prix-comant. Luxembourg (1847.) 8.

Catalogue of plants and seeds sold by Conrad Loddiges, nurseryman at llackney. Loudon 1777. 8 .

Catalogue of plants in the collection of Corrad Loddiyes. London 18141836.8.

Orchidene in the colluction of Conrad Loddiges. London (1842.) 12.

Catalogue by Luker and Smith in the city road and at theirgnursery at Dalston. London 1783,8.

Muc Malion, Catalogue. Priladelplia 1806.8 .

Malcohn. William, urserynan near Kennington turnpike, Surry. Catalogue. Loudon 1771.8.

Mills et Co., at Flushing near New York, Catalogue. 1827. 8.

Nieurokerk, Grand catalogue hollandais. Ilarlem 1789. folin.

Noiselle, Calalnguc des arores fruitiers cultivés dans les pépinieres á Brunoy. Paris 1825-1826. 8.

Sedy, Catalogue do ses jarlins. Lyon 1810.8.

Thomas Silies, Esq. at Hackney. (London 1799.) 8.

Foorhelm el Schneevooyt, flowrists al Ilaerlem, Calalogues. Haerlem 1783. 1788. 1792. 8 .

II"elb, John, secalsman at the Acorn, near Westminster bridge, Lomdon. Catalogue: 1760.8 .

Whitley, Brames and Milue, at Fulham nursery near Loudon, Catalogue s. a. 8 .

Goumy, IIortus epkomensis. Iondon 1828. 12.

Zigra, Verzeichniss. Riga 1805. 8. - ib. 1817.4. - Mitau 1819.4 


\section{Musca varia.}

Oliv6. Nusdeum Culcoluru. V'enetiis 15\$4. 4

Bester, Fasciculus variondum et aspectu dignomun varii generis, s. I. 1616 1623,4

Montalbanus, Index plantarum omniun herlarii. Bononiae 1624. 4.

Besler, Gazophylacium rerum naturalium. Lipsiae 1642. foliu. - il). 1733. folio.

Locher, Rariora musei Besleriani. s. 1. 1716 folio.

Seger, Synopsis rariorum in musaen Oles II'ormii. Ilafniae 1653. 4.

Tradescant. Musaeum Tradescantionum. London 4656.8.

Moscardo, Nute overo memorie del museo di Lodovico Moscardo. Paduva 165\%. folio.

Fuiren, Rariosa musei llenrici Faren. Ilavuicie 1663. 4

Girew, Musaeum regalis societatis. Lundon 1681. folio.

Jacobaeus, Buseum regium. Hafniae 1696-1699. folio.

Petiver, Musaei Petiveriani centuria 1-X. Londini 1695. (1692-1703.) 8 Gazophylacii naturae et artis decades X. Londini 1702-1709. S. et folio.

(Cidtalogus: Londjui 1709-1711. folin.

Zarmichelli. Catalogus platutarum ijuilus domus ejus ornitie eratu in festo corporis Christi. Venetiis 1711. 1712.

Mermann, Musaei indici catalogus. Lugduni Bat. 1711, 8.

Musaeum zeylanicum. Lugduni Bat. 1717. 8.

Petiver, Petiveriand seu naturae collectanea 111. Londini 1717. folio.

Vater, Catalogus exoticorun musei sni. Wittembergae 1726. 4

Sela. Locupletissini rerum naturaliun thesauri descrij)tio. Amstelaedani $1734-1765$. folio.

Zannichelli, Masseum. Venetiis 1736.4

Linné, Instructio musei rerum naturalium. Upsaliae 1753.4. germanice. )

Thunbery, Museum naturalium academide upsaliensis. Upsaliae 17871798. 4

Janson, Etablissement d'un cabinet et bureau des plantes médicales. Paris 1790.4

Polt, luden herbarii mei vivi. Brunovici 1805. \&.

Catalogus herbarii J. Ryani. Havuiae 1809.8.

Don, Account of the Lambertian llerbarium. In Lambert, Description of the genus Pinus. London 1824. folio. - ib. 1828 . folio.

Catalogrue of Lambert's lotanical library. London 1842. 8. (no. 5511 .)

Catalogue of Lambert's botanical Museum. London 1842. 8. (no. 5512. )

(Robillard D'Argentelle) Catalogue du Carporama. Paris (1827?) \&.

Wallich, A mumerical list of thied specinuens of phants in the East India Compranys Museun. London 182S. folic.

- Tist of indian woods collected. London s. a. 8

Morelli, Sopra alcuni erbarj del Padre Bocrone conservati uella imp. biblioteca di Vienna. Pavia 1830. 8.

(Jan) Ai cultore delie scienze naturali. Parma 1838 . \&

parlatore, Sullo statu attuale deal eribirio centrate ttaliano. (Napoli 1845.) 8 .

Laségue, Musée botanique de Mr. Benjamu Delessert, Paris 1845.8 .

- Notice sur Je Mlusce botanique de Mr. Benjamin Detessert. Paris 1845.8

\section{Itinera.}

Beckmann, Literatur der alteren Reisebeschreibungen. Goutingen 1808. \& Linne. Peregrinationum intra patrian necessitas. Upsaliac 1741.4.

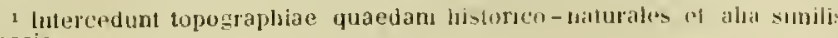
seneris.
Limue. Instructio peregrimatoris. lipsaliae 1759.4.

Besson, Ohsorvitions sur les moyens de remdre utiles les voyages des naturalistes. (Jourual d'hist. nat. I1, $185-210$.

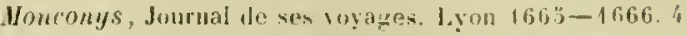

Biron) Curiositez lo la Hature apporteces des lurlea. Paris 1703. 12.

(Poive) Vinagros diu philosophe. Trerdun 1768. 12.

Thumbrry, Resa uti liuropa, Ifrica, Asia. Cpada 1788-1793.8. (cyermaniee, alıglice, gallice.

Clarlere, Trivels in ratious eountries of Eurupe. Asia and Africa London $1813-1823.4$.

Bennet, Wauderings in New Soutl Wales, Batavia, Peolircoast simgajore aud Clina. London 184\%.8.

Dampier, Voyge round the world. London 1697.8. (gallice.)

Jehrens, Reise un die Welt. Frankfurt und Leijzig 1737. 8.

Forster, OJservations made during a voyage round tho world. London 1778.4 (Hallice, germanice.)

De la Billardiére, Relation du voyage a la recherche de La Perouse. Paris 1799.8 .

Krusenstern, Reise un die Welt. St. Peterslurg 1810-1812. 4 (italice, gallice, hollandice, arglice.)

lioss, John, A voyage of discovery. London 18.19. \&

Erman, Reise un die Erde. Berlin $1833-1839.8$. und naturlist. Allas.

Meyen, Reise um die Erle. Berlin 18.34-1833. '

Luetke, Voyage autour du monde. Paris $1835-1836$. 5. et Atlas.

Chamisso, Reise um die Welt. Leipziy 1836. 8.

Bennett, Narrative of a whaling royage round the mlobe. London 1840. 8.

Vaillant, Voyge autour du monde sur la corvetle La Bonite. Paris 1839 -1846 . S. et Atias.

Dumont d'Urville, Expédition au pole nustral et dans l'Océanie des corvettes $L$ Astrolabe et La Zelée. Paris 1839 . ช.

- Voyage au pole sud et daus l'océanie sur les rorvettes $L$ istrolabe et La Zelée. Paris $1841-1847$. 8. et Allas.

Bentham, The Botany of the voyage of II. II. S siulphur. London is44.4.

Beleher, Narrative of a voyage round the world. Loudon 1843.8

koss, James Clark, A voyage of discovery. Londun 184\%. 8 . germanice.

Ray, Travels tlurough the Low-countries, Germany: italy and Francic. London 1673.8

Sestint, Lettere seritte dalla Sicilia e dalla Turchia. Firenze 17791784.12.

Schmilel, Descriptio itmeris per llelvetiam, (ialliam etc. Errangae 1794. 4.

bronn. Ergebmisse meine naturhistorisch-okononnschen Reisen. Heidelhrerg $1826-1831.8$.

Agardh, Berattelse ou en botanisk Resa till Uesterihe och Jalien. Sluchholin 1828. 8.

germatuice.

Tenore. Viangio per diverse parti d'talia, sizzera, Frincia, Inghiltera e Germania. Napoli 1828.8

Haum, Banerkungen uber Landwirthacluaf, hlima und Vegetation un Sudfankreich, Welschland und Malta. Charlottenburg is/4. 8 .

1

Merrell, Pinas resum naturalium britanicarum. Lomdini 1667.8 .

I'lot, The natural history of stralfond-shire. Osford 1656 . folio.

Hallace, Deseriptiun of the isles of Orkney. Eulinburat 1693 \&

Leigh, Nitural hishory of Lancasbire etc. Oxford 1700. folio

Plot. The urtural history of Oxfordshire. Ox ford 1705. folio.

INorton, I natural history of Northamptonshire. Louclon 17 12. folio.

Ray, ltineraries. In ejus "Select remains". London 1760. 8. p. 103-310.

Berkenhoul. Outlines of the natural histors of froat-britain. Loudon 1770.8 . 
IVhile, Natural history of Selborne. London 1789. 4. - ib. 1836. 8.

Garnell, Observations on a tour throngh the highlands of Scotland. London 1800.4 . (grrmanice.)

Philippar, Voyage agrononique en Angleterre. Paris 1830.8

Hastings, Illustrations of the natural history of Worcestershire. London 1834.8 .

Hooker, Notes on Nurway. Glasgun 1839. 8

Bellamy, Natural history of South Devon. London 1840.8 .

Garner, Natural histury of the connty of Stafford. Iondon 1844.8.

Strobelberger, Galliae politica-medica descriptio. Jenae 1620. 12.

(Astruc) Némoires pour l'histoire naturelle de Languedoc. Paris 1737. 4

(Latourrelle et Rozier) Voyage au Mont Pilat. Avignon 1770.8.

Darluc, Histoire naturelle de la Provence, Avignon 1782-1786.8.

Sainl-Amans, Fragmens d'un royage dans les Pyrénées. Metz 1789.8.

(Ramond) Observations faites dans les Pyrénées. Paris 1789.8.

_- Voyages au Mont-Perdu. Paris 1801. \&.

Young, Voyages en France. Paris 1794. 8 (anglice.)

Noel, Essais sur le dép. de la Seine inferieure. Rouen 1795-1797.8.

(Cambry) Voyage dans le Finistere. Paris 1799. 8.

Description du département de l'Oise. Paris (1803.) 8.

De Candolle, Rapports sur les voyages botaniques en France. Paris 1508 -1813.8 .

Dralet, Description des Pyrénées. Parıs 1813. 8 vot. II.)

De la Peyrouse, linéraire des botanistes dans les Pyrénés. Impr. cum ejus "Histoire abrégé des plantes des Pyrénées". Toulouse 1813. 8.

Thiebaut-de-Berneaud, Voyage à Ermenonville. Paris 1826. 8.

Lecoq et Bouillet, Itinèraire du dép. du Puy-de-Dome. Paris 1831. 8

Arrieta, De la fertilidad y ahundancia de Espanna. Madrid 8578.8.

Torrubia, Aparato para la historia natural española. Madrill 1754.4

Loefling, Iter hispanicum, eller Resa till Spanska landerna. Stockholm 1758.8.

(germanice, anglice.)

Bowles, Introduccion a la historia natural y a la geografia lisica de España. Madrid 1775. 4. - Ed. I11: ih. 1789.4 (gailice, italice.)

Townsend. A journey through Spain. London 1791. \& (germanice, gallice.)

Cavamilles, Observaciones solore el reyno de Valencia Madru 17951797. folio.

Link, Bemerhungen auf einer Reise durchi Frankreich, Spranien und Portugal. Kiel $1799-1804.8$. (anglice, gallice.

Cambessedes, Excursions dans les iles Baléares. Paris 18268

Cook, Sketchos in Spain. Lomtun 1834. 8 .

Le Play, Observations sur l'histoire naturelle de l'Espigne. Paris 1834.8.

$1 \mathrm{He} b \mathrm{~b}$, Iter hispaniense. Paris et London 1838. 8.

Boissier, Voyage botanique dans le midi de iEspagne. Paris $1839-$ 1845. 4

Wicherl, Beitrag zur Kulturgeschichne Hispanient. Konigsherg $1845-$ 1846. 4 .

Targioni-Tozzelli, Prodromo della corografia toscana. Firenze 1754.8 Matani, Delle produzione naturali del territorio pistojese. Pistoja 1762.4 Targioni-Tozzelli. Relazione d'alcuni viaggi. Firenze $1768-17798$ Ginanni, Istoria civile e naturale delle pinete ravennati. Roma 1774 4. fie, Viaggio al monte Ventasso. Milano (1789.) 8 .

Spatoni, Lettere odrporiche sulla montagna ligustica Bologuta 17938. Nocra, De itineribus all varid loca (Turici 1791.) 8

Pritcel, Thes lit bot
Santi, Viaggio al Montamiata e per le due provincie senesi. Pisa 17951806 . S. (gallice;

Young, Voyage en lialie. Paris 1796. 8 anglice.)

Maimi da Ponle, Osservazioni sul dipart, del Seno. Bergamo 18038.

Bartalini, Raguaglio di alcume produzioni naturali dell' agro senese. Siena s. a. 4 .

Viviani, Voyage lans les Appenins. Gènes 1807. A

Rufuesgue ef Ortalani, Statistica generale di Sicilia. Parte I: lisica della Sicilia. Palermo 1810. 8 .

Maszucato, Viaggio butanico ali alpi giulie. Udine 1811.8.

Tenore. Raccolta di viaggi fisico-botanici. Napoli 1812.8

Brignoli a Brumhhoff et Bodtei. Alcuni cenni sulle produzione naturali del dip. del Metauro. Urbino 18I3. S.

Thiebaul-de-Berneaud, Coup d'oeil sur le Monte Cireello Paris 1814. 8

Martens, Reise nach Ventedig. Ulm 1824.8

Risso, llistoire naturelle les protuctions de l'Eurupe meridionale et des environs de Nice. Paris 1826-1828. 8.

T6nore, Viaggio in alcune luoghi della Basilicata e dellit Calabria citeriore. Napoli 1827. 8

Brunner, Streifug durch das ostliche Ligurien, Elba, Sicilien und Malta. Winterthur 1828.8

Tenore, Succinta relazione del viaggio in Abruzzo. Napoli 1830.4.

- Belazione del viaggio in alcune luoghi di Abruzzo citeriore $\mathrm{Na}$ poli 1832.8

Berloloni, Conmentarius de itinere neapolitano. Bononiae 1837.4

- Iter in Apenuinum bononiensem. Bononiae 1841. 4

Gussone, Tre articoli risguardante le peregrinazioni fatte in alcuni luogh del regno di Napoli. Napoli 1838.8

Simler, Vallesiae descriptio. Tiguri 15748.

II agner, Historia naturalis Ilelvetiae. Tiguri 1680. 12

Silieuchzer, Oupestфotng helveticus, sive itinera per Helvetiae alpunas regiones facta annis $1702-1711$. Lugd. Bat 1723 \%.

Ilaller, Jter helveticum anni 1739. Goettingae 1740.4

De Saussure, Voyages dans les Apes Neufchatel 1779-1796 4 germanice.

Reynier, Mèmoires a l'histoire physique et naturelle de la Suisse. Lausanne 1788. 8.

Villars, Lauth et Nestler, Précis d'un voyage botanique fait en Suisse. Paris 1812.8

Velden, Der Monte Rosa Wien 1824. 8.

Hegetschweiler, Reisen in den Gebirgsstock zwischen Glarus und Graubunden. Zurich 1825.8

Ifeer, Der Kanton Glarus. St, Gallen und Bern 1846.8 , (Pllanzenwelt: p 121-158)

Calzolaris, Il viaggio di Monte Baldo. Venezia 1566. 4 (latine.)

Tollius, Epistolae itinerariae. Amstelaedami 17004

Behrens, Hercyuia curiosa, llartzwalı. Nordbausen 17034

Burghart, Iter sabothicum. Breslau 1736. 8.

Zuechert, Naturgeschichte des Ober- und Unterharzes Berlin 17621763.8 .

Taube, Beitrage zur Naturkunde des Herzogthums Zelle. Zelle 17661769.8

IIacquet, Mlineralogisch-botanische Lustreise vom Terglou in hrain zum Glockner in Tirol. Wien $178,38$.

Physikalisch-politische Beise aus den Dinarischen durch die Julischen Camischen, Rhatischen in die Noriscben Alpen Leipzig 1785.8 .

Iruold, Reise nach Mariazell. Wien 17854 . 
Schrank und Moll, Naturhisurischo Hriefo aber Oestreich, Salzhurg. Passau und Berclutesgaten. Salzburg 1785. 8.

Sichrank, Baiersche Reise. Munchen 1786.8.

IIacquet, Reise durch die norischon Alpen. Nurnberg 1791. \&.

Jiraset, Haenke, Gruber et Gerstner, Beohachtungen auf Reisen nach Ifem Riesengebirge. Dresten 1791. 4

Reiner und-Hohenwarth, Butanische Reison nach einigen oberkarmtnerischen Alpen. Klageıfurt 179z-1812.8.

Schrank, Reise nach den sudlichen Gebiryen von Baiern Munchen 1793.8.

_- Briefe uber das Donaumoos. Mannlıcim 1795. 4

Ilacquet, Neueste physikalisch-politische Keisen durch die dacischen und sarmatischen oder nordlichen Karpathen. Nurnbery 1790-1796. 8.

Weigel, Geographisch-naturhistorische Beschroibung Schlesiens. Berlin $1800-1806.4$.

Schultes, Austluge nach dem Schneedsuge. Wien 1802. 12. - Ed. 11: ib 1807. 8.

Sternberg, Reise durch Tirol nach Oberitalien. Regensburg 1806. folio min. Botanische Wanderung in den llöhmer Wald. Nürnberg 1806.8 Reise in den rhatischen Alpen. Nürnberg 1806.8

Schultes, Reisen durch Oberostreich. Tubingen 1809.8.

Pollini, Viaggio al lago di Crardit e al munte Baldo. Verona 1816. 8.

Osservazioni intorno al viaggio al lago di Garda es al nonte Baldo. s. 1. 1817.8.

1817. 8.)
(Risposta di Elenterio Benacese alle Osservaziom etc. Timepoli

Moretti, Lettera al autore delle osservazioni intoruo all viaggio al lagu di Garda e al mente Baldo del Dr. Pollini. Pavia 1817. 8.

Hoppe et Hornschuch, Tagebuch einer Reise nach den Küsten des adratischen Neeres. Regensburg 1818.8.

Uchne, Spaziergang von Leipzig nach dem Ilarze. Leipzig 1819,8

Uechtritz, Kieine Reisen eines Naturforschers. Breslau 1820.8.

Schulles, Reise auf den Glockner. Wien 1821. 8.

Braune, Salzburg und Berehtesgaden. Wien 1821. 8.

Bray, Voyage pittoresque dans le Tirol. Ed. III. Paris 1825. folio.

Sternberg, Bruchstuche einer naturhisturischen Reise von prag nach Istrien. Regensburg 1826.8.

(Forbes) Journal of a lerticultural tour in Germany. London 1837.8.

Ratzeburg, Forstnaturwissenschaftliclıe Reisen durch Deutschland. Berlin 1842,8

Brederlow, Der Harz. Braunschweig 1845. 8

(Klima, Vegetation und Ftora des Harzes, von Hampe, p. 86-111.)

Kirtix et Quetelet, Relation d'un voyage a la grotte de Han Bruxelles 1823. 4

(Forbes) Journal of a horticultural tour through Flanders, Hulland and France. Edinburgh 1823.8.

Raffeneau-Delile, Notice sur un voyage horticole et botanique en Relgique et en Ilollande. Montpellier 1838. 8.

Schaeffer, Lappenia. Francofurti 1673.4.

(germanice, anglice, gallice, hotlandice.)

Rudbeck, Nera Samolad sive Laponia illustrata. (Iter per Uplandiam.) Upsalae 1701. 4.

Ugla, De praefectura Naesgardensis Dalekarliae. Ipsalis 1734. 6.

Linné, Öländska och Gothlandska Resa. Stockholm 1745. \&. (germanice.)

Wästgota Resa. Stock holm 1747. 8 (germanice.)

Skånska Resa. Stockholm 1751. \&. (germanice.)

Kalm, Wästgötha uch Bahuslandska Resa. Stockholm 1746. 8.

Hagstroem, Jaemtlands oeconomiska beskrifning. Stockholm 1751. 8.

Pontoppidan, Det forste forsög paa Norges naturlige historie. Kiobenhayn $1752-1753.4$ (anslice, germanice.)

Linne, Mariora Norvegiae. Upsaliae 1768.4.
Olafsen og Povelsen, Reise igiennem Island. Soroe 1772. 4. (germanice.)

Arerbi, Travels through Sweden, Finland and Lapland. London 1802. 4. (germanice, gallice.)

Weber und Mohr, Naturhistorische Reise durch Schweden. Gollingen 1804.8 .

Buch, Reise durch Norwegen und Lappland. Merlin 1810.8 (suecice, gallice.)

Linné, Lachesis lapponica. Loudon 1811.8

Hedren, Sokn-l3eskrifning ofver Wisnum och hil i Wermlands Lan. Carlstad 1811.8

Hooker, Journal of a luur in Iceland. Yarmuuth 1811 8. - Londen 18138.

Mackenzie, Travels in the island of Jceland. Ed. 11. Edinburgh 1812. 4.

Zetlerstedt, Resa genom Sveriges och Norriges Lappmarker. Lund 1822. 8 . - Resa genom Umeå Lappmarker. Örebro 1833. 8.

Thienemann und Guenther, Reise im Norden Europas, vorzuglich in Island. Leipzig 1824-1827.8.

Sommerfell, Bestrivelse over Saltdalens Praestegjeld i Nordlandene. Trondlijem 1827. 4

Lessing, Reise durch Norwegen nach den Loffoden. Berlin 1831. \&.

Wikstrom, stocklıolms-tractens naturbeskaflenhet. Stockholm 1839.8.

Lund, Reise igjennem Nordlandene og Vestfinmarken. Christiania 1848.8. (germanice.)

Voyages de la commission scientifique du nort; cf. Tlıes, lit. bot, mo. 6576 .

Marsigli, Danubius pannonico-mysicus. Hagae Comitum 1726. felio. (gallice.)

Piller et Mitterpacher, Iter per Poseganam Slavoniae provinciam. Bulae 1783. 4.

Townson, Travels in Hungary. Lonelow 1797. 4. (gallice.)

Seenus, Beschreibung ener (botanischen) Reise nach Istrien und Dalmatien. Nurnberg 1805.8

Rochel, Naturhistorische Niscellen uber den nordwestlichen Karpath in Oberungarn. Pesth 1821. 8 .

Vernau, Rudimentum physiographiae Moldaviae. Budae 1836. S.

Rochel, Botanisehe Reise in das Banat. Pesth 1838. 8.

Biasoletto, Viaggio di S. MI. Federico Augusto re di Snssonia per l'lstria, Dalmacia e Muntenegro. Trieste 1841.8. (germanice.)

Ehel, Zwölf Tage auf Montenegre. Konigsberg 184⿻一 1 \$44.8.

Belon, Les observations de plusieurs singularités. Paris 1554, 4. (latine.)

Rauwolf, Augentliche Beschreibung der Raiss in die Morgenlander. Laugingen 1583.4 (hollandice, anglice, )

Baumgarten in Brailenbach, Peregrilsatio in tegyplum, Arabiam, Palaestinam et Syriam. Noribergap 1594. 4. (anglice.)

Thevenot, Relation d'un voyage fajt an levant. Paris $1664-1674.4$ (angtice, germanice.)

Andersen und Lersen, Orieutalische Reisebeschreibung. Schleswig 1669, folio.

Tavernier, Six voyages en Turquie, en Perse, au Indes. Paris 1676. 4. (anglice, germanice, italice.)

Kaempfer, Amoenitatum exoticarum fasciculi Y. Lemgeriae 171z. $\}.$

La Roque, Voyage dans l'Arabie heureuse. Amsterdam 1716. 12 (anglice.)

Tournefort, Relation d'un voyage du Levant. Paris 1717.4 (anglice, germanice.)

Shaw, Travels or observations relating to several parts of Barbary and the Levant. Oxferd $1738-1747$. folio. (germanice, gallice:

Hasselquist, Iter palaestinum. Stockholn 1757.8 anglice, gallice, sermanice. 
Mariti, Viaggi per l'isela di Cipro e Palestina. Torino 1769-1770.8.

Niebuhr, Reisebeschreibung nach Arabien. Kopenhagen 1774-1778.4. (gallice.)

Sestini, Lettere odeporiche, ossia viaggio per la penisola di Cizico. Livorno 1785.8 ( yallice.)

Opuscoli. Firenze 178512.

Viaggi e opuscoli diversi. Berliuo 1807.8

Bolta, Storia naturale del' isola di Corfu. Mlilano 1797. 8. - ib. 1823.8

Scrofani, Voyage en Grèce. Paris 1804. 8. (italice.)

Sonnini, Voyage en Grèce et ell Turquie. Paris 1801. 8 (germanice, anglice.

Olivier, Voyage dans l'empire othoman, IEgyple et la Perse. Paris 1801 - 1804 . 4. et Atlas bot.

Morier, A journey through Persia, Armenia and Asia ninor. Londen 1812. 4 .

(gallice, germanice.)

A second journey etc. London 1818, 4

(italice, gallice, germanice.)

Sieber, Reise nach der Jısel Creta. Leipzig 1823.8

Reise von Cairo nach Jerusalem. Prag 1823. 8.

Berggren, Resor uti Europa och Österlanderne. Stockholm 1826-1828. 8. (germanice.)

Rueppel, Reise in Nubiea, Kordofan und dem petraischen Arabien Frankfurt a/ M. 1829.8.

Parrol. Reise zum Ararat. Berlin 1834.8

Friedrichsthal, Reise im sudlichen Nengriechenland Leipzig 1838. 8. (Botanischer Anhang von Fenzl und Cesat, p. 261-311.)

Boue, La Turquie d'Europe. Paris 1840, 8.

(Vol. 1. 408-476: Végétation de la Turqule dEurope: 111. 1-39: Agriculturo, horticulture.)

Fiedler, Reise durch Griechenland. Leipzig 1840-1841.8 (Gewachse Griechenlands : ]. 507-80̈8.)

Bolla, Relation d'un voyage dans l'Yémen. Paris 1841.8

Kitto, Palestine, The pliysical geography and natural listory of the Iloly I.and. London 1841.8.

Grisebach, Reise durch Rumelien und nach Brussa. Götingen 4841. 8.

Aucher-Eloy, Relations de voyages en Orient de 1830 a 1838. Paris 1843. 8 .

Webb, Topographie de la Troade. Paris 1844.8.

Rzacynski, Historia maturalis Poloniae. Sandomiriae 1721.4. - Auctuarium: Gedani 1745.4

Gmelin, Reise dureh Sibirien. Gotlingen 1751-1752. 8.

Krascheninnitow, Descriptio Kamtschatkae (rossice). Petropoli 1755. 4 (germanice, gallice, anglice.)

Laxmann, Sibirische Briefe. Goltingen 1769. 8.

Pallas, Reise durch verschiedene Provinzen des tussischen Reichs. st. Petersburg und Leipzig 1771-1776.4.

- Reise. Auszug. Frankfurt und Leipzig 1776-1778. 8.

Lepechin, Diarium itineris per varias Rossiae provincias (rossice). Petropoli $1771-1780.8$. (germanice.)

Steller, Beschreibung von dem Lande Kamtschatka. Frankfurt 1774. 8.

Rylschlow, Tagebuch über seine russische Reise. Riga 1774.8. (rossice.)

Gmelin, Reise durch Russland. Petersburg 17744.

Geargi, Bemerkungen einer Reise im russischen Reiche. Petersburg 1775. 4 .

Patrin, Relation d'un voyage aux monts d'Altai. St. Petershourg 1783. 8.

Hablial, Descriptio physica gubernii taurici (rossice). Petersburg 1785.8. (gallice, anglice, germanice.)

Gueldenstaedl, Reisen durch Russland und im kaukasischen Gebirge. Petersburg 1787-1791. 4.

Pallas, Tableau physique et lopographique de la Tauride. St. Petersburg 1795. gr. 4.

(germanice.)
Pallas, Bemerkungen auf einer Reje in die sudlichen Stathalterschaften des russischen Reichs. Leipzig 1799. 4. (anglice.)

Georgi, Geographiscls-plıysische und naturhistorische Beschreiluug des russischen Reiches. Königsberg 1797-1802.8.

Marschall von Bieberstein, Tableau des provinces situées sur la côte occidentale de la mer caspienne. Petersbourg 1798. 4.

Meere. Frankfnrt a/M. 1800.8

Meyendorff, Voyage d'Oreuboury a Boukhara. Paris 1826. 8. (germanice.

Ledebour, Reise durch das Altaigehirge und die soongorische Kirgisensteppe. Berlin 1829-1830. 8.

Eichwald, Naturhistorische Skizze vou Lithauen, Vollhymicu und Podolien. Wilna 1830.4 .

Humboldt, Fragmens de géologie et de climatologie asiatiques Paris 1831.8.

(germanice, rossice.)

Asie centrale. Paris 1843.8.

(grmanice.)

(Brumer) Ausllug uber Constantinopel nach Taurien. St. Gallen und Bern 1833.8

Gueldenstaedt, Beschreibung der kaukasischen Lánder. Berlin 1834. 8

Eichwald, Reise auf dem kaspisclien Meere und in den Kaukasus. Stultgart 1834-1837. 8.

Dubois de Nontpéreux, Voyage autour du Caucase. Paris 1836-1839. \&. germanice.)

Goebel, Reise in die Steppen des sudlichen Russlands. Dorpat $1837-$ 1838. 4 .

Demidof, Voyage dans la Russie méridionale et la Crimée. Paris 1842. 8.

hoch, Reise durch Russland nach dem kaukasischen Isthmus. Stuttgan $1842-1843.8$

Wanderungen in Oriente währeud der Jalıre 1843 und 1844. Wei$\operatorname{mar} 1846.8$

Linschollen, Linerariun. Ansterdam 1596. folio. (anglice, gallice, germanice.

Nieuhof, Het gezantschap der neerlandtsche oost-indische Companie etc Amsterdam 1665. folio. (germanice, latine, anglice.)

Kircher, China illustrata. Amstelodami 1667. folio. (gallice.)

Buldaeus, Beschreiving der oost-indische Kusten Nalabar, Coromandel Ceylon. Amsterdan 1672. folin.

Knox, Historical relation of the island Ceylon. London 1681.-folio. (germantice, gallice.)

Thevenot, Relation de l'Indostan. Paris 1684. 4. (anglice, germanice.)

Tachard, Second voyage au royaume de Siam. Paris 1689.4

Meister, Der orientalisch-indianische Kunst-und Lustzartner. Dresten 1692.4

Valentyn, Oud-en nienw Oost-Indien. Dordrecht et Amsterdam 17241726. folio.

Barchewilz, Ostindianische Reisebeschreibung. Chemnitz 1730.8.

Osbeck. Dagbok ofwer en ostindisk resa åren 1750-175z. Stuckholm 1757. 8

(anglice, germanice.)

Linne, Iter in Chinam. Upsaliae 1768. 4.

Turpin. Histoire civile et naturelle du royaume de Siam. Paris 1774. 12. (Caput X11. de arboribus redit germanice in "Berliner Sammluns", vol. vili. p. 137-167.)

Sonneral, Voyage aux Indes orientales et à la Chine. Paris 1782.4. (germanice.)

Turner, Account of an embassy to the court of the Teshoo Lama in Tibel. London 1800.4 (gallice, germanice.)

Barrow, Travels in China. London 1804.4 (gallice, germanice.) 
Barrou. Voyage to Cochin hina. London 1806 . (gallice.)

Ratic, Observations on the Neilgherrips. Calcutta 1838.8.

Royle, Essay on the antiquity of llindon mediciur. London 1837. 8 .

- Essay on the productive resourcess of India. London 1840. 8 .

Moorcroft et Trebeck, Travels in the Hinalayan provinces. London 1841. 8.

Jacquemont, Voyage dans l'Inde pendant les années 1828-1832. Paris $1841-1844.4$.

Scholt, Skizze zu einer Topugraphie der l'rochuhte des chinesischen Reichs. Berlin 1842. 4

Junghuhn, Reisen durch Java, Magdeburg 1845. 8.

__ Die Battalánder auf Sumatra. Berlin 184i. 8.

Sonnerat, Voyage a la vouvelle Guince. Paris 1776."

Forrest, A voyage to New Guinea and the Noluccas. Lundon 1779. 4. (gallice, germanice.)

Kaempfer, Geschichte unl Reschreiloung von Japan. Lemgo 1777 1779. 4 .

(anglice, hollandice, gallice.)

Siebold, De historiae naturalis in Japonia statu Bataviae 1824. 8 .

Rochefort. Histoire naturelle et morale des isles Intilles d'Amérique. Rotlerdam 1639. 4.

(hollandice, anglice, germanice.)

Laet, L'histoire du nouveau monde uu description des Indes occidentales. Leyde 1640. folio.

Ligon, History of the island of Barbatos. London 1657. fulio. (gallice.)

Du Tertre, Histoire générale des Antilles. Paris 1667-1671. 4.

Slaane, A voyage to the islands Madera, Barbados, Nieves, St. Christophers and Jamaica. London 1707-1725. folio.

Labal, Nouveau voyage aux iles de l'Amérique. Paris 1722.12.

IIughes, The naturd history of Barbados. Loudon 1750. folio.

Browne, The civil and natural history of Jamaica. Loudon 1756. folio. (Plantae jamaicenses: p. 71-37t, tah. 1-35.)

(Thibaull de Chancalon) Voyage à la Martinique. Paris 1763.4.

(Nicolson) Essai sur l'histoire naturelle de l'tle de St. Domingue. Paris 1776. 8

Swartz, Intràdes tal om Vestindien. Stochholm 1790. 8.

Edwards, History of the british colonies in the West Indies. London 1793. 4 . (gallice.)

I'est, Bidrag til beskrivelse uver Ste Croix. Kiobenhavn 1793. 8

Euphrasin, Reise nach den westindischen Inseln St. Barthelemy, St. Eustache und St. Christoph. Gottingen 1798. 8.

Descourtila, Voyages d'un naturaliste. Paris 1809.8.

Moreau de Jonnès, Histoire plıysique des Antilles françaises. Paris 1822. 8 .

Ritter, Naturhistorische Reise nach der westundischen Insel Hayti. Stuttgart 1 \$ 36.8.

Halliday, The West Indies. London 1837.8.

Outn, Reiseerinuerungen an Cuba, Nord- und Sudamerika. Berlin 1843.8.

Ramon de la Sagra, Histoire physique et politique de l'ile de Cuba. Paris 1844. 8 .

Thevet, Les singularitez de la France antarctique, autrement nommée Ainérique. Paris 1558.4.

Boucher, Histoire naturelle de la nouvelle France vulgairement dite le Canada. Paris 1664. 12.

Josselyn, New Englands rareties. London 1672. 12.

- An account of 1wo voyages to New England. London 1674.8.

Martens, Spitzbergische oder gronlandische Reiseheschreibung. Hamburg 1675.4

(italice, belgice. anglice, sallice.)

Lawson, A new voyage to Carolina. London 1709.4. (germanice.)
Catcsby, The natural history of Carolina, Florida and the l3ahama Islands. L.ondon $1734-1743$, folio.

(germanice.)

Brirkell, The natural history of North-Carulina. Dublin 1737.8 . (Vegetables. p. $5 \overline{7}-106$.

Egede, Det gamle Gronlands nye perlustration eller naturelhistorir. Kiobnhavn 1741. 4. (anglice, gallicr, germanier, hollandice.)

Inderson, Naclırichten von Jsland, Gronland und der Strassi Davids. Ilamburg 1746.8. (bollaudice, gallice.)

Bartram, Ohservations ete. in his travels from P'ensilvania tó Onondago, Oswego and the Lake Ontario in Canada. London 1751. 8

Kalm, En Resa til Nurra America. Stockholm 1753-1761. \$. (germanice, gallice, anglice.)

Bossu, Nouveaux voyages dans l'Aınérique septentrionale. Amsterlam 1777. 8 . (antslice.)

Castigliomi, Viaggio negli Stati Uniti. Nilano 1790.8.

Bartram, Travels through Nortı and South Carolina, Georgia, Florida elc. Philadelphia 1794.8.

(germanice, gallice.

Imlay, Description of the western territory of Nortl America. London 1792. 8 . (germanice.)

Voluey, Tahleau du climat et du sol des Etats Unis. Paris 1803. 8.

Michaux, Voyage à l'ouest des monts Alléghanys dans les états d'Ohio du Kentucky et du Tennessée. Paris 1804.8. (anglice, germanice.

Nutice sur les fles Bermudes. (Paris) 1806. 4.

Barrow, Voyages into the arclic regions. London 1818. 8.

Scoresby, Journal of a voyage to the northern whalefishery. Edinluurgh 1823. 8.

(germanice.)

Schweinitz, Narrative of an expedition to the source of St. Peters River. London 1825. 8.

Herzog Paul von IVurtemberg. Erste Reise nach dem nordlichen Amerika. Stuttgart 1835. 8 .

Wied-Neuwied, Reise in das innere Nortamerika. Koblenz 18391841.4 .

Gosse, The Canadian naturalist. London $4840 . \mathrm{s}$

Oviedo y Valdes, Sumario de la natural y general istoria de las Indias. Tuledo 1526 . folio.

- Primera parte de la historia natural y general de las Indias. Sevilla 1535. folio (gallice.)

Feuillée, Journal des observations faites sur les cutes orientales de l'Amérique méridionale et dans les Indes occidentales. Paris 1714-1725.4.

Frezier, Relation flu voyage aux cótes du Chily et du Pérou. Paris 1716. 4 .

(anglice, belgice, germanice.)

Lozano, Descripcion chorografica del gran Chaco, Gualamba. Cordoba 1733. 4 .

Barrère, Essai sur l'histoire naturelle de la France équinoctiale. Paris 1741.8.

(Plantes: p. 1-119.)

Nouvelle relation de la France équinoxiale. Paris 1743. 8.

De la Condamine, Relation d'un voyage dans lintérieur de l'Amérique méridionale. Paris 1745.8 .

(anglice, germanice.)

Ulloa, Relacion historica del viage à la America meridional. Madrid 1748. folio.

(gallice, anglice.)

Loefling, lter hispanicum, eller Resa till spanska lánderna. Stockholm 1758. 8.

(germanice, anglice.)

Bancroft, Essay on the natural history of Guiana. London 1769. 8 . (germanice.) 
Ulloa, Noticias americanas. Madrid 1772. 4 (germanice, gallice.)

Molinu, Saggio sulla storia naturale del Chile. Bulugna 1782. \&. - it. 1810.4 .

(germinice, gallice. I

Stedmann, Narrative of a five years expedition of Surinam and Guiana. London 1796. 4. (gallice.

Azara, Voyages dans l'Amérique méridionale. Paris 1 s09. \& (Butanique: vol. 11. 1. 182-301.)

Leblond, Description abrégèe de la Guyane française. Paris 1814. S.

Humboldt et Bonpland. Reise in die Aequinoctialgegenden. Stuttgart $1815-1832.8$

Miers, Travels in Chile and La Plata. London 1826. 8.

Noyer, Forels vierges de la Guiano françajse. Paris 1827. 8 .

Meyen, Unher die llochebenen im südlichen Peru. (Brrlin 1832.) 8.

llancock, Observations on the rlimate, soil aud productions of British Guiana. Lontlon 1835.8.

D'Orbigny, Yoyage dans l'Amerique méritionale. Tome Vll. Botanique. Paris 1839. (1834-1846.) 4.

Poeppig, Reise in Chile, Peru nnd auf Iem Amazonenstrome. Leipzig 1835-1836. 4.

Schomburgk, A deseription of British-Guiana. London 18\%0.8. (germanice.) -1839. Leipzig 1841.8.

Reisen in British-Guiana in den Jahren $1840-1844$. Leipzig $1847-1848 . \mathrm{gr} .8$

Lery, Histoire d'un voyage en Brésil. Paris 1578 . \& (latine.)

Mawe, Travels into the interior parts of Brazil. London 1813.4. (germanice.)

\{ried-Neuwied, Reise nach Brasilien. Frankfurt a/M. 1820-1821.8.

(Schreibers) Nachrichten von den k. k. Naturforschern in Brasilien: Brünn 1320-1822. 8.

Saint-llilaire. Aperçu d'un voyage dans l'intérieur du Brésil. Paris 1823. 4.

Geraes. Paris 1830.8 .

Voyage dans le district des diamans. Paris 1833.8.

Spix und Martius, Reise in Brasilien. Nunchen 1824-1831. 4. u. Atlas.

Pohl, Reise im Innern von Brasilien. Wien 1832-1837. 4.

Gardner, Travels in the interior of Rrazil. London 1846. 8.

Parkinson, A joumal of a voyage to the South Seas. London 1773.4.

Tench, Compleat account of the settlement of Port Jackson. London 1788. 8 .

(germanice.)

Collins, Account of the english colony in New Solth Wales. London 1804. 4.

Bory de St. Vincent, Essais sur les isles fortunées. Paris 1803. 4.

Flinders, A voyage to Terra australis. London 1814.4.

(Robert Brown, General remarks yeographical and systematieal on the botany of Terra anstralis, p. 533-6i3.

King, Narrative of a survey of the intertropical ant western coasts of Australia. London 1827.8.

Nightinyale, Oceanic sketches. Loudon 1833 . 12.

Mitchell, Three expeditions into the interior parts of pastern Australia London 1838,8.

Len Africànus, De totius Africae deseriptione libri IX. Antwerpiae 1556. 8.

(italice, gallice, anglice, germanice.)

Mueller, Die afrikanische Landschaft Fetı. Hamlurg 16738.

Loyer, Relation du voyage du royaume d'lssyny. Paris 1714. 12
Kolbe, Beschreibung des Vorgebirgs der guten Hoffunng. Nurndurg 1719. folio.

hollandice, anglice, gallice.

Labat, Nouvelle relation de l'A frique occirlentale. Paris 17gs ly

Russell. The natural history of Aleppo and parts arljacent. London 1756.

4. - ib. 1794. 4.

(hollandice, germanice.)

Adanson. llistoire naturelle du Sénegal. Paris 1757. A (auglice, germanice.)

Sparrman, Resa til Goda-Ilopps Udden. Stocklıolm 1783 \&. (germanice, gallice, anglice.)

Mallhens, A voyage to the river Sierra Leone. London 1788. 3 (germanice, gallice.)

Isert, Reise nach Guinea und den Caribaischen Inseln. Kopenhagen 1788.8 .

Poiret, Voyage en l3arbarie. Paris 1789.8 germanice.

Paterson, I narrative of four journeys into the country of the llotentots ancl Callrania. London 1789.4 (germanice, gallice.)

Bruce, Travels. Vol $\mathrm{V}$ : Select specimens of natural history collected in travels to discover the source of the Nile. Edinburgh 1790. 4. (germanice, gallice.)

Le Laillant. Voyage tlans l'imtériem de l'Afrique. Paris 1790.8 germinis", anglice.

____ Seconk voyage lans l'intérieur de l'Afrique. Paris (1795.) 8.

Sommi, Voyage daus la haste ef liasse Egypte. Paris 1799. 8. (germanice, anglice.)

Symes. Account of an embassy to the kingdom of Ava. London 1800.4 gallice.)

Burrow, Travels into the interior of southern Africa. Londou $1801-$ 1804.4 (gallice, germantce.)

Reynier, Considérations sur l'agriculture de l'Egypte. (Paris 1802.) 8.

Durand, loyage au Sénégal. Paris 1802. 8. et Atlas. (germanice.

Golberry, Fragmens ilun voyage eli Afrique. Paris 1802, 8 (germanice

Nectoux, Voyage dans la bante Égypte. Paris 1808, folio.

Tuckey, Narrative of an expedition to explore the river Zaire (Congo) in South-Africa. London 1818.4.

Burchell. Travels in the interior of sonthern Africa. London 1822-1824. 4. - Botanical index. ib. 1824. 4

Denham et Clapperton, Narrative of travels in northern and central Africa. London 1826.4

(Botancial appendix by Robert Brovn, p. 208-246.,

Cuillioud, Voyage à Méroé. Paris 1826-1827.8.

Schimper, Reise nach Algier. Stutgart 1834.8.

Bove, Observations sur les rultures de l'Égypte. Paris 1835.8.

l)esfontaines, Voyage dans les régences de Tunis el d'Algger. Paris 1838. 8 .

Brunner, Reise nacls Senegambien und nach ten luseln des grunen Vorgebirges. Berm 18408

Flacoum. Histoire de la gramle isle Nadagascar. Troyes 1661.4.

Saint-Pierre) Voyage a l'isle de France etc. Amsterdan 1773. 8.

kory de St. Vincent. Voyage ılaus les quatre principales îles des mers d'Afrique. Paris 1804.8 germanuce.)

Le Iru, Voyage an iles de Ténerifle etce l'aris 1810.8 (germanice.

Rauld, Breve osservazione sull Isola di Madera. lïrenze 1821.8.

Bowdich, Excursions in Madrita and Porto Santo. London 1825 i (Botany: p. $244-267$. (gallice.)

Burh, Physikalische Besclureibung der canarischen Inseln. Berlin 1825. 4. igaltice. 


\section{Geographia plantarum.}

Scherbius, De loco at silu plantarum. Basileae 1731 \&

Limne, Oratio de telluris labilabilis incremento. Upsaliáe 1743.4 (germánice, anglice.)

Leonhard, De plantis prope salinas crescentilus. In ojus "De novo aquae salsae fonten. Goellingae 1753.4

Linne, Stationes plantarum. Upsaliae 1754. 6.

Flora alpina. lipsaliae 1756.4.

De coluniis plantarum. Upsaliae 1768. 4

Retzius, Medjationes de distributione renu naturaliam. Lundae 1798.4.

Stromeyer, IIstoriae vegetabiliom geugraphicae spucimen. Goeltingae 1800.4

Kielmeyar. Otsservita de vegetatione in regionibus alpinis. Tubingae 1804.8 .

Ilumboldl, Idoan zn einer Physiognonik derGewachse. Tubingen 1806.8.

De Candolle, Géographie agrieole el Jotaniojue. 1809. 1822.

lumboldt et Bonpland, Essai sur la géographie des plantes. Paris, an XllI. 1805. gr. 4 . (germanice.)

Thunberg, Geographia plantarum cultarum. Upsaliae 1813. 4.

Humboldt, Notationes ad geographiam plantarum spectantes In ejus "Nova genera" etc. Lutetiae Par. 1815-1825. folio. 1816. $\mathrm{s}$

Nouvelles recherches sur les luis dans la distribution des formass végétales. (Paris) s. a. 8.

Schouw, De sedibus plantarum originariis. Ilavniae 1816.8

Humboldt, De distribotione geographica plantarum. Luteliae Parisiorum 1817.8

(germanice.)

De Candolle. Conjectures sur le nombre total des espèces, qui vógétent sur le globe. (Bibl. univ. de Genòve 1817. VI, 119-124.)

Boue, De methodo Floram regionis cujustam condueendi. Edinburgi 1817. 8 .

liouch, Régénération de la nature végétale. Paris 1818.8.

De Cundolle, Essai élementaire de guographie botanique. (Рaris 1820.) 8.

Wilbrand und Ritgen, Gemälde der organischen Nator. Giessen 1821. 8. und Atlas.

(suecice.)

schouw, Grundtraek til en almindelig plantegeographie Kiobenhava 1822. 8 .

germanice.)

Plantegeographisk Atlas. Kiobenhavu 1844. folio.

Moreou de Jonnés. Mémoire sur le déboisement des forêts Bruxelles 1825. 4 .

(germanice-)

Schoder, Die Erdarten im Gebiete der Planzenvegetation. Ludwigsburg 1S25. 8.

Barton, Lecture un the gengraphy of plants. London 1897. 12 . (gallice.)

Brisseau-Mirbel, Reclserclses sur la distribution géographique des végétaux phanérogames de l'ancien monde. Paris 1827. 4.

Schouv, Beitrage zor veryleichenden Klimatologie. Kopenhagen 1827. 8. Specimen geographiae physicae comparativae. Havniae 1828. 4

Brongniart, Considérations générales sur la nature de la végétation elc. Paris 1829.8 .

Aubuisson de Voisins, Traité de géognosie. Paris 1825-1834. 8

Lavy, État général des végétaux originaires. Paris 1830. 8 .

Beilschmied, Planzengeographie nach A. von Humboldis Werke. Breslau 1831.8.

Fries, Primitiae geographiae Lichenum. Lond. Goth. 1834. 8.

Schouw, Europa, en let fattelig naturskildring. Kiobenhavn 1839. 5 ib. 1835.8 .

gerwanice.)
Fenzl, Darstellun der geozraphischen Verbreitungsverhaltaisse der Alsineen. Wien 1833. 8 .

Canstein, Karte der Verbreitung der mutarsten Pnanzen uber den Erdkorper (und Begleitworte dazu). Berlin 1834.8.

De Candolle, Distribution geographique des plantos alimentaires. Geneve 18.36. 8 .

Mryen, Gromdriss Jer Pllanzengeographie. Berlin 1836.8 snecice.

Unger, lleber den Finfluss des Bowlens auf die Vertheilung der Gewachse. Wieu 1836 . gr. 8 .

Schouw, Naturshilntringer Kiobenhavn 1837 8. - Ed. II: il). $1839-$ 1846. s.

(germanice.)

Hoffmann, Physikalische Geographie. Berlin 1837.8.

Ilellrung, Allas der Weinláuder in Europa. Magdeburg 1837. 8.

- Karte des Weingebiets in den Zollvereinsstaaten. Augsburg 1846. gr. folio.

Brongniarl, Considérations sur la nature des végétaux, qui ont couvert la surface de la terre. Paris 183\$. 4.

IThite, On the geography of plants. Edinburgh 1838.8.

Oe Candolte, Statistique de la fanille des Composées. Paris 1838. 4

Mohl, Ueber den Einfluss des Bodens auf die V'erbreitung der Alpenpflanzen. Tubingen 1838.8

Malhieu de Dombasle, Des forêts considérées relativenent a l'existence des sources. (Nancy) 1839.8.

Martius, Die Verbreitung der Palmen in der alten Welt. Munchen 1839, 4.

Grisebach, Genera et sjecies Gentianearum adjectis observationibus phytogeographicis. Stutigartiae 1839.8.

Marlins, De la délimitation des regions végélales sur les inontagnes du continent européen. Paris 1840.8.

Quetelet, Resumé des observations sur la météorologie, sur le magnetisme, sur les températures de la terre, sur la floraison des plantes etc. (Braxelles) 1841.4 .

Roemer, Geographie und Geschichte der Pflanzen. Munclien 1\$41.8.

Grisebach, Bericlıt ubel dic Leistungen in der Pllanzengeographie wahrend der Jahre 1840-1846. Berlin 1841-1849. 8

Fries, Vàren. En butaniske betraklelse. Upsala 1842.8

Hinds, The regious of vegetation. London 1843. 3

Jussieu, Geographic botanique. Paris 1845. 3.

Meyer, Die Vertheilung der Nahrungspflanzen auf der Ëde. (Konigsbery 1846.8

Miquel, Oratio de regno vegetabili in telluris superficie mutanda efficaci. Anstelaedami 1846.4 .

Petersen, Ueber den Einfluss der Waldungen anf die Witterungsverialtnisse und das Klima. Altona 1846.8.

Pignol, De l'inlluence du climat sur les plantes. Lyon s. a. 8.

Barlon, Specimen of a geographical view of the trees and strulss of NorthAmerica. Philadelphia 1809. 4.

Moreau de Jonnés, Carte orographique et botanique du volcan du Pitondu Carbel à la Mlartinique. (Quérard, France lit. VI. ж96.)

Brown, General remarks geographical and systematical on the botany of Terra Australis. London 1814. 4

(Verm. Schriften 1. 1-166.)

Observations systematical and gevgraphical on the Herbarum collected Jy Prof. Christan Smith in the vicinity of the Congo. London 1818. 4. (gallice.)

(Verm. Schriften I. $167-336$. )

Bigelow, Facts serving to shew the comparative forwardness of the spring in diflerent parts of the United States. Cambridge 1818.4.

Buch, Allgeneine Uebersich der Flura auf den canarischen Inseln. Berlin 1819. 4

Leschenaull de la Tour, Notice sur la végétation de la Nouvelle-Hollande es de la terre de Diemen. Paris 1824.8 
Martius, Die Physiognomie des Pllanzenreiches in Brasilien. Munchen (1824.) 4 .

- Beitrag zur Kenntniss der Amarantaceen. (Bonnae 1825.) 4.

Cunningham, Botany of the mountain country between the colony round Port Jackson and the settlement of Bathurst. Impr. eum Fields Geographical Hemoirs on New Sud Wales. London 1825.8 . (germanice.)

Lesson, Observations générales sur lihistoire naturelle des diverses contrées visitées par la corrette La Coquille. In Duperrey Voyage. Zortlogie. Paris 1826. 4. vol. I, p. 187-360.

Cunningham, General remarks on the vegetation of Terra australis. Impr. in King. Narrative of a survey of the cuasls of Australia. London 1827. 8 .

germanice.

Ehrenbery, Beitrag zur Clarakteristik der nordafrikanischen Wusten. Berlin 1827.4.

Reinwardt, Ueber den Charakter der Vegetation auf den Inseln des indisehen Archipels. Berlin 1828. 4.

(Ritter) Die Verbreitung der Dattel-und Kohospalme in lndien. s. I. et a. 8.

(-) Die Verbreitung der Pfelferrebe, Banane und Mango in Indien. s. I. et a. 8 .

(—) Der indische Feigenbaum, Asvattha; die Banjane (Ficus indica) etc. s. I. et a. 8 .

(-) Die Opiumkultur und die Mohnpflanze. s. I. et a. 8

(-) Die Kultur des Zuckerrohrs in Isien und seine geographische Verhreitumy. s. J. et a. 8 .

- Uober die geographische Terbreitung des Zuckerrolirs. Berlin 1840.4.

Jussieu, Jémoires sur la groupe des Méliacées. (Paris 1830.) 4.

Martius. Die Pflanzen und Thiere des tropischen Amerika. Ein Naturgemẩde. (Leijzig) 1831.4.

Lund, Bemärkninger over vegetationen pad de indre housletter af Brasilien. Kjobenharn 1835.4 .

Berthelot, Coup d'oeil sur les foréts canariennes, sur leurs changements ot leurs alternances. Paris 1836 . folio

Mappa distributionem geographicas Laurinarum exhibens in Nees non Esenbecl, Systema Laurinarum. Berolini 1836.8.

Meinicke, Das Festland Australien. Prenzlau 1837. 8.

Saint-Milaire, Tahleau de la végetation primitive dans la province de Ninas Geraes. Paris 1837.8.

Griffth, Report on the Tea plant of Upper Assam. (Calcutta 1838.) 8.

Mac Clelland, Report on the plysical eondition of the Assam Tea plant. (Calcutta 1838.) 8.

Papers relating to the measures adopted for introducing the cultivation of the Tea plant in Jndia. Calcutta 1839 . folio.

Lindley, Swan River. Sketch of the regetation of this colony. London 1840. 8.

Webb et Berthelot, Géographie botanique des illes Canaries. (Ilistoire etc. tome 111 , première partie.) Paris 1840.4.

Marlens el Galeolli, Considérations sur la géographie botanique de Mexique. In "Némoires sur les fougères ". (Bruxelles 1842.) 4.

Drège, Zwei pflanzengeographische Dokunente. (Leipzig 1844.) 8 .

Raffeneau-Delile, Souvenirs d'Egypte. Ilerhorisatious au Jésert. Mantpellier 4844.8 .

Kitllitz, Vier und zwanzig Vegetationsansichten vun Küsten und lnseln des stillen Okeaus. Siegen 1844-1845. 4 .

Hohenacker, Höhenprofil und Kártchen vou Sulwestpersien nach Th. Kotschy. Esslingen 1846. folio.

Meyer, Neueste Nachrichten uber einge vegetabilische Eroberer in Sudamerika. (Konigsberg 1846.) 8.

IV ahlenberg, Berätelse on matninger etc. Stochholm 1808. 4. (anglice, germanice.)

Flora lapponica. Berolini 1812.8.

Hisinger, Anteckningar i physick och geognosi. Lpsala 1819-1837. 8.
If ahlenberg, Flora upsaliensis. Upsaliae 1820.8.

___ Anmarkningar om Ölands Natur. Stockbolm $1 \$ 22.8$

IIn/man, Skrivelse angaaende de paa det inddaemmede red llofmansgave fremkomne planter. Kiobenharn 182z. 8 .

loewis. Leber die ehemalige Verbreitung der Lichen in Lief-und EsthJand. Dorpat 1\$24.8.

Ilisinger. Profiler och tabeller ofver de formamsta bergshojder. Stnchholm 1827. 4. - ih. 1829.8.

Lessing, Pllanzengeographischer Anhang, in seiner Reise dureh Norwegen. Berlin 1831.8.

Lindblom, ln geographicam plantarum intra Sueciam distributionem adnotata. Lundae 1835.8 .

H'irzén, De geographica plantarum in provineia casanensi distributione. Helsingforsiae 1839. 8 .

Hisinger, Tahleau de la vègétation du Sneehătien sur le Dovrelield. s. I. 1841. 0 .

Kuprecht, Distributio cryjtoganarum vascularium in imperio rossico. Petropoli 1845.8.

Tengstram, In distributionem vegetationis per Ostrobothuian collectinea. Helsing forsiae 1846.8 .

Winch, Essay on the geozraphical distribution of plants though Northumberland, Cumberland and Durham. Newcastle 1819. $8 .-$ ib. 1825.8 (germanice.)

Trevelyan, On the regetation and temperature of the Faroe Islands. Florence 1837.4

ITatson, Outlines of the geographical distribution of litisht plants. Edinburgh (1832.) 8 .

- Remarhs on the geographical distribmtion of british plants. Jondon 1835.8 .

(germanice.)

The geographical distribution of british plants. Ed. III. Part. I. (Ranunculaceae, Nymphacaceae, Papaveraceae.) London 1843.8.

Cybele britanica: or british plants and their geographical relations. Part 1. London 1847.8.

Mfiquel, De plantarum regni hatavi distributione. Lugd. Bat. 1837. 8.

Michaull, Lellte sur la situation de lá Bourgogne par rapport a la botanique. s. 1. 1738. 8 .

Soulavie, Histoire naturelle de la France méridionale. If: L,es veggétaux. Contenaut les principes de la géographie physique du règne végétal. Paris 1783.8 .

Oberlin, Propositions géologiques. Strasshurg 1806. 8.

Amoreux, État de la végetation sous le climat de Montpellier. Nontpellier 1809. 8 .

De Candolle, Mémoire sur la géographie des plantes de France. (Ném. soc. d'Areueil 1817. 111 , 262-322.)

(Cordienne) Notico topo-phytographique de quelques lieux de Jura. Dole 1822. 8.

De Brébisson, Coup d'veil sur la végetation de la Basse-Nomandie. Caen 1829. 8.

Kirschleger, Statistique de la Flore d'Alsace et des Vosges. Nihlliausen $1831(-1832) 4$.

Steinheil, Observatious sur la régétation des Dunes a Calais. Versailles s. a. 8.

Lauvergne, Géographie bolanique dn port de Toulon el des iles de Hyères. Montpellier 1829.4 .

Delostre, Aperçu statislique de la régetation du dep. do la Vienne. Poitiers 1835.8.

Martins, Essai sur da topographie botanique du mont Ventoux en Provence. Paris 1838.8 .

Lagréze-Fossat, Notice géologico-hotanipue sur l'arrondissement de Noissac. Montauban (1838.) 8.

Des Moulins, État de la végétation sur Je Pic du Nidi de Bigorre an 17 oct. 1840 . Bordeaux 1844. 8 . 
Grenier, Thèse de gèographie botanique du dép. du Doubs. Strassburg 1844,8 .

Mougeol, Conslilérations générales sur la végétation spontanée du dép. iles Vosges. Epinal 1s45.8.

Martins, Essai sur la gréngraplie botanique de la France. Paris (1845.) 8 .

Godron, Sur une plante propre aux terrains saliferes de Sarrebuurg. Nancy 1846. 8

Cambessedes, Enumeratio plantarum in insulis Balearilsus earumque circa mare mediterraneum distributiu geographica. Parisiis 1827. 4.

Boissier, Voyage hotanique dans le midi de l'Espagne. Paris 18391845. 4.

Bartling, De littoribus ac insulis maris lihurnici. Ilannoverae 1820 . 8

Scuderi, Trattato dei boschi dell' Etna. (Catanẹa 1824.) 4.

Tenore, Cenno di geografia fisica et botanica del regno di Napoli. Napoli 1827. 8 .

Essai sur la geographie pluysique et botanique du ruyaume de Naples. Naples 1827. 8

De Candolle, Notice sur la géographie botanique de l'Italie. Geneve 1835.) 8 .

Schouw, Tableau du climat el de la végétation de l'ltalie. Copenhague 1839. 4 .

Cesati, Saggio su la geografia butanica della Lombardia. Milano 1844.8

Wahlenberg, De vegetatione et climate in llelvetia septentrionali. Turici 1813.8.

De Candolle, Projet d'une Flore pliysico-geographique de la vallée du Léman. Genève 1821.8.

Schuebler, De distributione geographica plantarum Helvetiae. Tubingae 1823. 8 .

llegetschweiler, Beiträge zu einer kritischen Aufzahlung der Schweizerplanzen. Zurich 1831.8.

Heer, Beiträge zur Pflanzengeograplie. Mit einem Gemalde der Vegetationsverhälnisse des Canton Glarus. Zurich 1835.8

Veber die obersten Grenzen des thierischen und pllanzlichen Lebens in den Schweizeralpen. Zurich 1845.4

Ltnk, Flurae goettingensis specimen, sistens vegetabilia saxu valtareo prapria. Goettingae 1789.8

Brocchi, Memoria sulla valle di Fassa. Milano 1811. 8.

Braune, Salzburg und Berehtesgaden. Wien 1821. 8

Meyer, Beiträge zur chorographischen Kenntniss des Flussgebiets der lnnerste. Goettingen 1822. 8.

Hoffmann, De vitlium in Germania bureali directiune congrua. llalse 1823. 8.

Suuter, Geographisch-botanische schilderung der Umgelsungen Wiens. Wien 1826. $\mathrm{s}$

Alberti, Die Gebirge Wurtembergs stutgart 1826. 8 .

Lachmann, Flora brunsvicensis. 1. Theil. Braunschweig 1827. 8.

Schuebler, Untersuchungen uber dit: phanzengeographischen Verhálniše Deutschlands. Tubingen 1827.8

Sternberg, Ueber einige Eigenthumlichkeiton der bohmischen Flora. Regensburg 1829. 8.

Schuebler, Ueber die Temperaturverhaltnisse der schwahisehen Alp. Tubingen 1834,8 .

Ueber die Regenverhalunisse der scliwabisclien Mp und des Schwarzwaldes. Tubingen 1832.8

_- Veher die geoguostischen Velıalunisse Tubingens. Tubingen 1832.8.

Zuccarini, Veber die Vegetationsgruppen in Baiern. Nunchen 1833.4.

Grof, Versuch einer gedranglen Zusammenstellung der Vegetationsverhaltnisse des Herzogthums Krain. Layllach 1837. \$.

Schneider, Die Vertheilung und V(rd)reitung der schlesischen Pllanen. Breslan 1838. 8 .

Larentin. Die Vegetation in der Hark lirandenlourg. Berlin 1840. i
Brueckner, Entwurf einer Pflanzengeographie Mecklenburgs. In Langmunn, l'Jara von Mecklenburg. Neustreliı 1841.8.

Stotler und /leufer, Geognostisch-batanisehe Bemerkungen (und Karte) auf einer Reise durcli Oetzthal und Schnals. Innslucuch 1840.8 .

Heufler, Die Ursaclien des Pflanzenreichthums in Tirol. Inuspruck 1842.8.

Machacka, Conspectus geognostico-botanicus circuli boleslaviensis in Bohemia. Vindolsonae 1843.8.

Heu/ler, bie Golazberge in der Tschitscherei. Triest 1845.4

Fallou, Die Gebirysformationen zuischen Mltweida und Boclilitz. der Zschopau und beiden Mulden und ihr Einlluss anf die Vegetation. Leipzig 1845. 4.

Schnizlein und Frickhinger, Die Vrgetationsvarbátuisse der Jura- und Knuperformation in den Flussgebieten der Wornitz und Altmuhl Nordlingen $1847 . \mathrm{gr} .4$

Wahlenberg, Flora Carpatorum principalium. Goettingae 1814.8.

Heuffel, De distributione plantarum geographica per comitatum pestiensem. Pestini 1827.8.

Rochel, Tractatus phytogeographicus, in ejus a Plantae Hanatus rariores. Pestini 1828. Solio.

Ebel, Zwolf Tage auf Montenegro. H. Heft. Konigsberg 184i. 8.

\section{Florac.}

Enumerationes topographicae singularum familiarum ct genarmm un sectone alonographiae" recensentur. Florae aeconomico-techuicae et saltuariae inter Botanicam applicatam leguntur; cryptogamicae inter plantas cryptogamas.j

Leswer, Nacluricht von einer von $D$. Menzel angegebenen botanischen Gisugraphio. (Pliysik. Belustig. I, 321-327.)

Kalm, Adumbratiu Flarae. Aboae 1754. 4

Linné, Flora alpina. Upsaliae 1756. 4.

Dr coloniis plantarum. Ipsaliae 1768.4

Dillenius. De plahtis novi orbis. veteris spontaneis et inquilinis factis. (Ephem. acall nat. cur. cent. III-N, p. 2S $1-282$. .)

Setzen, Ueher die Planzenverzeichnisse gewisser Gegenden. (Usterb, Annalen. $\mathrm{XV1}, 20-26$.)

Colmeiro, Principj clie devono regolare una Hlora applicati alla formazione della Spagnuola. Lueca is 43.8.

De l'Ecluse, Rariorun stirpiun per Pannoniam. Austriam et vicinas provineias abservatarum historia. Antwerpiae 1583.8.

hay, Catalogus stirpium in exteris regionibus observatarum. In ejus *Travels $\$$. London 1673.8

- Stirpium europaearum extra Britannias nascentium sylloge. Londini 1694.8.

Boccone, lcones et descriptiones rariorum plantarum Siciliae, Melitae, Galliae ot Italiae. Oxonii 1674, 4.

_- Museo di piante rare della Sicilia, Malta, Corsica, Italia, Piemonte e Germanid. Venezia 1697. 4

- Iconum Musei rariorum plantarum index. Venetiis s. a 4

Appendix al Museum de plantis siculis. Venetiis 1702.4

Barretier, Plantae per Gallian, Ilispaniam et ltaliam observatae. Parisiis 1744. folio.

Laicharding, Vegetabila europaea. Oeniponte 1770-1771.8.

Manuale botanicum. Lipsiae 1794. 8

lioemer, lilora curmpaea inchoata. Norimbergae 1797-1911.8

Boissien, Flore d'liurope. Lyon 1805-1807. 8. 


\section{Florae Britanniac.}

Johnson, Jinera in agrum cantianum. Londini $1629-1632.4$.

- Mercurius botanicus. Londini 1634-1641.4.

Coujunctim: Opuscula omnia botanica Thomae Johusoni. Lombini 1817. 1.)

(Jow) Pliytologia hritannica. Londini 1650.8

(Ray) Index plantarum agri cantabrigiensis. Cantabrigiac 1660.8 .

(-) Catalogus plantarum circa Cantalnigian nascentium. Cantabrigiae 1660.8. - Appendix: ib. 1663.8. - il. 1685. \$.

- Catalogus plantarum Ingliae et insularum adjacentium. Londini 1670.8. - ib. 1677.8.

Fasciculus stirpium britannicarum. Londini 1688. 8.

Synnpsis methodica stirpium britunicarum. Londiui 1690. 8. i). 1696.8 . - ib. 1724. 8 .

Sibbald, Scotia illustrata. (Pars II, tomus I: de plantis.) Edlinhurgi 1684. folio.

Peliver, Mr. John Ray his method of english plants. (AJemoirs for the Curious 1708. 13. 139-166, 191-196.)

Lawson, A list of several rare plants found in the mountains of Westmoreland and Cumberland. In Robinson, Natural history. London 1709. 8. p. $89-95$.

Peticer, Jledbarii britannici Raji catalogus cum iconibus. (London 1713.) folion.

Blair, A nore exact description of sereral indigenous plants. In ejus "Miscellaneous observations". London 17.18. 8.

Threlkeld, Synopsis stirpiun libernicarum. Dublin 1727. 8 .

Martyn, Methodus plantarum circa Cantahrigiam nascentium. Londini 1727. 8 .

Tournefort's listory of plants, will the plants growing in GreatBritain. London 1732. 8.

(Blaclistone) Fasciculus plantarum circa Haredield nascentium. London 1737. 12 .

Doering, A catalogue of plants alout Nottinglıam. Nottingham 473s. 8.

- Scarce plants etc. In ejus "Historical account". Nollingham 1754. 4. 3. $89-90$.

Irilson, Synnsis of british plants. New Casile 1744. S.

Blackstone, Plantarum rariorum Angliae loci natales. Londini 1746. 8.

Linne, Flora anglica. Upsaliae 1754.4.

Hill, The british herbal. London 1756 . folio.

- Flora britannica. Londini 1760. 8.

Hudson, Flora anglica. Londini 1762.8 , - ib. 177S. 8. - ib. 1798. 8.

Lyons, Fasciculus plantarum circa Cantabrigiam nascentium. Londini 1763.8 .

Martyn, Plantae cantabrigienses. London 1763. s.

List of the more rare plants growing in many parts of England and Wales. In ejus "Plantae cantabrigienses". Loudon 1763. S. 1). $44-114$.

Florá anglica. London 176\%. 8.

Ifill, Herbarium britannicum. Londini 1769. 8.

Warner, Plantac woodfordienses (Essex). I.6ndon 1771. 8.

Cullum, Florae anglicae specimen. s. 1. 1774. S.

Curlis, Cataloguc of plants in the environs of London. London 1774. 8.

Waving, on some plants found in several parts of England. (Philosoph. Transact. LIX, p. 23-38.)

Jenkinson, Description of british plants. Kendal 1775. 8.

Rose, Plants discovered in Norfolk and Sulfolk. In ejus "Elements of botany". London 1775. S.

Bolton, Catalogue of plants growing in the parish of 1Jalifax. In Wutson, llistn'y ctc. Loudon 1775. 4. p. 729-764.

IIthering, Arrangement of all the vegetahles naturaily growing in GreatBritain. Birmingluam 1776. 8. - Edinburgh 1 \$ $35 \%$. 8.

Jacob, Plantae favershamienses. London 1777. s.

Lightfool. Flora scotica. London 1777. S.

Robson, The british Flora. York 1777. 8.

Curtis, Flora londinensis. London 1777-1787, folio.

Pritzel, Thes. lit. Joat.
Curlis, Flora londinensis. A new edition by Graves and Hooker. London 1817-1828. folio.

Halcolt, llora britannica indigena. Bath 1778.8

Broughton, Enchiridion botanicum. Londini 178 ע. 8.

Curtis, Catalogue of cerlain plants in the environs of Settle in Yorkshire. 1782. Solio.

__ Catalogue of british plants, arranged according their periods of Howering. London 1783.8.

Bute, Botanical tables. s. l. et a. 4.

(Travis) Catalogus plantarum cirea Scarborough nascentium. s.l. et a. 4 .

Teesdale, Plantae eboracenses, or a catalogue of the more rare plantes, which grow wild in the neighourhood of Caste lloward, in the Nortl Riding of Yorkshire. (Transact, of the Linn. soc. I], 103-125.)

(Forster) Additions to II urner's Plantae woodfordienses. s. 1. 1784.8.

Belhan, Flora cantabrigiensis. Cantabrigiae 1785. 8. - Supplementum I-III: ib. 1786-1793.8.

Smith and Sowerby, Einglish Botany. London 1790-1814. S. - General indexes: il. 1814.8. - Supplement: ib. $1831 \mathrm{~s}(\mathrm{q} .8$.

Milne et Gordon, Indigenous botany. (Kent, Niddlesex.) London 1793.8. Shiercliff, Catalogue of plants, which grow on St. Vincent's Rocks. In ejus "Bristol and Jlotwell gnilles. Bristol 1793. \$. p. \$2-86.

Sibthorp, Flora oxoniensis. Oxonii 1794. s.

1 Trade, Catalogus plantarum comratus dublinensis. Dublini 1794. \$.

(Freeman) Select specimens of british plants. London 1797-1809. folio. Abbot, Floral bedfurdiensis. Bedforel 1798. 8.

Symons, Synopsis plantarum insulis britannicis indigenarum. Londini 1798. 8 .

Hull, The british Floro. Hanchester 179y. S.

Smith, Flora britannica. Londini $4800-1804$. S.

Compendium Florae britannicae. Londini 4800. 8. - Ed. V: ib. 4828. 12.

Forster, List of the rare plants of Tonbridge Wells. London 1804. 12.

- Flora tonbrigensis. London 1816. 8.

IVade, Plantae rariores Hiberuiae. Dublin 4804.8.

Turner and Dillwyn, The botanists guide through England and Wales. London 1805.8.

Galpine, A synoptical compend of british botany. London 1806.12. ib. 1820.8 .

Ordoyno, Flora nottinghamiensis. Newark 1807.8.

Thornton, The britisb Flora. London 4812.8.

Davies, Welsh botanology. London 1813.8.

Hopkirk, Flora glottiana. Glasgow 1843,8.

Purton, Britislu plants of the Midland counties. Stratford-upon-Avon 1817.8. Hooker, Flora scotica. London 4821. 8.

Greville, Flora edinensis. Elinburgh 1824.8.

Woodforde, Catalogue of plants growing in the neighourbood of Edinburgh. Edinburgh 1824, 12.

Smith, The english Flora. London 1824-1836. 8.

Mackiay, A catalogne of the plants found in Ireland. Dublin 1825. 4.

Henslow, A catalogue of british plants. Cambridge 1829. 8 .

Jones et Kirrgston, Flora devoniensis. London 4829.8.

Johnston, A Flora of Berwich-upon-Tweed. Edinburgh 1839-1831. 8.

Smith, Catalogue of rare plants collected in South-Kent. London 4829. 8.

- Compendium of the english Flora. Landon 1829. gr. 12. - Ed. II. by llooker. ib. 1836.8 .

Lindley, A syuopsis of the british Flora. London 4829. 12. - ib. 1841.12.

Hooker, The britisll Flora. Tol. 1: Phanerogamia, London 1830. 8. -

Ed. V: ils. 1842.8.

- The british Flor', Vol. Il: Gryptogamia. Lonılon 1333-1836.8.

Patrick, Judigenous plants of Lanarkshire. Edinhurgh 1831. 12.

Sweet and 11eddell, British botany. London 1831.8.

Weddell, Britisi botany. London 1831. 4.

Winch, Flora of Northumberland and Durham. Neweastle 1831.4.

- Contributions to the Flora of Cumberland. Newcastle 1833. 4. 
Halker, The Flora of Oxfordshire. Oxford 1833.8.

Anderson, Guide to the llighllands and lstands of Scotland. London 1834.8.

Babington, Flora bathoniensis. Loudon 1834. 12. - Supplement: ih. 1839. 12.

Baxter, British phaengganous botily:. Oxford $183 i-1843.8$.

Watson, The new botanist's guide to the lncalities of the racer plants of Brikain. London 1835-1837.8.

Francis, A catalogue of british flowering plants and ferns. Iondon 4835 . folio. - ib. 1840. folio.

Mackay, lilora hilsernica. Dublin 1836.8.

Murray, The northern (Scotland) Flora, Ediubnrgh 1836.8.

Ihind, Excursions. (Flora edinensis.) Edinburgh 1836. 12.

Cooper, Flora metropolitana. London 1837. 12.

Diclie, Flora abredonensis. Aberdeen 1838. 8.

Irvine, The London Flora. London 1838. gr. 12.

Luxford, A Flara of the neighbourhood of Reigate, Surrey. London $4 \$ 38$. gr. 12.

Babington, Primitiae Florae sarnicae, London 1839. 8.

Cowell, A floral guide for East Kent. Faversham 1839. 8.

Francis, The little englislı Flora. Lourlon 4839.8 .

Jall, A Flora of Liverpool. London (1839.) 12.

Ralfs, The british phaenogamous plants and ferns. London 1839. 8.

Salter, Account of the botany of Poole. Poole 1839. 8.

Baines, Flora of Yorkshire. London 1840. 8.

Jaclison, The pictorial Flora. Londan 4840. 8 .

Newman, Notes on irish natural bistory. London 1840.8 .

Balfour, Babington and Campbell, Catalogue of british plants. Eclinburgh 1841.8 .

Balfour and Babington, An account of the regetation of the onter Hebrides. Erlinburgh 1841.8.

Leighton, A Flora of Shropshire. Landon $18 \$ 1.8$.

Sowerby, The illustrated catalogue of british plants. London 1841. 12.

Deakin, Florigraphia britannica. London 1841-1845. 8.

Bloxam and Babington, Botany of the Charnwood Forest. In Potter, The history etc. London 1842. 4.

(Coxhead) Catalogue of plants of Great Britain. Londion 1842. gr. S.

Babington, Hanual of hritish bolany. London 1843. S.

Lees, The botany of the Malvern Hills etc. London (1843.) 8

Knapp, The botanical chart of british plants. Bath 1\$16. S.

Loudon, British wild-flowers. London 1846.4.

The irish Flora, Dublin 1847. 12.

\section{Florac Belgii foederati.}

Pilleterius, Plantarum in Walachria, Zeelandiae insula, nascentium synonymia. Middelburgi 1610.8 .

Knyf, Goylandine herbarum annium brevis onarratio. Amstelodami 1621. 4.

(Vorstius) Index plantarum indigenarum prope Lugdunum in Batavis. Lugd. Jatav. 1633. 12. - ib. 1636. 12. - ib. 1643. 12. - il. 1649. 12. - ib. 1658. 12. - (Scluyyl.) ih. 1668.8 .

IIauck, Index plautarum prope lugdunum in Bataris. Darmstadt 1679. 12. Gollschalch, Index plantarum circa Lugdunım. In ejus "Catalogo horti Lugduni Bat.p Plöen 1697. 8. - ih. 170\%. S.

Brumann, Jndex plantarum cirea Zuollam in Transsilvania crescontum. 1662.8 .

Commelyn, Catologus plantarum indigenarum Inllandiae. Amstelodami $16 \$ 3.12$.

Gorter, Flora geln-zutphanica. Jlarderovici $1745-1757.8$.

Limni, Flora helgiea. 1psaliae 1760.4.

Me'se, Flora frisica. Franeker 1760.8 .
Gorter, Flora belgica cum ll supplementis. Trajecti 1767- 17.7 .8$.

_- Flora septeı provinciarum Belgii. Jlarlemi 1781.8. l'lora zutphanica. Zutplaniae 1781.8.

Geuns, Mlantarnm Bolgii confoedlerati ineliggenarum spicilegiun. Ilarlervici 1788. 8 .

Loosjes, Flora harlemica. Ilaarlem 1779. 8.

Ehrhart, Meino Reiso nach der Grafschan lientheim und von da nach Holland. (Beitráge II, 73-166.)

lozin. Jlerbier portatif des plantes daus les environs de Jiege. (Jiegre) 1791.8.

Rouçel, Traité des plantes tans les environs de Gand, .1 rust, Trimonde et liruxelles. Paris 1792.8.

Bosch, Enumeratio plantarum Zeelandiae Lelgicae. s. 1. et a. 8.

Fiops et van Ilall, lilora batava. Amstordam $4800-1847$ sqlq. 4.

kouçel, Flore du Nord de la France. Paris 1803.8.

Kickx. Flora bruxellensis. Bruxellis 1812.8 .

Dekin et Passy, Florula brunellensis. Bruxellis 1814. 8.

Geer, Plantarnm Belgii confoederati indigenarum spicilnginm alterun. Trajecti a/Rh. 1814.8.

Ilocquart, Flore du dép. de Jemappe. Mons 1814. s.

Schuurmans Stekhoven, Krnidkundig llandbnek. Amsterdam $1815-$ 1818. 8

Mulder, Elenclıs julantarum, quae prope urbem Leidaın nascuntur. Lugdl. Bat. 1818.4 .

Nyst. Catalngue des plantes du plateau de St. Pierre a Maestricht. Paris 1821.8.

Hall, Flora Belgii septentrionalis (Flora van Noord-Nederland). Ainsterdam $1825-1836.8$.

Kityper. Eerste naamlyst van planten in de omstretien ran Breda. Breila 1826.8.

Dumortier, Florula belgica. Tornaci Nerviorum 1827. 8 .

Ilecart, Florula lannoniensis. Valenciennes $1 \$ 36$. \$.

Bruinsma, Flora frisica. Leeuwarden 1840. \&.

Molkenboer et Kerbert, Flow leidensis. Lugd. Bat. 1840. s.

Gevers Deynool, Flora rheno-trajectina (Flnra van Utrecht). Firecht 1843.8 .

\section{Florae Galliae.}

(Mont-Saincl) Le jardin senonois. Sens 1604. 12.

Belleval, Dessein touchant la recherche des plantes du pays de I,anguedac. Monepellier 1605.8 .

- Remontrance et supplication au Roy llenry $1 \mathrm{~V}$. s. a. 4.

Strobelberger, De plantis rarioribus, quae per totam Galliam, praecipue in Gallia narbonnensi, proventiali et Languedocia sponte virent. In ejus "Galliae description. Jenae 1620. 12. p. $175-271$.

Cormuli, Enchiridion balanicum parisiense. Impr. curn ejus Canadensium plantarum historia. Parisiis 1635.4 .

Prevost, Catalogue des plantes, qui croissent en Bearn, Navarre et Begorre ete. Pau 1655.8.

Magnol, Botanicon monspelienso. Lugrluni 1676. S. - Mlonspelii 16S6. \$.

Tournefort, llistoire des plantes, tui uaissent aux environs de Paris. Paris 1698. 12. - ib. 1725. 12.

(anglice.)

Collet, Catalogue des plantes autour de la ville de Dijon. Dijon (1702.) 12.

Barrelier, Plantae per Galliam, Hispaniam et lialiam observatae. Parisiis 1714. folio.

Callard de Ducquerie, Ager medicus cadomensis. Parisiis 1714. folio. (Isser. ?)

Garidel, listoire des plantes, qui naissant aux emvirons d'Aix. Aix 1 ils. folio.

Peliver, Mouspelii desideratarum Jlantarum catalogus. Londini 17 16. fulio. 
laillant, Botanicon parisiense. Operis majoris pladromus. Lugduni Bat. 1723. 8. - ib. 1743.8.

- Botanicon parisiense. Leide el Amsterdam 1727. folio.

Lindern, Tournefortius alsalicus. Argentorati 1728. 8.

Astruc, llétnoirez pour l'histoire naturelle de la province de Languedec. Paris 1737. 4.

Fabregou, Description des plantes aux cuvirons de J'aris. Paris 1740.8. I/apus, Historia plantarum alsaticarum postsuma. Argentorati 474. 4.

Le Monnier, Observations d'histoire naturelle. Paris 1744.4.

Guellard, Observations sur les plantes. (Flora ditionis stampanae et australioris Galliae.) Paris 1747. 8.

Lindern, Hortus alsaticus. Argentorati 1747. 8.

Dalibard, Florae parisiensis prodromus. Paris 1749. 8.

De Sauvages, Methodus foliorum seu plantae Flerae monspeliensis. A la Haye 1751. 8.

Limué, Flora monspeliensis. Upsaliae 1756. 4.

Gerard, Flora galloprovincialis. Parisiis 1761. 8.

Gauan, Jlortus regins monspeliensis. Lugduni 176џ, 8.

Flora monspeliaca. Lugduni 1765.8 .

Buchoz, Traité histerique des plantes, qui croissent dans da Lorraiue et les trojs Evechés. Paris $1762-1770 . \mathrm{s}$.

- Tournefortius Lotharingiae. (Nancy 1764.) 8.

Alleon du Lac, Mèmoires. Lyon 1765. 8.

(Spielmann) Prodromus Florae argentoratensis. Argentorati 1766, S.

Nectier, Deliciae gallo-belgicae sylvestres. Argeutorati 1768. 8.

Latourrelle, Botanicon pilatense. In ejus "Veyage au Mout Pilat". Avignon 1770. 8. p. 109-223.

Buchaz, Dictionnaire raisonne des plantes de Ja France. Paris $1770-$ 1771. 8 .

Forskicil, Florula lituralis Galliae ad Estac prope Mlassiliam. In ejus " Flora aegr-arabican. Havniae 1775. 4. p. I-ẌII.

Maulny, Flore du Mans. Avignon 1776. 8.

Bulliard, Flora parisiensis. Paris 1776-1780.8

De la Marck, La Flore française. Paris 1778. 8.

Jillars, Prospectus de l'histoire des plantes de Dauphine. Grenoble 1779. 8.

Bulliard, Hesbier de la France. Paris 1780-1795. folio.

Lestiboudois, Botanographie belgique. Lille 1781. 8. - ib. 1799. 8.

Palassa, Essai sur la minéralogie des Pyrénées, suivi d'un catalogue des plantes. Paris 1781. 8.

Durande, Flare de Bourgagne. Dijon 1782. 8.

Bonamy, Florae namnetensis Prodromus. Nannetis 1782-1785. 12.

Courel-lilleneuve, Prodromus Florae aurelianensis. Orleans 1784.8.

Latourrelle, Choris Ingdumensis. In Linne, Syst. plaut. ed. Gilibert. Lugduni 1785. 8. P. 43

lillars, Flora delphinalis. In Gilibert, Svst. pl. Eur. vel. I. Coloniae Allohr. 1785.8.

_ Histoire des plantes du Dauphiné. Grenohle 1786-1789. 8. '

Gaterau, Description des plantes inx environs de Montauban. Montauban 1789.8 .

Saint-Amans, Le beuquet des Pyrénées. In ejus "Fragmensn etc. Metz 1789. 8. p. 189-259.

Broussonet, Corona Florae monspediensis. Monspclii 1790. 8.

Thuillier, Flore des environs de Paris. Paris 1790. 8. - ib. 1799. 8.

We la Jarck, Extrait de la Flore française. Paris 1792. 8.

La Flore française. Ed. II. Paris 1793. 8.

De la Peyrouse, Figures de la Flure des Pyrénées. Paris 1795-1801. folio.

Delarbre, Flore d'Auvergne. Clermont-Ferrand 1795. 8. - Ed. Il: Riom et Clermont 1800.8 .

Gauan, Herhorisations des environs du Montpollier. Montpellier 1796. 8.

lioussel, Flore du Calvados. Caen (1796.) 8. - il). 1806.8.

(Buchoz) Flore écenounique des environs de Paris. Paris 1797.8.

(Froncoeur) Flore parisienne. Paris, an $1 X$. (1801.) 12.
Guillemeau, Calendrier de Flore des environs de Niort. Niort 1801. 8.

Stols, Flore des dép. du Ilaut-et Bas-Rhin. Strassburg 1802. 8.

Vincens, Flore de Nismes. In ejus "Topographic velc. Nismes 1802.4. p. $322-415$.

(Aubry de la Nottraie) Exercices dhistoire naturelle (i. e. Plantes indigenes de Morbihan). Vannes 1802-1505. 4.

Rousel, Flore du Nord de la France. Paris 1803. s.

Thore, Essai d’une Chloris du dép. des Landes. Dax (1803.) 8.

Boucher (de Crevecoeur), Extrait de la Flore d'Abbeville et du dép. de la Semme. Paris 1803.8.

Bergeret, Flere des Basses-Pyrẻnées. Pau, an XI. (1803.) 8.

Dubois, Méthode éprouvée à eonuaitre les plantes de la France. Orléans 1803.8. - Paris 1840.8.

Saint-Hilaire. Notices sur 70 espéces de plantes trouvées dans le dép. du Lairet. Orléans s. a. 8.

Pourret, Extrait de la Cloloris narbonnensis. (Toulouse) s. a. 4.

Puel, Catalogue des plantes du dép. du Lot. s. I. et a. 8.

Nouvelle Flore des envirens de Paris. Paris s. a. 12.

Renault, Flere du dép. de l'Orne. Alençon (1804.) 8.

Guérin, Descriptien de la fontaine de Vaucluse. Avignon 1804. 12.

- Flore du dép. de Vaucluse. In ejus "Fragmens etc. Montpellier (1807.) 4 .

Willemet, Flore de l'ancienne Lorraine. Naney 1805.8.

(Duponl) Double Flore parisienne. Paris 1805. 8. - ih. 1813. 8.

De Candolle et De la Marck, Flore française. Ed. III. Paris 4805. 8. ib. 1815.8 .

Jaune St. Ililaire, Plantes de la France dẻcrites et peintes. Paris (180弓-) 1822. 4.

De la Marck et De Candelle, Synopsis plantarum in Flora gallica descriptarum. Paris 1806.8.

Manin, Enumeratio plantarum circa Metas. Metis 1806. 4.

Loiseleur Neslongchamps, Flora gallica. Lutetiae 1806 - 1807. 8. Paris 1828. 8.

De Candolle, Icones plantarum Galliae rariorum. Paris 1808. 4.

(Bull. soc. phil. 1808 . p. 117.)

Amoreux, État de la végétation sous le climat de Montpellier. IIontpellier $1809 . \mathrm{s}$.

Bastard, Essai sur la Flore du département de Maine et Loire. Angers 1809. 8. - Supplément: Angers 1812. 8.

Guyétant, Catalogue des plantes du Jura el des plaines jusqu'a la Saone. Besauçon 4809. 8 .

Merlel de la Boulaye. Herborisations dans les dép. de Maine-et-Loire et des Deux-Sevres. Angers 1809. 12.

Loiseleur Deslongchamps, Plantes à ajouter à la Flore de France. Paris 1810,8

Tristan, Mémeire sur la Flore orléanaise. Orléans 1810. 8.

Tournon, Flere de Toulouse. Toulouse 1811. 8.

Lejeune, Flore des environs de Spa. Liège 1811-1813.8.

_- Bevue de la Flore des envirens de Spa. Liege 1824. \$.

Plée, Herborisations artificielles anx environs de Paris. Paris 1811 sqq. 8.

Lalerrade, Flore bordelaise. Bordeaux 1811. 12. - Ed. IV: ib. 1846. 12.

Desmazières, Agrostographie des départemens du Nord de la France. Lille 1812.8.

Meral, Nouvelle Flore des environs de Paris. Paris 1812. 8. - Erl. Y': Bruxelles 1837-1838. 8.

J'igneux, Flore pittoresque des environs de Paris. Paris 1812-1814.4.

Poileau et Turpin, Flore parisienne. Paris 1813. folio.

De la Peyrous", llistnire abrégée des plantes des Pyrénées. Toulouse $1813-1818.8$.

Le Turquier Delongchamp, Flore des environs de Ronen. Roveu 18161825. 12.

Desvaux, Ohservations sur les plantes des envirens dingers. Angers 1818. 12. 
Lrouard, Catalogie des plantes du dep. de l'iure. Livrem 1820. 12. prost, Notice sur la Floro du dép. de la loxiore. Mrne (1820.) 8.

Saint-dmans, Flore agenaise. Igen 1821. 8 .

baron, Flere des départomens meridionaus de la lianer et principalement de celui de Tarn el liaronne. Montauban 1843. \&

Desmazières, Catalogue des plantes nmises dans la loutanugraphic liclgi'lue. Lille 18.3. 8

(Bcrnard) Tableau de la Flore du Jura. Strassburg 1 1.23. 8.

Lorey et Duret, Catalogue des plantes dans le dép. de la Cite d'Or. Dijon 1825.8

Flore de la Cute d'Or. Dijon 1831. 8 .

Arnaud, Flore du département de lat llaute-Loire. Puy 1823. \$.

- Suppliment a la Flore de la llaute-I_oire. J'ur 1830. 8.

Bentham, Catalogue des plantes indigenes des Jyrinées et du Bas-Languedoc. Paris 1826.8.

(Belleval) Beautés méridionales de la Flore de Montpullier. Mtontpellier 1826. 8 .

Lefébure, Cours de promenades chanpetres aux environs te Paris. Paris 1826. 8. obl.

hirschleger, Liste des plantes rares d'Alsace et des Vosges. SIrassbury 1826. 8 .

Chevallier, Flore generale des environs de Paris. Paris $1826-1827.8$.

Lejeune et Courtois, Choix de plantes de la Belgique. Liègr 1826. Lolio.

Compendium Florae belgicac. Leodii $1828-1836$. s

Lestiboudois, Botanographic belgigue on Flore du nord de la France pt Je la Belgique proprement dite. Lille 1897. 8.

Loiscleur, Plaotes à ajouter à la Filore de lirance. Paris $182 \bar{\tau} .8$,

Balbis, Flore lyonnaise. Lyon 1827-1828. S.

- Supplément à la Flore lyonnaise. L you 1835.8.

Desuaux, Flore d'Anjou. Angers 1827. 8.

Statistique naturelle de la Naine et Loire. Angers 1834 . S.

(Botanique p. 4.06-582.)

Bauticr. Tablear analytique de la Flore parisienne. Paris 1827. 12. Ed. V: ib. 1843.12.

Boisduval, Flore française. Paris 1828.8 .

Loiscleur, Flore générale de la France. Paris 1828. 8.

Soyer-Willemet, Observations sur queluges plantes de Franee, stivies du eatalogue des plantes des curirons de Naney. Naney 1828 . \&.

Ihuby, Candollii Botanicon gallicum sive Synojssis Eul. II. Paris 18ஹS1830.8.

De Brribson, Coup d'oeil sur la régétition de la Basse-Normandie. Caen 1829. $S$.

Holandre, Flore de la Moselle. Melz 1829-1\$36. 8. - Ed.11: it. 1842.8

De Candolle, De quelques ruvrages sur la botaniciue de la Lorraine (Bihl. univ de Genere 1830. XLIV, 260-970.)

Mutel, Flore du Dauphiné. Grenoble 1830.8 .

Guipin, Floro de Maine et Loire. Angers 1830.12. - ib. I\$3S. 8. Ed. III: il). 1545.8.

Pauquy, Flore du dép. de la Somme et des environs de Paris. Amiens 1831. 8 .

hirschleger, Statistique de la Flore d'Alsace et des V'esges. Nublbausen 1831 (-1832). 4.

Boreau, Voyage aux montagnes du Norran. Nevers 1\$32. 12.

Boube, Bulletin de noureaux gisemens en France de botanique. Paris 1833.8 .

(Dujardin) Flore complète d'ludre et Loire. Tours 1833. S.

(lerreymond et liequien) Plantes phanérogames aux environs de Fréjus. Paris 1833.8

Polsterer, Hyères in der Provence. Wien IS34. S.

(Enumeratio 350 ptantarum indigenarum p. 36 - 46. .

Pouchet, Flore ou Statistique botanique de la Seine infericure. Roueu 1834.8 .

Mulel, Flore française destinée aux Jerlorisations. Paris $1834-183 \mathrm{~s} .8$

Boreau, Progranme de la Flore du centre de la lirance. Nevers 1835.8.

Doisy, Flore du dép. de la Meuse. Verdun 1835.16 llussenot, Chardons nancéiens ou prodronte d'un calilugue des plantes de la Lorraine. Nancy 1835.8.

Joume Saint llilaire, Flore parisienne. Paris $183 \%$. 4

(Lefelute) Flore le Paris. Paris 1835.8 .

Lesson, lilure rochefortine. Rachefort 1835. \&

Delastre, Aperçu statistique de la végétation du dép. de la Virane. Puitiers 1833.8 .

- Flore lu slep. de la vicnne. Poitiers 1842.8.

he Brebisson, Flore de la Normantic. Cam 1536. 1.

Dufour, Sur les excursions au Pic d'Anie ef au l'ir Amoulat. Jorteaux 1836.8

hïsshleger, prodrome de la Flore d'Alsace. Strassburg 1836. 8. - Appendice: ih. $1838,12$.

Serres, Flure abreque de Toulouse. Toulonise 1836.8 .

Grenier, Souvenirs botaniques des environs les Laux-lyomes. (Bor(ivaux) 1837.8.

Merat, synopsis de la nouvelle flore des environs de Paris. Paris 1837.12 .

Noulet, Fore dn bassin sors-pyrenèen. Toulouse 1\$37. S. - Mdlitions il). 1846.8 .

P'esneuu, Catalogue des plantes du dép. de Ja looire inferieure. Pantes 1\$37. 12

Desportes, Flure de la Sartle et de la Mayenne. Le Mans Iৎ3\$. S.

Grenier, Observations botaniques. Besaņun 1838. 8 .

(Robert) Plantes phanérogames aux environs de Toulon. Brignolle1838.8 .

Analyse des plantes du Lyonnais et du Mont-Milar. Lyon 183S. 12.

Catalogue des plantes do díp. de la Maronne. Laval is38. 18.

Delafons, Prodrome de la Flore des arroodissements de Laon ete. Xọn 1839. 8 .

Ernsts, Nizza und llyores. Bonn 1839. gr. 12.

Voisund, Flore nantaise. Nantes 1839.8.

Borean, Fore du centre de la France. Paris 1840.8 .

Catalogue de la Flore de la Charente-inférieure. La Roclielle i 840.4.

Schulta, Flora Galliae et Germaniae exsiccata. Herhim etc. Cent. 1--IV Bitche 1836-1840. folio. - Arehives ftc. Traités sur les plantes. Cent. $\mathrm{Y}-\mathrm{X}$ : ils. $1541-1847 . \mathrm{S}$.

Cosson eq Germain, Observations sur quelques plantes critipues des inviruns de Paris. Paris 1840.8

Des Houlins, Catalogue ratsonné des plantes de la Mordogne. liordeaus $1840-1846.8$

Des Etangs, Plantes observies dans te dep. de l'Iulue. Troyes 1s\$1. \$.

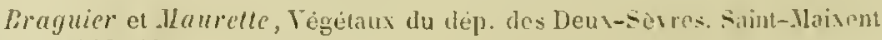
18:2. 18 .

I'ousolz, Catalngue des plantes qui eroissent naturellement dans le Gard. Nismes 18\%2. 4 .

Cosson, Germain et llerddell, Introduction a une Flore analytique et deseription des environs de Paris. Paris 1842. 8.

Cosson et Germain, supplèment au catalogue raisonne sles plantes do Paris. Paris 1843.8 .

Grenier, Catalogı des plantes pluauerogames du dép. rlu Doulss. (Besanson 1 \$ 43. s.

Godron, Catalogue des plantes du dep. de la Meurthe. Naney 1843. 8. - Flor de Lorraine (Neurthe, Moselle, Meuse, Vosges). Nancy IS43-1845. 8 .

Merat, Revue de la Flore parisienne. Paris $1 \$ 43-1 \$ 46.8$.

Boreau, Notes sur quolques plantes frangaises. Angers 1844.8.

Gras, Statistipue botanigue du dep. de livere. Grenoble 18 :4. 8

Lloyd. Flore de la loire-inférieure. Nantes 1844. 12.

Babey, Flore jurassienne. Paris i 4 45. 8 .

Castuyne, Catalogue des plantes dans les environs de Marseille. lis 1845.8 .

Choulette, Synopsis de la Flore de Lorraine et d'dlsilen. Strasturem 1845.12 
FLORAE HISPANIAE

Cosson el Cermain, Flore deseriptive et analytigue des environs de l'aris. Paris 1840. 8 .

ris. Paris 1845.8

Synopsis analytique de la Flore des cuvirons de $\mathrm{Pa}-$

Allas de la Flore des nuvirons de Paris. Paris 1845.8.

Lanbertye. Catalogne des plantes dans le dèp. de la Narne. Paris IS46. S.

Symopsis analyticpue de la Flore du Gard. Kimes 1847, 12.

Jordan, Olsservations sur plusieurs plantes nouvelles, rares ou critijues de la France. I-11. Lyon et l'aris 1846-1847. S.

Italle, Florula Corsicae. (Nise, taur. II, $214-218$. - Nov. Act. Acad. Nat. Cur. IV. App. 205-254.)

Biviani, Jorae Corsicae specierum novarum diagnosis. Genuae 1824. 4. - Appendices: ib. 1525-1830.4.

\section{Florac Hispaniac.}

De C Ecluse, Rariorum aliquot stirpiun per llispanias olsservatarum historia. Antverpiae 1576.8.

Barrelier, Plantae per Galliam. Ilispaniam et Italian observatae. Parisiis 1714. folio.

Breynills, l)e plantis rarioribus in llispania observatis. (Philos. Transact. XTIV, $2045-2050 .-$ Eph. acad. nat. eur. Cent. 5-6. Ap]s. p. 95 -100$.

Loefling, Plantae hispanicae rariores. In ejus "Mtinere hispanico". Stochholm 1758. 8. p. 111-175, $284-295$.

(uner y Hartincz, Flora española. Madrid 1762-1784. 4.

List of vegetables, growing upon munt Calpe, or llill of Gilıraltar. (Dillon's Travels p. $443-4+8$.)

Cneanilles, Icones et descriptiones plantarum. Natriti 4791-1801. folio. Catalogi plantarum spontancarum oceonomiearum Ilispaniac. In Samlalio. L.cciones de agricultura. Madrid 1816. 4. vol. II, p. 321-372.

Gamez, Ensayo sobre las aguas de Aranjucz. Madrid 177I. 4.

Orlega, Catalogo ale las plantas, que se crian en el sitio de los baños (de Trillo) y su immediacion. In ejus "Tratado de las aguas de Trillo Madrid 1778. 8. p. 37-47.

Asso y del tio, Synopsis stirpium Aragoniac. Nassiliae 1779. 4.

_ Mantissa stirpium Aragonia . Massiliac 1781.4.

1784.8.

Fisclier, Essai d'une Flore de Valence. In ejus "Description de Valence" Paris 1804 . S. p. $393-418$.

lioxas Clemente y Rubio, Tres listas ale plantas en que se caracterizan rarias repecies tuevas. In ejus "Ensayon ete. Nadrid 1807. 8.

Haenseler, Lista de las plantas de Carratraea. In ejus "Eusayon etc. Maloga 1817.4.

Cambessedes, Entmeratio plantarum, quas in insulis Balearilyus collegit Parisiis 1827. 4.

Boissier, Elenchus plantarum, yuas in ilinere hispanico legit. Generae 1838, 8 .

J1elb6, Iter hispaniense. Paris el London 1833. S.

- Otia hisplanica. Paris et London 1839. folio.

Boissier, Voyage botanique dans Je midi de l'Espagne. Paris $1839-$ 1845.4 .

Boissier ot Reuler, Diagnoses plantarum lispanicaruin. Ciencrae 18 42.8 . Reuter, Essai sur la vègétation de la Nouvelle Castille. Genève 1843.4.

Kelaarl, Flora calpensis. London 1846. S.

Kunze, Clloris austro-lispanica. Ratislsonae 1846. \&

\section{Florac Lusitaniac.}

Girsley, Viridarium lusitanun. Ulyssipone 1661. 19. - Veronao 1749. \$. - Olisijone 1789.8.

Vandelli, Viridarium Grisley Lusitanicum. Olisipone 1789. \&

(—) Florae lusitanicae et hrasiliensis specimen. Conimbricae 1788. 4.

Brotero, Flora lusitanica. Olissipono 1804.8.

folio miı.

(Fasc. I. voluminis primi jam anno 1801 prodierat.)

IIoffmannsegg et link, Flore portugaise. Berlin 1800-1840. folio.

Figuciredo, Flora pharmaceutiea e alimentar portugueza. Lisbod 1825. 8.

\section{Florac Helvetiac.}

Muralt, Botanologia, sive llelvetiae Paradisus. Tiguri 1710.8 . igermance.)

Ilaller, Enumeratio methodica stippium lJelvetiae. Goettingae 17 12. folio. Emendationes et aucluaria ad stirpium helveticarum historiam. (Bernae) 1759.4.

- Enumeratio stirpiun q̨uae in Iledvetia rariores proveniunt. s. I. 1760.8. fulio.

- Numenclator ex historia plantarum Helvetiae excerpitus, licruac 1769. 8.

- Icones plantarum Ilelvetiae ex ipsius Historia stirpium lielveticarum. Bernae 1795. folio.

De Lachenal, Emendationum et auctuariorum ad Hulleri llistoriam stirpium helveticartim specimen 1 . (Nov, act. helv. 1, 270-307.)

_ Corrections ete. (Mém. pour I'Hist. nat. de la Snisse. I, 64 -11s.)

Reynier, Liste des plantes rlecouvertes m Suisse depuis Haller. (Ném. pour l'Hlist. tlat. de la Suisse. I, 212-226.)

Schleicher, Catalogus plantarum Helvetiac. Bex (1800.) 8. - ib. 1807. S. - ib. 1815.8. - Ed. W' Camberii 1821.8.

Suter, Flora helvetica. Turici 1802. 12. - Ed. II. cur. Heyctschweiler. ib. 1822.12 .

(De Claircille) Manuel a'herborisation en Suisse et en Valais. Winterthur 1811. 8.

Hegetschweiler und Labram, Sammlung von Schweizerpflanzen. Base] 1826-1834. S.

Zollikofer, Versuch ciner Alpenllora der Schweiz. St. Gallen 1828, folio.

Gaudin, Flora helvetica. Turici 182s-1833. s.

- Topographia botanica helvetica. Turici 1833, 8.

(Chavannes) Introduction à la Flore helvétique de Gaudin. Lausanne 1830. 8.

Ilegetschweiler, Beitragge zu einer kritisehen Aufzahlıng der Schwcizerplanzen. Zurich 183 !. 8 .

Jloritzi, Die Pflanzen der Schweiz. Cluur 1832. 8.

Gaudin, Syuopsis Florae lıclseticae. Turici 1836. 8 .

Wegelin, Enumeratio stipinu Florae helveticae. Turici 1835.8.

Ulegetschuciler, Flora der selweiz, heriusugeben ron liecr. Zurich 1840. gre. 12.

Horitzi, Die Flora der Schweiz. Zurich I\$44.8.

(cf. Neue llelvetia 18\%. $300-362,122-\{33$. )

Aretius, Stochhornii et Nessi stirpium descriptio. In Cordi Operilns. Argentorati 1561 . folio. foll. 232-235.

Fabricius, Galandae nontis stirpium enumeratio. In Cordioperibus, fol. 235. Bauhin, Catalogus plantarum circa Basilean sponte uascentium. Basilene 1622.8. 
Peticer, A catalogue of plants found on the nountains about Geneva, as nsont Jura etc. 1709.

Cange, Catalogus plantarum cirea Luceman nascentium. Lucernae 1724. (Jlscr.!)

Scheuchzer, Pantae rarae in alpiluas rhaeticis anno 1709 repertae. (Scheuchzer, Astrographia. Tiguri 1775. 4. p. 68-y2.)

Cappeller, Vegetabilia Pilati. In ejus a'Pilati montis historia». Basileae 1767. 4 .

Murith, Le guide do botaniste dans le Valais. Lausanne 1810.6.

Venels, Catalogus plantarum Valesiae. Seduni is 17. S.

De Candolle, Projet d'une Flore plıysico-góographitue de la vallée du Léman. Genève 1821. 8.

IIagenbach, Tentamen Florae losileensis. Basileae 1821-1834. ×.

Supplementum Tentaninis Florae basileensis. Basileae 1843.8.

Krauer, Prodromus Florae lucernensis. Lucernat 1824. 12.

Reuter, Catalogue détaillé des plantes vasculaires aux environs de Genive. Geneve 1832.8. - Supplément: ib. 1841. 8.

(Hlanchel) Catalogue des plantes dans le canton de Viud. Vevey 1836.8.

(Thurmann) Plantes des environs de Porrentruy (Bero). Porrentruy 1838.4.

Koelliker, Verzeichniss der Gewähse des kantons Zurich. Zurich 1839. 8.

Morilsi, Die Planzen Graubundens. Nencliatel 1839. 4.

Kapin, Le guille du Lotaniste dans le exnton de Yaud. Lausanne 1842. $\mathrm{S}$.

Browon, Catalogue des plantes aux environs de Thoune et dans l'Oberland bernois. Thoune 1843.8 .

Wartmann, St. Gallische Flora. St. Gallen 1847. 8.

\section{Florae Italiae.}

barrelier, Plantae per Galliam, llispaniam et ltaliam observatae. Parisiis 1714 . folio.

Pontedera, Compendium tabularum botanicarun. Patavii 1718.4

(Turra) Florae italicae prodromus. Vicetiae 1780.8.

Bertoloni, Bariorum Liguriae (1taliae) plantarum decades I-lll. Genuae et Pisis $1803-1810.8$.

Fiviani, Florae italicae fragmenta. Genuae (1808.) 4.

Morelli, Osservazioni sopra diverse pitute italiani. Milano 1818.8.

Savi, Flora italiana. Pisa 1818-1824. folio.

Bertoloni, Amoenitates italicie. Bononiae 1819.4.

Morelli, Il botanico italiano. Pavia 1826. 4.

Bertoloni, Prolegomena ad Floram italicam. Bononia 1827. 8 .

Tenore, Saggio sulla botanica italinoa. Napoli 1832.8.

(Jan) Catalogus complectens prodromum Florar Italiate superioris. Parmae 1832. folio.

Bevtoloni, Flora italica. Bononiae 1833-1846. 8

De Candolle, Notice sur la gégraphie botanique de l'Italie. (Genève 1835.) 8 .

Cesali, Stirjues italiacae rariores vel novae. Mediolani 1840 . folio.

Parlatore, Sulla Jotanica in ltalia. Discorso. Parigi 1841. 8.

Observations sur quelques plantes d'ltalie. Paris 1841.8

\section{Ilalia superior}

Index plantarum juxta Liburnum. In Vallisneri, Prima Baccolta Tenezia 1701. 12. 1). 112.

Kamichelli, Opuscula botanica posthuma. Tenetiis 1730.4

Séguier, Catalogus plantarum agri veromensis. Veronae 1745.8 .

- Plantac veronenses. Veronae 1745. 8. - supplementum: ib. 1754.8.

Agosti, De re botanica tractulus. Belluni 1770. folio.

(Jarzari-Pencati) Elenco delle piante di Vicenza Milano 1802. 8.
Morelti, Piante da aggiunsersi alla Flora vicentina. Pavia $1813-18 z 0.4$. (Cf. ejus a Memorie ed osxervazioni n. Pavia 1820. 8. p. 234-30.7,

Pollini, llorli el provinciae verunensis plantae novae vel minus cognitar. Ticini 1816.4 .

Soeca et Ballis, Flora ticinensis. Ticini Is16-1821.4.

(C. . ejus a 11 eritico criticato o et a Al signor Arrlujal a)

Pollini, Flora veronensis. Verunae $182 z-1824.8$.

Morelti, Intorno alla Florat veronensis del Sign. Pollini osservazioni. Mlilano 1822. 8 .

Comolli, l'antarum in lariensi provincia lectarum enumerato. Sovo-Com :824, 8 .

- Flora comensis. (1'rospectus.) Novo-Comi $18 \geq 6$. S.

Flora comense. Como 1834-184x. 12.

homano, Lo piante fanerogame euganee. Padova 1828. 8. - ib. 1831. 8. Ace-Lallemant, De plantis quilusdam Italiae borealis. Berolini 1929.4.

Massara, Prodromo della Flora valtellinese. Sondrio 1\$34. 8.

Sandi, Eummeratio sticpium agri belluneasis. Belani 1837.8 .

Woretti, De regetablitus sponte crescentibus in caevallis archigymasii ticinensis. Ticini $1 \$ 38.8$.

De regetabilibus sponte crescentilus in cilevadio collegii Borromaei. Ticini 1838.8 .

(Trevisan) Prospetto della Flora euganea. Padova 1842.8.

Rola, Enumerazione delle piante rare della provincia bergamasca. Pavia 1843. 8 .

Cesati, Saggio su la Flora delia Lombardia. Milano 1844.8.

Passerini, Flora ltaliae superionis. Thalanillorae. Ilediolani 1844.8

Calzoluris, II viaggio di Nonte Baldo. Venezia 1566. 4. (latine.)

Pona, Plantae seu simplicia, quae in Baldo monte el in via ab Verona ad Baidum reperjuntur. Verona 1595.4 (jtalice.)

Passerini, Sogno nella licenza, chei prende da Monte Baldo. Trento 1684.12.

Martinis, Catalogus plantarmm in itinere montis Baldi inventarum. Veronae 1707.4 .

Donati, Trattato de semplici, che nascono uel lito di Venetia. Tenetia 1631.4

Zannichelli, Istoria delle piante che nascono ne' lidi intorno a Fenezia. Venczia 1735. folio-

Ruchinger, Hora dei Lidi veneti. Venezia 1818.8 .

Moricand, Flora veneta. Genevae 1820.8 .

(Morelti, Osservazioni; in Bibl. italiana.)

Martens, Flora veneta. In ejus "Reise nach Venedign. [Io 1824. 8. vu], 11, p. $539-6 \% 8$.

Naccari, Flora veneta. Venezia 1826-1828. 4.

Allione, Rariorum Pelemontii stimpim specimen. Alyg. Taur, 1755. \&.

- Stipium litoris et agri nicaensis emumeratio. \arisiis 1757.5 .

Flora pedemontana. Aog. Taur. 1785. folio.

Auctuarium ad Floram pedemontanam. Ang. Taur. 1789. 4.

Fasciculus stirpium Sardiaiae in dioecesi Calaris lectarum a . Hich. Ant. Plaza. (Mise. taur. 1, $88-103$. )

Bellardi, Osservazione lotanicle. (Appendice alla Flora pedemontana.) Torino 1788. 8 .

Appendis ad Floram pedemontanam. Aug. Taur. 1792. 4.

Bunica, Nonenclator Linnaeanus Florae pedemontanae. Augustae Taur. 1790. 12.

Azumi, Histoire maturelle de la Sardajgne. Paris 1798. 8. - ib. I802. 8. (kegne végétal. Il, 367-39s.)

Lacy, Stationes plantarum Pedemontii. Taurini 1801.8

Bulbis, Elenco delle piante di Torino. Torino 1801.8 .

Berloloni, Plantae genuenses. Genuae 1804.8.

Balbis, Miscellanea botanica. Taurini 1804-1806. 4.

Be, Flora segusiensis. Taurini (1805.) 8 . 


\section{FLORAE GERMANIAE}

Birali, Flora oeconomica del dipartimento dell Agogna. Vercelli 1805.8 Ralbis, Flora taurimensis. Taurini 1806.8 .

Turio, Specimen plantarum agri clavariensis. Clavari (1S06.) 4 .

Biroli, Flora aconiensis. (Novara) 1808.8.

Lavy. Plıyllographie piémontaise. (Turin 1816.) 8.

Re, Ad Floram pedemontanam appendix (prima). Taurini (1821.) 8 (Appondix altera exstat in Mem. d. R. A. di Torino, tom. XXXt 182'

- Flora torinese. Vol. I. (Cl. 1-XVI.) Torino 1823. 8

Moris, Stirpium sardoarum elenchus. Carali $1 \$ 27-1 \$ 29.4$.

Bertoloni, Memoria sopra alcune produzione naturali nel golfo della Spezia. Modena 1832 . 4,

Colla, Herbarium pedenontanum. Aug. Taur. 1833-1837. 8.

Noris, Flora sardoa. (Ranunculaceae - Ericaceae.) Taurini 1\$371843. 4.

Moris et De Notaris, Florula Caprariae. Taurini 1839. 4.

Moris, Stirpes sardoae novae aut minus notao. (Taurini 1839.) 4.

Flora ligustica. (Prospetto.) Genova (1844.) 4.

Risso. Flore de Nice. Nice 1844.8.

Tozzi, Specimina iconum pro catalogo plantarum Toscaniae. 1703.4.

Petiver, Plantirum Etruriae rariorun catalogus. Londini 1715. folio.

Bartatini, Catalogo delle piante di Siena. Siena 1776. 4.

Vitman, Istoria erbaria delle alpi di Pistoja, Modena e Lucca. Bologna 1773. 8 .

Santi, Plantae pisanae. In ejus "Analisi». Pisa 1789. 8.

Savi, Flora pisana. Pisa 179\$. 8

- Due centurie di piante appartenenti alla Flora etrusca. Pisa 1804.8. Botanicon etruscum. Pisis 1808-1825.8.

- Pugillo di piante da aggiungersi al Botanicon etruscum. s. 1. et a. S. Re, Florae atestinae prodromus. Mutinae 1816. 8 .

Bergamaschi, Gita botanica agli Apennini. Pavia 1823. 4.

Letlera sopre varie piante degli Apemini. Pavia 1823. 4.

Puccinelii, Synopsis plantarum in agro lucensi sponte nascentium. (Cl.1MIV.) Lucne 1841-1843.8.

Saci, Florula gorgonica. Firenze 1844.8

Zanoni, Indice delle piante di Castjglione ed altri monti di Bologna. Bologna 1652. folio.

- Descrizinne d'alcune piante. s. l. et a.

Monti, Catalogi stirpiun agri bononiensis prodromus. Bononiae 1719.4.

Brignoli a Brunnhoff, Fasciculus rariorum plantarum forojuliensium. Urbini 1810.4 .

Bertoloni, Mastissa plantarum Florae alpium apuanarum. Bononiae 1832. 4.

Panarolus, Plantarum amphithoatralium (i. e. in nmphitheatro Vespasiani Romae sponte crescentium ) catalogus. Romae 1652.4.

Sabbati, Synnpsis plantarum quae in solo romano luxuriantur. Ferrariae 1745. 4 .

Bonelli et Salbati, Hortus romanus. Romae 1772-1793. folio.

Sebastiani, Romanarum plantarum fasciculus I-1\%. Romae 18131815. 4 .

Sebasticni et Mauri, Florae romanae prodromus. Romae 1818.8 .

Mauri, Romanarum jlantarun centuria Xlll. Romae 1820.8.

Maratti, Flora romana; opus postlumum ed. Oliveri. Romae 1822. 8.

Fiorini-Mazzanti, Appendice ad Prodromo della Flora romana (aut. Sebastiani et Mauri). s. l. et a. 8.

Sanguinelli, Centuriae tres Prodromo Florae romanae addenlac. Romae 1837. 8 .

\section{Italia inferior.}

Bonfigliali, Index plantarum Aetua. Inpr. cum Currera. Montegibello deseritto. Catanea 1636. 4.

Boccone, Manifestum botanicum de plantis siculis. Cataneae 1668. folin.

- Programma botanico. (Targioni-Tozzetti, Dej progressi elc. III $250-256$.)

Cupani, Catalogus plantarum sicularum. Panormi 1692, folin.

- Syllabus plantarum Siciliae. Panormi 1694. 16.

Panphyton siculum. Panormi 1713. gr. 4.

Cf. titulum editionis Pamphysis siculae in Rafinesque promissae: Thes, lit, bot, no. 2087 .

Bertoloni, Lucuhrationes de re herbaria. (Commentirius in Cupani, Panphyton siculum.) Bononiae 1822.4.

Forski̊l, Florula melitensis. In ejus "Flora aeg.-arabica". Havniae 1775. 4. p. XIII-XIT.

Cavallini, Pugillus meliteus. (Bruecknann, Epist. itil. LXIl. Cent. II, 674 -691$.

Petagua, Institutiones botanicao, vol. II-V. Nenpoli 4787.8.

Cirillo, Plantarum rariorum regni neapotitani fasc. I et II. Neapoli 1788 -1792 . folio.

Bivona-Bernardi, Sicularum plantarum centuria I et It. Panormi 1806.4. Bisceglie, Flora della provincia di Bari. Napoli 1809.8.

Rafinesque, Caratteri di alcuni nuovi generi della Sicilia. Palcrmo 1810.4 Ronconi, Osservazioni su la Flora napolitana. Napoli 1811. 8

Analisi delle osservazioni su In Flora napolitana del Dr. Gussone. Napoli 1811.8

Tenore, Flora napolitana. Napoli 1811-1838. folio.

Bivona-Bernardi, Stirpium rariorum in Sicilia sponte provenientium descriptiones. Panormi 1813-1816.4.

Briganti, Stirpes rariores in regno neapolitano. Neapoli 1816. foliu.

Tineo, Plantarum rariorum Siciliae pugillus. Panormi 1817.8.

(Tenore) Ad Florae neapolitanae prodromum appendix quarta. Neapoli 1823. 8. - Appendix quinta : ib. 1826. 4

Presl, Flora sicula. (Ranunculaceac - Rutaceae.) Prigne 1896.8

Gussone, Plantae rariores itineris per oras ionii et adriatici maris et per regiones Samnii et Apruttii. Neapoli 1826.4.

Mauri, Orsini et Tenore, Enumeratio plantarum in itinere per Aprutium lectarum. Neapoli 1830. 4 .

Tenore, Sylloge plantarum Florae neapolitarıe. Neapnli $1831-1842.8$.

Gussare, Florae siculae prodromus. Neapoli 1\$27-1\$28. 8.

- Supplementum ad Florae siculae prodromum. Neapoli $1832-$ 1834.8

Flora sicula. Neápoli 1829. folio.

Florae siculae synopsis. Neapoli 1842-1845. 8.

Parlatore, Rariorum plantarum Siciliae fasc. 1-II. Panormi IS381840.8

Flora panormitana. Panormi 4839. 8.

Flora palermitana. Firenze 1845.8.

Sava, Lucubrazioni sulla Flora dell' Etna. Milano 1844.

Todaro, Rariorum plantarum Siciliae decas I. s. I. (1845.) 4.

\section{Florae Germaniae.}

Oeder, Schreiben betreffend einen Vorschlag zu einer Flora germanica. (Roth, Beitrage, 1. 93-103.)

(IIonckeney) Vollstandiges Verzeichniss der Gewächse Tculschlands. Leipzig 1782. S.

- Symopsis plantarum Germaniae. Berolini 1792-1793. \&.

Schluhr, Botanisches IIandbuch. Wittenbers 4783-1803.8. - lid. II. Leipzig 1508. 8.

- Anzeige von einigen Pllanzen in Deutschland. (Rocmer, Magaziu. 
lioth, Temamen Florae germanicae. Lijsice 1788-1800.8.

Hoffmum, Deutschands Florat. Eilingen 1791. 12. - ib. 1800-1804. 12. Schrader, Spicilegiun Florne germanicáe. Hannorerae 1794.8.

Rochling, Deutselulands 1\%lora. Bremen 1796.8 . - Fil. II : Franhfurt a/M. 1812-4813.8. - Ed. III: ron Mertens und Koch. Praukfurt a/AI. 1823-1839. 8 .

Borlihausen, Beitrage zur deutschen Flora. (Roemer, Neues Magazin, I. 1-3i.)

Ifrin, l)eutsclse Flora. Halle 1799. \&.

Stum, lyeutschlants Flora. Nurnberg 1798-1848. 13.

Je la ligne, Flore germanipur. Erlangen 1801-1802. 12.

Sach, Deutsclılands wilde frewachse. Berlin 1804. 8 .

Schrader, Flora germanica. Goeltingae 1806. 8 .

Borkhausen, Tentamen dispositionis plantarum Germaniac. Darmstadt 1809.8.

Treriranus, OJservationes botanicae. Rostockii 1812.4.

Bluff et Fingerhuth, Compendium Florae germanicae. Norimbergae 1821 $-1833.12 .-$ Ed. 1l: jb. 1836-1838. 12.

IVilbrand, Uebersicht der Vegetintion Deutschlands. (Regenshurg 1824.) 8. Steudel et Ilochstelter, Enumeratio plantarum Germaniae Helvetiaeque. Stuttgartiae 1826.8.

Koth, Enumeratio plantarum Germaniae. (Cl. I-V.) Lipsiae 4827. 8.

- Manuale botanicum. lipsiae 1830.8 .

Ave-Lallemant, De plantis quilusctam Germaniac australis. Berolini 1829. 4.

Arendt, Tabellarische [elsersicht ter Flora des mittleren und nördlichen beulsclland. Osnajoruch 1831. folio.

11 allroth, Flora eryptoganica Germaniae. Norinhergao 1831-1833. 12.

Dierbach, Beitrage zu Deutschlands Flora. Heidelherg 1825-1833. \&

Dietrich, Flora regni borussici. Berlin $1 \$ 33-1844$. 8. ıuax.

Deutschlands Flora. Jella 1833-4842. grr. 8.

Reichenbach, Flora gemanica excursoria. Lipsiae 1830-1833. 12. - lcones Horae germanicae el helveticae. Cent. I-X. Lipsiae $1834-1848.4$.

(germanice.)

Schultz, Hora Galliae et Germaniae exsiccata. Ilerbier etc. Cent. I-IV. Bitche 1836-1840. folic. Archires etc. Cent. Y $-\mathbf{X}$. ib. 18411847.8

Nees ron Esenbech jun., Genera plantarum Florac germanicae. Bonnae $1833-1845$ sij 1.8 .

Meigen, Deutschlands Flora. Essen 1\$36-1842. 8.

fittel, Taschenbuch der Flora Deutsclbands. Numberg 1837. 12. - ib. is 44.8 .

hoch, Synopsis Florae germauicae et helveticae. Francofurti a/N1. 1S37is3s. 8. - Ed. II: Lipsiae $1843-1845.8$ (germanice.)

(Berger, Catalogus herbarii. Wurzhurg 1841-1840.12.

Lincke, Deutschlands Flori. Leipzig 1840-1847.8.

Koch, Taschenduch der deutschen und schweizer Flora. Leipzig 1844, 8. Herold, Taschenbuch der teutschien Flora. Nordlıausen 4845.8 .

(Sub hoc nomine delituit mises yujeam librorum consarcinatos Schoepfer vel schroepfer dictus, qui tam insolenter Kochii synopisin
exscripsit, ut redemptore syonseos postulantc hanc fraudosam libr repetitionen anplius dis endi lege prohiberetur.

Brandes, Die Flora Deutschlands und der angranzenden Lander. Stollberar 1846.12.

Hess, Flera des gemanischen Tieflandes. In ejus "Pflanzenkunde". Berlin 1846. 8 .

Piper, Tasclienbuch der nordjeutschen Flora. Malchin 1840.8

Peternann, Deutschlands Flora. Leipzig 1846-1849. 4

Lurinser, Taschenbuch der Flora Deutschlands und der Schweiz. Wien 1847.8 .

Schnizlein, Die Flora vou Baiern. Wurtemberg und Baden. Eilangen 18478.
Schwenckfelt. Stirpium et fossilium Silesiae callalogus. Lipsiae 1600. 4.

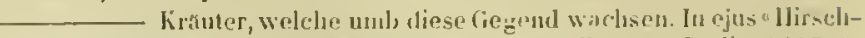
bergischen Warmen Bades einfálize 13-schreibung, Gorlitz 1607. 8 . p. $183-936$.

l'etiver, Plantae silesiacae rariores. Loudini 1717 . folio.

(iemeinhardt, Catalogus plantarnu cirea Laulan. Budisside 1724.8.

Burghart, Pllanzen des \%oltenterges. In ajus a Jter silubthicumn. Cirestau 1736. 8. 1). $841-137$.

J/alluschka, Heria silesiaca. Breslau $1776-1789.8$

- Enumeratio stirpium Silesian. Vralistavian 1779. s

Krocker, Flora silesiaca renovata. Vratislavian $1787-1823.8$.

Neygenfund, Enchiridion Jetanicum. Misenae 1821.8.

Guenther, Graboushi et II imuer) Enumeratio stirpium Silesiae. Tratislaviae 1824.8

11 immer el Graboushi, lifora Silesine. Tratislaviae 1827-1829. S.

Wiumer, Flora von Schlesien. Berlin $1 \$ 32, \mathrm{gr}, 8$.

- Flora von Schlesien preusischen und osterreichischen Autlucils.

Bres]au 1840. gr. 12. - il). 1844. gr. 12.

Schranm, Die Pllanzen des Leolsschúzer Stallwaldes. Ratilsor 1833. 8.

Die seltneren Pllanzen um Leolsschutz. Leoluschutz 1840.8.

Elsner, Flora von Ilirschlsery. Breslau 1837. S.

_._Synopsis Flarae cervimontanae. Yratislaviar 1839.8.

Schncider, Flora von Bunzlau. Breslau 1\$38. 8.

Die Vertheilung und Ferbrciung der sclulexischen PJliuzen.

Breslau 1838. 8.

Nees von Esenbeck und Flotove, Zur Flora Warmbrunns. In Jendt, Die Thermen zu Warmhrunn. Brestau 1840. 8. 1). 41-114.

Goeppert, Seltwere Pflanzen'um Altwasser. In $\|^{-}$endl, Altwasser. Bresliu 1841.8 .

Grabowski, Flora von Olserschlesien. Breslau 1843.8.

Scholtz, Flora der Imgegend von Breslau. Breslau 1843. 8.

Kabalh, Flora von Gleiwitz. Gleiwitz 1846. s.

Frenke, Hortus Lusatiae. Budissinae 1594. 4.

Oettel, Terzeichniss der in der Oberlausitz wildwachsenien Pllanzen. Gorlitz 1799. 8 .

Koelbing, Flora der Oberlausitz. Gorlitz 1828. 8.

liabenhorst, Flera lusatica. Leipzig 1839-1840. 8.

Patschlie, Catalogus stirpium in sylvis saxonicis anno 1667 reperiundarum, In Lehmain, Historischer Scliauplatz. Leipzig 1699. 4.

Rueckert, Beschreilung etc. Flora von Sachsen. Leipzig 1840. \&. Grimma (1844.) 8.

Reichenbach, Der leutsche Betaniher. II: Flora saxonica. Dresden 1842. 8. - ib. 1844.8 .

Ifoll et Heynhold, Flora von Sachsen. 1. Plianerogaruen. Dresden 1842.5. Heynhold, Clavis generum zur Flora von Saclsen. Dresden 1843. $\%$.

Schuläe, Nachricht ron rerschiedenen iu der dresdusclien Gegend hefind-

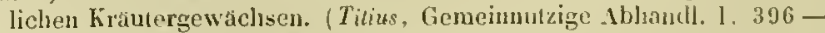
413. Neues [lamburs. Magazin is. 496-513.)

Pursch. Verzeichniss der Pflanzen in Plauischen Grunde. In Becher, Der Plauische Grund. Numberg 1799. folio. 1. 45-94.

Bucher, Florae dresdensis nomenclator. Dresdae 1806. \&.

Ficinus, Flora der Gegend um Dresten. Dresden 1807-1808 \&.

Ficinus und Schubert, Flora der Gegend um Dresden. Ed. 11. Dresden $1821-1823.8$.

Schmalz, Dispositio synoptica generum j]antarum circa Dresdam. Dresden 1822. folio.

Reichel, standorte der seltneren Pllanzen un Dresten. Dresden 1837. gr. 12.

Ficinus et IIcynhold, Flora der Gegend um 1resden. Lid. III. Dresten 1838.8. 
Ammann, Suppellex botanica. Lipsiae 1673 . \&

IVipacher, Flora lipsiensis bipartita. Lipsine 1726.8.

Roehmer, Flora Lipsiae indigena. Lijsiae 1750. S.

Schreber, Spricilegium Florae lipsicae. Lipsiae 1771. 8.

Jehn, Plantae circa Lipsian muper inventae. Lipsiae 1774. 4.

Baumgarten, Flora lipsiensis. Lipsiae 1790..

Scheacgrichen, Topographiae botanicae lipsicnsis specimen 1. II. IV. Lipsiac 1799-1806. 4

leichenbach, Flora lipsiensis pharmaceutica. Lipsiae 1817. S.

I'appe', Enumerationis plantarum lipsiensium specimen. Lipsiac 1927.8.

- Syuopsis plantarum agri lipsiensis. Lipsiao 1828.8.

klett el lichter, Flora der Ungegend von Leipzig. Leipzig 1330. 8.

Jetermann, Flora lipsiensis excursoria. Lipsiae 1838. 8.

Flora des Bienitz. Leipzig 1841. 16.

Analytischer Pflanzenschlussel. Leipzig 1846.8 .

Kaehnlein, Verzeichniss einiger um Wittenherg befindlichen líräuter. Wittenberg 1763.8.

Irenzel, Verzeichniss von Pfanzen un Wiltenberg. Witlenlerg 1799.8.

- Verzeichniss von Holzarten um Wittenberg. Wittenberg 1801. 8.

IIuensche, Enumeratio plantarum circa Vitebergam. Vitebergae 1804.8

Scholler, Flora barbiensis. Lipsiae 1775. S. - Supplementum: Barbii 1787.8 .

Schaefer", Deliciae botanicae hallenses. Ilallae Saxonum 1662. 12.

Kneuth, Enumeratio plantarum circa Halam Saxonum. Lipsiae 1687. 8.

Rehfeldt, Hodegus botanicus menstruas plantas circa Jlalam enumerans. Hlatae 1717. 8

Buxbaum, Enumeratio plantarum in agro hallensi. Halac 1721.8

Leysser, Flora halensis. Halae 1761.8. - Ed. Il: ib. 1783. 8.

Wohlleben, Supplementum ad Leysseri Floram halensem. Halae 1796. 8.

Sprengel, Florac halensis tentamen novum. Ilalae 1806. 8. - Mantissa I-II: ib. 1807-1811.8. - Ed. II: ih. 1832. S.

IVallroth, Anuus botanicus. Halae 1815. 8 .

Schedulae criticae de plantis Florae halensis splectis. Halae 1829. 8

Elshola, Flora marchica. Ferolini 1663.8 .

Beclimumn, Catalogus plantarum in tractu francofurtano sponte nascentium, in ejus "Memorandisn. Francofurti a/0, 1676. 亿. et in Jobst, Beschreibung von Frankfurt. ib. 1706 . folin.

Johren, Vademecum botanicum. (Flora francofurtana.) Colbergae (1710.) S. Gleditsch, Catalogus plantarum in vicinis Trebuizio locis sponte nascentium. Lipsiae 1737. 8 .

Bergen, Flora francofurtana. Francofurti a/T. 1750.8

Gleditsch, Catalogus plantarum Marchiae brandenburgicae, in Beckmann, Beschreibung Brandenburos. Berlin 1751. folio.

Jartmann, Plantarum prope Francofurtum ad Viadıu fasciculus. Francofurti a/V. 1767. 4.

Lueders, Nomenelator stirpium Marchiae brandenhurgicae. Berolini 1786..

IYilldenow, Florae berolinensis prodromus. Berolini 1787.8.

Brucchirer, Florac neobrandenburgensis prodromus. Jenae 1803. 8.

Kebentisch, Prodronus Florae neomarchicae. Berolini 1804. 8. 1803.8

kunth, Flora herolinensis. Berolini 1813. 8. - Ed. II: ib. 1838. 8.

Beitrag zur Flıra der Mittelmark. In Walter "Verzeichniss" ele. (Beslin) 18.5 .8$.

Schlechtendal, Flora berolinensis. Berolini 1823-1824. 8 .

Brandl, Flora berolinensis. Berolini 1824. 12

Dietrich, Flora der Gegend un Berlın. Berlin 1824. 8 .

Buek, Hortus francofurtanus. Frankfurt a/0.1824. 8

Ruthe, Flora der Mark Brandenburg. Berlin 1827., - ih. 1834. 8

Pkatzel, Thes lit. hot.
Kirchner, Pflanzen un Neustadt-Eberswalde. In ejus "Vebersicht" etc. Berlin 1830. 8 .

Stange, Judex plaularum agri francofurtani. Frankfurt a/0. 1839.4.

Barentin, Die Vegetation in der Mark Brandenburg. Berlin 1840.4.

Dictrich, Flora marchica. Berlin 1841. 8.

IIilclie, Flora gryphica. Gryphiae 1765.8

Koelpin, Florae gryphicae suppiementum. Gryphiae 1769.8

Ifeigel, Flora pomerano-rugica. Berolini 1769. 8. - Supplementum: Gryphiae 1773. 8.

Rosthovins et Schmill, Flora sedinensis. Sedini 1824. 8.

Jomam, Flora von Pommeru. Koslin 1828-1835. 8.

Schmidl, Flora von P'ommern und Rugen. Stellin 1840.8 .

Cartheuser, Enumeratio stirpium per ducatum ruegalopolitano-strelitzense observatarum. 'Trajecti a/V. 1777. \&.

Timm, Florae megalopolitanae prodromus. Lipsiac 1788.8.

Becher, Beschreibung der Bäume und Straucher in Meklenburg. Rostoch 1791. 8.

Irredou, Tahellariselie liehersicht der Pfanzen Nehlenburgs. Luneburg 1807. S. 1812. 8 .

(Detharding) Verzeichniss mecklenburgiseber Gewáchse. Rostock 1809. 8. Conspectus plantarum megalopolitanorum. Roslockii 1928.8.

Schullz, Prodromus Florae stargardiensis. Berolini 1806. 8. - Supplementum: Neobrandenliurgi 1819.8.

Prahl, Index plantaruin curca Gustroviam. Gustroviae 1837. 8.

Langmarm, Flora von Merklenburg. Neustrelitz 1841, 8.

(Weber) Primitiae Florac holsaticae. Kiliae 1780. 8.

Esmarch, Sclıleswig'sche Flora. Schloswig 1789-1791. (1792-1812 ?) 8, Rafn, Danmarks och Holsteens Flora. (CJ. I-X.) Kiobenhavin $1796-$ 1800.8 .

Nolte, Novitiae Florae holsaticae. Kilonii 1826. 8.

Trentepoht, Oldenburgische Flora. Oldenburg 1839.8.

Haecker, Lubechische Flora. Lubeck 1844. 8.

Sickmarn, Enumeratio stirpium circa Hamburgum. Hamburgi 1836.8.

Huebener, Flora der Umgegend von Hamburg. Hamburg 1846. gr. \&.

Schwabe, Flora auhaltina. Berolini 1838-1839.8.

Royer, De plantis montis gaterschlebensis. in ejus "Beschreibung des Gartens zu Hessem ». Ilalberstadt 1648. 4. p. 112-128.

Chemnitz, Index plantarum circa Brunsvigam. Brunsvigae 1652. 4.

Cappel, Verzcichniss der um Helmstedt wildwachsenden Pflanzen. Dessau 1784.8 .

Lachmann, Flora brunsvicensis. Braunschweig $1897-1831.8$.

Thalius, Sylva Ilercynia. Francofurti a/M. 1588.4.

Meyenberg, Flora einbeceensis. Goettingac 1712.8

Haller, Ex itinere in sylvam Ilereyniam observationes botanicae Gocttingae 1738.4 .

- Enumeratio plantarum hotti et agri gottingensis. Guttingae 1753.8. Zinn, Catalogus horti et agri goltingensis. Goltingae 1757..

Murray, Pradromus designationis stirpiom gottingensium. Goltingae 1770.8 .

Il'eber, Spicilegium Flot'הe gotlingensis. Gothae 1778. 8.

Rueling, Beschreibung der Stacit Nordheim. Gottingen 1779. 8.

Verzeiclinise der llarzflora. In Gutrer, Auleitung etc, Fottingen 1786.8. 
likk, Florae guetlingensis specimen. Goetlingae 1789. मे.

- Botanisclse Jemerhongen. In rjus "Aunalen». Gottingen 1791. 8 11. $27-38$.

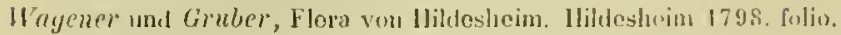

Londes, Verzcichniss ter Pflanzen um Guthingen. Gothingen 4805. \$.

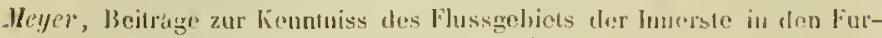
stenthumern (irulsenlaigen und Ilildesheim. Goltugen 1523.8.

Chloris hanoverana. Gottingen 1836.4.

Arendt, Scholit osmalıugensia in Chloritem lumoveranan. Osnabruch 1837. 8

llompe, l'rotromus Fiorac hereynicau. Halle $1 \$ 36-1814.8$.

Schatz, Flora halberstadeusis excursoria. Halberstadt 1839. $\mathrm{S}$.

II allroth, Erster Beitrag zur Flora hercynica. Halle 1s40. S.

Jungermam, Comucopias Florae giessensis. Giessae 1623. 4.

lalentini, Prorlronus histmiac naturalis Hassiae. Giessac 1707. 4.

Jillenius, Catalogus plantarum cirea Gissam nascentum. Francofurti a/A]. 1719.8.

Biller, Aninadversiones in Floram ricleseliam. Vratislaviac 1759.4 .

Joench, Enumeratio plantarum Hassiae. Cassellis 1777. s

Lieblein, Jilora fuldensis. Frankfurt a/M. 1784 . S.

Borlihausen, Flora der ohern Grafschalt Catzeneluhogen. (Rhein. Marizin, 1. $393-607$ )

Guertner, Conturic von Pllanzen un Hanaw. (Ehthart, Beiträgo, V. 163 -167$.

Moench, Methodus plantas horti el agri marlurgeusis descriluendi. Marburgi $1794-1802.8$

II ulther, libra von Giossen. Giessen 1802. S.

IIenderoth, Beitrage zur l'lora von Hessen. Mlaborg 1823. \&.

Heldmann, Ol,erbessische Flora. Marluws I\$3\%. S.

Hoyer, likna der (irafschaft Schaumburg. Rimteln 4838. 8.

Schnillspelm, lilora des Grossherzogthums Jiessen. Darustall 1S39. 8. ib. 1840.8 .

Wenderoth, Versuch einer Cbarahteristik der Vegetation ron liurhessen. Kassel 1839. 8.

FIora hassiaca, Kassel 1846.8.

L'feiffer, liehersicht der Pflanzen kurhessens. listsel 18 亿4. 8.

- Einige lWorte uber die subalpine lilora des Meissners. Lassel 1844.8 .

Flora ron Niederhessen und Munden. liassel 1847, S.

livicharl, lilora moeno-francofurtana. lirancofuria a/M. 1772-1778. S

Gaertuer, Mcyer et Scherbius, Ochonomiselt-technische Flora der IT $\mathrm{et}$ terau. Frumlifurt a/M. 1799-1802.8.

Beclice, Flora del Gegend un Fraukfurt an Haiu. Frankfurt a/M. IS2S, S. Fresenizs, Taschenbuch auf Excursionen um liraulfurt a/N. Fralkfurt a/Ml. $1831-1832.8$.

Fabricius, Primitiae J'lorae butisbacensis. Wetzlatriae 1743.8.

Leers, lilona herbornensis. Jorbornae 4775. 8. - Berolini 1789. 8.

l)oerrion. Verzeichuiss unel Beschreibung dor oranien-nassauischen Gewachse. Herborn 1777.8

Heryl. Tersuch einer Flora von Ilidanas. Hadmar IS22. 8.

Jung, lilora des fferzogthums Nassan. Iladamar 1832. S.

Thomede, Verzeichniss der Pllanzen um Wieshaden. Wieshaden IS 1. S.

Schenli, Auleitung zur Bestimmung der Pllonzen des llerzoghtums Nassau. (Wiesbaden 1846 .) 4 .

Mueller, Fora waldeconsis et iterensis. Brilon 1841.8.

Barelihausen, Fascieulus plantarum ex Flora comilatns lippiaci. Goethingae 1775.4.

Echerling. Terzcichniss der Pfanzen im Pursteuthum Lippe. Detmold 1846. 8 . llernelineli, Icones plantarum ejiseopatus monnsteriensts. Monisterii 1798. folio.

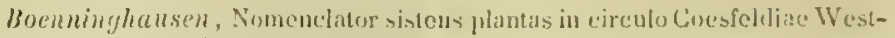
phalorunr. Coesfoldiac (1821.) 8 . asterii 18 \&. 8 .

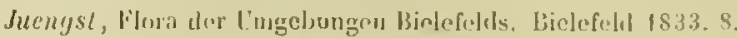

— litora von Jielefold und Westphalen. Birrlofeld 1837. S.

Gutheil, Beschreihung (und l*Jora) der Wesergegend un Ifoster und Heblzuninden. Jlolzminden 1837.8.

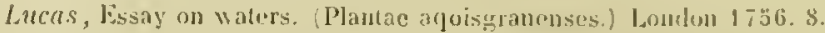
Alertersteck, lBonnischer lifora erster Theil. Bunu 1792. 8.

Mcigen und Ifeniger, Verzeichniss der an den I'form des Rheius, dur Rock, Jaas und Ourte wachscuclen Pllanzen. kivin 1819. s.

Icigen) Versuch einer Flora der Lfer des Niederrleins, der Roer, Maas umel Ourte. kisln 1823.12.

Schacfer, Trierische Flora. Trier 1826-1829.8.

Mucller, Verzeichniss Ifer Pflanzen um Aachen. Aachen $1 \$ 32.4$.

- Irodromus der Flora von Aachen. Iachen IS36. S.

Tinant, Flore lasenubourgeoise. Luxembourg $1836 . \&$.

Loele, lilura ron Coblenz. Coln 1838.8.

Gulkil, Grundzige ciner Flora von hreuznach. Remensburg 1839. S.

Minli, Aufzalilong der Phancrogamen un Crefeltl. Crefeld 1839. \&.

Schmitz el liegel, J'lora lwunousis. Punnac 1841.8.

Mirlyen, Flora des Regierungsbezishs lioblenz. linblenz 1\$41.8.

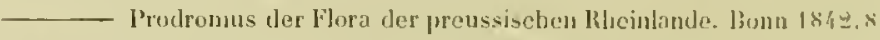

Doell, laheinisclic Flora Frankliurt o/A. I\$43. 8 .

Loeh", Tasehenbuch der Flora ron Trier und luxembure. Triel 1814. Ant und Clemen, Flora von Dusseldorf. Düsseldurf 1846.8.

Pollich, Jlsstoria plantarum in Palatinitu electorali sjonte niscentium Hannhemii $1776-1777.8$.

Livech et Ziz, Catalogus plantarum Florne Palatinatus. Noguntiae 1814, \&. Pelif. Enumeratio plantasum in ditione Florae Palatinalus. Jiponti $1 \$ 30$. is

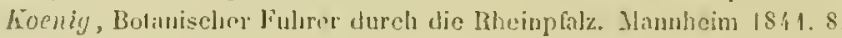

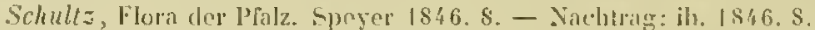

Franlic, Programmata ad herbaliones in agro heidelberenensi. Heidedlurpwive 1677-1687.

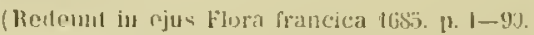

Ciallenhof. Stirpes agri of horti heidelhergensis. Jeidelbergase $178 \pm .8$.

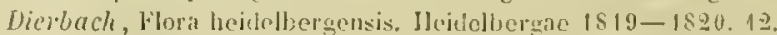

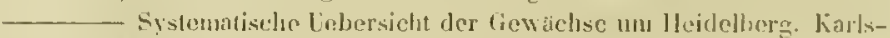
Tuho 1827.8

IJibel. Jrimiliarum Florate werthemensis prodromus. Jenne 1797. $\mathrm{s}$

Wrimitiac Florac werthemensis. Jenae 1799. \&

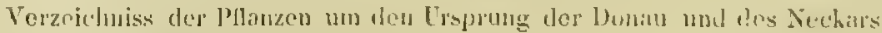
Wintertimur 1799. S.

Rot rou Schrelienstein und ron Engelberg, l'Iora der Gegond wm den Ursprung and Juau. Wonatseschingen iso 4.8 .

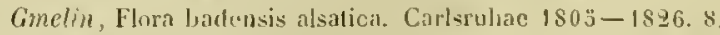

Succou, Flora mannhemicnsis ol vicinarum regionum. Alanuhenii is:2.3. 8 . Spenner, levber dio lieretation des Renchulales. In Zentner. Das Rucheldthal. Frrilurg 1827.8.

- Flora friburgensis. Friburgi Brisgovia 182ä-1\$23. 8.

Frank, Rastadts Florit. Ileielelbery is30. \&

Rankin, Ilistoria fonlis bollensis in ducatu wirtembergico. Montisbeligarli 1398.4 .

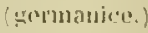

Schoepfisis, Ilortus umensis, Ilnischer Paradissgarten, Ulm 1629. \&

Duremon, J)esignatio plantarum eirca tuljingensem arcem lorentinm Tubingae 1723.8. 
Leopold, Deliciae silvestres Florae ulmonsis. Utm 1728. \&.

Cimclin, Fasciculus plantarum patriae urbi (Reutlingen) vicinarum. Tubiıwrae 176\%. 4.

-_- Enumeratio stirpium in agro tulingensi. Tuhingac 1772.8.

(homer) Flora stutgardiensis. Stutgart 1756.8.

Etwas uher Standorte der Pflanzen in Hohenlohe und Herwentheim. Mergentheim 1816. 8 .

Schuebler, Verzeichniss ter Pfanzen um Tuhingen. Tulsingen 1892. 8.

Schmidlin, Flora von Stultgart. Stultmart 1832. 12.

Schlleller, Beitrage zur Naturhunde (Florid) Oberschwahens. Tubingen 183 g. 8 .

Schuebler und Martens, Flora von Wurtemberg. Tubingen 1834. 8.

Lechler, Supplement zur Flora von Wurtemberg. Stutgart 1844.8.

Schabel, Flora vou Ellwangen. Stuttgan 1837. 8.

Grossmamn, flora vou Schwibisch Hall. In ejus "Elementarbuch». Stuttgart 1843.8.

Talct, Cobersicht der Pflauzen um Ulu. Ulm 1847.8.

Jungermann, Catalogus plantarum circa Altorfium. Altorfi 1615.4.

(IIenzel) Synonyma plantarum circa Jugolstaclium sponto nascentium. Ingulstadii 1618. 8 .

Kinobloch, Beschreibung des Burckbernbeiner Wildtbades. Onoltzbach 1620.12.

IIoffmann, Florae altdorfinae deliciae sylvestres. Altorfii 1669. 4.

Florilegium altulorfnum. Altdorfii 1676.4

Montis Mauriciani in agro Leimburgensium descriptio medicobotanica. Altulffii 1694. 4 .

Tolelamer, Flora noribergensis. Noribergae 1700.4.

11 ilhelm, Flora herhipolitana. Bamberg 1782. gr. 8.

Elwert, Fasciculus plantarum e Flora margaraviatus baruthini. Elangae 1786. 4 .

Weizenbech, Anzeige der Pflanzen um Mlunchen. Munchen 1786. s.

Schrank, Buirische Flora, Múuchen 1789.8.

(lix labellarischer Form: Regenshurg 1793. 8.)

fioclle, Flora les Furstenthums Bayreuth. Bayrouth 1798. 8.

Scherigger et hoerte, Flora erlangensis. Erlangae 1804-1811. 8.

Lehmran, Primae lineae Florae herbipolensis. Llerbipoli 1809. 8.

Heller, Flora wircelurgensis. Wirceburgi is $10-1815.8$.

Schulles, Baierns Flora. Landshut ISII. 8.

Schunli ct Meryrhoffer, Flora monacensis. Monachii 1811-1818. folio.

Ilinterschmidl, Nurnbergische Flora. Nurnber $1818-1821.8$.

Allen, Angrsurgische Blumenlese. Ausburg 1522. 8.

Ilunal, Flora ron Irthach. Regensburg 1823. \&.

Behlen, Flora des Spessart. In ejus: Der Spessart, rol. 1. 1. $78-138$. Leijuzig 1823. S.

Zacentini, Flora der Gegend um Nuxchen. Munchen 1829. $*$.

Reuss, Flora des Lnterdonaukreises. Passau 1831. 8.

- Flora von Passatu. Passau 1838. 12.

Fernohr, lilora ratisbonensis. liogenshurg 1839. \$.

(Nachtrage und Berichtigungen: Regensburg 18\}.̈. \&.)

Sirehter, Uebersiclit der Pflanzen um lirgolstant. Ingulstall (1841.) 4.

stmm und Schmislein, Verzeichniss der Pflanzen um Nurnberg und Erlangen. Exlangen 1847.8.

Schenchius, Catalogus plantarum horti et viciniae jenensis. Jenae 1659.12. Ruppius, Flora jenensis. Francofurti 1718. 8. - ib. 1726.8. - Jenae 1745.8

dialihinger, Index plantarum horti et agri jenensis. Goettingae 1773. s.

Rudolph, Florae jenensis plantae. (CI. XIII, 1.) Jenae ITSi. 4.

Graumiller, Systematisches Verzcichniss wilder Pllanzen un Jena. Jena 1803.8

1803.8 .

Charakteristik der un Jena wildwachsenden I'flanzen. Jena

Flura jeuensis. (Classis I-V.) Eirenled: 1524. 8 .
Dichich, Flora jenensis. Jenae 1826. 8 .

Zonker, Flora jenensis. In "Hist-topogr. Taschenbuch». Jena 1836.8. p. $258-286$.

hoch, Flora von Jena. Jena 1839.8.

Hoppe, Geraische lilori. Jena 1774.8.

Nome, Flora in territorio erfortensi indigena. Erfordiac 1763.8.

Plarrer, Index plantarum agri erfurtensis. Gathae 1788. 8 .

- Indici plantarum ingri erturtensis fungos et plantas nuper culectas addlit. Erfordiae 1788. 8 .

Bermhardi, Systematisches Verzeichniss der Pflanzen um Erfurt. Erfurt 1800.8

Dennstedt, Weimars Flora. Jena 1800.8 .

Adler, Elora des ziegenrucker Kroises. Neustadt 1819. s.

Nicolai, Verzeichniss der Pllanzen um Arustadt. Arnstadt 1836. gr. 12.

Zenker und Schenck, Flora von Tluringen. Jena $1836-1848$ sqq. 8.

Metsch, Flora hennobergica. Schleusingen 1845.8.

Richter, Flora von Saalfeld. Saalfelil 1846. 4.

Irmisch, Verzoichniss der Pllanzeı in den selıwarzlourgischen Pürstenthumern. Sondershausen 1846. 8 .

Crantz, Stirpes austriacae. Viennae 1762-1767. S. - El. Il: ib. 1769. 4.

Jacquin, Florae austriacae icones. Viennae 1773-1778. folio.

Maerter, Verzoichniss der ustreichischen Gewảchse. Wien 1780. $\$$.

Ilaenlie, Olsservationes Jotanicac. (Jucquin, Collectanca Il, 1-96.)

(Schultes) Oesterreiclss Flura. Wien 1794. 8. - Eil.11: ih. 1814.8.

Ilost. Synopsis plantarum Austriae. Iünlolionae 1797. 8 .

Johann, Er=herzog von Oestreich, lcones plantarum austriacarum ineditae, (Vinduhonse) s. a. folio.

Traltinick, Flora rles usterreichiselien kaiserthums. Wien 1816-1822.4. llost, Flora austriaca. Viennae 1827-1831.8.

Rohrer und Iayer, Vorarbeiten zu eines Flora von Mabren. Brum 1835.8 .

Schlosser, Anleitung die Pllamzen Mahrens zu bestimmelt. Brümn 1843. \&.

Iloffmann. De plantis rariorilms Boheniac. Pragae 1748.

Schmide, Flora hoenica inchoata. Pragae 1793-1794. folio.

I'ohl, Teutamen Florae Boheniae. Prag 1810-1815. s.

Presl, Flora cechica. J'ragae 1819. S.

Opiz, Boheims phanerogamische und hryptogamische Gewachse. Praz 1823. 8.

hosteletzly. Clavis analytica in Floran Bohemide. Pragae 1\$24. 8.

Sternberg, Vober cinige Eigenthumlicheiten der bohmischen Flora. liegensburg 1829.8 .

Prest, Flora von Carlsbad. In Curro, Essay on the mineral waters of Carlsbad. Prag 1833. 12.

Ortmann, Flora carlsbatensis. In Fleckles, Karlsbad. Stutgart 153\%.8.

Friedrich Jugnst, Mitregent von Sachsen. Pfanzen voin Mariendsal, herausges. von Heidler. Prag 1837.8.

Berchtold (Seidl, Opis, Fieber), Oekonomisch-technische Flora Bohmon. Prag 1836-1811.8.

hramer, Elenchus vegetabilium per tustriam inferioren ubservatsun. Viennae 1756.8.

Jacquin, Enumeratio stirpium in agro vintobonensi. Vinubbonne 1762. 8 .

Schulles, lileine l'lora der Gegend von Wien bis zum Schnecherge. In ejus "Ausfluge", Wien 1802. 12.

Kreatzer, Prodromus lilorate vindohonensis. Wien 18 io.s.

- Aufzalaluny der Pflanzen um Wien. Wien 1540.12.

Patzell, Thalamilloren der Limgelnungen Wiens. Wien $1 \$ 42.8$.

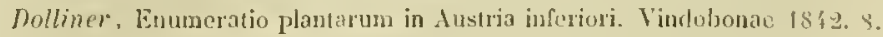
Neilreich, Florn von Wion. Wien 1846. ar. 8. 


\section{FLORAE GERMANIIE}

Sailer, Die Flora Oberöstreichs. Linz 1849,8.

Flora der Liozergegend. Linz 1844.8.

Schrank, Flora berchtesgadensis. In cjus "Naturhistorische Briefen. Salzburg 1785. 8. vol. H. p. $153-323$.

Primitiae Florae salisburgensis. Francofurti a/M. 1792.8.

Braune, Salzburgische Flora. Salzburg 1797. S.

Sartori, Specimen numenclatoris plantarum Styriae. Viennae 1808. \&.

Gebhard, Verzeichniss der von 1804-1\$19 in Steyermark gesanmelten Pflanzen. Grálz 1821, 12.

Maly, Jora styriaca. Gratz. 1838. gr. 12.

Tita, Iter per alpes tridentinas. In ejus Catalogo horti Hauracent. Palavi 1713. 8 .

Hoschmann, Regnum animale, vegetabile et medicum tyrolense. Deniponti 1738. 4.

Schoepfer, Flora oenipontana. Inusbruck 1805.8.

Scopoli, Flora carniolica. Viennae 1760. 8. - El. ll: ib. 1772. \$.

Hacquet, Plantae alpinae carniolicae. Viennae 1782. 4.

Scopoli, Deliciae Flurae el Faunae insubricae. Ticini 1786-1788. folin.

(Suffren) Catalngue des plantes du l'rioul et de la Carnia. In ejus "Principes de botaniquen. Venise 1802.8 .

Heiner, (Yest) und IJohenwarlh, Flora alpina. In "Botauische Reisen». vol. Il. Klagenfurt 1812.8. p. 127-261.

Tommasini, Der Berg Slavnik im Küustenlande. Ilalle 1839. 8.

biasoletto, Conspectus plantarum oeconomicarum Istriae. (Jmpr. in: Pittoreshes Oestreich, no. 13.) Wien 1840.4.

Meischmam, Uebersicht der Flora hrains. Laybach 1844. 8. (Supplementum in : Flora 18'6. [1. 239-2'0.)

Higandus, De herbis in Burussia nascentibus. In ejus "Vera historia etc. Jenae 1590.4. fol. 48-88

Qelhafus, Elenclus plantarum circa Dantiscum nascentium. Dantisci 1643. 4. - ib. 4656.8.

Wentzel, Centuria plantarum circa nobile Gedanum sponte nascentium. 1)antisci 1650.4 .

Locselines, Plantao in Borussia sponte nascentes. Regiomonti 163 i. 4.

Flora prussica, curante Gottsehed. Regriomonti 1703. 4.

Helving, Flora q̨uasimodogenita. Gedani 1712. 4.

- Supplementum Florao prussicae. Gedani (1726.) 4.

Wull, Plantae XXII in Borussia repertae. Regivmonti (1744.) 4.

-___ Flora borussica. Regiomonti 1765.8

Reyger, Teutamen Florae gedanensis. Dantisei 1764-1766. 8 .

Menzel, Centuria plantarum gedanensium. In Reyger, Tentamen Florae gedaneosis, vol. 11. Dantisci 1766.8.

Keyger, Die um Danzig wildwachsenden Pllanzen. Danzig 1768. 8.

Graft, Preussens Flora. Elbing 1809. 8.

(Ilenckel von Domnersmarck) Enumeratio plantamm circa Regiomontum. Regiomonti 1817.8 .

Ilagen, Preussens Pflanzen. Kouigsberg 1818. 8.

Chloris borussica. Reginmonti $1 \$ 19.12$.

Eyscnhardt, Ohservationes in Floram prussicam. Impr. cum ejus: De accurata plantarum comparatione. Regiononti 4823.4.

Reyger, Die un Danzig wildwachsenden Planzen, umgearbeitet von Weiss. Danzig 1825-1\$26. 8

Lorek, Flora prussica. Königsberg 1826-1837. 4. - Ed. Jll: ib. 1846is $4 \mathrm{x} .4$.

List, Stirpes muperrime in Lithuada detectae. Tilsae 1828. 4.

(Meyer) Elenchus plantarum Borussiae. (Regiononti 1835.) 8.

List, Plantae lithmanicae Chloridi borussicae IIagenii inserendac. Tilsae 1837. 4

Menge, Catalogus plantarum regionis grudentinensis el gedanensis. Grudentine 1839. 12.
4.12 FLORAE GALICIAE - HUNGARIIE - DALMATIAL

Sauge, Catalogns plantarum circa Brunsbergam crescentium. Brunshergac (1846.) 8

f'ampuch, flora tromesnensis. Trzemeronn 1840.8

\section{Florac Galiciac.}

Besser, Primitiae Flora Galiciae. Viennae 1809. 12.

Herbich, Additamentum al Flıram Galiciae. Leopoli 1831.8

Zauradsli, Enumeratio plantarum Galiciae et Bucowinae. lireslan 1835.8 . - F"lora der Stad Lemberg. Lemberg 1836. 8.

Herbich, Selectus plantarum rariarum Galiciae et Bucovinan. Czernovirii 1836.4 .

\section{Florac Hungariac.}

De l'Ecluse, Rariorum aliçunt stirpinm per Paunoniam, Austriam el vicinas provincias observatarum historia. Antverpiae $15 \$ 3.8$.

Bejthe, Stirpium nomenclator pannonicus. Impr. cum Clusw. Antverpian 1584.8 .

Fuves konyv fuvehnek. Németh-Ujvárot 1595. 4.

Locw, Epistola do Flora pannonica conseribenda. Sempronii 1739.4.

(Horvalonszliy) Florae tyroaviensis pars I. Tyruavii 4774.8.

Benlio, Transsylvauia. Vindobonae 1778. 8.

Balog, Plantace in Transsylyania provenientes. Lugd. Bat. 1779. 4.

Lumnitzer, Flora posoniensis. Lipsiae 1791. 8.

Fôldi, Rovidl kritika es rajzolat à Mlagyar fuvésztudomanyroil. Betsben 1793. 8.

Genersich, Florae scepusiensis elenchus. Leutschoviae 1798.8.

II aldsiein et Kitaibel, Descriptiones et icones plantarum rariorum Hurgariae. Viennae 1802-1812. folio.

II ahtenberg, Flora Carpatorum principaliun. Goctiogae 1814, 8.

Baumgarten, Enumeratio slirpium magno Transsilvaniac principatui pracprimis indigenarum. Vindobonae 1816.8 .

Sadler, Yerzeichniss der $и$ m Pesth und Ofen wildwachsentarn Crewachse Pesth 1818.8 .

Rochel, Pflanzenumrisse aus dem sudostlichen Karpath des liannats. Wirus 1820. folio

Lang, Enumeratio plantarum in Hungaria lectarum. Pestini 1822 . \&

Sadler, Flora comitatus pestinmsis. Pestini $1825-1826.8 .-$ il. 1360 .

hochel, Plantae Banatus rariores. Pestini 1828 . folir.

Endlicher, Flora posoniensis. Posooii I\$30. S.

Nendtvich, Enumeratio plaotarum in territorio quinque-ecelesienci spoute crescentinm. Budae 1836. 8 .

Rochel, Verzeichniss der Pflanzen des Banats. In ejus "Botanische Reisen. Pesth 1838.8.

\section{Florae Dalmatiae.}

Carallini, Purillus meliteus. Impr. cum ejus: Brevis enumeratio plantarum. Romac 1689. 12, p. 103-129.

Portenschlag-Ledermayer, Enumeratio plantarun in Dalnatia lectarum. Wien 1824, 8 .

(Plantae datmaticac a Welden sculptae servantur in hibl. Candolleana.)

Tisiani, Stirpium dalmaticarum specimen. Patavii 1826. 4.

Partsch, Plantae insulae Ncleda. In ejus "Bericlat etc. Wien 1\$26. \$. p. $19-22$ 
Zerapha, Florac melitensis thesaurus. Nelitao 1827. i.

pelter, botanischer Wegweiser in der Gearend von Sualato in Dalmatien. Zara 1832. 12. obl.

Atschinger, Flora jadrensis. Jaderae 1832. 8.

Visiani, Flora dalmatica. Lipsiae 1812-1847.4

Ebel, Zwolf Tage auf Nontenegro. H. Heft. Konigsberg 184\%.8.

\section{Florac Scandinaviac.}

Franke, Speculum botanicum. Ipsaliac 1638. 亿. - ih. 1659.4.

Fuiren, Index plantarum circa Nidlosiam. Imps. cum Bartholini Cista medica. Havniae 1662.8 . p. 278-293.

Bromelius, Chloris gothica. Gothoburgi 1694. 8.

Linder nobilis Lindestalpe, Flora wikshergensis. Stochholm 1716. \$.

laberg, Graesoea. Unsaliae 1727.4.

Linne, Flora lapponica. Amstelaedami 1737. S. - Londini 4792. S.

Leche, Primitiae Florae scanicae, Lunlie 174\%. 4.

Linne, Flora suecica. Stockholmiae 1745.8 . - ib. 1755. 8.

liosen, Observationos circa plantas quasdam Scaniae. Londini Gothorum 1749. 4 .

l.inne', Herbationes upsalienses. Upsaliae 1753.4.

(Zamzelius) Blomsterkrants af de uti Neriket befintliga wáxter. Örebro 1760. 12.

Trozelius, Catalogus plantarum paroeciae Mistelahs. In ejus aPliy's. oec. beskrifning netc. Lund 1766. 4 .

Gunner, Flora norvegica. Nidrosiae et Hafuiae 1766-1772. folio.

Lime , Fora åkeroensis. Upsaliae 1769. 4 Pandora et Flora rybyensis. 1Jpsaliae 1771. 4.

Retzius, Florae Scandinaviae prodromus. Ilolniae 1779. 8. - Ed. Il: Lipsiae 1795. 8. - Supplementum I et 11: Lundae 1905-1809.4.

Naezin, Index plantarum rariorum in urbis Ulricachamn Vestrogothias confiujis. Upsilliae 1782.4 .

Ifzelius, De vegretabilibus suecanis ohservationes. Upsalian 1785. 4.

Fischerstrom, Vauter omkring Măaren. In ejus: Utkast etr. Stockholm 1785. 8. p. $245-292$

Wahlbom, Catalogus plantarum oelandicarum. In ejus "Oelandiaw. Upsnliae 1786. 4. p. $42-44$.

Thunberg, Flora strenguesensis. Upsaliae 1791.4.

Liljeblad, Utkast til en svensk Flora. Upsala 1792. \&. - Ed, Ill: î, 1.816. 8 .

Hammer, Florae norvegicae prodromus. Kiobenhavn 1794. 8.

Srensk Botanih. Stockbolm 1802-1838. gr. S. (Tlies. no. 11827.)

Retzills, Forsok till en Flora oeconomica Sueciae. Lum 1806. 8. - Biliang: Lund 1812.4

lorselles, Tvenne nya växter fundne i Sverigo. Upsaliae 1807.8. (Poa remota Fors. Artemisia coarctata Fors.)

Liljeblad, Coloniae plantarum in Suecia. Upsaliae 1809.4.

Wahlenberg, Flora lapponica. Berolini 1812. 8.

Fries, Novitiae Florae suecicae. Lundae 1814-1823.4.

(Swartz) Summa vegetabilium Scandinaviae. Ilolmiao 1 S14. S.

Thunberg et Alquist, Flora runsteniensis. Upsaliae 1815-1517.4.

Osbeck et Montin, IIallands Flora. (Impr. in Bexcll, Ilallands Ilistoria, vol. 1, 386-404.) Gotheborg 1817.8.

Widegren, Sallsyntare vaxxter. In ejus "Östergothland». I linköping 1817 8. rol. 1 , p. $24-31$.

Fries, Flora hallandica. Lundae 1817-1818.8

Forsander, De vegetatione Scaniae. Lundae 1920.4.

llartman, Hanıbok i Skandinaviens Flora. Stockholm 1820. 8. - ib. 1538. 8 .

Wahlenberg, Flora upsaliensis. Upśaliae 1820. 8.

Thunbery et Wahlberg, Flora gnthoburgensis. Upsaliac $1820-1824.8$. 1htquist, Anmárhniugar on Olands Vegetation. Stockholm 1822. 8.

Billberg, Botanicon Scandinaviae. (Ieones.) Holmiae 1892. 8.

Zetterstedt, Register ofver văxter i Lappmarken. In ejus "Resa " etc. Lund 1822. 8. vol.11, p. $227-231$.

Aspegren, Fursok till en Rlekingsk Flora. Carlscrona 1823. 8.

Laestadius, Botaniska Anmtirkiningar. (Flora Lapponiae.) Stockholm 1823.8.

Wahlenberg, Flora suecica. Upsaliae 1824-1826.8. - ib. 1831 1833,8

Fries, Stirpium agri femsoniensis index. Lundae 1825-1826.8.

Sommerfelt, Supplementum Florae lapponicae (Wahleubergii). Christianiac 1826.8

Agardh et Lindblom, Stirpes agri rotnoviensis. Lundae $4826-1829.8$.

Agardh el Sillen, Flora parochiae Brḱnkyrka. Upsaliae 1827.8.

Ekström, Mörho Sockens Vaxter. In ejus a Beskrifningn enc. Stockbolm 1828, 8. p. 116-137.

Fries, Novitiae Florae suecicac. Ed. II. in formam commentarii in II uhlenbergii Floram redacta. Lond. Goth. 1828.4. - Continuatio (Mantissa 1-111.) Lundac 1832-1842. 8.

Bohman, Omberg in Ostrogothia. Linköping 1829.8.

Enumeratio plantarum Sueciae. (Upsala 1830.) 8.

Areschoug, Stirpes in regione cimbritshamnensi. Londini Golhorum I\$31.8.

Lindblom, Birdrag till Blekings Flora. Stochholm 1831.8

Gellerstedt, Nerikes Flora. Örebro 1831. 8.

Ilisinger) Forteckning på wàsterna i Westmanland. Stochholon 1832.8 .

Myrin, Anmarkniugar on Wermlands och Dalslands vegetation. Stockliolm 1832.8 .

Corollarium Florae upsaliensis. Upsaliae 1834. 8

Bredsclorff, Haandbog ved botaniske excursioner i Egnen on Soroo. Kiobnhavn $1834-1835.8$

Fries, Flora scanica. Upsaliae 1835. 8.

Agardh, Enumeratio plantarum in rogione landscronensi. Lundac.1835. 8. Areschoug, Plantale Florae gotholurgensis. Londini Gothorum 1836. 8.

Dueben, Conspectus vegetationis Scaniae. Lundae 1837. 8. (germanice.)

Wahlenbery, Synopsis Florae gothlandicae. Upsaliac 1837. 8.

Lilja, Skånes Flora. Lund 1838, 8.

Ringiu.s, Herbationes lundenses. Lundae 1838. 8.

Wessén, Plantae paroeciae Ostogothiae härna. Upsaliae 1838. 8.

Fries, De stirpibus in Norvegia recontius detectis. In ejus "Mantissa 11. Novit. Fl suecicae 1. Lundae 1839.8.

Thedenius, Anmarkuingar om Ilerjedalens vegetation. Stoch holm \$839. S. Schagerström, Plantae cotyledoneae paroeciae Roslagiae Rro. Upsaliae 1839-1840. S.

Bohman, Wettorn och dess Küster. Örebro 1840. 8.

Wikström, Stochholms Flora. I. Stockholm 1840.8.

Blylt, Enumeratio plantarum circa Christianiam. Christianiae 1844. 4.

Anderson, Plantae vasculares cirea Quickjock Lapponiae iulensis. Upsaliar $1844-1845.8$.

Schagerström, Conspectus vegetationis Uplandiae. Upsaliac 1845. 8. Fries, Sunma vegetaljilium Scandinaviae. Ilolmiae (1846.) 8.

Ilarman, Svensk och norsk Excursions-Flora. Stockholm 1846. 12.

\section{Florac Daniae.}

Paulli, Flora rlanica, det er: Dansk Urtehog. Kiohenhavn 1648. '́. Kylling, Viridarium danicum. Hafniae 1688, 4.

Linne, Prodromus llorae danicae. Upsaliae 1757. 4.

(Mueller) Flora fridricisdalina. Argentorati 1767. 8.

Oeder, Relatio de lilura danica. IIavniae 1761. folic. 
Oeder, leones plantarum sponte nasecntium in regruis l)aniae et Norvegino al illustrandum opus Florae danicae noming inscriplum. IJavniso 1761 -1845. fislio.

Nomenclator hotanicus inserviens Forme Janine. Ilavniae 1769.8.

Enumeratio plantarum Filorae Hanicao, J]avuiac 1770.8. (germinice.)

Tomming, Norsh medicinsk och oekonomisk Flora. Kinbenlava 1773.4. Ra/n, Daumarhs ogr Ilolstecus Flora. (Cl. I - X.) Kiobeuluavn 17961800.8 .

Schumarhar, Enumeratio plantarum Saellandian. Iavniae Is01-1803.8. Deu Jjolvenlarnstie Flora. Kjolienhavn iso4. 8.

Hofman, Shrivelse angarende de paa del indalaemmerde ved Ilofmansgave fremhomme planter. Kioblienhavis 1822. S.

Hornemumu, Nomenclatnra Filorne clanicac emondalla. Ilafuiae I\$27. S.

Mrej( ${ }^{\circ}$, Flora excursoria hafniensis. Hafuiac 1838.12.

Haller, Enumeratio stirpium in Islandia sponte erescentium, a Koenig lectarun. (Nov. act. acad. nat. cur. IV, 203-215.)

Zoeya, Flora islandica ex olservationibus of herlmariis Johanmis Gebhardi Koenig collecta et dispasila. In Olafsen et Povetsen, Reise. Soröo 1779. 4 .

(germanice.)

frottbocll, Afhatuling om en deel rare planter, som i Island og Gronland ere fundne. (Kiubenl. Selsh. Shrifter $\mathbf{X}$, 424-\$62.)

IIjallalin, Islenzk Grasafracti. Kappminnahofu I\$30. S.

liober, Otiservations sur la regetation en Istande, arec une liste des plantes que l'nn suppose exister en Jifande, dressec par l'aht. In Rober, loyage. Paris is 41 . \&. p. $337-379$

\section{Florac Rossiac.}

Beruluard, Gatalogus plantarum circa Varsaviam collectarum. lantisci 1652. 12

Til-Lrendz. Catalogas plantarum prope Aboan. Ahoat 1673. S. - il. 1683. 8 .

Jeones novae calalogo apjensac. Sboae 1683.8 .

Ermdl, Viridarium vel Catalogus plantarum circa Varsaviam nascentum. Cum cjus: Tarsavia plısice illustratal. 1)resdae 1730. 亿

Ammann, Stirpes rariores in imperio rutleno. Petropoli 1739.4.

Gorler, Flora ingrica. Petropoli 1761-1764. S.

fialm, Flore fenuicae pars prior. Ahote 1765. 4.

Jellas, lilura rossica. Petropoli 1784-1788. folio.

(Pullas, Flora russica. Francofurti 1759-1790.8.)

Justruder, Observatiotses listoriam phantarun fonniearum illustrantes. Hoan 1791.4

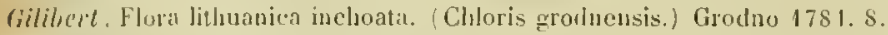
- Coloniare Allohr, 178 s. 8.

Inndzill, Symopsis plantarum Lilhuaniae. w Vilnie 1791. s. - i). IS11.8.

Stephren, Eummeratio stippium agri mosijuensis. Mosıuao 1792. 8.

- leones plantarum monquensium. Mostune 1798. fulio.

Clarlie, Plants in the Ginea. In Clurke, Travels. 11, 729-736

Soboleceslit, Flora petropolitana. Perropoli 1799. 8.

cf. Thes, lit. but. 110. 97,3?

Juigubsliy, Pradromus Florae mosqunusis. Mosquae 1802. S

Grimdel, Butanisches Taschenbuch for liv-, Ku- und Esaluland, Riga 18113.8 .

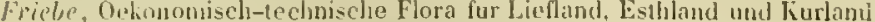
Riga Iso5. 8

Irrschall cun Bieberstein, Flora taurico-ciucasiea. Charhoviac isosIs่ 19.8

Dotampelmann, Flora livanica. Riga isog- isfo. folio

Marshall wou Bieberstein, Genturia plantarum rariorum Rossiae neri-

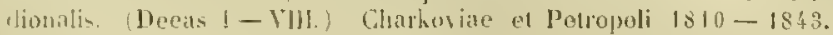
fisicis.

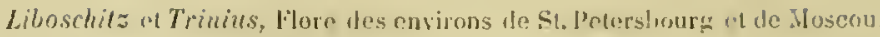
Si. l'etershourg 1811. 4.

Wurlins, Jrodrumus Forac maspuensis. Mosquac 1819.8.

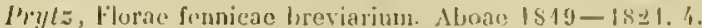

Besser, Eummeratio platarum in Toliynia, l'orlolia, Brosaralua el cirea

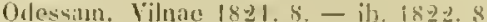

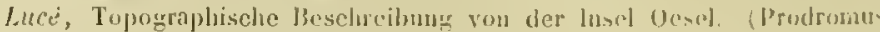
Florae osiliensis.) Riga is23. 8.

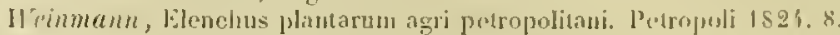

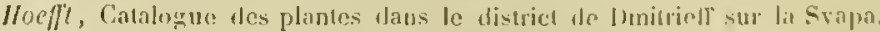
Moseou 1826. 8 .

Jwoigulisly, Fora mosquensis. Mosquae I82S. 12.

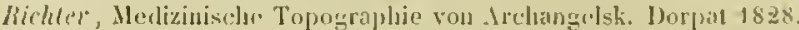

Ledebonr, Icomes plantarum novanm liluram rossieam illustrantex. Rigar $1829-183$ \%. Iolies.

Meyer, Verzoichuiss der $1829-1 \$ 30$ im kaukasus mul and hujpischun Meere resammolten Plianzen. St. Jetersburg $1 \$ 31.4$

Eichund, Plantarum novarum ex itinere easpio-caucasico fasciculi duo Vilıae 1831-1833. folı.

Levinin, Jcones Florae petropolitante. Petropuli is 36

Heimmana, linumeratio stipium agri petropolitani. "ouropoli 1837. s.

Fleischer, Vorzeichniss der Planeroganen Jer Ostsecprovinzen. Miliu $1 \$ 30,4$.

- Flura der devtschon Ostsecprovinzen. Mitiu 1839.8

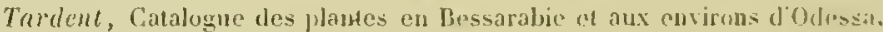
In ejus " Essain etc. Lausanne 1\$41. \$. [1. 27-\$8.

Livilli, Pantes reeucillies en Tanride. In Ibemiloff. Voyage. Paris isha. 8. vol. Il, p. 34-242.

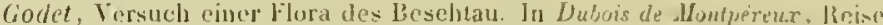

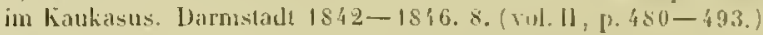

Ledebour, Flora rossica. Stutgartiae $1542-1847$ silf. S.

Hirzan, Seripures rei herbariae femicae. Helsingforsiae 1843. 8.

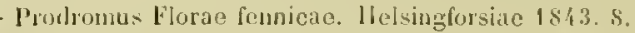

Nylander, spicilegiumplantarum fenuicarum. Ilelsingforniae 1843-1844.8.

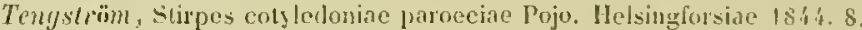

Meyer, Florula provinciae Tambow. (Bejtrage etc. l.) Petrojoli $1 \$ 44.8$

Tratetetter, Plantarm imagrines et deseriptiones Floram rossicam illısirantes. Monachii 1\$44-1\$46 squ. 4 .

liuprecht, Jilores Samojedurum cisuralensiun. Jerropoli 18403.5.

In historian stirpium Florae petropolitanac flatribac. Potrupul 1S:5. 8 .

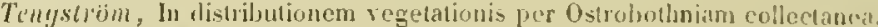
Helsingforsiac 1846.8 .

\section{Florac Gracciac, Turciac.}

Sestimi, Florac olympieae idea. In ejus "Lettere oflepuriches. I.ivormo 1785. S. 1ol. 11. 11.93-138.

Siblhorp, Florae graecae prodromus. Jomelini IS06- Is13. S

_- Flora graeca. Lomblini 1806-1840. folio.

Pieri, Della corcirese Flora centuric prima. Corfu 181/. 4, mas.

_ Flora corcirunsis. Cout. 1-11. Corciran 1524.8

IV alpole, Plants of Grece from Dr. Sibthory's papers. In rius a Memuirs elc. London isis. 4. 3. 233-23\%.

Sieber. Jerbasium Florae creticae. Tindobonae 1820 , folio,

Dumoul d'irille, Enumeratio plantarum ex insulis Archipelayi. Paris $18=2.8$

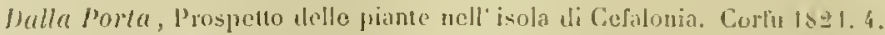
Bory de St. Intent, Expedition scientifiue de Noree. Tome III, פ. prortie: Butanique, Paris 1832.4.

friealdsliy, Ielsersicht der auf dem Balhan gesammelen Gewachise. In

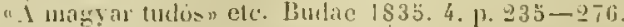

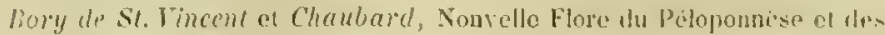
Cyciales. Jaris Is3s. folio. 
Cesati el Fenzl, Verzeichoiss von Plauzen aus Sudgriechenland. In Friedrichsthal. Reise. Leipzigy 1838. S. p. 261-311.

Fiedler. Uebersich der Gew ächse des kunigreichs Griechenland. In ejus "leviso". Leipzig 1840. S.1,507-874.

Nargot et Reuter, Essai d'une filore de l'ile de Zante. Geneve 1841.4. Tisiami, lllustrazione di alcune piante della Cirncia e del Asia minore. Venezia 1849.4 .

Poech, Enmmeratio flastarum insulde Cypri. Vindobonac is: 8.

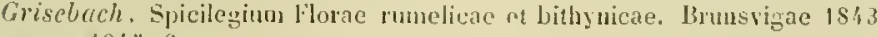
-1845.8 .

\section{Florac Asiac.}

Cimelin, Flora sibirica. Petropoli 1747-1769.4

Ledelour, Commentarius in J. G. Gmelini Floram sibiricam. (Ratishonae 1841.) 4 .

Limé, Plautae rariores eantschatcenses. Upsaliae 1750. 4.

— Necessitas promovendae etc. (Flora silbirica.) Upsaliac 1766.4.

Ledebour, Heycre el Bunge, Flora altaica. Berolini 1\$29-1\$34. S.

Bunye, Verzeicliniss der im Ostaitai gesammelten Pllanzen. Pelerslurg 1836. 8 .

Erman, Plantac itineris eirea trram plerumque kamtsehatkenses. In ejus "T'erzeichuiss, Berlin 4\$35. folio. p. 53-64.

Bongard, Descriptiones plantarum novarum. Petropoli 4839.4.

Bongard el Meyer, Verzejchniss der am Saisang-Nor und Irtysch gesammelien Pllanzen. Petersburg 1841.4.

(Fischer et Meyer) Enumeratio (I-II) plantarum novarun a el. Schrenk lectarum. Petropuli 1841-1842. S.

Larelin et Firilow, Enumeratio plantarum in tlesertis Songoriac orientalis "t in summo jugo Alatau eollectarum. (Mlosquae 1842.) $\mathrm{S}$.

Index plantarum ann 1840 a havelim ef Kimlow in regionilous altaicis collectarum. Mosquac is 彷. 亿.

Turcaninow, flora haicalensi-dialurica. Pars I. Mostjua 1842-1845. gr. 8 .

Traulcetle", Phtinogane Pflanzen aus den Hochorden. (Middendorf. Reise in den ansersten Norden und (Osten Siliriens. 1, 2.) St. Petershurer 1847.4 .

lielon, Portrits doyscan, herbes, ardures d'Arabie et d'Egypte. Paris 1557. 4.

Rounotf, Aigentliche Beschreihung der Raiss in die Morgenlandlor. Vierter Theil: "Eitlehe schone auslambische Liräuter ». Laugingen 1583.4

Gronorilts, lilora orientalis. Lugd. Ball. 1755. S.

llonorius Bellus, De rariorilus plantis creticis, aegpliis noris. Impr. cum Chesi Ilistoria plantarum. Antwerpiae 1601 . fulio. Monte Baldw. Basileae 1608, 4 .

Ray, Stimpinm oricutalium rariorum catalogi tres. In "A collection of curions travelso. Iondon 1093. 8.

fiacmpfer, Ambenilatum exoticarum fascienli 1 . Lemgoriae 1719. 4.

Buxbaum, Pantarun misus eognitarum centuriae, complectens plantas circa Byzantimn el in Oriente obscriatas. Petropoli 1728-1740.4.

Limne, Flora palacstina. Lpsaliae 1756.4 .

Schreber, leunes el deseriptiones plantarum (Gundelsheinerianarum) minu cognitirum. Hatae 1766. folio.

Forsliăl, Flora aegyptiaco-irahica. Haviae 1775.4

_- lcones rerum naturalium itinris orientalis. Ilavniae 4750.4.

De la billardiere, Icones plantarnu Syriac rariurm. Paris 1791-1812.4.

Clarke, List of all the plants collected in Greece, Egypt and the Iloly Land. In Clarke, Travels. I1, 716-724.

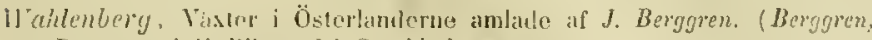
Resor, 1ol. 11. Biliang l.) Stockholm 1527. 8.

fiafineuu-Delile, firagmens d'une Flore do l"Arabie pétréc. Paris 1\$33.
Endlicher el Fenzl, Sertum cabulicum. Vindobolac 1836.4 .

Schenli, Plantarm species, quas in itinere per Acgyptum, Arabiam " Syriam collegerunt Schubert, Erdl et Roth. Monacliii 1 S10. S.

Ilohenacker, Enumeratio plantarum provinciae Talysch. s. 1. et a. $\delta$.

Boissiev, Diagnoses plantarum orientalium norarum. Lipsiae 184:1846.8 .

Jaubert et Spach, Illustrationes plantarun orientalium. Paris 1S彷 1846. 4 .

Fenal, Pugillus plantarum Syriac et Tauri oecidentalis. Vindulona 1 S4 4 . S

- Illustrationes et descriptiones plantarum novarum Syriae of Tauri occidentalis. Stutgart 1843, s.

Decaisne. Enmmération des plantes recucillies par Bove dans les deux Arahies, la Paléstine, la Syrie el l'Lgyule. (Florula sinaica.) Paris 1845. 8 .

Boym, lilora sinensis. Viennae 1656 . folio. (galliee.)

Buchoz, Collection précieuse: 1. Plantes de la Cline. Paris 1776. folio. - Collection des plantes medicales de la Chine. Paris 1781. folio.

Brown, Clatacters and descriptions of three new species of plants foum! in China lyy Clatke Abel Esi]. London is is. 4 (Vom. Schriften I, $3590-570$.)

Icones plantirum sponte China nasceutium. Lonelon 1891. folio.

liunge, Enumeratio plantarum, quas in China horeali cullegit. (Petropoli 1831.) 4 .

—_ Plutarum unongluolico-chinensium Decas 1. Casani 1835. 8.

Griffith. On the botanical collection brought frem the Eastwart liy Wi: Cantor. s. I. el il. 4.

Lourevo, Flora cochinchinensis. Ulyssipone 1790.4. - Berolini 1793. \& Jussieu, Sur quelques genres de la Flore de Cochinchina da Lourcino. (1-ill.) (Paris $1807-4810)$.4 .

Thunberg, Flora japonica. Lipsiao 1784. 8.

- leones plantarum japonicarum. Lpsaliae 1794-1505. folir.

haempfer. Jeones selectae plantarum, yuas in Japonia collegit et delineavit, ed. Joveph Bantss. Lomdini 1791. folio.

Morren et Decaisne, Observations sur quelques plantes du .Iapon. Bruxelles 1836.8

Sicbold of Zuccarini, Flora japonica. Lugd. Bat. 1835-1844 sty fuliu.

Acosta, Tractado de las drogas. Burgos 1578. 4.

(littinr, ilalice, gallice.)

Jlistoria natural y moral do las Indias. Sevilla 4590.4 .

(latim", anglice, gallice, mollatulice, italice.)

Rheede tot brabestein, Jertus indicus malabaricus. Amsteludani lo7 - 1703 . folio. (hollantice.)

1774. 4

IJortus indicus malabaricus, ed. Hill. Lundini

Dennstedt. Schlussel zum Mertus indicus malabaricus. Weimar is is. 4.

litumilton. Commentary of the fourth part of the Hortus malabaricus. 4826. $\therefore$.

Dillu'yn) I reviow of the relerences to the llortus malabaricus. Firansen 1\$39. 8 .

Commelyn, Flora malabarica. Liggl. 13at. 1696 . \&

Commelyn, lintanograplia. Luggd. Jat. 1696. folio. - ì). 17fs. bulin. est idem liber.)

Petieer. Aceount of sume indian plants (a Sun. Bromen prope Alatras fectac) (Plil. Transact. A. $313-335$. )

Brown, East Inclia flints (Madrats) will remalds by Jemes Petiver. (1'hil Transact. XI1I, 579-1029. AXI11, $1055-1460$.

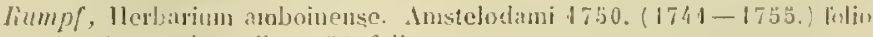
- Inctuirium: il. 1753. fulio.

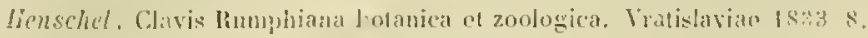

Limne, Ilerbarum amboinense. Upsaliae 1754. 4. 
Beze, bescription de quelques arbres et de quelques plantes de Malacque. (Impr. in Dodart, Mémoires p. 637-644.) Ansterdam 1758.4.

Burmann, Flora indica. Luyd. Bat. 1763.4.

Index alter in omnes tomos Iferbarii innboinensis. Luggd. Bat. 1769. folio.

Flora malabarica. Amstelaediuni 1769. folio.

(Milne) A descriptive eatalogue of plants from the East-ladies. London 1773.4.

Rollboell, Beskrivelse over nogle planter fra de malabarishe kyster. (Danske Vid. Selsk. Shrin. nye Saml. 11, 525-546, 593-594.)

Jones, The design of a treatise on the plants of India. (Transact. of the suc. of Bengal. 11, 345-352.)

Roxburgh, Plants of the coast of Curomandel. London 1795-1819. folio max.

pore 4813.4 .

Flora indica. (Cl. I-V.) Serampore 1820-1824.8.

Flora indica. Scrampare 1832.8.

Flora indica, vol. N. (Cryptogamae.) s. I. et a. 8 .

Wallich, Descriptions of some rare indian plants. (Calcutta 1818 .) 4.

List of indian woods collected. London s. a. S.

Roth. Novae plantarum species praescrtim Indiae orientalis. Halberstadii 1821. 8.

Ilamilton, Some notices concerning the plants of India. Edinburgh 1823.4 .

II'allich, Tentamen Florae napalensis illustratae. Calcutta and Serampore 1824-1826. folio.

fion, Prodromus Florae nepalensis. Londini 1825.8 .

Fallieh, A numerical list of dried specimens of plants in the East India Companys Museum. Loudon 1828. foliv.

De Candolle, Nolice sur la botanique de l'Jnde orientale. (Genève 1829.) 8

Wallich, Plantae asiaticae rariores. London 1830-1832. folio.

Hiddington, An english index to the plants of India. Caleutta 1832. 8.

Wight, Jllustrations of indian botany. Glasgow 1831. 4.

_- Catalogue of planis of East India. s. 1. 1833. 8.

Comuributions to the botany of India. London 1834. 8.

Wight et Walker-Arnott, Prodromus Florae peninsulae Indiae orientalis. London 1834. 8 .

Wight, Jllustrations of indian hotany. Madras 1838-1841.4.

Icones plantarum Indiae orientalis. Madras 1838-1847.4.

Belanger et Bory de St. Vineent, Voyage aux Indes orientales. Botanique. Phanérogamie. Paris s. a. 4.

Zenker, Plantae indicae ex montibus Neilgherries. Decas I. Jenae 1835. folio.

Royle, Illustrations of the botany of the llimalayan mountains and of the Flora of Cashmere. London 1839 . folio.

Graham, A catalogue of the plants growing in Bombay and its vicinity. Bombay 1839. 8 .

Jack, Deseriptions of Malayan plants. (Calcutta 1843.) 8.

Jacquemont, Plantae rariores, quas in India orientali collegit; auctore Cambessedes. Paris 1844.4

Wight, Spicilegium neilgherrense. Matras 1846-1847. 4.

Mermann, Musaeum zeylanicum. Logd. Bat. 1717.8

Bumann, Thesaurus zeylanicus. Amstelaedani 1737. 4

Linu, Flora zeylanica. Holmiae 1747. 8.

Jloon, A catalogue of the indigenous and exotic plants growing in Ceylon. Colombo 1824. 4 .

Thunbery. Horula ceilanica. Upsaliae 1825.4.

Radermacher. Naamlyst der planten, die gevonden worden op liet eiland Java Batavia 1780-1782. 4

Thunbery, Florula javanica. Lipsaliae 1825. 4.

Blume, Bijdragen tot de Flura van Nederlandsch Indie. Batavia $1825-$ 1826. 8
Blume, Fnumeratio plantarum Javae Lugd. Bat. 1827-1828.8

Blume et l'ische'r, l'Jora Javac. Bruxellis 18ะ8-182\%. folio.

Bennet, Plantae javanicae rariores. Loudini $1838-1844$. folio

B/ume, Rumplia. Lugd. Bat. 1835-18i6. folio.

fiorthals, lsotanie der nederlandsche overzeesclse Bezittingen. In Temminck "Verhandelingen etc. 1, ciden $1839-1842$. folio.

Junghuhn, Nova genera et species Florae javanicac. Jeejen 1840.8 .

Vriese, I'lantae novac et minus cognitae Indiae batavae orientalis. Insterdam $1845 \mathrm{~s}$ sq. 4 . max.

Jorilzi, Verzeichniss der von Zollinger auf Java grsamuelien I'flanzen. solothuru 1845-1846.8.

(Fungos recentuil Leveillé. Lichenes Schuerer, Muscus Duby.

Decaisne, IJerbarii timorensis deseriptio. Paris 1833. '

Lumel vel Camellus, Herbarum in insula Luzonn Philippinarun nascentinn icones ineditae. s. I. et a. folio.

Blanco, Flura de Filipinas. Manila 1837. 8.

\section{Florac Amcricac.}

Cormuli, Canadensium plantarum historia. Parisiis 1635. 4.

Forster, Flora Americae septentrionalis. London 17i. 8.

(cf. Bossu, Travels. London 17il. 8. vol. II, p. 17-67.)

Brown, List of plants collected on the coasts of Baffins liay and at Pussession Bay. (London 1819.) 4.

(V'erm. Schriften. 1, 336-356.)

Chloris Melvilliana. London 1823. 4.

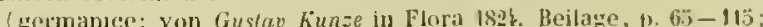
vost Erust Meyer in Verm. Schriften. 1, 367- 461 .)

Hooker, List of plants from the east coast of Greenlind. In Scoresby "Journal w efc. London 1893. 8. p. $410-415$.

(R. Brown, Verı. Sehriften. I, 5äl-53is.)

Richardson, Botanical appendix (to John Frunklin's Narrative of a journey from the Shores of Hudsons Bay and the Pular Sea). Lundon (1823.) 4 .

Hooker, Account of a collection of arctic plants formed by Eduard Sabine. London 1824.4.

Torrey, Aecount of a collection of plants from the Ruchy mountains. Ciew York 1827. 8 .

De la Pylaie, Flore de l'ile de Terre neuve et des iles St. Pierre ct díicluu. Paris 1829. 4.

Heyer, De plantis labradoricis libri tres. Lipsiae 1830.8

Hooker et IValker-Amoll, The botany of Capt. Becchey's voyage to the pacilic and Bering Strait. London 1841. 4.

Robin, Histoire des plantes nouvellement trowves a l'isle Virgine et autres lieux. Paris 1620.12.

Banister, Catalogus plantarum in Virginia observatarum. In Raji Ilisturia plantarum. II, p. 1926. Londini 1688. folio.

(Peliver) Herharium virginianun. (Memoirs for the Curious, 170 $\bar{i}, \mathrm{p} .927$ - 232.)

Culler, Account of the vegetable productions growing in New England. (Mem. of the amer. acad. 1, 396-493.)

Colden, Plantie Culdenghamiae in provincia noveloracensi Anerices sponte erescentes. (Act. soe. ups. 1743. p. $81-136$. $1741-1750$ p. $47-82$.

Cronocius, Flora virginica. Lugd. Bat. 1739-1743. 8, - lid. II: it. 1762.4.

Forster, Flora Americae septentrionalis. London 17TI. \&

Marshall. Arbustum americanum. Philadelplaia 1785.8. (gatlice, germanice.)

Walter, Flora caroliniana. London 1788.8.

Wuchlenberg, Index Florae lancastriensis. (Transact. of the americ. soc. III $15 i-154$. 
Nachrichten aus dem Pflanzeureiche in Georgien. (Ilamburger Magazin | XVII, 468-51s.)

Lamarck, Notice de quelques plantes rares on nouvelles, observées par Michaux. (Journ. d'Jist. nat. I, 409-419.)

Michaux (et Kichard), Flora boreali-americana. Paris 1803. 8.

Shecul, Flora carnlinaeensis. Charleston 4806. S.

Michaux, Histoire des arbres forestiers de l'Amérique septentrionale. Paris $1810-1813.4$. (anglice, et epitome anglice et gemanice.)

Barlon, Flora virginica. Philadelphia 1812.8.

Muehlenberg, Catalogus plantarum Americae septentrionalis. Iancaster 1813. 8. - Philadelplia 1818. 8.

Bigelow, Florula bostonieusis. J3oston 1814. 8. - ib. 1824. 8. - il). 1840. 8.

Pursch, Flora Americae septentrionalis. London $18: 4.8$.

Rafinesque, Florula ludoriciana. New York is 17. S.

Barton, Florae philadejphicae prodromus. Philadelphia 1815.4.

Eaton, Nanual of botany for North America. Albaay 1817. 12. - Ed. YllI ib. 1841.8 .

Bigelow, American medical botany. Boston 1817-1821. 4.

Bartou, Compendiun Florae philadelphicae. Plsiladelphia 1818.8.

Nullall, The genera of north-american plants. Philadelphia 1818.8 .

(Torrey) Catalogue of plants of New York. Albany 1819.8

Florula columbiensis. Washington 1819.8.

Rafinesque, Annals of ature etc. Levington 1820. 8.

- Neogenytot. S. 1. 4\$25. grr. 8.

Elliott, A sketch of the lookny of South-Carolina aud Georgia. Charleston 1821-1824. S.

Barton, A Flora of North America. Philadelphia 1820-1823.4.

Torrey, Flora of the northern and middle sections of the Uuited States. New York 1824. 8 .

Schweinitz, Catalogue of plants collected in the north-westem territory. In "Narrative" etc. London 1825. 8. vol. 11, p. 105-123.

Darlington, Florula cestrica. W' est Chester 1826.4.

Flora cestrica. West Chester 1837. 8.

Rafinesque, Medical Flora of the United States. Pluiladelphia 189S1830. 8 .

Hitchcock, Catalogue of plants in tlıe vicinity of Amherst College. Amherst 1829.8.

Torrey, Catalogue of north-american genera of plants. New Jork 1831.8.

Eaton, Plants from the vicinity of Troy. Lexington 1832. 8.

Beck, Botany of the northern and midland United States north of Virginia. Albany 4833. 8 .

Catalogue of plants of hentucky. Lexington 1833. S.

Croom et Loomis, Catalogue of plants in the neighbourhood of New IRem. New Bern 1\$33.8.

Hooker, Flora boreali-imericana. London 1833-4\$40.4

Nuttall, Collection towards a Flora of the territory of Areansas. s. 1. 1834. 4 .

Bacliman, Catalogue of plants in the vicinity of Chardeston. 1834.8.

Gibbes, A catalogue of plants of Columbia, S. C. Columbia 1835. 8.

Iliddel. A synopsis of the Flora of the western stutes. Cincinnati 1833.8 .

__ Supplementary catalogue of Ohio plants. Cincinnati 1836.8 .

Aikin, Catalogue of plants near lialtimore. 1836. 8.

liafinesque, New Flora and botany of North-America. Philadelplia 1.336. 8 .

Lapham, Catalogue of plants found near Nlilvankie, W. S

Eddy, Plantae plandomenses. New York s. a.

Croom. Catalogue of plants in the vicinity of New Bern. New York 1837. 8. Gray, Notes of a hotanical excursion to the mountains of North-Carolina. s. l. et a. 8 .

Torrey and Gray, Flora of Sorth-America. Yew York 1838-1843. 8.

Torrey, Report on the hotanical department of the Survey in New York. In ejus "Natural history of New Vork". Albany 1839. 8. vol. I, p. 113 -197 .

Prtrzes, Thes. lit. liot
Synopsis of the genera of american plants. Georgetown 1840.12.

(Dewey) Report on the plants of Massachusetts. Cambridge 1840.8.

Eaton et Wright. North american Botany. Publisted by $E$. Gates. 1840. 8 (Fortasse non differt al) ejus Manuat, ed. VIII)

Nees von Esembeck, in des Prinzen Max zu Wied-Neuwied Reise in das iunere Nordameriha. Koblenz 1841. 4, vol.11, 1. 429-454.

Nullall. The north-american Sylva. Philadelphia $1842 \mathrm{sg}$. imp. S.

Torrey, A Flore of the state of New York. Albany 1843.4.

- Icones ad Floran Philadelphiae illustrandam. s. 1. et a. 4.

Engelmann et Groy, Plantae Lindlheimerianae. Boston 1845. 8.

Hernandez, Quatro libros do la naturaleza y virtudes de la plantas en la nueva España. Hexico 1615.4. folio.

Ihughes, The american pliysician. London 1672. 12.

Plumier. Description des plantes de l'Amerique. Paris 1693. folio.

- Sova plantarum americanarum gencra. (Accelit catílogus etc.) Parisiis 1703. 4 .

Merian, De insectis surinamensibus et de plantis, quibus vescuntur et in quibus fuerut inventae. Anstelodami 1705. folio.

(Petiver) Account of some american plants. (Mem. for the curions, 1707. p. $345-352$.

Feuillée, Histoire des plantes médicales de Perou et Chile. In ejus a Journal». Paris $1714-1725.4 .11,703-767$. III, 1-74.

(germanice.)

Plumier, Plantarum americanarum fasciculi $\mathbf{I}-\mathbf{X}$, ed. Burmannus. Amstelodami $1755-1760$. folio.

Loefling, Plantae americanae. In ejus "Iter hispanicum». Stochlolmiae 1758.8.p. 176-283, $305-316$.

Jacquin, Enumeratio plantarum in insulis Caribaeis vicinaque Americes continente. Lugd. Bat. 1760.8 .

Selectarum stirpium americanarum historia. Vindobonae 1763 folio. - Nanhemii 1788. 8. - (Vindobonac 1780.) folio.

Prefontaine, Plantes et arbres qui naissent a Cayenne. In ejus "Majson rustique " ete. Paris 1763 . S. P. 135-911.

Merian, Recueil des plantes des lndes. Paris 1768. folio.

Linne, Plantae surinamenses. Upsaliae 1775. 4.

Aublet, Ilistoire des plantes de la Guiane française. Londres et Paris 1775. 4.

(Kunth, Ueber einige _lublet'selıe Gattungen. Berlin 1833. 4.)

Roltboell, Descriptiones rariorum plantarum (surinamensium). Havniae 1776. 4. - ib. 1798. folio.

Houstoun, Reliquiae Houstounianae. Londini 1781. 4.

Hernandez. Opera (quum edira tum inedita. (De bistoria plantarum Novae Hispaniae.) Natriti 1790.4.

Ruiz et Pacon, Florae pesuvianae et chilensis prodromus. Madrid 1794. folio. - Romite 1797. gr. 4.

likiz, Respuesta ... Capanilles. Nadrid 1796.4.

Ruiz el Pacon, Flora peruviana et chilensis. (Cl. I-VIJI.) Natriti 1798 1802. folio.

(De tahulis inclitis ef. Thes. lit. hot. 110.8859. )

Systema vegetabilium Florae peruvianae et chilensis. s. 1 . 1795. gI. 8 .

(Ruiz) All cl, Jussieum epistola de ejus dubiis cired nova genera Florde peruvianae. Natriti iso4. 4.

Richard, Catalogus plantarum e Cíyema missarum a D. le Blond. (Actes de la soc. (l'hist. nat. de Paris. J, 105-114.)

Fahl, Echgae americance. Havniae 1796-1807. folio.

- Icones illustrationi plantarum in Eclogis descriptarum inservientes. Havniae 1798 - 1799. folio.

Rulge, Plantarun fuianae rariorum icones et descriptiones. Londini 1805. folio.

Himboldt et Bompland, Plantae aecuinoctiales. Paris $1805-1818$. folio.

Ieyer, Primitiae Florae essequeboensis. Goettingae 1818. 4. 
Humboldt, Bonpland, Kunth, Nova genera et species plantarum orbis novi. Lutetiae Parisiorum 1815- 1825. folio.

hunth, Synopsis plantarum quas ad plagan aequinoctialem orbis novi collegeroul Ilumboldt et Boulland. Paris 1822-1825. 8 .

De la Slave el Lexarza, Novorum vegetabilium deseriptiones. Mexici $1824-1825.8$.

Phesl, Reliquiao llaenkeanae. Pragao 1830-1836. folio.

Jussien, Observations sur quelques plantes du Chili. (Paris 1831.) 8.

Colla, Plantao rariores in regionibus chilensilus a clar. Bertero nuper detectae. Aug. Taur. 1832-1833. 4 .

foeppig, Fragmentum synopseos phaneroganarum in Chilo lectarun. Lipsiae 1833.8.

Moricand, Plantae americanae rariores. Genevae $1 \$ 30$. folio.

Plantes nourelles d'Amérique. renève 1833-1846. gr. 4.

Poeppig et Endlicher, Nova genera ac species plantarum in regno chilensi, peruviano el in terra amazonica Iectarum. Lipsiae $1835-$ 1S45. folio.

Bentham, Plautae Jlartwegianae imprimis mexieanae. Londiui $1839-$ 1846. 8 .

Bertoloni, Florula guatimaleusis. Bononiae 1840.4.

lirongniart et Deccisne, Plantae phaneroganae ab Alcide dOrbigny collectae. in DOrbigny, Toyage. vol. VH. sectio I.

Splitgerber, De plantis novis surinamensibus. (Austelodami 1842.) 8.

Miquel, Iijst der planten, welke in de Kolonie Suriname gekweekt worden. s. J. et a. 8 .

Observationes de plantis quas in colonia surinamensi legit II. $C$. Focke. s. I. (IS43.) 8.

fay, Ilistoria fisica y politica de Clile. Botanica. Paris $1845 \mathrm{sqq} .8$. ot Allas.

Miers, Illustrations of south american plants. London 1846-1847. 4.

Remy, Analecta boliviana, seu novit genera el species flantarum in Bolivia crescentium. Paris 1847.8 .

Piso, De medicina brasiliensi. Lugduni Bat. 1648. folio. - Amstelodami 1658. folio. - Vindobonae 1817. 8.

( 1 andelli) Florae lusitanicae et brasiliensis specimen. Conimbricae 1788.4. Gomes, Observationes de nomullis Brasiliae plantis. Olisipone 1803.4.

Thunberg, Plantarum brasiliensium decas I-III. Upsaliae 1817-1821. 4.

Kaddi, Di alcune specie uuove di rettili e piate brasiliane. Modena 1820.4.

- Ouaranta piante nuove del Brasil Mordena 1820.4 .

Mikan, Delectus Florae et Faunae brasiliensis. Viudobonae 1820. folio.

Saint-Hitaire, Histoire des plantes remarquables du Brésil el du Paraguay. Paris 1824.4.

Plantes usuelles des Brasiliens. Paris $1824-1 \$ 28.4$

Martius et Zuccarini, Nova genera et species plantarum Brasiliae. Nonachii $1824-1832$. folio.

Saint-Hitaire (de Jussieu et Cambessedes), Flora Brasiliae meridionalis. Paris 1\$25-1833. folio.

(Vellozo de Miranda) Florae fluminensis icones. Parisiis 1827. folio max.

De Candolle, Notice sur la hotanique du Brésil. (Genève 1827.) 8.

Pohl, Plantarum Brasiliae icones el descriptiones hactenus inedilite. Vindobonae 1827-1831. folio.

Cumbessedes, Cruciferarum, Flatinearum, Caryophyllacearum, Paronychiarum, Portulacearum, Crassolacearum, Ficoidearum, Cunoniacearum Brasiliae meridionalis synopsis. (Paris 1829.) 8.

Martius, flerharium Florae brasiliensis. IIonachii 1837 (-1840). S.

Endlicher et Martius, Flora brasiliensis. Vindobonae 1840-1846. folio.

Casaretto, Novarum stirpium brasiliensium decades. Genuae $1842-$ 1845.8.

Monardes, Historia medicinal de Jas cosas que se traen de nuetras Indias occidentales. Sevilla 1569.4 .

tatine, anglice, italice, "allice.)

Sloane, Catalogus platarum, quae in insula Jamaica spoute proveniunt. Londini 1696.8 .
Chevalier, Sur les plantes de St. Domingue. Paris 1752.12.

Browne, The civil and natural history of Jamaica. London 1756. folio. (Plantae jamaicenses: p. $71-37$, tab. $1-38$. .)

Linné, Plantarum jamaicensium pugillus. Lpsaliae 1759. \%. Flora jamaicensis. Upsaliae 1759. 4.

Desportes, l'laotae domingenses in: Ilistoire des maladies de St. Domingue. Paris 1770.12. (vol. IjI, 3-56.181-309.)

Swartz, Nova genera el species plantarum, seu prodromus descriptionum vegetabilium Indiae occidentalis. IIolniae 1788.8. Observationes botanieae. Lirlangae 1791.8.

West, Flora insularum St. Croix et Thomas, in ejus "Bidrag o etc. Kiubenhava 1793.8. p. $259-336$.

Barham, Ilortus americanus. Kingston, Jamaica. 1794. 8.

Sivartz, lcones plantarum incognitarum Indiae accidentalis. Ërlangae 1794. folio

Flora Indiae accidentalis. Erlangae 1797-1806. 8.

Ledebour et Adlerstam, Plantarum domingensium decas. Iryphiac 1805. 4.

Tussac, Flora Autillarum. Parisiis $1808-1827$. folio.

Lunan, Ilortus jamaicensis. Jamaica 1814. 4.

Descourtilz, Flore médicale des Antilles. Paris 1\$21-1829.8.

IIamilton, Prodromus plantarum Indiae nccideatalis. Londini 1825.8.

Maycock, Flora harbadensis. London 1830.8.

Macfadyen, The Flora of Jamaica. (Vol. 1: Rauunculaceae - Leguminosae.) Loudon 1837.8 .

Maycack, Catalogue of plants in the British West India Colonies. Impr. cum IIalliday, The West Indies. London 1837. S. P. 389-408.

Kamon de la Sagra, llistoire pbysique, politique et naturelle de l'tle de Cuba. Botanique. Paris 1338-1842. S.

(Plantas cryptogamas exposuit ramille Montagne. phanerogamat incompletas reliquit Achille Richard.

Forster, Fasciculus platarum magellanicarum. (Goethingae 1787.) 4. (Comm. soc. gott. IX, 13-45.)

Dumont d'Urille, Flore des isles Nalouines. Paris 1825.8.

Hooker, Notes on the botany of the antarctic voyage. London I843. 8.

- The botany of the antarctic voyage. (Flora antarclica.) London $1844-1847$ squ?. 4 .

\section{Florae Africac.}

Alpinus, De plantis Aegypti liber. Venetiis 1592. 4. - Patavii 1640. 4. Opera posth. vol. II, p.1-70. Lugduni Bat. 1735. 4.

(Bruechmann, Xotae et animadversiones. Epist. jtin. 54. p. 706-716.)

Testing, De plantis aegyptiis observationes et notae. Patavii 1638, 4.

Ten Rhyne, Fasciculus rariorum plantarum in promoutorio Bonae Spei collectarum. Impr. cum Breyn, Ceaturia. Gedani 1678. folio.

Mentzel, Corollarium plantarum in promontorio bonae spei a Joh. Fr. Ruecker collectarum. In ejus a Lexiconn. Berolini 1696. folio.

Lippi, Description des plantes observes en Egypte en 1704. Mser. bibl. Hadr, de Jussieu. 4.

Petiver, Plantarum aegyptiacarum rariorum icones. Londini 1717. folio.

Burmann, Catalogi duo plantarum afjicannum. Amstelaedami 1737.4.

Rasiorum africanarum plantasum Decas 1 - X. Amstelacdami $1738-1739.4$.

Shaw, Specimen phytographliae africanae. In ejus "Travels». Oxford 1738. folio. p. $37-47$.

- Catalogus plantarum, quas in rariis Africae et Asiae partibus collegit. Oxonii 1738 , folio.

Adanson, Histoire naturelle du Senégal. Paris 1757. 4. (anglice, germanice.)

Linne, Flora capensis. L'psaliae 1759. 4.

- Plantao rariores africanac. Holmiae 1760.4 
Bergius, Descriptiones plantarum ex Capite Bonae Spei. Stockholmiae 1767. 8 .

Burmann, Prodromus Florae eajensis. Impr. cum ejus "Flora indica". Lugduni Bat. 1768. 4.

Roth, Observationes plantarum e Capite Bonae Spei. (Bot. Abhandlungen. Nurnberg 1787.4. p. 53-65.)

Thunbery, Prodromus plantarum eapensiun. Lpsaliae 1794-1800.8.

Flora capensis. Upsaliae 1807-1843. 8. - ILavniae 18181820.8. - Stuttgardiae 1823. 8.

Desfonlaines, Flora atlantica. Paris 1798-1800.4

Spoltswood, Phytologia tingitana. (1)hil. Transact. XIX, 239-249.)

Schousboe, Jagtlagelser over vestriget i Marokko. Kiobnlıavn 1800.4 . (germanice.)

Plantae senegalenses in Durand, Voyage au Senégal. Paris 1802. 8, et Atlas.

Afzelius, Genera plantarum guineensium. Upsaliae 1804. 4.

Palisot-Beauvois, Flore doware et de Benin en Arrique. Paris 18041807. (-1821?) folio.

Raffeneau-Delile, Mémoires botaniques $(1-V)$ extraits de la "Deseription de l'Egypte». Paris 1813. folio.

Afzelius, Remedia guineensia. Upsaliae 1813-1817.4.

_. Stirpium in Guinea medicinalium species novae. Lpsaliae 1818 -1829.4 . 1825.4

Brown, Observations systematical and geographical on the Herbarium collected by Prof. Christion Smith in the vicinity of the Congo. London 1818.4 . (gallice.)

(Verm. Schriften. I, 167-336.)

Sieber, Herbarium Florae aegsptiacae. Vindohonae 1820. folio.

Sabine, Some account of the edible fruits of Sierra Leone. London 1824. 4.

Tiviani, Florae lybicae specimen. Genua 1824. foliu.

Raffeneau-Delile, Centurie de plantes d'Afriłue du voyage á Neroé recueillies par Cailliand. Paris 1826. 8.

Brown, Observations on the structure and affinities of the more remarkable plants collected in Central Africa. London 1826.4

(Verm. Schriften. 11, 1-7w.)

Schumacher, Beskrivelse af guineishe Planter. hiobenhavil 1827.4

Iiviani, Plantarum aegyptiarum decades $\mathrm{N}$. Genuae 1830,8 .

(Savi) Rapporto sulla collezioni di piante raccolte in Egitto dal naturalista Giuseppe Ruddi. In ejus "Alla Memoria di Giusempe Raddi». Fïrenze 1830. 4. 13. 17-33.

Guillemin, Perrotlet et Richard, Florae Seneganulsae tentamen. Paris $1830-1833 . \mathrm{gr} .4$.

Jurosez, Plantae novac capenses. Berolini 1831.8 .

Eckion et Zeyher, Enumeratio plantarum Africae australis extratropicae. I-Ill. Jlamburgi $1834-1837.8$.

Aleyer, Commentariorum de plantis Africae australioris Dregeanis fasc. III. Lipsire 1835-1837.8.

Iisiani, Plantae quaedam Aegypti et Nubiae. Palavii 1836.8.

brége, Catalogus plantarum exsiccatarum Africae australioris. 1-11]. 4837 $-1840.8$

Hariey, The genera of South African plants. Cape Town 1835. 8.

Walpers, Animadversiones in Leguminosas capenses. Halae 1839. 8.

Brunner, Botaniscbe Ergebnisse einer Reise nach Senegambien und den Inseln des grunen Vorgebirges. s. 1. et a. 8.

Hochstetler. Nova genera plantarum Africae. Ratisbonae 1849. 8.

Fenzl, Pemptas stirpium novarum capensium. Halis a/S. 1843. 8.

liaffeneau-Delile, Souvenirs d'Egypte. Herborisations au Désert. Montpellier 1844.8.

Champy, Flore algerienne. Paris 1844.8 .

Munby, Flore de l'Algérie. Paris 1847.8\%

Exploration scientifique de l'Algérie. Paris $1846 \mathrm{sqq} g r .4$.
Forster, Plantae atlanticae ex insulis Madeira, St. Jacolsi, Adscensionis. St. Helenae el Fayal. (Goettingae 1787.) 4

H'illemet, llerbarium mauritianum. Lipsiae 1796.8 .

Aubert du Petit-Thouars, Histoire des végétaux recueillis sur les isles de France, Bourloon et Madagascar. Paris 1804. 4

Histoire des végétaux recueillies dans les isles australes d'Afrique. Paris 1806.4 .

Genera nova madagascariensia.(Paris 1806.$) 8$

Bojer, Description des plantes recueillies en Madagascar. (Bouton, Rapports. Naurice $1839-1843$. 4.)

Boxburgh, List of plants from the island of St. Helena. London 1816. 4.

Antommarchi, Esquisse de la Flore de St. Helène. Paris 1825. 8.

Pritchurd, List of plants growing on the island of St. Helena. Capetown 1836. 8

(W'atson) Flora Sta. Helenica. St. Hrlena 1825. 4

Lowe, Primitiae Faunae el Florae Maderae et Portus Sancli. Cambridge 1931.4 .

- Noviliae Florae maderensis. Cambridge 1838. 4.

Pobley, A selection of Madeira nowers. London 1845 . folio.

Penfold, A selection of Madeira flowers, fruits and ferns. London 4845. royal 4

Buch, Allgemeine Lehersicht der Flora auf den canarischen Inseln. Berlin 1819. 4

Nees ran Esenbeck, Plantarum canariensium species quatuor novae. In Hor. phys. ber. Bonn 1820, folio.

Hebb et Berthelot, Histoire naturelle des iles Canaries. Tome Ill: Botanique. Paris $1836-1847.4$.

Seubert, Florn azorica. Bonnde 1844. 4.

\section{Florac Occaniae.}

Plants of use for food, medicine etc. in Otaheite. In Parkinson, Voyage London 4773. 4. . . 37-50. (germanice.)

Forster, Characteres generum plantarun, quas in itinere ad insulas mari australis collegerunt. Londinj 1776.4 . germanice.

Florulae insularum australiun prodromus. Goettingae 17868

Smith, A specimen of the botany of New-Holland. London 1793. 4

Forster, Hetharium australe. Goettingae 1797. 8.

de la Billardiere. Novae Jollandiae plantarum specimen. Paris $1804-$ 1806. 4 .

Brown, Prodromus Florae Novae llollandiae et insulae Van-Diemen. Londini 1810.8. - (Jenae) 1824. 4. - Norimbergae 4827. 8.

Verm. Schriften, vol. lll.)

Bauer. Allustrationes Florae Norae llollandiae. Jondini 1813. folio.

Brown, General remarks geograplical and systematical on the botany of Terra Australis. LomJon 1814.4.

verm. Schriften. 1, 1-166.)

De la Billarliere, Sertum austro-caledonienm. Paris 1824-1825.4.

Cunningham, Botany of the mountain country between the colony round Port Jachson and the settlement of Bathurst. Impr, cum Fields, Geographical Nemoirs on New Sud Wales. London 1825. 8. germance.)

Guillemin, leones plantarum Australasiae rariorum. Paris 1827. folio

Cunningham, General renarks on the regetation of Terra australis. Inpr. in King. Narrative of a survey of the coasts of Australia. London 1827. 8 .

(germanice.)

Sucet, Flnra australasica. London 1827-1828. gr. 8 .

Broun, Supplementum priuum Prodromi Florae Novae Hollandiae. London 1830.8

(Verm. Schriften. V, $7 \overline{7}-116$. .) 
Richard, Essai d'une Flore de la Nouvelle \%élande. (Dumont d'irville, Voyage.) Paris 1832. 8. et Allas.

Endlicher, Prodromus Florae norfolhicao. Vindohonat 1833.8.

Richard, Sertum Astrolabiatum. (Dumont dVrille, Voyage.) Paris 1834. 8. et Allas.

Guillemin, Enumération des plantes dans les iles de la société principalement Taiti. Paris 1837.8 .

Mertens, Notices botaniques sur Jes Iles Carolines. In Luetke, Vojage. vol. 111, P. $132-144$.

(Endlicher, Bentham, Fensl, Seholt) Esumeratio plantarum quas in Nova Hollandia collegit Kart von Huegel. Viudobonau 1837. 8.

Fudlicher, Stirpium australasiearum decales tres. Vindohonae 1838. 4.

lindley, 77 novae species plantarm Australiae, in Mtchell, Three expeditions etc. London 1838. 8.

(Lelmann) Plantae Preissianae ex Australasia occidentali et meridionalioccidentali. Hamburgi $1844-4847.8$.

Raoui, Choix des plantos de la Nouvelic-Zulande. Paris 1846 . gr. 4.

Ilombron et Jacquinot. Plantes pluanérogames de la Voyage de L'Astrolahe et de La Zélèe vide: Dumont d'Trville.

\section{Calendaria Florae.}

Linne, Calendarium Florae (upsaliensis). Epsaliae 1756.4. (anglice, suecier.)

Stillingfeet, The calendar of Flora. London 1761.8 .

Leche, Några tráds blomningstid. (Vetensh. Acad. llandl. 1763. p. 259.)

Ferber, Blomster-almanach for Carlscronas elimat. (Vetensk. Aead. Ilandl. 1771. p. $75-88$.)

Bjerkander, Blomster-almanach ele. (ib. 1780. p. $130-137 .-1786$. p. $51-57$. - 1789. p. $303-310 .-1790$.p. $136-143 .-1791$. p. $281-293 .-1792$. p. $18-28,69-78,194-228 .-1794$. p. 197 -222.)

Wralch, Calendarium Palaestinae oeconomicuin. Goettingae (1785.) 4.

Buhle, Calendarium Palaestinae oeconomicum. Goettingae 1785. 4.

Hellenius, Specimen calendarii Florae aboérsis. Aboae 1786. 4.

Ilaenke, Blumenkalender fur Bohmes. (Ablanill. der bohm. Gesellsehaft. 1787. p. $94-135$.

Jirasek, Blutbenkalender. (ib. 1787. p.322-336.)

Schmidt, Bluthenhalender. (ib. 1788. p. 48-80.)

Enckel, Observationer gjorde i Sảdankyla Lappmark. (Vet. Acad. Ilandl. 1790. p. $78-79$.

Heigel, Schlesischer Pflanzenkalender. s. 1. 1791. 8.

Nordmeyer, Calendarium Aegypti oeconomicum. Goettingae 1792. 4.

While, Calendarium Florde of Selborne. London 1795. 8.

Blumenkalender finr das gemassigtere Europa und die Sehweiz. (Magazin fur die Bot. XI, 41-117.)

Amaud, Calendrier républicain botanique. Avignon 1799. 12.

(Chastenet) Calendrier de Flore. Paris 1802-1803.8.

Meyne, Pflanzenkalender. Leipzig 1804. 8.

Herrmann, Calendarium plantarum in Marehia media eirea Berolinum. Berolini 1810. 12.

Phelps, Botanieal ealendar. London 1810.8.

Neygenfind, Kalender der sellesisehen Flora. Meissen 1822. 8.

IVeise, Deutseblands Pflanzenblutekalender. Fotha und Erfurt 18311832. 8.

Dobel, Neuer Pllanzenkalender. Nurnberg 1\$35. 8.

Kreulzer, Authoebronologicon Europac merliae. Wien 1840.12.

Bluthenkalender Wiens. Wien 1840.12.

\section{Plantac fossiles.}

\section{Generalia.}

Scheuchser, IJerbarium diluvianum. Tiguri 1709. folio. - Ed. II : Lugduni Bat. 1723. folio.

II"allerius, De vestigiis diluvii universalis. Upsaliae 1760.4

Parkinson, Organie remains of a forner world. London 1811. 4.

Limk, Die Urwelt und das Alterthum. Berlin $1820-1822.8$. - ib. 1834.8 .

Schlotheim, Die Petrefactenkunde. Gotha 1820. 8. - Nachträge: ib. $1822-1823.8$.

Breda, Oratio de Florac mundi primizenii reliquiis in lithantluracum fodinis, Gandavi 1823. 4.

Brongniart, Des lignites. Paris 1823. 8.

De France, Talleau des eorps organisés fossiles. Paris 1824.8 . (rossice.)

Brongniart. Considẻrations générales sur la nature de lo végétation ete. Paris 1828.8.

Joll, llandbueh der Petrefaktentiunde. Dresden 1829-1830. 8.

Choulant, Die Vorwell der organisehen Wesen auf der Erde. Dresden 1830. 8.

Boue, llémoires géologịues et paléontologirques. Paris $1 \$ 32.8$.

Zentier, Beitráge zur Naturgesehichte der Lrwelt. Jena 1\$33. 4.

Goeppert, Ieber die Bestrehungen der Schlesier, die Flora der Vorwelt zu erlautem. Breslau 1834. 8 .

Dank und Bine an die Schlesier. (Breslau 1833.) 4.

Leuchart, Veler die Verbreitung der Reste einer vorweltitchen organischen Schopfung. Freiburg i/Br. 1835.4.

Bronn, Lethaea geognostica. Stuttgart 1835-1838. 8.

Buckland, Geology and mineralogy. London 1836. 8 . (germanice.)

Goeppert, Ueber den Zustand fossiler Pflanzen und den Versteinerungsprocess. Lemgo 1837. 8.

Brongniart, Considtérations sur la sature des végétaux qui ont cousert la surface de la terre. Paris 1838 . 4 .

Collegno, Distribution des débris rẻgtetaux dans les dépots, qui se forment de nos jours. Paris 1838.4 .

Muenster, Beitráge zur Petrefaktenhunde. Bayreuth 1\$39-1846. Vll Hefte. 4 .

Mantell, The medals of ereation. London 1844.8. (germanice)

Schmidt, Petrefaktenbueh. Stuttgart 1846. 4.

Durker, Palaeontographica. Cassel 1846 sqq. 4.

\section{Topographiae; animalia el plantae.}

Bueltner, Rudera diluvii testes. (Querfurt.) Leipzig 1710.4.

Mylius, Memorabilia Saxoniae subterraneae. Leipzig 1720. 4.

Tollmann, Silesia subterranea. Leipzig 1720. 4.

Schuebier, Systematische Vebersicht der Versteinerungen Wütembergs. Tulingen 1830.8.

Berger, Versteinerungen der Pflanzen und Fische im Coburger Sandstein. Coburg 1832. 4.

Kurlae, De petrefactis in schisto bituminoso mansfeldensi. llalae 1839. 4. Steininger, Geognostisclie Beschreibung des Landes zwischen der untern Saar und dem Rheine. Trier 1841.4 .

Rocmer, Die Versteinerungen des llarzgehirges. IIannover 1843.4.

Retuss, Die Versteinerungeu der bolmmischen hreideformation. Stutgart $1845-1846$. roval 4 .

Dunker, Monographic der norldeutschen Wealdenbildung. Braunschweig 1846.4 .

Quenstedt, Petrefaktenkunde Deutschlands. Tübingen 1846 suq. 8. 
Marlin, Petrificata derbiensia. Wigan 1809. 4.

Mantell, The fussils of the south downs. London 1892.4.

Buckland, Reliquiae diluvianae. London 1824. 4

Mantell, Illustrations of the geology of Sussex. London 1827. 1.

Hoodward, Synoptical table of british organic remains. Loudon 1830.8 .

Morris, A catalogue of britisl fossils. London 1843. 8 .

Etie do Beaumont, Notice sur un gisement des vẻgétanx fossiles et des Bólenniles. Paris 1828. 8 .

Matheron, Catalozue méthodique et descriptif des corps organisées fossiles du dejp. des Bouches-du-Rhòne. Marseille 1842. 8.

Torrubia, Aparato para la historia natural española. Madrid 1754. 4.

Kutorya, Beitrag zur Geornosio und Paltaontologie Dorpat's. St. Petersburg 1833.

Bromell, Lithographiao suocanae specinen secuudum. (Holmiae 1727.) 8. Ilisinger, Esquisse d'un tableau des pétrifications de la Suède. Stockliolm 1829.8. - ib. 1831. S.

Catalogue des fossiles de la Suède. Stockhulm 1831. \&

Lethaea suecica. Holmiae 1837-1841. 4.

Morton, Symopsis of the organic remains of the cretaceous groupe of the Luited States. Philadelphia 1834. 8.

\section{Ilantae fossiles generatim.}

Reichel, De vegetabilibus petrefaclis. Vitembergae 1750.4

Sehlotheim, Besclureibuog meshwurdiger lirauteralsdrucke. Fotha 1804 gr. 4.

Sternberg, Versuch ciner Uarstellung der Jlora der Vorwelt. Leipzig und Prag 1820-1838. folio. (gallice.)

Brongniart, Notice sur les végétaux fossiles. Paris 1821. 4.

1822.4.

Artis, Antediluvian phytology. London 1825. 4.

Brongniart, l'rodrome d'une histoire des végétaux fossiles. Paris 1828. 8 Histoire des végétaux fossiles. Paris 1828-1837.4.

Goeppert, Uebersicht der Gattungen der fossilen Ptlanzen. (Halle 1837.) 8 De llorihus in statu fossili. Vratislaviae 1837.4.

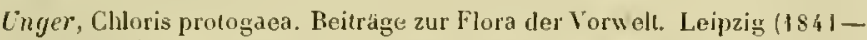
1847.4.

Geppert, Die Gattungen der fossilen Planzen. Bonn 18 12-1845. 4. obl Corda, Beitráge zur Flora der Torwelt. P'rag 1845. 4.

Unger, Synopsis plantarum fossiliun. Lipsiae 1845. 8

Plantae fossiles singularum regionum vel formationum.

Burtin, Des bois fossiles dans les Pay's-Bas. Haarlem 1781. 8.

Nau, Pflanzenabdrucke und Versteinerungen aus dem Koldenwerhe st. Jugbert in Lairischen Rheinkreise. Munclsen 1821.6.

Rhode, Beiträge zur Pllanzenkunde der Vorwelt. Breslau 1821-1823. folio.

Rozan, Conjectures sur les plantes fossiles du mont Bolci. In ejus "Essais». Naples 1823. 4 .

Bronguiart, Observations sur les végètaux fossiles renfermés dans les grès de hoer en Scanic. Paris 1825. 8.

Fischer von II aldheim, Notice sur les végétaux fossiles du gouvernement de Moscou. Moscou 1826. 4.

Jueger, Ueber die Pflanzenversteinerungen in Bansandstein. Stuttgart 1827. 4.

Brongniart, Notice sur les plantes (fossiles) d'Armissan près Narbonne. Paris 1828.8 .
Lindley et Ifutton. The fossil Elora of Great-Britain. London I\$311837.8.

Gutbier, Abdruche und Versteinerungen iles Zwichauer Schwarzhohlengebirges. Zwickau 1835.8.

Goldenberg, Grundzuge der vorveldichen Flora um Saarbruchen. Saarbruchen 1835.4.

Mammall, A collection ... the formation of the Ashby-coal-fielıl. Ashbyde-la-Zouch 1836. gr. 4.

Haillinger, Veber das Vorkommen ron Pflanzenresten in den Braunkohlenund Sandsteingebilden des Elhogner Kireises. Prag 1839. 4.

Rost, De Filicum ectypis in lithanthracum wothuensium fodinis. Halac 1839. 8.

Bowerbank, A history of the fossil fruits and seeds of the London Clay. Lonton 1840.8 .

Iloenninghaus, Ueber fossile Blatter im Susswasserkalk voun Membach. Crefelel 1840 , 年.

Kossmaessler, Bejträgo zur Versteinerungskunde. Dresden 1840. gr. 8.

Goeppert, Fossile Flora des Quatlersandsteins. Breslau 1841.4.

_ Fossile Flora der Gipsformation. Breslau 1842. 4.

Brongniart, Algues fossiles en Tauride. In Demidoff, Toyage. vol. I1. Paris 1842.8

Parlatore, Sullo impronte de' vegetabili fossili nella Maremma coscana (Firenze 1843.) $\mathrm{S}$.

Schimper et Jlougeot, Ionographie des plantes fossiles du grès bigarxé des Vosges. Leifrzig 1844. 4.

Goeppert, Uebersicht dor fossilen Flora Sclılesiens. (Breslau 1844.) 8.

Germar, Die Versteinerungen des Steinkohlengebirges von Wettin und Lobejun in Sialkreise. IIalle $\$ 844 \mathrm{sqq}$. folio.

kirr, Beitráge zur fossilen Flora ter Juraformation Wurtembergs. Stuttgart 1845.4.

Schleiden, Ueber die fossilen Pilanzenreste des Jenaischen Muschelkathes. In Schmid und Schleiden "Die geoguostischen Verlutlunisse des Saalthals v. Leijuzig 1846 . folio. D. $65-72$.

Unger, Ueber die fossile Flora von Parsclalug. (Grátz 1847.) gl. 8

\section{Monographiae plantarum fossilium.}

Langhanns, Programm vou einem versteinerten Baume. Landshut 1736.4. Schultze, Kutze l3etrachtung der verstenerten Holzer. Dresden 1754. 4. -_ Kurtze Betrachtung derer Kräuterabdrucke. Dresden 1755. 4.

Wraldin. Die Frankenberger Versteinemaen. Marbury 1778. 4.

Stelluti, Del legno fossile uuovamente scoperto. (B. B. IV, 175.)

Noeggerath, Ueber aufrecht im Gebirgsgestein eingeschlossene fossile Baumstámme. Bom 1819.8.

1891.8

Martius, De plantis nomullis antediluvianis ope specierum intra tropicns viventium illustrandis. Ratisbonae 1821, 4.

Unger, De Palmis fossilibus. In Martius, Genera et species Palmarum. Monachii 1823. folio.

Sprengel, Commentatio de Psarolithis. Halae 1828.8.

Writham, Observations on fossil vegetables. Edinburgh 1831.4

Cotta, Die Denrlrolittien in Beziehurg auf ihren inuern Bau. Dresden 1832.4.

If itham, The internal structure of fossil vegetables. Edinburgh 1833.4.

- Description of a fossil tree. Elinburgh 1833.4

Goeppert, Systema Filicum fossilimm. Breslau et Bonn 4836.4 .

Ptzholılt, De Calamitis et Lithanthracibus. Dresdae 1841.8 .

Ueber Calamiten und Steinkolslenbililung. Dresden 1841.8.

Gutbier, Veber einen fossilen Farrenstamm, Caulopteris Freieslebeni. Zwickau 1842. 8 . 


\section{Lithanthraces. Turfa.}

Buenting, Sylia suluteranea. llalle 1603. 12.

Mueller, Grundlicher Bericht vou Tarf von Taubenried. Ulm 1752. 8.

Bellery, lissertation sur la tourbe do Picardie. Paris 1754. 12.

- Mémoir e sur la tourbe de Picardie. Paris 1795. 8.

Abildgaard, Do caespite Jituminoso. Havniac 1761.8 .

(danice, germanice.)

Ilagen, Betrachtungen uher den Torf. Konigsherg 1761. 4.

Tilius, De cespite ustili vulgo Turfa. Wittebergae 1794. 4

Voigt, Versuch einer Geschichte der Steinkolılen, dor Braunkolılen und des Torfes. Weimar 1802-4805.8.

Schulae, Vom Entstelıen der Braunkolıle. Halle 1826.8.

Il'iegmann, Ueber die Eutstelıng des Torfes. Braunschweig 1837. gr. 8. Zippe, Die Steinkohlen. Prag 1842. gr. 8.

Stiehler, Ueber die Bildung der Steinkohle. Braunschweig 1843. S.

Lesquereux, Quelques recherches sur los marais tourhoux. Neuchatel $184 \% .4$.

1844.8

Grisebach, Ueher die Bildung des Torfs. Göttingen 1846.8.

\section{Succinum.}

Aurifaber, Succini historia. Königsberg 1551.4.

Peucer, Propositiones de origine ol causis succini. Wittebergae 1555. 8. Gocbel, De succiuo libri duo. (Francofordiac a/MI. 1558.) 8 .

Itermann, De rana et lacerta succino insitis. Cracoviae 1580.8.

Baumgarten, Der kostliche Agtsteil oder Bornstein. Magdelıurg 1587. 12. Wigandus, Vera historia de succino borussico. Jenae 1590.8.

Zoelner, De succino. Lipsiae 4604.4

Schulze, De succino marchico. Thoruni 1612.4.

Pauli, De succini natura. Dantisci 1614. 4.

Crueger, De succino. Regiomonti 1636. 4.

Thito, De succino. Wittebergae 164\$. 4.

Concius, De succino. Regiomonti 1660.4.

Gruenenberg, Exercitatio physica de succino. Regiomonti 1660. 4.

Thilo, De succino Borussorum. Lipsiae 1663. 4.

Schelwig, Theses de succino. Thorunii 1671. 4.

Schenckius, De succino. Jenae 1671. 4.

Ilartmann, Succini prussici plysica et civilis historia. Francofurti a/ $\mathrm{V}$. 1677. 8.

Kemper, De succino. Jenae 1682. 4.

Jartmann, Succincta succini prussici historia Berolini 1699. 4.

Yesti, Succinum plrysice et medice consideratum. Erfordiac 1702. 4.

Hartmann, De succino. Lugd. Bat. 1710. 4.

Sanden, De succino electricorum principe. Regiononti 1714.4.

Schrocler, De jure succini in regno Borussiae. Regiomonti 1722. 4.

Sendel, Electrologiae missus J-III. Elbingae 1795-1728. 8.

Kulm, De succino. Gedani 1728. 4.

Schulze, De succino. Halde 1734. 4

Ancher, De succino. Havniac 4737. 4.

Rappoll, De origine succini in litore sambiensi meditatio epistolaris. Regiomonti 1737. 4.

Sendel, Historia succinorum corpora alicna involventium. Lipsiae 1742. falio.

Stokar de Neuforn, De succiuo in genere et speciatim de succino fossili wilholzensi. Lugd. Bat. 1760. 4.

Bock, Naturgeschichte des preussischen Bernsteins. Konigsberg 4767. S

Hasse, Der aufgefundne Eridanus oder neue Aufschlusse uber den Bernstein. Riga 1796.8.

- Preussens Anspruch, als Bernsteınland das Paradies gewesen zu sein. Konigsberg 1799, 8.

John, Naturgeschiclute des Succin's. Koln 1816.8.
Schweigger, Bemerkungen uluer den Berustein. In ejus "Betraclutungenn. Berlin 1819.4.

Ayrke, liragmente zur Naturgeschichte des Berusteins. Danzig 1835. 8.

Roy, Ansichten uber Entstehung und Yorkonmen des Bernsteins. Danzig 1840. gr. 8.

Steinbeck, Ueber die Bernsteingewinnung bei Brandenburg an der Havel Brandenhurg (1841.) gr. 12 .

Goeppert ot Berendt, Dor Bernstein und die in ihm Jefindlichen Pflanzenreste der Vorwelt. Berlin 4845 . folio.

\section{Monographiac.}

\section{Plantae cryplogamae.}

Weiss, Plantue cryptogamicae Florae gottingensis. Gottingae 1770. 8.

Koelreuter, Das entdechte Gebeimniss der Kryptogamic. Karlsrulıe 1777.8.

Ilappe, Flara cryptoganica depicta. Berolini 4783. 4.

Hedwig, Theoria generationis et fructificationis plantarum cryptogamicarum. Petropoli 4784. 4. - Lipsiae 1798. 4.

Dickson, Fasciculi IV plantarum cryptogamarum Britanniae. Londen 1785 -1801.4 .

Iledwig, Descriptio et adumbratio Muscorum frondosorum et aliorum vegetantium o classe cryptogamica. Lipsiae 1787-1797. folio.

Rutström, Spicilegium plantarum cryptngamarum Succiac. Ahoae 1794. 4.

IIoffmann, Doutschlands Flora. Kryptogamie. Erlangen 1795. 12.

Kunze, Deutschlands kryptoganische Gewáchso. llamburg 1795. S.

Schrader, Systematische Sammlung kryptogamischer Gewachse. Götingen 1796-1797. 8 .

Sturm, Deutschlands Flora. Ḱryplogamen. (Lichenes, von Laurer, Jungermannieae und Algae, von Corda.) Nurnberg 1798-1839. 12.

Jolyclere, Cryptogamic complète. Paris (1790.) 8.

Mohr, Observationes hotanicac, quibus cryptogamarum ardines, genera et species illustrare conatus est. Kiliae 1803.8 .

Sprengel, Einleitung in das Studium der kryptogamischen fewachse. Ilalle 1804.8. - ib. 1818. 8.

IVeber, Anlang zu Sprengel's Einleitung etc. Kiel 1804. 8.

Willdenow, De vegetabilium cryptogamicarum dispositione. (Praefatio ad Rebentisch, Prodr. Fl. neom.) Berolini 1804. 8.

Nueller, Tentamen accuratioris cryptogamiae definitionis. Goettingae 1805.8

Duval. Verzeichniss der larrenkràter, Laubmoose und Flecluten an Regensburg. Nurnberg 1806-1808. 8.

Funck, Kryjutogamische Gewáchse des Fichtelgebirges. Leipzig $1806-$ 1838. 42 Hefte. 4.

IVeber und Mohr, Deutschlands hryptogamische Gewachse. Kiel 1807.12.

Raddi, Di alcunc specie nuove e rare di piante crittogame. (Firenze 1508.) 4.

Pinte criltogame ritrovate nei contorni di Firenze. (Fireuze 1808.) 4 .

Girod-Chantrans, Cryptogames du dêp. du Doubs. In ejus "Essai sur la géograplie $n$. Paris $1810,8$.

Hooker, Plantae cryptogamicae, quas collegerunt //umbold et Bonpland. Londini 1816.4 .

Opiz, Deutschlands kryptogamische Gewachse. Prag 1816. 8

Martius, Flora cryptoganica erlangensis. Norimbergac 1817.8.

Ritter, Versuch einer Beschreibung von Kryjtogamen in Schleswig-Holsteill. Augustenburg 1847. 8.

Steucart, Hortus cryptogamicus edineusis. Edinburgh 1819.

Le Turquier Delongchamp et Levicux, Concordance des figures des plantes cryptogames. Rouen 1820.8.

Maerklin, Betraclitungen uber die Urformen der niedern Organismen. Heidelberg 1823.8 .

Bischoff, De plautarum praesertin cryptogamicarum transitu el analogia. Ileidelbergie 1825. 8 
Libert, Mémoires sur les crjptogames aux environs de Malmédy. Paris 1826. 8.

Bisckoff, Dio kryptogamischen Gewächse. (Chareen, Equiseteen, Rhizoliarpen und Lycopodeen.) Nurnberg 1828.4.

Bory de St. Vincent, Cryptogamie, (Algae, Lycopodiaceae, Filices) faisant partie du voyage autour du mondo par Luperrey. Paris 1828. 4.

Prost, Liste des mousses, hépatiques et lichens du dép. de la Lozère. Mende 1828. 8.

De Brondeau, Recueil des plantes cryptogames de l'Agenais. Agen 1828 -1830.8 .

Martius, Icones plantarum eryptogamiearum Brasiliae. Mlonachii $1828-$ 1834. folio.

Numan et Marchand, Sur les propriétés nuisibles des fourrages par des productions cryplogamiques. Groningae 1830. 8. (hollandico.)

Wallroth, Flora cryptogamica Germanicte. Norimbergae 1831-1833. 12.

IIall, Miquel et Dassen, Flora Belgii septentrionalis. Cryptogamia. Amsterdam 1832-1\$36. s.

Martius, Eschweiler et Nees von Esenbeck, Flora Jurasiliensis. (Algae, Lichenes, Hepaticae.) Stultgardiae 1833,8.

Mohl, Ueber Entwicklung und Bau der Sporen der Kryptogamen. Regensburg 1833. 8 .

Roxburgh, The cryptogamous plants, forning the fourth part of the lilora indica. s. I. et a. 8 .

Montagne et Steinheil, Notice sur les eryjtogames recueillies aux environs de Bone. (Paris 1834.) 8.

Ifontagne, Cryptogamés découvertes par Guudichaud dans l'Amérịue méridionale. (Paris 1834.) 8.

Grateloup, Cryptoganie tarbellienne. (Bordeaus 1835.) 8.

Lickx, Flore eryptogamique des environs de Louvain. Bruxelles 1835. 8.

Montagne, Enumération des mousses et hépatiques recueillies par Leprieur dans la Guiane centrale. (Paris 4835 .) 8 .

_- Prodromus Florae fernandesianae. (Plantae cellulares.) (Paris 1835.) 8.

Notice sur les plantes cryptogames à ajouter a la Flore francaise. Paris 1835-1836. S.

Desmazières, Plantes cryptogames de la France. Lille 1825. 4. - Ed. II: ib. $1836-1945.4$.

Genth, Flora des Herzogthums Nassau. 1. Theil. Kryptogamie. Mlainz 1836.8 .

Yontagne, Plantes cellulaires des iles Caharies. (Webt et Berthetot, Histoire etc. tome III. sectio lil.) Paris 1836-1847.4.

Garovaglio, Delectus specierum novarum eryptogamicarum. Ticini 1837 1838. 8 .

Catalogo di alcune crittogame nella provincia di Como e nella Valtellina. (Musci frondosi et Lichenes.) Como, Mlilano e Pavia 1837 -1843.8 .

Mohl, Morphologische Betrachtungen uher das Sporangium der mit Gefässen verselienen kryptogamen. Tubingen 1837.8.

Montagne, Cryptogames algériennes. (Paris 1838. ) 8. Centuries $(\mathbf{I}-\mathbf{V})$ des plantes cellulaires exotiques nouvelles. (Paris $183 \mathrm{~s}-1845)$.8 .

- Lryptogamae brasilienses. (Paris 1839.) S.

Florula boliviensis. Paris 1839. 4. (D'Orbigny, Voyage.)

Sertum patagonicum et Florulae boliviensis stirpes novae vel ininus cognitae. In IJ Orbigny, Voyage. vol. Ill. sectio II.

Plantes cryptogames de la Voyage de L'Astrolabe el de La Zélèe vide: Dumont d'Urvilte.

Trevisan, Enumeratio stirpium eryptogamicarum frovinciae patavinae. Patavii 1840.8 .

Kickx, lecherches pour servir a la Flore cryptogamique des Flandres. Bruxelles 1840-1846. 4 .

Montagne, Cryptogamae nilgherienses. (Paris 1842.) 8.

Eisengrein, Einleitung in das Studium der Ahotyledonen. (Allgeneines. Algen. Flechten.) Freiburg 1842-1844.8.
Montagne, Cryptogamie. Exposition sommaire de la morphologie des plantes cellulaires. Paris 1843.8.

Mougeot, Index stirpium cryptogamarum vogeso-rhenanarum, fase. I-Xll. Bruyerii 1843.4

Dietrich, Deutschlands kryptogamische Gewachse. Jena 1843-1846.'8.

Saubinet, Notice sur les mousses et les fougères des environs de Reims. (Reims 1844.) 8.

Montagne, Plantae cellulares in insulis philippinensibus a cl. Cuming collectae. (London 1844.) 8.

_. Plantes cellulaires du Voyage au pole sud et dans l'Océanie par Dumont d'Urvilte. Paris 1845. 8. et Allas.

Hooker, The cryptogamic botany of the antarctic voyage. London 1845.4.

Ruprecht, Distributio cryptogamarum vascularium in imperio rossico. Petropoli 1845.8.

\section{Fungi.}

Jonghe vel Junius, Phalli in Ilollandiae sabuletis crescentis descriptio. Delphis 1564.4 .

Ciccarellus, Opusculum de Tuberibus. Patavii 1564.12. (gallice.)

Cornelissen, Sur les Tubera des anciens (Suttonius). S. I. el a, 8.

Sevcrinus, Epistolae de lapide fungifero et de lapide fungimappa. Patavii 1649. 4. (gallice.)

Sterbeck, Theatrum Fungorum. Antwerpen 1675. 4.

Breyn, De Fungis officinalibus. Lugd. Bat. 1702.4.

Lancisi, Dissertatio epistolaris de ortu, vegetatione et textura fungurum. Romae 1714. folio.

Marsigli, De generatione Fungorum. Romae 1714. folio.

Brucchmam, Fungi subterranei, vulgo tubera terrae dicti. Helmstadiae 1720. 4 .

De Fungo hypoxylo digitato. IJelmstadii 4725, 4.

Epistola itineraria $\mathbf{X X}$ de Tuberibus terrae. Wolfenbuetteliae 1730.4 .

Wedel, De Fungis. Jenae 1744. 4.

Gleditsch, Methodus Fungornm. Berolini 1753. 8.

Battarra, Fungorun agri ariminensis historia. Faventiae 1755.4.

Linné, Fungus melitensis. Upsaliae 1755. 4.

Hill, of the mushroom stone. London 1758.8.

Schaeffer, Vorlaufige Beobachtungen der Selıwämme um Regensburg. Regenslurg 1759.4.

- Der Gichtschwamm mit grïnschleimigem Ilute. Regenshuro 1760. 4 .

Icones et descriptio fungorum singularium. Abbildung ete. Regensburg 1761. 4.

- Fungorum qui in Bavaria el Palatinatu cirea Ratisbonam nascuntur, icones. Ratisbonae 1762-1774. 4.

Mueller, Efterretuing om Srampe. Kiobenhavn 1763.4.

(germanice.)

Marsili, Fungi carrariensis historia. (Patavii) 1766. 4.

Pennier, Sur les trulfes et sur les champignons. Avignon 1766. 12.

Scopoti, Fungi quidam rariores in Hungaria detecti. In ejus: Anno list. nat. 1Y. Lipsiae 1770. 8. p. 144-150.

- Plantae subterraneae. In ejus "Dissertationes». Pragae 1772.8. p. $84-120$, tab. $1-46$.

Duchesne, Description de deux champignons observés aux environs de Paris. 1772. 4.

Fellner, Prodromus ad historiam Fungorum agri vindobonensis. Viennae 1775. 8.

Boelhmer, De dubia Fungorum collectione. Wittebergae 1776. 4.

Huth, Vom Entstelien des Schwammes in den Gebauden. Jalberstadt 1776.8.

Lidbech, Fungi renno vegetabili vindicati. Londini Gothorum 1776. 4. 
Spallanzani, Osservazione e sperienze intono all origine lelle piantine dollo Mufle. lı ejus "Opuscoli di fisican. Modena 1776. 8. vol. II p. $255-277$. (gallice.)

Kichler, De Agarices. Goettingac 1778 ,

liubel, De Agarico officinali. Vindobonae 1778. 8.

Gruner, De virtutilus Agarici muscarii. Jenalo 1778. 4.

Borch, Lettres sur les truffes te Piémont. Milan 1780. 8

Bryant, Two species of Lycoperdon. London (1752.) 8.

Krapf, Boschreibung der un Wien wachsenden Schwanme. Wien 1782.4.

Necker, Traité sur la Mỵcitologie. Maunheiu 1783. 8.

Butseh, Jienchus Fungorum. Halae 1783-1789. 4.

Enslin, De Boloto suaveolente 1. Erlaugae 1784. 4. (germanice.)

herner, Giftige und esshare Schwtimme. Stutgart 1786. 8.

Picco, Nelethemata inanguralia. (De l'ungorum generatione ete.) Augustae Taurin. 1788.8

Dardana, In Igaricum campestrem reseno el patria infamem acta a Yictorium Picum. Aug. Taur. 1788. 8.

Planer, Fungi agri erfurteusis. Erforliae 1788. 8.

Bolton, A history of fungusses glowing about llalifax. Juddersfield 1788 $-1791.4$

(errmanice.)

(Ilofmarn) Nomenclator Jutugorum. (Agarici.) Berlin 1789-1790. 8.

Tode, Fungi mecklenburgenses selecti. Luenelsurgi 1790-1791. 8.

IJolm nobilis Holuskjold, Beata ruris otia Fungis danicis inpensa. Javniae 1790-1799.) Solio.

Paulet, Taluda plantarum fungosarum. Paris 1791. 亿.

Bulliard, Ilistoire des champignons de la France. Paris 1791-1798. folio. (Panches 601-602 fubluées par Raqpail. Paris 1810. folio.)

Buchoz, Collection curieuse des elrampignons. Paris 1792. folio.

(Forster) Peziza ruticulosa. (Iondon 1792.) 16.

JVulfen, Icones jictae Fungorum ineditae. s. a. 4.

IIumboldt, Florae fribergensis specimen. Berolini 1793. 8 .

Paulet, Traité des champignons. Paris 1793. (-1835.) 4.

l'ersoon, Observationes mycologicae. Lijssiae 1796-1799.8.

Blottner, De Fungorum origine. Ilalae 1797. 8.

Ulolm nobilis IVolmshold, Curiphani Clavarias Ramariasque complectentes. Lipsiae 1797.8 .

Persoon, Tentamen dispositionis methodicae Fungorum. Lipsiae 1797. 8. Commentatio de Fungis clavaeformibus. Lipsiae 1797. 8

lloffmann, Vegetabilia in Heregniae subterraneis vollecta. Norimbergae (1797-) 1811. folio.

Sowerby, Coloured figures of english Fungi or Muslirooms. London 1797 $-1809 .(-1815$.) folio.

De Candolle, Notice sur Io Reticularia rosea. Paris 1798.

Persoon, lcones et deseriptiones Fungorum minus cognitorum. Lipsiae $(1798-1800)$.

Ellrodt, Schwammpomona. Baireuth 1800.12

Persoon, Commentarius in Schaefferi Fungorum Bavariae icones pictas Erlangae 1800.4.

Hayer, Essbare Selowimme. Berlin 1801. folio.

Persoon, Synopsis methodica Furgorum. Goettingae 1801. \&

l)e Candolle, Note sur le gemre Rhizumorpha. (Bull. soc. plilos. 4803. p. 202.)

Persoon, Icones pictae rariorum Eungorum. Paris 1803-1806. 4.

Frenzel, Ueber die Entstohung der Erdschwamme. In ejus: Physiologisclie Beobachtungen. Weimar 1804. 8 .

Traltinick, Fungi austriaci. Wien 1804-1806.4. - ib. 1830.4.

Alberlini et Sichaveinitz, Conspertus Fungorun in agro niskiensi. Lij)siae 1805.8 .

Rebentiseh, Descriptiones alisuot Fungornu. In ejus "dudex". Rerolini 1805.8

Targioni-Tozzelli, Sopra alcuui funghi ritrovati nell apparechio di una fratura. Moulena 18u5. 4
Haberle, Das Gewdichsreich. Erste Familie: Pilze. Weinar 1806, S - Beobachtungen ulser das Entstehen der Sphaeria lagenaria Pers. so wie des Merulius destruens l'er's. Erfurt 1806. 8.

De Candolle, Sur les rlampignous parasitus. (Ann. Mus. dhist. 1807. vol. I.I, p. $56-74$.

Quadri, Notizie intorno arl una specie di fungo releooso. Milano 1907.4. Bayle-Barelle, Descrizione tei funghi nocivi o sospetli. Mlilano 1808.4.

Nysten, Revherches sur les maladies des vers a soie. Paris 1808. 8.

Siemssen, Naturgeschichto los llausschwammes. Leipzig 1809. 8.

Trallimich, Die esslsaren Schwanne des Kaiserstaates. Wion 1809. 8. i). 1830.8

Sturm, Deutsclilands Flora. Pilze. (Von Ditmar, Rosthorius, Corda und Preuss.) Nümberg 1813-1848. 12.

Fischer, Anleitung zur Trúlfeljagd. Karlsrulıe 1814.8.

Liboschitz. Beschreilung eines neuentdeckten Pilzes. Wien 1814, folio.

Malacarne, Di un fungo delle classe de Licoperdi. Verona 1814.4.

Bonato, Osservazioni sojra i funghi mangereccj. Padova $1815 . \mathrm{S}$. Sull' uso de funghi. s. l. et a. 4.

De Candolle, Mémoire sur les Rhizoctones, nouveau genre des cliampignons, qui attaque les racines des plantes. (Mém. Mus. d'hist. nat. is15. It, j. $209-216$.

- Mémoire sur le genre S.lcrotium el en parliculier sur l'ergot des Céréales. (Mém. Mus. d'híst. nat. 1815. IJ, 401-420.)

Lespiault, Notice sur les champignous compstibles. Ageu 1845. 8.

Fries, Observationes mycologicat. Javniae 1815-1818.8. - ib. 1894.8.

Nees von Esenbeck, Das System der pilze und Sillwanme. Wurzlourg 1816. 4.

Otto, Versuch einer Anordnuog der Agaricorum. Leipzig 1816. 8.

De Candolle, Némoires sur les champignons parasites: Xiloma, Asteroına, Polystigma et Stilbospora. (Mus, d'hist. nat. de Paris. 1817. III, 312 -340$.

Fries, Specimen systematis tnycologici. Lundae 1817.8 .

- Symbolac Gasteronycorum. Lundae 1817-1815. 4

Kunze et Schmidt, Mykologische Hefte. Leipzig 1818-1823. \&

Ehrenbery, Sylvar mycologicae berolinenses. Berolini 1818.4.

Persoon. Traité sur des elumpigmons comestil)les. Jaris 1818.8. (germanice.)

Nees eon Esenbeck jun., Radix plantarum mycetoidearum. Bonnae 1819.4.

Ehrenberg, Enmueratio Fungorum a Chamisso collectorum. Jn Hor. phys. ber. Bonn 1820 . folio.

- Syzygites, eine neue S.himudgattung. s. 1. et a. 4.

Krombholz, Conspectus Fungorum esculentorum. Prag 1821.8.

Schlechtendal, Erineum Pers. Regensburg 1824.4.

Fivies, Systoma mycologicum. Gryphiswaldiae 1821-1830. $\$$.

Eschueiler, J)e fructificatione generis RJizomol"phae. Elberfeldiae 1592. 1.

P'rsoon. Mycologia europaea. Erlangoe 1892-1828.8.

Desmazieres, Noticr sur les Lycoperdous de Limne. Arras 1823.8.

Cireville, Scotish eryptogamic Flora. Edinhurgh $1893-1829.8$.

Brigunti, De Fungis rarioribus regni neapolitani. Neapoli 1824.

De Brondeau, Description de deux champignons nouveaux. Paris 1824 . 8.

Link, Iyphomycetes el Gymnomycetes. (Linne. Speries plantarum. Ed. II. tomus VJ.) Berolini is24- 825.8 .

Bornholz, Der Trulfelbau. Quedlinlurg is25. 8. (gallice, itatice.)

Brongniart, Essai d"une classifieation naturelle tes ehampignons. Paris 1\$25. 8 .

Gmelin) Beschreibung ter Milchblatterschwämme in Baden. Karlsmbe 1895.8 .

Leveillé, Recberclies sur la famille des Agarics. Paris 1825. 8.

Observations sur deux Uredinées. (Paris 1825.) 8.

Description du Pleuropus eleuthereply rllus. (Paris 18פ5.) 8.

Description diuc nouvelle espece d'Agaric. (Paris 1825.) 8.

Description de deux especes nouvelles. (Paris 1825.) 8

Sur le genre Pilobulus. (I'aris 1825.) 8 
Letellier, Sur les propriétés des elıampignous aux environs de Paris. Paris 1826. 4 .

__ Ilistoire et descrigtion des champignans alimentaires et vénéneux aux environs de Paris. Paris 1826. 8 .

Montagne, Mémoire sur le genre Pilobolus. Lyon 1826. 8.

Cordier, Guide de l'amateur de champignons de Ja France. Paris 1826. 12.

(Cordier, Histoire et description etc. Paris 1836. 12. vix differt.) (germanice.)

Desmazières, Observations botaniques et zoologiques. Lille 1826. 8 .

Le. Turquier Delongchamp, Concordances de Persoon (Synopsis fungorums) avee De Candolle, Bulliard et Fries. Rouen 1826. 8.

Léveille, Note sur le genre Dictyophora. (Paris 1826.) 8.

Mémeire sur l'erget. (Paris 1826.) 8.

Villadini, Ammanitarum illustratio. Mediolani 1826. 4.

Bourwieg, Ahhandlung uber den Hausschwamm. Stettin 1827. 8.

De Brondeau, Observations sur l'Agaricus pilosus Huds. Paris 1827.8.

Descourtilz, Des champignons comestibles, suspects et vénéneux. Paris 1827. $s$.

Ascherson, De Fungis venenatis. Berelini 1828. 8.

Oesierreicher, Generalia de Fungis venenatis. Pestini s. a. 8.

Fries, Elenchus Fungorum. Grypliae 1828. 8.

Martin, Manuel de l'amateur de truffes. Paris 1828. 18.

Alberti, Del medo di eonoscere i Fungi. Milano 1929.4.

Dijk et van Beek, Onderzoekingen aangaande het zwart in de Melisbrooden. Amsterdam 1829. 8.

Larber, Sui funghi saggio generale. Bassano 1829. 4.

Lctellier, Figures des champignons servant de supplément aux planches de Bulliard (tab.603-710). Paris 1829-1842.4.

Fries, Synopsis Agaricorum eurepaeorum. Lundae 1830. 8.

Ulayne, Unterrich uber die schadlichen und nutzlichen Schwämme. Wien 1830.4 .

Peziza randanensis Lecoq, in Lecoq, Recherches sur Randan. Paris 1830.8 .

Desmazières, Monographie des genres Naenaspora et Libertella. Lille 1831.8 .

Lenz, Die nútzlichen und schädlichen Schwämme. Gotha 1834. 8. - ib. 1840. 8 .

Vittadini, Menographia Tuberacearum. Mediolani 1834. 4.

Krombholz, Naturgetreue Abbildungen und Beschreibungen der essbarelı, schadlichen und verdächtigen Sclıwamme. Prag 1831-1847. folio.

Roques, Histoire des champignons comestibles et vẹnéneux. Paris 1832. 8. - ib. 1841. 8. et Atlas.

Iitladini, Descrizione dei Funghi mangerecei e velenosi dell' Italia. Milano $(1832-) 1835.4$.

Secrelan, Mycographie suisse. Genève 1833. 8.

Fèe, Mémoire sur les Pliyllériées et le genre Erineum. Paris 1834. 8 .

Viviani, I Fuughi d'Italia. Geneva 4834 . folio.

Fries, Boleti, Fungorum generis, illustratio. Upsaliae 1835. 8.

hickx, Notice sur quelques espèces peu cennues de la Flore belge. Bruxelles 1835.8 .

Bassi, Del mal del segno, calcinaceio o moscardino. Lodi $1835-1836.8$.

Schmalz, Fungorum species illustratae. s. I. et a. 4.

Berkeley, Fungi. (Smith, Euglish Flora, vol. V. part. ll.) Lendon 1836. 8.

Fries, Synopsis generis Lentinorum. Upsaliae 1836.8.

Genera Hymenomycetum; nova expesitio. Lpsaliae 1836. 8.

- Anteckningar ofver de i Sverige váxande atliga Svampar. Upsala 1836. 4.

Moynier, De la truffe. Paris 1836. 8.

Opatowsli, De familia Fungorum boletaidearum. Berolini 1836. 8 .

Schmid, De Fungis esculentis et venenatis. Vindobonae 1836, 8.

Weinmann, Ilymeno- et Gasteromycetes imperii rossici. Petropoli 1836. 8 .

Fries, Epicrisis systematis nycologici seu Synopsis Ilymenomycetum. Upsaliae et Lundae 1836-1838.8.

Pritzel., Thes. lit. hot.
Berkeley, British Fungi. Fasc. 1-IV. J Jondon 1\$36-1843.4.

Chevallier, Fungorum et Byssorum illustrationes. Paris 1837. folio.

Corda, Ueber Spiralfaserzellen in clem Haargeflechte der Tricbien. Prag 1837. 4.

Fries, Fungi guineenses Adami Afzelii. Upsaliae 1837. 4.

- Spicilegium plantarum neglectarum. I. Agarici lyyperrhodii. Upsaliae 1837: 4 .

Léveillé, Recherches sur l'llymeniun des champignons. (Paris 1837.) 8.

Nees von Esenbeck jun. et Ifenry, Das System der Pilze. Bonn 1837. gr. 8 .

Raffeneau-Delile, Nouvel examen de la phosphorescénce de l'agaric de l'olivier. (Montpellier 1837.) 8.

Corda, Icones Fungerum hucusque cognitorum. Pragae 1837-1842. folio. Audouin, Recherches sur la Nuscardine. Paris 1838. 8.

Neuvelles expériences. Paris 1838. 8.

Ifaro, Tableau des champignens des environs de Metz. Metz 1838. 8.

Jakovcsich, Literatura doctrinae de Fungis venenatis et edulibus, aceedente synepsi specierum bungaricarum Amanitae. Pestini 1838.8

Junghuhn, Enumeratio Fungorum Javae. (Batavia 1838.) 8.

Mady, Synopsis Amanitarum in agro pragensi. Pragae 1838. 8.

Noulet et Dassier, Traité des champignons comestibles, suspectes et vénéneux. Toulouse 1838. 8.

Schummel, Ueber die giftigen Pilze. Breslau (1838.) 1840.4

Corda, Prachtllora europáischer Schimmelbildungen. Leipzig 1839. folio. (gallice.)

Kreutzer, Essbare Schwamme. Wien 1839. 8.

Léveillé, Recherches sur Je développement des Urédinées. (Paris 1839.) 8.

Majewski, O Grzyl)ach Jadowitych Krajowych. Kraków 1839. 8.

Proell, Fungi austriaci esculenti iisque similes virulenti. Vieunae 1839. 8.

Dufour, Notice sur les champignons comestibles du dép. des Landes. Mont-de-Marsan 1840.8 .

Léveillé, Notice sur le genre Agaric. Paris 1840. 8.

Fickx, Notice sur quelques champiguons du Mexique. Bruxelles 1844. 8.

Letellier, Avis au peuple sur les champignous. Paris 1841. 4.

Léveille, Espèces nouvelles de clampignons. (Paris 1841.) 8.

Monlagne, Esquisse organographique et plıysiologique sur la classe des cluampignons. Paris 1841.8 .

(germanice, hispanice.)

De Notaris, Micromycetes italici novi. (Taurini 1841-1844.) 4.

Gasparrini. Ricerclse sulla natura della pietra fungaja. Napoli 4841.4.

Brunner, Einiges uber den Steinloclserpilz (Polyporus Tuberaster Jacq.) und die Pietra fungaja der Italiener. Nenenburg 1842.4.

Corda, Anleitung zum Studium der Mykologie nebst kritischer Beschreibung aller bekannten Gattungen. Prag 1842. 8.

Coxe, Description of the Agarieus atramentarius. Philadelphia 1842. S.

Marquart, Beschreibung essbarer und schädlicher Schwämme. Brün 1842. 8 .

Oschats, De Phalli inspudici germinatione. Vratislaviae 1842. 4.

Venluri, Studi micologici. Brescia 1842. 4.

Villadini, Menographia Lyeoperdineorum. Aug. Taur. 1342.4.

Castagne, Urédinées recueillies dans le dép. des Bouches-du-Rhóne. Marseille 1842-1843. 8 .

Harzer, Naturgetreue Abbildungen der vorzüglichsten Pilze. Dresten 1842 $(-1845)$. gr. 4.

Fée, Mémoire sur l'ergot du seigle. Strassburg 1843. 4.

Léveillé, Observations sur quelques champignons de la Flore de Paris. (Paris 1843.) 8.

- Mémoire sur le genre Sclerotium. (Paris 1843.) 8.

Montagne, Considérations générales sur les Podaxinées et le nouveau geure Gyrophragmium. (Paris 1843.) 8.

Rabenhorst, Deutschlands Kryptegamenflera: Pilze. Leipzig 1844. 8.

Wallroth, Naturgeschichte der myketisclien Entomorphyten. In ejus "Beitrage II. Leipzig 1844. 8 .

Léveillé, Champignons exotiques. (Paris 1844-1845.) 8. 
De Nolaris, Cenno sulla tribù de' pirenomiceti gferiaci. Firenze 1844.4. Osservazioni su alcuni generi dei pirenomiceti sferjaci. Firenze 1845.8

Buchler, Der laufende Schwamm. Stuttgart 1845. 8.

IJarrivitz, De Cladosporio herbarun. Berolini 1845. 8.

Lund, Conspectus Hymenomycetum circa Holmiam crescentium. Christianiae 1845.8 .

Tenturi, 1 miceti dell' agro bresciano. Brescia 1845. folio.

Dozy et Molkenboer, Novae Fungorum species in Belgio septentrionali. Lugel. Bat. 1846. 8 .

Tonnini, Prospetto eromo-litografico confrontativo. Como 1846.4.

Trog, Tabula analytica Fungorum. Bernae 1846. gr. 12.

Mulsant, Nouvelle espece du genre Sphaeria Hall. Lyon 1847. 8.

Robin, Les végétaux qui croissent sur les atimaux vivants. Paris 1847. gyr. 8 .

Srhlechlendal, De Aseroes genere dissortatio. llalae Saxonum (1847.) 4.

\section{Algae.}

Ludwig, De vegetatione plantarum marinarum. Lipsiae 1736. 4.

Donati, Della storia naturale marina dell' adriatico. Venezia 1750.4. (gallice, germanice.)

Ginanni, Opere postume (tomo 1.) nel quale si contengono 114 piante che vegetano nel mare adriatico. Veusezia 1755 . folio.

Limné, Natura pelagi. Upsaliae 1757. 4

Klein, Dubia circa plantarum marinarum fal,ricam. Petropoli 1760. 4.

Baster, Opuscula subseciva de plantis quibusdam marinis. Harlemi 1762 -1765.4 .

Cimelin, Historia Fucorum. Petropoli 1768. 4.

Velley, Coloured figures of marine plants. Plantarum maritinarum etc. Bathoniae 1795. folio.

Correa de Serra, On the fructification of the submersed Algae. (1796.) 4

Roth, Bemerkungen über das Studium der hryptagamischen Wassergegewachse. Hannover 1797.8.

Esper, Icones Fucorum. (Abbildungen der Tange.) Nurnherg 1797 1808. 4.

De Candolle, Observations sur les plantes marines. (Bull. soc. phil. de Paris. 1799. p. 171.)

Stachihouse, Nereis britannica. Bathoniae 1801. folio. - Fd. 11: Oxonii 1816. 4.

Turner, Synopsis of the british Fuci. London 1802. 8 .

Wulfen, Cryptogama aquatica. Lipsiao 1803. 4.

Agardh, Dispositio Algarum Sueciae. Lundae 1810-1812. 4.

Algarum Decades I-IV. Lundae 1812-1815. 4.

Synopsis Algarum Scandinaviae. Lundae 1817. 8 .

Lyngbye, Tentamen Hydrophytologiae danicae. Havniae 1819. 4.

Link, Epistola de Algis aquaticis in genera disponendis. In Horae phys. ber. Bonu 1820. folio.

Gaillon, Essaj sur l'étude des Thalassiophytes. Ronen 1820.8.

Agardh, De metamorphosi Algarum. Lundae 1820. 8.

lcones Algarum ineditae. Lundae 1820-1822. 4.

Gaillon, De la fructification des Thalassiophytes symphysistées. Rouen 1821.8.

Agardh, Species Algarum rite cognitae. Gryphiae 1823-1828. S.

- Systema Algarum. Lundae 1824.8

Targioni-Tozzetti, Catalogus vegetabilium marinorum Musei sui. Florentiae 1826. folio.

Gaillon, Résumé mèthodique des classifications des Thalassioplıytes. Strassburg 1828.8.

Naccari, Algologia adriatica. Bologna 1828. 4.

Agardh, Ieones Algarum europaearum. Lipsiae 1828-1835. 8.

Bory de St. Vincent, Histoire des Hydrophytes recoltées par D V'ruille et Lesson dans leur voyage autour du monde sur la Coguille. Paris 1899. folio.
Delle Chiaje, Ilydrophytologiae regni neapolitani icones. Neapoli 1829. folio.

De la Iylaie, Flore de l'ilo de Terre newve. Paris 1829.4.

Greville, Algao britannicae. Edinburgh 1830. 8.

Berkeley, Gleanings of british AIgac. London 1833. 8 .

Agardh, Om bafs-algers germination. Stochliolm 1834. 8 . (gernianice.)

De Brébisson et Godey, Algues des environs de Palaise. Falaise 1835. 8. Nardo, Considerazioni generali sulle alghe. Venezia 1835.4.

Agardh. Noviliae Florae Sueciae ex Algarum familia. Lundae 1836. 8 .

Meneghini, Conspectus Algologiae euganeae. Patavii 1837. 8

- Cemni sulla organografia e fisiologia delle alghe. Padova 1838. folio Inin.

Areschouy, Symbolae Algarum rariorum Fiorae scandinavicae. Lundae 1838.8.

Montagne, Sertum patagonicum. Paris 1839. 4. (D'Orbrgny, Voyage.)

Postels et Ruprecht, Illustrationes Algarum in itinere circa orbem in Oceano pacifico collectarum. Petropoli 1840. folio max.

Kuetzing, Die Unwandlung niederer Algenformen in hŏhere. Ilaarlem 1841. 4 .

Neneghini, Quattro nuove specie di alghe. s. I. et a. 12.

Lettera al Dr. Corinaldi. s. I. (1841.) 8.

I rapporti di organizzazione tra le Ficee e le alghe terrestri n Licheni. (Firenze) 1841. 4

Zanardini, Synepsis Alyarum in mari adriatico collectarun. Tauriu 1841. 4 .

Harvey, A manual of the british Algae. London 1541. 8.

Plyycologia britannica. Vol. I. London 1846. 4.

Chauvin, Recherches sur l'organisation, la fruetification et la classification des algues. Caen 1842.4

Montagne, Prodromus generum specierumque Phycearum novarum in itinere ad polum antarcticum collectarum. Paris 1842.8 .

Decaisne, Essai sur une classification des algnes et des polypiers calcifères. Paris 1842. 8 .

Agardh, Algae maris mediterranei et ddriatici. Paris 1842.8.

De Notaris, Algologiae maris ligustici specimen. (Taurini 1842.) 4.

Meneghini, Alghe italiane e dalmatiche. Fascic. I-V. Padova IS\$21846. 8.

Unger, Die Planze im Nomente der Thierwerdung. Wien 1843. 8.

Zanardini, Saggio di classificazione naturale delle Ficee. Venezia 18:3.4.

Kuetzing, Phycologia generalis oder Anatomie, Physiologie und Systemkunde der Tange. Leipzig 1843. 4.

Oersledt, De regionibus marinis. Havniae 1844. 8 .

(Meneghini) Sulla teoria de' meritalli di Gaudichaud. Firenze 1844. 8.

Agardh, In systemata Algarum hodierua adversaria. Lundae 1844. S.

Hassall, A history of the british freshwater Algae. London 1845. 8.

Roemer, Die Algen Deutschlands. Hannover 1845.4.

kuetzing, Pliycologia germanica. Nordhausen 1845. 8.

Tabulae phycologicae. Nordhausen 1846 sqq. 8

Naegeli, Die neuen Algensysteme und Versuch zur Begrundung eines eignen Systems der Algen und Florideen. Zurich 1847. 4.

Rabenhorst, Deutschlands Kryptoganenflora: Algen. Leipzig 1547. 8.

\section{Confervaceae.}

Mont-Sainct) Lettre missive a un sien any sur le fait prodigieux dune pluye rouge conme sang. In ejus "Le jardiu senonoisp. Sens 1604.12.

Sccondat, Sur une espece d'Ulva, qui croit dans la fontaine bouiliante de Daix. Iı ejus "Observations ». Paris 1750.8 . p. 12-17.

Kniphof, Pbysikalische Untersuchung des Peltzes auf Wiesen. Erfurt 1753.4.

Strange, Lettera sapua lorigine della carta naturale di Cortona. Pisa 1764. 4 .

(anglice, gallice.) 
Corti, Osservazioni microscopiche sulla Tremella. Lucca 1774. 8.

Willan. Confervae species (Byssus lanuginosa) in aquis sulplureis Croft prope Darlingten. In ejus "Observations etc. Lenden 1782. 8. 1. $9-10$.

Scherer, Beobachtungen uber das pflanzenăhnliche Wesen in den Karlsbader unl Toplitzer Wássern. Dresden 1787.4.

Olivi, Dell' Ulva atropurpurea. (Padova) 1793. 4.

Bory de St. Tincent, Mémeire sur les genres Conferva et Byssus. Bordeaux 1797. 8 .

Carradori, Della trasfermazione del Nostoc in Tremella verrucesa etc. In Prate 1797. 12.

Hedwig, Tremella Nostoch. Lipsiae 1798, 4.

Vaucher, Mémoire sur les graines des Conferves. (Paris) 1800.4.

Dillwyn, British Confervae. Lendou (1802-1814.) 4. (germasice.)

Girod-Chantrans, Recherches sur les Conferves, Bisses, Tremelles. Paris 1802.4 .

De Candolle, Rapport sur les Conferves. (Journ. de pliys. 1802. val. LIV. p. 121.)

Vaucher, Histoire des Conferves d'eau douce. Genève 1803. 4.

Ducluzeau, Sur les Conferves des envirens de Alontpellier. Montpellier (1805.) 4.

Nees von Esenbech, Die Algen des sussen Wassers. Bamberg 1814.8.

Pollini, Sulle alghe vivente nelle terme eugavee. Milane 1817.8.

Nitzsch, Beitrag zur lufusorienhunde. Halle 1817.8.

Bauer, Some experiments on the red snow. Lendon 1820.4.

Gaillon, Essai sur les causes de la couleur verte des huitres. Rouen 1824. 8.

- Experiences sur une conferve marine, production animalisée. Rouen 1823.8.

De Candolle, Examen de la matière organique, qui a coloré en rouge les eau du lac: de Morat. (Mém. soc. de phys. et d'hist. nat. de Genève 1826. ill. 2. p. 29.)

Bory de St. Vincent, Essai monographique sur les Oscillaires. Paris 1827.8. Agardh, Conspectus criticus Diatomacearum. Lundae 1830-1832. 8 .

Biasolello, Di alcune alghe micrescopiche. Trieste 1832. 8.

Bailey, American Bacillaria. (Amer. Journ. of sc. and arts, vol. 41 et 42.)

Gaillon, Aperçu d histoire naturelle et observations sur les limites qui separent le règne végétal el animal. Boulogne 1833. S.

Kueling, Algarum aquae dulcis Germaniae decades I-XVI. Ilalle 1833 -1836.8 .

Comelli, Intorno alle alghe microscepiche del Dr. Biasolello. Udiue 1833. 8.

Beggiato, Delle terme euganee. Memeria. Padova 1833. 8.

Amici, Descriziene di un' Oscillaria. Firenze 1833. 8.

Kuetzing, Synopsis Diatemacearum. Halle 1834.8.

Comelli, lntorno alle alglıe di acqua dolce ed alle preduzioni animali che si credevano alghe. Udine 1835. 8.

Welwitsch, Synopsis Nostochinearum Austriae inferioris. Wien 1836. 8 .

Montagne, De l'organisation des Caulerpées et en particulier du Caulerpa Wobbiana. (Paris 4838. ) 8.

De Brébisson, Considérations sur les Diatomées. Falaise 1838. 8.

Morren, Histoire d'un genre nouveau de la tribu des Confervées, nonmé Aplianizoméne. Bruxelles 1838. 4.

Ehrenberg, Mikroskopische Analyse des curlandischen Meteorpapiers von 1686. Berlin 1839. folio.

Areschoug, De Hydrodictye utriculato. Lundae 1839. 8.

Zigno, Sepra alcuni corpi organici nelle infusioni. Padova 1839. 8.

Meneghini, Synopsis Desmidiearum. Halae 1840. 8.

Morren, Recherches sur la rubéfaction des eaux. Bruxelles 1841.4.

Stiebel, Die Grundformen der Infuserien etc. Frankfurt a/\$1. 1841. 4.

Zanardini, Menographia Siphonearum. In ejus "Synopsis Algarum ». Taurini 1841.4.

Meneghini, Monographia Nestochinearum italicarum, addito specimine de Rivulariis. Aug. Taur, 1842. 4.

Vicolucci, De quibusdam Algis aquae dulcis. Neapoli 1843. 8.
Montagne, Sur la phénomène de la coloration des eaux de la mer rouge. (Trichodesmium erythraeum Elırenb.) (Paris 1844.) 8 .

Kuetzing, Ueber die Verwandlung der Infusorien in niedre Algenfermen. Nordhausen 1844. 4 .

Die kieselschaligen Bacillarien oder Diatomeen. Nordhausen 1844. 4 .

Hassall, A histery of the british freshwater Algae. London 1845. S.

Meneghini, Sulla aninalità delle Diatemee, e revisione dei generi di Diatomee stabiliti dal Kutzing. Venezia 1845. 4.

Montagne, Sur un nouveau fait de celoration des eaux de la mer par une algue microscopique. (Paris 1846.) 8 .

Phyceae.

Gleditsch, Lucubratiuncula de Fuco subglehese, sessili et molli. Berolini 1743. 4.

(germanice.)

Pauli vel Povelsen, Circa plantarum quarundam maris islandici et speciatin algae sacchariferae originem observationes. Havniae 1749, 4.

Meese, Beschryving van een zonderlinge Zee-plant. Leeuwarden 1761. 8. Ruiz, De vera Fuci natantis fructificatione. Matriti 1798. 4.

Lamouroux, Dissertations sur plusieurs espèces de Fucus. Agen 1805. 4.

Turner, Fuci, sive plantarum Fucerum generi adscriptarum icones, descriptiones el historia. Lendon 1808-1819. 4.

Lamouroux, Essai sur les genres des Thalassiophytes non articulées. Paris 1813.4 .

Griffen, Botanical, chemical and medical properties of the Fucus edulis $L$. New York 1816. 8.

Guibourt, Notice sur la mensse de Jafna ou de Ceylan et sur les nids de Salangane. Paris s. a. 8 .

Hornemann, Om Fucus buccinalis L. Kiobenhavn 1828. 4.

Meyer, De Fuco vesiculese atque de Jodo. Kiliae 1830. 4.

Whilaker, Notice of the Fucus natans. Lewes 1830. 12.

Montagne, Considérations sur les Laminariées et genre Capea. (Paris 1840.) 8 .

Du genre Xiphophora. (Paris 1842.) 8.

Florideae.

Zannichelli, De Myriophylio pelagico et marina plantula anonyma. Venetiis 1714. 8 .

Ellis, Natural history of the Corallines. Londen 1755. 4. (gallice, germanice.)

Graleloup, Descriptiones aliquerum Ceramiorum novorum. In ejus "Oisservations" etc. Montpellier 1806. 4.

Lamouroux, Histoire des polypiers coralligènes flexibles. Caen 1816. 8.

Bivona-Bernardi, Scinaia, Algarum marinarum novum genus. (Palermo 1822.) 8 .

Link, Ueber Pflanzenthiere und die dazu gerechneten Gewăchse. Berlin 1834.4.

Duby, Mémoire sur le groupe des Ceraminées. I-IIl. Genève 1832 1836.4.

Krauss, Beitrag zur Kenntniss der Corallineen und Zoophyten der Südsee. Stuttgart 1837. 4 .

Johnston, A history of british Zoophytes. Edinburgh 1839. 8.

Montagne, Sur le Callithamnion clavatum. (Paris 1839.) 8.

Kutzing, Ueber die Polypiers calciferes des Lamouroux. Nordhausen 1841.4 .

Montagne, Structure et fructification des genres Ctenedus, Delisea et Lenormandia. (Paris 1844.) 8 .

Zanardini, Sulle Corallinee (polipaj ealciferi di Lamouroux) revista. Venezia 1844 . gr. 8.

\section{Lichenes.}

IIagen, Tentamen historiae Lichenum praesertim prussicorum. Regiomonti 1782. 8 .

Holfmann, Enumeratio Lichenun. Erlangae 1784. 4. 
Imoreux, Recherches sar les divers Lichens. Lyon 1787. 8.

IIoffmann, Vegetabilia cryptogama. Erlangae 1787-1790. 4.

Hofmamn, Plantac lichenosae. Lipsiae 1789-1801. folio.

Ilumboldt, Syuonymia Lichenum cástigata. In ejus "F゙lora fribergensisn. Berolini 1793. 8, p. 183-185.

Persoon, Einige Bemerhungen uber die llechten. (Zirrich 1794.) 8.

De Candolle, Premier essai sur la untrition des Lichens. Paris 1798. 4.

Acharius, Lichenographiae stecicae Prodromus. Lincopiae 1798. 8. 1803.8

II'estring, Svenska Lafvarnas Farohistoria. Stockholm 1805. (18031809.) 8.

Luyken. Tentamen historiae Lichenum. Geettingae 1809. 8.

Icharius, Lichenographia universalis. Goettingae $1810,4$.

Swartz, Lichenes anericani. Norimbergae 1811. 8.

Hikstrim, Mlusei upsaliensis appendix XXI. Upsaliae 1813.4

Acharius, Synopsis methodica Lichenum. Lundae 1814. 8 .

Fries, Lichenum dianome nova. Lundae 1817.4.

-_- Beskrifıing på nya Lafslägten. Stockholm 1822. 8.

Schaerer, Lichenes Helvetiae exsiccati. Fasc. I-XXIY. no. 1-600. Bernae $1823-1849.4$

Ilepp, Lichenenflora von Wurzburg. Mainz 1824. 8 .

Eschweiler, Systema Lichenum. Norimbergae 1824. 4.

Fee, Essai sur les cryptogames des écorces exotique officinales Paris 1824 $-1837.4$.

Hétlode lichénographique et genera. Paris 1824. 4.

Fries, Schedulae criticae de Lichenilus Sneciae exsiccatis. Lond. Goth. $1824-1833.4$.

Meyer, Nebenstumden. I : Die Entwicklung, Metamerphose und Fortpflanzung der Flechten. Göttingeu 1825.8.

Mann, Lichenum in Bohemia dispositio succinctaque descriptio. Pragae 1825. 8.

Ifallroth, Naturgeschichte der Flechten. Frankfurt a/M1. 1825-1827. \&.

Parasitische Flechten der officinellen Binden, in Goebel und Kunze, Pharmaceutische Waareukunde Baud I. Eisenach 1827-1829.4.

Fingerhuth, Tentamen Florulae Lichenum eifliacae. Norimbergae 1829.8.

Fries, Primiliae geographide Lichenum. Lond. Goth. 1831. 8.

Lichenographia enropaea refornata. Lundae et Gryphize 1834. 8.

Dietrich, Lichenographia germanica. Jena 1832-1837. 4 .

Bohler, Lichenes britanoici. Sheffield 1835-1837. 8 .

Fée. Némoires lichenographiques. (Bonnae) 1838.4.

(Borrer et Turner) Specimen of a Lichenographia britannica. Yarmouth 1839. 8.

Koerber, De genidiis Lichenum. Berelini 1839. 8 .

Floton, Lichenen des Riesengebirges. In Wend, Die Thermen zu Warmbrunn. Breslau 4840.8 .

Tuckerman, A further enumeration of some New England Lichenes. (Boston 1840.) 8 .

Flotow, Goeppert et Nees vou Escubeck, Ueber die Rinde Pao Pereira und dic darauf vorkommenden Lebermoose und Flechten. Breslau 1842. 8 .

Torssell, Enumeratio Lichenum et Byssacearum Scandinariae. Upsaliac 1843.12.

Rabenhorst, Deutschlands Kryptogamenflora: Lichenen. Leipzig 1845.8.

Tuckerman, Enumeration of uorth american Lichenes. Cambridge 1845. 8.

Montagne, Aperça morphologique de la famille des Lichens. Paris 1846. 8 .

Brueckmanu, De lapide violaceo sylvae Hercyniac. Guelpherbyti 1725.4. Rerwhardi, Lichenum gelatinosorum illustratio. (Achrader's Journal. I p. 1-17.)

Schrader, Alsermalige Bevision der Gattung Usnea. Gottingen 1799. 8.

Mannhardl, Loluariae parietinae analysis chemica. Kiliae 1819. 4.
Ehrenbery, De Caenoganio, novo Lichenum genere. In llor, phys. ber. Bunn 1820. folio.

Delise, Ilistoire des Lichens. Genre Sticta. Caen 182y-1823. 8. et Atlas. Chevallier, llistoire des Graphidees. (Histoire générale des 11 ypoxylons.) paris 1824.4.

Dufour, Revision des genres Cladonia. Scyphephorus, llelopodium et Baeomyces. Bruxelles s. a. 8.

Floerke, De Cladloniis. Rostockii 1828. 8.

Wallroth, Naturgesehichte der Sáulchenflechteu (Cenomyce Ach.). Naumburg 1529.8 .

Fee, Monographie du genre Chiodectoll. (Paris 18:9.) 8 Monograplie du geure Trypethelium. (Paris 1831.) 8 Monograplie du genre Grassiceurtia. (1lalle 1836.) 8. Monographic du genre Paulia. (IIalle 1836.) 8.

Montagne, Recherches sur la structure du uucléus des genres Sphaerophoron et Lichina. (Paris 1841.) 8.

Perktold, Die Umbilicarien von Tirnl. Innsbrnck 1842. 8.

Wallroth, Zur Naturgeschichte der Üsnea nigra Dill. In ejus "Boitráge». I. Leipzig 1842. 8 .

Koerber, Lichenographiae germanicae specinen, Parmeliacearum familiam continens. Yratislaviae 1846.4 .

\section{Hepaticne.}

Schwaegrichen, Ilistoriae Muscorum hepaticorum prolromus. Lipsiae 1814. 8 .

Weber, Historiae Anscormm hepaticorum prodramus, Kiliae 1815. 8

Ilooker, British Jungermauniae. London 1816. folio.

Raddi, Jungerıanniografia etıusca. (Modena 1820 .) 4. - Bonnae 1841.4. Schueinit, specimen Florae Americac septeutrionalis cryptogamicae. (Mlusci hepatici.) Raleigh 1821.8.

Raddi, Crittogame brasiliane. Medena 1822. 4.

Hooker et Taylor, Muscologia britanuica, Ed. II. Londen 1827. S.

Lindenberg. Synopsis Hepaticarum curopaearum. Bounae 1829.4

Corda, Genera Ilepaticarum. (Opiz, Beitrăge p. 643-655.)

- Monographia Rhizospermarum et Hepaticorum. Pragae 1829.4.

Vees ron Esenbech, Enumeratio plantarum cryptogamicarun Javae. 1: llepaticae. Vratislaviae 1830. 8.

Dumorlier, Sylloge Jungermannidearum Eurepac indigenarum. Tornaci Nerviorum 1831, 8

Ekarl, Synopsis Jungermanniarum Germaniae. Cnlungi 1832. 4.

Vees von Esenheck, Natnrgeschichte der europatischen Lebermoose. Berlin und Breslan 1833-i838. 8 .

Ihebener, llepaticologia germanica. Mannheim 4834. s.

Bischoff. De llepaticis imprimis tribuum Marchantiearum et Ricciearum. Heidelhergac 1835.4.

Montagne et Nees von Esenbeck, Jungermanniearum herbarii Montigucani species. (Paris 1836.) 8 .

Krémer, Monographie des Ilépatiques de la Moselle. Metz 1837. 8.

De Notaris, Primitiae llepaticologiae italicae. (Taurini 1838.) 4.

Lindenberg, Species llepalicarum. Bunnae $(1839-1847)$.

(Plagiochila. Jungermannieae. Trichomanoideac. Lepidozia.)

Tees von Esenbeck, Gottsche et Lindenberg, Synopsis II paticarum. IIamburgi $1844(-1847$.) 8 .

Schmidel, De Blasia. Erlangac 1759.4.

De Jungermanniae charactere. Erlangae 1760.4.

Libert, Notice sur un genre nouveau, Lejeunia. Bruxelles 1820.8

Montagne, Des organes mâles du genre Targaionia. (Paris 1838.) 8 .

Mohl, Ueber die Entwicklung der Sporen ron Anthoceros laevis. (Verm. Schriften, D. 84-93.)

Jerrat, Notice sur une hépatique regardéc comme lindividu màle du Marclantia conica L. (Nemoursia tuberculata.) Paris 1840.8 .

Montagne et Bory de St. Iincent, Sur un neuveau genre des Hepatiques Duriaea. (Paris 1844.) 8 . 
Montagne, Essai d'organographie de la famille des Hépatiques. Paris 1845. 8 .

\section{Musci frondosi.}

Dillenius, Historia Nuscorum. Oxonii 1741. 4.

Heinze (vel Bichter), De Inscorum notis et salubritate. Goettingae 1747. 4 .

Heinze, De incrementis botanicae contemplationis Mluscorum. Goettingae 1747. 4 .

Linné, Semina Jluscorum delecta. Upsaliae 1750. 4.

- Usus Muscarum. Upsaliae 1766. 4.

Necker, Methodus Nuscorum. Mannheimii 1771. 8.

- Physiologia Nnscornm. Mannheimii 1774. 8.

Curtis, Fructification of the mosses. (London) 1776.8.

Ludwig, De sexu Muscorum detecto. Lipsiae (1777.) 8.

Giseke, Index Limnaeanus in Dillenii Ilistoriam Muscorum. In ejus: Ind. Linn. in Plukeneti Opera botaniea. Hanburgi 1779. folio.

Linné fil. ( = Swartz), Methodus Mnscorum illustrata. Upsaliae 1781. 4.

Hedwig, Fundamentum historiae naturalis Mnscorum frondosorum. Lipsiae 178.4.

Mallhe, De generatione Muscorum. Goettingae 1787. 8.

Hedwig, Descriptio et adumbratio Mluscorum frondosorum. Lipsiae 1787 -1797 . folio.

Noehden, De argmmentis contra Hedwigii theorian de generatione Muscoruн. Goettingae 1797.4.

Bridel-Brideri, Muscologia recentiorum. Gotha 1797-1822.8.

Swartz, Dispositio Muscorum frondosorum Sueciae. Erlangae 1799. 12.

Hose, Ilerbarium vivum Nuscorum frondosorum. Lipsiae 1799-1800.8.

Rochling, Deutschlands Moose. Kremen 1800.8.

Hedwig, Species Muscorum frondosorum edid. Schwaegrichen. Lipsiae $1801-1842.4$.

Crome, Sammlung deutscher Laubmoose. Schwerin 1803-1806. 4

Turner, Muscologiae lihernicae spicilegium. Yermuthi 1804. 8.

Palisot-Beauvois, Prodrone des 5 et 6 familles de l'Aetheogamie. Les Nousses, les Lycopodes. Paris 1805.8.

Béheré, Muscologia rothomagensis. s. I. et a. 8 .

Blandow, Lebersicht der meklenburgischen Moose. (Neustrelizz) 1809. 8.

Schkuhr, Vier nud zwanzigste Klasse. II : Die deutschen Moose. Leipzig $1810-1847.4$.

Palisot-Beauvois, Nouvelles observations sur la fructification des Mousses et des Lycopodes. (Paris 1811.) 4.

Liboschitz et Trinius, Description des mousses de St. Petersbourg et de Moscou. Petersbourg 181\%. 8.

Voit, Ilistoria Muscorum frondosorum in Magno Ducatu herbipolitano. Norimbergae 1812.8.

Weber, Muscorum frondosorum genera. Kiliae 1813. folio.

Hooker, Musci exotici. London 1818-1820. 8.

Nees von Esenbeck jun., De Muscorum propagationc. Erlangae 1818. 4.

Hooker et Trylor, Muscologia britannica. London 1818. 8. - Ed. Jl : i). 1827. 8 .

Bridel-Brideri, Methodus nova Muscorum. Gotha 1819.4.

Bryologia universa. Lipsiae 1826-1827. 8.

Hornscluch, Musci frondosi exotici herbarii Willdenowiani. In Ilor. plyys. ber. Bonn 1820. folio.

Funch, Dentschlands Moose. Baireuth 1820.8

Palisot-Beauvois, Muscologie, ou traite sur les Mousses. Paris 1822. 8. Cassebeer, Entwicklung der Laubmuose. Frankfurt 1823. 8.

Nees von Esenbeck, Hornschuch et Sturm, Bryologia germanica. Nurnberg 1823-1831. 8 .

Walker-Arnolt, Disposition méthodique Jes espèces de Mousses. Paris 1825. 4.

Grceille et Walker-Arnott, A new arrangement of the genera of mosses. (Tentanen methodi muscorum.) (Edinburgh 1825.) 8.
Kittel, Rapport sur la nouvelle disposition des mousses par Walker-Arnoth. Paris 1826. 8.

Schwaegrichen, Specios Muscorum frondosorum. (Linne', Species plantarum. Ed. IV, tomus V, pars II, sectio 1.) Berolini 1830. 8.

Fiorini-Mazzanti, Specinen Bryologiae romanae. Romae 1831. 8. Ed. IJ: ib. 1841.8.

Ihebener, Muscologia germanica. Leipzig 1833. 8

Balsamo et the Notaris, Synopsis Muscorum in agro mediolanens. Mediolani 1833.8 .

1834. 8.

Ahnfelt, Dispositio Anscorum Scaniae. Lundae 1835. 8.

Gardner, Musci britannici arranged according to Hooker's British Flora. Glasgow 1836.8.

De Notaris, Nuscologiae italicae spicilegium. Mediolani 1837. 4.

- Syllabus Muscorum in Italia. Taurini 1838. 8.

Lisa, Elenco dei muschi di Torino. Torino 1837. 8.

Bruch, Schimper et Guembel, Bryologia europaea. Stuttgardiae 1837 sq7. 4.

Hornschuch, Musci brasilienses. In Florae brasiliensis fasc. I. 1840. folio. Valentine, Muscologia nottinghamiensis. (Hooker, Journal of botany. IIJ, p. 375.$)$

Garovaglio, Enumeratio Muscorum in Austria inferiore. Viennae 1840.8. Bryologia austriaca excursoria. Viennae 1840.8.

Angström. Dispositio Muscorum in Scandinavia. Upsaliae 1842. 12.

Hampe, Icones Muscorum novorum vel minus cognitorum. Bonnae 1844.8.

Lantsius-Béninga, De evulutione sporidiorum in capsulis Mnscorum. Goettingae 1844. 4 .

Dozy et Mollienboer, Muscorum fronrlosorum noväe species ex Archipelago indico. Lugd. Bat. 1844.8.

Fiedler, Synopsis Hypuearum magalopolitanarum. Rostock 1844.8.

- Synopsis der Laubmoose Necklenburgs. Schwerin 1844.8.

Lesquereux, Catalogue des mousses de la Suisse. (Neuchátel 1845.) 4

Dozy el Molkenboer, Musci frondosi inediti Archipelagi indici. Lugd. Bat. $1845-1846.4$

Sullivant, Musci alleghaniensis. Columbus in Obione 1846.8.

Contributions to the bryology and hepaticology of North-America. s. I. 1847.4.

Linné, Splachuum. Stockholmiae 1730.4

- Buxbaumia. Upsaliae 1757. 4.

Schmidel, De Buxbaumia. Erlangae 1758. 4.

Schreber, De Pliasco observationes. Lipsiae 1770. 4.

De la Pylaic, Etudes cryptogamiques ou Monographies de diver's genres de mousses. Paris 1815.8 .

Hooker, Orthotrichum. s. 1. et a. folio.

Hornschuch, De Voitia et Systylio. Erlangae 1818.4

Ilessler, De Timmia. Goettingae 1822. 4.

Brown, Characters and description of Lyellia. (Transact. of Linn. Society Xil, 560-583.)

(Verm. Schriften II, 701-74k.)

De Notaris, Specimen de Tortulis italicis. Taurini (1836.) 4.

Montagne, Nonographie du genre Conomitrium. (Paris 1837.) 8.

Mohl, Ueber die porösen Zellen von Sphagnum. Tubingen 1837. 8.

Pieper, Neckera Schlechteudali. Paderbornae 1838. 4.

\section{Equiseta.}

Wikströn, Trenne arter af vảxtsligntel Eynisetum. stockholm 1821. 8. Vaucher, Monographie des Préles. Genève 1822.4. 


\section{Filices.}

Stoamerdam, De Filice mare bodonaei dissertatiu epistolaris. Impr. cum ejus Bibl, nat. val. 11, D. $906-910$.

$$
\text { (anglice.) }
$$

Grosgebauer, Programma de agnis tartaricis. Vinariae 1690.4.

Ilumier, Filicetum americanum. Parisiis 1703. folio.

Traité des fougéres de 1 Amérique. Pariy 1705. folia.

Petiver, Pterigraphia americana. (Londini 1712.) folio.

Limne, Acrostichum. Upsaliae 1745. 4.

Kalm, De Pteride aquilina. Aboae 1754. 4.

Maratti, Descriptio de vera Ilorum existentia, vegetatione et forma in plantis dorsiferis. Romao 1760, 8.

Butanophili romani epistola, qua Marattium ab Adansonii censuris vindical. Romae 1768, 12.

Baldinger, De Filicum seminibus. Jenae 1770.4.

Necker. Eelaircissenents sur la propagation des Filicées. Mannheim 1775. 4.

Lammersdorff, De Filicum fructificatione. Goettingae 1781.8.

logler, Polypodium montanum. Giessae 1781. 4.

Gmelin, Consideratio generalis Filicum. Lirlangae 1784. 4

Bolton, Filices britannicae. Leeds 1785-1790. 4.

Smith, Tentamen de Filicum generibus dorsiferarum. (Turin 1793.) 4.

Ilthig, Filicum genera el species. Lipsiae 1797-1803. folia

lluperz, Je Filicum propagatione. Goettingae 1798. 8.

Bernhardi, Veber Asplenium und ilun verwandte Gattungen. Erfurt 1802. 8.

Villdenow, Ueber einige seltne Farrenkrauter. Erfurt 1802.8.

Fischer, De vegetabilium imprimis Filicum propagatione. Ilalae 4804. 8 .

Swartz, Synopsis Filicum. Kiliae 1806. 8.

Sichkuhr, Vier und zwanzigste Klasse oder Kryptogamische Gewachse. Erster Band. (Farnkrauter.) Wittenberg 1809.4

Langsdorff et Fischer, Jcones Filicum (cullectarum in expeditione Krusenstern). Tubingae 1810-1818. folio.

brown, On Woodsia. London 1812. 4.

$$
\text { (Verm. Schriften. II, 675-682.) }
$$

Raddi, Synopsis Filicum brasilieusium. Bononiae 1819. 4.

Saller, Descriptio plantarum epipliyllospermarum Hungariae et Transsylvaniae. Pestini 1820. 8.

Index alphabeticus rilicum in Linne Species plantarum ed. Willdenozo enumeratarum. Berolini 1821.8.

Strempel, Filicum berolinensium synopsis. Berolini 1822.8 .

haulfuss, Enumeratio Filicurn, quas in itinere circa terram legit Adatbertus de Chamisso. Lipsiae 1824. 8.

Macvicar, Observations on the germination of the Filices. Edinburgh 1824. 4 .

Raddi, Plantarum brasiliensium nova genera. Pars I: Filices. Florentiae 1825. folio.

Schlechtendal, Adumbrationes plantaruı. (Filices capenses.) Berolini $1825(-4832) .4$.

haulfuss, Das Wesen der Farnkráuter. Leipzig 1827. 4.

Filices in Blume, Flora Javae. Bruxellis 1828. folio.

Hooker et Greville, Icones Filicum. Londini 1829-1834. folio.

Sadler, De Filicibus veris Hungariae, Transsylvaniae et Creatiae. Budae 1830.8 .

Plaschnick, Ueber die Kultur der Farrenkrauter. Berlin 1834. 4.

Tenore, Memoria su di una nuova felce. Neapoli 1832,4

Siholt, Genera Filicum. Vindobenae 1834. 4. obl.

Hooker, List of the ferns in the collection made by Mr. Nightingate in the pacific isles. In Nightingale, Oceanic sketches. London 1835. gr. 12. p. $127-132$.

Kunie, Plantarun acotyledonearum Africae australioris recensio. I. Filices. Lipsiae 1836. 8.

Presl, Beschreibung zweier neuen Aspleniumarten. Prag 1836. 8.
Presl, Teutamen pteridagraphiae. Pragae 1836. 8.

- Supplementuin tentaminis pteridograpliace. Pragae 1845. 4.

Scholtz, linumeratio Filicum Silesiae. V'ratislaviae 1836.8.

Francis, Analysis of the british ferns. London 1837. 8. - ib. 1843.8.

Gasparrini, Osservazioni intorno Grammites leptophylla. (Napuli 1837.) 8.

Lunze, Analecta pteridographica. Lipsiae 1837. folio.

Agardh, Recensio specierum generis Pteridis. Lundae 1839. 8.

Newman, Notes on irish uatural history, especially ferns. London 1840.8.

A history of british ferms. London 1840. 8. - ib. 1844.8.

Splitgerber, Enumeratio Filicum et Lyeopodiacearun Surinani. I.ciden 1840.8.

hunze, Die Farnkrauter. (Supplement zu Srhkuhr's Farakrauters.) Leipzig $1840-1845$ squ. 4.

Link, filicum species horti berolinensis. Berohni $\$ 8+1.8$.

Riley, Catalogue of ferns. London 1841. 8.

Ilooker, Genera Filicum. London 1842. gr. 8.

Martens et Galeolti, Mémoire sur les fougères du Mexique. (Bruxelles 1842.) 4

Presl, llymenophyllaceae. Pragae 1843.4.

Roeper, Zur Flora Nechlenburgs. I. (Filices.) Rostock 1843. 8.

Taschner, De duabus novis Triehomanum speciebus. Jenae 1843. 4.

Fée, Mémoires sur la famille des fougères. Strassburg 1844-1845. folio.

Hooker, Species Filicum. Vol. I. Gleichenia - Dictyaxyphium. London 1846.8.

\section{Hydropterides.}

Schuebler (et Duvernoy), De Salvinia natante. Tubingae 1825. 4.

Corda, Monographia Rhizospermarum et Hepaticorum. Pragae 1899. 4.

Agardh, De Pilularia. Lundae 1833. \&.

(Dunal) Mémeire sur Marsilea Fabri. Orléans 1837. 8.

Griffith, On Azolla and Salvinia. (Calcutta 1844.) 8.

Mettenius, De Salvinia. Heidelbergae 1845. 4.

1846. 4

Beiträge zur Kenntuiss der Rhizokarpeen. Frankfurt a/M.

\section{Selagines.}

Palisot-Beauvois, Prodrome de la 5 et 6 familles de l'Aetlıéogamie. Les Mousses, les Ly copodes. Paris 1805. 8.

ses et des Lycopodes. (Paris 1811.) 4 .

Pagès, Remarques sur une arreur de synonymie relativement aux Lỵcopodes. Paris 1824. 8.

Spring, Lycopodiaceae brasilienses. In Florae brasiliensis fasc. I. 1540 . fulio.

\section{Characeae.}

Bruzelius, Observationes in genus Charae. Londini Goth. 1824. 8 (germanice.)

Kaulfuss, Erfahrungen uber das Keimen der Charen. Leipzig 1825. 8.

Barbieri, Osservazioni microscopiche. Mantova 1828. 8.

\section{Zamiae.}

(Cycadaceae.)

Heinzel, l)e Macrozamia Preissii. Vratislaviae 1844. 4.

Miquel, Monograpbia Cycadearum. Trajecti a/Rh. 1842. folio.

De Cycadeis Loddigesianis epistola. s. 1. 1842.8.

Vriese, Berigt aangaaende eene Cycas circinalis L. uit Java. Amsterdam 1842.8.

Cycadeae, in Miquel Commentarii 110. 111. Lugd. Bat. 1840. folio.

Lehmann. De Cycadeis praesertim Africae australis. Hamburgi 1834. folio. 
Mohl, Ueber den Bau des Cycadeenstammes. Munden 1832. 4.

kichard, Commentatio de Conifereis et Cycadeis. Stuttgardiae 1826. folio min.

Beeldsnijder, Catalogue des plantes à Rupelınonde. (Zamia Beeldsnijderiana.) Utrecht 1823.8.

\section{Rhizantheae.}

(Balanophoreae, Cytineae, Raffesiaceae.)

Linné, Planta Aphyteja. Upsaliae 1776. 4.

Jussieu, Mémoire sur le genre Phelipaea Thunb. (Paris 1808.) 4.

Brown, Account of a new genus of plants named Rafflesia. London 1821 4. (Verm. Schriften Il, 605-674.)

On the female flower and fruit of Rafflesid with observations on its affinities and on the structure of Hydnora. s. a. 8. (Verm. Schriften $11,761-763$.

Blume, Korte Beschrijving van de Patma der Javanen. Batavia 1825. 8. Rhizantheae in Blume, Flora Javae. Bruxellis 1828. folio.

Brown, On the female flower and fruit of Raflesia Arnoldi and on llydnora africana. London 1844. 4

\section{Gramineae.}

Bumaldus (i. e. Montalbanus), Individualis graminum omnium nonenclatura. Cum ejus Bibliotheca botanica. Bononiae 1657. 12. - Hagae 1740.4

Ray, Jethodus Graminum, Juncorum et Cyperorum specialis. In ejus alhodus plantarum nova”. Londini 1703. 8. p. 167-187.

Scheuchzer, Agrostographiae helveticae prodromus. Tiguri 170 S. folio.

Monti, Catalogi stirpium agri bononiensis prodronus, Gramina ac lmjusmodi affinia complectens. Bononiae 1719.4.

Scheuchzer, Operis agrostographici idea. Tiguri 1719.8.

- Agrostographia. Tiguri 1719.4. - Appendix: ib. 1775. 4.

Stillingfleet, Observations on grasses. In ejus "Mliscellaneous tracts». London 1759. 8. p. 202-218. - ib. 1762. 8. p. 363-390.

limné, Fundamenta Agrostographiae. Upsaliae 1767. 4.

Schreher, Beschreibung der Grâser. Leipzig 1769-1810. folio.

Roltboell, Descriptiones et icones plantarum rariorum. Ilafniae 1773. folio Haller, Appendices in Johannis Scheuchzeri Agrostographiam. Tiguri 1775. 4.

Linne' fil., Nova Graminum genera. Upsaliae 1779. 4.

Curtis, Enumeration of the british grasses. London 1787. folio.

Botanische Beschreibung der Gráser. Frankfurt a/MI. 178s. 8.

Curtis, Practical observations on the british grasses. Ed. II. Londou 1790. 8. - Ed. IV: ib. 1805.8

Esmarch, Gräser etc. in Schleswig-Ilolstein. Schleswig 1794. 8

IIost, Icones et descriptiones Graminum austriacorum. Vindobonae 1801 -1809 . folio.

Foeler, Descriptio Graminum in Gallia el Germania. Francofurti a/AI 1802. 12

Rabel (potius Sprengel), De Graminum fabrica. Ilalae 1804.4.

knapp, Gramina britannica. London 1804.4. - Ed. 11: ib. 1840.4.

White, Essay on the indigenous grasses of Ireland. Dublin 1808. 8.

Heller, Graninum in Magno Ducatu wirceburgensi enumeratio. Wirceburgi 1809.8 .

Gaudin, Agrostologia helvetica. Paris 1811.8.

Desmazières, Agrostographie des départemens du Nord de la France Lille 1812.8.

Palisot-Beauvois, Essai d'une nouvelle agrostographie. Paris 1812. 8.

Panzer, ldeen zu einer künftigen Revision der Gattungon der Gráser. München 1813. 4.

Jacquin, Eclogae Graminum rariorum. Vindobonae 1813-1844. folio.

Sinclair, Hortus gramineus woburnensis. London 1816. folio. - ib. 1825. 8. - ib. $183 \mathrm{~s} .8$.

(gallice, germanice.)
Muehlenterg, Descriptio uterior Graminum America septentrionalis. Philadelphia 1817.8 .

Presl, Gramineae siculae. Pragae 1818.8.

Thunberg et Ilartman, Genera Graminum Scandinaviae recognita. Upsaliae 1849.4 .

Turpin, Mémoire sur l'inflorescence des Graminées et des Cyperacées. (Paris 1819.) 4

Presl, Cyperaceae el Gramineae siculae. Pragae 1820. 8

Trinius, Fundamenta Agrostographiae. Viennae 1820.8

Hall, Synopsis Graminum indigenorum Belgii partis septentrionalis. Trajecti a/Rh. 1821.8 .

Graves, A monograph of the lritish grasses. London 1822. gr. 8.

Trinius, Clavis Agrostographiae antiquioris. Coburg 1822. 8.

Dumortier, Observations sur les Graminées de la Flore belgique. Tournay 1823.8.

Lestiboudois, Essai sur la plus interne des enveloppes florales des Gramiuées. (Lille 1 823.) 8.

Raddi, Agrostographia brasiliensis. Lucea 1823. 8.

Kaspail, Némoires sur la famille des Graminées. Paris $1 \$ 25.8$. (germanice.)

Trinius, Species Graminum. Petropoli (1823) 1828-1836. 4.

Nees von Esenbeck, Agrostologia brasiliensis. Stuttgardiae 1829. 8

Bujack, Botanisch-kritische Bemerhnngen uber die Graser. Konigsber" 1830.4 .

Kunth, Distribution méthodique de la famille des Graminées. Paris 1835 folio.

Petermann, De flore gramineo. Lipsiae 1835.8 .

Ruprecht, Tentamen Agrostographiae universalis. Pragae 1838. 8.

Bravais. Analyse d'un brin d'herbe ou examen de l'inflorescence des Graminées. Mans 1840.8.

Roeper. Verzeichniss der Gráser Meklenburgs. Rostoch 1840.8.

Nees von Esenbeck, lilurae Africae australioris illustrationes monographicde. I: Gramineae. Glogaviae 1841.8.

Darlington, Discourse on the natural fanily of Gramineae. West Chester 1841.8 .

Roeper, Zur Flora Mleklenburgs. II. (Granineae.) Rostock 1844. 8.

Parnell, The grasses of Britain. Edinburgh 1845. gr. 8 .

Hanham, Natural illustrations of the british grasses. London 1846.4

IVedel, De Maza. (Zea Mays?) Jenae 1693. 4

IVilscher, Prolusio de gramine Manua. Jenae 1747. 4.

Schreber, Beschreibung der Quecke. Leipzig 1772. 4.

Bruz, De gramine Mlannae. Viennae 1775. 8.

Vogler, De duabus graminum speciebus (Bromus scaber L. et Avena strigosa). Giessae 1776. 8 .

Fraser, Short history of the Agrostis Cornucopiae. London 1789. folio.

Marabelli, De Zea Mays planta. Papiae 1793.8 .

Tidyman, De Oryza sativa. Goettingae 1800. 4.

Mazzucuto, Sopra alcune specie di frumento. Padova 1807.8

Durand, De quiluusdam Cluloridis speciebus. Monspelii 1808.4

Provanzale, Mlemoria sulla Cannucia palustre, Arumlo Phragmiles. Firenze 1809.8 .

Fluegge, Graminum monographicae. Pars I. Paspalus. Reimaria. Hamburgi 1810.8 .

Lagasca, Sobre ol Cencro espigado. In "Amenidades n. Orihuela 181 1. 4 Mazzucato, Triticorum definitiones atque synonyma. L'tini 1812.8.

Richardson, On fiorin grass. London 18.14. 8

Schuebler, Characteristica et descriptiones Cerealium. Tuebingae 1818.8.

Seringe, Monographie des Céréales de la Suisse. (Mélanges I. 2.) Berne 1819.8.

De Candolle, Monographie et Ilerbarium des Céréales par Sernge. s. I. et a. 8 .

Trinius, De Graminihus unifforis et sesquifloris. Petropoli 1824.8

- De Graminibus paniceis. Petropoli 1826. 8 . 
Krause, Abbildungen und Beschreibung aller bekannten Getraidearten. Leij)zig 1835-1837. folio.

(Fischer et Meyer) Rericht uber die Gotraidearten. (St. Petersburg 1837.) 4. Ruprecht, Bambuseae. Petropoli 1839.4.

Krause, Das Getraidebuch. Leipzig 1840.8

Trinius, Agrostoidea: 1. Vilfea. 11. Callo rotundo. (Agrostea.) Petropoli $1840-1841.4$.

Seringe, Descrijtions el figures des Céréales européennes. Paris 1841 1847 squ. gr. 8.

Trinius et Ruprechl, Species graminum Stipaceorum. Petropoli 1842. 4.

Ilooker. Observations on the Tussacgrass of the Falkland islands. In ejus "Notes" etc. London 1843.8

(Comparanda sunt Gramina in sectione "Botanica oeconomica ».)

\section{Cyperaceae.}

Caylus, Dissertation sur le Papylus. (Paris) 1758. 4

(Guilandinus, Scaliger, Kirchmaier, Flachs, ef. p. 366.)

Thorstensen, De Scirpis in Dania sponte nascentibus. Havniae 1770.4.

Cirillo, Cyperus Papyrus. Parma 1796. folio.

Schlihi, Beschreibung und Abbildung der Riedgräser. Wittenberg 1801. 8. - Nachtrag: il.. 1806.8 (gallice.)

Preuschen, De Cypero esculento L. Erlangae 1801.8.

Gaudin, Etrennes de Flore. (Carices.) Lausanne 1804. 16.

II'illdenow, Caricologia. Berolini 1805,8

Agardh, Caricographia senensis. Lundae 1806. 4.

Jesvaux, Notice sui un nouveau genre des Cypéracées. s. I. 1808. 8 .

Lestiboudois, Essai sur la famille des Cypéracées. Paris 1849. 4.

Presl, Cyperaceae et Gramineae siculae. Pragae 1821. 8.

Schweinitz, Monograph of the north-american species of the genus Carex.

New York 1825.8

Hoppe, Caricologia germanica. Leipzig 1826. 8.

Degland, De Caricibus Galliae indigenis. Paris 1828. 8

Schrader, Analecta ad Floram capensem. 1: Cyperaceae. Goettingae 1832. 4 .

Schuebler, Ueber die Riedgräser Wurtembergs. Tübingen 1832. 8.

Redtenbacher, De Caricibus territorii viudolonensis. Vindobonae 1834. 8 .

Hoppe el Sturm, Caricologia germanica. Nürnberg 1833. 12.

Torrey, Mfonograph of torth-american Cyperaceae. New York 1836. 8.

Barralt, North american Carices. Middletown 1840.4

Malherbe, Notice sur le Papyrus. Netz 1840. 8.

Vrejer, Revisio critica Caricum borealium. Ilafuiae 1841.8.

Kunze, Supplemente der Riedgrảser zu Schluhr's Monographie. Leipziğ 1841 sqq. 8.

Nees von Esenbeck, Cyperaceae brasilienses. In Florae brasiliensis fasc. III-V. Lipsiae 1842. Tolio.

Savi, Descrizione della Fimbristylis cioniana. Pisa 1 \$43. 8.

Puccinelli, Lettera sul Pogonostylis squarrosus Bert. s. I. et a. 8.

Tuckerman, Enumeratio methodica Caricum quarundam. Schenecstadiae 1843.8.

Drejer, Symbolae Caricologiae. Hafniac 1844, folio.

\section{Resliaceae.}

Thunberg, Reslio. Upsaliae 1788. 4

\section{Eriocauloneae.}

Martizs, Die Eriocauleen. (Bonuae 1833.) 4.

\section{Alismaccae.}

Nolte, Botanische Bemerhungen uber Stratiotes und Sagittaria. Kopenlagen 1825.4
Juncacrae.

Rostkovius, Monographia generis Junci. Berolini 1801.8

Meyer, Junci generis monographiae specimen. Goettingae 1819.8

- Synopsis Juncorum. Goeltingae 1822. 8.

Syropsis Luzularum. Goettingae 1823. 8

De la Ilarpe, Essai d'une monographie des vraies Joncées. Paris 1825. 4.

Rapateae.

Schomburgk, Die Rapatea Friderici Augusti und Saxo-Fridericia regalis. krannschweig 1845. 4.

\section{Kingiaceae.}

Brown. Cliaracter and description of Kingid. (London 1823.) 8. (Verm. Schriften IV, 75-140.)

\section{Melanthaceae.}

Gray, Melanthacearum Americae septentrionalis revisio. Novi Eboraci 1837. 8

\section{Pontederaceac.}

Kunth, Eichhornia, genus novum. Berolini 1842. 8.

\section{Liliaceae.}

Gesner, Epistola de Tulipa Turearum. Impr. cum Valerii Cordi Annotationibus in Dioscoridem. Argentorati 1561. folio.

Pfauls, Descriptio Ampeloprasi proliferi. (Allium carinatum.) in ejus $₫ \mathrm{De}-$ scriptio ". Ulmae 1656.4 .

Vrsinus, Tulipa de Alepo. Lipsiae 1661. 4.

- Lilium album plenum. Lipsiae 1662. 4.

Schookius, De Tulipis. Francofurti 1680.4.

Tilling, Lilium curiosum, seu accurata Lilii albi descriptio. Francofurti a/M. 1683.8 .

Linné, Mlusa Cliffortiana. Lugduni 1736. 4.

Haller, De Alii genere naturali libellus. Goltingae (1745.) 4.

Vandelli, De arbore Draconis seu Dracaena. Olisipone 176s. 8.

Crantz, De duabus Draconis arboribus botanicorum. Viennae 1765. 4.

Berens, De Dracone arbore Clusii. Goettingae 1770. 4.

Maralli, Plantarum Romuleae et Saturniae specificae notae. Romae 1772. 8 .

Thunberg, De Aloe. Upsaliae 1785. 4.

Tilesius, Nusae paradisiacae icones quatuor. Lipsiae 1792.8.

De Candolle, De la Roche et Baffeneau-Delile, Les Liliacécs peintes par Redoute. Paris 1802-1809. Lolio.

Thunberg, De Dracaena. Upsaliae 1808. 4.

Tristan, Memoire sur les organes caulinaires des Asperges. Orléans 1813. 8 .

Salm-Reifferscheid-Dyck, Verzeichniss der verschiedenen Arten des Geschlechts Aloe etc. (Dissoldorf) 1817.8. (gallice.)

De Candolle, Rapport sur un livre du Prince de Salm-Dyck: "Catalogue raisouné des espèces el variẻtés d'Aloés. 1817. 8.

Saint-Milaire, Observations sur le geure Ilyacinthus. Orléans s. a. 8.

Colla, Sul genere Mlusa. Torino s. a. 4.

Andrzeiowsti, Czackia. hrzemieniec 1818. 4

(Paradisea Mazz. Viaggio. Udine 181\%. 8. = Czachia Andrz.)

Treviranus, Allii species. Vratislaviae 1822. 4

Bresler, Generis Asparagi historia naturalis atque medica. Berolini 1826. 8.

Cruse, De Aspraragi officinalis L. germinatione. Regiomonti 1525.8.

Lestiboudois, Notice sur le genre Hedychiun. Lille 1829. S 
Bury, A selection of Hexandrian plants. London ( $1831-1834$.) folio max. Keboul, Nonnullarum specierum Tuliparum agri florentini propriae notae. Florentiae 1829-1823.8.

— Selecta specierum Tuliparum agri llorentini sýnonyma. Florentiae 1538. 8 .

Wikstrüm, Nya arter af Fritillaria. Stockholm I\$22. S.

Douglas, Account of the species of Calochortus. London 1528. 4.

Tenore, Nemoria sul genere Musa. s. I. 1830.4

- Memoria sopra diverse sjeeie del genere Musa. Napoli 1832. 4.

Richard, De Musacois commentatio hotanica. Viralislaviae el Bonnae 1831.4.

Morren, Notico sur un dis du Japon. Gand 18:33. 8.

Berloloni, Descrizione di un nuovo gencre. (strangweja hyacinthioides Bert.) Nodena 1835.4

Salm-Reifferscheid-Dyck, Monographia gencris Aloes et Nrosemlurianthemi. Dusseldorf $1836 \mathrm{sqq}$. 4 .

IIa smann. Gagea und Jloydia. Wion 1541. 8.

\section{Smilaceue.}

Grisebach, Smilaceae brasilienses. In Florar brasiliensis fase. III $-\mathrm{V}$. Lipsine 1842. folio.

Ledehou", Monographia generis Paridum. Dorpati I827. folio.

Siegesbeck, De Najanthemo Liliun couvallium nuneupato. Petropoli 1736. 4 .

Browallius, De Convallariae specie. Mboate 1741-1744.

\section{Dioscoreac.}

Ciriscuach, Dioscoreae brasilienses. In Florae Lrasiliensis fasc. J]l-V. Lipsiae 1842. folio.

\section{Ensatae.}

De la fioche, Lescriptiones plantarum aliquot novarum. Lugduni batav. 1766. 4 .

Ecklon, Standorte und Blutezeit der Coronarien und Finsaten anı Cap. Esslingen 1827.8.

foemer, Synopses monographicae. JV: Ensatae. Wimariae 4847. S.

\section{Hydrocharideac.}

Bergen, be Aloide. Francofurti a// V. 1753.4

Rectificalio characteris Aloidis. (Nov. act. ac. nat. eur. 11, 150-153.)

Nolle, Botanisclie Bemerkungen uber Stratiotes und Sagittaria. Kopenhagen 18254 .

\section{Irideae.}

her, lridearum genera cum ordinis charactere saturali specierum que enuineratione. Bruxellis 1827.8.

Maralli, J'Iantarum Romuleae et Saturniae specifica notae. Romae 4779. 8.

'thunberg, Iris. Upsaliae 1782. 4.

- Ixia. Upsaliae 1783. 4 .

Gladiolus. Upsaliae 1784. 4.

Dietrich. Europaische Arten der Gattum Gladiolus. Berlin 1839. 4.

Nicliles, Notice sur les Gladiolus de France et d'Allemagne. (Strassburg 1840.) '4.

Thumbery, De Noraea. Lpsaliae 1787. 4.

De Caulnlle, Mémoire sur le Vieusseuxid. (Aun. Mus d'luist. nat. II, 136 $-1 i 1$.

—_ Note sur les genres Diasia el Montluretia. (Bull. sor. plitil. 1803. p. 251.)

Goldbach, Croci historia botanico-medica. Mosquiae 1816. 8.

(Ejusdem "Monographiae genejis Croci Tentamenx. in Mim de Hose. $V, 142-461$.

Poritzel, Thes. lit. bol
Berloloni, Descrizione de Zallerani italiani. Bologna 1826.4

Tenore, Memoria sulle specie e varieta di Cracelri della Flora napolitana. Napoli 1826. 4.

Gay, Observalions sur deun memoires (Bertoloni et Tenore 1)e Crocis italicis). Paris 1827. 8 .

Castiglioni, Monografia dello \%alierano. Milano 1899.8.

Morelli, Nonublil de Crocis ilalicis. Paviae 1834.8.

\section{Haemodoraceae.}

Burmann, Wachendorfia, Anstelaedami 1757. folio.

\section{Vellozieae.}

Schomburgk, Die Barbacenia Alexandriıde uıd Alexandra imperatrieis Braunselsweig 1845.4 .

\section{Hypurideac.}

Hyposideae, in Miquel Commenarii no. HI. Lugd. Bat. 1840. folio

\section{imaryllideae}

Douglas, Lilium sarniense. London 1725 , folio.

Heisler, Deseriplio novi generis Brunsvigiae. Brunsvigae 1753. folio. (germanice.).

Linne, PJanta Alstroemeria. Upsaliae 1762. 4.

Loiseleur, Recherehes sur les Narcisses indigènes. Paris 1810.4.

Tagliabue, Storia e descrizione delld Littaca geminiflora. Nilano 1816. 8.

ker, A review of the genus Amaryllis. London 1817. 8.

- On the genus Cripum. London 1817, 8.

On the genus Pancratium. London 1817. 8.

Haworth, Narcissearum revisio. In ejus Suppl. pi. succulentarum. Ln!dini 1819,8

Sprengel, Narcissorum conspectus. s. 1. 1820.8.

Ilerbert, Treatise on bulbots roots Amaryl]is, Brunsvigia, Ammocharis, Boophane, Imbofia; Nerine, Lyeoris eic. London 1821.8 .

Haworth, A monograph on thr Narcisseac. Jondon 1831.8. Narcissearum monograplia. Loncion 1831. 8.

Bury, A selection of llexandrian plants. London (1831-1834.) folio max. Herbert, Anaryllidaceac. London 1837. 8.

Neumam, Die Familie der Amarylliden. Weissensee 1844.8.

Hager, De Aloe aculeata americana, quae Chorae floruit. Alienburgi 1663. 4 .

Major, Amerikanische Alor. (Schleswig 1668.) 4.

Wundersame Aloe zu Schlieben bei Jena. 1669. 4.

Munting, Aloidariun. Amstolodami 1680. 4.

Pein, Eigentliehr Abhildung der amerikatuseben Aloe. Leipzig 1700. folio. lWaldschmicdt, Beschreibung derer Alom. Kiel 1705. 4

Amerikaniseher zu Gottorf bluhender Aloen lemere Beschreilung. Kiel 1706. 4.

Siricius, Beschreibung dreier bluhenden Aloen. Schleswig 1705.4

Beantwortung derer selur ungereimten, nichtswurdigen und injuriösen Jmputationen (Wuldschmiedl's). Kiel 1706. 4.

- Bajae cimbrieae. Sclılestvigae 1709. folio.

Scarella, Ragguaglio intorno al fiore dell' Aloe americana. Padova 1710.8. Die amerikanisclse Aloe zu Copenick. Berlin 1712. 4.

Olearius, Aloedarium historicum. Arnstadt 1713.8.

Treu, Beschreibung der grossen amerikanischen Aloe. Nuruberg 1727. 4. obl.

Account of the Aloe americana. London 1729. 8.

Tallisneri, Osservazioni intorno al fiore dell thoe anericana. In ejus "Opere fisico-medichen. Venezia 1733, folio. vol. II, p. 69-74.

Schullze, Ueber die grosse amerikanische Aloe, richtiger Agavo. Hamburg 1792.8 


\section{MONOGRAPHIAE}

Alams, $\Lambda$ stort account of the ancrican Alor. s. a. folio.

Vogel, Ueber lie anerikanische Agave. Atthorf 1800.8.

Rodali, Olsservationes circa duas species Agavos. Iu rjus "ludex lonti bononicusisn. Bononian (1802.) 4 .

Bremer, Mine ofver den americanska Aloen. Stochlolu Isos. falio.

Roubien, Dissertation sur Agave americana L. lo rojus "Opusculrsw "uc. Hontpellier 1816.8.

Wikström, l)en amoricanska Aqaves natural-historia. Stokklioln 1828, 8.

\section{Bromeliaceae.}

Lochuer, Commentatio de Ananasa. Norimbergac (1716.) í

Tiemeroth, Panta ac fruclus Ananas. Erfordiae 1723. 4.

De Candolle, Notice sur les graines de l'Aranas. (Genixr 1834.) 4

\section{Orchileae.}

(Rivinus) Ordo plantaruu, quae sunt flore irregulari hexapetalo. s. l. et a. folio.

IIandlwig, De Orchide. Rostockii 1747. 4.

Chatelain, Ve Corallorhiza. Basileae 1760. 4.

Koenig, Deseripliones Epidendrorum. (Retzius, Observationes fasc. III. Lipsiae 1783. Solio.)

Siwartz, Gencra et species Orchidearum. (Erfurt) 1805.8 .

Brown, of three species of the natural order Orehideac. London 1817. 4. Select Orchideae. London s. a. 4.

Richard, De Orchileis europaeis annotationes. Paris 1817.4.

Fleury) Orelides des environs de Rennes. Renars 1819.8.

Aubert du Prtit-Thouars, llistoire particuliere des plantes Ordidien recueillies sur les trois isles australes d'Afrique. Paris 1822.8.

Raddi, Descrizione di una nuova Orchidea brasiliana. Modena $1 \$ 23.4$

Colla, Observaliones sur le Limodorum purpureum Lan. Paris 1824.8 .

Blume, Tabellen en platen vool de javaassche Orehidecin. Batavia 1825. folio.

Lindley, Orehidearum sceleti. Londini 1826.8 .

Morren, Orchidis latifoliae descriptio botanica et anatonica. (Gandavii 1827.) 4 .

Breda, Genera et specics Orchidearum et Ascirpiadearum, guas in Java collegerunt Kuhl el van Hasselt. Gandavi 1827. folio.

Richard, Monograplie des Orchidees des iles de lirance el de Bourhon. Paris 1828. 4 .

Lindley et Bauer, fllustrations of orchidaccous plants. London $1830 \ldots$ 1838. folio.

Lindley. The genera and species of orchidaccous plants. London $1830-$ 1840.8.

Mayrhofer, De Orchideis in terrtorio vindobonensi erescentibus. Vindobonae 1832.8

Brown, Observations on the organs and modr of fecundation in Orchileae and Asclepiarleae. London, October 1831. 8. (Transactions of the Liunean Sociely 1\$33. 4. p. 685-745. - Verm. Schriften V, p. 11 ? - 189.)

Dumorlier, Notice sur le genre Maelenia. Bruxelles 1834.4.

Bateman, The Orchidaceae of Nexico and Guatemala. London I\$37 1843. folio.

Lindley, Scrum orchidaceum. London 4838 (1837-1842), gr. folio.

Mutel, Premier mémoire sur les Orchidées. Paris $183 \AA .8$.

Mémoire sur plusieurs Orchidées nouvolles. Paris 1842.4

Richard, Monographie des Orchìdées recueillies dans les Nil-Gherries par Perrottet. Paris 1841.4.

Splitgerber, Notice sur une nouvelle espèce de Varille. Paris 1\$41. 8.

Todaro, Orchideae siculae. Panormi 1842. 8.

Wallroth, Zur Naturgeschichte der Orchis bifolia Thal. In ejus "Beiträıe» I. Leipzig is 42.8 .

Orchideae in the collection of Conrad Loddiges. Landon (1812.) 19.

\section{HONOGRAPIHAE}

Hofmannsegy, Verzeichniss der Orchideen scines Gartens zu Mresilen. I) resten 1849.1843, 1844.8.

De Nolams, Isias, novum Orchidearum genus. Torino 184., 4

l'isiani, Fecondazione e fruttilicazinne della vaniglia nell' orto di l'ulova. Venezia 4844.4 .

Ilenshall, Treatiso on the cultivation of orchidacenus plants. I.ondon 1845.8.

(germanice.)

Ilucyel, Orchidcensammlung im Frulijahr 1845 . (Wien 1840.) 8

Jenisch, Kataloy seiner Orchidcensammlung zu Flotheck. IJamburg 1845.8.

Lyons, A practical treatise on orchiclaceous plants. lid. II. L.omlun 1845,8 .

Hoolier, A century of orchidaceous plants. Londou $1846 \mathrm{srg} .4$. Lindley, Ordhideae Lindenianae. London 1846.8.

\section{Scilamineae.}

Loeniy, Descriptiones Monandrarum el Epideudrorun in India oricutali factae. In Retzius, Observationes hotanicae, fase. 111. Lipsiae 1783. folio.

Rottboell, Beskrivelse over Strelizia reginac. Kiobenhaun 1790. 4.

Fraser, Thalia (?) dealbata; icon. 1794.

llergetschueiler, Descriptio Scitanimum L. nonnullorums. Turici 1813.

Ker et Bauer, Strelitzia depicta. Lnndon 1818. folio.

Roscoe, Momandrian plants of the order Scitannineac. Liverpool 1828 . folir). Colla, Novi Scitaminearum generis commentatio. Taurini 1830. 4.

Spligerber, beseription du genre Lrania non Schreb. nec Kich. (Amutordam 1843.) 4

\section{Najadeae.}

Cavolini, Phucagrostidum Theophrasti anthesis. Neapoli 1792. 4.

Zostcrae oceanicae Linnaei anthesis. Neapoli 1792. 4.

Cosentino, Nuove osservazioni e ricerche sulla Zostera oceanica. s.l. 1S2S. 4.

Tenore, Nuove ricerche su la Caulinia oceanica. (Napoli 1838. .) 4.

Thedemius, Bidrag till kännedomen om Najas marina L. Stoch/olm IS3K. \& (germanice.)

Fieler, Die Potamogeta Buhmens. lrag 1838. 8

\section{Lemnaceae.}

Vallisneri, De arcano Lenticulac palustrin semine ac admirama verevatione. In ejus "Prima Raccoltan p. 1-27, et "Opere finco-mediche. vol. II, p. $81-89$.

Ehwhart, Wiedergefundne Bluthe der Lemua giblua L. (Beitraģe I, p. i: -51$.

IIolff, De Lemna. Altdorfii 1801.4.

Ho/mann, is Lemna arrhiza ancl. cene standvastign underscheidene -mit? leeirlen 1838. S.

\section{Aroideae}

Bassi, Ambrosina. Bononiac 1763.4.

Hellenius, De Calla. Aboae 1782.4.

Roubicu, Description de JArum Colocasia 1. In ejus "Opuscules" etc. Montpellier 1816.8 .

\section{Typhaceae.}

Schnizlein, Die naturliche Pfanzenfamilie der Typlacen. Nordlingen 1845.8 .

\section{Pandaneae.}

Aubert du Petil-Thouars, Estrait d'uno némoire -ur les popeces de Pandanus. (Paris 1808 .) 


\section{MONOGRAPHIE}

\section{Palmae.}

Cluyl, Ilistoria uneis medieae Maldivensiunı. Ansterodami 1634.4. Calelenbach, De Palma. Tuebingae 1679. 4.

Celsius, Exercitationis de Palna caput prinum. Upsaliae 1711. 8.

liyclelius, De Palma. Londini Gothorum 1720.8.

Firsten, De Areca ludorum. Altorfii 1739.4

Sleck, De Sagll. Argentorati 1757, 4.

Observations on tho Oheeroo, a Palm-tree. London 1784. '.

Heynier, Observations sur le Palmier-rlattier et sur sa culture. In ejus "Considerations". (Paris 1502.) 8.

Paffeneau-Delile, Description du Palnier Doum de l.e Ilaute Egypte, ou Cucifera thebaica. In "Deseription de lEgypte". Paris 1810. folio.

Marlius, Genera et species Palmarum Brasiliae. (Fase. I-VTil.) Monachii $18 \pm 3-1845$. folio max.

Palmarum familia ejusque genera denuo illustrata. Jonachii 4824.4 .

Thunberg, De Palmis. L'psaliae 1\$25. 4.

Mohl, De Palnarum stuvetura. Monachii 1831. folio.

Marshall, Contribution to a natural and economical history of the Coconut tree. Edlinburgh 1832. 8. - ib. 1836. 8 .

Martius, Die Verbreitung rler Palmen in der allen Welt. Munchen 1839.4.

(Riller) Die Verbreitung der Dattel- und Kokospalme in Indien. s. I. et a. 8.

Jlarlius, Palmetum Orbignianum seu deseriptio Palnarum in Paraguaria et Bolivia erescentium. In l'Orbigny Voyage, vol. V'll. sectio III. Paris $(18: 3-1846) 4$.

Griffith, The Palms of Britisb East India. (Calculta 1845.) S.

\section{Coniferae.}

Belon, De arboribus coniferis. Parisiis 1553.4

Axtius, Tractatus de arboribus coniferis. Jenae 1679. 12.

Lambert, A deseription of the genus Pinus. London 1803-1824. folio. Ed. 11: ib. 1828-1837. folio.

Brolero, Historia natural dos Pinheiros e Abetos. s. l. 1817.8.

(Teste Gusmao in Revista literarea. Oporto 1813. 110. 83.

Richorrl, Commentatio botanica de Conifereis ei Cycadeis, Stuttgardiae 1\$26. folio min.

Jaryues, Monographie de la famille des Coniferes. Paris 1837. \&.

Mohl, Teber die mănnlicben Bluthen der Coniferen. Tubingen 1837. 8.

(Forbes) Pincum woburnense. Londini 8339 . gг. $S$.

Antoine, Die Coniferen. Wien 1840 sqq. folio.

Cocppert, De Coniferarum structura anatomica. Vratislaviae 1841. \%.

Linl, Abietinae horti berolinensis. Halse 1841. 8.

yeyer, Leber die Coniferen. (Konigsberg 1841.) S.

Coniferae: in Siebold et Zuccarini, Flora japonica, Cent. 11. fase. 1-5. Lugd. Bat. $1842-1844$. folio.

brown, On the plurality and development of the embryos in the seeds of Coniferae. London 1844.8

Vallisncri, De Pinu africana. In ejus “Prima Raccolta»p. 94.

Alströmer, Beskrifning på svenska Slok Granen, Pinus viminalis. Vetensk. Acad. Handl. 1777. p. $310-317$.)

Amold, Reise nach Nariazell. (Pinus nigra.) Wien 1785.4.

Hoess, Nonographie der Scluwarzfohre (Piuus ánstriaca). Wien 183\%. folin.

Treu, Cedforun Libani historia. Norimbergae 1757-1767.4.

Cough, In account of the Cedar of Libanus. (Lonrlon) 1788, folio.

Savi, Sul Cedro del Lilsano. (Pinus Cedrus L.) Firenze 18 t8. 8 .

Loiseleur. Histoire du cedre du Liban. Paris 1837 . \&

Morelti, De Cedro Libani. Paviae 1838. 8.'
Boehmer, De Taxo baceato. Wittehergae 1796. 4

Schuctz, De Tavo baccata ejusrpe veneno. Vratistavide 1840.8.

Gouan, Deseription du Gingho biloba. Nontpellier 1819.8.

De Candolle, Sur le Gingho biloba L. (Bib], univ. de Genere 1818. Vll $130-133$.

Jacquin, Veber den Ginkgo. Wieu 1819.8.

Meyer, Versuch einer Ilonographie der Gattung Ephedra. St. Petersburg 1846.

\section{Chloranthaceae.}

Cblorantheac in Blume, Flora Javae. Bruxellis 1828 . folio.

\section{Piperaceac}

Miquel, Disputatio taxononica et geographica de Piperaceis. (Commentarii I.) Lugd. Bat. 1839 , folio.

- Observationes de Piperaceis. (Commentarii II.) Lugd. Bat. 1840. folio.

Kunth, Benerkungen uber die Familie der Piperaceen. Halle 1840. S.

Miquel, Systema Piperacearum. Roterodami 1843-1844. 8.

\section{Saurureae.}

Heyer, De Houttuynia atyue Samrureis. Regiomonti 1827 . s.

\section{Ceratophylleae.}

Gray, Remarhs on the Ceratoplsyllaceae. Few York 1837. s.

\section{Mriceae.}

Nyriceae in Blume. Flora Javae. Bruxellis 1828. folio

\section{Belulaceae.}

Linne, Betula nana. Stochholmiae 1743. 4.

Lidbeck, De Betula Alno. Lundae 1779. 4.

Gleditsch, Leber Aluus quercifolia Gled. lu ejus: Vies Ablıandlungen. Ber$\operatorname{lin} 1788.8$.

Hartmann, De diserimine generico Betulae et Inn. Stuttgartiae 1794. 4.

Thunberg, Betula. Epsaliae 1807.4

Brisseau-Mirbel, Description de neuf especes de la famille des Imentacees. Paris 1827.4

\section{Cupuliferae.}

Du Choul, De varia Quereus historia. Lugduni 4558.8

Eysson, Sylvae Virgilianae prodromus. Groningae 1695. 1\%

De Fago. Groningae $1700,12$.

De Castaneis. Groningae 1703. 12

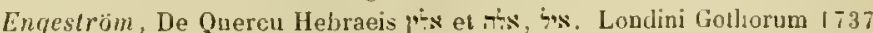
-1738.4 .

Secondat, llisloire naturelle du chène. Némoires. Paris 1785. folio. p. $1-31$.

Rooke, Descriptions and sketches of oaks in the park at Welbeck. London 1790. 4.

Michaux, Histoire des chênes de l'Amérique. Paris 1801. Solio (germanice.)

Bosc, llémoire sur les diffèrentes espèces de chenes en Frauce. Paris 1808.4 .

Michaux, Ilistnire des arbres forestiers de I'Amérique septentrionale. vol. II. Paris $1 \$ 10.4$. (anglice, germanice.)

Marquis, Recherches historiques sur le chine. Rowen 1812. s 


\section{HONOGRAPHIAL}

Cupuliferae in Blume, Flora Javae. Isruxellis 1828. folio

Malherbe. Notice sur quelupes chenes, of specialement (Hereus Suber. Metz 1839.8.

Lamy, Essai monographique sur le cluataignier. s. I. et a. §.

\section{Ulmaceas.}

Riddermarcli, De Ulmo. Londini Scaniac 1692. S.

Fischer, De Dirdar Innsinae Ulno arbore. Firfordiae $131 s$. 4.

Sachs, De Llmo. Argentorati 1738. 4

Michaux, Mémoire sur le Zelliona, Planera crenata. Paris 1\$31. \$.

Dunal, Description du Planera Richardi Mieh. Montpellier 18\%3. \$.

\section{Moreas:}

Lilbeck, De Moro alba. Lundae 1777. 亿.

Beggialo, Nuova specie di gelso delle Filippine. Padova 1836.8 .

Morelli, Proclromo di una monografia dolle specie del genere Morus. Milano 4842. 8 .

Sieringe, Notice sur le Minclure orangé. Lyon 1837.8 .

Linne, Ficus. Upsaliae 1744. 4.

Thunberg, Fieus genns. Upsaliae 1786. 4

De Candolle, Description de Ficus Saussureana. (Geneve 1Sł0.) 4.

Casparrini, Nova genera ruac super nonnullis Fici specicbus struebat. Neapoli 1844..4.

\section{Artocarpeae.}

Panzer, Beitrag zur Feschichte des ostindischen Brotbaums. Nurnbergy 1783. 8 .

Forster, Geschichte und Beselureilung des Brodbaums. Cassel 1784. 4.

Murray, A descriptive account of the Palo de Vaca or Cov-Tree of the Carracas. London 1837. gr. 8.

\section{Uricaceue.}

Slevogt, De Urticis. Jenae 1707. 亿.

Linne, Rariora Norvegiae. (Gmnera perpensa.) Upsaliae 1768.4.

Urtieaceae, in Miquel, Commentarii no. III. Lugd. Pat. IS40. folin.

\section{Balsamifluar.}

Balsamifluae, in Blume, Flor' Javae. Bruxcollis 1828. folin.

\section{Salirinae.}

Hofimann, Historia Salicum iconibus illustrata. Lipsiae 1785-1791. folio. Hacle, Salices. Dublin 1811.8 .

Seringe, Essai d'une monagraphie des Saules de la Suisse. Berne 1 S I 3̈. S. Dumortier, Yerhandeling over bet geslaclst der Wiigen. Amsterlam 1823. 8.

Hlost, Salix. Tindobonae 1828. folio.

hoch, De Salicibus europacis. Erlangae 1828. 8.

(Forbes) Salicetum woburnense. (London) 1899. 4.

Sadler, Synopsis Salicum Ilungariae. Pestini 1831. S.

De Candolle, Revue de quelques ouvrages sur le genre Saule. (Bibl. univ. de Geneve 1832. Xl1X, 15-27.)

Fries, Commentatio de Salicibus. In ejus "Mantisa 1. Novit. Florac suecicaen. Lundae 1832.5.

Trautvelter, salicetum. Petropoli 1836. 4.

List, Salicum prope Tilsam adumbrationes. Tilsie 1837.4.

Barratt, Sulices americanae. Middletown 1840.4

Traunsteiner, Monographie der Weiden von Tirol. Inuspruck is:2. 8.

IWallrolh, Zur Kenntniss der Salix hastata $\mathrm{I}$. In cjus "Beitrages. II. Leipzig 1844. 8 .

Anderson, Saliees Lapponiae. Upsaliae 1845.8

\section{MONOGRAPHLA:}

\author{
Chenopoleac.
}

Form, Mriplex salsum. Amsterdam 1661. 12.

Mobery, De Blito. Cpsaliale 1740.4.

l'allas, Illustrationes plantarmm imperfecte cosnitorum. Ilaloplintae hipsiac 1803. folio.

Schrader, De IJaloplıytis Pallasii. Goettingae is10. 4.

Lagasca, Memoria sobre las plantas Barilleras de España. Madrid 1817. \%.

Gussone, Flora sicula. (Salicornia.) Neapoli 1829. folio.

Babington, Nonograph of the british Atripliceac. Ediuburgl is:0. 8.

Hoquin-Tandon, Clienopolearum monugraplica enumeratio. Paris 1840.8 .

\section{Amarantaceue.}

Iilldenow, Ilistoria Amarantorum. Turici 1790. folio.

Jissieu, Observations sur la famille des Amarantacées. (Paris is03.1 4.

Martius, Beitrag zur Kenntniss der Amarantaceen. (Bounae 1825.) 4.

\section{Polygoneae.}

.lpinus, De Rlapontico disputatio. Patavii 1612. \&. - Lugduni Batas. 1718. 4

Wunting, De vera ánticuorum lierba britannica. Anstelodami 1681. 4.

Cannegieter, De Brittenburgo, britannica herba etc. Ilagae Comitum $173 \% .4$.

Lime , Rhabarbarum. Upsaline 1752.4.

Campdera, Monographie des Rumex. Paris 1819. 4.

Heisner, Monographine generis Polygoni prodromus. Generae 18zu. 4.

Meyer, Bemerkungen uber die Familie der Polygonaceae. St. Preterturum 18亿0. 4.

\section{Nyctagineae.}

Jussicu, Observations sur la famille des Nyetaginees. (Paris 1803.) i Kunth, Ueher eine neue Gattumgr der Nyctagineen. Berlin 18:3. 4.

Lheritier, Tricratus. s. 1. et a. Solio.

Oxybaplus. s. l. et ia folio

\section{Monimiaceae.}

Jussieu, Mèmoire sur les Monimies. (Paris 1509. ) 4.

\section{Laurineae.}

Caldenbach, De Lauro. Tubingae 1670. 4.

Wagner, Arhoreti saeri specimen, sistens Laurum. Helmstadii $1732 \mathrm{~S}$.

Agnethler, De Lauro. Ilalae 1751. 4.

Ruiz et Incon, Tahulae 28 generis Lauri ineditae. (cf. Flora peruviana vol. IV. Thes. lit. bot. no. $\$ \$ 59$.

Jussieu, Mémoire sur la réunion de plusieurs genres des Laurinèes. ( ris 1905.$) 4$.

Nees von Esenheck, De Cinnamomo disputatio. Bonnae 1823. 4.

Ilufelandiae illustratio. Vratislaviac 1833. i. Systema Laurinarum. Berolini 1836.8 .

\section{Santalaceae.}

Thunhery, Thesium. Ipsaliae 1806. 4.

\section{Daphnoideae.}

Wiksliöm, De Daphne. Ipsaliae 1817. 8. - Stocklıolm is20. 


\section{Elaeagneae.}

Mellenius, De llippophae. Aboae 1789. 4.

Lebret, Nolice sur Tllippophae rhamnoides. Ronen 1821.8 .

Sai, Deserizione di una specie di Elaeagnus. (Cornachinia fragiformis.) Mlodena 1836. 4.

\section{Proleaceae.}

Thunbery, De Protea. Upsaliae 1781. 4.

Knight, On the cultivation of the Proteaceae etc. Lourion 1 S09. 4.

Brown, On the natural order of plants called Prnteaccae. London 1810.4.

- Supplementum primum Prodromi Florae Novae llollandiae, exhi-

bens Iroteaceas novas. Londini 1830.8.

(Verm. Schrifteu. V, $77-116$.)

Giordano, Su di una nuova specie di Embothrio. Napali 1837.4.

\section{Nepentheae.}

Slevoyt, De Bandura Ceylonensium. (Nepenthes destillatoria.) Jenae 1719.4.

\section{Plantagineae.}

Rapin, Escquisse de l'histoire naturelle des Plantaginees. Paris 1827.8. Leydolt, Die Plantagineen. (Wien 1836.) 8.

Barnéoud, Recherches sur les Plantaginées et les Plumbaginées. Paris 1844.4 .

Mlonograplie générale des Plautaginées. Paris 1845.4

\section{Plumbagineae.}

Ebel, De Armeriae genere. Prodronus Plumbaginearum familine. Regiomonti 1840.4 .

11 allroth, Monographie der Gattung Armeria Willd. In ejus "Beiträge». Il. Leipzig 1844.8 .

\section{Ialerianeae.}

Dresky, De Valeriana officinali L. Erlangae 1776.4.

Du Fresne, Histoire naturelle et médicale de la famille des Valerinaes. Montpellier 1811.4.

Betcke, Animadversiones hotanicae in Valerianellas. Rostockii 1826.4.

De Candolle, Vénoire sur la lanille des Valerianées. Paris 1832.4.

Feueregger, l)e Valerianeis Hungariae, Croaliae elc Pestini 1837.8.

\section{Dipsareae.}

Couller, Mémoire sur les Dipsacées. Genève 1823. 1.

\section{Compositae.}

Mecse, llet XIX Classe van de Genern plantarum Liur. Lecuwardeu 1761.8.

Berlihey, Expositio eharacteristica structurae florum qui dicuntur Compositi. Lugduni Batavorum 1761. 4.

Heurlin, De Syngenesia. Loudini Golhorum 1771. 4.

Schmidt, Ueber Syngenesia, Polygamia aequalis, semillosculosi. In ejus "Sammlung" etc. Prag 1795. 8. p. 251-286.

schrank, Betrachtungen uber Syngenesia polygania fruslıanea. In ejus "Sammlung n ete. Nornberg 1796. 8. p. 33̈1-414.

De Candolle, Observations sur les Composées on Syngenises. (Ann. Mlus d'hist. nat. 1810. XVl, 135-138.)

Lagasca, Disertacion sobre un órden nuevo des las compuestas. In "Amendades". Orihuela 18\$1. 4.

Brown, Observations on the natural family of Compositae. London 18 \$7. 4. (Frorm. Sehritten. 11, 497-69k.)
Cassini, Opuscules plytologiques. Paris $1826-1834.8$.

Lessing, Synopsis generum Compositarum. Berolini 1\$32. s.

De Candolle, Genres nouveaux des Composées. (Paris 1833.) 8 don 1834.8.)

Observations sur la structure et la classification de la famille des Composées. Paris $4 \mathrm{~S} 3 \mathrm{~S} .4$.

- Statistique de la famille des Composees. Paris 1838.

Nuttall, Descriptions of new species and genera of Componitae. s. 1. 1840.4 .

Bauhin, De plantis Absyuthii nomen habentibus. Montisbeligardi 1593.8 . Boccone, Monitun de Abrotano marino. (Diotis maritima Desf.?) Cataneae 1668 . folio.

Boretius, De Hieraciis prussicis. Lugduni Batavorum 1720.4

hlein, An Tithymaloides frutescens folii Nerii Plum. nec Cacalia nec Cacaliastrum? (Kleinia.) Gedani 1730.4.

Lischwitz, De ordinandis rectius virgis aureis. (Solidago.) Lipsiae 1731 , i Limné, Anaudria. Upsaliae 1745. 4.

Stechmann, De Artemisiis. Gottingae 1775. 4.

Willdenow, De Achilieis. Halae 1789. S. Supplementum generis Tanaceti. In ejus "De Arhilleis n. Hlalae 1789. S. p. $47-53$.

Mellenius, De Cichorio. Aboae 1792. 4.

Bonato, Pisaura automorpha e Coreopsis formosa. Palosa 1793. 4

Lhéritier. Virgilia. s. I. et a. folio.

- Hymenopappus. s. 1. et a. folio.

Willemet, Willemetia Neck. s. I. et a.

Tillars, Nouvelle espece de Hieracium. s. l. et a. 8 .

Thunberg, Iretotis. Upsaliae 1799. 4.

Jussieu, Mémoire sur le líleinia et l'Actinea. (Paris 1803.) 4 .

Mémoire sur l'Acicarpha et le Boopis. (Paris 1803.) /4

Sur le Gymnostyles. (Paris-1804.) 4.

De Candolle, Deseription d'un nouveau genre Strophanthus (Mins. des savans étrangers $\{805.1,406$.

Gochnal, Tentamen de Cichoraceis. Argentorati 1808. 4.

Bivona-Bernardi, Monographia delle Tolpidi. Palermo 1809 . folio.

Tristan, Mémoire sur les aigrettes des fleurs conposées et les caractirles Ju genre Zinnia. Orléans 1811.8 .

Anderson, Dissertation on the Eupatorinm perfoliatum L. New Vorh I813. 8 .

Tees von Esenbeck, Symopis specierum generis Asterum herhaceirum. Erlangae 1818. 4.

Gay, Mlonographie des genres Xeranthemum et Chardinis. Paris 1827. 4.

Monnier, Essai monographique sur les Hieracium. Naney 1829.8 .

Meral, Examen des genres Apargia el Thrincia. Paris 1831.8.

Lessing, 1)e generilsus Cynarocephalarum et speciebus generis Arctotidis. Berolini 1832. 8 :

Nees von Esenbeck, Genera el species Asterearum. Tratislavian 1832. S.

Besser, Tentamen de Abrotanis. Moscoviac 1832.4.

- Dissertatio de Seriphidiis. (Cremeneci 4833.) 8

Trauletter, De Echinope genere. Mitaviae 1833. 4

Soyer, Gnaphalium neglectim. Naney 1836. \&

Fonzl, Charahteristik der Gnaphalien De Candolle 's. s. I. et a. \&.

Steudel, Leber ein neues Pllanzengenus (Frankia Schimperi). s. 1. 1836.8. Picard, Observations botaniques sur le genre Sonchns. Boulogne s. a. 8.

Zsigray, Enumeratio Centaurearum llungaride. Pestini 1838.8.

Larralt, Eupatoria rerticillata. Niddletown 1840 ? 4.

Vaegeli, Die Cirsien der Schweiz. (Neuclatel 1841.) i.

Parlalore, In Filaginis Evacisque species observationes. (Firenze 18 11.) s.

Savi, Sull Erigeron sicnlum L. (Jasonia sicula De Cand. Prodr.) Monlena 18 41.4.

Schultz, Analysis Cichoriacearum Palatinatus. Landau 1841.8 
I'rallroth, Naturgeschichte des Senecio paludosus L. In ejus a Beilragen I. Leipzig 1842.8.

Schultz, Ueber die Tantceteen. Neustadt a/d. Iliarde 1844.4.

llallroth, Zur Kenntniss der Anthemis tinctoria. Jn ejus "Beituagen II. l.eipzing 1844.8 .

Veber die Gattumg Lampsana Doclon. In ejus "Beitrage" II. Leipzig 184 4. 8

Monographie der Gattnog Xanthium Diose. In ejus "Beitrage" II. Leipzig 1844.8

Visiani, Osservazioni sopra alcunc specie di Matricaria. lïrenze 1843. 8.

\section{Lobeliaceae.}

Jussieu. Némoire sur les Lobeliacées et les Slylidiẻes. (Paris 1811.) 4. I'resl, Prodromus monographiae Lobeliacuarums. I'ragae 1836. S.

\section{Campanulaceae.}

L'hiritier, Michauxia. s. I. et a. folio.

Forsberg, De Campanulis suecanis. Lpsaliae 1829. 4

De C'andolle, Monographie des Campanulées. Paris 1830.4.

\section{Ruliaceae.}

Willemet, Monugraphie des plantes étoilees. Strasshurg 1791. 8. Jussieu, Sur la fanille des Rubiacees. (Paris 1820.) 4.

Cruse, De Rubiaeeis capensibus, praesertim de genere Anthosperno. Berolini 1825.4

Richard, Jémoire sur lo fanille des Rubiacées. Paris 1899.4.

Opiz und Berchtold, Die Rubiaceen Bohmens. Prag 1838. 8.

IItrffbain, De Rubea tinctorum. Basileae 1707. 4.

Steinmeyer, Do Rubia tinctorum. Argentorati 1762. 4.

Thunberg, De Gardenia. Upsaliae 1780.4.

L'heritier, Buchozia. s. I. et a, folio.

Ruis, Quinologia. Madrid 1792.4. - Supplemento: ib. 1801.4. . (1talico, germanice.

lahl, Dissertation on the genus Cinchona. In Lambert "A description". London 1797. 4

Selig. De Galii rotundifolii charactere botanico. Eirlangae 1502. 8.

Rohde. Monugraphia Cinchonae generis. Goetlingae 1804. S.

Jussieu, Memoire sur l'Opercularia. (Paris 1804.) 4.

De Candolle, Némoire sur le Cuviera. (Paris 1807.) 4.

Thunberg, De Cincliona. Lpsaliae 1811.4.

Guylielmi, Osservazioni sulla China-china officisale e quattro altre specie. Parna is 14.8 .

Harlung, De Cinchonae speciebus. Argentorati 1812. 4.

Richard, llistoire des différentes espèces d'lpécacuanha. Paris 1\$20.4.

Colla, Nenoire sur le Melaropsidium nigrum. Paris 1825.8 .

Decaisne, Examen botanique du genre Rubia el de ses especes. In ejus

"Recherches sur la garance». Bruxelles 1837.4.

forthals, Observationes de Naucleis inlicis. Bonnae 1839. 8.

Schomburyk, Deseription of Calycophyllum Stanleyanum. (London 1841.) 4.

\section{Lonicereae.}

Lioubieu, Precis sur les chève-feuilles des environs de Montpellier. In ejus "Opascules" etc. Montpellier 1816. 8.

\section{Contortae.}

Rollboell, Botanikens udstrahte nytte. Kiöbenhavn 17i 8.

Hedicus, Leber den unerkw urdigen Bau der Zeugungsglieder der Contorteı. (Nerium, Periploca, Koelrenteria, Cynanchum. Asclepias.) Manntrein 178 ?.

\section{Oleaceae.}

Caldenbach, De Olea. Tubingae 1679. 4.

L.chr, l)e Olea europaer. Goctingae 1779. ^.

\section{Loyaniaccae.}

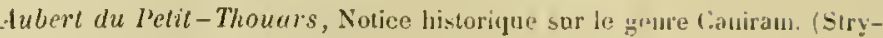
cluos.) Strasbourg 1806.8

\section{Apocyneae.}

Lochner, Nerium sire Rhododaphne. Norimbergae 1716. 4.

Thunberg, In genus Echitis observationes. Cisaliae 1519.4.

Griscom, Olsservations on the Apocyum carmabinum. Pliladelplia 1833.8.

\section{Asclepiadeae.}

Masson, Stapeliae novae. London 1796. folio.

Jacquin, Stapeliarun in hortis vindobonensibns cultarum descriptiones. Vindobonae $1806(-1819)$. folio.

Brouon, On the Asclepiadeae. (Edinburglı 1 S10.) S. - (Jatine a Prest. Progae 1819. 8.)

Verm. Sehriften, 11, 3i7-4k.)

Sonnini, Traili des Asclepiatlées. Paris 1810.8.

Jacquin, Genitalia Aselepiadearum controversa. Viennae 1811. S

Synopsis Stapeliarum. (Wien) 1816. S.

Breda, Genera et species Orchidearum et Isclepiadearam, quas in Java collegerunt Kuhl et van Hasselt. Gaudavi 1527. folio.

Brown, Observations on the organs and mode of fecundation in Orchideac and Asclepiadeac. London, October 1831 . 8 . (Transact. of the Linnean Society 1833. 4. p. $685-745 .-$ Vesm. Schriften. V, p. 117 - 189.)

Ehrenbery, Veber das Pollen der Asclepiaclecu, Berdiu 1831. 4.

\section{Gentianeae.}

IIartmann, Historia Gentianae. Trajecti a/ Y. 1777. 4.

Froelich, De Gentiana libellus. Erlangae 1796, S.

Marquis, Essai sur l'histoire naturelle des Gentianes. Paris $1810,4$.

Nees von Esenbeck, Veber die bartnundigen Enzianarten. (Erlangae 1S1S.) 4.

Bunge, Conspectus generis Gentianae, imprimis specierum rossicarum. (Nosquae) 1824. 4 .

Melen, De Erythraeis suecanis. Upsaliae 1826. 'A.

Schmidt, Do Erythraea. Beroliui 1828.4.

Polli, De Gentianis comensibus. Ticini 1832, 8 .

Lebert, De Gentianis Helvetiae. Turies 1834. 8.

Grisebach, De Gentiantearum familiae claracteribus. Berolini 1836. \&.

—_Genera el species Gentianearun. Stuttgartiale 1839.8 .

Splitgerber, Observationes de Voyria. (Leiden is:0.) 8.

\section{Labiatae.}

Schreber, Plantae verticillatae unilabiatae. Erlangae 1773. \&

Schnekiter, Jdea generalis ordinis plintarum verticillatarun. Fiessae 1777. 4.

lioch, De plantis lahiatis. Erlangae 1833.4.

Benthain, Labiatarum genera el species. London 1832-1836. \&.

Ellinger, De Salvia. Erlangae 1777.4.

Linigge, We Mentha Piperilide. Erlaugae 1780. 1

Limé fil., De Layandula. L'psaliae 1750.4.

Sole, Menthae britannicae. Bath 1798. folio min.

Gingins de Lassaraz, Histoire naturelle des Lavandes. Cienere 18 g6. 8. 
Ifltebrandt, Generis Dracocephali monographia. Goetlingae 1S05. 8. Fresenius, Syllabus observationum de Menthis, Pulegı et Preslia. Francofurti a/Al. 1829.8 .

Savi, Osservazioni sopra alcume specio del genere Origanum. Pisa 1S40. S.

\section{Verbenacea.}

Jussicu, Observalions sur la famille des Verbenacées. (Paris 1806.) 4. Kunth, Veber die Gattung Omplhalococca Willd. Berlin 1832. 4.

\section{Stiluineae.}

Kunth, Veber die Verwandtschalt der Gattung Stilbe. Berlin 1832. 4.

\section{Selagineae.}

Choisy, Mèmoire sur la famille des Selaginces. Genéve $1 \$ 23,4$.

\section{Asperifoliae.}

L.chnam, Beschreilunng einiger never Pflanzen. llalle 1817. S. Plantae e familia Asperifoliarum nuciferae. Berolini 1818.4. Icones rariorum plantarum e familia Asperifoliarum. Hamburgi 1821 (-1824). folio.

Schrader, De Asperifoliis Linnaei. Goettingae $1 \$ 20.4$.

Reichenbach. Amoenitates botanicae dresdenses. 1: Observationes in genus Myosotis. Dresdae 1820.8.

Die Vergissmeinnichtarten Deutschlands. Nuruber'g 1822.12 Schimper, Beschreilung des Symphytum Zeyheri. Heidellserg 1833. S. Fieber, Die Echien Bolmens. Pràg 4841.8.

\section{Convolvulaceae.}

Choisy, Convolvulaceae orientales. Geneve 1834-4841.4.

- Sur les Convolvulacées du Brésil et sur la Narcellia. Genève 1844. 4 .

Colla, Memoria cirea una nuova specie, Calonyction macrantholeucun. Torino (1840.) \&.

\section{Cusculeae.}

H'edel, De Cuscuta. Ienae 1715.4

\section{Polemoniaceae.}

Jussien, Ménoire sur le Cantua. (Paris 1804.) 4.

\section{IIydroleaceae.}

Choisy, Descriplion des Hydrolćaces. (Genève 1833.) h.

\section{Solanaceae.}

Gregorius de Regio, De varietate Capsicorum commentarius. In Clusii Curis posterioribus. Antwerpiae 1611. folio.

Ambrosinus, De Capsicorum varietato. Bononiae 4630.12.

(Thomasius) De Mlandragora. Lipsiae 1655. 4. - ib, 1769. 4.

Faber, Strychnomania. Augustae Vind. 1677. 4.

Schoon, Waare oelfening en ontleding der planten ctr. (Nicoliana.) Gravenlage 1692.8.

Stromeyer, Solanacearum ordo. Goeltingae 1772. 4.

Plaz, De Atropa Bellidonna. Lipsiae 1776. 4.

Jussieu, Sur le Pelunia. (Paris 1803.) 4.

- Sur le Solanum eornutum du Mexique. (Paris 1804.) 4.

Dunal, llistoire namrelle, médicale et éconornique des Solanum. Mont pellier 1813.4

- Solanorum generumfue affinium synopsis. Nonspelii 1816. 8.
Lehmann, Generis Nicotianarum historia. (llamburgi) 1818.4.

Agardh, Conspectus specierum Nicotianae. Lundae 1819. 12. (germanice.)

Balsamo-Crivelli. De Solanacearum familia in genere. Ticini $1824,8$.

Ponchel, Essai sur l'histoire naturelle ef médicale des Solances. Pari1827. 4 .

- Mistoire naturelle et módicale des Solanées. Roven 1829.8.

Fingerhuth, Monographia generis Capsici. Duessoldorpii 1 \$32. \$.

Schlechendal und Bouche, Veher die wilde hartolfel (Papa cinarron) ron Mexico. Berlin 1833. 4.

Bertoloni, Conmentarius de Mandragoris. Bonodiae $1 \$ 35.4$.

Naudin, Étucles sur la végétation des Solances. Paris 1842. 4.

Sendtne.', De Cyplromandra. (Monachii 1845.) S.

Sulanaceae et Cestrineae brasilienses. In lorae brasiliensis fasc. V'1. Lipsiae 1846 . folio.

\section{Scrophularinae.}

Bentham, Scrophularinearum revisio. (Lonton 1835.) 8 . Scrophularineae indicae. London 1835.8.

Risler, De Verbasco. Argentorati 1754. 4.

Schrader, Nonographia generis Verbasci. Goetungae 1813-1823. '. Lalsamo-Crivelli, Verbascurum Italiae monographia. Ticini 1824.8. Pfund, Monographiae generis Verbasci prodromus. Prag 1840.8. Ilofmann, I'eber die tirolischen Arten von Verhascum. Inmspruck 184 \&. \$.

Wydler, Essai monographique sur Je geore Serophularia. Geneve 1\$28. 4.

Chavannes, Monograplie des Antirrhinées. Paris 1833. 4.

Traltinick, Der Kaiserhranz (Franciscea uniflora Pohl) zum 12. Februar 1829. (Wien 1829.) 4.

Elmiger, Histoire naturelle el médicale des Digitales. Hompellier 1.812 .4 . Lindley, Digitalium monographia. Londini 1821. folio.

Trantvetter, De Pentastemone genere. Petropoli 1839.4.

Colsmann, Prodromus deseriptionis Gratiolae. Havniae 1793. \&.

Jussieu, Nole sur le genre Hydropityon Gaertneri. (Paris 1807.) 4. Sur le Curanga. (Paris 1807.) 4.

Colla, Freyliniae genus. Taurini s. a. 4.

Marlinis, Nuovo invento, cioé aggiunta a] genere delle Anagallidi acipuatiche etc. Verona 1717.8.

Haller, De Teronicis quilusdam alpinis. Goettingae 1737. 4.

Jlagen, Veronicarum prussicarum recensio. Regiomonti 1790.4.

Schrader, Commentatio super Veronicis spicatis Limaei. Goelliugae 1803. 8 .

bernhardi, Ueber minder bekannte Elrenpreisarten des sudlichen DentschJands. Erfurt 1S06.8.

lioch. Monographia generis Veronicae. Wircchurgi 1333.8 .

Moretti, Synopsis Veronicarum Italiac. Ticini 4834.8 .1

Roberg, De planta Sceptrum carolinum dicla. Upsaliae 1731. 4.

Haller, De Pedicularibus. Goetlingae 1737.4.

Stephan, De Pediculari comosa. Lipsiae 1791.8.

Steven, Mlonograplia Pedicularis. s. 1. 1\$22.4.

Schlechtendal, Genus Cymbaria revisum et 'mendalum. In 1lor. pliys. Ler. Bonnae 1820. folio.

Soyer-IVillemet, Euphrasia officinalis et espèces roisines. Nancy 1833.8. 


\section{Acanlhaceae.}

Jussicu, Mémoire sur le Vicliptera et le Blechum. (Paris 1807.) 4. Nees von Esenbech, Lepidagathidis generis Acunthacearum illustratio monographica. Vratislaviac 1841 . I.

\section{Bignoniaceae.}

Up Candolle, Revue sommaire de la famille des lignoniacées. (Genève 1838.) 8.

Ners von Esenbeck, Fridericia et Zollernia, ad socios literae. (Bonnae) 1827. 4.

Endlicher. Ceratoheca. Berlin 1832. 8

fenzl, Darstellung und Erlauterung vier ninder bekanuter Gattungen. s. 1. et a. 4 .

- Velser die Stellung der Gattung Oxera. s. 1. et a. 4.

\section{Gesneraceue.}

Brown, On Cyrtandreao. (From Horsfield, J'antae javanicae rariores.) London $1838-1839$. folio

\section{Pedalineate.}

hretsschmar, Beschreibung der Hartyniae anmuae villosae. Friedriclistalt (i. e. Dresden) $(1764)$.4 .

\section{Orobancheae.}

Hourebeke, Mémoire sur les Orobanches. Gand 1818.8.

Wallroth, Orobanches generis Diaskene. Francolurti a/M. 1825. 8 .

Vaucher, Monographie des Oroljanches. Geneve 1827.4.

Schullz, Beitrag zur Kenntniss der deutschen Orobanchen. Munchen 1829. folio.

Schlauter, Die Orobanchen Deutschlands. Qurdlinburg 1834. \$.

\section{Utricularieae.}

Sichebler, Utriculariae vulgaris arlumbratio. Tubiugae 1832.8.

Saint-llilaive et De Girard, Monographie des Lentiłulariées du Brésil meridional. Orjéans 1840.8

\section{Primulaceae.}

Duby, Memuire sur la famille des Primulacees. lienere 1844. 4 .

liranke, De Soldanella. Heidelbergae 1674.4

Sesler, Nuovo grenere Vitaliana. Venezia 1750.4

igallice, germanice.

Lehmann, Monographia generis Primularmn. Lipsiae 1817.4.

Velle Chiaje, Nemoria sul Ciclamino Poliano. Napoli 1824.4.

Moretli, De Primulis italicis. Ticini 1831.8 .

Saint-llilaire et De Girurd, Monographie des Prumulacées du Brési! méridional. Orléans 1840.8.

De donghe, Nonographie du genre Cyclamen. Bruxelles 1844. 19.

Scheencke, Norae plantae Selwwenckia dictae brevis descriptio. Hagas Comitum 1766. 8 .

\section{Myrsinear.}

Jussicu, Note sur l'Oncustemum. (Paris 1830.$)^{4}$

\section{Ebenaceae.}

Thunbery, De Styrace. Upsaliae $1813 \quad 4$

\section{Napoleonere.}

Jussieu, Sote sur le ggenre Napoleona Ja!. Joauv. (Paris 1864.) q.

\section{Ericaceap.}

lialm, De Erica volgari. Ahoae 4754.4

Murray, De Arbuto uva ursi. Goettingae 1764 ,

Linne, De Érica. Upsaliae 1770. 4.

De Ledo palustri. Upsaliae 1775.4

Thunberg, De Erica. Upsaliae 1783. 4.

Bater, Thirty plates of Ericas. London 1791-1800. folio.

II'endland, Ericarum icones et descriptionns. Ilannover 1798-1823,4.

Jussieu, Sur une plante nommé par les botanistes Erica Daboecia. (l'aris 1802.) 4 .

Andreios, Colonred engravings of Ileaths. London 1802-180\%. folio. The Ileathery. London 1804 . gr. 8.

Ifaila, Besclureibung der Heiden. Altenburg 1805.8.

Hadius, lue Pyrola et Chimophila. Specimen I botanieum. Lipsiae 1821. 4

(Forbes) Hortus ericacens woburaensis. (London) $1 \$ 230.4$

Prest, Epistola de Symplyysia. Pragae 1827.4.

Liunth, Veber die Gattung Sympieza Lichtenst. IBerlin 1832. 4.

Soyer-W'illemet, Erica vagans et E. multiflora. Nancy 1835. s.

Seidel und Heynhold, Die Rhodoraceae oder Rhododendreae. Inresden 1843. 8 .

Regel, Die kultur und Aufzálılungr der Eriken deutselier und englisclier Gisten. (Zurich 1843.) 4.

Aleksandrowitsrh, De fanilia plantarum ericacearum. Petropoli $184\{.8$.

\section{Uimbelliferae.}

Thurneisser zim Thurn, Historia aller Erdgeweclsen. (Lmbelliferae.) Berlin 1578. folio.

Morison, Plantarum Umbelliferarum distributio nova. Oxonii 1672. folio.

Crantz, Classis Umbelliferarum emendata. Lipsiae 1767. 8.

Jussicu. Extrait d'un mémoire de Cusson sur les Onbelliferes. (Ilist, de la soc. royale de médecine $1782-1783$.

Candy, Essai sur les plantes ombelliferes. Strassburer 1819.4.

Sprengel, Plantarum Unbelliferarum prodromus. Halae 1813. S.

Hofmann, Syllabus plantarum Limbelliferarum. Mosquae 1814.8. ib. 1816.8

Sprengel, Species Limbelliferarum minus cognitae. Ilalae is 18.4.

Fela, Disertacion sobre la familia natural de las plantas aparasoladas. In Lagasca" Amenidades ». Mladrid 1\$21. 4.

Layascu, Dispositio Innbelliferarum carpologica. In nAmenidades . Madrid 4821.4 .

_- Olservaciones solre la familia natural de las plantas injarasoladas. Londres 4826.8 .

De Candolle, Mémoire sur la famille des Ombellifores. Paris 1829.4.

Fenzl. Unhelliferarum genera nova et species. (Ratishonie 18.3.) S.

Slevogt, De Astrantiac charactere. Jenae 1721. 4.

Schmidel, De Oreoselino. Erlangae 1751. 4

Thumberg. De Ilydroeotyle. Upsaliae 1798.4.

Briganti. De nova Pimpinellae specie. Neapoli 1805. folio.

De Candolle, Mémoire sur le Drusa. (Paris 1807.) 4.

De la Roche. Eryngionum nee non generis Asclepicieae listoria. Paris is08. folio.

11 allenius. Nova Immeos species. Aboae 1810.4.

Richarl. Anonographic du genre Hydroeotyle. Bruxelles 1\$20. 3.

Tenore. Memoria su di una nuova specie di ingelica. Napoli 1837. 4. Arellino. No!a sulla Pastinaca lintifolia. Napoli $1843 . .8$. 


\section{Araliaceae.}

Araliaceae, in Miquel Commentarii no. III. Lugduni Bat. 1840. folio. Rudbeck, De Hedera. Upsaliae 1707. 4.

Lafitau, La plante du Gin seng de Tartarie deconverte en Canada. Paris 1718.8.

Vaillant, Etablissement d'un nouveau genre, Araliastrum. (Paris) 1718.4. Visiani, Sopra la Gastonia palmata Roxb). (Trevesia Vis.) Torino 1\$41.4.

Ampelideae.

vide infra Vitis el Vinum.)

\section{Corneae.}

L'héritier, Cornus. Paris 1788, folio.

Meyer, Ueber einige Cornusarten. St. Petersburg 1845.4.

\section{Loranthaceae.}

Lorauthaceae, in Blume, Flora Javae. Bruxellis 1828. folio.

De Candolle, Mémoire sur la famille des Loranthacées. Paris 1\$30. 4.

Notice sur la végétation des plantes parasites et en particulier des Loranthacées. (Genève 1830.) S.

Forthals, Verhandeling over de op Java, Sumatra en Borneo verzamelde Loranthaceae. s. l. et a. 8 .

- Over het geslacht Tupeia. s. l. et a. 8.

Baier, De Visco. Altdorfii 1706. 4.

koelderer, Viscum plerarunque arlıorum planta parasitica. Argentorati 1747. 4 .

Buchwald, Analysis Yisci, ejusque usus. Ilafniae 1753.4.

Sturm, Visci quercini descriptio. Jenae 1796. 8.

Savi, Sul Viscum album ed il Loranthus europacns. Pisa 1823. 8.

De Candolle, Mémoire sur la végétation du guy. (Mém. des savans étrangers vol. I.)

Gaspard, Mémoire physiologique sur le gui, Viscum allınm L. (Magendie, Journal de physiologie experim. et pathol. Vll, 227-333.)

Decaisne, Recherches sur le gui (Viscum album). Bruxelles 1840.4

\section{Bruniaceae.}

Thunberg, De Brunia. Upsaliae 1804. 4.

\section{Crassulaceae.}

Bradley, The history of succulent plants. Historia plantarum succulentarum. London 1716-1727.4.

De Candolle, Plantarum historia succulentarum. Paris 1799-1829. folio. - Mémoire sur la famille des Joubarlbes, Sempervivae Juss. (Rulletin soc. phil. 1801. p. 1.)

Haworth, Synopsis plantarum sueculentarum. Londini 1812. 8.

Supplementum plantarum succulentarum. Londinj 1819.8.

Revisiones plantarum succulentarum. In ejus "Saxifragearum enumeratio ". Londini $1 \$ 21.8$.

De Candolle, Ménoire sur la famille des Crassulacées. Paris 1828. 4.

Minuart, Cotyledon hispanica. (Madrid 1739.) 4.

Ortega, Do trova quadam stirpe, sen Cotyledonis Mucizoniae et Pistoriniae descriptio. Mlatritj 1772. 4.

Martelli, Braschiae plantae novae generis descriptio. Romae 1791. 4.

Jussieu, Note sur le genre Francoa. (Paris 1824.) 8.

Brown, Remarks on the structure and alfinities of Cephalotus. (Edinburgh 1832.) 8 .

Pritzel, Thes. lit. hot.

\section{Saxifragaceae.}

Pallas, De Chrysosplenio. Argentorati 1758. 4.

De la Peyrouse, Figures de la Flose des Pyrénées. (Saxifraga.) P’aris $1795-1801$. folio.

Ilaworth, Miscellanea naturalia. (Saxifraga.) London 1803.8.

- Saxifragearum enumeratio. Londini 1821.8

Moretti, Specie italiani del genere Saxifraga. Pavia 1823. 4.

Sternberg, Revisio Saxifragarum iconibus illustrata. Ratisbonae 1810. folio. - Supplementa: Katisbonae et Pragae 1822-1831. folio.

\section{Ribesiaceae.}

Berlandier, Ménıcire sur la famille des Grossulariées. Genève 1828. 4.

Thory, Monograplie du genre groseillier. Paris 4829. 8 .

Anonaceae.

Dumal, Monographie de la famille des Anonacées. Paris 1817.4. Anonaceae, in Blume, Flora Javae. Bruxellis 1828. folio.

De Candolle, Mémoire sur la famille des Anonacées. Genève 1832. 4

Martius, Anonaceae lrasilienses. In Florae Irasiliensis fasc. Il. Lipsiae 1841. folio.

\section{Schizandraceae.}

Schizandreae, in Blume, Flora Javae. Brusellis 1828. folio.

\section{Magnoliaceae.}

Ellis, Copies of two letters to Dr. Linnaeus and to Mr. Atton. (Illicium floridanum.) London 1771.4.

Soulange-Bodin, Nouvelle espèce de Mlagnolia. Paris 1826. 8 .

Nagnoliaceae, in Blume, Flora Javae. Bruxellis 1828. folio.

IIoffmann, Die Angaben schinesischer und japanischer Niturgeschichten vou dem fllicium religiosum. Leiden 1837.8 .

\section{Ranunculaceae.}

Helwing, Florae campana sen Pulsatilla. Lipsiae (1749.) 4.

Reinhold, De Aconito Napello. Argentorati 1769. 4.

Jussieu, Examen de la famille des kenoneules. (Paris 1773.) 4.

Linné, Planta Cimicifuga. Upsaliae 1774. 4.

De la Chenal, Observationes botanico-medicac. (Aquilegia.) Basileae 1776. 4.

Jagen, De Ranunculis prussicis. Regiononti 1784. 4

Mueller, De Clematide Vitalba L. Erlangae 1786. 4.

fioelle, Spicilegium observationum de Aconito. Erlangae 1788. 8.

Jussieu, Mémoirc sur quelques nouvelles espèces d'Anémones. (Paris 4804.) 4 .

Biria, llistoire naturelle et médicale des Renoncules. Montpellier 1811.4.

Encontre, Mémoire sur l'Aconir dos anciens. (Montpellier 1813.) 8.

De Candolle, Considérations génćrales sur les fleurs doubles des Renonculacées. (Ném. soc. d'Areueil 1817.111,385-404.)

Treviramus, De Delphinio el Aquilegia observationes. Vratislaviae 1817.4.

Seriuge, Esquisse d'une monographie du genre Aconitum. In Muscée helvétique. Bern (1818-) 1823.4. 1. 115-175.

Schlechtendal, Animadversiones botanicae in Ranunculaceas Candollii. I-11. Berolini 1819-1820.4.

Reichenbach, Uebersicht der Gattung Aconitum. Regensburg 4819.8. Monographia generis Aconiti. Lipsiae 1820 . folio.

folio.

Seringe, Observations sur le grenre Ranunculus. (Mélanges II. 4.) Genevin 1826.8. 
Spenter, Monographia generis Nigellac. Friburgi Brisgoviae 1829. 4.

Godron, Essai sur les Renoncules a fruits ridés transversalenent. Nancy 1840. 8 .

Avellino, Su di una nuova specie di Clomatide Memoria. Napoli 1842. 8.

Pritzel. Anemonarum revisio. Lipsiae 1842.8.

Dumas, Sur la structure de l'lhellébore fétide. Monıpellier 1844. 4.

\section{I'apaveraccae.}

IIofsteter, De Papavere etc. Halae 1704. 4.

Ou०, De Fumaria. Trajecti a/V. 1789. 4.

IYillemet, Neckeria capnoides Scop. s. I. et a.

Tiquier, Ilistoire des Pavots et des Argémones. Montpellier 1814. 4.

Lestibonlois, Hémoire sur lo fruit des Pajavéracécs. Lille 1\$23.8.

llandschuch, De plantis fumariaccis. Erlangae 1832..

Ellian. Tentamen monographine generis Papaver. Regiomonti Borussorum 1839.4.

Schultz, Vortrag uber llypecoun pendulum L. (1. Jahresb. der Pollichia.) Landau 1843.8.

Parlatore, Nonografia delle Fumariée. Firenze 1844.8.

\section{Cruciferae.}

Brendel. De plantis flore perfecto simplici regulari tetrapetalo. Wittebergae 1718.4.

Crantz, Classis Cruciformium ementata. Lipsiae 1769. S.

Bergere, Plyytonomatotechnie universelle. (In vol. 111 : Cruciéres françaises.) Paris $1783-1784$. folio.

Medicus, Pflanzengattungen. (Cruciferae.) Mannlacim 1792.8.

De Candolle. Notices sur quelques genres de Siliculeuses. (Ném. soc d'hist. nat. de Paris 1799. I, 140.)

- Jlémoire sur la famille des Cruciferes. (Paris 1821.) 4.

Lestiboudois, Némoire sur les fruits siliqueux. Lille 1823. 8.

Observations phytologiques. (Sur l'insertion des étamines des Cruciferes.) Lille 1826.8.

Monnard (et Gay), Observations sur quelques Cruciferes de De Candolle, Syst. vol. 11. Paris 1826. 8.

kunth, Ueber die Blüten- und Fruclıtbildung der Cruciferen. Berlin 1833.4.

Sturm, De Rosa hierochuntina liber unus. Lovanii 1608. 8 .

Mappus, De Rosa de Jericho vulgo dicta. Argentorati 1700.4.

Turra, Farsetia, novum genus. (Venetiis 1765.) 4.

Sebeoli de Szenl-Miklòs, De Tartaria hungarica. Viennae 1579. s.

(L'herilier) Kakile. 1788. folio.

De Candolle, Monographie des Biscutelles. (Ann. Mus. d'hist. nat. 1814. XVIII, 292-304.

IJémoire sur les différentes espèces de choux et de raiforts. Paris $1 \$ 22.8$.

(auglice, germanice.)

Wahlenbery, Anmärkaingar vid Cardamine parviflora Linn. Sıckholm 1823.8.

Wrangel, Cardamine parvilora L. Stockholı 1823. 8.

Lindblom, Skandinaviska arterna af slágtet Draha. (Stockholm 1840.) S.

Meyer, Das Alyssum minutum, und Uebersicht der fattung Isilonema. Petersburg 1840.4 .

Gay, Erysimorum novorum diagnoses. Paris 1842. S.

Des Monlins, Note sur le Sisymbrium lursifoliun Lap. Bordeaux 1845. 8

Sonder, Revision der Heliopliteen. (Ilamburg 1846.) 4 .

\section{Resedaceae}

Saint-Hilaire, Deuxième mémoire sur les Résédacées. Montp̣ellier 1837. 4

\section{Dulisceae.}

Targioni-Tozzelli, Sulla Datisca cannalsina. (F̈renze 1835.) $\$$.

\section{Nymphaeaceae.}

De Candolle, Jlémoire sur Ins affinités naturelles de la famille des .rymplacacées. (Geneve 1821.) 4.

Lindlcy, Victoria regia. (London 1837.) folio eleph.

Trecul, Reclıerclies sur la structure et le développement du Nuphar lutea. (Paris 1843.) 8 .

\section{Surracenieac.}

Croom, Olsservations on the genus Sarracenia. New York 1837. 8.

\section{Cistineac.}

Sweel, Cistineae. Londen 1825-1530.8

\section{Droseraceac.}

Brendel, De Rorella. Wittebergae 1716. 4.

Thumbery, De Drosera. Lpsaliac 1797. 4.

Ellis, Figure and description of Dionaea muscipula. Impr. cum ejus \& Directions v. London 1770.4. (germanice, gallice.)

Dumorlier, Notice sur le grenre Dionaca. Bruxelles s, a, 8.

Parlatore, Osscrvazioni sull' Aldrovanda vesiculona. Firenze 1844.8.

\section{Violarieae.}

Kessler, De Viola. Vindobonae 1763.4.

I'io, De Viola. Taurini 1813.4.

Gingins de Lassaraz. Mémoire sur la famille des Violacées. Genève 1823. 4.

Kirschleger, Notice sur les violettes de la vallée du Rlin. (SIrassbury 1840.) 4

\section{Bixaccae.}

Kunlh, Bixineae ete. Paris 1822. 8.

$$
\text { Passiflorcae. }
$$

(Parlesca) Il fiore della granadiglia. Bologna 1609. 4.

Rasciolti, Copia del fiore el frutto clse wasce nelle Indie occidentali. Venezia 1609. folio.

Vera effigies plantac Mlaraco (P. incarnata) qualis lloruit in horto Johannis Robini, mensibus Augusto et Septembri $1612 \mathrm{ct} 1613$. Folio.

Donato d'Eremita. Vera effigie della granadiglia. Napoli 1619.4.

- Granadiglia neero fior della passione. Napoli 1622.4.

Caslelli, Vera e natural offigie della granadilla. Venetia 1620 . folio.

Coppie de la fleur de la passion qui croist dans les lndes occideutales. Paris 1643, folio.

Limné, Passiflora. Holmiae 1745. 4.

Lawrance, l'assion-flowers. London s. a. folio.

Caranilles, De Passiflora. (Nonadelphiae classis dissertatio X.) Matriti 1790.4 .

Jussicu, Mémoires (I-ll) sur les Passiflorées. (Paris 1805.) 4.

Saint-Hilaire, Mémoire sur les Passiflorées etc. Paris 1823. 4.

\section{Loaseac.}

Jussicu, llémoire sur le Laasa. (Paris 1\$04.) 4.

Schrader, Blumenbachia. Gocttingae 1827.4 


\section{Cucurbilaceae.}

Sainl-Hilaire, Mémoire sur les Cucurbitacées, Passillorées el Nandthirobes. Paris 1823.4 .

Seringe, Mémoire sur la famille des Cucurbitacées. Genève 1825. 4.

De Candolle, De la famille des Cuenrbitacées. (Mém. soc. d'hist. nat. de Genève 1825. 111, 33-37.)

foemer, Synopses monographicae. II : Peponiferarum pars prima. Wimariae $1 \$ 46,8$.

Rubeus. Disputatio de Melonilsus. Venetiis 1607.4 .

Slevogt, De Momordica. Jenae 1719.4.

Ilandlwig, De Bryonia, von der lieiligen Rube. Rostoekii 1758. 4.

Scopoli, De Cuenrbita Pepone olsservationes. In ejus "Anno hist. nat. 11. Lipsiac 1769. 8. p. $97-106$.

Sari, Sujra una pianta cucurbitacea. (Beninsaca.) Midano 4818.8.

\section{Cacteae.}

Vater, De Cereo amoricano. Vitemhergae 1735. 4.

Boehmer, De Melocacto ejusque in Cereum transformatione. IVittehergae 1757.4 .

Link et Otto, Ueber die Gattungen Nelocactus und Eehinocactus. Berlin 1827. 4 .

De Candolle, Revue de la famille des Cactées. Paris 1829.4.

Turpin, Observations sur la famille des Cactees. Paris 1830.8.

Finclih, Dic Cactus. Stuttgart 1832. 8.

De Candolle, Mènoire sur quelques especes de Cacties. Paris 1834. 4.

Ifriffer, Beschrejlung und Synonynik der in deutsehen Gärten vorkommenden Kakteen. Berlin 1837. s.

- Enumeratio diaguoslica Cactearum. Berulini 1837. 8

Colla, Storia e deserizione del Cactos senilis. Torino 1838. 4.

Lemaire, Cactearum novarum hori Monvilliani descriptio. Paris 1838. 4.

Cactearum genera nova speciestue novae. Paris 1839.8.

Mliquel, Genera Cactearus deserijta el ordinata. Roterodami 1839.8.

Colla, Storia e descrizione del Cactus spiraeformis. Torino 1840.4.

Cacteae, in Niquel Commentarii no. 111. lugguni Bat. 1840. folio.

Lenaire, Jconographie descriptivo des Cactées. Paris 1841. folio.

Miquel, Monographia generis Melocacti. Tralislaviae 1841. gr. 4.

Salm-Reifferscheid-Dych, Leber die Fanilic der Cacteen. (Berlin 1840.) 8. 1844. Duesseldorpii et Parisiis 1841-1845.8.

Mittler, Taschenbueh fur Cactuslieblaber, Leipzig 4841-1844. gr. 16.

Giacomelli, Catalogo delle Cactene coltivate. Treviso 1842.4.

Schleiden, Beitrage zur Anatomie der Cacleen. St. Petersburg (1842.) 4.

Ilarting, Bijdrage tot de anatomie der Cacteen. s. I. et a. \$.

I'feiffer und Otto, Abbildung und Besehreibung bluhender Kakteen. Kassel $1843-1847.4$

Lemaire, Manuel de l'anateur des Cactus. Paris 1845. 12.

Foersler. Ilandbuch der Cacteenkunde. Leipzig 1846. 8.

\section{Mesembrianthemeae.}

Ifaworth, Olsservations on the genus Mesembrianthemum. Loudon 1794.8. Miscellanea naturalia. (Mesembrianthemum.) Londini 1803.8.

Salm-Reifferscheid-Dyck, Monograplia generis Aloes et Mesembriantheni. Dusselciorf 1836 sqq. 4.

\section{Portulaceae.}

Bradley, The history of succulent plants. Ilistoria plautarum sueculentarum. London 1716-1727.4.

Minuart, Cerviana. (Madrid 1739.) 4.

De Candolle, Plantarum listoria sneculentarum. Paris 1799-1829. folis.
Ilaworth, Misecellanea naturalia. (Tetrayonia, Portulacca.) Londini 1803. 8 - Syuupsis plantarum succulentarum. Londini 1819.8

Supplementum plautarum suceulentarum. Loudini 1819.8

Revisiones plautarum succulentarum. In ejus "Saxifragearum enumeratio. Londini 1821.8

De Candolle, Revuo de la Famille des Portulacées. (Paris 1828.) 4.

\section{Caryophylleae.}

bergen, Epistula do Alehinilla supina (Scleranthus perennis) ejusplue coccis. Francofurti a/ $/ 7.178 .4$

L'héritier, Lonichea. s. l. et a. folio.

Jussieu, Sur la nouvelle fanille des Paronycliées. (Paris 1815.) 4.

Saint-Ifilaire, Mémoire sur la nouvelle famille des Paronychies. Paris 1816.4 .

Cay, Histoire de l'Arenaria tetraquetra L. Puris 1824. 8 .

De Candolle. Mémoire sur la famille des Paronychiées. Paris 4829.4

Fenzl, Vorsuch einer Darstellung der geographisehen Verbreitungsverlatuluisso der Alsineen. Wien 1833.8 .

Grenier, Obsirvations sur les genres Moenchia et Malachium. (Besançon 4839.) 8.

Soyer-11'illemet, Sur le Cerastium manticum et autres. Naney 1839. 8

Grenier, Fragment al'une monograplie des Corastium. (Besançon 1840.) 8. - Monographia de Cerastio. Vesuntione 1841. ur.8.

Extrait des Numoires etc. (Alsine.) Besançon 1841.4.

Godron, Quelınes oliservations sur la famille des Alsinces. Nancy 1842.8. Gay, Ilolostei generis monographia. Paris 1845. 8.

Godron, Note sur le Dianthus virgineus de Linne. Nancy 1846. 8.

\section{Phylolacceae.}

Otto, De Pliytolacea. Trajecti a/ V. 1792.4.

\section{Malcaceae.}

Medicus, Ueber einige kunstliche Geschlechter der Malvenfunilie. Manuheinı 1787. 8.

Cavanilles, Observationes in quintum fasciculum de L'héritier. s. 1. et a. 4 . (gallice.)

Carta en respuesta. (Madrid 4789.) 12

Monadelphiae classis dissertationes decem. Madriti 1790. 4.

Boelmer, De plantis monadelplis praesortin a Cavanilles dispositis. Wittebergae 1797. 4 .

Kunth, Malvaceae ete. Paris 1822. 8 .

Giordano, Nenoria su di una nuova specie d'lbisco. (Hibiscus habeacfolius Giord.) Naproli 1833.4.

Bertoloni, Deserizione di una nuova specie di Sida. Modena 1843.4

\section{Sterculiaceae.}

Larreategui, Descrijution botanique du Chiranthodendron, (Cheirostemon H. B. li.) Paris 1805.4

Parlatore, Notizia sulla Pachira alba. Firenze 1843.8.

Brown, Pterocymbium, with observations on Sterculicae, the tribe to which it belongs. (From Ilorsfield, Plantae javanicae rariores.) London 1844. folio.

\section{Bueltneriaceae.}

Gay, Monograplijo de la tribu des Lasiopétalécs dans la famille des Buettneriacécs. Paris 1821.4

Kunth, Buetneriaceae ete. Paris 1822. 8.

De Candolle, Mèmoire sur quelgues genres nouveaux des Buettneriacées Paris 1823. 4 .

Gay, Fragment d'une monographie des vraies Buetlneriacées. Paris 1823.4 Thunberg, De Hermannia. Upsaliaə 1794. 4. 


\section{Tiliaceae.}

Steige, Beschreibung des Lindenbaums. Wittebergae 1617. 4.

Ilmer, De Tilia. Lipsiae 1669. 亿.

Ventenat, Monographic du genre tilleul. Paris 1802.4.

Jussieu, Mómoire sur le Grewis. (Paris 1804.) 4.

Finth, Tiliaceae etc. Poris 1822. 8.

Brunner, Observations sur l'uflorescence du tilleul. Genève 1846. 8.

\section{Diplerocarpeae.}

Dipterocarpeae, in Blume, Flora Javas. Bruxellis 1828. folio.

\section{Ternstroemiaceae.}

Jussieu, Revuo des Ternstroemiacées. (Paris 1824.) 8.

De Candolle, Mémoire sur la fanille des Ternstroemiacées. Genève 1823.4.

Cambessedes, Mémoire sur les famillès des Ternstrocmiacées et des Guttifères. Paris 1828. 4.

Ellis, Copies of two letters to Dr. Linnaeus and to Mr. Aiton. (Gordonia Lasianthus.) London 1771. 4 .

Chandler, Camellia britannica. London 1825. 4.

Baumann, Les Camellia de Bollwiller. Bollweilerer Camelliensammlung. Bollweiler 1829-1831. folio.

Chandler and Booth, Illustrations and descriptions of Camelliae. London 1831. folio.

Griffith, Report on the Tea plant of Upper Assam. (Calcutta 1838.) 8.

Bcrtèse, lconograplio du genre Camellia. Paris 1839. folio.

-__ Monographie du genre Camellia. Paris 1840.8. (germanice.)

Colla, Camolliografia. Torino 1843.8.

Planchon, Note sur le genre Godoya, Paris 1847. 8.

\section{Marcgratiaceae.}

Jussieu, Mémoire sur le Marcgravia. (Paris 1809.) 4.

\section{Ifypericineae.}

Limné, Hypericum. Upsaliae 1776. 4.

Jussieu, Sur quelques espèces du genre Hypericum. (Paris 1804.) 4.

Choisy, Prodrome d'une monographic de la famille des Hypéricinées. Genève 1824. 4.

IHuss, De Ilypericis Sueciae indigenis. Upsaliae 1830. 4.

\section{Olacineae.}

Jussieu, Description du genre Jeacina. (Paris 1821.) 4.

\section{Aurantiaceae.}

Pontanus, IJorti Ilesperidum libri duo. Florentiae 1514. 12.

Monardes, De Citriis, Aurantiis et Limoniis. Antwerpiae 1561. 16.

Ferrarius, llesperides. Romae 1646. 4.

(Morin) Instruction lacile pour connoistre toutes sortes d'orangers. Paris 1674. 12 .

Nati, Florentina phỵtologiea observatio de malo Limonia eitrata-aurantia Florentiae vulgo La Bizarria. Florentiae 1674, 4. (anglice.)

Commelyn, Nederlandize Hesperides. Amsterdam 1676. folio. (anglice.)

Franke, Do Malo citreo. Meidelhergae 1686. 4.

Volckamer, Nurubergische Hesperides. Numberg 1708-1714. folio. (latine.)

Civinnimi, Della storia degli agrumi. Firenze 1734.4.

Heister, De Aurantiis. Helmstadii 1741. 4.
Carmignani, Memorie sulle Mediche tornata et turbinata Linn. e sulla tuberculata e aculeata Willd. (I'isil) 1810.8.

Gallesio, Traité đu Citrus. Paris 1811.8.

lisso, Essai sur l'histoire naturelle des orangers ete. Paris 1813. 4

Michel, Traité du citronnier. Paris 1816. folio.

Risso et Poiteau, Ilistoire naturelle des orangers. Paris $1818-1819$. folio.

Piccioli, Pomona toseana. (Aurantiaceac.) Firenze 1820.8

(I/is) Notice sur les orangers. Paris 1829, 4.

Arrosto, Monografia degli agrumi. Messina 1835. 8.

Savi, Sul Citrus llystrix e sul Citıus salicifolia. (Firenze) 1837.8.

Gallesio, Gli agrumi dei giardini di Firenze. Firenze 1839. 8.

Tenore, Ricerche sull' arancio fetifero. Modeua 1843. 4.

Hoemer, Synopses monographicae. 1: llespericles. Wimariae 1846.8.

\section{Meliaceae.}

Jussieu, Mémoires sur la groupe des Mcliacées. (Paris 1830.) ‘.

\section{Cedrelaceae.}

Roxburgh, Description of a new specics of Swielenia. (London 1793.) 4.

\section{Acerinae.}

Mlahn, De Platano. (Acer Pseurloplatanus.) Abeae 1695. 8.

Lauth, De Acere. Argentorati 1781. 4.

Thunberg, De Acere. Upsaliae 1793. 4.

\section{Ifalpighiaceae.}

Jissieu, Malpighiacearum synopsis, monographiae mos edendac prodromus. (Paris 1840.) 8.

- Monographio des Malpighiacées. Paris 1843.4.

\section{Erythroxyleae.}

Martius, Beiträge zur Kenntniss der Gattung Erythrosylon. (München 1840.) 4 .

\section{Sapindaceae.}

Cambessedes, Mémoire sur la famille des Sapindacées. (Paris 1831.) Jussieu, Mémoire sur le Paullinia. (Paris 1804.) 4. Mémoire sur le Nelicocea. (Paris 1817.) 4.

\section{Rhizoboleae.}

Mutis, Monographia de Caryocar Almendron. Madrid s. a. i.

$$
\text { Polygaleue. }
$$

Jussieu, Mémoire sur lit famille des Polygalées. (Paris 1815.$) 4$. Saint-IJilaire, Conspectus Polygalearum Brasiliae meridionalis. Orleans 1818. 8.

Thunbery, De Krameria. Upsaliae 1822, 4.

\section{Pittosporeae.}

Putterlick, Symopsis Pittosporearum. Viudobonae 1839.8.

\section{Celastrineae.}

Hellenius, De Evonymo. Aboac 1786. 4.

\section{Rhamneae.}

Thunberg, De Phylica. Upsaliae 1804. 4.

Brongniart, Mémoire sur la famille des Rhamnées. Paris 18z6. 4 . 


\section{MONOGRAPHIAE}

\section{Chailleliacene.}

De Candolle, Description du Chailletia. (Ann. Mus. d'hist. nat. 1811. XVII, 153-159.)

\section{Euphorbiaceae.}

Linné, Euphorhia ejusque historia naturalis et medica. Upsaliae 1752. 4. Geiseler, Crotonis monographia. Halae 1807. 8.

Jussieu, Considérations sur lá famille des Euphorbiacées. (Taris 1823.) 4.

De Euphorbiacearum generibus. Paris 1824.4.

Roeper, Enumeratio Euphorbiarum Germaniae et Pannoniae. Goeltingae 1824. 4.

Daenzer, Des Euphorbiacées. Strassburg 1834. 4.

Czompo, De Euphorbiaceis Hungariae, Croatiae, Transsylvaniae, Dalmatiae et litoralis hungarici. Pestini 1837.8.

Colmeiroa buxifolia Reut. in Reuter "Essai». Genève 1843.4.

\section{Terebinthineae.}

Kunth, Terebinthacearum genera. Paris 1824, 8 .

Guibourt, Némoire sur l'origine et les earactères distinctifs des Térébinthines. Paris 1839.8.

\section{Juglandeae.}

Buechner, De nuce Juglande. Erfordia 1743. 4.

Plappart, De Juglande nigra. V'indobonae 1777. 8.

Juglandeae, in Blume, Flora Javae. Bruxellis 1828. folio.

\section{Anacardiaceae.}

Ileister, De floribus Piperadendri (Schini mollis). In ejus "De nominum" etc. Jlelmstadii 1741.4.

\section{Connaraceae.}

le Candolle, Mémoire sur les genres Connarus el Omphalobium. (Paris 1826.) 4 .

\section{Ochnaceae. Simarubeae.}

Ile Candolte, Némoire sur les Ochnacées et Simaroubées. (Ann. Mus. d'hist. nat. 1811. IVII, 398-425.)

Planchon, Noto sur le genre Godoya el les Ochnacées. Paris 4847.8.

\section{Diosmeae.}

Thunberg, De Diosma. Upsaliae 1797. 4.

De Candolle, Mémoire sur la tribu des Cuspariées. (Mlém. Mus. d'list. nat. de Paris 1822. 1X, 139-154.)

Barlling et Ilendland, Diosmeae descriptac et illustratae. Goettingae 1824. 8 .

Jussieu, Monographie du genre Plrebalium. (Paris 1825.) 4.

\section{Rutaceae.}

Jussieu, Mémoires sur les Rutacées. Paris 1825. 4.

Lroeber, Ueber die Ruta graveolens L. und die ilır verwandten Arten. Wúrzburs 1830.8 .

Scholt, Rutaceae. Vindobonae 1834. folio.

Colla, Observations sur la famille des Rutacées, sur le genre Correa, et formation du nouveau genre Antommarchia. Turin 1843.4.

\section{Geraniaceae.}

Burmann, Specimen botanicum de Geraniis. Lugd. Bat. 1759. 4.

L'héritier, Geraniologia. Paris 1787-1788. folio.

Willdenow, Geraniologia. Berolini 1800.8.

Andrew's, Geraniums. London 1805.4.

Sweet, Geraniaceae. London 1820-1830.8

\section{MONOGRAPHIAE}

Opiz, Die Pelargonien. Auszug aus DC. Prodromus. Prag 1825. 8.

Picard, Etude sur les Geraniées. Boulogne 1838. 8 .

Raffeneau-Delile, hndex seminum horti monspeliensis: Genus Erodium. (Monspelii 1839.) 8.

Soyer-IVillemet, Ėrodium clium et laciniatum. Naney 1839.8

\section{Lineae.}

Spadoni, Nuova specie di Lino di Siberia (Linum Beauharnaisianum). Macerata 1808.8 .

\section{Oxalideae.}

Thunberg, Oxalis. Upsaliae 1781. 4.

Jacquin, Oxalis. Viennae 1794.4.

Zuccarini, Monographie der amerikanischen Oxalisarten. München 1825. 4. - Naclıtrag: ib. 1831.4.

Hénon, Notice sur l'Oxalis Deppei Lodd. Lyon 1838. 8.

\section{Balsamineae.}

Kunth, Notice sur la Balsamine des jardins. Paris 1827. 4.

Roeper, De floribus et affinitatibus Balsaminearum. Basileae 1830.8.

Presl, Bemerkungen uber den Bau der Blumen der Balsamineen. Prag 4836. 8 .

\section{Tropaeoleae.}

Lochner, Do Aeriviola. (Norimbergae 1717.) 4

Hellenius, De Tropacolo. Aboae 1789. 4.

\section{Combretaceae.}

De Candolle, Mémoire sur la famille des Combrétacées. Genève 1828. 4 .

\section{Oenothereae.}

Scarella, Lettera intorno ad una pianta anonima (1snardia palustris). Padova 1687.4

Zuccayni, Lettera al Signor Cavanilles (sopra i fiori della Lopezia racemosa). s. 1. et a. 8 .

Jussieu, Observations sur la famille des Onagraires. (Paris 1804.) 4.

De Candolle, Mémorre sur la famille des Onagraires. Paris 1829.4.

\section{Halorageae.}

Hellenius, De Ilippuride. Aboae 1786. 4.

\section{Trapeae.}

Kirchmaier, Do Tribulis potissimum aquaticis. (Trapa natans.) Wittebergae 1692. 4

Lebret, Mémoire sur le Trapa natans. Rouen 1821. 8.

\section{Lythrarieae.}

Freyer, De Lythro Salicaria L. Goettingae 4802. 8.

De Candolle, Revue de la famille des Lythraires. Genève 1826. 4. Mémoire sur le Fatioa. (Zürich 1828.) 4.

\section{Melastomaneae.}

Ilumboldt et Bonpland, Monographia Nelastomacearum. Lutetiae Parisiorum 1806-1823. folio. (Melastomae: 1816. Rhesiae: 1823.)

De Candolte, Mémoire sur la famille des Mélastomacées. Paris 1828. 4. Seringe, Mémoire sur la famille des Mélastomacées. Genève 1830. 4.

Opatowshi, De Mlemecyleis ordine naturali a De Candolle constituto. Berolini 4838.8 .

Melastomaceae, in Hiquel, Commentarii no. II. Lugduni Bat. 1840 . folio. 


\section{Mlyrtacene.}

De Cundolle, Noto sur les Myrtacées. Paris 1826.8

Schauer, Chamaclaticicae. Vratislaviac 1841. 4.

De Candalle, Hénoire sur la famille des Myrtacées. Genève 4842.4.

Hoffmann, De Caryoplyyllis aromalicis. Halae 1701.4.

Thunbery, Do Caryophyllis aromaticis. Ipsaliae 1788. 4.

Ruditi, Di alcune specie di Pero indiano (Psidium). Bologna 1821. 4.

Schauer, Die Mclaleuken der deutschen (iárten. (Rerlin 1835.) 8.

Necs von lisenbecl, hamplzia. Vratislaviae a/V. Is/0. folio.

Tenore, Sopra i due nuovi genuri Syucarpia o Donzellia. Modena 1\$40. 4.

Schauer, De Regelia, Beaufortia el Calothamno. V'ratislaviae 1843. 4.

\section{Rosiflorae.}

(Ponaceac, Calycantheae, linsaceae, Anygrtaleae, Chrysohalaneae.

Syluius, Oratio de Rosis. Hafniae 1601.4.

Rosenbery, Rhodologia. Argentinae 1628. 8.

llagelgans, Rosa loquens. Coburgi 1652.12.

hosenfeld, De Rosa saronitica. Willebergae 1652.4.

Ursinits, De Rosa menstrua. Lipsiae 1661. 4.

Sallzmann, De Rosa. Argenlorali 1670.4.

hrause, De Rosa. Jenae 1674. 4.

Ilugendorn. Cynosbalologia. (Rosa canina.) Jenae 1651.8.

Parslius, Rosi aurea. s. L. 1728.4.

(Benemamn) Die Rose. Leipzig 1742. 8.

IIermann, De Rosa. Argentorati 1762. 4

Lavrance, A collection of Roses from nature. London 1799. (17901S10.) folio.

Roessig. Beschreibung der Rosen. Leipzig 1799-1803.8.

- Die Rosen nacl der Natur gezeichnet und holorirt. Leipzig (1802 -1820)$.4 .

Afzclius, De Rosis suceanis. Upsaliae 1804-1843. 4.

Andrews, Roses. London $1805-4828.4$

Rail, Enumeratio Bosarum circa Wirecburgum sponte crescentium. Norimhergne 1816.8 .

Thory, Rosa Redoutea. Paris 4817.8.

Rosa Candolleana. Paris 1S19.8.

licdonte, Les Roses. Paris 1817-1824. folio min

Dematra, Monographie des rosies's du canton de Fribourg. Fribourg isis. 8.

Pronville, Nomenclature raisonnée des espéces et varictés du genre rosier. Paris 1818 . 8 .

Seringe, Critique des Roses déséchés. (Mélanges I, 1.) Berne 1818. 8.

Lindley, Rosarum monographia. London 1820.8. (gallice.)

Thory, Prodroune de la monographic du gene rosier. Paris 1820. 8.

11 ikstróm, Nägra arter af kosi. Stockholn $1 \$ 21,8$.

Pronville, Sommaire d'une monographie du genre rosicr. Paris 1822.8. - Monographie du genre rosier. Paris 1524, 8.

Traltinick, Synodus botanica: Rosacearum monographia. Vindobonae 1823-1824. 8 .

Dumorlicr, Notice sur le nouveau genre IJultiemia el classicfiation des Roses. Tournay 1824.8.

Fibert, Ohservations sur la nomenclature des Roses. Paris 1824. 8 .

- Essai sur les Roses. Paris 1824.8.

Seits, Die Rosen nach ihren Fruchten. P’ag 1823.16.

Desportes, Rosetun gallieum. Le Mans et Puris 1825. s.

II ullroth, Rosae generia histeria succincta. Nortlusae 1828. 8.

Selbstherr, Diu Rosen in 25 Gruppen und 93 Arten. Breslau is 324.

Doering, Die Koniggin der Blumen. Elberfelel 1835. *

liedoute, Le bouquet royal. Paris 1843. folio
Meyer, Ueber die Zimntrosen. S1. Petersburg 1847. 4.

liomer, Synopses monographicae. III: Rosillorae. Wimariae 1847.8.

Frenzel, fraga. Wiltebergae 4662.4.

Baier, De Malo Punica. Alldorfii 1712.4.

Hoister, De Cydoniis. Ilelmstadii 1744. 4.

mechesne, llistoire naturelle des fraisiers. Paris 1766.8 .

Lime , Fraga vesca. Ipsaliale 1772.4.

Nestler, Monograpulia de Potentilla. Paris 1816.4.

1)e Candolle, Kerria el Purshia. London 1818.4. (Transactions Liun. Soc. XII, 2. $152-159$.)

Lehmann, Mlonographia generis Potentillarum. Hamburgi $1820-1835.4$.

Brager, Nolice sur une nouvelle plante (Brayera anthelninthica Kilı.). (Paris 1829.) 8 .

Cambessedes, Monographie du genre Spiraea. Paris 1824.8.

De Candolle, Note sur le feuillage des Cliflurtid. (Ann. des sc. nat. $1 \$ 24$. I, p. 447.)

Tenore, Nemoria sul Pruno Cocumiglia. Napoli 182.s. i.

Crész, De Potentillis Ilungariae, Croaliae, Transsilvaniae, Ialnatiae el litoralis hungarici. Pestini 1837. 8.

Wallroth, Monographischer Versuch uber Agrimonia. In ejus "J3eiragen J. Leipzig 1842. S.

Paullini, De Clamaemoro norvegica. Hambureyi 1676. 4.

Rudbecl, Irubus humilis fragariae folio fructu rubro. (R. al clicus.) Lpsaliao 1716.8 .

Camerarius, De Rubo idaro. Tubingac 1721.4.

Schulse, De Rubo idaco officinarum. Ilalae 1744. 4.

Thunberg, De Rubo. Ipsaliae 1813.4.

Weihe el Nees von Esenbeck, Rubi germanici. Bonnac $1822(-1827)$. folio.

Arrhenius, Mougraphia Ruborum Sueciae. Lpsaliae 1840. 8.

Babington, Synopsis of the Lritish Rubi. Edinburgh 1840. \$.

Godron, Monographie des Rubus aux environs de Nancy. Nancy 1843. S.

\section{Leguminosac.}

(Papilionaceae, Swartzieae, Minoseac.)

De Candolle, Note sur la monographie des Légumineuses biloculaires. (Bull. soc. phil. 1800. p. 123.)

Ilumboldt, Bonpland, Kunth, Mlimoses el autres plantes Légumineuses du nouveau contineut. Paris 1819 (-1824), foljo.

Rromn, De formis plantarum leguminosarum primitivis el derivatis. Ileidelbergae 1822 . 4 .

Ebermaier, Plantarum papilionacearum monographia medica. Beroliui 18:4.8

De Candolle. Nolice sur quelques genres des Légumineuses. (Aun, des sc. nat. $1825 . \mathrm{N}, 90$.

_._._. Mémoires sur la famille des Légumineuses. 1-XV. Paris 1825.4.

Eiscngrein, 1)ie Familie der Schmetterlingshlutigen. Stuthart 1836. S

Mortli, De papilionaceis Germaniae. Ticini 1836.8 .

Bentham, Commentationes de Leguminosarum generibus. Viulobonae 1837. 4.

Walpers, Animadversiones criticae in Leguminosis capenses. IJalae 1839. 8.

Camerarius, De herba Mlimosa seu sentiente. Tuljngan 1688. 4.

Bellardi, De llimosa sentiente. Torino 1764. S.

(sink, De Fabis. (Vicia Faba.) Groningae 1712.4.

Sloane. Account of four surts of strange Beans, frequently cast om shoar of the Orhney isles. (Philos. Transact. XIX, no. 222. p. 298-300.)

Picciuali, Ilortus l'anciaticus. (Pancialica purpurea.) Firenze 1783.4.

L'heritier, Cadia. s. I, et a. 8 .

Hedicus, Theodora speciosa. Mannheim 1786.8 
Scopoli, Specimen botanicum de Astragalo. In ejus "Deliciae Florae insubricaen. Ticini 1786-1788. folio. vel. 1I, p. 103-114.

Desfontaines, Description d'un nouveau geure Spaendoncea. (Paris 1795.) 8.

Pallas, Species Astragalarum. Lipsiae 1800. folie.

De Candalle, Memoire sur les genres Astragalus etc. (Bull. soc. philom. 1802. p. (30.)

- Astragalogia. Paris 1802. folio.

Hoppe et Sturm, Die Kleearten Deutschlands. Nürnberg 1804. 12.

Savi, Memoria sopra i trifogli. (Pisa 1809.) 8.

Observationes in varias Trifoliorum species. Florentiae 1810. 8.

Thiebaut-de-Berneaud, Du genet (Geuista). Paris 1810.8.

Thunberg, De Borbonia. Upsaliae 1811. 1.

Hegetschweiler, Descriptio Glycines heterocarpae. Turici 1813.4.

Colladon, llistoire naturelle et médicale des Casses. Montpellier 1816.4.

IVendland, De Acaciis aphyllis. Hannoverae 1\$20. 8.

Savi, Osservazioni sopra i generi Phaseolus et bohichos. Mlemoria l-JV. Pisa 1822. 8.

De Candolle, Note sur le Trifolium magellanicum. (Ann. des se. nat. 1895. 1V, p. 61.)

- Sur le nouvean genre Pictetia. (Bibl. univ. de Genève 1825. $\mathrm{XXIX}$, 1). 40-47.)

Nees mon Esenbeck, Fridericia et Zollernia, ad socios literae. (Bonnae) 1827.4.

Ekart, Frankens und Thuringens Flord. (Trifolium.) Bamberg 1828. 4.

Jartius, Socmmeringia. Monachii 1828.4.

Savi, Sopra alcune Acacie egiziane memoria. Pisa 1830.8.

Endlicher, Diesingia, nevum genus plantarum. (Ratisbonae 1832.) 8.

Agardh, Synopsis generis Lupini. Lundae 1835. 8.

Meyer, Bemerkungen über einige llymenobrychisarten. Pelersburg 1837.4.

I ogel, Generis Cassiae synupsis. Berolini 1837. 8.

Gasparrini, Descrizione di un nuove genere (Farnesia odora Gasp.). (Napoli 1838.$) 8$.

Tenore, Sopra i due nuovi generi Syncarpia e Donzellia. Modena 1840.4. Parlatore, Mlaria Antonia, novello genere. Firenze 1844. 4.

Schomburgk, Die Barbacenia Alexandrinae und Alexandra imperatricis. Braunschweig 1845. 4.

Basiner, Enumeratio monographica specierum Iledysari. Petropoli 1846.4.

Soyer-IVillemet et Codron, Revue des tréles de la section Chronosemium. Nancy 1847.8

\section{Monographiac plantarum officinalium.}

Acacia Catechu Willd, et Areca Calechu L.

Ilagendorn, De Catechu sive terra japonica. Jenae 1679. 8.

Wertmueller, De Catechu. Goeltingae 1779.4.

Amoreux, Dissertation sur l'origine du Cachou. Montpellier 1812. 8.

\section{Achillea Clavenae L.}

Chiavena (Clavena), Ilistoria Absynthii umbelliferi. Venetiis 1610.4. Sprechis, Antabsynthium Clavenae. Venetiis 1611. 4.

\section{Achillea Millefolium L.}

Baier, Millefolium. Altdorfi 1714. 4.

Henninger, De Millefelio. Argentorati 1718.4.

Iloffmann, De Nillefolio. Halae 1719. 4.

\section{Aconili species.}

Reimhold, De Aconito Napello. Argentorati 4769.4.

Koelle, Spicilegium observationum de Aconito. Erlangae 1788. 8.
Turnbull, On the medical properties of the Banunculaceae. (Aconitum, Delphinium.) London 1835. 8.

Wenderoth, Ueber wichtige einheimische Arzneipflanzen. (Aconitum.) hassel 1837. 12.

\section{Acorus Calomus $\mathbf{L}$.}

Wedel, De Calamo arumatico. Jenae 1708.4. - ib. 1718. 4.

\section{Adansonia diyituta $\mathbf{L}$.}

Frank, Sur l'efficacite du fruit de Boabab (Adansonia L.) dans la dyssenterie d'Egypte. In ejus "Collection d'opuscules". Paris 1812.8. T. $50-59$.

\section{Adiantum Capillus Veneris $\mathbf{L}$.}

Formi, Traité de l'adianton ou cheven de Venus. Montpellier 4644. 8 .

\section{Aesculus Hippocaslanum L.}

Zannichelli, Facoltà dell ippocastano. Venezia 1733.4.

$$
\text { Agaricus. }
$$

Richter, De Agarico. Goetlingae 1778. 4.

Rubel, De Agarico officinali. Vindobonae 1778. 8.

Gruner", De virtutibus Agarici muscarii. Jenae 1778. 4

\section{Agrimonia Eupaloria L.}

Becker, Eupatorium Graecorum seu Agrimeniae vires. Eirfordiae 1783.4.

\section{Alisma Plantago L.}

Irolf, Alisma Plantago L. gegen die Wasserscheu. Nurnberg 1817.4

Allium sativum $\mathrm{L}$.

Ifedel, De Allio. Jenae 1748. 4.

\section{Aloe spicala Thunb.}

Martines y Leache, De vera el legitima Aloes electione. Pompeiepeli 1644. 12

Marcquis, Aloe merbifuga. Antrerpiae 1663, 12.

Friderici, De Aloe. Jenae 1670.4.

Schulze, De Aloe. Altdorfii 1723. 4.

Murray, Succi Aloes anari initia. Goettingae 1785. 4.

\section{Aloexylon Agallochum Lour.}

Hedel, De ligno Aloes. Jenae 1693. 4.

Eysel, De Acallocho, Paradicsholtz. Erfordiae 1712.4.

\section{Alpinia Cardamomum Roxb.}

Krause, De Cardanomis. Jenae 1704. 4 .

Spielmann, Cardarnemi historia et vindiciae. Argentorati 1762. 4

\section{Alyxia aromatica.}

Nees von Esenbecli jun., Ueber ein neues Arzueimittel: Cortex Alyxiae aromaticae. Schmalkalden 1824.8.

\section{Amyglalus communs L.}

Srquarcialupus, De Anygdalarum amararum in elrietatem vi contra Plutarclum opinio. Pesclavii 1586. 8 .

Zwinger, Anygdalarum fructus analysis. Basileae 1703.4.

Jordan, De Amygdalo communi var. amaro. Goettingae 1834. 8

Bleisch, De Amygdalinie. Tratislaviae 1838. 8.

\section{Amygdalus Persica L.}

Ungnad, De Malo Persica. Francofurti a/V. 1757. 4.

\section{Amyridis species.}

Reche, Dc Amyridis speciebus officinalibus. Ilalae 1801.8. 
-Anagallis arvensis $\mathrm{L}$.

Bruch, De Anagallisle. Argentorati 1758. 4.

Schrader, De Anagallido. Halae 1760. 4

Holm nolsilis Holmskijold, Afhandling om Anagallis. Kiobenhavn 1761.8. Lemke, De Anagallidis virilus. Rostodiii 1790. 4.

\section{Anemone pratensis L.}

Stoerck, Libellus de usu medico P'ulsatilae nigricantis. Vindobonao 1771.8. Ancthum graveolens L.

Larcher, De Awetho. Argentorati 1734. 4.

Authemis nubilis L. et Matricaria Chamomilla $\mathrm{L}$.

Sclefer, Ne Chamomilla. Argentorali 1700.4.

Schulze, De Chamaemelo. IIalae 1739. 4.

Baldinger, Vires Chamomillac. Goetlingae 1775. 4.

Bodard, Propriétés febrifuges de la Chamomille noble. Paris 1810.8.

\section{Anthriscus Cerefolium Hoffm.}

Ulelvigius, De Claaerophyllo. Gryphiswaldiae 17 1, 4

Aquilegia vulgaris $\mathrm{L}$.

Eysel, De Aquilegiit scorbuticorum asylo. Erfordiae 1716. 4.

\section{Archangelica officinalis $110 \mathrm{ffm}$.}

Buchner, Chenische Untersuelıung der Angelikawurzel. Nurnberg 1842.4.

\section{Arctostaphylos officinalis Wimm.}

Quer y Martinez, Dissertacion solbre la Uva ursi ó garubas. Madrid 1763. 4 .

Girardi, De Uva ursina. Patavii 1764.8

Murray, De Arbuto uva ursi. Goettingae 1764. 4.

Ilartmann, Antinephritiea Uvae ursinae virtus merito suspecta. Trajecti a/V. 1778.4 .

\section{Aristolochiae species}

Wedel, De Serpentaria virginiana. Jenae 1710.4

Baier, De Aristolochia. Altdorfi 1719. 4.

Ruiz, Memoria sobre las virtudes de la planta Bejuco de la Estrella (Aristoloclia fragrantissima). Nadrid 1505.4

\section{Arnica montana $\mathrm{L}$}

Alberti, De Arnicae verae usu. Ilalae 1719.4.

Meisner, De herba Arnica. Pragae 1736. 4.

Buechner, De princip,iis el effectilsus Arnicae. Erfordiae 1741.4.

Schuett, De vírilus Arnicae. Goettingae 1774, 4

Martimi, De Arnica. Viennae 1779.8.

Birthols, De Arnicac virtute. Iipsiae 1785. 4.

Buchola, Versuche uber die antiseptischen hrafte der Arnica. Erfurt 1785. S.

Sala, Memoria sobre Ja Arnica de los montes. Bareelona (1786.) 4

Thunberg, De Arnica. Upsaliae 1799. 4.

Jeanjean, Sur les propriétés de l'Arnica montana. Montpellier 1817.4.

linieriem, De Arnica montana. Dorpati 1823. 8

Stelka, De Arnica montana. Pragac 1835. S

Uebersicht der Eigenschaften der WoldverJeilblume. Wieshaden 1835. \&. Sclumacher, De Arnica montana, Berolini 4836.4

Ilmoni, Om Aruikin oclı Senegan. Helsingfors 1\$39. 8.

$$
\text { Artemisiae species. }
$$

fiocardus, De plantis Absinthii tractatus. Venetiis 1589.4
Baukin, De plantis Alsyuthii nomen habentibus. Montisbeligardi 1593. 8. Fehr, Hiera picra vel de AJsinthio analecta. Lipsiae 1668.8 .

Baier, De Artemisia. Artdorf 1720. 4.

SIandruzzato, Del facolta feblbriluga del Santonico, Artemisia coerulescens I. Venezia 1800.8.

Tosetti, 1)e radice Arfemisiae vulgaris. Berolini 1827.8.

Michel, De Artemisiis usitatis. Iragae 1834.8.

Samson, De extracto seminum Cinae. Dorpati 1834. 8.

Rapp, Veber das Santonin. Heilloronn 1\$38. 8.

Kleiner, De semine Cinae ejusque praeparalis. Turici 1843.8

\section{Artemisia Moxa DC.}

Geilfusius, De Moxa. Marpurgi 1676. 4.

Thunberg, De Mosae usu. Lpsaliae 1788. 4

Arum maculalum L.

IVedel, De Aro. Jenae 1701. 4.

\section{Asarum europaeum L.}

Baier, De Asaro. Altdorff 1721. 4.

Schulse, De Asaro. Halae 1739. 4.

Graeger, De Asaro europaeo. Goettingae 1830. \&

\section{Asparayus officinalis $\mathrm{L}$.}

Baier, De Asparago. Altdorfi 1715. 4.

Franz, De Asparago ex seriptis inedicorum veterum. Lipsiae 1778. 4.

Bresler, Generis Asparagi historia naturalis atque medica. Berolini 1826 . \&.

Aspidium Filix mas Sw.

Balsó, De Aspidio Filice mare. Vindobonae 1826. 8.

Boederer, De radice Filicis maris. Jenae 1829. 4.

Erdmann, De virtute extracti Filicis maris resinosi. Dorpati 1833.8.

\section{Aster montanus L.}

Ragazzini, Analisi dell' Astro montano. Padova 1825. S.

Randich, De Astro montano, autidoto veneni viperini. VindoJsonae 1840.8.

$$
\text { Astragalus exscapus } \mathbf{l} \text {. }
$$

Endter, De Astragalo exseapo L. Goellingae 1789. 8

\section{Atropa Belladonna L.}

Sicliel, Diatribe de Belladoma seu Solano furioso. Jenae 1724. 4.

Alberti, De Belladonna. IIalae 1739.4.

Timmermann, Belladousa. Rintelii 1765.4.

Pla , De Atropa Belladonna. Lipsiae 1776. 4.

Muench, De Belladonna. Goellingac 1781. s

- Observationes circa usum Belladonnae. Goettugen 1783. 4.

- Praklische Al) andlung von der Belladonna. Göthingen 1785. 8.

- Beobaclstungen bei angewendeter Belladonna. Stendal 17901795. 8 .

Mimly, De la paralysie de l'iris etc. Paris 1502.8

Bieger, De Atropa Belladonna. Beroliui 1823.8.

Eppel, De Beliadonnae efficacia conra searlatiuam. Berolini 1824.8 Pauquy, De la Belladone. Paris 1825. 4.

Schuartze, De Belladouna scarlatinae praesidio. Lipsiae 18zi. S.

Bemich, Geschichte der Anwendung der Belladonna. Wurzburg IS3 1. S.

Preuss, De Belladonna. Rostocliii IS31. S.

Deininger, De .tropa Belladonua. Berolini I833. 8.

II'ulf, Mcletemata circa vim proprian Belladonnae. Dorpati 1834.8

II alser, De Atropa Belladonna. Monacluii 1 \$39. \& 


\section{Ballota lanata L.}

Brera, Del valore della Ballota lanata L. Modena 1832.4.

Balsamodendron gileadense Kunth.

Atpinus, De Balsamo dialogus. Venetiis 1591.4.- ib. 1592.4. - Patavii 1639. 4.

(gallice.)

De l'Obel, Balsami, Opobalsami, Carpobalsami et Xylobalsami explanatio. Londini 4598.4 .

Pona, Del vero Balsamo de gli antichi. Venezia 1623.4.

Donzelli, Synopsis de Opobalsamo orientali. Neapoli 1640.4.

Baldus, Opobalsami orientalis propugnationes. Romae 1640.4. (ilatice.)

Castelli, Opohalsamum. Venetiis 16:0.4.

Opobalsamum triumphans. (Venetiis 1640.) 4.

Campi, Al Signor A. Manfredi etc. Lucca 1640. 4.

- Indilucidotione etc. Pisa 1641. 4.

Perla, De orientali Opobalsamo. Romae 1641. 12.

Pitorius, Opobalsami romani censura. Venetiis 1642. 8 .

Donzelli, Lettera familiare sopra l'opobalsamo orientale. Padoa 1643. 4.

Vesling, Opobalsami veteribus cogniti vindiciae. Patavii 1644. 4.

Volckamer, Opobalsami orientalis examen. Norimbergae 1644. 12.

Wagner, Discursus de Balsamo. Regiomonti 1683.4.

Slevogt, Balsamum verun, vulgo Opobalsamum. Jenae 1705. 4.

De Opobalsamo. Jenae 1717. 4.

Vater, Balsami de Mecca natura et usus. Wittenbergae 1720. 4.

Amati, De Opobalsami specie. Neapoli 1722. 8.

Loescher, Balsamum de Mecca. Vitembergae 1726. 4.

II inneken, Bescbreibung des wahren Opohalsambaumes. Kopenhagen 1745.8.

Vogel, De verioribus Balsami meccani notis. Goettingae 1763. 4.

Linne, Opolalsanum declaratum. Upsaliae 1764. 4.

Cartheuser, De Opobalsamo. Francofurti a/V. 1774.8.

Gleditsch, Leber die ache Balsampflanze von Mecea. (Scbriften der Berl. naturf. Freunde. 1II, 103-131.)

\section{Balsamodendron Myrrha N. v. E.}

Fasch, De Myrrba. Jenae 1676, 4.

Polisius, Myrrhologia. Norimbergae 1688. 4.

Cartheuser, De eximia Myrrlae genuinae virtute. In ejus a Dissert. seleclis v. Francofurti 1775. 8. p. 28-55.

Afzelius, De origine Myrrhae controversa. Upsaliae 1825-1829. 4.

Ehrenberg, De Myrrbae et Opocalpasi in itinere per Arabiam et Habessiniam detectis plantis. Berolini 1841 . folio.

\section{Bambusa arundinaeea Willd.}

Bussell, An account of the Tabasheer. (Phil. Transact. LXXX, 273-283.) Luedgers, De medicamento nov-antiquo Tebaschir. Goeltingae 1794. 8.

\section{Bellis perennis $\mathbf{L}$.}

Eysel, Bellidographia. Erfordiae 1714. 4.

\section{Betoniea officinalis $\mathbf{L}$.}

Antonio Musae (false adscriptus) Liber de herba Vetonica; cum Apulejo. Romae 1471. 4.

(Du Peyrat) La Betoyne. s. 1. et a. 8.

Eysel, De Betonica. Erfordiae 1716.4.

\section{Bignonia Calalpa $\mathbf{L}$.}

Klement, De Bignonia Catalpa. Pragae 1834.8.

Pritzel, Thes. lit. bot.

\section{Brayera anthelminthica Kunth.}

Brayer, Notice sur une nouvelle plante (Brayera anthelminthica Kth.). (Paris 1822.) 8.

\section{Botrychium Lunaria Sw.}

(Martini) Die frucbtbare Boriza oder das heilsame Mondkraut. Brieg 1681. 8 .

\section{Bromelia Ananas L.}

Tiemeroth, Ananas hujusque usus medicus. Erfordiae 1723. $4 . \mathrm{i}$

$$
\text { Bryonia alba L. }
$$

Harmand de Montgarny, Sur les propriétés de la racine de Bryone. Yerdun (1783.) 8 .

Trautmann, De radice Bryoniae albae. Lipsiae 1825. 4.

Caesalpinia brasiliensis Sw. et C. eehinala L.

Helvigius, Do ligno hrasiliensi. Gryphiswaldiae 1709. 4.

Calendula officinalis $\mathrm{L}$.

Geiger, Do Calendula officinali. Heidelbergae 1818. 8.

\section{Calolropis Madarii.}

Casanova, Essai sur le Madar (Calotropis Madarii indico-orientalis). Calcutta 1833.8.

\section{Cannabis sativa L.}

Seidenschnur, De Cannabis vi medica. Halae 1803. 4.

Schuebler, Cliemische Untersuchnng der Hanfblătter. Tübingen 1821. 8.

Freudeustein, Do Cannabis sativae usu ac viribus narcoticis. Marburyi 1841.8.

\section{Capsici species.}

Ambrosinus, De Capsicorum varietate. Bononiae 1630. 12.

\section{Cardamine pratensis $\mathrm{L}$.}

Ilagen, De Cardamine pratensi. Regiomonti 1785.4.

Nagel, Cardamine pratensis. Trajecti a/V. 1793. 4.

\section{Carex arenaria $\mathbf{L}$.}

Maier, De Carice arenaria. Francofurti a/V. 1772. 4.

Merz, De Caricibus quibusdam Sarsaparillae succedaneis. Erlangae 1784. folio.

Hueser, De Carice arenaria. Goettingae 1502.8.

\section{Carum Carvi L.}

Milhau, De Carvi. Argentorati 1740. 4.

\section{Caryophyllus aromaticus $\mathrm{L}$.}

Hoffmann, De Caryophyllis aromaticis. Halae 1701. 4.

Thunberg, De Caryophyllis aromaticis. Upsaliae 1788. 4.

\section{Cassava amara.}

Herbert, De Cassavae amarae surinamensis radice. Marburgi 1753. 4.

\section{Cassiae species.}

Mizauld, Opusculum de Sena. Lutetiae 1572. 8.

Baier, De Senna. Altdorfi 1733. 4.

Soliva, Dissertacion sobre el Sen de España. Madrid 1774. S.

Neetoux, Observations sur les diverses espèces de Séné du commerce. In ejus « Voyage s. Paris 1808. folio. 
Frank, Sur l'efficacité de la scmenco do Chichn (Cassia alısus L.) dans l'ophthalmie. In ejus "Collection d'opuscules". Paris 1812. \$. j. 38 -49 .

Colladon, Histoire naturelle et médicale des Casses. Montpellier 1816. 4.

Fée, Note sur les sénés et notanment sul te séné Moka. Paris s. a. 8.

$$
\text { Cedrela febrifuga. }
$$

Forsten, De Cediela febrifuga. Lugd. Bat. 1836.4.

\section{Cephaelis Ipecacuanha Rich.}

Leibnitz, Relatio de novo antidysenterico americano magnis sumtibus conprobato. Hannoverao 1696. 8.

Valentini, De Ipeeacuanha novo Gallorum antidysenterico. Giessac 1698. 4. Wedel, De Ipecacuanha americana et germanica. Jenae 1705. 4.

Schulze, Do Ipecacuanha americana. Halao 1744. 4.

Bucchner, De radice Ipecacuanha. Erfordiac 1745. 4.

Gianella, De admirabili radicis Ipecacuanluae virtute. Patavii 1754.4.

Jimé, De Viola Jpecacuanha. Upsaliae 1774. 4.

Moeller, Do Ipecacuanha. Erfordiae 1795. 4.

Muenz et Raab, De cortico peruviano et radice Ipecacuandrae. Landishuti 1812. 8 .

De Candolle, Recherches sur les diflérentes espèces d'lpecacuanha. (Ním. de la soc. des prof. do l'école de méd. de Paris. vol. I, 178-194.)

lichard, llistoire naturello et médicale des diflérentes espèces d'Ipécacuanha du commerce. Paris 1820.4.

Iilinsmann, De Emetino et Cephaeli Ipecacuanha, Psychotria emetica, Richardsonia lurasiliensi. Berolini 1823.8.

Thunberg, De Ipocacuanla. Upsaliae 1824. S.

Dler $\approx o g$, De Ipecacuanha. Lipsiae 1\$26. 4.

Bock, De radice Ipecacuanliae. Jenae 1830. 4.

IIenkel, De radice Ipecacuanliae. Monachii 1835.8.

Borliert, De radicis Ipecacuanhac effectu. Vratislaviac 1841.8.

Tesanel, De radice Ipecacuanlae. VindoLonae 1841. 8 .

\section{Cetraria islandica Ach.}

Scopoli, Lichenis istandici vires medicac. In ejus "Anno hist. nat.»II. Lipsiae 1769. 8. p. 107-118.

Trommsdorff, Do Licheno islandico. Erfordiae 1778. 4.

Cramer, De Lichene islandico. Erlangae 1780. 4.

Renard, Llistoire du Licheı d'Islande. Paris 1836. 8 .

\section{Chaerophyllum bulbosum L.}

Londes, Do Chaerophyllo bulboso. Goettingac 1S01.4.

\section{Chelidonium majus L.}

Glumm, De Chelidonio maiori. Duislurgi 1786. 4.

Schallern, Chelidonii majoris virtus medica. Erlangao 1790.4.

Chenopodium ambrosioides L. et Ch. Botrys L.

Cartheuser, De Chenopodio ambrosioide. Francofurti 1757. 1.

\section{Chenopodium Bonus IIenricus L.}

Eysel, De Bonohcinrico oder Guten Iteinrich. Erfordiae 1714. 4.

\section{Chiococca anguifuga Mart.}

Heyland, Analysis chemica radicis Caincac. Liliae 1827. 4.

Laue, De radice Caincac. Lipsiae 1827. 4.

Loewenstcin, De radice Caincae. Berolini 1828. 8.

De Candolle, Notice sur la racine de Cainca. (Bibl. univ. de Geneve 1829. vol. XLII, 243-250.)

Wolf, De radico Caincae. Marburgi 1\$31. 8.

Wimmer, De Caincac radice. Honachii 1832. 8.

\section{Chondria crispa Lyngb.}

Rennie, Essays on the natural listory and origine of Peat moss. Edinburgh 1810. 8.

Meyer, De Fuco crispo seu Lichene Carrageno. Berolini $1 \$ 35.8$.

Hler zer, De Fuco críspo L. sive do Alga Carragéen. Turici 1836. 8.

Sigmond and Farre, Essay on the Ceylon Aloss. (Sphacrococcus lichenoides Kutz.) London 1840. 12.

Lovín, Om Geléers, surdeles Perl-Tangens auvandande. Lund 1841. 8.

\section{Cichorium Intylus L.}

Camerarius, De Cichorio. Tubingac 1690-1691. 4.

Gochnat, Tentamen de Cielsoraceis. Argentorati 1808. 4.

Cicuta virosa L. (ct Conium maculatum L.).

Wepfer, Cicutae aquaticao historia et noxac. Basileae 1679. 4.

Schwenche, Verlandeling aver Cicuta aquatica Gesneri. Gravenhage 1756. 8.

Stoerck, Libellus de Cicuta. Vindobonae 1760. S. (gallice.)

Quarin, Tentamina de Cicuta. Vindobonae 1761. S.

Leber, Nutzbarkeit des Schierlings. Wien 1762. 8.

Ehrhart, Do Cicuta. Argentorati 1763. 4.

Ortega, De Cicuta commentarius. Matriti 1763.4. (hispanico.)

Quer y Martinez, Dissertacion sobre el uso de la Cicuta. Mladrid 1764.4. IIuber, De Cicuta. Casselis 1764. 4.

Lange, Dubia Cicutae vexata. Hehnstadii 1764.4.

Ilaen, Epistola de Cicuta. (Vindobonae) $1765 . \mathrm{S}$.

__ Elucidatio epistolae de Cicuta. Vindobonac 1766.8.

Thiesen, Warnung vor den Schierlingswurzeln. Königsberg 1766. 4.

Faltschmied, De Cicuta. Jenae 1768. 4.

IIartmann, Insignis Cicutae Stocrkianae efficacitas. Trajecti a/V. 1772. 4. Schuchard, Do Cicuta officinarum. Goettingae 1S1S. 4.

Cherallier, Sur les cigués indigènes. Paris 1821.4.

\section{Cimicifuga foetida $\mathrm{L}$.}

Limnd, Planta Cimicifugi, 1774. 4.

$$
\text { Cinchonàe species. }
$$

Chiflet, Pulvis febrifugns orbis americani. s. 1. 1653. 8.

Baldus, Cortex peruvianus redivirus. Genuae 1656. 12.

Brunacci, De Cinn-Cina seu pulvere ad febres. Venetiis 1661. \&.

Ammann, Antiquartii peruviani listoria. Lipsiac 1663. 4.

Baldus, Anastasis corticis Peruviae. Genuac 1663. 4.

Monginot, De la guérison des fievres par le Quinquina. Paris 1679. 12. (tatine.)

- Nigrisoli, Febris chinachina expugnata. Ferrariae 1687.4.

Les admirables qualités du Quinquina. Paris $1689.12 .-$ it. 1705.12.

Jorbius, De felrifuga Chinac-Chinae virtute. Attorfii 1693. 4.

IJoffmann, Do Chinae Clinao usu. IJalae 1694. 4.

Valentini, De China Chinao. Giessae 1695. 4.

Fagon, Les qualites du quinquina. Paris 1703. 12.

Berger, De Clinchina. Wittenbergae 1711. 4.

Cogrossus, Della natura, effeti ed uso della Chinachina. Crema 1711. 4. Zendrini, Trattato delle China China. Venezia 1715. S.

Duverney, An largiorem semper exigit linakina cibum? Paris 1717. 4.

Iloffmann, Do recto corticis Chinac usu. IIalae 1798. 4.

Baalen, De cortice peruviano. Lugd. Bat. 1735. 4.

Rosén, De cortice peruviano. Londini Gothorum 1744.4.

Peyer, De cortice peruviano. Basileae 1745. 4.

Kniphof, Examen succedancorum corticis peruviani. Erfordiac 1747. 4. 
Cocchi, Vindiciae corticis peruviani. Lugduni Batavorum 1730.8 . Lursenius, De cortice peruviane. Lugduni Batavorum 1751.4. Langguth, De cortico peruviano. Lipsiao 175s. 4.

Limné, De cortico peruviane. Upsaliae 1758. 4.

Triller, De corticis peruviani usu. Witebergae 1758. 4.

IIartjens, De cortice peruviano. Trajecti a/1hh. 1762. 4.

Alcinet, Nuevas utilidades de la China. Madrid 1763. 4.

Lee, De cortice peruviano. Edinburgi 1764. 8.

Pulleney, De Cinchena officinali L. Edinburgi 1764.8.

Turra, Istoria del arbore della China. Livorno 1764. 4.

Torraca, Corticis peruviani vis antiseptica. Romae 1763.4.

Schenchbecher, Bericht von den heilsamen Wirkungen der Kinkina. Riga 1769.8 .

Held, De corticis peruviani usu. Goettingae 1775. 4.

Brown, De usu corticis peruviani. Edinburgi 1779.8 .

Jaeger, De corticis peruviani in plthisi historia et usu. Tubingae 1779. 4.

IIynne, De cortice peruviano. Edinburgi 4779. \$.

Saunders, Observations on the red peruvian bark. London 1782. 8.

Cothenius, Chemiscle Untersuchung der rothen Chinarinde. Berlin und Stralsund 1783. 8 .

Kentish, Experiments and ebservations on a new species of bark. London 1784. 8 .

Birkhols, De corticis peruviani virtute. Lipsiae 4785.4.

Neunes, De cortice peruviano. Jenae 1789. 4.

IIartmann, Usus corticis peruviani. Trajecti a/V. 1790. 4.

Asti, Lettera intorno alla nuova China-china. Venezia 1791. 4.

Gracenhorst, De Cinchonae corticibus. Geettingae $179 \mathrm{~J} .4$.

(Mutis) Instruccion relativá de las especies y virtudes de la Quina. Cadiz 1792. 4.

(Bertoloni, Notizia sopra la chinologia del Mutis; Ann. di storia nat. III, p. 411-412.)

Ruiz, Quinologia. Madrid 1792. 4. - Supplemento : ib. 1804.4.

- (italice, germanice.)

Relph, An inquiry into the efficacy of the yellow peruvian bark. Lendon 1794.8.

- (Lambert) A description of the genus Cincliona. Londen 1797. 4.

Velloso, Quinografia portugueza. Lisboa 1799. S.

Ruiz, Defensa del verdadero descubridor de las Quinas del reyno de Santa Fé. Madrid 1802.4.

Kicibel, De corticis peruviani usu medico. Ilalae $180 \mathrm{s̆.} 4$.

Renard, Die inländischen Surrogate der Chinarinde. Mainz 1809. 8.

Guglielmi, Sulla Clina-china officiuale. Parwa 1811. 8.

Neves Melto, Circa Cinchonam brasiliensen observationes. Rio de Janeiro 1814.8 .

Ilartung, De Cinchonae speciebus et medicamentis Chinam supplentibus. Argentorati 1812.4.

Mfuenz et Raab, De cortice peruviano et radice Ipecacuanhae. Landishuti 1812.8.

Laubert, Recherches sur lo Quinquina. Paris 1816.8.

- Lambert, An illustration of the genus Cincliona. Loudon 1821.4.

Pelletier et Cacentou, Analyse climique des Quinguina etc. Paris 1821.8.

Graf, De cortice peruviano. Vindobona 182\%. 8 .

Bergen, Versuch einer Monographie der China. Ilamburg 1826.4.

Boehler, De Chininio sulphurico. Lipsiae 1828. 4.

De Candolle, Notice sur les différents genres et espèces, dont les écorces ont été confondues sous le nom de Quinquina. (Bibl. univ. de Genève 1829. vol. XLl, 144-162.)

Folchi, Descrizione degli exemplari delle Chine-chine vere e false. Romae 1830.8 .

Brera, Delle piante chinifere sagg1e. Modena 1832.4.

Flume, De Chiniodino. Berolini 1832. 8.

Winkler, Die aiclıten Clinarinden. Darmstadt 1834. 8.

Hooker, Dissertation upon the Cinclonas. Glasgow 1839. 8 .
ITitzendorf, De Chinioidino. Lipsiae 1840.4.

Jori, Scoperta di due nuovi alcaloidi nella China gialla filosa. Reggio 1843.8.

\section{Cissampelos microcarpa DG.}

Lochner, Schediasma de Parreira brava. Norimbergae 1719. 4.

Dale, De Pareira brava et Serapia officinarum. Lugduni Bat. 1723, 4.

Teichmeyer, De Caapeba sive Parreira brava. Jenae 4730.4.

Buccher, De Pareira brava. Erfordiae 1744. 4.

\section{Cilrus medica L. et C. Aurantium L.}

Monardes, De Citriis, Aurantiis et Limoniis. Antwerpiae 1561. 16.

Ebenbitar, De Limonibus. Venetiis 1583.8.

Grube, Analysis Mali citrei. Hafuiae 1668.8.

Franke, De Malo citreo. Heidellsergae 1686. 4.

Lanzonus, Citrologia. Ferrariae 1690. 12.

Burggrave, De Nalo sinensi aureo. s. J. et a. 4.

Heister, De Aurantiis. Helmstadii 1741. 4.

Valcarenghi, In Ebenbitar tractatum de Malis Limoniis commentaria. Cremonae 1738.4 .

Dubuisson, Sur les acicles natifs du Verjus, de l'orango el du citron. Paris 1783. 8 .

\section{Clomalis Vitalba $\mathrm{L}$.}

Mueller, De Clematide Vitalba L. ejusque usu medice. Erlangae 1786. 4.

\section{Cnicus benedictus Gaertn.}

Petri von IIartenfelss, Asylum languentium seu Carduus sanctus benedictus. Jenae 1669.8.

Otto, De Carduo benedicto. Argentorati 1738. 4.

Cocculus palmalus DC.

Broecke, De usu radicis Columbo. Lugduni Batavorum 1\$22. 8.

Stromeyer, De radico Columbo. Goettingae 4829. 4.

\section{Cocculus Plulicnetii DC.}

Boullay, L'histoire naturelle et chimique de la coque du Levant (Menispermum Cocculus). Paris 1818. 8. - II : ib. 1848. 4.

Tschudi, Die Kokkelskorner und das Pikrotoxin. St. Gallen 1847. 8.

\section{Cochlearia officinalis $\mathbf{L}$.}

Moellenbrock, Cochlearia curiosa. Lipsiae 1674. 8. (anglice.)

\section{Coffea arabica $\mathrm{L}$.}

(Strauss) De potu Coff. Francofurti 1666.4. (germanicg gallice, anglice.)

Naironi, De saluberrima potione Calive seu Cafe discussus. Romae 1671.12.

Togni, Raceolta delle singolari qualità del Caffé. Venezia 1675. 12.

Marsigli, Bevanda asiatica. Vienna 1685.8.

Rambaldi, Ambrosia arabica. Bologna 1694. 12.

Mappus, De potn Lafé. Argenterati 4693. 4.

(Galland) De l'origine et du progrez du cafe. Caen 1699.8.

Andalorius, Il caffèe descritto ed esaminato. Messaniae 1703. 12.

Marsigli, Notizie di Constantinopoli sopra la pianta del Caffé. s. 1. 1703. folio.

Bradley, The virtue and use of ceffec. London 1721. 8.

I udolff, De fabis Coflee. Erfordiae 1724, 4.

Douglas, Botanical dissection of the colfeeberry. Inpr. cum ejus Lilium sarniense. Loudon 1725. foljo.

Supplement to Douglas, Description of the coffee-tree. London 1727. folio. 
MONOGRAPIIAE PLANTARUM OFFICINALIUII

Civinini, Della storia e natura del caffe. Jirenze 1731. 4.

Milhau, Dissertation sur le caffeyer. Montpellier 1746.8.

Dalla Bona, L'uso e l'abuso del Cafle. Verona 1751. 8.

Cmelin, De Coffee. Tubingae 1752. 4.

Kalm, Om Caffé. Ảho 1755. 4.

Linné, Potus Coffeae. Upsaliae 1761. 4.

Monnereau, Sur la culturo du cafó. Jı ojus a Le parfait indigotiern. Amsterdam $1765,12$.

Ellis, An historical account of coffee. London 1774. 4. (italice.)

Hofer, Alblandlung vom Kaflee. Frankfurt 1781. 8.

Buchoz, Dissertation sur le café. Paris 1787. 8 .

Gentil, Dissertation sur le café. Paris 1787. 8.

Hahnemann, Der Kaffee in seinen Wirkungen. Leipzig 1803. 8. (gallice.)

Cadet-de-Vaux, Sur le café. Paris 1806.8.

Fauchon, Dissertation sur le café. Paris 1815.4.

Virey, Sur le cafó ef le genre Coffea. Paris 1816. 12.

Abendroth, De Coffea. Lipsiae 1825. 4.

Kihlmann, Kaffé. Stockholın 1828. 8.

Weilenveber, Der arabische Kaffee. Prag 1835. 8.

Marcus, De Coffea. Lipsiae 1837. 4.

Enerich, De Coffeae facultatibus. Berolini 1839. 8.

Trappcn, De Coffea. Trajecti a/Rh. 1843.8.

\section{Colchicum autumnale I.}

Wedel, De Colchico veneno et alexiplarmaco. Jenae 1748. 4.

Wilhelmi, Colchieum wider die Pest. Leipzig 1721.4.

Stoerck, Libellus de Colchico autumuali. Vindobonae 1763. 8. (anglice, gallice.)

Kratochvill, De radice Colchici autumnalis. Francofurti a/V. 1764.8.

Ehrmann, De Colchico autumnali. Basileae 1772. 4.

Creutz, De Colehico autumnali. Berolini 1826. 8.

Noell, Ueber die Wirksamkeit des Colchicum autumoale. Würzburg 1826. 8.

Frisch, De Colchicacearum virtute medica. Pragae 1835. 8.

Hauser, De Colchico autumnali. Turici 1835. 8.

Schroeder, De seminum Colchici autumnalis virtute. Kiliae 1\$36. 4.

Goebel, De Colchico autumnali. Lipsia-1843.4.

Conium maculalum L.

(cf. Cicuta virosa L.)

Mischkovicsew, De Conio maculato. Budne 1834. s.

Christison, On the properties of lemlock (Conium maculatum). Edinburgh 1836. 4 .

Poehlnann, Uutersuchungen über das Couiu. Erlangen 1838. 8.

Bochm, De Conio maculato. Vratislaviae 1844.8.

Rossi, De effectu Coniini in organismum animalem. Marburgi 1844.8.

\section{Convallaria majalis $\mathrm{L}$.}

Baier, De Lilio convallium. Altdorfi 4718. 4.

Scnckenberg, De Lilii convallium ejusque baccae viribus. Goettingae 1737. 4 .

Schulze, De Lilio convallium. IIalae 1742. 4.

Convolvulus Jalapa L. et C. Purga Wender.

Donati, De radico purgante Mechioacan (i. e. Jalapa). Mantuae 1569. 4. Wedel, De Gialapa. Jenae 1668. 4.

Slevogt, De Jalapa. s. l. 1678. 4.

Paullini, De Jalapa liber singularis. Francofurti a/M. 1700. 8. Buechner, De damnis ex abusu resinae Jalappae. Halae 1750. 4. Schaller, De Jalappa. Argentorati 1761. 4.
Cadet de Gassicourt, Sur le Jalap. Paris 1817. 4.

Pelletan, Note sur deux espèces de Jalap du commerce. Paris 1834. 8.

$$
\text { Convolvulus scoparius L. }
$$

Chanbers, De (Ribes Arabum et) ligno Rhodio. Lugduni Bat. 1724. 4.

$$
\text { Convolvulus Soldanella L. }
$$

Franke, De Soldanclla. Jeidelbergao 1674. 4.

$$
\text { Copaiferae species. }
$$

Nebel, De Balsamo Copayba, lleidelbergae 1710.4.

Hoppe, De Balsamo Copayba. (Valentini, Ilist. simpl.p. 617-624.)

\section{Coriandrum sativum $\mathrm{L}$.}

Boecler, De Coriandro. Argentorati 1739. 4.

\section{Coronopus Ruellii.}

Juch, De Coronopo. Erfordiae 1739. 4.

\section{Crocus sativus All.}

Hertodt, Cracologia. Jenae 1670.8 .

Goldbach, Croci historia botanica-medica. Mosquac 1816. 8.

Castiglioni, Monografia dello Zafferano. Mlilano 1829.8 .

\section{Croton Tiglium L.}

Geiseler, Crotonis monographia. Halae 1807. 8.

Moeckel, De (Diosma crenata et) oleo Crotonis Tiglii. Lipsiae 18さ0. ‘. Conwell, Recherches sur l'buile de Crotan Tiglium. Paris 1824. \%. Cruse, De Grotonis Tiglii oleo. Berolini 1824.8.

Zeitner, Analysis et usus seminum Crotonis Tiglii. Kiliae 1827. '.

Lund, Do oleo Grotonis. Ilalae 1831. 8.

\section{Croton Eluteria Sw.}

Holmann, De cortice Cascarillae. IJalae 1738. 4.

\section{Cucumis Colocynthis L.}

Schulze, De Coloeynthide. Halae 1734. 4.

Ifiller, De Colocynthide. Lipsiae 1821. \&.

\section{Cucumis sativus L.}

Baldini, Tractatus de Cucumeribus. Florentiac 15S6. 4. IVedel, De usu Cucumerum innoxio. Jenae 1686 . 4

\section{Cucurbita Pepo L.}

Nati, Breve discorso intorno alla natura del Pepone. Fiorenza IGj6. 12

$$
\text { Cuminum Cyminum L. }
$$

Ehrmann, De Cumino. Argentorati 1733. 4.

\section{Curcuma longa $\mathrm{L}$}

Buechner, De Curcuma officinarum. IIalae 1748. 4.

\section{Curcuma Zedoaria Roscoe.}

Manitius, De aetatibus Zedoariae relatio. Dresdae 1691. 8.

\section{Cuscula curopaea $\mathrm{L}$.}

Franke, Das verschmachte und wieder erhöhete Flachssciclenkraut. I'Tm 1718.8. 
Cynanchum Vincetoxicum Pers.

Wedel, De Vinceloxico. Jenae 1720.4.

Ilarnier, De vi Cynanchi Vincetoxici. Marburgi 1844. 4.

\section{Cynoglossum officinale $\mathbf{L}$.}

Schreck, De Cynoglosso. Altdorfii 1753. 4.

\section{Dapline Gnidium L.}

Ifartmann, Super Daphnes Gnidii usu epispastico. Trajecti a/V. 1780. 4.

Daphne Mezercum L.

Justi, De Thymelaea Nezereo. Narburgi 1798. 8.

Gmelin, Chemische Untersuchung der Seidelbastrinde. Tubingen 1822. 8. Theile, De viribus Daphnes Nezerei. Lipsiae 1838. 8.

\section{Datisca cannabina L.}

Dammers, De Datiscae canuabinae usu. Goettingae 1799. 4.

\section{Datura Stramonium L.}

Harles, Ueber die Wirksamkeit der Datura Stramonium gegen dio llundswuth. Frankfurt a/AI. 1809. 4.

W'eler, De Daturae Stramonii viribus. Bonnao 1820. 8.

Engcllart, De Datura Stramonio. Trajecti a/Rh. 1822. 4.

\section{Dictamnus albus L.}

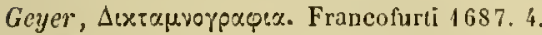

Buechner, De Fraxinella. Erfordiae 1712. 4.

\section{Digitalis purpurea L.}

Withering, Account of the foxglove. Birmingham 1785. 8. (germanice.)

Schiemann, De Digitali purpurea. Goetlingae 1786. 4.

Mers, De Digitali purpurea. Jenae 1790. 4.

Afzelius, Do viribus Digitalis purpureae. Upsaliae 1806. 4.

Fanzago, Sulla virti della Digitale. Padova 1810.8 .

Bidault de Villiers, Essai sur la Digitale pourprée. Paris 1812. 8.

Elmiger, Histoire naturelle et médicale des Digitales. Montpellier 1812.4.

Haase, De Digitali purpurea. Lipsiae 1812. 4.

Kaplinsti, Do Digitali purpurea. Berolini 1820.8.

Jessen, be Digitalis purpureae viribus. Kiliae 1820. 4.

Thunberg, De Digitali purpurea. Upsaliae 1822. 4.

Duval, De Digitali purpurea. Leodii 1824, 4.

Nicolle, Histoire de la Digitale pourprée. Paris 1824. 8.

Donath, De Digitali purpurea. Berolini 1826. 8.

II'itteld, De vera Digitalis indicatione. Bonnae 1826. 8.

Goethals, Do Digitali purpurea. Gandavi 1829. 4.

Schroen, De Digitali purpurea. Monachii 4829.8.

Schijchowskij, De Digitali purpurea. Dorpati $1 \$ 29$.

Engel, De Digitalis purpureae in delirio potatorum effectu. Lipsiae 1835. 4.

Rhodius, Die Digitalis purpurea. Nergenthein 1837.8

Winckler, De Digitali purpurea. Berulini 1837.8 .

Muth, De Digitali purpurea. Kiliae 1839. 8.

Teubern, De Digitalis purpureae vi pharmacodynamica. Jenae 4840.8 .

Diosma crenata, potius Barosma crenata et serratifolia Willd.

Noeckel, De Diosma crenata. Lipsiae 1820. 4.

Cadet de Gassicourt, Notice sur le Diosma crenata. Paris 1827. 4.

Nourij, Historia foliorum Diosmae serratifoliae, vulgo foliorum Bucluu. Groningae 1827. 8.

Bruinsma, De Diosma crenata. Lugduni Batavorum 1838.4
Dorcma armeniacum Don.

Thunberg, Do Gummi ammoniaco. Upsaliae 1828. 4.

Jaehnel, De Gummi ammoniacu. Lipsiae 1837. 8.

\section{Dorstenia Contrajerva L.}

IVedcl, De Contrayerva. Jenae 1712. 4

\section{Dracaena Draco L.}

Baier, De sanguine Draconis. Altdorfi 1712. 4.

\section{Drimys Winteri Forst.}

Siltemann, De cortice Winterano. Erfordiae 1711. 4.

Harsleben, De cortice Winterano (et Canella alba). Francofurti a/V. 1760. 4 .

\section{Drosera rotundifolia L.}

Eysel, De Rore solis. Erfordiae 1715. 4.

\section{Erythraea Centaurium Pers.}

Ledelius, Centaurium minus, auro tamen majus. Francofurti a/M. 1694. s. Wedel, De Centaurio minori. Jenae 1713.4.

Slevogt, Commendatio Centaurii minoris. Jenae 1713, 4.

Mossin, De Centaurio minore el Chelidonio minore. Javniae 1742. 4. Melén, De Erytlıraeis suecanis. Upsaliae 1826. 4.

\section{Éugenia Pimenta DC.}

Ortega, Historia natural de la Malagueta o pimienta de Tavasco. Madrid 1780.4 .

\section{Euphorbiae.}

Linné, Euphorlja ejusque historia medica. Upsaliae 1752.4.

Marincovich, De suceo Tithymalorum ejusque analysi. Venetiis 1823. S.

Jussieu, De Euphorbiacearum generibus medicısque viribus. Parisiis 1824. 4 .

Landsberg, Pharmacographia Euphorbiacearun. Berolini 1831.8 .

Daenzer, Des Euphorbiacées usitées. Strassburg 1834.4 .

Dubrenil, Histoire de quelques Euphorbiacées. Paris 1835.4.

\section{Euphrasia officinalis L.}

Franke, Spicilegium de Euphragia herba. Francofurti 1717. \$.

\section{Exostemma caribaeum Willd.}

Aufmkolk, De cortice caribaeo. Goettingae 1793. 8 .

\section{Ferula Asa foetida $\mathbf{L}$.}

Pundt, De Asa foetida. Goetlingae 1778. 4.

Koeck, De Assa foetida. Vindobonae 1840.8.

\section{Fevillea L.}

Drapiez, Notice sur le Nhandirobe. (Fovillea L.) Bruxelles 1819.8.

\section{Foeniculum vulgare Gaertn.}

Schenckius, Mapaspodoyia sive de Foeniculo. Jenae 1665. 4.

Boecler, De Foeniculo. Argentorati 1732. 4.

\section{Fraxinus excelsior L.}

Schroer, Curieuse Beschreibung des Eschenbaums. Frankfurt a/d. 0. 1700. 8 .

Helvigius, De Quinquina Europaeorum. Gryphiswaldiae 1712. 4.

Schreger, De corticis Fraxini excelsioris natura. Lipsiae 1791. 4.

Leroy, Mémoire sur le Kinkina français. Paris 1808. 8. 
Fraxinus Ormus L. et $F$. rolundifolia L.

Donatus ab Allomari, De Mannac differentiis. Venetiis 4562. 4. Magnenus, De Manna liber singularis. Ticini 1648. 8.

Hofwenius, De Manna. Upsaliae 1681. 8.

Salmasius, De Manna. In cjus "Exerc. do homonỹmis». Trajecti ad/Rls. 4689. folio. p. $245-254$.

Hofmann, De Manna. IIalae 1725. 4.

Ileister, De Mamua. Ilelmstadii 1725. 4.

Mangold, De Manna. Rinteln 1725. 4.

Sailly, De Manua. Jugduni Batavorum 1740. 4.

Trainer, Examen elomicum Nannac. Erlangac 1793. 8.

\section{Fucus vesiculosus L.}

Delius, De Aethiope vegetabili. Erlangac 1774. 4.

\section{Fumaria officinalis L.}

Camerarius, De Fumaria. Tubingae 1718.4.

Ummius, De herba Fumaria. Groningae 1793. 4.

Bonssy, De Fumaria vulgari. Argentoraii 1749. 4.

IIandschuch, De plantis fumariaceis. Erlangae 1832. 8.

Galipea febrifuga St.-Ilil.

(Cortex Augusturae genuinus.)

Meyer, Do cortice Angusturac. Goctlingae 1790. 8.

Brande, Experiments on tho Angustura bark. London 1791. S.

Filter, De cortice Angusturae. Jenae 1791. 4.

Thumberg, De cortice Angusturac. Upsaliae 1793. 4.

Bonutz. De corticis Angusturao patria, principiis usuque medico. Trajecli a/ $\mathrm{Y} .1804 .8$.

Autenrieth, Ueber die acluto Angusturarinde. Stuttgart 1841.8.

Berg, De Angusturac cortice spurio. Tratislaviae 1844. 8.

\section{Galium rotundifoliun $\mathbf{L}$.}

Selig, De Galii rotundifolii usu medico. Erlangac 1802.8 .

\section{Garcinia Cambogia Rosb.}

Jaeger, De Cambogiae Guttae sueco. Tubingae 1777.4

\section{Gentianae species.}

Sterogt, De Gentiana. Jenae 1720.4.

Hartmann, Historia Gentianac naturalis et medica. Trajecti a/V. 1777. 4. Marquis, Essai sur les Gemianes. Paris 1810.4.

\section{Geoffroya inernis Wright.}

filingsohr, De Geoffroea inermi cjusque cortice. Erlangae 1788.4.

\section{Geoffroya surinamensis Bondt.}

liondt, De cortice Geoffreae surinamensis. Lugduni Batavorun 1788. 8. (hollandice.)

Eggert, Geoffraeae surinamensis virtus anthelnintica. Marburgi 1791. \$. Schuartze, De virute corticis Geofraoao surinamensis. Goeltingae 1792. 4 .

Iluettenschmid, Analysis chemica corticis Geofroyac jamaicensis et surinamensis. Heidelbergac 1824,8 .

\section{Geranium Robertianum $\mathbf{L}$.}

Hinderer, De Geranio Robertiano. Gissac 1774. 4.

\section{Geum urbanum L.}

Buchlave, Observationes circa Gei urbani vires. Hafniac 1781. 8.
Anjou, Do radice Caryoplyyllatae vulgaris. Goetlingac 1783.4. Linderholm, De Geo urbano. Upsaliae 1827. 4.

\section{Glechoma hederacea L.}

Heder, Hedera terrestris. Altunfii 1736. 4.

Bender, Glecoma hederacea in atrophia. Erlangao 1787.4.

\section{Glycyrrhiza ylabra L.}

Goez, Do Glycyrrhiza. Altdorfii (1715.) 4.

I'edel, De Glyeyrrhiza. Jenae 1747. 4.

Deckmamn, Warenkunde. I, p. 392-410.

\section{Gratiola officinalis $\mathbf{L}$.}

Buerckel, De Gratiola. Argentorati 1738. 4.

hostracustit, De Gratiola. Viennae 1775. S.

IIartmam, Do Gratiola. Trajecti a/V. 1784. 4.

Sommer, De virtute Gratiolac offeinalis L. Rigae 1796. 4.

De la ligne, Do Gratiola officinali L. Erlangae 1799. 8.

Erhard, De Gratiola officinali. Lipsine 1818.4.

Marchand, Faits pour scrvir a l'histoirc climique de la Gratiole. Paris 1845. 8 .

\section{Grajacum officinale $\mathbf{L}$.}

Ulrich von Hutten, De Guajaci medicina. Moguntiac 1519.4. (anglice, sallice.)

Delicarlo, El modo de adoprare il legno de India occidentale. Venetiis 1529. 4 .

Riyf, Vom Guajaco. Strassburg 1541.8.

Blondhs, De ancipiti ligni indici proprietate. Venetiis 1542.12.

Paracelsus, Das IIolzbüchlcin. s. l. 1565.8.

Minettus, De (Sarzaparillae et) Ligni sancti viribus. Senis 1593.4.

Clemens, De natura el facultatilsus ligni saneti. Romac 1604. 4.

Canevarius, De ligno sancto eommentarius. Romac 1602. s.

Cagnatus, De ligno sancto disputationes binae. Romac 1603.4.

Friderici, Guajacan. Jenac 1665. 4.

\section{Haematoxylon campechianum $\mathrm{L}$.}

Weimrich, De Hacmatoxylo campechiano. Erlangae 1780.4

\section{Melianthus annuus L.}

Franlie, Gründlicbe Lintersuchung der unvergleichlichen sonnenblume. Ulm 1725. 8 .

\section{Hclleborus niger $\mathbf{L}$. et $H$. viridis $\mathbf{L}$.}

Me $z$ ger , Helleborus niger medice delineatus. Tubingae 1684. 4 .

IJollebius, De Helleboro nigro. Basileae 1721. 4.

Baier. De Helleboro nigro. Altdorfi 1733. 4.

Buechner, De usu Ellebori nigri. llalae 9751.4.

Bochmer, De Hellebori vigri atque praasertim viridis usu medico. Halae 1774.4.

Linclie, De llellebori nigri atque viridis usu. Ilalae 1774.4.

De llellebori viridis usu. Scrvestae 1775. 4.

Ilartmam, Virtus Ilellobori nigri lydogogoga. Trajecti a/T. 1786.4.

Halncmann, De Helleborismo veterum. Lipsiae 1812. \&.

Tobias, De Ilellebori nigri indole et usu. Berolini $1819 . \mathrm{s}$.

Ribleck, De Helleborismo veterum. Berolini 1844. 8.

\section{Ifelminthochortos officinalis $\mathrm{Lk}$.}

Schwendinamn, Ifelminthochorti historia atque vires. Argentorati 1780, 4. IIacmnerlen, De Fuco helminthochorto. Erlangae 1792. S.

De Candolle, Note sur la mousse de Corsc. (Bull. soc. pliil. 1\$05. p. 363.) 
MONOGRAPHIAE PLANTARUM OFFICINALIUM

Heracleum Sphondylium L.

Cartheuser, De Branca ursioa germanica. Francofurti 1761. 4.

\section{IIerniaria glabra L. et II. hirsula $\mathrm{L}$.}

Gruhlmann, De nova contra oculorum caliginem remedio, Herniaria. Jenae 4706. 4 .

\section{Ifumulus Lupulus L.}

Baier, De Lupulo. Altdorf 1718.4.

Deroches, De Hlumuli Lupuli viribus. Edinburgi 1803. 8.

Payen et Chevallier, Mémoire sur le houblon. Paris 1823. 8. - ib. 1828. 8.

\section{IIyoscyamus niger L.}

Slevogt, De virtute IIyoscyami cathartica. Jeлae 1715. 4.

Wedel, De Hyoseyamo. Jenae 1715. 4.

Stokar de Neuforn, De llyoseyami nigri virtutibus. Erlangae 1797. 8.

Schueplach, Von dem Gebrauche des Bilsenkrautes. Würzburg 1818. 8.

Re, Lettera sua semi del giusquiamo. Torino 1822.8 .

Huebner, De Hyoscyamo nigro. Berolini 1826. 8.

\section{Hypericum perforatum $\mathrm{L}$.}

Eysel, De Fuga Daemonum. Erfordiae 1714. 4.

IVedel, De IIyperico, aliis Fuga Daernonum. Jenae 1716. 4.

Das Johanniskraut. Leipzig 17S1. 8.

\section{nex Aquifolium L.}

Bandelow, Foliorum Ilicis Aquifolii analysis. Ilalao 1789.8.

Rousseau, De l'efficacité des feuilles du houx (Ilex Aquifolium). Paris 1831.8 .

\section{Illicii species.}

IIoffmann, Die Angaben schinesischer und japanischer Naturgeschichten von dem Illicium religiosum. Leiden 1837. s.

Siebold, Erwiederung auf II. H. de I'riese's tbhandlung (uber den Steruanis). Leiden 1837.8 .

\section{Indigoferae species.}

Roth, De Indico, medicamine. Berolini 1834.8.

Dercks, De pigmento indico. Dorpati 1836. 8.

\section{Inula IIelenium $\mathbf{L}$.}

Wedel, De Helenio. Jenae 1719. 4.

\section{Iridis species.}

Baier, De lride. Altdorf 1710.4.

\section{Juglans regia $\mathrm{L}$.}

Buechner, De nuce Juglande. Frfordiae 1743. 4.

Graef, De cortice nucis Juglandis regiae. Erlangae 1803.8.

Negrier, Sur le traitement des serofules par les feuilles de Juglans regia.

(Paris 1841.) 8. (germanice.)

Kreutzwald, De utilitate foliorum Juglandis regiae. Bonnae 1849. 8.

Mueller, De Juglandis regiae viribus. Lipsiae 1843. 8.

\section{Juniperus communis $\mathrm{L}$.}

Babst von Rochlitz, Juniperetum. Eisleben 1605.4.

Becker, Beschreibung von (Hollunder und) Wachlholder. Königsherg 1650.8.

Scharff, 'A pxeuSoloyix sive Juniperi deseriptio curiosa. Francofurti 1679.8.

Bang, De Junipero. Havniae 170s. 4.

\section{MONOGRAPHIAE PLANTARUII OFFICINALIUH}

IVilhelm, Juniperus. Argentorati 1718. 4.

Baier, De Junipero. Altdorf 1719. 4.

Lundman (Marlin?), De Junipero. IIarderovici 1727. 4.

Bruch, De radicis Juniperi decocto. Argentorati 1736. 4.

Semon, De olei Juniperi aetherei vi. Berolini 1844. 8.

\section{Juniperus Sabina L.}

Wedel, De Sabina. Jenae 1707.4.

Bichler, De Junipero Sabina. Wittenbergae 1803.4.

Elias, Analacta ad Sabinae bistoriam. Marburgi 1816. 8.

Matthei, De lincturae Sabinae efficacia. Jarburgi 1819. 4.

Voigt, De Junipero Sabina. Berolini 1 \$ 26.8 .

\section{Frameria triandra Ruiz.}

Ruiz, Disertacion sobre la raiz de la Ratánhia. Madrid 1799. 4.

Kleil, Ablandlungen und Versuche aber die Ratanhia. Stuttgart 1819. S.

Falco, De Ratanhia. Wirceburgi 1820.8.

Thunberg, De Krameria. Upsaliae 1822. 4.

Eckard, De radice Ratanliae. Berolini 1822. 8.

Bunsen, De Ratanhiae radice. Goettingae ISz8. 8.

\section{Laclucae species.}

Ganzel, De Lactuea sativa et Lactucario. Berolini 1819.8.

Klink, Laetucae virosae el sativae analysis chemica. Kiliae 1820.4.

Humble, De Lactucario. Ursaliae 1827.4.

Ihirschfeld, De Lactuca virosa et Scariola. Berolini 1833. 8.

II"als, Der Milchsaft des Giftlattichs. Teidelberg 1839. \$.

Lappa vulgaris Tournef.

Nordstedt, De Bardana. Upsaliae 1823. 4.

\section{Laurus Camphora L.}

Eichstad, An Camphora lippocrati, Aristeteli. Theophrasto fuerit incoguita? Dantisci 1650.4.

Moebius, Anatomia Camphorae. Jenae 1660. 4.

Cronberg, De Caphura. Marpurgi 1697. 4.

Wedel, De Camphora. Jeuae 1697. 4.

IIoffinann, De usu interno Camphorae. Halae 1714. 4.

Gronovius, Camphorae historia. Lugduni Batavorum 17 t5.4.

Alberti, De Camphorae usu medico. Halae 1722. 4.

Neumann, Lectio ehymiea von Camphora. Berlin 1727.4

Meisner, De Camphora. Pragae 1737.4.

Ilaenel, De Camphora. Lugduni Batayorum 1739. 4. (anglice.)

Gerike, De usu medico Camphorae. Helmstadii 1748. 4.

Kiechelen, De genesi Camphorae. Argentorati 1748. 4.

Pirck, De Camphora. Viennae 1767.8.

Grueno, De Camphora ex aliis stirpibus quam Lauro Camphora elicienda. Goettingae 1780.4.

Kosegarten, De Campbora. Goettingae 4785.4.

Weigel, De oleis Camphorae. Gryphiae 1786. 4.

Hartmann, Circumspectus Camplorae usus internus. Trajecti a/V. 178s. 4.

Graffenauer, Traité sur le camphre (Laurus Camphora L.). Strassburg 1803.8.

Courrant, Propriétés déletères du cemphre et de la coque du Leraut Paris 1815.4.

Godin, De Camphora. Leodii 1823.8.

Lankihorst, De Camphora. Gandavi 1829. 4.

Dunas, Mémoire sur les substances vẻgétales, qui se rapprochent du camphre. Paris 1832.8.

Wahlenberg, De Camphora. Lpsaliae 1834. 4. 
Ruecker, De Campherae virtute medica. Derpati $1 \$ 33.8$.

Nillot, llistoiro du cemplire. Strassburg 1837. 4.

\section{Laurus Cinnamomum L. et Laurus Cassia L.}

Schenckius, De Cinnameme. Jenae 1670.4.

Dexbach, De Cassia cinnamomea et Malabathro. Marpurgi 1700.4.

Slevogl, De Cinnamomo. Jenae 1707. 4.

Wedel, De Cinnamomo. Jenae 1707. 4.

Gocller, De Cinnamomo. Trajecti a/Rh. 1709.4.

Carlheuser, De Cassia aromatica. Francofurti 1745.4.

Nogueira da Gama, Memeria sobre o Loureiro Cinnamomo vulgo Caneleira do Ceylão. Lisbea 1797. 8.

Nees von Esenleck, De Cinuamemo disputatio. Bennae 1823. 4.

\section{Laurus Culitlawan L.}

Slevogt, De cortice Culilavan. Jenae 1705. 4.

Carlheuser, De cortice Culilawan. Francofurti 1753. 4.

\section{Laurus Sassafras L.}

Neander, Sassafraselogia. Bremae 1627. 4.

Saint-Evre, Recherches sur l'buile essentielle de Sassafras. Paris 1846.4

\section{Ledum palustre L.}

Linne, De Ledo palustri. Upsaliae 1775. 4.

Kingel, De natura et viribus herbae Ledi palustris. Halae 1824. 8.

\section{Lepidium ruderale $\mathrm{L}$.}

Glaser, De virtute et vi medica Lepidii ruderalis L. Dorpati 1816. 8.

\section{Lichen pyxidatus L.}

Dillenius, De Lichene pyxidato. Mloguntiae 1785. 8.

\section{Lilium candidum L.}

Tilling, Lilium curiesum. Francofurti a/M. 1683. 8.

\section{Linaria Cymbalaria Mill.}

Zuinger, De Cymbalaria. Basileao 1715. 4.

\section{Linnaea borealis Gronov.}

Lundnark, De usu Linnaeae medice. Upsaliae 1758. 4.

\section{Linum catharticum $\mathrm{L}$.}

Camerarius, Biga betanica. (Linum catharticum.) Tubingae 1712.4. Slevogt, De Lino sylvestri cathartice Anglorum. Jenae 1715. 4. Moritz, De Lini catbartici vi purgante. Derpati 1835. 8 .

Pagenslecher, Ueber Linum catharticum L. Mlunchen 1845. 8.

\section{Lolium temulentum L.}

Crassus, De Lelie tractatus. Bononiae 1600. 4.

Camerarius, De Lelie temulento. Tubingae 1710. 4.

\section{Lycopodium clavalum L.}

Wedel, De Musco terrestri clavate. Jenae 1702. 4.

Danzel, De Lycepodii herba et semine. Goettingae 1814. 8.

\section{Lyihrum Salicaria L.}

Sagar, De Salicaria. Viennae 1762. 4.

Schertius, De Lysinachiae purpureae sive Lytluri Salicariae L. virtnte. Jenae 1790.4 .

Freyer, De Lytbre Salicaria L. Goettingae 1802. 8.

\section{MONOGRAPHIAE PLANTARUM OFFICINALIUY}

Malvae species.

IIorst, MIalva arborescens lutea. Gissae 1654. 4.

Mandragura officinalis Mill.

Catelan, Discours sur la Mandragere. Paris 1639. 12.

Rudleck, De Mandragora. Upsaliae 1702. 8.

Hollzbom, De Mandragora. Trajecti a/Rl. 1704. 4. (a prieri nen differt.)

Maranta arundinacea L. el $M$. indica Tussac.

Ryder, Some account of the Maranta. Londen 4796. 8.

\section{Melalcuca Cajeputi Roxb.}

(Martini) De oleo Wittnebiano seu Kajuput. (Wolfenbuttel) 1751.4.

Adami, De oleo Cajeput. Geettingae 1783. 4.

Thunlerg, De eleo Cajuputi. Upsaliae 1797. 4.

Buchoz, Mémeires sur la Mélaleuque. Paris 1805.8

\section{Melissa officinalis $\mathbf{L}$.}

Schulze, De Melissa. Halae 1739. 4.

\section{Menthae species.}

Limne, De Menthae usu. Upsaliae 1767. 4.

Knigge, De Mentha Piperitide. Erlangae 1780. 4.

\section{Menyanthes Irifoliata L.}

Schroer, De natura et viribus Trifolii fibrini. Gubenae 1700.8.

Franke, Trifelii fibrini bistoria. Francofurti 1701.8.

Eysel, Trifelium fibrinum. Erfordiae 1716.4.

Bokelmann, De Trifelio paludeso. Lugduni Batavorum 1718. 4.

Elfwing, De Trifolio aquatice. Aboae 1724. 8.

Thunberg, De usu Menyanthidis trifoliatae. Upsaliae 1797. 4.

\section{Mesembrianthemum crystallinum $\mathrm{L}$.}

Lieb, Die Eispllanze (Mesembrianthemum crystallinum L.). Hof 1785 s. S.

\section{Mikania Guaco.}

Pellenkofer, Ueber Mikania Guaco. Munchen 1844. 8.

\section{Momordica Balsamina L.}

Franke, Thappuah Jeruschalmi seu Momerdicae descriptio. Ulmae 1720.8.

\section{Momordica Elaterium L.}

Everhard, Elaterium magnis mortalium usibus parari. Altderfii 1729. 4.

\section{Monarda didyma L.}

Martmann, De Menarda. Trajecti a/V. 1791. 4.

$$
\text { Monnina polystachya. }
$$

Kuiz, Memeria sobre las virtudes de la raiz Yallhoy (Monnina polystachya). Madrid 1805.4.

\section{Moringa plerygosperma Gaerln.}

Heister, De nuce Been. Helmstadii 1750. 4.

\section{Mucuna pruriens DC.}

Chamberlaine, On the efficacy of Stizolobium. Londop 1792. S.

Mfyristica moschala Thunb.

Diel๘, Moschokarpolegia. Ed. 11. Giessae 16\$1. 4. 
Paullini, Mooyoxapuoypapla seu Nucis moschatae curiosa descriptio. Erfordiae 1704.8.

Schullze, De Nuce moschata. Trajecti a/Rh. 1709. 4.

Valentini, De Macis. Giessae 1719. 4.

Thunberg, De Myristica. Lpsaliae 17S8. 4.

\section{Myraxylon peruiferum L. fil.}

Perez, De Balsamo. Sevilla 1530.4.

Ilo/fmann, De Balsamo peruviano. Halae 1703. 4.

Lehmann, De Balsamo peruviano nigro. Lipsiae 1707. 4.

Hadley, De Balsamo peruviano. Lugduni Batavorum 1718. 4.

\section{Nicotiana Tabacum L.}

Monardes, De Tabaco, bispanice. circa annum 1570. (gallico, italice.)

(Gohori) Instruction sur l'herbe Petum et sur la racine Mlechiocan. Paris 1572.12.

Everartus, De lierba Panacea. Antwerpiae 4583.12. - Ultrajecti 1644.12.

Deacon. Tobacco tortured. London 1616. 4.

Jacobus I., Magnae Britanniac Rex, Mlsocapnus sive de abusu Tobacci lusus regius. London 16 19. folio. (anglice.)

Neander, Tabacologia. Lugduni Batavorum 1622. 4. (gallice.)

Thorius, Hymnus Tabaci. Lugduni Batavorum 1628. 4.

Baumann, De Tabaci virtutibus. Basileae 1629. 4.

Franke, De pracelaris Nicotianae virtutibus. Upsaliae 1633.4.

Ostendorf, Traité de l'usage du tabac. Bordeaux 1636. 8.

Epistolac medicorum de Tabaco. Impr. cum Everharlo. Ultuajecti 1644. 12. p. $147-497$.

Magnenus, Exercitationes de Tabaco. Ticini 1648.4.

Ferrant, Traicté du tabac en sternutatoire. Bourges 1655.4.

Baldus, Satyra contra abusum Tabaci. Monachii 1657. 12.

Tappe, Oratio do Tabaco. Helmstadii 1660. 4.

Mander, Lauwcrkrantz voor alle Liefbebers des Souftobaks. Hafniae 1665. 4 .

Paulli, Commentarius de abusu Tabaci. Argentorati 1665. 4. (anglice.)

Friderici, De Tabaco. Jenae 4667. 4

Baillard, Discours du tahac. Paris 1668. 8.

Fagon, An cx tabaci usu frequenti vitae summa brevior? Paris 1669. 4.

Stella, Il tabacco. Romae 4669.8.

Barnstein, Mliraculum Tabacci. Francofurti 1673. S.

Dorstenius, Disputatio de Tabaco. Marpurgi 1682. 4.

Beinteme et Peima, Tabacologia. Hagae 1690.8. (germanice.)

Ileidecke, De usu Pethi in catarrhis. Duisburgi 1693.4.

Albinus, De Tabaco. Francofurti 1695.4

Berger, An ex Tabaci usu frequenti vitae summa brevior? Paris 1699. 4.

(Baillard) Le bon usage du tabac en poudre. Paris 1700. 12.

Appel, Tabaci hibulus. Coloniae Br. 1703. S.

Thebesius, Nachricht vom Rauch- und Schnupftaback. (IIalle) 1713.4.

Baruffaldi, La Tabaccheide. Ferrara 1714. 4.

Ludolf, De Tabaci noxa post pastum. Erfordiae 1723. 4.

Vandermonde, An a Tabaco naribus assumpto ecphalalgia? Paris 4733.4.

Loechstoer, De Nicotiana vera. Havniae 1738.4.

Beintema, Untersuchung, ob dem Frauenzimmer Taback zu rauchen erlaubt sci? Jenac 1743.8.

Buechner, De viribus Tabaci. Halac 1746. 4.

Menlzer, Beskrifning om bollandska tabak örtens ans. Stockholm 1747. 8.

Pajon de Moncets, An post cibum fumus Tabaci? Paris 1749. 4.

Langguth, De Tabaci abusu. Lipsiae 1750. 4.

Reichel, De Tabaco. Vitembergae 1750. 4.

Prutzel, Thes. lit. bot.
Barjolle, An Tabacum lentum sit venenum? Paris 1751. 4.

Jenichen, De Tabaco. Ed. II. Gissae 1756. 4.

Petilmaitre, De usu et abusu Nicotianae. Basileae 1756. 4.

Fowler, Medical rapports on the effects of tabacco. London 1785.8 .

Bucho:, Dissertation sur le tabac. Paris 1787. 8 .

Zell, De Nicotianae utilitate et noxis. Landishuti s. a. 8.

Meyer, De fumi Nicotianae suctu. Lipsiac 1803. 4.

Cadel-de-1'aux, Traité de la culture du tabac. Paris 1810.8.

1812. 12

Arvers, Essai sur lo tabac. Paris 1813.4.

Agardh, Conspectus specierum Nicotianac. Lundae 1819. 19. (germanice.)

Gory, Essai sur le tabac. Paris 1820. 4

Banning, De herba Nicotianae. Berolini 4824. 8.

Heulsfeld, De Nicotiana. Rerolini 4828. 8.

Antz, Tabaci historia. Berolini 1836. 8.

Couradi, De Nicotiana Tabaco. Goettingae 1838. 8.

Draeger, De vi et usu Nicotianae. Halac 4838. 8.

Jelenffy, De Nicotiana. Budae 1838. 8.

Piemschueider, De herba Nicotiana. Lipsiae 1840. 8.

Erhardl, Der Tuhack. Ileidelberg 1841.8.

Hueller, Der Taback. Emmerich 1\$42.8.

Ocotea Puchury Mart.

Harlmann, De Pechuri. Francofurti a/V. 1792. 8.

\section{Onopordum Acanthium L.}

Goelicke, De Onopordo. Francofurti a/V. 1739. 4.

Ophiorrhiza Mungos L.

Lochner, Nlungos animalculum et radix. Norimbergae 1715.4

Cartheuser, De radice Mungo. Francofurti 1769. 4.

Origanum creticum L.

Marquarl et Vogel, Beitráge zur Geschichte der Herba Origani crelici. (Nurnberg 1840.) 8

\section{Origanum Majorana L.}

Grav, Panacaea vegetabilis calida sive Majorana nostra. Jenae 1689. 12.

\section{Oxalis Acetosella $\mathrm{L}$.}

Franke, Herba Alleluja. Ulmae 1709.12.

De vera herba antiquorum Acetosella. Augustae Vindelicorum 1717. 12. (non differt.)

\section{Paeonia officinalis L.}

Berger, Yon der Påonicnwurzel. Frankfurt 1599

Friderici, De Paeonia. Jenae 1670. 4.

Huenerwolf, Anatomia Paeoniae. Arnsteti 1680.8

Panax quinquefolius L.

Breyn, De radice Gin-sem seu Nisi. Lugduni Batavorum 1700.4.

Vandermonde, An iofirmis a morloo viribus Ginseng? Paris 1736. 4.

Schuls, De radice Ginseng vel Ninsi. (Panax quinquefolius.) Dorpati 1836.8.

\section{Papaver et Opizm.}

Borrich, De somniferis maxime papavereis. Havaiae 1683. 4.

Fischer, De Papavere erratico. Erfordiae 1718. 4.

Viguier, Ilistoire des Pavots et dos Argémones. Montpellier 1814. 4 
Pelit, Mémoiro sur lo javot d'orient. Paris 1827.8 .

Ecliman, De Papavero somnifero. Upsaliae 1834. 8.

Iser, Do Papaveraceis venenatis Bolıemiac. Pragae 1834. S.

(Ritter) Die Opiunkultur und die Molnppllanze. s. I. ot a. 8.

Sala, Opiologia. ¿ la Hayo 1614.8. (anglice.)

Docring, Do Opii usu. Jenae 1620.8.

Reiter, De Opio el opiatis. Lipsiae 1623.4.

Freitay, Do Opii natura. Grouingae 1632. 8.

Harlmamn, Tractatus de Opio. Wittenbergae 1635. 8.

Winckler, De Opio tractatus. Lipsite 1635. 8.

Beclier, De (Pipere et) Opio. Regiomonti 1642. 4.

Wedel, Opiologia. Jenao 1674. 4.

Elımucller, Do virtute Opii. Lipsiae 1679. 4.

Waldschniedt, Nonita circa Opii et opiatorum usum. Marpurgi 1679. 4.

Ileigel, Onii natura et usus. Altdorfii 1684. 4.

Schocer, In naturam Opii inquisitio. Lipsiao 1696. S.

Lubeex, De Opio. Lugduni Batavorum 1699. 4.

IJofmann, De Opii correctiono. Halae 1702. 4.

Berger, De vi Opii calefacienti. Wittenbergae 1703.4

Ricichnau, De Opio. Lugduni Batavorum 1704. 4.

Birch, Do Opio. Lugeluni Batavorum 1716. 4.

Medley, De natura et viribus Opii. Lugrluni Batavorum 1716. 4.

Moncly, De Opio. Lugduni Batavorum 1739.4.

Buechner, Do eflectibus Opii. Ilalae 4748. 4.

Ilamberger, De Opio. Jeuae 1749. 4.

Oberlin, De Opio. Argentorati 4752. 4.

Haase, De usu Opii. Lipsiae $1757-1758.4$.

Linné, Opium. Upsaliae 1775. 4.

Reimarus, Do Opii usu. s. I. 1784. 4.

Wilson, Experimental essay on Opium. Edinburgh 1795.8 .

Meyer, De Opii usu. Goettingae 1800. 4.

Horn, De Opii abusu. Wittebergae 1804. 4.

Kilupsch, De effectibus Opii. IIajac 1804. 4.

Junghannss, De Opio. Lipsiae 1815. 4.

Pasta, De la vertu de l'opium. Lyon 1316.8. (italice.)

Ioppe, De Morplio et acillo meconico. Lipsiae 4820. 4.

Grape, De Opio. Berolini 1822.8.

Kindscher, De Morphio. Berolini 1328. 8.

Schotte, De Opio indigemo nonnulla. Berohini 1833.8.

Kostin, Veber das essigsaure Morphium. Nünchen 1838.8 .

Bugge, De Morphio. Berolini 1840. S.

\section{Parmelia parietina Ach.}

Monkewitz, Chemisch-medizinische Untersuchung uber die Wandflechte

(Liclsen parietinus) und Chinarinden. Dorpat 1817.8 .

Sty $x$, Ueber die Ileilkrifte der Wandllechte. Dorpat 1S47. 8.

Mannliarll, Lobariae parietine analysis chemica. Kiliae is 18.4.

\section{Pellidea canina Hoflun.}

Carlheuser, Do Licheno cinereo terrestri. Francofurti 1762. 4.

Petasites vulgaris Desf.

Bergen, De Petasitide. Francofurti a/V. 1759. 4.

Necker, Ilistoire naturello du tussilage et du pétasite. Mamlreim 1779. 4.

Bodarl, Propriétés du Tussilago Petasites. Paris 1 809. 8.

Peucedanum officinale $\mathrm{L}$.

Delius, De Peucedano germanico. Erlangac 1753.4.
MONOGRAPHIAE PLANTARUM OFFICINALIUM

Phellandrium aqualicum $\mathbf{L}$.

Fischer, De Plıellandrï aquatici usu. Wittelsergae 1699. 4.

Ernsting, Plıcllandrologia. Brunsvigao 1739. 4.

Lange, Ileilsame Wirkungen des Wasserfenclıels. Frankfurt 1771. S.

Ollo, De Pliellandrii aquatici charactore botanico et usu. Trajecti a/V. 1793. 4.

Elbinge, De Phellandrio aqualico. Groningáo 1802. 4.

Berthold, De seminis Phellaudrii atualici virtutibus medicis. Ilalae 1818.8 .

Pinpinclla Anisum L.

Ilenninger, De Aniso. Argentorati 1704. 4.

\section{Pimpinclla Saxifraga L.}

IIeimreich, De Pimpinella alba. Altdorfii 1723. 4.

Her, De Pimpinella Saxifraga. Giessae 1726. 4.

Ilarnisch, Aleditationes de Pimpinella nigra. Lipsiae 1757. 4.

\section{Pini species.}

Kempe, De anatomerade granen. llamburg 1671. 19. (germanice.)

IJoffmann, De Terebinthina. JJalae 1699. 4.

Wedel, Do Terebinthina. Jenae 1700. 4.

Camerarius, Biga botanica. (Pini coni). Tubingae 1712. 4.

Roberg, De Piceae Pinique silvestris resina. Upsalis 1714.4.

Baier, De Fuligine. Altorfi 1722. 4.

Brucckmann, Frutex Koszodrewina ejusque balsanum. Brunsvigae 1727.4. Arbor Libonedrewo ejusque oleum. Brunsvigae 1727. 4.

Buechner, De Pinastro seu Pino silvestri. Halae 1754. 4.

Liratzann, De Coniferis usitatis. Pragae 1835. 8 .

Caillot, Essai elsimique sur la Térébinthine des sapins. Strassbur 1830.4 .

\section{Piper Betle L.}

Piron, Sur l'usage du Betel, Paris 1804. S.

\section{Piper Cubeba L.}

Wedel, De Cubebis. Jenae 1703. 4.

Cortavilla y Sanabria, Informacion y pareçer de lo que son Cubrobs. s. l. et a. 4 .

Bacumler, De Piperis Cubebae efficacitate. Cassellis 1826. \$.

Miquel, De vero pipere Cubelo deque speciebus eognatis ac cum eo commutatis. (Commentarii I.) Lugtluni Batarorum 1839. folio.

Piper nigrum L.

Becker, De Pipere. Regiomonti 1642. 4.

Ilister, Do Pijere. Helmstadii 1740. 4.

\section{Pistacia Lentiscus L.}

Strabelberger, Mastichologia. Lipsiae 162s. S.

(Beckmam, Waarenkunde I, p. 573-591.)

\section{Pistacia Terebinthus L.}

IIofmamn van Hofmannsthal, Die Caruba di Giudea gegen Lungendampf. Wien 1842. 8 .

\section{Plantago major L.}

Wedel, De Plantagine. Jenae 1712. 4.

Platanus orientalis L.

Pepe ad Cupiclo, Analisi del frutto del Platano orientale. Napoli 1837. 8. 


\section{Polygala Senega L.}

Linné, Radix Sentega. IIolmiae 1749. 4.

Detharding, Do Seneca. Rostockii 1749. 4.

Burchiharl, Do radice Senecka. Argentorati 1750.4.

fieilhorn, De radicibus Senega et Salab. Fraucofurti a/V. 1765. 4.

Hellmuth, De rarlice Senega. Erlangae 1782. 4.

Thoss, De radice Senega. Lipsiae 1820.4.

Angelstein, De Senegae radice. Berolini 1\$34. 4.

\section{Polygonum amphibium $\mathrm{L}$.}

Schulze, De Persicaria acida Jungermanni. Halae 1735. 4

(Trew, in Comm. lit. nor. 1737 , p. $395-413$. )

\section{Polypodium Calaguala L.}

Gelmethii de radice Calaguala opusculum, latine per Noccam. (Turici 1793.) 8

Ruiz, Memoria sobre la legitima Calaguala (Polypodium Calaguala). Maarid 1805.4 .

\section{Polypodium vulyare L.}

Slevogt, De Polypodio. Jenae 1699. 4.

Wedel, De Polypodio. Jenae 1721. 4.

\section{Prunus Cerasus L.}

Doll/uss, Cerasologia medica. Basileae 1717. 4.

\section{Prunus Laurocerasus L.}

Vater, De Laurocerasi iudole venenata. Wittebergae 1737. 4.

Prunus Padus L.

Bremer, Ueber die Wirksamkeit der Cortex Pruni Padi. Berlin 1842. 8.

\section{Prumus spinosa L.}

Spiclmann, Acaciae officinalis historia. Argentorati 1768.4.

\section{Punica Granalum L.}

Baier, De nalo Punica. Altorfi 1712. 4.

Place, De usu corticis radicis Granati. Berolini 1825. 8.

Sichr, De cortice radicis Granati. Berolini 1829. 8.

\section{Pyrolae species.}

Wolf, De Pyrola umbellata. Gottingae 1817.8.

Radius, De Pyrola et Chimoplita. Specimen II medicum. Lipsiae 1829. 4.

\section{Pyrus Cydonia L.}

Jung, Kpurouniov seu malum aureum. Yindolonae 1673.8. Eysel, De medicamentis ex malo cydoniato paratis. Erfordiae 1717. 4. Ileiste' $r$, De Cydoniis. IIelmstadii 474. 4.

\section{Quassia amara $\mathbf{L}$.}

Limné, Lignum Quassiae. Upsaliae 1763. 4.

Paarmann, Ligni Quassiae examen. Argentorati 1772. 4.

Kiratzenstein, Do ligni Quassiae usu medico. Havniae 1775. S. Ebeling, De Quassia et Lichene islandico. Glasgow 1779. S. Luther, De praestantia ligni Quassiae. Erfordice 1779. 4. IIaerll, De Quassia. Landishuti 1826. 4.

\section{Querci species.}

Mikan, Ueber Galläpfel und Knoppern. (Prag 1816.) 4. Zwicrlein, Deutschlands Eichbaum. Leipzig 1824. 8.
Ranunculi species.

Biria, llistoire naturelle et médicale des Renoneules. Mont]jellier 1811.4.

Rhei species.

Belus, Quaestio de Rhabarbaro. Bononiae 1533. 4.

Alpinus, De Rltapontico disputatio. Patavii 1612. 4. - Luguluni Batavorum 171 s. 4.

Tilling, Rhabarbarologia. Francofurti a/A. 1679. 4.

Wedel, De Rhabarbari origine. Jenae 1708. 4.

- De Rhabarbari genere et differentiis. Jenae 1708. 4.

Mlollstein, Rhabarbari historia. Lugduni Batavorum 1718, 4.

Chambers, De Ribes Arabum et ligno Rhodio. Lugduni Batav. 1724, 4.

Bouillet, Letres au sujet de la rlıeubarbe. Beziers 1727. 4.

Buchwald, De diabetis curatione per Rhabarbarum. Havniae 1737. 4.

Gmelin, Rhabarbarum officinarum. Tubingae 1752. 4.

Linné, Rhabarbarum. Upsaliae 1752. 4.

Sandeman, De Rheo palmato. Ediuburgh 1769. 8.

Hohrbegh, Do Rhabubaro. Grypliae 1788. 4.

Clarion, Travail chimique sur les rhubarbes exotique et indigène. Paris 1803.8 .

(Coste) Précis historique de l'importation et de la naturalisation en France du Rheurn palmatum L. Paris 1805.8 .

Siephanitz, Do Rhabarbaro. Berolini 1838, 8 .

\section{Rhododendron chrysanthum L.}

Koelpin, Ueber den Gebrauch der sibirischen Schneerose (Rhododendron chrysanthum) in Gichtikrankiseiten. Berlin 1779.8.

Zahn, De Rhododendro chrysautho. Jenae 1783. 4.

\section{Rhois species.}

Du Fresnoy, Des propriétés du Rhus radicans. Paris 1788. 8

Alderson, Essay on the Rhus Toxicodendron. Hull 1793.8. (germanice.)

Horsfield, On the Rhus Vernix, Rhus radicans and Rhus glahrum. Plhitadelphia 1798. 8 .

Boelmer, De Toxicodendro. Wittebergae 1500.4.

Heusinger, Observata circa Rhoa Toxicodendron et radicantem. Ilelustadii 1809. 4.

Busse, De Rhoe Toxicodendro et radicante. Berolini 1 S11. S.

Targioni-Tozzctli, Malattia prodotta dal Rhus Vernis. (Firenze 1817.) S.

\section{Ricinus communis L.}

Fischer, De Ricino americano, Erfordiae 1719.4

Quelmals, Do oleo Palmae. Lipsiae 1750.4.

Canvane, On the Oleum Ricini. Bath (1766.) S. (gallice.)

Hungerbyhler, De oleo Ricini. Friburgi 1780.8 .

Bonelli, Olio di Ricino volgare. Roma $1782 . \mathrm{S}$.

\section{Rosae species.}

Monardes, De Rosa et partibus ejus etc. Antwerpiae 1561. 16.

Dercum, De Rosa. Wirceburgi 175i. 4.

\section{Rosmarinus officinalis $\mathrm{L}$.}

Rossmarinbüchloin. Ilalberstadı 1685.8.

Nebel, De Roremarino. Heidelbergae 1710. 4

Alberti, De Roremarino. Halae 1718. 4.

Spies, Rosmarini coronarii historia medica. Helmstadii 1718. 4.

Fick, Rusmarinum. Jenae 1725. 4. 


\section{Rubia linctorum L.}

Boelhmer, Radicis Rubiae tinctorun effectus in corpore animali. Lipsiae 1751.4 .

\section{Rubus Chamaemorus L.}

Werner, De herba Rubi Chamaemori. Vilnao 1815. 8.

\section{Rubus idaeus L.}

Camcrarius, De Rubo idaeo. Tubingae 1721. 4. Schulze, De Rubo idaeo officinarum. Halae 1744. 4.

\section{Rumicis species.}

Munting, Do vera antiquorum berba britannica. Amstelodami 1681. 4. Ilill, The power of water-dock. (Rumex aquaticus.) London 1777. 8. Anelli, Cenni mediei sul Lapazio acuto ete. Milano 1808.4.

Ruscus aculealus L.

Zannichelli, De Rusco. Venctiis 1727.8.

\section{Ruta graveolens L.}

Slevogl, De Ruta. Jenae 1715. 4.

Vater, De Ruta ejusdemque virtutibus. Vitembergae 1735.4.

Stenzel, Do Ruta medicamento et veneno. Wittebergae 1735.4.

Krocber, Ueber die Ruta graveolens L. Würzburg 1830. 8.

\section{Saccharum officinarum $\mathrm{L}$.}

IIofmann, Sacchari historia naturalis et medica. Halae 1701. 4.

De Pré, De arundine sacharina. Erfordiao 1719. 4.

(Quelus) Histoiro naturelle (du cacao et) du sucre. Paris 1719. 12.

Crump, De arundine saccharifera. Lugduni Batavorum 1720. 4.

Cartheuser, De Saccharo. Francofurti a/V. 1761. 4.

Plaz, De Saccharo. Lipsiae 1763. 4.

Lẻ Breton', Traité sur les propriétés et les effets du sucre. Paris 1789. 12.

Porter, Nature and properties of the sugar cane. London 18-. 8.

\section{Sagus Rumphii Willd.}

Brueckmann, Abhandlung vom Sego. Braunschweig 1751.4.

\section{Salicis species.}

Hartmann, De Salice laurea odorata, Linnaei pentandra. Trajecti $a / V$. 1769. 4.

Mcyer, De Salicis fragilis usu medico. Butzow 1770. 4.

Guens, De cortico Salicis cortiei peruviano substituendo. Lipsiae 1772. 4. - ib. 1787. 8 .

Koning, De cortice Salicis albae. Ilarderovici 1778. 4.

White, On the broadleaved willow bark. (Salix caprea.) Bath 1798. 8.

Besser, De Salicinio. Berolini 1831. 8.

\section{Salvia glutinosa.}

Anelli, Cenui medici sulla Salvia glutinosa etc. Nlilano 1808. 4.

\section{Salvia officinalis $\mathbf{L}$.}

Paullini, Sacra herba sive nobilis Salvia. Augustae Vindelic. 1688. 8. Hunaull, Sur les propriétés de la sauge. Paris 1689. 12.

Wedel, De Salvia. Jenae 1745. 4.

Stenlzel, De Salvia in infuso adlibenda. Wittebergae 1793. 4.

Ellinger, De Salvia. Erlangae 1777. 4.

Hill, Die Krafte der Salbei. Altenburg 1778. S.

\section{Sambucus Ebulus L.}

Juch, De Ebulo. Erfordiac 1745. 4.

\section{Sambucus nigra L.}

Blochwitz, Anatomia Sambuci. Lipsiae 1631.12 (anglice, germanice.)

Becker, Beschreibung ron IIollunder (und Wachliolder). Kenigslserg 1650.8.

Wedel, De Sambuco. Jenae 1720. 4.

Tidemann, Historia Sambuci vulgaris. Groningae 1733.4.

Boelemer, De Sambuco in totum medicinali. Wittebergae 1771. 4.

\section{Saponaria officinalis $\mathbf{L}$.}

Ludolf, Saponaria ejusque virtutes. Erfordiae 1756. 4.

Cartheuser, De radice Saponariae. Francofurti 1760.4.

\section{Scilla maritima L.}

Baier, De Scilla. Altdorfi 1715. 4.

Alberti, De Squilla. Halae 1722. 4.

Schulze, Examen chemicum radicis Scillac marinae. IIalae 1739. 4.

Caspari, De Scilla. Goettingae 1785.4.

\section{Scorzonerac species.}

Monardes, De dos medicinas (yerva Escorzonera). Sevilla 1569.8. (latine.)

Chiavena (Clavena), llistoria Scorzonerae italicae. Venetiis 1610.4.

Feler, Anchora sacra vel Scorzonera. Jenae 1666. 8.

Scrophularia nodosa $\mathrm{L}$.

Slevogt, De Scrophularia. Jenae 1720.4.

\section{Scutellaria galericulata L.}

Bacumlein, De Scutellaria galericulata. Erlangae 1789.4.

\section{Sculellaria lateriflora.}

Lyman Spalding, Geschichte der Einfubrung und des Gebrauchs der Scutellaria lateriflora. Leipzig $1822 . \mathrm{S}$

\section{Sccale cornutum.}

Lange, Schädlicher Genuss der Lornzapfeu. Luzern 1717. 8.

Schleger, Versuche mit dem Mlutterkorn. Cassel 1770. 4.

Baldinger, Secale cornutum perperam ab infamia liberari. Jenae 1771. 4.

Beguillet, Dissertation sur l'ergot. Dijon 1771. 4.

Model, Untersuchung des Mutterkorns. Wittenberg 1771. S.

Read, Traité du seigle ergoté. Strassburg 1771. \&.

Nebel, De Secali cornuto ejusque noxis. Giessae 1771. 4. (germanice.)

- Dissertationem suam de Secali cornuto ab objectionibus D. Schlegeri vindicat. Giessie 1772. 4.

Roessig, Ablıandlung ber das Mutterkorn. Leipzig 1786. 8.

Geiger, De Secalis eornuti viribus. Monachii 1820.8.

Keyl, De Secali cornuto. Berolini 1823. 8.

Lorinser, Ueber die Wirkung des Nutterkorns. Berlin 1824. 8.

Robert, Commentationes in Secalis cormuti historiam medico-physicam. Mlarburgi 1825.8 .

Léveille, Mémoire sur l'ergot. (Paris 1826.) 8.

Milchell, Treatise on the ergot of rye. London s. a. $\$$.

II aese, De Secali cornuto. Berolini 4829.8.

Ruesch, Ueber das Secale cornutum. Trogen 1929. 8.

Bouchor, Des effets du seigle ergote. Paris 1\$30. 4.

Huard, Sur les effets du seigle ergoté. Paris $1 \$ 30.4$.

Scluebler, De Secali cornuto. Tubingae 1830. S.

Padeira, Do Secali cornuto. Berolini 1831,8 .

Wiggers, Inquisitio in Secale cornutum. Goettingae 1831. 4. 


\section{MONOGRAPHIAE PLANTARUM OFFICINALIUM}

Galama, Verhandeling over het moederkoorn. Groningen 1834. 8. Maspero, Sulla segale cornuta opuscolo. Venezia 1835.8 . Glocke, De Secali cornuto. Dorpati 4837. 8.

Etzrodt. Das Nutterkorn. Wurzburg 1838. 8.

Sokolnicki, De Secali cornuto. Cracoviae 1839.8.

Spiering, Do Secali cormuto. Berolini $1 \$ 39.8$.

Morscher, De Secali cornuto. Vindobonae 1840.8.

Schubert, De Secali cornuto. Vindobonae 1840.8.

Bonjcan, Ilistoire du seigle ergoté. Paris 1842.8.

Fée, Némoire sur l'ergot du seigle. Strassburg 1843. 4.

Gross, De Secali cornuto. Tratislaviae 1844.8.

Szarzyriski, De Secali cormuto. Berolini 1844.8.

Kuechenmeister, De Secali cornuto. Lipsiae 18 '5. 8.

\section{Sedum acre L.}

IIartmann, De Sedo acri Linnacano. Trajecti a/V. 1784.4.

\section{Simaruba officinalis DC.}

Crell, De coltice Simarula. Helmstadii 1746.8.

Jussieu, An inveteratis alvi tluxibus Simaruba? Paris 1772. 4.

Wright, Account of the Quassia Simaruba. (Edinlurgh 4778.) 4.

\section{Sinapis nigra L.}

Storr, De semine Sinapis. Tubingae 4780. 4.

\section{Smilax China L.}

Vesalius, Radicis Chinae usus. Lugduni 1547.12.

Ryff, hurtzer Auszug und summarischer Bericht von der Wurtzel China, aus lateinischer und toskaniseher Sprach transferirt. Würaburg 1548. 4.

Furerius, De radico Clinae. Tolosa 1554. 8.

Schwalbe, De China officinarum. Lugduni Batavorum 1715. 4.

Juch, De radico Chinae. Erfordiae 1753.4.

Franzoja, Analysis Smilacis Chinze. Patavii 4825.8.

\section{Smilax syphilitica Humb. et Smilax officinalis Humb.}

Mineltus, De Sarzaparillae (et Ligni sancti) viribus. Senis 1393. 4 . Castclli, De Smilace aspera. Messanae 1652.4.

Boehmer, De viribus Sassaparillae antisyphiliticis. Wittebergae 1803. 4. Robinet, Observations sur la salsepareille. Paris 1825.8 .

Toensen, De analysi et usu Smilacis Sassaparillae. Kiliae 1\$26.4.

Iltnzilier, De Sassaparillae radice. Turici 1835. 8.

Feldmann, De decocto Zittmanni. Berolini 1842. 8.

Schleiden, Beitráge zur Kenutniss der Sassaparille. Llannover 1847.8.

\section{Solani species.}

Bromfeild, Account of the english nightshades. London 1757. 12. (gallice.)

Gatalier, On the internal use of the Solanum. London 1757. 8.

Siemsscn, Radicum Solani tuberosi innocentia. Rostockii 1798. S.

Dunal, Histoire naturelle, médicale et économique des Solanum. Montpollier 1813. 4.

Pouchet, Essai sur l'histoire des Solanées. Paris 1827. 4.

Histoire des Solanées. Rouen 1829. 8.

homma, Toxicologia Solaninarum indigenarum. Pragae 1834. 8.

Lucas, De Solano tuberoso ejusque principio nareotico. Hirschberg 1846.8.

\section{Solanum Dulcamara L.}

Spiessenhof, Solanum vulgo Dulcamara dictum. Heidelbergae 1742. 4. Linné, De Dulcamara. Upsaliae 1771. 4.
Carrère, Propriélés de la Douce-amèc. Paris 1780.8. (germanice.)

Miesend, De Dulcamara. Monachii 1837.8.

Spigelia Anthelmia L.

Linné, Do Spigelia Antluelmia. Ljpsaliae 1758. 4.

Spilanthes oleracea Jacr.

Breyn, De radice Gin-Sem seu Nisi et Chrysanthemo bidente zeylanico Acmella dicto. Lugduni Batavorum 1700. 4.

Slevogt, De Acmella ceylanica. Jenae 1703.4.

Nebel, De Acmella palatina (= Bidens cernua L.). Heidelbergae 1739.4. Spiraea Ulmaria L.

Camerarius, De Ulmaria. Tubingae 1717. 4

\section{Strychnos colubrina L.}

Linné, Lignum colubrinum Jeviter delineatum. Upsabae 1749.4.

\section{Sirychnos Ignatii Berg.}

Valentini, De fabis St. Ignatii. In ejus "Polychresta exotica ". Fraucofurt a/V. $1701.4 \cdot$ p. $4-14$.

Stein, De faba St. Ignatii. Erlaugae 1793. 8.

Enimneth, De faba St. Ignatii. Erlangae 4802. 8.

IIa a se, De faba St. Iguatii. Lipsiae 1822. 4.

\section{Strychnos nux vomica $\mathrm{L}$.}

Lossius, De nuce vomica. Willenbergae 1682. 4.

Seutter, De nuce vomica. Lugduni Batavorum 1691. 4.

Nicolai, De mucis vomicae viribus. Jenae 1784. 4.

Desportes, De la noix vomique. Paris 1810.4.

Diesing, De nucis vomicae principio effieaci. Vindobonae 1826. 8.

Pritzkow, De nuce vomica. Berolini 1831.8.

Frentrop, De nuce vomica. Berolini 1832.8 .

Groebenschuetz, De Strychnii in neurosibus vi atquo usu. Berolini 1833 . S.

Janka, De Strychmeis. Pragae 1834. 8.

Oppler, De Stryclunini nitrici usu. Berolini 1834. 8 .

Miehe, De Strychuinii applicatione endermatica. IIalae (1837?) 8.

Radzilbor, De nuce romica. Berolini 4837. S.

Polack, De nucis vomicae viribus atque antidotis. Goettingae 1840.4.

Slyrax Benzoin Dryand.

Thunberg, De Benzoë. Upsaliae 4793. 4.

\section{Styrax officinalis L.}

Kirsten, De Styrace. Altdorfii 1736. 4.

\section{Swietenia febrifuga Roxb.}

Roxburyh, Description of a new species of Swietenia etc. (London 1793.) 4 .

Duncan, Tentamen de Swietenia Soymida. Edinburgi 1794. 8.

Symphytum officinale $\mathbf{L}$.

II css, Theses. Basileae 1751.4.

Taraxacum Dens leonis Desf.

Delius, De Taraxaco. Erlangae 1754.4.

\section{Taxus baccala L.}

Boehmer, De Taxo baccata. Wittebergae 1796. 4.

Schuelz, Do Taxo baccata ejusque veneno. Vratislaviae 1840. S. 
Teucrium Scordium L.

Camerarius, De Scorlio. Tubingae 1706. 4.

Slevogl, Soumulla ad vires herlite Scordii. Jenac 1716.4.

IVolel, De Scordio. Jenne 1716. 4.

Gleinknechl, De Seordio lierba seliediasma. Itmae 1720.8.

\section{Teucriun Afurum $\mathbf{I}$.}

J'edel, De Maro. Jenae 1703.4.

Limui. De Mlaro. Upsaliae 1774. 4.

\section{Thea chinensis Sims.}

Molinaris, Ambrosia asiatica. Genuae 1672, 12.

Ten Rhyne, De frutico Thée excerpta ex ejus observationilus japonicis. Impr. cum Breyn, Centuria. Gedani 1678. folio.

Allinus, De Thea. Francofurti 1684. 4.

Pechlin, Theophilus bibaculus. Kilonii 1684. 4.

Francius, In lauclem Thiae sinensis anacreontica duo; graoce. AmsteloIani 1685.4

Iforrichen, De Thea lierla dericun melydrion, graece. Austeladami 1685. 4.

Petil, Thea. Lipsiae 1685.4.

Naldschmickl, De potu Theae. Marpurgi 1685. 4

Blankaarl, Gebruik en misbruik van de 'Tluee. Gravenhage 1686. S. (ger'manice.)

Blegny, Le bon usage du thé, ete. Paris 4687.12.

Thile, Theelogia medica. Wittebergae 1690. 4.

Mappus, De potu Thée. Argentorati 1691.4.

Waldschmich, De usu et alusu potus Theae. Kiliae 1692. 4.

Emmerich, Theeologia. Regiononti 1695. 4.

Ovington, Essay upon the nature and qualities of Tea. Loudon 1699. 12.

Wedel, De Thea. Jenae 1707. 4.

Silca, An senibus Thé? Paris 1712. 4.

Kacmpfor, Theae japonensis historia. (Amoen. exol. p. 605-634. Geschichte von Japan II, p. 442-464.)

Stahl, De veris herbae Thee proprietatibus. Eirfordiae 1734.4.

Berlin, Polus ex foliis Tlué. Paris 1739. 4.

Närager, De potu Thee. Ilavaiae 1740.4.

Garnier, An Parisinis frełuens potus Thé potu Calé salubrior? Paris 1749. 4 .

Shorl, Disserlation upon Tea. Lendon 1733. 4.

Geschichte der Einfuhung des Thee's in Engelland. (IIamburg. Magazin XIX, p. 230-232.)

Lime, Potus Theae. Lpsaliae 1765. 4.

Coakley-Leltsom, The natural listury of the Tea-tree. Lendon 1772. 4. (gallice.)

Buchoz, Dissertation sur le thé. Paris 1787.8.

Fougeroux, Minoire sur le the. (Journal de physique 1, 326-338.)

Buchoz, Histoire naturello du the de la Chine. Paris 1806.8.

Marquis, Du the. Paris 1820.8 . - ib. I\$34. 8.

Bergsma, De Thea. Trajecti a/kh. 189.̈. $\$$.

Kihlmann, Chinesisha Theet. Siockholm 4\$30. S

Savi, Notizie sul té della Clina. P’isa 1836. 8.

Mac Clclland. Report ou the pliysical condition of the dssam Tea plant. (Cialcutta 1838.) 8. the cultivation of the Tea plant in India. Calculta 1839. folio.

Houssage, Menograplie du thé. Paris 1843. gr. 3. (germanice)

Mérat, Memoire sur la possibilite de cultiver le thé en France. Paris 1844.8.

Pleischl, Der Thee. Wien 1844.8.

Weyda, Der chinesisclie Thee. Wien 1844.8 .

\section{Theobroma Cacao L.}

Colmenero, Curioso trattalo de la naturaleza y calidad del chocolate. Maurid 1631. 4.

(anglice, gallice, italice, latine.)

Stublie, The indian nectar or cliocolata. Londan 1662. 8.

Brancaccio, De usu et patu chocolatae diatribe. IRomae 1664. 4.

Maradon in Dufour, De l'usage elc. Lyon 1671. 12. p. 165-188.

Thughes, iı cjus American physician. London 1672. 12. p. 102-155.

Eysel, De chocolatae usu et alıusu. Erfordiae 169/. 4.

Mappus, De putu cliocolatae. Argentorati 1695. 4.

(Quelus) Hisioire naturelle du cacao el du sucre. Paris 1719. 8. (anglice.)

Spies el Brueckmann, De Avellana mexicana. Helmstadii 4721. 4.

Goelick, De Balsamo Cacno. Francofurli a/V. 1723. 4.

Brucclimann, De Arellana mexicana vulgo Cacao dicta. Ed. Il. Brunsvigao 1728.4 .

Maucharl, Bulyrum Cacao. Tubingae 1735. 4.

Milhau, Dissertation sur le cacanyer. Montpellier 1746. 8.

Limni, De polu chocolatae. IIolmiae 1765. 4.

(Navier) Observations sur le cacao et sur le chacolat. Paris 1772. 12.

Crill, Zerlegung der Cacaobutter. (Chem. Journal II, 152-158.)

Buchoz, Dissertation sur le cacno. Paris 1787. \$.

Gallais, Mlonographie du cacao. Paris 1827. 8.

\section{Triticum repens $\mathrm{L}$.}

Pfaulz, Descriptio graminis medici plenior. Ltmae 1656. 4.

hiniphof, De granine levidensi at praecellentissime. Erfordiae 1747. 4.

\section{Tropacolum majus L.}

Cartheuser, Do Cardamindo. Fracofurti 1755. 4.

\section{Tussilago Farfara L.}

Eysel, Filius ante patrem ('Tussilago Farfara). Erfordiae 1714.4

Ulmus campestris $\mathbf{L}$.

Baumgarten, De corlicis Ulmi campestris natura. Lipsiae 1791. 4.

\section{Urtica urens L.}

Franlic, Tractatus singularis de Urlica urente. Dilingae 1723. 8.

\section{Usnea cranii humani.}

Cocler, De L'snea seu musce cranii lumani. Lugduni Bataverum 1732. 4.

lalerianae species.

Spies, De Valeriana. Helmstadii 1724.4.

Allerti, De Valerianis officinalilıus. IIalae 1732. 4

Hill, The virtues of wild Valerian. London 1758. \&. (germanice.)

Dresliy, De Valeriana officinali L. Erlangae 1776. 4

Ackirn, De Valeriana. Halae 1789.8 .

Du Fresne, Histoire naturelle ct médicale de la famille des Valerianées. Mantpellier 1811.4 .

\section{Ianilla aromatica Sw:}

Spics, De siliquis Convolvuli americani vulgo Vanigliis. Ilelmstadii 1721. 4.

\section{T'erairum L.}

Castelli, Epistola de nomine Hellebori apud Ilippocratem. Romae 1622.4. - Epistola secunda de Helleboro. Romae 162. 4

Esche, De Veratriae effectibus. Lipsiae 1836. 4. 
MONOGRAPHIAE PLANTARUI OFFICINALIUM

Koell, De Veratrino ejusque usu medien. Trajecti a/RIı. 1\$37. 8. Rapp, Ueber die Veratrine. Tubingen 4839. S.

Cerbena officinalis L.

IVedel, De Verbena. Jenae 1721.4.

Teronica officinalis $\mathrm{L}$.

Franke, Polycresta herba Verouiea. Unmae 1690. 12.

Veronica theezans. Suabaci 1693. 12. (germanice.)

IIoffmamn, De infusi Teronicae efficacia. Halae 1694. 4.

Zwinger, De Thee helvetico. Basileae 1716. 4.

Eysel, De Veronica, Grundtheil, Ehrenpreis. Erfordiae 1717,4.

\section{Veronica Cymbalaria L.}

Bodard, Mémoire sur la Véronique cymbalaire, Pisa 1798. 8.

Viola odorala, tricolor, canina L.

Wedel, Dc Viola martia purpurea. Jenae 1717. 4.

lioeber, Schediasma in laudem Violae purpureo-coeruleac. Gerae (1667.) 4. Jenninger, De Viola matia purpurea. Argentorati 1718.4.

Triller, De morte subita ex nimio violarum odore oborta. Wittcbergae 1762. 4.

hessler, De Viola. Vindobonae 1763. S.

Haase, Viola tricolor. Erlangae 1782. 4.

Niemeyer, De Violae eaninae usu. Goettingae 1785.4.

Pio, De Viola specimen botanico-medicum. Taurini 1813.4.

\section{Viscum albrum $\mathrm{L}$.}

Baier, De Visco. Altdorf 1706.4

Colbatch, Dissertation on the guy. London 172x. 12. (gallice, germanice.)

Buchwald, Analysis Visci. Havniae 1753. 4.

Sturm, Visci quercini descriptio, analysis et usus medicus. Jenae 1796.8.

Vitis vinifera L.

(Cultura ritis; praeparatio, usus el historia vini.)

Tractatus de vini conservatione. Bononiae 1458.4.

Dieser Traetal helt yn von bereytung der wein. Strasslyurg 1506. 4.

Confalonerius, De vini natura. Basileae 1535.8

Praefectus, De diversorum vini generum natura liber. Tienetiis 1559.8.

Donalus ab Allomari, De vinaceorum facultate et usu. Venetiis 1563. 4. Gratarolo, De rini natura. Basileae 1565.8 .

Turner, A new boke of the natures of all wiues. London 1568.8.

Fodoens, IJistoria vilis vinique. Coloniae 1580.8 .

Jlorst, Opusculum de Vite vinifera. Jlelmstadii 1587.8 .

Paulmier vel Palmarius, De vino et pomaceo libri duo. Parisiis 158s. 8. (sallice.)

Bacci, De naturali vinorum historia. Romae 1595. folio.

Mini, Discorso della natura fel vino. Firenze 1596 , folio.

Soderini, Della coltivazione delle viti. Firenze 1600.4.

Turnebus, De vino libellus. Parisiis 1600.8.

Helbach, Oenographia. Frankfurt a/M. 1604. 4.

Textor, Traité de la nature du vin. Genève 1604. 8.

Meyden, Trattato della natura del vino. Parma 1608..

Canonhicrius, Le lodi e i biasimi del vino. Yiterbo 1608. 12.

Bostichi, Toscana coltivazione delle viti e delli arbori. Firenze 1621.4. Canonhierius, Do admirandis vini qualitatibus. Antwerpiae 1697. 12.

Dehn-Rothfelser, Ein schı̈n Weiubaubuch. Leipzig 1629. S.

Tirellus, De historia vini. Venetiis 1630.4.

Monlalbanus, Geoscopia ampelite. Bologna 1635.4.

IIauptmann, Uebcraus grosse Weinbaws lrrthumbe. Nurnberg 1642. 8.
Sperling, De uva, musto ac vino. Wittebergae 1642.4

II hitaker, Tractatus de sanguine uvac. Francofurti 4655.8 .

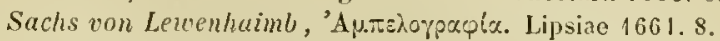

Kinohll, lỉein Vilikulturluchlein. Dresden 1663.8

Jering, De uva. Wittebergae 1666. 4.

Le Seurre, Description du vignolsle de Garaubaud. Lyon 1669. \$.

Folli, Dialogo intorno alla cultura delle vite. Firenze 1670. 8.

Hughes, The compleat rineyard. London 1670. S.

Portzius, Tini rhenani in specic baccharacensis anatomia chymica. lieydelbergae 1672.12.

Beck, Uva magna cananaea. Jenae 1679. 4.

Caldenbach, De Vile. Tuebingae 1683.4

Vanière, Carmina. (Vites ot vinum.) Parisiis 1696. 12.

Firchmaier, De arte projagandi vites apud Francos. Wittebergae 1697. 4.

Iloffmann, De natura et praestantia vini rhenani. Halae 1703.4.

Boulay, Manìre de bien cultiver la vigne dans lorléanais. Orléans 1712. 12.

Komaromy, De vino buugarico soproniensi. Basileae 1713.4.

Slevogt, Jenense rinum a nocentis calcis suspicione vindicalur. Jenac 1718. 4 .

Hofmam, De vini bungarici excellente natura. Halae 1721. 4.

Bruectimann, Fina loungarica. (Epist. itin. 97. cent. I.) Wolftenbutlelae 1740.4.

(Michaull) Dissertation historique sur le rent de Galerne. Basle (Dijon) 1741.19.

Prince, Do vino neocomensi. Basileae 1743.4.

Bidet, Traité sur la vigne. Paris 1759.19.

(italice, germanice.)

(Hebert) Discours sur les vignes. Dijon 1756.12

Du IIamel et Bidet, Traitó sur la vigne. Paris 1759. 12 (germanice.)

11 'ellevius, Do prima origine vinorum casuali. Holmiae 1760.4 .

Rumpelt, Abhandlung von den Eigenschaften des ungarischen Weins. Dresclen 1761.8.

Nast, Vollstädige Abhandlung des ganzen WVeinbaues. Frankfurt 17661767. 8 .

Schosulan, De vinis. Vienmae 1767. S.

Beguillet, Oenologie. Dijon 1770. 12.

Mariti, Del vino di Cipro. Firenze 1772. S.

Rosier, Mémoire sur les vins de Provence. Lansanne 1772. S.

Jaeger, Musla et vina neccarina. Tubingae 1773.4.

Tillifrenchi, Oenologia toseana. Firenze 1773. S.

Barry, Olservatiuns on the wines of the ancients. London 1775. 4.

(Spiclmann el) Fandel, De vilicultura richovillana. Argentorati [780. 1.

Croft, Treatise on the wines of Portugal. York 1787.8.

Fabbroni, Dell arte di fare i vino. Firenze 1787. S.

Speechly, Treatise on the culure of vine. Yolk 1790.4.

Derczen, Ueber Tohays Weibbau. Wien 1796. 8.

Cadel de l'uux, Jnstruction sur l'art de faire le vin. Paris (1800.) 8.

Chaptal, Rozier, Parnentier et Dussieux, Traité sur la culture de lat vigne avec l'ar' de faire lo vin. Paris 180 1. 8. - ib. 1839.8. (italice, germanice, latine, hungarice, anglice.)

Mueller, Deutschlands Weinbau. Leipzir 1803.8.

Lierner, Le raisin, ses espèces et varietés dessinées et coloriées d'après nature. Stultgart is03-1815, folio.

Frege, Versuch einer lilassitikation der Weinsorten. Meissen 1804. 8.

Nau, Anleitung über den Weinbau am Zurcher- und Bodensee. Frankfurt a/M. 1804.8.

lickel. Welterbeobachtungen in Bezug auf Scluitzmng der Weinherge. Bamberg 180i.s.

Die Witterung cies Jahres 1805 nit ilrem Einflusse auf den Weinbau. Bamberg 1806.8 .

Mennesson, Tableau des vignobles du départ. de la Marne. Epernay 1806.12. 
Roxas Clemente y Bubio, Ensayo sobre las variedades de la vid comun que vegetan en Andalucia. Martrid 1907.8. (gatlice, germanice.)

Boutelou, El cultivo de la vid en Jerez de la Frontera y Sanlucar de Barrameda. Nauliul 18 .. 4.

l'oggi, Manuel pour extraire le sucre dı raisin. Paris 1808.8 . (italice.)

Roslan, Fabrication du sucre liquide de raisin. Marseille 1808. 8.

Roulet, Recueil de mémoires sur la eulture de la vigne. Neuchâtel 1808.8.

(Olcese) Istruzione sul siroppo e zuccliero d'uva e sul siroppo di fichi. Genova 1810.8 .

l'armentier, Résultats de la fabrication des sirops de raisins. Paris 1S12. 8 .

Kecht, Methode den Weinbau zu verbessern. Berlin 1\$14. 8. - Ed. V1: ib. 1838.8 .

Jullien, Topographio de tous les vignobles conuus. Paris 1816. S. - ib. 1832. 8 .

(germanice.)

Loebenstein - Loebel, Die Anwendung und Wirkung der Weine. Leipzig 1816. 8

(gallice.)

Lambry, Exposé d'un moyen elc. Paris 1817.8.

(Henderson) The history of ancient and modern wines. London 1824. 4. (germanice.)

Acerbi, Delle viti italianc. Milano 1825. 8.

Bailly, De l'incisinu anmulaire. Paris 1825.8.

Bassi, Nuova maniera di Tabricare il viıo. Lodi $1 \$ 25.8$.

Pickel, Versuch ülser den walren Gehalı der Pflanzenfrüchte, insbesondre der Weine. Wurzburg 1525. 8.

Demerson, Histoire naturelle de la vigne. Paris 1826, 12.

Bosc, Vignes cultivées dans les pépinières de Luxemburg. Paris s. a. \$.

Vest, Versuch oiner Zusammenstellung der Weinreben Steyermarks. Grảtz 1826. 8.

Schuebler, Untersuchungen über Most- und Weintraubenarten Wrürtembergs. Tubingen 1526.8 .

Untersuchungen uber Obst- und Veintraubenarten Wurtembergs. Tubingen $1827, \mathrm{~s}$.

Metzger, Der rheinische Weinbau. Heidelberg 1827. 8.

Caroleau, Oenologie Irançaise. Paris 1828. 8.

Lenoir, De la culture de la vigne. Paris 1825. 8.

Leuchs, Vollstándige Weinkunde. Nürnberg 1829. 8.

kafinesque, American manual of the grape vines and the art of making wine. Plitadelphia 1830.12.

Schams, Betraclıtungeu uber Ungarns Weinbau. Pesth 1\$30. 8. (hungarice.)

Ungarns Weinbau in seinem ganzen Lmlange. Pesth 1832 1833.8.

lloerter, Die besten Setzreben. Koblenz 1\$32-1833. 12.

Foehr, De vini mosellani vi medicatrice. Berolini 1835 . 8.

Babo und Mctzger, Dic Wein- und Tafeltrauben. Mannleim 1836. 8.

Gok, Die Weinrebe und ihre Fruchte. Stuttgart 1836-1839. Colio.

Ilellrung, Allas der Weinländer in Europa. Magdeburg 1837. Folio.

Kindermann, De usu vini therapentico. Lipsiae 1837. 8.

Keller, Der Wein und der Frankewwein als lleilmittel. Würzburg 1838. 8.

lllubek, Charakteristik und Kilassifikation der Rebensorten. Grâtz 1841. 8.

Trummer, Klassifikation und Beschreibung der Rebensorten Steiermarks. Gratz 1841. 8 .

Petershagen, kultur des Weinstocks. Quedlinburg 1843. 8.

Babo, Der Weinstock und seine Varietáten. Frankfurt 1844.8.

Blanchet, Essai sur l'art de tailler la vigne. Lausanne 1844. 8.

Rubens, Anleitung zur Erzielung des Weinstocks. Mannlıeim 1844. 8.

IIellrung, Karte des Weingebiets in den Zollvereinsstaaten. Augsburg 1S 46. gr. folio

Schneyder, Ueber den Wein- und Obstbau der alten Römer. Rastatt 1846. gr. 8 .

Soutainc, Essai sur lhistoire des rins de la Champagne. Reims 1846. 12.
Xanthorrhoea hastilis Sm.

Kite, Medicinal effects of the resin of Acoroides resinifera from Botany Bay. Londm 1795. 8.

$$
\text { Zea Mays L. }
$$

Lespes, Essai sur le maıs. Paris 1825.4.

\section{Zingiber officinarum Roscoe.}

Marlinelli, Raggionamenti sopra l'Amomo e Calamo aromatico novamente avuto di Mlalacea. Venezia 1604. 4.

(Cf. Gjudizio sopra i ragionamenti di Cecchino Martinelli etc. JanLova 1603.4 .)

Iarogna, Commentarius in tractatus Droscoridis et Plinï de Amome. Bisileae 1608.4.

(italice.)

Gesner, De Zingibere. Altdarfii 1723.4

Bickmann, Waarenkunde. 1, p. $224-241$

\section{Cultura arborum pomiferarum.}

Estienne vel Stephanus, Seminarium et plantarium fructiferarum arborum Paris $1540-1548.8$.

Dany, La manièro de semer et faire pépinières. Paris 1560.8 .

Mizauld, De hortensium arborum insitione opusculum. Lutetiae 1560.8 .

Hascall, A booke of the arte and maner howe to plant and gratle all sortes of trees. Lomdon (1572.) 4.

Porta, Suae villae pomarium. Neapoli 1583.4 .

Delhicke, Gardeners labyrinth. s. I. et a. $(1586$ ? $) 4$.

linabe, Hortipomolegium. Nürnberg 1621. 4.

Een nyy tráăgårdz book. Cum Mănsson, Örtabook. Stockholm 1643. S.

Le Gendre, La manière de cultiver les arbres Iruitiers. Paris 1652. 12. ib. 1665.12.

(Autor est Antoine Le Maistre.)

Mascall, The conntry mans new art of planting and graftug. London 1652.4 .

Austen, A treatise of fruit-trees. Oxford 1655.4.

Samt-Estienne, Nouvelle instruction pour conuoistre les bons fruits. Paris 1660.12

Evelyn, Pomona. London 1664. folio. - ib. 1729. Talio.

Merlet, L'abrégé des bons fruits. Paris 1667.12.

Iusten, Dialogue between husband and Iruit-1rees. London 1670.4.

Langford, Instructions to raise all sorts of fruit-trees that prosper in England. London 1681.8.

De la Quintinye, Instruction pour les jardins frutiers et potagers. Paris 1690.4 .

(anglice, italice.)

Branche, Jardinier de grande expérience. Cologne 1692. 8.

Dahuron, Traite de la taille des arbres. Celle 1692. 12. (italice, germanice.)

(Facio de Duillier) Fruitwalls improved. London 1699. 4.

Gründliche Anweisung zur wohleingerichteten Baumschule. Hamburg 1702.8.

Liegelsteiner, Wolılversuebter Zwergbaum. Frankfurt a/Ml.1702. S.

Collins, Paradise retrieved. Landon 1717. s.

Laurence, The Iruitgarden kalendar. London 1718. 8 .

Ileber, Grundliche Einleitung zur Baumzucht. Hamburg 1725. S.

Dahlman, Den fárdigo trảdgårdmástaren. Stockholm 179 S. 8.

Langley, Pomona. Loudon 1729. folio.

De la Rivière et Du Moulin, Méthode pour cultiver les arbres a fruit. Paris 1738. 8 .

Hill, Treatise of fcuittrees. London 1755. 8. 


\section{CULTURA ARBORUM POMIFERARUI}

Kalm, Frukt-trans planterande i Finland. Åbe 1757. 4.

Linne, Frutetum suecicum. Upsaliae 1758. 4.

Knoop, Pomologia. Leeuwarden 1758-1763, folio. (germanice, gallice.)

Barnes, A new method of propagating fruit-trees. London 1759.8. (yermanice.)

Doeller: Beschreibung der besten Arten ron Kernobst. Berlin 1759. 8.

Chambray, L'art de cnltiver les pommiers. Paris 1765. 8 .

Du llamel, Traité des arbres fruitiers. Paris 1768. 4. (germanice.)

Lissander, Aumärkuingar vid svenska trăgårds-skötseln. Stockbolm 1768. 8 .

Henne, Anweisung zur Baumschule. Halle 1769. 8. - ib. 1796. 8.

Kalm, Apple-trăns ans och skötsel i Fiuland. Ảbo 1769. 4.

Salzmann, Pomologie. Potsdam 1774. 8.

Benckendorff, Abhandlung von Baumsehulen. Berlin 1776. 8.

Mayer, Pemona franconica. Nürnberg 1776-1S01.4.

Bergius, Tal em frukt trägårder. Stockholm 1780.8. (germanice.)

Trozelius, Landtmanna genväg til frukt-tran. Lund 1780.4.

Manger, Pomologie. Leipzig 1780-1783. Solio.

Abercrombie, The complete wall-tree pruner. London 4783. 12.

De la Brelonnerie, L'école du jardin fruitier. Paris 1784. 12. — ib. 1808. 12.

Le Brocq, A description of certain metlods etc. London 1786. 8.

Saint-Germain, Les présens de Ponone. Paris 1786. 12.

Buck, Ankündigung einer Pomologie. Hamburg 1787.8.

Uriver, The Ponona britannica. London 1788. 4

Hirschfeld, Handbuch der Fruchtbaumzucht. Braunschweig 1788 - 1789.8. (danice.)

Ilellenius, Fruhtıråns skötsel i Finland. Åbe 1789. 4.

Krafl. Pomena austriaca. Wien 1790-1796. folio. - ib. 1791-1794.4.

Forsyth, Observations on the diseases of Iruit and forest trees. London 1791. 8 .

Benekendorff, Ablandlung von Anlegung eines Olustgartens. Berlin 1792. 8 .

Butret, Taille raisonnée des arbres fruitiers. Paris 1793. 8. - Ed. XVT: ib. 1822.8 . (germanice.)

Meyen, Physikaliseb-okonemische Baumschule. Stettin 1795. 8.

(Renault) Mémoire sur la eulture des poinmiers. Roven (1795.) 8.

Knight, Treatise on the culture of the apple and pear. Ludiow 1797.8. Ed. V: London 1818.8.

Leibitzer, Haudbuch der Obsthaumzucht. Wien 1798. 8. - Lentschau 1504.8 .

Diel, Versuch einer systematischen Besehreibung dentseher liernobstsorten. Frankfurt a/M. 1799-1832.8.

Adam, Ceber die Veredlung des Obstes. Erfurt 4800.8 .

heyser, Ueler die Veredlung des Obstes. Erfurt 1800. 8.

IVilldenow und Homeyer, Gekrönte pomologisehe Preisselıriften. Erfurt 1S01. 5 .

Des Kurfursten August von Sachsen Kunstliches Obstgartenbuchlein, horausgegeben von Sickler. Weimar 1802. S.

Clrist, Pomologisches Handworterbuch. Leipzig 1809. 4.

For syth. Treatise on the culture of fruit-trees. London 4802 . S. (gallice, germanice.)

Kinight, Some doubts to the efficacy of Mr. Forsyth's plaister. Londen 1802. 4 .

Sickler, Allgemeine Geschichte der Obstkultur. 1: Von den Zeiteu der Urwelt bis zu Konstantin dem Grossen. Frankfurt a/M. 1802. 8.

Bogsch, Anleitung Obstbäume zu ziehen. Wien 1803.8.

Calvel, Trailé sur les pépinières. Paris 1803. 12.

Zigra, Der Banmgartuer. Riga 1803. s.

(1ntlice . rossice.)

Ackermann, Sammlung von Obstsorien. 1. Theil : Birnen. Sorau 1804.8. Prutzel, Thes, lit. bet.
Dubois, Du pommier, peirier et eormier. Paris 1804. 8. Leibitzer, Handluch der Zwergbaumzucht. Wien 1804. S.

(Roland) Lettre sur les pépinières. Careassonne 1804. 12.

Theuss, Obstbaumzucht. Halle 1804.8.

Guenderrode et Borhhausen, Die Pflaumen. Darmstadt 1504-1S0S. \&.

Diel, Anlegung einer Obstorangerie in Scherben. Frankfurt a/M. 1805. s.

Maerler, Tafelobstsorten in der Baumschule zu Herrenals. Wien 1505.8.

Christ, Die Krankheiten, Uebel und Feinde der Obstbäume. Frankfurt a/N1. 1808.8 .

Du IIamel, Traité des arbres fruitiers. Nouvelle údition par Poileau et Turpin. Paris 1808-1835. folio.

Rosenberger, Anleitung die Fruclıtbăume zu kopuliren. Königsherg 1808.8. Christ, Vollstandige Pemolegie. Frankfurt a/MI. 1809-1813. 8.

Geiger, Unterricht im Pfropfen. Esslingen 1811. 8.

Brookshaw, Pomona britannica. Lendon 1812. Colio.

Lelieur, Maladies des arbres fruitiers. Paris $1 \$ 12.12$

Perotti, Observations physiques sur les arbres fruitiers. Carmagnole 1812.8.

Wallrolh, Geschichte des Obstes der Alten. llalle 1812. gr. 8.

Baumann, Unterricht in der Obstbaumzucht. Bamberg 1813.8.

Hooker, Pomona londinensis. Londen 1813 sqq. 4.

Manteuffel, Deutscher Obst- und Fruclıtgärtner. Berlin 1813.8.

hinight, Pomona lierefordiensis. London 1814. 4.

Aubert du Petil-Thouars, Recueil des rapports et des mémoires sur la eulture des arbres fruitiers. Paris 1815. 8.

Dewora, Monatliche Verrichtungen in der Obstbaumzucht. Iladamar 1815. 8.

Montpellier, De la cultivation des arbres à fruit. Castelnaudary 1815. 8.

Aubert du Petit-Thouars, Le verger français. Paris 4817.8.

Boulelou, Tratado del ingerto. Madrid 1817. 4.

Christ, Handbuch der Obstbanmzucht und Obstlehre. Frankfurt a/N. 1817. s.

Coxe, View of the cultivation of fruittrees. Philadelphia 1817. 8.

Gallesio, Pomona italiana. Pisa 1817-1834. folio.

Lelieur, La Pomene française. Parıs 1847. 8.

Diel, Systematisehes Verzeichniss deutseher Keruobstsorten. Frankfurt a/M. 1818. 1829. 1833.8 .

Heim, Klassifikation und Beschreibung der Kirschensorten. Stuttgart 1819. 8 .

Tschudy, Essai sur la greffe de l'herbe. Metz 1819. 8.

Phillips, Pomarium britannicum. London 1820. gr. 8.

Piccioli, Pomona toscana. Firenze 1820, 8.

Beaunier, Le guide des propriétaires. Paris 1821. 8.

Précis sur les gretres. Paris 1821. 8.

Gautier, Le jardinier fruitier. Paris 1821. 4.

Noisetle, Le jardin fruitier. Paris (1813-) 1821. 4.

Le jardin fruitier. Ed. II. Paris 1832-1839.8.

Thouin, Monographie des greffes. (Paris 1821.) 4.

(germanice.)

Van Mons, Catalogue des arbres fruitiers. Louvain 1823.8.

Palladius, De insitionibus (de re rustica liber XIV) impr. cum Poet. lat. min. ed. N. E. Lemaire. Paris 1824-1826. S. vol. Vli.

Schmidberger, Unterricht von der Érziehung der Obstbáume. Leijziğ 1824. 8 .

Uarrison, Culture and menayement of fruit-trees. London 1825. 8.

Schmidberger, Beitrảge zur Obstbanmzuclt. L.eipzig 1827-1\$36. S.

Moretti, Alberi fruttiferi. (Bibl. agraria tom. XX.)

Diecker, Der Obstgărner im Zimmer. Passau 1826. 12.

Meyer, Anweisung zur Obstbaumzucht. IIof 4826-1829. 8.

Jaume Saint-llilaire, La Flore et la Pomone françaises. Paris $1825-$ 1833. Solio.

Meyer, Die Obstfruchte: 1. Steinobst. Ilof $1830^{\circ}-1834.8$.

Tristan, Rappert sur la neuvelle methode d'éeusson-grefre. Nantes 1830. s. 
Lindley, Considerations upon the cultivation of fruit trecs. London 1831.8. Lundsträm, Handbok i Trădgårds-skotseln. Stockholm 1831.8. - Ed. II: ib. 1841.8 .

Beskrifning on Frukt-trads uppdragning. Stockholm 1833.8. Ronalds, Pyrus Malus breutfordiensis. London 1834. gr. 4.

Couverchel, Leure à l'Aeademic des seiences. Paris 1833. S.

Lexa von Aehrenthal, Deutschlands Kiernobstsorten. I.citneritz 1833 $184 \times 4$.

Systematische Uebersicht der deutschen Kiernobstsorten. Leitmeritz 1833. 4.

Thoms, Anleitung zur Belandiung der Obstbáume. Sternberg 1\$35. 8.

Van Mons, Arbres fruitiers ou Pomonomie belge. Jouvain 18351836. 12.

Hinkerl, Handbuch der Pomologie. München 1836. 8.

Dittrich, Systematisclies Handbuch der Obstkunde. Jena 1837-1841. 8.

Geiger, Die Obstbaumzucht. Niunchen 1837. 8.

Hoyer, Inbegrill der Obstbaumzucht. Minden 1837. 8.

Liegel, Systematische Auleitung zur Kenntniss der Pflaumen. Passau und Linz 4838-1841,8.

Poiteau, Pomologie française. Paris et Strassburg 1838 sqq. folio.

Couverchel, Traité des fruits. Paris 1839.8.

Fintelmamn, Die Obstbaumzucht. Berlin 1839. 8.

Niaudet, Des pépinières. Pasis 1839. 12.

D'Albrel, De la taille des arbres fruitiers. Paris 1840.8 .

Lexa von Athrenthal, Verzeichniss der Obstsorten in den Aehrenthalschen Gärten. Leitmeritz 18\$0. 8 .

Lilja, Tidning for trảgårds-skötsel. Lund 1840-1842. 8.

Harlin, Die Naturkunde des Obstbaues. Stuttgart 1841.8.

Main, Fruit-trees. London 1841. 18.

Pomaria el vinaria Horatiana. Zittau 184 J. 8.

Schmidt, Handledning i trädgårds-skotseln. Nykopiug 1841. 12.

Kubens, Anleitung zur Obstbaumzucbt. Essen 1843. 8.

Siemers, Trădgårdsskötsel. Örebro 4844. 12.

Lexa von Achrenthal, Anleitung zur Auswahl von Kerubbstsorten. Prag 1845. 8.

Vallier, Die Obstlehre der Griechen und Römer. Reutlinæran 1845.8 .

Rubens, Der Obstbaumfreund. Stutigart 1846. 8 .

Schneyder, Ueber den Wein- und Obstbau der alten Romer. Rastat, 1846. gr. 8.

\section{Botanica hortensis.}

Domitzer, Ein newes Pfantzuchlin. s. I. 1531. 8. - Augspurg 1534. 8. (latine, danice.

Estienne vel Stephanus, De cultu ef satione hortorum. Paris 1535.8 . Je re hortensi libellus. Lusduni 1536. 8.

Le Court vel Curtius, Hortorum libri triginta. Jugduni 1560. folio.

Mesnil, L'art d'enter, planter el cultiver jardius. Paris 1560.8.

Mizauld, Secretorum agri euchiridion primum, hortarum curam complectens. Lutetiae 1560.8.

Ilill, The profitabie arte of gardening. London 1568.4

Incier, Paralipomena hortulaniea. Strasshurg 1568.8.

Milius, De hortorum cultura libri tres. Brixiae 1574.8 .

Mizauld, Ilistoria lortensium quatuor opusculis contexta. Coloniae Agrippinae 1577.8. (gallice.)

Mountaine, The gardeners labyrinth. Lnodon 1577.4.

Franeau, Jardiu d'liyver ou cabinet des lieurs. Jovay 1616.4.

L'Anglois, Livre tle fleurs. Paris 1620. folio.

Ponu. Il paradiso de fiori overo lo archelypo de giardini discorse. Verona 1622. 4.
Parkinson, Paradisi in sole Paradisus terrestris. London 1629. fnlio.

Cluyl, Memorie der vreender biom-bollen. Ansterdam 1631. 8.

Lauremberg, Horticultura, lirancofurti a/M. (1632.) \&.

Apparatus plantarius. Francofurli a/M. (1639.) 4. (germanice.)

Ferrari, l'tora seu do florum eultura libri W. Romae 1633.4 . (italice.)

Monlalbanus, Kiposcopia. Bologna 1638. 4.

Boiceau, Traité du jardinage. Paris 1638. folio.

Khagorius, Pflantz-Gart. Beru 1639. 8. - Basel 1669. 8.

Bloch, Iforticultura Janica. Havniae 1647.4.

Collaert, Florilegium. s. l. et a. 4.

Mandirola, II ggiardino de' fori. Ferrara 1650. 12.

- Manuale de' giardinieri. Vicenza 1652. 12. (germanice, gallice.)

Mollet, Le jardin de plaisir. Stockhoim 1654. folio. (anglice.)

Tlıéatre des plans et jardiuages. Paris 1639.4

(Thomasius) De laudibus florum. Lipsiae 1652.4

Toulouze, Livre des bouequets de fleurs. Nontpellier 1655. folio

Morin, Remarques necessaires poul la culture des flours. Paris 165\%. 4.

Mollel, Théatro des jardinages. Faris 1660. 12.

Sharrock, Tho history of the propagation and improvement of vegetables. Oxford 1660.8 .

Plat, The garden of Eden. London 1660. S.

Lavoson, A new orchard and garden. London 1660.4.

Baumgaertner, Garten-Memorial. Nüruberg 1662. 8.

Aengelen, Verstandige gardenier. Amsterdam 1663. 4. (germanice.)

Jiebener, Horticultura. Briog 1664. 8 .

Blake, The compleat gardeners practice. London 1664. 4.

Rea, Flora, seu de florum cultura. (Flora, Ceres, Pomona.) London 1665. folio.

Rapinus, Hortorum libri W. Parisiis 1663. 4. (gallice, auglice.)

Elsholz, Neuangelegter Gartenbau. Colln a/d. Sprec 1666. 4. - Ed. K* Leipzig 1715 . folio.

Seultetus, Plantarum cultura oratione exculta. Norihercan 1666. 12

Groen, Den nederlandzen hovenier. Anisterdam 1668. 4. (gallice, germanice.)

Grubel, Kritohoyis sive consideratio horti. Jenae 1670. 4.

Mieller, Deliciae hortenses. (Kurzer Entwurf ete.) Stuttgart 167\%. 12. ib. 1745.8 .

Munting, Waare oeffening der planten. Amsterdam 1672. i.

Cause, De koninglycke hovenier. Ansterdam (1676.) fulio.

flughes, The llower-garden enlarged. Lonflon 1677. 12

Aristote, lustruction sur le jardin potager. Paris 1678. 8.

Meager, The english gardener. London 1679. 8.

Perrot, Les leçous royales. Paris 1681. 12.

Gilbert, The gardeners almanack. Loudon 1683. 12.

The Florists Vademecum. Lonton 1683. 12.

Rudbeck, Propagatio plantarum botanico-pliysica. Lpsaliae 1656. s.

Woolridge, Ait of gardening. Loudun $165 s .8$.

Senfftel, Seninarium viridum. Augsburg 1689.8.

Hesse, Neue Gartenlust. Leipzig 1690.4.

Holyk, Vernevertes Gartenbuclilein. Wiltenberg 4693.8 .

Evelyn, Calendarium borteuse. Loudon 1694. folio. - ib. 1706 . s

Packbusch, De varia plantarum propagatione. Lipsiae 1695.4.

Tschiffelli, L'école des jardiniers. Berne 1696. 12.

Stisser, Botanica curiosa. Heinstedt 1697. 8.

Sacconi, Ristretlo delie piante. Vienna 1697. 4.

Iontif, Neue Giarlenlust. Ulin 1698, 12.

Schwinmer, 1'hysikalische Fargotzlichleiteu. Erfurt 1701 \& 
Gollschalck, Flora hortensis. Cothen 1703.8.

Liger, Le jardinier floriste. Paris 1703. 12. - Avignon 1821. 8.

Besnier, Le jardinier botaniste. Paris 1705. 12.

Fischer von Atzendorf, Unterrichteter Hausvater und kluger Gartner. Ilannover 1705.12.

Vallemont, Curiosités de la nature et de l'art sur la végétation. Paris 1705. 8 . (germanice.)

Besnier, Abrégé curieux touchant Jes jardinagges. Paris 1706.12.

Oosten, Nickerłändischer Obst-, Blumen- und Orangeriegarten. Ilannover 1706. 8 . (hollandice, anglice, gallice.)

Leblond, La théoric et la pratique du jardinage. Paris 1709. 4. (anglice, sermanice.)

Hesse, Teutscher Gärtner. Leipzig 1710. folio.

Meager, Tho new art of gardening. London 1713. 12.

Pein, Wörterbüchlein der Gárınerey. Leipzig 1713. 8.

Laurence, The gentleman's recreation. London 1716. 8.

The clergy-man's recreation. London 1716. 8.

Bradley, New improvements of planting and gardening. London 1717.8. - Ed. VI: ib. 1731.8. (gallice.)

- The gentleman and gardeners kalendar. London 1718.8. (gallice.)

Lelimamn, Yollkommener Blumengarten. Leipzig 1718. 4. - ib. 1750. 4. (hollandice.)

Fairchild, The city gardener. London 1722. 8.

Ahlich, Den svenske Lust-Örle och Trä-Gärden. Stockholn 1722. 8

Miller, The gardeners and florists dictionary. London 4724. 8.

- The gardeners dictionary. London 1731, folio. - Ed. IX by Thomas Martyn. London 1797-1804. folio. hollandice, gernanice, gallice.)

IVeber, Anleitung zum Gartenhau. Hamburg 1725. 4.

Clarici, lstoria e coltura delle piante. Venezia 1726.4.

Townsend, Der vollkommene Samenhıandler. Leipzig 1727.8. (anglice.)

Langley, New principles of gardening. London 1728. 4.

Bradley, Dictionarium botanicum. London 1728. 8.

Pictorius, Der grundlich instruirte Gärtner. Nürnberg 1729. 8.

Baungaertner, Vollstandige Gartenlust. Nürnberg 1730. 8.

Gartenlust in Geheimnissen. Nurnbers 1732.8.

Cowell, The courious and profitable gardener. London 1730. 8 .

Affaitat, Il semplice ortolano. Milano 1734. 12. - ib. 1515. 8.

Miller, The gardeners kalendar. Lourlon 1732. 8. - Ed. XV: ib. 1769. 8. (germanice, hollandice.)

Bradley, Ten practical discourses concerning the growth of plants. London 1733. 8 .

Moore, A flower-garden. London 1734. 4.

Miller, The gardeners dictionary abridged. London 1735. 8. - ib. 1771.4 .

(germanice.)

(De la Courl) Aenmerkingen over landhuizen, Justhoven, plantagien. Leiden 1737.4.

(gallice, germanice.)

(Benemann) Gedanken über das Reich derer Blumen. Dresden 1740.8.

Ungebauer, De plantarum cultura. Lipsiae 1741. 4.

Jartenfcls (i. e. Kaesersberg), Neuer Garten-Saal. Frankfurt 1745. 8.

Grotjan, Physikalische Winterbelustigung. (Cultur der Zwiebelgewáchse.) Nordhausen 1750.8 .

Kalm, kirydd- och trágårds anlággaude. Âbo 4754. 4.

- Om möjeligheten af krydd - och trägårdars anlkiggande i Finland. Äbo 1754. 4 .

Limnè, De horlicultura academica. Upsaliae 1754. 4.

Gesner, De thermoscopio botanico. Tiguri 1755. 4.

(gallice, germanice.)
Itill, Eden. London 1757. folio.

(Morel) L'art de distribuer les jardins suivant l'usage des Climois. Londres 1757.8.

Itill, The gardener's new kalendar. London 1758.8.

- The practice of gardening. London 1759.8

- The origiu and production of proliferous flowers. London 1759. 8. (germanico, hollandice.)

Kampen, Traité des fleurs à oignons. Harlem 1760.8 The dutcly florist. London 1764. 8.

Plaz, De plantarum eultura. Lipsiae 1764. 4.

Justice, The british gardeners director. Edinburgh 1764.8.

Gadd, Upmuntran til plantagers vidtagande. Åbo 1765-1768. 4.

Kalm, Utkast til en blomstergård. Ảbo 1766. 4.

Lidbeck, Tal om planteringer. Stockholm 1766. 8.

Arena, La natura e coltura do' fiori. Palemo 1767-1768. 8.

Lueder, Briefe über die Bestellung eiues Küchengartens. Hannover 1768. 8. - Ed. Ill : ib. 1778-1783. S.

Stevenson, The gentlemen gardener. London 1769.12.

Olafsyn, lslendsk urtagards bok. (Horticultura lslandorum.) KaupmannaJiofn 1770.8.

Schabol, Dictionnairo du jardinage. Paris 1770. S.

Ilanbury, A complete body of planting and gardening. London $1770-$ 1771. folio.

IVeston, Botanicus universalis et hortulanus. The universal botanist and nurseryman. Londini $1770-1777.8$.

Brocke, Beobachtungen von einigen Blumen. Leipzig 1771. 8.

(Buchoz) Toilette de Flore. Paris 1774. 12.

Diclis, The new gardener's dictionary. London 1771, folio. (germanice.)

(IVhately) L'art de former des jardins anglais. Paris 1771.8 (anglice.)

Schabol, La théorie du jardinage. Paris 1771. 8.

La pratique du jardinage. Paris 1772. 12. (germanice.)

Chambers, On oriental gardening. London 1773. folio (gallice, germanice.)

Gleditsch, Pflanzenverzeichniss fur Lust- und Baumgärner. Berlin 17 i3 8.

Watelet, Essai sur les jardins. Paris 1774. 8.

Ifirschfeld, Neue Theorie der Gartenkunst. Leipzig 1775. 8. - Theorie der Gartonkunst. Leipzig 1775-1780. 4. (gallice.)

(Le Berryais) Traité des jardins, ou Je nouveau De ta Quintıtze. I'ani1775. 8. - ib. 1789.8 .

Abrégé du traité des jarrlins. Avranches 1791.8.

Mawe et Abercrombie, Every man is own gardener. London 1776. 8. Ed. XXIV, by Main. ib. 1839. 12.

(Morel) Théorie des jardins. Paris 1776. 8 .

Lueder, Briefe uber die Anlegung eines Blumengartens. Hannover 1777. 8. - ib. 1786.8 .

Swinden, The beauties of Flora, London 1778. 8

Brookes, The complete british gardener. London 1779. 12.

Meader, The planters guide. London 1779. 4.

Feuereisen, Abhandlungen über Gegenstănde der Gartnerei. Hannover 1780.8 .

Georgy, De lucis arte instructis. Goettingae 1780.4.

Lueder, Anleitung zur IVartung aller Küchengartengewáchse. Lubech 1780. 8.

Abercrombie, The complete forcing gardener. London 1781. 12. (germanice.)

Franke, Erzeugung der Blumen im Winter. Leipzig 1781.8.

Fleischer, Forsog til en dansk havebog. Havniae 1782. 8.

Medicus, Beilrăge zur schönen Gartenkunst. Mannheim 1782. \&.

Hirschfeld, Gartenkalender. Hamburg 1782-1785. 16.

Jueder, Botanisch-prahtische Lustgärtnerei. Leipzig 1783-1786. 4. $59^{\circ}$ 
Abercrombie, The propagation of plants. London 1781. 8.

De Grace, Le jardinier portatif. Paris 1784. 12.

Abercrombie, The gardeners poeket-journal. London 1786. 12. - ib. 1842. 12.

Buchoz, Catalogue des plantes pour la décoration des jardins. Londres 1786. 12.

Abercrombie, The complete kitchengardener. London 1789. 12. The garden-Vademecum. London 1789. 12.

The hot-Jiouse gardener. London 1789. 8.

The universal gardeners kalendar. London 1789.12

Fillassier, Dictionaire du jardinier français. Paris 1789. 8.

(Servais) Korte verhandeling van de boomen etc. Mechelen 1789. 8.

Sowerby, Flora luxurians. London (1789-1791.) folio.

Bryant, Dietionary of ornamental trees, shrubs and plants cultivated in Great Britain. Norwich 1790.8.

IIirschfeld, Kleine Gartenbibliothek. Kiel 1791. 8.

Adelkofer, Grundliche Gartenschule. Augsburg 1792. 8.

Steele, Essay upon gardening. York 1793.4.

Dieskau, Vortheile in der Gártnerei. Koburg 1794. 8.

Vollstandige Abhandlung von den Nelken und Tulpen. Riga 1794. 8.

Bechsledt, Der Küchengarteubau. Schleswig 1795. 8.

Mason, An essay on designing gardening. Lonclon 1795.8.

Albonico, Nützliche Bemerkungen fur Garten- und Blunenfreunde. Leipzig $1795-1800.8$.

Becker, Taschenbuch für Gartenfreunde. Leipzig 1795-1799. S.

Ideler, Der Gartenfreund. Berlin 1795-1805. S.

Achard, Verzeichniss seines Gartens. Berlin 1796. 8.

(Roessig) Handiuch fül Liehhaber englischer Pflanzungen. Leipzig 1796. 8 .

Mheller, Behandlung des Obst- ind Gemusegartens. Franhfurt 1796. 8. ib. 1820.8 .

Grohnann, Neue Theorie der schonen Gartenkunst. Leipzig 1797. 8.

Mueller, Der vollståndige Monatsgărtner. Franklurt 1797.8. - ib. 1820. S.

Koemer, Encyclopådie für Gàrtner. Tübingen 1797. 8.

Robertson, A collection of various forms of stoves. Loudon 1798. 4. (gallice.)

Bastien, Annee du jarlinage. Paris 1799. 8.

Mueller, Die wichtigsten Lehren des Gartenbaues. Leipzig 1800 . \$.

Nicol, The practical planter. London 4800.8. (germanice.)

Zigra, Kultur der Kuclıengewachse. Riga 1800. S. (lettice.)

Boutelon, Tratado de la huerta. Madrid 1801. \&.

Guenderrode et Borkhausen, Vorschläge zur Verbreitung des Gemüseund Obstbaues. Darmstadi 1801.8.

Batsch, Der geoffiete Blumengarten. (Le jardin ouvert.) Weimar 1802.8.

Berger, Taschenbuclı fur Blumenfreunde. Leipzig 1902. 8.

Friedrich, Der Kuchengarten. Schwerin 1802.8.

(Ludwig) Studien für den neuern Gartenküustler. Leipzig 1802.8.

Tassalli, Della fecondazione arteficiali delle piante. (Torino 1802.) 12.

Berger, Ideal eines Praclitgartens im Kleinen. Leipzig 1803.8.

Boutelou, Tratado de las flores. Madrid 1804. 4.

Calvel, Manuel des plantations. Paris 1804, 12.

Loudon, Observations on plantations. Edinburgh 1804. $\mathrm{S}$.

Poinsot, L'ami des jardiniers. Paris 1804-1805. 8.

Sprengel, Gartenzeitung. Halle 1804-1806. 4.

Mordant de Launay, Le bon jardinier. Almanach. Paris 1804-1515.8.

Loudon, Improvements recently made in hot-houses. Edinburgh 1805.8.

Meriale, L'ami des jardins. Liege 1805. 12.

Prevost, Collection des fleurs et des fruits peints d'après nature. Paris 1805. folio.

Wolter, Anleitung zur Bestellung eines Küichengartens. Mitau 1805. 8.

Zigra, Verzeichniss yun 2000 seltnen in Russland 1804 eingefuhrten Pflanzen. Riga 1805.8
Medicus, Beitráge zur Kultur exotischer Gewáchse. Jannheim 1806. 12.

Waller, Der Stubengärtner. Nordhausen 1806. 8.

Zigra, Der nordische Blumengärtuer. Riga 1806.8 . (rossice.)

Bastien, Nouveau manuel du jardinier. Paris 1807.12

Mac Donald, A complete dictionary of practical gardening. Londos 1807. 4.

Tod, Plans, elevations and sections of hot-houses etc. London 1807. folio.

Bessa, Fleurs et fruits gravés et coloriés. Paris 1808. folio max.

De la Borde, Description des nouveaux jardius de la France. Paris 1808. folio max.

Denhardt, Taschenbuch für Gartenfreunde. Leipzig 1808. 12.

Leibit:er, Vollständiger Gartenkalender. Wien 1808. 8.

Bastien, La Flore jardinière. Paris 1809. 8.

Braeunicke, Lebrbuch des Blumenlaues. Wien 1809. 8.

Hellbach, Handbuch über den Küchengartenbau. Erfurt 1809.8.

Crosfield, Calendar of Flora. Warrington 1810. 8.

Bouche, Der Zimmer- und Fenstergarten. Berlin 1811. 8. - ib. 1833. 8.

Du Mont de Courset, Le botaniste cultivateur. Paris 1\$02. 8. - Eu. II:

Paris 1811-1814.8.

(germanice, italice.)

Haynes, Interesting discoveries in horticulture. London 1811.8.

Sickler, Gartenhandlexikon. Erfurt 1811.8. - Gatha 1829.8.

Theuss, Allgemeines Blumenlexicon. Weimar 1811. S.

Titford, Sketches towards a Hortus botanicus americanus. London 1811. 4.

Bastien, Calendrier du jardinier. Paris 1812.12.

Broegelmann, Beschreibung im letzten Jalırzehend entdeckter Pflanzen. Frankfurt a/M. 1812.8 .

Cushing, The exotic gardener. London 1812.8 . (germanice.)

Dietrich, Aesthetische Pflanzenkunde. Berlin 1812.8.

Nicol, The gardeners kalendar. London 1812. 8.

ke, ll giardiniere avviato. Milano 1812.8.

Colla, L'antologista botanico. Torino 1813-1814. 8.

Antoine, Les beautés de la nature. Paris 1814. 12.

Frege, Gartenfiora. Zeitz 1814. 8.

Corthum, Handbuch fur Gartenliebltaber. Leipzig 181/1-1\$16. 8.

Beyer, Tabellarische Vebersicht der huchengewächse. Halle 1815.4.

Malo, Guirlande des fleurs. Paris 18.15. 8.

Bernhardi, Allgemeines deutsches Gartenmagazin. VIll voll. 1S131824. 4.

Edwards et Lindley, The lotanical Register. London 1815-18;6. XXXII voll. 8 .

Zigra, Handbuch der Gartenkunst. Riga 1816. 8. (rossice.)

Abercrombie, The gardeners companion. London 1\$18. 12. - il. 1838. 12 . Ifayward, The science of horticulture. London 1818.8.

Scliell, Beiträge zur bildenden Gartenkunst. Nünchen 1S18. \&. - ib. 1825.8.

IVodzicki, 0 chodowaniu, użytku etc. W Krakósie 1S1S. S. - i . 1893. \&.

Wredow, Gartenfreund. Berlin 1818. 8. - Ed. V1: ib. 1847. 8.

Abacher, Vollkommener Blumengartner. Regensburg 18.19. 8.

Thouin, Plans raisonnés de toutes les espèces de jardins. Paris 1819. folio.

Lupin, Dıe Gärten; mit einem Gartenroman. Munchen 1820. s.

Graffen, Der praktische Gärtner. Llannover 1\$22. 8 .

Loudon, Encyclopaedia of gardening. London 1822. S. - ib. 1841. s. (germanice.)

Maddock, The Florist's directory. Lond(ıll 1822. 8. (germanice.)

Nagel, Monatliche Terrichtungen im Obst - und Küchengarten. Ninclıen 1823. $S$.

Phillips, Sylva florifera. London I\$23. 8

Bailly, Manuel du jardinicr. Paris 1824. 8 . 
Ilosack, Discourse before the New York liorticultural sociely: New York 1824. 8.

Morris, The botanists manual. London 1824.8.

Phillips, Flora historica. London 1824. 8.

Pirolle, L'horticulteur français. Paris 1824-1826. 12.

Salzmann, Allgemeines deutsches Gartenbuch. Müchen 1824. 8.

Thornton, The greenliouse companion. London 1824. 8 .

Zigra, Nordiseher Blumenfreund. Riga 1824.8.

Brookshaw, The horticultural repository. London 1825.8 .

Bouche, Der Zimmergarten im Grossen. Berlin 1825. 8.

Morvis, Flora conspicua. London 1825. 8.

Pirolle, Galendrier du jardinier français. Paris 189.5. 18.

Spaendonck, Fleurs dessinées d'après nature. Paris s. a. folio.

Souvenirs de Tan Spaendonck. Paris 1825. 4.

Noisette, Manuel complet du jardinier. Paris 1825-1828.8. (germanice.)

Dietrich, Handbuch der botanisclıen Lustgärtnerei. Hamburg 18261828.8.

Loudon, The Gardeners Mlagazine. London 1826-1843. XLX voll. 8.

Olagnier, Le guide de l'amateur botaniste. Paris 1826. 12.

Otto und Schranm, Kurze Anleitung zum Bau der Gewächsháuser. Berlin 1826. 4.

Mayer, Gartenbuch. Wien 1S27.8.

Aedoute, Ghoix des plus belles fleurs. Paris 1827. folio.

Reichenbach, Taschenbuch für Gartenfreunde. Dresden 1827. 8.

Soulange-Bodin, Discours sur l'importance de l'horticulture. 11827.8 .

Fessenden, New american gardener. Boston 1828. 8.

Jaume Saint-Hilaire, La Flore et la Pomone françaises. Paris $1828-$ 1833. folio.

Soulange-Bodin, De la culture des plantes dites de terre de bruyère. Paris 1828. 8.

Stewart, The planters guide. Edinhurgh 1828. S.

Felton, Gleanings on gardens. London 1829. 8.

Johrson, History of english gardening. London 1829.8

Metzger, Gartenbuclı. Ileidelberg 1829. 8.

Piccioli, Nuovo metodo per la riproduzione delle piante. Firenze 1829. 8. Roscoe, Floral illustrations of the seasons. No. I. Spring. London 1829. 4. Moretti, Orti. (Bibl. agraria tom. VIIl-X.)

Loudon, Hortus britannicus. London 1830-1832. 8. - ib. 1839. 8 .

Weise, EnkykJopådisches Gartenwörterbuch. Erfurt 1830.8.

Dachroeden, Beschreibung von Topfpflanzen. Leipzig 1831.8.

Loudon, Illustrations of landseape-gardening. London 1831. folio. (anglice-gallice-germanice.)

Lindley, Guide to the orchard and kitchen garden. London 1831. 8.

Reider, Das Ganze der Blumenzucht. Nürnberg 1831. 8. - ib. 1847.8. Wennström, Handbok i blomsterkulturen. Stockhoim 1831.8.

Aguillon, Caiendrier horticultural toulonnais. Toulon 1832.8.

Noisette et Doitard, Manuel du jardinier des primeurs. Paris 1839.18. (germanice.)

Lindley, An outline of the first principles of horticulture. London 1832.12. (germanice, gallice.)

Ritter, Allgemeines deutsehes Gartenbuch. Quedlinburg 1832. 8. - Ed. VI: ib. 1846.8.

Courtois, Magazin d'lorticulture. Liège 1833. 8.

Otto und Dietrich, Allgemeine Gartenzeitung. Berlin 1833-1847. gr. 4.

Baboo Radhakant Deb, Translation of an extract from a liorticultural work. London 1834.8.

Boitard, L'art de decorer les jardins. Paris 1834.4.

Pueckler-Muskau, Andeutungen üher Landschaftsgärtnerei. Stuttgart 1834. S. und Atlas in folio.

Labram, Sammlung der Zierpflanzen. Basel 1835. 8.

Reider, Der schnell unterrichtete Botaniker und Blumist. Nünberg $1 \$ 35.8$.
Gerstenberg, Der Gartenbeobachter. Eine Zeitschrift. Nürnbeı म 1001 1842. 8 .

Hevvey, Reflexions on a floweryarden. London 4836.8 .

Hornemann, Om de indenlandske plauter anveudte som zurplanter. Kinbenliavn 1836. 8 .

Leconte, Collection de jolies petites fleurs. Paris 1836.4.

Leibitzer, Der Gartenbau. Pesth 1836. 12.

Morren, Quelques mots sur l'histoire de l'horticulture. Liege 1836. gr. 8.

Fintelmann, Praktische Anleitung zur Fruchttreiberei. Potsdam 1837. 8.

Soulange-Bodin, Considérations sur les anciens parterres. Paris 1837.8. Pépin, Notes horticulturales. Paris 1837-1838. 8.

Booth, Anlegung und Erhaltung eines englischen Rasens. Hamburg 1838.4 Loudon, Tho suburban gardener and Villa companion. London 1838. 8 .

Marnocli, Floricultural Magazine. London (1838?) 8.

Morren, Horticulture et philosophie. Liège 1838. 8.

- De la spécialité des cultures de Liège. Liège 1838.8.

Perman, Underráttelser om blomstervăxter. Örebro 1838. 19.

Vogel, Gartenkalender. Grimma 1838-1841. gr. 12.

Lemaire, L'horticulteur univer'sel. Paris 1839-1844. 8.

Main, The planter's and pruner's assistant. London 1839. 12.

Mangles, The floral calendar. London 1839. 8.

Neubert, De Modepflanzen. (Camellien, Cactus, Rosen.) Stuttgart 1839 -1842.8 .

Towers, The lomestic gardeners manual. London 1839. 8 .

Bosse, Handbuch der Blumengärtnerei. Hannover 1840-1842.8.

Bouclie, Belıandlung der Pllanzen in Zimmer. Berlin $1 \$ 40.8$.

Dietrich, Zeitsclırift für Gărner und Botaniker oder Repertorium. Jena 1840-1846.4.

Ekart, Ueber bildende Landschaftsgartenkunst. Potsdam 1840. gr. 4.

Ileynhold, Nomenclator botanieus hortensis. Dresden 1840-1847. gr. 8.

Lindley, The theory of horticulture. London 1840.8 . (germanice.)

Loudon, Instructions in gardening for Ladies. London 1840. S.

The Ladies flower-garden of annuals. London 1840.4.

The Ladies flower-garden of perennials. London 1840. 4.

Neill, The fruit-, flower- and kitehengarden. Edinìurgh 1840. gr. 8 .

Nietner, Die Küchengärtnerei. Berlin 1840. 8.

Paxton and Lindley, Botanical pocket dietionary. London 1840. 12.

Dietrich, Der Sommergärtner. Ulm 1841. 12.

Downing, A treatise of landscape gardening. New York 1841.8.

Loudon, Ladies Companion to the flower-garden. London 1841.12. ib. 1846.12.

- The Ladies fower-garden of ornamental bullons plants. London 4841. 4.

Mac Intosh, Practical gardener. London 4841. 8.

Main, The kitelien-garden. London 1841. 18.

Flowers. London 1841. 18.

Bouche, Die Blumentreiberei. Berlin 1842. 8.

Christ, Al!gemeines praktisches Gartenbuch. Heilbronn 1842. $\$$.

Lilja, Hanibok i de odlade váxternas Flora. Örebro 4842. 8.

Loulon, The suburban horticulturist. London 1842. 8.

Reider, Der Hausgarten. Leipzig 1842. 8.

II ard, On the growth of plants in closely glazed cases. London 1842. s.

Denisse, Flore l'Amérique. (leones florum.) Paris 1843-1846. folio.

Dietrich, Die Herbst- und Winterflora. Ulm 1843. 12.

Lemaire, Essai sur l'histoire et la culture des plantes bulbeuses. Paris 1843.8.

Schnidlin, Die bürgerlielıe Gartenkunst. Stuttgart 1843. 8.

Dietrich, Vermelırungsarten der Ziergewachse. Nordhausen 1844. 8.

Dietrich, Ilandbuch des Gärtners. Nordhausen 1844. 8 .

llitzer, Die Lobensdauer der Pflanzen. Berlin 1844. 8.

Lemaire, Des genres Camellia, Rhodendendron etc. Paris 1844. \&. 


\section{CULTURA FLORUM HORTENSIUM}

Jacques, Manuel général des plantes. Paris 1845 sqq. 8.

Loudon, Self-instruction for young gardeners. London 1845.8.

Reinhold, Garteukalender. Sulzbach 1845. 8.

Seringe, Flore des jardins et des grandes cultures. Lyon 1845. 8. et Atlas in folio.

- Flore et Pomone lyonnaises. Lyon 1847. 4.

llocquart, Le jardinier pratique. Paris 1846. 18.

Loiseleur, Roseraies et promenades horticulturales. Paris 1846. 8.

Wuestemann, Ueber die liunstgártnerei bei den alten Romern. (Getha) 1846. 8.

Poilcau, Cours d'horticulture. Paris 1847.8.

Schmidlin, Dor Wintergarten. Stuttgart 1847. 16.

\section{Cultura florum hortensium.}

(CI. Monographias, p. 422 sqq.)

Neumann, Die Familie der Amaryllideen. Weissensce 1844. 8.

Finckh, Die Cactus. Stuttgart 1832.8.

Mittler, Taschenbuch fur Cactusliebhaber. Leipzig 184t-1844. gr. 16.

Lemaire, Manuel de l'amateur des Cactus. Paris 1845.12.

Foerster, Ilandbuch der Cacteenkunde. Leipzig 1846. 8.

Chandler, Camellia britannica. London 1825. 4.

Baumann, Les Camellia de Bollwiller. Bollweiler 1829-1831. folio.

Seidel, Die Camellien. Wien 1830. 8.

Chandler et Booth, Illustrations and descriptions of Camelliae. Londen 1831. folio.

Fiscler, Vermehrung und Veredlung der Camellia japanica. Freiburg i/Br. 1836. 8 .

Seidel, Anleitung zur Kultur der Camellien. Dresden 1837. 8.

Berlise, lconegraphie du genre Camellia. Paris 1839. folio.

- Nonographie du genre Camellia. Paris 1840. 8. (germanice.)

Colla, Camelliografia. Torino 1843.8.

Stein, Künstliche Befruchtung der Levkoyen. Minden 1787. 8.

Sornini, Culture de la Julienne. Paris 1804. 8.

Kannegiesser, Abbildungen der Levkoyen. Dresden 1807. 4.

Dreysig, Der Levkoyengärtner. Leipzig 4823. 8.

Martini, Ueber Anzucht der Levkoyen. Quedlinburg 1842. 8.

Saal, Die Kultur der Sommerlevkoyen. Weimar 1843. 8.

Rupprecht, Ueber das Chrysanthemum indicum. Wien 1833.8.

Sicet, Cistineae. London 1\$25-1830.8.

De Jonghe, Monographie du genre Cyclamen. Bruxelles 1844. 12.

Ardene, Traité des Oeillets. Avignen 1762. 12.

Wallet, Beauté de la nature. (Cultura Dianthi.) Paris 1775. 12.

Weissmuntel, Die Nulke. Leipzig 1779. 8.

Henne, Nelkenkalender. Halle 4785. 8.

Rudolphi, Nelkentheorie. Neissen 1787. 8. - ib. 1799. 8.

Huelle, Sammlung von Nelken. Bremen 1790.8.

Roessig, Dio Nelken nach der Natur gezeichnet und kolorirt. Leipzig (1806-1807.) 4 .

Ifuenzel und von Behr, Das Ganze der Nelkenzuelı oder System der Nelke. Leipzig 1840. 8.

It'rtel, Kurze Geschichte der Nelken. Schwerin 1812. 8.

Tagliabue, Coltivazione del garofano. Milano 1837. 8.
Feund, hultur der Gartenelhe. Quedlinburg 18:0.8.

liagonol-Godefroy, 'Traité sur la culture des Oeillets. Paris 1842. 8.

Waitz, Beschreibung und Kultur tler lleiden. Alteulıurg 1805. \$.

Mac Nab, A treatise on the propagation and cultivation of Capeheaths. Edinburgh 1832.8.

kegel, Die Kultur und Aufzahlung der Eriken deusscher und englischer Carten. (Zurich 1843.) 4.

Mlaschnick, Ueber die Kultur der Farrenkräter. Berlin 1831.4.

De Candolle, Noto sur les Georgina. Montpellier 1809. 8.

Jaume Saint-Ililaire, Les Dahlia. Paris s. a. folio.

Jacquin, Essai sur la culture des Dahlia. Paris 1828. 8.

Soulange-Bodin, Catalogue des Dahlias nains. Paris 1831.8 .

Lelieur, Mémoire sur le Dahlia. Paris 1829. \&.

Thiébaul-de-Berneaud, Mémoire sur les Dahlias. Paris 1834.8.

Sinclair, Ilistory and description of the Georgina or Dahlia. Lenden $1 \$ 35$.

Gerhard, Zur Geschichte, Kultur und Klassifikation der Georginen. Leipzig 1836. 8 .

Paxton, A practical treatise on llie cultivation of Dahlia. London 183\$. 12. (gatlice, germanice, suecice.)

Pirolle, Traité spécial el didactique du Dahlia. Paris 1839. gr. 12.

Neumann, Dic Kultur der Georginen. Weissensee 1\$41. \$.

Pollmann, Anweisung zur lienntniss und Behandlung der Georginen. Mlagdeburg 1\$41. \$.

Berger, Immortell eı- oder Immerschönen-Taschenbuclı. Leipzig 1817. 19.

Buchoz, Mémoire sur l'Hortensia. Paris 1805.8.

Dreysig, Behandlung der Hortensia mutabilis. Erfurt 1812. 8.

Olearius, Ilyacinth-Betrachtung. Leipzig 1665. 12.

Voorkelm, Traité sur la Jacinte. IIarlem 1752. 8. - ib. 1773. 8 (germanice.)

Ardene, Traité des Jacintes. Avignon 1759. 12. (italice.)

(Saint-Simon) Des Jacintes. Amsterdam 1768. 4

Buchoz, Collection de Jacinthes. Paris 1781. folio.

Henshall, Treatise on the cultivation of orchidaceouy plants. London 1845. 8 .

(germanice.)

Lyons, A practical treatise on the management of orchidaceous plants. Ed. 11. London 1845.8.

Klier, Kultur der Päonien. Wien 1845. 8.

Dietrich, Die Linneischen Geranien. Weimar 1809. 4.

Sweet, Geraniaceae. London $1820-1830.8$.

Trallinick, Neue Arten von Pelargonien. Wien 1825-1843. 8.

Klier, Kultur der Pelargenien. Wien 1826. 12.

Reider, Beschreibung aller Pelargonien. Nurnberg $1 \$ 29.8$.

De Jonghe, Traité de la culture du Pelargonium. Bruxelles 1844.8.

Weissmantel, Die Aurikel. Erfurt 1783. 8.

Kannegiesser, Aurikelflora. Dresden 1800-1802. s.

llecart, Sur la culture de l'areille d'ours. Bruxelles 1890.8.

Knight, On the cultivation of the Proteaceae. London 1809.4.

Ardene, Traite des Renoncules. Paris 1746.8.

(germanice.) 
Kannegiesser, Abbildungen der Ranunkeln und Anemonen. Dresden 1807. 4.

Seidel, Die Rhodaraceae ader Rhododendreae. Dresden 1843. S.

(Benemann) Die Rose zum Ruhm ihres Selıöpfers. Leipzig 1742. 8.

Lawrance, A collection of Roses from nature. London(1790-1810.) folio. Roessig, Beschreibung der Rosen. Leipzig 1799-1803. 8.

Guillemeau, Histoire naturelle de la Rose. Paris 1500.12.

Roessig, Die Rosen wach der Natur gezeichnet und kolorirt. l.einzig (1802 -1820) 4$.

Buchoz, Monographie de la Rose et de la Viclette. Paris 1804. 8.

Malo, Ilistoire des Roses. Paris s. a. 12.

Kannegiesser, Die Arten der Rosen. Dresden 1805.4.

Andrews, Roses. London 1\$05-182S. 4.

Guerrapain, Almanacl des Roses. Paris 1811. 8.

Lelieur, De la culture du rosier. Paris 1S11. 12.

ITrede, Verzeichniss meiner Rosen. Braunsehweig 1814.8.

Redouté, Les Roses. Paris 1817-1824. folio min.

Pronville, Nomenclature du genre rosier. Paris $1818 . \mathrm{s}$.

Dechesnel, La Rose. Toulouse 1820. 8. - Paris 1838.12.

Lindlcy, Rosarum monographia. London 1820. 8. (gallice.)

Thory, Prodrome de la monographie du genre rosier. Paris 4820.8.

Pronville, Sonmaire d'une monographie du genre rosier. Paris 1822. 8.

Monographie du genre rosier. Paris 1824. 8.

Memoirs on the Rose. Loudon 1824. 12.

Vibert, Observatious sur la nomenclature des Roses. Paris 1824. 8.

- Essai sur les Roses. Paris 1824. 8.

Desportes, Rusetum gallicum. Le Mans et Paris 1828. 8.

De Tarade, Culture des rosiers ecussonnès. Paris $182 \mathrm{~s} .8$.

Selbstherr, Die Rosen in 25 Gruppen und 95 Arten. Breslau 1932. 4.

Booth, Gegen Prof. Lehmann in Betreff der Prachtrose "Konigin von Dánemark ». Altona 1833. 8.

Lehmann, Entgegnung an die Gebrüder Booth. (Hamburg 1834.) 8.

Siemers, Darlegung meiner Verhandlung mil Herrn John Booth. Altona 1834.8.

Docring, Die lionnigin der Blumeu. Elberfeld 1835. 8.

Boitard, Manuel de l'amateur de roses. Paris 1836. 12.

Vibert, Catalogue des Roses. Paris 1836. 8.

Niclicls, Benennung und Reschreibung der Rosen. Presshurg 1836-1837. 8. - ib. 1846.8 .

Gore, The hook of Roses. London 1837.8.

The Rose fanciers manual. London 1838. 8.

Biedenfeld, Das Buch der Rosen. Eine populare Monographie. Teimar 1840, 12.

Rosell. Diisseldorf 1840, gr. 8.

kilier, hibur dor Rosa reclinata (Pyramidalrose). Wien 1843. 8.

Redoute, Le bouquet royal. Paris 4843. folio.

Merrat, Notice sur ln destruction des Roses naissantes par une larve. Paris 1844. 8 .

Pfau, Die Kultur der Rosen. Heilhronn 1846. 8.

De la Chesnep-Monstereul, Le Floriste français. (Tulipa.) Rouen 1650.8 .8 Elsholz, Theatrum Tuliparum. Berolini 1661. folio. (Mser.)

Stapcll, Tulipanen Geheimniss. Lüheck 1663. 12.

(Benemann) Die Tulpe zum Ruhm ihres Schöpfers. Dresdeu 1741. S.

Ardene, Traité des Tulipes. Avignon 1765. 12.

Buchoz, Collection de Tulipes. Paris 1781-1797. folio.

Roessig, Versuch eines neuen Systems der Tulpen. Leipzig (1807.) S.

Diez, Vom Tulpen- und Narcissenbau in der Turkei. Halle 1815. 8.

Malo, Histaire des Tulipes. Paris 1821.8.

Tulpen und Staatspapicre. Ilamburg 1830.8.

\section{Botanica occonomica.}

Scriptores rei rusticae. Venetiis 1472. folio. (Thes. lit. bot. no. $11852-$ 11863.)

Calo, De re rustica. Ed. princeps: Venetiis 1472, folio. - Lipsiae 1794. \&. Columella, De re rustica libri XII el liber de arboribus. Venetiis 1523.4. Lipsiae 4794. 8. (germanice, gallice.)

Palladius, De re rustica libri. Ed. princeps: Venetiis 1472. folio. Lipsiae 1793.8 .

(italice, anglice, germanice.)

Varro, De re rustica lihri tres. Ed. princeps: Venetiis 1472. folio.

Vettori, Explicatio suarum in Catonem, Varronem, Cotumellam castigationum. Lugduni 1542.8.

- Exereitationes in Seriptores de re rustica. Paris 1543.8.

Rottboell, Anmärkinger til M. Portius Calo de re rustica. Kiöbenhavu 1790. 4.

Petrus de Crescentiis, Opus ruralium commodorum. Ed. princeps: Aug. Vind., Schuszler. 1471. folio. (pluries.)

(germanice, gallice, italice, polonlce.)

Llerrera, Obra de agricultura. Alcalá de Henares 1513. folio. - Madrid 1848-1819. 4 .

(latitue, italice.)

Grapaldus, De partibus aedium. Parmae 1516. 4.

Robertus Britannus, Agriculturae encomium. Parisiis 1539. 4.

Estienne vel Stephanus, Sylva, Frutetum, Collis. Paris 1538. 8. Arbustum, Fonticulus, Spinetum. Paris 1538. 8. Pratum, Lacus, Arundinetum. Paris 1543. 8. Praedium rusticum. Lutetiae 1554. 8.

(gallice, italice.)

Alamanni, La coltivazione. Parigi 1546. 4. - ib. 1832. 12.

Tatti, Della agricoltura libri V. Venezia 1560. 4.

Tarelli, Ricordo d'agricoliura. Venezia 1567.8.

Heresbach, Rei rusticae libri quatuor. Caloniae 1570. 8. (anglice.)

Tusser, Five bundreth points af good husbandry. London 15i3.4. - New edition by Mavor. ib. 1812.4 .

Camerarius, Opuscula de re rustica. Noribergae 1577. 4.

Bussato, Giardino di agricultura. Venezia 1592. 4. - Ed. V: Venezia 1781.8 .

Porta, Villae libri Xil. Francofurti a/11. 1592. 4.

Serres, Le théâtra d'agriculture et mesnage des champs. Paris 1600. folio. - ib. $1804-1805.4$.

Quiqueran, Nouvelle agriculture. Tournon 1616.8 .

Deça, Governo politico de agricultura. Madrid 1618. 4.

Tanaro, L'Econonia del citadino in villa. Bologna 1644. 4'.

Austen, Observations upon some part of Sir Francis Bacon's Natural listory. Oxford 1655. 4.

Houghton, Collection af letters for the improvement of husbandry. Lolldon 1681.4.

Liger, Économie générale de la campagne. Paris 1700.4.

Nourse, Campatia felix. London 1700. 12.

Liger, Dictionnaire de l'agriculture. Paris 1703.8.

Vaniere, Pracdium rusticum. Carmen, libri X. Tolosae 1706.12. - Paris 1829. 12.

(gallice, germanice.)

Angran de Rueneuve, Observations sur l'agriculture et le jardinage. Paris 1712. 8 .

Liger, Lo nouveau théâtre d'agriculture. Paris 1712. 8.

Agricola, Neu- und nieerhorter Versuch der Universalvermelırung. Kegensburg 1714. folia.

(gallice, hollandice.)

Nenci, Riflessi supra la collivazione. Siena 1715. 12.

blair, Some botanical improvements communicated to Mr. Petiver. In cjus "Miscellaneous observations n. Lonclon 1718. 8. 
Buechner, Sonderbare Vermehrung der Feldfruchte. Schneeberg 1718. 4. (Micheli) Relazione dell' erba detta da' lootanici Orobanche. Firenze 1723. 8. - ib. 1754. 8 .

Laurence, A new system of agriculture. London 1726. folio.

Mentzer, Svenska akermannen etc. Ilolmiae 1727. 8 .

Evelyn, Terra. London 1729. folio. - York 1786. 4.

Tull, Horse-lıseing husbandry. London 1733. folio. - El. III : ib. 1751. 8.

Trowel, On busbandry and gardening. London 1739. $\mathrm{S}$. (germanice.)

Allward, Betrachtung über die Endte. Stralsund 1747. 8.

Linné, Flora neconomica. Upsaliae 1748. 4. (suocice.)

Brodin de la Jutais, L'abondance ou véritable pierre philosophale. Paris 1752. 12.

Montelatici, Raggionamento sopra l'agricoltura. Firenze 1752. 8 .

Wallerius, De artificiosa foecundatione immersiva seminum. Holmiae 1752. 4.

Ehrhart, Unterricht von einer zu verfassenden PAanzenhistorie. Memmingen 1752. 4 . 1762. 8 .

Du Ilamel, Trailé de la culture des terres. Paris $1753-1761.8$.

Nolin et Blavet, Essai sur l'agriculture maderne. Paris 1755. 12.

Kalm, Om ogrảsens livarjelıanda nytta. Åbo 1757. 4.

Targioni-Tozzelli, Ragionamenti sull' agricoltura toscana. Lucca 1759. 8.

Buchoz, Lettres périodiques. P’aris 1759-1770.8.

(germanice.)

Des Allets, L'agronome. Paris 1760. 8. - ib. 1799. 8.

lillbek, De arena volatili scanensi. Lundae 1760.4.

Trozelius, Tankar om en Ilushållares upmarksambet vid vaxtriket. Lund 1760. 4 .

Aquela y Vigil, Cartilla de la agricultura de Morenas. Malrid 1761. 4.

Bochmer, De serendis vegetalilium seminibus. Wittebergae 1761. 4.

Paulli, Dansk oeconomisk urte-bog. Kiobenhavn 1761, 8.

Wallevius, Elementa agriculturae physico-chemica. Upsaliac 1761. 4. (germanice, gallice.)

In Ilamel, Élémens d'agriculture. Paris 1762. 8. (grrmanice.)

liehler, De nexu studii botanici cum oeconomico. Lipsiae 1763.4.

Prefontuine, Maison rustique a l'usage des liabitans de Cayenne. Paris 1763. 8 .

Zanon, Dell' agricaltura elc. Venezia 1763-1771. 8.

Olt, Kurzer Rericht fur den Landmanu. Zurich 1764. 8.

Schreber, Abhandlung rom Grasbaue. Leipzig 1764.8.

Arduino, Memorie di osservazioni etc. Padova 1766. 4.

Bergius, Tal on svensha áng-shötseln. Stochholm 1769. 8.

Arcluino, Modu di preparare la semenza. Venezia 1770 . 8 .

Ifoyen, Vortheile der Oeknnomie aus der Physik. Berlin 1770. 4.

Ronconi, Dizionario d'agricoltura. Venezia 1771. 8. - Ed. V: ib. 1804.8.

Schreber, Beschrcilung der Queclie. Leipzig 1772. 4.

Bechstedt, Niedersáchisisches Land- und Gartenbuch. Flensburg $1772-$ 1773.8.

Le Rouge, Principes du cultivateur. Fontenay 1773. 8.

Pohl, De soli differentia in cultura plantarum attendenda. Lipsiae 1773. 4.

Thym, Die Nutzbarkeit, fremde Pflanzen einzufulren. Berlin 1775. 8.

Gentil, Essai d'agronomie ou diétėtique générale des végétaux. Dijon $177 \% .8$.

siuckow, Oekonomische Botanik. Mannheim 1777.8. (rossice.)

Tschudy, De la transplantation et naturalisation des végétaux. Londres et l'aris 1778.8 .

Gimetin, Abliandlungen von den Arten des Unkrauts. Lubeck 1779. 8.

llillemet, Pliytographie économique de la Lorraine. Naucy 1780. 8.

Lorenz, Grundriss der Botanik fur Landwirthe. I.eipzig 1781. 8.
Rozier, Cours complet ou Dictionnaire d'agriculture. Paris $1781-1501$ 4. - Ed. 11 : ib. 1809. 8.

Gleditsch, Betrachtung utuer den Ilaideboden der Mark Braudenburg. Be: lin 1782.8 .

Maerter, Vorstellung eines okonomischen Gartens. Wien 1782. 8.

Bertholon, De l'électricité des vègétaux. Paris 1783. 8. (germanice.)

Brugmans, Quaenam sunt plantac inutiles of renenatae, quae prata inficiunt? Groningae 1783.8.

Bochmer, De satione mixta. Wittebergae 1784.4 .

Fabricius, Kultur der Gewáchse. Leipzig 1784. 8.

Belgrove, A treatise upon husbandry and planting. Baston 1785. 4.

Buhle, Calendarium Palaestinae aeconomicum. Goettingae 1785. 8 .

Kerner, Abbildung aller okonomischen Pflanzen. Stuttgart 1786-1796. 4 .

Harasti, Metodo per accrescere gli ingrassí. Milano 1787. 4.

Stein, Versuche üher Angewöluusng auslandischer Pflanzen an den westphálischen Himmelsstrich. Mannlıeim 1787. 8.

Bernard, Mémoires pour servir à l'histoire naturelle de la Provence. Paris $1787-1788,12$.

Mund, Vom Unkraute. Leipzig 1787. 8.

Viborg, Efterretning om Sandvexterne. Kiolsenhavn 1788.4. (germanice.)

- Bestemmelse af de i danshe Lov omtalte Sandvexter. Kiöbenhavı 1795. 8.

De la Brousse, Nélanges d'agriculture. Nismes 1789.8 .

Ilellenius, Ogràsen uti Orihvesi socken af Tavastland. Nho 1789.4.

Curtis, Practical observations on the british grasses. Ed. II: London 1790. 8. - Ed. N: Loncion 1805.8.

Giobert, Trattato di agricoltura etc. Torino 1790.8.

Leonhardi, Symbolac ad historiam agriculturae veterum Germanorum. Bipsiae 1790.4.

Swayne, Gramina pascua. Bristol 1790. folio.

Hagen. De plantis in Prussia cultis. Regiomonti 1791-179x. 8.

(Moser) Ueber Feld-und Gartenprodulte. Leipzig 1791-1794.8.

Boe/mer, De plantis segeti infestis et auctoritate publica exstirpandis, custodiendis et e foro proscribendis. Wittebergac 1792. 4.

Happe, Abluldung okonomischer Pflanzen. Berolini 1792-1794. folio.

Marlyn, llora rustica. London 1792-1794. S.

Suckow, Bezeichnung der vornelimsten Pflanzen. Jena 1794. 8.

Hornemann, Forsog til en dansk oeconomisk plantelacre. Kjolouharn 1795. 8. - Ed. III : ib. 1821-1837. S.

Niemecsky, De plantis parasiticis aliisque segeti obstantibus. Francofurti a/MI. 1795.8 .

Moser, Deutschlands okonomische Flara. Leipzig 1796. 12.

(Buchoz) Flore économique des environs de Paris. Paris 1797. 8.

Gaertner, Meyer et Scherbius, Oekonomisch-technische Flara der Wetteras. Franhfurt a/M. 1799-1S02. S.

Darwin, Phytologia, or the philosophy of agriculture and gardening. London 1800.4 .

(germanice.)

Twent, Proeve of aanteckeningen wegens het planten op Duisıen van Raaphorst. Gravenbage 1800.8 .

Maute, Grasbüchlcin. Leipzig 1801. 4. - ib. 1818.4.

Pictet, Traité des assolemens. Genève 1804. 8.

Simonde de Sismondi, Tableau de l'agriculture toscane. Gcneve 1801.8 (germanice.)

Dichson, De l'agrieulture des anciens. Paris 1802.8.

Tassin, Rapport sur les Dunes du golfe de Gascogue. Mlont de Mirsan (1802.) 8 .

Targioni-Tozzelli, Lezioni di agricoltura. Firenze 1802-1804.8.

De Candolle, Mémorre sur la fertilisation des dunes. Paris 1503.8.

Hashington, Letters to Sir Arthur Sinclair on the rural economy of the Linited States. Alexandria 1803.4.

Biroli. Flora ecunamica del dipartimento dell" Agogna. Vercelli 1805.8 . 
Friebe, Oekonomisclı-technische Flora fur Liefland, Esthland und Kurland. Riga 1803.8 .

Mansky, Der Feld-, Wiesen- und Gartenbau Sudpreussens. Posen 1805. 8.

Tollard, Traité des végétaux qui eomposent l'agrieulture française. Paris 1805. 8. - ib. 1838. 12.

Whistling, Oekonomische Pflanzenkunde. Leipzig 1805-1807.8.

Tavanti, Memoria I-II. Firenze 1805-1807.4.

Cambry, Notiee sur l'agriculture des Celtes et des Germains. Paris 1806.8.

Re, Elementi di agricoltura. Venezia 1806. S.

kelsius, Försobk till en Flora oeconomica Sueciae. Lund 1S06. 8. - Bihang: ib. 1812.4 .

Dickson, Practical agriculture. London 1807.4.

Yvart, Coup d'oeil sur le sol, le climat et l'agriculture de la France. Paris 1807. 8.

Gondinet, Les plantes nuisibles qui infostent les prairies. Limoges 1 \$ 08.8 .

Targioni-Tozzetli, Prospelto per la Flora economica fiarentina. Verona 1808.4 .

Biroli, Georgiea dell' Agogna. Novara 1809. 8.

Pollini, Dell' influenza delle scienze naturali sull' agricoltura. Verona 1809. 4 .

Gallizioli, Elementi botanico-agrari. Firenze 1509-1812.8.

Toll, Guter Rath fur den Landmann. Reval 1810. 8 .

Crome, Pflanzenkunde fur Landwirthe. Hannover 1810-1811. 8.

Lagasca, Lista de plantas de la China, del Japon, Amboyna, Malabar y Filipinas eonaturalizadas en España. In "Amenidades". Orihuela 1S11. 4

Willy and Rind, The agriculture museum. Georgetown 1811. 8 .

Wredow, Oekonomisch-teehnische Flora Meklenburgs. Luneburg $1 \$ 11$ 1812.8 .

Crome, Der Boden und sein Verhältniss zu den Gewälısen. Jlannover 1812. 8

Qucnin, Mémoire sur les prairies artifieielles. Aix 1 \$ 12.8 .

Davy, Elements of agricultural chemistry. London $1813.4 .-$ ib. 1839.8. (gullice.)

Gouffé de la Cour, Mémoire sur les végétaux exotiques qui peuvent etre naturalisés dans le midi de la France. Marseille 1813. 8.

Veith, Abriss der Kräuterkunde. Wien 1813.8.

Boutelou, Discurso acerea del origen y progresos de la agricultura. Alicante 1816.4 .

Ilornemamn, Om Berberissen kan frembringa kornrust? Kiobnhavn 1816.8.

Morel, Notice sommaire sur les assolemens. Paris 1816. 8.

- Observations sur la théorie des assolemens. l'aris 1822-1823. 8.

Sinclair, Hortus gramineus woburnensis. London 1816 . folio, - ib. 1825. 8. - ib. 1838.8 .

(gallice, germanico.)

Murphy. Treatise on agricultural grasses. London 18.. S.

North, An aecount of the different Kinds of grasses propagated in England. London s. a. 8.

Sandalio, Leeciones de agricultura. Madrid 1816. 4

IJoorebelie, Mémoire sur les Orobanehes. Gand 1818. 8.

(Pollini) Osservazioni meteorologiche ed agrarie. Verona 1818. 8.

Giobert, Del sovescio. Torino 1\$19.8.

- Del sovescio di segale. Torino 1519. $\mathrm{S}$.

Verri, Risposta alle Iettere sul sovescio di segale. Milano 1819.8 .

Sinclair, Collo of agriculture. London 181.8 (germanice, gallice.)

Berchlold et Presl, O Přirozenosti Rostlin, ancb Rostlinár̆ ete. W Praze 1820.4.

Leuchs. Anbau auslàndiseher Pflanzen. Nurnberg 1821.8.

Schucbler, Uebersicht der wichtigsten Eigensehaften der Achererden. Stuttgart 1821. folio.

Phillips, History of cultivated vegetables. Landon 1822. 8.

Sari, Sulla naturalisazione delle piante. (Pisa 1822.) 8 .

Zenneck, Oekonomische Flora. Stuttgart und Prag 1822.4.

Pritzel, Thes. lit. bot
De Candolle, Discours de eloture d'un cours de botanique agricole. Genève 1823. 8 .

Bosc, Traité élémentaire de physique vẻgétale appliquée à l'agriculture. Paris (1824.) 8.

(rossice.)

Morogues, De l'influence des réeoltes intercalaires sur les blés, qui leur suecèdent. Orléans 1824.8

Setle, Memoria sull' arrossimento di aleune sostanze alimentose. Venezia 1824.8 .

(Sadler) De Stipae noxa. Pestini 1825. 8

(germaniee, luungarice.)

Schoder, Die Erdarten im Gehiete der Pflanzenvegetation. Ludwigsburg 1825.8.

Smith, Traité d'agrieulture el horticulture. Paris 1825. 12.

(anglice.)

Gasparin, Des effets des climats sur les assolemens. Paris 1826.8.

Jeppe, Herbarium vivum der vorzüglichsten Futtcrkräuter und Gräser. Hamburg 1826. 4. - Rostock 1835.4.

Moretti, Biblioteca agraria. Milaue 1\$26-1\$39. XXIll voll. $s$. (X: Gelsi. XX: Alberi fruttiferi. XXII : Nosologia vegetabile. VIll-X: Orti.)

Fischer, Besehreibung aller Gift-, Arznei- und Futtergewaiehse. Neuzelle 1S27.8.

Teindl, Die Unkrautpflanzen. Wien 1827. 8.

Thouin, Cours de culture et de naturalisation des végétaıx. Paris 1827. 8. ot Atlas.

Ilundeshagen, Lelırbuch der forst- und landwtrtıschafilichen Naturkiunde. Tubingen 1827-1 830.8 .

Schmidt, Allgemeine ohonomiseh-technische Flora. Jena 1827-1829. 8.

Numan et Marchand, Sur les propriétés nuisibles des fourrages par des productions eryptogamiques. Groningue 1830. 8.

(hollandice.)

Perrottet, Observations sur les essais de culture tentés au Sénégal. Paris 1831.8.

Schuebler, Grundsătze der Agrikulturehenie, Leipzig 1\$31. 8. - ib. 1838. 8

De Candolle, Essai sur la théorie des assolemens. Genève 1832. 8.

Lecoq, Reeherches sur l'emploi des engrais salins. Clermond-Ferramil 1832. 8 .

Sinclair, llints on vegetation. London 1832, 8 .

Jacobi. De rehus rustieis veterum Germanorum. Lipsiae 1833, 8.

Porter, The tropical agriculturist. London 1833.8

Reum, Dekonomische Botanik. Dresden 1833. 8.

Lastri, Corso di agricoltura pratica. Milano 1834. 8.

_ Calendarj pei contadini. Nilano 1834. 8

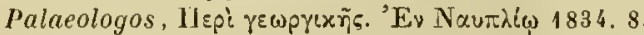

Wahlberg, Anvisning till svenska foder-växternas kännedon. Stochholn 1835. 8.

Latuson, The agriculturists manual Edinburgh 1 \$ 36.8 .

Baflenea $u$-Delile, Essais d'acelimations a Montpellier. (Moupellier 1836.) $\mathrm{S}$.

Vogeli, Flore fourragère. Paris 1836. 8.

Dierbach, Grundriss der okonomisch-technischen Botaniti. Heidelherg 1836-1839. \&.

Berchtold, 0ekonomiseh-teehnische Flora Bohmens. Prag 1836-1841.8.

Millet d'Aubenton, Notice sur la eulture des oseraies dans le depart. de l'Aisne. Lyon 1837. 8.

Pabst, Der landwirtlischaftliehe Pflanzenhan. Darmstadt 1839. 8 .

Taunay et Riedel, Manoal do agrieultor brasileiro. Rio de Janeiro 1839.

Lilja, Flora ofver Sveriges odlade vexter. Stockholm 1839-1840. S.

Biusoletio, Conspectus plantarum oecononicarum lstriae. (Impr. in: Pittoreskes Oestreich, no. 13.) Wien 4840.4.

Schmalz, Theorie des Pflanzenbaues. Konigsbery 1840.8 .

Faux, Outlines of tilling land. London 1840.8 .

IHuebener, Beitráge zur Agronomie. (Duwoek = Equisetum.) Hamburg 1841. 8 . 
Metzger, Landwirthschaflliche Pflanzenkunde. 1leidelbery 18:1. 8. Seringe, Le petit agriculteur. Paris 1841. 12.

Dietrich, Deutschlands okonomische Flora. Jena 1841--1843.8.

Langethal, Lehrbuclı der landwirıhschaftliclien Pflanzenkunde. Jena 1841 -1845.8 .

Scheidweiler, Cours raisonné et pratirque d'agriculture el de chimie agricole. Bruxelles 1841-1843.8

Avellino, Sulla necessita etc. Napoli 1842. 8.

Boutelou, Aclimatisacion de plantas ecsóticas. Sevilla 1812.4

Loebe, Naturgeschichte fur Landwithe. Leipzig 1842. S.

Schmalz, Anleitung zur lienntniss und Auwendung eines neuen Acherbausystems. Leipz!g 1842.8 .

Bellani, Delle rotazione agrarie. Pesara 1843. 8.

Jaune Saint-Ifilaire, Catalogue raisonné desplantes iuutiles et nuisilıles. Paris 1843.4.

Solly, Rural chemistry. London 4843.8.

Kreyssig, Die Mlenge- und Zwischensaaten der Feldgewächse. Braunschweig 1844. 8.

Lecoq, Traité des plantes fourragères. Paris 1844. 8.

Philippar, Programme raisonnć du cours de culture. Versailles 1844.3.

Uslar, Die Bodenvergiftung dureh die Wurzelausscheidungen. Aliona 1844.8.

Braconnot, De l'influence du sel sur la végétation. Nancy 1845.8 .

Hofmann, Die Kultur der Handelsgewaichse. Prag 1845.8.

Sauvanau, Rechercbes sur la compesition des terres végétales des dép. du Rhone el de l'Ain. Lyon 1845.8.

Bouchardat, Recherches sur la végétation appliquées à l'agriculture. $\mathrm{Pa}$ ris 1846.12.

Hermann, Oekonomische Pllanzenkunde. Kolberg 1846.8.

Paquet, Traité de la culture des plantes potagères. Paris 1846.12.

Paulet, Chimie agricole. Saint-Denis-du-Port 1846. 8.

Strehler, Ueber das Missrathen der Erndten. Straubing 1846.4.

Schlipf, Der Pflanzenbau. Reutlingen 1847.8.

Sprengel, Erfahrungen im Gebiete der Phanzenkultur. Leipzig 1847. 8.

IVolf, Die ehemischen Forschungen auf dem Gebiete des Agrikultur und Pflanzenphysiologie. Leipzig 1847.8.

\section{Cultura et usus plantarum singularum.}

Montalbanus, Geoscopia cereale. Bologna 1636. 4.

Castelli, De qualitatibus frumenti. Neapoli 163\%. 4.

Wolf, Entdeckung der walıren Ursaclie vou der Vermehruug des Getraides. Halle 17is. 4. - ib. 1750. 4.

Erláuterung der Entdeckung ete. ib. 1718. 4.

Du Hamel, Von der Erhalıng des Getraides. Leipzig 1755-1768. S.

Kolb, Laodbetrachtung vom Getraide. Frankfurt 1764.8.

Ledermueller, Zergliederung des Korns oder Rockens. Nurmberg.1764. folio.

1765. fulio.

Griselini, Maniera di coltivare il frumento. Venezia 1765. 4.

Manelti, Delle specie diverse di frumento di pane. Firenze 1765. 4.

Gadd, Försok om utlandske sảdesarter. Ả bo 1770. 4.

(Moscati) Dissertazioni sopra una gramigna che nella Lombardia iufesta la Secale. Mlilano 1772. 4.

Parmentier, Analyse du bled et des farines. Paris 1776. 8.

Sage, Analyse des blés. Paris 1776. 8.

Vogler, Vom Sonmerspelz oder Emmer. Wetzlar 1777. 4.

Poncelet, Histoire naturelle du froment. Paris 1779. 8.

Joerlin, Avena elatior. Lundae 1781. 4.

Harasti, Colivazione del frumento. Vicenza 1784.8.
Arduino, Del genere degli olchi o sorghi. Paduva 1786.8 .

Viborg, Afhandling om Bygget. Kiöbenharn 1788. 4. (germanice.)

Arduino, Del genere delle avene. Padova 1789.4.

Memoria sopra Arena altissima. 1792. 8.

Parmentier, Rozier, Lasteyrie et Delaluuse, Traité sur la culturn des grains. Paris $180 \mathrm{z} .8$.

Mazzucalo, Sopra alcune specie di frumento. Padova 1807.8 .

Bayle-Barelle, Monografia agronomica dei Cereali. Mlilano 1809. 8.

Fischer, Anbau ausländischer Getraidearten in Deutschland. Nurnberg 1810. 8.

Mazzucato, Triticorum definitiones atque synonyma. Lini 1812. s.

Lamouroux, Rapport sur le blé Lammas. Caed 1813.8.

Lagasca, Instruccion sobre el modo .... a la perfeccion de La Ccres españold. (Mladrid 1816.) 4 .

Tenore, Osservazioni intorno la collezione de' Cereali. Napoli 1817. 8.

Schuebler, Characteristica et descriptiones Cerealium. Tubingae 1818.8.

Seringe, Monographie des Céréales de la Suisse. Berne 1819.8.

Toll, Anleitun zum Anbau der Gerste. Reval 1819. 8.

D'Artigues, Memoire sur la conservation des blès. Paris 1820. 8.

Sinet, Perfectionnement de la culture des Céréales. Paris 1821. 8.

Brun de Beaumes, Comple de quelques essais de culturc sur 10 plantes céréales. Paris 1822. 8.

Metzger, Europáische Cerealien. Heidelberg 1824. folio.

Hoclbling, Ueber das Versetzen der Getreidepflanzen. Wien s. a. $\$$.

Krause, Abbildungen und Beschreibung aller bekannten Getraidearten. Leipzig 1835-1837. folio.

(Fischer et Meyer) Bericht etc. (St. Petersburg 1837.) 4.

Lirause, Das Getraidebuch. Leipzig 1840.8.

Trautvelter, Anleitung zum Bau der Himalayagerste. Dresden 1840. S. Der Schilfroggen. Dresden 1840.8.

Melzger, Die Getraidearten und Wiesengráser. Heidelberg $1841 . \mathrm{S}$.

Seringe, Deseription et figures des Céréales européennes. P'aris $1841 \mathrm{~s} \mid \uparrow$. gr. 8.

Loiseleur, Considérations sur les Céréales. Paris 1842-1843. 8.

Le Conteur, Veber Varietáten und Klassifikation des Weizens. Laipzig 1843. 8 .

(anglice.)

Gérard, Notice sur le froment. Paris 1845.8.

Spolverini, La coltirazione del riso. Verona 1758.4

Chinaglia, Orizomanio manuale. Mantova 1782.8 .

Toso, Sopra la coltura delle risaje. Verona 1786.8.

Cacanilles, Sobre el cultivo del arroz en el rẹno de Valmonria. Madrid 1798. 8 .

Tidyman, De Oryza sativa. Goettingae 1800.4.

Biroli, Del risu trattato economico rustico. Mlilano 1807 . S. - it. 1825.8. In difesa delle risaie lombarde e piemontesi. Milano 1817.8 .

Astolf, Coltura del riso secco o chinese. Bologna 1827. 8 .

Boutelou, Instruccion sobre el cultivo del arroz de secano. Iladrid $18 . .4$.

Ormea, Saggio sul riso Bertone e mezzi per prerenire la malattia del brusone. Toripo $1833-1834$. 8 .

Wedel, De Maza. Jenae 1693. 4.

Parmentier, Procédé pour eonserver le mais. Bordeaux 1785.4 .

Harasti, Della coltirazione del maiz. Vicenza 1788. 8 .

M/arabelli, De Zea Mlays planta. Papiae 1793. 8 .

Lelieur, Culture du mais et de la patate douce. Paris 1807.8 .

Burger, Naturgeschichte des Mais. Wieo 1809. 8.

Parmentier, Le maıs ou blé de Turquie. Paris 1812.8.

Neufchate'au, Supplément au Jémoire de Parmentier sur le maiz Paris 1817. 8.

Colbell, A treatise on Culbett's curn (Zea Maṛs). London I\$2S. 8 . 
CULTURA ET USUS PLANTARUM SINGULARUM

De Candolle, Resumé de quelques travaux récents sur le mais univ. de Genève 1830. vel. XLJIJ, $80-92$.)

Duchesne, Traite du mais. Paris 1835.8. (germanice.)

Bonafous, Histoire naturelle du mais. Paris 1836 . fobio.

Broune, An essai un indian corn. Philadelphia 1837. 8 .

Aquilanıs, Origine, qualitá e specie de' peponi. Firenze 1602. 4.

Maistre, Le procès du melon. Paris 1607. 4.

Mollet, La manière pour eslever des melons. s. I. 1659. 4.

Pons, Traité des melons. Lyen 1680. 12.

Duchesne, Histoire naturelle des courges. s. J. et a. 8.

Calvel, Du melon. Paris 1810.8.

herner, Les melons. Stuttgart 1810. felio.

Sageret, Nemoires sur les Cucurbitacées. Paris 1826-1827. S.

Martin, Wavuel de l'amateur de melons. Paris 1827. 18.

11'cise, Der Melonen-, Gurhen- und Spargelgártner. Illmenau 1830. 8.

Jacquin, Monograpbie complète du melen. Paris 1832. 8.

Chambray, Culture du melon. Paris 1835. 8.

Ilofmann, Anweisung zum geregelten Anhau des Kurbis. Wien 1837. 8.

Loisel, Traite de la culture des melens. Paris 1841. 12. (germanice.)

Mills, On the culture of eucumbers, melons etc. Lenden 1841. 8 .

Smith. On the growth of cucumbers and melons. Lendon 1841.8 .

Trozelius, Anmarkningar vid Hvit- och Rutkảhls planteringen. Lund 1762. 4 .

Griselini, Della coltura del napo sävatico detto ravizzone. Venezia 1771. 4.

Nanière de cultiver la navette et le colzat. Paris 1774.8.

Instruction sur la culture des navets. Paris 1785. 8.

Sonnini, Sur la culture du chou-navet de Laponie. Paris 1788. 8.

De Commerell, Culıure et l'usage du cheu-à-faucher. Paris 1789. 8.

Hoeller, Versuche den englischen Senf als Oelpflanze zu bauen. Dortmund 1796. 8.

Curtis, Directions for cultivating the Crambe maritina. Lendon 1799. S.

Grandi, Cultivazione del rafano oleifere cinese. Piacenza 1807. 8. (germanice.)

(Olcese) Sulla collivazione delle biete rape. Genova 1811.8 .

De Candolle, Mëmoire sur les différentes espèces, races et variètés de choux et de raiforts en Europe. Paris 1822. 8.

(anglice, germanice.)

Metzger, Systematische Beschreibung der kuitivirten hohlarten. Heidelberg 1833.8 .

Pepin, Sur la culture du Chou Pè-Tsaie, Brassica sinensis L. Paris 1840.8.

Hoppe, l'ericht von denen Erdäpeln. Wolfenbuttel 1747. 4.

Montelatici, Estratti sopra coltivazione delle patatc. Firenze 1767.4.

Zanon, Delle coltivazione delle patate. Venezia 1767.8.

Mustel, Némoire sur les pemmes de terre. Rouen 4768.8

- Némoire sur la culture des pommes de terre. Rouen 1770. 8.

Ludwig, Alhandlung von den Erdapfeln. Bern 1770. 8.

Naegeli, Luterricht von Pflanzung der Erdapfel. Zuriclı 1771. 8.

Parmentier, Examen ehimique des pommes de terre. Paris 4773. 12.

- Sur les pommes de terre, le froment et le riz. Paris 1774.12.

Vigo, Tuhera terrae. Taurini 1776. 4. (italice.)

Alströmer, De cultu pattatas. Stockholm 1777. 12.

Parmentier, Nanière de faire le pain des pommes de terre. Paris 1779. 8. L_._. Les pommes de terre. Paris 1781. 12.

Baldini, De' pemi di terra ragiouamento. Napoli 1783.8 .

Bavegem, Prijsverbandeling over de ontaarding der aardappelen. Derdrecht 1782. 8 . 1783.8

\section{CULTURA ET USUS PLANTARUM SINGULARUM}

Parmentier, Instruction sur la conservation et les usages des pommes de terre. Paris 1787.8.

- Sur la culture et Jes usages des pomnes de terre, de la $\mathbf{P a -}$ tate el du Tepinambeur. Paris 1789. 8.

Kirkpalrik, An account of Patateos. Warrington 1796. 8.

Maerter, Naturgeschicbto der Bataten. Wien 1797.8.

Amoretti, Della coltivazione delle patate. Milano 1804. 8 .

Stockmar, Ueber den verderblichen Nisswachs oder die unfruclutbare Abartung der Karteffeln. Berlin 1802. 8 .

Dandolo, Coltivazione de' pomi di terra. Ceme 1810. 8.

Dunal, Histoire naturelle, médieale et économique des Solanun. Nontpellier 1843. 4.

Sageret, Mémoire sur le semis de la Solanée parmentière. Paris 1814.8. Bella, La coltivazione delle patate. Verona 1816.8 .

Bassi, Del pemo di terra. Lodi 1817.8.

Re, Saggio sulla coltivazione del pomo di terra. Milano 1817.8.

Moretti, Sulla coltivazione della Batata dolce. Milano 1818. 8 .

Juch, Das Ganze des Karteffelbaues. Ulm 1818. 8.

Pulsche, Versuch einer Nonegraphie der Kartoffeln. Weimar 1819.4.

Martinel, Tableau $(\mathbf{I}-\mathrm{V})$ sur la culture de la Solanée-Parmentière. Lyen 1821-1824. folio.

- Tableaux usuels destinés aux agriculteurs. Lyon 1824.4.

De Candolle, premier rapport sur les pommes de terre. (Bibl. univ. de Genève 1822. VII, 275-288.)

Payen et Chevallier, Mémoire sur la culture des pommes de terre. paris 1823. S.

Traité de la pomme de terre. Paris 1826.8.

Trappen, Historia Solavi tuberosi L. Trajecti a/Rh. 1835.8 .

Girardin et Du Breuil, Deuxième mémoire sur la pomme de terte. Rouen 1841.8.

Berchtold, Die Kartoffelı. Prag 1842.8.

Most, Das Karteffelbuch. Quedlinburg 1842. 8.

Preiss, Die Kartoffelpflanze. Leipzig 1844, 8 .

Mauz, Ueber KartofYelbau und lirankheiten der Kartoffeln. Stuttgatt. 1845.8.

Plack, Anweisung zur Verbesserung der Kartaffeln. Breslau 1846. ৪

Schinz, Menographio des Kartoffelbaues. Aarau 1846. 8.

Loebe, Die Krankheiten der Kartoffeln. Leipzig 1842.8.

Martius, Die Kartoffel-Epidemie der letzten Jahre. München 1842. 4. (hollandice.)

Wallroth, Die Naturgeschichte der Erysibe subterranea Wallr. (Karteffelbrand). In ejus "Beitrage" J. Leipzig 1842.8.

Berkeley, Observations on the Potato Murrain. (Lendon 1845.) 8.

Bergsma, De aardappel epidemie in Nederland. Utrecbt 4845.8.

Blanchet, De l'épidemic des pommes de terre. (Lausanne 1845 .) \&.

Dumortier, Sur la cloque de la pomme de terre. Bruxelles 1845.8.

Philippar, Notice sur la maladie des pommes de terre. Paris 1845. 8.

Richard, Die Karteffelkranklieiten. Hamburg 1845. 8.

Seringe, Rapport sur la maladie des pemmes de terre. Lyon 1845.8.

Vrolik, Waarnemingen over de ziekte der aardappelen. Ansterdam 1845.8 .

- Observations rélatives a la maladie des pommes de terre. Amsterdam 1846. gr. 8.

Decaisne, Histoire de la maladie des pommes de terre en 1843. Paris 1846. 8 .

Focke, Die Krankheit der Kartefleln. Bremen 1846. gr. 4.

Greff, Les pommes de terre régénẻrées. Metz 1846.8.

IIarting, Recherches sur la maladie des pommes de terre. Insterdam 1846. 8.

(Laine) Encore la maladic des pommes de terre. Paris 1846.4.

Martens, Sur la maladio des pommes cle terre. (Bruxelles 1846.) 8.

Martius, Sendschreiben üher die Kartoffelkrankheit. Utrecht 1846.8 . 
(Morand) Mémoire sur la maladie dos pommes de terre. Gap 1846.8. Mucnter, Die Krankbeiten der Kartoffeln. Berlin 1846. 8.

Opitz, Das Wesen der Kartolfelkrankheit. Sclneeberg 1846.8.

P'elzholdt, Die sogenannte kiartoffelfutule. Dresten 1846,8.

l'avis, Notice sur la maladie de la ponme de terre. Boury 1846.8 .

Schauer, Die Stockfáule der Kiartoffeh. Anclam und Swinemunde 1846. 8. Smee, de la ponme de terre et do la cause de sa maladie actuelie. London 1846.8 .

Mauz, Erörterungen uber die Kartolfelkranklıeit. Stuthgart i\$47. 8.

Payen, Enquete sur la maladie des ponunes de terre en France. Paris 1847. 8.

Pluskal, Die sámmtlichen Krankheiten der Kartoffeln. Brunn 1847.8.

Townley, The diseases, regeneration and culture of the Potato. London 1847. 8.

Zerzog, Fün und zwanzig IIauptrogeln wher Abhulfe der KartoffelkrankLeiten. Bayreuth 1846.8 .

Zinker, Beobachtungen uber die Kartoffelkrankheit. Mtunchen 1847.8

Zuppinger, Die glucklich entdechte Ursache der Kartoffelhrankheit. Zurich 1847.8.

Observations sur la maladie des pommes de terre. Paris 1847.8.

Griseom, Observations on the Apocynum cannabinum. Pliladelphia 1833. 8 .

Brisman, Våra kunskaper om Fiorin-gräset (Agrostis alba 1..). Stockholm 1818. 8. - Bihang: ib. 1818. 8 .

Frémont, Note sur l'Arachirle. Poitou 1806. 8.

Vassalli, Saggio sopra l'Arachis hypogaea. Torino 1807. 8.

Tenore, Memoria sull' Arachide americana. Napoli 1807.4.

Sonnini, Traité de l'arachide. Paris 1808.8.

Biroli, Memoria sulla collivazione dell' Arachis hypogaea e del Cypero esculento. Novara 1809. 8 .

Grigolati, Della Arachide ipogea. Rovigo 1836. 8.

Sprengel, Gesammelte Nachrichten von der Arakatscha. Dreseleu 1808. 8. De Candolle, Notice sur l'Arracacha. (Genève 1829.) 8.

Gadd, Afhandling om Asclepias syriaca. Ảbo 1778. 4.

Jlocller, Ueber die Asclepias syriaca. IIamm 1793. 8.

Capece-Latro, Memoria su l'Apocino. Roma 1804. s. (gallice.)

Sonnini, Traité des Asclepiaclées. Paris 4810.8.

Mueller, Von Anbau und Nutzen der Asclepias syriaca L. Frankfurt a/MI. 1802. 8 .

Fillassier, La culture de la grosse asperge dite de Hollande. Paris 1783. 12.

Hellenius, De Asparago el quibusdam liujus succedaneis. Aboac 1788. 亿.

(Roland) Méthode pour faire un fossé d'asperges. Carcassonne 1807. 12.

Niven, Verbesserte Kultur des Spargels. Quedlinburg 1841.8. (anglice.)

Loisel, Traité de la culture de l'asperge. Paris 1846.8 .

Fallèn, De Beta pabulari. Lundae 1792. 4.

Noeldeehen, Veher den Anbau der Runkelruben. Berlin 1797-1800. 8.

Achard, Ausfuhrliche Beschreibung der Methode etc. Berlin 1799. 8. (gallice.)

Nicolai, Ueher den Zucherbau in den preussischen Stanten. Berlin 1799.8. Roessig, Botanische Bestimmung der Runkelrüben. Leipzig 1800. 8.

Leibitzer, Abbandlung von der Runkelrübe. Leutschau 1804. S.

Wolf, Deutschlands Gemuse. (Nangoldarten, Beta.) Nurnberg 1805.4.

Barruel et Isnard, Extraction du sucre des betteraves. Paris 1811. 8.

Calvel, De la belterave. Paris 1811.8.
Sangiorgio, Sulla coltivazione della barbietola come pianta da zucchero. Mliano 1812. 8.

Tessier, Instruction sur la culture de la letterave. Paris 1812. 8.

Bonafous, Della coltivazione della barbabictola. Torino 1836.8 .

Hlubek, Die Runkelrube. Laibach 1839.8.

Péligot, Recherches sur l'analyse et la composition chimiques de la betterave a sucre. Paris 1839.8 .

Speechly, Treatise on the culture of the pine apple. York 1779. 8. (hollandice.)

Griffin, Culture of the pine apple. Newark 1808. 8.

Knight, Das Ganze der Ananaszucht. Ilmenau 1825. 8. (anglice.)

Piccioli, Nuovo e sicuro mezzo etc. Firenze 1828. 8.

Hamilton, Treatise on cultivation of the pine apple. London $18-, 12$.

Loudon, Modes of cultivating the pine-apple. London 184-8.

Baruffaldi, Il canapajo. Bologna 1741. 4.

Berli, Coltivazione della canape. Impr. cum Baruffuld, II canapajo. Bologna 1741. 4.

Marcandier, Traité du chanvre. Paris 1758. 12. (auglice, germanice.)

Rozier, Mémoire sur la culture el le rouissage du chanvre. Lyon 1787. \$. (italico.)

Brulles, The mede of cultivating and dressing hemp. (London) 1790.4.

Wisselt, On the cultivation and preparation of hemp. London 1804. 4.

Mauz, Verbesserung des Hanfbaues. In ejus a Versuclıes. (Tubingen 1822.) 8.

Gallesio, Nemoria sulla canapa. Torino 1829. 8.

Baumann, Mémoire sur la cbicorée en France. Paris 1818.8 .

Targioni-Tozzelli, Sulle Cicerchie memoria. Firenze 1793. \&.

Targioni-Tozzelli, Sulla Datisca cannabina. (Firenze 1\$35.) 8.

Mazzucalo, Sullo zucchero dei Diospyros. s. I. et a. 8 .

Thiel, Anleitung zum Anbau der Weberkarde. Prag 1824. s.

De Commerell, Culture et l'usage de la diselle. Lansanne 1786. \$. (hollandice.)

Duchesne, Histoire naturelle des fraisiers. Paris 1766. 8. Essai sur l'histoire natnrelle des fraisiers. s. l. et a. ๖.

Du Ilamel, Histoire naturelle des fraisiers. In ejus "Traité des arohres fruitiers $\$$. Paris 1768. 4. (germanice.)

Nietner, Das Ganze der Erdbeerzucht. Berlin 1\$42. \$.

Quatremere d'Isjonval, Essai sur les caractires qui dislingent les cotons. Paris 1784. 4.

Rohr, Anmerkungen uber den Cattunl,au. Altona 1791-1793. 8. (gallice.)

Traltiniek, Anleitung zur hultur der Baumwelle in Oestreieh. Wien 1797. 8 .

Leblond, Mémoire sur la culture du cotonier. Cayenne 1801. 4.

Tessier, lnstruction sur la culture du coton en France. Paris 1807. 8. ib. 1808 . 5 .

De la Steyric, Du cetonuier et de sa culture. Paris 1808.8 . (Iatine, germanice, slowacice.)

Martin, Culture du coton dans le dép. du Var. Toulon 1808. \$.

Paris, Mémoire sur la culturo des cotonniers. Paris 1810.8 .

$\mathrm{Re}$, Del cotone. Nilano 1811. 8.

Roxas Clemente y Rubio, Nemoria sobre el cultivo y cosecha del Algodon. Madrid 1818. $\mathrm{s}$. 
Blumenhain, Die krautartige Baumwollenpflanze. Brunn 1826. 8. Pelouze, Expesé complet de la culture du ceton aux Antilles. Paris 1838. 8.

Tenore, Memoria sulle diverse specie e varietà di cotone. Napoli 1839.4.

St. Foine improved. Londen 1671. 4.

Do la culture du sainfoin. (Hedysarum Onobrychis L.). Paris 1797. 8.

$R e$, Saggie sepra la steria e il celtivamento dell' erba medica. Milano 1816. 8.

Scot, A perfite platforme of a heppe garden. Lenden 1574. 4.

Bromelius, Lupologia. Stockliolm 1687. 12.

Bradley, The riches of a hopgarden. London 1729. 8 .

Thoering, Preisfrage, ob der baiersche Hopfen dem böhmischen an Gúte gleich sei? München 1769. 8 .

Payen et Chevallier, Mémoire sur le heublon. Paris 1823. 8. - ib. 1828. 8.

Denis, Notice sur la culture du houblon. Tenl 1828. 8.

Speck-Sternburg, Darstellung des Hopfenbaues zu St. Veit in Oberbaicrn. Leipzig 1840.8.

Hocke, Bohmens IIopfenbau. Wien 1843. 4.

Dorn, Anleiung zum Ingberbau. Leipzig 1805. 8.

Mueller, Anbau der Erdmandeln. Frankfurt a/M. 1802. 8.

Bennet, Om Lins planterande. Stockbolm 1738. 4.

Berch, Natra sokns Lin-sáde i Angermanland. Upsala 4733. 8.

Kalm, Om det grona Linets plantering. Ảbo 1757. 4 .

Harasti, Della piu utile celtivazione del lino. Vicenza 1783.8.

Gadd, Anmárhningar om Lin - och Hampe vaxterne. Ảbe 1786, 4.

(Trecco) Coltivaziene e governo del lino marzulo. Vicenza 1792. 4

Sacco, Metodo di preparare il line e la canapa. Milane 1823. 4.

Nagel, Lnterricht zum Leinbau. München 1831. 8.

Veit, Anleitung zum Leinbau. Augsburg 1841. 8.

Girardin, Sur le Madia oleifere. Rouen 1841.8.

Pasquier, Monographie du Madia sativa. Liège 1\$41. 8.

David, Mémoire sur le Madia. Caen 1842.8.

Nagel, Unterricht zum Mohnbau. Münclien 1828. 8.

Hayne, Arten und Abarten essbarer Fasolen. Mser. horti vindob.

Faujas-de-Saint-Fond, Mémoire sur le Phermium tenax. Paris 1813.4. Gillet de Laumont, Sur la fructification du Phormium tenax a Cherbeurg et à Toulon. (Paris) 1824. 8.

Meyer, Ueber Seidenflachs. besonders den nenseelandischen. (Kionigsberg 1842.) 8 .

Arduino, Memoria sepra la coltura dell' herba Pimpinella. Venezia 1773.8.

Coste) Précis listorique de l'importation et de la naturalisation en France du Rheum palmatum L. Paris 1805.8.

Casaux, Petite culture des cannes à sucre. London 1779. 4.

Essai sur l'art de cultiver la canne. Paris 1781.8.

Lebreton, Traité sur Je sucre. Paris 1789. 12.

Dutrone La Couture, Précis sur Ja canne. Paris 1790. 8.

Nocca, Lettera sull' origine dello zucchero e su la coltivazione antica del cannarneli in Calabria. Pavia 1812. 4.

- Lettera iı conforma dell' oppinione, che il cannamele nou fu mai coltivato in Calabria. Pavia 1813.4.
(Vaccari) Sul richiame della canna zuccherina in Sicilia. Palermo $18 z ;-$ 1826. 8.

(Ritter) Die Kultur des Zuckerrohrs in Asien. s. I. et a. 8.

Casagrande, Della pianta del sanguigno. Roma 1787. 8.

(Maugin) Question du Sésame. Pétition adressée aux chambres législatives. Douai 4843.8 .

Arduino, Della coltura del Solano di Guinea. Padova 1793. 8.

Baumann, Ueber die Kultur der spanischen Pfeferpflanze. Wien 1812. 8. Csiliy de II. Oklind, De Spilanthe oleracea. Pestini 1836. 8.

Zuccagni, Istoria di una pianta panizzabile del Abissinia, Tef. Firenze 1775. 8.

Buechner, De Soda hispanica. Ilalae 1758. 4.

Imlin, De Soda et ejus peculiari sale. Argentorati 1760. 4.

Dejean, Historia, analysis et usus Sodae hispanicae. Lugduni Bataverum 1773. 4.

Arduino, Istruzione per coltivare il hali. Venezia 1780. 8.

Velloso, Alegraphia des alkalis fixos vegetal ou potassa. Lisboa 1798. 8.

Paris, Mémoire sur la culture de la sende. Paris 1810.8.

Hesselius, Om Tobaksplantering uti America. Stockholm 1733. 4.

Gavelli, Storia del tabacce. Pesaro 1758. 8.

Carver, Culture of the tobacco plant. London 1779.8.

Duburgua, Sur la culture du tabac. Agen 1805. 8.

Cadet-de-Vaux, Traité de la culture du tabac. Paris 1810.8 .

1812. 12.

Erhardt, Der Taback. Heidelberg 1841. 8.

Mueller, Der Taback. Emmerich 1842. 8 .

Joerlin, Trifolium hybridum. Lundae 1780.4.

Klapmeier, Vom Kleebau Riga 1797. 8.

Loefwenhielm, De cultura Trifolii pratensis. Upsalide 1805.8.

Bissari, Metode di liberare dal grongo o lovere i trifogli. Milane 1809. 8. Mathieu de Dombasle, Notice sur le Trifolium incarnatum. Paris 1823.8.

Pépin, Sur la culture de I'Urtica nivea L. Paris 184-. 8.

\section{Plantae tinctoriae.}

La Rochefaucaut, Le Safran. Poitiers 1568. 4.

Crolachius, Isatis lierba. Tiguri 4575.12.

Strobelberger, Tractatus novus do Cocco Baphica et confectione Alelsermes. Jenae 1620. 4.

IVedel, De Anil, Indico, Glasto. Jenae 1689. 4.

Marsigli, Brieve ristretto del saggio interno alla storia del mare ed alla grana detta Kermes. Venezia 1711. 4.

(gallice.)

Linder nobilis Lindestolpe, Svenska fărgakenst. Stockhelm 1720. 8.

Hencliel, Beschreibung des Salzkrautes oder Kali geniculati. Ju pjus "Flora saturnizans ". Leipzig 1722.8.

Schreber, Beschreibuug des Waides. Halle 1752. 4.

Buechuer, De Indo germanico ex glasto. IJalae 1756. 4. (germanice.)

Bohad.sch, Gcbraucl cles Waidtes. Prag s a. 4. 
Du llamel, Mémoires sur la garance et sa culture. Paris 1757.4, - ib, 1765.8 .

(hispanice.)

Mémoire sur le safran. s. I. et a. 8 .

Miller, The method of cultivating nadder. (Rubia tinctorum.) London 1758. 4 .

(germanice.)

Linne. Plantae tinctoriae. Upsaliae 1759. 4.

Kalm, Norra americauke fărge-orter. Aho 4763.4.

Monnereau, Le parfail indigotier. Ansterdam 1765. 12.

(Samzelius) Beskrifning på svanska fargegråsen. Örebro 1765. 8.

De la Taille des Essarts, Mémoire sur le safran. Orleans 1766. 8.

Des Blos, Traité de la garance. Paris 1768. S.

Gadd, Om akta Saffran ocb dess plantering. Äbo 1769. 4.

Revelli, Istruzione sulla coltura e preparazione della garanza, Torino 1770.8.

Althen, Mémoire sur la culture de la garance. Paris 1772.4.

Gadd, Om Solidago canadensis. Äbo 1772. 4.

Gunner, De usu plantarum indigenarum in arte tinctoria. Jafniae 1773. 8.

Marili, Della Robbia e sua coltivazione. Firenze 1776. 8.

(Reuss) Kenntniss der Malern und Färbern mutzlichen Pflanzen. Leipzig 1776. 8 .

Svenonius, De usu plantarum Jslandae in arte tinctoria. Hafniac 1776. 8.

Zucchini, Sopra la Luteola sativa. s. 1. 1779. 8.

Vogler, Versuche mit den Scharlachbeeren (Grana Kermes). Wetzlar 1780.4 .

Jambourney, Teintures solides, que les végétaux indigènes communiquent aux lainages. Paris 1786. 8.

Thiery le Menonville, Traité de la culture du Nopal. Au Cap-français 1787. 8 .

Dambourney, Culture de la garance. Paris 1788.4.

Cossigny, Treatise on the cultivation and nanufacture of Indigo. Calcutti 1789. 4 .

l.eblond, Essai sur l'art de Y'indigotier. (Paris) 1791. 8.

Lamboumey, Histoire des plantes qui servent à la teimture. Paris 1792. S.

Olivi, Dell' Ulva atropurpurea. (Padova) 1793. 4.

Buchoz, Manuel tinctorial des plantes. Paris 1800.8.

De Candolle, Note sur le Carthane des teinturiers. (Journ. des arts 1804. il, 1. $65-69$.)

- Note sur le Réséda gaude. (Anı. des arts 1801.)

Westring, Svenska Lafvarnas Färghistoria. Stockholm 1805. (18031S09.) 8 .

(germanice.)

Julian, Rapport sur Ja plantation d'Anil ou lndigo français. Paris 1804. 8.

Puymaurin, Notizia intorno al guado (Isatis tinetorum). Milano 4810.8. Igallice.

Thiebaut-de-Berneand, Du genet. Paris 1810.8

Bellenglit, Processo sulle tinte. Aucona 1811.4.

Je la Steyrie, Du pastel, de l'indigotier et des autres végétaux dont on peut extraire tue couleur blene. Paris 1811.8.

(irassi, Sur l'Isatis tinctoria. Geneve 1811.8.

Ileinrich, Ueber die Kultur dos Waids. Wien 1812. 4.

Pesch, Sieg des Waid-ludigs üler den auslandischen Indig. Weinar 1812.4.

(iiobert, Traité sur le Pastel (Isatis tinctoria). Paris 1813.8.

Megerle van Miihlfeld, Oestreichs Farbepflanzen. Wien 1813. 8.

Puymaurin, Instruction sur l'art d'extraire l'indigo contenu dans les feuilles du Pastel. Paris 1813. 8.

Ullgren, De plantis tinctoriis suecanis. Upsaliae 1815. 4.

Dingler el von Kurrer, Ueber die Nymphaea alba L. Wien 1820.8.

Runge, Je jigmento indico. Berolini 1822. 8.

Gasparin, Mémoile sur la culture de la garance. Toulouse 1824.8.

Prescts, lustruccion para el cultivo de la planta Nopal etc. Mlalaga 1825. is max.
Jaume Saint-Milaire, Mémoire sur les indigoféres du Bengale et do la Chine. (Paris 1826.) folio.

Lassobe, Guide du teinturier moderne. Bordeaux 1826. 8.

- Notice sur le bablah ou la gousse du Mimosa. Bordeaux (1827.) 8.

Nagel, Unterriclit zum Saflorbau. Munclien 1827.8.

Jubuc, Mémoire sur Je PJytolacca decandra. Rouen 1831. S.

Perrollet, Némoire sur la culture des indigofères tinctoriaux. Paris 1832. 8.

Decaisne, Recherches sur la garance. Bruxelles 1837. 4.

Saint-Hilaire, llistuire de l'indigo. Orléans 1837.8.

Opiz und Berchlold, Die Rubiaceen Bóheims. Prag 1838. 8.

Bonafous, Sul Polygonum linetorium. Torino 1839.8.

Joly, Sur les plantes indigeferes et le Polygonum tinctorium. Montpollier 1839. 8 .

- Observations sur les plantes qui peuvent fournir des couleurs bleues (Polygonium tinctorium, Chrnzophora tinctoria). Montpellier 1839. 4.

Morren, Mémoire sur la formation de J'Indigo dans les feuilles du Polygonum tinctorium. Bruxelles 1839. 4.

Perroltet, Art de l'indigotier, suivi d'une notice sur le Wriglitia tinctoria. Paris 1842,8 .

Ituehnefeld, Die Indigofalırikation. Quedlinburg 1846.8.

\section{Plantac utiles.}

Butler, The feminine monarchie. (Plantae apilus gratae.) London 1623.4. Schmidt, De frondibus festivis pentecostalibus. Ilelustadii 1707.4 . Amali, De Opobalsami specie ad sacrum charisma. Neapoli 1722. 8.

Rohr, Traktat von dem Nutzen der Gewäclsse. Coburg 1736. s.

Westbeck, Underrättelse om tvanne slags svensk bomull. Stockholm 1744 4. - ib. 1745. 4 .

halm, Nyttan samt stoótsel af några wáxter hembragt frän Norra America. Stockliolm 1751.8.

- Nyttan af våra inlandstia văxter. Ảbo 1753.4.

Martini, De thuris in veterum Cloristianorum sacris usu Lipsiae 1759. 4.

Linné, IIospita insectorum Flora. Upsaliae 1752. 4.

halm, Om americanska náfverbåtar. (Naviculae c cortice Betulae.) Ảbo 1753.4.

- Possibilitas vegetabilia fabricis utilia colendi. Aboae 1754. 4.

Bohadsch, Beschreibung nutzbarer Krajuter in Bulımen. Prag 1755. 8.

Kalm, On nyttan af vâra inhemska văxter kánuande. Ảbo 1760. 4.

(Duchesne) Manuel de botanique. Paris 1764.8.

Strange, Lettera sopra l'origine della carta naturale di Cortona. Pisi 1764.4 .

(anglice, sallice.)

Barbeu-Dubourg, Usage des plantes. Paris 1767. 12.

Hadelich, De Gossipio quod in terris nostris nascitur. Erfordiac (1768.) 4. Joerlin, De usu plantarum indigenarum. Londini frotlıorum 1769. 4.

Trozelius, Tankar om Sảcker och Sirup af inhemska vànter. Lund 1771.4. Beunie, Welk zyu de profytelykste planten van dit land? Brüsel 1772.4. Du Rondeau, Plantes utiles des Pays-Bas. Bruxelles 1772. 4.

Plants of use for food, Iuedicine etc. in Otaheite. In Parkinson, Voyage. London 1773. 4. p. 37-50.

(germanice.)

Gunner, Tractatus de divitis Florae dano-norvegicae. Hafhiae 1774. \$.

Gleditsch, Geschichte aller in Arznei und Haushaltung nutzlich befunduen Pllanzen. Berlin 1777. 8 .

Kluk, Plantarum utilium cultura (polonice). W Warszan ie 177- 7 780. 8. Julizans, De resina elastica Cajennensi. Trajecti a/RJ. 1780.4.

Nalldorsson, Gras-nytiar. Kaupmanmahön 1783. 8.

fierner. Ilandlungsprodukte aus dem Planzenreich. Stuttgart 1781-1786. folits. 
Amoreux, Recherches sur les divers Lichens. Lyon 1787. \$.

Geuns, Verhandeling over de inlandsche nyttige plantgewassen. Haarlen 1789.8.

Wenzel, Mémoire sur une manufacture des végétaux artificiels. Paris 1790. 4 .

L_art d'imiter les végétaux. Paris 1802. 8.

Castiglioni, Osservazioni sui vegetabili piu utili degli Stati Uniti. In cjus "Viaggio v. Nilano 1790. 8. vol. Il, 169-402.

Brez, La Flore des insectophiles. Utrecht 1791. 8.

Cervantes, De resina elastica el ejus arbore. Hexico 1794. 4.

Tarnow, Ueber die zur Lohe tanglichen Gewächse NJeklenburgs. Rostock 1794. 8.

Boehmer, Technische Geschichte der Pflanzen. Leipzig 1794. 8.

Segerstedt, Inledning til kunskapen om de Jordiske Kropparne. Strengntis 1798. 8 .

Senger, Die alteste Urhunde der Papierfabrikation. Dortmund 1799. 8.

(Kritik dieser Schrift: Essen 1800.8.)

(Mueller) Von Furtrefflichkeit der Gewáchse in Dánnemark und Norwegen. Hamburg s. a. 8.

Duplessy, Des végétaux résineux. Paris 1802.8.

Kierner, Beitráge zur Kenıtniss der llandelswaaren. Hannlieim 1804. 4.

Buchoz, Avantage des plantes. Paris 1806.8.

Retzius, Om Berberis buskens nytta och skada. Lund 1807. 4.

Nemnich, Beiträge zur Cigarrenkunde. Leipzig 1808.8.

Parmentier, lnstruction sur les moyens de suppléer le sucre. Paris 1808.8 .

Magnien et Deu, Dietionnaire des productions du commerce de la France. Paris 1809. 8.

Mikan, Die Zuckererzeugung aus Ahornsaft. Prag 1811. 4.

Arduino, Istruzione sull' olco di Cafreria. Padova 1811. 8.

- Nuovo metodo per estrarre etc. Padova 1813.8.

Lehmann, Graestangs brug til udstopuing. Kiobnhavn 1812.8. (germanice.)

Nocca, Storia ragionata delle piante, dalle quali si puo' estrare z!ıcelıero Pavia (1812.) 4.

Thunberg, De utilitate plantarun suecicarum. Upsaliae 1813.4.

Geuns, Plantarum indigenarum usualium index systematicus. Trajecti a/Rh. 1816. 8 .

Hofman-Bang, De usu Confervarum in occonomia naturae. Ilafniac 1818. 8.

Dalla Porta, Prospetto delle piante nell' isola di Cefalonia. Corfu 1821.4.

Deschaleris el Chereau, Essai sur les cryptogames utiles. Paris 1826. 8.

Siebold, Tabulae synopticae usus plantarum. Dezima 1827. folio.

Synopsis plantarum oeconomicarum universi regni japenici. (Dezima 1827.) 8.

Chamisso, Vebersicht der nutzbarsten und schădlichsten Gewăchse. Berlin 1827. 8 .

Zenlipr uml Schenk, Merkantilische Waarenkunde. Jena 1831-1835. 4.

Seringe, Mémoire sur l'emploi des Céréales pour la fabrication des chapeaux et des tissus de paille. (Mélanges II, 6.) Lyon 1834.8.

Delanoye, Traitó des productions naturelles indigènes et exoliques. Paris 1831. 8.

(Bocris) Beschreibung aller im llandel vorkommenden Tabacksgattungeı. Bremen 1833. 8.

D’Hombres lïrmas, Notes sur quelques végétaux. Nismes 1\$34. 8.

Netzger, Geselze der Pflanzen- und Nineralienbildung angewendet auf altdeutschen Baustil. Stuttgart 1835. 8.

(D'Elreillis et Dammien) Sur lesplantes marines du genre Zostère. Paris 1835.8.

Duchesne, Repertoire des plantes utiles. Paris 1836. 8 .

Siegfried, Die Pllanzen in ilser Anwendung elc. Zurich 1840. 8.

Nelzger, Onamente aus deutschen Gewächsen. Nünchen 1841-1842. royal folio.

Jubbert, Nouveau manuel complet du fabricant et de l'amateur de tabac. Paris 1844.8.
Hasskarl, Aanteekeningen over het nut doer de Bewoners von Jas a dan eenige planten van dat Eiland togesclireven. Ansterdam 1845.8 .

Eichelberg, Naturgetreue Abbilclungen und Beschreibungen der Ilandelsgewächse. Zurich 1845 . gr. 8 .

\section{Materia alimentaria.}

Caelius Apicius, De opsoniis et condimentis libri X. Venetiis 1500.4. Aquaeus, Encomium brassicarum. Parisiis 1531. 8.

Sethi, De cibariorum facultate syntagma. Basileac 1538. 8.

Bigoutier (Bigotherius), Rapina seu raporum encomium. Lugduni 1541.8. Estienne vel Stephanus, De nutrimentis libri tres. Paris 1550.8.

Bock, Teutsche Speisskammer. Strassburg 1550. 4.

Bruyerinus, De re cibaria libri XXII. Lugduni 1560. 8. - Norimbergae 1659.8.

Julius Alexandrinus, Salubrium Jibri XXXIII. Coloniac 1575. folio.

Bonamicus, De alimento libri V. Florentiae 1602.4.

Arnaldus a Villanova, De salubri hertensium usu. Parisiis 1607. 8 .

Mueller, Vom Brodtbacken. Leipzig 1616. 4.

Massonio, Archidipno overo dell' insalata. Venezia 1627. 4.

Nonnius, Diaeteticon, sive de re cibaria libri IV. Antwerpiae 1646. 4.

Sebisch, De alimentorum facultatibus libri quinque. Argentinae 1650.4.

(Montalbanus) Formolario oeconomico. Bologna 1654. 4.

Sperling, Carpologia plysica posthuma. Wittebergae 1664.8 .

Montalbanus, La fabrica del pane soventizio dichiarata. Bologna 1679.4.

Elshols, Diaeteticon (Arznei-Garten und Tisclbucls). Colln a/d. Spree 1682. 4. - Frankfurt 1690. 4.

Lémery, Traité des alimens. Paris 1702. 12. - Ed. III: ib. 1755. 12.

Berreau et Winslow, Cerealia et olera agri parisiensis salubria. Paris 1703.4.

Evelyn, Acetaria, a discourse of sallets. London 1706.8 .

Pagenslecher, De Rapis. Groningae 1710. 12.

Orth, Flora deliciosa. Jlerbipoli 1723. 8.

Stahl, De pane speciatim triticeo. Erfordiae 1727. 4.

Ledel, Succincta Mannae excorticatio. Sorau 1733.8.

Cornelius, Cibi, potus et condimentorum consideratio medica. l_ugduni Batavorum 1736. 4 .

Geoffroy, An onne esculentum vegetabile cultura salubrius? Paris 1747.4.

Linné, Pan suecicus. Upsaliae 1749. 4. (germanice, gallice.)

Plantae esculentae patriae. Upsaliae 1752.4. (suecice.)

Kalm, De praerogativis Finlandiae praecipue quoad plantas spontaneas in bellariis adhibitas. Aboae 1756. 4

Limne, De acetariis. Upsaliae 1756.4.

Stech, Do Sagu. Argentorati 1757. 4.

Linne', Culina mutata. Upsaliae 1757. 4.

kimiphof, Ablandlung vom Salat. Erfurt 1757. 4.

Linné, De pane diactetico. Upsaliae 1757. 4.

Bergius, Rön om spannemåls-bristens ärsăttjande medelst Quickrot. stochliolm 1757. 4.

Kesselmeyer, De quorundam vegetabilium principio nulriente. Argentorali 1759. 4 . (italice.)

Linné, Macellum olitnrium. IJolmiae 1760.4.

Scheuchzer, De alimentis farinaceis. Lugduni Batavorum 1760. 4.

Limné, Fructus esculenti. Upsaliae 1763. 4.

Ilortus culinaris. Holmiae 1764. 4.

Cartheuser, De radicibus esculentis. Francofurti 1765. 4.

Spitlmann, Olerum argentoratensium fasc. 1-II. Argentorati $1769-$ 1770.4. 
Zuectiert, Materia alimentaria. Berolini 1769.8.

Von den Speisen aus den l'llanzenreiche. Berlin 1778. 8.

Buchoz, Manuel alinentaire des plantes. Paris 1771. 8.

Gadd, Onı Skidsfrukts-wáxter och legumer. A ho 1772. 4

Kalm, Öfver swarta winbärshuskars nyttu. Ảbo 1772.4.

___ Nyttan af Manna-grás. Ảbo 1779. 4.

Parmentier, Végétaux qui pourraient suppléer en temps de disette aux plautes alimentaires. Paris 1772. 12.

Gunuer, Om Dannemarks og Norges naturlige fordecle til fode for mennesket af planteriget. Kiobubavn 1774. 8.

Ellis, A description of the Mangostan and the bread-fruit. London 1775. 4.

Kalm, Ou nyttan af Hallon. (Rubus idaeus.) Áho 1778. 4.

Linguet et Tissol, Ueber das Getraid und Brodt. Zurich 1780.8. (gallice.)

Parmentier, Recherches sur les végétaux nourrissans. Paris 1781. 8.

Hellenius, Om Finska allmogens nüdbrod. Abo 1782. 4.

Bryant, Flora diaetetica. London 1783. 8. (germanice.)

Forster, Geschichte und Beschreibung des Brodbaums. Cassel 1784. 4.

Menck, Bromatologia. Viennae 1784.8.

Bergius, Tal om Lackerlıeter. Stockholm 17858. (germanice.)

Blom, Register ofver Bergii Tal om Láckerheter. Stockholm 1785. 8 .

(Strom) Underretning on den islandshe Noos, Nariegraesset och Gejtnaskoven. Kiolseuhavn 1785 . S.

Ileigel, De fructibus esculentis Javae. Gryphiae 1786.4

Forster, De plantis esculentis insularum oceani australis. Berolini 4786. 8 .

Navarro, Instruccion sobre la nueva planta llamada la raiz de la miseria o de la abuulancia. Barcelona (1788.) 4.

Hellenius, Frukthärande buskars skotsel. Âbo 1789. 4.

Villars, Catalogue des substances végélales qui peuvent servir â la nourriture de l'homme. Grenoble, an II. 8.

Matllei, De vegetabilibus ad diaetan spectantibus. Marburgi 1794, 8 .

Olin, Plantae suecauae annonae difficultate urgente victui humano inservientes. Upsaliae 1797-1798.4.

Muclertz, Nytten af adskillige norske vilde Raer. Kjöbnlıavn 1804.8 .

Roluna) Lettre sur l'utilité de la racine pivolante. Carcassonne 1805 . 12.

Gravander, Alimenta Sueciae succedaneá e regno vegetabili. Upsaliae 1805.4 .

lielzius, De plantis cibariis Ronanorum. Lundae 1808.4.

Marzari-Pencati, Sull introduzione del Lichene islandese come alimente in Italia. Venezia 1815.4.

(imelin, Nothluulfe gegen Mangel aus Nisswachs. Karlsruhe 1817. 8.

Kolb, Brontatologie. 11: Nalırhafte Vegetabilien. Hadamar 1829.8.

Sabine, Some account of the edible fiuts of Sierra Leone. London $1 \$ 24.4$.

Briganli, Sulla preparazione della pania dalle bacche del Loranta europeo. Neapoli 1827. 4.

Morren, Les siécles et les legunes. Liege 1\$37. 8.

Guibourt, Notice sur les nids de Salangane. Paris s. a. 8.

Yain, Hortus diaetetica. London 1845. S

\section{Varia potus genera.}

Panlli, Commentarins de alusu (Tabaci et) herbae Thee. Argentorati 1665.4 .

(anglice.)

Jufour, De l'usage du caphé, du the et du chocolate. Lyon 1761. 12. anglice.)

Traitez nouveaux du café, du the el du cliocolate. Lyon 1685.12. (latine.)

Alliechl. Ki lar eutdeckte Lnschuld der Thee- und Kaffeegetranke. Bremen 1696. S.
Bontckoe, Tractat van Kruyd Thee, Coff, Chocolate. Graveuhage 1679. S. Aignan, Le prétre mérlecin. Paris 1696. 12.

Sponius, Tractatus novi de potu Caphé, Thé Clocolata. Paris 1685. 1 I. - Bevanda asiatica. Li|siac 1705.4.

Lochner, De novis et exoticis Thee et Café suceedaneis. (Norimbergae 1717.) 4.

Meisner, De Caffe, Cloccalata, Thee et Xicotiana. Pragae 1720.4.

Neumann, Lectiones von Tbee, Kaffee, Bier und Wein. Leipzig 1735. 4. krucger, Gedanken rom Katlee, Thee und Toback. Jlalle 1743. 8. (gallice.)

Beintema, Von der Vortrefflichkeit des Thees und Kaflees. Leipzig 1743. 8

Zannichelli, Abuso della Colfea e nuovo The veneziano. Venezia 1755. 4.

Foerster, Erfindung und Einfülırung des Cichorienkaffee. Bremen 1773.8.

Langstedl, Thee, Kaffee, Zucker. Nürnberg 1800. 8.

Barton, Some account of a plant used as a substitute for Clıcolate, Iloleus hicolor Will. Philadelphia 1816. 8 .

Mousinus, Discours de lyvresse et yrrognerie. Toul 1612.8. (latine.)

Kirchmaier, De veterum Celtarum Celia, Oelia et Zytho. Wittebergae 1695.4 .

Brueckmann, Appellationes omnium potus generun. Helnstadiae 1722. 4.

Linne, Inebriantia. Upsaliae 1762.4. Spiritus frumenti. Upsaliae 1764.4.

Zosimi Panopolitaui de zythorun confectione fragunentum, cum Gruneri historia zythorum. Solishaci 1814.8.

Muehlpfort, Yon den Breslischen oder Schòpsenbieres Eigensclıaften. Brieg 1694. 4.

Schookius, De cerevisia liher. Groningae 1661. 12.

Meibomius, De cerevisiis. Helmstadii 1668. 4.

Eysel, De cerevisia erfurtensi. Erfordiae 1689.4. - ib. 1727. 4.

Limmer, De cerevisia servestana. Servestae 1693.4.

Brueckmann, De cerevisia regio-lothariensi Duckstein. Helmstadii 1722.4 . (germanice.)

Epistola itineraria XXXYlll de cererisia goslariensi. TTolfonbuetteliae 1735.4 .

Epistola itineraria Lill de Muma Brunsvicensium. Wolfenbuetteliae 1736. 4 .

Trozelius, Forsligg til nya lorygg- och drickes amnen. Lund 17i2. 4.

\section{Botanica saltuaria.}

Belon, Les remonstrances sur le default de labour etc. Paris 1558. 8 (batine.)

Evelyn, Sylva. London 1664. folio. - York 1786.4.

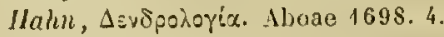

Carlowils, Sylvicultura oeconomica. Leipzig 1713. folio.

Cook, The mauner of raising forest trees. London 1794. 8 .

Langley, Plautation of timber-trees. London 1728. 8.

Rohr, Historia nnturalis arborun silvestrium Germaniae. Leipzig 1732. folio.

Ellis, The timbertree improved. London 1738. 8.

Cederhjelm, Tal on wilda trans plantering i Sverige. Ljosala $17 i 0.8$.

Roux, Traite sur la culture des arbres a ouvrer. Paris 1750.8

IVallins, Treatise on forest-trees. London 1733. 8.

Du Hamel, Traité des arbres et rrbustes qui se cultirent en lirance en pleine terre. Paris 1755.4 . (germanice.)

Kalm, Fulu-och Gran-slogars vård. Hbo 1757. 4

Eksliggarnes rảrd i Finland. Abo 1757. 4 
Lidbeck, De silvicultura Scaniae. Lundae 1757. 4.

Linné, Arboretum suecicun. Ipsaliao 1759. 4.

Du Ilamel, Des semis et plantations des arbres. Paris 1760.4. (germanice.)

Catesby, Hortus britanno-americanus. London 4763. folio.

kinoop, Dendrologia. Leeuwarden 1763. folio.

O $\ell$, Dendrologia Europae mediac. Zurich 1763.8

Du Ilamel, De l'exploitation des bois. Paris 1764. 4. (germanice.)

Meyer von Kinonau, Entwuıf, Zürich nit Holz zu versehen. Zurich 1765. 8 .

Cramer, Anleitung zum Forstwesen. Iraunsclıweig 1766. folio.

Tokelem, Beschreibung der Holzer des nordlichen Russland. Petersburg 1766. 8 .

Du Hamel, Du transport, conservation et foree des hois. Paris 1767. 4.

Oelhafen von Schoellenbach, Ablildung der wilden Baume, Stauden- und Buschgewachse. Nurnberg $1767-1804.4$. (gallice.)

Lidbeck, De utilitate plantationum arborum. Lundae 1768.4

Brocke, Wahre Gründe der Forstwissenschaft. Leipzig 1768-1775. 8.

Scopoli, Tabula ostendens usum lignorum. In ejus "Anno hist. nat. $\mathrm{IV}$. Lipsiae 1770.8 . p. 124.

Du Roi, Observationes botanicae (de arboribus Americae septentrionalis). llelmstadii 1771.4 .

- Die Harbkesche wilde Baumzucht. Braunschweig 1771-1772. 8. - Ed. 1l. von Poll. il). 1795-1800. 8.

Poederle, Manuel de l'arboriste et du forestier belgiques. Bruxclles 1772 $-1779.8$

Houlluyn, loutkunde. Icones lignorum. Anstelodami 1773 (-1791). 4. (germanice.)

Boutcher, Treatise on forest-trees. Edinburgh 1775.4.

Gleditsch, Einleitung in die Forstwissenschalt. Ferlin 1775. 8.

Weiss, Entwurf einer Forstbotanik. Gottingen 1775. 8.

Dieskau, Das regelmässige Versetzen der Băume. Meiningen 1776. 8.

Agricola, Miscellaneous observations on planting timber-trees. Edinburgh 1777. 8 .

Fleischer, Underviisning i det shovvaesen. Havniae 1779. 8.

Deiman et l'aets van Troosheyli, Nut van den groei der boumen en planten tot zuivering der lucht. Amsterdam 1780.8.

Maerter, Verzeichniss der ostreichischen Băume. Wien 1781.8. - ib. 1796. 8 .

Trozelius, Om trăn och buskar i allmänhet. Lund 1781. 4.

IVangenheim, Beschreibung nordamerikanischer Holz- und Buscharten. Göttingen 1781.8.

Mustel, Traité théorique et pratique de la végétation. Paris 17811784.8.

Meerburgh, Naanlyst der boom en heestergewassen. Leyden 1782. 8.

Burgsdorf, Geschichte vorzüglicher Holzarten. Berlin 1783-1787. 4.

Luhwig, Die neuere wilde Baumzucht. Leipzig 1783.8.

Kerner, Beschreibung und Abbildung der Baume und Gestrăuche Wirtembergs. Stuttgart 1788. (1783-1792.) 4 .

Burgsdorf, Aufmunterung zur Niterforschung. s, I. 1785.4.

Marshall, Arbustum americanum. Philadelphia 1785. 3.

(germanice, gallice.)

Burgsdorf, Anleitung zur Erzjelnung der Holzarten. Berlin 1787. 8. Jlarburg 1806. 8.

IVangenheim, Die Anpllanzung nordamerikanischer llolzarten. Göttingen 1787. folio.

Gleditsch, Vier Abhandlungen das praktische Forstwesen betreffend. Berlin 1788.8 .

Wileke, Anleitung die Bảume zn erkennen und zu unterscheiden. Halle 1788. 8 .

Emmerich, The culture of forests. London 1789.8 .

Andreae, Charakteristik inlandischer Forstbäume. Frankfurt 1790.8.

Senebier et Blanquart. Dictionnaire des forets et bois. Paris $1790-$ 1815. 4.

Pritzel, Thes. lit. bot.
Borkhausen, Beschreibung der llolzarten in llessendarmstadt. Franhfurt a/M. 1790.s.

Juge de St. Martin, Notice des arbres dans le Limousin. Limoges 1790.8. lieiller ind Abel, Abbildung der hundert dentschen wilden Holzarten. Stuttgart 1790. 4. - Fortsetzung: ib. 1803.4.

Becker, Beschreibung der Baume und Stratucher in Meklenburg. Rostock 1791. 8 .

Herneck, Anleitung zur Kenntniss der Holzplanzen. Frankfurt a/M. 1791. 8 .

Bordiga, Storia delle piante forestiere. Milano 1791-1794. 4.

Gadd, Om medel at underhålla och öka skogsvásten i Finland. Åbo 1792.4.

Schultz, Abbildung der Bảume Oesterreichs. Wien 1792-1804. folio.

Schmidt, Oesterreiclss allgemeine Baumzucht. Wien 1792-1822. folio.

Barneveld et Miller, Verhandeling over het planten van hoomen bimnen en romdon de steden. Utrecht 1793.8

Castiglioni, Storia delle piante forestiere. Milano 1794. (?)

Moser, Die wesentlichen línnzeichen der Holzarten. Leijzzig 1794, 8.

Sierstorpf, Ueber die forstmassige Erziehung aler llolzarten. Hannover $1794-1813 . g \mathrm{r} .4$.

IIecart, Essai suj les arlures du dép. du Nord. Valeneiennes (4795.) 4

fierner, Darstellung auslandischer Baume und Gesträuche. Leipziğ 1796 . 4.

Ililldenow, Berlinische Baumzucht. Berlin 1796. s. - ib. 1841. 8.

Bechstein, Taschenblatter der Forstbotanik. Weimar 1798. 8. - ib. 1828, 8 .

Hildı, Beschreihung in- und ausländischer Holzarten zur technologischen Kenntniss. Weimar 179s-1799. 8 .

Abercrombie, A general system of trees. Loudon s. a. 4.

Borlihausen, llandbuch der Forstbotanik. Giessen 1800. 8.

Burgsdor\%, Einleitung in die Dendrologie. Berlin 1800. folio.

Morel, Tableau dendrologique. Lyon 1800.4 . oll].

Frenzel, Verzeichniss von Holzarten um Wittenherg. Wittenberg 1804. 8.

Savi, Trattato degli alberi della Toseana. Misa 1801. 8. - Firenze 1811. 8.

Hagner und Hebig, Botanisches For sthandbuch. Giessen 1801. 8.

Du Ilamel, Traité des arbres et arbustes, que l'on cultive en France en pleine terre. Seconde édition, ("Nouveau Du Hamel») par LoiseleurDelongchamps et Michel. Paris $180 \mathrm{i}-1819$. folio.

Aikin, The woolland companion. London 1802. 8.

Ilammer, Verzeicbuiss der Bäume zur Beplanzung der Landstrassen. Strassburg $180 \mathrm{z} . \mathrm{s}$.

Kospoth, Beschreibung und Abbildung ter Bäume und Stràuclıer. Ëfunt 1802. 4.

Lobliowitz, Anweisung zur Forstwissenschaft. Frankfurt 1802. 8.

Londes, Vorlesungen uber Forst- und ohonomischo Botanik. Gottingen 1802.8.

Corthum, Catalogus von Bäumen und Sträuchen. Zerbst 1803. 8.

Lorenz, Manuel du forestier. Sarrebourg (1803.) 8.

(Krauss) Afbeeldingen der Boomen en Heesters tot verciering van engelsche bosschen en tuinen. Amsterdan 1803-1808. 4.

Beclier. Ueber Kultur, kunstliche Bildung und Fállung des Scbiffsbauholzes. Leipzig 1804.8 .

IIartig, Anweisung zur Holzzucht. Mlarburg 4804. 8 . (gallice.)

lluber, Naturgeschichte der Ilolzarten. Landshut 1804.4.

Wendt, Deutschlands Baumzucht. Eisenach 1804. 4.

Zsehocke, Die Alpenwälder. Tübingen 1804. 8.

Michaux, Mémoire sur la naturalisation des arbres forestiers de l'Amérique septentrionale. Paris 1805.8 .

Krueger von Kriegsheim, Forstwissenschaftiche Bemerkungen. Dorpa: 1S06.8.

Ilartig, Verhälıniss der Brenubarkeit der deutschen Waldbaumhölzer. Herborn 1807. 8

IVerneck, Versuch einer Pflanzenpathologic und Therapie. Mannheim 1807.8.

61 
Huber, Vollständige Naturaseschichte der deutschen Bau- und Baumhözer. Munchen 1808.4.

Linlz, Dissertations forestières. Trèves 1808. 8.

Desfontaines, llistoire des arbres et arbrisseanx. Paris 1809. 8 .

Fallenstein, Tasclienbuch der Forstlytanik. lirfurt 1809. folio.

Bechstein, Forstbotanik. Lrfurt 1810. 8. - Funfte Ausgabe von Behlen. il. 1843.8 .

Michaux, llistoire de's arbres forestiers de l'Amérique septentrionale. l'aris $1810-1813.4$

(anglice, et epitome anghice ot germanice.)

Talin, Principes de la culturo de's arbres. Paris $18 \mathrm{d1} .8$

Rumford, Recherches sur les bois el le charlson. Paris 1812.4.

Giaticri, Dell' influsso de' hoschi sullo stato fisico de' paesi. Milano 1814. S.

Lopvis, Anleitung zur Forstwirthschaft. Riga 1814. S.

Viemann, Allgemeine Waldbaumhundo. Altona 1814.8 .

Reum, Forstbotanik. Dresden 1814. 8. - Ed. III: ib. 1\$37. 8.

Jaume Sainl-Ililaire, Mémoires sur l'administration des forêts. Paris 1814.8

Jester, Anleitung zur Kenntniss der Nutzlober. Königsberg 18151816. 4 .

Sartorelli, Degli alberi dell' ltalia superiore trattato. Milano 1816.8 .

Guimpcl, Ollo el llaync, Albildung der Holzarten. Berlin 1819-1830.4.

Niemann, Vaterlandische Waldberichte. Altona 1820-1822.8.

Bose, De la culturo des arbres. Paris 1824.8.

Tabellarische Uebersichıt der liundert deutsclien llolzarten. Tübingen 1822. folio.

Hayne, Dendrologische Flora Berlins. Berlin 1822. 8.

Borchmeyer, Teutschlands Baumzucht. Hunster 1823. 8.

Collin, Forslag af nigra Nord-Americas träd. Stockholn 1823. 8.

Silva Lisboa. Riqueza do Jirasil em Madeiras de construcção e carpiuLaria. Rio de Jimeiro 1823.8.

Behlen, Klima, Lage und Boden in ihrer Wechselwirkung auf die Waldvegelation. Bamberg 1823. 8 .

- Der Spessart. Tersuch einer Topographie dieser Woldgegend.

Leipzig 1823-1827. 8 .

Lehrbuch der Forstbotanik. Frankfurt a/M. 1824. 8.

Diagnostik der Forstgewacluse. Bamberg 1824. 8.

Scuderi, Trattato de boschi dell Etua. (Catanea 1824.) 4.

berghes, Abbilclung sammliclier Holzpllanzen. Koln 1825.8.

Bosson, Memoire sur l'nfluence du déboisement des forèts. Paris 1825.8.

Duchesne, llerbier forestier. Paris 1825. 4.

Morean de Jomés, Hémoire sur le déboisement des forêts. Bruxelles 1825. 4.

(termanice.)

Pernilsch, Flora von Deutschlands Wäldern. Jeipzig 1825.8.

Watson, Dendrolagia britannica. London 1\$25. gr. 8.

Sarlorelli, Mlezzi di conservare i bosclii. Milano 1826. 8.

Noyer, Forets vierges de la Guiane française. Paris 1827.8.

Sainl Moulin, De arboribus in Delgiu cultis. Trajecti a/Rh. 1827. 8.

Schubert, Opisanie drzew i hrzewow leśnych królestwa polskiego. arborihus sylvaticis Poloniae.) w Warszawie 1827. 8.

Krebs, Vollståndige Beschreibung und Abbildung der im mittlern und vordlichen Deutschland wildwaclisenden llolzarten. Braunschweig 1827-1835. folio.

Brincken, Mémoire descriptif sur la forêt impériale de Bialowieża. Varsovie 1828. 4.

Mitchell, Dendrulogia. London 1828.8.

Dietrich, Forstlora. Jena 1828-1833. 8. - ib. 1838-1840. 8.

Kasthofer, Der Lehrer im Walde. Bern 1828-1829. 8. (gallice.)

IIricarl de Thury, Notice sur la plantation de la montagne do St. Martin Je Pauvre. Paris 1829. 4.

Zuccarini, Charahteristik der deutschen Holzgewächse im blattlosen Zustande. Munchen 1829-1831. 4

Hoess, Anleitung die Băume Oestreichs zu erkennen. Wien 1830. 12.
Smidh, Arlonretum scandinavicum. lijubenhavn 1831. 1 .

Strult, Sylva brttannica, ur portraits of forest trees. Londan (1831-1836. folio.

Browne, Sylva americana. lusson $183 \pm .8$

Noirot, Traitó do la culture des forets. Paris 1832. 8.

Irincken, Ansicliten uher die Bewaldung der Steppen des europaischen Russlands. Braunsclu cig 1833. 4.

Hoess, Das Nothigste uber die Organe der Ilolzgewachse. Wien 1833. 8. Soulange-Bodin. Sur l'introduction des arbres forestiers exotiques. Paris 1833. 8 .

Wallis, Dendrology. London 1833. 8.

Buelow, Deutschlands Walder. Berlin 1834.8.

Diebl, Die Feldbaumwirthseltaft. Brunn 1834.8.

Ifartig, Forstliches und Corstnaturwissensehafliches Comvrsationslexicon. Berlin 1834. 8.

Bchlen und Desberger, Naturgeschichte der ilcutschen Forsthryptogamen. Erfurt 1833̈. 8.

Dickson, A lecture on the dry rot. London 1837.8.

Faraday, On the practical prevention of dry rot in timber. London 1836.8.

IIarlig, Erfahrungen uber dic Daner der llolzer. Berlin 1836. S.

_- Belsandlung und Kultur des Waldes. Berlin 4837.8.

- Jahresberichte uber die Fortschritte der Forstwissensehaf. Berlin 1837-1839. 8 .

Loudon. Hortus lignosus londinensis. Londou I838. 8.

Arboretum et Fruticctum britannicum. London 1\$38. 8

Schullze, Die Walderzichung. Leipzig 1\$39.8.

Zigra, Dendrologisch-okonomisch-trelunische Flora Russlands. Dorpat 1839.8.

Boncherie, Memoire sur la conservalion des bois. Paris 18 i0. 8.

Wachter, Ueber die Reprodulitionshraft der Holzpllanzen. Hannover 1840.8.

Hartig, Naturgeselichte der forstichen Kulturplanzen Deutschlanis. Berlin $1840-1 \$ 46.4$.

Fintelmann, Die Willbaunzuelut. Berlin 1841.8.

Crebe, Do conditionibus ad arborum saltuensium vitam necessariis. Marbursyi 1841.8 .

Grigor, The Eastern Arboretum. London 1841. 8.

IJacussler, Das forstlichic Verhalten der wichtigsteu deutschen Waldbăume. Stutgart 1841.8.

Selby, History of british forest trees. London 1841-1\$42.8.

(Lardy) Mémoire sur les dévastations des forets. Zurich 1842.4.

Loudon, Encyclopredia of trees and shrubs. London 1842. 8.

Nullall, The nortl-american Sylva. Philalelphia 1842 sqq. imp. 8.

Bock, Abbildungen der in Deutschland eimleimischen wilden Holzarten. Augsburg $1844 \mathrm{sqg}$. 4 .

Chevandier. Recherches sur la composition élémentaire des différents bois. Paris 1814.8

- Recherehes sur l'influence de l'eau sur la végétation des forêts. St. Germain 1s44. 5.

Des Elangs, Némoire sur les bois employés dans les charpentes des anciens édifices. Troyes (184\%.) 8.

Loiscleur, Considérations sur les boutures les arlores forestiers. Paris 1\$46. 8.

Syruc

Uxkull-Gyllenband, Ueber Saat- und Phanzenschulen. Tubingen 1846. \&.

Kalm, Tráu til bäckar. Ảbo 1756.4

—— Trán tjenliga lefvande hackar. Åbo 1775.4.

Amoreux, Traité des haics vives. Paris 1787. 8. - Lyon 1809. \&.

Riboud, Mémoire sur les haies dans le dép. de lAin. Paris 1810.8.

Jlécarl, Mémoire sur les haies. Valenciennes 1812.8.

Spadoni, Delle siepe vive di spino bianco. Bologna 1790.8.

Schenk, Der lebente W eisilorn-Spalierzaun. Lemberg 1844 . 8 .

(hungarice.) 


\section{Cultura et usus arborum singularum.}

Ferrari, llesperides sive de malorum aureorum cultura libri 1V. Romae 1646. folio.

(Morin) Instruction facile pour connoistre et cultiver les oranges et citronniers. Paris 1674. 12.

Commelyn, Nederlandize Hesperides. Amsterdam 1676. folio (angtice.)

Sterbect, Citricultura. Antwerpen 1689. 4

Lanzoni, Citrologia. Ferrariae 1690. 12.

Volckamer, Nurnbergische Hesperides. Numberg 1708. fulio. - Continuation: ib. 1714. folio. (lative.)

Civinini, Della storia degli agrumi. Firenze 1734. 4.

Gallesio, Traité du Citrus. Paris 1811. 8.

Sickler, Der vollkommne Orangeriegärner. Weimar 1816.4.

Arrosto, Monografia degli agrumi. Messina 1835. 8 .

Gallesio, Gli agrumi dei giardini di Firenze. Firenze 1839.8.

Vellori, Delle lodi e della collivazione degli ulivi. Firenze 1569. 4.

Sicuve, Mémoire .. sur les oliviers. Paris 1769.8.

De la Brousse, Traitè de la culture du fignier. Paris 1774. 8

Beccadilli, Sulla nuova manufattura dell' olio di Napoli. Napoli 1776.8.

Lethr, De Olea europaea. Goetlingae 1779. 4.

Grimaldi, Istruzioni sulla nuova manufattura del l'olio. Napoli 1777. \$.

- Nemoria sull' econumia olearia. Napoli 1783. 8.

(Amoreux) Traité de l'olivier. Monipellier 1784.8.

Dalla-Bella, Modo de aperfeiçoar a manufactura do azeite do oliveira em Portugal. Lisboa 1784.4

Cultura das oliveiras cm Portugal. Coimbra 1786. 4.

Couture, Traite de l'olivier. Aix 1786. S.

Presla, Degli ulivi. Napoli 4794. 4.

Moschellini, Leltera della collivazione degli ulivi. Napoli 1794-1796. 8. Picconi, Sagri sull' economia olearia. Genova 1808-1810. 8.

Arici, La coltivazione degli ulivi. Brescia is 18.8 .

IIillhouse, Description of the curopean olive tree. (Paris 18.18.) 4 .

Wichitiam, Culture of fig trees in England. London 1818.4.

Tavanti, Trattato sull' ulivo. Firenze 1819. 8.

(Gallesio) Pomona italiana. (Tratlato del ficu.) Pisa 1820,8.

Gouffé de Troisvilles, Mémoire sur l'olivier. Marscille 1823. 8

De Caudolle, Notice sur la culture de l'olivier. (Bibl. univ. de Genève 1823. I, 3-22.)

Kisso, Mémoire sur les êtres nuisibles aux gliviers. s. I. et a. 8

Serres, La cueillete de la soye. 1599. 8. - Paris 1843.8.

La seconde richesse du weurier blanc. Paris 1603.8 . (anglice.)

Bauthor, Manière des pépinières de meuriers blancs. Paris 1604. 12.

De Sauvages, De la culture des muriers. Nismes 1763.8

Thomé, Sur la culture du meurier blanc. Lyon 1763. 8 .

Bolet, Cullure du meurier blanc. Dijon 1766. 8."

Griselini, Coltura de' mori bianchi. Venezia 1768. 4

Scopoli, De cultura Mori albae in Tyroli australi. In ejus «Anuo hist. nat.»

1V. Lipsiae 1770. S. p.120-124.

Fineschi, Maniera di coltivare i mori gelsi. Siena 1783. 8 .

Giriselini, Il setificio. Verona 1783.8.

Bruni, Sulla potatura de' gelsi. Milano 1784.4.

(Fabbroni) Della coltivazione del gelso. Perugia 1784. 16.

Duvaure, Culture du murier blanc greffé. Paris 1790. 8. - Valence 1817.8.

Dionis-dn-Sijour, Manière de multiplier le nứrier blanc. Paris 1812. 8. Bonafous, Culture des múriers. Lyon 1822.8. - Ed. IV: P’aris 1840. S. Sul gelso delle Filippine (Morus cucullata). Torino s. a. 8.
Loiseleur, Essai sur l'histoire des mùriers. Paris 1824. 8.

Oestberg, Om odling af mullbarstrad i Sverige. Stockhalm 1894.8.

-. Vägledning for dem sum vilja odla mullbärstráal. Slochholm 1831.8 .

Madiot, De la culture du múrier. Lyon 1826.8.

Etude, culture et propagation du mùrier en France. Lyคn 1827.8.

Boilard, Culture du mùier. Paris 1828. 8.

Morelti e Chiolini, Sui gelsi. (Bibl. agraria tom. Xll.) Milano 1829.8

Tuerli, Anleitung zur Plege der Maulbeerbúnme. Potsdam 4829. 8. Leipzig 1841. 8 .

Loiscleur, Mûricrs et vers à soie. Paris 1832.8 .

Bonafous, Des feuilles de Maclura aurantiaca. Paris 4833.8 .

Beggiato, Nuova specie di gelso delle Filippine. Padova 1836.8 .

Allemandi-Ehinger, Die MaulbeerJáume in der Scluweiz. Basel 1837. S.

Julien, Resumé des trailés chinois sur la culture des muriers, paris 1837.8.

Loiseleur, Rapport sur la culture du mùrier. (Paris 1837.) 8.

Tinelli, llints of the cultivation of the mulberry. New York 1837. 8 .

lílla de Montpascal, Sur l'utilité du mùrer des Philippines (Morus cucullata). Turin 1838. 8.

Perrollet, Sur la culture du murier etc. Paris 1840.8 .

Rammlow, Seidenzuch und Maulbeerbaum. Berlin 1540.8.

Moegling, Anleitung zur Maulbeerpflanzung. Tubingen 1841. \&

Perrollet, Rappert adresse au ministre de la marine et des colonies su une inission dans l'hute etc. Paris 1842.8 .

Baumé, Mémoirc sur les marrons d'Inde. Paris 1797. \$.

(Canzoneri) Saggio sul castagno d'India. Palermu 1523, 8 .

Vergnaud-Romagnési, Mémoire sur le maronnier d'Inde. Paris 1825. 8.

Bernard, Premier mémoire sur l'amandier. Paris 1777. 4.

Pépin, Sur la culture dn Bignonia grandiflora Thunb. Paris 1839. \&

Mithau, Dissertation sur le cacaoyer. Montpellier 1746. 8.

La Roque, Mémoire concernant l'arbre et le fruit du café. In cjus "Voyage dans l'Arabie heureuse ». Amsterdam 1716. 12 (anglice, germanice.)

Le Monnier, Lettre sur la culture du café. Amsterdam 1773. 12.

Guerin-Mencville et Perrollet, Mémoire sur un insecte et un champignon qui ravagent les cafier's aux Antilles. Paris 1842.8.

Guisan, Culture du giroflier et du cannellier a l'usage des habitans de la Guiane francaise. Cayenne 1788. 4.

Lebloud, Observations sur lo cannelicr de la Guyane française. Cayenne 1795. 8.

(Gomes) Memoria sobre a canella. Rio de Janeiro 1809. 8.

(- Modo di cultivar a canelleira. Rio de Janeiro 1809. 8.

Leschenault de la Tour, Notice sur le cannellier de l'ile de Ceylan. st Denis (Bgurbon) 1821. 4.

Hâry, Mémoire sur la culture des caroubiers. Paris 1844.8

Pielsch, Abhaudlung von Anziehuug dier hastanienbäume (Castanea vesca). Halle 1776. 8 .

Parmentier, Traité de la chataigne. Bastia 1780.8.

Cubières, Mémoire sur Celtis L. Paris 1808. 8.

Cadet de Gassicourt, Sur l'arbre cirier. Paris s. a. 8

Buee, Manner of cultivating the clove tree in the island of Dominica. London 1797. 4 . 
(Cossigny) Lettre sur les arbres a épicerics. (Paris 1775.) 12.

Kalm, Beskrifniug ofver vår sienska Ilassel. Ả bo 1759.4.

Maerler, Kullur des Mahalebkirschbaums. Wien 1813.8.

Cubières, MIémoire sur Je Magnolier auriculó. Paris 1810.8.

Huard du Plessis, Traité de la culture du noyer. Paris 1847.8.

Jaume Saint Llilaire, Mémoise sur la culture du poivrier noir. (Paris 1827.) folio.

Guerrapain, Natice sur la culture du Soplora, du Platane ef de l'Aune. paris 4809.8 .

Buchoz, Dissertations sur les sorbiers et les viornes. Paris 1804. 8.

(iviffith, Report on the Tea plant of Upper Assam. (Calcutla 133S.) 8.

Cubières, Mémoire sur le Tulipier. Versailles 1803. 8.

halm, Beshrifning om Stickel-eller lírusbärs-buskars ans och nytta. Ảbo 1757. 4 .

llaynes, Culture of the strawberry, rasploerry and gooseberry. Landon 1812. 8 .

Barret, Description of the different varictics of strawberries. London 1825. 4 .

Thompson, Engliselie Stachelbeersorten. Arnstadt 1\$46.8. (anglice.)

Remarks on Maple sugar. Philadelplia 4790, 12.

Jefferson, An ancount of the sugar mapple tree. (Acer sacharinum). Philadclplia 1792. 8 .

Cubières, Alémoire sur Acer Negrundo. Versailles 1804.8.

IValberg, Kultır und Benutzung des Ahornbaums. Wien 1810. 8.

Schmidt, Anleitung zur Erziehung der Ahornarten. Wien 1812.4.

Il'ernecli, Anleitung zur Ahornzuclut. Kassel 1814. 8.

Bonde, Tal on Ashe-trädets nytta. Stockholm 1756. 8.

Kalm, Om Aspens egenstiaper och nytta. Ảbo 1759. 4.

Pelie de Saint Maurice, L'art de cultiver les peupliers d'ltalie. Paris 1762. 8 .

(germanice.)

1.eonhardi, Erziehung und Planzung der Pappeln. Leipzig. 1798.4.

Viborg, Vigtigste Aspe-og Pilearter. (Populus et Salix.) Kiobenhavn 1800.8 .

Ilagen, Ueber die sechszelu nutzbaren Weidenarten Preussens. Konigsberg 1769. 4 .

Biorn, Ueber die Erlen und deren Behandlung. Danzig 1819. 8.

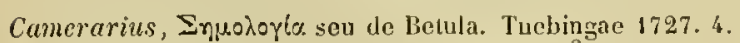

Kalm, Öfver Björckens egenskapor ach nytta. A bo 4759. 4.

Bohadsch, Dienst- und nutzbarer patriotischer Varschlag. Prag 1758. S.

Balan, Nouveau traité sur l'arbre Acacia. Bordeanx 1766. S. (germanice.)

Moeller, Empfelılung zun Anbau der Akazie. Dortmund 1796. 8.

Stumpf, De Robiniae Pseucloacaciae praestantia el cultu. Gryphiae 1796. 4.

Medicus, Unăchter Akazienbaum. Leipzig 1794-1803. 8.

- Auszug aus dem Unáchten Aliazienbaum. Düsseldorf 1798 1802. 8 . Bericht uber die Akazienanlage zu Mannbeim. Leipzig 1\$02.8.
Neufchateau, I.chres sur le Rol,inier, Paris 1802. 12.

Juglar, Le triomphe le l'Acacia. Jaris 1808. 8.

Dralet, Traité du hêtre (Fagus sylvatica). Toulouse 1824.8.

IIartig, Untersuchangen uher den Ertrag der Rothusche. Berlin 1847. gi. 4.

Juge de St. Martin, Traité de la culture du chène. Paris 1788.8.

Nichols, Observations on the propagation ind managenent of oak trees. Southampton (1794.) 8.

Sierstorpf, Besclureibung der Eiclıe. Hannover 1794. 4.

Bose, Memoire sur les différentes espèces de clienes en France. I'ari. 1808. 4.

Loewis, Veber die ehemalige Verhreitung der Eichen in lief - und bisthland. Dorpat 1824.8.

Axtius, Tractatus de arboribus coniferis. Jenac 1679. 12.

Lengefeld, Anmerkungen von Tanne, Fichte und hicnhaum. Surulerg 1762. 4 .

Tselualy, Traité des arbres résineux coniferes. Mletz 1768. \&.

Falm, Öfver Eenens egenskaper och nylta. Abo 1770. 4.

Ginanni, Istoria delle Pincte Ravennati. Roma 1774, 4.

Anderson, Letters for the culture of bastard cedar trees. Madras 179\% :

Drais et Ilaltershausen, Abhandlungen vom Lerchenbaume, Clm I801.S.

Cubières, Mémoire sur les cyprès de la Louisiane. Paris 1809. 8.

- Mémoire sur le Cèdre rouga. Paris s. a. 8.

Fornaini, Sur la cullure des sapins. Paris 1813.8.

Sierstorpf, Beschreibung eler Fichte. Hannover 1813. 4.

Dralct, Traité des forcts d'arbres résineux. Toulouse 1820 . S.

De la Marre, Traité pratique de la culture des pins. Paris 1821,8.ib. 1826.8 .

Lemeke, Ueber don Lerchenbaum. Hannover 1829. 8.

Hoess, Monographie der Schwarzfuhre (Pinus austriaca). Wien 1\$31. folio.

Nardo, Su alcuni usi ed applicazioni del Pinus maritima. Venezia $4834 . S^{\circ}$.

Serres, Notice sur la culture du pin maritime dans les Landes. Bordeaux 1837. 8.

Lioenig, Notize sur la molèze. Colmar 1840.8.

Chambray, Traité pratique des arbres résineux coniferes. Paris 1845.8 .

Uxkull-Gyllenband, Kurze Beschreibung der ustreichischen Schwarzkiefer. Frankfurt a/M. 1845.8.

Manteufel, Anweisung zum Hügelpflanzen der Nadelhölzer. Loipzig 1846.8.

\section{Materia medica vegetabilis.}

Alberti, Antidotarium medicamentorun simpliciun. folio.

Nobili, Erbario. s. 1. et a. 4 .

A boke of the propreties of herbes. London, by Wyllyam Copland. s. a. 8.

Petrus de Abano, Conciliator differentiarum et Tractatus de renenis. Nlantuae 1472. folio.

Simon Januensis, Synonymi medicinae seu Clavis sanationis. Ed. princeps. Merliolani 1473 . folio.

Apulejo false adscriptum Herbarium, seu de herbarum virtutibus. Romac s. a. 4. - Paris $152 \mathrm{~s}$. folio, - Norimbergae 1788. S.

Macer Floridus, De viribus herbarum. Neapoli 1477. folio. - Ed, nos iss. cur. Lud. Choulant. Lipsiae 1839. 8.

(auglice, sallice, danice.)

(Boerner, De Aemilio Macro. Lipsiae [1754.] 4.)

(Harpestreng, Danske Lagebog. Kiobenham 4\$26. 8.)

Fiera, Coena de herbarum virtutibus. Argentorati s. a. 8. - Patavii 1649.4. 
Orlolf von Bayrlandt, alias IJegtenberger, Artzneibuch. Aug. Vindel. s. a. folio. - Nurnberg 1477. folio, - Iugsburg 1479. folio. - ib. 1482. folio. - Lubeck 1484. folio. - Augsburg 1488. folio. - ib. 1490. folio.

Celsus, De re medica libri VIIl. Ed. princeps. Florentiae 1478. folio.

Matthaeus Sylvaticus, Liber pandectarum medicinae. (Argentorati) s. a. folio. - Venetiis 1480. folio.

Herbarius. Naguntie impressus 1484. 4.

(Editiones ot iranslationes $\mathrm{cf}$. in Thes. lit. Lot. no. 11867-11875.

Hortus sanitatis. s. I. el a. folio.

(Editiones et translationes ef. in Thes. Lit. bot. 110, 11576-11906.

Leonicenus, De Plinii et aliorum medicorum errorilus. Ferrariae 1492. 4. - Basileae 1529. 4. - ib. 1532. folio.

Liber aggregationis sive secretorum de virtutibus herbarum. Argentine 1493. 8.

Tollat von Tochenberg, Ain meisterlichs buchlein der artzney. (Wien) 1497. 4.

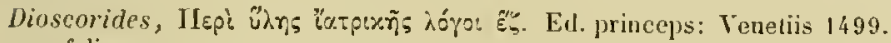
folio.

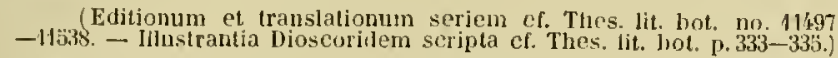

Nicander, Alexipharmaca ef Theriaca. Ed. princeps: Venetiis 1499. folio. - Ed. nov. recognovit Lehrs. Paris 1846. Lex. 8.

Jicronymus Brunsthoygk von Salcrn, Von der liunst der distillirung. Strassburg 1500 . folio.

(anglice.)

(Suardu.s) Thesaurus aromatariorum. (Tenetiis 1504.) folio.

Nocilo, Lucidarium medicinae. Neapoli 1511. 4.

Fries, Synouyma und gerechte Pllegung der Wörter. Strassburg 1514. 4. (latine, gallice.)

Manardus, Epistolarum medicinalium libri XX. Ferrara 1521.4. 。

- In Mesue Simplicia annotationes et censurae. In ejus a Epistolis 1. Ferrara 1529.4.

Fries, Spiegel der Arzney. Strassburg 1526 . folio.

Treveris, The grete herball. London 1526. folio.

Valla, De simplicium natura liber unus. Argentinae (I528.) 8.

Scribonii Largi De compositionibus medicamentorum liber unus. Parisiis 1529. folio.

Serapionis, Averrois, Rasis De simplicibus medicinis opuscula edidit Otho Brunfels. (Argentorati 1531.) 4.

Brunfels, Theses seu communes loci totius rei medicae. Argentorati 1532. 8 .

Champier, Hortus gallicus. Lugduni 1533.8.

Caimpus Elysius Galliae. Lugduni 1533. 8.

Gesner, De stirpium collectione tabulae. In Lyberi Lexicon. Argentinae 1533. 8. p. $467-548$.

Oribasii De simplicibus libri quinque. Argentorati 1533. folio.

Brunfels, Onomastikon medicinae. Argentorati 1534. folio.

Brasavola, Examen omnium simplicium medicamentorum. Romae 1536. folio.

Aristolelis Problemata quae ad stirpium genus et oleracea pertinent. Lugduni Batavorum 1537.8.

Lovicz, Enchiridion medicinae. Cracoviae 1537. S.

Mundella, Epistolae medicinales et Annotationes in Brasovolas simplicium examen. Basileae 1538. 8.

Fuchs, Apologiae tres. Basileae 1538. 4.

Actuarius, De medicamentorum compositione. Parisiis 1539.8.

Agricala, Nedicinae lserbariae libri duo. Basileae 1539. 8.

Mecum, Von den Kräuterı und ihrer Kraft. Wittebergae 1539. 4.

Dorstenius, Bolanicon. Francefurli 1540. folio.

Fusch vel Fuscus, Plantarum omnium apud pharmacopolas nomenclaturae. Paris 1541. 8 .

Gesner, Historia plantarum et vires ex Dioscoride, Paulo Aegineta etc. Basileae 1541.8.

- Apparatus el delectus simplicium medicamentorum. Lugoluni 1542. 8 .
Fusch vel Fuscus, be plantis antea ignotis. Venctiis 1542. 12.

Dantz, Tabulae simplicium medicamentorum. Basileae 1543. folio.

Fusch vel Fuscus, De herbarum notitia. Antwerpiae 1544.8.

(Brunfels) In Dioscoridis historiam plantarum certissina adaptatio. Argeniorati 1543. folio.

Fuchs, Apologic 'jua refellit Gualtheri Ryff reprehensiones. Basileae 1544.8 .

Lanye, Epistolae medicinales. Basileae 1344. 4.

Fuchls, Cornarius furens. Basileae 1545.8.

Adversus mendaces Christiuni Egenolphi calumnias. Basileae 1545.8.

Ryff, Das neue grosse Distillirbuch. Frankfurt 1345.4.

Smilh, Een skon loestig ny urtegaardt. Nalmo 1546.8 .

Benedelli, De re medica opus insigne. Basileae 1549. folio.

Asham, A littel herbal. London 1550. 12.

Turner, A new Ilerball. London et Collen 1551-1562. folio. - Ed. II: Collen 1568 . folio.

Brunfels, Epitome ox gravissimis authorihus totius rei medicae summam complectens. Parisiis 1552. 12.

Cordus, Dispensatorium, h. e. pharmacorum conficiendorum ratio. Lugd. 1552. 12.

Jacobi Silvii appenthx pro instruetione plarmacopolarun. Impr. cum Cordi Dispensatorio. Lugduni 1552.12.

Esteve vel Slevius, Dictionario de las yetvas y plantas medicinales. (1552?)

Baccanellus, De consensu medicorum in cognoscendis simplicibus. Lutetiae 1554. 12

Desscnius, De composilione medicamentorum libri $\boldsymbol{X}$. Francofurti 1555. folio.

Evonymi Philiatri (Conradi Gesneri) Thesaurus de remedüs secretis. Lugduni 1555.16. (anglice.)

Spiczyristi, 0 ziolach tutecznych i zamorskich etc. Cracoviae 1556. folio min.

Guilandinus, De stirpium aliquot nominibus vetustis ac novis epistolae. Basileae 1557. 8. - Patavii 4558.8.

Schneeberger, Catalogus stirpium. Cracoviae 1557. 8.

Guilandinus, Apologiae adversus Muthiolum liber primus, qui inscribitur Theon. Patavii 1558.4.

Mattioli, Apologia adversus Amatum Lusitanum. Venetijs 1558. 8.

Tarlaglini, Erbolario. Fiorenza 158\$S. 12.

Maranta, Methorli cognoscendorum simplicium libri tres. Venetiis 1559. 4. Anguillara, Semplici. Vinegia 1564.8. (latine.)

(Du Pinet vel Pinacus) Historia plantarum. Lugduni 1561.12.

Fuchs, De componendorum medicamentorum ratione. Lugduni 1561. 12.

Galcnus, (Operum) Quinta classis. Basileae 1561. folio.

Mesvar Opera ounnia, cum annotationibus Andreae Marini. Venetiis 1561. folio.

Sansovino, Delle materia medicinale. Venezia 1561.4.

Schneeberger, Catalogus medicamentorum simplicium. T1guri (1561.) 8.

Bulleyne, The booke of simples. London 1562 . folio.

llessus, Defensio riginti problematum Guilandini. Patarii 1562. 8.

Nattioli, Adversus viginti problemata Melchioris Gulandini disputatio. Falavii 1562.8 .

Juhász vel Mclius, Herbarium. Debrecini 1562.4. - Kolosvárolt 1578.4.

Garcia del Jlucrto, vel ab IIorto, Coloquios dos simples. Goa 1563.4. (latine, anglice, italice, gailice.)

Nevianus, De plantarum virihus poematium. Lovanii 1563.8.

Mizauld, Alexikepus seu auxiliaris hortus. Lutetiae 1564. 8.

Nova el mira arteficia. Lutetiae 1565.8.

(germanice.)

Fragoso, Catalogus simplicium medicamentorum. Compluti 1566.8.

Mallioli, De cura morbi gallici opusculum. Venetiis 1566. folio.

Fernetius, Therapia. s. I. 1567. folio.

Mizauld, Memorabilium centuriae novem. Lutetiae 1567. S. 
Badanus, Aduatationes centum in Simplicia Mesaue. Papiae 1568. 8.

Siennik, Herbarz. Krakuwie 1568 . folio min.

Matlioli, Opusculum de simplicinm medicamentorum Iacultatibus. Venetiis 1569. 12.

Monardes, llistoria medicinal de las cosas fue se traen de nuestras Judias occidentales. Sevillia 4569.4. (batine, anglice, ilalice. gallice.

- Tratado del efecto de varias jervas. Hispali 175. 8.

Winckler, Claronica Iserbarum. Augustae Viudelicorum 1571. 4. (germanice.)

Fragoso. Discursos de las cosas aromaticas. Madrid 1572. 8. (latiue.)

Uarchius, Encliridion medicum. Basileae 1573.8.

Carricher, Krituterbuch. Strassburg 1575. 8 .

Belidas, Tabula simplicium medicamentorum. Embdae 1576.8.

Les figures et pourtraiets des plantes. Paris 1576.12.

Bacci, Tabula simplicium medicamentorum. Romac 1577. 4.

Gesner, Epistolarmu medicinalium libri Ill. Tignri 4577.4.

- Epistolarum medicinalium liber IV. Wittebergae 1584.4.

Acosta, Tractado de las drogas. Burgos 1578. 4.

(latiue, italice, gallice.)

Thurneisser zum Thurn, Ilistoria sive descriptio plantarum onnium. Berlini 1578 . folio. - Ilistoria und Beschreibung influentischer Wirckungen aller Erdgewechsen. Berlin 1578. folio.

Langhain, The garden of health. London 1579.4 .

Oczko, Descriptio lierbarum medicarum. Cracoviae 1581.4.

De l'Ecluse, Alinjot notae in Garciae Aromatum historiam. Antwerpice 1582. 8 .

Linocier (= Du Pinel), L'histoire des plantes. Paris 1584. 12.

Anguisola, Compendium simplicium. Placentiae 1587. 12.

Gesner, De stirpium collectione tabulae. Tiguri 1587. S.

Porta, Plyytognomica octo libris cuntenta. Neapoli 1588 . Folio. - Francolurti a/M. 1591.8. - ib. 1608. 8. - Rothomagi 1650.s.

Roscnbach, Paradiesgärtlein. Frankfurt a/A. 1588. 12.

Paracelsus, Bucher und Schriften, herausgegeben durclı Huserum. Ease! $15 \$ 9-1590.4$

Operum tomi XII. Francolurti a/AJ. 1603.4. - Opera omnia. Genevae 1658. fulio.

Acosta, Historia natural y moral de las Indias. Sevilla 1590.4.

(laline, anglice. gallice, hollandice, italice.)

Pabst von Kochlitz, Artznei-Kunst und Wunderbuch. Nuhlhausen 1590. 4. Gilijagendes Kunst und Hauslıucl. Leejzig 1591. 4.

Bejthe, Füves honyv fúveknek. Némelb-Ujvárot 1595. 4.

Urzędowo, Herbarz polski. w Krakowie 1595. folio.

Perez, De medicamentorum delectu. Toleti 4599.

De l'Obel, In G. Rondelletii methodicam pharmacenticam officinam animadversiones. Londini 1605 . Sulio.

llorst, Hortulus medicus. Cassellis 1610. 4.

Syreniusz Syrenshi, Zielıik, Herbarzen htóry z jẹzka Laciúshiego zowią etc. Cracoviae 1613. fulio.

Hernandez, Quatro libros de la naturaleza y virtudes de las plantas en la nueva España. Mexico 1615. 4.

folio.

Opera (de historia plantarum Novae llispaniac). Matriti 1790.4

Colladon, Adversaria. Coloniae Allobrogum 1615. S.

Franke, Signatur, d. i. Gründlliche und wahrhaltige Beschreibung dor Gewachsen. Rostock 1618,4.

Baukin, De remediorum formulis. Francofurti 1619.8.

(Linocier) Entier discour's el maniere de distiller les eaux de toutes sortes de plantes. Ed. II. Paris 1619.12.

Colombina, Il bomprovifaccia. Padova 1621. 8.

Becher, Parnassus medicinalis illustratus: Phytologia d. i. das Kràuterbuch. Uliw 1622, folio. llarlequin, Nouveau jardin des vertus et propriétés des herles. Aix 1624.8.

Jacobs, Den cleynen herbarius ofle cruyt boexken. Amsterdam 1627. 8. Muehlpforl, Medizinisclses Spaziergánglein. Schleusingen 1627.8.

Contant, Les oeuvres diviseses en cinq traictez. Poictiers 162S. folio.

Les divers exercices. Poictiers 1628. folio.

Märsson, Eu mycket nyttig Ortabuok. Calmar 162S. 8.

( Kenmann) Tabula locun "t tempus exprinens, quibus uberius plantae vigent. Willebergae 1629.4. - Jirancofurti a/ M. 1715 folio.

Ilorst, llerbarium IIorstianum. Narpurgi 1630.8.

Mousinus, Hortus iatroplyysicus. Nanceii 1632.8.

Alaymus, Do succedaneis medicamentis. Panormi 1637.4

Villa, Ramillete de plantas. Burgos 1637. 4.

Paulli, Quadripartitum hotanicum de simplicium facultatibus. Rosloclsii 1639. 4. - Ed. III: Francofurti a/11. T708. 4.

Bontius, De medicina Indorum libri IV. Lugduni Latarorum 1642. 12.

Jillu, Libro de simples incognitos. Burgos 1643. 4.

Munting, Hortus et universae materiae inedicae gazophylacium. Groningae 1646. 12

Clavenna, Clavis Clavennac. Tarvisii 164S. folio.

Piso, De medicina brasiliensi libri WV. Lugduni Batayorun 1648. folio. Ed. II: Amstelodimi 1658. folio. - Ed. nova: Vindobonae IS $17 . \mathrm{S}$.

Martinez y Leache, Pliarmacopales. Pumpeiopoli 1650.4.

Culpeper, The english physician. London 1653. S. - Ed. II: London 1792.8.

Pancliow, Herbarium portatile. Berlin (1654.) 4.

Hippocrates, Opera omnia. Genevae 1657. folio.

Tilemann, Praxis botanica. Herbipoli 1657. 8.

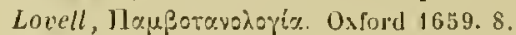

Melvetius, Xystus herbarum, Lustiger Spatzierweg der hranter. Hegdelberg 1661.12 .

$\longrightarrow$ Berillus medicus. Heydelberg 1661, 12.

Bartholinus, Cista nedica havniensis. Ilavniae 1662. \$.

Aengelen, Herbarius. Amsterdam 1663.8.

Turner, Botanologia, the brittish physician. London 1664.8.

Blagrave, Supplement to Nich. Culpeger's Englisch Physician. London 1666. 8 .

An englislı herbal. London s. a. 12.

Borel, Hortus seu armamentarium simplicium. Castris 1666. 8

Merrell, Frands and abuses committed by apothecaries. London 1667. \&.

Burtholinus, Epistula de simplicibus medicamentis inquilinis cognuscendis. Javniae 1669.8.

Montaluanus, Catalogus alphabeticus plantarum officinalium. Bulogna 1670. folio.

Franke, Lexicon vegetabilium usualium (Flora francica). Argentorati 1672. 12

(germanice.)

Ilughes, The american pbysician. London 1672. 12.

Archer, Compendious herbal. London 1673.8.

Marygravius, Materia medica contracta. Lugduni Batavorum 1674. 4.

Michelus, Lexicon botanicum. Romac 1675. 12.

Mucller, De virfute herbarum medicamentosa. Wittebergae 1676. 4.

II'edel, De compositione medicanentorum. Jenae 1677 . folio.

- Plıarmacia iı arlis formam redacta. Jenae 1677. 4.

De medicanentorum compositiene. Jenae 1678. 4.

De medicamentorum Iacultatibus. Jeuae 1678.4 .

Baccanellus, De ratione instituendi medicamina. Amstelodami 1680. S.

Ilonupleriis, Stirpium nomisa in pharmacopolio Mininorum reperiundarum. Romae $16 \mathrm{~S} 2.4$.

Charas, Plirmacopoea regia galenica. Genevae 16\$3. 4.

Palmberg, Serta florea suecana, eller: svenske ortekrantz. (Strengnaas) 1684. s. - Slockholm 173s. S.

IItedel, Imoenitates materiae medicae. Jenae $1684 \quad 4$ 
Abercrombie, Nova medicinae clavis. Londini 1685.8 .

Mueller, Vademecum botanicum. Franhfurt 1687.8 .

Wagner, De natura et virtulibus plantarum. Regiomonti 168s. 4.

Borrich, De usu plantarum indigenarum in medicina. Havniae 1690. 4. (germanice.)

Berlu. The treaswry of drugs unlock'd. London 1693. 12. - ib. 1733. 12.

Dale, Pharmaeologia. Londini 1693. 12. - ih. 1737. 4.

Ballus, Hel secrel boek. Leeuwarden 1694. 12.

Boogh, Nederiluitsch woordenboek: Catalogus omnium simplicium. Amsterdam 1694. 8.

Pechey, The compleat berlad of physical plants. Iondon 1694, 8.

Pomet, Jlistoire générale des Jrogues simples el composées. Paris 1694. folio. - ib. 1735.4 .

(anglice, germanice.)

Droguier curieux. Paris 1695.8.

Blankaart, De nederlandschen Herbarius. Austerdam 1698, 8 .

Lémery, Dictinnnaire des drogues simples. Paris 1698.4. - Ed. augmentée par Morelot. ib. 1807.8 . italice, germanice.)

Jyde, De religionis veterum Persarum historia, Oxonii 1700.4.

Le Clerc, Catalogne des drogues. Paris 1701. 12.

Valcutini, Polychresta exntica. Francofurti a/M. 1701.4.

lledel, Theoria saporum medica. Jende 1703.4.

Valentimi, Museum Museorum oder Vollstandige Schaububne aller Materialien und Spezereien. Franhfurt a/M. 1704-1714. Solio.

—. Historia simplicium relormata. Francofurti a/M. 1716. folio.

Mueller, Curioser Botanicus. Dressden 1706. 8.

Vcbel, De plantis verno tempore efflorescentibus usualibus. Marburgi 1706. 4 .

- De plantis incipiente aestate eflorescentihus usualibus. Mlarburgi 1707. 4 .

IJaldschmiedt, De vegetabilium usu in medicina. Kiliae 1707.4.

Chomet, Abrégé do l'histoire des plantes usuelles. Paris 1712. 8. - ib. 1803. 8 .

Bracmer, Thesuurus sanitatis. Dritter Theil oder Kráuterbuch. Franklurt 1713. S. - ib. 172s. 8

Zorn, Botanologia medica. Berlin 1714. 4.

Feuille, Ilistoire des plantes médicales de Perou et Chili. In ejus "Journal o, Paris $1714-1725.4$. vol. II, 703-767. III, 1-71. (germanice.)

Petiver, Hortus peruvianus medicinalis. (Operum vol. II.) London 1715. folio.

Kracutermann, Compendioses Blumen- und Krinterbuch. Frankfurt 1716.8.

De Pré, De regno regetabili morborum curandorum principe. Erfordiae 1717. 4.

Tourncfort, Traité de la matière médicale. Paris 1717. 12. (anglice.)

Vigier, Historia das plantas etc. Lion 1718.8.

Buchwald, Explicatio virtutum plantarum indigenarum. Havuiae 1720. 4. (germanice.)

Zamboni, Icones plantarum CCV cum earum virtutibus. Florentiae (1721?) 4.

Miller, Botanicum officinale. London 1722. 8.

Heister, De collectione simplicium. Helmstadii 1722.4.

Knowles, Matcria medica botanica, Londini 1723. 4.

Blair, Pharmaco-botanologia. Loudon 1723-1728. 4.

Monti, Exoticorum sinplicium varii inclices. Bononiae 1724. 4.

(Martyn) Tabulae synopticae plantarum officinalium. Londini 1726. folio.

Chomel, Catalogus plantarum olficinalium secundum facultates. Paris 1730.8 .

Kraeuternann, Compendiöses Lexicon exoticorum et materialium. Arnstadt 1730.8 .

Hermann, Cynosura materiae medicae. Argentorati 1726-1731. 4.

Boecler, De neglecto vegetabilium circa Argentinam nascentium usu Argentorati $1732-1733.4$.
Alberti, De erroribus in pharnacoproliis ex neglecto studin botanico. Halae 1733.4 .

Alleyne, New english dispensatory. London 1733. 8.

Ludolf. Anfangsgrunde der Arzneiwissenschaft. Berlin 1734. S.

IIalouin, Chymie nédicinale. Paris 1734.12. germanice.)

Turgioni-Tozzelli, De praestantia el usu plantarum. Pisis 1734. folio.

h'Eogh, Botanologı hibernica. Corke 1735. 4.

Wedel, Syllabus materiao medicae selectioris. Jenae 1735. 4.

Blackicell, A curious lierbal. London 1737. Solio. - Lerbarium Blackoellianum emendatum el auctum. Norimbergae $1750-1773$. folio.

IIamnerin, Vires medicae plantarum indigenarum. Upsaliae 1737. 4.

Suarez, Clave botanica. Maclrid 1738. 4.

Abel, Medizinisches lirăuter-Paradiesgártlein. Frankfurt 1740. 12.

Albrecht, De aronatum exoticorum noxa. Erfordiae 1740. 4.

Geoffroy, Tractatus de materia medica. Paris 1741. S.

Traité cle la matièro méclicale. Paris 1757. 12.

Ricyer, Intrnduclio in notitiam rerum naturalium. lJagae 17424.

Lagusi, Erbuario italo-siciliano. Palermo 1743. 4.

Ludwig, Radicum officinalium bonitas ex vegetationis historia dijudicanda. (I-II.) Lipsiae 1733.4.

Morandi, Osservazioni intorno al sinonimo altabetico dell" erlee usuali. Mliano 1743.4.

- Riposta etc. Milano 1743.4. (contra Cesare Carini.)

Historia botanica practica. Mediolani 1744. folio.

Short, Medicina Lriannica. London 1747. 8.

Limné, Materia merlica, liber 1. De plantis. Holmiae 1749. 8. - Ed. V: Lipsiae 1787 . 8 .

Cartheuser, Fundamenta materiae medicae. Parisiis 1749-1752. 12

Illll, A history of the materia medica. London 1751. 4.

Linne, Sapor medicanentorum. Ilolmiae 1751. 4.

Buccher, De quibustam remediis restituendis. Ilalae 1752.4.

Haller, De praestantia remeliorum vegetabilium. Goellingae 1752. 4.

Linné, Odores medicamentorum. Stacklıolniae 1752. 4.

Plantae officinales. Upsaliae 1753. 4.

- Censura medicamentorum simplicium vegetabilium. Upsaliae 1753.4 .

Cartheuser, De genericis quibusdam plantarum principiis. Francolurti 1754,8 .

Catalogue des plantes usuelles. Amiens 1754. 19.

Banal, Calalogue des plantes usuelles. Montpellier 1753.8

Hill, The usefull family herbal. London 1755.8.

Hille. De actione plantarum in partes solitas. Goettingae 1755.4.

Sheldrake, Botanicum medicinale. London s. id. folio.

Linné, Specifica Canateusium. Scarae 1756. 4.

Beckerstedt, Örtebook. Stnckholis 1758. 4.

Limne, Medicamenta graveolentia. Upsaliae 1758. 4

Crantz, An plantarum officinalium recepta nomina recte mutentur? Viennae 1760.4 .

Gauthier, Introduction à la connaissance des plantes. Paris 1760. 8.

Meder, Medicamenta simplicia, entbelarliclse. Goettingae 1760. 4.

Vogel, Historia materiae medicae. Lrancofurti 1760. 8.

Biruega, Examen pharmacentico-galenico-bistorico. Madrit 1761.8

Bochmer, De virtute Inci natalis in vegetabilia. Wittebergae 1761. 4.

(Arenstorff) Comparatio nominum plantarum officinalium. Berlin 1762.8 .

Crantz, Nateria medica. Viennae 1762.8 .

Kalm, Praestantia plantarum indigenarum prae exoticis. Abo 1762. 4.

brookes, Natural history of vegretalles. London 1763. 12.

Aken, Svenska Medicinal Vaxterna. Örebro 1764. 8.

Lange, De remediis Brunsvicensinm domesticis. Brunsvigae 1765. S.

(Latourelle et liozie'r) Denonstrations élémentaires de botanique, vol. Il. Lyon 1766. 8 .

Schwencke, Kruidkundige beschryving etc. Gravenbage 1766. S.

Arnauld et Salerne, Description des plantes usuelles. Paris 1767.12. 
Dagoly, Collection des plantes usuelles. Paris 1767 . folio.

Garsault, Description, vertus et usazes de 719 plantes. Paris 1767. 8.

Gleditsch, Anleitung zur Erkenntniss roher Arzncinittel. Berlin 1768. 8.

- Verzeiclıniss der gewöhnlichsten Ar'zneigewachse. Berlin 1769.8

Bochmer, De justa plantarum inligenarum aestimatione. Wittebergae 1770. 4

Buchoz, Manuel médical des plantes. Paris 1770. 8.

Carl, Botanisch-medizinisclıer Garten. Ingolstadt 1770. 8.

Carthcuser, Plıarmacologia. Berolini 1770.8.

Desportes, Abrégé des plantes usuelles de S. Domingue. In ejus "Histoire etc. Paris 1770. 12. tom. 111, p. $3-56$.

Edwards, The british herbal. London 1770. folio.

(Edwards, Select collection of 100 plates. London 1775 . folio. vix differt.)

Vitman, 1)e medicatis herbarum facultatibus liber. Faventiae 1770. 8 .

IIaller, Praefatio ad Pharmacopoean helvetican. Basileae 1771. folio.

Jussieu, Traitó des vertus des plantes. Nancy 1771. 8.

Ilill, Virtues of british herbs. London $1772 . \mathrm{S}$.

Linne, Observationes in materiam medicam. Upsaliae 1772.4.

En liten örte-bok. Wásterås 1772. 8 .

Ludwig, De plantarum viribus medicis. Lipsiae 1772.4.

De plantarum viribus specificis. Lipsiae 1772.4.

De plantarum viribus cultura mutatis. Lipsiae 1772.4 .

Mellenius, Finska medicinal-waxter. Ảbo 1773. 4.

Koenig, De remediorun indigenorum ad morbos endemicos expugnandos efficacia. Hafniae 1773 . S.

Marquet, Venimecum de botanique. Paris 1773. 12.

Tonning, Norsk medicinsk och oekonomisk Flora. Kiobenhavn 1773.4.

Eisen, Unterricht von der Krauter- und Wurzeltrochnung. Riga 1774. S.

(Regnault) La botanique mise à la portée de tout le monde. Paris 1774. folio.

Spielmann, Institutiones materiae medicae. Argentorati 1774. 8. (germanice.)

Jaskicuvicz, Pharmaca regni vegetabilis. Viudobonae 1775.8.

Vicat, Matière médicale tirée de Halteri Historia stirpinn Helvetiae. Bern 1776. 8. - ib. 1791.8.

(germanice.)

Murray, Apparatus medicaminum. Goeltingae 1776-1792. 8. - ib. 1793 -1794.8 .

Gleditsch, Einleitung in die Wissenschaft der rolıen und einfaclıen Arzneimiltel. Berbin 1778-1787. 8 .

Baldinger, Alexiteria et alexiplsarmaca con(ra diabolun. Goettingae 1778. 4.

Bergius, Materia medica e regno vegetabili. Stochlolmiae 1778. 8. ib. 1782.8

W'uertz, Conamen mappae medicamentorum simplicium. Argentorati 1778. 4.

Coste el Hillemet, Essais sur quelques plantes indigènes substituées à des végétaux exotiques. Nancy 1778 . \&.

Murray, Dulcium natura el vires. Gottiugae 1779.4.

(Zorn) Icones plantarum medicinalium. Nurnberg 1779-1784.8.

Banal, Catalogue des plantes múdiciuales. Montpellier 4780.8. - ib. 1784. 8.

Buchoz, Collection des plantes médicales de la Cline. Paris 1781. folio.

Schreber, Mantissa ad Linnaci Mat. medicae ed. 1Y. Frlangae 1782. 8.

Lichtenstein, Anleitung zur medizinischen Krtuterkunde. Ilelnstedt 1789 -1786.8 .

Lestiboudois, De viribus plantárum. Duaci 1783.4.

Spielmann, Pharmacopoea generalis. Argentorati 1783. 4.

Burtin, Quels sont les végétaux indigènes à substituer aux végétaux exotiques? Bruxelles 1784.4.

(latine.)

IFauters, De plantis belgicis in locum exolicarum sufficiendis. Gandavii 1785.8 .

Thunberg, De medicina Africanorum. Upsaliae 1785. 4
Retzius, Einleitung in die Lelıre von den Arzneien des Pflanzenreiclıs. Leipzig 1786.8. (latine.)

Segerstedt, De plarmacis indigenis. Upsaliae 1787.4

Happe, Botanica pharmaceutica. Berolini 1788 (-1806). folio.

Plencl, lcones plantarum medicinalium. Viennae 1788-1812. folio.

Gleditsch, Botanica medica. Berlin 1788-1789.8.

Culten, Treatise of IIateria medica. Fdiuburgh 1789. 8 . (gallice.)

Grahl, Medicamenta quaedam Rossorum domestica. Jenao 1790. 4.

Meyrick, The sew family herbal. Birmingham 1790. 8 .

Woodville, Medical botany. London 1790-1794. 4. - Ed. III: by Hooker and Spratt. ils. 1832.4.

Carminati, Ilygiene, terapeutice et materia medica. Paf̧iae 17911795.8 .

Marterstck, Bonnischer Flora erster Theil. Bonn 1792. S.

Roussel, Tableau des plantes usuelles. Caen 1792. 8.

Schrader, Dio norddeutschen Arzneipllanzen. Berlin 1792.8.

Cusle et IVillemet, Matière médieale indigène. Nancy 1793. 8.

Ebermaier, Vergleichende Beschreibuog der in Apotlıetien leiclıt verweclsselten Pllanzen. Braunseluweig 1794.8.

Valentin, De plantarum succis. Marburgi 1795. 8.

(Krauss) Afbeeldingen der artsenygewassen. (Icones plantarum usedicinalium.) Amsterdam 1796-1800.8.

Barton, Materia medica of the United States. Philadelpluia 179s-1804. S. Peyrilhe, Cours d'hist. nal. médicale. Paris 1799. 8. - ib. 1804.8.

Norclot, Cours d'list. nat. pharmacentique. Paris 1800 . S.

- Ilistoire naturelle appliquée etc. Paris 1809. S.

Schwediaur, Plarmacologia seu materia medica. Paris 1800. 12. - ib. 1803.12.

Vietz, Icenes plantarum medico-oeconomico-teclmelogicarum. Wien 1800 -1820.4. - Supplementum: ib. 1822. 4.

Walter, Plantae officinales. (Argentorati)s. a. 4.

Nocca, Istituzione di botanica pratica. Pavia 1801 . \$.

Dietrich, Der Apothekergarten. Berlin 1802. S.

Ebermaier, Von den Standortem der Pflanzen. Munster 1802. \&.

Grindel, Plsarmaceutische Botanik. Riga 1802. 8.

Hofmann, Syllabus plattarum officinaliun. Götingen 1S02. 8.

Noehden, Entwuri zu Vorlesungen über pharmacologiscbe Botanik. Goltiugen 4802.8.

Wenderoth, Materiae pharmaceuticae hassiacae specimen. Marburyi 1802.8 .

Gomes, Observationes de nonnullis Brasiliae plantis. Olisipone 1803.4.

Vitet, Matiere médicale. Lyon 1803.8.

Alibert, Natière médicale. Paris 1504. \&. - ib. 1826. 8.

Schvilgué, Traité de natière médicale. Paris 1805. 12. - ib. 1\$1\$. \$.

Kelch, Flora medica borussica. Regiomonti 1805.8.

Savi, Materia medica vegetabi]e. Firenze 1805 . folio.

Irolik, Catalogus plantarum medicinalium pharmacopeae batavae. Amstelodami 1805.8.

Hayne (Brandt, Ratzeberg et Klotzsch), Getreue Darstellung der in der Arzneihunde gebrablilichen Gewachse. Berlin 1805-1846.4.

Barbier, Principes généraux de pharmacologie. Paris 1806.8 .

Roques, Plantes usuelles indigènes et exotiques. Paris $1807-1808$. 4.

Dziarkowski, Wybór roslin krajowych. Warszawie 1808. 8. - ib. 1821.8.

Schumacher og Ilerholdl, De oflicinelle Laegemidler af Planteriget. Kjobenhavn 1808.4.

Tenore, Saggio sulla qualita medicinali delle piante della Flora napolitana. Napoli 1808.8 . - ib. 1820.8 .

Nocca, Istituzioni di botanica pratica. Pavia $1808-1809.8$.

Dubuisson, Plantes usuelles indigènes et exotiqnes. Paris 1809.8 .

Sangiorgio, Istoria delle piante medicale. Milano $1809-1810.8$

Bodard, Analyse du cours de botanique médicale comparèe. Paris 1809.4 Cours de betanique roédicale comparée. Paris $1810 . \mathrm{s}$. 
Arruda da Camara, Dissertaçao sobre as plantas do Erazil. Rie de Janeiro 1810.8 .

Cassel, Iober die naturlichen Familien der Pflanzon mit Rucksicht auf ibre Heilhrafte. Koln 1810. 8 .

Fleming, $A$ catalogue of Indian medicinal plants and drugs. Calcutta 1810.8 .

Titlmann, Darstellung der Medizinalpflanzen Saclisens. Dresden 1810 . gr. 8 . Hauters, Repertorium remediorum inligenorum exoticis substituendorum. Gandao 1810.8.

Balbis, Materics medica. Taurini 1811.8 .

Berlero. Nonnullae indigenao stirpes cxoticis suecedaneae. Taurini 1\$11.4.

Stohes, A botanical Materia medica. Loudon 1812. S.

Graumiller, Handbuch der medizinisch-pharmaceutisclıen Botanik. Eisenleerg $1813-1819.8$.

I eith. Boschreibung der Arzneigewăclsse Oestreichs. Wien 1813.8.

Ainstic, Materia medica of Hindostaau. Mladras 1813. 4.

Afzelius, Reinedia guineensia. Upsaliae 1813-1817.4.

Lunan, Ilortus jamaicensis. Jamaica 1814.4.

Chanmeton, Chamberet et Poiret, Flore midicalo. Paris 1814-1820.8. Granmiiller, Flora plrarmacentica jenensis. Jenae 1815.4

Bodard, Tahleau des plantes médicinales. Paris 1815.4 .

Thunbry. In narcolicis observationes. Lpsaliae 1816.4.

Vollberg, Illarmaca quaedam indigena. Dorpati 1816.8.

Bigelow, American roedical botany. Boston 1847-1821.4.

Alberti, Flora medica. Nilano 1847.8.

Reichenbaih, Flora lipsiensis pharmaceutica. Lipsiae 1817. 8.

Jarton, Veretablo materia medica of tuc United States. Pliladelphia 1817 -1818.4 .

Campana, Farmacopen ferrarese. Firenze 1818. 8.

Goetz, Deseriptio plantarum exoticarum oflecinalium. Viennae 1818. 8.

Gra!l, A supplement to the pharmacopoeas. Londen 1818.8.

Afzelius, Slirpium in fruinea medicinalium species novao. Upsaliae 1918 -1829.4 .

Loiselmur. Hanuel des plantes usuelles indigènes. Paris 1819.8.

Dierbach, Handbuch der medizinisch-pharmacentisehen Botanik. HeidelJers 1819.8.

Iornemann, De iudole plantarum guineensium. Havniac 1819.4.

Barbier, Traité de matièro médicale. Paris 1819-1820.8.

Lejeune, De indigenarum plantarum virtutibus, Leodii 1820.4.

(.Masius) Tentamen pharmacopoeae pauperum una cum catalogo plantarum mediciualium megapolitanarun. Rostochii 1820. 8 .

Sterler et Mayerhoffer, Europa's medizinische Flora. Muinclien 1820 $(-1824)$, folio.

Hofimann, Compendium plarmacologiae. Mosquae 1821. S.

Loeuillarl-D".1 trigni, Priocipes de botanique medicalc. Paris 1821. 12.

Roques, Phytographia médicale. Paris 1821.4. - ib. 1835.8.

Sternbery, Ciatalogus plantarum ad septem editiones Mallioli in Dioscoridem. l'ragae 1821. folio.

Descourlilz, Flore médicale des Antilles. Paris 1821-1829. 8 .

Nees von Esenbeck jun., Weihe, Wolter und Funke, Plantae officinales oder Samunlung offzineller Pflanzen. Dusseldorf 1921-1833. folio. (Textus scorsim "Beschreibung" etc. Dusseldorf 1829. folio.)

Limbche, Flora liamburgensis pliarmaceutica. Hamburg 1922. S.

Gautier, Horbier médical. Paris 1822.12.

Manuel des plantes médicinales. Paris 1829. 8.

Guibourl, llistoire ahrégè des drogues simples. Paris 1822. 8. - ib. 1836. \&.

(italice.)

Goldbach, De plantis officinalibus Rossiac. (rossice.) Mlosquae 1823. 4.

Richaid, Botanique médicale. Paris 1823. 8. (gernanice.)

Tenore, Flora medica universale e particolare della provincia di Napoli. Napoli 1823.8.

Herbarium pluarmacenticum. Kiobenhava 1824. 8 .

Pritzel., Thes. lit. bot.
Martius, Specimen materiae medicae brasiliensis. (Monachii) 182\%.4. Saint-Hilaire, Plantes usuelles des Brasiliens. Paris 1524-1828. 4.

Delle Chiaje, lconografia od uso delle pianto medicinali. Napoli $1826-$ 1825. 8 .

Afzelius, Stirpinm in Guinea medicinalinm species cognilae. Upsaliae 1825. 4.

Figueiredo, Flora plarmacentica e alimentar portugueza. Lisłoa 1823.8.

Sehumacher, Aledicinsk Plantelaere. Kiobenharn 1895-1826. S.

Ainslie, Materia indica. London 1826. S.

(Duncan) Catalogue of medical plants. Ediaburgh i\$26.8.

Harpestreng, Danske Lägebog. Kibbenhavn 1826. 8.

Leo, Taschenhuch der A'zneipflanzen. Berlin is96-1897.4.

(Nocca) Flora farmaceutica. Pavia 1826. S.

Thunberg, Anvisning till de svenska pharmaceutiska virsternas igenkúnnande. Ipsala 1826. 8.

Kickx, Deseriptio plantorum officinalium et venenatarum in agro lovanicnsi. Lovauii 1827.8.

Chevallier et Richard, Dictionnaire dos drogues simples et composées. Paris 1897-1829.8.

Stephenson et Churchill, Medical botany. London $1927-1830.8$. - ib. 1837.8 .

Thomson. Botanique du dreguistc. Paris 1827. 42. (anglice.)

Coebel et Kunze, Plarmaceutische Waarenkunde. (Rinden. Wurzeln.) Eisenach 1827-1834. 4.

Jourdan, Pharmacopée universelle. Paris 1828. S. - ib. 1840. 8.

Julia de Fontenelle et Tollard, Manuel de Mherhoriste. Paris 1828. S.

Tollard, Manuel de l'herboriste. Paris 1028, 18.

Bhuff, Heilkräfte der Kuchengewàchse. Nürnberg 1828. 8.

Dierbach, Die ncuesten Entdeckungen in der Materia medica. Heidelberz 1828. 8. - Ed. 1l: ib. $1837-1845$." s.

Fée, Cours d'histnire naturelle pharmaceutique. Paris 1828. 8.

Wagner, Pharmaceutisch-medizinische Botanik. Wien 1828. gr. folio.

Recluz, Des sucs végétaux aqueux en général. Paris 1928. 8 .

Rafinesque, Nedical Hlora of the United States. Philadelphia 182S-1830.8.

Duigubsky, lcones plantarum medicinalium rossicarum. Nosquac $1828-$ 1834. 4.

Bischoff, Plantae medicinales. Heidelhergae 1829. 4.

Bussy et Boutron-Charland, Moyen de reconnaitre les falsifications des drogues. Paris 4829.8.

De Smyttere, Phytologio pharmaccuticue et médicale. J'aris $1829 . \mathrm{gr}$. S. - Tablcaux synoptiques d'histoire naturelle medicalo. Paris 1829. gr. folio.

Hartmann, Plarmacologia dyuamica. Nindobonae 1829. 8.

Horaninow, Systema pharmacodynamicum. Petropoli 1829. gr. 12.

Maravigna, Saggio di una Flora medica catanese. Catania 1829. 4.

Anslijn, Afbceldiug der Artzenijgewassen. Amsterdam 1829-1839. folio.

Brandt, Tabellarische Lebersicht der offizinellen Gewäclıse. Berlin $18 \geq 9$ -1830 . folio.

llayne, Brandt und Ralzeburg, Darstelluag und Beschreibung der Arzneigewachse der neven preussischen Pharmakopoe. Berlin 18291841. 4.

Dobel, Synonymisches Worterbuch der Arznei- und Handelsgewäclse. Kempten is30. 8 .

Loiseleur, Histoire nedicale des succédauées. Paris 1830. 8.

Peixolo, Dissertation sur les médicamens brésiliens. Paris $1 \$ 30.4$.

Nees ron Esenbeck jun. et Ebermaier, Handbuch der medizinisch-pharmaceutischen Rutauik. Dusscldorf $4830-1839.8$.

N1ann, Die auslúudischen Arzneipflanzen. Stuttgart 4830-\$833. folio.

Seligmann, Liber fundamentorum plarmacologiae, anclore Abu Mansur Morcafil Ben Ali el IIerwi. Vindobonae 1830-1833.8. 1533. s.

Guimpel et von Schlechlendal, Abbildung und Beschreibung aller in der Pharmacopoea horussica aufgefuhrten frewáchse. Berlin $1830-1837.4$. 
Siegl, De calendario plantarum officinalium. Vindobonae s. a. 8.

Aluslijn, Ilandloiling. Amsterdam 1831, 8, - Leijd 1835-1838. 8.

.Lscherson, Pharmaceutische Botanik. Berlin 1831.4.

Bischof, Grundriss der medizinischen Botanik. Ileidelherg 1831.8.

Dietrich, Hora medica. Jena 1834. 4.

lichard, Gúmens d'lustoire naturelle múdicale. Paris 18:31.8.

Sehlichlirull, De officinelle planter. Kiobnhavn 1831. 8 .

Schmill, Beschreilıung der offizinellen Pflanzen der proussischen Pharlnakopoe. Berlin 1831. folio obl.

Kosteletzliy, Allgeneine medizinisch-pharmacentische Hora. Prag 1 \$s 1 -1836.8 .

Re'g, Anleitung zur Erkonnung der Arzueigenăchse, Berlin 1832. S.

Bock, Plantarum officinalium in Transsilvania descriptio. (Cibinii 1832. 8.

Ehrmann, Pharmaceutische Botanik. Wien 1832. 8.

Marlius, Grundriss der PJarmakognosie des Pllanzenreiclis. Frlangen 1839. 8.

Schmidt, Ilandbuch der medizinischen und Farbekrtuter. Gotha 1832. \&.

Winkler, Abbildungen sămmtlicher Arzneigowachso l)entsclılands. Leipzig 1832 sqq. 4.

Graves, IIortus medicus. London 1833. 4.

Henschel, Specimen materiae medicae amboinensis, In ejus "Clavis Rumphiana n. Vratislaviae 1833.8.

Jsensee, Elemeuta geographiae et statistices nedicinalis. Berolini 1833.8 .

Rennic, Alphabet of medical botany. Ediuburgh 1833. 8 .

Kunll, Anleitung zur Kentuiss ler in der Pharmacopoca borussica aufgefulhrten Gewáchse. Berlin $1 \$ 3$ 4. 8.

Turpin, Flore usuelle. Paris 1\$34. 8.

IVinkler, Haudbuch der Gewáchskunde. Leipzig 1\$34. gr. \$.

Spenner, llandluch eler angewandten Botanik. Freiburg 1834-1836. 8.

Winller, Abbildungen (und Beschreibungen) der homöepathisch gepruften Arzneigewdiclise. Leipzig (1834-1836.) 4.

Ditrich, Plantae officinales indigenae. Budae 1835. 8.

Gocppert, Sclilesiens offizinelle Pflauzen. Breslau 1835. 8.

Jacobavics, Elenchus plantarum officinalium Hungariac. Pestini 1835. S.

Iriese, Plantenkunde voor Apothekers en Artsen. Leiden 1\$35-1\$38. \$.

Delle Chiaje, Flora modica. Napoli 1836. 8.

Forshall, Lárobok i plarmacien. Norrköping 1\$36.8.

Sprall, The medico-botanical pocket-book. London 1836.8.

Cap, Principes élémentaires de pharmaceutique. Paris 1\$37.8.

Castle. Intraduction to the medical hotany. Inomdon 1837.8.

De Smyltere, Précis de bolanique médicale. Paris 1837. S.

Dietrich, Handbuch der pharmaceutischen Botanili. Berlin 1837. 8.

llmoni, Enumeratio plantarum officinaliun Fenniac. Jelsingforsiae 1837.8.

Maly, Systematische Beschreibung der deutschen Arzneigewächse. Grảtz. 1537. 8 .

Ronano, Plantae officinales Europae. Viemna 1837. S.

Royle, An essay on the antiquity of IIndoo medicine. London 1837. 8.

Barton et Castle, The british Flora medica. London 1837-1838. 8.

Guillomin, Synthèses de pharmacie et de chinie. Paris 1838.4.

Cuimpel et hlotssch, Pflauzenabbildungen und Beschreibungen zur Frkenntniss offizineller Gewáchse. Merlin 1838 . 1

Lindley, Flora medica. London 1838.8 .

Miquel, Leerboek tot de kennis der artsenijgewassen. Amsterdam 1838.8 Roques, Nourcau trailé des plantes usuelles. Paris 1837-1S3S. \&.

Walther, Pharmakognostisch-pharmakologische Tabellen. Mainz 1 \$38. folio obl.

Dictrich, Taschenbuch der Arzneigewächse Deutschlands. Joua 1838.8.

- Taschenbuch der auslándiselen Arznoigewáchise. Jena 1839.8.

(Quarizius) Naturhistorisch-pharmaceutisch-botanisches Lesebuch. Mingdeburg 1839. 8 .

Iruschauer, Elemente der medizinisehen Chemie und Botanik. Crabtz 1839. 8 .

Geiger, Plıarmaceutische Botanik, hearbeitet von Nees von Esenbeck und Dierbach. lleidelberg $1839-1843.8$.
I rejer, Compendium i den medicinske Bolanik. Kiolnnhasn 1840. 8.

liatzer, liebersicht der affizinellen l'flanzen der ustreichischen l'harmacopoe. Wien 1840.8.

Loew, Botanica clıemico-physiographica principalium pharmacorum. V'indobona 1840.8.

Silhultzc, Compendium der offizinellen Gewachse. Herlin 1840.8.

(Strumpf) Dio offizinollon Gewaehse in Tahellen. Herlin 1840. gr. folio.

Sibthorp, Catalogus plantarum graecarum Lioscorill nutarum. Iı ijus "Flora graecan. Londini 1840. folio. vol. X; p. 83-88.

II inhler, Real-Lexicon der medizinisch-pllarmaceutischen Naturgeschichte? und liolwaarenkunde. Leipzig 1840-1842. 8.

JIarquart, Plıarmaceutische Naturgeschichte. Mainz 1841-1842.8.

Pasquale e Avellino, Flora medica della provincia di Sapoli. Xaproli 1841. S.

Polencrl, De plantis medicinalibus. Tinduhonac 1841. 8 .

Stupper, Meclizinisch-pharmaceutischo Hotanik. Wien 1841-1843. … 4.

Dierbach, Synopsis Materiae nedicae. Heidelberg 1841-1842. 8.

Walchner, Verfalschungen der Arzneimittel und Droguen. Karlsu uhe 1842.8.

Endlicher, Die Medizinalpflanzen der ustreichischen Pharınacopoe. Wïи 1842. 8 .

lioebcr, Explicatio systematis plantarum naturalis fharmaco-dynamina. Herbipoli 4842.8 .

Percira, Matcria medica. London 1842. 8.

(germanice.)

Maschin, Plantae medicinales Bohemiac. Vintolsonae 1843. 8.

Martius, Systema materiae medicae regetalilis brasilicusis. Lipsiac 1813. 8 .

Naturell, Trankheiten und lleilmittel der L'rbewolmer Brasilieıs. Münclien 1843.8. (usitanice.)

Bischoff, Mediziniscb-pharmaceutische Botanik. Erlangen 1 \$43. S.

Reicholdt und Reider, Dic pharmaceutische Waarenkunde. l.eipzig 1844.8.

Suśrutas, 'Ayurvédas. Erlangae 1844-18-. S.

IVinlier, Pharmaceutische Waarenkunde. Leipzig 1844 sq̣! 4.

Berg, Handbueh der pharmaceutisehen Botanik. Berlin is 45.8.

__ Charakteristik der für die Arzmeikunde und Technik wichtigen lylanzengenera. Berlin 1845-1849. 4.

Zieglev, Die offazinellen Gewáchse. liannover 1845.4 .

Strumpf, Systematisches liandbuch der Arznemittellehre. Berlin isis$1848 \mathrm{squ} .8$.

ITiuliter, Charaktere der offizinellen Pflanzen. Leipzig (1S46.) S.

- Handbuch der medizinisch-pharmaceutischen Botanik. Leipzig (1846.) sq7. S.

Dietrich, Taschenluch der pharmaceutisch-vegelabilischen Rohwarenkunde. Jena 1842-1846.8.

Engelhardt, Die deutschon Arzneigewáchse. Nordhausen 1846.8.

Wiukler, Getreue Abbildung aller offizinellen Gewáchse. Leipzig $1846 \leq 17 \gamma$. 4. (Text.)

Royle, A manual of materia medica. London 1817.8 .

Schmidt, Taschesluch der plamaceutiselı-vegetabilisclien Rohwarenkunde. Jena $4 \$ 47 \mathrm{sqq}$. .

Friese, Chloris medica. Ansterdam $1547 \mathrm{~s} 19.4$.

\section{Medicamenta varia.}

Jlorst, De Turpeto et Thapsia. Romae 1344.4.

Ocyorus vel Schnellenberg, Experimenta von zwentzig Pestilentz Wurtzeln. Francfurdt a/\$1. (1546) 8. - Strassburg 1700.8.

(Del'Ecluse) Petit recueil, auquel est contenue la description d'aucunes gommes et liqueurs. himpr. cum cjus traluctione Dodonaei. Antwerpen 1557.4. 
Mallioli, Epistola de Bulbocastanco, Oloconitide, Mamire, Traso, Moly etc. Pragae 1558. 12.

Claf, De ligni Cotonei natura et viribus. Ingolstadii 1580, 4.

Bruxius, Balsambüchslein oder Bericht von 27 Balsamen. Hallo 1616. 12. Minderer, Aloedarium marocostinum. Augustae Vindelicorum 1616. 8. Reudenius, De uovo Gummi purgante epistola. Lugrduni Bat. 4625. 12. Merta, Ocnopolium polypharmacum, in qua succus Ilarin etc. Ilerbijoli 1652.4.

Kirchnaier, De Coralio, Balsanzo et Saccharo. Wittebergae 1661.4. Murillo y Telarde, Tratado de raras y peregrinas yervas. Madrid 1674.4 Iyde, De herbae Cha collectione. Oxonii 1688. \&.

Camerarius, Biga botanica. Tubingae 1712. 4.

Baier, De Sanguine Draconis. Altdorfii 1712.4.

Zucinger, Examen plantarum nasturcinarum. Basileae 1714. 4.

Slevogt, De Thea romana et hullgarica sive silesiaca. Jenae 1721. 4.

Nueller, De aqua traumatica. eau d'arquebusade. Heidelberg 1722. 4.

Neumann, Lectiones von vier Subjectis pharmaceuticis. Berlin 1730. 4.

Roberg, De succedaneis Acaciae aegzptiacac. Upsaliae 1737. 4.

Schulze, De fructibus horaeis. Halao 1737. 4.

Richter, De Huscorum notis et salubritate. Goettingae 1747. 4.

Cartheuser, De ligno nepbritico, colubrino et semine santonico. Francofurti 1749.4 .

De Marrubio albo et Alchimilla. Francofurti 1753.4.

De praecipuis balsamis nativis. Francofurti 1755.4 .

Stoerck, Libellus de Stramenio, Hyoscyamo, Aconito. Vindobonae 1762.8. (gallice.)

Bose, De olerum vernalium praestantia. Lipsiae 1763.4.

Buechner, De gummi-resinis Kikekunemalo, Look etGalda. Ilalae 1764.4.

Limné, Usus Muscorum. Upsaliae 1766. 4.

Will, The family practice of physic. London 1769. 8.

Struve, Vires plantarum cryptogamicarum medicac. Kiliae 1773. 4.

Selilling, Descriptio trium plantarum in curatione leprae adhiberi solitarum. Lugduni Batavorum 1778.8.

Razoux, Do Cicuta, Stramonio, Ilyoscyamo et Aconito. Nemausi 1780 . S.

Dollfuss, Specimen Jotauico-medicum (Veronica, Caucalis). Basileae 1781.4 .

Gruelmann, De usu Cicutae, camphorae et corticis peruviani. Goettingae 1782.4.

Hofmann, De vario Lichenun ysu. Erlangae 1786. 4.

Joffmann, Amoreux et Villemet, Némoires sur I'utilité des Lichens. Lyou 1787.8.

Amoreux, Recherches sur les divers Liclıens. Lyon 1787. 8.

Balmis, De las eficaces virtudes de Agare y do Begonia. Madrid 1794. S. (germanice.)

Unamue, Disertacion sobre la famosa planta del Perú, nombrada Caca. Lima 1794. 4.

Mons. Ueber die Anwendung ies wurzelnden Sumaclis, der gelben Narzisse und des Pfefferschwamms. Ilalle 1801.8.

Gandy, Essai sur les plantes ombelifeeres. Strassluurg 1812.4.

Pelletier, Essai sur la nature des gommes résines. Paris 1812.4.

Guibourt, Némoire sur les résines Dammar, Copal et Animé. Paris s. a. 8.

Weile, De Umbelliferis officidalibus. Lomgoviae 1817.8.

Ebermaier, Plantarum papilionacearum monographia medica. Beroliai 1824.8 .

Nerrem, Ueber den Cortex adstringens brasiliensis. Köln 1828. 8.

11 ail z, Beobachungen über einige javanische Arzneimittel. Leipzig 1829.8. (hollandice.)

De Candolle, Noto sur l'buile de Ramtilla. 1833.

Treviranus, De plautis Orientis, unde pharmaca quaedaun colliguntur, accuratius determinandis. s. I. et a. 8 .

Flolow, Gocpperl el Nees von Esenbeck, Ueber die Rinde Pảo Pereira. breslau 1849.8.

Scribe, Mémoire sur la résine icica. Paris 1845. 8.
Esteve vel Stevius, In Nicundri Colophoni Theriacam interprotationes. Valentiae 1532.8.

Maranta, Della theriaca e del mithridato. Vinegia 1579.4. (latine.)

Perez, De la teriaca. Toledo 1575.

Bonvinius, De theriaca. Vratislaviae 1610.8.

Ampsing, De theriaca Andromachi. Rostockii 1611.4.

Eichstad, De theriaca el milluridatio. Stettin 1614-1624. 4.

Doering, Mithridateiotechuia. Jena 1620.8.

Jonston, De theriaca Andromachi. Lugduni Batavarum. 1634. \&.

Loeselius, Theriaca Andromachi. Regjomonti 1654. 4.

Barra, L.es abus de la thériaque. Lyon 1667. 12.

Bartholinus, De theriaca in officina Heerfordiana. Havniae 1671.4.

Charas, Theriaci Andromachi compositio. Genevae 1684. 4. (gallice.)

II'edel, De theriaca. Jenae 1700.4.

Paullini, De theriaca coelesti reformata. Francofurti a/M. 1701.8.

Iredel, De theriaca coelesti. Jenae 1703. 4.

Pietseh, Theriaca Andromachi. Regiomonti (1704.) 4.

Christoplle de Jussieu, Nouveau traité de la thériaque. Trevoux 1708.12. Martini, Sopra la theriaca magna. Valentiae 1727.4.

Andromacluts, Antiquissimum de theriaca carmen. Norimbergae 1754. 4.

\section{Classes medicamentorum.}

Tayault, De medicamontis simplicibus purgantibus. Basileae 1537.4. Dodoens, Purgantium herbarum bistoria. Antverpiae 1574. 4.

Rollfuk, Liber de purgautibus vegetabilibus. Jenae 1667.4 .

Lischwitz, De plantis diaphoreticis et sudoriferis. Kïlonii 1734. 4.

Plantae diureticae. Kilonii 1739.4

Plantae anthelminthicae. Kilonii 1742. 4.

Buechner, De oleis expressis. Ilalae 1747. 4.

Leidenfrost, De succis herbarum recenter expressis. Duisburgi 1751.4 Buectiner, De oleis essentialibus. IIalae 1752.4.

Mueller, De oleis acthereis vegetabilium. Giessae 1756. 4.

Linne, Medicamenta graveolentia. Upsaliae 1758. 4.

Trommsdor $f$, De oleis vegetabilibus essentialibus. Erfordiae 176.5. 4.

Altmann, Aualysis plantarum autiscorbuticarum. Viennae 4766.8.

Linné, Purgautia indigena. Upsaliae 1766. 4.

Percival, Essays on the adstringent and bitters. London 1767. 8.

Limné, Medicamenta purgantia. Upsaliac 1775. 4.

Dagoty, Plantes purgatives. Paris 1776. 4.

Murray, Dulcium natura et vires. Goeltingae 1779. 4.

Schaeffer, Anthelmintica rcgni vegetabilis. Altdorfi 1784. 8.

Arnemann, De oleis unguinosis. Goettingae 1785. 4.

Brandis, De oleorum unguinosorum 1aatura. Goettingae 1785. 4.

Jeine, De medicamentis vegetabilibus adstringentibus. Goettingar 1785.4.

Li̊stbom, De oleis seminum expressis. Upsaliae 1788. 4.

Boelmer, De oleis expressis. Wittebergae 1792. 4.

- De salibus a plantis paratis. Wittebergae 1792. 4.

liueln, De extractis vegetabilium Garayanis. Lipsiae 1799. 4.

Febrifuga remedia. Lipsiae 1810.4.

Wilmanns, De antbelminticis regni vegetabilis. Gottingae 1826. 4

Wackenroder, Do authelminthicis regni vegetabilis. Goettingae 1826. 4 .

Schuebler, Untersuchungen über die fetten Oele Deutschlands. Tubingen 1828. 8 .

Dulk, De materiis plantarum extractis dictis. Regiomonti 1833. 8.

Silva Manso, Enumeração das substancias brazileiras, que poden fromover a catarze. Rio de Janeiro 1836.8 . 


\section{Virium investigatio.}

Cirube, De node simplicium medicancntorum faculates cognosecndi. llafniae 1669.8 .

Ririmus, $\Lambda_{1}$ jelatarum vises ex figura et colore cognosci possint? Lipsiae 1070.4.

l'uter. Jrogramma ad plantarums histrationes. Wittebergae 1692. 4.

Camerarius, bo convenientia plantarum in fructificatione el viribus. Tubingae 1699.4.

IIo/fmam, De methotlo compendiosa plantarum vires indagandi. Ilalae 1721. 8.

llebenstreit, De sensu cxterno facultatum in plastis julice. Lipsiae 1730.4.

Thomson, Method of discorering the virtues of plants. I.endon 1734. S.

Gleditseh, De methodo botanica dubio et fallaci virtutum in plantis indice. Francofurti a/V. 1742. 4.

Blot. An naturali cuique plantarum classi eadem medica facultas? (Cadomi 1747.) 4.

Limné, Vires planlarum. lpsaliac 1747.4.

De methodo investigandi vires medicamentorun ehenicai. Lpsaliae 1754.4 .

Cimelin, Botanica et chemia ad medican applicata praxin. Tubingae 1755. 4 .

Monte Pigati, Nova ad praxin botanices rudimenta. l'atavii 1757. f.

$P l a z$, Je plantarum virtutilus ex characterc haucifuaguam addiscendis. Lipsian $1769-1763.4$

Isenflamm, Methodus plantarum medicinae clinicae adminiculunt. Erlangae 1764. 4.

Wilclie, Do usu systematis sexualis in medicina. Grylliswalliae 1764. 4.

Vicolai, De virilus medicamentorum explorandis. Jenae 1770.4.

IVillemet, An vires plantarum ex characteribus hotanicis sunt inferendae? Nạncy 1782. 4 .

A short attempt to recommend the study of botanical analogy. I,ondon 1784. 8 .

Modéer, Tal on några ámnet etc. Stockholm 1791. 8. (germanice.)

I’olik, De viribus plantarum ex principiis botanicis dijudicandis. LuguJuni Balavorum 1796. 8.

f)e Candolle, Essai sur les proprietés médicales des plantes. Paris 1804. is. - Erl. Il: ilo. 1816. S

(Lermanice.)

Maly. De analogis jlantarum alfinium virilsus. Pragae 4823.8 .

Bunge, De relatione methodi naturalis in rires vegetabilium. Dorpati 1825.8

hieseritzly, Ratio inter systema plantarum naturalo earunque vires modicinales. Rigae 1826.8.

Backer, De radicum virtulihus medicis plantarum playsiologia illustrandis. Amstelodani 1829.8 .

Dierbach, Abhandlung uber die Arzneihralte der Pflanzen. Lemgo 1\$31. 8.

Lehmann, De ronvenientia plantarum in habitu et viribus. Vratislaviae 1831.8.

JVahlenbery, Om mogligheten att, enligt vegetabiliernas naturliga analogier, a priori bestamma deras egenstiaper. Uissala 1834.8 .

\section{Signatura plantarum.}

Asham, A littel herbal. London 1550. 12.

Carrichter, kriuterbuch. Strassburg 1575. 8. - Tuhingen 1739. 8.

folio.

llorn des Hoyls menschlicher Blodigheil. Strasshurg 1576.

Das Buch von der llammie, Sympathic und Intipatlic der Krauter. Nuruberg 1686.8
Thurneisser zum Thurn, Ilistoria sive deseriptio plantarun onnium. Burlini 1578 . folio.

kungen aller Erdgewechsen. Berlin 1578 . folio.

Bodenstein, kurtze Besclıreibung und Nut\% der fréuler, so den zwrils limmlischen Zeichen sich vergleichnn. lansileac 1391. folin.

Porta, l'hytognomica octo libris contenta. Neapoli 1588. folio.

Menier, Le blason des fleurs. Paris s. a. 16.

Franke. Signatur der Gewaichse. Rostoch 16 18. i.

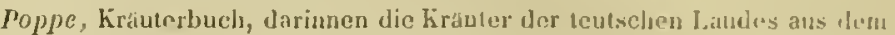
Licht der Natur ete. Leipzig 1623.8.

Muehlpfort, Medizinisches Spazierganglein, flatinne der mit heilizen Varmen bchannten liráuter atc. Sclileusingen 1627. \&.

A pollinaris, hurzes llanduüchlcin. Strasslurg 1633. \&. (latine.).

Forget, Aitis signatae designata fallacia. Nancei 1633. 1․

Lozali a frachien, Septimanae loorolngii macrocosmi liLer ruartus de vegetalilinm specielous, partibus ef signaturis. Vosaliar 1640.4.

Fischer, Methodus neva herbaria. Erunopoli 1616. 8.

Anatemia et plysingnomia simplicium. Nurnbers $1697,12$.

Rosencreutzer, Newe Practica des Wurtz- und Kruuterkalenders. Murnberg 1659. 4.

Fabricius, be signatura plantarum. Norimlsergae 1653. 4.

Gudrius ron Tours, Anatomia el plỵsiognomia simplicimm. Stutgart 1659.8 .

Ilelvetius, Xystus berbarum, Lustiger Spazierwes der hrinter. Ileydalbers 1661.12.

Berillus medicus. IJeydelberg 1661.12.

(Martini) Dio fruchtbare Boriza oller das lınilsame Mondhraut. Lirn:1681.8

Schlegel, Tractatus.... darbey die Signatur etzlicher Gewachse. Iumluerg 1686.8.

Lirause, De signaturis regetabilium. Jenae 1697 .

Gohren, Medicorum priscorum de signatura plantarum doctrina. Jenac 1840.8.

\section{Plantac venenatao.}

(cr. Monegraphins plantarum officinitiun el Fumeros.

Petrus de Abano, Tractatus de venenis. Nantuae 14:2. Solio.

Ardoymis, Liber de venenis. Venetiis 1492. folio. - Basileae 1562. Soliu Ionzelli, De venenis libri tres. Basileae 1362 . folio.

Irma, Opus de venenis. Taurini 1537. 8.

Grevin, Deux livres des venins. Anvers 1368.4 .

(Latine.)

Bacci, Prolegomena de venenis. Romae 1586.4 .

Crassus, De Lulio tractatus. Bononiae 1600.4.

Faber, Stryctmomania. (Atropa Belladoma.) Augustia Vindel. 167\%. i.

Sicelius, Diatrihe de Belladonna. Jenae 1724.8

Fater, 1)e Laurocerasi indole renenata. Wittebergae 1737. $\%$.

Mead, A mechanical account of peisons. Fil. 111: London 1745. S. (Iatine.)

Buechner, De venenis. Ilalae 1746. 4.

Ilerbert, De Cassavae amarae surinamensis (Jatrephat Maniluof) radien. Marburgi 1753. 4.

Rossi, De nonnullis plantis venenatis. Jisis 1762 . s.

Triller, De morte subita ex nimio violarum odore nbosta. Witfehergir? 1762. 4.

Linne, Do Raphania. (Raphanus Raphanistrum.) Lpsilliae 1763. 4.

Cimelin, De materia toxicorum regetabilium in medicamentum convertertda. Tubingac 1765 . 4.

Triller, be planta copiis Antonianis olim exitiali. Wittelergac 1765. 4. 
kiap Experinenta de nonfullorum Ranunculorum renenata qualitate. Viennae 1766. 8 .

Spiclmann, De vegetabilibus venenatis Alsaliac. Argentorati 1766, 4. Duvernoy, De Lathyri quadam venenata specie. Basileae 1770.4.

Langgulh, De planlarum renenatarum arcendo scelere. Wittelsergae 1770.4.

Finolle, Plantae venenatae umbelliferae. Lipsiae 1771.4

Poh!, De plantis venenatis umbelliferis. Lipsiae 1771. 4.

Cadd, Anmaerkningar an forgiftiga waxter i gemen. Abo 1773.4.

Caels, De Belyii plantis venenatis. Bruxellis $177 \% .4$.

Gmelin, Alhandlung von den giftigen frewaelisen. IJm 1775. 8 .

Ficat, Ilistoire des plantes vénéneuses de la Suisse. Yverdun 1776. S.

Ginclin, Algemeine Geschichte dur Planzengifte. Nurnlserg 1777. S, ib, 1803.5 .

Spalowshy, De Cicura, Flammula Jovis ctc. Vindobonae 1777. 8.

IIirsel, Geschichte einer giftigen Art Erbsen (Lathyrus sativus). In Linguet et Tissol. Zürich 1780.8.

Mayr, De venenata Ranunculorum indole. Vionnae 1783.8.

Bulliard, llistoiro des plantes vénéneuses el suspectes de la France. Paris 1784 . folio.

IIalle, Die deutschen Gifpflanzen. Berlin 1784-1793. S. - ib. 18011803.8 .

Menck, Toxicologia. Viennae 1785.8.

Puihn, Materia renenaria regni vejelabilis. Lipsiae 1785 s. 8.

Bochmer, Cyano segetum nuper impotatum virus limitatus. Wittchergac 1787.4 .

Schulze, Toxicologia veterum. Halae 17SS. 4.

Thunberg, Arbor toxicaria macassariensis. Ujusaliac 1788, 4.

Kolbani, Ungarische Giftplanzen. Pressburg 1791, \&.

Bochmer, De plantis.... e foro proserilsendis. Wittebergae 1792. 4.

Martius, Ueber den Macassarischen Gifthaum. Erlangen 1792. S.

Dunler, Besclureibung der Giftpllanzen. Brandenlurg 1796-1797. 12.

Frege, Anleituog zur Kenntniss der Giftplanzen. Kopenhagen 1796. 8.

Erdmann, Sammlung săchsischer Giftpflauzen. Dresden 1797. folio.

Kerner, Deutschlands Gift]flanzen. Ilannover 1798.4.

Siemssen, Radieum Solani tuberosi innocentia. Rostockii 1798. ४.'

Ifayer, Einlıcimische Giflgewächse. Bcrlin 1798-4800. folio.

Buhle, Die wichtigsten deulschen Gilpflanzen. Cuthen 1804, folio.

Hechenberger, Salzburgische Giftplanzen. Salzburg 1804-4306. folio.

lohlhaus, Giftplanzen. Regenshurg J\$05. 4.

Laisney, Dissertation sur quelques plantes venunetuses. Mlunipullier, an Xiv, 4.

Kaffeneau-Delile, Sur les effets d'un poison de Java, ajpelé L'pas tieuté, et sur la noix vomique, la fève de St. Ignace, le Stryelonos polatorum et la pomme de Tontac. Paris 1809.4.

Magendic, Examen de l'action de quelques végétaux sur la moêlle épinière. Paris $1 \$ 09.8$.

Tesnière, Essai sur les poisons végétaux. Montpellier 1809. 4.

Orfilu, Traité des puisous, ou Toxicologie générale. Paris $1813-181$ : 8. - Ed. Ill: ib. $1 \$ 96.8$. (germanice.)

Goctz, Ablildungen deutscher Gifipflanzen. Weimar 1817. 8.

Juch, Die Giftpflanzen. Augsliurg 1817. folio.

Targioni-Tozzetli, Mlaldtlia prodotta dal Rlus Vernix. (Firenze 1817.) 8. Ljungbery, De plautis venenatis. Upsaliae 1822. ‘.

Dietrich, Deutschlands Giftpllanzen. Jena 1826.8.

licord-IHadiama, Recherches el expériences sur ies poisons d'Amiri(que (Spiegelia anthelminthica L. et Ilippomano Mancinella I.). Budeaux 1826. 4 .

Buchner, Toxicologie. Nurnberg 1827. S. (suecice.)

Jegetschweiler und Labram, Die Giftphastzen der Schwciz. Zurich s. ^. \&. Munn, Deutschlands Giflpflanzen. Slutgart 1829. folio.

Seluulz, Deutsclılands Giftpflanzen. Berlin (1\$20.) 4. obl.
Toget, Anleitung zur Kemıtniss der Giftpflanzen. Crefeld 1829.8.

Plalo, Deutschlands fiftpflanzom. Lripzig 1899-1840. \&.

I'inkler, Sammtliche Giftgewachse Deutschlands. Berlin 4831.8.

IT'unschmam, Deutselı]ands Giftpflanzen. Berlin 4833. 8.

Iser, De Papaveraceis venenatis Bohemiae. Pragae 4 \$34. \$.

Komma, Toxicologia Solaniharum indigenarum. Pragae 1834. 8.

Lilienfeld, Umbelliferae venenatae Cechiae. Pragae 1834. 8.

Ruda, Phytotoxicalogiae cechicae tentamen. (Ranunculaceae venenatae). Pragate 1834.8 .

Schedlbauer, Playtotoxicologia cechica. Pragae 1834.8.

Otto, Die vorzuglichsten in TJüringen wildwachsenden Giftpflanzen. Rudolstadt 1834.8 . - il). 1842.8 .

(Jakuboneski) Gpis roślin i bodlek jadowitych. Poznan 1835. 8.

Taddei, Repertorio dei veleni e contravveleni. Firenze 1835. s.

Henry, Die Giftptanzen Doutschlands. Boun 1\$36. S.

Miquel, De nord-neederlandsclse vergifige gewassen. Amsterlam 1836. folio.

Rullmann, Dic Giftpflanzen Deutsehlands. Kassel 1837.8.

Schottlaender, Giftplanzen Deutschlands. Vim 4837.8.

Wahlenberg, De notione antidoti. Upsaliae 1837. 8 .

Brandt, Phoebus ot Ratzeburg, Abbildung und Beschreilung der deutschen Gifigewáclıso. Berlin 1×3s. 4.

Lireutser, Oestreiclus Giflgewachse. Wien 1838. S.

Thoebus, Deulschlands hryptogimische Giftgewáchse. Berlin 1835.4.

Schmidt, Wilhelms Wanderungen. Erfurt 1838. S.

Derive, Flore vénéneuse de la province de Liège. Verviers 1839. 12.

Grabacher, De venenis narcolicis. Yindobonae 1840.8 .

Guenther et bertuch, Pinakothek der deutschen Giftgewähse. Jena 1840.4 .

Praschil, Plantae venenatae in territorjo vindobonensi. Viennae 1840.8 .

Schuetz, De Taxo baceata ejusque veneno. Tratislaviae 1840.8 .

Spieler, De plantis venematis Silesiae. Vratislaviae 1841. \$.

Prestele, Die wichligsten Giftpflanzen Deutschlands. Friedberg 1843. \&.

Ilochstetter, Die Giftgewachse Deutschlands und der Schweiz. Esslingell 1844.8.

Spielierhoetter, Die Giftplanzen Deutschlands. Minden 1844. 8.

Anleitung zur lienntniss der Giftphanzen. Minlen 1844 . 8.

Berge und Riecke, Giftplanzenbuch. Stuttgan 1845.4.

Lucas. We Solano tuberoso ejusque principio narcotico. Hirsolibery 18:6. 8 .

Schneider, Die vorzuglichsten Giftplanzen. Konstanz 1846. imp. folio.

\section{Microscopium.}

Schrader, De microscopiorum usu. Goetlingae 1681. 8.

Joblot, Descriptions et usages des plusiers nouveaux microscopes. Paris 1748. 4.

Ledermucller, Versuch die Vergrosserungswerkeuge anzuwenden. N'unlerg 1764 . folio.

Savi, Sopra un illusione ottica frequentissima nell ossarvazioni microsconpiche. Pisa 1822.8 .

Fresnel, Sur le microscope achromatique de M. Selligue. Paris 182\%. 8 .

Doellinger, Nachricht von einem verbesserten aplanatisehen Jihroshopur. (Nunchen) is29. 4.

(Slack. Turrell and Jlliand) Improvements in the uicroseope. Inndin 1 s33. S.

Chevalier, Notes rectificatives pour servir al histoire des nicrosepes. Piris $1835,4$.

Marlins, Du nicroscope. Paris 1839.4.

Togel, Anleitung zum Gebrauch des Mlicrosiopes. Leipzig 1841.8. 
Dujardin, Nouveau nanuel complet de l'olservateur au mieroscope. Paris $1842-1843.8$. et Atlas.

Kothkirch, Kubikindalt yon 300 Kugeln etc. Breslau 1843. 4.

Uerz, Die neucren Verbesserungen am Mieroscope. Munelıen 1843. \$.

Mohl, Ueber die Gróssenbestimmung mikroskopiseher Objecte. (Verm. Schriften p. 429-442.)

- Mikrographie. Tuhingen 1846.8.

\section{Comparatio plantarum et animalium.}

Ortlob, Analogia nutritionis plantarum et animaliun. Lipsiae 1683.4. Sturm, De plantarum animaliumque generatione. Altdorf 1687.4. Winslow, Do macelninae plantauimaljs occonomia. Havniae 1694. 4. Jussieu, De analogia inter plantas et animalia. Londini 1721. 4.

Schmidt, De analogia regni vegetabilis cum animali. Basileae 1721.4.

Boretius, De anatome plantarum et animalium analoga. Regiomonti 1727.4.

Feldmann, Comparatio plantarum et animalium. Lugduni Batavorum 1732. 4 - Berolini 1780.8.

(Roberg) Vegetabilium cum animalibus comparatio. Upsaliae 1737. 12.

Bazin, Observations sur les plantes et leur analogie avec les insectes. Strasburg 1741.8.

(germanice.)

Browallius, De harmonia fructifieationis plantarum cum generatione animalium. Aboae 1744. 4.

Harmens, De similitudine vitae pluysicae in animalibus et plantis. Londini Gothorum 1752.4.

parsons, On the analogy between the propayation of animals and that of vegetables. London 1752. 8 .

Moro, Sopra la grenerazione degli animali e vegetabili. Bassano 1753.4.

Kapp, Notus humorum in plautis el animalibus. Lipsiao 1763.4.

Bourre, Num pili, plantae? Paris 1764. 4.

llarmens, De differentia Lumorum in animalibus et plantis. Lendini Gathorum 1771. 4.

Schulze, Tanker om planternes dyriske liighed. Kiöhenhavn 1772. 8.

1/arum, Quousque consentiunt motus fluidorum et alia animalium of plantarum functiones? Greningae 1773.4.

Tessier, All similis vegetantiom et animantium generandi modus? Paris 1775. 4 .

Bernard de Jussieu, An compar animantium el vegetantium perspiratio? Parisiis 1777.4 .

De la Mtheric, Vues physiologiques sur l'organisation animale et végétale. Amsterdam 1781. 12.

Harrington, Philosophical and experimental enquiry into the first and general principles of animal and regetable life. London 4781. 8.

Bondl, Overeenkonst twesehen dieren en planten. Amsterdam 1782.8.

Spallanzani, Expérieuces sur la génération des animaux et des plantes. Geneve 1786.8 . (germanice.)

Desrousseaux, An ut in plantis sie in animantibus perspirationi noderandac inserviat epidormis? Paris 1789.4

Hedwig, De fibrae vegetabilis el animalis ortu. Lipsiae 1789.4.

Lidbeck, De limitibus inter regna naturae. Luudae 1790. 4.

Schrank, De discrimine plantarum ab animalibus. In ejus "Primitiae Florae salisburgensis». Francofurti a/M. 1792. 8.1' 1-46.

Brera, De vitae vegetabilis ot animalis analogia. Ticini 1796. 8 .

freysig, Vitae vegotabilis cum animali convenientia. Wittebergae 1796. 4.

I'eschier, De irritabilitate animalium el vegetabilium. Edinburgh 1797. S.

Ihumbo!dt, Versuelse.... uber den eliemischen Process des Lebens in der Thier- und Pllanzenwelt. Berlin 1797. 8.

Ilebenstreil. Monenta comparationis regni animalis cum vegetabili. Lipsiae 1798.4

Hunter, Analooy between vegetable and animal parturition. 1.ondon 1799.) 8 .
Lahleyss, De vegetabilium el animalium differentiis. Ilalae 1802.8. De la Métherie, Considérations sur les ctres nrganisées. Paris 1\$04. S. Carena, Do aumalium et plantarun analogia. Taurini 1805.8 .

Laan, Quinam sunt limites inter vitam aninalium et vegetabilium? (1.ryden) 1821.4.

Ihutrochet, Reeherches anatomiçues et jhlysiologigues. Paris 1824.8. L'agent inmédiat du mouvement vital. Paris 1826.8 .

Barlels, Ueher innere und aussere Bewegung im IPflanzen - und Jlierreiche. Harburg 1828, 8.

Nestler, Discours. Strassluurg 1829. 4.

Jumortier, Recherelies sur la structure comparée des animaux el des veigétaux. Bruxelles 1832. 4.

IIillrand, Vergleichende Physiologie der Pflanzen und Thiere. Ilevilelberg 1833.8.

Eichner, I)e tela cellılosa vegetabili et animali. Monachii 1834.8.

Dutrochet, Mémoire pour servir à l'bistoire anatoniugue et physiologiques des végétaux el des animaux. P’aris 1837. 8. et Allas.

Schwann, Uutersuchungen uber die Uebereinstimmung in der Strukilır und dem Waclssthum der Thiere und Pflanzen. Berliu 1839. 8.

Karsten, De cella vitali. Berolini (1843.) 8.

Unger, Die Pllanze im Nemente der Thierwerdung. Wien 1843. 8.

Sicbold, De finibus inter regnum animale el vegetabile constituendis. Hirlangae 1844.4 .

\section{Actiones vitales.}

Lidld cl, De facultate vegetante ejusque functionibus. Helnustadiae 1392.4 . Kinderling, De corpore animato vegetabili. IIelmstadii 1622.4.

Proilisius, De anima vegetativa. Lipsiae 1629. 4.

IIcinricus, De anima vegetante. Lipsiae 1630. 4.

Reyher, De anima vogetante. Lipsiae 1632. 4.

Itligius, De anina vegetante. Lipsiae 1656.4.

Grube, De vita et sanitate plantarum. Jenae 1664 . 4.

Langheinrich, De sensu plantarum. Lipsiae 1672.4.

Haldschmiedt, De plantarum vegetatione. Kiliae 1710. 4 .

Bose, De motu plantarum sensus acmulo. Lipsiae 1728. 4.

Chicoyneau, Discours sur les plantes sensitives. Montpellier 1739. 4.

Gricnwald, De vita plantarum. Alturfii 1732.4.

Gortor, Exercitationes medieae quatuor. (Vis vitalis.) Amstelodami 1737.4.

Sticff, De vita nuptiisque plantarum. Lijsiae 1741. 4

Linné, Somnus plantarum. Upsaliae 1755. 4.

Ilill, The sleep of plants explain'd. London 4757. 12 (gallice, germanice, italico.)

Thiesen, De plantarum anima. Regiononti 1758. 4.

Vagel, De statu plantarum, quo noctu dormire dicuntur. Gocllingae 1759. 4 .

(Conolo) Discorso della irritabilita d'alcuni fiori. Firenze 1764. 8. (anglice, germanice.)

Un=er, Vom Gefuhle der Pllanzen. In ejus aśammlung ete. I. 1766 p. $242-255$.

Oetinger et Gmelin, Irritabilitas plantarum in singulis plantarum partihn. explorata. Tubingae $176 \mathrm{~s}, 4$.

Fortemps, Vita plantarum illustrata. Vindobenae 1780.8 .

Lerner, Beobachtungen uber die beweglichen Blätter des Iledysarum gyrans. Stultgart 1784.4.

Thibaud, Disquisitio utrum in plantis existat princijum vitale? Monspelii 1785. 4 .

Hope, Do plantarum motibus et vita. Edinluurgi 4787.8 .

Cirillo, Disenrsi academici (Del moto o della irritabilita de' regetabili) s. I. 1789.8 .

Percival, speculations on the pereeptive nower of vegetables. (Men. soc. Nauchester voll. II. p.114-130.) 
Betrachtungen üher das Empfindungsvermogen der Pflanzen. (Sammlungen zur Plyysik, Band 1Il. p. 666-678.)

Also laátten die Pflanzen Vorstellungen? Fraukfurt 1790. 8.

Schrank, Vom Pflanzenschlafe. Ingolstadt 1792. 8.

Bourne, De plantarum irritabilitate. Edinluurgi 1794.8.

Peschier, De irritabilitate animalium et vegetabilium. Edinlsurgh 1797. 8.

Fallén, Do irritabilitate motus causa in plantis. Lundae 1798. 4.

Draparnaud, Discours sur les moeurs et la maniere de vivre des plantes. Montpellier IX. 8.

Guersent, Quels sont Ies caractères des propriétés vitales dans les végétaux? Paris 1803.8 .

Nocea, ll sonno delle foglie. Pavia 1805.4.

Carradori, Sulla vitalità delle piante. Nilano 1807.8 .

lubuisson, Essai sur les propriétés de la force vitale dans les végétaux. Paris 4808.8 .

Carradori, Sopra l'irritabilitá della lattuga. s. I. 1808.8.

Tupper, An essay on the probability of seusation in vegetables. London ISI3. 8. - ib. 1817.8 .

lioubieu, Aperçu sur la sensibilité des plantes. In ejus "Opuscules" ete. Montpellier 1816.8.

Blumenhain, Die Pfanzenulır in Garten und Zimmer. Brunn 1826. 8.

Dumortier, Recherches sur la motilité des végétaux. Gand $1 \$ 29.8$.

Labat, De l'irritabilite des plantes. Paris 1834.8.

Marlius, Reden und Vortrăge. Stuttzarl 1838. 8.

Morren, Reclierches sur le mouvement et l'anatomio du Stylidium graminifolium. Bruxelles 1838.4.

Recherches sur le mouvement et l'anatomic du style de Goldfussia anisophylla. Bruxclles 1839. 4.

Presl, Vermischte hotanische Aufsátze. s. 1. et a. 8.

Bianconi, Di alcuni movimenti che si osservano nelle piante per la diffusione de' semi. Bologna 1841.8.

1)raper, Treatise on the forces which produce the organization of plants. New York 1844. 4.

Wohl, Ueber dic Reizbarkeit der Blatter von Robinia. (Verm. Schriften p. $372-374$.

Keichenbach, Die Pllanzenulı. Leipzig 1846.16.

\section{Calor ct electricitas plantarum.}

Ammersin, De electricitate propria lignorum. Lucernae 1754. 12.

Crell, Ueber das Vermogen der Planzen, Wärme zu erzeugen und zu vernichten. Helmstedt 1778. 8.

Berlholon, De l'électricité des végétaux. Paı is 1783.8 (germanice.)

Amoretti, Elettrometria de' vegelali. Milano 1816. 8

Schuebler, Beobachtungen uber die Temperatur der Vegotal,ilien. Tubingen 4826. 8 .

Unłersuclıungen über die Temperaturveranderungy der Vegentabilien, Tübingen 1829.8 .

Goeppert, Uober die Wärmeentwicklung in den Pflanzen unt deren fiefrieren. Breslau 1830.8 . 1532. 8 .

Ueber Warmeentwicklung in der lebendon Pflanze. Wion

Beek et Bergsma, OLservations thermo-électriques sur l'élévation de tenpérature des feurs de Colocasia odora. Ctrecht 1838. 4

Hasskarl, Over de ontwikkeling van warmte in planten. Batavia 1838.8 . Neugebauer, De calore plantarum. Vratislaviae $1844^{\circ} .8$.

\section{Effectus externi in plantas.}

Hoepffiner, Das verkehrte Jalır. Jena (1696.) 4.

Buechner, De memorabilibus Voiztlandiae ex regno vegetabili. (Greizae 1743.) 4 .

Bose, Tentamina electrica. (De regetatione electricitatis vi accelerata.) Wittebergac 1747. 4.

IIoegström, Tal om orsakena etc. (Frigoris efiectus in plantas.) Stochholm 1755. 8.

Robert de Limbourg, Quelle est l'influence de l'air sur les végétaux? Borileaux 1758. 4.

Unzer, Untersuclung wie die Bäume vor dem Erfrieren zu bewahren. In ejus "Sammlung" etc. I. 4766. p. 140-450. (Neues Hamb. Mlagazin, 86. Stuck, p. 120-132.)

IIebenstreit, De vegetatione lyyemali. Lipsiae 1777. 4.

Suckow, Tersuche über dic Wirkungen verschiedener luftarten aul dic Vegetation. Nunchen 1782. gr. 4.

Senebier, Mémoires sur l'iulluence de la lumière solaire. Genève 1782. S. (germanice.)

Brugmans, Natuurkundige Verhandeling over een zwavelagtigen novel Groningen (1783.) 8 .

Senebier, Recherelıes sur l'influence de la lumière solaire. Genève 1783.8.

Gardini, De influxu electricitatis atmospltaericae in vegetantia. Aug. Taur. 1784. 8 .

Hosenthal, Versuche, die zum Wachsthum der Pfanzen nothige Warme zu bestimmen. Erfurt 1784. 4

Sencbier, Expériences sur l'action de la lumière solaire dans la végćtation. Genève 1798.8

I'assalli, Esperienze recate contro l'influsso dell' eletıricità nella vegetazione. Torino 178S. 8 .

Sierstorpf, Bemerkungen uber dje im Winter 1788-1789 erfrorenen Batume. Braunscliweig 1790. 8 .

Zuceagni, De naturali liliorum ante simulacra Deiparae fructificatione. (Florentiae 1796.) 8.

De Candolle, Expériences relatives à l'influence de la lumière sur quelques végétaux. (Mém. des savaus étrangers 1805. I. 370.)

fielmeyer, De effectibus arsenic! in varios organismos. Tuluingae 4808.8.

De Candolle, Note sur la cause de la direction des tiges vers la lumière. (Hém. soc. r'Areueil 1809. 11. 104.)

Gase, Mlémoire sur l'influence de l'électricité dans la fécondation des jlantes. Mayence 1811.8.

Neves Mello, Circa Stipae arenariae aristam observationes. hio de Jianeiro 1811.8 .

Amorelli, Jegli efletti de' turbini sulle piante. Pavia 1813. 4.

lvart, Sur l'influence qu'exeree le vinettier (Berberis vulyaris) sur bn fructification du froment. Paris 1\$16. S.

Aubert du Petit-Thouars, Le verger français. (Etrectus frigoris in jlantas.) Paris $4817 . \mathrm{s}$.

Boon Meseh, De vi lucis in vegetabilia. Lugduni Batavorum 1819. 4.

Glocker, Versuch uber die Wirkungen des Lichtes auf die Gewachse. Breslau 1820.8.

Bosc, Collection de Mémoires relatives aux effets sur les oliviers de la gelée du 11 an 12 janvier 1820. Paris 1822. 8.

Jaeger, De effectibus variarum aéris specierum in plantas. Stuttgartiae 1823. 4 .

Léveillé, Influence du froid sur quelques Agaricoidées. (Paris 4825.) \&.

Schuebler, Ueber die Einwirkung verschiedener Stoffe auf das Leben de Pflanzen. Tulingen 4826. 8 .

Goeppert, De acidi hydrocyanici vi in plantas. Vratislaviae 1827.8.

Suecow, De lucis eflectibus chemicis in corpora organica. (De lucis in plantas eflectu chemico: p. 43-62.) Jenae 1828. 4.

Schuebler, De efficacia Natri muriatici in plantis. Tubingae 1830. 8 .

De Candolle, De l'iuluence de la température btunosphérique sur le développement des arbres au printems. (Genève 1831 .) 8. 
Massen, De Scillitino additis experimentis de vencuorum vi in plantas. Groningae 1834. 8.

Jaubeny, On the action of light upon plints, ant of plants upon the atmospliere. London 1836. 4.

110relli, Sul inflesso della luna nella vergelazione, Parma 1838. 8 .

\%anon, Sul' influenza elettrochimica delle terre sulla regretazione. Belluno 1840.8.

Merschel, On the action of the riys of the solar spectrum on vegetable colours. London 1849. 4.

Zantedeschi, Dell' influenza dei raggi solari rifratti dai vetri colorati sulla vegetazione. Venezia 1843.4.

Grix. De laction des compensés ferrusinemx solubles sur la verétation. Paris 1843.8 .

_- Nouvelles experiences sur l'action etc. Chitillon 1 \$44.8.

Dove, Uelser don Zusammenhang der Warmeveránderungen der Atmosplláro mit der Entwichlung der Phanzen. Berlin 1846. gr. 4.

\section{Chemia generalis. Nutritio.}

Fiel, De jlantarum extra terram vegetatione. Jenae 1688. 4.

Bradley, New improvements of planting and gardening. London 1717. 8. - Ed. VI: London 1731. 8. (sallice.)

Steuehius, Do nutritione arborum. Upsaliae 1722.8.

Hales, Statical essays vol. I. London 1727. 8. - il). 1731. S. - ib. 1738. 8 .

(gallıce, italice, germanice.)

Kulm, De plantis earumque nutritione. Gedani 1728. 4.

Bradley, Ten practical discourses concerning the growth of plants. London 1733. 8.

Memander, De nutrimento plantarum. Ahoae 1747. 4.

IJ"allerins, De principis vegetationis. Jolniae 1751.4. (germanice.)

Linni, De methodo investigandi vires medieamentorum chemica. Upsaliae 1754.4 .

Ilahn. Sermo de clsemiae cum botanien conjunctime utili ac pulchra. Trajecti a/Rh. 1759.4 .

Home, Jrinciples of agriculture and vegatation London 1759. S. (gallice, germanice. italice.)

lirozclius, De generatione el nutritione arlsorum. Londini Goth. 1768. 4.

Beguillet, De principiis vegetationis et agriculturae. Divione 1769.8. (gallice.)

Siguart, De vegetabilium ulterinri indagine. Tulingae 1769.4.

Dullenhofer, Vou dem Pflanenleben in Bezielung auf den Ackerbau. stutigart 1779. 4.

Lindsay, De plantarum incrementi causis. Ediulurewi 1781 . S.

Demel, Analysis plantarum. Viennac 1782. 8 .

Beclier, Chemische Untersuchung der Pllanzen und deren Salze. leipzig 1786.8 .

Jiche, De chemia regetabilium. Aveniono 1786.8. (gallice.)

Ingenhousz, Proeven over liet voedzel der planten. Delft 1796. 8. anglice, germanic:.)

Inumboldt, Versuche über die gereizte Nuskel- und Nervenfaser nebst Vormuthungen über den chemischen Process ales Lebens in der Thier- und Pflanzenwelt. Berlin 1797. 8.

DC' Candolle, Premier essai sur la nutrition des Lichens. Paris 1798. 4.

Elsner, De plantorum mutrimento. Regiononti 1798. 8.

Jordan, Disquisitio chemica evictorum regni animalis et vegetabilis elementorum. Gnettingae 1799. 4.

Schraler und Neumann, Preisscliriften uher die Beschatlenheit utu Erreugung der exdigen Bestandheile in den Getraidearteu. Berlin 1800 \&
Clarion, Olsservations sur l'analyse des végetanx. Paris 1803. 8.

Oppenhrim, De pluytochemia pharmacologiae lucem foenerante. Ilali1803.8 .

De Sanssure, Recherches climiques sur la végćtation. Paris 1804.8 (germanice.)

Wahlenberg, De sedibus materiarum immediatarum in plantis. Ipraliso $4806-1807.4$.

Craullau, Comment les engritis agissent-ils an genéral? IBordeau 1807.8.

Ruhloul, liragmenta de nuiritione plantarum. Landishuti 1809.8.

(irindel, Die organischen Korper rhemisch betraclutet. Riga 1811. 8. ib. 1818.8 .

Javy, Filements of agricultural chemistry. London 1813. 4. - ib. 1839. 8 . (gallice.)

John, Chemische Tahellen der Pflamenanalysen. Nürnjerg 1814. folin.

Erikson, Reflexiones cirea nutritionem vegetabilium. Ipsaliae 1815.4.

John, Ueber die Einahurung der Pl]auzen und den l'rsprung der l'ottssche und andrer Salze in ilmen. Berlin 4819, 8.

Nees ron Esenherk, Bischof und Rothe, Die Entwicklumg der l'flanzensulstanz. Jirlangen 4819.4

Thunberg, De nutritione plantarum. Lpsaliae 4819.4.

Runge, Neueste phytochemische Entdeckungen. Berlin $1 \$ 20-1821$. \$.

Mathieu do llombasle, Du mole de nutrition des plantes. Paris $1 \$ 21$. \&.

Davids, De fontibus vegetationis plantarum. Lugduni Batavorum 182?. ¿.

Chaplal, Chimie appliquée à l'agriculture. Paris 1922.8. - Ed. Il: il. 1829. 8.

Pelri, Der thierische Magnetismus in seiner Anwendung auf die Pflanzenwelt. Ilmenau 1824. S.

Johnson, Anwendung des Koehsalzes auf deu Feld- und Gartenlsau. I, eijr zitg $1 \$ 25.8$.

$$
\text { (anglice.) }
$$

Goeppert, Nomulla de plantarum nutritione. Berolini 1825.8.

Berzelius, Lurboh i kemien. Stockhohn 4826-1828. S. (germanice, gallice, italire, hollandice.)

Fecliner, Resultate der bis jetzt unternommenen Pflanzenanalysen. Leipzig 4829.8.

Schuebler, Grundsatze der Agriculturelımie. Leipzig 1831.8. - ib. 1538. 8.

Jablonski, De conditionibus vegetationi necessariis. Perolini 1832.8 .

Fie, Examen de la théorie des rapports hotano-chimiques. Strasslurgs 1833.4 .

Girou de Buzarcinges, Mémoire sur l'évolution des plantes et sur l'aceroissement en grosseur des exogènes. Paris $1833 . \delta$.

Raspail, Nouveau système de chimie organique. I'aris 1833. 8 .

Reuler, Der Boden und die atmosphatrische Luft in Einwirkung auf Ernalirung der Pflanzen. Frankfurt a/A. 1833. 8 .

Edwards, Mémoire de plyysiologie agricole sur la végétation des ceréales sous de hautes températures. Versailles 1835.8 .

Claus, Grundzuge der analytisclien Plyytochemie. Dorpat 1837.8.

Thomson, Chemistry of organic bodies. Vegetables. London 1838. \&.

JVemlig, Die Plitnzenchumie. Leipzig 1839. S.

Chalin, Sur les théories de l'accroissement. Paris 1840 . s.

Licbig, Die organische Chemio in ihrer Anwendung auf Agrikultur und Pliysiologie. Braunschweig 1840. 8. - Ed. V7: ib. 1846.8.

(gallice, italice.)

Dumas, Lecon sur la statique chimique des ctres organises. J'aris 1841 -1842.8 .

Gruber, Ueher den Zustand der neuern organischen (Agrihultur-) Cibemic. Wien 184.4.

Illubek, Die Ernahrung der Pflanzen und die Statik des Landbaues. I'rag 1841.8.

Schcidweiler, Cours raisome et pratique d'agriculture ot de chimie agricole. Bruvelles 1841-1\$43.8.

Payen, Hemoires sur les développements des végétaux. 1'aris 18 \$2. 4.

Schleiden, Offnes Sendsclureiben an Liebig. Leipzig 1842.8. 
Schleiden, Hr. Justus Liebig und die Pflanzenphysiologie. Leipzig 1842.8. Hirgmann und Polstorf, Ueber die nnorganischen Bestandtheilo der Pllanzen. Braunscluweig is42. gr. \&. (hollandice.)

Winlielblech, Veber Liebig's Theorie der Pflanzenernabung. liassel 1842.8 .

Benerkungen zu Schleiden's Sundsclureiben an Liebig. Braunschweig 1842. 8 .

Illubels, Beantwortung der wichtigsten liagen des Ackerbanes. Graiz 1842.8.

Johnston, Lectures on agricultural chomistry. Edinburgh 4842. 8.

- Elements of agricultural clemistry. Ediolurgh 1842. 8.

Sichmid, Dr. J. Liejigy's Zustand der Chemic in Osterroich und Preussen. Stuttgart 1842, 8 .

Blanchel, Influence de l'annoniaque sur la végétation. Lausamne 1843.8.

Catinelli, Kritische Bemerkungen uber Hlubelis Beleuchtung der Organiselien Chemie Liebig's. Wien 1S43. S.

Loesche, De causis naturae chemicae el efficaciae plantarum. Lipsiae 1843. 4.

Loewiy, Ueber Bildung und Zusammensetzung der organischen Verbindungen. Zürich 1843.4.

Mohl, Dr. Justus Liebig's Verháltniss zur Pflanzenpluysiologie. Tubingen 1843. 8 .

hueder, Ueber die Ernăhung der Pflanzen und die Statik des Landlıaues. leipzig 1843.8.

Solly, Rural chemistry. London 1843.8 .

Berard, Mémoire sur la maturation des fruits. Paris s.a. 8.

Ihrschfeld, Die Enahlnung und das Wachsthum der Pflanzen. Kiel 1844. s.

Johnson, Von der Nalırung der Kulturpflanzen. Petersburg 4844.8.

Lopsche, Das vegetabilische Leben und die clremische Affinität. Leipzig 1844.8 .

Petzholdt, Populare Vorlesungen aber Agrikulturalchemie. Leipzig 1844. S. - ib. 1846.8.

Schultz, Die Entdeckung der wahren Pflanzennahrung. Berlin 4844. S.

Geubl, Die plysiologische Chemie der Planzen mit Rucksicht auf Agriliultus: Frankfurt a/ MI. 1845, 8 .

(Gray) The chemistry of vegetation. (New York) 4845.8.

Bouchardat, Reclıerches sur la végétation appliquées à l'agriculture. Paris 1846.12.

Ilirschfeld, Versuch oiner Materialrevision der wahren Pfanzonnalırung. Ilamburg 1846. 8 .

Ho/fmann, Schilderung der deutschen Pflanzenfamilien vom plysiologischeliemischen Standpunhte. Giessen 1846. 8.

Schleiden, Ueber Ernăhrung der Planzen. Leipzig 4846. S.

Rochleder, Beitráge zur Phytochemie. Wien 1847. S.

Wolff, Die chemischon Forsehungen anf dem Gelsiete der Agrikultur und Pfanzenphysiologie. Lripzig 1847.8.

\section{Motus fluidorum.}

Verdries, De succi nutritii in plantis circuitu. Giessae 1707.4.

In la Baisse (Sarrabat), Dissertation sur la circulation de la seve dans les plantes. Bordeaux 1733. 12.

Kiesling, De succis plantarum. Lipsiae 1752.4. (germanice.)

Bose, De secretione humorum in plantis. Lipsiae 1755.4.

De motu husuorum in plantis. Lipsiae 1764. 4.

Plaz, De motu humorum in plantis vernali tempore vividiore. Lijpsiae 1764. 4 .

Lulwig. Ile elaboratione succorum plantarum. (I-III.) Lipsiae 17681772. 4.

Narum, De motu fluidorum in plantis experinentis et observationibus inlagato. Groningae 4773.4.

Prit 7el, Thes. lit. bot.
Corti, Osservazioni microscopiche sulla Trcmella e sulla circolazione (lel fluido in una pianta acquajuola (Chard). Lucea 1774. 8.

llebenstreil, Causae lsumorum motum in plantis commutautes. Lipsiae 1779. 4 .

Coulon, lle mutata liumorum in regno organico indole. Lugduni Batavorum 1789.8.

Walker, Experiments on the motion of the sap in trees. Eibuburgh s. a. 4. (germanice.)

Vauquelin, Expériences sur les sèves des végétaux. Paris (1799.) 8.

Degland, La seve circule-t-elle dans les plantes? (Montpellier 1802.) 4

Gouan, Discours sur les causes du mouvement de la sève dans les plantes. Montpellier 1802.4.

Frenzel, Physiologische Bcobachturgen uljer den Inulauf dles Saftes. WVeimar 180 千. 8.

Colta, Naturbeobachtungen über die Bewegung und Funetion des Saftes in den Gewachsen. Weinar 1806. 4.

Anici, Osservazioni sulla circolazione del succhin nolla Chara. Modena 1818. 4.

Sageret, Discussion sur l'existence des deax sives dites de priutemps el d'aoút. Paris 1818 . 8 .

Amici, Osservazioni microscopiche sopra varie piante. Modena 1823. 4.

Schullz, Veher den Kreislauf des Saftes im Schöllhrauto. Berlin 1822. 8.

- Uober den Kreislauf des Saftes in den Pflazen. Berlin 1824.8.

Bailly, De l'incision amnulaire. Paris 1825. 8 .

Mayer, Supplemente zur Biologie des Blutes und des l'flanzensaftes. Bonn 1827. 4 .

Barbieri, Osservazioni microscopiche. (Circulatio succi in Charis.) Mantova 1828.8.

Moretti, De retrogradu lynuphae vegetabilis motu. Ticini 1831. 8.

Meyen, Ueber die Bewegung der Safte in den Pflanzen. Berlin 1834. s.

Morren. Considérations sur le mouvement de la sève des Dicotylédone's. s. 1. (1838.) 8 .

Schulls, Sur la circulation et sur les vaisseaux lactiferes dans les plantes. Paris 1839. 4.

Die Cyklose des Lebenssaftos in den Pfanzen. Breslau und Bonu 1841.4.

Mohl, lo welcheru System des llolzes wird der rohe Nahrungssaft zu den Organen geleitet? Tubingen 1843. 8.

Schleiden, Ueber Ernábrung der Pflanzen und Safthowegung in denselbon. Leipzig 1846. 8 .

\section{Chemia specialis.}

Nedel, De sale volatili plantarum. Jenae 1682. 12.

Scepin, De acido vegetabili. Lugduni Batavorum 1758.4.

WTallerius, De origine oleoruns in regetabilibus. Upsaliae 1761.4.

Allmann, Analysis plantarum antiscorbuticarum. Vicnnale 1766. 8.

Baer, Experimenta chemica de Gummi-resinis nonnullis. Erlangae 1788. 4

Titius, De acido vegetabilium elementari. Lipsiae 1788. 4.

Marabelli, De Zea Mays planta analytica disquisitio. Papiae $1793 \mathrm{~s}$.

Trainer, Examen chemicum Mlanuao. Erlangae 1793. 8.

IIempel, Ueber die Natur der Pflanzensauren. Berlin 1794. 8.

_- Chemische Intersuchung der Winter- und Sommerejelse. In ejus "Pharm--chem. Abhandlung" etc. Berlin 1794.8.

Lehr, De carbone vegetabili. Mlarburgi 1794. s.

Titius, De aere in Coluteae leguminibus contento. Wittehergae 4800.4.

Clarion, Travail chimique sur les rlsubarbes exotique et indigène. Paris 1803.8.

De Candolle et Cuvier, Examen diun sel recueilli sur le Reaumuria. (Bull. soc. phil. 1803. p. 251 .)

Langlès, Recherches sur la découverte de l'essence de rose. paris 1804.12. 


\section{RESURRECTIO PLANTARUN}

Melandri et Morelli, Inalisi delle radici di Lariofilata umnale e dell uva orsina. Pavia 1805.8.

kiclmetyer, Observationes eliemicae de acreding nonnullorum vegetabilium. Tulsingao 1805.8 .

De materiis narcoticis regni vegetabilis. Tubingac 1808.8.

Gaullier de Claubry, Recherebes sur l'existener do l'Jude dans les plantes ctc. Paris 1815. 4.

Itomlereitz, Chemisch-medizioische Untersuchung uher dic Wandflechte (Lichen parielinus) und Chinarinden. Dorpat 4817.8 .

Berthold, De scminis PJiellandrii aquatiei analysi chemics. Ilalac 1818.8

Isoullay, L'histoire chimique de la coque du Levant (Monispermum Cocculus). Paris is18. 8. - 11 : ib. 1818.4.

Mannharll, Lobariae parietinae analysis chemica. Kilias I8I8. 4.

logel, Chemische Analyse der Nymplaea alla; in Dingler, Veloer die Nymphaea alba L. Wien 1820.8.

liunge, De pigmento indico. Berolini 1822.8.

(Canzoneri) Saggio sul castagno d'India. Palermo 1823. \&.

Marincovich, De sueco Tithymalorum ejusque analysi. Venetiis 1833. \&.

Martin Solon, Ncalia vegetabilia novissime inventa. Paris 1824. 4.

Franzoja, Analysis Suilacis Chinae. Patavii 1825. S.

- Analysis Arundinis Donacis. Patavii 1825. 8.

Raspail, Analyse microseopique of le dérroppement de la Jécule dans les céréales. Tn ejus "Mémoires sur les Graminées». Paris 1825. \$. (germanice.)

Batsú, De Aspidio Filice mare. Vindobonae 1896.8.

Petit, Mémoire sur le parot d'orient. Paris 1827 . 8 .

Kunge, Resultate elımiscber Untersuchungen der Cynareen, Lupatorineeb etc. Breslan 1828 . 4.

W'alll, Das Amylon und Inulin. Nuruberg 1829. S.

Cailliot, Essii chimique sur la Térébinthine des sapins. Strassburä 1830. 4.

Graeger, De Asaro europaeo. Goettingae 1830.8 .

Besser, De Salicinio. Berolini 1831, 8.

Cinllemin, Consilèrations sur l'amertume des végétanx. P’aris 1832. 4.

Hartrodt, Dio Alkaloide. Leipzig 1832. 4.

Scluebler, Seminum Sorghi vulgaris analysis. Tubingae $1 \$ 32$. \&.

Jassen, De Scillitino. Groningae 1834.8.

Jacquin, Veber die geistige Gälurung der starkemellhaltigen Stoffe. (Wien 1834.) 8 .

Schucbler, Untersuchungen über die Bestandtheile des IJirse, Panicum miliaceum L. Tubingen 1834.8.

Himly, De Caoutschouk et de Caoutsehino. Goettinga 1835.8 .

Struie, De silicia in plantis nonullis. Berolini 1835. 8.

Christison, On the properties of hemloek (Conium maculatum) and its alcaloid conia. Edinburgh 1836.4.

Murray, Chemical analysis of the milk and bark of the palo de Vaca. London 1837. gr. 8.

Pepe et Cupido, Analisi del frutto del Platano orientale. Napoli I\$37. \&.

Bleisch, De Amyglalinio. Vratislaviae 1838. 4.

happ, Ueber das Santonin. Ileilbronn 4\$38..

- Ueber die Veratrine. Tubingen 4\$39. \&.

Meyer, Ueher das Amylum. (Konigsberg 1839.) 8.

Payen, Mémoire sur l'Amidon. Paris 1839. 8.

Péligot, Recherches sur l'analyse et la composition chimiques de la betterave à sucre. Paris 1839.8 .

IValz, Der Milchsaft des Giftattichs elemisch untersucht. Ueidelberg 1839. 8 .

Zuenger, Nonnulla de Catedino. Gissae 1841.4.

\section{Resurrectio plantarum.}

Voigt, Curiositates physicae. (Comtra resurrectionen.) Gustrovii 1668. \&. Schmid, Resurrectio (vegetabilinm) artificialis. Iipsiae 1677. 1.
Hannemann, Phoenix botanicus. (Kilonii 1678.) 4.

Franke, Programma ad herbationes anni 1680. Heidelbergae 1680. 4. El. Il: De P'alingenesia liber singularis commentario illustratus a $J .(\%$. Nehring. Halae 1717. 4.

Ifoegling. Palingenesia sive resurrectio plantarum. Tubingae 1883.4 Barnstorff, Prouramma de resuscitatione plantarum. Rostochii 1703.4. Ilenckel, Flora saturnizans. Leiprig 1722. S. - ib. 1755.8. (gallice.)

Wallerius, De Palingenesia. Upsaliae 1764.4

\section{Color plantarum.}

Brueclimamn, De Oeymastro flere viridi pleno. Walfenbuttelae 1734. 4. Ludwig, De colore jlantarum observata. Lipsiae 1756. 4.

De colore flonm mutabili. Lipsiae 1758. 4.

De colore plantarum species distinguente. Lipsiac 1759 . 1.

Beclier. Experimenta circa mutationem colerum vegetabilium a corporilus salinis. Goettingae 1779. 4 .

Boelımer, De coeruleo culore raro. Wittebergae 1786.4 .

Ilopkirli, Flora anomala. Glasgow 1817.8 .

Schuebler, Untersuchungen über die Farben der Bluten. Tul,iogen $1 \$ 25.8$.

Macaire-Princeps, Mémoire sur la coloration automnaln des feuilles. Genève 1828.4.

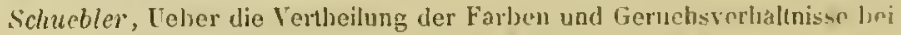
den Asperifolien, Primulaceen ete. Tubingen 1831. 9.

- Leber die Vertheilung der Farben und feruchssedhaltnisse in der Familie der Rubiaceen. Túlingen 1831. 8.

-_Leber die Vertheilung der Farhen und Geruchsirerhalluisso in den wichtigeron Familien. Tubingen 1831 . 8 .

Ueber dio Farbenverltaltnisse in den Blïten der lilora l)eutschlands. Tubingen 1833.8 .

- Untersuchungen uber die Farbenreränderungen dor Blutcu. Tubingen 1833 . \&.

- Veluer die Farbenverluảltnisse in den Bluten der F'ora Franhreichs. Tülingen 1833.8 .

Pieper, Das weehselnde Farbenverláltniss des Blattes. Berlin 1834. \&.

Ciordano, Cemo sulla decolorazione delle fọlie in antumon. Turino 1835.8.

Marquart, Die Farben der Bluthen. Benn 1835.8.

Morio, Sugl innesti, sulla colorazione dei regetabili c sulla fosforenza del lig̣no. Vigevano 1836 . $\$$.

Mohl, Untersuchungen aber die winterliche Färbung der latter. Thibingn is 37.8 .

preisser, Sur l'origine et la nature des matières coloranles mrganiques. Rouen 1843.8.

\section{Odor plantarum.}

(C. Schuebler in sectione: Color plantarum.,

Taglini, Su IAglio trapiantato al pie del Rosaio possa conferire alla Rosa una maggior Iragranza? In ejus "Lottere scientifiche ${ }^{\circ}$ l'irenze 1747. 4. p. $37-94$.

Limne. Odores medicansentorum. Stochlolmiae 1752.4.

- Medicamenta graseolentia. I psaline 1758.4.

Michalowsky, De principio plantarum odoro. Regiomonti 17S\&. \&.

Cloquet, Sur les adeurs. Paris 1815. 4.

Morren, Rappert sur le mémoire te Trinchinetli: De odolihus Ilorun cxperimenta. Bruxelles 1839 . \&.

Duméril, Des odeurs, de leur nature ef de leur action physiolngique. Paris isi3. 8 . 


\section{MORBI PLANTARUM}

\section{Respiratio plantarum.}

lleptrl. The plantarum transpiratione. Lipsiae 1735.4.

Mernander, Theses de transpiratione plantarum. Aboae 1750.4.

Bomnet, Recherehes sur l'usage des feuilles. Goettingae 1754. 4. (hollandice, germanice.)

Harmens, De transpiratione plantarum. Londini Golhorum 1756.4.

Ingenhous , Experiments upon vegrables. London 1779. 8. (gallice, germanice, hollandice.

Barnereld et Mueller, Verhaudeling over het planten van boonzen. Utrecht 1793. 8 .

S'encbier, Traité sur les rapports des plantes avec l'air atmosphérique. Genève 1807.8.

Gautieri, Dell' influsso de' boseli sullo stato fisico de' paesi. Milano 1814.8 .

Gilly, De mutationibus quas ea quae e terra gignuntur, acri inferunt Edinburgi 1815.8 .

Cimelin, De plantarum exhalationibus. Tubingae $1817 . \mathrm{s}$.

Rees, Disquisitio de decompositione acidi carboniei in vegetatione. Trajecti a/Rh. 1818.8

Grischou", Plysikalisch-chemische Untersueluungen uber dio Athmungen der Gewáclıse. Leipzig 1819. S.

Bosson, Mlémoire sur l'influence du déboisement des forets. Paris 1825. 8.

Foclie, Do respiratione vegetabilium. Heidelbergae 1833.4.

Hohl, Teber die Functionen der Blatter. Tübingen 1836. S.

Reimers, Respirationis plantarum explicatio. Kiliae $1 \$ 39.4$.

Byczliowski, Das Verbaltniss der Pllanzen zur Atmospháre, Dorpą I\$ 46.8.

\section{Arbores vetustae.}

Ilmer, 1)e Tilia (prope Neustadt ad magnam tiliam). Lipsiae 1669. 4.

fiulm, De literis in ligno Fagi repertis. Gedani 1730. 4.

Alami. Freye Gedantien über einen Buchenbaum. Breslau 1756. S.

(Mutule) An account of the oak of Cowthorp. s. 1. 1774. 4.

Cough, Cedar of Libanus growing in the garden of Queen Elizabeth's Palace at Enfield. (London) 1788. folio.

looke, Deseriptions and shetches ef some remarkable oaks in the park at Welbeck. London 1790. 4 .

Todd. The north-west prospect of Whinfield forest. folio.

lloeller, Der König und die Königin der Lubrbaume. Brün 1820. 4.

Deshayes, Notice sur une ehene extraordinaire, appelé la Cuve. Rouen 1826. 8 .

Agardh, Om Inshrifter i lefvande trát. Lund 1829.8.

Strull, Sylva britannica, or portraits of forest trees distinguished for their antiquity, magnitude or heauty. London $(1831-1836$.$) folio.$

De Candolle, Notice sur la longévité des arbres. (Genève 1831.) 8 .

-..._. De quelques arbres très-anciens mesurés au Mexique. (Bibl. univ. de Genève 1831. XLVl. 387-394.)

Berthelot, Observations sur l'accroissement et la longévité des arbres. Fenèvo 1839.8 .

\section{Morbi plantarum.}

(Norbi Solani tuberosi ef. p. 475 ; Seeale cornutum cf. p. 460.)

Le Seurre. Diseours sur la crapule. In ejus a Description». Lyon 1669. 8. If eiss, De excrescentijs plantarum animatis. Lipsiae 1694. 4

Tromsdorff. Ros mellis, non ros, nee mellis ros. Erfurti 1699. 4. 7tuinger, De valetudine plantarum secunda et adversa. Basileae 1708. 4.
Camerarius, De ustilagine frumenti. Tulningae 1709.4

Eysel, Die wundernsw urdige Weidenrose. Erfordiae 1711.4.

Eysfarth, De morbis plantarum. Lipsiae 1723. 4.

Ililscher, De natura et origine roris mellei et rubiginis vegetabiliun. Jeniale 1736. 4 .

Ilassellom, Aphorismi de morbis plantarum. Aboae 174s. 4.

Curieuse Nachricht von Weyden-Rosen. Erfurt (1747.) 4.

(4lbrecht) De Salicum rosis fictis. Coburgi 1748. S.

Hoppe, Einige Nachricht von den sogenanuten Eichen-. Weidelı- un] Dornrosen. Leipzig 1748, 4

Schreiber, Vermunflige Gegenantwort an Tobias Konrad Iloppe. (Rosae Salicis.) Gera 1748.4

Gedanken uber die Rosen und Nelken der Weiden. (Nassan) 1750.4

Plaz, De plantarum plethora. Lipsiae 4754. 4.

Tillet, Dissertation sur la cause, qui corrompt et noircit les graina de bled dans les épis. Bordeaux 1755. 4. - Suite: Paris 1755. 4. (sermanice.)

- Précis des expériences sur la corruption des bleds. Troyes 1756.12 Bring, De morbis plantarum. Londiui Gothorum 1758. 4.

Engel, Abhandlung vom Roste in Getraide. Zürich 1758. 8.

Ginami, Delle malatie del grano in erba. Pesaro 1759. 4.

Gacld, Om sádesarternas sjukdomar. Abo 1766. 4.

(Cattaneo) Della idropisia de' gelsi. (Milano 1767.) S,

Fontana, Osservazioni sopra la ruggine del grano. Lucca 1767.8.

Hagen, Physikaliseh-botanische Betrachtungen uber die Veidenrosen. Konigsberg 1769. 4.

Scopoli, Do lue epitemica Mori alLae. In ejus "Anno hist. nat.»lV. Lipsiae 1770. 8. p. $115-120$

Read, Traité du seigle ergoté. Strasslurg 1771. 8.

Alberti, Dell' epidemica mortalità de' gelsi. Salò 1773.4.

Localelli, Sulla corrente malatia de' gelsi. Verona 1773. 4.

Zallinger, De morbis plantarum. Oeniponti 1773.8 .

germanice.

Fonlana, Saggio di osservazioni sopra il falso ergot e Tremella, Firenze 1775. 4

1/oschellini, Della brusea malattia degli olvi. Napoli 1777.12.

Tessier, Traité des maladies des grains. Paris 1783.8.

Bryant, Causes of that disease in wheat called Brand. Nor wich (1784.) 8

Inhof, Zeae Mayelis morbus ad ustilaginem vulgo relatus. Argentorati 1784. 4 .

San Af artino, Memoria sopra la nebbia dei vegetabili. Viceniza 1785.8.

Préeis et expériences sur la eause de la corruption des blés. Paris 1783. 4.

Tessier, Résultats et expériences faites à Rambouillet sur la carie. Pari. 1785.8 .

- Moyens pour préserver les fromens de la carie. Avignon 1786.8. Saint-Amans, Rechercbes sur la maladie, qui détruit les arbres des promenades d'Agen. Agen 1789.8.

Seetaen, Systematum generaliorum de morbis plantarum brevis dijudicatio. Goltingae 1789. 8 .

Forsyth, Observationy on the diseases of fruit and forest trees. London 1791. 8 .

(germanice, gallice.)

Plenck, Physiologia et pathologia plantarum. Viennae 1794.8 (germanice, gallice, italice.)

De Candolle, Observation sur une espece de gomme, qui sori des lubches du helre. (Journ. de plyysique 1799. vol. XLVIII. p. 447.)

Doria, Lettera agronnmiea sulla ruggine del grano. Roma 1801, 8 .

Banlis, Account of the cause of the disease in corn. London 1805. S.

Gaulieri. Della ruggine del frumento. Milano 1807.8.

Prevost, Mémoire sur la cause immédiate de la carie ou cliarlıon des blès et autres maladies des plantes. Montauban 1807. 4 .

Re, Saggio di nosologia regetabile. Firenze $180 \%$. s.

- Saggio teorico-pratico sulle malattie delle piante. Venezia 1807. \$. Eil. Il : Milano 1817.8 
Ilerneck, Versueh einer Pllanzenpallologie und Therapir. Mannhein 1807. 8.

Christ, Die Krankheiten, Uebel und Feinde der Obstbaume. lrankfurt a/ 11. 1s08. 8.

Auersperg (Zallinger), Die Krankleiten der Baume. Brunu 1809. S.

Maccary, Sur la maladie forficulaire lu múrier. Paris 1810.8.

Losance. Delle malattic del grano in erba non curate. Carmagnola 1811.8.

Lelieur, Maladies les arbres fruitiers, Paris 1812. 12.

Hornemann, Om Berborissen kan frembringa kornust? Kiobnhavn 1816. 8 .

1'ollini, Sopra alcune malattie degli ulivi. Milano 1818. S.

Tenzel, Beselweibung einer Pflanzenkranhheit. Kempten 1819. S.

l'éburier, Sur les moyens pour préserver les blés de la carie. s. I. (1824.) 8 .

Fries, Om Brand och Rost på wáxter. Lund 1821. S.

Bauer, Microseopical observations on the Vilurio Tritici. London 1523. 4.

Matanir, Sopra una essudazione spontanea della quereia. Catania 1825. 4.

Léveille', Mémoire sur l'ergot. (P’aris 1826.) 8.

Kalchberg, Ueber dio Natur, Entwicklungs - und Eintheilungsweise der Pllanzenauswuchse. IVien 1828.8.

Losana, Sagrio sopra il carbone del Mais. Torino 1828. 8.

Bayle-Barelle, Della malattia della golpe del gran tureo. Nilano s. a. 8.

Turpin, Mèmoire de nosologie végétale. (Paris i833.) 4.

Unger, Die Exantheme der Pfanzen. Wien 1833. 8.

Gulama, Verhandeling over liet moederkoorn. (ironingen 1834.8.

the Candolle, Sur les maladies des mélèzes dans la firande-Brétagne. (Genève 4835.$) 8$.

'hilippar, Traité sur la carie, le charbon, l'ergot, la rouille et autres maladies des Ceréales. Versailles 1837.8.

Turpin, Notice sur une maladie des tiges des mùriers. Paris 1838, 8.

Vandamme, Mémoire sur les maladies lles Graminées. Hazebrouck 1838. 8 .

Morelli, Compendio di nosologia vegetahile. (Bibl. agraria tom. XXill,) Milano 1839.8 .

- De vegetabilium rhachitide. Ticiıi 1839. 8.

IVieymann, Die Krankheiten und krankhaften Missbildungen der Gewächse. Braunschweig 1839. 8.

(danice, hollandice.)

Unger, Beiträge zur vergleichenden Pathologie, Wien 1840.4.

Meyen, Pl]anzenpathologie. Lelure von dem kranken l,eben und Bilden der Pflanzen. Berlin 1841,8 .

Bonjectl, Histoire du seigle ergote. Paris 1849. \&.

Fée, Mémoire sur l'ergot du seigle. Strassburg 1843.4.

Raspail, llistoiro naturelle cle la santé et te la maladie chez les vigétax et elez les animaux. Paris 1840. 8 .

Regel, Die ăussern Einflusse auf das Pflauzenlelen. Zurich 1847.8.

\section{Anatomia. Organographia. Physiologia.}

Mizauld, Dendranatome. Lutetiae 1560.8.

Bacon de Verulam, Sylva sylvarum or a naturall histeric. London 1627. folio.

(latine, gallice.)

Sperling, De traduetione formarum in plantis. Wittebergae 1648. 4.

ligby, $\perp$ discourse concernimg the vegetation of plants. London 1661. 12. (latine, gallice.)

Joolie, Micrographia. London 1665. folio.

(irew. The anatomy of vegetables begun. London 1672.8 . (Iatine, gallice.)

An idea of a phytological history. Lonclon 1673.8 . (latine.)

Walpighi, Anatome plantarum. Londini 1675-1679. iolio
Bayle, De forma plantarum, yuae explicatur ex generatione fungi vquı est planta simplicissima. Tolosae 1677. 12.

Ciassus, Meditationes de natura plantarum. Venetiis 1677. 12.

Mariolte, Premier essay de la régétation des plantes. Paris 1679. 19.

Ziegra, De morle plantarum. Wiltebergae 1680. 4 .

Dedu, De l'ame des plantes. Paris 1682.12.

(latine.)

Grew, The anatomy of plants. Lonclon 16\$2. folio.

Triumfelli, Observationos de ortu ac vegetatione plantarun. lamar 1685. 4.

Lecuwenhoek, Epistolae ad societatem anglicam. (98-14G.) Leidno et Delft 1686-1704,4. - Continuatio: Lugduni Batavorum 1689.4.ib. 1715.4 .

Malpighi, Opera omnia, seu thesaurus locupletissimus botanico-nedicnanatomicus. Londini 1686. folio. - Lugduni Batavorum 1687. 4.

Buonanni, Micrographia curiosa. Romae 1691. 4.

Leeuvenhoek, Areana naturae. Delphis 1695.4. - Continuatio: il. 1697. 4. - Lugduni Batavorum 1719. 4.

(latine.)

Anatonia seu interiora rerum. Lugduni l3atavorum 1697.4.

Malpighi, Opera nostluma. I.ondini 1697. folio. el pluries.

Triumfelli, Vindiciae veritatis. Romae 1703.4.

Wagner, Gyros Convolvulorum evolvere tentabit. Helmstadii 1705.4.

Leeuwenhoek, Opera omnia seu areana naturae. Lugduni Batavorum 1715 -1722.4 .

Select works; by Samuel IIoole. London 1798. 1.

Thuemmig, Experimentum singulare de arboribus ox folio edueatis. IIalato 1721. 4 .

(germanice.)

Wolf, Allerhand nutzliche Versuche zu Erkenntniss dor Natur, Ilalle 1721. 8.

Thuemmig, Versuch einer gründlichen Erlauterung der merhwurtigsten Begebeuheiten in der Natur. Hallo 1723. 8 .

Wolf, Vernünftige Gedanken von den Wirkungen ren Natur. Ilalle" 1723. 8 .

- Vernunftige Gedanken von den Absichten der natulliclien llinge. Halle 1724. 8.

- Vernunftige Gedanhen von dem Gebrauche der Theile etc. Frunhfurt 1725. 8 .

Jacobeeus, De plantarum struetura et regethione schedion. Havnare 1727. 8 .

llales, Statical essays. Vol. I: Végelable statichs. Lonolon 1727. S. - il. 1731. 8. - ib. 1738 . 8 .

(gallice, italice, sermanice.)

lioyen, Le anatome et oeeonomia plantarum. Lugduni Batav. 172S. i

Bourguet, Sur la génération et lo mechanisme des plantes. Imsterdam 1729. 12.

Calandrini, De vegetatione el generatione plantarum. Genevar 173я. 亿.

Wallher, De plantarum structura. Lipsiae 1740. 4.

Gesner, Dissertationes de partium vegetalionis et fruetificationis stuctura, differentia et usu. Lugdluni Batavorum 1743. s.

Needham, An account of some new microseropical discoverirs. Inndon 1745.8 .

(gallice, germanice.)

Adams, Micrographia illustrata. London 1746. \&

Schier $\ell$, Dissertatio de constanti plantarum affectione ad perpeneluculum. Mediolani 1750.8 .

Pla: Organicarum in plantis partium historia physiologica. J.ipsiao 175 1.4. IIill, Essays in natural history. Lomlon 1752. 8.

(germanice.)

Schilling, Phytologiae seu physices plantarum specimen 1-III. I)isburgi 1752.4 .

Boehmer, De regetahilium celluloso contextu. Wittebergae 1753. 4.

Joblol, Observations faites avec le mieroscope. Paris 1754-1755. 4.

Jampert, Dubia contra vasorum in plantis probabilitatem. llalae 1753.4 . 


\section{ANATOMIA. ORGANOGRAPHIA. PHYSIOLOGIA}

Du Ilamel, La pliysique des arhres. Paris 1758. 4. (germanice.)

Reichel, De vasis plantarum spiralibus. Lipsiae 1758.4.

Ledermueller, Mikroskopische Gemüths- und Augenergotzungen. Nurnberg $1759-1762.4$. (gallice.)

Schmidel, De medulla radicis ad florem pertingente epistola. Lugduni Batavorum 1759. 4

Bonnet, Considérations sur les corps organisés. Amsterdam 1762. 8 . (germanice.)

- Contomplation de la nature. Amsterdam 1764.8. (germanice.)

Gleichen genamt Russwurm, Das Neueste aus dem Reiche der Pflanzen. Nìirnberg 1764. folio. (gallice.)

Nürnberg 1777-1781. gr. 4 . (gallice.)

Bochmer, Planta res varia. Wittebergae 1765.4.

limé, Mundus invisibilis. Upsaliae 1767.4.

Ledernucller, Reponse à quelques objections à lui faites jar le liarun de Gleichen. Nurenberg 1768.4.

Letzte Beobachtungen. Núrnberg 1776. 4.

Hill, The construction of imber. London 1770. folio.

(Spielmann) Tegetatio. Argentorati 1773. 4.

Mauksch, De partibus plantarum. Tyrnaviae 1776. S.

Spallanzani, Opuscoli di fisica animale e vegetabile. Jlodena 1776. S. (gallice.)

Bell, De physiologia plantarum. Edinburgi 1777. 8. (anglice.)

Moldenhawer, De vasis plantasum speciatim radicem herbanque adeuntibus. Trajecti a/V. 1779.4

Feuereusen, Pflanzenorzanologie. Jlannover 1780. 8.

Mustel, Traité théorique et pratique de la végétation. l'aris 17811784.8 .

Spallanzani, Fisica animale e vegetabile. Venezia 1782. 12. (germanice.)

Ingenhousz, Nourelles experienees sur divers objets de physique. Parji 1785.8 . (anglice.)

Adams, Essays on the microscope. London 1757. 4.

Brugmans, Do mutata lumorum in regno organico indole a vi vitali vasorum derivanda. Lugduni Balavorum 1789. 8.

Donovan, Essay on tho minute parts of plants. London 1789-1790. 4

Oslamp, Nonnulia plantarum fabricam et veconomiam sjectantid. Trajecti a/Rh. 1789.4.

Sienebier, Dictionnaire des forets et bois. Paris 1790-1815. 4.

Comparelli, Prodromo di fisica vegetabile. Padova 1791-1799. 8.

Humboldl, Aphorismi ex doetriua physiologiae clıemicae plantarum. Impr. eum ejus Flora Fribergensis. Berolini 1793. 8. (germanice.)

IIedwig, Sammlung zerstreuter Abhandlungen. Leipzig 1793-1797. 8.

Boehmer , De vegetatione plantarum inversa. Wittebergae 1794. \&.

Plencli, Physiologia el pathologia plantarum. Vionnae 1794. 8. (germinice, sallice.)

Schrank, Von den Nebengefassen der Pflanzen. Halle 1794.8.

Uslar, Fragmente neurer Pllanzenkunde. Braunschweig 1794.8. (anglice.)

Darwin, Zoonomia or the laws of organic life. London 1796.4. (gallice, germanice, italice.)

Rafn, Udkast till en plante-physiologie. Kiöbenhavn 1796. \& (germanice, suecice.)

Hooper, Observations on the structure and economy of plants. Oxiurd 1797. 8 .

IJumboldt, Einleitung ther einige Gergenstande d'tr Planzenphysiolngie. In Ingenhousz, Leber Emáliruag der Pflanzen. Leipzig 1798. 8.

Giboin (rovera Draparnaud), Fragmens de plysiologie végétale. Mlontpellier 1799. 4 (germanice.)

Medicus, Beiträge zur Pflanzenanatomie und Plysiologie. Leipzig 17991801.8

- Pflanzenphysiologisclıe AbLandiungen. Leipzis 1803.12.

Ganser, Observationes circa nutritionem et anatomiam plantarum. Salisburgi s. a. 4.

Brunn, De vasis plantarum. Ilalac 1800.8 .

Meyer, Naturgetreue Darstellung der Entwicklung der Pllanzen. Leipzis 1800.8.

Senebier, Physiologio végétale. Genève $(1800) 8$.

Brisscau-Mirbel, Trailé d'anatomie el de plyssiologie végétales. Paris, an X. (1802.) 8 .

IVitt, De legibus quibusdam ad processum vegetationis pertinentibus. llalae 1802.8 .

Bermhardi, Beobachtungen uber Pflanzengefässe. Erfurt 1805.8.

Aubert du I'elit-Thoners, Essais sur l'organisation des plantes. Paris 1806. S.

Treviranus, Vom inwendigen Bau der Gewàchse. Guttingen 1806. 8.

Barisch, Observationes phytotomicae. Halie (1807 ?) 8 .

Fray, Essai sur l'origine des substances organisées et inorganiscies. Berlin 1807.8.

Link, Grundlehren der Anatomie und Physiologie der Pllanzen. Guttingen $1807-1812.8$

Rudolphi, Anatomie der Pflanzen. Berlin 1807. \&.

Kieser, Aphorismen aus der Physiologie der Pflanzen. Gouttingen 1808. s.

Brisseau-Mirbel, Exposition ef défense de ma théorie de l'organisation végétalc. Erláuterung ete. À la Haye 1808. 8.

Paris 1809. 8

Aubcrt du Petil-Thouars, Essais sur la végétation. Paris 1809.8

Grindel, Ideen diber die Vegetation. Riga 1809. 8.

Meineclie, Ueber das Zahlenverhaltniss in den Fruhtifikationsorganen und Beiträge zur Pilanzenply'siologio. Halle 1809.8

Gérardin, Essai de physiologio végétale. Paris 1810.8.

Goube, Traité de la vie et de l'organisation des plantes. Rouon I\&I0. \&.

Perolli, Fisiologia delle piante. (Barge) 1810.8 .

Treviranus, Beiträge zur Pflanzenphysiologie. Gollingen 1811. 8.

Fíburier, Essai sur les phénomenes de la végétation. 1'aris 1812.8 .

-__ Notice sur la moelle el l'étui médullaire des arlores dicolylédones. Paris 1812.8.

Kieser, Mémoire sur l'organisation (les plantes. Harlom (1S12.) 4.

Moldenhawer, Beitrage zur Anatomie der Pflanzen. Kiel 1812.4.

Sprengel, Von dem Bau und der Natur der Gewsichse. Ilalle 1812. s. (suecice.)

Link, liritisclıe Bemerkungen zu Sprengel "Leber den Bau und die Natur der Gewächse. Halle 1812. \&.

Ciallesio, Teoria della riproduzione vegetale. Viena 1813.8 (germanice.)

Lemairc-Lisancourt, Nolions sur la plysique végétale. Paris 18.13. s.

Ánselmo, Discorsi fiśiologici. Torino 1815. 8.

Aubert du Petil-Thouars, llistoire d'un morceau de hois. Paris 1815 . 8 .

1815.8 .

Recueil des rapports et des mémoires. Paris

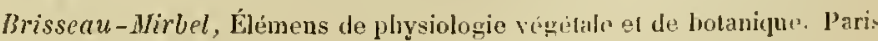
1815. 8.

(anglice.)

Kïeser, Grundzüge der Inatonie der Pflanzen. Jena 1815.5.

Pollini, Osservazioni sulla vegetazione degli alberi. Verona 1815.8.

Keith, A system of physiological botany. London 1816. S.

Godefroy, Essai sur la formation des substances végétales. Strassbur: 1818.4.

Pollini, Sopra la teoria della riproduzione vegetale del Signor foulleso Milano 1818.8 .

Rauch, Régẻnération de la nature végétale. Paris 18 is. S.

Boon Mesch, De ratione inter structuram et formam externam plantarum Lugduni Batarorum 1819.4. 


\section{ANATOHIA. ORGANOGRAPHIA. PHYSIOLOGLA}

Tipes ron Esenbeck, Bischof und Rothe, Die Entwicklung der Pnanzensubstanz. Erlangae 1819. «.

Cassel, Morphonomia botanica. Colonias Igrippinae 1820.8.

Fischer, De interna plantarum fabrica. Mlosiguae 1820.8 .

Félurier, Observations sur la physiologie végótale. Versailles (1821.) S.

Treciranus, Vermischte Schriften anatomischen und plysiologisehen lnhalts. Biemen 1821. 4.

Aubert du Petit-Thouars, La physiologie végétale et lo prix Monthion. Paris 1822.8 .

liobertson, Colloquia de relus praecipuis plıysiologiae regetabilium. Lovaniae 1822.8 .

Schullas. Die Natur der lebendigen Pnanze. Berlin und Stuttgant 18231828. 8.

Héurier, Prúcis d'anatonie régétale. Versailles 1894.8.

link, Elementa philosophiae hotanicac. Berolini 1824, s. - il. 4\$37. 8.

Sichubert, Rosprawa o skladzie nasienia. (De anatumia et germinatione plantarum.) w Warszawie 1894.8.

Leschevin, Plıysiologie végétalo. Paris 1825.8.

sniadecki, Théorie des êtres organiques. Paris 1825. S. (polonice.)

Bory de St. lincent, Le la matiere. Paris $1826 . \mathrm{s}$.

Meyen, De primis vitae phaenomenis in fluidis formativis. Berolini $1 \$ 26.4$

Bluff, Entwicklungscombinationen organischer Wesen. liöln 1827. 8.

He Cundolle, Organograplie végétale. Paris 1827.8. (germanice, anglice.)

limelin et Palm, Ueber das Winden der Pflanzen. Tubingen 1827. S.

Mohl, Ueber den Bau und las Winden der Rauken und Schlingplanzen. Tülingen 1897. 4 .

l.ecoq, Recherches sur la reproduction des végétaux. Clermont 1827. 4.

Turpin, Organographie végétale. Paris 1827. 4.

Ayardh, Essai de réduire la physiologie végétale etc. Lund 1828. 8.

Biürlingsson, De elementis plyysiologiae plantarun. Upsaliae 1828. 4.

Bischoff, Die kryptogamischen Gewächse ... anatomisch, plysiologisch bearbeitet. Nurnberg 1899. 4.

Browon, A brief account on microscopical observations made in the montlis of June, July and August 1827 on the particles contained in the pollen of plants; and on the general existence of active molecules in organic and anorganic bodies. London 1S28, 8. - Additional remarks on active molecules. London 1829.8 .

$$
\text { (Verm. Scluriften IV, } 141-\$ 14 .)
$$

Sichultae, Mlikroscopische L'ntersuchungen uber Rober Brou'n's Entdeckung Icbender selbst im Feuer unzerstorbarer Theilchen in allen liorpern. Cirlsruhe is 2 S. 4

mutrochet, Nouvelles recherches sur l'endosmose et l'exosmose. Paris 1898.8 .

Kilinkhardh, Betrachtung des Pflanzenreichs Berlin 1 S2S. 8.

Jeyen, Untersuchungen uber den lnbalt der Pflanzenzellen. Berlin 1828.8.

llohl, Leber die Poren des Pfanzenzellgewebes. Tubingen 1898. 4.

Roeper, De organis plantarum. Basileae 1828. 4.

I garlh, Essai sur le développenent iutérieur des plantes. Lund 1829. \$. lischoff. De vera rasorum plantarum spiralium structura et functione. bonnae 1829. 8 .

Tundeshayen, Lelrtbuch etc. Il: Anatomic, Chemismus und Pliysiologie der Pllanzen. Tubingen 1829. 8

Bourdon, Principes de physiologie comparée. Paris 1830.8.

1he Candolle, Notice sur la végétation des plantes parasites. 9830.18.

Meyen, Phytotomie. Berlin 1830. 8. uud Allas in 4.

.l1 archand, De radicibus et rasis plantarum. Utrecht 1830.8.

Ifohl, De Palmarom structura. Monachii 1831. folio.

I'oitenn, La théorie de Lahire sur l'origine et la direction des filnes ligneuses daus les végétaux. Paris 1831. S.

richuebler, Beobachtungen periodischer Frscheinungen im Thier- und Plianzoureiche. Tubingen is31, S.
Viviani, Della struttura degli organi elementari nelle piante. Cienuvia 1831. 8.

De Candolle, Physiologie végétale. Paris 183z. 8. (germanice.)

Dumortier, Recherches sur la structuro comparéc des animaux el des vtogétaux. Bruxclles 1832. 4.

Florio, Caso singolare d'inuestu. Torino 1832.8

Schultz, Naturlicles System des Pflanzenreiclıs nach sciner innern Orgauisation. Berlin 1832.8 .

Amici, Descrizione dì un' Oscillaria. Firenze 1833. S.

Fé, Do la reproduction des végetaux. Strassluurg 1833, 4.

Martig, Verwandlung der polyhotyledonischen Pflanzenzelle im l'ilz- und Schwammgebildo. Berlin 1833.8.

Lindley, On the principal cuestions at present debated in the philosojply of botany: London 1833.8 .

Main, Illustrations of vegetable pbysiology. London 1s33. \$.

Murray, The physiology of plants. London 1833 . 19

Muvernoy, Untersuclungen uher Keimung, Bau und Wachsthum der Ilonukotyledonen. Stuttgant 1834.8.

Mohl, leber die Verbindung der Pflanzenzellen unter einander. Tubingen 1835.4 .

- Ueber die Vernehrung der Pllanzenzellen durch Tlueilung. Tubinges 4835. 4 .

Morelti, Sopra alcuni punti di fisiologin vegetabile. Pavia 1835.8.

Neumann, Die lebendige Natur. Berlin 1835.8.

Virey, Philosophie de l'histoire naturelle. Paris 1835.8 .

Friese, Oratio de progressu physiologiae plantarum. Amsteludani IS3.5. S.

Reum, Pflanzenplyysiologie. Dresuen 1533. S.

Treviranus, Plı)siologic der Gewachse. Bonu 183j-IS3S. S.

Turpin, Obscrvations générales sur lorganugenie el la plyjsiologie dos végétaux. Paris 1835.4.

Cesali, Sugli studii fito-fisiolugici degli ltaliami et particorlamenti del Prof. Giuseppe Morelli. Milanu is 36 . s.

Frignet, Essai sur l'histoire de la blastogenie foliaire. Strassburg 1836. 4.

Meyen, Ueber die neusten Fortschritte der Anatomie und Physiologio der Gewachse. Haarlem 1836. gr. 4.

Moht, Erlauterung und Vertheidigung meiner Ansicht von der Structur der Pflanzensubstanz. Tubingen 1836. 4.

- Leber die Symmetrie der Pflanzen. Tubingen $1 \$ 36$. s.

Berg, Die Biologie der Zwiebelgewăchse. Neustrelitz 1\$37. 8.

Heyen, Ueber die Sekretionsorgane der Planzen. Berlin 1837.4.

- Jabresberichte uber physiologisclie Botanik in den Jahiren $1836-$ 1839. Berlin $4837-1840.8$.

(anglice.)

Link, Jahresberichte uber die Arbeiten fur plıysiologiselıe Botanik in den Jahisen 1840-1\$43. Berlin 1842-1846.8.

Mohl, Ueber den Bau der vegetabilischen Zellenmembran. Tubinges 1837. 8.

- Untersuclunngen uber die anatomischen Verlálanisse des Claluroplaylls. Tubingen 4837. S

(ruvis) Observations sur la dégenération les variétés des végétaux etc. Bourg s. a. $s$.

- De la dégénération el de lexstinction des variétés des régetaux Paris 4837. S.

Raspail, Nouveau systeme de physiologie végétale. Paris $1 \$ 37,8$. et Atlas.

Link, Icones anatonico-botanicae. Berolini 1537-1842. folio.

- Jcones selectae anatomico-butanicae. Berolini 1539-1842. fulio.

Anatumia plantarum iconibus illustrata. Berolini $1843-1 \$ 47,4$.

Meyen, Neues System der Pflanzenphysiologie. Berlin 1837-1839. S.

Audouin, Recherches sur la Muscardine. Paris $1 \$ 3 \$$. $\$$.

Nouvelles expériences. Parls 1938. 8.

Morelli, De plantarum morploologia. Ticini 1838.8.

Spring, Leber die Lrsachen der Abartungen. In ejus aleber die naturlistorisclie Begrifien etc. I.eipzig 1835. 8 . 


\section{ANATOMIA. ORGANOGRAPHA. PHYSIOLOGIA}

Steinheil, Qu'entend ou par endosmose et exosmose? (Paris 1838.) 4.

Tornabene, Sopra aleuni fatti di anatomia e fisiologia vegetale. Catania 1838.4.

Unger, Aphorismen zur Anatomie und Plysiologie der Pllanzen. Wien 1838. 8 .

Chalin, Anatomie comparée végétale appliquée à la classificalion. Paris 1840. 4 .

Decaisne, Mémoire sur le développement du pollen, de l'ovule et sur la structure des tiges do gui (Viscurn allsum). Bruxelles 1840.4.

Doleschall, Plysiologia plantarum (hungarice). Pestini 1840. S.

Lestiboudois, Kiudes sur l'anatomie et la jhysiologie des végétaux. Paris 1\$40. 8 .

Unger, Ueber liristallbildungen in den Pflanzenzellen. (Wien 1840.) 4.

Waechter, Ueber die lieproduktionshraft der fewäclsse. Hannover 1840.8 .

Gaudichaud, Recherches générales sur l'organographie, la physiologie et l'organogénie des végétaux. Paris 1841. 4.

(ioeppert, De Coniferarum structura anatomica. Vratislaviae 1841. 4.

Maupied, Considérations sur le caractère de la végétabilité. Paris 1\$41.4.

Morren, Prémices (Éludés) d'anatomie et de physiologie vegétales. Bruxelles $1 \$ 41.8$.

Pleniger, Veber Pflanzenjhysiologie. Wien 1841. 8.

Turpin, lconographie végétale, ou organisation des végétaux illustréc. Paris 1841.4 .

I'aucher, Histoire physiologique des plantes d'Europe. Paris 1841 . gI. S. (Vol. 1. jam anno 1830 prodierat.)

Brisseau-Mirbel, Nouvelles notes sur le candjium. Paris 1842. 4

Fries, Varen. En botanisk betraktelse, Upsala 1842. 8.

Schleiden, Beiträge zur Anatomie der Cacteen. St. Petersburg (1842.) 4. Ofrenes Sendschreiben an Hr. Dr. Justus Liebig. Leipzig 1842. 4. 1842. 8 .

Grundzuge der wissenschaftlichen Botanik. Leipzig 18424843. 8 .

Irmisch, Der Anorganismus. Die Pflanze. Jas Thier. Sondershausen 1S43. 8 .

harsten, De cella vitali. Berolini (1843.) 8 .

Mohl, Dr. Jusius Liebig's Verhalıiss zur Pflanzenphysiologie. Tubingen 1843.8.

Schults, Die Anaphytose oder Verjüngung der Pflanzen. Berlin 1843. 8.

Barnéoud, Recherelses sur le développement, ot la structure générale des Plantaginées. Paris 1844. 4.

Martig, Das Lehen der Pllanzenzelle. Merlin 1844. 4.

huelzing, Die Sophisten und Dialehtiher. (Streilschrift gegen Schleiden.) Nordhausen 1 \$4 4.8 .

l'arlatore, Osservazioni sull' anatomia dell'Aldrovanda vesiculosa. Fircnze 1844.8 .

Schleiden, Beiträge zur Botanik. Gesammelte Aufsátze. Leipzig 1844. 8. _ Schelling $\underline{S}_{S}$ und Jlegels Verlıáltniss zur Naturwissenschaft. Leipzig 1844.8 .

und Nueyeli, Zeitschrift fur wissenschaftliche Botanik. Zurich 1844-4846.8.

Unger. Ueber merismalisehe Zellenbilalung bei der Entwieklung des P'ollens. s. 1. 1S44. 4.

Mohl, Vermischte Schriften botanischen Inhalts. Tübingen 1845.4

Schleiden, Grundzüze der wissensclıaftlichen Botanik. Zw eite gånzlich ungearbeitete Aullage. Leipzig I \$45-1846.8.

Harting, Bijdrage tot de anatomie der Cacteen. s. J. et a. 8 .

- Aikrochemische onderzochingen over deu aurd en de ontwihkeling van den plantaardigen celwand. s. I. et a.

Steenstrup, Untersuchungen über das Vortiommen des Hermaphroditismus in der Natur. Greifswald 1846. 4.

Unger, Grundzuge der Anatomie und Physiologie der Planzen. Wien 1846. 8.

Schultz, Neues System der Morphologie der Pflanzen. Berlin 1847. 8.

New theory of vegetabie physiology. Edinburgh 1848.12.

\section{RADIX. TRUNCUS}

\section{Radix.}

Plaz, Mistoria radicum. Lipsiae 1733.4.

Mennander, De radicibus plantarum. Aboae 1748. \&

Bose, De radicum in plantis ortt et directione. Lipsiae 1754. 4

Preiss, Rhizographie. Prag 1 \$23. S.

Wiegmann, Ceber das Einsaugungsvernögen der Wurzeln. Marburg 1828. 8 .

Backer, De radicum plantarum plı̣siologia. Amstelodani 1829.8 .

Triese, Quid hactenus ex plantarum physiologia de forma, directione, struetura et funclione radicum innotuerit? Groningae 1829. 4.

Marchand, De radicibus et vasis jhantarum. Utrecht 1830.8 .

Decaisne, Recherches anatomiques et physiologifues sur la garance. Bruxelles 1837.4 .

Morelli, De radicis vegetabilium officiis. Ticini 1837.8 .

Mohl, Untersuchungen uber die Wurzelausscheidung. Tubingen I 838 . S.

Decaisne, Sur lorganisation anatonique de la betterave a suere. Paris 1339.8 .

Carradori, Degli organi assor Jenti delle radici. Firenze s. a. 8.

Bellani, Sulle funzioni delle radici. Milano 1843. 8.

Trinchinetli, Sulla facoltà assorbente delie radici. Milann 1843.4.

\section{Truncus.}

Grew, The comparative anatomy of trunks. Londun l675. S (Iitine.)

Vater, Anatome trunci Ulmi, cui cornu cervinum innlitum. Vitombergae 1741.4 .

- Cornu cervinum monstrosum a trunco arboris Fagi resectum. Vitembergae 1744. 4.

Plaz, Caulis plantarum explicatus. Lipsiae 1743 . 4 .

Bose, De nodis plantarum. Lipsiae 1747. 4.

boehmer, Plantao caule bulbifero. Lipsiae 1749. 4.

Commoda quae arbores a cortice accipiunt. Wittebergae 1773.4.

(louttuyn) Ilouthunde. Jeones liguorum. Anstelasdami $1773(-1791)$. 4. (germanice.)

Cioube, Traité de la plyysique végétale cles bois. Paris 1801.8.

Palisot-Beauvis, Sur la moelle des régètaux ligneux et sur la cunversion des coucles corticales en hois. (Paris 1812.) 4.

4ubcrl du Petit-Thouars, Sur la formation des arbres. Paris 1823.8.

Turpin, Mlémoire sur l'organisation des tubercules du Solanum tuberosm el de l'Heliantlsus tuberosus. Paris 1828. $\{$.

Mohl, Ueber den Bau des Cycadeenstammes. Munchen 1932. \&

Corda, Ueber den Bau des Pllanzenstanmes. Prag 4836. 8.

Meneghini, Hicerche sulla struttura del caule nelle piante monoculiledoni. Padova 1836.4.

Mohl, Ueber die Entwicklung des Korkes und der Barhe. Tubingen 1836.4.

- Untersuchungen uber den Mitelstoch von Tanns mephantipes L.

Tubingen 4\$36. 亿.

- Ueber den Bau des Stammes von Isoetes lacusiris. (Verm. Scluiften, p. 122-128.)

Unger, Ueber Bau und Wachsthum des Dikotyledonenstammos. I'etersburg 1840.4 .

Menter, Observationes phytophysiologicae (de caulis incrensento). Bernliıi 1841.8 .

Meyer, Das Leberwallen abgehauener Baumstumpfe. (Konigsherg 184Z.) S. Goeppert, Ueberwallen der Tannenstocke. Bom 1842. 4.

_ Zur Erläuterung des Baues und des Wachsthums der Băune. (Breslau 1843.) 4. 
Loiseleur, Rellexions sur la formation du bois. Paris 1843.8.

llarling, Entwickiung dor Elementartheile des jalırlichen Stammes der Dikotylen. llalle 1847.8.

\section{Plantarum supcrficies ct cpidermis.}

(inellarl, Observations sur les plantes. (1'ili, glandulae.) Paris 1747.8. Kuechelbeclier, De spinis plantarum. Lipsiae 1756. 4.

Plaz, De ustura plantas muniente. Lipsiae 1764. 4.

(De Saussure) Observations sur l'écorce des fenilles ot des pétales. Geneve 1762.8.

boelhner, De plantarum superficie. Wittebergae 1770. 4.

Lullwiy, De plantarum munimentis. Lipsiae 1776. 4.

hroclier, Anton. De plantarum epidermide. llalae $1800 . \mathrm{s}$.

lo Candolle, Mémoire sur les pores de l'écorce de feuilles. (Móm. des savans étrangers vol. l.)

Moretti, De epidermidis plantarum structura et evolutione. Ticini 1823.8 . De Candolle, Premier mémoire sur les lenticelles des arbres et le développernent des racines, qui en sortent. (Paris 1826.) 8 .

Eble, Die Lehre vou den llaaren. Wien 1831.8 (Pflanzenhaare, vol. 1. p. 1-60.)

Lirocker, llermann. De plantarum epridermide. Vratislaviae 1833.4

Mohl, Untersuclungen uber die Lenticellen. Tulingen $1 \$ 36.4$.

Sind die Lenticellen als Wurzelknospen zu betrachten? (Verm. Schriften, p. 229-232.)

Ueber dic Spaltoffnungen auf den Blattern der l'roteaceen. (Verm. Schriften, p. $2 \xi \%$ - 231. )

Veber die Entwicklung der Spalıöflnuugen.

(Verm. Schriften, p. 252-259.)

Ueher die Cuticula der Gewáchse. (Verm. Schriften, p. 260-967.)

Ciasparrini, Ricerche sulla struttura degli stomi. Napoli 1842.4 Nuove ricerche sulla struttura dei cistomi. Napoli 4844 .

\section{Folia.}

I'la, Foliorum in plantis historia. Lipsiae 1740.4

Mennamer, De foliis plantarum. Alooae 1747. 4.

Treu, Die Nahrungsgefüse in den Blattern. Nurnberg 1748. folio.

Ledermueller, Zergliederung einer Knospe von Aesculus Hippocastanum. Nurnberg 1764. folio.

mohl, Animadversiones in strncturam ac finuran foliorum in plantis. Lipsiae 1771. 4.

Desvaux, Plyyllographie. Paris 1809.8

Suringar, De foliorum ortu, situ, fabrica et functione. (Lugduni Batavorum 1820.) 4.

Itsenen, De foliorum plantarum orlu, situ, fabrica et functione. Lugduni Batavorum 1S21. 4.

Berla, Iconografia di scheletri di diversn foglic. Parma 1828.4.

—_ Memoria sull anatomia della foglie delle piante. Parma 1829. 4.

lconografia del sistema vascolare delle foglie. Parma 1830. 4.

Hicper, Das wechselnde Farbenverhtaltniss des Blatles. Berlin 1834. 8.

Drejer, Elementa plyyllologiae. llafniao 1840.8.

Payer, Essai sur la nervation des feuilles dans les plantes dicolylées. Paris 1840.4

Merchlin, Zur Entwicklungsgeschichte der Blatterestalten, Jena 1546. S.

\section{Defoliatio.}

Bucci, Discorso della generazione dolle piante, in quella maniera alcune nel corso dell' anno si spogliano delle foglie e perclie áltre conservinu, la perpetua lor verdura. Venezia 1697. folio. (Galeria di Minrria, tom. II. p. 395.)

Nicolai, De ptiyilobolia. Francofurti 1698. s.

I'rolik, De defoliatione vegetabilium. Lugduni Batavorum 1796. 8.

Boelmer, De foliis arborum deciduis. Witteljergae 1797. 4.

I'ancher, Mlómoire sur la chủte des feuilles. Genève 1828.4.

Giordano, Cenno sulla decolorazione e caduta delle foglie in autumno. Torino 4835.8 .

Wenzlaff, De defoliatione plantarum. Berolini 1844.8.

\section{Foliorum ramorumquc situs.}

Liuné, Gemnae arborum. Upsaliae 1749. 4.

Vernatio arhorum. Upsaliae 1753. 4.

loeler, Lettre a Mr. Tentenut sur les houtous et ramifications des plautes. Nayence 1805.4.

Palisot-Beauvois, Sur l'arrangement et la disposition des fenilles. (Paris 1812.) 4 .

lioeper, Observations sur la nature des fleurs et des inllorescences. (In Seringe, Mélanges II. 5.) Genève 1826.8.

Traulveller, Ueber die Nebenblatter. Mitau 1831. \&

Bravais, Mémoire sur la disposition géométrique des feuilles et des inHorescences. Paris 1838.8. (germanice.)

Essai sur la disposition générale des feuilles rectiséries. (Clermont-Ferrand 4839.) 8. (germanice.)

Analyse d'un brin d'herbe ou examen de l'inflorescence des Graminées. Mans 1840.8.

Silfverstrahle, Bestamning af Blad och Knoppars divergence. Stockholn 1839. 8 .

11 ydler, Uober dichotome Verzweigung der Blutenaxen dikotyledonischer Gewachse. Halle 1843. S.

fiunth, Ueber Blattstellung der Dikotyledonen. Berlin 4843.8.

Naumann, Ueber den Quincunx als Grundgesetz der Blattstelhng vichlis Pllanzen. Leipzig 1845.8 .

hïschleger, Sur les folioles carpiques dans les plantes angiospermes. Strasshurg 1846.8 .

\section{Metamorphosis plantarum.}

Junyius, Doxoscopiae physicae minores. Jamburgi 1662. 4.

- Isagoge plyytoscopica. llamburgi (1678,) 4. (Conjunctim. Opuseuta hotanico-physica. Coburgi 175. 4.)

IVolf, Theoria generationis. Ilalae 1759, 4. - il), 1774. 8 . (germanice.)

Linné, Mctamorphoses plantarum. Holniae 1755. 4.

— Prolepsis plantarum. Lissaliae 1760.4.

Disquisitio de prolepsi plantarum. Upsaliae 1763.4.

Goethe, Versucl die Metamorphose der Pflauzen zu erklären. Gotha 1790.8.

Engelmamn, De antholysi prodromus. Francofurti a/MI. 1832.8 .

Niquel, De organorum in vegetabilibus ortu et metamorphosi. Lunduni Batavorum 1833.4.

I'resl, Vermischte botanische Aufsätze. s. I. et at $S$.

llamburger, Symlolae ad doctrinam de plantarum melamorphosı. Viratislaviae 1842.4. 
Traulvelter, Das Lanbwerk oder der Spross als eine Rlume in Nacheinanderfolge. (Hitau) 1844.8.

Brunner, Observations sur l'inforescence du tilleul. Geneve 1846.8 .

Kirschleger, Sur les folioles carpiques dans les plantes angiospermes. Strassburg 1846.8 .

Wigand, Kritik und Geschichte der Metamorphoseulebre. Leijzig 1846.8.

\section{Monstra. Plantac hybridac.}

Eigentliche Ahbildung des wundersohonen Waitzenstocks vou 72 Jlalmen aus einen Wurzlein. Strassburg 1563.

Ein wunderbarliches Gewaelss einer Weizen-Ähre. Augspurg 1569.

Eine neue Geschichte von einem Weintrauben. 1577.

Montalbamus, Mlonstrosarum observationum indicatio, de quibus in Aldrovandaca mox edenda Dendrolugia difusa dabitur historia. In ejus a Jortus botanographicus ». Bononiae 1660. 8. p. 100-110.

$$
\text { s. a. folio. }
$$

Major, De planta monstrosa gottorpiensi. Schleswigae 1665. 4.

Nali, Florentiua plıytologiea observatio de malo Limonia citrata-aurantia Florentiae vulyo La Bizarria. Florentiae 1674.4 (anglice.)

Berielıt einiger hornahren. Arustadt (1695.) 4.

Krause, De naturac in regna vegetabili lusihus. Jerae 1706.4

Wolf, De Nalo pomifera absque floribus. Mlarburgi 1727. 4.

Brueclimann, Je Ocymastra flure viridi pleno. Wolfenbuetteliao 1732 folio.

Lischwitż. De variis naturae Tusibus ac anomaliis cirea plantas. Kilonii 1733.4 .

Abriss eines wunderbaren Kornstengels. 3.1. 1741. 4

Limne, De Peloria. Upsaliae 1744. 4.

_ Plantae hybridae. Upsaliac 1751.4

Boehmer, De plantis faseiatis. Wittebergae 1752. 4.

Zinn, Olsservationes botanicae (de caulibus fasciatis et variis moustrosis formis). Goettiugae 1753. 4.

Deutliche Abbildung der wunderbaren Kormálse aus Struppen. s. 1. 1757.4. Hill, The origin and production of proliferous flowers. London 1759.8. (germanice, hollanthee.)

Boelumer, Planta res varia. Wittebergae 1765. 4

Nonne, De plantis notlis, occasione spicae Tritiei, cui Avenae fatuae aliquot semina inuata erant. Erfordiae (1765.) 4.

Alströmer, Finy̧lliğa fár afweln. (Plantae hybridae.) Stockholm 1770.8.

Abbildung eines Gerstonstocks. (Petersburg) 1789. gr. folio.

Abbildung einer Ilirsenstaude. (Potersburg) 1789. gr. folio.

Voigt, Conspectus tractatus de jlantis hybridis. Jenae (1802.) \&.

Bellardi, Saggio intorno l'ihridismo delle piante. Milano 1809. 8.

Jaeger, Ueber dia Mlissbildungen der Gewächse. Stuttgart 1814. 8.

Rrown, On some remarkable deviations from the usual structure of seeds and fruits. Loudon 1816.4.

(Verm. Schriften Il, $743-760$. )

De Candolle, Considérations générales sur les fleurs duubles. (Mum soc. d'Aicueil 1817. 111. 385-404.)

Hopkirk, Flora anomala. Glasgow 1817.8.

Ratzeburg, Observationes ad peloriarum indolem definieodam spectantes. Borolini (1825.) 4.

Moquin-Tandon, Essai sur les dédoublements d'organes dans les végétaux. Mentpellier 1826, 4.

Schiede, De jlantis hyloridis sponte natis. Cassellis Cattorum 1825.8.

Lindley, Observations upon the natural laws which govern the production of double flowers. London 1826. 4.

Jaeger, De quibusdam Pini silvestris munstris. Stuttgartiae 1828. 4.

Pritzel, Thes. lit. het.
Wiegmann, Ueher tie Bastarderzeugung im Pflanzenreiobe. Braonsehweig 1828. 4.

Bishop, Causal botany. London 1829. 8 .

Schuebler, De antherarum excisione ad efficiendos flores plenos. Tubingae 1830. 8.

Henslow, Examination of a hybrid Digitalis. Cambridge 1831. 8 .

- On a monstrosity of the commen Mignionette (Reseda odorata L.). Cambridge 1833.4 .

Turpin, Examen d'une chloranthie ou monstruosité dans l'inflasescence du saule marcean. Paris 1833.8 .

Presl, Vermisehte botanische Auísátze. s. 1. et a. 8 .

Mohl, Beobachtungen uber die lmwandlung von Autheren in Carpello. Tulingen 1836. 8 .

De Candolle, Monstruosités végétales. Neufchâtel 1841. 4.

Jussieu, Note sur les fleurs monstruouses d'Acer laciniosum. (Paris 1841.) 8 .

Moquin-Tandon, Ėlemens de tératologie végétale. Paris 1841. 8. (germanice.)

Berg, Bericht uber an Ptlanzen beobachtete Ausartungen. Neubrandenburg 1843.4.

Gaerther, Beitrige. Stuttgart 1844. 8.

Godron, Description d'une monstruosité dans la fleur des Crucifères. Nancy $4 \$ 45.8$.

De l'hy̧bridite dans les végétaux. Nacy 1844. 4.

Kirschleger, Essai historique sur la tératologie végétale. Strassburz 1845.4

\section{Perigonium.}

Vaillant, Sormo de structura florum. Discours etc. Lugduni Batavorum 1718,4

Pontedera, Anthologia. Patavii 1720. 4.

Bose, Calycem Tournefortii explicat. Lipsiae 1733. 4.

Liljemark, Bereltelse on blomman. (Cpsaliae) 1735. 4.

Burchard, De optima florum anatome. Bustock 1743. 4.

Ejpistola de calyce et calycistis. Restock 1743.4.

Plaz, De flere plantarum. Lipsiae 1749. 4.

Koelpin, De stylo ejusque differentiis externis. Gryphiswaldiao 1764.4. Thunberg, Fructificationis partium varietates. Upsaliae 1800-1802.4.

Jussieu, Noto sur le calice et la corolle. (Paris 1812.) 4.

Uurray, Experimental researches on the painted corolla of the flewer. Londou 1824. 8.

Boreau, Observations sur les enveloppes florales des végétaux menocotylédons. Paris 1827. 8.

Dunal, Considérations sur les organos de la feur. Montpellier 1829. 4.

- Considérations sur les fonctions des organes floraux colorés et glanduleux. Nompellier 1829. 4.

Guillard, Sur la formation et le développement des organes floraux. Paris 1835. 4 .

Marquart, Die Farlien der Bluthen. Bonn 1835. 8.

Mohl, Ueber die mănnlichen Bluthen der Coniferen. Tubingen 1837.8.

Dumas, Sur la structure de l'Jellébore fétido el sur l'évalution de ses organes floraux. Muntpellier 1844. 4.

\section{Nectarium.}

Boehmer, Do nectariis florum. Wittebergae 1758. 4.

- De ornamentis in foribus practer nectaria. Wittebergae 1758.4. De nectariis flurum. Wittebergae 1762. 4. 
Linné, Nectaria florum. Upsaliae 1762.4.

(suecice.)

Eschenbach, Nectariorum usus. Lipsiae 1776. 4.

K7ipstein, De nectariis plantarum. Jenae 1784.4.

Weihe, De neclariis. llalae 1802.8 .

Henckel ron Donnersmarck, lettera sul nettario dei fiori. Milano 1816.8

Desvaux, Rechercbes sur les appareils sécrétoires du nectar. Paris 1826.8 .

Soyer-Willemet, Mémoire sur le nectaire. Paris 1826.8 .

Dunal, Considerations sur les organes floraux glandulenx. Nontpellier 1829. 4.

Schuebler ( $=$ Kurr), Untersnchnngen uber die Bedeutung der Nektarien. Stutugart 1832.8. 1833. 8 Ueber die Beziehung der Nektarien zur Befruchtung. Tubingen

\section{Anthera.}

Bosseck, De antheris florum. Lipsiae 1750. 4.

Luduig, De pulvere antlerarum. Lipsiae 1778. 4.

Purlinje, De cellulis autherarum fiibrosis nec non de granormm pollinarium formis. Vratislaviae 1830.4.

Ehrenberg, Ueber das Pollen der Ask]epiadeen. Ein Beitrag zur Auflösung der Anomalien in der Pllamzenlyefruclstung. Berlin 1831. 4.

Fritzsche, Beiträge zur Kenntniss des Pollen. Berlin 1832. 4.

De plantarum polline. Berolini 1833. 8.

Ueber den Pollen. St. Petersburg 1837. 4.

Moh, Peitrage, 1: Ueber den Bau und die Formen der Pollenkorner. Bern 1834. 4 .

Leber die fibrosen Zellen der Antheren.

(Verm. Schriften. II, p. 62-66.)

Naegeli, Zur Entwicklungsgeschichte des Pollens. Zurich 4842. 8.

Unger, Ueber merismatische Zellenbildung bei der Entwicklung des Pollens. s. J. 1844. 4.

\section{Sexus plantarum. Generatio.}

Camerarins, Epistola de sexu plantarum. Tulbingae 1694. 8. (Redit in J. G. Gmelin, Sermo. ib. 1749.3. p. $83-148$.

Waldschmiedt, De sexu ejusdem plantae gemino. Kiliae 1705.4.

Ponledera, Anthologia, sive de floris natura libri tres. Patavii 1720.4.

Bradley, New experiments and observations relatiug to the generation of plants. London 1724.8.

Wallin, Táuc qútwv, sive Nuptiae arborum. Upsaliae 1729. 4.

Burggrave, Bedenken von dem Werke der Erzeugung. Frankfurt 1737.4.

(Roberg) Berettelse om blomman och dless åtskilliga delars verkan och gagn. Upsaliae 1737. 4.

Ludheig, De sexu plantarun. Lipsiae 1737. 4.

Koberg, Plantarum generatio leviter adumbrata. Upsaliae 17384.

Loyan, Experimenta et meletemata de plantarum generatione. Lugrduni Batavorum 1739.8.

(anglice, germanice.)

Oelreich, Generatio aequiroca ut absona demonstrata. Londini Gothorum 1739. 4.

Stieff, De vita nuptiisque plantarum. Lipsiae 1741.4.

linne, Sponsalia plantarum. Stockholm 1746. 4.

(suecice.)

llebenstreit, De foetu regetabili. Lipsiae 1747.4.

Cmelin, De novorum vegetabilium post creationem divinam esortu. Tolingae 1749. 8.

Needham, Oliservations upon the greneration elc. London 1749.4 (gallice.)
Schier a, Dissertatio de plantarum sexu el foecundatione. Mediolani 1750.8.

Kalm, De foecundatione plantarum. Aboae 1757. 4 .

Ihill, Outlines of a system of regetable generation. I.ondon 1758.8. (gerunanice.)

Wolf, Theoria generationis. Ilalat 1759. 4. - 1b. 1774. 8 .

limné, Disquisitio de quaestione "Sexum płantarumo elc. Petropoli 1760.4. (anglice.)

Buchoz, be Ja génération des plantes. Pont-à-Mousson 1760.4.

Kröyer, De sexualitate plantarum ante Linnaeum cognita. Hafniae 1761. 4.

Koelrenter, Vorlaufige Nachricht von Versuehen und Beobachtungen uber das Geschlecht der Pflanzen. Leipzig 1761-1766. 8 .

Erusting, Beschreibung der Geschlechtor der Pflanzen. Longo 176z. 4.

Hernandez, Nuevo discurso de la generacion de plantas mc. Madrid 1767.4 .

logel, De generatione plantarum. Altdorfi 1768. 4.

Hoppe, Abhandlung von der Begaltung der Pflanzen. Altenburg 1773.8.

Leske, De generatione vegetalilium. Lipsiae 1773. 4.

Berwald, Abluanillung vom Geschlecht der Pfanzen und ter Befruclitung. Hamburg 1778. 8.

Colbiörnsen, Programma de sexu plantarum. Harniae 1782. folio.

Kall, De duplici plantarum sexu Arabibus cognito. Jlafniae 1782-1783. folio.

Bunita, De generatione plantarum. Augustae Taurinorum 1788. 8.

Rotheram, The seses of plants vindicated. Edinburgh 1790. 8 .

Marli, Experimentos y observaciones solbre los sexos y fecundacion de las plantas. Barcelona (1794.) 8 .

Sprengel, Das entdeckte Geheimuiss der Befruchtung. Berlin 1 i93. 4.

Rossi, Istoria di cio che è stato pensato intorno alla fecondazione delle piante. Verona 1794. 4.

Gerard, Sur deux plantes dont la fructification s'exécute dans l'intérieur et à l'extérieur de la terre. (Paris 1800.) 8.

Hellcr, Organa plantarum functioni sexuali inservientia. Wirceburgi 1800.8 .

Zetterstedt, De foecundatione plantarum. Lundae $1810-1812.4$.

Schelver, Kritik der Lehre von den Geschlechtern Iler Pflanze. Jleidelber'g $1812-1823.8$.

Treviranus, Von der Entwichlung des Embryo. Berlin 1815.4.

Ilenschel, Yon der Sexualitait der Pflanzen. Breslau 1820.8.

Autenrieth, De discrimine sexuali jam in seminibus apparente. Tuebingaf 1821. 4 .

Mauz, Versuche und Beobachtungen uber das Geschlecht der Phanzen. (Tubingen 1822.) 8 .

Treviranus, Die Lelire von Gesclulechte der Pflanzen. Bremen 1822. S.

Brown, Charater and descrijution of hingia, with observations on the structure of its unimpregnated ovulum and on the female flower of Cycarleae and Coniferae. (London 1825.) 8.

(Verm. Schriflen. IV, 7̈-140.)

Targioni-Tozzetti, Della necessita di osservare le parti della frutificazione. Hodena 1525.4 .

Brongniart, Mémoire sur la génération el le dévélopjement de l'embryon dans les végétaux phanérogames. Paris 1827 . 8.

Anecdoton Linneanum (de nuptiis el sexu plantarum) ed. Afaclius. Ipsaliae 1827. 8.

Limme, De nuptiis el sexu plantarum el. Afzetius. Upsaliae 1828. S.

Hoffmann, Drei plyysiologisch-botanische Ablandlungen. Warsclan 1828. 8.

Treviranus, De ovo vegetabili ejusque mutationibus. Vratislaviae 1828.4.

Moretti, Della fecondazione telle prante. Nilano 1830.8 .

Broun, Obserrations on the organs and mode of fecundation in Orchideae and Asclepiadeac. London, October 1831.8. (Transactions of the Linuean Society 1833. 4. P. $685-745$.

(Verm. Sehriflen r, p. $11 i-184$. .)

Schuebler, Leber dje Beziehung der Nektarien zur Befruchtung und Simmenbildung der Gewächse. Tubiugen 1833. S. 
Endlicher, Grundzuge einer neuen Theorie der Pllanzenzeugong. Wien 1838. 8 .

Meyen, Noclı einize Worte uber den Befruclıtungsakt und die Polyembryonie. Berlin 1840.8.

Harlig, Neue Theorie der Befruchtung der Pflanzen. Braunschweig 1849. 4.

-_- Beitráge zur Entwicklungsgeschichte der Pflanzen. Berlin 4843.4.

Brown, On the plurality and development of the embryos in the seeds of Coniferae. London 1844.8.

Gaertner, Beitráge zur Kenntniss der Befruchtung. 1. Thieil. Stuttgart 1844.8.

Planchon, Considerations sur les ovules de quelques Veroniques et de l'Avicennia. Montpellier 1844. 4.

Schleiden, Die neueren Einwurfe gegen meine Lehre von der Befruchtung. Leipzig 1844.8.

Gasparrini, Ricerche sulla del caprifieo e del fico e sulla caprificazione. Napoli 4845.4.

Gérard, De la génération spontanée. Paris 1845. 8 .

Lecoq. De la fécondation naturelle et artificielle des végétaux. Paris 1845. 8

\section{Fructus.}

Kellander, De seminibus. Lugduni Batavorum 1720.4.

Plaz, De plantarum seminibus. Lipsiae 1736. 4.

Parsons, The microscopical theatre of seeds. London 1743.4.

Mennander, De seminibus plantarun. Aboae 1752. 4

Linne, Fundamenta fructificationis. Upsaliae 1762.4.

Zallinger, De ortu frugum ex mechanismo plantarum. Oemponti 1769.4. (germanice.)

- De incremento fruguid. Oeniponti 1771. 4 germanice.

Eschenbach, De physiologia seminum. Lipsiae 1777.4.

Boehmer, Spermatologiae vegotabilis pars 1-VIJ. Wittebergae 17771784. 4 .

Commentatio physico-botanica de plantarum semine. Wittebergae 1785.8

Gaertner, De fructibus el seminibus plantarum. Stuttgurtiae 1788-1807. III voll. 4.

Medicus, Philosophisclse Botanit. 1: Yon den mannichfaltigen Cmbullungen der Samen. Mannheim 1789.8.

Bodard, Sur les plantes hypocarpogées. Pisa 1798.4.

De Candolle, Note sur la graine des Nymphaea. (Bull. soc. phil. 1802. p. 68.)

Richard, Démonstrations botaniques, ou Analyse du fruit considéré en général. Paris 1808. 8. (anglice, germanice.)

- Analyse botanique des embryous endorthizes et particulierement de celui des Graminées. Paris 1811. 4

Titmamn, Ueber den Embryo des Samenkorns. Dresden 1817. 8.

Seits, Allgemeine Samen - und Fruchtelehre. Salzburg 1822.8.

Schuebler, Untersuchungen uber das specifisclze Gewicht der Samen. Tübingen 1826. 8 .

Schychoushy, De fructus plantarum phanerogamarum natura. Dorpati 1832. 8 .

Dumortier, Essai carpographique. Bruxelles 1835.4

Couverchel, Traité des fruits. Paris 1839. 8 .

Jussieu, Mémoire sur les embryons monocotylédonés. (Paris 1839.) 4.

Fratzmann, Die Lehre vom Samen der Planzen. Prag 1839. 8.

Tengstrom, De fructus in phanerophytis evolutione. Ilelsing forsiae. 1841.4.

Planchon, Mémoire sur les vrais el faux arilles. Montpellier 184\%. 4.

\section{Germinatio.}

Josephus de Aromatariis, Epistola de genoratione plantarum ex seminibus. Venetiis 1625. 4.

Duve, De acceleranda per artem plantarum vegctatione. Lipsiae 1717.4. Wallerius, De vegetatione seminum vegetabilium per mortem. Upsaliae 1761.4

Gehler, De usu macerationis seminum in plantarum vegetatione. Lipsiae 1763. 4.

Iluber et Senebier, Mémoires sur l'inflnence de l'air dans la germination. Genere 1801.8. (germanice.)

Lefcbure, Sur la germination des plantes. Strassburg (1801.) 8.

Fischer, De vegetahiliun imprimis Filicum propagatione. Ilalae 1804. 8.

hielmeyer, De matierum guarundam oxydatarum in germinationen efficientia. Tubiugae 1805.4.

Gérardin, Sur la propriété des graines do conserver longtemps leur vertu germinative. (Paris 1809. ) 4 .

Tittmann, Die Keimung der Pflanzen. Dresden 1821.4.

Cruse, De Asparagi officinalis L. germinatione. Regiomonti 1828. s.

De Saussure, De l'influence du desséchement sur la germination de plusieurs graines alimentaires. Genève 1828. 4.

Trotzky, De plantarum phanerogamarum germinatione. Dorpati 1832.8.

Agardh, Om hafs-algers germination. Stockholm 4834. 8 .

(germanice.)

Edwards et Colin, De l'intluence de la température sur la germination. Paris 1834.8 .

Des Moulins, Nolice sur des graines trouvées dons les tombeaux romains. Bordeaux 1835. 8 .

Abbene, Saggio sulla influenza della Magnesia nella germinazione. Torino 1838. 8

Unger, Die Pflanze im Momente der Thierwerdung. Wien 1843. 8.

\section{Transmutatio specicrum.}

Browallius, De transmutatione specierum in regno vegetabili. Aboae 1745. 4 .

Linné, De transmutatione frumentorum. Upsaliae 1757. 4.

Fergin, Om sädesartenes forwandling. Stockholm 1757. 8.

(hollandico.)

Camerarius, De Lolio temulento. (Ephem. Acad. Nat. Cur. Dec. III. Ann. III. p. $238-243$.)

Olmi, Discorso, nel quale si esamina, se il Loglio sia prodotio in alcune occasioni dalla semenza del grano. (Atti del Accad. di Siena, tomo IV. p. $297-320$.)

Verrin, Proefneeminge, aangaande eene wonderlyke verbetering van Graan. Harlem 1758. 8. (Holland's Magazyn III. nr. 2. p. 18.)

Nozeman, Uitreksel etc. omtrent eene wonderbaare verbetering van de Haver, door J. B. Vergin. (Uitgezogte Verhandelingen III. 401-412, $481-494$, IV. $49-66$.)

Linne, Brief aan Cornelius Nuzeman over de verandering van Haver in Rogge. (Uitgezogte Verhandelingen IV. 67-71.)

Nonne, De plantis nothis. Erfordiae (1765.) 4 .

Agardh, De metamorphosi Algarum. Luntae $18 \pm 0.8$

(Meneghini) Sulla metamorfosi delle piante. s. I. et a. 4.

Kuetzing, Die Unwandiung niedrer Algenformen in lohere. Harlem 1841.4.

- Veber die Verwandlung der Infusorien in niedre Algenformen.

Nordhausen 1844. 4 . 


\section{Opera varia ante Linnacum.}

lVimmer, Phytologiae Aristuteliean fragmenta. Vratislaviae 1838. 8.

Frie's, Grunddragen af Aristoletis Vándlira. Upsala 1842. 8.

Theophrastus Lresius, De Historia et de Caussis plantarum libri. Tarvisii 1483. folio.

(Editomun seriem, Iransatines et commentatores vide in thes lit. bot. 1). 291 - 2942 .

Plinius, llistorite naturalis libri XXXVIJ. Ed. princeps: Venotiis 1469. folio. p. $230-231$.

Hermolaus Barbarns. Castigatinues Plinianae. Romae 1492-1493, folio Valle, Plinianorum locorum difficilium explanatio. Paris (1500.) 4. min.

Aquacus, In Plinii libros Commontaria. Parisiis 4530 . folin.

Fée, Commentaires sur li botanique et la matière médicale de Ptine. Paris 1833. 8 ,

Janus, Observationes criticae in Caji Plinii Secundi historiae naturalis libros. Nonachii 1830.4.

Lectiones Plinianae. Particula I. (Norimbergae) 1834. 4.

De plantis lilri Juo Aristoteli falso adscripti. Basileae 1539. 8.

sicaliger, In libros duos de plantis (Nicolai Damasceni) libri duo. Lutetiae 1556. 4 .

Albertus Magnus, De vegetabilibus et plantis libri septen. Venetiis $15 \mathrm{f7}$. folio.

Ilildegardis de Pinguia, Pliysica seu Ėlementorum etc. libri quatuor. Argentorati 1533. folio. - ib. 1544 . folio.

Rouss, He lihris physieis S. Hltdegurdis commentatio. Wirceburgi 1835.8.

Biunfels, Jlerbarum vivae eicones ad naturae initationem. (Ilerlsarium.) Tomus I - 1II. Argentorati 1530-1536. folio.

(germanice: Contrafeyt kräuterbuch. Strassburg 1:332-1537, folio.

Dodoens, De frugum historia liber unus. Antwerpiae 1532.8.

Cordus, Bolanologicon. Coloniae 1534. 12. - Parisiis 1551. 12.

Falimierz, Herbarium polonicum. 1534. folio.

liuelle, De natura stirpium libri tres. Parisiis 1536. folin.

Bock, New Kreuterbuch. Strassburg 1539. folio.

Figulus, Dialogus qui iıseribitur botanomethodus. Coloniae 1540.4

Rrohon, Je stirpibus epitome. Cadomi $15 \% 1.8$.

lichs, De historia stirpium eommentarii insignes. Basilene 1542 . folio. (germanice, belgice, gallice.)

Bock, Verae atque ad vivum expressac imagines ete. Eigenllicbe und walırlaftige Abbildung etc. Strassburg 1550.4.

De stirpium uomenelaturis etc. Argentorati 4559.4.

Lonitzer, Naturalis historiae opus novum. Franeofurti $1551-1555$, folio. - Botanicon: ib. 1565 . folio.

Dodoens, De stirpium historia commentariorum imagines. Antwerpiae 1553-1554.8. - Ed. II: ib. 1559. 8.

Cnyrlehoeck. Antwerpen 1554, folio. - ib. 1644. folio.

(gallice, anglice.)

Cesner, De raris et admirandis herbis, quae lunariae noninantur. Tiguri 1555. 4.

Lonilzer, Kreuterbuch. Frankfurt a/AI. 1557 . folio.

Freige, Quaestionum mediearum libri XXXV. (Dendrographia, Phyturgia, Botanologia.) Basileae 1558. 8.

Maranta, Methodi eognoscendorum simplicinm libri llt. (Novum herbarium.) Venetiis 1559.4 .

Cordus, Ilistoriae stirpium libri JV. Impr. eum Operum editinne Gesneriana. Argentorati 1561. folio. foll. 850216.

- Stirpium descriptionis liber quintus. Argentorati 1563 . folio. Norimbergae 1751. folio. I. p. 1-14

Dodoens, Frumentorum, leguminum, palustrium et aquatilium herbarum Jistoria. Antwerpiae 1566.8.

Maplet, A greenc forest, or a naturall historie. London 1567.8 .

Dodoens, Florum et coronariarum herhanm historia. Antyerpiae 1568. 8.

Pera el De $l$ Obel, Stirpium adversaria nova. Londini 1570. folin.
Cajus, De rariorum animaliun ot stipjum bistoria liber l. Londini 1570.8. Maltioli, Compendium de plantis omnibus. Venetiis 1571. 4.

De l'Obel, Plantarum sen stiryium histaria. Intwerpiae 1576. folio.

Jodoens, Stirpinm ali(juot historiae jam recens cnnscrintac. Impr. in cjus Ilistnria vitis. Colonine $1580,8 . n .47-96$.

Caesalpino, De plantis libri $5 \mathrm{~V} 1$. lilarentac 1583.4.

Dodoens, Stirpium listoriae finmptades sex. Intrerpiae 1583. folio.

I urante, IJerbario nuovo. Rroma 1585. Folio. - Venntia 1684. folio. (germanice.)

Alberti, Tres orationes. Norimbrergae 1585. 8.

Maltioli, De plantis epilome utilissina. Francofurti a/.II. 1585.4.

(Dalechamps) Ilistoria generalis plantarum. I.ugduni 1587. folio. (gallier.)

Pons, In listoriam gneneralem plantarum Rorillii hreves annotationes. Lugduni 1600.8 .

Baulin, Animatversiones in historiam generalem plantirum Lugiluni erlitam. Franeofurti 1601.4.

Camerarius, Hortus medicus et philosoplicus. Francofurti a/M. 1588. 4 . - Icones: ib. 1588.4.

Tabernaemontanus, Neuw Kreuterhuch. Frankfurt a/M. 15\$s-1591. folio.

Bauhin, De plantis a divis sanctisve nomen habentibus. Basileae 1591. \$.

Gretscher, De plantis ex Aristotele potissimum collecta. Ingolstadii 1591.4.

Colonna, Pbytobasanos, sive plantarum aliquot historia. Neapoli 1592.4.

Baulin, Phytopynax. Basileae 1596. 4.

Gerarde, The Ilerball, or generall historie of plantes. London 1597. folin. ib. 1633. folio.

Mylius, Ilortus philosophicus. Gorlicii 1597. 12. (germanice.)

Mallioli, Opera omnia. Basileae 1598. folio.

Pion, Pliytologia. Wirechurgi 1598. 4.

Imperato, Dell historia naturale libri XXVIII. Napoli 1599. folio. - Vea metia 1672 . folio.

(latine.)

De l'Ecluse, Rariorum plantarun historia. Antwerpiac 1601 folio.

Gran, De plantis. Cassellis 1601.4.

Jessenius a Jessen, De plantis. Wittebergae $160 \mathrm{I}$. 4.

Roelsius, Epistola de quibusdam plantis. Autwerpiae 1601 . folio.

Knobloch, De plantis. Wittebergae 1603.4.

De l'Ecluse, Exoticorum lihri decem. Antwerpiae 1605. folio.

Muret, Histoire admirable des plantes. Paris 1605.8 .

Mueller, De plantis in genere. Lipsiae 1607. 4.

Seidel, Theses de causis, speciebus ete. plantarum. liryphiswaldiac 1610.4 .

Tilemann, De metallis, jlantis ac brutin. Wittebergae 1610.4.

De l'Eeluse, Gurae pnsteriores. Antwerpiae 1611. folio.

Reneaulme, Speeimen historiae plantarum. l'arisiis 1611.4

Pauli, Decas problematum de plantis. Dantisci 1614.4 .

Forer, De plantis. Dilingae 1615.4.

Colonna, Ninus cognitarum stirpium Ekphrasis. Romae 1616.4.

Olorinus, Centuria arborum mirabilim. Magdeburgk 1616. 12.

Centuria herbarum mirabilium. Nagdeburgk 1616.12.

Schacnfeld, De plantis in genere. Lipsiae 1619.4.

Baulin et Cherler, Llistoriae plantarum generalis Prodromes. Elrodun 1619. 4 .

Baulin, Prodronus Theatri botanici. Francofurti 1620.4 .

Ireilisius, De plantarum natura. Lijsiac 1620.4.

Chesnecophorus, Disputationes de plantis. Upsaliae 1621-16z6. 4.

Baukin, Pinax theatri botanici. Basilnae 1623. 4.

Beyer vel I'eyer, Quaestiones de plantis. Basileae 1623.4.

Petracus, De.... stirpium natura, plantarum partilus et summis groneribus. Ipsaliae 1625.4.

Schleifentay, De plantis. Lipsiae 1625. 4. 
Securius, De plantis. Lipsiae 16230 . 4 .

Alpinus, De plantis exoticis libri duo. Yenetiis 1627.4 .

Raspe, De plantis. Lipsiae $16 \pm 7.4$.

Stalenus, De plantis. Lpsaliae 1634. 4.

IIannann, De plantis in genere. Lipsiae 1635. 4.

Vieremberg, llistoria naturae. Antwerpiae 1635 . folim. hispanice.

Franke, Speculum botanicum. Ipsaliae 1638.4. - il. 1639.;

Slegelius, Programma ad hortense: lectiones. Jenae 1639. 4.

Parkinson, Theatrum botanicum. London 16:0. folio.

Meursius, drboretum sacrum. Lugduni Batarorum 1642. S.

Ausius, De plantis in genere. Ipsoliae 164. 4.

Jonston, Synlagmatis dendrologici specimen. Lesnae 1645. \&.

bu l'al, Phytologia sive plilosophia plantarum. Paris 1647. S.

Ericus, De plantis. Dorpati 1647.4.

Tronius, De plantis. Ipsaliae 1647.4.

Eichstad, De plantis in grenere. Gedani 1, 4 k. 4.

Bauhin et Cherler, Historia plantarum universalis. Ẻbroduni 1650-1651. folio.

Tulpe, Olsserrationes medicae. Amstelndami 1652. S.

Schenchius, De re herbaria. Jenae 1653. 4.

Serpetro, 11 mercato delle maraviglie iella natura. Venezia 1653.

Comradinus, spicilegium botanicum. Lucae 1654. 4.

De l'Obel, Stirpium illustrationes. Londini 1655 . 4.

Brotbeck, De plantis. Tubingae 1656. 4.

Gyllenstâlpe, De reguo vegetabili in yenere. Aboae 1656. 4 .

Schenckius, Historia plantarum generalis. Jenae 1656. 4.

Sperling, Mleditationes in Sculigeri Exoticas exercitationes. Wittebergae 1656.8 .

Coles. The art of simpling. London 1636. 12.

- Adam in Eden. London 1657, folio.

Ambrosinus, Novarum plantarum listoria. Bonuniae 1657. 4.

Bauhin, Theatri botanici liber primus. Basileac 1658 . folio.

Horst, De plantis in genere. Ulmae 1659.4 .

hirchmaier, De raris atque admiraodis arboribus. Wittebergae 1660. 4. Montalbanus, Hortus botanographicus. Bononiae 1660. 8 .

niae 1660 . folio.

Nova antepraeludialis dendranatomes adumbratio. Liono-

Jonston, Notitia regni vegetabilis. Lipsiae 1661. 12.

- Dendrographias libri decem. Francofurti a/Al. 1662. folio.

Strasburg, Positiones botanicae. Regiomonti 1663. 4.

Chabrey, Stirpium icones et sciagraphia. Genevae 1606. foljo.

Ammann, Ilanta est homo inversus. Lipsiae 1668. 4.

Turre, Jumonis et Nestis vires. Opus botanieum. Patavii 1668. \{.

Alarotanlus, Dendrologiae libri dno. Bononiae 1668. folio.

Legati, In $\mathrm{Cl}$. Aldrovandum ac ejusdem de arboribus historian siosos. Bononiac 1668. 4.

Morison, Praeludia botanica. Londini 1669.12.

Tylkouski, Plysica curiosa. Cracoviae 1669. 4.

Fylandt, Der nederlandsche herbarius of Kruydtboech. Amsterdam I 670. i. (germanice.)

Gervasius, Bizarrie botaniche d'alcuni semplicisti di Sicilia. Napoli 1673. f.

Major, Catalogus plantarum in Rollfink libro secundo de regetabilibus. Kilonii 1673. 4.

Caldarone, Epistola botanica. Neapoli 1674.4

Zanoni, Istoria Jotanica. Bologna 167 s. folio.

(Scarella) Postille ad alcuni eapi della Storia botanica lel sign. Fracomo Zanoni. Padova 1676. 1 .

Zanoni, Rariorum stirpium historia, ed. Cajetanus Montius. Bononiae 1742. folio.

Ammann, Character plantarum naturalis. Lipsiae 1676. 12.

Dodart. Mémoires pour servir à l'histoire des plantes. Paris 1676. folio - Ed. 11I: Amsterdam 1758.4.
Praetorius, De plantis. Ilalae 1677.4.

Breyn, Exolicarum plantarum centuria prima. Gedani 1678. folio.

Vutius, Fasciculus sive elenchus herbarum. Venetiis 1678. 12.

lersascha, Nen vollhoumenes Krauterbuch. Basel 1678. folio.

Koenig, Generalia regni regetabilis. Basileae 1680. \&

Le Grand, llistoria naturae. Londini 1680. 4.

Ereyn. Prodromi rariorum plantarum fasc. I-II. Gedani 1680-89. 4. ib. 1739.4 .

Morison, Plantarum historile universalis oxoniensis pars II-ll1. Oxonii 1680-1699. folio.

Majus, De plantis et arboribus. Marpurgi 1681. 4 .

Tozzi, Medicinac theoreticae pars 1. (De vegetatione.) Lugduni 1681. 8.

Mentzel, Pugillus plantarum rariorum. In ejus "Ifivašn. Berolini 168z. folio.

(Deville) Ilistoire des plantes de l'Europe. Lyon 16\$3. \$. - ib. 1737. \$.

Cappellinus, De plantis. D. I. Havniae 1684. 4.

Eglinger, Positionum botanico-anatomicarum centuria. Basileac 1685.4.

Turre, Dryadum, llanadiryadum, Chloridisque triumphus. Patavii 1683. folio.

Tritumfetti, Novarum slirpium historia. In ejus a De ortun etc. Romae 1685. 4. p. $63-106$.

- Novarum plantarum icones et historia. In ejus "Praelusion etr". (1700.) 4. p. 49-64.

Ilalden, Plantarium philosophicum seu problemata phytologica de plantis. Dillingae $1686 . \mathrm{s}$.

Ray, Historia plantarum. Londini 1686-1704. folio.

Camerarius, De plantis vernis. Tubingae 1688. 4 .

Waldschmiedt, De vegetabilium ortu, vita et morte. Marpurgi 1638.4

Magnol, Prodromus historiae generalis plantarum. Monspelii 1689.8.

Nevton, Enchiridion universale plantarum. s. I. (cirea 1689.) s.

Rivinus, Introductio generalis in rem herbariam. Lipsiae 1690. folio. Ed. Ill : it, $1720,12$.

Limmer. De plautis in genere. Servestae 1691.4.

Plukenett, Opera omnia botanica, in sex tomos divisa. (Plhylographio. Almagestum, Almatheum.) Londini 1720 . (1691-1705.) 4.

Phelsum, Explicatio partis [V Plytographiae Pluc'neti. Harlingae 1769. 4.

Giscle, Index Liunaeanus in Plukenetii Opera botanica. Hamburgi 1779. folio.

Tenzel, Nomenclator systematicus in Leonardi Plukenetii Phytographiam. Erlangae 1820. 8 .

Aldrovandus. Pomarium curiosum. Bononiae 1692. folio.

Nebel, De novis inventis botanicis. Mlarburgi 1694. 4.

Munting, Naauwheeerige beschryving der aardgewassen. Leyden 1696. folio.

Zuinger, Theatrum botanicum. Basel 1696. folio. - ib. 1744. l'olio.

(Collet) Lettres sur la hotanique. (Paris 1697.) 12.

Chomel, Reponse à deux lettres de Collet sur la botanique. '(Paris 1697.) s. Zuinger, Circa plantarum doctrinam in genere. Basileae 1698. 4.

Ilermann, Paradisus batavus, ed. Sherard. Lugduni Batavorum 1698. 4.

Below, De regetabilibus in genere. Londini Gothorum 1700.4.

Kudbeck, Campi Elysii liber secundus. Lpsaliae 170 1. folio. fulio.

Munting, Phytographia curiosa. Lugduni Batavorum 1702. folio.

Plumier, Nova plantarum americanarum genera. Parisiis 1703. 4.

Kinaut, De variis doctrinam plantarum tradendi methodis. Halae 1705. 4.

Johren, Vademecum botanicum. Colbergae (1710.) 8.

(Petit) Letres d'un médecin. Namur 1710.4.

Salmon, Botanologia. London 1710-1711. folio.

Eglinger, Theses anatomicae ct botanicae. Basileae 1711. 1721. 4.

lipa, Historiae universalis plantarum scribendae propositum addito specimine. Patavii 1718.4.

Ialentini, Viridarium reformatum. Frankfurt a/al. 1719. fulio. 
Alaynol, Sovus character plantarum. Nonspelii 4720. 4.

Beruouilli, Positiones anatonicu-Jntanicas. Basileae 1721. 4

hoeniy, Theses botanicae. Basileae 1721. 4.

Martyn, Ilistoria plantarum rariorun. Londini 1728. gr. folio (latiue, germanicr.)

Michcli, Nora plantarum genera. Florentiae 1729. gr. 4.

(Roberg) Aetrebemes, Grundvahl til plantehjanningn. Upsaliace 1730. 12.

Hebenstreit, Definitiones plantarum. Lipsiae 1731. 4.

Koevig, Adrersaria quacdam botanica. Basileae 17314

Sicherlius, De loco et situ plantarum. Basileas 1731. 4.

Stehelinus, Olsservationes anatomico-hotanicae Basileae 1731. 4.

Zwinger, Positiones anatomico-l,otanieae. Basileae 1731.4

- Theses anatomico-botanicae. Basileae 1733. 4.

Halliny, Theses botanicac. IIafuiae 1733. 4.

l'assarant, Theses anatomico-futanicae. Basileae 17334 .

liespinger. Theses anatomico-botanicae. Basileae 1733.4.

Weimman, Phytanthozaiconograplia. Ratislonae 1737-1745. folin

(Index syst. Gesneri. Augusta Vindelicorum 1787. 8.)

\section{Icones florum et plantarum *).}

Eyenolphus, Herbasun inagines vivae. Francoforti 1536.4.

Fuchs, Labliche Abbildung und Contrafaytumg aller hreuter. Baseli 15458. (gallice, hispanue, latine.)

(De l'Obel) Plantarum seu stirpium icunes. Antwerpiae 1581. 4. obl.

(Tabernaemontanus) Eicones plantarum seu stirpium. Francofurti a/M. 1590.4. oll

Bry, Florilegiam novum. (Oppenheim) 1612. folio.

Sweert, Florilegium. Francofurti a/M. 1612. folio.

Collaert, Florilegium. s. I. el a. 4.

Passaeus vel Du Pas, Hortus floridus. Arnhemii 1614. 4. obl. (anglice.)

Icones. (Cognoscite Jilia agri etc.) s. 1. et a. 4. obl.

Franeau, Jardin d luyver, ou Calrinet des fleurs. Dovay 1616.4.

L'Anglois, Livre de fleurs. Paris 1620 . folio.

Theatrum Florae. Lutetiae Parisiorum 1622, folio.

Londerseel. Icones animalium et plantarum. 1625. 4.

Bry, Authologia magna. Francofurti 162e. folio.

A booke of beast, hirds, flowers, fruits etc. 1630.

Boetius de Boot, Florum, herbarum ac fructumn selectionum icones et vires. Brugis 1640.4 .

Van der Aa, Icones arborum, fruticum et herharum. Lugdani Batavorum s. a. folio obl.

Bry, Florilegium renovatum et auctum. Francofurti 1641.4.

Ehret, Plantae et papiliones rariores. (London 1648-1659.) folio.

Toulouze, Livre de boncquets de lleur's. Nontpellier 1655. folio.

Dunstall, A booke of flowers, fruils, beastes etc. I-IHJ. London 1661. 4. ohl.

Perrot, Les leçons royales. Paris 16x1. 12.

fiobet, Variae et multiformes Dorum species. Paris s. a. 4.

Robert, Bosse et de Chastillon, Recueil de plantes. (Paris 1701.) folio.

petiver. Plantarum Itatiae mariutrun et graminum ieones. Londini 1715 folio.

Schmidel, lcones plantarum. Norimbergae 1747. folio.

Treu, Plantae selectae. Norimbergao 1750-1773. fulio. (hollaudice.)

Ilortus nitidissimis superbiens Horibus. Nurnberg $1750-1786$. Polio.

F) ef. Horti et Onsersationes botanicae.
Nezeton, A compleat lorbal. London 1732. \&

Mueller, species jlantarum delineatae. Berliı 1757, folio.

Miller. Figures of plants deseriled in the gardener's dietionary. Lomion 1760. folio. (sermanice.)

Srhmidel, Icones plantarum. Normbergae 1762 . folio,

Treu, Plantae rariores. Norimberqae $1763-1779$. folio

Hoffmann, Samnlung merkwurdiger Pfanzen. s. l. et a. folio

Ilill, Exatic botiny illustrated. Lundon 1772. folio.

$A$ decade of curious trees and plants. London 1773 . folio.

Meerburgh, Afbcelelingen van zeldsaame gewassen. Leydcu 1775. folio

Buchoz. Ilistoire universelle du règue végétal. Paris 1775-1778. follo. (A-Penn.)

- Centuries des planclies. Paris 1775-1778. folio.

Collection précieuse el enlanineo des fleurs. Paris 1776 folio.

Bry, Anthologia Aleriana. Francofurti 1776. folin.

Miller, Icones animaliun et plantarum. s. 1. 1776-1794. folio.

lcones plantarum ed. Giseke, Schulze, Abendroth et Buek. Ilamhurgi 1777-1778. fulio.

Delany, Catalogue of plants copyed from nature. 17is. 8.

Wirsing, Eclogae botanicae. Norimbergace 1778. folio.

Buchoz, Dons merveilleux dans règne végetal. Paris $1779-1783$. folio.

Meeller, An illustration of the sexual system of Linnaeus. London $1779-$ 1789.8 .

(-, lcones plantarum. Londini 1780 .) gr. fulio.

Buchoz, Le jardin d'Eden. Paris 1783. folio.

Le grand jardin de l'univers. Paris 1785. folio.

Noureau traité de toutes les plantes. Paris 1787-1788. foliu.

Kerner, Abbildung aller okonomischen Pllanzen. Stuttgart 1786-1796. 4

Meerburgh, Plantae rariores depictae. Lugduni Batavorum 1789. folio:

Socerby, Flora lusurians. London (1789-1791.) folio.

Donovan, The botanical review or the beauties of Flora. London 1790.8 .

Hupje, Flora depicta. Berolini 1791. folio.

Salisbury, Icones stirpiun rariorum. Londini 1791. folio max.

Happe, Abbildung okonomiscler Pnanzen. Berolini 1792-1794. folio.

Martyn, Flora rustica. London 1792-1794. 8.

Schmidel, Jcones plantarum. Erlangae 1793-1797. folio.

Schneevoogt, Icones plantarun rariorum. Harlein 1793-1794. folio.

Meyrick, Miscellaneous Lotany. Birmingham 1794. folio.

Sowerby, Introduction to drawing fowers. London (1794.) 4 (germanice.)

Dreves, Botanisches Bilderbuch. (Getreue Abbildungen und Zergliederungen.) Leipzig 1794-1801.4

Dreves et Hayne, Choix des plantes d'Europe. Leipzig 1802. 4.

herner, llortus sempervirous. Stuttgardiae 1795-1830. foliv elepl.

- Jenes plantarum selectiorum. Stuttgardiae 1802. folio

Andrews, Botanists Repository. London 1797-1804.4.

Jleerburgh, Plantarum selectarum icones pictae. Lugduni Batavorum 179 folio.

Thornton, selects plants. London 4799. inm?. fol

- A new illustration of the sexual system of Linnaeus. Lomlon $(1799-1809$.$) folio.$

Batsch, Der geolfinete Blumengarten. (Le jarlin ouvert.) Weimar 1802.8 . Flora universalis. Dresden 1805 . folio.

Prevost, Collection des theurs et des fruits peints d'apres natuje. Paris 1805. folio.

Trallinick, Thesaurus hotanicus. Viennae (1S05-) 1819. folic.

Bessa. Fleurs et fruits gravés et coloriés. Paris 1808. folio mal

Kevner, Genera plantarum selectarum. Stuttgartice 1811-1828. Coliu.

Tratlimick, Archiv der Gewälistiunde. Wien $1812-1818.4$.

Bollione, Stirpes quas vivas pinsit. Taurini 1813. S.

Mordant de Lamoy et loiscleur. Herbier géneral do Jamateur. Paris $1816-1827.4$. 
METHODLS PLANTARUII
METHODUS PLANTARUM
Trattinick, Auswahl vorzuglich sehöner und seltner Gartenpflanzen. Wien 1821.4.

Sweet, The british flower-garden. London 4823-1829. $\therefore$.

Spaendonck, Fleurs dessinées d'après natıre. Paris s. a. folio.

Souvenirs de ran Spaendonek. Paris 1825.4.

Vees von Esenbeck et Sinning, Sammlung sehonlubhender Gewtiehse. Dusseldorl 1825, 4.

Haund, The botanie garden. London 1825-1842. IX voll. 4.

Redoute, Choix des plus belles lieurs. Paris 1827. folio.

Sertum botanicum. Bruxelles (182s -) 1536. folio min.

Roscoe, Floral illustrations of the seasons. No. l. Spring. London 1829.4

Loiseleur, Nouvel herbier de l'amateur. Paris 1830.4.

Dietrich, Flora universalis. Jena 1831 sqq. folio.

Drapiez, Encyelographie du règne vegretal. Bruxeltes 1833-1838, folio

Flore des serres et jardins de Paris. Paris 1834. 4.

Labram, Sammlung der Zierpflanzen. Basel 1835.8 .

Leconte, Collection de jolies petiles lleurs. Paris 1836.4.

Twamley, The romance of nature. Lonton 1836. 8.

- Flora's Gems. London 1837. 4.

- Our will flowers. London $183 \mathrm{~s} .8$.

Huegel, Botanisehes Archiv der östreichisehen Gartenbaugesellschaft. Wien 1837.4 .

Knowles et IIestcolt, The Floral Cabinet. Lendon 1837-1840.4.

Marnock, Florieultural Magazine. London (1\$38?) 8.

Miscellanea botanica. Bruxelles (1838 ?) gr. 8 .

Lenaire, L'borticulteur universel. Paris 1939-1844. 8.

Loiseleur et Lemaire, llerbier général de l'amateur. Paris $1839-$ 1843. 4 .

Maund et Henslow, The Botanist. London 4839 sqq. 4.

Loudon, The Ladies flower-garden of annuals. London 1840.4.

_ The Ladies flower-garden of perennials. London 1840.4.

- The Ladies flower-garten of bulljons plants. London 1841. 4.

Kedouté, Le bouquet royal. (Roses.) Paris 1843. folio.

Denisse, Flore d'Amérique. (leones florum.) Paris 1843-1846. folio.

Harlinger, Paradisus Vindobonensis. Wien $1844 \mathrm{sqq}$. folio.

Weber, Alpenpflanzen Doutschlands. München 1845. 12.

Lemaire, Scheidweiller et van Houlte, Flore des serres et jardins de l'Europe. Paris 1845 sqq. 8.

Dietrich, Abbildungen ron mehr als 30,000 Pflanzenarten. Jeni 1846 s0! 4.

Seringe, Flore des jardins et des grandes eultures. Lyon $1845 \mathrm{~s} 4 \mathrm{q}$. 8 . et Atlas in folio.

Flore et Pomone lyonnaises. Lyon 1847 sqq. 4.

\section{Mcthodus plantarum.}

Cuesulpino, De plantis libri XV!. Florentiae 1583.4.

Zaluziansliy à Zaluzian, Nethodi herbariae libri tres. Pragae 1592. \&. Ray, Nethotlus plantarum nova. (Londini) 1682. 8. - ib. 1703. 8.

Rivinus, Introduetio in rem leebariam. Lipsiae 1690. tolio.

1690. fulio.

Ordo plantarum, yuae sunt flore irregulari tetrapetalo. Lipsiae 1691, folio.

Schelhammer, De nova plantas in elasses digerendi ratione. Hamburgai 1635. 4 .

Ray, De variis plantarum methodis. Londini 1696. 8 .

Tournefort, De optina methodo instituenda in re herloria. (Paris 1697.) 8. Ricinus, Ordo plantarum, quae sunt flore irregulari pentapetalo. Lipsiae 1699. Iolio.

(- ) lcones plantarum, quae sunt flore irregulari hexapetalo. s. l. et a. folio.
Koenig, Spieilegium hotanicum et anatomienm. Basileae 1703.4.

IUugo, De variis plantarum methodis. Lugduni Batarorum 1711. 4

Knaul, Methodus plantarum genuina. Lipsiae 1716. $\mathrm{s}$.

Mangold, De conciliandis methodis .Tournefortii, Rivini, Hermanni et Raji. Basileae 1716. 4 .

Jussieu, Introluetio in rem herbariam. Impr. cum ejus "Diseours". Paris 1718.4 .

Burelihard, Epistola ad Leibnitzium de eharactere plantarum naturali. Wolfenbüttel 1720. 4. - Ed. Il: Helmstadii 1750.4.

Leibnits, Epistola ad A. C. Gackenholtsium de methodo botanica. In Lebnitz, Opera omnia ed. Dutens. Genevae 1768. 4. vol. 11, p. 169-17\%.

Lischwitz, De continuanda Rivinorum industria in eruendo plantarum charactere. Lipsiae 1726. 4. .

hramer, Tentameu botanicum sive nethodus Rivino-Tournelortiand. Vienuae 1728. 8. - ib. 1744. folio.

Heister, De foliorum utilitate in constituendis plantarum generibus: Ilelnstadii 1732.4 .

lluber, Positiones anatomico-botanicae. Basileae 1733. 4.

Limné, Systema naturae. Lugduni Batavorum 1735. folio. - Ed. NIll Lipsiae $1788-1793.8$. (germanice, anglice, sueeice, galtice.)

Methodus sexualis. Lugduni Batavorum 1737. 8.

Classes plantarum. Lugduni Batavorum 1737. 8 .

Siegesbeck, Botanosophiae verioris brevis sciagraphia. Petropoli 1737. 4.

(Browallius) Examen Epieriseos Siegeshechianae in systema sexuale. Aboae (1739.) 4. - Lugiluni Batavortun 1743.8.

Ludwig, Observationes in methodun sexualem Limnuei. Lipsiae 1739. 4

Gleditsch, Consideratio Epieriseos Siegesbeehianae. Berolini 1740. 8.

Siegesbeck, Vaniloyuentiae botanicae specimen. Petropoli 1741. 4.

Heister, Neditationes in novum systema botanicum Linncei. Helmstalli 1741. 4.

Ilebenstreil, De melhota plantarum ex fruetu optima. Lipsiae 17:10. 4

Ludwig, De minucudis plantarum speeiebus. Lipsiae 1740.4.

Wallerins, Decacles binae thesium. Upsaliae 1741. 4.

Bergen, Ultri systematum an Tournefortiano an Linncano potioses partes deferendae sint? Francofurti a/V. 4742. 4.

Fubricius, Observationes methodos Tournefortii, Rivini, Raji, Kuauthii ef Linnaei concernentes. In ejus Primitiis Florae Butisbacensis. Wetzlaride 1743 . 8. p. $34-64$.

Ludolf, Synopsis dissertationum duarum perfectiones methodi botanicar euncerneutium. Berolini 1746.8.

Heister, Systema plantasum generale ex fruetificatione. Helmstadii 1748. 8. De Sauvages, Hethodus foliorum. I la Jlaye 1751. \&.

Seopoli, Methodus plantarum. Viennae 1754.4.

Du Hamel, Dissertation sur les methodes de botaniques. Impr. cum ejus Pliysique des arbres. Paris 1758. 4. (vol. 1, p.XXIX-1.XV.) (hispanice.)

Ludvig, De colore plantarum species distinguente. Lipsiae 1759. 1

Biomlund, Fundamentum differentiae specificae plantarum. Cirypliae 1761. 4 .

sdanson, Familles des plantes. Paris 1763.8.

Cleditsch, Systema plantarum a staminum situ. Bervlini 1764. 8.

Senelier, De Polygamia. s. 1. 1765.4.

Ineling, De ordinilus naturalibus plantirum. Goettingae 1766.4

Tilius, Systema plantarum sexuale al naturam compositum. Wittenbergae 1767. 4 .

(germanice.)

Giseke, Systemata plantarum reentiora. Goettingae 1767.4.

llill, Jlerbarium Jotanicum sceundum methodum floralen novam. Londini 4769.8 .

Mitchell, De principiis botanicorum, cum generibus recens conditis. Norimbergae $176 \%$. 4 .

Scopoli, Dubia botanica. In ejus .Inno hist. natur. IV. Lipsiae 1770. 8. p. $48-114$. et anno V, p. 14 .

Bueling, Ordines naturales plantarum. Goettingae 1774. 8 . 
Jussien, Limposition d'un nouvel ordie ters plantes, aclopté dans les demunstrations du jardin royal. (Paris 177\%.) 4 .

Schimert, De systemate sexuali. Tymaviae 1776.8.

Augustin, Prolegomena in systema sexuale. Vienuse 1777. 8.

Mueller, Illustratio systematis sexualis Limbaei. 1.ondini 1777. folio.

(anglice-latine, germanier-latine.) 1789.8 .

$$
\text { (1atune.) }
$$

Roth, Verzeichniss der Pflanzen, welche nicht in. den gehurigen Klassen des Linueschen systems stehen. Altenburg 1781.8 .

Je Las, Phytographie universelle ou nonveau systeme de botanirue. Stoekholm et Lyon 1783. 8

Oahl, Observationes botanicae circa systema vegetabilium divi a Limué. 1lavniae 1787.8.

Gische; Tabula genealogico-geographica aftinitatum plantarum. s. 1. 1789. folio.

Olto, Theses alipuot botanicae. Trajecti a/V. 1789. 4.

Cothenius, Disjrositio vegetabilium a staminum uumero. Berolini 1790.8 .

Necher", Phytozoologie philosophinue. Neuwied 1790. 8.

Mocnch, Methodus plantas horti et agri matburgensis a staminum situ describendi. Marburgi 1794- 1802.8 .

Limne, Praelectiones in ortines naturales plantarum. Ilamburgi 1792. 8.

Medirus, Geschichen der Botanik unsrer Zeiten. Mamlueim 1793. 8.

Link, Dissertationes botanicae. Suerini 1795. 4

Liljeblad, Patio plantas in sedecin classes disponendi. Lpsaliae 1796. 4.

kullberg, De affinitate genermn plantarum in classibus Linnaeanis. Lundae 1796. 4 .

Lorente, Nova generum Polygamiae classifieatio. Valentiae (1796.) 4.

Schmidt, Aeusserungen uber cin System in der Pflanzenkunde. (Boitzenburg) 1797.8 .

Soennerbery, Dijudicatio emendationum systematis Linnaei. Lundae 1798. 4 .

Lorente, Systema botanieum linneano-anomalisticum. Valentiae 1799. 4.

Retzius, Je genere in historia naturali. Londini Gothorum 1799. 4.

Quistorp, De serie vegetabilium. Gryphiae 1800.4.

Illiger, Ueber die Begriffe Art und Gattung. In ejus "Versuchn etc. HeImsterlt 1800.8 .

(suecice.

Augier, Essai d'une nouvelle classification des végétaux. Lyon 1801. \&.

Batsch, Tabula affinitatum regni vegetabilis. Wimariae 1802.8 .

(Dobrowsliy) Entwurf eines Pllanzensystens nach Zahılen und Verhadunissen. Prag 1802, 8.

Cramer, Enumeratio plantarum in systenute Linneano false disposttarum. Marpurgi 1803.8 .

Eckerberg, De reformationibus Classium plantarum Caroli a Linne. Londini Gothorum 1804. 8

Réflexions sur les différents systemes de botani,jue. Paris 1804.4.

Jussicu, Mémoires (I-XIII) sur les caractères génèraux des fanilles tirés de graines. (Paris $1804-1830$. ) 4 .

Retzius, Methorlus Tournefortiana a Guart filio reformata. Lundae 1805. 4.

Caylus, Histoire du rapprocheurent tes végétaux. Pairis 1806.8.

Unger, Arimadversiones circa Jussieui methodum plantarum naturalem. Ilalae 1806.8

Borkltausen, Tentamen dispositionis plantarum Germaniae. Jarmstadt 1809. 8 .

Jussieu, Mémnires (1-11) sur les genres de plantos a ajouter on a retrancher a diverses familles connues. (Paris $1809-1810$.) 4 .

Stemler, specimen paralelismi iuter systema Litneamum et Jussieuanum. Jenae 1810.4.

Fischer, Beitrag zur botanischen Systematik, die Existenz der MonokotyJedunen und Polykotyledonen betreflend. Zurich IS12. 4.

Lefebure, Sur le principe essentiel de l'ordre en botanique. Paris 1812.8.

Lary, Phyllographie piemontaise. (Turin 1816.) 8 .
Lefelure, Concortance des trois systemes de Tournefort. Limueus et Jutsieu. Paris 1816.8 .

- Le vrai systime des fleurs. P'aris 1817.8.

1 gardh, Aplorismi botanici. Lundae 1817-1825. 8

Bredsdor $/$, De regulis in classificatione observandis. Ilavniac 1817.8.

lest, Grundzuge eines nenen naturlichen Systems. In ojus a Anlrituny. Wien 1818.8.

Wallman, De systematilus regetabilium. L L saliac 1818 . \&

Scheeigyer", Bo plantarun classificatione naturali. Regiomonti 1820.8.

Ifall, Commentatio de systematilus botanicis. Trajecti a/Rh. 1821. \$.

Lefebure, Systeme fleral. Paris 1821.8.

Oken, Esquisse du systeme d'anatomie et physiologie et d'listoire naturelle. Paris 1821.8 .

Entwurf von Oken's philosophischem Pljanzenșsteme. s. 1. el d. 8.

Eysenhardt, Je accurata plantarum comparatione. Regiomonti 1823.4

Lestibondois, Menoire sur lit structure des Monocotylédonces. Lille 1823. 8 .

Jussieu, Principes te la methode naturelle des segrtaux. Paris 182

Thunberg, Examen classium l)iandriae. Gynandriae, Monoeciae. Diocciae et Polygamiae. Cpsaliae 1824-1823.4.

Agardh, Classes plantarum. Lundae 1820.8

fries, Systema orbis vegetabilis. Par's I: Plantae homoncmeae. Lundae 1825. 8

Fée, Memoire sur les Monocolyledones. 1-11. s. I. 1826 . 8

Bicheno, On systems ant methods in natural history. London 1827. 4

Aspegren, Vivi-Rikets Familje-Trad. Carlscruna 1828. fulio.

Jartins, Ordinum plantarum characteres stenographice expositi. (Berolini 1828.) 4.

Reichenbach, Conspectus regui vegetabilis. Cehersicht des Gewachsreiches. Lipsiae 1828.8 .

Dumortier, Aualyse des familles des plantes. Tuurnay 1829.8 .

Opiz, Jloclssles Ziel der reinen lotanik. Prag 1829. 8.

Ratzebury, Untersuchungen uher Formen und Zahlenverlultnisse der Naturhurper. Berlin 1829.4.

Uebersichn der Pllanzenfamilien. Berlin 1829. 4

Bartling, Ordines naturales plantarum. Goeltingae 1830.8 .

De la Peyrouse, Essais sur les fleurs a enreloppe uni(jue. Paris 1830.4.

Lindley, An infroduction to the natural system of botany. London $1 \$ 30$. 8. - ib. 1839.8 . germanice.)

Rudolphi, Systema orbis regetabiliun. Gryphiae 1830.8 .

Ruland, Leber das botanische System des Rivinus. Wurzburg 183z. \&.

Schullz, Naturliches System des Pllanzenreichs nach sniner inneru Organisation. Berlin 1832.8 .

De Candolle, Nole sur la division du règne végetal en quatre grandes classes. (Genéve 1833.) 8.

Lindley, Nixus plantarum. Londini 1833. 8.

(yermanice.)

Bernhardi, Ueber den Begriff der Pीanzenart. Erfurt 1834.4.

Horaninow, Primar lineae systematis naturae. Petropoli 1834.8.

Schrader, De Nonocotyletonearım et Dicotyledonearum circa genımarum explicationem tlifrerentia. Bonnae 1834.8 .

Willrand, Die 11uturlichen Pllanzenfamilien. Giessen 1834. 8.

Frics, Mappa botanica ex affinitate et analogia. Upsala 1835. folio.

(Lefebure) Flore de Paris. Genera et species etc. Paris 1835. 8.

Martins, Couspectus regui vegetahilis. Nurnbers $1 \$ 35.8$.

Seringe et Guillard, Essai de formules botaniques. Paris 1835.4 .

Leydolt, Die Plantagineen in Bezug anf die naturhistorische Species. Mien (1836.) 8

Stemheil, De l'individualité considèrée dans le règne végétal. (Strassburg 1836.) 4 .

Lindley. A uatural system of botany. London 1836.8.

Féc, Les Jussien et la methode naturelle. Strassburg 1837. S. 


\section{GENERA PLANTARUM}

Rerclenbach, Ilandbuch des naturlichen Pflanzensystems. Dresden 1537.4. Perleb, Clavis classium, ordinum et familiarum atque index generum regni vegetabilis. Freiburg i/Br. $183 \mathrm{~s} .4$.

Somnenburg, Arithmonomia naturalis. Dresdae 1838. folio min.

Spring, Ueber die Begriffe von Gattung, Art und Abat. Leipzig 1838. 8.

Elsner, De speciei definitionibus duiestiuncula eritica. In ejus Synopsi Fl. Cerv. Vratislaviae 1839.8 .

Zunck, Die naturlielsen Pllanzensysteme greschichtlich entwicheh. Leipzig 1840.8 .

Moritzi, Reflesions sur l'espèce en hisloire naturelle. Soleure 1842. 8.

Trautcetter, De novo systemate botanico. (Mitau 1842.) 8.

Horaninow, Tetractys naturae. Petropoli 1843.8.

Bischoff, Handhuch der butanischen Systemkunde. Nurnlerg 4844.4.

Payer, Des classifications et des méthodes en histoire naturelte. Paris 184 i. 4 .

(ierard, Rellexions critiques sur le genre en histoire naturelle. Paris 1845. 8.

Lindley, The vegetable Kingdom. London 1846.8.

\section{Gencra plantarum.}

Linne, Genera plantarum; cum corollario. Lugduni Batavorum 1737. 8. - Ed. X: Goettingae 1830-4831. 8 .

Luduig, Definitiones plantarum. Lipsiae 1737. S.

- De minuendis plantarum generibus. Lipsiae 1737. 4 .

Linne, Nova plantarum genera. IIolmiae 1747. 4.

Ludwig. Definitiones grenerum plantarum. Ed. II. Lipsiae 1747. 8.

Wedel, Tentamen botanicum. Jenae 1747. 4.

Sendschreiben an Hailer. Jenae 1748.4

Iteister, De generibus plantarum medicinae causa augendis. Ilelmstadii 1754.4.

Linne, Nova plantarum genera. Lpsalide 1754. 4.

Schaeffer, Botanica expeditior. Ratisbonae 1760.4

Ludwig, Definitiones generum plantarunt. Ed. III. ed. Bothmer. Lipsiae 4760.8 .

Meese, Plantarum rudimenta. Leovardiae 1763. 4.

Hernischeck, Genera plantarum secundum numerum laciniarum corollae. Vindobonae 1763.8.

Bose, De disquirendo charactere plantarum essentiali. Lipsiae 1765. 4

Linne, Mantissae plantarum Generum ed. VI. Specierum ed. II. Holmiae $1767-1774.8$

Hernquist, Genera Tournefortii stilo reformata. Londini Goth. 1771. 4.

Kalm, Genera plantarum fennicarum. Aloae 1771. 8.

Milne, Institutes of botany. London $1771-4772.4$.

(Wolf) Genera plantarum. (Marienwerder) 1776.8.

liot, Do generibus plantarum. Tyrnaviae 1776. 8 .

Forster, Characteres generum plantarum. Londini 1776.4. (germanice.)

Schrader, Genera plantarum selectá. Llalae 1780. 8.

Thunberg, Nova genera plantarum. Upsaliae 1781-1801. 4.

Batsch, Dispositio generum plantarum jonensium. Jenae 1786. 4 .

Jussitu, Genera plantarun. Parisiis 1789. S.

Batsch, Analyses florum. Ilalae 1790.4

Necker, Elementa botanica. Noowedae a/Rh. 1790.8.

Medikus, Philosophische Botanih. II : Ueber Pflanzengattungen. Mannheim 1791.8.

(Liljeblad) Svensha Oertslagen. Upsala (1792.) S.

Suckow, Diagnose der Pflanzengattungen. Leipzig 1792. 8.

Balsch, Syuupsis universalis analytica generum plantarum. Jenae 1794.4. - Dispositio generum plantarum Europae. Jenae 1794. 4.

Pritzel, Thes. lit. bot.
Gesner, Tabulae phytographicae analysin generum plantarum exhilyentes. Turici 1795-1\$26. folio.

Schrater, Nova genera plantarum. Lipsiae 1797. folio.

Lavy, Genera plantarum subalpinam regionem exornantium. Taurini 1802. 8 .

Trattinick, Genera plantarum methode naturali disposita. Vindobonae 1802.8

Aubert dlu Petil-Thouars, Genera nova madagaseariensia. (Paris 1806.) \& Hedwig, Genera plantarum. Lipsiae 1806. 8.

Salistury, The gencric eharacters in the English botany. London 1806.8 . Sclrader, Genera nonnulla plantarum emendata. Goettingae 180 4.4.

Ventenat, Deeas generum novorum. Paris 1808.4.

Liboschitz, Tableau botanique des genres. Wien 1814. fulio.

Mouton-Fontenille, Tableaux de concordance des genres d'un Pinax des Jlantes europécunes. Pasis 1814-1815.8.

Nuttall, The genera of the north-american plants. Philadelphia 181S. 8

Schmalz, Dispositio synoptica generum plantarum circa Dresdam crescenlium. Dresden 1822. folio.

Trallinick, Genera nova plantarum. Viennae 1825. 4.

Characters of genera extracted from Hooker British Flora. Edinburgl 1830.8 .

Nees von Esenbeck jun., Genera plantarum Florae germanicae. Bonnae $1833-1845 \mathrm{sqg} .8$.

(Trinius) Genera plantarun ad familias suas redacta. Petropoli 1835.4.

Spenier, Deutschlands phanerogamische Pllanzengattungen. Freiburg 1836. 8

Enhlicher, Generd plantarum. Vindobonae 1836-4840.4. - Mantissa [-III. ib. 1842-1845. 4 .

Meisner: Planturum vasculariun genera. Lipsiae 1836-1543. folio.

Harvey, The genera of South African plants. Cape Town 1838. 8.

Meycr, Preussens Pflanzengattungen. Konigsberg 1839. 12

Schnizlein, Iconographia familiarum naturatium regni vegetabilis. Bouı $1843 \mathrm{su}$ s. 4

Engetmann, Genera plantarum. Mitau 4844. \&.

Plée, Types de chaque famille et des principaux genres de France. Paris 1844 sqव. 4

\section{Pinaces. Systemata.}

Ifill, A history of plants. London 4751. folio.

Linné, Species plantarum. Holmiae 1753. 8.

Eltrharl, Oekonomische Pllanzenhistoric. Ulm 1753-1762. 8.

Hill, The vegetable system. London 1761-1775. folio.

Linné, Species plantarum. Ed. II. Holmiae 1762-1763. 8.

Agosti, De re botanica 1ractatus. Belluni 1770. folio.

Weston, Botanicus universalis et hortulanus. Londini $1770-1777.8$.

Dieterich, Pllanzenreich nach dem Natursysteme Linné's. Erfurt 1770. 8. Ed. II. Leipzig 1798-1799. 8.

finorr, Thesaurus rei herbariae hortensisque universalis. Numberg 1770 -1772 . folio.

Linne, Systema vegetabilium. Ed. XIll, ed. Mlurray. Goettingae 1774. 8. - Supplementum: Brunsvigae 1781.8.

Houlluyn, Natuurlyke historie. Deel Il. Planten. Amsterdam 17741783.8.

Linne, Systema plantarum. Ed. novissima eur. Reichard. Francofuru a/N. $1779-1780.8$.

(germanjce, anglice, gallice, italice, Iusitanice.)

(Holf) Genera et species plantarum. Marienwerder 1781.8.

Lime, Systema vegetabilium. Ed. XIV, ed. Murray. Goettingae 1784. 8.

Sainl-Germain, Manuel des végétaux. Paris 1784. 8.

Gilibert, Caroli Linnaei Systema plantarum Europae. Coloniae Allobrogum $1785-1787.8$. 
The families of plants. Lichfield 1787. 8.

litman, Summa plantarum. Mediolani 1789-1802.8.

Linue, Systema vegetabilium. Ed. XV, ed. Persoon. Goettingae 1797. 8. Ed. XV, od. Murray. Paris 1798. 8.

Species plantarum. Ed. IV, curante Willdenou. Berolini $1797-$ 1830 . VI voll. 8 .

Jolyclerc, Phytalogie universelle. Paris 1799. 8.

Brisseau-Mirbel, Histoire naturelle générale el particuliere des plantes. Paris 1800-1806. 8.

De la Marck et Brisseau-Mirbel, llistoire naturelle des végétaux. (Suiles de Buffon.) Paris 1802. 12. - ib. 1830. 12.

l'ahl, Enumeratio plantarum. (Cl. I-III.) flavniae 1804-1806.8.

Persoon, Synopsis plantarum. Paris 1805-1807. 12.

Gilibert, llistoire des plantes d'Europe et étrangères. Ed. II. Lyon 1806.8.

Linué, Systoma vegetabilium. Ed. XVI, curantibus Roemer et Schultes. Stuttgartiae 1817-1830.8. - Vol. I. ed. nova ib. 1820. 8. - Mantissae in vol. I-III: ib. 1822-1827. 8.

De Candolle, Regni vegetabilis systema naturale. Paris 1818-1821. 8.

Prodromus systematis naturalis regui vegetabilis. Paris 1824 sqণ. 8 .

Linue, Systema vegetabilium. Ed. XVI, eurante Sprenget. Goettingae 1825 -1828.8 .

Poiret, Histoire philosophique, littératre, économique des plantes de l'Europe. Paris $1825-1829.8$.

Loudon, Eneyclopaedia of plants. London 1829. 8. (germanice.)

Limue, Species plantarum. Ed. VI, autore Atbert Dietrich. Temus I, pars I, sectio 1-2. (Cl. I-III.) Berolini 1831-1833. S.

Don, A general history of the dichlamydeous plants. (A general system of gardening and botany. London $1831-1838.4$.

kunth, Enumeratio plantarum omnium hucusque cognitarum. Stutgardiae 1833-1843.8.

Presl, Repertorium botanicae systematicae. Pragae 1834. 8.

Spach, llistoire naturelle des végétaux. Phanéroganıes. Paris $1834-$ 1848. 8 .

linné, Systema, genera, species plantarum uno volumine, sive Codex Linnaeanus, ed. Richter. Lipsiae 1835-1840. 4.

Dietrich, Synepsis plantarum. Vimariae 1839 sqq. 8 .

Loudon, Eneyclopaedia of plants. Ed. II. Lendon 1841. 8. (germanice.)

I'alpers, Repertorium botanices systematicae. Lipsiae 1842-1848.8.

\section{Nomenclatores.}

Limne, Nemenclator botanicus. Ilolmiae 1759. 4.

Oeder, Index plantarum in Linne Systema ed. X. Ilavniae 1761. 12.

Phelsum, Explicatio partis IV. Phytographiae Pluc'neti. Harlingae 1769. 4.

(Jacquin) Index ad Linne' Systema ed. XII. Viennae 1770. 4.

Nomenclator botanicus. Lipsiae 1772. 8.

(Mikan) Catalogus plantarum omnium juxta Linné, Systema veget. ed. XIII Pragae 17768.

Giscke, Index Linnaeanus in Plukenetii Opera betanica. Ilamburgi 1779. folio.

Jlartmann, lconum botanicarum Gesnerio-Camerarianarum minorum nomenclator Linneanus. Trajecti a/V. 4781. 4.

Nomenclator botanicus. Ed. II. Lipsiae 1782. S.

(Jaequin) Index ad Linne, Systema nat. ed. XIV. Viennae 1785. 8.

Gesner, Weinmanni Thesaurus rei herbariae locupletissimus indice systematico illustratus. Augustae Vindeljcorum 1787.8.

Groening, Nomenclater Linnaeanus in Ilerlarium Blackwellianum. Lipsiae 1794. 8 .
OBSERVATIONES BOTANICAE

Forsyth, A botanical nemenclator. London 1794, 8.

Raeuschel, Nomenclator botanicus. Ed. III. Lipsiae 1797. 8.

Pollini, Synonymia botanica moderna. Milano 1804.8 .

Jenckel von Donnersmarck, Nomenclator botanicus. Ilalae 1803. 8.

IVidnmann, Catalogus systematicus ... Herti Eysteltensis. Norimbergar 1805.4 .

llendel, Index generum ad Linne. Species plantarum. Halac 1806.8

Lichtenstein, Index generum in Willdenow Spec. plant. at in Persoon Synopsin. Ilelmstadii 1814.8.

Dennstedt, Schlussel zum Hortus indicus malabaricus. Weimar 1818. 4.

Tenzel, Nomenclator systematicus in Leonardi Plukenetii Plı̣tographiam. Erlangae 1820.8.

Henckel von Donnersmarck, Nomenclator botanicns. Ed. II. IJalae 1821. \&.

Sternberg, Catalogus plantarum ad septem editiones Matholi in Hoscortdem. Pragae 1821. folio.

Steudel, Nomenclator botanicus. Stuttgardiae 1821. gr. 8. - F.d. I1: il) 1840-1841. gr. 8.

Ilamilton, Commentary of the IV. part of the llortus malabaricus. 1826. 4 .

Ilenschel, Clavis Rumphiana. Vratislaviae 1833. 8.

Courtois, Commentarius in Dodonaei Pemptades. (Nov. Aeta Nat. Cur. XVII, 2.)

(Dillwyn) Review of the references to the Ilertus malabaricus. Swansea 1839. 8.

Steudel, Nomenclator botanicus. Ed. II. Stutigardiae 1840-1\$41.gr. 8 .

Buek, Genera, species et synonyma Candolleaua alphabetico ordine disposita. Berolini 1840-1842.8.

Heynhold, Nomenclator botanicus hortensis. Leipzig 1840-1847. gr. 8 . Berger, Catalogus herbarii. Wirceburgi 1841-1846. 12.

Reentgen, Commentarius in Dodonaei Pemptades. Wirceburgi 1842. 8.

\section{Observationes botanicac ${ }^{*}$ ).}

Buechner, De memorabilibus Voigtlandiae e regno vegetahili. (Creizae 1743.) 4.

Linné, Plantae Nartine-Burserianae. Upsaliae 1745.4.

Willich, Observationes botanicae. Gottingae (1747.) 4 .

Buettner, Enumeratio methodica plantarum carmine cl. Cunn recensit:rum. Amstelodami 1750. 8.

Hess, Theses anatomico-botanicae. Basileae 1751. 4.

Socinus, Theses anatomico-botanicae. Basileae 1751.4.

Stehelinus, Specimen observationum botanicarum. Basileae 1751. 4.

Theses miscellaneae. Basileae 1751.4.

Stupanus, Specimen anatomico-botanicum. Basileae 1751 . \&

Thurneysen, Theses medicae. Basileae 1751. 4.

Ramspecli, Selectarum observationum specimen I-II. Rasileae 17511752. 4.

Hess, Observationes medicac. Basileae 1753, 4.

Stehelinus, Specimen observationum medicarum. Basileae 1753. 4.

Mieg, Specimen observationum botanicarum. Basileae 1753. 4.

Zinn, Observationes quaedam bot. et anat. Goettingae 1753.4.

Koelreuter, De plantis quibusdam rarioribus. Tubingae 1755. 4.

Linné, Centuria prima plantarum. Unsaliae 1755.4.

Centuria altera plantarum. Upsaliae 1756.4.

Scepin, Annotationes botanicae. In ejus a De acido vegetabilin, Lugduni Batavorum 1758. 5. p. 21-44.

Arduino, Animadversiones botanicae. Venetiis 1759-1764. 4.

Willich, De plantis observationes. Gottingae 1762. 8.

Jacquin, Observationum botanicarum pars $1-I V$. Vindobonae $1764-$ 1771. folio.

-) ef. Horti et Icones florum et plantarum. 
Turra, Farsetia; accedunt Observationes botanicae. Venetiis 4765.4.

De la Roche, Descriptiones plantarum aliquot novarum. Lugduni Batavorum 1766.4.

Schreber, lcones el descriptiones plantarum minus cognitarum. Halae 1766. folio.

Willich, Illustrationes botanicae. Gottingae 1766. S.

Du Roi, Observationes botanicae. Helmstadii 1771. 4.

Vandelli, Fasciculus plantarum. Olisipone 1771. 4.

Weigel, Observationes botanicae. Gryphiswaldiae 1772. 4 (danice.)

Rottboell, Descriptiones plantarum rariorum indicit. IIavniae 1772. 8. 773. folio.

Gouan, Illustrationes et observationes botanicae ad speciernw historiam facientes. Tiguri 1773. folio.

Battarra, Epistola selectas de re naturali observationes complectens. Arimini 1774.4.

Retzius, Fasciculus observationum botanicarum. Luıdini 1774. 4.

De la Chenal, Observationes botanico-medicae. Basileae 1776. 4.

Mieg, Specimen II. Observationum botanicarum. Basileae 1776. 4.

Retzius, Observationes botanicae. Lipsiae 1779-1791. folio.

Panzer, Observationum botanicarum specimen. Norimbergae 1781. 8.

Schrank, Eine Centurie botaniseher Anmerkungen. Erfurt 1781. 4.

Jacquin, Icones plantarum rariorum. Vindobonae 1781-1793. [olio.

Vedicus, Botanische Beobachtungen. Manuheim 17\$3-1754. s.

Cirillo, De essentialibus nonn. plant. characteribus. Neapoli 1784. 8

Eschenbach, Observationum botanicarum specimen. Lipsiae 1784. 4

Weber, Plantarum miluus cognitarum decuria. Kiloniae 1784. 4.

L'héritier, Stirpes novae aut minus cognitae. Paris 1784-1785. folio

Gloxin, Observationes botanicae. Argentorati 1785. 4.

Hoffmann, Observationes botanicae. Erlangae 1787. 4.

Kolh, Botanische Abhandlungen und Beobachınngeu. Nurnberg 1787. 4.

Curtis, The Botanical Magazine. London 1787-1\$46 sqq. 8. - General indexes. Loldon 1828.8.

Ehrhart, Beitrage. Ilannover 1787-1792.8.

L'hérilier, Sertum anglicum. Paris 1788. folio.

Gil et luarez, Osservazioni fitologiche sopra alcane piante esuticlie. Roma 1789-1792. 4

Smith, Plantarum icones lactenus isteditae. Londun 1789-1791. folio.

- Icones pictae plantarum rarjorum. London 1790-1793. folio max. Spicilegium botanicum. London 1791-1792. folio.

Vahl, Symbolae botanicae. Havniae 1790-1794. folio

Batsch, Botanische Bemerkungen. Halle 1791, 8.

Swartz, Observationes botanicae. Erlangae 1791. 8.

Cavanilles, Icones et descriptiones plantarum. Matriti 1791-1801. folio. Naumburg, Delineationes Veronicae Chamaedryos etc. Erfordiac 1792.8. Medicus, Kritische Bemerkungen. Mannheim 1793. 8.

Nocea, Observationes botanicae. (Turici 1793.) 8 .

Rutström, Positiones botanici argumenti. Harderovici 1793. 4.

Schmidl, Neue und seltne Pflanzen. Prag 1798. 8.

Willdenow, Phytographia. Erlangae 1794. folio.

rahl, Eclogae americanae. Havniae 1796-1807. folio.

- Icones ad Eclogas. Havniae 179S-1799. folio.

Roth, Catalecta botanica. Lipsiae 1797-1806. 8 .

IVendland, Botanische Beobachiungen. IJannover 1798. Colio.

Hedwig, Observationum botanicarum fasciculus I. Lipsiae 1802. 4

Roth, Neue Beitráge zur Botanik. Frankfurt a/M. 1802.8.

Pallas, Illustrationes plantarum imperfecte cognitarum. Lipsiae 1S03. folio.

Ventenat, Chois des plantes. Paris 1803. folio.

Smith, Exotic Botany. London 1804-1805. 4.

Wulfen, Plantarum rariorum deseriptiones. Lijsiae 1805.4.

Biehler, Plantarum novarum ex herbario Sprengelii centuria. Halae 1807.8.
Roth, Botanische Bemerkungen und Berichtigungen. Leipzig 1807. 8. Desfontaines, Choix des plantes du corollaire de Tournefort. Paris 1808.4 Targioni-Tozzetti, Observationum botanicarum decas I-V. (Florentiae $1808-1810)$.

IVendland, Collectio plantarum. Sammlung auslándischer und einheimischer Pflanzen. Ilannover 1808-1819.4.

Jacquin, Fragmenta botanica. Viennae 1809. folio.

Schultes, Oliservationes botanicac in Linne Species plantarum ed. Willdenow. Oeniponti 1809. 8.

Retsius, Observationum botanicarum pugillus. Lundae 1810.4.

Trattinick, Observationes botanicae. Viennae 1811-1812. 4.

Jacquin, Eclogae plantarum rariorum. Vindobonae 1811-1844. folio.

De Candolle, Recueil des Mémoires sur la botanique. Paris 1813,4.

Sprengel, Plantarun minus cognitarum pugilli I- II. IIalae $1813-$ 1815. 8.

Rafinesque, Anilyse de la nature. Palerme 1815. 8.

Edwards and Lindley, The Botanical Register. London 1813-1846 sq. 8 .

Lagasca, Genera et species plantarum novarum. Matriti 1816. 4.

Savi, Osservazioni sopra diverse piante. Pisa 1816. 8.

Loddiges, The Botanical Cabinet. XX voll. London 1818-1833. 4.

Bertoloni, Excerpta de re lierbaria. Bononiae 1820.4.

Sprenget, Seue Entdeckungen. Leipzig 1820-1822.8.

De Lessert, Jcones selectae plantarum. Paris 1820-1846. folio.

Gussone, Adnotationes ad catalogum horti in Boccadifalco. Neapoli 1821. 8

Lindleg, Collectumea botanica. Loudon 1821 . folio.

Reichenbach, Magazin der disthetischen Botanik. Icones et descriptiones etc. Leipzig 1821-4826.4.

Rertoloni, Lucubrationes de re herbaria. Bononiae 1822.4.

Dumorlier, Commentationes botanicae. Tournay 1822.8 .

Hooker, Botanical illustrations. Edinburgh 1822. folio obl.

Wikström, Mindre kunda váxter. Stockholm 1823-1824. S.

Hooker, Exotic Flora. Edinburgh 1823-1827. gr. 8.

Reichenbach, Iconosraphia botanica, scu Plantae criticae. Ceut. I-X. Lipsiae $1823-1832.4$.

Bartling et Wendland, Beitráge zur Botanik. Göttingen 1824-1825. S

Sylloge plantarum novarum. Ratisbonae 1824-1828. 8.

Hegetschweiler, Versuch einer theilwejen Monographie von Aretia, Cerastium, Aconitum, Potentilla, Saxifraga, Hieracium. In ejus "Reisen" etc. Zurich 1825.8 .

Gaudichaud, Botanique du Voyage autour du monde sur les corvettes L'Urame et La Physicienne. Paris 1826. 4. el Allas.

Reichenbach, Iconographia botanica exotica, sive Hortus botanicus. Lipsiae $1827-1830.4$.

Lehmann, Novarum et minus coguitarum stirpium pugilli. Hamburgi 1828 sqq. 4.

Brongniart, Botanique du Voyage de La Coquilte autour du monde. Paris $1829 \mathrm{~s}$ sI. 4.

Swartz, Annotationes botanicae. (Panicum. Rosae. Orchideae. Musci.) Holmiae 1829. 8 .

Stokes, Botanical Commentaries. London 1830.8.

Hooker, Botanical Miscellany. London 1830-1833. 8.

Tenore, Memorie. Napoli 1834. 4.

Treviranus, Symbolae phytologicae. Goettingae 1831. 4.

Bertolowi, De plautis novis aliisque minus cognitis. Bononiae 1832. 4

Presl, Symbolae botanicae, sive descriptiones et icones plantarum novarum aut minus cognitarum. Pragae $1832-1833$. folio.

(Halophytae.) Savi, Cose botaniche. Pisa 1832. 8.

Scholl et Endlicher, Meletemata botanica. Vindobonae 1832. fulio.

Endlicher, Atacta botanica. Vindobonae 1833. folio.

Kafinesque, Ilerbarium Rafinesquianum. Prodromus. Philadelphia 1833.8.

Richard, Sertum Astrolabiauum. (Dumont d'Urville, Voyage) Paris 1834. 8. et Atlas. 
Reiehenbach, Flora exotica. Leipzig 1834-1836. folio.

Paxton, Magazine of Botany. London 1834 sqq. 8.

Bertoloni, De quibusdam novis plantarum specielus. Bononiae 1835.4. Hooker, lcones plantarum. London $1837 \mathrm{sqj} .8$.

Endlieher, Iconographia generum plantarum. Vindobonae 1838. 4.

Reliquiae Schraderianae. Halle 1838. 8.

Viviani, Memoria sopra aleuni plagi in botanica. Milano 1838. 8.

Miquel, Commentarii phỳtographici. Lugduni Batavorum 1838-1840. folio.

Corinaldi, Notizie storiche della accademia Valdarnese. Pisa 1839. 8.

(Endlicher el Fenzl) Novarum stirpium decades I-X. Vindobonae 1839. 8 .
Bentham, Plantae Hartwegianac. Londini 1839 squ. 8.

Bongard, Deseriptiones plantarum novarum. Petropuli 1939. 4.

Marsili, Notizie inedite. Padova 1840.8.

Miquel, Sertum exoticum. Boterdam 1842. royal 4.

Parlatore, Plantae novac vel minus notae. Paris 1842.8

Bertoloni, Miscellanea botanica. Bononiae 1842-1846. 4.

Bentham, The Botany of the voyage of II. M. S. Sulphur. London 1844. 4.

Fielding et Gardner, Sertum plantarum. London 1844 sị. 8.

Presl, Botauische Bemerkungen. Prag 1844.4.

Kirschleger, Notices botanirnes. Strasslurg 1845. 4.

Raffeneau-Delile, Éelaircissemens sur diverses parties de la botanique. Uontpellier 1845.8 . 


\section{INDEX NOMINUM}

\section{ADJUTORUM, BiograPhORUM, COLLABORATORUH, COLLECTORUM, COMNENTATORUM, CONTINUATORUM. EDITORUi, NAVARCHORLII NAYUMOUE, PEREGRINATORUM, PICTORUM, PRAEFATORUI, PSEUDONYMORUY, PRAESIDUM, RESPONDENTIUII, SCULPTORUM, TRADUCTORUM, ALIORUMQQE **).}

\section{Literae singulae.}

C. A. IR. Caesarangustanus vide Asso $321-322$. J. Fr. B. = Bourgoing 560 .

V. D. $\mathrm{C}^{* * *}$. vide Chastenet 1807.

$\mathrm{D}^{* *}$ (le Citoyen $\mathrm{D}^{* *}$ ) vide Deshayes $249 \mathrm{~S}-2500$ D. vide Dupont 2838.

N. F. D. vide Nicolas Facio de Duillier 3089.

L. B. F*** vide Louis Benj. Francoeur 3314.

M. F. H. $=$ Mortin Fogelius Hamburgensis 4990

J. v. K. = Kviakousha 5477.

L. B*** vide Le Berryais 5603 .

J. B. de M. vide Montbrison 7116 .

M. vide Motty 7247.

J. G. 0. = Joh. Gollfr. Olearius 7628 .

M. A. $P^{* *}=$ A. Puvis 8263 .

$\mathrm{D}^{* * *}=$ Dezallier dArgenville $9055-9056$

Dr. W. Y. W. $=$ Waldschmiedl 9673

F. P. $=$ Franz Peters 9954.

G. V. e.P. $=$ Gaspare Vaccari 10613.

Chr. Fr. v. $W^{* *}=W_{\text {elling } 11142 .}$

II. F. L ***. vide Anon. 11595

J. L. = Laurent vide Anon. 11596.

$\mathrm{II}^{\text {the }} \mathbf{B}^{* * *}$. vide Anon. 11603

$\mathrm{C}^{* *} .=$ Clairville 11622 .

M. R. T. P. D. S. M. $=$ Triquel 11652

J. G. vide Anon. 11700.

L. H. P. $\mathrm{T}^{* * *}=$ Hanin 14710 .

J. C. B. $=$ Joh. Chr. Beckmunn 11720 .

Aasheim vide Ronthoell 8768 .

Ab Agris vide Fesling 10717.

Ah Altemari vide Donalus $2684-2685$.

Abano vide Petrus de Abano 7949-7950

Abel vide Brown 1367. 1384.

Abel vide Reiller 8473-74.

Ibendroth vide Giseke 3666 .

— vide Anon. 11846

Abercrembie vide Mnue 6686.

Ab) Herto vide Huerto 4758 .

Abildgaard vide Bibl. Banks. HIJ. $4 z 6$.
Ab Ucria vide Ucria $\uparrow 0567$.

Abu Mansur Mewafik vide Seligmann 9551.

Acerbi vide Morelli 7152.

Aclıard vide Bibl. Banks. IlJ. 432. 438.549.

Acharius vide Linne 6132.

- vide Anon. 11827. vide Bibl. Banks. III. 343 .

Acidalius vide Scholz 9245.

Ackerman, J., vide Osgood 7666 .

A Clericis vide Baier 405 .

Acoluthus vide Bibl. Banks. III. 406 .

Acerambonus vide Theophrastus 10167 .

Acosta vide De l'Ecluse 2411. vide Huerto $475 \mathrm{~S}$.

Acrel, Erik, vide Thunberg 10276. J. G., vide Lundmark 6368 .

Adam vide Dioscorides, p. 334.

Adams vide Ulloa 10572.

Adanson vide Cuvier 2105.

—_ vide Maralt 6494. - vide Bibl. Banks. III. 217, 301. ¿08. 410.414 .530 .

Adlerstam vide Ledebour 5636 .

Aejmelaeus vide Thunberg 10242. 10250.

Aclvebemes vide Roberg 8618 .

Aemilius Hacer vide Macer 6385.

Aesculapius vide Hildegardis $4458-4459$.

Aizelius, Adam, vide Fries 3404 .

- vide Linné 6149 .

\section{80 .}

J. A. vide Linné $6139-6140$.

Agardlı vide Lindblom 5907. vide Linne 6152.

vide Betzius 8504.

_ vide Sprengel 9842.

- vide Sicartz 10016.

Agassiz vide Buchlond 1502 .

- vide Perrollet 7892.

Agnetlller vide Linné 5978.

Agoty vide Dagnly 2112-2113.

Agrelius vide Anon. 11827.

Agricola vide Dioscorides, p. 334.

Agris, Ign. ab, vide Vesling 10717.
Agy vide Curier 2106.

All vide Bibl. Banks. III. 500

Allgren vide Heurlin 4445 .

Ahlquist vide Thunberg 10280 .

Ajasson de Grandsagne vide Plineus 8082 .

Aigue vide Aquaeus $258-239$.

Aimen vide $B i b l$. Banks. Ill. 425.

Aiten vide Bauer 571.

- vide Ellis 2963.

Akerman vide Trozelius 10512.

Alander vide Limné 6094.

Albertus Maguus vide Anon. 11849.

Albrecht vide Bibl. Banks. IIJ. 380. 399. 403 $408,432,545$.

Alcesto vide Brown 1367.

Aldiuus vide Castelli 1733-1741

Aldrevandi vide Crassus 2047.

- vide Legati 5692.

vide Montalbanus 7112.

Aldus vide Dioscorides 11497-11498

Alefeld vide Bibl. Banks. 111. 359.

Alexander, navis, vide Broien $\uparrow 369$. vide Ross 8735.

Alexander Benodictus vide Plinius 8076 .

Alexandre vide Bastien 546 . vide Anon. 14626

Alexandrinus vide Cyrillus Alex, 2107 .

Altredus vide Meyer 6866 .

Al zéen vide Kalm 5107.

Alire vide Raffenenu-Delile $8304-8314$

Allamand vide Bibl. Banks. 111, 35.

Allieni vide Buniva 1557. - vide Valle 10639. vide Bibl. Banks. III. 80. 109. 149.245.

Aln vide Linré 6128.

Almeloveen vide Bheede 8540 . vide Bibl. Banks. [1]. 179

Alpinus vide Huerto 4758 .

- vide Vesling 10715

Alsarius vide Rubeus 8813

Alsted vide Rosenbach 8727

Alsten vide Linné 5979.

—_ vide Bibl. Banks. III. 392.

Alstreemel, Clas, vide Bibl. Banks. HI. 323.

; Additu sunt nomina autorum, quarum commentarioli ex Actis socjetatum et Diariis in Bibliotheca Bauksiana indicantur. 
Alstruemer, Jolın, vide Bibl. Banles. Jll. 628. Patrich, vide Bibl. Banks. Hl. 627

Altena vide Richard 8550 .

Althans vide Muenster 7307 .

Althof vide Murray 7340 .

Allomari vide Donatus ab Allomuri 2684-2685.

Alvalat vide Bibl. Banks. V. 103.

Alvares da Silva vide Bibl. Banks. Ill. 569.

Amanu vide Linné 6065.

Amans vide Saint--Amans 8925-8929.

Amatus Lusitanus vide Dattioli 6655, 6663. vide Dioscorides, p. 334.335.

Amberise vilie Bacon 394

Ammann, Joh., vide Bibl. Barkis. III. 35. 220. 935. 270.273.276.306.319.350. 407. Paul, vide Bibl. Banks. 111. 332.

Ammonius vide Agricola 97.

Amoreus vide Ciccurellus 1854 vide Hoffmann 4575

vide Bibl. Banks. Ill. 201. 20y. 369 599.

Anorim Castro vide Bibl. Bunks, IJI. s90.

Amorosi vide Delinhardl $\mathbf{2 3 3 9}$.

Amsterdam vide Cornelius v. Amsterdim 1991

Andlanus vide Brunfels 1424-1425.

Andreas Belluis. vide Yalcurenghi 10623.

Andreoli vide Moretti 7173 .

Andrew vide Richard 8550 .

Andrews ride Twamley 10563 .

Indromaehus vide Ampsing 208

vide Charas 1806 vide Pietzsch 8023.

Andry vide Mandiralt 6459 .

Anelli vide Horetli 7179

Angar vide Achard 23

Angelo vide Anon. 11723

Anglicus vide Burtholomaeus Anglicus 511.

Anglois vide $L^{\prime}$ Anglois $\mathbf{5} 552$.

Alikarcrona vide Bibl. Bunks. JJJ. 268.

Anonymi ef. Thesaurus p. 236-239. carmen vide Macer 6385 vide Nicander 7479

Inthophilus vide Mueller 7280 .

Anthropo-lJago-Botanoplilus vide Anon. 11732.

Autic vide Basc 1154-1157.

Antonius Musa vide Apulejus 257. vide Brasavola 1235.

Aplonin vide Linne 6111.

Apicius vide Dierbuch 2578 .

Apinus vide Bibl. Banks. III. 407.

Apononsis vide Petrus de Abano 7049-7950.

A Poot vide Rheede 8540.8542 .

Appianus vide Trille" 10474

1 Quereu vide Duchesue 2759.

Arringhelli vide Hales 4053 .

Arduino, Luigi, vide Bibl. Banks. Jll. 583

vide Nace 7539

Arduino, Pietre, vide Bibl. Banks. 1ll. 239.583.

Arenius vide Mennander 6782 .

Aretius vide Cordus 1982.

Argentelle vide Robillurd 8635 .

Argenville vide Anon. 11631.

Arias y Costa vide Sandulio 8983

I Ripa vide Ripa 8592.

Aristateles (Pseudo-) vide Scaliger 9044 .

vide Nicolaus Dumasc. 7491. Problemata vide Hessus 294.

vide Brasuvola 1238

Armistead vide Hall 4062 .

Arnold, J. Chr., vide Bonnet 1105

Samuel, vide $\mathrm{H}^{\top}$ edel 11101.

Arnott vide $1 H^{2}$ alker-Arnott 10920-10921.
Amolt vide Greville 3871 . vide Iloolier 4665.

vide Killel 5246. vide Wight 11219

Arnz vide Anon. 11780

Aromatariis vide $J$ ung 4992.

Arrabida vide l'elloza 10696

Arrot virle Bibl. Banks. Ill. 475.

Artedi ville Zeipel 11420.

Arligues vide DArtigues 2146.

Aschan vide Thunberg 10256.

Aschenborn vide Cartheuser 1713.

Ascholin vide Hellenius 4323.

Aslaan vide Ascham 316.

Askelöf vide Detzius 8499.

Aspegren vide Kalm 5117.

Aspelin vide Linné 6028.

Astrelabe vide Dumont 2801-2802.

- vide Montagne 7097 . vicle Bichard 8557.

Ast vide Dioscorides $11535-11536$

Astrue vido Bibl. Banks. Ill. 381.

Asulanus vide Dioscarides 11498 .

Atrociauns vide Macer 6385 .

Atti vide .Malpighi 6449

A Turre vide Turre 10557-10559.

ttzendorf vide Fischer vor Atzendorf 3222.

Aube, corvette, vide Raoul 8351 .

Aubenton vide Millet 6942 .

Aubert Du-Petit-Theuars vide Feburier 3115.

vide Flourens 3248 .

Aubriet vide Desfontaines 2494.

vide Vuillant 10620 .

Aubry, Jean, vide Alyon 178.

Aucher-Eloy vide Schubert 9355.

Audouin vide Anon. 11627.

Auersperg, Gral, vide Zallinger 11391-11394.

Aufschlaeger vide Kirschleger 5232.

August von Sachseu vide Sickler 9621.

Auisson vide Roberl 8632

Aureli vide Ferrari 3166

Aurell vide Thunberg 10301

Ausonius Popma vire Varro 10665.

Austen vide Bacon 394.

Austin vide Linné 6138.

Avantius Rhodiginus vide Fiera 3156 .

Avé Lallemant vide Marlius 6611

Avellan vide Gadd 3460

Avellar vide Brotero 1337.

Avellino vide Pasquale 7794

Averrhoes vide Brunfels 1424

Avitus Magnus vide Månsson 6476.

A vrigni vide Loeuillart 6223.

Axenborg victe Thunberg 10301

Azconovieta vide Bibl. Banks. III. $\$ 34$.

Baade vide Bibl. Banks. Jll. 123.

Babel vide Sprengel 9835.

Babington vide Balfour 449-450.

- vide Polter 8175 .

Baceius Baldinus vide Baldini 442 .

Bach vide Jirtgen 11319.

Bachelot vide De la Pylaie 2389-2390.

Baclimaun vide Rivinus $8611-8617$.

Bachovius vide Buier 414

Bacon, Francis, vide Austen 358

Bacon. Vincent, vide Bibl. Banks. III. 550 .

Badcoek vide Bibl. Banks. Ill. 388.

Badier vide Bibl. Banks. Ill. 473.635.

Badus vide Baldus 446-447.

Baech vide Linrie 6142. vide Bibl. Barks. J15. 303.539.
Bace vide Gmelin 3693.

Baeumlin vide Bibl. Banks. III. 230.

Bảgenlıolm vide Thunbery 10293.

Bali vide Plenck 8074.

Baier vide I'eiss 11133

- vide Bibl. Banks. III. 266.

Baillière vide Anon. 11608

Baird vide Peschier 7904 .

Baisse vide De la Barsse 2346.

Bake vide Bondl 1095.

Baker, George, vide Bibl. Banks. Ill. 511.

Baker, JJenry, vide Bibl. Banks. III. 359.391 398.

Balan vide Anon. 11685. 11770

Balber vide Locher-Balber 6196

Balbis vide Collu 1911.

- vide De Candolle 2298. vide Nocca 7538.

Baldinger vide Ludwiy 6324 .

Balland vide Allent 151.

Ballard vide Sniadecki 9729.

Ballon vide Anon 11688.

Balsamo-Crivelli vide Jussieu 5021

Bamboli vide Parlatore 7559.

Bandini vide Nacander 7478 .

Banesius vide Naironi 7379 .

Banister vide Bibl. Bunks. III. 185.

Banks vide Curtis 2101.

— vide Cuvier 2105.

- vide Dryander 2736-2737.

vide Duncan 2826 .

-.- vide Housloun 4728.

— vide Kaempfer 5083 .

- vide Roxburgh 8786.

Barba vide Bibl. Banks. III. 441.

Barbarus vide Brunfels 1423.

Barek vide Linne 6047 .

Barelle vide Bayle-Burelle 612-616.

Barker Webb vide Webb 10999-11002.

Barkhausen vide Barchhausen 475.

Baron vide Bibl. Banks. JIl. 644.

Barrell vide Bibl. Banks. III. 329.

Barrington vide Bibl. Banks. llI. 135.

Barthelemy vide Jussieu 5069.

Bartlılinus vide Gesner 3596 . vide Grube 3929. vide $B$ bl. Barkis. III. 73 sqq.

Bartling vide Schomburgh 9248.

Bartolozzi vide Bibl. Banks. III. 225. 368. 413. 425. 638 .

Barton, B. Sm., vide Bibl. Banks. Ill. 290.

Baruerde ville Arrieta 309.

Bassaeus vide Tabernaemontanus 10037

Bastard, W., vide Bibl. Banks. 111. 630 .

Baster vide . Miller 6938.

vide Bibl Banks. Ill. 401.557.

Bastien vide Alexandre 144.

Batard vide Bastard $539-541$.

Batini vide Areon. 11651.

Batsch vide Bibl. Banks. III. 13.

Baudouin vide Howel 4732 .

Baudrillart vide $D_{\text {e }}$ Siltestre 2508 . vide Hartig $\$ 151$.

Baver, Ferdinand, vide Endlicher 2986. vide Flinders 3240. vide Lindley 5923. vide Siblhorp $961 \mathrm{~S}$.

Bauer, Franz, vide Jlooker 4666 . — vide Ker 5170 . 
Bauer, J. Fr., vide Bibl. Banks. III. 439.

Bauhiu, Gaspard, vide Anguillara 233. vide Dioscorides, p. 334. vide Hagenbach 4039 vide Jonequet 4935. vide Mallioli 6663 . vide Morison 7196. vide Tabernaemonlanus 10036

Bauhin, Jean, vide Gesner 3606 . vide Morison 7196. vide Rocordus 864 4.

Bauhin, Jean Gaspard, vide Eglinger 2919.

Baulin, Jerone, vide Tabernaemontanus 10036.

Baumes vide rincens 10759.

Bautzmann vide Bibl. Banks. III. 406 .

Baxter vide Brown 1376.

Bayle-Darelle vide $M_{u}=\bar{z} u c a 106705$.

Bayrlandt vide Ortolf v. Bayrlandt 7663.

Beal vide Bibl. Banks. Ill. 376. 570.571.

Bealson vide Boxburgh 8787 .

Beaufort vide Magund 6408-6409.

Beaumes vide Brun des Beaumes 1421.

Beaumont vide Elie de Beaumont 2958.

Beaumont vide Kiggelaer 5211.

Beaupré vide Gaudichaud-Beaupré 3527-3528.

Beauvais vide l"incentius 10760 .

Beauvois vide Bibl. Banks. III. 442. 444. - vide Cuvier 2105. vide Palisol-Beauvois 7705-7711.

Bechnann vide Sturm 9981 .

Beck vide Schuebler 9387.

Becker, Chr. Ludw., vide Gesner 3612.

Becker, Daniel, vide Blochwit 942.

Becker, Eb. Pl., vide Bibl. Banks. ill. 536.

Becker, Joh. Konr, vide I'alentini 10635.

Becker, S. J., vide Fasch 3107.

Beckius vide Wedel 11099.

Beckmann, Johann, vide Linné 5978.

583. 592.

Beckmanı, Joh. Chr., vide Anon. 11720.

Bedford, Duke of, vide Davy 2158. vide Forbes $3265-3268$. vide Hooker 4664 . vide Sinclair $9665-9666$.

Beechey vide Hooker 4665.

Beek vide Dijk 2630.

Beer, Leonhard, vide Anon. 11729.

Behlen vide Bechslein 626-627.

Behr vide Muenzel 7311.

Behr vide Olto 7683.

Behrens vide Berens 729.

Beier vide Friderici 3375 .

Beilschmied vide Brown 1375. 1384. - vide Cunninghum 2081 vide Humboldt 4783. vide Lindley 5933. 5938.

- vide Watson 10991. - vide Wikstroem 11226. vide Winch 11288.

Beima vide Humbold 4787 .

Beithius vide De lEcluse 2409.

Belcher vide Bentham 722.

Bell vide Rodon y Bell 8654 .

Bella vide Dalla Bella 2193.

Bellart vide Matthews 6654 .

Belienden Ker vide Ker 5167-5171.

Belleval vide Amoreux 200. - vide Broussonet 1348. - vide Dorthes 2697. vide Gilibert 3635 . vide Latourrette 5577.
Bellonius vide Belon $694-697$. vide De l'Ecluse 2411.

Bellovacensis vide Fincentius 10760 .

Bellus vide De l'Ecluse 2410. - vide Pona 8151.

Belonius vide Belon 694-697.

Benedietus vide Benedelli 704.

vide Plinius 8076 .

Benevides vide Brotero 1337.

Bengel vide Gmelin 3706.

Ben Ilonain vide Meyer 6866 .

Benigne Le Roy vide Anon. 14645.

Béninga vide Lantzius-Béninga 5558.

Benistant vide Oelhafen 7607.

Bennet vide White 11195 .

Benoist vide Bartrum 530 .

Bentlıam vide Belcher 671.

- vide De Candolle 2256.

—_ vide Endlicher 2992. - vide Knight 5287.

Bentsch vide Schuebler 9378 .

Benvenuti vide Bibl. Banks. III. 428.

Beraud vide Bibl. Banks. III. 634.

Berchen vide Bibl. Banks. III. 622 .

Bercheur vide Berchoire 725.

Berchore vide Berchoire 725.

Berchtold vide Ficber 3179. - vide Opiz 7644. vide Pfund 7980.

Berendt vide Goeppert 3758 .

Berens, J. Fr., vide Murray 7341.

Berens, Reinhold, vide Ludwig 6324.

Berg, C. F. W., vide De Candolle 2251. vide Thouin 10223.

Berg, P. U., vide Thunberg 10239. 10244. Bergantini vide Savustuno 9011.

Bergen vide Bibl. Banks. IIl. 81. 293. 642.

Berger vide Dumont 2798.

Berger vide Linné 6066.

Berggrén vide Thunberg 10295.

Berghuis vide Isink 4964 .

Bergier vide Geoffroy 3569 .

Bergius, Bengt, vide Blom 943.

357. vide Bibl. Banks. Ill. 298. 356. 357.

—— P. J., vide Linné 6036. 6105. vide Bibl. Banks. Ill. 212 sqq.

Bergmant vide Goebel 3732.

Bergner vide Trog 10496.

Bergonzoli vide Moretti 7174 .

Bergrot vide Celsius 1779.

Bergsma vide Beek 647.

- vide Martius 6614.

- vide Trappen 10401.

Berkeley vide Bartholomaeus A. \$11.

Berkeley vide Hooker 4659.

vide Smith 9724.

Berkhey vide Bibl. Banks. III. 643.

Berland vide Vonière 10662.

Berlandier vide De Candolle 2256.

Berlin vide Linne 6112.

Bernard vide Cauture 2024.

Bernardi vide Bivonu-Bernurdi 913-916.

Bernardin vide Saint Pierre 8952-8954.

Berndisun vide Bibl. Banks. IlI. 596.

Berneaud vide Thiebaut de Berneaud 1017610183.

Berner vide Bibl. Banks. III. 367.

Berniz vide Bibl. Banks. Ill. 214.550.

Beroaldus vide Anon. 11856-58.

Beronius vide Stumpf 9975.
Berryais vide Le Berryars 5603.

Bertero vide Colla 1912.

$\longrightarrow$ vide Montagne 7073.

Berth vide Kniphof 5991.

Berthelot vide Irebb 10999.

Berthollet vide Cuvier 2105.

Berti vide Baruffaldi 532 .

Bertoloni vide De Candolle $9293.231 \mathrm{R}$ vide Linné 6158.

Bertuch vide Dennsted 2445 . vide Guenther 3943. vide Pulsche 8261 .

Berzelius, Bengt, vide Linne 6087 .

Bessa vide Du Hamel 2788.

— vide Loiselen 6238 .

— vide Malo 6445.

_- vide Noiselte 7557 .

Besler vide Widmann 11205.

Besnier vide Toumefort 10387

Besser vide Baehmer $102 \mathrm{~S}$.

Best vide Richard $\$ 550$.

Betlune, Duc de Sully, vide Du-Peyrat 2836 .

Betiken vide W'edel 11098.

Betti vide Belus 699.

Beudant vide Jussieu 5021.

Bevilacqua vide Bibl. Banks. III. 430.

Bewick vide Tharnton 10211.

Beyersten vide Bibl. Banks. III. 547.

Beze vide Dodart 2648.

Bianchini vide Vellori 10727 .

Biasoletto vide Comelli 1935.

Biberg vide Linné 6030 .

Bidet vide Du llamel 2780.

Bidloo vide Commelyn 1944.

Bieber vide $B$ iber $\$ 64$.

Bieberstein vide Murschall $6530-6533$.

Bieler vide Weinmann 11124 .

Bielitz vide Heister 4309 .

Bjelke vide Bibl. Banks. III. 595. 598. 600.

Bjerkander v. Oedmann 7605. 420. 422.429 .

Bjerkén vide Thunberg 10247

Bigot vide .Horogues 7207.

Bigotherius vide Bigoutier 876

Bilderdyk vide Brissean-Mirbel $1 \geq 91$.

Bilfinger, Chr. L., v. Gmelin 3714.

Bilfinger, G. B., vide Bibl. Banks. III. 372. 402. 404.

Bilhard vide Wedel 11059.

Billardière vide De la Billardiere 2347-2350.

Billberg vide Aron. 11827.

Björkstrom vide Gudd $345 \overline{7}$.

Björno vide Pauli 7815.

Biondo vide Theophrastus 10157.

Birkbolz vide Niemann 7499 .

Bischof, Gustav, vide Nees v. Esenbeck 7420.

Bischoff vide Nees v. Esenbeck 7445.

vide Roehling 8658 .

Bischoff vide Schmidel 9483.

Bisignano, Principe, vide Tenore 10097.

Bismarck vide Spies 9816 .

Bjuur vide Linne 6048 .

Bivona-Bernardi vide Parlntore 7752.

Biwald vide Linné 5997.

Blackburne vide Neal 7393.

Blakwell vide Groening 3916.

Blagden vide Crell 2048.

Blair vide Brudley 1220.

- vide Bibl. Bunks. III. 390.447.

Blankenhorn yide Nebel 7403

Blane vide Bibl. Banks. Ill. 202.649. 
Blamuant vide Semebier 9562.

Blanvillain vide scrofuni 9513 .

B] aver vide Nolin 7561 .

Bleeck vide Eysel 3069 .

Blegny vide bedu 2330 .

Bloch vide Bibl. Banks. III. 53\%.

Blom vide Bergius 762.

- vide Linne 6102.

vide Bill. Bunlis. 1ll. 320.545 .625

Blomlserg vide Kolm 5124.

Blond vide Leblond $5606-5611$.

Blos vide Des Blos 2480 .

Blossom, navis, vide llooker 4665 .

Bloxanı vide Potter 8175 .

Blume vide Nees v. Esenbeck 7428

Blumenhach viele Bruce 1391. vide Rudolyhi 8844. vide Bibl. Banks. 111. 124.

Blumnbergre vide Thunberg 10239.

Blumer-Heer vide Heer $\$ 271$.

Blumliof vide Euphrusen 3049

Blytl ville Fries 3380 .

Bobartius vide Morison 7198 .

Boccene ville Morelti 7161.

- vide Bibl. Banks. 111. 149.

Bock vide Brunfels 1423.

Bodaeus a Stapel vide Theophrustus 10163.

Bodard vide Santi 8995

Boddaert vide Bibl. Banks. III. 47. 199.

Bodei vide Brignoli 1281.

Bodiu vide Soulange-Bodin 9758-9763.

Boelier vide Bibl. Bunks. Ill. 172.

Boechli vide Bonnel 1105 .

Boeeler vide Henninger 4362 .

- vide Hermunn 4398 .

Boelumer, G. R., vide Biackwell 920.

- vide Knorr 5304. vide Ludurig 6324. 6329.

Boeliner, $\mathrm{Pl}$. A. vide Hoffmann 4569 .

Doerhaave vide Marsigli 6538.

- vide Panzer 7736.

- vide Schultens 9405.

_ vide l"aillant 10629.

Beerner, Fr., vide Macer 6385.

Boerner, Nic, vide Fick 3177.

Boetius de Boot vide Passaeus 7796.

Boetliger vide Vater 10675 .

Begdanus vide Sethi 9598 .

Bogenlard vide 1 irtgen 11319.

Bolnnsacls vide Bıbl. Banks. III. 639 .

Bojer vide Boulon 1209

Bois vide Dubois $2738-2740$.

Boisdural vide Loiseleur 6245.

Boitard vide Dubois 2738.

vide Noisette $7559-7560$

Bolstatten vide Allertus , 129.

liolton vide IVatson 10994.

Bomare vide l"almont 10649

- vide Anon. 11629 .

Bombast rou Ilolienheim vide Paracelsus $7341-$ 7744 .

Bumme vide Bill. Banks. III. 407.

Bou vide Bul. Banks. III. $59 \mathrm{~s}$.

Bona vide Dulla Bora 2125.

Bonafuus vide Florio 3242 .

- vide .Holtard 7246.

vide Serres 9591

vide Villa de Montpascul 10745.

Bunanieus vide Roptsus 8354 .

Bonato vide Pontedera 8160

Bonde vide Bill. Banks. IIl. 383.

lougiovanni vide Bibl. Banks. 11I. 553 .
Bonite vide Montagne 7100. vide I'aillani 10618.

Bonnefons vide Anon. 11670

Bonnet vide Desvuux 2532.

vide Trembley 10443.

vide Bibl. Bunls. 111: 383. 394.642.

Bonpland vide Hooker 4645.

— vide Humboldt 4772-4750. vide Kunth 5452 .

Bontius vide Piso 8036 .

Bonvoisin vide Bibl. Bunks. III. 434.

Boot vide Boètius de Bloot 1040.

Booth vide Lehmunn 5708 .

vide Siemers 9645 .

W. B., vide Chandler 1801 .

Borbonius, Pr. Juventutis, vide Gussane 39873988 .

Borelı vide Bang 463 .

— vide Forsyth 3296 .

Burchlıasen vide Borkhausen 1133-1137.

Borda vide Bibl. Banks. IlI. 422.

Borde vide De la Borde 2351 .

Burde vide Ruffeneau 8307.

Borellus, Joh., vide Malpighi 6449 vide Nebel 7399.

Borellus, Petrus, vide Borel $\$ 129$.

Borkhausen vide Dietrich 2619.

- vide Guenderrode 3941-3942.

vide Mueller 7283. vile Boellling 8660 .

- vide Bibl. Banks. III. S9. 152. V. 65 $-104$.

Bornemann vide Hoffmunn 4568 .

Borrich vide Bibl. Banks. Ill. 73. 345.402.

Borromée vide Damont 2802 .

Bory de St. Vincent vide Belanger 670 .

- vide Montugne 7094 vide Anon. 11627. 11641

Bose vide $D e$ Silvestre 2505.

vide Paris 7746.

vide Poileau 8120.

vide Bill. Banks. 111. 237. 291. 327. 357.

Bose, E. G., vide Blachwell 920.

vide Zieger 11440

Bose, G. M., vide Bose 1170.

Base, haspar, vide Pein 7847-7S48

- vide Probst 8234. vide Wehmann 11106

Bosquillon vide Cullen 2077.

Bossart vide Scholler 9241

Bosse, A., vide Dodart 2648.

- vide Robert 8632.

Bosse, J. F. W. , vide Henshull 4373

Bosse, harl, vide Ritter $\$ 602$

Bosseck vide Bose 1161.

- vide Pla $\$ 055-\$ 056$.

Bostangi-Bachi vide holand $8699-8701$.

Bostichi vide Soderini 9734.

Botanoplilos vide Richter $\$ 576$.

Botanophilus remanus vide Maratt 6494.

Botello vide Bibl. Bunks. Ill. 569.

Bouclue vide Schlechtendal 9148.

Boucher vide Bibl. Banks. III. 540 .

Boudon vide Suint-dinans \$925-\$929.

Bouillet vide Lecon 5629 .

Bouillon de la Grange vide Babl. Bankis. III. 435. I. 59.93 .95 .

Boulanger vide Buch $1455^{\circ}$.

Boulard vide Pulteney $\$ 2054$

Boulaye vide Herlet 6807

Boulelouc vide Bibl. Banks. III. 407 sqq

Boumann vide Sinclair 9670.
Buurdelot vicle Collet 1920 .

Buurgeois vide $D_{e}$ la Borde 2351.

Bourgoing vide Balsch 560 .

Boutelou vile Herrera 4411.

Bouton vile Bojer 1057.

- vide Desjardns 2501.

Bousron-Clnarland vide Bussy 1596

Buuvier vide Bill. Banks. 11I. 534.

Bore vide Decuisne 2174

Bowie, James, vide Prilchard $82 \div 9$.

Bove vide Luetke 6358.

Buyle vide Greio 3874 .

Braad vide Bibl. Banks. Ill. 360.697

Bradley vide Anon. 11553. 11661.

- vide Bibl. Bunks. 111. 358.373

Braitenbaclı vide Baumgarten 605

Brames vide Whitley 11198 .

Bramieri vide Bibl. Banks. Ill. 629.

Brand vide Linné 5999.

Brander vide Hellenius 4322

Brandis vide Molina 7047 .

Brandstrom vide Trozelius 10510.

Brand vide Hayne 4227-4228

Branston vide Loudon 6983.

Brauzell vide Thunberg $1024 i$

Brasavola vide Mundella 7318

Brassai vide Lindley 5940 .

Braun, Al., vide Braruis 1241-1242

Brauu, Nic., vide Tubernaemontanus 10036

Braunschweig vido Hieronymus 4457.

vide Dioscorides 11536.

Brauser vide Agricala 96.

Bray vide Hurtius 6604.

_- vide Silernberg 9916.

Brébisson vide De Brébisson 2161-2164.

Breda vide Jugenhousz 4\$9S 4899 . vide Linné 6002.

Bredin vide Bibl. Bunks. V. 96.

Breitenbacl vide Baumgurken 605 .

Bremer vide Limué 6061 .

Brera vide Bonato 1092-1093.

Breten vide Lebreton $5616-5617$.

Bretonnerie ville De la Bretonnerie 2352.

Bretnor vide Sula 8956 .

Breuel vide Boehmer 1026

Brevil vide Dubreuil 2741

- vide Girardin 3658

Brevet vide Bibl. Bunks. III. 230 .

Brejdenbach vide Baungarten 605

Breyn vide lleluing 4347 .

- vide Reyger 8533 .

- vide Blbl. Banks. III. $145 \mathrm{sqq}$

Brichenden vide Bibl. Banks. 1. 99 .

Brideri vide Bridel-Brideri $1270-1272$.

Briganti vide lluerto 4758 .

- vide Ilonardes 7058

Briguoli vide Linne 6162 .

- vide Tagliabue 10042.

Bring vide Lidbeck 5866 .

Brion vide $P_{a s t a} 7802$

Brisseau-Xlirhel vide Brown 1384

— vide De la Jarek \pm 379

- vide Rachard 8562 .

Brissot vide Brisseut-Mirbel 1288-1296.

Broca vide Pichon 8009.

Broeq vide Le Brock 5618.

Brodin vide Elfuring 2956

Brodturann vide Hegelschweller 4276.

Brolıon vide Duchesne 2759.

Brandeau vide $D_{e}$ Brondeun $2165-2167$.

Brongniart vide Bory 1451 .

vide Broun 1384. 
Brongniart vile Demidor 2436. vide DOrbigny 2690

Brookes, R., vide Quelus 8273.

Brosse vide De lu Brosse 2353-2359. Brotbequius vide Brotbeck 1336 .

Bretero vide Fonseca Benevides 3260.

Brotherton vide Bibl. Banks. Ill. 366.

Brolier vide Plinius 8078.

Broughton vide Edwords 2908 .

Breuneus vide Browne 1390.

Brousse vide De la Brousse 2360-2361.

Broussonet vide Belleval 694. - vide Cuvier 2405.

- vide De Candalle 2221.
vide Limne 6007.
Browallius vide Anon. 11647.

vide De Candalle 2221.
vide Limné 6007 .
vide Anon. 11647 .
Browallius vide Limie 5989.6012

vide De Candalle 2221.
vide Limné 6007 .
vide Anon. 11647 .
Browallius vide Limie 5989.6012

Browallius vide Limie 5989.601
Brewn, Robert, vide Aitan 109.

- vide Bauer 570

vida Bennet 709 .

vide Denhum 2440. vide Flinders 3240. vide King 5217 . vide Rass 8735 . vide Schultze 9438. vide Scaresby 9509. vide Tuchey 10523.

Hruce vide Patersan 7803 .

vide Stachouse $986 \mathrm{z}$.

vide Bibl. Banks, III. 539.

Bruce, Robert, vide Bibl. Banks. Ill. 413.

Brueckmann vide Heister 4309.

Brueckmann vide Severinus 9604 . vide Spies 9815

vide Bibl. Buuks. III. 398.

Bruechuer vide Larignann 5553.

Brugières vide Cuvier 2105.

Bruhier vide Lemery 5750 .

Brunelli vide Bibl. Banks. III. 602.

Brunellus vide Cyrillus 2107.

Brunfels vide Diascorides, p. 333

vide Bock 977.

vide Fries 3413

Brunner vide Bibl. Banks. III. 429.

Brunnloff vide Brignoli a Brumnaff 1279-1289.

Brunnew vide Hahnemann 4048.

Brunstlowygk vide Hieranymus 4457.

Brunsvicensis vide Hieronymus 4457 .

Bruyjer vide Morison 7196.

IBrutelle vide L'heritier $5841-5853$.

Bruzelius vide Jaerlin 4908 .

Bry vide Linschotten 6173.

Buchanan vide Daa 2675.

C. vide Hamiltan 4098-4099.

Buchhave vide Bibl. Banks. III. 576. 580 .

Buchheim vide Pereira 7868 .

Buchoz vide Wirsing 11316.

Buckingham vide Chandler 1802 .

Budeus vide Peucer 7965 .

Buechner vide Bibl. Banks. III. 354. 408.

Buek vide Giseke 3666 .

- vide Pursch 8259 .

- vide Anan. 11846

Buettner vide Burchardt 1564 .

Buetuner vide Cana 2082.

Buettner vide Miller 6938 .

Buettner vide Sperling 9794.

Buffon vide Brisseau-Mirbel 1290.

- vide Hales 4053

vide spach 9775 .

—_ vide Bibl. Banks. IlI. 370.421, 591.617.

Buisson vide Dubuisson 2743-2746.

Pritzel, Thes. lit. bot.
Bulliard vide Letellier 5810 .

Bulos vide Davy 2158.

vide Smith 9728.

Bumaldus vide Montalbanus $7101-7115$.

—_ vide Séguier 9534.

Bunge vide De Candalle 2178.

- vide Ledebaur 5641.

Buniva vide Bibl. Banks. Ill. 394.

Burat vicle Aubuissan 347.

Burchard vide Forer 3269 .

Burg vide Linne 6069 .

Burger vide Simonde 9664 .

- vile Zallinger 11393.

Burghardi vide Hamberger 4095.

Burgsdorll vide Reitter $\$ 473$.

vide Bibl. Banks. Ill. $208,419.619$.

Burmanu, Joh., vide Plumier 8091. - vide Rumpf 8874.

- vide Heinmann 11124.

___ vide Bibl. Bunks. III. 299.

Burrmanu, Nic. L., vide Valle 10639. vide Bibl. Banks. JII. 298.

Burmeister vide Taschenberg 10069 .

Burnett vide Stepherssen 9906.

Bushecq vide Dioscorides, p. 335.

Buscali vide Guibaurt 3961 .

Buttersack vide Lohenschiold 6932 .

Buxbaum vide Bibl. Banks. Ill. 34. 76. sqq.

Buxlerl vide Stehelinus 9880.

Buzareinges vide Girou 3662 .

Cachetius vide Mousinus 7251 .

Caclius vide Apicins 249.2578 .

Caetani Dux vide Valente 10624.

Caesalpine vide Baccane 973. vide Fuchs 3424

Caesar vide Nocea 7532.

- vide H'einmann 11123.

Caesaraugustanus vide Assa $321-322$.

Caesius vide Ilernandez 4404 .

Caille vide Mizauld 6986.

Cailliaud vide Raffeneau-Delile 8306 .

Caillié vide Janard 4934.

Caisne vide Decaisne 2169-2175.

Calagius vide Schalz 9245.

Calceolarius vide Calzolaris 1633. vide Mattiali 6661-6662. vide Olivi 7631 . vide Séguier 9538.

Caley vide Brown 1376.

Camara vide Arruda 311.

Cambessedes vide Ferrund 3164 . vide Jacquemont 4814

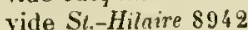

Camellus vide Kanel 5129 vide Ray 8380.

Camerarius, E. K., vide Brotbect: 1336.

Camerarius, Joachin, vide.Maranta 6493. - vide Mattiail 6662. vide Peucer 7965. vide Preu 8219. vide Diascorides, p. 334.

Camerarius, R. J., vide Gmelin 3696. 3704. vide Mezger 6898 . vide Jalentini 10631.

Campbell vide Balfour 449

Campe vide Bibl. Bunts. Ill. 367 .

Campegius vide Champier 1798-1799.

Campi vide Conradıus 1957.

Canal vide Nawadwarshy 7576 .

C. - vide Tausch 10076-10077.

Candolle vide De Candolle 2176-2323.
Cane vide Bibl. Banks. IIJ. 432.

Cantor vide Griffith 3884

Cap vide Lindley 5940.

Capello vide Boccane 974

Capieux vide Batsch 550 .

Cappel vide Nicolai 7487

Carbennière vide Ramond $8343-8344$.

Cardanus vide Scaliger 9045.

Carey vide Raxburgh 8790-8791.

— vide Voigt 10824.

Carini vide Morandi 7136 .

Carl vide Baldinger 437.

Carlander vide Lime 6144.

Carlbohm vide Linne 6053 .

Carli vide Bibl. Banks. III. 591

Carlson vide Thanberg 10254 .

Caronelli vide Bibl. Banks. III. 629 .

Carpenter vide Snan. 11591.

Carpow vide Handwoig 4112.

Carradori vide Bibl. Banks. III. 343.

Carramone vide Bibl. Banks. III. 336

Carrera vide Banfigliali 1100.

Carrichter vide Poppe 8164.

Carrion vide Mantagne 7086 .

Carro vide Dupont 2837

Cartheuser vide Schnekker 9229.

- vide Bibl. Banks. III. 253, 402.435. 593

Carvalhe vide Manteiro 7117.

Caryophilus vide Gurafalo 3504 .

Carystius vide Mizauld 6982.

Casearius vide Rheede 8540 .

Caselius vide Turnebus 10533 .

Casenas vide Castelli 1733.

Casmannus vide Bruyerinus 1441.

Cassebeer vide Pfeiffer 7978 .

Cassini vide Gassin 3792.

Castellylanco (Amatus Lusitanus) vide Dioscorides, p. $334-335$.

Castéra vide Barrous 501.

- vide Bruce 1391.

—_ vide Symes 10031.

- vide Turner 10539

Castiglioni vide Maretti 7175.

Castle vide Bartan 522 .

Catelan vide Strobelberger 9960.

Catherina II. vide Pallas 7717.

Catholica, Princeps, vide Cupani 2085.

Cato vide Roltbaell 8769.

— vide Vettari 10725-10796.

- vide Anan. 11852-11863.

Cate, Hercole, vide Estienne 3043.

Cattley vide Lindley 5923.

Caulinus vide Cavalini 1770-1771.

Caumels vide Roxas Clemente 8783 .

Cavanilles vide Larente 6266 . vide Ruiz $8856 . \$ 862$

——— vide Bibl. Banks. III. 229. 599

Cavendislı vide Cuvier 2105.

Caventou vide Pelletier 7855

Cavelini vide Bibl. Bunks. III. 90, 317, 337, 443.

Cels vide Cuvier 2105

- vide Ventenat 10700. 10702.

- - vide Anon. 11648.

Celsius vide Unonius 10597.

- vide Bibl. Bunks. III. 168. 194

Cenomanus vide Belon $694-697$.

Cervi vide Minuart 6957.

Cesalpine vide Caesalpina 1612-1613.

Cesati vide Friedrichsthal 3379.

Cesi vide Caesius 1614.

— vide Hernande 4404 
Chabot vide Ribl. Banks. IlI. 633. Clabraeus vide Chabrey 1787-1788. Cliabrey ville Bauhin 589. Chaillet vide $D_{e}$ Candolle 2320. Chaleris vide Deschaleris $\mathbf{2 4 8 3}$. Cliauberet vide Chaumeton 1811 Clsamberlayn vide Dufour 2768. vide Anan. 1928.11546. Clıamisso vide Kaulfuss 5147. - vide Kunth 5450 . vide Nees v. Esenbeck 7421 vide Walter 10964

Changeux vide Bibl. Bunks. III. 407.432. Chanin vide Plench 8072.

Channing vide Bibl. Banks. IIl. 466.

Chantrans vide Girod-Chantrans 3660-3661.

Chanvalon vide Thibuult 10175.

Clappellet ville Payen $\mathbf{7 8 3 5 .}$

Chaptal vide Hichaux 6907.

Charas vide $C_{a p} 1678$.

vide Henckel 4351.

Charton vide NIougeat 7249 .

Chartre vide Duchartre 2750.

Chastillon vide Dodart 2648

- vide Robert 8632.

Chaubarl vide Bory 1151-1152.

Chazal vide Webb 10999.

Chazelles vide Miller 6936 .

Chenal vide De la Chenal 2362.

Chenaux vide Dechenaux 2324.

Chênaye vide Delachénaye 2363.

Chêne viule Duchêne 2751.

Chenon vide Linné 6039.

Cheradame vide Hutten 4799.

Clúreau vide Deschaleris 2483.

Cherler vide Bauhin 588 .

Clıesne vide Duchesne $2752-2759$.

Chesuee vido De la Chesnee 2364

Chesnel vide De Chesnel $2325-2326$.

Chevalier vide Sonnini 9755.

Chevallier vide Puyen 7835.

Chiaje vide Delle Chiaje 2422-2425

Chiarellii Ires vide Cupani 2087

Chiavena vide Clavena $\mathbf{1 8 7 0 .}$

vide Sprecchis 9828

Chifletius vide Baldus 447.

- vide Tristan 10486

Chiliani vide Wedel 11086-11087.

Chiolini vide Moretti $\mathbf{7 1 6 0 .}$

Chisaux vide Deschisuux 2484

Choisy vide $D_{e}$ Candolle 2256.

Chomel vide Bibl. Banks. 111. 305. 310.313

Choul vide $D_{u}$ Choul 2760.

Clioulant vido Holl 4623. vide Hacer 6385.

Christ vide Forsyth 3296 .

Christian IV. Rex vide Sperling 9796

Christmamn vide Linné 6010.

Christufori vide $\operatorname{Jan} 4857-4858$

Christophersson vide Hernquist 4407

Churchill vide Stephenson 9906.

Cibot vide Bibl. Brenks. 11I. 351

Cigalinus vide Plinius 8076.

Cirillo vide Bibl. Banks. 1II. 53 :.

Clairville vide $D e$ Clairville 2327 vide Rousseau 8776.

Clapperton vide Brown 1374. 1384. vide Denham 2440.

Claret vide Latourrette $5577-5579$

Clark, Arabella, vide Rennic 8491

_- James, vide Bibl. Bunks. 111. 552. 589 Jolın, vide Bibl. Banks. IIJ. 3 so.
Claubry vide Gunltier 3333 .

Claudius vide Ausius 356 .

Claudius vide Pfun 7970 .

Claus vido Goebel 3732.

Clavena vide Sprecchis $\mathbf{9 8 2 8}$.

Clayton, John, ville Gronovius 3913. Richard, vide De la Croix 2367

Clelland ville Muc Clellond 6382-6383.

Clenen vidé Antz 248 .

Clemente vide Raxas Clenente 8783-8784. vide Ierrera 4411.

Clerc vise Le Clerc $5621-5622$

Clerck vide Linné 5978 .

Clericis vide Baier 405 .

Clewberg vide Hoffuenius 4611.

Cleyer vide Falentini 10632.

C vicle Bibl. Banks. III. 75. 183. 576.

Clifford vide Linné $5981-5983$

Clouet vide Bibl. Banks. IIl. 594

Clotte vide Houton-Fontenille 7253-7257.

Clusius vide De lEcluse 2406-2413.

Clutius vide Cluyt 1879.

Cluzeau vide Ducluzeau 2761.

Coellso vide Bibl. Ranles. III. 569.639.

Coelln vide Linne 6068 .

Colcien vide Bibl. Banks. III. 185

Colin virle Acosia 31.

- virle Alpinus 166 .

- vide Eduards 2912.

- vide IIuerto 4758

— vide Monardes 7058

Colin Nilne vide Milue 6946-6949.

Collet vide Chomel 1839.

Colliander vide Linne 6076 .

Colliander vide Thunberg 10248.

Collie vide Hooker 4665 .

Collin vide Stoerck 9939

Collinson vile Colden 1897.

—_ vide Fothergill 3301.

Colliuus vide Gesner 3601.

Collinutius vide Brunfels 1423

Colonna vide Donato 2683.

C_ vide Hernande $\mathbf{4} 404$.

Colopllonius vide Nicander 7478

Columella vide Fiera 3186.

C_L_ vide Fettori 10725-10726. vide Anon. 11852-11863.

Columna vide Colonna 1931.

Combes vide Anon. 11640.11708.

Commelinus vide Commelyn 1937-1946.

Commelyn, J., vide Rheede 8540 . Kaspar, vide Meriun 6805.

Commerell vide De Commerell $2328-2324$

Commerson vide Anon. 11663.

Comparetti vidle Bibl. Banks. III. 414. V. 87

Concina vide Suffren 9993.

Condamine vide De la Condamine 2365.

Conradisus vide Campi 1668.

Constantini vide La Roque 5564.

Constantinus vide Sealiger 9047

C._ vide Theophrastus 10163. 10167. vide Dioscarides, p. 335.

Contant vide Dioscorides, p. 335 .

Conte vide Leconte 5623

Conteur vide Le Conteur 5624.

Cook vide Farster 3290.

Cooke, Benj., vide Bibl. Banks. III. 395-396. George, vide Loddiges 6207.

Copin vide Achard 23.

Copland vide Anon. 11539.

Coppens vide Mussche 7347

- vide Anon. 11702.
Cer vide Lecon $5625-5634$

Coquebert de Hontbret vide $D_{\theta}$ Silvesire 2507 .

Coquereau vide Hérissaut 4389.

Cocjuille visle Bory 1150 .

vide Brongniart 1324.

Corazzi vicle Monti 7121.

Corlichen vide Burtholamaeus A. 511.

Corda vide Carro 1700.

- vide Siurm 9979.

Cordus, Euriels, vilte Kahler 5084 vide Diascorides 11521

Valerius, vilo Gesner 3607 vide Mellesinus 6763.

et p. 335 .

Corinaldi visle Meneghini 6770-6771.

Cornarius vide Fuchs 3434 . vide Macer $6385^{\circ}$ vide Diascarides 11199. 11527.

Cornelius Celsus vide Celsus 1782.

Corniani vide Bibl. Banks. Ill. 428.

Corronius vide Actuarius 33 .

Corti vide Bibl. Banks. III. 375.

Cortusi vide Schenchius 9100.

Corvinus vide Bater 404 .

Corvisart virle Cuvier 2105.

Coscluwitz vide Buxbaum 1601.

Costa vide Acasta $31-32$.

Coste vide Necker 7406

- vide Willentet 11272 .

Cotereau vide Columella 1933.

Cothenius vite Otto 7675 .

Cotte vide Bibl. Banks. III. 404.

Cottereau vide l'uvasseur 10689.

Couailhac vide Bernard 785.

Couleius vide Conley 2030 .

Couperus vide Bibl. Banks. III. 247.

Courset vile Dumont 2798.

Court vile De la Courl 2366.

Court vide $L_{e}$ Court 5635.

Courtilz vide Descourtil: $2485-24.97$.

Courtois vide Dodoens 2659 .

- vide Lejeune 5727-5728 vide Morren 7218

Cousmont vide Turgat $10529-10530$.

Couture vide Dutrone 2856.

Cowell vide Anon. 11553.

Coxe vide Linne 6142.

- - vide Ramoud 8343.

— vide Stillingfleet 993 .

Cramer vide Fick 3176 .

Crawer vide Fischer 3202.

Crantz vide Ilurtmann 4172.

Crato vide Gesner 3603.

Crausius vide Krause $5395-5399$.

Cremonensis vide Otho Cremonensis 7671 .

Crepulin vicie Agardh 83 vide Wuhlenberg 10895.

Crescentiis, Crescentio, Crescenzi ville Petrux de Crescentiis 7951-7956.

Creveceeur vide Boucher 1186.

Criclıton vide Bibl. Banks. IIl. 519. 333

Crivelli vide Balsama $453-455$.

Croix vide De la Croix 2367.

Crolachius vide Schreber 9325.

Cronstedt vide Bibl. Banks. III. 385, $6 \geq 7$.

Cropp vide Haller $\mathbf{4 0 6 8 .}$

Cruciger vide Cordus 1983

Crusell vide Kalm 5106.

Crusius vide Ditue 2866

Cuba vide Lonitzer 6261 .

- vide Anon. 11876-11906. 
Cubieres ride De Silvestre 2504.

Cuming vide Montugne 7096.

Cunningham vide Brown 1376

vide King 5217.

Cunningham vide Bibl. Bunks. IJl. 183.

Cuno vide Buettner 1536 .

Cupido vide Pepe 7860.

Curteis vide Bibl. Bunks. 641 .

Curtio Trojano di Navò vide Dioscorides 11529.

Curtis vide Batsch 561 .

- vide Hooker 4669.

Curtius vide Le Court 5635. J. D., vide Eysel 3070 . Jes., vide Slevogt 9697.

Cusson vide Anon. 11663.

- vide Bibl. Banks. HI. 488.

Cutler vide Bibl. Banks. Jll. 185.

Cuvier, Fr., vide De Candolle 2205. G., vide Bowdich 1211.

_ vide De Candolle 2307

Cyrillus vide Cirillo 1855

Da Arrabida vide lellozo 10696

D'Abriel vide Linné 6153.

Dit Camara vide Arruda 311 .

Da Fonseca Benevides vide Brotero 4337. vide Fonseca 3260

Da Gama Machado vide Gama Machado 3489

Da Gama vide Nogueira 7554.

Dahlberg vide Linne 6060 .

Dahlgren vide Linne 6120.6126.

D'Aiguebelle vide Aiguebelle 105.

D'Albret vide Albret $13 \mathrm{~S}$.

Dal Corolo vide Covolo 2027

Dalechamps vide Clutenna 1879

- vide Plinius 8076. vide Pons 8154.

Dalla Bella vicle Bella 675 .

Dalla Decima vide Bonato 1092-1093.

Dall' Horto vide Huerto 4758 .

Dalman vile Thunberg 10281. 10304.

Dal Toso vide Toso 10379.

Damascenus vide Meyer 6866 .

Dammien vide $D$ Etreillis $254 \mathrm{~s}$.

Dana vide Bibl. Banks. 583.

Danet Gendre vide Foillant 10622

Daureitter vide Leblond 5606 .

D'Antic vide Bosc 11054-11057.

Dantz von Ast vide Dioscorides $11535-11536$.

Da Ponte vide Maironi 6433.

Dapper vicle Digby 9629

Darcet vide Cuvier 2105.

D'Ardene vide Ardene 263-266.

Darelius vide Linne 6031. vide Wallerius 10930.

D'Argentelle vide Robillard 8635 .

D'Argenville vide Anon. 11631.

Daries vide Plız 8064.

Darin vide Retzius 8506

Darlington vide Boldwin 448 .

Darwin vide Seward 9605 .

Da Silva Lisboa vide Silva Lisboa 9658

Da Silva Manso vide Silva Munso 9659

Das Neves Mello vide Neres Mcllo 7468 .

Dassdorfl vide Jloegling 6993 .

Dassen vide Holl 4059 .

Dassier vide Noulet 7.572.

Dassow vide Linne 6027

Daubenton vide Bibl. Banlis. 111. 643.

Daubenton vide Cuvier 9105.

$$
\text { vide Bibl. Banks. III. } 332 \text { 369. } 371 .
$$$$
\text { 372. } 404.592
$$

D'Aubenton vide Millet 6949

Daubeny vide Sibthorp 9618 .

Davanzati vide Bostichi 1175. vide Soderini 9734 vide Veltori 10727.

Davidson vide Bibl. Banks. IIJ. 473.

Davies vide Rochefort 8645 .

Davies vide $B_{\imath} b l$. Bunks. 1lI. 343.

D'Avrigni vide Loeuillart 6223

Davy de La Roche vide Merlet 6507.

Davy, Humpliry, vide Sinclair 9666 . vide B.bl. Banks. V. 88.

Da San Martino vide San Martino 8992.

De Abano vide Petrus de Albano 7949-7950.

De Arias y Costa vide Sandalio $\$ 983$.

De Aromatariis vide Aromataris 305 .

De Asso vide Asso $321-322$.

De Azara vide Azara 369.

Delo vide $B_{a b o o} 384$.

De Beaufort vide Magaud 6408-6409.

De Beaumont vide Elie de Beoumont 2958.

De Beunie vide Beunie 855.

De Belleval vide Belleval $687-691$.

- vide Broussontet 1348.

—_ vide Dorthes 2697. vide Gilibert 3635 .

De Berghes vide Berghes 760 .

De Berneaud ride Thiébaut 10176-10183.

De Beze vide Beze $\$ 59$.

vide Dodurt 2648.

De Blegny viıle Blegry $937-938$.

De Boissiel vide Boissieu 1063.

De Bomare vide I'almont 10649

De Boot vide Boëtius de Boot 1040.

De Borch vide Barch 1419.

- vide Forsyth 3296

De Brutelle vide L'heritier 5841-5853.

De Bry vide Bry 1444-1447.

vide Linscholten 6173.

De Butret vide Butret 1599 .

De Buzareinges vide Girou 3662 .

Decaisne vide $D_{e}$ Candolle 2256.

- vide Delessert 2414.

—_ vide D'Orbigry 2690.

_ vide Jacquemont 4814

—_ viste Le Maout 5748 .

- vide Morren 7215.

vide Péligol 7852.

vide Raoul 8351 .

vide Anon. 11660

De Candolle, Alphouse, vide De Candolle 2228. 2255. 2256.2322-2323.

De Candolle, A. P., vide Brossurd $1334^{7}$.

— vide De la Marck 2375.2380.

vide Delessert 2414.

vide Duby 2747.

vide Dunul 2822.

vide Flourens 3247.

vide Goethe 3761 .

vide Monnard 7064:

vide Moritzi 7204.

vide Marren 7228.

vide Presl 8207.

vide Redoute 8411.

vide Sprengel 9852.

De Carbonnière vide Ramond $\$ 343-8344$.

De Carro vide Corro 1700.

De Cassini vide Cassini 1729.

De Caus vide Caus 1759.

De Caylus vide Coylus $1772-1773$

De Chaillet vide De Candolle 2320 .

De Chambray vide Chambroy 1793 - 4795 .
De Chanvalon vide Thibaull 10175.

De Chaptal vide Chaptal 1803.

De Chastenet vide Chastenet 1807

De Chastillon vide Robert 8632 .

De Chazelles vide Miller 6936 .

De Christofori vide Jan 4\$57-4858

Decima vide B Bonato $1092-1093$.

De Claf visle Claf 1864.

De Clairville vide Rousseau 8775. vide Anon. 11622.

De Claubry vide Gaultier 3533 .

De Collegno vide Collegno 1919.

De Combes vide Anon. 11640.11708.

De Courset vide Dumont 2798.

De Cousmont vide Turgot 10529-10530.

Do Crescentiis vide Petrus de Crescentiis 7931 7956.

De Crevecoeur vide Boucher 1186.

De Cubières vide Cubieres 2069-2075.

Dedu vide Grew 3874

De Duillier vide Facio 3089 .

Deering vide Doering 2662-2663.

De Flacourt vide Flacourt 3229.

De Foigny vide Jussieu 5026

De Fontenelle vide Julia 4981.

De Fourtou vide Roland $8699-8701$.

De Francois vide Francois 3315.

De Freminville vide Cambry 1641.

De Ereycinet vide Gaudichaud 3527

De Freylin vide Freylin 3371.

Defroom vide Potiez-Defroom 8173.

De Garsault vide Garsault 3509 .

De Gasparin vide Gasparin 3512-3513.

De Gassicourt vide Cadet 1608-1610.

De Genlis vide Genlis 3564

De Gingins vide De Candolle 2256.

De Girard vide Saint-Hilaire 8950.

De' Grandi vide Grandi 3821.

De Grandmaison vide Millin 6943.

De Grandmont vide Favasseur 10689

Degrandpré vide Barrow 499.

De Haen vide Yundelli 10655.

Dehne vide Bibl. Banks. III. 433. 434. 437

De Honupluriis vide Honuphriis 4636 .

De Jean vide Chevalier 1820.

De Jonnès vide Horeau 7140 .

De Jussieu vide Jussier 5007-5070.

Dekkers vide Breyn 1266.

De la Bellerie vide Le Seurre 5782 .

De la Beyrie vide Anon. 11629. 11633

De la Bigarre vide Bibl. Banks. $111.63 \mathrm{~s}$

De la Billardière vide Flourens 3245.

De Laborde vide Paterson 7803.

—_ vide Raffeneuи 8307 .

De la Boulaye vide Merlet 6807.

De la Brousse vide Bibl. Banks. JlI. 623. 641.

De la Caille vide Mizuuld 6986.

De la Cause vide Pormentier 7781.

De la Clotte vide Mouton-Funtenille 7253-7257.

Je la Condamine vide Bibl. Banks. Ill. 437.475

De la Cour vide Gouffé 3806 .

De la Court vide Anon. 11675.

De Laet vide Laet 5487.

- vide Piso 8036

De la Fons vide Cumbray 1642.

De la Gardie vide Rudbeck 8821 .

De la Gardie, Eva, vide Bibl. Banks. III. 596

De la Hire, J. N., vide Bibl. Banks. III. 337. 412 .

De la Hire, Phil., vide Bibl. Banks. IlI. 373. 381

De la llitte vide Roessig 8687 .

De l'Aigue vide Aquoeus $258-259$. 
De la Jutais vido Brodin 1301.

Delalande vide Lebouidre De la Lande 5612 5613.

De Lambertye vide Lambertye 5513.

De la Narehe vide Alberti 119.

De la Mlarek vide De Candolle 2208. vide Thunberg 10233.

De la Mútherie virle Bibl. Banks. V. 85.

De la Morinière vide Noel 7550 .

De la Mottraie vide Aubry 346 .

De la Pryme vide Bibl. Banks. III. 399.

De la Quintinye vide $L e$ Berryais 5603 . vide Weber 11003.

Delarbre vide Bibl, Banks. III. 94.

De la Roche vide De Candolle 2197. vide Merlet 6807.

vide Redoute 8411.

De la Roque vide $L_{\text {a }}$ Roque 5564.

De la Sagra vide Ramon de la Sagra $8340-8342$.

De Lassaraz vide Gingins $3646-3647$.

De la Tour vide Leschenault $5779-5780$.

De la Tour d'Aigues vide Bibl. Banks. Ill. 426.

De la Tourrette vide Latourrette $5577-5579$.

De Laumont vide Gillet de Laumont 3642.

De Launay vide De la Brelonnerie 2352. vide Loiseleur 6238. vide Mordant 7138.

De la Vigne vide Schkuhr 9139.

Delaville vide Bibl. Banks. V. 97.

De l'Eeluse vide Acosta 31 .

\begin{tabular}{l}
\hline vide Belon $695-696$. \\
\hline vide Dodoens 2654. \\
vide Horst 4713. \\
vide Muerto 4758. \\
vide Monardes 7058. \\
vide Roelsius 8662. \\
\hline vide Treviranus 10465. \\
vide Torstius 10839. \\
vide Triese 10849.
\end{tabular}

De Ledesma vide Colmentro 1928.

De Lens vide Mérat 6795.

Delessert vide Laségue $5567-5568$.

Deleuze vide Darwin 2147. vide Gouan 3802 .

Del IIuerto vide Huerto 4758 .

De Liergues vide Monconys 7060 .

Delile vide Raffeneau-Delile \$304-8314. vide Redoute' 8411.

Delile, Eulalie, vide Ilumbold 4778. vide Saint-Hilaire 8942

Della Rocea vide Bibl. Banks. III. 337.

Delongchamp vide Le Turquier 5813-5815.

De Longehamp vide Penuier 7859 .

De l'Obel vide Pena 7837.

Del Pozzo vide Nicosia 7495.

De Mancy vide Tirgilius 10766 .

1) Manliis vide Brunfels 1423.

De Manoncour vide Sonuini 9749-9755.

De Martinel vide IIartinel 6558-6559.

De Martinis vide Murtinis 6569-6570.

De Mauvillon vide Ulloa 10572.

Do Mélicoq vide Delafons 2369.

De Menonville vide Thiery 10187.

De Mèré vide Guenurd 3940 .

Jemidof vide Pallus 7716.

De Miranda vide J"ellozo 10696.

De Mirecourt vide Gerardin 3581-3584.

De Molinariis vide Molinoriis 7048 .

De Moncets vide Pajon 7701.

De Moneonys vide Monconys 7060

De Monginat vide Monginal 7061 .

De Monnet vide De la Marck $2375-2380$.
De Montbéliard vide Bernard 784.

De Montbret vide De Silvestre 2507.

De Monthrison vide Montbrison 7116.

De Nonte Pigati vide Jlonte Pigati 7120.

De Montgarny vide llarmand 4136 .

De Montpascal vide Iilla 10745.

De Montpéreux vide Dubois 2739

De Morogues vide Morogues 7207.

lle Nangis vide Regnault 8421.

De Nenfelsateau vide Francois 3315 .

Denlan vide Brown 1374. 1384.

De Notaris vide Balsame 454-455. vide Moris 7192.

Denso vide Cuno 2082. vidle Bibl. Banks. IIl. 620 .

Dentan vide Bibl. Banks. Il]. 643.

De Palma vide Cossinny 2003.

De Pinguia vide llildegardis $4558-4459$.

De Peuzolz vide Pouzolz 8185.

De Prefontaine vide Prefontaine 8191.

De Pronville vide Pronville 8237-8239.

De Puisieux vide Anon. 11661 .

De Quelus vide Quelus 8273.

Dereum vide Beringer 769 .

De Regio vide Gregorius 3859 .

D'Eremita vide Doanato 2682-2683.

Derlam vide Ray $8385-8386$.

vide Bibl. Banks. 11l. 421.

De' Rinaldi vide Rinaldi 8588 .

De Rochefort vide Rochefort 8645 .

De Roussel vide Roussel 8778-8779.

De Roxas Clemente vide Roxus Clemente 87838784.

De Rozan vide Rozan 8806 .

Desaguliers vide Bibl. Bunks. 111. 366 .

De Sailly vide Sailly 8924.

De Saint-Agy vide Cuvier 2106 .

De Saint-Amans vide Saint-Amans 8925-8929.

De Saint-Aubin vide Genlis 3564 .

De Saint-Fond vide Faujas 3110 .

De Saint-Germain virle Saint-Germain $8932-$ 8933.

De Saint-lJilaire vide Saint-llilaire 8934-8950.

De Saint-Martin vide Juge 4977-4978.

De Saint-Naurice vide Pelée 7851.

De Saint-Mlichel vide Maurille 6679.

De Saint-1]oulin vide Suint-Joulin 8951

De Saint-Péravi vide Anon. 14706.

De Saint-Pierre vide Sain-Pierre 8952-8954.

De Saint-Simon vide Saint-Simon 8955 .

De Saint-Vincent vide Bory 1144-1152.

Des Allets vide Allets 154 .

De Saussure vide Cuviev 2105. vide Senebier 9568.

Des Beaumes vide Brun des Beaumes 1421.

Desberger vide Behlen 660 .

Descemet vide Anon. 11614

Déscurain vide Guettard 3953.

De Secondat vide Secondat 9524-9525.

De Serres vide Serres 9590-9592.

vide Belleval 691.

De Servais vide Servais 9593.

Desessarts vide Cuvier 2105.

Des Essarts vide De la Tuille 2402.

Desfontaines vide De Candolle 2312.

—_ vide Flourens 3245. vide Plinius 8079.

- vide Bibl. Banks. III. 25. 176. 201 sqq.

Desgenettes vide Linne 6141.

Desgranges vide Poisle-Desgranges 8117 .

Deshayes vide Anon. 11643.
Desjardins vide Bouton 1209.

De Sismondi vide Simonde 9664 .

Deslandes vide Bill. Barks. III. 399.

Deslongelsamps vide Loiseleur 6235-6253.

Desmarets ville Curier 2105.

Desmoneux vide Callurd 1627.

Des Moulins vide Dalechamps 2121.

vicle Dioscorides, p. 335.

De Spin vide Spin 9818.

- vide Rodali 8652

Dessaix vide Saiadecki 9729.

Desvaux vide Ecorchard 2905. vide Gérardin 3584.

Dethardius vide Bibl. Banks. III. 405.

De Théis vide Thëis 10149.

De Thevenot vide Therenot 10170-10172.

De Thury vide llericart 4387 .

De Touruefort vide Tournefort 10381-10388.

De Trehan vide Inon. 11636.

De Troisvilles vide frouffe 3807.

De Tussac vide Tussac 10560.

Deu vide Magnien 6412.

Deusing vide Bibl. Banks. I11. 196.204. 464.

De Valle vide I alle 10640.

De Vallemont vide Vallemont 10641.

De Vallouise vide Rossignol 8740.

De Vaniere vide Vaniere $10661-10669$.

De-Yaux vide Cadet-de-laux 1604-1607.

De Velnos vide Anon. 11639 .

De Villa vide Jilla 10743-10744.

De Ville vide Anon. 11644.

Deville, Nadame, vide Loiseleur 6239.

De Villiers vide Bidault $\$ 66$.

De Vinde vide Morel de T'inde $7142-7143$.

De Voisins vide Aubuisson 347.

Devosne vide Achard 23.

De Vriesa vide I'riese 10841-10855.

Deynoot vide Gevers Deynonl 3620 .

Dezallier vide Schabol 9055-9056

D'Hanvantare vide Susrutus 9997.

Dickson vide Broun 1383.

- vide Bill. Banks. Ill. 138. 3\$0.630.

Dierbach vide Geiger 3558 .

vide Persoon 7902.

Dieterichs vide Weiamann 11124 .

Dietrielı, A., vide Linné 6004 . vide Otla 7682 vide Tilldenow 11262.

Dietrieh, D., vide Loudon 6283.

Dietz vide Juch 4968 .

Dieze ville Ulloa 10573.

Dighy vide Anon. 11636.

Dillenius vicle Giseke 3664 . vide Ririnus 8611.

Dillenius, J. J., vide Shaw 9608 .

Dillon vide Ortega 7656.

Dillwyn vide Turner 10536 .

vide W'aison 10990

Diocles Carystius vide Mizauld 6982 .

Dioscorides vide 11497-11538.

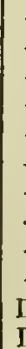

vide Brunfels 1423. 1428 . visle Jacquin $4 \$ 42$.

vidle Lonilzer 6269. vide II Iuttioli 6663 . vide Pasini 7793. vide Petrus 7945. vide Pona 8152. vide Sibthorp 9618. vide Sternberg 9917 vide Texior 10142.

D'sjonval ride Quatremère $\$ 271$. Ditmar vide Sturm 9979. 
Djupedius vide Thunberg 10236.

Dixon vide Bibl. Banks. H1l. 347.

Dizé vide Bibl. Banks. IIl. $\mathbf{5 8 6 .}$

Dobrowsky vide Ritter von Rittersberg 8601 .

Dobson vide Crell 2048.

Dodart vide Bibl. Banks. 111.

Dodeon vide Dodoens 2654.

Dodoens vide Meerbeeck 6731.

Dodonaeus vide Dodoens 2649-2659.

Doederlin vide Baier 406 .

Doehler vide Wildvogel 11245.

Doellinus vide Wedel 11085 .

Doering vide Boehmer 1023.

Dolnn vide Kuempfer 5082 .

Dolltuss vide Bibl. Banks. III. 473.

Donbasle vide Mathiea de Dambasle 664\$-6650.

Dombey vide L'heritier 5842 .

- vide Mouton-Fonterille 7256.

Don, David, vile Lambert $5509-5510$.

Don, George, vide Sweel 10024.

Don, P. N., ville Don 2686.

Donald vide Macdonald 6384 .

Donato d'Altomare vide Nati 7384 .

Dondis visle Anon. 11867-11875.

Donizer vide Domilzer 2674.

D'Orbigny vide Martits 6615 . vide Montagne 7083-7084. vide Anon. 11635 .

Dorla vide IIuerto 4758 .

Dorthes vide Bibl. Banks. III. 256. 305.

Doucette vide De la Daucette 2368.

Doudeauville, Duc de, vitle Anan. 11625.

Douglas, David, vide Benthum 716. ville Hooker 4662 .

Donglas, James, vide Bibl. Banks. III. 235. 538. 624 .

vide Anon. 11552.

Douglass, Sylv., vide Bibl. Banks. III. 570.

Dozy vide Iriese 10853.

Draakestein vide Rheede $8540-8542$.

Draparnaud vide Giboin 3625 .

vile Poilevin 8124

Drapiez vide Richard 8550.

Drechssler vide Slevogt 9696.

Drège ville Aleyer 6863.

Drejer vide Martius 6604.

vide Oeder 7601

visle 11 iegmann 11211.

Driver vile Anon. 11582-11585.

Dronnecke von Caub vide Lonitzer 6261

Drossander vide Rudbeck 8827 . vide $A$ nnon. $11876-11906$.

Dru vide Le Dru 5654.

Drummend vide Hooker 4662

Drusius vide Driessche 2731.

Dryander, Joh., vide Petrus de Abano 7950.

Dryander, Jonas, vide Ailon 109. vide Lidbeck 5869.

vide Wahlenberg 10883

- vide Bibl. Banks, 111. 89. 261. 278. 321,339

Dryfhout vide Bibl. Banks. Ill. 367.

Dubois vide Saint-Hilaire 8936.

— vide Anon. 11648.

Dubourg vide Barbeu-Dubourg 468-470.

Du Breuil vide Gilibert 3658 .

Dubuisson vide Bibl. Banks. III. 268.

Duby vide Muritzi 7205 .

Ducarel vide Bibl. Banks. Ill. 6. 135.

Duchesne, A. N., vide Du Ilamel 2787. vide Prevast 8223.
Duchesne, A. N., vide Bibl. Banks. III. 290. 369. 651.

Duchesne, Leger, vide Brohon 1304.

Du Choul vide Gesner 3596.

Dudley vide Bibl. Banks. JlI. 366. 548. 565.

Duerrius vide Bibl. Banks. III. 549 .

Dufour vile Sponius 9826 .

Du llamel vide Cuvier 2105.

Dide Le Berryois 5603. ride $01 t 7672$

—.. vide Tull 10525.

- vide Bibl. Banks. Ill. 287 sq.

Duillier vide Facio de Duillier 3089.

Du Lac vide Alleon du Lac $\$ 52$.

Dullaart vide Rochefort 8645 .

Du Nonceau vide Du Homel 2774-2789.

Dumont de Courset vide Jarques 4817 . vide Bibl. Banks. V. 88 .

Dumont d'Urville vide Bory 1150.

- vide Marlagne 7090. 7097. vide Bichard 8557.

Du Mloulin vide De la Riviëre 2394. vide Anon. 11689

Dunal vide $D e$ Candolle 2256.

Du Pas vide Passaeus 7796-7797.

vide Boëtius 1046.

Duperrey vide Bary $1149-1150$. vide Brongniart 1324.

Du Petit vide Petil 7919.

Du Petit-Thouars vide Aubert 327-343. vide Fiburier 3115 . vide Flourens 3248

Du Pinet vide Linocier 6169. vide Plinius 8076 visle Diascorides, p. $334-335$

Du Plessis vide Heard 4737.

Du Ponceau visle Demidoff 2436.

Du l'ont, André, vide Thory 10219.

Dupont, J., vide Inuval 2863 . vide Paivre 8126. vide Bibl. Bunks. 111.318

Du Pradel vide Serres $9590-9592$.

Dupuy des Esquiles vide Anon. 11663.

Durande vide Bibl. Banks. IIl. 4. 431. 381. 616 .

Durcau de la Malle vide Desfontanes 2496

Duret vide Lorey 6270-6971.

Durieu de Maisonneuve vide Anon. 11641.

Du Roi vide Bibl. Bunks. III. 335.

D'Urville vide Dumont d'Urville 2799-2802.

Du Séjour vide Dionis-du-Sejour 2641.

Dussieux vide Chaptal 1803.

Dutens vide Leibnitz 5722 .

Dutrocleter vide Bravets 1242.

Duval vile Richard 8561 . vide Bibl. Banks, 1ll. 454 .

Duvau vide Belanger 669.

Duvernin vide Delurbre 2393.

Duvernoy vide Schuebler 9370.

Du Vivier vide Anon. $1 \$ 667$.

Dwigubsky vide Lindley 5931.

Dyck vide Salm-Rei/ferscheid-Dyck $8965-\$ 974$.

Dygbaeus vide Digby 2629.

Eandi vide Vassalli $10666-10668$

East vide Broughton 1344-1346.

- vide Edweirds 2908.

Ebel vide Buechrer 1519 .

Ebenbitar vide Y"ulcurenghi 10623 .

Eber, Paul, vice Peucer 7965.

Ebermaier vide Nees von Esenbeck 7444.

Ebersbach vide Hebenstreit 4240.

Echeandia vide Anon. 11696.
Ech harul vide 11 edel 11090

Ectuse vile De l Eeluse 2406-2413.

Eder vide Menzel 6792.

Edwards vide Calesby 1751.

Edwards vide Dancer 2132.

Egenolply vide Cornarius 1985-1987. vide Fuchs 3435. vide Lonitzer $6260--6262$.

Egnatius vide Dioscorides 11508 .

Elhinger vide Allemandi-Ehinger 150 .

Ehinger vide Baier 407 .

Elylers vide llimlu 4499.

Ehrenberg vide Brow 1384. vide Nees von Esenbech 7421.

Ehrenclou vide Bibl. Banks. III. 630 .

Ehrenreich vide Bibl. Banks, III. 632.

Ehret vide Linne' 5982.

— vide Treu 10447.

- vide $B i b l$. Bunks. 111.78 sqq.

Ehrhart vide Lonitzer 6261.

Ehrlich vide Slevagt 9700.

Elurmann, J. Chr., vide Boecler 894. vide Mappus 6489.

vide Michaux 6907

Eichstadius vide Oelhafius 7608 .

Eidous vide Krascheninnikono 5383.

Eisenberger vile Blackwell 920.

- vide Lengefeld 5759 .

Eisenhardt vide Eysenhardt 3072 .

Eisfarth vide Eysfurth 3073 .

Ek vide Thunbery 10268

Ekeberg vide Osbeck 7664 .

Ekeberg vide Thunberg 10247.

Ekcberg vide Bibl. Banks. 11l. 581 .

Ekelund vide Thunberg 10247.

Ekermark vide Thunberg 10304.

Ehman, O. J., vide Thunberg 10240.

Elfwendahl vide Fallen 3098.

El Herwi vide Seligmann 9551.

Eller vide Bibl. Bunks. IIJ. 400.

Ellis vide Trowel 10503 .

vide Bibl. Banks. 11l. 248 sqq.

Ellrodt vide Kaelle 5323.

Elmgren, Gabriel, vide Linne 6085 .

Elmgren, Jolıan, vide Linué 6095.

Eloy vide Aucher-Eloy 348 .

Eltz vide Boehmer 1034.

Elvebemes vide Roberg 8618 .

Ely vide Bibl. Banks. III. 491.

Embarl vide $1 l^{\circ}$ edel 11094 .

Enckel vide Bibl. Banks. IIl. 419.

Enckell vide Kaln 5116.

Enckelmanu vide $F_{\text {tscher }} 3216$.

Encroe vide De la Croix 2367.

Endeavour vide Parkinson 7750 .

Endlicher vide Brown 1384 . - ville Hartinger 4167. vide Linné 6160. - vide Nees von Esenbeck 7445. - vide Poeppig 8098 - vide Schutl 9253. vide Tuckerman 10522 .

Endress vide Gay 3547.

Engel vide Camerarius 1644.

Engelberg vide Rot van Schreckeststein 8747.

Eugelluart vide Lidbeck 5870.

Engeström vide llesslén 4433 .

Engestrom vide Bibl. Banks. III. 602

Enklaar vide II iegmann 11211.

Ennes vide Leche 5619 .

Eunichmanu vide Schenckius 9103.

Eogh vide $K^{\prime} E$ ogh 5166 . 
Eppli vile Gmelin 3716 .

Erasmi vide Eysel 3062 .

Erill vide Schenk 9107.

Erdmann vide Bibl. Burks. III. 89.

Erebus vide Hooker $4638 \rightarrow 4639.4667$.

Eremita vide Donato d'Eremita $2682-2683$.

Ermel vide Juch 4970.

Erudelius vide Errull $3022-3023$.

Erile Bibl. Banks. III. 164.

Erotianus vide llippocrates 4503 .

Esclienbach vide Erhard 3046. vide Hiller 4491.

Eselsweiler vicle Martins 6597.

Essarts vide De la Tuille 2402.

Esslinger vide Berzelius 839.

Estimne vido Liger 5880 .

Estienne vide Saint-Estienne 8930

Etangs vide Des Ettmgs $2488-2490$.

Etler vide Roessig 8689.

Etreillis vide D Etreillis 2548 .

Euplırasén vide Linné 6137.

Euteenus Sophista vide Nicander 7478 .

Evelyu, Clarles, vide Bibl. Banks. III. 607.

Evelyn, John, vide De la Quintinye 2394. vide Nitchell 6976 . vide Rapuns 8354 . vide Bibl. Banks. Ill. 421

Everhartus vide Thorius 10208.

Evonymus Philiater vide Gesner 3597

Evre vide Suint-Eure 8931.

Ewer vide Bibl. Banks. III. 335

Eyries vile Humbold 4779 .

Eicle Krusenstern 5429.

Fabbroni vide Cuver 2105 .

- vide Bibl. Banks. V. 98

Falser, Joh., vide Ilernande 4404.

Faber, J. MI, vide Bibl. Banks. JII. 316 .

Fabre, Esprit, vide Dumal 2821.

Fabriano vide Herreru 4411.

Fabricius, Joh., vide Bibl. Bants. III. 152

Fabrieins, Joll., vide Heucher 4437.

Fabricius, Jols. Clal:, vide Lime 6136.

Fabure vide Martius 6576 .

vide Bibl. Bants. III. 425

Fagon vide Jussieu 5027.

vide Anon. 14674.

Fagraeus vide Limé 6079.

vide Bibl. Banks. III. 371. 622.

Falılberg vide Bibl. Banks. JII. 209. 304.326 .635

Falander vide Mennander 6784

Falek, J. P., vide Linné 6096.

Falck, J. W., vide Bibl. Banks, 111, 493.

Faleoner vide Bibl. Banks. III. 564. Y. 96

Fant vide Thunberg 1027 .

Farquhar, Jenny, vide Colden 1897

Farquhar vide Anon. 11358

Farre vide Sigmand 9652.

Fasano vide Bibl. Banks. Ill. 87.

Fatio vide Facio de Duillier $30 \$ 9$.

Fauelsé vide Bory 1151.

Faudel vide Spielmann 9811.

Fausto da Longiano vide Dioscorsdes 11529.

Fane vidlo Bibl. Banks, III. 572 .

Faye vile Humbaldi 4787.

Fée vide Linné 5978.6156.

- vide Spach 9775.

Fehr vide Bibl. Banks. III. 403.519

Feil vide Schuebler 9385.

Felsing vide Mueller 7283.

Fenzl vide Endlicher 2988. 2992. 2994

- vide Friedrichshal 3379.
Fenzl vide Kotschy 5374.

vide Jacquin 4820-4821.

Ferber vide Lime 6103. vide Bibl. Bunks. Ill. 418.

Fernandez vide Blunco 932.

Fernandez vide Bibl. Banks. V. 98.

Ferrante Imperato vide Imperala 4897.

Ferro vide Durante 2844.

- vide imperala 4897.

Furroni vide Anan. 11807.

Fersclius vide Schal 9245

Feschius vile Bry 1446.

Feuillée vide Peticer 7934

Fैeyerabend vide Stentzel 9900 .

Ficinus, Marsilius, vide llieronymus 4457

Ficiuns vide Heynhold 4451 vide Schmal= 9174.

Fick vide Paulli 7818 .

Fieber vide Berclitold 728 .

Fieloig vide Fibig 3474.

Fiebiger vide Titius 10339.

Fields vide Cunningham 2080.

Fiera vide Severinus 9604

Fignlus, Ben., vide Bibl. Banks. III. 454 ,

Fikke ville Fick 3176-3177.

Fingerhuth vide Bluff 948 .

vide Wirlgen 11319.

Finhli vide Schuebler 9381 .

Firens vide Anon. 11865.

Firmas vide DIllombres 9556 .

Fiselser in Weimar vide Paxton 7833.

Fiselıer, Fr. E. L., vide Langsdorff 5554.

Fischer, Gottheif, vide Ilumbaldt 4770 . vide Ingenhous 4899. vide Linne 6157.

Fiseher, Joh. Bapt., vide Blume 956.

Fide Wait 10896.

Fiseher, Joh. Bernh., vide Bibl. Banks. III. 496. 577.

Fitch vide Hoaker 4669 .

Fitzgerald vide $B i b l$. Banks. III. 621.

Flachs vide Klein 5251.

Flachsenius virle Gyllenstulpe 4001.

Fleiseber vide Schuebler 9389.

Fliesen vide Bibl. Bank's. Ill. 630.

Floeck vide Wirlgen 11319.

Florianus vide Leo 5764 .

Floridus vide Mucer 6385 .

Flotow vide Wendt 11161 .

Floyer vide Bibl. Bants. JII. 449.

Flygare vide Linne 6117.

1 vide Bibl. Banks. III. 168

Focke vide Miquel 6971.

Foersch vide Bibl. Banks. III. 204.

Foerster vide De Pre 2460.

Foesius vide llippacrates 4503.

Fogelius vide Fagel 3257

- vide Jung 4990—4992.

- vide Martens 6546 .

Foigny vide Jussieu $\$ 026$.

Folez vide Macer 6385.

Fond vide Faly as de Saint-Fond $3 / 10$.

Fons vide Delafons 2369.

Fonseea Benevides vide Brotera 1337

Eontaine vide De la Fontaine 2370.

Fontaine, Mlle., viele Anon. 14679.

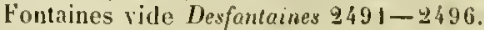

Fontana, F., vide Bibl. Banks, Ill. 375. 4 15. 427.

Fontana, J., vide Bibl. Bunks, III. 332 .

Fontana, N., vide Bibl. Banks. Ill. 327.

Fontenelle vide Julia 4981.

Fontenille vide Moutan-Fontenille 7353-7257.
Fornander vide Linné 6050

Forsbon vide Hellenius 4330 .

Forskålıl vide Linne 6046 .

Forslin vide Kalm 5122.

Forssander vide Retzius $\$ 503$.

Forssberg vide Segerstedt 9532.

Forster, David, vide Bauhin 587.

Forster, Geory, vide Farsyth 3296.

vide Sparrman 9784 .

vicle Bibl. Banks. 111. 184.254.

Forster, J. Reinhold, vide Bergius $\mathbf{7 6 2}$.

vide Bossu 1474.

vide Kalm 5091.

- vide Osbect 7664 .

vide Paterson 7803.

vide Thunberg 10233

202. 583.

Forster, W. E. vide Buier 408.

Fortelius vide Mennander 6783.

Fosse vide Delufasse 2371-2372.

Fothergill vide Coakley-Leltsam 1883. vide Anon. $1153 \mathrm{~s}$. vide Bibl. Banks. IIl. 506.514 .538 .

Fougeronx vide Bibl. Banks. III. 324.

Fougeroux, A. D., vide Bibl. Banks. III. 203. 233. $254 \mathrm{sqq}$.

Fourcroy vide Cuvier 2105. vide Palisol 7707. 88.

Fournel vide Jlara 4142.

Fourtou vide Raland de Fourtou 8699-8701.

Fouseh vide Fuchs 3431 .

Fragoso vide Bibl. Banks. III. 638. 639.

Frampton vide Monardes 7058 .

France vide Defrance 2331.

Franchelti vide Mascati 7235.

Franclieville vide $B i b l$. Banks. III. 270. 581 .

Franeis vide .Meyen 6845 .

Franciscus I. Borbonius vide Gussane 3993.

Franciscus Medicis Dux vide Caesalpino 1612.

Francius vide Herrichen $\mathbf{4 4 1 2 .}$

Franck, J. Chr, vide lerdries 10709

Francke vide Franke 3319-3341.

Franco, Vic. Ign., vide Cavanilles 1768

Francois vide Neufchateau 7458-7459.

François, ehartreux, vide Anon. 11679.

Franef vau Berkhey vide Berkhey 777.

Francus vide Frante $3319-3341$.

Franeus de Franekenau vide Franke $3319-3328$

Franke, Georg, vide Aldrovandus 141.

ride Montalbanus 7112.

Franke, G. F., vide Bibl. Banks. III. 349.403.

Franke, Jolı, vide Kleinlinecht 5258.

Franke, Joh., vide 11 almstedl 10959.

Franklin vide Broun 1384.

- ville Hoaker 4662.

- vide Bichardson 8566 .

Franz I., imper. Austriae, vide Clavmeton $1 \mathrm{~S} 11$.

Franz vide Sternbery 9918.

Fraser, Jolun, vide Broun 1376.

Fraser, Tloomas, vide Bibl. Banks. JII. 524

Fraylino di Buttigliera vide Bitl. Banks. Ill. 631.

Freeman vide Calbatch 1895

Freigius vide Freige 3353.

Freitag vide 11 inchler 11294 .

Fréminville vide Cambry 1641

Frenckell vide Gadd 3462 .

Fresne vide Dufresue 2771.

Fresnoy vide Du Fresnoy 2778.

Freycinet vide Gaudichaud 3527 . 
Freycinet vide Leschenault $\mathbf{5 7 8 0 .}$

Frichliuger vide Schnizlein 9235.

Friedel vide Hoffmann 4560 .

Friederici vide Boehmer 1024.

Friederici, von, vide Bibl. Banks. UII. 560 .

Friedland vide 1 Talter 10964 .

Friedrich August von Sachsen vide Biasoletto 863.

- vide Heidler 4281.

Friedrichsthal vide Grisebach 3905 .

Fries vide Areschoug 287.

- vide Lund 6365.

vide Trog 10496

vide Tuckerman 10522

Friese vide Eysel 3068.

Frisch vide Bibl. Banks. 111, 370.

Frisius vide Fleischer 3224.

Frivaldzhi vide Grisebach 3905 . vide Anon: 11801.

Freelich vide $D_{e}$ Candolle 2256.

- vide Bibl. Banks. IIJ. 308.

Froriep vide Alderson 140

Fnelıs, Fr. Chr, , vide Bibl. Banks. III. 503. 533.

Fuchs, G. E., vide Buectner 1518.

Fuchs, L., vide Bruafels 1423.

- vide Cornarius 1985-1987.

vide Cornarius $1985-$

vide Hizler $\mathbf{4 5 2 5 .}$

vide Dioscorides, p. 334.

Fucus vide Fuchs 3432.

Fuelleborn vide Bibl. Banks. III. 539

Fuernrolor vide Bruzelius 1443.

Fuessel vide Boehmer 1028.

Funck vide Bibl. Bunks. III. 154.

Funk ville Bibl. Banks. V. 70.

Funhe vide Nees von Esenbech 7440-7441.

Furber vide Anon. 11581 .

Fuselı, Fuschs vide Fuchs 3431.

Fuscus, Remaelus, vide Fisch $3452-3454$.

Fosée Aublet vide Aublet 345

Fuss vide Baumgarten 604

Gackenholtz vide Leibnitz $\mathbf{5 7 2 2 .}$

Gadd vide Hasselbom 4206.

- vide Bill. Banks. III. 256. 423. 582. 586 V. 83 .

Gadebuseh vide Hasselquist 4207 .

Gaertuer vide Deleuze 2415 . vide Bibl. Banls. III. 34.90. 174.

Gacrtner fil. vide Bibl. Banks. III. 156.

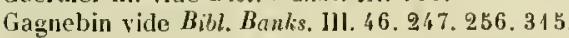
319.

Galu, Mlenr., vide Linne 6114.

Gabn, Nils, vide Limne' 6052.

Galırliep vide Bibl. Banks. III. 40 B.

Gaimard vide Martins 6576 .

Gale vide Bibl. Banks. 111. 399.

Galenns vide Brunfels 1424.

- vide Mundella 7318.

Galeotti vide Martens 6548 .

Galetti vide Moretti 7176 .

Gallén vide Thunberg 10247.

Gallesie vide Pollini 8142.

Galleus vide Collaert 1918

Galliselı vide Ludwig 6.321.

Gama vide Nogueira da Gama. 7554.

Games vide $L$ blond 5606 .

Gandanus vide Gulenus 3477.

Gandoger do Feigny vide Jussien 5026

Gareia del Huerto vide Ifuerto 4758. vide $A$ costa 31

vide Bontius 1111. vide De l'Ecluse 241 l.
Garcin vide Bibl. Banks. Ill. 243. 272. 281. 282. 333

Garden vide Linné 6154.

- vile Bibl. Banks. 11J. 307. 472

Garduer vide Fielding 3185 .

Gardiner vide Raminus $\$ 354$.

Gargilius Martialis vide Airon. 11861.

Garmery vide De Cundolle 2185.

Garnier vide duon. 11688.

Garsault vide Geoffroy 3569.

Gaspari vide Campi 1666-1667.

Gassicourt vile Cadet de Gussicourt 1608-1610.

Gates vide Eaton 2885

Gatinara vide Brunfols 1423

Gatterer vide Bonnet 1105 vide Iruis 2707 .

Gaudichaud vicle Meneghini 6774 . vide Mantagne 7071.

- vide Vaillant 10618.

Gaudin vide Chavames 1813.

Gault vide Prevost 8223.

Gaupp vide Jaeger 4845 .

Gauss vide Paxton 7833.

Gautluier de la Peyronie vide Pallas 7714

Gautier vide Bibl. Banks. 111.565.

Gantier Dascoty vile Daryoty 2112-2113.

Gautier, L. A., virle Noisette 7556.

Gavinelli vide Malpighi 6449 .

Gawler vide $\operatorname{Ker} 5167-5171$.

Gay, Claude, vide Mentagne 7100.

Gay, Jacques, vide Monnard 7064

Gay, Mlume., vide Webl 10999.

Gaza vide Throphrastus 10450-10153̈. 10159 10463.

Gazen-Dourxigné vide Ruyinus $\$ 354$

Gebauer vide Isenflamm 4958.

Geduer vide Linne 6045.

Geel vide Anon. 11698.

Geier vide Geyer 3621.

Geijer vide Linne 6139.

Geinitz vide Friderici 3376.

Geissler, sculptor, vide Pallas 7722

Gellerstedt vide Sillen 9655 .

Gelmethius vide Nocea 7349 .

Gelnitius vide Pauli 7814.

Gemmingen vide Besler 840

Gemnenden vide Berlése 780 .

Gendre vide Le Gendre 5694

Genge vide Allinus 130.

Gennari vide Pentedera 8.157.

Genuensis vide Simen Januensis 9663.

Geoffroy, C. J., vide Bibl. Banks. III. 348.355. 390.

Geoffroy, E. F., vide $B i u l$. Banks. III. 538.564.

Georgi, Joh. Gottlieb, vide Osbeck 7664. 5.16

Georgii, A. K., vide Lossius 6277

Georgii, G. E. vide Linné 6130 .

Georgii, J. Chr. S., vide Gmelin 3707.

Georgius vide $B_{0}$ ehmer 1027.

Gera vide Moretti 7166 .

Gerard vidle Bibl. Banks. III. 255. 644. V. 73.

Gerardimentanus vide Nevianus 7469.

Gerarclus Gandanus vide Galenus 3477

Gerber, Trauzett, vide IIertel 4420.

Gerhard vide Gleditsch $3684-3685$.

Gerliardt vide Liebig $\mathbf{5 8 7 6}$

Gerlach vide Hering 4388 .

Germain vide Cosson 2004-2009.

Germain vide Saint-Germain 8932-8933.

Germar vide Muenster 7307.
Gerstenberg vide $\boldsymbol{B}$,bl, Banks. III. 460.

Gerstner vide Jirasek $4 \$ 88$.

Gertzensee vide Bouhin 589 .

Gervais vide Bezmard 785

Gervasius vide Boccone 968 .

- vide Cupani 2087

fresenius vide Haller 4074 .

Gesner Joh, ville Linné 5979.

vide Schine 9435.

vide II olf 11342.

Gesner, J. N., vide Cato 1755. - vide Columella 1933.

vide Palladius 7712

vide I arro 10665.

vide Anon 11861-11862.

Gesner, Kenr., vide Actuarius 34. ride liauluin 585 .

vide Bock 979.

vide Cordus 1982

vide De t'Ecluse 2413.

11521 vide Dioscorides $11504.11520-$

vide Guilandinus 3964-3!65

ide Ilanhart 4145

vide IIarmann 4183.

vide Kiberus 5478 .

vide Simler 9660-9661.

vide Treviranus 10465.

Gestrinius vide Celsius 1777.

Geuns vicle fieer 3550 .

vide Schreevoort 9225

ville Bibl. Bonks. IIl. 48.

Gevalin vide Thunberg 10237.

Gezelius vide Lund 6362.

Gherardini vide Darwin 2147

Ghiaresclit vide $B$ ibl. lianks. IJ]. 642.

Giachini vide Soderini 973 \%.

Giers ville Trozelius 10508 .

Giesehe vide Giseke $3603-3666$.

Gilbert vide Cuvier 2105.

- vide Anon. 11648.

Gilibert vide Belleval 691

— vide Latourrette 5575-5579.

vide Linné 5979.5989.6002.

Gillenius vide Gille 3641 .

Gillet de Grandmont vide Iravasseur 10689.

Gimignano vide Dioscorides $1 \$ 531$.

Gingins vide $D_{e}$ Candolle 2256.

vide Goethe 3760

Gjös ride Gadd 3459 .

fiovene virle Bibl. Banks, 111. 430.635.

Girard virie Saint-Hilaire 8950 .

Giraud-Soulavie vide Soulavie 9764.

Girault vide Rousseau 8775.

Girod-Chantrans vide $D_{e}$ Candolle 2192.

vide Bibl. Banks. III. 348 . V. 90.

Girena vide Yamez 11382.

Gisbertus Longelius vide Figulus 3188

Giseke vide Linne 6134. 6136

- vide Anon. 11546.

— vide Bibl. Banks. Ill. 68. 211. 215.

Gisers vide Serres 9590

Glaclenbach vide Carrichter 4699.

Glainville vide Bartholonaeus Anglicus $\$ 11$

Gland vide Degland 2332-2333.

Glanvilla vide Burtholomaeus Anglicus 511

Gleditscls vide Bechmann 645 .

- vide Linne 6002. vide Siegesbeck 9640.

vide Hilldenow 11255

vide Bibl. Bunks. 11l. $32.160 \mathrm{suq}$.

Gleichen vide Ledernueller 5652 
Glendeuberg vile Bibl. Banks. III. 437. Glueckselig vide Sieber 9629 .

Gmelin, Chr., vide Klein 5251.

Gmelin, Ferd. G., vide Palm 7723. vide Palmer 7725.

Gmelin, G. Fr., vide Camerarius 1654.

Gmelin, Joh. Fr., vide Linne 5978 .

vide Ludicig 6324. vide Oetinger 7615 . vide Russell 8886 .

Gmelin, J. G., vide Ledebur 5643 . vide Bibl. Banlis. HI. 587.

Gmelin, Plil. Fr., vide Ehrhart 2931. vide Knorr' 5304.

Gmelin, Sam. G., vide Bill. Banks. III. 81. 173. 245. 280.448.

Gniditseh vide Ludurig 6322.

Gobelin vide Anon. 14674.

Goclenius vide Apollinaris 250.

Godefroy vide Ragonot-Godefroy 8334 .

Godeheu vide Bibl. Banks. III. 337.

Godet vide Dubois de Montpereux 2739.

Godley vide De Brébisson 2162.

Godren vide Soyer-Willemet 9774 .

Gocekelius vide IIeister 4305.

froekelius vide 17 edel 11084 .

Geeppert vide Flotow 3244.

- vide Muenster 7307 . vide Wendt 11161-11162. - vide Wimmer 11286.

Geeppert, sculptor, vidle Mlueller 7284.

Goeritz vide Bibl. Banks. III. 198, 264, 578 .

Goethe vide Darlington 2143. vide Heidler 4281.

Goez vide Bibl. Basks. III. 515.

Geeze vide Bontet 1106. vide Mueller 7294. vide Neellham 7414 .

Gohori vide Lemnius 5754 . vide Monardes 7057 .

Gejer vide Nieuhof 7507 .

Geodenough vide Bibl. Banks. III. 318,345 .

Googe vide Ileresbach 4385 .

Gerden vide Milue 6949.

Gorraeus vide Nicander 7478 .

Grorter vide Geer 3550 .

vide Geuns 3616.

vide Bitl. Banks. Ill. 199.417.645.

Gettsche vide Lindenberg 5915 vide Nees van Esenbeck 7437.

Gettsched vide Loeselius 6222.

Gonan vide Amoreux 207.

- vide Anon. 14663.

Gouffier vide Bibl. Banlis. III. 433.548 .632$.

Gough vide Bill. Banks. III. 400 . V. 85.

Geulin vide Anon. 11629. 11633.

Geupylos vide Dioseorides 11501.

Goyon de la Plombanie vide Bibl. Banks. III. 592. 637.

Grabowsi vide Guenther 3944 .

vide 11 immer 11282.

Grace vide De Grace 2334.

Graeber vide Thilo 10191.

Graefe vide Boehmer 1028.

Graellinger vide Aerigelen 54.

Grafenbery vide Schenchius 9100.

Graff vicle Merian 6805 .

Graffenried vide Bawhin 589

Grand vide Le Grand 5695.

Grandi vide De' Grandi 2335.

Grandmaison vide Millin 6943.

vide Pulteney 8233.
Grandmont vide Tavasseur 10689.

Grandpré vide Barrow 499.

Grandsagne vide Plinius 8082 .

Granlund vide Bibl. Banks. I1I. 170.

Granroth vide Kalm 5100 .

Grant llerbier vide Anon. $\$ 1664$.

Gräberg vide Linne 6098.

Grassius vide Bill. Bunks. III. 408.

Grateloup vide Dufour 2766 .

Grauer vide Weber 11014.

Gravel vide Wedel 11092.

Graves, G., vide Curtis 2090.

- vide Hootier 4666 .

Graves, R., vide Bibl. Bonks. III. 548.

Gravius vide Gran 3830.

Gray, Asa, vide Colden 1897.

___ vide Engelmann 3007.

- vide Sullivent 9994.

- vide Torrey 10372-10373.

Gray, John, vide Bibl. Banks. III. 475.

Greenway vide Bibl. Banlis. IIl. 542. 598.

Gregorius de Regio vide Bibl. Banks. III. 251.

Gregorius Nazianzenus vide Cyrillus 2107.

Greiselins virle Tollius 10359 .

Greville vide llooker 4655 .

Grevin vide Nicander 7478 .

Grew vide Dedu 2330.

- vide Nigrisoli 7510.

Griesebach vide Grisebach 3902-3908.

Grieve vide Krascheninniliow 5383 .

Griffith vide Ioigt 10824 .

Grimaldi vide Durazzo de Grimaldi 2846.

Grimm vide Bill. Bunks. 11I. 160. 298.

Grimoard vide Caylus 1773.

Griper vide Brown 1372.

Grisebach vide Endlicher 2995.

- vide Schomburgk 9248.

Griselini vide Bibl. Banks. II]. 392.

Grisley vide Vandelli 10656.

Groenberg vide W'eigel 11111.

Groening vide Modéer 6988 .

Grohnert vide Hagen 4034

Grenenberg vide Gesner 3605 .

Gronovius, J. F., vide Colden 1897

Gronovius, L. Th., vide Séguser 9535.

Grool ville Anon. 11675.

Groskurt vide Sparrman 9784. - vile Thunberg 10233.

Gross vide Beck 629.

Grube vide Bortholinus 510.

Gruber vide Jirasek 4888.

Gruber vide Higener 10874 .

Gruembke vide Brönlund 883 . - vide Bose 1159.

Gruendler vide Bibl. Banks. 11I. 334.

Grufberg vide Linne 6055 .

Grundberg vide Kalm 5113 .

Gruner vide Graumueller 3836 .

- vide Zosimus 11464

Gruterus vide Bacon 394.

Gruvel vide Molina 7047.

Gualteri vide Ortega 7659.

Guarini vide Berzelius 839 .

Guckenberger vide Hablizl 4040.

Gudrius von Teurs vicle Anon.' 11717.

Gueldenstaedt vide Bibl. Bailis. Ill. 319.

Guembel vide Bruch 1394.

Gucinin vide Aron. 11707.

Guenther, Aug., vide Lime 5993.

Guenther, G. B., vide Thienemann 10186.

Guerin vide Syielmann 9806.

Gueroult vide Hacer 6385.
Guettard vide Bibl. Bunks. IIT. 49. 227 squ

Gugenmus vide Bibl. Bonks. III. 626 .

Guiart vide (false!) Goviart 3957-395s. vide helzius 8504 .

Guicciardi vide Morett 7167.

Guilandinus vide Gesner $3598-3599$.

- vide Itessus $\$ 436$.

- vide Mattioli 6658 .

vide Pisunski 8035.

vide Scaliger 9043 .

vide Schenchius 9100. vide Dioscorides, p. 335.

Guillard vide Seringe 9579.

Guillemin visle Chevallier 1821. vide De Candolle 2185.2303. vide Lasegue 5566. vide Redoute 8:14.

Guillon, Nanine, vide Jaune 4875.

Guisau vilte Bibl. Banks. V. 78.

Gullett ville Bibl. Banls. MII. 597.

Gummerus vide Gadd 3456.

Gundelsheimer vide Schreber 9327.

Gunner vide Bibl. Banks. 11I. 129. 167.

Gusmae vide Brotero 1340-13i1.

Gussone virle Ronconi 8711.

Gutselmid ville Biusoletto 863 .

Guttadauro vide Tornaberse $\mathbf{4 0 3 6 6 .}$

Guy de la Brosse ville De la Brasse 2333 - 2359 .

Gyllenband vide Uxliull-Gyllenband 10614. 10612.

Gyraldus vide Sethi 9598.

Haartman, J., vide Linne 5978.6040.

Hastman, J. G., vide Rutstroem $8 \$ 90$.

Haas viele: Sinclair 9666 .

IJaase vide Luduig 6328.

Hablizl vide Bibl. Banks. III. 594. 634 .

llacquet vide Bibl. Banks. III. 347.

Iladelich vide Bibl. Bunks. III. 199.

Ilaen vide I'andelli 10655.

Jaenke vide Jirusek 4888 .

- ville Linne 5985 .

- vide Presl 8205 .

- vide Bibl. Banks. III. 129. $164 \quad 417$

llaggek vide Dioscorides, [. 334.

llagelberg vide Trozelius 10506 .

llagemann vide Bibl. Bunks. III. 198.

llagen vide List $6189-6190$.

—_ vidle Ludwig 6324 .

— vide Bibl. Banks. III. 2S8, 328.

Hagena vide Trentepoht 10444.

Hagenbut vide Cornarius 1985-1987.

I lager vide Linné 6072.

Haggren vide Bibl. Banks. III. 368.

llagka z Hagku vide Dioscorides, p. 334.

llagstrom vide Bibl. Banks. III. 595.

Ilalin, H. J., vide Hill 4467 .

Hahn, J. E., vile Unger 10593.

Hahnemann vide Haller 4084 .

Haill vide Treu 10447.

ride 11 einmam 11124.

Hain vide Bill. Banks. III. 550.

Halder vide Schuebler 9372.

Halenius vide Linne 6037.

Hall, B. M., ville Linne 6097 .

Jlall, H. Chr. van, vide Kops 5358. vide Linne 6155.

Hallberg vide Ullgren 10571.

Hallé vide Cuvier 2105.

- vide Bibl. Banks. III. 375.

Hallenberg vide Linne 6191.

Ilaller vide Baldinger 439. 
Ilaller vide Hamberger 4094 . vide Murr 7330. ville Ruppius 8879. vide Shewchzer 9115 . vile Senebier 9561 . vide Wedel 11104. vide Weinmann 1112 ? vide Zimmermann 1143 ว̈. ville Anon. 11601. vide Bibl. Banks. HII. 7. 79 silq. Haller, A. von, fil., vide !" "menat 10699. vide Bibl. Bunks. V. To

IJallman, D. Zach., vide Zuchar 11389. Hlallman. J. G., vide Limne 6022. vide Thunbery 10253

Hamberger vide IIetel 11103-11104.

Hamel vide Lu Hamet du Honcenu 277, - 2789.

Ilamilton, Charles, vile Bibl. Bunks. III. 282

— vide Culpeper 2079.

llamilton, Francis, vicle Don 2675

llampe vide IFallroth 10957.

- vide Anon. 11796

Hanbut vide Comarius 1995-1987.

Hancke vide Siultelus 9 วั16.

Handsch vide Diuscorides. P. 334.

Ilanin vide Anon. 11686 . 11710.

Mannehen vide 17 edel 11077 .

llamelins vide Bromallius 1332 .

Hannemaun vide Bibl. Banks. IHI. 20 으.

Hanow vile Ribl. Banks. III. 34 4.

Ilarder vide Bibl. Banks. III. 541.546.

llardt, von ter vide speps 9816.

Hardman vide Joerlin 4907.

llarduinus vide Plinius $8076-8077.8079$.

Ilarnisch ride Lueben 6347

llaro vile Fouruel 3302.

Harpe ville De la Harpe 2373.

Harris ville Babl Ranks. III. I\$3.

llartenfelss vide Petri un Harlonfelss 7946.7

Ilartig. (r. L., vide Bul. Bunks. HII. 592.

Hlartig, Th., vile Schleiden 9138.

Hartman vide Thunberg 10286.

IJartmann, Aug., vide Scluebler 9399.

Jlartmann, Frdr., vide Scluebler 9382.

Hartmasn. Gustar, vile Schuebler 9390.

llartmann, J. Fr., vide Bibl. Bauks. 111. 14.

Ilartmann, Karl, vile Mntell 6479.

llartug vide Burmanu 1579.

_- ville Kolle 533 .

Hartweg vide Benthan 721.

Hase vide Lepechin 5773 .

- vile Rytschlow 8897 .

Hasenest vide Bibl. Banks. III. 545.

Hasselquist, 1, vide Mahn 4047 .

llasselquist, Fr., vide Linne 6026 . vide Bibl. Banks. III. 336.

Ilasselt vide Bibl. Banks. III, 638 .

Ilisselt vide Blame 953.

- vide Breda 1249.

Hassenfratc vide Bibl. Banks. IlI. 378.

Ilast vicle Thurberg 10238 .

llastedt vide Bibl. Banks. III. 135.

IIatton vide Boccone 969.

llautl vide Boget 8692 .

Haughe vide Langhemrich 5547 .

Haunanu vide Cartheuser 1703.

Hausmann vide Hohlenberg 10883.

llauy vide Cucier 2105.

__ vide Bibl. Banks. III. 13

Havell, R., vide Burg 1593.

- vide Roscae 8721

llavet ville Marquis 6528 .

Pritre. , Thes. lit. bot.
Hlawkins vide Bibl. Banks. III. 497.

llawks vide Croom 2001.

llay vide Thunberg 10263.

Inayes vide Deshuyes 2497-2500.

Haviluut vide Cornorius 1985-1987.

Havne vide Oreves $2727-2728$.

_ vide Guimpel 3979.

- vide Bibl. Banks. V. 77.

llebenstriat, Ernst, vile Durwin 2149.

llebenstreit, J. Chr., vide Cngebouer 10578. 297

Hebenstreit, J. E., vide Lischucit 6183.

Heberden vide Bibl. $\boldsymbol{R}_{a n k s .}$ III 532.552.

Ilebiy vide llagner 10872 .

lleckheler vide Mappus 6485 .

llecla ville broven 1372.

Hedlenberg vide Linné 6054 .

Hedlu vide Lime 6123.6144.6147.

Iledren, Ad., vide Thunberg 10285.

Iledrén, E., vide Thunberg 10295.

Iledren, J. J., vicle Thunbery 10258.

Iledwig vide Dileuze 2415. vide Humboldt 4770 .

vide Noehden 7548 .

ville Bibl. Bunks. Ill. 49. 384

Hee vide Bibl. Banks. HII. 347 .

Heer vide Moritzi 7203.

vicle Hegetschueeiler 4278 .

Heering vide laier 400 .

Heermann vide Eysel 3066 .

Hegarelt vide Lime 60 !s.

Hegel vide Schleiden 9160

Hegetschweiler vide Suter 9999.

Hegner vide Zuinger 11492.

Heidenberger vide Ortolff i. B. 7663.

Heiland vide Bibl. Banks 111. 117.

Heiligtag vide Limé 6024

Hein vide Babl. Banks. 1II. 544.

Heinricli vile Fischer 3220 .

Heinsius, Daniel, vide Theoplrastus 10862.

lleinsius, J. S., vide slenogt 9698 .

Heinz vide Schulae 9455.

Heinze vide Richter 8573 .

Ileister, El. Fr., vide Heinter 4303. vide Bibl. Banks. III. $4 \times 4$.

Heister, L., virle Burchlhard 1567 vide Leporin 5775.

vide $11^{T}$ ernsdorf 11175

_ vide Bibl. Bunks. III. 367.

Ilelligk vide Eysel 3058 .

Helbling vide Bibl. Ronks. III. 549.

Helcher vide Bupchner 1508.

Helek vide Bibl, Banks. III. 407.

Helfenzriecler vida Bibl. Banks. III. 401.

Ilellenius, Carl, ride Linné 6133. vide Bibl. Bauks. III. 277.331.

Hellmius, Jols., vide $K$ alm 5123.

llellwig, Chr., vide Franke 3319.

Hellwig, J., vide Pott 8174

Helm vide 11 redow $\$ 1365$.

Hempel vide Roehmer 1025.

Hemprich vide Ekrenberg 2926.

Henchel vide Bibl. Banks. III. 183. 403 .

Henckel von Donnersinarck vide Sprecchis 9828 .

Henderson vide Thornton 10211.

Henne vide Bibl. Bunks. IHI. 288.

Ilenninius vide Tollius 10359.

Henri IV. vide Amoreux 200

$\longrightarrow$ vide Belleral 690.
IIenri IV. vide I allet 10643.

Henriques Ferreira vide B،bl. Banks. HIt $5 \$ 9$.

Henry vide Nees von Esenbeli 7440.7446.

Henry virle Stedmann 9872 .

Henslow vide Maund 6674 .

Heppe vide Bibl. Banks. III. 619.

Herbarius vide Anon. 11867-11875

Herbert vide Anon. 11638.

Herbolario vide l liascorides 113228.

Herbouville riele Bibl. Banks. V. 103.

Herloldt won Schumacher 9462.

Herissant ridl. Callard 1627.

Héritier vide L'heritier $5 \$ 41-5853$.

Hermann, Gotfried, ville Macer 6385.

Hermann, G. E., vile Baier $\$ 10$.

Hermann, f. S., vide Rivinus \$616.

Hermann, J., ville Hermunn $\$$ \$1 4 . vide $1 / 2 \lg 4315$. - vide Lauth 5590. vide Spielmann 980 \%.

Hermaun. J., vile II etel 11078.

Ilermann, J. II., vide Zuinger 11495.

Hermann, Paul, vide Bidloo 868. vide Bumunn 1579. ville Linne 5993 vide T'alentini 10627

- vile Harton 10983.

Hermbstaedt vile Orfila $76: 9$.

- virte Bibl. Banks. V. 96

Herminier vide Guibourt 3960.

Hermolaus Barbarus vite Brunfels 1423.

11308.11514 ; et p. 333.

Hernquist vide Hullin 10946

Ilerold vide Ludolf 6316.

Herr, Mlichael, vide brunfels 1423.

vide Columelln 1933.

Hertz vide Lindley $\$ 936$.

llezzog virle Schulze 9454

Ilesselyren vide Linne 6034.

Ilesselius, A., ville Thunberg 102:3.

Hesselius, J, vide Koberg $\$ 620$.

Hessler vide Susrulas 9997.

Heuller ville Stotter 9950 .

Heyer ride Bibl. Banks. III. 437.

Heyhe vide Bibl. Banks. III. $\$ 96$.

Heyland ride Delessert 2414.

- vide 11 ebo 10949.

Heyne, Benj., vide Roth sijs.

Heynbold vite Ficinus 3475. visle Iloll 4625. - vide Seidel 9544.

Hiarne vide Bibl. Banks. III. 436.

Hieronymus Braunsehweig viele Dioscorides II 536.

— vide Anon. 11901.

I Heronymus Cardanus vide Curlenus 1684.

Hieronymus Mereurialis vide Mercurialis 6803.

llilaire vide doume $4867-4575$.

llilaire vide Stuint-Hilaire $8934-8950$.

Hilchen vide Jlert 4418 .

Hildegarilis vide Reuss 8524 .

1 lill ville Klem 5256.

IIill, B. L., vide Lischwitz 6195.

Hill, Jolm, vile Rheode $85+1$.

Hiller, D. G., vide Otto 7676 .

Hiller, K. Clu., vide Sigmuri 9633.

Hillius vide $1 \mathrm{og}$ oger 10875.

Ilimmelstieru vide Samson 8980.

Ilinds vide Belcher 671.

___ vide Bentham 729. 
IJintou liast vide Broughton 1344-13/6. IJimueber vide Bibl. Hanks. 1II. 423. Iliortbere vide Bibl. Mankis. III. 633. Jjorth vish Linne 60 id.

Ifiortzberg vile Lame' 6057

Ilippneral's vide Dierbach 2572 . vide Panlet 7808 .

Jirschorn vide Bib!. Bunks. III. 493.

Jirzal vicla" linguel 3951 .

llispalensis vide lsidorus 4963

IIlubreh vite (atinelli 1754 vicle Rueder 8845 .

Hohson visle Bibl, Runks. Hl. 401.

Jlochlorerg vide Pohl 8107.

Hochenwarth vile Bibl. Bunks. III. 134.

Joclistetter vide Seubert 9600 .

- vile Steudel 9923.

llocelistettror vide Schenchius 9105.

Hogmasus vide Kolm 5102 .

IJogstròn viłle Bibl. Banlis. 111. 624.

llojer visli Lime 6040

Ilojer vists Thubery $1030 \mathrm{l}$.

Iloelserlin vide Cumerarius 1646

Jlorlzol vidu Selmidel 9188 .

Hoijor vide 11 allerius 10938.

Hofer vida Bibl. Banks. IIf. 79. 214.245.

Holfuau, Anton, ville Linue 6107.

Holimanu, Chr. Frilr., vide Marshall 6535.

IJollmann, Frietrich, vide Buxbuum 160 i.

- visle Hecties 4248.

lluflmann, Georg Frz., vide Smith 9718.

290.

Hollmanu, Gottlieb, vide llauchart 6667.

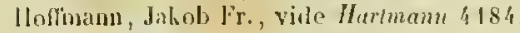
Hoffmann, J., virlo Siebold 9635.

lloffuann, Johm, vide Bibl. Banks. III. 546. IJolfmann, J. M., vide Bibl. Banks. IIJ. 403. llollmanu, Kaspar, vide Theophrustus 10167. Holfminu, Molitz, ville Lruremberg 5584.

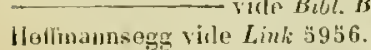

Ilofmann, Gabriol, ville Titius 10339

Hofmam, lisspar, vide Jungermunn 4995.

Ilofstcule visle Bill. Runks. III. 19 ?.

Hohnolusim virle Paruielsus $7741-7744$.

Jlolienwarth vide Reimer $\$ 466$.

Holbach vide Ilenckel 4351

- vile 11 allprius $10 \$ 28$.

Holed vide Bibl, Banks. Ill. 595.

Iloll vide Heymhold 4452 .

Iholland vide Plinius 8076.

Holland vicle Slawk 9676.

Hollandre vide Miller 6936.

Hollherg viele Kalm 5 IIS.

Ilolluann vide Kibl. Bunks. 111. 385.

Holm viule Linné 6070 .

Holmberger vide Bibl. Banks. 111, 557, Y. 87

Holmsliolll vide Bibl. Banks. 111. 224.

Holtzachius vile Dioseorides, p. 335.

Holtzbon vide Rudbect $8 \$ 30$

Ilolwell visle Bibl. Bautis. III. 322.

Holyk vide Kirchmaier 5295.

llomann visle IIarmann 4189.

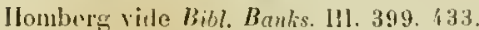

llombron vide $D_{\text {umont }} 2802$.

- vile Montagne 7097

Ilomeros vide Hiquel 6961.

llomeger vide Willdenow 11260.

Ilonigborger virle Endlicher 2988.

llonoratus Faber vide Fuber 3079

Honorins Bellus vide Pona sI5I.
Hooker, J. 1)., virte Ros.s \$734.

llowher, William, ville Silisbury 8962.

Hooker, WI. J., vide Berkeley 771.

- vide Branch 1384.
- vish" Curtis $2090-2092$. ville Nightingale 7509.

visle Scoresby 9509.
9725.
vide Simih 9711.9721. 9794.

9725

Hoole vide Leencenhoeli 5677.

Huop visle lirese 10844.

lloper, Jolın, vide Ituncan 2824.

- vile Bibl. Bumlis. IIt. 240.242 .275 482

Hopje, II. II, ville Martius 6612. - viele Seesus 9529.

ville siurm 9979

Hoppe, Fr. IT., vide Nebel 7402.

llopje, T. K., vide Schreiber 9337. vide Bibl. Banlis. Ill. 79, 219. 405.

Horatianus vide Hillegard is 4459 .

Horatius viale - Inou. 11777.

Horn vide Nienhof 7507

llornlors, B., vide Lime 6123.

Jlomborg, J., vide Limue 6074 .

llortemana vide Agardh 83.

- vide Oeder 7601

Hornsclouch vide Agarlh $\mathrm{S} 3$.

- vide Endlicher 2995

vide Fries 3407 .

__ vide Hoppe $467 \mathrm{~S}$

viale Nees von Esenleck 7421.7425

- vile Steenstrup 9875.

Iloruschuch, V. M., vide Huechner 1504.

Holnstedt ville Usteri 10609. vide Weigel 11112 .

Horumug vide Baier 399.

Ilorsfield virle Bennet 709

- vile Brom 1380. 1389

llorst, Gregor, vide llorst 4713.

llor'st, Jakol, vill. Lemnius 5754 .

I forto vide Huerto $475 \mathrm{~s}$.

Hortus saniatis ville Anon. $11582-11585.11664$. $1\{668,11876-11906$

Hosang ville Spielmanu 9809 .

llose vide 11 ollebius 11354.

Ilose vide Bibl. Banks. V. 70.

llotinger vide Bibl. Banks. III. 406.

Ilotton vide Buerhuave 1041.

—_ vide Bibl. Banks. 111. 517.

Ilouch virle $\mathrm{I}^{\mathrm{r}} \mathrm{cl}$ el 11091 .

Houghton ville Hibl, Banks. 111. 574 .

Houlston vide Bibl. Bumks. IH, 548

Houstoun vide Ribl. Ranks, II]. 321 .

Hout visle Woisetfe 7560 .

llowtun viale I) la Billardiere $2347-2350$.

Houtti ville lon lloutte 10660 .

Houtuyn ville Limne 5978.6010 .

- vitie Bill. Banks. III. 234. 466. V. s4

How viule lle lobel 2430 .

llow ard ride Ribl. Bumls. HIJ. 624

How ell vile bibl. Banks. III. 54 S.

Iluber vidr De Cundolle 2306

- vide Diascarides, p. 334.

Huebener vide Gemth 3566 .

Hueher vide Schulze 9459.

Huegel vile Endlicher 2992-2993.

Hueliferich vide Brunfels 1423.

lluenerwolff vile Bibl. Ranks. III. 403.

Huerto vide Arosin 31 .
Huerto vide Buntius 1111. - vide He l'Ecluse $2 \$ 11$.

Iluether vide Barrow 301 .

Hngo vide I aillam 10620.

IIugurs side Leblond s 6.10 .

Ilulunan vide. Limze 6031.

Ilumbolilt ville Beiluchmied 605. - vid" Bowdich 12 \&1.

- vile Defrance 2331

vide Hower 4645.

- ville lugenhousz 4\$99.

vilir Kunlh 5 159.

vide Lambert 5308 .

ville Paxton is3.3.

vide Schamburyk 9250 .

- vide Bitl. Bantis. III. 220. 239, 406

$414,424.1 \% .87$.

Ilumalbergius virle Apulejus 2535.

Ilunueman vide Pamplin 7728

Ilunter, 1., vile Crell $20 \div 8$. vide Evelyn 3050.3054.

628.

Itumter, W., vide Bibl. Banks. III. 5 s3.

Iluot vides Demido/f 2436.

Juperz vide IJaratti 6494.

Huser vide Paracelsus 77 ig.

lluss, Il., vide Bibl. Minks. III. 630 .

Iluss, J. L., vide Bibl. Bunks. III. 622.

Ilutchinson vide 11 inch 11290 .

Julh, G. I., vide Cutesty 1751.

- vide Fenillie 3173.

vith. Hill 4470.

— vidle Knoop, 5y99.

_ vide Hiller 6936 .

—. vide. Joorhelm 10533.

Ilutl, J. Chr., vile Hupjus 6487.

Jutton vide Lindley 593.5.

Juysum vide Hurtyn 6619.

Juzart vile Anon. 14648.

IJll ville Mill 4489 .

Jacobaeus vide Biul. Bankis. III. Is0.

Jacubi vide Schulze 9448.

Jacobus de Manliis vide Brmfels 1/23.

Jacquin, J. F. v., vide Biul. Minks. III. 36. vite Cupani 2086.

Jacquin, N.J. r., vile liamams $\$ 335$. vide Inon. 11749. vide Bibl. Bunks III S1

Jicquinot ride Humont 2802.

Jaeger, G. F., vile hirhmeyer 5003.

Jaeger, H de, vide Bih. Bunka. Jll. 63:5.

Jager vide I"ulentini 10632.

Janus vide Punlli 7891

Jaminy ville Allertus II. 129

Jan vile Gallesio 3484 .

Jan, I. rle, vide llimms sost.

Janin, Jules, visle Boitarl 1074.

Jannack vide Ifo/fmannsegg 4607

Janot vile Anon. 11664.

Jansonius ab Almeloreen virle Rheede 8540 .

Jansson vide Suint-Pirre 8953.

Januensis vile Simon Januensis 9663

Jarava vide Fuchs 3432.

Jarlin vide Dujardin $2790-2791$

Jardins vide Desjardins 2501.

Jartoux vide Bibl. Wanks. H11. 532.

Jaubert vile Aucher-Eloy 348 .

… ville Meyendorff 6553.

Jaume ville Anon. 11680.

Jaussin vide lalle 10639 
Hiun Beitar vide Valcarenghi 10623.

Jean vitle Chevalier 1820 .

Jenisch vile Schuebler 9400 .

Jemson vide Cato 1755.

Jentsch vide Eysel 3064 .

Jerlin virle Limne 6090.

Jetze vile Bibl. Banks. III. 491.

Jeunet vide Duval $2858-2860$.

thasz vide Juhisz 4980 .

Jirasek vide Bibl. Banlis. Ill. 417.

Imbert vile Anon. 11663.

Incarville vitle Bibl. Banks. IIl. 584.

Indreen virio Gudd 3458 .

Ingerilıousz vide lassulli 10656 .

Intosh vile Juac Intosh 6389.

Investigator vile Plinders 3240

Joannicy vide Syreniusz 10033.

Jubst vide Bechmann 644 .

Jonchers vide Gerike 3586 .

Jorlin vide Linne 6082 .

— vide Hibl. Bamks. HI. 593.

Joflrin vide Lindley 5022.

— vide Pronville 8239.

Johannes vile Actuarius 33 .

Johannes Bruyerinus vide Bruyermus 14 in

Jolanuot vile Miller 6939 .

dohansson vide: Thunbery 10283 .

Jolusson, J., vide Bibl. Benks. 111. 544 .

Johnson, Thomas, vide Gerarde 3580 . ville Anon. 11540.

Jolyelere vide Brisseau-Jirbel 1290.

-.. vide Linne 6010 . vide Tommefort 10381.

Jones vide Bubl. Banks. 131. 178. 202.648.649. Junghe viule $D_{2}$ Jonghe 23:3-2344.

Jonnes vide Moreau de Jonnes 7140 .

Jordanus vide Theophrastus 10159

Jouanguy vicle Steinheil 9\$\$S.

Joubert vide Anon. 11651

Jourdan vide Berzelius $\$ 39$.

Jovianus Pontanus vile Ponlunus 8156.

Ippolito vide Cupani 2087

Jronside vide Ribl. Bunks, IIt 591.

Irvine vide Jolnson 492 \}.

Isaacns Ben Ifonain vide Heyer 6866 .

Isabella vide Brown 1369 - vide Ross 8735 .

Isenfiumm vile Gleichen $3686-3687$

Isert vide $\boldsymbol{B}_{\imath} b l$. Banks. Iht. 290.

Isingrin vide Fuchs 3427.3431

Isjonval vile Quatremere 8271 .

Ismailow vicle Rousseur 8775 .

Isuard viJe Barrel 503 .

vide Lippi 6177.

vide Bibl. Bunks. Jli. 245. 251.283 .295$. 297. $299,313$.

Juch vide klein 5251 .

Juillet vile Girardin 3656 .

- vide $L$ ecoq 5630 .

Julin vide Bibl. Banks. IIl. 648 .

Julins Mlexandrinus vide Alexundrinus 145146.

Julius Cacsar vide Nocca 7532 .

- vide Heinmonn 11123

Jung vide Berlese 779.

Jungek vide Sprengel 9837 .

Jungermanu vide Baier 413.

Jumgius vide Fogel 3257

vide Guhrauer 3956 .

vide Leibnilz 5722.

- vide $J_{u n g} 4990-4992$.

Junius ville Jonghe 4939 .
Juslenius vide Limné 6059 .

Jussieu, Adrien de, vide Burrelior 495.

vide Buccone 975

- vide Duchesne 2753.

vide L Anglois 5552 .

vide Lippi 6177.

vide Paxton 7833.

vide Saint-llilaire $\$ 942$

vide $T_{0 z \text { zi }} 1039$ s̆.

vide Vaillant 10622 .

vide Yentenat 10705

Jussieu, Antoine de, vide Barrelier 495. vide Tournefort 10381.10385

231 squ.

Jussieu, A. L. de, vide Brongniurt 1323. vide Deshayes 2498.

vide $D$ O Orbigny 2691 . vide Flourens 3246.

visle Wichot 6918 .

vide Ruiz $8 \$ 62$.

vide Suint-llilaire 8937. - vile Unger 10594.

Jussieu, Bernarl de, vide Coulus 1773. vide Tournefort 10384

338.650.

Justander, J., vide Browallus 1353.

Justander, J. G., vide Gutd 3463 . vide Hellenius 4324.

Jutais vile Brodin 1301.

Iversen vide Audersen 211

Istatt vide 11 olf 11349.

Kaalund vide Coppellinus 1683

Kaempfer vide Bibl. Busks. III. 183.360 sqq].

liaesersberg vide IIortenfels 4149 .

Kaestner vide Hoeller 6999.

- vile Bibl. Bunks. HI. 379. 388.

liahl vide Ziegler 11441

Kall vile Domizer 2674.

Kalm vite Bartrem 529

— vile Odhelius 7597.

ville Bibl. Banks. Hil. 170. 320 sqd.

Kallsclunied vicle Schenckius 9104.

kanel ride Ray \$380.

vide Bibl.'Bunks. 11]. 182. 200.479

Kandel, llavil, ride Bock 980 .

Kapp vise Bose 1164 .

Kapp vide Broun 1384.

Karanyscliew vide Lime 6110 .

Karpe vide Klein 5251.

Kastner vide Bouruieg 1200

Keating vide Solueninil= 9486 .

lieil virle Hot/mann 4564 .

Keisor vide Nieuhof 7507 .

Kiellander vide Rudbeck $8 \$ 32$

vile Bibl. Banks, III. 380 .

Keller, Chrr., vide Praetorius 8187.

Kieller, J. Chr, vide Gleichen 3686.

—__ vide Schmidel 9183.

- vide Tren 10452 .

Kendrick vide Crosfield 2062.

Kennrily vide $L$ ee 5657 .

Kentmann, Joh., vide Gesuer 3605 .

Kentmanu, Theophilus, vide $\boldsymbol{J}_{\text {rajor }} 642 \mathrm{~S}$.

vide Panchou 7733

Ker vide Anon. IIS4́i. vide Colentini 10627.

Kerbert vide Ilolkenboer 7049.

Kern vide Schuebler 9386 .

liernal ride Plenck s07।
Kerner virle Forster 3989 - vide Hichaux 6904 ville Bibl. Banks, Ili. 416.

Kerr, James, vide Bibl. Banks. Hll. 505.530. Kerstens vide 11 eber 11013

kessel vide Neumann 7466

Kettuer vide Tater 10673.

heventer vide Hormens 4138 .

Keyser vide Friderici 3373.

Kickx vide J/orren 7210.

Kjellluerg vide sillen 9655 .

Kjellenberg vide Thunberg 10294.

lijellman vide Thunberg 10262

Kíclmann vide Kielmeyer 5200

Kielmeyer vile Mlartius 6613 .

Kiclsen vide Batsch 560 .

- vide Schumacher 9i61.

hiernanter vile Linne 6032 .

K̈iesling vide Boehmer 1020.

liggelaer vide Conmelyn 1947.

- vide Munling 7324.

King vide Broun 1373. 1384

- vide Cunningham 2081.

hingdon vide De Condolle 2269.

Kingston vide Jones 4937 .

Kirch vide Bibl. Bunks. III. 429.

hircher vide Vieuhof 7507.

Kirehmajer vide Sperling 9792.

Kirejewsh vide Pogonkov $8099-8100$.

Kintow vide Karelin $5140-5141$.

Kirkall vide Jartyn 6619.

Kirsten, J. J., vide Bibl. Banks, 11l. 285

hirsten, I. vide Fogel 3257.

Kissling vide Jussiez 5021.

Kitailsel vide lloticzky 4054

vide 11 aldsiein 10919.

kittel vide Richard 8550 .

Kittlitz vite Luetke 6358.

Klase vide Limne 6017

hlein, J. K., vide Baier 409

Kilein, J. T., vide Itendel 4356 .

vide Bibl, Banks. Jll, 14. 249.379.

Klein, K. E. vide Limne 6003.

Klein, M., vide Bibl. Ranks. III. 557.

lileintineclit vide Franke 3339 .

lilenm vide Caldenbach 1624 .

Élier, J., vide Tratlinick 10419

Klier, Pl., vide Scherkel 9109

lifopsch vide Curtheuser 1706

Klotzsch vide Dietrich 2590.

—_. vido Guimpel 3981.

- vide Mayne 4227.

- - vide Link 5972.

—— vide Schomburgli 9248.

Lineussel vide I'alentini 10630 .

linght vide Bibl. Banls. IIf. 62 1. Y. 86

Kiniplzof vide Brueckmann 1407.

Knonau vide Jifyer von Knonau 6854.

Kunorr vide Schmidel 9183

Koch vide Berger 750 .

_- vide Herold 4409.

— vide Roehling 8658 .

— vide Sturm 9979.

Koebler, Frz. Jos., vide Soluebler 9384

Koehler, Frolr, vide Schueller 9375.

Kouelyler, J. T., vide Kraschenimikow 53 S3.

Koelpin vide Loefling 6213.

Koelreuter vide Bibl. Banks. IIi. So. 216 sqq

Koenig, Charles, vide Konig 5335.

Koenig, J. G., vide Colsmurn 1934.

- vide Olafsen 7620.

vide lietzius $\$ 497$. 
Koenig, d. G., visle Bibl. Banles, III. 87, 167.271. 336.

hoenigk vide Zigru 11446.

lioenigstuerfer vide Hoppe 4696 .

Koerte vide Stherigger 9479 .

Kocstlin vide Kielmeyer 5204

Kohl vide Blume 955

Rohlhaas vite Bild. Banks. III. \&

Hops vide IItIll 4057

Korenzaey ville Albert 123.

Kosegarten vilo fournett 3502 .

Kotschy vide Hohruacker 4621.

Kotzebue vide ('humisso 4796.

kirallt, G. W., vide Bibl. Banks. III. 400.

hirallt vou Glitlenbach vide Currulder 1699

liraft, Jeus, vide Bibl. Banks. III. 370.

liralt, Joh., vide Anor. 11778.

liralix vide Riralit 5378

Krascheninnikow vile Gorter 3783 . vill Soboleushi 9734. vide Bibl. Banks. III. 77. 335.

Krause, C. II., vide Bubl. Bunks. III. 638.

Kirause; Chr. L., ville Roloff 8704.

vide Bibl. Brnks. III, 631.

Kratuse, L. vide Riller $\$ 609$.

hrausuld vide 11 edel 11081 .

hraul, G., vide Illilegardis 4459 .

Kiaut, J. H., vide Curtheuser 1712.

hresse vide Meyer 6879.

lireutzwald ride Negrier 7447.

Kreyssig ville Ralmis 451.

Kries vide Seareshy 4509

Krombliolz vide $B$ olzam 1080.

hruenilz vide ITrallerius 10928.

- vide Bibl. Brotis. 111. 334. 575

Krusenstern vide Lumgselorff 5554 .

Kiruizsch vide Schuebler 9364.

Kuechelhecher vide Bosserk 1172

Kivehn, Chr. Fr., vile Bibl. Bunts. III. 160.

Kuelı, J. F. W', virle Otto 7677 .

Kuclio, K. G., ville Pulleney 8254 .

Kuchn, O. B., ville Orfilu 7649

Kuersner vide 11 aldschmied 10907

Kuelzing vide Deneghini 6777

Kuhl vide Breda 1249

Kulmus, J. E., vicle Kulnz 5448 .

Kunmer vide Richard 8553.

Kunsemueller vide Bibl. Banks. IHI. 495.

Kunst vide Cartheuser 1709.

Kunth vide llumballe $4776-4778$

vide 11 alter 10264

liunze, G., vide liroich 1372 .

- vide Goebel 3731 .

vide Kichard 8553

vide T'ellozo 10696.

hurr vide Schuebler 9395.

liurrer vide Dingler 2640.

Kiviahowska vide Anon. 11755.

Kyber, David, vide Bock 979.

Kylander vide Stalenus $9 \$ 65$

Kylling vide Bibl. Bunlis, III. 166

Kyronius vide Bibl. Pantis. IIl. 640.

Labarlie vide Bibl. Banks, V. 97.

La Basse vide De la Bacsse 2346.

La Billardière vide De la Billardière 2347-2350

- vide Bibl. Banks. 11I. 311. 314

La Bonite vide Montagne 7100.

vide I'ullane 106 is.

La Borde, Al., vielo De la Barde 2354

Laborde, J. B., vidle Puterson 7803

Labordo, Leon, vide Raffeneau 8307.
Lat Boulaye vidus Merlet 6807

Labram viele Hegetsclueiler 4275-4276.

La Bretonnerie vide De lu Aretonnerie 2352.

La J'rosse ville De lie Brasse $2353-2339$.

I. a Brousse vida $D_{\varepsilon}$ la Brousse $2360-2361$

La Caille ville Mratuld 6986.

lacépede vide cuvier 2105.

Iachausse vide Spielmamn 9807 .

La Chenal vide De lu (Thenal 2362 .

- vide Bibl. Banks. IIJ. 80. 151.

La Chenaye vile Delachenaye 9363 .

La Chenaye des Bois vide Anon. 11634

Lachenmeyer vide Sibubler 9396.

La Chesneo vide De lu Chesnce 2364.

La Clolte vide Itoutont Honternille $72333-7257$.

La Condamine vile De lu Condumine 2365.

Iat Coquille vide bory $\$ 150$.

- vide Brongmart 1394

La Count visle De lu Court 2366.

La Coutme vide Dutrune 2856.

La Croia ride De la Croix 2367.

Lacuna vide Lagma 5497.

— vide Dioscarides, p. 335.

La Doucottu vide De la Doucette $236 \%$

Laestadius vide Anon. 11897

Laet viele Piso 8036.

Lafond vide Blnuco 933.

Lafons vide Delifons 2369

Lafout vide Kroyer 5421 .

La Fontaine vide De la Fontuine 2370.

Lafosse vite Delafosse 2371 - 3374 .

Layasea vide Herrere 4411.

- vile Yunnes 11389

Lagerlof vide 11 callerius 10934.

L.aguna vide Dioscorides 11537 et p. 333.

Lagus vide Kiulm 5099

La Harne vide the la Hurpe 2373.

Lahire vide Poileuu 8121.

Lihitte ville Roessig 8687.

L'Aigue vide Aquaeus $258-259$.

La Julais viule Bradin 1301.

Lalezari vide Diez 2628

Ld Llave vide de la Llave 2374.

Lillemant vide toé-Lallemunt 362 .

La March vide De la Aurck $2375-2380$.

_ vide De Candolle 2208

— vide Bibl. Banlis. III. 48. 86 sqq.

La Narre vide De la Varre $238 \mathrm{f}$.

Lambert vile Antaine 245.

- vide Bibl. Banks. Y. 83.

La Nétherie vide De la .Wetherie $2382-2383$

La Mottraie vide Aubry $3 / 6$.

La Horiniere vide Vael 7550 .

Lamouroux, Jean, vide Zanardıni 11400.

Lamouroux, Sophie, vile De Brondean 2167. 5523.

Lampe vide Hennius 4889

Lancisi vido Marsigli 6539

Landino vide Plinius 8076

Landz vide Til-Land 1031 1 - 10315

Lane vide Buier 403

Lange, Joh., vide Harmam 4179.

Lange, Joh., vide Anon. 11769

Lange, Joh. Heinr., vile Engestrum 3009.

Lauge, Joh. Joach., vide Limne 5978.

Lange, Peter, vide Sthenk 9108.

Lange, Samuel, vide Eysel 3063.

Langethal vide Zenker 11428.

Langius vide Lunge 5529-5535.

Langles vide loinve 5126 .

—_ vide Thunberg 10233

Lanoye vile Delanoye 2384 .
Jantin vile .Mursatte 6509.

Iantingshausen vide Bibl, Barks. III. 627 .

Lany vide Delany 2385

Lásljon vide Jiljeblud 5891 .

La Perouse vide De la Ballerdiere $13: 7$.

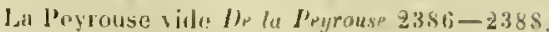

Lat Dlysicienue vide Gandichund 3527 .

Lappe vide Linne 61 ( 9 J.

La Pylaic vide De lis Pylaie $2389-2390$.

La Quintinge vide De la Quintmye 2391.

Larbie vide Delarbre 23y2-2343.

Lardner vide Menstom $437 \pi$.

La liecherche ville durkins 6576 .

Larwus vide Scribonius Laryus 9512.

La Rivière vide to la Ruere 2394.

La Roche vide Je lic Rnche $2395-2396$

- vide Derlet B807.

- ride liedlouli sill.

Las vide He Las 2397.

La Sirgra vide Raman de la Sugra $\$ 340-\$ 342$.

Litsaraz vile fringins $3646-3647$.

Lassus vide Cuvier 2105.

Lit Stegrie vide De la Stryrie $2398-2399$

- - vids Parmentier Tisl.

- vide Bubl. Banks. V. 101.

Lastre vidle Delastre $2100-2101$

L. Istrolalse vide Jumont $2801-2802$. - vilie Moutagne i097. vide Richard 8557

L.astrop vide Lange 5530.

La Taille des Essarts vide De lu Tirille zfog.

Latipico vide $11 \%$ zately 11189.

La Tour vide De la Tuar 2403.

Latumrette vide Bibl. Bants. III. 20. 149. 534. V. 69 .

I atro vide Capece-Latro 1679.

Latluarla vidu Murelli 7168 .

L'Aube, corvette vide Ruoul \$351.

Laumont vide Gillet de Litumon 3649.

Launay vide Mordant de Lounay 7133. vide De la Bretonaerie $935 \%$

vide Loiseleur 6238

Lillrell vide Hipllenius 4398.

Laurell vide . Inom. 11814 .

Lituremberg vide Iloffman 4600 . vide Paulli is is. 7820.

Laurent vide .Miquel $696 \mathrm{I}$.

Laurent vide Lhan. 11596

Laurer vide Sturm 9979

l.aurin vide Lime 6115.

Lauli vide Villars 10754

Lavallee vide Acerbi 20.

La Vigne vide De la ligne 240 - 2403

Lavirotte vide Needham 7415.

Lawsolk, Thonas, vide Bibl. Banks. III. 138.

Laxmann vide Bibl. Bunks. III. 174, 271.

Lay vide llooker 4665 .

La Zélér vide Dumont $2801-2802$. vide Montagne 7097 .

Leache vide Hartines y Leache $6561-6562$.

Lebiume de Presle vide Starek 9939.9941.

- vide Anon. 11632.

Le bilond vide Bibl. Bunks. III 597.

Lebreton vide Casur.r 1722.

- vide Bibl Banks. Ill. 590

Lebrija vide Diascorides 11537.

Leche vide Bibl, Banks, III. 169. 418.

Leclere de Bufton vide Brisseau-Mirbel 1990.

Leclerc, Daniel, vide Marsigh 6538.

Leclore, Oscar, vide Thouin 1022$\}$.

L'Ecluse vide De l'Écluse $2406-2413$.

Lectier vide Le Lectier 5732. 
Ledebour vide Heinmann 11119.

Ledermayer vide Portenscilag 8168.

Ledesma vide Colmenero 1928.

Leennius vide Leonicenus 5771.

Leeuw enloek vide Fleck 3220 . vile Halbertsma $403 \mathrm{~s}$ vide Bibl. Ronks. [II. 339. 371.

Lefébure vide Bıbl. Banks. III. 628.

Lefobure de Villebrune virlo Ullaa 10573.

Lelorestier vitle Lefebure 568.

Le Francy van Berkhey vide Berkhey 777.

Legendre, Mlle., vide II ebb 10999

Lelimann, Imm., vide Ho/mann 4563.

Lehmanı, J. G. Chr., vide Booth 1117.

Lehmann, .1. Go., vide Bibl. Banks. III. 537.

Lehrs vide Nicander 7479.

Leincker, J. L., ville Wedel 11079

Leincker, J. S., vide Crell 2049.

Leloir vidle Richard 8550.

Le Lon: vide Agricala 96.

Lemaire vide Laiselete 6240.

Lemaire, N. E., vide Palluthus 7712

- vide Plinius 8079

Le Naistre, A., vide Le Gendre 5694.

Le Maistre, Mathieu, vide Jaistre 6434

Lemaont vide Bernard 785.

Lenlhe vide Ilelvigius 4344 .

Lemery, L., vide Bibl. Banlss. III. 433.

Lémery, N., vide Cap 1677 visle Bibl. Bumks. JII. 493. vide Anon. 11629

I.mnius, Lev, vide l'allesius 10649

l.e Moino visle Linne 6106.

Lcmonner, Cerall, ride Rousseau 8777.

Lemonnier, L. G., vide Cumer 2105. vide Bibl. Bunks. 111. 552 . vide Anon. 11677.

Lens vide Merat 6795 .

Leutilius vide Bibl. Banks. 111.204.

Leodegarius a Quercu vide Brohan 1304.

Leoni vide Itoretti il 78 .

Leonicenus vide Brunfels 1423.

Leopold, C. Fr., vide Kalm 5094. 5097.

Leepoltl, C. G., victe Acerbi 21.

Leopold, J. D., vide Camerurius 1643 .

Lepage vide Hougeat 7249.

Lepechin vide Demidow 2437

344. 462

Le Play vicle Deniduff 2436.

Leprieur vide Grillemin 3974.

L vide Jontagne 7072.

Lerche vide B,bl. Banks. III. 174. 291.

Lerius vide Lery 5778 .

Le Roy vide Anon. 11645.

Lersner vide Caldenbuch 1626.

Lescallier vide Larréategui 5565 . vide Bibl. Banlis. III. 616

L. Escluse vide De lÉrirse 2406-2414.

Le Sẻniavine vide Luethe 6358.

Leske vicle Pohl 8103

Lesser vide Bibl. Banks. Jll. $\{28$.

Lessert vide De Lessert 2414.

Lesson vide Borg 1150.

- vide Richard 8557 .

Lestibeudois vide $B_{l} b l$. Banks. III. 596.

Le Tourneur vide Sparman 9784.

letschius vide Albinus 131 .

Lettsom vide Caakley-Lettsom 1881.

Leutwein vide Buier 412.

Leuze vide Delenze 2415-2416.
Le Vasseur vide Grew 3874.

Le Vasseur vile Bibl. Banks. III. 473.

Leveillé, J. B. F. vide Bibl. Bunks. III, 343

Léveillé, J. H., vide Demidafl 2436. vicie Moritzi 7205 . vide lanllunt 10618.

Levieux vide Le Turquier 5814.

Levin vide llellenins 4318 .

Levv vide Cuylus 1773

Lowenhaimb vitle Sachs von Lewenhaimb 8909.

Lewin vide Thunberg 10271

Lexa vide Aehrenthal $49-52$.

Lesarza ville De la Llave 9374

Lrvde vide Krassow 3385 .

Leysser vide II ohlleben 11336

- vide Bibl. Banks. Ill. 224

Lezermes vide Marshall 6535.

L'Heritier vide Cavanilles 1763. - vide Cuvier vios. vide Bibt. Bunls. IJI. 229. 276 sqg.

L'Herminier ville Guibant 3962.

Lidluech, A, vide Bibl. Brnhs. III. 650 .

Lidljeck, E. G., vide Bibl. Bonks. IlI. 379 sqq.

Liden vida Linne 6140

Liclén vide Thunberg 10293 .

Lieb vide llandteig 4113.

Liebautl vide Liger 5880 .

Liebentantz, Iol., vide Liebentantz 1660

Lishig vide Catinelli 1754 .

- _ vide Illubeli 4529.

-____ vide Nohl 7038 .

—_ vitu Schleiden $9156-9157$

—— vide schmid 9179

-_ vide IIrikelblech 11294- 11295

Liebmann vicle Oeder 7601

Liergues vide Honconys 7060 .

Lieur vide Lelieur $5733-5737$.

Liger vide Serres 9590

- vide duno 1159

Liljeblad vide $B_{1} b l$. Banks. III. 318.339.

Liljenarck vicle Robery 8623.

Liljevaleh vide Bruzelius 1443

Lilius vide Brawallius 4351

Limberger vide Nebel 7401.

Limbourg vide Rabert de Limboury 8628 .

Limprecht vide Bibl. Banks. III. 366. 547

Linck, J. H., vide Bibl. Banks. [1I. 249.

Linck, J. W., vide Eschenbaih 3031 .

Lineoln vide Bibl. Banks. III. 378.

Liudlilom vitle Agardh 75 .

Lindegaard vide Pontoppidan 8162.

Lindemann, E., vide Fleischer 3236 .

Lindeumann. $\mathbf{F r}$., vide Isidoras 4963

Linden vide Lindley 5949.

Lindenberg ville Nees von Esenbeck 7437.

Liudestolpe vide Linder $5916-5917$.

Litulheimer vide Enyelmam 3007.

Lintley vide Buner 575. vitle Don 2686

- vide Eduards 9911 .

- vide Knight 5887.

- vide Loudon 6283.

vicle Mitchell 6978 .

vide Paxton i\$34.

vide Pronville 8239

vide Richard 8561

vide Sibtharp 9618

vide Tounley 10391.

Lindner vide Ilmer 4891.

Lindrolls vide Thunberg 10285.

Lindsay, Jolu, vidle Bibl. Banks. III. $277.441 \mathrm{sqg}$.

Lindsteen virle Kalm 5096 .
Lindstron vide Trazelius 10509

Lindwall vide Kalm 5120. vide Linné 6124.

Lingg vide Schuebler 9394

Link vide Berg 735.

— ville Dietrich 2587.

- vitle Ioflimumsegg 4606. 4609 .

vide Lea 5765.

- vide Linne 6004

vide Nees van Esenbeck 7421.

- vide Schultz 9424.

- vide Sprengel 9\$42.9849.

- vide Theophrastus 10165.

vide IVilldenaw 11256. 11262. 11265.

vide Bibl. Bunks. IIJ. $\{20$. V. 62. 85. 86 .

Linné vide Alston 169

vide Beckmum 646

vide Bertoloni 831

vide Bianchi 860

vide Colden 1897

vide Dabl 2114.

vide De Cindolle 2304.

vide Ellis 2963.

vide Fee 3131.

vitle Farsyth 3298 .

vide Fuerurohr 3438

ville Gilibert 3633

vide Huller fil. $4086-4089$.

vide Husselquist $\$ 207$.

vide Henckel von Dannersmarck 4352.

vide Hendel 4357

ville IIll 4467

vide Houttuyn 4730

vide Lipp 6175

vide Laefling 6213

vide Lorente 6267

vide Ludwig 6334.

vide Manetti 6463 .

visle Murquis 6524 .

vicle Martius 6604.6605 .6608

ride Martyn 6628.

vide Merrem 6811 .

vitle Mikan 6927

vide Nilne 6947 .

viele Mitchell 6975.

vide Mueller $7283-7284$

vide Murray 7342.

vide Nerker 7412

vide Oeder 7599.

vide Ortegu 7659.

vide Petermann 7910

vide Planer 8046.

- vicle Palteney 8253.

vitde Raeuschel 8303.

vide Retzius 8511.

vide Richard $\$ 560$.

vide Roemer 8674 .

vide Bose $\$ 722$

vide Saint-Amans 8927

visle Schreber 9334

vide Schultes 9409

vide Siegesbeck $9639-9610$.

vide Saennerberg 9736.

vide Sprengel 9855 .

vide Suljren 9993.

vide Thorntan 10209-10210.

viule Titius 10335.

vide Vandelli 10655 .

vide IValmstedl 10959

vide 11 peizenbect 11138

vide Zeipel 11420.

vide Anon. 11579 
Linue vide Bibl. Banks. J11. 29, 35. $169 \mathrm{sug}$.

Linué fil. vide laturig 632 h.

__ vide Sithul= 9440. vile Wulmstedt 10959 vide Bitl. Kionks. III. 273.

Linne, Elizabeth Ghristina, vide Bibl. Bantre. III. 368 .

Linocier vide Robin 8639 .

Lippert viur Limue 6010.6034

Lippi vide Petion 79:0.

Lipsius, Justus, vile Rapinus 8334.

l,isancourt vide Lemaire 5746 .

Lishoa vide Silua Lishoa 9658

Lischwitz vido Rivinus 8614.

Lise vidle Melise 2418 .

Lisler vide Apricius 209.

—— vidl Bill, Banks. III. 371. 373. 442.

Ljungstedt vide Fries 3389.

Lker vildo laker 6359

Llave vide De lu Llave 2374.

L'Obel vide lle $\left(0 b^{2} \mathrm{2} 2426-2430\right.$

lobetius vide De 10 bel 2426-2430.

- vide Pena 7857.

Lobo vide Bibl. Banks. III. 211.

Lobstein vido Loebenstein 6211.

Lochner vide Besler 843.

L vide Bill. Bunks. III. 76.

Lodin vice Thunberg 10239

loeber vide Seadel 9341.

Loednann vidts Trozelius 10313

Loelling vide: Bossu 117 : vide: Lime 6033 riele Bibl. Binks. 111.19

Loehs vide N"irtgen 11319

Loenberg vide Liljeblud 5894.

Loenquist vide Rosen $87 \pm 3$.

loenwall vide Hahn 4046 .

loeser vicle Ilthger 4012

Loew vidi ITedel tlage.

- ville Bibl. Banlis, III. 172. 648.

Locwe vislo Bibl. Banks. Ill. 31 5. 330

Loewenherer vide /lumboldt 4785 .

Lolırman vide Rudbeck \$\$20.

Loiseleur vide lia llamel 2788. vide Mordunt 7138 .

vide Amon 11660

London vide Inon. 11591.

L.ong vide lgrionta 96.

Longchanp vide Pennier de Longchamp 7859

Lonmiano vide Diosrorides 11529.

Longolius vile Figulus 3188 .

Lonicerus vide Lonitzar 6260-6262

Lonitzer vide Domitzer 2674. vide Nicander 7478 vide Dioscorides 11518 et p.334.

Loo vider Line 6080.

Loomis vide Croom 2059.

Lopez vide Ruiz \$\$54-8867.

Lorrain vide Tallemont 10641 .

Lorsbach vide Leo 5764 .

Lortel yide hoffacier 8691 .

Lossberg vide Robery 8623.

Losthom vide Lastbom 5571

Loteri ville Bibl. Banks. III. 594.

Iotrian visle Anor. 11664

Louiche vide Desfontaines $2491-2496$.

Loureiro vide Bibl. Bunks. III. 635. Y. 93.95.

Louis Xlll, vide I'allet 10644 .

Louis le Juste virle De la Brosse 2357. 2359.

Lonise vide Meypn 6838.

Lucé vide Bibl. Bunks. 111. 142. V. 103.

Iuchini vide Spiessenton/f 9817.
Indeen vide hurbeck 8831 .

Judlovici vide Hibl. Brenks. III. 196

Iudwig, Chr. Fr., vithe Dieterith 2585. vile Iflumboldt 4770 .

Ludwig, Chr. Gottlieh, vide Blackuell 920. vide Hebenstreit 4239 vide Ruinus $\$ 615$.

Lueders, A. F., vide Linne 6154

Lurders, F. W. A., viche Gleditsch 3683.

Luctke vide Postels 8172. vide Kittlitz 5248.

Lund, C. F., vide Bibl. Barks. III. 363

Lund, G. vide Bibl. Banks. III. 522.

Lund, .1., vide Trozelies 10505.

Lund, N. T., vide Bibl. Banks. III. Ky9.

Lund vide Bache 391.

I andelius vide Budbeck 8831 .

Lundequist vide Sillen 9655 .

C._. vide Anon. 11814

Lundmark, J. D., vide Linue 6166.

L vide Bibl. Bunks. III. 320.

Lundmark, P., vide Thunbery 10249.

Li Uranie vide Grusdichurd 352 .

Lusitanus vide Droscorides, p. $334-335$.

Lunt vide Linne 6119

Lycosthen's vide Mylius $736 !$.

- vide Wollhart 11353.

Lvnacro vide Jacer 6385.

Lyons vide Hooker 4669.

Lysarch vide Zignu 11466.

Lyte, Henry, vide Dodoens 2634

Lith vide Hidlerius 10937

Macaire vide Mrercet 6500 .

Macdonald vide $B_{3} b l$. Banks, III. 536

Mac Encroe vide De le Croix 2367.

Macer vido Bomerner 1044

- vide IIarpestreng $\$ 143$.

vide Lovitz 6305 .

vide Renss $\$ 523$.

Vacgillivay vide Richard 85 șo. vide Smith 9721.

- vide llithering 11329 .

Machado ville Gumu Machado 3489.

Machy ville Bibl. Banks. III. 524.

Macie vide B,bl. Bunks. 111. 487

Nachiprang vide Butheald 1499.

Naclure vide Horton 7234.

Macquer vide Bibl. Banks. III. 438

Madden vide Bibl. Banks. J11. 549.

Maderna vide Bibl. Banks. III. 594.

Madianna vide Ricord-Wudiamna 8579

Maederjan vide Ho/fmann $\$ 559$.

Maerkfin ville Bibl. Banks. III. 89.443.

Magdeleine do St. Agy viste Curier 2106.

Magendie vidle Baffeneau-Dilile \$304.

Magnus vide Mlinsson 6476.

Nagnus a Tengstrom vide Nylunder 7585 .

Mablmann vide Humboldt 4786.

Vahon vide Uac Mahon 6393.

Majer vide Schuebler 9380.

Maillard vide Chomel 1841 .

Mailly vide De Mailly 2431

Main vide Mawe 6686 .

Mainardes vide Brunfels 1423.

Mainardus vide .Munarlus 6456

Major vide Kentmam 5165.

_- vide Jalentini 10632.

— vide 11 aldschmiedt 10914.

- vide Bibl. Bunls. 111. 438

Maire vicle Lemaire $5738-5746$.

Maironi vide Babl. Bunlis. III. 552.
Makowsi vide Munli 7813.

Malabaila te Canal ville Nounduorsti 7576 .

Nallac vide Anon. 11558 .

Mallet vide Bibl. Banks. III. 473.

Malmarelu vide Relzius 8502.

Malınsten vide Hullerius 10929.

Malpighi vide Danielli 2134 vide Festa 3169.

- vide frew 3877.

Malsch vide Bergen 745 .

Malte Brun vide Barrow 500.

Malvezzi vicle Bih. Runks. III. 590.

Manardus vide Marino 6508.

Mancy vide lirgulius 10766 .

Mandar vide Puterson 7803

Mlanetu vide Linne 5978 .

Manfredi vide lialdus 44 .

- vile r'umpi 1666.

Manget vide Dufour 2770.

_ - vide Sponius 9826 .

Danliis vide Brunfels 1423.

Manoncour vide Sonnini 4749-9755

Manquer vide Sienchius 9921.

Mlanso virle Silua Manso 9659.

Manteullel vide Maddack 6397.

Manutius vide Plinius 8076.

Naout vide $L e$. Neout $5747-5748$. vide Beruaral 785.

Marabelli vide Bibl. Manks. III. 434 .

Marcet vidle De Candulle 2303.

Marcgravius vide $\boldsymbol{P}_{\text {iso }} 8036$.

Marchais de Mignraux vide Sinclazr 9666 .

Marchal vide Barton 521 .

Marchand vido Numan 7578.

Marchant vide Morison 7196.

- vide Bibl. Banks. 111. 302.303 जाu

March vide De la Mrarck $2375-2380$.

- vide De Ciandolle 2208.

Marchlan vicle Sulisbury $8959-8962$.

Jlarcorelle vide Bibl. Kanks. IIT. 253. 369. 436

Marcus vide IIfrtmann 4183 .

Marcus Novianus vide Nevianus 7469.

.Harggral vide Bibl. Banks. III. 435. 564.555

Narinello vide Inguillara 233.

Niarius vide Meier 6743.

Jarklin vide llliger 4890 .

Markussen vide Ra/u $\$ 332$.

Marmocchi vide Humboldt 4779.

Maronea vide Marogua 6514.

.lanogna vide Dioscorides, p. 333 .

vicle Pona 8151.

Marquardus II. Episc. visle Besler 840.

Marradon vide Bitl. Banks. III. 579.

Marre vide De lu .Marre 2381.

Mlarschislch vide Bibl. Bonks. ItI. s\$9.

Marsham vide Bibl. Banks, III. 377. 420. 619. 654.

Marsilius vide Mursigli ot Marsili $6536-654.3$.

Marsigli, L. F. vide Dufour 2770 .

Marsili, Giovanni, vide Lancisi 5526 .

—_ vide Bibl. Burks. HI. 281.326.

Marsilli, A. F., vide Triumpetti 10492.

Marskussen ville Sichousboe 9264 .

Martelli vide Bonelli 1098 .

Martens, G. v., vide schuebler 9.365

Martialis ride Anon. 11861 .

Martignoni virlo Morelti 7165 .

Martiu, Aimé, vide Suint-P'ierre 8953

Martin, Anton Rol., vide Limne 6073.

Martin, llugh, vide Bibl. Banks. III. 5sz

Martin. L. A. vide De la Tour 2403. 
Martin, Petrus, vide Bibl. Banks. III. 76. V.64. vide Lundmar 6366.

Ilartin, Roland, vide Linze 600 .

Martin vide Juge de Suint Martin 4977-4978.

Marlinet ride Knoap 5299. vide Bibl. Banks. III. 316.

Martinez vide Quer $8276-8278$.

Martini, Fr. II. W. vide Adanson 44. vide Cartheuser 1707 vide Bibl. Banks. III. 563 .

Martini, Jakob, vide Aron. 11744.

Martiniere vide Murtens 6346 .

Jartino vide San Harlino $\$ 992$.

Martins vide Browais 1241-1242.

- ride Goethe 3761 .

Martius, E. W. vide Flatou 3244. ride Bibl. Bunks. III. 5. 154.

Ilartius, Jeremias, vide Grevin 3873 .

Martius; K. Fr. Ph., vide D'Orbigny 2690. vide Endlicher 2995. vide Goethe 3761 . vide Linne 6159.6161

Martyn, Jolsa, vide Gorham 3780. vide Tournefort 10384. vide loirgilius 10764-10765. - vide Biul. Bunks. Ill. 244. 350 .

Martin, Tloomas, vide Gorham 3780. vide Miller 6936.

- vide Roussean 8775.
videl. Banks. 111. 27. 259 1. $s 8$.

Mascon vide Roxas Clemente $\$ 7 \$ 3$.

Uassi vide Parlatore 7759 .

Nasson-Four vidle Lindley 5931.

ב- vide Rapinus 8354 .

Matsiru de Dombasle viele Sinclair 9668.

Matolai vide Bibl. Banks. V. 97.

Maton ride Lmne $61+3$.

_- vide Putteney 8253.

Mathaeolus vide Mattioli $665 \mathrm{j}-6663$.

Natthaeus a S. Josopho vide Barrelier 495.

Mathaeus Sylvaticus ride Simm Januensis 9663 .

Matthee virle Dioscorides 11538.

Matthinlus vide Mattioli $6655-6663$.

Mattioli side Dioscorides 11325-11526. 11530. $11332-11534$ et p. $334-335$. - vide Fuilandinus $3966-3967$. vide Hessus 4436 . vide Moretti 7164. vide Pasini 7793. vide Stemberg 9917 vide Zwinger 11490 .

Mauchart vide Schmidt 9214.

Mauduit vide Bibl. Banks. III. 3 \$ I.

Maughan vide Boehmer 1035.

Maurette vide Braguier 1226.

Maurj vide Fiorini-1Iazzanti 3200.

- vide Sebastiani 9520

Mauroceni vide Tita 10333.

Mauvillon vide l'llow $105 i 2$.

Mavor vide Tusser 10561.

May vide Palladius 7732.

Jaycock vide Halliday 4090 .

Mayer, I. F. II., vide lloessler 7009

Mayer, August, vide Rohrer $\$ 698$.

Mayer, Johann, vide Thuemmig 10228.

Mlayer, Juhann, vide Bibl. Banks. III. 164. 174 sqq.

Maver. Johann Clir. A, vide Bibl. Banks. III. 372. 375.1 .92 .97$.

Mayer, Joseph, viule Bill. Banks. Y’. $\mathbf{8 2}$

.lays vide Hoppe 4675.
Mayr vide Bibl. Banks. III. 597.

Maỵrholler vide Schrank 9323.

- vide Sterler 9910.

Mazéas vide Bibl. Banks. Jl1. $5 \$ 4$.

Mazières vide Desmazieres 2309-2514.

Mazzanti vide Fiorisi-.Uazanli 3199-3200.

Nazzuoli vide Bibl. Banks. 1]1. 443.

Mean vide Abercrombie 16.

Mechin vide Anon. 11696

Medemblich vide Dioscorides 11505 .

Meder vide Schultze 9453.

Medicus vide Vaumburg 7390.

— ride Stein 9884 .

— vide Bibl. Banks. IIJ. 48. 83.207 sq4.

Neerbeech vide Dodoens 2659.

Meerburgh virle Bibl. Banks. III. 643.

Neermann vide Brundon 1233.

Neese, B. Chr, vide Bibl. Banks. III. 423.

Mleese, David, vide Babl. Banks. III. 441.602 .

Megenberg vide Inon. 11764.11768.

Megtenberger vide Ortolf $v, B, 7663$.

Mehuert vide Leonhardi 5768 .

Neihomius vide Turnebus 10533.

Neidinger vide Bibl. Banks. III. 407.

Neinecke vide Forsyth 3297.

Meisner, J. Fr., vide Boehmer 1022.

Meisner, K. Fr, vide De Candolle 2Z56. 2969.

Meisser vide Anon. 11679. 11681.

Melancithon vide Peucer 7965.

Melander vide Bibl. Banks. IIJ. 428 .

Mélicog vide Delafons 2369.

Melippus Protimus vide Baldus 446 .

Melius vide Juhusz 4980 .

Mello vide Veres Mello 7468 .

Mendel vide Cartheuser 1710.

Meneghini-Faluris vide Romano 8708.

Menegoti vide Scarella $9048-9050$.

Méneville vide Guerin-Meneville 3947.

Mengenberger vide Anon. 11764. 11768.

Menglinus vide Bibl. Banks. III. 494.

Mennander vide Kalm 3112 .

Ilenourille vide Thiery 10187.

Mensinga vide Ifunting 7324 .

Mlenizel, Clur, vide Reyger 8533 . vide Bibl. Banks. III. 12s. ว32.

Menzies vide Bibl. Banks. Y. S2.

Nerat vide Boreu 1125. vide Anon, 11686 .

Merck, J. A. vide Feldniann 3149.

Mercurialis vide Guilandinus 3967 .

Meré viele Guenard 3940.

Mergiletus vide Mappus 6488 .

Meriall, Mathaeus, vide $B_{r y} 1446-1447$.

- vide Jonston 4044 .

Méril vide Dumeril 2796-2797.

Merrem vide Limue 6010.

Dlerrett vide Bibl. Banks. III. 370. 373.

Merson vide Demerson 2434-2435.

Mertens vide Roehling 8658 .

Jlerveille vitle $L u$ Roque 5564 .

Mery vide Lemery $3730-5752$.

Mesch ride Boon Mesch 1114-1115.

Mesue vile Badanus 395.

- vide Hamardus 6456 .

- vide Marino 6308 .

- vide Iartine $6561-6562$.

Métherie vide toe la .Hètherie 23\$2-2383.

Mettayer vidle Serres 9591 .

Metzger vide Babo 379.

Neurling vide Kalm 5125.

Meursius vide Rapinus 8354

Meyen vide Brown 1384.
Meven ride J'riese 10845

Mever, Bernlard, vide Gaertner 3468.

Meyer, Cluristoph, ride Loeselius 6221.

Meyer, Ernst, vide Albertus Magnus 129.

- vide Brown 1384.
vide Drege 2717.
vide Goethe 3761 .
vide Nicolaus Damascenus 7491.
vide Titius 10337 .

Meyer, F, vide Duncan 2 S25.

Heyer, F. A. A., vide Bibl. Banks. III. 414.

Neyer, Hermann von, vide Dunker $2830-2831$

Mever, II., vide Diel 2567

Meger, H., sculptor, vide II olf 11342.

Mever, J. A, vide Schulze 9458.

Meyer, J. D., vide Martyn 6619.

Mever, K. A., vide Bongard 1103.

—— vide Fischer 3207-320y.

Nleyer, L., vide Agardh $\$ 3$.

Michael vicle Gyllenstälpe 4001 .

Wicluaelis, Chr. I., vide Rudbeck 8834 .

Nichaelis, Clır. Fr., vide Withering 14330.

Michaelis, Joh. Dar, vile Celsius 1781.

Nichaux, A., vide Bibl. Banks. III. 185.

Michaux, F. A. vide Cubieres 2072.

Micliel vide Du Vamel 2788.

Nielueli vicle Mursili 6544

- vide Taryioni-Tozzetli 10054.

- vide Zumboni 11396.

Middendorif vide Trautuetler 10437

Mieg, Ach., vide Stupanus 9976.

Mieg, J. R., vide Zu'inger 11494 .

Mieg. II. vidle Hieg 6920 .

Mlikan, J. Chr., vide Camerarius 1662.

Milchsack vide Dorstenius 2693.

Miles vicle Bibl. Banks. III. 339. 359.

Millard vide Kunth 5456 .

Miller vide Vueller $7283-7285$.

Niller, Charles, ride Bibl. Bunh's. III. (101.

Miller, John, vide Bute 1597.

Miller, Plilip, vide Buster 543.

—_ vide Tschudy 105016. 613.641

Willin vide Botton 1179.

—_ vide Limné 6143.

_ - vide Pulleney 8253.

Millin vide llillemet 11267 .

- vicle Bill. Banks. 11I. 354.

Millinglon vide Bibl. Banks. IIl. 486 .

Mills et Co. vide Anon. 11556.

Milne vide Whitley 11198.

Nilne-Edwards vide Jussieu 5021

Minsiuger vide Zuccurini 11474.

Miquel vide Hall $\& 059$.

- vide hopss 5358.

Miranda vide l'cllo=0 10696.

Mirbel vicle Brisseau-.llirbel $1288-1296$. - vide Brown 1384

- vide De la Marck 2379

- vide Richard 8562 .

Mirecourt ville Gerardin $3581-3584$.

Mirza Labat KJuan vide Labat 5482.

Misilmeris, Dux, vinle Cupani 2085.

Hitterpacher vide He la Steyrie 2398.

- vide Piller 8025 .

Mizolilus vide Mizauld $6980-69 \$ 6$.

Nizler vide K̈irchmaier 5226 .

Modin vide Thunbery 10301. 
Moedring vide Bibl. Banks, 11I. 77 squ.

Mochsen visle Besler 840.

Mochsen vide Bibl. Banks, III. 380 .

Moeller vide Bibl. Banks. III. 382. 388.

Moet vide Anon. 11709

Molsl vide Martius 6585

Molmike vide Thunbery 10301.

Mohr, Janiel, vide Millwin 2637 ville Iteber 11003-11008.

Molı, Nic, vide Thorstensen 10217.

Moilsanus vidro Dioscorides 11504.

Molbech vide IIarpestreng $\$ 143$.

Moldenhawer vile Theophrustus 10162

Molinaeus vide Dalechumps 2121. vidle Dioscarides, p. 335 .

Molitor vido Ingenlousz 4901.

Molkenboer vide Dozy 2703-2i05.

vide l'riese 10853.

Moll vide Schrank 9309.

Noller vide Major 6430 .

Mollin vide Hellenius 4319.

Molthe vide IIPrmann 4397.

Molyneux vide Threlkeld 10227 .

Monardes virle Ite l'Eclase 2411.

vide Gohori 3766 .

vide lluerto 4758 .

Monceau ville Du llamel du Sonceau 2774-2789.

Moncets vile Pajon de Moncets 7701.

Mondani vide Bibl. Banlis. 11. 626 .

Monde vide Tundermonde 10657-10658.

Monnard vite Grutio 3332 .

Nonnet vide t)e lu Marck $2375-2380$.

Monney vide Kasthofer 5145

Monnier vide Le Honnier $5756-5757$.

Monro vide Bibl. Banks. III. 466 .

Nons vide I an Jons 10663- 10664

_- vide Qícetelet 8280 .

Monstereul virle De la Chesnee-Monstermul 2364.

Nont vide lumont $2798-2802$.

Montagne ville DOrbigny 2690

- vide Damont 2802.

vide Ramon de la Sagra 8341.

vide I'ctillant 10618 vide Welb 10999. 11001.

Montalbanus vide didrowandus 141

— vide Legati 5692. vido Siguier 9334.

Montanus vide Fipra 3186.

Montbéliard visle Berwerl is4.

Montbret vide De Silvestre 2507 .

Montesanto vide Theophrastus 10167.

Montet vide Bibl. Banks. III. 469.

Montuarny vide Ilarmund 4136.

Ilonti, Gaetano, vide Monti $7123-7124$ vide Zanoni 11416.

vide Bibl. Bitnks. 111. 243.258.

Monti, Giuseppe. vide Quer 8276. vide Bibl. Banks. III. 14.77 stg

Mouti. Ignazio vide Bibl. Banks. III. 466.

Montigiano da S. Gimignano vide Dioscorides 11581

Montin vide Bexell 836

- vide Limné 6035 .

- vide Bibl. Buths. III. $170 \mathrm{sqq}$

Hontpascal vide I'illa 10745.

Montpéreux vide Dubois 2739

Nontyon vide fraudicluad 3528 .

Moquin-Tandon vide De Cendolle 2236.

Horaeus vide Bibl. Butnks. III. 550 .

Morealdi vide Rozun 8806 .

Mordant de Launay vide De lo Bretonnerie 2352.

- vide Loiselcur 6238
Mordant de Launay vide Anon. 11660.

More, Rohert, vide Bhbl. Banks. III. 531

Morean vide Colmenero 1928 .

Morean de St. Mery vile Bibl. Bumks. III. 596. 635.

Morel vide Anon. 11657. 11701.

Morelot vide Lémery 5752 .

Moretti vide Cesuti 1784.

— vide Dioscorides 11530

- vile Melandri 6761.

_-_ vide Morirand 71\$0.

- vide Polti 8146.

Moretus vide IIuthaens Sylrutienes 6651 .

Mrrgenlesser ville Lulirig 6327.

Morhart vide Fuchs 3433 .

Morinière ride Noel 7530

Morison vide Bauhin 583.

- vide Boccone 969

Morland vide Bibl. Binks. III. 390.

Moro, P'ietro, vide Bibl. Bunks. III. 431.

Morozzo vide Bibl. Bunks. III. 432.

Morren vide Lindley 5936.

Mortier vide Dumortier 2\$03-2815.

Hortiner ville Bill. Banks. III. 550.

Morwyng vide Gester 3597.

Mossilorf vide Sichulae 9457

Mussill vide Ulenrici 4366

Mottini vide Morelti 7170.

Motraic vide dubry 346 .

Noucheron vile De Woucheron 2438

Nougeot vide Sehimper 9132.

Moulin vide De la Rividre 2394.

Moulin vide saint-1loulin 8951.

Moulins vide Des Moutung $2515-25$ Is

- vide Dalechamps 2121.

Monlt vide Bibl. Banks. III. 322.

Mourgue vide Bibl, Barlis, III. 422.

Mouton-Fontenille vide Lime 6010 .

Mowafik vide Seligmanm 9351.

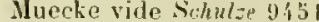

Nueblenberg vide Bibl. Benlis. III. 185.

Muelalfeld vide Megerte ron shuhlfeld 6740.

Alueller, Frz. X, vide Schuebler 9383.

Mueller, Jeremias, vide Waldsehmiedt 10909.

Mueller, Jachim, vide $\boldsymbol{B}_{\text {arneveld }} 485$

Mueller. Joh., vide Beilschmied 666.

Mueller, Joh. M., vide Bitl. Bunks. III. $\$ 47$

Mueller, Joh. N., vide Valentini 10633.

Mueller, Karl, vile llarting 4165.

Mueller, O. Fr. visle Oeder 7601 . vide Bibl. Banks. III. 167 sqi].

Nueller, Paul Chr., ville Eysfarth 3073

Mueller, Ph. L. St, vide Lime 5978.

Mueller, Samuel, vide Anon. 11725.

Mluenzel vide Belur 651.

Muhammed Lalézari vide $\|_{i e}=2628$.

Mulder, Claas, vide Richard \$350.

Munnichis vide Rherde 8549 .

Mluñoz vide /lernandez $\$ 405$

Munting vide Cannegieter 1670. vide Yercton 7473.

Mureau do Clierval vide .lichaull 6903.

Murr visle Limne 6051.

Murray vide Kilm 5091.

—__ vile Limne 6009.

- vide Bibl. Banks, III 119. 263. 530.

Musa vide Apulejus 257

Muskau vide Pueckler-d/uskru 83áti.

Mustel vide Bibl. Binks. III. 368.

Mutis vide Ribl. Banks. III. 331, 33 .

Mutonus vide Jocring 2664

Mygind sifle Jurruin ises.
Mylius vide Bill, Banks. 1II. 336. 392 .

Myller vide Mueller 7297-7298. 11797

Mylphortus ville Muphlpfort 726:-7964.

Myrstedt vide Detreirh 7609 .

Nab ville Mac Nab 6394.

Nuleshda vide Kinsenstern 5424

Nargeli visle Korh 5314 vide Scluciden 9150

Naezén virlo Linne $616 \%$.

Nangis-Regllault vide Regarull 8 亿21.

Nanine vide Inargossies 2140.

Narcinsus ville /lelvigius 4345.

Nasse ville Jlons 7068.

Nabhlorst vide Linne 6067.

Nau vile Schrunk 9320.

- vile Bibl. Bunks. V. 87.

Naucler vide Limé 6021.

Naumburg vide Bisl. Baulis. III. 349

Navis vide floscarules 11529

Nebel. D., vile Ammann 192

vide frente 3327.

Necker vide Itillemet $1126 \%$.

- vide Bibl. Banks. III. 156.311, 440.411.

Nectoux vide Bibl. Banks. III. 613 .

Nees von Esenbeck. Chr. (i., vide Blafl 948 - vide Bolton 1079 vide Bruvais 1292.

vicle biown 1386.

visle De Candulle $2 \pm 256$.

ride Endicher. 2953

vide Flotou 3ei4.

vide Fuhlrolt 3 i i2.

vide Goethe 3761 .

vide Junghulen 5005.

vide Lindley วัy3s. vide Martius 6597 . ville Heyen 6849.

vide Monlagne 7073 .

viele Sloquin-Tundon 7133 .

vide Raddi 8990

vile sthleiden 9160.

vide 11 cihe 1111 .

vide Ilendt 1116 !

virle llied-Neuried $1120 \overline{0}$

Nees von Esenbeck. Friedrich, vile Bollon 1079. vide Geiger 3338.

Negelein vide Schroeder 9343 .

Nohring vicle Franke 3323.

Neile vide Bibl. Bunks. III. 570

Nelly vide Mellomius 4331 .

Nesle vide Dr Nesle 2439.

Nesller vide Ehrmann 2934 - vide Fee 3130. - vide Jlougeot 2848 vide rillars 10754.

Netwald vide Lipbig 5876 .

Newenare, Comes, vide Brunfels líg.

Neufchtaleau vide Fruncois 3315

Neuller vide schuebler 9379.

Neuforn vide Stokur de Neuform 9943.

Neunar, Comes, vide Brunfels 1423.

Neumann, J. S. B., vide Schrader 9300.

Nenmanu, Kispar, ride Bibl. Bunks. 1II. 436-137. 
Teuuanu vide Anon. 11660 .

Neuwied vide Wied-Newuied 11206-11207 vide IIartius 6597.

lewa vide Krusenstern 5499.

Newburgh vide Bibl. Banks. III. 570

Newton. Thomas, vide Lemnius $575 \%$

Niblaeus vicle Thunberg 10270.

Nicander vide Diuscorides 11497

vide Esteve 3037.

vide Grevin 3873

Nicholls, Frank, vide Bibl. Bauks. III. 38 ;

Nicolai vide Loescher 6219.

Nicolaus Alex. vide Agricola 97

Nicolaus Damascenus vide $D u$ Val 2862 - vide Meyer 6866. vide scaliger 9044 . vide Anon. 11836

Niebulur vide Forshil $3278-3279$.

Niemann vide Birkhol= 887 .

Nigrisoli vide Zannichelli 11404

Nilssou vicle Areschoug 289.

vile Ringius 8590 .

Nimmo vide Graham 3819.

Ninham vide Grigor 3889 .

Niny de Claret vide Quiqueran $8 \geq 81$.

Nisse vide Denisse 2443.

Nissole vide Bibl. Banks. Ill. 34. 241, 304.323.

Nitsehe vide Hebenstreit $423 \mathrm{~S}$.

Nobleville vide Arnauld 301.

Nocca vide Balsamo 453.

- vide Bibl. Banks. III. 89

Noehden vide Bibl. Barks. Y. 86 .

Noeldechen vide Nicol 7484 .

Noisette vide Gautier 3537 . - vide Hocquart 4535. - vide Mordant $713 \mathrm{~s}$. vide Anon. 11660.

Sonne vide Planer 8044 - vide Bibl. Banks. III. 400.

Foorden vide Martyn 6631 .

Norberg vide Bibl. Banks. 11I. 400.

Nordblad vide Linne 6081.

Nordenskjöld vide Bibl. Banks. 1Il. 592.

Nordling vide Kalm 5105

Nordmann vide Demidoff 2436.

Norona, F., vide B.bl. Banks. Ill. 181.

\begin{tabular}{l} 
Notaris vicle De Notaris $2449-2458$ \\
\hline
\end{tabular}

vide Muris 7192.

Noye vide Delanoye 2384.

Nozeman vide Bibl. Banks. 1ll. 275. 410.592. 653

Nunes vide Thompson 10200.

Nuttall vide Michaux 6910.

Ny vide Delany 2385.

Nygren vide Bibl. Bunks. III. 630

Nyman vile $A$ non. 11812 .

Nysten vide Schuilgue 9496.

Obel vide De l'Obel $2496-2430$

Obermann vide Nebel 7400 .

Obnen vide Poederle 8094.

Oehs ride Baier 401

Orlhelius vide Bibl. Banks, 11I. 387. 474536.

Odonus vide Theophrastus 10167 .

Odus vide Cordus 1982.

Deder vide Dil Hamel 9774

Oégger vide Bornholz $1 \uparrow 39$.

Oehme vide Bibl. Bunks. 111.412

Öhngren vide Anon. 11815.

Deler vide Stohr 9944.

Oelhafen v. Seh, vide Du Hamel. 27772782.

Pritzel, Thes lit. bot.
Oelsehlaeger vide Olearius $7626-7628$.

Osterman vide Linne 6075

Oestmark vide Thunberg 10277

Oestreielı vide Johann, Erzherzog, 4910 .

Oetinger, F. Chr., vide Gmelin 3697.

Ogilhy vide Nienhof 7507 .

Oken vidle Tuckerman 10522

Okland vide Csiky de II. Oklaind 2068

Olavins vide Olufsyn $7621-7622$.

Oldenland vide Burmann 1579.

- vide Kolbe 5351 .

Olearius vide Andersen 211

Olin vide $R$ af $\mathbf{8 3 3 2}$

- vide Thunberg 10266.

Olivarius Vredius vide Boëtius 1046

Oliver vide Bibl. Banks. 111.473 .

Oliveri vide Maralti 6496.

Olivi vide Bibl. Banks. Ill. 346.415 .

Olivier, G. A., vide Cuvier 2105. vide De Silvestre 2503.

624.

Olivier de Serres vide Serres $9590-9592$. vide Belleval 691.

Olmi vide Bibl. Banks. 1ll. 410

0 Neale vide Todd 10349

Opiz vide Berchtold 728 .

Opoix vide $B_{\imath} b l$. Banks. 1II. 503.

Orbigny vide D'Orbigny 2690-2691. vide Murtius 6615.

vide Montagne 7083-7084. vide Anon, 11635

Oribasius vide Hildegardis $4458-4459$.

Orloff vide Pursch 8259.

Orraeus vide Kalm 5098 .

Orsini vide NIauri 6678 .

Ortega vide Du Hamel 2779

vide Hernande $\mathbf{4} 405$.

vide Linné 6002

vide Quer 8976.

Ortelius vide Colius 1900 .

Ortmann vide Fleckles 3221. vide Anon 19507

Ortolani vide Rafinesque $\$ 315$.

Ortus sanitatis vide Anon. 11876-11906.

Osbeek vide Bexell 856.

vide Oedmann 7606. vide $B i b l . B a n k s$. III. $239 \mathrm{sqq}$

Oscar 1. Rex vide Blytl 961.

Oshamp vide Anslijn 241.

- vide Krauss 5402

Ossipowitseh vide Uschokow 10606 .

Otho Cremonensis vide Macer 6385

Otth vide De Candolle 2256.

Ottin vide Wallerius 10936.

Otto, Chr., vide Eysel 3065 .

Otto, Friedrich, vide Guimpel 3979 .

5972. vide Link $5962-5963.5965$

vide Nees v. Esenbeck 7421. vide Pfeiffer 7976

Otto, Fr. W., vide Isidorus 4963 .

Oudney vide Broun 1374.1384.

Ovidius Montalbanus vide Montulbanus 7101$71: 5$.

Owen vide Palladius 7712

Paduanensis vide Dioscorides $11505-11507$

Paets van Troostwyk vide Deiman 2341.

Paillet vide Lemaire 5743 .

Pajot vide Bibl. Banks. III, 584
Palassou vide Bibl. Banks. III. 142.

Palau y Verdera vide Linné 6002 vide Ortega 7659 .

- vide Bibl. Banls. V. 99. 100

Palier vide Bibl. Banks, IIl. 592.

Palisot de Beanvois vidle Thiébaut 10178

Palladius vide Anon. 11852-11863.

Pallas vide Cuvier 2105 vide Demidow 2437.

— vide Gueldenstaedt 3938.

- vide Bibl. Banks. III. 174. 557

Palletta vide Bibl. $B_{a n k s}$. III. 431 .

Palm vide Gmelin 3695.

Palma ride Cossigny 2003.

Palmarius vide Paulmier 7827.

palmegreen vide Rydelius 8892 .

Palmer vide Gmelin 3694.

Palmstjerna vide Bibl. Banks. III. 622.

Palmstruch vide Anon. 11827.

Paludanus vide Linschotten 6173

Panazio vide Baldus 444.

Panciatiehi vide Picciuoli 8006 .

Panekoueke vide Chaumeton 1814.

Pancovius vide Panckow 7733.

Pander vide Meyendorff 6953.

Pandulphus Collinutius vide Brunfels 1423 .

Pansuer vide Thonipson 10201.

_ vide Anon. 11741.

Panzer vide Linne 6010

Pide Martyn 6619.

Papadopolus vide Pontedera 8159 .

Parkinson vide De l'Obel 2430.

vide Nexton 7473.

Parlatore vide Birana-Bernardi 916.

Parlasea vide Petrelli 7944.

Parmentier vide Chaptal 1803.

_-_ vide Cuvier 2105.

- vide De Sileestre 2502.

__ vide Miquel 6959.

- vide Neufchateau 7459. vide Rozier 8509.

vide Anon. $1164 \mathrm{~s}$

vide Bibl. Banks. 11l. 430.626.

Parry vide Broun 1372.

Parsons vide Bibl. Banks. III. 398 .

Paseal vide Anon. 11839.

Pasini vide Dioscorides, p. 335.

Passaens vide Boëtius 1046 .

- vide $B$ ry 1444

Passinges vide $B$ ibl. Banks. III. 422 .

Passy vide $D_{\text {ekin }} 2345$

Pasteur vide Bibl. Banks. III. 426.

Patouillat vide Bibl. Banks. Ill. 545.

Patris vide Bibl. Banks. 111. 498 .

Patschke vide Lekmann 5696 .

Pauer vide Schmidel 9190.

Pavirle vide Agricola 97.

Paul vide Wuertemberg 11368 .

Paulet vide Theophrastus 10167. vide Biul. Bunks. IIl. 348. 55 g.

Paulin vide Kalm 5126.

Paulli vide $B i b l$. Banks. III. 549

Paullini vide Dahlborn 2115.

Pauls vide Broum 1384

Paulsen vide Hartig 4162.

Pavon vide Ruiz $8855.8858-88.59$.

Pawius vide Paaw 7693.

Paynel vide Itutten 4799

Pechlin vide Petit 7921

Peéchi vide Pétsi 7957.

Peima vide Beintema 667

Peine vide Probst $8234-8235$. 
Peirson vide Bibl. Manks. 11I. 4. 393.

Péligot vide Decuisne 2171.

Pelletir vidle Zanon 11412.

Pelouze vide Thomson 10204 .

Pelshofes ville Hurtanam $\$ 17$ h.

Pena vide De lObel 2429.

Pencati vide Murzari-Pencali $6635-6636$.

Penchienati vide Bibl. Banks. 111.623.

Pentz vide Thurbery 10261.

Pepin vile Anon. 11660.

Percival vide Anou. 11716.

_ vicle Bibl. Bumks. III. 413.476 .522$.

Jereboom visle Tren 10447 .

Pereira Robello vide Bibl. Bants, III. 569.

Perfect vide IIill 4474 .

Pergamenus vide Oriberius Pergamenus 7650

Periander vide Lochner 6197.

Perleb vido De Candolle 2207.

Péran vide Leschenanil 5780.

Pérouse vide De la Billardiere 2347.

Perrault vicle Bibl. Banlis. III. 406.

Perrottet vide Guerin-1leneville 3947.

- vide Guillemin 397 . - vide Montagne $708 \mathrm{~s}$ - vide Richard 8558 .

Persoon vide De Bromdean 2165.

- vide $1 /$ olm 4629

- vide Limé 6009 .

vide Thuberg 10267.

___ vide Bibl. Barks. III. 90. 225. 144

Perugino vide Ferrari 3166.

Pesta vide Perla 7875.

Pestalozza vide Grisebach 3905.

Pestels vide Cayjus 1773.

Petermann vide Lime $60 \$ 1$.

Peters, Frz., vide Strauss 9954.

Peters, .l. P', vide Buek 1599.

Petersen, J., vidle Vibarg 10732.

Petersen, J. Clir., vide Linne 6077.

Peterson vide Kellander $5 \$ 59$.

Petit vide Anon. 11637.

Petit-Raclel vicle Acerbi 20.

Petit-Thouars ville Aubert $327-343$.

Petiver vide Brom 1385 .

- vide Bibl. Banh's. II1. 75. 93 sqq.

Petraens vide Bring 128 s.

Petrus I. Imperator, vide l'ellozo 10696.

Petrus de thano vide drma 295. vide Dioscorides $11305-11307$

Petrus, Corn., vide llioscorides, p 333.

Petzsch vide Hoffinam 4565 .

Peyer vide Beyer 857.

Peyrat vide Du-Peyrat 2834.

Peyrouse vide De la Peyrouse 2386-2388.

Peyssonel visle Bbl. Bunks. 111. 344.552.

Prall vide Itirchfeld 4511 .

Pfaler vide Hellentus 4329.

Pfeffel viclo Schenchzer 9120

- Pfeller vicle lleister 4304 .

Pfeiffer vide Linné 6062.

Pfister vide lliller 4493.

Pfotemhaner vide Titius 10335.

Pfund vide Jussieu 5021.

- vide Montagne 7056.

Platimirus vide Falanier: 3097

Phelippe le Noir vide Bartholomaeus 511.

Pliliater vide Gesner 3397 .

Philomousos vide Carrichter 1699.

Phoebus vide Brandt 1236.

Phrysius vide Fries $3412-341,3$

Physicieme ride Gaudichrul 3527.
Piatti vide Alicheli 69lä.

Jieco vide Durdama 2139.

Pickering vide Bibl. Bantis. 111. 443.

Picot vide De lu Peyrous 2386-2387.

- vide Bibl. Banks. 111. 142. 426. ‥ 78. \$1.

Pictet-Mallet vide Fursyth 3297.

Pietorius vide Macer 6385 .

Picus vide Picco 8007 .

— vide Durdunu 2139.

Pielnluber visle hirchmuier 5223.

Picrre vide Saint-Pierre 8952-\$954.

Pigati vide Monte Pigali 7120.

Pigou vide Bibl. Banks. III. 655

Pihlman vide II allerius 10932.

Pinaeus vide $D_{u}$ Pinet 2835 .

- ville Dioscorides, p. 331 - 333.

Pinel ride Cuvier 2105.

Pinet vide $D_{u}$ Pinet 2835 .

Pingeron vide Sestini $9594-9495$.

Pinguia vide IIildegurdis 4458-4459.

Pislorius vide Petraeus 7943.

Pitton vide Tournefort 10381-10388

Pius V1. vide Murtelli 6545.

Placeius vide Imperalo 4897.

Placentinus vide Azalus 368 .

Plancus, Janus, vide Coloma 1931.

Planer, J. A., vide Camerarius 1656.

Planer, J. J., vide Limne 5983.

Play vide Le Play 5774

- virle Demidoff 2436.

Plazza vide Bibl. Banks. 111.149.

Penpius vide Baldus 446-447.

Plessis vide /Hurd 4737.

Plessy vide Duplessy 2836.

Plinius vide Aquacus 258

—_ vide Brunfels 1423.

— vide Fée 3119. 3134

-__ vide Guilandinus 3967

- ville Ilermolaus 4401.

- vide Jamus $4861-4862$

— vide Leonicenus $5770-5771$.

_- vide Sauma ise $9004-9005$.

- ville Scaliger 9043 .

- vicle Talle 10640

Plot vide Bibl. Banls. 11!. $\{21$.

Pluche vide Bill. Banks. III. 428.

Plukenet vide Giseke 3664 .

- vide Phelsum 7982 vide Tenzd 10130.

Poeclerle vide Bill. Banks. III. 423

Poiret vide Chaumeton is 11 .

— vide De la Marck 2377-2378.

Poiteau vide $D_{u}$ II $u$ mel 2789.

- vide Risso $\$ 596$.

- vile Anon. 11660 .

Polstianus vide Rapinus 8354 .

Pollich vite Bibl. Banks, 111. 546 .

Pollini vide Moretti 7151.7155.

Polstorf ride I'riese 10850.

Pide Hiegmann 11212

Polycarpus vide Jessenius 4886 .

Pomatrius vide Baumgarten 600 .

Pomel vide Bibl. Banlis. III. 343.

l'ona vicle De l'Ecluse 2410.

- vide Marogna 6514.

Ponceau ricle Demidoff 2436.

Pontchartrain vicie Toumefort $1038 \mathrm{~s}$.

Ponte ville Maironi 6133.

Pontedera vide Genmuri 3565 . ville Tilli 10320.

Pontén vide Quistory) $\$ 2 \$ 2$.
Pontén vide Thunbery 1026

Pontiu vide Linne 6084.

Ponzetti vicle Artornis $268-269$.

Poot vide Rheede \$340.8542.

Poppe vide Carrichser 1699 .

Porro vide Corfusi 1999.

Porta vide Dallaporta 2126.

Porta vite louchine 2751

Portes vide Desportes $2522-2525$

Pory vide Leo 5764 .

Pose ville Clewhery 1873 .

l'ossevinus vide Petrelli 7944 .

Postels vide Luethe 6358 .

Pott, J. F., vide Du Roi 2849 .

Pott, K. W., vide Alberti 120 .

Poltier vide Brierre 1273.

l'ouppé vide Drequartes 2523.

Poutfour du Potit viate Petil is19.

Pourret vide Bibl. Banks. III. 143. 236 .

Povelsen vide Pauli 7815 .

- vide Olafsen 7620

Pozzo ride Nicasia 7495 .

Prachien vide hozak u Prachien כ̌373.

Pradel visle Serres 9590-9392.

I'ranker vide Todd 10349.

Pré vide DE Pré 2460-2'162.

Precht vide Zigra 11413 .

Preiss vide Lehmum 5710.

Prenzler ville 11 aldschmieds 10:113.

Presl, J. S., vide Berchtold 726

Presl, K. B., vide Broun 1359.

- vide Carro 1700.

Preuss, C. G., vide Suurm 9979.

Preuss, G. B., vide Bibl. Banks. III. $\{00$.

Pricro, Marchesa, vide Anon. IISOS.

l'riestley vide Cuvier 2105.

- vidle Uarrington $\mathbf{4 1 4}$.

Princeps viale Macuire-Princeps 6390 .

Printz vide Linné 6092.

Prinzess Louise vide Meyen 6838

Pronville vide Lindley 5922 .

J'rotrimus vide Baldus 446 .

Proust ride Bibl, Bunks. 111. 437.

Prouvensal vide Saint-lliluire $8934-\$ 930$.

Pryss vide Hellenius 43ํㅡ.

Psellionoros vide $1 y_{y l i u s} 7361$.

Pucia des Natur vide Anon. 1176911768.

Puerari vide ll'est 11178.

Puisieux vide Anon. 11661 .

Pulteney vide Lime 6113.

$54 \mathrm{~s}$. V. 83.

Purslo vide Pursch 8957-8239.

P vide Don 2656.

Pulius vide Bibl. Banks. 11!. 25T.

Putterlich vide Nees ron Esendeck 74 亿3.

J'yl vide Bibl. Bonks. III. 473.

Pylaie vile De la Pylaie 2389-2390.

Quarizius virle Meerfels 6736.

Quensel vide Anon. 11827.

Quercu vide Duchesne 2759.

- vide Brohon 1304.

Quesnè vile Linne 6002.

Quetelet vide kickx 5193.

Quintinye vile De la Quintinue 2391.

Quintus Apollinaris vide Apollinaris 250 .

Raab vide Hucnz 7310 .

Rabe vile Heisler 4301.

Raczynshi vide Racynski ss98 - \&\$90.

Radclille vide IIabli=l 4010. 
Rateli vide Sari 9033.

Ritdel vide Petit-Radel 7924 .

Riullakant Del, vide Bubon $3 \mathrm{SI}$.

Ratloll vide Thunberg tozةI.

Rulleneau-Delile viule De Cundulle a bu vide Redouti sill.

Rafinesque viele Cupuni 2087.

- vide Gray 3850 .

Raflet vide llemidaff 2436 .

Rahn vide Bibl. Banks. 111. 4 76

Rahise vide Kulm 5114.

Rainville vide Bibl. Banks. 111. 42\$.

Rajus vide Ray $8375-8386$.

Raut vide Hodoerls 2634

Ramatuelle vide Bibl. Banks. 111. 312. 382. 384

Raman ale la Sagra vide Montagne 7086.

Ramond vide Bibl. Banks. 1. 69. ss.

Ramus ville lieen 649.

Rand vide J/arlyn 6619.

Randi vielo. Mandirola 6459

Ranzovius vide Macer 6385.

Rapidius Piso vide Ruppolt 8358.

Rases ville Branfels 1424.

Raspail vide Bulliard 1550 .

Ratzeluurg vide Btand $\mathbf{1 2 3 6}$

- vise Hayne 4227-4228.

Rau vile Bißl. Bunks. III. 546 .

Rauchmann vide Beintema 667

Rautenfels vide Hartens 6546 .

Rauroolf vide fromovius 3920.

Rawley vide Bacan 394

Ray, R., vide Bibl. Bunks. 111. 201.

Ray, Jolın, vide Damper 2131.

- vide Grisley 3913.

vide Jeliver 7934 .

vide Schchammer 9092.

- vide Tournefort 10353. 10386.

vide Bibl. Bunlis. 111. 43 sqq.

Rayger vide Bibl. Banks. III. 356.

Razunowski vide $F_{\text {ischer }} 3205$ vide Redonski 8416 .

Reaunur ville Bibl. Banks. III. 3'3, 344, 351.

Rechus vide Mernandez 4404 .

Recherclie vile Martins 6576 .

Rerltel ville Schulze 9452 .

Redoute vide Bonpland 1109

_ vide De Candolle 2185.2197

—_ vile De la Peyrouse 2356

- vile Du llamel 2785.

vide Leconte 5623.

ville Michanx 6904.

- vide Piralle $\$ 034$

vide Rausseau 8775.

ville Fentenat 10700.10703

Reed vile Bibl. Bunks. 11I. 57 .

Rees ville Smith 9726

—_ vide Inon. 11578 .

Reftelius ville Limné 6099.

Regel viule schmit 9221 .

Regio vide Greqorius 3559 .

Regis vile Jlulpighi 6449.

Regius vide Ron 879 \%.

Reichard ville Linné 5985.6010

- vide Anon. 11579.

vide Bibl. Banks. III. 84, 352.

Reicluel, Abr., vide Stahl 9864 .

Reichel, G. Chr, vide Kiesling 5210.

Reichenlsach vide Lauremberg \$583.

Rejeloenbach, A. B., vide Plato 8051 .

vide Reirholdt $\$ 458$.

Reichenhaclı, Gustav, vifle Ilofmannsegg 4610.

Reichenbach, Ludwig, vide Marzer 4201.
Roichenbach, Ludw, vide Heynhold 4 亿33. vide kletl 5261 . vide Miltuz 6950 vide lloessler 7011 vide Sturm 9909.

Reider vile Richoldt 8458

Reiflerscheid vide Salm $\$ 963$ - $\$ 97$ 个

Rein vide Mink 6956 .

Reiulroth ville Eysel 3061 .

Reineccius vide Rosenfeld 8731

Reinhard vide Anon. 11685.11770.

Reiniger vide Leske 5783.

Reirwarlt vile Blume 955

- vide Nees won Esenbed 7428

Reiselius vide Bibl. Banks. III. 378.

leising vide Ziegra 11443

llenard vide klein 5251.

Rentu vide Leblond 5607

Renealmus vide Reneaulme $\$ 4 \$ 8$. ville be Thau 2546 .

Reneaume vide Bibl. Banks. III. 323. 373

Remues vilo De Renues 2467.

Renz vide Schuebler 9373 .

Requien vide Perreymond 7884 .

Ressons vile bibl. Banks. III. 62 I.

Retzius vide Bibl. Banks. III. 170 sug.

Reusch vide Folckumer 10826.

Reuss, Ch. Fr., vide Bill. Bunks. ill. sso

Reuss, F. A. vide lliddegurdis 1459 .

- _ vide Strabo 9951.

Reuss, G. J)., vide Schulze 9436 .

Reuss, J. J., vide Jarger is 44

Reuter vite Rojissier 1060.

- vide Mlargol 6506.

Reverovicius ville Summarse 9002

Revigin vide Trozelius 10507.

Reynier vide Bal. Banks. Ill. 151 squ.

Rhanius vile Crumer 2038.

Rhases vide Brunfels 1424.

Rheede van Draakeusiein vide Dillwyn 2638.

Rhein vile hrouse 5398 .

Rhellicanus vide Gesuer 3596 .

Rlodiginus vile Richerius Rhodiginus 8570 .

Rhodion vide Anon. 11901 .

Rhoulius vide Scribonims 9512.

Rhy ne vide Breyn 1262.

- vide Talendini 1063 .

- vide Bibl. Banls. III. 2.

Riheiro vide Peixoto 7850.

Riearlus vide 11 "ionius 11314.

Richard, Achille, vide Chevallier 1821 vide Ferrand $316 \%$.

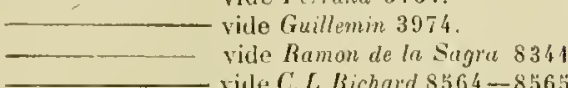
vile C.L.Richard $8564-8565$. vide Turpin 10553.

Richard, L. C., visle Bulliard 1548.

vide Cuvier 2105.

- viele Duval 2863.

- vide Kunth 5434 .

vide Michaux 6906.

vide Nestler 7454

vide Thuillier 10230

354

Richarelson, John, vide Brown 1384.

- vide Iluoker 4669

Riche vide ruvier 210 ö.

Richelieu vide Priezac \$225.

Richer de Belleral vide Belleval 657-691. vide Amareux 200 vide Rroussonel 1348
Rieher de Belleval vide Dorthes 2697

vide Gilbert 3635

Richers vile Haller 4067

Ricltter, A. Gottfrierl, vide lagt 10813.

Richter, Chr. Fr., vide Lemery 5752

Ricliter, G. Fr., vide Bibl. Brmls, III. 380

Richter, 11. Eb., vide Klett 5261 vide Linne 6011

Richter, J. G., vide Allerli 121

licley vide Cusanova 17:20.

Ritulinger vide $1 T^{\top}$ einmann 11124.

Riecke vide Berge 738 .

Ricckius vide Camerarius 1660.

Riedel vide Tunnay 10075 .

Riculinus vide Bibl. Banks. Ill. 5 i6.

Riegrls vide Bache 390.

Rieger vide Zeyher 11439.

Ribel, W. et J., vide Bock 979-981

Rimrod vide Bibl. Banks. III. 275.

Rind vide 11 illy 11278 .

Ringier vide Schuebler 9368 .

Riocreux vile Delessert 2414.

- vide Dumont 2802

- visle Raoul 8351.

- vile 11 ebb 10999.

Rippelius vide Stehelinus 9873 .

vide Zwinger 11488

Risler, Jakob, ville Rabl. Runks. III. 286

Ritgen vide II ilbrand 11237

Ritter, J. J., vile Bibl. Buntis. 11I. 447.

Rive vide Derive 2471.

Rivera vide Sunrez de Rivera 9985 .

_- vide Dioscorides 11537 .

Riviore vicle De la Rivière $\mathbf{2 3 9 4}$

Rivière viale Bizl. Banks. III. 544 .

Rivinus, A. Q., vite Dillenius 2632.

vide Lischwit 6180.

-_-_ vide Ray $\$ 382$.

vide Rivinus 8617 .

vide Ruland 8568 .

vitle Schelhammer 9092

Rivius vile Dioscorides 11518.11520-11521

Robert, Nic., vide Dodart 2648.

Robertus Britanuus vide Britennus 1297.

Rohiati vide Goctle 3760 .

Robin, C. C., vide Rafinesque 8322.

Robin, Jean, vide Linocier 6171-6172. vide l'allet 10643.

Robinson vide Bibl. Banks. III. 355.

Rolinus vide Rolin $8637-8640$.

Robson vide Bibl. Ranks. III. 651.

Rocardus vielo Baukin 556 .

Roclie vide De la Roche $2395-2396$.

- vide Redoute 8411 .

Roclse, Dory de la, vide Merlet 6807 .

Rochefaucaul vide Lu Roclefaucant 5563.

Roches vide Deroches 2472 .

Rochlitz vide Babst ron Rochlitz $382-334$.

Rocle viele Schuebler 9366

Roeiler vile Schuebler 9398.

Roclsius vide De lEcluse 2410.

Rocmer, Rudolf von, vide Pacini 7695.

Roemer, G. Chr., vide Zeyher 11437.

Roemer, J. J., vide De Candolle 2228

vide lime 6009.

__ vide Smith 9718.

- vile Bill. Banks. III. $6 \$ 6$.

Roenuow vide Sprengel 9849 .

Roeper vide De Candolle 2303.

- vide Seringe 9574 .

Roeslin vide 1 nor. 11901.

Roessler vide Bibl. Ranks. III. 649. 
Roffredi vide Bibl. Bunls. IIJ. 427. Roger-Schabol vide Schabol 9054-9056. Roget vide De Candolle 2303.

Roliard vide C'astel 1732.

Roi vide $D u$ Roi 2848-2849.

Roland vide Bibl. Bunks. III. 422.629.639.

Rolander vide Hornemann 4696 vide Bibl. Banks. 111. 290

Rolfincius vide Rollfink $8702-8703$

- virle Mrajor 6432

Romagnési vide J'ergnaud 10711

Romano vide Dumont 2798.

Romanson vicle Thunberg 10268.

Romanus vide Pion 8029.

Rondeau vide $D u$ Rondeau 2850 .

Rondelettius vide De lObel 2429

Roos vide Linne 6113

Roque vide La Roque 5564 .

Rosa vide Mascati 7238.

Rosa vide Wedel 11056.

Roscius vide Dioscorides 11498

Rosenbaum vile Sprengel 9856.

Rosenblad vide Rosén 8723

Rosensten vide Bibl. Barks. I11. 629.

Rosenthal, Chr. F., vide Lime 6089.

Rosenthal, H. A., vide IVilcke 11242.

Rosinus vide Wigandus 11215.

Ross, J. Clarke, vide llooker 4638-4639. 6667

Ross, John, vide Brown 1369.

Rossi vide Bibl. Banks. Jll. 395.

Rossignol vide De Grace 2334.

Rossing vide Hoyberg 6549.

Rostan vide Bibl. Banks. IIl. 575 .

Rostkovius vide Sturm 9979.

Roth, A. W., vide Bibl. Banks. III. 64.85 sqd

Roth, J. R., vide Scherrek 9107

Rothe, II. A., vide Nees von Esenbech 7420.

Rotheram vide Linne' 6095.6131

Rothfelser vide Dehn-Rothfelser 2337.

Rothius vide Camrarius 1655.

Rothmau, G., vide Linne 6100 . vide W'allerius 10935

Rothman, J., vide Bibl. Banks. III. 351.

Rothmann, Chr., vide Ammann 189.

Rotbschild vide Anon. 11792

Rotthoell vide Koenig 5340 . vide Bibl. Banks. III, 6, 33.83. 178

Rottendorf vide Ferrari $3 \$ \mathbf{6 6 .}$

Roucel vide Morren 7213 .

Rouelle vide Ilenckel 4351 .

Rourge vide Le Rouge 5776.

Rougier vide Bibl. Banks. V. $\$ 8$.

Rouille vide $F$ uchs 3431

Roulhac vide Janièrc 10662

Rousseau, J. J., ville Deville 2552

virlo Marlyn 6627.

vide Meinecke 6751

vide Redoute 8412

- vide Anon. 11606.

Rousseau vide Demidof 2436 .

Rousseaux vide Desrousseaux 2526.

Roussel vide Montugne 7079.

Roux vide llenekel 4351 .

Rovillius vide Halechamps 2121.

$$
\text { vide Fuchs } 3431 .
$$

vide Pons 8.154

Roxas Clemente vide Ilerrera 4441

Rexburgh vide Beatson 618

vide Brown 1383.

vide Bibl. Banks. III. $304 \mathrm{sqq}$

Roy vide Leroy 5777

Royeı, A., vide Gmelin 3713.
Royen, D., vide Schuencke 9490

Royer ville Delewze 2416.

Royle vide Bentham 717.

Rozier vide Chaptal 1803

- vide Latourretle $5577-5578$.

- visle Parnentier 7781.

- vide Anon. 11678 .

- vide Bibl. Banks. III. 640

Rubesch vide heuss 8519 .

Rubini vide Bibl. Bunks. Ill. 527

Rulio vide Roxas Clemente 8783-8784.

Rucker vide Bibl. Banks. 1II, $\$ 46$

Rutbeck, Jolı. Olof, vide Roberg 8622.

Rulbeck, Olof, vide Iloltz̈bom 4631

vide Walmstedl 10959.

Rudbeck, Olof, filius, vide I'almstedt 10959.

vide Zeipel 11420

Rudherg, D., vide Linné 6019.

Rudberg, J., vide Linné 6038 .

Rudberg, O., vide Below 698.

Rudenschold vide Bibl. Banks. H1. 324

Rudolphi vide Nees von Esenbeck 7 49.

Ruecker vide Mentzel 6789.

Rueller vide Le Conteur 5624.

liuelfer vide Boehmer 1021.

liuelis vide Acerbi 21.

Ruellius vide Ruclle 88500 .

$\longrightarrow$ vide Actuarius 33 .

vide Duchesne 2759.

__ vide Scribonits 9512.

— vide Dioscorides $11501.11509 .11512-$ 11524 .

Rueneuve vide Angran de Ruereuve 231

Ruiz vide Lambert $\$ 508$.

— vidle Orlega 7660

Rumberg vide Jorlin 4906 .

Rumforal vide Cuvier 2105 .

Rumpel virle Bibl. Barks. 11l. 491.

Rumplius vide Rumpf $8874-8875$.

- vitle Blume 958 .

vide Burmann 1583

vide Henschel 4370 .

vide l'alentini 10632 vide Bibl. Buntis. IH, 286.

liung vide Thunberg 10241

Ruppins vide Bibl. Barks. Ill. 29.

Ruprecht vide Meyer 6888. vide Postels 8172 vide Trinius 10485

Rurik vide Chamıso 1796.

Rush vide Bibl. Bantis. III. 565. V. 96.

Russel, Duke of Redford, vide Forbes $3265-$ 3268 .

Russell, A., vide Bibl. Banks. III. 472.

Ressell, $\mathrm{Cl}$, vide Bibl Banks. III, 65\%

Russwurm vide Gleichen $3686-3687$.

Rutger vide Hermannides 4399.

Ruthe vide Eysson 3076.

Rutty vide Bibl. Bank's. III. 3̌so.

Ruyseh vide Commelyn 1946.

Ryan vide Anon. 11828 .

Ryfl vide Dioscorides $11518,11520-11521$

- vide Fuchs 3433.

Ryhinerus vide $B, b l$. Banks. 1ll. 575.

Sabhati vide Bonelli 1098

Sabin Berthelot vide Berthelot $80\{-805$

Sabine, Edward, vide Hooker 4652. vide Humboldl 4787

Sacerdoti vide Marsili 6342.

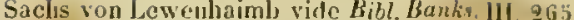
408.

Sachsen, Künig von, vido Biasoletto 863 vide Heidler 4281.

Saclısen, Kurfirst von, vide Sickler 9631 . Sackléu vide Ilellenius 4321.

Saevo vide Wahlenberg 10894.

Sage vide Bibl. Banks. III. 436

Sagra vide Kamon de la Sagra $8340-8312$

Sagredo vide Clarici 1865

Sahlin vide Thunberg 10301.

Sablstedt vidle Retzius 8496

Saillet vide De Saillet 2473 .

Sainson vide Demidoff 2436 .

Saint-Agy vide Curier 2106.

Saint-Allsan vile Bacon 394.

Saint-Amand vide Tristan 10486

Saint-Amans visle De Brondeau 2167 vide Lirne 6145

Saint-Aubin vide Genlis 3564 .

Saint-Fond vide Faujas 3110.

Saint-Gemain vide Prevost 8223.

Saint-llilaire vide Jaume $4867-4873$.

Saint-llilaire, A. de, ville Lontngne 7081

vide l'illemin 10756

Saint-Jean Crevecoeur vide Bibl. Banks. 1ll. 600. Saint-Legar vide Bibl. Bunlss. V. 101.

Saint-1lartin virle Juge 4977-4978.

Saint-Mlartin viıle Kibl. Banks. Ill. Ј⿰亻 6 .

Saint-Marrice vide Pelée 7851.

Saint-Michel vide Maurille 6679.

Saint-Péravi vide Anon. 11706.

Saint-Vincent vide Bory $1144-115 z$.

Saladin vide $D_{e}$ Candolle 2276.

Salberg, C. H., vide Thunberg 10339.

Salberg, J., vide Linné 6101.

Salern vide Ilieronymus 4457.

Salene vide Arnauld 301. vide Bibl. Bunks. I11. 429

Salisbury, R. A., vide Thunberg 10243. 316 .

Salm-Dyck vide De Candolle 2235.

Salmasius vile Saumaise $9001-9005$

Salmuth vidle Gulandinus 3967.

Salovius, A., vide Hellenius 4326

Salovius, S., vide Kalm 5110

Salvador vide Pourrel $\$ 183$.

Salvinius vide Nicunder 7478.

Samonicus vide Macer 6385

Samzelius vide Zumzelius 11397.

Sanabria viıle Cortavilla 1994

San Angelo e San Poli, Principe, vide Capsus 1614.

San Antonio vide Bibl. Banks, V. 100

Santahl vide Trozelius 10504 .

Sander vide Bibl. Bantis. 111. 570.62s

Sandhagen vide Heister 4306 .

Sandmark, C. G., vide Linne 60.56

Sandnzark, G., vide Retzius 8500 .

Sandström vide Wilbrand 11937

San Gianne vide Nicosin 7495 .

Sangiorgio, G., vide Moscati 7238.

Sangiorgio, P. vide Pollini 8131 .

San Ilarlino vide Bibl. Banks. IIl. 378. 369

Sausovino vide Palladius 7712 .

- _ vide Petrus de Crescentiis 7956.

Santes de Ardoynis vide Ardoynis $267-269$.

Saracenus vide Dioscorides 11502 . 11528.

Sarrabat vide De la Raisse 2346.

Sarwey vide Camerarius 1661.

Sattler vide $110 / f \operatorname{mann} 4556$. 
Saul vide Boreau 1125.

Saussure vide De Saussure 2474-2477

- vide Cuvier 2105. vide Senebier 9568. vide Bibl. Banks. III. 415 . V. \&5

Sauvages vide De Sauvages 2478-2479.

Savi, Gaetana, vide Bibl. Banks. V. 65.

Savi, G. B., vide The is 10149 .

Say vide von Schweinit 94 S6.

Sbaragli vide Danielli 2134.

Scaliger vide Faber 3080 .

vide Sperling 9795.

- vide Theophrastus 10163.10167. - vide I'arro 10665.

Scalius vide J'allisneri $10640^{\circ}$.

Seannagati vide Limne 6010.
vide Bibl. Banks. III. 594.

Scarella vide Jenegoti 6778. vide Jallisneri 10645.

Schaeffer vide Persoon 7898.

vide Bibl. Banks. III. 557

Sehaerer vide Moritzi 7205 .

Scharffus vide Bibl. Bunks. III. 551.

Sehaner vide Bluff 948 .

- vile Brown 1384.

vide De Candolle 2256.

vide Moquin-Tandon 7133.

Schedler vide Schneider 9226

Seheelhase vide Neubert 7457 .

Seheffer vide Bibl. Bauls. III. 638 .

Sehefferus vide Schaeffer 9066 .

Schefler vide Baier 411 .

Seheieh Muhammed Lalézari vide Dicz 2628.

Selieidler vide Meyendorff 6853.

Seheidweiler vide Lemaire 5745.

Sehellammer vide Bibl. Banks. III. 352. 399. 405.

Sehelhass vide Wedel 14076.

Sehelling vide Schleiden 9160 .

Selielver vide Ilenschel 4368.

Schenck von Grafenberg vide Guilandinus 3968 .

Sehenk, Ernst, vide Groebel 3731 .

- vide hrause $\$ 393$.

vide Langethal 5539.

vide Zenker 11424. 11428.

Scherbius vide Guertner 3468 .

Scherer, J. A., vide Ingenhous: 4898. 4902.

Seherer, J. B., vide Steller 9895.

Scheuchzer, J., vide Ilaller 4082.

Seheuchzer, J. K., vide Kaempfer 50\$2.

Schiller vide Brunfels 1423.

Sehimper, Karl, vide Bruvais 1241-1242.

Selimper, Wilh. Ph., vide Bruch 1394. vide Hougeal 7248

Schindler vide Ramspeck 8345 . vide Stehelinus 9878.

Schinz, Chr. Sal., vide Gesner 3643

Schinz, Sal., vide Bibl. Banks, III. 367 .

Sehkuhr vide Kunze $5469-5470$. - vide Bibl. Banlis. III. S9. 152.

Sehlechtendal vide Guimpel 3980 . - vide . Nees von Escnbeck 7421 vide Schomburgk 924 S.

- vide Zenker 11428.

Schlechtendal, pater, vide Jilldenow 11264.

Sehlegel vide Slegelius 9677 .

Selleger vide Nebel 7397.

- vide Bibl, Banks. Jll. 498.

Seltleicher vide Bibl. Bunks Y. 70.

Selıleiden vide Ilartig $\$ 160$.

vide Schmid 9179.

vide Winkelblech 11294-11295.

Sehlincke vide Cartheuser 1708.
Schloezer vide Laxmunn 5604.

Schlosser vide Morelti 7172.

Schlotterbeek ride Bibl. Bantis. III. 349. 403.

Sclimaltz vide Rafinesque-Schmaltz $8315-8330$.

Sclumeer vide Orllob 7662 .

Schmeisser vide Uslar 10607.

Sehmersahil ride Bibl. Banks. IlI. 622. 631.634 639.

Schmid, Bernhard, vide Zenker 11426.

Schmid, E. E., vide Schleiden 9163.

Schmid, Joh. Andr, vide IV'edel 11093

Schmid, Jol. Phil., vide Fischer 3217.

Schmid, Joh. Ulr., vide $W_{\text {edel }} 11073$

Sehuidel, C. Chr., vide Gesner 3607.

Schmidel. Joh., vide Thomasius 10198 .

Schmider vide Lehnann 5697.

Schmidlin vide Christ 1850 .

Schmidt, Chr. Fr., vide Bibl. Bunks. III. 619.

Schmidt, Chr. II., vide Duchesne 2756.

Schmidt, Franz IV., vide Mayer 6693. sqq.

Schmidt, Fr., vide Sinclair 9666.

Schmidt, Jol. Liarl, vide Kunze $5 / 66$.

Sclımidt, J. St., vide Muucliart 6666 .

Selunidt, Karl Will., vide Bochmer 1033.

Sehmidt, Matth. Eust., vide Orth 7661.

Sehmidt, IV. L. L., vide Rosthorius 8746 .

Schnidt-Goebel vide Jussicu s021.

Schmiedel vide Sclimidel $9183-9190$.

Sehmieder vide Bibl. Bunks. 1lI. 233. 403.

Selnecher vide Scluatker 9229.

Sclneevoogt vide Joorkelm 10834-10836.

Sehneider, Saxo, vide Cato 1755. vide Columclla 1933 - vide Nicander 7478. vide Palladius 7712

- vide Theophrastus 10165 vide I'turro 10665. vide Anon. 11863.

Sehneider vide II'eissmantel 11135.

Schnellenberg vide Ocyorus 7595.

Schnizlein vide Sturm 9982.

Sehnurrer vide Kielmeyer 5201 .

Sehnyder vide Bibl. Banks. III. 214

Schober, C. G., vide Bibl. Banks. III. 371.

Sehober, G., vide Bibl. Banks. III. 544.

Schobingér vide Spiessenhoff 9817.

Sehoeffer, Joh., vide ILuten 4799.

Schoelfer, P., vide Anon. 11867.11884

Schoellenbach vide Oelhafen 7607.

- vide Du Ilamel 2777. 2782.

Sehoen vide Freusel 3361 .

Sehoenen vide Anon. 11738

Seboenfeldt, J. W., ville Schminckius 9220 .

Schoenfeldt, Melchior, vide Currichter 1699.

Schoepf vide Bibl. Banks. Jll. 369.

Schoepfer vide Herold 4409.

Scholz vide Scultetus 9515.

Schourdoril vide IIoffmann 4557.

Schot, II., vide Endlicher 2992.

- vide Schreibers 9338 .

Schott, Joh., vide Brunfels 1423. 1426. 1428

Schottus, liaspar, vide Ilmer 4891.

Sehouw vide Iofmun 4612.

- vicle Oeder 7601 .

Schow vide Noerager 7553 .

Selirader, II. A., vide Sprengel 9849.

Schrader, J Chr. Li., vide Bibl, Bunhs, III. 498.

Schramm, Fr., vide Ollo 7681 .

Schramm, J. D., vicle Solvoeder 9342.
Sehrank vide Brown 1384.

- vide Howorth 4220 .

- vide Martius 6595. 6602. vide Bibl. Banks. Ill. 12 squ

Schreber vide Adanson 44.

- vide Ellis 2962.

vide Hoppe 4677.

5996

vide Linne 5985.5991-5992.5995-

— vide Sturm 9979.

- vide Bibl. Banks. Ill. 81 squ

Schreckenstein vitle Rot von Schreckenstein 8747.

Sclireiber, Ilier., vide Cordus 1983.

Schreiber, J. F., vide Bibl. Bunks. Jll. 653

Sclireibers vide Linné 6160 .

- vide Sinclair 9668 .

Sehreibers, Isabeile, vide Jacquin $\mathbf{1 8 2 0}$.

Schrenk vide Fischer 3209.

Sehrender vide Kuasbäl 5074.

Sclirick vide Tollut von Tochenberg 10358.

Schroechius vide Bibl. Banks. III. 265 sijq.

Seliroeder, Fr., vide Dilius 2420.

Schroeder, J., vide Mundelstrup 7319.

Schroepfer vide Ilerald 4409.

Schroter, J. S., vide Bibl. Bunks. III. 353, 408. Schroeter, K., vide Grube 3927.

Schulsart vide Eysel 3067 .

Schubert, G. H., vide Held 4312.

vide Nees von Esenbech 7422. vide Schenk 9107.

Schubert, Karl, vide Ficinus 3175 .

Sehuebler vide Alberti 116.

- vide Duvernoy 2872

Schuette vicle Ruppius $\$ 879$.

Schuez vide Scluzebler 9369.

Seluultes, Jos. A., vide Linne 6009.

ㄴ._ vide Roemer $\$ 674$

visle Smith 9721.

vide Thunbery 10235.

vide Townson 10394 . vide 11 illdenov 11256.

Scluultes, Jul. Herm., vide Linne 6009.

- - vide Rocmer 8674 .

Schulı, G., vide Schenckius 9106.

Schultz Bip. vide Schomburgk 924 S.

Sehultze, Sam, vide Bibl. Banks. Ill. 625

Schultzenstein vide Schullz 9424-9432.

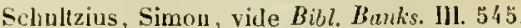

Sclıulz von Schuizenhein vide Linné 6168.

Schulze, Chrr. Fr, vide Kretzschnar 5408

vide Bibl. Banks. III. 94. 161.

494.

Sehulze, Joh. Dom., vide Giseke 3666.

-_ vide Anon. 11846.

Schumacher, C. A., vide Humbold 4787.

Schumaeher, Chr. Fr., vide Bibl. Bunls. III. $233^{-}$

Seliuster vile Bibl. Banlis. 1Il. 406.546.

Schwaggrichen vide Hediong 4262.

- vide Ileyre 4450.

vide Linné 6004

— vide Schkulir 9138

Sehwalhe vide Jampert 4855 .

Seliwan vide Otto 7678 .

Sehwankhardt vide Vassalli 10666 .

Sehwartz, Paul von, vide Zigra 11448-114i9.

Schwar, Chr. G., vide Popowitsch 8163.

Seliwarz, J. Fr., vide Lange 5535.

Seliwegman vide Schnevooge 9225.

Schweighaenser vide Giboin 3625 .

Schweinitz vide Albertini 127.

Schwencke vide Bibl. Banks. III. 233. 
Schwenchfeld vide betiver 7938 . Schwendimann vides Spiemann 9810. Scdrychowsli vill: De Candolle 2178. seliyller vielo Brunfels 1 193. scounoli vide Bibl. Banks, 111. 434 seoll vido Ray 8356 .

Scoular vide Brotro 1344.

Scribouius largus vide Bruefers 1423.

feriptores rei rustirá vide Anon. 11852-11863. Scultedus vide Cormarius 1988.

Sebal vile Bih. Bants. III. $384,465$.

Seloastiaui vide Finrini-J/azanti 3200 vide Nluuri 6677 .

Sebisclu vide bock 979 .

Selizius vitle Sebisch 9323 .

Seaber viste Kuechellercher 5430

sechatter vide liuechuer 1521 .

Seazen vide Bibk. Banks. 1il. 128. 634

Segursted vide Ullyren 10571

Seguier vide Grononius 3921

Ségur visle II ukefield 10898 .

Selimeyer vide 11 Firlgen 11319.

Seidel vide Tellellech 10140

Scitll vide Bercthtold 728.

Séjour ville Dionis-du Séjour $26+1$.

Scizius vide Boehmer 1028 .

Seligmann, J. M., vide Jreu 10446. 10448.

Selligue vide Fresnel 3365 .

Sellow vide Martius 6597.

Sendel vide Bibl. Bunks. V., 95

Senduler vide Eitlicher $2993^{\circ}$

senelsier vide IIuber 4740 .

vide Ingenhous: 4901 .

vide Spallan=ani 9780.9782 .

vide Bib\%. Banks. 11I. 347 sıg.

Sencuerdius vide Gronovius 3918 vide Sithealue 9474

Senjawin ride Kimlitz 3248 .

_ vide Luelke 6358 . vide Pustels 8179.

senuser vide Buier 415 .

Senter vide Weinmann 11126 .

sepp vicle Kops 5358.

— vide Krauss $\$ 402-5403$.

Serajio vide Brunfels 1924.

Serenus Samonicus vide Men'er 6385

Seringe vide Jle Candolle 2239. 2256. - vicle llamilton 4097.

serra vide Correa de Serra 1993.

Serres vitle Belleval 691.

Servetus vide Murr 7330

Servieres vide Bibl, Banks. III, 637.

Sesler vide Donati 2681.

sellermark vide hinm s10

Seubert, Fr., vide Gok $376 x$.

seure vide Le Srurre 5782.

Severinus vide Colmenero 192x.

seybl vide Ross $\$ 734$.

seyffert virle Wedel 11102 .

Sherard, Jac., vile Dillenius $2633-2634$

sherard, Wu., vide Hermann 4395. vide Bibl. Banks. III. 5 is

Sherley vide diofllenbroth 6998.

siltherp vide II wlpole 10962.

vide Diascorides , 17.335.

-icelius vide Sickel 9619

Sichler vide Butret 1599.

Siver vido siber 9615.

Sicher vide Brown 1376

Sielfert vide Bibl. Bankis. 11]. 389

Siegesbeck vide Brendel 1234

- vide Browallius 1350
Siewesbock vide Gloutseh 36699

Fiemerling vide Dethardiny 23 亿

Sicurin vide Annh. 11812.

Sicvers vide Bibl. Banke, IIl. 274.

sigaull de la Fond vile Ireles 4053

Sirvel vide Bitu, Banks. III. 307. V. 96.

Sigwart, G. Fr., vide Kuplreute $\$ 330$.

Sigwart, G. C. L., vicle Vinselte 7559.

Silues vide Anon. 115 il.

Silander vide Ribl. Brumlis. III. 607.

Sillén vide Agarih 76.

— vide Iluss 4796 .

sillig vide 11 acer 6385

— vide Plinius 8081

Silvestre vide be siluestie $250 \rightarrow-250$ s

Silvius vide Cordus 19St.

Simler vide Gesner 3603 .

Simon vide Saint-Simon 8953.

Simon Januensis vide Hathacus Sighntures 6031

Sims vide Curtis 2091 .

- vide konity 5355 .

Sinclail, Arilur, vide 11 a shington 10984

Sinclair, G., vicle Donn $26 \$ 6$.

Sinning vide $N$ ecs von Esenbeck 7424.7443

Sjusted vide Gadd 3464.

Sjosteen vicle Bill. Bunks. III. 64f.

Sismoudi virle Simonde 9664 .

Sixius vide Cartheuser 1711 .

Skoge vide Bibl. Banks. III. 635.

Skytte vide Bibl. Banks. II. 596.

Slare vide Bibl. Banls. 11I. 564.

sloane vide Potiver 7931 .

vide Bibl. Banks. III. 129 squ]

Smellie vide Rotheram 8762

Smitl, Clır., vile Broun 1368. 1384 vicle Tuckey 10523

Snith, E. D., vide Sireet 10021.

Smith, J. E., vide Berkeley 771.

- vile Dioscorides, p. 335

ville Hooker 4659 .

vide Linné 5982.5984.6007,6135.

6138. 6148 .

viule Rudbeck 8826.

- viele Sibhorp 9617-9618.

visle Aron. 11578.

vide Bibl. Bantis. HI 154 squ

smith, Lady, vide Simith 9726 .

Smill vide Evelyn 3051.

smitl, hortulanus, vide Luker 6359.

simyth, buhu, vide Bibl. Banks. 1II. 463.

smyllere vide $D_{e}$ Smyttire 2519-2321.

suares Pariosa vide Bih, Bunks. 111. 654. V S.

Suderberg vile Lime 6029.6129.

Suderberis vide Thunberg 10294.

Soderstedi vide Thunberg 10260.

Solander vide Limne 60 !) 5

- vide Bibl. Banks. 111. 248.506.

Solclan vicle Prestele 8217.

Sulinus vide Saumaise 9005.

Solitander vido Mennumler 6755.

Solon vide Martin Solon 6556 .

Sommerfeldt vide Btbl. Bunks. III. 611

Somnerat vide Bibl. Bamls. III 248. 313.359.

Somnini vide Rrisseau-d/rbel 1290 .

_ - vide Le Dru 5034 vilu Rozier 8809 .

Snrel vide Goethe 3760 .

sorolla vide Theophrustus 10167.

- vide lioscorides 11537.

Soulange-Bodin vitle $D_{p}$ Candolle 2303.

Soules vile Young 11386 .

Soutaine vide Soulaime 9g!s.
Sowerdy vide Duckson y 560

vide Loudon $6 \geq 8$ :

vide Simith 9711. 971";

Soyer-Willemel vide Beucomot 1215 .

Spach vide Juubert 4865.

Spachius vide Frugoso 3307.

Spatoni vide Bibl. lianks. 111. 4 (16.

Spalding vide Lymun Spalding 6376

Sparman, J. W. , vide dluerti i Is

Sparrman, A., vide Linne 6118.

330.

Sparman, N. G. . vide Thunberg 10208.

Sparscluucls vide Linne 6093

Sperkbuck vide IIurtmann 4177 .

Spengler vide Bitl, Banlis. 111. 359.

Spenner vide Neer ron Eisenbeck 7445 .

Speramza vide Theophrastur 10167

Sperting, Oto, ville Fuiren 3444. viale Bibl. Banks. III. 166.

Spiezy ńshi vide Dioscorides, p. 334.

Spiegel vide Morren 7217.

Sulelmann vide Herrmann 4414.

vide Hosang 4719.

ville Schucendimamn 9493.

Spielmann fil, viso Spielmann 9808.

Spies vile Bruerkmarn 1402

Sprigelius vitle Spiegel 9800.

Spin viule Rodali 8652.

Spindler vide Buechuer 1506.

Spittler vide Bibl, Bankis. 111. 429.

Sprix vile .lartius 6584 .

Spongia vide risiami $1076 \mathrm{~s}$.

Sponius vide Dufour 2770.

Spoltswood vide Bill. Bonks. 111. 176

Sprat vide Coutey 2030.

Spratt vide ll'oodville 11358 .

Sprengel, Auton, vide Lime 6009.

Sprengel, Kurt vide Babel 379

- ville Bergius 762

vile Biehler 871

- vide Vinscorides 113003.

vide Encontre 2950.

- vide Krocker 5417.

- vide Link 5959.

- vicle Lmué 5985. 60026009. vide Hillin 6943.

vide Paulet 7809. vite Sert $=10016$.

viste Theophrasius 10166

- vide Turner 10539.

vide Wallrolh 10930-10951. vide 11eber 1:004.

Sipritg vide Enallicher 2995 .

- vite latllant 106 Is.

Springsfeld vide Bibl, Banks. III. 76

Stachlonuse vide Paulet 7810. vide Thenplirasess 10164.10167 vile Bill. Bunkis. IIl. 634

Stalpart vile Bibl, Bumk, HI. 547.552.

Stang vide Genlts 3564.

stantche vide Alberti 122

Ställammar vitle Bibl. Banks. III. 566

Staliel ville Theophrushus 10163.

staphorst vide Ramuolf 8373.

Starchen vide II agner 10878

Starke bide Carrere 1696.

Stedman vide Bibl. Bunks. 111. 545

Siectz vide Schomburyk 9248.

Steflens. Henrik, ride 11 illdenom 11256.

Sleger vide Dresin 9723.

Stehelinus. J. R., vide Bib! Banks. III. 396. 
Steigius vide Steige 9881.

Steinheil, Ad., vide Montagne 7070 .

Steinheil, L., vide Le Ilaout 5748 .

Stekhoven vide Schurmans Stehhoven y4689469.

Steller vide Bibl. Banks. Jll. 557.

Stelliis vide Talentyn 10636.

Stclliola vide Imprato 4897 .

Stenberg vide Ilellenius 4327

Stenhannuar visle Fries 3359

Stenisch vide Alizauld 6983.

Stenius vide II ullerius 10931 .

Stenmeyer vile Palmberg 7724.

Stephanus Atheniensis vile Dioscorides, p. 335.

Steplanus vide Estienne $3038-3044$.

Stephanus, Carolus, vide Baccanellus 385.

Stephanus, Phil., vide Broune 1390.

Stephanus, Robertus, vite Alamami 112

Stepliens vide De Candolle 2317.

Sternberg, J. Chr., vide Stentzel 9901.

Sternbers, Joachim, vide Bibl. Banks. JJl. 37 S

Sternberg, Kaspar, vide Brown 1339. vicle Palacky 7702 viste Sturm 9979.

Sternburg viele Spect-Sternburg 9785.

steudel ville Kielmeyer 5202.

Stevius vide Esteve 3037.

Stewart vide Lee 5656 .

Steyrie vide De la Steyrie $2398-\mathbf{2 3 9 9}$.

Sticknan vide Linne 6056.

Stiefl vide Bibl. Bunlis. III. 285.

Stieler vide Berger 733 .

Stierna vide Kalm 5101

Stillingfleet vitle Linne $5993-5999.6012 .6066$.

Stirbes vide llumbold 4772 .

Stobaeus vide Bibl. Banks. Jll. 405.

Stoblye vide Zigra $11 \$ 46$.

Stoever vide Linne 6140.6146-6147.

Stokes vide Withering 11329

stolberg vide Cordus 1992.

Stoltefoht vide Bibl. Banks. IHI. 202.

Sterk vicle Bibl. Banks. III. 630.

Stesch ville Petiver 7940 .

Strabo vitle Macer 6385. ville Reuss 8323.

Strand vide Linné 6064

Strandman viele Limé 6109.

Straub vide Kielmeyer $\mathbf{5} 205$

Strickland vide Freeman 3348 .

Stridsberg vide Bibl. Banlis. III. 640.

Strom, G. T., vide Thunberg 10239.

Strom, Jlans, ville Bibl. Bunks. JII. 130, 167, 222.

Stromer vide Bibl. Banks. III. 421.

Stroner von Reichenbach vide Lanremberg 5583.

Strumplf vide Linne 5985.

Strutt vitle Loudon 6259.

Struwe vide Thunberg 10245.

Stumpf vicie Bill, Banks. V. 73.

Stupanus ride bioscorides, 1). 335

Sturm viele be la l'igne $2 \$ 05$.

__ vide Hoppe 4677. 4651 .

- vide Nees von Esenbeck $7 \$ 25$. vide Swartz 10013

Sturm, J. WT., vide Sturm 9979.

Sturz vicle Theopherastus 10167.

Suarez de Rivera vide Dioscorides 11537.

Suckow, G. A., vide Bibl. Banks. III. 12. 582583.595 .

Suctonius vide Comelissen 1989

Sulphur virle Belcher 671.

vide Bentham 722

Sundberg vide Thutuerg 10301
Sundelius vide Loefwenhjelm 6214.

Surgy vile Kalm s091.

Sutton vide Bibl. Banlss. V. 79

Svensti Botanik vide Billberg 877-878. vide Anon. 11827

Svensson vide Linne 6071

Swagerman vide Bibl. Banks, 11J. 285. 372. 412.

Swartz, Er., vide Thunberg 10294

Swartz, N., vide Clewberg 1876.

Swartz, 0. , vide Linné 6167

- vide Ludwig 6324

vicle IVikstrom 11232

—_ ville Anon. 11827.

Sworliaur vide Schuediaur 9478.

Sweet vide Trattinick 10419.

Swinrlius vide Bry 1446.

Syen vide theede 8540 .

- vide Bibl. Banks. 1JI. 292.

Sylvaticus vide Mathaeus Sylvaticus 665 !

Sylvius, Jac. visle Jlarino $650 \mathrm{~S}$.

Symanski vide Anon. 11737.

Symmons vide Salisbmy 8963

Symplıorianus vicle Le Court 5635 .

Syreunius vide Syreniusz Syrenishi 10033.

Szent-Wiklos vide Sebeok 9522 .

Szubcrt vide Schubert $9356-9359$

Tahares de Ellea virle Anon. 11696

Taillant, Eurenia, vide Ruoul 8351

Taille vide De la Taille 2402.

Talbot vide Anon. 11674.

Tamlander vide Justunder 5071 .

Tan Chet-0ua vide Chambers 1792.

Tandon vide lloquin-Tandon $7131-7133$.

Tapie vicle Lutapie 5575.

Tappius vide Tuppe 10045 .

Tarade viele De Tarade 2541.

Tarbe vide Jlont-Sinet 7:28.

Targioni-Tozzetti, Giov, vide Micheli 6915-6916.

Targioni, J. Ant., vide Zamboni 11396.

Targioni-Tozzetti, O., vide Bertoloni 829 .

Tarquinius Ocyorus vide Schnellenberg 7595.

Taschenberg vile Burmeister 1588.

Tavernier, J. B., vide sichubert 9355

Tavernier, Helchior, vide Anon. 11703.

Taylor, Silas, vile Bibl. Banks. IJJ. 570.

Tavlor, Thomas, vide Hooker 4647.4654 .

Teesdale vide Bibl. Banks. UI. 438.

Teichmeyer vide Hedel 11080 vide Bibl. Banks. III. 380 .

Tellier vide Letellier $5808-5811$.

Temminck vide Korthals 5361 .

Tengborg vide Linne 6104 .

Tengmalm vide Linné 6034 .

Tengstrom vide Nylander 7585

Tenon vide Cuvier 2105

Tenore vide Gussone 3994.

vide llani 6678.

Ten Rluyse vicle Breyn 4262.

Tenzel ville stuhl 9863 .

Terjaew vide Suchow 9988

Terrade rite Laterrade 5576

Terrentius vide Ilernande 3404

Terror vide Hooker 4638-4639. 4667 .

Tertre vide Du Tertre 2851 :

Tessier vide Paris 7746.

Tide Anon. 11696.

- vile Bibl. Bank's, IIl. $286 \mathrm{sqq}$

Tessin, Connitissa, vide Limé 5975 .

Tettoll ach vide $L i s c h w:=618$ 亿.
Textor vide Bock 979 vicle Dioscorides, n. 331 .

Teyler vide $M_{e y e n ~} 6840$.

Thalius vide Camerarius 1648 . vide Lesser 5789

Therlenius vide Anon. 11812

Theis vide Duverger 2867 .

Thelning vide Thunberg 10289.

Theocritus vide Fie 3129.

- vide Tenore $1010 \mathrm{~s}$

Tleodorus vidle llildegardis 4,58-4459.

Theodorus vide Tabernatmontanus 10036

Theoplurastus vide kratzensiein 5387. vide Moldenhaner 7046 . vide Odonus 7598 vide Poulet 7808. 7810. vide Scaliger $9046-9047$. vide Sorolla 9757. vide Sprengel 9854 vide Stackhouse 9861-9869. vide Stillingfleet $9934-9933$ vide Vigna 10739

Therenot vide Boym 1214 .

Thiolisch vide Bibl. Banks. 111. 550.

Thilo vide Franke 3319.

Thiolat vite $\mathrm{T}^{\mathrm{T}} \mathrm{eb} \mathbf{4} \mathbf{0 9 9 9 .}$

Thiriat vicle Berkenkamp 776 .

Tholér vide Thunberg 10292.

Thomae vide Fischer 3215.

Thomasinus vide lesling 10717.

Thomasius, G., viule Bibl. Banks. 111 578 .

Thomé vicle Bibl. Banks, Ill. 589.

Thomson vide IVeinlig 11118.

Thon vide Boitard 1066-1067.

Thoner vide Ilorst 4714 .

Thonning vide Schumacher 9464

Thorlacius vide Senonius 10001 .

Thornton vide Curtis 2102 .

Thorpe vide Bibl. Banks. Jll. 133 .

Thorstensen ride Kall 5087 . vide Kratzenstcin 53388

Thory vide kedoute 8413.

Thouars vide Aubert $327-343$

Theuin vide Cuvier 2105 . vide Rozier Ssog. vitle Bibl. Banks. 111. 207.611.619.

Thran vide Resler 8594 .

Thryllitius vide Ileucher 4440 .

Thuanus vide $D_{e} T / 10 u 2546$.

Tlubbieres visle Caylus 1773

Thuemmig vile Bibl. Banks, H11. 383.

Thuillier vide Deshayes 2500 .

Thumbers vile Ahtquist 101. visle Billberg 878 vide IIartman 4168 vide Inmble 4769 vide Linderholm 5918 viule Ljunglerg 6191. vide velein 6762 . vide . Vordstedt 7569 vile Hahlberg 10579 vide Wahlenberg 1088. vide Walmsted 10959 . vide II ihstrom 11224-11225. vide Bibl. Banks. III. 184 sul]

Thury vide llericart 4387.

Tiburtius vide Bibl. Banks. 111. 625. 641.

Tiemanu vide Bochmer 1028

Tietz vide Titius $10335-10343$.

Tilebein vide Bibl. Bunks. III. 435 .

Tilingius vide Tilling 10321-10322.

- virle Bibl Banks. IIl. 451. 
Tillaneus vide Linne 6108 .

Tillandz vide Fengstrom 10088

Tillel vile Anon. 11693.

- vide Bibl. Brmks. III. 344. 431

Tilli vide Culvins 1632.

Tinelli vide Bertani 801.

Tiphaigne vide Anoit. 11690.11695.

Tissat vide Lingupt 5951. vide Bill. Banks, III. 429.

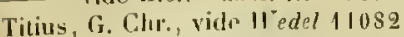

Titius, J. D., vide Bomnet 1107 . vide Du Hhmel 2786.

Tillmann vide Anon. 11785.

Tolias Aldinus vide Castelli 1733-1741.

Todd vide Bibl. Banks. III. 322.

Tode vide libl. Banks. 111. 224. 348. 351-353.

Tornsteu vide Berch 724.

Tollard vide Julic 4981 .

_ vicle Rozier 8809

Tenge vide Bibl. Banks. 111. 373.376

Tomujug vide Linné 6116

Toreen vide Osbeck 7664

Toruberg vide Bjorlingsson 881 .

Torner vide Linné 6063.

Torrey vide Croom 2061.

__ vide Lindley 5933

_ rite von Sclueviniz 9485 .

Torssell vide Meyen 6841 .

Tot Drakestein ville Rheede $8540-8512$.

Toulet vide Champy 1800

Teur vide De la Tour 2403 .

Tournefort vide Desfontuines 2494 - vide Liljemark $5 \$ 96$. - vide Martm 6622. - vide Panzer 7736. vide Paulli 781 S. vide Quer 8276 .

- vide Ray 8380.8384

- vide Roberg 8623.

— vide Valentin 10627.

_ viule Warton 10983. vide Bibl. Banks. III. 34 sig!]

Teurrette vide Latourrette $5577-5579$

Tours vile Gudrius von Tours 3937.

Tewnley vide Bibl. Banks. IIl. 698 .

Townson vide Bibl. Banks. III. 413.

Toxites vide Carrichter 1699.

Tozzetti vide Turyioni-Tozrelli 10048-1006i

Tozzi vide Petiver iy\&1.

Trafvenfeldt vide Thunlerg 10239.

Tragus vide Bock $977-9$ S 1 vide Brunfels 1423

Trampe vide Kniphaf 5294 - vide Luduig 6332

Trant vide Bibl. Banks. III. 31'

Trapp vide Limé 6146 .

Trappen vide Kops 5358 .

Tratliniek visle Scthmidt 9200 . vide Bibl. Banks, 111. 696.618.654.

Trautnann vide Bose 1162 .

Trebeck vide Moorofoft 7130 .

Trehan vide Anon. 11636.

Treise vide $\mathbf{W}$ edel $\mathbf{1 1 0 9 5}$

Tremblay vide Ifacer 6385

Trenix ville Destremx 2528 .

Troveris vide Anon. $11582-11585$

Treviranus vide $D_{e}$ lEcluse 2413

_- vide Lindley 5948.

- vide Sehmilz 9221

Trew vide Treu 10445-10452. vide Blackwell 920

vide Bibl. Banks. $111.76 \mathrm{sqq}$
Triowald vide Bibl. Banks. 111.399 squ.

Trinclinetil vide Morelli 7171. vide Morren 7226.

Trinius vide Liboschil $5856-5857$ vide Raspail 8360 .

Triquet vide Aron. 11652

Triumfetti vide Nalpighi 6449 .

Triverims vide Treveris 10454. vide Anon. 11582-11585.

Trecliet ville Dutrochet $2852-2855$.

Troeltzsel vide Schmidel 9187.

Troil vide Linné 6138 .

Troisvilles vide Gouffe 3807 .

Trombelli vide Bibl. Banks, III. 590.

Trommsderf, J. B., vide Bibl. Bunks, [I], $\$ 82$.

Trommsdorff, W. B., vide Bibl. Bunks. III. 434. 493.

Trône vide Dutröne 2856.

Troestwyk vide Deiman 2341 .

Trotula vide Itildegardis 4459

Treyel vide $B i b l$. Banks. III. 425.

Truchsess von Wetzhausen ville Herm 4283.

Tsehudi vide Miller 6936

Tuckey vide Brown $\$ 368$.

Tudecius vide Bibl. Barks. III. 403.

Tull vide Du Hamel 2775 .

Tulpius vide Tulpe 10526 .

Turberville vide Needham $7414-7415$

Turgot vide Willer 6936 .

Turnebus vicle Neibomius 6742.

Turner, Dawsen, vile Borrer 1141. vide Holer 4664 . vide Richardson 8567 . vide 1 Falson 40990 . vide Winch 11290 .

Turner, Willian, vide Gesner 3602 .

Turner, Mrs., vide Rootsey 8714.

Turpin vide Brisseau-Mindel 1293.

- vide Chaumet on 1811.

- vide De Candolle 2211.

vide De la Billardiere 2348. 2350

vide Delessert 2414.

vide $D u$ Hamel 2789 .

vide Goethe 3761 .

vide Humboldt 4774-4777.

vide Poiret $\$ 114$.

vide Poiteau 8118

vide Raffencau-Delile $\$ 305$

vitle Saint-llitaire $\$ 942$.

vide Tussac 10560

vide Ventenat 10702.

Turcjuier vide Le Turquier 5813-5815.

Turra vide Bibl. Banks. Ill. 249. 488.

Turrell vide Slack 9676.

Tursén vide Linné 6023

- vide Bibl. Banks. Ill, 639.

Turten vide Linué 5978 .

Tuscan vide Bennelt 711

Tyrholm vide Du Hamel 2774.

Tzscheppe vide Schuebler 9367.

Tzsclieppius vide Lischuil: 6187.

[Henluach vicle Duranle 2844

___ vide Lonizer 6261 vide Dioscoriles 11536

Ugla vide Wallin 10945.

Uhlich, Clir. G., vide Boehmer 1028.

Lhlich, R. E., vide Boehmer 1028

Vilkens vide Hall 4061 .

Ullmark vide Linné 6091

Ulloa vide Anon. 11696.

Ulmgrelin vide Riddermarck 8582.
Urich vide Westring 11187.

Ulriclser vide Hrunfels 1424-1405.

Underwoed vide Anon. 11560.

Ungebauer vide Plaz 8054 .

Unger vide Endlicher 2999

— vide Martius 6535 . vide .Huenster 7307.

L'nzendorf vide Urzędou 10605.

Unzer vide Bibl. Banks. 131. 193. 412. \{2z.

Uranie vide Gaudichaud 3527.

Urville vide Dumont dUrville 2799-2802 vide Bory 1150.

Usteri vide Dickson 2560 .

—_ vide Jussieu 5029.

_ vide Locher-Balber 6196

vide Afurruy 7345.

vide Roenter $\$ 665$.

vide IIilldenow 11255.

vide Bibl. Banks. III. 12.

Llierbon vide Jorlin 4905.

Vacher vicle Bibl. Banks. III. 541.

Vagetius vide Jung 4990-4992.

Yahl, J., vide Drejer 2724.

— vide Martins 6576 .

vide Oeder 7601

- vide Robert 8629 .

Vahl, Martin, vide Ilornemam 4701. vide Lambert 5507. vide Oeder 7601 . vide Bibl. Bunks. III. $36 \mathrm{sqq}$.

Vaillant vide Le I'nillant $5819-5820$.

Vaillant, S., vide De la Croix 2367.

vide Merat 6799.

- vide Peliver 7940. vide $B$ ihl. Banks. III. 34. 44. 218.

Val vide Duval $2858-2864$

Valdes vide Oviedo y Valdes $7659-7690$.

Valentini vide Camerarius 1653. vide Kentmann 5165. vide Bibl. Banks. 1II. 545.

Valini vide $H_{t m b o l d t} 4787$.

Valkenburgh vide Hazen $\$ 235$.

Vallan vide Schultze 9439.

Vallet vide Bry 1444.

— vide Bobin 8638 .

Vallisneri vide Confuliachi 1955.

— vide Martinis 6569 .

Vallouise vide Rossignol 8740 .

Van Aengelen vide Aengelen $53-54$.

Van Altena vide Kichard 8550.

Vau Baalen vide Bualen 371 .

Van Barneveld vide Barneveld 485

Van Bavegem vide Bavagem 608-600.

Van Beek vide Beek 647 . vide Dijk 2630

Van Berkhey vide Berkhey 77 .

Van Breda vide Breda 1247- 1249.

ride Ingenhousz 4898-4899.

Vandelli vide Grisley 3913 .

—_ vide Bibl, Banks. III. 430.590. V. 69.

Vau den Broeche vide Broecke $130 z$.

Van den Driessche vide Driessche 2731

Van der Aa vide An 1.

Fan der Boon Nesch vide Boon. Vesch 1114,1115

Vau der Boseh vide Bosch 115 .

Vanderesse vide Bibl. Banks, III. 380 .

Van der Groen vide Groen 3915.

Vanderlaert vide Blume 958 .

Van der lloeven vide Hoeven 4548 .

Van der IJoop vide I'riese 10844 .

Van der Smissen vide Smissen 9706 


\section{INDEX NOMINUM}

Vernin vide Duernin 2868.

Veruisy vide Bibl. Banks. III. 343.

Vernoy vide Duvernoy $2870-2874$

Verri vide Giobert $\mathbf{3 6 5 1}$.

Verulam vide Bacon 394

Verzascha vide Zwinger 11490.

Vesling vide Alpinus 163. 165.

Vest vide Reiner \$ $\$ 66$.

Viano vide Bibl. Banks. III. 429.

Viborg vide $H_{\text {olm }}$ i628.

Vicat vide llaller $4083-4084$.

Vicq d'Azyr vide Linaé 6010 . vide Tessior 10134.

Victorius vide Fettori $10725-10797$ vide Varro 10665.

Videmar vide Moscrti 7238.

Vigier vide Deville 2551. 11644

Vigna vide Theaphrastus 10167.

Vigne vide De lu Figne 2104-2405.

- vide Schkuhr 9139.

Vignot vide Bibl. Banks. III. 653.

Villanova vide Arnaldus 297.

Villar vide lillars 10748

Villars vide De la Doucette 2368.

- vide Bibl, Banlis. III. 144. 311

Ville vide Deville $2551-2552$.

Villeneuve vide Couret-Fillenurve 2021.

Villeneuve vide $A n \cdot n .11704$.

Villiers vide Biduult 866 .

Villiuganus vide I $_{\text {acer }} 6385$

Vilmoriu vide Morlant 7138 .

$\longrightarrow$ vide Anon. 11648,11660

Vincent vide Bory 1144-1152.

Vindé vide Morel de Finde $7142-7143$.

Virey vide Robinet 8641.

Virgander vide Linue 6075 .

Virgilius vide Fee 3120 .

- vide Kirsten 5243 vide Nocer 7542

- vide Puulet 7811 .

- vide Retzius 8509 vide Tenore 10107.

Visiani vide Jacquin $\mathbf{4 8 3 5}$

Visscher vide Londerseel 6254

Vilaliano vide Donati 2681.

Viviani ville Cuvanulles 1769.

- vide Dinegro 2639

Vivier vide Anon. 11667.

Vochenberg vide Tollat von Fochenberg 10358

Vogel, Aloys, vide Vincentius 10760.

Vogel, B. Chr., vide Treu 10447. 10452.

Vogel, Jlermann, vide Schuebler 9391.

Vogel, H. A., vide Dingler 2640

vide Klein 5251

Vogel, Karl, vide Pompper 8149.

Vogel, Theodor, vide Marquart 6517

Vogelius vide Fogel 3257

Vogler, J. Ph., vide Bibl. Banks. IJI. 584-5\$6

Vogt, Tr. K. A., vide Boehmer 1049 vide Richter 8573 .

vide W'uensche 11367.

Voigt, Fr. Sgm., vide $D_{e}$ Saussure 2476

- vide Bichard \$561.

Voisins vide Jubuisson $3: 7$

Volckanser, J. Chr., vido Bibl. Banhs. IJI. 248.

Volckamer, J. G. I., vide Bibl. Banlis. Ill. 350.

Volckamer, J. G. II., vide Bibl. Banles. III. 280. 385. 399.403 .

- vide Panzer 7736 .

Volkmann, Gottlob Isr., vide Hofmann 4567.

Volkmann, J. J., vide Bruce 1391.

\section{INDEX NOMINUM}

Volkmann, J. J., vide Tounsend 10393.

Volta vide Bibl. Banks. III. 198.

Von den Brincken vide Brincken 1283-1284.

Von der Luehe vide Luehe 6356-6357.

Voorst vide Forstius $10838-10839$.

Vor'm vide IIobius van der Vorm 4530. 10837.

Vorstius vide De l'Ecluse 2412.

- vide Kralitz 5378

Vossius vide Boëtius 1046.

Vossler vide Tschudi 10519.

Vredius vide Boëlius 1046.

Vries vide Martens 6546.

Vriese vide $D_{e}$ l'Ecluse 2413 vide Siebold 9635 vide Wiegmanr 11212

Vrolik vide Anon. 11837.

Wachtel vide Scultelus 9516.

Wadsberg vide Afzelius 56 .

Wannmau vide $L$ inné 6083 .

Wasström vide Bibl. Banks. III. 428.

Wagenitz vide Limmer $5901-5902$

Wagner, J. A., vide Zuccarini 11477.

Wagner, J. J., vide Triller 10471.

545.

Vagner, K. Clır., viłle Reichel 8430 .

Wagner, P. Clir. L., vide lelius $2 \$ 19$.

Wagnitius vide Limmer $5901-5902$.

Wahlberg vide Thumberg 10287. 10299. vide Anon. 11827.

Wablbom vide Lanp 6025 .

Walleuberg vide Berggren 759. vide Fries $\mathbf{3 3 8 0 .}$ vide Sommerfell 9743. vide Thunberg 10247. vide IValmsted 10959 vide Wrangel 11361 vide Anon. 11827.

Waitz vide Roessig 8687 .

Walafridus vide Strabo 9951 vide Reuss 8523 .

Walch vide Hoppe 4687.

Walckenaer vide dzara 369.

Waldheim vide Fischer von $1 V^{\top}$ luhein 3211 3213.

Watdnelius vide Passreus 7797.

Waldsclimied vide Siricius 9673.

Walker virle Anon. 11550.

Walker-Arnott vide Greville 3971. vicle Hooker 4665 vide Kittel 5246 vide Hight 11219.

Wallenius, C. G., vide Gudd 3 4 61 .

IVallenius, J. F., vide Hellenius $4,320$.

Wallerius vide Linne 6141 .

Wallich vide Don 2675.

Walliser vide $B r y$ 1445-1446.

Wallman vide Liljeblud 5893

Wallroth vide Bluff 948 .

Walpers vicle Rlanco 933 .

vide Bravais 1242.

Waltersliausen vide Drais 2707

Walther, F. I., visle Bibl. Banks. III. 324.

Walther, J. F., vide Schulze 94; 9 .

Wangenheim vide Colden 1897.

\section{5}

Wâhlin vide Linné 6043

Warenius vide Thunberg 10301.

Wargeliu vide $\mathrm{Kalm} 5127$.

Waring vide Bibl. Banlis. III. 135. 
Warner vide Forster 3292

Watson, William, vide Trudescant 10397. - vide Bibl. Banks. III. 93 sqı.

Wauters vide Burtin 1592.

Webh vide Parlature 7768.

Weber, Fr. vide Dillwyn 2637.

Weber, G. H., vide Nolte 7563.

vide Siruce 9972

Weber, J. A., virle Slevagt 9699.

Weddell, $\Lambda$., vido Cosson 2005.

Weddell, 11., vide Siceet 10026 .

Werlel, Christian, vide II'edel 11075.

Wedel, G. W., vitlo Bibl. Banks. III. 402. 403. 518. 544 .

Werlel, Joh. Ad., vide Wredel 11074.

Weilel, J. W. vide llumberger 4093-4094.

Weigel vide Bibl. Barks. Ill. 82.

Weihe vide Nees vor Esenbeck 7/40-7141.

Weiland vile Acerbi 20.

Weinmann, J. G., vide Gmelin 3715.

Weinmann, J. W., vide Gesner 3612 .

Weis vide Weiss $11130-11132$.

Weise vide Sickler 9622 .

Weisius vide Plinius 8083 .

Weiss, Fr. W., vide Mueller 7284

Weiss, J. Clir., vide Baier $40 \mathrm{O}$.

Weiss, J. Goturt, ville Reigger 8535 .

Weissenborn vide Namburg 7389.

Weissheit ville W'edel 1 loss.

Weissmann vidle Slevogt 9695 .

Wide Bibl. Banks, III. 527.

Weizenbeck vide Linné 6010.

Welden vide Portenschlag $\$ 168$.

- vide Anur. 11818.

Wencker vide Mappus 6486.

Wenckh vide Bibl. Banks. IIl. 526.

Wendland vide Barlling 513 . vide Schrader 9281 vide Bill. Banks. V. 65.

Weult, Capt. W., vide Meyen $683 \mathrm{~s}$.

Weniger vide Meigen 6745.

Wennmohs vide Masius 6640 .

Wenzlius vide Ilalden 4052.

Wepfer vide Bibl. Banks. Ill. \$3 6 .

Werner vide Syme 10030.

Werner, Abr, vide Cuvier 2105.

Weruer, Adan, vide Roberg 8628 .

Werner, Georg, vide Schuebler 9393.

Wernle vide Schuebler 9397.

Wernsdorf vide Philes 7953 .

Westbech vide Bibl. Banks. III. 357.

Westcott vide Knowles 530 ?

Westfetd vide Bill. Banks. 111. 132

Westman vide If allerius 10933 .

Westmann vide Limié 6013.6016.

Westring vide Limé 6129. vide Bibl. Bunks. 111. 387. V. 99

Westrumb ville Retzius 8501 .

Westre vide B. Banks. III. 133.

Westzynthius vide Kalm 5093 .

Wetterlund vide Stumpf 9975 .

Wexionius vide Wichael 6899 .

Whistling vide Gruner' 3936 .

White, Taylor, vide Bibl. Banks. III. $\$ 93$.

Whytl vide Bibl. Butis. III. 305.

Wieknan vitle Linne 6127.

Widdrington vide Cook 1965.

Wiulenius vide Kolm 5109.

Widenmann vide Moreau de J. 7141.

Widnmann vide Besler' 840 .

Wiegmann vide Iriese $10 \$ 50$.

Wiese vide Lamouroux 53291 .
Wieso vide Anon. 1177:

Wiest vide Schuebler 9376.

Wigand, Otto, vide Limne 6011.

Wigand, Wolracl, vide 11 edel $1109 \%$.

Wiggers vide 11 eber $110+3$.

Wihstroem vide Beilschmied 666 . - vide Sucurt 10016. - vide Thanberg 10252

Willserding vide lleister 4307 .

Wilcke, H. Chr. D., vide Linné $608 \mathrm{~s}$

Wilcke, J. C., vide Bibl. Banks. III. $36 s$.

Witkinson vide Bibl. Banks. [II. 536.

Will vide Kirsten 5242.

Willdenow vide Bollon 1079.

- vicle Henclcel von Donnersmarcle 4352. vide Mendel 4357. vide IIerrmann 4415.

vide Hoffmann 4594. ville Ionckemy 4635 . vicle Ideler $\$ 876$. vide Leers 5658 .

- vide Lirk 5967.

vide Linné 6002.6004

virle Lourriro 6302.

vide Rebentisch 5403.

- virle II aller $1096 \%$

- vide Bibl. Banlis. Ill. 49 sqrt.

Willemet, H. F., vide Soyer-U1"illemet 97699774 .

Willenet, P. R., vide Hoffmann 4575 .

$\longrightarrow$ vide Lamouroux 5516.

Willemet, Remi, vide Coste $2011-2012$. $540, \mathrm{Y} .80$

Williams vide Bibl. Bunls. 11I. 535 .

Willich, Chr. L., vide Bibl. Bunks. III. 77.

Willich, M. U., vide Heigel 1 1 108 .

Willius vide Bibl, Banks. 1ll. 166.

Willkonm vide Kunze 5471 .

Willughby vide Ray $\$ 385$. vide Bibl. Banks III. 373.

Wilrenk vide Plato 8051 .

Wilso11, H. vide Moorcroft i 130.

Witsoa, M, vide Bibl. Banks. III. 422.

Wiman vide Linné 60 亿2.

Wimmer ville Aristoteles $29 \%$.

vide Guenther 3944.

- vide Theophrastus $1016 \bar{i}$.

Winckler, G. Cbr., vide Bibl. Banks. III. 108.

Winblad vide Thunberg 10301.

Winkelblech vide Schleiden 9157. vide Schmid 9179

Winkler vide Plato 803 t.

Winslow ville Berreau 796.

Wiaterboven vide Anon. 11813.

Wintersehniclt vide Oelhofen 7607 . vide Wolf 11339.

Winthorp vide Bibl. Burks. 111. 600 .

Wirsing vide Treu 10448. 10452.

Wise vide Anon. 11591.

Withering vide Bibl. Banks. Ill 14.

Wiltewal rille 11 illdenow 11262.

Witlie vide Birkholz 886 .

Woelıler vide Berzelius 839

Woellner vide Heister 4310 .

Woellner vide Ilome 4633.

Woerz vide Schuebler 9399.

Woestyne vide Tan de Woestyne 10659.

Wohlhernser vide Mueller 7296.

Wolfart vicle Valentini 10620

Woll, G. Chr., vide II edel 11100.

Wolt, J., vide Oelinfen 7607 .
Wolt, J. Ph. I., vide Bibl. Banks, Ill 3 s.

Wolrf, J. [']. II. vide Baldinger 434

vide Laduig 6324.

Wolr, Sal. Beer, vide Cartheuser 1702.

Wolleb, Daniel, vide De la Chenul 2362

Wollrath vide Limue 6058 .

W'olplius vide Gesner 3595. 3597. 3603, 360 \%. vide Dioscorides, J. 333 .

Wolter vide Nees von Esenbeck T460-7/61.

Wonneche von Caub vide Anon. 11576-11906

Wood vide Aron. 11578

Woodville vide Anon. 11578 .

Woodward, J., vidle Bibl. Banks. III. 37-.

Wuodward, Th, vide Bibl. Kenles, III. 34h-36.5. $356-357$. V. 83.

Worm visle Seger 9531.

Woschkius vide Hagner 1087i

Woyt vide Puclobusch 7696 .

Wray vide Ray $8375-8402$.

Wriglut, John, vide Eaton 2882. 2883.

Wright, 1 W. virle Bibl. Banks. 111. 463. 476.513

Wuestenfeld ville Henninger 1363.

Wulten vide Kunilzsch $5 \$ 49$. - vide Bibl. Banks. III. 153.

Wulud vide $B i b l$. Banks. 11l, 570 .

Wurnb vide Bibl, Banks. IIf, w11

Wratt vide Ilarvey 4199 .

Ximenez vide Ilern'mdez 4403.

Xuarez vide Gil 3626 .

Young, Th., vide Bibl. Bunks. III, 63ั1

Ypey vide Bibl. Banks. 111. 372.

Yvard vide Bibl. Banks. III. 558.

Ivart vide De Silvestre 2506.

Zachar vide Hallnun 4092.

Zanzelius vide Sanzelius $\$ 981-\$ 982$.

Zani vide Horelli 7169.

Zannichelli, G. J., vide Zcmmichelli 11:03-11;06.

Zanolini vide Uorelli $\mathbf{7}$ Ti.

Zanoni vide Meneyoti 6778.

- vide Scarella 9048 .

Zanotti virle Palladius 7712.

Zapf vide Bibl. Banks. III. 263.

Zauschner vide Bibl. Buntis, III. 261. 997.

Zea vide Ruiz $\$ 867$.

Zebuhte vide Curthesser 1705.

Zedora vide Lrzedow 10605.

Zeilser vide Dicks 2558 .

Zélée viule Dumont $2801-2802$.

- vicle Montngne 7097.

Zeller vicle Schuebler 9374.

Zeune vide Nicander 7478 .

Zeuthen vide Ilule 7314 .

Zeviani vide Bibl. Banks. III. 552.

Zeylier vile Echlon 2901.

Ziecardi vide Gussone 3993 .

Ziervogel vide Linné 6044.

Zieten vide Gleditsch 3668 .

Zimara viule Albertus $\boldsymbol{A l} .129$.

Zinmermann vide Burtram $\$ 30$.

vicle Imlay 4895.

Zimmermann, J. Chr, vide Neumanu 7666.

Zimmermann, J. Chr., vide Schmidel 9189.

Zinn vide Bibl. Banks. III. 79 sqq.

Ziz vide Koch 5311.

Zoega vide Olafsen 7620 .

Zollinger vide Ilorit:i 7205. 
Zorn vide Panckow 7733.

Zuccagni vide Bibl. Banks. V. 77

Zuccarini vide Martius 6586. 6604 . vicle Siebold 9634 .
Zucchini vide Bibl. Banks. H1. 626.

Zumbach vide Hermann 4394.

Zum Thurn vide Thurneisser 10303-10304

Zwinger, Fr., vide Bibl. Banks. III. 359. \%winger, Theodor, vide Ardoynis 269. - vide II 11 pper 11167

Zyro vide Anon. 11747.

Zyllardus vide Figulus 3188 .

\section{NOMINA EMEND.INDA:}

No. $655-656$ lege Karl Traugott Beilschmicl.

- 3421-3424 lege John Frost.

- 3497-3498 lege George Gardner.

- 3957 lege D. L. (iuiart.

- 1394 lege Theodor Guembel.

- 5307-5310 lege Karl Heinrich Emil Koeh.

- 9144-9150 lege Diederich Franz Leonhard von Schlechtendal.

Impressio partis alphabeticae aunis $1847-1849$, partis systematicae annis 1850-1851 absoluta est. 
LIPSIAE: TYPIS F. A. BROCKHAUSH. 





